\title{
THE FUTURE OF ENERGY GASES
}

David G. Howell, Editor

Associate editors:

Katryn Wiese

Michael Fanelli

Laura Zink

Frances Cole

U.S. GEOLOGICAL SURVEY PROFESSIONAL PAPER 1570

An examination of the origin and distribution of natural gases and the economics and environmental effects

of developing gas resources for energy

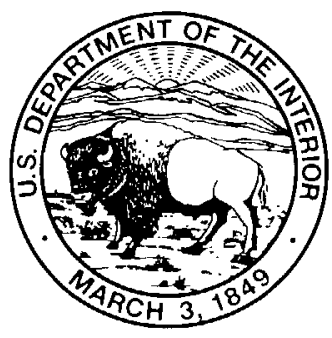

UNITED STATES GOVERNMENT PRINTING OFFICE, WASHINGTON : 1993 


\title{
U.S. DEPARTMENT OF THE INTERIOR BRUCE BABBITT, Secretary
}

\author{
U.S. GEOLOGICAL SURVEY \\ Robert M. Hirsch, Acting Director
}

For sale by U.S. Geological Survey

Books and Open-File Reports

Federal Center, Box 25286

Denver, CO 80225

Any use of trade, product, or firm names in this publication is for descriptive purposes only and does not imply endorsement by the U.S. Government

Project coordinated by Carolyn Donlin Text and illustrations edited by Carolyn Donlin, Helen Gibbons, and James W. Hendley II Book designed by Lisa Baserga, Linnea Larsen, and Carolyn Donlin Cover designed by Joe F. Vigil

\section{Library of Congress Cataloging in Publication Data}

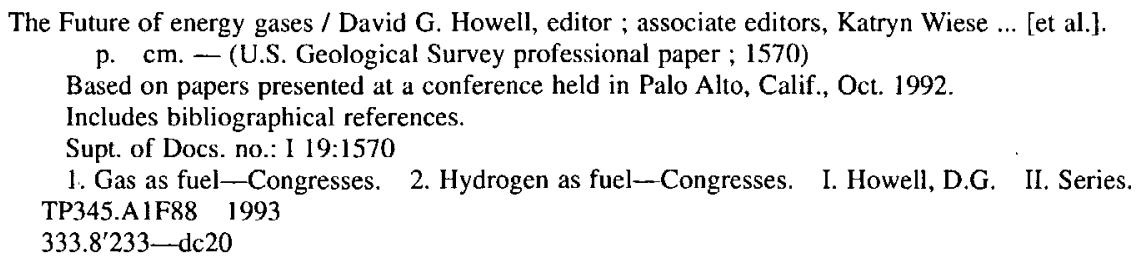




\section{PREFACE}

The ever-present concern of meeting U.S. energy needs led the Geological Survey in 1992 to initiate a series of publications that addresses the potential for an expanding role of energy gases to help sustain our domestic energy needs. This series is drawn from the Survey's own wealth of research as well as from academic, business, other government facilities, and private sources. We use the term "energy gases" to distinguish those natural gases, primarily methane, that have utility for energy purposes from the many other forms of natural gas.

Recent discussions among economists, environmentalists, lobbyists, and scientific research groups within the energy industry have focused on the contributions of energy gases to the world's energy requirement. These discussions center around questions of gas supplies, assessing economic risk, future prices, and uncertainties of deliverability. What is often missing from these discussions, however, is a firm understanding of the fundamentals of energy gases: What are they? How do they form? Where are they found? How can they be exploited and at what costs? What are the environmental consequences associated with an expanded role of energy gases?

Energy gases, particularly methane, are commonly associated with oil, and, indeed, huge supplies of methane have been found while exploring for oil. But only a small share of all methane is associated with oil and, importantly, methane forms in some settings totally independent of oil. Methane is found in association with coal; it is a byproduct of metabolic processes in microorganisms; it originates from great depths in the Earth's crust (it may even occur in the mantle); it occurs in the molecular lattice of ice in the Arctic and offshore areas below the sea floor; and it is often dissolved in water in large aquifers. Thus exploration efforts for gas are in many ways fundamentally different from exploration strategies for oil. Additionally, a variety of these settings contain truly enormous amounts of gas, but it is either dispersed throughout low-permeability horizons or concentrated in an ice lattice (hydrates); therefore, exploitation of these resources involves unique engineering problems rather than exploration uncertainties.

To start the process of addressing these energy-gas issues, we organized a workshop in October of 1992 to which a spectrum of researchers was invited from government, universities, and the gas industry. Approximately 75 specialists participated in discussions ranging from the origin of energy gases to how methane may provide a bridge to a hydrogen-based energy system in the future. This volume reflects the themes discussed at the workshop; it makes no attempt to offer new resource assessments because a variety of such studies already exists. Rather, its goal is to provide the fundamental information about energy gases, describe the attributes that make gas a beneficial fuel, provide ideas on how gas could be more fully integrated into an energy strategy, and explore the problems that may lie ahead if society shifts toward heavier use of energy gases. Woven throughout the volume are indications that a great deal is still unknown; these unknown factors may provide the focus for future research.

Besides this volume, two additional companion products have been produced as follow-up products to the workshop. One is a 30-minute video entitled The Future of Energy Gases that is directed to nontechnical audiences and provides a general introduction to energy gases. The second is a pamphlet, also entitled The Future of Energy Gases (U.S. Geological Survey Circular 1115), which provides a nontechnical summary of energy-gas issues with numerous illustrations. Together, the three products constitute a package offering a look at the topic of energy gases ranging from very general to highly technical. We would appreciate comments from readers, both in terms of the effectiveness of each piece as well as any suggestions for future products and research directions.

And finally, we of the U.S. Geological Survey ad hoc Energy Gases committee must credit Gary Hill for challenging us to take on this project. Additionally, we would like to express our thanks and gratitude to the large cast of authors, editors, and production staffers whose collective effort allowed this volume to be conceived, written, and published in record time. Not included in the list of credits are Jim Pinkerton and Jeffrey Troll without whose confidence and guidance we could not have completed this volume. Special mention must go to Carolyn Donlin, the technical editing coordinator of the professional paper, whose patience, flexibility, and tenacity helped steer the 57 chapters through a rigorous and complicated review and production'schedule.

Don Gautier, U.S. Geological Survey, MS 960, Federal Center, Box 25046, Denver, CO 80225 (electronic mail address: gautier@bpgsvr.cr.usgs.gov)

Robert Halley, U.S. Geological Survey, 600 4th Street South, Studebaker Bldg., St. Petersburg, FL 33701 (electronic mail address: rhalley@ wayback.er.usgs.gov)

David Howell, U.S. Geological Survey, MS 902, 345 Middlefield Rd., Menlo Park, CA 94025

(electronic mail address: dhowell@octopus.wr.usgs.gov)

Jill McCarthy, U.S. Geological Survey, MS 999, 345 Middlefield Rd., Menlo Park, CA 94025

(electronic mail address: mccarthy @ octopus.wr.usgs.gov)

David Scholl, U.S. Geological Survey, MS 999, 345 Middlefield Rd., Mcnlo Park, CA 94025

(electronic mail address: dscholl@octopus.wr.usgs.gov) 



\section{CONTENTS}

An Introduction to "The Future of Natural Gas"

By David G. Howell, Frances Cole, Michael Fanelli, and Katryn Wiese

\section{ORIGINS OF ENERGY GASES}

Introduction to Microbial and Thermal Methane

By Katryn Wiese and Keith A. Kvenvolden

Stability and Flux of Methane in the Deep Crust-A Review

By Robert C. Burruss

Abiogenic Hydrocarbons and Mantle Helium in Oil and Gas Fields

By Peter D. Jenden, David R. Hilton, Isaac R. Kaplan, and Harmon Craig

The Origin of Methane in the Crust of the Earth

By Thomas Gold

Energy Gases of Abiogenic Origin in the Earth's Crust

By John A. Apps and Peter C. van de Kamp

Prospects for Commercial Abiogenic Gas Production: Implications from the

Siljan Ring Area, Sweden

By John R. Castaño

\section{HABITATS OF GAS ACCUMULATION}

\section{CONVENTIONAL GAS}

Conventional Gas Resources of the Gulf of Mexico Outer Continental Shelf-

Past Experience, Current Activities, Future Potential

By Gary L. Lore

\section{DEEP GAS}

Geologic Studies of Deep Natural-Gas Resources in the United States

By T.S. Dyman, D.D. Rice, J.W. Schmoker, C.J. Wandrey, R.C. Burruss, R.A. Crovelli,

G.L. Dolton, T.S. Hester, C.W. Keighin, J.G. Palacas, W.J. Perry, Jr., L.C. Price,

C.W. Spencer, and D.K. Vaughan

Challenges of Ultradeep Drilling

By Richard E. Wyman

Empirical Observations Regarding Methane Deadlines in Deep Basins and

Thrust Belts

By David W. Houseknecht and Christoph Spötl-

\section{TIGHT GAS}

Gas in Tight Reservoirs-An Emerging Major Source of Energy

$B y$ Ben E. Law and Charles W. Spencer

\section{ORGANIC-RICH SHALES}

Autogenic Gas (Self Sourced) from Shales-An Example from the Appalachian Basin

By Robert C. Milici

\section{HYDRATES}

A Primer on Gas Hydrates

By Keith A. Kvenvolden 


\section{HABITATS OF GAS ACCUMULATION-Continued}

\section{HYDRATES-Continued}

Rock Physics for Characterization of Gas Hydrates

By Jack Dvorkin and Amos Nur

Natural Gas Production from Arctic Gas Hydrates

By Timothy S. Collett

Gas Hydrates on the Atlantic Continental Margin of the United States-Controls

on Concentration

By William P. Dillon, Myung W. Lee, Kristen Fehlhaber, and Dwight F. Coleman -

Velocity and Amplitude Structures on Seismic-Reflection Profiles-Possible

Massive Gas-Hydrate Deposits and Underlying Gas Accumulations in the

Bering Sea Basin

By David W. Scholl and Patrick E. Hart

\section{ACCRETIONARY PRISMS}

Generation, Migration, and Resource Potential for Hydrocarbons in Accretionary

Subduction Systems-A Large, Unconventional Hydrocarbon Resource?

$B y$ Andrew J. Stevenson

\section{LANDFILLS}

An Energy Perspective on Landfill Gas

By Peter J. Hutchinson

\section{DISSOLVED GASES}

A Survey of Natural Gas Dissolved in Brine By Sullivan Marsden

\section{COALBEDS}

Coalbed Gas-An Undeveloped Resource

By Dudley D. Rice, Ben E. Law, and Jerry L. Clayton

Coal as a Source Rock of Petroleum and Gas-A Comparison Between Natural and Artificial Maturation of the Almond Formation Coals, Greater Green River Basin in Wyoming

By Mario García-González, Donald B. MacGowan, and Ronald C. Surdam-

\section{GAS SEEPS}

Biochemistry of Natural Gases in Three Alkaline, Permanently Stratified

(Meromictic) Lakes

By Ronald S. Oremland and Laurence G. Miller-

A Comparison of Hydrocarbon Gases from Natural Sources in the Northwestern United States

By Thomas D. Lorenson and Keith A. Kvenvolden

Atmospheric Methane Flux from Coals-Preliminary Investigation of Coal

Mines and Geologic Structures in the Black Warrior Basin, Alabama

By Jerry L. Clayton, Joel S. Leventhal, Dudley D. Rice, Jack C. Pashin, Byard Mosher, and Peter Czepiel 


\section{GAS-RESOURCE ESTIMATES}

U.S. Geological Survey Estimates of Natural-Gas Energy Resources

By Gordon L. Dolton, Donald L. Gautier, Richard F. Mast, and David H. Root

National Petroleum Council Source and Supply Study-The Potential for

Natural Gas in the United States

By Donald L. Gautier and Robert L. Brown

Domestic Conventional Natural-Gas Reserves-Can They Be Increased by the Year 2010?

By Thomas S. Ahlbrandt and David J. Taylor

A Primer in Field-Growth Estimation

By David H. Root and Emil D. Attanasi-

Gas Hydrates as a Potential Energy Resource-A Review of Their Methane

Content

By Keith A. Kvenvolden

Use of Seismic Data in Estimating the Amount of In-Situ Gas Hydrates in

Deep Marine Sediment

By Myung W. Lee, Deborah R. Hutchinson, William P. Dillon, John J. Miller,

Warren F. Agena, and Barbara A. Swift

Biogenic Gas: Controls, Habitats, and Resource Potential

By Dudley D. Rice

World Resources of Natural Gas-A Discussion

By Charles D. Masters -

\section{THE ENVIRONMENT AND SOCIETY}

Environmental Consequences of Increased Natural-Gas Usage

By Frances Cole

An Introduction to the Use of Natural Gas and Opportunities for Greater

Consumption

By Michael Fanelli

Methodology for Estimating Volumes of Flared and Vented Natural Gas

By Timothy R. Klett and Donald L. Gautier-

Energy Gases-The Methane Age and Beyond

By Nebojša Nakićenović

\section{TECHNOLOGY}

Logistical Considerations for the Exploration and Production of Natural Gas

By Russ D. Cunningham and Daniel R. Rowe -

Overview of the U.S. Department of Energy/Morgantown Energy Technology

Center Natural Gas Program

By Abbie W. Layne

Alternative Development Strategies for Natural Gas

By Emil D. Attanasi-

Survey of Natural Helium Occurrences

By Dennis W. Hinnah and John E. Hamak 


\section{TECHNOLOGY - Continued}

Methods of Gas Analysis

By David E. Emerson-

Hydrogen: Its Comparison with Fossil Fuels and Its Potential as a Universal Fuel

By T. Nejat Veziroglu and Frano Barbir

Hydrogen Storage Systems

By James A. Schwarz and K.A.G. Amankwah

\section{ECONOMICS}

\section{HISTORY OF CONSUMPTION}

History of Natural-Gas Consumption in the United States

By Michael Fanelli

MODELING

An Economic Approach that Links Volumetric Estimates of Resources with Cost and Price Information

By Dale M. Nesbitt-

Natural Gas-How Much, At What Cost?

By Jairam S. Gopal and W. William Wood, Jr.

\section{EXPLORERS' VISIONS}

Natural Gas and the Role of Competition in the United States

By Keith E. Anderson-

Reflections After 62 Years of Exploration

By Michel T. Halbouty

New Thinking About Natural Gas

By Robert A. Hefner III

Natural-Gas Resources of North America

By John A. Masters

The Future of Methane and How We Get There

By Michael Roberts

\section{THE FUTURE}

Sustainable Operation-Natural-Gas Contribution

By Rex T. Ellington and Mark Meo-

The New Downstream: Increased End-Use Efficiency and Renewable Forms of

Energy as Competitive Energy Resources

By Evan Mills

How Ultimate is Ultimate Gas Recovery?

By Thomas J. Woods

The Gas Gap: Uncertainty in the Supply of Natural Gas

By David G. Howell, Katryn Wiese, and Jonathan Swinchatt

Appendix 


\title{
An Introduction to "The Future of Natural Gas"
}

\author{
By David G. Howell ${ }^{1}$, Frances Cole ${ }^{2}$, Michael Fanelli ${ }^{3}$, and Katryn Wiese ${ }^{3}$
}

\section{CONTENTS}

Introduction

Origins of Energy Gases

Energy Gas Resources

Natural Gas and the Environment

Economic Benefits of Using Natural Gas

Natural Gas as a Bridge to Future Energy Systems .......

Economics of and Obstacles to Increased

Natural-Gas Use

Summary

Acknowledgments

\section{INTRODUCTION}

The earliest humans gained warmth and protection almost 500 millenia ago when they learned how to harness fire. Wood, dung, and animal fat were the sources of this energy. Over time these sources of energy have steadily evolved towards ever more efficient and cleaner forms: from biomass to coal to oil. That trend continues today with increased global use of natural gas, a fuel with environmental, economic, and political benefits. In the long term, during the 21 st century, it seems likely that the trend will

'U.S. Geological Survey, MS 902, 345 Middlefield Rd., Menlo Park, CA 94025-3591.

${ }^{2}$ U.S. Geological Survey, MS 955, 345 Middlefield Rd., Menlo Park, CA 94025-3591.

${ }^{3}$ U.S. Geological Survey, MS 999, 345 Middlefield Rd., Menlo Park, CA 94025-3591.

Manuscript approved for publication September 9, 1993. continue with the development of nonpolluting, renewable energy sources such as solar and various forms of nuclear energy. Before societies achieve this goal, however, it is likely that natural gas will increase its role in the energy mix. Nonetheless, a great deal of uncertainty and confusion surround the global supply of natural gas as well as the consumption of it. This professional paper addresses a breadth of issues regarding natural gas-how it forms, the environments in which it forms, how much remains, and the economics that affect these natural-gas issues. To continue the quest for a better understanding of the future of energy gases, all such issues must be explored.

The information contained in this brief review is drawn exclusively from the chapters contained in this volume. Because a reference to each chapter was deemed cumbersome, readers are advised to peruse this volume for original source materials.

\section{ORIGINS OF ENERGY GASES}

Natural gas usually refers to methane, although small amounts of other hydrocarbon gases such as ethane, propane, and butane are also present in natural-gas mixtures. Methane is the simplest of the hydrocarbon moleculesone carbon surrounded by four hydrogen atoms-and it exists in variable concentrations throughout the Earth's atmosphere, water, and rock layers.

Natural processes that form methane are divided into three types: biogenic (expelled gas from micro-organisms during the digestion of organic compounds), thermogenic (decomposition of organic matter by heat and pressure), and abiogenic (reactions of deep crustal gases with minerals or seepage of hydrogen- and carbon-rich primordial gases from the Earth's interior). Most of the methane that is extracted from the large natural-gas accumulations found in the Earth's crust is probably either biogenic or thermogenic in origin (fig. 1). The role of abiogenic methane in the formation of gas accumulations is a controversial issue. 


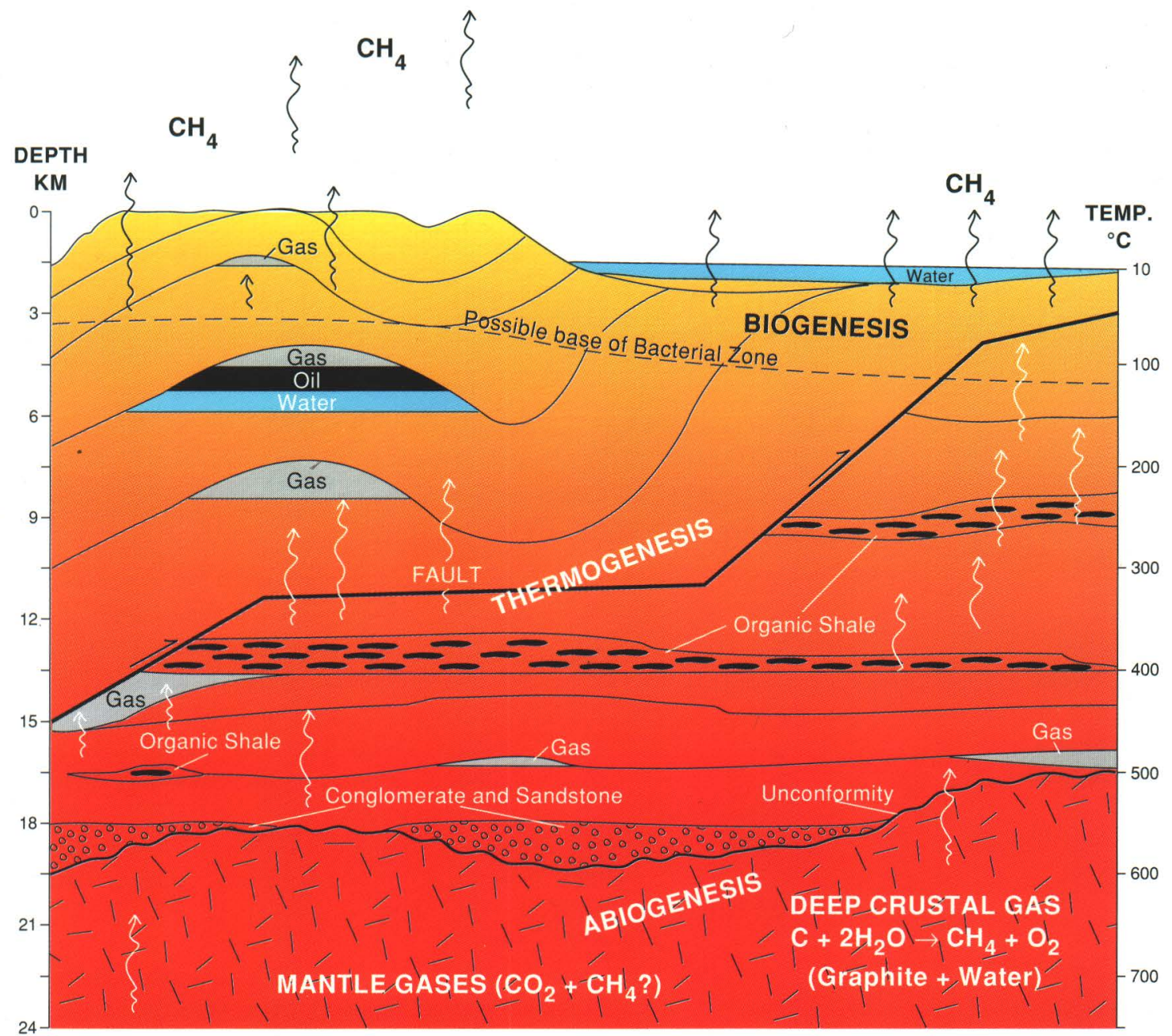

Figure 1. Schematic cross section of the Earth's crust, showing origin, migration, and accumulation of methane $\left(\mathrm{CH}_{4}\right)$. Origins of methane include conversion of organic material by micro-organisms (biogenesis), thermal decomposition of buried organic matter (thermogenesis), and deep crustal processes (abiogenesis). Buoyant methane migrates upward through rock pores and fractures and either accumulates under impermeable layers or eventually reaches the surface and dissipates into the atmosphere.

Biogenic methane results from the decomposition of organic matter by methanogens, which are methane-producing micro-organisms and which pervade the near surface of the Earth's crust in regions devoid of oxygen, where temperatures do not exceed $97^{\circ} \mathrm{C}\left(207^{\circ} \mathrm{F}\right)$. Methanogens also live inside the intestines of most animals (people included) and in the cud of ruminants such as cows and sheep, where they aid in the digestion of vegetable matter. Because the methane generated in the subsurface is less dense than the rocks in which it is produced, it diffuses slowly upward through tiny, interconnected pore spaces and fractures, and it can eventually reach the Earth's surface and dissipate into the atmosphere. In places, however, the diffusion of methane is impeded by impermeable rock layers, and gas can become trapped in structures. If enough gas accumulates under these imper- meable layers, the structures can be drilled and gas can be extracted for use as an energy source.

Thermogenic methane is formed in a manner similar to oil. As organic particles deposited in mud and other sediment become deeply buried and compressed, higher temperatures cause carbon bonds in organic compounds to break down and form oil with minor amounts of gas. At increased temperatures (caused by increased burial depth), methane becomes the dominant product until it eventually replaces oil altogether. The simultaneous formation of both oil and gas in the early stage of the thermal decomposition process is the principal reason for the association of oil and gas in accumulations present in the upper 2 to $3 \mathrm{~km}$ of the Earth's crust. In deep parts of basins and possibly even in subduction zones methane may be the only hydrocarbon formed. 
At greater burial depths, metamorphism may drive off all hydrogen atoms from organic compounds and leave a residue of carbon, often in the form of graphite. Under certain conditions in the deep crust, graphite may react with water; this reaction results in the recombining of carbon and hydrogen into methane. Recent studies on quartzvein systems indicate the presence of large fluxes of deep crustal gases and fluids; the volume of methane transported can be as large as 50 to 500 trillion cubic feet (Tcf) ${ }^{\dagger}$ for a single giant vein system.

Abiogenic methane is formed by another process that involves nonorganic carbon- and hydrogen-rich gases, which exist deep within the Earth. They form as either primordial gases that seep from our planet's interior or as gases liberated from crustal rocks during metamorphism. As these gases migrate upward and interact with crustal minerals, they react to form the elements and compounds present in the atmosphere (nitrogen, oxygen, carbon dioxide, argon, and water). In volcanic regions today, there is a continual outgassing of carbon dioxide and water, which originated deep in the Earth. If these same gases were to migrate through rocks at high pressures, and in the absence of oxygen, methane would be the dominant stable compound. Perhaps methane is forming in this manner deep beneath the Earth's large continental regions where high pressure and low oxygen conditions prevail.

Other planets and moons in our solar system have methane and other hydrocarbons as dominant elements in their atmospheres and surfaces. The ethane oceans and methane clouds of Titan and the methane ice on the surface of Pluto are examples. The theory that methane exists in the Earth's interior is generally accepted, but most geologists do not believe that methane migrating from deep within the Earth can or has formed economic accumulations. Questions of gas origin remain controversial and are important because they challenge the very foundations of our modern understanding.

\section{ENERGY GAS RESOURCES}

The role that natural gas will play in contributing to the world's primary energy requirements will depend ultimately on the availability and cost of sufficient supplies to meet a growing demand. Yet considerable uncertainty and disagreement prevails concerning the world's natural-gas resources. In fact, debates over fundamental issues such as the origin of natural gas and where to search for new, exploitable accumulations have caused many to wonder whether natural gas is a very well understood resource.

${ }^{\dagger}$ A Tcf of gas at the Earth's surface would occupy a space roughly 2 miles long, 2 miles wide, and 2 miles high. This amount of gas would weigh 20 million tons.
Commercial quantities of methane are present in many geologic environments and the modern era of exploration for natural gas has stimulated the development of new technologies and strategies that enhance and expand our capabilities of finding gas accumulations. The most common accumulations are generally associated with oil. In these subterranean traps, gas commonly forms a pocket between the denser oil below and the impermeable cap rock above. For oil production that is far from any naturalgas distribution system, gas produced in association with oil is often considered a nuisance. If it cannot be used as a fuel source for field operations, gas is sometimes vented or flared. For example, countries belonging to OPEC flared 2.9 Tcf in 1991, an amount which accounted for two-thirds of all recorded gas flared that year in the world. Nigeria flared 76 percent $(0.8 \mathrm{Tcf})$ of its gas production in 1991 . More commonly, however, especially in the United States, excess gas is injected back into the well to help maintain the reservoir pressure, which aids the flow and extraction of oil.

Other natural-gas accumulations are termed unconventional. Unconventional resources are either more expensive to extract or require new technologies for extraction. For instance, where reservoir rock permeability is low, gas accumulations are referred to as tight gas. There may be large pore spaces to hold the gas, but there is little if any connection between pore spaces in these reservoirs; therefore, the flow of gas to the well bore is greatly restricted. Because the gas is highly disseminated and difficult to extract, its ultimate resource potential remains uncertain. Currently, some wells are drilled with a horizontal trajectory through the zones of tight gas to intersect "sweet spots," spatially restricted zones where natural fracture systems enhance the flow of gas.

Coalbed gas is another unconventional resource. Coal is simply carbon-rich, woody terrestrial plant material that has been compressed and transformed. A byproduct of this transformation is methane. Synthetic gas can also be produced from coal as was the practice in the $18 \mathrm{th}, 19 \mathrm{th}$, and early 20th centuries when "town gas" was used for street lighting. Liquid hydrocarbons can also be produced from coal, and since World War II a number of plants worldwide have been producing gasoline from this source. The presence of methane in coalbeds is one of the greatest dangers of underground coal mining-at high concentrations in mines, methane causes explosions. Historically, because canaries are very sensitive to minor concentrations of methane, they have been used as early warning indicators of dangerous methane build-ups in mines. By extracting coalbed gas prior to mining, the potential danger is reduced and an energy resource is gained.

By the late 1970's, estimates of domestic natural-gas resources had become quite pessimistic: gas reserves were estimated to be $200 \mathrm{Tcf}$. At an average consumption rate of $20 \mathrm{Tcf} / \mathrm{yr}$ in the 1970's, the United States was assured 
of gas supplies for only 10 years. In 1978 regulations were passed restricting use of natural gas by industry and electric utilities. Proponents of this policy at that time believed that the Nation should not waste natural gas by producing electricity, because coal could produce electricity for less money. Since the late 1970 's, U.S. natural-gas consumption has remained fairly constant. Consumption has ranged between 16 and 20 Tcf per year, and our reserves have also remained fairly constant because new discoveries have kept pace with depletions.

The current wellhead and pipeline capacity of natural gas is more than adequate to deliver sufficient supplies to meet current U.S. demand. Most of the gas demand is met by production from domestic wells, but lately, pipeline-imported Canadian gas has provided as much as 10 percent of total U.S. requirements for natural gas. Despite a current domestic gas-supply surplus, large reserves of natural gas in Canada are being developed, produced, and delivered to U.S. markets at lower prices than some of the domestic supply. As a result, those domestic gas supplies that have higher production costs remain undeveloped or shut in until gas-market prices increase to the point that production be- comes economic. With increasing levels of gas consumption in the United States, the current excess gas production and delivery capacity of domestic wells and pipeline imports will rapidly be absorbed. To establish and maintain higher levels of gas production and consumption, there is a need to either replace declining reserves by drilling new wells, or to substantially increase gas imports or both.

The productivity of the average U.S. gas well has declined substantially over the past two decades. Of the world's 26,556 gas fields, 20,273 are domestic U.S. fields. Of these, nearly 19,000 are small fields, each with an ultimate yield ranging from 1 to 250 billion cubic feet (Bcf). Small fields are generally characterized by wells with low rates of production. In 1990, the average gas well produced only one-third the amount of gas as the average well in 1970 (fig. 2). Discoveries of gas fields with higher production rates, such as those found during the 1950's and 1960's in the Gulf of Mexico, have declined. Most of the new gas-field discoveries today are much smaller with lower rates of production. Much of the recent natural-gas exploration and development activity in the United States has focused on unconventional accumulations of gas; un-

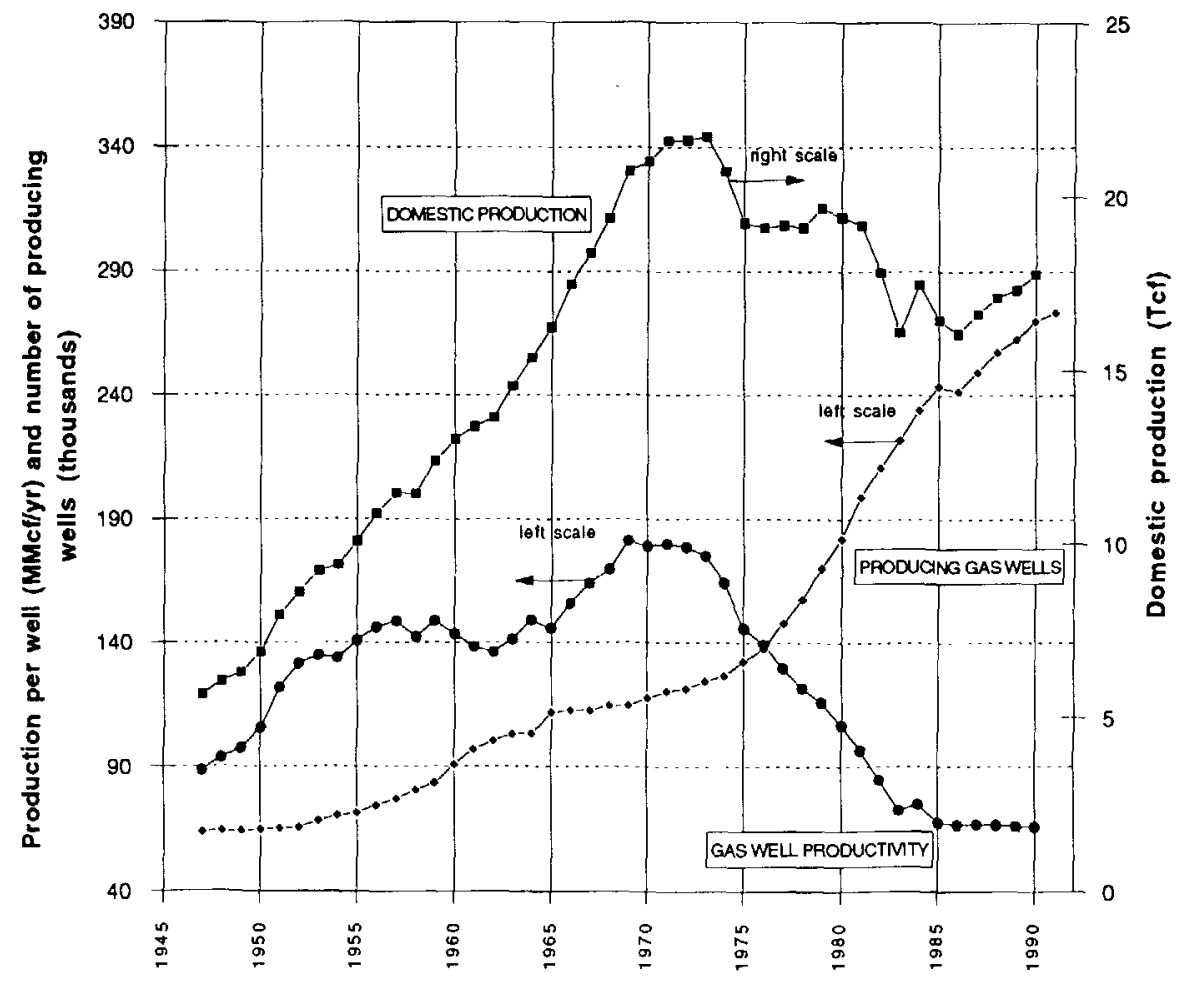

Figure 2. Number (in thousands) of producing natural-gas wells in the United States, the average annual rate of gas production per well (MMcf/yr is million cubic feet per year), and U.S. annual natural-gas production (in trillion cubic feet or Tcf) from 1945 to present. As average productivity of gas wells has declined from a peak in the early 1970's, domestic gas production capacity has been maintained only by a dramatic increase in number of producing gas wells. Future production capacity is likewise dependent on adequate levels of exploration and development drilling activity to augment and replace declining production from aging, depleted, and abandoned wells. 
conventional gas includes that associated with coalbeds, that in "tight" reservoirs, and that in shale beds. Wells tapping unconventional resources, however, commonly produce much smaller amounts of gas and at lower rates. Consequently, many more producing wells are needed to maintain the same level of gas production. The total number of producing gas wells in the United States has increased since 1970, from little more than 110,000 gas wells in 1970 to more than 270,000 wells in 1991 .

For the current level of natural-gas production to be maintained or increased, exploration and development drilling must continue. In fact, the rate of drilling must increase significantly above current levels to replace the decline in productivity of the high-volume fields in the U.S. Gulf Coast. To maintain the current level of total U.S. gas-production capacity, the industry must return to the historically high levels of exploration and development activity of the late 1970's and early 1980's, a time when the price of gas was higher (fig. 3). A significant percentage of the gas drilling in recent years has been in coalbeds, tight reservoirs, and shale beds. Because most of this drilling has been done with the economic benefit of tax credits for developing these unconventional gas resources, the expiration of these credits on January 1, 1993, suggests that significantly fewer of these wells will be drilled in the future. Consequently, even more drilling for conventional gas reserves will be required not only to achieve higher domestic production but also to simply maintain the current level of production.

The current low price of natural gas does not provide enough economic incentive for significant increased gas exploration and development activity. The increasing cost, difficulty, and risk of drilling wells in the Unites States under more stringent environmental regulations will continue to reduce these activities. Furthermore, the industry may find it difficult to quickly return to the historically high levels of activity for several reasons. One reason is that over the past decade nearly half a million people have lost employment in the U.S. energy industries owing to greatly diminished levels of exploration, production, and marketing activities. Another reason is the fleet of available drilling rigs is considerably smaller now than during the height of activity during the late 1970's and early 1980's. Many rigs have been permanently removed from service because they are now obsolete, they have been cannibalized for parts, or they were reduced to scrap. Additionally, large sums of capital would be required to fund more drilling and production activities. These resources may be difficult to secure owing to recent losses in similar investments.

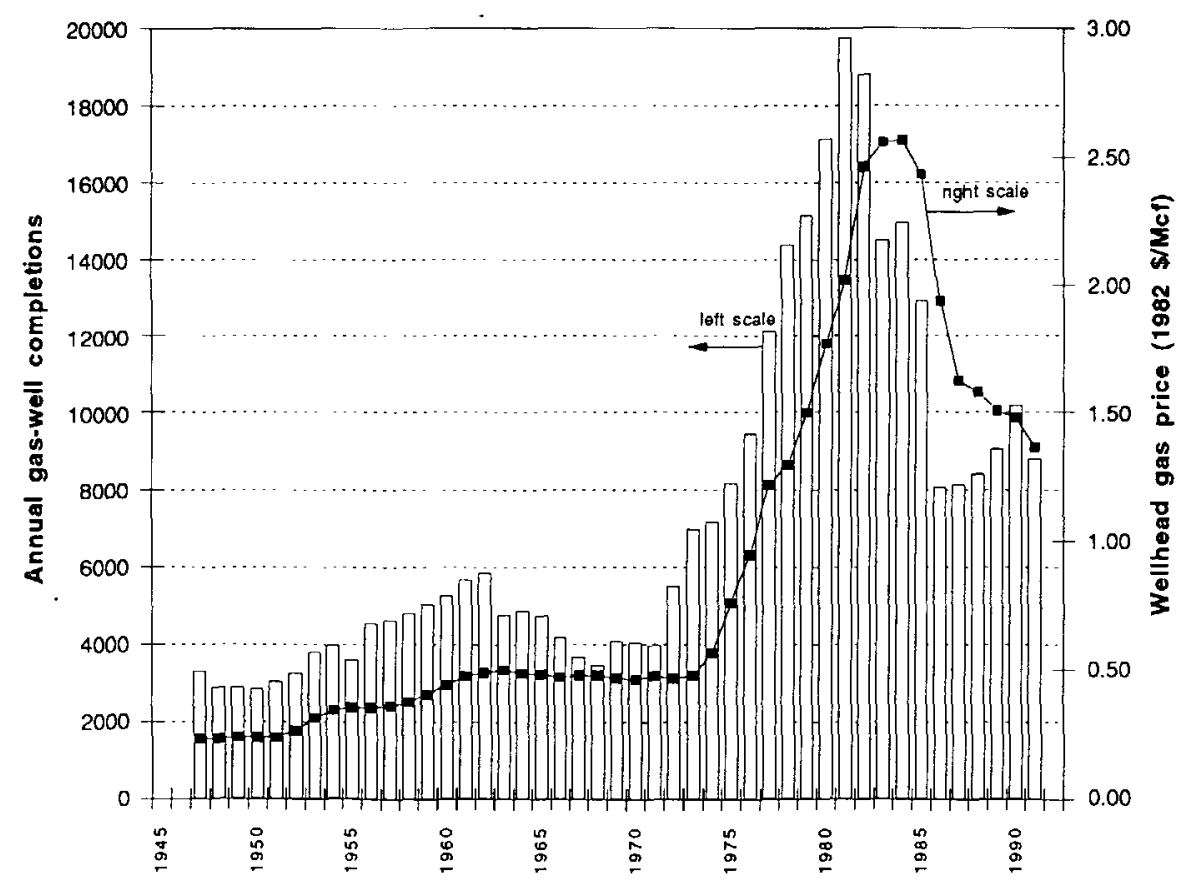

Figure 3. U.S. annual gas-well completions and wellhead gas prices (in 1982 dollars per thousand cubic feet or Mcf) from 1945 to present. Historically, activities of natural-gas exploration and development companies has correlated closely to the wellhead price of natural gas. Because exploitation of natural-gas resources involves substantial capital investment over several years with significant risk, the market value of natural gas determines a company's economic incentive to undertake activities to find, produce, and market it. An extended period of stable prices would facilitate this process. 
The interplay between supply, demand, and regulations has resulted in low wellhead prices for gas, which in turn negatively affects gas exploration. Nonetheless, new discoveries have been made. Current forecasts of the future endowment of domestic natural-gas resources suggest a U.S. supply of at least $900 \mathrm{Tcf}$, assuming that the price of gas will rise to $\$ 3.50$ per thousand cubic feet (Mcf), twice the current cost. These new supply estimates would provide a 65-year supply at current consumption rates. But even this resource estimate may be low, because other unconventional sources of gas accumulation are being evaluated for their resource potential. These new sources potentially contain vast supplies, if only the technology necessary for extraction can be developed at low enough costs. Deep gas, located at depths greater than $4,000 \mathrm{~m}$, represents one of the promising new sources. The petroleum industry has drilled more than 3 million wells in the United States in search of oil and some gas, but only about 16 thousand have probed depths greater than 4,000 meters. Methane remains stable to great depths whereas oil tends to concentrate in more shallow parts of the crust either because it has been displaced upward by the gas or because it breaks down at the higher temperatures found at depths greater than about $5 \mathrm{~km}$. Additionally, with increasing pressures, gas compresses; the compression of gas results in more British thermal units (Btu's) per volume and, therefore, potentially enhances the desirability of deep exploration.
Gas is also trapped in media other than rock. In shallow crustal horizons, enormous volumes of gas can be dissolved in brines. Although believed to be largely uneconomic, similar to the vast quantities of gold dissolved in sea water, local circumstances and ingenuity may result in such gas having limited resource potential. Gas trapped in the atomic lattice of ice is another unexplored, unconventional resource. These so-called hydrates look a lot like dry ice (frozen carbon dioxide), but hydrates will burn. In hydrates, the guest molecule of gas (which is methane 99 percent of the time) is housed within the crystalline structure of the ice, where it is packed at densities 160 times greater than those at normal atmospheric pressures. Although huge quantities of gas exist in hydrate form, the commercial value of this gas is yet to be demonstrated, except for one commercial venture in northern Russia. Recent work suggests that over 100 million Tcf of methane exists in gas hydrates worldwide with a potential resource of as much as $700,000 \mathrm{Tcf}$. This is roughly 10,000 times larger than the global natural-gas consumption in 1990, a truly immense quantity. Indeed there is great incentive to learn more about methane in gas hydrates and the technology required to exploit it.

Recent global estimates of inferred recoverable resources are shown in figure 4. At recent (1990) world consumption rates of about $74 \mathrm{Tcf} / \mathrm{yr}$, there is nearly a 125 -year supply of natural gas. Whereas natural-gas resources appear

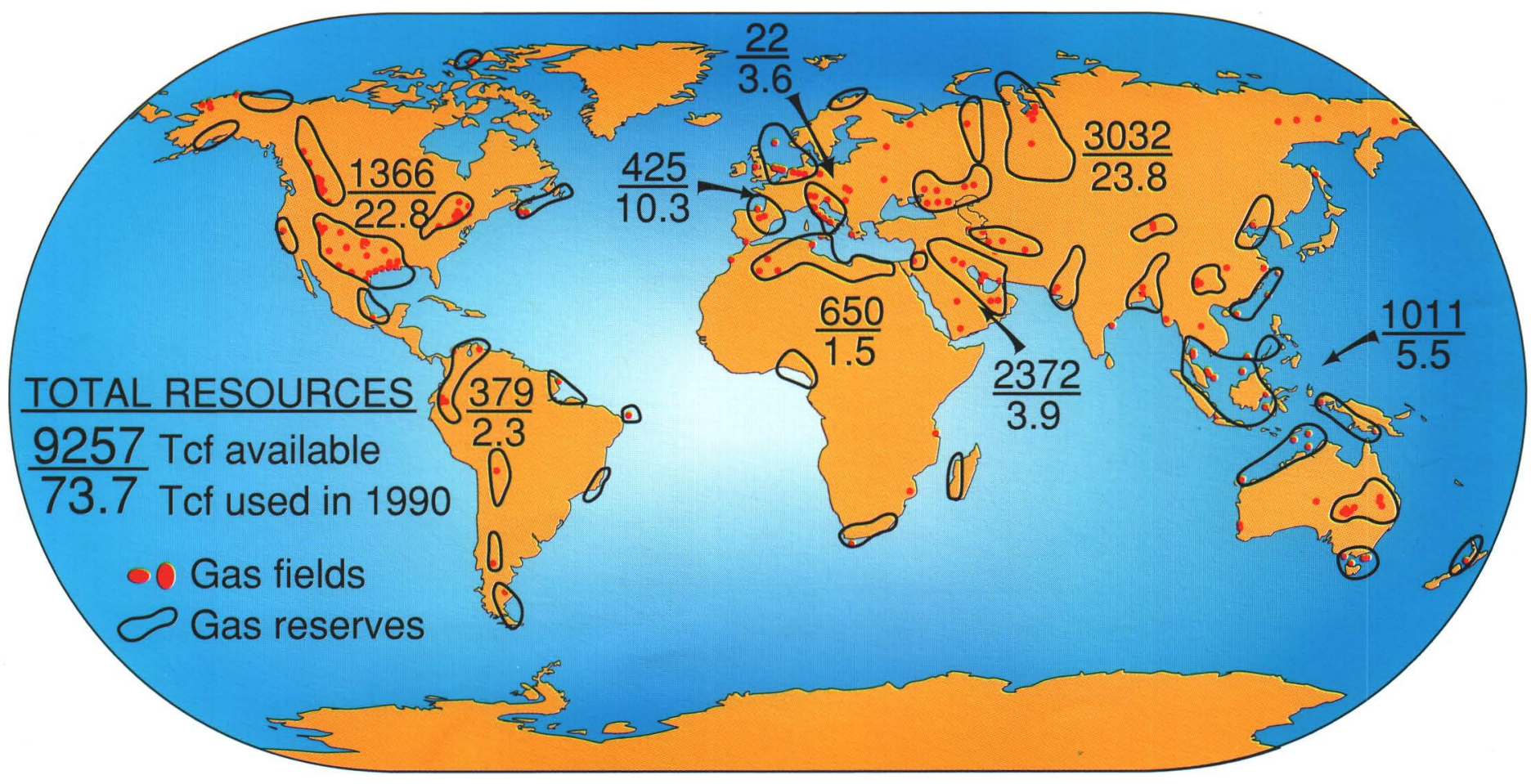

Figure 4. Global natural-gas resource estimates and consumption rates for 1990. Major gas-producing basins are shown. Natural-gas resources are widely and plentifully distributed throughout the world. At current consumption rates, many countries have several decades, if not centuries, of estimated natural-gas resources. 
to be abundant, it is only necessary to have sufficient supplies to provide the bridge to different fuels and energy systems of the future. Human beings have never fully exploited a resource, because the quest for cleaner, more convenient, and more efficient fuels has led to energy substitutions prior to resource exhaustion. It seems most pertinent to consider the advantages of switching now to a greater dependency on natural gas.

\section{NATURAL GAS AND THE ENVIRONMENT}

At present, roughly 90 percent of all energy consumed in the United States comes from the combustion of fossil fuels (fig. 5). The remainder comes from nuclear, hydro, and small amounts of geothermal, wind, and solar power. Natural gas is the lightest of the fossil fuels; it contains only one carbon atom for every four hydrogen atoms. Upon combustion, the carbon-hydrogen bonds are broken, and heat is released in the process. The carbon combines with atmospheric oxygen to form $\mathrm{CO}_{2}$, which is released into the atmosphere, while the hydrogen atoms combine with oxygen to form water vapor. Because of its lower carbon content, methane combustion produces roughly one-half the $\mathrm{CO}_{2}$ emissions of coal, and about two-thirds as much $\mathrm{CO}_{2}$ as oil, while delivering the same amount of thermal energy.

Carbon dioxide and water vapor are the two most abundant of the greenhouse gases. These gases, which also include methane, ozone, nitrogen oxides, carbon monoxide and chlorofluorocarbons (CFC's), linger in the atmosphere

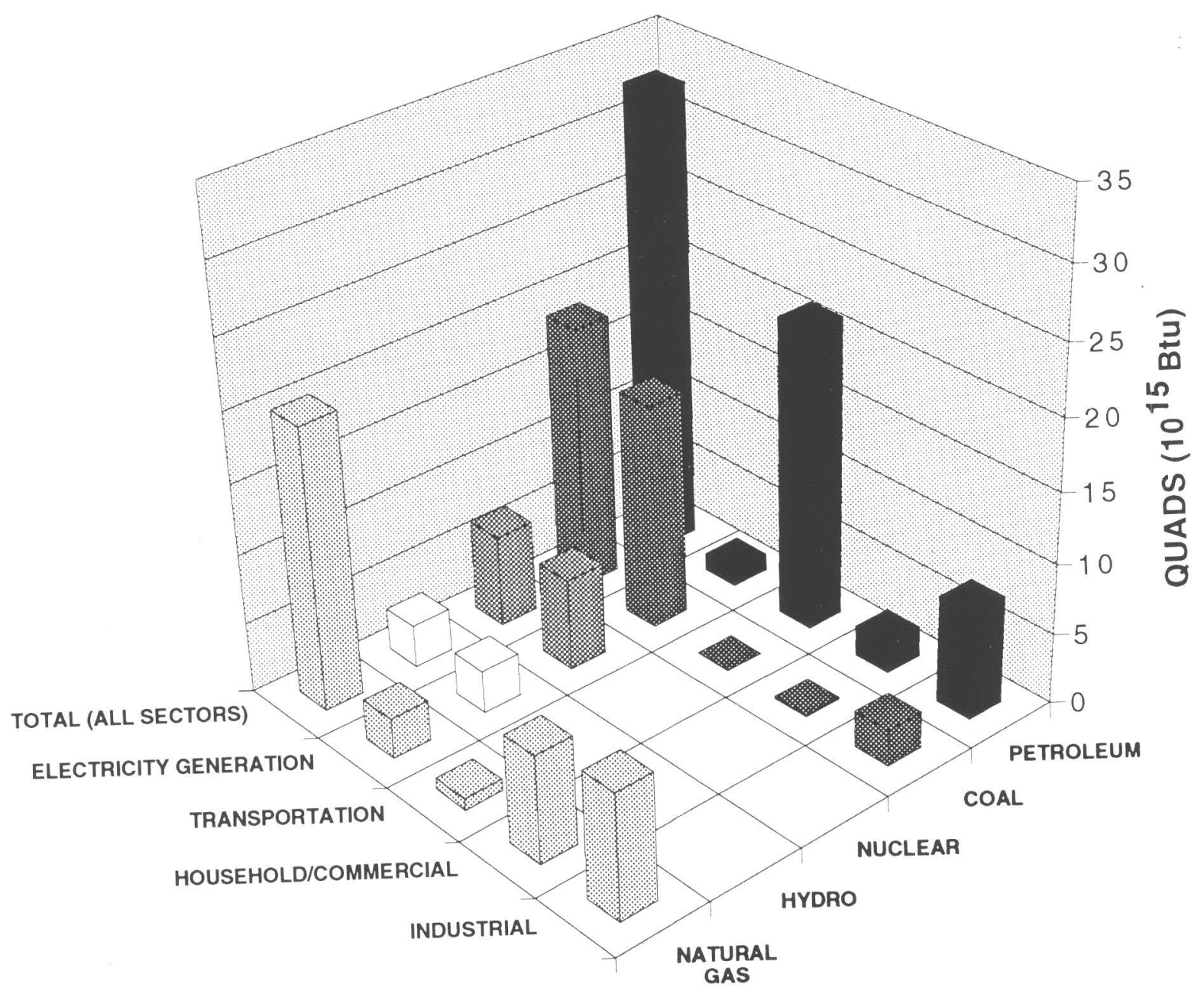

Figure 5. U.S. total energy consumption for 1991 by economic sector (left scale) and energy source (right scale). The Nation's largest share of energy is consumed during electricity generation, predominately by coal-fired steam plants. Transportation, the second largest energy-consuming sector, is very heavily dependent on gasoline, diesel, and aviation fuels which are refined from crude oil (petroleum); most petroleum products are currently imported from foreign countries. Technological developments, which lead to greater efficiency of energy consumption during electricity generation and transportation, will substantially mitigate the Nation's total energy requirement. 
where they can affect the temperature of the Earth's surface. Short-wavelength energy from the sun passes through the atmosphere and reaches the Earth, but the greenhouse gases prevent some of the longer wavelength reradiated energy from escaping back into space. By absorbing some of this outgoing radiation, the greenhouse effect keeps the planet warm and comfortable, at an average temperature of $14.5^{\circ} \mathrm{C}\left(58^{\circ} \mathrm{F}\right)$. Without the greenhouse effect, the average surface temperature would be a chilly $-18^{\circ} \mathrm{C}\left(0^{\circ} \mathrm{F}\right)$. Recent concern is over manmade changes in the composition and concentration of greenhouse gases that may cause overheating of the planet.

Since the Industrial Revolution, the concentration of $\mathrm{CO}_{2}$ in the atmosphere has increased by about 25 percent, largely because of increased input of $\mathrm{CO}_{2}$ through burning fossil fuels. The impact of global warming on human society will not be sudden or disastrous, but it may cause some serious and expensive problems in places. Although the consequences are uncertain, the cure is clearly understood. To reduce the manmade contribution of greenhouse gases to the atmosphere, we must replace high-carbon fuels with low- or zero-carbon forms of energy. In this respect, natural gas is a large improvement over coal and oil. The ideal fuel, however, would contain zero carbon, such as pure hydrogen gas. Unfortunately, hydrogen is not present in nature in amounts large enough to extract and, therefore, it must be created synthetically. However, the cessation of fossil-fuel burning would not immediately affect the atmosphere. Because the residence time of $\mathrm{CO}_{2}$ in the atmosphere is estimated to be several hundred years, reducing the $\mathrm{CO}_{2}$ overload will be a very slow process.

As mentioned above, methane is a potent greenhouse gas, roughly 25 times more potent than $\mathrm{CO}_{2}$. In contrast to $\mathrm{CO}_{2}$, however, it has a short residence time in the atmosphere. Methane remains in the atmosphere roughly ten years before it is oxidized and converted to $\mathrm{CO}_{2}$ and water vapor. Like $\mathrm{CO}_{2}$, atmospheric methane is increasing at an exponential rate. Its sources are poorly quantified, but roughly one-third is emitted from natural sources, such as wetlands, volcanic regions, termites, and decomposition of methane hydrates. Approximately two-thirds comes from manmade sources. Of the manmade sources, more than one-half comes from agricultural activities (rice paddies and cattle), and the remainder comes from oil and gas drilling, deliberate venting, pipeline leakage, biomass burning, and methane leakage from landfills. An increased dependence on natural-gas use will require more gas production, processing, and transportation infrastructure. This means the addition of more wells, tanks and pipelines from which methane can escape to the atmosphere. If methane is to endure as a relatively clean fuel, it is essential that these leakages are minimized. On the other hand, burning methane emits only $\mathrm{CO}_{2}$ to the atmosphere, and does so in considerably less volumes than the other hydrocarbons. For example, burning one gallon of gasoline in an automobile produces 21 pounds (approximately $9.5 \mathrm{~kg}$ ) of $\mathrm{CO}_{2}$ exhaust, whereas the energy equivalent in natural gas $\left(125\right.$ cubic feet or $\left.3.54 \mathrm{~m}^{3}\right)$ would produce 11 pounds (approximately $5 \mathrm{~kg}$ ) of $\mathrm{CO}_{2}$. As long as methane can be prevented from leaking into the atmosphere, using natural gas as a fuel source will be considerably more beneficial to the planet than using the other carbon-rich fuels.

Another environmental concern associated with energy use is air pollution. Air pollution has short-term, localized effects compared to the global problems of the greenhouse effect. Because of its relative purity, methane combustion has the lowest emissions of all the hydrocarbon fuels; its combustion generates no particulates or associated trace metals and no $\mathrm{SO}_{2}$. Nitrogen oxides and $\mathrm{SO}_{2}$ produce additional environmental problems when they attach to water droplets and fall to the ground as acid rain and snow. A modern, high-technology gas-fired electricity plant generates one-fifteenth as much $\mathrm{NO}_{2}$ as coal-fired electric plants and one-fifth as much as oil-fired electric plants; additionally, gas plants release no $\mathrm{SO}_{2}$ or particulates.

\section{ECONOMIC BENEFITS OF USING NATURAL GAS}

The United States has a long history of being an international importer and exporter of energy products such as coal, oil, and gas. For several decades now the United States has been an exporter of surplus coal supplies, most of it destined for Canadian, European, and Japanese markets. At the same time, the United States has become an importer of oil and gas supplies. Most of the oil has come to us over the seas from many parts of the globe, most notably Nigeria, Mexico, and the Middle East, whereas nearly all of the gas imports have come through pipelines from Canada. Very small quantities of gas in liquefied form have been imported in tanker ships. In total, the United States is a net purchaser of very large quantities of imported energy supplies from foreign producers. In 1991, for example, the United States had a net energy trade deficit with other countries amounting to approximately $\$ 50$ billion, nearly 95 percent of which was for crude oil and other refined petroleum products. Many economists would argue that because of the decline of the domestic oil industry, the U.S. energy trade deficit is actually larger.

An alternative national energy policy might be to encourage and support domestic energy resources, particularly natural gas. Support could include greater investment in research for exploration and development technologies, which will increase the availability of domestic supplies. It could also include research and investment in consumption technologies, which will improve the cleanliness and efficiency of energy consumption. Natural gas is a domestically available energy supply that, if utilized to its fullest potential, could reduce U.S. dependence on international energy trade. 


\section{NATURAL GAS AS A BRIDGE TO FUTURE ENERGY SYSTEMS}

Increased use of natural gas helps create the infrastructure necessary for the use of gaseous fuels. This infrastructure includes storage capability, pipelines and distribution facilities, and the advanced technology necessary to use gaseous fuels in homes, industries, electric utilities, airplanes and cars. Gaseous fuels hold the promise of being the fuel of the future, whether as a natural fuel source such as natural gas or as an energy carrier such as hydrogen. An energy carrier is a combustible, synthetic gas used to carry energy derived from an unusable or undesirable source to the consumer. In this case, hydrogen or methane gas can be formed from coal when coal is too polluting to use in its original form. Hydrogen can be formed from water using solar-generated electrical heat, thereby allowing the energy to be transported great distances by pipeline, which is more efficient than transportation by electricity. By increasing the use of natural gas today, we can begin to develop the infrastructure necessary to carry, store, and use gaseous fuels. This use paves the way to the ultimate conversion of our present liquid- and solid-based fuel system to a gaseous-based fuel system of the future.

\section{ECONOMICS OF AND OBSTACLES TO INCREASED NATURAL-GAS USE}

Electricity generation and transportation are the two largest uses of energy in the U.S. economy, consuming 37 perçent and 27 percent, respectively, of the Nation's 1990 total energy requirement. As our population grows and spreads, the increased consumption of fuels for electricity generation and transportation is unavoidable, and technologies for this consumption will have to keep pace.

For electricity generation, steam-driven turbines continue to be the predominant method of power generation. While steam-boilers have been fueled by coal, oil, and gas for decades, the percentage of steam generation by coal combustion has steadily increased to the point that coal now generates nearly 75 percent of the total steam produced. But, the forecasted growth in demand for electricity will require the construction of new generation capacity. Environmental regulations may increasingly restrict plant emissions, and electricity generators will need increased flexibility to meet seasonal, weekly, daily, and even hourly fluctuations in electricity demand. These conditions favor increased use of natural gas in electricity generation.

The design and construction of gas-fired plants can be completed in half the time at less than half the cost of coal-fired plants. Gas-fired technologies are more efficient than coal-fired technologies, and, therefore, consume much less fuel per unit of electricity generated. As discussed previously, gas combustion generates far less pollution than coal. New gas-fired technologies, such as gas turbines and combined-cycle plants, are also much more flexible in their day-to-day operation; this flexibility allows utilities to respond much more easily to daily and hourly fluctuations in electricity demand.

Additional savings in avoided costs can be realized by increased energy efficiencies. For example, lighting consumes 20 percent of all electricity. By simply replacing one 100-watt incandescent bulb with a compact fluorescent lamp, 75 percent less energy is used while the same amount and quality of light are delivered. For the lifetime of one compact fluorescent lamp, 10,000 hours, the savings is tantamount to 630 pounds (approximately $286 \mathrm{~kg}$ ) of coal or a barrel of oil, or nearly 7,000 cubic feet (approximately $198 \mathrm{~m}^{3}$ ) of gas. Furthermore, a half ton of greenhouse gases would be averted.

The transportation industry continues to be nearly exclusively dependent on crude-oil derivatives, principally motor gasoline as well as diesel and aircraft fuels. Extensive research has shown, however, that natural gas can perform very well as a motor vehicle fuel, while at the same time emitting roughly one half as much pollution from the tailpipe as normal gasoline-powered vehicles. At current prices, the fuel-cost-per-mile is far lower for vehicles using natural gas than for those using gasoline. Natural-gas powered vehicles are increasingly popular in countries all over the world, such as Canada, Italy, Russia, and New Zealand. In the United States they can be found primarily as public and private fleet vehicles in major metropolitan regions such as Los Angeles and New York City and are rapidly spreading to other urban areas (Houston, Fort Worth, and Austin, Texas).

Energy and (or) carbon taxes are gaining interest here and abroad as means for generating revenue to mitigate externalities, which are costs to society as a consequence of using energy fuels. Examples of externalities include costs associated with air pollution, ground water contamination, acid rain damage to rivers, lakes, and forests, perhaps even military operations to protect foreign held resources. A carbon tax levies a tariff on a fuel in proportion to the amount of $\mathrm{CO}_{2}$ it emits. Because $\mathrm{CO}_{2}$ is a pollutant, and because other pollutants generally track with $\mathrm{CO}_{2}$, a tax proportional to $\mathrm{CO}_{2}$ targets the principal polluters. One idea for reducing $\mathrm{CO}_{2}$ emissions is to establish national or per capita limits on pollution. These carbon/ pollution credits could be traded among countries. Underdeveloped countries could acquire revenues by polluting less and selling their excess pollution credits to developed countries. In developed countries, it would be cost effective to reduce the flux of pollution. All countries would benefit with such a system. More importantly, all countries would be doing their part to reduce $\mathrm{CO}_{2}$ emissions.

Because large regional disparities exist in the United States in relation to the types of energy that are available, a domestic carbon tax is believed by some to be unfair. For 
example, the northwest has a large percentage of nonpolluting hydroelectric energy, whereas the central region depends on coal, and the east coast relies on oil for home heat. An alternative is to implement some form of a Btu tax where all forms energy are taxed, regardless of the type. This scheme too will surely generate much debate--simple solutions to this complex problem are not clearly at hand.

\section{SUMMARY}

Though many are optimistic about the future supplies of natural gas, the numbers are still uncertain. Furthermore, a distinction must be made between resources in the ground and supplies available for immediate use. Resources can be estimated rigorously, but supplies have the most practical application. Our production supply of natural gas is currently running low, therefore development drilling must be increased. To find and develop our domestic energy gas resources, there has to be an increase in the number of exploratory wildcat and development wells. Because of the low price of gas, and the consequently small economic benefit to gas companies, the drilling of development and wildcat wells is decreasing. In 1980, about 17,000 development wells, and 700 wildcat wells were drilled in the United States. This brought the total number of gas-producing wells in the United States to 180,000 . By 1991 that number had risen to 270,000. To support increased natural-gas use ( $>20 \mathrm{Tcf} / \mathrm{yr}$ ), we will need even more producing wells; this increased use requires as many as 20,000 new development wells and more than 1,000 wildcat wells, per year.

Solutions to these potential problems are not obvious, and they are certainly not easy. We are left with a twocomponent dilemma: (1) Increased drilling will increase reserves, which would satisfy demand, but drilling will not increase significantly until the price goes up, and higher prices could diminish demand. (2) Natural gas is intended to reduce the effects of environmental damage due to fuel use, but to get adequate supplies of natural gas, numerous wells, many in environmentally sensitive areas, will have to be drilled. We must continue to do more research to improve exploration success, we must develop new production and consumption technologies, and, finally, we must look toward the future. But research must go handin-hand with action, for as Al Gore states in his book, Earth in the Balance, "*** research in licu of action is unconscionable. Those who argue that we should do nothing until we have completed a lot more research are trying to shift the burden of proof even as the [environmental] crisis deepens."

Natural gas appears to be a good short-term solution to our society's energy needs. It is plentiful, clean, and good for the economy; it also provides a needed bridge to future energy systems. However, it is also plagued with a perception of uncertain supplies, which results in a lack of confidence in natural gas as a long-term, reliable fuel source. More research and more drilling should help to alleviate these concerns, and the results could be highly beneficial to our society and our environment.

\section{ACKNOWLEDGMENTS}

This paper, and the entire volume, would not have been possible without the enthusiastic response of all the authors. Additionally, the motivation and support from Gary Hill and the guidance provided by Jim Pinkerton, Ken Bird, and Keith Kvenvolden ensured the timely completion of this volume. 
Methane, the dominant component of natural gas, forms through at least three different processes. One involves the breakdown of organic material during a thermogenic cracking process by which long-chained hydrocarbons, typically in solid or liquid form, dissociate at high temperatures and pressures to form short-chained hydrocarbons-butane, propane, ethane, and the shortest, methane. Continued heating (or cracking) may result in a pure carbon residue of graphite. This graphite residue forms deep in the Earth's crust. Under favorable conditions, this graphite can react with water to form more methane. That this has happened is evidenced by methane fluid inclusions in quartz-vein systems, which suggest large fluxes of methane-rich fluids from the deep crust.

Methane also forms as a result of the metabolic processes of methanogens, bacteria-like microorganisms. These organisms commonly flourish in swamps, landfills, and in numerous places in the Earth's crust where temperatures are less than $97^{\circ} \mathrm{C}$, oxygen is lacking, and an organic food source is present. Methanogens are also found in the intestines, cuds, and tooth plaque of several types of animals.

This section also addresses the question of mantle-derived gases, sometimes called abiogenic gases. Mantle-derived gases are formed from carbon and hydrogen that were originally part of the primordial Earth. One report argues that most hydrocarbons in the Earth's crust are fundamentally inorganic and originate in the mantle. Evidence cited includes similarities in isotopic composition and chemical character of methane occurrences in large geographic areas that span long ranges of geologic time; additional evidence is the occurrence of methane elsewhere in the Solar System, where no known life forms exist. One report discusses how in 1986 the hypothesis of mantle-derived gas was tested by drilling a deep well into granitic basement in Sweden. No free gas was discovered, but trace amounts of both thermogenic and abiogenic natural gas dissolved in water were recovered. The hypothesis of abiogenic gas is challenged in other reports in which the chemistry of economic gas accumulations is evaluated to determine the origin of gas. The data presented suggest that all known economic gas accumulations, while potentially containing very small amounts of abiogenic gas, are dominantly organic and form through either thermogenic or biogenic processes. 

THE FUTURE OF ENERGY GASES

U.S. GEOLOGICAL SURVEY PROFESSIONAL PAPER 1570

\title{
Introduction to Microbial and Thermal Methane
}

\author{
By Katryn Wiese ${ }^{1}$ and Keith A. Kvenvolden 1
}

\section{CONTENTS}

Abstract

13

Introduction

Microbial Methane

Microbiology and Ecology of Methanogens ........ 14

Metabolism of Methanogens ............................ 15

Methanogenic Environments ............................ 15

Thermal Methane

Thermogenesis and Thermal Maturity of

Source Rocks

Isotopic Composition of Thermal Methane

Molecular and Isotopic Compositions of Microbial

and Thermal Gas

Atmospheric Methane

Summary

References Cited
Microbial methane is produced in strictly anaerobic environments such as numerous aquatic environments, both marine and freshwater. Methanogens exist at surprising depths in the Earth's crust, at temperatures as high as $97^{\circ} \mathrm{C}$. The primary metabolic processes by which methanogens gain energy are fermentation of acetate $\left(\mathrm{CH}_{3} \mathrm{COO}^{-}\right)$and reduction of $\mathrm{CO}_{2}$. Other processes can occur depending upon the species of methanogen and the type of available organic matter (such as conversion of formate, methanol, methylamines, and methylated reduced sulfur compounds to methane), but in most cases these processes are not significant ones in nature. $\mathrm{CO}_{2}$ reduction dominates in marine sediments, whereas acetate fermentation is most common in freshwater sediments.

Thermal or thermogenic methane is formed as organicrich sediments move through progressively higher thermal maturity regimes found during increasing depths of burial. Thermal methane results from the thermochemical decomposition of organic matter. During early thermal maturation, thermal methane is accompanied by other hydrocarbon and non-hydrocarbon gases and is often associated with crude oil. At the highest thermal maturities, methane alone is formed by cracking of carbon-carbon bonds in kerogen, bitumen, and oils.

\section{INTRODUCTION}

Two major natural processes are known to form methane in amounts large enough for economic accumulations. These two processes are referred to throughout this paper as biogenic processes, because they both involve the decomposition of organic matter by either biochemical or thermochemical reactions. The process which is dominant in near-surface environments is microbial; in contrast, thermal methane generation takes place at greater depths where temperatures are sufficient to break chemical bonds CA 94025 .

'U.S. Geological Survey, 345 Middlefield Rd. MS 999, Menlo Park, 
in organic matter. The microbial process has been referred to in the past as the biogenic process, whereas the term 'thermogenic' implied a nonbiogenic process. This definition has been misleading, however, as thermogenesis involves organic matter whereas other non-biological processes of methane formation, termed abiogenic, do not. Abiogenic methane refers to methane which originates from carbon and hydrogen which were not tied up in organic materials and processes which involve no biologic assistance; the carbon and hydrogen instead may originate from primordial material deep in the Earth's crust or mantle, and the process of methane formation is simply one of chemical synthesis. For a more thorough discussion of abiogenic processes, see Jenden and others, Apps and van de Kamp, and Gold (this volume).

Thermal and microbial methane both require organic compounds and, in the case of microbial methane, the assistance of microorganisms for their generation. Microbial methane is formed when numerous organic substrates (compounds undergoing biochemical conversion) are converted to methane during the metabolic processes of the methanogens, methane-producing microorganisms. Thermal methane is generated during the chemical decomposition of organic matter including long-chained hydrocarbons. This process produces shorter-chained hydrocarbons, among which methane is the dominant gaseous product. Both of these biogenic processes are well-studied and occur in different thermal regimes (fig. 1; Rice, 1992), microbial in low-temperature, near-surface sediment accumulations and thermal in hightemperature, deeply buried sediments. The intent of this paper is to provide a basic summary of each process, to discuss differences between the methane formed from the two processes, and to distinguish between the two kinds of methane in naturally occurring gas accumulations; the paper is intended for nonspecialists who would find introductory material on natural-gas formation helpful. For more comprehensive information on petroleum gas generation, see Hunt (1979), Tissot and Welte (1984), and Vially (1992).

\section{MICROBIAL METHANE}

\section{MICROBIOLOGY AND ECOLOGY OF METHANOGENS}

Methanogens are methane-producing microorganisms that occupy a newly defined prokaryote group called archaebacteria. Eubacteria (also from the prokaryote group), eukaryotes, and archaebacteria make up the three evolutionary domains of life (Oremland, 1988; König, 1992; Stanier and others, 1986). Sixty-one species of methanogens have been discovered, making up three orders, seven families, and eighteen genera (König, 1992). Other microbes within the new kingdom of archaebacteria consist of extreme thermophilic microbes and sulfur metabolizers.

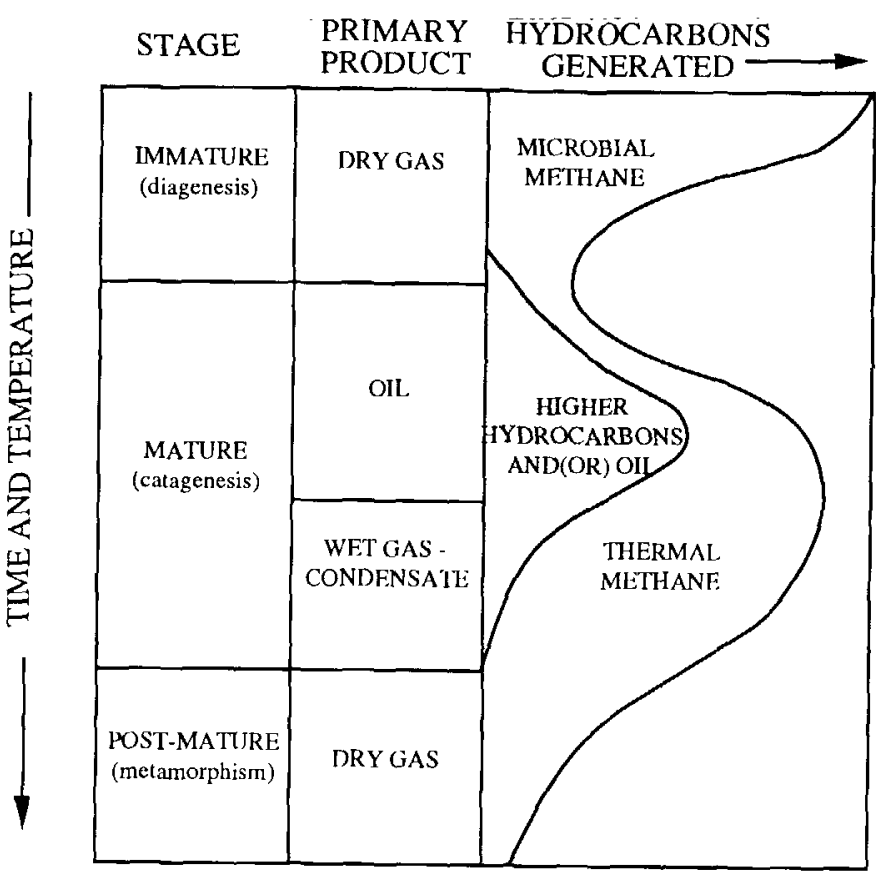

Figure 1. Major stages during hydrocarbon generation as thermal maturity (time and temperature) of source rock increases. Microbial gas is generated at low temperatures and shallow depths. Thermogenic gas is generated throughout a large temperature and depth range; at the highest stages of thermogenesis the ratio of methane to higher alkanes and oil increases until dry gas is produced.

Methanogens exist in a wide variety of strictly anaerobic environments (Cicerone and Oremland, 1988). Even a few parts per million (ppm) of oxygen is enough to kill them. In order to grow they feed on decomposed organic matter. These two requirements (no oxygen and plentiful organic substrates for energy) are usually found in environments such as freshwater and marine sediments, sewage sludge, flooded soils, animal gastrointestinal tracts, geothermal regions (such as hot springs or seafloor hydrothermal vents), and the heartwood of trees. Methanogens have also been found to survive conditions of hypersalinity and extreme $\mathrm{pH}$.

Other nutrient and growth requirements for methanogens have been described by Oremland (1988) and include availability of ammonium ions $\left(\mathrm{NH}_{4}{ }^{+}\right)$to satisfy the bulk of nitrogen requirements. Trace elements such as $\mathrm{Co}, \mathrm{Fe}$, $\mathrm{Mo}, \mathrm{Ni}, \mathrm{Mg}$, and $\mathrm{K}$, and the compound $\mathrm{NaCl}$ stimulate methanogenesis for some species, whereas a smaller number of species are stimulated by $\mathrm{W}$ and Sc. This stimulation is actually a result of the inhibition of competing processes. A narrow pH range is normally preferred, between 6 and 8 , but some strains of methanogens are known to exist at $\mathrm{pH}$ ranges which are much higher and much lower. The dominant temperature range of methanogenesis is from 4 to $55^{\circ} \mathrm{C}$, with the optimum temperature for the majority of methanogens around $35^{\circ} \mathrm{C}$. One species, however, is known 
to exist at temperatures as high as $97^{\circ} \mathrm{C}$. (Other species of archaebacteria, such as thermoacidophilic microorganisms, can exist at temperatures as high as $110^{\circ} \mathrm{C}$, but these species are not methane producing.) Inhibitors of methanogenesis include parts per million levels of oxygen, the presence of sulfite, ferrous ion $\left(\mathrm{Fe}^{3+}\right)$, elemental sulfur, oxides of nitrogen, compounds with unsaturated carbon bonds, and the presence of nitrates and sulfates that channel the electron flow to microorganisms which are thermodynamically more efficient than methanogens.

\section{METABOLISM OF METHANOGENS}

Methane production is controlled by physical, chemical, and biological factors (Cicerone and Oremland, 1988). For each species of methanogen there is an optimal temperature range. As temperature trends toward this optimal range, production of methane will increase. Methane production is also dependent on the type and availability of decomposed organic matter. Substrates upon which methanogens can feed include hydrogen and carbon dioxide, formate, acetate, methanol, carbon monoxide, methylamines, and some methylated reduced-sulfur compounds (table 1). These substrates are produced as intermediate or end products of an intricate food web, beginning with complex organic biopolymers such as cellulose. Intermediary, nonmethanogenic, anaerobic bacteria break down these complex organics into the compounds which methanogens can use.

The reduction of carbon dioxide by hydrogen and the fermentation of acetate are the two dominant methanogenic processes in nature. Nearly all methanogens (different species) are able to form methane through reduction of $\mathrm{CO}_{2}$, and about half of the known species are able to use formate to create methane: The formate is actually converted first to $\mathrm{CO}_{2}$ and $\mathrm{H}_{2}$ and then the reduction process takes over to produce methane (Marty, 1992). The other substrates described above are used by only a small fraction of the available species. In natural environments, however, the species which can cause reduction of $\mathrm{CO}_{2}$ by hydrogen and fermentation of acetate are the dominant ones.
The species of methanogen present and the metabolic process employed are dependent upon the conditions of the environment. Where large amounts of sulfate are present, sulfate-metabolizing microbes will dominate, and little to no methane will be produced. Where sulfate amounts are low, however, the conditions for proliferation of methanogens are more optimal, and methane generation will proceed at greater rates. Similarly, other important parameters for methanogenesis are optimal temperature range for the metabolic processes and availability of substrates as discussed in the previous section (Oremland, 1988).

The processes of fermentation of acetate and reduction of $\mathrm{CO}_{2}$ can be distinguished by comparing $\delta^{13} \mathrm{C}$ values and $\delta \mathrm{D}$ values of the produced methane (fig. 2). Methane from acetate fermentation is generally more depleted in deuterium and less depleted in ${ }^{13} \mathrm{C}$ than methane formed through $\mathrm{CO}_{2}$ reduction (Burke, 1992; Whiticar and other, 1986). This information can be used to characterize the type of environments in which each process is dominant as long as secondary fractionation does not occur or can be quantified (see "Molecular and Isotopic Compositions" section).

\section{METHANOGENIC ENVIRONMENTS}

Aquatic environments in which methanogens are found include freshwater (where fermentation of acetate is the dominant metabolic process) and sulfate-depleted marine sediments (where reduction of $\mathrm{CO}_{2}$ is the dominant metabolic process), eutrophic lake sediments, salt marsh slurries, sediment slurries from estuarine muds, and anoxic water columns in meromictic (stratified) lakes (Oremland, 1988; Whiticar and other, 1986). In freshwater sediments, hydrogen and acetate are the important precursors to methane, with some of the produced methane coming from hydrogen reacting with $\mathrm{CO}_{2}$ and the majority originating from acetate (fig. 3). In marine sediments, competition for acetate and hydrogen by sulfate reducers (when the sulfate ion concentration is high) makes methanogenesis highly dependent upon sulfate concentration (Marty, 1992) (fig. 3). When sulfate concentration is more than 1.0 millimolar, or the

Table 1. Energy yields by important methanogenic substrates (modified from Oremland, 1988; Marty, 1992).

[ $\Delta \mathrm{G}$, gibbs free energy; $\mathrm{kJ} / \mathrm{mole}$, kilojoules per mole of methane]

\begin{tabular}{llc}
\hline \multicolumn{1}{c}{ Methanogenic substrates } & \multicolumn{1}{c}{ Reaction } & $\Delta \mathrm{G}(\mathrm{kJ} / \mathrm{mol})$ \\
\hline carbonate-carbon dioxide & $4 \mathrm{H}_{2}+\mathrm{CO}_{2} \rightarrow \mathrm{CH}_{4}+2 \mathrm{H}_{2} \mathrm{O}$ & -139 \\
formate & $4 \mathrm{HCOO}^{-}+2 \mathrm{H}^{+} \rightarrow \mathrm{CH}_{4}+\mathrm{CO}_{2}+2 \mathrm{HCO}_{3}-$ & -127 \\
methanol & $4 \mathrm{CH}_{3} \mathrm{OH} \rightarrow 3 \mathrm{CH}_{4}+\mathrm{CO}_{2}+2 \mathrm{H}_{2} \mathrm{O}$ & -103 \\
monomethylamine & $4 \mathrm{CH}_{3} \mathrm{NH}_{2}+2 \mathrm{H}_{2} \mathrm{O}+4 \mathrm{H}^{+} \rightarrow 3 \mathrm{CH}_{4}+\mathrm{CO}_{2}+\mathrm{NH}_{4}+$ & -102 \\
acetate & $\mathrm{CH}_{3} \mathrm{COO}^{-}+\mathrm{H}_{2} \mathrm{O} \rightarrow \mathrm{CH}_{4}+\mathrm{HCO}_{3}$ & -28 \\
dimethylsufide & $\left(\mathrm{CH}_{3}\right)_{2} \mathrm{~S}+\mathrm{H}_{2} \mathrm{O} \rightarrow 1.5 \mathrm{CH}_{4}+0.5 \mathrm{CO}_{2}+\mathrm{H}_{2} \mathrm{~S}$ & -74 \\
\hline
\end{tabular}




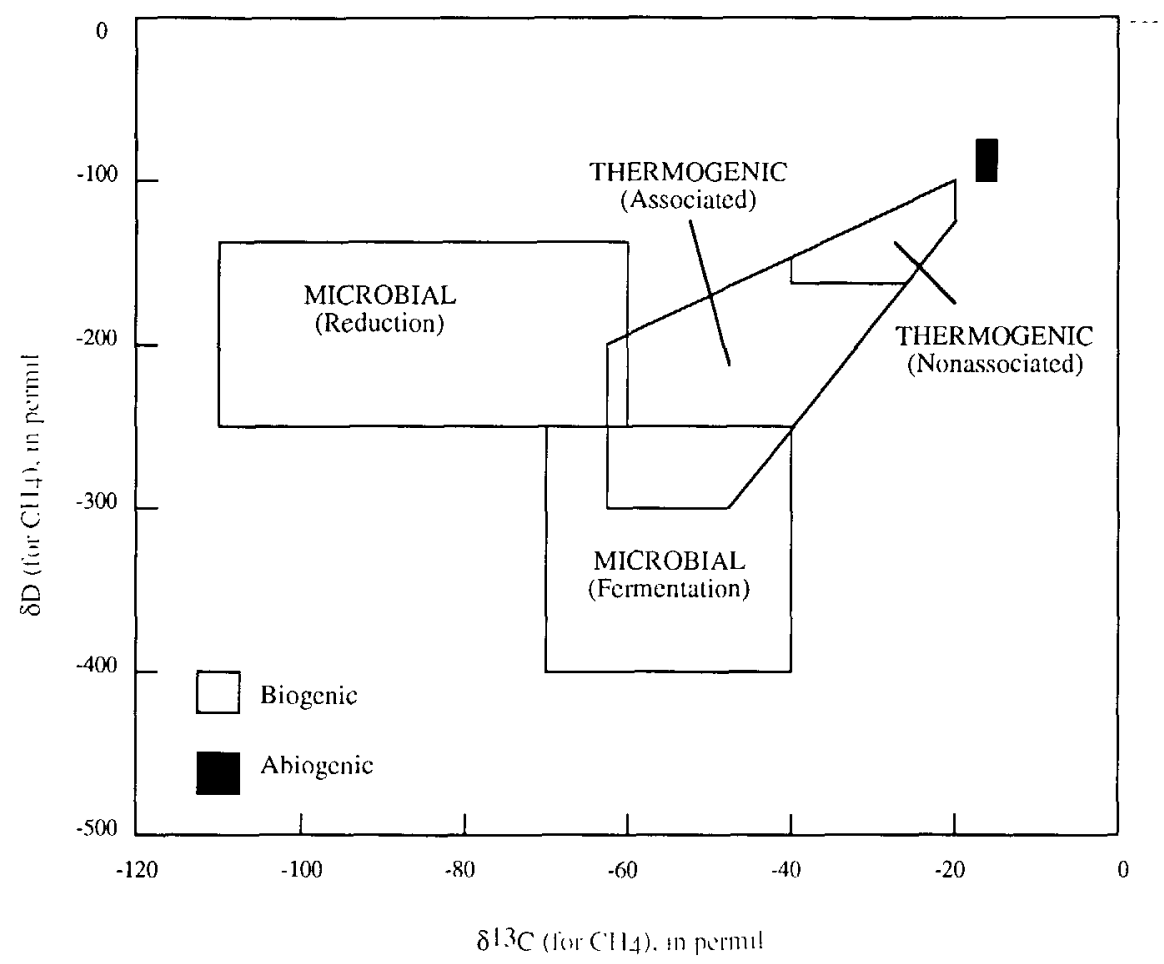

Figure 2. Carbon isotope ratio $\left(\delta^{13} \mathrm{C}\right)$ versus hydrogen isotope ratio $(\delta D)$ for microbially produced and thermogenically produced methane. Designated fields represent observed values resulting from fermentation and $\mathrm{CO}_{2}$ reduction process, and thermogenically produced oil-associated and dry (nonassociated) gas (as labeled). Modified from Whiticar and others (1986).

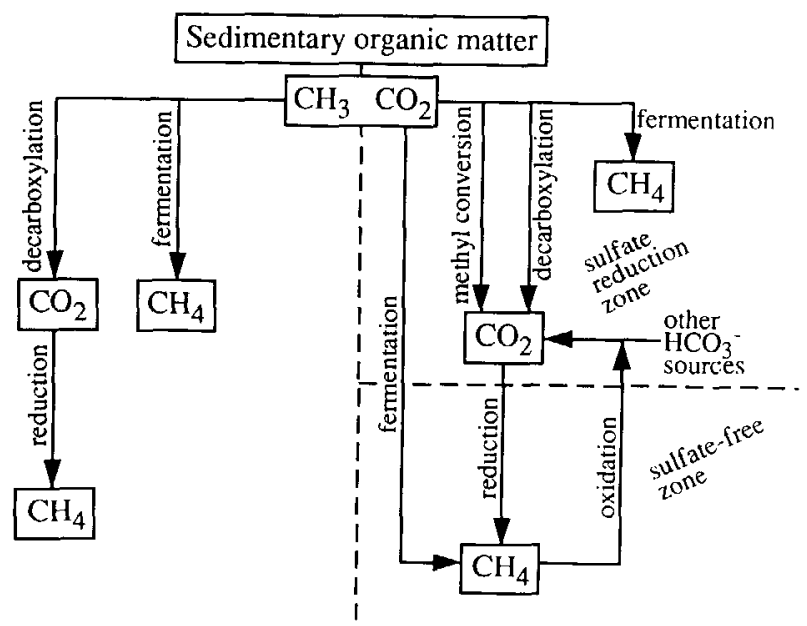

Figure 3. Flow diagram comparing methanogenesis pathways by acetate fermentation and $\mathrm{CO}_{2}$ reduction in freshwater and marine sediments (modified from Whiticar and others, 1986). Dashed lines distinguish between regions where sulfate is present for reduction and where sulfate is absent.

presence of nitrate or oxygen is high, little methane is found. Only after microorganisms have used up all free oxygen, nitrate, $\mathrm{Mn}$ and $\mathrm{Fe}$ oxides, and sulfate, will reduction of carbon dioxide take place and methane be produced. All of these inhibitors to methane production can be exhausted quickly at depths less than 2 meters, allowing for methane production and possible accumulation to begin below this depth (Whiticar and others, 1986). Methane from freshwater and marine sediments can be distinguished by isotopic values: $\delta^{13} \mathrm{C}$ ranges from -110 to -60 permil and $\delta \mathrm{D}$ ranges from -250 to -170 permil (mean value of -192 permil) in marine sediments, whereas in fresh-water sediments methane has $\delta{ }^{13} \mathrm{C}$ values between -65 and -50 permil and $\delta D$ values between -400 and -250 permil (mean value of -318 permil). These different isotope values are due to different fractionation factors for the two processes (reduction versus fermentation) (fig. 2) and the different isotopic ratios of the substrates.

Methanogens can be found in geothermal regions where their requirements for energy sources (decomposed organic matter) is no longer necessarily biologic. Geothermal $\mathrm{H}_{2}$ enters hot springs, geological rift zones (such as Lake Kivu, Africa), and sea-floor hydrothermal vents where methanogens use the $\mathrm{H}_{2}$ to reduce the available $\mathrm{CO}_{2}$ to produce $\mathrm{CH}_{4}$ (Oremland, 1988). Another near-surface environment in which methanogens are found, and microbial methane is produced, are landfills, where a richness in organic matter and a lack of oxygen makes meth- 
ane production a large and important product. For more information, see Hutchinson (this volume).

Relative to surface processes, little work has been done on subsurface (depths in the range from tens to hundreds of meters) methanogenic activity (Oremland, 1988). The active presence of methanogens at depth has been indicated, however, by direct observation of methanogens from material recovered during several Deep Sea Drilling Program (DSDP) projects, as well as from the isotopic values of known gas accumulations that indicate microbial activity. Methanogens have been recovered in deep aquifers in regions of Montana, Florida, and the Caspian Sea (Oremland, 1988). A necessity for methane production at depth in sediments is sufficient pore space for the methanogens to exist and grow (Rice, 1992).

\section{THERMAL METHANE}

\section{THERMOGENESIS AND THERMAL MATURITY OF SOURCE ROCKS}

Organic matter in buried sediments can be converted to hydrocarbons through thermal decomposition. During sedimentation and burial, strata move through deeper, hotter environments, referred to as different thermal maturity regimes. Together with the component of time, organic matter composed mainly of kerogen will decompose to form crude oil and other liquid and gaseous hydrocarbons such as those found in natural gas. Kerogen is the term used to identify the insoluble organic matter in rock. Kerogens can be divided into three types by their hydrogen/carbon $(\mathrm{H} / \mathrm{C})$ and oxygen/carbon $(\mathrm{O} / \mathrm{C})$ ratios, labeled $\mathrm{I}, \mathrm{II}$, and III in figure 4, as discussed by Tissot and Welte (1984). Type I and II kerogens (together called sapropelic) form oil and gas during decomposition, whereas type III kerogen (humic) dominantly produces gas, being least important of the three types for oil generation. These differentiations are primarily due to the available carbon and hydrogen in the organic matter. Type I kerogens have a high proportion of lipids, resulting either from selective accumulation of algal material, or from a severe biodegradation of the organic matter during deposition. Type II kerogens are usually related to marine sediments with a mixture of phytoplankton, zooplankton, and microorganisms and are deposited in reducing environments. Type III kerogen is derived mainly from continental plants.

From the decomposition of kerogen, soluble organic matter (bitumen) is produced, and then crude oil. Gas is generated from kerogen, bitumen, and oil, throughout maturation of the sediments, though it dominates in the more mature sediments. Gas forms from decomposition of kerogen in the earliest stages, and then from cracking (thermal breaking of carbon-carbon bonds) of kerogen, bitumen, and oil in the later stages (Lewan, 1991, oral commun.,

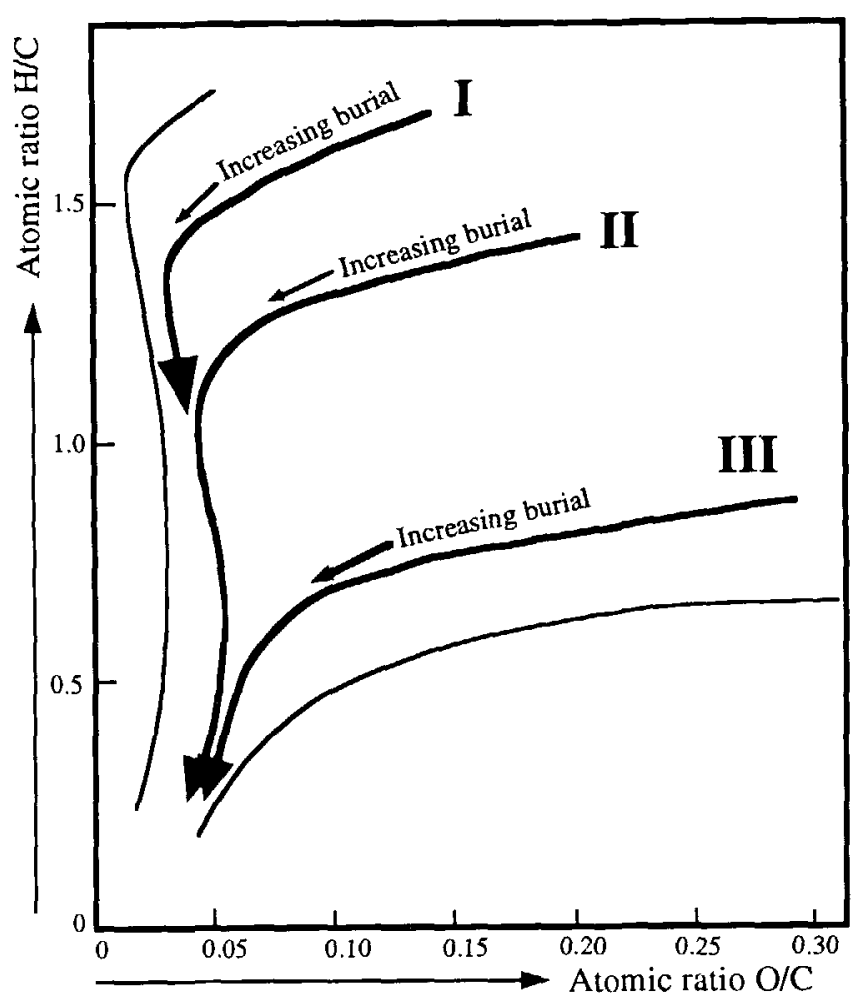

Figure 4. Principle types and evolution paths of kerogen. Types I, II, and III are the dominant kerogen types. Evolution of kerogen composition with increasing burial is marked by an arrow along each evolution path. The different curves start with different $\mathrm{H}: \mathrm{O}$ ratios according to original organic material and conditions of composition. The curves come together for very deep samples as the kerogen approaches 100 percent carbon. Modified from Tissot and Welte (1984) and van Krevelen (1981).

1993; Hunt, 1979). Oil forms mainly from type I and II kerogens, where the ratio of hydrogen to carbon is high enough to produce the liquid, heavy hydrocarbons.

The amount and variety of hydrocarbon components generated is a function of the type of organic matter present in the source rock, and the time, temperatures, and pressures to which the source rock has been subjected. Figure 1 shows the changes in relative proportion of methane to oil and hydrocarbon gases as organic matter and source rocks are moved through progressively higher thermal maturity regimes. The proportion of liquid to gaseous hydrocarbons decreases, and the proportion of methane to the higher alkanes $\left(\mathrm{C}_{2}+\right)$ increases as temperature increases. Thus in the later stages, methane is the dominant product and liquid hydrocarbons cease to be generated (fig. 1).

Methane can form from the decomposition of oil, when it remains trapped in the sediments as they become more deeply buried and more thermally mature. Methane can also form from bitumen. Distinguishing between methane formed from decomposition of original source rock kerogen and that formed from thermal cracking of oil and bitumen is difficult (McCabe and others, in press). Because ${ }^{13} \mathrm{C}$ 
bonds are stronger than ${ }^{12} \mathrm{C}$ bonds, however, methane formation from thermal cracking of carbon-carbon bonds produces lower ${ }^{13} \mathrm{C}$ values in the methane (Tissot and Welte, 1984). Because little oil or heavy hydrocarbons are generated from type III kerogens, there is less material available for cracking and methane formation. Even though methane is the dominant product of type III kerogens, the actual amount of methane produced from type III is less than the total amount formed from type I and II kerogens.

When methane is found in association with oil, it is called associated gas; when found alone, independent of oil, it is termed nonassociated, or dry gas. Dry gas, predominantly methane (contains less than 0.1 percent of condensable liquids per 1,000 cubic feet of gas, Hunt, 1979), forms from microbial processes at shallow depths, or from thermal processes at high temperatures at great depth. As temperature increases during thermal maturation, each of the hydrocarbon species is formed during an optimal thermal window. For methane, optimum generation occurs at $150^{\circ} \mathrm{C}$. Ethane, propane, and the butanes $\left(\mathrm{C}_{2}+\right)$ have a lower optimal generation temperature, $120^{\circ} \mathrm{C}$. This means that higher maturation regimes will produce fewer of the higher hydrocarbons and more methane (dry gas).

Between 40 to 60 percent of the original organic matter in a sedimentary layer will be converted to hydrocarbons before reaching the final stage of thermal maturity - that is, the beginning of metamorphism (McCabe and others, in press). At this final stage (high temperatures and pressures) the organic material in the rock is converted to graphite (Burruss, this volume). Water remaining in the rocks, or coming from surrounding regions, can react with the graphite to form carbon dioxide and methane. These gases may then be liberated from the region through faults and fractures in the surrounding rocks, often evidenced through fluid inclusions in quartz vein systems (Burruss, this volume). This method of forming methane derives its carbon from a source which was originally organic (graphite). It is not in the strictest sense of this paper thermogenic, because instead of involving decomposition of complex organic matter, it involves a synthesis of carbon and hydrogen from simple compounds (carbon dioxide, pure carbon, and water) to form a simple hydrocarbon, methane. The amount of this kind of methane which is found in economic accumulations with thermogenic gas is believed to be negligible.

The various or evolving stages of thermal maturation are labeled (1) diagenesis, the least thermally mature stage where microbial gas dominates, (2) catagenesis, the intermediate stage where oil and methane are generated from kerogen decomposition, and (3) metagenesis, the final stage where formation of almost pure methane (dry gas) occurs from thermal cracking of mainly oil and bitumen. The methane formed from cracking of kerogen at the highest thermal maturity stages is minor in comparison to the methane that comes from the cracking of bitumen and oil. At high thermal maturity most of the kerogen has already undergone cracking during earlier thermal stages. Similarly, the bitumen will begin to form oil at early stages and in the higher thermal maturity regimes will form only methane (Lewan, 1991, oral commun., 1993)

\section{ISOTOPIC COMPOSITION OF THERMAL METHANE}

Isotopic composition of thermal gases is dependent on three factors: (1) isotopic composition of source-rock organic carbon, (2) degree of fractionation during thermogenesis, and (3) degree of fractionation after methane formation. The first factor, source-rock isotopic composition, is dependent upon the kerogen type of the source rock and its degree of maturation. Isotopic fractionation during thermogenesis is a function of the differences in bonding energies for carbon-carbon bonds. The ${ }^{13} \mathrm{C}-{ }^{12} \mathrm{C}$ bond is stronger than the ${ }^{12} \mathrm{C}-{ }^{12} \mathrm{C}$ bond, and so the first-formed methane is preferentially enriched in ${ }^{12} \mathrm{C}$. As thermal maturation increases, so too does the ${ }^{13} \mathrm{C}$ concentration (Faber and others, 1992).

Fractionation after formation of methane is affected by the following:

1. Isotopic equilibration between $\mathrm{CH}_{4}$ and $\mathrm{CO}_{2}$. This process has been deemed unimportant, with isotopic effects too small to be significant (Fuex, 1977).

2. Bacterial degradation (by methane-oxidizing microorganisms) which preferentially oxidizes ${ }^{12} \mathrm{C}$ and thus enriches the residual methane in ${ }^{13} \mathrm{C}$.

3. Fractionation effects during migration. This process can affect the ${ }^{13} \mathrm{C} /{ }^{12} \mathrm{C}$ ratio of the residual product by increasing, decreasing, or leaving the ratio unchanged, depending upon the conditions of the system, whether closed or open, with or without mass loss. In steady-state systems (continual recharge and discharge of material), this fractionation is most likely not a major factor (Fuex, 1977).

4. Time and migration of material can create an appearance of fractionation, as the earliest formed material (from a source with a certain $\delta^{13} \mathrm{C}$ value) is channeled away first, while the last-formed material, having a different isotopic signature (due to previous preferential breaking of ${ }^{12} \mathrm{C}-{ }^{12} \mathrm{C}$ bonds), migrates last.

Thermal methane has a range of carbon isotopic values from -25 permil to -60 permil (Fuex, 1977; Schoell, 1988), though some authors place the maximum end of this range at -50 permil (Whiticar and others, 1986; Oremland, 1988). The lightest end of this range (most negative values) represents maximum fractionation of the lightest source material. This fractionation can be demonstrated by a source rock with organic carbon having $\delta^{13} \mathrm{C}$ of approximately -30 permil that experiences a fractionation which decreases $\delta^{13} \mathrm{C}$ by -30 permil, producing methane which has a $\delta^{13} \mathrm{C}$ isotope signature of -60 permil. The heaviest end of the range 
of carbon isotope values for thermal methane (most positive values) represents minimum fractionation of the heaviest source material. This relation can be demonstrated by a source rock with organic carbon having $\delta^{13} \mathrm{C}$ of approximately -19 permil that experiences a fractionation which decreases $\delta^{13} \mathrm{C}$ by -6 permil, producing methane which has a $\delta^{13} \mathrm{C}$ isotope signature of -25 permil (Fuex, 1977).

\section{MOLECULAR AND ISOTOPIC COMPOSITIONS OF MICROBIAL AND THERMAL GAS}

Microbially produced gas can be distinguished from thermogenically produced gas by use of stable isotope and methane/(ethane+propane) $\left[\mathrm{C}_{1} /\left(\mathrm{C}_{2}+\mathrm{C}_{3}\right)\right]$ ratios (Bernard and others, 1976). Microbial methane is enriched in ${ }^{12} \mathrm{C}$, depleted in $D$, and contains only trace amounts of the higher alkanes: $\mathrm{C}_{1} /\left(\mathrm{C}_{2}+\mathrm{C}_{3}\right)$ ratios are typically $>1,000(\mathrm{Ci}-$ cerone and Oremland, 1988; Faber and others, 1992). Thermogenic methane, formed during catagenesis, is depleted in ${ }^{12} \mathrm{C}$ and has an abundance of higher alkanes (table 2 ), with values of $\mathrm{C}_{1} /\left(\mathrm{C}_{2}+\mathrm{C}_{3}\right)<100$. The reasons behind these distinguishing characteristics are due to the different isotope fractionation factors and the different end-products of methanogenesis and thermogenesis. Methanogens cause enrichment of the lighter isotope during methanogenesis, producing values of $\delta^{13} \mathrm{C}<-60$ permil, whereas thermogenic values are typically $>-60$ permil (Fuex, 1977; Schoell, 1988) (fig. 5) or >-50 permil (Whiticar and others, 1986; Oremland, 1988). Values between -50 and -60 permil are often attributed to mixing of thermal and microbial methane. Late-stage thermal gases (formed during metagenesis) have lower hydrocarbon ratios because methane forms exclusive of the other hydrocarbon gases during the late maturation stage and have heavier isotopic signatures because the available organic matter is enriched in ${ }^{13} \mathrm{C}$ due to earlier fractionation which preferentially removed ${ }^{12} \mathrm{C}$.

Important exceptions to the above description of microbial versus thermal gas exist; however, they are rare and do not characterize the majority of gas accumulations. One exception occurs when methane generation has ceased and the gas accumulation enters a regime where aerobic methane-oxidizing bacteria enter the methane-rich environment. These methane-oxidizing bacteria will destroy or oxidize a certain amount of methane but will also cause a fractionation resulting in the residual methane being isotopically heavier, because the oxidizing bacteria prefer light methane. This effect can usually be identified by comparison of methane $\delta^{13} \mathrm{C}$ values with $\delta^{13} \mathrm{C}$ values for other alkanes, such as ethane, which are not affected by these microorganisms (Faber and others, 1992). Also, in certain environments, such as meromictic lakes, anaerobic bacteria have similar fractionation effects, thereby shifting the isotope
Table 2. Distinguishing characteristics of microbial and thermal methane (modified from Cicerone and Oremland, 1988).

$\left[C_{1}\right.$, methane: $C_{2}$, ethane; $C_{3}$, propanel

\begin{tabular}{lccc}
\hline \multicolumn{1}{c}{ Source } & $C_{1} /\left(C_{2}+C_{3}\right)$ & $\delta{ }^{13} C_{1}$ (permil) & $\delta D C_{1}$ (permil) \\
\hline Microbial & $>100$ & $<-60$ & $<-150$ \\
Thermogenic & $<100$ & $>-50$ & $>-275$ \\
\hline
\end{tabular}

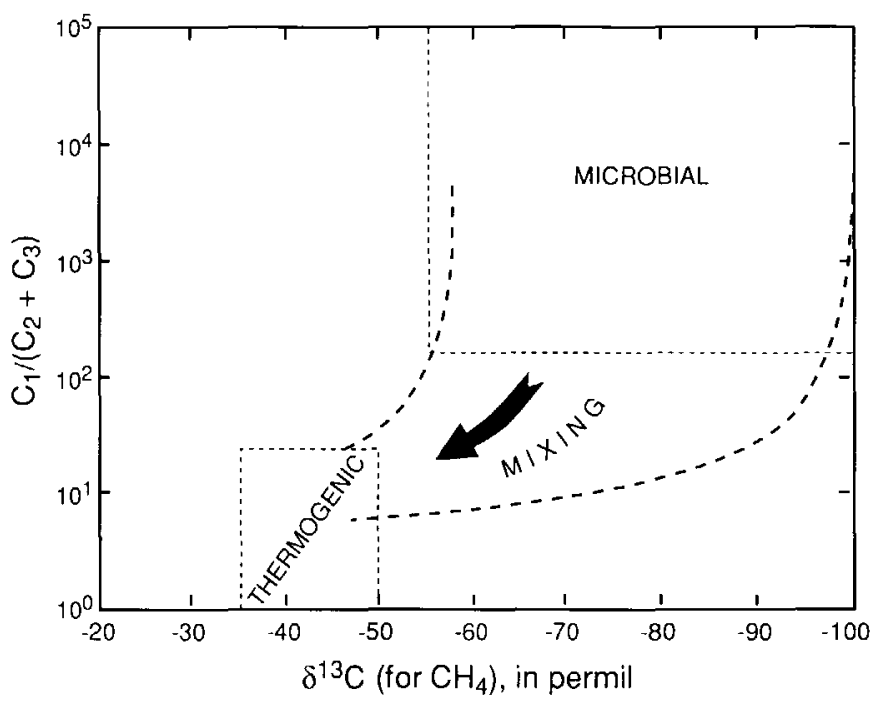

Figure 5. Carbon isotope ratio $\left(\delta^{13} \mathrm{C}\right)$ versus $C_{1} /\left(C_{2}+C_{3}\right)$ for naturally occurring methane. Designated fields represent thermogenic and microbial methane and the corresponding mixing zones (as labeled). Modified from Bernard and others (1976). $\left[C_{1}\right.$, methane; $\mathrm{C}_{2}$, ethane; $\mathrm{C}_{3}$, propane]

values to the heavy end such that a different origin is inferred than would otherwise be predicted. Finally, in certain rare circumstances, methanogens can form $\mathrm{C}_{2}$ (Cicerone and Oremland, 1988), which would skew the $\mathrm{C}_{1} /\left(\mathrm{C}_{2}+\mathrm{C}_{3}\right)$ ratio. Fortunately, these secondary effects or exceptions are uncommon and can usually be identified.

\section{ATMOSPHERIC METHANE}

A significant amount of microbial gas is currently produced in surface and near-surface environments and often emitted to the atmosphere. Roughly $5 \times 10^{8}$ tons of biologically generated methane is emitted into the atmosphere each year (Cicerone and Oremland, 1988). Use of radiogenic carbon isotopes $\left({ }^{14} \mathrm{C}\right)$ indicates that 80 percent of this gas comes from recently formed microbial methane, originating from animals, rice paddies, termites, and landfills. The remaining 20 percent comes from methane older than the $20 \mathrm{Ka}$ age range of ${ }^{14} \mathrm{C}$, originating from the use of fossil fuels, and from the destabilization of methane hydrates (see 
Kvenvolden, this volume). In contrast to atmospheric methane, only 20 percent of all known commercial gas accumulations are composed of microbial gas, whereas 80 percent are of thermogenic origin (Rice, 1992, this volume).

\section{SUMMARY}

Methane is produced in nature through two dominant processes, methanogenesis and thermogenesis. During methanogenesis the two dominant metabolic processes forming microbial methane are reduction of $\mathrm{CO}_{2}$ and fermentation of acetate. These two processes are each dominant in a different depositional environment: reduction of $\mathrm{CO}_{2}$ in marine settings and fermentation of acetate in the freshwater settings. Methanogens, the microorganisms which perform methanogenesis, are archaebacteria which live only in anaerobic, reducing environments and can survive a temperature range of 4 to $97^{\circ} \mathrm{C}$.

Thermal methane is formed as organic matter in buried sediments, is subjected to high temperatures, and undergoes decomposition. Typically this process involves generation of oil and other higher weight hydrocarbons as well as methane. In the late stages of thermogenesis, however, as temperatures increase above $120^{\circ} \mathrm{C}$, methane becomes the dominant product, generated by thermal cracking of kerogen, bitumen, and oil.

Thermal and microbial gas can be distinguished from one another through $\delta \mathrm{D}$ and $\delta^{13} \mathrm{C}$ isotope values for methane, as well as $\mathrm{C}_{1} /\left(\mathrm{C}_{2}+\mathrm{C}_{3}\right)$ ratios of the gas. Thermal gas has $\delta^{13} \mathrm{C}$ values (for methane) $>-50$ permil, $\delta \mathrm{D}$ values (for methane) $>-250$ permil, and $\mathrm{C}_{1} /\left(\mathrm{C}_{2}+\mathrm{C}_{3}\right)$ values $<100$. Microbial gas has $\delta^{13} \mathrm{C}$ values (for methane) $<-55$ permil, $\delta \mathrm{D}$ values (for methane) $<-150$ permil, and $\mathrm{C}_{1} /\left(\mathrm{C}_{2}+\mathrm{C}_{3}\right)$ ratios $>100$. Commercial gas accumulations contain about 20 percent microbial gas and 80 percent thermal gas.

\section{REFERENCES CITED}

Bernard, B.B., Brooks, J.M., and Sackett, W.M., 1976, Natural gas seepage in the Gulf of Mexico: Earth and Planetary Science Letters, v. 31, p. 45-54.
Burke, R.A., Jr., 1992, Factors responsible for variations in stable isotope ratios of microbial methane from shallow aquatic sediments, in Vially, R., ed., Bacterial gas: Paris, Editions Technip, p. 47-62.

Cicerone, R.J., and Oremland, R.S., 1988, Biogeochemical aspects of atmospheric methane: Global Biogeochemical $\mathrm{Cy}$ cles, v. 2, no. 4, p. 299-327.

Faber, E., Stahl, W.J., and Whiticar, M.J., 1992, Distinction of bacterial and thermogenic hydrocarbon gases, in Vially, R., ed., Bacterial gas: Paris, Editions Technip, p. 63-74.

Fuex, A.N., 1977, The use of stable carbon isotopes in hydrocarbon exploration: Journal of Geochemical Exploration, v. 7, p. $155-188$.

Hunt, J.M., 1979, Petroleum geochemistry and geology: San Francisco, W.H. Freeman and Company, 617 p.

König, H., 1992, Microbiology of methanogens, in Vially, R., ed., Bacterial gas: Paris, Editions Technip, p. 3-12.

Lewan, M., 1991, Primary oil migration and expulsion as determined by hydrous pyrolysis, in Proceedings of the Thirteenth World Petroleum Congress: New York, John Wiley and Sons, p. 215-223.

Marty, D.G., 1992, Ecology and metabolism of methanogens, in Vially, R., ed., Bacterial gas: Paris, Editions Technip, p. 1324.

McCabe, P.J., Gautier, D.L., Lewan, M.D., and Turner, C., in press, Energy gases: U.S. Geological Survey Circular 1115.

Oremland, R.S., 1988, Biogeochemistry of methanogenic bacteria, in Zehnder, A.J.B., ed., Biology of anaerobic microorganisms: New York, John Wiley and Sons, Inc., p. 641-705.

Rice, D.D., 1992, Controls, habitat, and resource potential of ancient bacterial gas, in Vially, R., ed., Bacterial gas: Paris, Editions Technip, p. 91-118.

Schoell, M., 1988, Multiple origins of methane in the Earth: Chemical Geology, v. 71, p. 1-10.

Stanier, R.Y., Ingraham, J.L., Wheelis, M.L., and Painter, P.R., 1986, The microbial world [4th ed.]: Englewood Cliffs, New Jersey, Prentice-Hall, $689 \mathrm{p}$.

Tissot, B.P., and Welte, D.H., 1984, Petroleum formation and occurrence [2d ed.]: New York, Springer-Verlag, 699 p.

Whiticar, M.J., Faber, E., and Schoell, M., 1986, Biogenic methane formation in marine and freshwater environments: $\mathrm{CO}_{2}$ reduction vs. acetate fermentation-Isotope evidence: Geochimica and Cosmochimica Acta, v. 50, p. 693-709.

van Krevelen, D.W., 1981, Coal-Typology, chemistry, physics, constitution: Amsterdam, Elsevier, $514 \mathrm{p}$.

Vially, R., ed., 1992, Bacterial gas: Paris, Editions Technip, 242 p. 
THE FUTURE OF ENERGY GASES

U.S. GEOLOGICAL SURVEY PROFESSIONAL PAPER 1570

\title{
Stability and Flux of Methane in the Deep Crust-A Review
}

\author{
By Robert C. Burruss ${ }^{1}$
}

\section{CONTENTS}

\begin{tabular}{|c|c|}
\hline \\
\hline Introduction & \\
\hline Objectives ............ & \\
\hline Temperature, Pressure, and Fluids in the Crust: & \\
\hline Metamorphic Facies & \\
\hline The Natu & \\
\hline Basic C & \\
\hline Time of Trap & \\
\hline Analysis of $\mathrm{Cr}$ & \\
\hline Reliability & \\
\hline $\lg \ldots .$. & \\
\hline Diffu & \\
\hline tability of $M$ & \\
\hline Fluid Incl & \\
\hline Therr & \\
\hline Evidence for Flux & \\
\hline & \\
\hline Gian & \\
\hline Meta & \\
\hline Does Cru & \\
\hline onclusions . & \\
\hline or Future Re & \\
\hline 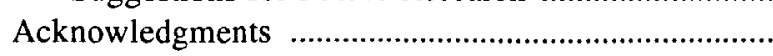 & \\
\hline eferences Cited ... & \\
\hline
\end{tabular}

\begin{abstract}
Empirical observations and theoretical calculations demonstrate that methane is stable in the crust to tempera-

\footnotetext{
${ }^{1}$ U.S. Geological Survey, Branch of Petroleum Geology, Box 25046, MS 973, Denver, CO 80225.
}

tures of $800^{\circ} \mathrm{C}$ and pressures of $10 \mathrm{kbar}$ or greater. These conditions are equivalent to depths of at least 35 to $40 \mathrm{~km}$. Methane is most stable in metasedimentary crustal rocks that contain graphite. The concept of a "deadline" for methane is clearly irrelevant in graphitic metasediments. Based on the volume of fluid necessary to form quartz veins, the estimates of the possible flux of methane from depth in the crust are large, on the order of 10's to 100's of Tcf ( 3 to $30 \times 10^{11} \mathrm{~m}^{3}$ ) from single giant vein systems or from areas of focused flow in metamorphic terranes. Crustally generated methane can accumulate through phase separation and buoyant rise of a separate gas phase but may be accompanied by significant amounts of carbon dioxide and nitrogen. The estimated fluxes of methane needed for accumulation of natural gas resources are difficult to assess. Methane can be lost from crustal gases by oxidation in nongraphitic rocks at high temperatures. Methods are needed to chemically identify and ultimately quantify crustally generated methane accumulations that are accessible to drilling and production.

\section{INTRODUCTION}

\section{OBJECTIVES}

Methane is stable and present at great depths (on the order of $30 \mathrm{~km}$ ) in the crust. Recent studies demonstrate that there are significant fluxes (10's to 100's of trillion cubic feet (Tcf) or 3 to $30 \times 10^{11} \mathrm{~m}^{3}$ ) of fluids including methane from deep to shallower levels in the crust. This review identifies the geologic and geochemical constraints for the accumulation of natural gas resources from these fluxes and addresses whether these supplies are accessible to drilling and production. The evidence for the existence of these fluxes comes from recent advances in metamorphic petrology and the geochemistry of mineral deposits, with particular emphasis on the use of fluid inclusion 
observations to determine the composition, temperature, and pressure of fluids in the crust.

With the exception of a very small number of deep scientific drill holes, essentially all the direct information on fluids in the deep crust comes from observations of fluid inclusions in metamorphic and igneous rocks. Reviews of fluid inclusion observations and methods of analysis can be found in Hollister and Crawford (1981); Crawford and Hollister (1986); Roedder (1984) Most of the evidence for the presence of methane at deep crustal levels (10 to $35 \mathrm{~km}$ ) comes from graphite-bearing metasedimentary rocks where reactions with graphitic carbon are the source for $\mathrm{CH}_{4}$ (Burruss, 1977; Duke and Rumble, 1986; Hollister and Burruss, 1976). The source of the graphite in these metasedimentary rocks is the biogenic, carbonaceous detritus buried with the original sediments. Therefore, the methane generated from graphite in metasediments can be classified as an energy gas of organic origin.

\section{TEMPERATURE, PRESSURE, AND FLUIDS IN THE CRUST: METAMORPHIC FACIES}

Most of our knowledge of pressures (P), temperatures $(\mathrm{T})$, and fluid compositions (X) in the crust comes from petrologic interpretations of mineral assemblages and thermodynamic models of mineral reactions. Some minerals have limited ranges of stability in $\mathrm{P}$ and $\mathrm{T}$ and their presence or absence defines the ranges of $P$ and $T$ experienced by a rock during burial, metamorphism, uplift, and exhumation. This concept of limited ranges of mineral stability is the basis for the general concept of metamorphic facies that in regional metamorphic terranes are generally known as greenschist, amphibolite, and granulite facies (P-T ranges are shown in fig. 1). Research over the last 15 to 20 years in mineral analysis, thermodynamic modeling, stable isotope geochemistry, and radiogenic isotope geochronology has led to significant advances in our ability to define pressure, temperature, and time paths of metamorphic rocks that were once buried deeply in the crust.

Our concepts of the composition of the fluid phase in metamorphic rocks are based on the requirements of thermodynamic equilibrium among mineral species. The coexisting fluid was initially assumed to be pure water in pelitic rocks and $\mathrm{CO}_{2}-\mathrm{H}_{2} \mathrm{O}$ mixtures in siliceous carbonate rocks. However, it was pointed out by French (1966) that when graphite is part of the mineral assemblage, other fluid species, such as $\mathrm{CH}_{4}, \mathrm{CO}$, and $\mathrm{H}_{2}$ can be important components of the fluid. The discovery by Dolgov and others (1967) that $\mathrm{CO}_{2}$-bearing fluid inclusions are common in high-pres-

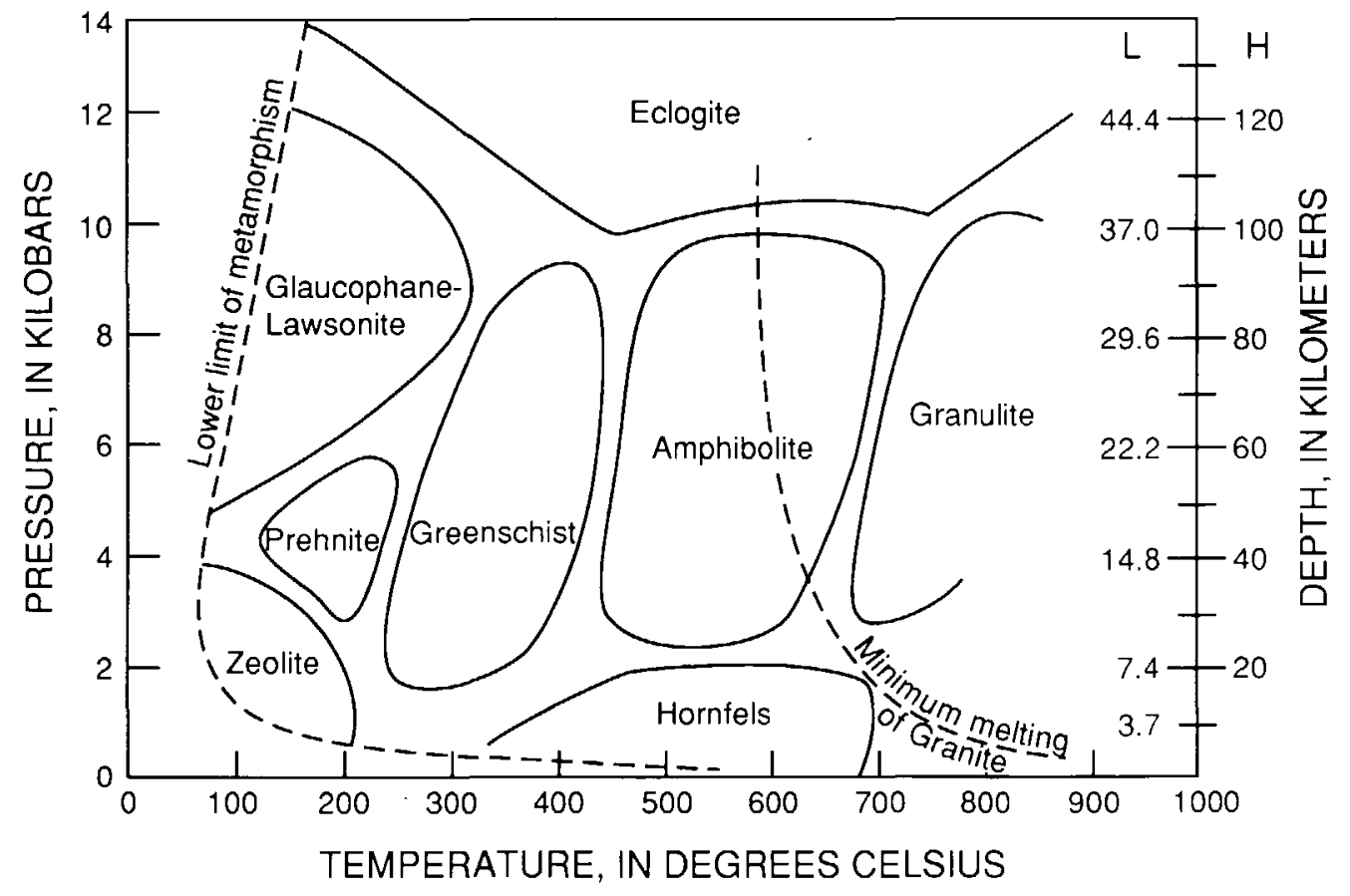

Figure 1. Pressure-temperature diagram of metamorphic facies. Modified from Verhoogen and others (1970). Vertical pressure axis is shown as approximate depth in the crust on the right. Numbers labeled " $L$ " on the inside of the axis are calculated on the basis of a lithostatic pressure gradient ( $270 \mathrm{bars} / \mathrm{km}$ ) for an average crustal density of $2.7 \mathrm{~g} / \mathrm{cm}^{3}$. Outer numbers labeled " $\mathrm{H}$ " are calculated on the basis of a hydrostatic pressure gradient $\left(100\right.$ bars $/ \mathrm{km}$ ) for an average fluid density of $1.0 \mathrm{~g} / \mathrm{cm}^{3}$. Measured pressure gradients in deep sedimentary basins change from hydrostatic to lithostatic in the depth range of 3 to $10 \mathrm{~km}$. 
sure, pelitic metasediments led to studies in a number of laboratories around the world of fluid inclusions in metasediments. These studies form the basis of this discussion.

\section{THE NATURE OF FLUID INCLUSION OBSERVATIONS}

\section{BASIC CONCEPTS}

The basic principles of fluid inclusion studies are discussed in detail in Roedder (1984). The key to interpreting inclusion observations is to determine the time of trapping of the inclusions and then use the assumption that once the inclusions formed, they do not change volume or composition. This is also known as the assumption that inclusions "do not leak." The assumptions of constant volume and composition are critical for accurate interpretation of the PTX conditions of the fluid at the time of trapping. There are geologic processes that occasionally violate these assumptions. Failure to recognize such processes causes incorrect interpretations of inclusion observations, but their recognition can lead to greater insight into the P-T history of samples.

\section{TIME OF TRAPPING}

Evidence for the time of trapping of fluid inclusions is based on the petrographic setting of the inclusions. Primary fluid inclusions form during mineral growth, most commonly along growth zones. Secondary inclusions are any inclusions that formed later than crystal growth, most commonly along healed microcracks that cross mineral grain boundaries. A subset of secondary inclusions called pseudosecondary inclusions form on healed microcracks that occur during crystal growth. In this case the microcrack terminates at a growth zone within the crystal, indicating that the fluid was trapped at some time during crystal growth, but not at a precisely identifiable stage of mineral growth. Although primary inclusions yield the least ambiguous evidence for the time of trapping, secondary inclusions can also yield useful information based on crosscutting relationships of fractures and microcracks (Cathelineau and others, 1990).

\section{ANALYSIS OF COMPOSITION AND DENSITY}

Determination of the pressure and temperature of formation (trapping) of fluid inclusions is based on analysis of both the composition and the density of the fluid within the inclusion. The basic method involves observation of phase equilibria within inclusions with a microscope equipped with a heating and cooling (heating/freezing) stage. This is generally known as microthermometry. Procedures for making observations are discussed in Hollister and Craw- ford (1981) and Roedder (1984). The assumptions and basic methods of interpreting phase equilibria are discussed in Burruss (1981a, 1981b) and Van den Kerkhof (1988).

There are a number of instrumental methods available for analyzing fluid inclusions such as mass spectrometry, gas chromatography, laser Raman microprobe spectroscopy, Fourier-transform infrared microscopy, and ion chromatography. Each method has limitations. The best analytical data result from a combination of techniques that include microthermometry.

\section{RELIABILITY}

\section{PRESSURE AND TEMPERATURE OF TRAPPING}

The soundness of any interpretation of fluid inclusion observations is based on the fundamental assumption that fluid inclusions do not leak or reequilibrate (in other words, once formed, they do not change volume or lose or gain fluid species). In general, this assumption is valid (Roedder, 1984). There are, however, a number of well-defined processes that can cause reequilibration such as stretching or collapse (plastic deformation of the host mineral around the inclusion), decrepitation (brittle fracturing of the inclusion wall), and chemical diffusion. There is a growing body of evidence that these processes affect natural samples; however, in most cases they can be recognized.

\section{DIFFUSION OF WATER AND HYDROGEN}

Of the reequilibration processes, the one that has the most serious consequences for the occurrence of methane in fluid inclusions is diffusion of water and hydrogen through the host mineral. Quartz $\left(\mathrm{SiO}_{2}\right)$ is the most common host mineral for fluid inclusions in metamorphic rocks. Because quartz is an iron-free mineral, we do not have to be concerned about oxidation-reduction reactions involving iron $\left(\mathrm{Fe}^{2+} / \mathrm{Fe}^{3+}\right)$ that complicate the diffusion of hydrogen- and oxygen-bearing species through ferromagnesian host minerals like hornblende or olivine. Hydrogen diffusion can affect the amount of methane in fluid inclusions through the following reaction (Burruss, 1977; Hollister and Burruss, 1976):

$$
\mathrm{CH}_{4}+2 \mathrm{H}_{2} \mathrm{O}=\mathrm{CO}_{2}+4 \mathrm{H}_{2}
$$

Diffusive loss of hydrogen can decrease the amount of methane as reaction 1 proceeds to the right. Methane could be completely lost from inclusions that have more than a 2:1 molar ratio of water to methane. Diffusive addition of hydrogen to an initially $\mathrm{CO}_{2}$-rich inclusion could drive reaction 1 to the left and cause methane to be added to inclusions. Experimental and empirical evidence for both processes is discussed by Morgan and others (1993) and Hall and Bodnar (1990). 


\section{STABILITY OF METHANE IN THE DEEP CRUST}

\section{FLUID INCLUSION OBSERVATIONS}

The methane content of fluid inclusions is determined by instrumental chemical analysis and by phase equilibrium observations (microthermometry). The results of the earliest attempts at instrumental analysis of methane in crustal rocks were fraught with ambiguity, owing to sampling problems (see review by Roedder, 1972). Some of the earliest reliable observations of methane in fluid inclusions from crustal environments were made by micro-thermometry (Mullis and others, 1973; Touret, 1971). Microthermometry was used to document the occurrence of methane in fluid inclusions from a granulite facies terrane (Hollister and Burruss, 1976). The identification of methane in fluid inclusions from deep crustal environments was confirmed by laser Raman microprobe spectroscopy of individual fluid inclusions (Dhamelincourt and others, 1979; Rosasco and others, 1975).

The $\mathrm{P}-\mathrm{T}$ ranges of methane-bearing fluids in a variety of crustal environments are shown in figure 2 . The ranges of $P$ and $T$ for the individual metamorphic terranes and ore deposits are based on pressures and temperatures determined from fluid inclusions and from mineral equilibria. In other words, the methane-bearing fluids that are now trapped as inclusions were present in the crust at these P-T conditions. One common feature of all the occurrences of methane in the deep crust is the presence of graphite in the highest metamorphic grades and carbonaceous material or graphitic carbon at lower grades. On the basis of observed occurrences of methane, there is no upper temperature limit to the stability of methane in the crust in graphitic rocks.

Evidence for an upper pressure limit or greatest depth of occurrence of methane is limited. Typical maximum pressure estimates for inclusions in granulite facies rocks are on the order of $10 \mathrm{kbar}$, or a depth of about $37 \mathrm{~km}$, for a crust with an average density of $2.7 \mathrm{~g} / \mathrm{cm}^{3}$. Inclusions are found in rocks from greater depths, as deep as 70 to $90 \mathrm{~km}$, in eclogite facies rocks (Andersen and others, 1989; Selverstone and others, 1992), but to date the evidence for methane is very limited. $\mathrm{CO}_{2}-\mathrm{H}_{2} \mathrm{O}$ fluids coexisting with saline brines and $\mathrm{H}_{2} \mathrm{O}-\mathrm{N}_{2}$ mixtures are documented (Andersen and others, 1989; Selverstone and others, 1992). References for the occurrence of $\mathrm{CH}_{4}$ in eclogitic fluids have been cited (Andersen and others, 1989), but the references are relatively obscure and difficult to confirm.

\section{THERMODYNAMIC MODELING}

The first attempts at thermodynamic modeling of equilibrium in metamorphic rocks required that the fluid either be pure $\mathrm{H}_{2} \mathrm{O}$ or $\mathrm{H}_{2} \mathrm{O}-\mathrm{CO}_{2}$ mixtures. However, the presence of graphite in metasediments can lead to fluid compositions

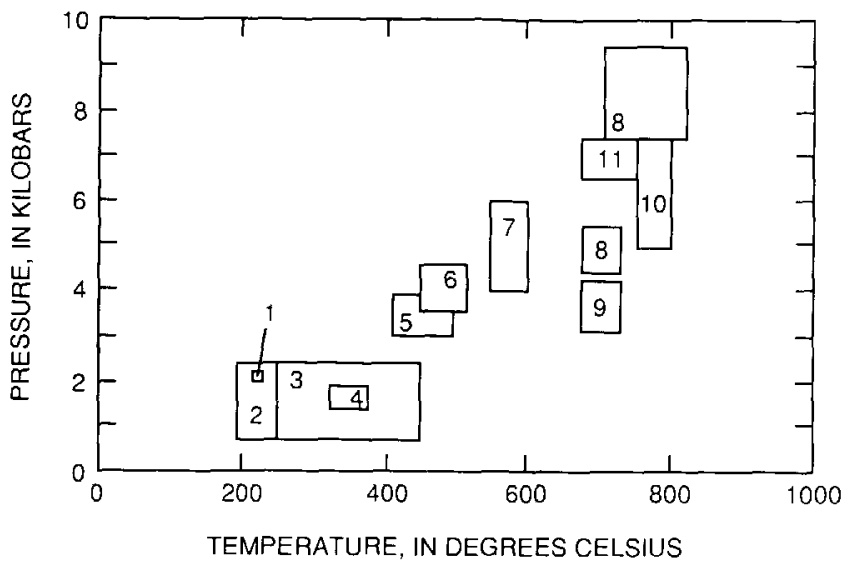

Figure 2. Pressure-temperature diagram of crustal conditions in which methane occurs as a stable component of fluid as observed in fluid inclusions. Numbered boxes refer to the pressure-temperature conditions discussed in the following publications: 8 , Althaus and Istrate (1989); 4, Bastoul (1989); 3, Boiron and others (1990); 6, Cathelineau and others (1990); 7, Duke and others (1990); 11, Istrate and Althaus (1989); 2, Kisch and Van den Kerkhof (1991); 1, Mullis (1988); 5, Nwe and Morteani (1993); 9, Poutiainen (1990); 10, Whitney (1992).

that are $\mathrm{CH}_{4}$ rich (French, 1966). The equilibrium compositions of $\mathrm{C}-\mathrm{O}-\mathrm{H}$ gases in the crust were calculated more than 20 years earlier (French, 1966) than the recent attempts (Barker and Takach, 1991; Takach and others, 1987) to apply equilibrium thermodynamic calculations to gas compositions in deep sedimentary basins. One of the most thorough discussions of modeling gas compositions in graphitic rocks is the work of Ohmoto and Kerrick (1977). The fundamental reaction for generation of methane in graphitic rocks in the crust is

$$
2 \mathrm{C}+2 \mathrm{H}_{2} \mathrm{O}=\mathrm{CO}_{2}+\mathrm{CH}_{4}
$$

If we apply a thermodynamic constraint that the hydrogenoxygen $(\mathrm{H}: \mathrm{O})$ ratio is fixed at 2:1 (oxygen fugacity of the fluid is internally buffered), then this reaction describes the solubility of graphite in water and shows that methane and carbon dioxide will always occur in equimolar concentrations. The concentration of methane in the fluid as a function of $\mathrm{P}$ and $\mathrm{T}$, to reaction (2), with $\mathrm{H}: \mathrm{O}$ fixed at $2: 1$ is shown in figure 3 .

In many crustal rocks the concentration of methane is controlled by the oxidation state of iron in the rocks. In this situation the oxygen fugacity of the fluid is externally buffered by reactions such as

$$
4 \mathrm{Fe}_{3} \mathrm{O}_{4}+\mathrm{O}_{2}=6 \mathrm{Fe}_{2} \mathrm{O}_{3}
$$

When oxygen is externally controlled by mineral reactions, the gas composition can vary widely through coupled reactions involving reaction (3) and reactions such as 


$$
\mathrm{CH}_{4}+2 \mathrm{O}_{2}=2 \mathrm{H}_{2} \mathrm{O}+\mathrm{CO}_{2} \text {. }
$$

If the rock has a high oxygen fugacity, then methane is consumed and carbon dioxide becomes the dominant carbon-bearing species in the fluid phase. On the other hand, if the rock has a low oxygen fugacity, then carbon dioxide is consumed and the methane is the dominant carbon-bearing species in the fluid phase.

\section{EVIDENCE FOR FLUX OF METHANE FROM THE DEEP CRUSTAL LEVELS}

\section{GIANT VEIN SYSTEMS AND MINERALIZATION}

The flux of gases in the deep crust can be estimated by determining the amount of water necessary to form quartz veins and then estimating the amount of gas that would be transported with the water. The measured solubility of quartz in water as a function of temperature, pressure, and salinity (Holland and Malinin, 1979) can be used

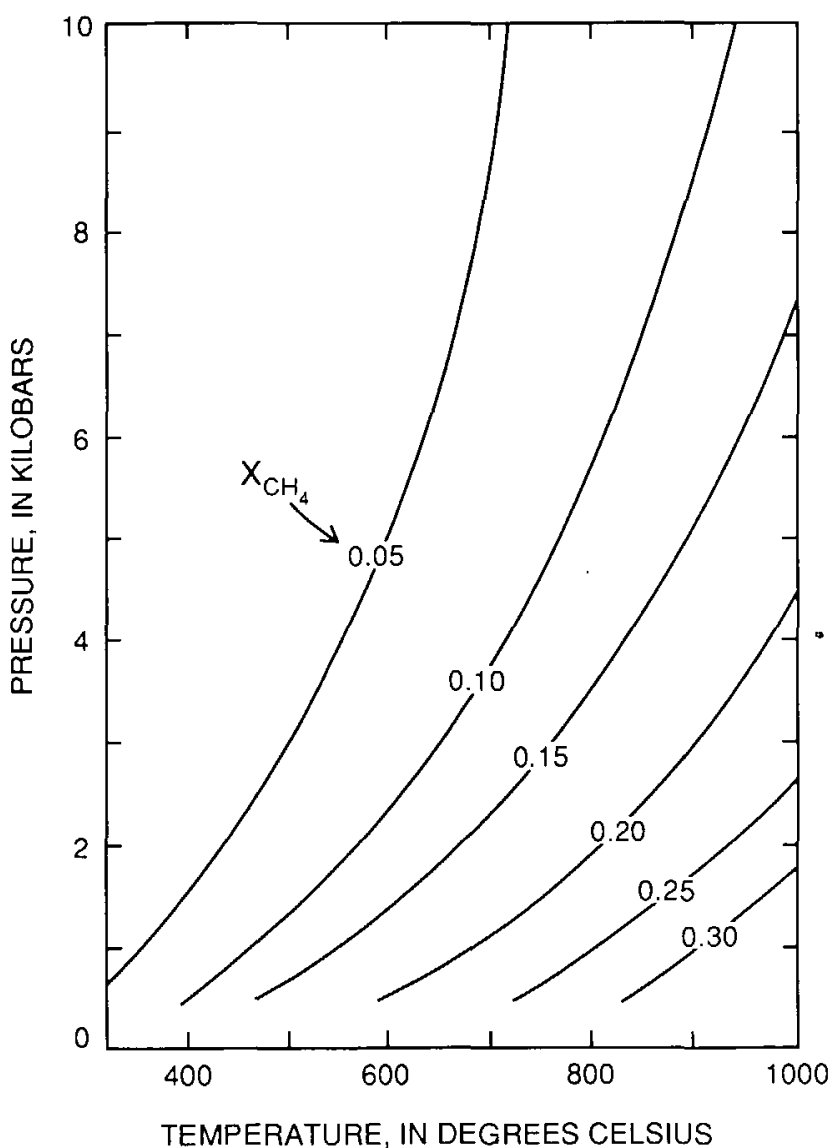

Figure 3. Pressure-temperature diagram of isopleths of methane content $\left(\mathrm{X}_{\mathrm{CH}_{4}}\right)$ of a $\mathrm{C}-\mathrm{O}-\mathrm{H}$ fluid in equilibrium with graphite with hydrogen-oxygen $(\mathrm{H}: \mathrm{O})$ ratio fixed at $2: 1$. Modified from Ohmoto and Kerrick (1977). to calculate the quantity of quartz precipitated per volume of water in a vein system at a given depth in the crust. From the volume of quartz veins that can be measured in the field, we can estimate the total volume of water necessary to form the vein system. The ratio of hydrocarbon and non-hydrocarbon gases to water can be determined from fluid inclusion measurements (Burruss, 1981a; Landis and Hofstra, 1991; Van den Kerkhof, 1988). Therefore, we can estimate the volume of gases that are transported with the water that forms quartz veins at depth in a given tectonic setting.

An extensive series of studies (Kerrich and Feng, 1992) documented the geochemical processes and tectonic setting of formation of giant quartz-vein systems, which in many cases have associated gold mineralization (see Goldfarb and others, 1991). In one example of a giant vein system, an estimated $6 \times 10^{18} \mathrm{~g}$ of aqueous fluid $\left(6 \times 10^{3} \mathrm{~km}^{3}\right)$ deposited about $6 \times 10^{15} \mathrm{~g}$ of quartz and in the process transported $3 \times 10^{15} \mathrm{~g}$ of $\mathrm{CO}_{2}$ (Kerrich and Feng, 1992). This is 1,500 trillion cubic feet (Tcf) of $\mathrm{CO}_{2}$. On the basis of the range of methane-carbon dioxide ratios (1:3 to 1:40) observed in fluid inclusions in quartz from one of these giant vein systems, "southern Alaska mesothermal veins" (Landis and Hofstra, 1991), a single giant vein system may transport on the order of 50 to $500 \mathrm{Tcf}$ of $\mathrm{CH}_{4}$ to shallow crustal levels. The 12 giant vein systems that are documented (Kerrich and Feng, 1992) range in age and location from Archean (2,700-2,600 Ma) in the Canadian and Australian shields to Tertiary (38-27 Ma) in the European Alps. The number of these systems is biased by the fact that those documented are now exposed at the surface where they can be readily studied.

\section{METAMORPHIC FLUID CIRCULATION}

Evidence of and theoretical constraints on fluid flow during dynamo-thermal metamorphism of the crust have generated a significant volume of research and discussion in the last 15 years. A variety of issues is discussed in a recent, special issue of "Earth Science Reviews" (Fyfe, 1992). J. Ferry is a major proponent of the flow of large volumes of fluid during metamorphism (Ferry, 1983). Recent work in the metamorphosed Waits River Formation along the Connecticut River valley, in the State of Vermont, has used reaction progress variables (Ferry, 1992) and stable isotope analysis of carbonate and silicate minerals (Stern and others, 1992) to calculate time-integrated fluid fluxes yield focused flows of 10 to $>23 \times 10^{4} \mathrm{~cm}^{3} / \mathrm{cm}^{2}$ at crustal depths of about $25 \mathrm{~km}$. Focused flow occurs in the crests of antiforms and around the margins of plutonic rocks. Calculated on a square-kilometer basis, these fluxes are 10 to $>23 \times 10^{15} \mathrm{~cm}^{3} / \mathrm{km}^{2}$. Ferry (1992) and Stern and others (1992) indicate that the highest fluxes occur over areas $>100 \mathrm{~km}^{2}$, which yield total fluid fluxes of similar 
magnitude to Kerrich and Feng's (1992) estimates (as discussed above) for a single giant vein system.

The volume of methane that may be part of the fluid flux calculated by Ferry and coworkers could be highly variable. Order of magnitude estimates are in the Tcf range calculated for Kerrich and Feng's (1992) giant vein systems. If the metamorphic rocks are graphitic, however, it is possible that the volume of methane could be high, on the order of 100's of Tcf generated during focused flow through an area on the order of $100 \mathrm{~km}^{2}$.

\section{DOES CRUSTAL METHANE CONTRIBUTE TO RESOURCES?}

Although the evidence for the stability of methane in the deep crust is strong, questions still remain about the significance of the estimated fluxes for natural gas resources. In this case, I use the word resource in the conventional sense, meaning gas that is economically recoverable by present or near-future technology. In other words, does this methane accumulate in porous and permeable rocks accessible to drilling? The simple answer is that we do not know because we do not have good criteria to differentiate between deep crustal methane and normal thermogenic methane. However, there are three questions that should be addressed before we consider the problem of identifying deep crustal methane: (1) Can methane generated in graphitic metasediments survive migration out of the source rock through non-graphitic rocks to shallow crustal levels? (2) Are there mechanisms that could concentrate the methane into a gas accumulation? And (3) what is the tectonic setting for high fluxes of deep crustal methane and is the area being studied favorable for the occurrence of reservoirs?

Methane that is generated in graphitic metasediments can be consumed by two different types of reactions. In the first reaction, the methane can be oxidized by reactions with minerals that contain ferric iron. Reactions (3) and (4) discussed above can be combined as follows:

$$
\mathrm{CH}_{4}+12 \mathrm{Fe}_{2} \mathrm{O}_{3}=8 \mathrm{Fe}_{3} \mathrm{O}_{4}+2 \mathrm{H}_{2} \mathrm{O}+\mathrm{CO}_{2} \text {. }
$$

Methane is consumed (oxidized) by the reduction of ferric iron in hematite to ferrous iron in magnetite. However, the stoichiometry of reaction 5 indicates that this mechanism for oxidizing methane is not very efficient because it requires 12 moles of hematite to reduce one mole of methane. If significant volumes of methane are concentrated along a flow path, then the oxidizing capacity of the rocks along the path may be rapidly exhausted, allowing methane to migrate. The second reaction that consumes methane is the reverse of reaction (2), the graphite solubility reaction. A methane and carbon dioxide mixture migrating to lower P$\mathrm{T}$ levels of the crust will precipitate graphite if thermody- namic equilibrium is maintained. There is petrographic and stable isotopic evidence for this reaction. Overgrowths of graphite on original metasedimentary graphite that are isotopically distinct from the host graphite (Duke and Rumble, 1986) and intergrowths of graphite with retrograde, hydrous minerals (Duke and Rumble, 1986; Hollister and Burruss, 1976) demonstrate that this reaction occurs in the crust. The volume of methane that may be consumed by these two reactions is unknown.

Methane in the deep crust occurs as mixtures with other components such as $\mathrm{N}_{2}, \mathrm{CO}_{2}$, and $\mathrm{H}_{2} \mathrm{O}$. The total fluid composition may contain 10 to $20 \mathrm{~mol}$ percent $\mathrm{CH}_{4}$ and in many cases as little as 1 to 5 mol percent. The methane can be concentrated from the aqueous fluid by phase separation (immiscibility). The critical curve for the $\mathrm{CH}_{4}-\mathrm{H}_{2} \mathrm{O}$ system is shown in figure 4 along with isopleths

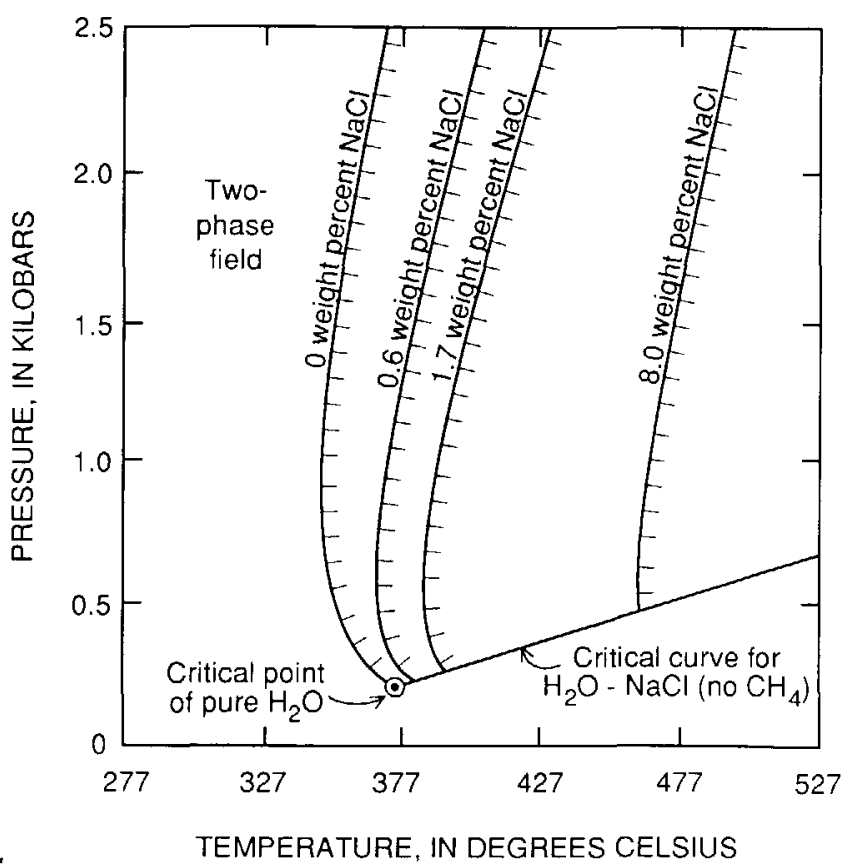

Figure 4. Pressure-temperature diagram showing the critical curve of $\mathrm{CH}_{4}-\mathrm{H}_{2} \mathrm{O}$ system (labeled 0 weight percent $\mathrm{NaCl}$ ) and the calculated critical point curves for the $\mathrm{CH}_{4}-\mathrm{H}_{2} \mathrm{O}-\mathrm{NaCl}$ system at three different concentrations of $\mathrm{NaCl}$ (solid curves with hachures). Unhachured line is the critical curve for the $\mathrm{H}_{2} \mathrm{O}-\mathrm{NaCl}$ system with no $\mathrm{CH}_{4}$. At pressure-temperature (P-T) conditions to left of curves in the region labeled "two-phase field," separate liquid $\left(\mathrm{H}_{2} \mathrm{O}\right.$ rich $)$ and gas $\left(\mathrm{CH}_{4}\right.$ rich) phases can exist. At higher $\mathrm{P}-\mathrm{T}$ conditions on hachured sides of curves, methane is soluble in all proportions in pure water or brines of indicated $\mathrm{NaCl}$ content. As more $\mathrm{NaCl}$ is added to the system, the two-phase field expands to higher temperature. If an initially homogeneous fluid generated at P-T conditions on the hachured sides of curves migrates to shallower levels (lower P-T conditions on the left sides of curves), then it will separate into an $\mathrm{H}_{2} \mathrm{O}$-rich liquid and a $\mathrm{CH}_{4}$-rich gas. Gas can then migrate and accumulate by buoyancy. Modified from Krader and Franck (1987). 
for increasing salinity (Krader and Franck, 1987). As an initially homogeneous, water-rich fluid rises to shallower levels in the crust, $\mathrm{CH}_{4}$ and other gases will form a separate vapor phase at temperatures less than $400^{\circ} \mathrm{C}$. The gas-rich vapor phase will rise buoyantly and separate from the aqueous phase. If this rising gas encounters an impermeable seal, it will accumulate. One difficulty with this mechanism is that it concentrates all gases that are immiscible in water. The methane will be accompanied by nitrogen and carbon dioxide, which will decrease the Btu content of the gas.

Another factor in the possible contribution of deep crustal methane to natural gas accumulations is the tectonic setting in which crustal methane is generated. The examples of metamorphic terranes given above are all Barrovian, dynamo-thermal metamorphic terranes typically associated with continental plate collision. The giant vein systems described by Kerrich and Feng (1992) and others are typically associated with collisional regimes. Both terranes tend to have significant components of rapid, vertical tectonic movement that lead to rapid uplift and denudation that in turn would lead to reservoir leakage. One need only consider the European Alps or the Himalayas to realize that the probability of preservation of major gas reservoirs in such terranes is relatively low. The possibility exists, however, that intermontane basins of collisional zones such as the Vienna or Pannonian basins of Europe might serve as traps for deeply generated, crustal gases.

Whether or not one can identify sedimentary basins that are possible repositories of crustally generated methane, a crucial question that remains is how can we identify a crustal component of the gas? Only two methods appear to be available. One method is analysis of the stable isotopic composition, $\delta^{13} \mathrm{C}$ (the variation in the abundance of ${ }^{13} \mathrm{C}$ in parts per thousand) and $\delta \mathrm{D}$ (the variation in the abundance of the hydrogen isotope deuterium (D) in parts per thousand) of the methane itself. A second possibility is analysis of the isotopic composition of the other major components of the gas, primarily nitrogen and carbon dioxide, and of the trace amounts of noble gases reservoired with the methane (see, for example, Ballentine and O'Nions, 1991). Once we know the geochemical criteria that uniquely identify crustally generated methane, then we can begin to assess the contribution of this source of energy gas to natural gas resources that are accessible to drilling.

\section{CONCLUSIONS}

1. On the basis of empirical observations and theoretical calculations, methane is stable in the crust to temperatures of $800^{\circ} \mathrm{C}$ and pressures of $10 \mathrm{kbar}$ or greater. These conditions are equivalent to depths of at least 35 to $40 \mathrm{~km}$. The concept of a "deadline" for methane is clearly irrelevant in graphitic metasediments.
2. Estimates of the possible flux of methane from depth in the crust are large, on the order of 10's to 100's of Tcf ( 3 to $30 \times 10^{11} \mathrm{~m}^{3}$ ) from single giant quartz-vein systems or from areas of focused flow in a Barrovian metamorphic terrane. Crustally generated methane can be concentrated through phase separation and buoyant rise of a separate gas phase.

3. The significance of these estimated fluxes for natural gas resources is difficult to assess at this time. Methods are needed to identify the chemical and isotopic characteristics of crustally generated methane: Once these characteristics are identified, they can be used to estimate the fraction of crustally generated methane that is present in commercial reservoirs as has been done by Jenden and others (this volume) for abiogenic methane.

\section{SUGGESTIONS FOR FUTURE RESEARCH}

Several aspects of this review suggest areas for future research. First, we clearly need to carefully evaluate possible methods to identify crustally generated methane in sedimentary basin reservoirs. Second, detailed analysis of methane-bearing fluid inclusions in deep crustal rocks should provide insight into additional methods of addressing the first research area. In particular, stable isotopic studies of methane in fluid inclusions will document the range of values we can expect from this environment. Also, studies of the isotopic composition of noble gases in fluid inclusions should help identify the signature of gases generated at depth in the crust.

\section{ACKNOWLEDGMENTS}

My interest in this topic began during my dissertation research many years ago. L.S. Hollister's encouragement at Princeton University to pursue this research is still greatly appreciated. At Gulf Research and Development Co., T.J. Weisman's interest in deep methane ultimately led to my employment at that late, great research lab. Several colleagues at the U.S. Geological Survey, especially Dave Leach, Rich Goldfarb, and Mike Lewan have encouraged me to maintain my interest in this topic. To all of them and the many metamorphic petrologists currently pursuing fluid inclusion studies, I offer my thanks. This review would be impossible without them.

\section{REFERENCES CITED}

Althaus, E., and Istrate, G., 1989, Nitrogen-methane fluids in granulite facies rocks from Valle Strona/Ivrea zone, W. Alps: Their bearing on the evaluation of P-T conditions of formation [abs.]: Berichte der Deutschen Mineralogische Gesselschaft, v. 1, p. 7. 
Andersen, T., Burke, E.A.J., and Austrheim, H., 1989, Nitrogenbearing, aqueous fluid inclusions in some eclogites from the Western Gneiss Region of the Norwegian Caledonides: Contributions to Mineralogy and Petrology, v. 103, p. 153165.

Ballentine, C.J., and O'Nions, R.K., 1991, The nature of mantle neon contributions to Vienna Basin hydrocarbon reservoirs: Earth and Planetary Science Letters, v. 113, p. 553-567.

Barker, C., and Takach, N.E., 1991, Prediction of natural gas composition in ultradeep sandstone reservoirs: American Association of Petroleum Geologists Bulletin, v. 76, p. 1859-1873.

Bastoul, A.M., 1989, The Tichka gold deposit, Morocco: Mineralogical and fluid inclusion data [abs.]: Terra Abstracts, v. 1, p. 24-25.

Boiron, M.C., Cathelineau, M., Dubessy, J., and Bastoul, A.M., 1990, Fluids in Hercynian $\mathrm{Au}$ veins from the French Variscan belt: Mineralogical Magazine, v. 54, p. 231-243.

Burruss, R.C., 1977, Analysis of fluid inclusions in graphitic metamorphic rocks from Bryant Pond, Maine, and Khtada Lake, British Columbia-Thermodynamic basis and geologic interpretation of observed fluid compositions and molar volumes: Princeton University, unpublished Ph.D. dissertation thesis, $156 \mathrm{p}$.

1981a, Analysis of fluid inclusions: Phase equilibria at constant volume: American Journal of Science, v. 281, p. 1104-1126.

1981b, Analysis of phase equilibria in C-O-H-S fluid inclusions, in Hollister, L.S., and Crawford, M.L., eds., Fluid inclusions: Applications to petrology: Calgary, Mineralogical Association of Canada, v. 6, p. 39-74.

Cathelineau, M., Lespinasse, M., Bastoul, A.M., Bernard, C., and Leroy, J., 1990, Fluid migration during contact metamorphism: the use of oriented fluid inclusion trails for a time/space reconstruction: Mineralogical Magazine, v. 54, p. 169-182.

Crawford, M.L., and Hollister, L.S., 1986, Metamorphic fluids: the evidence from fluid inclusions, in Walther, J.V., and Wood, B.J., ed., Advances in Physical Geochemistry: Springer-Verlag, v. 5, p. 1-35.

Dolgov, Y.A., Makagon, V.M., and Sobolov, V.W., 1967, Fluid inclusions in kyanite from metamorphic rocks and pegmatites of the Mama region (northeastern Transbaikel): Doklady Akademii Nauk S. S. S. R., v. 175, p. 164-166.

Duke, E.F., Galbreath, K.C., and Trusty, K.J., 1990, Fluid inclusion and carbon isotope studies of quartz-graphite veins, Black Hills, South Dakota, and Ruby Range, Montana: Geochimica et Cosmochimica Acta, v. 54, p. 683-698.

Duke, E.F., and Rumble, D., III, 1986, Textural and isotopic variations in graphite from plutonic rocks, South-Central New Hampshire: Contributions to Mineralogy and Petrology, v. 93 , p. $409-419$.

Ferry, J.M., 1983, Regional metamorphism of the Vassalboro Formation, south-central Maine, USA: a case study of the role of fluid in metamorphic petrogenesis: Journal of the Geological Society, London, v. 140, p. 551-576.

1992, Regional metamorphism of the Waits River Formation, Eastern Vermont: Delineation of a new type of giant metamorphic hydrothermal system: Journal of Petrology, v. 33 , p. $45-94$.
French, B.M., 1966, Some implications of equilibrium between graphite and a $\mathrm{C}-\mathrm{H}-\mathrm{O}$ gas phase at high temperatures and pressures: Reviews of Geophysics, v. 4, p. 223-253.

Fyfe, W.S., ed., 1992, Metamorphic Fluids: Earth-Science Reviews, v. 32, 146 p.

Goldfarb, R.J., Snee, L.W., Miller, L.D., and Newberry, R.J., 1991, Rapid dewatering of the crust deduced from ages of mesothermal gold deposits: Nature, v. 354, p. 296-298.

Hall, D.L., and Bodnar, R.J., 1990, Methane in fluid inclusions from granulites: A product of hydrogen diffusion?: Geochimica et Cosmochimica Acta, v. 54, p. 641-651.

Holland, H.D., and Malinin, S.D., 1979, The solubility and occurrence of non-ore minerals, in Barnes, H.L., ed., Geochemistry of hydrothermal ore deposits: New York, John Wiley and Sons, p. 461-508.

Hollister, L.S., and Burruss, R.C., 1976, Phase equilibria in fluid inclusions from the Khtada Lake metamorphic complex: Geochimica et Cosmochimica Acta, v. 40, p. 163-175.

Hollister, L.S., and Crawford, M.L., ed., 1981, Fluid inclusions: Applications to petrology: Calgary, Mineralogical Association of Canada.

Istrate, G., and Althaus, E., 1989, Methane and nitrogen in granulite facies rocks from the Sila Massif, Calabria, southern Italy: Neues Jahrbuch fuer Mineralogie, Monatschefte, v. 1989 , p. $97-108$.

Kerrich, R, and Feng, R., 1992, Achean geodynamics and the Abitibi-Pontiac collision: implications for advection of fluids at transpressive collisional boundaries and the origin of giant quartz vein systems: Earth-Science Reviews, v. 32, p. 33-60.

Kisch, H.J., and Van den Kerkhof, A.M., 1991, $\mathrm{CH}_{4}$-rich inclusions form quartz veins in the Valley-and-Ridge province and the anthracite fields of the Pennsylvania Appalachians: American Mineralogist, v. 76, p. 230-240.

Krader, T., and Franck, E.U., 1987, The ternary systems $\mathrm{H}_{2} \mathrm{O}-$ $\mathrm{CH}_{4}-\mathrm{NaCl}$ and $\mathrm{H}_{2} \mathrm{O}-\mathrm{CH}_{4}-\mathrm{CaC}_{12}$ to $800 \mathrm{~K}$ and $250 \mathrm{MPa}$ : Berichte der Bunsen-Gesellschaft fuer Physikalische Chemie, v. 91 , p. 627-634.

Landis, G.P., and Hofstra, A.H., 1991, Fluid inclusion gas chemistry as a potential minerals exploration tool: Case studies from Creede, CO, Jerritt Canyon, NV, Coeur d'Alene district, ID and MT, southern Alaska mesothermal veins, and mid-continent MVT's: Journal of Geochemical Exploration, v. 42, p. 25-59.

Morgan, G.B., Chou, I.-M., Pasteris, J.D., and Olsen, S.N., 1993, Re-equilibration of $\mathrm{CO}_{2}$ fluid inclusions at controlled hydrogen fugacities: Journal of Metamorphic Geology, v. 11, p. 155-164.

Mullis, J., 1988, Rapid subsidence and upthrusting in the Northern Apennines, deduced by fluid inclusion studies in quartz crystals from Porretta Terme: Schweizerische Mineralogische und Petrographische Mitteilungen, v. 68, p. 157-170.

Mullis, J., Poty, B., and Leroy, J., 1973, Nouvelles observations sur les inclusions a methane des quartz du Val d'Illiez: Compte Rendus, v. 277, p. 813-816.

Nwe, Y.Y., and Morteani, G., 1993, Fluid evolution in the $\mathrm{H}_{2} \mathrm{O}$ $\mathrm{CH}_{4}-\mathrm{CO}_{2}-\mathrm{NaCl}$ system during emerald mineralization at Gravelotte, Murchison Greenstone Belt, Norhtest Transvaal, South Africa: Geochimica et Cosmochimica Acta, v. 57, p. $89-103$. 
Ohmoto, H., and Kerrick, D., 1977, Devolatilization equilibria in graphitic systems: American Journal of Science, v. 227, p. 1013-1044.

Poutiainen, M., 1990, Evolution of a metamorphic fluid during progressive metamorphism in the Joroinen-Sulkava area, southeastern Finland, as indicated by fluid inclusions: Mineralogical Magazine, v. 54, p. 207-218.

Roedder, E., 1984, Fluid Inclusions, in Ribbe, P.H., ed., Reviews in mineralogy: Mineralogical Society of America, v. 12, p. 644 .

Selverstone, J., Franz, G., Thomas, S., and Getty, S., 1992, Fluid variability in $2 \mathrm{GPa}$ eclogites as an indicator of fluid behavior during subduction: Contributions to Mineralogy and Petrology, v. 112, p. 341-357.

Stern, L.A., Chamberlain, C.P., Barnett, D.E., and Ferry, J.M., 1992, Stable isotope evidence for regional-scale fluid migration in a Barrovian metamorphic terrane, Vermont, USA: Contributions to Mineralogy and Petrology, v. 112, p. 475-489.
Takach, N.E., Barker, C., and Kemp, M.K., 1987, Stability of natural gas in the deep subsurface: Thermodynamic calculation of equilibrium compositions: American Association of Petroleum Geologists Bulletin, v. 71, p. 322-333.

Touret, J., 1971, Le facies granulite en Norvege Meridionale II. Les inclusions fluides: Lithos, v. 4, no. 423-436.

Van den Kerkhof, A.M., 1988, The system $\mathrm{CO}_{2}-\mathrm{CH}_{4}-\mathrm{N}_{2}$ in fluid inclusions: Theoretical modelling and geological applications: Free University Amsterdam, unpublished Ph.D. thesis.

Verhoogen, J., Turner, F.J., Weiss, L.E., Wahrhaftig, C., and Fyfe, W.S., 1970, The Earth: An introduction to physical geology: New York, Holt, Rinehart and Winston, Inc.

Vrolijk, P., 1987, Tectonically driven fluid flow in the Kodiak accretionary complex, Alaska: Geology, v. 15, p. 466-469.

Whitney, D.L., 1992, Origin of $\mathrm{CO}_{2}$-rich fluid inclusions in leucosomes from the Skagit migmatites, North Cascades, Washington, USA: Journal of Metamorphic Geology, v. 10, p. $715-725$ 



\title{
Abiogenic Hydrocarbons and Mantle Helium in Oil and Gas Fields
}

\author{
By Peter D. Jenden ${ }^{1,2}$, David R. Hilton ${ }^{3,4}$, Isaac R. Kaplan ${ }^{1}$, and Harmon Craig ${ }^{3}$
}

\section{CONTENTS}

\begin{tabular}{|c|c|}
\hline 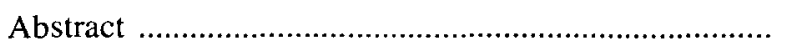 & 1 \\
\hline Introduction .................. & 2 \\
\hline Methane in the Mantle? & 2 \\
\hline Samples and Analytical Techniques & 3 \\
\hline Recognizing Mantle-Derived Hydrocarbons in the & \\
\hline Crust & 36 \\
\hline Carbon Isotope Distribution in Methane .............. & 36 \\
\hline Carbon isotope Variations Among the & \\
\hline 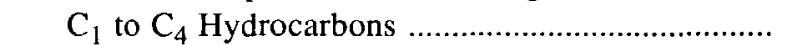 & 38 \\
\hline Helium Isotope Ratios in Commercial Gases ...... & 0 \\
\hline Methane Concentration and Helium-3 Abundance ...... & 12 \\
\hline Methane $\delta^{13} \mathrm{C}$ and Helium-3 Abundance ..................... & 46 \\
\hline Nonhydrocarbon Gases ......... & 49 \\
\hline Concluding Remarks ....... & 50 \\
\hline Acknowledgments ...... & 51 \\
\hline References Cited .. & \\
\hline
\end{tabular}

\footnotetext{
ABSTRACT

Most carbon degassed from Earth's interior is released as volcanic and hydrothermal carbon dioxide along oceanic spreading ridges and as volcanic and geothermal carbon

'Global Geochemistry Corporation, 6919 Eton Ave., Canoga Park, CA 90604 .

${ }^{2}$ Current address: Chevron Petroleum Technology Company, P.O. Box 446, La Habra, CA 90633.

${ }^{3}$ Scripps Institution of Oceanography, University of Califomia, San Diego, La Jolla, CA 92093.

${ }^{4}$ Current address: Free University of Berlin, FB 24, WE1 FR Geochemie, 1000 Berlin, Germany.
}

dioxide in continental regions. The chemistry of the earth's interior is poorly understood, however, and methane, rather than carbon dioxide, may be the dominant form of carbon throughout much of the mantle. According to one hypothesis (see Gold, this volume), methane from the mantle is continuously injected into the deep crust at lithospheric plate boundaries, ancient suture zones, and other areas of crustal weakness such as large meteorite impact sites. Where introduced beneath sedimentary basins this methane could accumulate in the conventional structural and stratigraphic traps in which we find petroleum. Geochemical evidence strongly argues that crude oil is of sedimentary (biogenic) origin, but the origins of natural gas are more complex and the proportion that may be derived from mantle (that is, abiogenic) sources is unknown.

Three specific analytical criteria have been used to help identify mantle-derived hydrocarbons in oil and gas fields: (1) methane $\delta^{13} \mathrm{C}>-25$ permil, heavier (more positive) than $\delta^{13} \mathrm{C}$ of methane derived from sedimentary organic carbon and more characteristic of known abiogenic methane occurrences; (2) "isotopic reversals" of the form methane $\delta^{13} \mathrm{C}>$ ethane $\delta^{13} \mathrm{C}>$ propane $\delta^{13} \mathrm{C}$, which are consistent with methane polymerization rather than hydrocarbon cracking; and (3) ${ }^{3} \mathrm{He} /{ }^{4} \mathrm{He}>0.1 \mathrm{R}_{\mathrm{A}}\left(\mathrm{R}_{\mathrm{A}}=\right.$ atmospheric ratio), possibly indicative of the presence of mantle-derived helium. Only 2.4 percent of the 1,700 commercial gases for which data have been assembled meet the first criterion. The small number of isotopic reversals that are present (second criterion) can be explained in many instances by mixing and oxidation of "isotopically normal" biogenic gases (methane $\delta^{13} \mathrm{C}<$ ethane $\delta^{13} \mathrm{C}<$ propane $\delta^{13} \mathrm{C}$ ) or by generation from isotopically heterogeneous organic matter. More than half of the 340 commercial gases for which ${ }^{3} \mathrm{He} /{ }^{4} \mathrm{He}$ ratios are available meet the third criterion, however, and the proportion of helium in these gases originating in the upper mantle ranges from undetectable to nearly 100 percent. 
Using a geometric mean of $3 \times 10^{6}$ for the molar $\mathrm{CH}_{4} /{ }^{3} \mathrm{He}$ ratio in uncontaminated, mantle-derived fluids from spreading ridges, mantle plumes and summit fumaroles of arc volcanoes (Welhan and Craig, 1983), the median abiogenic methane content of commercial gases is estimated to be less than $200 \mathrm{ppm}$ by volume (range $=0$ to $12,000 \mathrm{ppm}$ ). While admittedly a rough estimate, this calculation suggests that little confidence should be placed in the resource potential of abiogenic natural gas. In rift or convergent margin basins, hot magmatic fluids can strip methane and other volatiles from metamorphic basement and overlying sedimentary rocks, however, and commercial accumulations of this type of gas may be present (see Burruss, this volume). The economic value of such reserves could be impaired by dilution with carbon dioxide and possibly nitrogen.

\section{INTRODUCTION}

Inorganic, or "abiogenic," hypotheses for the origin of crude oil and natural gas can be traced back at least to the early 19th century when associations were first noted between mud volcanoes, petroleum seeps and igneous activity (see review by Dott and Reynolds, 1969, p. 15-45). In the late 19th century, M. Berthelot suggested that petroleum might originate by the reaction of deep-seated alkali metal with recycled crustal carbon dioxide. Shortly afterwards, Dmitri Mendeléeff proposed his famous hypothesis that oil and gas are generated by the hydration of iron carbides (Dott and Reynolds, 1969). A highly detailed modern version of the carbide hypothesis has recently been proposed by Hunt and others (1992). Among the variety of other mechanisms which have been suggested, FischerTropsch-type synthesis from carbon dioxide and hydrogen has figured prominently in many modern proposals (for example, see Szatmari, 1989).

The most far-reaching abiogenic proposal in recent years is the "deep-earth gas" hypothesis (Gold, 1979, 1985, 1987, this volume; Gold and Soter, 1980, 1982). Gold postulates that mantle methane is continuously injected into the crust at areas of weakness: lithospheric plate boundaries, ancient suture zones, and meteorite-impact sites. Under conditions of slow upward migration and cooling, some of this methane is assumed to polymerize, forming higher molecular weight hydrocarbons and crude oil.

Numerous arguments for the abiogenic origin of oil and natural gas have been offered in the above references and in other papers (Porfir'ev, 1974, 1975; Kropotkin and Valiaev, 1976; Giardini and Melton, 1983; MacDonald, 1983; Kropotkin, 1985). Often-cited arguments are (1) the abundance of methane in the outer planets of the solar system, (2) the abundance and variety of organic compounds in certain meteorites that may have been incorporated into the primitive earth, (3) the occurrence of bitumen and hydrocarbon gases in igneous rocks, (4) the association be- tween prolific hydrocarbon accumulations and major faults that could act as migration pathways for deep-seated fluids, and (5) the fact that mantle-derived helium is found together with methane and higher molecular weight hydrocarbons in some geothermal and commercial natural gases.

Most geochemists view these arguments as weak and circumstantial, the solid consensus being that economic accumulations of oil and gas are "biogenic," a byproduct of the bacterial and thermochemical alteration of biological detritus in deeply buried sedimentary or metasedimentary rocks. Hydrocarbons filling vugs and fractures in many igneous rocks may have a biogenic origin (Parnell, 1988). Faults associated with prolific oil and gas production often cut great thicknesses of organic-rich sedimentary rocks (Price, 1980). Furthermore, although it merits attention, the occurrence of mantle-derived helium in some oil and gas fields does not prove a nonsedimentary origin for the associated hydrocarbons. Claims by Gold and others that biological marker studies, pyrolysis experiments, kinetic modelling, and stable-isotope data do not provide strong evidence for the biogenesis of crude oil have met with sharp criticism (Treibs and Hirner, 1982; Planetary Sciences Unit, University of Cambridge, 1982; Marland, 1984; Philp and Brassell, 1986). However, as Gold (1979) and MacDonald (1983) have noted, the evidence for biogenesis of natural gas is not as strong. Low-molecular-weight hydrocarbons do not retain structural information about their precursors (for example, see Mango, 1987). The carbonisotope geochemistry of the light hydrocarbons is not sufficiently constrained to rule out mixing between biogenic hydrocarbons and small amounts of abiogenic hydrocarbons (see, for example, Schoell, 1984a; Jenden and others, 1988b). In addition, the origin of many dry, nonassociated gases, particularly those with high concentrations of carbon dioxide and nitrogen, is not clearly understood (Smith and others, 1985; Jenden and others, 1988a).

\section{METHANE IN THE MANTLE?}

The thermodynamic stability of methane in the Earth's mantle is a critical, unresolved issue. Considerable differences exist between measured and calculated oxygen fugacities $\left(f_{\mathrm{O}_{2}}\right)$ in ultramafic mineral assemblages from the uppermost mantle (Ulmer and others, 1987; Wood and others, 1990). If the measured $f_{\mathrm{O}_{2}}$ values near the ironwustite oxygen buffer are reliable, then $\mathrm{CH}_{4} /\left(\mathrm{CH}_{4}+\mathrm{CO}_{2}\right)$ ratios may range from $<0.1$ to nearly 1 . In any case, Wood and others (1990) suggest that methane may become increasingly abundant below the transition from spinel to garnet (approximately $70 \mathrm{~km}$ ) if ferric iron enters the garnet phase.

The presence of methane in the deeper mantle is qualitatively consistent with the occurrence of reduced gases in fluid inclusions in diamonds (formed at depths $\geq 150 \mathrm{~km}$ ) 
and the distribution of diamond $\delta^{13} \mathrm{C}$ values (Deines, 1980b; Haggerty, 1986; Galimov, 1991). Although fluidinclusion studies show that carbon dioxide is by far the most abundant volatile carbon compound in volcanic rocks, fluid inclusions rich in methane, hydrogen, and complex organic compounds occur in many alkalic intrusives and kimberlites (Roedder, 1984, p. 404, 507-514). Thermodynamic data show that, in the presence of graphite and an oxygen-buffering mineral assemblage, fluid inclusions initially charged with carbon dioxide could become methane-rich upon cooling (Gerlach, 1980; Kreulen, 1987; Burruss, this volume).

Another important issue is how mantle volatiles get into crustal reservoirs. Where sedimentary basins are formed by crustal extension, mantle volatiles could be introduced by melting of the underlying asthenosphere (Oxburgh and others, 1986). Lawrence and Taviani (1988) speculated that isotopic anomalies in the interstitial waters of sediments beneath the Norwegian Sea were generated by the oxidation of abiogenic methane and hydrogen derived from the upper mantle. A second possibility is that in basins near convergent plate margins (and possibly in intraplate basins overlying ancient suture zones), mantle volatiles might be entrained in hydrothermal fluids generated from subducted lithosphere (Gwilliam, 1982). Here, however, mantle-derived methane could be diluted to insignificant concentrations by crustal volatiles, making its presence a matter of academic rather than commercial interest. It is worth noting that Poreda and others (1988) found no evidence for mantle helium in gases from the Barbados accretionary prism. A third possibility, proposed by Gold (1979) and Gold and Soter (1985), is that fluids migrate continuously out of the mantle and into the crust guided by fracture propagation. This speculative mechanism could provide a means for the injection of abiogenic methane into almost any crustal reservoir, regardless of its tectonic environment.

Although skepticism is prudent (North, 1982), the potential contribution of abiogenic methane to world gas reserves could be large. The net accumulation rate of organic carbon in sedimentary rocks is approximately $3.2 \times 10^{9} \mathrm{~kg} / \mathrm{yr}$ (Tissot and Welte, 1984, p. 9). Given this figure, and an overall thermal alteration reaction of the form

$$
\mathrm{CH}_{1.0} \text { (kerogen) } \rightarrow 0.75 \mathrm{C} \text { (graphite) }+0.25 \mathrm{CH}_{4} \text {, }
$$

the maximum annual production of biogenic methane cannot exceed $1.5 \times 10^{9} \mathrm{~m}^{3}\left(0.8 \times 10^{9} \mathrm{~kg} \mathrm{C}\right)$. In comparison, roughly $26 \times 10^{9} \mathrm{~kg}$ of mantle carbon $\left(48 \times 10^{9} \mathrm{~m}^{3} \mathrm{CO}_{2}\right)$ are annually degassed into the ocean at spreading ridges (Des Marais, 1985; Marty and Jambon, 1987), and an additional large amount is released by subaerial volcanism and geothermal activity. These data suggest that if methane composed only 1 percent of the total flux of carbon out of the mantle, the biogenic and abiogenic methane production rates would be of comparable magnitude. (For comparison, the worldwide total of produced gas and recoverable reserves as of 1990 is estimated to be $1.7 \times 10^{14} \mathrm{~m}^{3}$ (Masters and others, 1992).)

In order to quantify the resource potential of abiogenic methane, two questions must be addressed: (1) What are the chemical and stable-isotope characteristics of abiogenic gas? and (2) What proportion of commercial natural gas reasonably can be attributed to abiogenic sources? To help answer these two questions we have combined published data with carbon and helium isotope measurements from more than 600 commercial natural gases collected from 1981 to 1987 by Global Geochemistry Corporation under contract to the Gas Research Institute (GRI), Chicago (see Jenden and Kaplan, 1989a). Question (1) is very difficult to address with certainty and some will no doubt object strongly to our conclusions. In response, we suggest that because the biogenic theory can easily account for most (if not all) commercial oil and gas accumulations, the resource potential of abiogenic petroleum is likely to be dismissed until proponents offer an alternative scheme for distinguishing abiogenic and biogenic hydrocarbons.

\section{SAMPLES AND ANALYTICAL TECHNIQUES}

GRI samples were collected primarily from U.S. oil and gas fields, in Precambrian to Pleistocene reservoirs, at depths ranging from less than $150 \mathrm{~m}$ to nearly $7,000 \mathrm{~m}$. A description of the GRI samples together with sampling procedures, analytical methods, and results is available from the National Technical Information Service (Jenden and Kaplan, 1989a). Sampling and analytical procedures are also discussed by Poreda and others (1986), Jenden and others (1988a), and Jenden and Kaplan (1989b).

${ }^{13} \mathrm{C} /{ }^{12} \mathrm{C}$ ratios for methane, ethane, propane, $n$-butane, and carbon dioxide were measured at Global Geochemistry Corporation and are reported in $\delta$-notation as parts-perthousand (permil) deviations from PDB (Peedee belemnite) standard:

$$
\delta^{13} \mathrm{C}(\text { permil })=1000 \times\left[\left({ }^{13} \mathrm{C} /{ }^{12} \mathrm{C}\right)_{\text {sample }} /\left({ }^{13} \mathrm{C} /{ }^{12} \mathrm{C}\right)_{\mathrm{PDB}}-1\right] .
$$

The $1 \sigma$ precision of these measurements is approximately 0.1 permil.

${ }^{3} \mathrm{He} /{ }^{4} \mathrm{He}$ ratios were measured at Scripps Institution of Oceanography and have been corrected for atmospheric contamination as follows:

$$
\begin{aligned}
& \left({ }^{3} \mathrm{He} /{ }^{4} \mathrm{He}\right)_{\text {corrected }}= \\
& {\left[\left({ }^{3} \mathrm{He} /{ }^{4} \mathrm{He}\right)_{\text {measured }} \times \mathrm{X}-\left({ }^{3} \mathrm{He} /{ }^{4} \mathrm{He}\right)_{\text {air }}\right] /[\mathrm{X}-1]}
\end{aligned}
$$

where $\mathrm{X}=(\mathrm{He} / \mathrm{Ne})_{\text {measured }} /(\mathrm{He} / \mathrm{Ne})_{\text {air }}$ The ratios are reported in table 1 relative to the air ratio $\left(R_{A}=1.4 \times 10^{-6}\right)$ in the form $R / R_{A}$ and have a relative precision of better than \pm 3 percent. 
Table 1. Helium isotope data for commercial gases collected in Gas Research Institute (GRI) study (Jenden and Kaplan, 1989a).

[Abbreviations as follows: Cret, Cretaceous; Dev, Devonian; Eoc, Eocene; Jur, Jurassic; Mio, Miocene; Olig, Oligocene; Ord, Ordovician; Penn, Pennsylvanian; Perm, Permian; Plei, Pleistocene; Plio, Pliocene; Sil, Silurian; $m$, meters; ppm, parts per million; R/R $\mathbf{A}$, ratio in sample divided by ratio in air; $\%$, volume percent; --, not available]

\begin{tabular}{|c|c|c|c|c|c|c|c|c|c|c|c|c|}
\hline $\begin{array}{l}\text { Sample } \\
\text { No. } \\
\end{array}$ & Field & $\begin{array}{c}\text { Reservoir } \\
\text { age }\end{array}$ & $\begin{array}{l}\text { Depth } \\
\text { (m) }\end{array}$ & $\begin{array}{c}C_{1} \\
(\%)\end{array}$ & $\begin{array}{l}\mathrm{C}_{2+} \\
(\%)\end{array}$ & $\begin{array}{l}\mathrm{CO}_{2} \\
(\%)\end{array}$ & $\begin{array}{l}\mathrm{N}_{2} \\
(\%)\end{array}$ & $\begin{array}{c}\mathrm{O}_{2} \\
(\%)\end{array}$ & $\begin{array}{c}\mathrm{He} \\
(\mathrm{ppm})\end{array}$ & $\begin{array}{c}\delta^{13} \mathrm{C}\left(\mathrm{CH}_{4}\right) \\
\text { (permil) }\end{array}$ & $\begin{array}{c}{ }^{3} \mathrm{He} /{ }^{4} \mathrm{He} \\
\left(\mathrm{R} / \mathrm{R}_{\mathrm{A}}\right)\end{array}$ & $\begin{array}{c}\mathrm{CH}_{4} /^{3} \mathrm{He} \\
\left(\mathrm{x} 10^{9}\right)\end{array}$ \\
\hline \multicolumn{13}{|c|}{ Northern California } \\
\hline 1197 & Tompkins Hill & Plio & 1,628 & 91.4 & 1.30 & 0.043 & 3.61 & 0.919 & 4.5 & -32.2 & 0.150 & 145 \\
\hline 1196 & Tompkins Hill & Plio & 1,463 & 94.3 & 1.61 & 0.025 & 1.36 & 0.354 & 5.0 & -31.9 & 0.145 & 134 \\
\hline 1123 & Sutter Buttes & Cret & 1,122 & 98.8 & 0.202 & 0.048 & 1.01 & 0.021 & 10.6 & -28.0 & 0.823 & 66.6 \\
\hline 1132 & Bounde Creek & Cret & 1,896 & 96.8 & 0.247 & 0.040 & 2.33 & 0.014 & 15.1 & -26.0 & 0.730 & 45.8 \\
\hline 1119 & Rio Vista & Cret & 2,717 & 94.8 & 5.08 & 0.457 & 0.697 & 0.018 & 16.6 & -36.0 & 0.144 & 40.8 \\
\hline 1126 & Freeport & Cret & 2,213 & 62.3 & 0.070 & 0.001 & 38.4 & 0.013 & 26.0 & -15.2 & 1.16 & 17.1 \\
\hline 1125 & Poppy Ridge & Cret & 2,198 & 80.3 & 0.150 & 0.194 & 19.5 & 0.019 & 27.0 & -19.1 & 0.829 & 21.2 \\
\hline 1122 & Sutter Buttes & Cret & 1,856 & 94.8 & 0.292 & 0.114 & 3.86 & 0.510 & 30.0 & -29.8 & 1.10 & 22.6 \\
\hline 1110 & Rio Vista & Cret & 1,384 & 94.2 & 4.15 & 0.642 & 1.43 & 0.027 & 31.9 & -38.5 & 0.111 & 21.1 \\
\hline 991 & Union Island & Cret & 2,972 & 86.9 & 0.379 & 0.615 & 11.1 & 0.027 & 33.0 & -23.8 & 1.26 & 18.8 \\
\hline 1031 & Florin & Cret & 1,158 & 87.9 & 0.026 & 0.020 & 10.1 & 0.007 & 38.3 & -29.2 & 0.421 & 16.4 \\
\hline 1004 & Butte, West & Cret & 1,554 & 92.1 & 0.358 & 0.052 & 7.00 & 0.005 & 44.5 & -31.1 & 1.71 & 14.8 \\
\hline 1030 & Harte & Cret & 1,387 & 94.7 & 0.486 & 0.062 & 4.66 & 0.006 & 52.1 & -52.4 & 0.256 & 13.0 \\
\hline 1121 & Wild Goose & Cret & 765 & 77.9 & 0.024 & 0.003 & 21.8 & 0.020 & 52.6 & -27.0 & 1.97 & 10.6 \\
\hline 1129 & Robbins & Cret & 2,038 & 12.2 & 0.061 & 0.032 & 87.4 & 0.026 & 54.0 & -22.3 & 0.990 & 1.61 \\
\hline 1130 & Robbins & Cret & 2,051 & 12.6 & 0.037 & 0.030 & 87.2 & 0.009 & 59.2 & -21.2 & 0.861 & 1.52 \\
\hline 1127 & Nicolaus & Cret & 1,737 & 35.3 & 0.041 & 0.011 & 65.1 & 0.046 & 59.4 & -20.0 & 0.990 & 4.25 \\
\hline 1124 & Moon Bend & Cret & 1,576 & 80.1 & 0.590 & 0.002 & 17.6 & 0.018 & 67.7 & -30.7 & 2.74 & 8.45 \\
\hline${ }^{1} 1025$ & Corning & Plio & 430 & 75.0 & 0.006 & 0.002 & 23.8 & 0.005 & 91.3 & -42.9 & 0.602 & 5.87 \\
\hline 1079 & Lodi, Southeast & Eoc & 905 & 51.3 & 0.006 & 0.094 & 48.4 & 0.008 & 97.0 & -46.0 & 1.01 & 3.78 \\
\hline 1146 & Chowchilla & Cret & 2,415 & 40.6 & 0.482 & 0.012 & 59.1 & 0.040 & 102 & -34.0 & 0.900 & 2.84 \\
\hline 1151 & Gill Ranch & Cret & 1,753 & 90.2 & 0.929 & 0.007 & 8.35 & 0.014 & 104 & -47.9 & 0.307 & 6.19 \\
\hline 1150 & Moffat Ranch & Eoc & 1,246 & 91.4 & 0.370 & 0.059 & 7.61 & 0.021 & 104 & -51.7 & 0.320 & 6.27 \\
\hline 1107 & Crossroads & Cret & 1,234 & 92.0 & 0.094 & 0.036 & 7.64 & 0.017 & 106 & -46.1 & 0.138 & 6.20 \\
\hline 1043 & Durham & Eoc & 649 & 70.3 & 0.051 & 0.004 & 29.2 & 0.043 & 117 & -26.7 & 0.624 & 4.29 \\
\hline 1148 & Chowchilla & Mio & 794 & 88.2 & 0.029 & 0.192 & 10.8 & 0.013 & 129 & -53.8 & 0.361 & 4.88 \\
\hline
\end{tabular}

Southern California

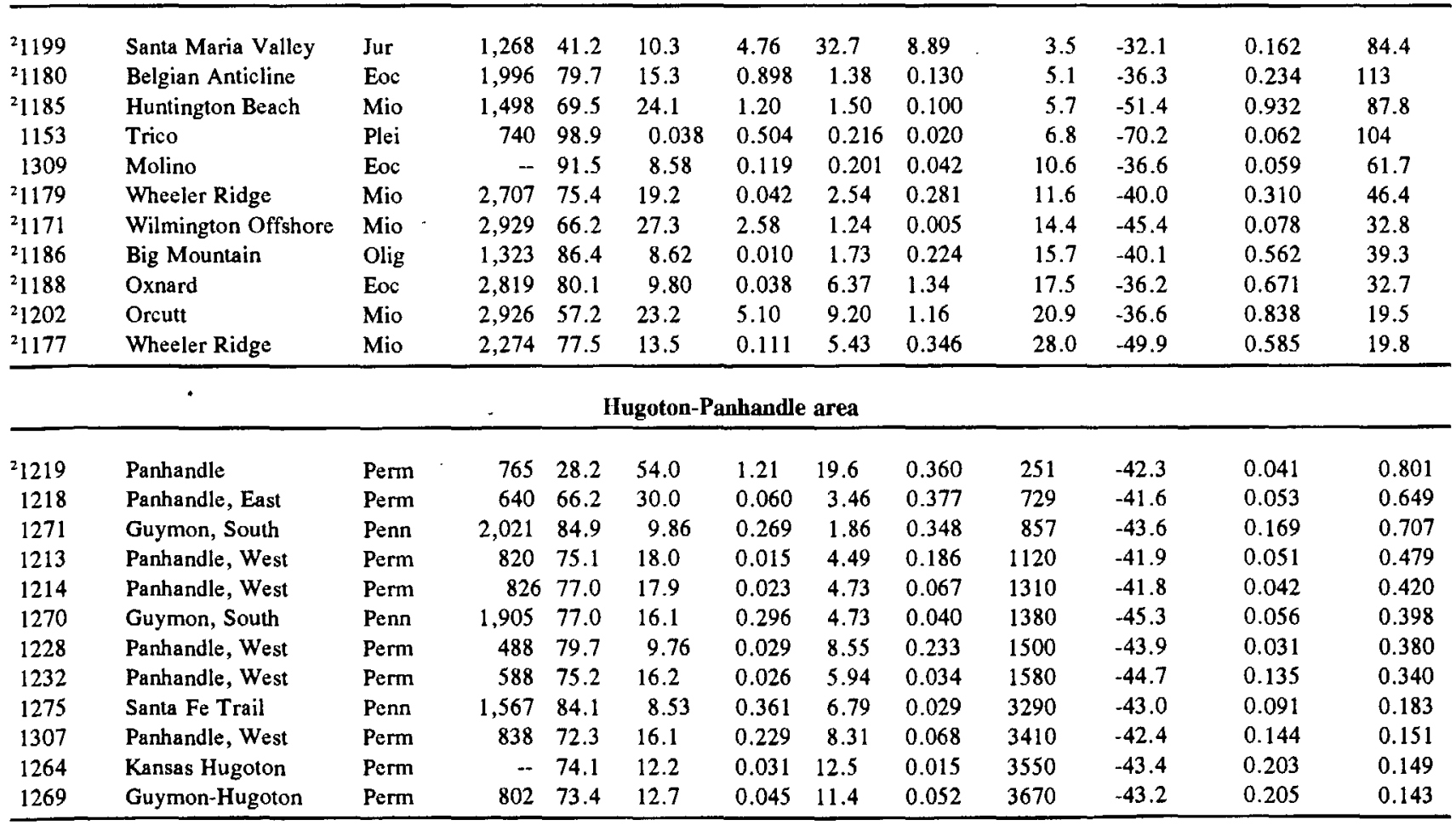

See footnotes at end of table. 
Table 1. Helium isotope data for commercial gases collected in Gas Research Institute (GRI) study (Jenden and Kaplan, 1989a)Continued.

\begin{tabular}{|c|c|c|c|c|c|c|c|c|c|c|c|c|}
\hline $\begin{array}{l}\text { Sample } \\
\text { No. } \\
\end{array}$ & Field & $\begin{array}{c}\text { Reservoir } \\
\text { age }\end{array}$ & $\begin{array}{c}\text { Depth } \\
(\mathrm{m})\end{array}$ & $\begin{array}{l}\mathrm{C}_{1} \\
(\%) \\
\end{array}$ & $\begin{array}{l}\mathrm{C}_{2+} \\
(\%) \\
\end{array}$ & $\begin{array}{l}\mathrm{CO}_{2} \\
(\%) \\
\end{array}$ & $\begin{array}{l}\mathrm{N}_{2} \\
(\%)\end{array}$ & $\begin{array}{r}\mathrm{O}_{2} \\
(\%) \\
\end{array}$ & $\begin{array}{c}\mathrm{He} \\
(\mathrm{ppm})\end{array}$ & $\begin{array}{c}\delta^{13} \mathrm{C}\left(\mathrm{CH}_{4}\right) \\
\text { (permil) } \\
\end{array}$ & $\begin{array}{c}{ }^{3} \mathrm{He} /{ }^{4} \mathrm{He} \\
\left(\mathrm{R} / \mathrm{R}_{\mathrm{A}}\right)\end{array}$ & $\begin{array}{c}\mathrm{CH}_{4} /{ }^{3} \mathrm{He} \\
\left(\times 10^{9}\right) \\
\end{array}$ \\
\hline \multicolumn{13}{|c|}{ Hugoton-Panhandle area - Continued } \\
\hline 1262 & Kansas Hugoton & Perm & 780 & 73.8 & 12.3 & 0.020 & 14.2 & 0.000 & 3890 & -43.4 & 0.198 & 0.135 \\
\hline 1252 & Kansas Hugoton & Perm & 768 & 73.0 & 12.2 & 0.021 & 14.4 & 0.115 & 3960 & -43.5 & 0.197 & 0.132 \\
\hline 1274 & Guymon-Hugoton & Perm & -- & 74.2 & 12.0 & 0.026 & 11.8 & 0.017 & 4010 & -43.2 & 0.197 & 0.132 \\
\hline 1256 & Kansas Hugoton & Perm & 738 & 70.7 & 12.2 & 0.025 & 16.3 & 0.035 & 4160 & -43.8 & 0.163 & 0.121 \\
\hline 1281 & Kansas Hugoton & Perm & 759 & 70.3 & 11.7 & 0.018 & 17.1 & 0.241 & 4210 & -43.8 & 0.161 & 0.119 \\
\hline 1278 & Kansas Hugoton & Perm & 814 & 70.9 & 11.9 & 0.030 & 16.5 & 0.210 & 4520 & -43.7 & 0.186 & 0.112 \\
\hline 1245 & Guymon-Hugoton & Perm & 817 & 72.0 & 11.7 & 0.056 & 14.9 & 0.119 & 4610 & -43.0 & 0.191 & 0.111 \\
\hline 1276 & Kansas Hugoton & Perm & 689 & 68.7 & 11.0 & 0.033 & 19.2 & 0.432 & 5250 & -43.6 & 0.192 & 0.093 \\
\hline 1259 & Kansas Hugoton & Perm & 783 & 66.1 & 9.58 & 0.058 & 23.8 & 0.097 & 5410 & -44.3 & 0.093 & 0.087 \\
\hline 1277 & Dunkle & Penn & 899 & 65.6 & 7.84 & 0.046 & 25.2 & 0.240 & 5830 & -43.5 & 0.159 & 0.080 \\
\hline 1231 & Panhandle, West & Perm & 866 & 66.7 & 20.2 & 0.198 & 10.9 & 0.022 & 6080 & -42.6 & 0.125 & 0.078 \\
\hline 1265 & Guymon-Hugoton & Perm & 817 & 48.2 & 11.4 & 0.054 & 36.6 & 0.252 & 6220 & -42.6 & 0.244 & 0.055 \\
\hline 1273 & Guymon-Hugoton & Perm & 863 & 70.3 & 9.58 & 0.022 & 17.0 & 0.275 & 6270 & -43.9 & 0.043 & 0.080 \\
\hline 1258 & Kansas Hugoton & Perm & 814 & 61.6 & 10.4 & 0.024 & 27.2 & 0.088 & 6330 & -43.9 & 0.103 & 0.070 \\
\hline 1221 & Panhandle, West & Perm & 814 & 76.0 & 10.7 & 0.152 & 12.6 & 0.085 & 6500 & -43.3 & 0.147 & 0.083 \\
\hline 1280 & Kansas Hugoton & Perm & 820 & 70.4 & 4.01 & 0.017 & 24.5 & 0.121 & 6590 & -45.4 & 0.073 & 0.076 \\
\hline 1242 & Texas Hugoton & Perm & 960 & 68.6 & 13.8 & 0.340 & 14.8 & 0.084 & 7000 & -42.8 & 0.183 & 0.070 \\
\hline 1237 & Panhandle, West & Perm & 994 & 71.6 & 11.6 & 1.13 & 13.7 & 0.158 & 7300 & -42.6 & 0.144 & 0.070 \\
\hline 1243 & Texas Hugoton & Perm & 930 & 67.2 & 11.9 & 0.098 & 18.5 & 0.104 & 7710 & -42.3 & 0.175 & 0.062 \\
\hline 1283 & Kansas Hugoton & Perm & 780 & 51.5 & 7.71 & 0.021 & 39.1 & 0.054 & 7830 & -43.6 & 0.084 & 0.047 \\
\hline 1240 & Texas Hugoton & Perm & 945 & 70.8 & 11.6 & 0.003 & 15.7 & 0.097 & 8000 & -44.5 & 0.183 & 0.063 \\
\hline 1260 & Kansas Hugoton & Perm & 811 & 55.8 & 5.51 & 0.016 & 37.1 & 0.147 & 8030 & -44.8 & 0.057 & 0.050 \\
\hline 1257 & Kansas Hugoton & Perm & 683 & 49.6 & 6.71 & 0.001 & 43.5 & 0.008 & 9150 & -42.1 & 0.132 & 0.039 \\
\hline 1248 & Guymon-Hugoton & Perm & 820 & 58.2 & 11.6 & 0.085 & 28.2 & 0.059 & 12600 & -42.7 & 0.228 & 0.033 \\
\hline 1236 & Panhandle, West & Perm & 997 & 65.6 & 6.74 & 0.939 & 24.1 & 0.157 & 13700 & -43.0 & 0.105 & 0.034 \\
\hline
\end{tabular}

Central and eastern Kansas

\begin{tabular}{|c|c|c|c|c|c|c|c|c|c|c|c|c|}
\hline${ }^{1} 1048$ & Wilde & Penn & 403 & 67.3 & 4.13 & 0.125 & 26.3 & 0.003 & -- & -42.2 & 0.100 & -- \\
\hline${ }^{2} 1204$ & Silver City & Cret & 274 & 94.6 & 0.328 & 0.207 & 3.30 & 0.040 & 416 & -63.2 & 0.092 & 1.62 \\
\hline 1090 & Thayer & Penn & 154 & 96.8 & 0.090 & 0.351 & 2.33 & 0.013 & 1330 & -65.0 & 0.070 & 0.520 \\
\hline 1049 & Wilde & Perm & 148 & 78.0 & 6.46 & 0.001 & 14.2 & 0.009 & 6680 & -41.2 & 0.091 & 0.083 \\
\hline${ }^{1} 1047$ & Wilde & Penn & 422 & 73.7 & 7.80 & 0.088 & 17.4 & 0.003 & 6810 & -41.1 & 0.091 & 0.077 \\
\hline 1098 & Sterling & Perm & 591 & 69.1 & 4.44 & 0.035 & 24.2 & 0.101 & 9360 & -41.0 & 0.097 & 0.053 \\
\hline 1136 & Reichel, West & Perm & 629 & 63.6 & 3.82 & 0.007 & 30.5 & 0.025 & 21100 & -40.0 & 0.097 & 0.022 \\
\hline 1145 & Zook & Ord & 1,234 & 68.1 & 6.79 & 0.208 & 22.0 & 0.022 & 22800 & -39.6 & 0.082 & 0.021 \\
\hline \multicolumn{13}{|c|}{ New York } \\
\hline 1343 & Bradford & Dev & 1,315 & 83.6 & 15.6 & 0.024 & 0.512 & 0.017 & 227 & -44.4 & 0.013 & 2.63 \\
\hline 1337 & Painted Post & Dev & 1,128 & 95.1 & 2.86 & 0.078 & 0.415 & 0.022 & 276 & -37.4 & 0.016 & 2.46 \\
\hline 1335 & Elmira, East & Dev & 893 & 96.8 & 1.54 & 0.028 & 0.733 & 0.033 & 292 & -35.8 & 0.015 & 2.37 \\
\hline 1347 & Reading Center & Ord & 2,466 & 98.4 & 0.790 & 0.005 & 1.02 & 0.041 & 437 & -30.7 & 0.035 & 1.61 \\
\hline 1340 & Houghton & Dev & 689 & 78.0 & 20.5 & 0.001 & 1.08 & 0.047 & 444 & -47.2 & 0.020 & 1.25 \\
\hline 1346 & Lebanon & Sil & 834 & 97.8 & 1.44 & 0.014 & 0.461 & 0.014 & 518 & -34.8 & 0.018 & 1.35 \\
\hline 1333 & Dansville & Dev & 448 & 84.0 & 14.4 & 0.005 & 0.914 & 0.029 & 661 & -47.3 & 0.026 & 0.908 \\
\hline${ }^{2} 1345$ & Ellery Center & Sil & 811 & 71.3 & 26.2 & 0.023 & 1.91 & 0.206 & 755 & -47.8 & 0.020 & 0.674 \\
\hline 1334 & Beech Hill-Indepen & Dev & 366 & 81.3 & 15.1 & 0.007 & 0.518 & 0.044 & 907 & -46.2 & 0.021 & 0.640 \\
\hline 1342 & Lakeshore & Sil & 1,190 & 92.8 & 3.20 & 0.008 & 3.54 & 0.017 & 1040 & -35.4 & 0.016 & 0.637 \\
\hline 1336 & Fayette-Waterloo & Ord & 607 & 96.2 & 1.45 & 0.008 & 2.06 & 0.061 & 1120 & -30.9 & 0.019 & 0.613 \\
\hline 1341 & Lakeshore & Sil & 1,241 & 90.3 & 4.22 & 0.000 & 4.56 & 0.029 & 1300 & -36.8 & 0.019 & 0.496 \\
\hline 1339 & Auburn & Sil & 360 & 96.2 & 0.912 & 0.010 & 1.61 & 0.039 & 1540 & -31.5 & 0.023 & 0.446 \\
\hline${ }^{2} 1344$ & Fredonia & Dev & 320 & 78.9 & 18.4 & 0.090 & 1.83 & 0.132 & 1550 & -47.9 & 0.018 & 0.363 \\
\hline 1338 & Bergen & Sil & 180 & 86.6 & 7.69 & 0.012 & 4.04 & 0.025 & 2150 & -42.6 & 0.022 & 0.288 \\
\hline
\end{tabular}

See footnotes at end of table. 
Table 1. Helium isotope data for commercial gases collected in Gas Research Institute (GRI) study (Jenden and Kaplan, 1989a)Continued.

\begin{tabular}{|c|c|c|c|c|c|c|c|c|c|c|c|c|}
\hline $\begin{array}{l}\text { Sample } \\
\text { No. }\end{array}$ & Field & $\begin{array}{c}\text { Reservoir } \\
\text { age }\end{array}$ & $\begin{array}{l}\text { Depth } \\
\text { (m) }\end{array}$ & $\begin{array}{l}C_{1} \\
(\%)\end{array}$ & $\begin{array}{l}\mathrm{C}_{2+} \\
(\%)\end{array}$ & $\begin{array}{l}\mathrm{CO}_{2} \\
(\%)\end{array}$ & $\begin{array}{l}\mathrm{N}_{2} \\
(\%)\end{array}$ & $\begin{array}{l}\mathrm{O}_{2} \\
(\%)\end{array}$ & $\begin{array}{c}\mathrm{He} \\
(\mathrm{ppm})\end{array}$ & $\begin{array}{c}\delta^{13} \mathrm{C}\left(\mathrm{CH}_{4}\right) \\
\text { (permil) }\end{array}$ & $\begin{array}{c}{ }^{3} \mathrm{He} /{ }^{4} \mathrm{He} \\
\left(\mathrm{R} / \mathbf{R}_{\mathrm{A}}\right)\end{array}$ & $\begin{array}{c}\mathrm{CH}_{4} /{ }^{3} \mathrm{He} \\
\left(\mathrm{x} 10^{9}\right)\end{array}$ \\
\hline \multicolumn{13}{|c|}{ Miscellaneous U.S. locations } \\
\hline 1066 & Puckett-WestBend, TX & Penn & 6,774 & 93.2 & 0.178 & 4.99 & 0.359 & 0.009 & 125 & -31.6 & 0.013 & 5.32 \\
\hline 1063 & Greasewood, TX & Sil & 3,137 & 92.5 & 0.390 & 5.74 & 0.567 & 0.007 & 143 & -36.6 & 0.099 & 4.62 \\
\hline 1037 & Sheep Mountain, CO & Jur & 960 & 2.13 & 0.254 & 97.3 & 0.666 & 0.004 & 180 & -40.8 & 0.980 & 0.085 \\
\hline 1034 & Sheep Mountain, CO & Cret & 959 & 4.21 & 0.278 & 94.8 & 1.54 & 0.005 & 612 & -41.1 & 1.02 & 0.049 \\
\hline 1203 & Sidney, West, NE & Cret & 1,509 & 73.1 & 15.8 & 3.99 & 4.23 & 0.035 & 733 & -54.6 & 0.233 & 0.712 \\
\hline 1192 & Wildcat, WV & Sil & 2,490 & 13.0 & 0.138 & 83.5 & 2.23 & 0.107 & 1060 & -35.7 & 0.331 & 0.087 \\
\hline 1074 & Indian Creek, WV & Sil & 2,058 & 33.4 & 0.277 & 61.3 & 2.73 & 0.012 & 1140 & -34.5 & 0.210 & 0.209 \\
\hline \multicolumn{13}{|c|}{ Gulf of Thailand } \\
\hline 1291 & Erawan & Mio & 2,652 & 62.2 & 17.5 & 21.6 & 0.351 & 0.025 & 15.2 & -41.1 & 0.037 & 29.2 \\
\hline 1299 & Platong & Mio & 2,097 & 24.3 & 4.00 & 71.9 & 0.800 & 0.025 & 24.8 & -39.2 & 1.89 & 6.98 \\
\hline 1292 & Erawan & Mio & 1,929 & 67.5 & 18.5 & 8.68 & 1.18 & 0.053 & 25.3 & -41.7 & 0.032 & 19.0 \\
\hline 1298 & Platong & Mio & 1,908 & 57.7 & 18.1 & 24.8 & 0.315 & 0.027 & 27.1 & -44.6 & 0.345 & 15.2 \\
\hline 1296 & Erawan & Mio & 2,174 & 66.4 & 16.3 & 13.6 & 1.81 & 0.020 & 30.7 & -40.5 & 0.039 & 15.4 \\
\hline 1288 & Erawan & Mio & 1,378 & 80.0 & 17.7 & 3.15 & 0.652 & 0.016 & 34.0 & -45.9 & 0.025 & 16.8 \\
\hline
\end{tabular}

${ }^{1}$ Ratio ${ }^{3} \mathrm{He} /{ }^{4} \mathrm{He}$ measured by R.I. Hill and R.K. O'Nions, University of Cambridge.

${ }^{2}$ Associated gas (produced from reservoirs containing an oil phase).

Many of the GRI data have been published in papers that address the origin and characteristics of gases from the California Great Valley (Poreda and others, 1986; Jenden and others, 1988a; Jenden and Kaplan, 1989b), U.S. Midcontinent (Hilton and others, 1988; Jenden and others, 1988b), Gulf of Thailand (Poreda and others, 1988), Los Angeles basin (Jeffrey and others, 1991), and northern Appalachian basin (Hilton and others, 1988; Jenden and others, 1993).

\section{RECOGNIZING MANTLE-DERIVED HYDROCARBONS IN THE CRUST}

At present there is little consensus regarding the compositional and stable isotopic variability of abiogenic gas in the crust. As a conservative first approximation we suggest that natural gases derived in whole or in part from abiogenic sources will be characterized by one or more of the following properties: (1) methane $\delta^{13} \mathrm{C}>-25$ permil, (2) methane $\delta^{13} \mathrm{C}>$ ethane $\delta^{13} \mathrm{C}>$ propane $\delta^{13} \mathrm{C}>n$-butane $\delta^{13} \mathrm{C}$, and (3) helium isotope ratios significantly greater than crustal radiogenic values (for example $>0.1 R_{A}$ ). The absence of suitable sedimentary source rocks provides additional support for an abiogenic origin, but the application of this criterion would limit our discussion to noncommercial hydrocarbon occurrences. The rationale behind the three criteria listed above and a discussion of their implications and limitations are presented below.

\section{CARBON ISOTOPE DISTRIBUTION IN METHANE}

There are relatively few carbon isotope data for methane occurrences that are widely considered to be abiogenic (fig. 1). Perhaps the best known occurrence is in the hydrothermal vents issuing from the East Pacific Rise at $21^{\circ} \mathrm{N}$. latitude (Welhan and Craig, 1979, 1983). East Pacific Rise methane is characterized by $\delta^{13} \mathrm{C}$ values between -18 and -15 permil. Sediments are absent atop this area of the Rise, and high vent-temperatures $\left(350^{\circ} \mathrm{C}\right)$, the occurrence of mantle ${ }^{3} \mathrm{He} / 4 \mathrm{He}$ ratios $\left(7.8 \mathrm{R}_{\mathrm{A}}\right)$, and the $\delta^{13} \mathrm{C}$ value of carbon dioxide ( -7 permil) all point strongly to an abiogenic origin. A second example of abiogenic methane is in fluid inclusions of alkalic igneous rocks from the Kola Peninsula of Russia (Galimov, 1975; Petersil'ye and Pripachkin, 1979) and southern Greenland (Konnerup-Madsen and others, 1988). $\delta^{13} \mathrm{C}$ measurements on fluid-inclusion methane vary from -18 to -1 permil, overlapping the range observed at $21^{\circ} \mathrm{N}$. East Pacific Rise and extending to much heavier (more positive) values. Los Fuegos Eternos, a methane-hydrogen seep issuing from the Zambales Ophiolite in the Philippines, may also be abiogenic ( $\mathrm{ZO}$ in fig. 1; Abrajano and others, 1988, 1990). The Zambales gas is characterized by methane $\delta^{13} \mathrm{C}=-7$ permil and a large component of mantle-derived helium $\left({ }^{3} \mathrm{He} /{ }^{4} \mathrm{He}=4.1 \mathrm{R}_{\mathrm{A}}\right)$. No sedimentary rocks outcrop at the Earth's surface within $15 \mathrm{~km}$ of these seeps. 


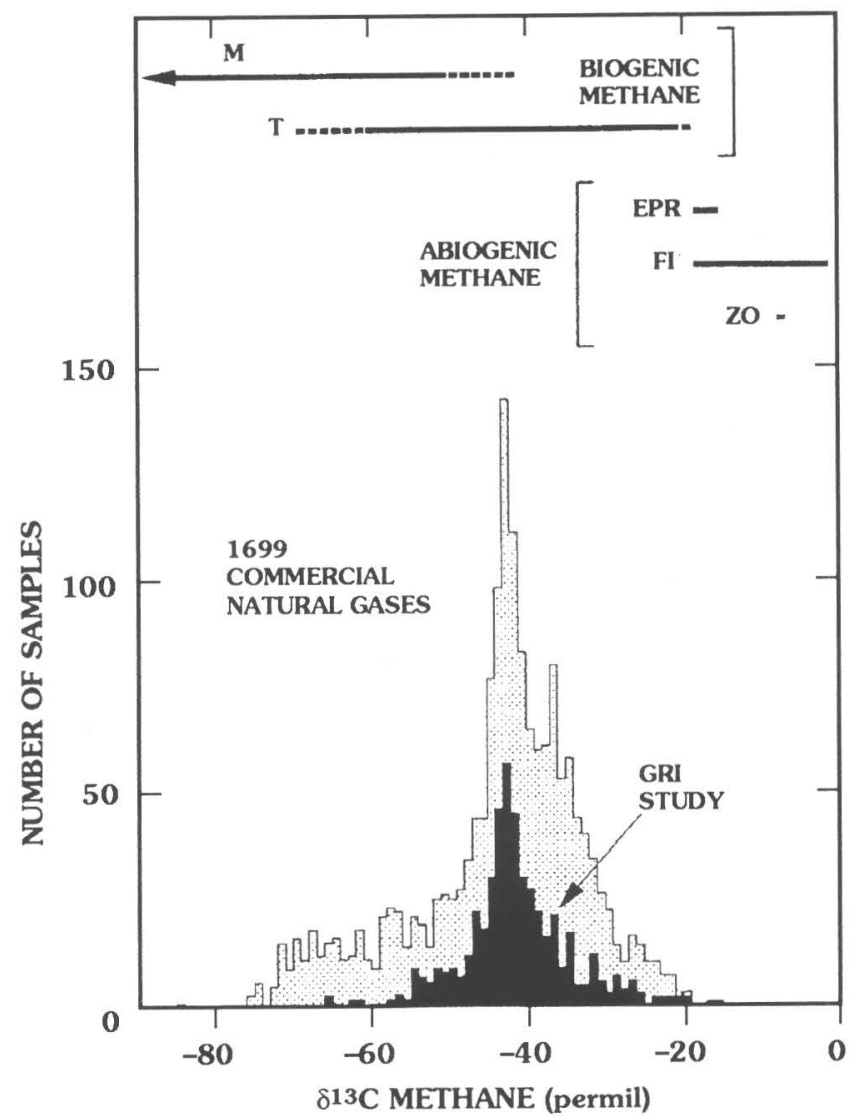

Although used interchangeably in this paper, the terms "abiogenic" and "mantle-derived" are not strictly synonymous. Sherwood and others (1988), for example, have proposed that methane and hydrogen venting from seeps and boreholes in the Canadian Shield are generated by abiotic reactions between hydrogen and graphitic carbon in the crust. This type of gas appears to have little economic significance and is not considered further in this paper. However, the ubiquitous occurrence of secondary alterations within the crust makes it necessary to qualify our use of the word "mantle-derived." Methane in the East Pacific Rise and Zambales Ophiolite fluids, for example, may be formed in the crust by the abiotic reduction of igneous carbon with hydrogen derived from serpentinization of olivine. Fluid-inclusion methane in alkalic igneous rocks may originate from the crustal reequilibration of high-temperature, carbon-dioxide-rich fluids (for example Gerlach, 1980). A small proportion of sedimentary carbon may have been incorporated into all of these gases by melting of intruded country rocks or by hydrothermal circulation of water containing dissolved organic matter and bicarbonate. For practical purposes, East Pacific Rise, fluid-inclusion, and Zambales Ophiolite methane is characterized as "mantle-derived" because it appears to be abiogenic and is associated with igneous intrusives carrying mantle helium.

In this connection, it is important to note that the concept of "methane" actually existing as the molecule $\mathrm{CH}_{4}$ at
Figure 1. Histogram of methane $\delta^{13} \mathrm{C}$ in commercial natural gases from Australia, Thailand, Japan, Canada, United States, Europe, and Commonwealth of Independent States (former Soviet Union). Data are from Gas Research Institute (GRI) study (Jenden and Kaplan, 1989a) and from Colombo and others (1966), Galimov and others (1970, 1973), Stahl and Carey (1975), Stahl and others (1977), Claypool and others (1980), Rigby and Smith (1981), Mattavelli and others (1983), Rice (1983), Sundberg and Bennett (1983), Barker and Pollock (1984), Schoell (1984b), Whiticar and others (1986), Rice and others (1989), Clayton and others (1990), James (1990), Johnson and Rice (1990), Kotarba (1990), Rice and Threlkeld (1990), Tanner and Fuex (1990), Wakita and others (1990), Sakata (1991), and Hiyagon and Kennedy (1992). M, microbial methane from unconsolidated sediments (Whiticar and others, 1986; Jenden and Kaplan, 1986); T, thermogenic methane (inferred from sediment pyrolysis studies; Sackett, 1978; Chung and Sackett, 1979, 1980; Rohrback and others, 1984; Des Marais and others, 1988); EPR, geothermal methane from $21^{\circ}$ N. East Pacific Rise (Welhan and Craig, 1983); FI, methane in fluid inclusions from igneous rocks (Galimov, 1975; Petersil'ye and Pripachkin, 1979; Konnerup-Madsen and others, 1988); ZO, methane issuing from Zambales Ophiolite, Philippines (Abrajano and others, 1988).

ambient temperatures and pressures in the mantle is not a necessary part of the abiogenic natural-gas hypothesis. It is only essential that when abiogenic $C$ and $H$ atoms actually emerge in the upper crust, they are combined as the molecule $\mathrm{CH}_{4}$. Throughout this paper we will therefore ignore the question of the molecular species in which $\mathrm{C}$ and $\mathrm{H}$ occur in the mantle and along the transport routes to the surface, and when we use the term "methane," it is to be taken as descriptive of the actual molecule we see in natural and volcanic gases, and of whatever form $\mathrm{C}$ and $\mathrm{H}$ are in below the crust.

Other occurrences of methane with a likely abiogenic origin include fumarolic and hot spring gases from Kirishima Volcano, Japan $\left(\delta^{13} \mathrm{C}=-23.7\right.$ permil; Wakita and others, $1990)$, and Iceland $\left(\delta^{13} \mathrm{C}=-40\right.$ to -18 permil; Poreda and others, 1992). The lighter (more negative) Iceland $\delta^{13} \mathrm{C}$ values may reflect additions of biogenic methane. This interpretation would be consistent with the view of Welhan (1988) that methane $\delta^{13} \mathrm{C}$ variations in geothermal systems primarily reflect changes in the source of the carbon. Alternatively, the lighter methane $\delta^{13} \mathrm{C}$ values may be produced by isotopic exchange with magmatic carbon dioxide $\left(\delta^{13} \mathrm{C}=\right.$ $-6 \pm 2$ permil). If isotopic equilibration between methane and carbon dioxide is attainable at temperatures as low as $300^{\circ} \mathrm{C}$ (for example, see Giggenbach, 1982), then fractionation factors (Craig, 1953; Richet and others, 1977) indicate that abiogenic methane $\delta^{13} \mathrm{C}$ values could be as low as 
-32 permil. Lighter values might be explained either by isotopic equilibration at lower temperatures or by kinetic fractionation during the reduction of $\mathrm{CO}$ or $\mathrm{CO}_{2}$ to $\mathrm{CH}_{4}$.

Gold and Soter (1982) and Gold (1987, p. 175-181) suggested that methane $\delta^{13} \mathrm{C}$ values far lighter than -40 permil could be produced by isotopically selective oxidation of mantle methane diffusing upward through the crust. The best evidence for this is the progressive increase in methane $\delta^{13} \mathrm{C}$ observed with increasing depth in many sedimentary basins. This phenomenon is, however, readily explained by burial alteration of sedimentary organic matter (for example, see Schoell, 1983), and the experimental data of Kiyosu and Krouse (1989) suggest that isotopically selective oxidation (acting alone) would increase rather than decrease $\delta^{13} \mathrm{C}$ of the residual methane.

Biogenic methane generally has lighter $\delta^{13} \mathrm{C}$ values than the occurrences described above. Studies of young, poorly consolidated sediments indicate that $\delta^{13} \mathrm{C}$ values of microbial methane are almost always less than -45 permil and very frequently less than -60 permil (fig. 1; Whiticar and others, 1986; Jenden and Kaplan, 1986). Thermogenic methane, produced by the thermal degradation of sedimentary organic matter, is somewhat heavier, but still lighter than the abiogenic gases noted above. A $\delta^{13} \mathrm{C}$ range of -60 to -20 permil (and possibly extending to values as light as -70 permil) is suggested for thermogenic methane on the basis of isotopic distribution of Phanerozoic kerogen and coal $\left(\delta^{13} \mathrm{C}=-35\right.$ to -20 permil; Deines, 1980a, Lewan, 1986) and the results of laboratory pyrolysis studies (Sackett, 1978; Chung and Sackett, 1979, 1980; Rohrback and others, 1984; Des Marais and others, 1988).

Although there is clearly some overlap between abiogenic and biogenic methane carbon isotope values, the best constrained $\delta^{13} \mathrm{C}$ values for abiogenic methane are $>-20$ permil, and almost all of the examples mentioned have $\delta^{13} \mathrm{C}>-25$ permil. It is therefore of interest to ask what fraction of commercial natural gases fall within this range. The histogram in figure 1 presents carbon isotope data for methane from commercial oil and gas fields throughout the world. The $\delta^{13} \mathrm{C}$ values range from -84.4 permil for shallow glacial drift gas in Illinois to -15.2 permil for nitrogen-rich gas from northern California. A pronounced mode occurs at -42.5 permil. Although the histogram is not necessarily representative of world production, it is noteworthy that out of the 1,699 measurements plotted, only 41 (2.4 percent) are heavier than -25 permil and 5 ( 0.3 percent) are heavier than -20 permil.

\section{CARBON ISOTOPE VARIATIONS AMONG THE $\mathrm{C}_{1}$ TO $\mathrm{C}_{4}$ HYDROCARBONS}

The cracking of complex hydrocarbons to light-hydrocarbon gases generally yields an isotopic distribution in which methane $\delta^{13} \mathrm{C}<$ ethane $\delta^{13} \mathrm{C}<$ propane $\delta^{13} \mathrm{C}<n$ butane $\delta^{13} \mathrm{C}$ (Des Marais and others, 1981; Jeffrey, 1981; McCarty and Felbeck, 1986; Chung and others, 1988; fig. 2). The isotopic composition of the light-hydrocarbon products is kinetically controlled, primarily reflecting the slightly lower strength of ${ }^{12} \mathrm{C}-{ }^{12} \mathrm{C}$ bonds relative to ${ }^{13} \mathrm{C}-{ }^{12} \mathrm{C}$ bonds, and has been modelled mathematically by Smith and others (1971), James (1983), Sundberg and Bennett (1983), Galimov (1988), Clayton (1991) and others. Mechanisms of light-hydrocarbon formation which involve the polymerization of $\mathrm{C}_{1}$ units to give higher molecular weight hydrocarbons, such as in spark discharge experiments with methane (Des Marais and others, 1981; Chang and others, 1983), give the reverse distribution, in which methane $\delta^{13} \mathrm{C}>$ ethane $\delta^{13} \mathrm{C}>$ propane $\delta^{13} \mathrm{C}>n$-butane $\delta^{13} \mathrm{C}$. The possibility that the latter distribution might be characteristic of abiogenically formed hydrocarbon gases is suggested by data from fluid inclusions in alkalic igneous rocks (Galimov, 1975; Konnerup-Madsen and others, 1988) and meteorites (Yuen and others, 1984) (fig. 2).

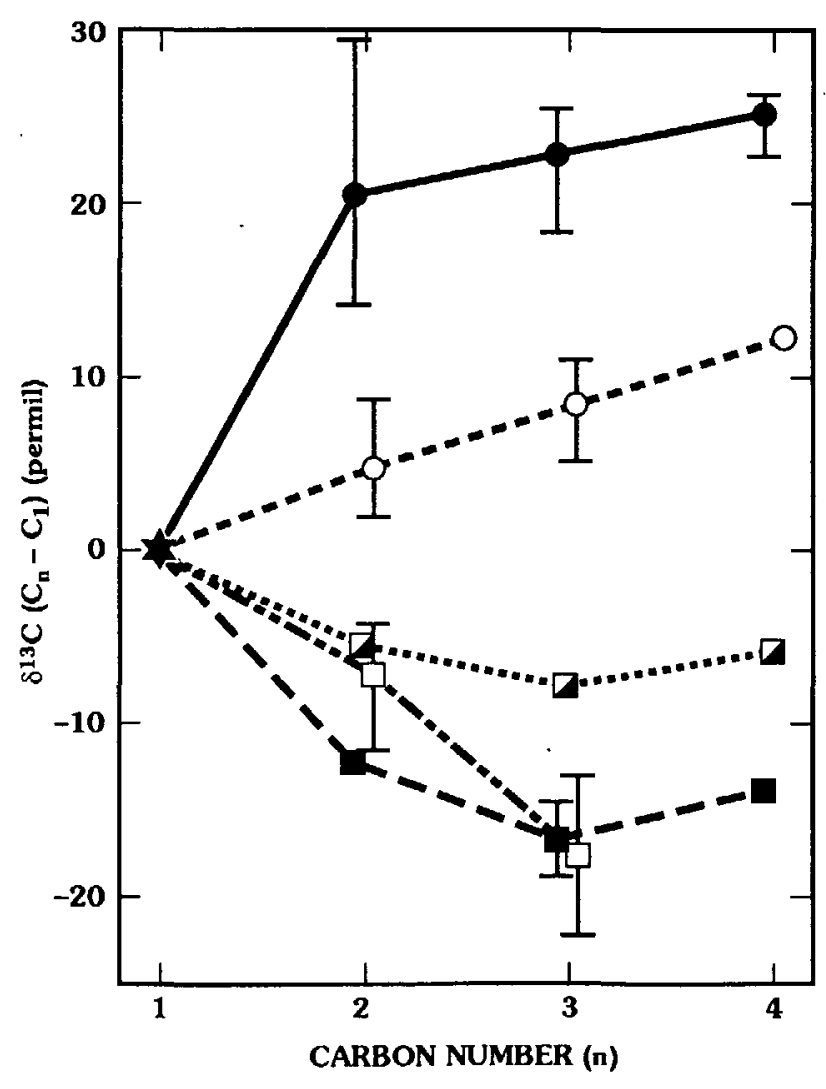

EXPLANATION

OCTADECANE PYROLYSIS (JEFFREY, 1981)

OIL-SHALE PYROLYSIS (MCCARTY AND FELBECK, 1986)

METHANE POLYMERIZATION (DES MARAIS AND OTHERS, 1981) MURCHISON METEORTTE (YUEN AND OTHERS, 1984) IGNEOUS-ROCK FUID INCLUSIONS (GAJMOV, 1975)

Figure 2. $\delta^{13} \mathrm{C}$ distribution in $\mathrm{C}_{1}$ to $\mathrm{C}_{4}$ hydrocarbons from various sources. Vertical bars indicate range of values measured in different samples or experiments. 
Fuex (1977) recognized that isotopic reversals in which methane $\delta^{13} \mathrm{C}>$ ethane $\delta^{13} \mathrm{C}$, ethane $\delta^{13} \mathrm{C}>$ propane $\delta^{13} \mathrm{C}$, and propane $\delta^{13} \mathrm{C}>n$-butane $\delta^{13} \mathrm{C}$, do occur in some com-
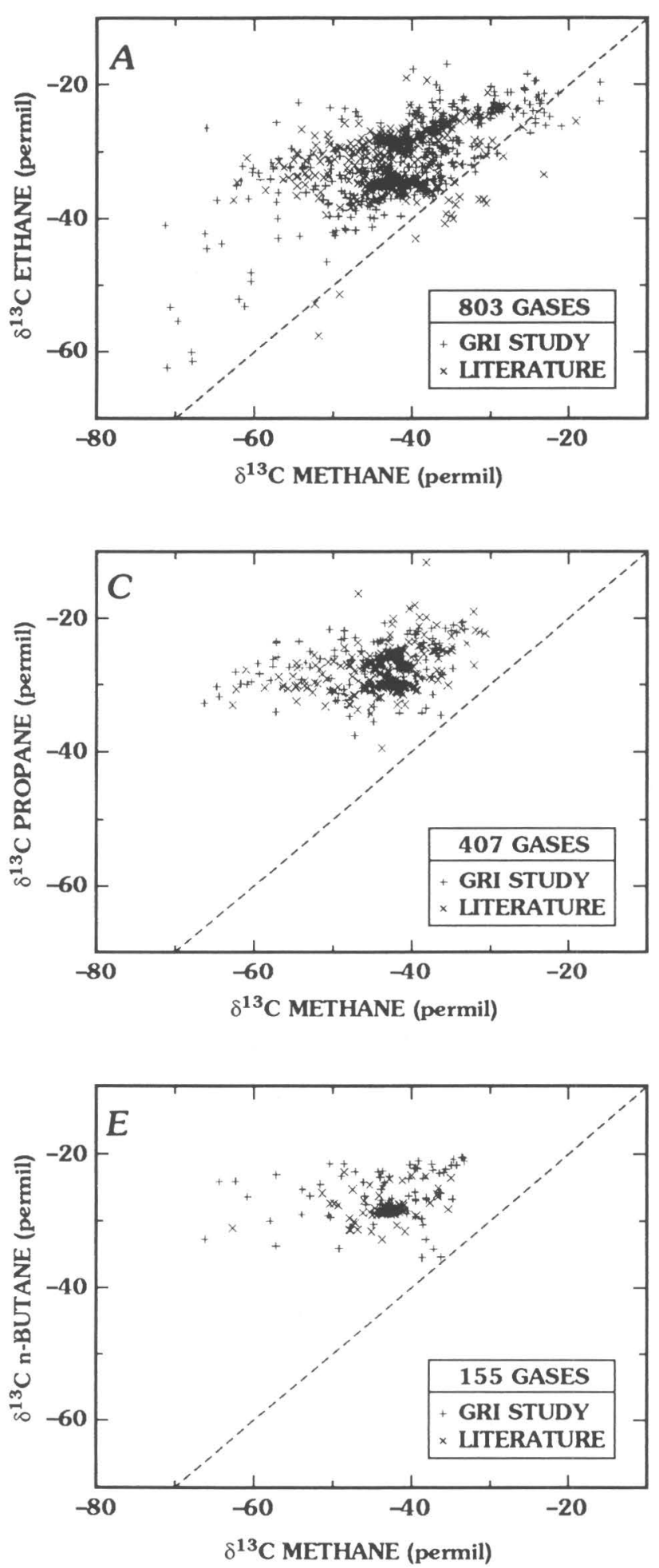

mercial natural gases. Illustrated in figure 3 is the lighthydrocarbon isotope distribution in natural gases from this study and from a number of published sources. Of 803 gases
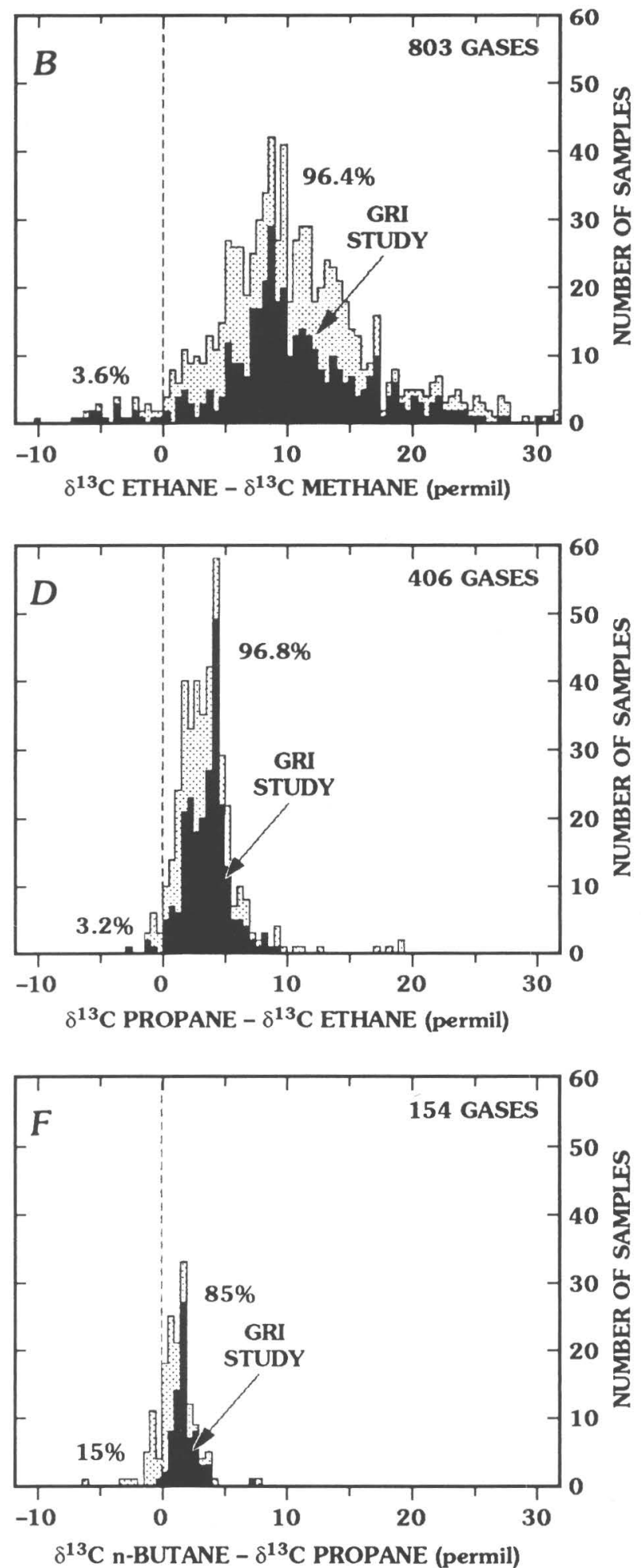

Figure 3. Distribution of methane, ethane, propane, and $n$-butane $\delta^{13} \mathrm{C}$ values in commercial natural gases. Data are from Gas Research Institute (GRI) study (Jenden and Kaplan, 1989a) and from Erdman and Morris (1974), Fuex (1977), James (1983), James and Burns (1984), Smith and others (1985), Sofer (1985), Chung and others (1988), Jianyu and Bingjun (1990) and references listed in figure 1 . In figures $3 B, 3 D$, and $3 F$, percentages indicate proportion of samples that plot on either side of dashed lines. 
with methane and ethane data, 29 gases (3.6 percent) have methane $\delta^{13} \mathrm{C}>$ ethane $\delta^{13} \mathrm{C}$ (figs. $3 A, 3 B$ ). However, none of these gases for which propane or butane data are available show methane $\delta^{13} \mathrm{C}>$ propane $\delta^{13} \mathrm{C}$ or methane $\delta^{13} \mathrm{C}$ $>n$-butane $\delta^{13} \mathrm{C}$ (figs. $3 C, 3 E$ ). Because the concentrations of ethane, propane, and butane in these gases far exceed those in a mixture in chemical equilibrium (Takach and others, 1987), their carbon isotope compositions cannot be explained by isotopic equilibration in crustal reservoirs. Instead, the data suggest that natural gases do not arise from methane polymerization reactions as suggested by Gold and others (1986).

The methane-ethane, ethane-propane, and propane- $n$ butane isotope reversals shown in figures $3 B, 3 D$, and $3 F$ might be caused by a number of mechanisms. Many of the methane-ethane reversals occur in natural gases from northwestern Germany and the northern Appalachian basin, where vertical and lateral migration are extensive and mixing of gases from different sources may have occurred (Schoell, 1984b; Jenden and others, 1993; M. Schoell, oral commun., 1993). Mixing between different natural gases with normal isotopic distributions can produce a gas with one or more reversals, as illustrated in figure 4 . In the Sacramento basin, isotopic reversals between methane and ethane could reflect either mixing (Jenden and Kaplan, 1989 b) or isotopic heterogeneity in the source organic matter (see lignite pyrolysis results of Des Marais and others, 1988). The relatively high percentage of reversals between propane and $n$-butane shown in figure $3 F$ may be caused by shallow microbial oxidation, which can be selective for propane (James and Burns, 1984; Jeffrey and others, 1991).

\section{HELIUM ISOTOPE RATIOS IN COMMERCIAL GASES}

Since the discovery in the late 1960's of ${ }^{3} \mathrm{He}$ anomalies related to East Pacific Rise hydrothermal activity (see review in Craig and Lupton, 1981), the value of helium isotopes as tracers of mantle volatiles has been firmly established. Crustal helium, produced by radioactive decay of $\mathrm{U}$ and $\mathrm{Th}$ (yielding ${ }^{4} \mathrm{He}$ ) and the (n, $\alpha$ ) reaction of ${ }^{6} \mathrm{Li}$ (yielding ${ }^{3} \mathrm{He}$ ), is characterized by average ${ }^{3} \mathrm{He} /{ }^{4} \mathrm{He}$ ratios $<0.04 \quad \mathrm{R}_{\mathrm{A}}$, where $\mathrm{R}_{\mathrm{A}}=$ atmospheric ${ }^{3} \mathrm{He} /{ }^{4} \mathrm{He}=1.4 \times 10^{-6}$ (Mamyrin and Tolstikhin, 1984, p. 97-104; Andrews, 1985). Mantle-derived helium, on the other hand, is a mixture of radiogenic and primordial helium, the latter having ${ }^{3} \mathrm{He} /$ ${ }^{4} \mathrm{He}=100$ to $300 \mathrm{R}_{\mathrm{A}}$ (Craig and Lupton, 1981; Mamyrin and Tolstikhin, 1984, p. 90-94). As a consequence, mantle ${ }^{3} \mathrm{He} /$ ${ }^{4} \mathrm{He}$ values are much higher than crustal values and vary from an average of $8 R_{A}$ in midocean-ridge fluids and basalts to at least $35 R_{A}$ in hotspots such as Hawaii and Iceland (Craig and Lupton, 1981; Welhan and Craig, 1983).

In the last few years, numerous studies have addressed the distribution of helium isotopes in commercial oil and gas fields (fig. 5). Fields overlying ancient cratonic crust and in foreland basins formed by thrust-plate loading are characterized by ${ }^{3} \mathrm{He} /{ }^{4} \mathrm{He}$ ratios close to radiogenic values (Oxburgh and others, 1986; Hilton and others, 1988; Hiyagon and Kennedy, 1992). Fields located near active plate margins in forearc, backarc, and rift basins, on the other hand, may have ${ }^{3} \mathrm{He} /{ }^{4} \mathrm{He}$ ratios approaching mantle values (Poreda and others, 1986; Sano and others, 1987; Poreda and others, 1988; Wakita and others, 1990). The helium isotope data compiled in figure 5 range from $0.004 R_{A}$ for a Paleozoic gas from the tectonically stable Russian platform (Kamenskiy and others, 1971) to $7.5 \mathrm{R}_{\mathrm{A}}$ for a Cenozoic gas from Japan (Sakata, 1991).

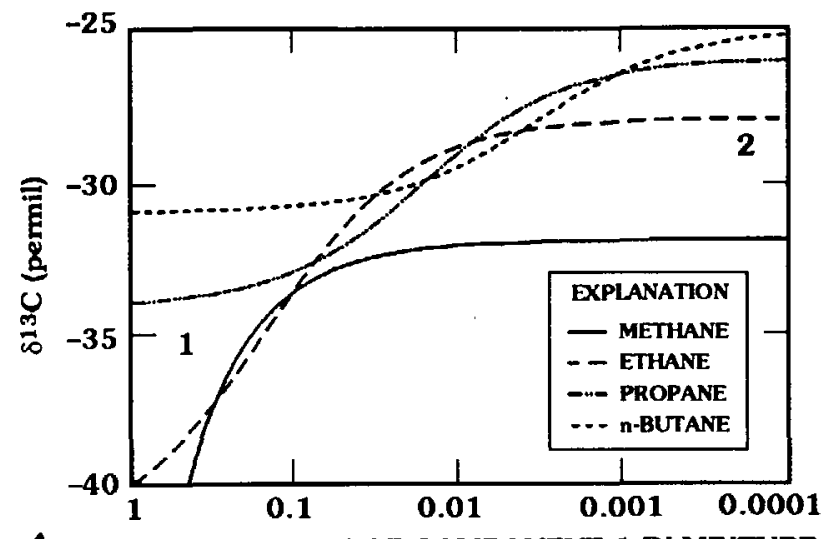

$A$ MOLE FRACTION OF COMPONENT 1 IN MIXTURE

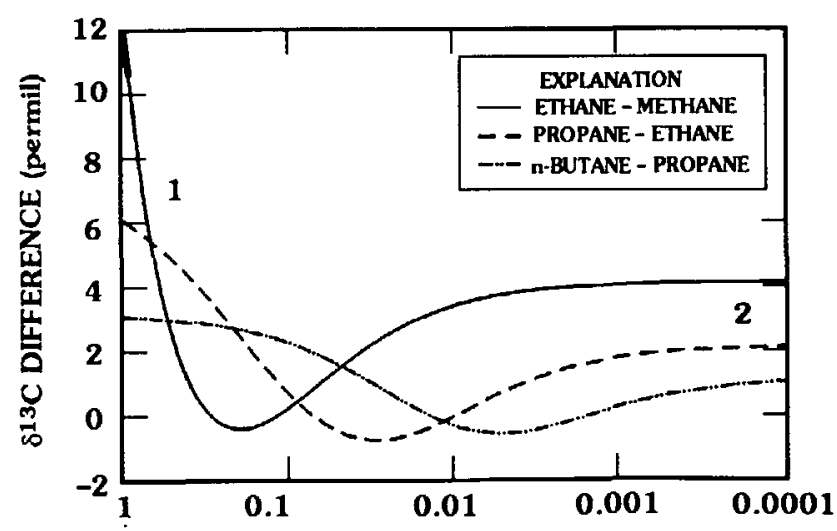

B MOLE FRACTION OF COMPONENT 1 IN MIXTURE

Figure 4. $\delta^{13} \mathrm{C}$ values $(A)$ and $\delta^{13} \mathrm{C}$ differences $(B)$ for range of hypothetical gas compositions produced by mixing between two biogenic endmembers (components 1 and 2) with a normal isotopic distribution (that is, $\delta^{13} \mathrm{C}_{1}<\delta^{13} \mathrm{C}_{2}<\delta^{13} \mathrm{C}_{3}<\delta^{13} \mathrm{C}_{4}$ ). The model shows how, in a gas mixture, isotopic reversals could arise between two or even three hydrocarbons (for example, $\delta^{13} \mathrm{C}_{1}>\delta^{13} \mathrm{C}_{2}$ or $\delta^{13} \mathrm{C}_{2}>\delta^{13} \mathrm{C}_{3}>\delta^{13} \mathrm{C}_{4}$ ). A complete reversal among all four hydrocarbons would be highly unlikely. Component 1: 76 percent $\mathrm{CH}_{4},-52$ permil; 15 percent $\mathrm{C}_{2} \mathrm{H}_{6},-40$ permil; 6 percent $\mathrm{C}_{3} \mathrm{H}_{8},-34$ permil; 3 percent $\mathrm{C}_{4} \mathrm{H}_{10},-31$ permil. Component 2: 97.89 percent $\mathrm{CH}_{4},-32$ permil; 2.00 percent $\mathrm{C}_{2} \mathrm{H}_{6},-28$ permil; 0.10 percent $\mathrm{C}_{3} \mathrm{H}_{8},-26$ permil; 0.01 percent $\mathrm{C}_{4} \mathrm{H}_{10},-25$ permil. 
Using simple mass-balance principles, ${ }^{3} \mathrm{He} /{ }^{4} \mathrm{He}$ ratios can be used to estimate the fraction of helium which has been derived from the upper mantle. Where $\mathrm{R}$ refers to the ${ }^{3} \mathrm{He} /{ }^{4} \mathrm{He}$ ratio, the relevant equation is

$$
\mathrm{He}_{\text {mantle }} / \mathrm{He}_{\text {total }}=\left(\mathrm{R}_{\text {gas }}-\mathrm{R}_{\text {crust }}\right) /\left(\mathrm{R}_{\text {mantle }}-\mathrm{R}_{\text {crust }}\right) \text {. }
$$

Calculations made assuming that $\mathrm{R}_{\text {crust }}=0.01 \mathrm{R}_{\mathrm{A}}$ and $\mathrm{R}_{\text {mantle }}=$ $8 R_{A}$ yield a range of 0 to 94 percent mantle-derived helium with a median value of 2.3 percent (fig. 6).

An upper mantle ${ }^{3} \mathrm{He} /{ }^{4} \mathrm{He}$ ratio of $8 \pm 1 \mathrm{R}_{\mathrm{A}}$ is well constrained by studies of midocean-ridge basalts and hydrothermal vents (Craig and Lupton, 1981; Welhan and Craig, 1983). However, crustal ${ }^{3} \mathrm{He} /{ }^{4} \mathrm{He}$ values may vary locally from less than $0.01 \mathrm{R}_{\mathrm{A}}$ to values in excess of $0.04 \mathrm{R}_{\mathrm{A}}$ depending upon a variety of factors including the $\mathrm{Li}$ con- tent of the sediments and underlying crust, the spatial distribution of $\mathrm{Li}$ relative to $\mathrm{U}$ - and Th-bearing minerals, the relative abundance of ${ }^{3} \mathrm{He}$-enriched cosmic dust particles in the sediments, and the relative release rates of ${ }^{3} \mathrm{He}$ versus ${ }^{4} \mathrm{He}$ (Andrews, 1985; Martel and others, 1990; Hiyagon and Kennedy, 1992). Using a higher average crustal ${ }^{3} \mathrm{He} /{ }^{4} \mathrm{He}$ value will yield lower estimates of mantle-derived helium, so that for a crustal ${ }^{3} \mathrm{He} /{ }^{4} \mathrm{He}$ ratio of $0.1 \mathrm{R}_{\mathrm{A}}$, the median contribution of mantle-derived helium drops to 1.2 percent.

Kamenskiy and others (1971) were probably the first to suggest that the low ${ }^{3} \mathrm{He} /{ }^{4} \mathrm{He}$ ratios observed for many commercial natural gases argued against an origin in the mantle. This assessment must be qualified because the combined effect of helium loss through reservoir caprocks and helium addition from radiogenic sources could cause

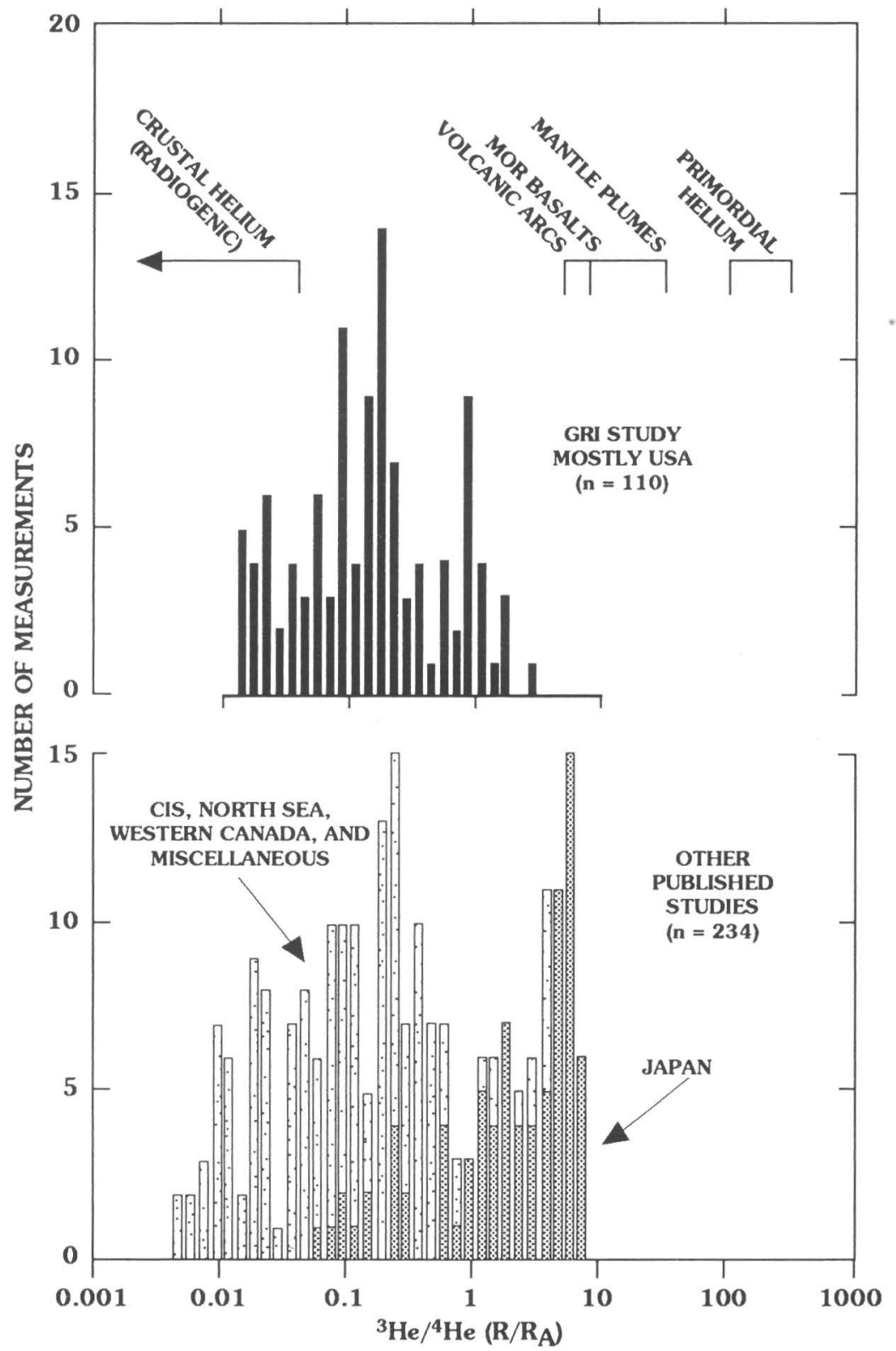

Figure 5. Histogram of ${ }^{3} \mathrm{He} /{ }^{4} \mathrm{He}$ ratios (expressed as $R / R_{A}$, or ratio in sample divided by ratio in air) in commercial natural gases from Thailand, New Zealand, Indonesia, Philippines, Taiwan, and Barbados (Sano and others, 1987; Poreda and others, 1988); Japan (Wakita and others, 1990; Sakata, 1991); western Canada (Hiyagon and Kennedy, 1992); United States (Aldrich and Nier, 1948; Welhan and others, 1988; Gas Research Institute (GRI) study-Jenden and Kaplan, 1989a); North Sea (Hooker and others, 1985); central Europe (Ballentine and others, 1991; Ballentine and O'Nions, 1991); and the Commonwealth of Independent States (CIS) (Kamenskiy and others, 1971). Isotopic fields for radiogenic, volcanic, and primordial helium are adapted from Craig and Lupton (1981) and Mamyrin and Tolstikhin (1984). MOR, midocean ridge. 


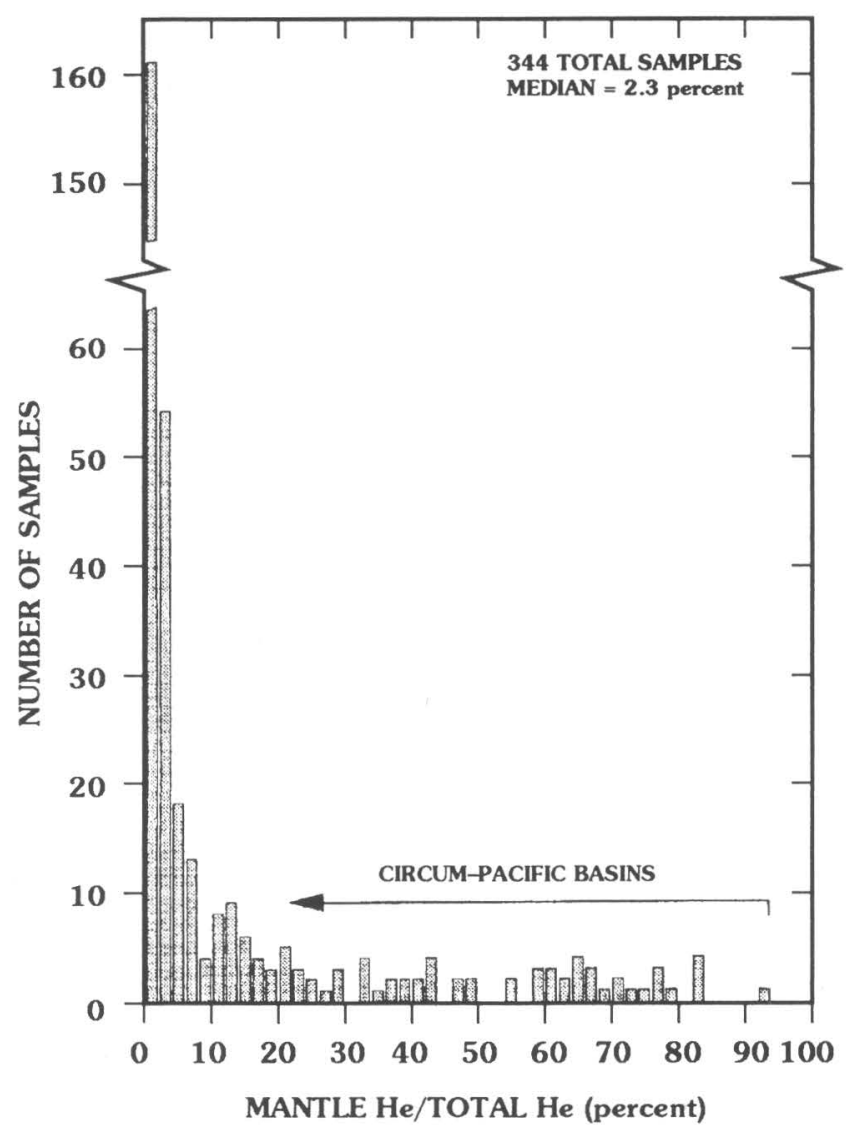

Figure 6. Proportion of mantle-derived helium in natural gases. Calculations are based on the data in figure 5 and assume ${ }^{3} \mathrm{He} /$ ${ }^{4} \mathrm{He}=0.01 \mathrm{R}_{\mathrm{A}}$ for crustal (radiogenic) helium and ${ }^{3} \mathrm{He} /{ }^{4} \mathrm{He}=8 \mathrm{R}_{\mathrm{A}}$ for upper-mantle helium. Arrow labeled "Circum-Pacific basins" shows range of data from New Zealand, Philippines, Taiwan, Japan, and California.

initially high ${ }^{3} \mathrm{He} /{ }^{4} \mathrm{He}$ ratios to decrease with time. ${ }^{3} \mathrm{He} /{ }^{4} \mathrm{He}$ ratios near $0.01 \mathrm{R}_{\mathrm{A}}$ might be expected for very old accumulations regardless of their origin. On the other hand, the absence of elevated ${ }^{3} \mathrm{He} /{ }^{4} \mathrm{He}$ ratios in many Cenozoic oil and gas fields does argue against a significant contribution of mantle-derived methane.

With this problem in mind, Gold (1987, p. 109) suggested that pure methane moving up through the mantle would quickly strip primordial helium from established migration pathways and that low, radiogenic ${ }^{3} \mathrm{He} /{ }^{4} \mathrm{He}$ ratios therefore do not rule out a contribution of mantle-derived fluids. Gold's suggestion is at odds with the finding that volcanic and geothermal activity, which commonly accompanies the introduction of mantle volatiles into the crust, is nearly always associated with elevated ${ }^{3} \mathrm{He} /{ }^{4} \mathrm{He}$ ratios (for example, Welhan and others, 1988; Poreda and Craig, 1989; Griesshaber and others, 1992). In the absence of supporting evidence, the proposal that abiogenic methane can be completely decoupled from mantle ${ }^{3} \mathrm{He} /{ }^{4} \mathrm{He}$ ratios is speculative at best.
Although many gases appear to have little or no mantle contribution, figure 6 indicates that 10 to perhaps 85 percent of the helium in many circum-Pacific reservoirs of Cretaceous and Tertiary age may be derived from the upper mantle. This result is important but does not, by itself, imply the presence of large quantities of abiogenic hydrocarbons. ${ }^{3} \mathrm{He} /{ }^{4} \mathrm{He}$ ratios as high as $7.5 \mathrm{R}_{\mathrm{A}}$ have been measured in oil and gas fields of the Green Tuff region of Japan, for example, yet methane $\delta^{13} \mathrm{C}$ values range from -62 to -33 permil (well within the biogenic range) no significant isotopic reversals are observed among the $C_{1}$ to $C_{4}$ hydrocarbon gases, and biomarker studies have correlated the oils to local, organic-rich Miocene shales (Sakata and others, 1989; Sakata, 1991). Although a large abiogenic contribution has been suggested (Wakita and Sano, 1983; Wakita and others, 1990), an alternative explanation is that magmatic fluids introduced mantle helium into the Green Tuff basins and also heated local source rocks, causing oil and gas generation (H. Craig and Y. Horibe, written commun., 1984).

A second example of biogenic methane associated with mantle-derived helium is provided by geothermal vents along the East Pacific Rise in the Guaymas Basin, Gulf of California (Welhan and Craig, 1979, 1982; Welhan and Lupton, 1987). Although ${ }^{3} \mathrm{He} /{ }^{4} \mathrm{He}=8.0 \mathrm{R}$, approximately equal to that measured for similar vents at the $21^{\circ} \mathrm{N}$. East Pacific Rise site (discussed above), the Guaymas methane-to-helium ratio is nearly three orders of magnitude higher than that at the $21^{\circ} \mathrm{N}$. site. This difference is attributed to the circulation of hot fluids through overlying organic-rich sediments in the Guaymas Basin. Indeed, whereas methane $\delta^{13} \mathrm{C}$ values at the $21^{\circ} \mathrm{N}$. East Pacific Rise site range from -18 to -15 permil, methane $\delta^{13} \mathrm{C}$ values at the Guaymas site range from -51 to -43 permil, far too light for an abiogenic origin.

\section{METHANE CONCENTRATION AND HELIUM-3 ABUNDANCE}

If abiogenic (magmatic) hydrocarbons are present in oil and gas fields, one might expect to see evidence for mixing relationships in cross plots involving the concentrations and isotopic compositions of helium and methane. After Wakita and Sano (1983) suggested that Japanese gases in the Green Tuff region had a large component of abiogenic methane, H. Craig and Y. Horibe (written commun., 1984) showed that the Green Tuff data could readily be explained by mixing small amounts of magmatic helium with a crustal gas composed of biogenic methane and traces of radiogenic helium. In figure 7, a modified version of the plot used by Craig and Horibe (written commun., 1984), the original data of Wakita and Sano (1983) are shown together with the more recent results of Wakita and others (1990) and Sakata (1991). The illustrated mixing 
line also fits gases from hot springs, mudpots, and fumaroles in the eastern Kamchatka Peninsula (Kamenskiy and others, 1976).

The crustal endmember in figure 7 has been assigned a hypothetical composition with $\mathrm{CH}_{4} /{ }^{3} \mathrm{He}=3 \times 10^{13}$ and ${ }^{3} \mathrm{He} /{ }^{4} \mathrm{He}=0.01 \mathrm{R}_{\mathrm{A}}$. The magmatic endmember is taken to be the same as a fumarole gas from Usu Volcano in western Hokkaido, for which $\mathrm{CH}_{4} /{ }^{3} \mathrm{He}=1.1 \times 10^{6}$ and ${ }^{3} \mathrm{He} /{ }^{4} \mathrm{He}=$ $6.2 \mathrm{R}_{\mathrm{A}}$ (H. Craig and Y. Horibe, written commun., 1984). On the basis of these endmembers, $0.1 \mathrm{ppm}$ to $1,000 \mathrm{ppm}$ ( 0.1 percent) of the methane in the Japanese commercial gases could be abiogenic (magmatic).

This type of calculation obviously depends strongly upon the $\mathrm{CH}_{4} /{ }^{3} \mathrm{He}$ ratio of the magmatic endmember, a figure which is not well constrained. If we use the $\mathrm{CH}_{4} /{ }^{3} \mathrm{He}$ ratio of $12 \times 10^{6}$ measured for Hakone Volcano, southwest of Tokyo, the proportion of abiogenic methane in the Japanese commercial gases could reach up to 1 percent. On the other hand, fumaroles on volcanoes in the Banda arc of Indonesia have $\mathrm{CH}_{4} /{ }^{3} \mathrm{He}$ ratios of $0.1 \times 10^{6}$ or less (Poorter and others, 1991), for which abiogenic methane contents $<100 \mathrm{ppm}$ would be calculated. Actually, so long as the volcanic ${ }^{3} \mathrm{He} /{ }^{4} \mathrm{He}$ ratio is constant at approximately $6 \mathrm{R}_{\mathrm{A}}$, an equally good fit to the data can be obtained for any $\mathrm{CH}_{4} /{ }^{3} \mathrm{He}$ ratio less than $3 \times 10^{8}$ (this figure corresponds to the minimum ratio measured for Green Tuff gas).

Similar two-component mixing models can also be fitted to data from other oil- and gas-producing regions, including

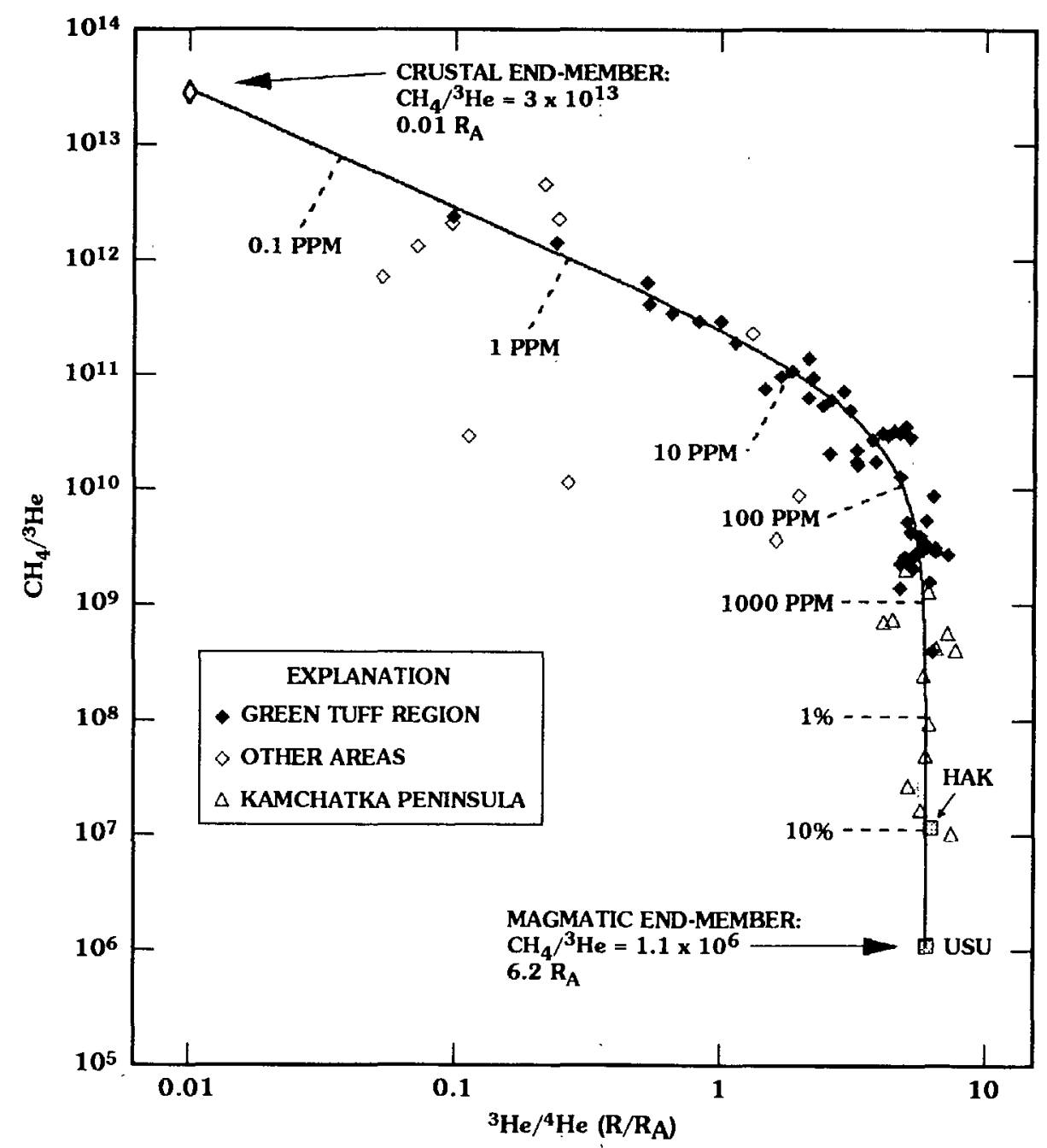

Figure 7. Mixing model for origin of helium and methane in Japanese natural gases (modified from H. Craig and Y. Horibe, written commun., 1984). Dashed lines indicate proportion of methane (in parts per million and in percent) derived from the magmatic endmember, Usu Volcano (USU). Natural-gas data for Green Tuff region and other areas from Wakita and others (1990) and Sakata (1991); data for Kamchatka Peninsula volcanic and geothermal gases from Kamenskiy and others (1976); data for Usu and Hakone (HAK) Volcanoes from Craig and others (1978) and H. Craig and Y. Horibe (written commun., 1984). $R / R_{A}$, ratio in sample divided by ratio in air. 
the Commonwealth of Independent States, Canada, the United States, the North Sea, and Central Europe (fig. 8). Two mixing curves encompass the data in figure 8 and illustrate the compositional variation of potential crustal and magmatic endmembers. Crustal $\mathrm{CH}_{4} /{ }^{3} \mathrm{He}$ ratios, shown with ${ }^{3} \mathrm{He} /$ ${ }^{4} \mathrm{He}=0.01 \mathrm{R}_{\mathrm{A}}$, range from $3 \times 10^{9}$ to $2 \times 10^{13}$ and are grossly related to reservoir age. The arrows in figure 8 illustrate the effects of adding pure radiogenic helium $\left({ }^{3} \mathrm{He} /{ }^{4} \mathrm{He}=0.01 \mathrm{R}_{\mathrm{A}}\right)$ to young reservoirs lying along the uppermost mixing line. Using the arrows as a guide, one can visually remove the effects of radiogenic helium addition and see that many of the Paleozoic reservoirs were initially charged by gases with $\mathrm{CH}_{4} /{ }^{3} \mathrm{He}$ and ${ }^{3} \mathrm{He} /{ }^{4} \mathrm{He}$ ratios similar to those observed in Mesozoic and Cenozoic reservoirs.
Although the range of magmatic ${ }^{3} \mathrm{He} /{ }^{4} \mathrm{He}$ values in figure 8 is not as well constrained as in Japan (see fig. 7), somewhat lower values are suggested and the mixing lines employ endmembers at 1 and $4 \mathrm{R}_{\mathrm{A}}$. Magmatic ${ }^{3} \mathrm{He} /{ }^{4} \mathrm{He}$ ratios significantly lower than the upper mantle value of $8 R_{A}$ suggest that radiogenic helium (and possibly other volatiles) may have been incorporated into the magmatic endmember during migration through the deep crust (see, for example, Poreda and others, 1986, 1988). Magmatic $\mathrm{CH}_{4} /{ }^{3} \mathrm{He}$ ratios appear constrained to lie at or below $1 \times 10^{8}$, but as in the case of the Japanese gases, values as low as 0 could be fitted to the data.

The abundance of abiogenic methane in the gases shown in figure 8 is very difficult to estimate because the ${ }^{3} \mathrm{He} /{ }^{4} \mathrm{He}$

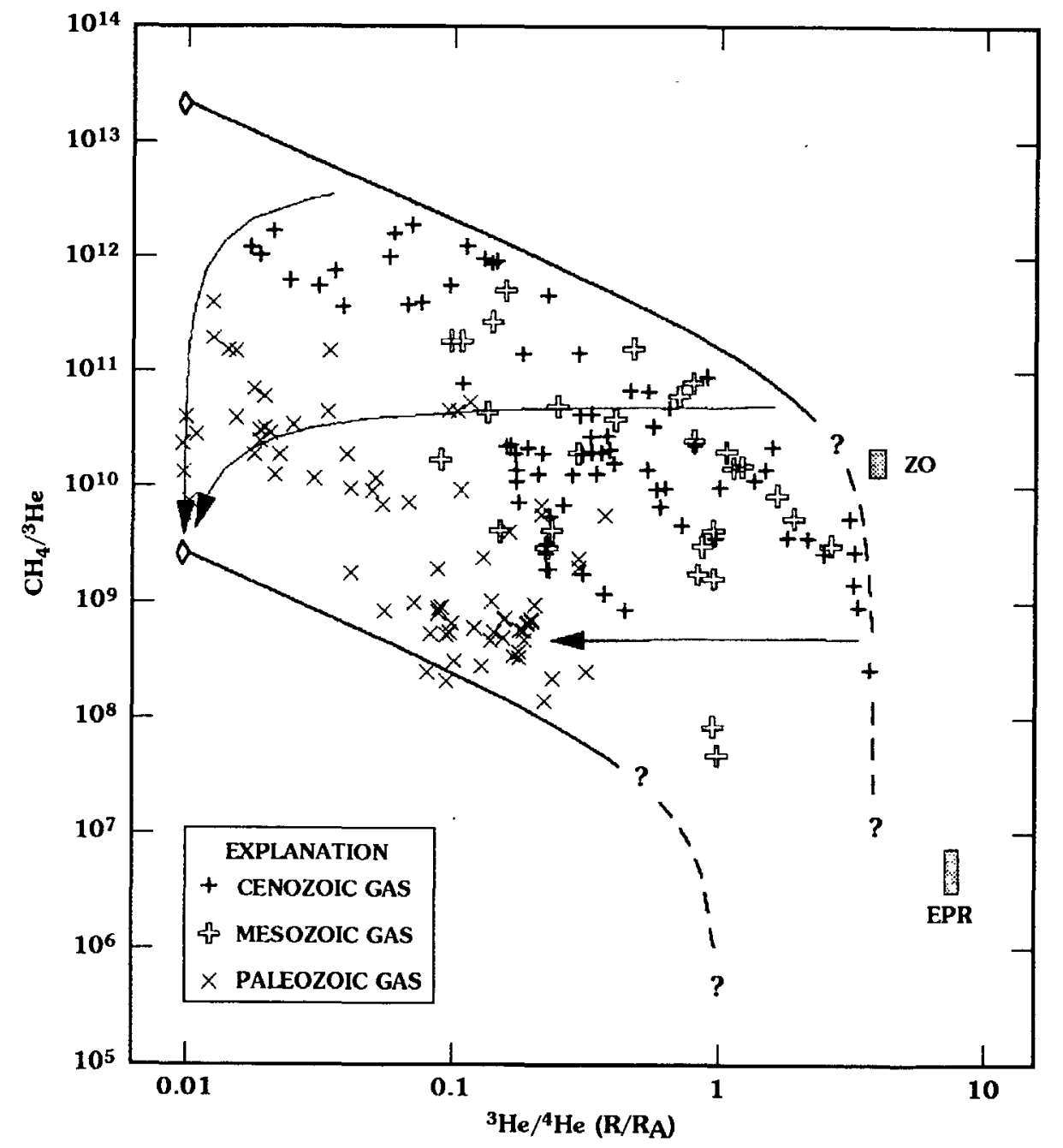

Figure 8. Methane-helium relations in 179 commercial gases classified by reservoir age. Data are from Thailand, New Zealand, Indonesia, Philippines, Taiwan, Barbados, western Canada, United States, and central Europe (references listed in fig. 5 caption). EPR, geothermal fluids from $21^{\circ}$ N. East Pacific Rise (Welhan and Craig, 1983); ZO, gas seeps from the Zambales Ophiolite in the Philippines (Abrajano and others, 1988). Solid lines illustrate mixing between hypothetical crustal gases (diamonds) and magmatic gases; queries and dashed lines indicate uncertainty in the compostion of the latter. Arrows show the effect of adding radiogenic helium with ${ }^{3} \mathrm{He} /{ }^{4} \mathrm{He}=0.01 \mathrm{R}_{\mathrm{A}}$ to gases lying near the upper mixing line. $\mathrm{R} / \mathrm{R}_{\mathrm{A}}$, ratio in sample divided by ratio in air. 
and $\mathrm{CH}_{4} /{ }^{3} \mathrm{He}$ ratios of the magmatic endmember are both relatively unconstrained. A further problem is that two-component models may not fully describe mixing relations in some oil and gas provinces. In the California Great Valley, for example, a third component characterized by high nitrogen content and ${ }^{3} \mathrm{He} /{ }^{4} \mathrm{He}$ near $1 \mathrm{R}_{\mathrm{A}}$ may be derived from subducted metasedimentary rocks (Jenden and others, 1988a). A simple approach which sidesteps the problems created by assimilation of crustal volatiles into the magmatic component is to calculate, for each gas, the amount of ${ }^{3} \mathrm{He}$ ultimately derived from the mantle. The concentration of abiogenic methane can then be estimated from $\mathrm{CH}_{4} /{ }^{3} \mathrm{He}$ ratios measured in volcanic and geothermal systems where contamination with organic carbon is unlikely.

The relevant calculation is

$$
\begin{aligned}
& \mathrm{CH}_{4} \text { abiogenic }(\text { percent })= \\
& \quad \mathrm{F} \times \mathrm{He}(\text { percent }) \times\left({ }^{3} \mathrm{He} /{ }^{4} \mathrm{He}\right)_{\text {mantle }} \times\left(\left.\mathrm{CH}_{4}\right|^{3} \mathrm{He}\right)_{\text {geothermal }} \text {, }
\end{aligned}
$$

where $\mathrm{F}$ is the fraction of helium derived from the mantle (discussed above in fig. 6) and $\mathrm{He}$ is the helium concentration. The greatest uncertainty in this equation is the $\mathrm{CH}_{4} /{ }^{3} \mathrm{He}$ ratio of geothermal fluids derived from the mantle. As noted above, $\mathrm{CH}_{4} /{ }^{3} \mathrm{He}$ ratios of summit gases from circum-Pacific volcanoes range from $<0.1 \times 10^{6}$ to $12 \times 10^{6}$ (Craig and others, 1978; Welhan and others, 1988; Poorter and others, 1991). $\mathrm{CH}_{4}{ }^{3} \mathrm{He}$ ratios in midocean-ridge basalts and geothermal vent fluids from open-ocean spreading ridges are reported to range from $<<0.1 \times 10^{6}$ to at least $20 \times 10^{7}$ (Welhan and Craig, 1983; Jean-Baptiste and others, 1991; Javoy and Pineau, 1991). Finally, $\mathrm{CH}_{4} /{ }^{3} \mathrm{He}$ ratios measured in geothermal samples from mantle hotspots (Easter Island, Loihi Seamount, Iceland, and Reunion Island) vary from $<0.1 \times 10^{6}$ to $100 \times 10^{6}$ (Craig and others, 1984; Gamo and others, 1987; Poreda and others, 1992; Marty and others, 1993). As there is no clear evidence for contamination with organic carbon in these gases, this broad range of $\mathrm{CH}_{4} /{ }^{3} \mathrm{He}$ ratios presumably reflects differences in the cooling history of the fluids (Giggenbach, 1982) and variations in the oxygen-buffering capacity of the surrounding rocks.

For illustrative purposes, we start with a $\mathrm{CH}_{4}{ }^{3} \mathrm{He}$ ratio of $3 \times 10^{6}$, the geometric average of the extreme values of $0.1 \times 10^{6}$ and $100 \times 10^{6}$ noted above, which is approximately equal to that measured for fluids from the $21^{\circ} \mathrm{N}$. East Pacific Rise site $\left(3.5 \times 10^{6}\right.$ to $6.5 \times 10^{6}$; Welhan and Craig, 1983). The mantle ${ }^{3} \mathrm{He} /{ }^{4} \mathrm{He}$ ratio is taken to be $8 \mathrm{R}_{\mathrm{A}}$. Given these values, the calculated abundance of abiogenic methane in commercial gases (for which $\mathrm{He}$ abundance and ${ }^{3} \mathrm{He}$ / ${ }^{4} \mathrm{He}$ data are available) ranges from 0 to 1.2 percent and has a median of 0.016 percent ( $160 \mathrm{ppm}$ ) (fig. 9). The highest concentrations are calculated for gases from the supergiant Hugoton field of southwestern Kansas, Oklahoma, and Texas. Neither the Lower Permian dolomite reservoir rock of the Hugoton field nor the underlying sedimentary section are associated with igneous intrusives (Pippin, 1970), but Hugoton gases have modestly elevated ${ }^{3} \mathrm{He} /{ }^{4} \mathrm{He}$ ratios $(0.06$ to $\left.0.24 \mathrm{R}_{\mathrm{A}}\right)$ and contain large quantities of both helium $(0.4$ to 1.3 percent) and nitrogen (11 to 44 percent) (table 1 ). Somewhat lower concentrations of abiogenic methane (up to 0.6 percent) are calculated for the circum-Pacific gases because even though many have extremely high ${ }^{3} \mathrm{He}^{4} \mathrm{He}$ ratios, they contain less than $200 \mathrm{ppm}$ helium.

The values plotted in figure 9 suggest that in most oil and gas fields, the abundance of abiogenic methane is vanishingly small. Even if the $\mathrm{CH}_{4} / 3 \mathrm{He}$ ratio of geothermal fluids derived from the mantle were assigned the maximum value of $100 \times 10^{6}$, the median concentration of abiogenic methane in commercial oil and gas fields would still amount to only 0.53 percent. If the minimum value of $0.1 \times 10^{6}$ were used, the median concentration of abiogenic methane would drop to just $5 \mathrm{ppm}$.

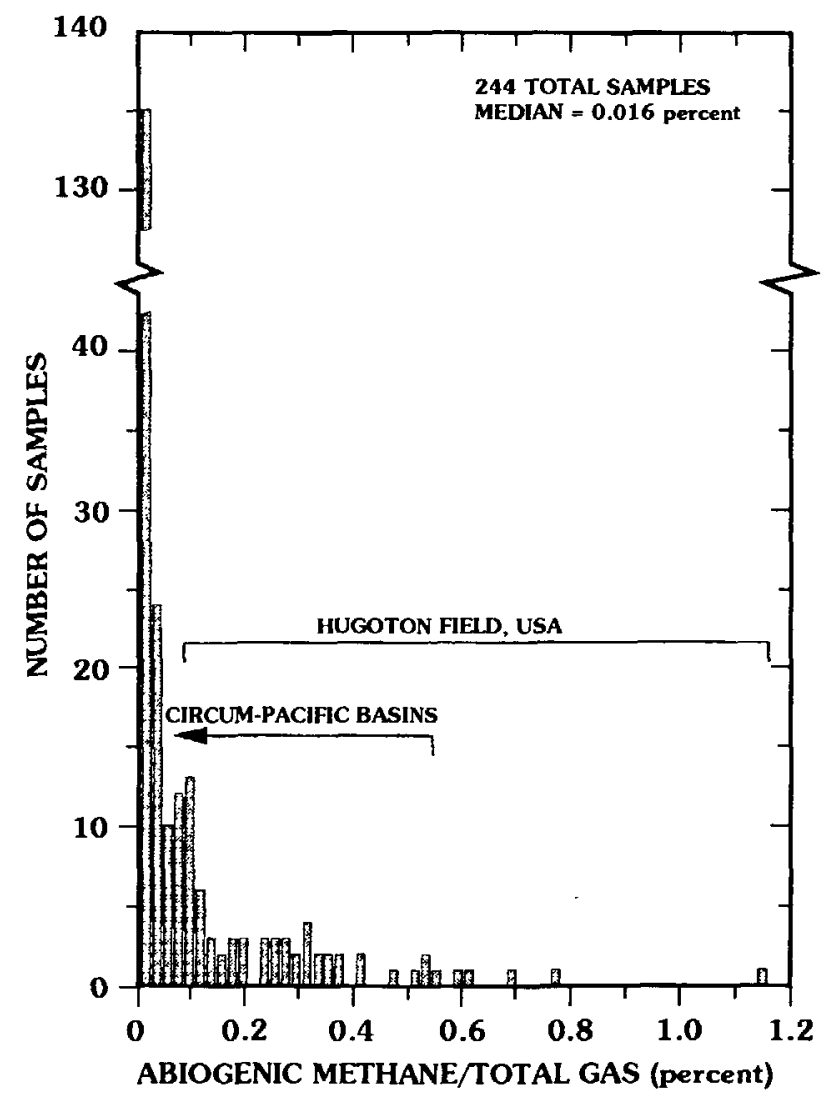

Figure 9. Estimated abundance of abiogenic methane in 244 commercial gases from Thailand, New Zealand, Indonesia, Philippines, Taiwan, Barbados, Japan, western Canada, United States, and central Europe (references listed in fig. 5 caption). Calculations assume a geometric average $\mathrm{CH}_{4} /{ }^{3} \mathrm{He}$ value of $3 \times 10^{6}$ for magmatic fluids in circum-Pacific volcanoes, spreading ridges, and mantle hotspots uncontaminated by organic carbon (Welhan and Craig, 1983; Gamo and others, 1987; Poorter and others, 1991; Poreda and others, 1992). Results are only order-of-magnitude estimates since $\mathrm{CH}_{4} /{ }^{3} \mathrm{He}$ ratios actually vary from $<0.1 \times 10^{6}$ to $100 \times 10^{6}$. Brackets indicate range of values calculated for gases from circum-Pacific basins and the supergiant Hugoton field, United States. 
It is worth noting that for the supergiant Hugoton field, calculations employing $\left(\mathrm{CH}_{4} /{ }^{3} \mathrm{He}\right)_{\text {geothermal }}=100 \times 10^{6}$ yield abiogenic methane abundances as high as 40 percent. Since the entire Hugoton-Panhandle production complex is estimated to have ultimate recoverable gas reserves of more than $2 \times 10^{12} \mathrm{~m}^{3}$ (Pippin, 1970), this would imply a huge absolute contribution of abiogenic methane. Even if we took $\left(\mathrm{CH}_{4} /{ }^{3} \mathrm{He}\right)_{\text {geothermal }}=0.1 \times 10^{6}$ and averaged the results for all of the Hugoton-Panhandle samples, the estimated contribution of abiogenic methane would still be $2 \times 10^{8} \mathrm{~m}^{3}$. (On the basis of systematic variations in helium, nitrogen, and methane across the field, Gold and Held (1987) have argued that the entire Hugoton-Panhandle accumulation has an abiogenic origin.)

Although this result might be viewed as evidence for a significant abiogenic hydrocarbon resource, it should be mentioned that because Hugoton ${ }^{3} \mathrm{He} /{ }^{4} \mathrm{He}$ ratios are only slightly elevated, the calculated abundance of abiogenic methane is quite sensitive to the ${ }^{3} \mathrm{He} /{ }^{4} \mathrm{He}$ ratio assumed for the crustal mixing endmember. In their discussion of helium isotope ratios in western Canadian gas fields, Hiyagon and Kennedy (1992) suggested that localized Li-rich evaporitic clays could yield radiogenic helium with ${ }^{3} \mathrm{He} /{ }^{4} \mathrm{He}$ ratios as high as $0.5 \mathrm{R}_{\mathrm{A}}$. Because the Hugoton reservoirs interfinger with red beds and are overlain by evaporites, it is conceivable that the relatively high ${ }^{3} \mathrm{He} /{ }^{4} \mathrm{He}$ ratios observed in this field are radiogenic and that the abundance of mantle helium and abiogenic methane has been grossly overestimated. Although our explanation is speculative, it should be noted that methane $\delta^{13} \mathrm{C}$ values in the HugotonPanhandle complex ( -45.4 to -41.1 permil) are clearly biogenic and that no isotopic reversals occur among the $C_{1}$ to $\mathrm{C}_{4}$ hydrocarbons (Jenden and others, $1988 \mathrm{~b}$; Jenden and Kaplan, 1989a).

\section{METHANE $\delta^{13} \mathrm{C}$ AND HELIUM-3 ABUNDANCE}

If isotopically heavy abiogenic methane were a significant component of commercial oil and gas accumulations, one might expect to see a correlation between helium and methane carbon isotope compositions. It can be seen in figure 10 that the shape of the mixing lines depends critically upon the ratio $\left(\mathrm{CH}_{4} /{ }^{3} \mathrm{He}\right)_{\text {crustal }}:\left(\mathrm{CH}_{4} /{ }^{3} \mathrm{He}\right)_{\text {magmatic }}$. If the crustal ratio were as much as $10^{6}$ times the magmatic ratio, a significant correlation would not be expected. On the other hand, if the crustal ratio were on the order of $10^{3}$ times the magmatic ratio, methane $\delta^{13} \mathrm{C}$ values would tend to increase with increasing ${ }^{3} \mathrm{He} /{ }^{4} \mathrm{He}$. In actuality, the expected relationships are complicated by variability in both the biogenic and magmatic methane $\delta^{13} \mathrm{C}$ values. In addition, conclusions about the abundance of abiogenic methane are difficult to draw from these curves since hot magmatic fluids may become contaminated with organic carbon from invaded sedimentary and metasedimentary rocks.

The relationship between methane $\delta^{13} \mathrm{C}$ values and ${ }^{3} \mathrm{He} /{ }^{4} \mathrm{He}$ ratios for Japanese natural gases from the Green Tuff region and surrounding districts is shown in figure 11. The mixing lines are purely hypothetical and have been drawn so as to bound the data as tightly as possible. The isotopic compositions of methane in the crustal component vary from -76 permil (microbial origin) to near -36 permil (thermogenic origin). This large variation in $\delta^{13} \mathrm{C}$ values makes the endmember abundances present in any given sample impossible to determine.

Some insight can be gathered by examining points lying near the margins of the data field. The gas marked " $A$," for example, has a ${ }^{3} \mathrm{He} /{ }^{4} \mathrm{He}$ ratio of $5.5 \mathrm{R}_{\mathrm{A}}$, very near that of the magmatic endmembers, and a $\delta^{13} \mathrm{C}$ value of -61.3 permil, at least 30 permil lighter than that of the magmatic endmembers. The origins of helium and methane in this sample are clearly decoupled: the helium is essentially all derived from the magmatic component and the methane is essentially all derived from the crustal endmember. The actual $\left(\mathrm{CH}_{4} /{ }^{3} \mathrm{He}\right)_{\text {crustal }}:\left(\mathrm{CH}_{4} /{ }^{3} \mathrm{He}\right)_{\text {magmatic }}$ ratio is probably greater than the value of $6 \times 10^{3}$ illustrated by the lower mixing line. A ratio of approximately $10^{5}$ would be required if the crustal endmember that mixed to form gas $\mathrm{A}$ had a methane $\delta^{13} \mathrm{C}$ value as heavy as -62 permil.

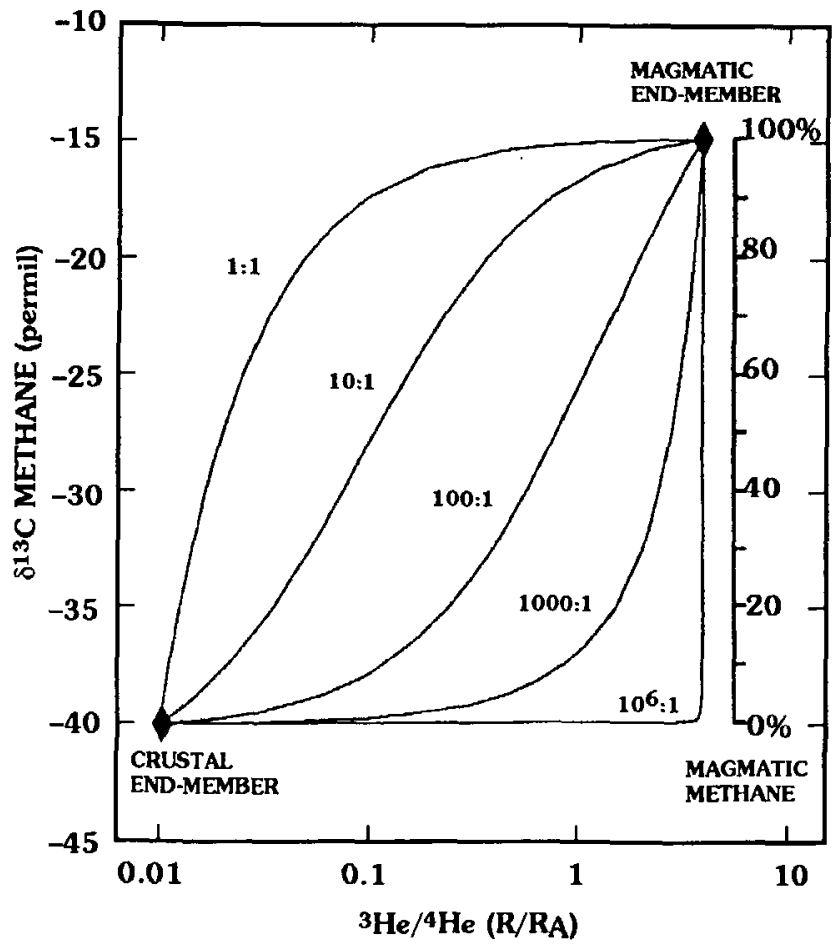

Figure 10. Mixing lines between hypothetical crustal and magmatic endmembers on plot of methane $\delta^{13} \mathrm{C}$ versus ${ }^{3} \mathrm{He} /{ }^{4} \mathrm{He}$ (expressed as $R / R_{A}$, or ratio in sample divided by ratio in air). Shape of mixing lines depends on ratio $\left(\mathrm{CH}_{4} / 3 \mathrm{He}\right)_{\text {crustal }}:\left(\mathrm{CH}_{4} /\right.$ $\left.{ }^{3} \mathrm{He}\right)_{\text {magmatic }}$, for which values from $1: 1$ to $10^{6}: 1$ are illustrated. 
The shape of the upper mixing line, for which $\left(\mathrm{CH}_{4} / 3 \mathrm{He}\right)_{\text {crustal }}:\left(\mathrm{CH}_{4} /{ }^{3} \mathrm{He}\right)_{\text {magmatic }}=1.5 \times 10^{4}$, is suggested by the distribution of several gases in the area marked "B." The crustal endmember at ${ }^{3} \mathrm{He} /{ }^{4} \mathrm{He}=0.01 \mathrm{R}_{\mathrm{A}}$ presumably represents the most mature thermogenic methane generated in the Green Tuff basin without the involvement of magmatic fluids. The magmatic endmember, fitted with ${ }^{3} \mathrm{He} /{ }^{4} \mathrm{He}=5.5 \mathrm{R}_{\mathrm{A}}$ and methane $\delta^{13} \mathrm{C}=-25$ permil, is similar to several methane-rich Kamchatka Peninsula gases and is interpreted to originate from contact between mantle-derived fluids and sedimentary organic matter. If the crustal $\mathrm{CH}_{4} \beta^{3} \mathrm{He}$ ratio is taken to be $3 \times 10^{13}$ (fig. 7), a $\mathrm{CH}_{4} /{ }^{3} \mathrm{He}$ ratio of roughly $2 \times 10^{9}$ is inferred for the magmatic component. The latter is similar to the $\mathrm{CH}_{4} / 3 \mathrm{He}$ ratio observed for the isotopically heaviest Green Tuff gases.

Relationships between methane $\delta^{13} \mathrm{C}$ values and ${ }^{3} \mathrm{He} /{ }^{4} \mathrm{He}$ ratios for commercial gases outside of Japan are illustrated in figure 12. As before, methane $\delta^{13} \mathrm{C}$ values inferred for the crustal component vary widely $(-70$ to -30

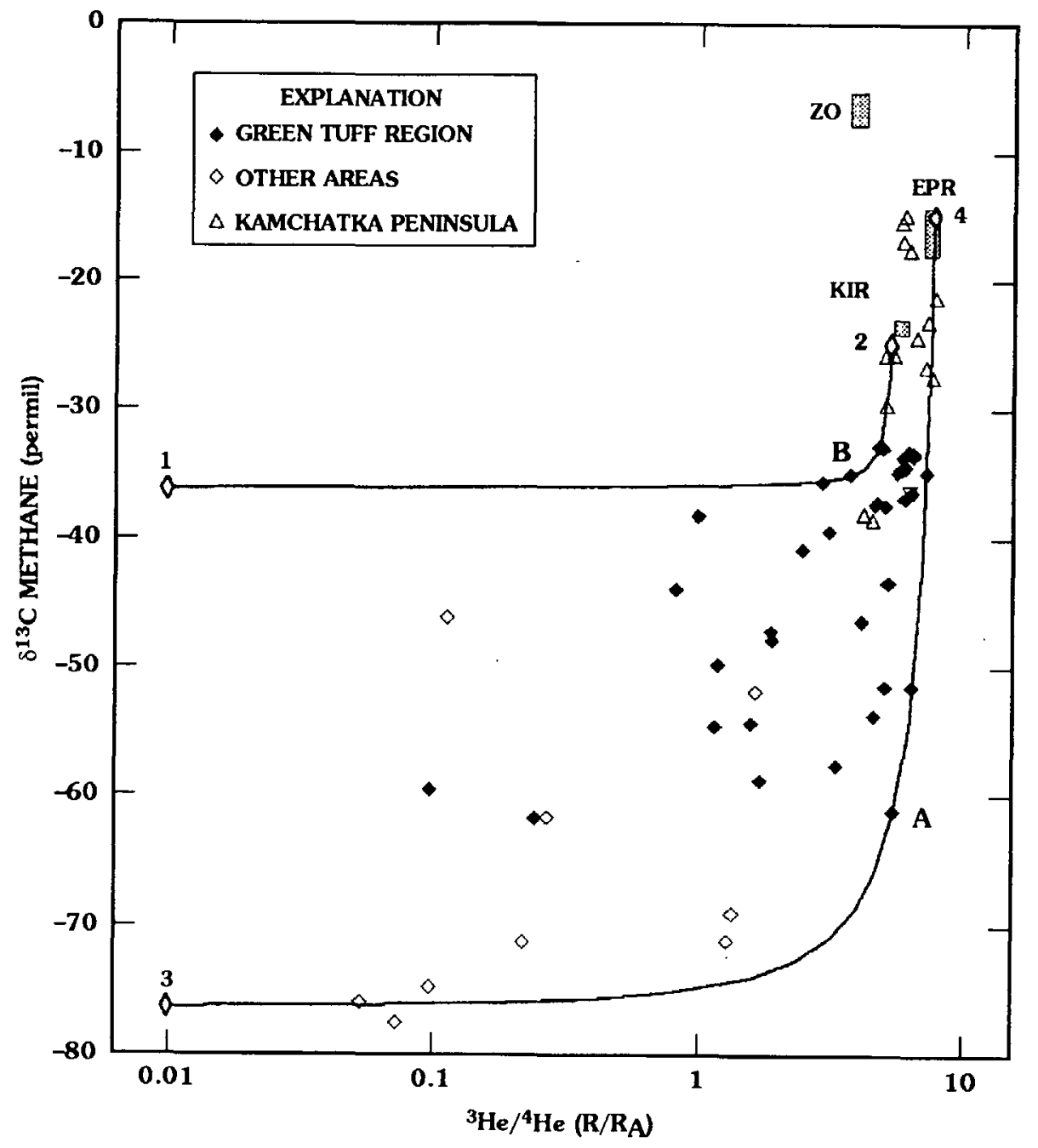

Figure 11. Plot of methane $\delta^{13} \mathrm{C}$ versus ${ }^{3} \mathrm{He} /{ }^{4} \mathrm{He}$ (expressed as $\mathrm{R} / \mathrm{R}_{\mathrm{A}}$, or ratio in sample divided by ratio in air) for natural gases from Japan (data from same sources as those cited in fig. 7). EPR, geothermal fluids from $21^{\circ} \mathrm{N}$. East Pacific Rise (Welhan and Craig, 1983); ZO, gas seeps from the Zambales Ophiolite in the Philippines (Abrajano and others, 1988); KIR, Kirishima Volcano (Wakita and others, 1990). Mixing lines are drawn between hypothetical crustal and magmatic endmembers. The magmatic endmembers $\left({ }^{3} \mathrm{He} /{ }^{4} \mathrm{He}=5.5\right.$ to $8.0 \mathrm{R}_{\mathrm{A}}$ and $\delta^{13} \mathrm{C}=-25$ to -15 permil) were chosen to match data for volcanic and geothermal gases from the Kamchatka Peninsula (Kamenskiy and others, 1976) and are interpreted to originate from variable contact between hot magmatic fluids and sedimentary organic matter. The illustrated $\left(\mathrm{CH}_{4} /{ }^{3} \mathrm{He}\right)_{\text {crust }}:\left(\mathrm{CH}_{4} /{ }^{3} \mathrm{He}\right)_{\text {magmatic }}$ values are $1.5 \times 10^{4}$ for line $1-2$; and $6 \times 10^{3}$ for line 3-4. " $\mathrm{A}$ " and " $\mathrm{B}$ " refer to data discussed in text. 
permil), making it impossible to estimate the endmember abundances in any given sample. No relationship can be discerned between methane $\delta^{13} \mathrm{C}$ values and reservoir age. The distribution of data do, however, support an association between high ${ }^{3} \mathrm{He} /{ }^{4} \mathrm{He}$ ratios and isotopically heavy methane $\left(\delta^{13} \mathrm{C}\right.$ values up to -15 permil). If one assumes a magmatic endmember with methane $\delta{ }^{13} \mathrm{C} \geq-15$ and ${ }^{3} \mathrm{He} /{ }^{4} \mathrm{He}=1$ to $4 \mathbf{R}_{\mathrm{A}}$, several gases from the Great Valley of California (GV) would appear to be dominated by this component.

The mixing lines which so neatly bound the data were both drawn with $\left(\mathrm{CH}_{4} /{ }^{3} \mathrm{He}\right)_{\text {crustal }} /\left(\mathrm{CH}_{4} /{ }^{3} \mathrm{He}\right)_{\text {magmatic }}=400$. Since $\mathrm{CH}_{4}{ }^{3} \mathrm{He}$ values for Cenozoic gases with crustal
${ }^{3} \mathrm{He} /{ }^{4} \mathrm{He}$ ratios $\left(\leq 0.04 \mathrm{R}_{\mathrm{A}}\right.$ ) reach up to $2 \times 10^{13}$, one might infer $\mathrm{CH}_{4} /{ }^{3} \mathrm{He}$ values for the so-called magmatic component as high as $5 \times 10^{10}$. Because this ratio is more than one order of magnitude larger than the average $\Sigma \mathrm{C} /{ }^{3} \mathrm{He}$ ratio (where $\Sigma \mathrm{C}$ is total carbon summed from all $\mathrm{C}$-bearing compounds) inferred for the upper mantle $\left(2 \times 10^{9}\right.$; Marty and Jambon, 1987), contamination with biogenic methane is indicated. Such high $\mathrm{CH}_{4} /{ }^{3} \mathrm{He}$ ratios in the magmatic endmember are intriguing because they imply that contact between igneous fluids and sedimentary rocks could generate commercially significant quantities of natural gas (Poreda and others, 1986, 1988).

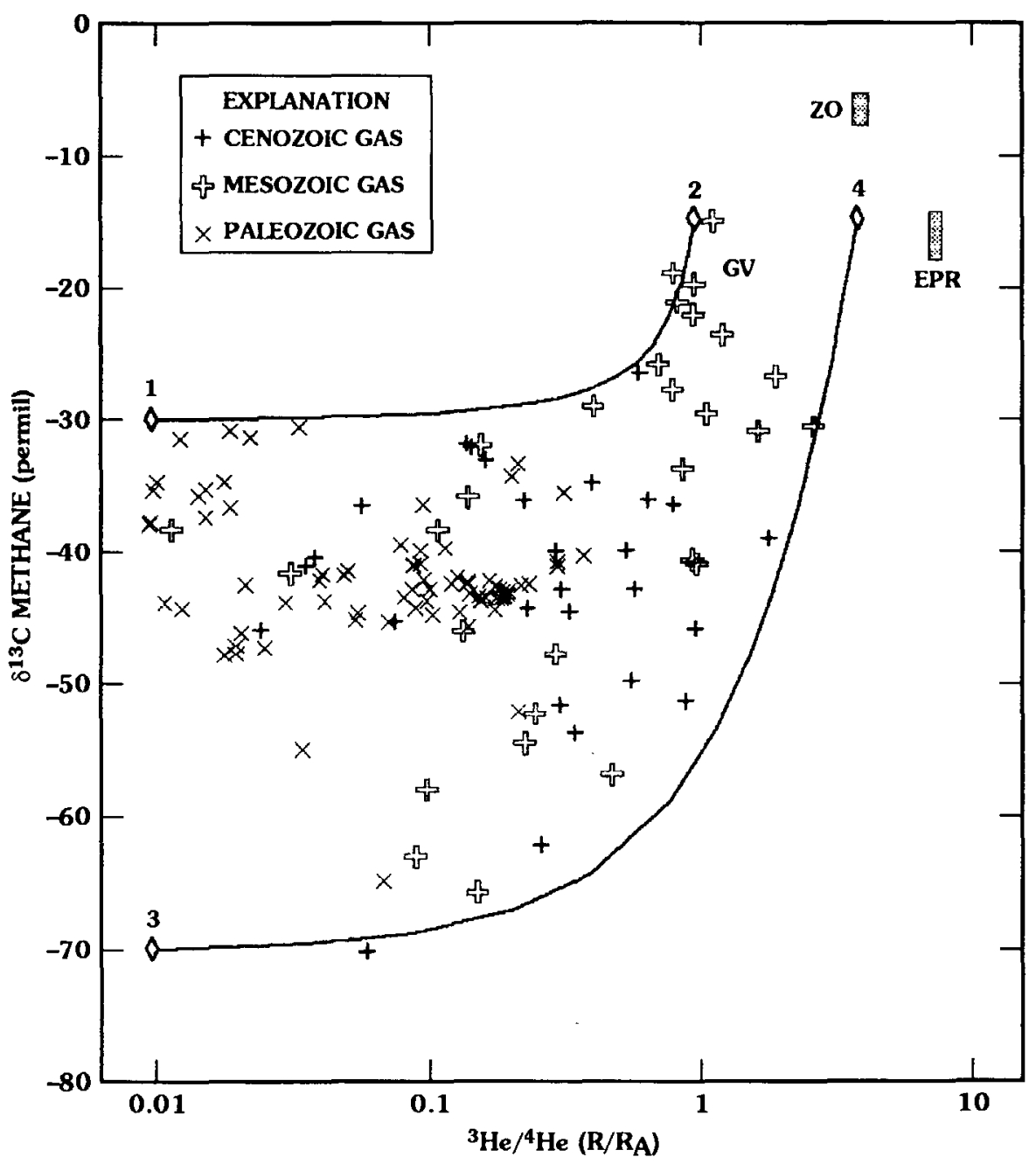

Figure 12. A plot of methane $\delta^{13} \mathrm{C}$ versus ${ }^{3} \mathrm{He} /{ }^{4} \mathrm{He}$ (expressed as $\mathrm{R} / \mathrm{R}_{\mathrm{A}}$, or ratio in sample divided by ratio in air) for 133 commercial gases from Thailand, western Canada, United States, and central Europe (references listed in fig. 5). Lines illustrate mixing paths between hypothetical endmembers with $\left(\mathrm{CH}_{4} /{ }^{3} \mathrm{He}\right)_{\text {crustal }} \cdot\left(\mathrm{CH}_{4} /{ }^{3} \mathrm{He}\right)_{\text {magmatic }}=400$. Endmember 2 is similar to several nitrogen-rich gases from the California Great Valley (GV) which are interpreted to originate from subducted metasedimentary rocks (Jenden and others, 1988a). EPR, geothermal fluids from $21^{\circ} \mathrm{N}$. East Pacific Rise (Welhan and Craig, 1983); ZO, gas seeps from the Zambales Ophiolite in the Philippines (Abrajano and others, 1988). 


\section{NONHYDROCARBON GASES}

Nitrogen and carbon dioxide compose less than 5 percent of most natural gases but can occur at concentrations in excess of 50 percent. Such high concentrations severely diminish natural-gas heating values, creating economic problems for gas producers. The origin of nitrogen- and carbon-dioxide-rich gases is not understood, but ${ }^{3} \mathrm{He} /{ }^{4} \mathrm{He}$ measurements suggest, in some instances, the presence of a magmatic gas component.

Due to the paucity of available data, it is difficult to evaluate whether the mantle itself is an important source of nitrogen in natural gases. However, mantle volatiles may strip nitrogen from the deep crust. Nitrogen-rich fluid inclusions are commonly reported in metasedimentary rocks (Kreulen and Schuiling, 1982; Glassley and others, 1984; Darimont and others, 1988), where they may form by the oxidation of ammonium in silicate minerals (Honma and Itihara, 1981; Bos and others, 1988). On the basis of their geological occurrence and their association with methane $\delta^{13} \mathrm{C}$ values as heavy as -15 permil, ${ }^{3} \mathrm{He} /{ }^{4} \mathrm{He}$ ratios of $1 \mathrm{R}_{\mathrm{A}}$, and $\mathrm{N}_{2} / \mathrm{Ar}$ ratios up to 22,000 , nitrogen-rich gases in the California Great Valley are thought to have originated from subducted metasedimentary rocks underplating the crust (Jenden and others, 1988a). $\delta^{15} \mathrm{~N}$ data for Great Valley nitrogen gas ( 0.9 to 3.5 permil) and $\delta^{15} \mathrm{~N}$ values of total nitrogen in Franciscan Complex-equivalent rocks (1.9 to 4.3 permil; Bebout and Fogel, 1992) support this conclusion.

In contrast to the uncertainty surrounding deep sources of nitrogen, mantle-derived carbon dioxide is widely recognized in hot springs, volcanic and geothermal gases, and carbonatite magmas. Bicarbonate-rich springs are commonly associated with zones of major seismicity, Tertiary to present-day volcanism, and elevated ${ }^{3} \mathrm{He} /{ }^{4} \mathrm{He}$ ratios, indicating the presence of mantle-derived volatiles (Irwin and Barnes, 1980; Matthews and others, 1987; Griesshaber and others, 1992). Carbon isotope studies suggest that faulting and igneous activity have introduced magmatic carbon dioxide into gas reservoirs and coal seams in several Australian basins (Smith and Gould, 1980; Rigby and Smith, 1981; Smith and others, 1985). Natural gases with 98 percent or more carbon dioxide, carbon dioxide $\delta^{13} \mathrm{C}=-4$ permil, and ${ }^{3} \mathrm{He} /{ }^{4} \mathrm{He}$ ratios near $3 \mathrm{R}_{\mathrm{A}}$ have been reported from Queensland, Australia (Chivas and others, 1987), and New Mexico, United States (Staudacher, 1987), and probably have a magmatic origin. Chivas and others (1987) have proposed that the accumulation of magmatic carbon dioxide in shallow crustal reservoirs may be responsible for the occurrence of violent, near-surface explosions in regions of basaltic volcanism.

A plot of carbon dioxide concentration versus $\delta^{13} \mathrm{C}$ for 140 commercial natural gases collected in this study is shown in figure 13. Gases with less than 40 percent carbon dioxide have $\delta^{13} \mathrm{C}$ values ranging from -33 to +24 permil, reflecting a variety of crustal origins including hydrocarbon oxidation and kerogen decarboxylation (Irwin and others, 1977; Krouse and others, 1988), microbial methanogenesis (Jenden and Kaplan, 1986), and oil field biodegradation (Dimitrakopoulos and Muehlenbachs, 1987; Jeffrey and others, 1991). Of particular interest is the fact that gases with 40 to 100 percent carbon dioxide have $\delta^{13} \mathrm{C}$ values of $-4 \pm 2$ permil, outside the range of most marine carbonates. Similar observations have been made for carbon-dioxiderich gases in the Bekes Basin of Hungary $\left(\delta^{13} \mathrm{C}=-8\right.$ to -3 permil; Clayton and others, 1990). Although $\delta^{13} \mathrm{C}$ values in this range can be explained by mixing between organic and inorganic carbon sources, in tectonically active basins such data could indicate the presence of mantle carbon dioxide (approximately -4 permil; Marty and others, 1989, 1993; Javoy and Pineau, 1991; Poreda and others, 1992).

In this study, ${ }^{3} \mathrm{He} /{ }^{4} \mathrm{He}$ measurements were made on five carbon-dioxide-rich gases, four from the United States and one from the Gulf of Thailand (table 2). Carbon dioxide concentration in these gases ranges from 61 to 97 percent, carbon dioxide $\delta^{13} \mathrm{C}$ values range from -6.1 to -2.9 permil, and ${ }^{3} \mathrm{He} /{ }^{4} \mathrm{He}$ ratios range from 0.210 to $1.89 \mathrm{R}_{\mathrm{A}}$. The ${ }^{3} \mathrm{He} /{ }^{4} \mathrm{He}$ ratios are related to the age of the producing

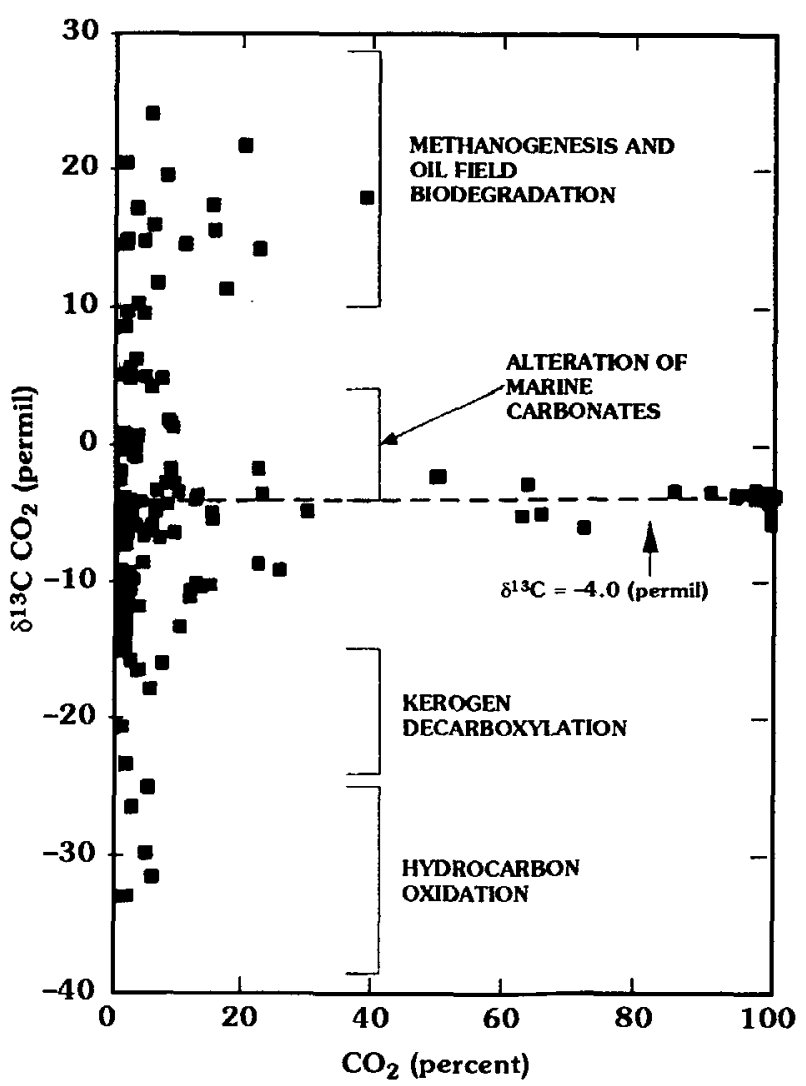

Figure 13. $\delta^{13} \mathrm{C}$ versus concentration of carbon dioxide in 140 commercial natural gases from the United States and Thailand (this study; Jenden and Kaplan, 1989a). Brackets show ranges of $\delta^{13} \mathrm{C}$ values expected for $\mathrm{CO}_{2}$ derived from various sources. 
Table 2. Chemical and stable isotopic composition of some $\mathrm{CO}_{2}$-rich natural gases (Jenden and Kaplan, 1989a).

[ $\mathrm{O}_{2}$ content less than or equal to 0.1 volume percent for all samples. Abbreviations as follows: Cret, Cretaceous; Jur, Jurassic; Mio, Miocene; Sil, Silurian; m, meters; ppm, parts per million; $R / R_{A}$, ratio in sample divided by ratio in air; $\%$, volume percent]

\begin{tabular}{|c|c|c|c|c|c|c|c|c|c|c|c|c|}
\hline $\begin{array}{l}\text { Sample } \\
\text { No. }\end{array}$ & Field & $\begin{array}{c}\text { Reservoir } \\
\text { age }\end{array}$ & $\begin{array}{c}\text { Depth } \\
\text { (m) }\end{array}$ & $\begin{array}{l}C_{1} \\
(\%) \\
\end{array}$ & $\begin{array}{l}\mathbf{C}_{2+} \\
(\%)\end{array}$ & $\begin{array}{l}\mathrm{CO}_{2} \\
(\%)\end{array}$ & $\begin{array}{l}\mathrm{N}_{2} \\
(\%)\end{array}$ & $\begin{array}{c}\mathrm{He} \\
(\mathrm{ppm})\end{array}$ & $\begin{array}{c}\delta^{13} \mathrm{C}\left(\mathrm{CH}_{4}\right) \\
\text { (permil) }\end{array}$ & $\begin{array}{c}\delta^{13} \mathrm{C}\left(\mathrm{CO}_{2}\right) \\
\text { (permil) }\end{array}$ & $\begin{array}{c}{ }^{3} \mathrm{He} /{ }^{4} \mathrm{He} \\
(\mathbf{R} / \mathbf{R} \boldsymbol{N})\end{array}$ & $\begin{array}{c}\mathrm{CO}_{2} /{ }^{3} \mathrm{He} \\
\left(\times 10^{9}\right)\end{array}$ \\
\hline 1299 & Platong, Thailand & Mio & 2,097 & 24.3 & 4.001 & 71.9 & 0.800 & 24.8 & -39.2 & -6.1 & 1.89 & 11.0 \\
\hline 1037 & Sheep Mountain, CO & Jur & 960 & 2.13 & 0.254 & 97.3 & 0.666 & 180 & -40.8 & -4.1 & 0.980 & 3.94 \\
\hline 1034 & Sheep Mountain, CO & Cret & 959 & 4.21 & 0.278 & 94.8 & 1.54 & 612 & -41.1 & -4.0 & 1.02 & 1.09 \\
\hline 1192 & Wildcat, WV & Sil & 2,490 & 13.0 & 0.138 & 83.5 & 2.23 & 1060 & -35.7 & -3.5 & 0.331 & 1.70 \\
\hline 1074 & Indian Creek, WV & Sil & 2,058 & 33.4 & 0.277 & 61.3 & 2.73 & 1140 & -34.5 & -2.9 & 0.210 & 1.83 \\
\hline
\end{tabular}

rocks and reflect dilution in the reservoir with radiogenic helium. Platong gas $\left(1.89 \mathrm{R}_{\mathrm{A}}\right)$ is produced from Miocene sandstone, Sheep Mountain gas $\left(0.98\right.$ to $\left.1.02 \mathrm{R}_{\mathrm{A}}\right)$ is produced from Jurassic and Cretaceous sandstones, and the West Virginia wildcat and Indian Creek gases $(0.210$ and $0.331 R_{A}$ ) are produced from Silurian sandstones. Past tectonic activity may be a common factor in the origin of these gases: the Sheep Mountain field is closely associated with Tertiary intrusive rocks, the West Virginia wildcat and Indian Creek field are located near the eastern United States overthrust belt, and the Platong field produces from a rift basin with high heat flow: Carbon isotope data do not permit distinction between a magmatic source and a mixture of crustal carbonate and organic carbon sources, but the $\mathrm{CO}_{2} /^{3} \mathrm{He}$ ratios of the Sheep Mountain, West Virginia wildcat, and Indian Creek samples are very close to the estimated bulk-earth degassing ratio of $2 \times 10^{9}$ (Marty and Jambon, 1987). The high $\mathrm{CO}_{2}{ }^{3} \mathrm{He}$ ratio of the Platong sample $\left(1 \times 10^{10}\right)$ may indicate some contamination with crustal carbon.

\section{CONCLUDING REMARKS}

As we have noted earlier, the economic significance of magmatic volatiles in oil and gas fields cannot be estimated without quantitative assumptions regarding methane $\delta^{13} \mathrm{C}$ values, ${ }^{3} \mathrm{He} /{ }^{4} \mathrm{He}$ ratios, and $\mathrm{CH}_{4} /{ }^{3} \mathrm{He}$ ratios in gases of mantle and crustal origins. Reasonable estimates for these parameters suggest that commercial accumulations of abiogenic hydrocarbons have not been discovered by the petroleum industry. Methane $\delta^{13} \mathrm{C}$ values in oil and gas fields exhibit a sharp mode near -42 permil, and 97.6 percent of the available measurements are lighter (more negative) than -25 permil, characteristics compatible with biogenic sources but inconsistent with gases known to be abiogenic. While superficially similar to the patterns observed for some abiogenic gases, isotopic distributions in which methane $\delta^{13} \mathrm{C}>$ ethane $\delta^{13} \mathrm{C}$, ethane $\delta^{13} \mathrm{C}>$ propane $\delta^{13} \mathrm{C}$, or propane $\delta^{13} \mathrm{C}>n$-butane $\delta^{13} \mathrm{C}$, can be ex- plained by isotopic heterogeneities in sedimentary organic matter, and by mixing and oxidation of biogenic gas. Helium isotope ratios in oil and gas fields vary from 0.004 to $7.5 \mathrm{R}_{\mathrm{A}}$, indicating mixing between crustal helium of radiogenic origin and helium derived from the mantle. Calculations assuming a magmatic component with a $\mathrm{CH}_{4} / 3 \mathrm{He}$ ratio similar to that in gas from hydrothermal vents at $21^{\circ} \mathrm{N}$. on the East Pacific Rise suggest that far less than 1 percent of the methane in most oil and gas fields is of abiogenic origin.

These findings are subject to several qualifications:

1. By themselves, methane $\delta^{13} \mathrm{C}$ values are not a very reliable means of distinguishing abiogenic and biogenic sources. Abiogenic methane with $\delta^{13} \mathrm{C}<-25$ permil can be produced by Fischer-Tropsch synthesis (Lancet and Anders, 1970; Yuen and others, 1990) and may be widespread in crystalline cratonic rocks (Laier, 1988; Sherwood and others, 1988). Isotopically light abiogenic carbon is well known in diamonds and meteorites (Deines, 1980b; Pillinger, 1984). On the other hand, Chung and Sackett (1979) have shown that isotopically heavy biogenic methane can be produced by laboratory pyrolysis of high-rank coals. Therefore, methane with $\delta^{13} \mathrm{C}>-20$ permil could originate in low-grade metasedimentary rocks and is not necessarily abiogenic.

2. The light hydrocarbon gas $\delta^{13} \mathrm{C}$ distribution observed for fluid inclusions in igneous rocks and meteorites may not be characteristic of abiogenic hydrocarbons in general. Even if it were, few $\delta^{13} \mathrm{C}$ data for $\mathrm{C}_{2+}$ hydrocarbons have been published for very dry commercial gases $\left(\mathrm{C}_{2+}\right.$ /total hydrocarbons $<1$ percent $)$, so many isotopic reversals might be undiscovered.

3. Calculations have assumed a radiogenic crustal ${ }^{3} \mathrm{He} /{ }^{4} \mathrm{He}$ ratio of only $0.01 \mathrm{R}_{\mathrm{A}}$. Because much higher ratios may be produced by uncommon crystalline and sedimentary rock types rich in $\mathrm{Li}$ and by helium contributions from cosmic dust (Andrews, 1985; Hiyagon and Kennedy, 1992), the abundance of abiogenic methane in some fields (for example, the supergiant Hugoton) may have been seriously overestimated. 
4. Calculations of abiogenic methane abundance depend on $\mathrm{CH}_{4} /{ }^{3} \mathrm{He}$ ratios of mantle fluids in apparently uncontaminated geothermal and volcanic systems; these ratios vary by more than three orders of magnitude. The highest ratios (approximately $100 \times 10^{6}$ ) suggest that abiogenic methane could account for as much as 20 percent of the gas produced from a number of small, circum-Pacific basin accumulations. Most, if not all, of these hydrocarbons could have been generated by contact of hot magmatic fluids with organic-rich sedimentary rocks. On the other hand, the overall abundance of abiogenic methane could be seriously underestimated if reduction of magmatic carbon dioxide to methane in the crust is more extensive than predicted from volcanic and geothermal data. Theoretically, at least, "magmatic" $\mathrm{CH}_{4} /{ }^{3} \mathrm{He}$ ratios could approach the average upper mantle $\mathrm{C} /{ }^{3} \mathrm{He}$ ratio of $2 \times 10^{9}$ (Marty and Jambon, 1987).

The conclusion that abiogenic methane is not a commercial resource is consistent with findings from the Gravberg 1 well at the Siljan Ring in Sweden (Juhlin and others, 1991; Castaño, this volume). Drilled, in part, to test the "deep-earth gas" hypothesis (Fish, 1986), the Gravberg 1 well penetrated a fractured granite structure which was thought to be capped by an impermeable seal of calcite cement. No commercial reserves were discovered, but several thin dolerite sills yielded minor shows of presumably abiogenic methane with less than 10 percent $\mathrm{C}_{2+}$ hydrocarbons and methane $\delta^{13} \mathrm{C}$ values ranging from -26 to -11 permil (Laier, 1988; Jeffrey and Kaplan, 1988). Perhaps due to the great age of the country rock, gas samples uncontaminated by air yielded typical crustal ${ }^{3} \mathrm{He} /{ }^{4} \mathrm{He}$ ratios of approximately $0.02 \mathrm{R}_{\mathrm{A}}$ (Hilton and Craig, 1989).

\section{ACKNOWLEDGMENTS}

We gratefully acknowledge the many oil companies that provided gas samples and well data for the GRI natural-gas study. Special thanks for assistance in collecting samples for helium isotope analysis are due Dudley Rice and Chuck Threlkeld at the U.S. Geological Survey in Denver, David Newell and Lynn Watney at the Kansas Geological Survey, and Don Drazan at the New York State Department of Environmental Conservation. We are indebted to Martin Drut and others at Global Geochemistry Corporation who measured gas compositions and carbon isotope ratios on what seemed to be innumerable samples. Robert Poreda made many of the helium isotope measurements and provided valuable comments and assistance. Helpful discussions and critical support were provided throughout the project by Ferol Fish, Paul Wescott, and Anthony Gorody of the Gas Research Institute.

We wish to express our gratitude to Barbara Sherwood-Lollar and Joel Leventhal, who went out of their way to provide rapid and thoughtful reviews of this paper.
Chevron Petroleum Technology Company kindly supported us with drafting and word processing. Research funding was provided by the Gas Research Institute, contract no. 5081-360-0533.

\section{REFERENCES CITED}

Abrajano, T.A., Sturchio, N.C., Bohlke, J.K., Lyon, G.L., Poreda, R.J., and Stevens, C.M., 1988, Methane-hydrogen gas seeps, Zambales Ophiolite, Philippines-Deep or shallow origin?, in Schoell, M., ed., Origins of methane in the Earth, Chemical Geology, v. 71, p. 211-222.

Abrajano, T.A., Sturchio, N.C., Kennedy, B.M., Lyon, G.L., Muehlenbachs, K., and Bohlke, J.K., 1990, Geochemistry of reduced gas related to serpentinization of the Zambales Ophiolite, Philippines: Applied Geochemistry, v. 5, p. 625630.

Aldrich, L.T., and Nier, A.O., 1948, The occurrence of ${ }^{3} \mathrm{He}$ in natural sources of helium: Physical Review, v. 74, p. 15901594.

Andrews, J.N., 1985, The isotopic composition of radiogenic helium and its use to study groundwater movement in confined aquifers: Chemical Geology, v. 49, p. 339-351.

Ballentine, C.J., and O'Nions, R.K., 1991, The nature of mantle neon contributions to Vienna Basin hydrocarbon reservoirs: Earth and Planetary Science Letters, v. 113, p. 553-567.

Ballentine, C.J., O'Nions, R.K., Oxburgh, E.R., Horvath, F., and Deak, J., 1991, Rare gas constraints on hydrocarbon accumulation, crustal degassing and groundwater flow in the Pannonian Basin: Earth and Planetary Science Letters, v. 105, p. 229-246.

Barker, J.F., and Pollock, S.J., 1984, The geochemistry and origin of natural gases in southern Ontario: Bulletin of Canadian Petroleum Geology, v. 32, p. 313-326.

Bebout, G.E., and Fogel, M.L., 1992, Nitrogen-isotope compositions of metasedimentary rocks in the Catalina Schist, California-Implications for metamorphic devolatilization history: Geochimica et Cosmochimica Acta, v. 56, p. 2839-2849.

Bos, A., Duit, W., van der Eerden, A.M.J., and Jensen, J.B.H., 1988, Nitrogen storage in biotite-An experimental study of the ammonium and potassium partitioning between $1 \mathrm{M}$ phlogopite and vapor at $2 \mathrm{~Kb}$ : Geochimica et Cosmochimica Acta, v. 52, p. 1275-1283.

Chang, S., Des Marais, D., Mack, R., Miller, S.L., and Strathearn, G.E., 1983, Prebiotic organic synthesis and the origin of life, in Schopf, J.W., ed., Earth's earliest biosphere, its origin and evolution: Princeton, N.J., Princeton University Press, p. 54-92.

Chivas, A.R., Barnes, I., Evans, W.C., Lupton, J.E., and Stone, J.O., 1987, Liquid carbon dioxide of magmatic origin and its role in volcanic eruptions: Nature, v. 326, p. 587-589.

Chung, H.M., Gormly, J.R., and Squires, R.M., 1988, Origin of gaseous hydrocarbons in subsurface environments; theoretical considerations of carbon isotope distribution, in Schoell, M., ed., Origins of methane in the Earth: Chemical Geology, v. 71, p. 97-103.

Chung, H.M., and Sackett, W.M., 1979, Use of stable carbon isotope compositions of pyrolytically derived methane as 
maturity indices for carbonaceous materials: Geochimica et Cosmochimica Acta, v. 43, p. 1979-1988.

1980, Carbon isotope effects during the pyrolytic formation of early methane from carbonaceous materials, in Douglas, A.G., and Maxwell, J.R., eds., Advances in organic geochemistry 1979: New York, Pergamon Press, p. 705-710.

Claypool, G.E., Threlkeld, C.N., and Magoon, L.B., 1980, Biogenic and thermogenic origins of natural gas in Cook Inlet basin, Alaska: American Association of Petroleum Geologists Bulletin, v. 64, p. 1131-1139.

Clayton, C., 1991, Carbon isotope fractionation during natural gas generation from kerogen: Marine and Petroleum Geology, v. 8, p. 232-240.

Clayton, J.L., Spencer, C.W., Koncz, I., and Szalay, A., 1990, Origin and migration of hydrocarbon gases and carbon dioxide, Bekes Basin, southeastern Hungary: Organic Geochemistry, v. 15, p. 233-247.

Colombo, U., Gazzarrini, F., Gonfiantini, R., Sironi, G., and Tongiorgi, E., 1966, Measurements of ${ }^{13} \mathrm{C}^{12} \mathrm{C}$ isotope ratios on Italian natural gases and their geochemical interpretation, in Hobson, G.D., and Louis, M.C., eds., Advances in organic geochemistry 1964: New York, Pergamon Press, p. 279-292.

Craig, H., 1953, The geochemistry of the stable carbon isotopes: Geochimica et Cosmochimica Acta, v. 3, p. 53-92.

Craig, H., Kim, K-R., and Rison, W., 1984, Easter Island Hotspot-I. Bathymetry, helium isotopes, and hydrothermal methane and helium [abs.]: EOS, v. 65, p. 1140.

Craig, H., and Lupton, J.E., 1981, Helium-3 and mantle volatiles in the ocean and the oceanic crust, in Emiliani, C., ed., The sea, v. 7: New York, John Wiley and Sons, p. 391-428.

Craig, H., Lupton, J.E., and Horibe, Y., 1978, A mantle helium component in circum-Pacific volcanic gases-Hakone, the Marianas and Mt. Lassen, in Alexander, E.C., and Ozima, M., eds., Terrestrial rare gases: Tokyo, Japan Scientific Society Press, p. 3-16.

Darimont, A., Burke, E., and Touret, J., 1988, Nitrogen-rich fluids in Devonian metasediments from Bastogne, Belgium: Bulletin de Mineralogie, v. 111, p. 321-330.

Deines, P., 1980a, The isotopic composition of reduced organic carbon, in Fritz, P., and Fontes, J., eds., Handbook of environmental isotope geochemistry, v. 1: New York, Elsevier, p. 329-406.

-1980b, The carbon isotopic composition of diamonds; relationship to diamond shape, color, occurrence and vapor composition: Geochimica et Cosmochimica Acta, v. 44, p. 943-961.

Des Marais, D.J., 1985, Carbon exchange between the mantle and the crust, and its effect upon the atmosphere--Today compared to Archean time, in Sundquist, E.T., and Broecker, W.S., eds., The carbon cycle and atmospheric $\mathrm{CO}_{2}$ natural variations Archean to present: Geophysical Monograph 32, American Geophysical Union, Washington D.C., p. 602611.

Des Marais, D.J., Donchin, J.H., Nehring, N.L., and Truesdell, A.H., 1981, Molecular carbon isotopic evidence for the origin of geothermal hydrocarbons: Nature, v. 292, p. 826-828.

Des Marais, D.J., Stallard, M.L., Nehring, N.L., and Truesdell, A.H., 1988, Carbon isotope geochemistry of hydrocarbons in the Cerro Prieto geothermal field, Baja California Norte, Mexico: Chemical Geology, v. 71, p. 159-167.
Dimitrakopoulos, R., and Muehlenbachs, K., 1987, Biodegradation of petroleum as a source of ${ }^{13} \mathrm{C}$-enriched carbon dioxide in the formation of carbonate cement: Chemical Geology (Isotope Geoscience Section), v. 65, p. 283-291.

Dott, R.H., Sr., and Reynolds, M.J., 1969, Sourcebook for petroleum geology: American Association of Petroleum Geologists Memoir 5, $471 \mathrm{p}$.

Erdman, J.G., and Morris, D.A., 1974, Geochemical correlation of petroleum: American Association of Petroleum Geologists Bulletin, v. 58, p. 2326-2337.

Fish, F., 1986, GRI's basic research on gas origin, migration: Oil and Gas Journal, 10 February, p. 118-126.

Fuex, A.N., 1977, The use of stable carbon isotopes in hydrocarbon exploration: Journal of Geochemical Exploration, v. 7, p. $155-188$.

Galimov, E.M., 1975, Carbon isotopes in oil-gas geology: U.S. Department of Commerce, National Technical Information Service, N75-27563, 395 p.

-1988, Sources and mechanisms of formation of gaseous hydrocarbons in sedimentary rocks, in Schoell, M., ed., Origins of methane in the Earth: Chemical Geology, v. 71, p. 77-95. 1991, Isotope fractionation related to kimberlite magmatism and diamond formation: Geochimica et Cosmochimica Acta, v. 55, p. 1697-1708.

Galimov, E.M., Ivlev, A.A., and Kuznetsova, N.G., 1970, Carbon isotope composition of gaseous hydrocarbons in petroleum and the problem of their origin: Geochemistry International, v. 7, p. 594-603.

Galimov, E.M., Teplinskiy, G.I., Tabassaranskiy, Z.A., and Gavrilov, E.Ye., 1973, On the conditions of formation of gas deposits in the eastern part of the Turan plate as revealed by the carbon isotopic composition of the gases: Geochemistry International, v. 10 , p. 1259-1271.

Gamo, T., Ishibashi, J-I., and Sakai, H., 1987, Methane anomalies in seawater above the Loihi submarine summit area, Hawaii: Geochimica et Cosmochimica Acta, v. 51, p. 2857-2864.

Gerlach, T.M., 1980, Chemical characteristics of the volcanic gases from Nyiragongo Lava Lake and the generation of $\mathrm{CH}_{4}$-rich fluid inclusions in alkaline rocks: Journal of Volcanology and Geothermal Research, v. 8, p. 177-189.

Giardini, A.A., and Melton, C.E., 1983, A scientific explanation for the origin and location of petroleum accumulations: Journal of Petroleum Geology, v. 5, p. 117-138.

Giggenbach, W.F., 1982, Carbon-13 exchange between $\mathrm{CO}_{2}$ and $\mathrm{CH}_{4}$ under geothermal conditions: Geochimica et Cosmochimica Acta, v. 46, p. 159-165.

Glassley, W.E., Bridgwater, D., and Konnerup-Madsen, J., 1984, Nitrogen in fluids effecting retrogression of granulite facies gneisses-A debatable mantle connection: Earth and Planetary Science Letters, v. 70, p. 417-425.

Gold, T., 1979, Terrestrial sources of carbon and earthquake outgassing: Journal of Petroleum Geology, v. 1, p. 3-19.

1985, The origin of natural gas and petroleum, and the prognosis for future supplies: Annual Review of Energy, v. 10 , p. $53-77$.

1987, Power from the Earth: London, Dent and Sons, $208 \mathrm{p}$.

Gold, T., Gordon, B.E., Street,W., Bilson, E., and Patnaik, P., 1986, Experimental study of the reaction of methane with petroleum hydrocarbons in geological conditions: Geochimica et Cosmochimica Acta, v. 50, p. 2411-2418. 
Gold, T., and Held, M., 1987, Helium-nitrogen-methane systematics in natural gases of Texas and Kansas: Journal of Petroleum Geology, v. 10, p. 415-424.

Gold, T., and Soter, S., 1980, The deep-earth gas hypothesis: Scientific American, v. 242, no. 6, p. 154-161.

1982, Abiogenic methane and the origin of petroleum: Energy Exploration and Exploitation, v. 1, p. 89-104.

1985, Fluid ascent through the solid lithosphere and its relation to earthquakes: Pure and Applied Geophysics, v. 122 , p. $492-530$.

Griesshaber, E., O'Nions, R.K., and Oxburgh, E.R., 1992, Helium and carbon isotope systematics in crustal fluids from the Eifel, the Rhine Graben and Black Forest, F.R.G.: Chemical Geology, v. 99, p. 213-235.

Gwilliam, W.J., 1982, Subducted origin hypothesis for deepsource methane, in Gwilliam, W.J., ed., Deep Source Gas Workshop: Technical Proceedings: Morgantown Energy Technology Center, U.S. Department of Energy, DOE/ METC-82-50, p. 140-161.

Haggerty, S.E., 1986, Diamond genesis in a multiply-constrained model: Nature, v. 320, p. 34-38.

Hilton, D.R., and Craig, H., 1989, The Siljan deep well-Helium isotope results: Geochimica et Cosmochimica Acta, v. 53, p. 3311-3316.

Hilton, D.R., Jenden, P.D., Jeffrey, A.W.A., Kaplan, I., and Craig, H., 1988, Helium isotopes in continental natural gases; results from Siljan, the Hugoton Panhandle and Appalachian Basin [abs.]: Chemical Geology, v. 70, 202 p.

Hiyagon, H., and Kennedy, B.M., 1992, Noble gases in $\mathrm{CH}_{4}$-rich gas fields, Alberta, Canada: Geochimica et Cosmochimica Acta, v. 56, p. 1569-1589.

Honma, H., and Itihara, Y., 1981, Distribution of ammonium in minerals of metamorphic and granitic rocks: Geochimica et Cosmochimica Acta, v. 45, p. 983-988.

Hooker, P.J., Onions, R.K., and Oxburgh, E.R., 1985, Helium isotopes in North Sea gas fields and the Rhine rift: Nature, v. 318 , p. $273-275$.

Hunt, C.W., Collins, L.G., and Skobelin, E.A., 1992, Expanding geospheres-Energy and mass transfers from Earth's interior: Calgary, Polar Publishing, 421 p.

Irwin, H., Curtis, C., and Coleman, M., 1977, Isotopic evidence for source of diagenetic carbonates formed during burial of organic-rich sediments: Nature, v. 269, p. 209-213.

Irwin, W.P., and Barnes, I., 1980, Tectonic relations of carbon dioxide discharges and earthquakes: Journal of Geophysical Research, v. 85 (B6), p. 3115-3121.

James, A.T., 1983, Correlation of natural gas by use of carbon isotopic distribution between hydrocarbon components: American Association of Petroleum Geologists Bulletin, v. 67, p. $1176-1191$.

1990, Correlation of reservoired gases using the carbon isotopic compositions of wet gas components: American Association of Petroleum Geologists Bulletin, v. 74, p. 1441-1458.

James, A.T., and Burns, B.J., 1984, Microbial alteration of subsurface natural gas accumulations: American Association of Petroleum Geologists Bulletin, v. 68, p. 957-960.

Javoy, M., and Pineau, F., 1991, The volatiles record of a "popping" rock from the Mid-Atlantic Ridge at $14^{\circ} \mathrm{N}-$-Chemical and isotopic composition of gas trapped in the vesicles: Earth and Planetary Science Letters, v. 107, p. 598-611.
Jean-Baptiste, P., Charlou, J.L., Stievenard, M., Donval, J.P., Bougault, H., and Mevel C., 1991, Helium and methane measurements in hydrothermal fluids from the mid-Atlantic ridge-The Snake Pit site at $23^{\circ}$ N.: Earth and Planetary Science Letters, v. 106, p. 17-28.

Jeffrey, A.W.A., 1981, Thermal and clay catalyzed cracking in the formation of natural gas: College Station, Texas A\&M University, Ph.D. dissertation, 123 p.

Jeffrey, A.W.A., Alimi, M.H., and Jenden, P.D., 1991, Geochemistry of Los Angeles Basin oil and gas systems, in Biddle, K.T., ed., Active margin basins: American Association of Petroleum Geologists Memoir 52: p. 197-219.

Jeffrey, A.W.A., and Kaplan, I.R., 1988, Hydrocarbons and inorganic gases in the Gravberg-1 well, Siljan Ring, Sweden, in Schoell, M., ed., Origins of methane in the Earth: Chemical Geology, v. 71, p. 237-255.

Jenden, P.D., Drazan, D.J., and Kaplan, I.R., 1993, Mixing of thermogenic natural gases in northern Appalachian basin: American Association of Petroleum Geologists Bulletin, v. 77, p. $980-998$.

Jenden P.D., and Kaplan, I.R., 1986, Comparison of microbial gases from the Middle America trench and Scripps Submarine canyon; implications for the origin of natural gas: Applied Geochemistry, v. 1, p. 631-646.

1989a, Analysis of gases in the Earth's crust: Final report to the Gas Research Institute, Chicago, Contract No. 5081360-0533. National Technical Information Service, Accession Number PB91-104273/XAB.

$1989 \mathrm{~b}$, Origin of natural gas in the Sacramento basin, California: American Association of Petroleum Geologists Bulletin, v. 73, p. 431-453.

Jenden, P.D., Kaplan, I.R., Poreda, R.J., and Craig, H., 1988a, Origin of nitrogen-rich natural gases in the California Great Valley; evidence from helium, carbon and nitrogen isotope ratios: Geochimica et Cosmochimica Acta, v. 52, p. 851-861.

Jenden, P.D., Newell, K.D., Kaplan, I.R., and Watney, W.L., 1988b, Composition and stable isotope geochemistry of natural gases from Kansas, Midcontinent, U.S.A. in Schoell, M., ed., Origins of methane in the Earth: Chemical Geology, v. 71, p. 117-147.

Jianyu, C., and Bingjun, H., 1990, The character and genesis of condensate in the north of Liaodong Bay, China: Organic Geochemistry, v. 16, p. 561-567.

Johnson, R.C., and Rice, D.D., 1990, Occurrence and geochemistry of natural gases, Piceance Basin, northwest Colorado: American Association of Petroleum Geologists Bulletin, v. 74, p. 805-829.

Juhlin, C., and others, 1991, Scientific summary report of the deep gas drilling project in the Siljan Ring impact structure: Stockholm, Vattenfall, $257 \mathrm{p}$.

Kamenskiy, I.L., Lobkov, V.A., Prasolov, E.M., Beskrovnyy, N.S., Kudryavtseva, E.I., Anufriyev, G.S., and Pavlov, V.P., 1976, Components of the upper mantle in the volcanic gases of Kamchatka (according to $\mathrm{He}, \mathrm{Ne}, \mathrm{Ar}$, and $\mathrm{C}$ isotopy): $\mathrm{Ge}-$ ochemistry Intemational, v. 13, p. $35-48$.

Kamenskiy, I.L., Yakutseni, V.P., Mamyrin, B.A., Anufriyev, S.G., and Tolstikhin, I.N, 1971, Helium isotopes in nature: Geochemistry Intemational, v. 8, p. 575-589.

Kiyosu, Y., and Krouse, H.R., 1989, Carbon isotope effect during abiogenic oxidation of methane: Earth and Planetary Science Letters, v. 95, p. $302-306$. 
Konnerup-Madsen, J., Kreulen, R., and Rose-Hansen, J., 1988, Stable isotope characteristics of hydrocarbon gases in the alkaline Ilimaussaq complex, South Greenland: Bulletin de Mineralogie, v. 111, p. 567-576.

Kotarba, M., 1990, Isotopic geochemistry and habitat of the natural gases from the Upper Carboniferous Zacler coal-bearing formation in the Nowa Ruda coal district (Lower Silesia, Poland): Organic Geochemistry, v. 16, p. 549-560.

Kreulen, R., 1987, Thermodynamic calculations of the C-O-H system applied to fluid inclusions-Are fluid inclusions unbiased samples of ancient fluids?: Chemical Geology, v. 61, p. 59-64.

Kreulen, R., and Schuiling, R.D., 1982, $\mathrm{N}_{2}-\mathrm{CH}_{4}-\mathrm{CO}_{2}$ fluids during formation of the Dome de l'Agout, France: Geochimica et Cosmochimica Acta, v. 46, p. 193-203.

Kropotkin, P.N., 1985, Degassing of the earth and the origin of hydrocarbons: International Geology Review, v. 27, p. 12611275.

Kropotkin, P.N., and Valiaev, B.M., 1976, Development of a theory of deep-seated (inorganic and mixed) origin of hydrocarbons, in Vassoevich, N.B., and others, eds., Combustible mineral resources, problems of geology and geochemistry of petroleum bitumen and bituminous rocks: Akademia Nauk SSSR, p. 133-144. [See Marland (1984) for English translation.]

Krouse, H.R., Viau, C.A., Eliuk, L.S., Ueda, A., and Halas, S., 1988, Chemical and isotopic evidence of thermochemical sulphate reduction by light hydrocarbon gases in deep carbonate reservoirs: Nature, v. 333, p. 415-419.

Laier, T., 1988, Hydrocarbon gases in the crystalline rocks of the Gravberg-1 well, Swedish deep gas project: Marine and Petroleum Geology, v. 5, p. 370-377.

Lancet, M.S., and Anders, E., 1970, Carbon isotope fractionation in the Fischer-Tropsch synthesis and in meteorites: Science, v. 170 , p. $980-982$.

Lawrence, J.R., and Taviani, M., 1988, Extreme hydrogen, oxygen and carbon isotope anomalies in the pore waters and carbonates of the sediments and basalts from the Norwegian Sea; methane and hydrogen from the mantle?: Geochimica et Cosmochimica Acta, v. 52, p. 2077-2083.

Lewan, M.D., 1986, Stable carbon isotopes of amorphous kerogens from Phanerozoic sedimentary rocks: Geochimica et Cosmochimica Acta, v. 50, p. 1583-1591.

MacDonald, G.J., 1983, The many origins of natural gas: Journal of Petroleum Geology, v. 5, p. 341-362.

Mamyrin, B.A., and Tolstikhin, L.N., 1984, Helium isotopes in nature: New York, Elsevier, 273 p.

Mango, F.D., 1987, An invariance in the isoheptanes of petroleum: Science, v. 237, p. 514-517.

Marland, G., 1984, A workshop on the origin of natural gas: Final report to the Gas Research Institute, contract no. 5082260-0624, Gas Research Institute, Chicago.

Martel, D.J., O'Nions, R.K., Hilton, D.R., and Oxburgh, E.R., 1990 , The role of element distribution in production and release of radiogenic helium; the Carnmenellis Granite, southwest England: Chemical Geology, v. 88, p. 207-221.

Marty, B., and Jambon, A., 1987, $\mathrm{C}^{3} \mathrm{He}$ in volatile fluxes from the solid earth-Implications for carbon geodynamics: Earth and Planetary Science Letters, v. 83, p. 16-26.

Marty, B., Jambon, A., and Sano, Y., 1989, Helium isotopes and $\mathrm{CO}_{2}$ in volcanic gases of Japan: Chemical Geology, v. 76, p. $25-40$.
Marty, B., Meynier, V., Nicolini, E., Griesshaber, E., and Toutain, J.P., 1993, Geochemistry of gas emanations-A case study of the Reunion Hot Spot, Indian Ocean: Applied Geochemistry, v. 8, p. 141-152.

Masters, C.D., Root, D.H., and Attanasi, D., 1992, World resources of crude oil and natural gas, in Proceedings of the Thirteenth World Petroleum Congress, v. 4, Chichester, John Wiley and Sons, p. 51-64.

Matthews, A., Fouillac, C., Hill, R., O'Nions, R.K., and Oxburgh, E.R., 1987, Mantle-derived volatiles in continental crust-The Massif Central of France: Earth and Planetary Science Letters, v. 85, p. 117-128.

Mattavelli, L., Ricchiuto, T., Grignani, D., and Schoell, M., 1983, Geochemistry and habitat of natural gases in Po Basin, Northern Italy: American Association of Petroleum Geologists Bulletin, v. 67, p. 2239-2254.

McCarty, H.B., and Felbeck, G.T., Jr., 1986, High temperature simulation of petroleum formation-IV. Stable carbon isotope studies of gaseous hydrocarbons: Organic Geochemistry, v. 9, p. 183-192.

North, F.K., 1982, Review of Thomas Gold's deep-earth gas hypothesis: Energy Exploration and Exploitation, v. 1, p. 105110.

Oxburgh, E.R., O'Nions, R.K., and Hill, R.I., 1986, Helium isotopes in sedimentary basins: Nature, v. 324, p. 632-635.

Parnell, J., 1988, Migration of biogenic hydrocarbons into granites-A review of hydrocarbons in British plutons: Marine and Petroleum Geology, v. 5, p. 385-396.

Petersil'ye, I.A., and Pripachkin, V.A., 1979, Hydrogen, carbon, nitrogen and helium in gases from igneous rocks: Geochemistry International, v. 16 , no. 4 , p. 50-55.

Philp, R.P., and Brassell, S., 1986, Arguments against abiogenic origin for hydrocarbons: Chemical and Engineering News, 15 December, p. 2 ff.

Pillinger, C.T., 1984, Light element stable isotopes in meteor- . ites-From grams to picograms: Geochimica et Cosmochimica Acta, v. 48 , p. 2739-2766.

Pippin, L., 1970, Panhandle-Hugoton Field, Texas-OklahomaKansas; the first fifty years, in Halbouty, M.T., ed., Geology of giant petroleum fields: American Association of Petroleum Geologists Memoir 14, p. 204-222.

Planetary Sciences Unit, University of Cambridge, 1982, Mantle methane-Fool's gold?: Nature, v. 300, p. 312-313.

Poorter, R.P.E., Varekamp, J.C., Poreda, R.J., van Bergen, M.J., and Kreulen, R., 1991, Chemical and isotopic compositions of volcanic gases from the east Sunda and Banda arcs, Indonesia: Geochimica et Cosmochimica Acta, v. 55, p. 3795-3807.

Poreda, R.J., and Craig, H., 1989, Helium isotope ratios in circum-Pacific volcanic arcs: Nature, v. 338, p. 473-478.

Poreda, R.J., Craig, H., Arnorsson, S., and Welhan, J.A., 1992, Helium isotopes in Icelandic geothermal systems; $1 .{ }^{3} \mathrm{He}$, gas chemistry and ${ }^{13} \mathrm{C}$ relations: Geochimica et Cosmochimica Acta, v. 56, p. $4221-4228$.

Poreda, R.J., Jeffrey, A.W.A., Kaplan, I.R., and Craig, M., 1988, Magmatic helium in subduction-zone natural gases, in Schoell, M., ed., Origins of methane in the Earth: Chemical Geology, v. 71, p. 199-210.

Poreda, R.J., Jenden, P.D., Kaplan, I.R., and Craig, H., 1986, Mantle helium in Sacramento basin natural gas wells: Geochimica et Cosmochimica Acta, v. 50, p. 2847-2853. 
Porfir'ev, V.B., 1974, Inorganic origin of petroleum: American Association of Petroleum Geologists Bulletin, v. 58, p. 3-33.

-1975, Inorganic origin of petroleum; reply: American Association of Petroleum Geologists Bulletin, v. 59, p. 886889.

Price, L.C., 1980, Utilization and documentation of vertical oil migration in deep basins: Journal of Petroleum Geology, v. 2, p. 353-387.

Rice, D.D., 1983, Relation of natural gas composition to thermal maturity and source rock type in San Juan Basin, northwestern New Mexico and southwestern Colorado: American Association of Petroleum Geologists Bulletin, v. 67, p. 11991218.

Rice, D.D., Clayton, J.L., and Pawlewicz, M.J., 1989, Characterization of coal-derived hydrocarbons and source-rock potential of coal beds, San Juan Basin, New Mexico and Colorado, U.S.A.: International Journal of Coal Geology, v. 13, p. 597-626.

Rice, D.D., and Threlkeld, C.N., 1990, Natural gas analyses from offshore Gulf of Mexico, in Gulf Coast oils and gasesTheir characteristics, origin, distribution, and exploration and production significance-Proceedings of the Ninth Annual Research Conference-SEPM: Denver, Society of Economic Paleontologists and Mineralogists, p. 367-371.

Richet, P., Bottinga, Y., and Javoy, M., 1977, A review of hydrogen, carbon, nitrogen, oxygen, sulphur and chlorine stable isotope fractionation among gaseous molecules: Annual Review of Earth and Planetary Sciences, v. 5, p. 65-110.

Rigby, D., and Smith, J.W., 1981, An isotopic study of gases and hydrocarbons in the Cooper basin: Australian Petroleum Exploration Association Journal 21, p. 222-229.

Roedder, E., 1984, Fluid inclusions-Reviews in mineralogy, v. 12: Washington, Mineralogical Society of America. 644 p.

Rohrback, B.G., Peters, K.E., and Kaplan, I.R., 1984, Geochemistry of artificially heated humic and sapropelic sedimentsII: Oil and gas generation: American Association of Petroleum Geologists Bulletin, v. 68, p. 961-970.

Sackett, W.M., 1978, Carbon and hydrogen isotope effects during the thermocatalytic production of hydrocarbons in laboratory simulation experiments: Geochimica et Cosmochimica Acta, v. 42 , p. $571-580$.

Sakata, S., 1991, Carbon isotopic geochemistry of natural gases from the Green Tuff Basin, Japan: Geochimica et Cosmochimica Acta, v. 55, p. 1395-1405.

Sakata, S., Takahashi, M., Igari, S., and Suzuki, N., 1989, Origin of light hydrocarbons from volcanic rocks in the "Green Tuff" region of northeast Japan-Biogenic versus magmatic: Chemical Geology, v. 74, p. 241-248.

Sano, Y., Wakita, H., and Giggenbach, W.F., 1987, Island arc tectonics of New Zealand manifested in helium isotope ratios: Geochimica et Cosmochimica Acta 51, p. 1855-1860.

Schoell, M., 1983, Genetic characterization of natural gases: American Association of Petroleum Geologists Bulletin, v. 67 , p. $2225-2238$.

$1984 a$, Recent advances in petroleum isotope geochemistry: Organic Geochemistry, v. 6, p. 645-663.

1984b, Wasserstoff- und Kohlenstoffisotope in organischen Substanzen, Erdolen und Erdgasen: Geologisches Jahrbuch D67, $164 \mathrm{p}$.

Sherwood, B., Fritz, P., Frape, S.K., Macko, S.A., Weise, S.M., and Welhan, J.A., 1988, Methane occurrences in the Canadi- an Shield, in Schoell, M., ed., Origins of methane in the Earth: Chemical Geology, v. 71, p. 223-236.

Smith, J.E., Erdman, J.G., and Morris, D.A., 1971, Migration, accumulation and retention of petroleum in the earth, in 8th World Petroleum Congress Proceedings, v. 2: London, Applied Science Publishers, p. 13-26.

Smith, J.W., and Gould, K.W., 1980, An isotopic study of the role of carbon dioxide in outbursts in coal mines: Geochemical Journal, v. 14, p. 27-32.

Smith, J.W., Gould, K.W., Hart, G.H., and Rigby, D., 1985, Isotopic studies of Australian natural and coal seam gases: Bulletin of the Australasian Institute of Mining and Metallurgy, v. 290 , p. $43-51$.

Sofer, Z., 1985, An unusual occurrence of light hydrocarbon gases in a well offshore northeast Palawan Island, The Philippines: Precambrian Research, v. 30, p. 179-188.

Stahl, W.J., Boigk, H., and Wollanke, G., 1977, Carbon and nitrogen isotope data of Upper Carboniferous and Rotliegend natural gases from North Germany and their relationship to the maturity of the organic source material, in Campos, R., and Goni, J., eds., Advances in organic geochemistry 1975: Madrid, ENADIMSA, p. 539-559.

Stahl, W.J., and Carey, B.D., 1975, Source-rock identification by isotope analyses of natural gases from fields in the Val Verde and Delaware basins, West Texas: Chemical Geology, v. 16, p. 257-267.

Staudacher, T., 1987, Upper mantle origin for Harding County well gases: Nature, v. 325, p. 605-607.

Sundberg, K.R., and Bennett, C.R., 1983, Carbon isotope paleothermometry of natural gas, in Bjoroy, M., ed., Advances in organic geochemistry 1981: New York, John Wiley and Sons, p. 769-774.

Szatmari, P., 1989, Petroleum formation by Fischer-Tropsch synthesis in plate tectonics: American Association of Petroleum Geologists Bulletin, v. 73, p. 989-998.

Takach, N.E., Barker, C., and Kemp, M.K., 1987, Stability of natural gas in the deep subsurface; thermodynamic calculation of equilibrium composition: American Association of Petroleum Geologists Bulletin, v. 71, p. 322-333.

Tanner, J.A., and Fuex, A.N., 1990, Chemical and isotopic evidence of the origin of hydrocarbons and source potential of rocks from the Vicksburg and Jackson Formations of Slick Ranch area, Star County, Texas, in Gulf Coast oils and gases-Their characteristics, origin, distribution, and exploration and production significance-Proceedings of the Ninth Annual Research Conference-SEPM: Denver, Society of Economic Paleontologists and Mineralogists, p. 79-97.

Tissot, B.P., and Welte, D.H., 1984, Petroleum formation and occurrence: New York, Springer-Verlag, 699 p.

Treibs, A., and Hirner, A., 1982, Is there an abiogenic formation of petroleum-Critical remarks on the thesis of Gold and Soter: Erdoel und Kohle, Erdgas Petrochemie, v. 35, p. 170172.

Ulmer, G.C., Grandstaff, D.E., Weiss, D., Moats, M.A., Buntin, T.J., Gold, D.P., Hatton, C.J., Kadik, A., Koseluk, R.A., and Rosenhauer, M., 1987, The mantle redox state; an unfinished story?: Geological Society of America Special Paper 215, p. 5-23.

Wakita, H., and Sano, Y., $1983,{ }^{3} \mathrm{He} /{ }^{4} \mathrm{He}$ ratios in $\mathrm{CH}_{4}$-rich natural gases suggest magmatic origin: Nature, v. 305, p. 792-794. 
Wakita, H., Sano, Y., Urabe, A., and Nakamura, Y., 1990, Origin of methane-rich natural gas in Japan-Formation of gas fields due to large-scale submarine volcanism: Applied Geochemistry, v. 5, p. 263-278.

Welhan, J.A., 1988, Origins of methane in hydrothermal systems: Chemical Geology, v. 71, p. 183-198.

Welhan, J.A., and Craig, H., 1979, Methane and hydrogen in East Pacific Rise hydrothermal fluids: Geophysical Research Letters, v. 6, p. 829-831.

1982, Abiogenic methane in mid-ocean ridge hydrothermal fluids, in Gwilliam, W.J., ed., Deep Source Gas Workshop, Technical Proceedings: DOE/METC-82-50, Morgantown Energy Technology Center, p. 122-129.

1983, Methane, hydrogen and helium in hydrothermal fluids at $21^{\circ} \mathrm{N}$. on the East Pacific Rise, in Rona, P.A., Bostrom, K., Laubier, L., and Smith, K.L., Jr., eds., Hydrothermal processes at seafloor spreading centers: New York, Plenum Press, p. 391-409.

Welhan, J.A., and Lupton, J.E., 1987, Light hydrocarbon gases in Guaymas basin hydrothermal fluids; thermogenic versus abiogenic origin: American Association of Petroleum Geologists Bulletin, v. 71, p. 215-223.
Welhan, J.A., Poreda, R.J., Rison, W., and Craig, H., 1988, Helium isotopes in geothermal and volcanic gases of the western United States, I. Regional variability and magmatic origin: Journal of Volcanology and Geothermal Research, v. 34, p. 185-199.

Whiticar, M.J., Faber, E., and Schoell, M., 1986, Biogenic methane formation in marine and freshwater environments; $\mathrm{CO}_{2}$ reduction vs. acetate fermentation-Isotope evidence: Geochimica et Cosmochimica Acta, v. 50, p. 693-709.

Wood, B.J., Bryndzia, L.T., and Johnson, K.E., 1990, Mantle oxidation state and its relationship to tectonic environment and fluid speciation: Science, v. 248 , p. 337-345.

Yuen, G., Blair, N., Des Marais, D.J., and Chang, S., 1984, Carbon isotope composition of low molecular weight hydrocarbons and monocarboxylic acids from Murchison meteorite: Nature, v. 307, p. 252-254.

Yuen, G.U., Pecore, J.A., Kerridge, J.F., Pinnavaia, T.J., Rightor, E.G., Flores, J., Wedeking, K., Mariner, R., Des Marais, D.J., and Chang, S., 1990, Carbon isotopic fractionation in Fischer-Tropsch type reactions [abs.]: XXI Lunar and Planetary Science Conference, Lunar and Planetary Institute, Houston, p. 1367-1368. 


\title{
The Origin of Methane in the Crust of the Earth
}

\author{
By Thomas Gold ${ }^{1}$
}

\section{CONTENTS}

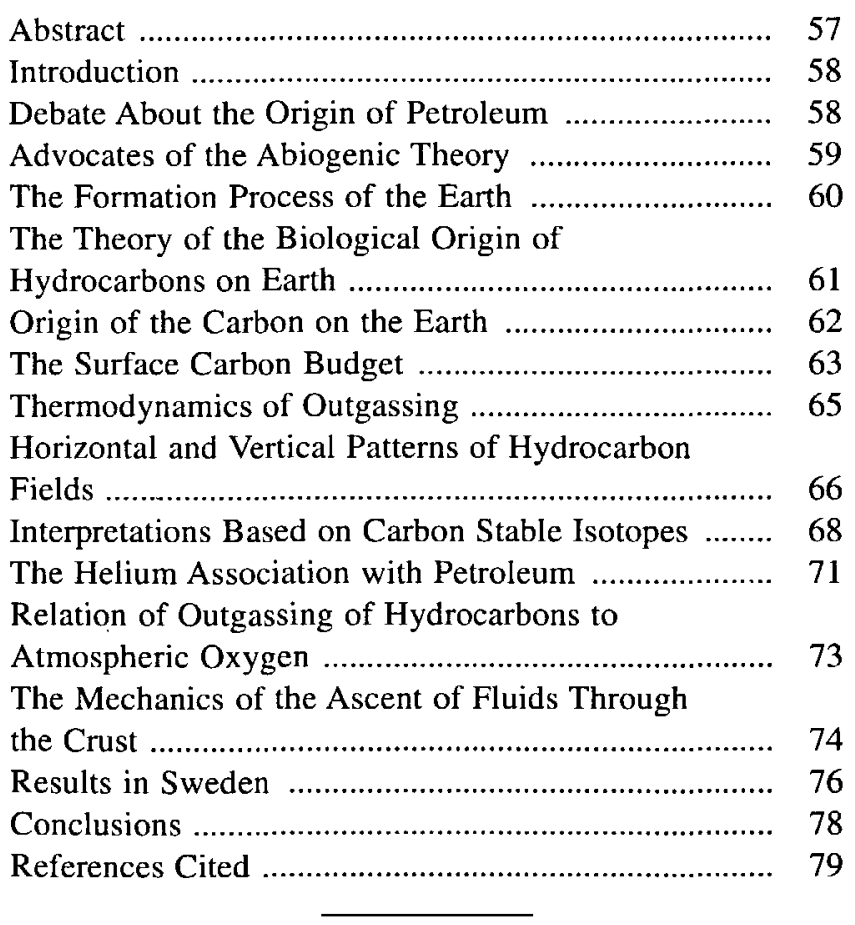

\begin{abstract}
The deposits of hydrocarbons in the crust of the Earth have long been regarded by many investigators as being derived from materials incorporated in the mantle at the time of the Earth's formation. Outgassing process-
\end{abstract}

\footnotetext{
${ }^{1} 7$ Pleasant Grove Lane, Ithaca, NY, 14850.
}

es, active in all geological epochs, then transported the liquids and gases liberated there into porous rocks of the crust. The alternative viewpoint, that biological debris was the source material for crustal hydrocarbons, gained widespread acceptance when molecules of clearly biological origin were found to be usually present in hydrocarbon fluids.

Modern information redirects attention to the theories of a nonbiological, primeval origin. Among this information is the prominence of hydrocarbons-gases, liquids, and solids-on many other bodies of the solar system, as well as in interstellar space. Advances in high-pressure thermodynamics have shown that the pressure-temperature regime of the Earth would allow hydrocarbon molecules to be formed and to survive between the surface and a depth of 100 to $300 \mathrm{~km}$. Outgassing from such depth would bring up other gases present in trace amounts in the rocks, thus accounting for the known association of hydrocarbons with helium. Recent discoveries of the widespread presence of bacterial life at depth point to this as the origin of the biological content of petroleum. The carbon budget of the crust requires an outgassing process to have been active throughout the geologic record, and information from planets and meteorites, as well as from mantle samples, would suggest that methane rather than $\mathrm{CO}_{2}$ could be the major source of surface carbon. Isotopic fractionation of methane in its migration through rocks is indicated by numerous observations, providing an alternative to biological processes that have been held responsible for such fractionation. Information from deep boreholes in granitic and volcanic rock of Sweden has given support to the theory of the migration of gas and oil from depth, to the occurrence of isotopic fractionation in migration, to an association with helium, and to the presence of microorganisms below 4 $\mathrm{km}$ depth. 


\section{INTRODUCTION}

The gas methane, $\mathrm{CH}_{4}$, the principal component of natural gas, does not contain sufficient evidence in itself from which to deduce its origin on the Earth. There is some evidence from its isotopic composition, but interpretations of that are not unique. Information, however, exists in the mode of occurrence of natural-gas reservoirs, in the geographic and geological relationships, in associated chemicals, and, above all, in the frequent association with other hydrocarbons, specifically crude petroleum and bituminous coal. Although there are numerous occurrences of natural gas without the heavier hydrocarbons, the association is generally so clear that one cannot contemplate an origin for the natural-gas deposits independent of those for petroleum. I shall therefore first consider the origin of the whole set of hydrocarbons, including natural gas, and then discuss aspects that are specific to methane.

\section{DEBATE ABOUT THE ORIGIN OF PETROLEUM}

It is remarkable that in spite of its widespread occurrence, its great economic importance, and the immense amount of fine research devoted to it, there perhaps still remain more uncertainties concerning the origin of petroleum than that of any other commonly occurring natural substance.

H.D. Hedberg, 1964

Actually it cannot be too strongly emphasized that petroleum does not present the composition picture expected from modified biogenic products, and all the arguments from the constituents of ancient oils fit equally well, or better, with the conception of a primordial hydrocarbon mixture to which bio-products have been added.

Sir Robert Robinson, 1963 President, Royal Society, London

The capital fact to note is that petroleum was born in the depths of the Earth, and that it is only there that we must seek its origin.

D. Mendeleev, 1877

The origin of petroleum has been a subject of many intense and heated debates, ever since this black fluid was first discovered in large quantities in the pore spaces of many rocks. Is it something brought in from space when the Earth was formed? Or is it a fluid concentrated from huge amounts of vegetation and animal remains that may have been buried in the sediments over hundreds of millions of years?

Arguments have been advanced for each viewpoint, and although they conflict with each other, each line of argument sounds strangely convincing. In favor of the biogenic origin of petroleum, the following four observations have been advanced:
1. Petroleum contains groups of molecules that are clearly identified as the breakdown products of complex, but common, organic molecules that occur in plants, and that could not have been built up in a nonbiological process.

2. Petroleum frequently shows the phenomenon of optical activity, that is, a rotation of the plane of polarization when polarized light is passed through it. This property implies that molecules which can have either a right-handed or a left-handed symmetry are not equally represented, but that one symmetry is preferred. This property is normally a characteristic of biological materials and absent in fluids of nonbiological origin.

3. Some petroleums show a clear preference for molecules with an odd number of carbon atoms over those with an even number. Such an odd-even effect can be understood as arising from the breakdown of a class of molecules that are common in biological substances, and may be difficult to account for in other ways.

4. Petroleum is mostly found in sedimentary deposits and only rarely in the primary rocks of the crust below; even among the sedimentary deposits, it favors those that are geologically young. In many cases such sedimentary deposits appear to be rich in carbonaceous materials that were interpreted as of biological origin, and as source material for the petroleum deposit.

On the other side of the argument, in favor of an origin from deeply buried materials incorporated in the Earth when it formed, the following observations have been cited:

1. Petroleum and methane are found frequently in geographic patterns of long lines or arcs, which are related more to deep-seated large-scale structural features of the crust than to the smaller scale patchwork of the sedimentary deposits.

2. Hydrocarbon-rich areas tend to be hydrocarbon-rich at many different levels, corresponding to quite different geological epochs, and extending down to the crystalline basement that underlies the sedimentary deposits. An invasion of an area by hydrocarbon fluids from below could better account for this distribution than the chance of successive deposition.

3. Some petroleums from deeper and hotter levels lack almost completely the biological evidence. Optical activity and the odd-even carbon-number effect are sometimes totally absent, and it would be difficult to suppose that such a thorough destruction of the biological molecules had occurred as would be required to account for this, yet leaving the bulk substance quite similar to other crude oils.

4. Methane is found in many locations where a biogenic origin is improbable or where biological deposits seem inadequate: in great ocean rifts in the absence of any substantial sediments; in fissures in igneous and metamorphic rocks, even at great depth; and in active volcanic regions, even where there is a minimum of sediments. 
Futhermore, there are massive amounts of methane hydrates (combinations of methane and water ice) in permafrost and ocean deposits, where it is doubtful that an adequate quantity of biological source material is present.

5. The hydrocarbon deposits of a large area often show common chemical or isotopic features, quite independent of the varied composition or the geological ages of the formations in which they are found. Such chemical "signatures" may be seen in the abundance ratios of some minor constituents such as traces of certain metals that are carried in petroleum; or a common tendency may be seen in the ratio of isotopes of some elements, or in the abundance ratio of some of the different molecules that make up petroleum. Thus a chemical analysis of a sample of petroleum could often allow the general area of its origin to be identified, even though quite different formations in that area may be producing petroleum. For example, a crude oil from anywhere in the Middle East can be distinguished from an oil originating in any part of South America, or from the oils of West Africa; almost any of the oils from California can be distinguished from those of other regions by the carbon isotope ratio.

6. The regional association of hydrocarbons with the inert gas helium, and a higher level of natural helium seepage in petroleum-bearing regions, has no explanation in the theories of biological origin of petroleum.

\section{ADVOCATES OF THE ABIOGENIC THEORY}

Among the early advocates of a nonbiological origin of petroleum was the great Russian chemist Mendeleev, the originator of the periodic table of the elements. His arguments, presented in a paper on the origin of petroleum (Mendeleev, 1877), are still valid today. He already knew of the large-scale patterns of hydrocarbon occurrence, but his information on the processes that shaped the Earth was not our present understanding and made his explanations much more complex than would need to be the case now.

Sokoloff (1889) discussed the "cosmic origin of bitumina" (carbonaceous substances from petroleum to pitch and $\operatorname{tar}$ ), and he related these to the meteorites, knowing then already about meteorites' hydrocarbon content. He stressed that oil and tar occur in basement rocks, such as in the gneiss of Sweden. He could find no relationship to the fossil content of rocks, and he stressed that porosity was the sole circumstance that relates to the accumulation of bituminous substances.

Vernadsky (1933) gave reasons why he considered that with increased pressure and decreased oxygen availability with depth, hydrocarbons would be stable and largely replace carbon dioxide as the chief carbon-bearing fluid.

Kudryavtsev (1959), the most prominent and strongest advocate of the abiogenic theory in modern times, argued that no petroleum resembling the chemical composition of natural crudes has ever been made from genuine plant material in the laboratory, and in conditions resembling those in nature. He gave many examples of substantial and sometimes commercial quantities of petroleum being found in crystalline or metamorphic basement rocks, or in sedimentary rocks directly overlying those. He cited cases in Kansas, California, western Venezuela and Morocco. He pointed out that oil pools in sedimentary strata are often related to fractures in the basement directly below. The Lost Soldier Field in Wyoming has oil pools, he stated, at every horizon of the geological section, from the Cambrian sandstone overlying the basement rocks to the Upper Cretaceous strata. A flow of oil was also obtained from the basement itself.

Hydrocarbon gases, he noted, are not rare in igneous and metamorphic rocks of the Canadian Shield. Petroleum in Precambrian gneiss is encountered in wells on the eastern shore of Lake Baikal, Russia. He stressed that petroleum is present, in large or small quantity, but in all horizons below any petroleum accumulation, apparently totally independent of the varied conditions of formation of these horizons. This statement has since become known as "Kudryavtsev's rule," and many examples of it have been noted in different parts of the world. Commercial accumulations are simply found where permeable zones are overlaid by impermeable ones, he concluded.

Kudryavtsev introduced a number of other relevant considerations into the argument. Columns of flames have been seen during the eruptions of some volcanoes, sometimes reaching 500 meters in height, such as during the eruption of Merapi in Sumatra in 1932. The eruptions of mud volcanoes have liberated such quantities of methane that even the most prolific gasfield underneath should have been exhausted long ago. Also, the quantities of mud deposited in some cases would have required eruptions of much more gas than is known in any gasfield anywhere. The water coming up in some instances carries such substances as iodine, bromine, and boron that could not have been derived from local sediments and that exceed the concentrations in seawater one-hundredfold. Mud volcanoes are often associated with lava volcanoes, and the typical relationship is that the mud volcanoes nearer the lava volcanoes emit incombustible gases, while the ones further away emit methane. Kudryavtsev knew of the occurrence of oil in basement rocks of the Kola Peninsula of Russia, and of the surface seeps of oil in the Siljan Ring formation of central Sweden (which I shall discuss later). He noted that the enormous quantities of hydrocarbons in the Athabasca tar sands in Canada would have required vast amounts of source rocks for their generation in the conventional discussion, when in fact no source rocks have been found.

Beskrovny and Tikhomirov (1968) noted, as did Anders, Hayatsu, and Studier (1973), that of the many 
possible isomers of petroleum molecules, the particular subset found in natural petroleum is also the one preferentially produced in artificial oil production from hydrogen and carbon rather than from biological substances.

Porfir'ev (1974) argued that so-called source rocks have no identification that proves their hydrocarbons to be primarily biogenic. He also discounted the hypothesis, often advanced, that the transport and deposition of oil from supposed source rocks to the final reservoir was accomplished by solution in gas: the quantities of gas that would be required would exceed by orders of magnitude the quantities that could be derived from the supposed source materials.

Levin (1958) concerned himself with the formation process of the Earth, claiming that the class of meteorites called carbonaceous chondrites, a low-temperature condensate that was probably responsible for bringing in solids that contained water, could have brought to the forming Earth several times larger quantities of carbonaceous materials than all the ocean water.

Kravtsov (1975) presented much observational material. He showed that the natural seepage of methane in many areas was far more than could be supplied by any kind of gas field known. If the volcanic gases of the Kurile Islands, for example, are typical of the gases emitted over the timespan of the volcanic activity there, the amount of methane emitted would far exceed the conventional estimate of the present-day total world reserves. He also gave many examples of Kudryavtsev's rule.

Kropotkin and Valyaev $(1976,1984)$ and Kropotkin (1985) developed many aspects of the theory of deep-seated, inorganic origin of hydrocarbons. They concluded that petroleum deposits were formed where pressure conditions permitted the condensation of heavier hydrocarbons, transferred from great depth by rapidly rising streams of compressed gases. In volcanic regions, they noted, decomposition of hydrocarbons would be favored, resulting in the formation of carbon dioxide and water, while in cooler, nonvolcanic regions, hydrocarbons would be preserved and could accumulate in alluvial traps and highly fractured beds, depending on the presence of adequate reservoirs and caprocks. According to these authors "vertical migration of hydrocarbons from levels far below formations rich in biogenic organic matter, which have been considered the source material for the oil, can be demonstrated in a majority of deposits." Kropotkin also presented numerous examples in which Kudryavtsev's rule is satisfied in a striking way.

Most of the papers cited so far are by Russian authors, but there were several voices outside Russia (or the Soviet Union) who also argued for a nonbiogenic origin. Most notable among them was Sir Robert Robinson (1963, 1966) who, like Mendeleev, can be considered among the most distinguished chemists of his day. He studied the chemical make-up of natural petroleums in great detail, and concluded that they were mostly far too hydrogen-rich to be a likely product of the decay of plant debris. Olefins, the unsaturated hydrocarbons, would have been expected to predominate by far in any material that was derived in that way.

Sylvester-Bradley $(1964,1972)$ pointed out that the meteorites have hydrocarbons, and hypothesized that hydrocarbons on the Earth derived in major part from such material. He proposed that hydrocarbons streaming up through the crust from great depth would have provided energy sources for simple forms of life. He knew about the biological materials in petroleum, but, like Robert Robinson, he thought that they were due to contaminating additions from microbiota in such locations.

Before discussing further the possible origins of hydrocarbons on the Earth, it is necessary to discuss the present state of knowledge of the process of formation of the Earth and the planetary system, and the materials that contributed to that formation.

\section{THE FORMATION PROCESS OF THE EARTH}

The Earth is a body with a most complex history. None of its sister planets display signs of the processes that appear to have been the major ones to shape this planet. On all the other solid bodies of the solar system the effects of impact cratering can be seen very clearly. Craters spanning a range of size from a few to several thousand kilometers can be clearly recognized. Impacts of solid objects upon all the planetary bodies in the process of their formation must have been a common occurrence.

Strangely, on our Earth similar cratering events can only be seen, if at all, in a very subdued form. We see arcs of circles appearing in the midst of a topography shaped by other effects. It seems reasonable to interpret such circular features as the remains of impacts, now deeply buried but affecting the outer crust at a later stage in some way that makes the buried impacts recognizable again. One has to suppose that other events occurred here that obscured most of the evidence of this early bombardment.

Nevertheless, it is now quite clear that the Earth, like the other solid planetary bodies, also formed by the accretion of solid objects, probably largely in the form of small grains, but interspersed with occasional major pieces. It appears that then a partial melting took place, causing materials of lower density to make their way to the surface, while presumably melts of high density sank down toward the center. The heat for this melting was the result of radioactivity contained in the material, as well as the heat resulting from compression. Once partial melting occurred, two other sources of heat came into play: firstly the gravitational energy that is released as materials can move and sort themselves out according to density. Sec- 
ondly there is the chemical energy that results from all the chemical reactions that can then take place, either between different liquids or between liquids and solids. The original diverse materials that accreted as cold objects would certainly not have been chemically equilibrated with each other, but would be left in an uneven distribution by the chances of the impact events. After the original materials gained mobility by melting, many chemical reactions would take place that would, on average, release energy and thus provide more heat, as well as give rise to volatile substances.

Both of these last two sources of energy - gravitational and chemical energy-have the interesting property that they make the heating unstable: where more heating has occurred and more melt has been produced, more of these actions can take place and therefore still more heat will be produced. One may well speculate that the very uneven distribution of internal heat sources that we recognize at the surface is derived from such an instability. The circum-Pacific "belt of fire" is the most striking example, but there are also many other lanes characterized by high heat flow and volcanic activity. They are also characterized by the outflow of fluids-gases and liquids-that are thought to have a deep origin. Deposits of hydrocarbons frequently show a clear association with such patterns (an example is shown in fig. 3).

If the major volume of the Earth has never been molten, the mantle of the Earth underneath the crust must still contain the diversity of chemistry, the chemical energy sources, and the sources of gases and liquids that would be the legacy of an accretion process from diverse and initially cold solids. Major impacts would have thrown up ring patterns of mountains, which, as on the Moon, would convert vertical patterns of chemical inhomogeneity into regional patterns. Many arcuate patterns on the Earth of surface topography and of chemical features or of heat flow may be a consequence of such impacts.

\section{THE THEORY OF THE BIOLOGICAL ORIGIN OF HYDROCARBONS ON EARTH}

Oil, hydrocarbon gases, and coal on the Earth were thought to have been derived entirely from biological debris for several reasons. One reason was the belief in earlier times that hydrocarbons were specifically organic substances: hence the name "organic carbon" for all forms of unoxidized carbon. The knowledge that hydrocarbons are abundant in the universe, and on many of the other planetary bodies of our solar system, was not available at that time. Now we know that carbon, the fourth most abundant element in the universe after hydrogen, helium, and oxygen, is almost certainly also the fourth most abundant in the planetary system; there it is predominantly in the form of hydrocarbons. The major planets Jupiter, Sat- urn, Uranus, and Neptune have large amounts of methane and other hydrocarbon gases in their atmospheres. Titan, a large satellite of Saturn, has methane and ethane in its atmosphere, and these gases form clouds and behave much like water does in the atmosphere of the Earth. Triton, a large satellite of Neptune, appears to have hydrocarbons mixed with water ices on its surface, as does the outermost planet known at this time, Pluto. A large fraction of all the asteroids show a surface reflectance closely resembling that of tar, and the comets have hydrocarbons among the gases they emit. The surface of the core of Comet Halley, recently observed by spacecraft, is most reasonably interpreted as one of tar. Complex, polycyclic hydrocarbon molecules similar to those in natural petroleum have been observed to be a prominent component of interplanetary dust grains that currently enter the Earth's upper atmosphere (Clemett and others, 1993).

Hydrocarbons in our planetary system are certainly very abundant, and in all the extraterrestrial examples mentioned they are almost certainly not related to biology. Also, hydrocarbons are prominent among the gases identified in the molecular clouds of the galaxy, and it is from such clouds that the solar system formed initially. The presence and great abundance of hydrocarbons is universal, and no special mechanism for their generation on the Earth needs to be invoked, unless one knows with certainty that hydrocarbons could not have survived the formation process here, although they did so on many of the other planetary bodies. (No evidence of hydrocarbons has yet been seen on Mars, the Moon, Venus, and Mercury. The atmosphere of Venus is too hot to have maintained gaseous or liquid hydrocarbons; the other three bodies lack an adequately protective atmosphere to have maintained hydrocarbons on their surfaces.)

In earlier times there was the belief that the Earth had formed as a hot, molten body. In that case no hydrocarbons or hydrogen would have survived against oxidation, nor would any of these substances have been maintained in the interior after solidification. With that belief, there seemed no possibility of accounting for the hydrocarbons embedded in the crust other than by the outgassing of carbon in the form of $\mathrm{CO}_{2}$, produced by materials that could have survived in a hot Earth, and subsequent photosynthesis by plants that converted this $\mathrm{CO}_{2}$ into unoxidized carbon compounds. This consideration is irrelevant now that we know that a cold formation process assembled the Earth and that hydrocarbons could have been maintained, and could be here for the same reasons that they are on the other planetary bodies.

The common existence of molecules of clearly biological origin in most petroleum and bituminous coal is no longer an argument for a biological origin of hydrocarbons, now that we know of the wide reach of microbiology in the crust (Jannasch, 1983; Yanyanos, 1986; Gold, 1992). Before this reach had been identified, the possibility of 
widespread biological contamination at depth had not been considered. Now, especially after the discovery of the volcanic vents on the ocean floors and the profuse chemosynthetic life that exists there, the outlook is different. It is now seen as not only possible, but very likely, that microbiota are common in the crust down to depths of between 5 and 10 kilometers, a level below which the temperature will reach values too high for any microbial life we know, thought to be between $110^{\circ} \mathrm{C}$ and $150^{\circ} \mathrm{C}$. This deep microbial life uses as its energy source the various chemical imbalances that the outgassing process creates as gases and liquids stream up through rocks with which they have never been chemically equilibrated. Knowing now of the occurrences of such deep microbial life, it seems likely that no location that could support such life has been kept sterile from it for the long periods of geologic time. Hydrocarbons, together with oxygen donors such as sulfates or metal (principally iron) oxides, substances that are common in the rocks or water, would provide a usable energy source for microorganisms. Hydrocarbon deposits would therefore acquire biological debris in the course of time. The molecules that are commonly regarded as proof of the biological origin of petroleum and of bituminous coal have all been found to be also produced by subsurface bacteria; indeed some of them can only be produced by bacteria (Ourisson and others, 1984). Pristane, phytane, steranes, hopanes are unquestionably of biological origin, but do not certify the biological origin of either petroleum, coal, kerogen, or whatever other deposits in which they are seen. With the photosynthetic theory of their origin, they seemed to certify that these materials were all once at the surface. But this is no longer a valid inference. Many other conclusions in geology were based on this inference, and should also be reconsidered now.

\section{ORIGIN OF THE CARBON ON THE EARTH}

The surface and surface sediment on the Earth contain approximately one hundred times as much carbon as would have been derived from the grinding up of the basement rocks that contributed to the sediment. The surface is enormously enriched in carbon, and this enrichment needs an explanation.

Of the carbon we have on the surface or in the sediment of the Earth, four-fifths is estimated to be in the form of carbonate rocks, and one-fifth in unoxidized form, frequently referred to as "organic." (The word "organic," given at one time to all unoxidized carbon, is of course now a misleading misnomer.) The quantities are large: if expressed as the mass of the element carbon per square centimeter of total Earth surface area, the estimate of carbon on the surface or in the sediment of the Earth is about 20 kilograms. (I will be referring to this quantity again later.)
During formation of the Earth by the accumulation of cold solids, very little gaseous material was incorporated, as indicated by the extremely low level of the nonradiogenic noble gases in the atmosphere of the Earth. Among those gases, only helium could have escaped into space, and only xenon could have been significantly removed by absorption into rocks. Neon, argon, and krypton would have been maintained as an atmospheric component. The proportions of noble gases in the Sun and in space are known. Any acquisition of such a mix of gases in the formation of the Earth would not have allowed selective exclusion of the noble gases, which have no significant chemical interactions. One is forced to conclude that the acquisition of gases, or substances that would be gaseous at the pressures and temperatures that prevailed in the region of formation of the Earth, was limited to the small value implied by the low noble-gas values. The carbon supply the Earth received initially could not have been in the form of hydrocarbon gases, high-volatility hydrocarbon liquids, or $\mathrm{CO}$ or $\mathrm{CO}_{2}$.

Could meteoritic infall of carbon at later times be held responsible for the current excess of surface carbon? Such a massive infall would have left much other evidence in the geologic record, and such evidence is absent. The only alternative is that carbon came up from the interior as a liquid or gas, just as is true for the water of the oceans (approximately $300 \mathrm{~kg} / \mathrm{cm}^{2}$ ), the nitrogen of the atmosphere (approximately $1 \mathrm{~kg} / \mathrm{cm}^{2}$ ) and the (largely radiogenic) argon of the atmosphere.

Perhaps one might consider the possibility that the Earth once had a massive atmosphere of carbon dioxide that evolved early, from materials that could have survived the formation process, and that these materials then became converted into the carbon deposits we now have; but that also does not seem an acceptable explanation, for in that case we should see many more very early carbonate rocks than the amounts laid down later. This pattern is not what the geologic record shows. What it does show is a reasonably continuous accumulation of carbonate rocks; no epoch having enormously more carbonate deposition per unit of time, nor enormously less. If outgassing from depth is responsible for surface carbon, then one has to discuss what the source material in the Earth might have been, what liquids or gases might have come from the source material, and what their fate would have been as they made their way up through the crust.

The meteorites represent some samples of material left over from the formation of the planets. While they may not be representative of the quantities of the different types of material that made up the Earth, they appear to represent at least samples of all the major components. Only one type of meteorite, the carbonaceous chondrites, contain significant amounts of carbon, and they contain it mainly in unoxidized form, a substantial fraction in the form of solid, heavy hydrocarbons. This material, when 
heated under pressure as it would be in the interior of the Earth, would indeed release hydrocarbon fluids, leaving behind deposits of solid carbon.

The quantitative information on carbonaceous chondrites is difficult to evaluate. These chondrites are much more friable than most other meteorites, and therefore survive the fall through the atmosphere less often than the others. Carbonaceous chondrites also are destroyed by erosion on the ground much more rapidly. The result must be that far fewer than the original proportion are ever discovered. They may well represent even now the largest quantity of meteoritic material still available for collection by the Earth; the infall of interplanetary dust to which $I$ have referred contains similar carbonaceous material.

By contrast, carbonates, which would be a source material for $\mathrm{CO}_{2}$, exist in meteoritic materials only in very small concentrations, so that an origin of the Earth's surface carbon from an initial $\mathrm{CO}_{2}$ source seems unlikely. If the carbonaceous chondrite material is the principal source of the surface carbon we have, then the initial material that could be mobilized in the Earth at elevated temperatures and pressure would be a mix of carbon and hydrogen. What would be the fate of such a mix? Would it all be oxidized with oxygen from the rocks, as some chemical equilibrium calculations have suggested? Evidently not, for we have clear evidence that unoxidized carbon exists at depths between $150 \mathrm{~km}$ and $300 \mathrm{~km}$ in the form of diamonds. We know diamonds come from this depth range, because it is only there that the pressures would be adequate for their formation. Diamonds are known to have high-pressure inclusions that contain $\mathrm{CH}_{4}$ and heavier hydrocarbons, as well as $\mathrm{CO}_{2}$ and nitrogen (Melton and Giardini, 1974). The presence of at least centimeter-sized pieces of very pure carbon implies that carbon-bearing fluids exist at the depth of diamond formation, and that they must be able to move through pore spaces at that depth, so that a dissociation process may selectively deposit the pure carbon-a process akin to mineralization processes as we know them at shallower levels. The fluid responsible cannot be $\mathrm{CO}_{2}$, since this molecule has a higher dissociation temperature than the hydrocarbons that coexist in the diamonds; the diamonds must therefore have been laid down by hydrocarbons.

Diamonds will survive a transport to the low pressure at the surface only if that transport is accompanied by rapid cooling; if diamonds are cooled slowly they will turn to graphite, the equilibrium form of carbon at low pressure. Diamond is a metastable form of carbon at the low surface pressure, but the surface temperature is too low for a relaxation to the stable form. Indeed, diamonds are found predominately in the vicinity of sites of explosive gas eruptions, diamond pipes, where rapid gas expansion caused quick cooling. There is also evidence for pure carbon transported up from depth at a slow rate: pseudomorphs of diamonds. Spaces showing the octahedral sym- metry of diamond have been found filled with graphite, in mantle rocks that have come to the surface in Morocco (Pearson and others, 1989). These rocks came up presumably in a slow ascent; they contain a dense array of octahedral spaces filled with graphite, clearly fitting the interpretation as pseudomorphs of diamond. This discovery suggests that a very high density of diamonds exists in at least some locations in the mantle, and that the rarity of diamonds on the surface is to be attributed to the rarity of the explosive events that could bring them up sufficiently quickly. It is noteworthy that hydrocarbons are found in diamond pipes together with the diamonds, suggesting that the gases involved in the explosive events were not oxidizing (Kravtsov and others, 1976, 1981).

\section{THE SURFACE CARBON BUDGET}

The deposition of carbonate rocks has been an ongoing process throughout the times of the geologic record. Most but not all of this carbonate has been an oceanic deposit, deriving the necessary $\mathrm{CO}_{2}$ from the atmospheric-oceanic $\mathrm{CO}_{2}$ store. The amount of carbon that is at present in this store is, however, only a very small fraction of the amount required to lay down the carbonates in the geologic record. The atmospheric-oceanic reservoir holds at present only about $0.01 \mathrm{~kg}$ of carbon per $\mathrm{cm}^{2}$ of the Earth's surface area. If we take the figure quoted earlier (see section "Origin of the Carbon on the Earth"), of about $20 \mathrm{~kg}$ of carbon per $\mathrm{cm}^{2}$ laid down over the time of the identified geologic record, there must have been a supply renewing the atmospheric-oceanic $\mathrm{CO}_{2}$ store gradually, but by an amount 2,000 times the present content. This amount of carbon, if calculated as having a continuous and steady outgassing rate and initially all coming up as methane, would translate into a 1-m-deep layer of methane at standard temperature and pressure (STP) being created all over the Earth every 2,700 years. If the rate is regionally variable, so that, for example, one-tenth of the area produces nine-tenths of the amount, then in the gas-prone areas, a 1-m-deep layer of methane at STP would come up every 300 years. If naturalgas fields are filled from outgassing methane, such a supply rate would be much more than adequate in the timespans available to create all the known fields.

If the supply of carbon from below ceased, the present rate of carbonate deposition would deplete the atmospheric-oceanic reservoir of carbon in something on the order of 500,000 years, a very small fraction of geologic time. Outgassing of carbon in some form must have been a continuous process; it is not likely that humans evolved just in the last period, just before the death of all plant life. We must therefore inquire what quantities of carbon would have been available at deep levels, what form this carbon took, and in what manner the resupply of the atmosphericoceanic $\mathrm{CO}_{2}$ reservoir could have taken place. It is also 
clear that one cannot discuss human-caused additions to the atmospheric carbon gases without taking into account the large and surely variable natural carbon emission that has taken place throughout geologic time.

The resupply of carbon must be from juvenile sources. Recycling of sedimentary rocks cannot account for it, both for reasons of the quantities involved and for reasons of the isotopic composition. If the repeated subduction of carbonate rocks occurred on the necessary massive scale, it would seem that old carbonate rocks should have disappeared almost completely. This is not the case. The isotopic information, to which we shall return later, also would say that in a process of continuous recycling the proportion of ${ }^{13} \mathrm{C}$ would continuously increase in the atmosphere, and hence the younger carbonates would be isotopically heavier than the older ones; this also is not the case. Marine carbonates of all ages back to the Archaean show the same narrow range of the carbon isotopic ratio (Schidlowski and others, 1975; see also fig. 4).

How much carbonaceous chondrite material would have been required to provide the supply of the surface carbon? Let us make a simple calculation. Suppose that in the depth range between 100 and 300 kilometers we have a patchwork of which the carbonaceous chondrite material composes 20 percent on average. In this material, carbon amounts to 5 percent. Given these figures, each squarecentimeter column through the 200-kilometer layer would contain, on average, 1 percent of carbon (5 percent of 20 percent), which would translate into 660 kilograms per square centimeter. If one-thirtieth of this carbon had been mobilized and reached the outer crust, it would suffice to account for all the carbon of the carbonate sediments and the deposits of unoxidized carbon. Of course the proportion of carbonaceous chondrite type of material may have been very much larger, and the producing layer much thicker. The fraction that needs to have been mobilized would then be much smaller. All one can really say at this stage is that there is no quantitative problem. Volatile-rich material of sufficient quantity to have supplied the water of the oceans, as discussed by Levin (1958), could quite easily have supplied the quantity of hydrocarbons for all the surface carbon.

As we have seen, the primary source material in the Earth that would yield a carbon-bearing fluids is likely to be a hydrocarbon mix, not a substance that would first produce $\mathrm{CO}_{2}$. As the carbon-bearing fluids moved up toward the Earth's surface, however, some unknown fraction would come up on pathways held open by magma, where these fluids would largely be oxidized to $\mathrm{CO}_{2}$ and water. Along other pathways, created by pressure fracturing in solid rock, the direct oxidation would be minimal and these fluids might arrive at the surface as methane and other hydrocarbon gases or liquids. However, even in the solid rock a substantial proportion of carbon-bearing fluid is frequently oxidized at shallow levels, as indicated by the common presence of carbonate cements in oil- and gas-rich regions. These cements are derived from metal oxides initially present in the rocks and from $\mathrm{CO}_{2}$ derived apparently from the oxidation of methane with some oxygen supplied from the rocks; the carbon isotope ratio of these pore-filling cements is not compatible with a derivation from atmospheric $\mathrm{CO}_{2}$, and their distribution is such that they fill the pores in a vertical column, suggesting an origin from ascending fluids. This oxidation is probably due to the action of microorganisms that obtain oxygen from components of the rock, and it is then limited to the outer levels of the crust where the temperature is in the range in which microbial activity can take place. It can be presumed quite reasonably that only a fraction of the $\mathrm{CO}_{2}$ so produced will in fact remain in the ground as carbonate, and a substantial fraction, quite possibly the major amount, will escape into the atmosphere.

A supply of hydrocarbons at depth may thus provide $\mathrm{CO}_{2}$ to the atmospheric-oceanic reservoir in three different ways. One is through volcanic pathways and oxidation with oxygen supplied by the magma; another is by ascent of hydrocarbons through solid rocks and oxidation at shallow levels, most likely by bacterial action, with subsequent escape of $\mathrm{CO}_{2}$ to the atmosphere; a third process is the escape of methane and other hydrocarbons into the atmosphere, where, in the presence of atmospheric oxygen, they would reside on average 10 years before oxidation to $\mathrm{CO}_{2}$. What fraction of carbon resupply comes by each of these pathways is still not known directly, but some limits can be placed by considerations of the maintenance of the atmospheric oxygen level within the bounds suggested by the geologic record, and possibly by some other more direct measurements.

Methane is present in the atmosphere at about 1.7 parts per million (ppm) by volume. Much or most of this methane represents a cycling of atmospheric carbon through biological processes, but the quantitative estimates of the magnitudes and speeds of these processes are not sufficiently precise to determine whether the observed methane concentration is the one to be expected from biological recycling alone. One may therefore inquire whether a contribution to this methane directly from outgassing sources is a possibility. Fortunately there is a clear possibility of distinguishing biologically recycled methane from juvenile methane: the radiocarbon $\left({ }^{14} \mathrm{C}\right)$ proportion of the biological contribution should be the same as that of atmospheric $\mathrm{CO}_{2}$, since such recycling would almost all take place in a short time compared with the half-life of ${ }^{14} \mathrm{C}$ (5,700 years). Thus carbon from deep sources would be free from ${ }^{14} \mathrm{C}$. A measurement of the fraction of ${ }^{14} \mathrm{C}$ in atmospheric methane can therefore supply the information. Several such measurements have been attempted, but there are difficulties and uncertainties connected with the sampling method and with the measurement itself. The latest measurements have given values of approximately 32 per- 
cent of non- ${ }^{14} \mathrm{C}$-bearing atmospheric methane (Lowe and others, 1988). Would such values be compatible with a supply of carbon from juvenile sources?

We may take, for a simple calculation, methane with a concentration in the atmosphere of $1.7 \mathrm{ppm}$ and a lifetime of about 10 years before oxidation. Let us suppose that 30 percent of this methane is juvenile, and see how this amount compares with the requirements of the terrestrial carbon budget. The measurements quoted would give an amount of juvenile carbon at present in $\mathrm{CH}_{4}$ in the air of $2 \times 10^{-7} \mathrm{~kg} \mathrm{C} / \mathrm{cm}^{2}$. If this amount of carbon were replenished on a 10-year timescale (the presumed lifetime of atmospheric methane), the average supply of juvenile carbon would have to be $2 \times 10^{-8} \mathrm{~kg} / \mathrm{cm}^{2}$ year. To form the estimated global carbon deposits of $20 \mathrm{~kg} / \mathrm{cm}^{2}$ entirely from this source would therefore take 1 billion years, a figure compatible with the geologic record. While this calculation cannot be taken to be a confirmation of the results that have been reported, nor of the proportion of the juvenile supply of $\mathrm{CH}_{4}$, it does demonstrate that measurements of the ${ }^{14} \mathrm{C}$ content of atmospheric methane are worth doing, and that a substantial fraction of the atmospheric methane may in fact be juvenile. If it is, one must suspect that such a contribution would have large variations over time, as have all other tectonic processes, and that therefore much higher or much lower values of juvenile atmospheric methane could be registered at the present time, or at any one time, than the long-term average value. The time variations of atmospheric $\mathrm{CH}_{4}$ reported from ice cores should be seen in the light of these considerations.

\section{THERMODYNAMICS OF OUTGASSING}

Assuming the carbonaceous chondrite type of material is the prime source of the Earth's surface carbon, the question arises as to the fate of this material under heat and pressure, and under the conditions it would encounter as buoyancy forces drove some of it toward the surface.

This problem has been tackled by thermodynamicists, most thoroughly by Chekaliuk (1976). His conclusion was that at sufficient pressure, such as that at a depth of 200 $\mathrm{km}$ or so, the equilibrium configuration would be a mix of hydrocarbon molecules, despite a temperature that would be far in excess of the dissociation temperature for these molecules (fig. 1). The pressure would provide these molecules with some stability, although any one molecule might indeed have sufficient internal energy to fall apart at the elevated temperature. At high pressures the assembly as a whole would not have enough energy to generate the increased volume that the dissociated molecules would demand. Fragments would instantly be reformed in such a way as to satisfy the volumetric constraint. No molecule would have permanent stability, but a statistical assembly of hydrocarbon molecules would represent an average equilibrium. The detailed mix of molecules would depend on pressure and temperature, and on the carbon-hydrogen ratio. Other atoms that might also be present, such as oxygen and nitrogen, would form a variety of complex molecules with the carbon and hydrogen. Metal atoms that might be present in the surroundings would form a range of organometallic molecules under these circumstances.

Even with the knowledge that diamonds and their highpressure inclusions have provided, it has been argued that hydrocarbons could not come from the deep levels Chekaliuk (1976) considered, because they could not survive at temperatures reached in the crust at a depth below 20 kilometers (Hunt, 1975); but these discussions in the petroleum literature have not included the effects of pressure.

The statistical mix of hydrocarbon molecules Chekaliuk (1976) expected from a carbonaceous chondrite source material, being less dense than the surrounding rock,

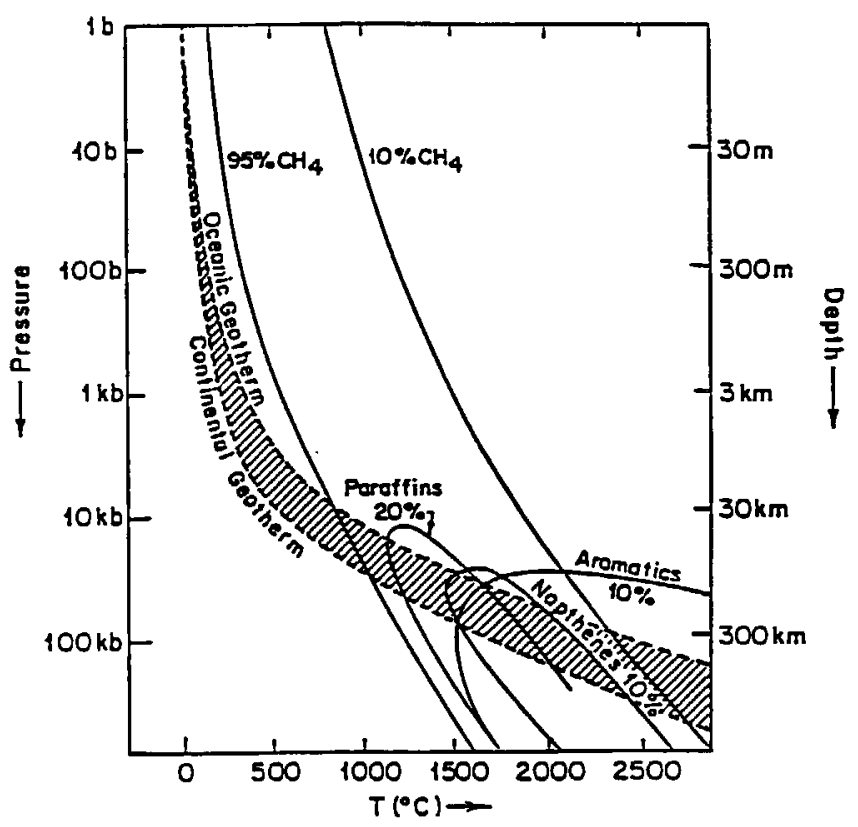

Figure 1. Stability of hydrocarbons at temperatures and pressures in the Earth (from Chekaliuk, 1976). Pressure-temperature regime of Earth is indicated by the shaded region. Thermodynamic calculations indicate domains in which various hydrocarbon molecules are stable. The lines marked Paraffins, Naphthenes, and Aromatics enclose domains in which a mix of hydrocarbon molecules would be set up from hydrogen and carbon, and on crossing outward from these domains the percentages indicated would be retained. Methane is essentially stable to the left of the line marked 95 percent, and 10 percent would still be retained on crossing to the right of the line so marked (that is, 90 percent would dissociate into hydrogen and carbon). According to these calculations, most of the petroleum components would be present in equilibrium of a carbon-hydrogen mix at a depth between 100 and $300 \mathrm{~km}$, and methane streaming up could bring a significant fraction of these petroleum components toward the surface. $b$, bar; kb, kilobar; km, kilometer; m, meter; $\mathrm{T}$, temperature. 
would have buoyancy forces driving it toward the surface. If present in sufficient concentration, the fluid would fracture the solid rock and ascend in such fracture porosity. (Molecular diffusion in rock over large distances is too slow a process to be of any significance, even on the long timescales of geology.) In that upward travel, the temperature and the pressure would be decreasing, and the various molecules would reach levels where the temperature was low enough for them to achieve stability. Each one of these molecules would then cease the temporary dissociations described above and become effectively permanent. If there is a high ratio of hydrogen to carbon in the stream, saturated hydrocarbons would become a major component; and, with sufficient hydrogen, methane, the most stable of all the hydrocarbon molecules, might become by far the dominant component. At depth methane would behave chemically like a liquid, and it would dissolve the heavier hydrocarbons that may be present, and therefore greatly reduce the viscosity of the entire fluid.

The continuing upward stream would acquire more and more of such stable molecules, and the final product that may be caught in the reservoirs we tap for oil and gas would be the end product of this process. The detailed chemistry of the oils in each region would then represent this final phase of the oil molecules on their way up, and that chemistry would be determined by the pressure-temperature regime the flow had experienced, the initial hydrogen-carbon ratio of the mix, and possibly surface catalytic actions and contributions from the rocks through which the flow had gone.

At shallow levels and low pressures, methane, now a gas, would separate out from the heavier components, leaving those as fluids of higher viscosity, and therefore much more subject to retention in reservoir rocks: the quantity of methane that would need to have been in the stream to facilitate the transport of oils would be many times larger than that of the oils, but because of the great mobility of methane gas, most of it would fail to be retained in the ground at shallow levels.

\section{HORIZONTAL AND VERTICAL PATTERNS OF HYDROCARBON FIELDS}

Everyone now thinks of the Middle East-especially Saudi Arabia, the Persian Gulf, Iran, and Iraq-as being the oil region of the world. It is indeed one large patch that is oil-rich, stretching for $2,700 \mathrm{~km}$ from the mountains of eastern Turkey down through the Tigris Valley of Iraq, through the Zagros Mountains of Iran, into the Persian Gulf, into Saudi Arabia, and further south into Oman (fig. 2). There is no feature that is common to the geology or the topography of the parts that make up this entire large region and that would give any hint as to why the whole region is oil and gas rich. The various oil deposits are in different types of rock, in rocks of quite different ages, and they are overlaid by quite different caprocks. They are in a topography of folded mountains in Turkey and the high Zagros mountains of Iran, in the river valley of the Tigris in Iraq, in the Persian Gulf itself, in the flat plains of Saudi Arabia, and in the mountainous regions of Oman. It cannot have been a matter of chance that this connected region had so prolific a supply of oil and gas, but resulting from totally different and independent circumstances in different parts of the region. These hydrocarbon-bearing formations represent times so different from each other that there would have been no similarity in the climate or in the types of vegetation that existed there during deposition, just as there is no similarity in the reservoir rocks or in the caprocks of the different regions now. Yet it is a striking fact that the detailed chemistry of these oils is similar over the whole of this large region (Kent and Warman, 1972). Surely this is an example of the need to invoke a larger scale phenomenon for the cause of the oil supply than any scale we can see in the geology of the outer crust.

The island arc of Indonesia, of which Java and Sumatra are the main islands, belongs to a much larger arc that stretches from the westem tip of New Guinea through these Indonesian islands into the Indian Ocean, through

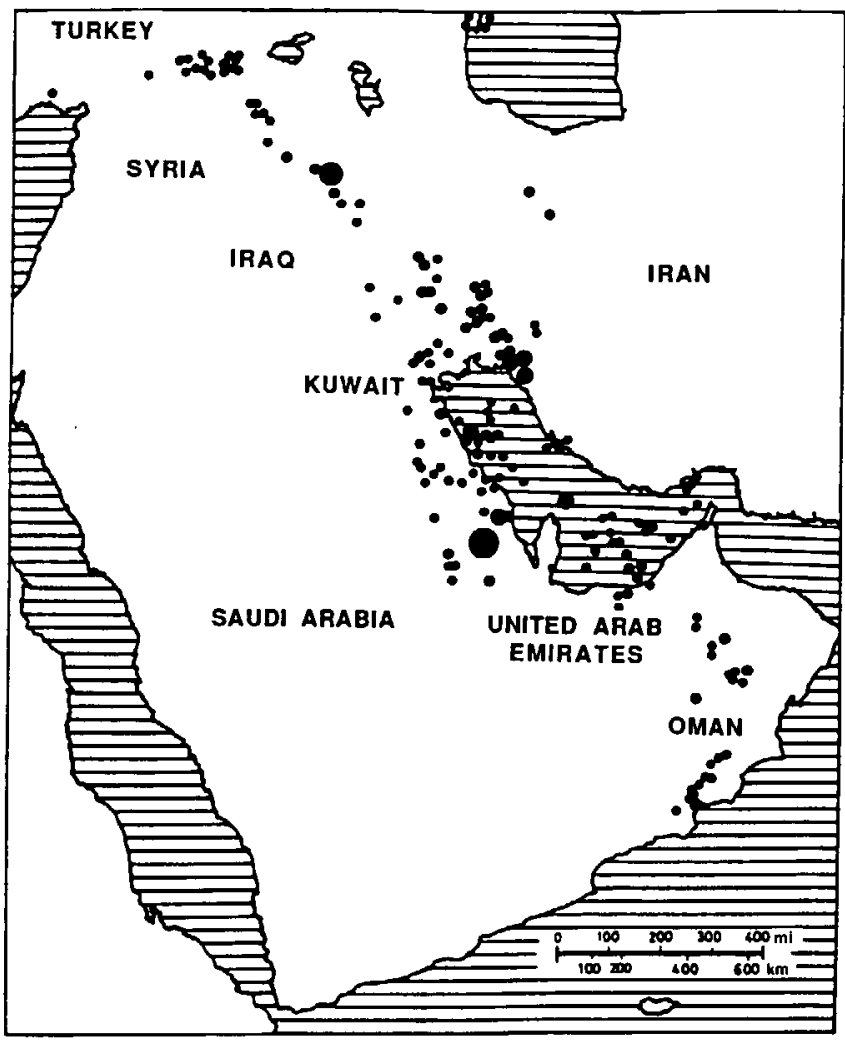

Figure 2. Oil fields of the Middle East, showing continuous region from Turkey to Oman. The dots represent individual fields, and the size of each dot indicates the magnitude of the field. 
the Andaman Islands, into the Irrawaddi valley of Burma, and into the high mountains of southern China, over a total length of $6,000 \mathrm{~km}$ (fig. 3). That it is one connected arc all the way cannot be doubted because the frequency of earthquakes along the whole of this arc is hundreds of times greater than it is away from the arc. Along the whole of this arc petroleum is very abundant. But at one end, this arc is made up of volcanic islands; at the other end, in Burma and China, it is in continental material with folded mountains. Again there are great age differences and differences in every aspect of the geology in which the oil fields exist; but here we have a unifying feature, namely the belt of earthquakes and volcanoes which stretches over this entire length and which points to causes in the deeper crust or in the mantle.
Many other examples can be cited, and they all point to the same conclusion: oil-rich regions seem to be defined by much larger scale patterns than those we see in the surface geology or topography of the region.

Another global observation of similar significance is the vertical stacking of hydrocarbons deposits according to Kudryavtsev's rule: "Any region in which hydrocarbons are found at one level will be seen to have hydrocarbons in large or small quantities, but at all levels down to and into the basement rock." The most common sequence is to find gas at the deepest levels, oil above, sometimes more gas above the oil, and coal at the shallowest levels. If one examines gas, oil, and coal maps of different parts of the globe, one finds this rule upheld very frequently. It holds in most of the Middle East: many oil wells in Iran have

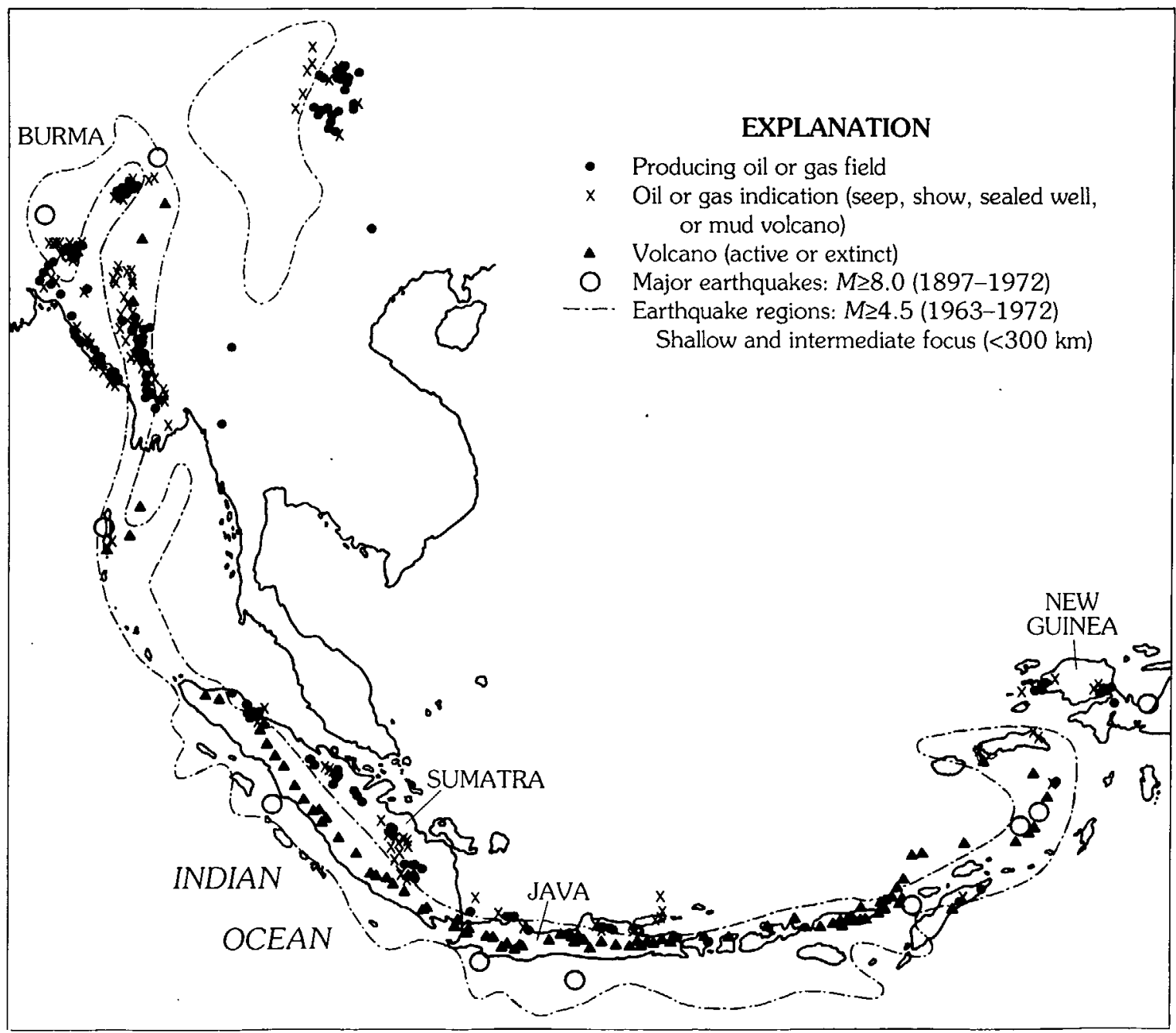

Figure 3. Petroleum and tectonic map of Southeast Asia. The map shows the belt of hydrocarbon occurrence paralleling the volcanic and earthquake belt from New Guinea, through the southern islands of Indonesia, Java, and Sumatra, through the Andaman Islands and on into the Irrawaddy valley of Burma and the mountains of southern China. Data compiled from World Seismicity Map (Tarr, 1974) and from the Oil and Natural Gas Map of Asia (revised 1975), published by the United Nations Economic and Social Commission for Asia and the Pacific (ESCAP). $M$, earthquake magnitude. 
penetrated through large coal deposits. Deep underneath the oil of the Gulf States, large gas fields have been discovered. Almost all the oil wells of Java and Sumatra have drilled through coal, and even the deep gas of Oklahoma is often underneath coal. What we are seeing is principally a succession of hydrocarbons with diminishing hydrogen content as one goes from the deepest to the shallowest. One presumes that bacterial action, which attacks the hydrogen-rich hydrocarbons first, has been largely responsible for the progressive hydrogen depletion of upwelling hydrocarbons. For coal, the situation is more complex because biological factors can be involved in another way also. In a hydrocarbon outgassing area, the groundwater is strongly anoxic because hydrocarbon-oxidizing bacteria are abundant there and quickly remove atmospheric oxygen carried in that water. The result is that the normal processes of fermentation of plant material, which would turn the carbon back into the atmospheric $\mathrm{CO}_{2}$, will be interrupted. Hydrocarbon outgassing areas tend to become swamps filled with the insoluble carbon of plant material. What plant fossils there are in bituminous coal (frequently there are none) are often themselves filled with the same homogeneous coal as that which surrounds them, suggesting a carbon source different from the fossilized plant material itself. It would not seem possible that plant material was converted into the homogeneous coal, and yet that a fraction survived as fossils with a precise maintenance of detail, and that these fossils were then filled by the homogeneous coal derived from similar material.

The huge gas deposits in the form of methane hydrates in the oceans may not have an adequate explanation in terms of the plant debris of the ocean mud. There is often little organic mud, and its gaseous products would not have migrated downward. Yet it has been said by the Russian investigators (for example, Makogan, 1988) that, so far as they could see, in every location on the ocean floor and in the permafrost of the northern areas where the temperature-pressure situation would make methane hydrates stable, such hydrates are found. As the deeper ocean regions are being investigated for hydrates, the inadequacy of a biological source material for them may become even more obvious, since the biological deposits in the deep ocean tend to be much smaller than in the continental shelf regions that have been the principal targets of gashydrate investigation so far.

Every deep hole that has been drilled into crystalline basement-by several Soviet deep drilling programs, by the German ongoing deep-drilling efforts, by deep drilling into Swedish granite-has shown the presence of hydrocarbons at depth. While the quantities vary regionally, the indications we now have point to a ubiquitous presence of some amounts of hydrocarbons at deep levels everywhere. Even small amounts of methane or of hydrogen at the deeper levels in the rocks show that equilibration between the oxygen fugacity of the rocks and of the fluids has not taken place, since in chemical equilibrium these fluids could not be present. The explanation for this disequilibrium is that only a small fraction of the volume of the rocks could equilibrate by diffusive processes with the fluid streaming through pores; the pore fluids determine the oxygen levels in these cracks, the rest of the rock takes no part. Chemical equilibrium calculations are meaningful only in situations where the rocks and the fluids are much more tightly intermixed, such as in gases streaming through molten rocks. There each moving gas bubble keeps meeting new rock material to provide oxygen, and in such circumstances most carbon reaches the surface in oxidized form as $\mathrm{CO}_{2}$. In solid rock there is a mixture of various proportions of methane and $\mathrm{CO}_{2}$, frequently with methane as the major quantity.

Since methane-hydrate formation is a very efficient means of retaining any upward-streaming methane, even regions with low rates of methane emission would still build up hydrates in the long course of time. $\mathrm{CO}_{2}$ hydrates could exist also, but very few of these have so far been found, presumably because the cool, nonvolcanic regions produce mainly methane, and the hot regions do not allow formation of hydrates. If plant debris were responsible for the formation of the hydrocarbons, $\mathrm{CO}_{2}$ would be a major component of the gases produced, and $\mathrm{CO}_{2}$ hydrates should be common.

If hydrocarbon outgassing is in fact a major source of the surface carbon excess, then one must of course consider whether it is also a major source of all the carbonaceous deposits that are found in the crust. Any other mode of deposition could not explain the frequent compliance with Kudryavtsev's rule.

It has often been argued that oil deposits are in the vicinity of "source rocks," rocks that contain carbonaceous materials which have been assumed to come from biological deposits. Most commonly these rocks are shales, and their hydrocarbon content often shows a close chemical match to that of the oil pool in the vicinity. This match has been taken to verify the source-rock concept, but it would only do so if these shales were generally particularly rich in discernible fossils. This is not the case, and there is no reason for attributing their hydrocarbon content to anything other than a supply from the same source as that of the neighboring oil. The so-called source rocks can be regarded as a further demonstration of Kudryavtsev's rule.

\section{INTERPRETATIONS BASED ON CARBON STABLE ISOTOPES}

Carbon has two stable isotopes: ${ }^{12} \mathrm{C}$ ( 6 protons, 6 neutrons) and ${ }^{13} \mathrm{C}$ (6 protons, 7 neutrons). The natural carbon on the Earth contains predominantly ${ }^{12} \mathrm{C}$, and ${ }^{13} \mathrm{C}$ is mixed in at a level of approximately 1 percent. This mixing ratio must have been determined in the nuclear pro- 
cesses in the stars that cooked up the elements and eventually supplied them to form the planets. There are no processes that could occur on the planets that would be able to change this ratio greatly. Only small variations can be produced, not by any effects on the nuclei themselves, but by processes that show a slight preference and select in favor of either the light or the heavy isotope.

The study of the distribution of the carbon isotopes in relation to petroleum and natural gas has a very extensive literature. We shall discuss here only one aspect of it: can isotope measurements determine whether a hydrocarbon compound was derived from biological material or whether it is primordial? Because many petroleum geologists have considered that such a distinction can be made, and that petroleum and natural gas appear on that basis to be usually of biological origin, it is clear that we must address this aspect here.

A selection process that enriches one or the other isotope is usually referred to as a process of fractionation. The resulting fractionated material is referred to as isotopically light or isotopically heavy, depending on the ratio of the lighter to the heavier isotope. Measurements of the slight variations in the carbon isotope ratio in different samples is usually not done in absolute terms, but by comparison with a standard, and the small departures from this standard are then the quantities noted. The standard that has been selected for this purpose is $\mathrm{CO}_{2}$ prepared from belemnites collected from the Upper Cretaceous Peedee Formation of South Carolina, a marine carbonate rock. The standard is called Peedee belemnite, or PDB, and it has a carbon isotope value that is about in the middle of the distribution of values for all the marine carbonates. The measurements are then quoted as the departure of the ${ }^{13} \mathrm{C}$ content of the sample from that of the standard, and the figure is usually given in parts per thousand (permil) and referred to as the $\delta^{13} \mathrm{C}$ value of the sample.

Unoxidized carbon in plants is derived from atmospheric $\mathrm{CO}_{2}$ by the process of photosynthesis. In this process the light isotope, ${ }^{12} \mathrm{C}$, is slightly favored. As a result this carbon is slightly depleted in ${ }^{13} \mathrm{C}$ relative to atmospheric $\mathrm{CO}_{2}$, and the effect is larger than that occurring in any other single nonbiological chemical process recognized in nature. When it was found that most of the deposits of unoxidized carbon, such as petroleum, methane, coal, and kerogen, show also a marked depletion of ${ }^{13} \mathrm{C}$, it was considered that this depletion confirmed the deposits' biological origin. $\delta^{13} \mathrm{C}$ for plant organic carbon is generally in the range of -8 to -35 permil (PDB standard). The atmospheric $\mathrm{CO}_{2}$ from which that carbon was derived has a $\delta^{13} \mathrm{C}$ value of -6 permil, showing the possibility of a large fractionation effect. Marine carbonates laid down from atmospheric $\mathrm{CO}_{2}$ dissolved in ocean water have $\delta^{13} \mathrm{C}$ values ranging from about +5 to -5 permil (average 0 ), and thus evidently a fractionation averaging 6 permil occurs in favor of the heavy isotope during that process.
In the production of methane from plant debris a further fractionation takes place that again favors the light isotope, and plant-derived methane is therefore isotopically even lighter and its $\delta^{13} \mathrm{C}$ plots at -50 to -80 per mil. In the literature we now find that some arbitrary division has generally been assumed, so that carbon with $\delta^{13} \mathrm{C}$ values lighter than -30 permil is regarded as of biological origin, whereas heavier carbon is taken to be from some other source.

There is no clear division in the actual data. Carbonaceous materials have $\delta^{13} \mathrm{C}$ values spanning the range from +20 to -110 permil on the Earth, and these values span an even larger range in the carbonaceous meteorites. There is no natural dividing point in the data, and the use of a particular figure in this continuous distribution to make the distinction between organic and inorganic origin seems very arbitrary. The question is, of course, what other fractionation processes can select in favor of the light isotope.

A look at the distribution of the carbon isotope ratio in different natural forms of carbon gives immediately a strong suggestion (fig. 4). Methane, the only carbon-bearing molecule that is light enough to suffer significant isotopic fraction, shows the largest spread of values. The atmospheric $\mathrm{CO}_{2}$ from which marine carbonates have been deposited throughout geological time seems to have had a remarkably constant isotopic ratio, so that $\delta^{13} \mathrm{C}$ values for nearly all these carbonates fall into the range of -5 to +5 permil. $\delta^{13} \mathrm{C}$ in petroleum has a fairly narrow range, from -20 to -38 permil. Carbonate (calcite) cements in the rocks have $\delta^{13} \mathrm{C}$ values spanning the second-widest range. This fact by itself would suggest that the carbonate cements are generally produced from methane. That the range of $\delta^{13} \mathrm{C}$ values for carbonate cement is 20 to 40 permil heavier than the range for methane suggests that a fractionation occurs when methane is oxidized in the ground and then

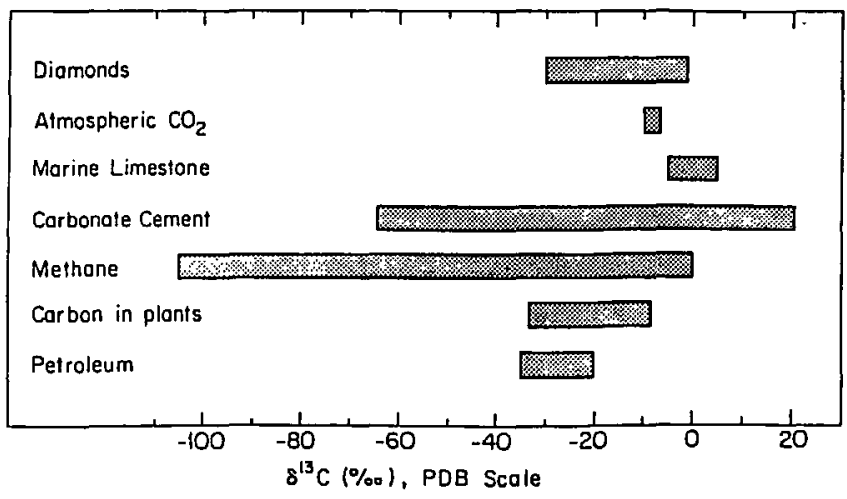

Figure 4. Distribution of ratio (expressed as $\delta^{13} \mathrm{C}$ ) of the stable isotopes carbon- 13 and carbon- 12 in different terrestrial materials. Methane and carbonate cements span a much larger range of these isotope ratios than all other forms of terrestrial carbon. PDB, Peedee belemnite. 
combined with calcium oxide to produce the carbonate cement. Everything in the data points to such a process. These cements are found in great quantities overlying gas and oil fields. They are usually isotopically lighter than marine carbonates, the lightest among them having $\delta^{13} \mathrm{C}$ values as light as -65 permil. Where methane and carbonate cements are found in the same location, the methane is usually isotopically lighter than the carbonate by $\delta^{13} \mathrm{C}$ differences ranging from 20 to 60 permil. The overall isotopic distribution of methane and carbonate cements show a similar shift.

Galimov (1969), a major contributor to the carbon isotope investigations, saw that in any vertical column methane tends to be isotopically lighter at progressively shallower levels. This appears to be true irrespective of the type or age of the formation from which the sample was taken (fig. 5). It is most unlikely that in all those cases methane from two different sources mixed to produce the observed trend. A much better explanation is that a progressive fractionation of the methane took place in its upward migration. Some of this methane appears to be lost to oxidation, ending up as $\mathrm{CO}_{2}$ (fig. 6), and a fraction of that $\mathrm{CO}_{2}$ is transformed, in turn, into calcite cement. This oxidation process seems to select the heavy isotope, and so the remaining methane gets isotopically lighter on the way up. At each level the calcite is thus derived from the already-fractionated methane, and so it also will be lighter, tracking the methane but always remaining heavier than the methane at that same level.

Progressive fractionation is an important process because it can drive the remaining material to a very much greater fractionation than could be done by any single chemical step. It is of course the technique used for com-

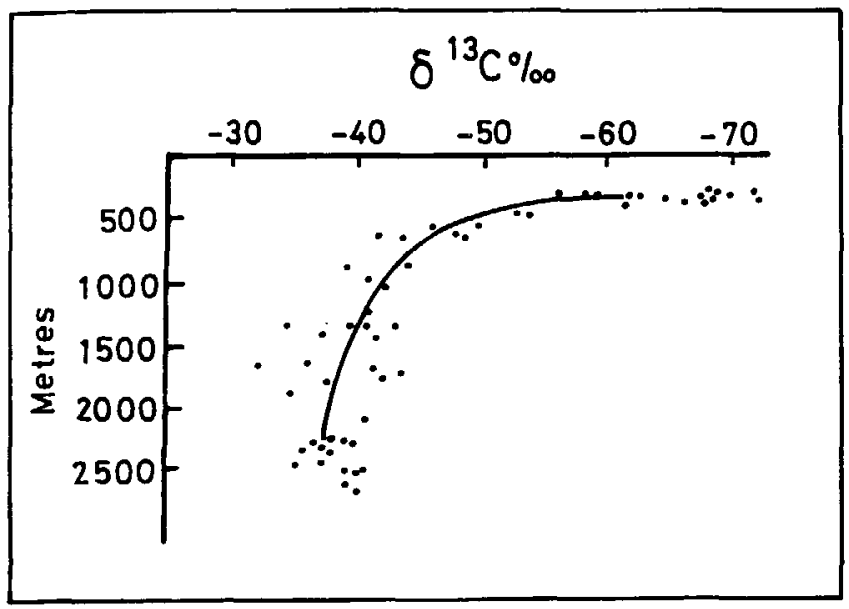

Figure 5. Carbon isotope ratios (expressed as $\delta^{13} \mathrm{C}$ ) of methane plotted against depth of occurrence (from Galimov, 1969). Although there is much variability in this relationship, it is almost always true that where methane is found at different levels in the same area, the methane is isotopically lighter (contains less carbon-13) the shallower the level. mercial isotope separation, in which extremely large fractionation factors are required. In the case of progressive fractionation of methane, two effects help to create the result. One is the tendency for the oxide to bind slightly more tightly with the heavier carbon isotope (in $\mathrm{CO}_{2}$ ); in equilibrium conditions at a low temperature the heavy isotope will therefore be enriched in the oxide and depleted in the remaining methane. The other effect is the diffusion speed, which for methane with the heavier isotope and a mass number of 17 will be 3 percent slower than for light methane with a mass number of 16 . This difference means that in any circumstance where methane is diffusing through a barrier to fill a reservoir, the methane entering initially will have a 30-permil enrichment in the light isotope $\left({ }^{12} \mathrm{C}\right)$. If this reservoir were to fill another, the light-
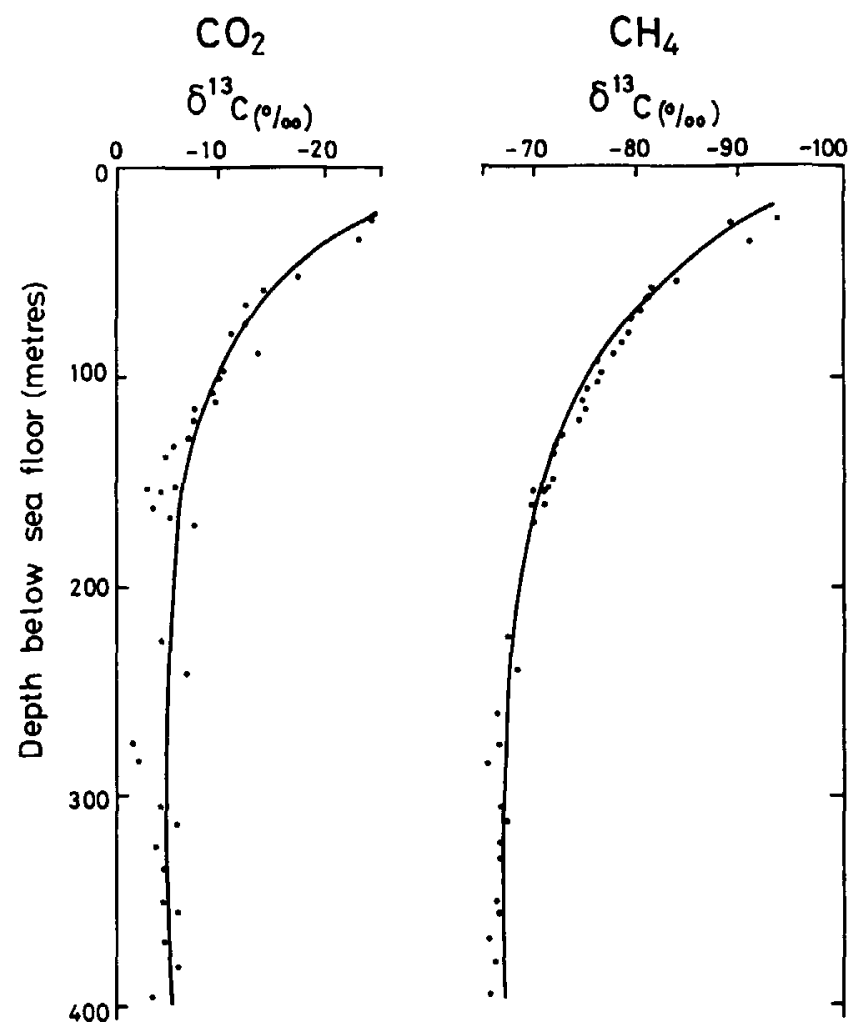

Figure 6. Comparison of the carbon isotope ratios (expressed as $\delta^{13} \mathrm{C}$ ) of methane and coexisting carbon dioxide in ocean-floor sediments (from Galimov and Kvenvolden, 1983). The carbon isotope ratios of the two gases seem to follow the same depth dependence, but with the $\mathrm{CO}_{2}$ always isotopically heavier than the methane. This is the pattern to be expected if progressive fractionation were happening, with the $\mathrm{CO}_{2}$ produced (probably by bacterial oxidation) from methane moving upward through the crust. Both the methane and the $\mathrm{CO}_{2}$ produced would become isotopically lighter on the way up, but the $\mathrm{CO}_{2}$ would be heavier by a constant amount than the methane from which it was derived. (This is not the interpretation given by the authors of the article). 
isotope enrichment would augment. Differential removal by oxidation, by different solubilities in water, by different adsorption on solids, and by bacterial attack will affect the final result of a slow percolation of methane through diverse strata of rock. Since in any such progressive fractionation the final effect can be arbitrarily large, one cannot conclude that a large fractionation implies as its cause a single-step process, namely the one that occurs in plants.

The constancy of the isotopic ratio of marine carbonates spanning all ages deserves further comment. If at any time between the Archean and the present a large change had taken place in the amount of plant debris that was buried, and if this plant debris was, as is usual, isotopically light, then more of the light isotope would have been taken out of the atmospheric-oceanic $\mathrm{CO}_{2}$ reservoir. The remaining $\mathrm{CO}_{2}$ in that reservoir would have been driven to a slightly heavier composition. If as much as one-fifth of the buried carbon was in the form of such plant debris, then the shift in the isotopic composition of the remaining atmospheric carbon and the resulting shift in the isotopic composition of the carbonate deposits laid down from it should have been readily observable. When land vegetation suddenly proliferated in Silurian time, for example, one might well think that twice as much unoxidized plant material was buried as before this event. Why is there no change in the isotopic ratio of marine carbonates deposited in that epoch? An explanation that the primordial carbon supply suffered a change in the isotopic ratio just sufficient to compensate is improbable. A more likely explanation is that the quantity of biological debris that is buried is a much smaller fraction than is usually assumed. The reason for this may be that the identification of much of the buried carbonaceous material as plant debris is not correct and that a large proportion of this material was derived directly from hydrocarbons ascending from the mantle. The extra contribution made by the time-variable burial of plant debris may then be so small an effect that it does not show in the isotopic ratio of the carbonates. This would be the case if all the dispersed kerogen and the oil shales, which have been regarded as source material for oil pools, were derived from the primary hydrocarbons. It is worth noting that the amount of carbon that would have been contained in certifiable fossils is a very small quantity by comparison.

The remarkable constancy of carbon isotope values of marine carbonates also sheds light on the question mentioned earlier, about the amount of carbon that may be coming up as a result of the heating of subducted sediment. In such heating some or all of the carbonates may be dissociated and the $\mathrm{CO}_{2}$ may come to the surface. Much of the unoxidized carbon that is in the same sediment, whether derived from plants or from a primordial hydrocarbon supply, is known to be isotopically much lighter than the carbon in marine carbonates. Of the unoxidized carbon, only a fraction would be turned into liquids or gases, limited by the availability of hydrogen; the remainder would eventually turn into elemental carbon-graphite or anthracite-and in that form it would be insoluble and stable, and would not be returned to the atmosphere. A process of multiple recycling of sedimentary carbon would therefore always take away more of the light isotope than of the heavy, and this would drive the atmospheric-oceanic $\mathrm{CO}_{2}$ to a heavier isotope value. Because such a trend is not observed, recycling of sediments cannot account for a significant fraction of the resupply of atmospheric $\mathrm{CO}_{2}$ over geologic time.

\section{THE HELIUM ASSOCIATION WITH PETROLEUM}

On the basis of hydrocarbon outgassing from great depth, we understand immediately why various trace elements, especially helium, should be so commonly associated with deposits of oil and gas. The long pathway through pressure-created fracture porosity in the rocks will, of course, sweep up whatever helium was available in those pores. Helium is generated in the rocks by the radioactive decay of uranium and thorium, but at too low a concentration to create a fracture porosity or hold it open. Its transport is therefore dependent entirely on a carrier gas, such as the more abundant hydrocarbons may provide. Helium is not only strongly associated with hydrocarbon deposits, it has even been noted to be particularly enriched in gas-oil reservoirs, more so than in drygas reservoirs (Nikonov, 1973). Helium is also particularly enriched in reservoirs having a high nitrogen content. Any chemical or biological cause for the enrichment can be ruled out for the chemically inert helium. Only variations in the concentrations of the parent radioactive elements, and variations in the length of pathway through the rocks from which the helium has been swept, can come under consideration as an explanation of the great regional differences of the observed helium concentration. Where large variations have to be explained, such as by a factor of 100 or more from one location to another, the length of pathway through which the carrier gas has swept is likely to have been the dominant variant. If carrier gases from a depth of $300 \mathrm{~km}$ are involved in one case, whereas gases only from the depth of sediment are involved in another, then this variant will outweigh any likely variation in the concentration of the radioactive elements. The helium concentration in a gas is then mainly an indication of the depth from which this gas has come. With this explanation one would conclude that of all the volatile elements or compounds, nitrogen frequently is derived from the deepest levels, oil from the next deepest, dry methane sometimes from shallower levels still, but all from levels far deeper than the sediment. Helium enrichment is not found 
in sediment in the absence of larger amounts of hydrocarbons or nitrogen, and 10-percent helium in methane-nitrogen gases is the highest concentration that has been found. Yet if helium could flow without a carrier gas, there should be many locations where amounts of helium had accumulated that were similar to the amounts of helium in some gas fields, but, in the absence of methane or nitrogen, these accumulations would be pure helium fields. Such fields would have been discovered and would be very valuable. Their absence thus supports the carrier-gas concept for helium transport.

Some information can be gained from a study of the isotopic composition of the helium. Helium has two stable isotopes, helium-4 and helium-3. Most of the helium found on Earth is helium-4, the result of the radioactive decay of uranium and thorium. In the atmosphere helium is present at a concentration of $5.24 \mathrm{ppm}$ by volume. The helium-3 isotope, which is much less abundant, is present in the atmosphere at about 1.4 parts of helium- 3 to a million parts of helium-4. In the surface of the Sun and in the solar wind one observes a ratio of helium- 3 to helium -4 of $3 \times 10^{-4}$, or about 200 times higher than the ratio in our atmosphere.

The primordial helium that was incorporated in the Earth as a small impurity in the rock grains must have been more similar to the solar composition and thus much richer in helium-3 than any present-day terrestrial helium. But the total quantity that was brought in by the grains was small, and so the continuous production of helium-4 from the radioactive decay became the major contributor to helium in all locations on the Earth.

While a small proportion of helium-3 can also be produced by radioactivity in an interaction involving uranium and lithium, this interaction is not thought to be a major contribution to the Earth's helium-3. The lithium production of helium-3 in the most ideal circumstances, where lithium and uranium are in close association, could be as high as to give ${ }^{3} \mathrm{He} /{ }^{4} \mathrm{He}$ ratios of $1.2 \times 10^{-5}$, or ten times the ratio in the atmosphere (Morrison and Pine, 1955). But this high production would occur only in some rare minerals, and the average production of helium-3 in the crust of the Earth has been estimated as at least a hundred times lower. These figures mean that in any location where we find a helium-3 to helium- 4 ratio of more than one-tenth the atmospheric value, it is probably due to a contribution of some primordial helium. In those cases we then know that we are dealing with a gas that has at least a component that must have come from deep rocks, since the crust in its formation would have largely outgassed, and primordial helium would not have been maintained there.

However, we cannot assume the converse. Where the proportion of helium-3 is low, the gas may well have come from mantle depths also, since in a mantle that was never all liquid, the gas content could never have become a uniform mix, nor could it have remained a uniform mix if the rates of outgassing were different in different regions.
Where a carrier gas has washed through pore spaces that it has created, it will have transported the mix of primordial and radiogenic helium that happens to have been there. If such a flow has been going on for a long time, then the primordial component will have been depleted, while the continuously produced radiogenic component will still be present. The helium-3 proportion will have suffered a dilution throughout the existence of this flow. Pore spaces that have been flushed for a long time would have low helium- 3 values, but there would be no reason to assume that such gases were derived from a smaller depth. While high helium-3 values indicate young pathways from mantle depths, low helium-3 values do not give a firm indication of the depth of origin of the helium. A great concentration of any helium, however, suggests that sweeping by a carrier gas on long pathways has been responsible, and thus a high concentration is in itself an indication of a deep origin for the helium.

The partial pressure at which helium is found, whether under a caprock or anywhere else, may also serve as in indication of its depth of origin. As an inert gas, helium cannot have had its partial pressure increased from that of its point of origin by any chemical action. In any flow, its partial pressure must always decrease; only the (unlikely) circumstance of a mechanical pumping action could ever cause an increase. Helium must have been derived generally from a location where the radioactive decay could produce the partial pressure at which the helium is found, or a yet higher one. This is an important consideration in estimating whether helium in a given location could come from the radioactivity of the surrounding rocks or whether it has come from greater depths. For this calculation one has to take into consideration not only the local concentration of uranium and thorium, but also the rock's helium porosity (the volume of pore spaces large enough to be occupied by the helium atom, which includes many imperfections in the rock crystals and will therefore represent a larger volume than the porosity presented to a gas of larger molecular size). At deeper levels, where the rocks are subjected to a high lithostatic pressure, the helium porosity will be small, and a given radioactive concentration will send the resulting helium into smaller volumes, and therefore set up correspondingly higher partial pressures. This consideration shows that in many locations, even where natural gas has a comparatively high helium content, the local rock cannot have supplied the helium. It explains why helium measurements at or near the surface seem to be successful as a means of finding hydrocarbons underneath (Roberts, 1980), but rarely successful as a means of prospecting for uranium deposits.

Regional patterns of helium abundance have been observed in which the helium concentration and the helium partial pressure are far higher than the sediments could have produced in their entire age (Pierce and others, 1964), but where the patterns of gas composition (ratios of 
components) span horizontally over areas very large compared with that of any particular gas field of the region. The helium must certainly have come from below the sediment, and it must have arrived there already in regionally well-defined mixing ratios with methane and nitrogen, so that the different fields of the region could all be filled with the same or a closely similar mix. Only a mix that had entered the sediment and its individual gas fields from below could achieve that effect (Gold and Held, 1987).

\section{RELATION OF OUTGASSING OF HYDROCARBONS TO ATMOSPHERIC OXYGEN}

The problem of the maintenance of the atmospheric oxygen levels within the bounds suggested by the geologic record has not yet been solved satisfactorily, but it is clearly closely related to the carbon supply. Photosynthesis in the plants produces free oxygen by the dissociation of water. If none of the products of photosynthesis escaped from the circulation of atmosphere and biosphere, if fermentation returned all the content of carbon and hydrogen in plant debris back to the atmosphere as carbon dioxide and water (the form in which it was taken up by the plants), then there would be no net gain or loss of atmospheric oxygen. If some hydrogen were to escape, however, as hydrogen does escape from the upper atmosphere into space, or if it were laid down in hydrides or other hydrogen compounds in the sediment, then for every two hydrogen atoms so removed, there would be one oxygen atom that would constitute a net addition to the atmosphere.

If all the fresh carbon supply that the atmosphere receives came in as $\mathrm{CO}_{2}$, and if all the carbon laid down in the sediment were in the form of carbonate rocks (that is, $\mathrm{CaO}$ from rocks combining with $\mathrm{CO}_{2}$ to make $\mathrm{CaCO}_{3}$ ), then also this process would neither add to nor subtract from the atmospheric oxygen. If, however, as is generally thought, about one-fifth of the carbon that is laid down is in the form of plant debris, then there would constantly be a large addition to the atmospheric oxygen. For each carbon atom that is so buried there would be at most one oxygen atom and at most two hydrogen atoms (polysaccharides such as cellulose are $\left.\left(\mathrm{C}_{6} \mathrm{H}_{10} \mathrm{O}_{5}\right)_{\mathrm{x}}\right)$. Every carbon atom that came up from the mantle in the form of $\mathrm{CO}_{2}$ provides two oxygen atoms, while the burial of that carbon atom would bury only one oxygen atom and take away possibly as many as two hydrogen atoms that had been derived from the dissociation of water and would not now be available to reform a water molecule with its photosynthetically liberated oxygen atom. Thus, for every carbon atom laid down as biological debris, approximately two oxygen atoms would be liberated. For the figures given, of $20 \mathrm{~kg} / \mathrm{cm}^{2}$ of total carbon laid down, one-fifth in biological materials, the total amount of oxygen left over to join the atmosphere would be $10.6 \mathrm{~kg} / \mathrm{cm}^{2}$ of $\mathrm{O}_{2}$. That is more than 50 times the present atmospheric oxygen content. All carbon being supplied as $\mathrm{CO}_{2}$-one-fifth being laid down in plant debris and the rest as carbonate rocks-does not seem a possible scenario over long periods of geologic time.

If a fraction of the juvenile carbon was supplied as $\mathrm{CH}_{4}$, the oxygen excess would be diminished because both the carbonates and the organic carbon would lay down some oxygen, and the left-over hydrogen would form water, using up more atmospheric oxygen. Of course this scenario could shift the balance toward no gain or even loss of atmospheric oxygen. But to maintain the atmospheric oxygen level within the bounds given by the geologic record, firstly the supply of carbon as methane and as $\mathrm{CO}_{2}$ and secondly the laying down of carbon in the sediment would have to be balanced very precisely, since both processes involve such large quantities of oxygen compared to the atmospheric oxygen content. One could not attribute such constancy, nor the chance of just producing the balance, to tectonically controlled events over long periods of time. Some powerful stabilizing effect would have to be at work.

What are the limits on the excursions of atmospheric oxygen content that the geologic record can provide? In all the times that forests have existed, oxygen levels cannot have been higher than at present by more than a few percent, for we are now not far from that concentration at which fires would make it impossible for forests and many other major land plants to survive. In earlier times, before the emergence of land plants in the Silurian, there may have been periods of higher oxygen values, and such periods have been suggested to account for the oxidation states of iron in some ancient sediments. The other limit, that of low oxygen values, can only be estimated from the oxygen requirements of animals both in seawater and on land, and from the oxidation state of some sediments. Again this limit cannot be set very far below the present values for all the periods back to the Devonian, in which oxygen-breathing fishes have existed. Before these epochs the limits may have been wider.

What could be the stabilizing influences that are at work? The laying down of inorganic sediments may have a stabilizing effect, as these sediments can become more highly oxidized than the basement rocks from which they are derived. A large amount of sulfur may be present now in a more highly oxidized state than that in which it came to the surface. Another stabilizing effect may be the escape of hydrogen from the Earth into space. In the presence of smaller atmospheric oxygen values, more hydrogen liberated by photosynthesis could diffuse into the outer atmosphere without being caught by oxidation, thereby leaving more oxygen behind. It is doubtful, however, that such large quantities of oxygen could have been liberated or absorbed in these processes as would be required, or that the 
stabilizing effect could have the required strength to keep the atmospheric oxygen levels within the narrow bounds.

Perhaps the strongest stabilizing effect would be the control that the atmospheric oxygen concentration must have on the amount of plant debris that will be buried before being reoxidized. Higher oxygen levels in the air, and hence in groundwater, will diminish the areas of swamps and of anoxic lakes, ponds, and seas, the locations in which plant material would escape the fermentation processes that would turn the carbon back to $\mathrm{CO}_{2}$, thereby taking away atmospheric oxygen. Conversely, low oxygen would favor anoxic deposition, leaving more oxygen behind. Possibly this effect could be sufficiently powerful. However with the imprecise knowledge of the amounts of plant material buried in different epochs, with the strong possibility that deposits of organic carbon are in part due to hydrocarbons from great depths and not all to plant debris, and with the inexact knowledge of the ratio of oxidized to unoxidized carbon in the primary carbon supply to the surface, no firm judgment can yet be made.

\section{THE MECHANICS OF THE ASCENT OF FLUIDS THROUGH THE CRUST}

There are two principal methods of ascent toward the surface of fluids that are liberated in the mantle and that are of lesser density than the rock and hence buoyant relative to it. One is the ascent in volcanic regions, where magma, with its density closely similar to that of the surrounding rock, can hold open vertical pathways down to depths of 100 kilometers or more. Any other fluids that can pressure-fracture the rock and make their way through cracks into such lava channels can then move upward by buoyancy forces and quickly reach the surface. Hydrogen and hydrocarbons would, as we have said, be largely oxidized in bubbling through magma, but the extent of this oxidation would of course depend on the relative proportions of hydrocarbons and magma at any time. There are strong indications that small amounts of gases coming out of volcanoes at quiet times are largely oxidized, whereas in violent eruptions the unoxidized gases-hydrogen and methane-are prominent. On many occasions flames have been reported during major eruptions and have been seen as quite distinct from the ejection of hot material. During the episodes of the Krakatoa eruption below the sea surface, following the major eruption in 1883 , large regions of flames above the water were observed, in this case of course in the complete absence of any confusing sprays of lava. But even at quiet times some volcanoes emit enough combustible gases to burn above the lava lake. This phenomenon has been observed in the Hawaiian volcanoes and also in volcanoes of the African Rift. Volcanic eruptions in Java have delivered ashes containing several percent of unoxidized carbon.
The other possible manner of ascent of fluids from the mantle is the buildup of sufficient fluid pressure to fracture the rock and create pathways (Gold and Soter, 1984/85). For such pathways to stay open, the pressure in the rock due to the weight of the overburden (the lithostatic pressure) must be closely similar to the fluid pressure in the pore spaces. Since rock is extremely weak in tension, a fluid pressure higher than the lithostatic value will quickly create more fractures. In compression rock is much stronger and pore-spaces will only be crushed shut when the pore-pressure deficit exceeds a certain value. If one considers fluids that are less dense than the rock, then any connected system of pore spaces filled with such fluids will have a smaller pressure gradient with depth than that of the surrounding rock. At the top of such a domain the pressure may be close to that in the rock (the lithostatic pressure). The bottom of such a domain will then have a deficit of pressure, and since this deficit cannot exceed a value defined by the compressive strength of the rock, there will be a limit to the vertical height that such a domain can occupy (fig. 7). In the volcanic case, the dense lava with its pressure gradient closely similar to that of the surrounding rock can keep open a channel to a depth of 100 kilometers or more. In the case where the fluid is a hydrocarbon or water, and hence of much lower density, only an interval of a few kilometers can be held open: an interval whose height can be calculated from a knowledge

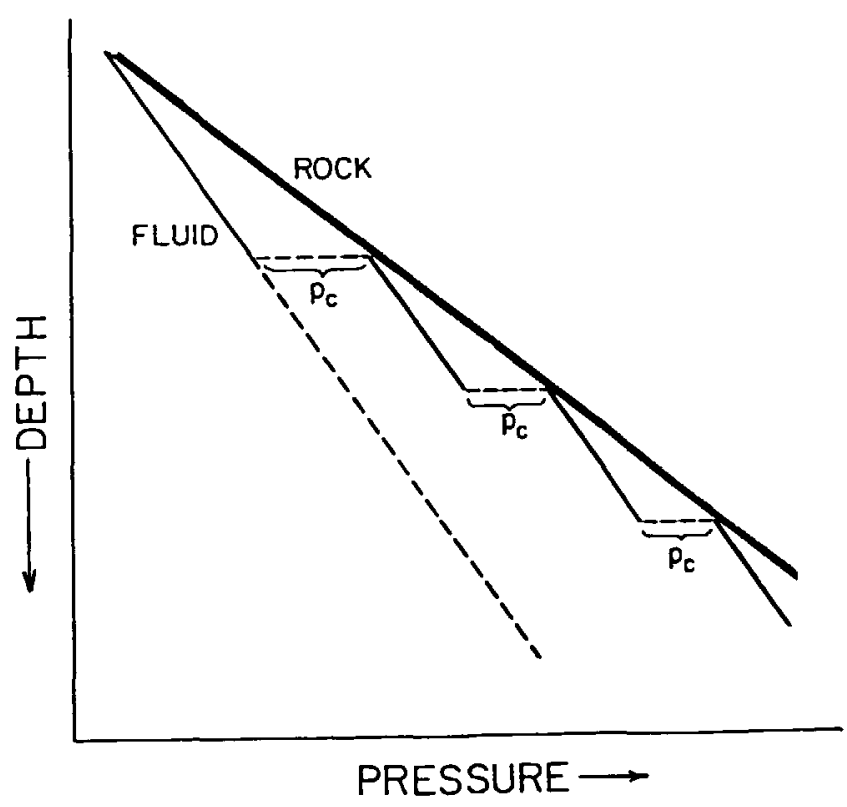

Figure 7. Schematic diagram showing pressure of rock due to overburden and pressure of fluid (less dense than the rock) in connected pore spaces. $P_{c}$ denotes critical pressure difference (between rock pressure and fluid pressure) at which the rock compressive strength is inadequate to maintain pores. Dashed lines indicate fluid pressures that are physically unrealizable because of the limited compressive strength of the rock. 
of the compressive strength of the rock and the vertical pressure gradients in rock and fluid, given by their respective densities.

These limitations do not mean that gases or liquids are prevented from making their way up. If fluids are evolving as a consequence of an increase of temperature or of chemical reactions taking place at depth, they may create fracture porosity and increase the pressure in such a domain of pore spaces. As more fractures are being created, the vertical height of the domain will increase. As soon as the height spanned exceeds the critical value, the rock at the bottom of the domain will crush shut. Such a domain may then be unstable and migrate upwards, driven by the force of buoyancy, much like a bubble of gas in a liquid makes its way up. Only here, in the presence of solid rock, it is not a round bubble but a region of rock with connected pore spaces. Just as the liquid above the bubble will split open while the liquid below it closes again, so will be the case with the rock above and below the pore-space domain. The rock itself does not move upward, but the domain of pore spaces with its fluid makes its way up through the rock. Above strongly outgassing regions in the mantle one may have a frequent dispatch of pore-space domains toward the surface.

Another mode of upward flow is also possible. If the generation of fluid is continuous, a set of adjoining, stationary pore-space domains may be set up, and the flow may be in the form of a continuous or intermittent leakage from one to the next one above. The stability of such a flow will require that the drop in pressure from the top of one domain to the base of the next will occur as a result of the flow through the low permeability of the dividing layer (fig. 7). However the flow occurs, it must always adopt a stepwise pressure profile, with domains in which the fluid pressure gradient has almost precisely the static value, given by the density of the fluid, divided from the next domain by a region in which the fluid pressure gradient has a much higher value. (If the mass of fluid is small compared to the mass of rock, as would mostly be the case, then the average pressure gradient over a large vertical interval must be the lithostatic one in both rock and fluid.) Such a flow can be compared with a flow of a river from the mountains, which creates a system of cataracts. Consider the potential energy in the flow: pressure in one case, height in the other. In the case of the river, almost all loss of height occurs at the cataracts, the flow between them being almost quiescent and level. Similarly, in the former case, almost all the drop in pressure would occur not continuously but in a few sharply defined locations (fig. 7).

If we look at this situation from the surface down we may find a system of connected pore spaces frequently filled with water, and we therefore define a pressure in the pore spaces that is called hydrostatic, and a pressure in the rock, called lithostatic. As the two pressure gradients with depth are dissimilar, a level must be reached where the rock will close. I have referred to this level as the "critical layer." Beneath the critical layer we can again have open pore spaces, but now only provided that they are filled with a fluid at a pressure exceeding the hydrostatic value that would be calculated for that depth, but not exceeding the lithostatic value. We may then have another domain of fluid-filled pores, but again only of a limited vertical height. The uppermost domain can be calculated to reach from the surface down to a depth of between 3 and 5 kilometers in soft rock, and possibly as much as 10 kilometers in hard rock. This is the domain in which most of the oil and gas exploitation has been done so far, but a comparatively small number of cases exist where the drill has gone through a sharp pressure transition and tapped the second domain.

It should be emphasized that such a critical layer is a necessity dictated by the finite compressive strength of rock. It is thus a caprock layer which must overlie any region in which outgassing is occurring. As the strength of the rock is of course regionally quite variable, this critical layer may be far from level. It may be of a complex shape with large variations in height, and there may even be locations where it doubles over on itself. The main thing is that it has to be a continuous sheet. This is not to say that there may not be other layers of caprock in an outgassing region where a material of low permeability was laid down, and presumably all shallow gas fields have required the presence of such a caprock. The importance of the critical layer is that an outgassing region will inevitably possess that type of caprock at a sufficiently deep level.

The critical layer, like other layers of caprock, will not have zero permeability, and there will be some leakage through it, as we have discussed. In a long-term steady state of a continuous upward flow, the leakage through the critical layer (and through all the similar layers at deeper levels) must occur at the mean supply rate. Nothing can change the flow rate of this upward stream: it is given by the production rate of the fluid below. All that any caprock or any critical layer can do is to increase the amount that is dammed up underneath it. The situation is similar to that of the flow of a river from the mountains to the sea, where, we may suppose, the rainfall producing the water all occurs up in the mountains. On the way down, the river will transport all the water that has been collected, and if the river is dammed up anywhere along its length, the steady state flow rate will not be changed. All that the dam will do is create a lake on the upstream side of it, but finally the amount of water flowing over the dam will be exactly the same as that which would have flowed without the dam.

This is an important consideration from a practical point of view. One has observed that over natural-gas producing regions the amount of methane and other hydrocarbons in the soil is greatly enhanced, sometimes by a 
factor of one hundred or more, and any attempts at deducing a flow rate to account for this enhancement gives such high rates of methane seepage as to appear incompatible with a supply coming only from a gas field below. The technique of surface chemical prospecting, such as measuring the soil methane, has been described by some as necessarily in error, since it was not conceivable that the outflow rate could be so high that the gas field would be exhausted in a few thousand years. But of course if there is a continuous gas supply from below, and at rates that in no way conflict with the limits we can place on such outgassing processes, then it will make good sense to observe the surface concentrations of hydrocarbon gases. It would also make good sense to extend this technique and introduce tracer gases in a well at some depth, and observe the time it takes for the tracer gases to appear in the surrounding soil. From this, and the knowledge of the porosity of the ground, an actual flow rate can be established, and so one could evaluate for any region how much methane per day or per year is seeping out.

Regions that have a high seepage rate will in general be favorable ones for finding good reservoirs, since for a seal or caprock of a given quality a larger quantity of gas is likely to be dammed up underneath that seal. Surface gas prospecting has been certified over many known gas fields, the outstanding example being the Cement Field of Oklahoma. The technique is yet to be used on a large scale in the search for more gas.

In several regions of the United States, drilling to 5 kilometers (approximately 15,000 ft) or deeper has revealed the sharp pressure discontinuity (at the critical layer) to which I have referred. All of the deep gas in the Anadarko Basin is below this discontinuity, and there all the deep gas seems to form essentially one reservoir. In Louisiana and neighboring areas of the Gulf Coast, the pressure discontinuity is a little shallower and the continuous sheet represented by it has been carefully mapped (Jones, 1980), with the information available from a large number of wells and the interpolation between them from seismic data. In Oklahoma there is, in some instances, a dramatic increase in the porosity below the critical layer. Porosities as high as 18 percent have been found below 20,000 feet in the carbonate rocks (Hefner, this volume). It is clearly not possible to account for this large porosity by any process of enclosing a rock volume tightly and then compressing it to achieve the gas pressure in the pores. Since that gas pressure is roughly twice that above the critical layer, one would have to contemplate an initial gas-filled porosity of 36 percent, and then compression of these pores to half their initial volume. Thirty-six percent is not a value that has ever been seen. The conclusion must be, therefore, that the gas has entered from even higher pressure regions deeper down, and that it has expanded pore spaces to these values. Investigations of the details of the fracture patterns in the rocks confirm such an explanation.
We may then describe how a flow of hydrocarbons from depth may take place. As I have discussed, a high proportion of saturated compounds would indicate that methane was a major component that dilutes the stream. But at shallow levels where the pressure is low, the heavier hydrocarbon molecules will be shed from the stream. The largest such effect will take place at the flow through the last pressure discontinuity on the way up, the shallowest critical layer. It is there that the oils are likely to be deposited, being now viscous and easily retained, while much or all of the gases can continue upward and largely escape into the atmosphere. Oil deposits are concentrated laterally because major faults have facilitated their ascent and have caused a confluence toward them, and the oil deposits are concentrated vertically because of the sharp pressure changes in going from one pore-space domain to the next, at which oil and gas get separated.

\section{RESULTS IN SWEDEN}

The distinction between hydrocarbons derived from biological materials and hydrocarbons of primordial origin would be made most clearly by examining igneous or metamorphic rocks that could not have maintained either hydrocarbons or biogenic materials capable of producing them before they froze to their present condition. If crude oil, methane, and other hydrocarbon gases can be found in such locations, at depths that would exclude a seepage down from above, then their presence would demonstrate an origin from sources below.

Crude oil has been found and produced from crystalline basement rocks in numerous locations, but mostly in places where transport from neighboring sediments could be invoked as an explanation. The clearest example we have of a location where hydrocarbon production from sedimentary materials can be excluded comes from two deep boreholes in the granitic rock of central Sweden (Gold, 1991).

As already noted, the granite and gneiss of Sweden have many signs of impregnation - with hydrocarbons. Tar is frequently found during tunneling and mining operations as a substance filling cracks in the granite. Methane explosions and prominent shows of methane have been seen frequently. If hydrocarbons come from depth, one might judge that the large granitic block which makes up most of Sweden overlies an area of mantle that is particularly hydrocarbon rich, and one might think that the hydrocarbons of the Norwegian Trench or of the countries surrounding the Baltic Sea signify an outflow from this area of the mantle. Fractures of the rock within Sweden may then have been conduits for hydrocarbons from the same source.

It is with this consideration in mind that I persuaded the Swedish government to study the region of a giant 
meteoritic impact crater, the Siljan Ring in central Sweden. An impact that left a circular formation 44 kilometers in diameter would undoubtedly have fractured the rock to great depth, and one might therefore expect this to be a particularly favorable location for finding upwelling hydrocarbons.

It was quickly ascertained that just the area of the Siljan structure was quite anomalously rich in soil methane and other light hydrocarbons, that many ordinary water wells produced copious amounts of gas, and that a number of stone quarries in the area had oil seeping out of the rocks and making oil pools in the ground. It is true that the stone quarries were in the sedimentary rock that fills a ring-shaped depression, but those sediments are nowhere deeper than 300 meters. Oil seepage generated after 360 million years from such a small quantity of sediments seems improbable. Aside from the ring-shaped depression, the basement rock is very close to the surface in the whole area; there is barely enough soil for the trees to grow both inside and outside the Siljan Ring.

As a result of the clear demonstration that the area was quite anomalous for its hydrocarbon content, it was decided to engage in a major drilling operation. Since 1986 two wells have been drilled: one to a depth of 6.7 kilometers, the other to a depth of 6.5 kilometers. Both holes showed the presence of methane and of other hydrocarbon gases, as well as of crude oil. Whereas in the first hole (Gravberg 1) diesel oil was used for a time as a component of the drilling mud, only water-based mud was used in the second hole (Stenberg 1), which is situated in the center of the ring and is $12 \mathrm{~km}$ distant from the ring sediments and from Gravberg 1. Although the detailed chemical makeup of the oil found at deep levels in Gravberg 1 was not the same as diesel oil, many considered nevertheless that the diesel drilling oil could be held responsible. Some 15 tons of oil were pumped up, oil that had hydrocarbon components and organometallic compounds that are frequently in natural crude oils, but were absent or present only in very much lower abundance in any of the drilling fluids. Some biological molecules, steranes, were found to be from the same set and in closely similar ratios as had been seen in the surface seepage oils (fig. 8), and this similarity strengthened the case that the two oils had a common origin. Steranes are thought to be derived from sterol, a component of methane-oxidizing bacteria.

In both holes the hydrocarbon content of the rocks increased with depth, and in both holes high spots in methane and also in heavier hydrocarbons were in the locations in which volcanic intrusive rock, dolerite, was present (fig. 9).

The carbon isotope ratio $\left({ }^{13} \mathrm{C}\right)$ of the methane became heavier with increasing depth, and in the dolerite zones and their immediate surroundings it was as heavy as between -12 to -15 permil in the Gravberg 1 well, and -7.2 to -7.8 permil in the Stenberg 1 well. In both wells the

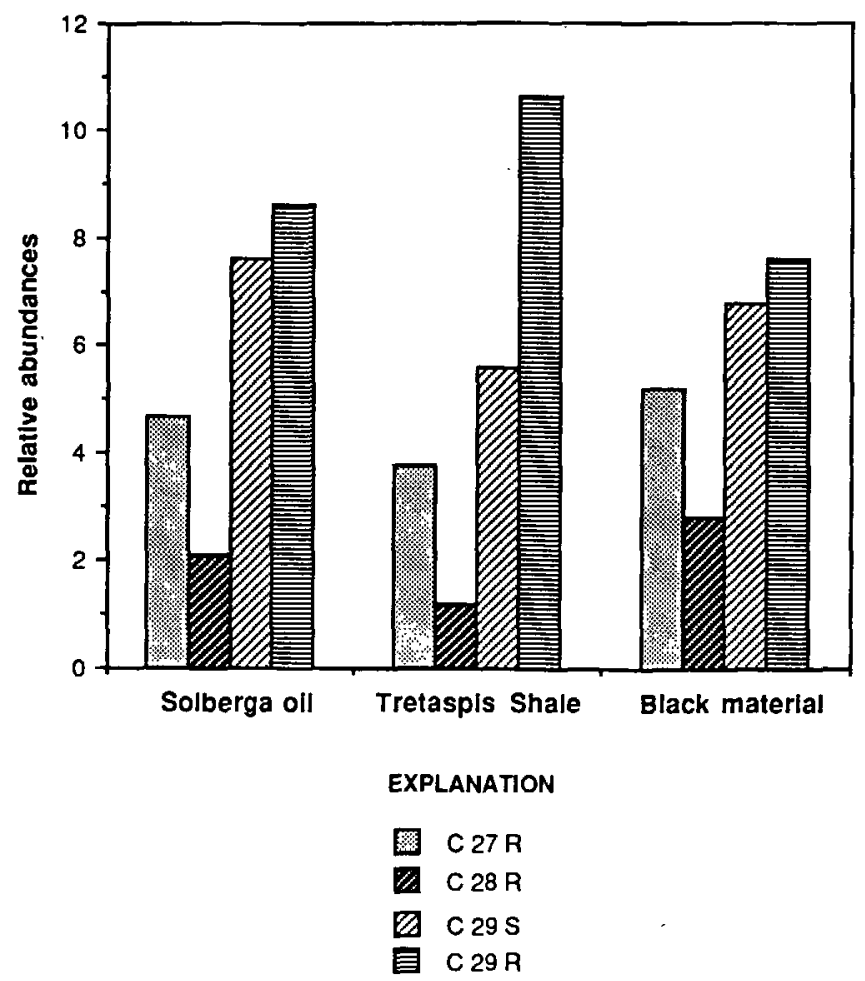

Figure 8. The four most prominent biomarker molecules, steranes, found in the oils of the Siljan region, Sweden. The steranes are present in similar proportions in surface-seep oil (Solberga quarry), local near-surface oil shale (Tretaspis Shale), and oil in black sludge obtained from $5.6 \mathrm{~km}$ depth in Gravberg 1 well. This similarity indicates a common origin of all three oils. The identity of the four sterane molecules is given in the usual notation by the number of carbon atoms and the right or left symmetry of the molecule.

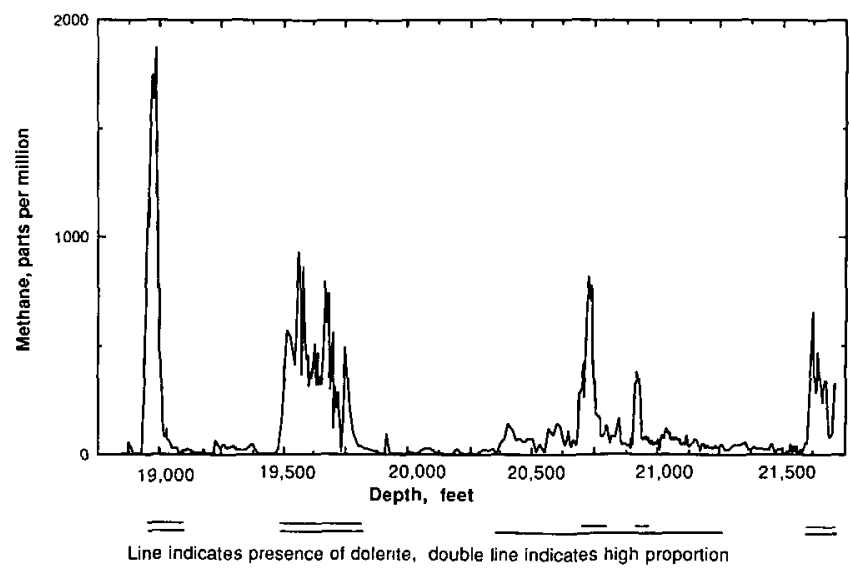

Figure 9. Stenberg 1 well, Sweden: Methane content of drill cuttings as function of depth. Presence of intrusive volcanic rock, dolerite, is marked below graph, showing correlation with high spots of methane readings. Heavier hydrocarbons were also measured, and were largely in step with methane. 
helium concentrations were frequently as high as several percent of the total gas present, and possibly exceeding the highest concentration seen in any well.

The investigations during the drilling of Stenberg 1 gave the clearest indication that a range of hydrocarbon gases and liquids had indeed entered from deep levels. The content of hydrocarbon gases and liquids (aromatics) in the drill cuttings was carefully measured at every 5 - $\mathrm{ft}$ interval during drilling. It showed very large increases in the dolerite and in the granite closely adjoining it (fig. 9). Since the dolerite has undoubtedly intruded from below, one has to conclude that the pathways which guided it up, or the pathways which it generated in the intrusion, are the pathways later used by the hydrocarbons. This relationship also confirms that contaminants introduced during drilling were not responsible for the observed hydrocarbons.

In both holes large amounts of a magnetite/oil sludge were discovered. The magnetite was present as very small grains, mostly submicroscopic, and was highly concentrated in the sense that it formed more than 95 percent of the mineral content of the sludge. Twelve tons of this substance were pumped up from Gravberg 1 from a depth below 5.2 kilometers. It was suspected that the magnetite had been refined and concentrated by bacterial action, as has been seen in other oil-bearing regions at shallower levels (Sparks and others, 1990). Sample collection of liquids that entered the Gravberg 1 wellbore below a 5.2: kilometer depth was carried out by the Swedish State Bacteriological Laboratory in Stockholm, and several strains of previously unknown thermophilic and anaerobic microorganisms were cultured from these samples (U. Szewzyk, R. Szewzyk, and T-A. Stenström, Swedish National Bacteriological Laboratory, written commun., 1993).

During the test procedure of the Stenberg 1 well, a gas cylinder was brought up containing free gas that would readily burn. Apart from nitrogen contamination (due to nitrogen used to expel the drilling water), the gas consisted principally of methane with approximately 10 percent helium and 10 percent hydrogen. No continuous flow could be obtained, apparently due to the blocking effect of the entry of dense magnetite sludge into the wellbore.

The oil brought up with this sludge was investigated in detail by the Danish Geological Survey and considered to be a biodegraded crude oil. Chromatograms of it matched closely those obtained from the oil pumped up in Gravberg 1.

The scientific investigations carried out on products of the two holes have thus demonstrated that hydrocarbons are present deep in granitic rock in the complete absence or lack of proximity of any sedimentary materials and in a distribution that leaves no reasonable doubt that they have come from deeper levels. The mix of the different hydrocarbon molecules, both of the gases and the oils, is quite typical, as it is found in other oil- and gas-producing regions. The quantities of oil and gas that appear to be present in this 44-km-diameter formation, tested in two distant locations, appear to be very large, as judged by the porosity measurements and the vertical intervals showing high concentrations. Production flow rates could not be achieved in either hole, apparently because in a confluent flow towards the wellbore, the sludge quickly concentrates and blocks the pores. The observed concentration of iron oxides in the rock is too low for the magnetite sludge to have been generated in the depth intervals in which it was found, and it must have been gathered and concentrated by a flow. We presume that this flow was that of the oil with which the magnetite is now associated. In that case, deeper levels than those that could be reached by the two boreholes $(6.7$ and $6.5 \mathrm{~km})$ would tap into liquids and gases that contain smaller concentrations of magnetite, and would therefore cause less obstruction to a flow.

\section{CONCLUSIONS}

If the main supply of the commercial quantities of hydrocarbons, both gas and oil, is indeed derived from mantle depths and from materials that were incorporated in the Earth at its formation, then many points in petroleum geology and in other aspects of geology will have to be reconsidered. The quantity and locations of gas and oil that can be found, the method of prospecting for them, and the technology involved will all be affected.

It was thought previously that gas could only be found where there was a particularly impermeable caprock, tight enough to hold gas, above sediments rich in biological debris. Now one would judge that gas can be found wherever a seepage of gas can be found at the surface, and where there is an adequate porosity at some depth below. If a low-permeability layer exists over a porous region, then this layer may have dammed up the flow sufficiently for production. But at deeper levels the critical layer will in any case provide a caprock. Thus in searching for gas, the requirement of a special caprock and the requirement of biological debris have both disappeared. The porosity requirement may be satisfied in many more locations than was previously thought, since beneath the critical layer the fluids coming from high pressures will frequently have created fracture porosity (as is clearly seen in Oklahoma).

If hydrocarbons have been a major source of all the carbon supplied to the surface, then of course the quantities that would be involved are orders of magnitude larger than was previously estimated. The shallow zone above the shallowest critical layer, which is almost everywhere the only zone that has been the subject of oil and gas prospecting, will be seen to be the zone low in hydrocarbons, because they have largely escaped from these shallow levels. Oils, which became concentrated at shallow levels by the escape of the much more abundant gases, have been the chief object of the petroleum explorers. The deeper 
levels, which must be expected to have maintained the much more abundant gas, have not been explored at all outside of the United States, and in the United States the few areas that have been so explored have been found to be very productive.

Drilling to below 5 or 6 kilometers is still expensive, and not much exploration to these levels will be done so long as the good prospects there are not recognized. But despite the expense of drilling, which would no doubt greatly decrease if more of it were done, the productivity from deep levels has frequently shown itself to be very high (Hefner, this volume). Gas at depth below the critical layer tends to have a pressure approaching the lithostatic value, which may be on the order of 2,000 bar. The gas density is thus hundreds of times higher than it is in shallow wells, and may be as high as half the density of oils; therefore the content of gas in a given volume of pore spaces is hundreds of times greater than in shallow wells. The high pressure differentials into the wellbore mean that very high flow rates can be obtained, even from rock which at shallower levels would be regarded as of insufficient permeability for production. The ultimate production from a given well will be greater, because a greater pressure gradient will drive gas to the wellbore, and the expansion of the gas will allow a large proportion of the initial gas in place to be produced. It is therefore by no means true that gas production from the deep horizons must be expensive, and many examples exist already that show that production of deep gas can be quite competitive with production of shallow gas (Hefner, this volume; Cunningham and Rowe, this volume). The initial investment in an area will be higher, but so will be the returns.

Because deep gas does not have many of the special requirements for its accumulation that oil has, one may expect it to be in many more locations than oil. Many countries in all parts of the world will benefit from a more widely distributed fuel source.

Prospecting by the search for surface seepage of gas is a rational procedure, since large quantities of gas must constantly be escaping. Oil was found mainly by the attention that oil seeps drew to an area; instruments are needed to detect gas seeps but, with more gas than oil coming up and escaping more readily, gas seeps are good indicators of the presence of gas underneath. The quality of available prospecting methods is an item of major economic importance, especially for the deep horizons where exploratory drilling is expensive.

A flow of hydrocarbon fluids through the crust will have affected much of the crust's chemical development. The concentration of many types of mineral deposits, especially of metal ores, has not had adequate explanations. The leaching out of particular components from the rocks requires fluids that can dissolve these components, and it requires large pressure differentials to drive these fluids through the pores of a sufficient quantity of rock to gain access to the components. Hydrocarbons ascending from depth may provide these requirements. The hydrocarbons will be present at a high temperature and pressure, conditions under which organometallic compounds can readily form. Such compounds are largely soluble in hydrocarbons, and may thus be transported upward by them. These metals may include some that have solubilities quite inadequate for transport by aqueous fluids, but that can form organometallic compounds. Silver, gold, and the platinum group are in that category, and many others may come under consideration for such processes. It is interesting to note that gold in particular has been found in many locations together with elemental carbon. Vanadium and nickel have shown a strong association with petroleum, both by the presence of vandium and nickel compounds in the petroleum, and the deposition of such compounds in or near oil fields. Several of the elements that would have a high vapor pressure at mantle temperatures have been found associated with hydrocarbons, not only helium but also mercury and all the halides. A range of new processes will have to be investigated for the understanding of mineralization in the crust, and the search for hydrocarbons may become associated with the search for certain minerals. The microorganisms in the ground that are fed by hydrocarbons may have contributed to highly selective processes; just as magnetite has been concentrated in the boreholes in Sweden, apparently by microbial action, so perhaps all the large magnetite deposits of Sweden have a similar origin. Judging from the quantities of microbial material that have been identified in hydrocarbon regions (Ourisson and others, 1984), microbial processing may have been of major importance in the evolution of the crust.

\section{REFERENCES CITED}

Anders, E., Hayatsu, R., and Studier, M.H., 1973, Organic compounds in meteorites: Science v. 182, p. 781-790.

Beskrovny, N.S., and Tikhomirov, N.I., 1968, Bitumens in the hydrothermal deposits of Transbaykal, in The genesis of oil and gas: Izdvo Nedra.

Chekaliuk, E.B., 1976, The thermal stability of hydrocarbon systems in geothermodynamic conditions: Degazatsiia Zemli i Geotektonika (P N. Kropotkin, ed.), p. 267-272.

Clemett, S.J., Maechling, C.R., Zare, R.N., Swan, P.D., and Walker, R.M., 1993, Measurement of polycyclic aromatic hydrocarbon in interplanetary dust particles: Lunar Planetary Science, v. 24.

Galimov, E.M., 1969, Isotopic composition of carbon in gases of the crust: International Geology Review, v. 11, no. 10 , p. $1092-1104$.

Galimov, E.M., and Kvenvolden, K.A., 1983, Concentrations and carbon isotopic compositions of $\mathrm{CH}_{4}$ and $\mathrm{CO}_{2}$ in gas from sediments of the Blake Outer Ridge, Deep Sea Drilling Project Leg 76: Initial Reports of the Deep Sea Drilling Project, v. 76, p. 403-407. 
Gold, T., 1991, Sweden's Siljan Ring well evaluated: Oil and Gas Journal, Jan 14, 1991, p. 76-78.

1992, The deep, hot biosphere: Proceedings of the National Academy of Sciences USA, v. 89, p. 6045-6049.

Gold, T., and Held, M., 1987, Helium-nitrogen-methane systematics in natural gases of Texas and Kansas: Journal of Petroleum Geology, v. 10, no. 4, p. 415-424.

Gold, T., and Soter, S., 1984/85, Fluid ascent through the solid lithosphere and its relation to earthquakes: Pageoph, v. 122, p. 492-530.

Hunt, J.M., 1975, Is there a geochemical depth limit for hydrocarbons?, in Thermal stability of hydrocarbons: Petroleum Engineering, March 1975, p. 112 -127.

Jannasch, H.G., 1983, Microbial processes at deep sea hydrothermal vents, in Rona, P.A., and others, eds., Hydrothermal processes at seafloor spreading centers: New York, Plenum Press.

Jones, P.H., 1980, Role of geopressure in the hydrocarbon and water system, in Roberts, W.H., III, and Cordell, R.J., eds., Problems of petroleum migration: Tulsa, Okla., American Association of Petroleum Geologists, p. 207-216.

Kent, P.E., and Warman, H.R., 1972, An environmental review of the world's richest oil-bearing region-The Middle East: International Geological Congress 24th, Sect. 5, p. 142-152.

Kravtsov, A.I., 1975, Inorganic generation of oil and criteria for exploration for oil and gas: Zakonomern. Obraz. Razmeshchniya Prom. Mestorozhd. Nefti Gaza (G.N. Dolenko, ed.), p. 38-48. Naukova Dumka: Kiev.

Kravtsov, A.I., Ivanov, V.A., Bobrov, V.A., and Kropotova, O.I., 1981, Distribution of gas-oil-bitumen shows in the Yakutian diamond province: International Geology Review, v. 23, p. 1179-1182.

Kravtsov, A.I., Voytov, G.I., Ivanov, V.A., and Kropotova, O.I., 1976, Gases and bitumens in rocks of the Udachnaya pipe: Akademiya Nauk SSSR Doklady, Earth Science Section, v. 228, p. 231-234.

Kropotkin, P.N., 1985, Degassing of the Earth and the origin of hydrocarbons: International Geology Review, v. 23, p. 12611275.

Kropotkin, P.N., and Valyaev, B.M., 1976, Development of a theory of deep-seated (inorganic and mixed) origin of hydrocarbons: Goryuchie Iskopaemye: Problemy Geologii i Geokhimii Naftidov i Bituminoznykh Porod (N.B. Vassoevich, ed.), p. 133-144. Akademiya Nauk SSSR.

-1984, Tectonic control of Earth outgassing and the origin of hydrocarbons: Proceedings of the 27th International Geological Congress, v. 13, p. 395-412. VNU Science Press.

Kudryavtsev, N.A., 1959, Geological proof of the deep origin of petroleum: Trudy Vsesoyuz. Neftyan. Nauch.-Issledovatel. Geologoraz Vedoch. Inst., no. 132, p. 242-262.

Levin, B.J., 1958, Über den Ursprung der Meteoriten: Chemie der Erde, v. 19, no. 3, p. 286-295.

Lowe, D.C., Brenninkmeijer, C.A.M., Manning, M.R., Sparks, R., and Wallace, G., 1988, Radiocarbon determination of atmospheric methane at Baring Head, New Zealand: Nature, v. 332, p. 522-524.

Makogan, Yu.F., 1988, Gas hydrate accumulations and permafrost development: Proceedings Fifth International Conference (K. Senneset, ed.), p. 95-101.

Melton, C.E., and Giardini, A.A., 1974, The composition and significance of gas released from natural diamonds from Africa and Brazil: American Mineralogist, v. 59, p. 775-782.
Mendeleev, D., 1877, L'origine du petrole: Revue Scientifique, 2e Ser., v. 8, p. 409-416.

Morrison, P., and Pine, J., 1955, Radiogenic origin of helium isotopes in rock: Annals of the New York Academy of Sciences, 62, p. 71-92.

Nikonov, V.F., 1973, Formation of helium-bearing gases and trends in prospecting for them: International Geology Review: v. 15 , no. 5 , p. 534 and following.

Ourisson, G., Albrecht, P., and Rohmer, M., 1984, The microbial origin of fossil fuels: Scientific American, v. 251, no. 2, p. 44-51.

Pearson, D.G., Davies, G.R., Nixon, P.H., and Milledge, H.J., 1989, Graphitized diamonds from a peridotite massif in Morocco and implications for anomalous diamond occurrences: Nature, v. 338, p. 60-62.

Pierce, A.P., Gott, G.B., and Mytton, J.W., 1964, Uranium and helium in the Panhandle gas field, Texas, and adjacent areas: U.S. Geological Survey Professional Paper 454-G, p. G1-G57.

Porfir'ev, V.B., 1974, Inorganic origin of petroleum: American Association of Petroleum Geologists Bulletin, v. 58, p. 333.

Roberts, A., 1980, Helium emanometry in exploring for hydrocarbons, part II, in Proceedings of Symposium II on unconventional methods in exploration for petroleum and natural gas: Institute for the Study of Earth and Man, Dallas, Southern Methodist University Press.

Robinson, R., 1963, Duplex origin of petroleum: Nature, v. 199, p. 113-114.

1966, The origins of petroleum: Nature, v. 212, p. 1291295.

Schidlowski, M., Eichmann, R., and Junge, C.E., 1975, Precambrian sedimentary carbonates-Carbon and oxygen isotope geochemistry and implications for the terrestrial oxygen budget: Precambrian Research, v. 2, p. 1-69.

Sokoloff, W., 1889, Kosmischer Ursprung der Bitumina: Bulletin de la Société Imperiale de Naturalistes de Moscou, n.s., v. 3, p. $720-739$.

Sparks, H.N.C., Mann, S., Bazylinski, D.A., Lovley, D.R., Jannasch, H.W., and Frankel, R.B., 1990, Structure and morphology of magnetite anaerobically produced by a marine magnetotactic bacterium and a dissimilatory iron-reducing bacterium: Earth and Planetary Science Letters, v. 98 p. 14 22.

Sylvester-Bradley, P.C., 1964, The origin of oil and life: Discovery, v. 25 , p. $37-42$.

1972, The geology of juvenile carbon: Exobiology (C. Ponnamperuma, ed.), p. 62-94.

Tarr, Arthur C., 1974, World seismicity map-Lat $70^{\circ} \mathrm{S}$ to $84^{\circ} \mathrm{N}$, long $105^{\circ} \mathrm{E}$ to $65^{\circ} \mathrm{W}$ : U.S. Geological Survey special map, scale 1:39,000,000.

Vernadsky, V.I., 1933, The history of minerals of the Earth's crust, Vol. 2, Pt. I [in Russian]: Moscow-Leningrad.

Yanyanos, A.A., 1986, Evolutional and ecological implications of the properties of deep-sea barophilic bacteria: Proceedings of the National Academy of Sciences USA, v. 83, p. 9542-9546.

Further reading: Gold, T., 1987, Power from the Earth: Deep Earth Gas-Energy for the future: London, J.M. Dent and Sons, 201 p. [U.S. distributor: The Bookery, 215 N. Cayuga Street, Ithaca, NY 14850] 


\title{
Energy Gases of Abiogenic Origin in the Earth's Crust
}

\author{
By John A. Apps ${ }^{1}$ and Peter C. van de Kamp ${ }^{2}$
}

\section{CONTENTS}

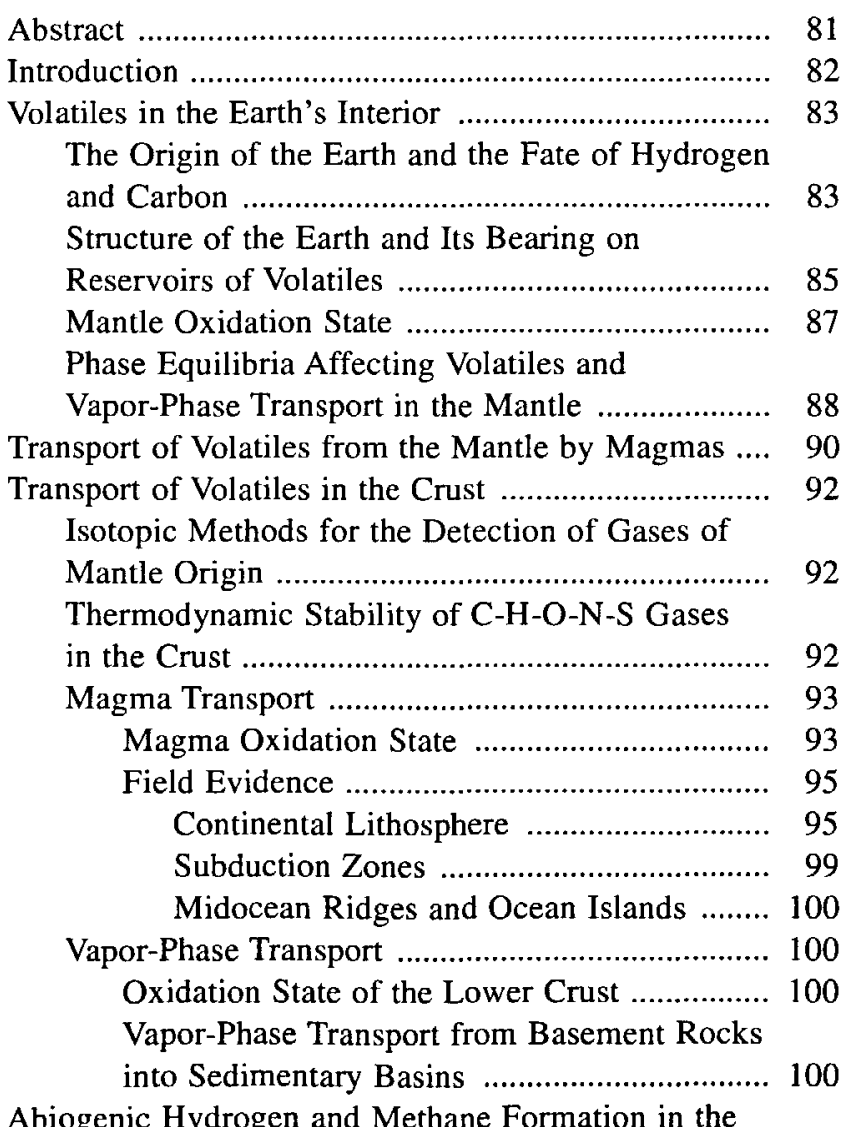

Abiogenic Hydrogen and Methane Formation in the Crust

\footnotetext{
'Lawrence Berkeley Laboratory, Earth Sciences Division, 1 Cyclotron Road, Berkeley, CA 94720.

${ }^{2}$ Cornelis Corporation, 1750 Cabernet Lane, St. Helena, CA 94574.
}

Abiogenic Hydrogen and Methane Formation in the Crust-Continued

Hydrogen Generation .................................... 103

Water Radiolysis ...................................... 103

Cataclasis ................................................. 104

Hydrolysis by Ferrous Minerals .................... 105

Relationship of Methane to Hydrogen .................. 105

Field Evidence for Hydroloysis by Ferrous

Minerals .......................................................... 106

Closed Systems ........................................ 106

Autogenous Generation of Methane During

the Cooling of Agpaitic Magmas ................ 106

Cooling of Layered Mafic Intrusions ....... 108

Deuteric Reactions in Igneous and

Metamorphic Rocks ............................. 109

Open Systems ............................................ 110

Oceanic Spreading Centers ..................... 110

Subducting Plate Margins ....................... 111

Mafic and Ultramafic Igneous Rocks

in the Continental Crust .......................... 115

Economic Significance of Abiogenic Gases in the

Earth's Crust ........................................................... 120

Conclusions .............................................................. 122

Acknowledgments ......................................... 122

References Cited ................................................... 123

\section{ABSTRACT}

Overwhelming evidence supports the belief that the world's natural-gas resources come from the decomposition of organic matter in sedimentary rock formations. Yet alternative arguments supporting an abiogenic origin have been advanced for more than 100 years. In recent years these arguments have centered on the concept that large 
quantities of primordial methane were trapped in the Earth during planetary accretion and that this gas is migrating into the Earth's crust and accumulating in reservoirs in sedimentary rock. The economic implications of these arguments could be profound and merit a thorough review of all evidence that might clarify this issue.

In this paper, we explore the likelihood that methane might be migrating from the Earth's interior. We show that the Earth's upper mantle is too highly oxidized to support the presence of other than minor concentrations of methane or hydrogen. Gases from the mantle are transported to the Earth's surface mainly dissolved in magmas. Gases released from these magmas are composed of $\mathrm{CO}_{2}(+\mathrm{CO})$, $\mathrm{H}_{2} \mathrm{O}$, and $\mathrm{SO}_{2}$ or $\mathrm{H}_{2} \mathrm{~S}$. The concentrations of methane in these gases are insignificant, and they could not be the source of commercial gas fields. Although gases including methane could migrate advectively from the mantle by flow through intergranular pores, there is no evidence that methane is transported this way. Gases migrating out of basement rocks into sedimentary basins containing natural-gas reservoirs are primarily of crustal origin and contain no detectable methane.

Abiogenic hydrogen and methane are generated in the Earth's crust through hydrolysis by ultramafic and mafic rocks at temperatures below $500^{\circ} \mathrm{C}$. The quantities of gas that could form from bodies of such rocks can be of the same order of magnitude as those of typical gas fields. Commercial reservoirs of abiogenic energy gases have, however, never been found. It appears that most sites where hydrogen and methane can be generated abiogenically are also those where no structural traps are present, where water access is limited, or where the presence of other substances such as sulfate inhibit hydrolysis. We therefore conclude that resources of abiogenic energy gases in the Earth's crust are probably small and of little or no commercial interest. Exploration strategies for such resources should be critically evaluated in the light of currently available evidence to assess the potential risks involved.

\section{INTRODUCTION}

Modern research in petroleum geology and geochemistry indicates that most hydrocarbons were derived from parent organic matter originally formed at the Earth's surface. Upon burial in enclosing sediments, organic matter is diagenetically transformed into kerogen, a precursor of petroleum. At depth, when heated to temperatures in excess of $50^{\circ} \mathrm{C}$ for a sufficient time, hydrogen-rich kerogen is transformed into oil and gas plus carbon-rich solid residue. This transformation has been conclusively demonstrated (Tissot and Welte, 1978). Furthermore, organic-rich rocks (source rocks) and oil and gas accumulations have been correlated in numerous sedimentary basins. The fluids are called "thermogenic" when derived from kerogen by heat- ing or pyrolysis, and "biogenic" when derived at surface and near-surface conditions by microbial processes.

Hydrocarbons produced by combining carbon and hydrogen not derived from natural organic matter are termed "abiogenic." Abiogenic hydrocarbons have been made in the laboratory (Chang and others, 1983) to determine how basic organic compounds were developed in the early history of the Earth prior to the appearance of living organisms. Similar, naturally occurring abiogenic syntheses suggest the potential of organic source materials for petroleum. In this paper, we provide evidence for sources of naturally occurring abiogenic hydrogen and hydrocarbons in the Earth as potential energy sources.

In recent years, several scientists (for example, Gold 1978, 1979a,b, 1980, 1987, this volume; Gold and Soter, 1980; Giardini and Melton, 1981; Giardini and others, 1982) have advanced the view that carbon trapped deep in the Earth during planetary accretion and differentiation some $4.5 \times 10^{9}$ years ago is the principal source of many of the world's oil and gas deposits. Gold maintains that methane (or hydrogen) should be chemically stable in the upper mantle and that it is migrating into the crust. Many phenomena have been cited (Gold, 1979a, 1987, this volume; Gold and Soter, 1980) in support of this position. These phenomena include kimberlitic diatreme formation, phenomena associated with seismic activity and surface manifestations of faulting, mud volcanoes, vitroclastic volcanic eruptions, evidence of mantle helium, and the distribution of oil and gas fields in relation to plate margins and fold belts. Gold (1987) also presented arguments supporting alternative interpretations for the origin of oil and gas fields. These interpretations, which are offered in support of an abiogenic origin of petroleum and gas deposits, have been fiercely challenged by the scientific community over the past decade. The general consensus is that the weight of evidence overwhelmingly favors an organic origin for the world's petroleum and gas deposits (Marland, 1984).

The release of gases from the mantle over geologic time is a complex issue. It involves questions regarding planetary accretion, the nature of material originally incorporated in the Earth, and processes leading to the segregation of the Earth's core. The outer shell of the Earth was possibly molten during the latter stages of accretion, and may have governed the evolution and composition of the primitive atmosphere. Evidence also points to a mantle and core that are continuously convecting and releasing heat due to radioactive decay and gravity segregation. The convection induces the formation of magma in the upper mantle, which rises buoyantly and often invades the Earth's crust. The continuous process of magmatic differentiation depletes the upper mantle and enriches the crust with lithophilic elements. Volatiles, dissolved in magmas, have also been flushed continuously from the Earth's interior throughout geologic time, but it is not certain what quantity of these volatiles may also have escaped by intergranular transport. 
Mantle convection is also responsible for the continuous shifting of lithospheric plates and both construction and destruction of oceanic crust. Cold oceanic crust traps volatiles and organic material, which are subducted into the mantle and recycled. These phenomena are incompletely understood and poorly quantified. As yet, there are only tentative answers to such questions as the following:

1. How much carbon and hydrogen were incorporated in the Earth at the time of its formation?

2. What was the oxidation state of the primitive atmosphere, and to what extent did it influence the oxidation state of the upper mantle?

3. How extensive was melting of the Earth's outer shell?

4. At what rate is the upper mantle being oxidized due to recycling of the oceanic crust?

5. What is the impact of recycled water and organic material on the volatile content and oxidation state of the upper mantle?

6. What is the oxidation state of the lower mantle?

7. What are the volatile fluxes between upper and lower mantle?

8. Is magma flow or advective flow of vapor the principal mechanism for conveying hydrogen and carbon from the mantle to the Earth's crust?

9. To what extent does an oxidized upper mantle act as a barrier to reducing gases migrating upward from the lower mantle?

In this paper, we review what is known or inferred about the volatile content of the Earth's mantle and core, how degassing occurs, and what controls the composition of the gases. The magnitude and significance of energy-gas (that is, hydrogen and hydrocarbon) accumulation in the crust due to mantle processes is reviewed. We then focus on processes that lead to the formation of abiogenic hydrogen and methane in the Earth's crust, and the potential for these gases to accumulate as commercial resources.

The paper is subdivided into four principal sections. In the first we consider the content and composition of volatiles in the Earth's interior. In the second we consider mechanisms by which the volatiles are transported to the Earth's crust. In the third we examine the fate of mantle volatiles in the Earth's crust, and in the fourth we discuss mechanisms by which energy gases form abiogenically under crustal conditions. In particular, in the fourth section we review processes through which mafic and ultramafic igneous rocks from the mantle hydrolyze and produce methane and hydrogen. A fifth section addresses the economic significance of abiogenic gases in the Earth's crust.

\section{VOLATILES IN THE EARTH'S INTERIOR}

One of the central arguments for an abiogenic origin for oil and gas deposits is that primordial methane was trapped in the Earth's interior during planetary accretion and that this methane is migrating into the crust. In order to establish the plausibility of this argument, we need to examine what is known about the behavior of hydrogen and carbon during the formation of the Earth. In this section we discuss various aspects concerning the fate of these elements and how they were distributed early in the history of the Earth.

\section{THE ORIGIN OF THE EARTH AND THE FATE OF HYDROGEN AND CARBON}

The concentrations of hydrogen and carbon within the Earth's mantle and core are not precisely known. While it is possible to estimate the concentrations of hydrogen and carbon in crustal material, this material represents only a tiny fraction ( $<1$ percent) of the Earth's total mass. Zemann and others (1969) presented carbon analyses of tholeiites and peridotites containing an average of 474 and 373 parts per million (ppm) of carbon respectively. If the tholeiites resulted from 20 percent partial fusion, the average carbon content of the mantle rock precursor would be 393 ppm. Vinogradov (1962) proposed a lower carbon content, $100 \mathrm{ppm}$, for both ultramafic and mafic rocks, but this value could still be within the range of present uncertainties for the upper mantle as a whole. Holland (1978) estimated that the concentration of hydrogen in the whole Earth is $25 \mathrm{ppm}$, the concentration of carbon is $30 \mathrm{ppm}$ (excluding that in the mantle), and the concentration of nitrogen is 2 ppm. Tajika and Matsui (1992) gave estimates of the carbon and water contents of the Earth and estimated the carbon abundance in the mantle as $156 \mathrm{ppm}$. Assuming a homogeneous mantle, this value is equivalent to a total of $5.2 \times 10^{22}$ moles (mol) and compares with a crustal and atmospheric carbon content of $1 \times 10^{22} \mathrm{~mol}$. The amount of water at the Earth's surface is $7.8 \times 10^{22}$ $\mathrm{mol}$, and the water content of the mantle is $0.1 \mathrm{ppm}$ or $2.4 \times 10^{23} \mathrm{~mol}$. Five times as much carbon remains in the mantle as in the Earth's crust, whereas only three times as much water remains in the mantle.

The concentrations of carbon and hydrogen in the Earth are generally less than the primordial abundances of these elements in the Solar System, which are estimated from chemical analyses of meteorites entering the Earth's atmosphere and from the composition of the Sun's atmosphere. Carbon and hydrogen and their compounds are much more volatile than the elements that make up the bulk of the Earth. They were therefore lost from the material composing the Earth either prior to, during, or subsequent to the Earth's formation.

Although many details concerning the origin of the Earth are still being debated, a consensus has been reached regarding the general mode of formation (Ringwood, 1979; Holland, 1984). Initially, about $4.6 \times 10^{9}$ years ago, the Sun was surrounded by a disc-shaped nebula of condensed 
interstellar dust, the integrated residue of stellar nucleosynthesis. The average composition of the primordial solar nebula is believed to have been similar to that of carbonaceous chondrites, a class of stony meteorite. With the exception of volatile elements such as nitrogen, carbon, and hydrogen, which are depleted, the composition of these meteorites correlates closely with that of the solar photosphere, (Ross and Aller, 1976). Solar radiation may have heated the inner region of the solar nebula sufficiently to sublime the volatile constituents, which condensed in its outer regions. The composition of the solar nebula was therefore probably zoned with only the least volatile components present within the innermost regions, and increasingly volatile compounds condensed sequentially with increasing distance from the sun.

Through a process of aggregation and collision, the dust grew into fewer but larger particles. Some of the particles eventually attained dianeters of several hundred kilometers and acquired their own gravitational fields. These so-called planetesimals were then able to capture smaller particles through gravitational attraction and grow at a comparatively more rapid rate until the solar nebula had been reduced essentially to the few large planetary bodies composing the present Solar System. This process is inferred to have taken about $10^{8}$ years. Accretion was probably erratic as some of the collisions involved breakup of colliding planetesimals. The temperature at which accretion occurred is not known, although initially it appears to have been low. Decaying short-term radionuclides such as ${ }^{26} \mathrm{Al}$ may, however, have heated planetesimals to such an extent that transient melting and metallic core formation was possible, even in bodies only $250 \mathrm{~km}$ in diameter (Goldstein, 1964).

With increasing size of a planetary body, the energy released by impacting material increased dramatically. Recent modeling of the accretion process for the Earth suggests that energy dissipation was so great that extensive melting of the surface occurred. Calculations by Matsui and Abe (1986a) indicate that surface melting first occurred when the radius of the Earth was only 0.4 times its final value. With continuing accretion, however, the melting temperature of the predominantly magnesium-iron silicates composing the infalling material also increased because of increasing pressure. The magma ocean therefore solidified continuously as accretion proceeded. The maximum thickness of the magma ocean is not known with any certainty, but it probably never exceeded $500 \mathrm{~km}$. Continuous melting of the surface layer would have aided in the segregation of metallic iron to form the core.

Several arguments support the hypothesis that segregation of the Earth's core took place within $5 \times 10^{8}$ years after accretion and that the gravitational energy released by core formation led to intense convection and mixing. Both the upper and lower mantle are therefore believed to have a relatively uniform composition.
With the exception of the refractory oxides of $\mathrm{Mg}, \mathrm{Al}$, $\mathrm{Ca}, \mathrm{Si}$, and $\mathrm{Fe}$ metal, all major elements are strongly depleted in the Earth's mantle, the depletions clearly related to the elements' volatilities. Ringwood (1979) concluded that the Earth formed by accretion of depleted chondritic material and that only 10 to 15 percent of the accreted material could have originated from carbonaceous chondrites. Using both petrologic and cosmogenic arguments, he estimated the composition of the Earth's mantle, which he referred to as "pyrolite." Pyrolite consists primarily of $\mathrm{SiO}_{2}$ (45 weight percent), $\mathrm{MgO}$ (38 weight percent), $\mathrm{FeO}$ (8.0 weight percent), $\mathrm{Al}_{2} \mathrm{O}_{3}$ ( 3.3 weight percent), and $\mathrm{CaO}$ (3.1 weight percent).

The material accreting during much of the growth of the Earth melted and released volatile components to the newly forming atmosphere. Earlier estimates of the mass of the Earth's protoatmosphere, which were based on the contents of volatiles in the solar photosphere or in carbonaceous chondrites, neglected volatile loss from the inner nebula, the substantial fusion of the outer layer of the Earth, and the dissolution of volatiles in the magma ocean. This omission led to the conclusion that the Earth's early atmosphere was enormously larger than at present, and various mechanisms were invoked to explain how the bulk of this early atmosphere was blown away, perhaps during $\mathrm{T}$-Tauri stage of the Sun's evolution. Fanale (1971) argued that the present constitution of nonradiogenic rare gases, with the exception of xenon, corresponds very closely with that in normal chondrites. He suggested that catastrophic degassing of almost all the rare gases had not occurred early in the Earth's history and that these gases, with the exception of helium, which continuously escapes from the Earth's gravitational field, have remained in the Earth's atmosphere until this day. Regarding volatiles such as $\mathrm{CO}_{2}$ and $\mathrm{H}_{2} \mathrm{O}$, he argued that the bulk of these had dissolved in the substantially molten Earth and have remained there to the present. While some details of Fanale's hypothesis must be rejected in light of subsequent discoveries, the conclusion that the protoatmosphere was not lost to space and that much of the carbon and hydrogen (as water) remained in the mantle appears valid.

We refer to $\mathrm{CO}_{2}$ and $\mathrm{H}_{2} \mathrm{O}$ as being the principal atmospheric components in the primitive atmosphere because it is assumed that the atmosphere was initially relatively oxidizing. The temperature range in the primitive atmosphere is not known, but the Fischer-Tropsch reaction,

$$
\mathrm{CH}_{4}+2 \mathrm{H}_{2} \mathrm{O}=\mathrm{CO}_{2}+4 \mathrm{H} 2 \text {, }
$$

is displaced strongly to the right at around $1,200^{\circ} \mathrm{C}$, the temperature of the magma ocean. Methane would react with water to produce carbon dioxide and hydrogen, the latter escaping into space. Any hydrocarbons introduced by carbonaceous chondrites would have been consumed. 
Ringwood (1979) claims that meteoritic iron would also tend to oxidize during ablation in the primitive atmosphere and generate hydrogen gas. Abe and Matsui (1985) do not believe this process to have been important.

The distribution of sulfur species in the primitive atmosphere has not been investigated. The reactions

$$
\begin{gathered}
2 \mathrm{H}_{2} \mathrm{~S}=\mathrm{S}_{2}+2 \mathrm{H}_{2}, \\
\mathrm{~S}_{2}+4 \mathrm{H}_{2} \mathrm{O}=2 \mathrm{SO}_{2}+4 \mathrm{H}_{2} \text {, and } \\
\mathrm{SO}_{2}+2 \mathrm{H}_{2} \mathrm{O}=\mathrm{H}_{2} \mathrm{SO}_{4}+\mathrm{H}_{2}
\end{gathered}
$$

could have played an important role in buffering the oxidation state of the primitive atmosphere, but more study is needed of the dynamics of the primitive atmosphere and saturation of the magma ocean before the role of sulfur is understood.

The mechanism of hydrogen generation and escape from the Earth's atmosphere, which may have been operative for about $1 \times 10^{8}$ years must have progressively oxidized the magma ocean even though it was buffered by iron-containing minerals and carbon and its gaseous oxides. How much hydrogen was lost by gravitational escape during this period may never be known, but it is worth noting that much of the upper mantle is now too highly oxidized to support the presence of species more reduced than $\mathrm{CO}_{2}$ and $\mathrm{H}_{2} \mathrm{O}$.

Various estimates have been made of the vapor pressures of $\mathrm{H}_{2} \mathrm{O}$ and $\mathrm{CO}_{2}$ of the primitive atmosphere in assumed equilibrium with the magma ocean. Holland (1984) calculated that $\mathrm{P}_{\mathrm{H}_{2} \mathrm{O}}$ in the primitive atmosphere was about 0.05 megapascals (MPa), assuming that all water now present in the crust and oceans was originally incorporated in the Earth during accretion. The low partial pressure is a consequence of the high solubility of water in silicate melts, which can incorporate as much as 10 to 40 mole percent water before attaining saturation (Spera, 1974). In contrast, the water vapor pressure was assumed by Matsui and Abe $(1986 a, b)$ to be approximately $10 \mathrm{MPa}$.

Holland (1984) calculated that a substantial pressure of $\mathrm{CO}_{2}$ would build up in the primitive atmosphere until the concentration of carbon as $\mathrm{CO}_{2}$ in the melt was approximately equal to the concentration of carbon in the infalling material. Holland estimated that about one-third of the carbon dioxide in the accreting material accumulated in the atmosphere, the remainder dissolving in the magma ocean. The $\mathrm{CO}_{2}$ pressure was believed to be in the range from $2 \mathrm{MPa}$ (Holland, 1984; Kasting and Ackerman, 1986) to as high as $10 \mathrm{MPa}$ (Sato, 1991). According to Kasting and Ackerman (1986), carbon dioxide at a partial pressure of approximately $6 \mathrm{MPa}$ is currently bound up in carbonate rocks.
The solubility of $\mathrm{CO}_{2}$ in magma is far lower than that of water. Hence, it would be expected that a far larger concentration of water than carbon dioxide was dissolved in the magma ocean. Upon solidification, much of the $\mathrm{CO}_{2}$ and $\mathrm{H}_{2} \mathrm{O}$ was expelled, although some of the carbon was undoubtedly reduced and remained as graphite or diamond.

Tajika and Matsui (1992) designed a model to study thermal behavior of the Earth and the evolution of the $\mathrm{CO}_{2}$ protoatmosphere. Their model indicated that most $\mathrm{CO}_{2}$ degassed early in the Earth's history, and the crustal and atmospheric inventory has remained relatively constant for the last $3.5 \times 10^{9}$ years. The case for water is similar although the initial degassing was much less. For most of geological time, the amount of water and $\mathrm{CO}_{2}$ entering the mantle at subducting plate margins has been roughly equivalent to that being released through volcanic action.

\section{STRUCTURE OF THE EARTH AND ITS BEARING ON RESERVOIRS OF VOLATILES}

Direct observations of the subcrustal interior of the Earth are not possible, so our understanding of its structure must be deduced by reconciling observations drawn from nucleosynthesis, seismology, and meteoritics, and fundamental knowledge concerning the density of the Earth and its angular momentum. This information is supplemented by high-temperature and high-pressure studies of simplified chemical systems simulating subcrustal chemistry, and the study of xenoliths that were transported from the upper mantle to the surface in mafic magmas. These rocks often show evidence of deformation, annealing, and secondary alteration.

The Earth's interior is composed of a series of layers (fig. 1) that subdivide the Earth into the upper and lower mantle and outer and inner core. The boundaries between the principal layers are interpreted as sharp changes in material density due to phase or compositional changes. The discontinuity at $2,900 \mathrm{~km}$ is assumed to be due to the segregation of a metallic nickel-iron core, the inner part of which is solid and the outer part liquid. This is surrounded by a mantle consisting principally of $\mathrm{MgO}, \mathrm{SiO}_{2}$, and FeO, the pyrolite of Ringwood (1975, 1979).

The subdivision of upper and lower mantle at $680 \mathrm{~km}$ depth is attributed to a major phase transition in which the $\beta(\mathrm{Mg}, \mathrm{Fe})_{2} \mathrm{SiO}_{4}$ phase breaks down to form magnesium perovskite $\left(\mathrm{MgSiO}_{3}\right)$ and magnesiowustite, $((\mathrm{Mg}, \mathrm{Fe}) \mathrm{O})$ (Ringwood, 1979; Jeanloz and Knittle, 1989). At $400 \mathrm{~km}$ depth in the upper mantle, a somewhat smaller transition occurs, and this is attributed to the transformation of olivine, $(\mathrm{Mg}, \mathrm{Fe}) \mathrm{SiO}_{4}$, into the $\beta$ form.

There is abundant evidence that subsequent chemical partitioning and fractionation processes during convection 


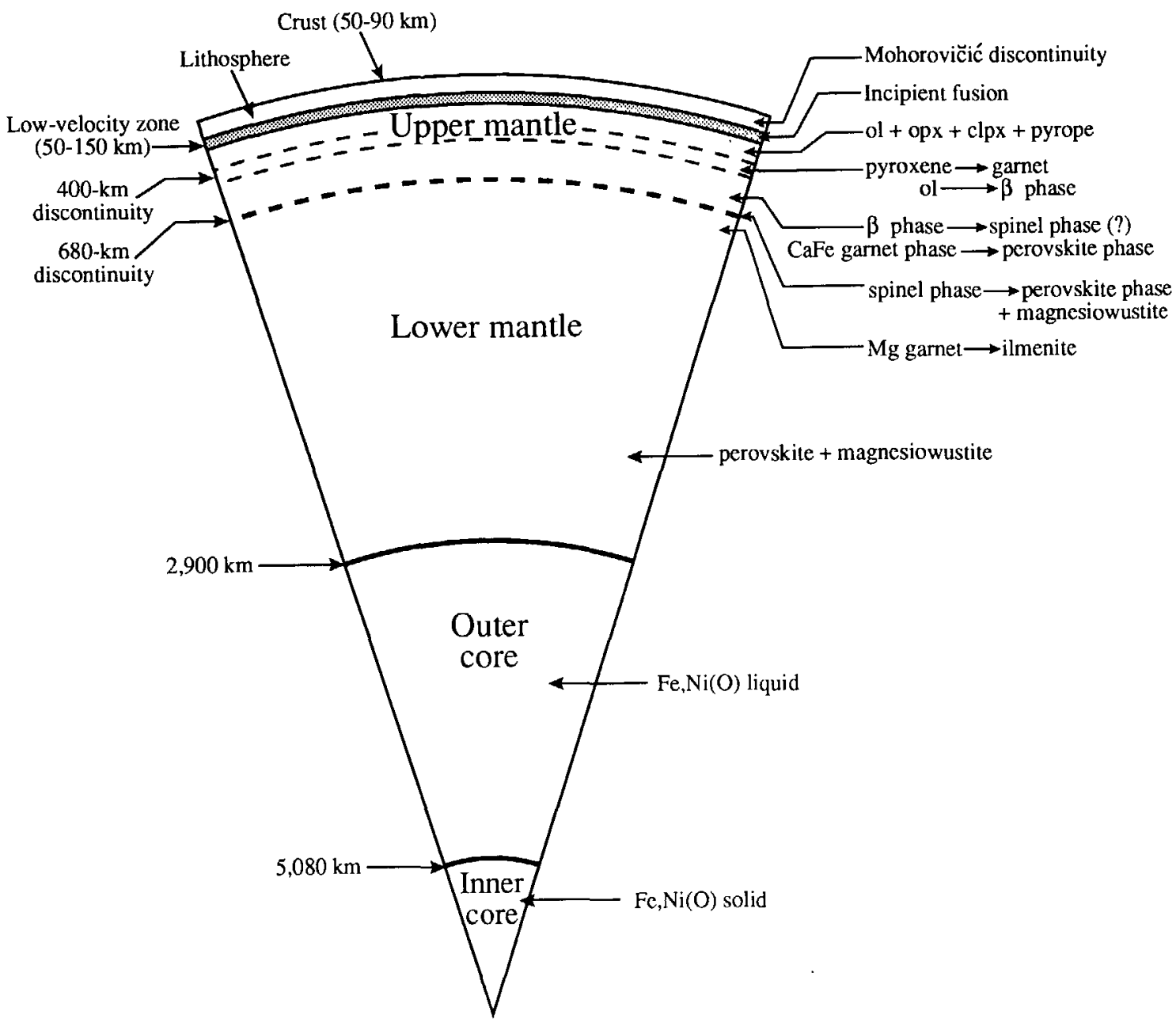

Figure 1. Internal structure of the Earth. clpx, clinopyroxene; ol, olivine; opx, orthopyroxene. Modified from Ringwood (1979).

have resulted in a mantle with extensive inhomogeneities. Thus, the boundary between the upper and lower mantle, attributed to the magnesium perovskite phase transition, may also be stabilized by compositional differences, as has recently been concluded by Jeanloz and Knittle (1989). Implicit in this conclusion is the postulate that the mantle is now segregated into two independently convecting systems within the upper and lower mantle, respectively (Christensen, 1989). Only restricted mass interchange occurs across the interface. Geochemical evidence (Hofmann, 1989) also implies that there exist today at least two chemical reservoirs, both of which are depleted in certain elements with respect to primordial material. Rare-gas isotopic analyses show quite clearly that a reservoir (or reservoirs) exists deep within the Earth, possibly in the lower mantle, which still retains rare gases that have been present since the first 100 million years after formation of the planetary nebula.

The role of mantle convection and plate tectonics need not be discussed further, as many standard texts adequately cover the subject. One aspect is of interest, however, as it might be influential in modifying the oxidation state, and hence the volatile components, in the lower mantle.

Subducting oceanic crust melts, leaving a dense residue, eclogite, which falls by gravity to the $680 \mathrm{~km}$ phase/ composition boundary, (Ringwood, 1975, 1979). Whether eclogite penetrates this boundary is open to question. Ringwood (1975) and Christensen (1989) believe that it does and that it descends to the lower mantle/core interface where it accumulates as "dregs" in the so called D layer.

Eclogite, if it accumulates within the D layer of the lower mantle, could have a significant impact on the lower mantle's oxidation state. Conductivity and oxygen-fugacity experiments (Peyronneau and Poirier, 1989; Wood and Nell, 1991) suggest that the magnesiowustite of the lower mantle is partially oxidized and therefore cannot be in equilibrium with the iron in the core (McCammon, 1993). Yet, the core itself may also be partially oxidized. Because the Earth's core is less dense than it would be if it consisted of iron and nickel alone, Ringwood (1979) concluded that the core must be diluted with FeO. 


\section{MANTLE OXIDATION STATE}

The oxidation state of the mantle is a critical parameter in defining the composition of any vapor phase that might be present. Therefore, in this section we discuss vapor components and idealized solid-phase buffers under upper-mantle conditions in relation to measurements that were made to estimate the mantle oxidation state.

In figure 2, phase relations of relevant solid and gaseous species are plotted as a function of RTln $f_{\mathrm{O}_{2}}$ (where $\mathrm{R}$ is the universal gas constant, $\mathrm{T}$ is temperature, and $f_{\mathrm{O}_{2}}$ is natural $\log$ of oxygen fugacity) between 600 and $1,400^{\circ} \mathrm{C}$ along an average geothermal gradient, with appropriate corrections for pressure. This representation, originally used by Marakushev (1981) and here contoured for $\log f_{\mathrm{O}_{2}}$, displays phase relations more conveniently than if $\log f_{\mathrm{O}_{2}}$ were to be used as the vertical axis over the depicted temperature range.
Potential redox buffers represented by the following mineral assemblages-iron-magnetite (IM), iron-wustite (IW), wustite-magnetite (WM), hematite-magnetite (HM), carbon (graphite)-carbon dioxide + carbon monoxide (CCO), iron + quartz-fayalite (IQF), fayalite + quartz-magnetite (QFM) and pyrrhotite-pyrite + magnetite (PPM) - are also included. Other buffers in the figure are represented by the assemblages graphite-enstatite-dolomite-olivine-diopside (GEDOD; reaction 5) and enstatite-magnesite-olivinegraphite (EMOG; reaction 6) (Blundy and others, 1991):

$$
\begin{aligned}
& \underset{\mathrm{Mg}_{2} \mathrm{SiO}_{4}+0.5 \mathrm{CaMgSi}_{2} \mathrm{O}_{6}+\mathrm{C}+\mathrm{O}_{2} \text { (gas) }=}{\text { olivine }} \quad \begin{array}{c}
\text { diopside graphite } \\
\mathrm{Mg}_{2} \mathrm{Si}_{2} \mathrm{O}_{6}+0.5 \mathrm{CaMg}\left(\mathrm{CO}_{3}\right)_{2} \\
\text { enstatite dolomite }
\end{array} \\
& \mathrm{MgSiO}_{4}+\mathrm{C}+\mathrm{O}_{2} \text { (gas) }=0.5 \mathrm{Mg}_{2} \mathrm{Si}_{2} \mathrm{O}_{6}+\mathrm{MgCO}_{3} \\
& \text { olivine graphite } \quad \text { enstatite magnesite }
\end{aligned}
$$

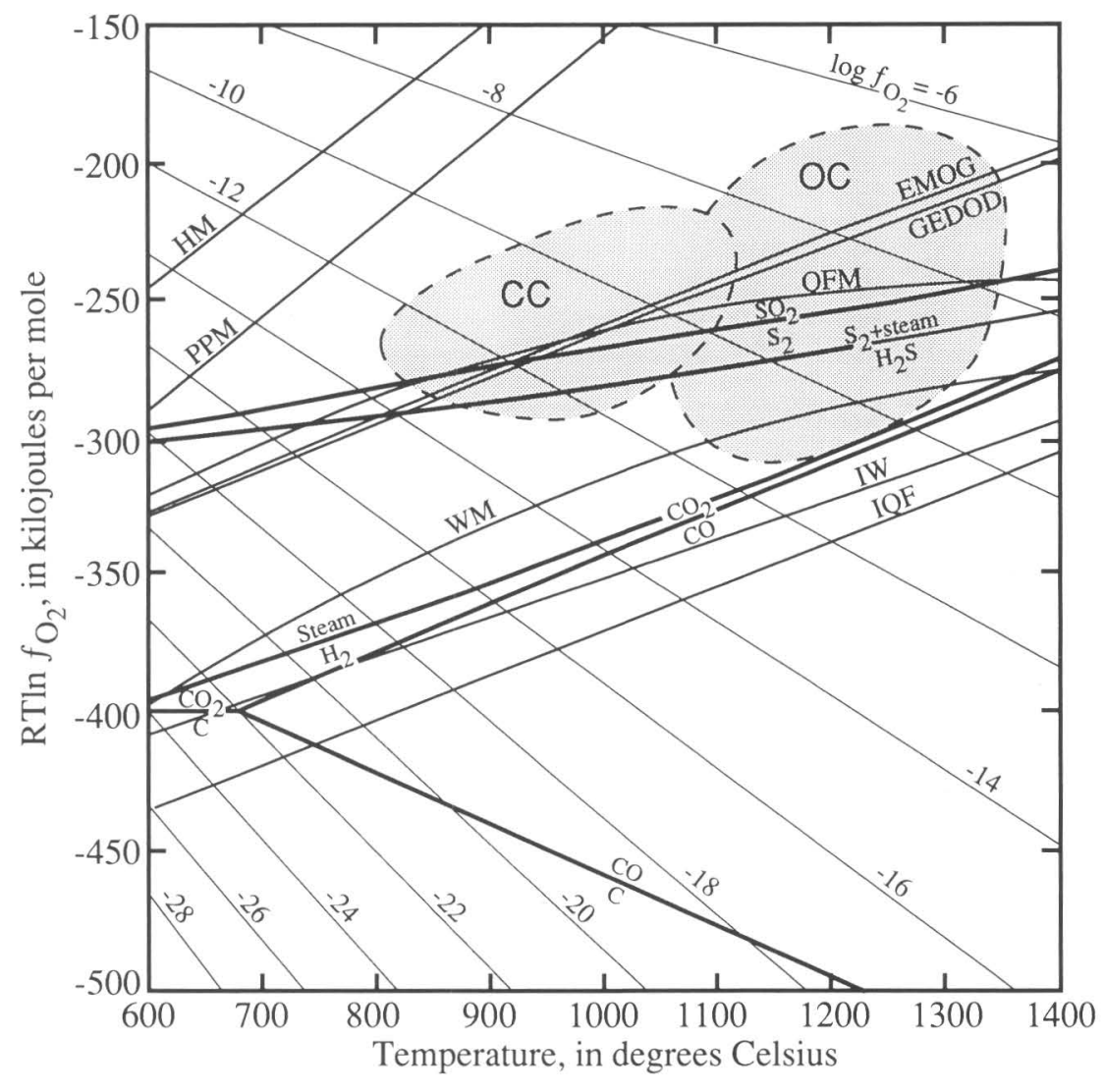

Figure 2. Gas-gas and gas-solid-phase equilibria as function of RTln $f_{\mathrm{O}_{2}}$ (where $\mathrm{R}$ is universal gas constant, $\mathrm{T}$ is temperature, and $\ln f_{\mathrm{O}_{2}}$ is natural $\log$ of oxygen fugacity) and temperature on hypothetical $25^{\circ} \mathrm{C} \mathrm{km}^{-1}$ geotherm. Shaded areas show measured redox equilibria beneath oceanic crust (OC) and continental crust (CC). EMOG, enstatite-magnesite-olivine-graphite; GEDOD, graphite-enstatite-dolomite-olivine-diopside; HM, hematite-magnetite; IQF, iron + quartz-fayalite; IW, iron-wustite; PPM, pyrrhotitepyrite + magnetite; QFM, fayalite + quartz-magnetite; WM, wustite-magnetite. Light lines from upper left to lower right are lines of equal $\log f_{\mathrm{O}_{2}}$, in bars. 
Vapor-phase reactions include those involving hydrogen, steam, methane, carbon dioxide, and carbon monoxide.

Calculations were carried out using the thermodynamic data of the SUPCRT92 code developed by Helgeson and his coworkers (Johnson and others, 1992). However, we used the 1987 version of the code, which incorporates a corresponding state version of the Redlich-Kong equation of state, formulated by Edmister (1968), with improvements by Holloway (1977) and Flowers (1979). The critical temperatures and pressures for the vapor phases were obtained from Mathews (1972).

The curves delineating the reactions between nonoxygen gases and between nonoxygen gases and solids do not represent the stability limits of those gases, but merely indicate where the product of the activities of all reactants and products (except oxygen) are equal to unity. Therefore, gaseous species in a vapor phase extend over a wider range of stability than is indicated by the univariant reaction curves. The reaction curves do, however, generally delineate the regions where particular gases predominate.

Blundy and others (1991) have shown that the most reliable estimates of upper-mantle oxygen fugacities $\left(f_{\mathrm{O}_{2}}\right)$ fall on distinct trends along the geotherms of continental and oceanic crust. The regions covered by such estimates are shaded in figure 2 . The oxygen fugacities associated with the continental geotherm are somewhat less oxidizing than those associated with the oceanic geotherm. The former straddle the QFM buffer and the GEDOD and EMOD buffers. In contrast, oxygen fugacity data along the oceanic geotherm are less well defined and extend to the wustite-magnetite (WM) buffer, an environment in which $f_{\mathrm{O}_{2}}$ is two to three orders of magnitude lower than that underlying the continental crust.

Sato (1978a, b; 1991) concluded that the oxidation state of the upper mantle is generally controlled by reactions involving carbon (as graphite or diamond) and coexisting oxides of carbon, or $\mathrm{CCO}$ buffer:

$$
\begin{gathered}
\mathrm{C}+\mathrm{O}_{2}=\mathrm{CO}_{2}, \\
2 \mathrm{C}+\mathrm{O}_{2}=2 \mathrm{CO}
\end{gathered}
$$

or by solid carbonates, as described above. This conclusion may be valid beneath continental crust, but it is not clear whether the upper mantle beneath oceanic crust is buffered by carbon and its oxides or by $\mathrm{Fe}^{\mathrm{II}}$ and $\mathrm{Fe}^{\mathrm{III}}$.

Conditions may have been more reducing where diamond has formed in the upper mantle beneath the continental crust (that is, to at least $400 \mathrm{~km}$ depth), because native iron and djerfisherite, a complex iron-potassium sulfide, have been observed as inclusions in diamond (Marakushev, 1981). These inclusions suggest an oxidation state close to that of the iron-wustite (IW) buffer. Sato's calculations (Sato, 1978b) show the oxygen fugacity of the IW buffer to be about $2 \log$ units less than that of the $\mathrm{CCO}$ buffer at 10 gigapascals (GPa). Moissanite (SiC) has also been found in diamondiferous pipes and as inclusions in diamond, but its mode of formation is obscure (Leung and others, 1990). Calculations indicate that moissanite's formation in the upper mantle is thermodynamically implausible.

If the residues of subducted oceanic crust founder and accumulate in the lower mantle, mass transfer must occur in the opposite direction. Several investigators, notably Taylor and Green (1987), Green and others (1987), and Haggerty $(1986,1987)$ believe that the lower mantle is substantially more reducing and that an upwelling volatile flux from the lower mantle contains methane and smaller quantities of hydrogen. In figure 2 it can be seen that in most of the upper mantle, any vapor phase associated with mineral assemblages or melts from which the $f_{\mathrm{O}_{2}}$ estimates cited by Blundy and others (1991) were derived would have consisted dominantly of $\mathrm{CO}_{2}, \mathrm{H}_{2} \mathrm{O}$, and $\mathrm{N}_{2}$, with only trace quantities of reducing gases, such as $\mathrm{CH}_{4}$, $\mathrm{CO}$, and $\mathrm{H}_{2}$. Sulfur species should be present primarily as $\mathrm{H}_{2} \mathrm{~S}$ along the oceanic crustal geotherm, but could be either $\mathrm{SO}_{2}$ or $\mathrm{H}_{2} \mathrm{~S}$ on the continental crustal geotherm, depending on the quantity of water present (Ohmoto and Rye, 1979). These findings are corroborated by field studies, analyses of volcanic gases, experimental studies under mantle conditions, and examination of fluid inclusions.

\section{PHASE EQUILIBRIA AFFECTING VOLATILES AND VAPOR-PHASE TRANSPORT IN THE MANTLE}

The presence of certain minerals in xenoliths-such as carbonates, amphiboles, micas, graphite, and diamondaids in defining the oxidation state of the upper mantle. The distribution of these minerals suggests that reduced species (methane, hydrogen, and ammonia) are expected to be present only in minor concentrations in the upper mantle. The upper mantle is not homogeneous, however, and because of convective transport from the lower mantle, regions exist in which the oxidation state could be much lower and methane could be the predominant species (Taylor and Green, 1989; Green and others, 1990; Taylor, 1990; Saxena and Fei, 1988; Saxena, 1989). Our findings are summarized in figure 3.

Carbonates are infrequently found as inclusions in mantle xenoliths, (for example, see Sobolev and Stankovskiy, 1979; McGetchin and Besancon, 1983), because they are unstable and tend to decompose in basaltic magmas during transit to the surface. The solubility of carbon dioxide in tholeiitic magmas, even in the mantle source regions, is very low, ranging from 1.5 weight percent at 3 GPa to much less than 0.05 weight percent at the surface (Spera and Bergman, 1980). Carbon dioxide is commonly found as liquid $\mathrm{CO}_{2}$ inclusions in olivines in mantle xeno- 


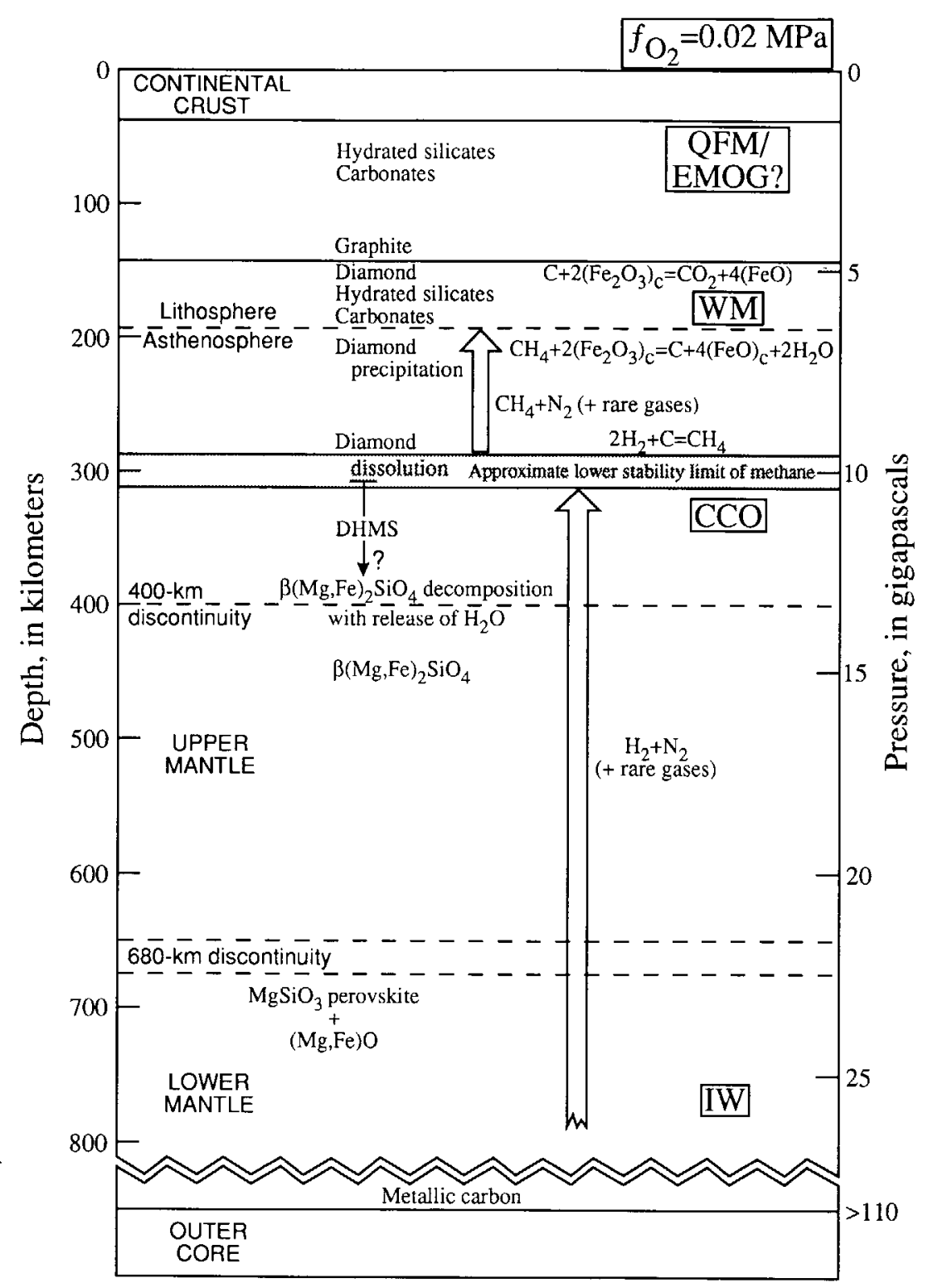

Figure 3. Subsolidus reactions and vapor transport in the mantle beneath the continental crust. c, crystalline phase; $\mathrm{CCO}$, carbon + carbon dioxide + carbon monoxide; DHMS, dense hydrated magnesium silicate; EMOG, enstatite-magnesite-olivinegraphite (query indicates uncertainty that magnesite is present); $f_{\mathrm{O}_{2}}$, oxygen fugacity; IW, iron-wustite; MPa, megapascals; QFM, fayalite + quartz-magnetite; WM, wustitemagnetite. Large, open arrows indicate gas fluxes; small arrow indicates range of stability, queried to indicate uncertainty about depth limit of stability.

liths (Green and Radcliffe, 1975; Roedder, 1965, 1972, 1984). The presence of carbonates and liquid $\mathrm{CO}_{2}$ in the upper mantle is consistent with the independent determinations of the oxidation state in the upper mantle and strengthens the argument that neither methane nor hydrogen could originate from this region.

The shallower parts of the upper mantle are believed to be relatively anhydrous, with all hydrogen present as hydroxyl groups in olivine (Mackwell and Kohlstedt,
1990; Bai and Kohlstedt, 1992; Bell, 1992), in $\beta$-(Mg, $\mathrm{Fe})_{2} \mathrm{SiO}_{4}$ (Young and others, 1991), in enstatite (Mackwell, 1991), and in minor hornblende, phlogopite, and apatite, although the hydroxyl sites of the apatite are partly occupied by fluoride (Aoki and Kanisawa, 1979). Marakushev (1981) notes that biotite from an African kimberlite pipe is very rich in $\mathrm{F}$ and $\mathrm{Cl}$, suggesting a low partial pressure of water during its formation. The presumed very dry state of this region of the upper mantle is explained by 
repeated generation of magma into which water partitions preferentially during partial fusion.

Peridotites commonly contain small amounts of graphite or diamond. The presence of these minerals indicates an oxygen-fugacity range of the upper mantle, defined by the CCO, GEDOD, or EMOG family of buffers. Tingle and others (1988) have demonstrated that carbon solubility in olivine is negligible to $1500^{\circ} \mathrm{C}$ and $3.5 \mathrm{GPa}$. The presence of carbon in solid solution in mantle silicates therefore appears doubtful.

The stability fields of carbonates and hydroxyl-bearing phases are important, because they govern both the existence and the composition of a coexisting fluid phase. Volatiles lower the melting point of peridotite, and the uptake of the volatiles in an incipient melt limits the quantity of melt formed for any given heat input.

Double-shock-wave experiments to $90 \mathrm{GPa}$ on methane (Nellis and others, 1981), also show that above $10 \mathrm{GPa}$ and $725^{\circ} \mathrm{C}$ (that is, at a depth of about $300 \mathrm{~km}$ ), methane decomposes to diamond+hydrogen. In the lower mantle therefore, methane would not be present in any vapor phase. Hydrogen could migrate upward in the presence of metallic carbon or diamond. As the hydrogen penetrated upward, it could corrode diamond and generate methane. The actual composition of reducing gases in the system C-H-O can only be surmised, as it depends on the oxidation state of the lower mantle (about which almost nothing is known), the presence of solid carbon phases and hydrated silicates, and lastly the stability of methane.

If reduced fluids invaded the upper mantle, they would also depress the melting temperature of peridotites, but to a much lesser extent than would more-oxidized water-rich fluids. Hence the reduced fluids would be less likely to induce incipient melting. Both $\mathrm{H}_{2}$ and $\mathrm{CH}_{4}$ can, however, reduce $\mathrm{Fe}^{\mathrm{III}}$ in peridotite minerals and alter the oxidation state of the upper mantle. Reactions involving the oxidation of $\mathrm{H}_{2}$ to $\mathrm{H}_{2} \mathrm{O}$ by $\mathrm{Fe}^{\mathrm{III}}$,

$$
\begin{aligned}
& \mathrm{H}_{2} \text { (vapor) }+\mathrm{Fe}_{2} \mathrm{O}_{3} \text { (forsterite,enstatite) }= \\
& 2 \mathrm{FeO}(\text { forsterite,enstatite })+\mathrm{H}_{2} \mathrm{O} \text { (vapor), }
\end{aligned}
$$

and the oxidation of methane,

$$
\begin{aligned}
& \mathrm{CH}_{4} \text { (vapor) }+2 \mathrm{Fe}_{2} \mathrm{O}_{3} \text { (forsterite,enstatite) }= \\
& 4 \mathrm{FeO} \text { (forsterite,enstatite) }+\mathrm{C}+2 \mathrm{H}_{2} \mathrm{O} \text { (vapor) }
\end{aligned}
$$

will lead to the reduction of $\mathrm{Fe}^{\mathrm{III}}$ to $\mathrm{Fe}^{\mathrm{II}}$, the precipitation of diamond, and the formation of water vapor. The water vapor will in turn depress the solidus and induce melting. The occurrence of microsized crystals of diamond in kimberlites suggests that such reactions occur. As Taylor and Green (1989) have pointed out, in the event that ascending vapors do not induce melting, they could migrate toward the surface, locally reducing the mantle, precipitating in- terstitial carbon, and producing hornblende and phlogopite mica if sufficient potassium is present from earlier metasomatizing episodes.

\section{TRANSPORT OF VOLATILES FROM THE MANTLE BY MAGMAS}

We now consider several physical chemical aspects of magma generation in the upper mantle, and how this magma generation affects transport of volatiles into the crust. Many magmas erupting in the continental crust and all magmas in oceanic settings have their origins in the upper mantle. Magmas are subject to many chemical and physical processes during their ascent-including assimilation, fractionation and phase segregation, and loss or gain of volatiles-leading to a host of different evolutionary paths and an enormous variety of igneous rocks as end products. In mantle source regions, the magma composition is defined by several critical parameters, of which the most important are the geothermal gradient and the presence or absence of volatiles.

In figure 4 are displayed the relevant univariant reactions and invariant points in pressure-temperature, or depthtemperature, space for a peridotite- $\mathrm{CO}_{2}-\mathrm{H}_{2} \mathrm{O}$ system. This diagram, originally developed by Wyllie (1980, 1989), shows the subsolidus stability fields of the hydrated minerals amphibole (hb), phlogopite mica (ph), and dense hydrated magnesium silicate (DHMS), and the carbonate minerals dolomite (dol) and magnesite (mag). The anhydrous peridotite solidus increases in temperature with increasing depth; but with the addition of water, the solidus temperature falls with increasing depth until a minimum is attained between 60 and $70 \mathrm{~km}$. Vapor components probably consist of a mixture of $\mathrm{CO}_{2}$ and $\mathrm{H}_{2} \mathrm{O}$ under most upper mantle conditions. The family of solidi representing mixtures of $\mathrm{CO}_{2}$ and $\mathrm{H}_{2} \mathrm{O}$ fall between the $\mathrm{H}_{2} \mathrm{O}$-saturated and anhydrous solidi. The solidus illustrated is for a $\mathrm{CO}_{2} /\left(\mathrm{CO}_{2}+\mathrm{H}_{2} \mathrm{O}\right)$ mole fraction of 0.8 . The magma's initial composition is expected to be rich in volatiles, but little is known otherwise of its composition. Wyllie and others (1990) discussed the experimental basis for believing that incipient melting would produce a magma containing between 20 and 40 weight percent $\mathrm{CO}_{2}$; such a magma would be carbonatitic rather than silicic (kimberlitic) in composition.

Two geotherms are shown on figure $4: G_{1}$, representing a typical continental geotherm found beneath stable cratons, and $G_{2}$, representing a typical geotherm found beneath oceanic crust. Initial melt formation occurs wherever the geotherm intersects the solidus, as at $T_{m_{1}}$ and $T_{m_{2}}$. For the continental geotherm $\left(G_{1}\right)$, this intersection falls between depths of approximately 200 and $300 \mathrm{~km}$. When the continental geotherm just grazes the solidus, the generation of magma is very sensitive to local variations in the geothermal 


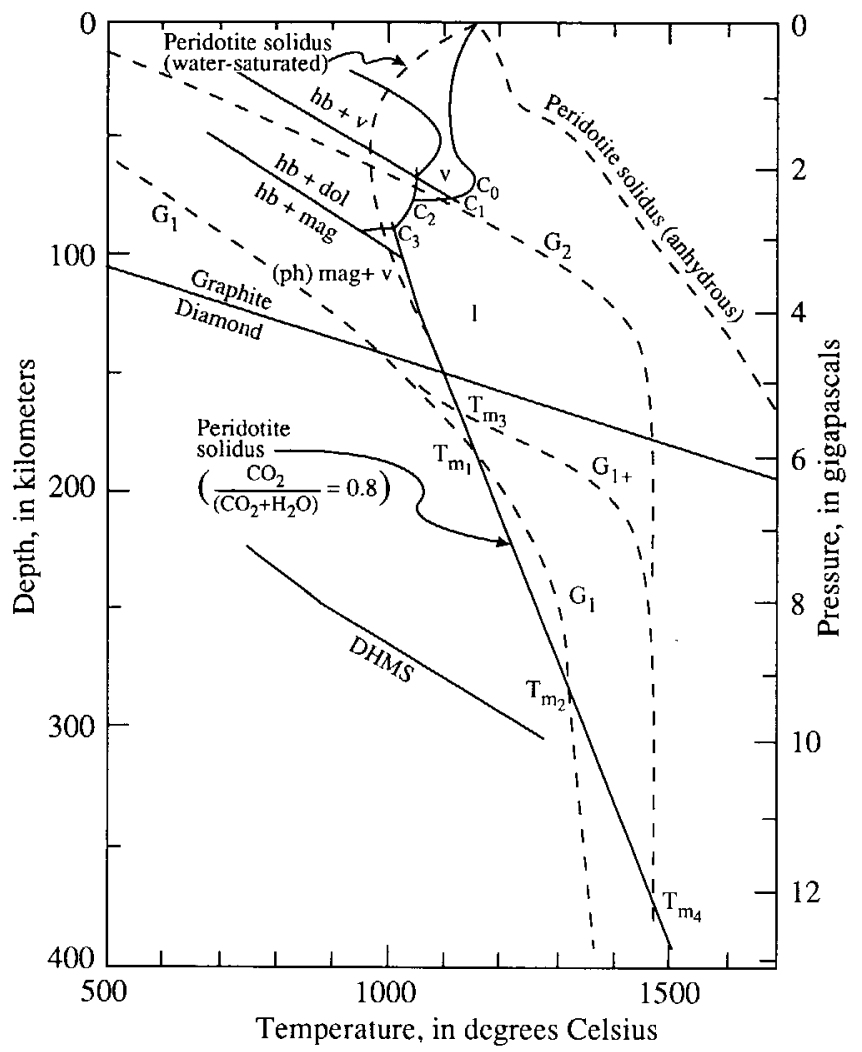

Figure 4. Simplified representation of solidus and subsolidus relations in the system peridotite- $\mathrm{CO}_{2}-\mathrm{H}_{2} \mathrm{O}$ in the upper mantle. $\mathrm{C}_{0-3}$, positions on solidus that influence dissolved volatile content of magmas; DHMS, dense hydrated magnesium silicate; dol, dolomite; $G_{1}$, continental geotherm typical of that below a stable craton; $\mathrm{G}_{1+}$, continental geotherm displaced to higher temperatures by increase in thermal convection in upper mantle; $G_{2}$, geotherm typical of that below oceanic crust; hb, hornblende; mag, magnesite; $\mathrm{ph}$, phlogopite mica; l, liquid; $\mathrm{T}_{\mathrm{m}_{1-4}}$, points at which solidus intersects geotherm and melting occurs; $\mathrm{v}$, vapor. Modified from Wyllie (1989).

gradient and to volatile and local peridotite composition. Increased thermal convection in the upper mantle could displace the continental geotherm $\left(\mathrm{G}_{1+}\right)$ to higher temperatures at the lithosphere-asthenosphere boundary, and this increase in temperature would increase the region of melting to much greater depths, as at $\mathrm{T}_{\mathrm{m}_{4}}$. Melting could be induced by an increase in heat flow and by volatiles ascending from lower in the mantle. Because both hydrates and carbonates are stable within this region, a coexisting vapor phase at thermodynamic equilibrium will contain neither $\mathrm{CO}_{2}$ nor $\mathrm{H}_{2} \mathrm{O}$. The vapor could, however, contain methane and (or) hydrogen or inert gases such as nitrogen (and rare gases) from the lower mantle.

If deep-seated magmas were to migrate adiabatically, they could ascend to the surface along fractures and erupt with release of dissolved gases and the formation of diatremes. Diatreme eruptions of carbonatitic magmas from such depths are, however, rarely reported (Bailey, 1989). It must be presumed therefore, that incipient magmas transporting volatiles from such great depths very rarely ascend directly to the surface. It is more likely that the magmas cool partially during the ascent, become trapped under the solidus overhang between $\mathrm{C}_{0}$ and $\mathrm{C}_{3}$, and solidify. If the magma solidified between $\mathrm{C}_{0}$ and $\mathrm{C}_{1}$, it would release vapor composed of both $\mathrm{H}_{2} \mathrm{O}$ and $\mathrm{CO}_{2}$. The vapor, especially if rich in $\mathrm{CO}_{2}$, could produce extreme local overpressures and induce fracturing. If the fractures were to propagate to the surface, high-pressure gases and residual magma could produce a characteristic diatreme eruption. Between $C_{1}$ and $C_{2}$ the vapors would react with peridotite to form hornblende, and the residual vapor would be depleted in $\mathrm{H}_{2} \mathrm{O}$. Between $\mathrm{C}_{2}$ and $\mathrm{C}_{3}$, both dolomite and hornblende are stable and therefore the residual fluid would be depleted in $\mathrm{H}_{2} \mathrm{O}$ and $\mathrm{CO}_{2}$.

The trapping and solidification of magmas under the solidus overhang is believed to be responsible for extensive upper-mantle metasomatism in the subcontinental lithosphere. The extent of metasomatism is limited by the capacity of the rock to react with the volatiles to form carbonates and hydrates. Eventually unreacted residual gases could accumulate until the vapor pressure exceeds the lithosphere overburden pressure. Release of vapor and entrained kimberlite and carbonatite magma would then ensue, as may have occurred in formation of diatremes observed in Utah (McGetchin and others, 1973).

With increasing mantle convection and higher temperatures, the lithosphere/asthenosphere boundary is deformed to shallower depths; this deformation leads eventually to continental rifting and sometimes the formation of an oceanic spreading center. Under these conditions the geotherm is displaced upward to the position represented by $\mathrm{G}_{2}$ on figure 4. Eventually, extensive melting and magma production occurs from the region $\mathrm{C}_{0}$ downward to indefinite depths. Large volumes of basaltic magma ascend to shallow depth in the crust or erupt as copious flood basalts. Between the two extremes of deep, incipient melting at about $400 \mathrm{~km}$ and shallow mantle melting underneath oceanic spreading centers, magmas can range from carbonatitic and extremely silica-poor ( 40 weight percent $\mathrm{SiO}_{2}$ ) kimberlitic magmas through the alkaline basaltic to ocean tholeiitic magmas with in excess of 50 weight percent $\mathrm{SiO}_{2}$. The deeper seated the source of the magmas, the greater the potential volatile content, because of increasing $\mathrm{CO}_{2}$ and $\mathrm{H}_{2} \mathrm{O}$ solubility with pressure and increasing $\mathrm{CO}_{2}$ solubility in alkaline magmas. It is therefore not surprising that deep-seated kimberlitic magmas often form diatremes, which through their structure and shape provide evidence of substantial volatile loss from the mantle (McGetchin and Ullrich, 1973; Novikov and Slobodskoy, -1978).

The loss of $\mathrm{CO}_{2}$ from the mantle is also evident in the formation and extrusion of carbonatitic magmas. Most carbonatites are composed primarily of calcite and dolomite, although alkaline carbonatites such as at Oldoinyo 
Lengai, Tanzania, have been observed. Carbonatites are usually found in complex volcanic centers comprising large suites of alkaline basalts and related rocks. Such associations point to a relatively shallow lithospheric subcrustal source region where a primary silicic magma differentiated and exsolved immiscible carbonatite magma. Wyllie and others (1990) summarized experimental data in support of this interpretation. It is probable that such volcanic complexes arise from the melting and assimilation of previously metasomatized mantle either during a renewal of volcanic activity or perhaps during the cumulative phase of thermal upwelling. Although details of the differentiation process are not clear, the ample field evidence for emplacement of carbonatitic magmas in the continental crust prior to or during intracratonic rifting convincingly demonstrates that the oxidation state of the upper mantle lies within the carbonate stability field; reducing gases such as methane or hydrogen are not significant vapor components under these conditions.

\section{TRANSPORT OF VOLATILES IN THE CRUST}

\section{ISOTOPIC METHODS FOR THE DETECTION OF GASES OF MANTLE ORIGIN}

For many years it was possible only to speculate on the release of juvenile gases from the mantle because there was no unambiguous means of distinguishing gases of mantle origin from those derived from crustal sources. Now it is recognized that the ${ }^{3} \mathrm{He}$ balance in the Earth's atmosphere provides quantitative evidence for mantle degassing. Helium is a light noble gas comprising ${ }^{4} \mathrm{He}$, formed primarily from the radioactive decay of uranium and thorium isotopes, and ${ }^{3} \mathrm{He}$, an isotope that forms from the radioactive decay of ${ }^{3} \mathrm{H}$ and from nucleogenic reactions involving ${ }^{6} \mathrm{Li}\left({ }^{6} \mathrm{Li}(\mathrm{n}, \alpha){ }^{3} \mathrm{He}\right)$, when the primary source of free neutrons are $\alpha, n$ reactions involving such light elements as $\mathrm{O}, \mathrm{S}$, and $\mathrm{Mg}$ in cosmic-ray interactions in the upper $-300 \mathrm{~cm}$ of the Earth's crust. Because helium isotopes have low atomic weight, they readily escape into space from the Earth's atmosphere. The quantity of helium in the atmosphere must therefore reflect the competition between the rate of loss to space and rates of production and addition by auroral precipitation. Helium produced in crust of average composition will have a ${ }^{3} \mathrm{He} /{ }^{4} \mathrm{He}$ ratio of about $10^{-8}$ (for example, see Mamyrin and Tolstikhin, 1984). The present atmosphere is enriched 100 -fold in ${ }^{3} \mathrm{He}$ relative to this crustal production ratio. Aldrich and Nier (1948) discovered that the ${ }^{3} \mathrm{He} /{ }^{4} \mathrm{He}$ ratio varied greatly in minerals and well gases, and concluded that the ${ }^{3} \mathrm{He}$ in the Earth's atmosphere must be derived from some primordial source. Only 10 percent of the required flux of ${ }^{3} \mathrm{He}$ could be accounted for until Clarke and others (1969) discovered that helium enriched in ${ }^{3} \mathrm{He}$ relative to that of the atmosphere was being released from the mantle at oceanic spreading centers. The mantle ${ }^{3} \mathrm{He} /{ }^{4} \mathrm{He}$ ratio is about $10^{-5}$, three orders of magnitude larger than that due to crustal production. The higher ratio is presumed to be due to the presence of primordial ${ }^{3} \mathrm{He}$ that was trapped in the Earth's interior during the early stages of planetary accretion. The large difference between mantle and crustal helium isotopic compositions makes helium the most efficient detector of mantle volatiles in the crustal regime.

Measurements of the ${ }^{3} \mathrm{He} /{ }^{4} \mathrm{He}$ ratios in gaseous and aqueous samples increased greatly with the discovery that ${ }^{3} \mathrm{He}$ is diagnostic of mantle involvement. This discovery stimulated further interest in the isotopic abundances of neon, argon, and xenon, which are now also studied in order to differentiate between mantle, crustal, and atmospheric sources.

In the subsurface environment, rare gases are derived in varying amounts from the atmosphere (usually dissolved in water) from crustal nuclear reactions, and from the mantle. Gases from each source are characterized by distinctive isotopic ratios. The study of rare-gas abundances and isotope ratios in sedimentary basins together with associated gas-phase compositions is a powerful tool for interpreting the processes that lead to the formation of oil and gas fields. Although such studies are as yet in their infancy, many of the resultant findings are relevant to the central issue concerning the source(s) of hydrocarbons in sedimentary basins. Often implicit in such studies is the assumption that the oil and gas resources were derived by bacterial or thermogenic processes from organic matter contained in the sediments; this organic origin can be distinguished from a primordial origin on the basis of the isotopic components of the carbon.

It should be noted that neither ${ }^{3} \mathrm{He}$ nor other rare gases can substantiate a mantle origin for the carrier gas in which they are found, as the carrier gases could have been released and mixed with mantle-derived noble gases anywhere between the source and the sampling point. Methane (and hydrogen) emissions are commonly observed during hydrolysis by mafic and ultramafic igneous rocks, which also releases helium with a distinctive mantle signature. The emissions of crustal origin are discussed in a later section. Although a mantle ${ }^{3} \mathrm{He}$ signature is clearly associated with the methane, arguments in favor of a mantle origin for the methane cannot be justified from field or theoretical arguments (Jenden and others, this volume).

\section{THERMODYNAMIC STABILITY OF C-H-O-N-S GASES IN THE CRUST}

Before considering the evidence for vapor-phase transport in the crust, it is worth examining the thermodynamic 
relations of components composing a vapor phase as a function of depth in the continental crust. In figure 5 , phase relations of relevant solid and gaseous species are again plotted as a function of RTln $f_{\mathrm{O}_{2}}$, on this occasion between 0 and $1,000^{\circ} \mathrm{C}$ along a continental geothermal gradient averaged at $17^{\circ} \mathrm{C} / \mathrm{km}$, with appropriate corrections for pressure. In addition to the reactions depicted in figure 2 , other reactions defining the oxidation state with respect to volatile species have been included:

$$
\begin{gathered}
2 \mathrm{H}_{2} \mathrm{~S}+\mathrm{O}_{2}=\mathrm{S}_{2}+\mathrm{H}_{2} \mathrm{O}, \\
0.5 \mathrm{~S}_{2}+\mathrm{O}_{2}=\mathrm{SO}_{2}, \\
0.67 \mathrm{H}_{2} \mathrm{~S}+\mathrm{O}_{2}=0.67 \mathrm{SO}_{2}+0.67 \mathrm{H}_{2} \mathrm{O}, \\
0.5 \mathrm{SO}_{2}+\mathrm{O}_{2}=0.5 \mathrm{SO}_{3} \text {, and } \\
1.33 \mathrm{NH}_{3}+\mathrm{O}_{2}=0.67 \mathrm{~N}_{2}+2 \mathrm{H}_{2} \mathrm{O} .
\end{gathered}
$$

The reaction

$$
\mathrm{CH}_{4}=\mathrm{C}+\mathrm{H}_{2}
$$

defines the decomposition of methane to graphite + hydrogen. The following text, on clarifying vapor-phase relations, refers repeatedly to figure 5 .

\section{MAGMA TRANSPORT}

\section{MAGMA OXIDATION STATE}

The oxidation state of a magma can be correlated with the composition of any evolving gases. Unmodified magmas should possess an oxidation state similar to that of their source regions in the upper mantle. Therefore, magmas can under favorable circumstances shed further light on the oxidation state of the upper mantle and the stability of vapor components

In practice, direct measurement of the oxygen fugacity of a magma can currently be achieved only through the use of an yttria-stabilized zirconia electrode probe inserted into a lava lake. Because this technique is limited in its application, and sometimes dangerous, other indirect methods have been used to interpret the oxygen fugacity. Such methods involve certain assumptions that cannot always be

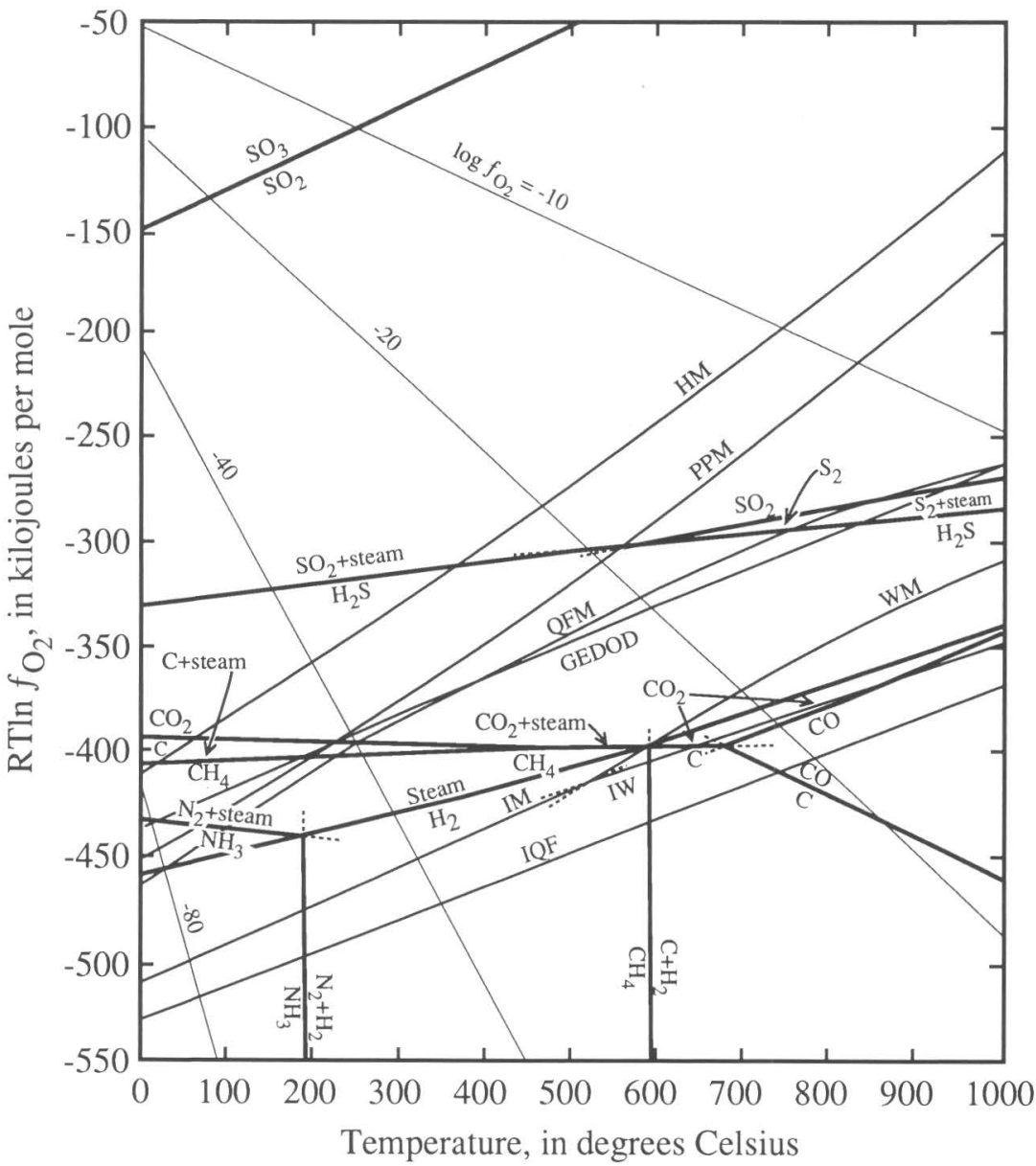

Figure 5. Gas-gas and gas-solid-phase equilibria involving volatile components in system C-H-O-N-S as function of RTln $f_{\mathrm{O}_{2}}$ (where $\mathrm{R}$ is universal gas constant, $\mathrm{T}$ is temperature, and $\ln f_{\mathrm{O}_{2}}$ is natural log of oxygen fugacity) and temperature on a $17.3^{\circ} \mathrm{C} \mathrm{km}^{-1}$ geotherm. Black curves are dashed where equilibria are metastable. Light lines from upper left to lower right are lines of equal $\log f_{\mathrm{O}_{2}}$, in bars. GEDOD, graphite-enstatitedolomite-olivine-diopside; HM, hematitemagnetite; IM, iron-magnetite; IQF, iron + quartz-fayalite; IW, iron-wustite; PPM, pyrrhotite-pyrite + magnetite; QFM, fayalite + quartz-magnetite; WM, wustite-magnetite. 
tested or proven. These include measurement of (1) the $f_{\mathrm{O}_{2}}$ of reheated rock samples using an yttria-stabilized zirconia electrode, (2) the residual gas-phase and condensate composition in lava vesicles or fluid inclusions in glasses, and (3) the $\mathrm{Fe}^{\mathrm{III}} / \mathrm{Fe}^{\mathrm{II}}$ ratio in the quenched glass or minerals that precipitated from the magma. These studies suggest that the oxidation states of magmas derived from the mantle range from -3 to $+1.5 \log$ units with respect to the oxidation state of the QFM buffer (Carmichael, 1991).

In recent years the validity of results obtained by method (1) has been questioned. The presence of deuteric graphite can cause misleadingly low measurements of oxygen fugacity. Mathez (1984) pointed out that early-crystallized minerals toward the base of large layered mafic intrusions imply oxidation states close to that of the IW buffer (for example, see Elliot and others, 1982, and Sato and Valenza, 1980), which is much lower than that of effusive basalts sourced in the mantle. $f_{\mathrm{O}_{2}}$ measurements on spinels from mantle lherzolites using method (1) (Arculus and Delano, 1980) also implied that the oxidation state of the mantle was near that of the IW buffer. The possibility that the loss of volatiles might affect the oxidation state and hence the $\mathrm{Fe}^{\mathrm{III}} / \mathrm{Fe}^{\mathrm{II}}$ ratio in minerals or quenched glass led Mathez (1984) and others (for example, see Anderson and Wright, 1972; Sato, 1978a; Gerlach, 1980; Sakai and others, 1982; Carmichael, 1991; Wallace and Carmichael, 1992) to consider this question further. Of particular relevance are these reactions:

$$
\begin{gathered}
\mathrm{O}_{2}(\mathrm{~m})=\mathrm{O}_{2}(\mathrm{v}) \\
\mathrm{H}_{2} \mathrm{O}(\mathrm{m})=\mathrm{H}_{2} \mathrm{O}(\mathrm{v}) \\
2 \mathrm{H}_{2} \mathrm{O}(\mathrm{m})=\mathrm{O}_{2}(\mathrm{~m})+2 \mathrm{H}_{2}(\mathrm{v}) \\
\mathrm{H}_{2} \mathrm{O}(\mathrm{m})+\mathrm{O}^{--}(\mathrm{m})=2 \mathrm{OH}^{-}(\mathrm{m}) \\
\mathrm{S}^{--}(\mathrm{m})+\mathrm{H}_{2} \mathrm{O}(\mathrm{m})=\mathrm{O}^{--}(\mathrm{m})+\mathrm{H}_{2} \mathrm{~S}(\mathrm{v}) \\
2 \mathrm{~S}^{--}(\mathrm{m})+\mathrm{O}_{2}(\mathrm{~m})=2 \mathrm{O}^{--}(\mathrm{m})+\mathrm{S}_{2}(\mathrm{v}) \\
\mathrm{S}^{--}(\mathrm{m})+1.5 \mathrm{O}_{2}(\mathrm{~m})=\mathrm{O}^{---}(\mathrm{m})+\mathrm{SO}_{2}(\mathrm{v}) \\
\mathrm{S}_{2}(\mathrm{~m})+2 \mathrm{O}^{--}(\mathrm{m})=2 \mathrm{~S}^{--}(\mathrm{m})+\mathrm{O}_{2}(\mathrm{~m}) \\
\mathrm{SO}_{4}^{--}(\mathrm{m})=\mathrm{S}^{--}(\mathrm{m})+2 \mathrm{O}_{2}(\mathrm{~m}) \\
\mathrm{CO}_{3}^{--}(\mathrm{m})=\mathrm{O}^{--}(\mathrm{m})+0.5 \mathrm{O}_{2}(\mathrm{~m})+\mathrm{CO}(\mathrm{v}) \\
\mathrm{CO}_{3}^{--}(\mathrm{m})+2 \mathrm{H}_{2} \mathrm{O}(\mathrm{m})+2 \mathrm{O}_{2}(\mathrm{~m})+\mathrm{O}^{--}(\mathrm{m})+\mathrm{CH}_{4}(\mathrm{v}) \\
\mathrm{CO}_{3}^{--}(\mathrm{m})=\mathrm{O}^{--}(\mathrm{m})+\mathrm{CO}_{2}(\mathrm{v}), \text { and } \\
2 \mathrm{Fe}^{+++}(\mathrm{m})+\mathrm{O}^{--}(\mathrm{m})=2 \mathrm{Fe}^{++}(\mathrm{m})+0.5 \mathrm{O}_{2}(\mathrm{~m})
\end{gathered}
$$

where $(\mathrm{m})$ represents the melt species and $(\mathrm{v})$ the vapor or gaseous species. Melt species are represented formally for convenience. Because melts are partially to completely polymerized, some species may be complexed with the silicate structure, here represented as $\mathrm{O}^{--}(\mathrm{m})$, whereas others are present as ionic or molecular species. Complexation in a melt can affect the activities of other dissolved species and the fugacities of vapor components. For example, water in small concentrations in the melt is almost wholly complexed as $\mathrm{OH}^{-}$, decreasing the activity of $\mathrm{H}_{2} \mathrm{O}(\mathrm{m})$ and the fugacity of $\mathrm{H}_{2} \mathrm{O}(\mathrm{v})$.

The loss or gain of volatiles in the magma can cause shifts in the oxidation state, which will in turn affect the internal distribution of species. Sulfur species, for example, are sometimes saturated with respect to a ferrous sulfide melt (Wallace and Carmichael, 1992), thus:

$$
0.5 \mathrm{~S}_{2}(\mathrm{v})+\mathrm{Fe}^{++}(\mathrm{m})+\mathrm{O}^{--}(\mathrm{m})=\mathrm{FeS}(\mathrm{m})+0.5 \mathrm{O}_{2}(\mathrm{v}),
$$

in which $f_{\mathrm{S}_{2}} / f_{\mathrm{O}_{2}}$ is constant at a given pressure and temperature.

Volatile loss can occur either through diffusive transport through the magma boundary interface or through exsolution during depressurization or cooling. It is evident from reactions $19,22,23,26$, and 27 that volatile loss will change the oxidation state.

Sato (1978a) and Dyar and others (1992) believed that the diffusive loss of hydrogen gas from magmas, reaction 19 , led to their progressive oxidation. Mathez (1984) invoked reaction 26 under near-surface conditions to justify his belief that midocean-ridge basalt (MORB) is more oxidized than the source region. Wallace and Carmichael (1992) argued, and presented with supporting field evidence, that because sulfur is present in mafic magmas primarily as $\mathrm{S}^{--}$, the loss of $\mathrm{SO}_{2}$ from oceanic-island basalt (OIB) magmas causes their reduction (reaction 23). The relative importance of these processes and their effect on the $\mathrm{Fe} \mathrm{III}^{\mathrm{II}} \mathrm{Fe}^{\mathrm{II}}$ ratio in magmas and in the coexisting mineral phases crystallizing from magma depends on many thermodynamic, kinetic, and transport processes that need not be enumerated further. The distribution of species in the evolved gas phase depends on the contributions of volatiles dissolved in the magma and the concentration of iron in the magma. If lavas derived from deep in the upper mantle, such as primary carbonatites or kimberlites with a relatively high carbonate content, were to ascend into the shallow crust, they could evolve $\mathrm{CO}_{2}(+\mathrm{CO})$ when the volatile pressure exceeded the lithostatic pressure and become more oxidized during emplacement, as is well illustrated by Bailey (1989). There is, however, no evidence to indicate that typical MORB or OIB magmas contain sufficient volatiles to release gas and modify their oxidation states before emplacement in shallow crustal reservoirs (Wallace and Carmichael, 1992). Pressure changes between the source region and the crust will also not signifi- 
cantly alter the distribution of species dissolved in the melt. Any shift in oxidation state due to the release of volatiles is therefore likely to take place relatively near to the Earth's surface.

Because basaltic magmas are unlikely to lose volatiles during ascent, they would be expected to retain an oxidation state somewhat similar to that of the environment in which they are generated. All evidence (Gerlach and Nordlie, 1975c; Sato, 1978a; Mueller, 1971; Gerlach, 1993) strongly suggests that the oxidation states of such magmas are too high to support methane, and that exsolution of gaseous components results in volcanic gases rich in carbon dioxide, water, sulfur dioxide, and hydrogen sulfide. The oxidation state of more-reduced gases from the ultrapotassic lavas of Nyiragongo, Zaire (Gerlach, 1980) are $-0.5 \mathrm{log}$ units relative to the $Q F M$ buffer. In these lavas, the dominant vapor species are $\mathrm{CO}_{2}(+\mathrm{CO}), \mathrm{H}_{2} \mathrm{O}$, and $\mathrm{SO}_{2}+\left(\mathrm{S}_{2}+\mathrm{H}_{2} \mathrm{~S}\right)$. In spite of the uncertainty in establishing the mantle oxidation state from crustal igneous rocks, the constraints are such that even lavas from Nyiragongo are too oxidized to permit significant formation of methane or hydrogen. Thus we conclude that most if not all source regions in the upper mantle are too oxidizing to permit the presence of methane.

Few magmas migrate to the crust or extrude intact on the Earth's surface without any exchange of chemical components. Many accumulate in magma chambers, where they can become contaminated with crustal rocks, lose or gain volatiles, and differentiate through precipitation of rock-forming minerals. Large bodies of basaltic magmas, upon crystallization, precipitate ferromagnesian minerals enriched in the $\mathrm{Fe}^{\mathrm{II}}$ component over $\mathrm{Fe}^{\mathrm{III}}$. The residual magma is therefore increasingly concentrated in $\mathrm{Fe}^{\mathrm{III}}$ and becomes progressively more oxidized until titanomagnetite saturates and precipitates (for example, see Carmichael, 1991; Snyder and others, 1993).

As noted earlier, in very large layered mafic intrusive bodies, the lowest horizons are sometimes more reduced than higher ones. The history bearing on the emplacement of these intrusions is complex, and the oxidation state of the lowermost horizons may not necessarily reflect the oxidation state of the source region. Late-stage volatile enrichment, the incorporation of volatiles from the country rock, and metasomatism in these bodies could impose a reducing signature that was not originally present in the magma. Recently, however, Snyder and others (1993) have critically evaluated the temperature- $f_{\mathrm{O}_{2}}$ path taken during the crystallization of the Newark Island layered intrusive in Labrador and have supported their evaluation with experimental studies. They concluded that the oxidation state of the parent tholeiitic magma was probably within about $0.5 \mathrm{log}$ units of the IW buffer. They further concluded that many other layered intrusives probably followed similar trends in $f_{\mathrm{O}_{2}}$. Their estimates are somewhat lower than the range of oxidation states proposed by
Blundy and others (1991) for the upper mantle beneath the continental crust. It is possible that the oxidation state of tholeiitic magmas is buffered initially by the CCO reaction (reactions 7,8 ). This oxidation state is still too high to stabilize methane.

\section{FIELD EVIDENCE}

In this section, we discuss field observations that provide direct evidence for the composition of the principal gaseous or vapor components emitted from magmas in either the shallow regions of the crust or in the atmosphere. We consider available evidence for a range of magma types from kimberlite to andesite and dacite. All of these magmas are known to be derived from the mantle, and exsolving vapors, when measurable, have ${ }^{3} \mathrm{He} /{ }^{4} \mathrm{He}$ mantle signatures. Their magmas' modes of origin in the mantle permit classification into four distinct groups: (1) magmas generated beneath the continental lithosphere and intruded into stable cratons, (2) magmas generated during subduction of oceanic crust, (3) magmas generated at spreading oceanic centers, and (4) magmas generated at oceanic islands. Field evidence for gas evolution in these environments is discussed further below.

\section{CONTINENTAL LITHOSPHERE}

Continental crustal cratons are subject to rifting and breakup. The initial stages of rifting are characterized by kimberlitic magmatism with diatreme formation. Diatremes form near the Earth's surface during the rapid and continuous exsolution of volatiles from a magma body. During the initial stages, magmas penetrate upwards along fractures that propagate as a result of regional stresses. During ascent, volatiles exsolve from the magma, thus decreasing the mean density of the ascending melt-fluid mixture. With breakthrough at the surface, the gas and entrained magma in the upper parts of the channel can attain very high velocities, estimated by McGetchin and Ullich (1973) to be up to $350 \mathrm{~m} \mathrm{~s}^{-1}$. The venting high-velocity gas and entrained magma carry fragments of wall rock and comminuted particles from great depth. The particles ablate the vent channel and cause it to develop an oblong or circular cross section beneath the vent (Novikov and Slobodskoy, 1978). With dissipation of the exsolved gas, the high-velocity jet stage of the eruption terminates. In kimberlitic and primary carbonatitic eruptions, magma and the initially dissolved gases ascend from depths of between 200 and $400 \mathrm{~km}$. Those associated with alkalic magmatism may originate at somewhat shallower depths. Diatreme eruptions are probably somewhat similar if not identical to a classical Plinian eruption, with formation of a typical maar-type explosion crater surrounded by pyroclastic ejecta. It should be emphasized, however, that not all maars 
form through diatreme activity, and not all diatremes vent at the surface to produce maars. Some diatremes dissipate upward into megabreccias, which in turn grade into undisturbed country rock (McGetchin and others, 1973; Gabelman, 1977).

Bratus and others (1987) studied the compositions of fluid inclusions in chilled glass spherules from some kimberlite breccias and from the Udachnaya-Zapadnaya, Yakutia, Russia, kimberlite pipe. The kimberlite pipe contained a few native iron inclusions, and all spherules were similar to melilite in composition. The gases contained in the inclusions were primarily nitrogen (75-96 percent), methane (4.4-16 percent) and carbon dioxide (2.4-9.5 percent). The gas-phase composition is consistent with the presence of native iron and indicates strongly reducing conditions near the iron-wustite phase boundary. The presence of such a large concentration of nitrogen is unexpected, and raises questions as to whether the reduced gases in the inclusions correspond in composition to fluids in the source region of the kimberlitic magma. However, Kravtsov and others (1979) have also reported high nitrogen contents in gases evolved upon crushing samples from the Mir pipe in Yakutia. It is possible that such gases are representative of very deep sources where reduced gases are oxidized to diamond and a nitrogen residue remains.

What gas-phase composition is associated with kimberlitic diatreme formation, therefore, remains an open question. With the meager information available, an inconsistency exists between the inferred oxidation state of kimberlitic magmas, which suggests relatively oxidizing conditions, and the gas-fluid-phase composition in the erupted glass spherules, which suggests strongly reducing conditions. Hydrocarbon gases and bitumen were also found in the Udachnaya-Zapadnaya pipe (Kravtsov and others, 1976), but it is not clear whether such occurrences are due to the primary release of gases during diatreme formation, or whether the hydrocarbons and bitumen have formed as a result of hydrothermal alteration after emplacement. Organic material could also have migrated from adjacent sedimentary host rocks as is inferred from the gas chromatography studies of the bitumens in the pipe (Vdovykin and others, 1979). Abundant circumstantial evidence, such as the association of kimberlites with carbonatitic magmas and the presence of liquid $\mathrm{CO}_{2}$ inclusions in olivines incorporated in kimberlitic magmas suggest that the vapor phase of kimberlite eruptions is likely to be predominantly carbon dioxide (Murck and others, 1978; Pasteris, 1988). Clearly, further study of this question is needed.

Although kimberlite pipes are widespread in continental crust, the cumulative release of vapor during pipe formation is unlikely to have contributed significantly to natural-gas resources over geologic time even if the gases released were pure methane. No natural-gas reservoirs have ever been linked to diatremes. Assuming that carbon dioxide is present and near saturation at mantle depths, a kimberlitic magma would contain about 3.5 weight percent $\mathrm{CO}_{2}$. If all of this gas were released to the atmosphere, it would be equivalent to about $1.9 \times 10^{-3} \mathrm{~m}^{3} \mathrm{~kg}^{-1}$ of kimberlite. Kimberlitic intrusions are small, however, and therefore an isolated intrusive event is unlikely to discharge more than $6 \times 10^{8} \mathrm{~m}^{3}$ gas for $0.01 \mathrm{~km}$ of magma. This quantity is of the same order of magnitude as the quantity of gas discharged from Lake Nyos in Cameroon in 1986 , to be discussed further, below.

Volatiles associated with carbonatitic magmas are rich in $\mathrm{CO}_{2}$ and $\mathrm{H}_{2} \mathrm{O}$, and are sometimes responsible for extensive carbonate and potassic metasomatism of surrounding crustal rocks. Treiman and Essene (1984) found that a late-stage carbonatite dike in the Oka, Quebec, alkaline complex contained all minerals necessary to define uniquely the oxidation state of the magma. At the inferred eutectic of the melt at $640^{\circ} \mathrm{C}$ and $100 \mathrm{MPa}$, oxygen fugacity was near that of the QFM buffer, and the gas fugacities, in $\mathrm{MPa}$, were as follows: $\mathrm{CO}_{2}, 11.0 ; \mathrm{H}_{2}, 0.46 ; \mathrm{H}_{2} \mathrm{~S}$, 0.27 ; $\mathrm{CO}, 0.05$; and $\mathrm{CH}_{4}, 0.01$. It was assumed that the difference between the sum of the pressures of the cited gases and the 100-MPa total pressure was made up by a pressure for $\mathrm{H}_{2} \mathrm{O}$ of $88.2 \mathrm{MPa}$. Although the $\mathrm{H}_{2} \mathrm{O}$ partial pressure seems high, even for a late-stage carbonatite, the oxidation state is consistent with a mantle $f_{\mathrm{O}_{2}}$.

Agpaitic magmas, which are genetically related to carbonatitic magmas, sometimes produce strongly reducing conditions upon solidification and cooling, owing to the formation of hydrogen and methane as well as smaller amounts of $\mathrm{C}_{2} \mathrm{H}_{6}$ to $\mathrm{C}_{5} \mathrm{H}_{12}$ and dispersed bitumens. There is no evidence, however, of significant methane in gases released during volcanic eruptions of such magmas. Gerlach (1980), using analyses of gases collected in 1959 from the ultrapotassic nephelinite lava in the lake at Nyiragongo (Chaigneau and others, 1960), estimated that the venting gas was composed of 35 to 50 percent $\mathrm{CO}_{2}, 45$ to 55 percent $\mathrm{H}_{2} \mathrm{O}, 1$ to 2 percent $\mathrm{SO}_{2}, 2$ to 3 percent $\mathrm{CO}$, 1.5 to 2.5 percent $\mathrm{H}_{2} \mathrm{~S}$ and traces of other volatiles including $S_{2}$ and COS. The oxidation state of this lava lake, as noted previously, is about $0.5 \log$ units below that of the QFM buffer.

When mafic magmas fail to penetrate to the surface before congealing, the gases released can be trapped in overlying sedimentary formations, or they can leak through to the surface as gas vents or springs releasing copious quantities of gas. In all such documented occurrences, discussed below, the residual gas is always carbon dioxide. Whenever measured, all known occurrences of crustal carbon dioxide accumulations display evidence of mantle carbon (via $\delta^{13} \mathrm{C}$ values) and helium $\left(\right.$ via ${ }^{3} \mathrm{He} /{ }^{4} \mathrm{He}$ ratios). Furthermore, most are found in the vicinity of continental rifts and are associated with mafic magmatism. The carbon dioxide is the residue of a gas phase that undoubtedly includes $\mathrm{H}_{2} \mathrm{O}, \mathrm{SO}_{2}$, and $\mathrm{H}_{2} \mathrm{~S}$. But the latter 
components condensed and (or) reacted with the country rocks and are therefore no longer evident.

One of the best described examples of crustal carbon dioxide accumulations is in the region bordering the Rio Grande Rift in New Mexico and the adjacent Four Comers area of Arizona, Colorado, New Mexico, and Utah. This region is characterized by numerous isolated centers of Tertiary and Quaternary mafic magmatism and scattered clusters of diatremes, some of which contain kimberlite and (or) carbonatite (McGetchin and Silver, 1970; McGetchin and others, 1973). This region includes the southeastern corner of the Colorado Plateau, an uplifted cratonic block long known for extensive occurrences of sandstone-hosted uranium deposits. Speculation on the origins of these deposits is controversial (Nash and others, 1981). Gabelman (1977) suggests that uranium mineralization in this area might be derived from mantle diatreme activity, but it could also originate from the weathering of Tertiary intermediate to felsic igneous rocks that are distributed over the Colorado Plateau.

A distinctive feature of the area is the occurrence of carbon dioxide gas reservoirs. They have been discovered in sedimentary rocks in the McElmo Dome, Montezuma County, Colorado, at Sheep Mountain in Colorado, and in the Bravo Dome in Harding and Union Counties, New Mexico (Krivanek, 1978; Broadhead, 1985, 1987, 1990). The carbon dioxide is currently being recovered from these reservoirs for enhanced oil recovery in West Texas oil fields. Two smaller fields closer to the Rio Grande rift, the Estancia and Union Des Moines fields, have been abandoned.

The quantity of $\mathrm{CO}_{2}$ in these reservoirs is substantial. The Bravo Dome alone contains between 5.3 and 9.9 trillion cubic feet (Tcf) $\left(1.5\right.$ to $\left.2.8 \times 10^{11} \mathrm{~m}^{3}\right)$ over a 324,000 hectare area (Broadhead, 1987). Staudacher (1987) reviewed all prior information pertaining to rare-gas isotopic ratios for $\mathrm{CO}_{2}$ gas wells of the Bravo Dome and showed that helium, neon, argon, and xenon isotope ratios were all consistent with an upper-mantle origin with negligible contributions from crustal sources and minor atmospheric contamination. Furthermore, $\delta^{13} \mathrm{C}$ values for the $\mathrm{CO}_{2}$ were typical of those for $\mathrm{CO}_{2}$ in vesicles of $\mathrm{MORB}$, implying that the carbon dioxide also had a mantle origin.

Although Tertiary and Quaternary basalts are present in the vicinity of the Bravo Dome and other $\mathrm{CO}_{2}$ fields in Colorado and Nèw Mexico, direct evidence for carbon dioxide degassing from basaltic magma has not been established. Indeed, Broadhead (1987) notes that the areas with volcanic rocks and the areas with the largest known $\mathrm{CO}_{2}$ occurrences in northeastern New Mexico are mutually exclusive. Very little volcanic activity has occurred in and around the Bravo Dome field. He believes that $\mathrm{CO}_{2}$ ascended along deep-seated basement faults from the lower crust or mantle. A much closer connection with volcanic activity can be made for the McElmo Field of the Four
Corners region (Krivanek, 1978). The southern flank of the McElmo Dome plunges towards the Ute Mountain laccolith, $4 \mathrm{mi}$ distant, and an exposed northeast-striking dike radiating from the laccolith is even closer to the top of the dome.

Numerous anticlinal structures in Mississippian rocks of the Four Corners region have been explored for oil and gas. Many of the wells on these structures have produced gases very rich in carbon dioxide, nitrogen, and helium (Picard, 1960, 1962; Casey, 1983). Gases with $>50$ percent $\mathrm{CO}_{2}$ are concentrated in the Utah and adjacent Colorado quadrants, whereas those with $>50$ percent nitrogen are found principally in the New Mexico quadrant of the Four Corners area.

Of particular interest is the high concentration of helium (2-8 percent) in gases of the New Mexico quadrant and adjacent Arizona (Casey, 1983). Since the late 1940's, these gases have been exploited for their helium content; Casey (1983) estimated remaining reserves of 3 to 5 billion cubic feet (Bcf) $\left(0.8\right.$ to $\left.1.4 \times 10^{8} \mathrm{~m}^{3}\right)$ containing 5 to 8 percent $\mathrm{He}$.

One such example is the Dineh-bi-Keyah field in northeastern Apache County, Arizona, which produces oil and He-bearing gas (Pohlmann, 1967; McKenny and Masters, 1968). The gas is composed largely of nitrogen (approximately 79-92 percent) with lesser helium (5.2-6.2 percent) and carbon dioxide (1.4-11 percent) and traces of other gases, but with very little methane (0.14-3.4 percent). A distinctive feature of this field is that the oil and gas reservoir is a lamprophyre sill, 0 to $180 \mathrm{ft}$ thick covering an area of about $6 \mathrm{mi}^{2}$. The rock is characteristic of those with a deep-seated origin in the upper mantle. The sill is slightly altered and has a primary vugular porosity averaging 10 percent, suggestive of a high initial concentration of gas dissolved in the parent magma. The oil presumably migrated from nearby source rocks into the porous igneous sill. Assuming that the sill was intruded at a depth about $1,250 \mathrm{~m}$ below the surface, at $1,200^{\circ} \mathrm{C}$ and that the primary vugular porosity was 8 percent, the total gas released by this sill must have been on the order of $1 \times 10^{9} \mathrm{~m}^{3}$ at standard temperature and pressure (STP).

Unfortunately, isotopic studies of gases from the Four Corners region have not yet been published. The extent of mantle gas contribution is thus unknown, even though many of the numerous volcanic rocks in the region suggest a deep-seated mantle origin. The $\mathrm{CO}_{2}$ content of these gases could therefore have been due to degassing of primary magma, but it could also be attributed to metamorphism of Mississippian limestones by the numerous intrusions in the region, although the metamorphic origin seems less likely.

The gases with high helium content occur in proximity to uranium deposits hosted in sandstones of the Jurassic Morrison Formation and are probably radiogenic. Helium could be derived from crustal uranium or from uranium 
concentrated in the shallow lithosphere by metasomatic processes. If the helium is radiogenic and has its origin in the crust, the observed correlation of helium concentration with nitrogen concentration might be expected, as will be discussed below. The Four Corners region evidently has a complex tectonic history, and the isotopic compositions of the gases merit further study.

Carbon dioxide accumulations in sedimentary rocks and associated with recent intraplate basaltic volcanism have also been observed near Mount Gambier in South Australia (Chivas and others, 1987). At this locality, $\mathrm{CO}_{2}$ is produced from a single well at depths below $2.5 \mathrm{~km}$ from a carbonate-poor Cretaceous sandstone at $92^{\circ} \mathrm{C}$ and $24 \mathrm{MPa}$. Chivas and others report a production rate of 28,000 tonnes/year $\left(1.6 \times 10^{7} \mathrm{~m}^{3} \mathrm{yr}^{-1}\right)$.

The association of maar formation with alkaline basaltic magmatism is quite common and lends credence to the hypothesis that most maars are due to $\mathrm{CO}_{2}$ degassing from magmas, as suggested by Chivas and others (1987), rather than the generation of superheated steam through magma contacting ground water. An occurrence of maar formation associated with the release of $\mathrm{CO}_{2}$ gas was documented by Barnes and McCoy (1979). In April 1977, two maars formed on the Alaska Peninsula during a few days of intense phreatic eruptions during which olivine basalt was extruded. Gas Rocks, $3 \mathrm{mi}$ from the newly formed maars, was observed in July 1977 to be emitting "enormously greater discharges of $\left[\mathrm{CO}_{2}\right.$-rich $]$ gas than previously." The gas contained 97 percent $\mathrm{CO}_{2}$ with $\delta^{13} \mathrm{C}=-6.36$ permil, typical of a mantle origin. Although the maars are associated with a subduction zone, their formation has much in common with continental cratonic environments.

The more quiescent loss of $\mathrm{CO}_{2}$ from wells and fissures in the Eiffel districts, adjacent to the Rhine Graben in Germany, is also noteworthy. In a region containing numerous maars, $\mathrm{CO}_{2}$ is being released to the atmosphere at a rate of 0.5 to $1 \times 10^{6}$ tonne $\mathrm{yr}^{-1},\left(2.8-5.6 \times 10^{8} \mathrm{~m}^{3} \mathrm{yr}^{-1}\right)$ (Puchelt, 1983). The magmas in both the West and East Eiffel districts are alkaline (Illies and others, 1979). Those in the West Eiffel are mainly undersaturated nephelinites and leucitites, whereas those in the East Eiffel range from intermediate to phonolitic in composition.

Recently, Griesshaber and others (1992) reported on the helium and carbon isotopic systematics in mineral springs and gas discharges from the Eiffel, Rhine Graben, and Black Forest areas. All discharges show a mantle helium component ranging from $<1$ percent to nearly 70 percent. $\mathrm{CO}_{2}$ isotopic signatures likewise reveal apparently simple binary mixtures of mantle and crustal thermogenic components. In the Eiffel districts, especially, the mantle component is very high, with ${ }^{3} \mathrm{He}$ content ranging from 0.8 to 5.6 times that found in the atmosphere. The highest values are clustered in two small regions of 10 and $125 \mathrm{~km}^{2}$, the first of which is bordered by the Rieden, Wehr, and Lacher See calderas. Griesshaber and others
(1992) showed that the regions with high mantle ${ }^{3} \mathrm{He} /{ }^{4} \mathrm{He}$ ratios are far more widespread than the surface volcanic rocks and concluded that much of the magmatic activity fails to break through to the surface. In this respect, the Rhine Graben is similar to the Sacramento Valley of California (Poreda and others, 1986; Jenden and others, 1988a) and the Four Corners area gas fields.

$\mathrm{Xu}$ and others $(1990,1991)$ described several gas fields in China, all of which have strong mantle helium signatures. With the exception of one field with $R / R_{A}=0.27$ (where $R={ }^{3} \mathrm{He} /{ }^{4} \mathrm{He}$ in measured sample, and $\mathrm{R}_{\mathrm{A}}={ }^{3} \mathrm{He} /{ }^{4} \mathrm{He}$ in air, or $1.4 \times 10^{-6}$ ), all others have $\mathrm{R} / \mathrm{R}_{\mathrm{A}}$ ratios between 2.65 and 5.01. With two exceptions, all $\delta^{13} \mathrm{C}$ values for $\mathrm{CO}_{2}$ are typical of $\mathrm{CO}_{2}$ from the mantle $(-8.9$ to 1.0 permil). The compositions of gas from a number of these fields are almost entirely $\mathrm{CO}_{2}$, ranging from 85 percent to $>99$ percent. The most $\mathrm{CO}_{2}$-rich fields, in eastern China, are all associated with the Cathaysian rift and Mesozoic and early Tertiary volcanic activity.

Evidence that basaltic magmatism might be the source of large accumulations of $\mathrm{CO}_{2}$ in the crust was also made apparent by the Lake Nyos disaster in Cameroon. Lake Nyos occupies a maar crater $1,400 \mathrm{~m}$ long, $900 \mathrm{~m}$ wide, and $200 \mathrm{~m}$ deep (Sano and others, 1987b), one of several resulting from diatreme eruptions in the area (Kusakabe and others, 1989). The diatremes form part of the Cameroonian Volcanic Line, a chain of alkaline volcanic centers trending northeast across Cameroon from the Atlantic Ocean. Pyroclastic deposits containing mantle xenoliths are present on the north and east flanks of the Lake Nyos crater.

In 1986, a large volume of $\mathrm{CO}_{2}$ gas, estimated by Giggenbach (1990) to be 240,000 tonnes $\left(1.2 \times 10^{8} \mathrm{~m}^{3}\right)$, erupted from the lake and asphyxiated 1,700 people and all animal life as far as $14 \mathrm{~km}$ away. A similar but smaller event in nearby Lake Monoun killed 37 people in 1984. Subsequent investigations of the rare-gas content of waters from both lakes showed that the ${ }^{3} \mathrm{He} /{ }^{4} \mathrm{He}$ ratio was typical of those found in circum-Pacific volcanic zones, and after correction for atmospheric contamination using the ${ }^{4} \mathrm{He} /{ }^{20} \mathrm{Ne}$ ratio, indicated that the rare gases were almost entirely derived from the mantle. Furthermore, $\delta^{13} \mathrm{C}$ values were also consistent with a magmatic (that is, upper mantle) origin (Sano and others, 1987b; Kusakabe and others, 1989). Tuttle and others (1992) concluded that the distinctive dense carbonate- and iron-rich waters of the hyperlimnion in Lake Nyos are being recharged from the underlying diatreme. These waters form when ascending magmatic $\mathrm{CO}_{2}$ dissolves in water saturating the mafic pyroclastics in the diatreme neck and leaches $\mathrm{Fe}^{++}, \mathrm{Mg}^{++}$, and $\mathrm{SiO}_{2}$ (aqueous).

Finally, reference must be made to gas emissions accumulating in Lake Kivu in eastern Central Africa. Enormous quantities of methane, about $6 \times 10^{9} \mathrm{~m}^{3}$, are dissolved in the stratified lake. The methane concentration in- 
creases with depth, the highest abundances occurring at the lake bottom, (Tietze and others, 1980; Schoel and others, 1988). Gold and Soter (1980) and Gold (1987) attributed the source of this methane to the mantle because the lake occurs in a rift zone and Nyiragongo, an active volcano emitting silica-poor alkaline basaltic lavas is found on the north shore of the lake.

Less attention has been paid to the fact that the lake contains five times as much $\mathrm{CO}_{2}$ as methane, about $3 \times 10^{10} \mathrm{~m}^{3}$. This $\mathrm{CO}_{2}$ has a typical magmatic or mantle $\delta^{13} \mathrm{C}$ signature (Tietze and others, 1980; Schoell and others 1988). Apparently the nutrients in the lake promote planktonic growth, which reduces the $\mathrm{CO}_{2}$ to organic matter that settles through the hyperlimnic, anoxic lower regions of the lake and accumulates on the lake floor. Methanogenic bacteria subsequently destroy the organic detritus and release methane to the water. $\delta^{13} \mathrm{C}, \delta \mathrm{D}$, and ${ }^{14} \mathrm{C}$ values confirm bacterial activity in methane gas generation (Schoell and others, 1988).

\section{SUBDUCTION ZONES}

Although less commonly recognized, carbon dioxide degassing is also associated with calc-alkaline magmatism above subduction zones at island arcs and continental margins. One such example occurs in the Cascade Range of North America. Subsurface accumulations of $\mathrm{CO}_{2}$ with $\delta^{13} \mathrm{C}$ between -5.38 and -6.10 permil have been found in a well at the Klickitat $\mathrm{CO}_{2}$ field near the Columbia River in Washington state (Barnes and others, 1982). The size of the gas accumulation is unknown and little is known about the associated igneous rocks, but its presence in the heart of the Cascades Volcanic Belt suggests subsurface degassing of magmas that are forming through subduction and fusion of the underlying Juan de Fuca Plate. Another example is from the Indonesian archipelago. Carbon dioxide gas released from a fissure during a phase of active volcanism on the Dieng Plateau in Java asphyxiated 142 villagers (Le Guern and others, 1982). The previously cited maar eruption on the Alaska Peninsula (Barnes and McCoy, 1979) is also an example of carbon dioxide release during subduction-zone magmatism.

Volcanism associated with the subduction of oceanic crust is known for violent pyroclastic eruptions in which the release of volatiles from the magma plays a major role. Gold (1987) has suggested that these eruptions, particularly those which produce large calderas, are manifestations of the catastrophic releases of enormous quantities of mantle gases. Petrologic data provide overwhelmingly evidence for the exsolution of water vapor with smaller quantities of carbon dioxide, hydrogen sulfide, and sulfur dioxide from such magmas during eruption. $\mathrm{H}_{2}$ and $\mathrm{CH}_{4}$ are only very minor constituents. Therefore the presumption that volcanic eruptions in subduction zones release large, uncontrolled volumes of mantle methane cannot be substantiated by field evidence. The oxidation state of these magmas is commonly near the QFM buffer or higher. Pyroclastic magmas inherit water from the fusion of a subducting oceanic crust, but could also take up significant quantities of water during ascent through a hydrous crust.

The concentrations of water in such magmas is sometimes quite high. For example, a dacite pumice erupted by Mount St. Helens, Washington, some 3.5 million years ago contains 6.4 weight percent $\mathrm{H}_{2} \mathrm{O}$, and a pre-1991eruption dacitic magma from Pinatubo, Philippines, was found to contain 5.5 weight percent $\mathrm{H}_{2} \mathrm{O}$ (Rutherford, 1993). Experimental studies also indicated that magmas erupting from Mount St. Helens between 1980 and 1985 originally contained about 4.6 weight percent $\mathrm{H}_{2} \mathrm{O}$ (Rutherford and Devine, 1988). These water contents are equivalent to water fugacities of approximately 150 to $200 \mathrm{MPa}$ in the magma. Although $\mathrm{H}_{2} \mathrm{O}$ is the dominant volatile dissolved in pyroclastic magmas, $\mathrm{CO}_{2}(+\mathrm{CO})$ is also present in significant concentrations. Measurements of the $\mathrm{H}_{2} \mathrm{O} / \mathrm{CO}_{2}$ mass ratios are difficult to come by, but the ratio appears to be on the order of 10 to 100 . The quantity of $\mathrm{CO}_{2}$ emitted by a mafic eruption is therefore very large. Assuming a ratio of 30, the May 1980 pyroclastic eruption at Mount St. Helens would have released over $3 \times 10^{9} \mathrm{~m}^{3} \mathrm{CO}_{2}$ at STP. Harris and others (1982) estimate that Mount St. Helens emitted a further $9.1 \times 10^{5}$ tonnes $\left(5 \times 10^{8} \mathrm{~m}^{3}\right)$ of $\mathrm{CO}_{2}$ during the months of July to October following the eruption.

The $\mathrm{CO}_{2} / \mathrm{SO}_{2}$ mass ratio during the Mount St. Helens eruption is better known but fluctuated with time, ranging from 2 to 15 , with an average around 7. According to Casadevall and Greenland (1982), most of the sulfur dissolved in the Mount St. Helens magma was in the sulfide, that is, in the form $\mathrm{HS}^{-}$, and it was released as $\mathrm{H}_{2} \mathrm{~S}$. The principal sulfur species in the plume of El Chichón, Mexico, after its eruption in March 1982 was also $\mathrm{H}_{2} \mathrm{~S}$ (Kotra and others, 1983). Increased water vapor fugacity shifts the reaction

$$
0.67 \mathrm{H}_{2} \mathrm{~S}+\mathrm{O}_{2}=0.67 \mathrm{SO}_{2}+0.67 \mathrm{H}_{2} \mathrm{O}
$$

to the left (Ohmoto and Rye, 1979). Because pyroclastic magmas contain so much dissolved water, $\mathrm{H}_{2} \mathrm{~S}$ is stabilized, even though the oxidation state of the magma is near the QFM buffer. Apparently, once the sulfur species are released to the atmosphere, they are rapidly oxidized to $\mathrm{SO}_{2}$ and eventually to $\mathrm{H}_{2} \mathrm{SO}_{4}$ aerosol, the reaction probably being catalyzed by the surfaces of ash particles.

In some subduction-zone volcanoes, the magmas also contain so much sulfur and the oxidation state is sufficiently high that primary anhydrite and magnetite crystallize from the magma prior to eruption as was the case at El Chichón and Pinatubo (Rutherford, 1993). Both Pinatubo in 1991 and El Chichón in 1982 erupted enormous quantities of sulfur species that could be readily identified 
by airborne detection methods and satellite imagery (Bluth and others, 1992; Arnold and others, 1990; Hirono and Shibata, 1983). The Pinatubo eruption released $1.8 \times 10^{7}$ tons or $7.3 \times 10^{9} \mathrm{~m}^{3}$ of $\mathrm{SO}_{2}$ (Rutherford, 1993). The quantities of $\mathrm{CO}_{2}$ and water vapor released have not been computed but were undoubtedly of similar magnitude or greater.

\section{MIDOCEAN RIDGES AND OCEAN ISLANDS}

Gases emitted by magmas at midocean-ridge spreading centers and ocean-island plumes are somewhat more reducing than those erupting from subduction zones, and they contain substantially less water. The carbon and sulfur species are approximately equivalent to the water content (Nordlie, 1971; Gerlach and Nordlie, 1975a, b, c; Mathez, 1984). The predominant species are $\mathrm{CO}_{2}, \mathrm{H}_{2} \mathrm{O}$, $\mathrm{CO}, \mathrm{SO}_{2}, \mathrm{~S}_{2}$, and $\mathrm{H}_{2} \mathrm{~S}$, in order of abundance. Hydrogen and methane contents are negligible.

Gases associated with ocean-island volcanism are released from magma chambers subaerially, as in Hawaii, or from the sea floor. Almost all gases released from midocean ridges, with the exception of those released on Iceland, are released from the sea floor. Structural traps containing gases from these sources have not been reported.

Gases from magma chambers underlying midocean ridges are discharged through hydrothermal vents and may be mixed with gases produced during ultramafic- and mafic-rock hydrolysis. A later section in this report deals in greater detail with the origin of gases from midoceanridge hydrothermal vents.

\section{VAPOR-PHASE TRANSPORT}

Field observations provide overwhelming evidence that volatile transport from the mantle takes place primari$1 y$, if not entirely, through magma incursions into the crust, and that mantle gases derived from depressurized and cooling magmas release their gases into structural traps or the atmosphere. Within the crust, gaseous components can migrate considerable distances from their source, dissolved in and transported by aqueous fluids. The nature of the species transported depends very much on the oxidation state of the crustal environment.

\section{OXIDATION STATE OF THE LOWER CRUST}

The oxidation state in the lower continental crust appears to be similar to that in the subcontinental upper mantle. The presence of carbonate-bearing meionite scapolite in granulites of basaltic composition (Lovering and
White, 1964, 1969; Edwards and others, 1979) suggests a higher oxidation state. The lower crust would also tend to become depleted in water during lower-crustal magmatism. With partial anatexis, $\mathrm{H}_{2} \mathrm{O}$ would partition into the silicate melt, leaving residual fluids enriched in liquid $\mathrm{CO}_{2}$ (Pineau and others, 1981) and possibly associated with an immiscible brine component (Sisson and others, 1981). The lower continental crust appears unlikely to support the presence of a vapor phase containing significant concentrations of methane. Fluid inclusions in many minerals in granulites are commonly rich in $\mathrm{CO}_{2}$ and $\mathrm{N}_{2}$ with rare $\mathrm{CH}_{4}$ (Touret, 1986), thus an oxidizing environment is indicated in the lower crust. Carbon dioxide inclusions in Archean granulites in southern India contain mantle-derived helium indicative of an oxidizing environment in the ancient upper mantle and lower crust (Dunai and others, 1992). These and further data cited by Valley and Lamb (1986) indicate that metamorphic rocks from the lower crust are oxidized and could not equilibrate with methanerich fluids.

Calculations of the oxidation state of the lower continental crust using mineral assemblages are uncommon. Glassley (1982) estimates that the oxygen fugacity, determined by the biotite-muscovite-feldspar assemblage at $\mathrm{T}=700^{\circ} \mathrm{C}, \mathrm{P}=700 \mathrm{MPa}$, would result in coexisting fluids consisting dominantly of $\mathrm{CO}_{2}$ and $\mathrm{H}_{2} \mathrm{O}$. We therefore conclude that the lower crust, like the upper mantle, could act as a redox potential barrier to the migration of any reducing gases from the lower mantle.

\section{VAPOR-PHASE TRANSPORT FROM BASEMENT ROCKS INTO SEDIMENTARY BASINS}

Gases from deep sources could also migrate along pores and fractures from the upper mantle into continental and oceanic crust, without being transported in and exsolved from a melt. Small quantities of reducing gases such as methane, hydrogen, and carbon monoxide would probably be oxidized in the upper mantle to $\mathrm{CO}_{2}+\mathrm{H}_{2} \mathrm{O}$ before reaching the lower crust. Below $800^{\circ} \mathrm{C}$, any carbon monoxide would disproportionate into graphite+carbon dioxide. Graphite films observed in gneisses from the lower crust (for example, see Mareschal and others, 1992) might be a relic of carbon monoxide infiltration.

The evidence for infiltration of methane or its precursor gases from the mantle is generally lacking. Gold (1987) contended that the migration of mantle gases into the shallow crust is sufficiently rapid that chemical interactions between the invading gases and the mantle and crustal rocks do not occur. Green and others (1987) and Taylor and Green (1989) have also suggested that the persistent upward migration along the fracture zones in the lithosphere would eventually overwhelm locally oxidizing conditions and permit the accumulation of methane in 
continental crust. Unfortunately, there is no field evidence in support of such transport processes. Indeed, the evidence for any form of subsolidus degassing from the upper mantle is tenuous and conjectural. Estimates have yet to be made of rates of reactions between reduced gases and mantle or crustal rocks with a higher oxidation state. It is therefore impossible at this stage to confirm or deny the slow migration of reducing gases from the mantle without developing alternative lines of evidence. It would be of great scientific interest if researchers using current diagnostic methods in isotope chemistry could find a single case that unequivocally demonstrated the release of deep-mantle reducing gases.

A key argument advanced by Gold (for example, see Gold, 1987; Gold and Held, 1987) for the abiogenic origin of oil and gas deposits is that methane from the mantle has migrated upward through rocks of the continental lithosphere and penetrated into shallow crustal oil and gas traps. Because this argument is critical to Gold's hypothesis, it is worth examining the evidence for vapor transport from the underlying crust into oil and gas reservoirs.

In several natural-gas fields, as in the Panhandle and Hugoton fields of Texas and Kansas (Pierce and others, 1964; Gold, 1987; Gold and Held, 1987), in Chinese gas fields (Xu and others, 1982 1990, 1991), in gas fields of Alberta (Hiyagon and Kennedy, 1992), and in the Four Corners Region of Arizona, Colorado, New Mexico, and Utah (Picard, 1960, 1962; Pohlmann, 1967), a strong correlation is observed between helium and nitrogen contents. These correlations are probably the result of mixing between gases from different sources and with different compositions. Although the correlation is commonly quite uniform within a given field and occasionally even extends to adjacent fields, the correlation coefficient can vary considerably. Usually, a field with a high helium content is also high in nitrogen, although the converse is not necessarily the case (Jenden and others, 1988b). The helium and nitrogen concentrations in some of above-cited fields are high, with helium attaining more than 8 percent, and nitrogen more than 90 percent.

Several lines of reasoning suggest that the helium and nitrogen originate either in sedimentary formations or in basement rocks at greater depths than the formations containing the oil or gas reservoir. Pierce and others (1964) noted that the quantities of helium and argon present in the Panhandle and Hugoton fields is so great that they could not have been derived from the uranium, thorium, and potassium in the reservoir host rocks. In United States gas fields, and in an undisclosed oil- and gas-producing region of southwest China, Tongish (1980) and $\mathrm{Xu}$ and others (1982), respectively, showed that both the helium and ${ }^{40} \mathrm{Ar}$ concentrations are linearly correlated with the nitrogen concentration. Although $\mathrm{Xu}$ and others (1982) considered that uranium associated with organic matter in the sediments could have caused the radiolytic decomposition of amine functional groups and thereby explain a heliumnitrogen correlation, this argument could not explain the linear correlation of nitrogen with ${ }^{40} \mathrm{Ar}$. Furthermore, in conformity with comments by Pierce and others (1964) concerning the Panhandle and Hugoton fields, $\mathrm{Xu}$ and others (1982) argued that the accumulation of helium and ${ }^{40} \mathrm{Ar}$ indicates an age far greater than that of the enclosing Permian sediments. Gold (1987) also concluded that, although some of the nitrogen in the Panhandle and Hugoton fields is derived from the enclosing sediments, this nitrogen could be readily distinguished from the nitrogen associated with the helium because the minimum nitrogen concentration for any given helium concentration defines a sharp boundary to the field of data points in a heliumversus-nitrogen plot. Tongish (1980), in a comprehensive survey of helium occurrences in the United States, investigated the relationship between helium, nitrogen, carbon dioxide, and argon in gas wells. As expected, he found a generally positive correlation between helium, nitrogen, and argon, but a negative correlation between helium and carbon dioxide.

More direct evidence that some of the nitrogen (and accompanying helium) is derived from basement structures has been reported on several occasions. Pierce and others (1964) showed that the helium and nitrogen in the Texas Panhandle gas field appear to be discharging from deep-seated faults adjacent to the Amarillo Uplift. They concluded that the helium source, together with the natural-gas source beds, is located at depth in the Palo Duro Basin to the south. Jenden and others (1988b) cited Headlee (1962) and Beebe and Curtis (1968), who observed that the nitrogen content increases toward the basement in some gas-producing regions. Hiyagon and Kennedy (1992) also observed a similar phenomenon in Alberta gas fields. Maksimov and others (1976) argued in support of a deepseated origin for nitrogen gas accumulations underlying the impermeable Zechstein salt in the Rotliegende of Germany and Poland. The nitrogen concentration increases adjacent to tectonic zones or ancient lineaments.

Dobbin (1935) and Picard (1962) noted that the helium content of gases increases with depth in the wells and with proximity to the underlying Precambrian crystalline basement rocks. This evidence suggests the helium-rich gases are derived from the basement rocks and migrate upward into the overlying sedimentary rocks.

Evidence that mantle volatiles have penetrated sedimentary basins is provided by ${ }^{3} \mathrm{He} /{ }^{4} \mathrm{He}$ ratios in natural gases drawn from structural traps. In many cases, these ratios indicate very clearly that helium with a mantle signature found in basins that are associated with basaltic magmatism, the younger the basin and the more recent the magmatism, the stronger the mantle signature. ${ }^{3} \mathrm{He} /{ }^{4} \mathrm{He}$ signatures are especially strong in gas accumulations that have formed in and adjacent to continental rifts, as in the Rhine Graben (Hooker and others, 1985; Oxburgh and others 
1986; Griesshaber and others, 1992), adjacent to the Dead Sea in Israel (Bosch and others, 1989), and associated with the Cathaysian rift zone in eastern China (Xu and others, $1990,1991)$. In older basins, where volcanic activity took place early in the history of basinal subsidence, the mantle helium signature is weaker. In many basins where there is no magmatic activity, there is also no mantle-derived helium The association of mantle helium signatures with mafic magmatism led Oxburgh and others (1986) to speculate that the only mechanism by which gas volatile transfer from the mantle could occur is through magma transport. However, recent studies, especially those by Hiyagon and Kennedy (1992) and Kennedy and others (1992), indicate that some basins with no evidence of basaltic magmatism nevertheless contain helium with elevated concentrations of ${ }^{3} \mathrm{He}$. In the Alberta gas fields, this anomalous helium is not associated with the nitrogen and helium from the basement, but is found higher in the sedimentary sequence. The helium accompanying the nitrogen is entirely radiogenic. The origin of the anomalous helium is currently unknown, but its location in the field shows that it cannot have been derived directly from the mantle by way of the lower crust.

The preceding evidence indicates that the natural gas in sedimentary basins could not have been derived from the mantle by advective transport through the underlying basement rocks. Because the gases emerging from the basement contain no ${ }^{3} \mathrm{He}$ mantle signature and have mixed with the natural gas, the natural gas must be derived independently from source rocks in the sedimentary basin.

Because evidence supports the release of $\mathrm{CO}_{2}$ from the upper mantle through mantle magmatism, it is expected that mantle-derived $\mathrm{CO}_{2}$ in sedimentary basins would contain mantle-derived helium. The $\mathrm{CO}_{2}{ }^{3} \mathrm{He}$ ratio in the mantle gases has been determined to be about $2 \times 10^{9}$ (Marty and Jambon, 1987; see also Wainger, 1988; Marty, 1989). The ${ }^{3} \mathrm{He}$ concentration in sedimentary basins can be correlated in favorable circumstances with the quantity of mantle $\mathrm{CO}_{2}$ carrier gas, particularly if many samples are taken that reveal mixing of $\mathrm{CO}_{2}$ with differing $\delta^{13} \mathrm{C}$ values (Poreda and others, 1986; Taylor, 1986; Matthews and others, 1987; O'Nions and Oxburgh, 1988; Griesshaber and others, 1992). It is doubtful, however, that $\delta^{13} \mathrm{C}$ values in $\mathrm{CO}_{2}$ alone would unambiguously reveal a mantle signature in oil or gas fields, because of the overwhelming contribution of $\mathrm{CO}_{2}$ from the decay of kerogen and other organic material trapped in the sediments during deposition, and the fixation of $\mathrm{CO}_{2}$ in secondary carbonates. It would be far more difficult to identify methane from the mantle in a sedimentary basin, given the expected very low concentrations of this gas in a vapor phase from the mantle. Furthermore, thermogenic methane would swamp any mantle ${ }^{13} \mathrm{C}$ or D signature from mantle-derived methane (see Jenden and others, this volume). Hence the mantle $\mathrm{CH}_{4} /{ }^{3} \mathrm{He}$ ratio could be used only to set an upper limit to the concentration of mantle methane in a sedimentary basin.
Rare-gas isotopic signatures in sedimentary basins provide no evidence that mantle helium (or other rare gases) were carried by liquid or vapor hydrocarbons, although there is strong evidence that mixing between atmospheric crustal and mantle components occurred in ground water prior to gas-phase separation and fractionation (Ballentine, 1991). No correlation exists between the mantle helium signature and the quantity of gas or petroleum present in an oil or gas field. Furthermore, carbon isotopic data and mass spectrographic data of $\mathrm{C}_{n}$ distribution in associated oils in oil fields suggest biogenic or thermogenic origins (Whiticar, 1990), and potential sedimentary source rocks can usually be identified. The weight of evidence is therefore against a mantle origin for hydrocarbons in sedimentary basins whether or not a mantle helium signature is present.

The ratios of $\mathrm{CH}_{4} / 3 \mathrm{He}$ in magmatic gases range from approximately $10^{6}$ to possibly as high as $10^{8}$, depending on the redox potential of the magma and the degassing temperature (Charlou and others, 1991). Some CO in the magma could also be eventually converted with $\mathrm{H}_{2}$ to $\mathrm{CH}_{4}$ by the subsolidus Fischer-Tropsch reaction (see section "Ocean Spreading Centers," below). Given the assumption that vapor-component transport into the crust occurs primarily through magmatism rather than advective vapor-phase flow, this ratio can be used to calculate the approximate concentration of mantle-derived methane in natural-gas fields. Two examples from the literature suffice to show that even when ${ }^{3} \mathrm{He} /{ }^{4} \mathrm{He}$ ratios are very high, the concentration of magmatic, that is, mantle-derived, methane is very small.

The first example is the Green Tuffs region of northern Japan, (Sakata and others, 1986; 1989; Wakita and others, 1990). The Green Tuff rocks are Miocene and Pleistocene sediments interstratified with volcaniclastic rocks, breccias, agglomerates, and lavas accumulated in backarc basins in and adjacent to the Japan Sea. The tuffaceous rocks have been extensively altered by diagenetic and hydrothermal activity. Some of the associated organicrich sedimentary rocks in the Green Tuff formations are excellent, thermally mature petroleum source rocks. Natural gas, primarily methane, has accumulated in the porous volcaniclastic reservoirs. ${ }^{3} \mathrm{He} /{ }^{4} \mathrm{He}$ ratios in these gases are very high, as would be expected, ranging from 0.10 to 6.7 $\mathrm{R}_{\mathrm{A}}$ (Wakita and others, 1990). Sakata and others (1989) calculated the concentration of mantle-derived methane using a $\mathrm{CH}_{4} /{ }^{3} \mathrm{He}$ ratio of $1 \times 10^{6}$ and assuming that the magmatic ${ }^{3} \mathrm{He} /{ }^{4} \mathrm{He}$ ratio is $>10.9 \times 10^{-6}$. They considered the magmatic $\mathrm{CH}_{4}$ fraction in the natural gas to be $\leq 10^{-3}$. Even allowing for $\mathrm{CH}_{4}{ }^{3} \mathrm{He}$ of $10^{8}$, the concentration of mantle-derived methane does not exceed 10 percent. Most of the gases were mixtures containing far less than the calculated upper limit of magmatic methane.

The second example is gas fields of the Sacramento Valley, California (Poreda and others, 1986; Jenden and others, 1988a), where a major accumulation of Mesozoic and late Tertiary sediments, up to $5,000 \mathrm{~m}$ thick, formed in 
a forearc basin. Dacitic magmas intruded these sediments in the Pliocene and Pleistocene time. Except in two instances, the intrusions failed to break through to the surface, but they did create domal structures in the overlying sediments, into which thermogenic gas migrated. Not all of the gas fields, however, have obvious or inferred associations with the intrusives. ${ }^{3} \mathrm{He} /{ }^{4} \mathrm{He}$ ratios in most of the fields are high, ranging from 0.11 to $2.75 \mathrm{R}_{\mathrm{A}}$, indicating that between 1 and 34 percent of the helium is derived from the mantle. The $\mathrm{CH}_{4}{ }^{3} \mathrm{He}$ ratios range from $2 \times 10^{9}$ to $10^{12}$, (Poreda and others, 1986). Hence the magmatic methane content is less than 0.05 and 5 percent, depending on the presumed ${ }^{3} \mathrm{He} /{ }^{4} \mathrm{He}$ ratios.

Similar arguments can be applied to gas fields in other areas. In all cases, the quantity of magmatic or mantlederived methane is very small. Thus the concentration of mantle methane in natural-gas fields is inconsequential. It should be noted in passing that Sakata and others (1986, 1989) concluded that the abiogenic methane content in Green Tuff gases is considerably less than 0.1 percent. In contrast, Wakita and others (1990) assumed that magmatic $\mathrm{CO}_{2}$ is reduced to methane during hydrothermal diagenesis and alteration of the Green Tuff rocks, a plausible mechanism for crustal generation of. abiogenic methane from mantle-derived igneous rocks.

\section{ABIOGENIC HYDROGEN AND METHANE FORMATION IN THE CRUST}

Abiogenic hydrogen and methane are produced in the Earth's crust through a variety of inorganic processes, of which hydrolysis is the most important. Because hydrolysis produces hydrogen in the absence of carbon, we consider hydrogen formation first. Afterwards, we consider the thermodynamic relationships between hydrogen and methane in the natural environment, and the conditions under which methane would form in preference to hydrogen in the crust. Finally, we examine field occurrences of these gases.

\section{HYDROGEN GENERATION}

There are at least six possible processes in which crustal hydrogen is generated: (1) reaction between dissolved gases in the system C-H-O-S in magmas, especially in those with basaltic affinities; (2) decomposition of methane to carbon (graphite) and hydrogen at $\mathrm{T} \geq 600^{\circ} \mathrm{C}$; (3) reaction between $\mathrm{CO}_{2}, \mathrm{H}_{2} \mathrm{O}$, and $\mathrm{CH}_{4}$ at elevated temperatures in vapors; (4) radiolysis of water by radioactive isotopes of uranium, thorium, and their daughters, and potassium; (5) cataclasis of silicates under stress in the presence of water; and (6) hydrolysis by ferrous minerals in mafic and ultramafic rocks.
Gas-phase equilibrium in magmas-process (1), has been discussed in a preceding section. Hydrogen produced through this process is a minor component and has no economic significance. Processes (2) and (3), represented by reactions 16 and 1, respectively, are kinetically favored at elevated temperatures and relatively low pressures in the Earth's crust. In figure 5, the reaction

$$
\mathrm{CH}_{4}=\mathrm{C}+2 \mathrm{H}_{2}
$$

shifts to the right near $600^{\circ} \mathrm{C}$, suggesting that local reducing conditions generated, for example under hydrothermal conditions near magma chambers at oceanic spreading centers, could liberate hydrogen and leave residual graphite.

Process (3), the well-known Fischer-Tropsch reaction, reaction 1 , can generate methane below $600^{\circ} \mathrm{C}$ depending on the fugacity of hydrogen. How fast this reaction proceeds in the natural environment and how it is affected by natural catalysts is currently unknown. We will assume as a working hypothesis that in favorable environments, equilibrium between the participating species is achieved, but further study of this process under natural conditions is needed.

\section{WATER RADIOLYSIS}

Process (4) is of particular interest because field evidence suggests it could be significant in facilitating the formation and maturation of oil and natural gas. The radiolysis of water proceeds mainly through the following reactions:

$$
\begin{gathered}
\mathrm{H}_{2} \mathrm{O}+(\alpha, \gamma)=\mathrm{H} \cdot+\mathrm{OH} \cdot \\
2 \mathrm{OH} \cdot=\mathrm{HOOH} \\
2 \mathrm{HOOH}=2 \mathrm{H}_{2} \mathrm{O}+\mathrm{O}_{2} \\
2 \mathrm{H} \cdot=\mathrm{H}_{2}
\end{gathered}
$$

where "." denotes a free radical.

The source of the radioactivity is primarily uranium and thorium and their daughters. According to Dubessy and others (1988), the dose of absorbed $\gamma$ rays is only 0.02 times the dose of absorbed $\alpha$ particles in a given time. Therefore the primary cause of water radiolysis is $\alpha$ particle radiation. Also, according to Spinks and Woods (1976) (cited in Dubessy and others, 1988), a single 1-megaelectronvolt $(\mathrm{MeV}) \alpha$-particle can ionize $10^{5}$ molecules as it loses energy.

The intermediate oxidation products of radiolysis are quite reactive in contrast to hydrogen, which, in shallow crustal environments, is almost inert. Thus, $\mathrm{HOOH}$ would oxidize other species-for example, $\mathrm{HS}^{-}$to sulfate, or $\mathrm{Fe}^{\mathrm{II}}$ to $\mathrm{Fe}^{\mathrm{III}}$ in surrounding iron-bearing minerals-or form 
unstable organic peroxides in organic-rich sediments. If supersaturation with respect to anhydrite or celestite occurred, these minerals would precipitate in the vicinity.

Voytov and others (1967) studied the distribution of gaseous species in formation waters in Triassic and Permian rocks penetrated by a 6,000-m-deep well in an interdomal trough of the Caspian depression. They found that dissolved gases were predominantly $\mathrm{CO}_{2}$ and $\mathrm{H}_{2}$. But in intervals characterized by sharp increases of undersaturated $\mathrm{C}_{2}-\mathrm{C}_{4}$ alkenes (up to 15 percent of total hydrocarbon gases), there was a clear deficit of hydrogen. Conversely, in the intervals with excess free hydrogen, the alkene concentration fell by several orders of magnitude. A correlation between the concentrations of the $\mathrm{C}_{2}-$ $\mathrm{C}_{6}$ alkenes and their saturated homologs was also found. The explanation of these observations is that hydrogen participates in the saturation of alkene intermediates during thermogenesis. Voytov and others (1967) attributed the origin of the hydrogen to hydrolysis due to radiation from nuclear transformations, although no supporting evidence was given.

The foregoing observations are consistent with the conclusions of Eisma and Jurg (1969) and Weres and others (1988) that the low-temperature hydrous pyrolysis of organic matter in sediments may be explained in terms of free-radical chain reactions in which heavy hydrocarbons crack to produce free radicals. These reactions permit radiolytic hydrogen free radicals to saturate alkene intermediates and form light alkanes.

Vovk (1987) contended that water radiolysis is a contributing factor to the increasing salinity of ground waters with depth, as is typically observed in igneous and metamorphic rocks of shield areas (for example, see Frape and others, 1984; Fritz and Frape, 1987; and Nurmi and others, 1988). The release of hydrogen is coupled with concurrent oxidation of $\mathrm{Fe}^{\mathrm{II}}$ in host rock minerals and reduced species in ground water (for example, $\mathrm{HS}^{-}$and $\mathrm{NH}_{4}{ }^{+}$). The hydrogen eventually escapes to the Earth's surface or is trapped in impermeable structures in overlying sedimentary strata, where it is available to react with and saturate hydrocarbons. Implicit in this process is the assumption that hydrogen is relatively unreactive in comparison with oxygen (or hydrogen peroxide). One would also expect a qualitative if not quantitative relation between ${ }^{4} \mathrm{He}$ or ${ }^{40} \mathrm{Ar}$ and hydrogen. A crude correlation does exist in some cases, such as in the Gravberg deep hole in Sweden. Also relevant to this issue is the close correlation of $\mathrm{He}$ with nitrogen observed in several sedimentary basins, as noted earlier.

Vovk (1987) conducted experiments in which he irradiated various water-saturated rocks and extrapolated the resulting observations to geologic time scales. When using conservative assumptions, he showed that very high salinities could be achieved in $3.5 \times 10^{9}$ years. This figure is consistent with estimates by Dubessy and others (1988). Radiolysis probably contributes only moderately to the concentration of dissolved salts. Other processes such as secondary alteration, the breakdown of fluid inclusions, and desorption of chloride salts from silicate minerals (Neil and Apps, 1981) could also contribute.

\section{CATACLASIS}

Hydrolysis can be induced during the fracturing of silicate minerals (Sugisaki and others, 1983):

$$
\begin{gathered}
\equiv \mathrm{Si}-\mathrm{O}-\mathrm{Si} \equiv=\equiv \mathrm{Si}+\cdot \mathrm{O}-\mathrm{Si}= \\
\equiv \mathrm{Si} \cdot+\mathrm{H}_{2} \mathrm{O}=\equiv \mathrm{Si}-\mathrm{OH}+\mathrm{H} \cdot \\
\equiv \mathrm{Si}-\mathrm{O} \cdot+\mathrm{H}_{2} \mathrm{O}=\equiv \mathrm{Si}-\mathrm{OH}+\mathrm{OH} \cdot \\
2 \mathrm{H} \cdot=\mathrm{H}_{2} \\
2 \mathrm{OH} \cdot=\mathrm{HOOH}
\end{gathered}
$$

Silicate cataclasis in rocks occurs wherever host rocks are subject to strain in excess of that which permits stress relief through stress corrosion or intracrystalline elastic or plastic deformation. Cataclastic deformation is both pressure and temperature dependent and is normally encountered at temperatures and pressures characteristic of the upper $10 \mathrm{~km}$ of the Earth's crust, that is, $\mathrm{T}=0$ to $300^{\circ} \mathrm{C}$ and $\mathrm{P}=0$ to $350 \mathrm{MPa}$. Although cataclasis is normally associated with faulting, it occurs in all brittle rocks, where it is manifested by extensive joints and microfractures. Sugisaki and others (1983) demonstrated in the laboratory that the grinding of silicates under water releases hydrogen. Giardini and others (1976) stressed circular rock discs of granite and gneiss at progressively higher pressures until rock failure, while measuring the gases evolved. They showed that both the total volume of gases released and the percentage of hydrogen (and methane) increased dramatically with departure from linearity of the stressstrain curve before rock failure around 470 to $480 \mathrm{MPa}$. About 0.5 and $1.08 \mathrm{~cm}^{3}$ of gas at STP per gram of granite and gneiss, respectively, was released between $400 \mathrm{MPa}$ and failure. These data, though limited in scope, provide some qualitative guidance as to the potential magnitude of the phenomenon in nature.

The quantity and rate of hydrogen generation by cataclasis in sedimentary basins during compaction and subsidence has not been investigated, but is probably small. Hydrogen emissions along faults are quite common (Sugisaki and others, 1983; Sato and others, 1985, 1986), but it has not been demonstrated that such emissions are due to cataclasis. It should be mentioned that drilling is itself cataclastic and liberates hydrogen both from comminution of the rock penetrated and through wear and tear of the drill bit (MacDonald, 1988). 


\section{HYDROLYSIS BY FERROUS MINERALS}

With falling temperature, $\mathrm{Fe}^{\mathrm{III}}$ becomes progressively more stable with respect to $\mathrm{Fe}^{\mathrm{II}}$ at lower oxygen fugacities (see line labeled QFM on fig. 5). The oxidation of $\mathrm{Fe}^{\mathrm{II}}$ must be coupled with the reduction of another species (such as $\mathrm{H}_{2} \mathrm{O}$ to $\mathrm{H}_{2}, \mathrm{CO}_{2}$ to $\mathrm{C}$, or $\mathrm{C}$ to $\mathrm{CH}_{4}$.)

There are two broad classes of reactions in which Febearing minerals participate and hydrogen and hydrocarbons are generated: (1) closed-system reactions in which the local chemical system bulk composition is fixed and there is no loss or gain of chemical components, and (2) open-system reactions in which chemical components are exchanged with the surrounding environment. Almost all natural systems are to a certain extent leaky, but it is convenient to adopt this classification as a basis for comparing field examples.

Closed systems are represented by crystallizing mafic magma bodies in which a residual exsolved aqueous or $\mathrm{CO}_{2}$-CO-rich phase reacts with the iron-bearing minerals at temperatures both above and below the solidus. The temperature range represented by both super- and subsolidus reactions extends from over $1,000^{\circ} \mathrm{C}$ down to ambient temperature. Deuteric reactions refer specifically to those reactions that take place within an igneous rock during cooling below the solidus. They are often constrained by slow reaction rates, especially below $250^{\circ} \mathrm{C}$, by the rapidity with which a cooling igneous body loses heat to its surroundings, and by exhaustion of accessible reactants such as water.

A corollary is the process of prograde metamorphism of sedimentary or igneous rocks. During this process, minerals dehydrate and liberate water, carbonates react with silica and release carbon dioxide, and minerals containing $\mathrm{Fe}^{\mathrm{III}}$ are reduced by hydrogen, methane, or ammonia. The process can be reversed during retrograde metamorphism. The relevant open systems are those in which water penetrates mafic and ultramafic rock masses in various crustal settings. This class has a greater potential for generating substantial volumes of hydrogen and methane.

Essentially, all mafic and ultramafic rocks in the crust are derived from the upper mantle, either as a result of partial fusion, or through tectonic processes resulting in physical translocation of a depleted mantle. Such rocks contain between 5 and 15 weight percent of the $\mathrm{FeO}$ and minor concentrations of $\mathrm{Fe}_{2} \mathrm{O}_{3}$ in olivine and pyroxene. Referring to figure 5, it can be seen that the QFM buffer intersects the water decomposition curve at $25^{\circ} \mathrm{C}$.

Summing both reactions leads to the following:

$$
3 \mathrm{Fe}_{2} \mathrm{SiO}_{4}+2 \mathrm{H}_{2} \mathrm{O}=3 \mathrm{SiO}_{2}+2 \mathrm{Fe}_{3} \mathrm{O}_{4}+2 \mathrm{H}_{2} \text {. }
$$

In the absence of carbon, hydrogen is generated through the decomposition of fayalite, and the creation of quartz and magnetite.
In a natural system, a basalt or peridotite containing olivine and pyroxene will alter hydrothermally, and the $\mathrm{FeO}$ component will react at somewhat higher temperatures than would fayalite at the QFM buffer. Evidence suggests that greenschist formation occurs at 350 to $400^{\circ} \mathrm{C}$ (Ernst, 1990). Peridotites alter at temperatures ranging from less than $100^{\circ} \mathrm{C}$ (Wenner and Taylor, 1971) to an upper limit between 500 and $600^{\circ} \mathrm{C}$, above which olivine is stable (Bowen and Tuttle, 1949; Scarfe and Wyllie, 1967). Serpentinization of ultramafic rocks and propylitization of mafic rocks will induce strongly reducing conditions in which water is reduced to hydrogen as $\mathrm{Fe}^{\mathrm{II}}$ is oxidized to $\mathrm{Fe}^{\mathrm{III}}$. There is ample field evidence that hydrolysis by $\mathrm{Fe}^{\mathrm{II}}$ is the principal mechanism through which energy gases are generated abiotically in the Earth's crust.

\section{RELATIONSHIP OF METHANE TO HYDROGEN}

Hydrolytic hydrogen can be consumed through reactions with other components. Of these, carbon is particularly relevant in regions where hydrogen is unstable with respect to graphite or methane, that is, where reactions 1 and 16 would shift to the left, hydrogen would be consumed and methane or methane+water would be produced. As noted previously, hydrogen is also consumed during the thermogenesis of organic matter. Experimental evidence also shows that hydrocarbons can be generated during grinding and cataclasis (Melchanov, 1967). Where mafic minerals induce hydrolysis, similar processes of reduction involving $\mathrm{CO}_{2}$, graphite, and methane operate. Referring again to figure 5, we see that the QFM buffer intersects the graphite- $\mathrm{CO}_{2}$ and $\mathrm{CH}_{4}$-graphite $+\mathrm{H}_{2} \mathrm{O}$ (vapor) boundaries at about $250^{\circ} \mathrm{C}$, where carbon dioxide could be reduced to graphite, and graphite to methane in the presence of water, thus:

$$
\begin{gathered}
\mathrm{CO}_{2}+3 \mathrm{Fe}_{2} \mathrm{SiO}_{4}=3 \mathrm{SiO}_{2}+2 \mathrm{Fe}_{3} \mathrm{O}_{4}+\mathrm{C} \\
\mathrm{C}+2 \mathrm{H}_{2} \mathrm{O}+3 \mathrm{Fe}_{2} \mathrm{SiO}_{4}=3 \mathrm{SiO}_{2}+2 \mathrm{Fe}_{3} \mathrm{O}_{4}+\mathrm{CH}_{4}
\end{gathered}
$$

In figure 6 is shown the calculated $\log f_{\mathrm{CH}_{4}} / f_{\mathrm{H}_{2}}$ and $\log$ $f_{\mathrm{CH}_{4}}$ plotted as a function of temperature between 0 and $300^{\circ} \mathrm{C}$ for several hypothetical secondary mineral assemblages that might form during the hydrothermal alteration of mafic and ultramafic rocks. These assemblages represent the IM, QFM, and HM redox buffers with the addition of carbon, either as graphite or as calcite. It is clear that the region between the QFM-calcite and IM-graphite assemblages is where most of the observed occurrences of abiogenic hydrogen and methane occurrences fall.

Under relatively oxidizing crustal conditions, defined by the QFM-calcite assemblage, hydrogen predominates over methane by between seven and ten orders of magnitude, but the hydrogen partial pressure is low, ranging 


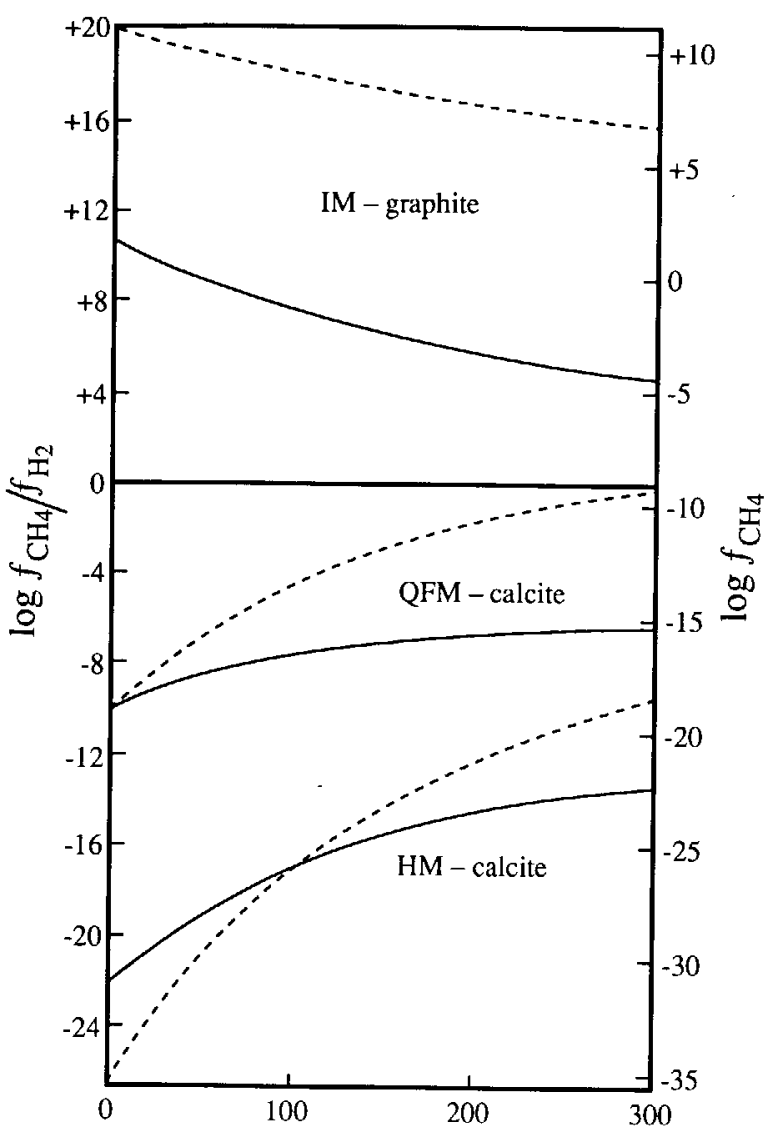

Temperature, in degrees Celsius

Figure 6. $\log f_{\mathrm{CH}_{4}} / f_{\mathrm{H}_{2}}$ (solid lines) and $\log f_{\mathrm{CH}_{4}}$ (dashed lines) as functions of temperature for various redox buffers with either calcite or graphite. HM, hematite-magnetite; IM, iron-magnetite; QFM, fayalite + quartz-magnetite.

from $10^{-10.3}$ to $10^{-3.9} \mathrm{MPa}$ between 0 and $300^{\circ} \mathrm{C}$. Thus, typical water-saturated granitic rocks would not be expected to yield methane, and only minor quantities of hydrogen would be present.

The IM-graphite assemblage represents extremely reducing conditions experienced in hydrothermally altered ultramafic rocks. In the presence of liquid water, very high $\mathrm{CH}_{4}$ and $\mathrm{H}_{2}$ partial pressures would be generated. Overburden pressures would be exceeded, and the gases would be released during rock failure. In nature, such high gas pressures would not be sustainable and would, in any case, probably be limited by the availability of water.

\section{FIELD EVIDENCE FOR HYDROLOYSIS BY FERROUS MINERALS}

\section{CLOSED SYSTEMS}

Drill holes penetrating mafic igneous rocks and some metamorphic rocks sometimes encounter gas pockets or fractures yielding methane and other heavier hydrocarbons. Such rocks show little evidence of hydrothermal alteration or metasomatism. Field evidence suggests that the reactions leading to the generation of methane occurred within the rock in the absence of meteoric water. In this section we discuss the environments in these rocks that lead to the observed occurrences of abiogenic hydrocarbons.

\section{AUTOGENOUS GENERATION OF METHANE DURING THE COOLING OF AGPAITIC MAGMAS}

Several large intrusive complexes of agpaitic alkaline rocks contain natural gas in fluid inclusions in the rockforming minerals, and a variety of bitumens and asphaltenes in pores and fractures. Petersil'ye (1962) estimated that the closed pores alone in one such complex, the Khibiny massif of the Kola Peninsula in Russia, contain $7 \times 10^{8}$ $\mathrm{m}^{3}$ of hydrocarbon gases, predominantly methane, whereas the open pores and fractures contain two to three times more mass in solid hydrocarbons. The methane content in these rocks ranges from 8 to $283 \mathrm{~cm}^{3}$ per kilogram of rock $\left(\mathrm{cm}^{3} \mathrm{~kg}^{-1}\right)$ and averages $28.5 \mathrm{~cm}^{3} \mathrm{~kg}^{-1}$. Agpaitic intrusions are relatively rare, however, and therefore the total amount of recoverable hydrocarbons is insignificant when compared with that of thermogenic gas reservoirs. Although they have very limited economic potential, these igneous rocks contain enough organic matter to raise questions regarding their genesis.

Several alternative theories have been proposed to account for the origin of the hydrocarbons (for example, see discussions by Petersil'ye, 1962; Gol'dberg and Chernikov, 1969; Gold, 1987). Isotopic and fluid-inclusion studies, however, overwhelmingly support the interpretation that the hydrocarbons in the fluid inclusions evolved during crystallization of the magma and during subsequent deuteric alteration (Galimov and Petersil'ye, 1967; Petersil'ye and Pripachkin, 1979; Konnerup-Madsen and others, 1979; Konnerup-Madsen and Rose-Hansen, 1982; and Welhan, 1987). No significant exchange of components with the country rocks is anywhere indicated in agpaitic intrusions of the Kola Peninsula. Yet the penetration of agpaitic intrusions by thermogenic hydrocarbons from adjacent sediments undoubtedly occurs, and cannot be discounted in all instances (for example, see Gol'dberg and Chernikov, 1969).

The crystallization temperatures for agpaitic melts range from about $1,100^{\circ} \mathrm{C}$ to below $450^{\circ} \mathrm{C}$ depending upon the volatile concentration. Petrologic and thermodynamic arguments, supported by melt-inclusion homogenization temperatures and field observations, show that the initial volatile content of these magmas must be quite low (Kogarko and Romanchev, 1977; Kogarko, 1987). Konnerup-Madsen and Rose-Hansen (1982) estimated that the $\mathrm{CO}_{2}$ content of the primary magma at llimaussaq, Greenland, could have been no more than 0.2 weight percent, a 
concentration that would have saturated the melt at total pressures of 200 to $300 \mathrm{MPa}$. Kogarko and Romanchev (1977) and Kogarko (1987) believe that the partial pressure of $\mathrm{H}_{2} \mathrm{O}$ is only about 10 to $30 \mathrm{MPa}$ in such magmas, and that the water content in hyperalkaline melts approaches 1.5 weight percent, (Kogarko and Romanchev, 1977). The initial solidus must therefore be near the upper temperature limit for anhydrous melts.

Some agpaitic melts initially crystallize anhydrous minerals such as nepheline and potash feldspar, causing a progressive concentration of volatiles in the residual magma and a depression of the final solidus temperature. This depression of the solidus temperature permits a reequilibration of dissolved volatiles with precipitated phases, which cannot occur to the same extent in magmas with higher solidification temperatures. Of particular relevance is the interaction between $\mathrm{Fe}^{\mathrm{II}}$-bearing phases and the $\mathrm{H}_{2} \mathrm{O}$ and $\mathrm{CO}_{2}$ components; in such interactions, for example, magnetite could oxidize to maghemite:

$$
8 \mathrm{Fe}_{3} \mathrm{O}_{4}+\mathrm{CO}_{2}+2 \mathrm{H}_{2} \mathrm{O}=12 \mathrm{Fe}_{2} \mathrm{O}_{3}+\mathrm{CH}_{4}
$$

After crystallization of the magma, iron-bearing minerals undoubtedly continue to react with residual fluids to form more methane and hydrogen. In homblendes, ferrous iron might oxidize to ferric iron while the hydroxyl groups lose hydrogen. Pyroxenes are probably unaffected.

The changing vapor-phase composition and hydrocarbon formation during the cooling history of an agpaitic intrusion is recorded in fluid inclusions and vein fillings. An abundant literature details petrology and fluid-inclusion history in several of these intrusions, for example, at Ilimaussaq (Galimov and Petersil'ye, 1967; Petersil'ye and Sorensen, 1970; Petersil'ye and Pripachkin, 1979; Konnerup-Madsen and others, 1979, 1988; Konnerup-Madsen and Rose-Hansen, 1982), at Khibiny (Petersil'ye, 1962; Galimov and Petersil'ye, 1967; Kravtsov and others, 1967; Zezin and Sokolova, 1967; Petersil'ye and Pripachkin, 1979; Ikorskiy and Shugurova, 1975), and at Lovozero, Russia (Galimov and Petersil'ye, 1967; Kogarko and Romanchev, 1977).

Several generations of fluid inclusions are found in agpaitic intrusions (Kogarko and Romanchev, 1977; Konnerup-Madsen and others, 1979; Konnerup-Madsen and Rose-Hansen, 1982). At Ilimaussaq, primary fluid inclusions in nepheline, the first mineral to crystallize from the melt (Kogarko and Romanchev, 1977), contain more than 60 percent $\mathrm{CO}_{2}$, nearly 30 percent nitrogen, and nearly 5 percent CO (Sobolev and others, 1970). Similar primary fluid inclusions containing 88 to 54 percent $\mathrm{CO}_{2}$ were also observed elsewhere in nepheline by Sobolev and others (1974). These inclusions were entrapped at a temperature of approximately $1,000^{\circ} \mathrm{C}$. According to Konnerup-Madsen and others (1979), a highly saline aqueous phase was also entrapped as primary inclusions in minerals between about 500 and $1,000^{\circ} \mathrm{C}$. Postdating the brine inclusions is a more abundant third stage of gas-phase inclusions, which are found in healed fractures of the rock-forming minerals. The sequence of fluid-inclusion types indicates successive supersaturation of the magma during crystallization with a $\mathrm{CO}_{2}$-rich gas, a saline brine, and a methanerich gas.

Konnerup-Madsen and others (1979) determined that the temperature range of hydrocarbon fluid-inclusion entrapment was between 800 and $500^{\circ} \mathrm{C}$ at pressures between 100 and $140 \mathrm{MPa}$. The temperature range is consistent with that required for complete crystallization (Larsen, 1976). But independent thermodynamic calculations by Gerlach (1980) on Nyiragongo lava gases and by Kogarko (1987) suggest that these inclusions must have formed below about $600^{\circ} \mathrm{C}$ to account for the high methane content.

According to Kogarko and Romanchev (1977), gas and gas-liquid inclusions in nepheline and apatite from the Lovozero and Khibiny intrusions were secondary and formed between 200 and $400^{\circ} \mathrm{C}$. At Ilimaussaq, a few other inclusions containing aqueous liquid and gas, and with a salinity less than 10 percent, homogenized at temperatures as low as $140^{\circ} \mathrm{C}$. The presence of these low-temperature fluid inclusions suggests that a residual aqueous phase might have been expelled from this igneous complex upon complete crystallization. It is evident, therefore, that the formation of hydrocarbons in agpaitic intrusions takes place over a wide range of temperatures and conditions, from $600^{\circ} \mathrm{C}$ under presolidification conditions to as low as $200^{\circ} \mathrm{C}$ under deuteric conditions.

Petersil'ye (1962) found variations in the gas content of different igneous rocks of the Khibiny massif, which correlated with variations in their aluminum content. $\mathrm{He}$ attributed a catalytic effect to the aluminum in synthesizing the hydrocarbon gas. He also noted variations in the hydrocarbon content in individual minerals from pegmatoids in the massif. Konnerup-Madsen and others (1979) also found a variation in the total gas content of different minerals in naujaite from Ilimaussaq. In the latter case, the concentration decreased progressively according to the sequence of crystallization and ranged from approximately $1,000 \mathrm{~cm}^{3} \mathrm{~kg}^{-1}$ in sodalite to approximately $170 \mathrm{~cm}^{3} \mathrm{~kg}^{-1}$ in arfvedsonite. The gas composition was mainly $\mathrm{CH}_{4}$, but significant amounts of $\mathrm{C}_{2} \mathrm{H}_{6}$ (5-18 percent), $\mathrm{H}_{2}$ (4-34 percent), and nitrogen (4-25 percent) were also present. The concentration of helium, probably of radiogenic origin, ranged widely, from $<0.01$ to 2.8 percent. Very minor amounts of other hydrocarbons and $\mathrm{CO}_{2}$ were also present. No clearly discernible trend in gas-phase compositions can be correlated with the crystallization sequence. Noteworthy, however, were the relatively high $\mathrm{H}_{2}$ (16-34 percent), $\mathrm{C}_{2} \mathrm{H}_{6}$ (13-8 percent) contents and relatively low $\mathrm{CH}_{4}$ (43-49 percent) and $\mathrm{N}_{2}$ (4-8 percent) contents in eudialyte, a mineral known to host uranium and thorium. 
The distribution may be due to radiolysis of the trapped gas.

Although Konnerup-Madsen and others (1979) observed some of the gaseous fluid inclusions in contact with secondary exsolved microcrysts of aegirine $\left(\mathrm{NaFeSi}_{2} \mathrm{O}_{6}\right)$ in nepheline, fluid inclusions in sodalite and eudialyte are not in contact with iron-bearing minerals. Furthermore, Konnerup-Madsen and Rose-Hansen (1982) showed that regardless of the present fluid composition, the molar $\mathrm{H}: \mathrm{C}$ ratio in all fluid inclusions is relatively uniform at about 20:80, indicating that the initial hydrocarbon gas was nearly pure methane. Therefore the gaseous hydrocarbon inclusions may have remained closed, but reequilibration at lower temperatures was facilitated by radioactivity or $\mathrm{Fe}^{\text {Il }}$ catalysis in arfvedsonite.

Most of the analyzed hydrogen probably formed naturally. It is doubtful that much hydrogen was produced through grinding the minerals with steel balls to release the gases from fluid inclusions. Otherwise it would be difficult to explain the relative uniformity of the $\mathrm{C}: \mathrm{H}$ ratio observed in the gaseous fluid hydrocarbons. Petersil'ye (1962) believed that the source of hydrogen in methanerich gases in the Khibiny massif is due to reduction by $\mathrm{Fe}^{\mathrm{II}}$ in ferrous minerals, in accordance with Gerlach (1980). Kravtsov and others (1967), however, maintained that the hydrogen is the consequence of radiation-induced hydrolysis. Because agpaitic rocks often contain elevated concentrations of uranium and thorium, radiolysis may be a contributing factor, especially in the polymerizarion of hydrocarbons in veins and open pores and in the formation of bitumen and asphaltene.

A fully integrated study in which all aspects of the mineralogy and geochemistry of agpaitic rocks is evaluated has yet to be made. It is therefore not possible to weigh the relative contributions of $\mathrm{Fe}^{\mathrm{II}}$ hydrolysis and radiolysis in the evolution of the gas-phase composition during cooling, or the importance of catalysts in achieving thermodynamic equilibrium. Furthermore, the original water content of the parent magmas is not known with certainty, and there are no reports of water contents in the gaseous inclusions.

The most likely scenario is that consumption of $\mathrm{H}_{2} \mathrm{O}$ by reaction 42 and precipitation of hydrous minerals leads to undersaturation with respect to the brine phase. This undersaturation is followed by a shift in volatile content of the magma as $\mathrm{CH}_{4}$ forms at the expense of $\mathrm{CO}_{2}$ and $\mathrm{H}_{2} \mathrm{O}$. The shift raises the vapor immiscibility curve until it intersects the solidus curve of the residual magma, and causes the exsolution of a vapor-rich phase in the melt.

\section{COOLING OF LAYERED MAFIC. INTRUSIONS}

Large layered intrusions such as the Bushveld complex (South Africa), the Musk Ox (Northwest Territories, Canada), the Skaergaard (Greenland), and the Stillwater
(Montana, United States) form through the invasion of very large quantities of basaltic magma into the continental crust. The intrusions are usually sill-like in configuration, although funnel-shaped and dike forms also occur. They presumably form during early stages of continental rifting and are sometimes found on continental margins. When rifting fails to form an ocean, the layered intrusions are left embedded in the continental crust.

Most layered intrusions contain graphite. Some of this graphite appears to be the result of deuteric alterations or metasomatism, although some could be primary (Mathez and others, 1989). In those intrusions in which mafic minerals, particularly olivine, have been serpentinized, the graphite is secondary (Pasteris, 1988). During mining to recover platinum-group metals, high-pressure gas emanations are encountered, which contain methane and hydrogen or hydrogen sulfide and hydrogen gas, especially in areas containing so-called potholes (Elliot and others, 1982). "Potholes" are breaks in the otherwise uniform layers within the intrusion and are found in platinum-producing horizons in the Bushveld and Stillwater complexes (for example, see Elliot and others, 1982; Ballhaus, 1988). Graphite appears to be ubiquitously correlated with these potholes and is clearly related to their formation.

Also of relevance are the platiniferous dunite pipes: the Onverwacht, Mooihoek, and Driekop in the eastern Bushveld. These pipes contained relatively high concentrations of platinum-group metals and were mined out early in the development of platinum resources of the Bushveld. The orebody in the Driekop pipe was 18 to $25 \mathrm{~m}$ across and was mined to a depth of $200 \mathrm{~m}$. The alteration zone around the orebody, however, extended into the intrusion $300 \mathrm{~m}$ farther. These pipes also contained graphite, which precipitated along pipe fractures (Stumpel and Rucklidge, 1982; Schiffries, 1982).

According to Schiffries, the Driekop pipe formed through dissolution of plagioclase, replacement of pyroxene by olivine with release of $\mathrm{SiO}_{2}$, and iron enrichment of olivine with respect to the unaltered host rocks. Residual plagioclase in the margins of the pipe was also enriched in calcium (Schiffries, 1982). Dissolution of plagioclase and replacement of pyroxene with olivine resulted in a substantial volume reduction leading to downwarping of the layering toward the core and eventual collapse and breakup of the rhythmic layering within the core of the pipe (Schiffries, 1982).

Before discussing the proposed origin of the pipes and potholes and their associated methane and hydrogen, consideration must be given to vapor-phase equilibria during the crystallization of large mafic intrusions. This subject has been investigated by Mathez and others (1989), particularly in relation to the Bushveld and Stillwater complexes. Mathez and others (1989) were confronted with several ill-defined parameters in their estimation of the vaporphase composition and the oxidation state of the magma. 
On the basis of evidence that primary graphite precipitated from the magma during cooling and circumstantial evidence that the chlorine content of the Bushveld magmas was relatively high, they arbitrarily assumed that the $\mathrm{HCl}$ component in a saturating vapor phase was 10 atomic percent. They also fixed $\log f_{\mathrm{O}_{2}}$ equal to the $\log$ of the nickel-nickel oxide (NNO) buffer minus 2.8 (=log QFM-2.1) on the assumption that graphite began crystallizing from the Bushveld magma at $1,050^{\circ} \mathrm{C}$ and $400 \mathrm{MPa}$. To simplify their evaluation, they also discounted the impact of sulfur species.

Although Mathez and others' (1989) assumptions will undoubtedly require modification as further research reveals new data, particularly in relation to the magma's chlorine content and its saturation state with respect to a vapor phase, they reached some striking conclusions, which could be relevant to pipe and pothole formation. They found that the dominant species in the magma at graphite saturation were $\mathrm{CO}_{2}, \mathrm{HCl}$, and $\mathrm{CO}$. With cooling, the $\mathrm{CO}_{2}$ content decreased rapidly and the $\mathrm{H}_{2} \mathrm{O}$ and $\mathrm{CH}_{3} \mathrm{Cl}$ (chloromethane) contents rose. At $750^{\circ} \mathrm{C}, \mathrm{H}_{2} \mathrm{O}$ and $\mathrm{CH}_{3} \mathrm{Cl}$ predominated with minor $\mathrm{HCl}$ and $\mathrm{CH}_{4}$. The formation of $\mathrm{CH}_{3} \mathrm{Cl}$ inhibits the formation of $\mathrm{H}_{2} \mathrm{O}, \mathrm{CH}_{4}$, and $\mathrm{H}_{2}$, which would otherwise form in the absence of chlorine.

The formation of chloromethane in such environments needs confirmation, but it should be noted that Afanas'yev and others (1972) identified chloroform in the Beden pluton in Russia. It would also be interesting to compare these findings with the contents of vapor components in alkaline magmatic systems as described in the preceding section. Presumably the $\mathrm{H}_{2} \mathrm{O}$ content is less in alkaline magmatic systems, and the $\mathrm{Cl}$ component is present as $\mathrm{NaCl}$ or $\mathrm{KCl}$, both of which have lower vapor pressures. Hence, the chloride component tends to remain in the magma.

Schiffries (1982), in his studies of the Driekop pipe, concluded that it formed as the result of metasomatism by chloride-rich (aqueous) solutions at about $600 \pm 150^{\circ} \mathrm{C}$ and $350 \pm 100 \mathrm{MPa}$. Where these solutions come from is open to question. One interpretation is that the pipes formed as a result of vapor release by the sedimentary formations underlying the Bushveld complex. The relative contributions of deuteric and hydrothermal fluids are difficult to assess without further study. Yet many of the chemical reactions hypothesized by Schiffries (1982) to have occurred during pipe formation can be reconciled with purely deuteric reactions. It is, however, noteworthy that little if any alteration to olivine took place, implying, as Schiffries points out, that metasomatism and pipe formation ceased above the stability limit of serpentine, and therefore any residual aqueous phase was probably consumed during $\mathrm{Fe}^{\mathrm{II}}$ hydrolysis and the dissolved constituents precipitated or sublimed in the metasomatized rock.

Given the high pressures and temperatures during pipe formation, either a vapor containing $\mathrm{H}_{2} \mathrm{O}$ and $\mathrm{CH}_{3} \mathrm{Cl}$
$\left(+\mathrm{HCl}+\mathrm{CH}_{4}\right)$ or a highly saline chloride brine was present. The high $\mathrm{Cl}$ content of hornblendes in the pipe and the need to transport $\mathrm{SiO}_{2}+\mathrm{Na}_{2} \mathrm{O}$ out of and $\mathrm{CaO}$ and $\mathrm{FeO}$ into the altered region argues for a saline brine. But residual $\mathrm{CH}_{3} \mathrm{Cl}$ in a vapor could have played a role in graphite precipitation through a reaction such as

$$
\left.2 \mathrm{CH}_{3} \mathrm{Cl}+\mathrm{Na}_{2} \mathrm{O} \text { (plagioclase }\right)=\mathrm{C}+\mathrm{CH}_{4}+\mathrm{H}_{2} \mathrm{O}+\mathrm{NaCl} \text {, }
$$

in which the chloromethane. is consumed with formation of graphite and a chloride-rich brine. Although metasomatism led to enrichment of olivine with the fayalite component, as would be expected during crystallization of a basaltic magma, reactions typical of those involving the oxidation of $\mathrm{Fe}^{\mathrm{II}}$ also appear to have been influential. The excess graphite and deficiency of water in this system undoubtedly buffered the oxidation state and prevented more reducing conditions with the formation of kamacite or awaruite. In some respects, the pipe metasomatism is a high-temperature, water-poor equivalent to the serpentinization processes to be discussed in a subsequent section.

\section{DEUTERIC REACTIONS IN IGNEOUS AND METAMORPHIC ROCKS}

Deuteric reactions refer to those autogenous processes that take place during the subsolidus cooling of igneous rocks. Residual fluids react with the previously formed host-rock minerals, or with glass, to produce secondary minerals. The reactions occur as soon as a disequilibrium state is induced by cooling and continue with falling temperature. The most extensive deuteric alteration therefore takes place between 700 and $200^{\circ} \mathrm{C}$. Of particular interest are those reactions between residual trapped fluids and minerals containing ferrous iron.

Residual carbon monoxide disproportionates and leaves a residue of graphite below $700^{\circ} \mathrm{C}$, probably as a thin coating on mineral grains. Ferrous iron in mafic minerals hydrolyzes and releases hydrogen at temperatures below about $500^{\circ} \mathrm{C}$. Any unreduced sulfur species are reduced to $\mathrm{H}_{2} \mathrm{~S}$, which in turn reacts to form additional quantities of sulfide minerals. Remaining hydrogen reacts with the graphite coatings to produce methane. If all water is consumed during ferrous iron hydrolysis, and all graphite is reduced to methane, nitrogen may be reduced with formation of ammonia. The ammonia neutralizes $\mathrm{HCl}$ which in turn reacts with phyllosilicates and feldspars to form $\mathrm{KCl}$ by ion exchange. Ammonium ion exchange drives down $f_{\mathrm{NH}_{3}}$ and limits back reactions. The reverse sequence of reactions is likely to be observed during prograde metamorphism.

The scenario outlined is consistent with the thermodynamics of the participating chemical components and with field observations of residual gases in some, but not all, 
igneous and metamorphic rocks. Neither the mechanisms of deuteric reduction nor the kinetics of the reactions are known fully over the temperature range of interest. Furthermore, radiolysis could modify the composition and oxidation state of the rocks and residual gases over time.

An interesting example can be seen in the distribution of gases in fluid inclusions from the Dome de l'Agout, France (Kreulen and Schuiling, 1982). This dome comprises an ellipsoidal mass of gneisses and migmatites, $60 \mathrm{~km}$ by $20 \mathrm{~km}$ in area, surrounded by chlorite-sericite schists. The dome reflects a localized hotspot in which five zones of increasing metamorphic grade are distinguished. Estimated temperatures of metamorphism range from less than $500^{\circ} \mathrm{C}$ in zone $I$ the margin of the dome, to about $700^{\circ} \mathrm{C}$ in zone $\mathrm{V}$ at the center of the dome. Two major kinds of fluid inclusions were observed: those containing $\mathrm{CH}_{4}$ and $\mathrm{N}_{2}$, and those containing $\mathrm{CO}_{2}, \dot{\mathrm{CH}}_{4}$, and $\mathrm{H}_{2} \mathrm{O}$. Trends in $\mathrm{N}_{2}, \mathrm{CH}_{4}$, and $\mathrm{CO}_{2}$ contents with metamorphic grade are erratic, but the nitrogen content increases quite steadily toward the center. $\mathrm{CH}_{4}$ content generally increases towards the margin, whereas $\mathrm{CO}_{2}$ content increases erratically toward the center. In zone $\mathrm{I}, \mathrm{CO}_{2}$ content is high and methane content low, in conflict with the general trend.

Evidently, as the temperature increased toward the center of the dome, $\mathrm{NH}_{4}^{+}$was oxidized to nitrogen, and $\mathrm{CH}_{4}$ was oxidized to $\mathrm{CO}_{2}$, accounting for the reciprocal relationship between $\mathrm{CH}_{4}$ and $\mathrm{CO}_{2}$ contents. The increased temperatures caused decarbonation reactions and formation of calc-silicates in the country rock around the periphery of the dome, accounting for anomalously high $\mathrm{CO}_{2}$ contents of the fluid inclusions in zone I. Kreulen and Schuiling (1982) did not investigate changes in $\mathrm{NH}_{4}{ }^{+}$contents in phyllosilicates with increasing temperatures but noted that the $\mathrm{NH}_{4}{ }^{+}$contents in biotite of the Dome de l'Agout were very high, ranging from 200 to $1,000 \mathrm{ppm}$. Also noteworthy is the observation that little if any free water was present within the dome.

\section{OPEN SYSTEMS}

Reducing conditions are observed wherever ultramafic rocks have been serpentinized below about $500^{\circ} \mathrm{C}$ in crustal environments. Mantle peridotites immediately underlying oceanic crust are hydrothermally altered adjacent to oceanic spreading centers. They are sometimes incorporated in accretionary wedges overlying subduction zones together with contiguous fragments of oceanic crust and sedimentary cover. These so-called ophiolite assemblages are usually exposed as long narrow belts paralleling present or former converging-plate margins. Ultramafic rocks are also found in the lower horizons of large layered mafic intrusions such as the Bushveld, Musk Ox, Skaergaard complexes, and in intrusive alkaline complexes in continental crust, and where ultramafic magmas, such as kimberlites, have solidified in diatremes. The following sections cite some of the field evidence for the development of reducing conditions in these environments.

\section{OCEANIC SPREADING CENTERS}

Hydrothermal circulation at oceanic spreading centers has been recognized for nearly two decades (Wolery and Sleep, 1976). The first high-temperature hydrothermal vents to be observed and sampled on the sea floor were those at $21^{\circ} \mathrm{N}$. on the East Pacific Rise (Spiess and others, 1980). Since then, hydrothermal activity, characterized by black and white "smokers" and chimneys composed of massive sulfides or silicates has been discovered in various tectonic settings, including slow and fast spreading centers, backarc regions, and ocean-island hotspots (Charlou and Donval, in press). The venting fluids contain carbon dioxide, methane, hydrogen, some hydrogen sulfide, and helium with typical upper mantle ${ }^{3} \mathrm{He} /{ }^{4} \mathrm{He}$ ratios, that is, approximately eight times those found in the atmosphere (Welhan and Craig, 1979; Jean-Baptiste and others, 1991). The vents are characterized by benthic communities of tube worms and giant clams. The organisms exist by deriving their energy from bacteria that metabolize hydrogen sulfide and methane emanating from the vents. Because ${ }^{3} \mathrm{He}$, a conservative tracer, is released at concentrations some 3,000 times that found in sea water, and methane, while not conservative, is present in the vent fluids at concentrations some 1,000 times above background, both species have been used as tracers in locating hydrothermal discharges (CharIou and others, $1991 \mathrm{a}, \mathrm{b}$ ).

The fact that carbon dioxide and hydrogen sulfide are also present in concentrations from 5 to 100 times greater than methane (Welhan, 1987; Charlou and Donval, in press) has not been emphasized in the literature. Welhan (1987) pointed out that the $\mathrm{CH}_{4} / \mathrm{CO}_{2}$ and $\mathrm{CH}_{4} / \mathrm{H}_{2}$ ratios in East Pacific Rise hydrothermal fluids are remarkably similar to those in MORB vesicles (about 0.01 and 0.2 , respectively). Furthermore, citing $\delta^{13} \mathrm{C}$ isotopic data of the coexisting methane and carbon dioxide from Welhan and Craig (1983), he argued convincingly that the gases could have been in isotopic equilibrium only at temperatures between 550 and $750^{\circ} \mathrm{C}$. At such high temperatures, neither methane nor hydrogen could be generated by olivine or enstatite hydrolysis because these minerals are thermodynamically stable with respect to their hydrolysis products. The dissolved gases in high-temperature hydrothermal vents are therefore the products of degassing of molten or quenched basaltic magma with an oxidation state in the region of the QFM buffer. They are typical of $\mathrm{CO}_{2}$-rich magmatic gases and do not result from hydrolysis by mafic rocks. The $\delta^{13} \mathrm{C}$ ratio of the $\mathrm{CO}_{2}$ from the East Pacific Rise vents is typically magmatic, ranging from -5 to -7 permil relative to the PDB (Peedee belemnite standard), and is 
inferred to be of mantle origin. Although the water from the vents must originally have been seawater containing about $129 \mathrm{mg} \mathrm{L}^{-1} \mathrm{CO}_{3}^{--}$(Nordstrom and others, 1979), most if not all of this carbonate probably precipitated as calcite in the descending limbs of hydrothermal convection cells. Evidence for seawater carbonate in $\mathrm{CO}_{2}$ in the hydrothermal vents could be checked through examination for the presence of ${ }^{14} \mathrm{C}$.

Although high-temperature vents might contain dissolved gases of presumed magmatic origin, it would be surprising if no methane or hydrogen in hydrothermal vents were derived through serpentinization or greenschist metamorphism. Some clues to relative magnitudes of the two sources might be gleaned from comparisons of the $\mathrm{CH}_{4} /{ }^{3} \mathrm{He}$ ratios in fluids from MORB vesicles with those in fluids from hydrothermal vents. Charlou and others (1991a) have summarized these ratios from various submarine sites around the world. The ratio in basalts varies between 0.7 and $2.5 \times 10^{6}$, whereas the ratio in and around hydrothermal vents varies, with the exception of ratios from the Guaymas Basin, between 0.15 and $100 \times 10^{6}$. Given the possibility that some of the methane observed in the quenched basalts might have formed during cooling as a result of $\mathrm{CO}$ reaction with water vapor:

$$
\begin{gathered}
\mathrm{CO}+\mathrm{H}_{2} \mathrm{O}=\mathrm{CO}_{2}+\mathrm{H}_{2} \\
\mathrm{CO}_{2}+4 \mathrm{H}_{2}=\mathrm{CH}_{4}+2 \mathrm{H}_{2} \mathrm{O},
\end{gathered}
$$

it would not be surprising if the $\mathrm{CH}_{4} /{ }^{3} \mathrm{He}$ ratios in the magma were somewhat less than those reported in quenched basalts. The similarity between the ratios in basalts and those in high-temperature hydrothermal vents reinforces the proposition that the gases are primarily of magmatic origin.

Isotopic equilibrium between carbon species during the reduction of $\mathrm{CO}_{2}$ to graphite or $\mathrm{CH}_{4}$ by mafic or ultramafic rocks is unlikely to be achieved in hydrothermal vents at temperatures much below $500^{\circ} \mathrm{C}$ (Welhan, 1987). In the presence of magmatic $\mathrm{CO}_{2}$ with $\delta^{13} \mathrm{C}$ values of about -7 permil, $\delta^{13} \mathrm{C}$ values for coexisting methane would not normally be less than about 22 permil. $\delta^{13} \mathrm{C}$ values for mixtures of methane from different sources should therefore range from -22 permil to more positive values, superficially conveying the impression of being derived from even higher temperature sources than the magmatic methane. $\delta \mathrm{D}$ and $\delta^{13} \mathrm{C}$ isotopic evidence from other hydrothermal vents is minimal, and therefore the quantity of mixing of methane with different isotopic signatures must await future study.

Recently, Charlou and others (1991b, 1992), Rona and others (1992), and Charlou and Donval (in press) have reported the existence of a large plume of methane in the vicinity of diapiric domes of serpentinite in the Mid-Atlantic Ridge rift valley at $15^{\circ} \mathrm{N}$. This plume appears to be related to the pervasive release of fluids from serpentiniz- ing peridotite. The plume is distinctive in that the molar ratio of total dissolved manganese to methane in the plume is only 0.11 , compared with 3.60 over the so-called TAG site, an active black-smoker field located at $26^{\circ} \mathrm{N}$. on the Mid-Atlantic Ridge (Charlou and Donval, in press), or 7.4 over hydrothermal vents on the East Pacific Rise (Charlou and others, 1991a). The much lower manganese content is primarily a reflection of elevated $\mathrm{pH}$ of pore waters and (or) lower temperature in the serpentinizing ultramafics. These recent discoveries substantiate the belief that serpentinization is active at oceanic spreading centers and that methane is being generated as a result.

In summary, there are two distinct sources of methane emissions from oceanic crust at spreading centers and other regions of high heat flow. The first source is related to the degassing of mafic magmas and (or) cooling of mafic igneous rock. Emissions occur at high-temperature hydrothermal vents characteristically associated with black smokers. Methane is only a small fraction of the total gas composition in the vent fluid, the principal species being carbon dioxide and hydrogen sulfide. The second source of methane emissions is serpentinizing ultramafic rocks and, perhaps, hydrothermally altering mafic igneous rocks. Vents emitting methane from the second source are cooler and much more diffuse. The relative magnitudes of contributions from the two sources and the extent to which the two sources are interrelated is not currently known. Further study is needed to characterize the magnitude and distribution of fluids discharging from the second source.

\section{SUBDUCTING PLATE MARGINS}

Recognition of plate tectonics nearly three decades ago led inevitably to the question of whether subducting oceanic crust would lead to rapid thermogenesis of organic matter contained in the sedimentary rocks. Gwilliam (1982) reviewed the initial development of ideas concerning oil and gas found in subduction zones and credited Hedberg (1970) with first recognizing the potential for oil and gas generation in this environment. Since that time, scientific investigations of subduction zones and associated accretionary wedges have proceeded with ever-increasing scope and detail. The potential for hydrocarbon thermogenesis in subduction zones is now recognized (Underwood and Laughland, 1990), but the release of hydrogen and methane during serpentinization of oceanic crust and mantle rocks and their role in saturating thermogenic hydrocarbons is unknown. The purpose of this section is to explore this and related issues.

Because seawater fills pores and fractures in the oceanic crust, accelerated hydrolysis of ferromagnesian minerals could continue until the remaining water is expelled or consumed. Deeper in the subduction zone, at approximately 400 to $500^{\circ} \mathrm{C}$, water of dehydration could migrate 
back up the descending plate and also be hydrolyzed. How much unaltered ferromagnesian minerals are available has not been determined. Basaltic crust and peridotite are altered and lose $\mathrm{CH}_{4}$ and $\mathrm{H}_{2}$ to the ocean adjacent to spreading centers. Alteration probably continues at a lower rate during the time it takes the oceanic crust to reach a subduction-plate boundary. The residual primary ultramafic and mafic rocks may therefore be insufficient to act as a significant source of hydrogen or methane.

During subduction, some of the lower density surficial hemipelagic abyssal-plain deposits and forearc sediments (for example, turbidites, pyroclastic deposits, and cherts), low-density serpentinite, and altered crust are scraped off. The scrapings accumulate as an accretionary wedge in advance of the subduction zone. The material is heterogeneous and complexly faulted.

In figure 7 is shown a schematic cross section of a typical accretionary wedge (that associated with the Lesser Antilles subduction zone in the southeastern Caribbean Sea) illustrating commonly observed structural features. The size of the accretionary wedge varies depending on the character of the subduction. A subduction zone adjacent to a continental margin may accumulate large masses of land-derived erosional products and organic matter in the forearc basin.

Measured subduction rates range from 0 to $10 \mathrm{~cm} \mathrm{yr}^{-1}$, although most average 3 to $5 \mathrm{~cm} \mathrm{yr}^{-1}$. At average subduction rates, sediments can be buried rapidly at depths and temperatures where entrained organic matter pyrolyzes to yield petroleum and natural gas. Such hydrocarbons could be generated both within the accretionary wedge and in the sediments subducted with the oceanic crust. Horizontal tectonic compression of the accretionary wedge can increase pore-fluid pressures, which in some cases approach local lithostatic pressure (Von Huene and Lee, 1983). Such high pressures are observed in boreholes penetrating the Barbados accretionary wedge (Moore and others, 1982), the Gulf of Alaska accretionary complex (Hottman and others, 1979), and the accretionary wedge of the Oregon-Washington thrust belt (Moore and others, 1990). Modeling of the latter by Wang and others (1990) confirms that fluid pressures can approach the lithostatic overburden pressure under certain conditions. Pore-water heating, the production of thermogenic methane, and water released during the dehydration of smectites could also contribute to the overpressures. The elevated pore pressures weaken the rocks and facilitate rock failure and thrusting as is typically observed in accretionary wedges (Moore and others, 1982, Vrolijk and others, 1991).

Elevated pore pressures in the accretionary wedge may cause poorly consolidated sediments to disintegrate entirely and mobilize as mud. Because the porosity of the mud approaches 50 percent, the mud is less dense than the surrounding rocks and is displaced upward along fractures or is deformed and intruded as mud diapirs. Dissolved methane in mud diapirs exsolves with falling pressure during ascent, encouraging the formation of mud diatremes (Brown, 1990). Surface manifestations of mud intrusions in the form of mud volcanoes, mounds, and extrusive features have been observed at scattered subaerial localities around the world (Gold and Soter, 1980; Brown, 1990). Recently, similar phenomena have been observed in submarine environments by Kvenvolden and Field (1981), Westbrook and Smith (1983), Silver and others (1986), Langseth and others (1988), Henry and others (1990), Le Pichon and others (1990), Kulm and Suess (1990), and L.D. Kulm (pers. commun., 1988, cited in Wang and others, 1990) and Shipley and others (1990).

An interesting variation of diapir formation has been observed in the Mariana forearc (Haggerty, 1991). In this subduction zone, only minor accretionary complexes occur, but about 50 to $150 \mathrm{~km}$ arcward of the subduction zone trench, numerous mounds and seamounts with serpentine cores were found by Fryer and others (1985). The mounds and seamounts are believed to be sea-bottom expressions of serpentine diapirs that forced their way through formations in the overlying plate; fluids for serpentinization were provided during dewatering of the sedimentary slab. Sea-floor observations show that one such mound is covered with flows of particulate serpentine ma-

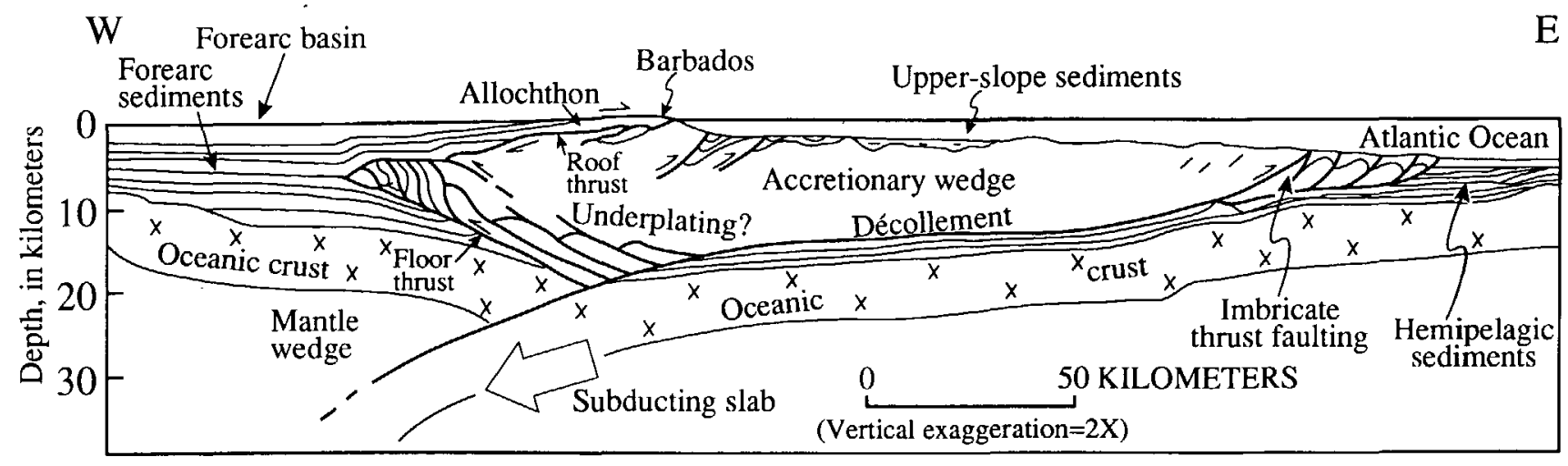

Figure 7. Cross section of the Barbados accretionary wedge. Modified from Speed (1990). 
terial whose genesis is unexplained. According to Haggerty (1991), pore fluids extracted from cores of this material were deficient in chlorine and bromine in comparison with seawater, but they contained twice the sulfate and were very alkaline, with $\mathrm{pH}=12.6$. Methane, propane, and ethane as well as acetate and formate were present. Fluid inclusions in carbonate chimneys from the same seamount also contained methane, as well as aromatic compounds and aliphatic acids. Vent-fluid temperatures were cold. It is interesting that a sympathetic variation between alkalinity and ammonia concentration was observed in pore waters sampled from this mound (Shipboard Scientific Party, 1990b, cited in Haggerty, 1991). This sympathetic variation suggests extremely reducing conditions within the serpentine body, due possibly to hydrogen saturation of hydrocarbons containing amine functional groups with release of ammonia. Somewhat less likely, though not impossible, is the reduction of nitrogen by hydrogen in the serpentine body.

The fluids emerging from the serpentine mound have been modified by serpentinization, but Haggerty (1991) believed the mode of the hydrocarbon formation to be thermogenic alteration of carbon derived from organic detritus in the sedimentary mantle of the subducting plate. The presence of relatively high sulfate concentrations in the fluids is surprising and is thermodynamically inconsistent with the presence of light alkanes, suggesting that the fluids are mixtures from different sources.

The compaction of sediments in the accretionary wedge and subducting plate leads to reduction of porosity from as much as 40 to 50 percent to as little as 5 percent. Large quantities of pore fluids and dissolved methane must therefore be expelled. Recent sea-floor exploration has discovered submarine venting of pore fluids offshore Oregon, at the north end of the Nankai Trough, in the Japan Trench, and in Sagami Bay adjacent to the Sagami Trough (Kulm and others, 1986). Offshore Oregon vents range in size from a few square meters to about $400 \mathrm{~m}^{2}$. Their locations appear to be controlled by back thrusting in the fault-bend fold overlying the most forward frontal thrust, and by the underlying décollement and frontal thrust (Moore and others, 1990). The fault planes might therefore channel the expelled fluids. Although it has been suggested otherwise (Wang and others, 1990), the fault planes are probably barriers to fluid migration and force ascending fluids to migrate updip toward the exposed fault traces. Fluids undergoing expulsion should also convey heat from greater depths and accelerate diagenesis and thermogenesis of organic matter. The hydrology of water expulsion and heat transfer in rocks undergoing deformation and subduction at plate margins has not been studied extensively (but see Wang and others, 1990, for references to earlier work), and therefore much remains the subject of speculation.

Geochemical studies of the fate of methane in accretionary wedges and subducting plates are very preliminary, and not enough is known to identify all processes involved. We have therefore linked the limited factual information from accretionary-wedge environments with observations based on field evidence in other sedimentary environments to present a synthesis of probable mechanisms. In figure 8 is a schematic representation of the geochemical processes affecting the evolution of water advectively ascending from subducting oceanic crust through overlying sedimentary rocks and ultimately discharging through the sea floor. It is not certain whether expelled fluids from the oceanic crust are able to cross the décollement interface and enter the overlying accretionary wedge. Further study of this issue is needed. At present it is assumed that interflow between the subducting slab and the accretionary wedge is possible as is inferred by Moore and others (1990) and Vrolijk and others (1991).

We start at the top and work downward. In this way we can consider the progressive steps in diagenesis and metamorphism as sediments and oceanic crust are buried. Temperatures and pressures range from about $2^{\circ} \mathrm{C}$ and $30 \mathrm{MPa}$ at the ocean bottom to $600^{\circ} \mathrm{C}$ and $750 \mathrm{MPa}$ in the descending plate, covering a wide diversity of geochemical processes affecting the generation of abiogenic methane and hydrogen and the reactions of these gases in the accreted sediments.

Submarine sites where pore waters are expelled often reveal carbonate crusts, pillows, or tubes composed of calcite, aragonite, or dolomite (Kulm and Suess, 1990). The origins of the carbonate precipitates are complex. Some of the carbonate forms from the oxidation of methane. There is, however, no evidence that this methane was abiogenic in origin. Some of the methane is derived from the action of methanogenic bacteria immediately below the sea floor (Kulm and Suess, 1990). Methane is also generated at temperatures between 50 and $300^{\circ} \mathrm{C}$ in the subduction zone through thermogenesis, which occurs relatively rapidly in a subducting environment.

In the subducting oceanic crust, at temperatures between about 200 and $500^{\circ} \mathrm{C}$, basalts and gabbros are altered to greenschist-facies rocks, and peridotites are altered to serpentinites. The water required for alteration is seawater trapped prior to subduction, or water of dehydration ascending the slab from greater depths. Some of the resulting hydrogen or methane permeates upward. The hydrogen is consumed by reacting with thiol and amino functional groups, releasing $\mathrm{H}_{2} \mathrm{~S}$ and $\mathrm{NH}_{3}$. It also participates in the saturation of alkenes through free-radical reactions, thereby increasing the yield of saturates with lower molecular weight; that is, higher gravity oil is produced, and the yield of light alkanes such as methane is increased.

Saturation of cyclic hydrocarbons also decreases the asphaltene residue. It is unlikely that any hydrogen released at depth will penetrate upward beyond the thermogenesis zone, and therefore hydrogen discharge into the overlying ocean, as observed in hydrothermal vents at spreading centers, would not be expected. 


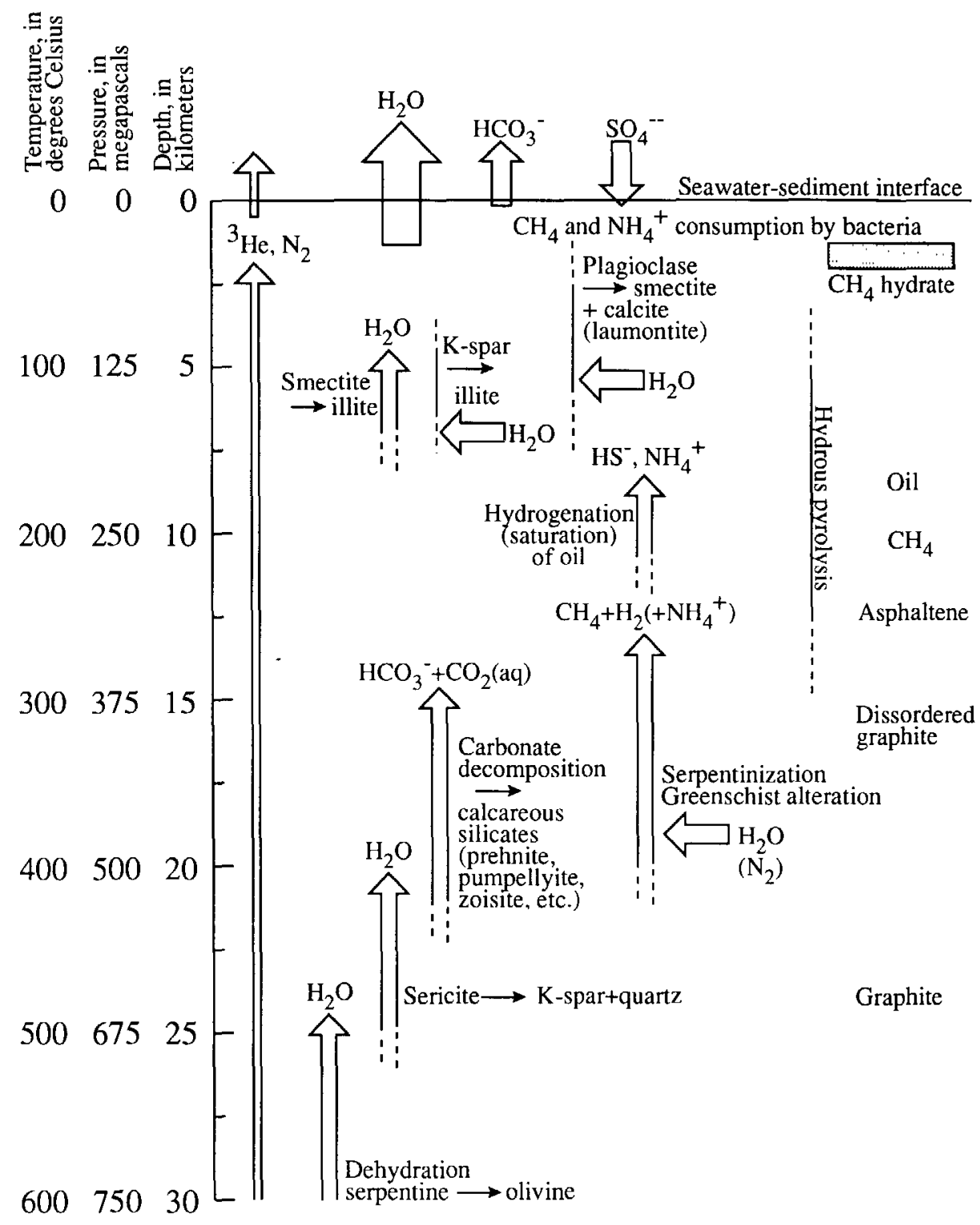

Figure 8. Diagenetic reactions involving vapor components at various depths (and corresponding pressures and temperatures) in an accretionary wedge. Open vertical arrows indicate regions of generation and upward migration of volatiles; they are dashed to indicate uncertainty in the upper limits of temperature and pressure of volatile generation. Open horizontal arrows indicate water uptake. Vertical lines indicate regions where diagenetic reactions occur; they are dashed to indicate uncertainty in temperature and pressure ranges.

Evidence for hydrogen saturation of hydrocarbons in subduction zones and accretionary wedges is circumstantial and inconclusive. Several oil fields in Cuba occur in large serpentine bodies in a complex overthrust belt (Wassall, 1956; Gurko and others, 1982; Echevarria-Rodriguez and others, 1991). Gurko and others (1982) studied the hydrocarbon compositions in three fields in Cuba, one of which, Jarabucca, is in serpentinite host rock. Oil from this field is characterized by low density $(0.5331)$, low viscosity, the absence of asphaltenes, low resin contents, and low aromatic contents. All of these characteristics could be attributed to maturation in a hydrogen-rich environment, as might be expected in a serpentinizing peridotite. Gurko and others believed, however, that these characteristics are the result of sorption during migration of the oil from source rocks, leading to relative enrichment of the migrated oil with low-molecular-weight hydrocarbons. It is noteworthy, however, that these characteristics seem to be most highly developed in the serpentinite-hosted oil field.

With greater depths of burial, at temperatures $>300^{\circ} \mathrm{C}$, carbonates react to form hydrated calcium aluminum silicates-such as prehnite, pumpellyite, and actinolite (Ernst, 
1990) - and residual organic matter is decomposed to asphaltene. Whether secondary porosity is created in this environment is open to question, but if it is, ascending hydrogen and methane could be trapped with carbon dioxide beneath the carbonate seal unless the seal is ruptured by greater-than-lithostatic overpressures. Both the temperature and duration of reaction could be such that local equilibrium would be established between $\mathrm{CO}_{2}, \mathrm{CH}_{4}$, and $\mathrm{H}_{2}$. Given the possibility of excess hydrogen being released from the underlying oceanic crust, some of the $\mathrm{CO}_{2}$ could be reduced to carbon or methane. Very high pressure abiogenic methane accumulations under the thermogenic carbonate seal might be found. It is possible that convective circulation within imbricated thrust sheets might also enhance the creation of closed cells, as has been suggested by Hunt (1990) and by Dewars and Ortoleva (1988).

As far as we are aware, no concerted efforts have been made to investigate potential gas traps in accretionarywedge and subduction-zone environments (however, see Stevenson, this volume). The limited evidence in the published literature is not encouraging. Fisher and Brantley (1992) investigated second-generation quartz-vein formation associated with the development of platy cleavage in shales in the Kodiak accretionary complex (see also Vrolijk and others, 1988). Conditions of formation of the quartz veins were similar to those of prehnite-pumpellyite-facies development in adjacent volcaniclastic sandstones and are therefore representative of conditions under which carbonates decompose. Fluid-inclusion thermometry and barometry suggested temperatures between 180 and $270^{\circ} \mathrm{C}$ and pressures between 220 and $300 \mathrm{MPa}$. The composition of the fluid inclusions was predominantly water and $\mathrm{CO}_{2}$ with varying amounts of salt and $\mathrm{CH}_{4}$ (Myers, 1987). Fisher and Brantley (1992) found that the quartz veins were repeatedly disrupted and refilled with secondary quartz at intervals of $10^{2}$ to $10^{4} \mathrm{yr}$. They suggested that upward fluid flow occurred intermittently from the décollement into a fracture network in the overlying wedge. It is not known whether the fracturing was triggered by the buildup of lithostatic pore pressures or was due to fluctuations in the partial pressure of $\mathrm{CO}_{2}$ under varying deviatoric stress due to seismic activity. The periodic fluid releases, and fluid inclusion compositions in which $\mathrm{CO}_{2}$ is in excess of $\mathrm{CH}_{4}$, do not make such an environment a tempting target for seeking economic reservoirs of abiogenic natural gas if we are to generalize from this isolated study.

As temperatures exceed about $500^{\circ} \mathrm{C}$, serpentinized ultramafic rocks will dehydrate to forsterite and liberate water (Bowen and Tuttle, 1949; Scarfe and Wyllie, 1967). Between 650 and $700^{\circ} \mathrm{C}$, chlorite in greenschists will decompose (Delaney and Helgeson, 1978). Thus, there will be a tendency toward dehydration and release of water. The water could either penetrate updip into lower temperature regimes or be subducted and participate in fusion of the slab and overlying mantle wedge. The high water con- tent of some andesitic and dacitic magmas erupting over subduction zones is persuasive evidence that at least some of the water eventually returns to the surface through volcanic activity.

Rare-gas isotopic studies of expelled pore fluids provide indirect evidence for hydrolysis of oceanic crust and underlying peridotites. Sano and Wakita (1985), Sano and others (1987a), and Jeffrey and others (1988) have found a mantle ${ }^{3} \mathrm{He}$ signature in gases from several convergent plate margins. In the forearc region in New Zealand, $R / R_{A}$ ratios range from 0.08 to 2.7 , with most below 0.30 (Sano and others, 1987a). Wakita and others (1990) sampled natural gases from the forearc regions of the Japan trench. Here, $R / R_{A}$ ratios ranges from 0.07 to as high as 2.0 , although most cluster around 0.1 to 0.2 . Elderfield and others (1990) report measurements of ${ }^{3} \mathrm{He} /{ }^{4} \mathrm{He}$ ratios from pore fluids in cores of the Peruvian continental margin that are 0.088 and 0.092 times that of the atmosphere. The $R / R_{A}$ values from most forearc regions indicate a small, and for the most part insignificant, involvement of mantle material.

\section{MAFIC AND ULTRAMAFIC IGNEOUS ROCKS IN THE CONTINENTAL CRUST}

Within the continental crust, mafic and ultramafic bodies are commonly exhumed or, in the case of layered intrusives, are mined for valuable metals. It is therefore possible to examine the alteration mineralogy and draw inferences about the actual or former presence of reducing gases. In this section we review some of the field observations concerning such rocks in the continental crust.

Field evidence of the extremely reducing conditions induced by serpentinization of peridotites in ophiolite suites is very widespread. The occurrence of nickel-iron alloys is commonly reported (Eckstrand, 1975; Grudinin and Sekerin, 1979; Deutsch and others, 1977; Hahn-Weinheimer and Rost, 1961; Krishnarao, 1964; Ramdohr, 1952). Graphite, which may be primary or may be the result of carbonate reduction, has been observed in several ultramafic rocks (Cady and others, 1963; Krishnarao, 1964; Shteynberg and Lagutina, 1978). Shteynberg and Lagutina (1978), in particular, have documented the correlation between graphite and cohenite $\left(\mathrm{Fe}_{3} \mathrm{C}\right)$ contents of ultramafic rocks and the degree of serpentinization. Afanas'yev and others, (1972) even reported the existence of chloroform, volatile organics, and carboxylic acids in serpentinized ultramafic rocks of the Beden pluton in the former USSR.

With respect to the evolution of methane and hydrogen from such sources, Thayer (1966) reports two analyses of gas seeps from peridotite in the Zambales ultramafic complex of the Philippines near Mount Lanat containing 41.4 and 45.6 mole percent hydrogen and 52.6 and 53.8 mole percent methane, respectively. Similar results were obtained by Abrajano and others (1988, 1990), who also 
analyzed coexisting noble gases and concluded that the gases are products of peridotite hydration. The presence of reducing gases in serpentinites in Germany has also been noted by Hahn-Weinheimer and Rost (1961), and in the Semail ophiolite, Oman, by Neal and Stanger (1983) and Fritz and others (1992). The Semail ophiolite methane, ethane, and hydrogen are apparently forming at a groundwater temperature of 23 to $25^{\circ} \mathrm{C}$ (Fritz and others, 1992). Johan and LeBel (1980) noted that fluid inclusions in secondary chromite from altered ophiolites contain methane. Methane, together with small amounts of hydrogen, ethane, and propane has also been observed emerging from ultramafic rocks of the Moncheyorsk ultramafic pluton of the Kola Peninsula, Russia (Petersil'ye and others, 1970). Soda springs of the Sierra Nevada, California, whose waters have contacted ultramafic rocks at depth also contain small concentrations of methane (Barnes and others, 1981). A somewhat similar environment favorable for methane production has been described by Bezrodnov (1979) from the Pechenga synclinorium of the Kola Peninsula. The synclinorium is filled with a sedimentary volcanogenic sequence and gabbro-diabasic and peridotitic rocks. The volcanogenic rocks consist of basalts, diabases, and pillow lavas. All the rocks have been metamorphosed to greenschist facies. Wells in the synclinorium intersect fissures containing water of alkaline bicarbonate-soda-lime or chloride-lime-soda composition, and these waters contain dissolved gases having a predominance of methane (up to 81.5 percent) and hydrogen (up to 24.8 percent).

Methane has been observed in several wells drilled in basalt flows in the Pasco Basin of the Columbia River Basin, Washington (Gephart and others, 1979; Rockwell Hanford Operations, 1982), although in this case it is not clear whether the methane originates from the basalt or from organic matter in the occasional sedimentary interbeds. Methane and bitumens in kimberlite pipes (Kravtsov and others, 1976; Vdovykin and others, 1979) and methane of residual gases present in mantle xenoliths (Chaigneau, 1975; Lutts and others, 1976; Petersil'ye and Pripachkin, 1979) are probably due also to hydrolysis. But, as noted earlier, these rocks are subject to alteration and contamination, and therefore should be examined carefully for evidence suggesting alternative explanations of the origin of methane.

Numerous occurrences are known of methane and associated gases in crystalline basement rock of shields. Abiogenic gases-many flammable and containing methane (up to $>80$ percent), hydrogen (up to 30 percent), nitrogen (up to 80 percent), helium (up to 20 percent), argon (up to 4 percent) and minor amounts of noble gases and higher molecular weight hydrocarbons-are common in crystalline igneous and metamorphic rocks of Precambrian shield areas in Canada and Fennoscandia, as reported by Fritz and others (1987), Sherwood and others (1988), Sherwood-Lollar and others (1989), Nurmi and others, (1988), Guha and Kanwar (1987), and Lahermo and Lampen (1987). Vovk
(1987) documented methanic gases of abiogenic origin found in boreholes of the Ukrainian and Baltic shields at depths of a few hundred to $12,000 \mathrm{~m}$.

The Canadian gases are found in fractures and boreholes in mines from 300 to $2,000 \mathrm{~m}$ in depth and are commonly associated with alkaline saline waters and brines. Flows of flammable gas with flow rates up to $8 \mathrm{ft}^{3} / \mathrm{min}$ (225 $\mathrm{L} / \mathrm{min}$ ) persisting for months from boreholes 1.25 inch $(3.2 \mathrm{~cm})$ in diameter have been recorded, implying the presence of a significant gas reservoir and (or) rapid generation and evolution of gas in crystalline rocks. The sustained gas flow after drilling of the holes indicates that the gases are not artifacts of the drilling process.

The abiogenic gases from shield areas are distinguished from biogenic and thermogenic gases by their high contents of $\mathrm{He}$ and $\mathrm{Ar}$ and distinctive heavy $\mathrm{C}$ and light $\mathrm{H}$ isotopic compositions in methane (fig. 9; Whiticar, 1990), and they are comparable to gases found in granitic and diabasic rocks in the Gravberg 1 well in the Siljan Ring impact structure, Sweden (see Castaño, this volume). Dissolved gases in the formation waters in Finnish mines (Nurmi and others, 1988) are dominantly $\mathrm{CH}_{4}$ (with heavy carbon relative to biogenic $\mathrm{CH}_{4}, \delta^{13} \mathrm{C}=-24.9$ to -25.3 ) and $\mathrm{N}_{2}$ with lesser $\mathrm{H}_{2}, \mathrm{O}_{2}, \mathrm{CO}_{2}, \mathrm{Ar}$, and $\mathrm{He}$. These compositions are similar to those of abiogenic gases elsewhere in Fennoscandia and Canada. The $\mathrm{CH}_{4}$ and $\mathrm{H}_{2}$ components are most abundant in intervals of graphitic schist and serpentine in one Outokumpu, Finland, borehole examined by Sherwood-Lollar and others (1989).

Host rocks in mines of shield areas where abiogenic methane occurs have been documented by Fritz and others (1987), Sherwood and others (1988), and Sherwood-Lollar and others (1989). These papers are summarized below with additional information from Douglas (1969) and Thurston and others (1991).

In the Strathcona Mine, North Range, Sudbury, host rocks are norite, mafic footwall rocks (metamorphic), and metasedimentary rocks. At the Thompson Mine, Manitoba, nickel ores occur mainly in peridotite and also in adjacent metasediments and gneisses. In the Red Lake Camp, Ontario, host rocks for gold occurrences are mafic to felsic metavolcanic greenstones, including komatiites, basalts, and gabbro. The Kidd Creek mine, Ontario, exploits massive sulfides in mafic to felsic greenstones including komatiites, tholeiites, and rhyolites. Gold is recovered from shear zones in basaltic greenstones at the Sigma Mine, Val d'Or, Quebec. At Matagami Lake and Norita, Quebec, gold ore is hosted in mafic-felsic volcanic rocks with associated gabbro and anorthosite. Host rocks at the Consolidated Giant Mine, Yellowknife, Northwest Territories, are metavolcanic rocks including chlorite schist and amphibolitized pillow lavas, with interlayered argillaceous and quartzose graywacke. At Outokumpu, Finland, the ore host rocks are serpentine and graphitic schist, among other schists, carbonates, skarns, and gneisses. 
In the Denison Mine, Elliot Lake, Ontario, uranium ore occurs in quartz-rich sandstone and conglomerate of the basal Matinenda Formation originally deposited on granitic Archean basement rocks. High-reflectance $\left(R_{0}=3.0\right.$, where $R_{0}$ is vitrinite reflectance in oil) kerogen is common in subgreenschist- to greenschist-facies uraniumore-bearing rocks (Willingham and others, 1985) and is the likely source of thermogenic methane. Gas at this site is very high in He (14 and 19 percent in two samples), apparently due to uranium decay. If hydrogen was originally present in the gas, it probably contributed to formation of saturated hydrocarbons.

Mafic and (or) ultramafic rocks are present at all sites except Elliot Lake. At Outokumpu, graphite-rich schist is also present. The evidence that the host rocks hydrolyzed to yield abiogenic methane is persuasive. At Elliot Lake, the Huronian sedimentary rocks yield helium-rich methane gas, which likely developed by thermogenesis from the kerogen occurring with the uranium ores.

Frape and others (1984) found concentrated $\mathrm{Na}-\mathrm{Ca}-\mathrm{Cl}$ brines at depths greater than $650 \mathrm{~m}$ in the Canadian shield. They suggested that these brines may have been concentrated by removal of water under closed-system conditions. The gas flows observed from fractures and borings in basement rocks described by Sherwood and others (1988) and the compositional data on saline waters and brines documented from these rocks by Fritz and others (1987) support our proposed hypothesis that hydrolysis by plagioclase, amphibole, and biotite has produced Fe-oxides, secondary sili- cates, hydrogen, methane, and waters rich in $\mathrm{Na}, \mathrm{Ca}$, and $\mathrm{Cl}$. Circulation of meteoric waters with accompanying hydrolysis by silicates evidenced by oxygen and deuterium isotopic exchange to depths of 10 to $15 \mathrm{~km}$ in the crust has been documented by Wickham and others (1993). Radiolysis may have contributed to increased salinity as noted earlier in this report.

Methane associated with diabase (dolerite) sills in granites beneath the Siljan Ring, Sweden, is a typical example of the widespread phenomenon outlined above. Because the occurrence has been well studied (see Castaño, this volume), it is worth discussing some of the implications of observations made during and after the drilling of the Gravberg 1 hole into this structure.

Several techniques were employed to obtain samples of gas during drilling. These have been described by Jeffrey and Kaplan (1988), who analyzed the samples for light hydrocarbons including methane, hydrogen, carbon dioxide, and occasionally helium. A.W.A. Jeffrey, then of Global Geochemistry Corp., kindly provided us with data of the gas analyses from various samples collected for evaluation during the drilling of the Gravberg 1. Numerous problems were caused by contamination during sampling (see Castaño, this volume). The interpretations are therefore preliminary in nature.

It is not possible to relate the concentrations of gaseous species in samples used for analysis with the concentration of those species in interstitial fluids in the host rock, because it is not known to what extent dilution by drilling fluids

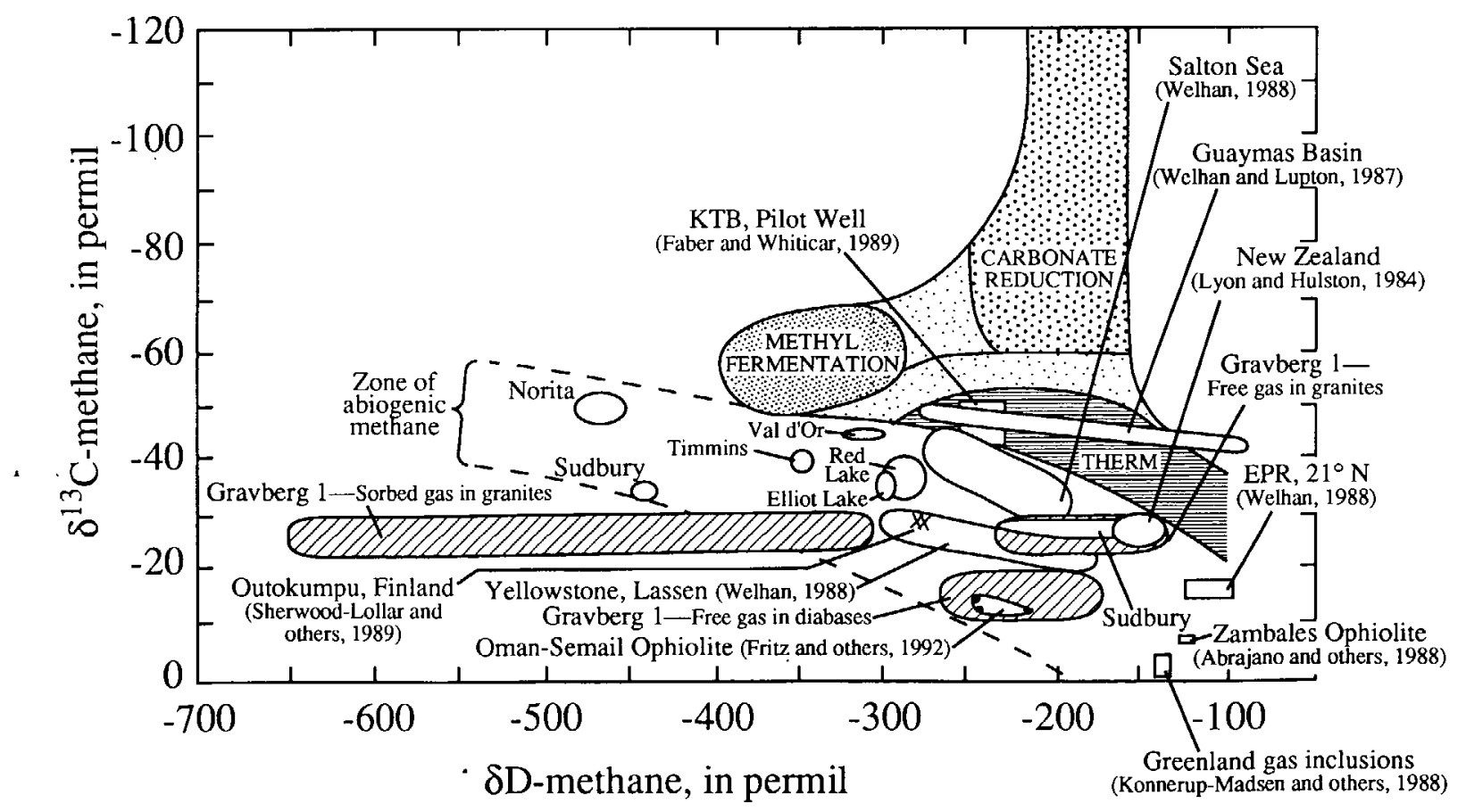

Figure 9. Isotopic compositions of methane from various biogenic and abiogenic sources, modified from Whiticar (1990). Data for Norita, Timmins, Val d'Or, Red Lake, Elliot Lake, and Sudbury (all in Canada) are from Sherwood and others (1988). Data for Gravberg 1 well (Sweden) are from Jeffrey and Kaplan (1988). EPR, East Pacific Rise; THERM, thermogenesis. 
occurred. Furthermore, gases released from fluid inclusions in the rock-forming minerals during drilling would have mixed with fluids filling the continuous pores in the granite, and the two could be of completely different compositions. Hence, the samples collected could not be used to make quantitative estimates of dissolved-gas concentrations in the ground water for comparison with calculated gas-species distributions at thermodynamic equilibrium.

Castaño (this volume) notes that two distinctive formation waters were present: (1) a dilute meteoric water down to $5,000 \mathrm{~m}$ depth, and (2) a highly saline brine observed below $5,000 \mathrm{~m}$.

Samples of the connate brine from below $5,453 \mathrm{~m}$ were recovered from the well during an extensive pumping operation in 1990 (Castaño, 1990). Chemical analyses of the brine, in conjunction with the mineralogical descriptions, permit a provisional assessment of the geochemical environment, and an evaluation of the expected partial pressures of gaseous species $\left(\mathrm{P}_{\mathrm{CO}_{2}}, \mathrm{P}_{\mathrm{H}_{2}}, \mathrm{P}_{\mathrm{CH}_{4}}\right)$ that would coexist in equilibrium with the brine at that depth. The chemical analysis of sample 14 reported by Castaño (1990) is shown in table 1. Of those analyzed, this sample is believed to be the least contaminated by extraneous fluids.

Gases separated from the brine were also analyzed and estimated by Castaño to yield the concentrations in solution at depth reported in table 2.

The oxygen gas is probably due to atmospheric contamination. Subtraction of the oxygen and corresponding nitrogen contamination yields the corrected aqueous concentrations shown in the righthand column in table 2.

A temperature of $119^{\circ} \mathrm{C}$ was estimated from the ratio $\left[\mathrm{Na}^{+}\right] /\left[\mathrm{K}^{+}\right]$, (Apps and Chang, 1992), assuming that potash feldspar and low albite are in equilibrium with the formation water. This temperature corresponds to a depth of $6,705 \mathrm{~m}$ below the surface, which is consistent with downhole measurements.

We calculated the distribution of species, mineral saturation indices, and gas fugacities in the brine, assuming saturation with respect to muscovite, quartz, low albite, pyrite, and hematite. Given the limitations of the model used and associated thermodynamic data, results are, for the most part, consistent with an equilibrium state between the ground water and the host-rock granite.

Some of the relevant information from the calculation is reported in table 3. Species reported at or near saturation have not all been observed as secondary minerals in the granite. The calculated saturation index for calcite, +1.30 , is too high but probably within the limits of uncertainty of the model. The most significant discrepancy is the calculated hydrogen fugacity $\left(\log f_{\mathrm{H}_{2}}=-4.72\right.$ at oxidation potential (Eh) $=-0.28$ volts) in comparison with that estimated from the gas analysis $\left(\log f_{\mathrm{H}_{2}}=-0.85\right.$ at $\mathrm{Eh}=-0.42$ volts). Furthermore, were the hydrogen at equilibrium with carbon dioxide and methane, according to the Fischer-Tropsch re-
Table 1. Chemical analysis of formation brine recovered from Gravberg 1 well, Sweden, in 1990.

[Analysis of sample 14 of Castaño (1990)]

\begin{tabular}{|c|c|}
\hline Species & $\begin{array}{l}\text { Concentration } \\
\left(m \mathrm{~L} \mathrm{~L}^{-1}\right)\end{array}$ \\
\hline $\mathrm{Na}-\ldots$ & 17,725 \\
\hline K ….....- & 335.5 \\
\hline Mg - - & 1.5 \\
\hline $\mathrm{Ca}+. . . . .$. & 43,613 \\
\hline Si _.......--- & 445 \\
\hline $\mathrm{Cl}$ & 93,000 \\
\hline $\mathrm{HCO}_{3}$ & 89 \\
\hline $\mathrm{SO}_{4}$ & 300 \\
\hline
\end{tabular}

Table 2. Concentrations of gases in solution formation brine recovered from Gravbeg 1 well, Sweden, in 1990.

[Analysis of gases recovered from sample 14 of Castaño (1990). $\mathrm{cm}^{3}$. cubic centimeter; L, liter; mol, mole]

\begin{tabular}{ccc}
\hline Gas & $\begin{array}{c}\text { Reported concentration } \\
(\text { Castaño, 1992) } \\
\left(\mathrm{cm}^{3} \mathrm{~L}^{-1}\right)\end{array}$ & $\begin{array}{c}\text { Corrected concentration } \\
\text { (this study) } \\
(\text { mol L-1) }\end{array}$ \\
\hline $\mathrm{N}_{2} \ldots \ldots$ & 137.9 & $4.96 \times 10^{-3}$ \\
$\mathrm{Ar} \cdots-$ & 4.45 & $1.74 \times 10^{-3}$ \\
$\mathrm{He}$ & 113.15 & $4.62 \times 10^{-3}$ \\
$\mathrm{H}_{2}$ & 3.01 & $1.23 \times 10^{-3}$ \\
$\mathrm{O}_{2}$ & 4.41 & 0.0 \\
\hline
\end{tabular}

action, $\log f_{\mathrm{CH}_{4}}$ would be about $+6.0(\mathrm{MPa})$, and $\log f_{\mathrm{NH}_{3}}$ would be about $-2.0(\mathrm{MPa})$.

The amount of dissolved hydrogen is clearly in excess of what would be expected if the ground water were in homogeneous equilibrium. The hydrogen concentration could be an artifact of the drilling and sampling procedures, but the extended pumping to acquire the formationwater sample militates against such interpretations. The hydrogen and other gases have been migrating from much deeper and higher temperature domains, either by diffusion or by convective transport through fracture conduits. Because the mineralogy and composition of the rocks at greater depths are not known, the temperature and depth at which the measured hydrogen concentration would approach equilibrium with the formation water and host rocks cannot be estimated precisely, but the temperature probably falls between 200 and $450^{\circ} \mathrm{C}$ and the depth between 10 and $25 \mathrm{~km}$. The hydrogen could be the product of radiolysis due to uranium and thorium decay. Because some of the intervals in the granite contain relatively high concentrations of thorium, and a crude correlation of heli- 
Table 3. Analysis of brine chemical equilibria in the Gravberg 1 well, Sweden, at about $6,000 \mathrm{~m}$ depth.

[Calculations assume that $\mathrm{T}=119^{\circ} \mathrm{C}$ and groundwater is saturated in the minerals quarz, muscovite, low albite, pyrite, and hematite. aq, aqueous; $f$. fugacity; $m$. molality, or moles per kilogram of water; MPa, megapascals]

\section{COMPUTED AQUEOUS SPECIES CONCENTRATIONS}

\begin{tabular}{|c|c|}
\hline Species & Concentration $(m)$ \\
\hline $\mathrm{Fe}^{++}-{ }_{---}$ & $3.15 \times 10^{-4}$ \\
\hline $\mathrm{Fe}^{\mathrm{t++}}+$ & $<1.00 \times 10^{-10}$ \\
\hline $\mathrm{Al}^{+++}$ & $2.60 \times 10^{-7}$ \\
\hline $\mathrm{SiO}_{2}(\mathrm{aq})$ & $1.20 \times 10^{-3}$ \\
\hline $\mathrm{HS}^{-}$ & $2.57 \times 10^{-7}$ \\
\hline $\mathrm{pH}(\mathrm{mol}) \ldots$ & 6.76 \\
\hline Eh (volt) - - - & -0.28 \\
\hline $\begin{array}{c}\text { Mean charge } \\
\text { imbalance } \\
\text { (percent). }\end{array}$ & +5.30 \\
\hline
\end{tabular}

\begin{tabular}{|c|c|c|}
\hline \multicolumn{3}{|c|}{ SATURATION INDICES } \\
\hline Mineral & Saturation index & \\
\hline Ca-beidellite ---.-- & -0.04 & \\
\hline Calcite -------- & +1.31 & • \\
\hline Clinochlore------- & +0.94 & \\
\hline Dolomite----------- & +0.27 & \\
\hline Epidote-- & 2.06 & \\
\hline Heulandite--..--- & -0.21 & \\
\hline Illite ------- & -0.04 & \\
\hline K-feldspar -.......... & -0.01 & \\
\hline Kaolinite - & -0.63 & \\
\hline Laumontite ------ & -0.01 & \\
\hline Magnetite--..----- & +2.29 & \\
\hline Paragonite -.......- & -0.04 & \\
\hline Prehnite -..--..-... & +1.93 & \\
\hline 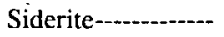 & +0.03 & \\
\hline Strontianite -....-..- & +0.28 & \\
\hline Tremolite --.-- & -0.17 & \\
\hline Zoisite------ & +0.58 & \\
\hline
\end{tabular}

GAS FUGACITIES

\begin{tabular}{lc}
\hline \multicolumn{1}{c}{ Gas } & $\log f(\mathrm{MPa})$ \\
\hline $\mathrm{NH}^{3}$ - & -5.67 \\
$\mathrm{CO}_{2}$ & -2.12 \\
$\mathrm{H}_{2} \mathrm{~S}$ & -5.72 \\
$\mathrm{~N}_{2}$ & 1.00 \\
$\mathrm{H}_{2}$ & -4.72 \\
$\mathrm{CH}_{4}$ & -8.58 \\
\hline
\end{tabular}

um with hydrogen is observed with increasing depth, this potential explanation has some merit. Finally, the hydrogen could be the result of cataclasis. Hydrogen evolved during the meteorite impact would not still be present in the granite, but the region is currently experiencing postglacial isostatic rebound, and therefore the crustal rocks are currently under stress.
The calculated concentration of methane in the recovered brine should be nearly four orders of magnitude less than that of hydrogen; this prediction is partially verified by the gas analysis, as methane was not detected by Castaño (1990).

The most notable feature observed in gas samples collected during drilling was the anomalous concentration of methane when drilling through the diabase sills, as illustrated in figure 10. Records of the thickness and number of sills penetrated are not detailed, and the anomalous methane is not coincident with every sill. The methane anomalies are, however, undoubtedly due to the reducing conditions caused by the secondary alteration of olivine in the diabase. Current descriptions of the secondary mineralogy and the available thermodynamic data are inadequate to predict whether the present environment would support a redox potential sufficiently low to produce the observed $\mathrm{CH}_{4}$ (gas) $/ \mathrm{H}_{2}$ (gas) ratio in the samples, even if it reflects ambient conditions.

Within the limits of the sampling intervals, the methane anomalies appear to be very strong and localized. If the diabases were altering in response to the incursion of present-day ground waters, the methane peaks would be less pronounced due to $\mathrm{CH}_{4}$ (aqueous) diffusion into the surrounding granites. Alternatively, the granites could oxidize all methane that diffuses out. The latter explanation is not justified by the small redox buffering capacity of the granite and the lack of visible evidence that the hematite staining of the feldspars is being reduced to magnetite adjacent to the sills. The most plausible explanation is that the methane is contained in closed pores or fluid inclusions that were ruptured during drilling. Although fluid inclusions have been observed in the diabases, their compositions have not been determined (Castaño, this volume).

The qualitative distribution of hydrogen with depth in the Gravberg 1 hole shows some interesting patterns. As illustrated in figure 10, hydrogen appears to show higher concentrations adjacent to diabase sills in the granite than within the diabase sills where the methane anomalies occur. This distribution raises the interesting question of whether the hydrogen anomalies are relics of hydrogen released by the mafic magma at the time of intrusion when it interacted with and reduced connate water in the host granite.

The fugacity of oxygen in mafic magmas is about $10^{-9}$ $\mathrm{MPa}$ at $1,200^{\circ} \mathrm{C}$, and $f_{\mathrm{H}_{2}}$ would be about $1.0 \mathrm{MPa}$. On cooling, the hydrogen would react with $\mathrm{CO}_{2}$ (aqueous) according to the Fischer-Tropsch reaction with the formation of methane, thereby consuming hydrogen and producing methane in the cooling sill. Reaction equilibrium shifts to the right at $600^{\circ} \mathrm{C}$ at $100 \mathrm{MPa}$ pressure. The persistence of a relic halo of hydrogen can be explained only if the hydrogen-rich fluid were also trapped in fluid inclusions and isolated from fluids in continuous fractures. It should be noted, however, that Komor and others (1988) detected only $\mathrm{CO}_{2}$ in fluid inclusions in rock samples from the Gravberg 1 well. 

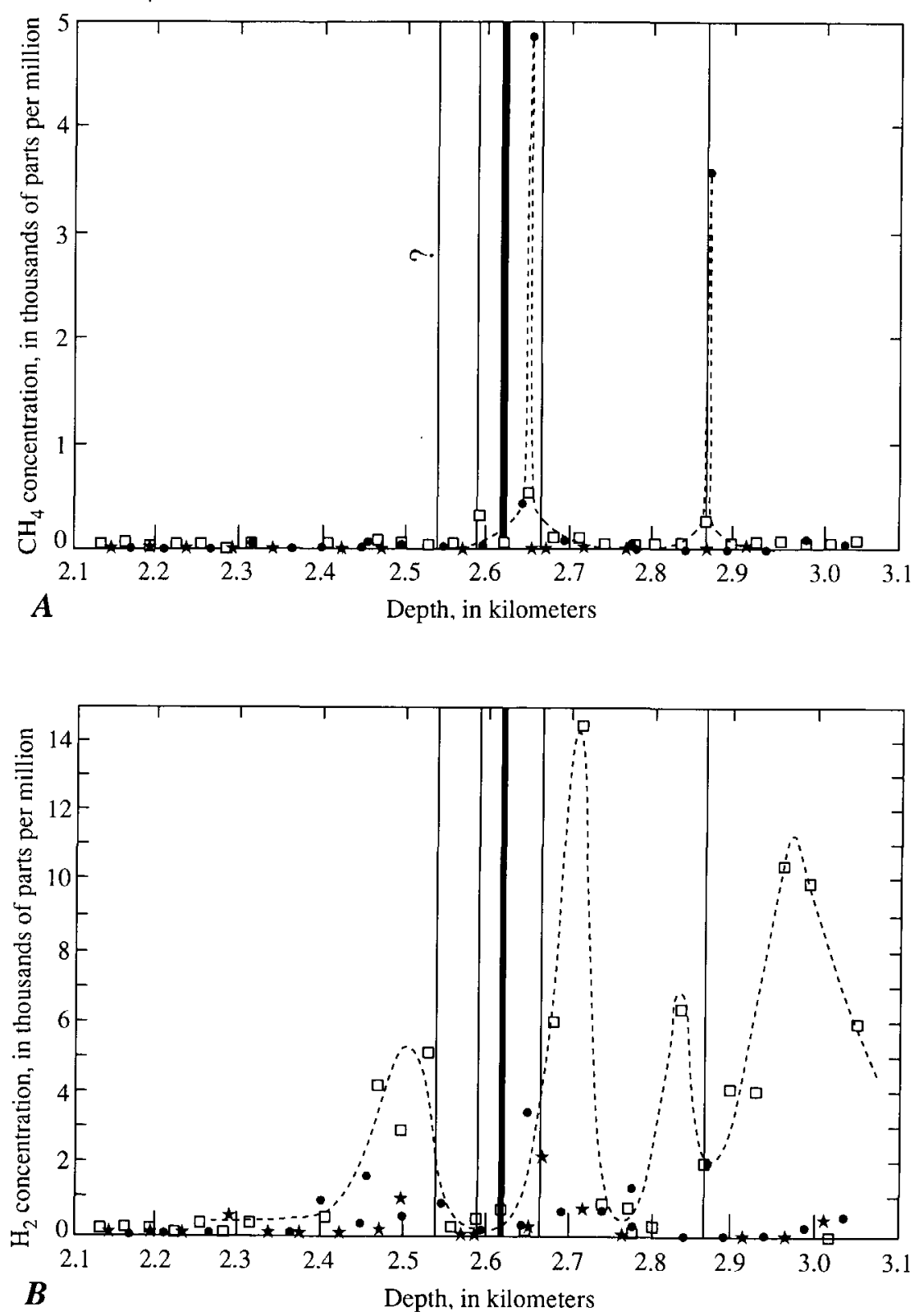

Figure 10. Comparison of methane $(A)$ and hydrogen $(B)$ anomalies in fluids recovered from depths between 2,100 and 3,100 m during drilling of Gravberg 1 well, Sweden. Squares, fluids from canned headspace of outgoing fluid and cuttings; stars, outgoing drilling fluid; dots, fluids from dunk-tank vacutainers (see Jeffery and Kaplan, 1988, for further details). Solid bars - represent diabase (dolerite) sills, queried where presence is uncertain. Dashed lines bound interpreted envelope of maximum concentrations of gas.

Verification of the release and entrapment of hydrogen, and the generation of methane within the diabase sill during cooling, might be established with more detailed studies of fluid inclusions and the mineralogy and petrography of the thermal alteration zones about the sills, and suitable modeling of the thermal history of a sill and adjacent granites subsequent to emplacement.

\section{ECONOMIC SIGNIFICANCE OF ABIOGENIC GASES IN THE EARTH'S CRUST}

Although there are numerous reports of methane and hydrogen of undoubted abiogenic origin, none can be described as of economic significance. The dilution of ther- 
mogenic natural-gas reservoirs by methane of mantle origin is in all cases trivial. Hydrogen generated by maficrock hydrolysis, by the radiolysis of water, or by cataclasis might have contributed to the maturation of petroleum and natural-gas resources, but its significance has not been established. Therefore, it remains to be determined whether energy gases of undoubted abiogenic origin might be concentrated in hitherto unexplored regions of the Earth's crust.

The most promising sources of abiogenic energy gases are ultramafic, and to a lesser extent, mafic igneous rock masses that have undergone alteration in the presence of water. If we consider the most promising scenario, the alteration of a peridotite, we can determine the maximum potential of such rocks to produce methane or hydrogen through hydrolysis.

By combining reactions 40 and 41 , we get

$$
\mathrm{CO}_{2}+2 \mathrm{H}_{2} \mathrm{O}+6 \mathrm{Fe}_{2} \mathrm{SiO}_{4}=6 \mathrm{SiO}_{2}+4 \mathrm{Fe}_{3} \mathrm{O}_{4}+\mathrm{CH}_{4}
$$

For a peridotite containing 8 weight percent FeO, about $27 \mathrm{~cm}^{3}$ of methane would be released per gram of rock. For $1 \mathrm{~km}^{3}$ of peridotite of density $3.3 \mathrm{~g} / \mathrm{cm}^{3}$, about $9 \times 10^{10} \mathrm{~m}^{3}$ ( $3 \mathrm{Tcf}$ ) methane would be produced.

Mafic rocks usually contain $\mathrm{FeO}$ in the range of 9 to 10 weight percent. Therefore, it would be expected that they, too, could produce similar amounts of methane upon hydrolysis. The alteration of large mafic bodies such as the Bushveld complex would have the potential of producing giant gas fields. Some gas wells in Kansas produce anomalously high quantities of hydrogen (Coveney and others, 1987), which appear to be related to deep-seated gabbroic intrusions associated with the Midcontinent Rift. But major gas accumulations associated with mafic rocks are unknown.

Several explanations for the absence of significant resources can be advanced:

1. Water must be transported into the interior of the ultramafic or mafic igneous rock body in order to permit hydrolysis. Most igneous bodies, although commonly heavily fractured, possess low fracture permeabilities and very low matrix permeabilities. Therefore water access is poor. Peridotites alter to hydrated magnesium silicates with larger molal volume than the primary minerals. This alteration decreases permeability around the margins of such bodies and inhibits further ingress of water.

2. Although peridotite alteration can take place below $100^{\circ} \mathrm{C}$, reaction rates are slow. Extensive serpentinization or greenschist-facies metamorphism requires sustained temperatures between 200 and $500^{\circ} \mathrm{C}$. Considerable burial depth is necessary to achieve such temperatures, together with sufficient access of water to permit alteration. Many exhumed mafic and ultramafic rocks show incomplete alteration, suggesting a lack of water access or inadequate burial.
3. According to reaction 45 , nearly 5 weight percent $\mathrm{CO}_{2}$ must be present to generate methane. It is unlikely that such a large concentration of $\mathrm{CO}_{2}$ is accessible to altering ultramafic or mafic rocks. During serpentinization, highly alkaline waters containing $\mathrm{CaO}$ are released, which would tend to precipitate $\mathrm{CO}_{2}$ as calcite in veins and outside the body, limiting the access of $\mathrm{CO}_{2}$ and retarding the inflow of water. Therefore, complete methanization of $\mathrm{CO}_{2}$ would not be expected, and altering rocks would release both $\mathrm{CH}_{4}$ and $\mathrm{H}_{2}$, the ratio depending on the availability of carbon and the oxidation state.

4. From-figure 5 it can be seen that any sulfate present or introduced during serpentinization must be reduced to hydrogen sulfide or metallic sulfides. Such reactions would interfere with methane and hydrogen generation and decrease the quantity of methane and hydrogen that could be produced. An environment favorable for the production of abiogenic methane must therefore be depleted in sulfate. Because seawater contains about 2,700 ppm sulfate, its participation in the hydrothermal alteration of oceanic crust would cause the suppression of methane unless the sulfate were removed. Sulfate and calcium are readily precipitated as anhydrite during the albitization of plagioclase, and thus the concentration of sulfate in solution could be reduced to a low level in the descending limb of a hydrothermal convection cell. Removal of the bulk of the sulfate and reduction of the remainder to sulfides would ensure that sulfate-poor seawater would then be available to generate methane and hydrogen locally. Meteoric waters typically contain $<20$ ppm sulfate, so with such waters there would be little interference with hydrolytic methane and hydrogen generation.

5. Alteration of ultramafic and mafic rocks usually occurs in tectonically active regions. These regions are subject to faulting, and atmospheric venting is possible.

Regions where methane is most likely to be generated are also those where the resultant gases are unlikely to be trapped in suitable reservoir structures. This applies particularly to continental rifts, constructive plate margins, and flood-basalt accumulations. Even in accretionary wedges or in subducting oceanic crust, the potentially large overpressures generated by decarbonation and by methane and hydrogen formation could exceed overburden pressures and release gases along well-established thrust fault planes. Gas building up along transform plate margins, could also be released along the principal faults. It is therefore quite likely that Earthquake activity could be triggered by and lead to the transient release of flammable gases. Anecdotal documentation of lights and flames arising from surface ruptures during Earthquakes (Gold, 1987) could reflect the presence of abiogenic methane, hydrogen, and (or) hydrogen sulfide, particularly when faulting is in the vicinity of serpentinite bodies, as occurs along the San Andreas Fault in California. 
Very large buried mafic igneous bodies-emplaced at relatively shallow depths but deep enough to undergo extensive alteration, in contact with an abundant supply of low-sulfate water, and overlain by sediments that could provide impervious structural traps-would constitute favorable environments for abiogenic gas accumulation. Such environments are relatively rare but might be found in and adjacent to infilled graben structures associated with failed continental rifts.

Deep drilling of accretionary wedges might also locate high-pressure abiogenic methane resources, but thermogenic sources of methane may overwhelm abiogenic sources. As noted earlier, the little information on such environments is not encouraging. Difficult drilling conditions would be expected in active accretionary fronts, and the attendant cost may not be justified by the rewards.

In summary, we recommend very selective targeting of favorable environments only after comprehensive geologic, geophysical, and geochemical evaluation to establish their potential. The opportunities for abiogenic gas recovery appear to be very limited, as borne out by the lack of evidence for commercial resources even though the generation of abiogenic methane and hydrogen in crustal environments is well documented.

\section{CONCLUSIONS}

Below, we summarize the most important conclusions of this paper.

Abiogenic methane and hydrogen are derived largely from crustal sources, of which the most important is ultramafic and mafic igneous rocks hydrolyzing at temperatures below $500^{\circ} \mathrm{C}$.

Abiogenic methane and hydrogen are also found in significant quantities in mines in crystalline rocks in the Canadian and Fennoscandian shields. The gases were apparently generated by hydrolysis from meteoric waters circulating through fractures in mafic and graphitic igneous and metamorphic rocks.

Hydrogen can also be generated by radiation- and cataclasis-induced hydrolysis. The significance of these processes has not been established. Hydrogen is relatively inert, but it might participate in the saturation of thermogenic hydrocarbons.

There is no evidence that methane is present in the upper mantle in other than minor concentrations, because the oxidation state of the upper mantle is too high.

No evidence has come to light indicating that volatiles are transported to the Earth's surface from the mantle by any means other than through the agency of magmas.

The oxidized state of the upper mantle could be due to initial oxidation of a surficial molten layer early in the Earth's history, or to loss of hydrogen into the crust and atmosphere over geologic time through basaltic magmatism and formation of oceanic crust.

Magma volatiles are dominated not by methane and hydrogen, but instead by $\mathrm{CO}_{2}+\mathrm{CO}, \mathrm{H}_{2} \mathrm{O}, \mathrm{SO}_{2}$ and $\mathrm{H}_{2} \mathrm{~S}$. The proportions of these gases vary depending on the source of the magma and its history. No magmas contain significant concentrations of methane.

Gases sourced in the mantle and released from magmas are readily identified by their ${ }^{3} \mathrm{He} /{ }^{4} \mathrm{He}$ ratios, because this ratio is up to 3,000 times higher in the mantle than in the continental crust.

The lower continental crust is too oxidized top permit transit of reduced gases such as methane. Therefore, even were the upper mantle sufficiently reducing to stabilize methane, the methane could not penetrate into the upper crust without being oxidized. Nowhere is there any evidence that large volumes of methane have ever overwhelmed the oxidation capacity of the lower crust and migrated into the upper continental crust.

Gases that leak from crystalline basement rocks into overlying sedimentary basins hosting natural-gas reservoirs do not contain significant concentrations of methane. They are distinguished by relatively high concentrations of radiogenic helium and nitrogen, which mix with natural gas. Basement gases therefore cannot be the primary source of natural gas in the reservoirs in these basins. Hence, any methane from the upper mantle does not enter such reservoirs through basement rocks.

Some natural-gas reservoirs in sedimentary basins are enriched in ${ }^{3} \mathrm{He}$ where no magmatism is evident. However, this enrichment is not associated with gases emerging from the basement rocks underlying these reservoirs.

Abiogenic methane and hydrogen, produced through hydrolysis by ultramafic and mafic rocks, are in structural environments where the generated gases are likely to be lost to the atmosphere. No commercial abiogenic gas reservoirs have ever been identified in structurally favorable areas.

Careful a priori evaluation of sources is required before drilling targets for abiogenic methane and hydrogen because the likelihood of finding a commercial reservoir of these gases is small.

\section{ACKNOWLEDGMENTS}

We are indebted to R.C. Burruss, D.G. Howell, and M.D. Lewan of the U.S. Geological Survey; B.M. Kennedy, M.J. Lippmann, and H.A. Wollenberg, Jr., of the Lawrence Berkeley Laboratory; and I.S.E. Carmichael of the University of California, Berkeley, for their constructive reviews and helpful suggestions regarding this paper. We thank A.W.A. Jeffrey for providing (while at Global Geochemistry Corp.) data on the gas compositions in samples obtained during drilling of the Gravberg 1 well in Sweden. 
This work was supported in part by the Director, Office of Energy Research, Office of Basic Energy Sciences, Engineering Sciences Division of the U.S. Department of Energy under Contract No. DE-AC03-76SF00098.

\section{REFERENCES CITED}

Abe, Y., and Matsui, T., 1985, The formation of an impact generated $\mathrm{H}_{2} \mathrm{O}$ atmosphere and its implications for the early thermal history of the Earth, in Ryder, G., and Schubert, G., eds., Proceedings of the Fifteenth Lunar and Planetary Science Conference, Part 2: Journal of Geophysical Research, v. 90, Supplement, p. C545-C559.

Abrajano, T.A., Sturchio, N.C., Bohlke, J.K., Lyon, G.L., Poreda, R.J., and Stevens, C.M., 1988, Methane-hydrogen gas seeps, Zambales ophiolite, Philippines-Deep or shallow origin?: Chemical Geology, v. 71, p. 211-222.

Abrajano, T.A., Sturchio, N.C., Kennedy, B.M., Lyon, G.L., Muehlenbachs, K., and Bohlke, J.K., 1990, Geochemistry of reduced gas related to serpentinization of the Zambales ophiolite, Philippines: Applied Geochemistry, v. 5, p. 625-630.

Afanas'yev, G.D., Karpushin, V.M., Kachurin, V.F., Knyazeva, D.N., Miller, A.D., and Ploshko, V.V., 1972, Halogens and carbon in ultramafic rocks of the Beden Pluton in the northern Caucasus: Doklady, Academy of Science of the USSR, Earth Science Section 202, no. 1-6, [English translation] p. 35-37.

Aldrich, L.T., and Nier, A.D., 1948, Occurrence of $\mathrm{He}^{3}$ in natural sources of helium: Physical Review, v. 74, p. 1590-1594.

Anderson, A.T., and Wright, T.L., 1972, Phenocrysts and glass inclusions and their bearing on oxidation and mixing of basaltic magmas, Kilauea volcano, Hawaii: American Mineralogist, v. 57, p. 188-216.

Aoki, K., and Kanisawa, S., 1979, Fluorine contents of some hydrous minerals derived from the upper mantle and lower crust: Lithos, v. 12, p. 167-171.

Apps, J.A., and Chang, G.H., 1992, Correlation of the $\mathrm{Na} / \mathrm{K}$ ratio in geothermal well waters with the thermodynamic properties of low albite and potash feldspar, in Kharaka, Y.K., and Maest, A.S., eds., Water-rock interaction: Rotterdam, A.A. Balkema, p. 1437-1440.

Arculus, R.J., and Delano, J.W., 1980, Implications for the primitive atmosphere of the oxidation state of Earth's upper mantle: Nature, v. 288, p. $72-74$

Arnold, F., Buehrke, T., and Qiu, S., 1990, Evidence for stratospheric ozone-depleting heterogeneous chemistry on volcanic aerosols from El Chicón: Nature, v. 348, p. 49-50.

Bailey, D.K., 1989, Carbonatite melt from the mantle in the volcanoes of south-east Zambia: Nature, v. 338, p. 415-418.

Bai, Q., and Kohlstedt, P.L., 1992, Substantial hydrogen solubility in olivine and implications for water storage in the mantle: Nature, v. 357, p. 672-674.

Ballentine, C.J., 1991, He, Ne and Ar isotopes as tracers in crustal fluids: Cambridge University, Ph.D. dissertation.

Ballhaus, C.G., 1988, Potholes of the Merensky Reef at Brakspruit Shaft, Rustenburg platinum mines-Primary disturbances in the magmatic stratigraphy: Economic Geology, v. 83 , p. $1140-1158$.
Barnes, I., Johnston, D.A., Evans, W.C., Presser, T.S., Mariner, R.H., and White, L.D., 1982, Properties of gases and waters of deep origin near Mount St. Helens, in Lipman, P.W., and Mullineaux, D.R., eds., The 1980 eruptions of Mount St. Helens, Washington: U.S. Geological Survey Professional Paper 1250, p. 233-237.

Barnes, I., Kistler, R.W., Mariner, R.H., and Presser, T.S., 1981, Geochemical evidence on the nature of the basement rocks of the . Sierra Nevada, California: U.S. Geological Survey Water-Supply Paper 2181.

Barnes, I., and McCoy, G.A., 1979, Possible role of mantle-derived $\mathrm{CO}_{2}$ in causing two "phreatic" explosions in Alaska: Geology, v. 7, no. 9, p. 434-435.

Beebe, B.W., and Curtis, B.F., 1968, Natural gases of North America-A Summary, in Beebe, B.W., and Curtis, B.F., eds., Natural gases of North America: American Association of Petroleum Geologists Memoir 9, p. 2245-2355.

Bell, D.R., 1992, Water in mantle minerals: Nature, v. 357, p. 646-647.

Bezrodnov, V.D., 1979, Subsurface chloride waters of the Kola Peninsula: International Geology Review, v. 24, no. 5, p. 533-540.

Blundy, J.D., Broadholt, J.P., and Wood, B.J., 1991, Carbon-fluid equilibria and the oxidation state of the upper mantle: $\mathrm{Na}-$ ture, v. 349, p. 321-324.

Bluth, G.J.S., Doiron, S.D., Schnetzler, C.C., Kreuger, A.J., and Walter, L.S., 1992, Global tracking of the $\mathrm{SO}_{2}$ clouds from the June 1991 Mount Pinatubo eruptions: Geophysical Research Letters, v. 19, p. 151.

Bosch, A., Bayer, R., Schlosser, P., Sano, Y., Wakita, H., and Mazor, E., 1989, Mantle helium detected in oil and gas reservoirs of Israel: Israel Geological Survey, Annual Meeting 1989 , p. 22-24.

Bowen, N.L., and Tuttle, O.F., 1949, The system $\mathrm{MgO}-S i O_{2}-$ $\mathrm{H}_{2} \mathrm{O}$ : Bulletin of the Geological Society of America, v. 60 , p. $439-460$.

Bratus, M.D., Tatarintsev, V.I., and Sakhro, B.E., 1987, Fluidinclusion compositions in chilled particles from explosive ring structures and kimberlite pipes: Geochemistry International, p. 50-55.

Broadhead, R.F., 1985, Enhanced oil recovery with carbon dioxide flooding in New Mexico: New Mexico Geology, v. 7, no. 1, p. 10.

1987, Carbon Dioxide in Union and Harding Counties, in New Mexico Geological Society Guidebook, 38th Field Conference, p. 339-349.

1990, Bravo Dome carbon dioxide gas field, in Beaumont, E.A., and Foster, N.H., eds., Treatise of petroleum geology, atlas of oil and gas fields-Structural traps I, Tectonic fold traps: American Association of Petroleum Geologists, p. 213-232.

Brown, K.M., 1990, The nature and hydrologic significance of mud diapirs and diatremes for accretionary systems: Journal of Geophysical Research, v. 95, no. B6, p. 8969-8982.

Cady, W.M., Albee, A.L., and Chidester, A.H., 1963, Bedrock geology and asbestos deposits of the upper Mississquoi Valley and vicinity, Vermont: U.S. Geological Survey Bulletin 1122-B, p. B1-B78.

Casadevall, T.J., and Greenland, L.P., 1982, The chemistry of gases emanating from Mount St. Helens, May-September 
1980, in Lipman, P.W., and Mullineaux, D.R., eds., The 1980 eruptions of Mount St. Helens, Washington: U.S. Geological Survey Professional Paper 1250, p. 221-226.

Casey, T.A.L., 1983, Helium potential of the Four Corners Area, in Oil and gas fields of the Four Corners Area: Four Corners Geological Society, v. 3, p. 749-754.

Carmichael, I.S.E., 1991, The redox states of basic and silicic magmas-A reflection of their source regions?: Contributions to Mineralogy and Petrology, v. 106, p. 129-141.

Castaño, J.R., 1990, Geochemistry of the Gravberg-1 well: Sector Report, Deep Gas Project, Vattensall RD\&D Report $\mathrm{U}(\mathrm{G}) 1990 / 61,86 \mathrm{p}$.

Chaigneau, M., 1975, Essai sur la composition des gaz magmatiques profonds: Bulletin Volcanologique, v. 39, no. 3, p. $407-419$.

Chaigneau, M., Tazieff, H., and Fabre, R., 1960, Composition des gaz volcaniques du lac de lave permanent de Nyiragongo (Congo Belge): Comptes Rendus de l'Academie des Sciences, Paris, Serie D., v. 250, p. 2482-2485.

Chang, S., DesMarais, D., Mack, R., Miller, S.L., and Strathearn, G.F., 1983, Prebiotic organic syntheses and the origin of life, in Schopf, J.W., ed., Earth's earliest biosphere: Princeton, New Jersey, Princeton University Press, p. 53-92.

Charlou, J.L., Bougault, H., Appriou, P., Jean-Baptiste, P., Etoubleau, J., and Birolleau, A., 1991a, Water column anomalies associated with hydrothermal activity between $11^{\circ} 40^{\prime}$ and $13^{\circ} \mathrm{N}$ on the East Pacific Rise-Discrepancies between tracers: Deep-Sea Research, v. 38, p. 569-596.

Charlou, J.L., Bougault, H., Appriou, P., Nelsen, T., and Rona, P., 1991b, Different TDM/ $\mathrm{CH}_{4}$ hydrothermal plume signatures-TAG site at $26^{\circ} \mathrm{N}$ and serpentinized ultrabasic diapir at $15^{\circ} 05^{\prime} \mathrm{N}$ on the Mid-Atlantic Ridge: Geochimica et Cosmochimica Acta, v. 55, p. 3209-3222.

Charlou, J.L., Bougault, H., and FARANAUT Scientific Party, 1992, Intense $\mathrm{CH}_{4}$ plumes in seawater associated to ultramafic outcrops at $15^{\circ} \mathrm{N}$ on the Mid-Atlantic Ridge: American Geophysical Union [abstract], 1992 Fall Meeting Program, p. 585.

Charlou, J.L., and Donval, J.P., In press, Hydrothermal methane venting between $12^{\circ} \mathrm{N}$ and $26^{\circ} \mathrm{N}$ along the Mid-Atlantic Ridge: Journal of Geophysical Research.

Chivas, A.R., Barnes, I., Evans, W.C., Lupton, J.E., and Stone, J.O., 1987, Liquid carbon dioxide of magmatic origin and its role in volcanic eruptions: Nature, v. 326, p. 587-589.

Christensen, V.R., 1989, Models of mantle convection-One or several layers: Royal Society of London, Philosophical Transactions, Series A, v. 328, p. 417-424.

Clarke, W.B., Beg, M.A., and Craig, H., 1969, Excess ${ }^{3} \mathrm{He}$ in the sea-Evidence for terrestrial primordial helium: Earth and Planetary Science Letters, v. 6, p. 213-220.

Coveney, R.M., Jr., Goebel, E.D., Zeller, E.J., Dreschhoff, G.A.M., and Angino, E.E., 1987, Serpentinization and the origin of hydrogen gas in Kansas: American Association of Petroleum Geologists Bulletin, v. 71, no. 1, p. 39-48.

Delaney, J.M., and Helgeson, H.C., 1978, Calculation of the thermodynamic consequences of dehydration in subducting oceanic crust to $100 \mathrm{~Kb}$ and $>800^{\circ} \mathrm{C}$ : American Journal of Science, v. 278, p. 638-686.

Deutsch, E.R., Rao, K.V., Laurent, R., and Sequin, M.K., 1977, New evidence and possible origin of native iron in ophiolites of eastern Canada: Nature, v. 269, p. 684-685.
Dewars, T., and Ortoleva, P., 1988, The role of geochemical selforganization in the migration and trapping of hydrocarbons: Applied Geochemistry, v. 3, p. 287-316.

Dobbin, C.E., 1935, Geology of natural gases rich in helium, nitrogen, carbon dioxide, and hydrogen sulfide, in Geology of natural gas: American Association of Petroleum Geologists, p. 1053-1072.

Douglas, R.J.W., 1969, Geology and economic minerals of Canada: Ottawa, Geological Survey of Canada, Economic Gieology Report No. 1, 838 p.

Dubessy, J., Pagel, M., Beny, J.M., Christensen, H., Hickel, B., Kosztolanyi, C., and Poty, B., 1988, Radiolysis evidenced by $\mathrm{H}_{2}-\mathrm{O}_{2}$-bearing fluid inclusions in three uranium deposits: Geochimica et Cosmochimica Acta, v. 52, p. 1155-1167.

Dunai, T.J., Rouret, J.L., and Villa, I.M., 1992, Mantle derived helium in fluid inclusions of a $2.5 \mathrm{Ga}$ old granulite, Nilgiri Hills, southern India, in Kharaka, Y.K., and Maest, J., eds., Water-rock interaction: Rotterdam, A.A. Balkema, p. 919-922.

Dyar, M.D., McGuire, A.V., and Mackwell, S.J., 1992, $\mathrm{Fe}^{3+} / \mathrm{H}^{+}$ and $\mathrm{D} / \mathrm{H}$ in kaersutites-Misleading indicators of mantle source fugacities: Geology, v. 20, p. 565-568.

Echevarria-Rodriguez, G., Hernandez-Perez, G., Lopez-Quintero, J.O., Lopez-Rivera, J.G., Rodriguez-Hernandez, R., Sanchez-Arango, J.R., Socorro-Trujillo, R., Tenreyro-Perez, R., and Yparraguirre-Pena, J.L., 1991, Oil and gas exploration in Cuba: Journal of Petroleum Geology, v. 14, p. 259274.

Eckstrand, O.R., 1975, The Dumont serpentinite-A model for control of nickeliferous opaque mineral assemblages by alteration reactions in ultramafic rocks: Economic Geology, v. 70, p. 183-201.

Edmister, W.C., 1968, Corresponding state version of the Redlich Kwong equation: Hydrocarbon Processing, v. 47, p. 239.

Edwards, A.C., Lovering, J.F., and Ferguson, J., 1979, High pressure basic inclusions from the Kayrunnera kimberlitic diatreme in New South Wales, Australia: Contribution to Mineralogy and Petrology, v. 69, no. 2, p. 185-192.

Eisma, E., and Jurg, J.W., 1969, Fundamental aspects of the generation of petroleum, in Eglinton, G., and Murphy, M.T.J., eds., Organic Geochemistry-Methods and Results, Chapter 28 , p. 676-698.

Elderfield, H., Kastner, M., and Martin, J.B., 1990, Compositions and sources of fluids in sediments of the Peru subduction zone: Journal of Geophysical Research, v. 95, no. B6, p. $8819-8827$.

Elliott, W.C., Grandstaff, D.E., Ulmer, G.C., Buntin, T., and Gold, D.P., 1982, An intrinsic oxygen fucacity study of platinum-carbon associations in layered intrusions: Economic Geology, v. 77, p. 1493-1510.

Ernst, W.G., 1990, Thermobarometric and fluid expulsion history of subduction zones: Journal of Geophysical Research, v. 95, no. B6, p. 9047-9053.

Faber, E., and Whiticar, M.J., 1989, C- und H-isotope in leichtfluchige Kohlenwasserstoffen der KTB: KTB Report.

Fanale, F.P., 1971, A case for catastrophic early degassing of the Earth: Chemical Geology, v. 8, p. 79-105.

Fisher, D.M., and Brantley, S.L., 1992, Models of quartz overgrowths and vein formation-Deformation and episodic fluid flow in an ancient subduction zone: Journal of Geophysical Research, v. 97, no. B13, p. 20043-20061. 
Flowers, G.C., 1979, Correction of Holloway's 1977 adaptation of the modified Redlich-Kwong equation of state for calculation of the fugacities of molecular species in supercritical fluids of geologic interest: Contributions to Mineralogy and Petrology, v. 69, p. 315-318.

Frape, S.K., Fritz, P., and McNutt, R.H., 1984, Water-rock interaction and chemistry of groundwaters from the Canadian Shield: Geochim. Cosmochim. Acta, v. 48, p. 1617-1627.

Fritz, P., Clark, I.D., Fontes, J.C., Whiticar, M.J., and Faber, E., 1992, Deuterium and ${ }^{13} \mathrm{C}$ evidence for low temperature production of hydrogen and methane in a highly alkaline groundwater environment in Oman, in Kharaka, Y.R., and Maest, J.S., eds., Water-rock interaction: Rotterdam, A.A., Balkema, p. 793-796.

Fritz, P., and Frape, S.K., eds., 1987, Saline water and gases in crystalline rocks: Geological Association of Canada Special Paper 33, $259 \mathrm{p}$.

Fritz, P., Frape, S.K., and Miles, M., 1987, Methane in the Crystalline rocks of the Canadian Shield, in Fritz, P., and Frape, S.K., eds., Saline water and gases in crystalline rocks: Geological Association of Canada Special Paper 33, p. 211-223.

Fryer, P., Ambos, E.L., and Hussong, D.M., 1985, Origin and emplacement of Mariana forearc seamounts: Geology, v. 13, p. 774-777.

Gabelman, J.W., 1977, Migration of uranium and thorium-Exploration significance, Studies in Geology No. 3: American Association of Petroleum Geologists, Tulsa, Oklahoma, $168 \mathrm{p}$.

Galimov, E.M., and Petersil'ye, I.A., 1967, Isotopic composition of carbon from hydrocarbon gases and $\mathrm{CO}_{2}$ held in alkalic igneous rocks of the Khibiny, Lovozero, and Illimaussak plutons: Doklady Akademii Nauk SSSR, v. 176, p. 200-203. [English translation.]

Gephart, R.E., Leonhard, L.S., Spane, F.A., Jr., and Strait, S.R., 1979, Ch. III, Pasco Basin Hydrology, in Hydrologic Studies within the Columbia Plateau, Washington-An integration of current knowledge, RHO-BWI-ST-S: Rockwell Hanford Operations, Richland, Washington, $236 \mathrm{p}$.

Gerlach, T.M., 1980, Chemical characteristics of the volcanic gases from Nyiragongo lava lake and the generation of $\mathrm{CH}_{4-}$ rich fluid inclusions in alkaline rocks. Journal of Volcanology and Geothermal Research, v. 8, p. 177-189.

1993, Oxygen buffering of Kilauea volcanic gases and the oxygen fugacity of Kilauea basalt: Geochimica et Cosmochimica Acta, v. 57, p. 795-814.

Gerlach, T.M., and Nordlie, B.E., 1975a, The C-O-H-S gaseous system-Part I, Composition limits and trends in basaltic cases: American Journal of Science, v. 275, p. 353-376.

1975b, The C-O-H-S gaseous system-Part II, Temperature, atomic composition, and molecular equilibria in volcanic gases: American Journal of Science, v. 275, p. 377-394.

1975c, The C-O-H-S gaseous system-Part III, Magmatic gases compatible with oxides and sulfides in basaltic magmas: American Journal of Science, v. 275, p. 395-410.

Giardini, A.A., and Melton, C.E., 1981, Experimentally-based arguments supporting large crustal accumulations of non-biogenic petroleum: Journal of Petroleum Geology, v. 4, no. 2, p. 187-190.

Giardini, A.A., Melton, C.E., and Mitchell, R.S., 1982, The nature of the upper $400 \mathrm{~km}$ of the Earth and its potential as the source for non-biogenic petroleum: Journal of Petroleum Geology, v. 52, p. 173-190.

Giardini, A.A., Subbarayudu, G.V., and Melton, C.E., 1976, The emission of occluded gas from rocks as a function of stress-Its possible use as a tool for predicting earthquakes: Geophysical Research Letters, v. 3, p. 355-358.

Giggenbach, W.F., 1990, Water and gas chemistry of Lake Nyos and its bearing on the eruptive process: Journal of Volcanology and Geothermal Research, v. 42, p. 337-362.

Glassley, W., 1982, Fluid evolution and graphite genesis in the deep continental crust: Nature, v. 295, p. 229-231.

Gold, Thomas, 1978, Terrestrial sources of carbon and Earthquake outgassing, paper presented at International Scientific Forum on an Acceptable World Energy Future, University of Miami, Florida, Nov. 27-Dec. 1, 1978.

- 1979a, Terrestrial sources of carbon and Earthquake outgassing: Journal of Petroleum Geology, v. 2, p. 3-19.

1979b, The Earthquake evidence for Earth gas, presented at Conference on Energy for Survival, Sydney, Australia, Aug. 27-Sept. 7: Pergamon Press, p. 65-78.

1980 , Outgassing and the power source for plate tectonics, presented at the NATO advanced study institute on the mechanism of continental drift and plate tectonics, Newcastle on Tyne, United Kingdom, March 27-April 10, 1979, p. 343-344.

1987, Power from the Earth-Deep Earth gas energy for the future: London, J.M. Dent and Sons, $197 \mathrm{p}$.

Gold, T., and Held, M., 1987, Helium-nitrogen-methane systematics in natural gases of Texas and Kansas: Journal of Petroleum Technology, v. 10, p. 415-424.

Gold, T., and Soter, S., 1980, The deep-Earth-gas hypothesis: Scientific American, v. 243, p. 154-170.

Gol'dberg, I.S., and Chernikov, K.A., 1969, The nature of bitumens in the alkalic and ultramafic rocks of the northern part of the Siberian Platform: Geochemistry International, v. 5, p. $402-407$

Goldstein, J.I., 1964, The growth of the Widmanstatten pattern in metallic meteorites: Cambridge, Mass., Massachusetts Institute of Technology, doctoral thesis, 122 p., plus appendix.

Green, D. H., Falloon, T. J., and Taylor, W. R., 1987, Mantlederived magmas-Roles of variable source peridotite and variable C-H-O fluid compositions, in Bysen, B.O., ed., Magmatic Processes: Physicochemical Principles, no. 1, p. 139-154.

Green, D.H, Taylor, W.R., and Foley, S., 1990, The Earth's upper mantle as a source for volatiles, in Herbert, H.K., and Ho, S.E., eds., Stable isotopes and fluid processes in mineralization: Queensland, Geology Department and University Extension, University of Western Australia, v. 23, p. 17-34.

Green, H.W., and Radcliffe, S.V., 1975, Fluid precipitates in rocks from the Earth's mantle: Bulletin of the Geological Society of America, v. 86, p. 846-852.

Griesshaber, E., O'Nions, R.K., and Oxburgh, E.R., 1992, Helium and carbon isotope systematics in crustal fluids from the Eifel, the Rhine Graben and Black Forest, F.R.G.: Chemical Geology, v. 99, p. 213-235.

Grudinin, M.I., and Sekerin, A.P., 1979, Native iron in ultramafic rocks of the Shamanskiy pluton: Doklady Akademia Nauk SSSR, v. 245, p. 160-162. [English translation.]

Guha, J., and Kanwar, R., 1987, Vug brines-fluid inclusions-A key to the understanding of secondary gold enrichment 
processes and the evolution of deep brines in the Canadian Shield, in Fritz, P., and Frape, S.K., eds., Saline water and gases in crystalline rocks: Geological Association of Canada, Special Paper 33, p. 89-95.

Gurko, N.N., Marrero, M., and Principe, M., 1982, Influence of secondary factors on the light hydrocarbon composition of oils in the central depression of Cuba: International Geology Review, v. 24, no. 1, p. 99-104.

Gwilliam, W.J., 1982, Subducted organic origin gas hypothesis for deep source methane, Chapter 3.9, in Deep-Source Gas Workshop Technical Proceedings, Morgantown Energy Technology Center: Morgantown, West Virginia, U.S. Department of Energy, Report DOE/METC/82-50, p. 140-161.

Haggerty, J.A., 1991, Evidence from fluid seeps atop serpentine seamounts in the Mariana Forearc-Clues for emplacement of the seamounts and their relationship to forearc tectonics: Marine Geology, v. 102, p. 293-309.

Haggerty, S.E., 1986, Diamond genesis in a multiply constrained model: Nature, v. 320, p. 34-38.

1987, Source regions of oxides, sulfides and metals in the upper mantle-Clues to the stability of diamonds, and the genesis of kimberlites, lamproites and carbonatites, in Fourth International Kimberlite Conference, Perth: Geological Society of Australia, Extended Abstracts, no. 16, p. 250-251.

Hahn-Weinheimer, P., and Rost, F., 1961, Akzessorische Mmineralen und Elemente in Serpentinit von Leupoldgrun (Munchberger Greissmasse), Ein Beitrag zur Geochimie ultabasischer Gesteine: Geochimica et Cosmochimica Acta, v. 21, p. 165-181.

Harris, D.M., Sato, M., Casadevall, T.J., Rose, W.I., Jr., and Bornhorst, T.J., 1982, Emission rates of $\mathrm{CO}_{2}$ from plume measurements, in Lipman, P.W., and Mullineaux, D.R., eds., The 1980 eruptions of Mount St. Helens, Washington: U.S. Geological Survey Professional Paper 1250, p. 201-207.

Headlee, A.J.W., 1962, Carbon dioxide, nitrogen crucial to oil migration?: World Oil, October, p. 126-144.

Hedberg, H., 1970, Continental margins from viewpoint of the petroleum geologist: Bulletin of the American Association of Petroleum Geologists, v. 54, p. 3-43.

Henry, P., Le Pichon, X., Lallement, S., Foucher, J.P., Westbrook, G., and Hobart, M., 1990, Mud volcano field seaward of the Barbados accretionary complex-A deep-towed side scan sonar survey: Journal of Geophysical Research, v. 95, no. B6, p. 8917-8929.

Hirono, M., and Shibata, T., 1983, Volcanic eruptions observed by laser radar, Bulletin of the Volcanological Society of Japan, v. 28 , no. 4, p. 337-356.

Hiyagon, H., and Kennedy, B.M., 1992, Noble gases in $\mathrm{CH}_{4}$-rich gas fields, Alberta, Canada: Geochimica et Cosmochimica Acta, v. 56, p. 1569-1589.

Hofmann, A.W., 1989, Geochemistry and models of mantle circulation: Philosophical Transactions of the Royal Society of London, v. A328, p. 425-439.

Holland, H.D., 1978, The chemistry of the atmosphere and oceans: New York, Wiley.

1984, The chemical evolution of the atmosphere and oceans: Princeton, N.J., Princeton University Press, 582 p.

Holloway, J.R., 1977, Fugacity and activity of molecular species of supercritical fluids, in Fraser, D.G., ed., Thermodynamics in geology: Reidel, p. 161-181.
Hooker, P.J., O'Nions, R.K., and Oxburgh, E.R., 1985, Helium isotopes in North Sea gas fields and the Rhine rift: Nature, v. 318, p. 273-275.

Hottman, C.E., Smith, J.A., and Purcell, W.R., 1979, Relationships among Earth stresses, pore pressure, and drilling problems offshore Gulf of Alaska: Journal of Petroleum Technology, v. 31, p. 1477-1484.

Hunt, J.M., 1990, Generation and migration of petroleum from abnormally pressured fluid compartments: American Association of Petroleum Geologists Bulletin, v. 74, no. 1, p. 1-12.

Ikorskiy, S.V, and Shugurova, N.A., 1975, Gas composition in Khibiny alkali-rock minerals: Geochemistry International, v. 11 , no. 3, p. 671 .

Illies, J.H., Prodehl, C., Schmincke, H.U., and Semmel, A., 1979, The Quaternary uplift of the Rhenish Shield in Germany: Tectonophysics, v. 61, p. 197-225.

Jean-Baptiste, P., Charlou, J.L., Stievenard, M., Donval, J.P., Bougault, H., and Mevel, C., 1991, Helium and methane measurements in hydrothermal fluids from the Mid-Atlantic Ridge-The Snake Pit site at $23^{\circ} \mathrm{N}$ : Earth and Planetary Science Letters, v. 106, p. 17-28.

Jeanloz, R., and Knittle, E., 1989, Density and composition of the lower mantle: Philosophical Transactions, Royal Society of London, series A, v. 328, p. 377-389.

Jeffrey, A.W.A., and Kaplan, I.R., 1988, Hydrocarbons and inorganic gases in the Gravberg-1 well, Siljan Ring, Sweden: Chemical Geology, v. 71, p. 237-255.

Jeffrey, A.W.A., Kaplan, I.R., Poreda, R., and Craig, H., 1988, The origin of natural gases from convergent margins: Paper presented at V.M. Goldschmidt Conference, Geochemical Society, Baltimore, Maryland.

Jenden, P.D., Newell, K.D., Kaplan, I.R., and Watney, W.L., 1988a, Composition and stable isotope geochemistry of natural gases from Kansas, Midcontinent, U.S.A.: Chemical Geology, v. 71, p. 117-147.

Jenden, P.D., Kaplan, I.R., Poreda, R.J., and Craig, H., 1988b, Origin of natural gases in the California Great Valley-Evidence from helium, carbon and nitrogen isotope ratios: Geochimica et Cosmochimica Acta, v. 52, p. 851-861.

Johan, Z., and LeBel, L., 1980, Genese des couches et podes de chromite dans les complexes ophiolitiques: International Geological Congress Abstracts, Resumés 26, v. 3, p. 950

Johnson, J.W., Oelkers, E.H., and Helgeson, H.C., 1992, SUPCRT92-A software package for calculating the standard molal thermodynamic properties of minerals, gases, aqueous species, and reactions from 1 to 5000 bars and $0^{\circ}$ to $1000^{\circ} \mathrm{C}$ : Computers and Geosciences.

Kasting, J.F., and Ackerman, T.P., 1986, Climatic consequences of very high carbon dioxide levels in the Earth's early atmosphere: Science, v. 234, p. 1383-1385.

Kennedy, B.M., Poths, J., and Hiyagon, H., 1992, Anomalous ${ }^{3} \mathrm{He}$ contents of $\mathrm{CH}_{4}$-rich gases in sedimentary basins, in Kharaka, Y.K., and Maest, J., eds., Water-Rock Interaction: Rotterdam, Balkema, p. 947-950.

Kogarko, L.N., 1987, Alkaline rocks of the eastern part of the Baltic Shield (Kola Peninsula), in Fitton, J.G., and Upton, B.G.J., eds., Alkaline Igneous Rocks: Geological Society of London Special Publication No. 30, p. 531-544.

Kogarko, L.N., and Romanchev, B.P., 1977, Temperature, pressure, redox conditions, and mineral equilibrium in agpaitic 
nepheline syenites and apatite-nepheline rocks: Geochemistry International, v. 14, p. 113-128.

Komor, S.C., Valley, J.W., Brown, P.E., and Collini, B., 1988, Fluid inclusions in Granite from the Siljan Ring Impact Structure and surrounding regions, in Boden, A., and Eriksson, K.G., eds., Deep drilling in crystalline bedrock: Berlin, Springer-Verlag, p. 180-208.

Konnerup-Madsen, J., Kreulen, R., and Rose-Hansen, J., 1988, Stable isotope characteristics of hydrocarbon gases in the alkaline Ilimaussaq complex, south Greenland: Bulletin of Mineralogy, v. 111, p. 567-576.

Konnerup-Madsen, J., Larsen, E., and Rose-Hansen, J., 1979, Hydrocarbon-rich fluid inclusions in minerals from the alkaline Ilimaussaq intrusion, South Greenland: Bulletin Mineralogique, v. 102, p. 642-653.

Konnerup-Madsen, J., and Rose-Hansen, J., 1982, Volatiles associated with alkaline igneous rift activity-Fluid inclusions in the Ilimaussaq intrusion and the Gardar granitic complexes (South Greenland), in Kreulen, R., and Touret, J., eds., Current research on fluid inclusions: Chemical Geology, v. 37, p. 79-93.

Kotra, J.P., Finnegan, D.L., and Zoller, W.H., 1983, El Chichón-Composition of plume gases and particles: Science, v. 222 , p. $1018-1021$.

Kravtsov, A.I., Voytov, G.I., Fridman, A.I., Grechukhina, T.G., Linde, I.F., and Polyanskiy, M.N., 1967, Hydrogen content of gas streams in Khibiny: Doklady Akademii Nauk SSSR, v. 177, p. 1190-1192. [English translation.]

Kravtsov, A.I., Voytov, G.I., Bobrov, A.P., Akimov, A.N., Ivanov, A.N., and Serdyukov, L.I., 1979, Composition and isotopes of gases in the Mir kimberlite pipe: Doklady Akademii Nauk SSSR, v. 2454, p. 950-953.

Kravtsov, A.I., Voytov, G.I., Ivanov, V.A., and Kropotova, O.I., 1976, Gases and bitumens in rocks of the Udachnaya pipe: Doklady Akademii Nauk SSSR, v. 228, p. 231-234. [English translation.]

Kreulen, R., and Schuiling, R.D., 1982, $\mathrm{N}_{2}-\mathrm{CH}_{4}-\mathrm{CO}_{2}$ fluids during formation of the Dome de l'Agout, France: Geochimica et Cosmochimica Acta, v. 46, p. 193-203.

Krishnarao, J.S.R., 1964, Native nickel-iron alloy-Its mode of occurrence, distribution and origin: Economic Geology, v. 59 , p. $443-448$.

Krivanek, C.M., 1978, McElmo Field, in Fasset, J.E., and Thomaidis, N.D., eds., Oil and gas fields of the Four Corners Area: Four Corners Geological Society, p. 148-151.

Kulm, L.D., and Suess, E., 1990, Relationship between carbonate deposits and fluid venting-Oregon accretionary prism: Journal of Geophysical Research, v. 95, no. B6, p. 8899-8915.

Kulm, L.D., Suess, E., Moore, J.C., Carson, B., Lewis, B.T., Ritger, S.D., Kadko, D.C., Thomburg, T.M., Embley, R.W., Rugh, W.D., Massoth, G.J., Langseth, M.G., Cochrane, G.R., and Scamman, R.L., 1986, Oregon subduction zoneVenting, fauna, and carbonates: Science, v. 231, p. 561-566.

Kusakabe, M., Oshumi, T., and Aramaki, S., 1989, The Lake Nyos gas disaster-Chemical and isotopic evidence in waters and dissolved gases from three Cameroonian crater lakes, Nyos, Monoun, and Wum: Journal of Volcanology and Geothermal Research, v. 39, p. 167-185.

Kvenvolden, K.A., and Field, M.E., 1981, Thermogenic hydrocarbons in unconsolidated sediment of Eel River Basin, off- shore Northern California: Bulletin of the American Association of Petroleum Geologists, v. 65, p. 1642-1646.

Lahermo, P.W., and Lampen, P.H., 1987, Brackish and saline groundwaters in Finland, in Fritz, P., and Frape, S.K., eds., Saline waters and gases in crystalline rocks: Geological Association of Canada Special Paper 33, p. 103-110.

Langseth, M.G., Westbrook, G.K., and Hobart, M.A., 1988, Geophysical survey of a mud volcano seaward of the Barbados Ridge accretionary complex: Journal of Geophysical Research, v. 93, no. B2, p. 1049-1061

Larson, L.M., 1976, Clinopyroxene and coexisting mafic minerals from the alkaline Ilimaussaq intrusion, south Greenland: Journal of Petrology, v. 17, p. 258-290.

Le Guern, F., Tazieff, H., and Faivre Pierret, R., 1982, An example of health hazard-People killed by gas during a phreatic eruption, Diëng Plateau (Java, Indonesia), February 20, 1979: Bulletin Volcanologique, v. 45, p. 153-156.

Le Pichon, X., Foucher, J.P., Boulègue, Henry, P., Lallement, S., Benedetti, M., Avedik, F., and Mariotti, A., 1990, Mud volcano field seaward of the Barbados accretionary complexA submersible survey: Journal of Geophysical Research, v. 95 , no. B6, p. 8931-8943.

Leung, I., Guo, W., Friedman, I., and Gleason, J., 1990, Natural occurrence of silicon carbide in a diamondiferous kimberlite from Fuxian: Nature, v. 346, p. 352-354.

Lovering, J.F., and White, A.J.R., 1964, The significance of primary scapolite in granulitic inclusions from deep-seated pipes: Journal of Petrology, v. 5:2, p. 195-218.

1969, Granulitic and eclogitic inclusions from basic pipes at Delegate, Australia: Contributions to Mineralogy and $\mathrm{Pe}$ trology, v. 21, no. 1, p. 9-52.

Lyon, G.L., and Hulston, J.R., 1984, Carbon and hydrogen isotopic compositions of New Zealand geothermal gases: Geochimica et Cosmochimica Acta, v. 48, p. 1161-1171.

Lutts, B.G., Petersil'ye, I.A., and Karzhavin, V.K., 1976, Composition of gases in rocks of the upper mantle: Doklady Akademii Nauk SSSR, v. 226, [English translation], p. 197200.

MacDonald, G.J., 1988, Major questions about deep continental structures, in Bodén, A., and Eriksson, K.G., eds., Deep drilling in crystalline bedrock, Volume 1-The Deep Gas Drilling in the Siljan Impact Structure, Sweden and Astroblemes: Berlin, Springer-Verlag, p. 28-48.

Mackwell, S.J., 1991, Diffusion of hydrogen in enstatite-Implications for the presence of water in the mantle, [abstract]: Eos, American Geophysical Union Spring Meeting 1991, Program and Abstracts, April 23, 1991, p. 143.

Mackwell, S.J., and Kohlstedt, D.L., 1990, Diffusion of hydrogen in olivine-Implications for water in the mantle: Journal of Geophysical Research, v. 95, no. B4, p. 5079-5088.

Maksimov, S.N., Muller, E., Botneva, T.A., Goldbecher, K., Zor'kin, L.M., and Pankina, R.G., 1976, Origin of high-nitrogen gas pools: International Geology Review, v. 18, p. 551-556.

Mamyrin, B.A., and Tolstikhin, L.N., 1984, Helium isotopes in nature, in Developments in geochemistry, v. 3: Amsterdam, Elsevier, 273 p.

Marakushev, A.A., 1981, The fluid regime in the formation of diamond-containing rock: International Geology Review, v. 24 , no. 11 , p. $1241-1252$. 
Mareschal, M., Fyfe, W.S., Percival, J., and Chan, T., 1992, Grain boundary graphite in Kapuskasing gneisses and implications for lower crustal conductivity: Nature, v. 357 , no. 6380 , p. 674-6765.

Marland, G., 1984, A workshop on the origin of natural gas, Gas Research Institute Report No. GRI-84/0166: Chicago, Ill., Gas Research Institute.

Marty, B., 1989, On mantle carbon flux calculated: Eos, Transactions of the American Geophysical Union, v. 70, no. 1, p. 1.

Marty, B., and Jambon, A., 1987, $\mathrm{C} /{ }^{3} \mathrm{He}$ in volatile fluxes from the solid Earth-Implications for carbon geodynamics: Earth and Planetary Science Letters, v. 83, p. 16-26.

Mathews, J.F., 1972, The critical constants of inorganic substances: Chemical Reviews, v. 72, p. 71-100.

Mathez, E.A., 1984, Influence of degassing on oxidation states of basaltic magmas: Nature, v. 310, p. 371-375.

1984, Influence of degassing on oxidation states of basaltic magmas: Nature, v. 310, p. 371-375.

Mathez, E.A., Dietrich, V.J., Holloway, J.R., and Boudreau, A.E., 1989, Carbon distribution in the Stillwater complex and evolution of vapor during crystallization of Stillwater and Bushveld magmas: Journal of Petrology, v. 30, p. 153-173.

Matthews, A., Fouillac, C., Hill, R., O'Nions, R.K., and Oxburgh, E.R., 1987, Mantle-derived volatiles in the continental crust-The Massif Central of France: Earth and Planetary Science Letters, v. 85, p. 117-128.

Matsui, T. and Abe, Y., 1986a, Evolution of an impact-induced atmosphere and magma ocean on the accreting Earth. Nature, v. 319 , p. 303-305.

1986b, Impact-induced atmospheres and oceans on Earth and Venus: Nature, v. 322, p. 526-528.

McCammon, C., 1993, Effect of pressure on the composition of the lower mantle end member $\mathrm{Fe}_{\mathrm{x}} \mathrm{O}$ : Science, v. 259 , p. 6668.

McGetchin, T.R., and Besancon, J.R., 1983, Carbonate inclusions in mantle derived pyropes: Earth and Planetary Science Letters, v. 18 , p. $408-410$.

McGetchin, T.R., Nikhanj, Y.S., and Chodos, A.A., 1973, Carbonatite-Kimberlite relations in the Cane Valley Diatreme, San Juan County, Utah: Journal of Geophysical Research, v. 78, p. $1854-1869$.

McGetchin, T.T., and Silver, L.T., 1970, Compositional relations in minerals from kimberlite and related rocks from the Moses Valley dike, San Juan County, Utah: American Mineralogist, v. 55 , p. $1738-1771$.

McGetchin, T.R., and Ullrich, G.W., 1973, Xenoliths in maars and diatremes with inferences for the Moon, Mars, and Venus: Journal of Geophysical Research, v. 78, p. 18331853.

McKenny, J.W., and Masters, J.A., 1968, Dineh-bi-Keyah field, Apache County, Arizona: American Association of Petroleum Geologists Bulletin, v. 52, p. 2045-2057.

Melchanov, V.I., 1967, Experimental synthesis of hydrocarbons by fine grinding of mineral matter in water: Doklady Akademii Nauk SSSR, v. 174, p. 194-196. [English translation.]

Moore, J.C., Biju-Duval, B., Bergen, J.A., Blackington, G., Claypool, G.E., Cowan, D.S., Deunneiber, F., Guerra, R.T., Hemleben, C.H.J., Hussong, D., Marlow, M.S., Natland, J.S., Pudsey, C.J., Renz, G.W., Tardy, M., Willis, M.E., Wilson, D., and Wright, A.A., 1982, Offscraping and underthrusting of sediment at the deformation front of the Barbados Ridge: Deep Sea Drilling Project Leg 78A: Geological Society of America Bulletin, v. 93, p. 1065-1077.

Moore, J.C., Orange, D., and Kulm, L.D., 1990, Interrelationship of fluid venting and structural evolution-Alvin observations from the frontal accretionary prism, Oregon: Journal of Geophysical Research, v. 95, no. B6, p. 8795-8808.

Mueller, R.F., 1971, Oxidative capacity of magmatic components: American Journal of Science, v. 270, p. 236-243.

Murck, B.W., Burruss, R.C., Hollister, L.S., 1978, Phase equilibria in fluid inclusions in ultramafic xenoliths: American Mineralogist, v. 63 , p. $40-46$.

Myers, G., 1987, Fluid expulsion during underplating of the Kodiak Formation-A fluid inclusion study: M.S. thesis, University of California, Santa Cruz.

Nash, J.T., Granger, H.C., and Adams, S.S., 1981, Geology and concepts of genesis of important types of uranium deposits, in Skinner, B.J., ed., Economic Geology 75th Anniversary Volume, 1905-1980, p. 63-116.

Neal, C., and Stanger, G., 1983, Hydrogen generation from mantle source rocks in Oman: Earth and Planetary Science Letters, v. 66, p. $315-320$.

Neil, J.M., and Apps, J.A., 1981, Results of albite stability measurements as a function of temperature $\left(125-350^{\circ} \mathrm{C}\right)$ : Annual $\mathrm{Re}-$ port 1980, Earth Science Division, Lawrence Berkeley Laboratory Report LBL12100, p. 41-43.

Nellis, W.J., Ree, F.H., van Thiel, M., and Mitchell, A.C., 1981, Shock compression of liquid carbon monoxide and methane to $90 \mathrm{GPa}$ (900 kbar): Journal of Chemical Physics, v. 76, p. 3055-3063.

Nordlie, B.E., 1971, The composition of the magmatic gas of Kilauea and its behavior in the near surface environment: American Journal of Science, v. 271, p. 417-463.

Nordstrom, D.K., Plummer, L.N., Wigley, T.M.L., Wolery, T.J, Ball, J.W., Jenne, E.A., Bassett, R.L., Crerar, D.A., and Florence, T.M., 1979, A comparison of computerized chemical models for equilibrium calculations in aqueous systems, in Jenne, E.D., ed., Chemical modelling in aqueous systems: American Chemical Society, ACS Symposium series 93, p. 857-892.

Novikov, L.A., and Slobodskoy, R.M., 1979. Mechanism of formation of diatremes. International Geology Review, v. 21, no. 10, p. 1131-1139.

Nurmi, P.A., Kukkonen, I.T., and Lahermo, P.W., 1988, Geochemistry and origin of saline groundwaters in the Fennoscandian Shield: Appl. Geochem., v. 3, p. 185-203.

Ohmoto, H., and Rye, R.O., 1979, Isotopes of sulfur and carbon, Ch. 10, in Barnes, H.L., ed., Geochemistry of hydrothermal ore deposits: New York, Wiley, p. 509-567.

O'Nions, R.K., and Oxburgh, E.R., 1988, Helium, volatiles and the continental crust: Earth and Planetary Science Letters, v. 90, p. 331-339.

Oxburgh, E.R., O’Nions, R.K., and Hill, R.I., 1986, Helium isotopes in sedimentary basins: Nature, v. 324, p. 632-635.

Pasteris, J.D., 1988, Secondary graphitization in mantle-derived rocks: Geology, v. 16, p. 804-807.

Petersil'ye, I.A., 1962, Origin of hydrocarbon gases and dispersed bitumens of the Khibina alkalic massif: Geochemistry, v. 1, p. 13-30. [English translation.]

Petersil'ye, I.A., Andreeva, E.D., and Sveshnikova, E.V., 1965, Organic matter in the rocks of some alkaline massifs of Si- 
beria: Isvestia Akademii Nauk SSSR, Geology Series, v. 6 , p. 26-38. [In Russian.]

Petersil'ye, I.A., Kozlov, Y.K., Belyayev, K.D., Sholokhnev, V.V., and Dokuchayeva, V.S., 1970, Nitrogen and hydrocarbon gases in ultramafic rocks of the Sopcha Stock of the Monchegorsk pluton, Kola peninsula: Doklady Akademii Nauk SSSR, v. 194, p. 200-203. [English translation.]

Petersil'ye, I.A., and Pripachkin, V.A., 1979, Hydrogen, carbon, nitrogen and helium in gases from igneous rocks: Geochemistry International, v. 16, no. 4, p. 50-55. [English translation.]

Petersil'ye, I.A., and Sorenson, H., 1970, Hydrocarbon gases and bituminous substances in rocks from the Ilimaussaq alkaline intrusion, South Greenland: Lithos, v. 3, p. 59-76.

Peyronneau, J., and Poirier, J.P., 1989, Electrical conductivity of the Earth's lower mantle: Nature, v. 342, p. 537-539.

Picard, M.D., 1960, Carbon dioxide, nitrogen and helium in Mississippian of Four Corners Region, preliminary statement, in Four Corners Geological Society Guidebook, Geology of the Paradox Basin fold and fault belt, Third Field Conference: Four Corners Geological Society, p. 138-140.

1962, Occurrence and origin of Mississippian gas in the Four Corners region: American Association of Petroleum Geologists Bulletin, v. 46, p. 1681-1700.

Pierce, A.P., Gott, G.B., and Mytton, J.W., 1964, Uranium and helium in the Panhandle gas field, Texas, and adjacent areas: U.S. Geological Survey Professional Paper 454-G, p. GI-57.

Pineau, F., Javoy, M., Behar, F., and Touret, J., 1981, La geochimie isotopique du facies granulite du Bamble Norvege et l'origine des fluides carbones dans la croute profonde: Bulletin Mineralogique, v. 104, p. 630-641.

Pohlmann, H.F., 1967, The Navajo indian nation and Dineh Bi Keyah, in Trauger, F.D., ed., Guidebook of the Defiance-ZuniMt. Taylor region, Arizona and New Mexico: N.M. Geol. Soc., 18th Field Conf., p. 63-69.

Poreda, R.J., Jenden, P.D., Kaplan, I.R., and Craig, H., 1986, Mantle helium in Sacramento basin natural gas wells: Geochimica et Cosmochimica Acta, v. 50, p. 2847-2853.

Puchelt, H., 1983, Carbon dioxide in the Rhenish Massif [abs.], in Fuchs, F., von Gehlen, K., Malzer, H., Murowski, H., and Semmel, A., eds., Plateau uplift, The Rhenish shield-A case history: Berlin, Springer-Verlag, p. 58.

Ramdohr, P., 1952, Uber Josephinit, Awaruit, Souesit, ihre Eigenschaften, Entstehung und Paragenesis: Mineralogical Magazine, v. 29 , p. $375-393$.

Ringwood, A.E., 1975, Composition and petrology of the Earth's mantle: New York, McGraw Hill, 618 p.

1979, Composition and origin of the Earth, in McElhinny, M.W., ed., The Earth-Its origin, structure and evolution: London, Academic Press, p. 1-58.

Rockwell Hanford Operations, 1982, Site characterization report for the basalt waste isolation project, DOE/RL 82-3, v. 1, ch. 5 , Hydrogeology, S.1 Regional and Site Hydrologic Investigations, p. 5.1-1 to 5.1-203: Washington, D.C., U.S. Department of Energy.

Roedder, E., 1965, Liquid $\mathrm{CO}_{2}$ inclusions in olivine-bearing nodules and phenocrysts from basalts: American Mineralogist, v. 50, p. 1746-1782.

1972, Composition of fluid inclusions, in Fleischer, M., ed., Data of geochemistry (6th ed.): U.S. Geological Survey Professional Paper 440-JJ, 164 p.
1984. Upper mantle environments, Chapter 17, in Roedder, E., ed., Fluid Inclusions: Mineralogical Society of America, Reviews in Mineralogy, v. 12, p. 503-533.

Rona, P.A., Bougault, H., Charlou, J.L., Appriou, P., Nelson, T.A., Trefry, J.H., Eberhart, G.L., Barone, A., and Needhan, H.D., 1992, Hydrothermal circulation, serpentinization, and degassing at a rift valley-fracture zone intersection-MidAtlantic Ridge near $15^{\circ} \mathrm{N}, 45^{\circ} \mathrm{W}$ : Geology, v. 20 , p. $783-$ 786.

Ross, J.E., and Aller, L.H., 1976, The chemical composition of the Sun: Science, v. 191, p. 1223-1229.

Rutherford, M.J., 1993, Experimental petrology applied to volcanic processes, EOS, Transactions, American Geophysical Union, v. 74, no. 5 , p. $49,55$.

Rutherford, M.J., and Devine, J.D., 1988, The May 18, 1980 eruption of Mt. St. Helens 3-Stability and chemistry of amphibole in the magma chamber: Journal of Geophysical Research, v. 93, p. 11949.

Sakai, H., Casadevall, T.H. and Moore, J.G., 1982, Chemistry and isotope ratios of sulfur in basalts and volcanic gases at Kilauea Volcano, Hawaii. Geochimica et Cosmochimica Acta, v. 46, p. 729-738

Sakata, S., Takahashi, M., and Hoshiro, K., 1986, Geochemical study on genesis of natural gases accumulated in deep volcaniclastic rocks: Journal of the Japanese Association of Petroleum Technology, v. 51, p. 228-237. [In Japanese.]

Sakata, S., Takahashi, M., Igari, S.I., and Suzuki, N., 1989, Origin of light hydrocarbons from volcanic rocks in the "green tuff" region of Northeast Japan-Biogenic versus magmatic: Chemical Geology, v. 74, p. 241-248.

Sano, Y., and Wakita, H., 1985, Geographical distribution of ${ }^{3} \mathrm{He} /{ }^{4} \mathrm{He}$ ratios in Japan-Implications for arc tectonics and incipient magmatism: Journal of Geophysical Research, v. 90, no. B10, p. 8729-8741.

Sano, Y., Wakita, H., and Giggenbach, W.F., 1987a, Island arc tectonics of New Zealand manifested in helium isotope ratios: Geochimica et Cosmochimica Acta, v. 51, p. 18551860.

Sano, Y., Wakita, H., Ohsumi, T., and Kusakabe, M., 1987b, Helium isotope evidence for magmatic gases in Lake Nyos, Cameroon: Geophysical Research Letters, v. 14, no. 10, p. 1039-1041.

Sato, M., 1978a, Oxygen fugacity in basaltic magmas and the role of gas-forming elements: Geophysical Research Letters, v. 5 , p. $447-449$.

1978b, A possible role of carbon in characterizing the oxidation state of a planetary interior and originating a metallic core: Lunar and Planetary Science, IX, p. 990-992.

_ 1991, Oxygen fugacities of FeO mineral assemblages in relation to carbon oxidation in the Earth: American Geophysical Union Spring Meeting 1991, Program and Abstracts, April 23, 1991, p. 142.

Sato, M., Sutton, A.J., and McGee, K.A., 1985, Anomalous hydrogen emissions from the San Andreas fault observed at the Cienega Winery, central California: Pageoph, v. 122, p. 376391.

Sato, M., Sutton, A.J., McGee, K.A., and Russell-Robinson, S., 1986, Monitoring of hydrogen along the San Andreas and Calaveras faults in Central California in 1980-1984: Journal of Geophysical Research, v. 91, no. B12, p. 12315-12326. 
Sato, M., and Valenza, M., 1980, Oxygen fugacities of the layered series of the Skaergaard intrusion, East Greenland: American Journal of Science, v. 280-A, p. 134-158.

Saxena, S.K., 1989, Oxidation state of the mantle: Geochimica et Cosmochimica Acta, v. 53, p. 89-95.

Saxena, S.K., and Fei, Y., 1988, Fluid mixtures in the C-H-O system at high pressure and temperature: Geochimica et Cosmochimica Acta, v. 52, p. 505-512.

Scarfe, C.M., and Wyllie, P.J., 1967, Experimental redetermination of the upper stability limit of serpentine up to $3 \mathrm{kbar}$ pressure: Eos, Transactions American Geophysical Union, v. 48 , p. 225 .

Schiffries, C.M., 1982, The petrogenesis of a platiniferous dunite pipe in the Bushveld Complex-Infiltration metasomatism by a chloride solution: Economic Geology, v. 77, p. 1439-1453.

Schoell, M., Tietze, K., and Schoberth, S.M., 1988, Origin of methane in Lake Kivu, (East-Central Africa): Chemical Geology, v. 71, p. 257-265.

Sherwood, B., Fritz, P., Frape, S.K., Macko, S.A., Weise, S.M., and Welhan, J.A., 1988, Methane occurrences in the Canadian Shield: Chemical Geology, v. 71, p. 223-237.

Sherwood-Lollar, B., Frape, S.K., Drimmie, R., Fritz, P., Weise, S.M., Macko, S.A., Welhan, J.A., Blomqvist, R., and Lahermo, P.W., 1989, Deep gases and brines of the Canadian and Fennoscandian Shields-A testing ground for the theory of abiotic methane generation, in Miles, D.L., ed., Sixth International Symposium on Water-Rock Interaction: Rotterdam, A.A. Balkema, p. 617-620.

Shipley, T.H., Stoffa, P.L. and Dean, D.D., 1990, Underthrust sediments, fluid migration paths, and mud volcanoes associated with the accretionary wedge of Costa Rica, Middle America Trench: Journal of Geophysical Research, v. 95, p. B8743-B8752.

Shteynberg, D.S., and Lagutina, M.V., 1978, Carbon balance in serpentinization of ultramafic rocks: Doklady Akademii Nauk SSSR, v. 243, p. 200-203. [English translation.]

Silver, E.A., Breen, N.A. and Prasetyo, H., 1986, Multibeam study of the Flores baskar thrust belts, Indonesia: Journal of Geophysical Research, p. B3489-B3500.

Sisson, V.B., Crawford, M.L., and Thompson, P.H., 1981, $\mathrm{CO}_{2^{-}}$ brine immiscibility at high temperatures, evidence from calcareous metasedimentary rocks: Contributions to Mineralogy and Petrology, v. 78, p. 371-378.

Snyder, D., Carmichael, I.S.E., and Wiebe, K.A., 1993, Experimental study of liquid evolution in an Fe-rich, layered mafic intrusion; constraints of Fe-Ti oxide precipitation on the T- $f_{\mathrm{O}_{2}}$ and T-P paths of tholeiitic magmas: Contributions to Mineralogy and Petrology, v. 113, no. 1, p. 73-86.

Sobolev, V.S., Bazarova, T.Y., Kostyuk, V.P., 1974, Inclusions in the minerals in some types of alkaline rocks [with comments], in Alkaline rocks, conditions of formation: London, John Wiley and Sons, p. 389-401.

Sobolev, V.S., Bazarova, T.Y., Shugurova, N.A., Bazarov, L.Sh., Dolgov, Yu.A., and Sorensen, H., 1970, A preliminary examination of fluid inclusions in nepheline, sorensenite, tugtupite and chkalovite from the Ilimaussaq intrusion, South Greenland: Medd. Gronland, v. 181(11), p. 1-32.

Sobolev, V.S., and Stankovskiy, A. F., 1979, Carbonate inclusions in chrome spinellids from kimberlite sheets: Doklady Akademii Nauk SSSR, v. 251, no. 6, p. 1477-1478.
Spera, F.J., 1974, A thermodynamic basis for predicting water solubilities in silicate melts and implications for the low velocity zone: Contributions to Mineralogy and Petrology, v. 45 , p. $175-186$.

Spera, F.J., and Bergman, S.C., 1980, Carbon dioxide in igneous petrogenesis: I. Aspects of the dissolution of $\mathrm{CO}_{2}$ in silicate liquids: Contributions to Mineralogy and Petrology, v. 74, p. 55-66.

Spiess, F.N., and others, 1980, East Pacific rise-Hot springs and geophysical experiments: Science, v. 207, no. 4438, p. 14211433.

Spinks, J.W.T., and Woods, R.J., 1976, An introduction to radiation chemistry ( $2 \mathrm{~d}$ ed.): John Wiley and Sons.

Staudacher, T., 1987, Upper mantle origin for Harding County well gases: Nature, v. 325 , p. 605-607.

Stumpel, E.F., and Rucklidge, J.C., 1982, The platiniferous dunite pipes of the eastern Bushveld: Economic Geology, v. 77, no. 6, p. 1419-1431.

Sugisaki, R., Ido, M., Takeda, H., Isobe, Y., Hayashi, Y., Nakamura, N., Satake, H., and Mizutani, Y., 1983, Origin of hydrogen and carbon dioxide in fault gases and its relation to fault activity: The Journal of Geology, v. 91, p. 239-258.

Tajika, E., and Matsui, T., 1992, Evolution of terrestrial proto$\mathrm{CO}_{2}$ atmosphere coupled with thermal history of the Earth: Earth and Planetary Science Letters, v. 113, p. 251-266.

Taylor, B.E., 1986, Magmatic volatiles-Isotopic variation of C, H and S, in Valley, J.W., Taylor, H.P., and O'Neil, J.R., eds., Stable isotopes in high temperature geological processes: Mineralogical Society of America, Reviews in Mineralogy, v. 16 , p. $185-225$.

Taylor, W.R., 1990, A reappraisal of the nature of fluids included by diamond-A window to deep-seated mantle fluids and redox conditions, in Herbert, H.K., and Ho, S.E., eds., Stable isotopes and fluid processes in mineralization: Queensland, Geology Department and University extension, University of Western Australia, v. 23, p. 17-34.

Taylor, W.R., and Green, D.H., 1987, The petrogenetic role of methane-Effect on liquidus phase relations and the solubility mechanism of reduced C-H volatiles, in Mysen, B.O., ed., Magmatic processes-Physicochemical principles: The Geochemical Society, Special Publication No. 1, p. 121-138.

-1989, The role of reduced C-O-H fluids in mantle partial melting, in Kimberlites and related rocks: Geological Society of Australia, Special Publication, v. 14, no. 1, p. $592-$ 602.

Thayer, T.P., 1966, Serpentinization considered as a constant volume metasomatic process: American Mineralogist, v. 51, p. $685-710$.

Thurston, P.C., Williams, H.R., Sutcliffe, R.H., and Stott, G.M., 1991, Geology of Ontario: Ontario Geological Survey Special Volume 4, parts 1 and 2, $1525 \mathrm{p}$.

Tietze, K., Geyh, M., Müller, H., Schröder, L., and Wehner, H., 1980. The genesis of methane in Lake Kivu: Geologische Rundschau, v. 69, p. 452-472.

Tingle, T.N., Green, H.W., Finnerty, A.A., 1988, Experiments and observations bearing on the solubility and diffusivity of carbon in olivine: Journal of Geophysical Research, v. 93, no. B12, p. $15289-15304$.

Tissot, B.P., and Welte, D.H., 1978, Petroleum formation and occurrence: Berlin, Springer-Verlag, 538 p. 
Tongish, C.A., 1980, Helium-Its relationship to geologic systems and its occurrence with the natural gases, nitrogen, carbon dioxide, and argon: U.S. Bureau of Mines, Report of Investigations $8444,176 \mathrm{p}$.

Touret, J., 1986, Fluid inclusions from the lower continental crust, in Dawson, J.B., Carswell, D.A., Hall, J., and Wedepohl, K.H., eds., The nature of the lower continental crust: Geological Society of London Special Publication No. 24, p. 161-172.

Treiman, A.H., and Essene, E.J., 1984, A periclase-dolomite-calcite carbonatite from the Oka complex, Quebec, and its calculated volatile composition: Contributions to Mineralogy and Petrology, v. 85, p. 149-157.

Tuttle, M.L., Briggs, P.H., Evans, W.C., Kling, G.W., and Lockwood, J.P., 1992, Influence of mafic minerals on water chemistry and water column stability of Lake Nyos, Cameroon, in Water-Rock Interaction: Rotterdam, Balkema, p. $449-452$.

Underwood, M.B. and Laughland, M.M., 1990, Thermal evolution of "hot" accretionary prisms in California and Japan [abs.]: American Association of Petroleum Geologists Bulletin, v. 74 , p. 783 .

Vdovykin, G.P., Bodunov, Ye.N., Izosimova, A.N., and others, 1979, Bitumens in the Mir kimberlite pipe: Doklady Akademii Nauk SSSR, v. 2454, p. 941-946.

Vinogradov, A.P., 1962, Average contents of chemical elements in the principal types of igneous rock of the Earth's crust: Geokhimiya, v. 7, p. 555-571. [English translation.]

Von Huene, R., and Lee, H., 1983, The possible significance of pore fluid pressure vs. subduction zones, in Watkins, J.S., and Drake, C.L., eds., Studies in continental margin geophysics: American Association of Petroleum Geologists, Memoir 34, p. 781-791.

Vovk, I.F., 1987, Radiolytic salt enrichment and brines in the crystalline basement of the East European Platform, in Fritz, P., and Frape, S.K., eds., Saline water and gases in crystalline rocks, Geological Association of Canada Special Paper 33 , p. $197-210$.

Voytov, V.I., Grechukhina, T.G., Levshvnova, V.P., and Polyanskiy, M.N., 1967, Chemical composition of plutonic gases as shown by data on the Aralsov abyssal well (Caspian depression): Doklady Akademii Nauk SSSR., v. 172, p. 192-195. [English translation.]

Vrolijk, P., Fisher, A., and Gieskes, J., 1991, Geochemical evidence and geothermal evidence for fluid migrastion in the Barbados accretionary prism (ODP Leg 110): Geophysical Research Letters, v. 18, p. 947-950.

Vrolijk, P., Myers, G., and Moore, J.C., 1988, Warm fluid migration along tectonic melanges in the Kodiak accretionary complex, Alaska: Journal of Geophysical Research, v. 93, no. B9, p. 10313-10324.

Wainger, L., 1988, Mantle carbon flux calculated: EOS, Transactions, American Geophysical Union, v. 69, no. 12, p. 169.

Wakita, H., Sano, Y., Urabe, A., and Nakamura, Y., 1990, Origin of methane-rich natural gas in Japan-Formation of gas fields due to large-scale submarine volcanism: Applied Geochemistry, v. 5, p. 263-278.

Wallace, P., and Carmichael, I.S.E., 1992, Sulfur in basaltic magmas: Geochimica et Cosmochimica Acta, v. 56, p. $1863-$ 1874.
Wang, C.Y., Shi, Y., Hwang, W.T., and Chen, H., 1990, Hydrogeologic processes in the Oregon-Washington accretionary complex: Journal of Geophysical Research, v. 95, no. B6, p. $9009-9023$.

Wassall, H., 1956, The relationship of oil and serpentine in Cuba: 20th International Geological Congress, Mexico City, Section 3, p. 65-77.

Welhan, J.A., 1987, Characteristics of abiotic methane in rocks, in Fritz, P., and Frape, S.K., eds., Saline water and gases in crystalline rocks: Geological Association of Canada Special Paper 33, p. 225-233.

Welhan, J.A., 1988, Organics of methane in hydrothermal systems: Chemical Geology, v. 71, p. 183-198.

Welhan, J.A., and Craig, H., 1979, Methane and hydrogen in East Pacific Rise hydrothermal fluids: Geophysical Research Letters, v. 6, p. 829-831.

1983, Methane, hydrogen, and helium in hydrothermal fluids at $21^{\circ} \mathrm{N}$ on the East Pacific Rise, in Rona, P., and others, eds., Hydrothermal processes at seafloor spreading centers: New York, Plenum Press, p. 391-401.

Welhan, J.A., and Lupton, J.E., 1987, Light hydrocarbon gases in Guaymas Basin hydrothermal fluids-Thermogenic versus abiogenic origin: American Association of Petroleum Geologists Bulletin, v. 71, p. 215-223.

Wenner, D.B., and Taylor, H.P., 1971, Temperatures of serpentinization of ultramafic rocks based on $\mathrm{O}^{18} / \mathrm{O}^{16}$ fractionation between coexisting serpentine and magnetite: Contributions to Mineralogy and Petrology, v. 32, p. 165-185.

Weres, O., Newton, A.S., and Tsao, L., 1988, Hydrous pyrolysis of alkanes, alkenes, alcohols and ethers: Organic Geochemistry, v. 13, p. $433-444$.

Westbrook, G.K., and Smith, M.J., 1983, Long decollements and mud volcanoes-Evidence from the Barbados Ridge Complex for the role of high pore-fluid pressure in the development of an accretionary complex: Geology, v. 11, p. 279-283.

Whiticar, M.J., 1990, A geochemical perspective of natural gas and atmospheric methane: Organic Geochemistry, v. 16, p. 531-547.

Wickham, S.M., Peters, M.T., Fricke, H.C., and O'Neil, J.R., 1993. Identification of magmatic and meteoric fluid sources and upward- and downward-moving infiltration fronts in a metamorphic core complex: Geology, v. 21, p. 81-84.

Willingham, T.O., Nagy, B., Nagy, L.N., Krinsley, D.H., and Mossman, D.J., 1985, Uranium-bearing stratiform organic matter in paleoplacers of the lower Huronian Supergroup, Elliot Lake-Blind River region, Canada; Canadian Journal of Earth Sciences, v. 22, p. 1930-1944.

Wolery, T.J., and Sleep, N.J., 1976, Hydrothermal circulation and geochemical flux at mid-ocean ridges: Journal of Geology, v. 84 , p. $249-275$.

Wood, B.J., and Nell, J., 1991, High-temperature electrical conductivity of the lower-mantle phase $(\mathrm{Mg}, \mathrm{Fe}) \mathrm{O}$ : Nature, v. 3, p. 309-311.

Wyllie, P.J., 1980, The origin of kimberlite: Journal of Geophysical Research, v. 85 , no. 12 , p. 6902-6910.

1989, The genesis of kimberlites and some low- $\mathrm{SiO}_{2}$, high-alkali magmas, in Kimberlites and related rocks: Special Publication-Geological Society of Australia (Division of Geological and Planetary Sciences), v. 14, no. 1, p. 603 615 . 
Wyllie, P.J., Baker, M.B., and White, B.S., 1990, Experimental boundaries for the original evolution of carbonatites: Lithos, v. 26, p. 3-19.

Xu, Y-C., Shen, P., Sun, M-L., and Xu, S., 1990, Nonhydrocarbon and noble gas geochemistry in natural gas of Eastern China: Science in China (series B), v. 33, no. 12, p. 1494-1503.

1991, Non-hydrocarbon and noble gas geochemistry: Journal of Southeast Asian Earth Science, v. 5, no. 1-4, p. 327-332.

Xu, Y., Wang, X., Wu, R., Shen, P., Wang, Y., and He, Y., 1982, Rare gas isotopic composition of natural gases: Geochemistry, v. 1, p. 218-232.
Young, T.E., Green, H.W., and Hofmeister, A.M., 1991, OH solubility and sp-(Mg, $\mathrm{Fe})_{2} \mathrm{SiO}_{4}$ [abs.]: American Geophysical Union, Spring Meeting, 1991, Program and Abstracts, Supplement to EOS, April 23, 1991, p. 144.

Zemann, J., Schwarz, H.P., Hoeffs, J., and Welte, D., 1969, Carbon, in K.H. Wedepohl, ed., Handbook of geochemistry, New York, Springer-Verlag, IU/I, Ch. 6.

Zezin, R.B., and Sokolova, M.N., 1967, Macroscopic occurrences of carbonaceous matter in hydrothermal deposits of the Khibiny pluton: Doklady Akademii Nauk SSSR, v. 177, p. 217-221. [English translation.] 


\title{
Prospects for Commercial Abiogenic Gas Production: Implications from the Siljan Ring Area, Sweden
}

\author{
By John R. Castaño ${ }^{1}$
}

\section{CONTENTS}

Abstract 133

Introduction 134

Expectation Model 134

Geologic Setting-Siljan Ring . 135

Pre-1986 Investigations 135

Geology and Geochemistry 135

Geophysics 137

Choice of the Gravberg 1 Drill Site 138

Operational Summary of the Gravberg 1 Well ........... 138

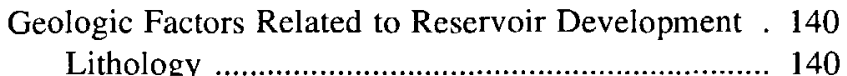

Alteration .................................................. 140

Fracturing ...................................................... 140

Structure and Correlations .................................. 140

Fluid Geochemistry ............................................... 140

Geochemical Sampling and Analysis ................ 140

Factors Affecting Gas Readings ........................ 141

Contamination .................................................. 142

Laboratory Experiments ................................. 142

Uncontaminated Samples ................................. 142

Synthesis-Background for Interpretation ................. 143

Composition of Hydrocarbon Gases ................. 143

Isotopic Composition of Hydrocarbon Gases ....... 143

Inorganic Gases ............................................. 146

Key Elements for Hydrocarbon Entrapment .............. 146

Synthesis-Interpreting Shows .............................. 147

Shows in Dolerite and Granite ........................ 147

Drill-stem Tests 1 Through 4 ............................ 148

Drill-stem Test 5 and Pump Testing in 1990 ....... 148

Gas Geochemistry ................................... 148

Water Geochemistry .................................. 149

'DGSI, 8701 New Trails Drive, The Woodlands, TX 77381.
Interpreting Fluid Geochemical Data ....................... 149

Discussion ................................................. 149

Summary-No Source ..................................... 150

Interpreting Reservoir Data ................................... 150

Interpreting Seal Properties ................................... 150

Epilogue-The Stenberg 1 Well ................................. 152

Conclusions ........................................................... 152

References Cited ................................................ 153

\section{ABSTRACT}

The Siljan Ring structure in central Sweden is a 360-Ma meteorite impact crater with an excavated diameter of $45 \mathrm{~km}$. The Gravberg 1 well, just outside the excavated region on the northeast rim, was drilled as a commercial venture to explore for abiogenic gas of mantle origin. The well reached a true vertical depth of $6,779 \mathrm{~m}$, penetrating only Precambrian granite porphyry, granite, quartz monzonite, and diabase (dolerite) sills. The sills correspond to prominent, low-dipping, high-amplitude seismic reflectors that afford the only good correlative horizons.

Key points for evaluation include reservoir, cap rock, and source. Porosity in the granite is related to macrofractures, microfractures, and mineral alteration. On the basis of well data, the influence of the impact drops off dramatically below 2,000 $\mathrm{m}$ and is absent below 4,000 m. Fracture intensity is highly variable, but generally decreases with depth. Below $3,000 \mathrm{~m}$, fracture zones are caused by regional tectonics. No continuous reservoir units were detected. Originally, calcite-cemented granite was expected to act as an impervious seal. Stable isotope studies of calcite show that mantle methane is not involved in any of the fractionation equilibria for these cements; instead there is equilibration with modern meteoric water. At depth, magmatic $\mathrm{CO}_{2}$ is the likely carbon source for the heaviest carbon isotopes measured. On the 
basis of leak-off and drill-stem tests, no caprocks were penetrated by the Gravberg 1 well. The pore-pressure gradient is essentially hydrostatic; the expectation model had predicted pressures approaching lithostatic. Hydraulic conductivity ranges from 0.07 to $7.5 \times 10^{-10} \mathrm{~m} / \mathrm{s}$. Evidence points to deep $(6 \mathrm{~km})$ circulation of fresh, meteoric water below which lies stagnant, high-salinity water $(150,000 \mathrm{ppm}$ total dissolved solids).

Contrary to expectations, no free gas was found. Water recovered from the most reliable drill-stem test is undersaturated with gas; gas concentration is 0.25 liter of gas per liter of fluid at standard temperature and pressure (STP). Average gas composition was 45 percent $\mathrm{He}, 2.5$ percent $\mathrm{H}_{2}, 2$ percent $A r, 0.3$ percent $\mathrm{O}_{2}, 150 \mathrm{ppm} \mathrm{CH}_{4}$, and traces of $\mathrm{CO}_{2}$ and $\mathrm{Ne}$. The remainder is $\mathrm{N}_{2}$. $\mathrm{He}$ (with $\left.\left({ }^{3} \mathrm{He} /{ }^{4} \mathrm{He}\right)_{\text {sample }} /\left({ }^{3} \mathrm{He} /{ }^{4} \mathrm{He}\right)_{\text {atmosphere }}=0.017\right), \mathrm{Ar}$, and $\mathrm{Ne}$ are radiogenic, originating from the breakdown of radioactive minerals in the crystalline rocks.

Samples of hydrocarbon gases from diabases and granite are distinctly different. Trace amounts (less than 1,000 ppm) of $\mathrm{CH}_{4}$ in the diabases are abiogenic $\left(\delta^{13} \mathrm{C}=-15\right.$ permil relative to $\mathrm{PDB}$ standard). Hydrocarbon gases in the diabases consist dominantly of methane (95 percent); unsaturated hydrocarbons are rare. Methane encountered in the granite is thermogenic, artificial (caused by drilling abrasion and (or) contamination), and possibly of abiogenic origin $\left(\delta^{13} \mathrm{C}=-23\right.$ to -55 permil). Hydrocarbon gases in the granite are present in much smaller amounts than in the diabases. As opposed to gases in the diabases, those in the granite contain a large amount of $\mathrm{C}_{2}+(30$ to 50 percent), including a large proportion of unsaturated hydrocarbons. Unsaturated hydrocarbons such as the alkenes are rare in nature; they could be formed in a Fischer-Tropsch reaction between $\mathrm{CO}_{2}$ and $\mathrm{H}_{2}$ catalyzed by magnetite or produced by a spark discharge induced during tectonic rock shearing. It is also possible that the unsaturated hydrocarbons are drilling artifacts.

There is no credible evidence of a dominant mantle source for hydrocarbons at Siljan, and very little hope for the development of any commercial gas fields in this setting.

\section{INTRODUCTION}

In 1982, Vattenfall (the Swedish State Power Board) began investigations in the Siljan Ring area as part of the broad search for alternative energy sources in Sweden. Their objective was to discover commercial abiogenic gas deposits in Europe's second largest impact crater. These wide-ranging studies were prompted by discussions with Thomas Gold, who championed the abiogenic methane gas hypothesis that implied an enormous new potential resource (see Gold, this volume). Except for oil production amounting to a few hundred barrels per day from the island of Gotland, Sweden has no oil, gas, or coal. Because Swe- den had passed a referendum to phase out nuclear power beginning in 1995, there was great incentive to replace the 50 percent of electrical power generated by nuclear plants. These are mostly operated by Vattenfall. The Siljan project has been highly controversial, because of the premises which led to the drilling and because of the great differences in the way the results have been interpreted.

During 1984 and 1985 Vattenfall carried out an extensive series of investigations in the Siljan Ring structure. The research included geological and geochemical studies including surface mapping, core drilling, soil surveys, and analysis of lake waters. Geophysical work included seismic, magnetotelluric, and gravity surveys. Although a group of independent experts judged that the project had very little promise of commercial success (Anonymous, 1984), Vattenfall determined that the undertaking was worth continuing and drilled the deep exploratory hole, Gravberg 1, starting in July 1986.

In 1985 the Gas Research Institute (GRI) contributed funding for the deep well to test Gold's hypothesis, in order to provide reliable documentation and analyses on gases, fluids, drill cuttings, and cores, and on both surface and downhole geophysical measurements. About the same time Vattenfall sold shares in the venture to public entities and private investors in Sweden, setting up an operating company, Dala Djupgas Provborrningar KB. Vattenfall kept a majority interest and directed the project. In 1990 Vattenfall sold its remaining shares to private Swedish investors who own the successor company, Dala Djupgas Produktions AB (DDP), which drilled the second deep well in the Siljan area, Stenberg 1, in 1991-1992. I worked as the Chief Scientific Officer for GRI mainly at the well site, and served as a consultant for DDP from 1990 to 1991.

Preliminary results of the investigations were reported by Bodén and Eriksson (1988), but the most up-to-date and complete evaluations are included in a series of internal reports issued by Vattenfall in 1990-1991 which have a very limited distribution. (These reports are available from Vattenfall Utveckling AB, Dokumentationscentralen, S-81070, Älvkarlesby, Sweden.) This report is an updated summary of many aspects of these studies.

\section{EXPECTATION MODEL}

The basic premises of the deep-gas hypothesis as proposed by Thomas Gold $(1979,1987$, this volume) are as follows:

1. Hydrocarbons were incorporated in the upper mantle as the earth accreted during the formation of the solar system. These hydrocarbons have outgassed as methane at a constant rate throughout geologic time.

2. The mantle-derived methane is a major contributor to all hydrocarbon and coal deposits.

3. Mantle outgassing occurs along rifts and faults and through solid rock. 
4. Fractures caused by the meteorite impact allowed mantle methane to migrate into the Siljan Ring structure.

5. Calcite formed by interaction with ascending methane helps create seals that will trap methane.

6. Methane gas collects in stacked domains below critical layers; pore pressure in these reservoirs approaches lithostatic pressure. The critical layers are characterized by lower pore pressures and porosity that has been reduced by weight of the overburden. When gas accumulations reach a particular concentration, lithostatic pressures are exceeded by pore pressures, fractures break through the critical layer, and gas migrates through the critical layer until it reaches the next critical layer or the surface of the earth. The first critical layer is expected to be present at a depth between 3 and $6 \mathrm{~km}$.

Although Gold is widely known for his views on the abiogenic origin of hydrocarbons, Russian scientists also have been very active proponents of the inorganic origin of petroleum (Kropotkin, 1985).

\section{GEOLOGIC SETTING-SILJAN RING}

The geologic map of the Siljan area shows a concentric distribution of Ordovician and Silurian sedimentary rocks surrounding the central cupola that contains the Järna and Siljan Granites (age about 1,700 Ma) that are intruded by late Precambrian diabases (dolerites) (age about 900 Ma) (fig. 1). Instead of being continuous, the Paleozoic ring is largely a megabreccia made up of meter- to kilometer-sized blocks. On the basis of seismic data, the Paleozoic section is up to $350 \mathrm{~m}$ thick.

The Siljan Ring impact structure has a diameter of about $52 \mathrm{~km}$ and is the second largest impact structure in Europe (Grieve, 1988). The characteristic ring configuration and the presence of shatter cones, breccias, impact melts, and microscopic planar features in the granites show that the Siljan structure is an impact structure (Svensson, 1973; Thorslund and Auton, 1975; Tamminen and Wickman, 1980; Wickman, 1980; Vlierboom and others, 1986). An estimated 1-2 km of section has been eroded. Impact melts have been dated at 359 to $362 \mathrm{Ma}$ (Bottomley and others, 1978; Lee and others, 1988).

In the formation of complex impact structures such as Siljan, the transient cavity floor is uplifted and the rim area collapses. At Siljan, the granites represent the eroded remnant of the cavity floor. Paleozoic sedimentary rocks along the rim were preserved as the result of downfaulting which accompanied the collapse of the rim of the transient cavity. The impact of a meteor $2-3 \mathrm{~km}$ in diameter would have melted and vaporized some $250 \mathrm{~km}^{3}$ of rock (Grieve, 1988). The resultant annular melt sheet about $200 \mathrm{~m}$ thick would have had an initial temperature of about $2,200^{\circ} \mathrm{C}$ (Grieve, 1988) and extended beyond the area of Paleozoic sedimentary rocks. This impact melt would have taken some $1,000-2,000$ years to crystallize, and perhaps 10,000 years to cool off.

Fracturing associated with the impact was extensive, perhaps extending to $50 \mathrm{~km}$ beyond the original rim of the crater (Anonymous, 1991). Initially, it was postulated that structural disturbances in the center of the crater would have extended to depths of 7 to $10 \mathrm{~km}$, with the potential for fractures penetrating to the lower crust. Moreover, erosion of 1 to $2 \mathrm{~km}$ of cover could have relieved the compressive stresses and increased fracture porosity. These speculations fit with the work of Donofrio (1981), who concluded that impact craters in crystalline rocks could have significant reservoir potential.

\section{PRE-1986 INVESTIGATIONS}

A broad range of geoscientific investigations led to the drilling of the Gravberg 1 well. In order to be concise, discussion of the geophysical findings for the entire span of the project have been consolidated in this section.

\section{GEOLOGY AND GEOCHEMISTRY}

Prior to the drilling of the deep exploratory hole, Gravberg 1, nine coreholes were drilled in the area (fig. 1). Ranging in depth from $100-700 \mathrm{~m}$, they were continuously cored with almost 100-percent recovery. In granite, high fracture porosity was associated with shear zones, microbreccias, and mylonites. However, hydrological tests showed that fracture permeability was very low, particularly in the center of the impact structure.

Interest in the area was heightened by shows of oil and gas, which included some well-documented accounts dating back to the 18th century (Hedberg, 1988). Occurrences of biodegraded heavy oil, seeps, oil shows, and solid bitumen are confined to Ordovician limestones in the Solberga-Boda area on the east side of the Siljan Ring (fig. 1). These oils have been correlated with closely associated source rocks in the Ordovician Tretaspis Shale (Vlierboom and others, 1986). The oils result from the maturation of source rocks heated by the impact event. The impact set up a convection system that circulated through a circular terrain about $52 \mathrm{~km}$ wide and at least $1.2 \mathrm{~km}$ thick (Komor and Valley, 1990).

Hydrocarbons from surface and shallow subsurface occurrences in the Siljan area fall into two general groups. The first group comprises microbial gases, composed almost entirely of methane, usually in trace amounts, with a very light isotopic signature; 12 samples average a $\delta^{13} \mathrm{C}$ value of -60.7 permil relative to the PDB standard (Castaño, 1990). Higher methane concentrations in surface waters are present in the central area of the ring: here there are large, rather flat areas with peat soils and small lakes that favor biological methane production. The highest methane shows occur within the 
Paleozoic sedimentary ring, possibly because of better reservoir conditions. The second group is made up of thermogenic gases that have heavier isotopic values and are associated with biodegraded oil in Ordovician reef limestones $\left(\delta^{13} \mathrm{C}=-45\right.$ permil; fig. 1$)$.

Helium isotope analysis of gases from Fåsås, Solberga, and Västanå yielded $\mathrm{R} / \mathrm{R}_{\mathrm{a}}\left(\left({ }^{3} \mathrm{He} /{ }^{4} \mathrm{He}\right)_{\text {sample }} /\left({ }^{3} \mathrm{He} /{ }^{4} \mathrm{He}\right)\right.$ atmo- sphere) of 0.015 to 0.11 . These values indicate that the helium is dominantly ${ }^{4} \mathrm{He}$ and that it is more than 98 percent crustal in origin (Castaño, 1990).

Hydrogen is generally absent from surface and water wells, but it is much more abundant than methane in most samples obtained from the deeper exploratory boreholes. However, hydrogen is absent in two drill-stem tests made

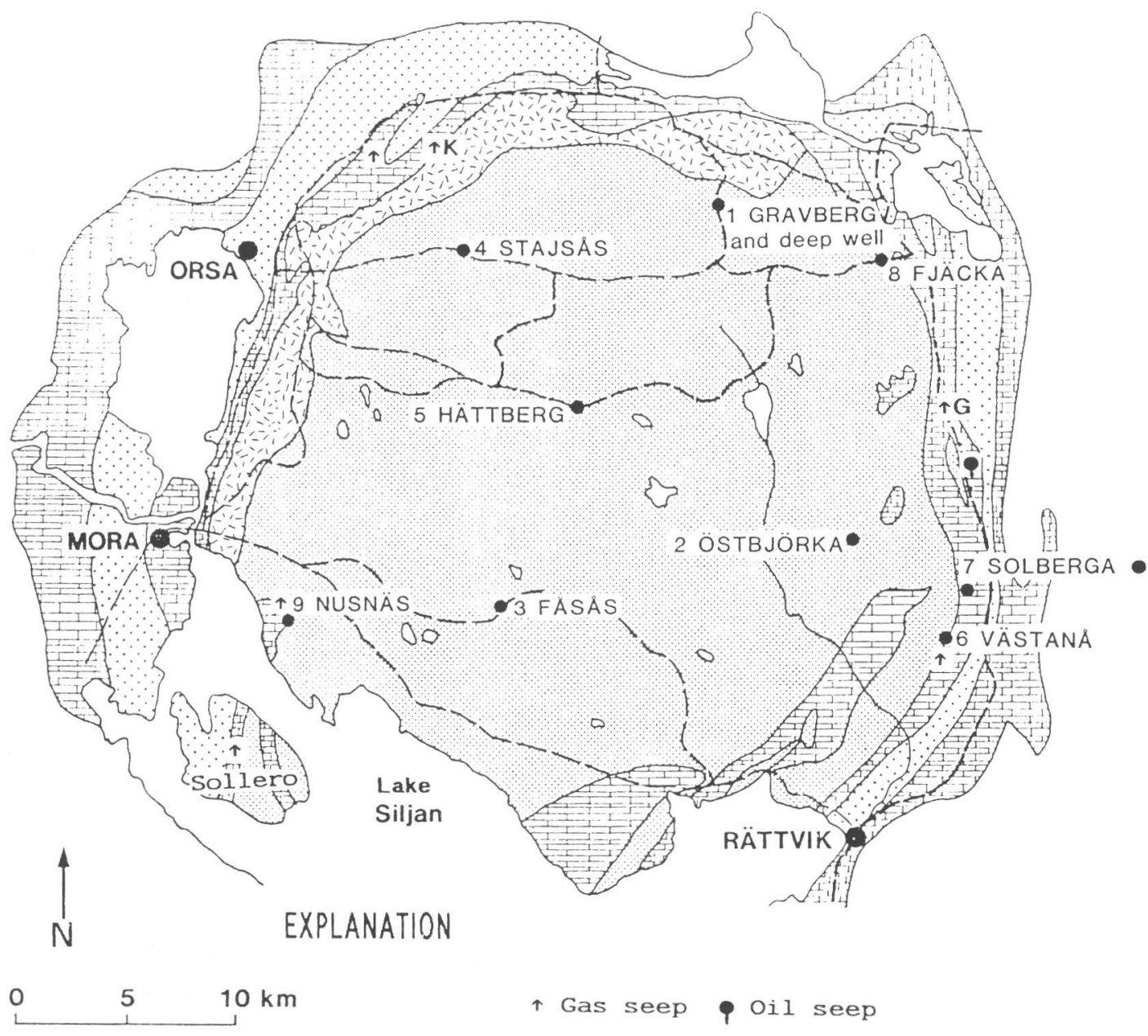

$\therefore \because$ Orsa Sandstone (Upper Silurian?)

Limestones and shales (Silurian and Ordovician)

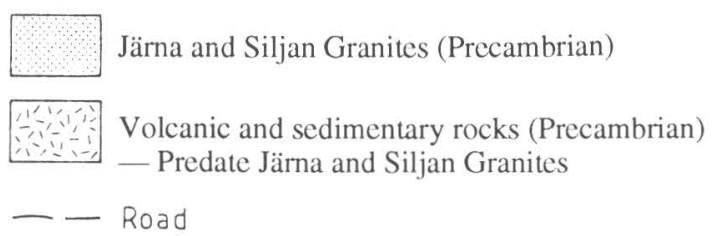

- Borehole

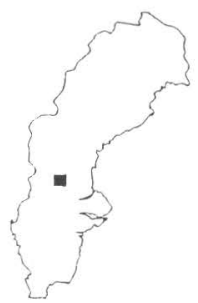

Sweden

Figure 1. Bedrock map of central part of Siljan ring structure showing location of major oil and gas seeps and nine shallow boreholes. Deep well and borehole at Gravberg have same location. Gas seeps at Kalkhohen $(\mathrm{K})$ and Gulleråsen $(\mathrm{G})$ are identified. Towns of Mora, Orsa, and Rättvik are shown. Unpatterned areas within ring structure are bodies of water. Map area is box in central Sweden. 
between packers. As will be shown later, the presence of hydrogen in the deep Gravberg well (Gravberg 1) is undisputed, but the manner of occurrence of hydrogen in the shallow subsurface does not permit us to make a definite statement as to its origin.

\section{GEOPHYSICS}

A series of seismic lines were shot in the Siljan Ring area in 1985 (fig. 2); the stacked seismic section from the north-south line 5 is shown on figure 3. In 1985 the lowdipping reflections (R1-R4) were considered to be fracture zones, zones of mineralization or gas entrapment, or perhaps diabase sills. The results of the Gravberg 1 well convincingly showed that these zones are diabase (dolerite) sills (Juhlin and Pedersen, 1987). All four reflectors are continuous along the northern end of line 5 in the vicinity of the Gravberg 1 well, but to the south in the central part of the crater, the deeper reflectors are more coherent whereas the shallow ones disappear quickly south of Gravberg (fig. 3). These data demonstrate clearly the effect of the meteorite impact on the rocks of the area: the center of the crater is highly fractured and broken up and the reflectors are largely missing, and the shallower units are more highly affected by the impact.

Surface gravity studies showed a strong residual negative anomaly of 15 milligals with a diameter of $40 \mathrm{~km}$ along the northern edge of the crater's rim. It was realized that some of the density contrast was due to differences in lithology of the granite bodies, but some of the contrast could have been caused by increased porosity within $6 \mathrm{~km}$ of the surface (Anonymous, 1991). On the basis of surface and downhole surveys, it was found that the gravity anomaly is

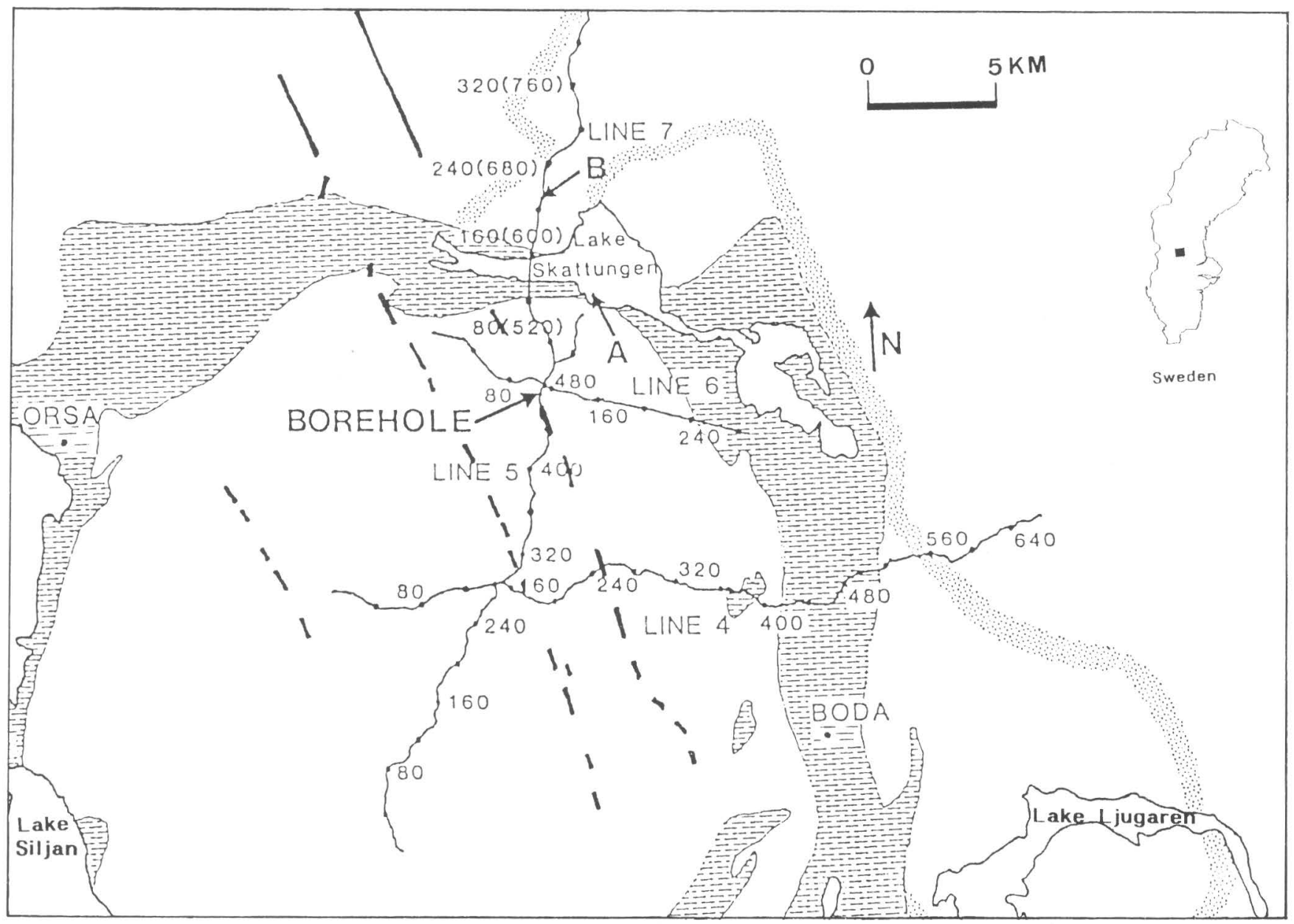

Figure 2. Location of seismic lines acquired in 1985 in Siljan Ring area. Heavy dashed lines are trends of steeply dipping dolerite intrusions. Dashed-line pattern indicates Silurian and Ordovician sedimentary rocks; dot pattern, the boundary between the older Svecofennian rocks and the Siljan and Järna Granites; unpatterned area in center of ring structure, Precambrian granite.
Dots along seismic lines are shot points; numbers beside selected dots indicate shot point numbers, with shot point numbers for line 5 in parentheses where it overlaps with line 7 . Line 6 divides line 7 from line 5 . Note position of line 5 ; the stacked section is shown as figure 3. BOREHOLE refers to Gravberg 1 well. Map area is box in central Sweden. From Anonymous (1991). 


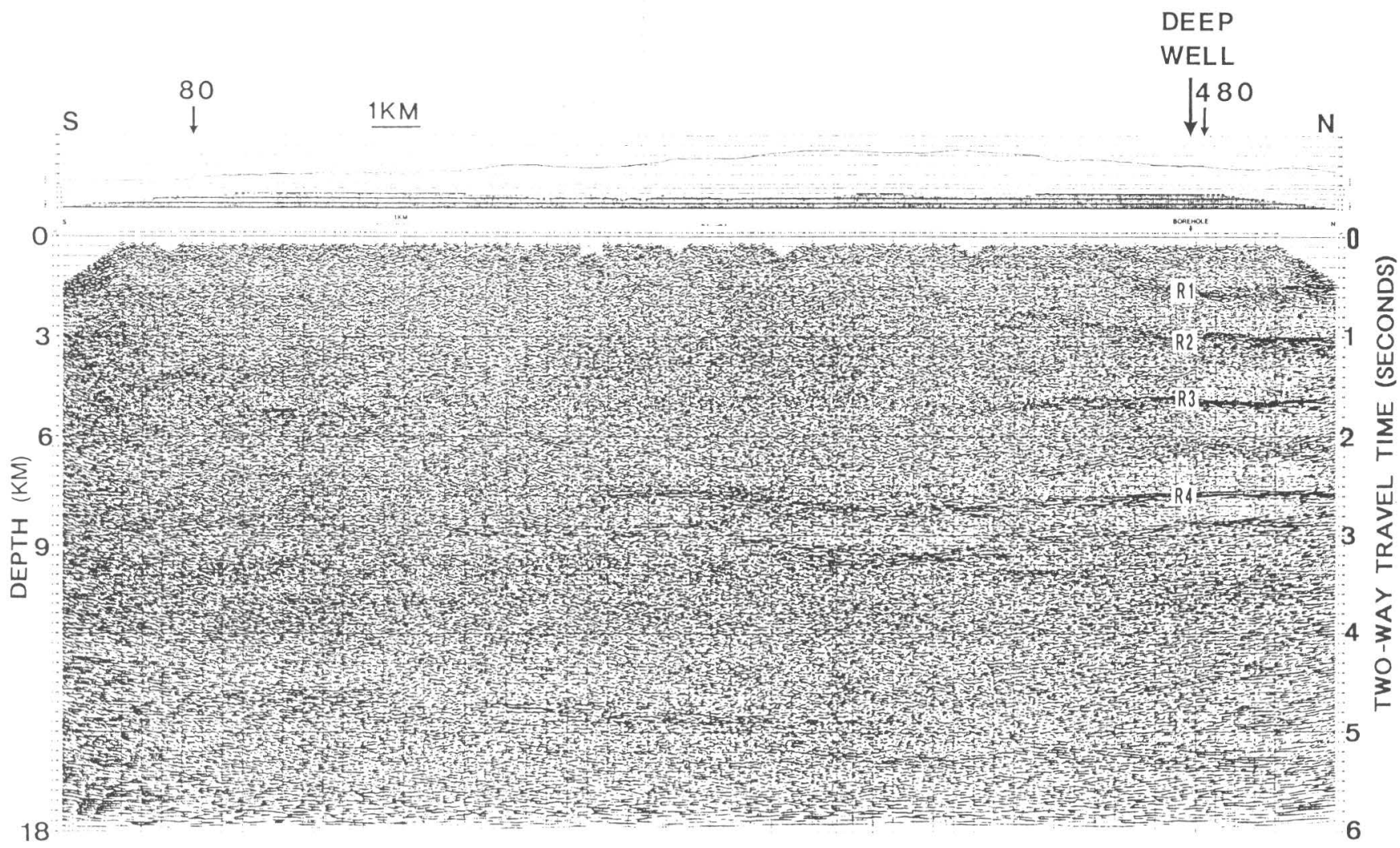

Figure 3. Stacked seismic section from line 5 (see fig. 2 for location). Depth scale on left assumes average velocity of $6 \mathrm{~km} / \mathrm{s}$. Modified from Anonymous (1991). DEEP WELL shows location of Gravberg 1; numbers 80 and 480 indicate shot points. R1 through R4 are reflections caused by diabase (dolerite) sills.

related mainly to the low-density Siljan granite $(2,600$ to $2,650 \mathrm{~kg} / \mathrm{m}^{3}$ ) present in much of the upper $5,000 \mathrm{~m}$ in the Gravberg 1 well. In addition, the gravity data indicate the presence of additional low-density rock below the total depth of the well, 6,763 m true vertical depth (TVD) (Anonymous, 1991); the low density of this rock is presumed to be caused by lithology or porosity characteristics.

Magnetotelluric data showed a low-resistivity anomaly that is restricted mainly to the center of the Siljan structure. Before the Gravberg 1 well was drilled, the resistivity low was interpreted as the result of the upward migration of deep crustal fluids, thereby suggesting the possibility of a pathway for gas migration from great depths (Anonymous, 1985).

\section{CHOICE OF THE GRAVBERG 1 DRILL SITE}

Two potential drilling locations were selected: in the center of the crater and near the village of Gravberg. The central location was favored because microfracturing was expected to be more intense in the center of the crater. In addition, the shallow core holes at Stajsås and Hättberg (fig. 1) showed exceptionally low permeabilities in the granite, suggesting the presence of adequate caprock. Surface geochemical surveys and magnetotelluric data also supported a central location, whereas gravity and seismic studies supported a northern location. The strong high-amplitude anomalies seen on the seismic records could have represented either caprocks or porous zones. Furthermore, velocity analyses suggested the presence of a low-velocity, possibly more porous zone between the R3 and R4 reflectors. Greater weight was placed on the geophysical data, as these data were considered to be the most reliable, and the northern site at Gravberg was chosen as the site for the deep well.

\section{OPERATIONAL SUMMARY OF THE GRAVBERG 1 WELL}

The Gravberg 1 well was spudded on July 1, 1986, and operations ended July 3, 1990. The several segments of the well history are subdivided as follows:

1. Original hole $(\mathrm{OH})$. After 265 days, a measured depth of $6,081 \mathrm{~m}$ was reached, corresponding to a true vertical depth (TVD) of 5,985 m (fig. 4). Drilling proceeded quickly to a depth of $3,931 \mathrm{~m}$; it then took six weeks to reach $4,167 \mathrm{~m}$. Fresh water was used as the drilling fluid to $3,932 \mathrm{~m}$. At this depth a polymer mud was used in an attempt to overcome breakouts (hole enlargements due to 
anisotropic rock stresses) and hole-deviation problems. Hole deviation became pronounced starting just below the $\mathrm{R}-3$ reflector (fig. 4). At $6,047 \mathrm{~m}$ all of the fluid in the well, some $150 \mathrm{~m}^{3}$ of a heavy mud $(1.62 \mathrm{~g} / \mathrm{cc})$, was lost into the formation as the result of hydraulic fracturing. Mud weight was then reduced, and drilling was resumed. The drill pipe twisted off at $4,700 \mathrm{~m}$ and was not recovered.
2. Sidetrack 1 (ST-1). ST-1 started on day 267 at 4,650 $\mathrm{m}$ and was drilled with fresh water and later with a polymer mud to a measured depth of $6,636 \mathrm{~m}$ (TVD of $6,324 \mathrm{~m}$ ). Once again the drill pipe twisted off, and ST-1 was abandoned.

3. Sidetrack 2 (ST-2). ST-2 started on day 378 at $6,054 \mathrm{~m}$, and was drilled with an oil-based mud made up of

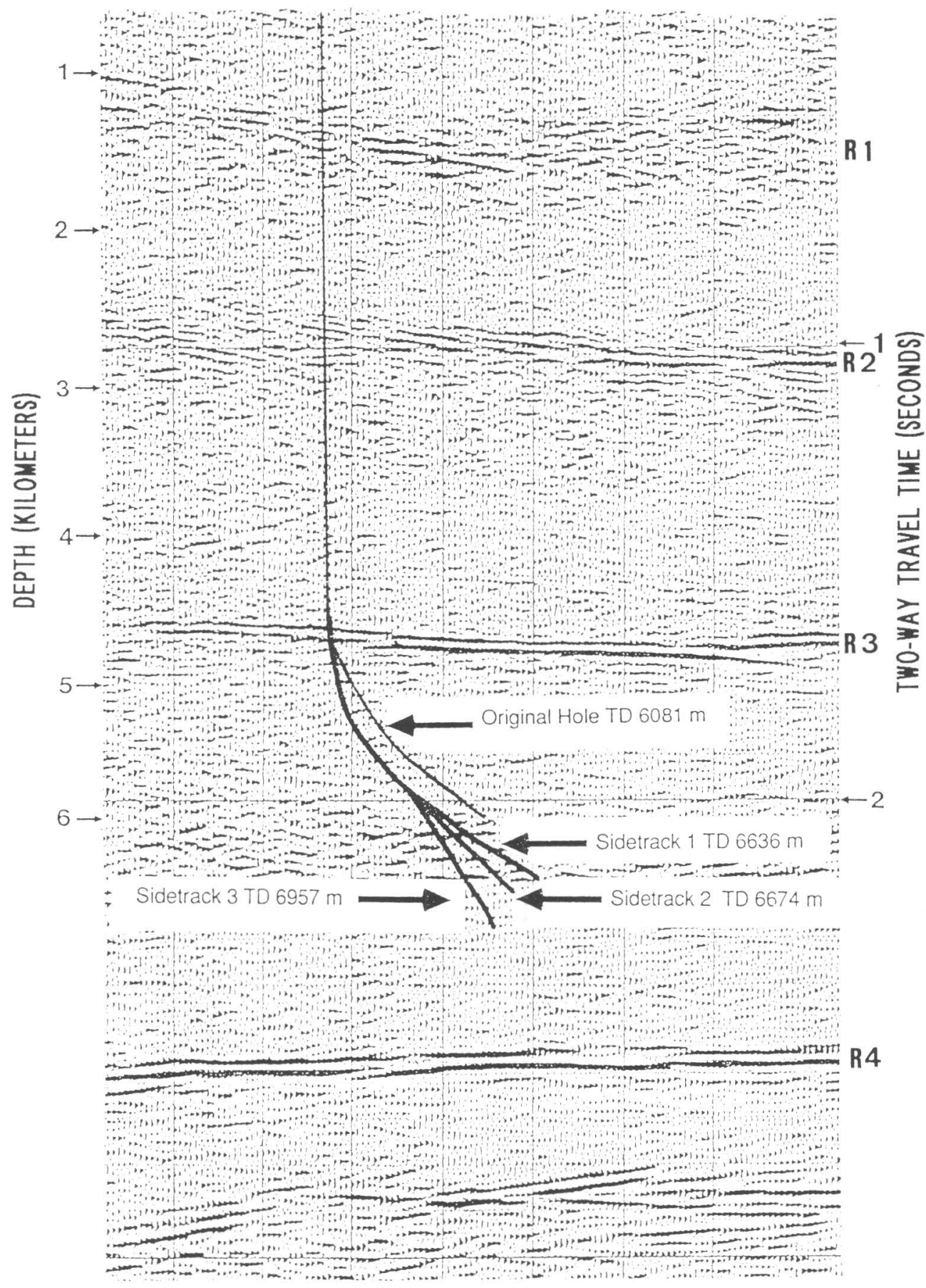

Figure 4. Borehole trajectories of the original hole and the three sidetracks of the Gravberg 1 well superimposed on seismic line 5 (see figs. 2, 3). TD, total depth; R1-R4, reflections caused by diabase (dolerite) sills. Depth scale on left is keyed to well depth. Modified from Anonymous (1991). 
80 percent diesel and 20 percent water. ST-2 reached a measured depth of 6,600 m (TVD, 6,337 m) on September 1, 1987, when operations were suspended to acquire additional funding. Drilling resumed in July 1988, but problems cropped up again, and ST-2 was abandoned at a measured depth of $6,674 \mathrm{~m}$ (TVD, $6394 \mathrm{~m}$ ).

4. Sidetrack 3 (ST-3). ST-3 started on day 480 at $5,850 \mathrm{~m}$ and used the same oil-based mud used in ST-2. However, hole instability due to highly anisotropic rock stresses led to another fishing job, and the drill string twisted off (top of the fish is at $6,332 \mathrm{~m}$ ). ST-3 has a total measured depth of $6,957 \mathrm{~m}$ (TVD, 6,792 $\mathrm{m}$ ).

5. Hydrofracturing, water injection, and testing took place from day 725 to day 824 . The hydrofracturing operation was designed to fracture the formation downward; this operation was important because with the fish in the hole from 6,332 to $6,957 \mathrm{~m}$, it was not possible to perform a conventional test at the bottom of the well (Castaño and others, 1990). Some $260 \mathrm{~m}^{3}$ of oil-based heavy fracture fluid was injected into the formation. The data suggest that the stimulation grew downward, perhaps by up to a kilometer or more, and reached the $\mathrm{R} 4$ reflector. Later, $410 \mathrm{~m}^{3}$ of water was injected into the formation in order to displace the oil-based fracture fluid deep into the rock and to leave the near-borehole fractures filled with fresh water and bauxite proppant (a granular material used to keep fractures open as fluid is withdrawn). Testing began by airlifting and bailing out $877 \mathrm{~m}^{3}$ of water. Then a conventional drill-stem test was run on the open hole below $5,453 \mathrm{~m}$.

6. Pump testing occurred from May 8 to July 3, 1990, when operations were finally halted.

\section{GEOLOGIC FACTORS RELATED TO RESERVOIR DEVELOPMENT}

\section{LITHOLOGY}

The section penetrated by the Gravberg 1 well consists entirely of Precambrian crystalline rocks (fig. 5). The sequence is composed of granite porphyry $(1,635 \mathrm{Ma})$ in the shallow subsurface, and deeper Siljan and Järna Granites (1,760-1,670 Ma). These rocks are in turn intruded by younger quartz monzonites $(1,450 \mathrm{Ma})$ and dolerite sills (970-900 Ma). The dolerite sills found in the well are the main seismic reflectors and are designated R1, R2, R3, and $\mathrm{R} 4$. The relatively ductile sills are less fractured and impede movement of fluids, whereas the brittle, fractured granites are, relatively speaking, the aquifers. The finegrained quartz monzonites are much more radioactive than the older, medium-grained Siljan and Järna Granites.

\section{ALTERATION}

Evidence from petrographic and binocular microscope study shows that alteration is most intense above $2,000 \mathrm{~m}$, decreases from 2,000-4,000 $\mathrm{m}$, and is minor below $4,000 \mathrm{~m}$. Alkali feldspars are significantly altered in the upper part of the well: they are brick red to light red down to about $1,500 \mathrm{~m}$. Below the $\mathrm{R} 1$ dolerite these feldspars are light red to pink, and they become progressively lighter in color to about $4,000 \mathrm{~m}$; below this depth the feldspars are dominantly white and gray. Hematite is common down to $2,000 \mathrm{~m}$, magnetite dominates below $4,000 \mathrm{~m}$, and 2,000$4,000 \mathrm{~m}$ is a transitional zone. AlDahan (1990) ascribed the alteration to extensive infiltration of meteoric fluids through fractures and to the generation of hydrothermal convection generated by the heat of the meteorite impact; his interpretations are supported by fluid inclusion studies by Komor and others (1988).

\section{FRACTURING}

The most altered zones down to $2,000 \mathrm{~m}$ are extensively fractured, and planar features are observed in quartz. Rock in the transitional interval from $2,000-4,000 \mathrm{~m}$ is less fractured, and there is no evidence of planar, shockinduced lamellae in quartz below $3,000 \mathrm{~m}$. Below 4,000 m fracturing is slight and alteration is evident only in extensively fractured zones occurring at dolerite and quartz monzonite contacts and at regional tectonic zones, such as the Granån-Styggforsen fault zone.

\section{STRUCTURE AND CORRELATIONS}

The main structural features in the vicinity of the Gravberg 1 well are the low-dipping dolerite sills. Highly fractured granites are associated with the sills, but the lateral extent of the fractured granitic zones is undetermined (Castaño and others, 1990). The original hole and the several sidetracks allow correlation of fracture zones within the granite itself. Highly radioactive intrusions of quartz monzonite and the related fracture zones dip $20^{\circ}-60^{\circ}$ south. These intrusions are not planar, but they most likely interfinger with one another and may end abruptly.

\section{FLUID GEOCHEMISTRY}

\section{GEOCHEMICAL SAMPLING AND ANALYSIS}

A comprehensive series of geochemical measurements were made at the well site (Castaño, 1988) and were coordinated with analyses carried out at off-site laboratories. The monitoring system was designed to analyze light hydrocarbons up to $\mathrm{C}_{5}$, and certain inorganic gases, such as hydrogen, helium, argon, radon, oxygen, and nitrogen, but not heavier hydrocarbons. Gas concentrations presented in this paper are in weight percent or ppm by weight.

Progressive changes in drilling-fluid properties created interpretation problems. Proper interpretation required con- 


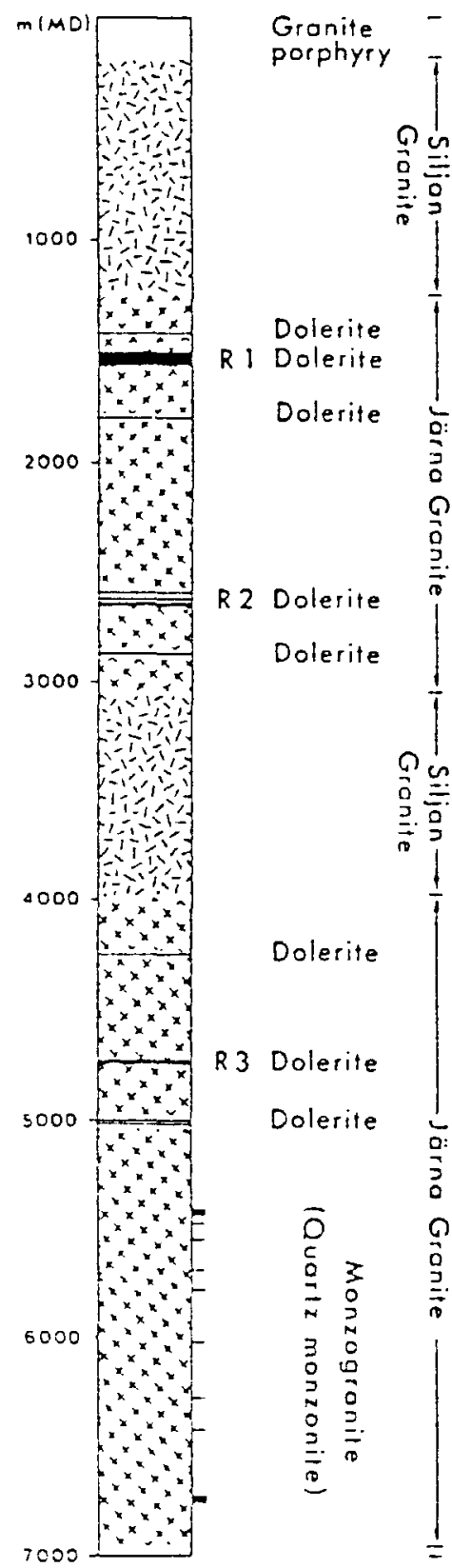

A

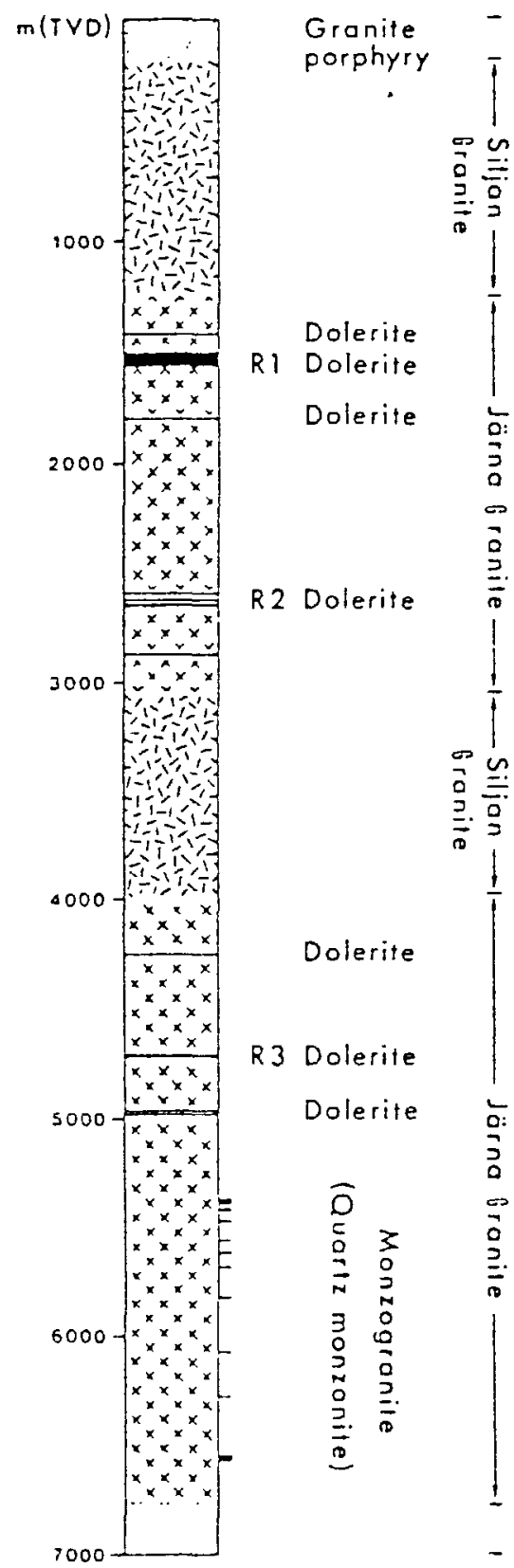

$B$

Figure 5. Lithologic column in Gravberg 1 well, presented according to $(A)$ measured depth (MD) and $(B)$ true vertical depth (TVD). Dolerite sills are indicated by horizontal lines across columns; R1-R3 are dolerite sills that produced prominent reflections on seismic records (see figs. 3, 4). Quartz monzonite intrusions are indicated by ticks to right of columns. Modified from Anonymous (1991).

sidering contamination and the different retentive properties of the drilling fluids used: fresh water, and bentonitebarite, polymer, and oil-based muds. Fortunately, because the well was sidetracked three times and because the same sections were redrilled using different drilling muds, it was possible to compare gas readings from correlative sections.

\section{FACTORS AFFECTING GAS READINGS}

Many factors affect gas readings. Each gas has a different solubility in water, controlled mainly by temperature and pressure and to a lesser extent by salinity (McAuliffe, 1966; Price, 1979). Methane is much more soluble in water than ethane; hydrocarbons of progressively higher molecular 
weight are progressively less soluble. The composition of headspace gas was affected greatly by drilling conditions; gas concentration varied inversely with the $\mathrm{pH}$ of the drilling fluid. When the drilling fluid was changed from a slightly acidic fresh water to an alkaline mud at $3,030 \mathrm{~m}$, headspace gas concentration dropped by an order of magnitude (Laier, 1990; Jeffrey and Kaplan, 1988). Because the drilling fluid was aerated, $\mathrm{N}_{2}$ and $\mathrm{O}_{2}$ data were of no value. In addition, because, $\mathrm{O}_{2}$ is scavenged by the drill pipe, the drilling fluid, and the cuttings, $\mathrm{N}_{2} / \mathrm{O}_{2}$ ratios could not be used to detect indigenous nitrogen.

A significant effect of the use of the oil-based mud (80percent diesel, 20-percent water) in ST-2 and ST-3 is that light hydrocarbons are very soluble in diesel. Because dissolved gases tend to remain in circulation in the oil-based mud, the monitoring system records higher background values. Higher mud weights of the oil-based drilling fluid (compared with weights of water used in the original hole and ST-1) may have suppressed gas readings because the system was strongly overbalanced (that is, because fluid pressure in the mud column was greater than the formation pressure). The same was true for the bentonite-barite mud used in the original hole.

\section{CONTAMINATION}

Contaminants were a source of great concern because the total amount of light hydrocarbons was below 1,000 ppm. We considered the possibility that hydrocarbons and hydrogen could be created artificially in the borehole ("bit metamorphism"). We also monitored and catalogued the types and amounts of additives and lubricants and the incidence of abnormal amounts of metal, rust, rubber, and other materials in the borehole.

Some of the organic additives are directly implicated in the generation of hydrocarbons. For example, while drilling was conducted in granite just below 5,000 to $5,671 \mathrm{~m}$ in the original hole, increases in the quantity of butene (up to 2,234 ppm) and propene (as high as 388 $\mathrm{ppm}$ ) and high methane values coincided with the addition of Idlube. Idlube, used to prevent drill-pipe sticking, contains a vegetable oil that is a mixture of polyunsaturated esters, called rape oil. If the increased butene, propene, and methane were derived from Idlube, they were the result of pyrolytic breakdown because rape oil contains only traces of volatile hydrocarbons. The corresponding interval in ST-1 contained only a few ppm of butene.

In ST-1 use of the lubricant "torque trim" below 5,500 $\mathrm{m}$ coincided with greatly increased shows of pentane (up to $445 \mathrm{ppm}$ ) and a drop in the $C_{1} / C_{2}$ ratio from $25-42$ to 1.5-6. "Torque trim" contains a small but significant amount of light hydrocarbons in proportions that can account for the shows in this interval. Again, the equivalent interval in the original hole lacked these shows, a lack which leads to the conclusion that much of the hydrocarbons encountered in this interval were artifacts.

\section{LABORATORY EXPERIMENTS}

Three laboratories conducted a number of experiments to investigate the origin of the gases in the Siljan area. The chemical and isotopic composition of gas obtained from headspace was compared with that of gas released by acid treatment (desorbed gas) and that of gas released from the samples by ball-mill crushing. The core and cuttings samples were carefully prepared so as to remove traces of contamination, such as iron from the drill string. (See section "Synthesis-Interpreting Shows" for additional details.)

The chemical or isotopic composition of gas in the dolerites was unaffected by acid treatment or ball-mill crushing. Included in this set was gas from a dolerite core at a depth of $97 \mathrm{~m}$ from the Fåsås corehole; the gas recovered by acid treatment of this dolerite core had the same chemical composition as the gases recovered from cuttings samples of dolerite from the Gravberg 1 well. The gas from the Fåsås core also has an isotopically very heavy methane: $\delta^{13} \mathrm{C}$ of -10.7 permil.

Most of the hydrocarbons released by acid treatment of the granite were associated with the magnetic fraction of the rock. An average of 5,800 microliter $/ \mathrm{kg}$ was measured in the magnetite-rich fraction, and only 60 microliter $/ \mathrm{kg}$ in the nonmagnetic fraction (Laier, 1990). The gases are rich in $\mathrm{C}_{2}+$ hydrocarbons, and the proportion of alkenes is high. In the dolerite, the nonmagnetic fraction has the higher gas concentration, although the difference is only a factor of 5 in the dolerite, in contrast to a factor of 97 in the granite.

Ball-mill crushing of granite and dolerite cuttings samples produced gases with compositions similar to those obtained in acid treatment, but the yields were significantly lower.

\section{UNCONTAMINATED SAMPLES}

After well stimulation in 1989 , the drilling manager noticed that gas was bubbling out of the top of the drill pipe as the drill string was being pulled out during a wet trip. (Normally, the drill string is removed from the borehole dry, without fluids. In special cases, the base of the drill string is plugged in order to recover fluids; this is classed as a wet trip.) Special sampling devices were built to sample this gas. A sampling line equipped with valves and a pressure gauge was attached to a short piece of drill pipe with a threaded connection to the top of the drill string. Because gas pressure at the top of the drill pipe was usually 1 to 2 bars, there was sufficient positive pres- 
sure for gas to displace air contained in the sampling system, and the samples were collected in evacuated steel cylinders as usual. These samples contained little air, and for the first time, good-quality high-volume gas samples were collected. During pump testing in 1990, samples that were collected from a modified gas separator were relatively free of contamination, and they also provided goodquality high-volume samples.

\section{SYNTHESIS-BACKGROUND FOR INTERPRETATION}

\section{COMPOSITION OF HYDROCARBON GASES}

The Earth's mantle is degassed along midoceanic ridges, and rehydration and possibly recarbonation occur along subduction zones (Wood and others, 1990). Measurement of oxygen fugacity in mantle xenoliths by Bryndzia and Wood (1990) and Wood and others (1990) shows that $\mathrm{CO}_{2}$ and $\mathrm{H}_{2} \mathrm{O}$ are the main fluids in the asthenosphere. Methane is comparatively rare in the mantle and would be found mainly at mantle hot spots. In Thomas Gold's (1979, 1987) expectation model, reduced carbon in the form of methane streaming up from anywhere in the mantle would provide the hydrocarbon charge for crustal structures. However, the model is not supported by the experimental work cited above and by the studies of Bath and others (1986), nor (as will be shown later) by the information gained from the Gravberg 1 well.

Fluid inclusions in igneous rocks and gases recovered from igneous rocks by grinding and heating contain unsaturated hydrocarbons in varying proportions (Freund and others, 1982; Konnerup-Madsen and others, 1988; Ferguson, 1987). The presence of some unsaturated hydrocarbons in undisputed free gases in the East Pacific Rise, in Yellowstone National Park (United States), in the Zambales ophiolite (Philippines), and in fluid inclusions show that unsaturated hydrocarbons can be stable over long periods of time. Traces of unsaturated hydrocarbons, such as the alkenes ethylene and propylene, occur in gases of bacterial origin (Burke and others, 1981; Zhizhchenko, 1978), but they are otherwise rare in biogenic or thermogenic gases. The high proportion of alkenes noted in igneous rocks is characteristic of a catalytic reaction, such as the Fischer-Tropsch reaction (Biloen and Sachtler, 1981). In this reaction, carbon monoxide and hydrogen combine in the presence of a suitable catalyst, such as magnetite, to form hydrocarbons and water. Because carbon dioxide and hydrogen equilibrate with carbon monoxide and water with a magnetite catalyst at lower temperatures, the concentration of carbon monoxide need not be high (Laier, 1988). Unsaturated hydrocarbons are compounds in which some carbon atoms are held together by double bonds and hence are not completely saturated with respect to hydrogen; they have the general formula $\mathrm{C}_{n} \mathrm{H}_{2 n}$. The two main groups of unsaturated hydrocarbons are the aromatics (closed ring compounds) and the alkenes (open chain compounds). The alkenes (also called olefins) are more reactive than saturated hydrocarbons. Saturated hydrocarbons are compounds that are saturated with respect to hydrogen. In this paper, references to unsaturated hydrocarbons refer only to the alkenes. In the Ilímaussaq alkaline igneous rocks of Greenland, Konnerup-Madsen and Rose-Hansen (1982) and Konnerup-Madsen and others (1988) found that condensation or polymerization reactions have led to the formation of a number of saturated hydrocarbons up to pentane.

\section{ISOTOPIC COMPOSITION OF HYDROCARBON GASES}

The carbon isotopic composition of methane is closely tied to process of gas generation, type of source rock, maturation history, migration, and fractionation (Schoell, 1984; Fuex, 1977; MacDonald, 1983). Three principal classes of hydrocarbon gases are known: microbial, thermogenic, and abiogenic. Microbial and thermogenic gases can generally be identified by their methane $\delta^{13} \mathrm{C}$ signature. Thermogenic gases are formed by the breakdown of organic matter; their $\delta^{13} \mathrm{C}$ values are usually heavier (less negative) than -50 permil, whereas microbial (bacterial) gases, formed only at temperatures less than $75^{\circ} \mathrm{C}$, generally have $\delta^{13} \mathrm{C}$ values lighter than -60 permil. Thermogenic gases become isotopically heavier with increased thermal maturity, and the $\delta^{13} \mathrm{C}$ value for methane will approach that of the source carbon at high maturity.

Whereas liquid petroleum compounds have $\delta^{13} \mathrm{C}$ values similar to those of the organic carbon source, hydrocarbon gases usually display a strong fractionation in comparison with the source carbon (Fuex, 1977). Primary fractionation of carbon isotopes takes place as a source carbon is trans-

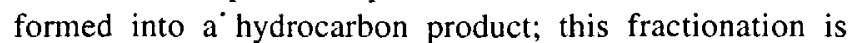
measured as the ratio of $\delta^{13} \mathrm{C}$ of the source to $\delta^{13} \mathrm{C}$ of the product $\left(\left(\delta^{13} \mathrm{C}_{\text {source }}+1000\right) /\left(\delta^{13} \mathrm{C}_{\text {product }}+1000\right)\right)$. Two factors dominate the fractionation process: maturity and organic-matter type. Derivation of methane from lipid organic matter will produce a fractionation that can lighten the $\delta^{13} \mathrm{C}$ values of methane by as much as -30 permil, whereas derivation from coal and humic matter produces a much smaller fractionation, about -10 permil (Fuex, 1977). With increasing thermal maturity, the fractionation decreases, and the $\delta^{13} \mathrm{C}$ value for methane approaches that of the source carbon, which normally ranges from -20 to -30 permil. The variation in fractionation between lipid and humic kerogen is probably related to differences in the structure of the organic matter and to the way ${ }^{13} \mathrm{C}$ is distributed in the kerogen (Fuex, 1977).

Migration fractionation (fractionation of carbon isotopes in the hydrocarbon after it has left the source rock) is probably not a major factor in establishing the methane 
carbon isotopic composition of major gas deposits, but fractionation effects can be significant in very dilute gas samples obtained from surface samples or from minor gas shows obtained while drilling (Fuex, 1977).

The isotopic composition $\left(\delta^{13} \mathrm{C}\right)$ of primordial carbon is generally assumed to be around -4 to -8 permil (Konnerup-Madsen and others, 1988), and abiogenic methane from a deep source should approach this range. Gases from the East Pacific Rise have a $\delta^{13} \mathrm{C}$ for $\mathrm{C}_{1}$ of -17 permil (Welhan, 1988). Abranjo and others (1988) measured a $\delta^{13} \mathrm{C}$ value of -7 permil for methane in the Zambales ophiolite in the Philippines. Even heavier methane was extracted from fluid inclusions in the llímaussaq alkaline complex in Greenland; $\delta^{13} \mathrm{C}$ in this methane ranges from -1 to -7 permil (Konnerup-Madsen and others, 1988).
Fuex and Baker (1973) studied the noncarbonate (combustion) carbon in a group of igneous rocks and found that $\delta^{13} \mathrm{C}$ of the carbon in granites ranged from -19.7 to -26.6 permil; in mafic and ultramafic rocks the range was -22.2 to -27.1 permil. These results imply that a simple mantle outgassing model for carbon is not likely. Instead, carbon has been incorporated in igneous rocks through partial melting of subducted sediments. On the basis of the work of Fuex and Baker (1973), the isotopic composition of methane derived from such rocks would have a $\delta^{13} \mathrm{C}$ of -20 to -27 permil.

The deuterium isotopic composition of hydrocarbon gases is very useful in establishing the genesis of natural gases (Schoell, 1984) and in detecting artificial gases (Faber and others, 1988). A useful plot is $\delta \mathrm{D}$ versus $\delta^{13} \mathrm{C}$ of methane (fig. 6). Abiogenic gases from llímaussaq

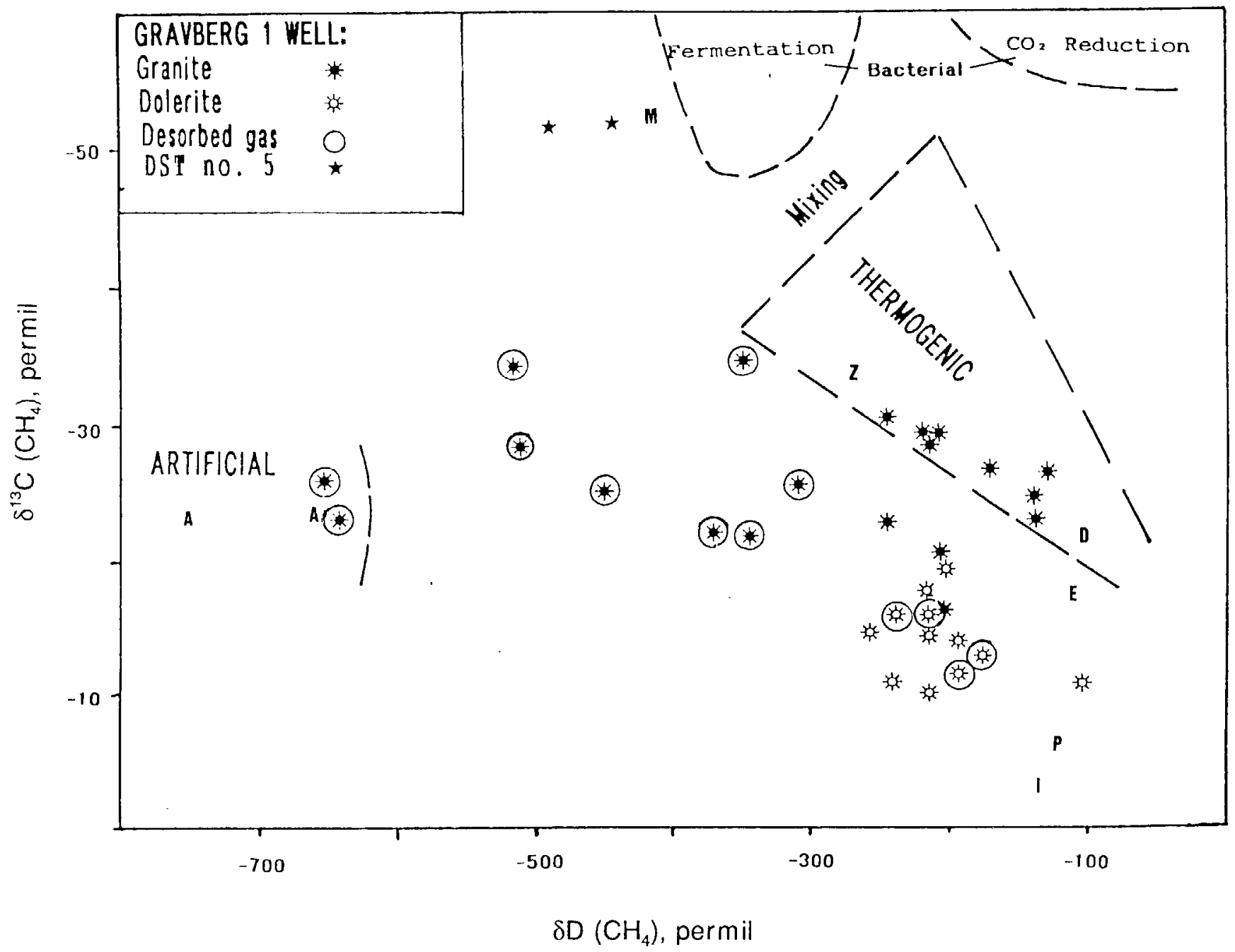

Figure 6. Plot of $\delta \mathrm{D}$ versus $\delta^{13} \mathrm{C}$ for methane, classification modified after Faber and others (1988), Gases from Gravberg 1 well plotted according to legend on figure; desorbed gas is gas released by acid treatment; DST no. 5 refers to drill-stem test 5 and includes gas recovered during the drill-stem test and also during later pump testing. Other symbols are as follows: A, artificial gases; D, diabase,
Massachusetts, USA (Jeffrey and Kaplan, 1988); E, East Pacific Rise (Welhan, 1988); I, Ilímaussaq, Greenland (Konnerup-Madsen and others, 1988); M, Matagami, Quebec, Canada (Fritz and others, 1987); P, Zambales ophiolite, Philippines (Abranjo and others, 1988); Z. Zinkgruvan, Sweden (Castaño, 1990). Siljan locality not plotted (off scale): Västanå, $\delta \mathrm{D}=-238$ permil, $\delta^{13} \mathrm{C}=-67.8$ permil. 
(Greenland) and the Zambales ophiolite (Philippines) are distinct from other gases in the figure, as is the gas from the East Pacific Rise, which comes out of basalt and is accompanied by helium with a mantle signature (Welhan, 1988). Faber and others (1988) identified artificial gases as those gases with extremely light $\delta D$ values (less than -600 permil) that were found mainly while drilling in granite. These gases are formed by an unknown mechanism, although Faber and others (1988) favored a Fischer-Tropsch reaction, with the carbon source being derived from the drill pipe, the lubricants, or the granite.

Another useful approach for identifying abiogenic hydrocarbons is comparison of the carbon isotopic compositions of the light hydrocarbons (fig. 7). James (1983) and Sofer (1985) showed that in typical thermogenic gases, the isotopic composition of the higher hydrocarbons becomes

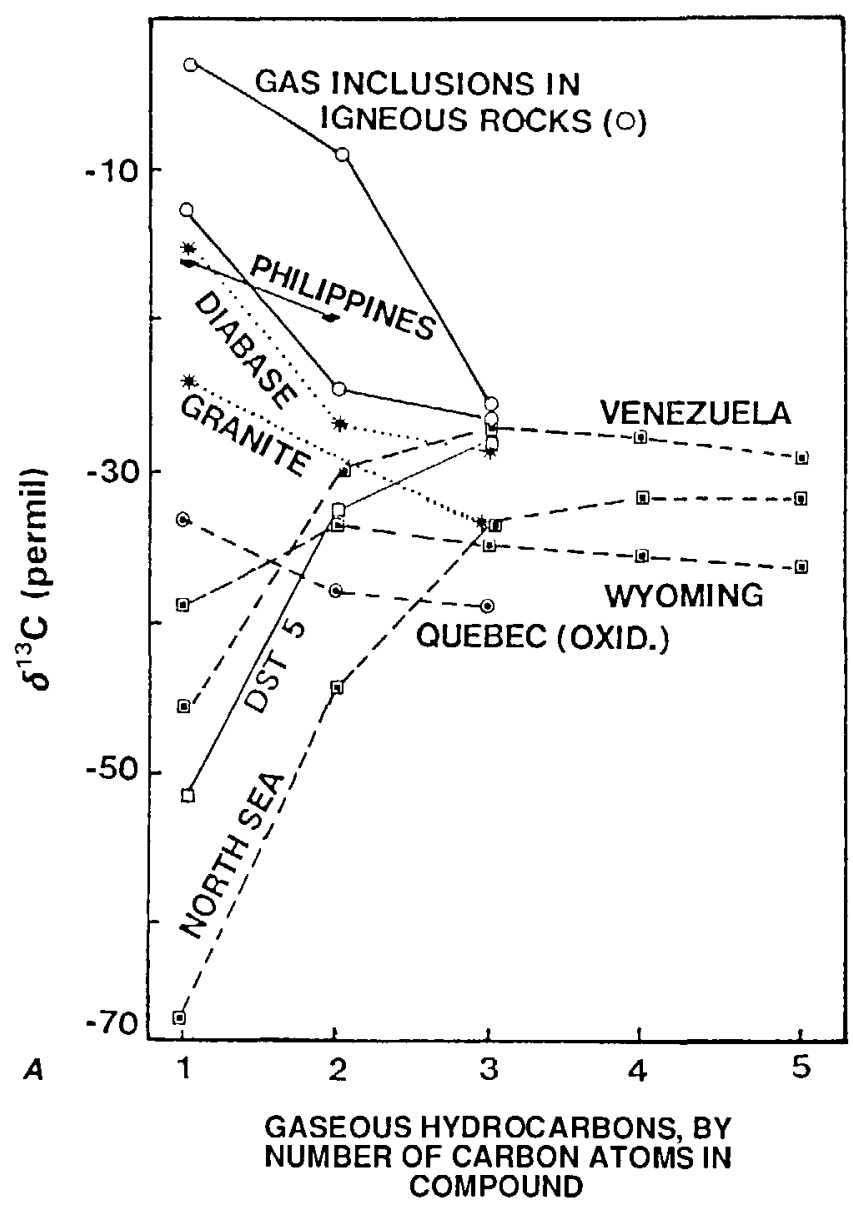

Figure 7. Isotopic composition of gaseous hydrocarbons. $A$, Note that trends for diabase (dolerite) and granite (both from Gravberg 1 well) (Castaño, 1990) are similar to those for abiogenic gases (Philippines (Sofer, 1985) and gas inclusions in igneous rocks), whereas trend for DST 5 (drill-stem test 5 on Gravberg 1 well) is similar to those for thermogenic gases (lines labeled Venezuela, Wyoming, and North Sea (Fuex, 1977)). Line labeled Quebec is for an oxidized thermogenic gas (Fuex, 1977). B, Isotopic trend progressively heavier (Venezuela, Wyoming, and the North Sea). In contrast, gases which are known or suspected to be of abiogenic origin have a characteristic trend: gas inclusions in igneous rocks and gas samples of suspected abiogenic origin obtained from drill-stem tests in a well from the Philippines become isotopically lighter with increasing carbon number. The example from Quebec shown on figure $7 A$ is a case in which the methane isotopic composition has become lighter due to oxidation, but ethane and propane have not been not affected (Fuex, 1977).

Des Marais and others (1981) studied hydrothermal gases; their isotopic curves (not shown) are very similar to the thermogenic gas profiles shown on figure $7 \mathrm{~A}$ and to results from their experiments on the thermal decomposition of hexane (see line labeled "Thermal decomposition of hexane" on fig. $7 B$ ). They concluded that the hydrocarbons

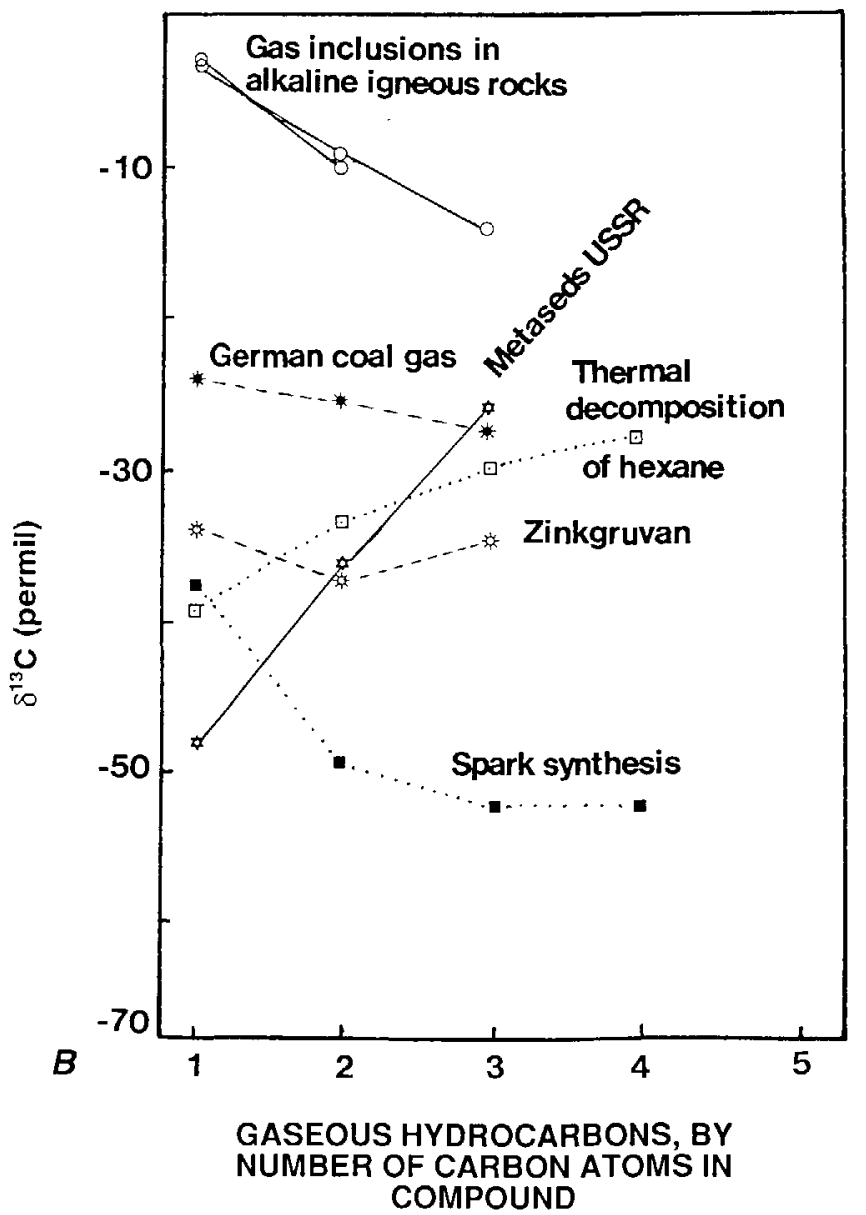

for spark synthesis (Des Marais and others, 1981) is similar to that for abiogenic gases (gas inclusions in alkaline igneous rocks from Greenland (Konnerup-Madsen and others (1988)), whereas trends for thermal decomposition of hexane (Des Marais and others, 1981), metasedimentary rocks in the (former) USSR (Petersil'ye and Pavlova, 1975), and Zinkgruvan, Sweden (Castaño, 1990), are similar to those for thermogenic gases (compare with fig. 7A). 
they studied were produced largely by the thermal breakdown of organic matter in hydrothermal gases. Their experiments with the formation of hydrocarbons from methane in a spark discharge produced an isotopic profile analogous to abiogenic profiles (see line labelled "Spark synthesis" on fig. $7 B$ ). Welhan (1988) concluded that there is no firm evidence for abiogenic production of methane at hydrothermal temperatures, but that in hydrothermal systems dominated by high-temperature rocks, such as in midoceanic-ridge settings, abiogenesis represents the main process of methane generation.

\section{INORGANIC GASES}

The nature of the noble gases, mainly helium but also argon and neon, is significant in establishing their origin. There is a marked difference between isotopic compositions of noble gases in the asthenosphere and those that result from various processes in the Earth's crust and biosphere. For example, the isotope ${ }^{3} \mathrm{He}$ is produced mainly in stellar reactions and was contributed to the Earth as primordial helium during accretion and planetary formation (Jeffrey and Kaplan, 1988). Although ${ }^{3} \mathrm{He}$ has degassed considerably from the Earth's crust, it is still present in high concentrations in the Earth's mantle, and in fact increases in concentration with depth in the Earth's interior. In contrast, ${ }^{4} \mathrm{He}$ is formed as the result of radioactive decay of uraniumand thorium-bearing minerals in the crust. The variation in the isotopic ratios of helium in various environments is shown on figure 8; helium ratios $\left(\mathrm{R}=\left({ }^{3} \mathrm{He} /{ }^{4} \mathrm{He}\right)_{\text {sample }}\right)$ are typically presented in comparison with atmospheric helium ratios $\left(\mathrm{R}_{\mathrm{a}}=\left({ }^{3} \mathrm{He} /{ }^{4} \mathrm{He}\right)_{\text {atmosphere }}\right)$. High $\mathrm{R} / \mathrm{R}_{\mathrm{a}}$ ratios (indicative of mantle gases) were measured in some of the localities where isotopically very heavy methane (also indicative of mantle gases) was found, such as the midocean-ridge basalts (MORB) and the Zambales ophiolite. Natural-gas deposits associated with active continental margins contain a significant mantle helium component (Poreda and others, 1988). Therefore if hydrocarbon gases (with enriched $\delta^{13} \mathrm{C}$ signatures) are associated with primordial ${ }^{3} \mathrm{He}$, there is reason to believe a mantle source.

Hydrogen is rarely found in sedimentary basins, although it is reported at a number of localities in igneous rocks (Coveney and others, 1987; Neal and Stanger, 1983; Konnerup-Madsen and others, 1988). Neal and Stanger (1983) described gases, containing mostly hydrogen, that emanate from serpentinized ultramafic rocks in Oman; these gases also include up to 5 percent methane and small (ppm) quantities of light hydrocarbons. In the Tønder wells in Denmark, tests of gases from the Zechstein Formation measured up to 16 percent hydrogen; the remainder was chiefly nitrogen with small amounts of hydrocarbons (Geological Survey of Denmark, written commun., 1988).

Hydrogen can be formed in nature by the serpentinization of ultramafic rocks, redox processes involving mafic minerals, shearing reactions in igneous rocks, and direct outgassing of the mantle. Isotopic analysis of hydrogen (determination of $\delta \mathrm{D}$ ) often is not very revealing, as the isotopic composition of hydrogen reequilibrates very rapidly with water, and any indication of a deeper, higher temperature source can thereby be erased.

\section{KEY ELEMENTS FOR HYDROCARBON ENTRAPMENT}

Several key elements are crucial for hydrocarbon entrapment: (1) a seal, (2) a reservoir, and (3) a source of hydrocarbons.

A seal must be configured to trap and retain oil or gas. The physical behavior of a seal depends on the hydraulic conductivity of the rock together with the water content of the void space. It is estimated that a caprock with a hydraulic conductivity of $10^{-15} \mathrm{~m} / \mathrm{s}$ could retain a $100-\mathrm{m}$ gas column (Anonymous, 1991). However, substantial losses due to diffusion can occur over a period of several million years; the amount of diffusion depends on seal character and time (Leythaeuser and others, 1982).

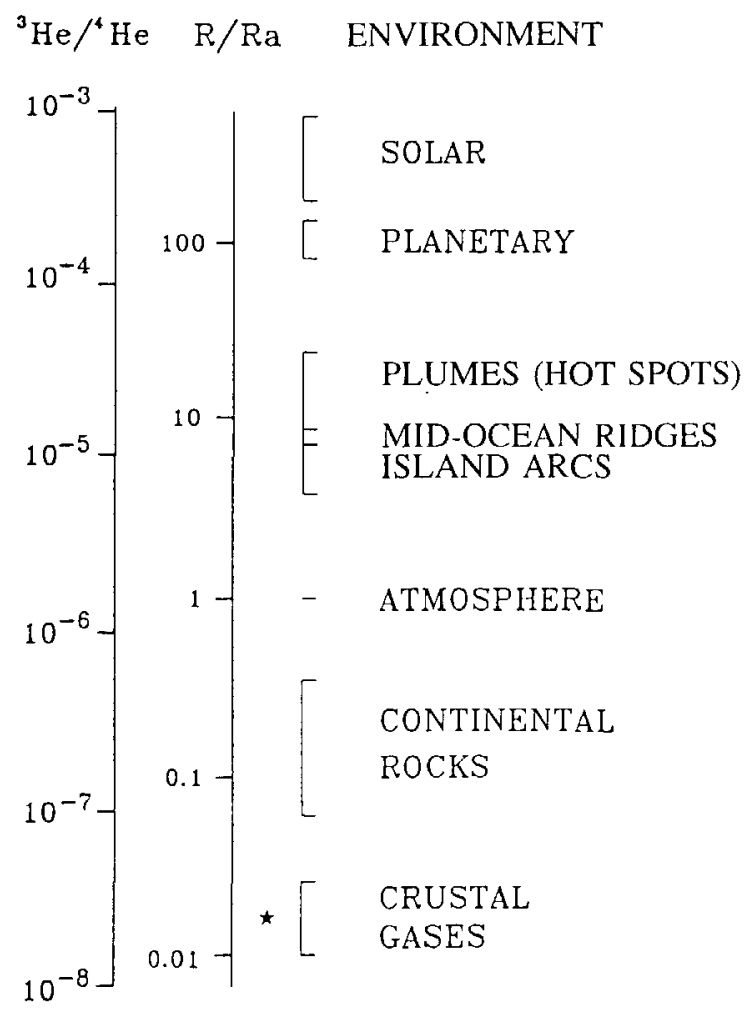

Figure 8. Variation in ${ }^{3} \mathrm{He} /{ }^{4} \mathrm{He}$ and $\mathrm{R} / \mathrm{R}_{\mathrm{a}}$ ratios in various environments. $\mathrm{R} / \mathrm{R}_{\mathrm{a}}=\left({ }^{3} \mathrm{He} /{ }^{4} \mathrm{He}\right)_{\text {sample }} /\left({ }^{3} \mathrm{He} /{ }^{4} \mathrm{He}\right)_{\text {at }}$ mosphere, normalized to the atmospheric value $\left(\mathrm{R}_{\mathrm{a}}\right)$ of $1.40 \times 10^{-6}$ from Mamyrin and others (1970). The star symbol represents the mean $R / R_{a}$ ratio of 0.015 to 0.018 obtained from the Gravberg 1 well. Modified from Jeffrey and Kaplan (1988). 
The best seals have low hydraulic conductivity, wide lateral distribution, and uniform lithology, and are relatively ductile. In a brittle rock such as granite, the formation of effective seals and traps would be much more complicated because fractures would tend to stay open. Gold's original expectation model called for calcite produced from the oxidation of mantle methane combined with other minerals to form a seal. A subsequently modified model proposed by Gold contended that mineral-healed fractures accompanied by closure of the remaining very thin water-filled fractures would be the sealing mechanism (Anonymous, 1991).

Conventional reservoirs have a much more homogenous porosity and permeability distribution than unweathered crystalline bedrock, such as the Järna and Siljan Granites and associated dolerites. In order to have a viable commercial reservoir at Siljan, porosities would have to be at least an order of magnitude higher than in typical Swedish granites, in the 1-5 percent range. Although typical tight gas sandstone reservoirs have porosities of 8 to 10 percent, fractured shale and carbonate reservoirs have porosities as low as 3 percent (R.M. Sneider, oral commun., 1987). Fractures in the crystalline rocks would have to be open and interconnected, with higher than normal hydraulic conductivity $\left(10^{-9}\right.$ to $\left.10^{-11} \mathrm{~m} / \mathrm{s}\right)$.

The concepts of generation and entrapment are so very well known that they will not be reviewed here (Hunt, 1979; Tissot and Welte, 1984). The association of worldclass source rocks with major oil and gas accumulations is well documented (for example, Demaison and Murris, 1984; Ulmishek and Klemme, 1990; Magoon and Dow, in press). Although commercial hydrocarbon deposits have been developed in igneous and metamorphic rocks throughout the world, these deposits have been correlated with organic-rich source rocks. Bath and others (1986) made a detailed study of oil and bitumen shows in crystalline rocks in the United Kingdom; they concluded that in all cases the hydrocarbon source was organic. Source rocks are present in Silurian and Ordovician sedimentary rocks on the periphery of the Siljan Ring (Vlierboom and others 1986); these rocks could contribute trace organic compounds within the crystalline rocks within the impact structure. A possible mechanism for the movement of organic compounds could be deglaciation. Deglaciation would have the effect of rejuvenating open fractures and allow the deep penetration of meteoric waters, which could carry with them dissolved organic compounds plus oil and gas.

\section{SYNTHESIS-INTERPRETING SHOWS}

\section{SHOWS IN DOLERITE AND GRANITE}

The dolerite intrusions have considerably higher hydrocarbon gas concentrations than the granite. The $\mathrm{R} 3 \mathrm{dol}-$ erite was analyzed at closely spaced intervals in ST-1; there is far more methane in the R3 dolerite (200 to 1,000 $\mathrm{ppm}$ ) than is typically found in the granite (10 to $80 \mathrm{ppm}$ ) (fig. 9). High concentrations of methane in the granite between and immediately below the two dolerite layers may reflect a contribution from the dolerite. Hydrogen content
Figure 9. Geochemical data in vicinity of R3 dolerite, sidetrack 1 (ST-1) of Gravberg 1 well. Horizontal scales are linear, except methane content (in ppm) which is logarithmic. Methane content in ppm is the measured methane content in headspace gas; methane content in percent is the percentage of methane with respect to the total of all hydrocarbons. Note contrast between the topmost granite and the dolerite in all data sets except $\delta \mathrm{D}$; data from the two lower granite units may be influenced by contribution from the dolerite.

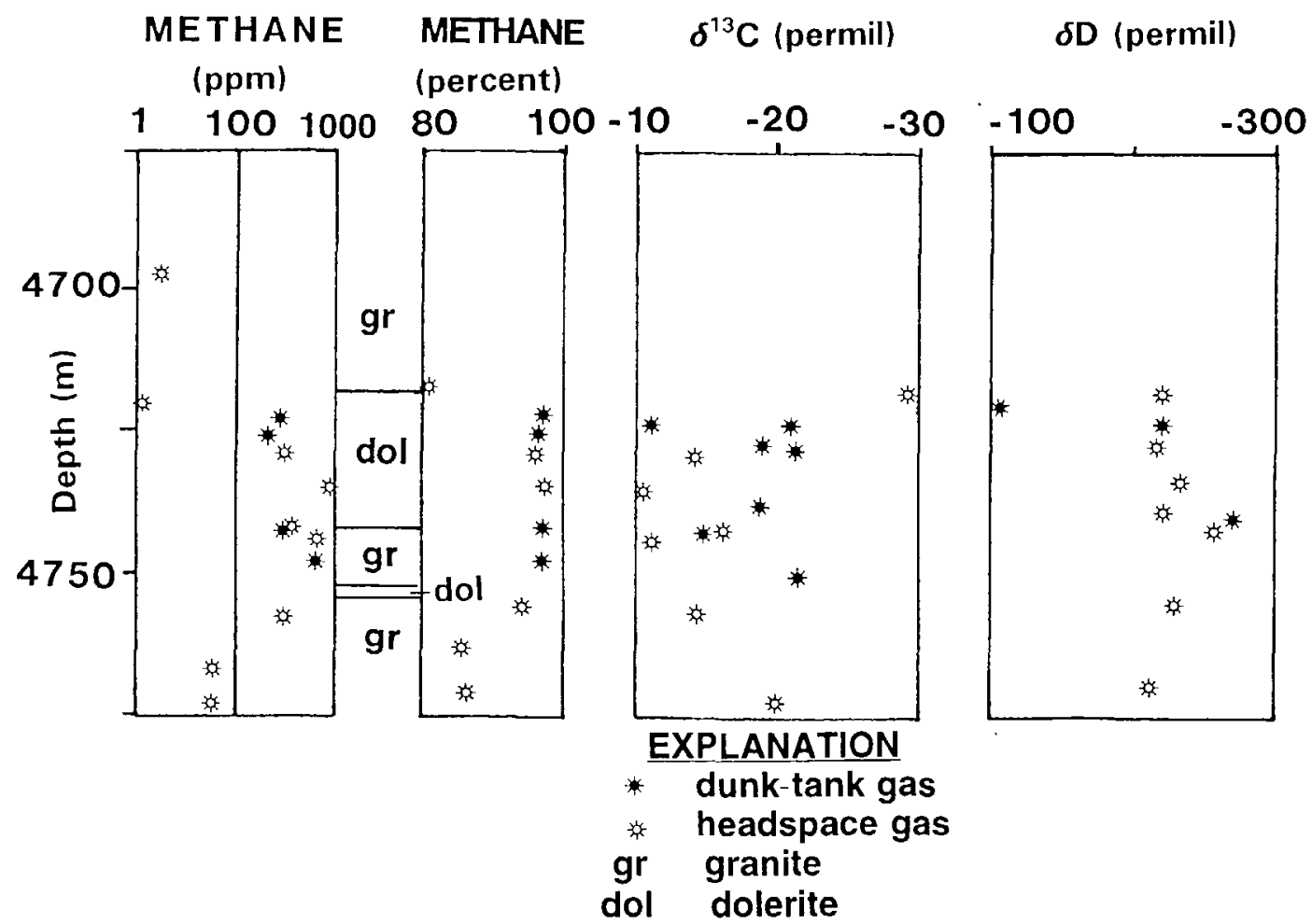


is much the same in both rock types. Shows in the various dolerites are similar: they have a very high proportion of methane ( 295 percent is typical). Unsaturated hydrocarbons are rare.

The R3 dolerite exhibits a very heavy isotopic composition: $\delta^{13} \mathrm{C}$ for $\mathrm{C}_{1}$ ranges from -10 to -21 permil, whereas methane in the granite immediately overlying the dolerite has a $\delta^{13} \mathrm{C}$ of -29.5 permil (fig. 9). Several of the granitederived gas samples below the main dolerite have a dolerite isotopic signature, which may due to the following explanations: (1) Diffusion of gas out of the dolerite can contribute to the total gas. (2) The gas could come from the thin dolerite below the main body. (3) Headspace gas samples below $4,750 \mathrm{~m}$ contain some dolerite cuttings, which would yield a heavy gas.

The gas in the dolerites has a very consistent molecular and isotopic signature, regardless of the method of analysis (headspace gas, gas released by acid treatment, or gas released by crushing in a ball mill (Laier, 1990). The headspace gas from a core taken from the $\mathrm{R} 1$ dolerite from a depth of $1,477 \mathrm{~m}$ yielded a $\delta^{13} \mathrm{C}$ for methane of -15.9 permil, a value which is similar to that of headspace gases from cuttings. The Danish Geological Survey obtained a $\delta^{13} \mathrm{C}$ of -10.5 permil at $1,591 \mathrm{~m}$ from gas released from dolerite cuttings by acid treatment. The Danish Geological Survey also used the same technique on a dolerite core from Fåsås; $\delta^{13} \mathrm{C}$ of methane was -10.5 permil. Laier (1988, 1990, 1992) reports the presence of abundant tiny fluid inclusions in the dolerites, but they were too small to analyze. He believes that the gas in the dolerite comes from these inclusions.

A sample from the $\mathrm{R} 2$ dolerite provided the only reliable helium data from dolerites in the well: according to Hilton and Craig (1989) a sample from 2,591 $\mathrm{m}$ had 539 ppm He with an $R / R_{a}$ value of 0.075 , which indicates a mixture of crustal and atmospheric helium. Any primordial helium in the dolerite would be overshadowed by radiogenic helium formed in the last 900 m.y.

Gases in the dolerites are abundant, are rich in methane, and lack unsaturated hydrocarbons. Gases in the granite are present in much lower concentrations, contain about 50-70 percent methane, and contain high percentages of ethane and propane $\left(C_{1} / C_{2}\right.$ ratio is 8 to 10$)$. Granite gases are also rich in unsaturated hydrocarbons: ethane/ethene and propane/propene ratios are both about one. The granite gases have a very high proportion of ethene and propene in comparison with other natural gases, but they are similar in that regard to gases manufactured by the Fischer-Tropsch reaction.

Gases in the granites fall into two groups: one is dominated by saturated hydrocarbons and the other by unsaturated hydrocarbons. The saturated hydrocarbon group is more closely associated with fracture zones. These could be indigenous gases generated abiogenically, or they could be derived mainly from sedimentary organic matter carried deep into the granite along fracture zones by meteoric water or as a result of the impact. The unsaturated hydrocarbon group does not have a clear association with any particular setting within the granite. These are abiogenic gases formed by a Fischer-Tropsch catalytic reaction between $\mathrm{CO}_{2}$ and $\mathrm{H}_{2}$; magnetite is the likely catalyst (Laier, 1988). The processes described in this paragraph take place at relatively low temperatures in the crust, not the mantle.

Hydrogen is present in quantities exceeding methane usually by at least one order of magnitude. In ST-3, $\mathrm{H}_{2}$ content averaged over $4,000 \mathrm{ppm}$ in two zones: from 6,705-6,751 $\mathrm{m}$ and 6,873-6,895 $\mathrm{m}$. Helium was noted sporadically throughout the well: where helium was present, concentrations were generally 50 ppm or less, except below $6,150 \mathrm{~m}$ where helium concentrations averaged $500 \mathrm{ppm}$.

\section{DRILL-STEM TESTS 1 THROUGH 4}

No hydrocarbons above background values were recovered from drill-stem tests (DST's) 1 through 4. Background values typically were 10 to $20 \mathrm{ppm}$, far below the background gas readings normally found in producing basins (where background gas readings often are $1,000 \mathrm{ppm}$ or more). In DST 3, the fluids collected from the interval between $1,963.5-1,990 \mathrm{~m}$ had radon values of 78 to 185 counts per minute (cpm), whereas the mud tested during drilling through this interval had radon values of less than $1 \mathrm{cpm}$. The presence of elevated radon levels in the fluid recovered from the test indicates that formation fluid was recovered. The water has less than $500 \mathrm{ppm}$ total dissolved solids, it is dominated by sodium bicarbonate, and, on the basis of a $\delta^{18} \mathrm{O}$ value of -11.3 permil and a $\delta D$ value of -86 permil (both relative to standard mean ocean water $(\mathrm{SMOW}))$, it falls directly on the meteoric water line.

\section{DRILL-STEM TEST 5 AND PUMP TESTING IN 1990}

\section{GAS GEOCHEMISTRY}

DST 5 tested the entire open-hole section of ST-3 from the base of the $73 / 4$ inch liner at $5.453 \mathrm{~m}$ to total measured depth at $6,957 \mathrm{~m}$, although the effective base of the tested interval may actually have been around $6,300 \mathrm{~m}$ because of uncertainties concerning the effectiveness of well stimulation. After a hiatus of 8 months, the same interval was pump tested from May to early July 1990.

During testing, the gas samples differed remarkably from those collected while drilling through the same interval. Because of improved sampling methods, the oxygen content (a measure of atmospheric contamination) of DST samples was less than 1 percent, and pump-test samples contained 1-2 percent instead of the 8-15 percent meas- 
ured while drilling. Much higher levels of i-butene were recorded during pump testing (an average of $62 \mathrm{ppm}$ ) than during DST 5 (less than $20 \mathrm{ppm}$ ). As i-butene is not a natural product, the increase in concentration shows that it is being formed in the borehole or the formation. Typical DST 5 gas composition was 2.7 weight percent hydrogen, 54 percent helium, 2.1 percent argon, 0.2 percent oxygen, 41 percent nitrogen, and $150 \mathrm{ppm}$ methane. Before testing and fracturing, hydrogen was the dominant gas and helium was next in abundance but in much smaller concentrations. Methane content was usually $100-500 \mathrm{ppm}$. After fracturing, helium became the dominant gas.

Water collected during DST 5 was undersaturated with gas; the volume of gas per unit volume of water was $0.25 \mathrm{~m}^{3} / \mathrm{m}^{3}$. For comparison, if formation water at about $6,000 \mathrm{~m}$ were saturated with gas, one would expect to measure an approximate saturation level for methane of $5 \mathrm{~m}^{3} / \mathrm{m}^{3}$, and for helium of about $3 \mathrm{~m}^{3} / \mathrm{m}^{3}$. During the pump-test period, gas saturation was measured at $0.3 \mathrm{~m}^{3} / \mathrm{m}^{3}$ of water from the gas separator. However, the separator was not operating very efficiently, and the saturation could have been as high as $1.0 \mathrm{~m}^{3} / \mathrm{m}^{3}$. The formation water throughout the entire well was similarly undersaturated with gas; therefore, gas in the formation was strictly in solution and no gas was present as a separate phase.

The isotopic composition of the hydrocarbon gases obtained after fracturing was different from that measured while drilling; the postfracturing gases had a $\delta^{13} \mathrm{C}$ for $\mathrm{C}_{1}$ of -44.8 to -56.9 permil, $\delta^{13} \mathrm{C}$ for $\mathrm{C}_{2}$ of -32 permil, and $\delta^{13} \mathrm{C}$ for $\mathrm{C}_{3}$ of -29.1 permil. $\delta \mathrm{D}$ for methane was -470 permil (fig. 6).

Helium $\left({ }^{3} \mathrm{He} /{ }^{4} \mathrm{He}\right)$ ratios yielded an $\mathrm{R} / \mathrm{R}_{\mathrm{a}}$ of 0.016 to 0.022 ; these values plus argon $\left({ }^{40} \mathrm{Ar} /{ }^{36} \mathrm{Ar}\right)$ ratios and neon isotopic data show that all these gases originated in the crust as by-products of the breakdown of radioactive minerals in granite. Hydrogen typically constituted 1 to 3 percent of the total gas; there seems little doubt that it is indigenous to the granite, but the precise mode of its origin remains uncertain.

\section{WATER GEOCHEMISTRY}

Although large volumes of fresh water were pumped into the formation as part of the hydrofracturing operation, the recovery of bona fide formation water was verified by the use of tritium analyses, conducted by Dr. R. Saxena of Uppsala University, Sweden. The injection water has a tritium content of 22 tritium units (TU), showing that it is a mixture of pre- and post- 1952 water. At the end of the test period the recovered water had a tritium content of 5 to 7 $\mathrm{TU}$; it is a mixture of formation water (around $0.5 \mathrm{TU}$ ) and injection water. The formation water is highly saline, with more than $150,000 \mathrm{ppm}$ total dissolved solids, and has a $\mathrm{Ca} / \mathrm{Na}$ ratio of 2.9 to 3.2 . The $173.67 \mathrm{~m}^{3}$ of water recovered during pump testing was similar in composition.

\section{INTERPRETING FLUID GEOCHEMICAL DATA}

\section{DISCUSSION}

The relationship of $\delta^{13} \mathrm{C}$ to $\delta \mathrm{D}$ in $\mathrm{C}_{1}$ in samples from this project together with data from the literature are shown in figure 6 . The dolerite gases group tightly together regardless of sample type, and they are unlike any other major group of natural gases; they are considered to be abiogenic in origin. In contrast, the gases from the granite show a great spread. Several granite gas samples fit fairly close to the dolerite grouping; they may have dolerite affinities. The other free gas samples collected from the granite fit in the thermogenic field, while the acid-treated (desorbed) gases are scattered over a wide area, which is unusual. Faber and others (1988) would consider these desorbed gas samples to be dominantly artificial, an interpretation which agrees well with the experiments of Laier (1990) and Jeffrey and Kaplan (1988).

Two gas samples from pump testing and DST 5 plot apart from samples obtained from the well during drilling (fig. 6). These gases have a $\delta^{13} \mathrm{C}$ for methane of -44.8 to -56.9 permil, $\delta^{13} \mathrm{C}$ for ethane of -32 permil, and $\delta^{13} \mathrm{C}$ for propane of -29.1 permil. It is possible that the light hydrocarbon gases represent isotopically very light gas of bacterial origin as a contaminant mixed with gas with a $\delta^{13} \mathrm{C}$ for methane of -29 to -38 permil (as measured on six samples obtained before the well was stimulated).

Three isotopic profiles are shown for Gravberg 1 on figure $7 A$ : granite, diabase (dolerite), and DST 5. The isotopic profiles for granite and dolerite display abiogenic characteristics. However, these data do not reveal where the gas originated (crust or mantle) or by what process. Possible processes are a catalytic reaction such as the Fischer-Tropsch reaction, or spark discharge during tectonic shearing of igneous rocks. DST 5 has a thermogenic isotopic profile, which also holds for samples collected during the drilling of ST-3. Oil-based mud may be an important influence on this distribution. In the test gases, the methane may represent a mixture of very light gas of bacterial origin as a contaminant and heavier methane produced by one of the crustal processes cited above.

Helium from Gravberg 1 is predominantly of crustal origin with an upper limit for mantle helium contribution of just 0.15 percent (Hilton and Craig, 1989). Its occurrence strongly correlates with the presence of high uranium and thorium content in quartz monzonites.

The stable isotope ratios of hydrogen in the gases at Gravberg 1 are consistent with a low-temperature origin (about $80^{\circ} \mathrm{C}$ ). This origin can be explained by one of the three following mechanisms: (1) Hydrogen is formed locally in the granite, most likely by the reduction of formation water by ferrous minerals. (2) Hydrogen is formed in a deeper, high-temperature setting, and is reequilibrated 
with water at formation temperature. (3) Hydrogen is formed by spark discharge during shearing.

\section{SUMMARY - NO SOURCE}

The evidence at hand shows that trace quantities of hydrocarbon gases in the dolerites are abiogenic, and they may be trapped in tiny fluid inclusions, adsorbed on mineral grains, or dissolved in the pore water. Because of the very low gas saturation in the formation water, there is no free gas in either the dolerites or the granites. The highest concentrations of hydrocarbon gases in the dolerites are less than $1,000 \mathrm{ppm}$.

Hydrocarbon gases in the granite are present in much lower concentrations than in the dolerites, and these gases contain a high percentage of ethane and propane and their unsaturated analogues. The unsaturated compounds are rarely found in nature, and they could be formed through catalytic reactions such as the Fischer-Tropsch reaction. They could also be formed by a spark discharge reaction which can cause condensation or polymerization (Des Marais and others, 1981; Enomoto and Hashimoto, 1990; Martelli and others, 1989). Another possibility is that many of the hydrocarbons in the granite are drilling artifacts. Although the processes discussed here are abiogenic, they take place in the crust or in the borehole, and they do not constitute a viable source of commercial hydrocarbons.

\section{INTERPRETING RESERVOIR DATA}

Prospective reservoir zones in fractured intervals were identified by integrating data from studies of cuttings with drilling parameters and wireline log data (Castaño and others, 1988, 1990).

Fracture zones are recognized using the following criteria: (1) no breakouts, hole remains in gauge (that is, the hole is only slightly larger than the diameter of the drill bit), (2) high rate of penetration, (3) increase in sonic transit time, (4) decrease in deep-resistivity-log readings, (5) increase in occurrence of fracture-zone minerals, and (6) observations of fractures in cuttings.

The criteria used to recognize fractured intervals in crystalline rock are similar to those used to recognize intervals of sedimentary rock. In the granites in Gravberg 1 , porosity is developed chiefly in altered feldspar, in authigenic epidote, and in mylonite.

Porosity and permeability data from cores and sidewall samples are shown in table 1 . Porosity and permeability are very low, although porosity in altered rock and in the shallow core holes is in the range of that in tight gas sandstone reservoir rocks. Correlation of sonic porosity and measured porosity is very good, and the zones that looked most porous on the sonic log were not cored.
Table 1. Porosity and permeability of samples from the Siljan Ring area, Sweden.

[All data are from Gravberg 1 well except as noted. Porosity of average Swedish granite shown for comparison (Stenberg, 1986). ---, not determined]

\begin{tabular}{|c|c|c|c|}
\hline & $\begin{array}{l}\text { Number of } \\
\text { samples }\end{array}$ & $\begin{array}{c}\text { Porosity } \\
\text { (percent) }\end{array}$ & $\begin{array}{l}\text { Permeability } \\
\text { (microdarcies) }\end{array}$ \\
\hline Granite --_- & 26 & 0.88 & 18 \\
\hline Quartz monzonite -...-- & 1 & .9 & $\cdots$ \\
\hline Dolerite -- & 6 & .75 & 11 \\
\hline Altered rock - & 2 & 2.35 & --- \\
\hline Shallow core holes --- & 40 & 2.0 & --- \\
\hline Average Swedish granite---- & --- & .25 & -- \\
\hline
\end{tabular}

The relationship of sonic porosity with depth (fig. 10) shows that porosity decreases rapidly with depth. In the shallow subsurface, porosity is conclusively related to the meteorite impact. Deeper in the well, higher porosities correlate with the incidence of fracture zones that are unrelated to the impact.

Breakouts (hole enlargements due to anisotropic rock stresses) caused the hole to be out of gauge and ovalized, which in turn induced large hole deviations, many fishing jobs, and several sidetracked holes. The main reason for this situation is that the magnitude of stress is low in fractured zones and higher in intervals where the rock is unfractured (Stephansson and others, 1990; Anonymous, 1991). In unfractured zones, spalling is the most common mechanism of failure. Stephansson and others (1990) showed that the horizontal stress is highly anisotropic and the minimum horizontal stress is close to 0.68 times the vertical stress.

In summary, porosity is marginal in rocks penetrated by the Gravberg 1 well. Porous units are discontinuous, and permeability is very low. Pore pressures close to lithostatic, predicted by the expectation model, do not exist.

\section{INTERPRETING SEAL PROPERTIES}

Leak-off tests and DST data provide valuable clues about pressures, permeability, and hydraulic conductivity. These data are summarized on figure 11 , which also includes information about formation-water salinity. Permeability is very low, especially below the R1 dolerite, and it is comparable to the permeabilities measured on cores. Although data are sparse, pore pressures throughout the well are less than or equal to hydrostatic. There are not enough data to determine if there are extensive rock units with conductivities low enough to qualify as a seal.

On the basis of resistivity logs and DST data, formation waters are quite fresh down to $4,000 \mathrm{~m}$, and below $6,000 \mathrm{~m}$ the water is highly saline, containing around 150,000 ppm total dissolved solids. Rissler-Åkesson (1990) found that pore-fiuid resistivity decreased below $4,000 \mathrm{~m}$, 


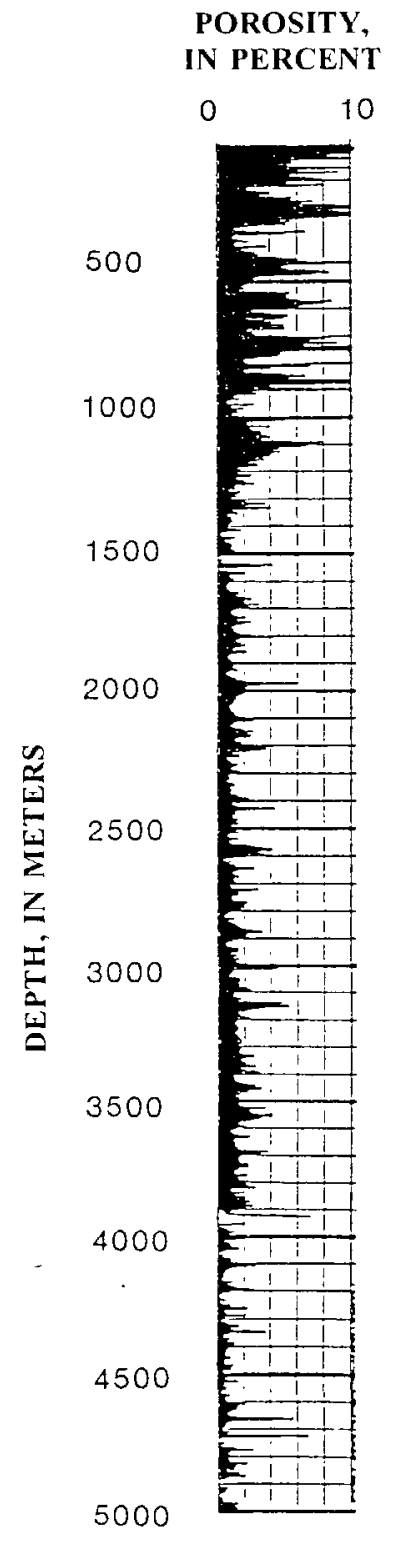

Figure 10. Sonic-log porosity trends in Gravberg 1 well. Not logged below $5,400 \mathrm{~m}$; interval $5,000-$ $5,400 \mathrm{~m}$ not shown.

with resistivities of $5 \mathrm{ohms}$ corresponding to salinities of $2,000 \mathrm{ppm}$ down to $5,660 \mathrm{~m}$ (fig. 11). Deep penetration of surface waters below $2,000 \mathrm{~m}$ (where pervasive feldspar alteration begins to taper off) is through fracture zones that contain altered granite (Komor and Valley, 1990).

Gold's expectation model calls upon calcite formed from the oxidation of ascending mantle methane to help form a seal in critical layers and trap methane in stacked domains. Stable isotope fractionation curves from carbon and oxygen isotopes of calcite, bicarbonate, carbon dioxide, and methane show that all but 6 of the 167 samples from the

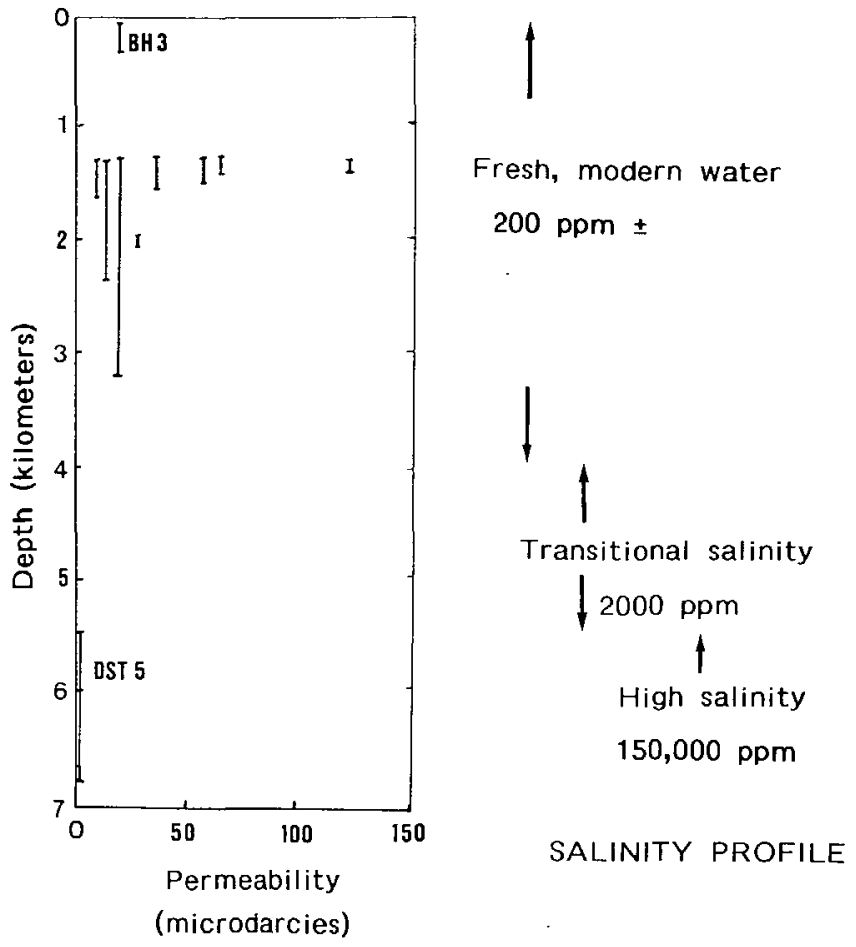

Figure 11. Permeability measurements obtained from leak-off tests and drill-stem test (DST) 5 in Gravberg 1 well. Data labeled BH3 are from leak-off test in borehole 3 (Fåsås; see fig. 1). Salinity measurements (to right of graph) were obtained from DST and wircline-log data; arrows indicate approximate depth ranges for fresh, transitional, and high-salinity waters. Pressure in the well was hydrostatic to slightly subhydrostatic with reference to a fresh-water gradient.

core holes and the Gravberg 1 well fall in the equilibrium field delimited by meteoric water, atmospheric $\mathrm{CO}_{2}$, and soil bicarbonate (Anonymous, 1991). Two of the six other samples fall directly on the magmatic $\mathrm{CO}_{2}$ line; they are from the chilled margins of the mineralogically unaltered $\mathrm{R} 1$ dolerite. The calcite carbon is derived from groundwater bicarbonate, limestone, and $\mathrm{CO}_{2}$ originating from magmatic sources. Particularly below the R1 dolerite, calcite oxygen becomes isotopically heavier with depth, reflecting an increased prevalence of magmatic $\mathrm{CO}_{2}$. If the source of calcite were oxidized mantle methane $\left(\delta^{13} \mathrm{C}\right.$ of -7 permil), calcite $\delta^{13} \mathrm{C}$ values would be greater than +40 permil. As an alternative, a Raleigh distillation process (Faure, 1986) resulting from continuous calcite precipitation from mantlederived methane would result in isotopic values between +40 and $<0$ permil. Because such trends are not observed, mantle methane cannot be considered as a source for calcite (Valley and others, 1988; Komor and Valley, 1990).

In summary, all seal properties are related to geochemical effects that act from the Earth's surface downward, and there is no evidence for the influence of ascending fluids. The presence of altered minerals in the granite as deep as 
$4,000 \mathrm{~m}$, the evidence from stable isotope studies of calcite cements, and the existence of fresh formation water down to almost $6,000 \mathrm{~m}$ support this conclusion.

\section{EPILOGUE-THE STENBERG 1 WELL}

DDP drilled the Stenberg 1 well in 1991-92; the site is near Hättberg in the central part of the Siljan Ring (fig. 1). From the scant data available, breakout problems were encountered in this well, as they had been in Gravberg 1. Drilling rates improved, largely because of the experience gained at Gravberg. Methane with a mantle isotopic signature is present in the dolerites penetrated by Stenberg 1, and shows in the dolerites are much higher than in the granites (T. Gold, oral commun., 1992). Only a small amount of free gas has been recovered in drill-stem tests, and the flow rate diminishes with time.

\section{CONCLUSIONS}

Data from the Gravberg 1 well have added conclusive evidence that the meteorite impact that created the large circular structure in the Siljan Ring greatly fractured and altered the underlying rocks. The heat created by the impact was sufficient to generate barely mature hydrocarbons in Ordovician source rocks on the perimeter of the ring. The influence of the impact drops off dramatically below $2,000 \mathrm{~m}$ and is entirely absent below 4,000 m. Fracture zones at depth are related to regional tectonics and not to the impact. The low-dipping, high-amplitude seismic reflectors are dolerite sills.

Under the stress conditions identified in the Gravberg 1 well, pore pressures close to lithostatic cannot exist. Fracture zones are discontinuities in the stress field and bound large blocks several hundred meters across. Lithologic units and fracture zones are very irregular and discontinuous, except for the dolerites, which are not part of the porous units.

All available evidence points to a very deep circulation of meteoric water in the Siljan Ring area. The whole circulation system is driven by the present-day topography. Below $6,000 \mathrm{~m}$, stagnant water is present; it is highly saline with $150,000 \mathrm{ppm}$ total dissolved solids. The pore-pressure gradient is essentially hydrostatic to slightly subhydrostatic, and permeabilities are very low, especially below $1,500 \mathrm{~m}$. Despite the low conductivities, effective seals were not recognized. Stable isotope studies of calcite show that mantle methane is not involved in any of the fractionation equilibria; instead, equilibration exists with modern meteoric water. At depth, magmatic $\mathrm{CO}_{2}$ is the likely carbon source for the heaviest carbon isotopes measured.

Because of the very low gas saturation in the water, about $0.25 \mathrm{~m}^{3}$ gas $/ \mathrm{m}^{3}$ water, there is no free gas in the formation. The gas may be in solution, it may be adsorbed on mineral grains, or it may be present in fluid inclusions.
Methane in surface seepages and in the shallow core holes is of microbial origin, and the associated helium is of crustal origin.

The dolerites yield the principal gas shows, which are generally less than $1,000 \mathrm{ppm}$. Dolerite gases are characterized by 95 percent methane with a very heavy isotopic composition $\left(\delta^{13} \mathrm{C}\right.$ of about -15 permil). The methane/ ethane ratio of these gases ranges from 20 to 45 , with minor unsaturated hydrocarbons present. These gases are abiogenic, but it is not certain whether the gases have a crustal or mantle origin.

Gases from the granite have a wide range of methane isotopic compositions, generally falling within a $\delta^{13} \mathrm{C}$ range of -20 to -35 permil during drilling and -42 to -56 permil during testing. Granite gases contain 50-70 percent methane, with a methane/ethane ratio between 8 and 10 . Hydrocarbon gases in the dolerite and the granite in the original hole display abiogenic isotopic signatures. Gas with a thermogenic profile was found during drilling of ST-3, DST 5, and pump testing; granite and quartz monzonite are the main rock units in which such gas was found. Interaction with the oil-based drilling mud is probably responsible for the differences between isotopic compositions measured during drilling and those measured during testing. Gases in the granites fall into two types: one rich in saturates, the other rich in unsaturated hydrocarbons. The saturated hydrocarbon group is more commonly found in fracture zones; it could be an indigenous group generated abiogenically, or it could be derived mainly from sedimentary organic matter driven deep into the granite. Unsaturated hydrocarbons are rare in nature, but they could be formed through catalytic reactions such as the FischerTropsch reaction or spark discharge reactions caused by tectonic rock shearing. The likely reaction in the granite is a Fischer-Tropsch reaction between $\mathrm{CO}_{2}$ and $\mathrm{H}_{2}$ with magnetite as the catalyst. Most of the gas in the granite is probably artificial. The effect of deglaciation in the rejuvenation of the deep penetration of meteoric waters carrying with them dissolved organic compounds (plus oil and gas) must be considered as a source of hydrocarbons.

Both hydrogen and helium have been found in greater abundance than expected, particularly below $6 \mathrm{~km}$. The association of helium and hydrogen in rather high concentrations strongly suggests that these gases are present in the formation. Hydrogen probably has been formed in the crust at fairly low temperatures, possibly by spark discharge reactions or fluid-rock reactions. Helium and the other noble gases argon and neon have a crustal origin. More than 99 percent of the helium can be accounted for by radioactive decay of uranium- and thorium-bearing minerals over a period of time much shorter than the age of the rocks.

There is no credible evidence for a mantle flux of methane or helium at Gravberg, and none of the basic premises for the deep-gas hypothesis (Gold, 1979, 1987) predicated for the Siljan Ring have been realized. 


\section{REFERENCES CITED}

Abranjo, T.A., Sturchio, N.C., Bohlke, J.K., Lyon, G.L., Poreda, R.J., and Stevens, C.M., 1988, Methane-hydrogen gas seeps, Zambales ophiolite, Philippines-Deep or shallow origin?: Chemical Geology, v. 71, p. 211-222.

AlDahan, A.A., 1990, Petrology and mineral alterations of granitic rocks from Gravberg-1 well, Siljan impact structure, central Sweden: Sector Report, Deep Gas Project, Vattenfall RD\&D Report U(G) 1990/50, 63 p.

Anonymous, 1984, The Siljan ring project-Independent expert evaluation, Deep Gas Swedish Premises: Vattenfall unnumbered report, $63 \mathrm{p}$.

1985, Deep gas, Swedish Premises, the Siljan ring structure-Investigations and evaluations: Vattenfall RD\&D report, Gas Project G.2 report no. 4.

1991, Scientific summary report of the deep gas drilling project in the Siljan Ring impact structure: Vattenfall RD\&D Report U(G) 1991/14, 278 p.

Bath, A.H., Brassell, S.C., Eglinton, G., Hill, R.I., Hooker, P.J., O'Nions, R.K., Oxburgh, E.R., Parnell, J., Robinson, N., and Spiro, B., 1986, Deep source gases and hydrocarbons in the U.K. crust: British Geological Survey Report FLPU 86-2, $129 \mathrm{p}$.

Biloen, P., and Sachtler W.M.H., 1981, Mechanism of hydrocarbon synthesis over Fischer-Tropsch catalysts: Advances in Catalysis, v. 30 , p. $165-215$.

Bodén, A., and Eriksson, K.G., eds., 1988, Deep drilling in crystalline bedrock, volume 1-The deep gas drilling in the Siljan impact structure, Sweden and astroblemes: Berlin, Springer-Verlag, $364 \mathrm{p}$.

Bottomley, R.J., York, D., Grieve, R.A.F., 1978, ${ }^{40} \mathrm{Ar}-{ }^{39} \mathrm{Ar}$ ages of Scandinavian impact structures: I Mien and Siljan: Contributions to Mineralogy and Petrology, v. 68, p. 79-84.

Bryndzia, L.T., and Wood, B.J., 1990, Oxygen thermobarometry of abyssal spinel peridotites-The redox state and C-D-H volatile composition of the Earth's sub-oceanic upper mantle: American Journal of Science, v. 290, p. 1093-1116.

Burke, R.A., Jr., Brooks, J.M., and Sackett, W.H., 1981, Light hydrocarbons in Red Sea brines and sediments: Geochimica Cosmochimica Acta, v. 45, p. 627-634.

Castaño, J.R., 1988, Geochemical studies, Gravberg-1 well, Sweden-Integration of well site and external laboratory analyses, in Deep drilling in crystalline bedrock, v. 1-The deep gas drilling in the Siljan impact structure, Sweden and astroblemes: Bodén, A., Eriksson, K.G., eds., Berlin, SpringerVerlag, $364 \mathrm{p}$.

1990, Geochemistry of the Gravberg-1 well: Sector Report, Deep Gas Project, Vattenfall RD\&D Report U(G) 1990/61, 86 p.

Castaño, J.R., Sneider, R.M., and Bolger, G.W., 1988, Characterization of lithology and reservoir rock for deep gas drilling in Siljan impact structure, Sweden [abs.]: American Association of Petroleum Geologists Bulletin, v. 72, p. $169-$ 170.

Castaño, J.R., Juhlin, C., Rissler-Åkesson, G., 1990, Reservoir evaluation: Sector Report, Deep Gas Project, Vattenfall RD\&D Report U(G) 1990/49, 92 p.

Coveney, R.M., Jr., Goebel, E.D., Zeller, E.J., Dreschhoff, G.A.M., and Angino, E.A., 1987, Serpentinization and the origin of hydrogen gas in Kansas: American Association of Petroleum Geologists Bulletin, v. 71, p. 39-48.

Demaison, Gerard, and Murris, Roelof J., eds., 1984, Petroleum geochemistry and basin evaluation: American Association of Petroleum Geologists Memoir 35, 426 p.

Des Marais, D.J., Douchin, J.H., Nehring, N.L., and Truesdale, A.L., 1981, Molecular carbon isotopic evidence for the origin of geothermal hydrocarbons: Nature, v. 292, p. 826-828.

Donofrio, R.R., 1981, Impact craters-Implications for basement hydrocarbon production: Journal of Petroleum Geology, v. 3, p. 279-302.

Enomoto, Y., and Hashimoto, H., 1990, Emission of charged particles from indentation fracture of rocks: Nature, v. 346 , p. 641 643.

Faber, E., Gerling, P., and Dumke, I., 1988, Gaseous hydrocarbons of unknown origin found while drilling, in Advances in organic geochemistry 1987: Organic Geochemistry, v. 13, p. 875-879.

Faure, G., 1986, Principles of isotope geology (2nd ed.): New York, John Wiley and Sons, $589 \mathrm{p}$.

Ferguson, J.,1987, A possible role for light hydrocarbons in $\mathrm{Pb} /$ Zn mineral exploration: Mineralogical Magazine, v. 51, p. 527-533.

Freund, F., Knobel, F., Wengeler, H., Kathrein, K., Oberheuser, G., and Schaeffer, R., 1982, Organic compounds in the early atmosphere formed abiotically from atomic carbon: Geologische Rundschau, v. 71, p. 1-21.

Fritz, P., Frape, S.K., and Miles, M., 1987, Methane in the crystalline rocks of the Canadian shield, in Fritz, P., and Frape, S.K., eds., Saline waters and gases in crystalline rocks: Geological Association of Canada Special Paper 33, p. 211-223.

Fuex, A.N., 1977, The use of stable carbon isotopes in hydrocarbon exploration: Journal of Geochemical Exploration, v. 7, p. 155-188.

Fuex, A.N., and Baker, D.R., 1973, Stable carbon isotopes in selected granitic, mafic, and ultramafic igneous rocks: Geochimica Cosmochimica Acta, v. 37, p. 2509-2521.

Gold, T., 1979, Terrestrial sources of carbon and earthquake outgassing: Journal of Petroleum Geology, v. 1, p. 3-19.

- 1987, Power from the earth: London, J M Dent \& Sons, 208 p.

Grieve, R.A.F., 1988, The formation of large impact structures and constraints on the nature of Siljan, in Deep drilling in crystalline bedrock, v. 1-The deep gas drilling in the Siljan impact structure, Sweden and astroblemes: Bodén, A., Eriksson, K.G., eds., Berlin, Springer-Verlag, 364 p.

Hedberg, H.D., 1988, The 1740 description by Daniel Tilas of stratigraphy and petroleum occurrence at Osmundberg in the Siljan region of central Sweden: Tulsa, Okla., American Association of Petroleum Geologists, $96 \mathrm{p}$.

Hilton, D.R., and Craig, H., 1989, The Siljan Deep Well-Helium isotope results: Geochimica Cosmochimica Acta; v. 53, p. 3311-3316.

Hunt, J.M., 1979, Petroleum geochemistry and geology: San Francisco, W.H. Freeman, 617 p.

James, A.T., 1983, Correlation of natural gas by use of carbon isotopic distribution between hydrocarbon components: American Association of Petroleum Geologists Bulletin, v. 67, p. 1176-1191.

Jeffrey, Alan, and Kaplan, I.R., 1988, Geochemistry of gases in the Gravberg-1 well: Vattenfall unnumbered report. 
Juhlin, C., and Pedersen, L.B., 1987, Reflection seismic investigations of the Siljan impact structure, Sweden: Journal of Geophysical Research, v. 92, p. 14.113-14.122.

Komor, S.C., and Valley, J.W., 1990, Deep drilling at the Siljan ring impact structure-Oxygen-isotope geochemistry of granite: Contributions to Mineralogy and Petrology, p. 1-17.

Komor, S.C., Valley, J.W., and Brown, P.E., 1988, Fluid inclusion evidence for impact heating at the Siljan Ring, Sweden: Geology, v. 16, p. 711-715.

Konnerup-Madsen, J., Kreulen, R., and Rose-Hansen, J., 1988, Stable carbon characteristics of hydrocarbon gases in the alkaline Ilímaussaq complex, south Greenland: Bulletin Minéralogique, v. 102, p. 642-653.

Konnerup-Madsen, J., and Rose-Hansen, J., 1982, Volatiles associated with alkaline igneous rift activity-Fluid inclusions in the Ilimaussaq intrusion and the Gardar granitic complexes (south Greenland): Chemical Geology, v. 37, p. 79-93.

Kropotkin, P.N., 1985, Degassing of the earth and the origin of hydrocarbons: International Geology Review, v. 27, 12611275.

Laier, Troels, 1988, Hydrocarbon gases in the crystalline rocks of the Gravberg-1 well, Swedish deep gas project: Marine and Petroleum Geology, v. 5, p. 370-377.

1990, Light hydrocarbon analyses on cuttings from Gravberg-1 well: Sector Report, Deep Gas Project, Vattenfall $R D \& D$ report $U(G) 1990 / 45,78$ p.

1992, Hydrocarbon gases from canned cuttings from the Gravberg-1 well: Geologiska Föreningens i Stockholm Förhandlingar, v. 114, p. 161-163.

Lee, J.K.W, Onstott, T.C., Henne, R., Krough, T.E., Castaño, J.R., $1988,{ }^{40} \mathrm{Ar} /{ }^{39} \mathrm{Ar}$ laser microprobe and U-Pb geochronology of Siljan Ring samples [abs.]: Geological Society of America Annual Meeting, p. A24.

Leythaeuser, D., Schaefer, R., and Yukler, A., 1982, Role of diffusion in primary migration of hydrocarbons: American Association of Petroleum Geologists Bulletin, v. 66, p. 408-429.

MacDonald, G., 1983, The many origins of natural gas: Journal of Petroleum Geology, v. 5, p. 341-362.

Magoon, L.B., and Dow, W.G., eds., in press, The petroleum system-From source to trap: American Association of Petroleum Geologists.

Mamyrin, B.A., and Tolstikhin, L.N., 1970, Helium isotopes in nature: Amsterdam, Elsevier.

Martelli, G., Smith, P.N., and Woodward, A.J., 1989, Light, radiofrequency emission and ionization effects associated with rock fracture: Geophysical Journal International, v. 98, p. 397-401.

McAuliffe, C., 1966, Solubility in water of paraffin, cycloparaffin, olefin, acetylene, cycloolefin, and aromatic hydrocarbons: Journal of Physical Chemistry, v. 70, p. 1267-1275.

Neal, C., and Stanger, G., 1983, Hydrogen generation from mantle source rocks in Oman: Earth and Planetary Science Letters, v. 66, p. 315-320.

Petersil'ye, I.A., and Pavlova, M.A., 1975, Organic compounds in volcanic and metamorphic rocks: International Geology Review, v. 20, p. 139-144.

Poreda, R.J., Jeffrey, A.W.A., Kaplan, I.R., and Craig, H., 1988, Magmatic helium in subduction-zone natural gases: Chemical Geology, v. 71, p. 199-210.
Price, L.C., 1979, Aqueous solubility of methane at elevated pressures and temperatures: American Association of Petroleum Geologists Bulletin, v. 63, p. 213-244.

Rissler-Åkesson, G., 1990, Wireline logging in the Gravberg-1 well; Sector Report, Deep Gas Project, Vattenfall RD\&D Report U(G) 1990/52, 86 p.

Schoell, M., 1984, The hydrogen and carbon isotopic compositions of methane from natural gases of various origins: Geochimica Cosmochimica Acta, v. 44, p. 649-661.

Sofer, Z., 1985, An unusual occurrence of light hydrocarbon gases in a well offshore northeast Palawan island, The Philippines: Precambrian Research, v. 30, p. 179-188.

Stenberg, L., 1986, Geophysical laboratory investigations on core samples from the Klipperas study site: Swedish Nuclear Fuel and Waste Management (SKB) Technical Report 86-09.

Stephansson, Ove, Bjarnason, Bjarni, and Savilahti, Tomas, 1990, Rock mechanics of the Gravberg-1 well: Vattenfall RD\&D Report (U)G 1990/46, 58 p.

Svensson, N.-B., 1973, Shatter cones from the Siljan structure, central Sweden: Geologiska Föreningens i Stockholm Förhandlingar, v. 95, p. 139-143.

Tamminen, J., and Wickman, F.S., 1980, Shock effects in pegmatitic quartz from the Siljan ring structure, central Sweden: Geologiska Föreningens i Stockholm Förhandlingar, v. 102, p. $275-278$.

Thorslund, P., and Auton, C., 1975, Evidence of meteorite impact in the Siljan structure, central Sweden: Bulletin of the Geological Institutions of the University of Uppsala, v. 6, p. 69 72.

Tissot, B., and Welte, D., 1984, Petroleum formation and occurrence, (2nd ed.): New York, Springer-Verlag, 699 p.

Ulmishek, G.F., and Klemme, H.D., 1990, Depositional controls, distribution, and effectiveness of world's petroleum source rocks: U.S. Geological Survey Bulletin 1931, 59 p.

Valley, J.W., Komor, S.C., Baker, K., Jeffrey, A.W.A., Kaplan, I.R., and Răheim, A., 1988, Calcite crack cements in granite from the Siljan Ring, Sweden-Stable isotopic results, in Deep drilling in crystalline bedrock, v. 1-The deep gas drilling in the Siljan impact structure, Sweden and astroblemes: Bodén, A., Eriksson, K.G., eds., Berlin, Springer-Verlag, p. 156-179.

Vlierboom, F.W., Collini, B., Zumberge, J.E., 1986, The occurrence of petroleum in sedimentary rocks of the meteor impact crater at Lake Siljan, Sweden: Organic Geochemistry, v. 10, p. 153-161.

Welhan, J.A., 1988, Methane and hydrogen in mid-ocean-ridge basalt glasses-Analysis by vacuum crushing: Canadian Journal of Earth Science, v. 25, p. 38-48.

Wickman, F.S., 1980, The impact center of the Siljan structure, central Sweden: Geologiska Föreningens i Stockholm Förhandlingar, v. 102, pt. 2, p. 105-109.

Wood, B.J., Bryndizia, L.T., and Johnson, K.E., 1990, Mantle oxidation state and its relationship to tectonic environment and fluid speciation: Science, v. 248, p. 337-345.

Zhizhchenko, B.P., 1978, Generation of hydrocarbon gases in recent sediments: International Geology Review, v. 21, p. 481490. 
Natural-gas resources accumulate in numerous geologic settings. Gas is fundamentally different from oil, both in physical properties and in origin, and it is found in some settings where oil is not. Nonetheless, in most oil accumulations, gas is dissolved in oil or is present as a cap to the oil reservoir. These types of gas accumulations are known as conventional resources.

Unconventional natural-gas resources are those that are found in unusual geologic settings, including settings where extraction is difficult. Economically viable extraction of - these resources usually requires more research and (or) more advanced technology. Because gas is more stable at higher temperatures and pressures than oil, gas occurrences increase with depth. Therefore, gas may be present in the deepest part of a sedimentary basin, at depths greater than 15,000 feet $(4,600$ meters), where oil is absent; such gas is called deep gas. Gas may be present in rocks with extremely small pore spaces. Such accumulations are referred to as tight-gas accumulations, which typically involve either an organic-rich shale where the gas originated or a sandstone where gas has accumulated over long periods of time. In Arctic regions and other cold environments, in particular permafrost regions and the cold layer 130 to 2,000 meters below the sea floor, gas can occur in cage-like structures in the molecular lattice of ice. Such gas accumulations are called gas hydrates. Gas is also found in association with coal, adsorbed onto the surfaces of coal molecules. This type of gas is referred to as coalbed methane. Gas may also be dissolved in water in some aquifers. Finally, gas is trapped beneath the clay seals of many municipal landfills. 



\title{
Conventional Gas Resources of the Gulf of Mexico Outer Continental Shelf-Past Experience, Current Activities, Future Potential
}

\author{
By Gary L. Lore ${ }^{1}$
}

\section{CONTENTS}

Abstract 157

Introduction 158

Historical Exploration and Discovery Patterns 158

Distribution of Fields and Original Recoverable

Proved Gas Reserves

Geographic Distribution 163

Water Depth Distribution 164

Recent Events and Emerging Plays ............................ 164

Norphlet Gas Play ................................................ 166

Flexure Trend and Upper Slope ............................ 166

Shallow Miocene Bright Spot Play ....................... 167

Seagull Play 167

Influences of Economics on Exploration, Lease

Acquisition, Exploitation, and Potential Resources 168

Conclusions

References Cited 170
Mexico. Federal Outer Continental Shelf (GOM OCS) are estimated to be 10.74 billion barrels of oil (Bbo) and 130.5 trillion cubic feet of natural gas ( $\mathrm{Tcfg}$ ). Eighty-one of these fields have been depleted and abandoned. Remaining reserves recoverable from the 738 active fields have been estimated to be $2.33 \mathrm{Bbo}$ and $32.0 \mathrm{Tcfg}$. An additional 70 active fields have not been sufficiently developed to warrant consideration as proved.

The GOM OCS is primarily a gas-prone province. Of the 819 proved fields, 676 are classified as gas fields. Cumulative production through 1991 was 8.41 Bbo and 98.5 Tcfg. On an energy-equivalent basis this production equates to nearly 68 percent natural gas. In recent years the area has contributed about 10 percent of the Nation's total domestic oil production and 22 to 25 percent of the gas. Even though three-quarters of the estimated original recoverable proved gas reserves have been produced, the GOM OCS, as the Nation's premier natural-gas-producing province, will continue to have a pivotal role in determining our future gas supply.

Historically, oil and gas exploration and development have gradually progressed seaward into the deeper waters of the Gulf of Mexico. The average size of fields discovered has decreased steadily over time, and the exploration effort required for each incremental reserve addition has increased.

Numerous significant discoveries in the deep Norphlet play and the deep-water Flexure Trend and upper slope areas are exceptionally large when compared to other GOM OCS discoveries of the past 15 years. However, the inordinately high development costs and technological advancements required to bring these resources to market cloud their commercial viability. 
Although not as promising as the Norphlet play or the Flexture Trend, the mature, well-explored areas of the shallow-water GOM OCS offer numerous opportunities to develop attractive prospects in today's economic climate. The keys to successful development in these areas are to be willing to take a fresh look, to employ modern and (or) novel integrated exploration concepts, and to use the latest technology such as the three-dimensional seismic data that are becoming increasingly available.

Assessments of potential undiscovered, economically recoverable conventional hydrocarbon resources on the GOM OCS are highly sensitive to assumptions concerning future cost-price relationships. These assessments suggest that as much gas may still be undiscovered as has already been discovered on the GOM OCS.

\section{INTRODUCTION}

The first field was discovered on the Gulf of Mexico Outer Continental Shelf (GOM OCS) in 1947. Through the end of 1991, 819 proved oil and gas fields have been established (fig. 1). Another 70 fields were active for which decisions concerning commercial viability had yet to be made. In the Minerals Management Service (MMS) reserves classification scheme, these 70 fields and their reserves are referred to as unproved. A detailed explanation of this reserves-classification system and a comparison with the Society of Petroleum Engineers definitions can be found in Melancon and others (1992).

Original recoverable proved reserves ${ }^{1}$ of hydrocarbons are estimated to be $10.74 \mathrm{Bbo}^{2}$ (billion barrels of oil) and $130.5 \mathrm{Tcfg}$ (trillion cubic feet of gas). Eighty-one of these fields have been depleted and abandoned. Cumulative production is $8.41 \mathrm{Bbo}$ and $98.5 \mathrm{Tcfg}$. Remaining proved reserves recoverable from the 738 active proved fields are 2.33 Bbo and $32.0 \mathrm{Tcfg}$. Eighty-three percent (676 fields) of the proved fields are gas fields ${ }^{3}$. The original recoverable proved reserves were present in 16,881 reservoirs, of which 9,473 were gas, 6,010 were oil, and 1,398 were combination reservoirs (table 1).

Annual total gas production in the GOM OCS has fluctuated between 4 and 5 Tcf since 1978, peaking initially in

${ }^{1}$ Estimates of proved reserves for liquids are expressed in barrels at $60^{\circ} \mathrm{F}$ and 1 atmosphere and for gas in standard cubic feet at $60^{\circ} \mathrm{F}$ and 15.025 psia. These are the commonly used GOM OCS reference conditions. To convert the gas volumes reported in this text to reference standard conditions of $60^{\circ} \mathrm{F}$ and 1 atmosphere (14.696 psia), multiply by 1.022 .

${ }^{2}$ The term "oil" as used in this paper includes crude oil and condensate. The cumulative product mix in the GOM OCS is approximately 90 percent oil and 10 percent condensate.

${ }^{3}$ Gas fields are defined as those fields having more than 50 percent of the estimated proved original recoverable hydrocarbon reserves on a Btu basis in the form of nonassociated gas.
1981 and again in 1990 at 4.9 Tcf and averaging about 4.5 Tcf (fig. 2). At the 1991 annual production rate of $4.7 \mathrm{Tcfg}$, the ratio of remaining proved reserves to production is 6.8 years. Throughout the 1980's and into the 1990's, the GOM OCS contributed about 22 percent of the total annual United States domestic gas production. In 1991 the GOM OCS gas production was nearly 26 percent of the national total. Clearly, this natural-gas-producing province is of national importance in the consideration of both current and prospective domestic supplies.

This report reviews the results of past exploration and production activities and presents current information related to the distribution of remaining proved reserves and potential undiscovered resources. All estimates of reserves, production and potential undiscovered resources were current as of December 31, 1991.

\section{HISTORICAL EXPLORATION AND DISCOVERY PATTERNS}

Lore (1992) reviewed the discovery and exploration history of the GOM OCS during the period 1947-1989. The analysis of the empirical discovery record showed that during each ensuing decade the number of proved fields discovered increased. However, this increase was accomplished only through a significant increase in the number of exploratory wells drilled, which was accompanied in turn by a decline in the observed annual exploration success rate. The initial success rate of more than 80 percent early in this period dropped to less than 10 percent recently. Coincident with the increased maturity of the GOM OCS was a marked decrease in the average size of new field discoveries. ${ }^{4}$ Meisner and Demiren (1981) applied the term "creaming" to this phenomenon. During exploration of a play or basin, prospects become increasingly smaller, increasingly more difficult to identify, and more expensive on a unit-recovery basis to exploit. This change is evident from table 2, which updates the previous analysis to include more recent reserve estimates and show further details by field type. Considering all fields on a barrel-of-oil-equivalent (boe) basis, even with the inclusion of an additional 49

\footnotetext{
${ }^{4}$ Caution should be used when considering both the number of proved fields and the quantity of reserves discovered in recent years. These estimates should be considered conservative because there are 70 active unproved fields that, if operators decide to develop them, will be classified as proved and credited to the appropriate discovery year. Initial estimates of proved reserves in fields typically exhibit significant appreciation with time. Preliminary analysis reported by Drew and Lore (1992) revealed that historically as a result of this field-growth phenomenon, MMS's initial estimates of proved reserves grew on average by a factor of 4.5. All estimates in this text, unless otherwise noted, are proved reserves as of year end 1991 and do not incorporate future reserves appreciation.
} 


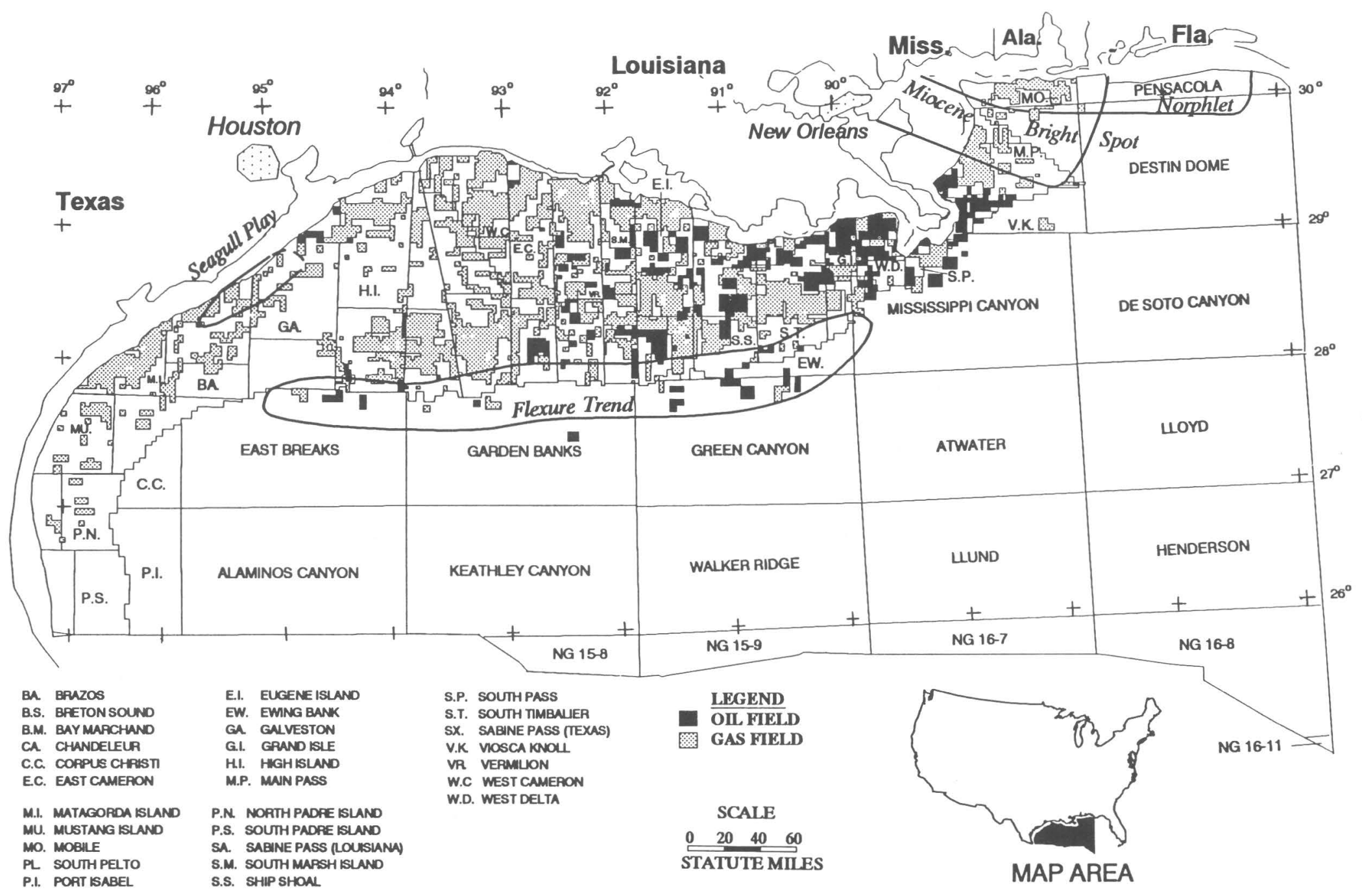

Figure 1. Location of proved oil and gas fields on the Gulf of Mexico Outer Continental Shelf. 
Table 1. Number of proved fields and reservoirs, original recoverable proved reserves, cumulative production, and remaining proved reserves arranged by field and reservoir type.

[MMbbl, million barrels; Bcf, billion cubic feet; boe, barrels of oil equivalent]

\begin{tabular}{|c|c|c|c|c|c|c|c|}
\hline & \multicolumn{3}{|c|}{ Field type } & \multicolumn{4}{|c|}{ Reservoir type } \\
\hline & Oil & Gas & All & Oil & Combination & Gas & All \\
\hline $\begin{array}{l}\text { Proved original recoverable } \\
\text { oil reserves (MMbb) }\end{array}$ & 8,876 & 1,862 & 10,738 & 6,841 & 2,806 & 1,091 & 10,738 \\
\hline $\begin{array}{l}\text { Proved original recoverable } \\
\text { gas reserves (Bef) }\end{array}$ & 27,872 & 102,625 & 130,497 & 9,180 & 10,487 & 110,830 & 130,497 \\
\hline $\begin{array}{l}\text { Proved original recoverable } \\
\text { boe reserves (MMbbl) }\end{array}$ & 13,835 & 20,123 & 33,958 & 8,474 & 4,672 & 20,812 & 33,958 \\
\hline $\begin{array}{l}\text { Number of } \\
\text { proved fields or reservoirs } \\
\text { with proved original } \\
\text { recoverable reserves }\end{array}$ & 143 & 676 & 819 & 6,010 & 1,398 & 9,473 & 16,881 \\
\hline $\begin{array}{c}\text { Cumulative oil } \\
\text { production (MMbbl) }\end{array}$ & 7,080 & 1,326 & 8,405 & 5,291 & 2,279 & 836 & 8,405 \\
\hline $\begin{array}{l}\text { Cumulative gas } \\
\text { production (Bcf) }\end{array}$ & 21,276 & 77,235 & 98,511 & 6,783 & 7,435 & 84,293 & 98,511 \\
\hline $\begin{array}{c}\text { Cumulative boe } \\
\text { production (MMbb) }\end{array}$ & 10,865 & 15,069 & 25,934 & 6,498 & 3,602 & 15,834 & 25,934 \\
\hline $\begin{array}{c}\text { Number of } \\
\text { proved fields or reservoirs } \\
\text { with } \\
\text { cumulative production }\end{array}$ & 139 & 635 & 774 & 5,539 & 1,311 & 8,148 & 14,998 \\
\hline $\begin{array}{l}\text { Proved remaining recoverable } \\
\text { oil reserves (MMbb) }\end{array}$ & 1,796 & 536 & 2,333 & 1,550 & 527 & 256 & 2,333 \\
\hline $\begin{array}{l}\text { Proved remaining recoverable } \\
\text { gas reserves (Bcf) }\end{array}$ & 6,596 & 25,390 & 31,986 & 2,397 & 3,052 & 26,537 & 31,986 \\
\hline $\begin{array}{l}\text { Proved remaining recoverable } \\
\text { boe reserves (MMbbl) }\end{array}$ & 2,970 & 5,054 & 8,024 & 1,976 & 1,070 & 4,978 & 8,024 \\
\hline $\begin{array}{l}\text { Number of } \\
\text { proved fields or reservoirs } \\
\text { with proved remaining } \\
\text { recoverable reserves }\end{array}$ & 134 & 600 & 734 & 2,688 & 906 & 4,980 & 8,574 \\
\hline
\end{tabular}

fields (43 of which were discovered during the 1980's) and two additional years of growth in the estimates for the previously established fields, the conclusions remain unchanged and are typical of experiences worldwide in mature hydrocarbon basins. The average size of fields discovered during the 1960's was 55 percent of those discovered between 1947 and 1959. Fields discovered during the 1970 's were on average also 55 percent of the size of fields discovered during the 1960's. This rate of decrease, however, changed with the fields discovered during the 1980's, which were only a third the size of discoveries in the previous decade. Obviously, the fields discovered during the 1980's have had less opportunity to experience reserves appreciation than the older fields. On the other hand, these fields are the product of modern seismic technology and exploration concepts and may show significantly different reserves-appreciation characteristics than older fields.

An interesting observation can be made when the same data are segregated by field type (oil versus gas fields). Oil fields discovered during each of the first three decades of exploration were, on a boe basis, on average, about twice the size of gas fields discovered during the same time period. During the 1980's, however, this ratio increased to about 3 to 1 . This increase may be partly explained by the shift in a significant portion of the exploration activity in the late 1980 's to low-risk, low-cost, relatively modest potential, shallow-water gas prospects easily targeted by new seismic techniques. These were principal objectives of the 
exploratory wells that were being drilled by independent operators in increasing proportions. This theory is supported by the observation that the average offshore water depth of new proved gas fields discovered decreased from $179 \mathrm{ft}$ to $136 \mathrm{ft}$ from the 1970 's to the 1980 's. At the same time the average water depth of oil field discoveries more than doubled, from $249 \mathrm{ft}$ to $548 \mathrm{ft}$ (table 2). This change reflects the emphasis of the major companies during the 1980 's on exploring the high-potential, oil-prone prospects of the deeper water areas. Overall, the mean size for proved oil fields is 97 million barrels of oil equivalent (MMboe) and for gas fields, 31 MMboe.

Until the latter part of the 1970's, exploration on the GOM OCS focused primarily on discovering large oil fields. Significant gas reserves were also discovered and developed, but principally as a byproduct of the search for oil fields. The initial giant oil field discoveries generally contained substantial quantities of associated gas reserves (fig. 2). Exploration activity directed toward the discovery of gas fields was stymied by price controls, the economic hurdles presented both by deep drilling and deep water, as well as the generally high cost of GOM OCS operations. The passage of the Natural Gas Policy Act in 1978 and the prevailing optimism concerning higher anticipated future prices, coupled with the continued decrease in the size of oil fields being discovered and the development of new seismic tools, fueled a surge in exploration activity aimed at discovering substantial gas reserves (Lore, 1992).
The number of gas fields discovered annually has been steadily increasing, while the number of oil fields discovered has varied, never exceeding 10 and averaging about 3.5 per year. Through 1959, 38 percent of all fields discovered were oil. This percentage declined steadily; only 10 percent of the fields discovered during the 1980's were oil fields. The hydrocarbons discovered in each time period also became progressively more gas prone, swelling from nearly 59 percent natural gas in the 1947-1959 time frame to 78 percent during the 1980's.

Eventhough 50 percent of the total number of proved gas fields have been discovered since 1979, they contain only 15 percent of the original recoverable proved gas reserves. Exploration statistics define a trend of continuously diminishing returns. Lore (1992) demonstrated consistent and dramatic annual decreases in the boe discovered per foot of exploratory drilling. From 1949 through the early 1980 's, the proved reserves discovered per foot of exploratory drilling decreased 100-fold, from 20,000 boe to about 150 boe per foot.

The quantity of proved gas reserves discovered each year and its distribution between oil and gas fields are shown in figure 2 . Nearly 80 percent of the $130.5 \mathrm{Tcfg}$ of original recoverable proved reserves are in gas fields (table 1). Discoveries during 5 specific years out of the entire 45-year history of the GOM OCS (1949, 1956, 1971, 1973 and 1974) account for 41.2 Tcfg, or 31 percent of the total proved gas reserves discovered. There

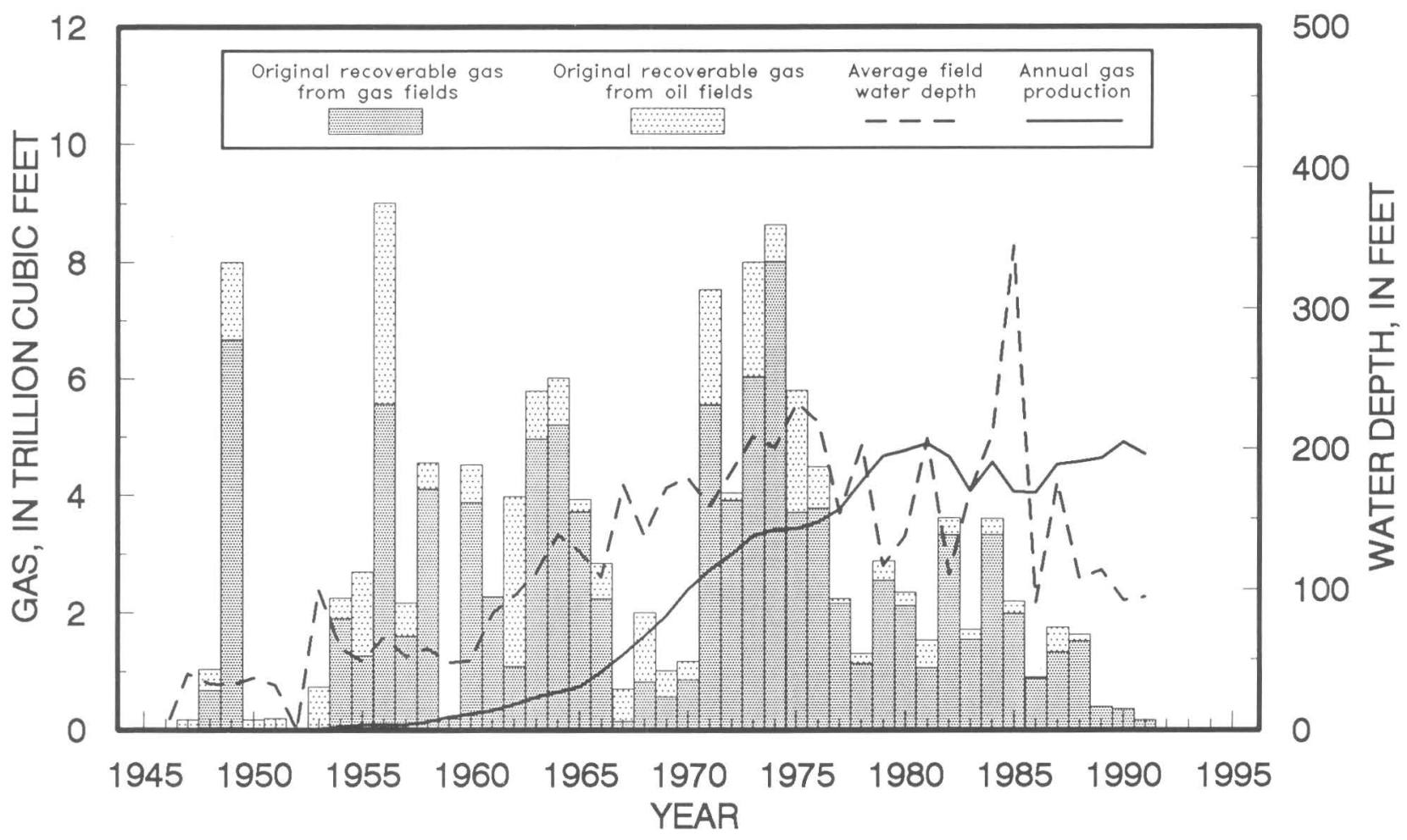

Figure 2. Annual gas production and original recoverable proved gas reserves and average water depth by field discovery year. 
Table 2. Number and type of wells drilled and proved fields, original recoverable proved reserves, average field size, and average water depth arranged by discovery decade

[MMbbl, million barrels, Bcf, billion cubic feet; boc, barrels of oil equivalent]

\begin{tabular}{|c|c|c|c|c|c|c|c|}
\hline \multicolumn{3}{|r|}{ Time period } & $1947-1959$ & $1960-1969$ & $1970-1979$ & $1980-1989$ & Total \\
\hline \multicolumn{3}{|c|}{$\begin{array}{c}\text { Number of exploratory wells } \\
\text { Total number of wells }\end{array}$} & $\begin{array}{r}442 \\
1,325\end{array}$ & $\begin{array}{l}2,377 \\
6,779\end{array}$ & $\begin{array}{l}3,356 \\
9,288\end{array}$ & $\begin{array}{r}4,356 \\
10,222 \\
\end{array}$ & $\begin{array}{l}10,531 \\
27,614\end{array}$ \\
\hline \multirow[b]{4}{*}{$\mathbf{F}$} & \multirow{3}{*}{0} & $\begin{array}{l}\text { Number of } \\
\text { proved fields }\end{array}$ & 27 & 32 & 49 & 35 & 143 \\
\hline & & $\begin{array}{l}\text { Proved original recoverable } \\
\text { oil reserves (MMbbl) }\end{array}$ & 3,556 & 2,552 & 1,991 & 776 & 8,875 \\
\hline & & $\begin{array}{c}\text { Proved original recoverable } \\
\text { gas reserves (Bcf) }\end{array}$ & 9,188 & 8,131 & 8,361 & 2,192 & 27,872 \\
\hline & \multirow[t]{3}{*}{$\mathbf{L}$} & $\begin{array}{c}\text { Proved original recoverable } \\
\text { boe reserves (MMbbl) }\end{array}$ & 5,191 & 3,999 & 3,479 & 1,166 & 13,835 \\
\hline I & & $\begin{array}{c}\text { Average } \\
\text { field size boe (MMbbl) }\end{array}$ & 192 & 125 & 71 & 33 & 97 \\
\hline $\mathbf{E}$ & & $\begin{array}{c}\text { Average } \\
\text { water depth (feet) }\end{array}$ & 63 & 156 & 249 & 548 & 266 \\
\hline $\mathbf{L}$ & \multirow{3}{*}{$\mathbf{G}$} & $\begin{array}{c}\text { Number of } \\
\text { proved fields }\end{array}$ & 43 & 87 & 216 & 299 & 645 \\
\hline D & & $\begin{array}{l}\text { Proved original recoverable } \\
\text { oil reserves (MMbbl) }\end{array}$ & 459 & 501 & 612 & 286 & 1,858 \\
\hline \multirow[b]{4}{*}{$\mathbf{T}$} & & $\begin{array}{c}\text { Proved original recoverable } \\
\text { gas reserves (Bcf) }\end{array}$ & 21,974 & 24,916 & 37,730 & 17,476 & 102,096 \\
\hline & \multirow[t]{3}{*}{$\mathbf{S}$} & $\begin{array}{c}\text { Proved original recoverable } \\
\text { boe reserves (MMbbl) }\end{array}$ & 4,369 & 4,934 & 7,326 & 3,396 & 20,025 \\
\hline & & $\begin{array}{c}\text { Average } \\
\text { field size boe (MMbbl) }\end{array}$ & 102 & 57 & 34 & 11 & 31 \\
\hline & & $\begin{array}{c}\text { Average } \\
\text { water dept h (feet) } \\
\end{array}$ & 43 & 104 & 179 & 136 & 140 \\
\hline $\mathbf{Y}$ & \multirow{3}{*}{$\mathbf{A}$} & $\begin{array}{l}\text { Number of } \\
\text { proved fields }\end{array}$ & 70 & 119 & 265 & 334 & 788 \\
\hline $\mathbf{P}$ & & $\begin{array}{c}\text { Proved original recoverable } \\
\text { oil reserves (MMbbl) }\end{array}$ & 4,015 & 3,053 & 2,603 & 1,062 & 10,733 \\
\hline \multirow[t]{4}{*}{$\mathbf{E}$} & & $\begin{array}{c}\text { Proved original recoverable } \\
\text { gas reserves (Bcf) }\end{array}$ & 31,162 & 33,047 & 46,091 & 19,668 & 129,968 \\
\hline & \multirow[t]{3}{*}{$\mathbf{L}$} & $\begin{array}{c}\text { Proved original recoverable } \\
\text { boe reserves (MMbbl) }\end{array}$ & 9,560 & 8,933 & 10,804 & 4,562 & 33,859 \\
\hline & & $\begin{array}{c}\text { Average } \\
\text { field size boe (M Mbbl) }\end{array}$ & 137 & 75 & 41 & 14 & 43 \\
\hline & & $\begin{array}{c}\text { Average } \\
\text { water depth (feet) }\end{array}$ & 51 & 118 & 192 & 179 & 163 \\
\hline
\end{tabular}

were 120 fields discovered during these years. Fifty percent of the original recoverable proved gas reserves were contained in the 197 fields discovered prior to 1970 . Since 1976, 407 oil and gas fields, nearly 50 percent of all proved fields, have been discovered, yet they contain only 19 percent of the original recoverable proved gas reserves and 11 percent of the proved oil reserves.

Meisner and Demiren (1981) partially attributed this creaming effect to declining success rates as the exploration process proceeded. They argued that exploratory suc- 
cess rates reflect depletion of a potentially productive volume of sediment. As additional wells are drilled within a particular area and volume of sediment, the chance of discovering a field of any given size is decreased; the resource potential is exhausted. Thus, initially, the probability of finding large fields and then successively smaller accumulations decreases as additional exploratory wells are drilled. If success is defined as the number of fields discovered per exploratory well drilled, then the long-term success rate on the GOM OCS during the period $1947-$ 1959 was 16 percent (table 2). This rate decreased to 5 percent during the 1960 's and remained at 8 percent during both the 1970's and 1980's.

Another measure of exploration performance is the ability to discover sufficient volumes of reserves to replace production. Not since 1977 has GOM OCS exploration consistently discovered sufficient quantities of natural gas to equal or exceed the yearly production. If gas reserves are credited to the field discovery year, then there has been an annual shortage (production minus new reserves discovered) in gas discoveries every year since 1977 (fig. 3). The cumulative shortfall during this period was $40.5 \mathrm{Tcfg}$. If the measure of choice for crediting gas discoveries is the reservoir discovery date, then industry performance in replacing reserves is slightly improved (fig. 4). In this case reserves discovered exceeded production in every year through 1978. There was an annual shortfall during 1979-1981, but surpluses in 1982-1984. The deficit has remained intact every year since and has totaled about $24 \mathrm{Tcfg}$. The $32 \mathrm{Tcf}$ of proved gas reserves estimated to remain at year end 1991 are the lowest since MMS began reporting reserves in 1975 (Melancon and others, 1992).

\section{DISTRIBUTION OF FIELDS AND ORIGINAL RECOVERABLE PROVED GAS RESERVES}

\section{GEOGRAPHIC DISTRIBUTION}

The 130.5 Tcf of original recoverable proved gas reserves on the GOM OCS are not as evenly distributed geographically as may appear in figure 1. Some areas are more gas prone than others. By the end of 1991, 819 proved fields had been discovered in the GOM OCS, 586 in the central portion offshore Louisiana, Mississippi, and Alabama; 232 in the western portion offshore Texas; and 1 offshore Florida. Original recoverable proved reserves in the central and eastern portions were 10.19 Bbo and 107.1 Tcfg, 95 and 82 percent, respectively, of the GOM OCS total. In the central portion, the original proved gas reserves were concentrated in fields located on the shelf off the central and western Louisiana coast (fig. 5). The central portion of the GOM OCS becomes increasingly more gas prone in a westerly direction. At the end of 1991, there were 55 proved fields in this area whose reserves were depleted and an additional 53 active fields classified as unproved. In addition to a single proved field, 3 unproved fields are active in the area off eastern Alabama and western Florida.

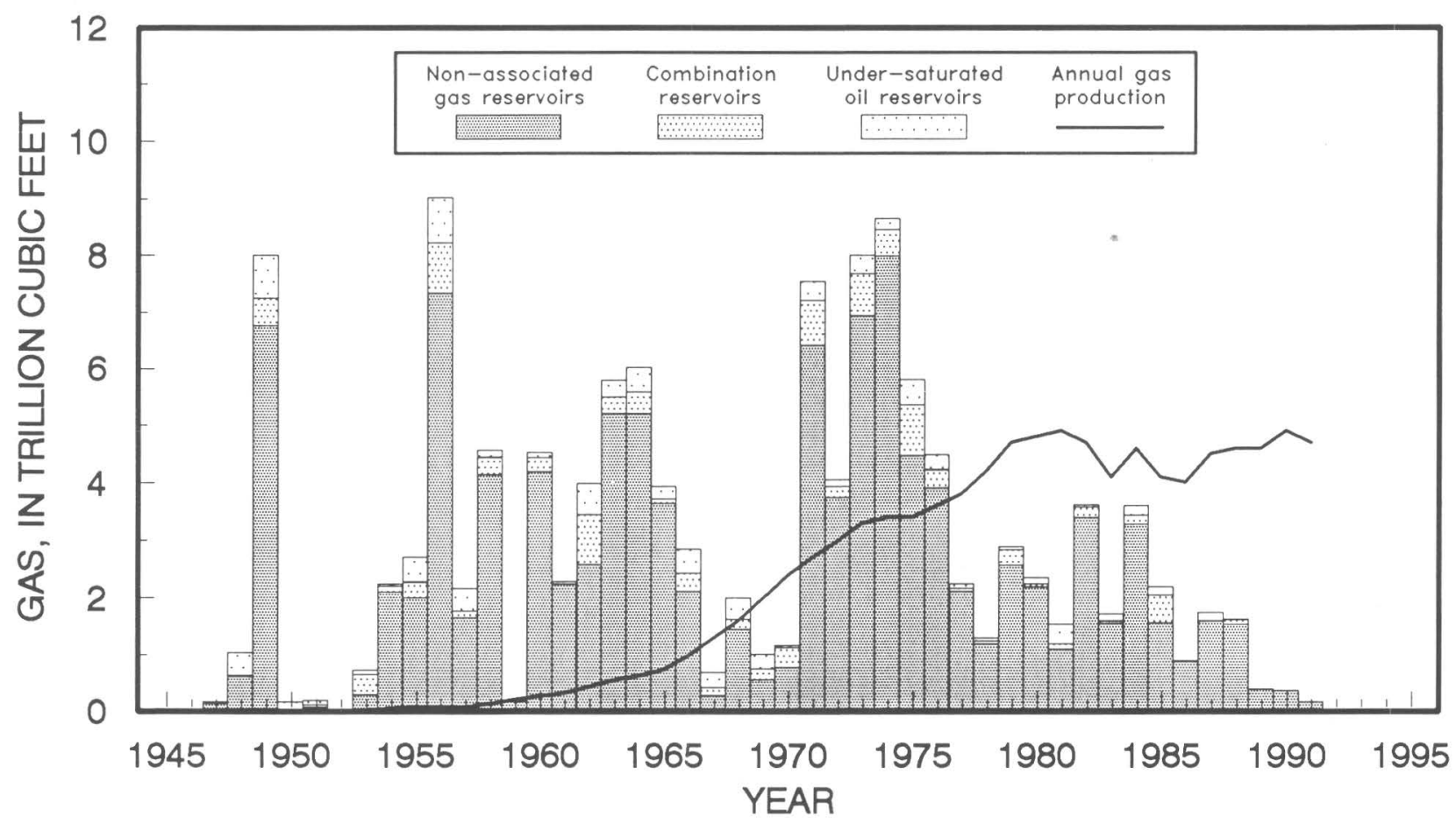

Figure 3. Annual gas production and original recoverable proved gas reserves by reservoir type and field discovery year. 
Estimates of original recoverable proved reserves in offshore Texas are $0.55 \mathrm{Bbo}$ and $23.4 \mathrm{Tcfg}$. The majority of the original recoverable proved gas reserves were located in the High Island area off eastern Texas. Except for the High Island area and some of the more recent large deep-water discoveries in the East Breaks and Garden Banks areas, offshore Texas is almost exclusively a gas-producing region. Through 1991, the proved reserves in 26 fields offshore Texas had been depleted and another 14 active fields were classified as unproved.

Cumulative production in the central portion of the GOM OCS was 8.13 Bbo and $83.6 \mathrm{Tcfg}$, nearly 80 percent of the original recoverable proved reserves. Offshore Texas produced 0.28 Bbo and $14.9 \mathrm{Tcfg}$. A larger percentage of the original recoverable proved reserves remains to be produced from offshore Texas, where 50 percent of the oil and 64 percent of the original gas reserves have been produced. For the GOM OCS as a whole, 78 percent of the original oil and 75 percent of the original gas reserves have been produced. The remaining proved gas reserves are located primarily in the area off central and western Louisiana and in the Matagorda Island, High Island, and Sabine Pass areas off eastern Texas.

\section{WATER DEPTH DISTRIBUTION}

More than 80 percent of both the original recoverable proved gas reserves and fields were located in water depths less than $200 \mathrm{ft}$ (fig. 6). The area on the continental shelf (less than $600 \mathrm{ft}$ of water) accounted for 97 percent of both the original gas reserves and fields. Reserves in the 22 proved fields in deeper water are 830 MMbo (million barrels of oil) and $3.2 \mathrm{Tcfg}$. Preliminary estimates of the unproved resources in 17 of the 22 active unproved deepwater fields that may ultimately be developed are about 390 MMbo and 1.67 Tcfg. The deep-water GOM OCS is discussed in more detail in the section entitled, "Flexure Trend and Upper Slope." It is an area where half the proved fields are under development and proved reserves can be expected to increase appreciably. It also contains several announced discoveries that have not yet qualified as fields. This frontier area holds great promise for the discovery of very large accumulations of hydrocarbons.

\section{RECENT EVENTS AND EMERGING PLAYS}

Exploration activity in the GOM OCS has decreased significantly in recent years. Evidence can be seen in the decrease in the traditional measures of exploratory activity: the number of geophysical permits issued, new leases issued, and exploratory wells drilled. During the past six years, however, some areas have shown a relatively steady level of activity and others are being studied with renewed interest. The "good prospects" have generally managed to attract needed funds. The single shining light in the overall depressed level of exploration activity is the acquisition of three dimensional (3-D) seismic data. In 1983, 16 permits were issued in the GOM OCS to acquire 14,460 line-miles of 3-D seismic data. In 1991, the number of permits issued

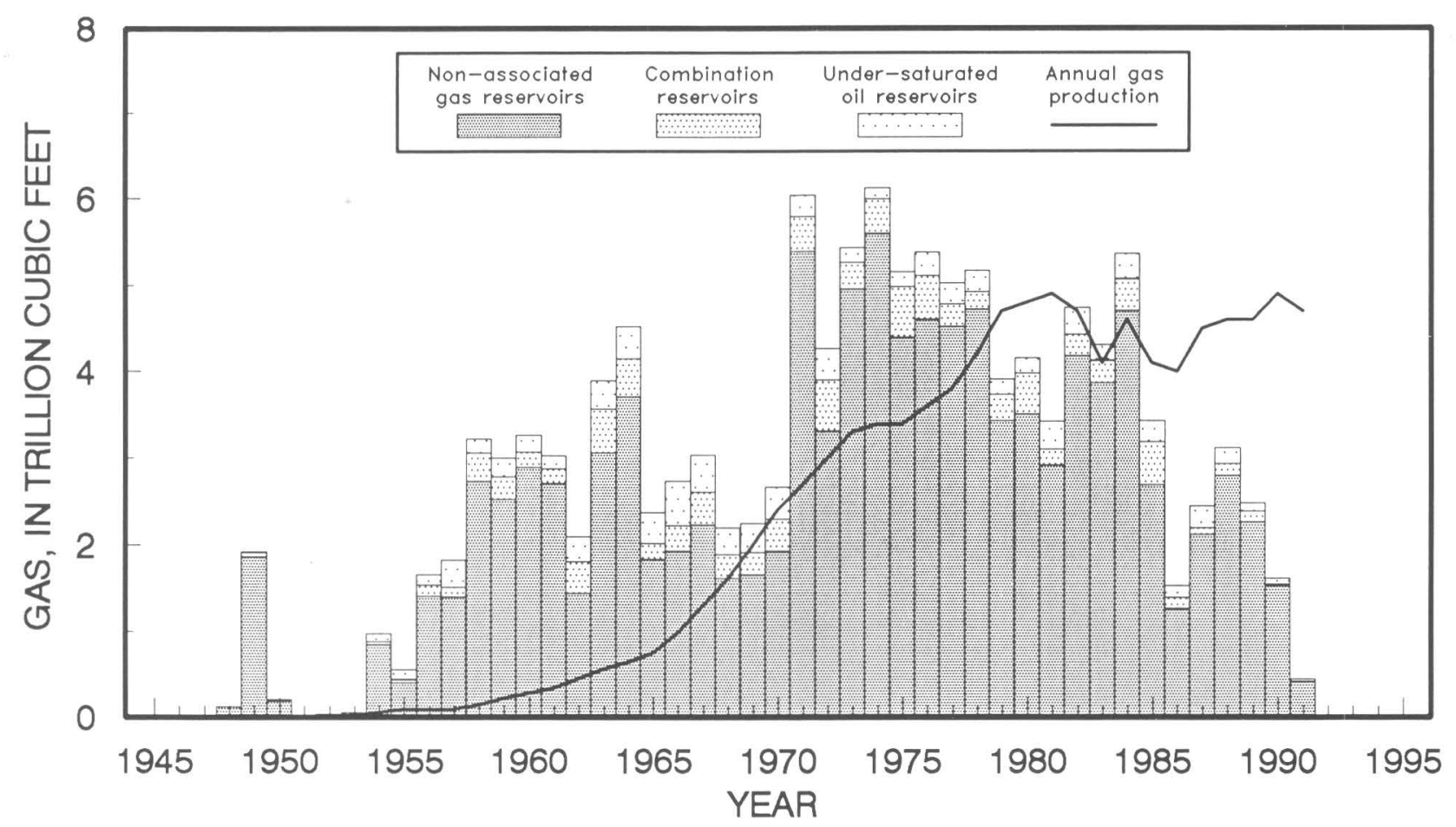

Figure 4. Annual gas production and original recoverable proved gas reserves by reservoir type and reservoir discovery year. 
increased to 45 , and the line-miles acquired mushroomed to 363,259 .

The following discussion highlights two high-potential, high-cost, high-risk frontier plays. While not experiencing historical peaks in terms of exploration, these plays have continued to attract interest as operators mull the results of previous efforts and consider the development possibilities of these high-profile projects. Discussed also are two gas plays illustrative of the dozens on the GOM OCS that offer modest reserves at equally modest costs and risks. One is a recent play employing modern technology and concepts, the other a new play in a well-explored area resulting from a fresh approach to a target that previously had yielded only failures.
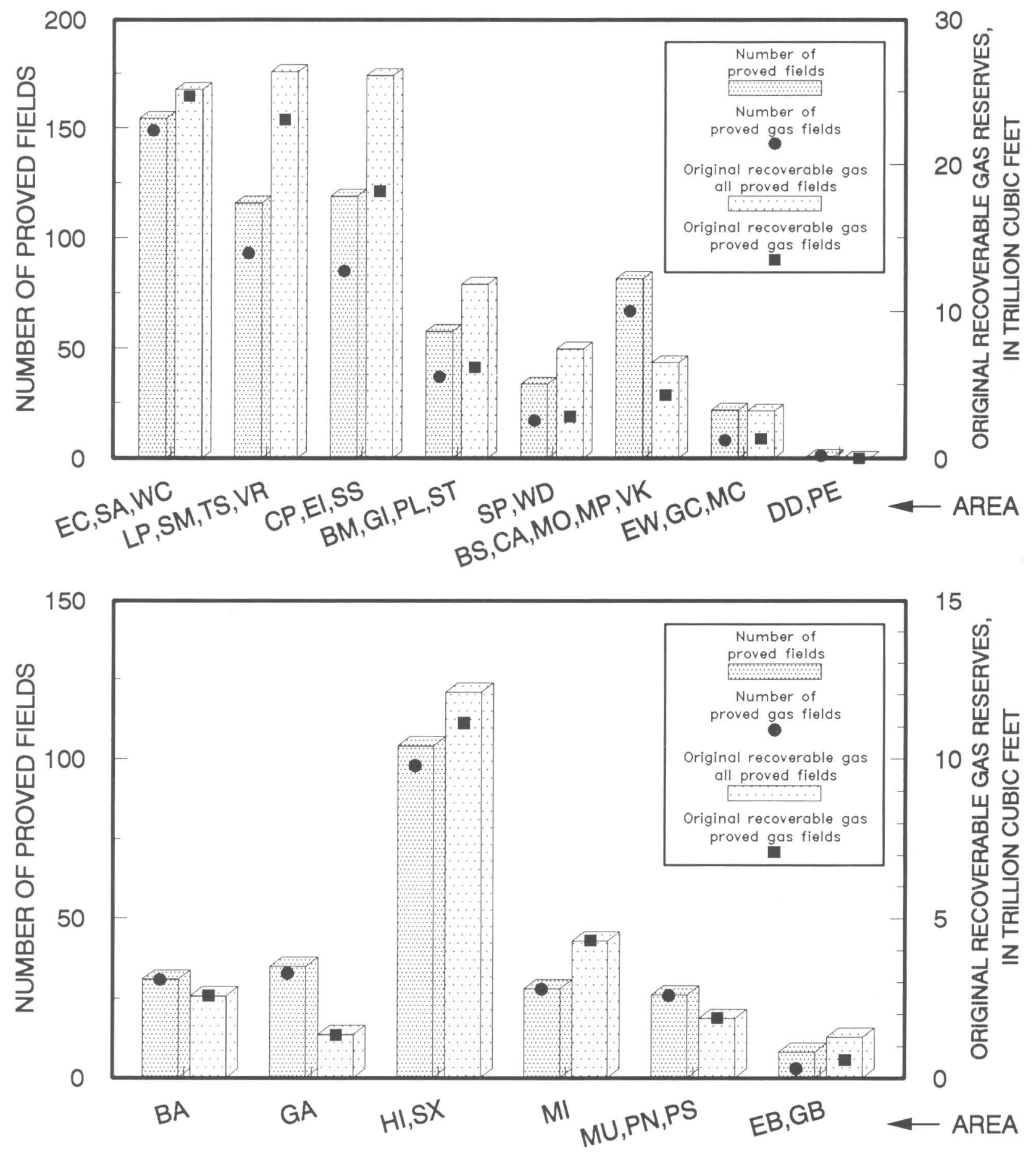

Figure 5. Geographic distribution of original recoverable proved gas reserves. See figure 1 for an explanation of abbreviations and area locations. 


\section{NORPHLET GAS PLAY}

Probably the single, most exciting natural-gas play in the United States in the last several decades is the prolific Jurassic Norphlet gas play in Alabama coastal waters and the GOM OCS. The play extends from onshore southeastern Mississippi, into Alabama through state waters, into the GOM OCS and eastward into the Destin Dome Area offshore the Florida panhandle (fig. 1). At least 43 fields have been discovered within the play (Mink and others, 1990). The first Norphlet discovery in the area was the Pelahatchie field in Mississippi in 1967. However, it was not until the initial 1979 offshore discovery of significant gas reserves in the Lower Mobile Bay-Mary Ann field that excitement began to run high concerning the Norphlet as an exploration objective. Subsequently, six fields have been discovered in Alabama state coastal waters and 12 in the GOM OCS. Reservoir depths in these fields are 20,000 to $25,000 \mathrm{ft}$, subsea. The intermediate estimate of original recoverable proved reserves in the state fields is about 4.17 Tcfg with an additional 2.35 Tcf of potential gas reserves (Mink and others, 1987). Seven proved Norphlet fields with original recoverable reserves of $1.01 \mathrm{Tcfg}$ were established on the GOM OCS prior to 1992. An additional five fields with unproved reserves of approximately 2.47 Tcfg were also active. Further enhancing the attractiveness of this play are the very prolific wells. Individual wells typically have production rates on tests as high as 20 to 30 MMcfpd (million cubic feet per day). One well tested at rates of nearly $100 \mathrm{MMcfpd}$. All are anticipated to have high ultimate recoveries per well.

The Norphlet Formation is predominantly nonmarine to shallow marine strata in the southern portions of the Mississippi Interior and Alabama Salt Basins and the offshore area. Eolian sandstone represents the primary reservoir lithofacies. The Norphlet sands were derived from erosion of the exposed southern Appalachian highlands, and, in the updip areas, were deposited as alluvial fan and braided stream complexes. The eolian sands are of two types: massive sheet sands and dune sands. The other common reservoir lithofacies present in the offshore fields is the reworked marine tidal sand in the upper part of the formation. This facies derived from the ensuing marine transgression (Marzano and others, 1989; Mink and others, 1985).

The natural gas is trapped in a series of generally eastwest-trending salt anticlines or pillows. Salt movement has created broad, low-relief anticlines, most of which exhibit small-scale extensional faulting.

\section{FLEXURE TREND AND UPPER SLOPE}

The steady march of GOM OCS exploration and development activities into progressively deeper waters has paid spectacular dividends. Many oil and gas fields have been discovered and are being developed along the TexasLouisiana shelf break in an area commonly referred to as the "Flexure Trend" (fig. 1). As of December 31, 1991, 35

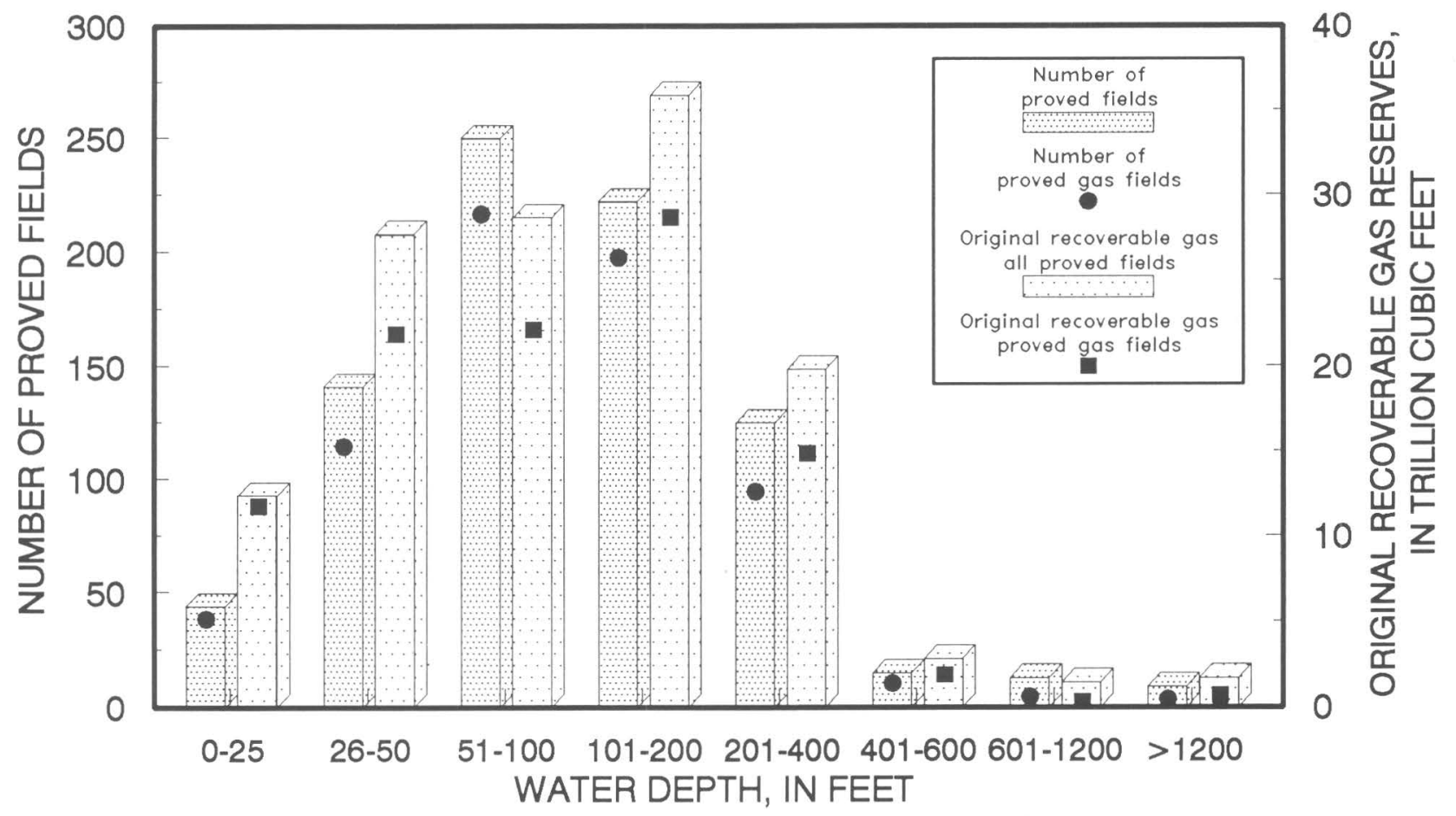

Figure 6. Distribution by water depth of original recoverable proved gas reserves and fields. 
proved fields (including one expired and depleted field) were in this trend. Original recoverable proved reserves were $527 \mathrm{MMbo}$ and $5.6 \mathrm{Tcfg}$. Cumulative production was $220 \mathrm{MMbo}$ and $3.3 \mathrm{Tcfg}$. The reserve potential for 8 of the unproved fields is about $115 \mathrm{MMbo}$ and $300 \mathrm{Bcfg}$ (billion cubic feet of gas).

Recent exploratory drilling in even deeper water on the continental slope both south and east of this trend has resulted in the discovery of significant giant accumulations like Shell's Auger and Mars fields, Amoco's Ram/Powell field and Exxon's Cooper field. Elsewhere on the slope there were 15 active unproved fields and more than a dozen other oil and gas discoveries, 13 of which were located in water depths between 3,000 and 7,800 ft. Estimates of original recoverable proved reserves for the 15 proven non-Flexure Trend fields on the slope exceed 585 MMbo and $2.9 \mathrm{Tcfg}$. Initial estimates of unproved reserves and resources for 13 of the remaining active fields are estimated at 567 MMbo and 1.78 Tcfg.

Unlike the Norphlet gas play, these areas are both oil and gas prone. In the Flexure Trend the 35 proved fields comprise 19 gas and 16 oil fields. The 18 proved nonFlexure Trend fields on the slope are equally divided between oil and gas fields. Khan (1992) identifies the three principal plays in this area as: (1) potential reservoir sands of predominantly Pleistocene age in the East Breaks, Garden Banks, and Green Canyon Areas; (2) reservoirs of mostly Pliocene age in the Ewing Bank, Mississippi Canyon, Viosca Knoll, Atwater and eastern portion of the Green Canyon Area; and (3) reservoir sands that are mainly middle and upper Miocene on the southeastern Louisiana slope in water depths greater than $3,000 \mathrm{ft}$. Pliocene and Pleistocene sediment accumulated locally to thicknesses of as much as $20,000 \mathrm{ft}$ in small, isolated, intraslope basins and troughs bounded by massive salt stocks, pillows, and ridges. The reservoir sandstones are typical of shelf and submarine-fan environments of deposition.

Hydrocarbon traps include those commonly characteristic of salt-dome-related features on the shelf. The style of salt tectonics, however, changes dramatically in a southward direction. Frequently present are salt tongues and tabular sheets that, due to up-dip sediment loading, spread laterally, overriding sediment of Miocene age and younger. These horizontal salt masses have recently been penetrated by several wells, most notably Exxon's Mickey Mouse prospect, which resulted in the discovery of a significant hydrocarbon accumulation. The discovery well was drilled in 1990 in over 4,000 ft of water and penetrated 3,000 ft of salt before encountering multiple oil and gas pays. This discovery, though not the first well to drill through a tabular salt body successfully, demonstrates that hydrocarbons can be trapped in the subsalt sediments and thus opens an entirely new play that extends over much of the outer edge of the continental shelf.

This expansive frontier area offers an important opportunity for continued long-term additions to the natural-gas- reserves base. The challenge facing operators is the effective implementation of existing technologies and the development of innovative new ones. Technology is the key to identifying commercially attractive hydrocarbon prospects successfully and developing discoveries in these water depths. Chief among the exploration keys is the use of 3-D seismic data prior to exploratory drilling in conjunction with analyses of relative amplitude anomalies and amplitude versus offset. Novel implementation of existing technologies and the development of new exploitation schemes are critical to production at these challenging water-depth frontiers.

\section{SHALLOW MIOCENE BRIGHT SPOT PLAY}

A 1979 onshore deep Jurassic Norphlet gas play test in southwest Alabama encountered hydrocarbons in shallow Miocene sands. This discovery established an exploration play that currently extends through Alabama state waters and into the GOM OCS (fig. 1). Since the initial discovery, 30 fields have been established onshore and 3 within Alabama coastal waters. An additional 34 proved and 4 unproved fields were discovered on the GOM OCS between 1981 and 1991. Original recoverable proved reserves in the GOM OCS fields are $917 \mathrm{Bcfg}$, a mean field size of 27 Bcfg. Preliminary estimates of reserves in the four unproved fields are about $33 \mathrm{Bcfg}$.

The hydrocarbon accumulations within this play are primarily stratigraphic traps representing lateral pinchouts of deltaic and reworked marine sandstone reservoirs. All hydrocarbons encountered are natural gas of biogenic origin (Bearden and others, 1986). Exploration targets within the play are identified principally on the basis of seismic relative amplitude anomalies, commonly referred to as direct hydrocarbon indicators or bright spots.

Exploration interest in this play has managed to remain relatively high due to several considerations that result in economically attractive prospects. These factors include shallow drilling depths $(1,500$ to $4,500 \mathrm{ft}$ ), shallow water depths in the offshore (50 to $150 \mathrm{ft}$ ), and high exploratory success rates on the order of 80 percent. The eastern portion of this play has benefited because it overlies the much deeper Jurassic Norphlet gas play and is a secondary objective of many of these deep tests. These objectives have also been targeted by some operators in this area as a means of retaining leases while awaiting developments that could improve the economics of the Norphlet gas play.

\section{SEAGULL PLAY}

The Seagull play occurs off the coast of Texas in the Brazos and Galveston areas (fig. 1). The active portion of the play covers an area approximately 15 miles wide by 75 miles long, the northern limit just seaward of the 
state/Federal boundary. The play is limited to a single reservoir sand within the middle Miocene section; the reservoir sand appears to be coincident with a disturbed interval identifiable on seismic data. The northern limit is well defined by the downdip section of a large regional extension fault. Individual accumulations within this play are not large by offshore standards, containing 10 to $60 \mathrm{Bcfg}$, but they offer attractive targets for independent operators. The play takes its name from the most active company in the play, Seagull Energy Exploration and Production Inc.

Prior to 1990, numerous wells were drilled to test this disturbed section, and, although the reservoir sand was always found, no commercial hydrocarbons were identified. Early in 1990, however, the first successful well was drilled. By the end of 1991 , as many as 18 wells may have been drilled in the play, resulting in five new proved fields being discovered. Since the initial discovery, leasing, exploratory, and development activity have maintained a steady pace. Preliminary estimates of proved reserves in these new field discoveries are $155 \mathrm{Bcfg}$.

Plays similar to the Seagull play and the shallow Miocene Bright Spot play do not offer the potential for the huge reserves of the deep Norphlet gas play or the deepwater Flexure Trend/upper slope areas, nor are they burdened by their equally immense financial risks. They are, however, typical of the many play concepts that are being actively pursued in the mature shallow-water areas of the GOM OCS. Some of these plays are the result of companies willing and able to fill a particular niche. Others are the direct result of unconventional thinking. Often this thinking evolves from a systematic analysis of past failures. In other instances it results from transferring lessons learned in one area to opportunities in another. Dozens of similar plays await conception in the mind of the innovative and persistent prospector. The critical ingredients in the identification and exploitation of these new plays in old areas are the direct consequences of using modern exploration techniques and innovative and unconventional concepts and methods. Whatever the play in these areas, it is a testimonial to the persistence of the oil and gas prospector.

\section{INFLUENCES OF ECONOMICS ON EXPLORATION, LEASE ACQUISITION, EXPLOITATION, AND POTENTIAL RESOURCES}

The exploitation of petroleum resources is a business venture. All aspects of these activities are subject to the vagaries of economic analyses. This is particularly true in offshore operations with their substantive capital requirements. Some impacts of changing economic expectations are immediate, obvious, and well documented-lease acquisition, drilling, seismic acquisition. Others are more subtle and long term.

An example of the immediate industry response to a price shock is the annual average water depth of new field discoveries. Historically through 1975 the average water depth of new discoveries continued to increase until it reached $233 \mathrm{ft}$ (fig. 2). Depths then fluctuated until they peaked in 1985 at $345 \mathrm{ft}$. The price collapse of the last quarter of 1985 resulted in a dramatic decrease in the average water depth of fields discovered during 1986 to only $91 \mathrm{ft}$.

A long-term changing of the guard has been occurring in the GOM OCS. For example, in 1991 smaller companies drilled more than 86 percent of the exploratory wells, a figure approaching the historical high of 91 percent in 1986, when industry was retrenching from the price collapse of late 1985. Both these figures are much higher than the intervening period, when smaller operators drilled 70 to 75 percent of the exploratory wells, and a decade earlier, when major companies drilled most of the wells. The shallower waters of the shelf are becoming the domain of the independent operator while the major operators have retained the high-cost, high-risk, high-technology frontiers such as the deep water and the Norphlet play.

The development of discovered hydrocarbons on the GOM OCS is sensitive to product prices and exploration, development, and production costs. One example of this sensitivity is marginal reserves in existing producing fields. Major integrated companies are increasingly assigning or selling their interests in marginal producing properties on the shelf to smaller independent operators who can more economically operate these fields. In a recent 12 -month period, 2,345 leases were reassigned, up from about 1,100 assignments in each of the two preceding 12-month periods.

The high cost of offshore operations requires large minimum economic field sizes. Significant volumes of resources in recently discovered new fields are economically marginal at certain cost/price relationships. Nowhere is this effect more obvious than in deep-water fields. There have been 74 fields discovered in water depths greater than 600 ft (fig. 6). The leases on 30 fields have since expired without production. Two other fields produced for a period of less than two years. Cumulative production in the fields was $0.5 \mathrm{MMbo}$ and $5.3 \mathrm{Bcfg}$. Therefore, 43 percent of the geologic successes are confirmed economic failures. Twenty fields are classified as proved, 14 of which are producing, and 22 are active unproved fields with development decisions still pending. Proved reserves in the deep-water GOM OCS are $841 \mathrm{MMbo}$ and $3.71 \mathrm{Tcfg}$. Not surprisingly, the average size of the 20 active proved fields is over 75 MMboe. In spite of such large fields, it appears, on the basis of preliminary estimates of unproved potential, that many will be economic failures. The average size of the 17 unproved fields waiting a development decision and for 
which preliminary estimates of resources are available is 40 MMboe. These fields represent a potential addition to the reserves base of $390 \mathrm{MMbo}$ and $1.67 \mathrm{Tcfg}$. Yet, despite these large field sizes (by domestic standards), many fields will not be developed.

Internal assessments of undiscovered economically recoverable resources affect long-term company policy, yet they are highly sensitive to economic perceptions. The MMS principal estimate of undiscovered economically recoverable conventional resources on the GOM OCS as of December 31,1991 , is 5.28 Bbo and $60.94 \mathrm{Tcfg}$. This estimate is an update of the previous assessment presented as the primary-case economic scenario (Cooke, 1991). The scenario assumes initial prices for oil of $\$ 18$ per barrel and $\$ 1.80$ per Mcf for gas, with a range of real price increases encompassing many possible product price paths. These assumptions are explained in detail in both Mast and others (1989) and Cooke and Dellagiarino (1990). The range of economically recoverable undiscovered oil and gas resources under the assumptions of this economic scenario are 0.18 to $16.10 \mathrm{Bbo}$ and 24.10 to $118.88 \mathrm{Tcfg}$ (table 3 ). Nearly three-quarters of the undiscovered oil and 70 percent of the natural gas are projected to exist in water depths exceeding $600 \mathrm{ft}$.

Resources were also assessed under different economic scenarios to show the sensitivity of the volumes of undiscovered resources to assumptions concerning future price/ cost relationships. The alternative-case scenario assumes starting prices of $\$ 30$ per barrel and $\$ 3.00$ per Mcf. In this higher price scenario the potential quantities of undiscovered natural gas resources increase to $75.52 \mathrm{Tcf}$ at the mean level and 143.34 Tcf at the high level, an increase of 24 and 21 percent over the respective primary-case estimates. The additional resources are derived primarily from high-cost deep-water prospects and deeper targets on the shelf. These prospects are subeconomic at lower prices, but have significant potential at higher prices.

The final set of undiscovered resource estimates presented in table 3 is referred to as the undiscovered re- source base. This assessment includes all quantities of undiscovered conventionally recoverable hydrocarbons estimated to exist in fields larger than 1 MMboe without consideration of technological accessibility or profitability. These additional resources result from increased recovery in fields that are economic in the primary case as well as from prospects that were not profitable. These are smaller targets on the shelf, high-cost targets such as deeper objectives on the shelf or in deep or ultra-deep waters, prospects in areas lacking a regional infrastructure, and (or) prospects with high geologic risk. As such, this assessment represents an upper bound to the volumes of undiscovered resources in the GOM OCS. The mean level quantity of undiscovered natural gas is nearly $100 \mathrm{Tcf}$ and more than 150 Tcf in the high case.

Any qualified critic or expert (and generally everyone qualifies) will readily proclaim that quantitative resource assessment is an imperfect process. It is constrained in the broadest sense by existing knowledge, which in practice is always limited and even myopic. The unequivocal geologic model perfectly explaining all aspects of petroleum generation, migration, entrapment, and production remains to be developed. Poorly understood plays as well as serendipidity, which embraces the unforeseen or unknown play(s), are inadequately incorporated in an assessment. This nearsighted view of the world order is subsequently subjected to at least equally imperfect perceptions of future technology and economic conditions. Nevertheless, all we can do is use the best tools and judgment available. Having dispensed with this disclaimer, both the alternative economic scenario and the resource base encompass undiscovered natural gas resources in quantities approaching or exceeding currently discovered volumes.

\section{CONCLUSIONS}

The discovery process as it unfolded on the GOM OCS was typical of most hydrocarbon-producing basins

Table 3. Estimates of undiscovered hydrocarbon resource potential.

[Bbbl, billion barrels; Tcf, trillion cubic feet]

\begin{tabular}{|c|c|c|c|c|c|c|}
\hline & \multicolumn{3}{|c|}{ OIL (Bbbl) } & \multicolumn{3}{c|}{ GAS (Tcf) } \\
\hline \hline Primary case & $95 \%$ & $5 \%$ & Mean & $95 \%$ & $5 \%$ & Mean \\
\hline Alternative case & 0.18 & 16.10 & 5.28 & 24.10 & 118.88 & 60.94 \\
\hline Resource base & 0.70 & 19.18 & 6.80 & 31.69 & 143.34 & 75.52 \\
\hline
\end{tabular}


worldwide. The largest fields were discovered relatively early during the exploration process. As exploration proceeded, discoveries became progressively smaller and more difficult to achieve. Coincident with this steady decrease in the mean field size of new discoveries was a decrease in exploratory-well success rates.

The GOM OCS offers a multitude of exploration challenges. The mature, well-explored shallow-water areas have an abundance of geological, geophysical, and production data available. The explorationist with a new concept or "wrinkle" will be able to manage risk and successfully explore for and discover modest individual accumulations. On the other hand, there are also world-class frontiers such as the deep-water areas and an emerging subsalt objective near the outer shelf edge. The frontier plays offer the potential of giant reserves, but exploring them involves high risk and high costs. Exploitation of geologic successes in these economically and technologically harsh environments is highly dependent upon available technologies and favorable cost-price relationships.

Seventy-five percent of the 130.5 Tcf of original recoverable proved natural gas reserves have been produced. The GOM OCS, however, will continue to be a significant source of domestic natural-gas supply in the future. Considerable quantities of unproved reserves exist in new field discoveries and in old fields. Continued activity in these old fields and plays spurred by the application of new technologies have reșulted in new reservoir discoveries in old fields and new field discoveries in old plays. Current assessments of undiscovered resources under favorable economic scenarios may exceed the volume of proved natural gas reserves discovered to date.

\section{REFERENCES CITED}

Bearden, B.L., Mink R.M., and Mancini, E.A., 1986, Regional geologic framework and petroleum geology of Miocene strata of Alabama coastal waters area and adjacent Federal waters area, Draft Interim Report to U.S. Minerals Management Service, Cooperative Agreement No. 14-12-000130296: Geological Survey of Alabama and State Oil and Gas Board, Tuscaloosa, Alabama, 47 p.

Cooke, L.W., 1991, Estimates of undiscovered economically recoverable oil and gas resources for the Outer Continental Shelf, revised as of January 1990: Minerals Management Service OCS Report MMS 91-0051, 30 p.

Cooke, L.W., and Dellagiarino, G., 1990, Estimates of undiscovered oil and gas resources for the Outer Continental
Shelf as of January 1987: Minerals Management Service OCS Report 89-0090, 115 p.

Drew, L.J. and Lore, G.L., 1992, Field growth in the Gulf of Mexico-A progress report, in Carter, L.M.H., ed., USGS rescarch on energy resources, 1992: U.S. Geological Survey Circular 1074, p. 22-23.

Khan, Abdul S., 1992, Hydrocarbon accumulations, exploration plays, and drilling on the Texas and Louisiana Continental Slope, in Hunt, M.C., Masterson, A.R., and Miller, L.A., eds., Program and Abstracts, Third Symposium on Studies Related to Continental Margins-A Summary of Year-Five and Year-Six Activities, November 15-18, 1992: Austin, Texas, p. 45-46.

Lore, G.L., 1992, Exploration and discoveries, 1947-1989: An historical perspective: U.S. Minerals Management Service OCS Report 91-0078, 87 p.

Marzano, M.S., Pense, G.M., and Andronaco, P.A., 1989, A look at the Norphlet in Mary Ann field: Oil and Gas Journal, v. 87 , no. 10 , p. $55-58$.

Mast, R.F., Dolton, G.L., Crovelli, R.A., Root, D.H., Attanasi, E.D., Martin, P.E., Cooke, L.W., Pecora, W.C., and Rose, M.B., 1989, Estimates of undiscovered conventional oil and gas resources in the United States-A part of the Nation's energy endowment: Washington, D.C., U.S. Department of the Interior, $44 \mathrm{p}$.

Melancon, J.M., Kinler, C.J., Marin, D.A., and Prendergast, M.T., 1992, Estimated proved oil and gas reserves, Gulf of Mexico, December 31, 1991: U.S. Minerals Management Service OCS Report 92-0037, 61 p.

Meisner, J., and Demiren, F., 1981, The creaming method, a Bayesian procedure to forecast future oil and gas discoveries in mature exploration provinces: Journal of Royal Statistical Society, v. 144, no. 1, p. 1-31.

Mink, R.M., Bearden, B.L., and Mancini, E.A., 1985, Regional Jurassic geologic framework of Alabama coastal waters area and adjacent Federal waters area, Final Interim Report to the U.S. Minerals Management Service, Cooperative Agreement No. 14-12-0001-30115: Geological Survey of Alabama and State Oil and Gas Board, Tuscaloosa, Alabama, $72 \mathrm{p}$.

Mink, R.M., Hamilton, R.P., Bearden, B.L., and Mancini, E.A., 1987, Determination of recoverable natural gas reserves for the Alabama coastal waters area, Oil and Gas Report 13: Geological Survey of Alabama, Tuscaloosa, Alabama, $74 \mathrm{p}$.

Mink, R.M., Tew, B.T., Mann, S.D., Bearden, B.L., and Mancini, E.A., 1990, Norphlet and pre-Norphlet geologic framework of Alabama and Panhandle Florida coastal waters area and adjacent Federal waters area, Report to the U.S. Minerals Management Service, Cooperative Agreement No. 14-12-0001-30387: Geological Survey of Alabama and State Oil and Gas Board of Alabama, Tuscaloosa, Alabama, $81 \mathrm{p}$. 


\title{
Geologic Studies of Deep Natural-Gas Resources in the United States
}

\author{
By T.S. Dyman ${ }^{1}$, D.D. Rice ${ }^{1}$, J.W. Schmoker ${ }^{1}$, C.J. Wandrey ${ }^{1}$, R.C. Burruss ${ }^{1}$, R.A. Crovelli ${ }^{1}$, \\ G.L. Dolton ${ }^{1}$, T.C. Hester ${ }^{1}$, C.W. Keighin ${ }^{1}$, J.G. Palacas ${ }^{1}$, W.J. Perry, Jr. ${ }^{1}$, L.C. Price ${ }^{1}$, \\ C.W. Spencer ${ }^{1}$, and D.K. Vaughan ${ }^{1}$
}

\section{CONTENTS}

\begin{tabular}{|c|c|}
\hline Abstract & 171 \\
\hline Introduction & 172 \\
\hline Distribution of Deep Wells in the United States & \\
\hline 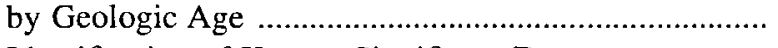 & 173 \\
\hline Identification of Known Significant Deep & \\
\hline 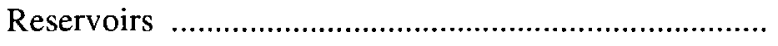 & 176 \\
\hline Distribution of Porosity in Sedimentary Rocks & \\
\hline as a Function of Time-Temperature Exposure .. & 178 \\
\hline Rocky Mountain Basins ................. & 178 \\
\hline Anadarko Basin & 180 \\
\hline Nonreservoir Sandstone & 181 \\
\hline Reservoir Sandstone ............................... & 181 \\
\hline Reservoir Properties of Clastic Reservoirs in the & \\
\hline Uinta, Wind River, and Anadarko Basins ......... & 182 \\
\hline Sequential Laramide Deformation of the & \\
\hline Rocky Mountain Foreland-Implications for & \\
\hline 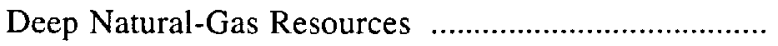 & 184 \\
\hline Potential for Deep Natural Gas in the & \\
\hline Hanna Basin-A Case Study .......................... & 187 \\
\hline Source-Rock Potential of Precambrian Rocks in & \\
\hline Selected Basins & \\
\hline Midcontinent Rift System ... & 189 \\
\hline Lake Superior Segment & 189 \\
\hline Minnesota Segment ....... & 190 \\
\hline Iowa Segment & 191 \\
\hline Kansas Segment & 191 \\
\hline
\end{tabular}

'U.S. Geological Survey, Denver Federal Center, Box 25046, Denver, CO 80225-0046.
Source-Rock Potential of Precambrian Rocks in Selected Basins-Continued

Grand Canyon Area, Northern Arizona 192

$\mathrm{C}_{15+}$ Hydrocarbon Thermal Destruction and High-

Rank Deep Basin Natural-Gas Accumulations 193

Migration of Large Volumes of Hydrocarbon and Nonhydrocarbon Gases from the Deep Crust:

Composition, Flux, and Tectonic Setting 196

Resource Assessment Methodologies for

Deep Natural-Gas Accumulations

Methodologies for Deep Natural-Gas Resources ... 197

Hypothetical Deep Basin Example ....................... 198

Conclusions ............................................................. 199

Acknowledgments ................................................. 200

References Cited ................................................... 201

\begin{abstract}
Deep parts of sedimentary basins in the United States contain large volumes of natural gas. Deep producing reservoirs, which are defined as reservoirs at depths greater than 15,000 feet (about $4,600 \mathrm{~m}$ ), accounted for 7 percent of the total cumulative gas production in the United States through 1989 (50 trillion cubic feet (Tcf) of $698 \mathrm{Tcf}$ ). The distribution and character of undiscovered deep gas accumulations can be better understood through the following: (1) Internally sourced hydrocarbons contribute to porosity preservation in some reservoirs at depth in the Anadarko Basin and Rocky Mountain Basins. This leads to the derivation of an empirical framework for predicting the porosity range of
\end{abstract}


sandstones as a function of vitrinite reflectance $\left(R_{o}\right)$. (2) Measurements of capillary pressure, which are very sensitive to confining stress, suggest that small-pore throats ( $<0.1$ micrometer), common in fine-grained clastic rocks, limit the flow of gas to the well bore. (3) In selected basins of the Rocky Mountain region, structural partitioning prior to thrusting, and sequential breakup of the foreland during the Late Cretaceous and Paleocene may have strongly affected the volume and distribution of deep natural-gas accumulations. (4) In flanking basins of the Midcontinent Rift and the Grand Canyon region, Middle Proterozoic source rocks, active hydrocarbon seeps, and favorable thermal maturities for generating and preserving natural gas, indicate a potential for economic gas accumulations. (5) Methane generation by thermal decomposition of $\mathrm{C}_{15+}$ hydrocarbons takes place at very high maturation ranks. $\mathrm{C}_{15+}$ hydrocarbons are thermally stable to ranks as high as $R_{0}=7.0$ to 8.0 percent in deep, unsheared basins. (6) Significant amounts of carbon dioxide and the presence of hydrogen sulfide indicate that thermochemical sulfate reduction and simultaneous oxidation of hydrocarbons to carbon dioxide may be the dominant control on nonhydrocarbon gas composition in deep carbonate reservoirs. Quartz-vein systems in convergent, transpressive plate-margin basins may act as conduits for migration of natural gas. (7) Where geologic information is available concerning known or suspected accumulations of deep gas, a "deposit simulation" based on a geologic model of reservoir volumes is the most appropriate assessment methodology.

\section{INTRODUCTION}

Because of lower worldwide oil prices, drilling activity in the United States has declined and exploration companies are looking overseas for oil and gas prospects. Concurrently, produktion from existing wells is declining, and U.S. reliance on imported oil is increasing. Even if oil prices were to increase drastically, it would take several years for domestic exploration to reach previous levels of intensity. Many drilling frontiers deserve review from a purely geologic perspective. One such frontier is natural gas in deep sedimentary basins (fig. 1).

In many respects, natural gas is more preferable than oil. The United States is rapidly exhausting its oil reserves whereas resource estimates of natural gas remain high. According to the National Petroleum Council (1992), the United States contains nearly 1,300 Tcf of recoverable natural-gas resources. Natural gas is a clean-burning fuel that is far less environmentally damaging than oil. Increased use of domestic natural-gas resources would lessen our reliance on foreign oil imports.

According to Petroleum Information Corporation's Well History Control System (WHCS) (Petroleum Information Corporation, 1991), more than 16,000 wells have

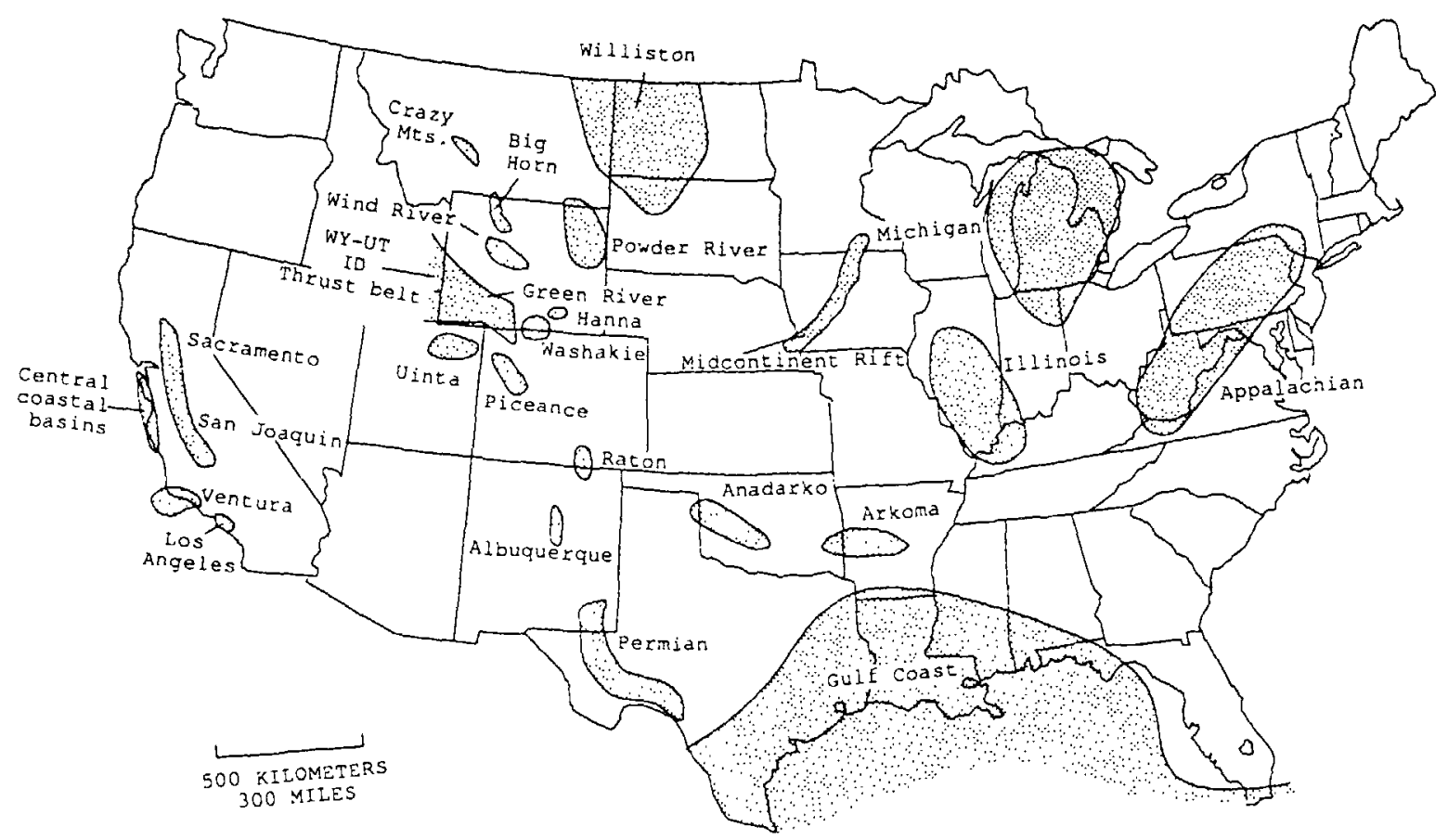

Figure 1. Basins and regions of the conterminous United States containing sedimentary rocks greater than 15,000 feet (about 4,600 m) deep. Shaded areas represent entire basins. Mts., mountains. 
been drilled deeper than 15,000 feet (about $4,600 \mathrm{~m}$ ) in the U.S. These deep wells are widely distributed and are drilled into rocks of various ages and lithologies, but they represent a very small number of the 2.2 million wells contained in the data file.

Almost one-fourth of the total undiscovered naturalgas resources of the onshore lower 48 States lie below 15,000 feet (139 of 577 Tcf; Potential Gas Committee, 1990). However, in some basins, only a few deep wells have been drilled, and the natural-gas potential of these and other deep horizons remains unknown.

One of the most significant new deep exploration plays in the United States is in the Jurassic Norphlet Formation of the eastern Gulf Coast Basin. Woods (1991) identified substantial growth in production for this play through the year 2005. Geologic and geochemical studies by Rice and others (1992) indicate significant potential for Norphlet and Smackover reservoirs in the eastern Gulf Coast region.

Of the total U.S. natural-gas resources (nearly 1,300 Tcf), about 40 percent ( $519 \mathrm{Tcf}$ ) is considered unconventional including such sources as coalbed methane, gas from shales, gas in low-permeability sandstone reservoirs, and deep-basin gas accumulations (National Petroleum Council, 1992). New geologic research dealing with all aspects of natural-gas exploration and production is needed to fully realize the potential of these unconventional sources.

The U.S. Geological Survey has initiated an active research program to investigate the geologic parameters controlling the distribution of deep natural gas. This report is a summary of part of this geologic research conducted as an outgrowth of work funded by the Gas Research Institute (Rice, 1989; Dyman, 1992).

\section{DISTRIBUTION OF DEEP WELLS IN THE UNITED STATES BY GEOLOGIC AGE}

Wandrey and Vaughan (1992), using Petroleum Information Corporation's WHCS file current to June 1991, published nine digital maps showing wells drilled deeper than 15,000 feet (about $4,600 \mathrm{~m}$ ). WHCS contains geologic and engineering data for approximately 2.2 million wells drilled in the United States; of these, 16,500 wells were drilled deeper than 15,000 feet (Petroleum Information Corporation, $1988 ; 1991)$. Figures 2 and 3 of this report are compilations of plates 1 through 9 of Wandrey and Vaughan (1992).

Wells that have produced hydrocarbons from depths of 15,000 feet or greater, color-coded by geologic age of the producing reservoir rocks are shown in figure 2 . Whereas the WHCS file is current, it is not always complete or entirely accurate. Various methods were used to ensure accuracy and completeness. Several checks were made to ensure that the wells shown on figure 2 did in fact produce from depths greater than 15,000 feet. Often the records indicated that a well was drilled to greater than 15,000 feet and produced hydrocarbons, but the depth of production was not identified in the WHCS data file. In these cases, wells were checked against subsurface geologic maps, depths to top of producing formations, and initial-potential (IP) data files. Information on individual wells in the Gulf Coast region was particularly misleading or lacking. In many cases, the wells in the Gulf Coast region were drilled into salt domes created by salt migration from older deeper salt beds into younger rock, and the age of the salt rather than the age of the surrounding rock was identified.

Nonproducing wells color-coded by the geologic age of the oldest rocks penetrated are shown in figure 3 . Nonproducing means that hydrocarbons were not economically producible at any depth at the time drilling was completed. Shows of oil and (or) gas may have been present but were insufficient to warrant production, or well-completion problems precluded production. Because the WHCS file uses the same code for dry holes and abandoned producers, some wells labeled as dry holes may in fact have produced hydrocarbons in the past or were temporarily "shut-in" until pipelines or production facilities were completed. The number of wells that have produced or are still producing hydrocarbons is relatively accurate, but dry-hole estimates may be high.

The yellow parts of figures 2 and 3 show areas of basins with sedimentary rocks at depths of 15,000 feet or greater. Sedimentary thickness data were compiled using a sedimentary rock depth contour map of the continental United States (Frezon and others, 1983), an unpublished basement map of the southwestern United States (W.C. Butler, written commun., 1992), and well-log and seismic data for the Midcontinent Rift System (Anderson, 1990).

A summary of deep wells and basin types from the WHCS data file is shown in table 1 . Of the 6,178 wells that produce or have produced hydrocarbons from depths greater than 15,000 feet, 4,547 are gas wells or gas- and condensate-producing wells. The total wells column of table 1 does not always equal the sum of the other three columns because some wells produced both oil and gas and were therefore listed twice. Some wells lacked final well-classification information indicating the type of production. Still other wells lacked a basin identification because of insufficient location information. More than 200 wells were not shown on figures 2 and 3 because well classification and location problems could not be resolved. Geologic age of formation at total depth of well was absent in the WHCS data file for many offshore wells in the Gulf Coast Basin, but approximate ages were determined by comparing the total depths to neighboring wells with age information. Wells outside the yellow areas on figures 2 and 3 may have inaccurate location data or the yellow area may not have been extended far enough because of 


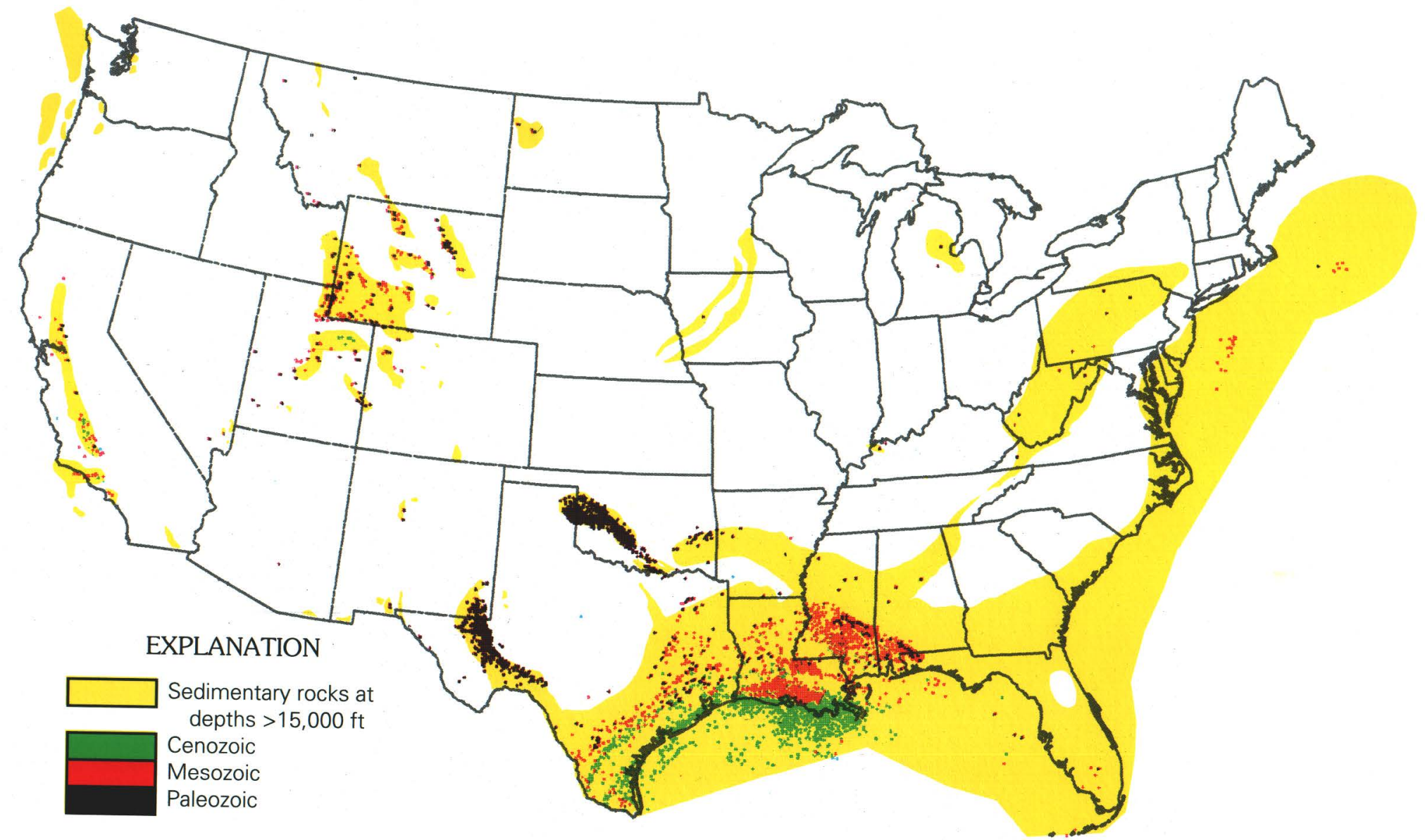

Figure 2. Petroleum exploration wells of conterminous United States drilled deeper than 15,000 feet (about 4,600 m) completed as dry holes, and color-coded by age of formation at total depth. Areas of basins containing sediment at a depths greater than 15,000 feet are shaded yellow. Data from Petroleum Information Corporation Well History Control System (Petroleum Information Corporation, 1991). Scale, 1 inch $(2.5 \mathrm{~cm})$ equals approximately 400 miles (about $670 \mathrm{~km}$ ). 


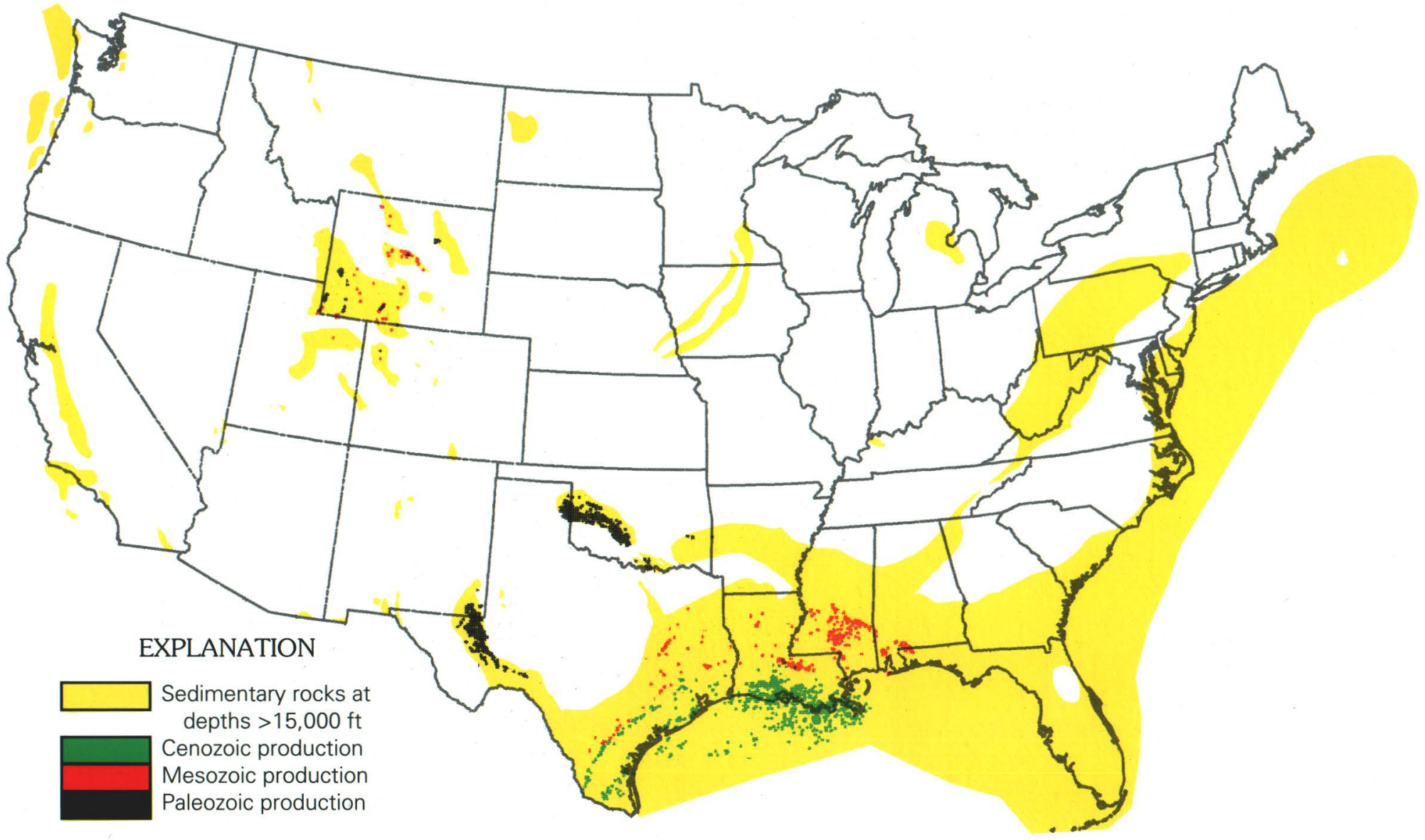

Figure 3. Petroleum exploration wells of conterminous United States drilled deeper than 15,000 feet (about 4,600 m) completed as producing wells, and color-coded by age of formation at total depth. Areas of basins containing more than 15,000 feet of sedimentary rock

are shaded yellow. Data from Petroleum Information Corporation Well History Control System (Petroleum Information Corporation, 1991). Scale: 1 inch $(2.5 \mathrm{~cm})$ equals approximately 400 miles (about $670 \mathrm{~km})$. 
Table 1. Summary of deep wells by production category for selected basins in the United States.

[Data from Well History Control System (WHCS) data file through 1991 (Petroleum Information Corporation, 1991)]

\begin{tabular}{|c|c|c|c|c|c|}
\hline Basin or province & Total ${ }^{1}$ & Oil & Gas & Oil/gas & Basin type \\
\hline Anadarko------------------ & 1,258 & 41 & 1,231 & 1 & Foreland \\
\hline 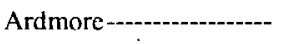 & 10 & 0 & 10 & 0 & Foreland \\
\hline Arkoma-----'------- & 6 & 1 & 10 & 0 & Foreland \\
\hline 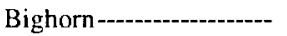 & 4 & 0 & 4 & 0 & Foreland \\
\hline Green River-----:------ & 107 & 24 & 81 & 0 & Foreland \\
\hline Gulf region ------------ & 3,465 & 999 & 2,411 & 35 & Passive margin \\
\hline Marietta ---------------- & 14 & 3 & 11 & 0 & Foreland \\
\hline 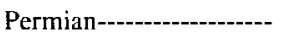 & 873 & 22 & 793 & 2 & Continental margin, rift \\
\hline Piceance ---------------- & 2 & 1 & 1 & 0 & Foreland \\
\hline Powder River---:------ & 32 & 31 & 0 & 0 & Foreland \\
\hline 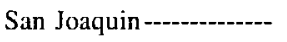 & 6 & 5 & 0 & 0 & Foreland \\
\hline Uinta - - & 154 & 152 & 2 & 0 & Foreland \\
\hline Ventura --..--- & 6 & 4 & 2 & 0 & Transpressive \\
\hline Wind River --.------ & 72 & 6 & 65 & 0 & Foreland \\
\hline
\end{tabular}

\footnotetext{
'Total wells column does not always equal the sum of the other three columns because some wells produced both oil and gas and were therefore listed twice. Total wells column does not equal the 6,178 wells discussed in text. Some wells lacked final well classification information indicating type of production, and in still other cases, location information was insufficient to determine the correct basin. Approximately 169 of these wells were not plotted on figures 2 and 3 because well classification and location problems could not be resolved.
}

insufficient data. The Uinta Basin and the Gulf Coast Basin, the two areas where there are significant numbers of deep oil wells, are producing from Mesozoic and Cenozoic rock. The success ratio of approximately 46 percent for these deep wells is higher than for all wells together.

\section{IDENTIFICATION OF KNOWN SIGNIFICANT DEEP RESERVOIRS}

Geologic conditions or variables favorable for naturalgas accumulations in deep sedimentary basins (Dyman and others, 1992) are derived from the digital maps of Takahashi and Cunningham (1987), Wandrey and Vaughan (1992), and from published information and computerized data files. Computerized data were taken primarily from the NRG Associates, Inc., field file (NRG Associates Inc., 1988; 1991) and Petroleum Information Corporation's WHCS file (Petroleum Information Corporation, 1988; 1991). NRG's field file contains geologic, production, and engineering data for significant reservoirs (reservoirs with 6 billion cubic feet ( $\mathrm{Bcf}$ ) of gas ultimately recoverable) in the United States.

Because a producing horizon may extend both above and below 15,000 feet, NRG retrievals were selected for all reservoirs below 14,000 feet (about 4,300 m) to capture all reservoirs near or below 15,000 feet. As many as 378 significant reservoirs in the United States produce from depths greater than 14,000 feet, and 256 produce from depths greater than 15,000 feet. These reservoirs are primarily in the Gulf Coast, Permian, Anadarko, Williston, Powder River, Wind River, and Green River Basins, and in the Wyoming Thrust Belt (fig. 1). A brief summary of the main geologic and production characteristics of significant reservoirs from these regions is outlined in table 2 . U.S. sedimentary basins contain additional deep gas reservoirs below 14,000 feet, but these reservoirs do not meet the minimum production qualifications for entry into the NRG Associates field file.

According to Dwight's Energy Data (1985), 1,998 total reservoirs produced below 14,000 feet in the United States at the end of 1985. Of the total cumulative naturalgas production in the United States (698 Tcf; Mast and others, 1989), deep reservoirs account for 7 percent $(50 \mathrm{Tcf})$ of the total, and significant deep reservoirs (NRG reservoirs) account for nearly half (21.4 Tcf; table 2$)$ of the deep reservoir total (Dyman and others, 1990). Deep gas reservoirs account for only a small part of the Nation's total cumulative production.

Sixty-six percent of the deep significant reservoirs are classified as gas producers. An additional 25 reservoirs are classified as oil and gas producers. Sixty-eight percent of all significant deep reservoirs are classified as structural or combination (combined structural and stratigraphic) traps. Fifty percent of these reservoirs (188 reservoirs) produce 
Table 2. Summary of significant deep reservoirs in selected deep basins and areas of the United States.

[Information based on data from NRG Associates ficld file (NRG Associates, 1988). There are 378 significant deep reservoirs in the United States, but 8 of these reservoirs from the Williston Basin and Pacific region are not included

\begin{tabular}{|c|c|c|c|c|c|c|}
\hline Basin & $\begin{array}{l}\text { Number of } \\
\text { reservoirs and } \\
\text { percent of total }\end{array}$ & $\begin{array}{l}\text { Cumulative gas } \\
\text { and percent of } \\
\text { total gas }\end{array}$ & $\begin{array}{c}\text { Known } \\
\text { recoverable gas } \\
\text { and percent of } \\
\text { total gas }\end{array}$ & $\begin{array}{c}\text { Stratigraphic and } \\
\text { lithologic } \\
\text { information }\end{array}$ & $\begin{array}{l}\text { Number of fields } \\
\text { discovered prior } \\
\text { to } 1970 \text { and } \\
\text { percent of total }\end{array}$ & Comments \\
\hline Gulf Coast -.....- & $\begin{array}{l}174 / 370= \\
47 \text { percent. }\end{array}$ & $\begin{array}{l}6.2 / 21.4= \\
29 \text { percent. }\end{array}$ & $\begin{array}{l}13.3 / 33.7= \\
40 \text { percent. }\end{array}$ & $\begin{array}{l}\text { Tertiary reservoirs } \\
\text { mostly clastic; } \\
\text { Jurassic and } \\
\text { Cretaceous } \\
\text { reservoirs mixed } \\
\text { carbonate and } \\
\text { clastic. }\end{array}$ & $\begin{array}{l}64 / 174= \\
37 \text { percent. }\end{array}$ & $\begin{array}{l}37 \text { percent of deep } \\
\text { reservoirs are Tertiary. }\end{array}$ \\
\hline Permian---_-_..- & $\begin{array}{l}89 / 370= \\
24 \text { percent. }\end{array}$ & $\begin{array}{l}12.4 / 21.4= \\
58 \text { percent. }\end{array}$ & $\begin{array}{l}15.1 / 33.7= \\
45 \text { percent. }\end{array}$ & $\begin{array}{l}\text { Middle Paleozoic } \\
\text { mixed clastic } \\
\text { and carbonate } \\
\text { reservoirs; } \\
\text { Silurian and } \\
\text { Devonian mostly } \\
\text { carbonate } \\
\text { reservoirs. }\end{array}$ & $\begin{array}{l}32 / 174= \\
36 \text { percent. }\end{array}$ & $\begin{array}{l}67 / 89 \text { reservoirs occur in } \\
\text { Devonian or older } \\
\text { rocks. Permian } \\
\text { reservoirs } \\
\text { stratigraphically } \\
\text { trapped. }\end{array}$ \\
\hline Anadarko-------- & $\begin{array}{l}85 / 370= \\
23 \text { percent. }\end{array}$ & $\begin{array}{l}2.4 / 21.4= \\
11 \text { percent. }\end{array}$ & $\begin{array}{l}2.8 / 33.7= \\
8 \text { percent. }\end{array}$ & $\begin{array}{l}\text { Mostly clastic rock } \\
\text { reservoirs. Some } \\
\text { production from } \\
\text { Cambrian and } \\
\text { Silurian } \\
\text { carbonate } \\
\text { reservoirs. }\end{array}$ & $\begin{array}{l}25 / 85= \\
29 \text { percent. }\end{array}$ & $\begin{array}{l}65 \text { percent of reservoirs } \\
\text { produce from } \\
\text { Pennsylvanian strata. }\end{array}$ \\
\hline $\begin{array}{l}\text { Rocky Mountain } \\
\text { Basins. }\end{array}$ & $\begin{array}{l}22 / 370= \\
6 \text { percent. }\end{array}$ & $\begin{array}{l}0.4 / 21.4= \\
2 \text { percent. }\end{array}$ & $\begin{array}{l}2.2 / 33.7= \\
7 \text { percent. }\end{array}$ & $\begin{array}{l}\text { Jurassic and } \\
\text { Cretaceous } \\
\text { clastic } \\
\text { reservoirs and } \\
\text { Paleozoic mixed } \\
\text { carbonate and } \\
\text { clastic reservoirs. }\end{array}$ & $\begin{array}{l}9 / 22= \\
41 \text { percent. }\end{array}$ & $\begin{array}{l}\text { Deep gas mostly from } \\
\text { Utah-Wyoming Thrust } \\
\text { Belt. Potential from } \\
\text { Hanna, Wind River, } \\
\text { Piceance, Green River, } \\
\text { Uinta, Crazy } \\
\text { Mountains, Big Horn, } \\
\text { and Raton Basins. }\end{array}$ \\
\hline
\end{tabular}

from Mesozoic or younger rocks, and 58 percent (221 reservoirs) produce from clastic rocks of any geologic age. As expected, the number of reservoirs decreases with increasing depth, but more than one quarter ( 26 percent) of the total significant deep reservoirs are below 17,000 feet (about $5,200 \mathrm{~m}$ ).

Of the 378 deep reservoirs, 174 (or 47 percent) occur in the Gulf Coast Basin (table 2). Reservoirs are primarily in Tertiary clastic rocks and deeper mixed carbonate-clastic rocks of Mesozoic age. Forty percent of the known recoverable natural-gas resources $(13.3 \mathrm{Tcf})$ in significant deep reservoirs occurs in the Gulf Coast Basin.

The other, significant deep reservoirs occur in the Permian, Anadarko, and Williston Basins, and in basins of the Rocky Mountain region, California, and Alaska (table 2). Large volumes of deeply buried sedimentary rocks are present in other basins in the United States where few or no wells have been drilled and where no significant gas production now exists. Recent work by
Palacas (1992) indicates that parts of the Midcontinent Rift System may contain Precambrian source rocks capable of generating natural gas below 15,000 feet. Deep Rocky Mountain Basins (fig. 1) including the Raton, AIbuquerque, and Crazy Mountains Basins have been sparsely drilled and the recoverable natural gas resource is unknown. Furthermore, drilling data analyzed by Wandrey and Vaughan (1992; figs. 2, 3) show that the deeper parts of many productive basins have not been adequately drilled even where promising source and reservoir rocks are presumably present. For the last U.S. Geological Survey national petroleum assessment (Mast and others, 1989), 59 of approximately 250 petroleum plays assessed contain reservoir rocks at least in part, below 15,000 feet (Dyman, unpub. data). Work with large computerized data files by Dyman and others (1990) and Dyman and others (1992) suggests that additional significant quantities of deep natural gas remain to be found in sedimentary basins of the United States. 


\section{DISTRIBUTION OF POROSITY IN SEDIMENTARY ROCKS AS A FUNCTION OF TIME-TEMPERATURE EXPOSURE}

One of the factors that has inhibited deep drilling for clastic and carbonate reservoirs is the knowledge that porosity and permeability can be too low to sustain economic hydrocarbon production (see Hefner, this volume). Better predictive relations for determining the porosity range of sandstones (Schmoker, 1992; Hester,1992) can aid in risk evaluation in deep-drilling programs. Porosity trends, as functions of thermal maturity, may be represented by vitrinite reflectance $\left(R_{0}\right)$. In this context, $R_{o}$ serves as a general index of burial history. In addition to $\mathrm{R}_{0}$, clay content, carbonate cementation, grain size, and hydrocarbon generation data are used to provide a probable porosity range.

\section{ROCKY MOUNTAIN BASINS}

Examples from the Rocky Mountain region are drawn from Cretaceous sandstones, with emphasis on the Lower Cretaceous Muddy Sandstone ("J" sandstone of drillers' usage, MacMillan and Weimer, 1976) of the Denver Basin, Colorado, and Upper Cretaceous sandstones of the Mesaverde Group of the Piceance and Uinta Basins, Colorado and Utah (fig. 4).

Porosity-thermal maturity relations, like porositydepth curves, do not provide much insight into the actual processes causing porosity change in the subsurface. The influence upon porosity by factors such as grain size and sorting, clay matrix, framework composition, early cementation, overpressuring, proximity to unconformities, dissolution (secondary porosity), and coating of framework grains is empirically accounted for by porosity- $R_{0}$ trends that represent the 10 th, 25 th, $50 \mathrm{th}, 75 \mathrm{th}$, and 90 th porosity percentiles of data sets (fig. 5).

The 90th porosity percentile, for example, represents strata of the data set that have rock properties relatively favorable for porosity preservation or development; in contrast, the 10th porosity percentile represents intervals of the data set with properties that result in low porosities at similar levels of thermal maturity. By depicting porosity using the 10th through 90th porosity percentiles (fig. 5), the porosity range at a given $\mathrm{R}_{\mathrm{o}}$ is taken into account.

An empirical approach for estimating the porosity and the porosity range of Cretaceous sandstone in Rocky Mountain Basins is based on two models (A and $\mathrm{B}$ ) (figs. $5 A, 5 B$ ). These two models better represent porosity$R_{0}$ data than regression lines fitted to the entire $R_{0}$ range. For $R_{0}$ values less than 0.9 percent, trendlines for models $A$ and $B$ are identical and represent all data. Model $A$ applies to strata in which porosity continues to decrease at a uniform rate as $R_{0}$ values increase above 0.9 percent. Model $B$ applies to strata in which the rate of porosity loss becomes more gradual as $R_{0}$ values increase above 0.9 percent. Models $A$ and $B$ do not directly represent variability in rock properties such as grain size and sorting, shale content, and composition of framework grains. The porosity variations induced by these factors are already incorporated in the porosity range defined by the 10 th through 90 th porosity

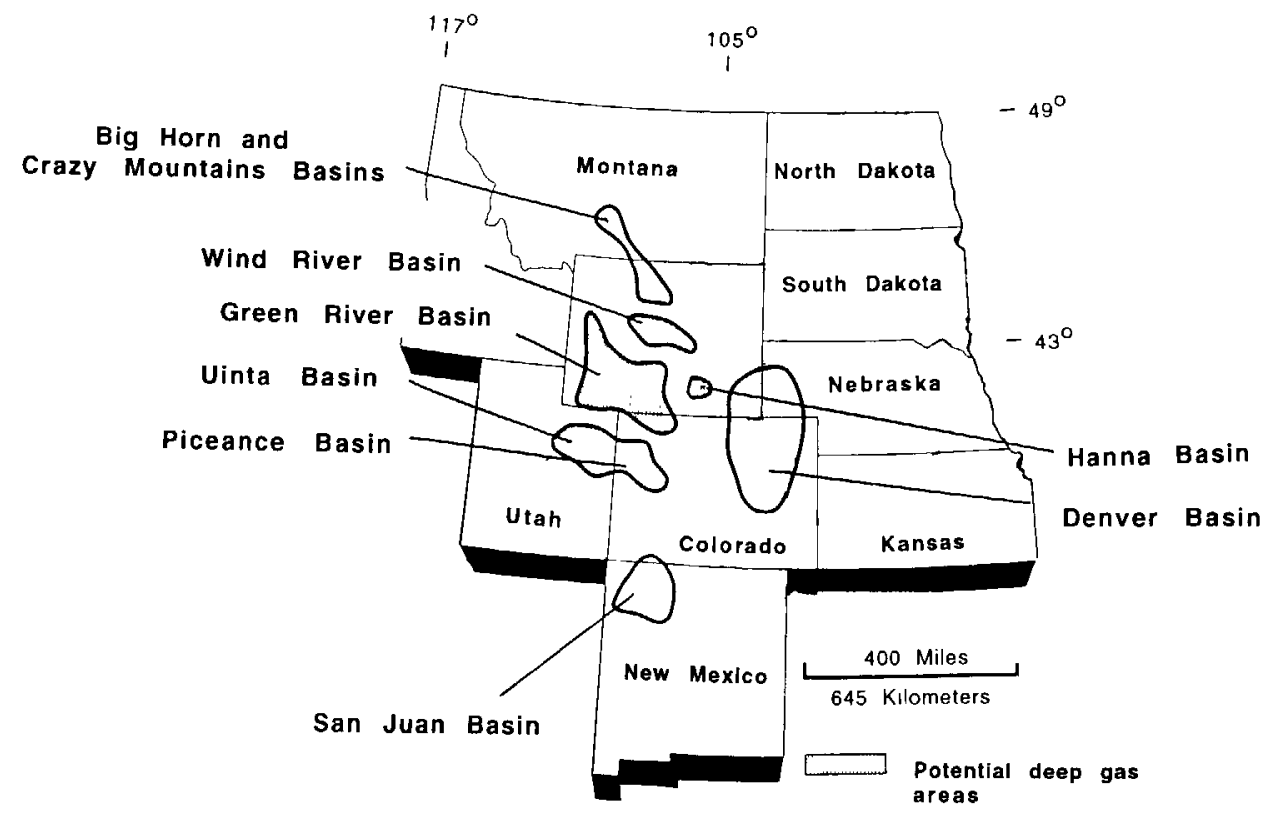

Figure 4. Rocky Mountain Basins where deep natural gas is interpreted to be present on the basis of gas shows, formation tests, geology, and known production. Potential deep gas areas are of depths greater than 15,000 feet . 

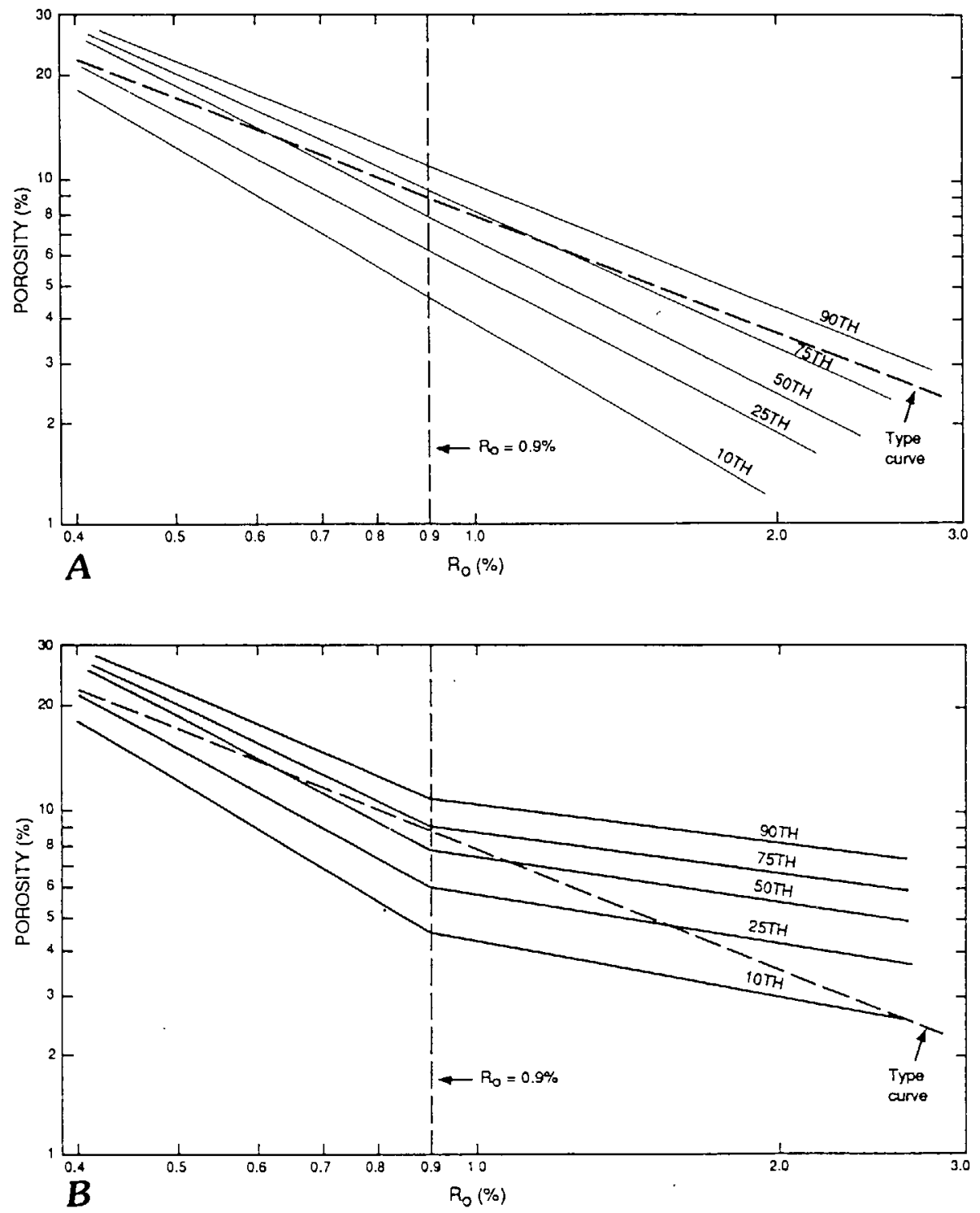

Figure 5. Plot of porosity (\%, percent) versus vitrinite reflectance $\left(\mathrm{R}_{\mathrm{o}}\right)$ showing subjective trendlines representing the 10 th, 25th, 50th, 75th, and 90th porosity percentiles for Cretaceous sandstone data set from Rocky Mountain Basins. The dashed type curve is a reference line that represents sandstone in general (Schmoker and Gautier, 1989). For $\mathrm{R}_{\mathrm{o}}$ values less than 0.9 percent, trendlines of Figure $5 A$ and $B$ are identical and represent all data (Schmoker, 1992). For $\mathrm{R}_{\mathrm{o}}$ greater than 0.9 percent, trendlines of $A$ (model $\mathrm{A}$ of text) represent strata in which porosity continues to decrease at a uniform rate; trendlines of $B$ (model $B$ of text) represent strata in which the rate of porosity loss becomes more gradual as $R_{0}$ values increase above 0.9 percent.

percentiles. Rather, models $\mathrm{A}$ and $\mathrm{B}$ are interpreted as sandstone in which porosity evolution follows one of two fundamentally different pathways. Models A and B are derived from observation of porosity- $R_{0}$ crossplot patterns (Schmoker, 1992) and represent a working hypothesis.

The choice of diagenetic pathway (model A versus model B) is important for sandstone porosity prediction in deep parts of Rocky Mountain Basins. At $R_{o}=2.0$ percent, for example, model A predicts median porosities of about 2 percent and 90th percentile porosities of only 4 percent; in contrast, model B predicts median porosities of about 5 percent and 90th percentile porosities of 8 percent. Extrapolating beyond the data to $R_{o}=3.0$ percent, model A predicts that the 10 th-through 90 th-percentile porosities are all less than 3 percent, whereas model B predicts some porosities of 6 to 7 percent. Maximum depths of production predicted by model $\mathrm{A}$ in a given area of a basin would be thousands of feet less than those predicted by model B. 
The particular strata of the data set that conform to model B are from the Upper Cretaceous Almond Formation in the Green River Basin and the Upper Cretaceous Mesaverde Group in the Piceance Basin (fig. 4). Lowpermeability sandstone in both formations is commonly overpressured, at $R_{0}$ greater than 0.9 percent, owing to hydrocarbon generation. Some Cretaceous sandstones in Rocky Mountain Basins may not follow "normal" diagenetic pathways because of the effects upon diagenesis of hydrocarbon generation from adjacent and interbedded coal and organic-rich shale.

The hypothesis that porosity evolution can follow distinctly different pathways as $R_{0}$ increases above 0.9 percent has significant implications for the economic production of deep hydrocarbons. Hydrocarbon generation in overpressured nonsubsiding basins of the Rocky Mountain region may retard porosity loss as $R_{o}$ increases in at least three ways. These are (1) hydrocarbons can inhibit cementation by displacing pore water, (2) carbon dioxide and organic acids produced by the thermal breakdown of kerogen can create secondary porosity by dissolving cements and framework grains, (3) overpressuring can slow pressure solution and associated porosity decrease by reducing the lithostatic load on grain contacts. Overpressuring can also reduce cementation by developing a fluid-flow system characterized by expulsion, rather than exchange, of liquids. Although the relative importance of these three reasons is difficult to determine, the presence of hydrocar- bons is the fundamental reason for porosity preservation at depth and an important factor in the presence of deep natural-gas resources.

If hydrocarbon generation is indeed the primary underlying process that causes some sandstone to deviate from porosity- $\mathrm{R}_{\mathrm{o}}$ trends similar to those of figure $5 A$ and instead follow trends similar to those of figure $5 B$, then the results of this analysis are not restricted to Rocky Mountain Cretaceous sandstone but are applicable to other deep sedimentary basins in the United States and elsewhere.

\section{ANADARKO BASIN}

Anadarko Basin sandstone-porosity trends can also be analyzed with respect to thermal maturity using the same techniques described for sandstone in the Rocky Mountain region (Hester, 1992). Hester based his analysis on three $R_{o}$ data sets (figs. 6 and 7). The first data set provides a porosity- $R_{0}$ trend typical of Anadarko Basin hydrocarbon-bearing sandstone reservoirs of Paleozoic age. Nonreservoir sandstone in the second data set is defined as Paleozoic sandstone typical of the Anadarko Basin and may be reservoir sandstone at other locations. Nonreservoir sandstone provides a background with which to compare other sandstone. The third data set represents sandstone samples of diverse ages, diagenetic facies, and thermal histories from regions outside the Anadarko Basin.

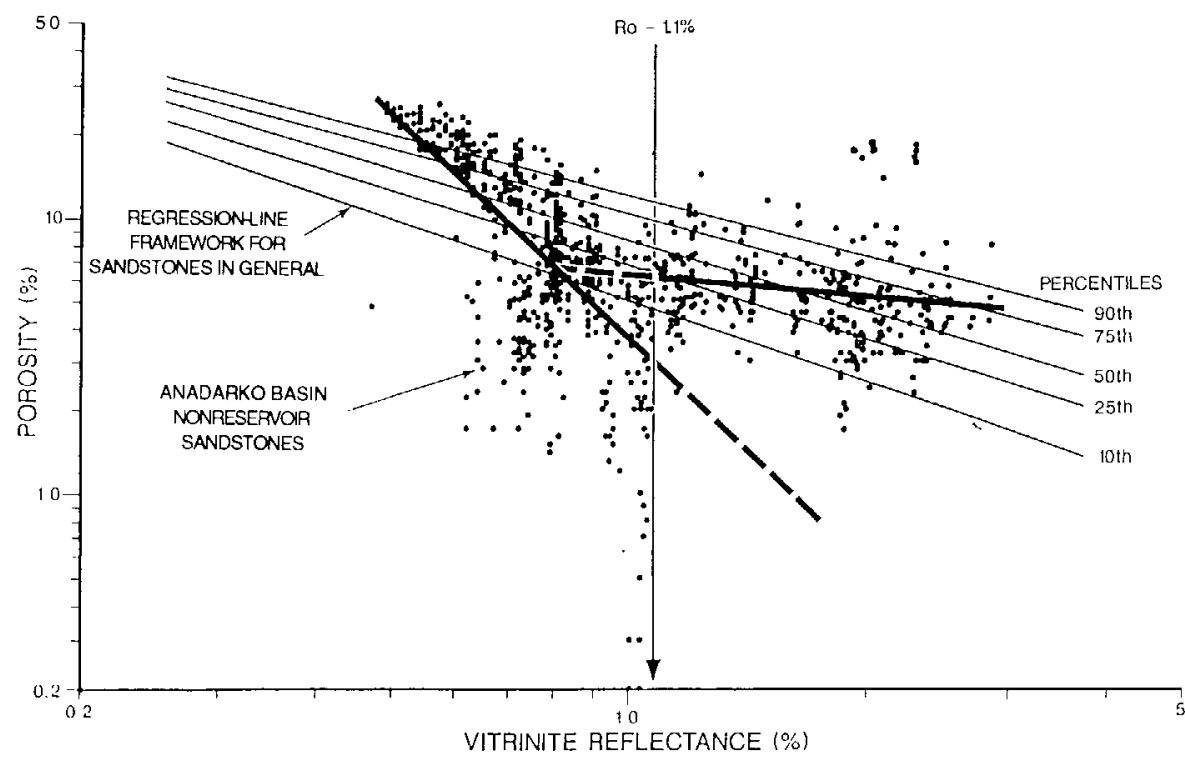

Figure 6. Porosity (\%, percent) of Anadarko Basin nonreservoir sandstone versus vitrinite reflectance $\left(R_{0}\right)$ plotted with least-squares regression lines fit to each of two nonreservoir sandstone data sets separated at $R_{o}$ values $=1.1$ percent (dashed where inferred). Also plotted are least-squares regression lines fit to the $10 \mathrm{th}, 25 \mathrm{th}, 50 \mathrm{th}, 75 \mathrm{th}$, and 90 th porosity percentiles of the framework data set representing sandstone in general (third data set of text, representing sandstones of diverse ages, facies, and diagenetic histories; Schmoker and Hester, 1990). 


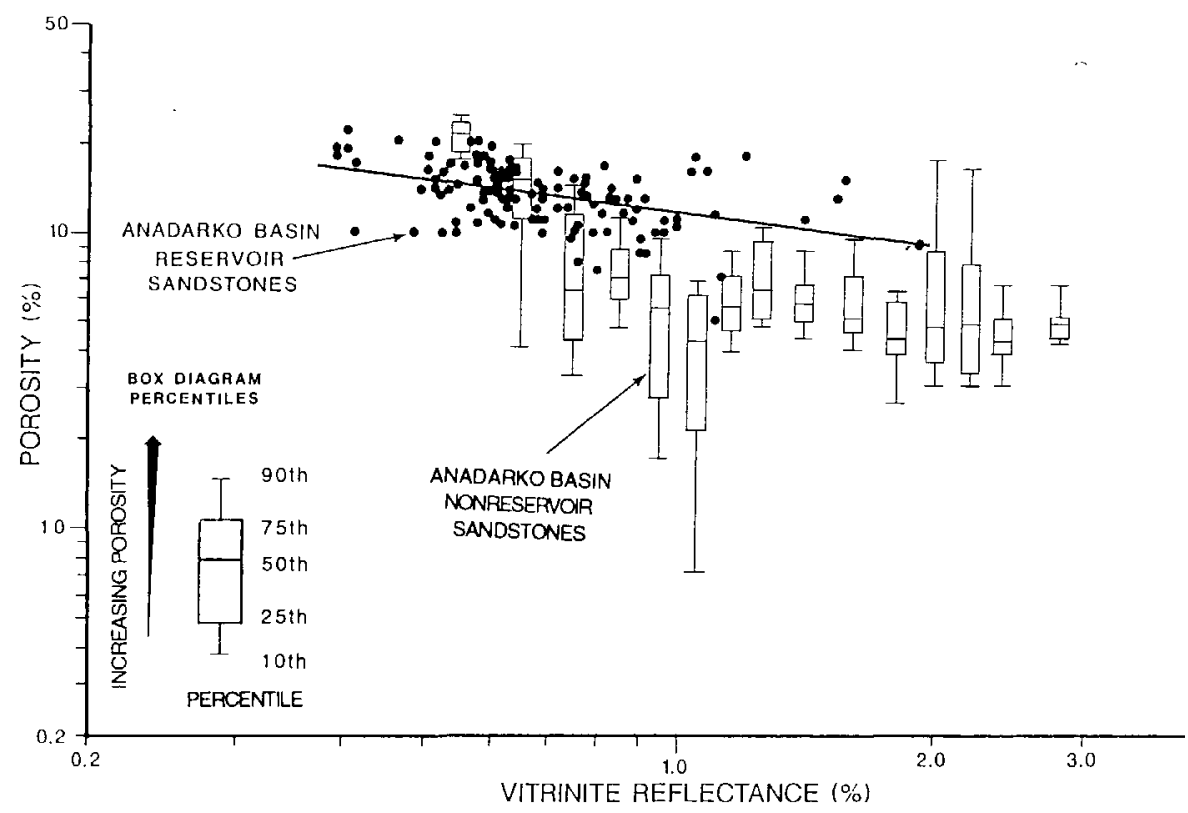

Figure 7. Porosity (\%, percent) of Anadarko Basin reservoir sandstone versus vitrinite reflectance $\left(R_{0}\right)$ values plotted with least-squares regression line. Box-diagram percentiles representing Anadarko Basin nonreservoir sandstone data are shown.

\section{NONRESERVOIR SANDSTONE}

A least-squares fit to the porosity- $\mathrm{R}_{\mathrm{o}}$ data for nonreservoir sandstone of the central and southern Anadarko Basin shows that sandstone porosity generally declines with increasing thermal maturity (fig. 6). However, the data appear to consist of two separate populations-a less thermally mature population represented by $R_{0}$ values of less than 1.1 percent, and a more thermally mature population represented by $R_{0}$ values of greater than 1.1 percent. Correlation coefficients of the least-squares fit to each population shows a much stronger dependence of porosity on $R_{0}$ for the less mature trend of nonreservoir sandstone than for sandstone in general. The improved correlation of the less mature trend over that of the entire data set suggests that the two data populations might best be considered separate trends. The two trends probably overlap to some extent as the more mature diverges from the less mature. Nevertheless, for the purposes of this report, a single preliminary boundary separating the two trends is placed at about $R_{0}$ values $=1.1$ percent.

In both the general and nonreservoir data sets, porosity generally declines as a power function of increasing thermal maturity. The least-squares fit to the data show that for $\mathrm{R}_{\mathrm{o}}$ less than 1.1 percent, the rate-of-porosity decrease with increasing $R_{o}$ for nonreservoir sandstone is more rapid than that of the average trend of the porosity $-R_{o}$ framework representing sandstone in general (fig. 6). For $R_{o}$ greater than 1.1 percent, the rate-of-porosity decrease for nonreservoir sandstone is less rapid than that of sandstone in general.
Sufficient data to substantiate a probable cause for the change of slope of the porosity trend of Anadarko Basin nonreservoir sandstone are not yet available. The two populations of nonreservoir sandstone-porosity data (fig. 6) may represent sandstones from different geographic areas, depositional environments, or subsurface pressure regimes, or sandstones with different burial or cementation histories.

\section{RESERVOIR SANDSTONE}

The porosity- $\mathrm{R}_{\mathrm{o}}$ trend of Anadarko Basin reservoir sandstone follows a different pattern than the nonreservoir sandstone. The least-squares fit shows that the rate-of-porosity loss for reservoir sandstones is much slower than that of both nonreservoir sandstone of the central and southern Anadarko $\mathrm{R}_{\mathrm{o}}$, and that of sandstone in general (fig. 7). This relatively slow rate of porosity decline with increasing $R_{0}$ may reflect overpressuring, the inhibiting effects of early hydrocarbon emplacement, or even economic factors such as the bias inherent in the selection of sandstone hydrocarbon reservoirs.

As $R_{o}$ increases from low levels to about 1.1 percent, the porosity trends of Anadarko Basin reservoir and nonreservoir sandstone cross (fig. 7). As thermal maturity levels increase above about 1.1 percent $R_{o}$, however, the slopes of these porosity trends are similar; these similarities suggest that sandstone of the Anadarko Basin may retain sufficient porosity for economic accumulation of hydrocarbons, even at high thermal maturities. 


\section{RESERVOIR PROPERTIES OF CLASTIC RESERVOIRS IN THE UINTA, WIND RIVER, AND ANADARKO BASINS}

An understanding of pore structures and how they are formed and modified with increasing depth and burial history is useful for optimizing production in deep sedimentary basins. Effects of confining stress on pore geometry, as well as on porosity and permeability in clastic reservoirs at various depths can be investigated by mercury-injection porosimetry on samples under confining stress (Keighin, 1992). Nineteen samples from three basins (Uinta, Wind River, and Anadarko Basins, see fig. 1, table 3), from different depths, and with different diagenetic histories, were analyzed. The samples varied primarily in the relative abundance of quartz, feldspar, and rock fragments (table 3); carbonate cementation is locally prevalent.

Mercury-injection porosimetry is based on volume distribution measurement of pore throats; the method depends on forcing mercury into small voids (or pore throats) within the rock. Pore throats control access to larger voids (pores), because greater pressures are required to force mercury, or other nonwetting fluids, into smaller spaces (Purcell, 1949). Therefore, pore throats are bottlenecks in the system, and it is necessary to exceed their critical capillary pressure to inject mercury into pores. By injecting mercury at incrementally higher pressures, and allowing time for equilibration between pressure increments, mercury is injected into increasingly smaller pores. It is then possible to calculate the size distribution of pore throats, and to determine how pore-throat size is affected by increasing confining stress to approximate reservoir conditions, and how this affects permeability. Klinkenberg (1941) showed that, especially in low-permeability media, permeability to a gas is a function of the mean free path of the gas molecules.

Porosity and permeability of samples show a wide range of values, although porosity is typically less than 8 percent and Klinkenberg determined permeability to be below 0.1 millidarcies (md) for all samples examined (table 3). Plots of in-situ Klinkenberg permeability against in-situ helium porosity (fig. $8 A$ ) and standard air permeability (fig. $8 B$ ) show a general decrease in porosity and permeability with depth, but depth is not the only factor affecting the decrease of both. Nor is the decrease in porosity with
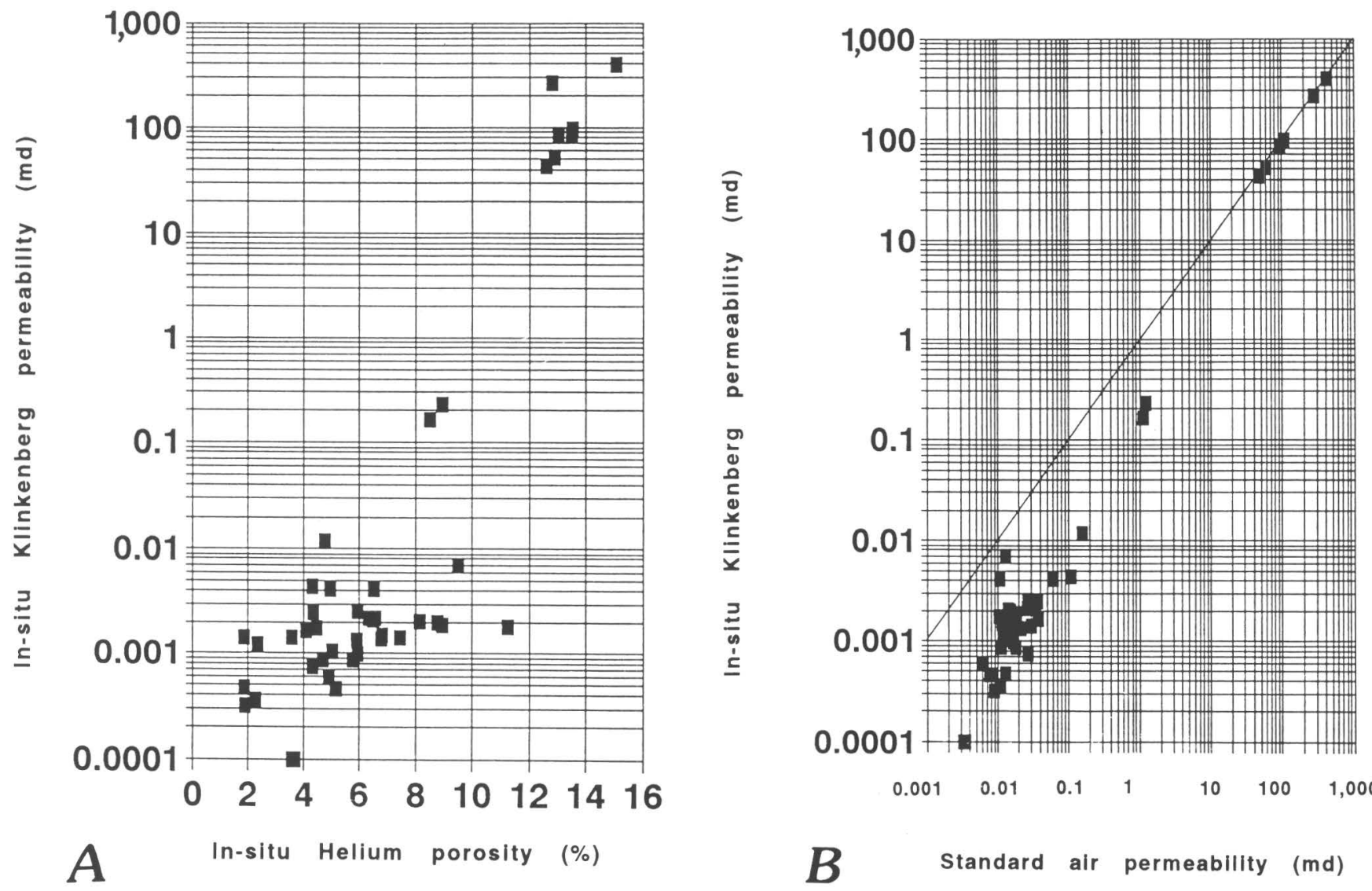

Figure 8. In-situ Klinkenberg permeability (md, millidarcies) versus in-situ helium porosity (\%, percent) and routine air permeability (md, millidarcies) for core samples from Anadarko, Uinta, and Wind River Basins. A, in-situ Klinkenberg permeability versus in situ helium porosity and $B$, in-situ Klinkenberg permeability versus routine air permeability. 
Table 3. Modal analyses of petrographic data, physical grain properties, and porosity and permeability of samples from Uinta, Wind River, and Anadarko Basins.

[-.-, zero or trace; ND, not determined]

\begin{tabular}{|c|c|c|c|c|c|c|c|c|c|c|c|c|c|}
\hline \multirow{2}{*}{ No. } & \multirow{2}{*}{ Sample } & \multirow{2}{*}{ Depth (ft) } & \multicolumn{3}{|c|}{$\begin{array}{l}\text { Modal analysis }{ }^{1} \\
\text { (volume percent) }\end{array}$} & \multicolumn{3}{|c|}{$\begin{array}{l}\text { Properties } \\
\text { (see below) }\end{array}$} & \multicolumn{2}{|c|}{$\frac{\text { Porosity }}{\text { (percent) }}$} & \multicolumn{2}{|c|}{$\frac{\text { Permeability }}{3}$} & \multirow{2}{*}{$\begin{array}{c}\text { Permeability } \\
\text { (percent) } \\
\text { (In-situ/Ambient) }\end{array}$} \\
\hline & & & $Q$ & $\mathrm{~F}$ & $\mathbf{R}$ & Size & Sort & Ang. & Helium $^{2}$ & Modal & Ambient & In-situ. & \\
\hline \multicolumn{14}{|c|}{ Uinta Basin, Utah } \\
\hline 1 & Ch $1-35$ & 11852 & 91.3 & 2.5 & 6.2 & 165 & 0.7 & 3.5 & 2.2 & 3.0 & 0.0065 & 0.0004 & 6.15 \\
\hline 2 & Ch $1-35$ & 11932 & 93.1 & 3.1 & 3.8 & 193 & 0.8 & 2.1 & 4.0 & 7.6 & 0.0165 & 0.0018 & 10.9 \\
\hline \multicolumn{14}{|c|}{ Anadarko Basin, Oklahoma } \\
\hline 3 & OK-1 & 18076 & 100.0 &.-- &.-- & 207 & 0.4 & 3.5 & 2.0 & 0.8 & 0.0050 & 0.0010 & 20.0 \\
\hline 4 & $\mathrm{OK}-2$ & 16078 & 98.1 & 0.8 & 1.1 & 148 & 0.4 & 2.9 & 4.9 & 8.5 & 0.0729 & 0.0078 & 10.69 \\
\hline 5 & $\mathrm{OK}-3$ & 11960 & 99.6 & 0.4 &.-- & 210 & 0.9 & 2.0 & 13.3 & 24.0 & 95.466 & 89.6 & 93.39 \\
\hline 6 & $\mathrm{OK}-4$ & 12072 & 100.0 &.- &.-- & 156 & 0.4 & 2.0 & 4.3 & 6.0 & 0.0477 & 0.0026 & 5.45 \\
\hline 7 & OK-5 & 16626 & 99.5 & 0.5 &.- & 140 & 1.0 & 2.5 & 8.8 & 10.8 & 0.5185 & 0.1975 & 38.09 \\
\hline 8 & OK-6 & 10161 & 98.7 & 0.9 & 0.4 & 166 & 0.5 & 3.6 & ND & 15.4 & ND & ND & ND \\
\hline 9 & OK-7 & 7096 & 91.4 & 1.0 & 7.6 & 321 & 0.4 & 3.8 & 14.0 & 25.0 & 343.75 & 330.20 & 96.06 \\
\hline 10 & $\mathrm{OK}-8$ & 7197.5 & 99.6 & 0.4 &.- & 209 & 1.7 & 3.8 & 12.8 & 22.0 & 50.75 & 47.65 & 93.89 \\
\hline 11 & OK-9 & 10378 & 98.7 & 0.65 & 0.65 & 101 & 1.5 & 0.6 & 9.6 & 4.8 & 0.0078 & 0.0032 & 41.03 \\
\hline \multicolumn{14}{|c|}{ Wind River Basin, Wyoming } \\
\hline 12 & WY-8 & 12097.5 & 85.5 & 2.0 & 12.5 & 317 & 0.7 & 1.5 & 6.5 & 12.2 & 0.0157 & 0.0022 & 14.01 \\
\hline 13 & WY-10 & 12111 & 85.2 & 0.5 & 14.3 & 162 & 0.5 & 1.5 & 8.2 & 9.5 & 0.0077 & 0.0017 & 22.07 \\
\hline 14 & WY-20 & 12709.4 & 75.8 & 2.4 & 21.8 & 255 & 0.8 & 2.0 & 5.5 & 6.1 & 0.0106 & 0.0012 & 10.85 \\
\hline 15 & WY-21 & 13483 & 60.4 & 3.9 & 35.7 & 330 & 1.0 & 1.8 & 5.9 & 5.7 & 0.0133 & 0.0010 & 7.52 \\
\hline 16 & WY-25 & 13517.3 & 69.7 & 4.3 & 26.0 & 226 & 1.2 & 1.2 & 3.7 & 4.1 & 0.0012 & 0.0001 & 8.33 \\
\hline 17 & WY-27 & 13527 & 77.8 & 3.9 & 18.3 & 317 & 0.8 & 1.5 & 5.2 & 3.3 & 0.0052 & 0.0005 & 9.62 \\
\hline 18 & WY-31 & 13602.5 & 80.0 & 10.9 & 18.3 & 397 & 0.5 & 2.1 & 4.7 & 4.9 & 0.0051 & 0.0011 & 21.57 \\
\hline 19 & WY-35 & 13631 & 62.1 & 15.9 & 22.0 & 272 & 0.5 & 2.2 & 6.7 & 7.2 & 0.0065 & 0.0024 & 36.92 \\
\hline
\end{tabular}

'Content of quartz (Q), feldspar (F), and rock fragments (R), normalized to 100 percent.

${ }^{2}$ In-situ values of helium porosity are listed.

${ }^{3}$ Permeability values, in millidarcies, were measured to correct for Klinkenberg effect; listed are averages of two or more determinations.

\begin{tabular}{|c|c|c|c|c|c|}
\hline \multicolumn{6}{|c|}{ Properties } \\
\hline \multicolumn{2}{|c|}{ Grain Size } & \multicolumn{2}{|c|}{ Sorting } & \multicolumn{2}{|c|}{ Angularity } \\
\hline Size (in m) & Wentworth size & Visual estimate & Degree of sorting & Class interval & Grade term \\
\hline $550-250$ & Medium sand & $0-0.35$ & Very well sorted & $2.0-3.0$ & Subangular \\
\hline $250-125$ & Fine sand & $0.35-0.5$ & Well sorted & $3.0-4.0$ & Subrounded \\
\hline \multirow[t]{2}{*}{$125-62.5$} & Very fine sand & $0.5-1.0$ & Moderately sorted & $4.0-5.0$ & Rounded \\
\hline & & $1.0-2.0$ & Poorly sorted & & \\
\hline
\end{tabular}

depth uniform. Examination of thin sections indicates that whereas compaction due to increasing burial depth appears to be a factor, the degree of compaction is greatly influenced by lithology, especially by the presence and quantity of labile rock fragments. Cementation, either by silica or carbonate minerals, reduces both porosity and permeability as well as significantly modifying pore structure.

The relative abundance of rock fragments may have a significant effect on both porosity (macro and micro) and permeability. Compression of labile rock fragments reduces intergranular porosity and creates intergranular pseudomatrix porosity; effective permeability is thus reduced. Partial dissolution of rock fragments commonly creates microporosity; micropores introduce micropore throats, which restrict fluid migration.

Confining stress has a varying effect on permeability. Plots of air-mercury capillary pressure versus wetting phase (that is, air) saturation, and pore-size frequency versus 
pore-throat diameter are plotted for four wells in figure 9. Data suggest that samples from King Stevenson No. 1 Anderson and Humble Patterson No. 1 (figs. 9A, 9B) wells from the Anadarko Basin are porous and have large visible pores. However, plots of pore-size frequency versus porethroat diameter for these wells, reveal that pore throats in these samples are most frequently in the $10 \mu \mathrm{m}$ or less range, which is significantly smaller than pores visible in thin section. Plots of air-mercury capillary pressure versus wetting-phase saturation for these samples show that pore throats are constricted by increased confining stress, although not as dramatically as in samples with lower initial porosity and permeability, and smaller measured pore throats. Data plotted for the Monsanto 1-35 Dolis well in the Wind River Basin (fig. 9C) and the Kerr McGee No. 1 Tentanque well (fig. 9D) in the Anadarko Basin indicate that for samples more typically fitting the tight sandstone designation, pore throats are more typically in the less than $0.1 \mu \mathrm{m}$ size range, and that these already small pores are further reduced by confining stress. Accordingly, even though pores visible in thin section may be relatively large, all pores must be accessed through pore throats, which are smaller (often much smaller) than the pores themselves. The data also suggest that pore throats, rather than stressrelief microfractures, are closed with increasing confining stress. Variations in the size and distribution of pore throats may be important factors in controlling reservoir quality in deep natural-gas reservoirs.

\section{SEQUENTIAL LARAMIDE DEFORMATION OF THE ROCKY MOUNTAIN FORELAND- IMPLICATIONS FOR DEEP NATURAL-GAS RESOURCES}

The structural setting and trapping mechanisms of deep natural-gas accumulations in different sedimentary basins in the Rocky Mountain region can be used as models from which to compare the structural characteristics of other deep basins (Perry, 1989; 1992; Perry and others, 1992). Also, the timing and structural style of Rocky Mountain Basins can be used to determine the evolution of deformation and to establish the timing of natural-gas entrapment.

A southeastward progression of major uplift and consequent basin development in the Rocky Mountain foreland began in extreme southwestern Montana during Cenomanian and Turonian time with the Blacktail-Snowcrest uplift (figs. 10, 11). The Late Cretaceous eastward progradation of the Laramide deformation front reached the Colorado Front Range (central Colorado, fig. 11) by $69 \mathrm{Ma}$. Subsequent Laramide deformation spread northeastward from the Granite Mountains-Shirley Mountains uplift in south-central Wyoming; the Laramide deformation front reached the
Black Hills by late Paleocene time. The Laramide first created the Wind River and then the Powder River Basins, and later it partitioned these basins from an earlier continuous foreland basin with minor welts (figs. 10, 11). These broad structural welts of low relief, such as the San Rafael swell in eastern Utah, had begun to grow in the Rocky Mountain foreland by mid-Cretaceous time.

South of the large-scale east-west crustal discontinuity along the Wyoming-Colorado border, which separates Archean basement rocks on the north from Proterozoic basement rock to the south, Laramide deformation proceeded from east to west; it culminated along and defined the eastern boundary of the Colorado Plateau during the late Eocene (fig. 11).

Economic implications of this new model of deformation of the Rocky Mountain foreland include progressive

Figure 9. Capillary pressure (psia, pounds per square in of air) versus wetting-phase (air) saturation (\%, percent) and poresize distribution ( $\mu \mathrm{m}$, micrometers) for samples at ambient temperature and pressure and under in-situ stress conditions. Measurements under ambient conditions are represented by rectangles; in situ measurements represented by triangles. The values of porosity and permeability which follow are in-situ values. $A$, Anadarko Basin, sample OK-8; porosity, 12.8 percent; permeability, $47.65 \mathrm{md}$. Shape and configuration of the capillary pressure versus saturation curve indicate that mercury entered pores at relatively low pressure, and essentially complete saturation occurred at approximately 7,000 psia. Although the larger pores are approximately $50 \times 100 \mu \mathrm{m}$, measured pore-size distribution shows the majority of pore throats to be smaller than approximately $15 \mu \mathrm{m}$. $B$, Anadarko Basin, sample OK-3; porosity, 13.3 percent; permeability, $89.6 \mathrm{md}$. Measured porosity and visible pores suggest properties very similar to those of sample OK-8. The capillary pressure vs. saturation curve indicates that more pore throats are being constricted by application of confining stress. The pore-size distribution curves reveal a slightly higher proportion of larger pores (although still in the $20 \mu \mathrm{m}$ size range) in this sample compared to OK-8; pore throats under confining stress are typically smaller than $15 \mu \mathrm{m}$. C, Wind River Basin, sample WY-21; porosity, 5.9 percent; permeability, $0.0010 \mathrm{md}$. Capillary pressure versus saturation curves show that mercury saturation of pore space is not accomplished, even at 10,000 psia, and that entry into pores is significantly restricted with increasing confining stress. Pore-size distribution curves reveal that unconfined pore throats are typically smaller than approximately $1 \mu \mathrm{m}$; when under confining stress, pore throats are reduced significantly in size and are typically less than $0.05 \mu \mathrm{m}$. $D$, Anadarko Basin, sample OK-1; porosity, 2.0 percent; permeability, $0.0010 \mathrm{md}$. Physical appearance of the sample suggests very low porosity and permeability (due, at least in part, to compaction and cementation by carbonate and silica overgrows). Examination of the thin section illustrated in Keighin (1992) suggests that the "thin-film" intergranular pores may be 1 to $2 \mu \mathrm{m}$ across. Pore-size distribution curves, however, show that pore throats are most often $<0.2 \mu \mathrm{m}$ (unconfined) to 0.04-0.1 $\mu \mathrm{m}$ (confined). See Keighin (1992) for sample and well location data. 


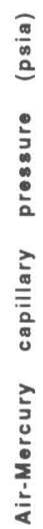

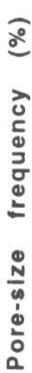

A

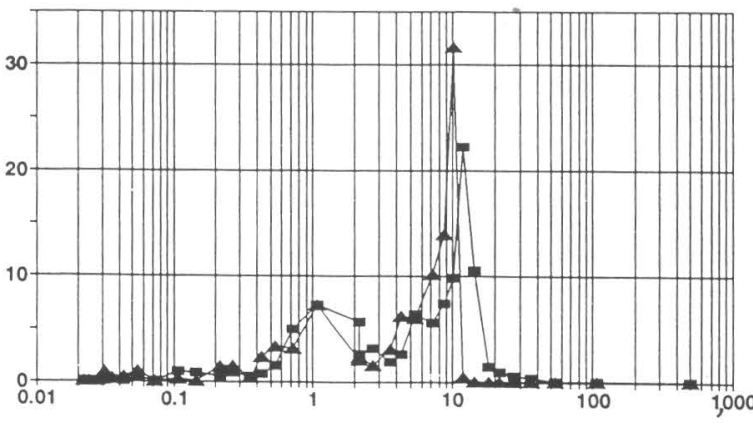

Pore-throat dlameter $(\mu \mathrm{m})$

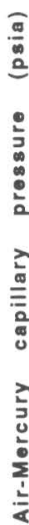

웅

0
0
0
$\frac{0}{0}$
0
0
0
2
$\frac{N}{40}$
0
$\vdots$
0
0

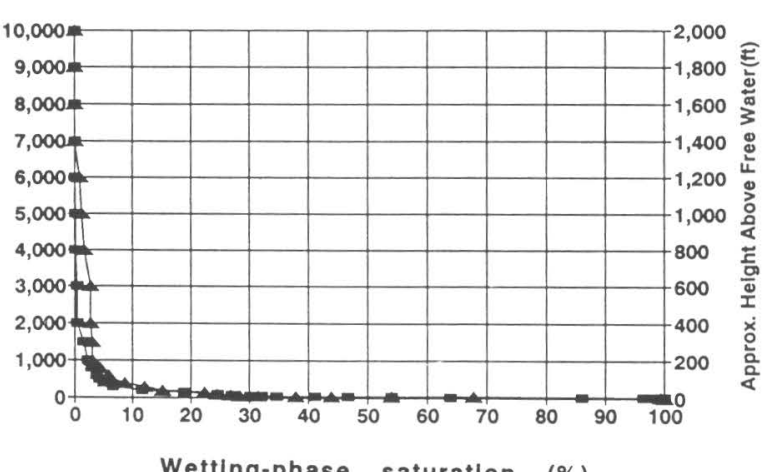

Wetting-phase saturation (\%)

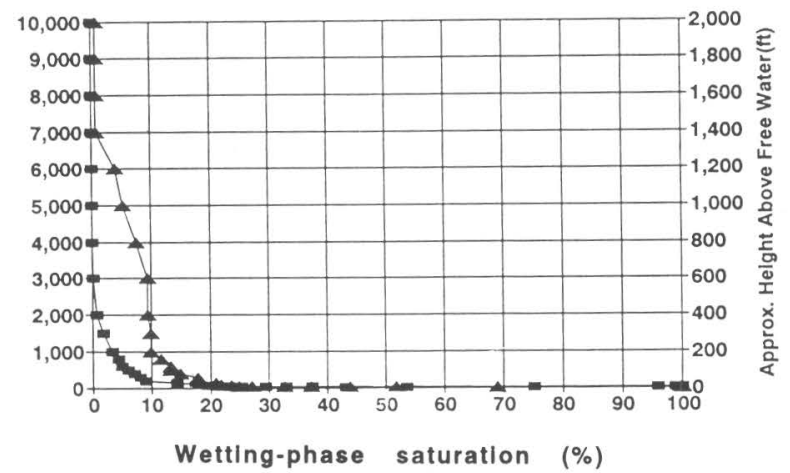

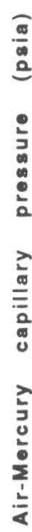

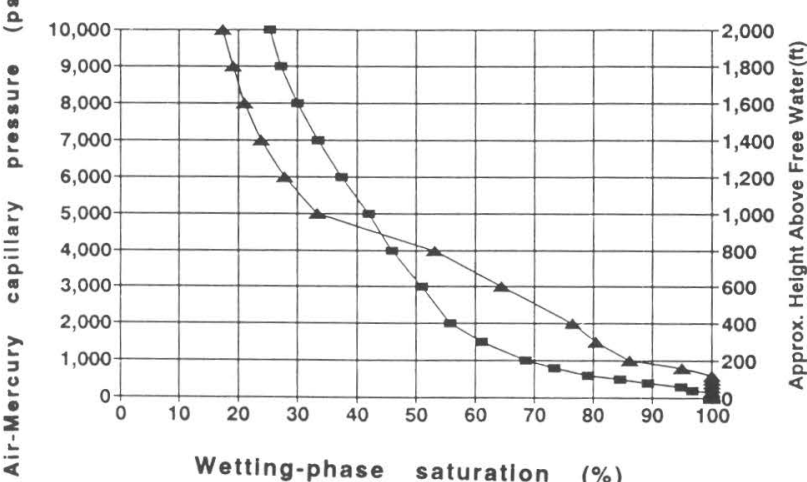

(\%)

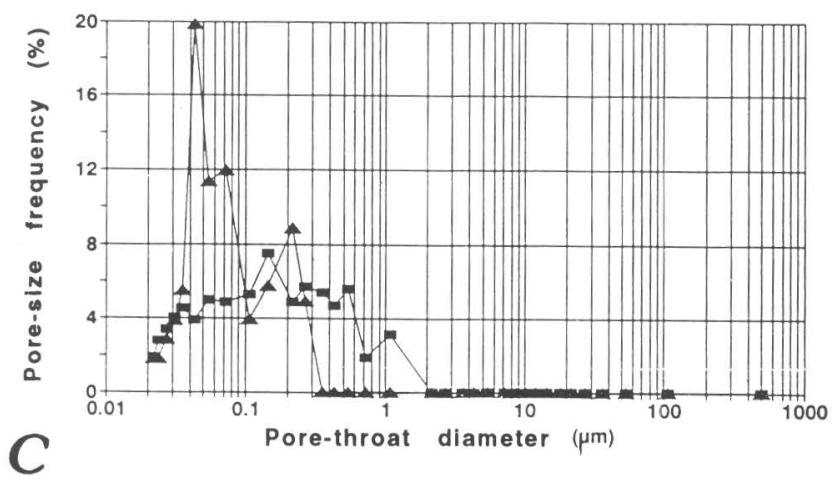

$\stackrel{\frac{\sigma}{\infty}}{\stackrel{0}{0}}$
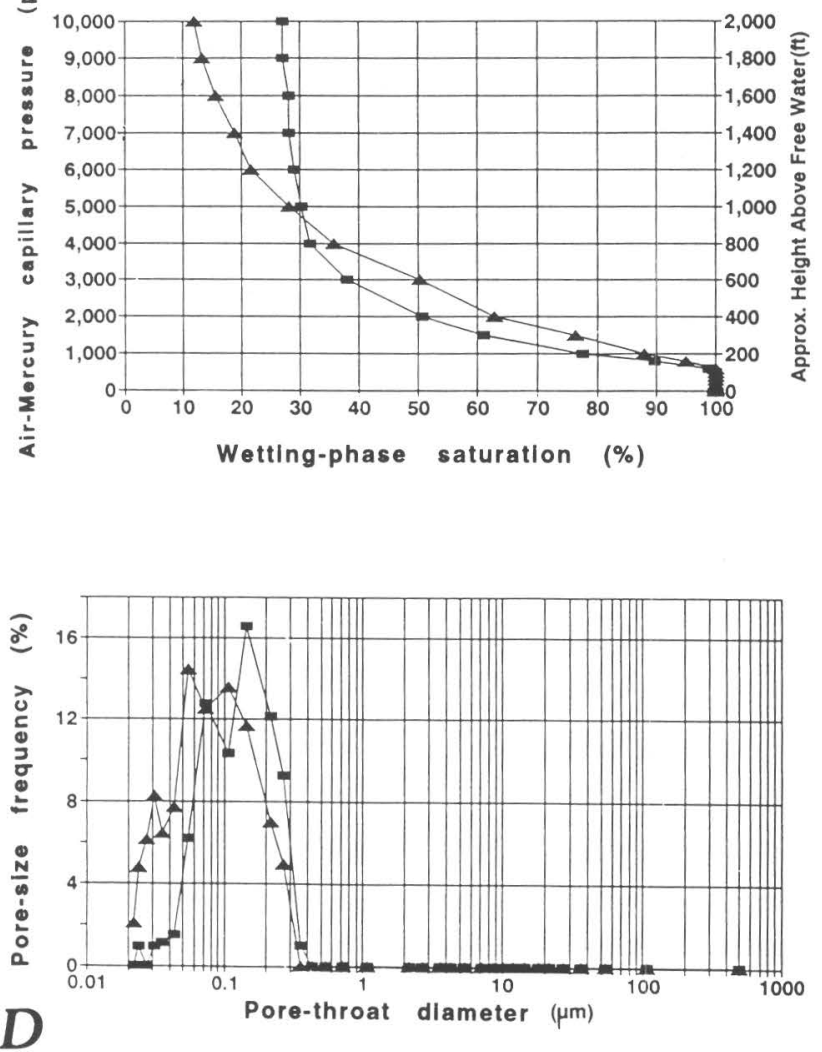
opening and subsequent blockage of migration paths for hydrocarbons generated from source rocks in southeastern Idaho, southwestern Montana, Wyoming, Colorado, and eastern Utah. Regional and basinwide exploration models for deep natural gas should consider trapping mechanisms in light of this deformation model.

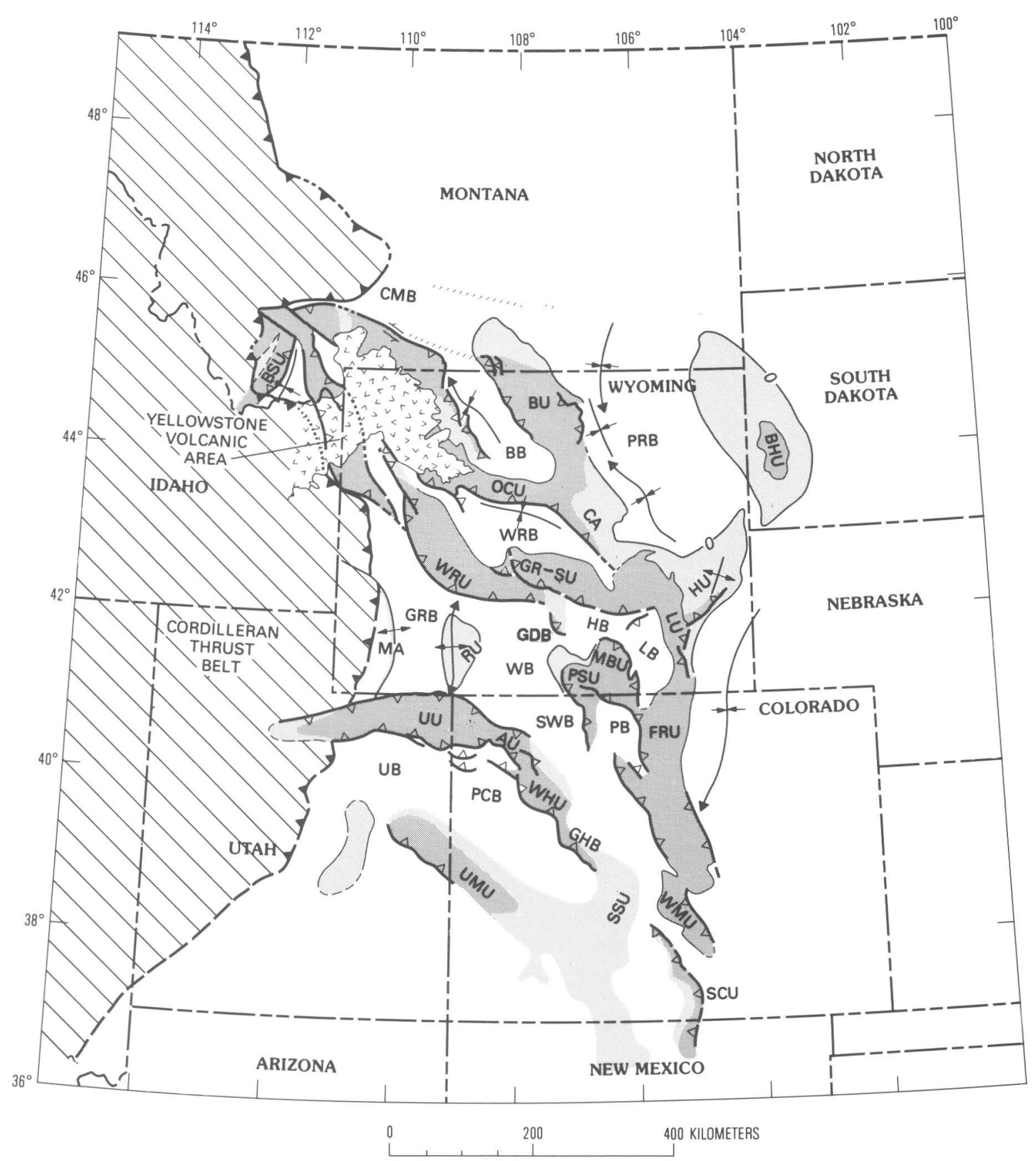

Figure 10. Rocky Mountain foreland province showing principal Laramide basins and uplifts. AU, Axial Uplift; BB, Bighorn Basin; BHU, Black Hills Uplift; BSU, Blacktail-Snowcrest Uplift; BU, Bighorn Uplift; CA, Casper Arch; CMB, Crazy Mountains Basin; FRU, Front Range Uplift; GHB, Grand Hogback Uplift; GRB, Green River Basin; GR-SU, Granite Mountains-Shirley Mountains (Sweetwater) Uplift; HB, Hanna Basin; HU, Hartville Uplift; LB, Laramie Basin; LU, Laramie Uplift; MA, Moxa Arch; MBU, Medicine Bow Uplift;
OCU, Owl Creek Uplift; PB, North and Middle Parks Basin; PCB, Piceance Creek Basin; PRB, Powder River Basin; PSU, Park-Sierra Madre Uplift; RAU, Rawlins Uplift; RU, Rock Springs Uplift; SCU, Sangre de Cristo Uplift; SSU, Sawatch-San Luis Uplift; SWB, Sand Wash Basin; UB, Uinta Basin; UMU, Uncompagre Uplift; UU, Uinta Mountains Uplift; WB, Washakie Basin; WHU, White River Uplift; WMU, Wet Mountains Uplift; WRB, Wind River Basin, and WRU, Wind River Uplift. Modified from Bayley and Muehlberger (1968). 


\section{POTENTIAL FOR DEEP NATURAL GAS IN THE HANNA BASIN-A CASE STUDY}

Source-rock and structural data can be used effectively to identify the deep natural-gas potential of the Hanna Basin in southern Wyoming (Perry, 1992). The Hanna Basin (fig. 12) contains more than 30,000 feet (about $9,150 \mathrm{~m}$ ) of Phanerozoic sedimentary rock of which more than 15,000 feet (about 4,600 m) is Upper Cretaceous and predominantly of marine origin. Less than 2,500 feet $(760 \mathrm{~m})$ of pre-Cretaceous Phanerozoic sedimentary rocks is present. Latest Cretaceous(?) and Paleocene nonmarine rock (the Ferris and Hanna Formations) is more than 14,000 feet (about $4,300 \mathrm{~m}$ ) thick.

The basin contains numerous horizons of Late Cretaceous(?) to Paleocene coals (Glass, 1975; Glass and Roberts, 1984). Analyses of pollen samples from these coals indicate that virtually the entire 8,150 -feet $(2,480 \mathrm{~m})$-thick coal-bearing section is Paleocene in age (D.J. Nichols in Perry, 1992). The nonmarine formations penetrated are gas prone, and shallow equivalent rocks are being exploited for coalbed methane.

Vitrinite samples were analyzed from the Hanna Unit No. 1 well (figs. 12, 13). The well was completed as a dry hole to a total depth of 12,496 feet $(3,809 \mathrm{~m})$ within the Paleocene part of the Ferris Formation. Vitrinite reflectance $\left(R_{0}\right)$ values rose rapidly to 1.23 percent near the bottom of the hole (Ben Law, unpub. data, U.S. Geological Survey). Because of these high reflectance values, the more deeply buried marine Cretaceous rocks should have generated thermogenic natural gas. However, only one small gas field has been developed on the northwestern flank of the basin.

\section{EXPLANATION}

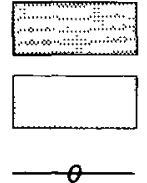

Area of major uplift

Area of subdued uplift

Sea-level contour at surface of Precambrian basement

$\longrightarrow$ Arch axis-Showing dircction of plunge

$\longrightarrow$ Syncline or basin axis-Showing direction of plunge

Foreland thrust-fault zone-Sawteeth on upthrown block; dashed where approximately located; dotted where inferred

F_n Front of Cordilleran thrust belt-Sawteeth on upthrown block; dashed where approximately located; dotled where inferred

"rrese, Left-slip fault zone-Obscured by younger cover

Figure 10. Contınued.
The Hanna Basin is surrounded by Laramide thrust faults, which are imprecisely dated. The coal-bearing nonmarine Hanna and Ferris Formations may represent the time of maximum thrust-related subsidence. Also, the northern margin of the Hanna Basin may represent the locus of a zone of latest Cretaceous to Paleocene strikeslip faulting. It may be the northern boundary of the zone of Colorado Front Range-Laramie Range Laramide shortening.

The sequence of three structural events are interpreted for the Hanna Basin region. First, the east-west trending Hanna trough sequence of thick marine Upper Cretaceous sediment developed across southern Wyoming. Second, the Hanna Basin was partially isolated as a subarea of the Greater Green River Basin by early Paleocene growth of the Granite Mountains-Shirley Mountains transpressive zone to the north. Third, southward tilting probably occurred during middle Paleocene time concurrent with growth of the Sweetwater Uplift and initial development of the Shirley Thrust Fault along the northern margin of the basin. The last phase of structural growth, uplift of the Medicine Bow Mountains and Rawlins Uplift, concurrent with development of the Arlington Thrust, appears to have been initiated in late Paleocene time. The geometry of the northern margin of the basin (figs. 12, 13) suggests the possibility of large gas fields in the undrilled northern part of the basin beneath the Shirley Thrust provided gas generation continued during and after thrusting. Published seismic data (Kaplan and Skeen, 1985) do not adequately define the structure of the northern margin of the Hanna Basin.

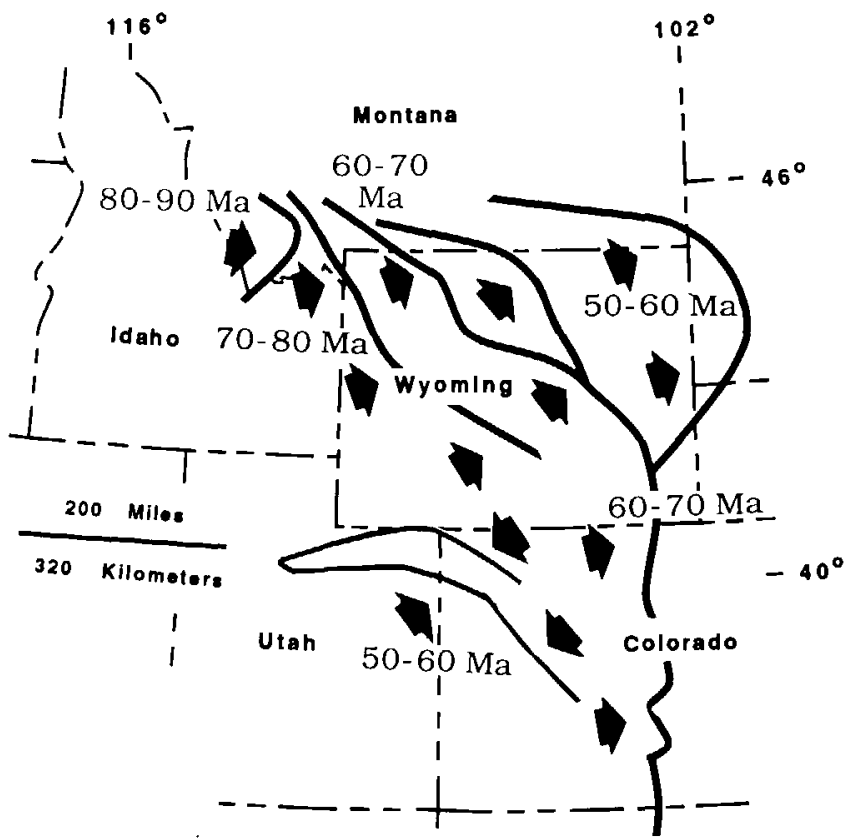

Figure 11. Sequence of inception of Laramide deformation in millions of years before present (Ma). Arrows represent migration of Laramide deformation front. 
If the scenario described herein is correct, many deep accumulations of natural gas remain to be found in Rocky Mountain Basins. Because of the high vitrinite reflectance values at depths of greater than 10,000 feet $(3,040 \mathrm{~m})$ in the Hanna Basin, deeper Cretaceous rocks should also yield natural gas.

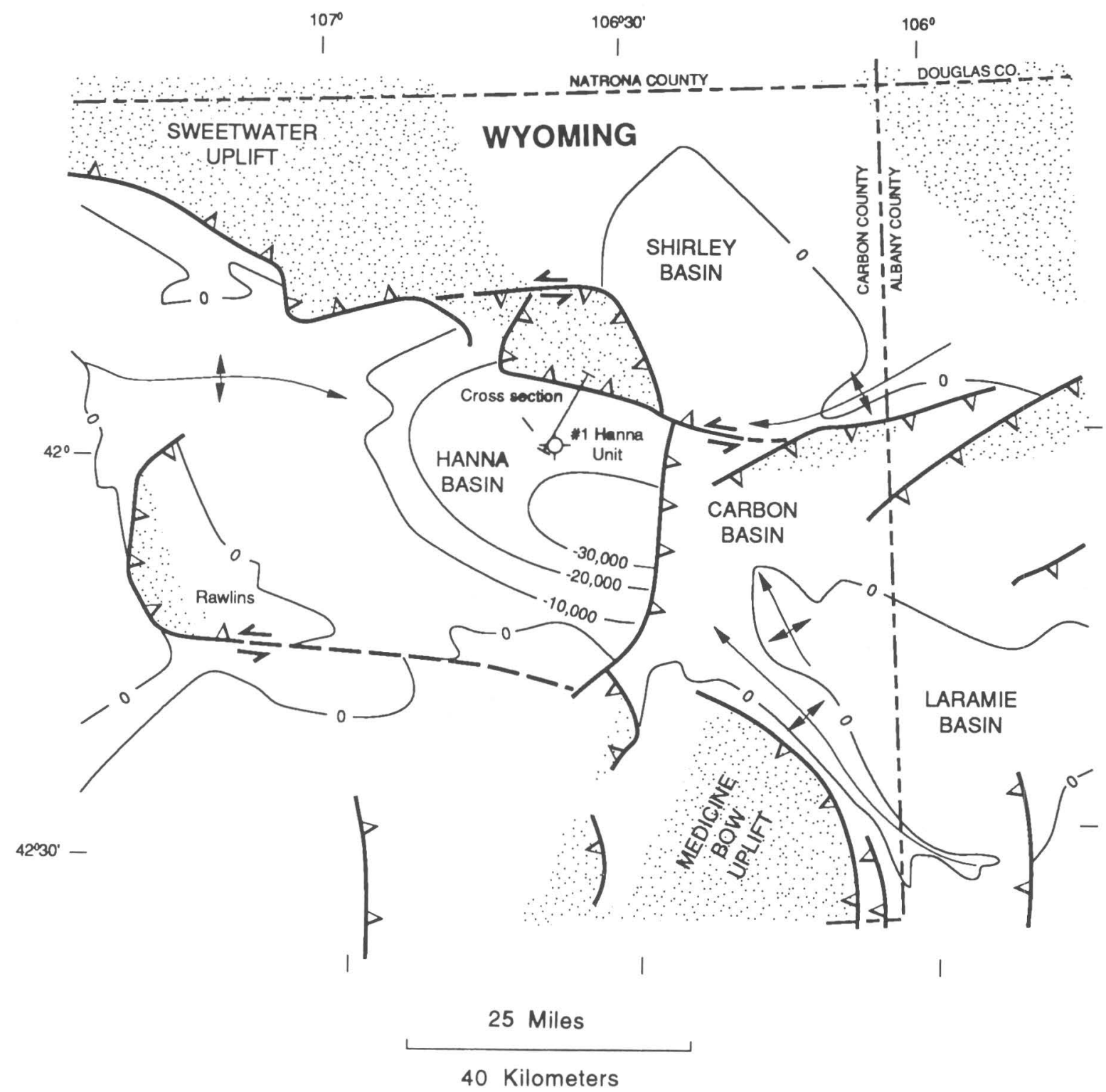

EXPLANATION

$\begin{gathered}\text { Sea-level contour at surface of Precambrian } \\ \text { basement }\end{gathered}$
Arch axis-Showing direction of plunge
$\begin{gathered}\text { Foreland thrust-fault zone-Sawteeth on upthrown } \\ \text { block; dashed where approximately located; } \\ \text { arrows show relative motion }\end{gathered}$

Figure 12. Tectonic map of the Hanna Basin region, Wyoming (modified from Blackstone, 1990), showing location of Hanna Unit No. 1 well and cross section (fig. 13). Stippled pattern shows areas of structurally elevated Precambrian basement significantly above sea level. 


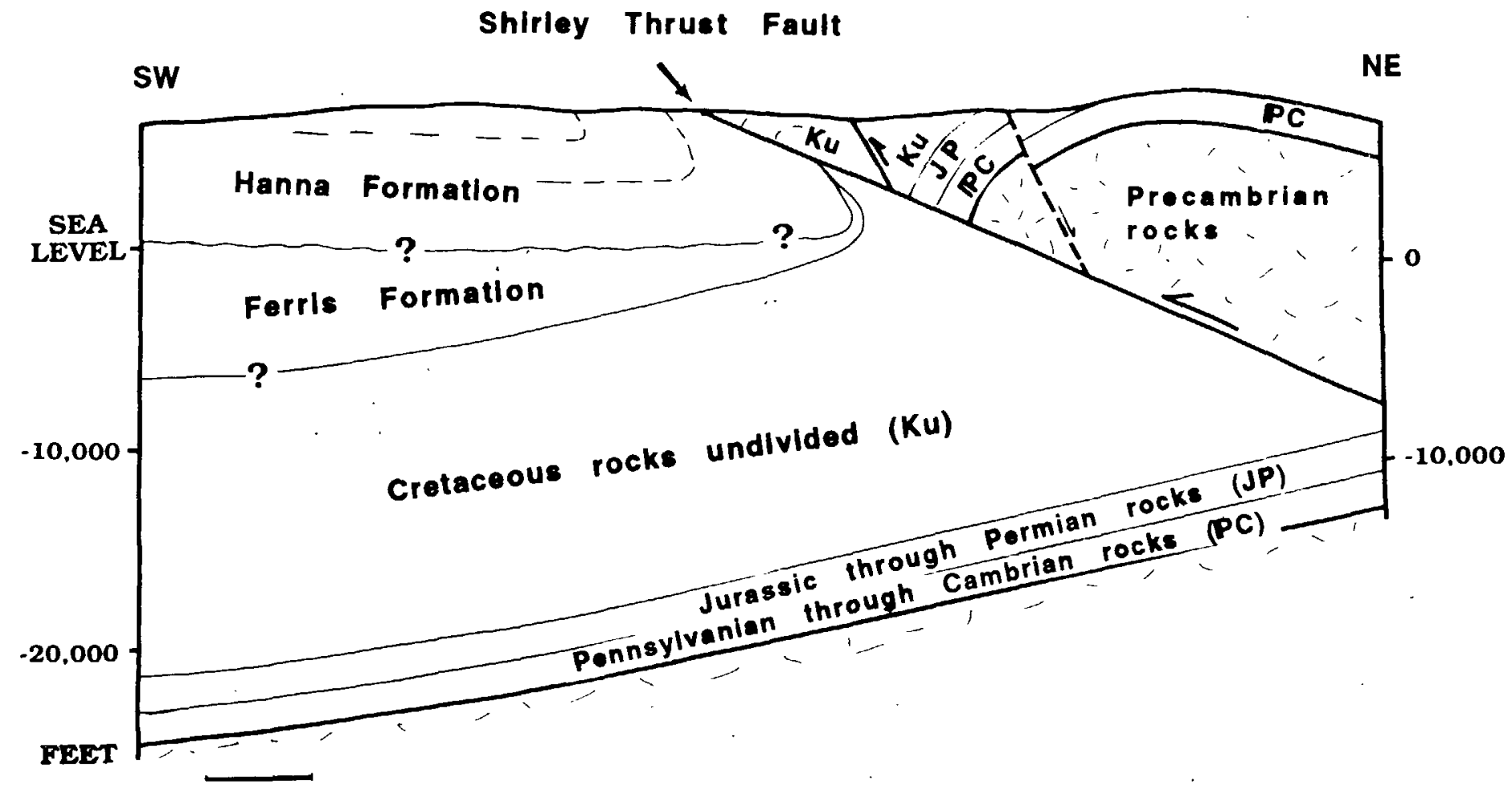

1 Mile $=1.6$ Kilometers

Figure 13. Diagrammatic cross-section through the northern part of the Hanna Basin, Wyoming (line of cross section shown in fig. 12). Modified from Blackstone, 1983.

\section{SOURCE-ROCK POTENTIAL OF PRECAMBRIAN ROCKS IN SELECTED BASINS}

Proterozoic rocks are widely distributed in the United States and commonly occur in the deeper parts of many sedimentary basins. Their petroleum source-rock potential, however, is poorly known (Palacas, 1992). The reason for assigning petroleum potential to Precambrian rocks in the United States is influenced by the actual production of commercial oil and gas derived from Precambrian rocks in other parts of the world such as in Russia, China, and Oman. Two regions of the United States, the Midcontinent Rift System and the Grand Canyon area of northern Arizona can be evaluated for their source-rock potential from Proterozoic rocks.

\section{MIDCONTINENT RIFT SYSTEM}

Middle Proterozoic rock of the Midcontinent Rift System define strong gravimetric and magnetic anomalies. The 940-mile-long (1,570-km) Midcontinent Rift System is a failed rift characterized by a series of asymmetric ba- sins filled with clastic rock, in places as thick as 32,000 feet (about 9,750 m). The Midcontinent Rift System is conveniently divided into four geographically identifiable segments: Lake Superior, Minnesota, Iowa, and Kansas (fig. 14).

\section{LAKE SUPERIOR SEGMENT}

The potential for petroleum reserves in the Midcontinent Rift System has long been recognized because of the active crude-oil seeps emanating from the approximately 1.1 billion-year-old Nonesuch Formation near the White Pine Mine in Minnesota. In this segment, the Nonesuch Formation consists of interbedded dark gray to green sandstone, siltstone, and silty shale with poor source-rock potential. However, for silty shale that occurs in thin intervals, total organic carbon (TOC) content ranges from 0.25 to 2.8 percent (table 4 ). Should thicker sections of this hydrocarbon-generating shale be present downdip from the outcrop belt and be subjected to higher levels of thermal maturation (but still within the wet gas to dry gas window; Rice, 1989), the gas source-rock potential for the Lake Superior segment and adjoining areas in northern Wisconsin may be considered good. 


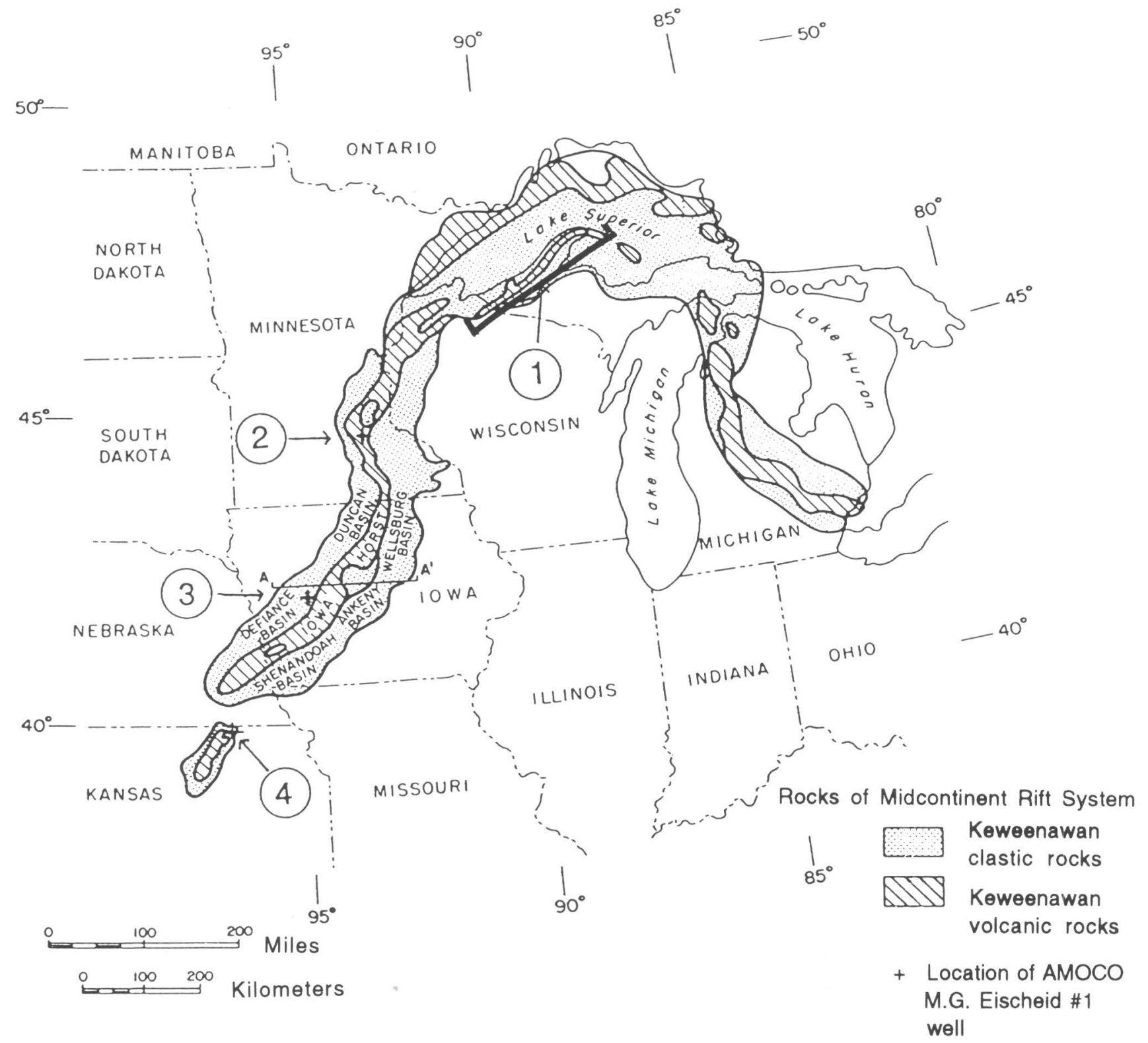

Figure 14. Location and major rock types of the Midcontinent Rift System and the location of the four sites in which potential Precambrian source rocks were studied. 1, Lake Superior segment outcrop belt (bracketed); 2, Minnesota segment, Lonsdale 65-1 well, Rice County; 3, Iowa segment, Amoco Eisc-

\section{MINNESOTA SEGMENT}

The source rock potential of the Minnesota segment of the Midcontinent Rift System is evaluated from examination of Precambrian Solor Church Formation as sampled in the Lonsdale 65-1 well, Rice County, Minnesota (fig. 14). The formation consists principally of interbedded conglomerate, sandstone, siltstone, and shale or mudstone. Analyses of core samples, mainly from the bottom 20 percent of the core, show TOC content ranging from 0.01 to heid No. 1 well, Carroll County; 4, Kansas segment, Texaco Poersch No. 1, Washington County, and Producers Engineering Finn No. 1, Marshall County (modified from Palacas, 1992). Line of cross-section $\mathrm{A}-\mathrm{A}^{\prime}$ shown from Palacas and others, 1990.

1.77 percent and averaging 0.24 percent; the TOC content indicates an overall poor source-rock potential for oil or gas for the entire formation (table 4). A very low average genetic potential $\left(\mathrm{S}_{1}+\mathrm{S}_{2}\right)$ is largely attributed to the advanced level of thermal maturation. On the basis of maturity evaluations for basins worldwide, Solor Church organic matter at the Lonsdale 65-1 locality has advanced to the transition stage between the wet gas and dry gas generating zones (table 4). Therefore, the natural gas source-rock potential of the Precambrian Solor Church 
Table 4. Summary of possible Precambrian hydrocarbon source rocks in the Midcontinent Rift System and Grand Canyon area of northern Arizona.

[TOC. total organic carbon; $T_{\max }$, maximum temperature]

\begin{tabular}{|c|c|c|c|c|c|}
\hline \multirow{2}{*}{ Location } & \multirow{2}{*}{ Stratigraphic unit } & \multicolumn{2}{|c|}{ TOC (weight percent) } & \multirow{2}{*}{$\mathrm{T}_{\max }\left({ }^{\circ} \mathrm{C}\right)$} & \multirow{2}{*}{ Maturity level } \\
\hline & & Range & Average & & \\
\hline \multicolumn{6}{|c|}{ Midcontinent Rift System } \\
\hline Lake Superior segment --- & Nonesuch Formation & $0.25-2.8$ & 0.6 & $418-427$ & $\begin{array}{l}\text { Marginally mature to } \\
\text { mature. }\end{array}$ \\
\hline Minnesota segment ----.... & $\begin{array}{l}\text { Solor Church Formation } \\
\text { (mudstones). }\end{array}$ & $0.13-1.77$ & 0.4 & 494 & Overmature. \\
\hline Iowa segment - & $\begin{array}{l}\text { Nonesuch Formation } \\
\text { equivalent (dark } \\
\text { shales). }\end{array}$ & $0.1-1.4$ & 0.6 & $497-508$ & Overmature. \\
\hline $\begin{array}{l}\text { Kansas segment } \\
\text { (Producers } \\
\text { Engineering Finn } \\
\text { No. } 1 \text { well). }\end{array}$ & $\begin{array}{l}\text { Keweenawan } \\
\text { (undifferentiated } \\
\text { siltstones). }\end{array}$ & $0.1-0.8$ & 0.6 & $445-450$ & Mature. \\
\hline \multicolumn{6}{|c|}{ Grand Canyon area, Northern Arizona } \\
\hline Eastern Grand Canyon---- & $\begin{array}{l}\text { Walcott Member of } \\
\text { Kwagunt Formation } \\
\text { of Chuar Group (dark } \\
\text { mudstones). }\end{array}$ & $1.0-9.0$ & $\sim 3.0$ & $424-452$ & Mature. \\
\hline
\end{tabular}

Formation, near the Lonsdale well and presumably in the neighboring areas, is poor.

\section{IOWA SEGMENT}

The hydrocarbon source-rock assessment of the Iowa segment of the Midcontinent Rift System was made from the thickest part $(14,898$ feet or 4,541 m) of the Precambrian sequence. Assessment is based on analyses of core and cuttings samples from the 17,851-feet-deep $(5,441-\mathrm{m})$ Amoco M.G. Eischeid No. 1 well, drilled in 1987 in an asymmetric half-graben-like basin northwest of the Iowa horst, Carroll County, Iowa (Palacas and others, 1990; Schmoker and Palacas, 1990; fig. 14). Most of the Precambrian sedimentary rock, composed of red and redbrown sandstone, siltstone, and silty shale, is oxidized and has no source-rock potential. Between 15,000 feet (about $4,600 \mathrm{~m})$ and 16,425 feet $(5,006 \mathrm{~m})$, however, 200 to 300 feet $(60$ to $90 \mathrm{~m})$ of gray to black, pyrite-bearing, organicrich laminated shale is present. This sequence may be equivalent to the Nonesuch Formation of the Lake Superior region. Maximum temperature $\left(T_{\max }\right)$ from Rock Eval analyses strongly indicates that the shales are thermally overmature and in the transitional zone between wet gas and dry gas, similar to the findings for the Solor Church Formation in southeastern Minnesota (table 4). The laminated shales have little remaining capacity for hydrocar- bon generation but may have generated significant amounts of gas in the geologic past. Equivalent laminated shale facies, as those observed in the Eischeid well, might have fair to good hydrocarbon source-rock potential if present at shallower depths of burial, under lower levels of thermal stress, along basin flanks, away from the frontal fault zone of the medial horst.

\section{KANSAS SEGMENT}

The Kansas segment of the Midcontinent Rift System was evaluated on the basis of well cuttings from two boreholes in northeastern Kansas: the Texaco Poersch No. 1 well and the Producers Engineering Finn No. 1 well (fig. 14). Samples from the two wells exhibit remarkably different lithologies; this difference probably indicates different structural, stratigraphic, and (or) depositional regimes. Hence, the two sections of rock may belong to two different subbasins. Geophysical and borehole data indicate that the Midcontinent Rift in northeastern Kansas is divided into small subbasins that probably are only a few tens of square miles in extent.

The Poersch well, drilled to a total depth of 11,300 feet $(3,440 \mathrm{~m})$, penetrated 2,846 feet $(867 \mathrm{~m})$ of Phanerozoic rock and 8,454 feet $(2,580 \mathrm{~m})$ of Precambrian (Keweenawan) rock, the latter of which is composed of nearly equal successions of highly oxidized arkosic 
sandstone and siltstone and mafic volcanic and intrusive rock. Organic matter was not identified in any of the oxidized sedimentary rock.

The Producers Engineering Finn No. 1 well showed some minor gas source potential in a $300-\mathrm{ft}(91-\mathrm{m})$ section of gray siltstone directly beneath the Precambrian-Phanerozoic boundary unconformity. Thermal maturity values contrasted dramatically with the much higher maturity values observed in the Minnesota and Iowa segments of the Midcontinent Rift System, but they demonstrate some gas source-rock potential (table 4). Because of the structural complexity and abrupt facies changes, individual subbasins need to be examined before complete source-rock evaluation can be made of the Kansas part of the rift system.

\section{GRAND CANYON AREA, NORTHERN ARIZONA}

The Late Proterozoic Chuar Group is exposed in the eastern part of the Grand Canyon (fig. 15). It is composed of a 5,370-feet-thick $(1,640$-m) succession of predominantly very fine grained siliciclastic rock that contains thin units of sandstone and stromatolitic and cryptalgal carbonate rock. More than half the succession consists of organic-rich gray to black mudstone and siltstone.

Geochemical analyses indicate that the 922-feet-thick (280-m-thick) Walcott Member, the uppermost unit of the Kwagunt Formation (fig. 15), has good to excellent petroleum source-rock potential. The lower half of the Walcott is characterized by TOC contents of as much as 8 to 10 percent (averaging approximately 3 percent, table 4), hydrogen indices of as much as 204 milligrams hydrocarbon per gram of rock $(\mathrm{mgHC} / \mathrm{g})$, genetic potentials $\left(\mathrm{S}_{1}+\mathrm{S}_{2}\right)$ of nearly $16,000 \mathrm{ppm}$, and extractable organic matter of as much as 4,000 ppm. Preliminary data for the upper Walcott suggest that these rocks are as rich or richer than the lower Walcott. Maturity assessment indicates that source rocks of the Walcott are within the oil generation window.

Strata of the underlying thermally mature Awatubi Member of the Kwagunt Formation and the thermally mature to overmature Galeros Formation are, in general, rated * as poor oil sources with genetic potentials generally less than 1,000 ppm, but they appear to be acceptable to good source rocks for gas generation.

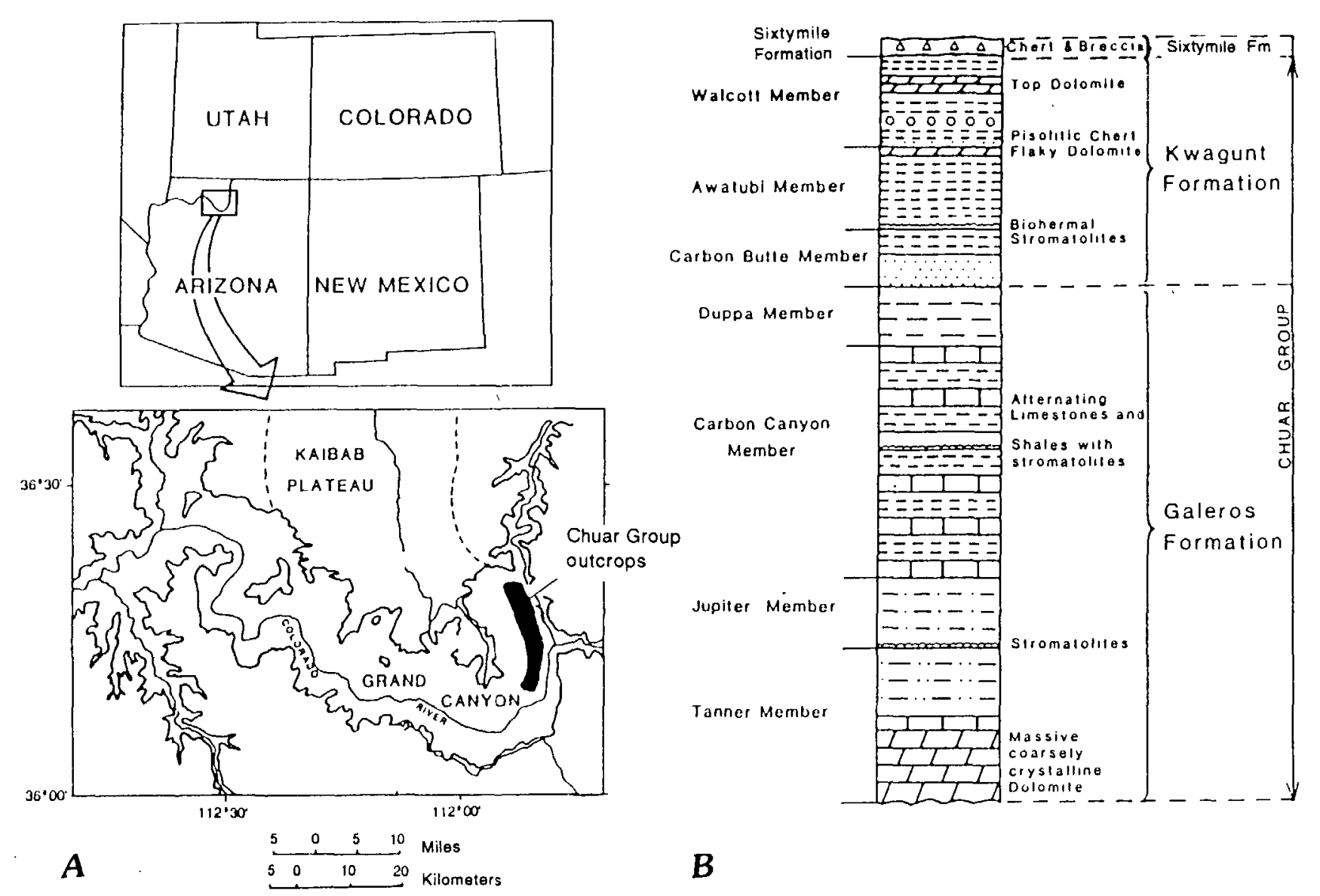

Figure 15. Map and section of eastern Grand Canyon, northern Arizona. A, Map showing eastern Grand Canyon in northern Arizona. Sampling area shown by solid black pattern, $B$, Simplified geologic section of the Precambrian Chuar Group. (Modified from Vidal and Ford, 1985.) 
Chuar Group strata may be potential sources for economic accumulations of gas and oil in upper Proterozoic or lower Paleozoic reservoir rocks in northwest Arizona and Utah. The relative proportion of gas or oil in any one area will depend in large part upon the degree of thermal maturation.

\section{C $_{15+}$ HYDROCARBON THERMAL DESTRUCTION AND HIGH-RANK DEEP BASIN NATURAL-GAS ACCUMULATIONS}

Thermal maturation models are questionable by predicting that $\mathrm{C}_{15+}$ hydrocarbons are thermally destroyed when $R_{0}$ values exceed 1.35 percent and that $C_{2}-C_{4}$ hydrocarbons are destroyed when $R_{0}$ values exceed 2.00 percent. Thermal destruction of $\mathrm{C}_{15+}$ hydrocarbons at temperatures corresponding to $R_{0}=1.35$ percent also would seem to contradict physical-chemical principles, because of the extreme bond strengths ( 82.6 to 117 kilocalories/ mole), which must be broken for hydrocarbon destruction. Data from Price (1992) indicate that $C_{15+}$ hydrocarbons may be thermally stable at $R_{o}$ values from 7.0 to 8.0 percent in the natural system, dependent on several variables in deep petroleum basins. The $\mathrm{C}_{2}-\mathrm{C}_{4}$ hydrocarbons are probably thermally stable well into greenschist metamorphism, and methane may persist to mantle conditions.

Evidence for significant thermal stability of $\mathrm{C}_{15+}$ hydrocarbons comes from a large petroleum-geochemical data base (Price, 1992), part of which is shown in tables 5 and 6. These data demonstrate that high to moderate concentrations of indigenous $\mathrm{C}_{15+}$ hydrocarbons and bitumen persist in deeply buried rocks at present-day $R_{0}$ values of 1.35 to 5.0 percent. Furthermore, moderate to low concentrations of $\mathrm{C}_{15+}$ hydrocarbons and bitumen persist in rocks with $\mathrm{R}_{0}$ values of 5.0 to 7.0 percent.

Qualitative analyses of bitumen from high-rank rocks ( $R_{0}$ of 2.0 to 7.6 percent), high-rank gases and gas conden- sates, and bitumen from aqueous-pyrolysis experiments in the hydrocarbon-thermal-destructive phase all provide significant insight into $\mathrm{C}_{15+}$ hydrocarbon thermal destruction. Characteristic carbon-isotopic and chemical assemblages occur both in hydrocarbon gases and $\mathrm{C}_{5+}$ hydrocarbons prior to, and during, $\mathrm{C}_{15+}$ hydrocarbon thermal destruction.

$\mathrm{C}_{15+}$ hydrocarbon thermal stability is controlled by organic matter (OM) metamorphism which includes all reactions involving the maturation of kerogen and the generation, maturation, and thermal destruction of methane, all $\mathrm{C}_{2+}$ hydrocarbons, and bitumen (Price, 1992). OM metamorphism is hypothesized to occur by a parallel series of first-order reactions and is thus controlled primarily by burial temperature and geologic. time. However, a large body of petroleum-geochemical data suggest that $O M$ metamorphic reactions are not first order but are higher ordered reactions. If this is the case, then geologic time would play little or no role in OM metamorphism. There are four controlling parameters, suggested by Price (1992), which have direct bearing on the genesis and persistence of deeply buried, high-rank gas accumulations. These are:

1. The absence or presence of water in the system is important because $\mathrm{C}_{15+}$ hydrocarbon thermal destruction is significantly promoted in water-barren systems and is suppressed in water-bearing systems.

2. Increasing fluid pressure suppresses all aspects of $\mathrm{OM}$ metamorphism, including $\mathrm{C}_{15+}$ hydrocarbon generation and thermal destruction.

3. Whether the reaction takes place in an open or closed system is also important, because a lack of product escape from reaction sites (closed systems) retards $\mathrm{OM}$ metamorphism, and product escape (open systems) promotes OM metamorphism.

4. Increasing temperature is the principal drive for $O M$ metamorphic reactions, which is in agreement with presentday petroleum-geochemical paradigms.

Oil and gas accumulations are zoned in many petroleum-bearing basins. Only dry gas is present in deep-basin

Table 5. Vitrinite reflectance $\left(R_{0}\right)$ for samples from selected wells extrapolated from vitrinite reflectance at well bottom.

[Extrapolation based on depth versus $R_{0}$ plots, all of which have correlation coefficients of less than 0.99 . Sediment age is range of rock ages penetrated in well bore]

\begin{tabular}{|c|c|c|c|c|c|}
\hline Well & Location & $\begin{array}{c}\text { Depth } \\
\text { (meters) }\end{array}$ & $\begin{array}{l}\text { Vitrinite reflectance } \\
\text { (percent) }\end{array}$ & Sediment age & Reference \\
\hline $\begin{array}{l}\text { Lone Star Bertha Rogers } \\
\text { No. } 1 .\end{array}$ & $\begin{array}{c}\text { Washita County, } \\
\text { Oklahoma. }\end{array}$ & $9,583.7$ & 8.0 & $\begin{array}{l}\text { Permian through } \\
\text { Cambrian. }\end{array}$ & Price and others (1981). \\
\hline Ralph-Lowe No. 1 -........ & $\begin{array}{l}\text { Pecos County, } \\
\text { Texas. }\end{array}$ & $8,686.4$ & 5.8 & $\begin{array}{l}\text { Permian through } \\
\text { Ordovician. }\end{array}$ & Price (1988). \\
\hline Shell McNair No. 1 --.--... & $\begin{array}{l}\text { Hinds County, } \\
\text { Mississippi. }\end{array}$ & $6,911.0$ & 2.8 & $\begin{array}{l}\text { Lower Tertiary through } \\
\text { Jurassic. }\end{array}$ & Price and others (1979). \\
\hline Chevron Jacobs No. 1 ------- & $\begin{array}{l}\text { Goliad County, } \\
\text { Texas. }\end{array}$ & $7,546.8$ & 7.5 & $\begin{array}{l}\text { Miocene through Lower } \\
\text { Cretaceous. }\end{array}$ & Price (1982). \\
\hline Pan Am Foester No. 1 ---.-- & $\begin{array}{l}\text { La Salle County, } \\
\text { Texas. }\end{array}$ & $6,703.7$ & 7.0 & $\begin{array}{l}\text { Lower Tertiary through } \\
\text { Jurassic. }\end{array}$ & $\begin{array}{l}\text { Price and Clayton } \\
\text { (1990). }\end{array}$ \\
\hline
\end{tabular}


Table 6. Vitrinite reflectance, bitumen and hydrocarbon content, and present day burial temperature for samples from selected wells in Texas and Oklahoma.

[NA, not available; ppm, parts per million; $\mathrm{mg} / \mathrm{gOC}$; milligrams per gram of organic carbon; TOC, total organic carbon (in percent). $\mathrm{C}_{15+}$ bitumen and $\mathrm{C}_{15+}$ hydrocarbons in ppm by rock weight and normalized to organic carbon: $S_{2}$ is the Rock Eval $S_{2}$ pyrolysis in ppm and mg/gOC, which is the hydrocarbon index (HI). Burial temperatures for the Foerster No. 1 well based on estimated geothermal gradient for LaSalle County, Texas of $\left.36.7^{\circ} / \mathrm{km}\right]$

\begin{tabular}{|c|c|c|c|c|c|c|c|c|c|c|}
\hline \multirow{2}{*}{ Depth (meters) } & \multirow{2}{*}{$\begin{array}{l}\text { Vitrinite } \\
\text { reflectance }\end{array}$} & \multicolumn{2}{|c|}{$\mathrm{C}_{15+}$ bitumen } & \multicolumn{3}{|c|}{$\mathrm{C}_{15+}$ hydrocarbons } & \multicolumn{2}{|c|}{$\mathrm{S}_{2}$} & \multirow{2}{*}{$\begin{array}{l}\text { Present day } \\
\text { burial temp. } \\
\quad\left({ }^{\circ} \mathrm{C}\right)\end{array}$} & \multirow{2}{*}{ Age } \\
\hline & & $\mathrm{ppm}$ & $\mathrm{mg} / \mathrm{gOC}$ & ppm & $\mathrm{mg} / \mathrm{gOC}$ & TOC & $\frac{\mathrm{HI}}{\mathrm{mg} / \mathrm{gOC}}$ & ppm & & \\
\hline \multicolumn{11}{|c|}{ Foerster No. } \\
\hline $4602-4724$ & 2.58 & 193 & 80.4 & 114 & 47.7 & 0.24 & $\mathrm{NA}$ & NA & 196 & Early Cretaceous. \\
\hline $4724-4846$ & 2.73 & 252 & 105 & 118 & 49.2 & 0.24 & NA & NA & 201 & Early Cretaceous. \\
\hline $4968-5151$ & 3.10 & 556 & 132 & 280 & 67.0 & 0.42 & NA & NA & 211 & Early Cretaceous. \\
\hline $5151-5334$ & 3.36 & 828 & 172 & 545 & 114 & 0.48 & NA & $\mathrm{NA}$ & 218 & Jurássic. \\
\hline $5334-5456$ & 3.60 & 740 & 154 & 476 & 99.1 & 0.48 & NA & NA & 224 & Jurassic. \\
\hline $5456-5578$ & 3.80 & 442 & 108 & 271 & 56.1 & 0.41 & NA & NA & 228 & Jurassic. \\
\hline $5761-5882$ & 4.37 & 467 & 31 & 165 & 10.8 & 1.51 & $\mathrm{NA}$ & NA & 238 & Jurassic. \\
\hline
\end{tabular}

Ralph Lowe No. 1

\begin{tabular}{|c|c|c|c|c|c|c|c|c|c|c|}
\hline $6026-6032^{1}$ & 3.08 & 358 & 26 & 179 & 13 & 1.39 & 7.0 & 94 & 187 & Pennsylvanian. \\
\hline $6629-6635^{1}$ & 3.20 & 500 & 37 & 332 & 25 & 1.34 & 0 & 0 & 204 & Pennsylvanian. \\
\hline $6882-6888^{1}$ & 3.38 & 451 & 14 & 251 & 8 & 3.08 & 0 & 0 & 211 & Pennsylvanian. \\
\hline $7080-7087$ & 3.57 & 1,410 & 41 & 1,030 & 30 & 3.46 & 9.2 & 306 & 216 & Mississippian. \\
\hline $7324-7330$ & 3.86 & 1,650 & 38 & 1,380 & 32 & 4.32 & 24.3 & 1,010 & 223 & Mississippian. \\
\hline $7391-7398$ & 3.93 & 3,590 & 151 & 1,610 & 68 & 2.87 & 127 & 2,550 & 225 & Mississippian. \\
\hline $7718-7724$ & 4.30 & 2,420 & 90 & NA & NA & 2.68 & 77.4 & 1,920 & 234 & Devonian. \\
\hline
\end{tabular}

\begin{tabular}{|c|c|c|c|c|c|c|c|c|c|c|}
\hline \multicolumn{11}{|c|}{ R.G. Jacobs No. 1} \\
\hline 6400.8 & 4.60 & 2,200 & 176 & NA & NA & 1.25 & NA & NA & : 254 & Early Cretaceous. \\
\hline 6401.7 & 4.60 & 1,400 & 303 & 1,100 & 239 & 0.46 & 100 & NA & 254 & Early Cretaceous. \\
\hline 6407.7 & 4.61 & 1,100 & 105 & NA & NA & 1.05 & NA & $\mathrm{NA}$ & 255 & Early Cretaceous. \\
\hline 6418.3 & 4.61 & 776 & 141 & 588 & 107 & 0.55 & 105 & $\mathrm{NA}$ & 255 & Early Cretaceous. \\
\hline 6698.7 & 5.22 & 1,800 & 367 & $\mathrm{NA}$ & NA & 0.49 & NA & $\mathrm{NA}$ & 265 & Early Cretaceous. \\
\hline 6705.8 & 5.22 & 805 & 267 & 590 & 174 & 0.34 & 85 & $\mathrm{NA}$ & 266 & Early Cretaceous. \\
\hline 6711.2 & 5.23 & 548 & 261 & 398 & 189 & 0.21 & 43 & NA & 266 & Early Cretaceous. \\
\hline 7000.0 & 5.95 & 200 & 74 & $\mathrm{NA}$ & NA & 0.27 & NA & $\mathrm{NA}$ & 276 & Early Cretaceous. \\
\hline 7005.7 & 5.95 & 483 & 172 & 365 & 130 & 0.28 & NA & $\mathrm{NA}$ & 276 & Early Cretaceous. \\
\hline 7297.7 & 6.80 & 1,025 & 214 & 844 & 176 & 0.48 & 110 & $\mathrm{NA}$ & 286 & Early Cretaceous. \\
\hline 7313.8 & 6.81 & 230 & 74 & 153 & 49.0 & 0.31 & 39 & $\mathrm{NA}$ & 288 & Early Cretaceous. \\
\hline 7539.1 & 7.50 & 165 & 72 & 104 & 45.0 & 0.23 & 37 & $\mathrm{NA}$ & 296 & Early Cretaceous. \\
\hline 7544.6 & 7.51 & 129 . & 64 & 65 & 32.5 & 0.20 & 44 & $\mathrm{NA}$ & 296 & Early Cretaceous. \\
\hline \multicolumn{11}{|c|}{ Bertha Rogers No. 1} \\
\hline $8357-8378$ & 5.20 & 306 & 278 & 140 & 145 & 0.11 & NA & $\mathrm{NA}$ & 224 & Mississippian. \\
\hline $8442-8470$ & 5.30 & 3,010 & 84 & 1,450 & 60 & 3.59 & NA & $\mathrm{NA}$ & 226 & $\begin{array}{l}\text { Mississippian to } \\
\text { Devonian. }\end{array}$ \\
\hline $8558-8723$ & 5.70 & 389 & 162 & 252 & 134 & 0.24 & NA & $\mathrm{NA}$ & 230 & Devonian. \\
\hline
\end{tabular}

reservoirs and increasing amounts of oil are present at shallower depths in many basins. Also, both American Petroleum Institute (API) gravity and gas-oil ratios of oil accumulations decrease at shallower depths on the basin shelves removed from the deep basin. However, the persistence of $\mathrm{C}_{15+}$ hydrocarbons to great depths ( 7 to $10 \mathrm{~km}$ ) and extreme maturation ranks ( $R_{0}$ from 5.0 to 7.0 percent) in fine-grained rocks in petroleum basins and methane carbon-isotopic compositions in the Anadarko basin both suggest that most deep-basin methane has been generated from kerogen during all stages of the $\mathrm{C}_{15+}$ hydrocarbon generative phase (Price, 1992). The basin zonation of hydrocar- 
bons probably results from condensation, buoyancy, and separation-migration processes. In deep basins, only methane remains in the gas phase owing to high fluid pressures. The $\mathrm{C}_{2}-\mathrm{C}_{4}$ hydrocarbon gases are condensed into, and behave as liquids. With continued $\mathrm{C}_{15+}$ hydrocarbon and methane generation from deep-basin sediment, deep-basin traps accumulate more and more methane and eventually are filled to the spill point with methane. Methane is more prevalent at depth because all other fluids (crude oil, condensed $\mathrm{C}_{2} \cdot \mathrm{C}_{4}$ hydrocarbon gases, and water) are displaced out of deep-basin traps, by methane, to shallower traps on the stable shelves of petroleum basins. This displacement is due to Gussow's (1954) "Principle of Differentiated Entrapment," which states that buoyancy differences exist between the different fluids in petroleum basins and methane, being the most buoyant, is found on top of, and thus displaces, all other fluids in traps.

Evidence exists that all water may have been flushed (displaced) from some deep-basin traps by methane. Both carbon dioxide and hydrogen sulfide are found in abundance in some deep-basin gas reservoirs and have existed in those reservoirs for tens to hundreds of millions of years since emplacement. Because those gases are highly soluble in water, their presence dictates that water is not in contact with such gas reservoirs. The absence of water in some deep-basin gas reservoirs carries implications for the deep-basin gas-resource base. There are two important implications. First, hydrocarbon thermal cracking reactions will be promoted in these water-free environments. Second, when water is introduced into such reservoirs during drilling and completion operations, reservoir damage may occur in the area around the well bore from the principles of two-phase fluid flow and the Jamin effect (discussed below). Such reservoir damage could greatly harm localized gas extraction, which could lead to an underestimation of the recoverability and economic viability of deep-basin gas-resource bases and the condemnation of individual wells.

The principles of two-phase flow (fig. 16) state that where two immiscible fluid phases (here water and gas) coexist in the same matrix porosity, both fluids have critical fluid saturation levels that must be exceeded before the solid has permeability with respect to either fluid. If the concentration of fluid under consideration is less than its critical fluid saturation level, the solid will have no permeability with respect to that fluid, which cannot move through the solid. If the concentrations of both fluids exceed their respective critical fluid saturation levels, then both fluids can move through the solid. However, their relative permeabilities will be greatly reduced with respect to what their permeabilities would be if one fluid were in the solid alone (fig. 16).

When two separate, immiscible fluid phases coexist in a rock, and one phase (water) is below its critical fluid saturation level, part of the water may be in the form of totally immobile spherical globules, which cannot be distorted, and which will occupy a percentage of connecting pore throats. This filling of connecting pore throats by immobile globules is called the Jamin effect. The globules decrease, or reduce to zero (stippled area, fig. 16), the permeability of the rock with respect to the other fluid phase (gas). Therefore, the introduction of water to a water-free, dry-gas, deep-basin reservoir can greatly damage reservoir productivity immediately around the well bore, as a result of the Jamin effect.

Most deep-basin gas accumulations probably originated from methane generation, which accompanies $\mathrm{C}_{15+}$ hydrocarbon generation, combined with condensationbuoyancy-separation-migration processes, which flush all fluids, other than methane, from deep-basin traps. However, carbon isotopic values of methane and carbon dioxide in some deep-basin gas accumulations indicate that highrank dry-gas accumulations, which originated from $\mathrm{C}_{15+}$ hydrocarbon thermal destruction, do exist. Such accumulations appear to be unusual, however.

Primary gas migration from the source rock, like primary oil migration, is very inefficient (Price, 1992). However, primary gas migration is greatly facilitated by large-scale faulting (with accompanying large-scale

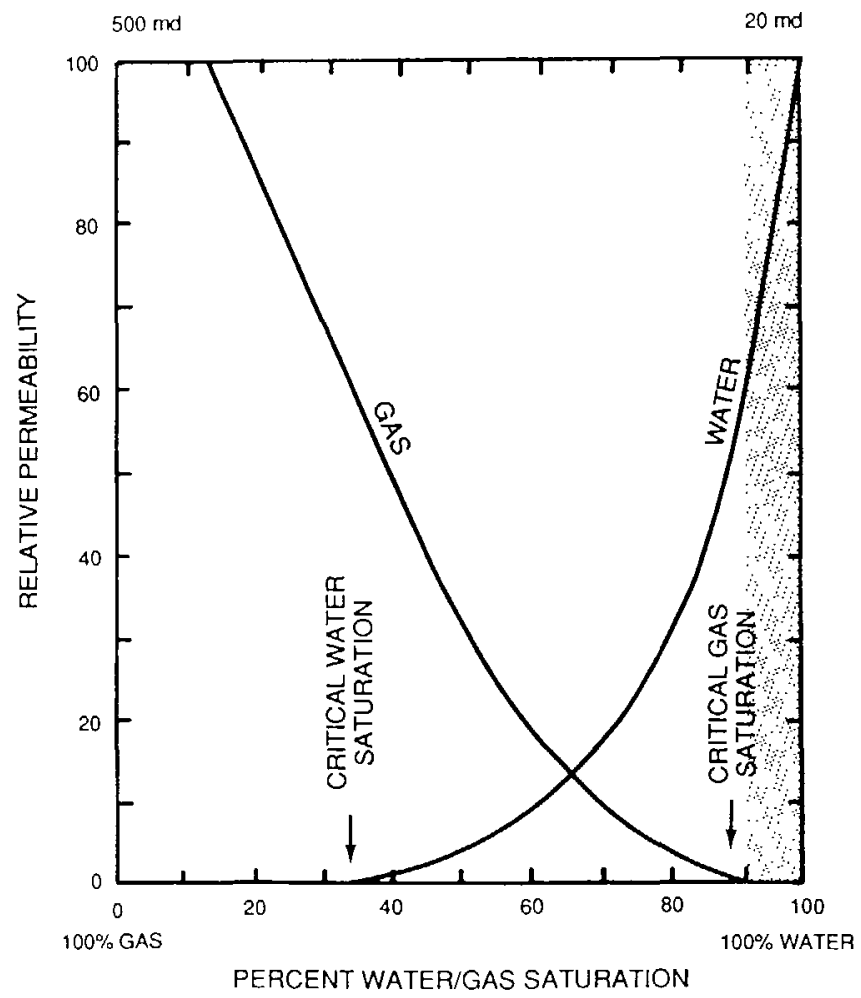

Figure 16. Idealized plot of relative permeabilities of gas and water. Stippled area is range of gas concentrations (below critical gas-saturation level for water) where Jamin effect can reduce or destroy relative permeability of rock with respect to water. md, millidarcies. 
fracturing). Such faulting disrupts source rocks (and the rocks adjacent to them) to allow gas to escape in significant volumes. Thus, conventional deep-basin dry-gas accumulations should have a strong correlation to significant deepbasin faults. Evidence suggests that deep basins may be largely closed systems with respect to fluid flow. Consequently, much of the natural gas generated in deep basins has probably been retained, resulting in larger and higher grade deep-basin gas-resource bases than previously estimated.

\section{MIGRATION OF LARGE VOLUMES OF HYDROCARBON AND NONHYDROCARBON GASES FROM THE DEEP CRUST: COMPOSITION, FLUX, AND TECTONIC SETTING}

Nonhydrocarbon gases such as carbon dioxide, hydrogen sulfide, and nitrogen, can dilute deep natural gas and contribute to the destruction of it (Burruss, 1992). Gas compositions in deep reservoirs can be compared to the compositions of gases generated in the deep crust. First, compositional similarities between the gases in the two crustal regimes can be identified. Second, evidence for volumetric fluxes of nonhydrocarbon and hydrocarbon gases in metamorphic rocks presently exposed at the surface can be used to estimate the potential flux of gases from great depths to shallow crustal levels accessible to the drill. Third, identification of crustal environments (tectonic and metamorphic terranes) that generate significant quantities of gas can be coupled with analysis of basin structural style and setting to identify basins where deep crustal sources may have contributed to the hydrocarbon resource base.

Analyses of trends in gas composition versus depth and reservoir lithology were performed on available gas data in the NRG Associates field file for 120 U.S. reservoirs at depths of 14,000 feet (about 4,300 m) or greater (NRG Associates Inc., 1991). When the fraction of total nonhydrocarbon gases is plotted as a function of reservoir temperature (to eliminate significant variations in geothermal gradient) two trends became apparent (fig. 17). One trend, of gradually increasing nonhydrocarbon gases with depth up to about 10 percent, is common to both carbonate and sandstone reservoirs from all basins. This trend is due to fluid-rock interactions involving organic matter and the dissolution and reprecipitation of carbonate cements. A second trend, of rapidly increasing nonhydrocarbon gas with depth is present in a small number of reservoirs, all but two of which are in carbonate rocks. The second trend is present in carbonate reservoirs of the Permian Basin (Ordovician Ellenberger Group) and carbonate and sandstone reservoirs in the Jurassic Smackover and Norphlet Formations of the
Gulf Coast. Although the dominant nonhydrocarbon gases in these reservoirs is carbon dioxide, hydrogen sulfide is also present (as much as 25 percent). The occurrence of high concentrations of nonhydrocarbon gases in carbonate reservoirs and the presence of hydrogen sulfide indicate that thermochemical sulfate reduction and simultaneous oxidation of hydrocarbons to carbon dioxide may be the dominant control on gas composition in these deep reservoirs.

Most of the evidence for the composition of fluids in the deep crust comes from observations on fluid inclusions in metamorphic and igneous rocks. Metasedimentary rocks, which contain graphitic carbon and carbonate minerals can act as a source of such carbon-bearing gas components as methane and carbon dioxide (Burruss, 1992; this volume). An additional source of information on fluids in crustal rocks is fluid inclusions in quartz veins associated with ore bodies. Recent information from ore deposits is important because it records the flux of fluids from deep to shallower levels of the crust and provides a basis for quantitative estimates of the flux of gases to shallow crustal levels.

The trends in nonhydrocarbon content of natural gases shown in figure 17 can be extended to deeper crustal levels by including data from fluid inclusions in rocks of known depth of burial. Figure 18 shows the data of figure 17 together with fluid-inclusion compositions in metamorphic rocks from three different terranes. Individual localities may show a significant range in composition, but even the highest temperature rocks still contain some methane and the compositions tend to lie along the extension of the dominant trend for sedimentary basins. Clearly,

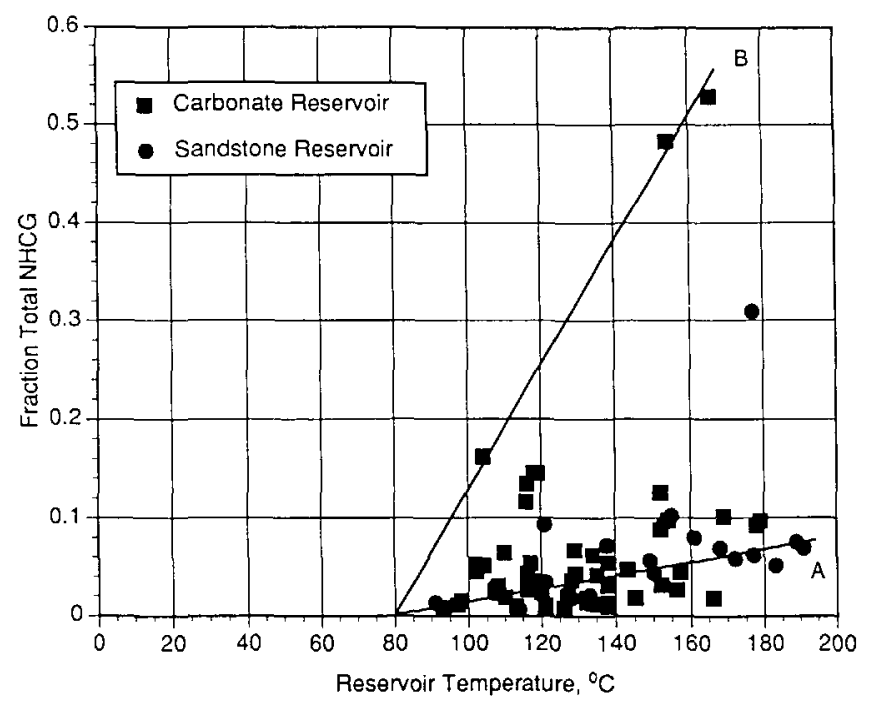

Figure 17. Fraction of total nonhydrocarbon gases (NHCG), as $\left(\mathrm{N}_{2}+\mathrm{CO}_{2}+\mathrm{H}_{2} \mathrm{~S}+\mathrm{He}\right) /($ Sum of all gases) versus reservoir temperature for all production data available in the NRG Associates field file (NRG Associates, 1991) from depths greater than $14,000 \mathrm{ft}$ $(4,300 \mathrm{~m})$. Fields separated by sandstone- and carbonate-reservoir lithologies. Lines $A$ and $B$ define general trends in the data and are not mathematical fits to the data. 
the "early burnout" of hydrocarbon gases predicted from the trend of rapidly increasing nonhydrocarbon gases, for carbonate reservoirs, does not occur in all crustal rocks. Work on a siliceous marble that equilibrated at $800^{\circ} \mathrm{C}$ documents the occurrence of about one mole percent methane in carbon dioxide at this temperature-this evidence indicates that methane is stable to great depths in the crust.

Metamorphic rocks that contain more than about 10 mole percent methane in fluid inclusions tend to be graphite bearing. The compositions of the inclusions are generally consistent with calculated compositions of aqueous fluids in equilibrium with graphite, especially when the possibility of hydrogen diffusion from inclusions is considered. This observation plus the textural evidence for precipitation of graphite from fluids clearly documents the generation and migration of methane- and carbon dioxide-bearing fluids in the deep crust. It also suggests that identification of geologic environments where carbon-rich sediments have been incorporated into metamorphic rocks will help define areas where there is the greatest probability of deep crustal gas sources that contribute to shallower natural-gas resources.

Estimates of the flux of gases from the deep crust are based on the measured solubility of quartz in water as a function of temperature, pressure, and salinity, which can be translated into a quantity of quartz precipitated per vol-

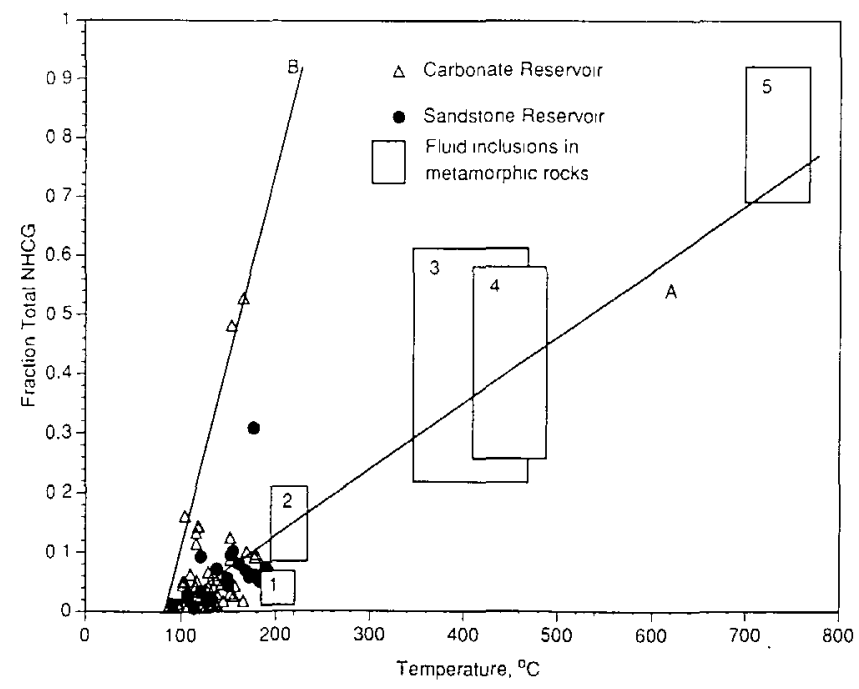

Figure 18. Data from figure 17 plotted over a wider range of composition and subsurface temperature for comparison with composition of fluid inclusions in metamorphic rocks. Numbered boxes define the range of temperature and composition of inclusions from five sample localities. Boxes 1 and 2, anthracite belt of the Valley-and-Ridge province, Pennsylvania, United States (Kisch and van den Kerkhof, 1991); Boxes 3 and 4, retrograded rocks in the granulites of Rogaland, Norway (van den Kerkhof, and others, 1991); Box 5, prograde granulite rocks of Khtada Lake, British Columbia, Canada (Hollister and Burruss, 1976; Burruss, 1977). Lines A and B are approximate extensions of same lines in figure 17. NHCG, nonhydrocarbon gases. ume of water in a vein system at a given depth. From the volume of quartz veins that can be measured in the field, the volume of water necessary to form the vein system can be estimated. The ratio of hydrocarbon and nonhydrocarbon gases to water can be determined from fluid-inclusion measurements. Therefore, we can estimate the volume of gases transported with the water needed to form quartz veins at depth in a given tectonic setting.

Studies have documented the geochemical processes and tectonic setting of the formation of "giant quartz-vein systems," which in many cases contain gold (Kerrick and Feng, 1992). In one giant vein system, an estimated $6 \times 10^{18} \mathrm{~g}\left(6 \times 10^{3} \mathrm{~km}^{3}\right)$ of aqueous fluid deposited about $6 \times 10^{15} \mathrm{~g}$ of quartz and, in the process, transported $3 \times 10^{15} \mathrm{~g}$ of carbon dioxide. This is equivalent to $1,500 \mathrm{Tcf}$ of carbon dioxide. On the basis of the range of methane/ carbon dioxide ratios observed in fluid inclusions in quartz from one of these giant vein systems (1:3 to 1:40), a single vein system may transport from 50 to $500 \mathrm{Tcf}$ of methane to shallow crustal levels. Twelve giant vein systems have been documented in the Canadian, European, and Australian shields (Kerrick and Feng, 1992).

Giant quartz-vein systems are an important component of any assessment of deep crustal sources of hydrocarbon and nonhydrocarbon gases for several reasons. First, quartz veins are direct evidence of focused flow of fluids from deep to shallow crustal levels. Second, the systems are present at convergent plate margins, especially those associated with transpressive tectonic regimes, a geologic environment with large hydrocarbon accumulations. Giant vein systems may be the best evidence to support earlier suggestions of natural-gas accumulations in accretionary terranes. On the negative side, convergent, transpressive tectonic regimes tend to have a component of vertical tectonism, which can lead to erosional exhumation and loss of potential reservoir rocks.

\section{RESOURCE ASSESSMENT METHODOLOGIES FOR DEEP NATURAL-GAS ACCUMULATIONS}

Quantitative resource assessment methods and models of undiscovered deep natural-gas resources can be developed in association with geologic studies of deep sedimentary basins (Dolton and Crovelli, 1992).

\section{METHODOLOGIES FOR DEEP NATURAL-GAS RESOURCES}

Review and analysis of resource appraisal methodologies and approaches allows methods for dealing with deep gas accumulations to be identified. These methods are 
ultimately dependent upon the level of geologic and engineering data available and understanding of the geologic model for the specific deep-gas accumulation. One or more may be appropriate in a given case, and multiple approaches are desirable as independent checks. The methods, which appear most appropriate to assessment of undiscovered resources of deep gas, are (1) deposit simulation, (2) reservoir performance, (3) analog, (4) discovery process and finding rate models, (5) mass-balance calculations, and (6) volumetric and areal yield determinations.

Geologic information in our companion studies indicates that many deep gas accumulations should be treated at a play level (Mast and others, 1989; Dolton and Crovelli, 1992). Furthermore, they should be analyzed by a method that will provide information on the size of the accumulations and their geologic characteristics, as well as a total resource value, so that economic and supply studies can be made. Several of the methods listed above meet these criteria. Where sufficient information is available concerning the geologic characteristics of known or possible accumulations of deep gas, a volumetric calculation of resources is most appropriate. This method is based on measurement of known or estimated physical properties of the traps, reservoir rock, and fluids and of the host environment in terms of temperature, pressure, and fluid dynamics. It has the advantage of working with the basic geologic properties of the accumulations and dealing with them in a rigorous, quantitative mode. The method allows for simulation of the hydrocarbon deposit(s) through estimation of properties where data are lacking or incomplete.

The calculation of gas resources is based on a fundamental reservoir engineering formula, expressed as follows:

$$
\begin{aligned}
\text { Gas volume }\left(\mathrm{ft}^{3}\right)= & 43,560 \mathrm{~A} \mathrm{~F} \mathrm{H} \mathrm{Por}(1-\mathrm{Sw}) \\
\text { where } \mathrm{A}= & \text { area of closure (acres), } \\
\mathrm{F}= & \text { trap fill }(\text { decimal fraction }), \\
\mathrm{H}= & \text { reservoir thickness }(\mathrm{ft}), \\
\mathrm{Por}= & \text { porosity (decimal fraction), } \\
\mathrm{Sw}= & \text { water saturation, } \\
\mathrm{Pr}= & \text { original reservoir pressure, } \\
\mathrm{Tr}= & \text { reservoir temperature } \\
& \left({ }^{\circ}\right. \text { Rankine) } \\
\mathrm{Psc}= & \text { pressure, standard conditions, } \\
\mathrm{Tsc}= & \text { temperature }\left({ }^{\circ}\right. \text { Rankine), and } \\
\mathrm{Z}= & \text { gas compressibility factor. }
\end{aligned}
$$

Simulation of properties of the accumulation or an aggregate of accumulations requires that the parameters be represented as estimates expressed as ranges of values, accompanied by probabilities of occurrence (probability distributions). Thus, the parameters represent the natural geologic variability of geologic characteristics and our uncertainty about them. Hence, the values shown represent the range of possibilities, which might be encountered at a randomly selected prospect within a population. The model can be used both at the scale of a single prospect or for an aggregate of prospects within a common geologic setting or play.

\section{HYPOTHETICAL DEEP BASIN EXAMPLE}

An example of a deep-gas accumulation in a hypothetical basin demonstrates the use of this model. Several U.S. basins meet the requirements for the conditions of this model such as the Anadarko Basin, the Gulf Coast Basin, and several deep Rocky Mountain Basins. This exercise is only intended to demonstrate the use and flexibility of this model rather than providing an actual assessment of recoverable resources.

In this case, a population of drillable prospects are identified. These prospects have been defined geologically or geophysically or are hypothesized to exist, and they have common geologic characteristics. The reservoir rock is a sandstone lying in structural traps at depths ranging from 18,000 to 22,000 feet (about 5,500 to $6,700 \mathrm{~m}$ ).

The input used for this example is shown in figure 19. In this case, the various play attributes for hydrocarbon accumulation (that is, source- and reservoir rock characteristics) have been met, hence no risk has been assigned. If questionable, then a probability of occurrence of less than 1 would be assigned.

It is possible that prospect attributes may not be present or favorable at a randomly selected prospect. For instance, on an individual prospect basis or at a randomly selected prospect, the trapping mechanism or trapping configuration has a 6 in 10 chance of existing (probability of trapping mechanism $=0.6$ ), and the necessary migration paths from source rocks to the trap have a 7 in 10 chance of existing (probability of hydrocarbon accumulation=0.7). Each attribute assessed is conditioned on the other attributes being favorable and also on the basis of being sufficient to meet the minimum values for hydrocarbon volume parameters of the accumulations to be considered (shown in lower part of, fig. 19).

For hydrocarbon volume parameters, the general characteristics and properties of deep-gas accumulations or occurrences, which have been documented elsewhere in the companion studies, were used. In this case, minimum values are: area of closure $=300$ acres; reservoir thickness $=10$ feet (about $3 \mathrm{~m}$ ); effective porosity $=5$ percent; trap fill $=10$ percent; and hydrocarbon saturation $=60$ percent. The program FASPU was used to calculate the estimates (Crovelli and Balay, 1990).

Results from calculation of the modeled play are shown in table 7. Several interesting relationships emerge from this calculation. First, there is a relatively modest amount of gas calculated, given the areal size of the prospect. This result is largely a function of the small amounts of effective matrix porosity assumed. Porosity loss is viewed as a significant factor in many deep gas reservoirs. 


\begin{tabular}{|c|c|c|c|c|c|c|c|c|}
\hline \multicolumn{4}{|c|}{ ATTRIBUTE } & \multicolumn{5}{|c|}{$\begin{array}{c}\text { PROBABII.ITY OF FAVORABLE } \\
\text { OR PRESENT }\end{array}$} \\
\hline \multirow{5}{*}{ 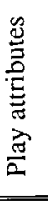 } & \multicolumn{3}{|l|}{ Hydrocarbon source } & \multicolumn{5}{|c|}{10} \\
\hline & \multicolumn{3}{|l|}{ Timing } & \multicolumn{5}{|c|}{1.0} \\
\hline & \multicolumn{3}{|l|}{ Migration } & \multicolumn{5}{|c|}{10} \\
\hline & \multicolumn{3}{|l|}{ Potential reservour facies } & \multicolumn{5}{|c|}{1.0} \\
\hline & \multicolumn{3}{|l|}{ Marginal play probability } & \multicolumn{5}{|c|}{10} \\
\hline \multirow{4}{*}{ 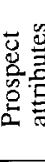 } & \multicolumn{3}{|l|}{ Trapping mechanısm } & \multicolumn{5}{|c|}{06} \\
\hline & \multicolumn{3}{|l|}{ Effective porosity $(>3 \%$ ) } & \multicolumn{5}{|c|}{1.0} \\
\hline & \multicolumn{3}{|l|}{ Hydrocarbon accumulation } & \multicolumn{5}{|c|}{0.7} \\
\hline & \multicolumn{3}{|l|}{ Conditional deposit probability } & \multicolumn{5}{|c|}{0.42} \\
\hline \multirow{4}{*}{ 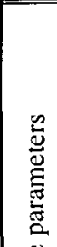 } & Reservoir luthology & \multicolumn{2}{|c|}{\begin{tabular}{|l|} 
Sand \\
Carbonate
\end{tabular}} & \multicolumn{5}{|c|}{$\overline{\mathrm{x}}$} \\
\hline & Hydrocarbon type & $\begin{array}{l}\text { Gas } \\
\mathrm{O}, 1\end{array}$ & & \\
\hline & \multirow[t]{2}{*}{ Fractules } & \multicolumn{7}{|c|}{ Probablluy of equal to or greate than } \\
\hline & & 100 & 95 & 75 & 5 51) & 25 & 5 & 0 \\
\hline \multirow{6}{*}{ 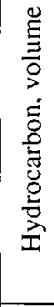 } & Area of closure $(1,0 \% 0$ acres $)$ & 0.3 & 0.7 & 0.9 & 1.7 & 3.0 & 4.6 & 62 \\
\hline & $\begin{array}{l}\text { Reservoir thickness/ } \\
\text { vertical closure (feet) }\end{array}$ & 10 & 20 & 35 & 50 & 70 & 100 & 120 \\
\hline & Effective porosity (\%) & 5 & 52 & 6 & 8 & 10 & 14 & 20 \\
\hline & Trap fill (\%) & 10 & 25 & 45 & 60 & 75 & 90 & $106)$ \\
\hline & Reservoir depth ( 1000 feet) & 18 & 18.75 & 195 & 20 & 2015 & 2125 & 22 \\
\hline & Hydrocarbon saturation (\%) & 60 & 65 & 70 & 75 & 80 & 85 & 90 \\
\hline \multicolumn{2}{|r|}{$\begin{array}{c}\text { Number of drillable prospects } \\
\text { (a play characteristic) }\end{array}$} & 10 & 12 & 14 & 15 & 17 & 20 & 22 \\
\hline
\end{tabular}

Figure 19. Oil and gas appraisal data form (from Dolton and Crovelli, 1992) completed for hypothetical deep natural-gas play. Reservoir variables as follows: original reservoir pressure is 0.46 $\mathrm{psi} / \mathrm{ft}$ (depth in $\mathrm{ft})+14.7$; reservoir temperature ( ${ }^{\circ}$ Rankine) is $0.013^{\circ} / \mathrm{ft}$ (depth in $\mathrm{ft}$ ) $+515^{\circ}$; gas compressibility factor is 1.2 ; gas recovery factor is 0.80 .

It affects not only the amount of resource but producibility, as a consequence of associated low permeability. In many cases, the presence of natural fractures is necessary for economic production. In fractured reservoirs, adjustment of reservoir porosity values must be made to include fracture porosity for volume calculations. Situations in which porosity is retained at great depth, as in some geopressured reservoirs, need to be considered in exploration, development, and assessment scenarios.

Note that in this calculation, independence of volume parameters is assumed, other than a positive correlation between porosity and gas saturation. However, dependencies may exist and may be dealt with. For instance, one might assume that a positive correlation or dependency exists between trap size and fill to effectively collapse the container size parameters into a single variable; in that case the field size possible at the 5 th fractile (the largest reported field size) increases from about 160 billion cubic feet $(\mathrm{Bcf})$ to approximately $200 \mathrm{Bcf}$. This recoverable resource represents a conservative case.
Alternatively, if the reservoir is considered overpressured, in which better reservoir conditions occur, resources increase significantly. Table 7 (case 2) shows the recoverable gas estimated for the improved reservoir conditions. For this case, an average reservoir porosity of 18 percent and a pressure gradient of $0.75 \mathrm{psi} / \mathrm{ft}$ (16.97 $\mathrm{kPa} / \mathrm{m}$-kilopascals/meter) were assumed (clearly an overpressured reservoir as is commonly associated with deep natural gas accumulations). In the original case (case 1), the mean resource value in these prospects contained 298 Bcf. In the second, more optimistic case, the prospects contained $1,017 \mathrm{Bcf}$ of gas, a three-fold increase due entirely to the increase in porosity and pressure. Other variables which particularly affect the overall reservoir volume include reservoir thickness and size of prospects. In both calculations, nonhydrocarbon gas is assumed present. Nonhydrocarbon gas may be accounted for by a percentage reduction of the gas calculated as part of the input recovery factor. This flexibility of the assessment method allows the geologist to model the geologic conditions controlling the resource values to reflect a wide range of geologic conditions.

\section{CONCLUSIONS}

1. Significant deep reservoirs (reservoirs with greater than $6 \mathrm{Bcf}$ of ultimate recoverable gas) occur primarily in the Gulf Coast, Permian, Anadarko, Williston, and Rocky Mountain Basins. Analysis of drilling, geologic, and production data for significant reservoirs indicate that a complex interplay of geologic and geochemical factors control the distribution of deep natural gas in sedimentary basins.

2. An empirical framework for predicting the porosity range of sandstone in Rocky Mountain Basins can be broadly applied to deeply buried sandstone in general and in the Anadarko Basin. For vitrinite reflectance $\left(R_{0}\right)$ greater than 1.1 percent, the rate of porosity decrease as thermal maturity increases is less rapid for Anadarko Basin reservoir and nonreservoir sandstones than for sandstone in general. Sandstone of the central and southern Anadarko Basin may retain sufficient porosity for economic accumulations of hydrocarbons, even at high thermal maturities.

3. Pore throats are a controlling factor in the flow of fiuids through pore networks. They are typically smaller than pores visible in thin section, or apparent in hand specimen. Pore throats, especially small $(<0.1 \mu \mathrm{m})$ ones, common in fine to very fine grained clastic rocks, are very sensitive to confining stress, and they probably act as limiting factors controlling the flow of gas to the well bore. Small pore throats are also very sensitive to the presence of formation fluids, which reduce their effective diameter. Measurement of capillary pressure under confining stress suggests that constriction of pore throats is the controlling mechanism affecting fluid flow at reservoir conditions. 
Table 7. Results of calculation for hypothetical deep natural-gas play.

IF, fractile; Bcf, billion cubic feet. Number of accumulations, accumulation size, and unconditional play potential based on fractiles. See Dolton and Crovelli (1992) for detailed cxplanation of methods]

\begin{tabular}{|c|c|c|c|c|c|c|}
\hline \multicolumn{7}{|c|}{ Case $1 \dagger$} \\
\hline & Mean & F95 & F75 & F50 & F25 & F05 \\
\hline Number of accumulations------ & 6.3 & 3 & 5 & 6 & 8 & 10 \\
\hline Accumulation size (Bcf)------- & 55 & 8 & 19 & 35 & 66 & 164 \\
\hline Uncond. play potential-------- & 345 & 122 & 207 & 298 & 430 & 726 \\
\hline \multicolumn{7}{|c|}{ Case $2 \ddagger$} \\
\hline & Mean & F95 & F75 & F50 & F25 & F05 \\
\hline Number of accumulations ------ & 6.3 & 3 & 5 & 6 & 8 & 10 \\
\hline Accumulation size (Bcf)---.--- & 185 & 27 & 66 & 122 & 226 & 547 \\
\hline Uncond. play potential--.--..-. & 1169 & 425 & 712 & 1017 & 1454 & 2431 \\
\hline
\end{tabular}

†For case 1: closure, 300 acres; reservoir thickness, $10 \mathrm{ft}$ (about $3 \mathrm{~m}$ ); effective porosity, 5 percent; trap fill, 10 percent; water saturation, 60 percent.

$\ddagger$ For case 2: closure, 300 acres; reservoir thickness, $10 \mathrm{ft}$ (about $3 \mathrm{~m}$ ), effective porosity, 18 percent; trap fill, 10 percent; water saturation, 60 percent; assumed overpressured reservoir with pressure gradient of $0.75 \mathrm{psi} / \mathrm{ft}$.

These data aid in defining reservoir properties under insitu conditions, and they are valuable for reservoir descriptions and in simulation studies.

4. In the Rocky Mountain region, structural partitioning prior to thrusting in selected basins, and sequential southeastward and later northeastward partitioning of the Rocky Mountain foreland during Late Cretaceous may be critical to the entrapment of deep natural-gas resources. Economic implications of this new model of deformation of the Rocky Mountain foreland include progressive opening and subsequent blockage of migration paths for hydrocarbons generated from source rocks in southeastern Idaho, southwestern Montana, Wyoming, Colorado, and eastern Utah.

5. The presence of geochemically identified source beds of Middle Proterozoic age, active hydrocarbon seeps, and favorable thermal maturities for generating and preserving natural gas, indicate a source-rock potential adequate for economic gas accumulations in many basins and regions such as the Midcontinent Rift System and the Grand Canyon region.

6. Methane generation (from thermal decomposition of $\mathrm{C}_{15+}$ hydrocarbons) takes place at very high maturation ranks. $\mathrm{C}_{15+}$ hydrocarbons are thermally stable to ranks as high as $\mathrm{R}_{0}=7.0-8.0$ percent in deep, unsheared petroleum basins. $\mathrm{C}_{2+}$ hydrocarbons are thermally stable to even higher ranks, well into rock metamorphism conditions. Methane is probably stable into mantle conditions. The vertical stratification of various hydrocarbon phases is probably a consequence of condensation, buoyancy, and segregation based on geochemical processes.
7. The presence of significant nonhydrocarbon gases in carbonate reservoirs and the presence of hydrogen sulfide indicates that thermochemical sulfate reduction and simultaneous oxidation of hydrocarbons to carbon dioxide may be the dominant control on gas composition in these reservoirs.

Giant quartz-vein systems in convergent, transpressive plate-margin basins may be associated with major deep gas accumulations such as in the deep Anadarko and Arkoma Basins. Based on the range of methane to carbon dioxide ratios observed in fluid inclusions in quartz from one of these vein systems (1:3 to $1: 40)$, a single giant vein system may transport anywhere from 50 to $500 \mathrm{Tcf}$ of methane to shallow crustal levels.

8. Review and analysis of resource appraisal methodologies and approaches has allowed identification of methodologies for dealing with deep gas accumulations. Modeling of assessment methodologies supports the possibility of large volumes of natural-gas resources in deep sedimentary basins. Where sufficient information is available concerning the geologic characteristics of known or possible accumulations of deep gas, a volumetric calculation of resources is appropriate.

\section{ACKNOWLEDGMENTS}

We wish to acknowledge the careful and critical reviews of this manuscript by Paul Westcott of Gas Research Institute (GRI) and Mahlon Ball, Jerry Clayton, and Michael Lewan of the U.S. Geological Survey. Ronald Charpenti- 
er and Raymond Obuch retrieved reservoir data from the NRG Associates field file and well data from the WHCS for quantitative analysis. James Baird and Diane Nielsen of the U.S. Geological Survey tabulated production data summaries and prepared graphical output for analysis. Many thanks go to Tom Kostick of the U.S. Geological Survey for his patience in preparing text figures for the final manuscript. Work was conducted in part under contract to Gas Research Institute, Chicago, Illinois (Contract Nos. 5087260-1607 and 5090-260-2040) and by the Onshore Oil and Gas Program of the U.S. Geological Survey.

\section{REFERENCES CITED}

Anderson, R.R., ed., 1990, The AMOCO M.G, Eischeid No. 1 deep Petroleum test Carroll County, Iowa preliminary investigations: Energy and Geological Resources Division Geological Survey Bureau, 98 p.

Bayley, R.W., and Muehlberger, W.R., 1968, Basement rock map of the U.S.: U.S. Geological Survey, scale 1:2,500,000.

Blackstone, D.L., Ir., 1983, Laramide compressional tectonics, southeastern Wyoming: Contributions to Geology, University of Wyoming. v. 22, p. 1-38.

-1990, Precambrian basement map of Wyoming-Outcrop and structural configuration, revised, 1990: Geological Survey of Wyoming Map Series 27, scale 1:1,000,000.

Burruss, R.C., 1977, Analysis of fluid inclusions in graphitic metamorphic rocks from Bryant Pond, Maine, and Khtada Lake, British Columbia: Thermodynamic basis and geologic interpretation of observed fluid compositions and molar volumes: unpublished Ph.D. dissertation, Princeton University, $156 \mathrm{p}$.

Burruss, R.C., 1992, Migration of 10's to 100's of Tcf of hydrocarbon and nonhydrocarbon gases from the deep crust: composition, flux, and tectonic setting, in Dyman, T.S., ed., Geologic controls and resource potential of natural gas in deep sedimentary basins: U.S. Geological Survey Open-File Report 92-524, p. 279-285.

Crovelli, R.A., and Balay, R.H., 1990, FASPU English and Metric conversion: analytic petroleum resource appraisal microcomputer programs for play analysis using a reservoirengineering model: U.S. Geological Survey Open-File Report 90-509B, 23 p.

Dolton, G.L., and Crovelli, R.A., 1992, Resource assessment methodologies and deep gas resources, in Dyman, T.S., ed., Geologic controls and resource potential of natural gas in deep sedimentary basins: U.S. Geological Survey Open-File Report 92-524, p. 286-297.

Dwights Energy Data, 1985, Petroleum Data System (through 1985), [Available from Dwights Energy Data Corp., Oklahoma City, OK 73108].

Dyman, T.S., Nielsen, D.T., Obuch, R.C., Baird, J.K., and Wise, R.A., 1990, Summary of deep oil and gas wells and reservoirs in the U.S. from the Well History Control System and Petroleum Data System: U.S. Geological Survey Open-File Report 90-305, 35 p.

Dyman, T.S., ed., 1992, Geologic controls and resource potential of natural gas in deep sedimentary basins in the United States: U.S. Geological Survey Open-File Report 92-524, 287 p.
Dyman, T.S., Spencer, C.W., Baird, J., Obuch, R., and Nielsen, D., 1992, Geologic characteristics of deep natural gas resources based on data from significant fields and reservoirs, in Dyman, T.S., ed., Geologic controls and resource potential of natural gas in deep sedimentary basins in the United States: U.S. Geological Survey Open-File Report 92-524, $287 \mathrm{p}$.

Frezon, Sherwood E., Finn, Thomas M., Lister, Jean H., 1983, Total thickness of sedimentary rocks in the conterminous United States: U.S. Geological Survey Open-File Report 83920 , scale 1:5,000,000.

Glass, G.B., 1975, Analyses and measured sections of 54 Wyoming coal samples (collected in 1974): Geological Survey of Wyoming Report of Investigations No. 11, 219 p.

Glass, G.B., and Roberts, J.T., 1984, Analyses and measured sections of 25 coal samples from the Hanna coal field of southcentral Wyoming (collected between 1975 and 1979): Geological Survey of Wyoming Report of Investigations No. 4, $104 \mathrm{p}$.

Gussow, W.C., 1954, Differential entrapment of oil and gas-A fundamental principle: American Association Petroleum Geologists Bulletin, v. 38, p. 816-853.

Hester, T.C., 1992, Trends in sandstone porosity in the Anadarko Basin with respect to thermal maturity, in Dyman, T.S., ed., Geologic controls and resource potential of natural gas in deep sedimentary basins in the United States: U.S. Geological Survey Open-File Report 92-524, p. 63-75.

Hollister, L.S., and Burruss, .R.C., 1976, Phase equilibria in fluid inclusions from the Khtada Lake metamorphic complex: Geochimica et Cosmochimica Acta, v. 40, p. 163-175.

Kaplan, S.S., and Skeen, R.C., 1985, North-south regional seismic profile of the Hanna Basin, Wyoming, in Gries, R.R., and Dyer, R.C., eds., Seismic exploration of the Rocky Mountain region: Rocky Mountain Association of Geologists and Denver Geophysical Society, p. 219-224.

Keighin, C.W., 1992, Pore throats, capillary pressures, porosity, and permeability of clastic reservoirs in the Uinta, Wind Rover, and Anadarko Basins, in Dyman, T.S., ed., Geologic controls and resource potential of natural gas in deep sedimentary basins in the United States: U.S. Geological Survey Open-File Report 92-524, p. 76-85.

Kerrick, R., and Feng, R., 1992, Archean geodynamics and the Abitibi-Pontiac collision: implications for advection of fluids at transpressive collisional boundaries and the origin of giant quartz vein systems: Earth-Science Reviews, v. 32, p. 33-60.

Kisch, H.J., and van den Kerkhof, A.M., 1991, $\mathrm{CH}_{4}$-rich inclusions form quartz veins in the Valley-and-Ridge province and the anthracite fields of the Pennsylvania Appalachians: American Mineralogist, v. 76, p. 230-240.

Klinkenberg, L.J., 1941, The permeability of porous media to liquids and gases: American Petroleum institute, Drilling and Production Practices (1941), p. 200-213.

MacMillan, L.T., and Weimer, R.J., 1976, Stratigraphic model, Delta Plain Sequence, "J" Sandstone (Lower Cretaceous) Turkey Creek area, Jefferson County, Colorado: Colorado School of Mines Professional Contr., no. 8, p. 228-241.

Mast, R.F., Dolton, G.L., Crovelli, R.A., Root, D.H., and Attanasi, E.D., 1989, Estimates of undiscovered conventional oil and gas resources in the United States-A part of the Nation's energy endowment: U.S. Geological Survey and Minerals Management Service special publication, $44 \mathrm{p}$. 
National Petroleum Council, 1992, The potential for natural gas in the United States-executive summary: National Petroleum Council, 24 p., with appendixes.

NRG Associates Inc., 1988, The significant oil and gas fields of the United states (through December 31, 1988), [Available from Nehring Associates, Inc., P.O. Box 1655, Colorado Springs, CO 80901].

NRG Associates Inc., 1991, The significant oil and gas fields of the United states (through December 31, 1991): Available from Nehring Associates, Inc., P.O. Box 1655, Colorado Springs, CO 80901.

Palacas, J.G., 1992, Source-rock potential of Precambrian rocks in selected basins of the U.S., in Dyman, T.S., ed., Geologic controls and resource potential of natural gas in deep sedimentary basins: U.S. Geological Survey Open-File Report 92-524, p. 161-172.

Palacas, J.G., Schmoker, J.W., Daws, T.A., Pawlewicz, M.J., and Anderson, R.R., 1990, Petroleum source-rock assessment of Middle Proterozoic (Keweenawan) sedimentary rocks, Eischeid No. 1 well, Carroll County, Iowa, in Anderson, R.R., ed., The Amoco Eischeid No. 1 deep petroleum test, Carroll County, Iowa: Iowa Department of Natural Resources, Special Report Series No. 2, p. 119-134.

Perry, W.J., Jr., 1989, Structural settings of deep natural gas accumulations in the conterminous United States, in Rice, D.D., ed., Distribution of natural gas and reservoir properties in the continental crust of the United States: Gas Research Institute report 89-0188, p. 62-72.

Perry, W.J.; Jr., 1992, Deep gas-prone basins of the Rocky Mountain region, in Dyman, T.S., ed., Geologic controls and resource potential of natural gas in deep sedimentary basins: U.S. Geological Survey Open-File Report 92-524, p. 148-160.

Perry, W.J., Jr., Nichols, D.J., Dyman, T.S., and Haley, J.C., 1992, Sequential Laramide deformation of the Rocky Mountain foreland of southwestern Montana, Wyoming, and north-central Colorado, in Thorman, C.H., ed., Application of structural geology to mineral and energy resources of the central and western United states: U.S. Geological Survey Bulletin 2012, p. C1-C14.

Petroleum Information Corporation, 1988, Well History Control System (through December 1988), [Available from Petroleum Information Corporation, 4100 East Dry Creek Road, Littleton, CO 80122].

Petroleum Information Corporation, 1991, Well History Control System (through December 1991), [Available from Petroleum Information Corporation, 4100 East Dry Creek Road, Littleton, CO 80122].

Potential Gas Committee, 1990, Potential Supply of natural gas in the United States: Potential Gas Committee, Colorado School of Mines, Golden, CO, 169 p.

Price, L.C., 1982, Organic geochemistry of $300^{\circ} \mathrm{C}, 7 \mathrm{~km}$ core samples, South Texas: Chemical Geology, v. 37, p. 205214.

Price, L.C., 1988, The organic geochemistry (and causes thereof) of high-rank rocks from the Ralph Lowe-1 and other boreholes: U.S. Geological Survey Open-File Report 91-307.
Price, L.C., 1992, $\mathrm{C}_{15+}$ hydrocarbon thermal destruction as related to high-rank, deep-basin gas resource bases, in Dyman, T.S., ed., Geologic controls and resource potential of natural gas in deep sedimentary basins: U.S. Geological Survey Open-File Report 92-524, p. 173-278.

Price, L.C., Clayton, J.L., and Rumen, L.L., 1979, Organic geochemistry of a 6.90 kilometer-deep well, Hinds County Mississippi: Transactions of the Gulf Coast Geological Society, v. 29 , p. $352-370$.

Price, L.C., Clayton, J.L., and Rumen, L.L., 1981, Organic geochemistry of the $9.6 \mathrm{~km}$ Bertha Rogers No. 1, Oklahoma: Journal of Organic Geochemistry, v. 3, p. 59-77.

Price, L.C., and Clayton, J.L., 1990, Reasons for and significance of deep, high-rank hydrocarbon generation in the south Texas Gulf Coast, in Schumaker, D., and Perkins, B.F., eds., Gulf Coast oils and gases: Proceedings of the Ninth Annual Research Conference Gulf Coast Section SEPM, p. 105-137.

Purcell, W.R., 1949. Capillary-pressures-their measurement using mercury and the calculation of permeability therefrom: American Institute of Mining, Metallurgical, and Petroleum Engineers, Petroleum Transactions, v. 186, p. 3948.

Rice, D.D., 1989, Distribution of natural gas and reservoir properties in the continental crust of the U.S.: Gas Research Institute Final Report GRI-89/0188, 132 p.

Rice, D.D., Schenk, C.J., Schmoker, J.W., Fox, J.E., Clayton, J.L., Dyman, T.S., Higley, D.K., Keighin, C.W., Law, B.E., and Pollastro, R.M., 1992, Potential for deep gas resources in eastern Gulf of Mexico: Proceedings of Natural Gas Research and Development Contractors Review Meeting, DOE/METC-92/6125, 1992, p. 151-166.

Schmoker, J.W., 1992, Distribution of porosity in sedimentary rock as a function of time-temperature exposure, in Dyman, T.S., ed., Geologic controls and resource potential of natural gas in deep sedimentary basins in the United States: U.S. Geological Survey Open-File Report 92-524, 296 p.

Schmoker, J.W., and Gautier, D.L., 1989, Compaction of basin sediments: Modeling based on time-temperature history: Journal of Geophysical Research, v. 94(B), no. 6, p. 73797386.

Schmoker, J.S., and Hester, T.C., 1990, Regional trends of sandstone porosity versus vitrinite reflectance-a preliminary framework, in Nuccio, V.F., and Barker, C.E., eds., Applications of thermal maturity studies to energy exploration: Rocky Mountain Section-SEPM, Denver, p. 53-60.

Schmoker, J.W., and Palacas, J.G., 1990, Porosity of Precambrian sandstones in the lower portion of the Eischeid No. 1 well, Carroll County, Iowa, in Anderson, R.R., ed., The Amoco Eischeid No. 1 deep petroleum test, Carroll County, Iowa: Iowa Department of Natural Resources, Special Report Series No. 2, p. 135-142.

Takahashi, K.I., and Cunningham, K.I., 1987, Map showing wells drilled for oil and gas deeper than 15,000 feet (about $4,600 \mathrm{~m}$ ) in the conterminous United States and offshore: U.S. Geological Survey Oil and Gas Investigations Map OM-220, scale 1:5,000,000. 
van den Kerkhof, A.M., Touret, J.L.R., Maijer, C., and Jansen, J.B.H., 1991, Retrograde methane-dominated fluid inclusions from high-temperature granulites of Rogaland, southwestern Norway, Geochimica et Cosmochimica Acta, v. 55 , p. 2533-2544.

Vidal, G., and Ford, T.D., 1985, Microbiotas from the Late Proterozoic Chuar Group (northern Arizona) and Uinta Mountain Group (Utah) and their chronostratigraphic implications: Precambrian Research, v. 28, p. 349-389.
Wandrey, C.J., Vaughan, D.K., 1992, Maps illustrating the distribution of deep wells in the U.S. by geologic age, in Dyman, T.S., ed., Geologic controls and resource potential of natural gas in deep sedimentary basins: U.S. Geological Survey Open-File Report 92-524, p. 114-116, 9 plates.

Woods, T.J., 1991, The long-term trends in U.S. gas supply and prices-1991 edition of the GRI baseline projection of U.S. energy supply and demand to 2010: Gas Research Institute, Washington, D.C., 54 p. 



\title{
THE FUTURE OF ENERGY GASES \\ U.S. GEOLOGICAL SURVEY PROFESSIONAL PAPER 1570 \\ Challenges of Ultradeep Drilling
}

\author{
By Richard E. Wyman ${ }^{1}$
}

\section{CONTENTS}

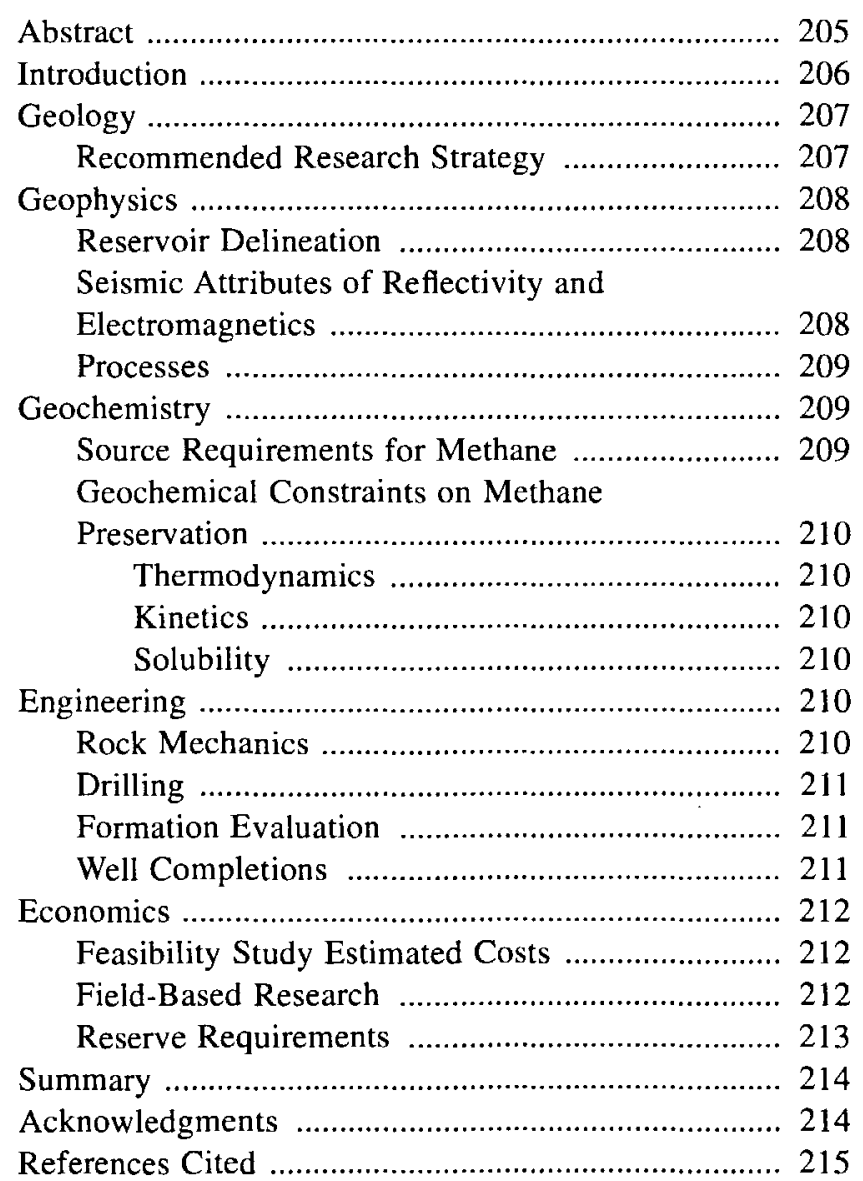

\footnotetext{
'Canadian Hunter Exploration Ltd., 2000 605-5 Ave. S.W., Calgary, Alberta, Canada T2P3H5.
}

\begin{abstract}
To successfully produce ultradeep gas (below 25,000 $\mathrm{ft}$ ), advances will be needed in geoscience and engineering. Combined thinking from experts in geology, geophysics, geochemistry, and engineering has outlined some of the challenges. Geologists will require assistance from geophysicists to identify the spatial distribution of sedimentary rocks. They will need to interpret the structural and tectonic framework and fit them into an integrated geological model.

Characterization of potential reservoirs including knowledge of the preservation or creation of porosity will be vital. Although seismic methods have the highest resolving power for delineating structure at depth and indicating other rock properties, other geophysical methods should also be utilized for additional information on deep sediments. A better understanding of the source requirements and chemical reactions for generation of methane is required.

Methane can survive at high temperatures and high pressures associated with depths of $40,000 \mathrm{ft}$ in an inert dry reservoir, but the stability of methane in the presence of complex mixtures of minerals and other fluids is uncertain. Further experimental studies and theoretical work are needed to understand the constraints on methane preservation.

Severe problems will be encountered in drilling, evaluation, and completion of ultradeep wells. Engineering challenges will come from higher in-place stresses, temperatures, pressures, and the probability of encountering corrosive and toxic fluids. Drill strings, casing, and other tubular materials used in the drilling and well completion process will need advanced metallurgy to reach and complete wells in deep targets. The economic returns at $\$ 3.00$ per Mcf can be attractive if $200 \mathrm{ft}$ of gas within a 7 percent porosity reservoir can be successfully completed at
\end{abstract}


30,000 to $40,000 \mathrm{ft}$. This assumes good productivity and draining gas reserves of $125 \mathrm{Bcf}$ from a single well.

\section{INTRODUCTION}

The potential for natural gas production from ultradeep sources (below 25,000 ft), although unknown, is probably very large. However, ultradeep sources are only one of many possible sources from which future gas may be produced. Such potential can be depicted with a resource triangle (fig. 1), where the least expensive and easiest-to-obtain gas is indicated at the top of the triangle. These sources, however, are relatively small. To tap the larger volumes of gas shown lower in the resource triangle, greater expense and advanced technology are required. Practically all of the gas that has been produced to date as well as the remaining recoverable resources from "conventional" rock (shallower than 25,000 ft) are shown at the top of the triangle. Beneath that is an almost unlimited amount of natural gas from "unconventional" sources.

Natural gas is currently being produced from some of these unconventional sources, particularly from tight formations, shales, and coal seams. The United States in particular has done extensive evaluation of unconventional sources of gas. Although the quantity of deep gas in place is probably large, it has received relatively little attention

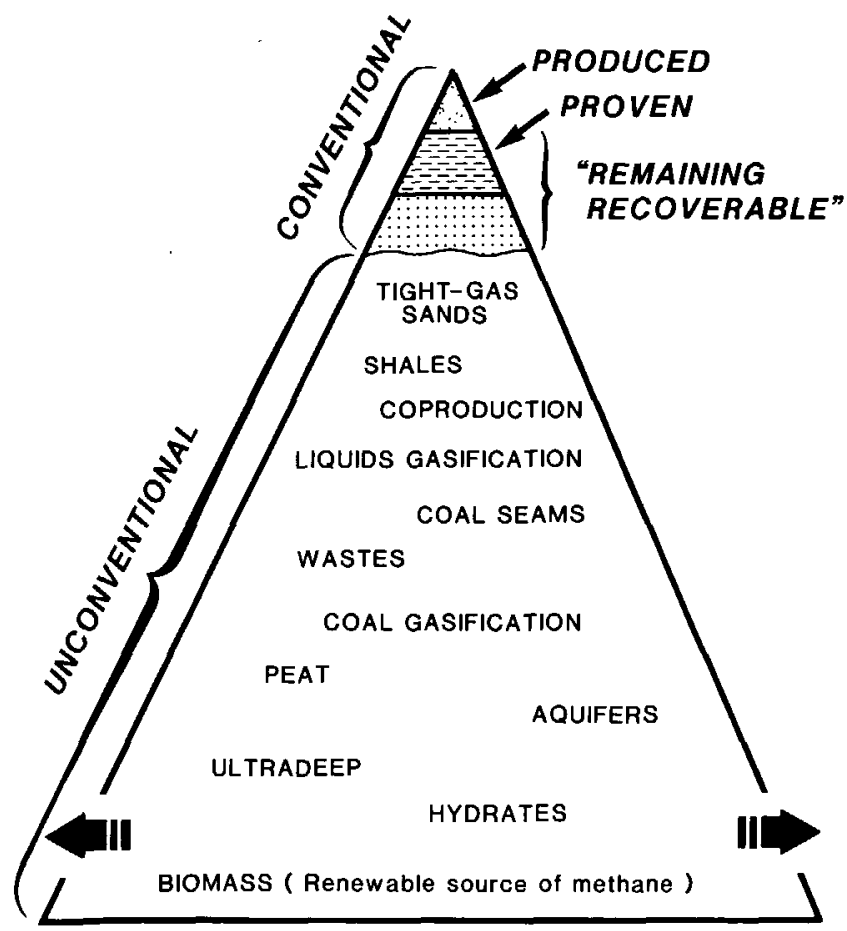

Figure 1. Resource triangle for natural gas. Volume of resources available increases toward base of triangle. Arrows at base indicate a virtually unlimited source of methane from renewable biomass. because of the difficult technical problems and anticipated high drilling costs. Deep-gas potential needs serious investigation, when considering the economic and national security of the energy resources in the United States.

Sedimentary deposits are believed to exist to at least $50,000 \mathrm{ft}$ depth in some areas of the United States. Research to date indicates that methane would remain stable under expected environmental conditions at depths of at least 40,000 ft and probably beyond (see Dyman and others, this volume). The temperatures at this depth, in excess of $600^{\circ} \mathrm{F}$, suggest that any oil will already have been broken down to methane. At depths below 25,000 ft, limitations to drilling equipment, evaluation tools, tubulars (for example, borehole casing, production tubing, or liners), and safety devices become severe. The problems of production are compounded by high temperatures and the probability of encountering hydrogen sulfide, carbon dioxide, hydrogen, and corrosive salt-saturated fluids.

The overall success ratio for wells drilled deeper than $15,000 \mathrm{ft}$ in the United States and around the world is close to 50 percent (Moore, 1992). Although the United States has more wells and a higher density of drilling than any country in the world, only a small fraction of the deep sedimentary deposits have been explored with a drill bit. Yet huge natural gas resources have already been identified. For example, the deep Anadarko Basin alone may contain between 60 and 360 trillion cubic feet (Tcf). The Tuscalousa trend in the Gulf Coast has been estimated to contain $60 \mathrm{Tcf}$; another $200 \mathrm{Tcf}$ may be in the deep Rocky Mountain Overthrust Belt. Although these resources, generally located between 15,000 and $25,000 \mathrm{ft}$, do not meet the ultradeep classification (below 25,000 ft), the implication is that there are large sources of ultradeep gas.

Further research is needed to better understand the role of organic matter in producing very large amounts of gas at great depths. Additional interest in deep-gas potential has been sparked by theories of inorganic sources of gas. The key to successful ultradeep drilling is finding rocks with the necessary porosity and permeability that can act as reservoirs and will allow economically feasible production rates (see Burruss, this volume; Apps and van de Kamp, this volume; and Gold, this volume).

Intensive investigations and research in geology, geophysics, geochemistry, and engineering are very important to deep drilling programs and cannot be overemphasized. Specific areas of investigation suggested by a panel of industry, academic, and government experts are outlined in this report (see "Acknowledgments"). When the basic technical problems have been solved, the creation of a sustained deep-drilling program will depend largely on economics.

By far the largest factor in ultradeep exploration and production activity will be high drilling costs; new technology to reduce these costs will be of primary importance. The investigations necessary to conquer the challenges of deep drilling will also have profound ef- 
fects on the more conventional oil and gas exploration and production programs.

Over the past decade many ultradeep wells have been drilled for scientific investigation. Although scientific ultradeep wells do not share the same potential hazards of oil and gas wells, many of the drilling technologies developed in this program would directly benefit scientific drilling programs.

\section{GEOLOGY}

There is relatively little understanding of the distribution and geologic characteristics of deep gas-bearing rock packages. Potential occurrences range from unconventional settings, such as subduction zones, to the deeper portions of mature hydrocarbon basins (fig. 2). Implicit in this concept is the assumption that the gas is organic rather than inorganic in origin (see Stevenson, this volume). Available databases can be used to prepare maps that identify and show the distribution of these rock packages. Conceptual models can be developed that characterize the geologic history and habitat of deep gas accumulations. From these models, the hydrocarbon potential of the identified rock packages can be assessed. However, testing of these models will ultimately require deep drilling operations.

\section{RECOMMENDED RESEARCH STRATEGY}

1. Identify the spatial distribution of packages of sedimentary rocks using available data including seismic reflection, magnetotellurics, potential fields (gravity and magnetics), and extrapolation of borehole petrophysical and geological data.

2. Undertake preliminary geohistorical analysis of all identified rock packages. On the basis of the above geophysical data and known geologic relations from appropriate regional data, the structure and tectonic framework can be developed, which will provide a basis for interpreting the stratigraphic and sedimentological character of deep rock packages.

3. Using the above geohistorical analysis, integrated geologic models can be constructed for determining hydrocarbon potential based on kinetic estimates of hydrocarbon generation potential. These integrated geologic models should include an assessment of the source beds, maturation and thermal history, and a characterization of potential reservoirs. Preservation of porosity is essential to maintaining high reservoir potential. Therefore, understanding of the interrelationships of porosity, permeability, fluid pressures, diagenesis, burial mechanisms, and subsequent tectonic activity is vital.

4. Additional data acquisition will be required for sitespecific recommendations to test the geologic models. Our

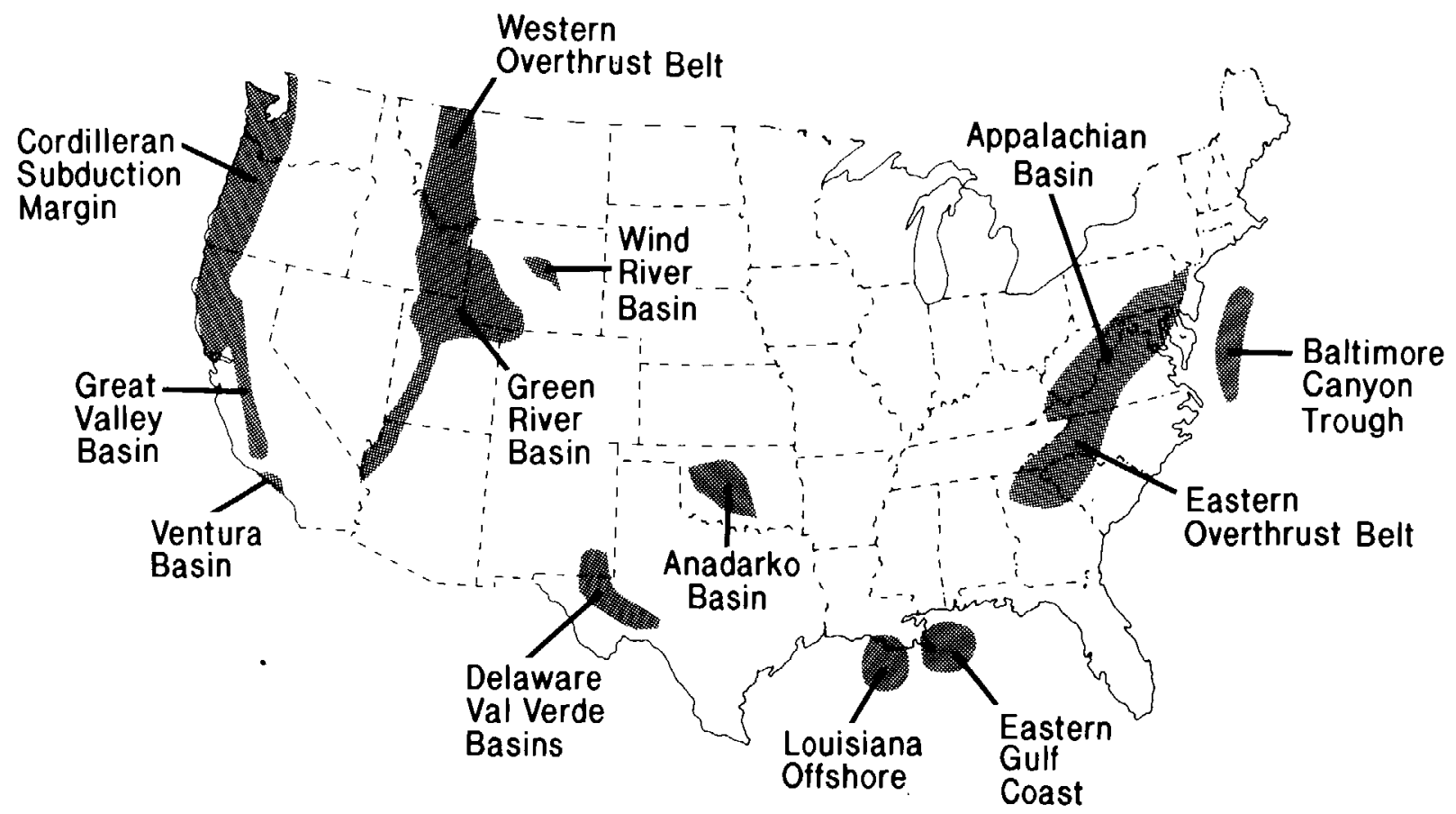

Figure 2. Potential deep-gas locations in United States. 
current knowledge is limited by our inability to project reservoir characteristics to depths below $25,000 \mathrm{ft}$. A detailed seismic-data acquisition program, including 3-dimensional data, will be important to define the parameter of any prospect.

\section{GEOPHYSICS}

\section{RESERVOIR DELINEATION}

There are certain geological frameworks that are thought to be preferable in the search for deep gas. To delineate the best "prospects," it is necessary that reconnaissance work be done using geophysical techniques. The use of all geophysical methods is desirable, but the selection of methods would depend upon local conditions.

The seismic reflection method has the highest resolving power for delineating structures at depth and indicating other physical properties of the rock mass. Further, under certain conditions we can expect to delineate the physical properties of the rocks, which can in turn be used to infer the existence of porosity and the presence of natural gas in pores. The electrical resistivity of deep sedimentary rocks is a key parameter used to infer the existence of gas (in the absence of drilling); for assessing the total volume of sedimentary rocks below a depth of $25,000 \mathrm{ft}$, this measurement must be relied upon to delineate deep sedimentary-rock packages where they have not been drilled. Magnetotelluric (MT) sounding surveys are essential for deep-gas studies in frontier regions, especially those where volcanic rocks or other conditions limit the effectiveness of seismic surveying. Specific research items recommended are MT surveys along existing deep reflection transects to verify existence of postulated deep sedimentary rocks and their possible fluid/temperature environment. Laboratory study of resistivities and other parameters of sedimentary rocks at high pressure is also an essential research item. Other geophysical methods such as gravity and magnetic techniques can be used to furnish additional input in defining sedimentary systems and aid in planning for deep seismic and MT surveys.

\section{SEISMIC ATTRIBUTES OF REFLECTIVITY AND ELECTROMAGNETICS}

After locating deep sediment packages, it is necessary to outline specific horizons of high porosity charged with gas. It would also be useful to estimate the hydraulic permeability in such packages prior to drilling. The most informative method, short of drilling, to infer these properties is to use geophysical data. In order to use these data (for example, seismic-impedance and seismic-amplitude information and electromagnetic impedance) it is neces- sary to understand how geophysical properties are influenced by porosity, pore pressure, gas saturation, fractures, and overburden pressure. In general, lower temperature gradients and younger rocks are more favorable to porosity preservation (see fig. 3). However, any gradient can abruptly shift toward higher porosity, especially if hydrocarbons were trapped from earlier migration; this would be expected with geopressured oil or gas.

Research is needed to better relate reservoir rock properties to parameters measured geophysically (for example, seismic velocities and electrical resistivity). This research must include laboratory measurements of rock properties utilizing the in-place conditions (for example, temperature and pressure) that prevail in deep gas environments. Rock property variables that affect geophysical measurements include mineralogy, porosity, fluid content, pore pressure, and temperature. In potential source rocks, carbon content, maturation, and other chemical components become important. Modern basin-modeling programs should assist in the studies of variables. In addition, studies will be needed to calibrate in-place geophysical

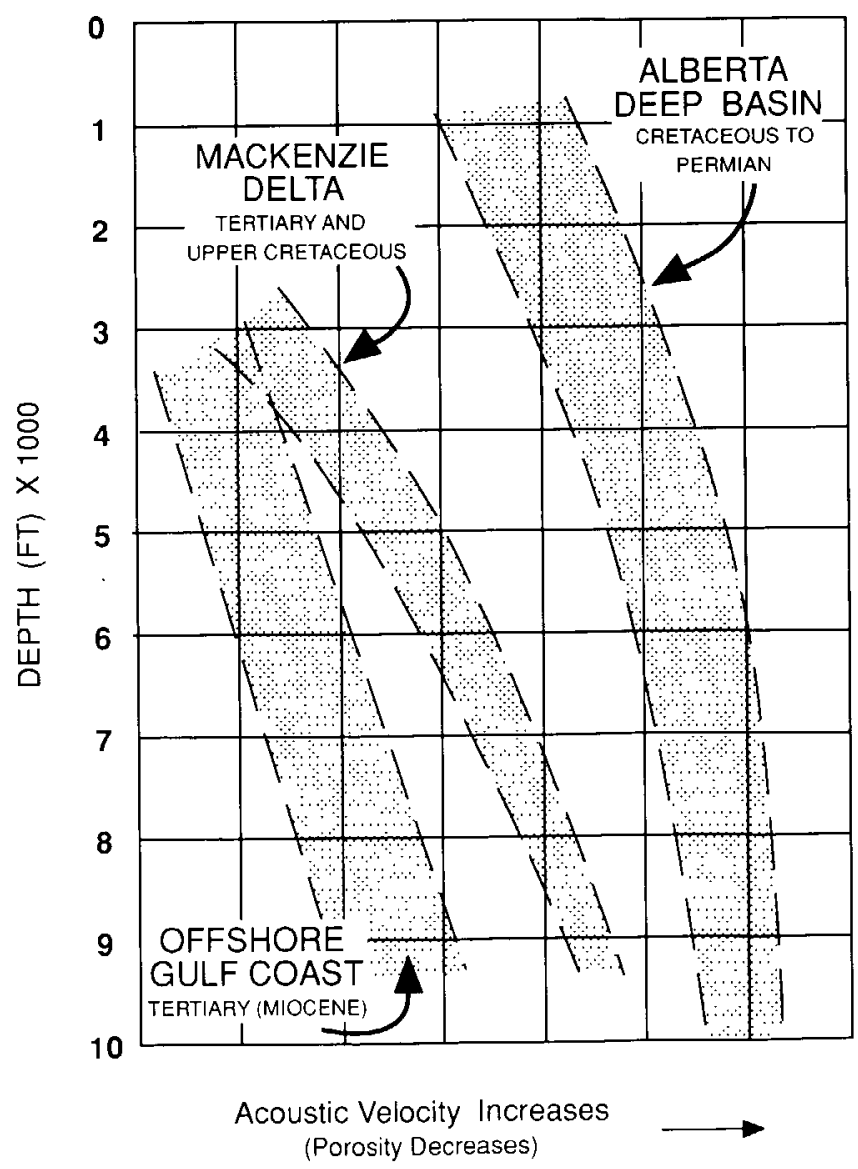

Figure 3. Trend curves of sand porosity in different geological provinces. Indicated trends are from water-bearing sands. Generally, younger formations will have higher porosity at a given depth. 
measurements to reservoir characteristics. Field measurements should utilize two new developments in reservoir seismology: (1) the use of drilling bits as a seismic source for doing wide-angle, continuous vertical seismic profiling of the rock mass around and beneath the borehole during drilling, and (2) the use of powerful downhole seismic sources and many surface receivers to describe the rock mass in the vicinity of the borehole after drilling has been completed.

\section{PROCESSES}

Important constraints on the presence and quality of natural gas reservoirs at great depth can also be obtained from better understanding of the processes that affect gas reservoirs. These include the inelastic reduction of porosity over time, development of pore pressure and naturally induced fracturing, reduction of permeability, and the maturation or migration of hydrocarbons under extreme pressure and temperature conditions.

Laboratory investigations are needed to better understand processes that cause porosity reduction over time and temperature and stress effects on porous rocks with reactive pore fluids. The results from these investigations can be compared with exhumed rock masses that are analogous or representative of deep sedimentary-rock packages. Engineers require data on the compressibility of reservoir rocks and fluids at high pressures and temperatures, on the solubilities of the relevant rock-forming minerals, and on the pore fluids that may exist in deep gas reservoirs (see Hefner, this volume).

Presently, even with observations from drill cores, we can only predict the behavior of some monomineralic rocks under different pressure, temperature, time conditions that are macroscopically unfractured, in limited stress states, and in chemically inert environments. The current needs, therefore, are to (1) extend our knowledge of the mechanical behavior of some rocks at depth to other rock types, both fractured and unfractured, and to other environmental conditions, (2) relate this mechanical behavior to composition, texture, and fabric, and (3) develop the geophysical technology to deduce rock composition, texture, and fabric so as to predict mechanical behavior.

Specifically, the above investigations need to be undertaken to extend our knowledge of inelastic properties to polymineralic partially clay-bearing rocks at high temperatures and pressures. These polymineralic rocks constitute about 40 percent of sedimentary rocks, and understanding their roles is critical in modeling the geologic deformation and mechanical characteristics of deep sedimentary-rock packages. The influence of chemically active fluids on deep sedimentary-rock packages requires laboratory study, as these effects may dominate other conditions. The timedependent behavior of chemical changes and compressibil- ity at the expected temperatures and pressures is still unknown. Additionally, the effects of existing fractures on the mechanical response of the rock mass remains largely undefined. Further theoretical and experimental studies will be needed to understand the geophysical responses of sedimentary-rock packages to deep burial.

\section{GEOCHEMISTRY}

In general, the basic geological and geochemical principles involved in the creation of natural gas (mainly methane) are known. In the near surface environment, methane forms as a result of biological processes in which anaerobic microbes digest organic molecules. Bacterially generated methane has been recognized in shallow reservoirs as old as the Cretaceous, and, in fact, 20 percent of the known methane deposits are believed to be of bacterial origin (see Rice, this volume).

As sediment burial depth increases, temperature and pressure increase. Methane forms under these conditions by processes involving the thermal alteration of organic matter in sediments (Barker, 1990). This generation process results because organic matter is thermodynamically unstable under the pressure and temperature conditions of the subsurface environment. Some organic matter survives deep burial only because the reactions that convert it to methane are very slow. Such reactions will leave behind an organic residue. As temperatures increase, however, the reactions proceed more quickly, approximately doubling for every $10^{\circ} \mathrm{C}$ increment. The kinetically controlled reactions tend toward thermodynamically stable end products of methane and graphite. During this alteration process, some kinds of organic matter are converted to oil, which is later transformed to methane during deeper burial, whereas other organic matter in the form of kerogen is changed, in part, to methane.

In deep reservoirs (greater than $25,000 \mathrm{ft}$ ), most of the methane should result from the high temperature alteration of kerogen and, possibly, hydrolysis of graphite $\left(2 \mathrm{C}+2 \mathrm{H}_{2} \mathrm{O} \rightarrow \mathrm{CH}_{4}+\mathrm{CO}_{2}\right)$. Methane from the thermal alteration of oil may also be present in deep reservoirs; however, it would represent an inherited product from the reservoir's burial history. Indeed, biologically derived methane also may survive in deep reservoirs, but the amount of methane would undoubtedly be small because most of this methane would be lost during the deep burial process. To date, no deep gas has been found that has an unequivocal isotopic signature of biogenic gas.

\section{SOURCE REQUIREMENTS FOR METHANE}

Although the origin of methane in most natural gas deposits seems to be understood, the limits to the 
chemical reactions that are taking place in the unique pressure-temperature regime found in sedimentary rock packages at depths greater than $25,000 \mathrm{ft}$ have not been clearly defined or quantified. For example, it is not clear how much organic matter must initially enter the system in order for significant methane to result after deep burial. Perhaps low-grade organic deposits, such as pelagic sediments and carbonates, may not contain enough organic matter to serve as a source of gas at greater depths. Highgrade organic deposits such as oil shales and coals may be necessary; however, intermediate-grade organic deposits could also be sufficient. It has been shown that 3,000 to $4,000 \mathrm{ft}^{3}$ of natural gas can be produced from one barrel of oil (Barker, 1990). Thus, it is important to define what initial concentration of organic matter is necessary to create methane at great depths.

Besides defining the characteristics of source materials for methane formation by thermal processes, studies should also be directed toward understanding the chemical reactions that are transforming organic matter to methane at subsurface conditions found at depths greater than $25,000 \mathrm{ft}$ The discussion thus far has been concerned with methane derived from the alteration of organic matter. It should also be mentioned that methane originating from inorganic sources, such as the mantle, could occur in deep reservoirs (see Gold, this volume).

\section{GEOCHEMICAL CONSTRAINTS ON METHANE PRESERVATION}

Previous evaluations of the stability of natural gas in the deep subsurface have considered simple systems involving pure methane. Methane alone in an inert dry reservoir can survive very high temperatures and pressures. For example even at $40,000 \mathrm{ft}$ more than 99 percent of the methane survives (Dyman and others, this volume). However, the stability of pure methane is not of great practical interest, because gas reservoirs generally contain reactive substances such as water and mineral phases. In order to understand what really happens in nature, it is important to investigate in greater detail the chemical reactions affecting methane and the fate of methane through solubility, mass transport, and diffusion. Research toward this goal is progressing (Takach and others, 1987).

\section{THERMODYNAMICS}

Any attempt to predict the stability of methane in the deep crust must consider the associated mineral assemblages. Thermodynamic data for gas species and minerals are needed to quantify the stability of methane in the lithosphere. Little is known about the thermodynamic properties of fluids at subsurface conditions below $25,000 \mathrm{ft}$.
With the present state of knowledge it is not possible to extrapolate what is currently known to higher temperatures and pressures. It is expected that higher temperatures rather than higher pressures will have the greatest effect upon gas compositions (Hefner and others, 1973). Thus, detailed experimental studies are called for which will focus on gas mixtures at appropriate conditions where deviation from the ideal state is greatest.

\section{KINETICS}

The rates of reactions, such as $\mathrm{CH}_{4}+2 \mathrm{H}_{2} \mathrm{O}=\mathrm{CO}_{2}+4 \mathrm{H}_{2}$, are another important aspect of methane stability. Preliminary data suggest that methane is quite unreactive in laboratory experiments below $500^{\circ} \mathrm{C}$. However, rate laws, rate constants, energies, and catalytic effects on the kinetics of methane are unknown, and experimental work is needed to clarify these issues.

\section{SOLUBILITY}

The ability of methane to dissolve in brines is poorly understood, particularly at the extremes of salinities, temperatures, and pressures encountered at depths below $25,000 \mathrm{ft}$. Previous studies of methane solubility in $\mathrm{NaCl}$ brine at conditions up to $25,000 \mathrm{psi}$ and $400^{\circ} \mathrm{F}$ are in good agreement. Further experimental work on this problem is required at higher pressures and temperatures, as well as for other salts and gases (especially $\mathrm{CO}_{2}$ ).

\section{ENGINEERING}

Engineering problems to be expected in drilling, evaluation, and production of deep gas will result from (1) higher in-place stresses, (2) higher formation temperatures, (3) the increased chances of encountering highpressure/high-temperature hydrogen, carbon dioxide, hydrogen sulphide, and corrosive fluids, and (4) longer lengths of drill string, subjected to high temperatures and pressures.

\section{ROCK MECHANICS}

At high pressure and high temperature, rock behavior can transform from brittle to ductile. High lithostatic stress states in a formation are translated to high shear stresses with removal of rock at the well bore during drilling and the fracturing process. Furthermore, the change of stress can result in creep, which can be further compounded by rock/fluid interaction with muds, fracturing fluids, and completion fluids. Borehole failure and creep at the bore- 
hole wall can result in complications, such as sticking of the drill string or hole collapse, with the accompanying possibility of "drill-string twist off."

Formation evaluation, completion, and production can be impaired by pore collapse, perforation collapse or plugging, and even casing collapse as pore pressure is reduced and the rock is subjected to higher effective confining stress.

If stimulation such as hydraulic fracturing is attempted at great depths, severe complications could occur. These may include failure of tubulars, difficulty of propagating the fracture owing to the high formation stresses, and complications owing to rock/fluid interaction.

Laboratory rock-mechanics research is required to evaluate some of these potential problems. Rock-mechanics facilities capable of duplicating confining pressures to $50,000 \mathrm{psi}$, controlled pore pressures to approximately $50,000 \mathrm{psi}$, and temperatures to $600^{\circ} \mathrm{F}\left(350^{\circ} \mathrm{C}\right)$ are recommended to investigate creep and stress-strain failure. The effect of fluid/rock interaction on the mechanical response can be evaluated by including the fluid of interest as pore fluid. Pore volume changes, permeability, and fracture propagation at these high pressure/temperature states are not well understood and need to be investigated.

\section{DRILLING}

Drilling at great depths will be challenging because of the hostile environment. At great depth, rocks may change from brittle to ductile; if rocks become too ductile, they can profoundly affect drilling penetration rates. One approach to mitigate this problem would be to develop drilling muds that not only withstand the high temperature/pressure but could change the surface physics of the rock being drilled while maintaining borehole stability. This would maintain brittle behavior during drilling. With increased depth, transferring of torque to the drill bit by use of downhole motors may be necessary to avoid the problems of friction that would be caused by rotating long drill strings. Drill bits, downhole motors, and drill strings need to be developed to operate at high temperatures in the presence of hydrogen gas or corrosive fluids. Drilling materials exhibiting high strength, high hardness, high fracture resistance, and appropriate ductility at high temperatures, along with resistance to corrosion and embrittlement in the presence of hydrogen gas and corrosive fluids must be substituted for the standard materials used by the gas industry; however, the combination of these properties are often mutually exclusive (for example, high hardness and high fracture toughness). Creating this combination of properties may require basic metallurgical research. If possible, the materials selected should be fabricated by techniques presently in use by the industry to control the costs of the final components. Prototype components need to be tested in the laboratory under simulated field conditions.

\section{FORMATION EVALUATION}

Most current technologies for formation evaluation from the borehole are limited to depths of less than 20,000 $\mathrm{ft}$ because of the high temperatures at these depths. These temperatures affect the (1) operation of electronic components essential to most wireline logging tools, and (2) elastomers essential to proper operation of packers, core barrels, and downhole reservoir sampling.

Some of the needed research is in progress as a part of other energy programs. For example, geothermal-reservoir evaluation problems are bringing about substantial advances in high-temperature electronics and elastomers; however, the tools are not being packaged for the high pressures associated with ultradeep drilling.

Laboratory research on sedimentary rocks under high pressure/temperature conditions is needed to address (1) methods to measure in-place stress, (2) the relationship between dynamic elastic properties deduced from sonic data and the static properties needed for well completion engineering, (3) the relationship between sonic, electrical properties, and nuclear $\log$ responses to reservoir properties (porosity, permeability, and fluid saturations), and (4) calibration of borehole measurements with remote geophysical measurements.

Research on field evaluation of deep-gas reservoirs is also essential. The stress, complex fluid interactions, and temperature cycling that are difficult to simulate in laboratory analysis of rock samples inevitably leave doubts regarding the applicability of lab results. Also, lab samples are minuscule and do not reflect the significant dimensions of reservoir heterogeneity. These problems are compounded in the drill stem by uncertainties with logging tool response. Other hardware development topics include (1) core and fluid sample collection hardware, including pressure core barrels, sidewall samples, and fluid sampling devices; (2) perfecting vertical seismic profiling in which the drill bit provides the acoustic source for a large array of surface receivers (looking up to $100 \mathrm{ft}$ ahead of the bit is particularly important to anticipate potential reservoirs, high pressures, and changes in lithology or pore fluids); and (3) measurement while drilling, with emphasis on the depth and temperature/pressure requirements for deep-gas exploration.

\section{WELL COMPLETIONS}

In general, the technology available to explore for gas and drill wells deeper than $25,000 \mathrm{ft}$ is more advanced than the technology required to complete, stimulate, and produce the gas: 
1. Current limits: Temperature is usually the limiting factor to our technology. For example, the following items have been identified at critical barriers: (1) fracture fluid stability $\left(350^{\circ} \mathrm{F}\right),(2)$ fracture proppants $(30,000 \mathrm{ft})$, (3) pumping pressures $(20,000 \mathrm{psi})$, (4) perforating systems $\left(400-500^{\circ} \mathrm{F}\right)$, and $(5)$ cementing $\left(1,000^{\circ} \mathrm{F}\right)$. When necessary, the gas industry can extend present technology to complete wells down to $\pm 25,000 \mathrm{ft}$; however, such systems are very expensive, risky, and unreliable as the bottom-hole temperature approaches $400^{\circ} \mathrm{F}$.

2. Technology needs: To make significant progress in well completion technology, we must improve the reliability of our systems at high temperature and pressure, as well as significantly reducing the costs of these systems.

Specific research needs for deep-well completions are as follows:

1. Fracture fluids: Completely new polymer (or other) systems need to be developed that will be stable at high temperatures $\left(+600^{\circ} \mathrm{F}\right)$ for long time periods (4-6 hours). In addition, research is needed to reduce the friction created by pumping these viscous fluids down long tubular strings and into the fractures.

2. Fracture stimulation: Most deep wells will require fracture stimulation to maximize deliverability. Substantial improvement in fracturing technology is considered a high-priority item if one plans to economically produce deep gas.

3. Rock mechanics: Research will be required to better understand rock failure during hydraulic fracturing, calculation of fracture dimensions, perforation stability, borehole stability during production, and bulk compressibility of the formation and fluids to improve our ability to predict long-term production performance.

4. Metallurgy: Research is needed to improve downhole equipment, such as tubular materials to withstand higher burst and collapse pressures (given limits on size and density), tubular goods that are more corrosion resistant, and better downhole tools and packers (to include sealing elements).

5. Miscellaneous: Several other research items have been identified that should be addressed are perforating systems, corrosion inhibition, scaling inhibition, and sealing elements for packers.

\section{ECONOMICS}

In an effort to determine the feasibility of exploring for deep gas, a rough approximation of costs and required reservoir characteristics are outlined. Because of the sizable costs, a feasibility study would probably have to be funded by a consortium of companies or by a government interested in defining deep-gas potential. We have divided our proposed research into two phases-(1) an initial feasibility study and (2) field-based research.

\section{FEASIBILITY STUDY ESTIMATED COSTS}

The following table summarizes the estimated costs of conducting an initial feasibility study:

\begin{tabular}{|c|c|}
\hline Feasibility study topics & Cost $(\$)$ \\
\hline \multicolumn{2}{|l|}{ (1) Geology: } \\
\hline Identify rock packages & 200,000 \\
\hline \multicolumn{2}{|l|}{$\begin{array}{l}\text { Stratigraphic analysis ( } 4 \text { areas) (review and } \\
\text { extrapolation of existing data plus allowance } \\
\text { for sampling and analysis of additional rocks } \\
\text { from outcrops or borehole data) }\end{array}$} \\
\hline \multirow{2}{*}{\multicolumn{2}{|c|}{ 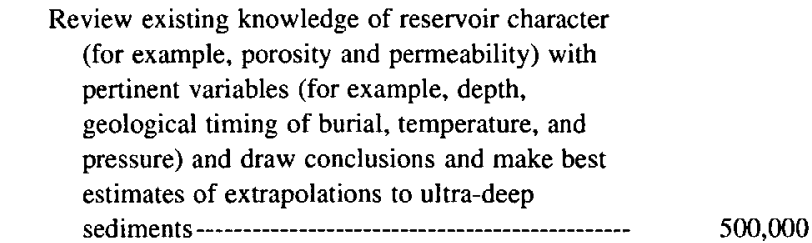 }} \\
\hline & \\
\hline \multicolumn{2}{|l|}{ Integrated geological, geochemical, and } \\
\hline geophysical models - & 500,000 \\
\hline Subtotal ---a-cen & $3,200,000$ \\
\hline \multicolumn{2}{|l|}{ (2) Geochemistry: } \\
\hline \multicolumn{2}{|l|}{ Source rock requirements -- } \\
\hline \multicolumn{2}{|l|}{ Geochemical constraints on methane in presence } \\
\hline Occurrence (theoretical and laboratory studies) ----- & $2,500,000$ \\
\hline Subtotal - & $3,600,000$ \\
\hline \multicolumn{2}{|l|}{ (3) Geophysics: } \\
\hline Summary of current technology & 200,000 \\
\hline \multicolumn{2}{|l|}{ Laboratory work (such as acoustical } \\
\hline conditions) -............... & $1,000,000$ \\
\hline Reprocess existing data-- & $1,000,000$ \\
\hline New seismic (4 areas) - & $4,000,000$ \\
\hline Subtotal --. & $6,200,000$ \\
\hline \multicolumn{2}{|l|}{ (4) Engineering: } \\
\hline Rock mechanics-- & $2,000,000$ \\
\hline Metallurgy - & $1,000,000$ \\
\hline Drilling and completion fluids----- & $1,000,000$ \\
\hline Formation evaluation & $1,000,000$ \\
\hline Subtotal ---.-.-. & $5,000,000$ \\
\hline Contingency fund ----- & $2,000,000$ \\
\hline Total -............. & $20,000,000$ \\
\hline
\end{tabular}

\section{FIELD-BASED RESEARCH}

To prove the concepts of and to improve the technology for deep-gas drilling, field-based research will be necessary. The cost of this work will be significantly greater than the $\$ 20$ million needed to establish the feasibility of deepgas drilling.

The deep Anadarko Basin has provided drilling experience below 25,000 ft. (Hefner and others, 1973). Modern drilling practices in this basin show that wells can be drilled to $25,000 \mathrm{ft}$ in about one year (Koenig, 1991); the geological section, drilling curves, and casing program are 
shown in figures 4 and 5. A round-number estimate of the cost to drill a well to $25,000 \mathrm{ft}$ would be about $\$ 10 \mathrm{mil}-$ lion. Assuming costs increase proportional to the square of the depth drilled, a well drilled to $40,000 \mathrm{ft}$ could cost anywhere from $\$ 25$ to $\$ 50$ million. A reasonable projection of costs to promote an ultradeep-drilling test, along with associated research and development activities, would be $\$ 50$ to $\$ 60$ million.

\section{RESERVE REQUIREMENTS}

It is important to determine what size geologic target is needed to justify the costs involved with deep-gas drilling. To get a feel for the magnitude of the required resource, the following simple assumptions are made: (1) Average well density will be 1 well/section ( 640 acre spacing), (2) necessary undiscounted return on investment is 5 to 1 , (3) cost to drill and complete a $40,000-\mathrm{ft}$ well is $\$ 50$ million, (4) initial flow rates would be at least 20 million cubic feet (MMcf) per day, (5) gas formation volume factor is 0.002 cubic $\mathrm{ft}$ of gas at reservoir conditions per cubic foot of gas at atmospheric conditions, (6) porosity is 7 percent, (7) water saturation is 30 percent, and (8) average gas recovery will be 65 percent of the original gas in place.

Using these assumptions, the following reserves and gas-in-place values can be computed:

\begin{tabular}{cccc}
\hline $\begin{array}{c}\text { Net gas price to } \\
\text { producer } \\
(\$ / M c f)\end{array}$ & $\begin{array}{c}\text { Necded reserves } \\
\text { per well } \\
\text { (Bcf) }\end{array}$ & $\begin{array}{c}\text { Gas in place } \\
\text { (Bcf/section) }\end{array}$ & $\begin{array}{c}\text { Net thickness of } \\
\text { producing interval } \\
(\mathrm{ft})\end{array}$ \\
\hline 2.00 & 125 & 192 & 312 \\
3.00 & 83 & 127 & 207 \\
5.00 & 50 & 77 & 125 \\
7.00 & 35 & 54 & 88 \\
9.00 & 28 & 43 & 70 \\
\hline
\end{tabular}

Mcf=thousands of cubic feet

$\mathrm{Bcf}=$ billions of cubic feet

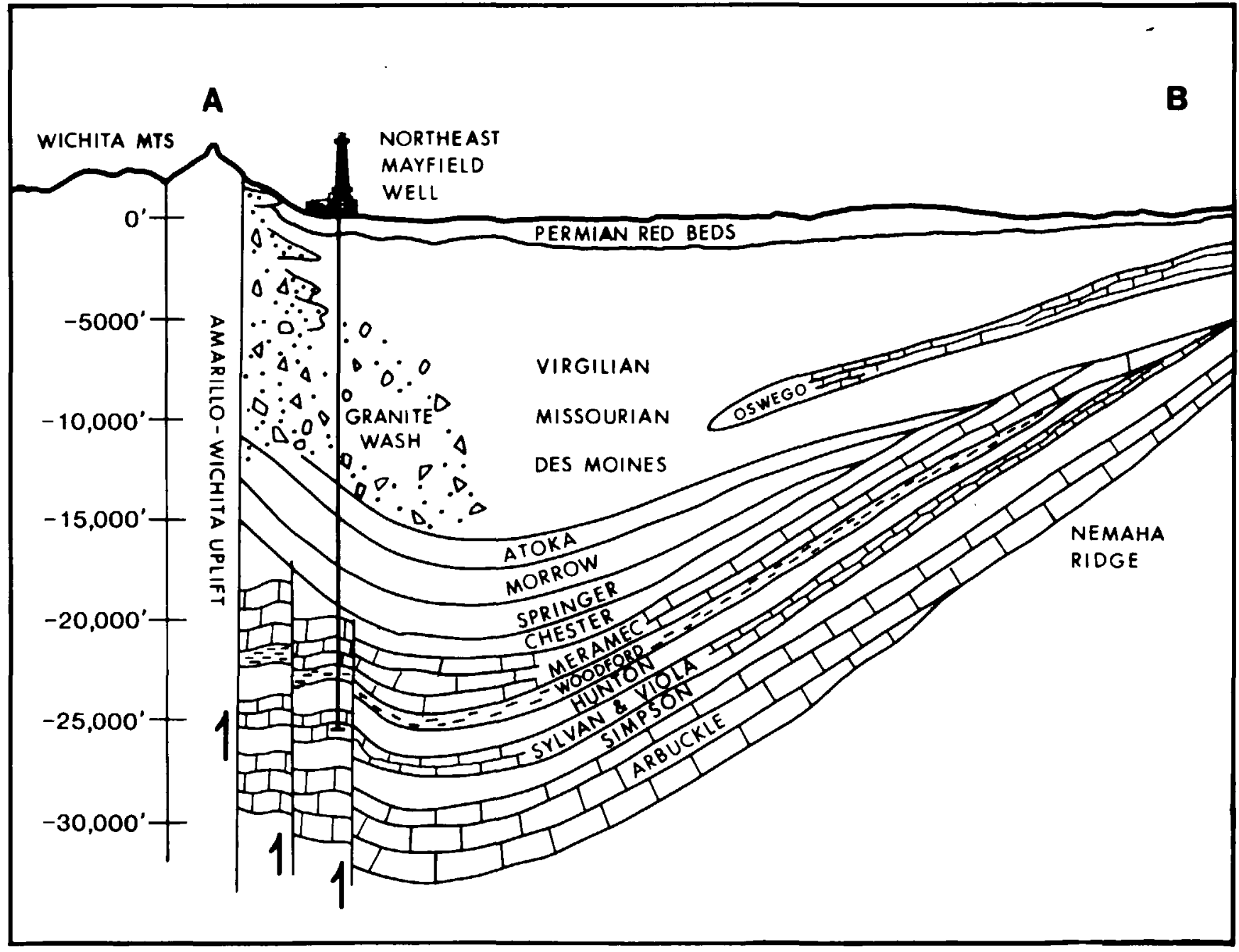

Figure 4. Generalized geological cross section of Anadarko Basin showing location of Northeast Mayfield well. From American Association of Petroleum Geologist (1989) and Koenig (1991). 


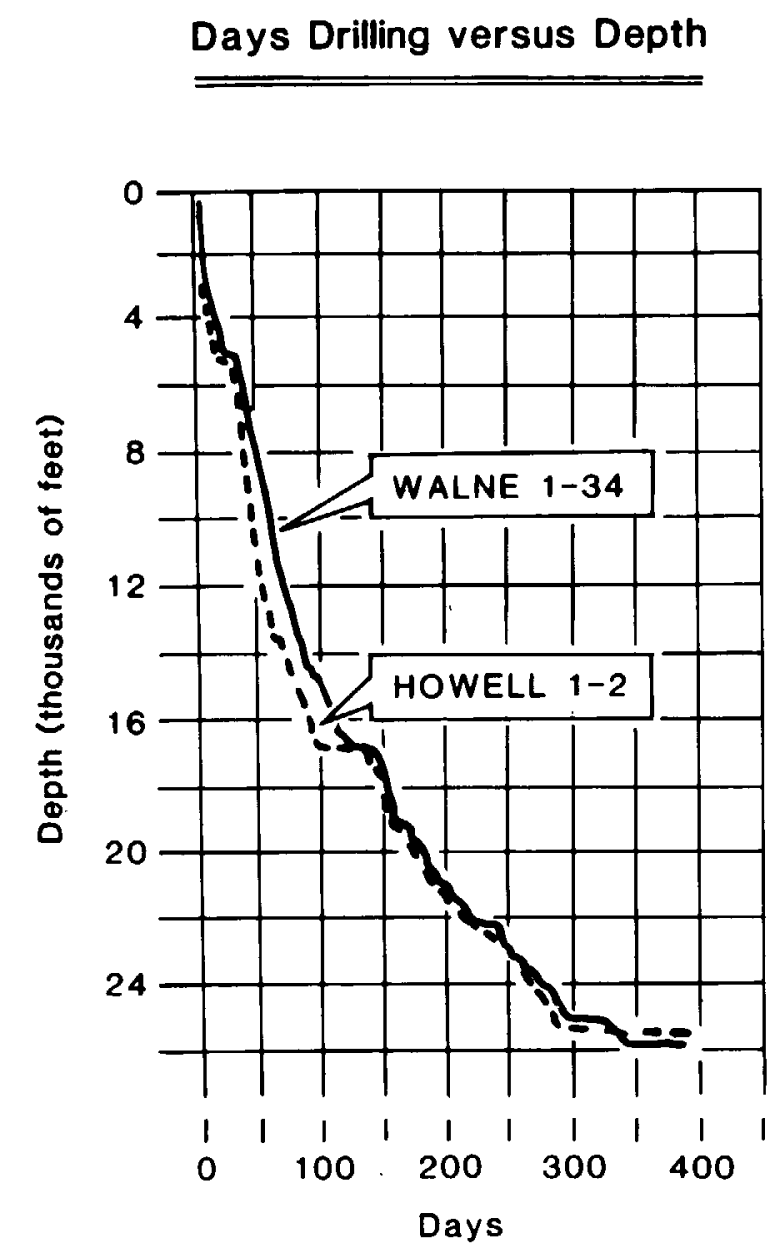

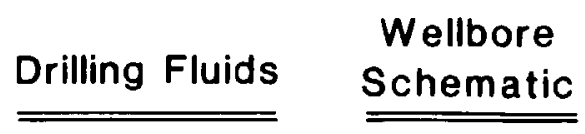

Fresh water

\& gel system

Fresh water \&

gel system

(High chlorides \&

Calcium encountered)

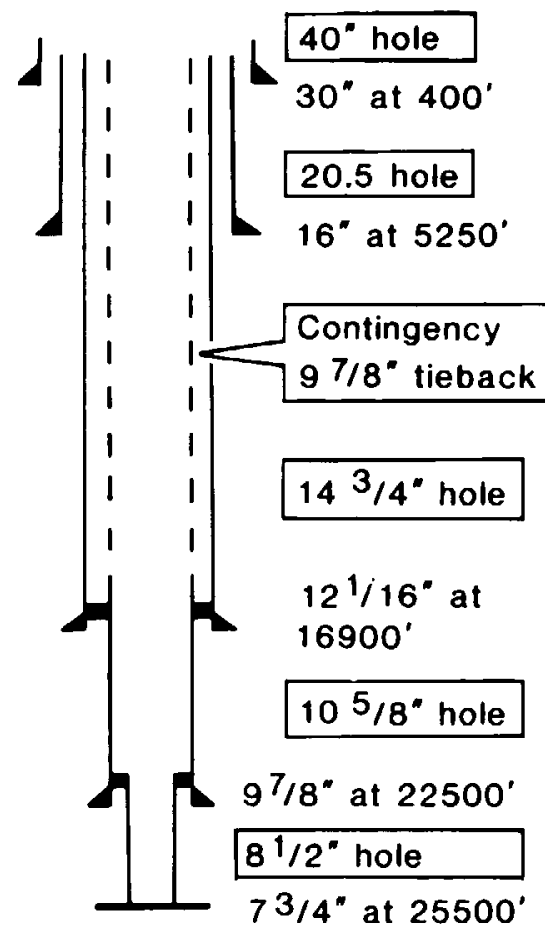

Fresh water-

extended

bentonite system

Mineral Oil

base system

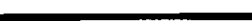

$73 / 4^{\prime \prime}$ at $25500^{\prime}$

Figure 5. Days to complete versus depth, including drilling fluids and well bore schematic, for deep wells in Northeast Mayfield, Anadarko Basin. From Koenig (1991).

One can conclude the following from these data: (1) Substantial reduction in drilling costs through improved technology can have a major impact upon the economic viability of drilling deep-gas prospects, (2) higher gas prices would provide needed incentives to look for deep gas, and (3) if the net gas price to the producer is $\$ 3.00 / \mathrm{Mcf}$, then one would need to successfully complete about $200 \mathrm{ft}$ of producing interval given the assumptions above (this assumes that the preliminary research has been successfully completed).

\section{SUMMARY}

Drilling costs will be high and therefore giant fields must be found to justify deep-gas exploration. All aspects of geology, geochemistry, geophysics, and engineering pertinent to deep drilling must be carefully investigated in order to enhance the probability of locating profitable targets. Research in drilling technology to substantially reduce drilling costs is perhaps the single most important aspect needed to achieve success with ultradeep drilling. Any progress made with this technology will undoubtedly benefit more conventional drilling. The spin-off value of all the geoscience and engineering research effort necessary to accomplish ultradeep drilling should prove of great value to the oil and gas industry.

\section{ACKNOWLEDGMENTS}

The contents of this paper were for the most part pulled together at a U.S. Department of Energy workshop on Deep Gas at Woodlands, Texas in May of 1987. Participants in this workshop were George Claypool, Bill Gwilliam, Steve Holditch, David Howell, Arfon Jones, 
Jim Jorden, Syd Kaufmann, Keith Kvenvolden, John Logan, Amos Nur, Phil Randolph, John Roen, Joan Spaw, Dal Stanley, Cheryl Wilgus, and the author. Also, Hans von der Dick, Ross Clark, and Murray Grigg have provided invaluable comments in their reviews of this subject.

\section{REFERENCES CITED}

Barker, C., 1990, Calculated volume and pressure changes during the thermal cracking of oil to gas in reservoirs: American Association of Petroleum Geologists Bulletin, v. 74, no. 8, p. 1254-1261.
Hefner, R.A., III, Wheeler, R., and Kinchloc, R., 1973, The drilling and production of ultradeep natural gas accumulations occurring below $20,000 \mathrm{ft}$ in the Anadarko Basin: 12th World Gas Conference, Nice, IGU/A 5-73.

Koenig, R.L., 1991, An extraordinary drilling challenge in the Anadarko Basin: 1991 Society of Petroleum Engineers Annual Technical Conference, SPE paper 22575.

Moore, S.D., 1992, International deep wells hit new high: Petroleum Engineer International, v. 64, no 6, p. 28-32.

Shirley, K., 1989, Anadarko's Arbuckle play heats up: American Association of Petroleum Geologists Explorer, v. 10, no. 7.

Takach, N.E., Barker, C., and Kemp, M.K., 1987, Stability of natural gas in the deep subsurface-Thermodynamic calculation of equilibrium compositions: American Association of Petroleum Geologists Bulletin, v. 71, no. 3, p. 322-333. 



\title{
Empirical Observations Regarding Methane Deadlines in Deep Basins and Thrust Belts
}

\author{
By David W. Houseknecht ${ }^{1}$ and Christoph Spötl ${ }^{1,2}$
}

\section{CONTENTS}

\begin{tabular}{|c|c|}
\hline & \\
\hline Introduction & 07 \\
\hline Thermal Maturity and $\mathrm{Hy}$ & \\
\hline Origins of Methane ...... & \\
\hline Preservation of Deep-Seated Methane & 19 \\
\hline Theoretical Considerat & 19 \\
\hline Experimental and Empirical Eviden & 20 \\
\hline Empirical Evidence from Conventional & \\
\hline Natural-Gas Exploration & 22 \\
\hline Methane at High Thermal Maturities in the Arkoma & \\
\hline Basin-Ouachita Thrust Belt & 2 \\
\hline Regional Thermal Matu & 2 \\
\hline Local T & 2 \\
\hline Natural-C & $2 ?$ \\
\hline $\operatorname{Red}$ & 2 \\
\hline Wilb & 226 \\
\hline Ouach & 226 \\
\hline ............. & . \\
\hline & \\
\hline ......... & \\
\hline$f$ & \\
\hline
\end{tabular}

\footnotetext{
ABSTRACT

Deep parts of many sedimentary basins and thrust belts have large natural-gas potential, but exploration in these settings has been limited by the widely held perception that

'U.S. Geological Survey, National Center, 12201 Sunrise Valley Dr., Reston, VA 22092.

${ }^{2}$ University of Missouri, Columbia, MO 65203.
}

natural gas and (or) reservoir quality are not preserved in strata of high thermal maturity. Review of pertinent literature plus new data from the deep Arkoma Basin and Ouachita thrust belt (Arkansas and Oklahoma) indicates that methane is not chemically destroyed by temperatures that produce vitrinite reflectance of 4 to 5 percent. In some settings, however, methane becomes diluted to noneconomic concentrations by nitrogen and carbon dioxide at vitrinitereflectance levels above 4 percent.

Methane production in the Arkoma Basin and Ouachita thrust belt occurs in strata with up to at least 4 percent vitrinite reflectance, and prolific methane production from wells located near the presently defined upper thermal maturity limit of production suggests that economic methane resources are likely to be discovered in strata of still higher thermal maturity. Excellent reservoir quality has been preserved in this natural-gas province, partly because reservoired hydrocarbons inhibited high-temperature diagenetic reactions that destroyed porosity below hydrocarbon-water contacts.

Although these observations suggest that strata of high thermal maturity have vast natural-gas potential, many geologic processes that influence the fate of methane during exposure to deep burial, high temperatures, and tectonic deformation are poorly understood. Concerted research on metagenesis of methane and nonhydrocarbon gases and on high-temperature diagenesis of reservoir and seal rocks is necessary for better evaluation of natural-gas potential in high thermal maturity provinces and for development of exploration strategies to test the potential of those provinces.

\section{INTRODUCTION}

Natural gas is viewed as a significant energy resource whose use may increase because it is thought to be 
domestically abundant in the United States (Gautier and Brown, this volume; Howell, Wiese, and Swinchatt, this volume) and because its use in place of coal and oil-based fuels would reduce substantially the emission of greenhouse gases and toxic elements to the atmosphere (Cole, this volume). However, increased use of natural gas is inhibited by the economically induced oil emphasis that has dominated the U.S. petroleum industry (see Hefner, this volume). In fact, natural-gas exploration and development strategies are, in essence, those that have been developed for oil, and our research-based knowledge of natural gas is less comprehensive than that of oil.

During the past decade, a relatively small segment of industry has focused on exploration and development of nonassociated natural gas (that is, natural gas not associated with oil accumulations). As a result, there is a growing realization that much (perhaps most) natural gas is not associated with oil and may be distributed differently through the earth's crust than oil. For example, discovery and development of deep-basin natural-gas accumulations, natural gas in tight sandstone reservoirs, and widespread coalbed methane accumulations have demonstrated the existence of significant resources that are not associated with oil and occur in very different settings than oil.

Among the many geologic habitats in which natural gas occurs, deep parts of sedimentary basins and thrust belts appear to have large potential. Exploration in these settings, however, has been inhibited by economic factors and by the poorly understood nature of natural-gas preservation at elevated temperatures. The purpose of this paper is to review empirical observations regarding the existence of a thermally controlled natural-gas deadline and to present data from recent exploration and research activity in the Arkoma Basin-Ouachita thrust belt that contributes to our understanding of the occurrence of natural gas in strata with elevated thermal maturity (see also Burruss; Wyman; and Dyman and others, this volume).

\section{THERMAL MATURITY AND HYDROCARBON OCCURRENCE}

Since the landmark work of David White (1915), it has been known that thermal maturity is a fundamental control of hydrocarbon distribution. White (1915) demonstrated that low, intermediate, and high coal rank (that is, thermal maturity) coincided with oil, gas, and no hydrocarbon production, respectively, in the Appalachian Basin. The relationships observed by White became a working paradigm to the petroleum industry and were summarized, along with additional examples, by Landes (1967), whose synopsis is shown in figure 1. A more comprehensive history of thermal maturity and hydrocarbon relationships was provided in tabular form by Bostick (1979).

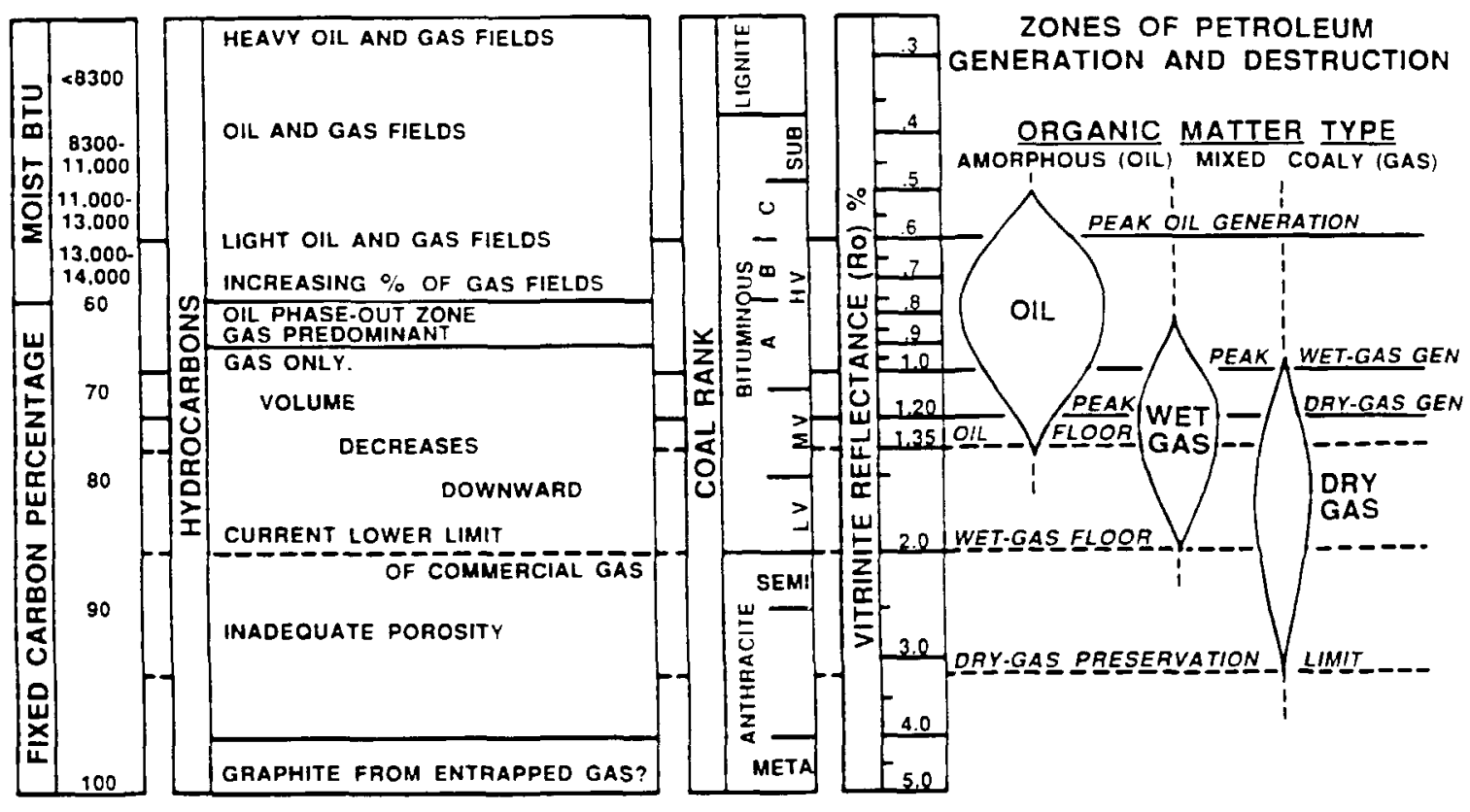

Figure 1. Relationship between thermal maturity and economic occurrence of hydrocarbons. Left half of figure summarizes knowledge as of 1967 (modified from Landes, 1967). Right half of figure summarizes more recent concepts of hydrocarbon windows, zones of thermal maturity in which oil, wet gas, and dry gas are chemically stable in economic volumes in reservoirs (modified from Dow, 1977). Note that dry-gas preservation limit likely is not valid in at least some geologic settings (see text for explanation). FIXED CARBON, total carbon content; GEN, generation; MOIST BTU, calorific value in British thermal units determined from moist samples (as mined); LV, low volatile; $\mathrm{MV}$, medium volatile; $\mathrm{HV}$, high volatile; $\mathrm{R}_{\mathrm{o}}$, reflectance in oil. Dashed lines indicate gradational boundaries. 
During the past two decades, research in organic geochemistry has emphasized thermal generation and thermal destruction of hydrocarbons. This emphasis resulted in the concept of hydrocarbon windows, specific ranges of thermal maturity within which oil, wet gas (gaseous hydrocarbons heavier than $\mathrm{CH}_{4}$ ), and dry gas occur (for example, see fig. 1). The hydrocarbon-window concept is based both on theoretical and experimental organic geochemistry of hydrocarbon generation and destruction, and on empirical relationships between thermal maturity and the occurrence of commercial hydrocarbon accumulations in the Earth's crust. This body of research has demonstrated that oil and wet gas have thermal-maturity deadlines, levels of thermal maturity above which those phases do not commonly occur in economic volumes, although those deadlines vary somewhat in absolute value depending upon the specific origin and composition of the hydrocarbons. Despite slight variations in oil and wet-gas deadlines, they are a powerful tool for predicting whether unexplored areas might contain oil or wet gas. Most organic geochemists agree that oil and wet-gas deadlines are fundamentally controlled by the thermal stability of the various organic geochemical compounds of which the hydrocarbons are composed, and are mostly independent of inorganic diagenesis of reservoir and seal rocks. An alternative point of view is expounded by Price (in press; and in Dyman and others, this volume), who presents evidence that hydrocarbons are chemically stable to much higher levels of thermal maturity in closed systems, such as fine-grained rocks. Price (in press; and in Dyman and others, this volume) suggests that the distribution of hydrocarbons is more a function of subsurface physical environment, pore-fluid pressure, and fluid dynamics than a function of chemical stability of hydrocarbon compounds.

Little consensus applies to a dry-gas (methane) deadline. In fact, various authors have suggested that methane deadlines span a wide range. The economic deadline for methane, defined by vitrinite reflectance or equivalent vitrinite reflectance from another scale of thermal maturity, has been placed at 2 percent by Landes (1967), 3 percent by Dow (1977) and Saxby (1982), 3.2 percent by Dow and O'Connor (1982), 3 to 3.5 percent by Teichmüller and others (1979), and 5 percent by Hood and others (1975). Although Saxby (1982) placed the economic deadline for methane at 3 percent, he suggested a tentative methane preservation deadline of 5 percent. The disparity of these estimates suggests that the existence of a methane deadline is in doubt. Moreover, the limited volume of literature that addresses this problem suggests that a variety of processes may influence the existence of a methane deadline, and that the preservation of methane exposed to elevated thermal regimes may be geographically and (or) stratigraphically variable depending upon specific temperature, pressure, and chemical histories of reservoirs, seals, and pore fluids. The methane deadline is the focus of this paper, and following sections provide an overview of research results that address this problem.

\section{ORIGINS OF METHANE}

Methane can be generated in several ways. Biogenic methane (also known as microbial methane and bacterial methane) is generated during diagenesis at temperatures generally lower than those for oil generation $\left(<50^{\circ} \mathrm{C}\right.$; locally up to $110^{\circ} \mathrm{C}$ ) by bacterial degradation of organic matter (Rice and Claypool, 1981; Coleman and others, 1988; Schoell, 1988; Tissot and Welte, 1984).

Thermogenic methane is generated by temperature-induced reactions during catagenesis at temperatures generally corresponding to oil generation (roughly $50-150^{\circ} \mathrm{C}$ ) and during metagenesis at temperatures generally higher than oil generation $\left(>150^{\circ} \mathrm{C}\right)$. In systems that contain humic kerogen, thermogenic methane is generated directly from kerogen ("primary cracking" of Welte and others, 1988) during catagenesis and metagenesis. In systems that contain sapropelic kerogen, thermogenic methane is generated during catagenesis as a by-product of oil and (or) wet-gas generation (primary cracking), and in greater volumes during metagenesis, as the result of cracking of heavier hydrocarbons that previously had been generated during catagenesis ("secondary cracking" of Welte and others, 1988).

Abiogenic methane originates from inorganic sources, commonly as the result of deep crustal reactions involving graphite $(\mathrm{C})$ and water $\left(\mathrm{H}_{2} \mathrm{O}\right)$ (see Burruss, this volume). It is generally thought to be present in concentrations insufficient to be considered of economic importance (see, for example, Tissot and Welte, 1984), although some authors disagree with that perspective (for example, Gold, this volume).

\section{PRESERVATION OF DEEP-SEATED METHANE}

Preservation of economic volumes of deep-seated methane is the focus of this paper, regardless of the methane's origin. The following sections address the chemical stability of methane at elevated temperature and the empirical evidence bearing on the preservation and destruction of methane accumulations exposed to high temperatures and (or) deep burial.

\section{THEORETICAL CONSIDERATIONS OF THERMAL STABILITY}

The chemical stability of methane at elevated temperature has been calculated on the basis of thermodynamics 
by Hunt (1975), Takach and others (1987), and Barker and Takach (1992). Takach and others (1987) determined that most methane would be preserved in an inert reservoir up to at least $320^{\circ} \mathrm{C}$ (the upper limit of their calculations), and Hunt (1975) calculated that methane is chemically stable in inert, dry reservoirs up to $550^{\circ} \mathrm{C}$. However, Hunt (1975) pointed out that if water and a source of sulfur are present, methane can be destroyed by oxidation to yield $\mathrm{H}_{2} \mathrm{~S}$ and $\mathrm{CO}_{2}$. Both Hunt (1975) and Takach and others (1987) concluded that reservoir diagenesis, and specifically the preservation of porosity, is probably more critical than the thermal stability of methane for deep natural-gas resources.

Barker and Takach (1992) calculated that reservoir mineralogy and the presence or absence of graphite (residue of thermally degraded oil) exert a significant influence on equilibrium gas composition in the deep subsurface $(3,000$ to $12,000 \mathrm{~m}$; corresponding to 96 to $325^{\circ} \mathrm{C}$ ). Their work suggests that methane can be totally destroyed by oxidation in reservoirs of certain composition, whereas it can be preserved to at least $12,000 \mathrm{~m}$ and $325^{\circ} \mathrm{C}$ in others, and that the presence of graphite generally extends the maximum depth to which methane persists. The results of Barker and Takach (1992) are influenced by the assumption of an initial water saturation of 40 percent in the pores of the reservoir, which results in dramatic increases in $\mathrm{CO}_{2}$ and hydrogen content at the expense of methane $\left(\mathrm{CH}_{4}+2 \mathrm{H}_{2} \mathrm{O} \rightarrow \mathrm{CO}_{2}+4 \mathrm{H}_{2}\right)$, even at relatively shallow depths $(3,000 \mathrm{~m})$ and low temperatures $\left(96^{\circ} \mathrm{C}\right)$. This assumption may be valid in some deep basins, but is not consistent with generally lower water saturations in many deep-basin gas accumulations.

\section{EXPERIMENTAL AND EMPIRICAL EVIDENCE FROM COALS}

The methane content of coalbeds has been of interest for decades, partly because of the explosion hazard posed by methane in coal mines and partly because of the resource potential of coalbed gas. Consequently, a relatively large experimental and empirical data base that relates gas content and composition to coal rank has been assembled.

Experimental work has shown that $\mathrm{CO}_{2}, \mathrm{CH}_{4}$, and $\mathrm{N}_{2}$ are the major gases generated from coal as it matures thermally, although specific products of coalification and their relative proportions are dependent upon the maceral composition, and therefore the elemental composition of the coal (Karweil, 1969; Hunt, 1979; Tissot and Welte, 1984). At low temperatures (diagenesis), biogenic methane is commonly generated from peat and lignite. As temperatures increase during burial (catagenesis), typical vitriniterich coals generate a large volume of thermogenic $\mathrm{CO}_{2}$, followed by an even larger volume of thermogenic $\mathrm{CH}_{4}$. Although peak methane generation occurs at about $150^{\circ} \mathrm{C}$, typically corresponding to bituminous rank, methane continues to be generated from coal at temperatures in excess of $220^{\circ} \mathrm{C}$, corresponding to anthracite rank (Karweil, 1969; also summarized by Hunt, 1979). Thermogenic $\mathrm{N}_{2}$ commonly is generated in much smaller volumes during catagenesis, and a large volume of $\mathrm{H}_{2} \mathrm{O}$ is expelled from coal throughout diagenesis and catagenesis.

Although $\mathrm{CO}_{2}$ is the principal constituent of early thermogenic gas generated from coals, $\mathrm{CO}_{2}$ is only a minor and extremely variable constituent of most gas in bituminous and anthracite coals. Rightmire (1984) suggested that the high solubility of $\mathrm{CO}_{2}$ in water facilitates its mobility and that both $\mathrm{CO}_{2}$ and water are flushed from coalbeds by the large volume of methane generated during later stages of catagenesis.

Methane is stored in coalbeds in three ways. It is estimated that about 90 percent of the gas is adsorbed onto the internal surfaces of pores, and the remainder is stored in fractures and macropores either as free gas or dissolved in groundwater (Rice, this volume). The adsorptive capacity, and therefore the potential gas content of coal, increases with rank (at least through anthracite) and depth (Jüntgen and Karweil, 1966a, b; Kim, 1977, 1978).

The gas content of high-rank coalbeds provides evidence for the retention of gases and for the dilution of methane by other gases in incipient metamorphic rocks. An example of the influence of increasing thermal maturity on coalbed gas has been documented in the DnieperDonets Basin and the Donbas foldbelt of Ukraine, an area that displays increasing thermal maturity in coeval strata from the basin into the foldbelt (Lapchinsky and Dzhamalova, 1987; Ulmishek and others, in press). Coalbed gas in the eastern part of the foldbelt is a mixture of $\mathrm{CH}_{4}, \mathrm{~N}_{2}$, and $\mathrm{CO}_{2}$. The coals are high metamorphic anthracite (meta-anthracite) in rank, corresponding to equivalent vitrinite-reflectance values of at least 5 percent and perhaps as high as 6 percent. Although the coals of the Donbas foldbelt provide evidence of an overall dilution of methane at meta-anthracite rank, gas compositions vary significantly by location. Among the coalbed gases, the $\mathrm{CH}_{4}$ content varies from 40 to 80 percent, the $\mathrm{N}_{2}$ content varies from 20 to 60 percent, and the $\mathrm{CO}_{2}$ content varies from 1 to 17 percent (Lapchinsky and Dzhamalova, 1987).

Similarly, coalbeds penetrated in the Saar \#1 borehole in northwestern Germany contain gas in which the concentration of methane decreases almost linearly with increasing depth and coal rank. At thermal maturities higher than about 4.5 percent vitrinite reflectance, the sum of $\mathrm{N}_{2}$ plus $\mathrm{CO}_{2}$ is greater than the $\mathrm{CH}_{4}$ content (Wehner and others, 1976; Teichmüller and others, 1983).

To summarize existing knowledge regarding gas in high-rank coals, methane is generated in large volumes during catagenesis of coal and continues to be generated in smaller volumes during metagenesis. The capacity of coal to retain methane by adsorption increases with ther- 
mal maturity at least into anthracite rank. Little is known about methane generation and retention into meta-anthracite rank because of the paucity of economically important coals of such high rank. Limited evidence suggests a tendency for methane to be diluted by nitrogen and carbon dioxide in coalbeds above approximately 4.5 percent vitrinite reflectance.

\section{EMPIRICAL EVIDENCE FROM CONVENTIONAL NATURAL-GAS EXPLORATION}

Exploration for natural gas in strata known to be characterized by elevated thermal maturities (vitrinite reflectance $>2$ percent) has been conducted in relatively few locations worldwide. This section summarizes the occurrence of methane resources in a few geologic provinces where information is available.

The north-central European gas province includes northern Germany, a large part of the Netherlands, and the southern portion of the North Sea. Reservoirs are mostly sandstones of the Permian Rotliegendes Formation, and source beds are considered to be underlying Carboniferous coal measures, which mostly are characterized by thermal maturities in the range of 1.2 to 3.2 percent vitrinite reflectance (Boigk and others, 1976; Van Wijhe and others, 1980; Cornford, 1986). Teichmüller and others (1979, 1984) have shown that Rotliegendes gas fields in northwestern Germany mostly are characterized by thermal maturities of 1 to 2 percent vitrinite reflectance, but thermal maturity in a few gas fields reaches 2.5 to 2.8 percent vitrinite reflectance, and in one gas field reaches 4.4 to 4.7 percent vitrinite reflectance (Uchte field). Igneous intrusions are thought to underlie those gas fields that display highest thermal maturities. Methane generally becomes diluted by increasing nitrogen content in higher-thermal-maturity reservoirs of northwestern Germany gas fields (Van Wijhe and others, 1980; Everlien and Hoffmann, 1991), a pattern similar to that observed in coalbed gases.

The Pripyat and Dnieper-Donets Basins and Donbas foldbelt of Byelarus and Ukraine represent northwestsoutheast elongate accumulations of strata deposited in Devonian rift basins and Carboniferous through Permian sag basins (Ulmishek and others, in press). Oil production in the Pripyat Basin in the northwest gives way to gas production in the Dnieper-Donets Basin, and there is no hydrocarbon production in the Donbas foldbelt in the southeast, apparently as a consequence of increasing thermal maturity from northwest to southeast. Conventional gas is produced from strata whose thermal maturity extends up to at least 3.5 to 4.0 percent vitrinite reflectance in the Dnieper-Donets Basin. No commercial gas production has been discovered in the anthracite to meta-anthracite (5 to 6 percent vitrinite reflectance) strata in the Donbas foldbelt, and gas from coal mines suggests dilu- tion of methane by nitrogen and carbon dioxide (Ulmishek and others, in press). These observations suggest that there may be limited natural-gas preservation in the thermal-maturity range of 4 to 6 percent vitrinite reflectance, although no specific methane deadline is indicated.

Gas is produced from several fields in the Kuangsi and South Sichuan provinces of China from great depths (as much as $7 \mathrm{~km} ; 23,000 \mathrm{ft}$ ), and from strata characterized by thermal maturities between 3.8 and 4.8 percent reflectance (Mo and others, 1984). Little is known in the Western literature about these prolific gas occurrences, other than that the reservoirs are Precambrian and Devonian carbonates.

Some of the deepest wells in the United States have been drilled into Paleozoic strata in the Anadarko Basin of Oklahoma and Texas. Data from many of those wells suggest that the deep Anadarko Basin contains some of the most thermally mature strata in the world from which prolific gas production occurs. In fact, the Chevron-Freeport \#1 Ruth Ledbetter well (Wheeler County, Tex.) holds the world record for gas production from the greatest depth, 7,330-7,955 m (24,435-26,518 ft) (Jemison, 1979; Hunt, 1984; Cardott and Lambert, 1985; Cardott, 1989; Davis and Northcutt, 1989). On the basis of a depth-versus-vitrinite-reflectance regression equation determined for the Woodford Shale in the Anadarko Basin, it has been estimated that vitrinite reflectance of the productive strata is in the range of 5.2 percent (Cardott and Lambert, 1985) to 5.4 percent (Cardott, 1989). However, these estimates are equivocal, and other researchers have suggested lower thermal maturities for the productive interval (Tarafa and others, 1988). Such controversy is not uncommon in samples of extreme thermal maturity because of the difficulties involved in measuring reflectance of dispersed kerogen that has been subjected to metagenesis (see Houseknecht and others, 1993). Moreover, gas production from this and many of the other deepest wells in the Anadarko Basin comes from Ordovician or Silurian strata, none of which contains indigenous vitrinite. Thus, vitrinite reflectance must be measured in younger strata, including the Devonian and Mississippian Woodford Shale, and projected to depths representative of production from older reservoirs.

Several other authors have documented gas production at elevated thermal maturities in the deep Anadarko Basin (see Hefner, this volume). Waples (1980) reported 3.8 percent vitrinite reflectance for a gas-producing zone in the Socal \#1 James (Wheeler County, Tex.) and 4.8 percent vitrinite reflectance for a gas producing zone in the Union of California \#1-33 Bruner (Beckham County, Okla.). The latter represents the highest thermal maturity gas production reported by Waples (1980). Using their empirically derived depth-versus-vitrinite-reflectance regression equation, Cardott and Lambert (1985) calculated vitrinite reflectance values of 4.2 to 4.6 for producing zones in some deep wells of the deep Anadarko Basin. 
Despite controversy regarding exact vitrinite-reflectance levels in specific wells, numerous gas fields have been developed within the deep Anadarko Basin where strata clearly display regional patterns of high thermal maturity (Hood and others, 1975; Waples, 1980; Price and others, 1981; Hunt, 1984; Katz and others, 1982; Cardott and Lambert, 1985; Cardott, 1989). Moreover, patterns of natural-gas productivity do not correspond closely with patterns of thermal maturity, suggesting that an abrupt methane deadline cannot be defined on the basis of thermal maturity alone.

\section{METHANE AT HIGH THERMAL MATURITIES IN THE ARKOMA BASIN- OUACHITA THRUST BELT}

The deep Arkoma Basin and frontal thrust belt of the Ouachita Mountains in Arkansas and Oklahoma recently have been the focus of one of the most active gas-exploration plays in the United States. This activity has been stimulated by numerous and prolific discoveries in strata characterized by high vitrinite reflectance (Houseknecht and others, 1992). The region provides a natural laboratory in which to evaluate the concept of a methane deadline. This section summarizes relationships between thermal maturity and methane production in this prolific gas basin.

The Arkoma Basin is a foreland basin that formed in response to convergent tectonism along the Ouachita thrust belt. The geology has been summarized recently by several authors (for example, Houseknecht, 1986, 1987; Viele and Thomas, 1989; Arbenz, 1989; Meckel and others, 1992). Geology of the Oklahoma portion of the deep Arkoma Basin and Ouachita frontal thrust belt recently has been discussed in Suneson and others (1990).

\section{REGIONAL THERMAL MATURITY}

The high thermal maturity of the Arkoma Basin has been known since publication of White's (1915) map of coal rank. That map also documented the increase in thermal maturity from west to east in strata at the surface and in the shallow subsurface, with thermal maturity contours oriented approximately perpendicular to stratigraphic and structural strike. Subsequently, several authors have refined, but not substantially changed, the pattern of thermal maturity defined by White in the Arkoma Basin and have determined the pattern of thermal maturity at the surface in the Ouachita Mountains (Croneis, 1927; Hendricks, 1935; Branner, 1937; Wilson, 1961, 1971; Burgess, 1974; Curiale, 1983; Houseknecht, 1984; Houseknecht and Matthews, 1985; Hathon and Houseknecht, 1987; Underwood and others, 1988; Arne, 1992; Houseknecht and others,
1992). The regional thermal maturity map shown in figure 2 is a compilation of all that work.

Interpretation of the regional thermal history responsible for the pattern of thermal maturity illustrated in figure 2 remains a topic of ongoing research and is beyond the scope of this paper. Although not completely understood, these patterns apparently reflect the combined influences of stratigraphic burial, tectonic burial, hydrothermal fluid flow, and igneous intrusion, with the relative role of each in determining thermal maturity varying geographically and stratigraphically (Houseknecht and Matthews, 1985; Underwood and others, 1988; Arne, 1992; Houseknecht and others, 1992).

Although gas exploration has been conducted in many parts of the deep Arkoma Basin and Ouachita frontal thrust belt, concentrated activity that bears on the topic of this paper mostly has occurred in Latimer and LeFlore Counties, eastern Oklahoma (fig. 3). This is a prolific gas-producing area that includes the giant Red Oak and Wilburton gas fields, each of which have cumulative production in excess of 1 trillion cubic feet ( 28 billion cubic meters), several smaller gas fields, and numerous recent gas discoveries in the Ouachita frontal thrust belt (fig. 3). The following sections discuss thermal maturity and gas productivity within this area.

\section{LOCAL THERMAL MATURITY}

Vitrinite-reflectance analyses were performed on shale samples from many wells in this area by Hathon and Houseknecht (1987), whose isoreflectance contour map of the basal Atokan (Middle Pennsylvanian) Spiro sandstone (widely used informal name for quartzose sandstone at base of Atoka Formation; Branan, 1968), one of the most prolific reservoirs in the region, appeared in Houseknecht and McGilvery (1990). That map shows that vitrinite reflectance increases from less than 2.0 percent in Wilburton gas field to more than 3.5 percent at the northeast end of Red Oak gas field (fig. 3), a pattern of increase that parallels that of the Hartshorne coalbed (within lowermost portion of Desmoinesian McAlester Formation; Wilson, 1935; Oakes and Knechtel, 1948) at shallow depths in the same area (fig. 2). As mean vitrinite reflectance increases to the east, the vitrinite reflectance populations of individual samples become more multimodal and their standard deviations increase significantly, phenomena that are thought to result from the increase in vitrinite anisotropy that is known to accompany increases in thermal maturity (Houseknecht and Matthews, 1985; Houseknecht and others, 1993).

In an attempt to resolve the uncertainties involved in measuring reflectance of dispersed vitrinite at these levels of thermal maturity, a microscope has been modified to measure rotational reflectance of dispersed vitrinite. This 


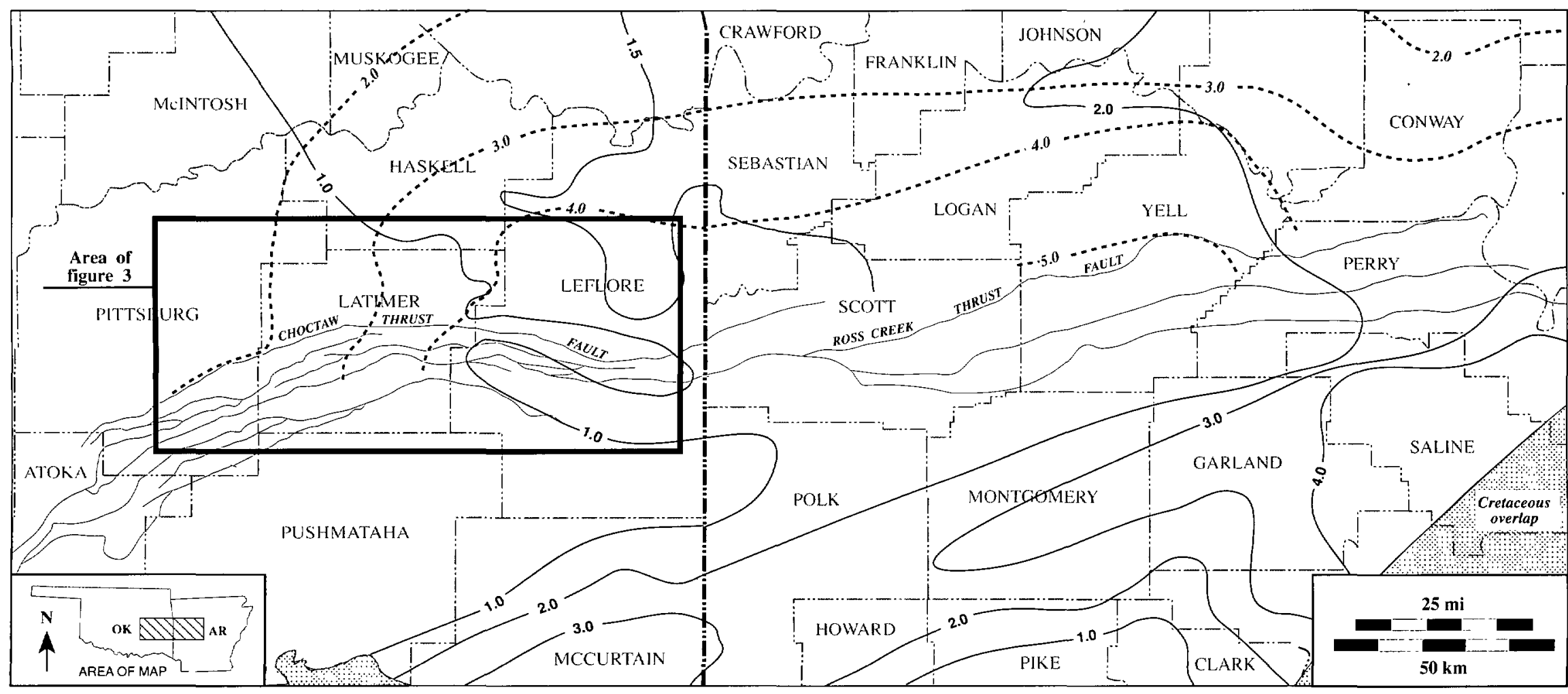

\section{EXPLANATION}

\section{Surface trace of thrust fault
Vitrinite reflectance (percent) contours in
Surface and near-surface strata}

Figure 2. Regional map of Arkoma Basin and Ouachita Mountains showing vitrinite reflectance contours (solid lines) based on analyses of surface and near-surface samples (compiled from Houseknecht, 1984; Houseknecht and Matthews, 1985; Hathon and Houseknecht, 1987; and previously unpublished data), and approximate vitrinite reflectance of basal Atokan strata (approximately equivalent to Spiro sandstone at base of Atoka Formation; Branan, 1968) in subsurface (heavy, dashed contours). Thrust faults that trend west to east across center of map define Ouachita frontal thrust belt. Northernmost thrust fault of significant displacement (Choctaw thrust fault in Oklahoma and Ross Creek thrust fault in Arkansas) defines boundary between Arkoma Basin (north) and Ouachita orogenic belt (south). Rectangle in Oklahoma shows area of figure 3. 


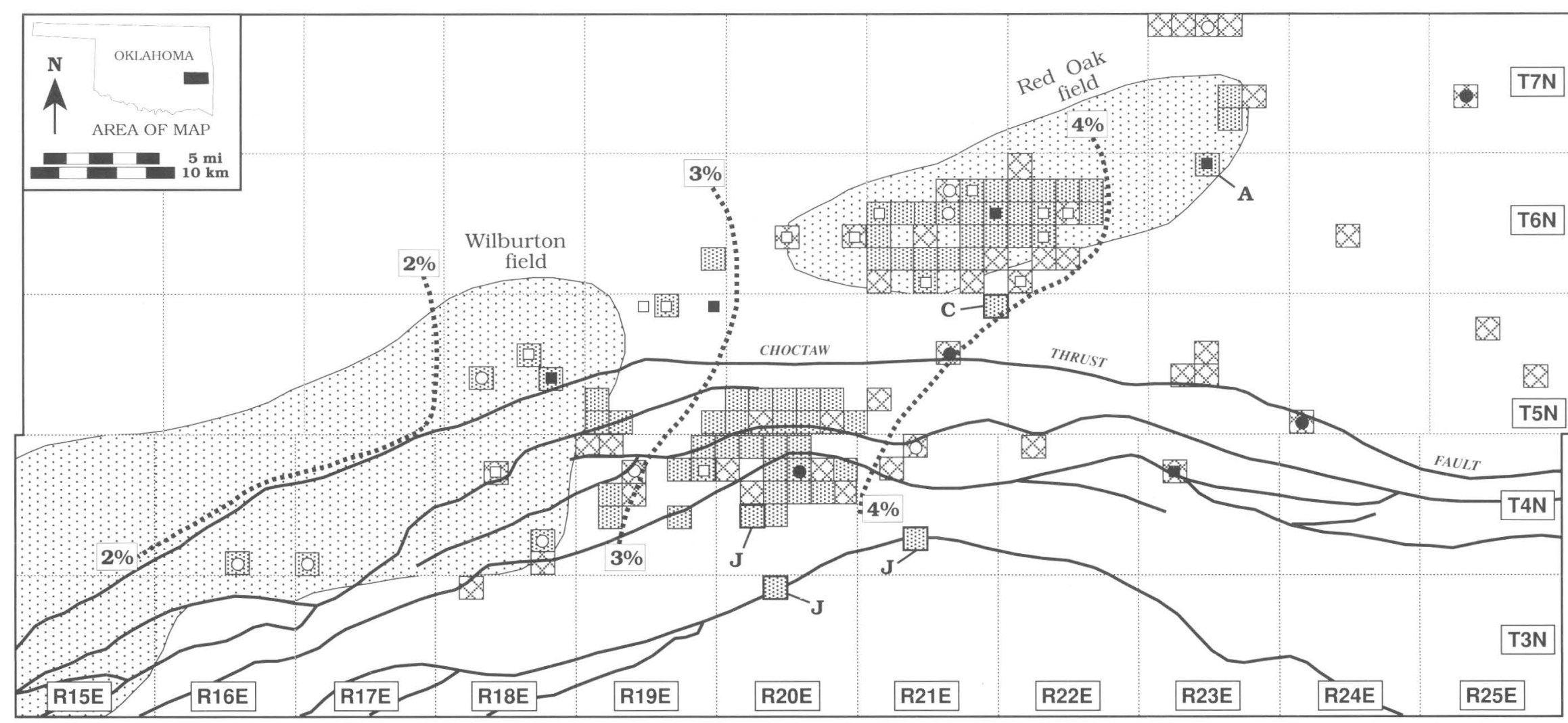

EXPLANATION

$\begin{array}{ll}\text { Generalized outline of gas field } \\ \text { Selected tests of Spiro sandstone: } \\ \text { Productive } \\ \text { Nonproductive } \\ \text { Selected production from strata older } \\ \text { than Spiro sandstone: } \\ \text { J Jackfork Sandstone (Morrowan) } \\ \text { C } & \text { Cromwell sandstone (Morrowan) } \\ \text { A } & \text { Arbuckle Group (Ordovician) }\end{array}$

$\ldots .3 \%$ Rotational-vitrinite-reflectance contour

Surface trace of thrust fault

Thermal-maturity control locations:

Thermal-maturity control locat
Rotational reflectance data:
Cuttings

- Cores

Conventional reflectance data:
Cuttings

A Arbuckle Group (Ordovician)

$\square \quad$ Cores

Figure 3. Map of deep Arkoma Basin and Ouachita frontal thrust belt in eastern Oklahoma showing generalized contours of mean rotational vitrinite reflectance and locations of natural-gas production from Spiro sandstone at base of Atoka Formation (Branan, 1968) or older strata. General outlines of Red Oak and Wilburton gas fields are shown, as well as large productive area south and west of Wilburton field. Results of most test wells drilled in the Spiro east of the 3-percent isoreflectance contour and selected wells drilled in the Spiro between the 2-percent and 3-percent isoreflectance contours are shown; sections in which the Spiro is productive and nonproductive are shown with patterns, and sections where the Spiro has not been tested are not patterned. Sections in which production has been established from strata older than the Spiro are patterned and labeled with bold letter indicating productive formation. Vitrinite-reflectance control points also are shown. 
new method facilitates collection of reflectance data while the microscope polarizer is rotated $360^{\circ}$, thereby allowing vitrinite anisotropy to be measured and more accurate estimates of thermal maturity to be made (Houseknecht and others, 1993). For a single particle of dispersed vitrinite, the polarizer is rotated $360^{\circ}$, stopping at 200 equally angled orientations to collect a reflectance measurement. The mean of those 200 measurements is the rotational reflectance for that particle. The mean rotational reflectance is the mean of rotational reflectance for all particles (usually 50) measured in a sample.

This new technique has been used to characterize thermal maturity of samples from several wells within the area shown on figure 3 . Resultant data clearly show increasing vitrinite anisotropy with increasing thermal maturity, as illustrated by the increasing difference between mean maximum and mean minimum reflectance with depth on figure 4 . For each sample, this technique yields several variables that can be used to evaluate thermal maturity, including mean maximum reflectance (essentially equivalent to the reflectance parameter commonly reported by coal petrographers), mean rotational reflectance, and mean minimum reflectance. At reflectance values below 2 percent there is little difference among these three parameters. However, as reflectance values increase above 2 percent these three parameters increasingly diverge (fig. 4), a direct indication of an increase in vitrinite anisotropy. We have chosen to use mean rotational reflectance as the optimum index of thermal maturity because that parameter displays low standard deviations and mostly unimodal histograms in our data sets, and because it is theoretically equal to reflectance measured in nonpolarized light, a technique used in many dispersed organic studies (Houseknecht and others, 1993).

Comparison of old and new data from several samples from the study area shows that mean vitrinite reflectance reported by Hathon and Houseknecht (1987) is virtually identical to mean minimum reflectance measured using the new technique. There is little difference between old and new data at vitrinite reflectance values less than 2 percent, but the difference becomes increasingly larger as reflectance values increase above 2 percent. Thus, the Spiro vitrinite reflectance map published by Houseknecht and McGilvery (1990) is accurate in the area of Wilburton gas field but depicts conservatively low values of reflectance to the east, in the area of Red Oak gas field.

In figure 3 is shown the vitrinite reflectance of the Spiro reservoir horizon in the deep basin and frontal thrust belt based on measurement of rotational reflectance of samples from 13 wells, and using the larger base of conventional vitrinite reflectance data (Hathon and Houseknecht, 1987) to constrain locations of boundaries between reflectance classes. In the deep basin, north of the Choctaw thrust fault, mean rotational reflectance of the Spiro horizon is about 2 percent in Wilburton gas field and increases to more than 4 percent in eastern Red Oak gas

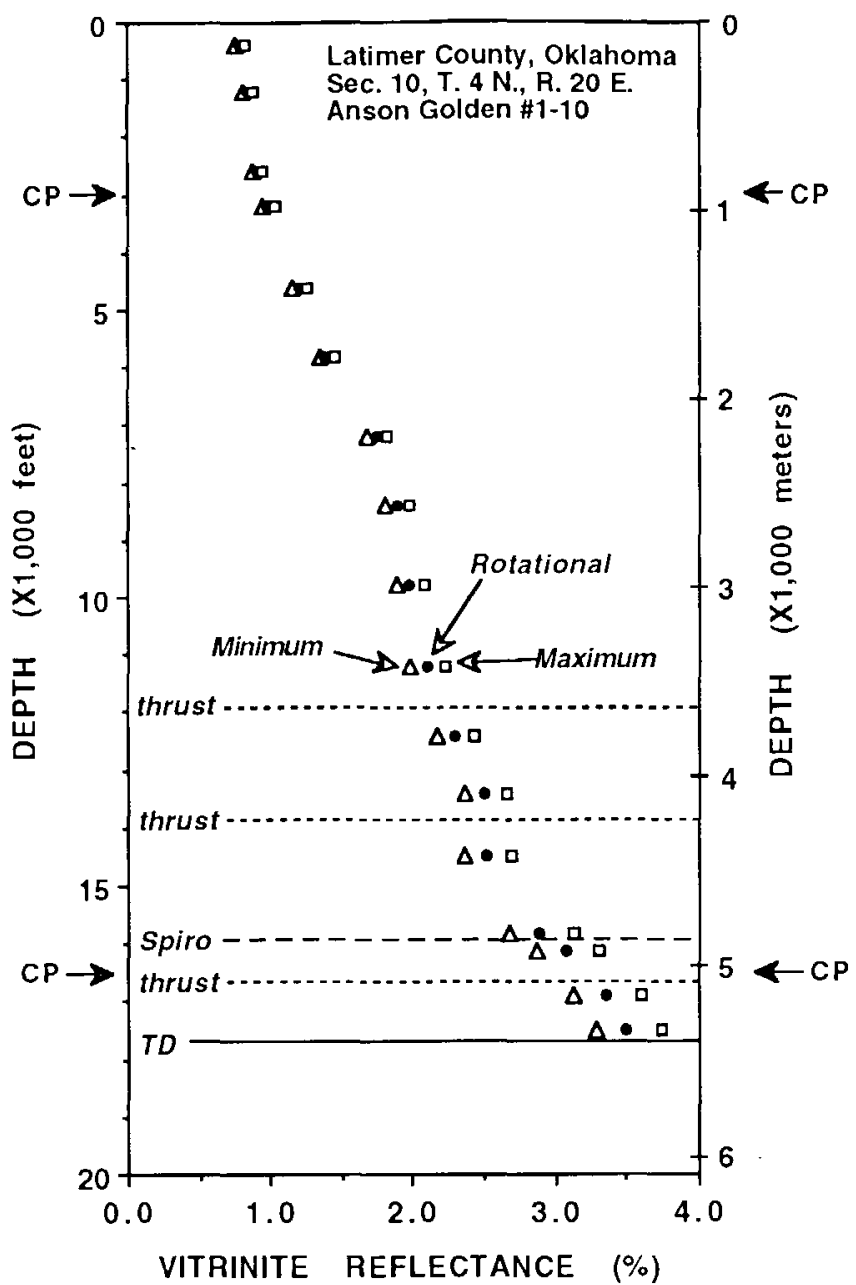

Figure 4. Plot of depth versus mean minimum, mean rotational, and mean maximum vitrinite reflectance for well located near the present eastern termination of production from the Spiro sandstone (base of Atoka Formation; Branan, 1968) in the Ouachita frontal thrust belt. An initial production potential of 32 million cubic feet $(900,000$ cubic meters) of natural gas per day from the thrusted Spiro reservoir at a depth of about $4,880 \mathrm{~m}(16,000 \mathrm{ft})$ was reported for this well. Note the increased divergence of the three reflectance parameters as vitrinite reflectance values increase above 2 percent. Arrows labeled " $\mathrm{CP}$ " indicate casing points. TD, total depth.

field (fig. 3). Reflectance in the frontal thrust belt shows a similar eastward increase, but absolute values are higher than in adjacent areas in the deep basin. Mean rotational reflectance is about 2.5 percent in the frontal thrust belt at the western edge of the map and increases to more than 4 percent in the easternmost wells analyzed (fig. 3).

Thermal-maturity data for one of the easternmost productive wells in the Ouachita frontal thrust belt is shown in figure 4. Mean rotational vitrinite reflectance of shales immediately above and immediately below the reservoir are 2.9 percent and 3.1 percent, respectively. 


\section{NATURAL-GAS OCCURRENCES}

\section{RED OAK FIELD}

The area depicted in figure 3 is characterized by prolific natural gas production. Natural gas originally was discovered in shallow reservoirs (400-550 $\mathrm{m}$ depth) in Red Oak field in 1912, and deep and more prolific production was discovered in 1959 (Houseknecht and McGilvery, 1990). Cumulative production from Red Oak field has surpassed 1 trillion cubic feet ( 28 billion cubic meters), and ultimate recoveries may exceed 3 trillion cubic feet ( 85 billion cubic meters). Although there are numerous productive reservoirs in Red Oak field, most production is from the middle Atokan Red Oak sandstone (2,000-2,500 $\mathrm{m}$ depth) and the basal Atokan Spiro sandstone $(3,300-4,000 \mathrm{~m}$ depth). From west to east, production from the Spiro sandstone in Red Oak field spans a range of vitrinite reflectance values from about 3 percent to more than 4 percent (fig. 3). Although productivity of the Spiro in individual wells varies widely throughout Red Oak field, most of that variability can be attributed to a combination of structural position and facies-selective diagenesis of the reservoir prior to hydrocarbon accumulation (Houseknecht and McGilvery, 1990). Moreover, the relative ages of pyrobitumen and late-stage cements at the base of the productive gas column indicate that reservoired hydrocarbons (at least partly liquid) were thermally cracked and that most porosity in the water leg was destroyed subsequently by high-temperature diagenesis. These observations provide evidence that reservoir quality was established largely by facies-selective diagenesis prior to hydrocarbon accumulation, and that the presence of reservoired hydrocarbons preserved that range of reservoir quality as elevated thermal maturities were attained (Houseknecht and McGilvery, 1990). Reservoir quality of the Spiro ranges up to 24 percent porosity and 800 millidarcies permeability, and lateral patterns of reservoir quality do not appear to be related to thermal maturity (see Branner, 1937; Houseknecht, 1984; Houseknecht and others, 1992; and Hayes, 1991, for additional discussion of thermal maturity-porosity relationships in this region). The eastern termination of production from the Spiro in Red Oak field corresponds to rotational reflectance of 4.0 to 4.5 percent. Unfortunately, this margin of Red Oak field is structurally unfavorable for prospecting (see Spiro structural map in Houseknecht and McGilvery, 1990), and consequently a lack of borehole data and accompanying samples precludes further evaluation of the relationship between thermal maturity and methane occurrence.

Significantly, a well drilled near the eastem margin of Red Oak field (sec. 4, T. 6 N., R. 23 E.) in 1986 established natural-gas production from the Ordovician Arbuckle Group, about $600 \mathrm{~m}$ deeper than the Spiro sandstone. The thermal maturity of the Arbuckle Group reservoir at that location exceeds 4 percent equivalent vitrinite reflectance (no indigenous vitrinite is present in the Arbuckle because of age), and may be as high as 5 percent. Conodonts from the Arbuckle in that well are characterized by color alteration index of 5, which corresponds to vitrinite reflectance values greater than 3.6 percent, according to Epstein and others (1977). Natural gas production ceased after a few months because of increasing water production, but that well confirmed the preservation of both methane and reservoir quality in the Spiro sandstone and older reservoirs at extreme thermal maturity in Red Oak field.

\section{WILBURTON FIELD}

Natural gas was discovered originally in shallow reservoirs at Wilburton field in 1925 (600-1,000 m depth; sandstones in middle and upper part of the Atoka Formation), deeper and more prolific reservoirs were discovered in $1960(2,100-2,700 \mathrm{~m}$ depth; mostly Spiro sandstone in thrust sheets), and still deeper and even more prolific reservoirs were discovered in 1987 (3,600-4,600 $\mathrm{m}$ depth; Spiro sandstone and Arbuckle Group carbonates on subthrust horst). Cumulative production from Wilburton field has surpassed 1 trillion cubic feet ( 28 billion cubic meters), and ultimate recoveries likely will exceed 2 trillion cubic feet ( 57 billion cubic meters).

The most recent drilling activity in Wilburton field has established production from the Spiro sandstone and Arbuckle Group on a subthrust horst structure. Vitrinite reflectance of the Spiro horizon ranges from 2.0 to 2.3 percent, and Devonian through Mississippian shale beneath the Spiro have yielded vitrinite reflectance values between 2.5 and 3.0 percent. These values suggest that prolific production in the Arbuckle Group occurs from reservoirs that are characterized by thermal maturities in excess of 3 percent equivalent vitrinite reflectance. Hendrick (1992) estimated the thermal maturity of Arbuckle reservoir rocks to be equivalent to a vitrinite reflectance between 3.5 and 3.8 percent. Considering these levels of thermal maturity, the performance of the Arbuckle reservoir is remarkable, with initial potentials commonly reported to be in the range of 10 to 35 million cubic feet ( 0.3 to 1.0 million cubic meters) of natural gas per day!

\section{OUACHITA FRONTAL THRUST BELT}

Exploration drilling in the Ouachita frontal thrust belt has established natural-gas production along a trend extending throughout the central and western part of the study area (fig. 3) (Suneson and Campbell, 1990). The thrusted Spiro reservoir horizon in this area is characterized by mean rotational vitrinite reflectance values that range from about 2.5 percent to more than 4.0 percent. 
Reservoir quality and productivity of the Spiro are locally variable along this trend; it is not uncommon for one location to be nonproductive or marginally productive whereas the adjacent location may have an initial potential of 10 's of million cubic feet (millions of cubic meters) per day.

Presently, production from the Spiro sandstone in the thrust belt ends at the eastern edge of R. 20 E., corresponding to a vitrinite reflectance around 4 percent (fig. 3 ). The easternmost wells, however, are among the most highly productive wells drilled in the Spiro in the thrust belt. For example, initial potentials of 32 and 3 million cubic feet $(900,000$ and 90,000 cubic meters) per day were reported for wells in sections 10 and 12, respectively, of T. 4 N., R. 20 E., and a calculated absolute open flow of 162 million cubic feet ( 4.6 million cubic meters) per day during testing was reported for, a well in section 14 of the same township!

Only a few wells have been drilled in the thrust belt east of R. 20 E. Two wells have tested the Spiro sandstone in T. 4 N., R. 21 E. (sections 4 and 8), and both encountered nonporous sandstone. Mean rotational reflectance of core samples from the Spiro in section 4 is 4.05 percent. One well has tested the Spiro sandstone in T. 4 N., R. 22 E. (section 5); it encountered nonporous Spiro sandstone but established production from a younger sandstone in the lower part of the Atoka Formation at a depth of 4,470 $\mathrm{m}$. Two wells drilled still farther east (sec. 8, T. 4 N., R. 23 E. and sec. 31 , T. 5 N., R. 24 E.) penetrated into the Ordovician Arbuckle Group on a subthrust horst, but the Spiro sandstone was absent in both wells because of thrust decapitation of the horst, and no production was established from either well. Mean rotational reflectance values of cutting samples from those two wells are more than 4 percent in strata superjacent and subjacent to the Spiro sandstone.

Significantly, three wells drilled in the thrust belt have established production from the Morrowan (Lower Pennsylvanian) Jackfork Sandstone, a deep-water-facies sandstone deposited in the Ouachita trough prior to uplift of the orogenic belt. These wells (sec. 20, T. 4 N., R. 20 E.; sec. 4 , T. 3 N., R. 20 E.; and sec. 28 , T. 4 N., R. 21 E.) have tested up to 3.5 million cubic feet $(99,000$ cubic meters) per day (initial potential), and their discoveries suggest that natural-gas production will be extended beyond the eastern and southern limits thus far defined in the Ouachita frontal thrust belt. Although no thermal-maturity data are available from these wells, regional patterns (fig. 2) suggest that production is from strata whose vitrinite reflectance must be in the range of 3.5 to 4.5 percent.

\section{DISCUSSION}

Three poorly understood geologic phenomena emerge as critical elements to the economic preservation of natural gas in strata of high thermal maturity (vitrinite reflectance $>3$ percent): dilution of methane by nonhydrocarbon gases, preservation of reservoir quality, and preservation of effective seals.

The information presented in this paper demonstrates that methane is not destroyed chemically, at least in many reservoirs, when exposed to temperatures high enough to produce vitrinite reflectance in the 4 to 5 percent range. Exceptions may occur in reservoirs with high water saturations, where methane may react with water to yield carbon dioxide and hydrogen (Barker and Takach, 1992). Evidence from both coalbeds and conventional reservoirs, however, demonstrates that in some geologic settings methane is diluted to marginally economic or noneconomic concentrations at elevated thermal maturities. Dilution by $\mathrm{N}_{2}$ and $\mathrm{CO}_{2}$ appears to be most common.

Although dilution of methane by nitrogen at elevated temperature and thermal maturity has been documented in both coalbeds and conventional reservoirs, the origin of the nitrogen is not well understood. Nitrogen generation during coal maturation has been documented by Karweil (1969) and Jüntgen and Klein (1975), and the cracking of organic nitrogen compounds has been suggested as the source of $\mathrm{N}_{2}$. In conventional reservoirs, the origin of $\mathrm{N}_{2}$ has been attributed to cracking of organic nitrogen compounds dispersed in shales (Lutz and others, 1975), reaction of ferric oxides with organic nitrogen compounds (Guseva and Fayngersh, 1973), reaction of ammonia generated during coal maturation with ferric iron (Getz, 1977), decomposition of ammonium-bearing clay minerals and feldspars (Everlien and Hoffmann, 1991), and degassing of crystalline basement rocks (Beebe and Curtis, 1968; Petersil'ye and others, 1970). The prominent role of ferric oxides in many of these hypotheses stems from the fact that gases containing high nitrogen concentrations are commonly found in red beds, or in reservoirs that are underlain by red beds.

Carbon dioxide at elevated thermal maturity appears to have multiple origins. $\mathrm{CO}_{2}$ may be a by-product of catagenesis and metagenesis of organic matter, particularly where humic (type III) kerogen is involved. Although recent literature emphasizes the pulse of $\mathrm{CO}_{2}$ expelled during early catagenesis (see, Hunt, 1979, his fig. 5-6), $\mathrm{CO}_{2}$ continues to be generated from humic organic matter throughout catagenesis and into metagenesis, to at least thermal maturity levels corresponding to anthracite coal rank (see, Karweil, 1969). Some authors have suggested that $\mathrm{CO}_{2}$ occurrences in areas of high thermal maturity may be the result of thermal decomposition of carbonates (see discussion in Hunt, 1979). This may be particularly true in areas of igneous intrusion into carbonate strata (Holmquest, 1965).

For several decades, geologists have proposed that high-temperature diagenetic destruction of reservoir quality may define the ultimate methane deadline (Branner, 
1937; Landes, 1967; Hunt, 1979; Houseknecht, 1984). However, in recent years many researchers have shown that diagenetic reactions are commonly inhibited by the presence of reservoired hydrocarbons (for example, Dixon and others, 1989) because inorganic chemical reactions that commonly destroy porosity are inhibited (or cease completely) where water is displaced from the pore system as hydrocarbons accumulate. Houseknecht and Hathon (1987) and Houseknecht and McGilvery (1990) attributed preservation of excellent reservoir quality at elevated thermal maturity in the Spiro sandstone in the Arkoma Basin to this process. They demonstrated that porosity was mostly destroyed by high-temperature chemical reactions below hydrocarbon-water contacts (that is, in the water $\mathrm{leg}$ ), whereas those same reactions were ineffective in reducing porosity above hydrocarbon-water contacts.

If natural gas is to be trapped for long intervals of geologic time and if reservoir quality is to be preserved by the presence of reservoired hydrocarbons, then the effectiveness and longevity of seals become significant elements in preserving natural gas in strata of high thermal maturity. This is particularly true in deep basins and thrust belts where sealing strata may be exposed to high-temperature mineral transformations and tectonic deformations that influence sealing properties. Seal effectiveness has been the topic of numerous papers, including recent overviews by Downey (1984) and Vavra and others (1992), but the emphasis has been placed on capillary properties as they now exist in seals. Seal longevity also has received considerable attention in recent years, with the emphasis on hydrocarbon diffusion through seals and consequences to gas leakage from reservoirs (Leythaeuser and others, 1982; Krooss and others, 1992; Nelson and Simmons, 1992). Despite these research achievements that have enhanced our understanding of seals, there has been no concentrated effort devoted to determining how the effectiveness and longevity of seals are influenced by elevated temperatures, abnormal fluid pressures, and high confining and (or) tectonic pressures that accompany deep burial in sedimentary basins and thrust belts.

Evaluation of the potential of natural-gas resources in areas of extreme thermal maturity and development of exploration strategies to test that potential require a better understanding of geologic processes that influence natural gas in deep reservoirs, under high-temperature conditions. Research is needed in at least three fundamental topics: (1) Dilution of methane by natural nonhydrocarbon gases at high temperatures and thermal maturities, including considerations of the origin, migration, and accumulation of methane, nitrogen, and carbon dioxide. (2) Deep-burial, high-temperature diagenesis of reservoir rocks, including considerations of the timing of hydrocarbon migration and accumulation relative to diagenetic events that destroy or enhance porosity and the roles of subsurface pressures and fluid migration (both water and hydrocarbons) on reservoir porosity histories. (3) Deep-burial, high-temperature diagenesis of seals, including interdependence of high-temperature mineral transformations, evolution of capillary properties, influence of dynamic fluid-pressure regimes, and response to tectonic deformation.

\section{CONCLUSIONS}

Theoretical, experimental, and empirical evidence indicates that methane is not chemically destroyed by temperatures high enough to produce vitrinite reflectance in the 4 to 5 percent range, although in reservoirs with high water saturation, methane may be consumed in a reaction with water to yield carbon dioxide and hydrogen. Methane may be diluted to noneconomic concentrations by nitrogen and carbon dioxide in certain geologic settings and at vitrinite reflectance levels above 4 percent.

Prolific methane production in the Arkoma Basin and Ouachita frontal thrust belt occurs in strata with thermal maturities of up to at least 4 percent vitrinite reflectance. Wells drilled in strata near the presently defined upper thermal-maturity limit of methane production are some of the most prolific in the region, suggesting that economic methane production will be extended to strata with thermal maturities above 4 percent vitrinite reflectance with additional drilling. This natural-gas province provides evidence that excellent reservoir quality has been preserved to extreme levels of thermal maturity because reservoired hydrocarbons inhibited inorganic diagenetic reactions.

Geologic processes that influence natural gas and its habitat during exposure to deep burial, high temperatures, and tectonic deformation are poorly understood. Evaluation of the potential of natural-gas resources in geologic provinces characterized by extreme thermal maturity and development of exploration strategies to test that potential require focused research on (1) the origin, migration, and accumulation of methane and nonhydrocarbon gases during metagenesis; (2) diagenesis of reservoir rocks exposed to deep burial and high temperatures; and (3) effectiveness and longevity of seals exposed to deep burial, high temperatures, and tectonic deformation.

\section{ACKNOWLEDGMENTS}

Much of this work was performed at the University of Missouri as part of the Arkoma Basin Thermal Maturity Research Program, funded by Amoco, Anadarko, Arco, Arkla, Conoco, Exxon, Maxus, Mobil, Nomeco, Oxy, Pennzoil, Shell, Texaco, Weyerhaeuser, and Yates petroleum companies. D.W. Houseknecht thanks the following former and current students who contributed to data collection: Lori Hathon, Paul Kastens, Chris Weesner, and 
Robert Jaques. We thank Neil Suneson (Oklahoma Geological Survey), Russ Cunningham (GHK Corp.), and Dan Patterson (Arco) for providing information from recent drilling activities, and Gregory Ulmishek for translating pertinent Russian literature. The manuscript was improved as the result of constructive reviews by Ed Pittman, David Howell, and Frances Cole.

\section{REFERENCES CITED}

Arbenz, J.K., 1989, The Ouachita system, in Bally, A.W., and Palmer, A.R., eds., The Geology of North America; An overview: Boulder, Colo., Geological Society of America, The Geology of North America, v. A, p. 371-396.

Arne, D.C., 1992, Evidence from apatite fission-track analysis for regional Cretaceous cooling in the Ouachita Mountain fold belt and Arkoma Basin of Arkansas: American Association of Petroleum Geologists Bulletin, v. 76, p. 392-402.

Barker, C., and Takach, N.E., 1992, Prediction of natural gas composition in ultradeep sandstone reservoirs: American Association of Petroleum Geologists Bulletin, v. 76, p. 18591873.

Beebe, B.W., and Curtis, B.F., 1968, Natural gases of North America-A summary, in Beebe, B.W., and Curtis, B.F., eds., Natural gases of North America: American Association of Petrolcum Geologists Memoir 9, v. 2, p. 2245-2355.

Boigk, H., Hagemann, H.W., Stahl, W., and Wollanke, G., 1976, Isotopenphysikalische Untersuchungen zur Herkunft und Migration des Stickstoffs nordwestdeutscher Erdgase aus Oberkarbon und Rotliegend: Erdöl und Kohle, Erdgas, Petrochemie, v. 29, p. 103-112.

Bostick, N.H., 1979, Microscopic measurement of the level of catagenesis of solid organic matter in sedimentary rocks to aid exploration for petroleum and to determine former burial temperatures-A review, in Scholle, P.A., and Schluger, P.R., eds., Aspects of diagenesis: Society of Economic Paleontologists and Mineralogists Special Publication 26, p. $17-$ 43.

Branan, C.B., Jr., 1968, Natural gas in Arkoma Basin of Oklahoma and Arkansas, in Beebe, B.W., and Curtis, B.F., eds., Natural gases of North America: American Association of Petroleum Geologists Memoir 9, v. 2, p. 1616-1635.

Branner, G.C., 1937, Sandstone porosities in Paleozoic region in Arkansas: American Association of Petroleum Geologists Bulletin, v. 21, p. 67-79.

Burgess, J.D., 1974, Microscopic examination of kerogen (dispersed organic matter) in petroleum exploration, in Dutcher, R.R., Hacquebard, P.A., Schopt, J.M., and Simon, J.A. eds., Carbonaceous materials as indicators of metamorphism: Geological Society of America Special Paper 153, p. 19-30.

Cardott, B.J., 1989, Thermal maturation of the Woodford Shale in the Anadarko Basin, in Johnson, K.S., ed., Anadarko Basin Symposium, 1988: Oklahoma Geological Survey, Circular 90 , p. 32-46.

Cardott, B.J., and Lambert, M.W., 1985, Thermal maturation by vitrinite reflectance of Woodford Shale, Anadarko Basin, Oklahoma: American Association of Petroleum Geologists Bulletin, v. 69, p. 1982-1998.
Coleman, D.D., Liu, C.L., and Riley, K.M., 1988, Microbial methane in the shallow Paleozoic sediments and glacial deposits of Illinois, U.S.A.: Chemical Geology, v. 71, p. 23-40.

Cornford, C., 1986, Source rocks and hydrocarbons of the North Sea, in Glennie, K.W., ed., Introduction to the petroleum geology of the North Sea: Oxford, Blackwell, p. 197-236.

Croneis, C., 1927, Oil and gas possibilities in the Arkansas Ozarks: American Association of Petroleum Geologists Bulletin, v. 11, p. 279-297.

Curiale, J.A., 1983, Petroleum occurrences and source-rock potential of the Ouachita Mountains, southeastern Oklahoma: Oklahoma Geological Survey Bulletin 135, 65 p.

Davis, H.G., and Northcutt, R.A., 1989, The greater Anadarko Basin-An overview of petroleum exploration and development, in Johnson, K.S., ed., Anadarko Basin Symposium, Oklahoma Geological Survey Circular 90, p. 13-24.

Dixon, S.A., Summers, D.M., and Surdam, R.C., 1989, Diagenesis and preservation of porosity in the Norphlet Formation (Upper Jurassic), southern Alabama: American Association of Petroleum Geologists Bulletin, v. 73, p. 707-728.

Dow, W.G., 1977, Kerogen studies and geological interpretations: Journal of Geochemical Exploration, v. 7, p. 79-99.

Dow, W.G., and O'Connor, D.I., 1982, Kerogen maturity and type by reffected light microscopy applied to petroleum exploration, in Staplin, F.L., Dow, W.G., Milner, C.W.D., O'Connor, D.I., Pocock, S.A.J., Gijzel, P. van, Welte, D.H., and Yuikler, M.A., How to assess maturation and paleotemperatures: Society of Economic Paleontologists and Mineralogists Short Course 7, p. 133-157

Downey, M.W., 1984, Evaluating seals for hydrocarbon accumulations: American Association of Petroleum Geologists Bulletin, v. 68, p. 1752-1763.

Epstein, A.G., Epstein, J.B., and Harris, L.D., 1977, Conodont color alteration-An index to organic metamorphism: U.S. Geological Survey Professional Paper 995, 27 p.

Everlien, G., and Hoffmann, U., 1991, Nitrogen in natural gas: Erdöl, Erdgas, Kohle, Petrochemie, v. 44, p. 166-172.

Getz, F.A., 1977, Molecular nitrogen-Clue in coal-derivedmethane hunt: Oil and Gas Journal, v. 75, p. 220-221.

Guseva, A.N., and Fayngersh, L.A., 1973, Conditions of accumulation of nitrogen in natural gases as illustrated by the central European and Chu-Sarysu oil-gas basins: Transactions (Doklady) of the USSR Academy of Sciences, Earth Science Section (Dokl. Akad. Nauk SSSR), v. 209, p. 210-212.

Hathon, L.A., and Houseknecht, D.W., 1987, Hydrocarbons in an overmature basin, I. Thermal maturity of Atoka and Hartshorne Formations, Arkoma Basin [abs.]: American Association of Petroleum Geologists Bulletin, v. 71, p. 993-994.

Hayes, J.B., 1991, Porosity evolution of sandstones related to vitrinite reflectance: Organic Geochemistry, v. 17, p. 117-129.

Hendrick, S.J., 1992, Vitrinite reflectance and deep Arbuckle maturation at Wilburton field, Latimer County, Oklahoma: Oklahoma Geological Survey Circular 93, p. 176-184.

Hendricks, T.A., 1935, Carbon ratios in part of Arkansas-Oklahoma coal field: American Association of Petroleum Geologists Bulletin, v. 19, p. 937-947.

Holmquest, H.J., 1965, Deep pays in Delaware and Val Verde basins, in Young, A., and Galley, J.E., eds., Fluids in subsurface environments: American Association of Petroleum Geologists Memoir 4, p. 257-279. 
Hood, A., Gutjahr, C.C.M., and Heacock, R.L., 1975, Organic metamorphism and the generation of petroleum: American Association of Petroleum Geologists Bulletin, v. 59, p. 986996.

Houseknecht, D.W., 1984, Influence of grain size and temperature on intergranular pressure solution, quartz cementation, and porosity in a quartzose sandstone: Journal of Sedimentary Petrology, v. 54, p. 348-361.

1986, Evolution from passive margin to foreland basinThe Atoka Formation of the Arkoma Basin, south-central U.S.A., in Allen, P.A., and Homewood, P., eds., Foreland basins: International Association of Sedimentologists Special Publication 8, p. 327-345.

1987, The Atoka Formation of the Arkoma Basin--Tectonics, sedimentology, thermal maturity, sandstone petrology: Tulsa Geological Society, Short Course Notes, 72 p.

Houseknecht, D.W., Bensley, D.F., Hathon, L.A., and Kastens, P.H., 1993, Rotational reflectance properties of Arkoma Basin dispersed vitrinite-Insights for understanding reflectance populations in high thermal maturity regions: Organic Geochemistry, v. 20, p. 187-196.

Houseknecht, D.W., and Hathon, L.A., 1987, Hydrocarbons in an overmature basin, II. Is there a thermal maturity limit to methane production in the Arkoma Basin [abs.]: American Association of Petroleum Geologists Bulletin, v. 71, p. 994.

Houseknecht, D.W., Hathon, L.A., and McGilvery, T.A., 1992, Thermal maturity of Paleozoic strata in the Arkoma Basin: Oklahoma Geological Survey Circular 93, p. 122-132.

Houseknecht, D.W., and Matthews, S.M., 1985, Thermal maturity of Carboniferous strata, Ouachita Mountains: American Association of Petroleum Geologists Bulletin, v. 69, p. 335-345.

Houseknecht, D.W., and McGilvery, T.A., 1990, Red Oak gas field, Arkoma Basin, Oklahoma, U.S.A., in Beaumont, E.A., and Foster, N.H., eds., Structural traps II, Treatise of petroleum geology, Atlas of oil and gas fields: American Association of Petroleum Geologists, p. 201-225.

Hunt, J.M., 1975, Is there a geochemical depth limit for hydrocarbons?: Petroleum Engineer, March 1975, p. 112-127.

1979, Petroleum geochemistry and geology: Freeman, San Francisco, $617 \mathrm{p}$.

1984, Generation and migration of light hydrocarbons: Science, v. 226, p. 1265-1270.

Jemison, R.M., 1979, Geology and development of Mills Ranch complex-World's deepest field: American Association of Petroleum Geologists Bulletin, v. 63, p. 804-809.

Juintgen, H., and Karweil, J., 1966a, Gasbildung und Gasspeicherung in Steinkohlenflözen. I. Gasbildung: Erdöl und Kohle, Erdgas, Petrochemie, v. 19, p. 251-258.

1966b, Gasbildung und Gasspeicherung in Steinkohlenflözen. II. Gasspeicherung: Erdöl und Kohle, Erdgas, Petrochemie, v. 19, p. 339-344.

Jüntgen, H., and Klein, J., 1975, Origin of natural gas from coaly sediments: Erdöl und Kohle, v. 28, p. 65-73.

Karweil, J., 1969, Aktuelle Probleme der Geochemie der Kohle, in Schenck, P.A., and Havenaar, I., eds., Advances in organic geochemistry 1968: Oxford, Pergamon Press, p. 59-84.

Katz, B.J., Liro, L.M., Lacey, J.E., and White, H.W., 1982, Time and temperature in petroleum formation-Application of Lopatin's method to petroleum exploration-Discussion: Amer- ican Association Petroleum of Geologists Bulletin, v. 66, p. 1150-1151.

Kim, A.G., 1977, Estimating methane content of bituminous coal beds from adsorption data: U.S. Bureau of Mines Report of Investigations $8245,22 \mathrm{p}$.

1978, Experimental studies on the origin and accumulation of coal bed gas: U.S. Bureau of Mines Report of Investigations $8317,18 \mathrm{p}$.

Krooss, B.M., Leythaeuser, D., and Schaefer, R.G., 1992, The quantification of diffuse hydrocarbon losses through cap rocks of natural gas reservoirs-A reevaluation: American Association Petroleum of Geologists Bulletin, v. 76, p. 403406.

Landes, K.K., 1967, Eometamorphism, and oil and gas in time and space: American Association Petroleum of Geologists Bulletin, v. 51, p. 828-841.

Lapchinsky, Yu.G., and Dzhamalova, Kh.F., 1987, Gas productivity and geochemical properties of gases in coal-bearing areas of the eastern Ukraine, in Trofimuk, A.A., Nesterov, I.I., and Zhabrev, I.P., eds., Regularities in distribution of hydro-carbon gases and associated components [Zakohomernosti razmeshcheniya uglevodorodnyky gazov i soputstruyushchikh im komponentov]: Moscow, Nauka, p. 98104.

Leythaeuser, D., Schaefer, R.G., and Yükler, A., 1982, Role of diffusion in primary migration of hydrocarbons: American Association of Petroleum Geologists Bulletin, v. 66, p. 408429.

Lutz, M., Kaasschieter, J.P.H., and Van Wijhe, D.H., 1975, Geological factors controlling Rotliegend gas accumulations in the mid-European Basin, in 7th World Petroleum Congress Proceedings (Mexico): London, Elsevier, v. 2, p. 47-60.

Meckel, L.D., Jr., Smith, D.G., and Wells, L.A., 1992, Ouachita foredeep basins-Regional paleogeography and habitat of hydrocarbons, in Macqueen, R.W., and Leckie, D.A., eds., Foreland basins and fold belts: American Association of Petroleum Geologists Memoir 55, p. 427-444.

Mo, F.J., Han, L.D., Fen, J.R., and Ding, D.Y., 1984, Distribution and origin of hydrocarbons in carbonate rocks (Precambrian to Triassic) in China, in Palacas, J.G., ed., Petroleum geochemistry and source rock potential of carbonate rocks: American Association of Petroleum Geologists Studies in Geology 18, p. 1-12.

Nelson, J.S., and Simmons, E.C., 1992, The quantification of diffusive hydrocarbon losses through cap rocks of natural gas reservoirs-A reevaluation-Discussion: American Association of Petroleum Geologists Bulletin, v. 76, p. 1839-1841.

Oakes, M.C., and Knechtel, M.M., 1948, Geology and mineral resources of Haskell County, Oklahoma: Oklahoma Geological Survey Bulletin 67, 136 p.

Petersil'ye, I.A., Kozlov, Ye.K., Belyayev, K.D., Sholokhnev, V.V., and Dokuchayeva, V.S., 1970, Nitrogen and hydrocarbon gases in ultramafic rocks of the Sopcha stock of the Monchegorsk pluton, Kola Peninsula: Transactions (Doklady) of the USSR Academy of Sciences, Earth Science Section (Dokl. Akad. Nauk SSSR), v. 194, p. 200-203.

Price, L.C., in press, Hydrocarbon thermal stability in natureLimits, evidence, characteristics, and possible controls: Geochimica et Cosmochimica Acta. 
Price, L.C., Clayton, J.L., and Rumen, L.L., 1981, Organic geochemistry of the $9.6 \mathrm{~km}$ Bertha Rogers No.1 well, Oklahoma: Organic Geochemistry, v. 3, p. 59-77.

Rice, D.D., and Claypool, G.E., 1981, Generation, accumulation, and resource potential of biogenic gas: American Association of Petroleum Geologists Bulletin, v. 65, p. 5-25.

Rightmire, C.T., 1984, Coal bed methane resources, in Rightmire, C.T., Eddy, G.E., and Kir, J.N., eds., Coal bed methane resources of the United States: American Association of Petroleum Geologists Studies in Geology 17, p. 1-13.

Saxby, J.D., 1982, A reassessment of the range of kerogen maturities in which hydrocarbons are generated: Journal of Petroleum Geology, v. 5, p. 117-128.

Schoell, M., 1988, Multiple origins of methane in the earth: Chemical Geology, v. 71, p. 1-10.

Suneson, N.H., and Campbell, J.A., 1990, Oil and gas exploration in the western Ouachita region, Oklahoma: Oil and Gas Journal, v. 88 , no. 15 , p. $65-69$, and no. 16 , p. 85-87.

Suneson, N.H., Campbell, J.A., and Tilford, M.J., 1990, Geology and resources of the frontal belt of the western Ouachita Mountains, Oklahoma: Oklahoma Geological Survey Special Publication 90-1, $196 \mathrm{p}$.

Takach, N.E., Barker, C., and Kemp, M.K., 1987, Stability of natural gas in the deep subsurface-Thermodynamic calculation of equilibrium compositions: American Association of Petroleum Geologists Bulletin, v. 71, p. 322-333.

Tarafa, M.E., Whelan, J.K., and Farrington, J.W., 1988, Investigation on the effects of organic solvent extraction on wholerock pyrolysis--Multiple-lobed and symmetrical P2 peaks: Organic Geochemistry, v. 12, p. 137-149.

Teichmüller, M., Teichmüller, R., and Bartenstein, H., 1979, Inkohlung und Erdgas in Nordwestdeutschland. Eine Inkohlungskarte der Oberfläche des Oberkarbons: Fortschritte Geologie Rheinland und Westfalen, v. 27, p. 137-170.

1984, Inkohlung und Erdgas-Eine neue Inkohlungskarte der Karbon-Oberfläche in Nordwestdeutschland: Fortschritte Geologie Rheinland uud Westfalen, v. 32, p. 11-34.

Teichmiiller, M., Teichmuiller, R., and Lorenz, V., 1983, Inkohlung und Inkohlungsgradienten im Permokarbon der Saar-Nahe-Senke: Zeitschrift der Deutschen Geologischen Gesellschaft, v. 134, p. 153-210.

Tissot, B.P., and Welte, D.H., 1984, Petroleum formation and occurrence: New York, Springer-Verlag, 699 p.
Ulmishek, G.F., Bogino, V.A., Keller, M.B., and Poznyakevich, Z.L., in press, Structure, stratigraphy, and petroleum geology of the Pripyat and Dnieper-Donets basins, Byelarus and Ukraine: American Association of Petroleum Geologists Memoir.

Underwood, M.B., Fulton, D.A., and McDonald, K.W., 1988, Thrust control on thermal maturity of the frontal Ouachita Mountains, central Arkansas, USA: Journal of Petroleum Geology, v. 11, p. 325-340.

Van Wijhe, D.H., Lutz, M., Kaasschieter, J.P.H., 1980, The Rotliegend in the Netherlands and its gas accumulations: Geologie en Mijnbouw, v. 59, p. 3-24.

Vavra, C.L., Kaldi, J.G., and Sneider, R.M., 1992, Geological applications of capillary pressure-A review: American Association of Petroleum Geologist Bulletin, v. 76, p. 840-850.

Viele, G.W., and Thomas, W.A., 1989, Tectonic synthesis of the Ouachita orogenic belt, in Hatcher, R.D., Jr., Thomas, W.A., and Viele, G.W., eds., The Appalachian-Ouachita Orogen in the United States: Boulder, Colo., Geological Society of America, The Geology of North America, v. F-2, p. 695-728.

Waples, D.W., 1980, Time and temperature in petroleum formation-Application of Lopatin's method to petroleum exploration: American Association of Petroleum Geologists Bulletin, v. 64, p. 916-926.

Wehner, H., Damberger, H., Leythaeuser D., Welte, D.H., 1976, Organisch-geochemische Untersuchungen an Kohlen, Gesteinen und Restgasen aus der Bohrung Saar 1: Geologisches Jahrbuch, v. A27, p. 455-488.

Welte, D.H., Schaefer, R.G., and Yalçin, M.N., 1988, Gas generation from source rocks-Aspects of a quantitative treatment: Chemical Geology, v. 71, p. 105-116.

White, D., 1915, Some relations in origin between coal and petroleum: Journal of the Washington Academy of Sciences: v. 5 , p. $189-212$.

Wilson, C.W., Jr., 1935, Age and correlation of Pennsylvanian surface formations and of oil nad gas sands of Muskogee County, Oklahoma: American Association of Petroleum Geologists Bulletin, v. 19, no. 4, p. 503-520.

Wilson, L.R., 1961, Palynological fossil response to low-grade metamorphism in the Arkoma Basin: Tulsa Geological Society Digest, v. 29, p. 131-140.

1971, Palynological techniques in deep-basin stratigraphy: Shale Shaker, v. 21, p. 124-139. 

THE FUTURE OF ENERGY GASES

U.S. GEOLOGICAL SURVEY PROFESSIONAL PAPER 1570

\title{
Gas in Tight Reservoirs-An Emerging Major Source of Energy
}

\author{
By Ben E. Law ${ }^{1}$ and Charles W. Spencer ${ }^{2}$
}

\section{CONTENTS}

Abstract 233

Introduction 233

Characteristics of Tight Reservoirs .......................... 234

Gas Quality and Source ...................................... 236

Drilling and Completion Practices .......................... 237

Estimates of Gas Resources ................................... 238

Selected Examples of Tight-Reservoir Gas

Accumulations

240

Northern Great Plains ........................................ 240

Greater Green River Basin ................................ 242

Appalachian Basin ....................................... 244

East Texas and North Louisiana Basins .............. 247

Summary .................................................................. 249

Acknowledgments ........................................... 249

References Cited ................................................ 250

\section{ABSTRACT}

Low-permeability (tight) gas reservoirs are gas-bearing rocks that usually have an in-situ permeability to gas, exclusive of fracture permeability, of less than 0.1 millidarcy $(\mathrm{mD})$. In the United States these reservoirs are estimated to contain in-place gas resources of at least 420 trillion cubic feet (Tcf) and possibly more than 5,000 Tcf. Estimates of recoverable gas in the United States range from less than 200 to more than 550 Tcf. 80225 . 80225 .

U.S. Geological Survey, MS 971, P.O. Box 25046, Denver, CO

${ }^{2}$ U.S. Geological Survey, MS 940, P.O. Box 25046, Denver, CO
Tight gas reservoirs occur in nearly all petroleum provinces. They occur at virtually all depths and in a variety of rock types that include sandstone, siltstone, shale, sandy carbonate rocks, limestone, dolomite, and chalk. Tight gas reservoirs may be thick and areally extensive or thin and areally limited. In contrast to normal (conventional) gas accumulations where the gas is concentrated in structural or stratigraphic traps, gas in tight reservoirs occurs as regionally pervasive accumulations that are usually abnormally pressured and are mostly independent of structural and stratigraphic traps. Artificial stimulation, such as hydraulic fracturing, is usually needed in order to produce the gas unless extensive fracturing is present. As a consequence of an improved understanding of tight gas reservoirs and improved drilling and completion practices, gas from these reservoirs is rapidly emerging as a major source of energy.

\section{INTRODUCTION}

Despite the widespread occurrence of tight gas reservoirs around the world, the development of this resource has been largely limited to the United States and Canada. The geographic distribution and geologic nature of these accumulations are not well known outside North America. Therefore, much of the information on tight reservoirs is from the North American experience. Although the presence of gas in tight rocks has been known for more than 30 years, only within the last 10 to 15 years has there been any concerted research efforts to geologically characterize these rocks. Prior to the oil embargo of 1973, the United States had become accustomed to seemingly unlimited sources of cheap energy. In 1973, that complacency abruptly ended, and the Nation suddenly became aware of its vulnerability to disruptions in the supply of oil and gas. As a consequence of the embargo, a major research effort was 
initiated to conserve energy as well as to develop additional sources of energy. As part of that effort, the Department of Energy (DOE), then known as the Energy Research and Development Administration (ERDA), launched a comprehensive study of tight gas reservoirs in the United States. With the support of the DOE, the U.S. Geological Survey initiated geologic studies of tight gas reservoirs in the Rocky Mountain region. Since then, additional geologic investigations supported by the Gas Research Institute and the Texas Bureau of Economic Geology have been conducted in the Texas Gulf Coast area, as well as in the Rocky Mountain region. In addition, Canadian Hunter and the Canadian Geological Survey have conducted extensive research on tight reservoirs in Canada and the United States. As a result of this research, there is currently a much better understanding of the nature of gas accumulations in tight reservoirs. The objectives of this report are to provide information on the nature of occurrence of gas in tight reservoirs, to geologically characterize the reservoir, and to summarize much of the research that has been conducted on tight gas reservoirs.

\section{CHARACTERISTICS OF TIGHT RESERVOIRS}

The distribution of the principal tight gas reservoirs in North America are shown on figure 1. Within these areas there are three main types of tight gas reservoirs as defined by geologic and engineering parameters. The three types are (1) marginal-marine blanket, (2) deep-lenticular, and (3) shallow-blanket reservoirs. Many areas have more than one type. These reservoirs are commonly abnormally pressured; they are either under- or overpressured with respect to hydrostatic pressures. They also occur at shallow to very great depths, ranging from 1,000 to more than $15,000 \mathrm{ft}(305-4,575 \mathrm{~m})$.

Marginal-marine blanket reservoirs may be carbonates or sandstones that were deposited in shallow-marine or marginal-marine environments (Finley, 1984, 1986; Dutton and others, 1993). Examples of marginal-marine reservoirs include sandstones such as the Upper Cretaceous Rollins Sandstone Member of the Iles Formation in the Piceance Basin of western Colorado and the Upper Cretaceous Almond Formation in the Green River Basin of Wyoming. Marginal-marine blanket reservoirs usually respond to artificial fracturing in a more predictable manner (Spencer, 1985) than other types of tight reservoirs.

Lenticular reservoirs include sandstone deposited by stream systems. Examples of lenticular reservoirs include the Upper Cretaceous Rock Springs and Lance Formations in the Green River Basin of Wyoming and the Upper Cretaceous Williams Fork Formation in the Piceance Basin of western Colorado. The distribution and nature of individual lenticular reservoirs is difficult to determine, and the effectiveness of artificial stimulation of these rocks is rarely predictable using current technology (Spencer, 1985). The results of stimulation in this type of reservoir range from poor to good. Marginal-marine and lenticular type reservoirs are nearly always abnormally under- or overpressured and commonly occur at depths greater than $7,000 \mathrm{ft}$ $(2,135 \mathrm{~m})$.

Shallow-blanket reservoirs, exclusive of gas-bearing shales in the eastern United States, consist of very fine

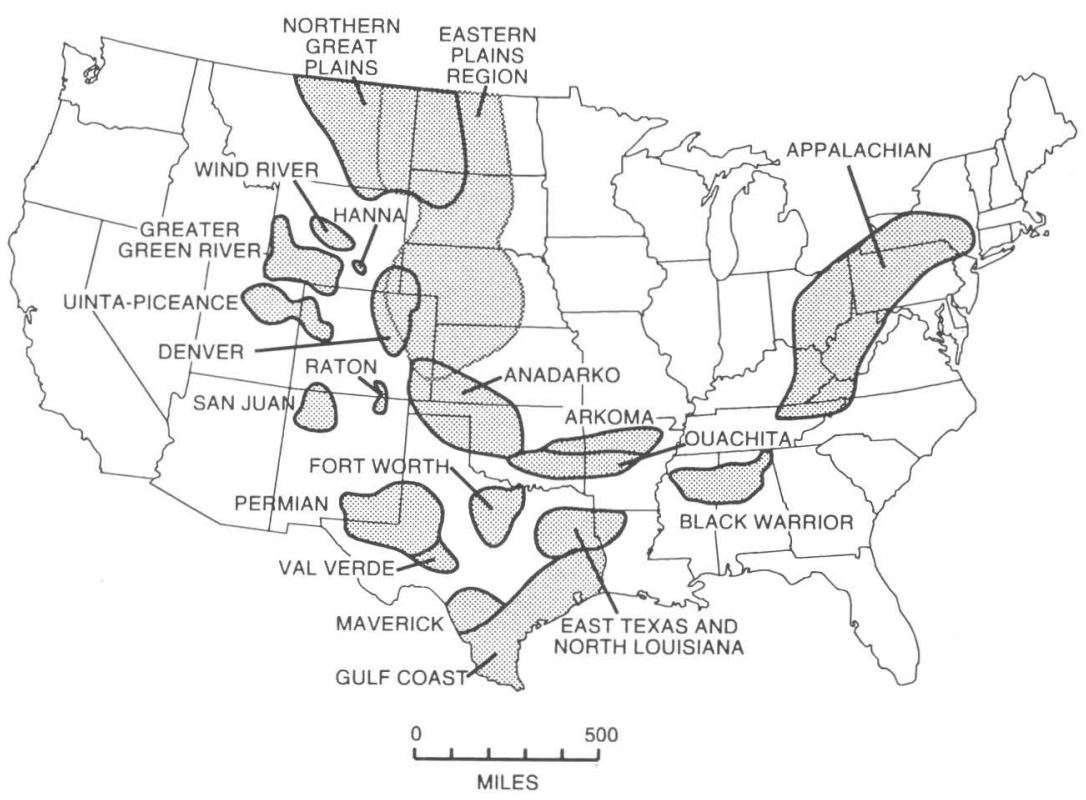

Figure 1. Principal gas-bearing, tight-reservoir regions (shaded) in the United States. 
grained sandstone, siltstone, silty shale, and chalk that were deposited in open-marine or marine-shelf environments (Rice and Shurr, 1980; Spencer, 1985). They occur at shallow depths, less than $4,000 \mathrm{ft}(1,220 \mathrm{~m})$, and many of these reservoirs have subnormal pressure. Subsurface correlation of these strata is usually easy. Shallow-blanket reservoirs are being actively developed in the southern plains area of Alberta and Saskatchewan, Canada, and to a lesser extent in eastern Montana. In the United States these tight reservoirs are present in the northern Great Plains and eastern Plains regions (fig. 1). Shallow-blanket reservoirs in the United States are estimated to contain recoverable resources of about 100 trillion cubic feet (Tcf) of gas (National Petroleum Council, 1980; Rice and Shurr, 1980).

It is generally accepted that tight gas reservoirs are rocks that have an in-situ permeability to gas of 0.1 millidarcy $(\mathrm{mD})$ or less, exclusive of fracture permeability. However, there is a full continuum of permeabilities ranging from those of conventional reservoirs to those of very tight reservoirs (from $>500 \mathrm{mD}$ to $<0.0005 \mathrm{mD}$ ). Rocks with intermediate permeabilities in this continuum are commonly described as "near tight" (fig. 2). In some basins, slight differences in sedimentology, diagenetic histories, and natural fracturing have created local areas of enhanced permeability, referred to as "sweet spots," in an otherwise tight reservoir. Identifying these "sweet spots" is, therefore, a prime exploration objective.

The porosity of tight reservoirs can range from less than 5 percent in sandstones, shales, and carbonates to more than 25 percent in chalks. Spencer (1985) has identified two main porosity types. One type has low porosity (generally $<12$ percent), low permeability, and high capillary pressure as the result of postdepositional cementation (diagenesis) of conventional reservoir rocks. The second type has high porosity (15 to $>35$ percent) and low permeability to gas because the rock is very fine grained. The fine grain size causes the reservoir rock to have a high pore-wall surface area and abundant very small (generally $<10$ micrometers) intergranular pore spaces coated with

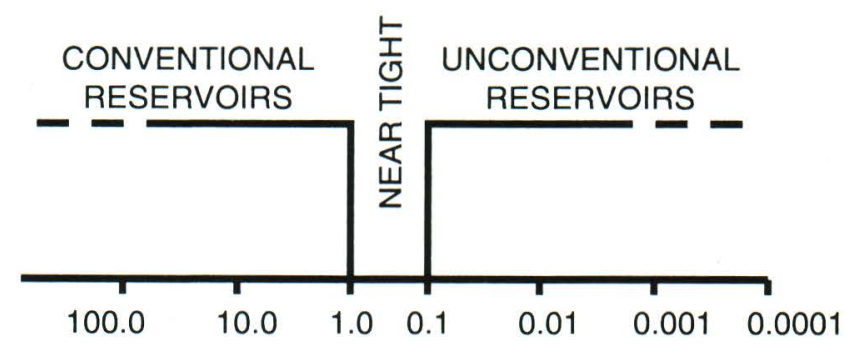

\section{IN-SITU PERMEABILITY TO GAS, IN MILLIDARCIES}

Figure 2. Permeability continuum in conventional through unconventional gas reservoirs. water. These rocks generally have high capillary pressures because of their fine grain size.

The lenticular and marginal-marine blanket rocks are the low-porosity type, and the shallow-blanket reservoirs are the high-porosity type. The low-porosity reservoirs are usually found at depths greater than $7,000 \mathrm{ft}(2,135 \mathrm{~m})$, whereas shallow-blanket reservoirs are found at depths generally less than $4,000 \mathrm{ft}(<1,220 \mathrm{~m})$.

A photomicrograph of a conventional sandstone reservoir from the Lower Cretaceous Muddy Sandstone in the Powder River Basin of Wyoming is shown in figure 3. In these conventional reservoirs it is easy to visualize how gas can move freely from the pores (blue color) into a wellbore. In contrast, a photomicrograph of a typical lowporosity sandstone reservoir from the Upper Cretaceous Ericson Sandstone, Green River Basin, Wyoming, is shown in figure 4 . In this type of reservoir, the pores are

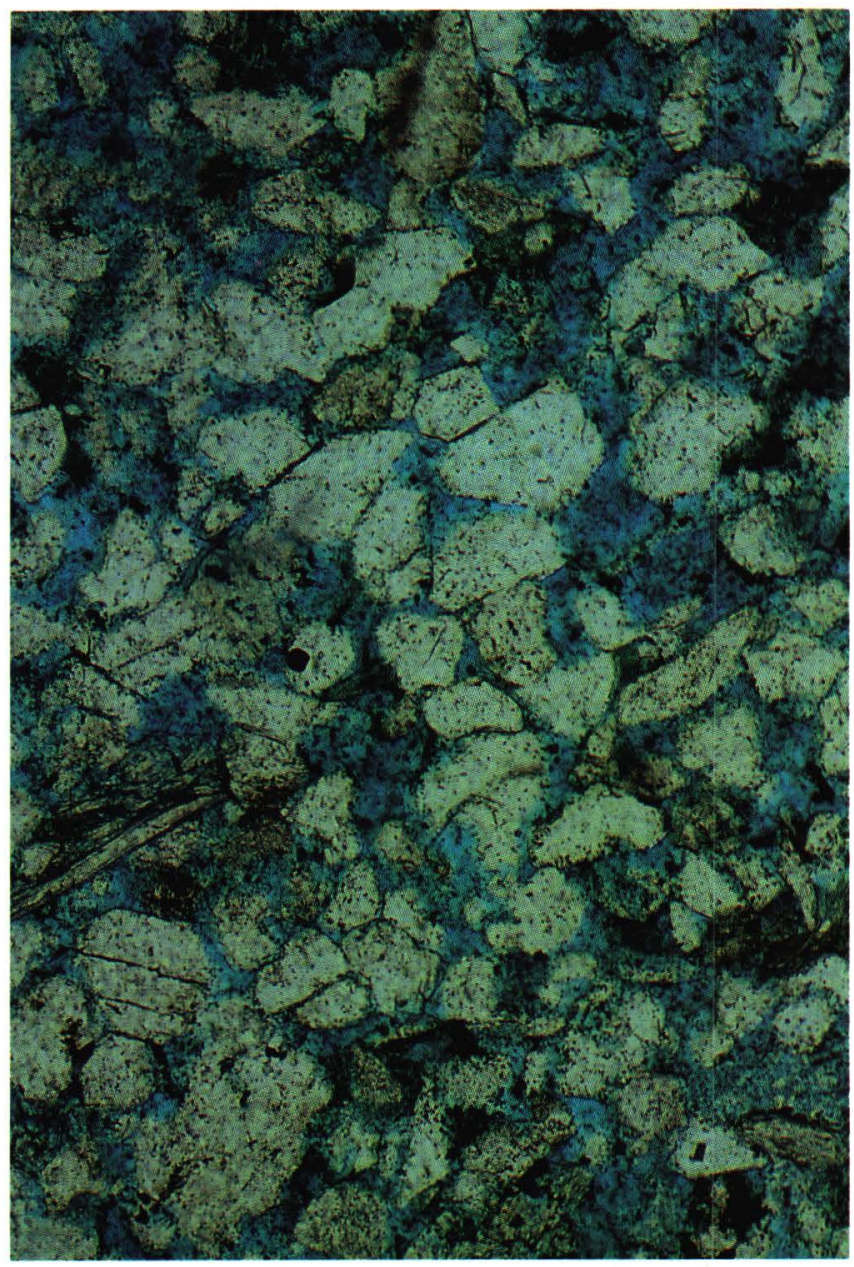

Figure 3. Photomicrograph of conventional sandstone reservoir that has been impregnated with blue epoxy. The epoxy fills the rock pore space. In the subsurface, this pore space is mostly filled with gas and the grains are coated with water. Sample is from the Lower Cretaceous Muddy Sandstone, Powder River Basin, Wyoming. 


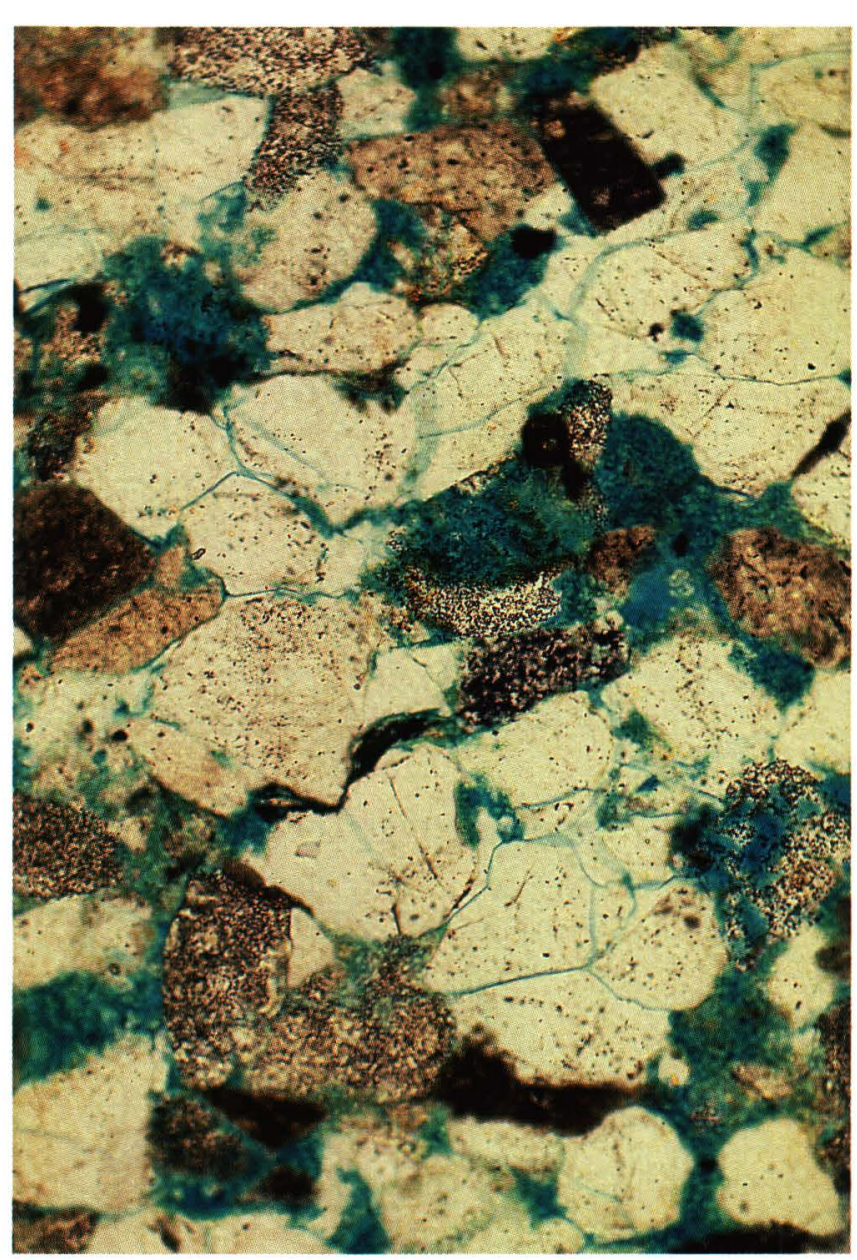

Figure 4. Photomicrograph of low-porosity-type, tight gas reservoir. The pores have been impregnated with blue epoxy. In the subsurface the gas resides in the blue areas, and these widely scattered pores (mostly secondary) are poorly connected by sheet-like capillaries. The pore walls are coated with water, and most of the capillaries are completely filled with water. Sample is from the Upper Cretaceous Almond Sandstone, Washakie Basin, Wyoming.

poorly connected and fluid flow is difficult. In low-porosity reservoirs, much of the porosity is secondary and developed as a consequence of dissolution of rock framework grains or cement. In contrast, primary (intergranular) pores characterize the high-porosity reservoirs. The low-porosity reservoirs are almost always naturally fractured, and the fractures have permeability orders of magnitude greater than that of the rock matrix.

In conventional gas traps, gas normally migrates to structurally higher areas because of the very high buoyancy of gas in water. Consequently, discrete gas/water contacts develop in conventional gas accumulations. Most tight reservoirs, however, have such low permeabilities that gas cannot migrate by buoyancy, and gas accumulations are, therefore, widely distributed through the reservoir with no discrete gas/water contact. Indeed, tight gas

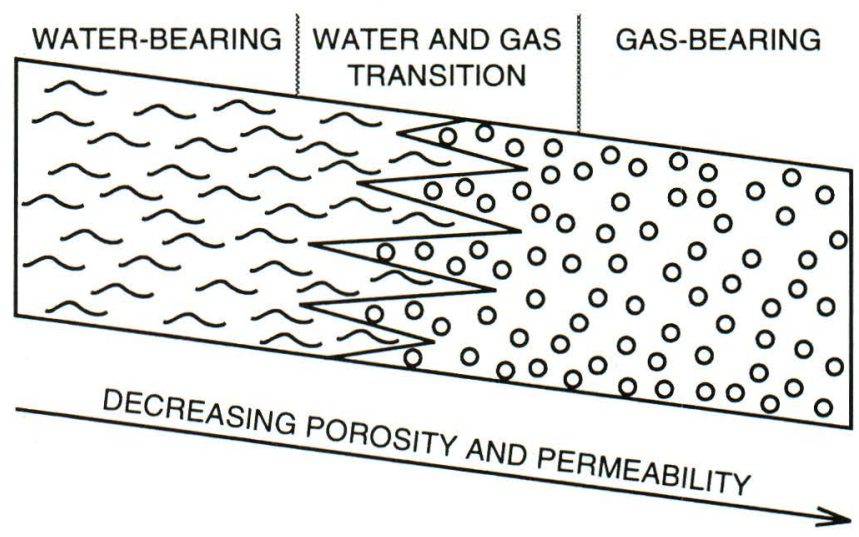

Figure 5. Schematic illustration showing relation between gas and water occurrence in basin-centered gas accumulation. Abnormally pressured, gas-bearing reservoir occupies deeper parts of basin and is downdip from water-bearing, normally pressured reservoir. Note gas- and water-bearing transition zone between the downdip, gas-bearing tight reservoir and the updip, waterbearing conventional reservoir. Modified from Masters (1979).

accumulations of the deeper, basin-center type are characterized by being downdip from water-bearing reservoirs. Typically, the updip water-bearing reservoirs are separated from the downdip gas-bearing reservoirs by an interval as thick as $2,000 \mathrm{ft}(610 \mathrm{~m})$ of mixed gas- and water-bearing reservoirs (fig. 5). As a consequence of the low permeability and the inability of the gas to accumulate by buoyancy, structural and stratigraphic traps are of secondary importance in tight reservoirs.

\section{GAS QUALITY AND SOURCE}

The gas contained in tight reservoirs is predominantly methane, typically more than 85 percent, with very low amounts of ethane and higher molecular weight hydrocarbons. Condensate is less common, and oil is rarely found. Carbon dioxide is generally present in amounts less than 2 percent. In most cases the gas is derived from humic, type II, or type III organic matter in interbedded coal and shale or from disseminated organic matter in the gas reservoir. In the deeper tight reservoirs, where the source rocks have been exposed to temperatures in excess of $100^{\circ} \mathrm{C}$, the gas is of a thermogenic origin, and in shallow reservoirs, where temperatures have not exceeded $100^{\circ} \mathrm{C}$, the gas is commonly of a bacterial origin.

In nearly all cases where there are sufficient data, the source of gas has been determined to be interbedded with or adjacent to the reservoir. In tight reservoirs in the western United States, interbedded coal, shale, and dispersed organic matter within the reservoir are the most likely sources of gas (Law, 1984; Meissner, 1984; Johnson and Rice, 1990). In some cases, however, the gas is inferred to have undergone appreciable migration distances from source rocks that 
are not interbedded with the reservoir. For example, according to Dutton and others (1987), the source rock for gas in tight reservoirs of the Travis Peak Formation in the East Texas Basin may have been underlying shales in the Jurassic Bossier Formation or carbonates of the Jurassic Smackover Formation, or both. Dutton and others (1987) further speculated that the gas may have been derived directly from these source rocks or that the gas may have been derived indirectly from these source rocks by the thermal cracking of oil, subsequent to the accumulation of oil in the Travis Peak Formation.

\section{DRILLING AND COMPLETION PRACTICES}

Tight reservoirs almost always need some type of artificial stimulation or special drilling and completion method in order to produce gas in commercial quantities. As noted earlier, production from tight reservoirs is strongly dependent on the presence of natural fractures. The open natural fractures are almost always vertical. The ideal completion technique is one that will connect the wellbore to the natural fracture system in the least damaging manner. The most commonly used technique has been artificial hydraulic fracturing. Hydraulic fracturing involves injecting a slurry of a proppant (usually well-sorted, clean sand) suspended in a liquid carrying medium. The mixture is injected at a pressure higher than the natural fracture gradient of the reservoir rock so that cracks will propagate away from the wellbore in two directions (commonly called wings); the wings are oriented $90^{\circ}$ to the minimum horizontal stress direction.

This stimulation method has worked reasonably well in blanket reservoirs and near-tight reservoirs. The method, however, has generally not worked in a predictable manner in shale or lenticular sandstone reservoirs. In other words, the actual results of the stimulation do not conform to the design model. One of the problems encountered during fracture treatment is the inability to create crossfractures that effectively connect the dominant, throughgoing fracture set. The fractures created during artificial stimulation are usually parallel to the dominant fracture set, with minimal development of cross-fractures connecting the principal fracture set. This results in an anisotropic drainage pattern with little or no gas production perpendicular to the dominant fracture direction.

Historically, drilling and completion practices have evolved parallel with our improved understanding of the nature of gas accumulations in tight reservoirs. Some of the earliest attempts to economically produce gas from tight reservoirs used nuclear explosives to fracture gas reservoirs. Information concerning these nuclear tests are found in articles by Randolph (1973, 1974a, b, c). The first nuclear stimulation was referred to as the Gasbuggy
Project, conducted in 1967 in the San Juan Basin of New Mexico. In that effort, a 29 -kiloton explosive was detonated at a depth of $4,240 \mathrm{ft}(1,290 \mathrm{~m})$ in the Upper Cretaceous Lewis Shale/Pictured Cliffs Sandstone interval. Two more such projects, the Rulison Project (1969) and the Rio Blanco Project (1973), were conducted in the Piceance Basin of western Colorado. These projects used explosive forces of 43 and 30 kilotons, respectively, and were detonated in the Upper Cretaceous Mesaverde Group and the Tertiary Fort Union Formation. A fourth nuclear stimulation, referred to as the Wagon Wheel Project, in the Green River Basin of southwestern Wyoming was planned but never materialized because of disappointing production tests from the first three wells and the concern about health issues related to radioactive contamination.

As an alternative to nuclear stimulation, several very large, massive hydraulic fracturing experiments were attempted. The objective of these experiments was to create very large hydraulic fractures and stimulate great thicknesses of tight rocks, thereby producing more gas at higher rates.

The definition of massive fracturing varies somewhat, but the intention was to create fractures of combined wing lengths of 2,000 to $4,000 \mathrm{ft}(610-1,220 \mathrm{~m})$. Proppant volumes (measured by weight) of more than $300,000 \mathrm{lbs}$ $(136,050 \mathrm{~kg})$ were typical. After much research and practical field testing, it was determined that these stimulations work fairly well where the reservoir is bounded above and below by shales that have a much higher fracture gradient (resistance to fracturing) than the fracture gradient of the objective reservoir. Under these bounding conditions, the artificial fractures could then be contained within the reservoir by the shales. Such reservoirs were called "blanket" reservoirs by stimulation engineers because they responded to fracturing in a predictable manner.

The massive fracture techniques have not worked well in thick sequences of lenticular rocks because the fractures "grow out of zone," that is, they do not propagate away from the wellbore in a predictable manner and they tend to be short and tall. Proppant embedment into the interbedded shales during fracturing also tends to decrease gas flow rates (Spencer, 1989a).

Finally, the general recognition of the importance of natural fractures to commercial gas recovery has focused attention on attempts to intersect the fracture system with horizontal or slant (inclined) wells. Horizontal and (or) slant wellbores can intersect more open, vertical fractures than a vertical well. This deviated well technology is currently being evaluated at the U.S. DOE Multiwell Experiment site in the Piceance Basin of western Colorado (fig. 1). At this site, a slant hole was drilled through lenticular tight gas reservoirs. The hole was then deviated to horizontal in a blanket reservoir. In the slant-hole portion of the hole, $266 \mathrm{ft}(81 \mathrm{~m})$ of core was taken and 52 fractures were reported, many open to partially open (Lorenz and 
Hill, 1991). In comparison, a nearby vertical hole, drilled through the same interval, encountered one fracture. In the horizontal portion of the hole, $115 \mathrm{ft}(35 \mathrm{~m})$ of core was recovered. This horizontal core contained 37 vertical extension fractures, most of which were open (Lorenz and Hill, 1991).

Deviated drilling in tight gas reservoirs is at a very early stage of development but will likely be used much more extensively in the future. Slant-hole drilling probably will be the method of choice for developing lenticular reservoirs, and horizontal drilling will be the best method in many blanket-like, marginal-marine and marine sandstones (Karl-Heinz Frohne, oral commun., 1987). Improved gas prices and lower completion costs will make deviated drilling more economic.

\section{ESTIMATES OF GAS RESOURCES}

The spot shortages of natural gas in the early 1970's focused attention on the large unconventional gas resources in the United States and, in particular, on tight gas reservoirs. Estimates of the in-place gas resources in tight reservoirs in the United States range from 335 to 5,486 Tcf (table 1). Estimates of recoverable gas from these reservoirs in the United States range from less than 200 to more than $550 \mathrm{Tcf}$. The wide range of estimates is primarily due to uncertainties about the nature of the gas accumulations, differences in assessment methodologies, and the number of basins, formations, and wells evaluated.
However, regardless of the large range of estimates, the resource is very large. Annual production from this large gas resource has been increasing for several years. For example, production of gas from tight reservoirs in 1990 was about $1.7 \mathrm{Tcf}$, or about 10 percent of the total gas produced in the United States (National Petroleum Council, 1992). The National Petroleum Council (1992) projected that by the year 2000 the proportion of gas produced from tight reservoirs would increase to about 11 percent of the total gas produced in the United States.

The first attempt to determine the magnitude of the resource was conducted in 1973, by the Federal Power Commission (FPC). The FPC estimated in-place gas resources of $596 \mathrm{Tcf}$ from only three Rocky Mountain area basins (Supply-Technical Advisory Task Force, 1973). The basins analyzed were the Greater Green River, Piceance, and Uinta (table 1). No estimates were made of the amount of gas recoverable from each basin. However, various scenarios were presented relative to recovery from hypothetical wells, including wells stimulated with nuclear explosives.

Kuuskraa and others (1978) studied the gas resources in tight reservoirs in 13 basins in the western United States, and they estimated in-place gas resources in the 13 basins of $411 \mathrm{Tcf}$ (table 1). They considered that $211 \mathrm{Tcf}$, or about 50 percent, of the gas in place was technically recoverable from the study basins using future technology. They considered that somewhat less than this volume, however, should actually be considered recoverable. In this regard, Kuuskraa and others (1978) assessed the recoverable resource

Table 1. Comparison of estimates of in-place gas resources in tight reservoirs in the United States.

[Values in trillion cubic feet. Sources: FERC, Federal Energy Regulatory Commission (Supply-Technical Advisory Task Force, 1978); FPC, Federal Power Commission (Supply-Technical Advisory Task Force, 1973); ICF, ICF-Lewin, Inc. (Haas, 1990); NPC, National Petroleum Council (1980); USGS, U.S. Geological Survey (Johnson and others, 1987; Law and others, 1989). ---, not determined. Modified from National Petroleurn Council (1992)]

\begin{tabular}{|c|c|c|c|c|c|c|}
\hline $\begin{array}{c}\text { Source } \\
\text { Basin }\end{array}$ & $\begin{array}{c}\text { FPC } \\
(1973)\end{array}$ & $\begin{array}{l}\text { FERC } \\
(1978)\end{array}$ & $\begin{array}{l}\text { Kuuskraa and others } \\
\qquad(1978)\end{array}$ & $\begin{array}{l}\text { NPC } \\
(1980)\end{array}$ & $\begin{array}{c}\text { USGS } \\
(1987,1989)\end{array}$ & $\begin{array}{c}\text { ICF } \\
(1990)\end{array}$ \\
\hline Northern Great Plains/Williston -- & --- & 130 & 74 & 148 & $\ldots$ & $\cdots$ \\
\hline Greater Green River --.--......- & 240 & 240 & 91 & 136 & 5,063 & --- \\
\hline Uinta --...-.-.-- & 207 & 210 & 50 & 20 & --- & --- \\
\hline Piceance--...... & 149 & 150 & 36 & 49 & 423 & 287 \\
\hline Wind River - & --- & --- & 3 & 34 & $\ldots$ & --- \\
\hline Big Horn -....... & --- & --- & 24 & --- & -- & --- \\
\hline Douglas Creek-..-- & --- & --- & 3 & --- & $\cdots$ & --- \\
\hline Denver--- & --- & --- & 19 & 13 & --- & --- \\
\hline 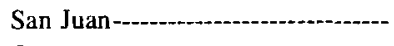 & --- & 63 & 15 & 3 & -- & 17 \\
\hline Ozona --1-- & --- & $+\cdots$ & --- & 1 & --- & $\cdots$ \\
\hline Sonora --1-1-_. & --- & -- & 24 & 4 & -- & -- \\
\hline Edwards Lime-......................... & --- & --- & -- & 14 & --- & -- \\
\hline Cotton Valley Sweet --.---.-..... & --- & --- & 53 & 22 & --- & 31 \\
\hline Cotton Valley Sour -.................... & -- & --- & 14 & $\cdots$ & $\cdots$ & --- \\
\hline 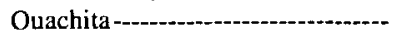 & --- & $-\cdots$ & 5 & $\cdots$ & --- & -- \\
\hline Other----- & -- & -- & $\cdots$ & 481 & -- & --- \\
\hline Total & 596 & 793 & 411 & 925 & 5,486 & 335 \\
\hline
\end{tabular}


using two models: (1) base-case technology and (2) advanced-case technology. Their base-case model assumed the level of technology anticipated to be developed by industry from 1979 to 1984 without additional Federal technological research. Their advanced case was based on "the level of the technology expected to be attained by virtue of active federal-industry collaboration" (Kuuskraa and others, 1978). The maximum price for gas considered was $\$ 4.50$ per thousand cubic feet (Mcf) in 1978 dollars. Using the base case, tight gas reservoirs in the basins studied were estimated to ultimately yield $107.5 \mathrm{Tcf}$, and the advancedcase estimate was 187.7 Tcf (Kuuskraa and others, 1978). The tight gas reservoirs were not well defined at the time of the study by Kuuskraa and others (1978), and a small but poorly defined amount of the reservoir volume they studied has permeability higher than $0.1 \mathrm{mD}$.

In 1978, the Federal Energy Regulatory Commission (FERC) studied gas resources from various unconventional sources (Supply-Technical Advisory Task Force, 1978). The FERC accepted the tight-sandstone formation gas estimates of about $600 \mathrm{Tcf}$ of in-place gas resources in three basins appraised by the previous Supply-Technical Advisory Task Force (1973) and added 63 Tcf of in-place gas in the San Juan Basin, New Mexico, and an additional 130 Tcf of in-place gas for the northern Great Plains shallow gas in Montana and North Dakota. These additions yield a total in-place gas resource estimate of $793 \mathrm{Tcf}$ for the five basins and areas.

In 1980, the National Petroleum Council Committee on Unconventional Gas Resources published estimates of recoverable resources in tight gas reservoirs in 113 gasproducing provinces and basins in the United States, both onshore and offshore in the lower 48 States (National Petroleum Council, 1980). However, only 12 basins, also in the western United States, were appraised in detail. The data from these 12 basins were then extrapolated to provide a resource figure for the other 101 areas, resulting in a total estimate of 925 Tcf of in-place gas in the 113 basins (table 1). The National Petroleum Council estimated that there were 12 Tef of already proven (identified) reserves and 574 Tcf of economically recoverable undiscovered tight gas in the 113 areas and basins. The $574 \mathrm{Tcf}$ estimate was derived assuming advanced technology and using a gas price of $\$ 9.00 / \mathrm{Mcf}$ in 1979 dollars and a 15 percent rate of return on investment.

The National Petroleum Council (1992) subsequently published an extensive report of all sources of natural gas in the United States. The report included both conventional and unconventional sources of natural gas. The National Petroleum Council estimated that tight gas reservoirs (not including eastern United States gas shales) in the lower 48 States contained 349 Tcf of technically recoverable gas. However, some areas were excluded in this assessment. The northern Great Plains was the most notable omission. Independent studies by the U.S. Geological Survey (Rice and Shurr, 1980) and the National Petroleum Council (1980) estimated about $100 \mathrm{Tcf}$ of undiscovered recoverable gas in this area.

The term "undiscovered," as applied to gas in tight reservoirs, is misleading since most of the areas included in the resource assessment have dry holes drilled through at least part of the potential tight reservoir section. These wells commonly had encountered gas shows and (or) tested noncommercial volumes of gas on drillstem tests or through perforations. Analysis of these dry holes forms the data base upon which much of the assessments were predicated, not only by the National Petroleum Council (1980, 1992) but also by Kuuskraa and others (1978) and the U.S. Geological Survey (Rice, 1980).

In another assessment of gas in tight reservoirs, the U.S. Geological Survey estimated in-place gas resources for two basins. The Survey estimated 423 Tcf for the Piceance Basin (Johnson and others, 1987) and 5,063 Tcf for the Greater Green River Basin (Law and others, 1989). The combined estimate of 5,483 Tcf for the Piceance and Greater Green River Basins is several times greater than the largest previous estimate of in-place gas for the entire United States. These estimates were based on extensive geologic studies that relied heavily on empirically derived relations between the occurrence of gas-bearing tight reservoirs and abnormal pressures. In the northern Great Plains, the U.S. Geological Survey (Rice and Shurr, 1980) estimated recoverable gas from shallow, tight reservoirs at more than 100 Tcf. The Survey did not estimate the inplace gas resources. The National Petroleum Council (1980) estimated in-place gas resources in the northern Great Plains at 147.7 Tcf.

The wide variation between the lowest estimate of recoverable gas in the United States (187.7 Tcf; Kuuskraa and others, 1978) and the highest estimate (574 Tcf; National Petroleum Council, 1980) is partly related to differences in methods of study, economic factors used, and interpreted lateral and vertical extent of the potential reservoir rocks. Another significant factor is the number of basins and formations considered to have potential for resources of tight gas. Kuuskraa and others (1978) based their resource estimate on 13 such areas, whereas the National Petroleum Council (1980) studied 12 western basins and extrapolated data to 101 more basins for a total of 113 basins. Kuuskraa and others (1978) did not assess gas resources deeper than $12,700 \mathrm{ft}(3,870 \mathrm{~m})$, and the National Petroleum Council (1980) did not include gas resources deeper than $15,000 \mathrm{ft}(4,575 \mathrm{~m})$. Tight gas reservoirs are present in some basins in excess of $20,000 \mathrm{ft}(6,100 \mathrm{~m})$. However, 13 western basins and areas studied by Kuuskraa and others (1978) are essentially the same as the 12 examined by the National Petroleum Council (1980), but it is difficult to make a direct comparison of the work because of the different approaches to assessment and different methods of data presentation. The National Petroleum 
Council (1980) included a very small amount of resources in reservoirs with up to $0.3 \mathrm{mD}$ of matrix permeability, but most of the assessed gas was in rocks with permeabilities of $<0.1 \mathrm{mD}$. For assessment of conventional gas accumulations, there are many productive analogs to draw from and a probabilistic methodology can be employed, but similar approaches are not entirely appropriate for assessment of tight gas reservoirs. The nature of the gas occurrence in tight reservoirs does not lend itself to a conventional assessment methodology, in that gas occurs in vertically stacked reservoirs that are regional in extent. In conventional reservoirs, the gas occurs in discreet traps.

At this time, estimates of gas resources in tight reservoirs vary considerably; however, there has been sufficient research on these reservoirs in the United States to indicate that the in-place gas resources are large; it seems quite likely that currently available estimates of the inplace gas resources in the United States are conservative. However, the more important question of how much of this large gas resource is recoverable remains problematical. Promising new drilling and completion techniques, coupled with more favorable gas prices, may be the key to converting this large gas resource into a viable source of energy.

\section{SELECTED EXAMPLES OF TIGHT- RESERVOIR GAS ACCUMULATIONS}

The principal regions containing tight gas reservoirs in the United States are shown on figure 1. In addition to these areas, there are many other areas where tight gas reservoirs of lesser significance occur. The following discussions of regions containing tight gas reservoirs are selected to provide examples of the different types of tight reservoirs.

\section{NORTHERN GREAT PLAINS}

The most thoroughly studied and best examples of shallow, tight gas reservoirs in the United States occur in Cretaceous rocks in the northern Great Plains (figs. 1, 6). In this region of approximately $120,000 \mathrm{mi}^{2}(311,000$ $\mathrm{km}^{2}$ ), Cretaceous tight reservoirs occur at depths less than $4,000 \mathrm{ft}(1,220 \mathrm{~m})$. The reservoirs, composed of sandstone, siltstone, shale, chalk, and limestone, were deposited on the shelf of the north-south-elongated Western Interior Seaway (Rice and Shurr, 1980). In ascending stratigraphic order, the reservoirs of primary importance include the Lower Cretaceous Mowry Shale and the Upper Cretaceous Belle Fourche Shale, Greenhorn Formation, Carlile Shale, Niobrara Formation, Gammon Shale, Eagle Sandstone, Claggett Shale, and Judith River Formation (fig. 7). The thickness of this interval is about $2,000 \mathrm{ft}(610 \mathrm{~m})$. Nearly all of the structural features in the area developed during the Laramide orogeny of Late Cretaceous and early Paleocene time (Rice and Shurr, 1980).

Within the Cretaceous tight-reservoir interval, the primary tight reservoirs in this area are thin, discontinuous sandstone and siltstone beds less than 1 inch $(2.5 \mathrm{~cm})$ thick that are interbedded with shale. Thin, low-permeability chalk and limestone reservoirs are of secondary importance. Reservoirs in the northern Great Plains are characterized by high porosity and low permeability; porosities

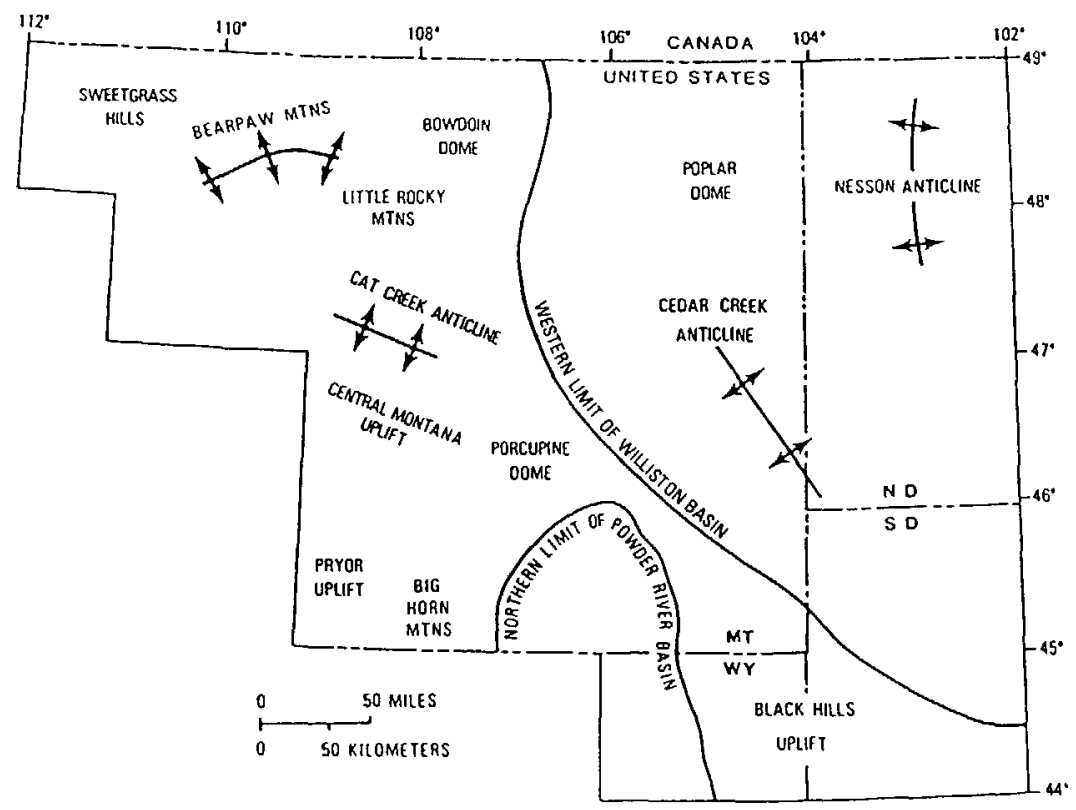

Figure 6. Northem Great Plains area and principal structural features. 
range from 15 to 25 percent, and in-situ permeabilities to gas are less than $0.1 \mathrm{mD}$ (Rice and Shurr, 1980; Rice and others, 1990). According to Rice and Shurr (1980), reservoirs developed in the shelf sandstone, siltstone, and chalk facies have the highest gas potential because they are enclosed by thick shales which are the source of the gas and also provide a good seal. The gas contained in these shallow reservoirs was generated from the interbedded marine shales at low temperatures and is of a bacterial origin (Rice and Shurr, 1980). The biogenic gas accumulated in the thin interbedded reservoirs. As a consequence of the interbedded nature of source and reservoir rock, the gas accumula- tion is regional in extent and is not dependent on structural or stratigraphic traps.

Currently, gas production from this large area is from both conventional and unconventional reservoirs. In the western part of the area, in the nonmarine and coastal facies of these Cretaceous tight reservoirs, gas is produced from high-permeability, conventional reservoirs. Farther east, gas is produced from tight reservoirs in the shelf facies (fig. 8). By analogy with resource estimates in Canada, Rice and Shurr (1980) estimated that tight gas reservoirs in the northern Great Plains of the U.S. may contain recoverable gas of about 100 Tcf. The National

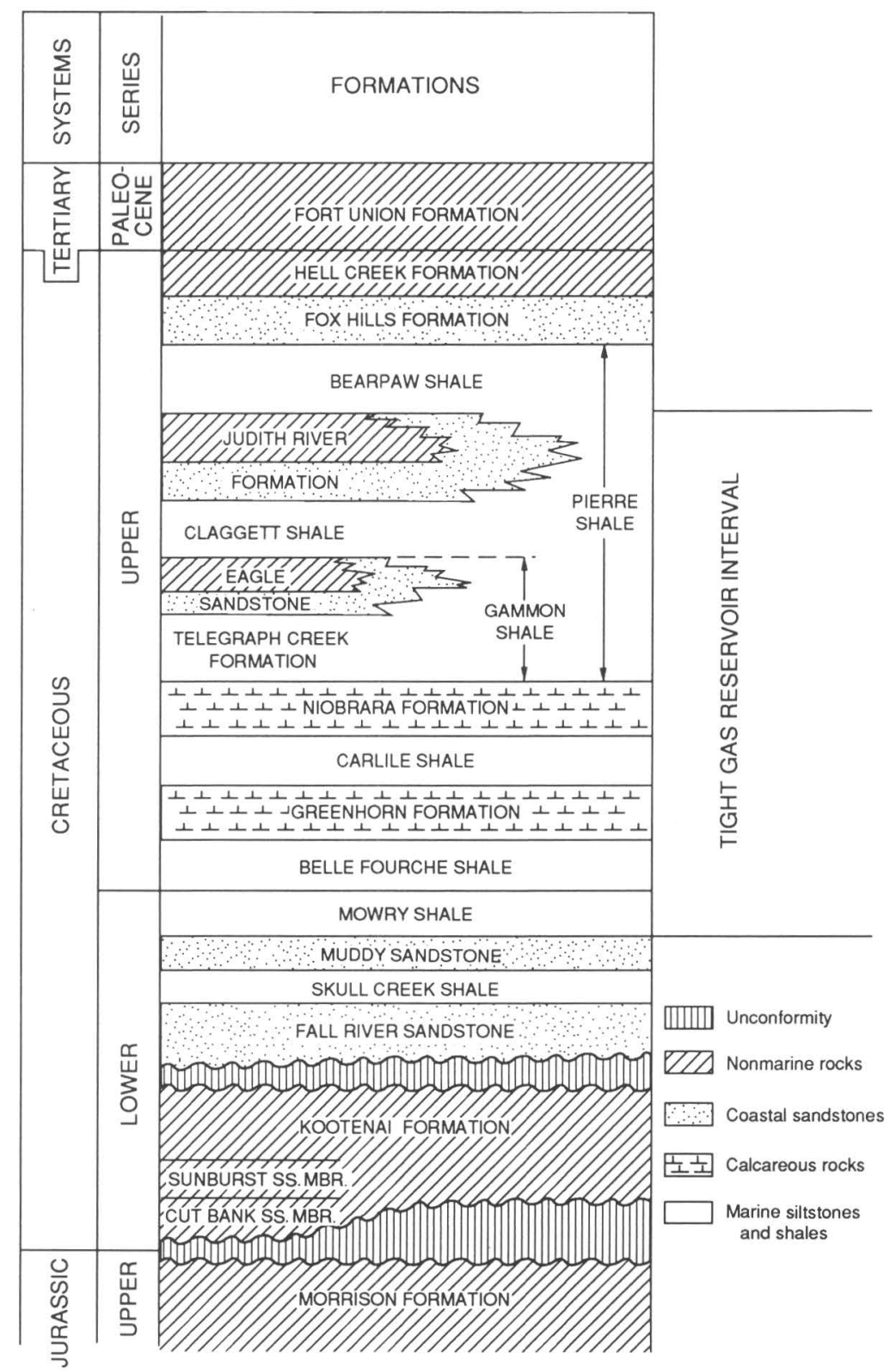

Figure 7. Geologic column for northern Great Plains area showing principal tight gas reservoirs. Modified from Rice and Shurr (1980). 


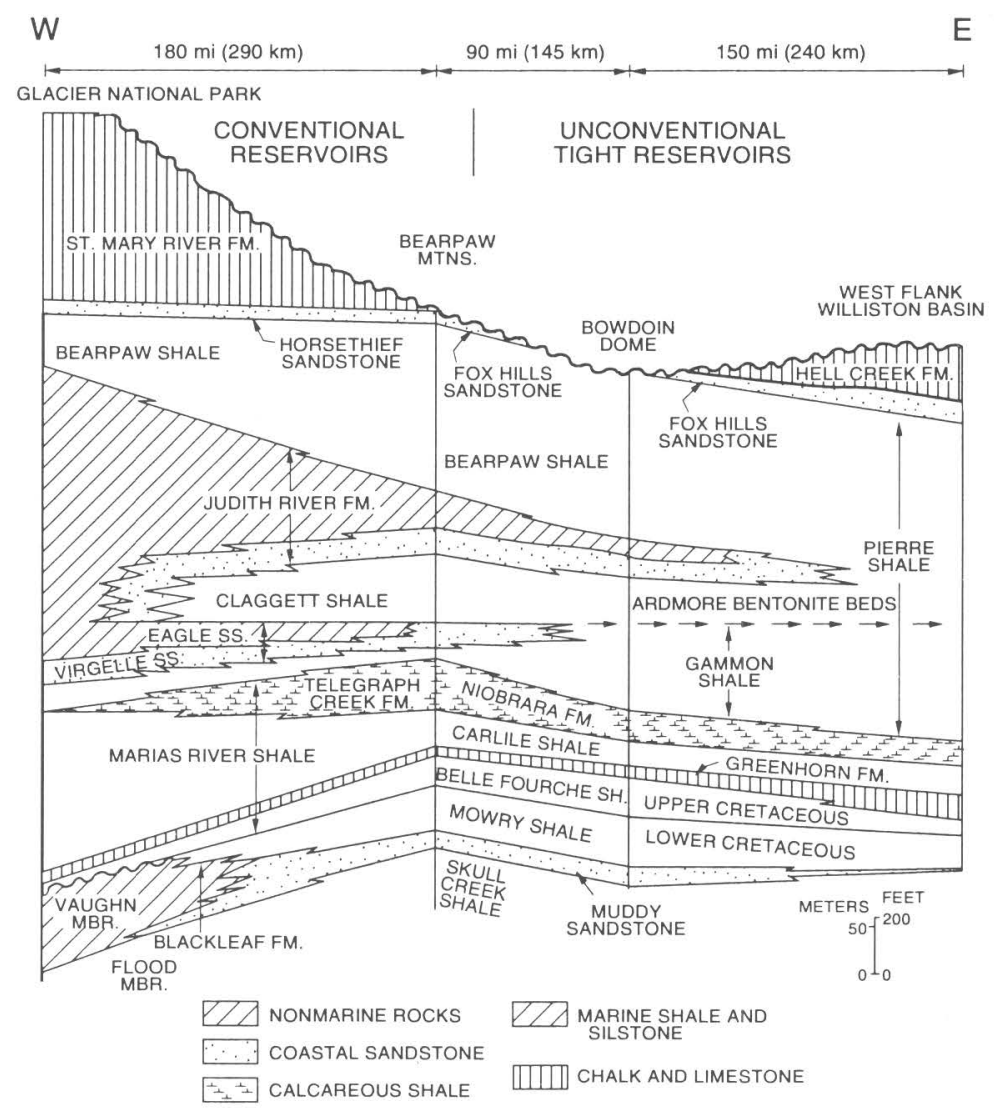

Figure 8. Diagrammatic cross section extending eastward from Glacier National Park through the northern Great Plains area. Tight gas reservoirs include the interval from the Lower Cretaceous Mowry Shale through the Upper Cretaceous Judith River Formation. Within this rock interval, the area west of the Bearpaw Mountains contains conventional gas reservoirs and the area east of the Bearpaw Mountains contains tight gas reservoirs. Modified from Rice and Shurr (1980).

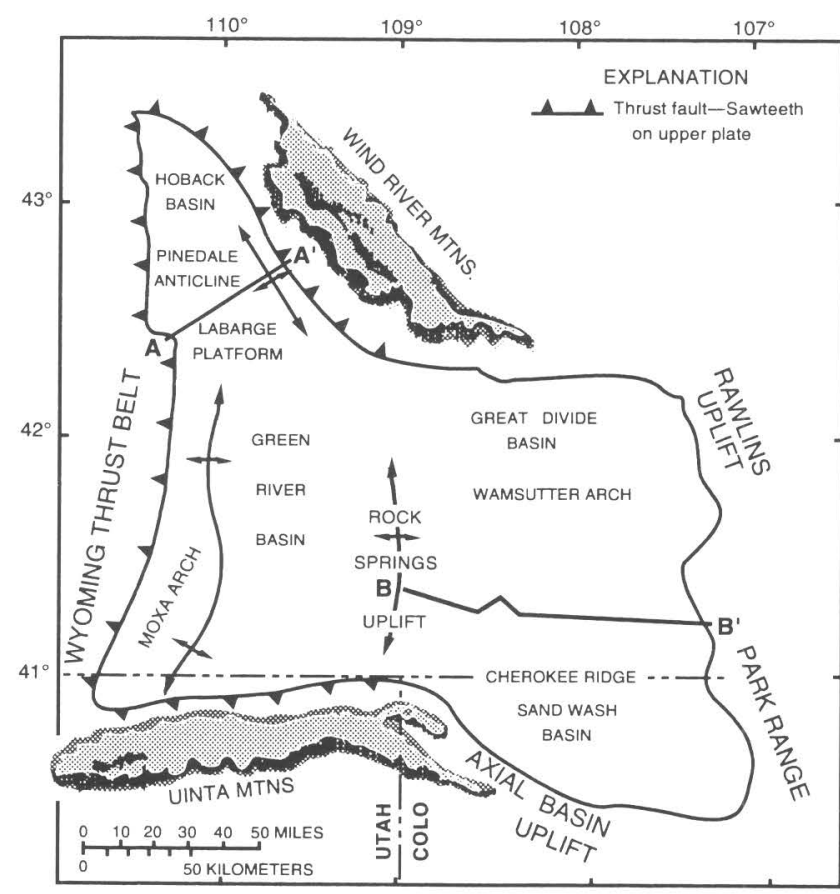

Figure 9. Map of Greater Green River Basin showing major structural elements, subbasins, and location of cross sections A$\mathrm{A}^{\prime}$ (fig. 11) and B-B' (fig. 12). Modified from Law and others (1989).
Petroleum Council (1980) assessed a similar volume of recoverable gas.

\section{GREATER GREEN RIVER BASIN}

The Greater Green River Basin of southwestern Wyoming (figs. 1, 9) is an example of a basin-centered gas accumulation. Common characteristics of this type of gas accumulation include the following: (1) gas is downdip from water-bearing reservoirs; (2) the reservoirs are either under- or overpressured; (3) water saturation is at irreducible (immobile) levels; (4) gas is the pressuring phase; (5) the gas is of a thermal origin. Other examples of this type of gas accumulation include the Piceance (Johnson and others, 1987, Spencer, 1989b), Uinta (Fouch and others, 1992; Nuccio and others, 1992), Wind River, Hanna, San Juan (Meissner, 1978, 1984; Masters, 1979), Denver, Raton (Dolly and Meissner, 1977; Rose and others, 1986), Anadarko, Arkoma, and Appalachian (Davis, 1984; Zagorski, 1988) Basins in the United States and the Alberta Basin (Masters, 1979, 1984) in Canada.

The Greater Green River Basin (fig. 9) is one of the largest $\left(19,700 \mathrm{mi}^{2}\right)$ and better documented basin-centered gas accumulations in the United States. It is a composite of five smaller basins bounded on the west by the Wyoming Thrust Belt, on the north by the Wind River Moun- 


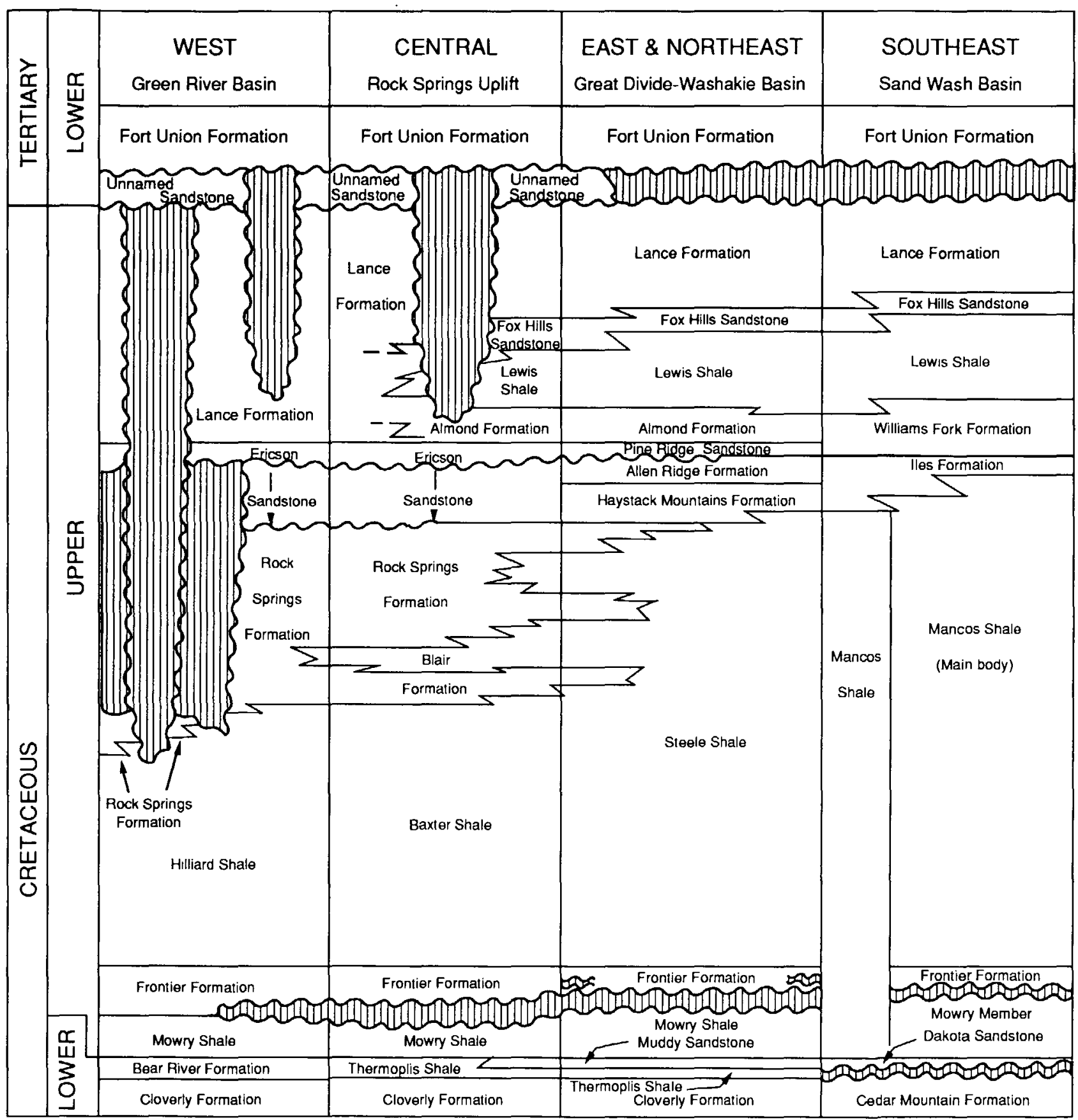

Figure 10. Stratigraphic correlation chart of Cretaceous and lower Tertiary tight gas reservoirs in Greater Green River Basin. From Law and others (1989).

tains, on the east by the Rawlins and Park Range uplifts, and on the south by the Axial Basin and Uinta Mountains uplifts (fig. 9).

Gas occurs in Cretaceous and lower Tertiary rocks that are as thick as $14,000 \mathrm{ft}(4,270 \mathrm{~m})$. The reservoirs, in ascending order, include the Lower Cretaceous Dakota Formation; the Upper Cretaceous Frontier Formation, Mesaverde Group, Lewis Shale, Fox Hills Sandstone, Lance Formation, and the lower Tertiary Fort Union For- mation (fig. 10). They are composed of sandstone and siltstone that were deposited in fluvial and deltaic environments. The top of the tight, gas-bearing rocks has been determined to coincide with the top of overpressured rocks, at depths ranging from 8,000 to $11,000 \mathrm{ft}(2,440$ $3,350 \mathrm{~m}$ ) (Law, 1984). The relationship among structure, stratigraphy, overpressuring, and occurrence of gas in tight reservoirs is shown in figures 11 and 12 . In-situ permeability to gas is less than $0.1 \mathrm{mD}$, and porosity ranges 


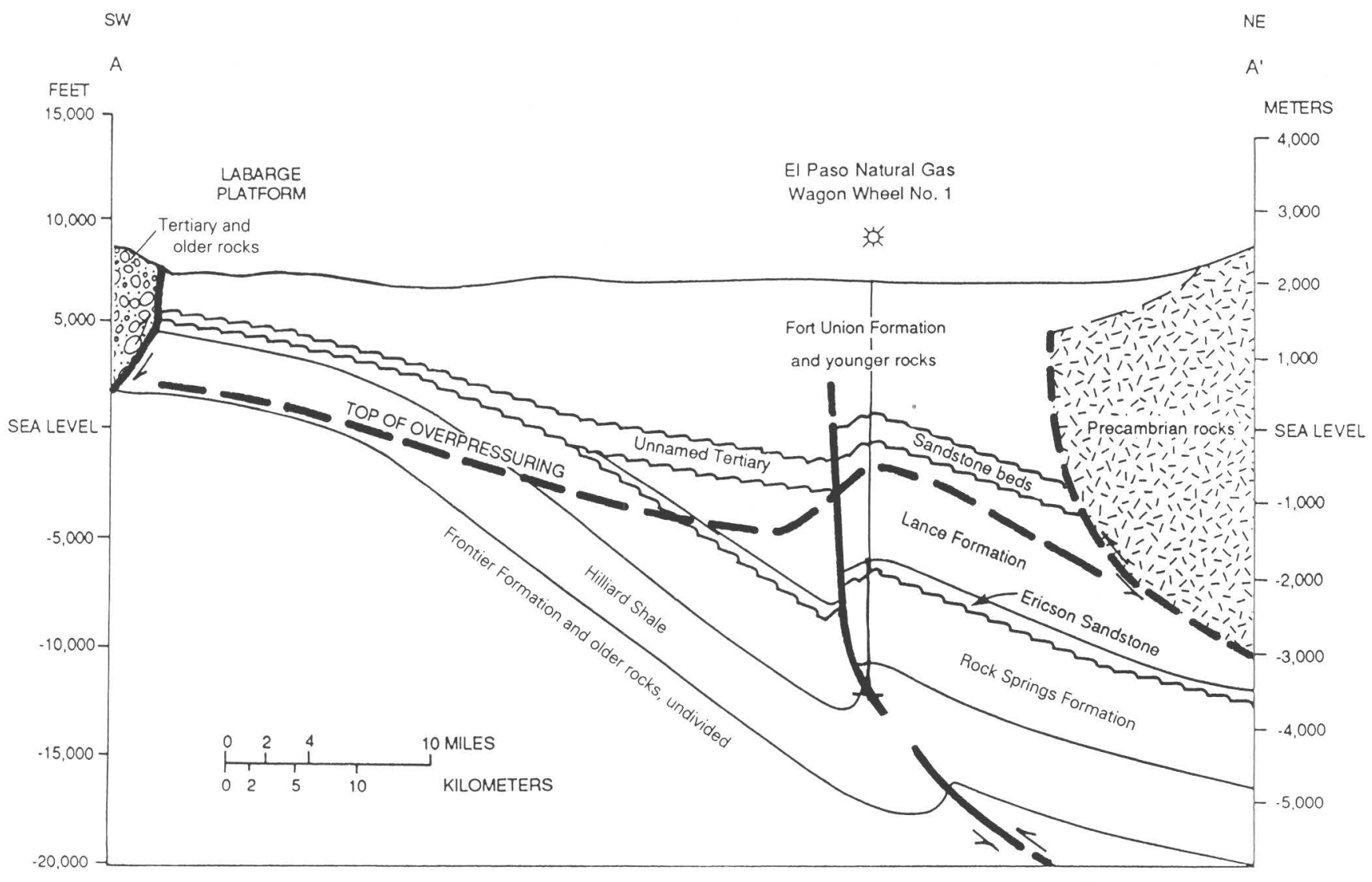

Figure 11. Cross section A-A' through northern part of Green River Basin, showing relationships among structure, stratigraphy, and top of overpressured, tight gas reservoirs. Location of section shown on figure 9. Wavy lines are unconformities; arrows show relative movement on faults, which are dashed where locations are uncertain; contacts are dashed where uncertain. Modified from Law (1984).

from 3 to 12 percent (Law and others, 1986; Keighin and others, 1989). Porosity is mainly secondary, created by the dissolution of unstable framework grains and cements (Law and others, 1986; Keighin and others, 1989; Dutton, and others, 1992).

The gas is sourced from interbedded carbonaceous shales and coals and is thermogenic (Law, 1984). Empirical relationships show that at temperatures of about $100^{\circ} \mathrm{C}$ and at levels of thermal maturity of about 0.8 percent vitrinite reflectance (percent $R_{0}$ ), thermally generated gas begins to accumulate in the reservoirs at rates greater than it is lost. With continued gas generation, mobile water is forcibly expelled from the pore network into overlying, normally pressured reservoirs, and a free-gas phase forms that eventually develops into an overpressured, gas-saturated reservoir system. The remaining water (irreducible water saturation) in the overpressured, gas-bearing reservoirs occupies the very small capillaries. These types of gas accumulations are not as dependent on structural and stratigraphic traps as are conventional gas accumulations. Indeed, the top of overpressured, gas-saturated reservoirs crosses structural and stratigraphic boundaries (figs. 11, 12). The in-place gas in these thick overpressured sequences is extremely large. The estimate of the in-place gas resources in tight overpressured reservoirs in the Greater Green River Basin is 5,063 Tcf (Law and others, 1989).

\section{APPALACHIAN BASIN}

The Appalachian Basin is, like the Greater Green River Basin, an example of a basin-centered gas accumulation. The Appalachian Basin, however, is different from the Greater Green River Basin in that the rocks are Paleozoic rather than Mesozoic and the reservoirs are underpressured rather than overpressured. The basin covers an area of about $230,000 \mathrm{mi}^{2}\left(596,000 \mathrm{~km}^{2}\right)$ and extends from New York southwestward to Alabama (fig. 13). The eastern edge of the basin is buried beneath the Piedmont thrust sheets. The western edge is defined by the Cincinnati and Findlay Arches (fig. 13). The deepest part of the basin is located in eastern Pennsylvania. Tight gas reservoirs occur in the Silurian Clinton and Medina sands, the 


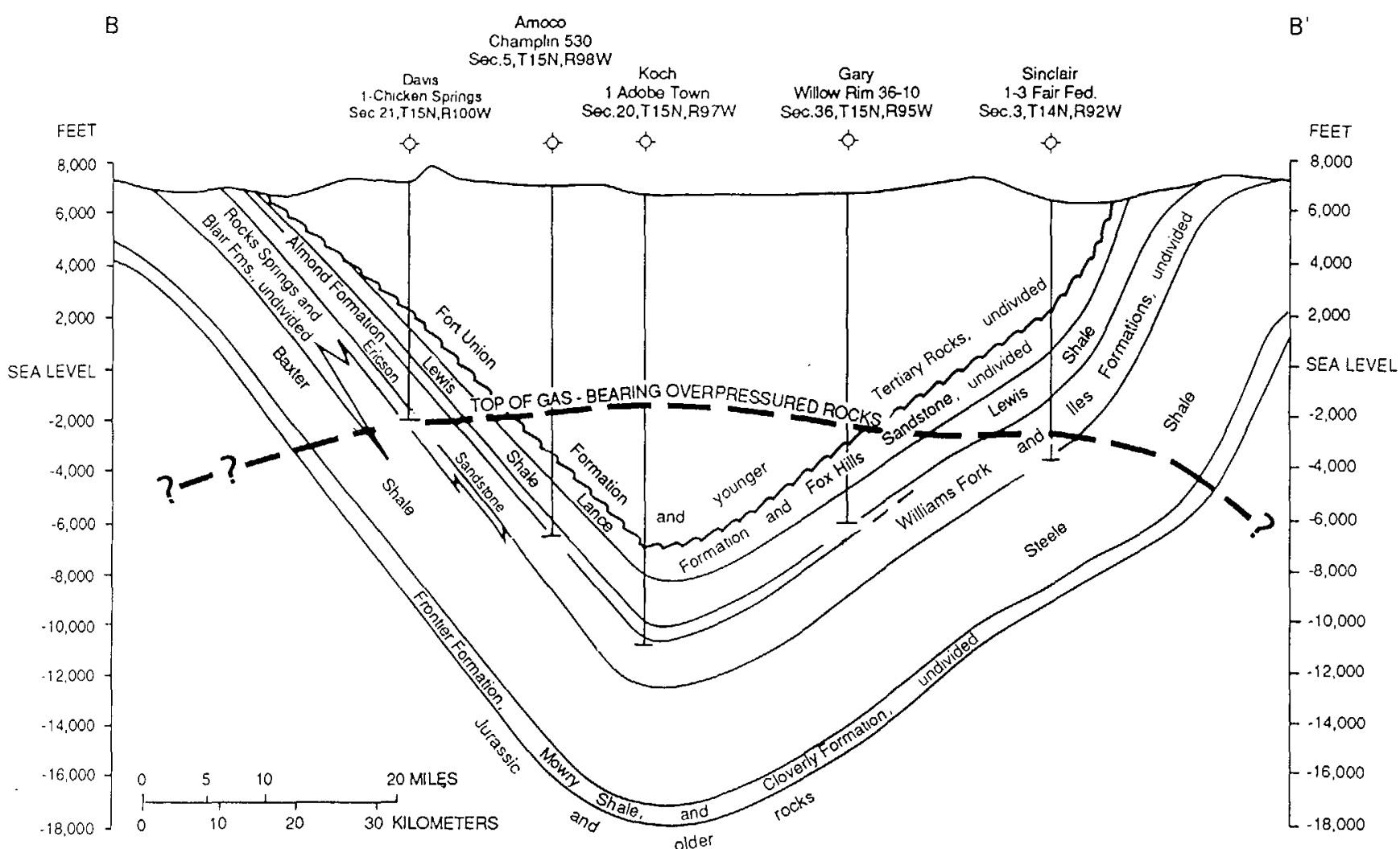

Figure 12. Cross section B-B' through Washakie Basin showing relationships among structure, stratigraphy, and top of overpressured. tight gas reservoirs. Location of section shown on figure 9. Wavy lines are unconformities; contacts are dashed where uncertain. Modified from Law and others (1989).

Upper Devonian Bradford and Venango Groups of Harper and others (1982), and the Mississippian part of the Berea Sandstone (fig. 14).

These rocks were generally derived from source terranes east, southeast, and north of the Appalachian Basin (Cotter, 1982; Martini, 1971; de Witt and McGrew, 1979; Potter and others, 1983) and deposited in fluvial, deltaic, and marginal marine environments (Martini, 1971; Laughrey, 1984; and Laughrey and Harper, 1986). The reservoirs are composed of interbedded conglomerate, sandstone and mudstone with minor amounts of carbonates. The Clinton and Medina sands are about $200 \mathrm{ft}(61 \mathrm{~m})$ thick in western Pennsylvania, thinning to less than $120 \mathrm{ft}(37 \mathrm{~m})$ northwestward, beneath Lake Erie (Laughrey and Harper, 1986). Cross section A-A' (fig. 15) shows the change of thickness of the Medina and its relationship to the Tuscarora Formation in western Pennsylvania. Upper Devonian rocks range from 0 to $5,000 \mathrm{ft}(0-1,525 \mathrm{~m})$ thick, and the Mississippian part of the Berea Sandstone is 20 to $60 \mathrm{ft}$ (6-18 $\mathrm{m})$ thick through most of the area where it is designated to be tight (Pepper and others, 1954) The depth to the Berea Sandstone ranges from $1,200 \mathrm{ft}(366 \mathrm{~m})$ in Ohio to $6,000 \mathrm{ft}(1,830 \mathrm{~m})$ in West Virginia (Finley, 1984).
Productive sandstones are composed of siliceous to dolomitic and calcitic subarkose, sublitharenite, and quartzarenite (Laughrey and Harper, 1986). Porosity is secondary and ranges from $<2$ percent to nearly 12 percent. Permeability ranges from 0.01 to $0.16 \mathrm{mD}$ (Laughrey and Harper, 1986). The reservoirs are abnormally underpressured with respect to hydrostatic pressure gradients of $0.43 \mathrm{psi} / \mathrm{ft}$ (pounds per square inch per foot) (Russell, 1972; Davis, 1984).

Gas fields producing from these tight reservoirs are generally considered to be stratigraphic accumulations where permeability discontinuities or facies changes provide the trap. Underpressured gas accumulations in these tight reservoirs may be similar to a basin-centered accumulation like the Elmworth Field in Canada (Davis, 1984; Zagorski, 1988). Indeed, many of the reservoir characteristics of tight reservoirs in the Appalachian Basin are similar to those in other basin-centered gas accumulations. The role of natural fractures in gas production is uncertain in the Appalachian Basin, although several studies have indicated that natural fractures may be very important to gas production (Laughrey and Harper, 1986; Dutton and others, 1993). Laughrey and Harper (1986) also suggested that natural fractures may have facilitated the migration of gas from source rocks. 


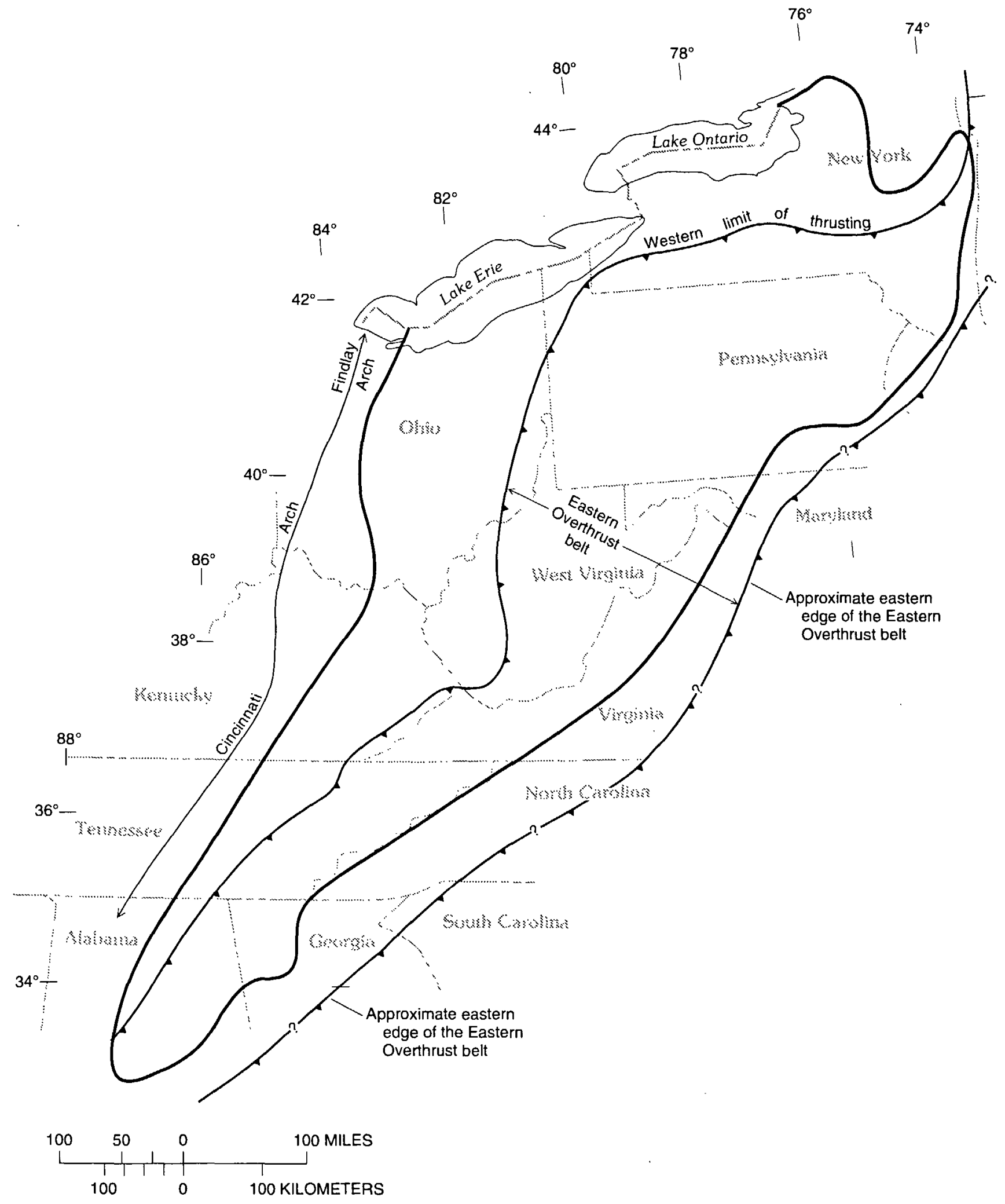

Figure 13. Map of Appalachian Basin (heavy outline) showing major structural elements. Modified from de Witt (1988). 


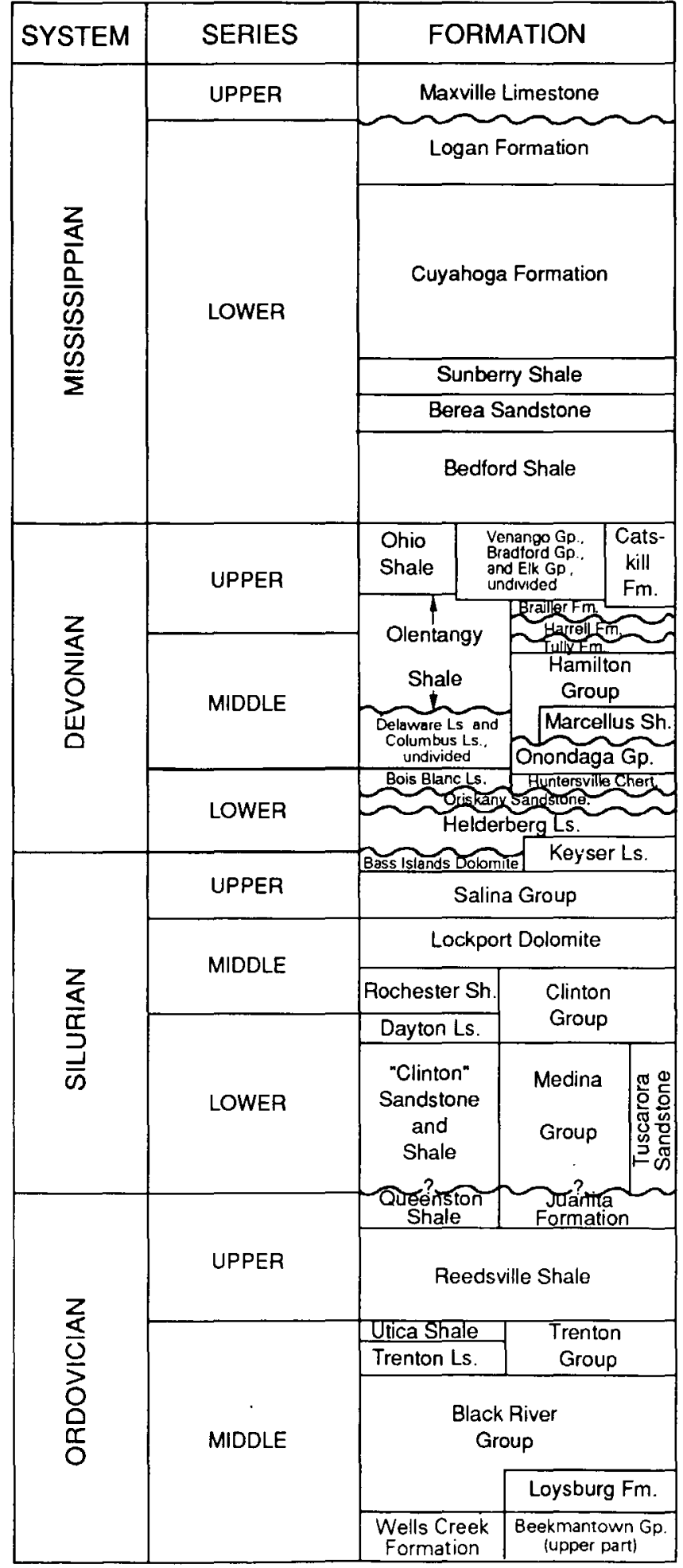

Figure 14. Geologic column of Ordovician through Mississippian rocks in the eastern Ohio and western Pennsylvania portion of the Appalachian Basin. Modified from Berg and others (1983), Patchen and others (1984), Milici and de Witt (1988), and Ryder and others (1992). (The stratigraphic nomenclature and unit age assignments used in this figure may not necessarily conform to current usage by the U.S. Geological Survey.)
The source of gas in Appalachian tight reservoirs is unknown. There are good source rocks, however, in Ordovician, Devonian, and Mississippian rocks (Cole and others, 1987; Wallace and Roen, 1989). On the basis of thermal maturity data presented by Cole and others (1987) for the Devonian Ohio Shale and the Ordovician Point Pleasant Formation in eastern Ohio, these rocks are probably in the oil window ( 0.6 to 1.3 percent vitrinite reflectance), although where they are more deeply buried along the eastern edge of the basin, they are most likely thermally overmature with respect to the oil window ( $>1.3$ percent vitrinite reflectance). Conodont alteration indices in Ordovician rocks indicate that these rocks are thermally mature (within the oil window) along the western edge of the Appalachian Basin and thermally overmature through most of the basin (Harris and others, 1978; Wallace and Roen, 1989).

Estimates of gas-in-place are $69 \mathrm{Tcf}$ for the Berea Sandstone (Dutton and others, 1993) and 94 Tcf for the Clinton and Medina sands (Dutton and others, 1993). However, these estimates are probably conservative. The estimates are only for reservoirs designated as tight by the Federal Energy Regulatory Commission and do not include the more deeply buried, stratigraphically equivalent rocks in the basin.

\section{EAST TEXAS AND NORTH LOUISIANA BASINS}

The East Texas and North Louisiana Basins (figs. 1, 16) formed during Late Triassic rifting (Buffler and others, 1980). These basins formed as a consequence of crustal extension and heating followed by cooling and subsidence during which Mesozoic and Cenozoic sediments accumulated (Dutton and others, 1993). The basins are bounded by down-to-the-basin faults (Finley, 1984). The Sabine Arch (fig. 16), which separates the two basins, formed during Late Cretaceous and Tertiary time (Jackson and Laubach, 1991).

The principal tight gas reservoirs in these basins are the Upper Jurassic to Lower Cretaceous Cotton Valley Formation and the Lower Cretaceous Travis Peak Formation (Finley, 1986; Dutton and others, 1993). Other tight gas reservoirs include sandstones within the Smackover Formation, the Upper Jurassic Haynesville Formation, the Lower Cretaceous James Limestone, and the middle part of the Cockfield Sandstone, equivalent to the Eocene Yegua Formation in east Texas (fig. 17).

The sandstones of the Cotton Valley and Travis Peak represent deposition of the first major clastic progradation into the East Texas and North Louisiana Basins after the opening of the Gulf of Mexico in the Jurassic (Seni and Jackson, 1983). They consist of interbedded conglomerate, sandstone, siltstone, and mudstone that were deposited in fluvial, deltaic, and nearshore marine environments associated with the ancestral Mississippi River (Coleman and Coleman, 1981; McGowan and Harris, 1984). The Cotton Valley ranges in thickness from 1,000 to $3,000 \mathrm{ft}(305-915 \mathrm{~m})$, and 


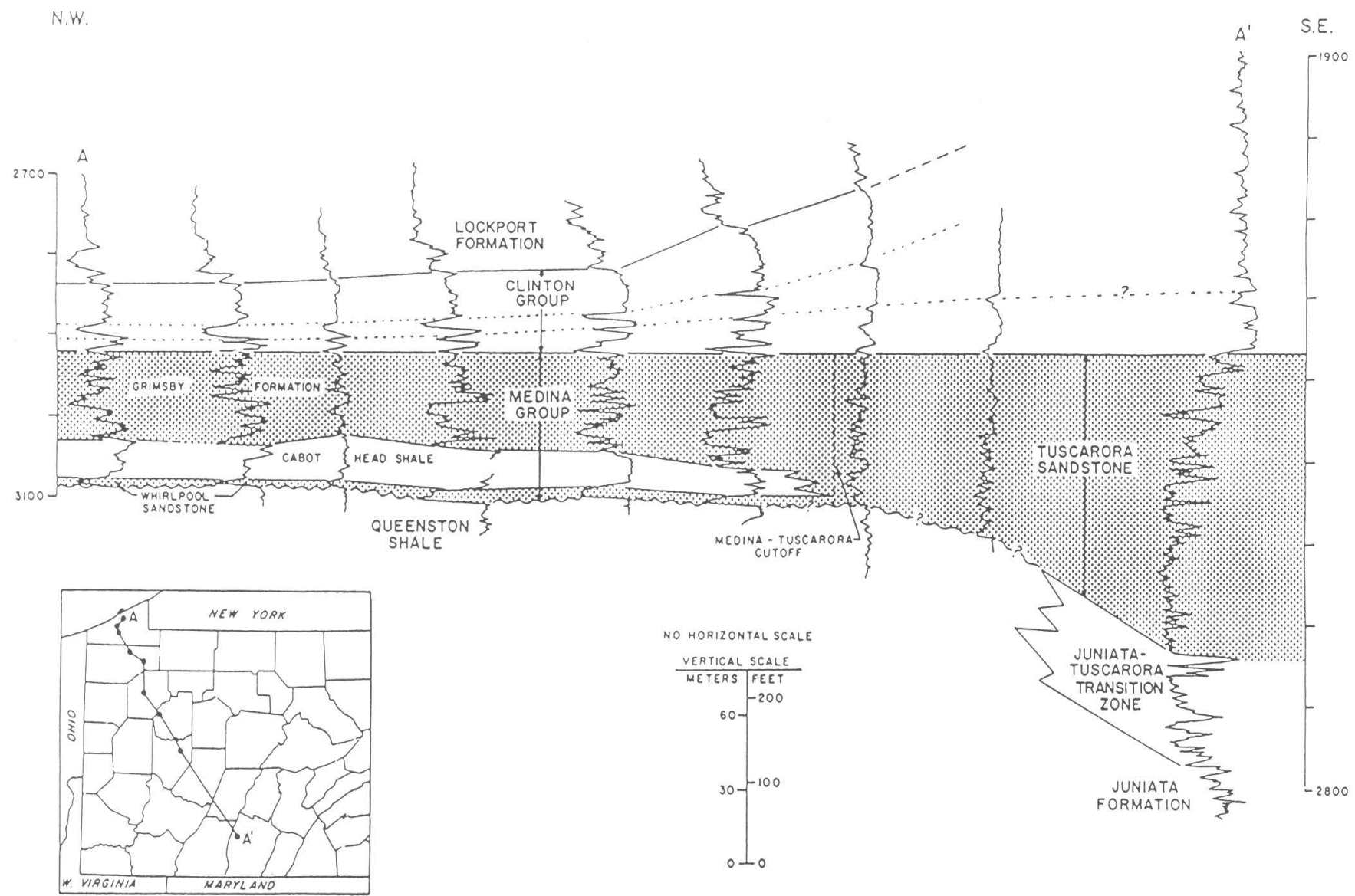

Figure 15. Cross section showing stratigraphic correlations of geophysical well logs and relationships of the Medina Group (shaded) in western Pennsylvania. From Pietrowski (1981) in Laughrey and Harper (1986).

the Travis Peak ranges in thickness from 1,400 to $3,200 \mathrm{ft}$ (430-975 m). Both units increase in thickness from northwest to southeast (Dutton and others, 1991). Depth to the top of the Cotton Valley ranges from 5,000 to 8,000 ft $(1,525-$ $2,440 \mathrm{~m}$ ) in the northern parts of the basins and 10,000 to $11,000 \mathrm{ft}(3,050-3,350 \mathrm{~m})$ in the southern part of the area. Depth to the Travis Peak ranges from 4,000 to $10,000 \mathrm{ft}$ $(1,220-3,050 \mathrm{~m})$.

Gas production from the Cotton Valley is from both conventional and unconventional reservoirs. In the shallower updip areas of the basins, gas production is typically from conventional, high-permeability reservoirs. Downdip from these areas, gas production is from low-permeability reservoirs (Collins, 1980). The reservoirs in the Cotton Valley and Travis Peak are normal to overpressured, with gradients of about $0.60 \mathrm{psi} / \mathrm{ft}$ in the Cotton Valley and 0.43 to $0.59 \mathrm{psi} / \mathrm{ft}$ in the Travis Peak (Finley, 1984). Finley (1984) reported that porosity in the Cotton Valley ranges from 6 to 10 percent and the average permeability in Texas and Louisiana is 0.04 and $0.01 \mathrm{mD}$, respectively.
Production from the Travis Peak is from structural and stratigraphic traps over the crest of the Sabine Arch and from combination traps associated with salt structures off the flanks of the uplift (Dutton and others, 1991). Both the Cotton Valley and Travis Peak are fractured (Finley, 1984; Laubach, 1989a, b). Finley (1984) concluded that the natural fractures seemed to enhance production. Porosity in the Travis Peak ranges from 1 to 21 percent, generally decreasing with increasing depth of burial from a mean of 10.6 percent at $6,000 \mathrm{ft}(1,830 \mathrm{~m})$ to 4.4 percent at $10,000 \mathrm{ft}(3,050 \mathrm{~m})$ (Dutton and Diggs, 1992). Permeability also decreases with increasing depth; mean matrix permeability at a depth of $6,000 \mathrm{ft}$ is $0.8 \mathrm{mD}$ and at $10,000 \mathrm{ft}$ is $0.0004 \mathrm{mD}$ (Dutton and Diggs, 1992). Dutton and Diggs (1992) attributed the loss of porosity and permeability to increasing amounts of quartz cement, decreasing secondary porosity, and increasing overburden pressure. Estimates of in-place gas are $24.2 \mathrm{Tcf}$ for the Cotton Valley Formation and 6.4 Tcf (Haas, 1990) for the Travis Peak. 


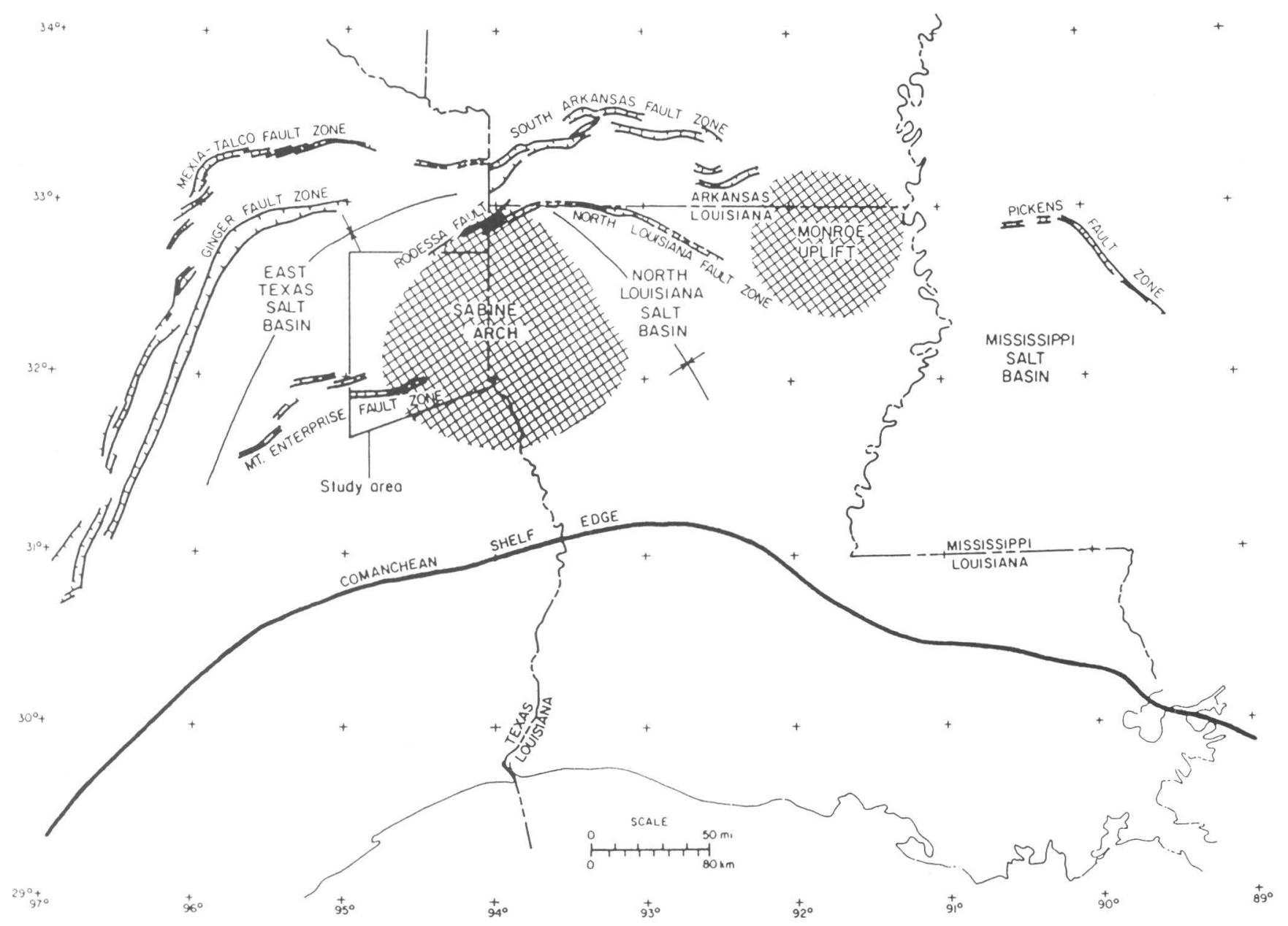

Figure 16. Map of East Texas and North Louisiana Basins showing major structural elements. From Dutton and others (1993).

\section{SUMMARY}

Low-permeability (tight) gas reservoirs contain very large amounts of gas. In-place gas resources in the United States may exceed 5,000 Tcf, and recoverable gas is estimated to range from less than 200 Tcf to more than 550 Tcf. Tight gas reservoirs are present in nearly every petroleum province. These reservoirs occur at very shallow to very deep depths and consist of a wide range of rock types. They are commonly abnormally pressured, and the gas accumulations, unlike conventional accumulations, are pervasive and independent of structural or stratigraphic traps. Tight gas reservoirs may be discrete, isolated thin beds a few feet thick, or they may be very thick, vertically stacked beds in intervals several thousand feet thick. Natural fractures play a prominent role in the economic production from these reservoirs. Wells drilled into tight gas reservoirs commonly require artificial hydraulic fracturing. However, currently used drilling and completion practices have resulted in mixed success. The use of slant and horizontal wells in tight-gas-reservoir sequences as an alternative to vertically drilled holes is in an early stage of evaluation. Because of the ability of slant and horizontal drilling techniques to intersect the natural fracture system, the gas industry is optimistic that deviated drilling will successfully exploit the very large gas resources in tight reservoirs.

\section{ACKNOWLEDGMENTS}

The U.S. Geological Survey research on tight gas reservoirs has been supported by the U.S. Department of Energy (DOE) since 1978. Karl-Heinz Frohne, C. Keith Westhusing, and Charles A. Komar of the U.S. DOE have provided valuable technical assistance and have been very supportive. U.S. Geological Survey programs on Onshore Oil and Gas, Oil Shale, and Evolution of Sedimentary Basins have also provided invaluable assistance and support. During our research, technical discussions with many individuals from industry and academic groups provided perspectives that in 


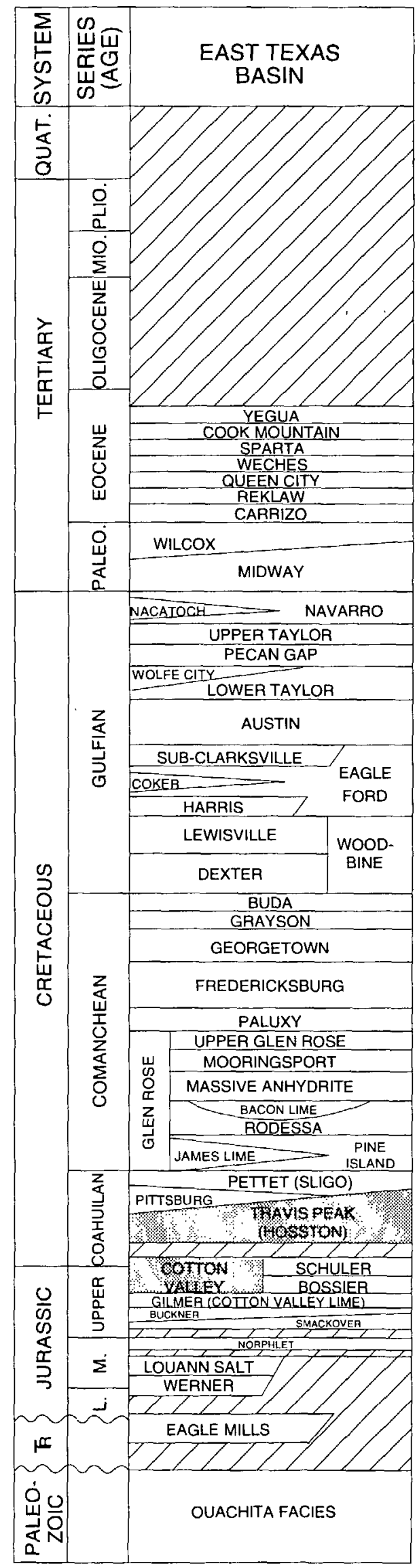

Figure 17. Geologic column for East Texas Basin. The Cotton Valley Formation and Travis Peak Formation, the principal tight gas reservoirs, are shown in a shaded pattern. From Dutton and others (1993).

many cases affected our research approach. Finally, the constructive reviews of this manuscript by Thomas D. Fouch, David D. Howell, and Laura Zink are appreciated.

\section{REFERENCES CITED}

Berg, T.M., McInerney, M.K., Way, J.H., and MacLachlan, D.B., 1983, Stratigraphic correlation chart of Pennsylvania: Pennsylvanian Topographic and Geologic Survey, General Geology Report 75, 1 sheet.

Buffler, R.T, Watkins, J.S., Shaub, F.J., and Worzel, J.L., 1980, Structure and early geologic history of the deep central Gulf of Mexico, in Symposium on the origin of the Gulf of Mexico and the early opening of the central North Atlantic Ocean: Baton Rouge, Louisiana State University, School of Geoscience, p. 3-16.

Collins, S.E., 1980, Jurassic Cotton Valley and Smackover reservoir trends, east Texas, north Louisiana, and south Arkansas: American Association of Petroleum Geologists Bulletin, v. 64 , no. 7, p. 1004-1013.

Cole, G.A., Drozd, R.J., Sedivy, R.A., and Halpem, H.I., 1987, Organic geochemistry and oil-source correlations, Paleozoic of Ohio: American Association of Petroleum Geologists Bulletin, v. 71, p. 788-809.

Coleman, J.L., Jr., and Coleman, C.J., 1981, Stratigraphic, sedimentologic and diagenetic framework for the Jurassic Cotton Valley Terryville massive sandstone complex, northern Louisiana: Gulf Coast Association of Geological Societies Transactions, v. 31, p. 71-79.

Cotter, E. 1982, Tuscarora Formation of Pennsylvania: Society of Petroleum and Mining Geologists, Eastern Section, 1982 Fieldtrip Guidebook, 105 p.

Davis, T.B., 1984, Subsurface pressure profiles in gas-saturated basins, in Master, J.A, ed., Elmworth-Case study of a deep basin gas field: American Association of Petroleum Geologists Memoir 38, p. 189-203.

de Witt, Wallace, Jr., 1988, Principal oil and gas plays in the Appalachian Basin (Province 131): U.S. Geological Survey Open-File Report 88-450S, 54 p.

de Witt, Wallace, Jr., and McGrew, L.W., 1979, Appalachian Basin region, in Craig, L.C., and Connor, C.W., eds., Paleotectonic investigations of the Mississippian System in the United States, Part I-Introduction and regional analyses of the Mississippian System: U.S. Geological Survey Professional Paper 1010, p. 13-48.

Dolly, E.D., and Meissner, F.F., 1977, Geology and gas exploration potential, Upper Cretaceous and lower Tertiary strata, northern Raton Basin, Colorado, in Veal, H.K., ed., Exploration frontiers of the central and southern Rockies: Rocky Mountain Association of Geologists, p. 240-270. 
Dutton, S.P., Clift, S.J., Hamilton, D.S., Hamlin, H.S., Hentz, T.F., Howard, W.E., Akhter, M.S., and Laubach, S.E., 1993, Atlas of major low-permeability gas reservoirs in the continental United States: Gas Research Institute Topical Report, GRI-93/0044, 470 p.

Dutton, S.P., and Diggs, T.N., 1992, Evolution of porosity and permeability in the Lower Cretaceous Travis Peak Formation, East Texas: American Association of Petroleum Geologists Bulletin, v. 76, p. 252-269.

Dutton, S.P., Finley, R.J., and Herrington, K.L., 1987, Organic geochemistry of the Lower Cretaceous Travis Peak Formation, East Texas Basin: Gulf Coast Association of Geological Societies Transactions, v. 37 , p. $65-74$.

Dutton, S.P., Hamlin, H.S., and Laubach, S.E., 1992, Geologic controls on reservoir properties of low-permeability sandstone, Frontier Formation, Moxa Arch, southwest Wyoming: Gas Research Institute Topical Report GRI-92/0127, 199 p.

Dutton, S.P., Laubach, S.E., Tye, R.S., 1991, Depositional, diagenetic, and structural controls on reservoir properties of lowpermeability sandstone, Travis Peak Formation, East Texas: Gulf Coast Association of Geological Societies Transactions, v. 41 , p. 209-220.

Finley, R.J., 1984, Geology and engineering characteristics of selected low-permeability gas sandstones-A National survey: The University of Texas at Austin, Bureau of Economic Geology Report of Investigations No. 138, $220 \mathrm{p}$.

- 1986, An overview of selected blanket-geometry, lowpermeability gas sandstones in Texas, in Spencer, C.W., and Mast, R.F., eds., Geology of tight gas reservoirs: American Association of Petroleum Geologists Studies in Geology No. 24, p. 69-85.

Fouch, T.D., Wandrey, C.J., Pitman, J.K., Nuccio, V.F., Schmoker, J.W., Rice, D.D., Johnson, R.C., and Dolton, G.L., 1992, Natural gas accumulations in low-permeability Tertiary and Cretaceous (Maastrichtian-Campanian) rock, Uinta Basin, Utah: U.S. Department of Energy Report DOE/MC/204223051 (DE92001132), $81 \mathrm{p}$.

Haas, M.R., 1990, Impact of improved technology on potential reserves of tight gas in East Texas and North Louisiana: ICF-Lewin, Inc., Topical Report GRI-90/0174, 119 p.

Harper, J.A., Laughrey, C.D., and Lytle, W.S., 1982, Oil and gas fields of Pennsylvania: Pennsylvania Geological Survey, 4th Series, Map No. 3

Harris, A.G., Harris, L.D., and Epstein, J.B., 1978, Oil and gas data from Paleozoic rocks in the Appalachian basin; maps for assessing the hydrocarbon potential and thermal maturity (conodont color alteration isograds and overburden isopachs): U.S. Geological Survey Miscellaneous Investigations Map I-917-E, scale 1:2,500,000 4 sheets.

Jackson, M.L.W., and Laubach, S.E., 1991, Structural history and origin of the Sabine Arch, east Texas and northwest Louisiana: The University of Texas at Austin, Bureau of Economic Geology Geological Circular 91-3, 47 p.

Johnson, R.C., Crovelli, R.A., Spencer, C.W., and Mast, R.F., 1987, An assessment of gas resources in low-permeability sandstones of the Upper Cretaceous Mesaverde Group, Piceance Basin, Colorado: U.S. Geological Survey OpenFile Report 87-357, 165 p.

Johnson, R.C., and Rice, D.D., 1990, Occurrence and geochemistry of natural gases, Piceance Basin, northwest Colorado:
American Association of Petroleum Geologists Bulletin, v. 74, p. $805-829$.

Keighin, C.W., Law, B.E., and Pollastro, R.M., 1989, Petrology and reservoir characteristics of the Almond Formation, Greater Green River Basin, Wyoming: Rocky Mountain Association of Geologists, p. 281-298.

Kuuskraa, V.A., Brashear, J.P., Doscher, T.M., and Elkins, L.E., 1978, Enhanced recovery of unconventional gas, the program-Volume II: U.S. Department of Energy, HCP/T2705$02,537 \mathrm{p}$.

Laubach, S.E., 1989a, Fracture analysis of the western flank of the Sabine Arch, East Texas: The University of Texas at Austin, Bureau of Economic Geology Report of Investigations No. $185,55 \mathrm{p}$.

1989b, Paleostress directions from the preferred orientation of closed microfractures (fluid-inclusion planes): Journal of Structural Geology, v. 11, no. 5, p. 603-611.

Laughrey, C.D., 1984, Petrology and reservoir characteristics of the Lower Silurian Medina Group reservoir sandstones, Athens and Geneva fields, northwestern Pennsylvania: Pennsylvania Geological Survey, 4th series, Mineral Resource Report 85, 126 p.

Laughrey, C.D., and Harper, J.A., 1986, Comparisons of Upper Devonian and Lower Silurian tight formations in Pennsylvania--Geological and engineering characteristics, in Spencer, C.W., and Mast, R.F., eds., Geology of tight gas reservoirs: American Association of Petroleum Geologists Studies in Geology no. 24, p. 9-43.

Law, B.E., 1984, Relationships of source-rock, thermal maturity, and overpressuring to gas generation and occurrence in lowpermeability Upper Cretaceous and lower Tertiary rocks, Greater Green River Basin, Wyoming, Colorado, and Utah, in Woodward, J., Meissner, F.F., and Clayton, J.L., eds., Hydrocarbon source rocks of the greater Rocky Mountain area: Rocky Mountain Association of Geologists, p. 469-490.

Law, B.E., Pollastro, R.M., and Keighin, C.W., 1986, Geologic characterization of low-permeability gas reservoirs in selected wells, Greater Green River Basin, Wyoming, Colorado, and Utah, in Spencer, C.W., and Mast, R.F., eds., Geology of tight gas reservoirs: American Association of Petroleum Geologists Studies in Geology no. 24, p. 253-269.

Law, B.E., Spencer, C.W., Charpentier, R.R., Crovelli, R.A., Mast, R.F., Dolton, G.L., and Wandrey, C.J., 1989, Estimates of gas resources in overpressured low-permeability Cretaceous and Tertiary sandstone reservoirs, Greater Green River Basin, Wyoming, Colorado, and Utah: 40th Annual Field Conference, Wyoming Geological Association Guidebook, p. 39-61.

Lorenz, J.C., and Hill, R.E., 1991, Subsurface fracture spacingComparison of inferences from slanthorizontal core and vertical core in Mesaverde reservoirs, in Rocky Mountain Regional/Low Permeability Reservoirs Symposium and Exhibition: Society of Petroleum Engineers, p. 705-716.

Martini, I.P., 1971, Regional analysis of sedimentology of Medina Formation (Silurian), Ontario and New York: American Association of Petroleum Geologists Bulletin, v. 55, p. 1249-1261.

Masters, J.A., 1979, Deep basin gas trap, western Canada: American Association of Petroleum Geologists Bulletin, v. 63, p. $152-181$. 
1984, Lower Cretaceous oil and gas in western Canada, in Masters, J.A., ed., Elmworth-Case study of a deep basin gas field: American Association of Petroleum Geologists Memoir 38, p. 1-33.

McGowan, M.K., and Harris, D.W., 1984, Cotton Valley (Upper Jurassic) and Hosston (Upper Cretaceous) depositional systems and their influence on salt tectonics in the East Texas Basin: The University of Texas at Austin, Bureau of Economic Geology Geological Circular 84-5, 41 p.

Meissner, F.F., 1978, Patterns of source-rock maturity in non-marine source rocks of some typical western interior basins in non-marine Tertiary and Upper Cretaceous source rocks and the occurrence of oil and gas in the west central U.S.: Rocky Mountain Association of Geologists Continuing Education Course Notes.

1984, Cretaceous and lower Tertiary coals as sources for gas accumulations in the Rocky Mountain area, in Woodward, J., Meissner, F.F., and Clayton, J.L., eds., Hydrocarbon source rocks of the greater Rocky Mountain region: Rocky Mountain Association of Geologists, p. 401-431.

Milici, R.C., and de Witt, Wallace, Jr., 1988, The Appalachian Basin, in Sloss, L.L., ed., Sedimentary cover-North American craton: Boulder, Colo., Geological Society of America, The Geology of North America, v. D-2, p. 427-469.

National Petroleum Council, 1980, Unconventional gas sources-Tight gas reservoirs, part I, in National Petroleum Council Unconventional Gas Resource: Washington, D.C., 222 p. with appendixes.

1992, The potential for natural gas in the United StatesSource and supply, v. II: National Petroleum Council, Committee on Natural Gas, 330 p. with appendixes.

Nuccio, V.F., Schmoker, J.W., and Fouch, T.D., 1992, Thermal maturity, porosity, and lithofacies relationships applied to gas generation and production in Tertiary and Cretaceous low-permeability (tight) sandstones, Uinta Basin, Utah, in Fouch, T.D., Nuccio, V.F., and Chidsey, T.C., Jr., eds., Hydrocarbon and mineral resources of the Uinta Basin, Utah and Colorado: Utah Geological Association Guidebook 20, p. 77-94.

Patchen, D.G., Avary, K.L., and Erwin, R.B., coordinators, 1984, Correlation of stratigraphic units in North America, northern Appalachian region correlation chart: American Association of Petroleum Geologists.

Pepper, J.F., de Witt, Wallace, Jr., and Demarest, D.F., 1954, Geology of the Bedford Shale and Berea Sandstone in the Appalachian Basin: U.S. Geological Survey Professional Paper 259, $61 \mathrm{p}$.

Potter, P.E., DeReamer, J.H., Jackson, D.S., Maynard, J.B., 1983, Lithologic and environmental atlas of Berea Sandstone (Mississippian) in the Appalachian Basin: Appalachian Geological Society Special Publication 1, 157 p.

Randolph, P.L., 1973, Nuclear stimulation of gas fields: Canadian Gas Association, National Technical Conference, Calgary, Alberta, Canada, October 17-19, 1973, 21 p.

1974a, Massive stimulation effort may double U.S. gas supply, Part 1: World Oil, p. 33-36.

1974b, Massive stimulation effort may double U.S. gas supply, Part 2: World Oil, p. 65-7I. 1974c, Massive stimulation effort may double U.S. gas supply, Part 3: World Oil, p. 131-134.

Rice, D.D., Nydegger, G.L., and Brown, C.A., 1990, Bowdoin field-U.S.A., in Beaumont, E.A., and Foster, N.H., eds., Treatise of petroleum geology atlas of oil and gas fields, structural traps III, tectonic fold and fault traps: American Association of Petroleum Geologists, p. 337-355.

Rice, D.D., and Shurr, G.W., 1980, Shallow, low-permeability reservoirs of northern Great Plains-Assessment of their natural gas resources: American Association of Petroleum Geologists Bulletin, v. 64, p. 969-987.

Rose, P.R., Everett, J.R., and Merin, I.S., 1986, Potential basincentered gas accumulation in Cretaceous Trinidad Sandstone, Raton Basin, Colorado, in Spencer, C.W., and Mast, R.F., eds., Geology of tight gas reservoirs: American Association of Petroleum Geologists Studies in Geology no. 24, p. 111-128.

Russell, W.L., 1972, Pressure-depth relations, Appalachian region: American Association of Petroleum Geologists Bulletin, v. 59 , p. $528-536$.

Ryder, R.T., Harris, A.G., and Repetski, J.E., 1992, Stratigraphic framework of Cambrian and Ordovician rocks in the central Appalachian Basin from Medina County, Ohio, through southwestern and south-central Pennsylvania to Hampshire County, West Virginia: U.S. Geological Survey Bulletin 1839-K, 32 p.

Seni, S.J., and Jackson, M.P.A., 1983, Evolution of salt structures, East Texas diapir province, part I-Sedimentary record of halokinesis: American Association of Petroleum Geologists, v. 67, p. 1219-1244.

Spencer, C.W., 1985, Geologic aspects of tight gas reservoirs in the Rocky Mountain region: Journal of Petroleum Technology, v. 37, p. 1308-1314.

- 1989a, Review of characteristics of low-permeability gas reservoirs in western United States: American Association of Petroleum Geologists Bulletin, v. 73, no. 5, p. 613-629.

$-1989 \mathrm{~b}$, Comparison of overpressuring at the Pinedale Anticline area, Wyoming, and the Multiwell Experiment Site, Colorado, in Law, B.E., and Spencer, C.W., eds., Geology of tight gas reservoirs in the Pinedale Anticline area, Wyoming, and the Multiwell Experiment Site, Colorado: U.S. Geological Survey Bulletin 1886, p. C1-C16.

Supply-Technical Advisory Task Force, 1973, Task force report; national gas supply, in National gas survey v. II: Federal Power Commission, 662 p.

1978, National gas survey, in Report to the Federal Energy Regulatory Commission by the Supply-Technical Advisory Task Force on Nonconventional Natural Gas Resources: U.S. Department of Energy Federal Energy Regulatory Commission, 108 p.

Wallace, L.G, and Roen, J.B, 1989, Petroleum source rock potential of the Upper Ordovician black shale sequence, northern Appalachian Basin: U.S. Geological Survey Open-File Report $89-488,66 \mathrm{p}$.

Zagorski, W.A., 1988, Exploration concepts and methodology for deep Medina Sandstone reservoirs in northwestern Pennsylvania: American Association of Petroleum Geologists Bulletin, v. 72 , p. 976 


\title{
Autogenic Gas (Self Sourced) from Shales- An Example from the Appalachian Basin
}

\author{
By Robert C. Milici ${ }^{1}$
}

\section{CONTENTS}

Abstract 253

Introduction 254

Shale Gas 254

A Source for Oil 254

Previous Studies 256

Present Study 256

Shale-Gas Production .......................................... 256

Tectonic Setting ….................................................... 258

The Catskill Delta .................................................. 258

Depositional Environments of Black Shale-

Anoxia Versus Productivity and Sedimentation

Rates 259

Stratigraphy 262

Devonian Formations ........................................ 262

West Falls Formation ....................................... 262

Java Formation ............................................ 263

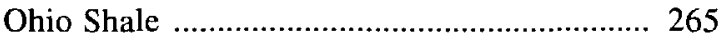

Mississippian Formations ................................... 265

Bedford Shale and Berea Sandstone ............... 265

Sunbury Shale ............................................... 266

Price Formation ............................................ 266

Resource Potential of the Shales ................................ 266

Content and Character of Organic Matter ............. 266

Thermal Maturity .................................................... 267

Source-Rock-Potential Maps ............................... 268

Role of Structure and Fracture Porosity ................ 268

Plays and Production Characteristics of the Devonian and Mississippian Sequence in the South-Central Appalachian Basin

'U.S. Geological Survey, Denver Federal Center, Box 25046, MS 939, Denver, CO 80225-0046.
Shale-Gas Plays and Potential in Other Basins ............ 272

Summary and Conclusion ........................................... 275

Acknowledgments ……................................................ 275

References Cited ....................................................... 275

\section{ABSTRACT}

Black gas shales of Devonian and Mississippian age occur over much of the Appalachian basin, extending from eastern Tennessee north- and northeastward into Ohio and New York. In general, these shales were deposited along the distal margin of the Acadian Catskill delta in response to episodes of tectonic subsidence and regional transgression during the Acadian orogeny. A major trend of high organic carbon content in the black shales extends along the western side of the Catskill delta, from southwestern Virginia to the southern shores of Lake Erie. The high content of organic detritus in these Devonian and Mississippian black-shale source beds is probably related to high organic productivity in combination with moderate sedimentation rates along the distal margins of the Catskill delta, rather than to the widespread establishment of a pycnocline and preservation in anoxic environments. In general, organic matter in the black shales is more marine and oil prone on the western side of the basin, away from the major sources of siliciclastic input, than it is to the east. Thermal maturity trends follow depositional strike and isopachs of the Catskill delta and, thus, are related to depth of burial. Fracture porosity within the black shale sequence appears to have been affected mostly by regional decollement within discrete stratigraphic units that were, perhaps, overpressured during deformation.

These shales are most productive in the south-central part of the Appalachian Basin, where they are thermally mature 
and are abundantly fractured. Shale gas is produced from relatively large fields in southwestern Virginia, eastern Kentucky, southwestern West Virginia, and southernmost Ohio. To the north, the strata rich in organic matter are thermally immature, and fields along the southern shores of Lake Erie in Ohio and Pennsylvania are only marginally productive. To the east in northwestern West Virginia, the organic content of the shales is diluted by increased amounts of siliciclastics; organic matter is not sufficient to sustain long-term gas production, and shale-gas wells are short lived.

\section{INTRODUCTION}

Black-shale formations intercalated within the gray shales, siltstones, and sandstones of the great Catskill delta of Late Devonian and Early Mississippian age are the principal source beds for much of the petroleum and natural gas generated in the Appalachian Basin (Claypool and others, 1978; Cole and others, 1987; Laughery, 1989). In general, hydrocarbons have migrated into and are produced from the more porous and permeable reservoirs that overlie these source beds, as well as from reservoirs that lie unconformably below the source beds in a broad region that extends from Tennessee north- and northwestward into Kentucky, Ohio, West Virginia, Pennsylvania, and New York. Cole and others (1987) demonstrated that much of the oil in Ohio reservoirs was derived from one Ordovician and three Devonian shale source beds. On the basis of relative thermal maturities of the oils and the reservoirs that contained them, they concluded that the oil must have migrated into Ohio from the east, from deep within the Appalachian Basin. Devonian shale, itself, has produced oil in a few places elsewhere in the Appalachian Basin.

Gas is produced from Upper Devonian and Lower Mississippian black shales and associated strata in three general regions as well as in many other widely scattered localities in the Appalachian Basin (fig. 1). A major shalegas-producing area occurs in the south-central part of the Appalachian Basin, in southwestern Virginia, eastern Kentucky, southwestern West Virginia, and southernmost Ohio (Wallace and deWitt, 1975). This region includes the Big Sandy Gas Field and several other smaller fields. A northward extension of the major shale gas-producing region occurs in northwestern West Virginia. This area is called the "emerging area" by Patchen and Hohn (1993) in their description of shale-gas geology and production in West Virginia. Another important area of shale-gas production occurs along the northern margin of the basin, where relatively small amounts of gas are produced from low-pressure fields along the southern shores of Lake Erie in Ohio, Pennsylvania, and New York (deWitt and others, 1993; Broadhead and others, 1982; Broadhead, 1993; Van Tyne, 1983).

\section{SHALE GAS}

The first well drilled specifically for natural gas in the United States was completed in 1821 in shale beds overlying the black Dunkirk Shale member of the Perrysburg Formation (Devonian) in Fredonia, Chautauqua County, New York. It was sited above a natural-gas seep and produced gas for local uses, probably from fractures at a depth of about $8 \mathrm{~m}$ (Weeks, 1886; Orton, 1899; Van Tyne, 1983; deWitt and others, 1993). This well was later drilled to a depth of $21 \mathrm{~m}$.

Since then, about 3.0 trillion cubic feet of gas (Tcf) have been produced from the Devonian shale formations in the Appalachian Basin, and it is estimated that about $20 \mathrm{Tcf}$ of gas can still be recovered from these formations using currently available methods (Charpentier and others, 1993). Most of the gas, by far, has been produced from the Big Sandy area, where more than 10,000 wells had produced more than 2.5 Tcf by 1985 (Brown, 1976; Charpentier and others, 1993, p. N3). Recent estimates of the in-place natural-gas resources in the Devonian shales of the Appalachian Basin range from $577 \mathrm{Tcf}$ at a 95 percent probability to $1,131 \mathrm{Tcf}$ at a 5 percent probability (Charpentier and others, 1993, table 2, p. N13).

\section{A SOURCE FOR OIL}

Oil has been extensively produced from the Appalachian Basin since its discovery in 1859 near Titusville, Pennsylvania, by Edwin Drake. Much of the oil produced in the Appalachian Basin is from Devonian and Mississippian reservoirs, and most of this oil apparently originated in the Upper Devonian and Lower Mississippian black shales (Laughrey, 1989).

The Oriskany Sandstone and its stratigraphic equivalents (Lower Devonian) have produced oil and gas, chiefly from anticlinal traps, over a wide area in West Virginia, Maryland, and Pennsylvania. These reservoirs are immediately below Devonian black shales in the northern and central parts of the Appalachian Basin, and in places the shales have served both as a source and a seal for the hydrocarbons. The anticlines, in general, do not involve strata from deep in the section. Instead, they are superficial and formed as the result of splay thrusting from subhorizontal decollement in the bedding of underlying Ordovician shales and Silurian salt measures (Gwinn, 1964).

The regional dip of the Appalachian Plateau is generally to the east from the crest of the Cincinnati Arch, a pre-Alleghanian structure, toward the interior of the Appalachian Basin. Thus, migration of oil westward away from the deformed Appalachians toward the arch was generally up the regional dip, although some of the Devonian oil apparently has entered reservoir rocks that are stratigraphically lower than the source beds. 
Much oil has been produced from Devonian sands younger than the Oriskany Sandstone, such as the Bradford sands, in an area that extends from western New York into central West Virginia. This oil also was probably derived from Devonian black-shale source beds (Laughrey, 1989). Oil is produced in small quantities from black-shale

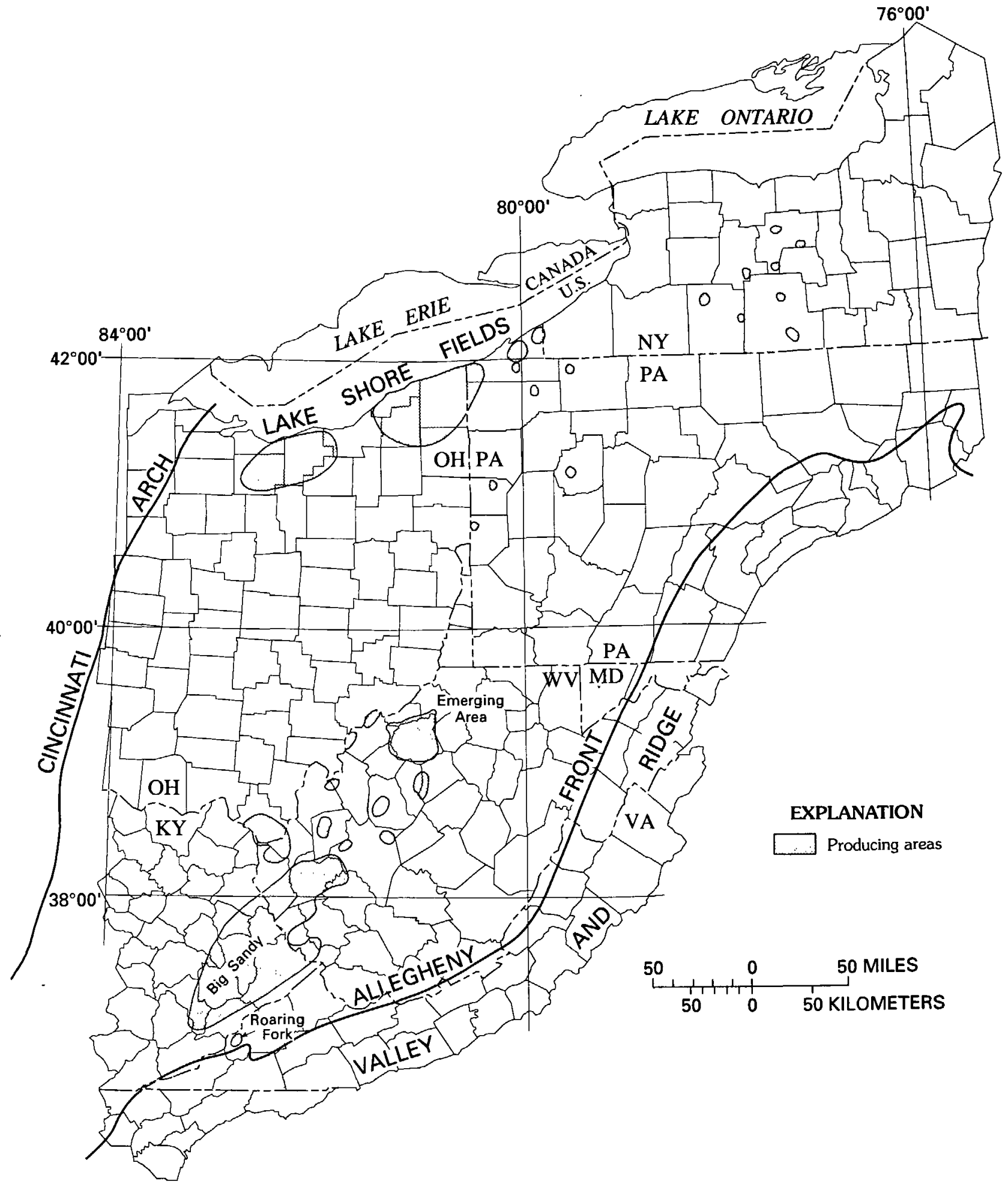

Figure 1. Regions and localities that produce gas from Upper Devonian and Lower Mississippian shales in the Appalachian Basin. 
reservoirs in west-central West Virginia, apparently because of a well-developed fracture porosity (Patchen and Hohn, 1993). In Virginia, condensate produced from oolitic and fossiliferous-fragmental carbonate strata of Mississippian age at the upper (easternmost) limit of the oil window probably had its origin in underlying Devonian and Mississippian black shales (fig. 2). Oil production from Carboniferous rocks in Tennessee is restricted generally to the northern part of the Cumberland Plateau. The origin of this oil is not known with certainty. There are, however, oil stains and residues in fractured carbonate rocks stratigraphically between black Chattanooga Shale (Devonian and Mississippian) source rocks and reservoirs in overlying (15 $\mathrm{m}$ above) porous carbonate reefs in the Fort Payne Formation that attest to the migration of oil through those strata, most likely from the Chattanooga into the carbonate reservoirs. It is no coincidence that commercial production of hydrocarbons in the Appalachian Basin, exclusive of the Black Warrior Basin, ceases to the south in Tennessee, where Chattanooga source beds are less than $15 \mathrm{~m}$ thick, and thus the total mass of organic carbon per square centimeter apparently decreases below 0.6 percent (Charpentier and others, 1993, p. N4; Schmoker, 1993; Milici, 1985).

\section{PREVIOUS STUDIES}

Because of the demonstrated capability and significant potential of the Devonian and Mississippian black shales in the Appalachian Basin to produce gas, the U.S. Department of Energy (DOE), then the Energy Research and Development Administration (ERDA), initiated and funded a multidisciplinary regional study in the mid-1970's to characterize the geology of these natural-gas resources as well as to design and develop new stimulation techniques that would enhance the recovery of the gas. Several state geological surveys, the U.S. Geological Survey (USGS), several universities, and industry were the principal cooperators. As a result of these studies, extensive geological and engineering literature was developed during the following decade that addressed a wide range of topics, including descriptions and interpretations of the stratigraphy, depositional environments, tectonics, geologic structure, paleontology and geochemistry of the shale formations as guides for exploration and development, as well as engineering topics dealing with drilling and more effective stimulation and completion of shale-gas wells.

In addition to the numerous reports published on the Devonian and Mississippian shale sequence during the past few decades, a report summarizing the work completed by USGS and others on the petroleum geology of these strata has been prepared for publication (Roen and Kepferle, 1993). The stratigraphy of the Appalachian Basin, including that of the Devonian and Mississippian Catskill delta, was summarized by Milici and deWitt (1988). Furthermore, a consortium of industry and academia (Appalachian Basin Industrial Associates) has compiled and published the results of their extensive studies in the Appalachian Basin (including discussions of the Devonian and Mississippian shale sequence) in several annual volumes during the past decade. A few state geological surveys, most notably the West Virginia Geologic and Economic Survey, have published the results of shale-gas investigations supported by the Gas Research Institute (GRI) (for example, Hohn and Timberlake, 1988).

\section{PRESENT STUDY}

This paper reviews and synthesizes the geology of the shale-gas fields in the south-central part of the Appalachian Basin, generally in southwestern Virginia, northeastern Tennessee, eastern Kentucky, southern Ohio, and southern West Virginia, in order to characterize the self-sourced shale-gas reservoirs of the region. These characteristics can then be used to define some elements of a general model that may be useful for identification of potentially commercial self-sourced shale-gas reservoirs elsewhere.

\section{SHALE-GAS PRODUCTION}

In general, commercial production of natural gas from shale depends upon the simultaneous occurrence of several conditions. The source rock must be of sufficient thickness and have a suitable type, amount, and thermal maturation of organic matter. Furthermore, a shale reservoir must have a trapping mechanism and have enough porosity and permeability to yield gas effectively above some minimum rate over the commercial life of a well. All of the characteristics favorable for gas production need not be precisely within the same bed or stratigraphic unit. More commonly they are distributed within packages of contiguous strata, with the different stratigraphic components exhibiting one or more of the desired characteristics. In some places, for example, gas apparently has migrated for relatively short stratigraphic distances from black-shale source beds rich in organic material into slightly more porous layers that consist of lighter gray or greenish-gray siltier or sandier shales, siltstones, and sandstones (Broadhead and others, 1982; Broadhead, 1993). In other places, where blackshale formations have served as hosts for major subhorizontal decollements, the shales are greatly fractured and when drilled may yield gas explosively (Young, 1957). Although these decollement zones generally are so fractured that they have lost much of the gas originally contained in the shale, the immediately overlying beds may be fractured sufficiently to serve as reservoirs.

Sustained commercial gas production from Devonian and Mississippian self-sourced shales in the Appalachian 


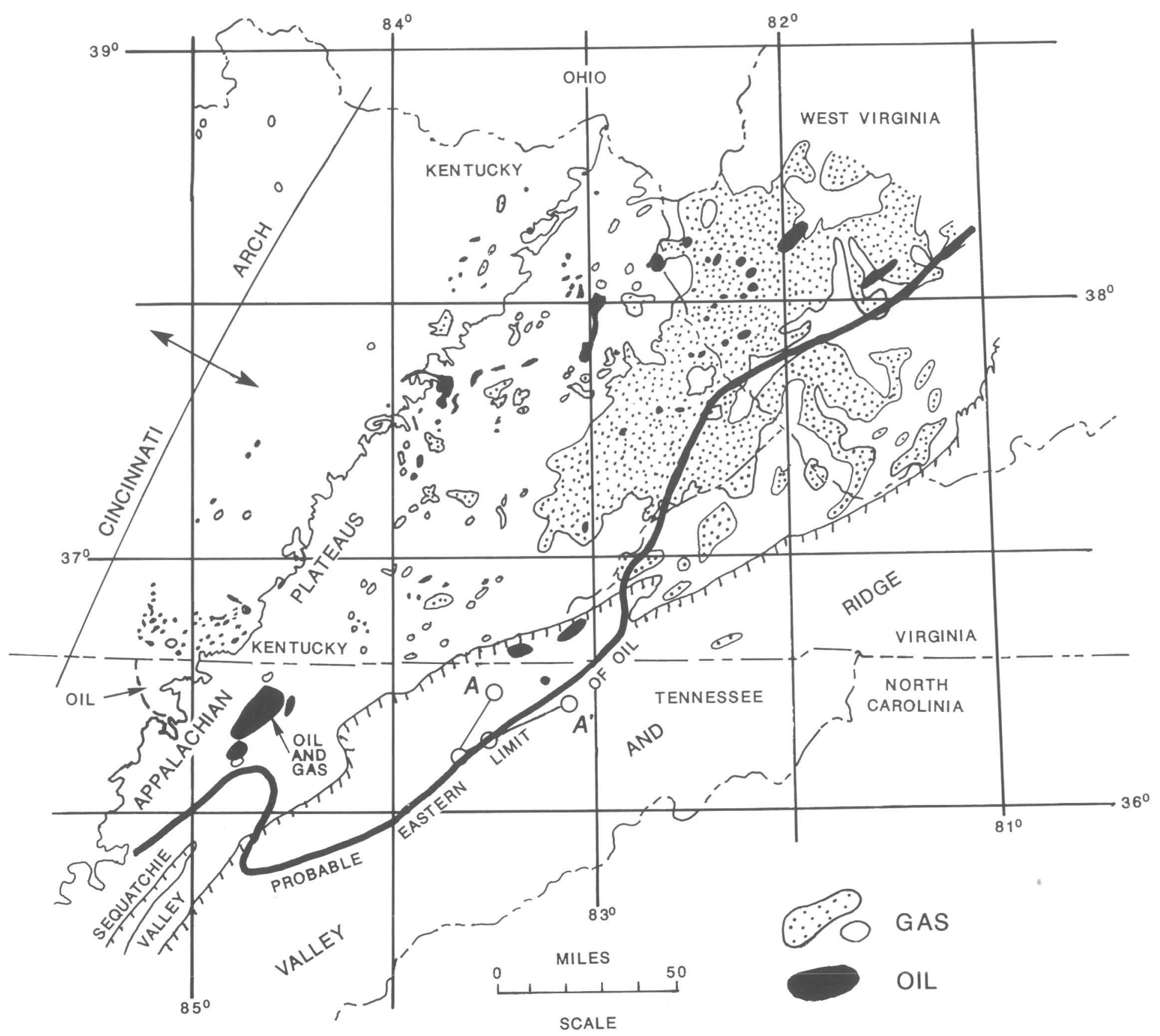

Figure 2. Eastern limit of oil window in south-central part of the Appalachian Basin. Line $A-A^{\prime}$ indicates location of section shown in figure 4. Eastern limit is based on fixed-carbon/free-carbon ratios (Miller and Fuller, 1954), conodont-alteration-index (CAI) isograds (Harris and others, 1978), 
Basin depends greatly on the porosity and permeability of natural fracture systems in the reservoir and the capability of that fracture system to be stimulated into commercial production. These fractured beds, when completed properly, constitute a major reservoir in the Big Sandy and associated gas fields in the south-central Appalachian Plateau (Shumaker, 1980, 1993) as well as in gas fields elsewhere in the basin. The geologic subtleties of these shale reservoirs, however, are commonly ignored by industry. Instead, completion practices are commonly designed to extend across a variety of lithologies as well as to bracket zones of fracture porosity identified on well logs.

\section{TECTONIC SETTING}

\section{THE CATSKILL DELTA}

In general, Catskill deltaic sedimentation was initiated by Acadian tectonic activity in the northern part of the Appalachian Basin late in the Early Devonian and then spread southward (Faill, 1985). Although this tectonism was apparently caused by the collision of several continental plates, Armorica with Laurentia (ancestral North America) and Baltica (northern European sialic crust) (Perroud and others, 1984), it produced only moderate deformation in the Appalachian foreland. In other words, the onset of the Acadian Orogeny initiated the subsidence of a basin in central Pennsylvania sufficiently deep to receive over 3,000 m $(10,000 \mathrm{ft})$ of Devonian sediment (Milici and deWitt, 1988) (fig. 3) and created mountains sufficiently high to yield the great amount of siliciclastic sediments that constitute the Catskill deltaic basin fill.

Relatively coarse-grained continental and marginal marine deposits mark the proximal regressive phases of Acadian sedimentation in the Appalachian Basin. These deposits were derived primarily from the two major depositional systems that had developed in the basin by the Early Mississippian-the Pocono delta of eastern Pennsylvania and adjacent states to the north and the smaller Price delta to the south in central Virginia (Milici and deWitt, 1988; Kreisa and Bambach, 1973). The depositional environments in which these coarser grained sediments accumulated range widely from littoral and deltaic on the east and north (Pepper and others, 1954) to marine shelf and associated deposits on the south and west (Potter and others, 1983).

Paleocurrent studies by Potter and others (1980, modified by Kepferle, 1993) show that the direction of sediment transport was predominantly toward the west over much of the delta and toward the southwest in the southern part of the basin, away from the principal source of sediments in and near the Pennsylvania depocenter and from the subsidiary sources along the Devonian and Mississippian shorelines to the south.

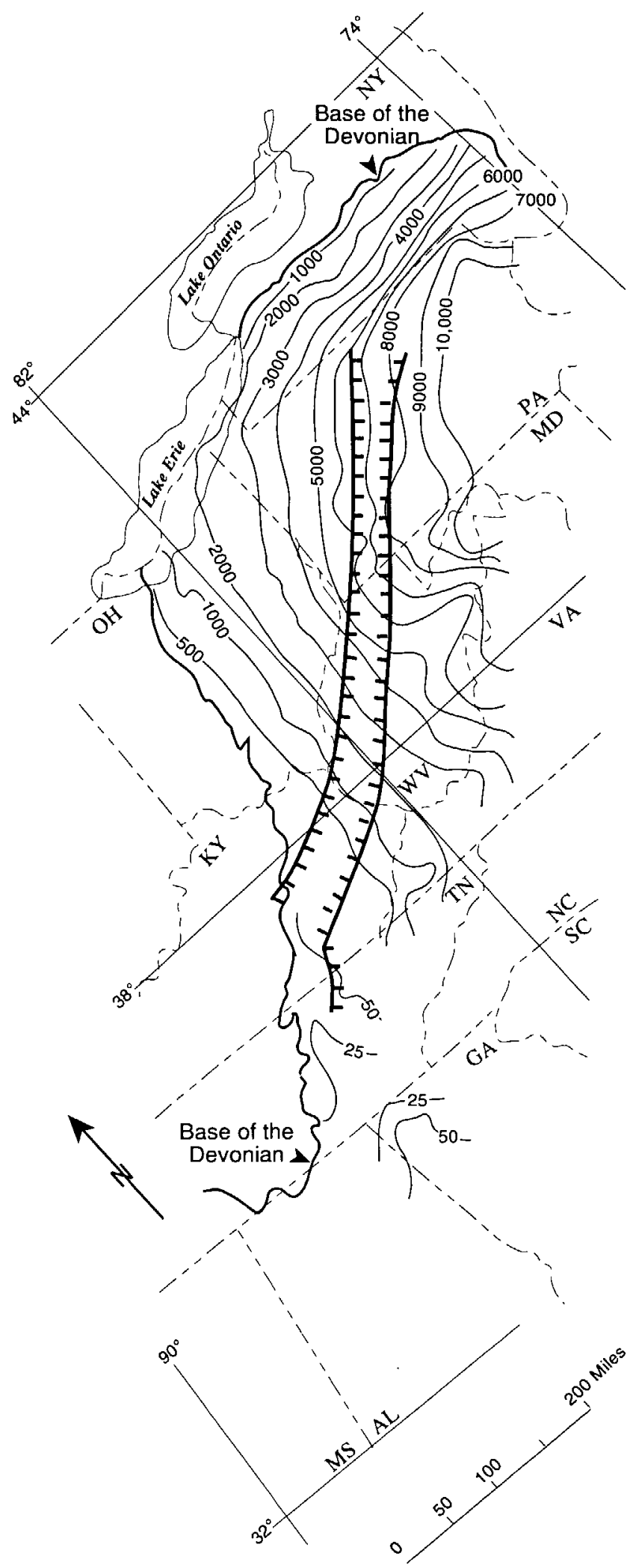

Figure 3. Isopach map showing thickness of Catskill delta sequence. Isopachs are in feet; hachured area is Rome Trough. Modified from Milici and deWitt (1988, fig. 6). 
To the west and south, in southwestern West Virginia and adjacent Kentucky, Ohio, Tennessee, and Virginia, the more distal part of the sequence consists mostly of prodelta deposits. This sequence is much thinner and is dominated by shale and siltstone. In these peripheral areas, black-shale units constitute a considerable proportion of the stratigraphic column, although their composite thickness is greater toward the north and east near the heart of the delta (deWitt and others, 1993). Data from gamma-ray logs and well samples indicate that the greatest thickness of combined Devonian black-shale units occurs in and near the central Pennsylvania depocenter, where they are about $425 \mathrm{~m}$ thick and constitute about 15 percent of the Devonian section. In comparison, in southwestern Virginia the combined thickness of Devonian black-shale beds is about $125 \mathrm{~m}$, or 40 percent of the section (see deWitt and others, 1975, for thickness data). Schmoker (1980; 1981; 1993, fig. 9) used data from density and gamma-ray logs and calculated that the thickness of Devonian shales rich in organic carbon (defined as total organic carbon (TOC) $\geq 0.6$ percent) exceeds $305 \mathrm{~m}$ in southern West Virginia and adjacent Kentucky and $275 \mathrm{~m}$ in eastern Ohio. Schmoker (1993) illustrates a major thickness trend in the total mass of organic carbon in the black-shale sequence, measured in kilograms per square centimeter, that extends from the coal fields of southwestern Virginia, through eastern Kentucky and Ohio to the southern shores of Lake Erie.

Subsidence of the Devonian foreland basin was episodic throughout the Middle and Late Devonian and was, perhaps, induced by intermittent Acadian tectonism and sediment loading. On a gross scale, this subsidence was not sufficient to maintain pace with sedimentation, and so the net effect of Acadian tectonism was to fill most of the foreland basin up to sea level or slightly above by Early Mississippian time. Only to the south and west are the uppermost Mississippian deposits entirely marine.

Depending upon location, there were four to eight transgressive and progradational events in the marine part of the foreland basin during the Late Devonian and Early Mississippian (Kepferle, 1993). Each of the radioactive black muds and silts that had been deposited by turbidity currents in the more distal parts of the delta during periods of basin subsidence (Ettensohn and Barron, 1981, 1982; Ettensohn, 1985; Kepferle, 1993) were subsequently overlain by the relatively less radioactive lighter colored gray and greenish-gray muds and silts that were being deposited along the advancing submarine toe or slope of the Catskill delta front. Almost all of these black-shale deposits are of regional extent. Indeed, the widespread distribution of the Devonian black-shale units from the Rhine-street Shale Member of the West Falls Formation to the Sunbury Shale (deWitt and others, 1993) indicates that they were deposited in response to regional transgressive events as the Devonian foreland basin subsided and filled.

\section{DEPOSITIONAL ENVIRONMENTS OF BLACK SHALE-ANOXIA VERSUS PRODUCTIVITY AND SEDIMENTATION RATES}

There are two principle theories concerning the processes that have resulted in the concentration of organic matter in the black-shale source beds. Most of the current workers in the Appalachian Basin and adjacent regions (for example, Kepferle, 1993; Russell, 1993) ascribe the high content of organic matter in the Upper Devonian and Lower Mississippian black shales both to high productivity of organic matter in surficial waters and to subsequent deposition of that organic matter in anoxic environments at the basin floor. In contrast, marine sedimentologists have determined that relatively high productivity of organic material in oxic marine environments in combination with moderate sedimentation rates, not anoxia at the site of deposition, are the principle factors that control the deposition of black muds rich in organic matter and, ultimately, the formation of black-shale source beds.

Ettensohn and Barron (1981, 1982) and Ettensohn (1985) speculated about a special set of geologic conditions that might have led to the extensive accumulation of muds rich in organic matter in the broad region across the interior of the proto-North American continent (Laurasia) during the Middle to Late Devonian and Early Mississippian (see Kepferle, 1993, and Russell, 1993, for similar discussions). The abundance of organic material preserved in the shales derived from these muds indicates that ambient marine environments that existed during sedimentation not only had to support a substantial amount of biologic activity at or near the surface of the sea but simultaneously had to preserve much of the produced organic debris as it accumulated within fine-grained sediments at depth. For this to have happened, the water column would have to have been partitioned, or stratified, so that surficial waters rich in oxygen and nutrients could have coexisted unmixed with deeper waters that were sufficiently anoxic to inhibit complete biodegradation of the abundant organic detritus (Potter and others, 1980). Furthermore, these conditions had to be maintained, perhaps intermittently over widespread areas of the marginal sea, for periods of time sufficient to account for the extent and volume of the existing black-shale formations (see deWitt and others, 1993, for black-shale distributions in the Appalachian Basin; Hasenmueller, 1993, for the Illinois Basin; and Matthews, 1993, for the Michigan Basin).

The causes of widespread anoxia in ancient and modern sedimentary environments have been summarized by Demaison and Moore (1980). As defined by them, an aquatic environment is anoxic when virtually all aerobic biologic activity ceases because of a lack of oxygen. In general, bioturbation decreases significantly when sea water contains less than $0.5 \mathrm{~mL}$ of oxygen per liter of 
water. Locally, the occurrence of oxic versus anoxic environmental conditions results from a flux in the balance between oxygen availability, which is controlled by water circulation, and oxygen consumption, which is related to the amount of biologic activity. Partitioning of the water column into oxic surficial waters and anoxic waters at depth requires that there be little or no turnover and mixing of the water column. Turnover is inhibited if there is a significant density contrast between the two layers, so that lighter surface waters "float" on denser layers below. This density contrast may be affected by differences in temperature (thermocline), composition (halocline), or both (pycnocline). Development of a permanent thermocline would be enhanced by lack of seasonal variation, such as would occur in tropical or subtropical environments; a permanent (or seasonal) halocline would occur where there was a substantial inflow of fresh water that could be layered with little mixing over sea water that had, perhaps, a greaterthan-normal salinity.

Ettensohn and Barron $(1981,1982)$ and Ettensohn (1985) noted that a Devonian and Mississippian "blackshale sea" stratified into oxic and anoxic layers might have occurred as the result of both temperature-induced and composition-induced density contrasts. Sediments deposited in these two types of environments would be markedly different and would produce strata significantly different in appearance. Thus, laminated, unfossiliferous black shales that contain an abundance of organic matter and that are intercalated in the rock record with burrowed and fossiliferous green and gray shales and siltstones may reflect the transition from anoxic sediments that had accumulated in the lower part of a water column upward through a pycnocline into fossiliferous sediments that were deposited in relatively shallow water under more rigorous oxic conditions.

The Late Devonian and Early Mississippian paleogeographic reconstructions illustrated by Ettensohn and Barron $(1981,1982)$ and Ettensohn (1985) permit the general conditions that might have led to the development of a long-term thermocline. They show that the southern part of the Laurasian landmass lay across the paleoequator during the latter part of the Devonian, and thus the epicontinental seas which extended from the Appalachians to and across the Transcontinental Arch into southern Alberta were in the tropics and subtropics. As a result, seasonal temperature changes would have been small, and a permanent thermocline could have been established over a significantly large region.

Tropical atmospheric conditions in combination with regional paleophysiography also may have contributed to the establishment of local areas of density stratification in the "black-shale sea." Because of the trade winds, which flow from east to west along the equatorial bulge of the Earth, the eastern part of Laurasia, including the area of black-shale deposition, must have been in the rain shadow of the Caledonian Mountains and the newly formed Acadian mountain chain. However, the amount of sediment contained in the Catskill delta and its antecedents, the Pocono and Price deltas, suggests that there must have been abundant accumulation of rainfall in these eastern mountain ranges that flowed westward to where they entered the "black-shale sea."

Substantial amounts of fresh water layered over sea water could have contributed to the formation of intermittent haloclines along the delta margin. These haloclines could have acted in conjunction with a regional thermocline to increase the density stratification of the water column at least locally. As local depocenters shifted from place to place along delta margins, less well-mixed waters in interdistributary areas might have become stagnant, and anoxic conditions would have prevailed on the sea floor. In addition, in some places tectonic subsidence and depression of the Middle to Late Devonian and Early Mississippian foreland basin might have restricted water circulation sufficiently to have enhanced the development of anoxic conditions at depth. When sedimentation rates diminished and remained low for extended periods of time because of subsidence and regional transgression, the deposition of muds rich in organic detritus would have migrated eastward and accumulated over waning coarser grained shallow-water deltaic deposits as anoxic conditions expanded.

Kepferle (1993) considered the alternations of blackshale strata with gray- and green-shale and siltstone units in the Devonian and Mississippian shale sequence to be the result of deposition during cycles of regional transgression and regression, which he termed "the black-shale cycle." In contrast with most other workers in the Appalachian Basin, he divided the water column into three regimes rather than two-aerobic, dysaerobic, and anaerobic. The anaerobic zone was characterized by deposition of black shales, generally in deep waters; gray and green shales and siltstone, commonly deposited as turbidites, represented deposition in the dysaerobic zone, whereas sandstones, siltstones, and shaly mudstones accumulated in the aerobic zone (Kepferle, 1993). Kepferle interpreted the black muds rich in organic matter to have accumulated in the deepest waters of the sedimentary basin, beneath the pycnocline, during a period of relative sea-level rise. The lighter-colored sediments were thought to have been deposited in a transition zone within or above the pycnocline during regression. Of all the black-shale cycles, only the one initiated by deposition of the Sunbury Shale is not truncated by an overlying black-shale unit (Kepferle, 1993). Fining- and coarsening-upward units (subcycles) identified in well logs, such as those illustrated by Milici and Roen (1981), within individual black-shale formations, attest to the complexity of local facies variations (fig. 4). Many of the well log signatures cannot be correlated with certainty between wells and reflect, instead, rapid local variations of coarsening and 


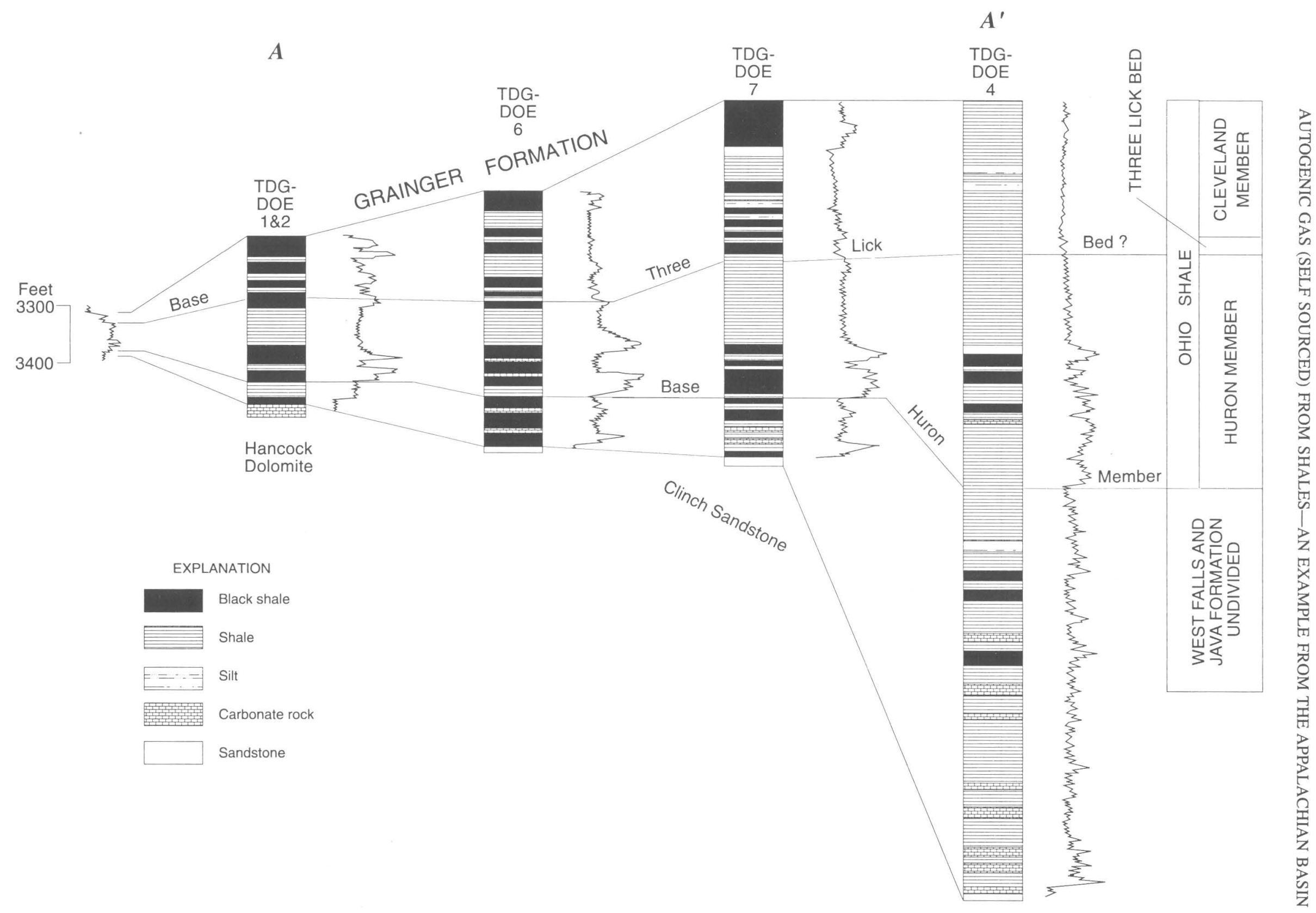

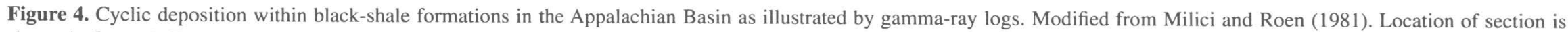
shown in figure 2. The stratigraphic nomenclature and unit assignments used in this figure may not necessarily conform to current usage by the U.S. Geological Survey. 
fining of the sediments vertically within the depositional basin.

In contrast with workers in the Appalachian, Illinois, and Michigan Basins, Pederson and Calvert (1990, 1991) pointed out that anoxia is not a requirement for the accumulation of black muds rich in organic matter in modern marine environments. Instead, they noted that recent research in marine sedimentology has demonstrated that substantial amounts of organic matter can accumulate and be preserved in sediments that were deposited in well-aerated oceanic waters that were producing large amounts of organic detritus.

In addition to productivity, sedimentation rates significantly affect the preservation of organic matter in newly deposited sediments, the subsequent formation of source beds, and ultimately the hydrocarbon potential of a sedimentary basin. Ibach (1982) pointed out that organic matter, in general, goes through four stages, or zones, of alteration as it is buried progressively deeper by younger sediments. The process begins with the deposition of the organic detritus and its host sediment in an oxic environment in a well-mixed shelf setting. This may be followed by progressive burial and successive transitions of the sediment through (1) zones of aerobic oxidation and sulfate reduction in which the organic matter is degraded by aerobic and anaerobic bacteria, respectively, (2) a zone of fermentation in which methane is produced, and (3) into a zone of thermal maturation, in which liquid hydrocarbons are produced.

Ibach (1982) showed that for certain sediment types TOC tends to increase with increasing sedimentation rates up to a maximum value, after which the effects of dilution predominate and TOC percentages decline. For black shales, this optimum sedimentation rate is about $41 \mathrm{~m}$ of uncompacted sediment per million years (Ibach, 1982).

In the Catskill delta, the places where sedimentation rates enhanced the preservation of organic detritus in black muds would have shifted across and along depositional strike as the local paleogeography changed in response to the integrated effects of tectonism, sea-level variations, and climate. These places, today, would contain the thickest and richest source beds and, in general, would occur in the areas intermediate between the principal deltaic sources on the east and the more distal regions of low sedimentation on the west.

Anoxia may not have been a requirement for the development of the extensive deposits of black shales that are preserved in the Upper Devonian and Lower Mississippian rock record of the Appalachian Basin. Instead, the initial geologic conditions necessary to form the basal black-shale units of the Devonian and Mississippian "black-shale cycles" may have occurred in those ancient seas where there was a coincidence of areas highly productive of organic matter with areas of optimal siliciclastic sedimentation rates. In other words, muds rich in organic material might have accumulated and been preserved where high productivity of organic detritus was associated with moderate sedimentation rates in the marine waters marginal to an active delta. In order to preserve the organic matter, sedimentation rates would have to be sufficient to bury and remove it quickly from the zones of biodegradation; however, the amount of sediment could not be so great as to dilute the content of the organic material significantly.

\section{STRATIGRAPHY}

With minor exception, the oldest beds of the Devonian shale sequence in the south-central Appalachians are of Late Devonian age. They overlie beds ranging in age from Ordovician to Middle Devonian that occur below a major regional unconformity (deWitt an others, 1993). In the south-central part of the Appalachian Basin, the black-shale sequence is generally called the Chattanooga Shale in Tennessee and southeastern Kentucky and the Ohio Shale in northeastern Kentucky and eastern Ohio (deWitt, 1981). The New Albany Shale and Antrim Shale (Matthews, 1993) are the approximate lateral equivalents of the Chattanooga and Ohio Shales in the Illinois and Michigan Basins, respectively. The stratigraphic nomenclature of Devonian and Lower Mississippian strata in the distal part of the Appalachian foreland basin is summarized in figure 5. DeWitt and others (1993) presented an overview description of the Devonian and associated Lower Mississippian strata of the Appalachian Basin and the following discussion of the units that occur in the south-central part of the Appalachian Basin is summarized mainly from their paper.

\section{DEVONIAN FORMATIONS}

\section{WEST FALLS FORMATION}

In general, the shale sequence in the south-central part of the Appalachian Basin consists of several radioactive black-shale units interbedded with units that consist of lighter colored gray and greenish-gray beds (fig. 6). In most places in this region, a radioactive black-shale unit, the Rhinestreet Member of the West Falls Formation, lies at the base of the section unconformably above Middle Devonian sandstones and carbonate rocks. The thickness of the Rhinestreet Shale Member is as much as $150 \mathrm{ft}$ in western West Virginia; it is $100 \mathrm{ft}$ or more in eastern Kentucky and adjacent Virginia (deWitt and others, 1993), and it thins to the west to where it pinches out in eastern Kentucky and Ohio. The Rhinestreet is recognized in the subsurface by its characteristic gamma ray signature. In outcrop, it consists of brownish-black and black shale, some gray shale, and numerous limestone nodules and concretions (deWitt and others, 1993). 


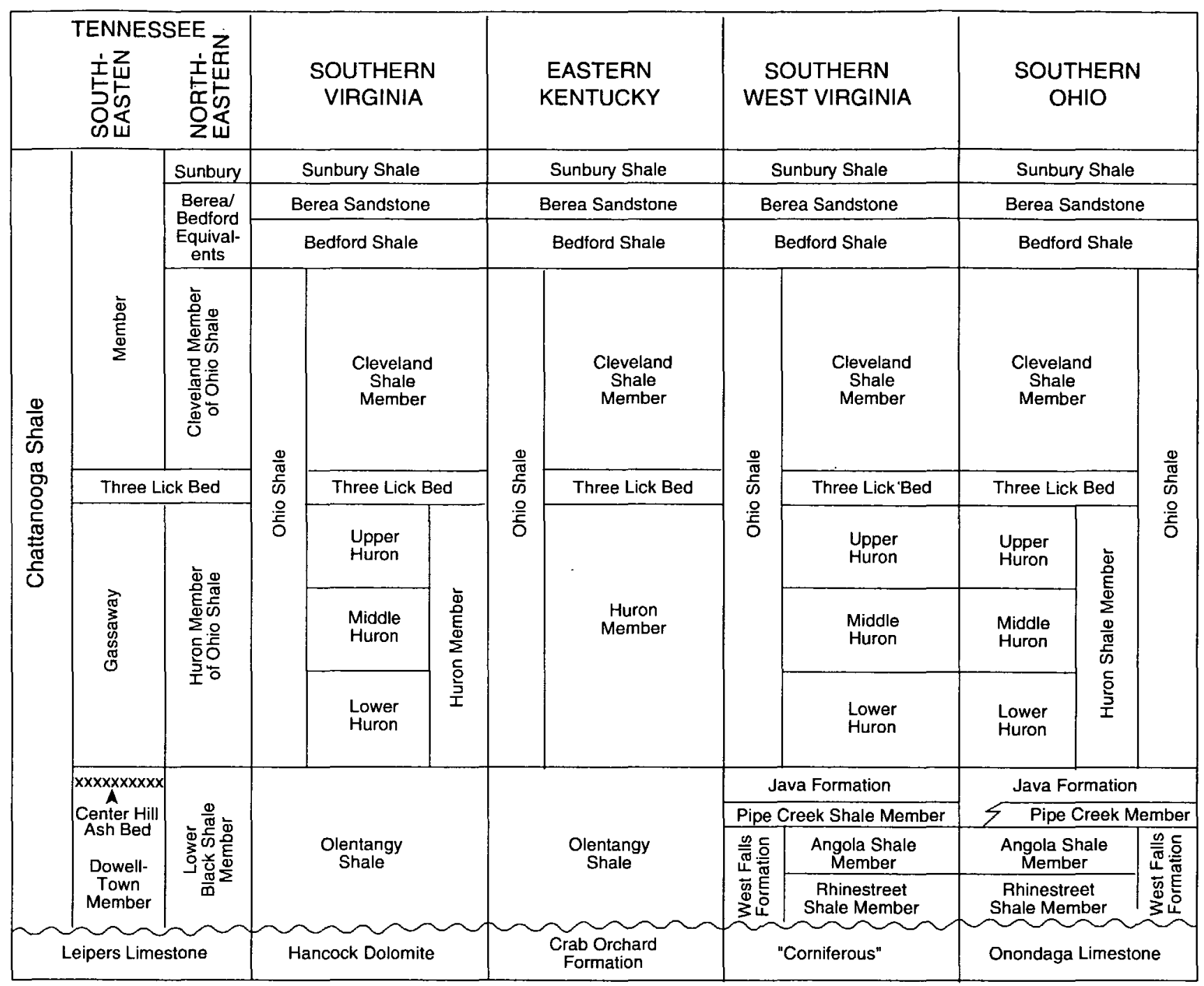

Figure 5. Stratigraphic nomenclature of the Devonian and Mississippian shale sequence in the Appalachian Basin. Data for Tennessee from Kepferle and Roen (1981) and deWitt and others (1993), Ohio from Baranoski and Riley (1988), Virginia from Jacobeen (1992), Kentucky from Provo and

The overlying Angola Shale Member of the West Falls Formation exhibits less radioactivity than the black-shale units and thus is readily defined on gamma-ray logs. The Angola ranges in thickness from about $50 \mathrm{ft}$ to over $300 \mathrm{ft}$ in the south-central part of the Appalachian Basin. Surface exposures of the Angola consist chiefly of medium-gray mudrock and shale, with limestone nodules, thin siltstones, and some black shales (deWitt and others, 1993).

\section{JAVA FORMATION}

The Java Formation consists of two members-a blackshale unit at the base that is overlain by a gray and greenish- others (1978), and West Virginia from Patchen and Hohn (1993) and deWitt and others (1993). The stratigraphic nomenclature and unit assignments used in this figure may not necessarily conform to current usage by the U.S. Geological Survey.

gray shale and siltstone unit. The basal Pipe Creek Shale Member of the Java Formation overlies the Angola Shale Member of the West Falls Formation. Like the Rhinestreet, the Pipe Creek is a regionally extensive radioactive black shale. It is much thinner than the Rhinestreet, however, and generally is less than $25 \mathrm{ft}$ thick except in parts of eastern Kentucky and adjacent West Virginia and Virginia where it is as much as $50 \mathrm{ft}$ thick (deWitt and others, 1993).

Overlying the Pipe Creek Shale Member is the Hanover Shale Member of the Java Formation. Like the Angola, the Hanover is less radioactive than the black shales and consists chiefly of gray and greenish-gray shale and mudrock that contains limestone nodules and some layers of siltstone and black shale. The Hanover ranges in thickness from about 


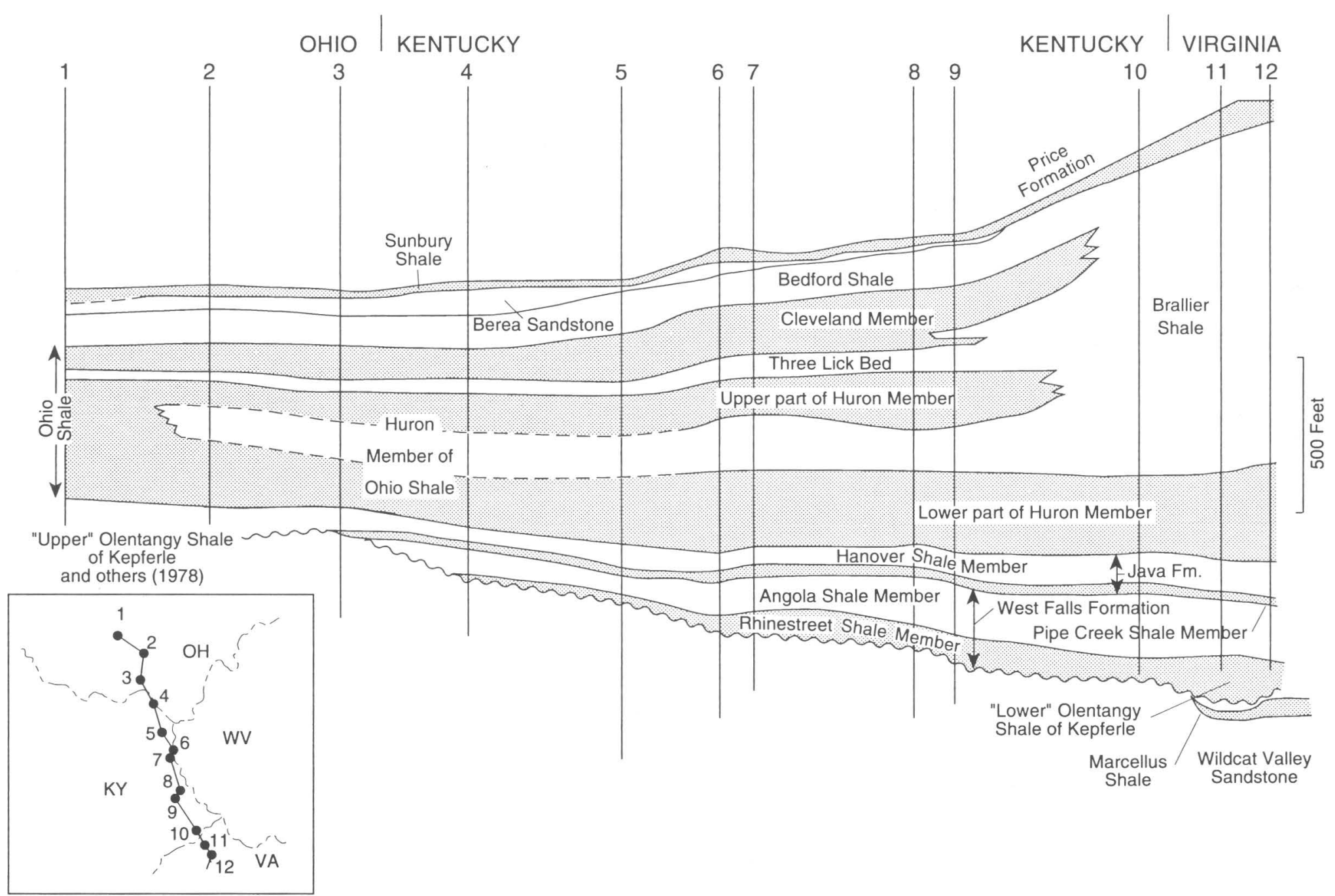

Figure 6. Stratigraphic section of Devonian and Mississippian shale sequence across Appalachian Basin. Modified from Kepferle and others (1978). The stratigraphic nomenclature and unit assignments used in this figure may not necessarily conform to current usage by the U.S. Geological Survey. 
$100 \mathrm{ft}$ in Virginia and southeastern Kentucky to about $50 \mathrm{ft}$ in northeastern Kentucky and Ohio, where it combines with the Pipe Creek and Angola and grades to the west into the Olentangy Shale (deWitt and others, 1993).

\section{OHIO SHALE}

The Java Formation is overlain by the Ohio Shale in the western part of the Appalachian Basin. The Ohio Shale consists of three members - (1) a lower radioactive blackshale unit called the Huron Member, (2) a middle member, the Three Lick Bed (Provo and others, 1978), which is a distinctive thin unit of intercalated gray and black shale, and (3) an upper radioactive black-shale unit, the Cleveland Member. To the east and south of Ohio, the black shales of the Huron Member are split and separated into two beds in Kentucky, West Virginia, and Virginia by intervening gray shales and siltstones.

In general, the Ohio Shale thickens greatly to the east, primarily by an increase in the thickness of these gray-shale units. The Ohio grades laterally into the Chagrin Shale in the northern part of the Appalachian Basin and into the Braillier Shale (Kepferle and others, 1978) to the south in Virginia and adjacent West Virginia (Potter, and others, 1980).

The Cleveland Member is the uppermost radioactive black shale of the Devonian sequence. It overlies the Three Lick Bed and in turn is overlain by the Mississippian Bedford Shale and Berea Sandstone. The Cleveland extends in a broad, elongate belt from the southern shore of Lake Erie, through central Ohio and eastern Kentucky, to southwestern Virginia (deWitt and others, 1993). Where it is thickest, it exceeds $50 \mathrm{ft}$ in the Big Sandy area (fig. 1) of eastern Kentucky; it is over $100 \mathrm{ft}$ thick in north-central Ohio.

Significantly, the thickest net accumulations of Devonian black shales occur in three places in the Appalachian Basin-(1) eastern Kentucky, adjacent Virginia, and West Virginia, (2) north-central Ohio, and (3) along the western part of the border between New York and Pennsylvania (deWitt and others, 1993). In the southern and northern parts of the basin, black shales collectively exceed $500 \mathrm{ft}$ in thickness, whereas they are about $400 \mathrm{ft}$ thick in Ohio.

\section{MISSISSIPPIAN FORMATIONS}

\section{BEDFORD SHALE AND BEREA SANDSTONE}

The Bedford Shale and Berea Sandstone represent a period of basin infilling during a late stage of Acadian deltaic sedimentation. In general, grain sizes in these formations increase both upward and toward their source areas and, except in northern Ohio where sand-filled channels cut into underlying finer grained clastics, the transition with the overlying strata is gradational (deWitt and others,
1993). In much of the area, the Berea is a relatively thick zone of relatively high porosity within the black-shale sequence. In Virginia, for example, the Berea is as much as $150 \mathrm{ft}$ thick and produces significant amounts of gas. Initial wellhead pressures commonly range from 500 to 800 pounds per square inch and final open flows commonly attain volumes up to 1,400 thousand cubic feet per day (Mcf/d), although in some wells they may be much greater (Nolde and Milici, in press).

Pepper and others (1954), in their study of the Bedford and Berea, provided the foundation for modern paleogeographic interpretations of the uppermost part of the Appalachian Devonian and Mississippian shale sequence (fig. 7). They showed that during deposition of the Bedford, Berea, and Sunbury, land was exposed over much of western Ohio, on the eastern flank of the Cincinnati Arch. Sediment input during the deposition of the Bedford was generally from the north and the east and extended southwestward and westward from Canada into the northern part of the Appalachian Basin in Ohio and westward from deltaic sources along a north-northeast-trending coastline from Pennsylvania to Virginia (Pepper and others, 1954). In general, the paleogeography and drainage patterns established during the time of deposition of the Bedford Shale persisted around the basin as coarser grained sediments prograded into the region and Berea sandstones began to accumulate within the basin.

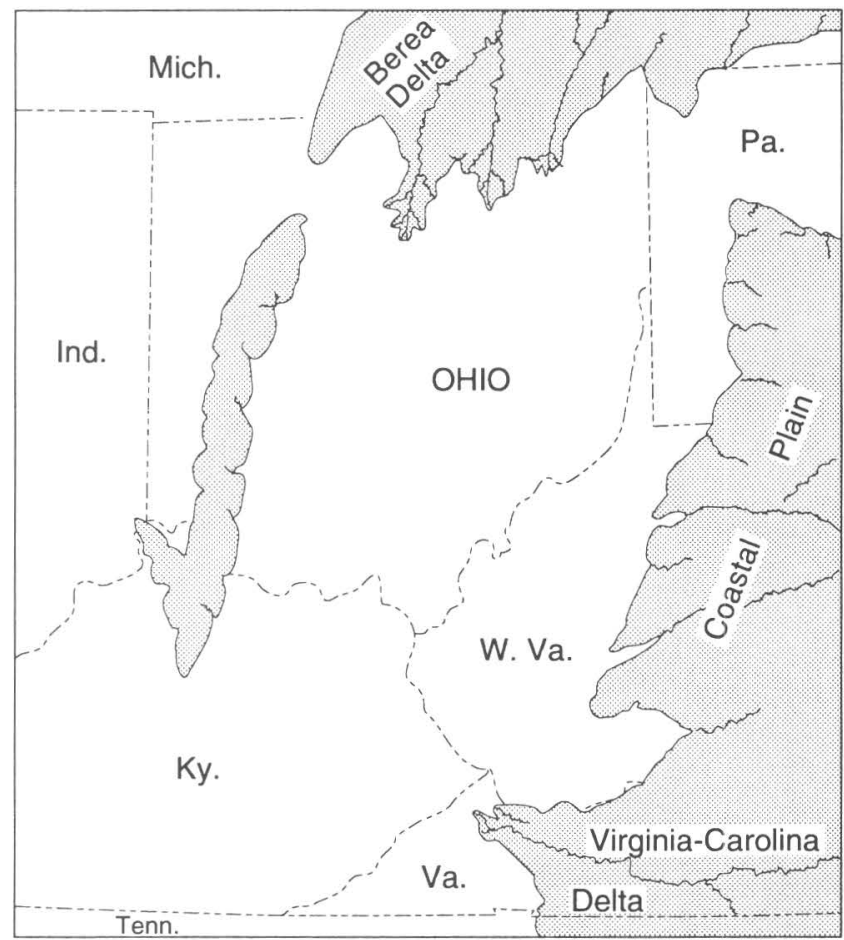

Figure 7. Generalized paleogeography, Bedford-Berea time. White area, marine black shale; stippled area, delta and coastal plain. Modified from Pepper and others (1954, pl. 13g). 
The Berea was deposited as nonmarine and marine sands on and seaward of a low-lying coastal plain that stretched around the periphery of the Appalachian Basin from Virginia northeastward to western Pennsylvania and then westward to Ohio. Sediments were transported into the region by relatively small rivers, named by Pepper and others (1954) the Gay Fink and Cabin Creek channels in West Virginia and the Virginia-Carolina delta in Virginia and eastern Kentucky. Perhaps the most significant source of sandy sediments was from the Canadian shield to the north via the Berea delta, which emptied into the basin in northern Ohio.

Recently, more detailed work in southwestern Virginia by Nolde and Milici (in press) has identified north-trending zones of relatively thick Berea Sandstone, which they interpret to represent coast-parallel marine bars that appear to have been deposited just offshore of the Virginia-Carolina delta. These bars are significant zones of gas production in the Virginia gas fields. To the west in Virginia, deposits contemporaneous with the Berea are compositionally immature finer grained sandstones and shaly siltstones that apparently were deposited in deeper waters on the nearby shelf (Potter and others, 1983).

\section{SUNBURY SHALE}

In the more distal part of the basin, the marine black Sunbury Shale is the uppermost radioactive shale of the Acadian Catskill delta sequence. Lithologically, the Sunbury is a dark-gray to black shale with thin siltstones or silty laminations. The Sunbury formed as a transgressive deposit during a final phase of Acadian tectonic activity (Kammer and Bjerstedt, 1986). The Sunbury overlies marine shelf siliciclastic deposits of Early Mississippian age, the Berea Sandstone and Bedford Shale, and is in turn overlain by the less radioactive siliciclastic deposits of the Borden and Price Formations in eastern Kentucky and adjacent Tennessee, by the Cuyahoga Formation in Ohio, and by the Pocono Sandstone or Price Formation in Virginia and West Virginia. Kammer and Bjerstedt (1986) included the Sunbury as a member within the lower part of the Price Formation in southwestern Virginia.

\section{PRICE FORMATION}

The Price Formation was deposited during the last stages of Acadian deformation and uplift, perhaps as a posttectonic molasse in prodelta, littoral, and nonmarine environments in the southwestern part of the Virginia Valley and Ridge Province (Kreisa and Bambach, 1973). The Price is noted for containing the oldest coalbeds in North America that have been exploited commercially. The formation is a progradational unit, with nonmarine coal-bearing beds overlying marine units. Progradation was generally from the northern and eastern part of the basin to the south and west; although the formation maintains approximately the same thickness along its outcrop, the proportion of marine units increases generally in the direction of progradation (Kreisa and Bambach, 1973, fig. 2). In general, the formation is 500 to $600 \mathrm{ft}$ thick, although in places it is as much as $800 \mathrm{ft}$ thick.

\section{RESOURCE POTENTIAL OF THE SHALES}

The potential of the Devonian black shales to produce natural gas is a function of the type, amount, and thermal maturation of their contained organic matter and the overall characteristics of the gas reservoir. The following review is based on only a few of the more comprehensive papers that have resulted from DOE's recently concluded Eastern Gas-Shales Project (EGSP) and several other smaller projects.

Zeilinski and McIver (1982), in a report prepared by the Mound Facility for DOE's Morgantown Energy Technology Center (METC), summarized the data from more than 2,000 core and several hundred cutting samples from numerous wells drilled in the Appalachian Basin. They concluded that the potential of the Devonian shale formations as a source for hydrocarbons could be related to three key parameters: (1) the quantity of organic carbon in the rock (total organic carbon, TOC), (2) the origin of the organic matter contained within the shales (for example, from normal marine life, the green algae Tasmanites, and (or) terrestrially derived plant matter); and (3) the extent of thermal alteration of the organic matter by the heat of the Earth, expressed as thermal alteration index (TAI) values.

\section{CONTENT AND CHARACTER OF ORGANIC MATTER}

Zeilinski and McIver (1982) and Maynard (1981) pointed out that the high proportion of organic matter in the Devonian black-shale units in the western half of the Appalachian Basin decreases eastward across the basin because of dilution by siliciclastic sedimentation. For example, Maynard (1981) showed that the weight percent of organic carbon ranges from 1.0 to 10.0 percent from the axial part of the Appalachian Basin westward to the Cincinnati Arch.

Schmoker $(1980,1981,1993)$ defined "organic-rich" Devonian shales as those containing 2 percent or more organic matter. Using data from gamma-ray logs, he calculated and mapped the "net thickness of organic matter in organic-rich Devonian shale facies." His map shows that 
the greatest net thickness of organic matter occurs in a broad north-south trend that extends from eastern Kentucky and adjacent West Virginia northward into central Ohio.

Zeilinski and McIver (1982) noted that on the western side of the Appalachian Basin, the kerogen type is principally derived from algae or other marine biota (types I or II), whereas on the eastern side of the basin, woody and coaly forms (type III) predominate. Palynological studies have determined that a very important source of organic material in the Devonian black shales is the fossil marine algae Tasmanites. In certain deposits, very large amounts, or blooms, of Tasmanites apparently overwhelmed and excluded other types of biota from the euphotic zone in the water column. Biofacies maps prepared by Zeilinski and McIver (1982, figs. 34-50) for several of the Devonian shale stratigraphic units illustrate the distribution of organic matter that was derived from terrestrial sources, from normal marine sources, and from marine sources that were dominated by Tasmanites. In general, these maps show that the organic matter in Devonian strata in the western part of the Appalachian Basin is dominantly of open marine and of Tasmanites origin, whereas in the eastern part of the basin, most of the organic matter was derived from nearby terrestrial sources. For some of the Devonian units, however, the distribution of the data points suggests that there may have been a western source for a part of the terrestrially derived organic matter, perhaps from an emergent part of the Cincinnati Arch. These units include the upper part of the Olentangy Shale and Hanover Shale Member of the Java Formation, the middle and upper beds of the Huron Member of the Ohio Shale, and the Chagrin Shale (Zeilinski and McIver, 1982). The distribution of these data points, however, leaves room for interpretation of the direction of the source of this carbon (type III).

Maynard (1981) studied the carbon isotopes in the organic matter, and showed that the only likely source of terrestrially derived carbon was to the east. In general, available carbon isotope ratios range in value from -24.8 permil (terrestrial origin) to -30.4 permil (marine origin). Values from intermediate data points become increasingly more negative (more marine) toward the west. This distribution was interpreted by Maynard (1981) as having resulted from a mixing and progressive dilution of the terrestrially derived carbon isotope with the isotope that was selectively metabolized by marine biota in the submerged part of the Appalachian Basin. On the basis of these data, Maynard (1981) concluded that the Cincinnati Arch was not emergent during the deposition of the blackshale sequence. A comparison of carbon-isotope data values derived from gas with those derived from the source rocks would indicate the direction and extent of gas migration within the Appalachian Basin. Isotope data from gas, however, are currently not available.

\section{THERMAL MATURITY}

The thermal maturity of the Devonian and Mississippian black-shale sequence in the Appalachian Basin has been mapped by several different methods, which include variations in conodont colors expressed as the conodont alteration index (CAI), variations in the colors of plant pollen, spores, and cuticle fragments (thermal alteration indices, TAI), and vitrinite reflectance $\left(R_{0}\right)$. Harris and others (1978) used CAI values to prepare a regional thermal maturation map of the Appalachian Basin. This method has the advantage of utilizing data from carbonate strata, which contain little or no woody or other plant material. In general, regional trends in thermal alteration as illustrated by the conodonts do not follow the structural grain of the Appalachians. Instead, they cut across the regional structural grain and follow the overall thickness trends of the Appalachian Basin fill, especially that contribution to the fill made by the Devonian and Mississippian Catskill delta.

Zeilinski and McIver (1982) used TAI to illustrate the range of thermal maturity of the Upper Devonian units of the Appalachian Basin. They noted that the rocks in the western part of the Appalachian Basin are thermally immature with respect to oil generation. Consequently, only a limited amount of hydrocarbons has been generated and only a part of the potential of the source rocks has been realized. In contrast, in much of the eastern part of the Appalachian Basin the Devonian and Mississippian blackshale sequence is overmature, and little potential remains for generation of liquid hydrocarbons.

The immature Upper Devonian and Lower Mississippian strata on the western side of the Appalachian Basin contain the greatest amount of oil-prone source beds. In comparison, source beds on the eastern side of the basin are more gas prone, occur in modest proportions to organically lean strata, and are mature to overmature with respect to oil generation. It is the intermediate part of the basin, where there is a coincidence of relatively high-quality source rock and an appropriate amount of thermal maturation, that had the greatest potential for generation of liquid hydrocarbons and has the potential for commercial production of locally sourced shale gas. The type of organic matter apparently does not affect the quantitative capacity of a source bed to yield gas. Instead, the total amount of organic matter and the degree of thermal maturation appear to be the significant variables that determine the gas-producing potential of the source rock (Claypool and others, 1978).

Interestingly, Zeilinski and McIver (1982) observed from the distribution of historical production data that oil apparently was first generated in the Devonian shales of the Appalachian Basin farther to the east and at higher temperatures than would normally be expected, at the $\mathrm{TAI}=3$ isoline, rather than at the $\mathrm{TAI}=2$ isoline. They 
suggest that the exceptionally low permeability of the shale required a greater-than-normal thermal stress for the generation of liquid hydrocarbons than otherwise would have occurred. Alternatively, the oil could have migrated into the area after maximum maturity levels were set.

Maynard (1981) and Schmoker (1993) used vitrinite reflectance values expressed as percent $R_{0}$ and arrived at the same general conclusion as Zeilinski and McIver (1982) concerning the thermal maturation of the Devonian and Mississippian shale sequence, even though their maps differ in detail. In general, $R_{o}$ values of vitrinite in the shale sequence increase from about 0.5 to 2.0 percent eastward across the Appalachian Basin, with the principal areas that are producing gas in Virginia, eastern Kentucky, and West Virginia generally having $R_{0}$ values between the 0.6 and 1.5 percent isolines. These $R_{0}$ values $(0.6$ to 1.5 percent) suggest that the gas produced is either biogenic or that some thermogenic gas has migrated to the west and is being produced from these relatively immature areas.

The probable eastern limit of oil in the hydrocarbonproducing region of the south-central part of the Appalachian Basin is illustrated in figure 2. This map encompasses all of the producing Paleozoic strata in the basin and is based on fixed carbon/free carbon ratios (Miller and Fuller, 1954), CAI isograds (Harris and others, 1978), and the observed distribution of oil and gas.

\section{SOURCE-ROCK-POTENTIAL MAPS}

On the basis of a regional study and synthesis of data from thermal alteration indices, organic carbon content, and an analysis of the biofacies of the Devonian and Mississippian shale sequence, Zeilinski and McIver (1982) prepared maps for several of the stratigraphic units in the sequence, illustrating these units' potential for oil and gas production in the Appalachian Basin. The map, which combines the effects of formation thickness with source quality, shows that the overall gas potential is greatest in southeastern Ohio, eastern Kentucky, western Pennsylvania, and southwestern New York (Zeilinski and McIver, 1982). In general, these areas are not the ones that are producing most of the shale gas today. The map illustrating the overall potential of the shale sequence as a source for oil shows a pattern similar to the map for gas; however, areas of potentially favorable source beds are smaller for oil (Zeilinski and McIver, 1982). Like the areas with the high potential for producing gas, the areas with the greatest potential for producing oil are not the areas from which most of the historical production has been obtained.

Vitrinite reflectance data, however, indicate that the high-potential areas of Zeilinski and McIver (1982) in much of Ohio are immature with respect to oil generation, whereas the areas in western Pennsylvania and adjacent New York are overmature. The delineation of geochemically favorable areas (Zeilinski and McIver, 1982) from areas of high historical production thus is partly related to the use of TAI data to determine thermal maturity and partly related to other factors, especially porosity and permeability, that are essential to ensure production of the resource in commercial quantities for a sustained period of time.

Schmoker (1993) adopted the 0.6-percent $R_{0}$ vitrinite reflectance contour as the approximate onset of oil generation and the 1.5-percent $R_{o}$ contour as marking the maturity at which oil breaks down to condensate and begins cracking to gas. He showed that the zone of oil generation coincides with the greatest accumulation of organic carbon in the Devonian shale in eastern Kentucky and adjacent West Virginia. With the exception of the Lake Shore Fields in Ohio, Devonian shale-gas production occurs generally to the east of the 0.6 -percent $R_{0}$ isoline. Vitrinite reflectance data thus appear to reflect the hydrocarbon potential of the Appalachian Basin more accurately than TAI data.

\section{ROLE OF STRUCTURE AND FRACTURE POROSITY}

The two major geologic structures that affect the accumulation of oil and gas in the Appalachian Basin are the Rome Trough, which is a Cambrian graben system that formed by extension and perhaps by strike-slip movemient in the Grenville-age crystalline basement, and the subhorizontal decollements and associated ramp anticlines that occur in the overlying Paleozoic sequence (fig. 8).

The Rome Trough (the Eastern Interior aulacogen of Harris, 1978) extends from the Mississippi Embayment generally eastward across Kentucky to West Virginia and then northeastward through Pennsylvania into southern New York. The trough forms a keellike feature beneath the Appalachian Basin that is filled with an overthickened sequence of Cambrian siliciclastics that are correlated crudely with the Rome Formation of eastern Tennessee and southwestern Virginia, hence the name "Rome Trough." Evidence from seismic cross sections and drilling indicates that the trough was first formed in Early Cambrian-or perhaps latest Precambrian-and was intermittently active at least into the Devonian (Harris, 1978; Shumaker, 1986). Cores taken from wells in the Rome Trough in West Virginia contain Middle Cambrian fossils (Donaldson and others, 1975).

Although late-stage movement on the Rome Trough appears to have had little effect on the location and production of natural gas from the Devonian and Mississippian shales, it may have produced late-stage fractures in these strata in some places in West Virginia (Shumaker, 1993, p. K9). In north-central Tennessee and south-central Kentucky, the coincidence of the Rome Trough with the Cumberland Saddle appears to have enhanced the production of hydrocarbons from fractures in Ordovician limestones.

Perhaps the single most widespread mechanism for producing structural traps and reservoir porosity within the Appalachian foreland is the subhorizontal bedding-plane 


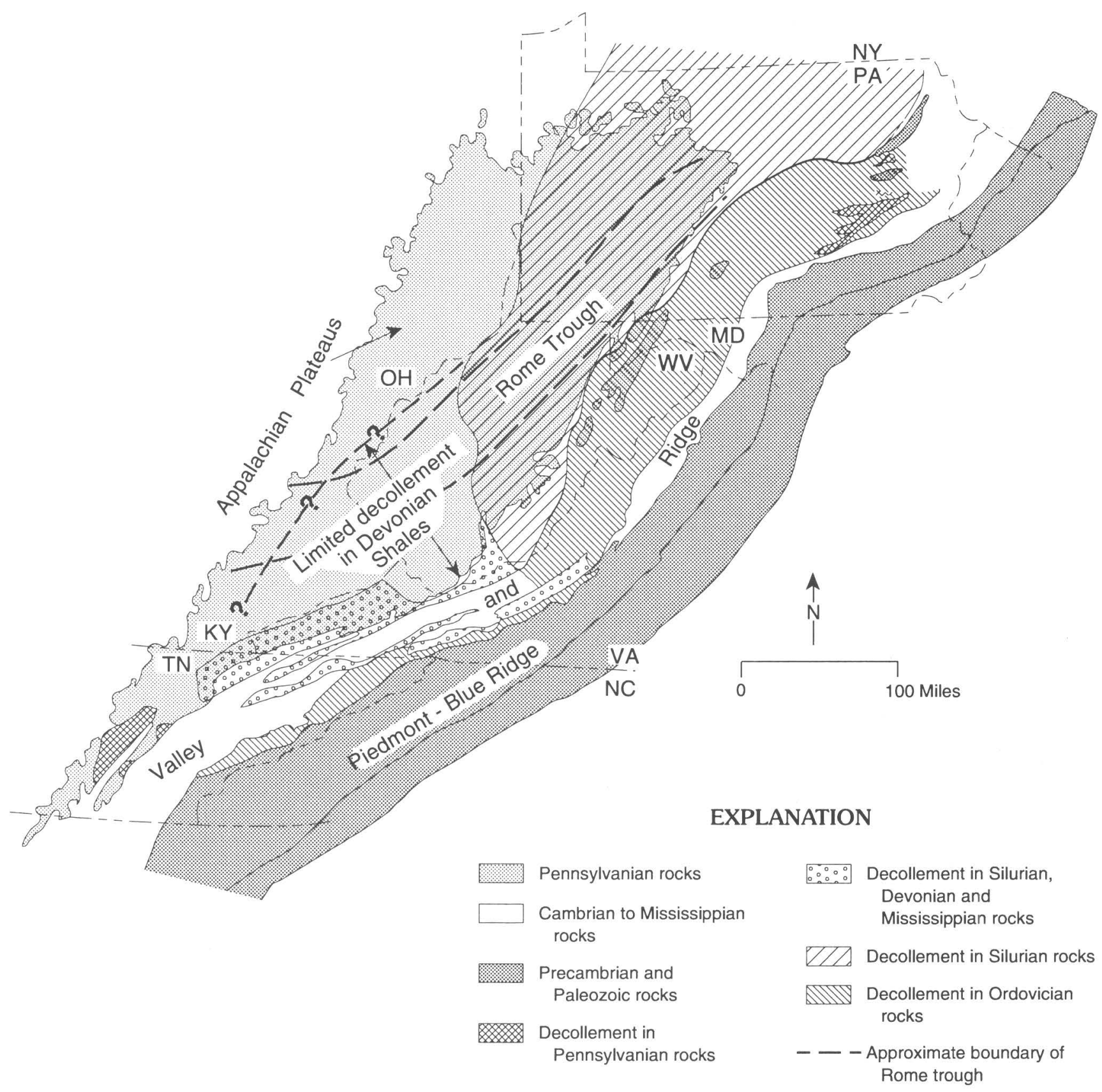

Figure 8. Location of Rome Trough and distribution of decollement zones in middle and upper part of Paleozoic sequence in the Appalachian Basin.

decollement (Milici, 1980a). Multilevel decollement occurs throughout the southern and central Appalachian Valley and Ridge Province and Plateaus in strata ranging in age from Cambrian to Pennsylvanian (Milici, 1980a). In the productive part of the Appalachian Plateau region, those subhorizontal decollements and associated structures that occur in the middle part of the Paleozoic sequence, from the Ordovician Martinsburg Shale to the Devonian shales, are the ones that most directly affect the formation of reservoirs and traps for hydrocarbons.
In much of the folded region of West Virginia and Pennsylvania, major oil resources are in porous beds that have been folded and faulted, primarily as superficial structures above decollement in salt and shale beds. Fracture porosity commonly augments intergranular porosity in tightly folded anticlines where strata were forcefully ejected from anticlinal cores during the folding process (deWitt and Milici, 1989). In addition, decollement is the principal mechanism for creating bedding-parallel zones of fracture porosity in selected sedimentary strata. 


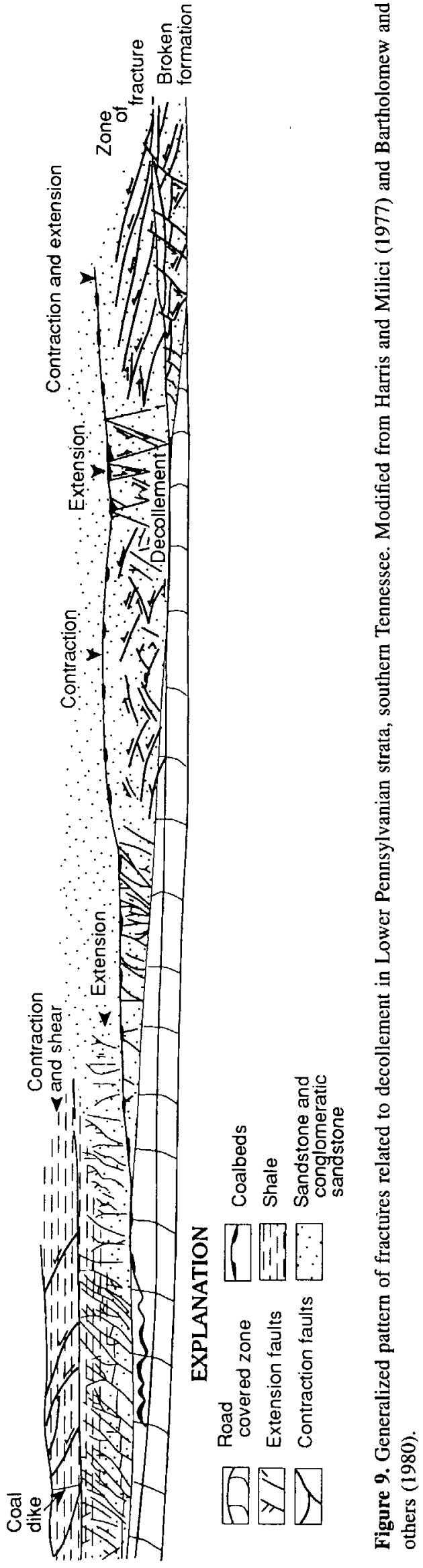

Effective fracture porosity is best developed where tectonic transport and deformation in the decollement zone is low to moderate. Extensive deformation within the decollement commonly results in the destruction of the fractured reservoir and a significant loss of the original volume of gas.

The nature of decollement tectonics and the generation of subsidiary fractures in the folded and faulted Appalachians was described by Harris and Milici (1977). They determined that the position and character of subhorizontal decollement within a given stratigraphic sequence is closely controlled by subtle lithologic variations. Of particular importance in localizing subhorizontal decollement in Devonian and Carboniferous rocks in the Appalachians are shale beds (especially if they are rich in organic matter) and coalbeds. These shale and coal beds are the principal sources of gas in the Appalachian Basin, and the release of gas from the source beds where they were tectonically deformed could have overpressured some of the fractured shale reservoirs (Shumaker, 1993).

Decollement and decollement-related structures commonly may be divided into two regimes-a zone of extremely fractured or brecciated rock called a broken formation and an overlying zone of fracture (Harris and Milici, 1977) (fig. 9). In the broken formation, fractures consist primarily of subhorizontal shears that are overprinted by later stage, relatively high-angle extensional and contractional faults. These latter faults commonly extend upward from the broken formation zone into a less-deformed zone of fracture. This pattern of deformation commonly encompasses all scales ranging from dimensions of a few $\mathrm{ft}$ to tens or hundreds of feet of strata, depending upon the local stress regime during deformation.

In many places in the Appalachian Plateau near the western limits of detachment, the contact between deformed and undeformed strata is abrupt, with little or no gradation between. The hanging wall may show little or no deformation that can be related to westward tectonic transport and shortening. In these places, the deformed strata in the decollement zone appear to have been squeezed like toothpaste between hanging and foot walls. For example, in some places in the plateau regions of Tennessee and Virginia, coalbeds normally a few feet thick are squeezed along the bedding into intensely deformed tectonic rolls $20 \mathrm{ft}$ or more thick. Where this has happened, several thick coal rolls may be connected to one another by thin leads (leaders) of coal (Nelson, 1925; Milici and Gathright, 1985; Milici and others, 1986).

Similar deformation has been observed in outcrop in the Devonian/Mississippian shales of Virginia and Tennessee (Milici and Statler, 1980; Milici, 1980b; Harris and Milici, 1977). In the subsurface of southwestern Virginia and eastern Kentucky, all gradations of deformation occur in the shale, from serving as the locus of a major decollement beneath the Pine Mountain thrust sheet (Young, 
1957; Jacobeen, 1992) to localizing the decollement of much lower magnitude that occurs as a blind thrust in the Big Sandy Gas Field (Shumaker, 1993) and, perhaps, to the toothpaste tectonics that occur in the lesser deformed regions of southeastern Ohio. Wilson and others (1980) and Shumaker (in press) observed this range of structural deformation in cores drilled into the black shales across the Appalachian Basin, and Shumaker noted the progressive decrease of subhorizontal shears westward from eastern Kentucky into Ohio. Schumaker (1980) coined the term "porous fracture facies" to describe the extensive fracturing that is related to subhorizontal deformation in the lower Huron black shales and hypothesized that these decollement zones were related to overpressured gas zones in the Devonian shale.

There is little doubt that in most of the Appalachian Basin, fracturing of the gas-producing shale zones was induced by tectonic forces. However, in the relatively low production Devonian shale-gas fields in the northern part of the basin, along the southern shores of Lake Erie in Ohio, Pennsylvania, and New York, shallow fractures may have been affected and (or) enhanced by the southward movement of ice sheets over the shales during the Pleistocene (White, 1992).

\section{PLAYS AND PRODUCTION CHARACTERISTICS OF THE DEVONIAN AND MISSISSIPPIAN SEQUENCE IN THE SOUTH-CENTRAL APPALACHIAN BASIN}

In general, the production characteristics of the shalegas-producing regions in the Appalachian Basin reflect major differences in (1) organic-carbon content, (2) thermal maturity, and (3) fracture porosity along and across the basin. Although production is obtained in areas that do not have the optimal conditions for long-term and relatively high-yield fields, the best results are obtained where all three conditions are optimal (table 1). In only one of the three major shale-gas-producing areas in the Appalachian Basin are the three conditions optimal. The Lake Shore Fields in northern Ohio and Pennsylvania (see fig. 1) are in a region that is immature for thermogenic gas, suggesting that the gas produced there may have migrated into the region from elsewhere in the Appalachian Basin. It is possible, however, that this gas was generated locally and is of biogenic origin. The subeconomic emerging area of West Virginia is located on the eastern margin of the main trend of high organic carbon within the black shales. Only in and near the Big Sandy area is there a coincidence of high organic-carbon content within the source beds, suitable thermal maturity, and a shale reservoir that is enhanced by decollement-induced fracture porosity.

The Big Sandy Gas Field in eastern Kentucky (see fig. 1) has produced gas from various reservoirs since 1914 and from Upper Devonian shales since 1921 (Hunter and Young, 1953). In this area, the potentially productive reservoir ranges from about 350 to $750 \mathrm{ft}$ in thickness. Without treatment, most of the wells drilled into these gas shales yielded little or no gas. For example, approximately 6 percent of the 3,400 wells studied by Hunter and Young (1953) were completed without treatment, and these wells had an average open flow of about $1,055 \mathrm{Mcf} / \mathrm{d}$. The approximately 3,200 wells remaining were shot with nitroglycerine; it was common practice in the early decades of exploration to stimulate the well by shooting the entire shale interval with at least 3,000 to 7,000 pounds of explosives. In these wells, initial open flows of gas averaged about $61 \mathrm{Mcf} / \mathrm{d}$ before shooting and final open flows averaged about $285 \mathrm{Mcf} / \mathrm{d}$ after shooting. Hunter and Young (1953) concluded that fractures enhanced by the explosives were the principal cause of porosity and permeability

Table 1. Generalized production characteristics of three shale-gas producing regions in the Appalachian Basin.

\begin{tabular}{|c|c|c|c|c|}
\hline Region' ${ }^{1}$ & $\begin{array}{l}\text { Organic-carbon } \\
\text { content }\end{array}$ & $\begin{array}{l}\text { Relative thermal } \\
\text { maturity }\end{array}$ & $\begin{array}{l}\text { Natural fracture } \\
\text { porosity }\end{array}$ & Production characteristics \\
\hline $\begin{array}{l}\text { Lake Shore Fields, Ohio and } \\
\text { Pennsylvania. }\end{array}$ & High to low---.---- & Immature------..- & Good ......--- & $\begin{array}{l}\text { Intermediate- to long-term low-production } \\
\text { wells. }\end{array}$ \\
\hline Emergin area, West Virginia--.......- & Medium to high-.- & Mature----------- & Good --...-- & $\begin{array}{l}\text { Final open flow after treatment is high; } \\
\text { organic carbon content not sufficient to } \\
\text { maintain long term production, and } \\
\text { wells decline in a matter of months. }\end{array}$ \\
\hline $\begin{array}{l}\text { Southern Ohio, southwestern West } \\
\text { Virginia, and eastern Kentucky } \\
\text { (Big Sandy Gas Field) and } \\
\text { Southwestern Virginia (Roaring } \\
\text { Fork Field). }\end{array}$ & High -........---- & Mature---------.. & Very good -..- & $\begin{array}{l}\text { Final open flow after treatment is high; } \\
\text { production decreases sharply at first; } \\
\text { wells stablilize at very long term, low- } \\
\text { to-moderate yields. }\end{array}$ \\
\hline
\end{tabular}

\footnotetext{
${ }^{1}$ Shown on figure 1.
} 
within the shales and that effects of porosity and permeability in silty and sandy zones within the shale sequence were relatively minor. Common practice at present is to stimulate selected zones within wells with a liquid nitrogen foam frac utilizing sand as a proppant.

Baranoski and Riley (1988) noted that the lower part of the Huron Member is the primary and most prolifically producing Devonian shale unit in southernmost Ohio. There, shale-gas wells that have an initial potential greater than $200 \mathrm{Mcf} / \mathrm{d}$ appear to have been drilled into reservoirs with a higher-than-normal fracture porosity that somehow may be related to local folds and faults. In general, data available for 29 shale-gas wells show that the average well in southernmost Ohio declines from about $45 \mathrm{Mcf} / \mathrm{d}$ to about $25 \mathrm{Mcf} / \mathrm{d}$ over a 10-year period. Thereafter, the decline rate flattens, and production is maintained at about $25 \mathrm{Mcf} / \mathrm{d}$ for 30 years or more. For a 30 -year period, the cumulative production from Ohio shale-gas wells averages 0.311 billion cubic feet (Bcf).

In the Roaring Fork Field in southwestern Virginia (see fig. 1), 16 shale-gas wells completed exclusively within the Devonian shales exhibit an average final open flow after completion of about $133 \mathrm{Mcf} / \mathrm{d}$. More commonly, production from Devonian shale in this field is comingled with gas produced from the Mississippian Berea Sandstone, Price Formation (Weir of drillers' usage), and (or) Greenbrier Limestone (Big Lime of drillers' usage). Final open flow data from comingled wells averages about $843 \mathrm{Mcf} / \mathrm{d}$.

Patchen and Hohn (1993) made a detailed study of production decline curves for wells in a three county area, the area of long-term historical production in southwestern West Virginia where the Big Sandy Gas Field enters the state from Kentucky, and compared them with production decline curves from the six county area immediately to the north in the more recently emerging area of shale-gas production (see fig. 1). They determined that the annual production rates of wells in the emerging area at the end of their first year were less than annual production rates from wells in the historical area to the south after 30 years.

Average shale-gas wells in the area of historical production in West Virginia generally have an initial production (IP) of between 250 and $300 \mathrm{Mcf} / \mathrm{d}$. They decline within 10 years to about $50^{\circ} \mathrm{Mcf} / \mathrm{d}$ and after 40 years are producing about $20 \mathrm{Mcf} / \mathrm{d}$. Patchen and Hohn (1993) estimated that the average shale-gas well in southern West Virginia produces $0.5 \mathrm{Bcf}$ after 40 years. In comparison, available production data from the northern part of the newly emerging area shows that wells there decline generally from about $36 \mathrm{Mcf} / \mathrm{d}$ to about $10 \mathrm{Mcf} / \mathrm{d}$ in 12 months. Patchen and Hohn (1993) concluded that in spite of a few good wells, the emerging area will prove to be noncommercial. This most likely is because of the relatively low amount of total organic carbon available for generation of hydrocarbons in that area (Schmoker, 1993) as well as the migration of generated gas westward, away from the deeper parts of the Appalachian Basin, during the Alleghanian orogeny.

Wells have been producing gas from the Devonian shales in the Lake Shore Fields of northern Ohio and adjacent Pennsylvania for more than 100 years. Drilling began in Pennsylvania during the 1850's and continued into Ohio a decade later (Janssens and deWitt, 1976). Many hundreds of wells were drilled, mainly for domestic purposes, and their initial production commonly ranged between 1 and $50 \mathrm{Mcf} / \mathrm{d}$. These wells have declined very slowly and some have produced gas for 50 years or more. Unlike the wells in fields in the south-central part of the Appalachian Basin, these wells have produced mainly from silty and sandy zones in the Chagrin Shale and Three Lick Bed. Fracture porosity is of secondary importance and apparently has served to conduct the gas from the black-shale source beds of the Marcellus, Rhinestreet, and Huron into the more porous units (Broadhead and others, 1982; Broadhead, 1993).

\section{SHALE-GAS PLAYS AND POTENTIAL IN OTHER BASINS}

Black shales of Devonian and Mississippian age occur in several basins in the Rocky Mountain region and interior of North America. The New Albany Shale of the Illinois Basin (Hansenmuller, 1993; Cluff, 1993) and the Antrim Shale of the Michigan Basin (Matthews, 1993; Gutschick and Sandberg, 1991; Decker and others, 1992) contain many of the aspects of their counterpart in the Appalachian Basin and, indeed, include some of the units named from the Appalachians. The Woodford Shale is an important source for hydrocarbons in the Anadarko Basin (Schmoker, 1989) as is the Bakken Formation in the Williston Basin (Price and LeFever, 1992; Schmoker, 1993). The locations of basins discussed herein are illustrated in figure 10.

Of these black shales, the Antrim has been the most explored in recent years for shallow gas. In general, exploration for Antrim shale gas is confined to the northern part of the Michigan Basin. Approximately 2,000 wells were completed in the Antrim Shale between the end of 1986 and the end of 1991, when about 1,350 wells were producing 123 million cubic feet of gas per day (MMcf/d) of shale gas (Decker and others, 1992). These shale wells typically produce 25 to $150 \mathrm{Mcf} / \mathrm{d}$ (average $70-80 \mathrm{Mcf} / \mathrm{d}$ ) from depths of about 305-500 m (Gordon Dolton, U.S. Geological Survey, written commun., 1993). The Antrim has produced gas since the 1940's and contains an estimated gas reserve of $76 \mathrm{Tcf}$ (Decker and others, 1992). These wells are commonly fractured with nitrogen foam, utilizing sand as a proppant. 


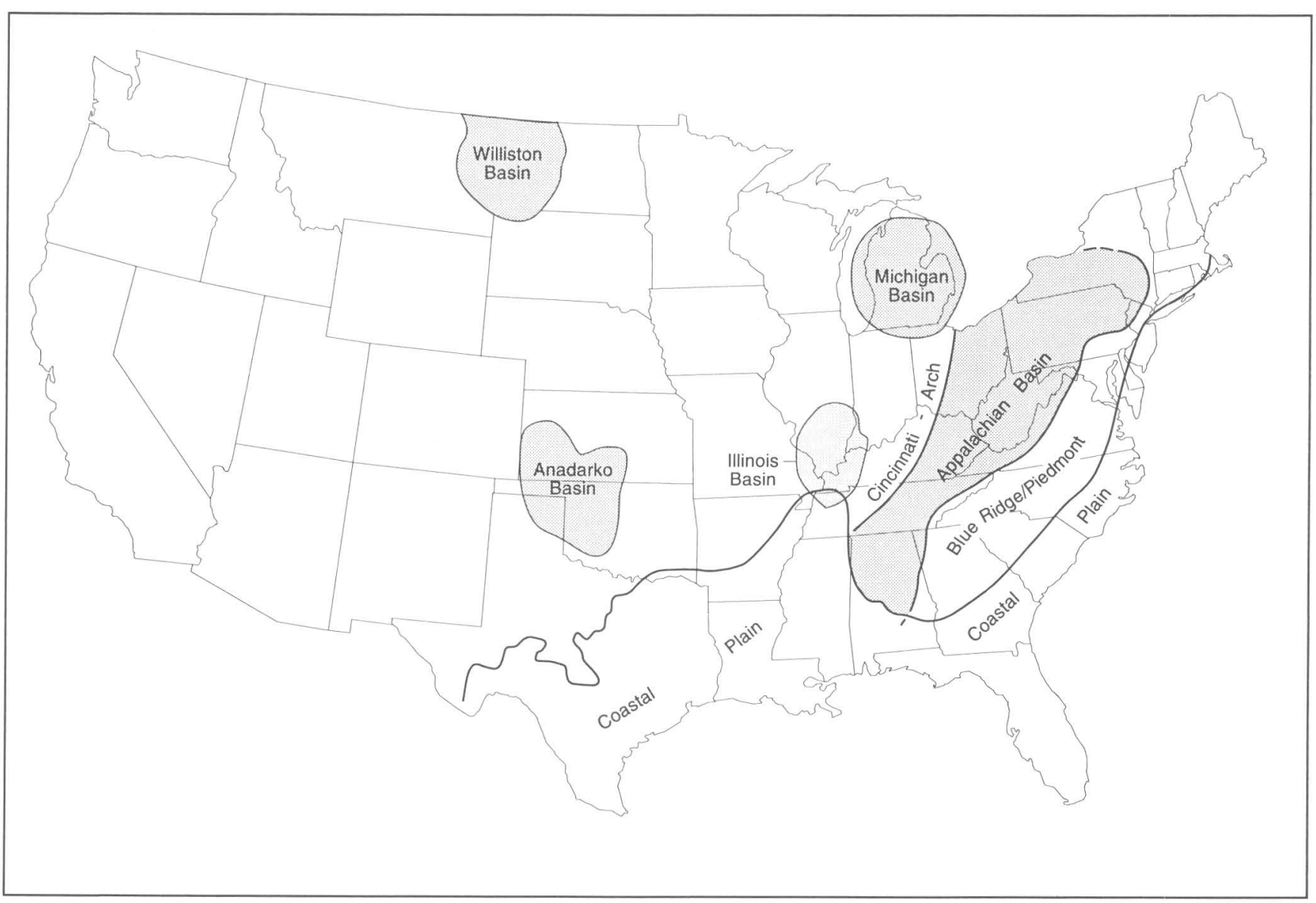

Figure 10. Locations of major black-shale basins in Eastern and Central United States.

Like Devonian-shale source beds in the Appalachians, the Atrim contains a great deal of organic matter. Total organic-carbon content, determined from analyses of several hundred samples, averages about 8 percent and ranges from 2 to 25 percent. Kerogen in the Antrim has been determined to be hydrogen rich and oil prone, the gas is thermogenic in origin, and thermal maturation is related to burial depth (Decker and others, 1992). As a result, the currently producing area occurs generally at shallow depth on the northern edge of the Michigan Basin, an area of relatively low thermal maturation. Delta carbon-13 $\left(\delta^{13} \mathrm{C}\right)$ isotope values, pyrolysis data, and total-organic-carbon measurements, however, indicate that Antrim gas has been generated in place by thermal maturation of kerogen within the black shales of the lower part of the Antrim (Manger and Curtis, 1991).

Although porosity in the Antrim as determined from core analysis ranges from 5 to 15 percent, matrix permeabilities are low. Thus, fracturing is essential to provide additional porosity and to convey the gas to the well bore. Unlike parts of the Appalachians, however, bedding-parallel decollement apparently does not play a role in fracture generation in the Michigan Basin. Instead, the principal mechanisms for fracture production within the Antrim shale are regional structures, including joints, fractures associated with folding and possibly fractures caused by isostatic movements related to glaciation (unloading fractures).

If favorable conditions of high organic content, thermal maturity, and porosity and permeability persist southward into the core of the Michigan Basin, the entire region has a substantial potential for the production of shale gas as well as for generation of oil from these enriched source beds. It should be noted that activity in the basin declined sharply in 1991, which probably reflects less favorable economic conditions for gas exploration.

It should be mentioned that production from shallow gas fields in the Niobrara Formation in the Denver Basin, Colorado, Kansas, and Nebraska, is in many ways similar to the production of gas from shales (Pollastro and Scholle, 1986; Lockridge and Pollastro, 1988). There, biogenic gas is produced from chalk beds that are sufficiently enriched in organic matter to be self sourcing; reservoir depths range generally from 300 to $1,000 \mathrm{~m}$. The chalk reservoirs have a relatively high porosity and a low permeability which must be enhanced by fracturing; initial production from wells stimulated with foam ranges from 100 to $1,200 \mathrm{Mcf} / \mathrm{d}$. 


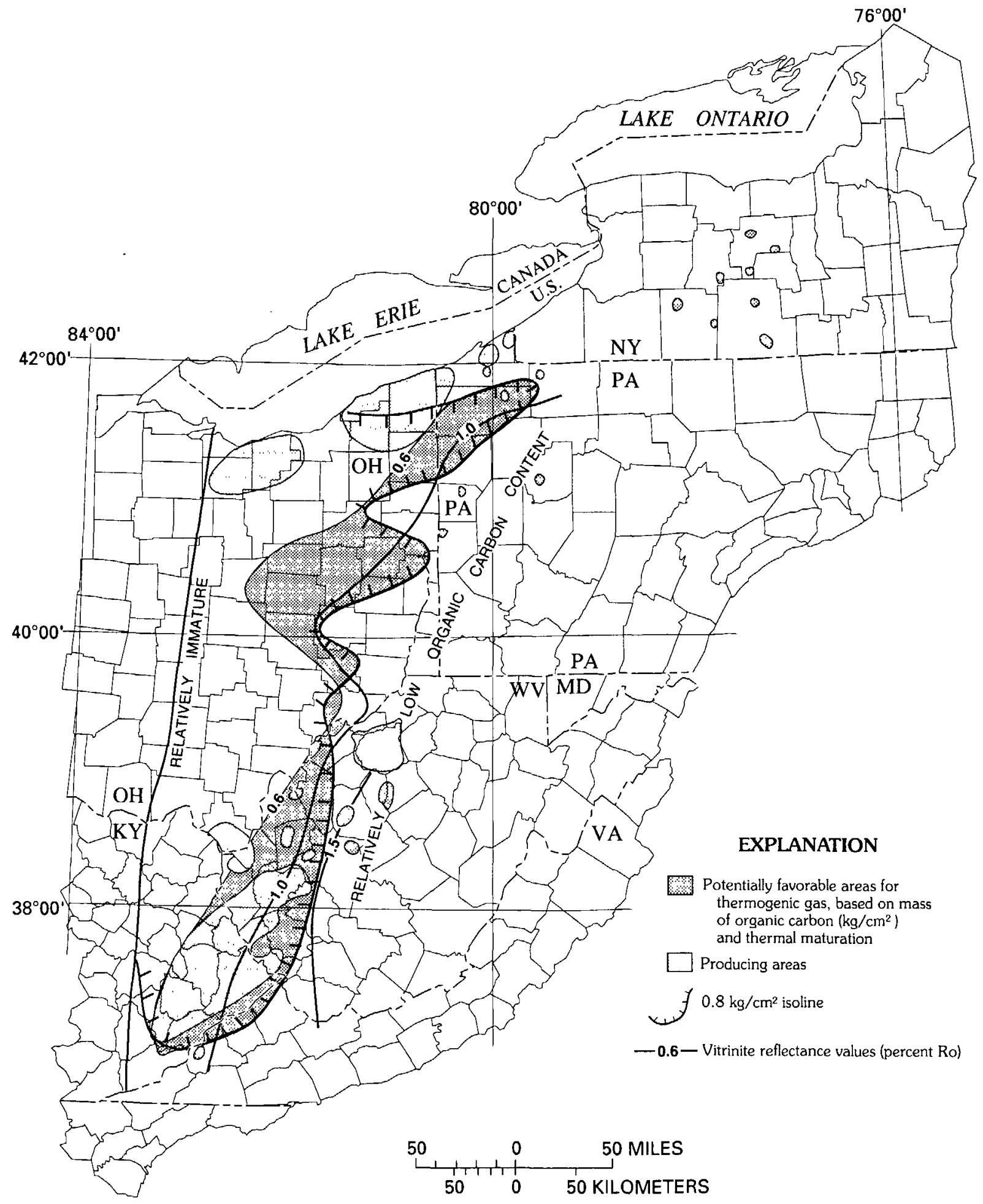

Figure 11. Relationship of areas producing gas from Devonian shales in the Appalachian Basin to mass of organic carbon (area with values greater than $0.8 \mathrm{~kg} / \mathrm{cm}^{2}$ ) and thermal maturation. Modified from Schmoker (1993, fig. 9). 


\section{SUMMARY AND CONCLUSION}

The Devonian and Mississippian shale-gas fields of the south-central part of the Appalachian Basin are in an area characterized by significant amounts of organic carbon, suitable thermal maturation, and decollement-induced fracture porosity. As a result, the wells are of relatively high yield and produce gas for many years at slowly declining rates after a relatively short period of sharp decline. Wells in the emerging area of West Virginia are sited in a similar geologic environment, except that available organic carbon apparently was not sufficient to generate enough gas for sustained gas production; in addition, some of the generated gas may have migrated out of the area during Alleghanian deformation. Wells in the emerging area decline sharply within a year and the area is, in general, subeconomic. Wells producing along the southern shores of Lake Erie are in an area that contains significant amounts of organic carbon and intergranular and fracture porosity. The area is thermally immature with respect to oil generation and the available gas is either biogenic or thermogenic gas that has migrated into the porous beds from sources deeper in the Appalachian Basin. Like wells in the Big Sandy Gas Field, these wells produce for a very long term but are low in yield.

There are two areas in eastern Ohio and northwestern Pennsylvania that currently do not produce shale gas but lie between the $0.8 \mathrm{~kg} / \mathrm{cm}^{2}$ organic matter isoline on the east and the 0.6-percent $R_{o}$ vitrinite reffectance isoline on the west, as mapped by Schmoker-(1993). These areas are potentially favorable for exploration and production of shale gas, providing that the potential reservoirs have sufficient fracture and (or) interstitial porosity (fig. 11).

Exploration targets for shale gas in areas outside of the Appalachian Basin will very likely require conditions similar to those in the Big Sandy Gas Field if they are to produce gas commercially. It should be noted that factors such as location with respect to market, the total potential volume of the resource, as well as local drilling depths and evolving techniques for stimulating wells will bear upon the economic feasibility of shale-gas production at any given.

\section{ACKNOWLEDGMENTS}

This manuscript was reviewed and improved by recommendations from Vito F. Nuccio, Robert T. Ryder, Paul G. Lillis, Katryn Wiese, and David G. Howell, U.S. Geological Survey.

\section{REFERENCES CITED}

Baranoski, M.T., and Riley, R.A., 1988, Analysis of stratigraphic and production relationships of Devonian-shale gas reser- voirs in Lawrence County, Ohio: Ohio Division of Geologic Survey Open-File Report 88-2, 30 p.

Bartholomew, M.J., Milici, R.C., and Schultz, A.P., 1980, Geologic structure and hydrocarbon potential along the Saltville and Pulaski thrusts in southwestern Virginia and northeastern Tennessee: Virginia Division of Mineral Resources Publication 23, part A, sheet 1 .

Broadhead, R.F., 1993, Petrography and reservoir geology of Upper Devonian shales, northern Ohio, in Roen, J.B., and Kepferle, R.C., eds., Petroleum geology of the Devonian and Mississippian black shale of eastern North America: U.S. Geological Survey Bulletin 1909, p. H1-H15.

Broadhead, R.F., Kepferle, R.C., and Potter, P.E., 1982, Stratigraphic and sedimentologic controls of gas in shale-Example from Upper Devonian of northern Ohio: American Association of Petroleum Geologists Bulletin, v. 66, p. 10 27.

Brown, P.J., 1976, Energy from shale-A little used natural resource, [Chap.] 6, in Natural gas from unconventional geologic sources: Energy Research and Development Administration Report FE-2271-1, p. 86-99.

Charpentier, R.R., deWitt, Wallace, Jr., Claypool, G.E., Harris, L.D., Mast, R.F., Megeath, J.D., Roen, J.B., and Schmoker, J.W., 1993, Estimates of unconventional natural gas resources in the Devonian shales of the Appalachian Basin, in Roen, J.B., and Kepferle, R.C., eds., Petroleum geology of the Devonian and Mississippian black shale of eastern North America: U.S. Geological Survey Bulletin 1909, p. N1-N20.

Claypool, G.E., Threkeld, C.N., and Bostick, N.H., 1978, Natural gas occurrence related to regional thermal rank of organic matter (maturity) in Devonian rocks of the Appalachian Basin, in Preprints for Second Eastern Shales Symposium: U.S. Department of Energy, Morgantown Energy Technology Center Report METC/SP-78-6, p. 54-65.

Cluff, R.M., 1993, Source rocks and hydrocarbon generation in the New Albany Shale (Devonian-Mississippian of the Illinois Basin)-A review, in Roen, J.B., and Kepferle, R.C., eds., Petroleum geology of the Devonian and Mississippian black shale of eastern North America: U.S. Geological Survey Bulletin 1909, p. I1-I15

Cole, G.A., Drozd, R.J., Sedivy, R.A., and Halpern, H.I., 1987, Organic geochemistry and oil-source correlations, Paleozoic of Ohio: American Association of Petroleum Geologists Bulletin, v. 71, p. 788-809.

Decker, D., Coates, J-M.P., and Wicks, D., 1992, Stratigraphy, gas occurrence, formation evaluation and fracture characterization of the Antrim Shale, Michigan Basin: Gas Research Institute Topical Report GRI-92/0258, 101 p.

deWitt, Wallace, Jr., 1981, Revision of the areal extent of the New Albany, Chattanooga, and Ohio shales in KentuckyField trip 3, in Roberts, T.G. ed., Field trip guidebooks for the annual meeting of the Geological Society of America, 1981, Cincinnati, Ohio, v. 2-Economic geology, structure: Falls Church, American Geological Institute, p. 331-334.

deWitt, Wallace, Jr., and Milici, R.C., 1989, Energy resources of the Appalachian orogen, in Hatcher, R.D., Jr., Thomas, W.A., and Viele, G.W., eds., The Geology of North America, v. F-2-The Appalachian-Ouachita orogen in the United States: Boulder, Geological Society of America, p. 495-510. 
deWitt, Wallace, Jr., Perry, W.J., Jr., and Wallace, L.G., 1975, Oil and gas data from Devonian and Silurian rocks in the Appalachian Basin: U.S. Geological Survey Miscellaneous Investigations Series Map I-917 B, scale 1:2,500,000.

deWitt, Wallace, Jr., Roen, J.B., and Wallace, L.G., 1993, Stratigraphy of Devonian black shales and associated rocks in the Appalachian Basin, in Roen, J.B., and Kepferle, R.C., eds., Petroleum geology of the Devonian and Mississippian black shale of eastern North America: U.S. Geological Survey Bulletin 1909, p. B1-B57.

Demaison, G.J., and Moore, G.T., 1980, Anoxic environments and oil source bed genesis: American Association of Petroleum Geologists Bulletin, v. 64, p. 1179-1209.

Donaldson, A.C., Heald, M.T., Renton, J.J., and Warshaver, S.M., 1975, Depositional environment of Rome Trough rocks, Mingo County well, West Virginia [abs.]: American Association of Petroleum Geologists Bulletin, v. 59, p. 1,735 .

Ettensohn, F.R.,1985, Controls on development of Catskill delta complex basin-Facies, in Woodrow, D.L., and Sevon, W.D., eds., The Catskill delta: Geological Society of America Special Paper 201, p. 65-77

Ettensohn, F.R., and Barron, L.S., 1981, Depositional model for the Devonian-Mississippian black shales of North America-A paleoclimatic-paleogeographic approach, in Roberts, T.G., ed., Field trip guidebooks for the annual meeting of the Geological Society of America, 1981, Cincinnati, Ohio, v. 2-Economic geology, structure: Falls Church, American Geological Institute, p. 344-361.

Ettensohn, F.R., and Barton, L.S., 1982, A tectonic-climatic approach to the deposition of the Devonian-Mississippian black-shale sequence of North America: Appalachian Industrial Associates Program-Fall Meeting, October 14-15, $1982,91 \mathrm{p}$.

Faill, R.T., 1985, The Acadian orogeny and the Catskill delta, in Woodrow, D.L., and Sevon, W.D., eds., The Catskill delta: Geological Society of America Special Paper 201, p. 15-37

Gutschick, R.C., and Sandberg, C.A., 1991, Late Devonian history of the Michigan Basin, in Catacosinos, P.A., and Daniels, P.A., Jr., eds., Early sedimentary evolution of the Michigan Basin: Geological Society of America Special Paper 256, p. 181-202

Gwinn, V.E., 1964, Thin-skinned tectonics in the Plateau and northwestern Valley and Ridge Provinces of the central Appalachians: Geological Society of America Bulletin, v. 75, n. 9, p. 863-900

Harris, L.D., 1978, The Eastern Interior aulacogen and its relation to Devonian shale gas production: U.S. Department of Energy, Morgantown Energy Technology Center Report METC/SP-78/6, v. 2, p. 55-72

Harris, L.D., and Milici, R.C., 1977, Characteristics of thinskinned style of deformation in the southern Appalachians and potential hydrocarbon traps: U.S. Geological Survey Professional Paper 1018, $40 \mathrm{p}$.

Harris, A.G., Harris, L.D., and Epstein, J.B., 1978, Oil and gas data from Paleozoic rocks in the Appalachian Basin-Maps for assessing hydrocarbon potential and thermal maturity (conodont color alteration isograds and overburden isopachs): U.S. Geological Survey Miscellaneous Investigations Series Map I-917-E, scale 1:2,500,000, 4 sheets.
Hasenmueller, N.R., 1993, New Albany Shale (Devonian and Mississippian) of the Illinois Basin, in Roen, J.B., and Kepferle, R.C., eds., Petroleum geology of the Devonian and Mississippian black shale of eastern North America: U.S. Geological Survey Bulletin 1909, p. C1-C19

Hohn, M.E., and Timberlake, K.J., 1988, Devonian shale fields and pools in West Virginia: West Virginia Geological and Economic Survey Map-WV34, 8 sheets, scale 1:125,000.

Hunter, C.D., and Young, D.M., 1953, Relationship of natural gas occurrence and production in eastern Kentucky (Big Sandy Gas Field) to joints and fractures in Devonian bituminous shales: American Association of Petroleum Geologists Bulletin, v. 37, no. 2, p. 282-299.

Ibach, L.E.J., 1982, Relationship between sedimentation rate and total organic carbon content in ancient marine sediments: American Association of Petroleum Geologists Bulletin, v. 66, p. $170-188$.

Jacobeen, F.J., Jr., 1992, Oil and gas well analyses of hydrocarbon potential of Buchanan, Dickenson, and Wise Counties, Virginia: Virginia Division of Mineral Resources Open-File Report 91-2, 15 p.

Janssens, A., and deWitt, Wallace, Jr., 1976, Potential natural gas resources in the Devonian shales in Ohio: Ohio Division of Geological Survey Geological Note no. 3, 12 p.

Kammer, T.W., and Bjerstedt, T.W., 1986, Stratigraphic framework of the Price Formation (Upper Mississippian-Lower Devonian) in West Virginia: Southeastern Geology, v. 27, p. 13-33.

Kepferle, R.C., 1993, A depositional model and basin analysis for the gas-bearing black shale (Devonian and Mississippian) in the Appalachian Basin, in Roen, J.B., and Kepferle, R.C., eds., Petroleum geology of the Devonian and Mississippian black shale of eastern North America: U.S. Geological Survey Bulletin 1909, p. F1-F23.

Kepferle, R.C., and Roen, J.B., 1981, Field trip No. 3-Chattanooga and Ohio Shales of the southern Appalachian Basin, in Roberts, T.G., ed., Field trip guidebooks for the annual meeting of the Geological Society of America, 1981, Cincinnati, Ohio, v. 2-Economic geology, structure: Falls Church, American Geological Institute, p. 259-362.

Kepferle, R.C., Wilson, E.N., and Ettensohn, F.R., 1978, Preliminary stratigraphic cross section showing radioactive zones in the Devonian black shales in the southern part of the Appalachian Basin: U.S. Geological Survey Oil and Gas Investigations Chart OC-85.

Kreisa, R.D., and Bambach, R.K., 1973, Environments of deposition of the Price Formation (Lower Mississippian) in its type area, southwestern Virginia: American Journal of Science, Cooper volume, 273-A, p. 326-342.

Laughrey, C.D., 1989, Distribution and significance of geochemical fossils in the petroleum source rocks of Pennsylvania: The Twentieth Annual Appalachian Petroleum Geology Symposium, March 27-30, 1989, Morgantown, West Virginia: I.C. White Memorial Fund Publication, no. 1, p. 37-44.

Lockridge, J.P., and Pollastro, R.M., 1988, Shallow Upper Cretaceous Niobrara gas fields in the eastern Denver Basin, in Goolsby, S.M., and Longman, S.M., eds., Occurrence and petrophysical properties of carbonate reservoirs in the Rocky Mountain region: Denver, Rocky Mountain Association of Geologists Carbonate Symposium [Proceedings], p. 63-74. 
Manger, K.C., and Curtis, J.B., 1991, Geologic influences on location and production of Antrim shale gas, in Devonian gas shales technology review: Gas Research Institute v. 7, n. 2, p. 5-16.

Matthews, D.R., 1993, Review and revision of Devonian-Mississippian stratigraphy in the Michigan Basin, in Roen, J.B., and Kepferle, R.C., eds., Petroleum geology of the Devonian and Mississippian black shale of eastern North America: U.S. Geological Survey Bulletin 1909, p. D1-D85

Maynard, J.B., 1981, Some geochemical properties of the Devonian-Mississippian shale sequence, in Kepferle, R.C., and Roen, J.B., 1981, Field trip no. 3, Chattanooga and Ohio Shales of the southern Appalachians, in Roberts, T.G., ed., Field trip guidebooks for the annual meeting of the Geological Society of America, 1981, Cincinnati, Ohio, v. 2Economic geology, structure: Falls Church, American Geological Institute, p. 336-343.

Milici, R.C., 1980a, Relationship of regional structure to oil and gas producing areas in the Appalachian Basin: U.S. Geological Survey Miscellaneous Investigations Series Map I-917-F, scale $1: 2,500,000$

$1980 \mathrm{~b}$, Saltville fault footwall structure at Stone Mountain, Hawkins County, Tennessee, in Geologic structure and hydrocarbon potential along the Saltville and Pulaski thrusts in southwestern Virginia and northeastern Tennessee: Virginia Division of Mineral Resources Publication 23, part C, sheets 5 and 6.

-1985, Oil and gas possibilities in eastern Tennessee and southwestern Virginia, in Important regulatory considerations: Tennessee Division of Geology Information Circular 18 , p. $27-40$

Milici, R.C., and deWitt, Wallace, Jr., 1988, The Appalachian Basin, in Sloss, L.L., ed., Sedimentary cover-North American craton, United States: Boulder, Geological Society of America, The Geology of North America, v. D2, p. 427469.

Milici, R.C., and Gathright, T.M., 1985, Geologic features related to coal mine roof falls-A guide for miner training: Virginia Division of Mineral Resources Publication 55, 13 p.

Milici, R.C., Gathright, T.M., Miller, B.W., Gwin, M.R., and Stanley, C.B., 1986, Subtle bedding plane faults-a major factor contributing to coal mine roof falls in southwestern Virginia, in McDowell, R.C., and Glover, Lynn, III, eds., The Lowry volume-Studies in Appalachian geology: Virginia Tech Department of Environmental Sciences Memoir 3, p. 83-95.

Milici, R.C., and Roen, J.B., 1981, Stratigraphy of the Chattanooga Shale in the Newman Ridge and Clinch Mountain areas, Tennessee: Tennessee Division of Geology Report of Investigations $40,102 \mathrm{p}$.

Milici, R.C., and Statler, A.T., 1980, Fractures related to major thrusts-Possible analogues to tectonically fractured Chattanooga Shale in Tennessee: U.S. Department of Energy DOE/METC/SP-80/23, p. 157-166.

Miller, R.L., and Fuller, J.O., 1954, Geology and oil resources of the Rose Hill district-the fenster area of the Cumberland overthrust block-Lee County, Virginia: Virginia Geological Survey Bulletin 71, 383 p.

Nelson, W.A., 1925, The southern Tennessee coal field: Tennessee Division of Geology Bulletin 33A, 239 p.
Nolde, J.E., and Milici, R.C., in press, Stratigraphic and structural controls of natural gas production from the Berea Sandstone (Mississippian), southwestern Virginia [abs.]: American Association of Petroleum Geologists Abstracts with Program, 1993 Eastern Section meeting, Williamsburg, Virginia.

Orton, E., 1899, Petroleum and natural gas in New York: New York State Museum Bulletin, v. 6, no. 30, p. 496-497.

Patchen, D.G., and Hohn, M.E., 1993, Production and production controls in Devonian shales, West Virginia, in Roen, J.B., and Kepferle, R.C., eds., Petroleum geology of the Devonian and Mississippian black shale of eastern North America: U.S. Geological Survey Bulletin 1909, p. L1-L28.

Pederson, T.F., and Calvert, S.E., 1990, Anoxia versus productivity-What controls the formation of organic-carbon-rich sediments and sedimentary rocks?: American Association of Petroleum Geologists Bulletin, v. 74, p. 454-466.

Pederson, T.F., and Calvert, S.E., 1991, Anoxia versus productivity: What controls the formation of organic-carbon-rich sediments and sedimentary rocks? Reply: American Association of Petroleum Geologists Bulletin, v. 75, p. 500-501.

Pepper, J.F., deWitt, Wallace, Jr., and Demarest, D.F., 1954, Geology of the Bedford Shale and Berea Sandstone in the Appalachian Basin: U.S. Geological Survey Professional Paper $259,111 \mathrm{p}$.

Perroud, H., Van der Voo, R., and Bonhommet, N., 1984, Paleozoic evolution of the America plate on the basis of paleomagnetic data: Geology, v. 12, p. 579-582.

Pollastro, R.M., and Scholle, P.A., 1986, Exploration and development of hydrocarbons from low-permeability chalks-An example from the Upper Cretaceous Niobrara Formation, Rocky Mountain region, in Spencer, C.W., and Mast, R.F., eds., Geology of tight gas reservoirs: American Association of Petroleum Geologists Studies in Geology, no. 24, p. 129142.

Potter, P.E., Maynard, J.B., and Pryor, W.A., 1980, Final report of special geological, geochemical, and petrological studies of the Devonian shales in the Appalachian Basin: Cincinnati H. N. Fisk Laboratory of Sedimentology, Department of Geology, University of Cincinnati; prepared for U.S. Department of Energy Eastern Gas Shales project, contract DEAC21-76-MO5201.

Potter, P.E., DeReamer, J.H., Jackson, D.S., and Maynard, J.B., 1983, Lithologic and environmental atlas of Berea Sandstone (Mississippian) in the Appalachian Basin: Charleston, W. Va., Appalachian Geological Society Special Publication $1,157 \mathrm{p}$.

Price, L.C., and LeFever, J.A., 1992, Does Baaken horizontal drilling imply a huge oil-resource base in fractured shales?, in Schmoker, J.W., Coalson, E.B., and Brown, C.A., eds., Geological studies relevant to horizontal drilling-Examples from western North America: Rocky Mountain Association of Geologists, p. 199-214.

Provo, L.J., Kepferle, R.C., and Potter, P.E., 1978, Division of black shale in eastern Kentucky: American Association of Petroleum Geologists Bulletin, v. 62, no. 9, p. 1703-1713.

Roen, J.B., and Kepferle, R.C., eds., 1993, Petroleum geology of the Devonian and Mississippian black shales of eastern North America: U.S. Geological Survey Bulletin 1909, p. A1-N20. 
Russell, D.J., 1993, Stratigraphy of the Kettle Point Formation (Upper Devonian of southwestern Ontario, Canada)-Implications for depositional setting and resource potential, in Roen, J.B., and Kepferle, R.C., eds., Petroleum geology of the Devonian and Mississippian black shale of eastern North America: U.S. Geological Survey Bulletin 1909, p. E1-E11.

Schmoker, J.W., 1980, Organic content of Devonian shale in the western Appalachian Basin: American Association of Petroleum Geologists Bulletin, v. 64, p. 2156-2165.

1981, Determination of organic-matter content of Appalachian Devonian shales from gamma-ray logs: American Association of Petroleum Geologists Bulletin, v. 62, p. 12851298.

1989, Thermal maturity of the Anadarko Basin, in Johnson, K.S., ed., Anadarko Basin Symposium, 1988: Oklahoma Geological Survey Circular 90, p. 25-31.

1993, Use of formation density logs to determine organiccarbon content in Devonian shales of the western Appalachian Basin, and an additional example based on the Baaken Formation of the Willeston Basin, in Roen, J.B., and Kepferle, R.C., eds., Petroleum geology of the Devonian and Mississippian black shale of eastern North America: U.S. Geological Survey Bulletin 1909, p. J1-J14.

Shumaker, R.C., 1980, Porous fracture facies in Devonian shales of eastern Kentucky and West Virginia: U.S. Department of Energy DOE/METC/SP-80/23, p. 124-132.

1986, The effect of basement structure on sedimentation and detached structural trends within the Appalachian Basin, in McDowell, R.C., and Glover, Lynn III, eds., The Lowry volume-Studies in Appalachian geology: Virginia Tech Department of Geological Sciences Memoir 3, p. 67-81.
1993. Structural param that affect Devonian shale gas production in West Virginia and eastern Kentucky, in Roen, J.B., and Kepferle, R.C., eds., Petroleum geology of the Devonian and Mississippian black shales of eastern North America: U.S. Geological Survey Bulletin 1909, p. K1-K38.

Van Tyne, A.A., 1983, Natural gas potential of Devonian black shales of New York: Northeastern Geology, v. 5, no. 3/4, p. 209-216.

Wallace, L.G., and deWitt, Wallace, Jr., 1975, Thickness and extent of Devonian black shale facies, sheet 2 , in deWitt, Wallace, Jr., Perry, W.J., Jr., and Wallace, L.G., Oil and gas data from Devonian and Silurian rocks in the Appalachian Basin: U.S. Geological Survey Miscellaneous Investigations Map I$917 \mathrm{~B}$, scale $1,250,000$.

Weeks, J.D., 1886, Natural gas, in Mineral resources of the United States, Calendar Year 1885: U.S. Geological Survey, p. 155-179.

White, W.A., 1992, Displacement of salt by the Laurentide ice sheet: Quarternary Research, v. 38, p. 305-315.

Wilson, T.H., Dixon, J.D., Shumaker, R.C., and Wheeler, R.L., 1980, Fracture patterns observed in cores from the Devonian shale of the Appalachian Basin: U.S. Department of Energy DOE/METC/SP-80/23, p. 100-123.

Young, D.M., 1957, Deep drilling in the Cumberland overthrust block in southwestern Virginia: American Association of Petroleum Geologists Bulletin, v. 41, p. 2567-2573.

Zeilinski, R.E., and McIver, R.D., 1982, Resource and exploration assessment of the oil and gas potential in the Devonian gas shales of the Appalachian Basin: U.S. Department of Energy Morgantown Energy Technology Center MLM-MU82-61-0002, DOE/DP/0053-1125, 326 p. 


\title{
THE FUTURE OF ENERGY GASES
}

\author{
U.S. GEOLOGICAL SURVEY PROFESSIONAL PAPER 1570
}

\section{A Primer on Gas Hydrates}

\author{
By Keith A. Kvenvolden ${ }^{1}$
}

\section{CONTENTS}

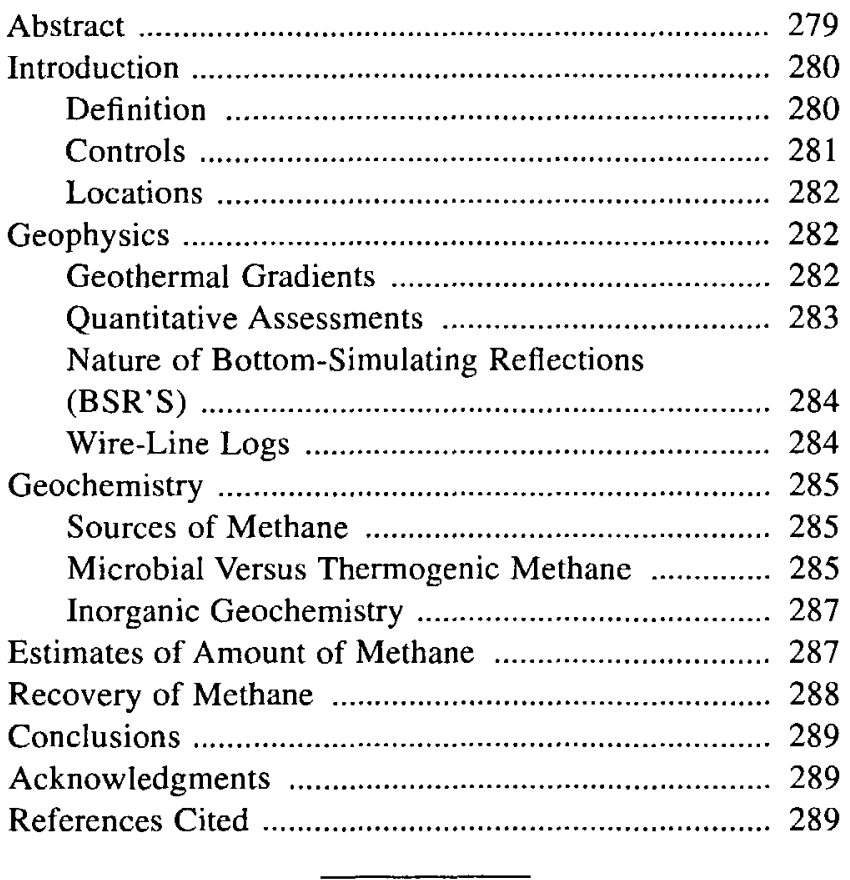

\begin{abstract}
Natural-gas hydrates are ice-like mixtures of gas and water in which the gas molecules, mainly methane, are trapped within a framework of cages, that is within a clathrate, of water molecules. Gas hydrates are stable under pressure and temperature conditions that occur worldwide in two
\end{abstract}

'U.S. Geological Survey, MS 999, 345 Middlefield Rd., Menlo Park, CA 94025. distinct locations: (1) in polar regions, where temperatures are cold enough for onshore and offshore permafrost to be present, and (2) in offshore sediment of outer continental and insular margins, where there are cold bottom-water temperatures and deep waters, exceeding 300 to $500 \mathrm{~m}$.

Samples of gas hydrates have been recovered in 14 areas of the world, and geophysical and geochemical evidence for them has been found in about 30 other areas. Many oceanic occurrences of gas hydrates are inferred, mainly on the basis of the appearance on marine seismicreflection profiles of a pronounced bottom-simulating reflection, commonly called a BSR. This reflection is inferred to coincide with the base of the gas-hydrate stability field. BSR's indicating gas hydrates are useful in estimating geothermal gradients and heat flow in oceanic sediments and, in conjunction with other seismic information, in assessing the amount of methane within and below the gas-hydrate interval. Wire-line well logs also provide a basis for estimating the quantity of methane.

Most methane in gas hydrates is microbial in origin, determined on the basis of molecular and isotopic compositions; however, thermogenic methane hydrates are known from the Gulf of Mexico and the Caspian Sea. During gas-hydrate formation, salt ions are excluded from the crystal structure; therefore pore-water freshening is observed with gas-hydrate occurrence. The total amount of methane in gas hydrates around the world likely exceeds $10^{19} \mathrm{~g}$ of methane carbon $\left(\sim 20 \times 10^{15} \mathrm{~m}^{3}\right.$ of methane gas $=7 \times 10^{5}$ trillion cubic feet $($ Tcf $)$ ). Because gas hydrates represent a large amount of methane within 2,000 $\mathrm{m}$ of the Earth's surface, they are considered to be an unconventional, potential source of fossil fuel. Because of unsolved technological problems in producing methane from gas hydrates, however, wide-scale recovery of methane from these substances probably will not take place until sometime in the 21 st century. 


\section{INTRODUCTION}

Chemists have known about gas hydrates since the early part of the 19th century (reviewed by Sloan, 1990). The petroleum industry became aware of these substances in the 1930's when gas-hydrate formation inside pipelines was discovered to cause blockage during transmission of natural gas (Hammerschmidt, 1934). In the 1960's naturally occurring gas hydrates were found in the Siberian Messoyakha gas field (reviewed by Makogon, 1981; Collett, this volume), and in the 1970's it was recognized that gas hydrates occur naturally not only in polar continental regions but also in the uppermost portion of deep-water sediment in oceanic regions at outer continental margins (Claypool and Kaplan, 1974). Kvenvolden and McMenamin (1980) reviewed the geological occurrences of natural gas hydrates. Since then it has become increasingly evident that naturally occurring gas hydrates are significant components of the shallow geosphere and a potential energy resource. The energy density (volume of methane at standard temperature and pressure (STP) per volume of rock) of methane hydrates is ten times greater than the energy density of other unconventional sources of gas, such as coalbeds, tight sands, black shales, and deep aquifers, and two to five times greater than the energy density of conventional natural gas within about $2,000 \mathrm{~m}$ of the surface (MacDonald, 1990a). Kvenvolden (in press) has recently reviewed societal aspects of gas hydrates, and the following discussion has been taken and modified from that report.

\section{DEFINITION}

Gas hydrates, also called gas clathrates, are naturally occurring solids composed of water molecules forming a rigid lattice of cages with most of the cages each containing a molecule of natural gas, mainly methane. Gas hydrates are essentially water clathrates of natural gas in which water crystallizes in the isometric crystallographic system rather than the hexagonal system of normal ice. Two structures, I and II, of the isometric (cubic) lattice are recognized in nature. Structure I (fig. 1) is most common; in this structure the cages are arranged in body-centered packing and are large enough to include methane, ethane, and other gas molecules of similar molecular diameters such as carbon dioxide and hydrogen sulfide. In structure II, the cages are arranged in diamond packing, resulting in some cages being large enough to include not only methane and ethane but also gas molecules as large as propane and isobutane (Sloan, 1990).

The maximum amount of methane that can occur in a methane hydrate is fixed by the clathrate or lattice-structure geometry. In a fully saturated structure I methane hydrate, one molecule of methane is present for approximately every six molecules of water. In theory, when appropriate

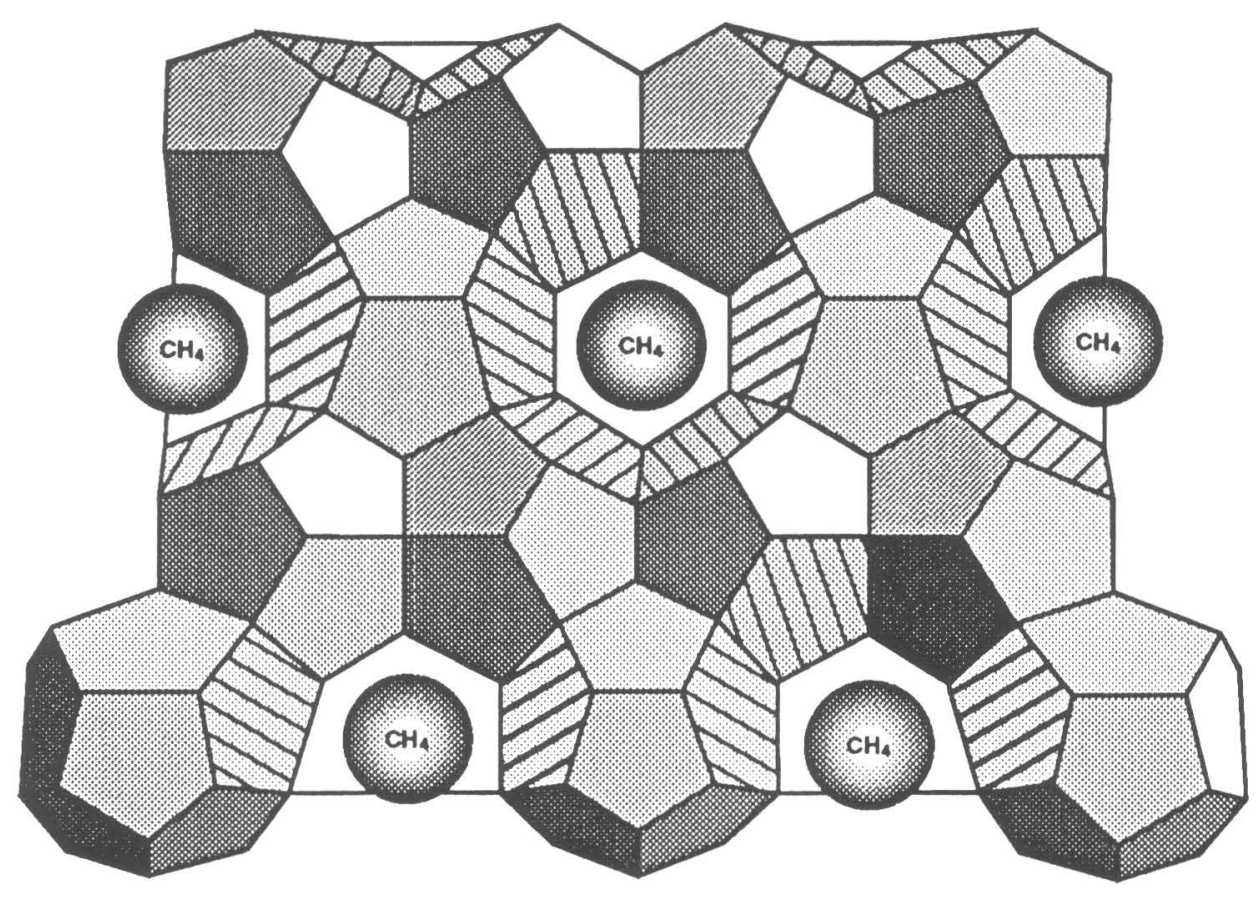

Figure 1. Gas hydrate structure. In this structure I methane hydrate, the rigid cages are composed of hydrogen-bonded water molecules. Each cage, both exposed and covered in this figure, can contain a methane molecule. Average cage diameter is about $8 \AA$. Modified from Hitchon (1974). 
hydrate expansion factors are considered, $1 \mathrm{~m}^{3}$ of methane hydrate can contain up to $164 \mathrm{~m}^{3}$ of methane gas at STP (fig. 2). Thus gas hydrates in shallow reservoirs less than about $1.5 \mathrm{~km}$ beneath the surface can have more methane per unit volume than can be contained as free gas in the same space (Hunt, 1979). This fact, along with the widespread occurrence of gas hydrates in the shallow geosphere, explains some of the serious interest in gas hydrates as a potential future energy resource.

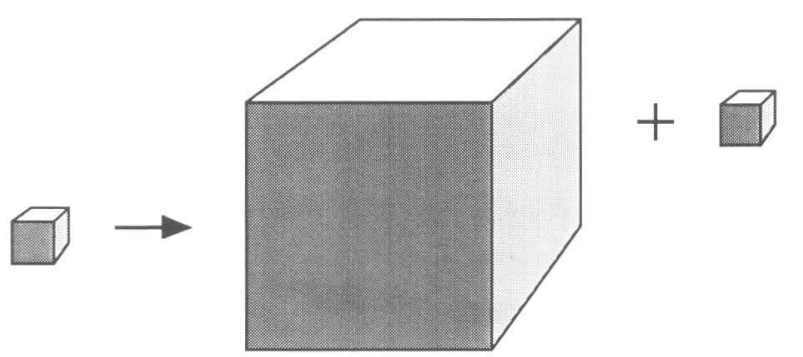
$1 \mathrm{~m}^{3}$
$164 \mathrm{~m}^{3}$
$0.8 \mathrm{~m}^{3}$
Gas Hydrate
Gas
Water

Figure 2. One $\mathrm{m}^{3}$ of gas hydrate yields $164 \mathrm{~m}^{3}$ of gas and 0.8 $\mathrm{m}^{3}$ of water at standard temperature and pressure (STP).

\section{CONTROLS}

The occurrence of gas hydrates in nature is controlled by conditions of temperature, pressure, and composition, as illustrated by means of a phase diagram (fig. 3). In the pressure-temperature domain of methane hydrates, the position of the hydrate-gas phase boundary is determined not only by the composition of the gas mixture, that is, the presence of gases other than methane, but also by the ionic impurities in the water. Because the exact composition of gas and water in sediment pore spaces is usually not known, a system of pure methane and pure water is commonly assumed to estimate the depth and temperature regime where naturally occurring gas hydrates are stable (Claypool and Kaplan, 1974).

Phase-boundary information (fig. 3) coupled with thermal information (fig. 4) suggests that the upper depth limit for methane hydrates is about $150 \mathrm{~m}$ in continental polar regions, where surface temperatures are below $0^{\circ} \mathrm{C}$. In oceanic sediment, gas hydrates occur where the bottom-water temperatures approach $0^{\circ} \mathrm{C}$ and water depths exceed about $300 \mathrm{~m}$. The lower limit of methane hydrate occurrence in sediment is determined by the geothermal gradient; the maximum lower limit is about $2,000 \mathrm{~m}$ below the solid surface, although the lower limit is typically much less depending on local conditions (fig. 4). Thus the occurrence of gas hydrates is restricted to the shallow geosphere.
One feature of gas hydrate occurrence that is not apparent from the phase diagram (figs. 3 and 4) is the amount of gas (methane) that is necessary for gas-hydrate formation. Gas hydrates will form with about 90 percent of the cages of the clathrate filled, that is with about 150 volumes of methane at STP per volume of water (Sloan, 1990). But methane solubility in seawater is very low, about 0.045 volumes of methane at STP per volume of water (Yamamoto and others, 1976). Thus the amount of methane required for gas hydrates greatly exceeds the solubility of methane in water. This requirement for large amounts of methane for gas-hydrate formation limits the regions on earth where gas hydrates can be expected to those regions having significant sources of methane.

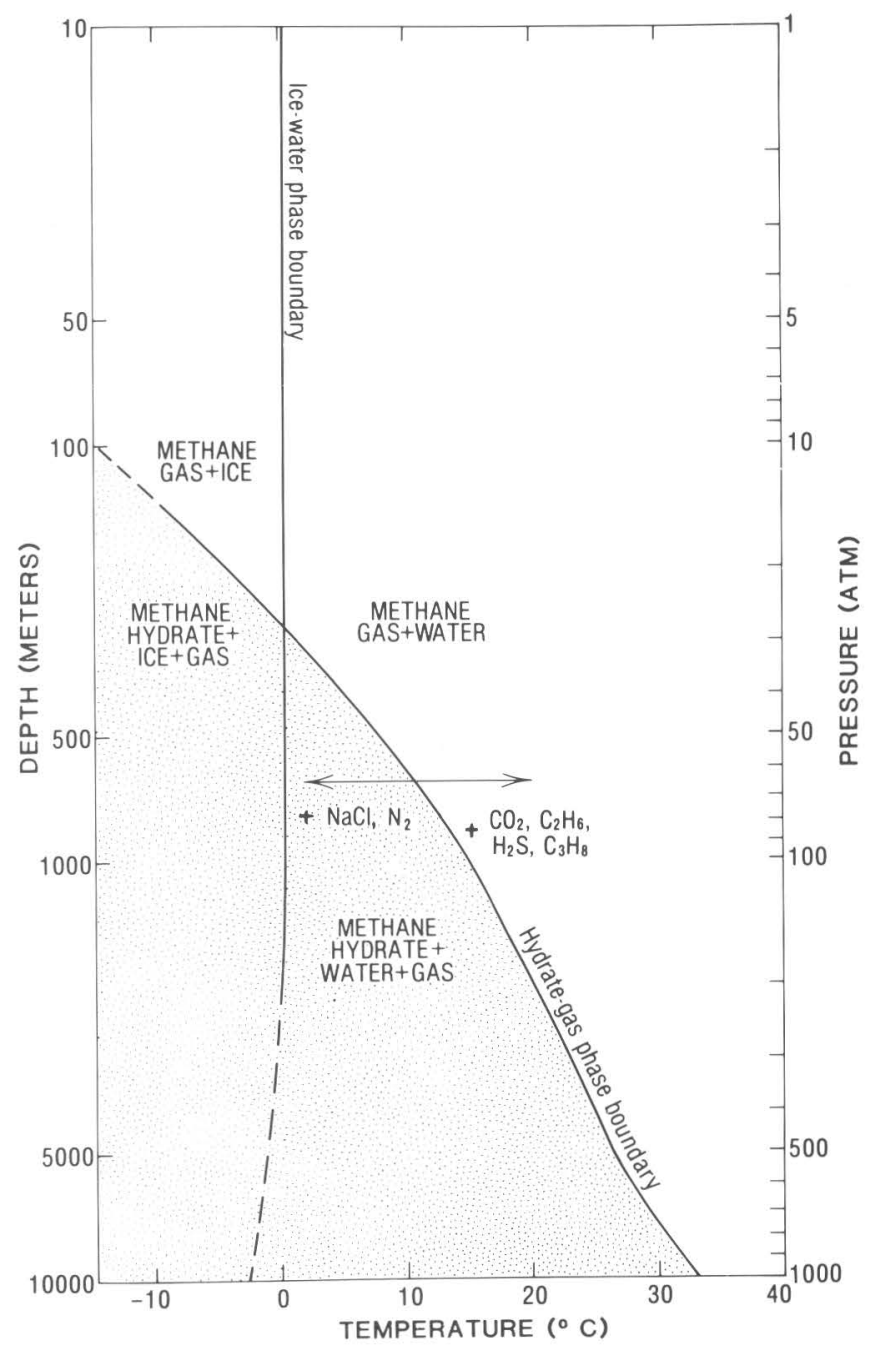

Figure 3. Phase diagram showing boundary between free methane gas (no pattern) and methane hydrate (pattern) for a pure-water and pure-methane system. Adding $\mathrm{NaCl}$ to water shifts boundary to the left. Adding $\mathrm{CO}_{2}, \mathrm{H}_{2} \mathrm{~S}, \mathrm{C}_{2} \mathrm{H}_{6}, \mathrm{C}_{3} \mathrm{H}_{8}$ to methane shifts boundary to right and thus increases area of hydrate stability field. Depth scale assumes a pore-water hydrostatic pressure gradient of $0.1 \mathrm{~atm} \mathrm{~m}^{-1}$. Modified from Katz and others (1959). 


\section{LOCATIONS}

Gas hydrates occur worldwide, but because of the pressure-temperature and gas-volume requirements, they are restricted to two regions, polar and deep oceanic. In polar regions, gas hydrates are usually associated with permafrost both onshore in continental sediment and offshore in sediment of the continental shelves. In deep oceanic regions, gas hydrates are found in outer continental margins in sediment of slopes and rises where cold bottom water is present. The worldwide occurrence of known and inferred gas hydrates is shown on figure 5. Samples of gas hydrates have been recovered on land in the West Prudhoe Bay oil field in Alaska (reviewed by Kvenvolden and McMenamin, 1980; Collett, this volume) and at 14 oceanic locations, providing irrefutable evidence of natural gas-hydrate occurrence (Kvenvolden and others, 1993). Deep-ocean drilling has recovered gas hydrates at nine locations (offshore from Peru, Costa Rica, Guatemala, Mexico, southeastern United States, western United States; two locations offshore from Japan; and in the Gulf of Mexico). Shallow sediment coring (using piston and gravity cores) has also recovered gas hydrates at six locations (Black Sea, Caspian Sea, offshore from northern California, northern Gulf of Mexico, and two locations in the Okhotsk Sea).

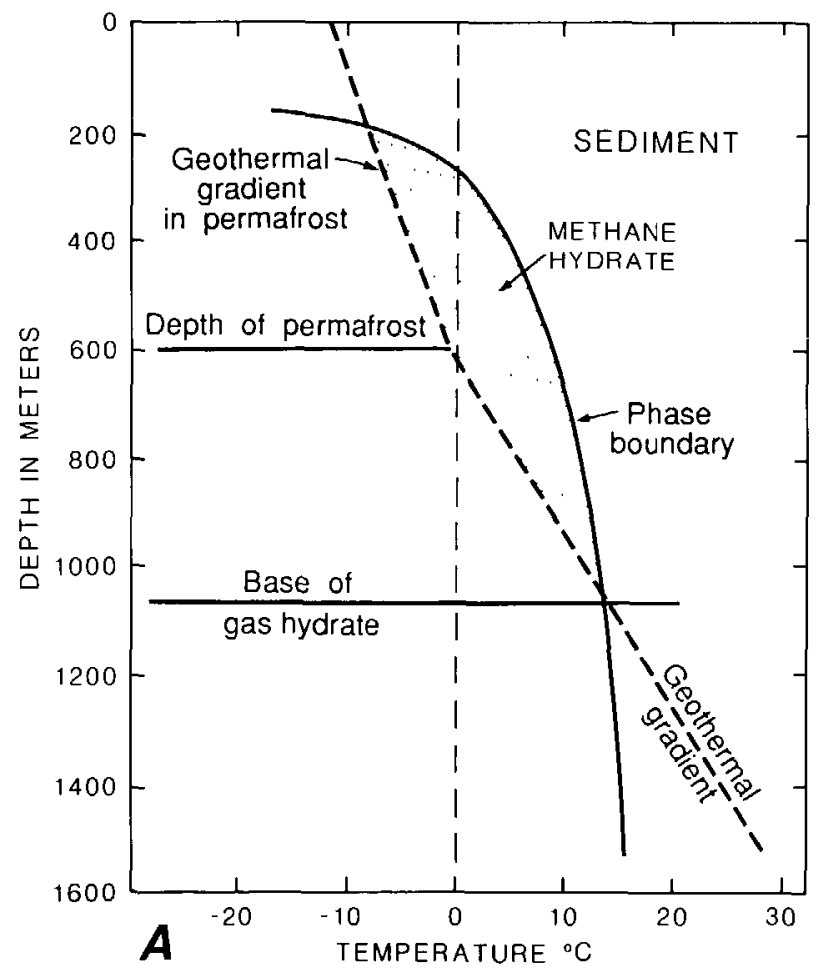

\section{GEOPHYSICS}

Most other oceanic occurrences of gas hydrates are inferred, mainly on the basis of the appearance on marine seismic-reflection profiles of a pronounced bottom-simulating reflection (BSR) (fig. 6). This reflection coincides with the depth predicted from the phase diagram as the base of the gas-hydrate stability zone (fig. 4). BSR's mark the interface between higher sonic velocity, hydrate-cemented sediment above and lower sonic velocity, uncemented sediment below. The seismic reflection from the base of a gashydrate zone is generally characterized by reflection polarity reversals (reflections opposite to those from the seafloor) and large vertical reflection coefficients, for example $-0.12 \pm 0.04$ for BSR's of the Blake Outer Ridge offshore from the southeastern United States (Shipley and others, 1979; Lee and others, this volume). Such negative reflection coefficients indicate a reflective interface between higher velocity strata overlying lower velocity strata.

\section{GEOTHERMAL GRADIENTS}

Bottom-water temperatures and the depths to gashydrate BSR's have been used in conjunction with gashydrate phase-boundary information (fig. 4) to estimate

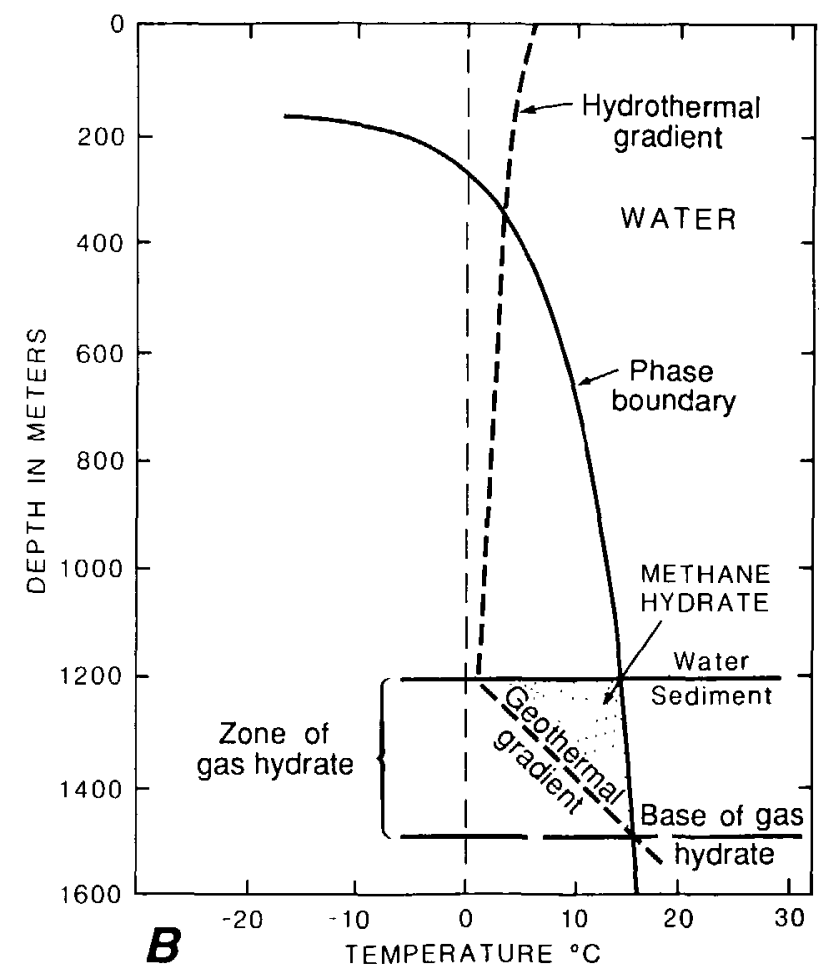

Figure 4. Examples of thermal gradients imposed on the gas-hydrate phase diagram (fig. 3), showing different depth-temperature zones for gas-hydrate occurrence. $A$, Conditions that are favorable for gas-hydrate formation where permafrost is present; $B$, Conditions in which gas hydrates are stable in outer continental margin sediments. From Kvenvolden and Grantz (1990). 


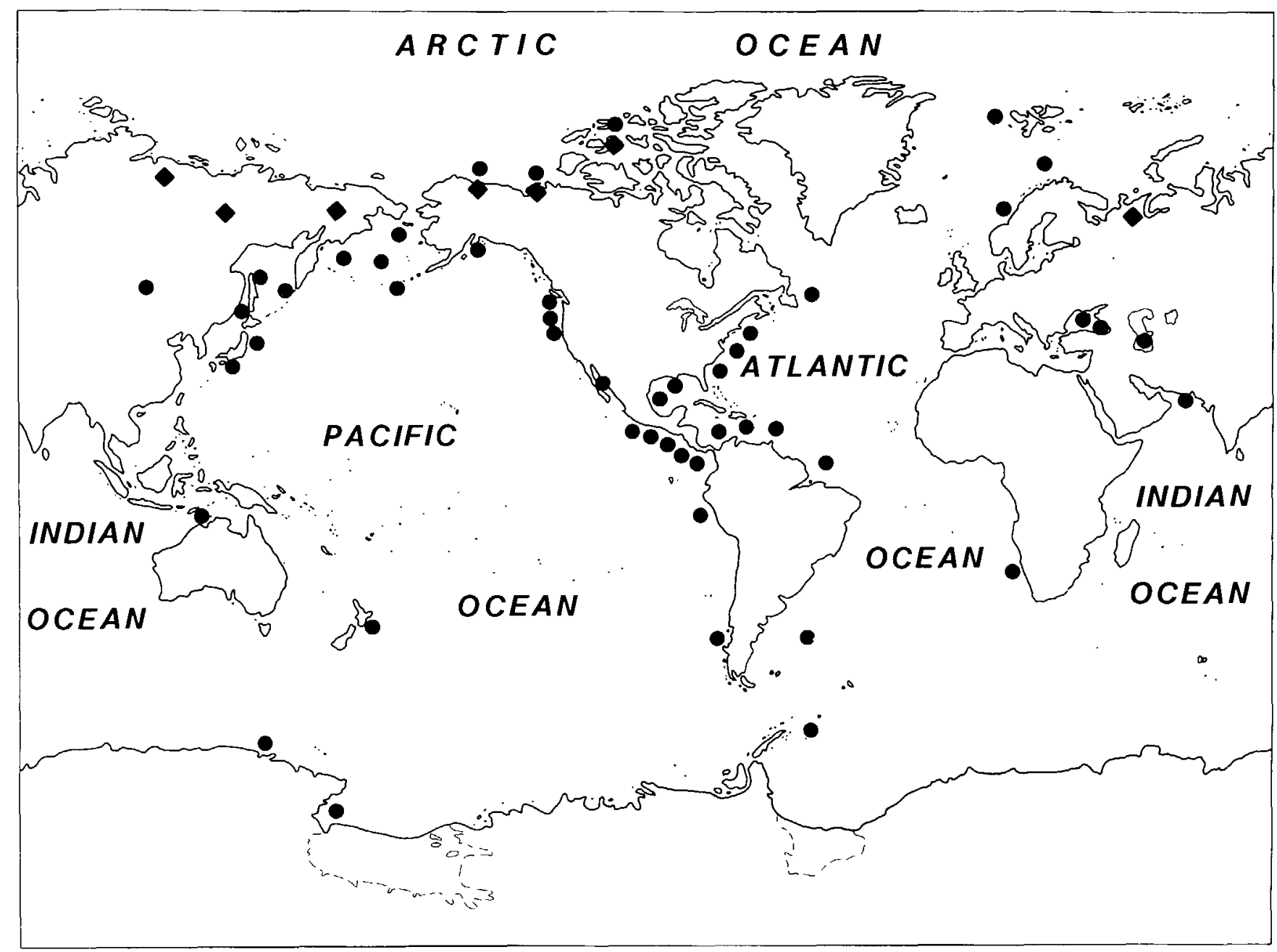

Figure 5. Worldwide locations of known and inferred gas hydrates in oceanic sediments (dots) and in regions of continental permafrost (diamonds). Dashed lines in Antarctica indicate continental edge of ice shelves. Modified from Kvenvolden (1988).

geothermal gradients and heat flow in oceanic sediment (Shipley and others, 1979; Yamano and others, 1982). This method has been applied to seismic data from the Blake Outer Ridge, around Central America, and in the Nankai Trough offshore from Japan. The estimated geothermal gradients and heat-flow values are consistent with results obtained by conventional means using downhole temperature and surface heat-flow measurements. An example of the use of the method comes from offshore Peru where geothermal gradients of 43 and $49.5^{\circ} \mathrm{C} / \mathrm{km}$ were estimated in two areas from BSR's (Kvenvolden and Kastner, 1990); these results are similar to those obtained by direct measurements (Yamano and Uyeda, 1990).

\section{QUANTITATIVE ASSESSMENTS}

Multichannel seismic reflection data have been used to analyze several aspects of the zone of gas-hydrate stability. For example, quantitative analyses of BSR's have been undertaken with reprocessed seismic records and synthetic seismograms to estimate the amount of gas hydrate at the BSR and the thickness of the underlying freegas zone for a site offshore from Peru (Miller and others, 1991). The results indicate that the BSR is laterally discontinuous. A free-gas zone 5.5 to $17 \mathrm{~m}$ thick beneath a zone where gas hydrate fills 10 percent of the porosity is estimated from BSR's of high amplitude. Where the BSR amplitude is low, the free-gas zone is much thinner than $5.5 \mathrm{~m}$ or is absent. In a seismic study of gas hydrates, Hyndman and Spence (1992) examined BSR's from offshore Vancouver Island in Canada using amplitude versus offset (AVO) and high-resolution velocity analyses as well as modeling of vertical incidence data. The results suggest that above the BSR is a 10 - to 30 -m-thick high-velocity layer with about 30 percent of its pore space filled with gas hydrate. Beneath the BSR there is no seismically detectable free gas. In this case the BSR records an interface between sediment with gas hydrate and sediment without gas hydrate. 


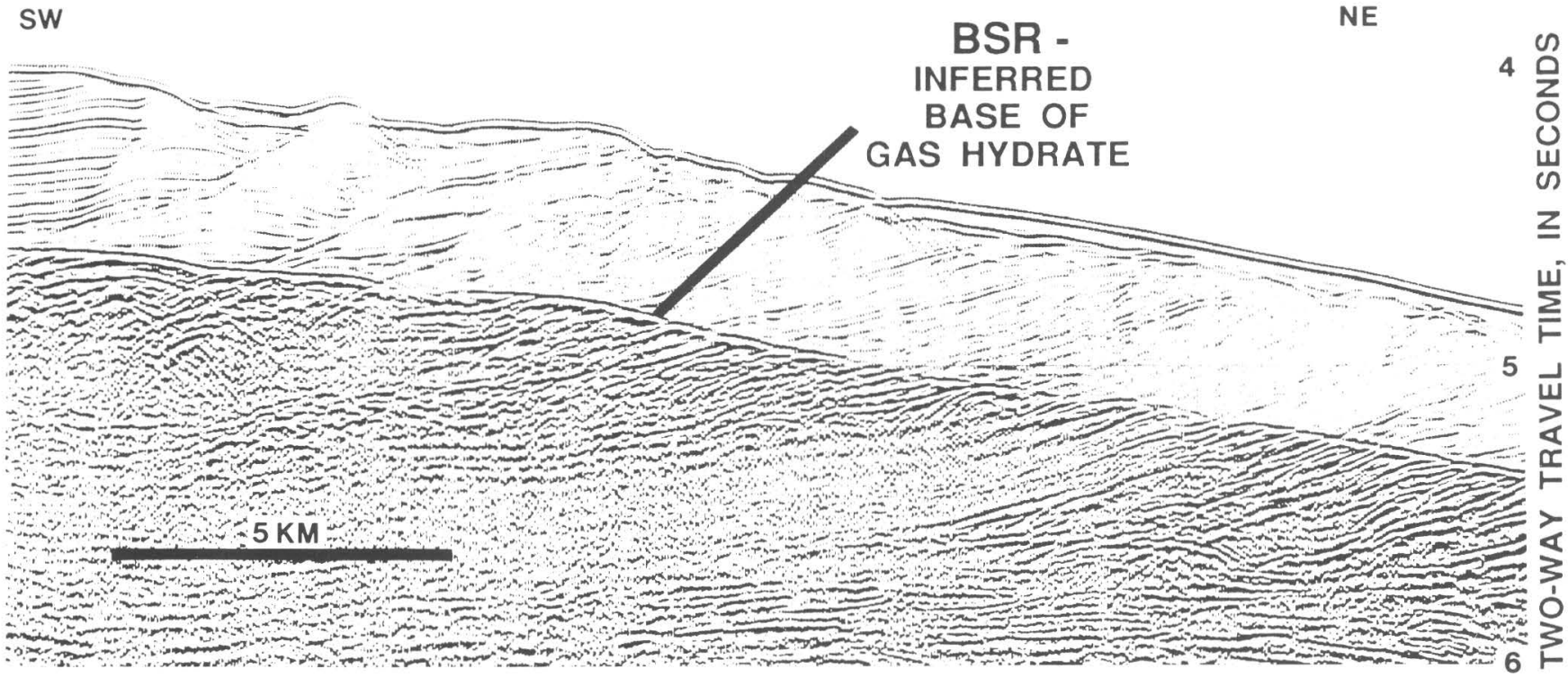

Figure 6. A 12-fold multichannel reflection profile from the crest and eastern flank of Blake Outer Ridge, offshore from southeastern United States. Strong bottom-simulating reflection (BSR) is inferred to represent base of gas-hydrate stability zone. Blanking of crosscutting strata above the BSR is likely due to masking by presence of gas hydrates. The well-defined, continuous BSR suggests that the gas hydrate here forms a seal that may be trapping free gas beneath the BSR. Modified from Shipley and others (1979).

\section{NATURE OF BOTTOM-SIMULATING REFLECTIONS (BSR'S)}

The presence or absence of free gas beneath BSR's is a controversial and as yet unresolved issue. Two models have been proposed to account for gas-hydrate formation and the development of BSR's. In the first, methane is assumed to be generated microbially from organic matter within the zone of gas-hydrate stability (Claypool and Kaplan, 1974). Gas-hydrate formation takes place concurrent with sedimentation. As the zone of methane hydrate thickens and deepens, its base eventually subsides into a temperature region where the gas hydrate is unstable. In this region free gas can occur, but this gas can migrate back into the overlying zone of gas hydrate stability if suitable migration pathways are available (Kvenvolden and Barnard, 1983a). A consequence of this model is that gas hydrates should occur throughout the zone of gas-hydrate stability and free gas may or may not be present beneath the BSR.

In the second model, gas hydrates are formed by the removal of methane from rising pore fluids as they pass from below into the gas-hydrate stability zone (Hyndman and Davis, 1992). This model postulates that most of the methane is generated microbially at depths below the stability zone but not at depths sufficient for the formation of thermogenic methane. A consequence of this model is that gas hydrates should be concentrated at the base of the stability zone near the BSR, and free gas is not to be expected beneath the BSR.

Tests of these models were possible on Ocean Drilling Program (ODP) Legs 141 (offshore from Chile) and 146 (offshore from Vancouver Island) where seismic re- flectors indicated by BSR's were purposely cored. Previously the coring of these kinds of reflectors during deepocean drilling had been avoided because of presumed safety hazards (Ocean Drilling Program, 1986). Unfortunately, results from Leg 141 are equivocal (Behrmann and others, 1992), and appropriate information from Leg 146 is not yet available.

\section{WIRE-LINE LOGS}

In addition to seismic data, geophysical information from wire-line well logs can be valuable in the detection and evaluation of gas-hydrate intervals (Kvenvolden and Grantz, 1990). Well logs for gas-hydrate studies include caliper, gamma ray, spontaneous potential, resistivity, sonic velocity, and neutron porosity (Goodman, 1980). Illustrated in figure 7 are the wire-line log responses, and a mud-gas $\log$, in one gas-hydrate-bearing interval drilled at the N.W. Eileen State No. 2 well on the North Slope of Alaska. The resistivity and sonic velocity responses have proved most useful in a comprehensive study of well-log data from 445 wells on the North Slope where six gas-hydrate-bearing intervals have been identified and mapped in 50 of these wells (Collett and others, 1988). A comparison between $\operatorname{logs}$ from the N.W. Eileen State No. 2 well and logs from Deep Sea Drilling Project (DSDP) Hole 570 located offshore from Guatemala showed similar characteristics and clearly defined the gas-hydrate zones (Mathews, 1986). Well logs provide a basis for estimating gas quantity, and, in conjunction with seismic data, hold the key to future worldwide gas-hydrate resource assessment. 

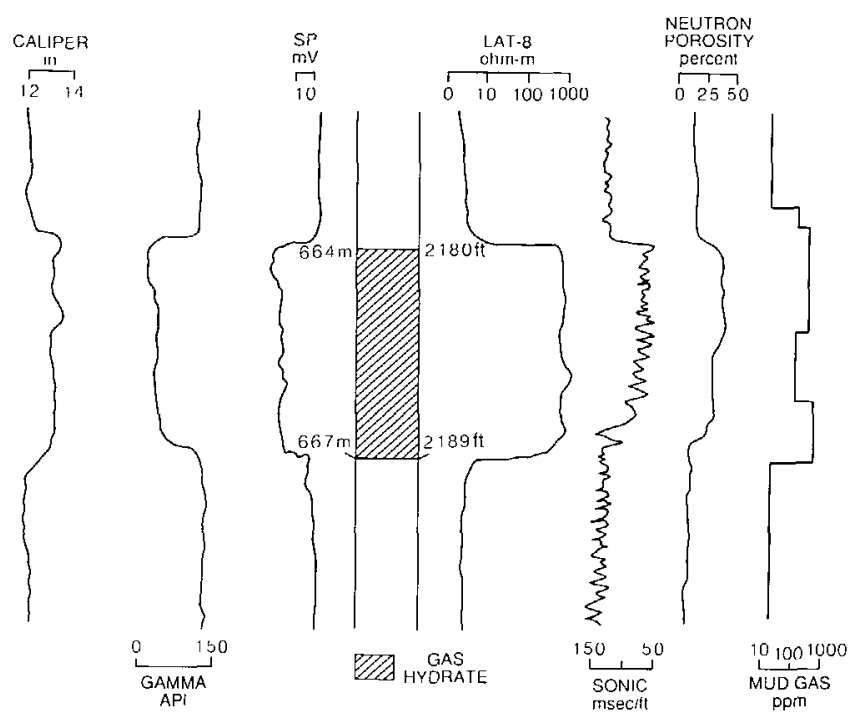

Figure 7. Comparison of wire-line logs (caliper, gamma-ray (GAMMA), spontaneous potential (SP), resistivity (LAT-8), sonic velocity (SONIC), and neutron porosity) and total mud-gas $\log$ for a gas-hydrate-containing interval $(664-677 \mathrm{~m})$ in the N.W. Eileen State No. 2 well on the North Slope of Alaska. Unit abbreviations: API, American Petroleum Institute; ft, feet; in, inches; $\mathrm{m}$, meters; msec/ft, milliseconds per foot; $\mathrm{mV}$, millivolts; ohm-m, ohm meters; ppm, parts per million. From Kvenvolden and Grantz (1990).

\section{GEOCHEMISTRY}

\section{SOURCES OF METHANE}

In both models for gas-hydrate formation discussed previously, the methane is considered to be mainly microbial in origin. This conclusion is based on geochemical investigations of recovered gas hydrates and of hydrocarbon gases from sediment sections known to contain gas hydrates, such as occur offshore from the southeastern United States, northern California, and Peru, and in the Black Sea and at some sites in the Gulf of Mexico (table 1). These investigations have shown that the molecular compositions of the hydrocarbon gases and the isotopic compositions of methane are consistent with results expected from microbial gas-generation processes. Methane in all of these investigations constitutes more than 99 percent of the hydrocarbon gas mixtures, and the isotopic composition of methane $\left(\delta^{13} \mathrm{C}\right)$ is usually lighter than -60 permil (parts per thousand) relative to the Peedee belemnite (PDB) standard. The molecular and isotopic ranges are diagnostic of gas of microbial origin (Bernard and others, 1976).

In a sedimentary section where methane is being microbially generated, there is a consistent relation between the carbon isotopic composition of methane (the product) and that of carbon dioxide (the immediate precursor), as illustrated in figure 8 . In this example from the Blake Outer Ridge (Galimov and Kvenvolden, 1983), carbon isotopic compositions of methane increase (become heavier) with depth from about -94 permil in the uppermost sediment to about -66 permil in the deepest sediment, reflecting a systematic but nonlinear depletion of ${ }^{12} \mathrm{C}$ with depth. The carbon isotopic compositions of carbon dioxide also increase with depth of sediment from about -25 permil to about -4 permil showing a depletion of ${ }^{12} \mathrm{C}$ that closely parallels the trend of isotopic compositions of methane. The magnitude and parallel distribution of carbon isotopic values for both methane and carbon dioxide are consistent with the concept that the formation of methane resulted from the microbial reduction of carbon dioxide derived from organic matter (Claypool and Kvenvolden, 1983). The results corroborate a microbial origin for methane in gas hydrates at this site. Other localities with similar depth trends in carbon isotopic compositions of methane and (or) carbon dioxide are offshore from Guatemala (Jeffrey and others, 1985) and offshore from Peru (Kvenvolden and Kastner, 1990) where gas hydrates have also been recovered in DSDP and ODP drilling, respectively.

\section{MICROBIAL VERSUS THERMOGENIC METHANE}

Methane in gas hydrates from the Gulf of Mexico (Pflaum and others, 1986; Brooks and others, 1986) is microbial at some sites and thermogenic at others (table 1).

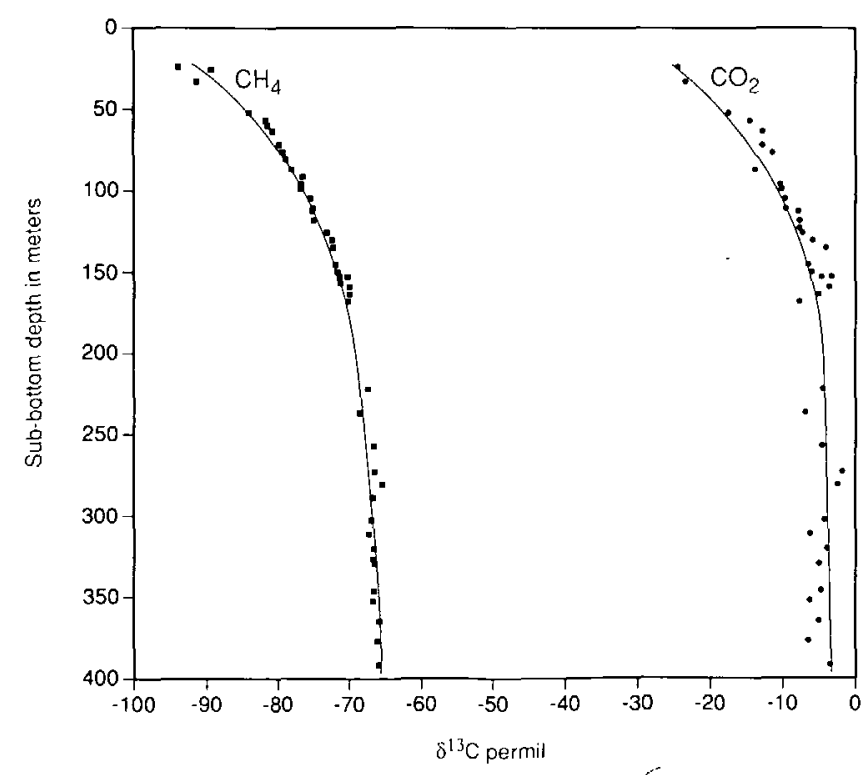

Figure 8. Distribution with depth of carbon isotopic compositions of methane (lefthand curve) and carbon dioxide (righthand curve) from site 533, DSDP Leg 75, Blake Outer Ridge, offshore southeastern United States. Modified from Galimov and Kvenvolden (1983). 
Table 1. Carbon isotopic compositions and concentrations of methane in natural-gas hydrates and hydratecontaining sediment.

[DSDP, Deep Sea Drilling Project; ODP, Ocean Drilling Program; do, ditto]

\begin{tabular}{|c|c|c|c|c|}
\hline Location & Type of sample & $\underset{\text { (percent) }}{\mathrm{CH}_{4}}$ & $\underset{\text { (permil) }}{\delta^{13} \mathrm{C}}$ & Reference \\
\hline \multicolumn{5}{|c|}{ Offshore southeastern United States, Blake Outer Ridge } \\
\hline DSDP Leg 11 & Sediment & $>99$ & -88 to -70 & Claypool and others (1973) \\
\hline DSDP Leg 76 & Sediment & $>99$ & -93.8 to -65.4 & $\begin{array}{l}\text { Kvenvolden and Barnard (1983b); } \\
\text { Galimov and Kvenvolden (1983) }\end{array}$ \\
\hline 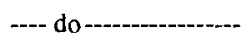 & Gas hydrate & $>99$ & -68.0 & Brooks and others $(1983)$ \\
\hline \multicolumn{5}{|c|}{ Offshore Peru, Peru-Chile Trench } \\
\hline ODP Leg 112 & Sediment & $>99$ & -79 to -55 & Kvenvolden and Kastner (1990) \\
\hline 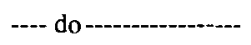 & Gas hydrate & $>99$ & $-65.0,-59.6$ & Kvenvolden and Kastner (1990) \\
\hline \multicolumn{5}{|c|}{ Offshore northern California } \\
\hline Eel River Basin & Gas hydrate & $>99$ & -69.1 to -57.6 & Brooks and others (1991) \\
\hline \multicolumn{5}{|c|}{ Gulf of Mexico } \\
\hline DSDP Leg 96 & Sediment & $>99$ & -73.7 to -70.1 & Pflaum and others (1986) \\
\hline ---- do--------------. & Gas hydrate & $>99$ & -71.3 & Pflaum and others (1986) \\
\hline Garden Banks & Gas hydrate & $>99$ & -70.4 & Brooks and others (1986) \\
\hline Green Canyon & Gas hydrate & $>99$ & $-69.2,-66.5$ & Brooks and others (1986) \\
\hline 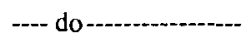 & Gas hydrate & $62,74,78$ & $-44.6,-56.5,-43.2$ & Brooks and others (1986) \\
\hline Mississippi Canyon & Gas hydrate & 97 & -48.2 & Brooks and others (1986) \\
\hline \multicolumn{5}{|c|}{ Offshore Guatemala, Middle America Trench } \\
\hline DSDP Leg 84 & Sediment & $>99$ & -71.4 to -39.5 & $\begin{array}{l}\text { Kvenvolden and McDonald (1985); } \\
\text { Jeffrey and others (1985) }\end{array}$ \\
\hline 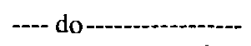 & Gas hydrate & $>99$ & -43.6 to -36.1 & Kvenvolden and others (1984) \\
\hline -...- do -................... & Gas hydrate & $>99$ & -46.2 to -40.7 & Brooks and others (1985) \\
\hline \multicolumn{5}{|c|}{ Eurasia } \\
\hline Black Sea & Gas hydrate & $>99$ & $-63.3,-61.8$ & Ginsburg and others (1990) \\
\hline Caspian Sea & Gas hydrate & 59 to 96 & -44.8 to -55.7 & Ginsburg and others (1992) \\
\hline
\end{tabular}

Samples of hydrate hydrocarbon gas from Garden Banks and Green Canyon contain more than 99 percent methane with carbon isotopic compositions lighter than -60 permil. In a different sample from Green Canyon and one from Mississippi Canyon the hydrate hydrocarbon gas is 62 to 78 percent methane, and this methane has carbon isotopic compositions ranging from -43.2 to -56.5 permil. Gas hydrates associated with mud volcanoes in the Caspian Sea contain hydrocarbon gases with 59 to 96 percent methane having carbon isotopic compositions of -44.8 to -57.3 permil. These samples fall within the molecular and isotopic compositional field diagnostic of thermogenic methane (Bernard and others, 1976).

Molecular and isotopic compositions of gases associated with gas hydrates found on DSDP Leg 84 offshore from Guatemala support either a microbial or thermal source for the methane (Kvenvolden and others, 1984). Hydrocarbon gases from cores of the deepest sediment samples and from dissociated gas hydrates all contain greater than 99 percent methane (Kvenvolden and McDonald, 1985). This observation suggests that the methane is microbial in origin. Many methane samples had carbon isotopic compositions lighter than -60 permil suggesting a microbial source, but at two sites, methane in sediments at depths below $210 \mathrm{~m}$ increased in carbon isotopic value to as heavy as about -40 permil; methane from a massive gas hydrate sample had a carbon isotopic composition of -44 permil (Jeffrey and others, 1985). A detailed study of the dissociation of this massive gas hydrate under controlled laboratory conditions showed car- 
bon isotopic compositions of methane ranging from -36.1 to -43.6 permil (Kvenvolden and others, 1984). These heavy carbon isotopic values are usually considered to reflect thermogenic gas.

The isotopically heavy methane found offshore from Guatemala was accompanied by isotopically very heavy carbon dioxide, +16.3 permil for gaseous carbon dioxide (Jeffrey and others, 1985) and +37 permil for total dissolved carbon dioxide (Claypool and others, 1985). The isotopically heavy methane could have been formed by microbial processes from the isotopically heavy carbon dioxide, similar to circumstances described previously for the Blake Outer Ridge. Alternatively, the isotopically heavy methane could have migrated up from deeper sediments where it was thermally derived from deeply buried organic matter. That is, deeply buried organic matter, experiencing temperatures from about $80^{\circ} \mathrm{C}$ to more than $150^{\circ} \mathrm{C}$, can be altered thermally to produce methane directly (Claypool and Kvenvolden, 1983). The association of isotopically heavy methane with isotopically heavy carbon dioxide could be coincidental or could be controlled by some unknown isotopic interaction between methane and carbon dioxide. The microbial explanation is preferred, but a thermal origin of the methane cannot be ruled out (Kvenvolden and others, 1984).

The ultimate source of hydrate methane is buried organic matter that can be altered microbially or thermally to produce methane. The amount and quality of organic matter present is critical to the methane generation process. Because gas-hydrate formation requires amounts of methane that greatly exceed the water solubility of methane, the amount of organic matter needed for gas-hydrate formation is very large. Observations of the present organic-matter content of gas-hydrate-containing sediments offshore from Guatemala suggest that 2.0 to 3.5 percent organic carbon is sufficient if only in-situ and not migrated methane is involved (Hesse and Harrison, 1981); on the Blake Outer Ridge, the present organic-matter content of sediment associated with gas-hydrate occurrence averages about 1 percent organic carbon (Kvenvolden and Barnard, 1983b). At the time of gas-hydrate formation, the organic carbon content in the zone of gas-hydrate stability was undoubtedly higher, perhaps double the present amounts.

\section{INORGANIC GEOCHEMISTRY}

During gas-hydrate formation, water molecules crystallize into a cubic lattice structure, and, as in the formation of normal hexagonal ice, the hydrate crystals exclude salt ions from the crystal structure. Measurements of chlorinity of pore-water samples recovered from gas-hydrate-bearing zones offshore from Guatemala ranged from 0.51 to 3.2 permil (Kvenvolden and McDonald, 1985) and from 1.8 to 8.2 permil for samples from offshore Peru (Kvenvolden and
Kastner, 1990). These samples, all of which were likely contaminated to varying degrees with seawater, had chlorinity values much less than the average seawater chlorinity of 19.8 permil. During DSDP Leg 67 drilling offshore from Guatemala, Hesse and Harrison (1981) first noticed that the chlorinities of pore-water samples in the gas-hydrate-bearing zones decreased significantly with depth from about 19 to 9 permil. Concurrently the oxygen isotopic composition $\left(\delta^{18} \mathrm{O}\right.$ relative to Standard Mean Ocean Water (SMOW)) of pore water increased with depth from near zero close to the sediment surface to values as large as +2.6 permil at depth. Oxygen isotopic fractionation of pore water apparently takes place during gas-hydrate formation, leading to ${ }^{18} \mathrm{O}$ enrichment with depth of pore fluids recovered after gashydrate dissociation. This same trend of oxygen isotopic compositions was observed in pore waters of gas-hydratebearing sediments recovered on ODP Leg 112 offshore from Peru (Kvenvolden and Kastner, 1990).

The trends of decreasing chlorinity with depth in gashydrate-bearing sediments as noticed on DSDP Leg 67 have been observed in the Blake Outer Ridge (DSDP Leg 76)(Kvenvolden and Barnard, 1983b; Jenden and Gieskes, 1983), offshore from Guatemala (DSDP Leg 84)(Kvenvolden and McDonald, 1985; Hesse and others, 1985), and offshore from Peru (ODP Leg 112)(Kvenvolden and Kastner, 1990). These chlorinity trends are derived to a large extent from the dissociation of gas hydrates during core recovery. The chloride concentrations are measured on mixtures composed of in-situ pore water and dissociated gas-hydrate water. Thus a progressive dilution artifact is produced in the pore water that can be squeezed from the sediment with increasing depths. Pore-water freshening is a useful signal of the presence of gas hydrates although it is not a unique signal. Freshwater migration in sediments near continents and clay mineral dewatering are also processes that can cause pore waters to have decreased chlorinities. However, where pore-water freshening is observed in sediments having large amounts of methane within the depth range of the gas-hydrate stability zone, gas hydrates are likely to be present.

\section{ESTIMATES OF AMOUNT OF METHANE}

Estimates of the amount of methane in gas hydrates are speculative and uncertain (Kvenvolden, 1988). Although it is generally known that gas hydrates occur worldwide (fig. 5), knowledge of their occurrence is incomplete, contributing to a wide range of estimates of the amount of methane in gas hydrates. The Potential Gas Committee (1981) has summarized such estimates. They reported ranges of methane values (reported as methane carbon) from a low of $7.5 \times 10^{15} \mathrm{~g}$ in Arctic permafrost regions to a high of $4.1 \times 10^{21} \mathrm{~g}$ in oceanic sediment. Current estimates of the amount of methane carbon in gas hydrates 
are in rough accord at $10 \times 10^{18} \mathrm{~g}$ (Kvenvolden, 1988) and $11.4 \times 10^{18} \mathrm{~g}$ (MacDonald, 1990b). The volume of methane at STP represented by $10^{19} \mathrm{~g}$ of methane carbon is equal to about $20 \times 10^{15} \mathrm{~m}^{3}$ or $6.6 \times 10^{5} \mathrm{Tcf}$ of methane gas. The relative magnitude of gas hydrates as a reservoir of organic carbon on the Earth is illustrated in figure 9. If these estimates of reservoir sizes are correct, then the amount of methane carbon in gas hydrates is a factor of two larger than the carbon present in known fossil fuel deposits (coal, oil, and natural gas).

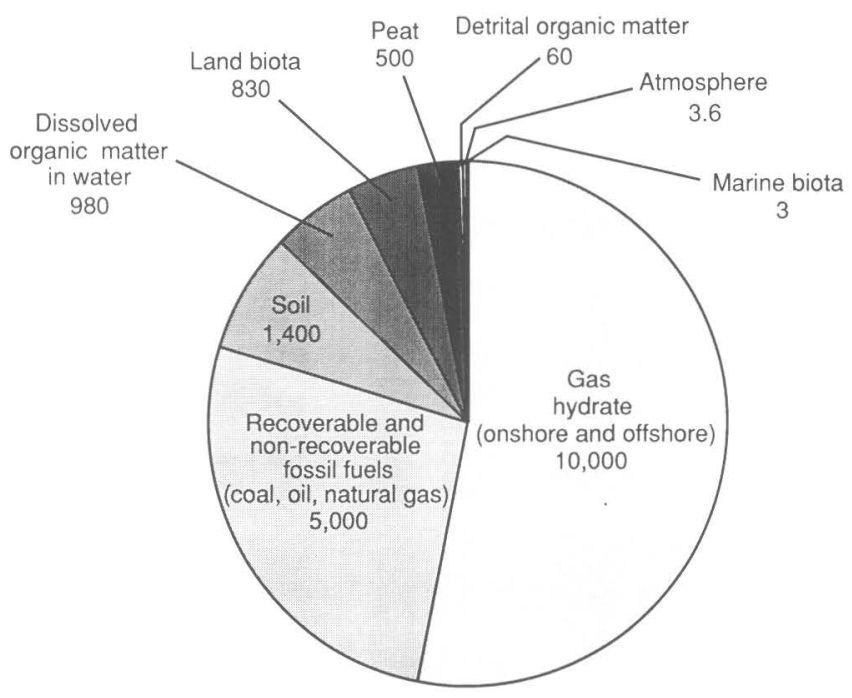

Figure 9. Distribution of organic carbon in the Earth, excluding dispersed organic carbon such as kerogen and bitumen, which equals nearly 1,000 times the total amount shown in the diagram. Numbers are in units of $10^{15} \mathrm{~g}$ of carbon. Modified from Kvenvolden (1988).

\section{RECOVERY OF METHANE}

Although naturally occurring gas hydrates were recognized in the 1960's, the gas industry has been slow to develop methods to recover methane from these substances. Three principal methods are being considered: thermal stimulation, depressurization, and inhibitor injection (Holder and others, 1984). In thermal stimulation, the gashydrate-bearing strata are heated in order to increase the local temperature enough to cause gas hydrates to dissociate. In depressurization, the pressure in the gas-hydrate deposit is lowered by pumping to cause gas-hydrate dissociation; heat for the depressurization process is provided by the natural geothermal heat flow. Injection of inhibitors, that is, agents such as methanol that cause gas hydrates to dissociate, shifts the pressure-temperature equilibrium (phase boundary) so that the gas hydrates are no longer stable at in-situ pressure-temperature conditions. Of these three production methods, depressurization combined with hot-water injection appears to be the most practical where free gas is trapped beneath the gas hydrate (Holder and others, 1984). That free gas is trapped beneath the gas hydrate has yet to be established with certainty as discussed previously. Gas hydrates will become a potential energy resource when it can be shown that the energy required to release methane from the hydrate itself is significantly less than the thermal energy of the methane that can be recovered from the dissociated gas-hydrate deposits. Circulation of warm surface water into gas-hydrate deposits and horizontal drilling techniques provide possible future approaches to the exploitation of hydrated methane.

The production of methane from gas hydrates requires that the deposit occur in geologic contexts wherein the elements of a conventional gas deposit are present; that is, in association with a reservoir of adequate porosity and permeability, with a methane source, and with a seal to form a trap. Dissociated gas hydrate can serve as one source of methane; migrated methane from below the gashydrate zone is another possible source. The ability of the gas-hydrate to act as a seal, however, has not been well established. Miller and others (1991) and Lee and others (this volume) present geophysical evidence from the Blake Outer Ridge that suggests gas hydrates are trapping gas beneath the BSR (fig. 6). Examples of possible traps caused by gas hydrates are shown in figure 10 . These examples assume that the gas-hydrate-containing interval is impermeable and that free gas can be trapped. The free gas below the gas hydrate has migrated up from depth and can be from both microbial and thermal sources. As free gas (methane) is removed by production and pressure is reduced, the gas-hydrate seal will begin to decompose, providing more producible methane from the hydrated sediments. Thus the seal becomes a source. Two of the trapping situations (figs. 10A, 10C) in figure 10 are in effect structural, caused by the domal or anticlinal shapes of the gas-hydrate layer. The other trap (fig. 10B) is stratigraphic, where gas-bearing strata are sealed at their updip ends by the presence of gas hydrates (Dillon and others, 1980).

Development of the Messoyakha gas field in western Siberia during the past 25 years has shown that methane can be recovered from naturally occurring gas hydrates (Makogon, 1981; Collett, this volume), but the methanol injection methods used for production proved to be prohibitively expensive. Recovery of gas hydrates in pressurized core barrels at the Arco-Exxon N.W. Eileen State No. 2 wildcat well on the North Slope of Alaska confirmed the presence of gas hydrates in the region of the Prudhoe Bay and Kuparuk River oil fields (Kvenvolden and McMenamin, 1980). It has been estimated that about $1.1 \times 10^{12}$ $\mathrm{m}^{3}$ of methane $\left(440 \times 10^{12} \mathrm{~g}\right.$ methane carbon) are present in gas hydrates of this region (Collett, 1992). This amount of methane is about 1.4 times the methane estimated to be in conventional reservoirs in the same region, but is only 9 
percent of the estimated conventional North American gas reserves (fig. 11). If methane from gas hydrates is ever to be recovered commercially in the U.S., larger accumulations will have to be identified and exploited. Initial production, however, is likely to come from the North Slope of Alaska where the industrial infrastructure for handling gas is already in place. Methane first produced from gas hydrates on the North Slope will likely be used for repressurization of waning oil fields rather than as a source of fuel. Although methane from gas hydrates should be considered a potential energy resource, wide-scale recovery of

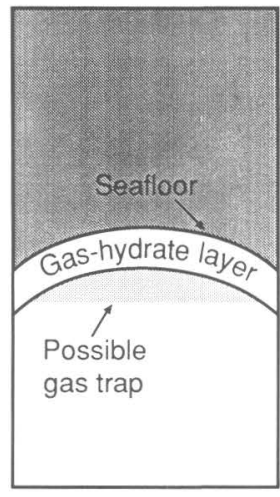

A

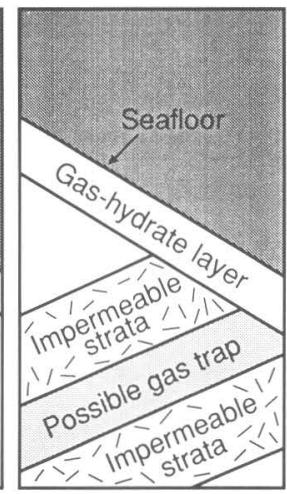

B

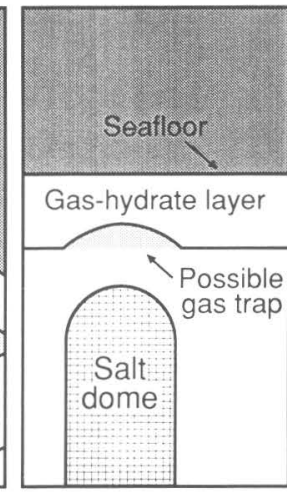

C
Figure 10. Schematic diagrams of geological situations in which gas hydrates serve as seals forming traps for methane. Developed from Dillon and others (1980). A, Gas hydrate layer forms anticline-like structure, trapping free methane below. $B$, Gas-hydrate layer seals methane-bearing strata at their updip ends. $C$, Base of gas-hydrate layer has migrated upward in response to the changed geothermal gradient caused by the emplacement of the salt dome, forming a gas trap.

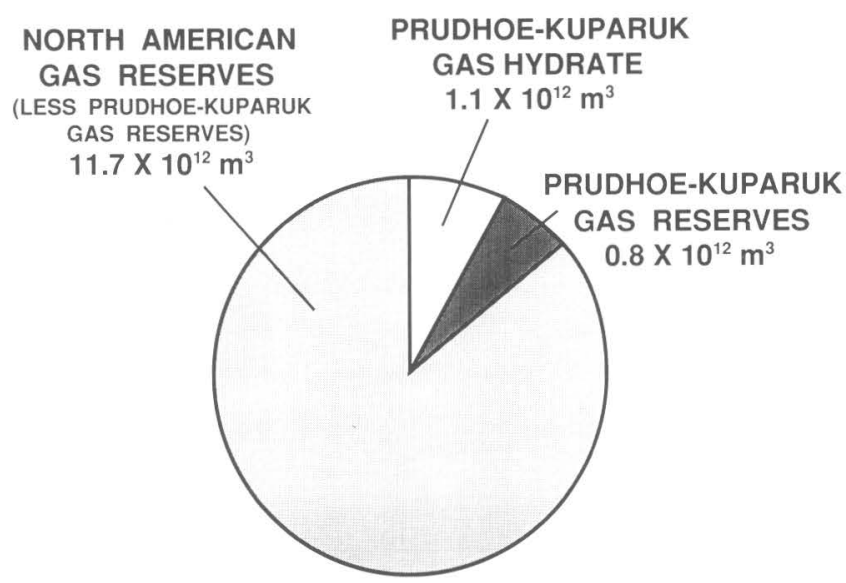

Figure 11. Comparison of the amount of methane estimated to be present in gas hydrate in the region of the Prudhoe Bay and Kuparuk River (Alaska) oil fields with the amount of methane estimated to be present in conventional reservoirs in the same region and in North America. methane from gas hydrates will probably not be accomplished until the 21st century (Sloan, 1990).

\section{CONCLUSIONS}

From a geologic perspective, gas hydrates are an important feature of the shallow geosphere. If current estimates are correct, gas hydrates contain more potential fossil fuel energy than occurs in conventional oil, gas, and coal deposits. Uncertain, however, is the proportion of this potential energy source that can actually be exploited. Because of unsolved technological problems in producing methane from gas hydrates, wide-scale recovery of methane from these substances probably will not take place until sometime in the 21 st century.

\section{ACKNOWLEDGMENTS}

I thank D.W. Scholl and R.E. Kayen for their reviews, and S.R. Vath and T.D. Lorenson for their assistance in the preparation of figures.

\section{REFERENCES CITED}

Behrmann, J.H., Lewis, S.D., Musgrave, R.J., and others, 1992, Proceedings of the Ocean Drilling Program, Initial Reports, v. 141: College Station, Texas, Ocean Drilling Program, $708 \mathrm{p}$.

Bernard, B.B., Brooks, J.M., and Sackett, W.M., 1976, Natural gas seepage in the Gulf of Mexico: Earth and Planetary Science Letters, v. 31, p. 48-54.

Brooks, J.M., Barnard, L.A., Wiesenburg, D.A., Kennicutt II, M.C., and Kvenvolden, K.A., 1983, Molecular and isotopic compositions of hydrocarbons at site 533, Deep Sea Drilling Project Leg 76, in Sheridan, R.E., Gradstein, F., and others, eds., Initial Reports of the Deep Sea Drilling Project, v. 67: Washington, D.C., U.S. Government Printing Office, p. 377-384.

Brooks, J.M., Cox, H.B., Bryant, W.R., Kennicutt II, M.C., Mann, R.G., and McDonald, T.J., 1986, Association of gas hydrates and oil seepage in the Gulf of Mexico: Organic Geochemistry, v. 10, p. 221-234.

Brooks, J.M., Field, M.E., and Kennicutt II, M.C., 1991, Observations of gas hydrates in marine sediments, offshore northern California: Marine Geology, v. 96, p. 103-108.

Brooks, J.M., Jeffrey, A.W.A., McDonald, T.J., Pflaum, R.C., and Kvenvolden, K.A., 1985, Geochemistry of hydrate gas and water from site 570, Deep Sea Drilling Project Leg 84, in von Huene, R., Aubouin, J., and others, eds., Initial Reports of the Deep Sea Drilling Project, v. 84: Washington, D.C., U.S. Government Printing Office, p. 699-703.

Claypool, G.W., and Kaplan, I.R., 1974, The origin and distribution of methane in marine sediments, in Kaplan, I.R., ed., Natural gases in marine sediments: New York, Plenum Press, p. 99-139. 
Claypool, G.W., and Kvenvolden, K.A., 1983, Methane and other hydrocarbon gases in marine sediment: Annual Review of Earth and Planetary Sciences, v. 11, p. 299-327.

Claypool, G.W., Presley, B.J., and Kaplan, I.R., 1973, Gas analyses in sediment samples from Legs 10, 11, 13, 14, 15, 18, and 19, in Scholl, D.W., and others, eds., Initial Reports of the Deep Sea Drilling Project, v. 19: Washington, D.C., U.S. Government Printing Office, p. 879-884.

Claypool, G.W., Threlkeld, C.N., Mankewicz, P.N., Arthur, M.A., and Anderson, T.A., 1985, Isotopic composition of interstitial fluids and origin of gases in sediments of the Middle America Trench, DSDP Leg 84, in von Huene, R., Aubouin, J., and others, eds., Initial Reports of the Deep Sea Drilling Project, v. 84: Washington, D.C., U.S. Government Printing Office, p. 683-691.

Collett, T.S., 1992, Potential of gas hydrates outlined: Oil and Gas Journal, v. 90, no. 25, p. 84-87.

Collett, T.S., Bird, K.J., Kvenvolden, K.A., and Magoon, L.B., 1988, Geologic interrelations relative to gas hydrates within the North Slope of Alaska: U.S. Geological Survey OpenFile Report 88-389, 150 p.

Dillon, W.P., Grow, J.A., and Paull, C.K., 1980, Unconventional gas hydrate seals may trap gas off southeast U.S.: Oil and Gas Journal, v. 78, no. 1, p. 124-130.

Galimov, E.M., and Kvenvolden, K.A., 1983, Concentrations and carbon isotopic compositions of $\mathrm{CH}_{4}$ and $\mathrm{CO}_{2}$ in gas from sediments of the Blake Outer Ridge, Deep Sea Drilling Project Leg 76, in Sheridan, R.E., Gradstein, F., and others, eds., Initial Reports of the Deep Sea Drilling Project, v. 76: Washington, D.C., U.S. Government Printing Office, p. 403407.

Ginsburg, G.D., Guseynov, R.A., Dadashev, A.A., Ivanov, G.A., Kazantsev, S.A., Solov'yev, V.A., Telepnev, E.V., AskeriNasirov, R. Ye., Yesikov, A.D., Mal'tseva, V.I., Mashirov, Yu. G., and Shabayeva, I. Yu., 1992, Gas hydrates of the southern Caspian: International Geology Review, v. 34, p. 765-782.

Ginsburg, G.D., Kremlev, A.N., Grigor'ev, M.N., Larkin, G.V., Pavlenkin, A.D., and Saltykova, N.A., 1990, Filtrogenic gas hydrates in the Black Sea: Soviet Geology and Geophysics (Allerton Press), v. 31, no. 3, p. 8-16.

Goodman, M.A., 1980, Insitu gas hydrates-Past experience and exploitation concepts: Proceedings 1st International Gas Research Conference, Chicago, Illinois, p. 376-391.

Hammerschmidt, E.G., 1934, Formation of gas hydrates in natural gas transmission lines: Industrial Engineering Chemistry, v. 26 , p. $851-855$.

Hesse, R., and Harrison, W.E., 1981, Gas hydrates (clathrates) causing pore-water freshening and oxygen isotope fractionation in deep-water sedimentary sections of terrigenous continental margins: Earth and Planetary Science Letters, v. 55, p. 453-562.

Hesse, R., Lebel, J., and Gieskes, J.M., 1985, Interstitial water chemistry of gas-hydrate-bearing sections on the Middle America Trench slope, Deep Sea Drilling Project Leg 84, in von Huene, R., Aubouin, J., and others, eds., Initial Reports of the Deep Sea Drilling Project, v. 84: Washington, D.C., U.S. Government Printing Office, p. 727-736.

Hitchon, B., 1974, Occurrence of natural gas hydrates in sedimentary basins, in Kaplan, I.R., ed., Natural gases in marine sediments: New York, Plenum Press, p. 195-225.
Holder, G.D., Kamath, V.A., and Godbole, S.P., 1984, The potential of natural gas hydrates as an energy resource: Annual Review of Energy, v. 9, p. 427-445.

Hunt, J.M., 1979, Petroleum geochemistry and geology: San Francisco., W.H. Freeman, 617 p.

Hyndman, R.D., and Davis, E.E., 1992, A mechanism for the formation of methane hydrate and seafioor bottom-simulating reflectors by vertical fluid expulsion: Journal of Geophysical Research, v. 97, no. B5, p. 7025-7041.

Hyndman, R.D., and Spence, G.D., 1992, A seismic study of methane hydrate marine bottom simulating reflectors: Journal of Geophysical Research, v. 97, no. B5, p. 6683-6698.

Jeffrey, A.W.A., Pflaum, R.C., McDonald, T.J., Brooks, J.M., and Kvenvolden, K.A., 1985, Isotopic analysis of core gases at sites 565-570, Deep Sea Drilling Project Leg 84, in von Huene, R., Aubouin, J., and others, eds., Initial Reports of the Deep Sea Drilling Project, v. 84: Washington, D.C., U.S. Government Printing Office, p. 719-726.

Jenden, P.D., and Gieskes, J.M., 1983, Chemical and isotopic compositions of interstitial water from Deep Sea Drilling Project sites 533 and 534, in Sheridan, R.E., Gradstein, F., and others, eds., Initial Reports of the Deep Sea Drilling Project, v. 76: Washington, D.C., U.S. Government Printing Office, p. 453-461.

Katz, D.L., Cornell, D., Kobayashi, R., Poettmann, F.H., Vary, J.A., Elenblass, J.R., and Weinaug, C.F., 1959, Handbook of natural gas engineering: New York, McGraw Hill, 802 p.

Kvenvolden, K.A., 1988, Methane hydrate-A major reservoir of carbon in the shallow geosphere?: Chemical Geology, v. 71, p. $41-51$.

- in press, Gas hydrates-Geological perspective and global change: Reviews of Geophysics.

Kvenvolden, K.A., and Barnard, L.A., 1983a, Hydrates of natural gas in continental margins, in Watkins, J.S., and Drake, C.L., eds., Studies in continental margin geology: American Association of Petroleum Geologists Memoir 34, p. 631640 .

1983b, Gas hydrates of the Blake Outer Ridge, Site 533, Deep Sea Drilling Project Leg 76, in Sheridan, R.E., Gradstein, F., and others, eds., Initial Reports of the Deep Sea Drilling Project, v. 76: Washington, D.C., U.S. Government Printing Office, p. 353-365.

Kvenvolden, K.A., Claypool, G.E., Threlkeld, C.N., and Sloan, E.D., 1984, Geochemistry of a naturally occurring massive marine gas hydrate: Organic Geochemistry, v. 6, p. 703-713.

Kvenvolden, K.A., Ginsburg, G.D., and Solovyev, V.A., 1993, Worldwide distribution of subaquatic gas hydrates: GeoMarine Letters, v. 13, p. 32-40.

Kvenvolden, K.A., and Grantz, A., 1990, Gas hydrates of the Arctic Ocean region, in Grantz, A., Johnson, L., and Sweeney, J.F., eds., The Arctic Ocean region: Boulder, Colorado, Geological Society of America, The Geology of North America, v. L, p. 539-549.

Kvenvolden, K.A., and Kastner, M., 1990, Gas hydrates of the Peruvian outer continental margin, in Suess, E., von Huene, R., and others, eds., Proceedings of the Ocean Drilling Program, scientific results, v. 112: College Station, Texas, Ocean Drilling Program, p. 517-526.

Kvenvolden, K.A., and McDonald, T.J., 1985, Gas hydrates of the Middle America Trench-Deep Sea Drilling Project Leg 
84, in von Huene, R., Aubouin, J., and others, eds., Initial Reports of the Deep Sea Drilling Project, v. 84: Washington, D.C., U.S. Government Printing Office, p. 667-682.

Kvenvolden, K.A., and McMenamin, M.A., 1980, Hydrates of natural gas-A review of their geologic occurrence: U.S. Geological Survey Circular 825, $11 \mathrm{p}$.

MacDonald, G.T., 1990a, The future of methane as an energy resource: Annual Review of Energy, v. 15, p. 53-83.

$-1990 \mathrm{~b}$, Role of methane clathrates in past and future climates: Climatic Change, v. 16, p. 247-281.

Mathews, M., 1986, Logging characteristics of methane hydrate: The Log Analyst, v. 27, no. 3, p. 26-63.

Makogon, Yu. F., 1981, Hydrates of natural gas: Tulsa, Okla., Pennwell Publishing Company, 237 p.

Miller, J.J., Lee, M.W., and von Huene, R., 1991, An analysis of a seismic reflection from the base of a gas hydrate zone, offshore Peru: American Association of Petroleum Geologists Bulletin, v. 75, p. 910-924.

Ocean Drilling Program, 1986, Guidelines for pollution prevention and safety: JOIDES Journal, v. 12 (Special Issue 5), 40 p.

Pflaum, R.C., Brooks, J.M., Cox, H.B., Kennicutt II, M.C., and Sheu, D-D., 1986, Molecular and isotopic analysis of core gases and gas hydrates, Deep Sea Drilling Project Leg 96, in Bouma, A.H., Coleman, J.M., Meyer, A.W., and others, eds., Initial Reports of the Deep Sea Drilling Project, v. 96:
Washington, D.C., U.S. Government Printing Office, p. 781784.

Potential Gas Committee, 1981, Potential supply of natural gas in the United States (as of December 31, 1980): Golden, Colorado, Potential Gas Agency, Colorado School of Mines, $119 \mathrm{p}$.

Shipley, T.H., Houston, M.H., Buffler, R.T., Shaub, F.J., McMillen, K.J., Ladd, J.W., and Worzel, J.L., 1979, Seismic reflection evidence for the widespread occurrence of possible gas-hydrate horizons on continental slopes and rises: American Association of Petroleum Geologists Bulletin, v. 63, p. 2204-2213.

Sloan, E.D., 1990, Clathrate hydrates of natural gas: New York, Marcel Dekker, 641 p.

Yamamoto, S., Alcauskas, J.B., and Crozier, T.E., 1976, Solubility of methane in distilled water and seawater: Journal of Chemical and Engineering Data, v. 21, p. 78-80.

Yamano, M., and Uyeda, S., 1990, Heat-flow studies in the Peru Trench subduction zone, in Suess, E., von Huene, R., and others, eds., Proceedings of the Ocean Drilling Program, scientific results, v. 112: College Station, Texas, Ocean Drilling Program, p. 653-661.

Yamano, M., Uyeda, S., Aoki, Y., and Shipley, T.H., 1982, Estimates of heat flow derived from gas hydrates: Geology, v. 10, p. $339-343$. 

THE FUTURE OF ENERGY GASES

U.S. GEOLOGICAL SURVEY PROFESSIONAL PAPER 1570

\title{
Rock Physics for Characterization of Gas Hydrates
}

\author{
By Jack Dvorkin ${ }^{1}$ and Amos Nur ${ }^{1}$
}

\section{CONTENTS}

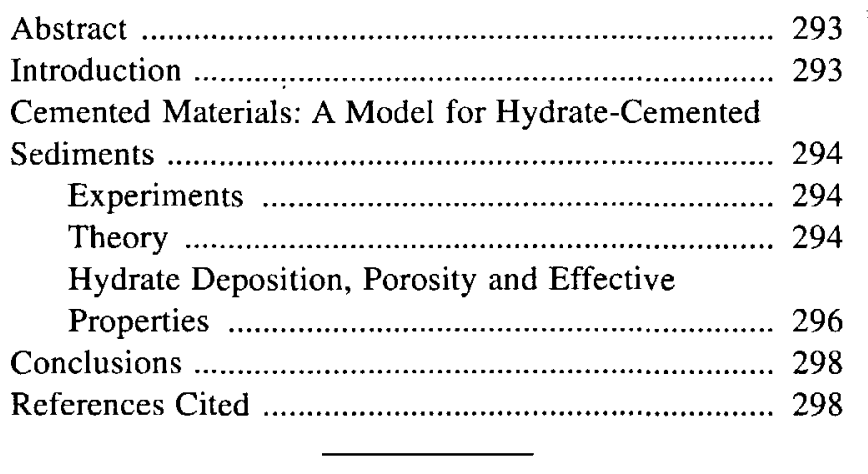

\begin{abstract}
Our theoretical and experimental results indicate that even small amounts of intergranular cementation can dramatically increase the stiffness of a granular material if the cement is placed around grain-to-grain contacts. This finding can explain the seismically discovered phenomenon of bottom-simulating-reflectors (BSR's): the gas-hydrate cementation above a reflector acts to strongly increase the elastic moduli of the rock, an effect that results in strong reflections at the base of a hydrated zone, and muted reflections at natural lithological boundaries within the zone.
\end{abstract}

\section{INTRODUCTION}

Gas-hydrate layers, marked by prominent bottom-simulating reflectors (BSR's) at continental margins, trap a sig-

\footnotetext{
'Stanford University, Department of Geophysics, Stanford, CA 94305-2215.
}

nificant proportion of global methane. The geophysical characterization of gas hydrates, including the percentage of pore space filled with gas hydrates, is among the central topics of gas-hydrate-layer characterization. In his overview of the National Workshop on Gas Hydrates, Dillon (1991) stated that "Seismic and geochemical studies probably will remain the most important approaches to studying gas hydrates, as they have in the past, but major changes in approach are necessary. Seismic studies must go beyond the analysis of the reflection from the base of the hydrate zone (the BSR) and begin to consider the acoustic velocity and reflection responses to hydrate occurrence across the entire zone of hydrate stability and relationships of hydrates to other geological factors." The quantitative mechanical characterization of gas-hydrate layers is necessary for assessing the likelihood of penetrating recoverable hydrates and for predicting possible engineering complications (such as drilling hazards and underwater landslides). Theoretical and experimental rock physics can provide a link between the seismically observable characteristics (seismic reflections and velocities) of sediments containing gas hydrates and their physical state (the amount of gas hydrates, their location within the pore space, and the strength of hydrated rock).

Our experimental and theoretical results show that even small amounts of intergranular hydrate cementation may dramatically increase the elastic moduli of the dry rock frame and thus produce the BSR effect. Therefore, there is no need to assume that the seismic contrast between hydrated and hydrate-free zones is due to free gas underneath a BSR, or some other pore-fluid arrangement. Our main assumption here is that gas hydrates change the properties of oceanic sediments by cementing grain-tograin contacts (fig. 1). This morphological arrangement may also explain why lithologically controlled reflectors have lower amplitude within the zone containing solid hydrates. Indeed, "advanced cementation makes all rocks look much the same" (Anstey, 1991). 


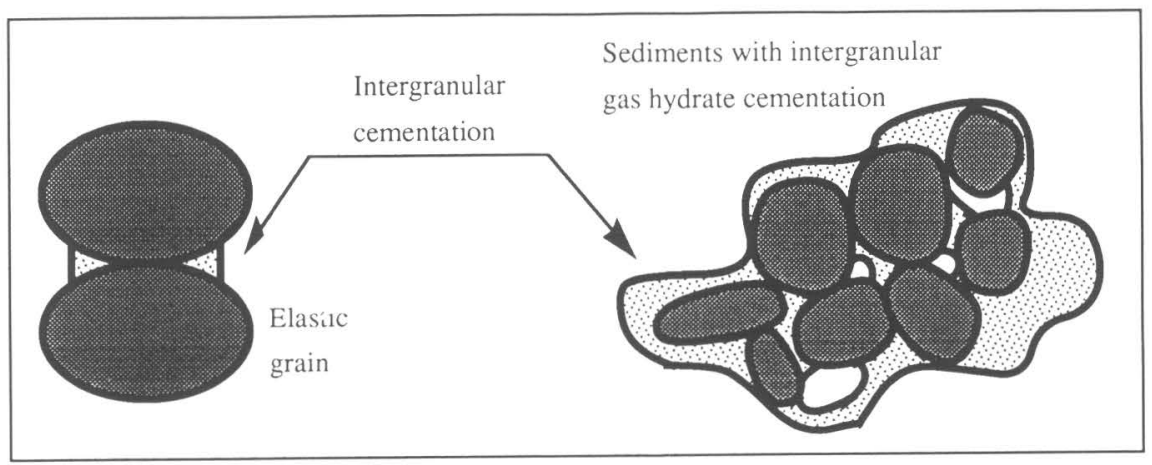

Figure 1. Two elastic grains (dark gray) with cement (light gray) at their contact, and a granular material (dark gray) with gas-hydrate cement (light gray) and some residual pore space (white).

In this short paper we present some experimental and theoretical results of our rock physics investigation of cemented granular materials. The experiments included measuring ultrasonic velocities in artificial granular samples (precompacted glass beads) that were cemented by (1) freezing capillary water accumulated at the grain contacts and (2) using epoxy as a cement.

The freezing experiments showed a strong increase of compressional-wave velocity at the freezing point, that is, at the point where the unconsolidated grains became icecemented. This experiment may be especially relevant to gas hydrates because the mechanical properties of hydrates and ice are similar (Sloan, 1989).

The second set of experiments, which used epoxy as a cement, also showed a strong increase in both compressional- and shear-wave velocities with the addition of only a small amount of the cement. The results of our theoretical modeling of cemented granular materials are in close agreement with the data from this second set of experiments.

Our conclusion is that similar intergranular cementation of sediments by gas hydrates may be responsible for the BSR effect. Moreover, the existence of a BSR may be due to only small amounts of gas hydrates above it, so these traces of hydrates may be easily missed in the extracted cores as well as in the well-log data.

\section{CEMENTED MATERIALS: A MODEL FOR HYDRATE-CEMENTED SEDIMENTS}

\section{EXPERIMENTS}

In our first set of experiments, a granular material was represented by identical glass beads. A container with the beads was filled with water that was allowed afterwards to slowly escape the sample through drainage. The process of cementation was simulated by freezing the capillary water accumulated at the bead contacts. The measured compressional velocity in the material had small constant values before freezing and increased sharply at

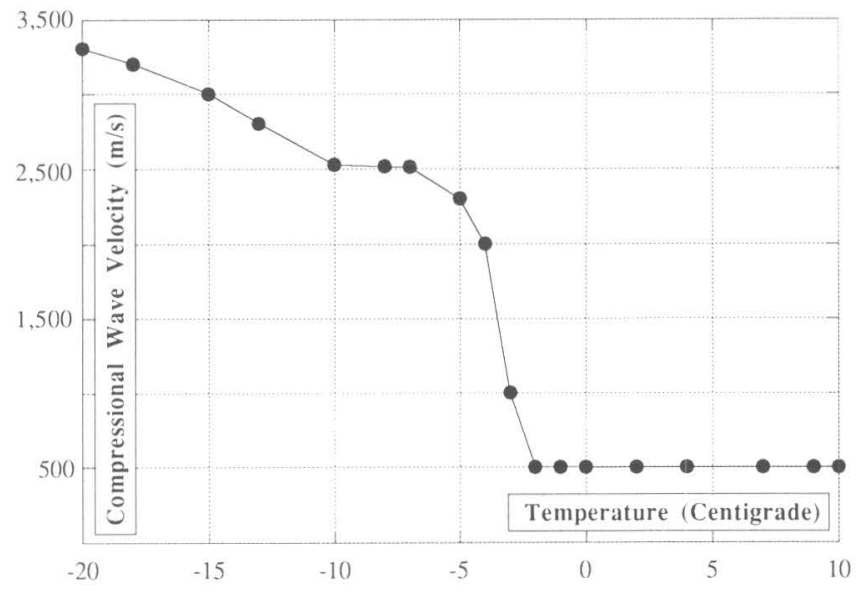

Figure 2. Our experimental results on compressional-wave ( $\mathrm{P}$-wave) velocity versus temperature in ice-cemented glass beads.

the freezing point (fig. 2). This effect is apparently due to the solidification of the small pendular rings that form ice intergranular cement.

We also measured compressional- and shear-wave velocities (hereinafter referred to as compressional and shear velocities) in epoxy-cemented glass beads at varying epoxy saturation of the pore space. The important experimental result is that the velocity increase with saturation is very large between 0 and 10 percent saturation and negligible between 50 and 100 percent saturation (fig. 3). Therefore, cementation can dramatically increase the stiffness of a granular material only if it is placed around grain-to-grain contacts.

\section{THEORY}

Our theoretical model allows one to calculate the effective elastic properties of a random packing of identical elastic spheres with elastic cement at their contacts. The effective bulk and shear moduli of a packing are calculated from the average number of contacts per sphere and 
porosity of the aggregate, and from the normal and tangential stiffnesses of a two-grain combination. These stiffnesses are found by solving the problems of normal and tangential deformation of two elastic spherical grains cemented at their contact.

The effective elastic properties of a random packing of identical spherical particles can be expressed through its porosity $(\varnothing)$, coordination number $(C)$ (the average number of contacts per sphere), the radius of a particle $(R)$, and the normal $\left(S_{n}\right)$ and tangential $(S \tau)$ stiffnesses of a two-sphere combination (Digby, 1981; Winkler, 1983). The normal and shear stiffnesses are defined as the ratios of a corresponding force increment to the displacement of the sphere center relative to the contact region (fig. 4):

$$
S_{n}=\frac{\partial F}{\partial \delta}, S_{\tau}=\frac{\partial T}{\partial \tau}
$$

where $F$ is normal force, $\delta$ is normal displacement, $T$ is tangential force, and $\tau$ is tangential displacement.

Effective bulk $\left(K_{e f f}\right)$ and shear $\left(G_{e f f}\right)$ moduli are as follows:

$$
K_{e f f}=\frac{C(1-\phi)}{12 \pi R} S_{n}, G_{e f f}=\frac{C(1-\phi)}{20 \pi R}\left(S_{n}+\frac{3}{2} S_{\tau}\right)
$$

Therefore, the effective compressional $\left(V_{p}\right)$ and shear velocities $\left(V_{s}\right)$ can be found as

$$
V_{p}=\sqrt{\frac{3 C}{20 \pi R \rho}\left(S_{n}+\frac{2}{3} S_{\tau}\right)}, V_{s}=\sqrt{\frac{C}{20 \pi R}\left(S_{n}+\frac{3}{2} S_{\tau}\right)},
$$

where $\rho$ is the density of the grain material.

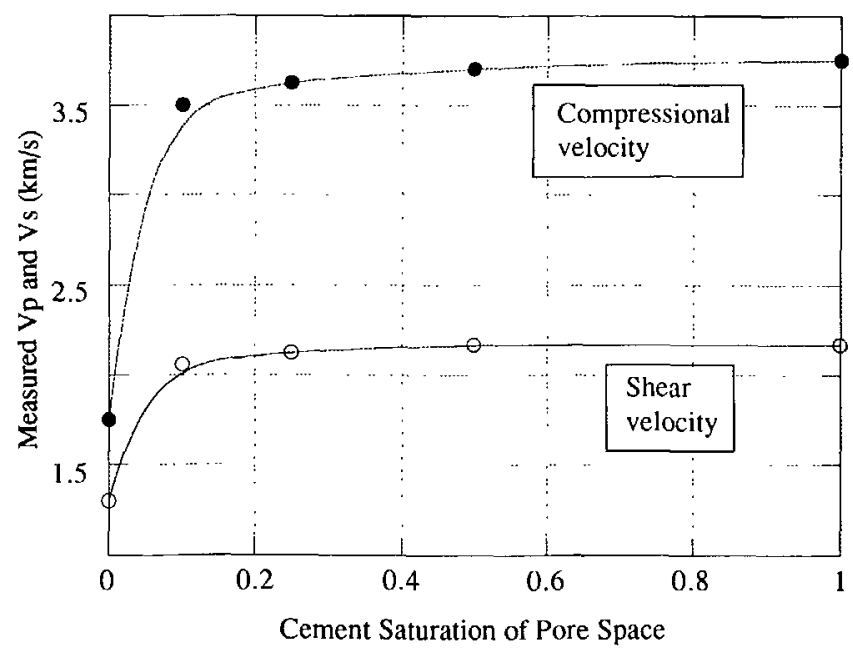

Figure 3. Compressional $\left(V_{p}\right)$ and shear $\left(V_{s}\right)$ velocities measured in epoxy-cemented glass beads at varying cement saturation (1 represents 100 -percent saturation). Circles indicate measurement points. The experiments were conducted using the ultrasonic pulse transmission method. The glass beads $(0.2-0.3 \mathrm{~mm}$ diameter) were precompacted at 20 megapascals $(\mathrm{MPa})$.
The solution to the problem of the normal and tangential deformation of two cemented grains is based on the assumption that the surface area of a contact region is small compared to that of the grain. The case of normal deformation was discussed by Dvorkin and others, 1991.

In the following example we explore the influence of the amount of cementation on the effective properties (compressional and shear velocities) of a random packing of identical spheres. The porosity of the packing (without cementation) was 0.36 (that is, 36 percent of the total volume was pore space), the coordination number was 9 . The properties of the grain material were as follows: density, 2,480 $\mathrm{kg} / \mathrm{m}^{3}$; bulk modulus, 49.9 gigapascals $(\mathrm{GPa})$; and shear modulus, $26.2 \mathrm{GPa}-$ parameters typical for glass. The density of the cement material was $1,160 \mathrm{~kg} / \mathrm{m}^{3}$. We explored four cases of the increasing stiffness of the cement: (a) $K_{c}=3.4 \mathrm{GPa}, G_{c}=1.0 \mathrm{GPa}$; (b) $K_{c}=6.8 \mathrm{GPa}, G_{c}=2.0 \mathrm{GPa}$; (c) $K_{c}=13.6 \mathrm{GPa}, G_{c}=4.0 \mathrm{GPa}$; and (d) $K_{c}=27.2 \mathrm{GPa}, G_{c}=8.0$ $\mathrm{GPa}\left(K_{c}\right.$ and $G_{c}$ are the bulk and shear moduli of the cement). The second case (b) corresponds to typical epoxy parameters. The ratio of the cement-layer radius to the grain radius varied from 0.01 to 0.5 .

Plots in figure 5 show that both compressional and shear velocities dramatically increase with the increasing radius of the cement layer. The influence of this parameter is clearly much stronger than that of the cement stiffness: even a small increase in the amount of relatively soft cement yields a significant rise in both velocities.

We explored the effect of cementation stiffness (fig. 6) in a random packing of identical spheres for a constant amount of cement (the ratio of the cement-layer radius to the grain radius was 0.1 ). The parameters of the grain material were kept constant with bulk and shear moduli 49.9 and $26.2 \mathrm{GPa}$, respectively, whereas the bulk and shear moduli of the cement were varied respectively from 3.4 $\mathrm{GPa}$ and $1.0 \mathrm{GPa}$ to $68 \mathrm{GPa}$ and $20 \mathrm{GPa}$. This dramatic increase in cement stiffness resulted in only about a 15 percent increase in compressional velocity and a 20 percent increase in shear velocity-an effect much smaller than that of increasing cement content.

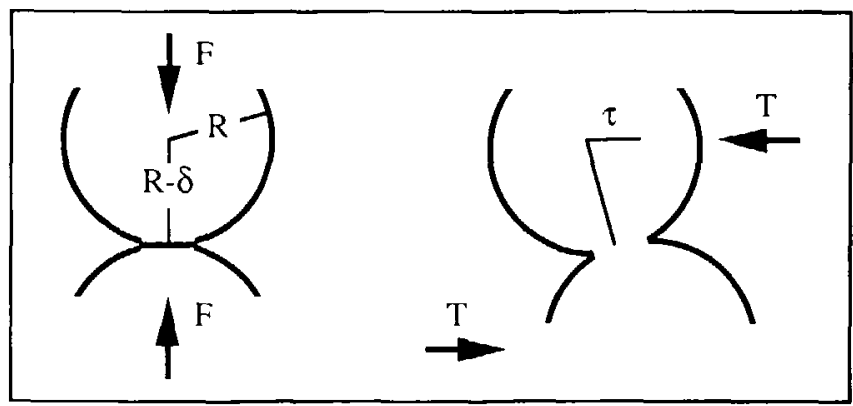

Figure 4. Normal and shear deformation of a two-grain combination. $F$, normal force; $T$, tangential force; $\delta$, normal displacement; $\tau$, tangential displacement. 


\section{HYDRATE DEPOSITION, POROSITY AND EFFECTIVE PROPERTIES}

The following example illustrates how two possible schemes of hydrate deposition may affect the porosity and the elastic moduli of a granular material.

The process of cementation starts at the critical porosity point (about 36 percent for a random identical-sphere packing) at which both bulk and shear moduli are zero in an unconsolidated granular material. In the first model, all added hydrate cement accumulates at the intergranular con- tacts. In the second model, the hydrates evenly cover the grains and the contact cement layer is formed as an intersection of these cement shells. It is clear that in the first model, the size of a contact cement layer is larger (for given porosity) than in the second model. This effect results in a steeper increase of the effective moduli with decreasing porosity in the first model as compared to the second (fig. 7). Both bulk and shear moduli steeply increase at the very beginning of cement deposition because even a small addition of cement at intergranular contact points leads to rapid widening of the cement layer.
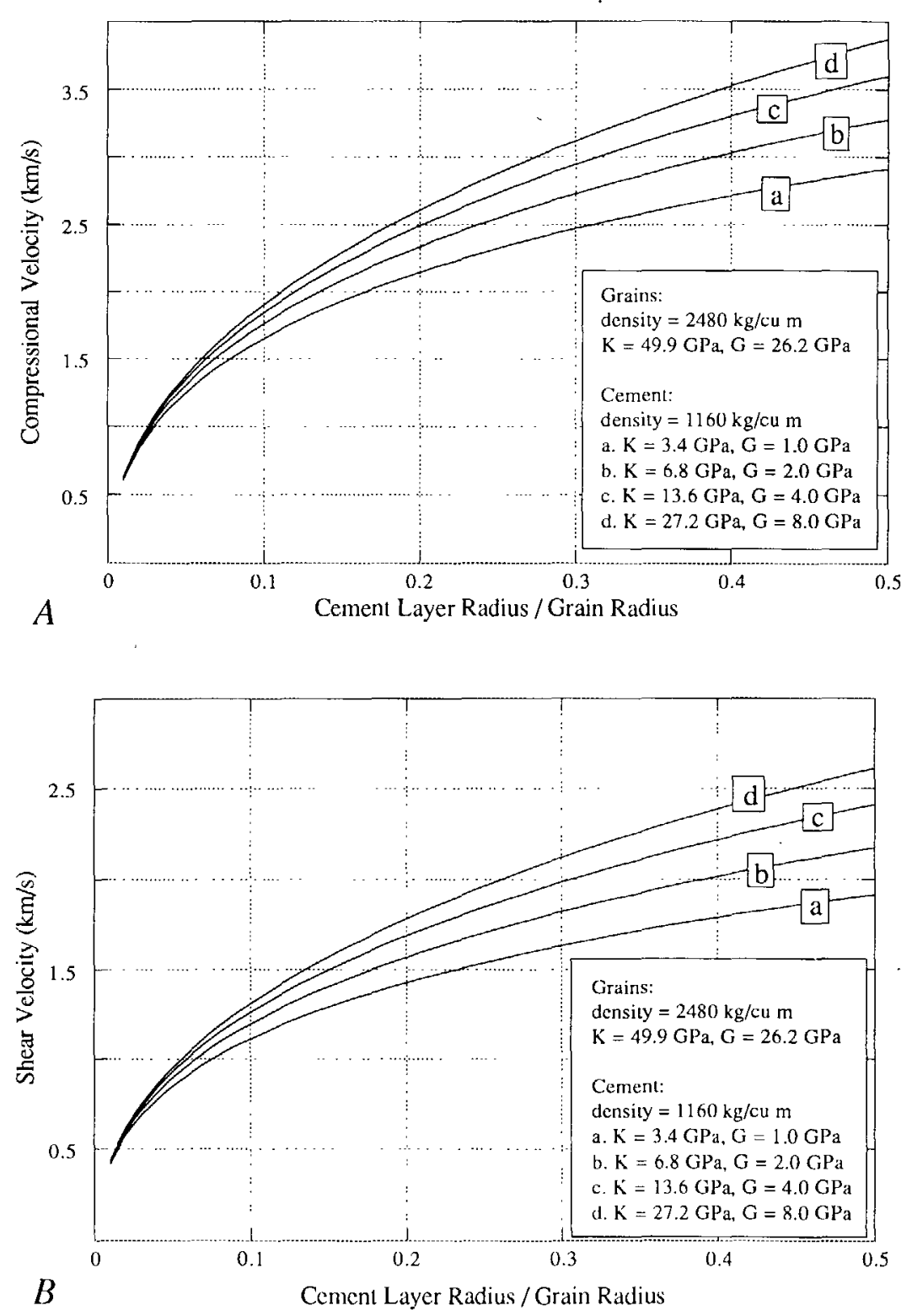

Figure 5. Compressional $(A)$ and shear $(B)$ velocities in random packings of identical cemented spherical particles as functions of the amount of cementation. The parameters of the grain material are constant; the parameters of the cement vary from soft (a) to stiff (d). Both velocities are strongly affected by the amount of cement rather than by the cement stiffness. $K$, bulk modulus; $G$, shear modulus. 

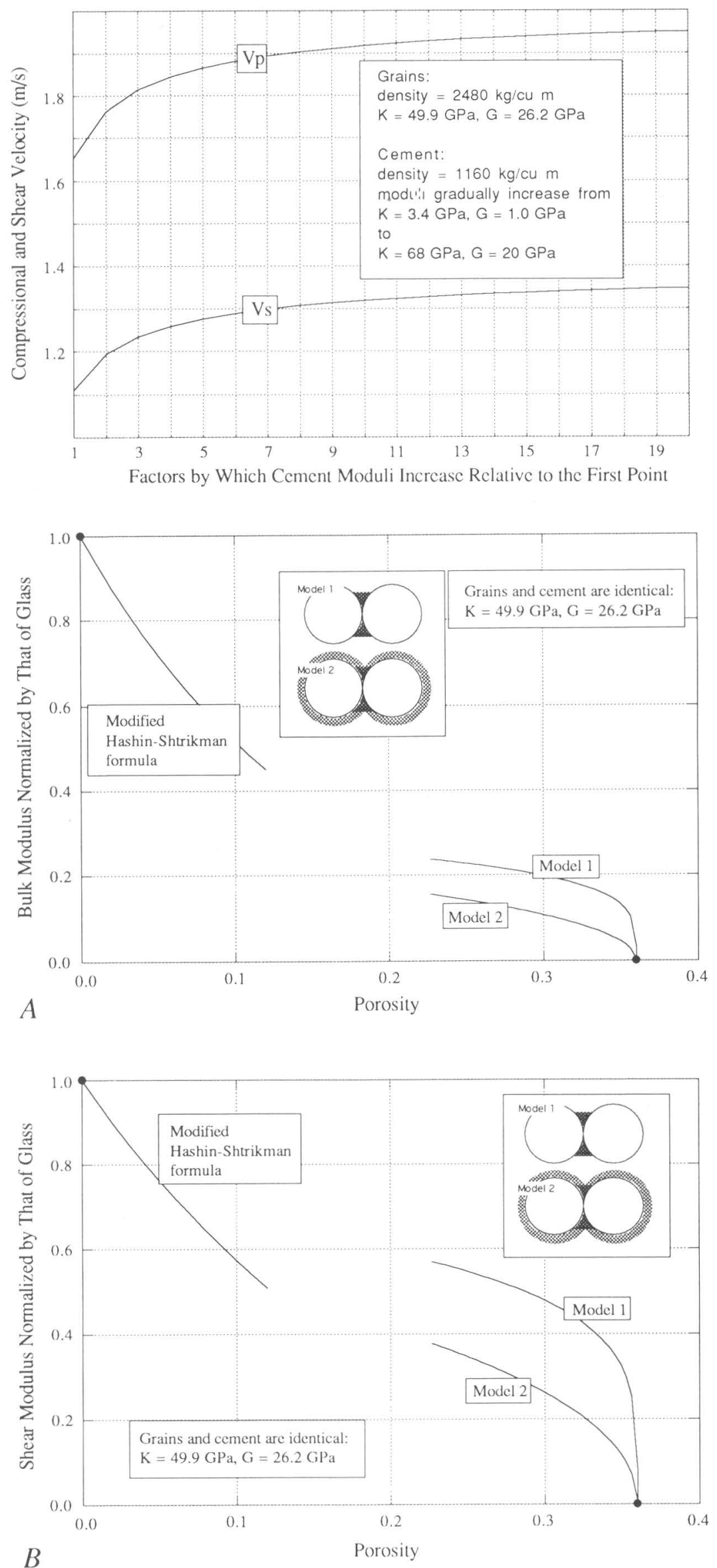

Figure 6. Compressional $\left(V_{p}\right)$ and shear $\left(V_{S}\right)$ velocities in a random packing of identical cemented spherical particles as a function of cement stiffness. Ratio of cement-layer radius to grain radius is constant and equals 0.1 . The effect of increasing cement stiffness on the effective properties of cemented granular materials is much smaller than that of increasing amounts of cement. $K$, bulk modulus; $G$, shear modulus.

Figure 7. Bulk $(A)$ and shear $(B)$ moduli of a random packing of identical glass beads for two models of cement deposition (see text for discussion of models). The moduli are normalized by those of glass, so a bulk modulus of 1 on the vertical scale in figure $7 \mathrm{~A}$ corresponds to the bulk modulus assumed here for glass $(=49.9 \mathrm{GPa})$. Porosity of aggregate decreases with increasing amount of cement. Moduli steeply increase at initial stage of cementation. Modified upper-bound Hashin-Shtrikman formulas (Chen, 1992) provide reasonable extensions of the moduli curves into the low-porosity domain. Both grains and cement are assumed to have a bulk modulus $(K)$ and shear modulus $(G)$ typical of glass. 
Our theoretical model is applicable only for small amounts of cement at intergranular contacts. We have found that a possible appropriate continuation of the moduli curves to the low-porosity region can be provided by the modified Hashin-Shtrikman upper bounds (Chen, 1992).

\section{CONCLUSIONS}

Both theoretical and experimental rock physics investigations of cemented granular materials show that even small amounts of cement at the grain contacts significantly increase rock stiffness. This fact explains the seismic contrasts observed at the boundaries of gas-hydrate zones, as well as muted reflections observed within these zones. Applying rock physics to gas-hydrate investigation can help in interpreting seismic data to determine the amounts of gas hydrates in sediments and, probably, to determine the strength of sediments containing gas hydrates.

\section{REFERENCES CITED}

Anstey, N.A., 1991, Velocity in thin section: First Break, v. 9, p. $449-457$.

Chen, Q., 1992, Critical concentration models for the mechanical and acoustic properties of porous materials: Palo Alto, Calif., Stanford University, Ph.D. dissertation.

Digby, P.J., 1981, The effective elastic moduli of porous granular rocks: Journal of Applied Mechanics, v. 48, p. 803-808.

Dillon, W.P., 1991, Overview of the National Workshop on Gas Hydrates: Report on National Workshop on Gas Hydrates, U.S. Department of Energy, p. 1-5.

Dvorkin, J., Mavko, G., and Nur, A., 1991, The effect of cementation on the elastic properties of granular material: Mechanics of Materials, v. 12, p. 207-217.

Sloan, E.D., Jr., 1989, Clathrate hydrates of natural gas: New York, Marcel Dekker.

Winkler, K.W., 1983, Contact stiffness in granular porous materials-Comparison between theory and experiment: Geophysical Research, v. 10, p. 1073-1076. 


\title{
THE FUTURE OF ENERGY GASES
}

\section{Natural Gas Production from Arctic Gas Hydrates}

\author{
By Timothy S. Collett ${ }^{1}$
}

\section{CONTENTS}

Abstract 299

Introduction 299

Prudhoe Bay-Kuparuk River Gas-Hydrate

Accumulation 300

Messoyakha Gas-Hydrate Accumulations 305

Messoyakha Production History 308

Potential Production from the Prudhoe Bay-Kuparuk

River Gas-Hydrate Accumulation .............................. 309

Conclusions 310

Acknowledgments 310

References Cited 310

\section{ABSTRACT}

The natural-gas hydrates of the Messoyakha field in the West Siberian basin of Russia and those of the Prudhoe Bay-Kuparuk River area on the North Slope of Alaska occur within a similar series of interbedded Cretaceous and Tertiary sandstone and siltstone reservoirs. Geochemical analyses of gaseous well-cuttings and production gases suggest that these two hydrate accumulations contain a mixture of thermogenic methane migrated from a deep source and shallow, microbial methane that was either directly converted to gas hydrate or was first concentrated in existing traps and later converted to gas hydrate. Studies of well logs and seismic data have documented a large freegas accumulation trapped stratigraphically downdip of the gas hydrates in the Prudhoe Bay-Kuparuk River area. The presence of a gas-hydrate/free-gas contact in the Prudhoe

${ }^{1}$ U.S. Geological Survey, Denver Federal Center, P.O. Box 25046, MS 940, Denver, CO 80225.
Bay-Kuparuk River area is analogous to that in the Messoyakha gas-hydrate/free-gas accumulation, from which approximately $5.17 \times 10^{9}$ cubic meters (183 billion cubic feet) of gas have been produced from the hydrates alone. The apparent geologic similarities between these two accumulations suggest that the gas-hydrate-depressurization production method used in the Messoyakha field may have direct application in northern Alaska.

\section{INTRODUCTION}

Large quantities of natural gas, composed mainly of methane, can occur in sediments in the form of gas hydrates. These substances are solids, composed of rigid cages of water molecules that trap molecules of gas. Cold surface temperatures at high latitudes are conducive to the development of onshore permafrost and gas hydrate in the subsurface. Gas hydrates are known to be present in the western Siberian platform (Makogon and others, 1972) and are believed to occur in other permafrost areas of northern Russia, including the Timan-Pechora province, the eastern Siberian craton, and the northeastern Siberian and Kamchatka areas (Cherskiy and others, 1985). Permafrost-associated gas hydrates are also present in the North American Arctic. Well-log responses attributed to the presence of gas hydrates have been observed in about one-fifth of the wells drilled in the Mackenzie Delta, and in the Arctic Islands over half of the wells are inferred to contain gas hydrates (Bily and Dick, 1974; Judge, 1988). Direct evidence for gas hydrates on the North Slope of Alaska comes from a core test, and indirect evidence comes from drilling and open-hole well logs that suggest the presence of numerous gas-hydrate layers in the area of the Prudhoe Bay and Kuparuk River oil fields (Collett, 1983; Collett and others, 1988). The combined information from Arctic gas-hydrate studies shows that in permafrost regions, gas 
hydrates may exist at subsurface depths ranging from about 130 to $2,000 \mathrm{~m}$. Because large quantities of gas hydrates are widespread in permafrost regions they may be a potential energy resource. Worldwide estimates of the amount of gas within continental gas hydrates range from $1.4 \times 10^{13}$ to $3.4 \times 10^{16}$ cubic meters $\left(5.0 \times 10^{2}\right.$ to $1.2 \times 10^{6}$ trillion cubic feet) (reviewed by the Potential Gas Committee, 1981).

The gas-hydrate accumulations of the Russian Messoyakha field, located in the West Siberian basin, and those of the Prudhoe Bay-Kuparuk River area of northern Alaska (fig. 1) are the most studied gas-hydrate accumulations in the world; however, language barriers have hindered previous attempts to compare these two hydrocarbon accumulations. The primary objectives of this paper are (1) to describe the geologic and geochemical nature of both the Messoyakha and the Prudhoe Bay-Kuparuk River gas-hydrate accumulations and (2) to characterize the potential for gas production from the Alaskan gas hydrates on the basis of the production history of the Messoyakha accumulation.

\section{PRUDHOE BAY-KUPARUK RIVER GAS-HYDRATE ACCUMULATION}

Gas hydrates exist under a limited range of temperature and pressure conditions, and the depth and thickness of the zone of potential gas-hydrate stability can be calculated (Makogon, 1981). Depicted in figure 2 is the calculated thickness of the potential methane-hydrate stability zone in the N.W. Eileen State No. 2 well of the Prudhoe Bay oil field in northern Alaska. The zone of potential methanehydrate stability in the N.W. Eileen State No. 2 well lies within the depth interval from approximately 210 to 950 $\mathrm{m}$. Regional analysis of subsurface gas chemistry, temperatures, pore pressures, and pore-water salinities indicates that methane hydrate would be stable beneath most of the

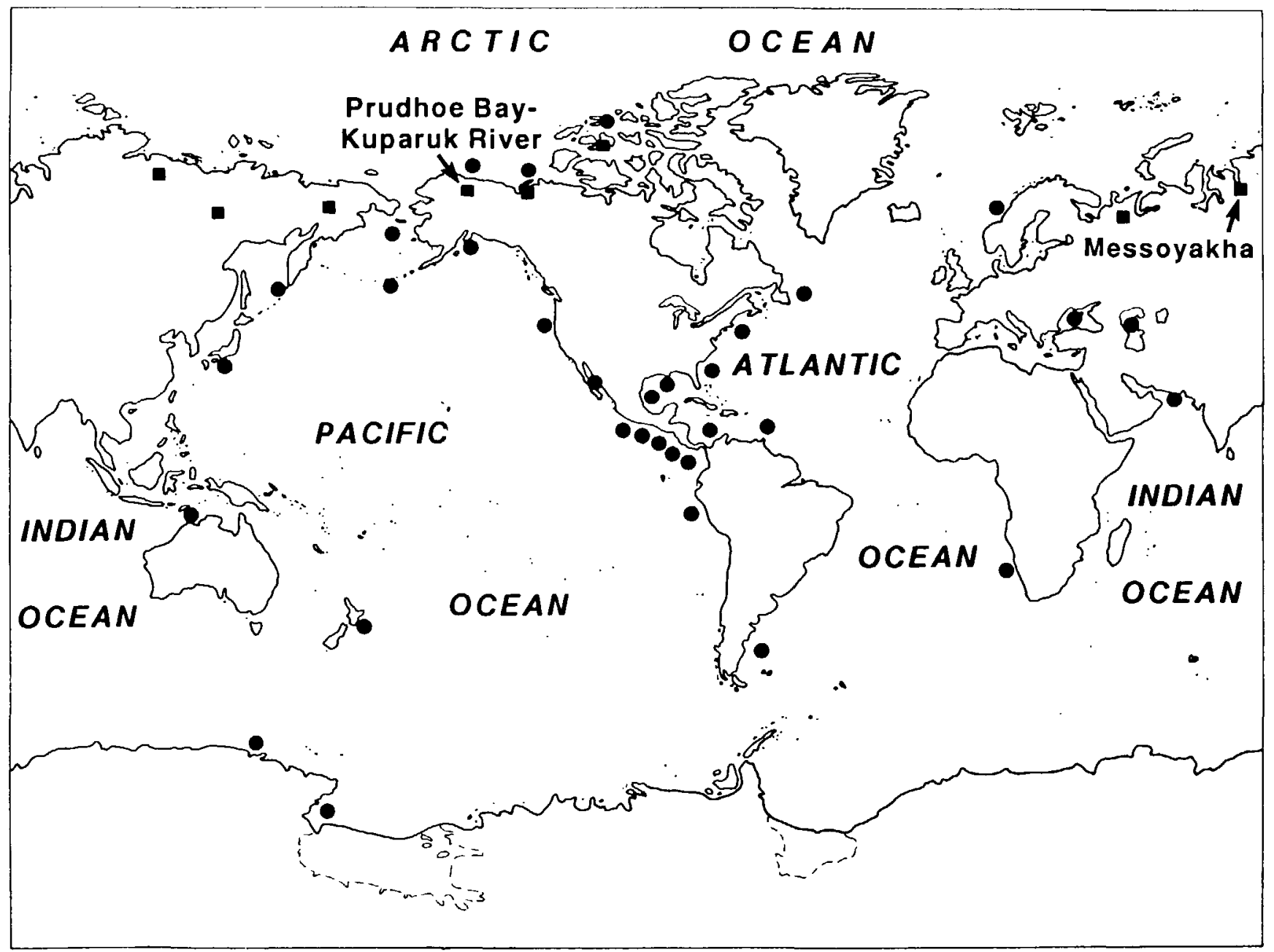

Figure 1. Locations of known and inferred gas hydrates in marine sediments of outer continental margins (dots), and in continental permafrost (squares). Dashed lines in Antarctica indicate edges of ice shelves. Modified from Kvenvolden (1988). 


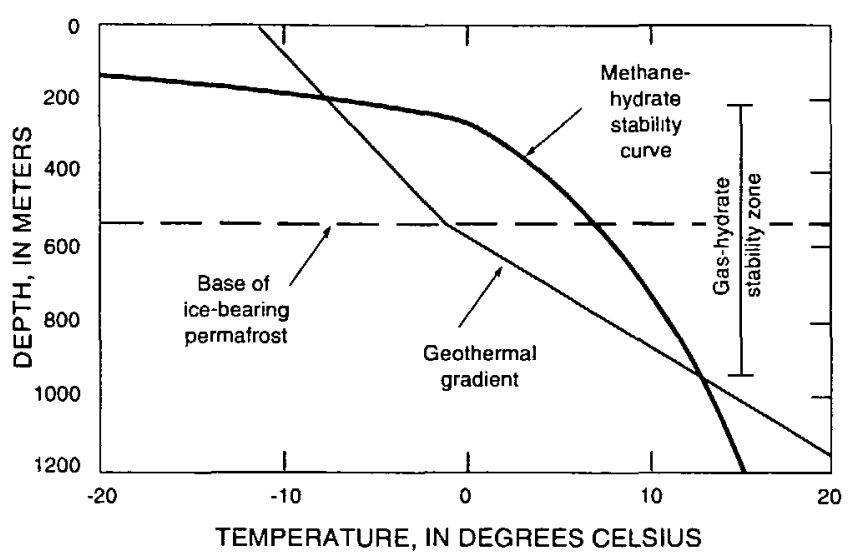

Figure 2. Phase diagram illustrating depth-temperature zones in which methane hydrates would be stable in N.W. Eileen State No. 2 well on North Slope of Alaska (modified from Collett, 1983). See figure 5 for well location.

coastal plain province of northern Alaska and that the stability zone would be thicker than $1,000 \mathrm{~m}$ in parts of the Prudhoe Bay oil field (fig. 3) (Collett and others, 1988).

Previous North Slope studies (Collett, 1983; Collett and others, 1988) indicate that gas hydrates occur only in rocks of the Cretaceous and Tertiary Sagavanirktok Formation (fig. 4) and are limited to the area overlying the Prudhoe Bay and Kuparuk River oil fields. The Sagavanirktok Formation consists of shallow-marine shelf and delta-plain deposits composed of sandstone, shale, and conglomerate whose provenance is the Brooks Range, to the south. In the Prudhoe Bay area, the Sagavanirktok Formation thickens from southwest (about $1,000 \mathrm{~m}$ ) to northeast (about 2,000 m), and conformably overlies marine shale of the Canning Formation. The regional structure of the Sagavanirktok Formation in the study area is a gentle $\left(1^{\circ}-2^{\circ}\right)$ northeasterly-dipping monocline. The Sagavanirktok Formation includes the informally named West Sak and Ugnu sands. These oil-bearing horizons have been extensively described by Werner (1987) and are estimated to contain more than approximately 6 million metric tons (40 billion barrels) of in-place lowgravity oil. In the Prudhoe Bay-Kuparuk River area, the Sagavanirktok Formation is cut by northwesterly striking

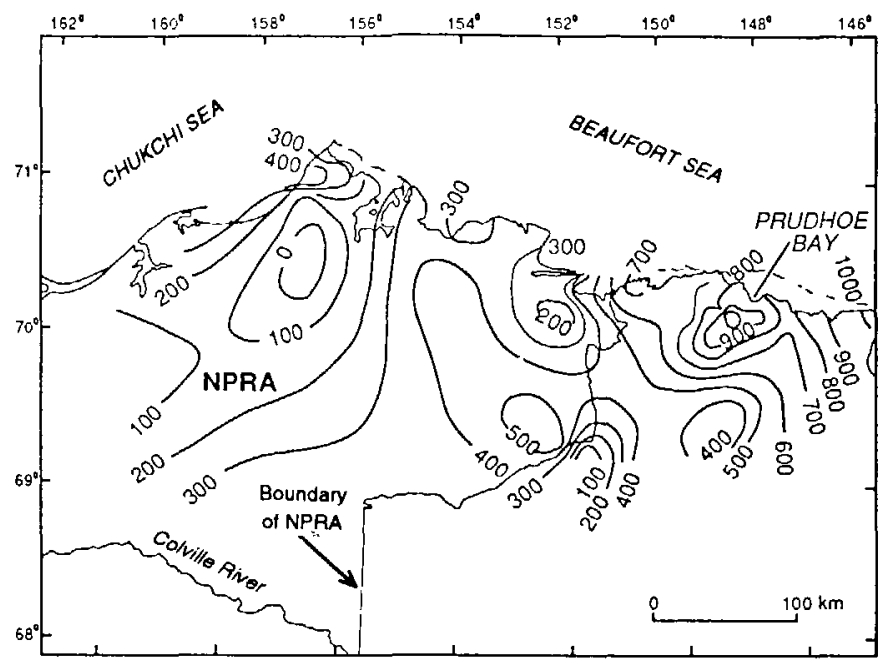

Figure 3. Isopach map of north-central Alaska showing calculated thickness (in meters) of methane-hydrate stability field. Isopachs are based on gas-hydrate-stability calculations from 124 wells (Collett and others, 1988). NPRA, National Petroleum Reserve in Alaska.

high-angle normal faults, generally downthrown to the east (Werner, 1987). A similar set of northwesterly striking faults cuts the older rocks in this area, suggesting a genetic linkage to the faults within the Sagavanirktok Formation. These faults are important in that they are interpreted to have served as conduits for oil and gas migration from the underlying Prudhoe Bay field (Carman and Hardwick, 1983).

The only confirmation of natural-gas hydrate on the North Slope was obtained in 1972 when Arco and Exxon successfully recovered gas hydrate in a core (reviewed by Kvenvolden and McMenamin, 1980). This gas-hydrate sample was from a depth of about $666 \mathrm{~m}$ in the N.W. Eileen State No. 2 well (cored interval 664 to $667 \mathrm{~m}$ ). After completion of this well, the gas-hydrate-bearing interval was perforated and tested. A drill-stem test of the perforated interval from 663 to $671 \mathrm{~m}$ flowed gas at a maximum rate of 112 cubic meters per day ( 3,960 cubic feet per day). Geochemical analyses (table 1 ) reveal that methane was the dominant gas recovered during the drill-stem test $(93$ percent methane, 7 percent nitrogen) and from the core sample

Table 1. Geochemical analysis of gas samples obtained from the hydrate-bearing core $(664-667 \mathrm{~m})$ and production flow test $(663-671 \mathrm{~m})$ in the N.W. Eileen State No. 2 well at Prudhoe Bay, Alaska

[From written commun., 1983, P. Barker, Arco Alaska Inc., Anchorage, Alaska. \%, percent of total gas volume; ---, not detected]

\begin{tabular}{|c|c|c|c|c|c|c|c|}
\hline Sample type & $\begin{array}{c}\text { Interval depth } \\
\text { (m) }\end{array}$ & $\begin{array}{c}\text { Carbon dioxide } \\
(\%)\end{array}$ & $\begin{array}{c}\text { Oxygen } \\
(\%)\end{array}$ & $\begin{array}{c}\text { Nitrogen } \\
(\%)\end{array}$ & $\begin{array}{c}\text { Methane } \\
(\%)\end{array}$ & $\begin{array}{c}\text { Ethane } \\
(\%)\end{array}$ & $\begin{array}{c}\text { Propane } \\
(\%)\end{array}$ \\
\hline Core & $664-667$ & $\cdots$ & 0.52 & 12.53 & 86.95 & Trace & -- \\
\hline Core & $664-667$ & --- & 0.02 & 0.84 & 99.14 & Trace & -- \\
\hline Core & $664-667$ & --- & 0.03 & 0.80 & 99.17 & Trace & --- \\
\hline Core & $664-667$ & -- & 0.05 & 1.46 & 98.49 & Trace & -- \\
\hline Flow test & $663-671$ & Trace & -- & 7.19 & 92.79 & 0.02 & Trace \\
\hline Flow test & $663-671$ & Trace & $\cdots$ & 7.23 & 92.76 & 0.01 & Trace \\
\hline
\end{tabular}


(87 to 99 percent methane) (written commun., 1983, P. Barker, Arco Alaska Inc., Anchorage, Alaska).

Well-log data from an additional 445 North Slope wells were examined for possible gas-hydrate occurrences (Collett and others, 1988). This review of all available data revealed that gas hydrates probably occur in 50 of the surveyed wells. Many of these wells have multiple gas-hydrate-bearing units, and individual occurrences range from 3 to $31 \mathrm{~m}$ thick. The gas hydrates inferred from well logs occur in six laterally continuous sandstone and conglomerate units and are geographically restricted to the east end of the Kuparuk River production unit and the west end of the Prudhoe Bay production unit (figs. 5,6). The six gas-hydrate-bearing rock units have each been assigned a reference letter (units A

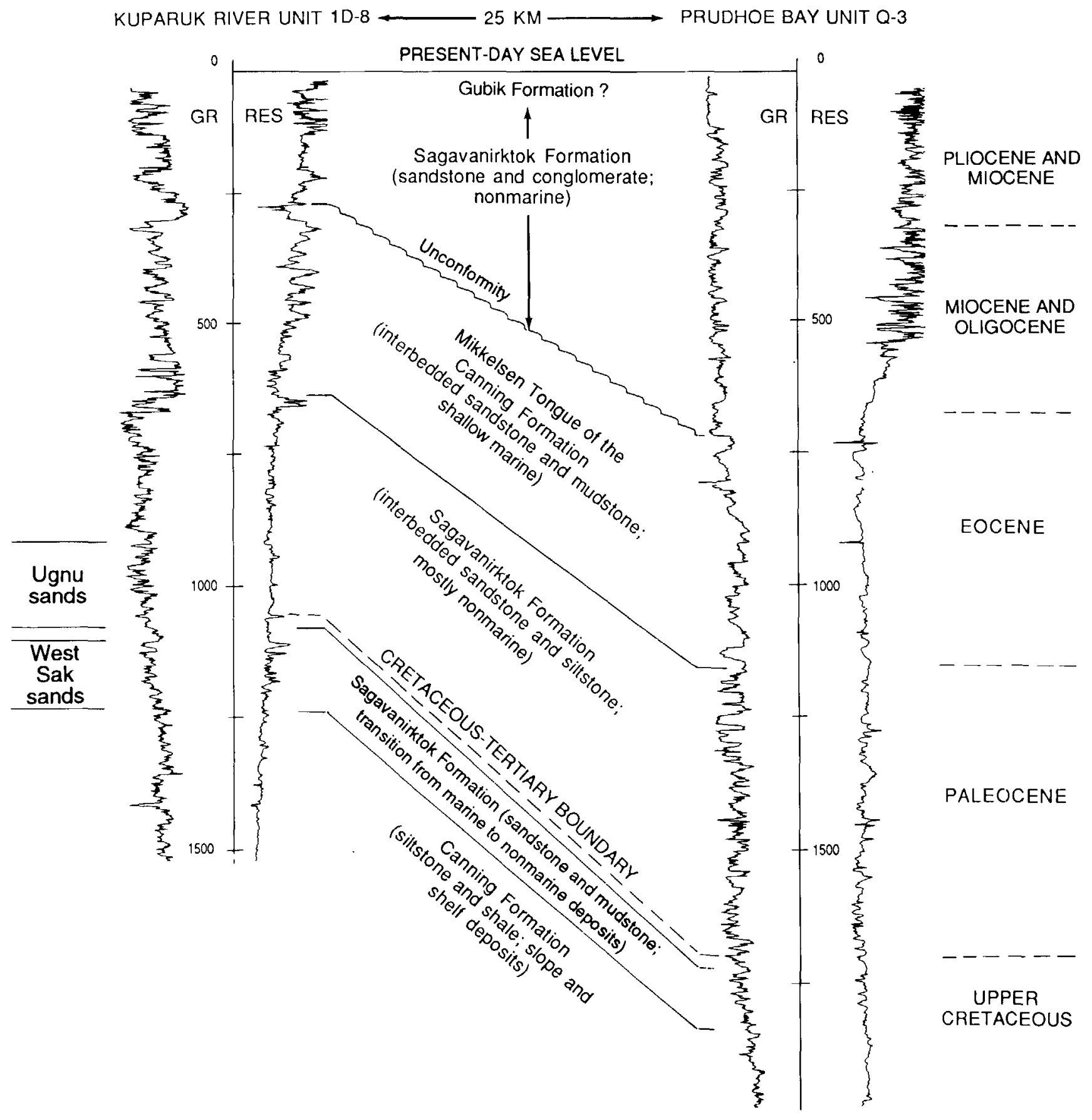

Figure 4. Well-log correlations between Kuparuk River Unit 1D-8 and Prudhoe Bay Unit Q-3 wells showing the North Slope stratigraphic relations and terminology used in this report. Locally the Sagavanirktok Formation is overlain by the Gubik Formation. Depths are in meters measured from the kelly bushing. GR, gamma ray; RES, resistivity. 
through F); unit A is stratigraphically the deepest (fig. 6). Recently completed three-dimensional seismic surveys have documented the probable occurrence of a gas-hydrate/freegas contact at the base of the methane-hydrate stability field in the west end of the Prudhoe Bay production unit (public presentation, 1987, C.G. Guderjahn, British Petroleum Exploration Inc., Anchorage, Alaska). Open-hole logs from wells in the west end of the Prudhoe Bay field also indicate the presence of a large free-gas accumulation trapped stratigraphically downdip from four of the log-inferred gas hydrates (figs. 5, 6; units A, B, C, D). The total mapped area of

Figure 5. Composite map showing location of all six gashydrate/free-gas units (A-F) in Prudhoe Bay-Kuparuk River area (modified from Collett and others, 1988). Also shown are locations of the N.W. Eileen State No. 2 well and the cross section in figure 6. Dots, well locations.
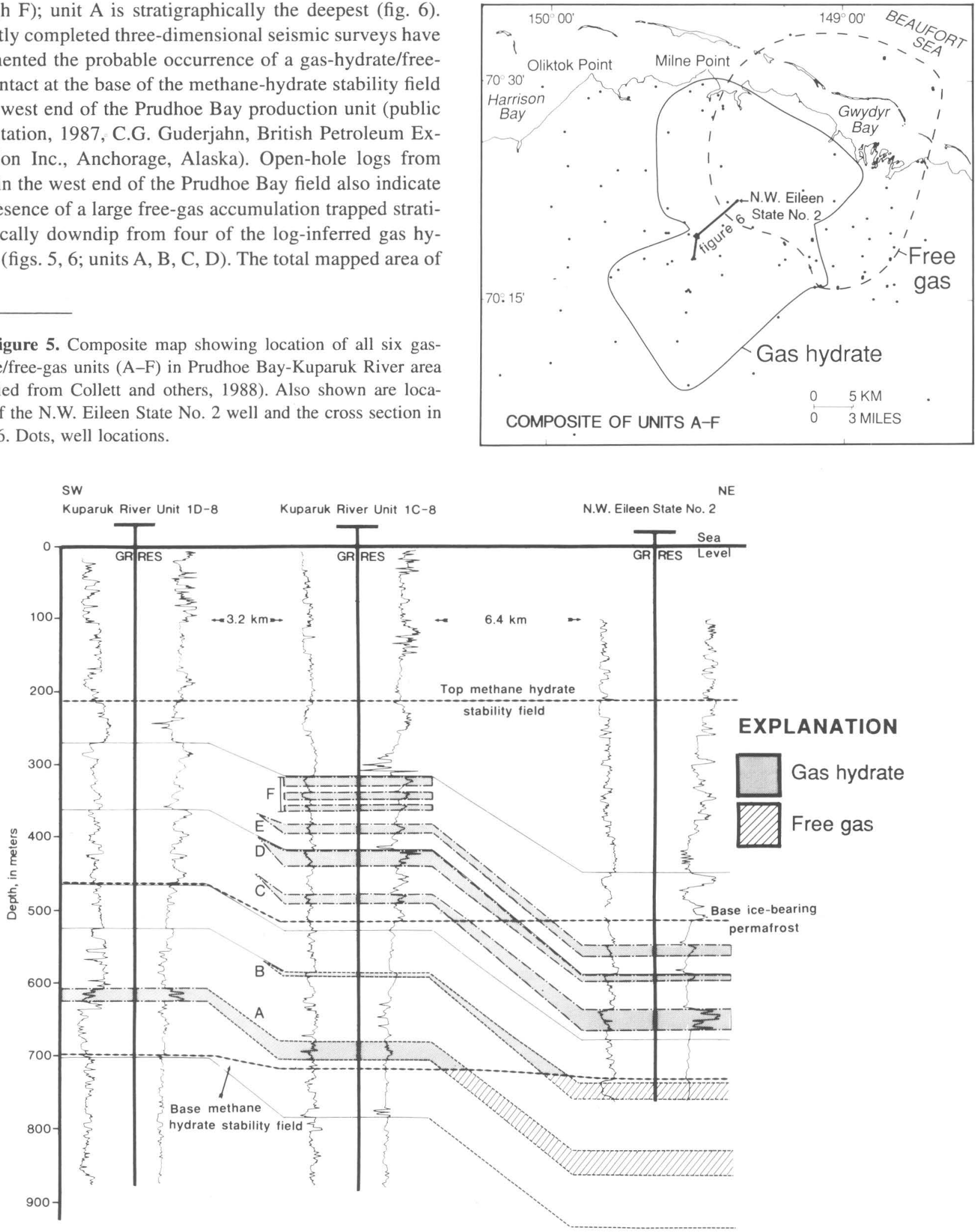

Figure 6. Cross section showing lateral and vertical extent of gas hydrates and underlying free-gas occurrences in Prudhoe Bay-Kuparuk River area. See figure 5 for location of cross section. Gas-hydrate-bearing units are identified with reference letters A through F. Gamma-ray (GR) and resistivity (RES) logs are shown for three wells. Solid lines are log correlation markers used to construct regional stratigraphic framework. Dot-and-dashed lines bounding units are known boundaries; dashed lines are inferred boundaries. Modified from Collett and others (1988). 
Figure 7. Schematic west-to-east cross section through Prudhoe Bay-Kuparuk River area illustrating possible gas migration paths and spatial relations between gas hydrates, free gas, oil, Eileen fault zone, base of icebearing permafrost (BIPF), and gas-hydrate stability field (modified from Carman and Hardwick, 1983, fig. 13). The Brookian sequence is primarily a passive-margin deposit composed of clastic sedimentary rocks derived from the Brooks Range to the south. The Ellesmerian sequence is composed of clastic and carbonate strata that were deposited on a south-facing margin of a stable continental landmass.
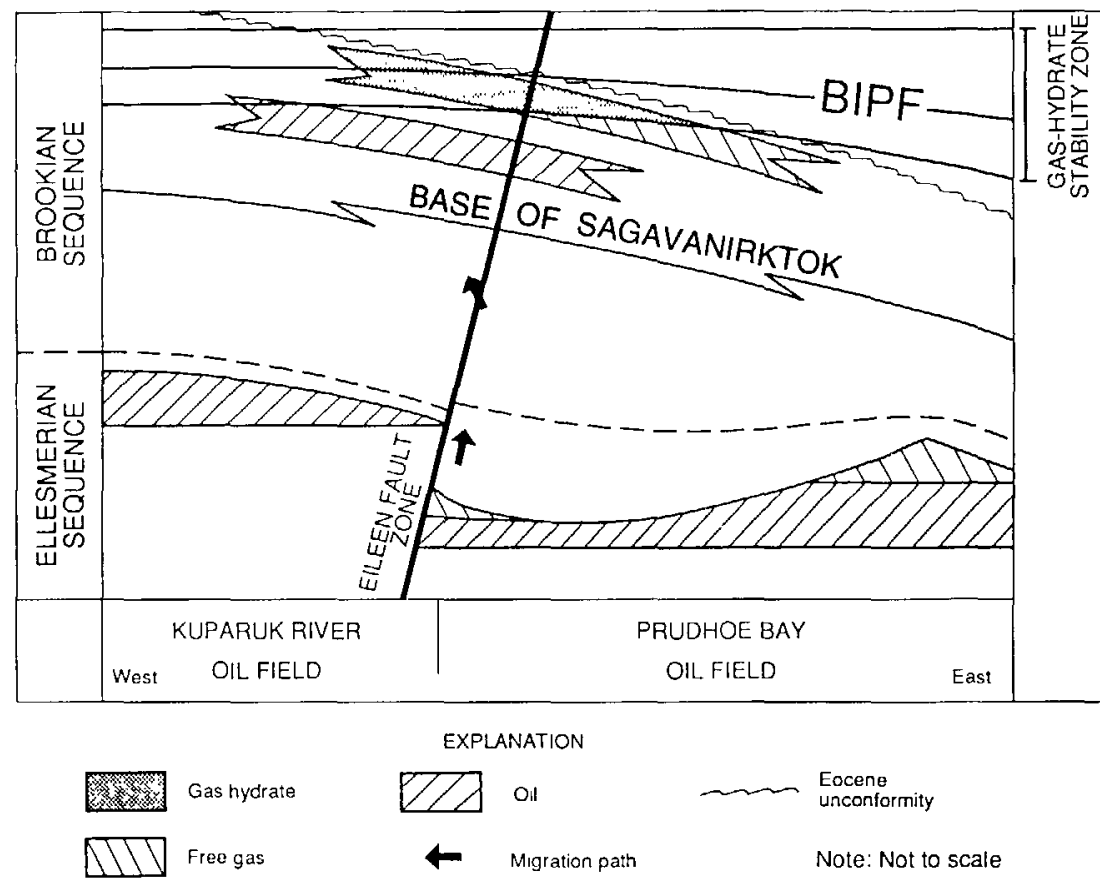

all six gas-hydrate occurrences is about $1,643 \mathrm{~km}^{2}$; the areal extent of the individual units ranges from 3 to $404 \mathrm{~km}^{2}$ (Collett and others, 1988). Porosities calculated from well logs and measured from core samples of the gas-hydrate reservoir rocks range from 37 to 42 percent, and the average degree of gas-hydrate saturation within these reservoirs is about 85 percent (Collett and others, 1988). The potential volume of gas within the identified gas hydrates (exclusive of the associated free gas) of the Prudhoe Bay-Kuparuk River area is approximately $1.0 \times 10^{12}$ to $1.2 \times 10^{12}$ cubic meters, or approximately 37 to 44 trillion cubic feet, of gas at standard temperature and pressure (STP).

Geochemical similarities suggest that oil, and presumably the associated gas, within the Sagavanirktok Formation was "spilled" from the underlying reservoirs in the Sadlerochit Group of the Prudhoe Bay field as a consequence of regional tilting during middle to late Tertiary time (Carman and Hardwick, 1983). As shown in figure 7, most of the gas hydrates and shallow heavy oils occur either updip from or near the Eileen fault zone. This fault zone may have acted as a conduit for free-gas and oil migration from deeper hydrocarbon accumulations. Geochemical analysis of headspace gases evolved from drill cuttings collected from seven development wells drilled in the Prudhoe Bay and Kuparuk River oil fields suggests that methane is the principal hydrocarbon gas in the near-surface $(0$ to $1,500 \mathrm{~m}$ ) strata (Collett and others, 1990). The plot of the carbon $\left({ }^{13} \mathrm{C}\right)$ and hydrogen $(\delta \mathrm{D})$ stable isotopic compositions of the methane (fig. 8) from the hydrate-bearing rock units indicates that most of the methane is from mixed microbial and thermogenic sources. The natural-gas genetic classification diagram in figure 8 also suggests that the microbial gas was generated by biogenic carbon dioxide re-

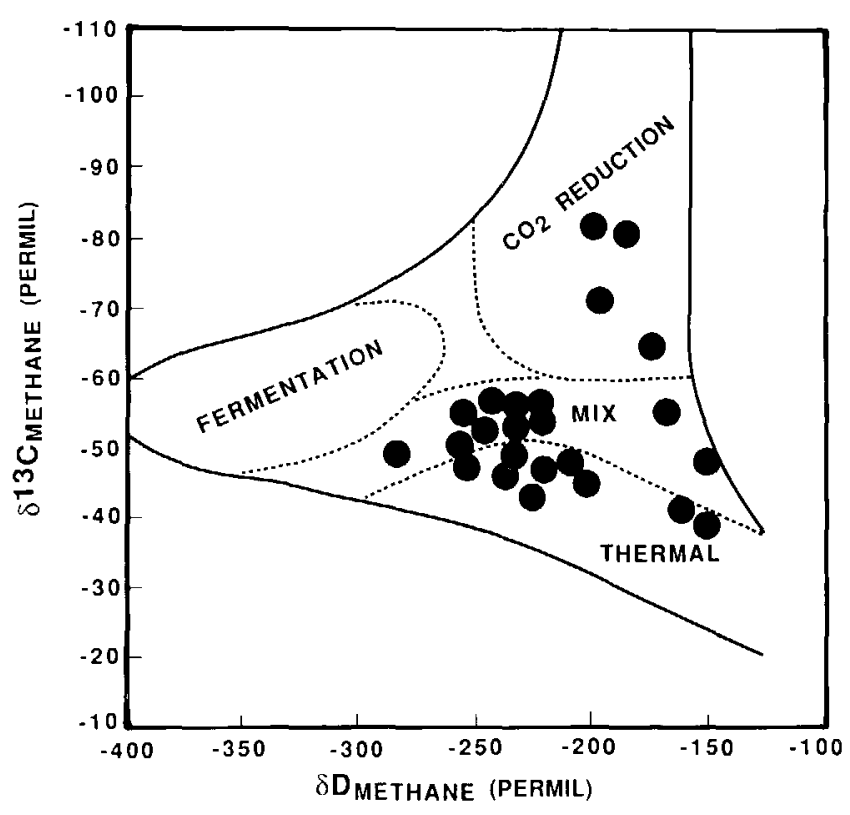

Figure 8. Natural-gas genetic classification diagram (modified from Whiticar and others, 1986) depicting the carbon $\left(8^{13} \mathrm{C}\right)$ and hydrogen $(\delta D)$ stable isotopic compositions (dots) of the methane within the hydrate-bearing rock units of two wells drilled in the west end of the Prudhoe Bay production unit. MIX indicates mixture of microbial (FERMENTATION and $\mathrm{CO}_{2}$ REDUCTION) and thermogenic (THERMAL) gases.

duction of the in-situ organic matter. Vitrinite reflectance $\left(R_{0}\right)$ measurements of about 0.4 percent show that the gashydrate-bearing rocks have never been subjected to temperatures within the thermogenic hydrocarbon window, which 
ranges from about 0.6 to 2.0 percent. Thus, the thermogenic gas must have migrated from greater depths.

The gas cap of the Prudhoe Bay field is composed primarily of methane ( 83 to 88 percent) along with small quantities of ethane (5 to 7 percent) and propane ( 1 to 2 percent) (written commun., 1989, M.C. Davidson, BP Exploration, Anchorage, Alaska). If the gas within the nearsurface sediments migrated from deeper structures, the shallow gas should have geochemical constituents similar to those of the deeper gas; however, no significant amounts of ethane or propane were detected within the interval of gas-hydrate stability. The depletion of heavier hydrocarbons such as ethane and propane from gas mixtures by stripping during migration has been suggested by Schoell (1983) and Jenden and Kaplan (1986) to explain natural gases containing thermogenic methane but only minor amounts of heavier hydrocarbons. The thermogenic component of the gas within the interval of gas-hydrate stability may have been stripped of most of its heavier hydrocarbons. Such a process could account for the molecular and isotopic compositions observed.

The carbon isotopic composition of the methane $\left(\delta^{13} \mathrm{C}\right)$ within the gas-hydrate-bearing rock units averages approximately -49 permil, suggesting that the hydrates contain a mixture of thermogenic and microbial gases. By comparing the methane carbon isotopic composition $\left(\delta^{13} \mathrm{C}\right)$ of this apparent gas mixture to the isotopic composition of the Prudhoe Bay gas cap it is possible to calculate the relative volume of gas from thermogenic versus microbial sources within the hydrate stability field. The methane-carbon isotopic value $\left(\delta^{13} \mathrm{C}\right)$ of the Prudhoe Bay gas cap averages approximately -39 permil (written commun., 1989, M.C. Davidson, BP Exploration, Anchorage, Alaska). The methane component from a microbial source likely had an original methane isotopic composition ranging from -60 to -70 permil. Because the mixing of two gases results in a linear and proportional change in isotopic composition (Schoell, 1983), it is estimated that about 50 to 70 percent of the methane within the hydrate stability field has migrated from the Prudhoe Bay gas cap. Thus, the occurrence of gas hydrates is controlled by the availability of a significant quantity of migrated thermogenic hydrocarbon gas.

To describe the history of gas-hydrate formation, I have modified a generalized cross section (fig. 7) from Carman and Hardwick (1983, fig. 4). As thermogenic gas moved up the Eileen fault zone, some of the gas may have been rechanneled updip along relatively porous and permeable northeast-dipping sandstone units of the Sagavanirktok Formation. The updip-migrating gas probably mixed with the in-situ microbial methane and collected in structural or stratigraphic traps where subsequent temperature changes deepened the permafrost sequence and converted the trapped gas into gas hydrate. Conversely, the updip migrating gas may have been converted to gas hydrate upon entering the pressure-temperature regime of gas-hydrate stability, thus forming its own trap. Because so little is known about the history of temperatures on the North Slope and the presence of traps for free gas in this area, either of these models is plausible.

Thermal conditions conducive to the formation of gas hydrates have probably persisted in northern Alaska since the end of the Pliocene (about 1.65 Ma); however, regional temperature fluctuations throughout the Pleistocene (about 1.65 to $0.01 \mathrm{Ma}$ ) have been great enough to repeatedly thicken and thin the zone of gas-hydrate stability (Collett and others, 1988). At this time adequate knowledge of climate and geologic changes on the time scale necessary to accurately assess the history of gas-hydrate formation in northern Alaska is not available; however, it is safe to say that the North Slope gas hydrates are likely no older than Pleistocene, and they could be as young as late Pleistocene (Wisconsin Stage; about 0.07 to $0.01 \mathrm{Ma}$ ).

\section{MESSOYAKHA GAS-HYDRATE ACCUMULATIONS}

The Messoyakha gas field was discovered in 1968, and it was the first producing field in the northern part of the West Siberian basin (fig. 1). By the mid-1980's, more than 66 gas fields had been discovered in the West Siberian basin, containing an estimated total gas reserve of 22 trillion cubic meters ( 777 trillion cubic feet)-approximately one-third of the world's reserves (Grace and Hart, 1986). Between 1969 and 1987 about 14.4 billion cubic meters (508 billion cubic feet) of gas were produced from the Messoyakha field and delivered by pipeline to the city of Noril'sk (Makogon, 1988). The geology (fig. 9) and petroleum geochemistry of the West Siberian basin is described in detail in many English language publications (Kortsenshteyn, 1970; Makogon and others, 1972; Alekseyev, 1974; Trofimuk and others, 1977; Kruglikov and others, 1983; Krason and Ciesnik, 1985; Grace and Hart, 1986; Galimov, 1988; Makogon, 1988; and Peterson and Clarke, 1989). Production in the northern part of the West Siberian basin is principally from the Neocomian reservoirs of the Vartov and Megion suites (average depth, 2,800 $\mathrm{m}$ ) and the Cenomanian reservoirs of the Pokur suite (average depth, 1,100 $\mathrm{m}$ ); about two-thirds of the region's gas production is from the Cenomanian reservoirs (Grace and Hart, 1986). The Pokur suite is a 700- to 800 -m-thick complex of interbedded marine and nonmarine sandstone and shale that was deposited during an Aptian to Coniacian marine regression. Coal and plant debris are also prevalent within the nonmarine parts of the Pokur suite. The Pokur suite is overlain by the shale sequence of the Kuznetsov suite, which forms a regional seal for most of the gas in the underlying sandstone reservoirs. Regional analyses of subsurface temperatures, formation pressures, and pore-water salinities suggest that the methane-hydrate stability zone may extend 


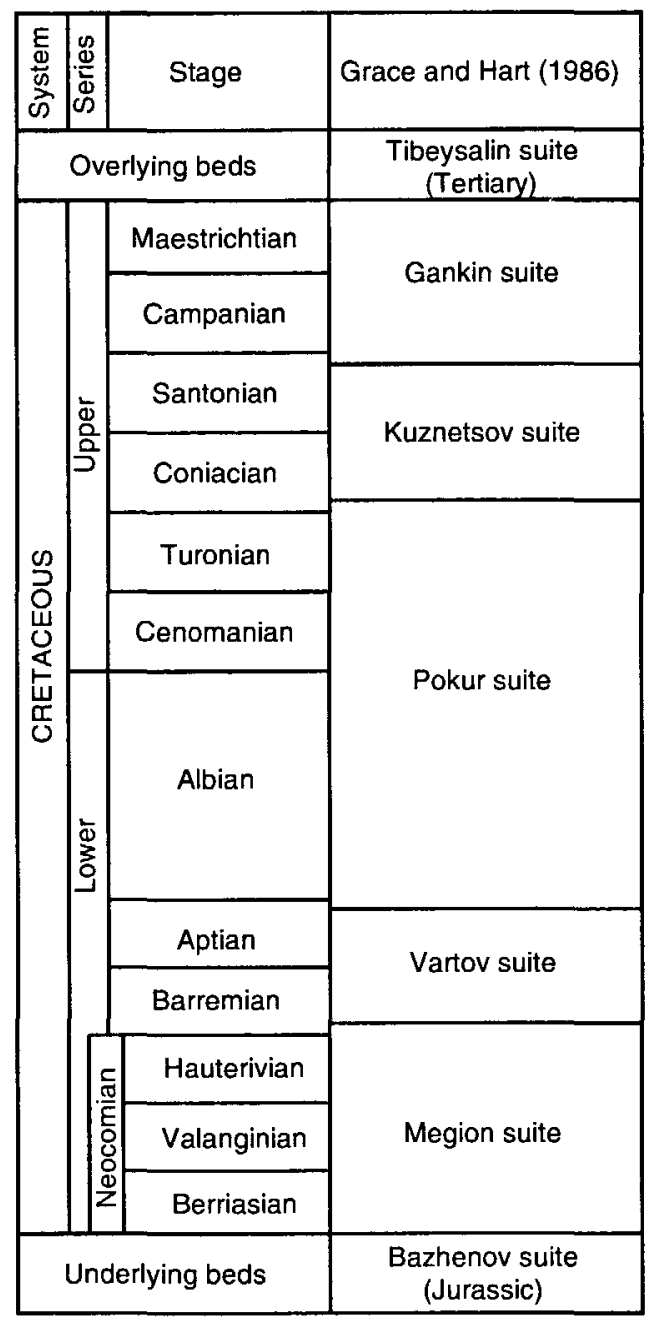

Figure 9. Stratigraphic column for northern West Siberian basin (modified from Grace and Hart, 1986).

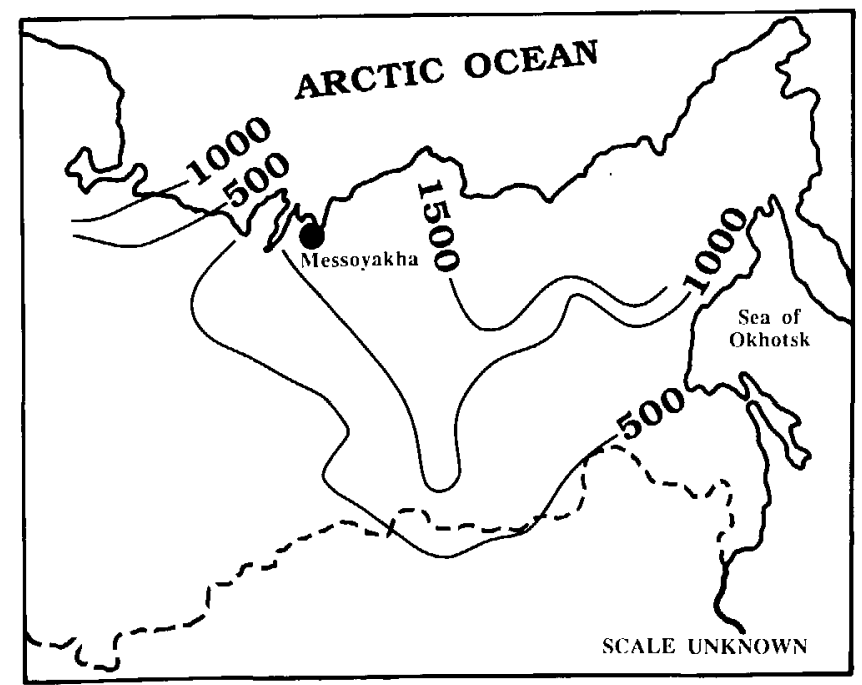

Figure 10. Depth (in meters) to base of methane-hydrate stability field in continental areas of Russia. Dashed line is southern boundary of former U.S.S.R. Modified from Makogon (1981). to depths of approximately $1,000 . \mathrm{m}$ in the northern part of the West Siberian basin (fig. 10). The Messoyakha gas accumulation is confined to the Dolgan Formation of the Pokur suite, and production has been established from the depth interval between 720 and $820 \mathrm{~m}$. The upper part (about $40 \mathrm{~m}$ ) of the Messoyakha field lies within the zone of predicted methane-hydrate stability (fig. 11). By assuming a reservoir pressure of $78 \mathrm{~kg} / \mathrm{cm}^{2}$, Makogon and others (1972) determined that the $10^{\circ} \mathrm{C}$ isotherm defines the lower limit of the in-situ gas hydrates, thus separating the Messoyakha field into an upper gas-hydrate accumulation and a lower free-gas accumulation (fig. 12).

Unusually low gas yields from production tests in the upper part of the Messoyakha reservoir were the first physical evidence of possible in-situ gas-hydrate occurrences (production data discussed in more detail later in this paper). Analysis of spontaneous-potential, caliper, and gamma-ray well logs from 62 wells drilled in the Messoyakha field reveal the presence of apparently "frozen" rock intervals within the Dolgan Formation (Makogon and others, 1972). Because these "frozen" layers are more than 250 to $350 \mathrm{~m}$ below the zone of permafrost and are at equilibrium formation temperatures near $10^{\circ} \mathrm{C}$, they have

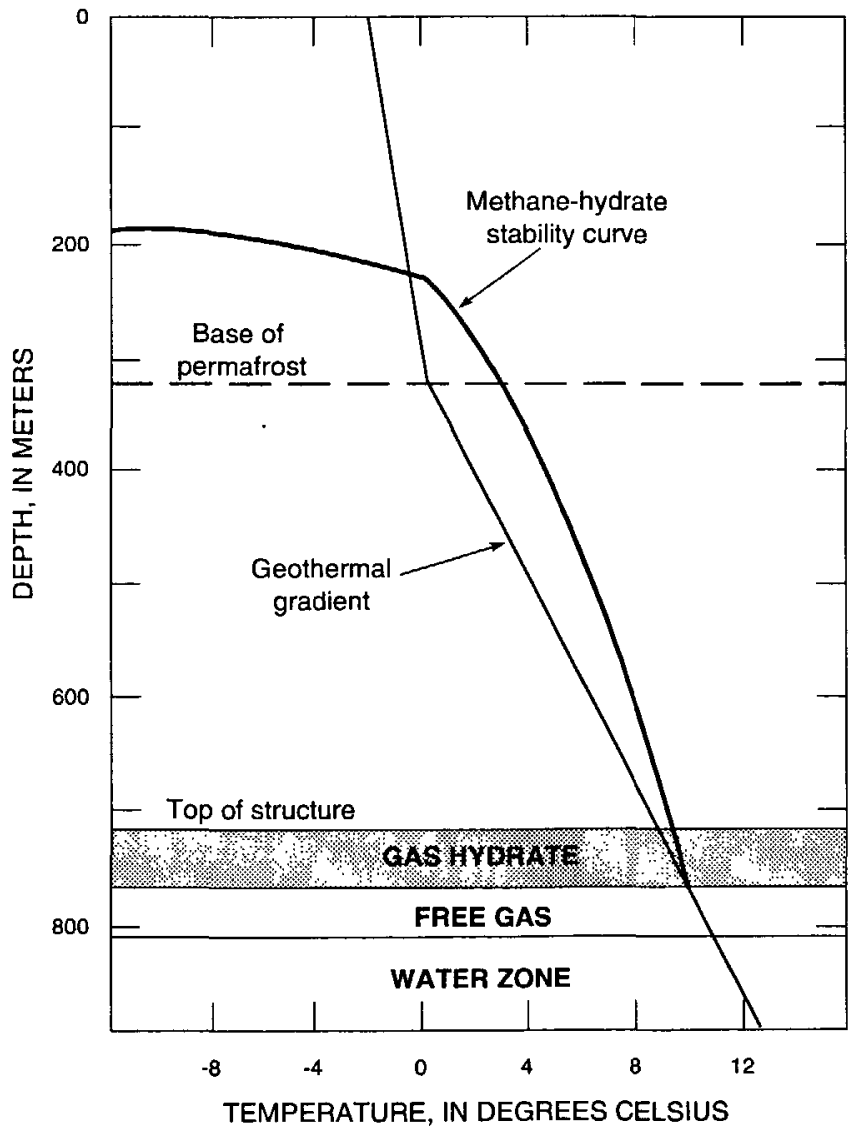

Figure 11. Phase diagram illustrating depth-temperature zone in which methane hydrates are stable in the area of the Messoyakha field of the West Siberian basin (modified from Sloan, 1990). 
been interpreted to contain in-situ gas hydrates rather than ice. Further analysis of electrical-resistivity well logs also indicates the presence of gas hydrates in the upper part of the Messoyakha gas accumulation (Makogon, 1981). The gas-hydrate and free-gas parts of the Messoyakha field are depicted in the generalized cross section in figure 12 . The detailed cross sections in figure 13 (Makogon and others, 1972; fig. 3) reveal that the well-log-inferred gas hydrates occur within a series of discrete, laterally continuous sandstone sequences that are separated by interbedded shales and siltstones. The Messoyakha structure as described by Makogon and others (1972) is a dome having dimensions

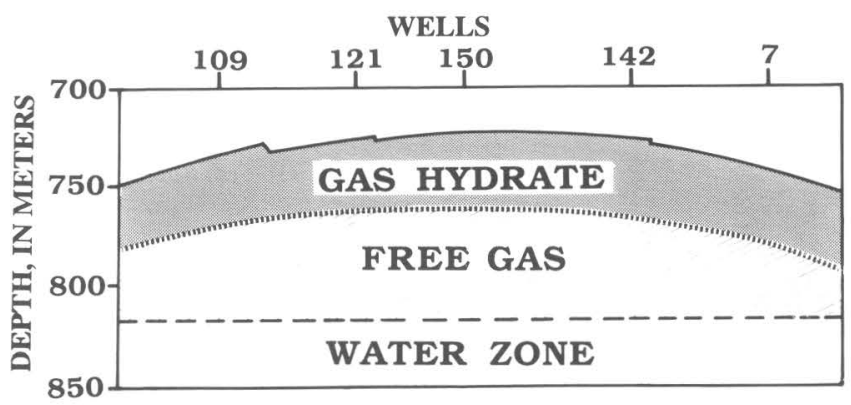

Figure 12. Generalized cross section illustrating the distribution of the gas-hydrate and free-gas parts of the Messoyakha field (modified from Makogon, 1988). of 12.5 by $19 \mathrm{~km}$ (fig. 14). Studies of cores, well cuttings, and well logs show that in the free-gas part of the Messoyakha field the Dolgan Formation is characterized by porosities ranging from 16 to 38 percent; permeabilities average about 125 millidarcies. Water saturations in the Dolgan Formation are reported to average about 40 percent (Makogon and others, 1972). Prior to production, the calculated total gas reserves within the gas-hydrate and free-gas parts of the Messoyakha accumulation were estimated to be about $80 \times 10^{9}$ cubic meters ( 2.8 trillion cubic feet), with about one-third of the reserves within the gas hydrates (Krason and Ciesnik, 1985).

The Cenomanian reservoirs of the Pokur suite in northern West Siberia contain mostly methane (92.5 to 99 percent), the source of which is a matter of controversy (reviewed by Grace and Hart, 1986). Elemental and isotopic compositions of the hydrocarbon gases within the West Siberian basin are available from several sources, including Yermakov and others (1970), Alekseyev (1974), and Galimov (1988). Most of the published isotopic data are limited to only stable methane carbon compositions. Additional isotopic data are required to accurately ascertain the source of a gas. However, by assuming that a gas with a stable methane-carbon isotopic composition of -50 permil and heavier is thermally generated and that an isotopic composition of -60 permil or lighter is indicative of methane from a microbial source (isotopic ranges from Schoell, 1983), it

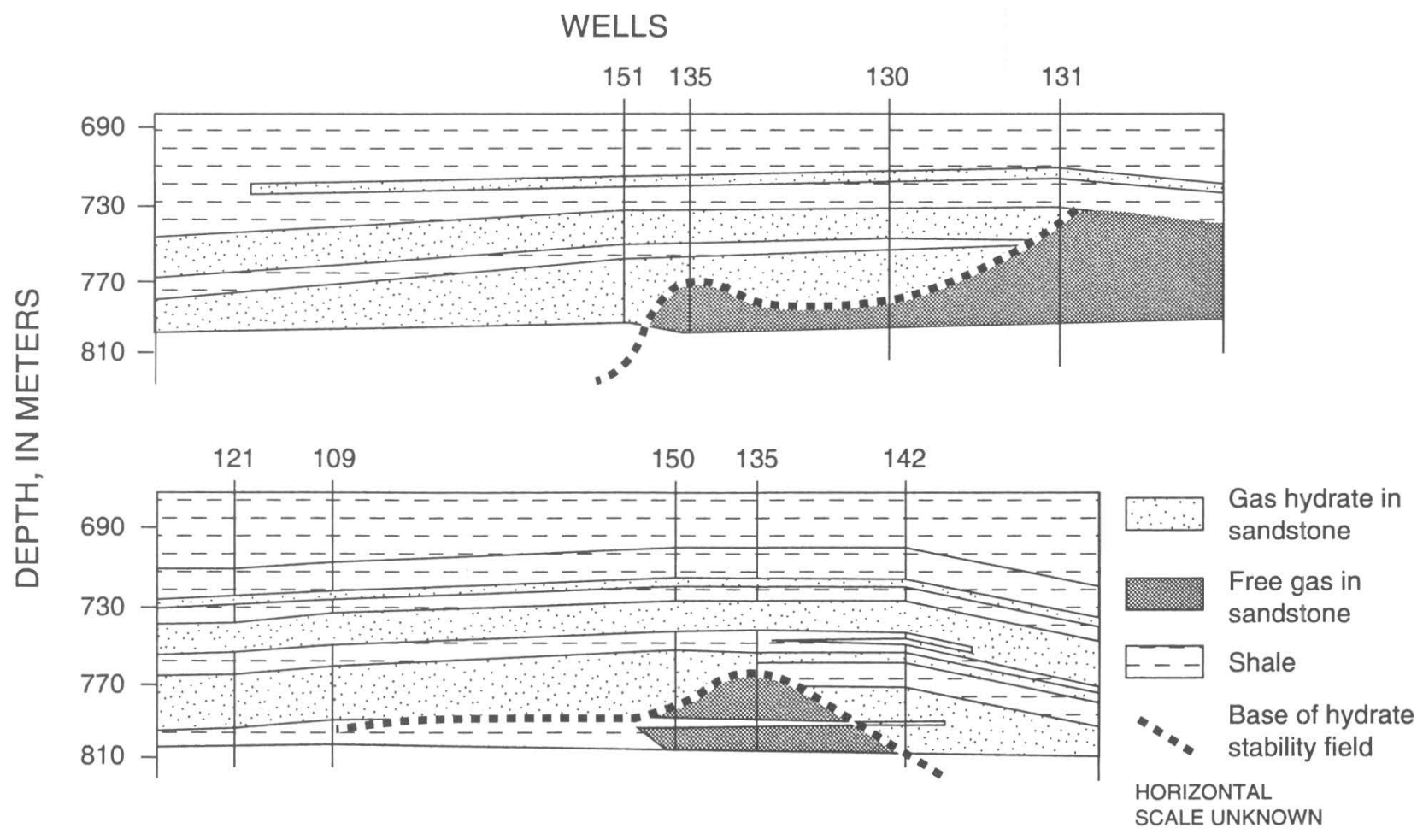

Figure 13. Multi-well cross sections showing the lateral and vertical extent of gas hydrates and underlying free gas in the Messoyakha field (modified from Makogon and others, 1972). Specific location of cross sections and horizontal scale are unknown. 


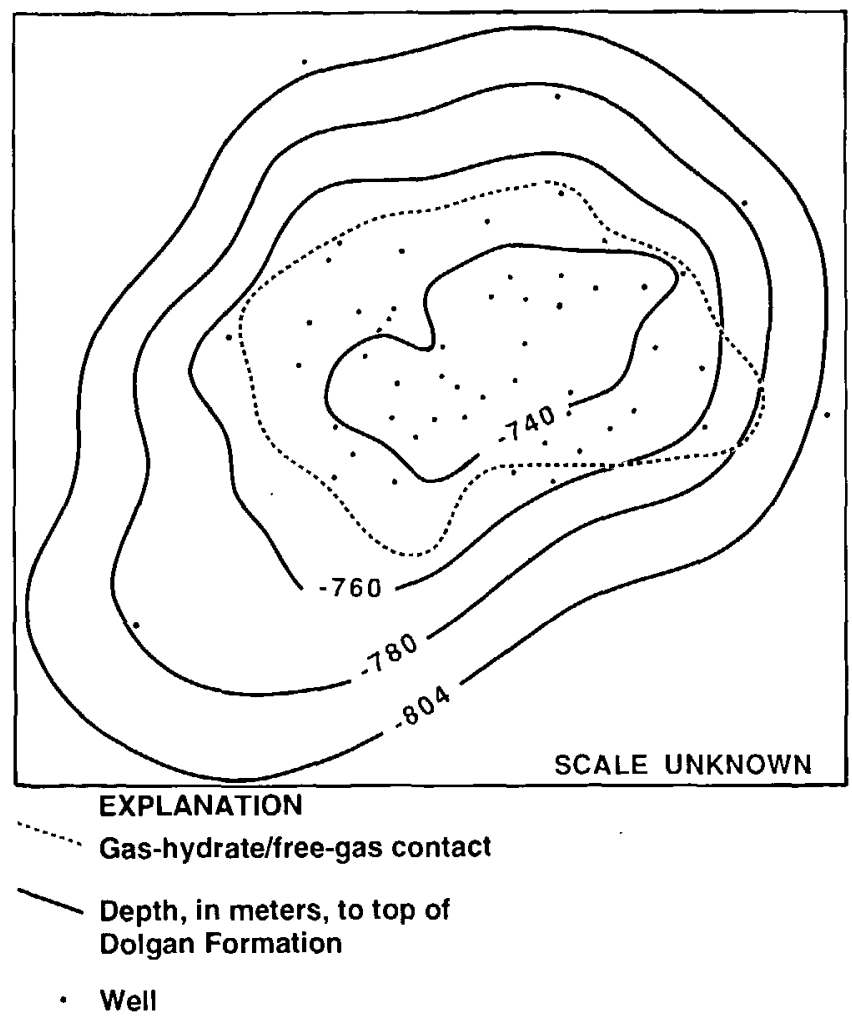

Figure 14. Structure map of the top of the gas-hydrate-bearing Dolgan Formation in the Messoyakha field (modified from Krason and Ciesnik, 1985).

is possible to approximate the source of a gas. Due to the arbitrary nature of these analytical boundaries, I have defined an isotopic transitional or mixing zone (values ranging from -65 to -45 permil) between the thermogenic and microbial end-members. The reported stable carbon isotopic compositions $\left(\delta^{13} \mathrm{C}\right)$ of the methane within the Neocomian reservoirs of the West Siberian basin range from -48 to -38 permil (Messoyakha values range from -44.2 to -38.5 permil), which are indicative of gases generated by mostly thermogenic processes. The Cenomanian reservoirs, however, contain methane with a stable carbon isotopic composition ranging from -68 to -41 permil (Messoyakha values range from -48.0 to -41.0 permil) (reviewed by Grace and Hart, 1986), which falls mostly within the transitional or mixing zone between the thermogenic and microbial endmember gases. The Messoyakha Cenomanian reservoirs, therefore, may contain gas that was formed by either microbial or thermogenic processes. The thermogenic gas component within the near-surface $(<900 \mathrm{~m})$ Cenomanian reservoirs of the Messoyakha field may have migrated from the deeper (about 2,600 m) Neocomian reservoirs or directly from Jurassic hydrocarbon source rocks. Kruglikov and others (1983) conclude from studies of argon isotopic data from the West Siberian basin that both deep (thermogenic) and shallow (microbial) sources have contributed to the $\mathrm{Ce}$ nomanian reservoirs. Galimov (1988), however, has sug- gested that the methane within the Cenomanian reservoirs may have been generated in situ by early-stage (low-temperature) geochemical transformation of terrestrial organic matter. His geochemical model suggests that the humic organic matter in the Cenomanian sedimentary deposits has a high methane-generation capacity at relatively low maturities and that the observed stable methane-carbon isotopic compositions indicate this low-temperature alteration. Some fraction of the methane in the hydrates of the Messoyakha field is probably from the microbial alteration of in-situ organic matter in the Cenomanian sediments; however, there is evidence that some methane has migrated from deep thermogenic sources. Most certainly, additional geochemical data are required to fully assess the source of the gas within the Cenomanian reservoirs of the West Siberian basin.

Several authors (Kortsenshteyn, 1970; Trofimuk and others, 1977; and DuRochet, 1980) suggest that conditions conducive to the formation of permafrost and gas hydrates have persisted in the northern part of the West Siberian basin since the early Pleistocene (about $1.65 \mathrm{Ma}$ ). Russian geologists generally conclude that pre-existing free-gas accumulations were converted to gas hydrates during Pleistocene glacial advances and that the gas-hydrate pools were transformed back into free-gas accumulations during subsequent interglacial periods. The present-day Messoyakha field is in transition from a gas-hydrate to a free-gas accumulation and it has not completely converted back to its preglacial free-gas state.

\section{MESSOYAKHA PRODUCTION HISTORY}

Production tests in the early development history of the Messoyakha field yielded highly variable results (table 2). Measured flow rates from the free-gas part of the reservoir were substantially greater than those from the gas hydrates. To confirm the presence of gas hydrates within the upper part of the Messoyakha field, a series of hydrate-inhibitor injection tests were conducted (table 3). During these tests, substances, such as methanol and calcium chloride, which destabilize and prevent the formation of gas hydrates, were injected into the suspected gas-hydrate-bearing rock units.

Table 2. Production-test data from the Messoyakha field, West Siberia (Makogon, 1981)

\begin{tabular}{cccc}
\hline Well No. $\begin{array}{c}\text { Depth of tested } \\
\text { interval }(\mathrm{m})\end{array}$ & $\begin{array}{c}\text { Distance above }(-) \text { or below } \\
(+) \text { the gas-hydrate/free-gas } \\
\text { contact }(\mathrm{m})\end{array}$ & $\begin{array}{c}\text { Gas flow } \\
\left(1,000 \mathrm{~m}^{3} / \text { day }\right)\end{array}$ \\
\hline 121 & $716-727$ & -64 & 26 \\
109 & $748-794$ & -6 & 133 \\
150 & $741-793$ & +6 & 413 \\
195 & $779-795$ & +29 & 626 \\
131 & $771-793$ & +59 & 1,000 \\
\hline
\end{tabular}


Table 3. Production results from gas-hydrate-inhibitor injection test in the Messoyakha field, West Siberia (from Sumetz, 1974, and Makogon, 1981)

\begin{tabular}{|c|c|c|c|}
\hline Well No. & Type of inhibitor & $\begin{array}{l}\text { Gas flow before } \\
\text { treatment } \\
\left(1,000 \mathrm{~m}^{3} / \text { day }\right)\end{array}$ & $\begin{array}{c}\text { Gas flow after } \\
\text { treatment } \\
\left(1,000 \mathrm{~m}^{3} / \text { day }\right)\end{array}$ \\
\hline 129 & Methanol -.....-... & 30 & 150 \\
\hline 131 & Methanol -----.-.---...---. & 175 & 275 \\
\hline \multirow[t]{5}{*}{133} & Methanol -- & 25 & 50 \\
\hline & & 50 & 100 \\
\hline & & 100 & 150 \\
\hline & & 150 & 200 \\
\hline & & 200 & 250 \\
\hline 138 & Methanol and $\mathrm{CaCl}_{2}$ & 200 & 300 \\
\hline 139 & Methanol and $\mathrm{CaCl}_{2}---$ & 120 & 180 \\
\hline 141 & Methanol and $\mathrm{CaCl}_{2}---$ & 150 & 200 \\
\hline \multirow[t]{4}{*}{142} & Methanol -...-............... & 5 & 50 \\
\hline & & 10 & 100 \\
\hline & & 25 & 150 \\
\hline & & 50 & 200 \\
\hline
\end{tabular}

Most of these tests (summarized by Sumetz, 1974, and Makogon, 1981) resulted in dramatic increases in production rates, which was attributed to the dissociation of the in-situ gas hydrates.

Long-term production from the gas-hydrate part of the Messoyakha field has been achieved by a simple depressurization scheme. The reservoir-pressure and production history of the Messoyakha field are depicted in figure 15. As production began in 1969, the reservoir-pressure decline curve followed the predicted path; however, in 1971 the measured reservoir pressures began to deviate from the

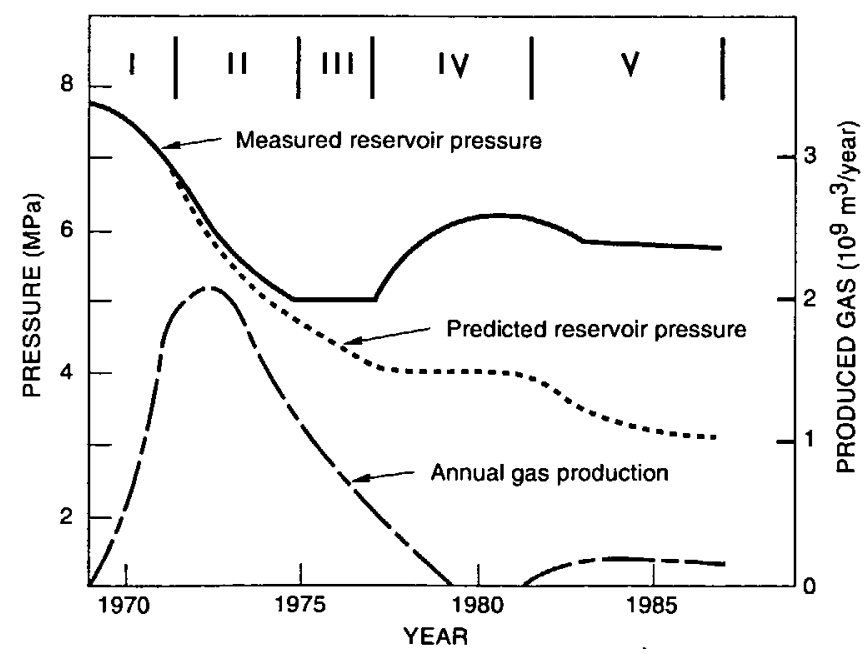

Figure 15. A plot of reservoir pressures and production history as a function of time for the Messoyakha field (modified from Makogon, 1988). The roman numerals across the top of the figure denote the stages of production discussed in the text. $\mathrm{MPa}$, megapascal. predicted values. This deviation has been attributed to the liberation of free gas from dissociating gas hydrates. The 17-yr production history of the Messoyakha field has been divided into five stages (fig. 15):

Stage I. From 1969 to 1971, the reservoir pressure did not fall below gas-hydrate stability conditions and gas production was only from the deeper free-gas part of the field.

Stage II. From 1971 to 1975, the actual reservoir pressures exceeded predicted reservoir pressures. This departure marked the start of gas-hydrate dissociation and gas production from the gas-hydrate part of the field.

Stage III. From 1976 to 1977, the volume of gas withdrawn from the reservoir was equal to the amount of gas liberated from the dissociating gas hydrates.

Stage IV. From 1978 to 1981, production from the Messoyakha field was reduced and eventually halted. The reservoir pressures began to rise as the gas hydrates continued to dissociate.

Stage V. Since 1982 there has been only modest production from the Messoyakha field. During this period the amount of gas liberated from the hydrates has been equal to the amount of gas produced.

Throughout the production history of the Messoyakha field, the depth of the gas-water contact has not changed, and it is estimated that about 36 percent (about $5.17 \times 10^{9}$ cubic meters or about 183 billion cubic feet) of the gas withdrawn from the field has come from the gas hydrates (Makogon, 1988). For more information on gas-hydrate production methods, see Yousif and others (1988) and Sloan (1990).

\section{POTENTIAL PRODUCTION FROM THE PRUDHOE BAY-KUPARUK RIVER GAS-HYDRATE ACCUMULATION}

Production data from the Prudhoe Bay-Kuparuk River gas-hydrate accumulation are limited to a single drill-stem test of the cored gas-hydrate interval of the N.W. Eileen State No. 2 well. The maximum gas-flow rate from the N.W. Eileen State No. 2 well of 112 cubic meters per day is similar to the production rates reported by Makogon (1981) for the untreated gas-hydrate intervals in the Messoyakha field (table 2). Other similarities between the Messoyakha and the Prudhoe Bay-Kuparuk River gas-hydrate accumulations suggest that the production history of the Messoyakha field may be used as an analog to predict the production potential of the Alaskan gas hydrates. For example, both the Messoyakha and the Prudhoe Bay-Kuparuk River gashydrate accumulations are in a series of friable sandstone reservoirs that are characterized by high porosities and low water saturations. Geochemical analyses suggest that the gas hydrates of the Messoyakha and Prudhoe Bay-Kuparuk River fields are almost identical in composition, and they have been interpreted to contain a mixture of thermogenic 
methane that migrated from deep, mature sources and insitu, microbial methane. These similarities suggest that the origin of both accumulations may be similar. The presence of a significant volume of free gas trapped below both the Messoyakha and the Prudhoe Bay-Kuparuk River gashydrate accumulations is most important when considering the potential production characteristics of the gas hydrates in Alaska. Use of the gas-hydrate-depressurization method of production requires that a portion of the accumulation be in a free-gas state. Therefore, the presence of free gas below the Prudhoe Bay-Kuparuk River gas hydrates suggests that the depressurization production method used in the Messoyakha field may work in northern Alaska. The most striking difference between the Messoyakha and the Prudhoe Bay-Kuparuk River gas-hydrate/free-gas accumulations is their size. The total mapped area of all six gashydrate occurrences in the Prudhoe Bay-Kuparuk River area is about $1,643 \mathrm{~km}^{2}$, whereas the Messoyakha field covers an area of only about $238 \mathrm{~km}^{2}$. This difference in field size accounts for the vast difference between the estimated gas reserves in the Messoyakha gas-hydrate/free-gas accumulation $\left(80 \times 10^{9}\right.$ cubic meters; 2.8 trillion cubic feet) and those in the Prudhoe Bay-Kuparuk River gas-hydrate accumulation $\left(1.2 \times 10^{12}\right.$ cubic meters; 44 trillion cubic feet). This difference suggests that the ultimate production capacity of the Prudhoe Bay-Kuparuk River gas-hydrate accumulation may be much greater than the historical production from the Messoyakha field.

\section{CONCLUSIONS}

The production history of the Messoyakha field in West Siberia has demonstrated that gas hydrates are an immediate producible source of natural gas and that production can be started and maintained by conventional methods. The geologic comparison of the Messoyakha and Prudhoe BayKuparuk River gas-hydrate accumulations suggests that the Alaskan gas hydrates may also be a producible source of natural gas. The gas hydrates of the Prudhoe Bay-Kuparuk River area are estimated to contain approximately 1.0 to 1.2 trillion cubic meters of gas, which is about fifteen times greater than the estimated gas reserves in the Messoyakha field. This estimate indicates that the gas hydrates of northern Alaska may be an important source of natural gas in the near future.

\section{ACKNOWLEDGMENTS}

This study was funded by the U.S. Department of Energy (interagency agreement No. DE-AI21-83MC20422) and the U.S. Geological Survey Climate Change Program.

\section{REFERENCES CITED}

Alekseyev, F.A., 1974, Zonality in oil and gas formation in the earth's crust based on isotopic studies: Geologiya Nefti i Gaza, April, p. 62-67: [English] Journal of Petroleum Geology, v. 12, p. 191-192.

Bily, C., and Dick, J.W.L., 1974, Natural gas hydrates in the Mackenzie Delta, Northwest Territories: Bulletin of Canadian Petroleum Geology, v. 22, no. 3, p. 340-352.

Carman, G.J., and Hardwick, Peter, 1983, Geology and regional setting of the Kuparuk oil field, Alaska: American Association of Petroleum Geologists Bulletin, v. 67, no. 6. p. 10141031.

Cherskiy, N.V., Tsarev, V.P., and Nikitin, S.P., 1985, Investigation and prediction of conditions of accumulation of gas resources in gas-hydrate pools: Petroleum Geology, v. 21, p. 65-89.

Collett, T.S., 1983, Detection and evaluation of natural gas hydrates from well logs, Prudhoe Bay, Alaska, Proceedings of the Fourth International Conference on Permafrost, Fairbanks, Alaska: Washington, D.C., National Academy of Sciences, p. 169-174.

Collett, T.S., Bird, K.J., Kvenvolden, K.A., and Magoon, L.B., 1988, Geologic interrelations relative to gas hydrates within the North Slope of Alaska: U.S. Geological Survey OpenFile Report 88-389, 150 p.

Collett, T.S., Kvenvolden, K.A., and Magoon, L.B., 1990, Characterization of hydrocarbon gas within the stratigraphic interval of gas-hydrate stability on the North Slope of Alaska: Applied Geochemistry, v. 5, p. 279-287.

Du Rochet, J., 1980, Une explication paleoclimatique des grands gisments superficiels de gaz sec du norde de la Siberie Occidentale (A paleoclimatic explanation for the shallow giant gas reserves of northern West Siberia): Bulletin des Centres de Recherches Exploration-Production Elf-Aquitains, v. 4, p. 119-142.

Galimov, E.M., 1988, Sources and mechanisms of formation of gaseous hydrocarbons in sedimentary rocks: Chemical Geology, v. 71, p. 77-95.

Grace, J.D., and Hart, G.F., 1986, Giant gas fields of northern West Siberia: American Association of Petroleum Geologists Bulletin, v. 70, no. 7, p. 830-852.

Jenden, P.D., and Kaplan, I.R., 1986, Comparison of microbial gases from the Middle American Trench and Scripps Submarine Canyon--Implications for the origin of natural gas: Applied Geochemistry, v. 1, p. 631-646.

Judge, A.S., 1988, Mapping the distribution and properties of natural gas hydrates in Canada: Proceedings of the American Chemical Society Third Chemical Congress of the North American Continent, June 6-7, Toronto, Ontario, Abstract Number 29.

Kortsenshteyn, V.N., 1970, Effect of periodic glaciations on the formation of the enormously large gas fields in the northern part of the Tyumen Oblast: Akademiya Nauk SSSR Doklady, v. 191, p. 1366-1369.

Krason, J., and Ciesnik, M., 1985, Geological evolution and analysis of confirmed or suspected gas hydrate localities, Volume 5-Gas hydrates in the Russian literature: Report for U.S. Department of Energy, Office of Fossil Energy, 
Morgantown Energy Technology Center, Morgantown, West Virginia, Contract No. DE-AC21-84MC21181, 164 p.

Kruglikov, N.M., Prasolov, E.M., Yakovlev, O.N., 1983, Gidrogeologicheskaya sostavlyayuchaya prognoza neftegazonosnosti: All Union Scientific-Research Institute for Geologic Exploration, p. 4-27: [English] Joumal of Petroleum Geology, v. 20 , p. $481-485$.

Kvenvolden, K.A., 1988, Methane hydrate-A major reservoir of carbon in the shallow geosphere?: Chemical Geology, v. 71, p. 41-51.

Kvenvolden, K.A., and McMenamin, M.A., 1980, Hydrates of natural gas-A review of their geologic occurrences: U.S. Geological Survey Circular 825, 11 p.

Makogon, Y.F., 1981, Hydrates of natural gas: Tulsa, Okla., Penn Well Publishing, 237 p.

1988, Natural gas hydrates-The state of study in the USSR and perspectives for its use: Paper presented at the Third Chemical Congress of North America, Toronto, Canada, June 5-10, 18 p.

Makogon, Y.F., Trebin, F.A., Trofimuk, A.A., Tsarev, V.P., and Cherskiy, N.V., 1972, Detection of a pool of natural gas in a solid (hydrate gas) state: Doklady Academy of Sciences U.S.S.R., Earth Science Section, v. 196, p. 197-200.

Peterson, J.A., and Clarke, J.W., 1989, West Siberian oil-gas province: U.S. Geological Survey Open-File Report 89-192, 142 p.

Potential Gas Committee, 1981, Potential supply of natural gas in the United States (as of December 31, 1980): Potential Gas Agency, Colorado School of Mines, Golden, Colo., 199 p.

Schoell, Martin, 1983, Genetic characterization of natural gases: American Association of Petroleum Geologists Bulletin, v. 67 , no. 12 , p. $2225-2238$.
Sloan, E.D., 1990, Clathrate hydrates of natural gases: New York, Marcel Dekker, 641 p.

Sumetz, V.I., 1974, Prevention of hydrate formation in gas wells zone: Gazovaya Promishlennost, v. 2, p. 24-26.

Trofimuk, A.A., Cherskiy, N.V., and Tsaryov, V.P., 1977, The role of continental glaciation and hydrate formation on petroleum occurrence, in Meyer, R.F., ed., The future supply of naturemade petroleum and gas: New York, Pergamon Press, p. 919-926.

Werner, M.R., 1987, Tertiary and Upper Cretaceous heavy oil sands, Kuparuk River area, Alaskan North Slope, in Tailleur, I.L., and Weimer, Paul, eds., Alaskan North Slope geology: Bakersfield, California, Pacific Section, Society of Economic Paleontologists and Mineralogists and the Alaska Geological Society, Book 50, v. 1, p. 109-118.

Whiticar, M.J., Faber, E., and Schoell, M., 1986, Biogenic methane formation in marine and freshwater environments; $\mathrm{CO}_{2}$ reduction vs. acetate fermentation-Isotopic evidence: Geochimica et Cosmochimica Acta, v. 50, p. 693709.

Yermakov, V.I., Lebedev, V.S., Nemchenko, N.N., Rovenskaya, A.S., and Grachev, A.V., 1970, Isotopic composition of carbon in natural gases in the northern part of the West Siberian Plain in relation to their origin: Akademiya Nauk SSSR Doklady, v. 190, p. 683-686.

Yousif, M.H., Abass, H.H., Selim, M.S., and Sloan, E.D., 1988, Experimental and theoretical investigation of methane gas hydrate dissociation in porous media: Proceedings of the 63rd Annual Technical Conference and Exhibition of the Society of Petroleum Engineers, October 2-5, Houston, Tex., p. $571-583$. 

THE FUTURE OF ENERGY GASES

U.S. GEOLOGICAL SURVEY PROFESSIONAL PAPER 1570

\title{
Gas Hydrates on the Atlantic Continental Margin of the United States-Controls on Concentration
}

\author{
By William P. Dillon ${ }^{1}$, Myung W. Lee ${ }^{2}$, Kristen Fehlhaber ${ }^{1}$, and Dwight F. Coleman ${ }^{1}$
}

\section{CONTENTS}

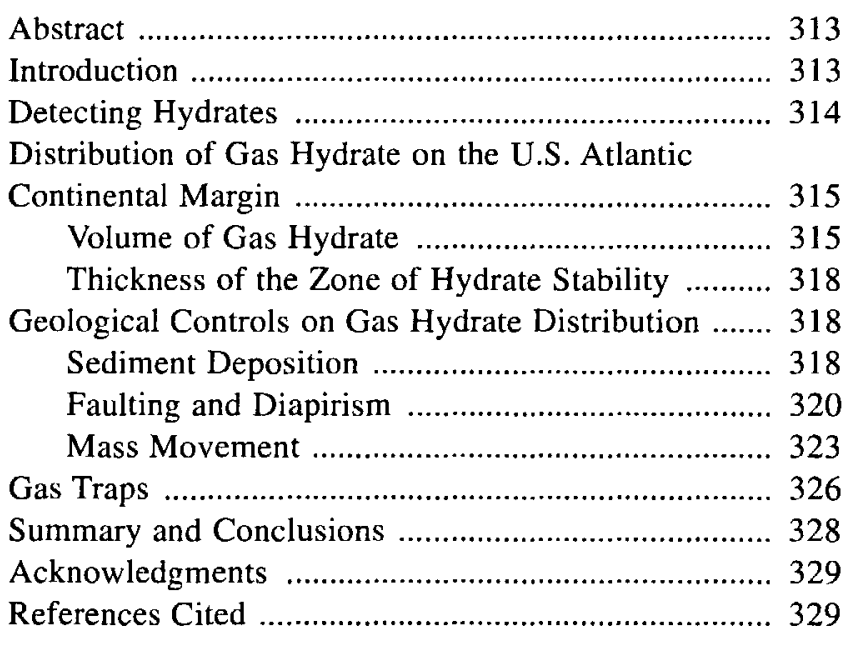

\begin{abstract}
Large volumes of gas hydrates exist within oceanfloor deposits at water depths exceeding about 300 to 500 $\mathrm{m}$. They cement a surface layer of sediments as much as about $1,000 \mathrm{~m}$ thick, limited at its base by increasing temperature. Gas hydrates are identified by drilled samples and by their characteristic responses in seismic reflection profiles. These seismic responses include, at the base of

\footnotetext{
${ }^{1}$ U.S. Geological Survey, Bldg. B, Quissett Campus, Woods Hole, MA 02543.

${ }^{2}$ U.S. Geological Survey, Federal Center, P.O. Box 25046, MS 960, Denver, CO 80225.
}

the hydrate-cemented surface layer, a marked velocity decrease and a sea-floor-paralleling reflection (known as the bottom-simulating reflection, or BSR) and, within the hydrate-cemented layer, a reduction in amplitude of seismic reflections (known as blanking), which is apparently caused by cementation of strata. By using seismic-reflection data we have mapped the volume of hydrate and thickness of the hydrate-cemented layer off the U.S. East Coast. Concentrations of gas hydrate are located at sites of present or past rapid deposition of sediments and at a linear group of diapirs and associated faults. The sources of gas at these concentrations are probably bacterial generation of methane at the locations of rapid deposition, and possibly the migration of deep, thermogenic gas up faults near diapirs. The thickness of the gas-hydrate layer decreases markedly at landslide scars, possibly due to breakdown of hydrate resulting from pressure reduction caused by removal of sediment by the slide. Gas traps appear to exist where a seal is formed by the gas-hydrate-cemented layer. Such traps are observed (1) where the sea floor forms a dome, and therefore the bottom-paralleling, hydrate-cemented layer also forms a dome; (2) above diapirs, where the greater thermal conductivity of salt creates a warm spot and salt ions act as antifreeze, both effects resulting in a local shallowing of the base of the hydrate; and (3) at locations where strata dip relative to the sea floor, and the updip regions of porous strata are sealed by the gas-hydrate-cemented layer to form a trap. In such situations the gas in the hydrate-sealed trap, as well as the gas that forms the hydrate, may become a resource.

\section{INTRODUCTION}

Natural-gas hydrates are stable at the temperature and pressure conditions that exist near and just beneath the sea 
floor almost everywhere in the world's oceans where water depths exceed 300 to $500 \mathrm{~m}$ (Kvenvolden, this volume). Hydrates in this setting probably contain very large quantities of methane (Kvenvolden, 1988). Furthermore, hydrates seem to have the capacity to fill sediment pore space and reduce permeability, so that hydrate-cemented sediments act as seals for gas traps. Thus, there are two ways in which hydrates can create deposits of energy gases (primarily methane, but other hydrocarbon gases as well): (1) by binding gas into hydrates within sediments and (2) by creating a trap, using hydrate-cemented sediments as the seal.

Where are the ice-like hydrates located in the marine setting? Temperature and pressure conditions are appropriate in deep-ocean water, but hydrates do not exist there because methane saturation generally does not exist. Furthermore, if hydrate did form in the water, it would float upward into warmer water and melt. Gas hydrates do exist within sea-floor sediments because the hydrate is trapped in intergranular pores and because gas is available, either biogenic gas produced by bacteria or thermogenic gas rising from deeper strata. Temperature increases downward through the sediments along the geothermal gradient, and although pressure also increases (which tends to make hydrate more stable), the conditions eventually become too hot for hydrate to exist. Because the thermal gradient is fairly constant within a restricted region, this stability limit will be reached at approximately the same subbottom depth everywhere in the region. The result is a zone of hydrate-cemented sediment that extends down from the sea floor and that is of fairly uniform thickness, commonly several hundred meters. Our work has focused on these questions: Where is the hydrate located? How much hydrate exists? What geological factors control its presence? We have concentrated our studies on the U.S. Atlantic continental margin.

\section{DETECTING HYDRATES}

How do we locate and map hydrate-cemented sediment in the deep sea? Although hydrates have been recognized in drilled cores, their presence over large areas can be detected much more efficiently by acoustical methods, using seismic-reflection profiles (Tucholke and others, 1977; Shipley and others, 1979; Dillon and Paull, 1983; Collins and Watkins, 1985; Miller and others, 1991; Rowe and Gettrust, 1993). Hydrate has a very strong effect on acoustic reflections because it has a very high acoustic velocity $(-3.3 \mathrm{~km} / \mathrm{s}$-about twice that of sea-floor sediments; Sloan, 1990), and thus cementation of grains by hydrates produces a high-velocity deposit due to the mixing of hydrate with the sediment. Sediments below the hydrate zone, if water saturated; have lower velocities (acoustic velocity of water is $-1.5 \mathrm{~km} / \mathrm{s}$ ), and if gas is trapped in the sediments below the hydrate, the velocity is much lower (even with just a few percent of gas; Brandt, 1960). Because reflection strength is proportional to the change of acoustic impedance, which is the product of velocity times density, the base of the hydrate-cemented zone produces a strong reflection. The reflection is also sharply defined, because the phase boundary is a distinct, not diffuse, limit to hydrate occurrence. The top of hydrate within the sediments has no such precisely defined boundary, so it does not produce a sharp reflection. As noted above, the base of hydrate stability occurs at an approximately uniform subbottom depth throughout a small area, and therefore the reflection from its base roughly parallels the sea floor. The reflection has become known as the bottom-simulating reflection or BSR; the BSR is characteristic of hydrate-bearing sediments. A very strong BSR is shown in figure 1 . Note how it approximately parallels the sea floor, which dips to the right, and cuts through reflections from sedimentary strata, which dip slightly to the left. The coincidence in depth of the BSR to the theoretical, extrapolated pressure and temperature conditions that define the hydrate phase boundary and the sampling of hydrate above BSR's give confidence that this seismic indication of hydrates is dependable (Kvenvolden and Barnard, 1982, 1983; Shipley and Didyk, 1982; Kvenvolden and Kastner, 1990).

A second significant seismic characteristic of hydratecementation, called blanking, is also well displayed in figure 1 ; blanking is the reduction of the amplitude of seismic reflections caused by hydrate cementation. The amplitudes of reflections (shown by the excursions of the filled wiggle traces) are much smaller above the BSR, where sediments are cemented by gas hydrates, than they are below the BSR. This phenomenon consistently appears in sediments containing gas hydrates, indicating that the changes in acoustic impedance between the strata are much reduced by hydrate cementation. A third characteristic of gas hydrates in a near-bottom layer of sediment is the abrupt velocity decrease at the BSR caused by moving from hydrate-cemented sediments above to noncemented sediments below that are water- or even gas-filled. This downward velocity decrease, known as an "inversion", is detected with some seismic techniques; for example, see Lee and others (this volume).

The three manifestations of hydrates in sea-floor sediments noted above (BSR, blanking, and velocity inversion) have all been used to recognize gas hydrates in seismic profiles on the U.S. Atlantic continental margin (Tucholke and others, 1977; Shipley and others, 1979; Dillon and others, 1980; Paull and Dillon, 1981; Krason and Ridley, 1985). The BSR and velocity inversion are related just to the bottom boundary of the hydrate zone. The blanking effect, however, occurs across the entire hydratecemented zone and can be quantified and mapped to estimate the amount of gas hydrate that is present (Lee and others, this volume; Lee and others, 1992; Lee and others, 
in press). We calculated the amount of hydrate in the most intensively blanked sediments by using known hydrate velocity from published laboratory studies, velocities that we determined for sea-floor sediments from multichannel seismic profiles, and porosity in our study area determined in scientific drilling. We assume that such a material is an end member, and in our computed seismic model, we mathematically "mix" it with a similar deposit having no hydrate, in order to model the range of possible blanking effects. The effect on reflection amplitudes of various mixtures of end-member, hydrate-cemented sediment with hydrate-free sediment is shown in figure 2. The increase of blanking with increase of hydrate is apparent. Three classes of blanking have been assigned; the boundaries between classes represent a change in the power of reflections by a factor of two. The class boundaries are indicated on figure 2, and these classes can be related to overall average amounts of hydrate in bulk sediment of approximately 7 percent (class 3), 12 percent (class 2), and 15 percent (class 1) in this example. To recognize classes in a profile, we determine and plot the amount of blanking (the reduction in reflection amplitude) along the profile in a subbottom window within the hydrate zone ( 0.25 to $0.5 \mathrm{~s}$ (two-way traveltime) below the sea floor); an example is shown in figure 3 . These measured values are used as a calibration, and the extent of the three classes is interpreted by eye along the profile. The total thickness for each class is plotted along each profile, and the total volume of each class is estimated by interpolating be- tween adjacent profiles in the area being mapped. Once the volumes for each class are estimated, they are multiplied by the appropriate percentages, and a volume estimate of hydrate is made.

\section{DISTRIBUTION OF GAS HYDRATE ON THE U.S. ATLANTIC CONTINENTAL MARGIN}

\section{VOLUME OF GAS HYDRATE}

The amount of gas hydrate within the sediments of the U.S. Atlantic continental rise south of Hudson Canyon is shown in figure 4 . The map indicates the volume of hydrate by isopach contours that show the thickness of hydrate that would appear if all hydrate were extracted from the sediment pores and piled on the sea floor.

The map shows that the greatest amount of gas hydrate is present south of $34^{\circ} \mathrm{N}$., where we identify three major concentrations; a fourth concentration occurs at the northern end of our survey area. One occurs in very deep water, greater than $5,000 \mathrm{~m}$, between $71.5^{\circ}$ and $74^{\circ} \mathrm{W}$. on the Lower Rise Hills, which are sediment waves built on the Hatteras Outer Ridge (Mountain and Tucholke, 1985; EEZ Scan 87, 1991; Schlee and others, 1992). A second concentration occurs on the Blake Ridge, mainly from $75^{\circ}$ to $76^{\circ} \mathrm{W}$. and $31^{\circ}$ to $32.5^{\circ} \mathrm{N}$. The third southern concentration is contiguous with the Blake Ridge hydrates and

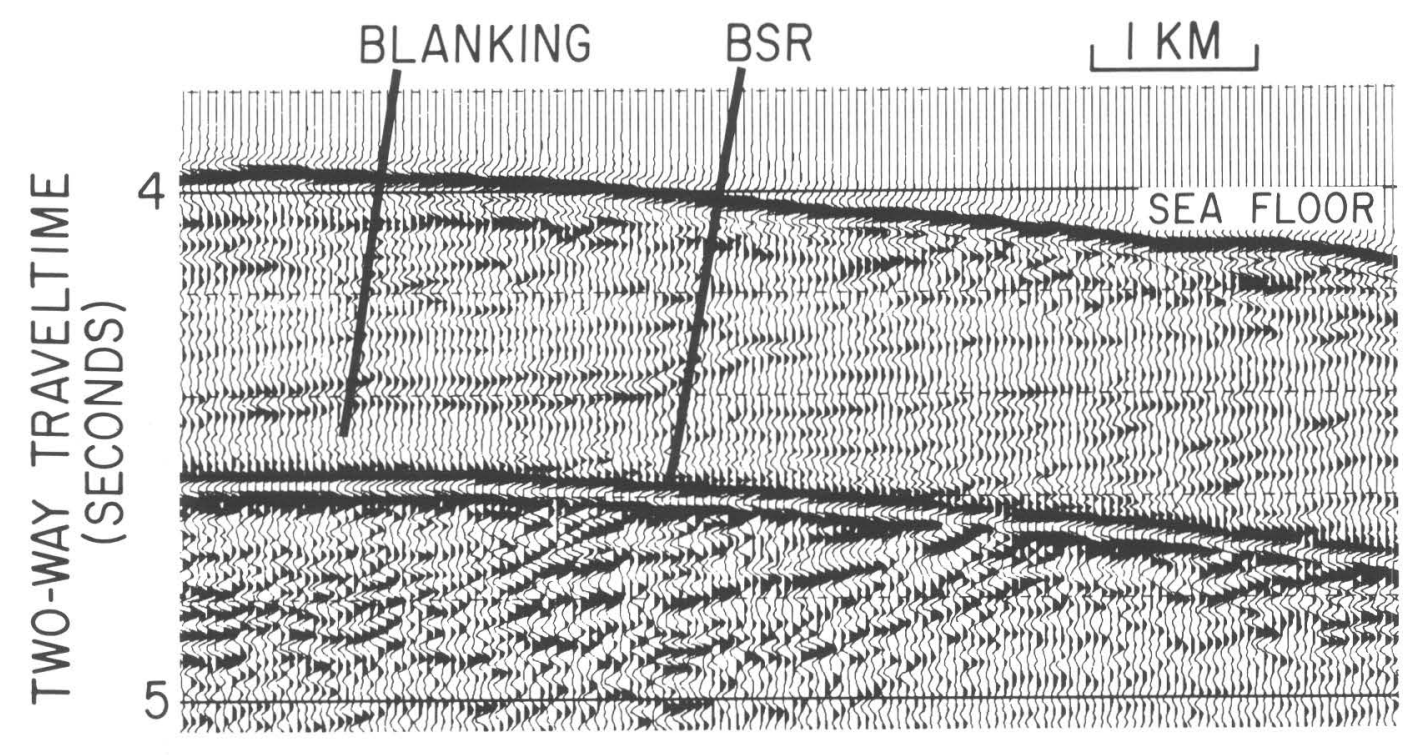

Figure 1. Part of U.S. Geological Survey 48-channel seismic-reflection profile BT1 off North Carolina, showing clear examples of the kind of effects of gas hydrate that are observed in seismic profiles. The base of hydrate-cemented sediments in contact with water- or gas-plus-water-filled sediments forms a very strong reflecting horizon that parallels the sea floor, known as the bottom simulating reflection, or BSR. Note that the BSR cuts through reflections from strata that dip to left in this example. Above the BSR, in the region where sediments are cemented by gas hydrate, the amplitude of reflections is reduced, a phenomenon known as blanking. 


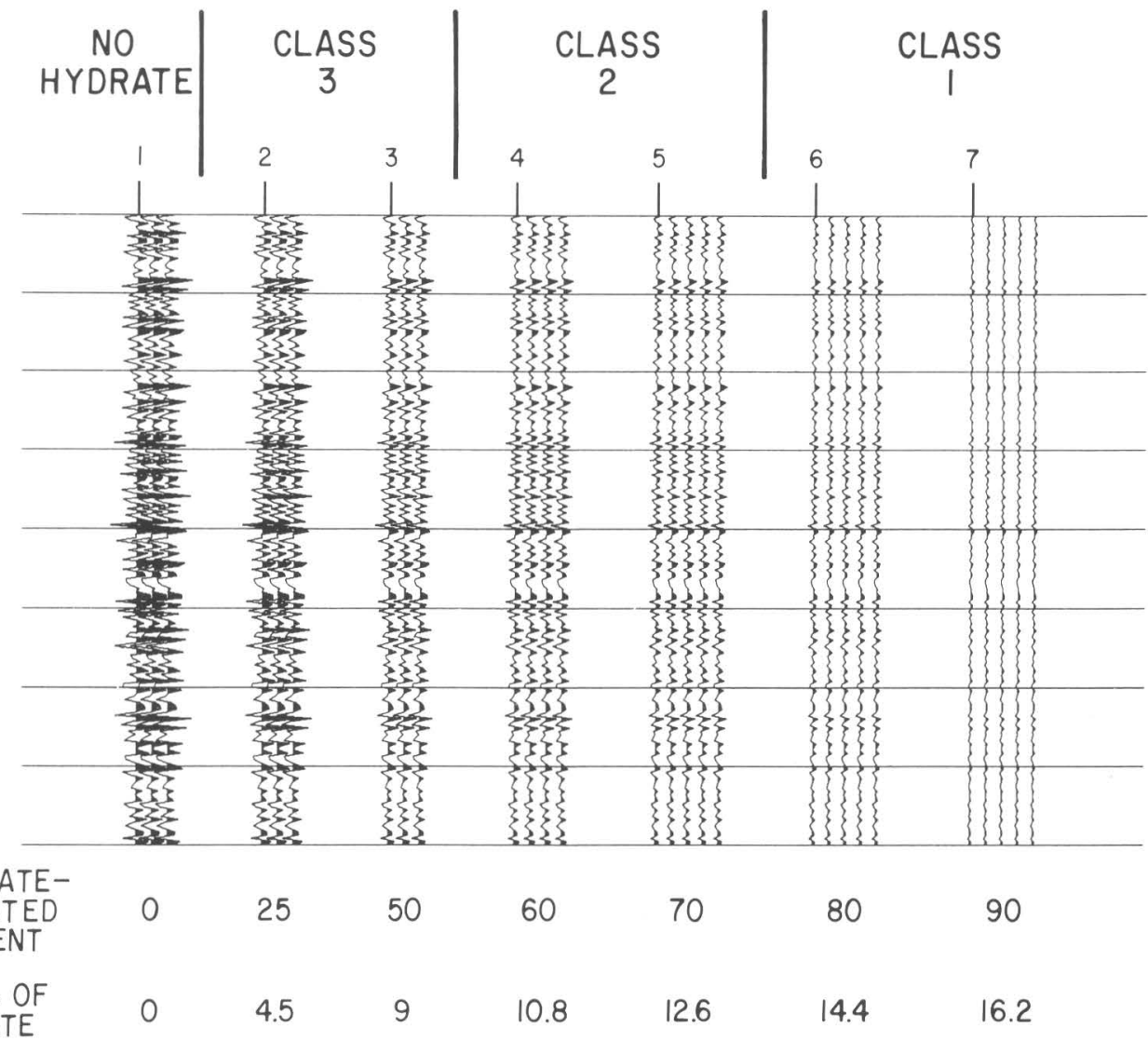

Figure 2. Synthetic seismograms showing the modeled effect of various amounts of gas-hydrate cement on the amplitude of reflections from acoustic impedance differences comparable to those of sedimentary strata. The reduction in reflection amplitude caused by hydrate cementation is the parameter called blanking. BULK $\%$ OF HYDRATE is percentage of hydrate relative to total volume of sediment (grains plus pore space containing hydrate plus pore space containing water).

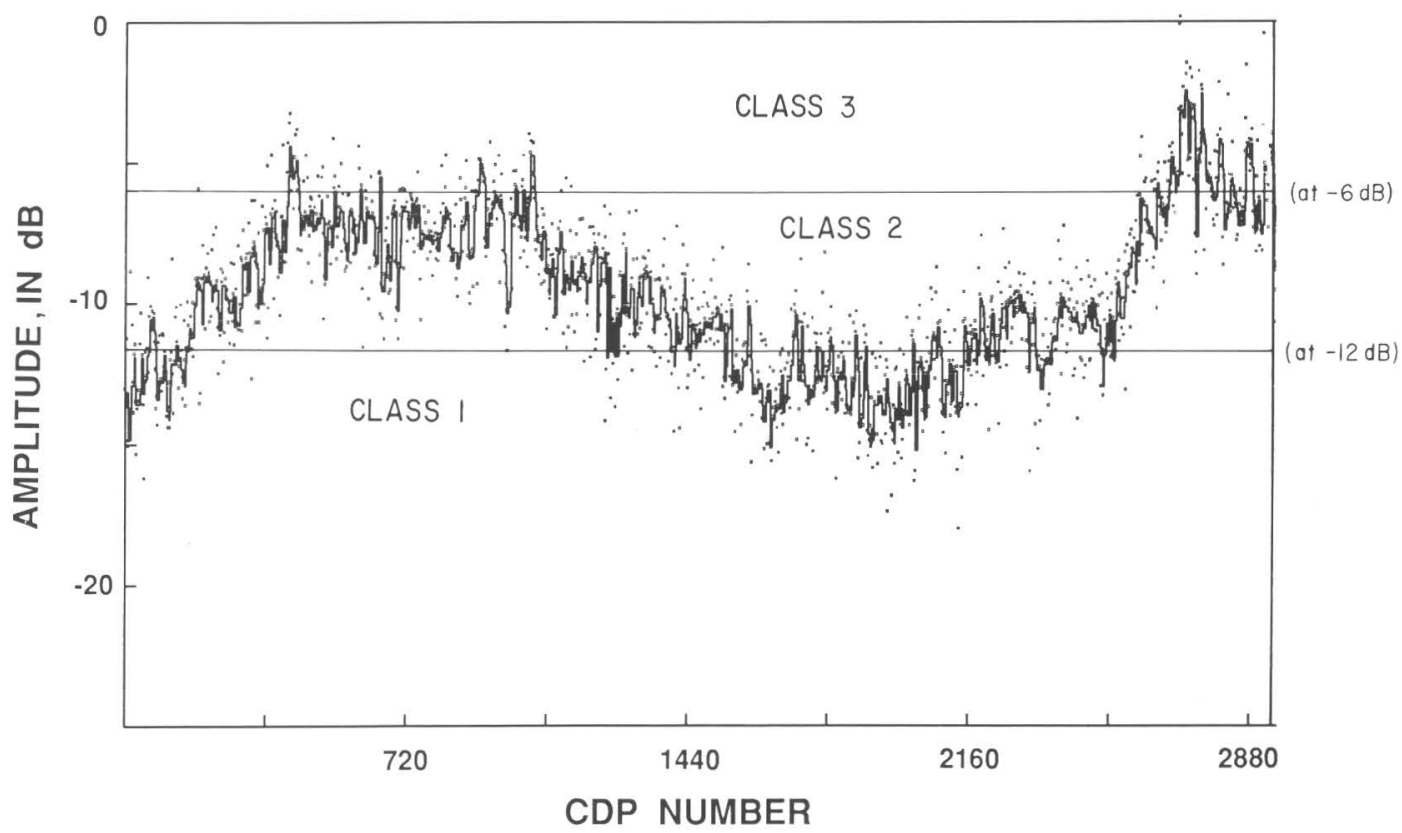

Figure 3. Plot of amplitude variations along profile in window from 0.25 to 0.5 seconds (two-way traveltime) below the sea floor, which is within the zone of hydrate cementation. Solid line is a moving average. Amplitude reductions related to blanking classes shown in figure 2 are indicated. $\mathrm{dB}$, decibel; CDP, common depth point. 
extends north-northeastward from $31.5^{\circ} \mathrm{N}$., $77^{\circ} \mathrm{W}$. to $34^{\circ}$ N., $75.5^{\circ} \mathrm{W}$; ; it is labeled Carolina Trough diapirs.

North of $34^{\circ} \mathrm{N}$., a series of relatively small, weak concentrations extend along the upper rise to $38^{\circ} \mathrm{N}$. At the northeast corner of the map, an extensive but relatively weak concentration of hydrate, labeled Hudson-Wilmington drape area, covers the region from approximately $37^{\circ}$ to $39^{\circ} \mathrm{N}$. and $71^{\circ}$ to $72^{\circ} \mathrm{W}$.

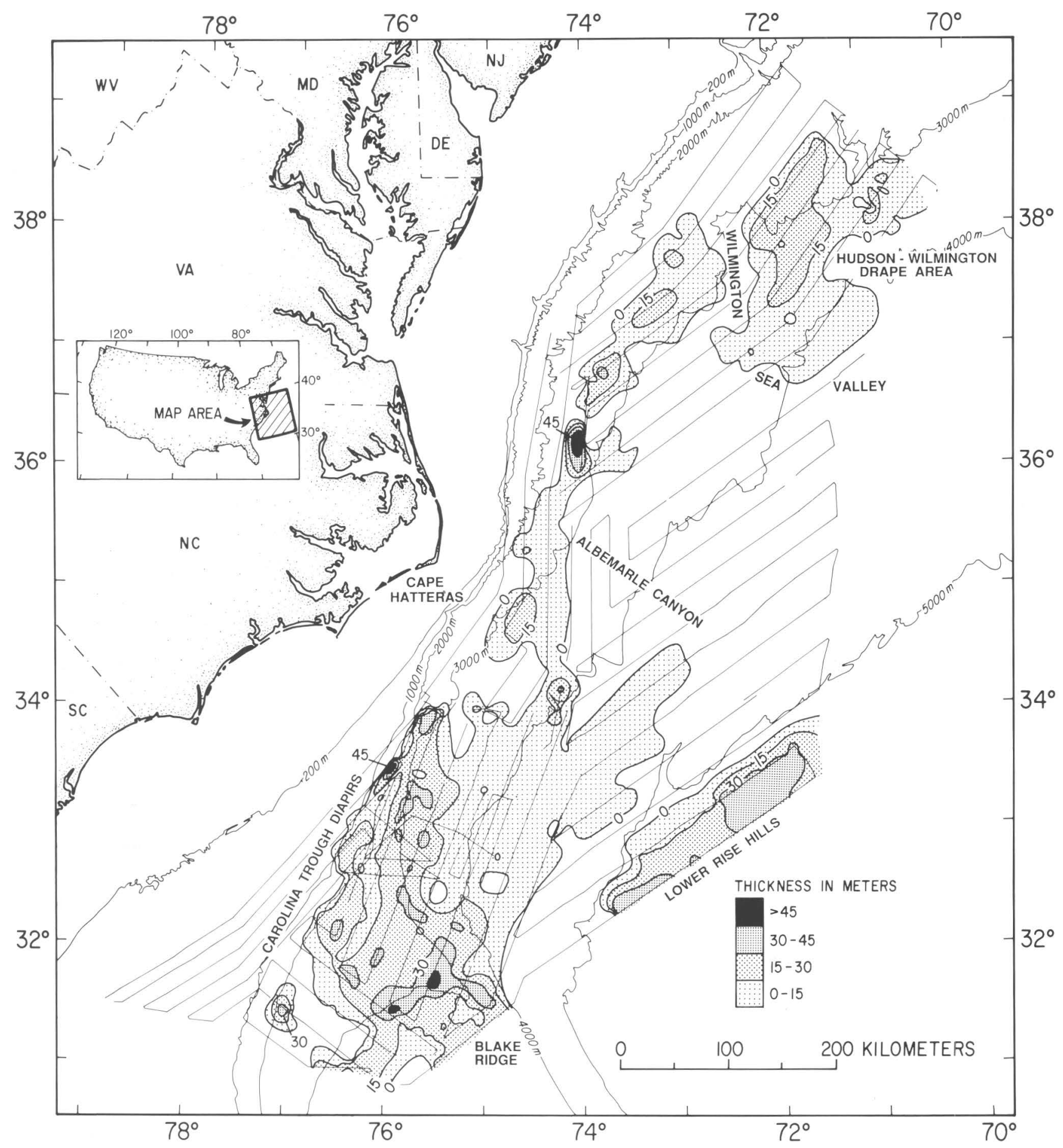

Figure 4. Contours of volume of gas hydrate existing within sediments of U.S. Atlantic continental margin. Volume is indicated as thickness in meters of total amount of pure hydrate existing in pore space. Volumes are estimated by mapping extent of blanking in seismic profiles in depth region where hydrate is stable and using a modeling approach to relate the blanking to proportion of gas hydrate in the sediment (Lee and others, this volume). Straight, lightweight lines are locations of seismic profiles used in this study. 
As an example of the inferred amount of hydrate and gas implied by figure 4, we calculated the amount of gas hydrate in the Blake Ridge concentration within the small area inside the main $30-\mathrm{m}$ contour on the Blake Ridge $\left(-31.5^{\circ}-32^{\circ} \mathrm{N} ., 75^{\circ}-76^{\circ} \mathrm{W}\right.$.) on the basis of results shown in figure 4 . The area within this $30-\mathrm{m}$ contour is approximately $3,000 \mathrm{~km}^{2}$. The calculated volume of hydrate within this area, $1.13 \times 10^{11} \mathrm{~m}^{3}$, would contain a volume of methane at standard temperature and pressure (STP) approximately equal to $1.8 \times 10^{13} \mathrm{~m}^{3}$, or 645 trillion cubic feet (Tcf) of methane.

\section{THICKNESS OF THE ZONE OF HYDRATE STABILITY}

A map of the depth of the BSR below the sea floor is shown in figure 5; this interval-from sea floor to BSR-represents the zone in which gas hydrate is stable. Because the thermal gradient is fairly constant over the continental rise region, and because gas hydrate becomes stable at higher temperatures as pressure increases, one would expect a simple pattern in which the BSR would become uniformly deeper as the water becomes deeper (Kvenvolden and Barnard, 1982). Clearly the pattern is far more complicated (fig. 5). A general trend of greater BSR depth with deeper water is shown in a plot of data from several profiles in the Blake Ridge area (fig. 6, from Dillon and Paull, 1983), but the scatter is great. In some places, such as the Hudson-Wilmington drape area (fig. 5), the tendency is reasonably pronounced to proceed from shallow to deep subbottom BSR as water depth increases. In mass movement areas, such as the Cape Lookout and Cape Fear slides (fig. 5), a distinct thinning of the hydrate zone is associated with the slide scars. Extreme complexity of the thickness of the hydratestable zone occurs in the Carolina Trough diapir area.

\section{GEOLOGICAL CONTROLS ON GAS HYDRATE DISTRIBUTION}

\section{SEDIMENT DEPOSITION}

The most significant control on hydrate accumulation appears to be rate of sediment deposition. Of the four concentrations of hydrate noted above, three are associated with areas of high deposition. The northernmost (HudsonWillmington drape area, fig. 4) occurs in a region of undisturbed recent sedimentation (Schlee and others, 1992) between the Hudson and Wilmington sea valleys. The valleys form two major channelways for transportation of sediments across the continental rise. The area between the valleys is a depocenter where more than $300 \mathrm{~m}$ of late Pliocene to Holocene sediment accumulated (Mountain and Tucholke, 1985).
The southeastern, deep-water hydrate concentration occurs on the Lower Rise Hills (fig. 4), a region of sediment-wave deposition that also was active in late Pliocene to present. Hydrates have not been sampled in either this or the drape area, but their abundance in these areas, as indicated by seismic interpretation, is not surprising. Most marine gas hydrates have been formed from biogenic methane (Kvenvolden and McMenamin, 1980). Areas of rapid hemipelagic deposition tend to accumulate considerable amounts of organic detritus and preserve it from oxidation at the sea floor by rapid burial, so that it is converted to abundant methane by bacteria within the sediments (Claypool and Kaplan, 1974). Therefore, abundance of gas hydrate in areas of rapid deposition would be expected.

The third concentration of gas hydrate in the mapped area is at the Blake Ridge (fig. 4). This also is a major depocenter, but at the site of the gas-hydrate concentration, the principal accumulation of sediments (to a maximum thickness of more than $1,200 \mathrm{~m}$ ) occurred in middle Miocene to late Pliocene time (Mountain and Tucholke, 1985). Deposition has continued more recently at a center slightly to the south of the main hydrate concentration. The source of gas in the Blake Ridge has been bacterial decay of organic material that accumulated in the sediment drift deposits (Kvenvolden and Barnard, 1983). A profile across the Blake Ridge (fig. 7) shows marked blanking of reflections. Blanking is strongest in the lower part of the hydrate zone just above the BSR. The blanking seems reasonably uniform across the ridge, indicating that the amount of hydrate in the sediments and the sediment velocities in the hydrate zone of stability are reasonably uniform. The profile also shows a very strong BSR under the crest of the ridge and a weak BSR under the flanks. The change in strength of the BSR probably is caused by significant changes of velocity beneath it from relatively high velocity on the flanks of the ridge to extremely low velocity beneath the crest region-a low velocity caused by the presence of gas in the sediment pore space.

The great volume of hydrate within the Blake Ridge sediments, which is the highest concentration observed, results from the anticlinal shape of the ridge and the capacity of hydrate-cemented sediments to trap gas. The Blake Ridge is a thick sediment drift deposit that accumulated rapidly in a ridge configuration between the late Oligocene and Holocene; accumulation rates reached 160-190 $\mathrm{m} / \mathrm{m}$.y. (Mountain and Tucholke, 1985). As the sediment accumulated, the ridge built upward and the deeper sediments became warmer; in essence, the surfaces of constant temperature - the isotherms-migrated upward as the sediment surface rose. This warming caused the hydrate in the deeper, older sediments to break down, releasing gas that moved upward through the sediments and was trapped at the relatively impermeable base of hydrate-cemented sediments, which, by its configuration, acted as a trap. The trapped free gas penetrated the hydrate-cemented zone by 
diffusion or perhaps along pathways provided by small compaction faults, and it was immediately converted to hydrate there, thus causing a concentration of hydrate at the base of the hydrate-stable zone. The trapping of gas at the axis of the ridge beneath the hydrate zone (beneath the
BSR) is shown by the variation in BSR strength in figure 7 , and the densest concentration of hydrate in the lower part of the hydrate zone is indicated by the presence of the strongest blanking there, just above the BSR. The process described accounts for the great concentration of hydrate

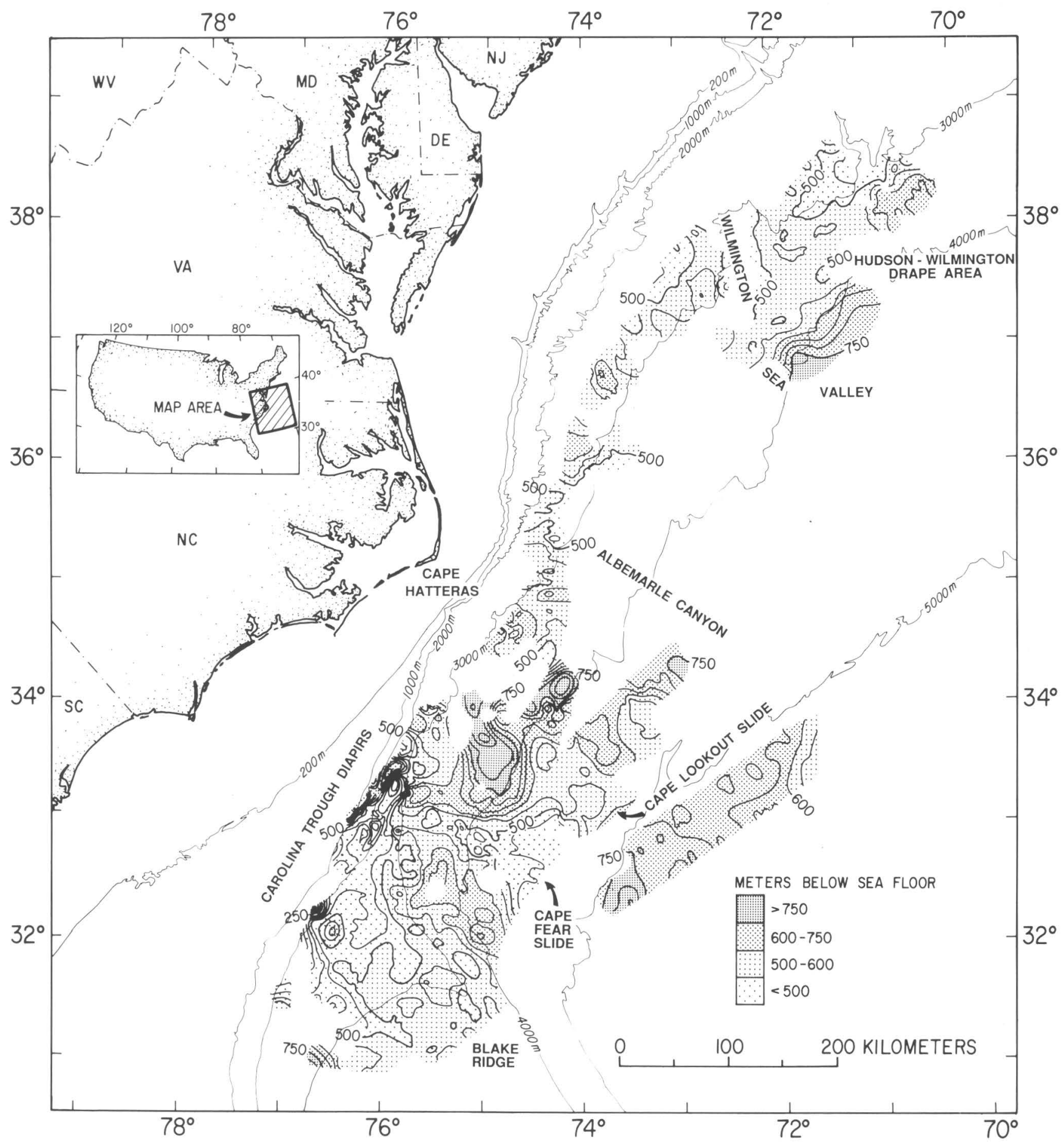

Figure 5. Contours in meters of thickness of layer of hydrate stability within sediments of U.S. Atlantic continental margin. This is distance from sea floor to bottom-simulating reflection (BSR). BSR represents bottom of zone of phase stability for gas hydrates. Contour interval for distance from sea floor to BSR is $50 \mathrm{~m}$. 


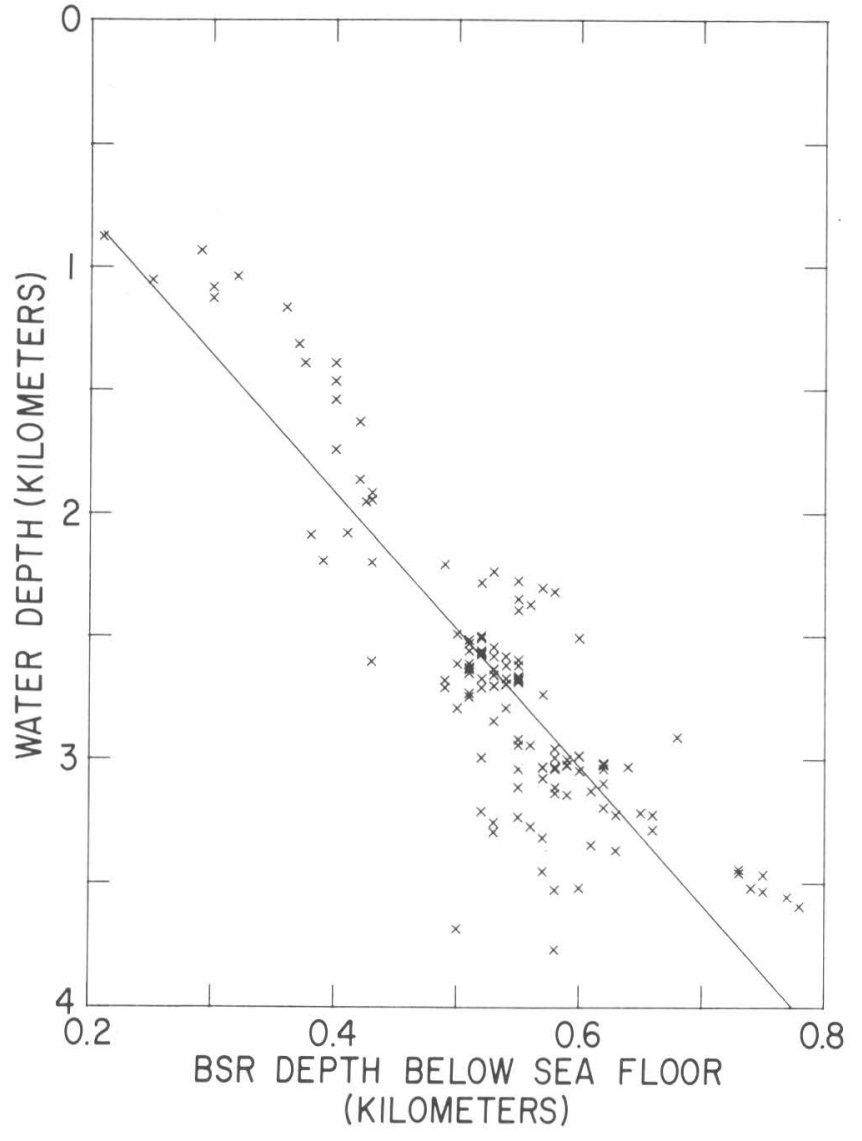

at the fast-depositing sediment drift of the Blake Ridge. It also explains why the main concentration occurs not at the depocenter of most recent accumulation (late Pliocene to Holocene) (Mountain and Tucholke, 1985), but rather at an older depocenter (middle Miocene to late Pliocene), where the upbuilding of the ridge and the resulting recycling of hydrate gas has gone on longer.

\section{FAULTING AND DIAPIRISM}

We mentioned above that free gas trapped beneath the BSR (beneath the zone of stability for gas hydrate) is likely to migrate upward through pathways provided by faults. Analysis of several seismic profiles (fig. 8, for example) shows (1) small offsets of reflections that represent faults and are marked by arrows (best seen below the BSR, where reflections are stronger); (2) presence of "fingers" of more intense blanking that extend upward from the BSR above the visible faults-this pattern seems to indicate that gas which has migrated upward through the

Figure 6. Plot of depth of bottom-simulating reflection (BSR) below sea floor versus water depth for several profiles in Blake Ridge area (from Dillon and Paull, 1983).

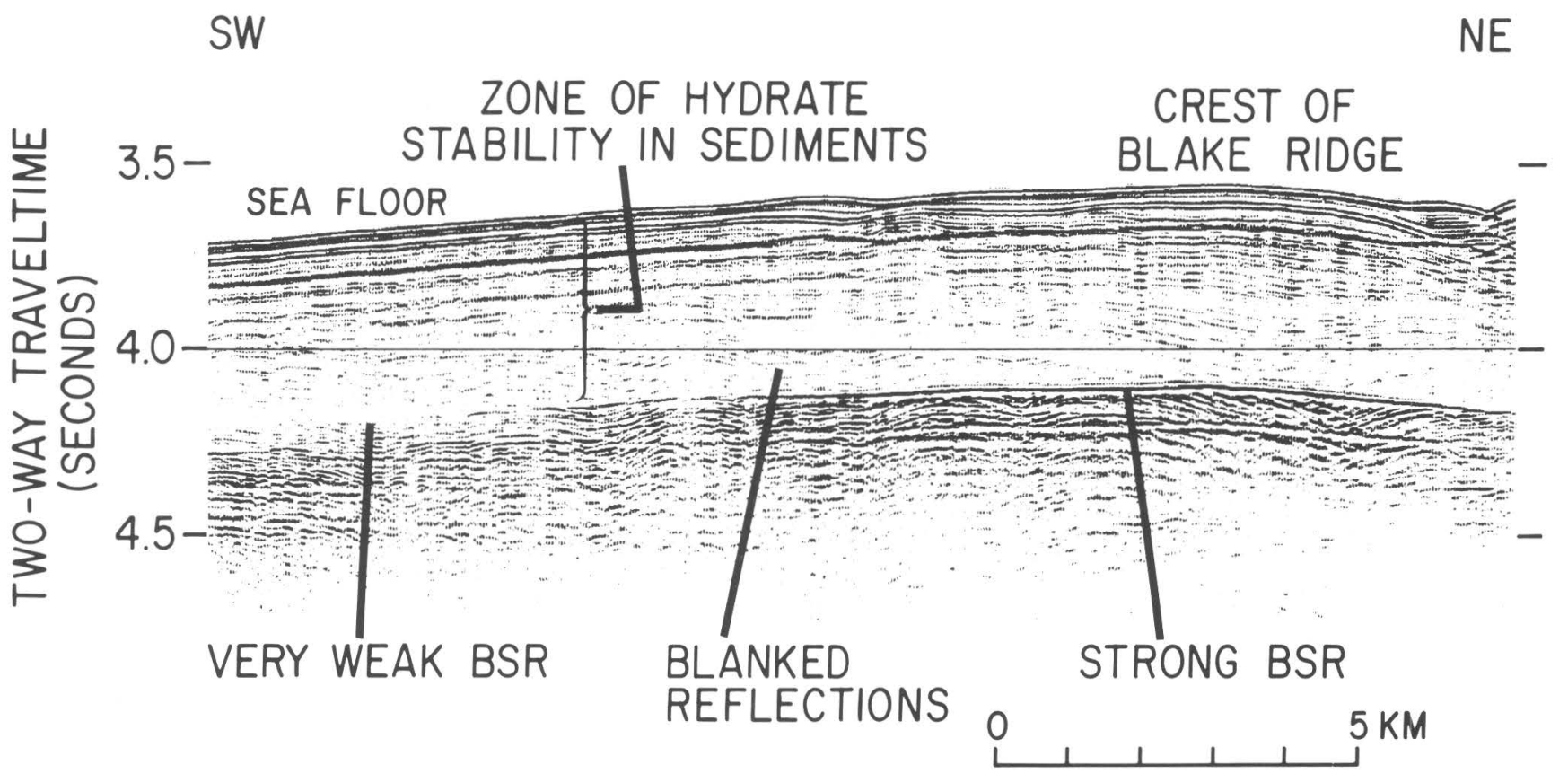

Figure 7. Seismic-reflection profile across Blake Ridge. This is a single-channel, digitally recorded and processed profile shot with a 160-cubic-inch airgun as the seismic source. Intensive blanking of reflections above bottom-simulating reflection (BSR) indicates considerable amount of gas hydrate cementing the sediments. Variations in strength of BSR probably are caused by differences in velocity below the BSR, from moderately slow on the flanks of the ridge, where hydrate-cemented sediments probably overlie watersaturated sediments, to extremely slow under the BSR beneath the crest, where we infer the presence of free gas in addition to water in the sediments. 


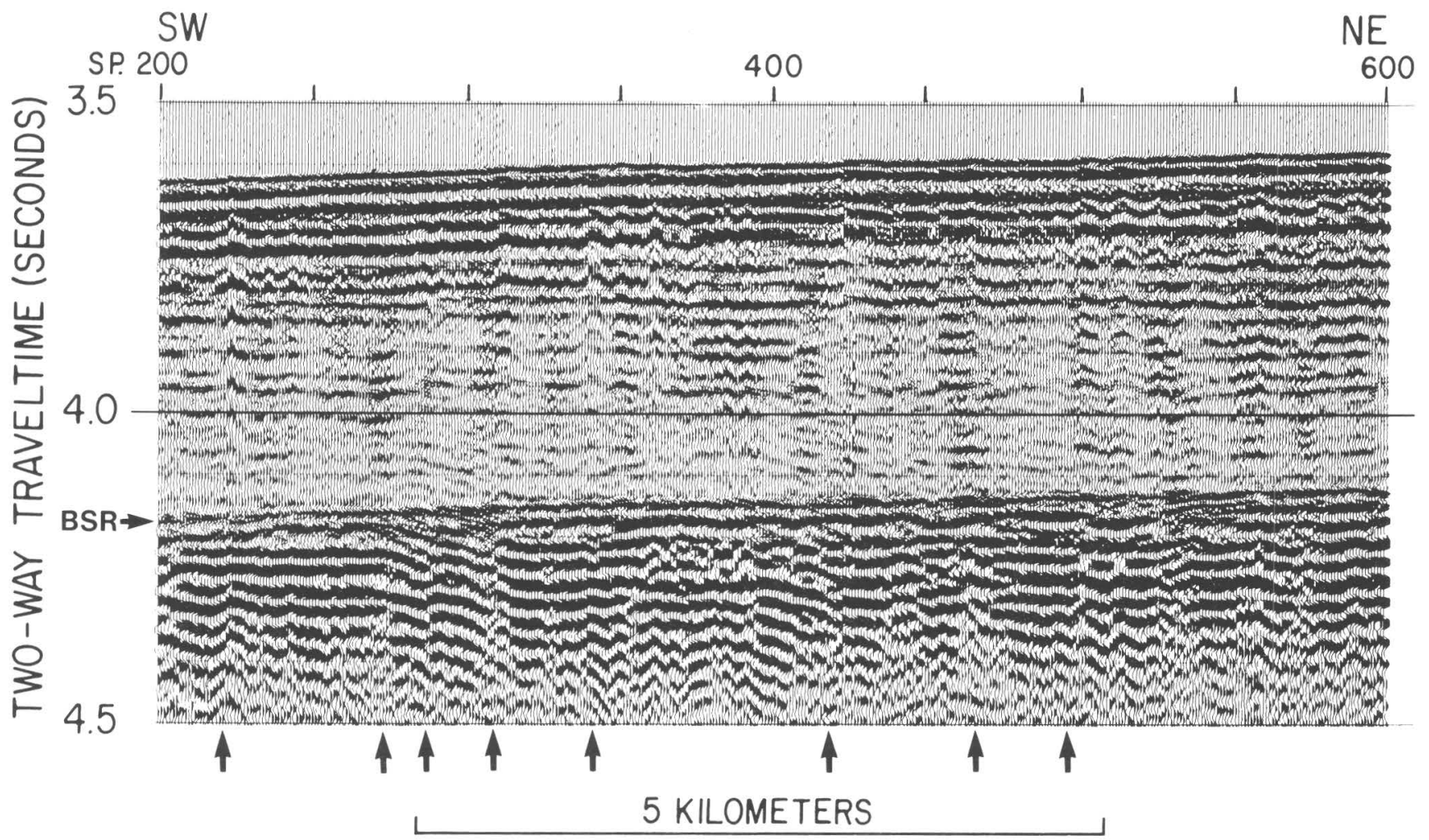

Figure 8. Seismic-reflection profile on flank of Blake Ridge, similar to figure 7. Small faults, marked by arrows, are indicated by offsets of stratal reflections best seen below bottom-simulating reflection (BSR), where reflections are stronger. These faults are probably caused by compaction of the thick sedimentary accumulation. Above BSR, fingers of more intense blanking extend upward above the faults into the hydrate-stable zone. This pattern may indicate increased amounts of hydrate at these locations, formed from gas that migrated up the fault channelways. SP, shotpoint.

faults has caused enrichment in the hydrate accumulation; (3) an increase in reflection strength of reflections below the BSR on moving away from faults-this pattern suggests that velocity contrasts are changing along strata, consistent with an increase in amount of gas away from faults, and that gas may be escaping up the faults (this pattern is not apparent on fig. 8 because of processing parameters designed to emphasize the faults). Of course, gas would be expected to form gas hydrate on entering the hydrate-stable zone, but warmer gas rising from below along newly opened fractures might penetrate a considerable distance before it cooled off and formed hydrate.

Migration of deeper gas along faults may be a major factor in concentrating hydrate in a fourth hydrate concentration that we identified, along the Carolina Trough diapirs (fig. 4). This concentration does not appear to be associated with a sedimentary depocenter, as are the other three. In the Carolina Trough diapir region a linear group of diapirs, probably formed of salt, extends along the seaward side of the deep Carolina Trough, one of the four major continental margin basins of the eastern United States (Dillon and others, 1983; Dillon and Popenoe, 1988). A profile through one of these diapirs in which a few of the associated faults are marked with arrows is shown in figure 9. The distribu- tion of diapirs in relation to the volume of gas hydrate is shown in figure 10. The Carolina Trough diapirs and, presumably, their associated faults rise from as deep as $12 \mathrm{~km}$ (Dillon and others, 1983). The faults may provide channelways that feed gas to shallow levels where hydrate is formed from deep, thermogenic sources in the Carolina Trough sediments. Whether the gas in these hydrates has a deep, thermogenic source, or a shallow, biogenic source is unknown at present and awaits sampling and analysis. However, as the Carolina Trough diapir trend is the only major diapir trend on the U.S. Atlantic continental margin and it is associated with the only concentration of hydrate in the survey area that is not correlated with a distinct depocenter, derivation of gas from a deep source appears likely.

Although gas hydrates are concentrated around the diapirs (fig. 10), a diapir itself (fig. 9) disrupts the seismic evidence for hydrate (BSR and blanking). Even when a diapir fails to reach up to the zone of hydrate stability, the BSR is observed to rise above the diapir, indicating that the hydrate-stable layer becomes thinner (Paull and Dillon, 1981). The structure of the hydrate-stable layer is very complex in the vicinity of the diapirs (fig. 11). Actually the correspondence of hydrate-layer structure to diapir location probably is much closer than indicated in figure 11 , 
SE

$3 \stackrel{\text { ล }}{\stackrel{2}{1}}$

Figure 9. Seismicreflection profile (2channel, 160-cubic-inch airgun source, digitally recorded and processed) across diapir that ruptures sea floor on continental rise off North Carolina, and that probably is salt-cored. A few of the possible faults are indicated by arrows. VE is vertical exaggeration. Lightweight scale across top of profile shows location of shotpoints.
Figure 10. Locations of landslides and diapirs plotted on the map of gashydrate volume (fig. 4) for the Carolina Trough diapir and Blake Ridge regions. Volume of hydrate is indicated as isopach contours of amount of hydrate existing in sedimentary pores.
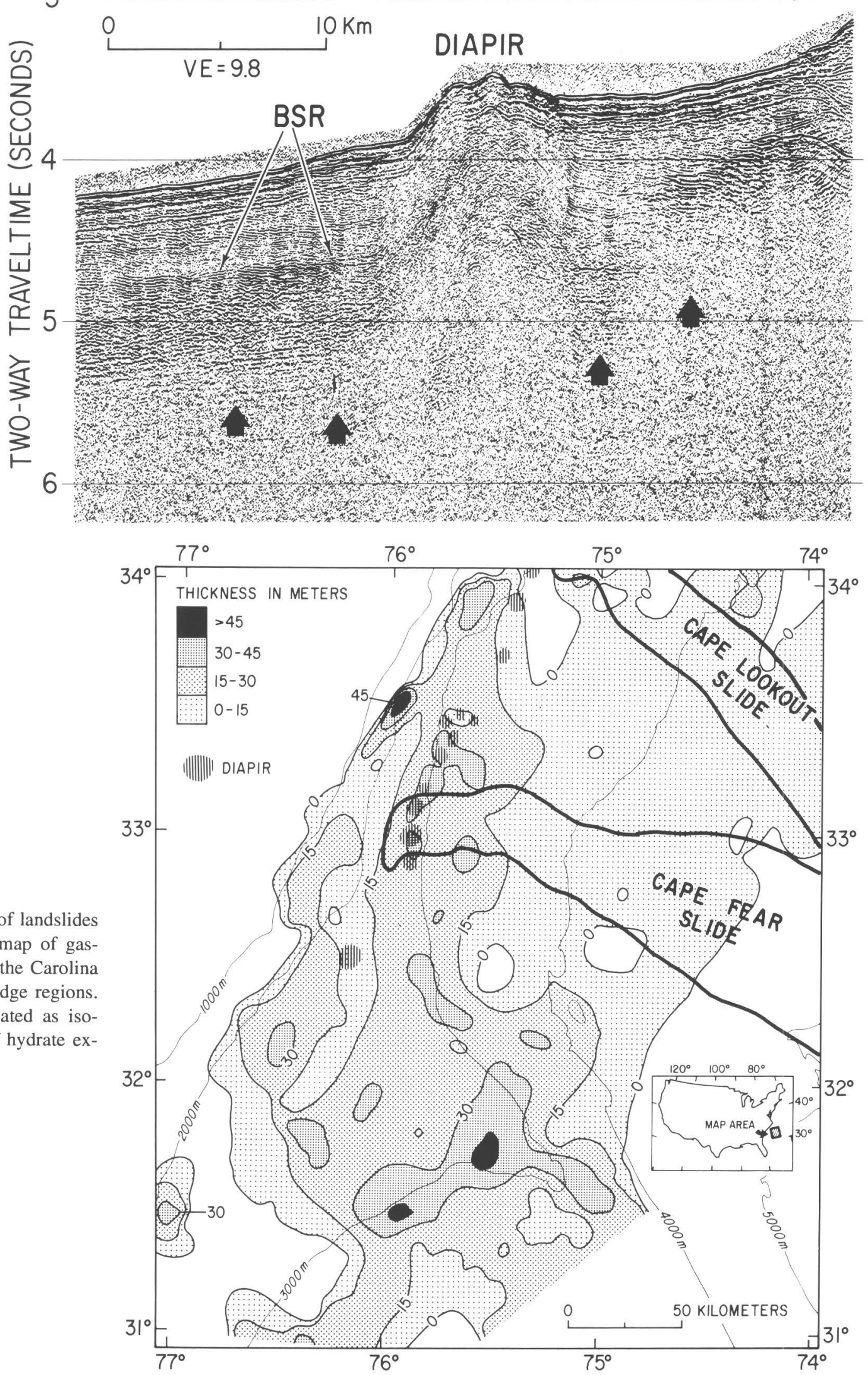
because the mapping of diapirs and the mapping of hydrate were, of necessity, done on different seismic-profile data sets. The effects on hydrates at salt diapirs may be related to the greater thermal conductivity of salt compared to sediment, which would produce a warm spot at a diapir, reducing the stability of hydrate (MacLeod, 1982). The effects also may be related to the presence of salt ions in interstitial fluids, which would act as antifreeze.

\section{MASS MOVEMENT}

Sea-floor mass movements seem to have significant effects on structure of the hydrate layer and on the abun- dance of hydrate. The effect on hydrate-layer thickness is noticeable in figure 11, where the locations of two major sea-floor landslide scars south of Cape Hatteras have been indicated (fig. 5). The landslide scars have been accurately located from a long-range sidescan sonar (GLORIA) survey of the Atlantic continental margin (EEZ-Scan 87, 1991), and part of the sidescan mosaic is reproduced in figure 12 to show the landslide effects. Of the two slides present in this area, the Cape Fear slide is obviously younger, as it crosses the Cape Lookout slide (fig. 12), and the Cape Fear slide also has the more significant influence on hydrate-layer thickness (fig. 11). These two major slides south of Cape Hatteras strongly affect the hydrate. North of Cape Hatteras, from Albemarle Canyon to Wilmington

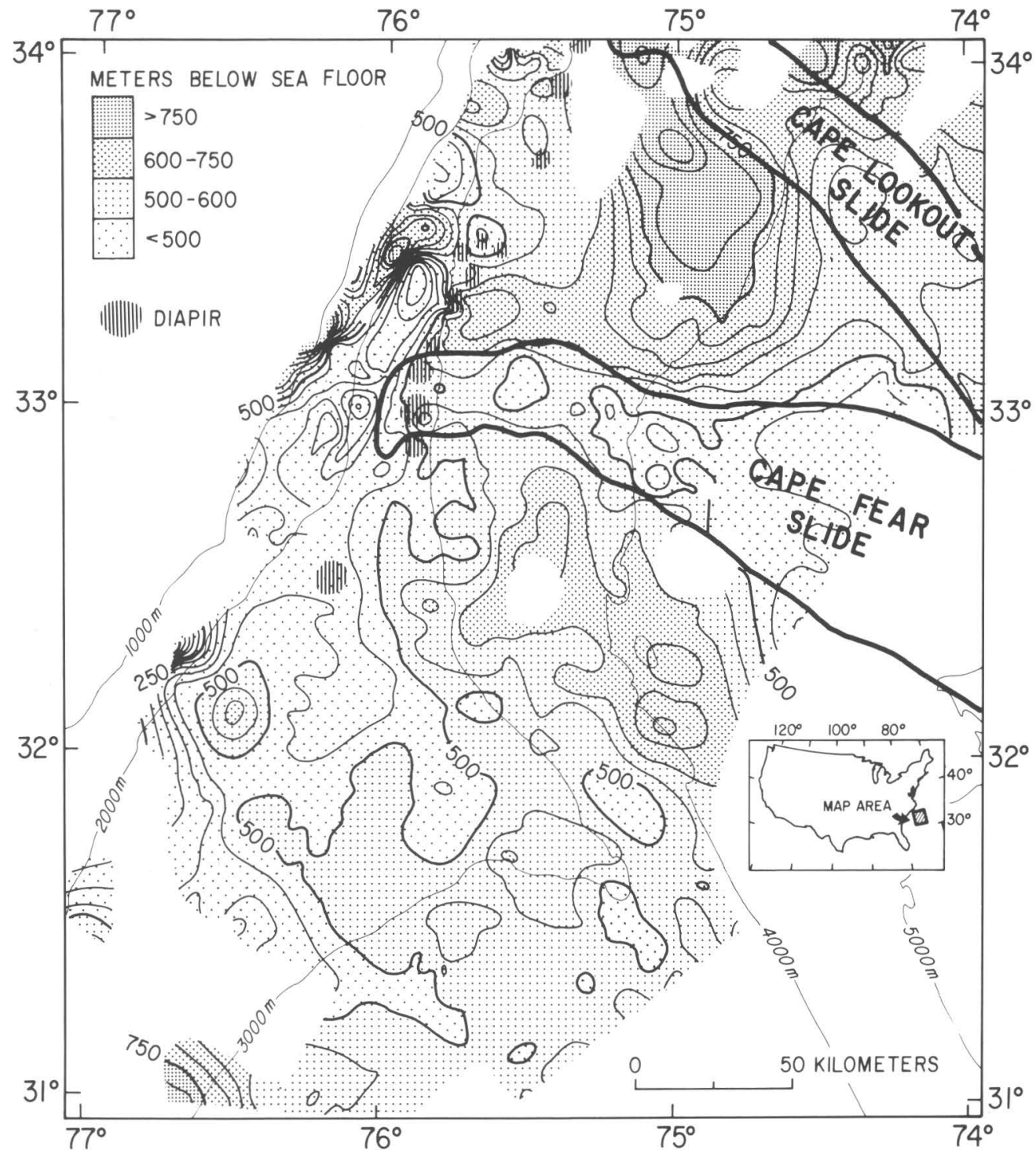

Figure 11. Locations of landslides and diapirs plotted on map of thickness of gas-hydrate layer (fig. 5) for the Carolina Trough diapir and Blake Ridge regions. Thickness of hydrate layer is equivalent to depth of bottom-simulating reflection (BSR) below sea floor. 

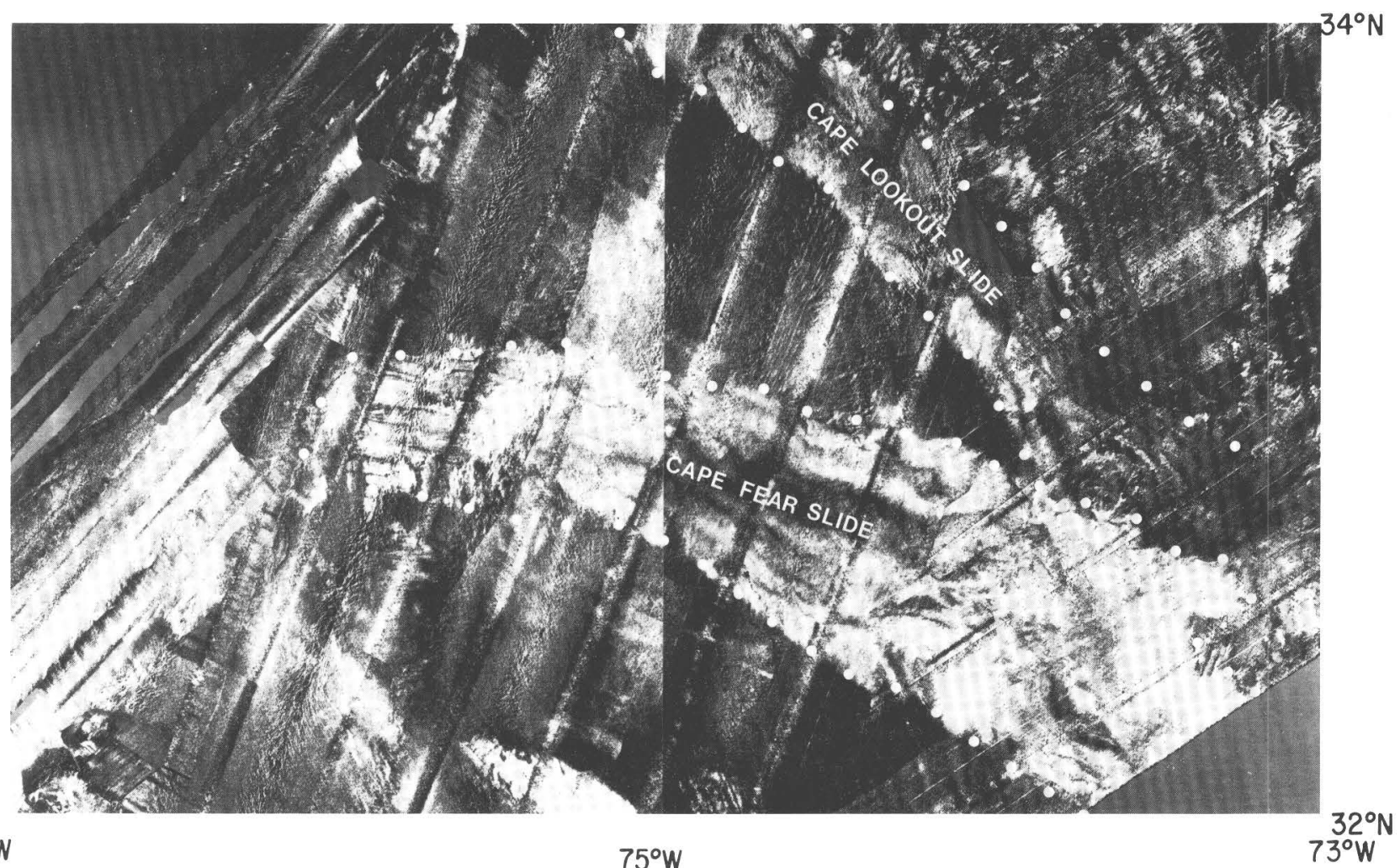

$77^{\circ} \mathrm{W}$

$75^{\circ} \mathrm{W}$
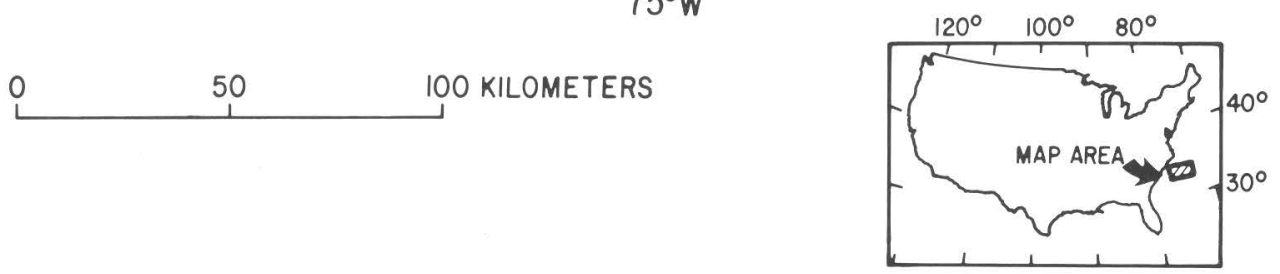

Figure 12. Long-range sidescan sonar (GLORIA) mosaic of the Cape Fear and Cape Lookout slide scar area (EEZ-Scan 87, 1991). White dots delineate boundaries of landslides.

sea valley (fig. 5), little seismic evidence of gas hydrate is observed in a region of complex smaller landslides and canyons on the middle and lower continental rise (figs. 4, 5 ), providing further evidence that mass movement is correlated to reduced gas-hydrate thickness and volume.

A profile across the Cape Fear slide scar (fig. 13) shows that the BSR disappears under the center of the slide, and that the BSR also rises slightly at the sides of the slide scar. Mapping shows that the BSR-to-sea-floor distance commonly decreases by 200 to $300 \mathrm{~m}$ from the center of the slide to surrounding, undisturbed areas (fig. 11), an amount greater than the thickness of slope strata removed by the mass movement. This shallowing of the BSR and the clear association of slide scars to thinning of the hydrate-stable zone suggest that removal of strata by mass movement causes breakdown of hydrate. This breakdown may result from a pressure reduction. Pore pressure within unconsolidated sediments is commonly considered to be hydrostatic, that is, equal to the height of a column of water from a point within the sediments to the sea surface; this assumption presumes that pressure is transmitted through the pore water. However, where hydrate fills the pore space and cements the sediments, that presumption may be incorrect. The deposits probably act as impermeable rock, in which overpressures are generated, and the pressure becomes lithostatic rather than hydrostatic. In such a case a landslide would reduce pressure in the sediments by removing overburden that acts like a slab of lithified rock. The pressure would be decreased, and this decrease would cause breakdown of hydrate where it is near its phase limit, at the BSR.

We suggest in the previous paragraph that mass movement may reduce pressure and cause breakdown of hydrate, but the converse also probably is true. If hydrate breaks down for some reason other than mass movement, this breakdown can weaken the sediments and foster landslides. In locations where the BSR is fairly near the sea floor, beneath the upper continental rise, breakdown of the hydrate might facilitate sliding by substituting a weak layer of gascharged sediment for a zone that previously had been essentially indurated material and thus providing a lubricating 
layer for the slide. On the U.S. Atlantic continental margin, slopes of $6^{\circ}$ or less would be expected to be stable given the materials that are present, but many landslide scars exist and thus some triggering or weakening mechanism is required (Booth and others, 1984, 1988). A plot of the distribution of frequency of the top of the landslide scars versus their water depth reveals a peak in frequency of landslides at a water depth from about 500 to $700 \mathrm{~m}$, very near the shallow-water limit of the hydrate-stable region (Dillon and others, 1991; James Booth, written commun., 1992). This is only circum- stantial evidence, but it suggests a relationship between landsliding and gas-hydrate breakdown.

Marine gas hydrate certainly would have broken down during glacial episodes, when total pressure on the hydrate was reduced by the lowering of sea level caused by sequestering of water in continental glaciers. An estimate from the data of figure 6 suggests that a sea-level lowering of $120 \mathrm{~m}$ (the magnitude of lowering during the last glaciation) would cause a rise of the base of the hydrate (BSR) of about $20 \mathrm{~m}$ (fig. 14), and this rise of the BSR could trigger landslides on

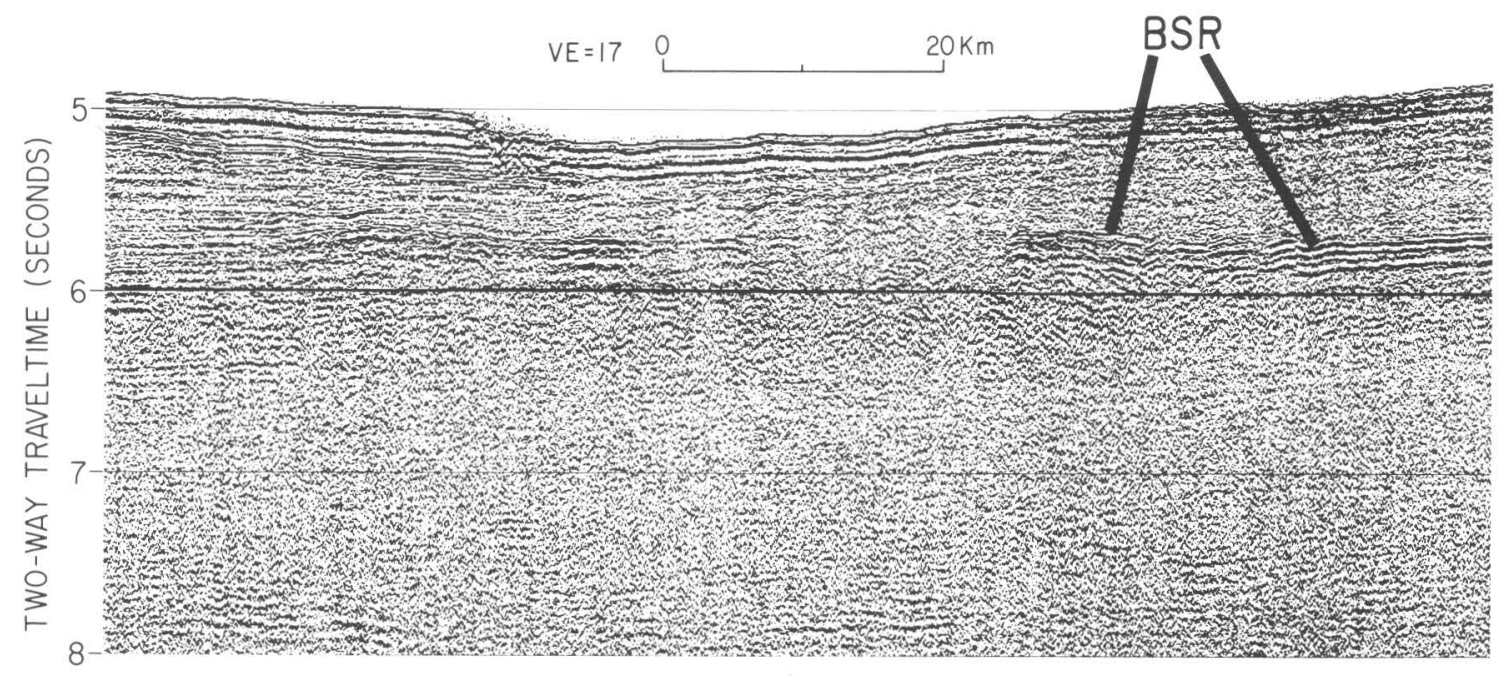

Figure 13. Seismic-reflection profile (similar to that in fig. 9) across Cape Fear slide scar. Bottom-simulating reflection (BSR) becomes shallower and weaker beneath slide scar. VE, vertical exaggeration.

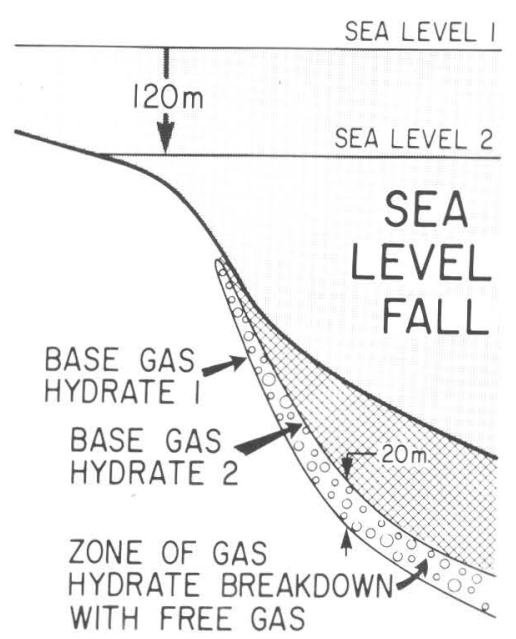

A

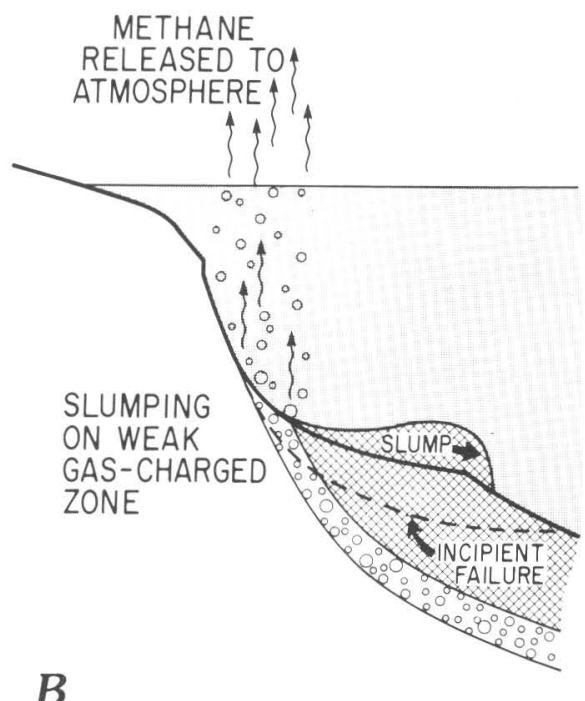

$B$

Figure 14. Conceptual diagram of the effect on a sea-floor gas-hydrate layer of a sealevel fall of $120 \mathrm{~m}$, comparable to the most recent glacial sea-level lowering. A, Reduction of pressure would cause a breakdown of gas hydrate just above the bottom simulating reflection (BSR), where gas hydrate is at its phase limit. $B$, This breakdown would produce a layer of gas-charged sediment that would be very weak and could provide a lubricating layer that would foster landsliding. 
the ocean floor all over the world (Paull and others, 1991). Of course, if such a great volume of methane escaped, it would greatly increase the greenhouse effect in the atmosphere, because methane is a much more potent greenhouse gas than carbon dioxide (Mitchell, 1989; Lashof and Ahuja 1990; Cole, this volume).

\section{GAS TRAPS}

The trapping of free gas beneath a seal formed by hydrate-cemented sediment has been indicated above to be important in the concentration of hydrate. Of course, such trapped gas might form a significant energy deposit as well (Dillon and others, 1980). The simplest case occurs where gas appears to be trapped in a dome of the hydratecemented sealing layer caused by a dome shape of the sea floor (fig. 7; diagrammed in fig. 15A). Even fairly small sea-floor hills can form potentially significant gas traps (fig. 16).

A dome also can be formed in the gas-hydrate seal above diapirs strictly by thermal and geochemical factors (figs. 9, 15B). Figure 17 shows high resolution (fig. 17A) and deep penetration (fig. 17B) profiles across a buried diapir on the North Carolina continental rise. The BSR in the deep penetration profile (fig. 17B) appears as a reflection that cuts through other reflections caused by strata and rises over the diapir at the center of the profile. The high resolution profile (fig. 17A) gives a better view of the true nature of the BSR, which appears as a series of terminations of

Figure 15. Possible configurations of sea-floor gas-hydrate layer that would produce gas traps with hydrate seal. $A$, Dome in gas-hydrate seal caused by dome in sea floor. $B$, Dome in gashydrate seal caused by thermal and chemical factors above a diapir. $C$, Gas-hydrate seal at updip end of permeable layer in set of dipping strata.
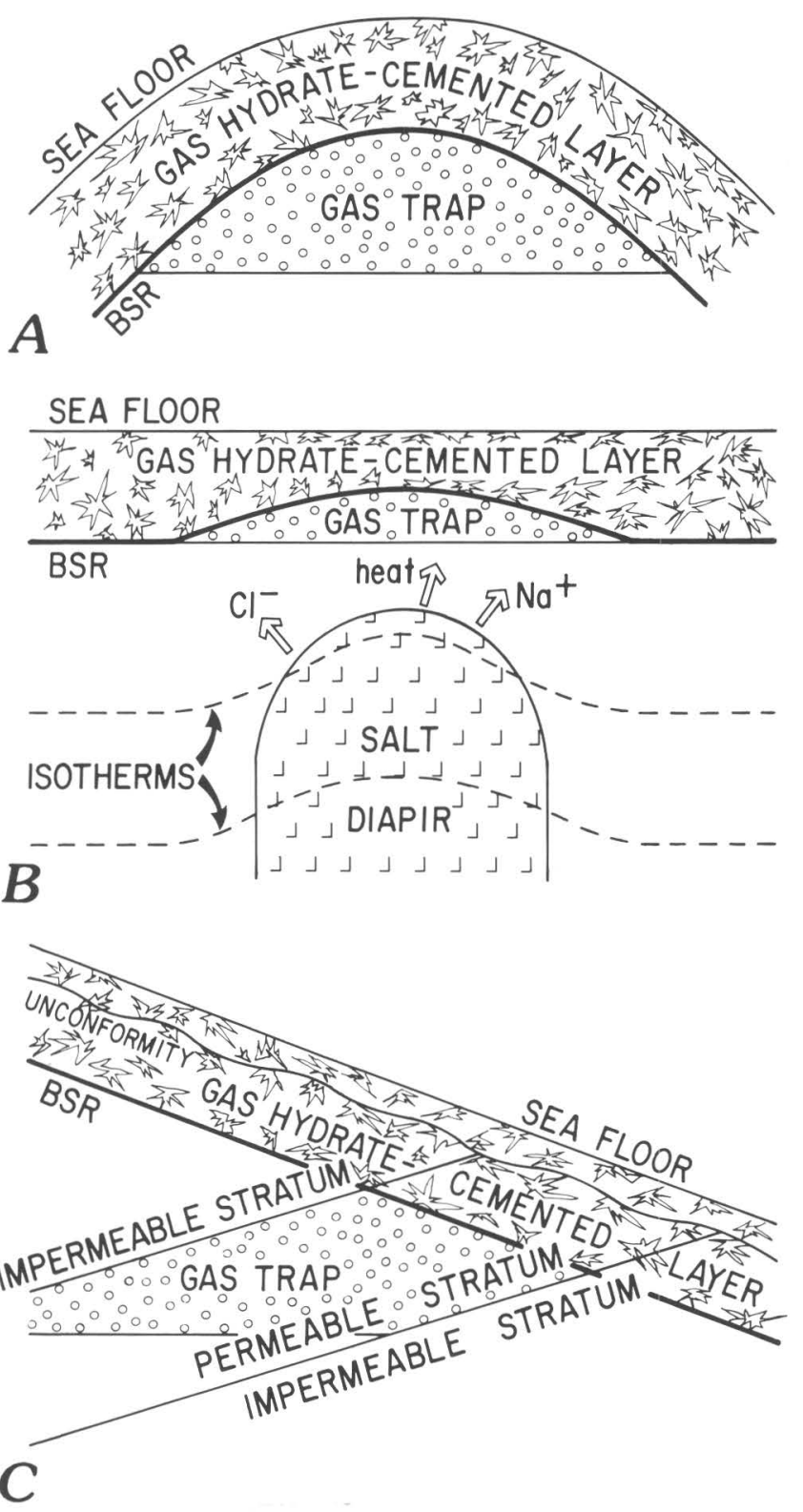

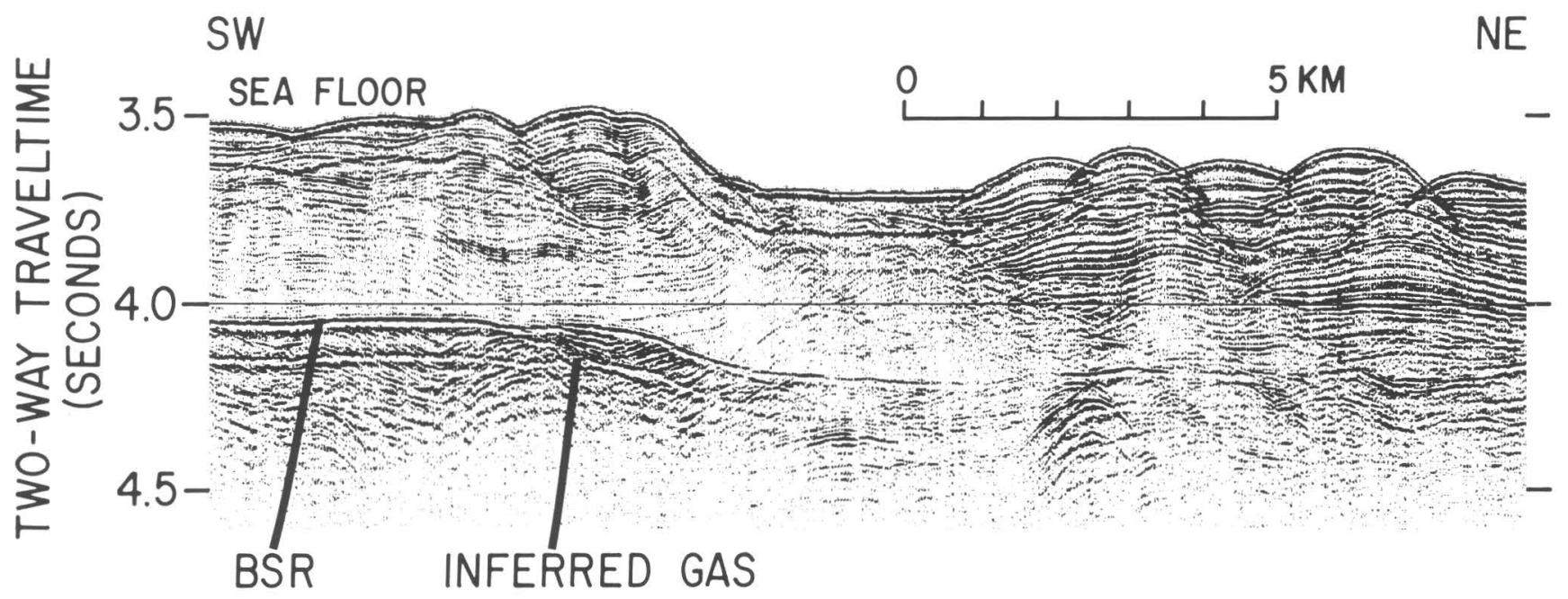

Figure 16. Seismic-reflection profile on Blake Ridge (similar to that in fig. 7) displaying probable gas traps beneath sea-floor hills, a situation comparable to that in fig. $15 \mathrm{~A}$. 


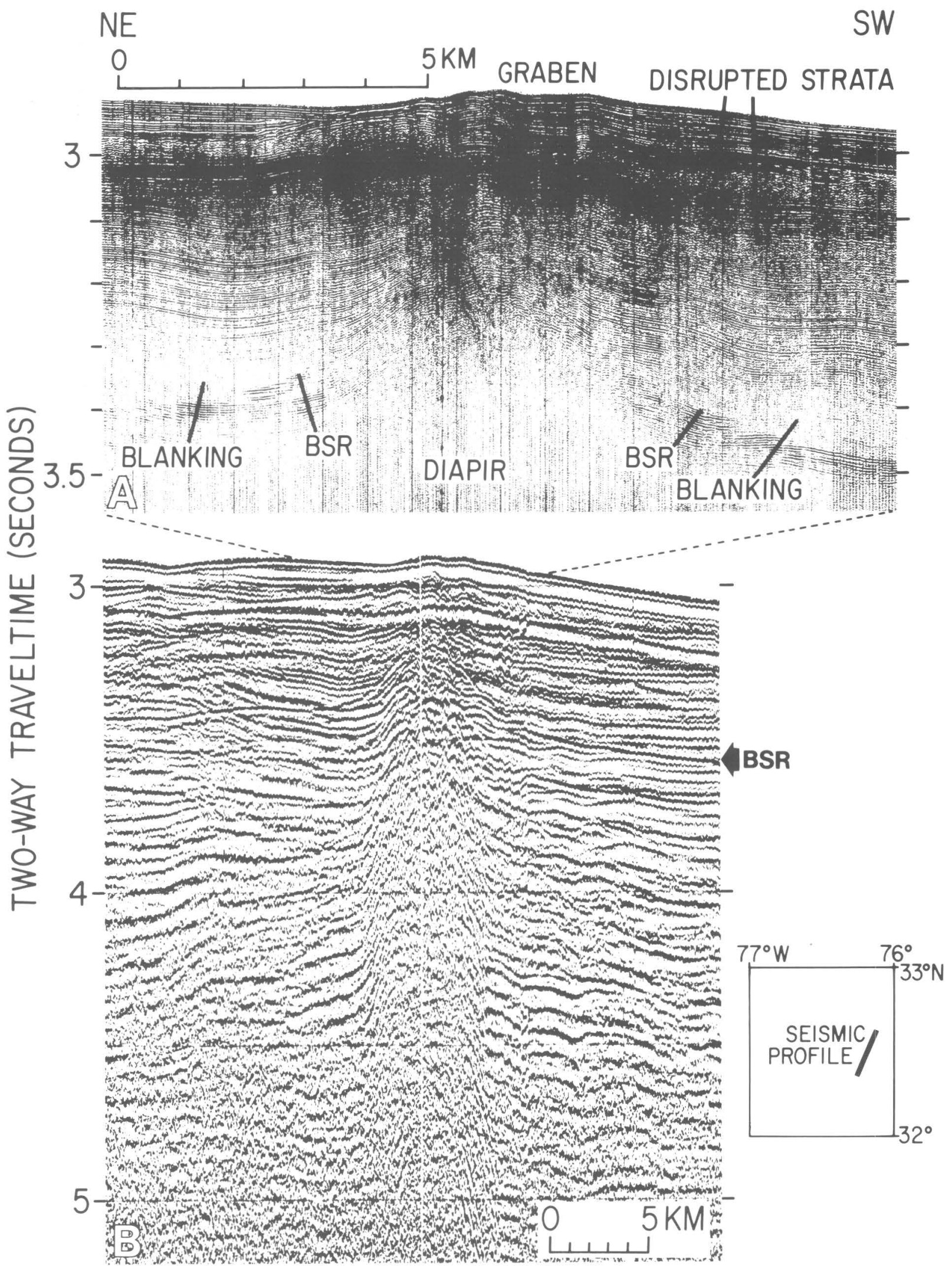

Figure 17. Two seismic-reflection profiles along same track (see small map to right of fig. 17B) across diapir that does not reach sea floor on North Carolina continental rise. $A$, High-resolution profile collected with 5-cubic-inch airgun source; $B$, Deep-penetration profile collected with pair of 540-cubic-inch airguns. Lower boundary of hydrate-cemented zone, shown by bottom-simulating reflection (BSR), is domed above the diapir, probably due to thermal and chemical changes in the sediments. The dome can trap gas as diagrammed in fig. $15 B$. 
strong reflections against a blanked zone. The blanked zone is assumed to be hydrate-filled, and the strong reflections below it are inferred to represent gas-charged strata within the dome in the base of the hydrate seal. Several faults are suggested by these data, including the faults that allow subsidence of the graben above the diapir.

In our surveys, a more common type of trap employing a hydrate seal is formed where dipping strata formed of alternating permeable and impermeable beds intersect the sea floor. In such cases a permeable layer can be sealed at its updip end by the gas-hydrate-cemented layer, forming a trap $(15 C)$. Locations where gas is trapped beneath the hydrate layer in dipping strata are marked by strong reflections below the BSR (figs. 18, 19).

\section{SUMMARY AND CONCLUSIONS}

1. Natural-gas hydrates (mostly methane hydrates) exist within marine sediments in a layer that extends from the sea floor down to a level where conditions are too warm for hydrate stability at the existing pressure. The layer commonly is several hundred meters thick and is present at water depths exceeding 300 to $500 \mathrm{~m}$.
2. Gas hydrates have been sampled in drilling, and they also can be recognized in seismic-reflection profiles. Characteristics that allow hydrate detection in seismic profiles are (1) a bottom-simulating reflection, or BSR, which is a reflection that parallels the sea floor and cuts through reflections from strata; the BSR is a reflection from the base of the hydrate-cemented layer; (2) a velocity inversion in which the velocity of hydrate-cemented sediment above the BSR is observed to have higher velocity than the sediment below; and (3) a reduction in amplitude of reflections within the hydrate-cemented zone, known as blanking. The BSR and the blanking phenomena allow us to map the distribution of gas-hydrate-cemented sediments and amount of gas hydrate on the U.S. Atlantic continental margin.

3. Four regions of gas-hydrate concentration have been mapped on the continental rise in the offshore region between New Jersey and Georgia. Three are correlated with sediment depocenters, and one occurs along a concentration of diapirs and their associated faults.

4. Concentration at depocenters probably occurs because most gas in hydrate is biogenic, produced by bacteria that feed on organic material that is preserved in fastdepositing accumulations. Of the three hydrate concentrations that are associated with depocenters, two are sites of

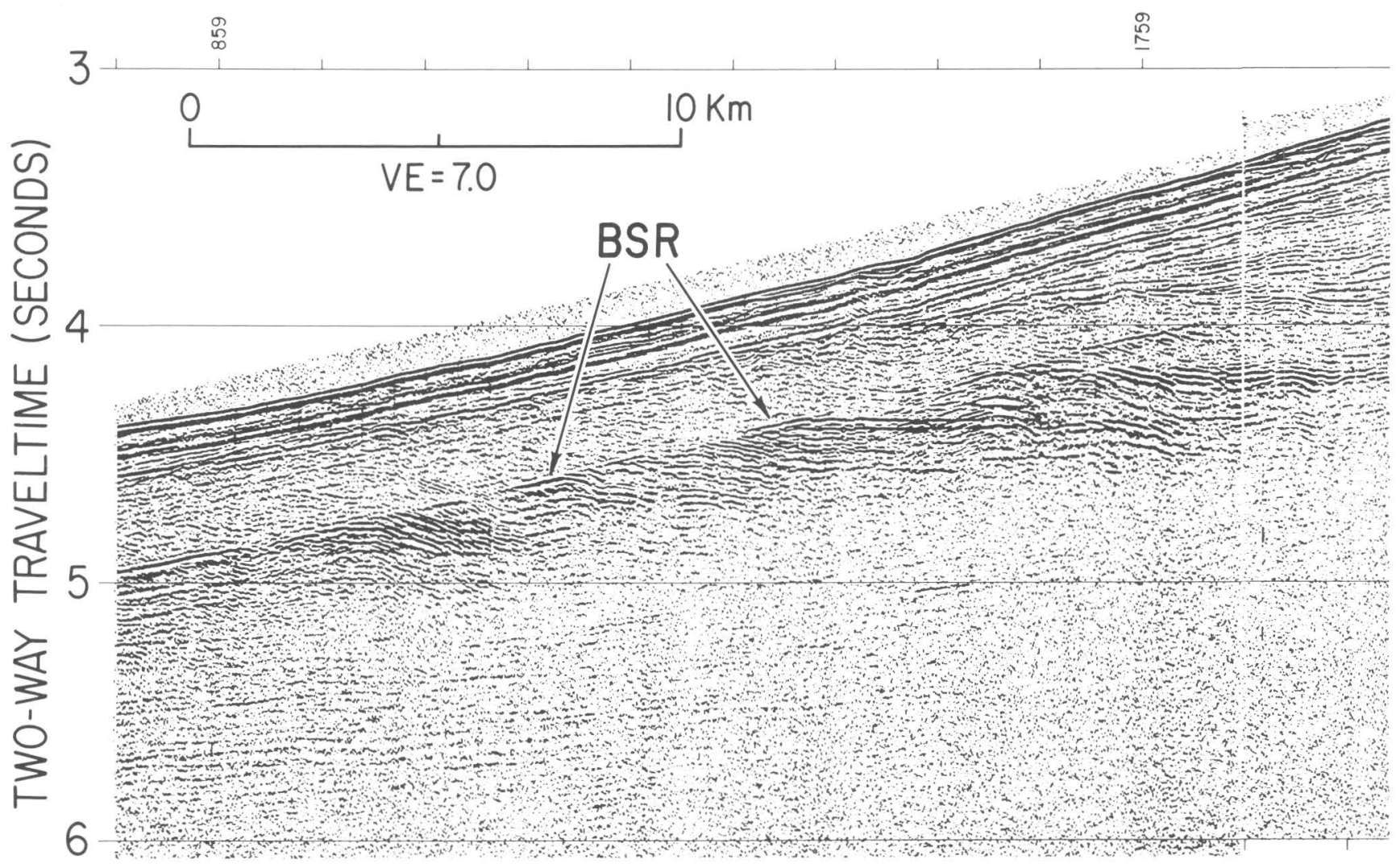

Figure 18. Seismic-reflection profile on North Carolina continental rise (similar to that of fig. 9) showing dipping reflections representing strata that are interpreted to contain gas and that are sealed at their updip ends by gas-hydrate cementation, a situation comparable to that in fig. $15 \mathrm{C}$. BSR, bottom-simulating reflection; VE, vertical exaggeration. Lightweight scale across top of profile shows location of shotpoints. 


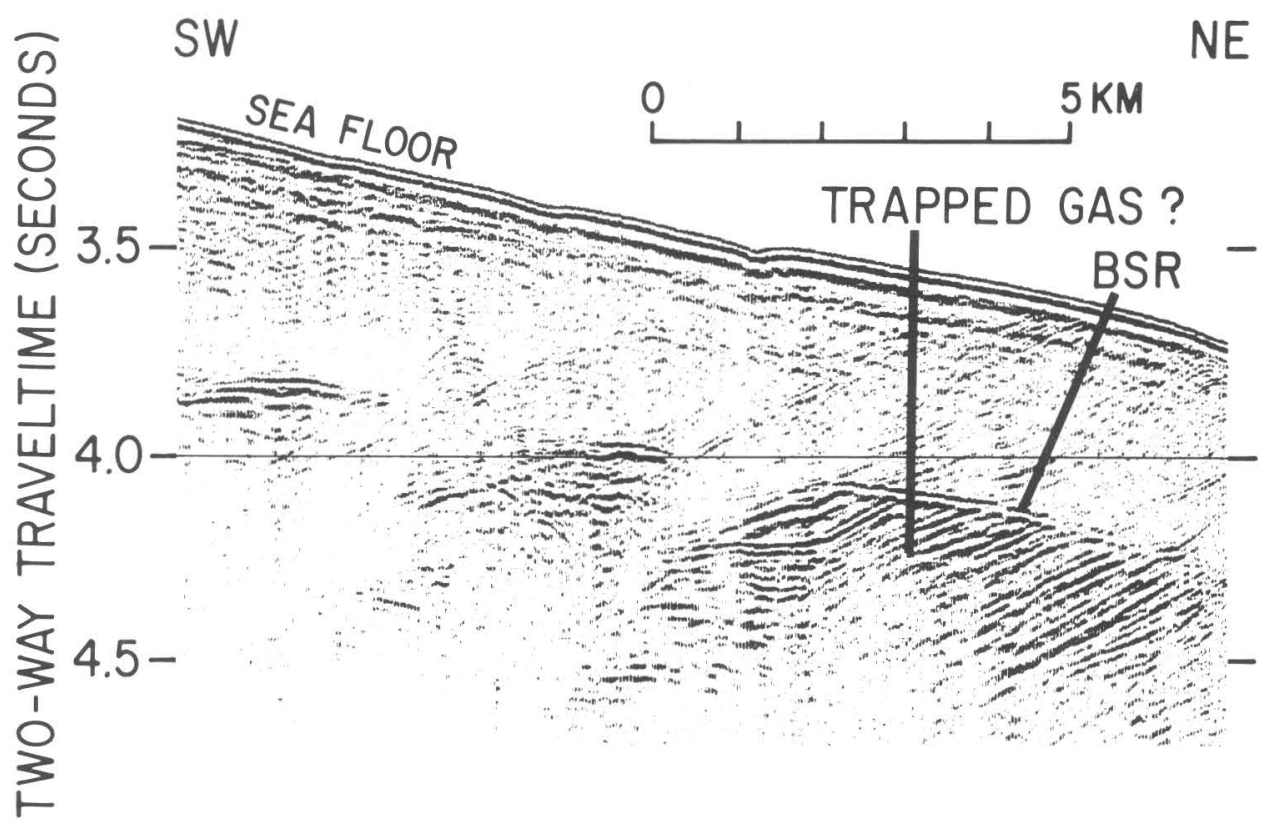

Figure 19. Profile (similar to that in fig. 7) showing dipping strata truncated at sea floor on flank of Blake Ridge. Strongly reflecting layers below bottom-simulating reflection (BSR) probably represent gas-charged strata sealed as diagrammed in fig. $15 \mathrm{C}$.

active sediment accumulation. The third, and largest of all four hydrate accumulations, occurs at a depocenter that was most active in middle Miocene to late Pliocene time, implying that gas from hydrates that formed in older sediments has been recycled into younger hydrates.

5. Faults seem to form channelways for the passage of gas upward into the hydrate layer, as interpreted in seismic profiles. A major concentration of hydrate, one not related to a distinct depocenter, is associated with a trend of diapirs with their associated faults.

6. Breakdown of gas hydrate and thinning of the hydrate layer has occurred at sites of mass movement, probably caused by reduction of pressure due to removal of sediment during landsliding. Conversely, breakdown of hydrate may cause mass movements by substituting a weak layer of gas-rich sediment for a strong layer of hydratecemented sediment. The hydrate breakdown that initiates landslide movement might be caused by pressure reductions that result from glacial sea-level lowerings. We are faced with a possible cascading chain of events in which a breakdown of hydrate could trigger landslides that would cause further breakdown of hydrate and result in considerable loss of methane from the marine hydrate reservoir.

7. Reduction in the amount of hydrate and thinning of the hydrate layer are also observed at diapirs, probably due to thermal and chemical anomalies caused by the diapirs.

8. Gas-hydrate-cemented sediments can form an impermeable seal and, if appropriately configured, will form traps. Gas traps with hydrate seals are observed at sea-floor hills and diapirs, and at locations where dipping strata inter- sect the sea floor and are sealed at their updip ends by gas hydrate. Production of gas from such traps would result in extraction of the free gas and of additional gas derived from the breakdown of the hydrate seal by depressurization.

\section{ACKNOWLEDGMENTS}

We gratefully acknowledge the support provided by the U.S. Department of Energy, Morgantown Energy Technology Center, through Interagency Agreement DE-A12183MC20422. Discussions regarding gas hydrates with Charles Paull, Keith Kvenvolden, Rodney Malone, Eric Schmuck, Michael Max, and many others have been invaluable. We thank the reviewers, James Booth, David Howell, and Michael Fanelli.

\section{REFERENCES CITED}

Booth, J.S., O’Leary, D.W., Popenoe, P., Robb, J.M., and McGregor, B.A., 1988, Map and tabulation of Quaternary mass movements along the United States-Canadian Atlantic continental slope from $32^{\circ} 00^{\prime}$ to $47^{\circ} 00^{\prime} \mathrm{N}$ latitude: U.S. Geological Survey Miscellaneous Field Studies Map MF2027, scale 1:2,000,000.

Booth, J.S., Silva, A.J., and Jordan, S.A., 1984, Slope-stability analysis and creep susceptibility of Quaternary sediments on the northeastern U.S. Continental Slope, in Denness, B., ed., Sea mechanics, International Union of Theoretical and Applied Mechanics-International Union of Geodesy and 
Geophysics Symposium Proceedings: London, Graham and Trotman, London, p. 65-75.

Brandt, H., 1960, Factors affecting compressional wave velocity in unconsolidated marine sand sediments: Journal of the Acoustical Society of America, v. 32, p. 171-179.

Claypool, G.E., and Kaplan, I.R., 1974, The origin and distribution of methane in marine sediments, in Kaplan, I.R., ed., Natural gases in marine sediments: New York, Plenum Press, p. 99-139.

Collins, B.P., and Watkins, J.S., 1985, Analysis of a gas hydrate off southwest Mexico using seismic processing techniques and Deep Sea Drilling Project Leg 66 results: Geophysics, v. 50, p. 813-828.

Dillon, W.P., Booth, J.S., Paull, C.K., Fehlhaber, K., Hutchinson, D.R., and Swift, B.A., 1991, Mapping sub-seafloor reservoirs of a greenhouse gas-Methane hydrates, in Kumar, M., and Maul, G.A., Symposium Directors, Proceedings of the International Symposium on Marine Positioning: Marine Geodesy Committee, Marine Technology Society, Washington, D.C., p. 545-554.

Dillon, W.P., Grow, J.A., and Paull, C.K., 1980, Unconventional gas-hydrate seals may trap gas off southeast U.S.: Oil and Gas Journal, v. 78, no. 1, p. 124, 126, 129, 130.

Dillon, W.P., and Paull, C.K., 1983, Marine gas hydrates-II; Geophysical Evidence, in Cox, J.L., ed., Natural gas hydrates-Properties, occurrences and recovery: Boston, Butterworth Publishers, p. 73-90.

Dillon, W.P., and Popenoe, Peter, 1988, The Blake Plateau and Carolina Trough, in Sheridan, R.E., and Grow, J.A., eds., The Atlantic Continental Margin, U.S.: Boulder, Colorado, Geological Society of America, The Geology of North America, v. 1-2, p. 291-328.

Dillon, W.P., Popenoe, Peter, Grow, J.A., Klitgord, K.D., Swift, B.A., Paull, C.K., and Cashman, K.V., 1983, Growth faulting and diapirism-Their relationship and control in the Carolina Trough, eastern North America, in Watkins, J.S., and Drake, C.L., eds., Studies in continental margin geology: American Association of Petroleum Geologists, Memoir No. 34, p. 21-46.

EEZ-Scan 87, 1991, Atlas of the U.S. Exclusive Economic Zone, Atlantic continental margin: U.S. Geological Survey Miscellaneous Investigations Series Map I-2054, 174 p.

Krason, J., and Ridley, W.I., 1985, Geological evolution and analysis of confirmed or suspected gas-hydrate localities, vol. 1., Blake-Bahama Outer Ridge-U.S. East Coast: DOE/ $\mathrm{MC} / 21181$ (DE86001006), $100 \mathrm{p}$.

Kvenvolden, K.A., 1988, Methane hydrate-A major reservoir of carbon in the shallow geosphere?: Chemical Geology, v. 71, p. 41-51.

Kvenvolden, K.A., and Barnard, L.A., 1982, Hydrates of natural gas in continental margins, in Watkins, J.S., and Drake, C.L., eds., Studies of continental margin geology: American Association of Petroleum Geologists Memoir No. 34, p. 631-640.

_ 1983, Gas hydrates of the Blake Outer Ridge, Site 533, Deep Sea Drilling Project Leg 76, in Sheridan, R.E., and Gradstein, F., and others, Initial reports of the Deep Sea Drilling Project, v. 76: Washington, D.C., U.S. Government Printing Office, p. 353-365.

Kvenvolden, K.A., and Kastner, M., 1990, Gas hydrates of the Peruvian outer continental margin, in Suess, E.R., von
Huene, R., and others, Proceedings of the Ocean Drilling Program, Scientific Results: Washington, D.C., U.S. Government Printing Office, v. 112, p. 517-526.

Kvenvolden, K.A., and McMenamin, M.A., 1980, Hydrates of natural gas-A review of their geological occurrences: U.S. Geological Survey Circular 825, 11 p.

Lashof, D.A., and Ahuja, D.R., 1990, Relative contributions of greenhouse gas emissions to global warming: Nature, v. 344, p. 529-532.

Lee, M.W., Dillon, W.P., and Hutchinson, D.R., 1992, Estimating the amount of gas hydrate in marine sediments in the Blake Ridge area, southeastern Atlantic Margin: U. S. Geological Survey Open-File Report 92-275, 24 p.

Lee, M.W., Hutchinson, D.R., Dillon, W.P., Miller, J.J., Agena, W.F., and Swift, B.A., in press, A method of estimating the amount of in situ gas hydrates in deep marine sediments: Marine and Petroleum Geology.

MacLeod, M.K., 1982, Gas hydrates in ocean bottom sediments, American Association of Petroleum Geologists Bulletin, v. 66 , p. $2649-2662$.

Miller, J.J., Lee, M.W., and von Huene, Roland, 1991, An analysis of a seismic reflection from the base of a gas-hydrate zone, offshore Peru: American Association of Petroleum Geologists Bulletin, v. 75, p. 910-924.

Mitchell, J.F.B., 1989, The "greenhouse" effect and climate change: Reviews of Geophysics, v. 27, p. 115-139.

Mountain, G.S., and Tucholke, B.E., 1985, Mesozoic and Cenozoic geology of the U.S. Atlantic continental slope and rise, in Poag, C.W., ed., Geologic evolution of the United States Atlantic Margin: New York, Van Nostrand Reinhold, p. 293-341.

Paull, C.K., and Dillon, W.P., 1981, Appearance and distribution of the gas-hydrate reflection in the Blake Ridge region, offshore southeastern United States: U.S. Geological Survey Miscellaneous Field Studies Map MF-1252, scale 1:1,000,000.

Paull, C.K., Ussler, William, III, and Dillon, W.P., 1991, Is the extent of glaciation limited by marine gas hydrates?: Geophysical Research Letters, v. 18, p. 432-434.

Rowe, M.M., and Gettrust, J.F., 1993, Fine structure of methane bearing sediments on the Blake Outer Ridge as determined from deep-tow multichannel seismic data: Journal of Geophysical Research, v. 98, p. 463-473.

Schlee, J.S., Dillon, W.P., Popenoe, Peter, Robb, J.M., and O'Leary, D.W., 1992, GLORIA mosaic of the deep sea fioor off the Atlantic coast of the United States: U.S. Geological Survey Miscellaneous Field Studies Map MF-2211, scale 1:2,000,000.

Shipley, T.H., and Didyk, B.M., 1982, Occurrence of methane hydrates offshore southern Mexico, in Watkins, J.S., Moore, J.C., and others, Initial Reports of the Deep Sea Drilling Project, vol. 66: Washington, D.C., U.S. Government Printing Office, p. 547-555.

Shipley, T.H., Houston, M.H., Buffler, R.T., Shaub, F.J., McMillen, K.J., Ladd, J.W., and Worzel, J.L., 1979, Seismic evidence for widespread possible gas-hydrate horizons on continental slopes and rises: American Association of Petroleum Geologists Bulletin, v. 62, p. 2204-2213.

Sloan, E.D., Jr., 1990, Clathrate hydrates of natural gases: New York, Marcel Dekker, $641 \mathrm{p}$.

Tucholke, B.E., Bryan, G.M., and Ewing, J.I., 1977, Gas-hydrate horizons detected in seismic profile data from the western North Atlantic: American Association of Petroleum Geologists Bulletin, v. 61, p.698-707. 


\title{
Velocity and Amplitude Structures on Seismic-Reflection Profiles-Possible Massive Gas-Hydrate Deposits and Underlying Gas Accumulations in the Bering Sea Basin
}

\author{
By David W. Scholl ${ }^{1}$ and Patrick E. Hart ${ }^{1}$
}

\section{CONTENTS}

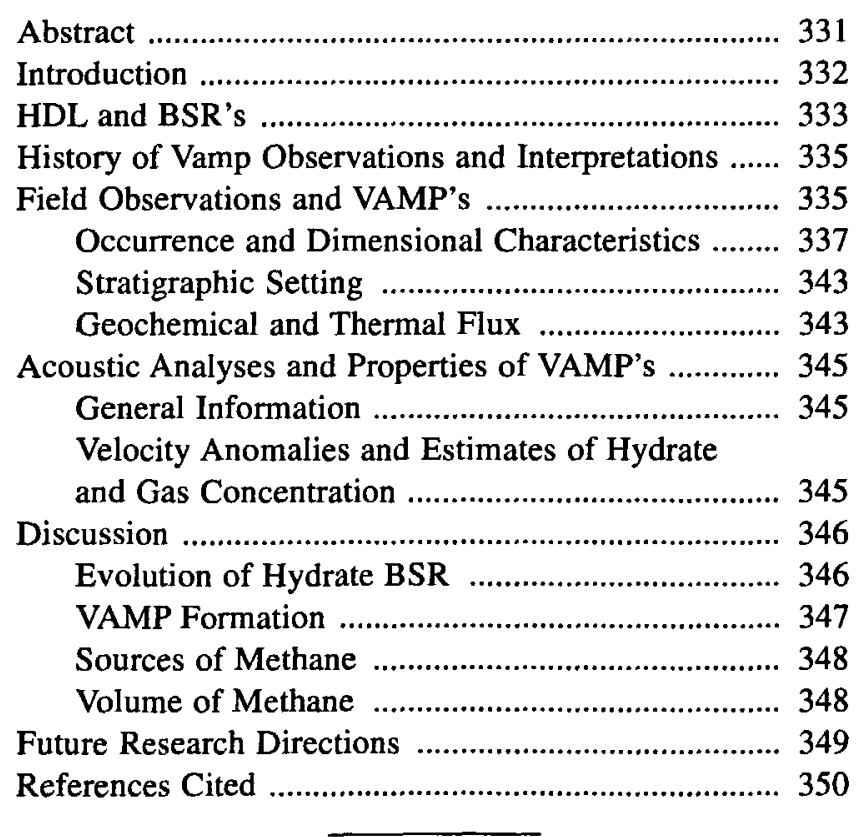

\begin{abstract}
Regional geologic and geophysical data imply that large areas of the deep-water $(3,700-4,000 \mathrm{~m})$ floor of the 94025 .
\end{abstract}

Bering Sea Basin are underlain by pore-filling deposits of methane gas hydrate. Hydrate deposits are hypothesized to occur in diatomaceous turbidite beds of middle Pliocene and younger age that cap the basin's 2- to 12-km-thick sedimentary fill. Methane hydrate deposits can theoretically occur only within the uppermost $\sim 450 \mathrm{~m}$ of surficial sediment, which thus constitutes the basin's hydrate layer (HDL).

Distinctive acoustic velocity and amplitude anomalies (VAMP's) are recorded widely within the HDL. VAMP's are displayed on seismic reflection records as vertical columns (1-2 km wide) of downflexed horizons commonly stacked directly beneath the crestal region of a series of arched or domed horizons. VAMP structures are most commonly recorded within flat-lying beds and in nonstructural settings. A prominent bottom simulating reflector (BSR) of negative polarity separates the upward arch from the underlying columns of downflexed horizons. The BSR is recorded at a subsurface depth closely matching that of the theoretical base of the HDL. These observations are interpreted to mean that VAMP's are compound-velocity pseudostructures (a pullup over a pushdown) recording a localized body of massive gas hydrate of high acoustic velocity overlying a column of low-velocity sediment containing free interstitial gas. Within the $\mathrm{HDL}$, hydrate deposits are thus inferred to occur in two principal modes: (1) disseminated deposits occupying probably less than $<$ 10-20 percent of available pore space, and (2) massive accumulations ( $>10-20$ percent) localized at VAMP structures and mainly concentrated in the basal beds of the HDL.

VAMP's occur over an area of approximately 400,000 $\mathrm{km}^{2}$, roughly equivalent to that of the states of Nevada 
and Utah combined. At VAMP's, a basinwide inferred average pullup effect of $10 \mathrm{~ms}$ is acoustically equivalent to at least a 12.5 -m-thick column of solid methane hydrate, and a measured average underlying pushdown of $23 \mathrm{~ms}$ is acoustically equivalent to a 77-m-thick column of sediment with pore space charged with at least 2 or more percent free gas. If VAMP's are discrete bodies of massive hydrate and free gas, then a conservatively estimated 12,000 VAMP's occur in the Bering Sea Basin. The corresponding total volume of methane occurring at them is approximately 1,100 trillion cubic feet (Tcf)-about $900 \mathrm{Tcf}$ in the form of massive hydrate and about $200 \mathrm{Tcf}$ as free gas. This basinwide volume is a minimum or low-end estimate of the methane potentially available in the Bering Sea Basin. The volume potentially available at a single large VAMP structure is about 0.3 Tcf. The methane is thought to be chiefly of thermogenic origin.
A major advance in information is needed to accurately map and model VAMP structures, to confirm their inferred relation to massive hydrate deposits, and to resolve the special geologic history that favors the widespread formation of VAMP's in the Bering Sea Basin.

\section{INTRODUCTION}

Anomalous acoustic structures in flat-lying basinal deposits are widely recorded on time-base seismic-reflection profiles from the abyssal floor $(3,700-4,000 \mathrm{~m})$ of the Bering Sea Basin (fig. 1; Cooper and others, 1987). These structures, termed VAMP's (velocity-amplitude anomaly), are displayed as vertical columns of downflexed horizons commonly nestled beneath a domed or upward-arched set of horizons. The domed, upper half of VAMP structures is

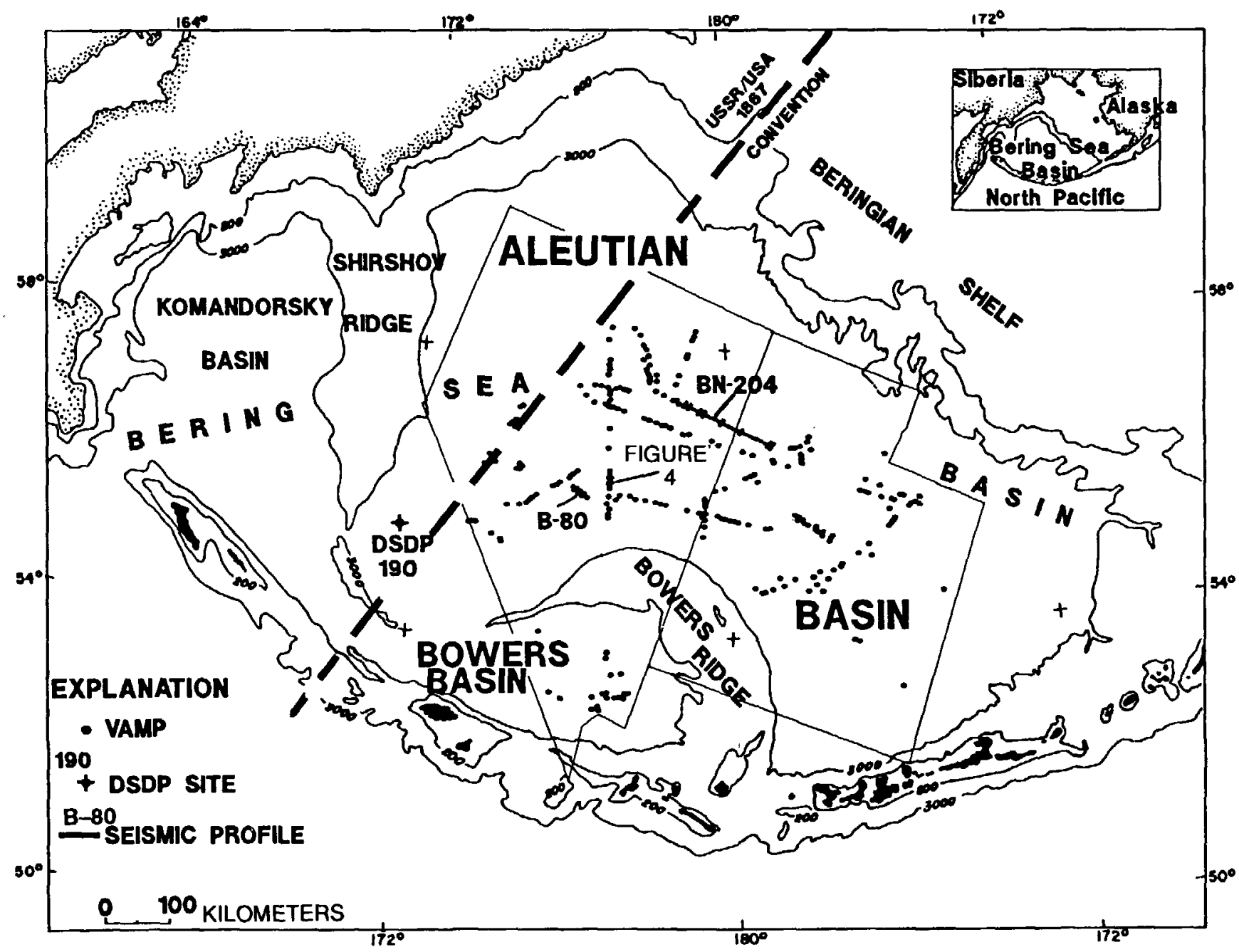

Figure 1. Index map of Bering Sea Basin showing location of velocity and amplitude structures (VAMP's) in the Aleutian and Bowers Basins known prior to 1980 and locations of seismic sections displayed on other figures. Other VAMP locations are shown on figure 5. Deep water Bering Sea Basin comprises the separate Komandorsky, Bowers, and Aleutian subbasins. 
not always observed (approximately 58 percent; Rearic and others, 1988); hence, the defining or diagnostic attribute of a VAMP's is the anomalous column of downflexures. Typical recordings of VAMP's are displayed on figures 2, 3, 4, and 7(see also Scholl and Cooper, 1978; Cooper and others, 1978, 1979, 1987).

The following general relations are typical of VAMP structures: 1) The sets of domed and downflexed horizons are vertically superimposed; 2) The sets of domed and downflexed horizons occur as isolated deflections within otherwise flat-lying beds; 3 ) Thousands of VAMP's occur, most of which are not localized over specific elements of basement relief; 4) A prominent negative-polarity reflection horizon, which is also a bottom simulating reflector (BSR), lies at the base of the arched horizons and at the top of the columns of downflexures; 5) The BSR separating the opposite flexed horizons occurs at a subsurface depth theoretically equivalent to that of the base of the methane-hydrate stability field; 6) The recorded vertical relief of both the domed and downflexed horizons increases with subsurface depth; 7) At some VAMP's, vertically beneath the column of downflexures a shallow depression is recorded in the surface of the underlying igneous oceanic crust.

Based on these observations, and others noted elsewhere in this paper, VAMP's are not interpreted as deformational structures but rather as acoustic artifacts or pseudostructures of large size ( $>1 \mathrm{~km}$ across). They are thought to be caused by the vertical superposition (duplexing) of a velocity pullup over a more prominent velocity pushdown. Following the suggestion of Scholl and Cooper (1978), VAMP structures are thus hypothesized to record the localized occurrence of massive hydrate deposits $(>10-20$ percent of pore space occupied by hydrate) of anomalously high acoustic velocity (pullup) overlying and sealing gaseous sediment of anomalously low velocity (pushdown). Minshull and White (1989) reasoned similarly that acoustic pseudostructures from the Gulf of Oman which are akin to Bering Sea VAMP's, are pods of gas entrapped beneath localized concentrations of hydrate deposits.

In this paper we summarize information about VAMP's occurring within the Bering Sea Basin and draw inferences concerning their probable origin as hydrate-related structures and about the volume of methane occurring in them. It is recognized that although the acoustic characteristics and field relation of VAMP's are consistent with vertically superimposed methane-hydrate and methane-gas accumulations, the concept has not been rigorously field tested nor "groundtruthed" by drilling.

\section{HDL AND BSR'S}

Regional heatflow data (Cooper and others, 1987) and the temperature/pressure constraints of the methane-hydrate stability field (Kvenvolden, 1993, this volume) imply that only the upper $400-500 \mathrm{~m}$ of the basin's $2-$ to $12-\mathrm{km}$ thick sedimentary section can contain methane-hydrate deposits. Using the regional thermal gradient of $55^{\circ} \mathrm{C} / \mathrm{km}$ for the Aleutian and Bowers Basins (Cooper and others, 1987), the corresponding temperature at a depth of $450 \mathrm{~m}$ is approximately $25^{\circ} \mathrm{C}$. In these basins, deeper sediment is too warm to accumulate hydrate deposits, and interstitial methane in excess of pore-water solubility can only exists as free gas (Kvenvolden, 1987, 1993). The roughly 450-ftthick surficial section that can contain methane-hydrate deposits is defined as the hydrated layer (HDL). The actual thickness of the HDL varies laterally because the basin's geothermal gradient is not everywhere the same. The HDL can theoretically include either disseminated or nonmassive deposits ( $>10-20$ percent saturation of pore space), massive hydrate deposits ( $>10-20$ percent), or no hydrate deposits at all. Hydrate deposition within the HDL depends upon the occurrence of methane in excess of porewater solubility.

The occurrence of lower velocity, potentially gas-bearing sediment beneath higher velocity, potentially hydratebearing basal beds of the HDL should, in theory, generate a high-amplitude, phase-inverted reflection event (see Shipley and others, 1979; Kvenvolden, 1993, this volume; Lee and others, this volume). This prominent reflection horizon should follow the subsurface isotherm marking the base of the hydrate stability field and thus roughly parallel the isotherm that is coincident with the overlying seafloor. A reflection horizon marking the base of the HDL should therefore be an example of a bottom simulating reflector (BSR) (Scholl and Creager, 1973).

Cooper and others (1987) emphasized that in the Bering Sea not all BSR's are linked to the occurrence of hydrate deposits. Drilling on Deep Sea Drilling Program (DSDP) Leg 19 determined that a prominent BSR is also generated by the diagenetic alteration of diatomaceous deposits, in particular the downsection conversion of biogenic silica, opal-A, to opal-CT (Scholl and Creager, 1973; Hein and others, 1978). As a note of historical interest, the expression "bottom simulating reflector" was coined to describe the seabed-emulating reflection horizon generated by the opal-CT diagenetic front that is widely recorded in the Bering Sea (Scholl and Creager, 1973). Below the flanking slopes of the Aleutian Basin, the gas-hydrate BSR (BSR-GH) occurs at a shallower subsurface depth than the silica-diagenetic-boundary BSR, (BSR-DB) of Cooper and others (1987).

The sea floor of the Aleutian and Bowers Basins is virtually horizontal and parallel to the stratification of underlying deposits. Thus, except where differential compaction or slight structural or depositional tilting has occurred, all BSR's parallel bedding, and their identification as distinct reflection horizons is difficult. On figure 2, two BSR's are identified that crosscut basin-floor deposits tilted by differential compaction over a deeply buried basement high 


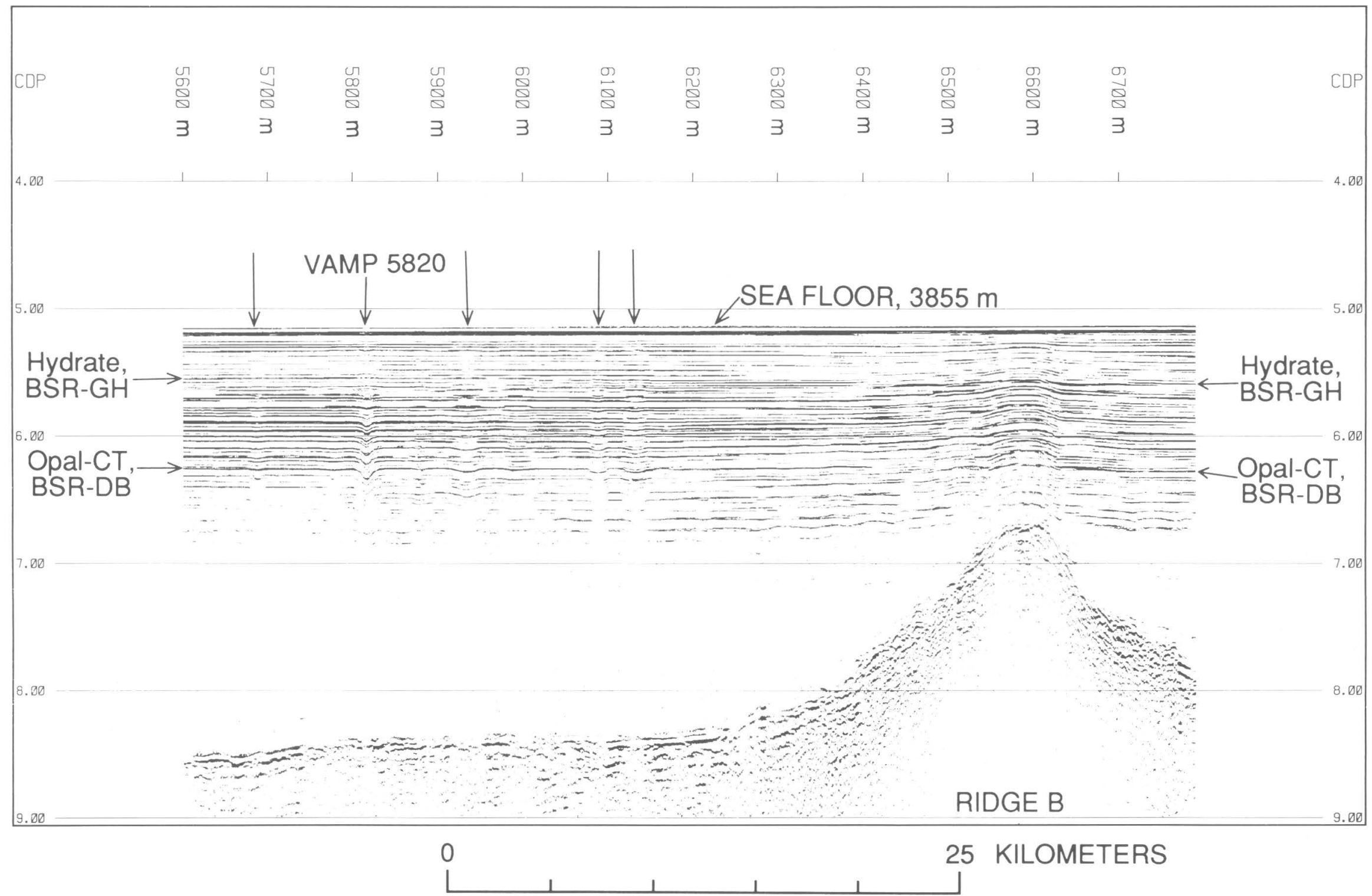

Figure 2. Migrated relative-amplitude plot of section of multichannel seismic reflection line L-44 (1976). Boxed area is velocity and amplitude structure (VAMP) 5820, which is shown in larger scale on figures 7 and 8. Other VAMP's are indicated by vertical arrows. Line of section is located on figure 5 (see also fig. 6). Both an upper gas-hydrate bottom simulating reflector (BSR-GH) and an inferred deeper silica-diagenic-boundary bottom simulating reflector (BSR-DB) (opal-CT) are identified (see Cooper and others, 1987). The BSR's cut across differentially tilted beds draped over buried seamount of Ridge B (Marlow and others, 1987) that rises above Vitus Arch (see fig. 5). No VAMP structures are localized over Ridge B. Insert diagram displays two reflection traces documenting that polarity of hydrate BSR is negative with respect to positive reflection event from sea floor. The deeper, positive-polarity BSR-DB is presumably top of latest Miocene and older strata or earliest Pliocene siliceous mudstone deposits, which exhibit weak internal reflectivity downsection. 
(Ridge B). The upper BSR, which is recorded at a two-way reflection time of $0.45-0.55 \mathrm{~s}$, can be traced laterally as a prominent reflection event that tops the downflexed columns of VAMP structures. Adopting an average interval velocity of $1.75 \mathrm{~km} / \mathrm{s}$ based on averaging the drilling results at Site 190 (Creager and others, 1973) and multichannel seismic reflections (MCS) stacking velocity analyses, the reflection time of $0.45-0.55 \mathrm{~s}$ corresponds to a subsurface depth of approximately $400-480 \mathrm{~m}$. In the Aleutian and Bowers Basins this depth matches well with that of the theoretical base (roughly $450 \mathrm{~m}$ ) of methane-hydrate occurrence (in other words, the base of the HDL).

The upper BSR is also a negative-polarity reflection event with respect to that of the overlying sea floor (fig. 2). The shallower of the two BSR's is thus interpreted as a BSR-GH, most likely (see discussion below) generated by the occurrence of low-velocity, gas-bearing sediment beneath the base of the HDL. The prominent velocity pushdowns at VAMP's support this notion. However, the amount of free gas associated with a BSR-GH is poorly understood (Max, 1990; Miller and others, 1991; Singh and others, 1993; Rowe and Gettrust, 1993; Kvenvolden, 1993; Carson and others, 1993; Bangs and others, in press) and the presence of much gas is questioned by Hyndman and Spence (1992). Throughout the Bering Sea Basin, the upper BSR is most conveniently identified as a prominent, polarity-negative horizon separating the base of the acoustic pullup from the top of the velocity pushdown (figs. 3 , 4). Beneath the Aleutian Basin the hydrate BSR is laterally discontinuous, but it is particularly prominent in the immediate vicinity of VAMP's and related acoustically anomalous structures (Rearic and others, 1988)

The deeper BSR identified on figure 2 is presumably the opal-CT or BSR-DB diagenetic front. This reflection horizon is coincident with the top of the indurated mudstone of Miocene age reached at a subbottom depth of 615 m at DSDP Site 190 (fig. 1; Creager and others, 1973). A relatively high acoustic velocity of $2.6-2.9 \mathrm{~km} / \mathrm{s}$ is characteristic of the indurated mudstone (Cooper and others, 1987). Unless otherwise stated, the notation "BSR" as used elsewhere in this text and on illustrations refers only to the BSR-GH or hydrate BSR.

\section{HISTORY OF VAMP OBSERVATIONS AND INTERPRETATIONS}

In the late 1960's and early 1970's, reconnaissance reflection profiling with low-power, single-channel seismic (SCS) technology first recorded anomalous structures beneath the abyssal floors of the Aleutian and Bowers Basins. These early profiles were collected by the U.S. Geological Survey and the U.S. Navy operating from the research vessels Davis, Bartlett, and Bent. Figure 3 exhibits examples of these early VAMP recordings. The high vertical exagger- ations of these records emphasize the upper dome structure but in particular the defining characteristics of VAMP'sthe slender columns of concave horizons starting at a subseafloor depth of $400-500 \mathrm{~m}$. The reconnaissance studies established that VAMP's are numerous (hundreds) but tended to be most abundant beneath the central region of the Aleutian Basin (figs. 1, 5).

The first digital recording of .VAMP structures was acquired in the middle 1970's, in particular along two MCS lines, one collected by Exxon Exploration and the other, line L-44 (figs. 6, 5), by the U.S Geological Survey from the R/V S.P. Lee. Both lines crossed the north-south width of the Aleutian Basin (Cooper and others, 1987). Additional industry (proprietary) MCS data cover some parts of the northernmost floor of the Aleutian Basin (Worrall, 1991). The entire network of nonindustry MCS data available for acoustic analyses and mapping of VAMP's covers approximately $2,000 \mathrm{~km}^{2}$ (fig. 6). MCS data collected by the R/V S.P. Lee in 1976 verified evidence from older ana$\log$ SCS records that many of the downflexed columns were capped by a prominent, phase-inverted reflection horizon (in other words, a BSR) (figs. 2, 4, 7, 8).

Not shown on figure 6 , which displays tracklines of digitally recorded reflection data available for study, are the locations of an eclectic collection of low-power analog SCS profiles recorded by various institutions and agencies between the mid-1960's and 1986. In 1977, a reconnaissance study was carried out from the RN Sea Sounder, then operated by the U.S. Geological Survey, to specifically learn more about the geologic setting and acoustic structure of VAMP's (Cooper and others, 1979). During the course of this exploration, SCS (180 kJ sparker) reflection profiles, geopotential data, cores of surface sediment, and heatflow data were gathered in target areas of the Aleutian Basin. No additional fieldwork focusing on the origin and implication of Bering Sea VAMP's has since been carried out.

In 1986 and 1987, a USGS program of GLORIA sidescan imaging conducted from the R/V Farnella included the collection of nearly $20,000 \mathrm{~km}$ of digitally recorded, low-power (160 in ${ }^{3}$ airgun) SCS data. The Farnella survey covered the entire area of Bowers Basin and most of the Aleutian Basin (fig. 6). The tracklines, which are nearly parallel, are spaced roughly $30 \mathrm{~km}$ apart and generally trend northwestward. These profiles provide regional information on the stratigraphy of the late Cenozoic beds that contain the HDL and included VAMP's. Although the deeper sedimentary sequences are only indistinctly imaged, the Farnella SCS profiles supply regional stratigraphic information on pre-Pliocene deposits filling the Aleutian and Bowers Basins.

\section{FIELD OBSERVATIONS AND VAMP'S}

Except for their occurrence within the thick sedimentary sequence of the Gulf of Oman (northwestern Indian 

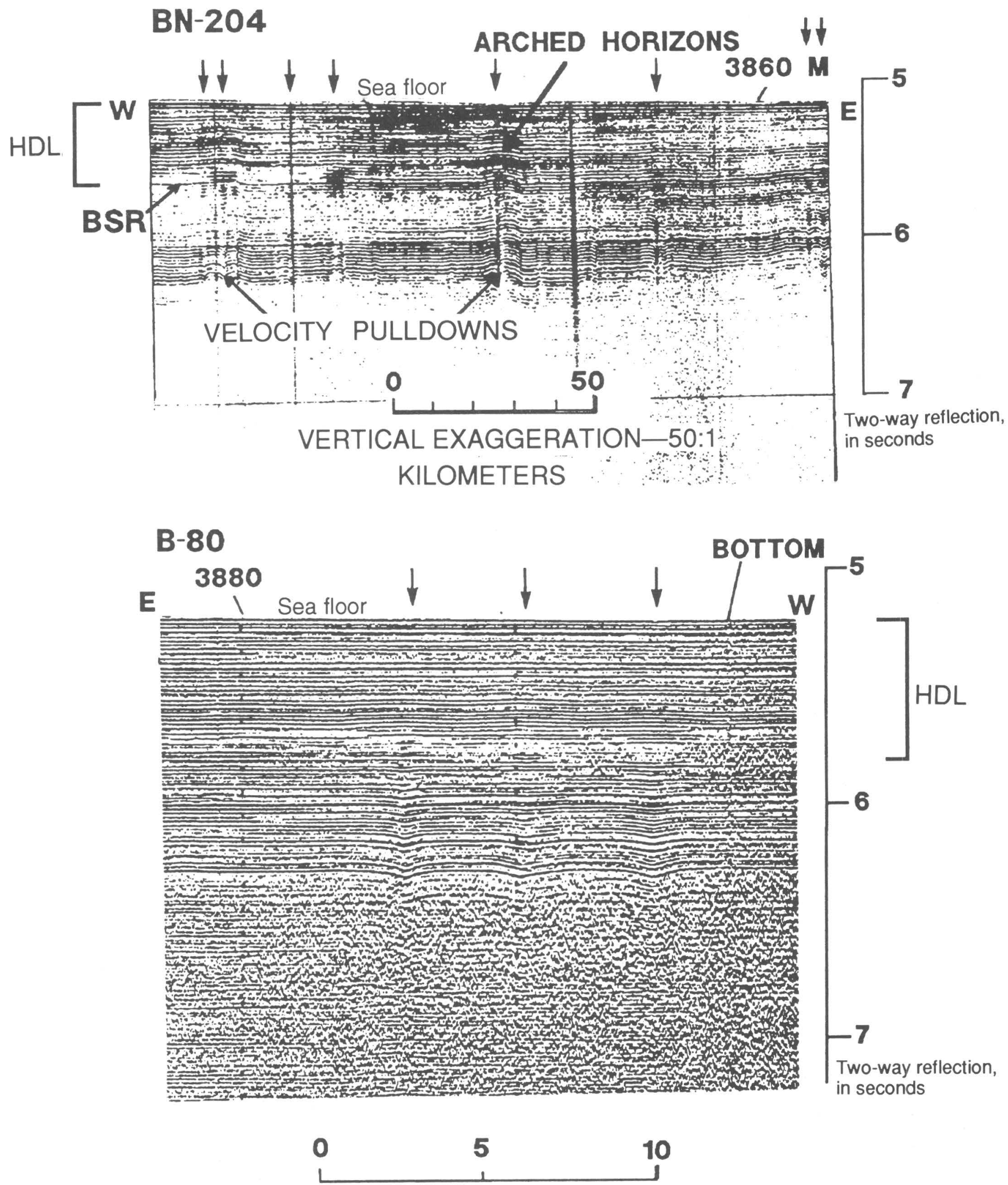

VERTICAL EXAGGERATION—9:1

KILOMETERS 
Ocean; White and Louden, 1983; Minshull and White, 1989), VAMP structures are not commonly reported outside of the Bering Sea Basin. The bulk of the information conceming VAMP structures and the HDL has been acquired as a by-product of efforts to explore the framework geology of the Bering Sea Basin (fig. 1; Cooper and others, 1987) or to sonographically image its abyssal floor (Rearic and others, 1988, Huggett and others, 1992). The great abundance of VAMP's recorded in the Bering Sea Basin implies a history of basin evolution and sediment infilling that has especially favored their formation (Scholl and Stevenson, 1987, 1990; Scholl and others, 1989). As a subject of research, the origin and geologic implications of VAMP's can thus be best pursued in the Bering Sea, in particular the Aleutian Basin.

\section{OCCURRENCE AND DIMENSIONAL CHARACTERISTICS}

VAMP's occur over a large region of the Aleutian and Bowers Basins. The area of occurrence is approximately $400,000 \mathrm{~km}^{2}(\sim 150,000$ square statute miles), which is roughly equivalent to that of the states of the Utah and Nevada combined (fig. 1). The occurrence region of VAMP's falls largely within the Exclusive Economic Zone (EEZ) of the United States, but the western part of the occurrence region lies west of the 1867 Convention Line and thus within the EEZ of Russia (figs. 1, 6)(Rearic and others, 1988).

Sufficient single-channel seismic reflection data exist in the Bering Sea to document that VAMP's are abundant. Rearic and others (1988) noted that acoustically "anomalous reflector zones" also occur widely. These VAMP-kindred structures exhibit one of the common attributes of VAMP's, typically evidence of localized zones of amplitude-enhanced reflection horizons (BSR-GH ?), but they lack a distinctive or narrow pushdown. The Rearic and others (1988) investigations established that the occurrence density of VAMP's increases toward the south-toward the bathymetrically deeper part of the basin floor (fig. 5). Their occurrence density is also high over the southwestern part of a deeply buried, northeast-trending basement swell,

Figure 3. Examples of high vertical-exaggeration singlechannel reflection profiles collected in the early 1970's that were among the first to record velocity and amplitude (VAMP) structures. Arrows point to VAMP's; location of sections shown on figure 1. HDL, hydrated layer; HDL, which is based on a thermal gradient of $50-60^{\circ} \mathrm{C} / \mathrm{km}$ (see fig. 9), is the theoretical thickness of approximately $450 \mathrm{~m}$ of surficial sediment that in the Aleutian Basin can contain methane-hydrate deposits. BSR-GH identifies a prominent, presumably phase-inverted, bottom simulating reflector generated by the occurrence of free gas in sediment underlying the HDL, the basal beds of which are presumed to contain gas-hydrate deposits. termed Vitus arch by Cooper and others(1992). A number of seamounts occur along Vitus Arch; for example, Ridge B of figures 5 and 2. VAMP-kindred structures are also common over the southwestern part of Vitus Arch.

Assuming that the SCS profiles sample the shallow subsurface with an effective beam width of one Fresnel zone, then for a water depth of $3,800 \mathrm{~m}$, the individual VAMP's plotted on figure 5 occur somewhere below an area of seafloor approximately $1.0 \mathrm{~km}$ in width centered along the vessel's trackline. Correspondingly, the average occurrence density of VAMP's within the shaded area $\left(-150,000 \mathrm{~km}^{2}\right)$ of the north-central basin floor outlined on figure 5 is 4.3 VAMP's/100 km² (213 VAMP's within a total swath area of $5,000 \mathrm{~km}^{2}$; Rearic and others, 1988). The range about this average, determined along trackline segments $250-400 \mathrm{~km}$ in length, is $0.3-9.7$ VAMP's $/ 100 \mathrm{~km}^{2}$. In the northern area of figure 5 VAMP density is only about $2 / 100 \mathrm{~km}^{2}$, but to the south, toward deeper water, the occurrence density progressively increases to a regional value of about $7 / 100 \mathrm{~km}^{2}$. During the 1977 R/V Sea Sounder cruise, a $450-\mathrm{km}^{2}$ area of the northern region was surveyed with a line density possibly adequate to determine the included VAMP density. Thirteen VAMP's identified within the surveyed area correspond to an occurrence density of about $3 / 100 \mathrm{~km}^{2}$ (Cooper and others, 1979), which compares favorably with that based on the $R /$ Farnella's SCS records.

In the north-central area of the Aleutian Basin, where VAMP's are ubiquitous, Rearic and others (1988) compiled information on both the areal distribution and attributes or characteristics below the sediment-water interface of 246 VAMP's occurring in the outlined and shaded area of figure $5\left(\sim 170,000 \mathrm{~km}^{2}\right)$. Although nearly three-fourths of the $R N$ Farnella's SCS data remain to be similarly examined, the statistical results from Rearic and others' (1988) study area (table 1) are representative of a major occurrence region of VAMP's and VAMP-kindred structures.

Table 1. Velocity and amplitude anomaly (VAMP) dimensional characteristics.

[Data are for VAMP's from outlined and shaded area shown in figure 5; data from Rearic and others, 1988]

\begin{tabular}{|c|c|}
\hline Characteristic & Numerical data \\
\hline (1) Mean depth to top of arched strata------ & $360 \mathrm{~ms}^{\mathrm{a}}$ \\
\hline (2) Mean depth to top of push-down---..-- & $610 \mathrm{~ms}^{\mathrm{b}}$ \\
\hline (3) Mean width of arched strata--- & $1.3 \mathrm{~km}(0.5-3.8 \mathrm{~km})$ \\
\hline (4) Mean time-delay relief of pushdowns ---- & $23 \mathrm{~ms}$ \\
\hline \multicolumn{2}{|c|}{$\begin{array}{l}\text { If overlying sediment velocity averages } 1.7 \mathrm{~km} / \mathrm{s} \text {, corresponding depth } \\
\text { below the sediment-water interface is about } 310 \mathrm{~m} \text {. } \\
{ }^{b} \text { If overlying sediment velocity averages } 1.7 \mathrm{~km} / \mathrm{s} \text {, corresponding depth } \\
\text { below the sediment-water interface is about } 535 \mathrm{~m} \text {. The reflection } \\
\text { depth to the top of the pushdown is below that of the overlying } \\
\text { bottom simulating reflector, which is typically recorded at } 450-550 \\
\text { ms }(400-480 \mathrm{~m}) \text {. }\end{array}$} \\
\hline
\end{tabular}




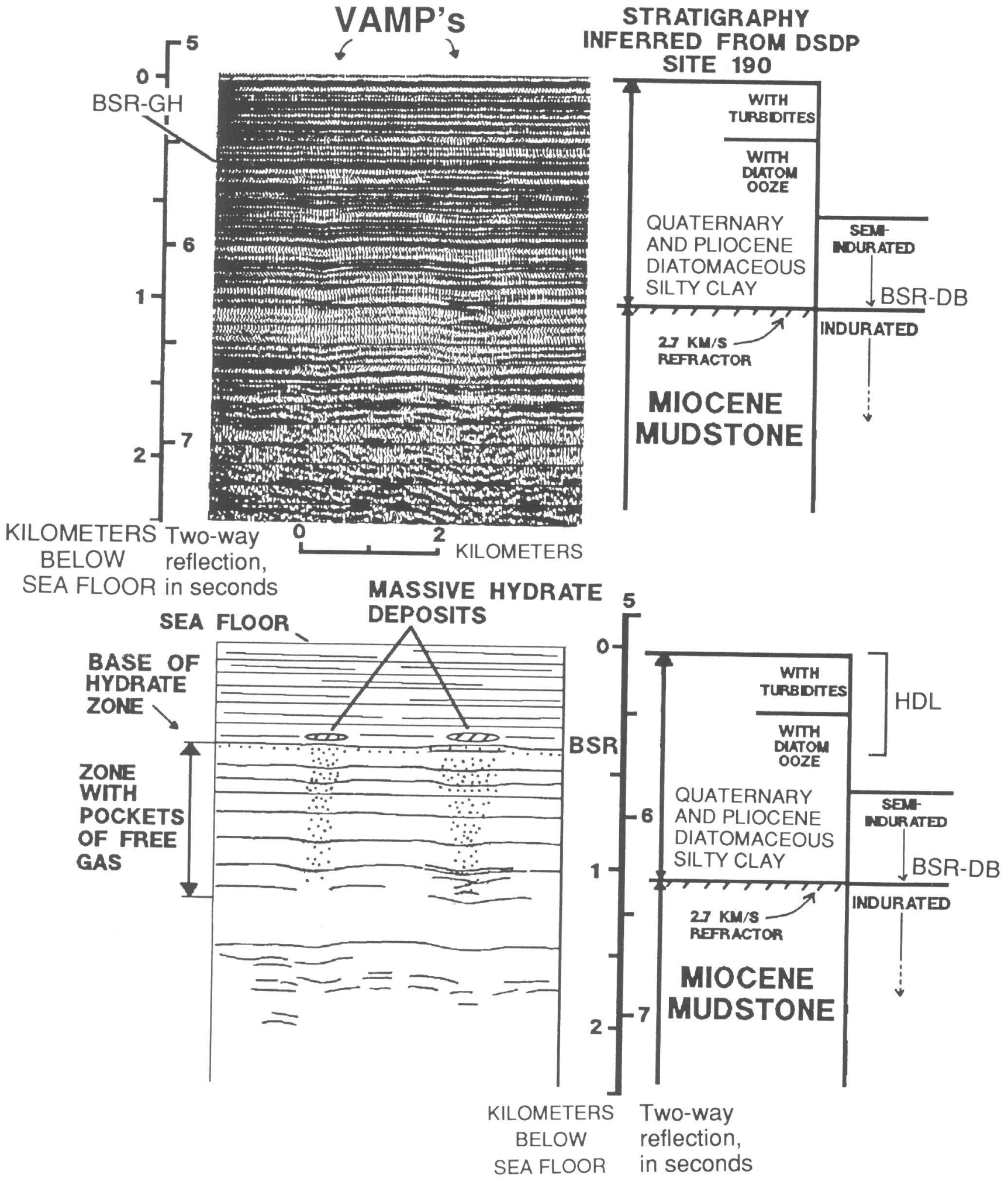

Figure 4. Upper, Multichannel profile of two unarched velocity and amplitude (VAMP) structures in western part of Aleutian Basin (see fig. 1 for location). Stratigraphic and lithologic columns inferred from drilling results at DSDP Site 190 (figs. 1 and 5) (Creager and others, 1973). Lower, Schematic model (adapted from Cooper and others, 1979) of VAMP structures showing thin, localized lenses of massive hydrate deposits at the base of the hydrate layer (HDL) overlying a prominent phase-reversed gas-hydrate bottom simulating reflector (BSR-GH) and localized columns of sediment containing free interstitial gas. Because velocity pullups are not recorded, massive hydrate deposits along line of profile probably occur only in basal 10-30 m of the HDL, and, on the basis of studies elsewhere, the saturation level probably does not exceed $20-30$ percent. 


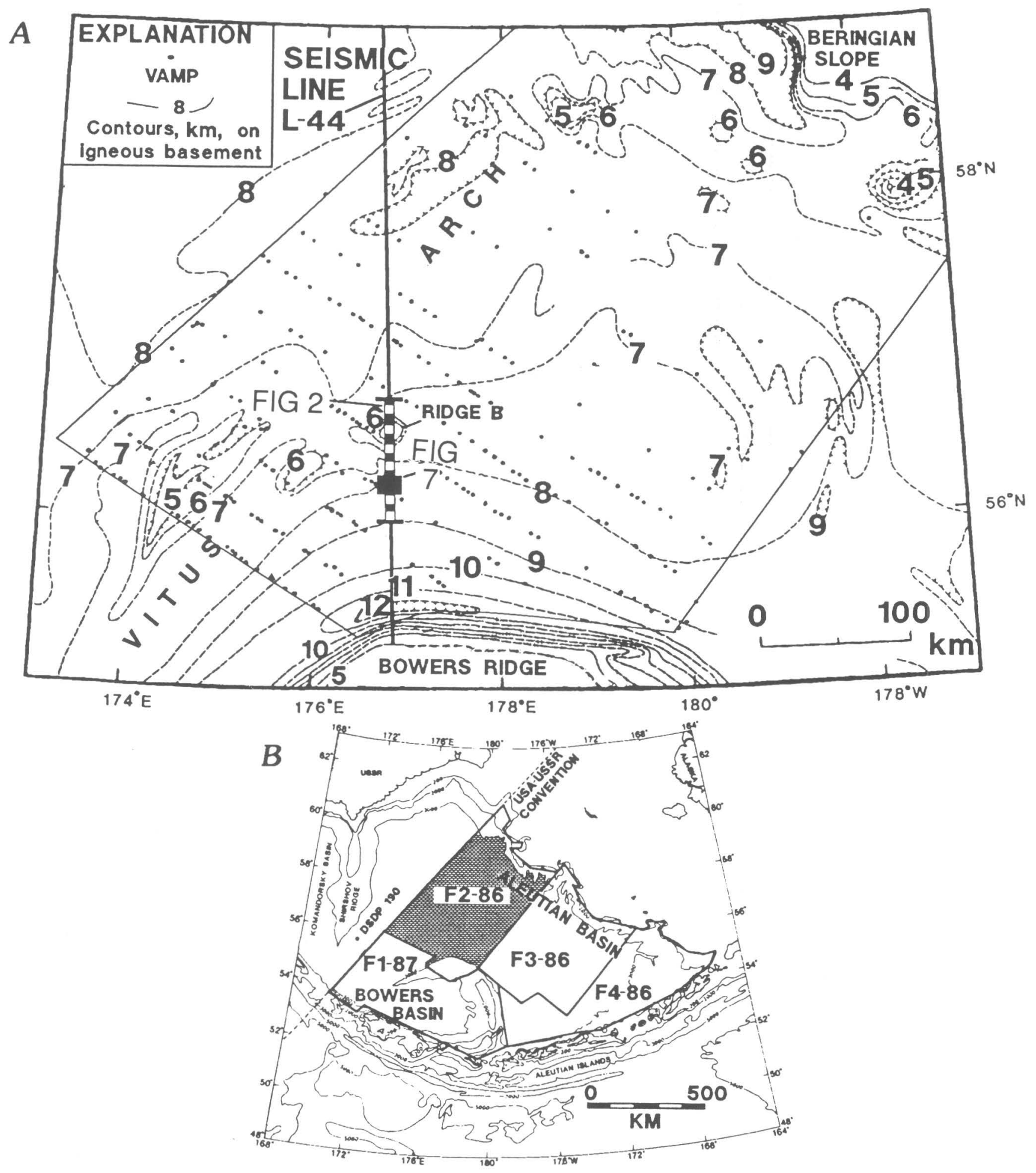

Figure 5. A, Distribution of velocity and amplitude (VAMP) structures in the west-central sector of Aleutian Basin along the dominantly northwest-trending tracklines surveyed on R/V Farnella cruise F2-86 (Rearic and others, 1988). Occurrence density of VAMP's increases southward toward basin's bathymetrically deepest part and somewhat in the vicinity of the buried basement highs along the southwestern part of Vitus Arch (see fig. 2). Water depth of the abyssal floor is approximately $3,800 \mathrm{~m}$, hence thickness in kilometers of basinal sedi- ment can be approximated by subtracting 4 from structural contours on igneous crustal basement. If VAMP's are discrete podlike deposits of hydrate and gas, it is estimated that about 12,000 VAMP structures underlie the abyssal floors of the Aleutian and Bowers Basins combined (see fig. 1). $B$, Index map showing area of figure $A$ with topographic contours showing outline of Aleutian Basin. Shaded and outlined box indicates region in which 246 VAMP's were mapped and characterized by Rearic and others (1988). 


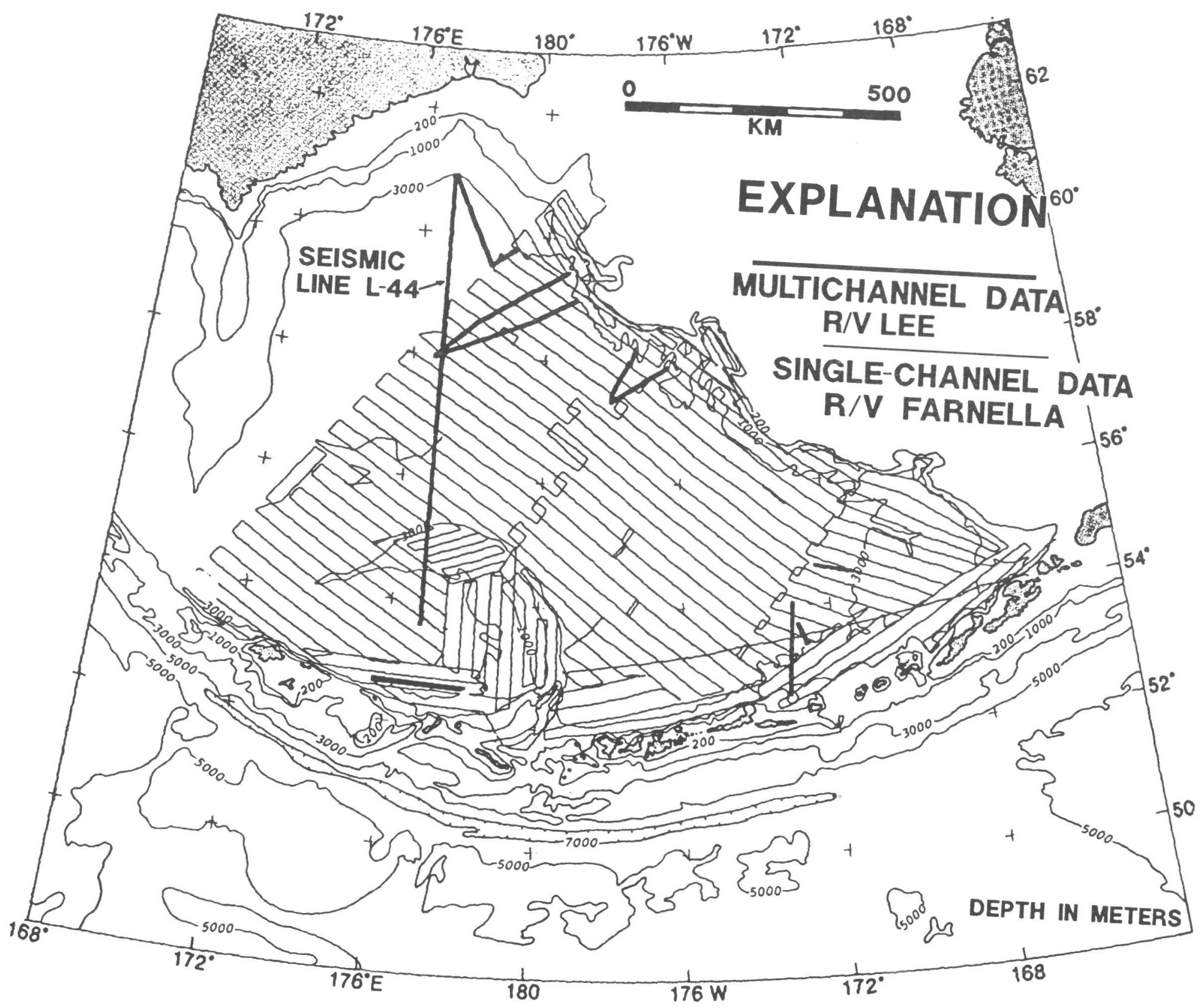

Figure 6. Trackline chart of available digitally recorded single-channel (R/V Farnella, 1986, 1987) and multichannel (R/V S.P. Lee, 1976-1982) seismic reflection data from abyssal region of Bering Sea Basin. Location of seismic line L-44 also shown on figure 5. 

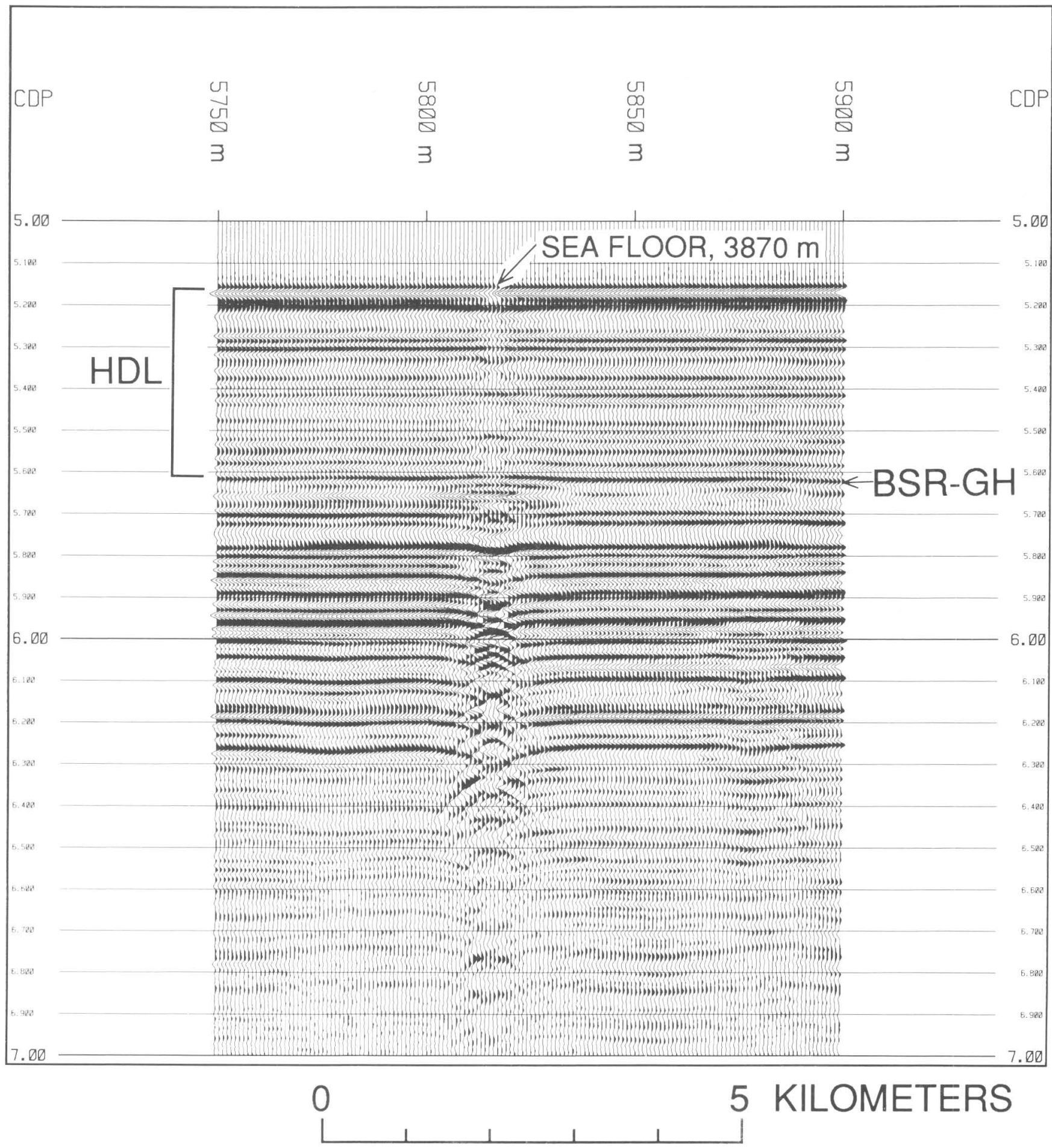

Figure 7. Velocity and amplitude (VAMP) structure 5820, located along a segment of multichannel seismic reflection line $\mathrm{L}-44$ (see figs. 5 and 2 for location). Plot is a standard common depth point (CDP) stack of 24 -fold data. A migrated section is shown on figure 8 (see also fig. 2). Diffractions are "bow ties" that re- sult from plotting of unmigrated data that does not properly image the narrow velocity pushdown structure. BSR-GH denotes a negative-polarity reflection horizon identified as a bottom simulating reflector generated by free gas underlying sediment containing gas-hydrate deposits. 

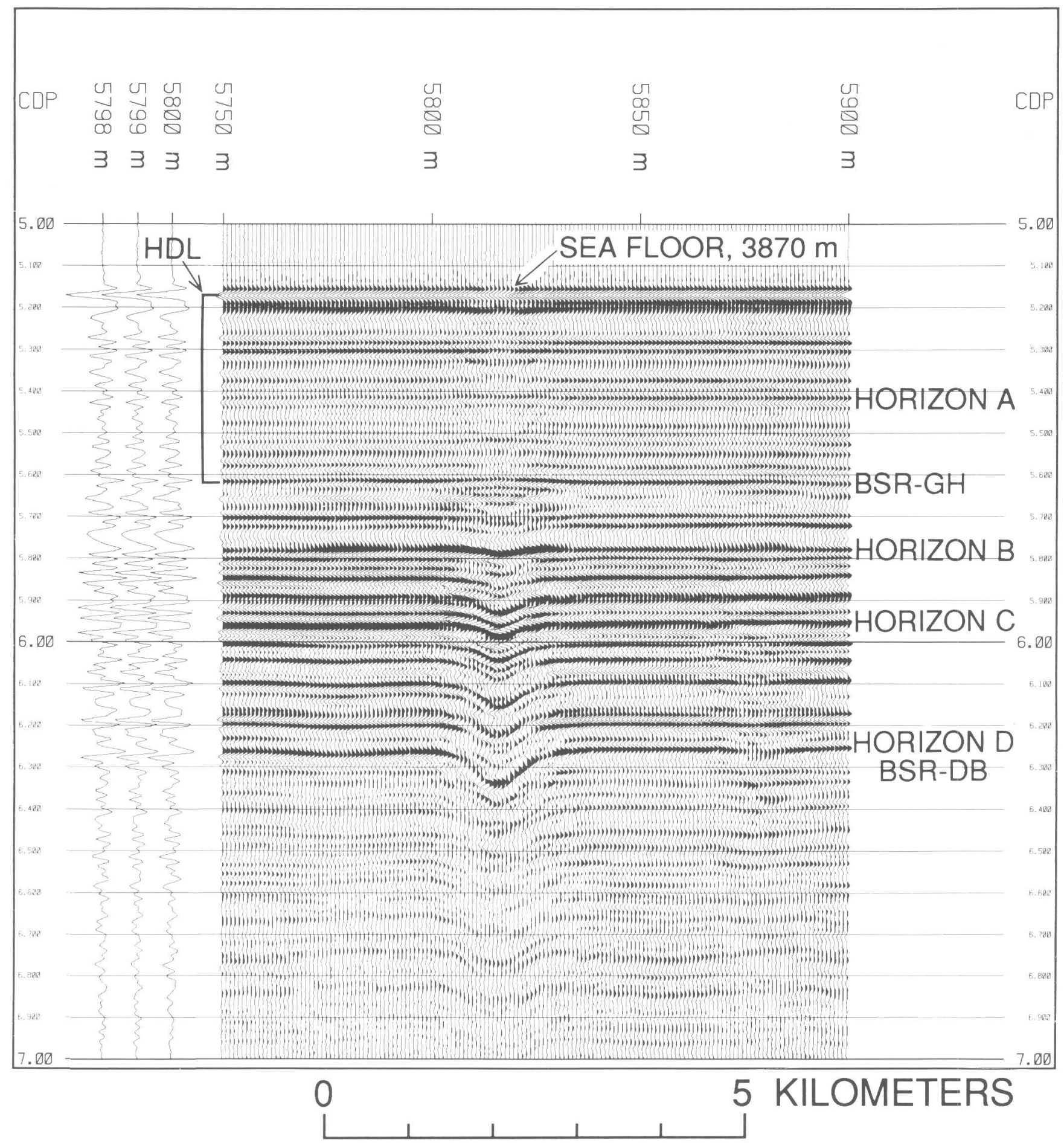

Figure 8. Migrated seismic section of velocity and amplitude structure (VAMP) 5820 located along multichannel seismic reflections (MCS) line L-44 (see figs. 2 and 5 for location). Horizon A marks the top of an 8-ms velocity pullup, which is most pronounced at the hydrate-related gas-hydrate bottom simulating reflector (BSR-GH). The pullup is inferred to record a localized body of massive hydrate deposits, filling from 15 to 55 percent of available pore space depending upon assumptions of the vertical distribution of hydrate concentration. Horizons B, C, and D exhibit the progressively accumulating time-delay effect of an underlying velocity pushdown, presumed to be caused by free interstitial gas below the BSR-GH. Horizon D is thought to be a silica-diagenetic-boundary bottom simulating reflector (BSRDB) (see fig. 2). HDL, hydrate layer. 


\section{STRATIGRAPHIC SETTING}

The Aleutian and Bowers Basins are underlain by a virtually undeformed sequence of mostly Eocene and younger sedimentary beds overlying igneous oceanic crust of Cretaceous or possibly earliest Tertiary age (fig. 2). Although the sedimentary sequence is as thick as $12 \mathrm{~km}$ (Cooper and others, 1987), in particular along the southern and northern borders of the Aleutian Basin, the typical thickness beneath the central basin region is $2-4 \mathrm{~km}$ (fig. 5). VAMP's have not been reported from the Komandorsky Basin, the geologically young, far western region of the Bering Sea Basin (fig. 1; Baranov and others, 1991).

As noted, in the Aleutian Basin the base of the upper domed structure of VAMP's and the position of the phaseinverted BSR, occur commonly at an estimated depth of 400-500 m. It can be inferred from the sedimentary sequence drilled at DSDP Site 190 (fig. 1) that the upper or domed part of the VAMP structure occurs within a sequence of diatom silty clay (see fig. 4). The base of the domed reflection horizons-the BSR-appears to correspond roughly with the downsection transitions $(375 \mathrm{~m}$ at Site 190) from weakly indurated diatom and silty turbidite beds to an underlying sequence of semi-indurated, wormburrowed, and more richly diatomaceous silty clay. The entire 630-m-thick sequence of diatom silty clay includes ash layers and turbidite beds; however, these components are apparently more abundant, and the turbidite beds coarser, in the upper part of the drilled section.

The turbidite deposits penetrated at Site 190 are part of a basinwide sequence of diatomaceous-rich terrigenous beds that flooded the basin floor beginning in the late $\mathrm{Ce}$ nozoic (Ewing and others, 1965; Cooper and others, 1987). Because Site 190 is located along the western edge of the Aleutian Basin and over a buried basement high (Scholl and Cooper, 1978; Cooper and others, 1979, 1987), the turbidite sequence is thin with respect to the turbidite sequence underlying the central basin area to the east, where the sequence thickens to more than $1 \mathrm{~km}$. Presumably, as is globally typical of other ocean-margin basins, the diatomaceous-rich terrigenous body accumulated in part as a consequence of glacially induced fluctuations in sea level and the accelerated flushing of terrigenous material to the ocean basins. Based on the appearance of icerafted detritus in north Pacific deep-sea sediment (Rea and Schrader, 1985) and the beginning of loess accumulation in interior Alaska (Westgate and others, 1990), rapid turbidite deposition in the Bering Sea Basin should have been well established by 2.5-3.0 Ma.

Paleontologic data and sediment accumulation rates indicate that at DSDP Site 190 the age of the basal finer grained and more diatomaceous beds of the turbidite sequence is somewhat older. Most probably, initial deposition of the upper turbidite sequence began in early Pliocene time at 4-5 Ma. At Site 190, the upper turbidite beds unconformably overlie an indurated section of mudstone draped over a buried seamount or basement high. The mudstone regionally exhibits a relatively high acoustic velocity of about $2.7 \mathrm{~km} / \mathrm{s}$ (fig. 4; Cooper and others, $1979,1987)$. The top of the mudstone section appears to be a silica-diagenesis (opal-CT front or BSR-DB) boundary rather than a chronostratigraphic horizon. Limestone beds in mudstone recovered at DSDP Site 190 enclose diatoms of middle Miocene age. However, on the basis of the implications of regional DSDP drilling results, the top of the mudstone sequence adjacent to the buried high at Site 190 is probably of latest Miocene or perhaps earliest Pliocene age (Creager and others, 1973). Little else is known about these mudstone deposits and older underlying beds., which on relative amplitude plots exhibit poor internal reflectivity (figs. $2,7,8$ ). Inferences about the age and lithology of the older Tertiary deposits of the Aleutian Basin are summarized by Scholl and others (1986), Cooper and others $(1987,1992)$, and Worrall (1991).

\section{GEOCHEMICAL AND THERMAL FLUX}

On the basis of the examination of seven, 2-m-long gravity cores, which were specially collected for shipboard geochemical analyses, the upper layer of bottom sediment exhibits a downward gradient of increasing concentration of pore-water methane of biogenic origin (Cooper and others, 1979). The gradient may be slightly higher in the vicinity of VAMP's than away from them. Along the short length of the cores, no evidence was found for a surface flux of thermogenic gases. However, considering that the sampling density is 1 core $/ 60,000 \mathrm{~km}^{2}$ of central Aleutian Basin floor, only conjectures are justified concerning the flux of gaseous hydrocarbons across the sediment-water interface-either at or away from VAMP's. However, as noted by Cooper and others (1979) the recording of disrupted reflection horizons in the shallow subsurface section (upper 100-200 m) overlying VAMP structures may be evidence that venting occurs at VAMP structures. Also, lateral disruptions in reflection-horizon continuity may signal localized deposition of denser hydrate deposits in the upper part of the HDL.

Thirty-one heatflow measurements are available from the central region of the Aleutian Basin (Cooper and others, 1987). On the basis of these determinations, the basinwide average thermal flux is 1.44 heatflow units (1 $\mathrm{HFU}=1.0$ microcalories $/ \mathrm{cm}^{2} / \mathrm{s}$, fig. 9). Langseth and others (1980), using basically the same data, calculated an average flux of $55 \mathrm{~mW} / \mathrm{m}^{2}$. The corresponding thermal gradient is relatively high, $50-60^{\circ} \mathrm{C} / \mathrm{km}$. Cooper and others (1992) noted that locally the thermal flux is higher over the south-central part of Vitus Arch, a possible reflection of early Tertiary crustal generation along this backarc basement swell. As noted, VAMP-kindred structures are 


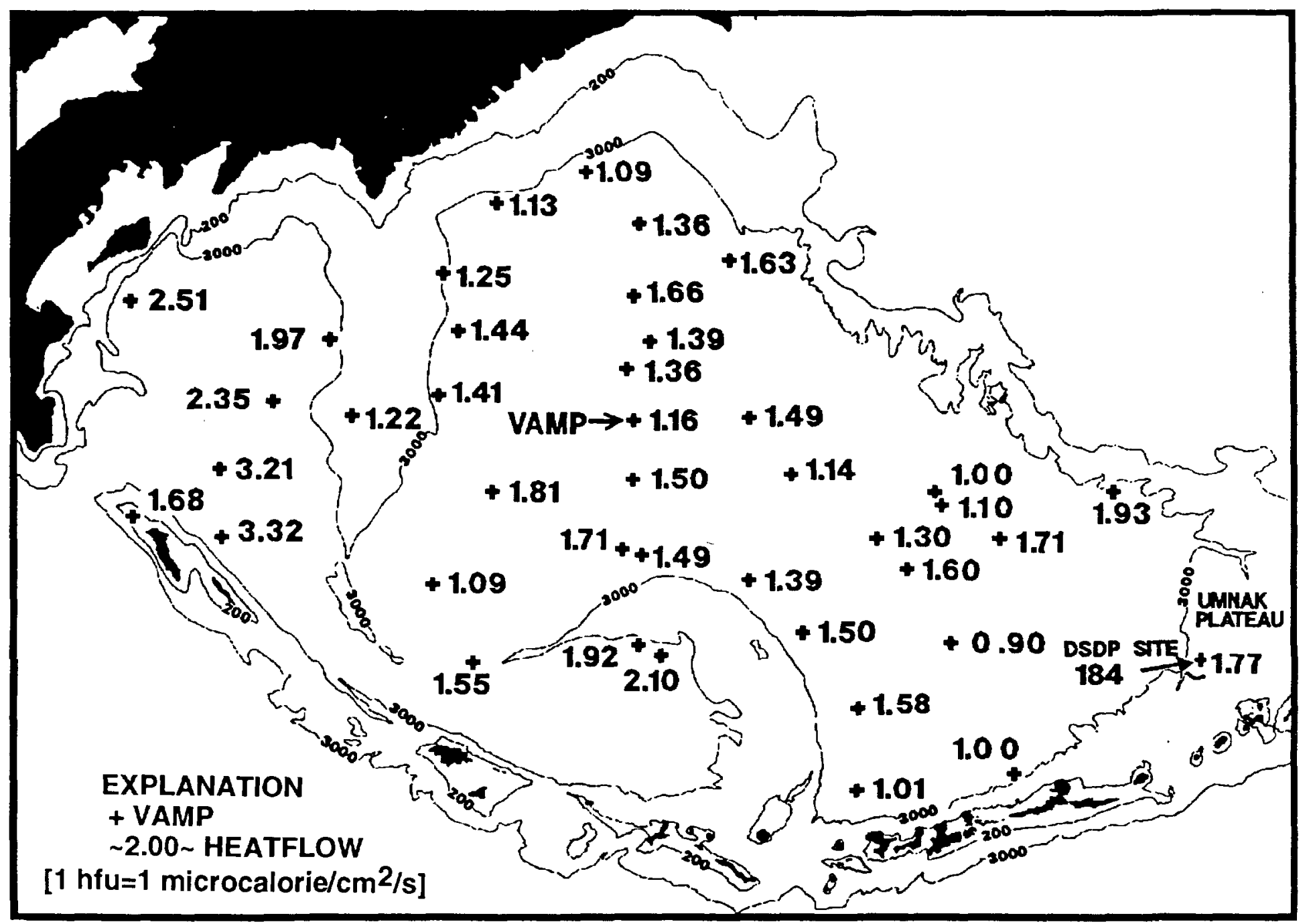

Figure 9. Heatflow data (in heatflow units, hfo) from various sources summarized by Cooper and others(1987). The corresponding basinwide geothermal gradient for Aleutian and Bowers Basins is $50-60^{\circ} \mathrm{C} / \mathrm{km}$, sufficient to generate thermogenic gases at subsurface depths as shallow as $2 \mathrm{~km}$. Water depth in meters. 
concentrated along this warm sector of the arch (Rearic and others, 1988).

\section{ACOUSTIC ANALYSES AND PROPERTIES OF VAMP's}

\section{GENERAL INFORMATION}

In 1976, $1840 \mathrm{~km}$ of 24-fold common-depth-point (CDP) MCS data were acquired by the R/V S. P. Lee using a 24-channel, 2,400-m-long hydrophone streamer and a tuned source array of five airguns (approximately $1,325 \mathrm{in}^{3}$ at 2,000 psi). MCS line L-44 of the 1976 data set (figs. 5, 6) crosses the north-south width of the Aleutian Basin and records a number of VAMP's, several examples of which are shown on figure 2. Data processing for the relative amplitude display of figure 2 includes spherical divergence gain correction, spiking deconvolution, velocity analysis, stack, migration, and bandpass filter. Migration was necessary to properly image the VAMP velocity pushdowns. Many of these pseudosynclines have buried foci and appear as "bow ties" on unmigrated displays (fig. 7)

On figure 2, the prominent structure at VAMP 5820 shows both the velocity pullup, attributed to a velocity enhancement caused by an increase in either hydrate concentration or thickness or both, and the more prominent underlying pushdown, attributed to a low velocity gaseous zone. A prominent reflector at the base of the upwardarched horizons exhibits a negative polarity with respect to that of the sea floor (see insert fig. 2). This distinctive horizon is interpreted to be a BSR generated by the occurrence of free gas in sediment underlying the base of the HDL (see, for example, Shipley and others, 1979; Miller and others,1991; Singh and others, 1993; Rowe and Gettrust, 1993; Carson and others, 1993; Bangs and others, in press).

Adjacent to VAMP 5820, the BSR can be traced within flat-lying deposits to the sediment-draped basement high (Ridge B; Marlow and others, 1987) at CDP 6600 on figure 2 . Here the BSR reveals itself by crosscutting bedding planes tilted by differential compaction. The slight shallowing of the BSR over the Ridge B most likely reflects a localized increase in subsurface temperatures caused by the elevated position of the igneous basement. After correction for spherical divergence, the amplitude of the BSR reflection in the vicinity of the ridge is approximately 60 percent of that of the overlying seafloor. At VAMP 5820, the amplitude ratio is approximately 50 percent. The recorded amplitude brightness of the BSR varies considerably, and in many places along the section of line $\mathrm{L}-44$ (fig. 2) the reflective amplitude is much lower than that of the seafloor. Although tuning and interference between closely spaced parallel reflections affect the recorded amplitude, the lateral variability may signify horizontal changes in either the hydrate concentration at the base of the HDL or the occurrence of underlying free gas.

The amount of gas hydrate filling pore space can be estimated by measuring sediment-layer interval velocity $\left(V_{p}\right)$, which increases with increasing degree of hydrated saturation (percentage of pore space filled with gas hydrate) (Miller and others, 1991; Hyndman and Spence, 1992; Bangs and others, in press). Similarly, the presence of free gas below the BSR is indicated by a significant drop in Vp (Domenico, 1976, Singh and others, 1993; Carson and others, 1933; Bangs and others, in press). Because the error involved in calculating interval velocities with the Dix (1955) equation is inversely proportional to the ratio of the thickness of an interval of sediment to its depth below the sediment-water interface (Hajnal and Serada, 1981), existing MCS data cannot accurately measure Vp and the inferred hydrate saturation within the HDL. The Dix (1955) equation calculates the interval velocity for reflectors from a sequence of flat-lying, parallel layers with small offsets. The uncertainty in $\mathrm{Vp}$ for the $\sim 450$-m thickness of the HDL is greater than $\pm 300 \mathrm{~m} / \mathrm{s}$, which implies that the thickness-average hydrate saturation in the HDL could vary from 0 to 50 percent. The error range is even larger when assuming that hydrate occurrence is concentrated primarily in the lowermost beds of the HDL. The consistency of dozens of velocity analyses establishes that the average interval velocity of $1,800 \mathrm{~m} / \mathrm{s}$ calculated for the HDL along MCS line $\mathrm{L}-44$ (fig. 2) is much more than $\pm 300 \mathrm{~m} / \mathrm{s}$. Nonetheless, small lateral variations in calculated stacking velocity may be partly due to seismic resolution problems and cannot with any certainty be attributed solely to lateral changes in hydrate saturation or lithology.

\section{VELOCITY ANOMALIES AND ESTIMATES OF HYDRATE AND GAS CONCENTRATION}

Velocity pullups and pushdowns associated with VAMP's provide a feasible method to calculate lateral velocity changes that can be ascribed to changes in hydrate saturation and volume of interstitial gas. Measured above the BSR, the magnitude or relief of the velocity pullup at VAMP 5820 is $8 \mathrm{~ms}$ (fig. 8). It is assumed that the sediment involved is flat lying and that the VAMP structure is caused entirely by lateral velocity changes. The pullup begins at Horizon A, indicating that assumed denser hydrate occurrence is confined to the lower $200 \mathrm{~ms}(\sim 170 \mathrm{~m})$ of the 450 ms-thick HDL. If a velocity of approximately $1.75 \mathrm{~km} / \mathrm{s}$ is assumed for the lower part of the HDL at some distance away from the VAMP structure, then a lateral velocity increase of 4 percent would create the observed 8-ms pullup beneath VAMP 5820. This calculation is insensitive to the actual velocity value assumed.

The effect of hydrate saturation on $\mathrm{Vp}$ can be calculated using a three-phase, time-average equation (see Miller and 
others, 1991). For a 170-m-thick sequence of lower HDL sediment taken to have a minimum average porosity of 60 percent (range is approximately $75-60$ percent), a 4-percent velocity increase can be caused by a 10 percent increase in average hydrate saturation (in other words, with respect to flanking areas, 10 percent more of the total available pore space is filled with hydrate at the VAMP). Where a prominent BSR is recorded, the hydrate saturation in the lower 10-30 meters of the HDL immediately adjacent to the VAMP pullup structure is estimated by analogy with other areas to range from 10 to 30 percent (Miller, 1991; Hyndman and Spence, 1992; Kvenvolden, 1993, this volume; Bangs and others, in press). If a conservative estimate of 5 percent background saturation (see, for example, Hyndman and Spence, 1992; Carson and others, 1993; Bangs and others, in press) is applied to the entire 170-m-thick section involved in the cumulative pullup, then the average hydrate saturation in these beds is 15 percent of available pore space.

Although hydration should occur throughout the HDL (Kvenvolden and Barnard, 1983; Kvenvolden, 1993), where vertically migrating or diffusing methane nourishes hydrate formation, a circumstance which is thought to occur at VAMP structures (see below), hydration mainly takes place at the base of the HDL (Hyndman and Davis, 1992). It is likely, therefore, that pore-space saturation is highest immediately above the BSR and trails off in concentration upward (see, for example, Max, 1990, and Hyndman and Davis, 1992). This expectation may be verified by the observation that pullup arching increases in amplitude downward (figs. 3, 8). If, for example, hydrate deposition at VAMP 5820 is mainly concentrated in the basal $50 \mathrm{~m}$ of the HDL, then to achieve the 4-percent relative velocity pullup, hydrate saturation within the HDL could be as much as 34 percent over background saturation. If the average background saturation in the lower beds of the HDL is 10-20 percent, then basal hydrate saturation at VAMP 5820 is approximately $45-55$ percent.

A similar approach can be taken to analyze free gas accumulations beneath the HDL at VAMP structures. Again it is assumed that the "synclines" observed at VAMP's are entirely caused by a low velocity zone and no structural component is involved. Domenico (1976) and Singh and others (1993) demonstrated that if as little as 2 percent of the pore space (sediment porosity $=60$ percent) below the base of the HDL is filled with gas, then the in-place Vp would be lowered from 1.7 to $1.3 \mathrm{~km} / \mathrm{s}$. For every 10 vertical meters of gaseous sediment, this velocity drop increases two-way traveltime to underlying reflection horizons by $3.0 \mathrm{~ms}$.

Figure 8 documents that the time-delay relief of the downflexures increases from a 10 -ms pushdown at horizon $\mathrm{B}$, to $25 \mathrm{~ms}$ at horizon $\mathrm{C}$, and $80 \mathrm{~ms}$ at horizon D. Several factors are involved in considering the implication of these readings. For example, the time-delay relief of the velocity pushdown must be based on the traveltime of primary rather than internal (peg leg) reflection events. Because horizons
B, C, and D are each regional in extent and prominent in recorded amplitude, they are presumed to be primary reflections from lithologic elements acoustically detected by only one-roundtrip ray path through the low velocity zone. For example, horizon $D$ is presumably the top of the mudstone sequence, which is also a prominent silica diagenesis BSR$\mathrm{DB}$ (fig. 2). Where a velocity pushdown underlies a pullup, measurement of the time delay of the pushdown includes the effect of the overlying pullup. The total time-delay relief of pushdown is thus the sum of the pullup and pushdown. The time-delay relief of the velocity pushdown also only measures the localized or relative increase in free gas with respect to immediately flanking areas.

Adjacent to VAMP's, where the reflective amplitude of the BSR is low compared to that of the sea floor (fig. 2), the thickness of a gaseous zone below the HDL, if present, is probably only a few meters. However, on the basis of the implications of studies elsewhere, where the BSR amplitude is prominent, the thickness of gaseous sediment is probably between 10 and $20 \mathrm{~m}$ (Shipley and others, 1979; Miller and others,1991; Singh and others, 1993; Rowe and Gettrust, 1993; Carson and others, 1993; Bangs and others, in press). As shown above, a 30-m-layer of $>2$ percent gas saturation would create a 9 -ms pushdown $(30 \mathrm{~m} \times 3 \mathrm{~ms} / 10 \mathrm{~m})$ relative to flanking areas that contain little or no gas. Away from VAMP's, no acoustic measurement can be satisfactorily linked to either the saturation level or thickness of gas-charged sediment. It is assumed that thick $(>10 \mathrm{~m})$ sub-HDL gaseous zones are localized only at VAMP structures.

Although a small percentage of free gas significantly lowers the $\mathrm{Vp}$, saturation levels greater than 2 percent have negligible additional effect (Domenico, 1976). Therefore, although the thickness of a zone of about 2 percent gaseous sediment can be calculated that would effect the observed 9-ms delay, the actual upper percentage of gas saturation within the column cannot be constrained. The cumulative pushdown at VAMP 5820 is $80 \mathrm{~ms}$; the calculated effective thickness of the corresponding column of gaseous sediment is thus $\sim 270 \mathrm{~m}$. ( $80 \mathrm{~ms} \times 10 \mathrm{~m} / 3.0 \mathrm{~ms}$ ). It is important to note that at most VAMP's for example those on figures 3,4 , and 8 , the observed downsection increase in pushdown accumulates over a stratigraphic thickness of several hundred to more than $500 \mathrm{~m}$. Accordingly, and presuming that no peg-leg reflection delays are involved, the actual column of sediment containing pockets of gas-charged sediment is much thicker than the effective thickness calculated$270 \mathrm{~m}$ in the example of VAMP 5820.

\section{DISCUSSION}

\section{EVOLUTION OF HYDRATE BSR}

Bangs and others (in press) stress that pooling of gas beneath a BSR is an enigma because it seems unlikely to 
them that the concentration of interstitial hydrate above the BSR, generally estimated at filling no more than 10-30 percent of available pore space, would be sufficient to seal off vertically migrating fluids. Methane dissolved in rising pore fluids should pass undeposited through the HDL and vent to overlying basin waters. Bangs and others (in press) reason that BSR's record the temporary residence of interstitial gas trailing an upward-moving front of melting or disassociating hydrate deposits.

In the Aleutian and Bowers Basins, deposition of the upper turbidite sequence, beginning most likely in earliest Pliocene time, should have caused a BSR to migrate upward through and in company with the thickening of this surficial unit. Over the central basin region, the upper diatomaceous turbidite pile accumulated at approximately $250 \mathrm{~m} / \mathrm{m} . \mathrm{y}$. (uncorrected for compaction effects). Deposition of these increasingly coarser grained and less waterrich beds would have enhanced subsurface geothermal warming and both the silica diagenesis and the flow of thermogenic hydrocarbons from the underlying mudstone section into the accumulating turbidite beds. In conjunction with rapid basin-floor sedimentation, both a hydrate BSR and an underlying opal-CT BSR-DB would have migrating upward at a rate of about $250 \mathrm{~m} / \mathrm{m}$.y.

\section{VAMP FORMATION}

Within the HDL, conditions that localize the formation of unusually dense hydrate concentrations are hypothesized to cause the recording of the commonly observed domed horizons of VAMP structures (figs. 3, 7, 8). Acoustic arching caps 58 percent of the VAMP structures in the north-central Aleutian Basin (Rearic and others, 1988). As earlier calculated for VAMP 5820 (figs. 2, 8), average methane hydrate clogging of as little as a 20 percent for a 170 -m-thick section and to as much as 64 percent of available pore space for a 50-m-thick section can account for the observed acoustic arching of $8 \mathrm{~ms}$. These calculations are sensitive to the thickness of hydrated HDL beds., the vertical distribution of hydrate saturation within them, and the background hydration levels in beds immediately surrounding the pullup structure.

It is recognized that differential compaction over buried basement highs can contribute to the amplitude of the upper arched horizons of VAMP's (Cooper and others, 1979). But Rearic and others (1988) determined that most VAMP's are not localized over basement-specific structural closures. Intriguingly, bathymetric and seismic profiles across VAMP's reveal that some of them are associated with a slight swelling or doming of the sea floor by a few meters (Scholl and Cooper, 1978; Rearic and others, 1988). The gentle sea floor upwarps can be viewed as supporting evidence for the occurrence of localized bodies of massive hydrate within the HDL. For example, doming of the sea floor would be an expected consequence of slight differential compaction of turbidite and diatomaceous beds., which are strong and consolidate only slowly (Lee, 1973) over a more rigid core of hydrate-cemented sediment in the lower part of the HDL. Because the density of gas hydrate is less than that of water (in other words, specific volume of gas hydrate is greater; Lewin and Associates Inc., 1983; Sloan, 1990), growth of a dense hydrate body can potentially occupy more space than the starting volume of pore-space water. Surface heave would accompany growth if rapid hydrate deposition prevented venting of the original volume of interstitial water available for conversion to hydrate. Arching of beds caused by differential compaction or heave lessen the calculated volume of hydrate, based on presuming that the relief of the domed section of VAMP's is entirely a velocity pullup effect.

If the arched reflection horizons are caused by massive deposits of interstitial hydrate, then the pooling of gas beneath their central region can be ascribed to pore sealing. Similar to the hydrate BSR, VAMP structures must migrate upward in concert with depositional thickening and subsurface warming. On the basis of the stratigraphic section penetrated at DSDP Site 190, the top of the gascharged sediment at VAMP's may occur stratigraphically close to a downsection change from virtually unindurated to semi-indurated diatom silty clay (fig. 4). Speculatively, the change in induration might be linked to early sediment diagenesis promoted by the upward migration of the BSR (Hyndman and Davis, 1992) through the lower, finer grained beds of the turbidite sequence.

In the underlying Miocene mudstone beds sediment diagenesis involved the solution-reprecipitation conversion of biogenic opal-A of the frustules of diatoms and other siliceous microfossil-taxa to opal-CT (Hein and others, 1978) and at greater depth possibly to chalcedonic quartz or chert. Each of these conversions causes a reduction of rock volume and expulsion of water. At least the middle and late Miocene beds of the mudstone sequence were formerly richly diatomaceous (Scholl and Creager, 1973). Therefore, it is likely that rapid burial and warming of the mudstone in response to deposition of the turbidite sequence caused the equally rapid upsection migration of one or more silica diagenetic fronts, the BSR-DB's of Cooper and others (1987).

Diagenetic alteration of siliceous mudstone beds embrittles them. Siliceous mudstone is readily fractured in structural settings (see, for example, Sadler, 1990). But at non-structural locations sediment-volume reduction in response to burial diagenesis should initiate microfracturing. If diagenetic microfracturing is accompanied by overpressures induced by rapid burial, the preferred orientation of the microfractures would be in the vertical plane (Snyder and others, 1983). Water liberated by opal diagenesis in conjunction with compaction-induced overpressures would likely hydrofracture brittle porcelaneous and cherty layers 
(Redwine, 1981). Fracturing would favor the vertical migration of thermogenic gases and other petroleum fluids. Lateral and vertical variability in the siliceous, terrigenous, and calcareous content of the mudstone would presumably determine the concentration and vertical continuity of the microfractures. Where they are particularly abundant, the fractures would provide localized, high-permeability ascent conduits for gases and liquid hydrocarbons generated from the Miocene mudstone and older underlying beds.

Relatively porous and permeable layers within the turbidite sequence occur at the base of the methane-hydrate stability field (Cooper and others, 1979, 1987). If VAMP's reflect the subsurface location of high-permeability ascent columns or zones for thermogenic methane, then these basal beds provide a suitable reservoir for the localized formation of massive hydrate deposits that initiate the VAMP-forming process.

\section{SOURCES OF METHANE}

Bottom water in the Aleutian Basin is presently well ventilated, but high surface-water productivity and rapid sedimentation favors the preservation of organic matter in bottom sediment. Lisitsyn (1966) reported the total organic carbon (TOC) content of surface sediment ranges from 0.5 to 1 percent. Other data summarized by Cooper and others (1979) give a similar range of values for both surface and subsurface deposits, including limited carbon isotope studies that imply methane in surficial sediment is largely of microbial origin. On the basis of these observations, some or much of the methane in potential hydrate deposits near the top of the HDL may mostly be of biogenic origin (Kvenvolden and Bernard, 1983; Kvenvolden, 1993, this volume).

At Bering Sea DSDP sites, thermogenic methane occurs in increasing quantities with subsurface depth, as well as where higher heatflow has been measured (Claypool and others, 1973). The basin's heatflow is sufficiently high to cause generation of thermogenic methane and other petroleum gases at depths as shallow as $2 \mathrm{~km}$ and at even shallower depths in the warmer Komandorsky Basin (figs. 1, 9; Cooper and others 1987). Rearic and others (1988) observed that some pull-downs begin at depths near $1 \mathrm{~km}$, depths which are near or at the base of the upper diatomaceous turbidite unit. The beginning of pulldowns at these great depths implies the accumulation of vertically migrating thermogenic gas. As speculated above, thermogenic gases may reach the basin's upper sedimentary sequence via fracture pathways in underlying deposits of diagenetically altered siliceous mudstone. Because the thickness of sediment within the petroleum-generation window is large $(>1 \mathrm{~km})$, the quantity of vertically migrating gas available to nourish hydrate deposition at the base of the HDL and localized gas pooling in warmer underlying beds is potentially large.
VAMP's appear to be most numerous over the bathymetrically deepest area of the south-central basin floor and VAMP-kindred anomalous structures over the southwestern part of Vitus Arch, which may be associated with an elevated heatflux. The abundance distribution of VAMP's can speculatively be connected to the basin's depocenter of finer grained and more organic rich sediment, to residual warming related to the early Tertiary formation of Vitus Arch, and, during the past 4-5 m.y., to deeper burial of older mudstone beds by deposition of the late Cenozoic turbidite sequence. If prior to the Pliocene the basin had poor circulation, enhanced preservation of organic matter would have been favored in deeper basinal areas. Regional information supports the chance that in the early Tertiary the Aleutian Basin (Bering Sea) had restricted deep-water water exchange with the north Pacific, a circumstance that would have improved the likelihood that oxygen-poor waters periodically occupied the Aleutian Basin floor (Scholl and Stevenson, 1987, 1990; Scholl and others, 1989).

VAMP's have not been reported from the Komandorsky Basin, which is a geothermally warm and geologically young basin formed by intrabasin spreading in middle to late Miocene time (Baranov and others, 1991). The missing VAMP's may reflect the fact that pre-Pliocene deposits are thin $(-500 \mathrm{~m}$; Cooper and others, 1987) and thus so are the source beds needed to nourish dense hydrate deposition in near-surface turbidite beds. A contributing factor may be the basin's high heatflow, which is approximately 3 heat-flow units on a basinwide average (Baranov and others 1991; fig. 9). Possibly, thermogenic gas generation was largely complete prior to the deposition of reservoir beds favorable to the accumulation of massive hydrate deposits. Owing to the basin's high thermal flux, the sedimentary deposits below about $500 \mathrm{~m}$ are thoroughly altered and cemented (Stewart, 1977), thus hindering the vertical venting of petroleum gases into cooler overlying turbidite reservoirs.

\section{VOLUME OF METHANE}

The occurrence area of VAMP's for the Aleutian and Bowers Basins is approximately $400,000 \mathrm{~km}^{2}$. Rearic and others, (1988) concluded that because the cross-sectional width of VAMP pull-downs falls within a fairly narrow range about a mean of $1.3 \mathrm{~km}$ (table 1), the acoustic anomalies causing VAMP's are generally circular in plan. Accordingly, the planimetric cross-sectional area of the typical VAMP cylinder is $1.3 \mathrm{~km}^{2}\left(1.3 \times 10^{6} \mathrm{~m}^{2}\right)$. If VAMP's are simple columns, then, by using a conservative estimate of a basinwide occurrence density of 3 VAMP's/100 km² (see above), at least 12,000 discrete pull-down structures exist in the Bering Sea Basin.

The velocity pullups allow for a relative measurement of the amount of hydrate deposits at VAMP structures. If 
only disseminated or nonmassive hydrate deposits occur in sediment immediately adjacent to VAMP's, the volume of hydrate at them can be used to estimate the total basinwide volume of massive deposits. For example, the 8 -ms velocity pullup at VAMP 5820 (fig. 8) requires a 10-percent increase in average hydrate saturation in the lower $170 \mathrm{~m}$ of the HDL. By using a sediment porosity of 60 percent for these beds (Cooper, and others, 1979), the total hydrate increase at VAMP 5820 is equivalent to an $\sim 10$-m-thick column of solid methane hydrate $(170 \mathrm{~m} \times 0.6$ percent $\times 0.10$ percent) centered beneath the crest of the Vitus Arch. Many pullups are less prominent than that of VAMP 5820 , but many others exhibit a relief of as much as $25-30 \mathrm{~ms}$ (fig. 3), which corresponds to a crest-centered solid-volume thickness of methane hydrate of $30-40 \mathrm{~m}$.

Assuming a basinwide mean pullup of $10 \mathrm{~ms}$, the corresponding column of solid hydrate is $12.5 \mathrm{~m}$ thick. If, for simplicity, the geometry of the massive hydrate mass is described as a low cone, then the volume at a typical VAMP of a 2-km-wide, 12.5-m-high lens of solid hydrate is $0.013 \mathrm{~km}^{3}$. Multiplying this term by the 12,000 estimated VAMP structures (discussed above) gives a basinwide solid volume of massive methane hydrate of approximately $160 \mathrm{~km}^{3}\left(160 \times 10^{9} \mathrm{~m}^{3}\right)$, probably the bulk of which resides in the lower beds of the HDL. Converting to free gas at standard temperature and pressure (temperature at BSR, $\sim 25^{\circ} \mathrm{C}$, is effectively equivalent to that of standard room temperature) requires multiplying the volume of solid methane hydrate by 164 (see Kvenvolden, 1993, this volume). The volume of methane stored in dense hydrate deposits at VAMP's is thus $26 \times 10^{3} \mathrm{~km}^{3}\left(26 \times 10^{12} \mathrm{~m}^{3}\right)$, which is equivalent to about 930 Tcf (trillion cubic feet).

The above estimate has meaning only if the hydrate body capping the VAMP pushdown structure is a simple lens- or cone-shaped mass. However, the planimetric cross-sectional form of the inferred massive hydrate deposits and underlying gas column, which is assumed to be circular, is unknown. The common recording of VAMPkindred acoustic structures (the wide and narrow anomalous zones of Rearic and others, 1988) implies that many recordings of VAMP's are fragmentary or out-of-plane detections of irregular masses of hydrate and gas that may be laterally extensive and connected to other accumulations. Thus, it is unlikely that the number of VAMP's provides a quantitative measure of the basinwide volume of massive hydrate deposits; however, the calculated volume is a useful low-end estimate of the amount of massive hydrate deposits in the Bering Sea Basin.

Rearic and others (1988) found an average pushdown at VAMP's of $23 \mathrm{~ms}$ (table 1), which, as calculated earlier, is equivalent to a 77-m-thick column of sediment of which at least 2 percent of the pore space ( 60 percent porosity) is occupied by free gas. Presuming that VAMP's are circular in plan and 12,000 in number, then the volume of sediment containing at least 2 percent free gas in existing pore space is $1,200 \mathrm{~km}^{3}\left(12,000 \times 1.3 \mathrm{~km}^{2} \times 0.077 \mathrm{~km}\right)$, or $1.2 \times 10^{12} \mathrm{~m}^{3}$, which converts to $0.014 \times 10^{12} \mathrm{~m}^{3}$ (2 percent of 60-percent pore space) of in-place gas under an hydrostatic head of approximately 400 bars. At atmospheric pressure and at $25^{\circ} \mathrm{C}$ (temperature at BSR), this later volume expands to $5.8 \times 10^{12} \mathrm{~m}^{3}$, which is a volume of roughly 200 Tcf. This volume must be viewed as a minimum estimate because of the planimetric reasons noted above and because the lowest possible saturation and inplace pressure (hydrostatic) terms were used in calculating the volume of gas causing the pushdown. The volume of gas could easily be many times greater.

By combining the estimates of hydrated-and free-gas accumulations, a minimum of 1,100 Tcf of methane gas is potentially available from the Aleutian and Bowers Basins. Approximately 80 percent of this volume is provided by the hydrate cap and 20 percent from underlying interstitial gas, but the amount of free gas is potentially much greater. Not included in this estimate is methane occurring away from VAMP structures, either as disseminated hydrate deposits or a free gas underlying the BSR.

At particularly large VAMP's (fig. 3), the cumulative pullup is much as $25-30 \mathrm{~ms}$ and the underlying pushdown in as much as $80-100 \mathrm{~ms}$. Accepting that VAMP's are circular structures and of the dimensions used above, a conservative estimate of the volume of methane gas stored at a single larger VAMP is $8.0 \times 10^{9} \mathrm{~m}^{3}(0.3 \mathrm{Tcf})$. This volume of methane is comparable to that found in large gas fields.

\section{FUTURE RESEARCH DIRECTIONS}

Although the supposition that VAMP's are acoustic artifacts caused by the vertically superimposed hydrate and gas accumulations is consistent with theoretical and observational data, the concept has not been rigorously field tested nor "groundtruthed" by drilling. The deficiency of HDL- and VAMP-specific information at both regional and local scales presently thwarts progress in hydrate research in the Bering Sea Basin. Major advances in information are needed to accurately characterize and model the structure and formative processes of VAMP and VAMP-kindred structures, assess their basinwide resource implications, and unravel the geologic history of the Bering Sea Basin that uniquely favors the widespread formation of these structures.

The major tasks of a nondrilling, hydrate-focused field investigation would be to: (1) regionally map the vertical and horizontal acoustic fabric of the HDL (the "blanket" of Max, 1990), (2) map in both depth and time domains the three-dimensional physical and acoustic fabric of specific VAMP's and VAMP-kindred structures, and (3) determine the relation of VAMP's and VAMP-kindred structures to (1) the stratigraphy of immediately surrounding and underlying 
Cenozoic strata, (2) regional and local basement relief, (3) regional and local heatflow, and (4) the geochemical flux of fluids and organic and inorganic compounds across the sediment-water interface at and away from VAMP's.

\section{REFERENCES CITED}

Bangs, N.L.B., Sawyer, D.S., Golovchenko, X., in press, Free gas at the base of the gas hydrate zone in the vicinity of the Chile triple junction: Geology.

Baranov, B.V., Seliverstov, N.I., Murav'ev, A.V., and Muzurov, E.L., 1991, The Komandorsky Basin as a product of spreading behind a transform plate boundary: Tectonophysics, v. 199 , p. $237-269$.

Carson, B.G., Westbrook, G., and Musgrave, R., 1993, Cascadia margin: JOIDES Journal, v. 19, no. 2, p.11-16.

Claypool, G.E., Presley, B.J., and Kaplan, I.R., 1973, Gas analyses in sediment sample from Legs 10, 11, 13, 14, 15, 18, and 19, in Initial Reports of the Deep Sea Drilling Project, v. 19: Washington D.C., U.S. Government Printing Office, p. 879-884.

Cooper, A.K., Marlow, M.S., Scholl, D.W., and Stevenson, A.J., 1992, Evidence for Cenozoic crustal extension in the Bering Sea Region: Tectonics, v. 11, p. 719-731.

Cooper, A.K., Scholl, D.W., and Marlow, M.S., 1987, Structural framework, sedimentary sequences, and hydrocarbon potential of the Aleutian and Bowers Basins, Bering Sea, in Geology and Resource Potential of the Continental Margin of Western North America and Adjacent Ocean Basins, Beaufort Sea to Baja California: Circum-Pacific Council for Energy and Mineral Resources, Earth Science Series, v. 6, p. 473-502.

Cooper, A.K., Scholl, D.W. Marlow, M.S., Childs, J.R., Redden, G.D and Kvenvolden, K.A., 1978, The Aleutian Basin, Bering Sea-A frontier area for hydrocarbon exploration: Proceedings of the Offshore Technology Conference, 1978, p. $353-359$.

Cooper, A.K., Scholl, D.W., Marlow, M.S., Childs, J.R., Redden, G.D., Kvenvolden, K.A., and Stevenson, A.J., 1979, Hydrocarbon potential of Aleutian Basin, Bering Sea: American Association of Petroleum Geologists Bulletin, v. 63, p. 2070-2087.

Creager, J. S., and others, 1973, Initial reports of the Deep Sea Drilling Project, v. 19: Washington D.C., U.S. Government Printing Office, 913 p.

Dix, C.H., 1955, Seismic velocities from surface measurements: Geophysics, v. 20, p. 68-86.

Domenico, S.N., 1976, Effect of brine-gas mixtures on velocity in an unconsolidated sand reservoir: Geophysics, v. 41, p. $882-894$.

Ewing, M., Ludwig, W.J., and Ewing, J. 1965, Oceanic structural history of the Bering Sea: Journal of Geophysical Research, v. 70, p. $4593-4600$.

Hein, J.R., Scholl, D.W., Barron, J.A., Jones, M.G. and Miller, J., 1978, Diagenesis of late Cenozoic diatomaceous deposits and formation of the bottom simulating reflector in the southern Bering Sea: Sedimentology, v. 25, p. 155-181.
Huggett, Q.J., Cooper, A.K., Somers, M.L., and Stubbs, A.R., 1992, Interference fringes on GLORIA side-scan sonar images from the Bering Sea and their implications: Marine Geophysical Research, v. 14, p. 47-63

Hyndman, R.D., and Davis, E.E., 1992, A mechanism for the formation of methane hydrate and sea floor bottom-simulating reflectors by vertical fluid expulsion: Journal of Geophysical Research, v. 97, p. 7025-7041.

Hyndman, R.D., and Spence, G.D., 1992, A seismic study of methane hydrate marine bottom simulating reflectors: Journal of Geophysical Research, v. 97. p. 6683-6698.

Kvenvolden, K.A., 1987, Gas hydrates offshore Alaska and western continental United States, in Geology and Resource Potential of the Continental Margin of Western North America and Adjacent Ocean Basins, Beaufort Sea to Baja California: Circum-Pacific Council for Energy and Mincral Resources, Earth Science Series, v. 6, p. 581-593.

1993, Gas-hydrates-Geological perspective and global change: Reviews of Geophysics, v. 31, p. 173-187.

Kvenvolden, K.A., and Barnard, L.A., 1983, Hydrates of natural gas in continental margins, in Walkins, J.S., and Drake, C.L., eds., Studies in Continental Margin Geology: American Association of Petroleum Geologists Memoir 34, p. 631-640.

Langseth, M.G., Hobart, M.A., and Horai, K., 1980, Heat flow in the Bering Sea: Journal of Geophysical Research, v. 85 , p. $3740-3750$.

Lee, H.J., 1973, Measurements and estimates of engineering and other physical properties, Leg 19: Initial reports of the Deep Sea Drilling Project, v. 19: Washington D.C., U.S. Government Printing Office, p. 701-719.

Lewin and Associates Inc., 1983, Handbook of gas hydrate properties and occurrence: Technical Information Center, Office of Scientific and Technical Information, U.S. Department of Energy, Morgantown, West Virginia.

Lisitsyn, A.P., 1966, Recent Sedimentation in the Bering Sea: Academy of Sciences of the USSR, Department of Earth Sciences, Commission of Sedimentary Rocks, Institute of Oceanology, p. 614 [Translated from Russian, Israel Program for Scientific Translations, Jerusalem, 1969]

Marlow, M.S., Carlson, P.R., Dadisman, S.V., Rearic, D.M., Maple, E.J., and Parson, L.P., 1987, GLORIA side-scan and geophysical surveys of the central Bering Sea, in Hamilton, T.H., and Gallow, J.P., eds., Geological Studies in Alaska by the U.S. Geological Survey during 1986: U.S. Geological Survey Circular 998, p. 152-156.

Max, M.D., 1990, Gas hydrate and acoustically laminated sediments: potential environmental cause of anomalously low acoustic bottom loss in deep-ocean sediments: U.S. Naval Research Laboratory Report 9235, Washington D.C., 68 p.

Miller, J.J., Lee, M.W., and Huene, R.V., 1991, An analysis of seismic reflection from the base of a gas hydrate zone, offshore Peru, American Association of Petroleum Geologists Bulletin, v. 75, p. 910-924.

Minshull, T., and White, R., 1989, Sediment compaction and fluid migration in the Makran accretionary prism: Journal of Geophysical Research, v. 94, p. 7387-7402.

Rea, D. K., and Schrader, H., 1985, Late Pliocene onset of glaciation: ice-rafting and diatom stratigraphy of north Pacific DSDP cores: Paleogeography, Paleoclimatology, Paleoecology, v. 49 , p. $313-325$. 
Rearic, D.M., Williams, S.R., Carlson, P.R., and Hall, R.K., 1988, Acoustic evidence for gas-charged sediment in the abyssal Aleutian Basin, Bering Sea, Alaska: U.S. Geological Survey Open-File Report 88-677, 40 p.

Redwine, L., 1981, Hypothesis combining dilation, natural hydraulic fracturing, and dolomitization to explain petroleum reservoirs in Monterey shale, Santa Maria area, California, in Garrison, R.E., Douglas, R.G., Pisciotto, K.E., Isaacs, C.M., and Ingle, J.C., eds., The Monterey Formation and Related Siliceous Rocks of California: Pacific Section, Society of Economic Paleontologists and Mineralogists, Los Angeles, CA, p. 221-248.

Rowe, M.M., and Gettrust, J.F., 1993, Fine structure of methane hydrate-bearing sediments on the Blake Outer Ridge as determined from deep-tow multichannel seismic data: Journal of Geophysical Research, v. 98 , p. $463-473$

Sadler, R.K., 1990, The relationship of lithology and tectonics to fracturing in the Monterey Formation, Point Arguello field, offshore California, in Keller, M.A., and McGowen, M.K., eds., Miocene and Oligocene Petroleum Reservoirs of the Santa Maria and Santa Barbara-Ventura Basins, California: Society of Economic Paleontologists and Mineralogists, Core Workshop 14, San Francisco, CA, Tulsa, Oklahoma.

Scholl, D.W., and Cooper, A.K., 1978, VAMP's-Possible hydrocarbon structures in Bering Sea Basin: American Association of Petroleum Geologists, Bulletin, v. 62, p. 2481-2488.

Scholl, D.W., and Creager, J.S., 1973, Geologic synthesis of Leg 19 (DSDP) results; far North Pacific, Aleutian Ridge, and Bering Sea, in Creager, J.S., and Scholl, D.W., eds., Initial reports of the Deep Sea Drilling Project: v. 19: Washington D.C., U.S. Government Printing Office, p. 897-913.

Scholl, D.W., and Stevenson, A.J., 1987, Ocean margin tectonics and north Pacific paleoceanography-Wonderments about the effects of the Pacific-Bering Sea connection, in Fourth International Congress on Pacific Neogene Stratigraphy, IGCP Project 246, Berkeley, California, July 29-31, 1987, Abstract Volume, Barron, J.A., and Blueford, J.R., eds.: Fremont, Calif., Math/Science Nucleus, p. 95-97.

1990, Was the Aleutian Basin more enclosed, its deeps oxygen deficient, and the geothermal gradient steepened in the middle Tertiary? Implications for the petroleum potential of the Bering Sea: American Association of Petroleum Geologists, Bulletin, v. 74, p. 1000.

Scholl, D.W., Stevenson, A.J., Vallier, T.L., Ryan, H.R., and Geist, E.L., 1989, Aleutian arc-trench system: perspective of ocean margin evolution controlled by regional changes in plate-boundary conditions: 28th International Geological Congress, Abstracts, v. 3, p. 52-53.

Scholl, D.W., Vallier, T.L., and Stevenson, A.J., 1986, Terrane accretion, production, and continental growth-A perspective based on the origin and tectonic fate of the AleutianBering Sea region: Geology, v. 14, p. 68-71.

Shipley, T.H., Houston, M.H., Buffler, R.T., Shaub, F.J., McMillen, K.J., Ladd, J.W., and Worzel, J.L., 1979, Seismic evidence for widespread possible gas hydrate horizons on continental slopes and rises: American Association of Petroleum Geologists, Bulletin, v. 63, p. 2204-2213.

Singh, S.C., Minshull, T.A., and Spence, G.D., 1993, Velocity structure of a gas hydrate reflector: Science, v. 260, p. 204-207.

Sloan, E.D., Jr., 1990, Clathrate hydrates of natural gases: New York, Marcel Dekker Inc., 641 p.

Snyder, W.S., Brueckner, H.K., and Schweickert, R.A., 1983, Deformational styles in the Monterey Formation and other siliceous sedimentary rocks, in Isaacs, C.M., Garrison, R.E., Graham, S.A., and Jensky, W.A., Il, eds.: Petroleum Generation and Occurrence in the Miocene Monterey Formation, California: Pacific Section, Society of Economic Paleontologists and Mineralogists, Los Angeles, CA, p. 151-170.

Stewart, R. J., 1977, Neogene turbidite sedimentation in Komandorsky Basin, western Bering Sea: American Association of Petroleum Geologists, Bull., v. 61, p. 192-206.

White, R.S., and Louden, K.E., 1998, The Makran continental margin: structure of a thickly sedimented convergent plate boundary, in Watkins, J. S., and Drake, C.L., eds., Studies in Continental Margin Geology: American Association of Petroleum Geologists Memoir 34, p. 499-513

Westgate, J.A., Stemper, B.A., and Pewe, T. L., 1990, A 3 m.y. record of Pliocene-Pleistocene loess in interior Alaska: Geology, v. 18, p. 858-861.

Worrall, D. M., 1991, Tectonic history of the Bering Sea and the evolution of Tertiary strike-slip basin of the Bering shelf: Geological Society of America Special Paper 257, 120 p. 

THE FUTURE OF ENERGY GASES

U.S. GEOLOGICAL SURVEY PROFESSIONAL PAPER 1570

\title{
Generation, Migration, and Resource Potential for Hydrocarbons in Accretionary Subduction Systems-A Large, Unconventional Hydrocarbon Resource?
}

\author{
By Andrew J. Stevenson ${ }^{1}$
}

\section{CONTENTS}

Abstract 353

Introduction 353

Sediment Input to the Subduction Zone 354

Structural Styles in Accretionary Settings 356

Thermal Structure of Accretionary Prisms

Origin and Migration of Fluids 359

Favorable Settings for Maturation, Migration, and Entrapment of Hydrocarbons 360 Global Hydrocarbon Resource Potential from

Accreted Sediment 361

Conclusions 361

References Cited 362

\begin{abstract}
Methane and other gaseous and liquid hydrocarbons are common components of accretionary complexes and have been observed in all environments within modern and fossil accretionary accumulations. Methane is generated in this setting by both microbial and thermal processes, but the limited number of samples analyzed prevents an accurate assessment of the relative importance of these two gas generation mechanisms. Large accretionary prisms are geologic settings which, owing to the large amounts of
\end{abstract}

'U.S. Geological Survey, MS 999, 345 Middlefield Rd. Menlo Park, CA 94025. organic detritus cycling through them, represent a large potential source of methane. Organic detritus in accretionary systems is primarily terrestrial in origin and thus gas prone. Variations in the sediment input, thermal structure, fluid flow regime, and structural style of accretionary prisms have a substantial effect on the amount of sediment that enters the gas generation window and on the amount and type of hydrocarbons generated. Factors favorable for maximum evolution of gas include a large, thick accretionary prism, a thick incoming sedimentary section, substantial axial trench sedimentation fed with continental detritus, development of the decollement near the top of the incoming section, substantial underplating, a young subducting plate, and slow to moderate plate convergence rates. On a worldwide basis, long-term methane generation potential is estimated at $1.5 \times 10^{10} \mathrm{~m}^{3}(0.5$ trillion cubic feet or Tcf) per year in the accretionary subduction setting. No commercial accumulations of gas have yet been identified in this setting; this lack of accumulations implies that much of the gas generated may escape to the oceans and the atmosphere. However, accretionary complexes have not been extensively explored for hydrocarbons, and the trapping of even a small part of the gas generated could result in a substantial commercial resource.

\section{INTRODUCTION}

Submarine subduction zones worldwide are associated with the underthrusting of oceanic lithosphere beneath an overriding plate, and they represent a prominent site of marine sediment accumulation, burial, and storage. Marine sedimentary rocks and their included organic carbon overlying 
oceanic basement are transported into a regime of rising temperature and pressure; these conditions are likely to result in the generation of hydrocarbons from this sediment within a subduction zone. The potential amount of hydrocarbons generated in this environment is large owing to the constant entrainment of "fresh" sediment carrying new, or unreacted, organic carbon into the subduction zone (McCarthy and others, 1984; Kvenvolden and von Huene, 1985; Larue, 1991). This constant rapid injection of fresh organic matter into a pressure/temperature regime conducive to the generation of gaseous and liquid hydrocarbons contrasts with the better understood sedimentary basin model of hydrocarbon generation. In the basin model, fresh organic matter enters the oil and gas kitchen comparatively slowly, via subsidence and burial, and the total available carbon is limited by the volume and tenor. Tenor is a mining term used to define the concentration of the economically important mineral in an ore. In this case it refers to the amount of organic matter contained in the sediment of the basin (Moore and Vrolijk, 1992, fig. 4).

Hydrocarbon gases, primarily methane, are ubiquitous in accretionary complexes; they are present in venting thermal waters, mud volcanoes, diapirs, and they are also present as gas hydrates in the sedimentary section (Scholl and Hart, this volume; Lee and others, this volume; Brown, 1990; Kulm and Suess, 1990). Gaseous hydrocarbons have been found within and beneath accretionary complexes, from the seaward frontal thrust to their subaerial landward limits, and from inclusions trapped in the deepest exposed parts of fossil accretionary complexes (Bebout, 1991) to shallow (surface) vents. Methane in this environment can result from both microbial and thermal processes. Limited isotopic analyses of methane from surface vents and near-surface fluids indicate that the greater proportion is of microbial origin, but the number of analyses and the range of occurrences analyzed are insufficient to provide a comprehensive estimate of relative abundances. Thermogenic gases are common and have been observed in all parts of the accretionary system-their presence attests to the widespread thermal generation of gas in this environment.

To evaluate the occurrence and hydrocarbon resource potential of accretionary systems, a brief description of the critical variables that influence the potential is discussed herein. Methane is not the only hydrocarbon species generated in accretionary complexes, but owing to the nature of the organic matter available for reaction it is the most dominant hydrocarbon species.

\section{SEDIMENT INPUT TO THE SUBDUCTION ZONE}

The composition of the sedimentary section and its included organic detritus entering a subduction zone is deter- mined by the age and motion history of the plate upon which it resides coupled with the magnitude of the neartrench and trench-floor sediment supply. The interaction of two sedimentary regimes (open ocean pelagic and nearshore terrigenous) commonly results in a sedimentary section entering the subduction environment which changes in origin and character from base to top. At the base, the section is dominated by biogenic debris derived from plankton, airborne dust, and chemical precipitates from seawater (pelagic). Upsection, the sediment grades into clays and fine silts of terrestrial origin derived from subaerial weathering processes mixed with pelagic material (hemiterrigenous). The upper section is often dominated by coarse grained silts and sands of continental origin (terrigenous). A typical sedimentary section is shown in figure 1 .

Initial sediment deposition on newly formed oceanic crust usually occurs near a spreading center far from a terrestrial sediment source, so the section is dominated by pelagic deposits containing primarily type II kerogen (Tissot and Welte, 1984). The organic carbon content of this sediment is generally low ( $<0.5$ percent) but can be sub-

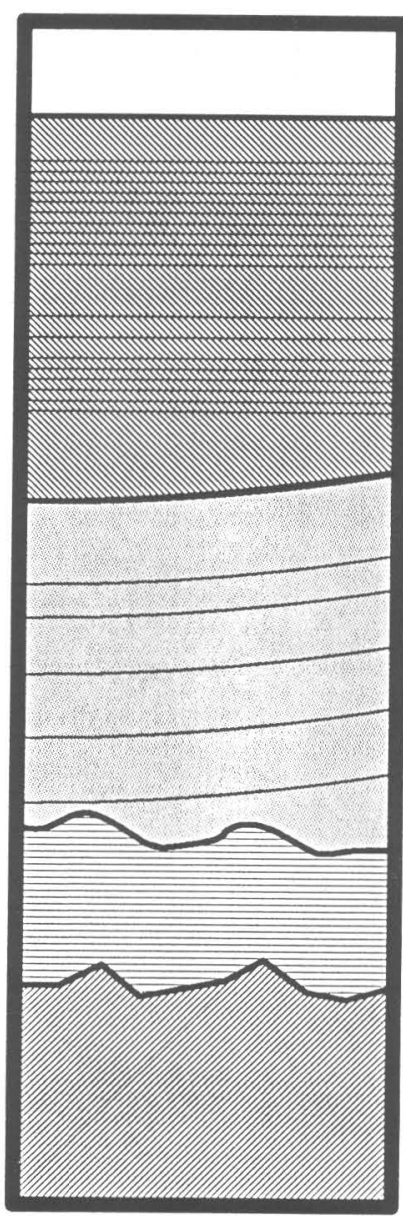

TRENCH FLOOR
AXIAL TRENCH FILL coarse-grained to fine-grained terrigenous sediments.

\section{DEEP SEA FAN BODY \\ fine-grained terrigenous, hemiterrigenous, and subordinate amounts of pelagic sediment.}

\section{PELAGIC SEDIMENTS includes pure pelagic and hemiterrigenous sediment.}

\section{OCEANIC CRUST}

Figure 1. Generalized stratigraphic column showing typical succession of pelagic, hemiterrigenous, terrigenous, and coarse terrigenous sediments of a subduction environment. 
stantially higher ( $>5$ percent) if the plate has passed beneath zones of high surface-water biologic productivity associated with a depressed oxygen minimum zone. Globally, such conditions are rare, and, therefore, do not materially affect the average carbon content of sediment entering subduction zones. However, the coastal location of subduction zones may also be the site of upwelling currents that can increase the rate of pelagic deposition and enhance the amount of carbon preserved as the trench is approached. The thickness of pelagic sediment entering the subduction environment is variable-it ranges from nil for a young plate generated proximal to a subduction zone (for example, northern Cascadia subduction zone, Davis and Hyndman, 1989) to at least $400 \mathrm{~m}$ (for example, Kamchatka Trench, Ludwig and Houtz, 1979).

In addition to pelagic sediment, many areas of the deep ocean floor are sites of significant terrigenous sedimentation. This sediment is primarily the result of continental (subaerial) erosion, and it is transported to the deep ocean by fluvial systems that feed large submarine fan systems. A subordinate amount of terrigenous sediment is contributed by airfall volcanic ashes and airbome dust. The organic carbon content of this sediment type is quite variable, but it is generally higher ( $>0.5$ percent) than pelagic deposits (Larue, 1991, table 2). The sediment deposited on the oceanic plate hosts most organic carbon available for thermal reaction. Under favorable conditions, total organic carbon (TOC) concentrations of more than 10 percent result (Babaie and others, 1992). The origin of the organic carbon in the terrigenous sediment is predominantly terrestrial plant remains (type III kerogen of Tissot and Welte, 1984), with lesser amounts of type II organic matter derived from planktonic debris. The thickness of a hemiterrigenous-terrigenous sedimentary section can be substantial; it can range from a few meters to over $6 \mathrm{~km}$ seaward of an accretionary prism (for example, southern Barbados) (Speed and others, 1984; see also von Huene and Scholl, 1991, table 2 for summary). By far the greatest volume of terrigenous debris is found seaward of continental collision zones undergoing active tectonism (for example, in the northern Indian Ocean, Aegean Sea, and Gulf of Alaska) which, owing to continued rapid uplift, proximal location to an ocean basin, and enhanced erosion by water and ice, provide the vast majority of terrigenous sediment to the oceans globally (Milliman and Meade, 1983). The incoming sediment, coupled with the axial trench sediment supply, are critical in initiating and maintaining an accretionary prism.

As the oceanic plate nears a subduction zone, gradually increasing amounts of hemiterrigenous and terrigenous sediment are deposited. The amount and character of the terrigenous contribution to the sedimentary section seaward of the trench is strongly influenced by the type of subduction zone encountered. Intraoceanic island arcs generally contribute little or no sediment to the oceanic plate seaward of the trench owing to limited subaerial areas subject to high rates of erosion and the ability of the trench to accommodate the sediment supply from the arc-forearc region. Continental margin trenches fed by large fluvial systems can become filled and thereby allow turbidite deposition to prograde onto the ocean floor seaward of the trench. This progradation adds to the oceanic sedimentary section entering the subduction environment (for example, Cascadia subduction zone, Snavely and others, 1986).

As the oceanic plate and its sedimentary cover transit the outer trench swell and enter the trench, substantial opportunities for further accumulation of sediment are encountered. In addition to the possibility of enhanced hemipelagic deposition, many trenches serve as zones of collection and transport of terrigenous material (Underwood and Bachman, 1982). Most trenches receive some sediment from the adjacent island or continental arc and many receive a substantial input from regions landward of the arc (continental interiors). Terrigenous sediment often flows axially down the trench and can be transported several thousand kilometers; this process introduces a significant terrigenous component onto a long reach of subducting plate (for example, Aleutian island arc, Scholl, 1974). The thickness of terrigenous material added to the sedimentary section immediately seaward of the subduction contact can be as great as $4 \mathrm{~km}$ (Scholl, 1982) and often forms the greater part of the sediment column. In terms of organic carbon content, sediment deposited in the trench shares the same characteristics as the terrigenous component of the deep ocean section, and it adds substantially to the carbon resource entering the subduction environment.

Trench sedimentation is crucial in initiating, growing, and maintaining an accretionary prism. No modern examples of an accretionary prism being nourished by even the thickest sequence of pelagic and hemipelagic deposits of an oceanic sedimentary section are known. Investigations of subaerial fossil accretionary complexes have shown a paucity of pelagic facies (Underwood and Bachman, 1982; Howell and Murray, 1986); this lack of pelagic facies indicates that regardless of the presence or absence of an accretionary wedge, most or all of the pelagic component is subducted deep beneath the overriding plate. Therefore, a substantial terrigenous input is required for significant accretion to occur (von Huene and Scholl, 1991). With the exception of those subduction zones that are consuming substantial deep sea fan bodies (for example, eastern Aleutian trench), the terrigenous section necessary for accretion to occur must be deposited or augmented within the trench environment.

This "ideal" superposition of depositional environments (fig. 1) leads to a coarsening upward sedimentary sequence (pelagic, hemipelagic, terrigenous) that may contain a significant proportion of sand in the trench-fill section. Proximal to sediment supplies from the continental interior, the trench wedge will likely contain mature, 
quartz-rich sandstones capable of acting as reservoirs to host hydrocarbon accumulations (McCarthy and others, 1984).

\section{STRUCTURAL STYLES IN ACCRETIONARY SETTINGS}

In an accretionary subduction zone, sedimentary rocks overlying oceanic basement can follow two general structural evolutionary paths, which are controlled by the position of the sediment with respect to the inter-plate contact, or decollement. Sediment that lies beneath the decollement remains, either temporarily or permanently, attached to the descending plate and is transported beneath the overriding plate. Underthrusting sediment may underplate the forearc region if the decollement moves downward through the sedimentary section, or, if the sediment remains below the contact, may be transported deep within the subduction zone to a depth where melting and reassimilation into the mantle is likely. Sediment located above the decollement becomes incorporated into the overriding plate either by frontal accretion or underplating and commonly forms an accretionary wedge composed of offscraped sediment of the descending plate overlain by slope sedimentary deposits derived from the overriding plate (Shipley and others, 1990; fig. 2).

The importance of frontal accretion versus underplating is difficult to assess in determining the structural style of large ( $>4 \mathrm{~km}$ maximum thickness) accretionary prisms, owing to the absence of deep drilling information and difficulty in obtaining an adequate seismic image of the deeper parts of the wedge. Underplating must play a major role in large accretionary prisms (von Huene and Scholl, 1991), because the frontally accreted packets, even if stood on end, cannot account for the observed thickness of the wedge (fig. 2). For medium to small prisms, frontal accretion and thrust imbrication can account for the wedge geometry. In the upper regions of large prisms that can be imaged seismically, frontal accretion and packet imbrication appear to be the dominant structural styles.

The process of frontal accretion and packet imbrication produces numerous antiforms, ramp anticlines, and drag folds in the uppermost part of the accretionary prism. These structures could act as traps to hydrocarbons migrating upward from deeper parts of the prism (fig. 3). These features are often large in plan view and have substantial structural relief. In the central Aleutian accretionary complex, 3- to 4-km-Iong folds with relief of 1 to $2 \mathrm{~km}$ have been delineated (McCarthy and others, 1984). Structures of similar morphology and size have been observed on seismic profiles from many large and medium size accretionary prisms (von Huene, 1986). Most fold structures are fault bounded on at least one side. These faults represent one possible path for focused fluid flow from deeper within the prism and from sediment subducted beneath the decollement. The close spatial arrangement of fluid, conduit, and trap provides an attractive site for pooling of migrating hydrocarbons generated deep within the prism and, if fault motion disrupts the subduction contact, for fluids traveling up the decollement.

In accretionary complexes that form landward of trenches receiving a substantial supply of coarse continental sediment, the upper frontally accreted and imbricated part of the sedimentary section is likely to contain thick, coarse sand bodies that can become deformed to form potential structural traps (McCarthy and others, 1984). In addition to the accreted sedimentary deposits, hydrocarbon traps may be formed by slope sediment deposited unconformably upon the accreted section (fig. 2). These sediment accumulations can take several forms-a blanket laid uniformly over the wedge (Shipley and others, 1990), ba-

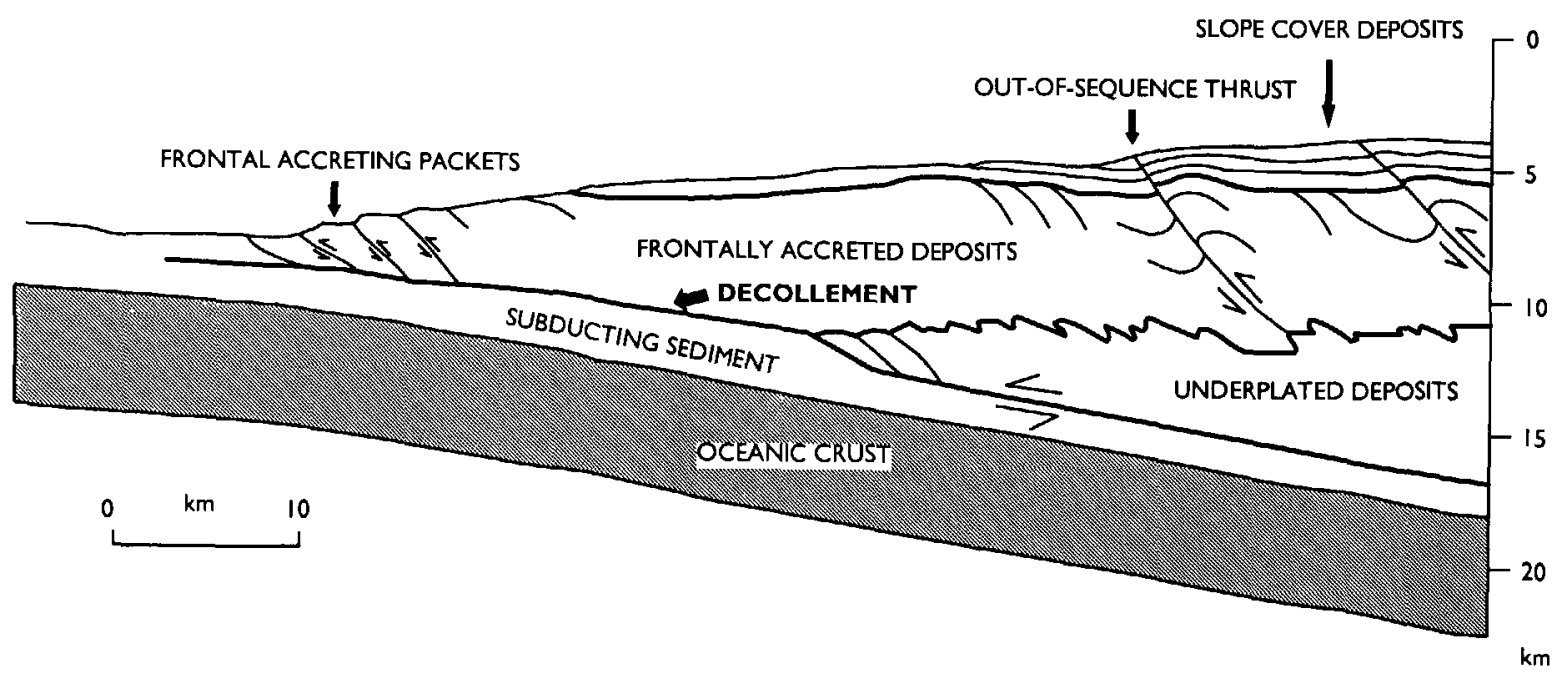

Figure 2. Structural elements of an accretionary prism. Modified from Moore and Vrolijk (1992). 
sinal accumulations in interpacket structural lows, and, where a forearc basin is present, thick accumulations of sedimentary strata derived from the upper slope and shelf (von Huene, 1986). This sediment often shows less intense structural disturbance compared to the accretionary prism, and it can contain large antiform structures (Bally, 1983; Ryan and Scholl, 1989).

\section{THERMAL STRUCTURE OF ACCRETIONARY PRISMS}

Accretionary prisms are broadly characterized as zones of lower than average heat flow owing to the thermal insulating effect of the cool subducting plate beneath the wedge and the rapid mechanical thickening of the offscraped sediment, which causes isotherms to spread (fig. 4A). The constant underthrusting of new cool oceanic crust by the subduction process prevents the overlying accreted sediment from reaching a typical continental crustal temperature profile by absorbing geothermal heat that would otherwise reach the prism base (Burch and Langseth, 1981; Ferguson and others, 1993).

Observed geothermal gradients in accretionary wedges range from 11 to $66^{\circ} \mathrm{C} / \mathrm{km}$ (Larue, 1991), an exceptionally wide range. The observed values are also substantially greater than predicted by purely theoretical models (see Wang and Shi, 1984). The primary modulator of prism thermal structure is the age of the subducting lithosphere, which controls the amount of heat delivered to the base of the wedge (fig. 4). Other important processes that affect the thermal state of the prism are the convergence rate, the taper, or slope of the wedge, the thickness of the incoming sedimentary section, and frictional heating at the base of the prism, all of which can vary independently (Langseth and others, 1990; Ferguson and others, 1993). Some thermal modeling studies of prisms underlain by old cold oceanic lithosphere, which use measured values obtained from surface probes and boreholes and which do not incorporate heat transfer by lateral fluid flow, show a low geothermal gradient throughout the wedge and moderate temperatures in the deepest parts of the prism (see Ferguson and others, 1993; fig. 4A). Prisms underlain by hot young crust can show a thermal structure that is quite different from the general case; prisms underlain by hot young crust have elevated isotherms, which result in a much higher temperature throughout the prism (fig. $4 B$; Hyndman and Wang, 1993). The discovery of submarine thermal springs, trench wedge geothermal anomalies (for example, Nankai margin), and recent Ocean Drilling Program drilling at the toe of large accretionary complexes (for example, Barbados and south Chile) attest that substantial, but unquantified, advective lateral and vertical heat transfer occurs via fluid flow. These processes introduce further uncertainties into any attempt to quantify a realistic geothermal model for accretionary wedges. The volumes of fluid involved and the high heat-transport capacity of water indicate that fluid flow can be an important process, at least locally, in modifying prism thermal structure.

Therefore, it is difficult to predict where in an accretionary complex the hydrocarbon generation window might be located $\left(50-250^{\circ} \mathrm{C}\right.$, Tissot and Welte, 1984). Beneath the decollement, similar uncertainty exists in predicting at what depth subducting sediment might encounter conditions favorable for the generation of hydrocarbons (compare figs. $4 A, 4 B$ ). The location of the hydrocarbon window represents one of the greatest uncertainties in any attempt

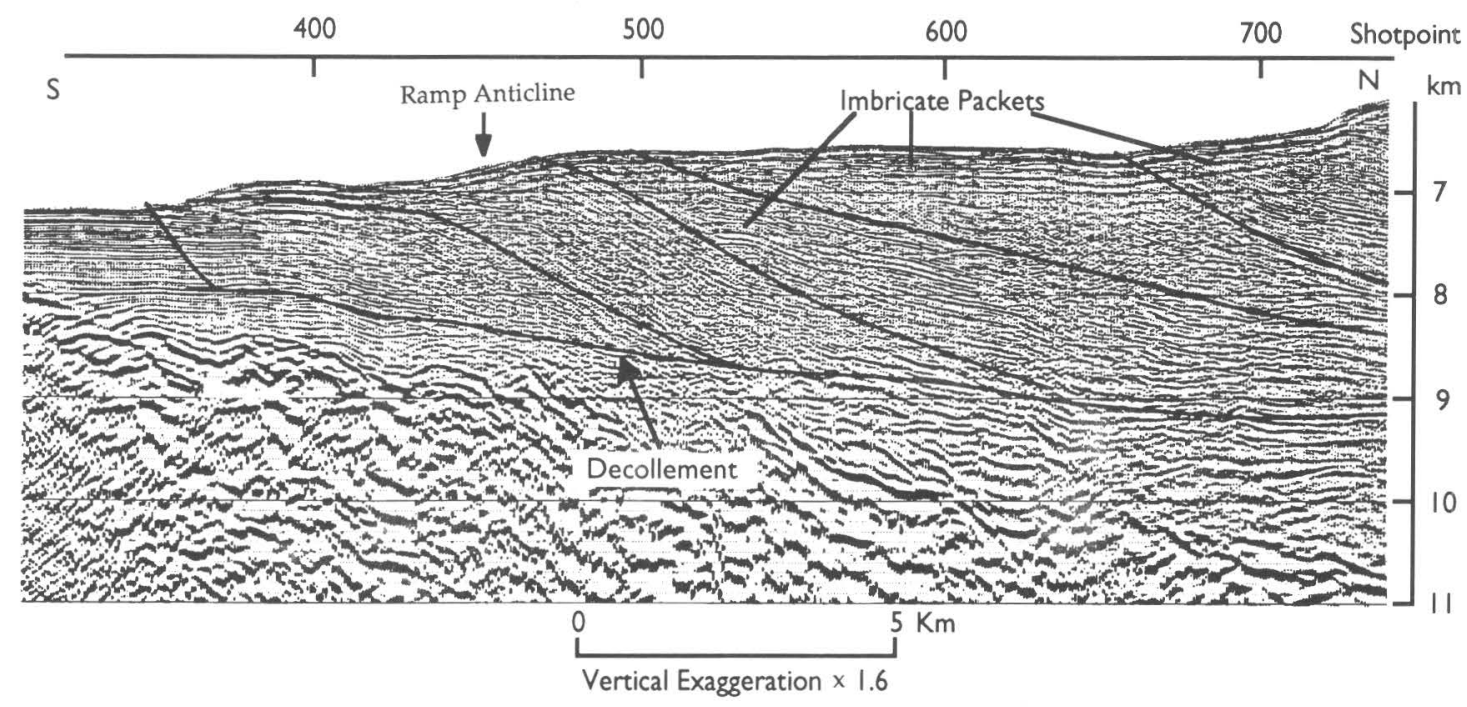

Figure 3. Migrated depth section from the toe region of the central Aleutian accretionary prism, Alaska. A ramp anticline is visible near shotpoint 450 and a drag fold is visible at $7.2 \mathrm{~km}$ depth beneath shotpoint 525 . Processed using finite-difference migration, stacking velocities determined from sonobuoy records and streamer moveout. From McCarthy and others (1984). 
to describe the structure of the hydrocarbon generation-migration-accumulation system operating in the accretionary environment, and it seriously hampers any attempt to evaluate the amount of sediment (thus carbon) subject to conditions favorable for hydrocarbon generation.

Seaward of the deformation front, more certainty exists with respect to the geothermal profile of the sedimentary section, and more meaningful estimates of the location of the hydrocarbon generation window can be made. In some situations, a significant part of the incoming sedimentary section may already be at temperatures higher than $50^{\circ} \mathrm{C}$, the floor of the hydrocarbon window, and thus be contributing thermally cracked hydrocarbon species to the pore fluids. These conditions are most common where the sedimentary section is several kilometers thick, such as in seaward of the Makran deformation front (Minshull and White, 1989), or where the subducting plate is young, such as in the Shikoku Basin (Shipboard Scientific Party, 1991). Where these circumstances combine, for example off southern Vancouver Island, British Columbia, temperatures at the base of the incoming sedimentary section may approach $250^{\circ} \mathrm{C}$ (Hyndman and Wang, 1993).

Convergence rate is a modulating force on basal prism temperature by controlling the amount of heat available for transfer. Rapid subduction of old cold plate results in greater thermal disequilibrium with respect to a steady-state heat flow, and it reduces heat flux to the prism base (Burch and Langseth, 1981). If the subducting lithosphere is
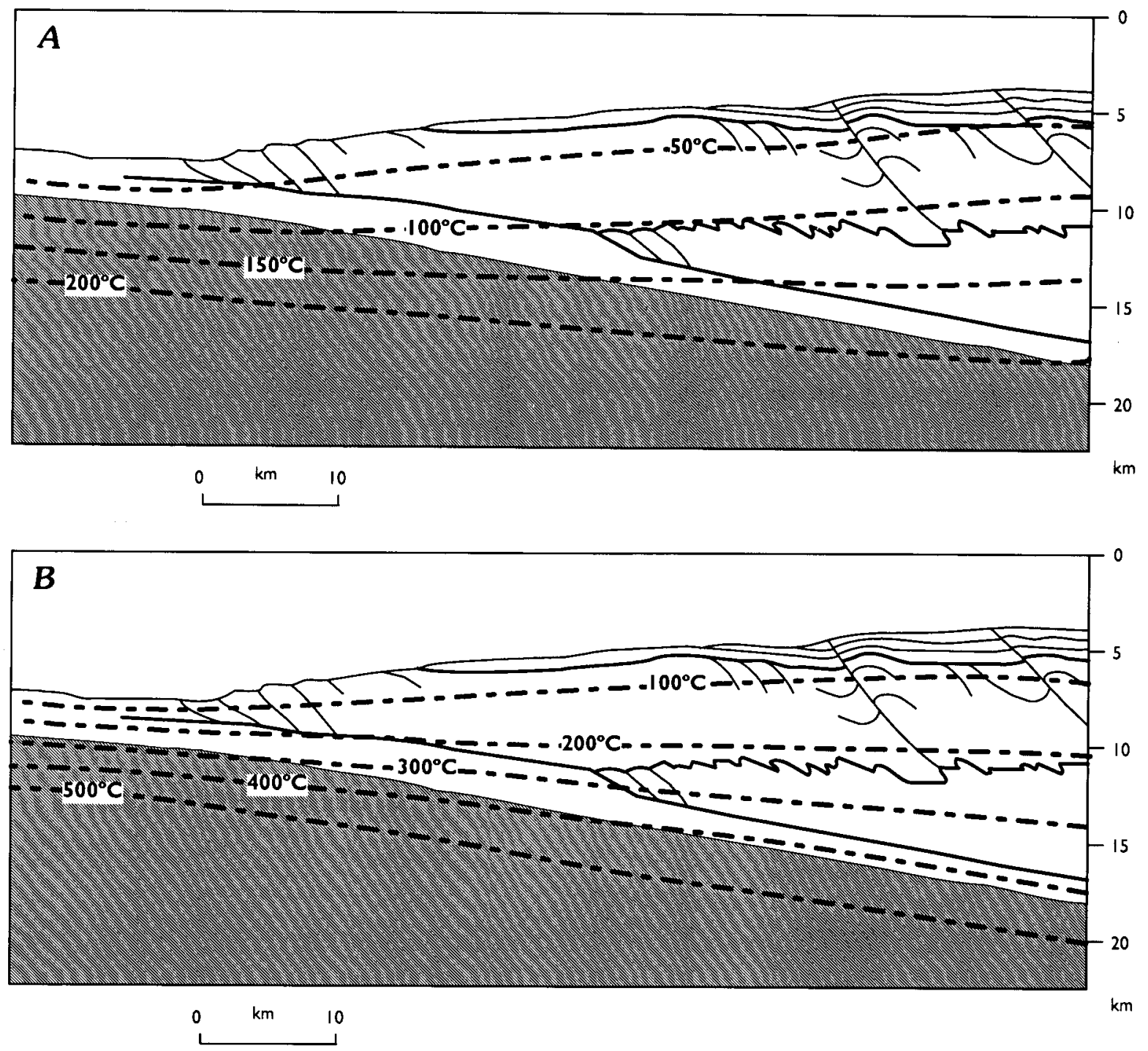

Figure 4. $A$, Diagrammatic isotherm configuration for an accretionary system, which is subducting old cold lithosphere. Note a low overall geothermal gradient and modest temperature at the base of the prism. $B$, Diagrammatic isotherm configuration for an accretionary system, which is underlain by young hot lithosphere. Note elevated isotherms in the prism, a high geothermal gradient, and high basal wedge temperatures. Modeled after Hyndman and Wang (1993), northern Cascadia accretionary prism. 
young and warm, thermal disequilibrium can be minimal, resulting in high heat transfer to the prism base and high geothermal gradients (Hyndman and Wang, 1993). Age trends of the subducting plate can also have an effect on the thermal structure of the prism if convergence rates are high. As the subducted plate gets older, high convergence rates will result in the removal of heat from the base of the wedge. This condition will result in a lower overall geothermal gradient and a low temperature at the base of the prism. In situations where the subducting lithosphere is young, high convergence rates will raise basal temperatures by increasing heat flux to the base of the wedge.

\section{ORIGIN AND MIGRATION OF FLUIDS}

A good understanding of the hydrogeology of accretionary complexes is key to interpreting the migration, entrapment, and to a lesser degree, generation of hydrocarbons in the accretionary environment. Reasonable qualitative descriptions of the mechanisms of fluid expulsion from the prism and subducting sediment exist, but the relative importance of the various pathways is unclear, and quantitative data are lacking.

The accretionary environment is a zone in which the rapid folding, stacking, and tectonic burial of poorly consolidated to unconsolidated sediment results in rapid loss of pore volume and the consequent expulsion of large quantities of pore fluids. In addition to pore water, lesser amounts of fluids are generated deep within the subduction zone by mineraloid and mineral dehydration reactions that reach the prism by traveling up and across the interplate contact of the decollement (Vrolijk and others, 1991). Evi- dence exists for fluid flow at all levels and in all environments within a subduction zone (see summary in Moore and Vrolijk, 1992). Hydrocarbons generated within the accreted or subducting sediment can be expected to become entrained in this fluid flow, to migrate along with the fluids, and to either become trapped or vent to the ocean.

Accreting sediment experiences rapidly increasing overburden loads, and this situation leads to rapid compaction and tectonically driven dewatering that is most active in the outer $20 \mathrm{~km}$ (high taper wedge) to $60 \mathrm{~km}$ (low taper wedge) of the prism (Bekins and Dreiss, 1992), where prism thickness is less than about $4 \mathrm{~km}$ (fig. 5). Landward of this zone, fluid expulsion continues, but the expelled volumes decline substantially. The primary control on the location of maximum fluid expulsion is the taper, or slope, of the wedge that determines the rate of burial (Bekins and Dreiss, 1992). The zone of maximum fluid expulsion is commonly characterized by numerous surface fluid escape structures, such as springs, carbonate pavements indicative of diffuse fluid flow, mud volcanoes, and diapirs, which all attest to a very active water drive (see Moore and Vrolijk, 1992 and references therein). Studies of older accretionary rocks from the lower reaches of prisms exposed by erosion show that significant diffuse and channelized fluid flow occurs in virtually all parts of the wedge (Cloos, 1984; Vrolijk, 1987), a circumstance that could aid in the migration of hydrocarbons formed anywhere within the complex (fig. 5).

Sediment that lies under the decollement and is transported beneath the wedge has a markedly different fluid expulsion history than accreted sediment. Observations of fluid content, pore pressure, and consolidation state are limited to the outermost reaches of the prism and provide

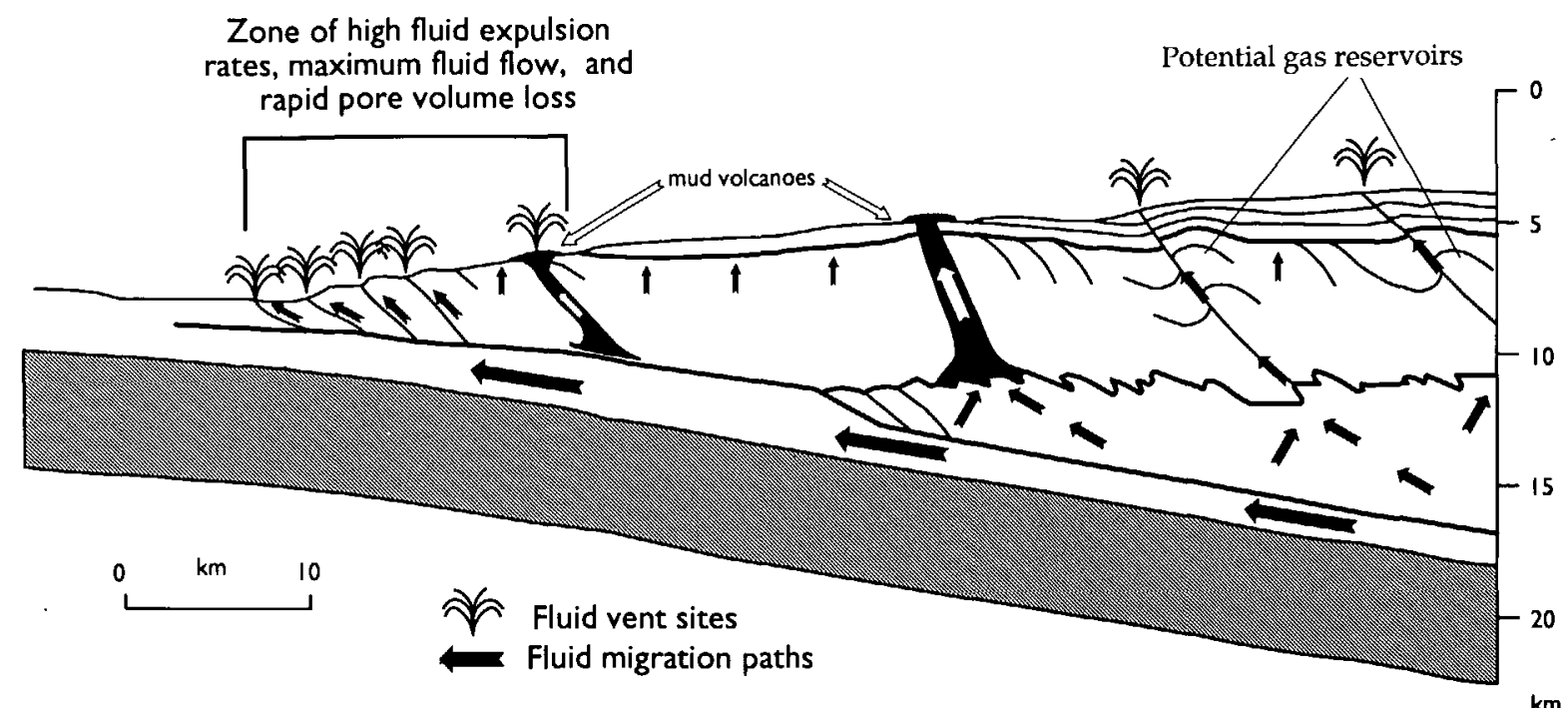

Figure 5. Generalized model of fluid flow within an accretionary prism showing the many possible channelized and diffuse fluid flow routes, and zone of maximum fluid expulsion. Base from Moore and Vrolijk (1992). Fluid expulsion zone from Bekins and Dreiss (1992). 
no direct evidence of conditions deeper beneath the wedge (Moore and Vrolijk, 1992). Where measured, pore pressures are substantially above hydrostatic and can approach lithostatic; these measurements attest to the slow rate of fluid escape (see Shipboard Scientific Party, 1991). Indirect evidence from seismic velocity studies (Shipley and others, 1990; Bangs and others 1990) and estimates of basal shear strength derived from taper angle measurements (Westbrook and others, 1982) indicate that overpressured conditions can persist deep under the prism. The addition of water to this section from mineral dehydration reactions can increase the fluid content of this section to an unknown, but potentially substantial amount (Moore and Vrolijk, 1992).

Fluid flow paths in the subducting sedimentary section appear to be primarily lateral, because the decollement and undisturbed low-permeability layers act as significant barriers to vertical fluid flow (fig. 5). Water chemistry anomalies (primarily low chloride concentrations) observed beneath the decollement and in association with the frontal thrust have been interpreted as evidence of fluids (dehydration water) migrating laterally from deeper within the subduction zone (Moore and Vrolijk, 1992, pl. 2).

The subdecollement sedimentary section represents a fluid reservoir that can be introduced by underplating into the basal portion of the accretionary prism at any location along the subduction contact. Migration of the decollement down section will transfer sediment and its accompanying fluids to the base of the wedge. In this location, vertical migration pathways can facilitate migration and entrapment of entrained hydrocarbons in the more stable structures landward of the zone of maximum fluid expulsion (fig. 5). If this transfer occurs during or after sediment has entered the oil and gas generation window, the fluids could contain a significant hydrocarbon fraction.

\section{FAVORABLE SETTINGS FOR MATURATION, MIGRATION, AND ENTRAPMENT OF HYDROCARBONS}

The lack of known commercial-size hydrocarbon accumulations in accretionary settings makes it difficult to describe favorable conditions for discovery on the basis of observed criteria. The known active oil and gas field that is reservoired in and sourced from an accretionary prism is in southern Barbados (Babaie and others, 1992). Commercial-size gas accumulations believed to be generated from accreted sediment, but reservoired in forearc basin strata, are present in northern California (Underwood, 1985), and in the Andaman forearc (J. Curray, oral commun., 1993). It is possible, however, to identify features of accretionary complexes that enhance the likelihood of generation, migration, and entrapment of hydrocarbons on the basis of theoretical considerations.
Subduction zones that are being fed thick terrigenous sections should have greater hydrocarbon potential owing to the greater total volume of carbon available for reaction and the generally higher tenor of terrigenous sections, compared to less organic-rich pelagic sections. A high trenchfloor sedimentation rate, with a significant continental (as opposed to volcanic arc) detrital component, both increases available carbon and enhances reservoir potential in the upper wedge by placing sand bodies high in the section, as a consequence of frontal accretion (fig. 5). High organic content in the sedimentary section is of obvious benefit.

From a structural standpoint, a large prism allows the upper landward region to become increasingly insulated from tectonic stress; such an isolation enhances the possibility of reservoir preservation, seal integrity, and hydrocarbon retention. The position of the decollement within the incoming section controls the amount of sediment that enters the generation window, because frontally accreted material rarely becomes deeply buried. A high decollement allows more of the section to pass beneath the outer wedge and be introduced into the higher temperature regime below. A greater amount of underplating of the prism is favorable for hydrocarbon generation, mobility, and entrapment, and it allows a greater transfer of sediment (and fluids) to the base of the wedge. Out-of-sequence thrusting is important in fostering and maintaining vertical fluid-migration pathways to the inner (landward) region of the wedge (fig. 5). The presence of slope-basin strata capable of hosting hydrocarbons is demonstrably favorable to hydrocarbon accumulation, as shown by the producing wells on Barbados (Babaie and others, 1992). Similarly a forearc basin can provide favorable settings for hydrocarbon accumulation.

The thermal structure of accretionary complexes, as deduced from heat-flow calculations, is variable and exerts important controls on the amount of organic matter within the wedge subject to maturation. Subduction zones characterized by rapid subduction of old cold lithosphere with a thin pre-trench sediment cover reduces heat flux to the base of the prism, resulting in low geothermal gradients within the wedge (fig. 4A). This circumstance can restrict the hydrocarbon generation window to great depths within the complex and thereby substantially reduce the amount of sediment that generates hydrocarbons. At the other extreme, a young hot subducting plate with a thick overlying sedimentary cover and a low decollement increases heat flux into the prism base. Incoming sediment may already be essentially thermally mature at the bottom of the incoming section (for example, the northern Cascadia accretionary complex, Hyndman and Wang, 1993). In the northern Cascadia prism, all but the uppermost part $(<3 \mathrm{~km})$ may have passed through or is lying within the thermal zone of hydrocarbon generation (fig. $4 B$ ).

Fluid flow within the accretionary complex can have an important effect on both the thermal structure of the wedge by advection of heat and on the fate of hydrocarbons that 
become entrained in the fluid. Buoyancy plays an important role in fluid flow in this regime (Moore and Vrolijk, 1992). Warm, less saline deep waters rise and transport heat into cooler, higher regions. This process increases hydrocarbon potential by elevating isotherms and exposing more sediment to temperatures suitable for organic maturation (fig. 5). Vertical fluid flow in the prism results in transportation and concentration of hydrocarbons in structural and stratigraphic traps. Too much vertical flow, however, can result in flushing of the wedge and venting hydrocarbons to the ocean. The vigorous water drive in the seaward, highvolume fluid-expulsion part of the prism is likely to prevent accumulation there. Fluids, added to the base of the wedge by deep underplating, rise through the landward part of the prism along channelized pathways (such as out-of-sequence thrusts, backthrusts, the accretionary wedge-crystalline basement contact). This migration sequence represents a favorable mechanism for introducing hydrocarbons into traps in the upper, more stable, landward region of the prism and into overlying forearc basin and slope cover strata. Large prisms, which require more underplating to maintain critical taper, enhance fluid transfer across the decollement. Fluid flow beneath the decollement is primarily lateral. Unless the permeability barrier at the subduction contact is broken, subdecollement fluid expulsion will take place at the frontal thrust; this process will result in venting or injection into the trench wedge, which will cause a loss of hydrocarbon potential in the prism. Consequently, decollement disruption and fluid escape into the overlying accretionary prism can actually favor hydrocarbon entrapment.

\section{GLOBAL HYDROCARBON RESOURCE POTENTIAL FROM ACCRETED SEDIMENT}

Regional estimates of hydrocarbon generation demonstrate the potential of some plate margins for gas production. In the eastern Aleutian subduction zone, Kvenvolden and von Huene (1985) estimate a production potential of $5 \times 10^{8} \mathrm{~m}^{3}$ of gas per kilometer of subduction zone length per million years. A worldwide estimate of thermogenic hydrocarbon generation potential from accretionary prisms by Larue (1991) indicates a maximum potential of $10^{12}$ moles of live (hydrocarbon) carbon per year. If all the carbon were present as methane, it would occupy a volume of $2.2 \times 10^{10} \mathrm{~m}^{3}(0.8 \mathrm{Tcf})$ at standard conditions. Large uncertainties exist in this estimate, and the numbers should be treated only as order of magnitude estimates. Recent, more detailed, estimates of the volume of globally accreted sediment (von Huene and Scholl, 1991) allow some of the uncertainties to be reduced.

Generation potential of thermally mature accreted sediment containing type III organic matter is $8.75 \times 10^{11} \mathrm{~mol}$ of live carbon (carbon contained in hydrocarbon species) per $\mathrm{km}^{3}$ (from Larue, 1991, table 4).

Solid volume of sediment accreted/subcreted annually in accretionary prisms is $0.44 \mathrm{~km}^{3} / \mathrm{yr}$ (long-term average, glacial effects removed, D.W. Scholl, oral commun., 1993).

Solid volume of sediment annually subducted landward of the accretionary prism and beneath the arc basement is $0.31 \mathrm{~km}^{3} / \mathrm{yr}$ (long-term average, glacial effects removed, D.W. Scholl, oral commun., 1993).

Hydrocarbon generation potential for accretionary complexes, yearly, is $8.75 \times 10^{11} \mathrm{~mol}$ of live carbon per $\mathrm{km}^{3} \times\left(0.44 \mathrm{~km}^{3} / \mathrm{yr}+0.31 \mathrm{~km}^{3} / \mathrm{yr}\right)=6.6 \times 10^{11} \mathrm{~mol}$ of live carbon (carbon contained in hydrocarbon species) per year. If all the live carbon appears as methane, it would occupy a volume of $1.5 \times 10^{10} \mathrm{~m}^{3}(0.5 \mathrm{Tcf})$

The estimate just described makes several assumptions that may, in part, be inaccurate and lead to an overestimation. The estimate assumes that all sediment in the accretionary prism reaches thermal maturity for oil and gas generation. This assumption is unlikely to be the case for all frontally accreted sediment, and it may not be true for all underplated material. Uncertainties in the thermal profile of the accretionary environment make it impossible to further constrain this parameter. The estimate also assumes that all hydrocarbons produced in the subducted but nonunderplated sediment escape into the accretionary prism or trench wedge and avoid reassimilation, which may also be a source of error. This error is probably small, however, as most subducted sediment passing beneath accretionary prisms probably passes through the oil and gas window prior to subduction beneath crystalline basement, and fluid escape from deeply subducted sediment is documented. The tenor of the sediment input is appropriate for modern accretionary settings, but it may not represent a viable long-term average rate. This source of error is also likely to be small because it is derived from measurements from many different environments and from sediment with a significant age distribution (Larue, 1991, table 1). There are two assumptions in the above estimate which may cause underestimation. The first is a sediment input rate 50 percent lower than modern rates is used to compensate for the input increase caused by late Neogene, Pleistocene, and Holocene glaciation, which has caused an increase in terrestrial sediment supply (von Huene and Scholl, 1991). The second is all organic matter is assumed to be type III, which yields much less live carbon per unit of organic carbon input compared to type II organic matter. Because of these uncertainties, the estimate is still poorly constrained, and it should be used with caution.

\section{CONCLUSIONS}

Accretionary complexes represent an environment in which marine sediment containing organic carbon of terrestrial and marine origin becomes rapidly buried and is 
transported into a regime where the generation of hydrocarbons via thermal cracking can occur. Methane, of both microbial and thermal origin, is ubiquitous in this setting and has been found in all regions and depths within modern and fossil accretionary complexes. Modern accretionary prisms show wide variations in volume of sediment input, organic matter input, thermal structure, fluid flow, and structural style. These factors make generalizations regarding hydrocarbon potential difficult. However, factors that favor the generation and entrapment of hydrocarbons have been identified. The most important favorable factor is the presence of a large, thick accretionary prism. Other favorable factors include a thick incoming sedimentary section, substantial axial trench sedimentation dominated by continental detritus, formation of the decollement high in the incoming section, substantial underplating, a young subducting plate, and slow to moderate plate-convergence rates.

Substantial quantities of methane and other hydrocarbons are likely generated in accretionary complexes. No commercial (producible at a profit) accumulations of gas and only one commercial oil and associated gas accumulation have been found in this setting. These two facts imply that most or all gas generated in this environment escapes to the oceans or the atmosphere. However, accretionary complexes have not been extensively explored for hydrocarbons, so this conclusion needs further testing, especially in complexes that have favorable factors. The magnitude of the potential is so large that even low percentages of entrapment and preservation could result in a substantial resource.

\section{REFERENCES CITED}

Babaie, H.A., Speed, R.C., Larue, D.K., and Claypool, G.E., 1992, Source rock and maturation evaluation of the Barbados accretionary prism: Marine and Petroleum Geology, v. 9, no. 6, p. 623-632.

Bally, A.W., editor, 1983, Seismic expression of structural styles: Tulsa, Okla., American Association of Petroleum Geologists Studies in Geology Series no. 15, v. 3.

Bangs, N.L.B., Westbrook, G.K., Ladd, J.W., and Buhl, P., 1990, Seismic velocities from the Barbados ridge complex-Indicators of high pore fluid pressures in an accretionary complex: Journal of Geophysical Research, v. 95, p. 8767-8782.

Bebout, G.E., 1991, Field based evidence for devolitization in subduction zones-Implications for arc magmatism: Science, v. 251, p. 413-416.

Bekins, B.A., and Dreiss, S.J., 1992, A simplified analysis of parameters controlling dewatering in accretionary prisms: Earth and Planetary Science Letters, v. 109, p. 275-287.

Brown, K.M., 1990, The nature and hydrogeologic significance of mud diapirs and diatremes for accretionary systems: Journal of Geophysical Research, v. 95, p. 8969-8982.

Burch, T.K., and Langseth, M.G., 1981, Heat flow determination in three DSDP boreholes near the Japan trench: Journal of Geophysical Research, v. 86, p. 9411-9419.
Cloos. M., 1984, Landward dipping reflectors in accretionary wedges; active dewatering conduits?: Geology, v. 12, no. 9, p. 519-522.

Davis, E.E., and Hyndman, R.D., 1989, Accretion and recent deformation of sediment along the northern Cascadia subduction zone: Geological Society of America Bulletin, v. 101, p. $1465-1480$.

Ferguson, I.J., Westbrook, G.K., Langseth, M.G., and Thomas, G.P., 1993, Heat flow and thermal models of the Barbados ridge accretionary complex: Journal of Geophysical Research, v. 98, p. 4121-4142.

Howell, D.G., and Murray, R.W., 1986, Model for continental growth and denudation: Science, v. 233, p. 446-449.

Hyndman, R.D., and Wang, K., 1993, Thermal constraints on the zone of major thrust earthquake failure-The Cascadia subduction zone: Journal of Geophysical Research, v. 98, no. B2, p. 2039-2060.

Kvenvolden, K.A., and von Huene, R., 1985, Natural gas generation in sediments of the convergent margin of the eastern Aleutian Trench area, in Howell, D.G., ed., Tectonostratigraphic Terranes of the Circum-Pacific Region: Houston, Tex., Circum-Pacific Energy Council Earth Science Series 1, Houston, Texas, p. 31-49.

Kulm, L.D., and Suess, E., 1990, The relation of carbonate deposits to fluid venting processes: Journal of Geophysical Research, v. 95, p. 8899-8915.

Langseth, M.G., Westbrook, G.K., and Hobart, M., 1990, Contrasting geothermal regimes of the Barbados accretionary complex: Journal of Geophysical Research, v. 95, p. 8829-8844.

Larue, D.K., 1991, Organic matter in the Franciscan and Cedros subduction complexes-The problems of "instantaneous maturation" and "missing petroleum" in accretionary prisms: Marine and Petroleum Geology, v. 8, no. 5, p. 468-482.

Ludwig, W.J., and Houtz, R.E, 1979, Isopach map of sediments in the Pacific Ocean basin and marginal sea basins: Tulsa, American Association of Petroleum Geologists, 2 sheets.

McCarthy, J., Stevenson, A.J., Scholl, D.W., and Vallier, T.L., 1984, Speculations on the petroleum geology of the accretionary body-An example from the central Aleutians: Marine and Petroleum Geology, v. 1, p. 151-167.

Milliman, J.D., and Meade, R.H., 1983, World wide delivery of river sediment to the oceans: Journal of Geology, v. 91, p. $1-21$.

Minshull, T., and White, R., 1989, Sediment compaction and fluid migration in the Makran accretionary prism: Journal of Geophysical Research, v. 94, p. 7387-7402.

Moore, J.C., and Vrolijk, P., 1992, Fluids in accretionary settings, Reviews of Geophysics: v. 30, no. 2, p. 113-135.

Ryan, H.R., and Scholl, D.W., 1989, The evolution of forearc structures along an oblique convergent margin, central Aleutian arc: Tectonics, v. 8, no. 3, p. 497-516.

Scholl, D.W., 1974, Sedimentary sequences in the North Pacific trenches, in Burk, C.A., and Drake, C.L., eds., The Geology of Continental Margins: New York, Springer-Verlag, p. 493504.

Scholl, D.W., 1982, Sedimentation and Deformation in the Amlia Fracture Zone Sector of the Aleutian Trench: Marine Geology, v. 48, p. 105-134.

Shipboard Scientific Party, 1991, Site 808, in Taira, A., Firth, J.V., and others, Proceedings of the Ocean Drilling Program: 
College Station, TX, Ocean Drilling Program, v. 131, p. 71269.

Shipley, T.H., Stoffa, P.L., and Dean, D.F., 1990, Underthrust sediments, fluid migration paths, and mud volcanoes associated with the accretionary wedge off Costa Rica-Middle America Trench: Journal of Geophysical Research, v. 95, p. 8743-8752.

Snavely, P.D. Jr., von Huene, R., Mann, D.M., and Miller, J., 1986, in von Huene, R., ed., Seismic images of modern convergent margin tectonic structure: Tulsa, Okla., American Association of Petroleum Geologists Studies in Geology no. 26, Tulsa, p. 26-27.

Speed, R.C., Westbrook, G., Mascale, A., Biju-Duval, B., Ladd, J., Saunders, J., Stein, S., Schoonmaker, J., and Moore, J., 1984, Lesser Antilles Arc and adjacent terranes-Woods Hole, Mass., Ocean Margin Drilling Program, Regional Atlas Series: Houston, TX, Marine Science International, Atlas 10, 27 sheets.

Tissot, B.P., and Welte, D.H., 1984, Petroleum formation and occurrence: New York, Springer-Verlag, 538 p.

Underwood, M.B., and Bachman, S.B., 1982, Sedimentary facies associations within subduction complexes, in Leggett, J., ed., Trench and Forearc Geology: London, Special Publications of the Geologic Society of London, no. 10, p. 537550 .
Underwood, M.B., 1985, Sedimentology and hydrocarbon potential of the Yager structural complex-Possible paleogene source rocks in the Eel River Basin, northern California: American Association of Petroleum Geologists Bulletin, v. 69 , p. $1088-1100$.

von Huene, R., and Scholl, D.W., 1991, Observations at convergent margins concerning sediment subduction, subduction erosion, and the growth of continental crust: Reviews of Geophysics, v. 29, no. 3, p. 279-316.

von Huene, R., ed., 1986, Seismic images of modern convergent margin tectonic structure: Tulsa, Okla., American Association of Petroleum Geologists Studies in Geology no. 26, p. 26-27.

Vrolijk, P., 1987, Tectonically-driven fluid flow in the Kodiak accretionary complex, Alaska: Geology, v. 15, p. 466-469.

Vrolijk, P., Fisher, A., and Gieskes, J., 1991, Geochemical and geothermal evidence for fluid migration in the Barbados accretionary prism (ODP leg 110): Geophysical Research Letters, v. 18, p. 947-950.

Wang, C.Y., and Shi, Y-L, 1984, On the thermal structure of subduction complexes: a preliminary study: Journal of Geophysical Research, v. 89 , p. 7709-7718.

Westbrook, G.K., Smith, M.J., Peacock, J.H., and Poulter, M.J., 1982, Extensive underthrusting of undeformed sediments beneath the accretionary complex of the Lesser Antilles subduction zone: Nature, v. 300, p. 625-628. 

THE FUTURE OF ENERGY GASES

U.S. GEOLOGICAL SURVEY PROFESSIONAL PAPER 1570

\title{
An Energy Perspective on Landfill Gas
}

\author{
By Peter J. Hutchinson ${ }^{1}$
}

\section{CONTENTS}

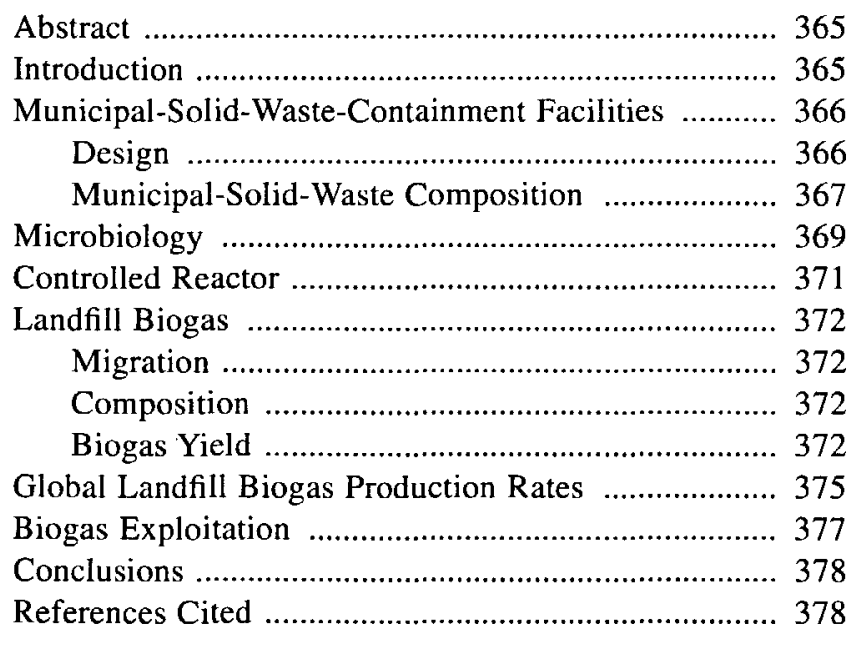

\begin{abstract}
Globally, one billion metric tons of organic waste in the form of municipal solid waste are placed into solidwaste containment facilities every year. Complete biodegradation of this waste can generate approximately $2.8 \times 10^{11} \mathrm{~m}^{3}$ (9.9 trillion cubic feet (Tcf) or $1.98 \times 10^{8}$ metric tons) of biogas. Biogas consists of approximately equal proportions of methane and carbon dioxide; thus a year's worth of waste can potentially generate $1.4 \times 10^{11} \mathrm{~m}^{3}(5$ Tcf or $9.9 \times 10^{7}$ metric tons) of methane. If we assume that 15668 .

${ }^{1}$ The Hutchinson Group, Ltd., 5124 Scenic Rd., Murrysville, PA,
\end{abstract}

landfill-biogas generation began only 20 years ago and has proceeded at a steady rate, then we can estimate that it can contribute $5 \times 10^{10} \mathrm{~m}^{3}$ (1.8 Tcf or $36 \times 10^{6}$ metric tons) of methane to the global atmospheric budget every year.

Landfill gas is difficult to recover and use. Exploitation of biogas includes use as a raw product for heat energy, dehydration to produce electric generator fuel, refinement for commercial transportation, and use as a chemical feedstock. Controlled-reactor landfills, called "biofills," are designed for optimum methane generation to ensure a steady and consistent rate of gas generation. Biofill mechanisms used to improve gas production include physical and chemjcal modifications to the modern landfill design. These methods can reduce the gas-generation time from 80 years to 5 years, can reduce the waste mass, and can reduce negative effects on the environment.

Everything we use comes in boxes, cartons, bins, and so-called packaging we love so much. The mountains of things we throw away are much greater than the things we use. In this, if no other way, we can see the wild and reckless exuberance of our production, and waste seems to be the index.

John Steinbeck

\section{INTRODUCTION}

The practice of putting waste in landfills dates back over 5,000 years (Senior, 1990). Archaeologists continually examine ancient waste-disposal sites to comprehend society's development and history (Rathje, 1991). Modern researchers are now examining municipal solid waste for its potential as an energy or gas resource (Hutchinson, 1990). Municipal solid waste has a caloric value upon incineration that can be converted to electric or steam energy (Seeker and others, 1989). The incineration of municipal solid waste, however, has had negative effects upon the 
environment and is currently in disfavor (Kiser and Sussman, 1991). Recently, the focus has shifted to the biogas that municipal solid waste produces. Through anaerobic decomposition, municipal solid waste generates methane in quantities that can be exploited (Hutchinson, 1989).

Municipal solid waste in landfills produces biogas, a mixture of nearly equal volumes of methane and carbon dioxide (Alpern, 1973; Anderson and Callinan, 1970). The generation of biogas has positive economic implications because biogas is an exploitable, moderately predictable, and reliable source of methane (Hutchinson, 1990, 1991). Bingemer and Crutzen (1987) estimated that global generation of methane from municipal solid waste is 30 to 70 million metric tons, or 1.5 to 3.5 trillion cubic feet (Tcf), per year.

Biodegradation of municipal solid waste under anoxic conditions in municipal-solid-waste-containment facilities reduces the waste volume, geochemically stabilizes the remaining waste (thereby limiting stress to the environment), and generates an energy source in the form of methane-rich biogas that can be an asset to the host community. This paper will address the global volume of landfill-generated biogas and the potential for the exploitation of this energy source.

\section{MUNICIPAL-SOLID-WASTE- CONTAINMENT FACILITIES}

Municipal-solid-waste-containment facilities are designed to inhibit the loss of three phases of waste material: solid waste, leachate, and biogas (fig. 1). Solid waste (for example, paper, household goods, construction materials, animal carcasses, refractory materials, and food products) is normally the only phase emplaced and buried at the municipal-solid-waste-containment facility. However, some liquids are introduced through disposal of municipal solid waste, water is added to the municipal-solid-waste-containment facility through infiltration of precipitation, and liquids are generated through decomposition of the waste (Senior and Shibani, 1990). The percolation of water through the landfill generates a liquid called leachate. Biogas is liberated from the waste mass during the decomposition of the organic material (Barlaz and others, 1987). Migration of this gas away from the municipal-solidwaste-containment facilities can be dangerous, especially if the gas collects with oxygen in confined spaces (Hartner, 1990).

\section{DESIGN}

In the past, landfills were merely dumping areas where waste materials were placed and either abandoned, covered, or burned. The modern landfill evolved through the need to limit vectors (for example, rodents, insects, birds), to better manage waste disposal, to insure prudent siting, to reduce the threat of contamination of soil and groundwater, and to minimize health-based risks of municipal solid waste. The modern municipal-solid-waste-containment facility consists of three phase-containment systems: two for containing and collecting leachate and gas, and one for containing solid waste.

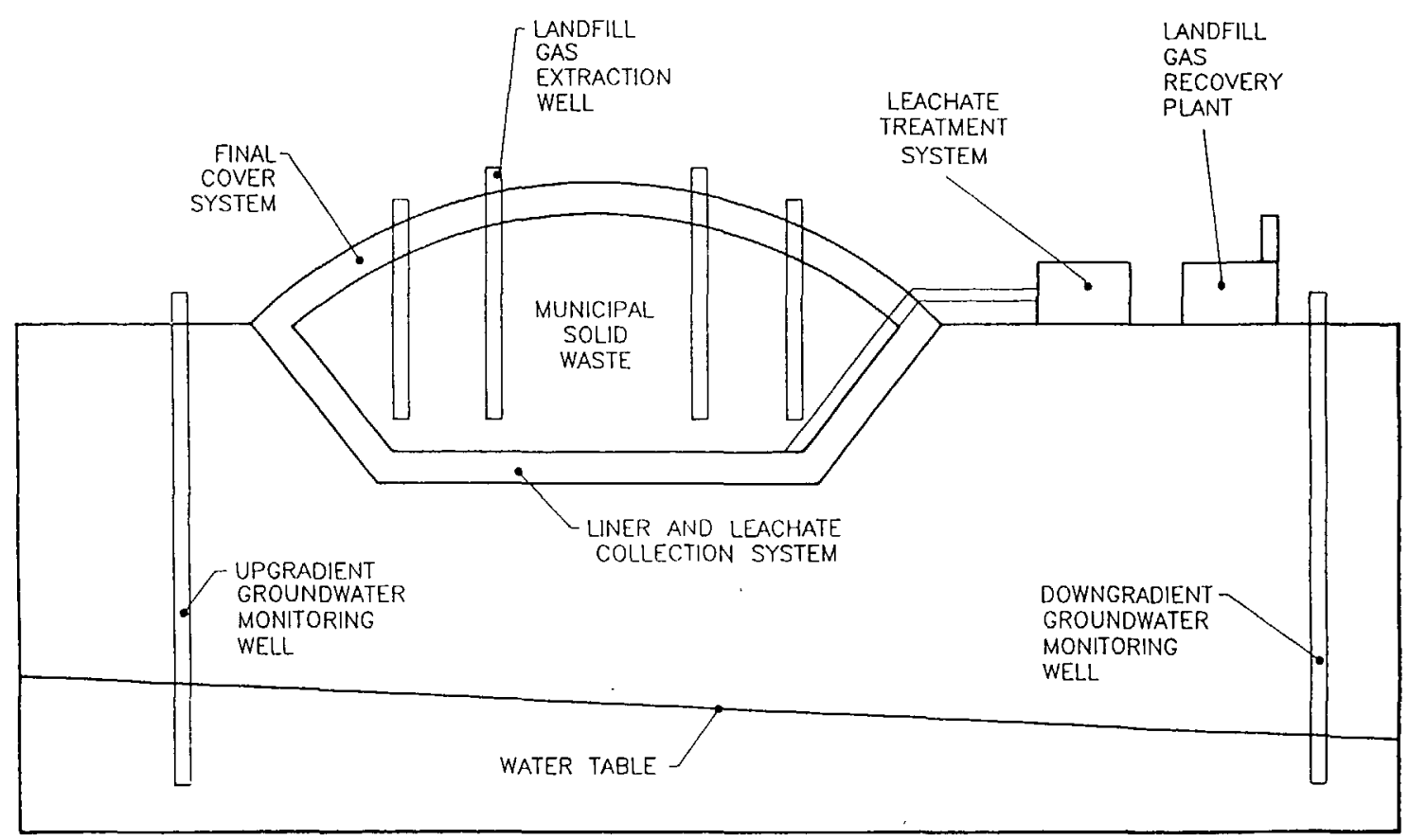

Figure 1. Schematic drawing of municipal-solid-waste-containment system. 
The hydrogeologic regime for the site often dictates the landfill design (Fetter, 1988). Landfills are often designed to protect groundwater in four site-specific hydrogeologic regimes (Walsh and O'Leary, 1991).

The primary component of the landfill consists of the liner (Haxo, 1976). The landfill liner prevents the escape of leachate, and the landfill cap contains gases. An alternative landfill design, natural-attenuation landfill, relies upon the cation-exchange capacity of the soils under the waste mass to remediate the leachate (Lisk, 1991). This type of landfill is now rare owing to the heterogeneity of soils and an often poor understanding of the cation-exchange capacity of soils below the landfill.

A municipal-solid-waste-containment system can employ one of seven types of liners: (1) compacted native fine-grained soils, (2) bentonite and other clay sealants, (3) asphalt, (4) portland cement, (5) soil sealants (such as lime and penetrating polymeric emulsions), (6) sprayed liquid rubber, and (7) synthetic polymeric membranes (Haxo, 1976). The most common type of liner is the synthetic polymeric membranes; these liners are thin, inexpensive, malleable, and allegedly dependable. Lee and Jones (1991), however, maintain that the life span of flexible membrane liners is short and that the failure of landfill caps and liners constructed of this material remain an imminent threat to groundwater.

Leachate that collects at the base of the landfill material can be pumped from the municipal-solid-waste-container and treated before disposal. The gas generated during decomposition of the waste mass is collected passively or actively. Passive systems consist of wells drilled or built into the waste mass and left open to the atmosphere to permit ventilation (Wegener and Lekstutis, 1989). Active vacuum gas-abstraction systems require rigorous design and engineering (Leach, 1990). Strategies for the removal of gas from the municipal-solid-waste-containment facility consist of vertical and horizontal collection systems; most of these are expensive and require continual maintenance (Marshall, 1988). Regulatory compliance provides most of the driving force for the installation of landfill gas-abstraction systems (Hartner, 1990; Pennsylvania Department of Environmental Resources, 1989).

\section{MUNICIPAL-SOLID-WASTE COMPOSITION}

Municipal solid waste consists of organic and inorganic materials (table 1). The inorganic materials consist of refractory waste (plastic, glass, metal), construction debris, and recalcitrant organic debris (such as lignin) and do not readily undergo bacterially mediated catabolism or decomposition. Organic materials include paper, cardboard, food, and coarse organic waste (wood/yard/textile). Barlaz and others $(1989 \mathrm{~b})$ found that municipal solid waste from Madison, Wisconsin, consisted of three groups of com- pounds sorted by their biodegradability: labile, recalcitrant, and inert. Labile compounds consist of cellulose (40-50 percent), hemicellulose ( 12 percent), and protein ( 4 percent); whereas recalcitrant compounds include the nonbiodegradable biomolecule lignin (10-15 percent) and various inert materials (30 percent). Westlake (1990) found that European municipal solid waste consists of 60 percent carbohydrates, 2.5 percent protein, 6 percent lipids, and 31.5 percent inert material.

Table 1 is a distillation of the work of many researchers and may overstate or understate the waste concentrations for each category. For example, one researcher may consider animal carcasses as food, which is in the Food Waste category, whereas another may consider animal carcasses as leather, which is in the Wood/Yard/Textile category. Nevertheless, these data display a normal distribution with low standard deviations, suggesting that these data are reasonable.

Globally, an estimated $1,165 \times 10^{6}$ metric tons of biodegradable organic municipal solid waste are generated per year (table 2 ). This amount is considerably larger than the $85 \times 10^{6}$ metric tons per year calculated by Bingemer and Crutzen (1987). However, Bingemer and Crutzen (1987) used a global population 34 percent smaller than that in the 1990 global census figures (Hoffman and others, 1991). The 12 studies in table 2 indicate that, on average, the municipal solid waste generated in the world is 75 percent organic (table 1). Bingemer and Crutzen considered the organic constituent of municipal solid waste to be 15 to 22 percent of the disposed waste. Considering these differences in the extrapolation from available data, current world population figures, and organic compositions cited for various parts of the world, the estimate of Bingemer and Crutzen (1987) can be recalculated to approximately $1,000 \times 10^{6}$ metric tons of organic waste per year.

Difficulties with this global yearly generation rate of biodegradable organic compounds are numerous, and many of these problems were reviewed by Bingemer and Crutzen (1987). Most underdeveloped countries currently or will soon exploit the landfill technologies of the developed countries. Modern landfill technologies encourage anoxic decomposition, or anaerobiosis (Emcon Associates, 1981a). Recent landfill installations in Hong Kong meet the specifications for U.S. Environmental Protection Agency Resource Conservation and Recovery Act of 1977, subtitle $D$, regulations for landfill construction. The West Indies, Mexico, Indonesia, and portions of Africa are currently installing modern landfills that will promote anaerobic conditions.

The major concern with estimates of the global yearly generation of biodegradable municipal solid waste is that municipal solid waste must be buried to initiate anaerobiosis. On a national level, improper waste placement techniques, scavenging, recycling, and composting can reduce the global yearly generation rate of organic municipal 
Table 1. Composition of municipal solid waste in selected locations around the world.

[Values in percent wet weight.Year (second column from right) indicates year for which data were compiled. n.a., not applicable]

\begin{tabular}{|c|c|c|c|c|c|c|c|c|c|}
\hline \multirow[b]{2}{*}{ Location } & \multicolumn{7}{|c|}{ Waste category } & \multicolumn{2}{|c|}{ Source of data } \\
\hline & $\begin{array}{c}\text { Paper/ } \\
\text { cardboard }\end{array}$ & Food waste & $\begin{array}{c}\text { Wood/yard/ } \\
\text { textile }\end{array}$ & Plastic & Glass & Metal & $\begin{array}{l}\text { Construction } \\
\text { debris }\end{array}$ & Year & Reference ${ }^{1}$ \\
\hline Australia ---..............- & 24.9 & 46.1 & 1.5 & 3.0 & 14.7 & 8.2 & 1.6 & 1988 & $\mathbf{k}$ \\
\hline Denmark -- & 33.0 & 37.0 & 10.0 & 5.0 & 6.0 & 4.0 & 5.0 & 1990 & 1 \\
\hline 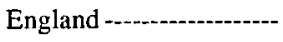 & 34.0 & 23.0 & 3.0 & 8.0 & 9.0 & 9.0 & 14.0 & 1988 & $\mathrm{f}$ \\
\hline $\begin{array}{l}\text { Federal Republic of } \\
\text { Germany (former). }\end{array}$ & 27.0 & 35.0 & 0.0 & 4.0 & 10.0 & 5.0 & 19.0 & 1977 & $\mathbf{j}$ \\
\hline Holland -.............- & 22.5 & 55.0 & 3.9 & 6.8 & 8.1 & 2.5 & 1.2 & 1983 & $\mathrm{e}$ \\
\hline Hong Kong---'--'-- & 5.0 & 2.6 & 73.2 & 8.7 & 0.3 & 2.9 & 7.3 & 1983 & $\mathrm{~g}$ \\
\hline 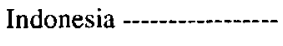 & 14.0 & 74.0 & 0.0 & 2.0 & 1.0 & 1.0 & 8.0 & 1984 & $\mathrm{i}$ \\
\hline Israel ---------------------- & 30.3 & 54.7 & 3.1 & 4.4 & 3.0 & 3.1 & 1.4 & 1979 & h \\
\hline Italy & 17.0 & 53.0 & 4.0 & 7.0 & 8.0 & 3.0 & 8.0 & 1977 & $\mathbf{a}$ \\
\hline 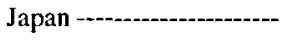 & 31.4 & 26.0 & 11.5 & 11.7 & 9.3 & 7.8 & 2.3 & 1980 & c \\
\hline 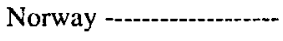 & 33.5 & 38.5 & 8.4 & 6.2 & 5.1 & 4.0 & 4.3 & 1981 & $\mathrm{~d}$ \\
\hline United States------------- & 34.2 & 8.5 & 29.5 & 9.1 & 7.1 & 8.4 & 3.2 & 1988 & b \\
\hline $\begin{array}{l}\text { Waste composition, } \\
\text { average. }\end{array}$ & 25.57 & 37.78 & 12.34 & 6.33 & 6.80 & 4.91 & 6.28 & n.a. & n.a. \\
\hline
\end{tabular}

IReferences:
a. Albonetti and Massari (1979)
g. Parker (1983)
b. Environmental Protection Agency (1990)
h. Senior (1990)
c. Hanashima and others (1983)
i. Soerjani (1984)
d. Heie and Minaas (1981)
e. Hoeks (1983)
j. Thomé-Kozmiensky (1977)
f. Mosey and Mistry (1990)
k. Ward (1988)
1. Willumsen (1990)

Table 2. Disposal of municipal solid waste by region.

[CIS, Commonwealth of Independent States (former Soviet Union)]

\begin{tabular}{|c|c|c|c|c|c|c|c|}
\hline Region --. & North America & Europe & CIS & Asia & Oceania & Latin America & Africa \\
\hline $\begin{array}{l}\text { Population } \\
\text { (millions) }\end{array}$ & 277 & 499 & 291 & 2,994 & 26 & 450 & 795 \\
\hline $\begin{array}{l}\text { Waste generation rate } \\
\text { (kilograms per capita per day) }\end{array}$ & 1.6 & 1.5 & 1.2 & 0.4 & 0.8 & 0.6 & 0.5 \\
\hline $\begin{array}{l}\text { Fraction of municipal solid waste } \\
\text { placed in landfills } \\
\text { (percent) }\end{array}$ & 87 & 85 & 85 & 71 & 85 & 80 & 70 \\
\hline $\begin{array}{l}\text { Organic fraction } \\
\text { (percent; from table 1) }\end{array}$ & 71.7 & 72.9 & 75 & 88 & 72.5 & 80 & 85 \\
\hline $\begin{array}{l}\text { Biodegradable organic fraction } \\
\text { (percent) }\end{array}$ & 60 & 60 & 60 & 60 & 60 & 60 & 60 \\
\hline $\begin{array}{l}\text { Organic municipal solid waste avail- } \\
\text { able for anaerobiosis } \\
\text { (million metric tons per year) ------.-- }\end{array}$ & 61 & 109 & 64 & 654 & 6 & 98 & 174 \\
\hline
\end{tabular}


solid waste. Current trends towards dehydration of the waste in modern municipal-solid-waste-containment facilities inhibits biodegradation (Lee and Jones, 1991). These factors may reduce the global total of available biodegradable organic municipal solid waste by about 30 percent of the calculated $1,165 \times 10^{6}$ metric tons of municipal solid waste generated per year. For the remainder of this article, $1,000 \times 10^{6}$ metric tons per year will be inferred for the global generation rate of biodegradable organic material.

\section{MICROBIOLOGY}

Farquhar and Rovers (1973) divided landfill-gas generation into four phases based upon the catabolic activity of landfill microorganisms. Subsequently, Rees (1980a) added an additional phase that reflected the terminal stages of anaerobiosis (fig. 2). Ward (1988) also summarized the five stages of landfill decomposition: I, initial adjustment; II, transition in landfill biota; III, acid formation; IV, methane fermentation; and $\mathrm{V}$, final maturation.

Zehnder (1978) found that three bacterial groups dominate progressive stages in the generation of biogas in an anaerobic digester. The first group consists of anaerobic and facultative anaerobic fermenting bacteria that catabolize complex organic material. At this stage, carbohydrates, proteins, and lipids are hydrolyzed and fermented to fatty acids, alcohols, carbon dioxide, ammonia, and hydrogen (fig. 3). Organic products of the first stage are converted to acetic acid, hydrogen, and carbon dioxide by obligate proton reducing acetogens, the second group. The third group consists of two microbial forms: anaerobic chemolithotrophs that use hydrogen to generate methane and eliminate acid buildup, and methanotrophs that form methane from the decarboxylation of acetate (fig. 3).

Similarly, Zeikus (1981) identified four physiologically different types of bacteria in anaerobic digesters. Initially, hydrolytic bacteria ferment complex hydrocarbons to fatty acids, methanol, carbon dioxide, ammonia, and hydrogen; whereas obligate and facultative hydrogen-producing acetogenic bacteria ferment complex organic acids and neutral compounds to hydrogen, carbon dioxide, and acetic acid (McCarty, 1981). Homoacetogenic bacteria continue to ferment carbon compounds to acetic acid, and methanogenic bacteria ferment $\mathrm{H}_{2} / \mathrm{CO}_{3}$, monocarbon compounds, and acetate to methane.

The landfill environment is similar to the anaerobic digester in that it is a site where organic compounds are mineralized (disintegrated to carbon dioxide, methane, and water); however, the decomposition of organic material in the landfill proceeds by slightly different physical, chemical, and biological processes (Ham and Barlaz, 1987). For example, comminution of the municipal solid waste prior to placement has positive effects upon the biogas generation rate (Naveau, 1984).

Initially, the waste decomposes through aerobic processes in which atmospheric oxygen and nitrogen are consumed within days (phase I, fig. 2) (Barlaz and others, 1989c). Subsequent to placement, there is little change in populations of cellulolytic, acetogenic, and methanogenic

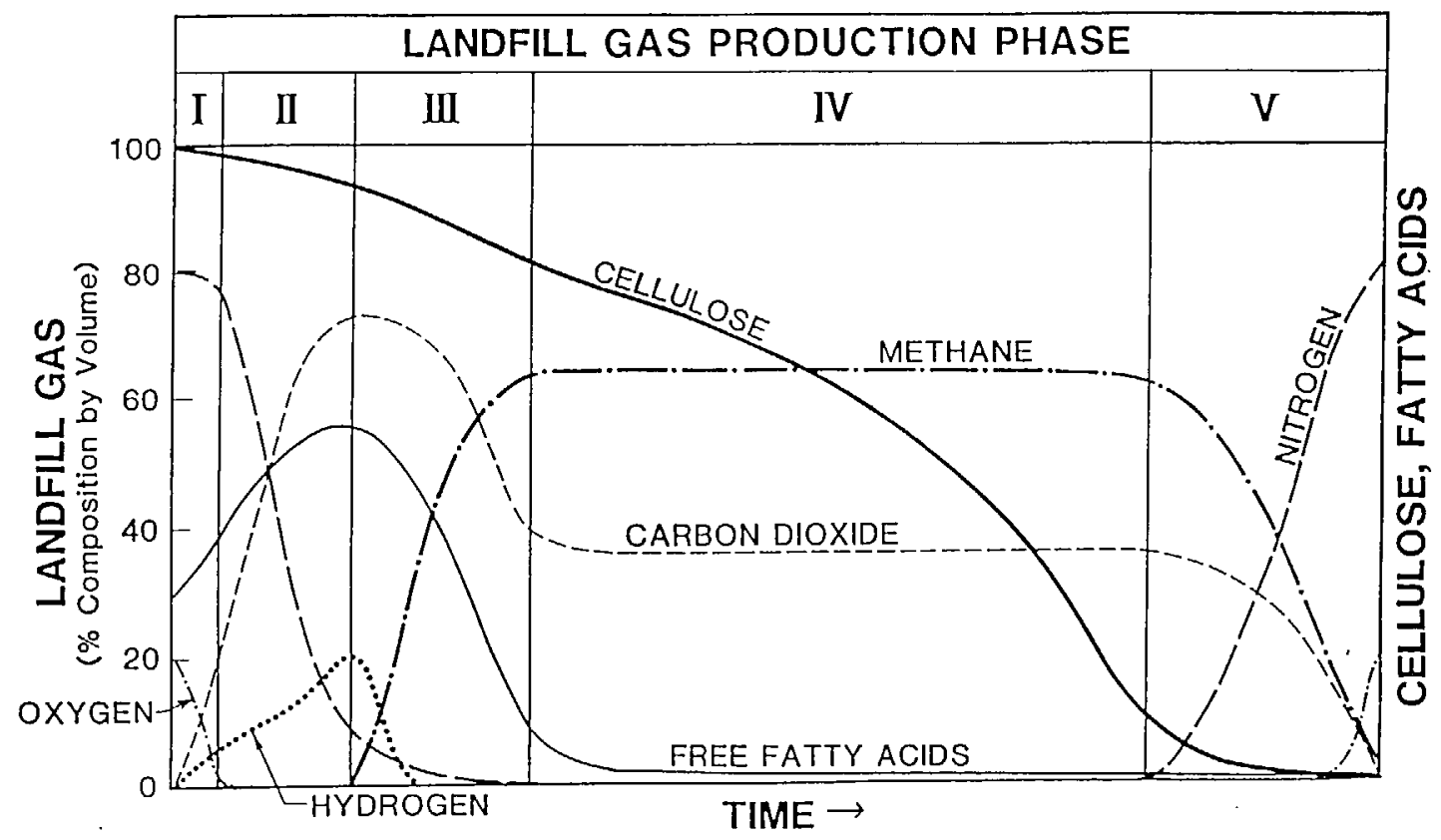

Figure 2. Typical landfill-gas-production pattern (from Farquhar and Rovers, 1973, and Rees, 1980b). The five phases of landfill-gas production (from Ward, 1988) are I, initial adjustment; II, transition in landfill biota; III, acid formation; IV, methane fermentation; and V, final maturation. See text for discussion. 


\section{COMPLEX ORGANIC MATERIAL}

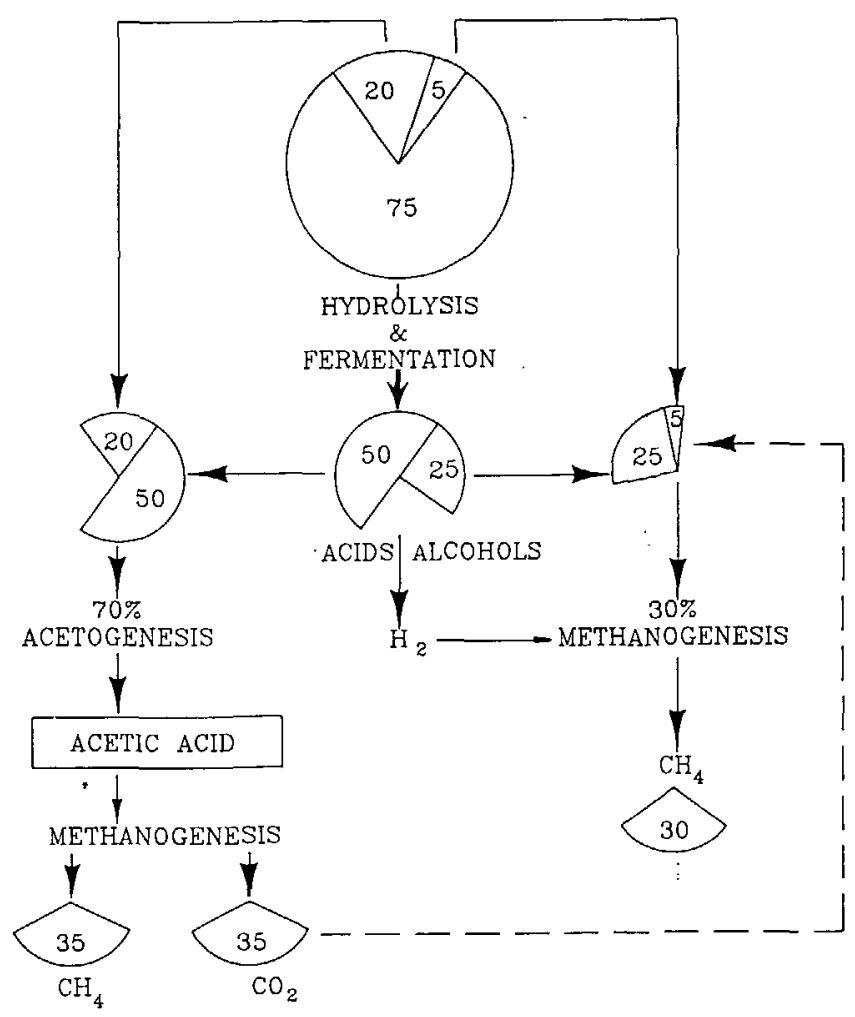

Figure 3. Biodegradation of complex organic material. Anaerobic and facultative anaerobic fermenting bacteria accomplish hydrolysis and fermentation; obligate proton reducing acetogenic bacteria perform acetogenesis; anaerobic chemolithotrophs and methanotrophs affect methanogenesis. Pie charts show inferred percentages of mass transfer. Dashed line indicates a potential pathway.

bacteria, and soluble sugars serve as the carbon source (Barlaz and others, 1992). During the aerobic phase (phase I), complete mineralization of an organic compound can be achieved by one microbial species, invertebrates can effect physical and chemical decomposition, and fungi can contribute to catabolism (Senior and Balba, 1990). Nitrogen is a rate-limiting factor for aerobic bacteria, and this phase generates a considerable amount of water (Senior and Balba, 1990).

The remaining four phases are anaerobic and are characterized by mineralization of organic compounds to carbon dioxide and methane (figs. 2, 3). Cellulose can be completely mineralized to equal volumes of carbon dioxide and methane:

$$
\mathrm{C}_{6} \mathrm{H}_{12} \mathrm{O}_{6}=3 \mathrm{CO}_{2}+3 \mathrm{CH}_{4}
$$

Senior (1990) divided anaerobic catabolism of organic compounds into four pathways; hydrolysis and fermenta- tion, propionogenesis (propionate generation), acetogenesis (acetate generation), and methanogenesis (methane generation). These processes occur together through the anaerobic phases of catabolism; however, some reactions are more active during certain phases.

Phase II is characterized by the presence of a large population of facultative anaerobic organisms that use a variety of inorganic electron acceptors; this phase can last up to 6 months (Ham and Barlaz, 1987). Carboxylic acids accumulate and the $\mathrm{pH}$ drops during the initial stages of phase II; however, catabolism of cellulose and hemicellulose begins and continues through the remaining phases (fig. 2) (Barlaz and others, 1989b). During phase II, hydrolysis and fermentation generate hydrogen, carbon dioxide, ethanol, lactate, and succinate. The generation of hydrogen and the manufacture of fatty acids depress the $\mathrm{pH}$. The lower $\mathrm{pH}$ adversely affects methanogenic bacteria (Augenstein and others, 1976; Westlake, 1990; White and Plaskett, 1981; Zehnder and others, 1981). Nitrogen is depleted from the system while carbon dioxide becomes the volumetrically most abundant gas (fig. 2).

Phase III, the acid formation phase, is noted for dramatic transformations in gas concentrations and is distinguished by the loss of nitrogen and hydrogen, and the initiation of methane generation. Propionogenesis may commence during this phase and consume some of the free hydrogen and consequently raise the $\mathrm{pH}$ (Senior and Balba, 1990). Phase III lasts from 3 months to 3 years, during which methane levels of biogas rise to 50 to 60 percent, carboxylic acid concentrations decline, and the populations of acetogenic, cellulolytic, and methanogenic bacteria increase (Barlaz and others, 1992; Barlaz and others, $1989 \mathrm{~b}, \mathrm{c}$.) At this phase, the waste mass is reaching a steady-state condition for gas generation in which the bacterial populations work symbiotically to maintain adequate conditions for survival of all species (fig. 3).

Methane-generation levels stabilize during the longest of the landfill-gas-generation phases, phase IV. Methanegeneration levels can be maintained at a 45 to 60 percent concentration in the biogas for as long as 80 years (Augenstein and Pacey, 1991; Emcon Associates, 1980). During this phase, population levels of methanogenic bacteria remain stable and the $\mathrm{pH}$ remains buffered (Ward, 1988).

Phase IV is characterized by high concentrations of two types of bacteria: acetogenic and methanogenic. Two types of acetogenic bacteria occur in the waste mass: hydrogen-producing acetogens that gain energy for growth by catabolizing alcohols and organic acids into acetic acid and hydrogen, and hydrogen-consuming acetogens that metabolize carbohydrates, hydrogen, and carbon dioxide to acetic acid (Senior and Balba, 1990). Seventy percent of the methane in the anoxic environment is derived from acetate mediated by methanogenic bacteria (Jeris and McCarty, 1965; Mah and others, 1977; Wolfe, 1982). 
Methanogens also perform a bioregulatory role in the maintenance of fermentation through the conversion of acetic acid, hydrogen, and carbon dioxide to methane; otherwise the $\mathrm{pH}$ would drop and stress the acetogenic bacteria. Senior and Balba (1990) found methanogenic bacteria to be involved in three bioregulatory roles including proton, electron, and nutrient regulation. Proton removal by the methanogenic bacteria maintains the system neutrality and electron regulation produces a thermodynamically stable and reduced carbon compound, methane. Senior and Balba (1990) speculated that methanogenic bacteria supply nutrients to the other species in the system.

The loss of cellulose, carbon dioxide, and methane characterize the final phase of municipal-solid-waste decomposition, phase V (Ward, 1988). During this phase, bacterial populations decrease dramatically and biogas generation declines (Rees, 1980a). Continued abstraction of gas during this phase can ventilate the landfill to atmospheric concentrations. This phase can last between 1 and 40 years. Complete landfill biodegradation can be achieved 10 to 80 years after emplacement.

\section{CONTROLLED REACTOR}

Municipal-solid-waste-containment facilities represent complex bioreactors where bacterial ecosystems are symbiotically maintained when other factors are preserved. Factors that can sustain and stimulate biogas generation are as follows (Barlaz and others, 1990; Farquhar and others, 1979; Ward, 1988): (1) Moisture levels kept at field capacity conditions, (2) leachate recycling, (3) neutral $\mathrm{pH}$, (4) a strongly negative redox potential $(<-200$ millivolts $(\mathrm{mV}))$, (5) mesophilic temperatures, (6) adequate nutrient levels, (7) municipal-solid-waste composition, (8) waste placement and compaction, (9) waste mixing, and (10) size reduction. Zehnder and others (1981) found that many of these factors are rate-limiting for the generation of gas.

Moisture levels at field capacity can significantly improve biogas generation rates (Barlaz and others, 1987; Emcon Associates, 1981a; Ward, 1988; Westlake, 1990). White and Plaskett (1981) found that optimum conditions for methanogenesis occur at saturation levels of greater than 40 percent. DeWalle and others (1978) found the greatest gas production occurred in containers with 99 percent saturation. High moisture levels have two main advantages: (1) water can solubilize and distribute substances and nutrients to the bacteria (Barlaz and others, 1987), and (2) recycling leachate (with neutralization) can substantially improve biogas generation by mixing waste and liquids and by increasing saturation (Barlaz and others, 1989b; Harper and Pohland, 1988; Hartz and Ham, 1983; Klink and Ham, 1982; Leckie and others, 1979; Rees, 1980b).

Methanogenic bacteria are very sensitive to acidic conditions and are stressed below a pH of 6 (Zehnder and others, 1981). Augenstein and others $(1976,1977)$ found that "souring" (reduction of $\mathrm{pH}$ and death of bacteria) occurred when organic acids were generated during catabolism and that methane formation was suppressed by low $\mathrm{pH}$. Buffering the waste with calcium carbonate significantly improves production of biogas. White and Plaskett (1981) contended that the ideal $\mathrm{pH}$ for the generation of biogas is between 6.8 and 7.2. Fortunately, a delicate chemical symbiosis between methanogenic and acetogenic bacteria maintains a buffered $\mathrm{pH}$ (Zeikus, 1983).

Anaerobic reactions occur only when the redox potential is less than $-200 \mathrm{mV}$ (Farquhar and others, 1979). Zehnder (1978) found that bacteria cannot initiate growth at a redox potential higher than $-330 \mathrm{mV}$. Farquhar and others (1979) suggested that a reducing agent, such as cysteine, must be present to initiate low redox conditions. Methanogenic bacteria may have a naturally low redox potential (Hartner, 1990).

Mesophilic or thermophilic conditions are more difficult for bacteria to maintain in anaerobic conditions than in aerobic conditions (White and Plaskett, 1981). However, after exothermic aerobic reactions cease, anaerobiosis is able to maintain mesophilic conditions (Farquhar and others, 1979). Zehnder and others (1981) observed that methanogenic bacteria generate gas under mesophilic conditions of 35 to $45^{\circ} \mathrm{C}$. Pfeffer (1974b) considers the optimum temperature range for biogas generation to be 37 to $42^{\circ} \mathrm{C}$. Hartz and others (1982) concluded from studies on landfill cores that the ideal temperature for biogas generation and for methanogenesis is $41^{\circ} \mathrm{C}$.

Several workers maintain that certain nutrientsnitrates and phosphates-have a rate-limiting effect upon biogas generation (Barlaz and others, 1989b; Farquhar and others, 1979; Ham and Barlaz, 1987; Pohland and others, 1983). Nutrient levels for optimal gas generation expressed as the ratio of chemical-oxygen-demand:nitrogen: phosphorous are 100:0.44:0.08 (Farquhar and others, 1979). Bogner and others (1990) and Bogner (1991) demonstrated that biogas generation can be slightly stimulated by the addition of a comprehensive aqueous nutrient media. Ham and Barlaz (1987) suggested that the heterogeneity of municipal solid waste conceals the nutrient rate-limiting effects, but the apparent zero-order kinetic reaction rates for landfill-gas generation at many landfills suggest that rate limitation is occurring.

Toxic xenobiotic compounds added to the waste mass can have a poisonous effect upon the bacteria that evolve biogas. Chlorinated hydrocarbons, heavy metals, and detergents are poisonous to the methanogenic bacteria (Senior and Kasali, 1990). Prudent disposal mechanisms can help to eliminate these toxic compounds. Wood and others (1986) found that certain toxic compounds are released during anaerobiosis. Vinyl chloride, a bacterial toxin, is generated enzymatically by microbial dehalogenation of halogenated hydrocarbons. 
Municipal-solid-waste composition, placement, and size reduction have beneficial effects upon the generation of biogas. Shredding and comminution of waste exposes more surface area to biodegradation (Augenstein and others, 1977; Rees, 1980b). Westlake (1990) contended that reducing refuse size and increasing density have positive effects on the generation of biogas through better mixing. Sorting, selecting, and mixing of waste improve gas evolution rates (Ham, 1976; Ham, 1992). Cellulose and hemicellulose, ubiquitous compounds in municipal solid waste, readily biodegrade under anaerobic conditions and are ideal waste products; however, cellulose is associated with lignin, a recalcitrant biomolecule (Barlaz and others, 1989a, b, 1992; Young and Frazer, 1987). Maximum gasgeneration rates are achieved through selection, comminution, and compaction; however, excess compaction reduces permeability of the waste mass and thus reduces infiltration and gas-generation rates (Bookter and Ham, 1982; Emcon Associates, 1981a).

\section{LANDFILL BIOGAS}

\section{MIGRATION}

Migration of gas away from landfills has caused numerous problems, including explosions, plant necrosis, and redolent fetor (for example, multiple deaths were associated with the Winston-Salem, N.C., National Guard Armory explosion in 1968). These problems have driven many studies of landfill-gas-generation rates and landfill-gas migration. Gas migration is attributed to molecular diffusion to regions of low gas concentration (Baker and others, 1984; Doyle, 1985; Parker and Roberts, 1985; Young and Parker, 1983). Hartner (1990) found that migration of gas is related to barometric pressure changes and temperature contrasts. Undesired migration of gas prompted the installation of gas recovery systems such as gravel-filled cut-off trenches and gas-abstraction systems (Bogardus, 1984). These recovery efforts, induced by gas-migration problems, have preceded many projects that now exploit the captured biogas.

\section{COMPOSITION}

Cellulose generates biogas in equal concentrations of methane and carbon dioxide (equation 1). Barlaz and others (1989a) found that 91 percent of landfill biogas methane is from biodegradation of cellulose and hemicellulose. The average methane concentration from six landfills in California is $\mathbf{3 0 . 4}$ percent; however, because many of these landfills produce oxygen, the intrusion of air is suspected (Freemon, 1989). Most landfills that follow appropriate abstraction protocols produce a methane concentration of 45 to 55 percent (Emcon Associates, 1980;
Farquhar and others, 1979; Pfeffer, 1974a). Carbon dioxide occurs in slightly lower concentrations, 35-45 percent, possibly due to its high solubility in leachate (Senior and Shibani, 1990).

Additional compounds have been identified in landfill biogas and are attributed to three sources: vaporization, chemical reaction, and biological decomposition (Emerson, 1990). These vapor-phased compounds can be toxic to the microbial populations in the landfill, corrosive to abstraction and processing equipment, and harmful to human health. More than 100 trace vapor-phased chemical compounds identified in landfill biogas are listed in table 3. The condensate associated with abstraction of landfill biogas is composed of two phases, a light organic phase consisting of trace hydrocarbons, and a heavier aqueous phase containing trace elements of dissolved trace compounds (Environmental Protection Agency, 1987).

\section{BIOGAS YIELD}

Zehnder (1978) considered oxygen to be a rate-limiting factor in the growth of strict anaerobes and used the Peter-Nernst oxidation-reduction-potential equation for determining rates of anaerobiosis. Emcon Associates (1981a) applied a modified version of the Monod (1950) kinetic expression to describe the rate of biogas production. Soluble-substrate and bacterial concentrations are the rate-limiting factors that can be set to a first-order kinetic equation for biogas production:

$$
\frac{d s}{d t}=\frac{K C S}{\left(K_{\mathrm{S}}+S\right)}
$$

where $K$ is the maximum rate of substrate utilization per unit mass of bacteria (time ${ }^{-1}$ ); $C$ is the concentration of bacteria (mass/volume); $S$ is the waste concentration surrounding the bacteria (mass/volume); and $K_{\mathrm{S}}$ is the substrate concentration, where the rate is one-half the maximum rate of substrate utilization (mass/volume). Equation 2 has been successfully employed to explain the observed generation rates for biogas (Emcon Associates, 1981a).

Augenstein and Pacey (1991) listed four models for the increase and decline of biogas production through time. The first model is a zero-order model with constant gas-generation rates through time. The second model follows an exponential gas-generation-rate decline from the onset of solid-waste placement. The remaining models include an exponential or constant rise followed by an exponential decline in generation rate. The Emcon model, the methane generation model, includes a lag period prior to a constant rise, followed by an exponential decline in the rate of gas generation. However, Ham and Barlaz (1987) 
Table 3. Trace constituents of landfill gas.

[--., constituent not detected or not determined]

\begin{tabular}{|c|c|c|c|c|c|c|c|c|c|c|c|c|}
\hline 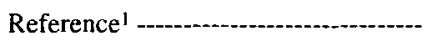 & A & B & $\mathrm{C}$ & $\mathrm{D}$ & $\mathrm{E}$ & $\mathrm{F}$ & $\mathrm{G}$ & $\mathrm{H}$ & I & $\mathrm{J}$ & $\mathrm{K}$ & L \\
\hline Comment $^{2}$ & 2 & 3 & 2 & 2 & 5 & 4 & 6 & 2 & 7 & 2 & 1 & 1 \\
\hline \multicolumn{13}{|c|}{ Trace aliphatic organic compounds (micrograms per liter) } \\
\hline n-BUTANE & --- & $\cdots$ & --- & 30,000 & 9,950 & 9,270 & -.- & 23 & -.. & --- & -- & $\cdots$ \\
\hline BUTENE-1 & --- & --- & -- & 3,000 & -- & $\cdots$ & -- & 21 & -- & $\cdots$ & --- & -- \\
\hline DECANE & --- & --- & --- & --- & --- & $-\ldots$ & --- & $\ldots$ & --- & $\ldots$ & -- & 157 \\
\hline n-DECANE & $\ldots$ & --- & $\ldots$ & 70,000 & --- & --- & --- & 137 & --- & --- & --- & 78 \\
\hline DECENE & $\cdots$ & $\cdots$ & -- & --- & -- & -- & $\cdots$ & $\cdots$ & -- & $\cdots$ & $\ldots$ & 57 \\
\hline DODECANE & -.. & --- & ... & $\ldots$ & --- & --- & --- & 4 & --- & --- & --- & -- \\
\hline ETHANE & --- & $\cdots$ & --- & --- & 802.500 & --- & -.- & -- & --- & $\cdots$ & --- & -- \\
\hline ETHYLENE & --- & --- & -- & -- & $\ldots$ & --- & --- & 31 & --- & --- & -.. & -- \\
\hline HEPTANE & -.- & --- & --- & 10,000 & --- & $\ldots$ & --- & 8 & --- & -.- & $\ldots$ & 6 \\
\hline HEXANE & --- & -- & --- & 75,000 & --- & 7,350 & -- & 11 & -- & -- & --- & 14 \\
\hline n-HEXANE & $\ldots$ & --- & --- & 160,000 & 8,245 & --- & --- & 18 & 7,800 & --- & --- & 13 \\
\hline HEXENE & --- & --- & --- & --. & --- & --- & -. & 6 & -- & $\cdots$ & --- & 3 \\
\hline 2-METHYLHEPTANE & --- & -. & --- & --- & --- & $\cdots$ & --- & 3 & $\cdots$ & $\cdots$ & --- & -- \\
\hline 3-METHYLHEPTANE & --- & -.- & $\ldots$ & --- & --- & ... & --- & 3 & --- & $\ldots$ & ... & --- \\
\hline 2-METHYLHEXANE & --- & $\ldots$ & --- & --- & -- & -.- & --- & 16 & --- & $\ldots$ & --- & --- \\
\hline 3-METHYLHEXANE & -- & -- & --- & --- & -- & --- & $\cdots$ & 13 & --- & -. & -.- & -- \\
\hline 2-METHYLPENTANE & ... & --- & --- & -.. & $\ldots$ & --- & --- & 2 & ... & --- & --- & --- \\
\hline 3-METHYLPENTANE & -- & -- & --- & --- & $\ldots$ & -- & --- & 2 & --- & -- & --- & $\ldots$ \\
\hline NONANE & $\cdots$ & --- & -- & $\cdots$ & -. & --- & --- & $\cdots$ & -- & -- & -- & 63 \\
\hline NONENE & --. & $\ldots$ & ... & --- & -.. & $\ldots$ & -.- & --- & --- & --- & --- & 12 \\
\hline n-NONANE & --- & --- & --- & 50,000 & --- & --- & -- & 400 & --- & --- & --- & 46 \\
\hline OCTANE & --- & --- & --- & --- & --- & --- & -.. & --- & --- & -- & --- & 11 \\
\hline n-OCTANE & --- & --- & --- & 110,000 & --- & --- & $\ldots$ & 75 & --- & --- & --- & 11 \\
\hline OCTENE & $\ldots$ & $\cdots$ & --- & -- & -.- & --- & -- & --- & -.- & -.. & --- & 4 \\
\hline iso-PENTANE & -- & -.- & -- & 250 & --- & $\ldots$ & --- & $\ldots$ & --- & --- & -- & 4 \\
\hline n-PENTANE & --. & --- & --- & 46,000 & 2,968 & 8,480 & --- & 12 & ... & ...- & --. & --- \\
\hline PROPANE & -- & $\cdots$ & ... & $\ldots$ & 29.000 & 19,410 & --- & 10 & --- & --- & -- & --- \\
\hline PROPENE & -.- & --- & -- & -.- & --. & -.- & 83 & --- & -.- & --- & ... & --- \\
\hline TERPENE & -- & --- & --- & --- & -- & --- & -- & -- & --- & -- & --- & 84 \\
\hline TRIDECANE & $\ldots$ & --- & --- & --- & -- & --- & --- & 1 & -- & -- & --- & -- \\
\hline UNDECANE & -.- & $\ldots$ & -.- & --- & $\ldots$ & $\ldots$ & -.- & $\ldots$ & --- & -. & -.. & 82 \\
\hline $\mathrm{n}$-UNDECANE & -- & --- &.- & 72,000 & --- & --- & $\ldots$ & 48 & --- & $-\infty$ & --- & 31 \\
\hline UNDECENE & --- & $\ldots$ & ... & --- & --- & --- & ... & --- & --- & $\cdots$ & -.. & 44 \\
\hline
\end{tabular}

Trace acids, esters, ketones, ethers, and alcohols (micrograms per liter)

\begin{tabular}{|c|c|c|c|c|c|c|c|c|c|c|c|c|}
\hline 1-BUTANOL & $\cdots$ & $\cdots$ & --- & -- & --- & $-\cdots$ & --- & $\cdots$ & -- & -- & --- & 19 \\
\hline iso-1-BUTANOL & --- & -.- & $\ldots$ & -- & $\cdots$ & --- & --- & --- & --- & --- & -- & 5 \\
\hline 2-BUTANOL & --- & $\rightarrow$ & --- & -- & --- & --- & $\ldots$ & --- & -- & --- & $\cdots$ & 116 \\
\hline ETHANOL & -- & --- & -- & --- & --- & --- & --- & --- & --- & -- & $\cdots$ & 650 \\
\hline METHANOL & $\cdots$ & --- & --- & --- & --- & --- & -- & $\cdots$ & 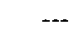 & --- & --- & 210 \\
\hline 1-PROPANOL & -- & --- & --- & $\cdots$ & $\ldots$ & $--\cdot$ & --- & --- & -- &.- & --- & 73 \\
\hline 2-PROPANOL & --- & --- & $-\cdots$ & 2,500 & --- & $\ldots$ & $--\cdot$ & --- & & --- & --- & 32 \\
\hline ACETONE & $\ldots$ & --- & -- & 240,000 & --- & 8,940 & -- & $\cdots$ & 4,800 & +- & --- & --- \\
\hline 2-HEXANONE & --- & 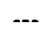 & $\cdots$ & 1,000 & --- & --- & --- & --- & --- & -- & -- & -- \\
\hline METHYL ETHYL KETONE & --- & --- & --- & 130,000 & --- & 1,030 & --- & --- & -- & --- & --- & 23 \\
\hline METHYL ISOBUTYL KETONE & -- & --- & --- & $1,200,000$ & -- & 1.950 & --- & -- & $\cdots$ & --- & --- & -- \\
\hline 2-PENTANONE & -- & $--\cdot$ & $-\cdots$ & -- & --- & $\cdots$ & $\ldots$ & $-\cdots$ & -- & --- & $-\cdot-$ & 17 \\
\hline ETHYL ACETATE & -- & -- & $\bar{\cdots}$ & 4,500 & --- & $\cdots$ & $\ldots$ & $\cdots$ & -- & -- & -- & 36 \\
\hline ETHYL BUTANOATE & --- & --- & --- & -- & --- & --- & --- & $\cdots$ & $\ldots$ & -- & -- & 10 \\
\hline ETHYL PENTANOATE & --- & 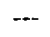 & -- & $\cdots$ & -- & --- & --- & -- & -- & --- & $\cdots$ & 27 \\
\hline METHYL ACETATE & --- & -- & --- & 5,000 & -- & --- & --- & --- & -- & --- & $\cdots$ & --- \\
\hline METHYL PENTANOATE & $\cdots$ & --- & --- & --- & --- & --- & -- & --- &.-- & --- & --- & 22 \\
\hline VINYL ACETATE & $\ldots$ & --- & $-\cdots$ & 240,000 & $-\infty$ & $\cdots$ & $\ldots$ & $-\cdots$ & -- & -- & --- & -- \\
\hline DIETHYL ETHER & $\cdots$ & -- & --- & 2,200 & -- & $\cdots$ & $\cdots$ & -+- & -- & -- & --- & 20 \\
\hline METHYL ISOPROPYL ETHER & $\cdots$ & --- & --- & 2,500 & $+\cdots$ & $\cdots$ & -- & --- & $\cdots$ & -- & --- & --- \\
\hline TETRAHYDROFURAN & +- & --- & $--\cdot$ & 50,000 & $\cdots$ & $\cdots$ & -- & --- & -- & $\cdots$ & --- & --- \\
\hline
\end{tabular}

See footnotes at end of table. 
Table 3. Trace constituents of landfill gas-Continued.

\begin{tabular}{|c|c|c|c|c|c|c|c|c|c|c|c|c|}
\hline 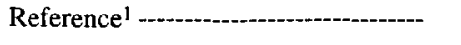 & A & B & $\mathrm{C}$ & D & $\mathrm{E}$ & F & G & $\mathrm{H}$ & I & $\mathrm{J}$ & $\mathbf{K}$ & $\mathrm{L}$ \\
\hline 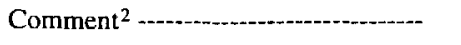 & 2 & 3 & 2 & 2 & 5 & 4 & 6 & 2 & 7 & 2 & 1 & 1 \\
\hline \multicolumn{13}{|c|}{ Trace aromatic and cyclic compounds (micrograms per liter) } \\
\hline BENZENE & 11,000 & 2,500 & 6,540 & 39,000 & 2,700 & 3,640 & 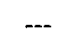 & $\cdot 7$ & 2,000 & 32,000 & -- & 4 \\
\hline $\begin{array}{l}\text { BICYCLO }(3,2,0) \text { HEXANO-2,2- } \\
\text { METHYL-4-METHYLETHYLENE }\end{array}$ & --- & -- & --- & -- & --- & --- & --- & 153 & --- & --- & --- & --- \\
\hline $\begin{array}{l}\text { BICYCLO }(3,2,1) \text { OCTANO- } \\
\text { 2,3-METHYL-4-METHYLENE }\end{array}$ & $\cdots$ & -- & --- & --- & --- & --- & -- & 350 & --- & -- & --- & $-\cdots$ \\
\hline BUTYL BENZENE & $-\ldots$ &.-- & --- & --- & --- & --- & --- & --- & --- & -- & --- & 78 \\
\hline CAMPHOR/FENCHONE & --- & --- & --- & 2,000 & --- & -.. & -- & --- & --- &.-- & $\ldots$ & 8 \\
\hline ETHYL BENZENE & 98,000 &.-- & --- & 87,500 & 12,425 & 21,940 & 99 & 236 & 6,200 & --- & --- & 20 \\
\hline ETHYLCYCLOPENTANE & --- & --- & -.- & 5,000 & --- & --- & $\ldots$ & --- & --- & --- & --- & -.. \\
\hline LIMONENE & --- & --- & --. & -- & --- & --- & --- & -.- & $\ldots$ & --- & --- & 119 \\
\hline MESITYLENE & $\cdots$ & $\cdots$ & -- & -- & $\cdots$ & $\ldots$ & $\cdots$ & 25 & -.- & --- & $\ldots$ & --- \\
\hline METHYL STYRENE &.- & --- & --- & --- & $-\cdots$ & --- & --- & --- & -.. & $-\ldots$ & $\ldots$ & 15 \\
\hline METHYLCYCLOHEXANE & -.. & --- & --- & 45,000 & --- & --- & $\ldots$ & --- & 7,200 & --- & -.- & $\ldots$ \\
\hline METHYLCYCLOPENTANE & --- & --- & --- & 7,500 & --- & $-\cdots$ & --- & --- & -- & --- & --- & $\cdots$ \\
\hline PENTYL BENZENE & --- & --- & --- & -- & --- & --- & --- & --- & --- & -- & --- & 17 \\
\hline PROPYL BENZENE & --. & --- & --- & --- & --- & --- & $\cdots$ & --- & --- & -.- & $\cdots$ & 94 \\
\hline PROPYL CYCLOHEXANE & --- & --- & --- & -- & --- & --- & $\ldots$ & --- & --- & $\cdots$ & --- & 4 \\
\hline STYRENE & 2,000 & --- & --- & 150,000 & --- & --- & -.. & --- & --- & - & --- & $\cdots$ \\
\hline TOLUENE & 143,000 & --- & -.- & 280,000 & 67,750 & 57,750 & 135 & 615 & 27,000 & 150,000 & --- & 58 \\
\hline XYLENE & 220,000 & ... & --- & 94,000 & 35,500 & 18,000 & 208 & 376 & 16,000 & --- & --- & 56 \\
\hline
\end{tabular}

\begin{tabular}{|c|c|c|c|c|c|c|c|c|c|c|c|c|}
\hline \multicolumn{13}{|c|}{ Trace halogenated hydrocarbons (micrograms per liter) } \\
\hline CARBON TETRACHLORIDE & 42,000 & 11 & 2,100 & 60 & --. & 6,220 & -.. & 1 & --- & --- & -.- & -.- \\
\hline CHLOROBENZENE & 330 & --- & --- & 1,350 & 473 & 2,020 & --- & 1 & --- & -.- & --- & --- \\
\hline CHLORODIFUOROMETHANE & --- & ... & --- & --- & 1,760 & 2,810 & --. & --- & --- & $\ldots$ & --- & $\ldots$ \\
\hline CHLOROETHANE & -- & --- & --- & 30,000 & 473 & 1,970 & -- & 264 & -.. & --- & --- & -- \\
\hline CHLOROFLUOROMETHANE & $\ldots$ & -... & --- & 10,000 & $\ldots$ & --- & $\ldots$ & --- & -.- & --- & ... & $\ldots$ \\
\hline CHLOROFORM & 70,000 & 360 & 3,260 & 12,000 & 2,500 & 350 & --- & 2 & ... & 610 & 42 & --- \\
\hline CHLOROMETHANE & -- & --- & --- & 23,000 & 5,740 & 3,720 & --- & $\ldots$ & --- & --- & -.. & -- \\
\hline CHLOROTRIFLUOROMETHANE & --- & -.. & --- & --- & -.- & -.- & -.. & 10 & --- & --- & --- & ... \\
\hline DICHLOROBENZENE & 130 & --. & $\cdots$ & 750 & --- & $\ldots$ & --- & --- & --- & --- & --- & 16 \\
\hline 1,1-DICHLOROETHANE & --- & $-\cdots$ & --- & 22,000 & 2,615 & 4,240 & -.. & --- & --- & -- & --- & -- \\
\hline 1,2-DICHLOROETHANE & 1,600 & 600 & 6,000 & 2,100 & 89 & 2,320 & 652 & 294 & 4,200 & 19,000 & --- & --- \\
\hline 1,1-DICHLOROETHENE & --- & --. & -. & 4,000 & 310 & 370 & --- & $\ldots$ & 800 & $\ldots$ & --- & -.- \\
\hline c-1,2-DICHLOROETHENE & -.. & --- & -.. & 20,000 & $\ldots$ & --- & --- & $\ldots$ & --- & --- & --- & --- \\
\hline t-1,2-DICHLOROETHENE & 37,000 & -.. & --- & 850 & 475 & 6,900 & $\ldots$ & --- & 9,100 & 59,000 & 22 & ... \\
\hline DICHLORODIFLUOROMETHANE & 49,000 & ..- & --- & --- & 130 & 16,440 & -- & 119 & --- & --- & --- & 23 \\
\hline DICHLOROFLUOROMETHANE & --- & --- & --- & 7,500 & 6,913 & 1,400 & $\ldots$ & $\ldots$ & --- & --- & --- & $\cdots$ \\
\hline DICHLOROMETHANE & 42,000 & --- & ... & 630 & --- & ..- & ... & --- & --- & --- & 33 & $\ldots$ \\
\hline 1,2-DICHLOROPROPANE & --- & --- & --. & 280 & 123 & 350 & 61 & --- & --. & --- & --- & $\ldots$ \\
\hline DICHLOROTETRAFLUOROETHANE & $\cdots$ & --- & --- & 900 & --- & -- & --- & --- & --- & -- & --- & -- \\
\hline DICHLOROTRIFLUOROETHANE & --- & --- & --- & 50,000 & --- & --- & --- & $\ldots$ & --- & --- & --- & --- \\
\hline ETHYLENE DIBROMIDE & --- & 4 & 6 &.-- & --- & --- & ... & --- & --. & -- & -.. & --- \\
\hline METHYLENE CHLORIDE & --- & 4,800 & 59,000 & --- & 16,125 & 19,310 & --- & 6 & 32,000 & -- & --- & --- \\
\hline PERCHLOROETHYLENE & 62,000 & 1,100 & 52,000 & 180,000 & 19,875 & 8,290 & -.- & 142 & 11,000 & 19,000 & 170 & 3 \\
\hline 1,1,2,2-TETRACHLOROETHANE & 500 & --- & --- & 16,000 & 110 & 1,100 & ... & --- & --- & -.- & $\ldots$ & -- \\
\hline 1,1,1-TRICHLOROETHANE & 15,000 & 650 & 12,000 & 14,500 & 353 & 1,110 & --- & 4 & 1,800 & 3,600 & 7 & 18 \\
\hline 1,1,2-TRICHLOROETHANE & 9,300 & --- & -- & 8,500 & -- & --- & -- & --- & $\ldots$ &.- & --- & -- \\
\hline TRICHLOROETHENE & 4,600 & 840 & 11,000 & 32,000 & 5,475 & 3,880 & --- & 182 & 3,100 & 13,000 & 92 & 11 \\
\hline TRICHLOROFLUOROMETHANE & --- & -.. & $\cdots$ & - & 428 & 960 & $\cdots$ & 84 & 2,500 & --- & --- & -- \\
\hline VINYL CHLORIDE & -- & 2,200 & 41,000 & 32,000 & 3,750 & 7,720 & --- & $\cdots$ & 6,900 & 44,000 & -- & -- \\
\hline \multicolumn{13}{|c|}{ Trace sulfur compounds (micrograms per liter) } \\
\hline BUTYLPROPYLDISULPHIDE & --- & --- & --- & --- & --- & --- & --- & $\ldots$ & --- & --- & 3 & --- \\
\hline CARBON DISULFIDE & --- & ... & --. & 3,400 & --- & --- & -.. & $\ldots$ & --. & --- & & --- \\
\hline DIETHYL DISULPHIDE & --- & --- & --- & -- & --- &..- & -- & --- & --- & -- & 3 &.- \\
\hline DIMETHYL DISULPHIDE & $\cdots$ & $\cdots$ & -- & --- & $\ldots$ & --- & $\ldots$ & -.- & $\ldots$ & --- & 30 & 40 \\
\hline
\end{tabular}

See footnotes at end of table 
Table 3. Trace constituents of landfill gas-Continued.

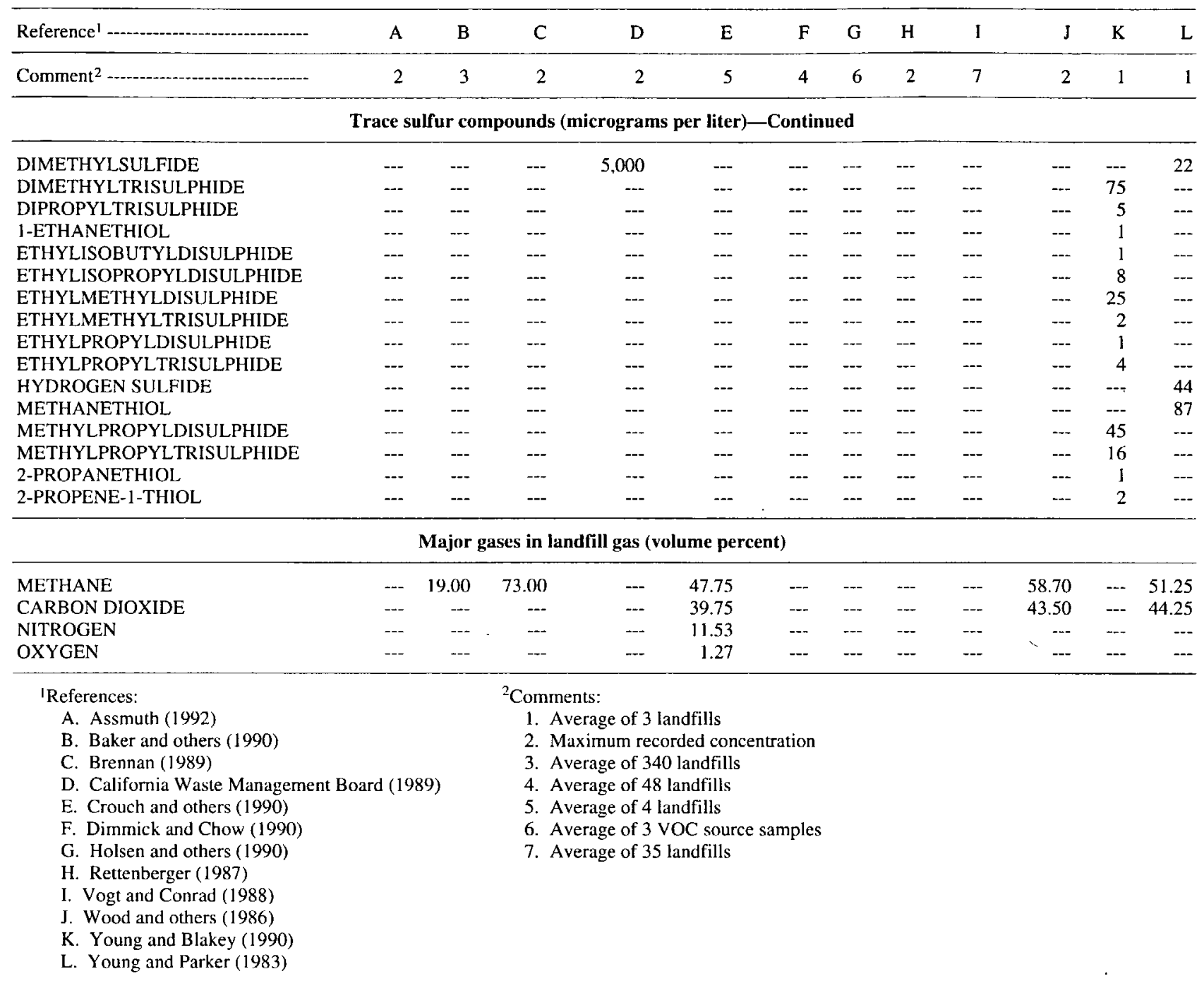

concluded that rate-limiting factors may lower biogas generation to fit a zero-order kinetic expression.

Landfill-gas-generation rates and volumes are predicted from experimental, theoretical, and field data (table 4). A review of these data indicates that the many disparate variables and methodologies have produced a wide range of predicted rates and volumes for methane and biogas production. Maxwell (1990) referred to an industry production rate for 36 biogas-to-electricity projects in the United States of $0.006 \mathrm{~m}^{3} \mathrm{~kg}^{-1} \mathrm{yr}^{-1}$. Ham (1979) reviewed the literature and found the range for gross production to be 0.047 to $0.45 \mathrm{~m}^{3} \mathrm{~kg}^{-1}$, or approximately $0.28 \mathrm{~m}^{3} \mathrm{~kg}^{-1}$, and the generation rate to range from 0.0026 to $0.0307 \mathrm{~m}^{3} \mathrm{~kg}^{-1} \mathrm{yr}^{-1}$. Ham concluded that a yearly rate of $0.005 \mathrm{~m}^{3} \mathrm{~kg}^{-1} \mathrm{yr}^{-1}$ is a good working estimate for landfill biogas generation in the United States (R.K. Ham, oral commun., 1989). I will use this figure to calculate global annual landfill biogas emissions.

\section{GLOBAL LANDFILL BIOGAS PRODUCTION RATES}

Predictions of municipal-solid-waste biogas generation volume and rates are difficult to produce because waste is continuously placed into landfills over time, gas flux occurs during and after placement, and gas generation is based upon many physical parameters that vary spatially and temporally. Consequently, the exponential rise and fall of landfill-gas generation (first-order kinetic reaction) is normally amortized over 10 to 80 years.

Globally, approximately $1,000 \times 10^{6}$ metric tons of organic waste are placed in landfills every year. If completely biodegraded at a rate of $0.28 \mathrm{~m}^{3}$ of biogas per kilogram, municipal solid waste has the potential to produce approximately $2.8 \times 10^{11} \mathrm{~m}^{3}$ of biogas $(9.9$ Tef or $1.98 \times 10^{8}$ metric tons). Assuming a 50-percent methane concentration in the biogas mixture, $1.4 \times 10^{11} \mathrm{~m}^{3}(5 \mathrm{Tcf}$ or 
Table 4. Methane and biogas production from landfill biodegradation.

$\left[\mathrm{m}^{3} / \mathrm{m} . \mathrm{t}\right.$, cubic meters of methane or biogas generated per metric ton of degradable waste; $\mathrm{m}^{3} / \mathrm{kgyr}$, cubic meters of methane or biogas generated per kilogram of waste per year; MSW, municipal solid waste; UK, United Kingdom; -.., not determined]

\begin{tabular}{|c|c|c|c|c|c|}
\hline \multicolumn{2}{|c|}{ Methane } & \multicolumn{2}{|c|}{ Biogas } & \multirow[b]{2}{*}{ Reference } & \multirow[b]{2}{*}{ Comment } \\
\hline $\begin{array}{c}\text { Gross } \\
\left(\mathrm{m}^{3 / m} \cdot \mathrm{t} .\right)\end{array}$ & $\begin{array}{c}\text { Rate } \\
\left(\mathrm{m}^{3} / \mathrm{kgyr}\right)\end{array}$ & $\begin{array}{c}\text { Gross } \\
\left(\mathrm{m}^{3} / \mathrm{m} \cdot \mathrm{t} .\right)\end{array}$ & $\begin{array}{c}\text { Rate } \\
\left(\mathrm{m}^{3} / \mathrm{kgyr}\right)\end{array}$ & & \\
\hline \multicolumn{6}{|c|}{ Experimental data } \\
\hline 130 & --- & -- & --- & Augenstein and others (1976) & $\begin{array}{l}\text { Conventional continuously stirred tank of dry sludge/waste } \\
\text { solids with calcium hydroxide. }\end{array}$ \\
\hline 128 & --- & $\cdots$ & - & Augenstein and others (1976) & $\begin{array}{l}\text { Conventional continuously stirred tank of dry sludge/waste } \\
\text { solids with calcium carbonate. }\end{array}$ \\
\hline 95 & $\cdots$ & --- & --- & Augenstein and others (1976) & $\begin{array}{l}\text { Conventional continuously stirred tank of sludge/waste } \\
\text { solids with calcium carbonate. }\end{array}$ \\
\hline 104 & --- & --- & -- & Augenstein and others (1977) & Shredded MSW and sludge in buffered packed-bed digester. \\
\hline 9.5 & --- & --- & --- & Augenstein and others (1977) & Shredded MSW in buffered packed-bed digester. \\
\hline $80-150$ & $0.0007-0.128$ & --- & --- & Barlaz and others (1987) & Dry grindable solids with anaerobic sewage sludge. \\
\hline $142.5-208$ & $\cdots$ & --- & --- & Barlaz and Ham (1990) & Gas recovery from labtop experiments. \\
\hline--- & -- & $310-390$ & --- & Brown and others (1976) & Organic fraction of MSW in laboratory digesters. \\
\hline$-\cdots$ & -- & $0-816.8$ & -- & Buivid (1980) & $\begin{array}{l}\text { Flailed, shredded, and ball-milled MSW in controlled } \\
\text { lysimeter. }\end{array}$ \\
\hline--- & $\cdots$ & $\cdots$ & 0.066 & DeWalle and others (1978) & MSW in laboratory lysimeters. \\
\hline--- & --- & $80-320$ & --- & Naveau (1984) & Reported laboratory tests. \\
\hline 94.2 & --- & 188.4 & --- & Pfeffer (1974) & Calculated from a digester with shredded refuse. \\
\hline \multicolumn{6}{|c|}{ Field data } \\
\hline$-\cdots$ & $0.005-0.009$ & -- & --- & Campbell and Croft (1990) & Test cells with 15,000 metric tons of MSW. \\
\hline$\cdots$ & -- & -- & 0.04 & Jenkins and Pettus (1985) & Incubation of landfill cores. \\
\hline-- & --- & --- & $0.01-0.025$ & Lawson and others (1991) & Test cell at Brogborough, UK. \\
\hline--- & $\ldots$ & 282.6 & 0.006 & Maxwell (1990) & Waste Management Inc. working field number. \\
\hline $37.7-94.2$ & --- & --- & --- & Pacey and others (1987) & Landfill cell at Mountain View, Calif., landfill. \\
\hline-- & 0.038 & --- & 0.098 & Rees $(1980)$ & Rates from Aveley (UK) landfill. \\
\hline--- & -- & $\cdots$ & $0.0025-0.0088$ & Wilke and others (1982) & Calculated from actual landfill production. \\
\hline$\cdots$ & -- & $217-418$ & --- & Willumsen (1990) & Tested cells of 240 metric tons (Denmark). \\
\hline \multicolumn{6}{|c|}{ Theoretical data } \\
\hline 213.5 & -- & 427 & -- & Alpern (1973) & Stoichiometric calculation. \\
\hline 244.9 & $\ldots$ & 414.5 & --- & Anderson and Callinan (1970) & Stoichiometric calculation. \\
\hline $62-110$ & -- & --- & --- & Augenstein (in press) & Generation model from Emcon Association. \\
\hline $62-125$ & --- & --- & --- & Augenstein and Pacey (1991) & Modelled from actual landfills. \\
\hline $77-107$ & --- & --- & --- & Barlaz and Ham (1990) & Calculated methane generation. \\
\hline 77.9 & - & 155.7 & --- & Dair and Schwegler (1974) & Biodegradability calculations. \\
\hline $62.8-188.4$ & $\cdots$ & $\cdots$ & -- & Emcon Association (1981) & First-order equations of submasses in the waste mass. \\
\hline $62.8-113$ & --- & --- & $\cdots$ & Emcon Association (1986) & First-order equations $/$ reference trade use of $188.2 \mathrm{~m} 3 / \mathrm{m}$.t.. \\
\hline 175.8 & --- & 207.6 & --- & Golueke (1970) & Calculations of biodegradability. \\
\hline 232.4 & --- & 358.1 & $-\cdots$ & Leckie (1974) & Stoichiometric calculations for food/paper waste. \\
\hline 270 & -. & 425.2 & --- & Leckie (1974) & Stoichiometric calculations for composited MSW. \\
\hline-- & 0.008 & $\cdots$ & -- & $\begin{array}{l}\text { Pennsylvania Dept. of Environ- } \\
\text { mental Resources (1989) }\end{array}$ & Estimation by Commonwealth of Pennsylvania. \\
\hline 125.6 & --- & 251.2 & --- & Pfeffer (1974) & Theoretical calculation. \\
\hline 415 & --- & 830 & -- & Ward (1988) & Stoichiometric calculation from cellulose. \\
\hline
\end{tabular}


$9.9 \times 10^{7}$ metric tons) of methane will evolve over time. On the basis of Ham's generation rate of $0.005 \mathrm{~m}^{3}$ of biogas per kilogram of organic waste per year, every year, $5 \times 10^{9}$ $\mathrm{m}^{3}$ (176 billion cubic feet (Bcf) or $3.5 \times 10^{6}$ metric tons) of biogas will evolve from municipal-solid-waste-containment systems and be added to the annual atmospheric budget.

Large modern municipal-solid-waste-containment systems with strong biogas-generation potential are a modern phenomenon. As a starting point, assume that biogas generation started only 20 years ago and that steady-state conditions (zero-order kinetic reaction rate) have prevailed for landfill-gas generation for the last 20 years. Consequently, we can estimate the cumulative yearly rate of methane generation by multiplying the annual global rate by 20 . This calculation yields an estimate of $10 \times 10^{10} \mathrm{~m}^{3}$ (3.6 Tcf or $72 \times 10^{6}$ metric tons) of biogas or $5 \times 10^{10} \mathrm{~m}^{3}(1.8 \mathrm{Tef}$ or $36 \times 10^{6}$ metric tons) of methane that could evolve globally from landfills this year.

Augenstein (1990) calculated through first-order kinetics that landfills in the United States generate 3 to $8 \mathrm{mil}-$ lion metric tons $(0.15-0.40 \mathrm{Tcf})$ of methane per year. Hutchinson (1990, 1991), through a zero-order kinetic model, calculated that 12 million metric tons $(0.6 \mathrm{Tcf})$ of methane per year are available from landfills in the United States. Colt and others (1990) estimated that the yearly methane emissions for the municipal solid waste in the United States are 8 to 11 million metric tons $(0.4-0.55$ Tcf). Bingemer and Crutzen (1987) imprudently assumed that all municipal solid waste generated yearly completely biodegrades yearly and, consequently, that 50 million tons ( $2.5 \mathrm{Tcf}$ ) of methane are emitted yearly to the atmosphere from all landfills. In reality, municipal solid waste generates biogas through time, and thus each year's volume of waste contributes only a portion of its generative capacity to the atmosphere.

Municipal-solid-waste-disposal rates, biodegradation rates, organic concentration, and numerous other factors dictate that these generation rates and gross generation values are nothing more than best guesses for global methane production. Recoverable energy from landfills could range between 1 and 2 percent of the total United States' energy use (Environmental Protection Agency, 1991; Dair and Schwegler, 1974). In effect, methane from landfills could supply 11 percent of the United States' current demand for natural gas (Pfeffer, 1974a).

\section{BIOGAS EXPLOITATION}

Landfill-gas recovery and exploitation is expensive and is driven by the energy economics or politics of the time (fig. 4). A steep, upward trend in the number of landfill-gas-recovery projects began in 1984. The increase in projects followed large increases in oil prices between 1980 and 1981. The 4-year time lag reflects the design, construction, and start-up time from the initial impetus (rise in cost of energy). The sagging energy prices of the late 1980's also prompted a decline in the growth in number of recovery projects. Currently, there are 157 landfillmethane-recovery projects (128 operational) in the United States (Berenyi and Gould, 1991). Richards and Aitchison (1990) indicated that 242 landfill-gas-recovery projects exist in 20 countries around the world, and that 78 percent of these are in the United States.

Four strategies for the exploitation of biogas are as follows: (1) raw gas sale to an end-user, (2) medium-Btu (British thermal unit) gas sales, (3) high-Btu-gas sales, and (4) chemical feedstock supply. Raw landfill gas, with its high, heat-robbing moisture content, is rarely used because of the low energy value ( $<400$ Btu per cubic foot) and high corrosivity and erosivity of the trace compounds (Zimmerman and others, 1985). Dehydration of the gas raises the energy value, and many projects are based on this strategy, including most electric-generation projects (Berenyi and Gould, 1991).

High-energy-gas recovery strategies include dehydration and stripping carbon dioxide and trace gases from the biogas. Hutchinson (1989) listed seven gas-separation techniques: (1) chemical absorption, (2) physical absorption, (3) chemical adsorption, (4) physical adsorption, (5) partial pressure separation, (6) distillation/dehydration, and (7) cryogenic fractionation. Physical absorption is considered the most economical technology for turning raw landfill gas into relatively pure methane (C-E Lummus and SCS Engineers, 1983; Keller, 1988; Zimmerman and others, 1985). Additional strategies can be employed after the gas is refined, such as compression for vehicular fuel (Augenstein and Pacey, 1992).

Biogas as a chemical feedstock is becoming a reality with the discovery of different catalysts. Lithium-promoted

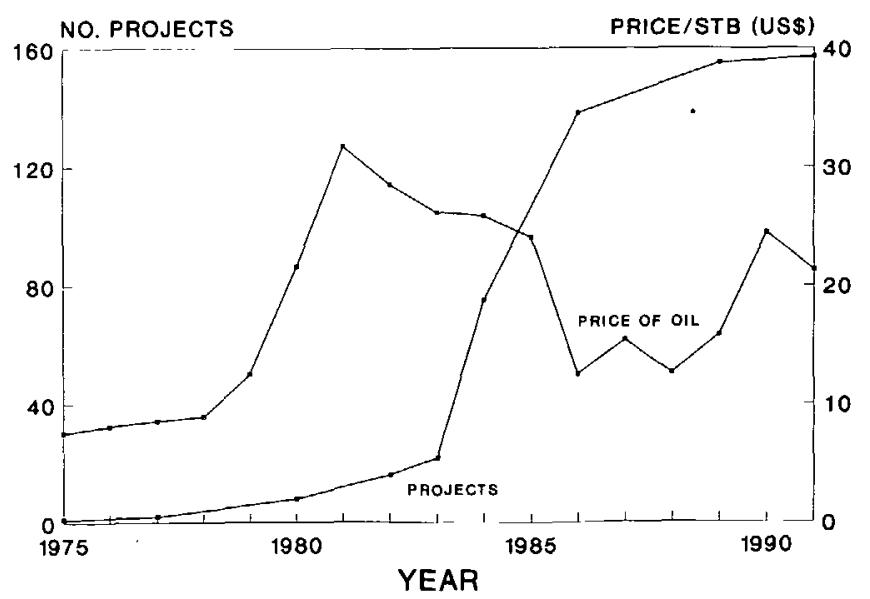

Figure 4. Cumulative U.S. landfill-gas-recovery projects and average yearly published price of oil in stock-tank barrels (STB) (yearly average crude price: written commun., American Association of Petroleum Geologists, 1993). See text for discussion. 
magnesium oxide can catalyze the partial oxidation of methane in a conventional flow reactor to make ethane and ethylene (Ito and others, 1985). Periana and others (1993) describe a successful method using methyl bisulfate to catalyze the oxidation of methane to methanol. High-energy fuel from biogas may be available through the generation of synfuel (Hickman and Schmidt, 1993) and diesel fuel (Thorneloe, 1990; Wald, 1991).

Biogas can be used as a low-energy gas to heat a greenhouse, with the advantage that the elevated carbon dioxide levels encourage plant growth (Graff, 1989; Miller and Quinn, 1990). Controlled oxidation of biogas can also produce carbon dioxide in economic quantities (Hutchinson, 1989).

Perhaps the best strategy for biogas exploitation is to generate the gas through selective disposal into controlledreactor landfills (Ham, 1992). Richards and Aitchison (1990) introduced the term "biofills" for landfills designed to optimize methane generation by recycling leachate and having internal permeable corridors. Biofill methane-generative capacity can also be ameliorated through the use of horizontal gas collectors and dispersers (Glockner, 1989). The horizontal dispersers are designed to reinject carbon dioxide, water, buffers, and nutrients into the landfill material. All of these strategies can reduce the gas-generation time from between 20 to 80 years to 5 years or less (Augenstein and Pacey, 1992).

Anaerobic biological digestion of organic materials has been economically demonstrated in reactor gasifiers (Levy and Rigo, 1976). Two-step anaerobic sludge blankets employ acid fermentation followed by methane fermentation and can yield 75 percent of the ultimate biogas yield in an operating time of 20 to 30 days (Lagerkvist, 1991; Rijkens and Voetberg, 1981). High-solids digestion systems are the most promising of the anaerobic digestion options because they are compact and have the best prospects for producing useful refined digestate products (Mosey and Mistry, 1990). Lynd and others (1991) found that conversion of municipalsolid-waste cellulose to ethanol can be cost effective.

\section{CONCLUSIONS}

Landfill gas is a resource that has reached a level of understanding and exploitation only within the last decade. Landfills are always associated with urbanized areas, thus the gas is spatially near potential applications. Highly urbanized areas generate large volumes of waste that can be biodegraded to biogas. Anaerobic digestion of the organic phase of Municipal solid waste can reduce the volume of waste, produce a more inert and environmentally favorable product, and help reduce the load on the world energy budget. Capturing the gas for exploitation reduces the greenhouse gas emission by (1) replacing another carbon dioxide-generating energy source and thereby reducing the carbon dioxide load to the atmosphere and (2) reducing the methane load to the atmosphere (methane's contribution as a greenhouse gas is 25 times greater than that of carbon dioxide on a mole percent basis).

The global volume of gas available for exploitation, approximately $5 \times 10^{10} \mathrm{~m}^{3}$ ( $1.8 \mathrm{Tcf}$ or $36 \times 10^{6}$ metric tons), warrants further refinement of the mechanisms for improving biogas generation rates, and capturing and processing the gas. Biogas is a unique feedstock that can be chemically manipulated to produce other more marketable products. Manipulation of the anaerobic reaction can induce rapid biodegradation of the waste, improve generation volume and rate, and minimize the impact to the environment. Biogas represents a technical challenge to the scientific community for the solution of waste placement, pollution, and energy production.

\section{REFERENCES CITED}

Albonetti, S.G., and Massari, G., 1979, Microbial aspects of municipal waste composting system: European Journal of Applied Microbiology and Biotechnology, v. 7, p. 91-104.

Alpern, R., 1973, Decomposition rates of garbage in existing Los Angeles landfills: Long Beach, California State University, M.S. thesis.

Anderson, D.R., and Callinan, J.P., 1970, Gas generation and movement in landfills, in Proceedings of the National Industrial Solid Waste Management Conference: Silver Spring, Md., Government Refuse Collection and Disposal Association.

Assmuth, T., 1992, Distribution and attenuation of hazardous substances in uncontrolled solid waste landfills: Waste Management and Research, v. 10, p. 235-255.

Augenstein, D.C., 1990, Greenhouse effect contributions of United States landfill methane, in Maxwell, G., Walsh, J., and Hirshfeld, S., eds., Proceedings from the GRCDA 13th Annual International Landfill Gas Symposium: Government Refuse Collection and Disposal Association, Silver Spring, Md., p. 95-126.

in press, The greenhouse effect and U.S. landfill methane: Journal of Global Environmental Change.

Augenstein, D., and Pacey, J., 1991, Landfill methane models, in Hickman, H.L., Jr., ed., Proceedings from the technical sessions of SWANA's 29th Annual International Solid Waste Exposition: Silver Spring, Md., Solid Waste Association of North America, p. 1-25.

Augenstein, D., and Pacey, J., 1992, Landfill gas energy utilization-Technology options and case studies: Washington, D.C., U.S. Environmental Protection Agency, Report EPA-600/R-92-116, $81 \mathrm{p}$.

Augenstein, D.C., Wise, D.L., and Cooney, C.L., 1977, Packed bed digestion of solid wastes: Resource Recovery and Conservation, v. 2, p. 257-262.

Augenstein, D.C., Wise, D.L., Wentworth, R.L., and Cooney, C.L., 1976, Fuel gas recovery from controlled landfilling of municipal wastes: Resource Recovery and Conservation, v. 2, p. $103-117$. 
Baker, J.M., Peters, C.J., Perry, R., and Knight, C.P.V., 1984, Odour problems associated with solid-waste disposal: Public Health Engineering, v. 12, p. 115.

Baker, L., Capouya, R., Cenci, C., Crooks, R., and Hwang, R., 1990, The landfill testing program-Data analysis and evaluation guidelines: Sacramento, Calif., California Air Resources Board, $27 \mathrm{p}$.

Barlaz, M.A., and Ham, R.K., 1990, The use of mass balances for calculation of the methane potential of fresh and anaerobically decomposed refuse, in Maxwell, G., Walsh, J., and Hirshfeld, S., eds., Proceedings from the GRCDA 13th Annual International Landfill Gas Symposium: Government Refuse Collection and Disposal Association, Silver Spring, Md., p. 231-241.

Barlaz, M.A., Ham, R.K., and Schaefer, D.M., 1990, Methane production from municipal refuse-A review of enhancement techniques and microbial dynamics: Critical Reviews in Environmental Control, v. 19, no. 6, p. 557-584.

Barlaz, M.A., Ham, R.K., and Schaefer, D.M., 1989a, Mass-balance analysis of anacrobically decomposed refuse: Joumal of Environmental Engineering, American Society of Civil Engineers, v. 115, no. 6, p. 1088-1102.

Barlaz, M.A., Ham, R.K., and Schaefer, D.M., 1992, Microbial, chemical and methane production characteristics of anaerobically decomposed refuse with and without leachate recycling: Waste Management and Research, v. 10, p. 257-267.

Barlaz, M.A., Milke, M.W., and Ham, R.K., 1987, Gas production parameters in sanitary landfill simulators: Waste Management \& Research, v. 5, p. 27-39.

Barlaz, M.A., Schaefer, D.M., and Ham, R.K., 1989b, Bacterial population development and chemical characteristics of refuse decomposition in a simulated sanitary landfill: Applied and Environmental Microbiology, v. 55, no. 1, p. 55-65.

Barlaz, M.A., Schaefer, D.M., and Ham, R.K., 1989c, Inhibition of methane formation from municipal refuse in laboratory scale lysimeters: Applied Biochemistry and Biotechnology, v. 20/21, p. 181-205.

Berenyi, E., and Gould, R., 1991, 1990-1991 Methane recovery from landfill yearbook: New York, Government Advisory Association, Inc., $386 \mathrm{p}$.

Bingemer, H.G., and Crutzen, P.J., 1987, The production of methane from solid waste: Journal of Geophysical Research, v. 92, no. D2, p. 2181-2187.

Bogardus, E.R., 1984, Should you recover landfill gas?: BioCycle, v. 25, p. 48.

Bogner, J.E., 1991, Energy Potential of modern landfills, in Bogner, J.E., ed., Illinois Energy Conference: U.S. Department of Energy, 11 p.

Bogner, J.E., Vogt, M., and Miller, R.M., 1990, Studies of soil, gas generation, and shallow microbial activity at Mallard North Landfill, DuPage County, Illinois, in Maxwell, G., Walsh, J., and Hirshfeld, S., eds., Proceedings from the GRCDA 13th Annual International Landfill Gas Symposium: Government Refuse Collection and Disposal Association, Silver Spring, Md., p. 195-212.

Bookter, T.J., and Ham, R.K., 1982, Stabilization of solid waste in landfills: Joumal of Environmental Engineering, American Society of Civil Engineers, v. 108, no. EE6, p. 1089-1100.
Brennan, T., 1989, Calderon air "SWATS"-What are they telling us?, in Myers, J.D., Van Heuit, R.E., and Haley, L.W., eds., Proceedings from the GRCDA 12th Annual International Landfill Gas Symposium: Silver Spring, Md., Government Refuse Collection and Disposal Association, p. 13-29.

Brown, J.W., Pfeffer, J.T., and Liebman, J.C., 1976, Biological conversion of organic refuse to methane: Urbana, Illinois, U.S. Energy Research and Development Administration Report COO/2917-3.

Buivid, M.G., 1980, Laboratory simulation of fuel gas production enhancement from municipal-solid-waste landfills: Dynatech Research and Development Co., Final Report to Pacific Gas and Electric Co. and Southern California Gas Co.

California Waste Management Board, 1989, Landfill gas characterization, in Myers, J.D., Van Heuit, R.E., and Haley, L.W., eds., Proceedings from the GRCDA 12th Annual International Landfill Gas Symposium: Silver Spring, Md., Government Refuse Collection and Disposal Association, p. 61-80.

Campbell, D.J.V., and Croft, B., 1990, Landfill gas enhancement-Brogborough test cell programme, in Richards, G.E., and Alston, Y.R., eds., Landfill gas-Energy and environment '90: Bournemouth, England, Harwell Laboratories, p. 281-303.

C-E Lummus, and SCS Engineers, 1983, City of San AntonioLandfill gas recovery project study: Houston, Report to the City of San Antonio, Tex., $98 \mathrm{p}$.

Colt, J., Harvey, R., Lockhead, M., Mayer, S., Bocutti, L., and Hogan, K., 1990, Methane emissions from solid-waste landfills in the United States, in ICF, Inc., ed., International Workshop on Methane Emissions from Natural Gas Systems, Coal Mining and Waste Management Systems: U.S. Environmental Protection Agency.

Crouch, E.A.C., Green, L.C., and Zemba, S.G., 1990, Estimation of health risk from landfill gas emissions, in Maxwell, G., Walsh, J., and Hirshfeld, S., eds., Proceedings from the GRCDA 13th Annual International Landfill Gas Symposium: Government Refuse Collection and Disposal Association, Silver Spring, Md., p. 87-94.

Dair, R.R., and Schwegler, R.E., 1974, Energy recovery from landfills: Waste Age, March/April 1974, p. 6-10.

DeWalle, F.B., Chian, E.S.K., and Hammerberg, E., 1978, Gas production from solid waste in landfills: Journal of the Environmental Engineering Division, American Society of Civil Engineers, v. 104, no. EE3, p. 415-432.

Dimmick, F., Chow, A., Kuo, I., Howle, R., and Crenshaw, J., 1990, USEPA Clean Air Act regulations for landfill gas emission, in Maxwell, G., Walsh, J., and Hirshfeld, S., eds., Proceedings from the GRCDA 13th Annual International Landfill Gas Symposium: Government Refuse Collection and Disposal Association, Silver Spring, Md., p. 243-255.

Doyle, A.A., 1985, New landfill breaks new ground: Public Works, v. 116, no. 11 , p. 59.

Emcon Associates, 1980, Methane generation and recovery from landfills: Ann Arbor, Mich., Ann Arbor Science Publishers, $139 \mathrm{p}$.

- 1981a, State of the Art of Landfill Gas Recovery: San Jose, Calif., Argonne National Laboratory Report ANL/CNSV-TM-85, $97 \mathrm{p}$. 
$-1981 \mathrm{~b}$, State of the art of methane gas enhancement in landfills: Chicago, Ill., Argonne National Laboratory Report ANL/CNSV-23.

1986, Estimating landfill gas yields, in, Proceedings of the Ninth International GRCDA Landfill Gas Symposium: Silver Spring, Md., Government Refuse Collection and Disposal Association.

Emerson, J., 1990, Suggested control measure for landfill gas emissions: Sacramento, Calif., California Air Resources Board, $54 \mathrm{p}$.

Environmental Protection Agency, 1987, Municipal landfill gas condensate: Washington, D.C., Environmental Protection Agency, Office of Solid Waste, Report EPA/600-2-87090, $45 \mathrm{p}$.

- 1990, Characterization of municipal solid waste in the United States-1990 Update: Washington, D.C., U.S. Environmental Protection Agency, Office of Solid Waste, Executive Summary, EPA/520-SW-90-042A, 15 p.

1991, Air Emissions from municipal solid waste landfills-Background information for proposed standards and guidelines: Washington, D.C., U.S. Environmental Protection Agency, Office of Air Quality Planning and Standards, Report EPA-450/3-90-011a, 35 p.

Farquhar, G.J., and Rovers, F.A., 1973, Gas production during refuse decomposition: Water Air and Soil Pollution, v. 2, p. 483-495.

Farquhar, G.L., Soyupak, S., Constable, T.W., and Sykes, J.F., 1979, Fundamentals of gas generation in landfills: Berlin, Technische Universität Berlin, Abfallwirtschaftsseminar, Einladung zum 10, p. 1-33.

Fetter, C.W., 1988, Applied hydrogeology: Columbus, Ohio, Merrill Publishing Company, 592 p.

Freemon, J.P., 1989, Landfill gas recovery projects of the county sanitation districts of Los Angeles County, in Myers, J.D., Van Heuit, R.E., and Haley, L.W., eds., Proceedings from the GRCDA 12th Annual International Landfill Gas Symposium: Silver Spring, Md., Government Refuse Collection and Disposal Association, p. 218-234.

Glockner, W.D., 1989, New opportunities in the landfill gas industry created by regulatory changes, in Myers, J.D., Van Heuit, R.E., and Haley, L.W., eds., Proceedings from the GRCDA 12th Annual International Landfill Gas Symposium: Silver Spring, Md., Government Refuse Collection and Disposal Association, p. 2-11.

Golueke, C.G., 1970, Comprehensive studies of solid wastes management, third annual report: Berkeley, University of California, SERL Report No. 70-2.

Graff, G.P., 1989, Green(hous)ing of the landfill: Waste Age, March 1989, p. 82-86.

Ham, R.K., 1976, Solid waste degradation due to shredding and sludge addition, in Genetelli, E.J., and Cirello, J., eds., Gas and leachate from landfills-Formation, collection, and treatment, U.S. Environmental Protection Agency, Report EPA-600/9-76-004, p. 168-189.

-1979, Predicting gas generation from landfills: Waste Age, November 1979 , p. 50-56.

_ 1992, Sanitary landfill-Proactive or reactive?: Waste Age, February 1992, p. 73-78.

Ham, R.K., and Barlaz, M.A., 1987, Measurement and prediction of landfill gas quality and quantity, in Proceedings of Inter- national Symposium on Process, Technology, and Environmental Impact of Sanitary Landfill: CISA, Environmental Sanitary Engineering Centre, p. 1-24.

Hanashima, J., Yamamaski, K., Matsufuji, Y., Tanaka, M., and Ikeguchi, T., 1983, Technological progress of inland reclamation in Japan, in Reclamation '83 Papers: Tunbridge Wells, England, Industrial Seminars, p. 327-336.

Harper, S.R., and Pohland, F.G., 1988, Landfills-Lessening environmental impacts: Civil Engineering, November 1988, p. 66-69.

Hartner, D.K., 1990, Evaluation of landfill methane monitoring: Pittsburgh, Pa., University of Pittsburgh, M.S. thesis, 152 p.

Hartz, K.E., and Ham, R.K., 1983, Moisture level and movement effects on methane production rates in landfill samples: Waste Management and Research, v. 1, p. 139-145.

Hartz, K.E., Klink, R.E., and Ham, R.K., 1982, Temperature effects-Methane generation from landfill samples: Journal of Environmental Engineering, American Society of Civil Engineers, v. 108, no. EE4, p. 629-638.

Haxo, H.E., Jr., 1976, Assessing synthetic and admixed materials for lining landfills, in Genetelli, E.J., and Cirello, J., eds., Gas and leachate from landfills-Formation, collection, and treatment, U.S. Environmental Protection Agency, Report EPA-600/9-76-004, p. 130-158.

Heie, A., and Minaas, J., 1981, Garbologists, in Bridgewater, A., and Lidgren, K., eds., Household waste management in Europe-economics and techniques: New York, Van Nostrand Reinhold, p.45-62.

Hickman, D.A., and Schmidt, L.D., 1993, Production of syngas by direct catalytic oxidation of methane: Science, v. 259 , p. $343-346$.

Hoeks, J., 1983, Significance of biogas production in waste tips: Waste Management and Research, v. 1, p. 323-335.

Hoffman, M.S., Foley, J., McGuire, T., Young, D., Georgiadis, A., and Northrop, M., 1991, The world almanac and book of facts: New York, Pharos Books, $960 \mathrm{p}$.

Holsen, T.M., Scheff, P.A., Chaberski, C.M., Hall, C.G., and Khalili, N., 1990, Determination of the composition of landfill gas, in Maxwell, G., Walsh, J., and Hirshfeld, S., eds., Proceedings from the GRCDA 13th Annual International Landfill Gas Symposium: Government Refuse Collection and Disposal Association, Silver Spring, Md., p. 35-44.

Hutchinson, P.J., 1989, Landfill gas-Results of investigation: Pittsburgh, Pa., Chambers Development Co., unpublished report, $21 \mathrm{p}$.

- 1990, Landfill gas-A significant resource [abs.]: American Association of Petroleum Geologists Bulletin, v. 39, no. 5 , p. 680 .

_-1991, Resource potential of municipal waste biogenic gas [abs.]: American Association of Petroleum Geologists Bulletin, v. 75 , no. 3 , p. 1385 .

Ito, T., Wang., J.-X., and Lunsford, J.H., 1985, Oxidative dimerization of methane over a lithium-promoted magnesium oxide catalyst: Journal of the American Chemical Society, v. 107 , p. $5062-5068$.

Jenkins, R.L., and Pettus, J.A., 1985, The use of in-vitro anaerobic landfill samples for estimating landfill gas generation rates, in Antonopoulos, A., ed., Proceedings of the First Symposium on Biotechnological Advances in Processing 
Municipal Wastes for Fuels and Chemicals: Chicago, Illinois, Argonne National Laboratory.

Jeris, J.S., and McCarty, P.L., 1965, The biochemistry of methane fermentation using $\mathrm{C}^{14}$ tracers: Joumal of Water Pollution Control Federation, v. 37, p. 178.

Keller, A.P., 1988, Trace constituents in landfill gas: Chicago, Ill., Gas Research Institute Report GRI-87/0018.2, 128 p.

Kiser, J.V.L., and Sussman, D.B., 1991, Municipal waste combustion and mercury-The real story: Waste Age, November 1991, p. 41-44.

Klink, R.E., and Ham, R.K., 1982, Effects of moisture movement on methane production in solid-waste samples: Resource Recovery and Conservation, v. 8, p. 29-35.

Lagerkvist, A., 1991, Two step degradation-An alternative management technique, in Margherita di Pula, S., ed., Proceedings Sardinia '91, Third International Landfill Symposium: CISA, Environmental Sanitary Engineering Centre, p. 1-8.

Lawson, P.S., Campbell, D.J.V., Lagerkvist, A., and Meijer, J.E., 1991, Landfill gas enhancement test cell data exchange: Didcot, England, Harwell Laboratory, 250 p.

Leach, A., 1990, Landfill gas abstraction, in Richards, G.E., and Alston, Y.R., eds., Landfill gas-Energy and environment '90: Bournemouth, England, Harwell Laboratories, p. 204-222.

Leckie, J.O., 1974, Estimation of potential methane production from solid-waste landfills: San Jose, Calif., Emcon Associates, unpublished report.

Leckie, O.J., Pacey, J.G., and Halvadakis, C., 1979, Landfill management with moisture control: Journal of the Environmental Engineering Division, American Society of Civil Engineers, v. 105, no. EE2, p. 337-355.

Lee, G.F., and Jones, R.A., 1991, Landfills and groundwater quality: Ground Water, v. 29, no. 4, p. $482-486$.

Levy, S.J., and Rigo, H.G., 1976, Resource recovery plant implementation-Guide for municipal officials: Washington, D.C., U.S. Environmental Protection Agency, Report SW-157.2, $81 \mathrm{p}$.

Lisk, D.J., 1991, Environmental effects of landfills: The Science of the Total Environment, v. 100, p. 215-468.

Lynd, L.R., Cushman, J.H., Nichols, R.J., and Wyman, C.E., 1991, Fuel ethanol from cellulosic biomass: Science, v. 251, p. 1318-1323.

Mah, R.A., Ward, D.M., Baresi, L., and Glass, T.L., 1977, Biogenesis of methane: Annual Reviews in Microbiology, v. 31, p. 309.

Marshall, B.N., 1988, Landfill gas collection systems-Cost, effectiveness, and maintenance, in Carolan, M.J., Martin, H.L., Flanagan, K.A., and Haley, L.W., eds., Proceedings from the GRCDA 11th International Landfill Gas Symposium: Silver Spring, Md., Government Refuse Collection and Disposal Association, p. 147-160.

Maxwell, G., 1990, Will gas-to-energy work at your landfill?: Solid Waste \& Power, June 1990, p. 44-50.

McCarty, P.L., 1981, One hundred years of anaerobic treatment, in Hughes, D.E., Stafford, D.A., Wheatley, B.I., Baader, W., Lettinga, G., Nyns, E.J., Verstraete, W., and Wentworth, R.L., eds., Anaerobic digestion 1981: New York, Elsevier Biomedical Press, p. 3-22.

Miller, M.J., and Quinn, J., 1990, Reclaiming landfill sites for urban agriculture, in Maxwell, G., Walsh, J., and Hirshfeld,
S., eds., Proceedings from the GRCDA 13th Annual International Landfill Gas Symposium: Government Refuse Collection and Disposal Association, Silver Spring, Md., p. $175-179$.

Monod, J., 1950, La technique de culture continue-Theorie et applications: Annals Institute Pasteur, v. 79, p. 390-410.

Mosey, F.E., and Mistry, P.B., 1990, Biological is best-How feasible is municipal solid waste digestion for the UK?, in Richards, G.E., and Alston, Y.R., eds., Landfill gas-Energy and environment '90: Boumemouth, England, Harwell Laboratories, p. 387-402.

Naveau, H., 1984, Anaerobic digestion in the European Economic Community, in Ferrero, G.L., Ferranti, M.P., and Naveau, $\mathrm{H}$., eds., Anaerobic Digestion and Carbohydrate Hydrolysis of Waste: London, Elsevier Applied Science Publisher, p. 182-187.

Pacey, J.G., Glaub, J.C., and Van Heuit, R.E., 1987, Results of the Mountain View controlled landfill project, in Hickman, L.H., Jr., ed., Proceedings of the GRCDA 10th International Landfill Gas Symposium: Silver Spring, Md., Government Refuse Collection and Disposal Association.

Parker, A., 1983, Behaviour of wastes in landfill-methane generation, in Holmes, J.R., ed., Practical waste management: New York, John Wiley \& Sons, chapter 8.

Parker, C., and Roberts, T., 1985, Energy from waste-An evaluation of conversion technologies: London, Elsevier Applied Science Publishers, $250 \mathrm{p}$.

Pennsylvania Department of Environmental Resources, 1989, Guidance Manual for Landfill Gas Management: Harrisburg, Pa., Commonwealth of Pennsylvania, Bureau of Waste Management, $218 \mathrm{p}$.

Periana, R.A., Taube, D.J., Evitt, E.R., Löffler, D.G., Wentrcek, P.R., Voss, G., and Masuda, T., 1993, A mercury-catalyzed, high-yield system for the oxidation of methane to methanol: Science, v. 259 , p. $340-343$.

Pfeffer, J.T., 1974a, Reclamation of energy from organic waste: Washington, D.C., U.S. Environmental Protection Agency, Report EPA-670/2-74-016, 35 p.

-1974b, Temperature effects on anaerobic fermentation of domestic refuse: Biotechnology and Bioengineering, v. 16, p. 771-781.

Pohland, F.G., Dertien, J.T., and Gosh, S.B., 1983, Leachate and gas quality during landfill stabilization of municipal refuse, in Proceedings of the 3rd International Symposium on Anaerobic Digestion, Evans and Faulkner, Cambridge, Mass., p. $185-201$.

Rathje, W.L., 1991, The history of garbage: Garbage, September 1991, p. 32-36.

Rees, J.F., 1980a, The fate of carbon compounds in the landfill disposal of organic matter: Journal of Chemical Technology and Biotechnology, v. 30, p. 161-175.

1980b, Optimization of methane production and refuse decomposition in landfill by temperature control: Journal of Chemical Technology and Biotechnology, v. 30, p. 458-465.

Rettenberger, G., 1987, Trace composition of landfill gas, in Proceedings of International Symposium on Process, Technology, and Environmental Impact of Sanitary Landfill: CISA, Environmental Sanitary Engineering Centre, p. 1-12.

Richards, K.M., and Aitchison, E.M., 1990, Landfill gas-Energy and environmental themes, in Richards, G.E., and Alston, 
Y.R., eds., Landfill gas-Energy and environment '90: Bournemouth, England, Harwell Laboratories, p. 21-44.

Rijkens, B.A., and Voetberg, J.W., 1981, Two-step process for anaerobic digestion of solid wastes, in Hughes, D.E., Stafford, D.A., Wheatley, B.I., Baader, W., Lettinga, G., Nyns, E.J., Verstraete, W., and Wentworth, R.L., eds., Anaerobic Digestion 1981: New York, Elsevier Biomedical Press, p. 382.

Seeker, W.R., Heap, M.P., Landrum, V., Lanier W.S., and Linz, D.G., 1989, Applications study and research needs assessment for natural gas use for waste management: Chicago, Ill., Gas Research Institute, Topical Report GRI-89/0012, $100 \mathrm{p}$.

Senior, E., 1990, Introduction, in Senior, E., ed., Microbiology of Landfill Sites: Boca Raton, Fla., CRC Press, p. 1-15.

Senior, E., and Balba, M.T.M., 1990, Refuse decomposition, in Senior, E., ed., Microbiology of Landfill Sites: Boca Raton, Fla., CRC Press, p. 17-57.

Senior, E., and Kasali, G.B., 1990, Landfill gas, in Senior, E., ed., Microbiology of Landfill Sites: Boca Raton, Fla., CRC Press, p. 113-158.

Senior, E., and Shibani, S.B., 1990, Landfill leachate, in Senior, E., ed., Microbiology of Landfill Sites: Boca Raton, Fla., CRC Press, p. 81-111.

Soerjani, M., 1984, Present waste management in cities in Indonesia: Conservation \& Recycling, v. 7, p. 181-185.

Thomé-Kozmiensky, K.J., 1977, Übersicht uber die Möglichkeiten und Alternativen des Material Recycling: Berlin, Technische Universität Berlin, Abfallwirtschafts seminar, v. 1, p. 5-35.

Thorneloe, S., 1990, United States research on enhancing landfill gas production, in Lawson, P.S., Campbell, D.J.V., Lagerkvist, A., and Meijer, J.E., eds., Landfill Gas Enhancement Test Cell Data Exchange: Bournemouth, England, Harwell Laboratories, p. 1-68.

Vogt, W.G., and Conrad, E.T., 1988, Landfill gas trace constituents-VOCs versus ROGs, in Carolan, M.J., Martin, H.L., Flanagan, K.A., and Haley, L.W., eds., Proceedings from the GRCDA 11 th International Landfill Gas Symposium: Silver Spring, Md., Government Refuse Collection and Disposal Association, p. 187-199.

Wald, M.L., 1991, From a pollutant, a cleaner fuel: New York Times, August 21, 1991, p. C5.

Walsh, P., and O'Leary, P., 1991, Sanitary landfill design procedures-Lesson 6: Waste Age, September 1991, p. 97-105.

Ward, R.F., 1988, Landfill gas production, in Carolan, M.J., Martin, H.L., Flanagan, K.A., and Haley, L.W., eds., Proceedings from the GRCDA 11th International Landfill Gas Symposium: Silver Spring, Md., Government Refuse Collection and Disposal Association, p. 161-186.
Wegener, R.W., and Lekstutis, J.P., 1989, LFG design for the long term: Waste Age, April 1989, p. 188-196.

Westlake, K., 1990, Landfill microbiology, in Richards, G.E., and Alston, Y.R., eds., Landfill gas-Energy and environment '90: Oxfordshire, England, Harwell Laboratories, p. 271-280.

White, L.P., and Plaskett, L.G., 1981, Biomass as Fuel: London, Academic Press, 355 p.

Wilke, M.L., Zimmerman, R.E., and Isaacson, H.R., 1982, Methane from landfills-Preliminary assessment workbook: Chicago, Ill., Argonne National Laboratory, Report No. ANL/CNSV-31, 24 p.

Willumsen, H.C., 1990, Registration and optimizing of gas production from closed waste test cells in landfills: Denmark, Ministry of Energy, Report J. No. 1383/86-9, 45 p.

Wolfe, R.S., 1982, Biochemistry of methanogenesis: Experimentia, v. 38 , p. $198-203$.

Wood, J.A., Porter, M.L., and Wadley, M.W., 1986, Toxics in Class II landfill gas: American Chemical Society Division of Environmental Chemistry, v. 26, no. 2, p. 347-350.

Young, C.P., and Blakely, N.C., 1990, Gases in, gases out: Monitored emissions from power generation projects, in Richards, G.E., and Alston, Y.R., eds., Landfill gas-Energy and environment '90: Oxfordshire, England, Harwell Laboratories, p. 317-329.

Young, L.Y., and Frazer, A.C., 1987, The fate of lignin and lignin-derived compounds in anaerobic environments: Geomicrobiology Joumal, v. 5, no. (3/4), p. 261-293.

Young, P.J., and Parker, A., 1983, The identification and possible environmental impact of trace gases and vapours in landfill gas: Waste Management and Research, v. 1, p. 213-226.

Zehnder, A.J.B., 1978, Ecology of methane formation, in Mitchell, R., ed., Water pollution microbiology: New York, Wiley-Interscience, p. 349-376.

Zehnder, A.J.B., Ingvorsen, K., and Marti, T., 1981, Microbiology of methane bacteria, in Hughes, D.E., Stafford, D.A., Wheatley, B.I., Baader, W., Lettinga, G., Nyns, E.J., Verstraete, W., and Wentworth, R.L., eds., Anaerobic Digestion 1981: New York, Elsevier Biomedical Press, p. 45-68.

Zeikus, J. G., 1981, Microbial intermediary metabolism in anaerobic digestion, in Hughes, D.E., Stafford, D.A., Wheatley, B.I., Baader, W., Lettinga, G., Nyns, E.J., Verstraete, W., and Wentworth, R.L., eds., Anaerobic Digestion 1981: New York, Elsevier Biomedical Press, p. 23-35.

1983, Metabolism of one-carbon compounds by chemotropic anaerobes: Advances in Microbial Physiology, v. 24, p. 215.

Zimmerman, R.E., Walsh, J.J., and Wilkey, M.L., 1985, Landfill gas-Resource Evaluation and development: Chicago, Ill., Gas Research Institute, Report No. GRI-85/0259, 137 p. 


\title{
THE FUTURE OF ENERGY GASES
}

U.S. GEOLOGICAL SURVEY PROFESSIONAL PAPER 1570

\section{A Survey of Natural Gas Dissolved in Brine}

\author{
By Sullivan Marsden ${ }^{1}$
}

\section{CONTENTS}

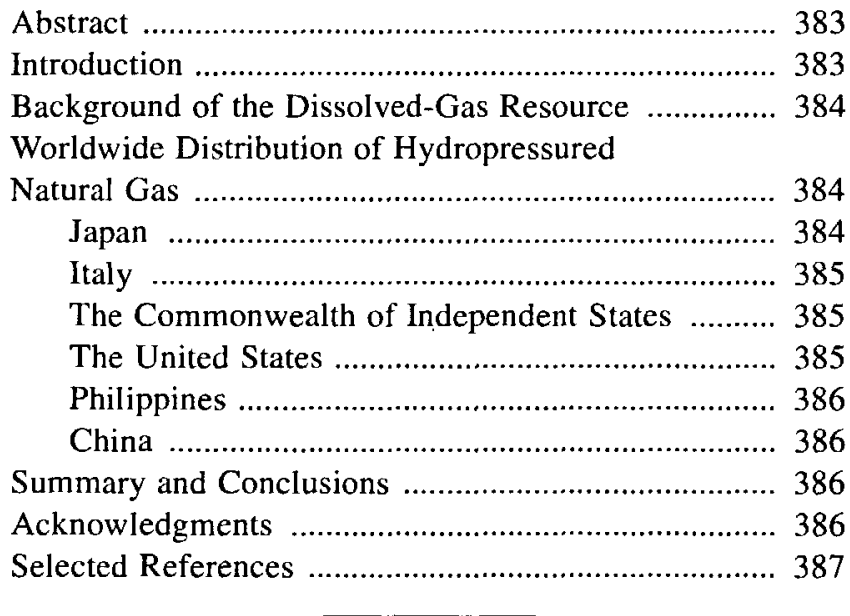

\begin{abstract}
Natural gas, composed primarily of methane, is found dissolved in aquifers in many parts of the world. This natural gas can provide an important energy source in those areas where conventional natural gas reserves are absent but where economical methods for drilling, development, and production of hydropressured natural gas are available. There are some distinct geological and geochemical signs which indicate the presence of natural gas dissolved in aquifers, such as the presence of iodine. Extraction of such iodine is a source of additional revenue to gas producers, thus improving the overall economics of exploita-
\end{abstract}

\footnotetext{
'Stanford University, Department of Petroleum Engineering, Stanford, CA $94305-2220$.
}

tion of dissolved natural-gas resources. The experience of those who have already found methods to exploit these resources, principally the Japanese, can be very valuable in the future development of this resource.

\section{INTRODUCTION}

Natural gas, along with petroleum, coal, and nuclear energy, is one of the major energy resources of the United States and many other countries around the world. Each of these resources has its own requirements for exploitation, such as geographical location, accessibility, estimates of available reserves, possible environmental problems, and costs of production and transportation. Because of the world's ever-growing energy demands, all of these resources, along with various so-called renewable energy sources, have been and will continue to be tapped.

The major sources of gas for domestic, industrial, and commercial use in the United States come from what are termed "conventional resources," usually involving gas associated with crude oil accumulations, although significant amounts of dry (no oil found in association) gas accumulations are also being exploited. There are, however, numerous unconventional settings for natural-gas accumulations that have received varying amount of attention. In recent years, the U.S. Department of Energy has supported research in production of natural gas from geopressured reservoirs, coal beds, and Devonian shales. These sources show promise, and some natural gas is being produced from them, but many experts have serious doubts about their economic viability. Besides the sources of natural gas mentioned above, there is another major source, which is mainly ignored in such energy-rich countries as the United States, but is utilized in energy-poor countries such as Japan. This resource is gas dissolved in underground brines under normal hydrostatic pressure, not at the abnormally 
high pressures of geopressured reservoirs. Gas dissolved in underground brines is called hydrostatic natural-gas (or brine gas) accumulations-the Japanese call them "suiyoseitennengasu" reservoirs. Hydrostatic brine and geopressured gas reservoirs are quite different and distinct in both their physical properties and problems involved in their exploration, drilling, completion, production, economics, and marketing.

I have studied hydrostatic brine reservoirs in Japan and elsewhere for the past quarter of a century and written a number of reports (Marsden and Kawai, 1965; Marsden, 1979 a 1979b) with several Japanese collaborators to supplement the rather extensive literature written in Japanese, which is inaccessible to most people. These studies have been supplemented by notes from field trips in Japan from 1963 to the present and discussions with scientists and engineers from other countries, in particular Italy, the People's Republic of China, the Philippines, and the Commonwealth of Independent States (the former Soviet Union), where brine gas is known and utilized whenever possible.

In the United States, hydropressured brine gas is produced on a limited scale, but this production is often not accurately reported owing to complex accounting procedures. Compared to dry or associated natural-gas fields, dissolved natural gas in brines occurs in relatively small and widely scattered reservoirs, which do not interest the large energy companies.

The purpose of this report is to present a brief summary of important aspects of the occurrence of hydropressured brine gas resources as it is described in the technical literature, and by various researchers in the field. Interested readers are encouraged to look to the literature for more data and more in-depth discussions. This was a subject of great interest a couple of years ago; but at the present time, especially in North America, it has been given less attention. My personal hope is that this paper will engender more interest in brine gas, as our full understanding as well as the resource potential of this energy source is incomplete. Although some reports describe both hydropressured and geopressured reservoirs, we shall omit discussion of the latter. References are made to the few reports in English on the subject of natural gas dissolved in brines, and the reader is referred to them for details and statistics on reserves, production, extent, and so forth. There is extensive literature written in Japanese, but except for abstracts written in English, this literature is generally inaccessible.

\section{BACKGROUND OF THE DISSOLVED-GAS RESOURCE}

To understand the nature of natural gas dissolved in brines, we must reconsider certain basic, well-known physical concepts. The solubility of a gas (for example, natural gas) in a liquid (for example, water) increases with increas- ing pressure and decreases with increasing temperature. It is also known that the hydrostatic pressure of underground fluids increases with depth and that the subsurface temperature increases with depth. Of these factors, which have opposing effects on the solubility of gases in underground waters, solubility is influenced much more by pressure than by temperature. Hence, the amount of natural gas dissolved in underground liquids increases greatly with depth.

Because of the chemical similarity of organic gases, such as methane, and organic liquids, such as crude oil, the solubility of methane in oil is far greater than in polar liquids, such as water or brine. The solubility of methane in water and brine is often considered by many people to be insignificant, but the Japanese natural-gas industry has produced methane from brine for many years. Since we (and the Japanese) know that gas is dissolved in brine in many locations, the primary concern is to find locations where the gas can be produced economically and without environmental damage. For reasons discussed below, the environmental damage caused by production of this resource in Japan has, in recent years, curtailed some production, even though the Japanese have now developed environmentally safe production methods. Environmental concerns involve subsidence and brine disposal. As the international price of crude oil and LNG (liquefied natural gas) are relatively low, the Japanese, with their high national energy demands, have favored these energy sources, while keeping "suiyoseitennengasu" as a reserve.

Although hydropressured natural-gas fields are only minimally developed in the United States, wells can be drilled relatively fast and inexpensively because the gas fields are found at depths ranging from a few hundred to a few thousand of feet and because they usually occur in relatively soft sedimentary rocks. Brines can introduce corrosion problems for steel, which is the normally used casing material in wells, so PVC (polyvinylchloride) casing is normally used, which also reduces completion and production costs. Other more modern plastic pipe might be even less costly and easier to use.

\section{WORLDWIDE DISTRIBUTION OF HYDROPRESSURED NATURAL GAS}

\section{JAPAN}

In terms of both production and reserves of natural gas dissolved in brines, the country of greatest importance is Japan. This has been discussed extensively in three reports written with Japanese colleagues (Marsden and Kawai, 1965; Marsden, 1979a, 1979b) and summarized briefly in a report by Bonham (1979). The reader is referred to these reports for details.

The production of natural gas dissolved in brines is a stable, profitable, and somewhat expanding industry in 
Japan, because the companies there have developed lowcost drilling, development, and production methods to provide for an indigenous energy source. Production from the older fields is reasonably stable, and the estimated reserves are very extensive. In addition, the recovery of iodine from the produced brines has improved the overall profits significantly. Land subsidence, which results from fluid withdrawal, has been arrested by brine reinjection after the methane and iodine have been removed.

Countries wishing to develop this resource would do well to consult with the natural-gas companies operating in Japan. For three decades, the Japanese have been very helpful in arranging many field trips and supplying information on their natural-gas production operations, as have some of the faculty in the Department of Mineral Development Engineering (formerly Petroleum Engineering) at the University of Tokyo.

In recent years technical interest in natural gas dissolved in brines has extended to two other universities in Japan. Starting in 1985, Professor Satoshi Akibayashi of Akita University has published a series of seven reports (Akibayashi and Zhou, 1985, 1986, 1988; Akibayashi and others, 1988, 1988; Zhou and others, 1989; Akibayashi and Yamaguchi, 1992) on the numerical simulation of the behavior of Mobara-type gas reservoirs. While most of these reports are in Japanese, all have at least an abstract in English and each presents a development beyond its predecessor. More recently, Prof. Toyohiko Yamazaki of Waseda University has presented a report with Yoshiyuki Tazoki of Kanto Natural Gas Development Company (Tazaki and Yamazaki, 1993) on another simulation study of Mobaratype dissolved natural-gas reservoirs.

\section{ITALY}

Hydropressured natural gas is produced with brine in the eastern Po River plain of northern Italy from wells that are usually less than $500 \mathrm{~m}$ deep. Early production data and information on reserves have been summarized briefly by Bonham (1979); a much older report by Reeves (1953) gives more information on the geology of the area. The production of natural gas from brines in Italy is mostly of historical interest-it started a half century ago-because it was discontinued by order of the Italian government in 1962. Brackish water produced was not reinjected and there was serious land subsidence.

\section{THE COMMONWEALTH OF INDEPENDENT STATES}

As far as I have been able to ascertain, hydropressured natural gas is not developed as a separate resource in the Commonwealth of Independent States. The massive re- serves and production of both dry and oil-associated natural' gas, as well as limited domestic financial resources, have encouraged the development, use, and export of geopressured natural gas to the rest of Europe. Bonham (1979) has quoted estimates of natural gas dissolved in formation water for both oil and ordinary natural-gas fields, stating they are "gigantic." However, I have found no indication that this resource is now utilized, even locally, in otherwise energy-deficient areas of the Commonwealth of Independent States.

\section{THE UNITED STATES}

It is best to divide hydropressured gas production in the United States into the three major States where it has been reported (Bonham, 1979), California, Oklahoma, and Texas (including parts of Louisiana). In terms of both production and documented reserves, hydropressured gas is not now a major resource in the U.S., but it could become one in the future.

It is common in some parts of California (and probably elsewhere) to find natural gas dissipating from fresh water in relatively shallow water wells. An example is natural gas dissolved in water discovered during excavation of a building site in Fresno (K.W. Campbell, oral commun., 1993). In a few areas this has led to further drilling to recover the gas for use as a domestic and industrial fuel. Sometimes brine gas has been blended with natural gas derived from other sources, because that produced from water wells has been insufficient to meet the supply requirements. In some rural areas, wells drilled to produce water for cattle have also produced natural gas which is run into stationary internal combustion engines, for electrical power generation. The power is used only for very local purposes. Some hydropressured gas has been found in connection with geopressured gas in Texas and parts of Louisiana, but the geopressured gas has been the major focus in these regions, and little is known about the hydropressured gas.

The association of natural gas dissolved in brine and iodine has been noticed elsewhere besides Japan, and this has led to the development of an iodine resource in the United States. Routine analyses of brines produced from oil- and gas-field exploration and development activities in the North Boiling Springs gas field of northwestern Oklahoma near the town of Woodward have demonstrated the existence of unusually high iodine concentrations (about 325 parts per million (ppm)) (W. Gerber, Woodard Iodine Company, oral commun., 1993). This iodine resource was developed originally by Amoco Production Company and Houston Chemicals, a subsidiary of Pittsburgh Plate Glass. The present operating company is the Woodward Iodine Corporation, which is now fully owned by Ise Chemicals Corporation, a subsidiary of Asahi Glass Company of 
Japan. The total gas production for the past one and onehalf decades has been about 8.9 billion cubic feet (Bcf); the overall gas/water ratio has been about 29 cubic feet per barrel $(\mathrm{cf} / \mathrm{bbl})$ and the present gas/water ratio is about $26 \mathrm{cf} / \mathrm{bbl}$ from 22 production wells serving 10 reinjection wells (W. Gerber, Woodard Iodine Company, oral commun., 1993). While the major component of this gas is methane (more than 90 percent) small amounts of ethane, nitrogen, carbon dioxide, and trace amounts of other aromatic hydrocarbons are also produced.

The interest that developed in the United States several years ago in geopressured natural gas has led to an occasional reference to hydropressured natural gas, but because the two kinds are "in competition," there has been very little new research on geopressured, and virtually none on hydropressured, natural gas. The report by Bonham (1979) cited earlier is an important early reference on hydropressured gas in the United States as is the extensive work of Buckley and others (1958), and later work by Doherty (1981) provides another general review.

\section{PHILIPPINES}

In the early 1980's a joint study of hydropressured gas by the Japan International Cooperation Agency and the Geological Survey of Japan with the Department of Energy of the Republic of the Philippines covered the Iloilo Basin of Parray Island. The results of this very extensive study are given in an unpublished, 152-page report $(\mathrm{H}$. Natori, Geological Survey of Japan, written commun., 1993).

Although he reported the potential for natural gas from this basin, the project was terminated because of lack of funds for exploratory drilling to establish the magnitude of the resource. It is noteworthy that the brine containing the dissolved gas also contained significant amounts of the iodide ion.

\section{CHINA}

Although deep, geopressured natural gas has been known in China for centuries, the documentation for shallow natural gas dissolved in brine is much more recent, perhaps because of the political disturbances over the past several decades. Since at least 1958, however, individuals and small industries have drilled for and produced brine gas for domestic use and in small factories. These reservoirs, which are mainly in Zhejiang and Jiangsu Provinces, but also in Shanghai City, are usually found at depths of only 6 to $50 \mathrm{~m}$ and have thicknesses of only 0.5 to $3 \mathrm{~m}$. Daily production ranges from 100 to $10,000 \mathrm{~m}^{3}$ at gas pressures of 1 to $6 \mathrm{~atm}$.
This shallow gas is believed to be a promising energy source. Within the past decade, the China National Petroleum Corporation has entrusted the Hangzhou Institute of Petroleum Geology, under the direction of Prof. Qian Yizhong, to conduct research on the exploration and development of shallow gas. This work is being carried out along the Yangtse River and coastal areas of southeastern China (Qian Yizhong, oral commun., 1993).

Although gas dissolved in brine has also been reported in Taiwan, up-to-date information on it could not be obtained for this report (Qian Yizhong, oral commun., 1993). Taiwan has had both significant amounts of dry and wet natural gas, which have been well developed in the past, but the major industrial needs are now supplied by imported LNG.

\section{SUMMARY AND CONCLUSIONS}

Natural gas dissolved in relatively shallow aquifers is an important resource in energy-deficient countries and areas such as Japan and the southern coast of China. Economical methods of drilling for and producing the dissolved gas are essential for its utilization. The recovery of iodine from the brines improves the economics considerably, as has been the case in Japan and may be so in the Philippines in the future. Sometimes iodine is the major product and natural gas a supplementary product, as in Woodward County, Oklahoma. There are indications that natural gas dissolved in brine is produced for local consumption in countries which also produce large quantities of ordinary natural gas such as the Commonwealth of Independed States (CIS), Indonesia, Malaysia, Thailand, and Taiwan, but reliable information is hard to find; the same is probably true in parts of the United States and in parts of Australia and in New Zealand.

Technical, environmental, and economic problems must be solved for the development and continued production of natural gas dissolved in brines. The Japanese industry has been very successful in these respects and can be looked to for guidance. Safe and effective disposal of the produced water or brines is essential, otherwise the industry may be shut down, as was the case in Italy. Deep exploratory drilling and production tests are necessary for definition of a very promising dissolved natural-gas prospect such as that in the Philippines. Investment funds, such as from an international investment organization like the World Bank, are also needed.

\section{ACKNOWLEDGMENTS}

The valuable contributions of many people to the preparation of this report must be recognized. Mrs. Char- 
lotte Darksen of the Branner Earth Sciences Library conducted an excellent literature search using several data bases. Mr. Yutaka Higuchi, Managing Director of the Kanto Natural Gas Company and his many colleagues have been very helpful in discussions, providing reports and arranging field trips in the Chiba Prefecture.

Professor Satoshi Akibayashi of Akita University and Professor Toyohiko Yamazaki of Waseda University have been generous in supplying me with their many reports on this subject which have unfortunately not found their ways into the data bases consulted. Mr. Rufino B. Bomasung of the Philippine Department of Energy has generously provided 'me with a full copy of the report written by Dr. Haroo Natori of the Geological Survey of Japan on the Japanese study of a major Philippine prospect. Finally, Mr. William R. Gerber of the Woodward Iodine Company has ably provided me with reports on the major field development in the United States.

\section{SELECTED REFERENCES}

Akibayashi, S., and Zhou, P., 1985, Simulation of production behavior in the water-dissolved gas field: Japan Underground Water Association Report, v. 27, no. 4.

1986, A numerical model for simulating production performance in the Mohara-type water-dissolved natural-gas field: Journal of Japanese Association for Petroleum Technology, v. 51, no. 6 , p. 10-15.

-1988, The production performance of the water-dissolved natural gas reservoir: 17th Offshore Southeast Asia Conference, Singapore, p. 582-590 (February).

Akibayashi, S., Zhou, P., and Takirawa, K., 1988, Simulation of gas water ratio behavior in the Mohara-type water-dissolved natural-gas field-Radial model: Journal of Japanese Association for Petroleum Technology, v. 50, no. 3, p. 24-28.

Akibayashi, S., Zhou, P., and Yuhara, K., 1988, A numerical model for simulating production behavior of multi-wells in the Mobara-type water-dissolved natural gas reservoir: Jour- nal of the Japanese Association for Petroleum Technology, v. 53, no. 3, p. 38-44, (May).

Akibayashi, S., and Yamaguchi, S., 1992, Simulation of high GWR behavior in the water-dissolved natural gas reservoir: Journal of the Japanese Association for Petroleum Technology, v. 57, no. 5, p. 427-433.

Bonham, L.C., 1979, Gas in subsurface waters: UNITAR Conference on long-term energy resources, Montreal, Canada (November, December).

Buckley, S.F., Hocott, C.R., and Taggart, M.S., Jr., 1958, Distribution of dissolved hydrocarbons in subsurface waters: Habitat of Oil. UL in American Association of Petroleum Geologists, p. 850-882.

Cotten, H.M., 1973, Iodine in Northwestern Oklahoma: Oklahoma Geological Survey Circular 79, p. 89-94.

Doherty, M.G., 1981, Natural gas production from hydro-pressured aquifers: International Conference on Small Energy Resources, Los Angeles, CA, p. 133-137.

Lyday, P.A., 1991, Iodine: U.S. Department of Interior, Bureau of Mines (October).

Marsden, S.S., 1979a, Natural gas dissolved in brine-A major energy resource of Japan: Society of Petroleum Engineers Annual Fall Meeting, Las Vegas, Nevada, Preprint 8355.

1979b, Hydropressured natural-gas reservoirs: UNITAR Conference on long-term energy resources, Montreal, Canada (November, December).

Marsden, S.S., and Kawai, K., 1965, Suiyoseitennengasu-A special type of Japanese natural gas deposit: American Association of Petroleum Gcologists, v. 49, no. 3, p. 286-295.

Reeves, F., 1953, Italian oil and gas resources: American Association of Petroleum Geologists Bulletin, v. 37, no. 4, p. 603625.

Tazaki, Y., and Yamazaki, T., 1993, Simulator for predicting the Mobara-type production performance: 1993 SPE Asia Pacific Oil and Gas Conference and Exhibition, Singapore, February 8-10, paper SPE 25337.

Zhou, P., Akibayashi, S., and Yuhara, K., 1989, Numerical model of the production behavior for the ordinary type water-dissolved natural gas reservoir during water reinjection: Journal of Japanese Association for Petroleum Technology, v. 54, no. 5, p. 1-7. 



\title{
THE FUTURE OF ENERGY GASES
}

U.S. GEOLOGICAL SURVEY PROFESSIONAL PAPER 1570

\section{Coalbed Gas-An Undeveloped Resource}

\author{
By Dudley D. Rice ${ }^{1}$, Ben E. Law ${ }^{1}$, and Jerry L. Clayton ${ }^{1}$
}

\section{CONTENTS}

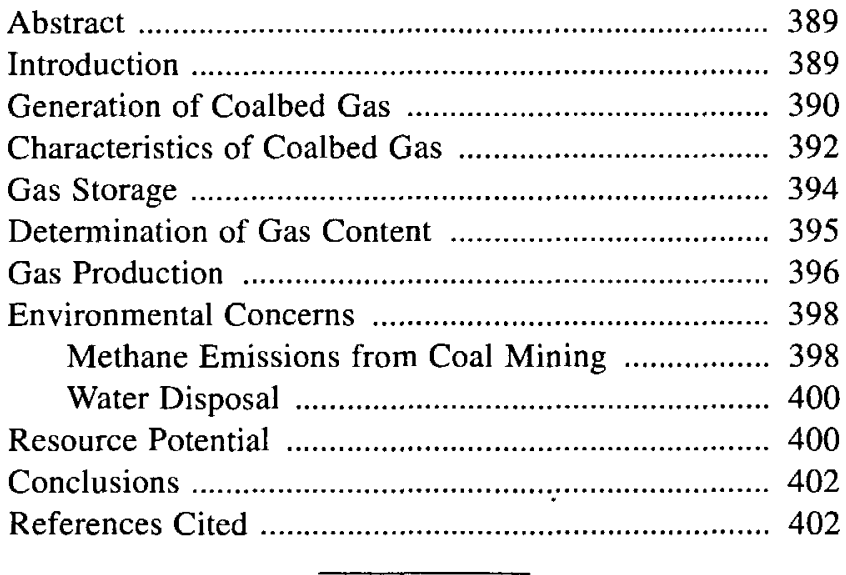

\section{ABSTRACT}

Coalbeds are both source and reservoir rocks for major quantities of natural gas. Large amounts of natural gas are generated in coalbeds throughout their burial history by both biogenic and thermogenic processes. Coalbed gases are variable in their molecular and isotopic composition. In addition to methane, they can contain significant amounts of heavier hydrocarbons and $\mathrm{CO}_{2}$. The primary controls of hydrocarbon gas composition are coal rank and composition, and depth/temperature. Coalbed gas is stored (sorbed) upon and within the molecular structure of the coal. As a result, coal has the ability to hold much more gas than the same rock volume of a conventional reservoir in which gas occurs as a free or dissolved phase. The amount of gas stored is a function of rank, pressure, and

${ }^{1}$ U.S. Geological Survey, Box 25046, Federal Center MS 971, Denver, CO 80225 . temperature. Matrix permeability is essentially nonexistent in coal and flow pathways for gas are provided by the fracture (cleat) system. Regardless of rank, nearly all coals contain at least some water (inherent moisture, meteoric, and (or) from adjacent aquifers). Economic quantities of natural gas can be produced from coalbed reservoirs; desorption results from dewatering and subsequent depressurization of the coalbeds. The main environmental concerns about coalbed gas extraction are related to (1) methane emissions from coal mining and (2) disposal of produced water. However, significant amounts of methane can be captured prior to and during mining, and the water produced can be disposed of in an environmentally acceptable manner, such as in injection wells. Estimated resources of coalbed gas are enormous and widely distributed around the world. However, this resource is essentially undeveloped, except in the United States where some production and technological advances have taken place.

\section{INTRODUCTION}

Coal is the most abundant energy source in the world; reserves are estimated to be more than one trillion metric tons. With the expansion of global economies, particularly in underdeveloped countries, world coal production has been increasing rapidly on a yearly basis. Total production totaled more than 5 billion metric tons in 1990; China alone produced more than 1 billion metric tons.

Coal is also a major source of gaseous hydrocarbons. The gas is a product of the coalification process whereby plant material is progressively converted to coal, generating large quantities of gas, which are stored within the coal matrix. The rank sequence from peat to meta-anthracite and other commonly used indices of rank and thermal maturity are shown in figure 1 . The presence of methane-rich gas in coal has been recognized for a long time because of 


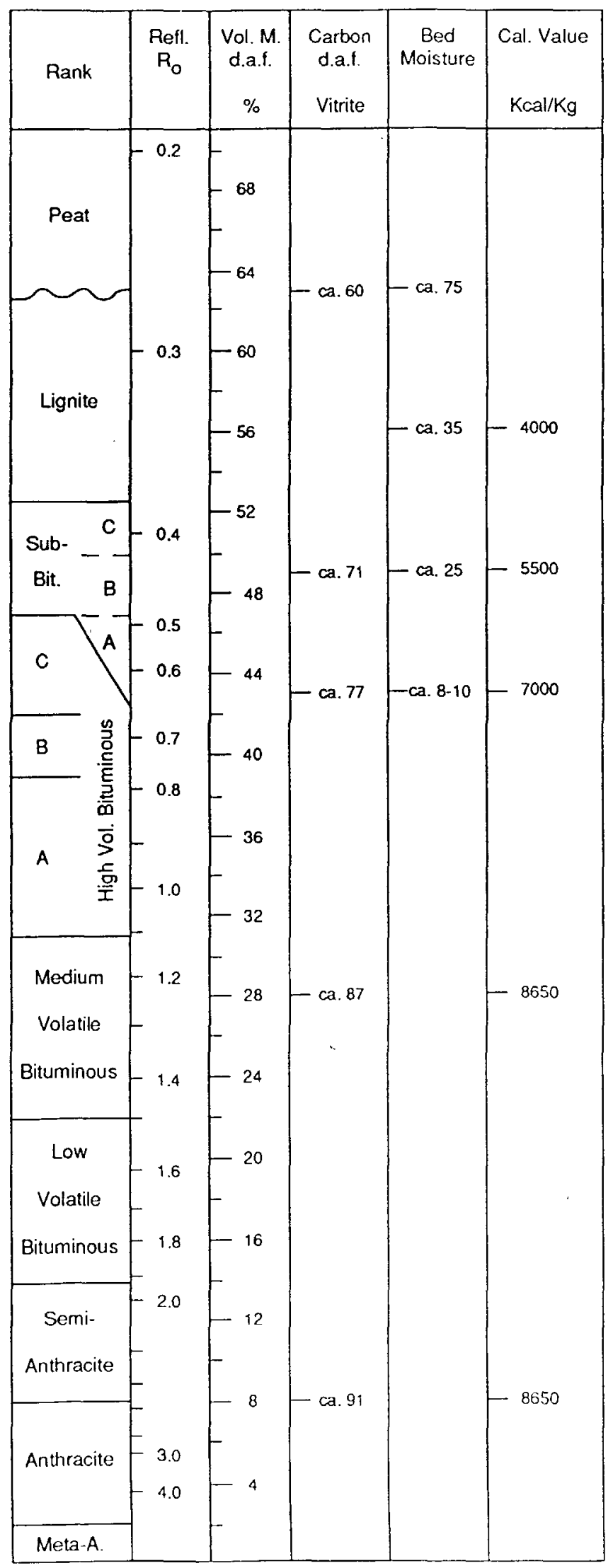

explosions and gaseous outbursts associated with underground mining. Only recently has coal been recognized as a reservoir rock as well as a source rock and thus represents an enormous undeveloped "unconventional" energy resource.

Some of the first attempts to produce gas from coal were undertaken in Europe in the late 19th century to reduce mining hazards (Bromilow and James, 1955). The date the first wells were drilled specifically for coalbed gas is uncertain; however, by the late 1970's some commercial production of coalbed gas had been established in the Black Warrior and San Juan basins in the United States (fig. 2). Significant exploration for and production of coalbed gas in the United States began in the mid-1980's because of a Federal tax credit given for the production of coalbed gas. Gas is commercially produced from coalbeds that range in thickness from 1 to 30 meters and occur at depths of 45 to 2,730 meters. By the end of 1991 , about 5,000 wells, located mainly in the Black Warrior $(2,800)$ and San Juan basins $(1,800)$, were producing about $28 \times 10^{6} \mathrm{~m}^{3}$ of coalbed gas per day. The tax credit not only increased drilling activity, but was also responsible for the development of new drilling and completion technology. The knowledge and technology gained from exploration and production in the United States is currently being transferred to other countries where there has been no significant coalbed gas production because of economic, logistical, political, and geological reasons. However, considerable exploration activity is currently taking place in Australia, Canada, China, the Czech Republic, the former Soviet Union, Poland, South Africa, Spain, and the United Kingdom.

\section{GENERATION OF COALBED GAS}

Generation of natural gas in coalbeds takes place by two distinct processes described as biogenic and thermogenic. Biogenic gas is composed primarily of methane and results from the decomposition of organic matter by microorganisms. The major requirements for the generation of significant amounts of biogenic gas by methanogenic microorganisms (assigned to the Archaea domain (Woese and others, 1990)) are (1) an anoxic environment, (2) low sulfate concentrations, (3) low temperatures, (4) abundant organic matter, (5) high $\mathrm{pH}$ values, and (6) adequate space

Figure 1. Coal ranks, from lowest (peat) to highest (metaanthracite), and common properties of measurement. Modified from Stach and others (1982). D.a.f., dry and ash free; vol. m., volatile matter; refl. $R_{0}$, vitrinite in percent; cal. value, caloric value; meta-A., meta-anthracite; sub-bit., subbituminous; vol., volatile. 


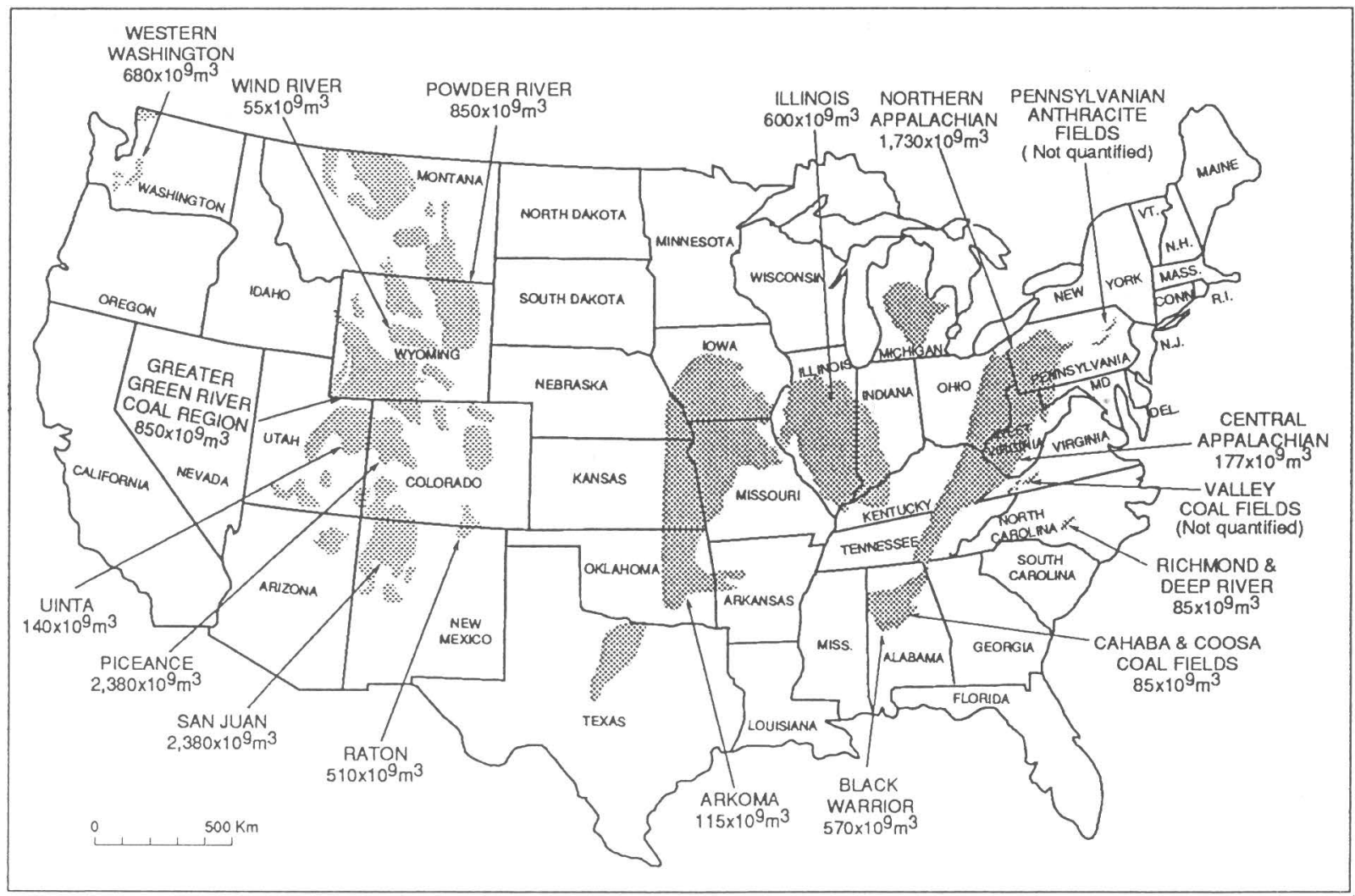

Figure 2. Map showing principal coal-bearing basins of the United States and estimates of inplace coalbed-gas resources. Coals in basins of central and eastern United States are of Paleozoic age and those in western U.S. basins are of Cretaceous and Tertiary age. Modified from ICF Resources (1990).

(Rice and Claypool, 1981; Rice, this volume). If these conditions are met, economically significant amounts of biogenic gas can be generated over a period of tens of thousands of years after burial.

Biogenic gas can be generated during two different stages in coalbeds (Rice, in press). Biogenic gas can form early in the burial history of low rank coals (peat to subbituminous rank-vitrinite reflectance $\left(R_{0}\right)$ values less than 0.5 percent). This biogenic gas is referred to as early stage, and its generation and accumulation are favored by rapid sedimentation. Biogenic gas can also be generated in coalbeds in recent time (tens of thousands to a few million years B.P.) where ground water flow has created a favorable environment for microbial activity. This type of biogenic gas is referred to as late stage, and its generation can take place in coalbeds of any rank provided that the requirements outlined previously have been met.

As the degree of coalification increases owing to higher temperatures and pressures, coals become enriched in carbon as large amounts of volatile matter rich in hydrogen and oxygen are released primarily as methane and carbon dioxide (fig. 3), and water (Stach and others, 1982).

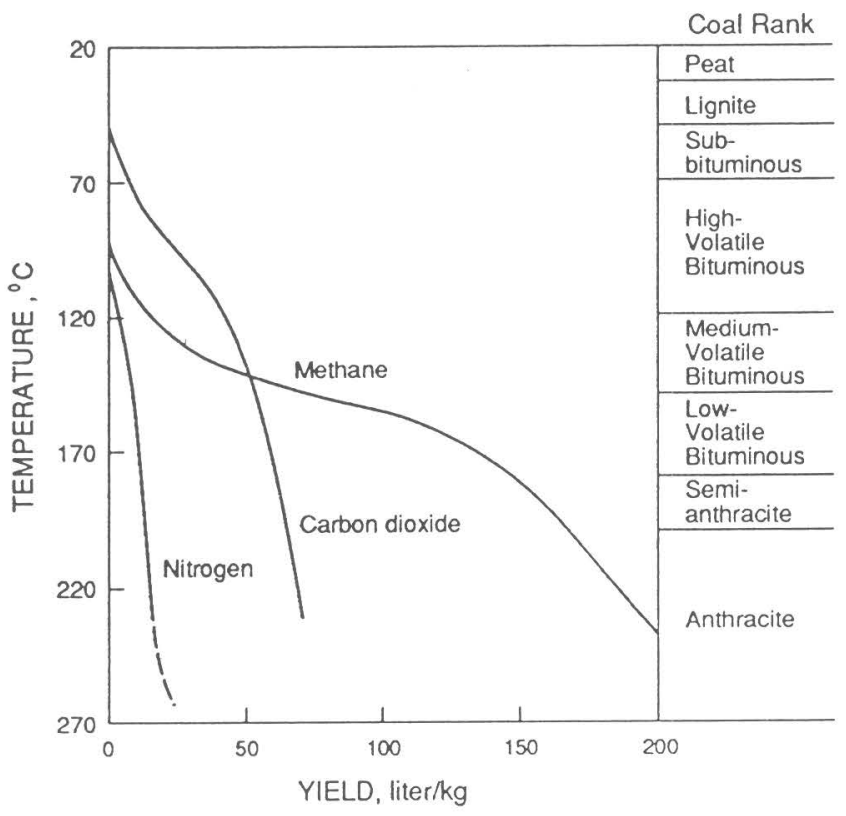

Figure 3. Calculated amounts of gases generated from coal during coalification. Modified from Hunt (1979). 
This methane is thermogenic and its generation begins at a rank of high-volatile bituminous $\left(R_{o}\right.$ values greater than 0.6 percent). The relative quantities of these main volatile products can be estimated using the major elemental composition of the coal $(\mathrm{C}-\mathrm{H}-\mathrm{O})$ which will vary for the different types of kerogen (Juntgen and Karweil, 1966). Four types of kerogen (I-IV) are recognized using major elemental analysis plotted on a van Krevelen diagram (fig. 4). These four types of kerogen generally correlate with the major organic constituents (macerals) identified by petrography-liptinite (I-II), vitrinite (III), and inertinite (IV). Liptinite-rich coals generally correspond to types I and II kerogen, vitrinite-rich coals to type III kerogen, and inertinite-rich coals to type IV kerogen.

Major amounts of methane are generated from coals during the coalification process. The estimates vary from about 100 to $300 \mathrm{~cm}^{3}$ of gas per gram of coal depending on the elemental values used, starting rank, and assumptions made about the gas product composition (Juntgen and Karweil, 1966; Hunt, 1979; Levine, 1987). Under natural conditions, the actual yield is probably in the range of 150 to $200 \mathrm{~cm}^{3} / \mathrm{g}$.

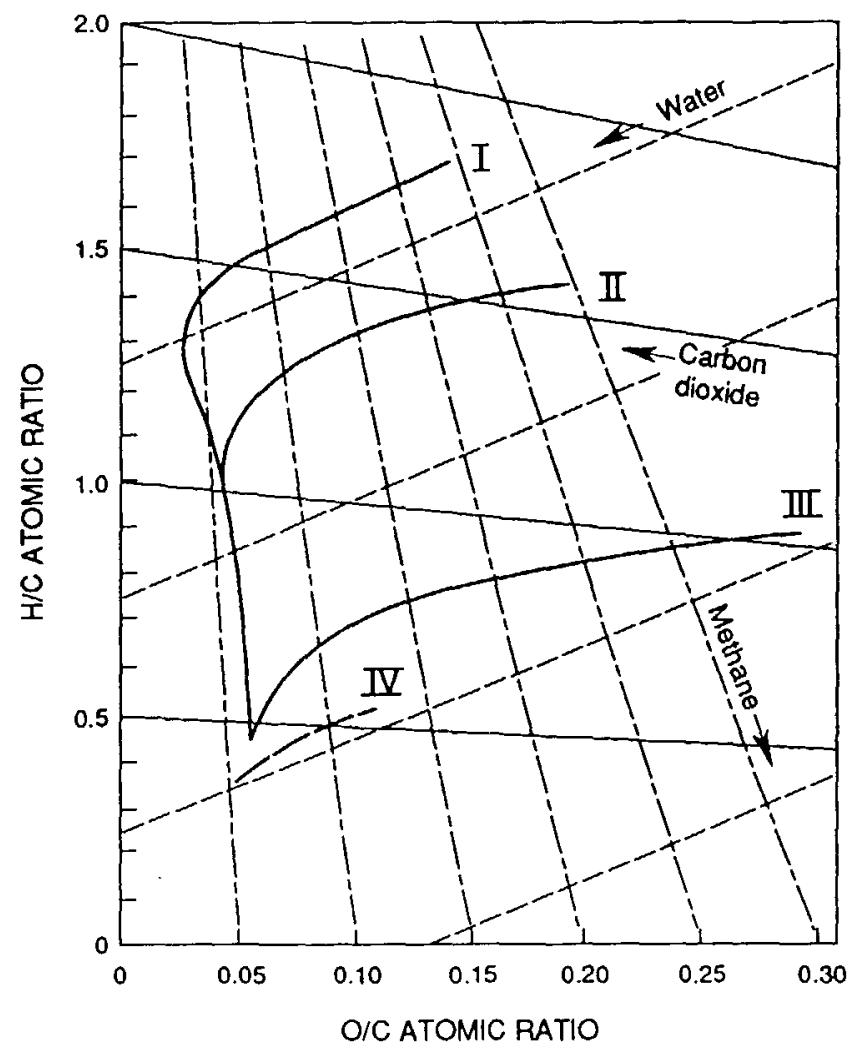

Figure 4. van Krevelen diagram showing types of kerogen and pathways for generation of methane and elimination of carbon dioxide and water during coalification. Liptinite corresponds to types I and II kerogen, vitrinite to type III, and inertinite to type IV. H/C, hydrogen/carbon; O/C, oxygen carbon. Modified from Levine (1987).
In addition to methane, some coals are capable of generating gas containing heavier hydrocarbons (wet gas) and oil. Generation of these heavier hydrocarbons takes place in coals having significant amounts of hydrogen-rich components, such as liptinite or certain components of the vitrinite maceral (such as humic gel) (Bertrand and others, 1986; Saxby and Shibaoka, 1986; Khorasani, 1987; Stanton and others, 1992).

\section{CHARACTERISTICS OF COALBED GAS}

Coalbed gases from which compositional data are determined are obtained from desorption tests of coal samples, underground mines and exploration boreholes, or production from coalbed reservoirs. Compositional data presented in this chapter are for gas samples collected from coalbeds and are not for gas samples from adjacent reservoirs that have been interpreted to be coal derived. Analyses of coalbed gas samples are available from Australia, Canada, China, Germany, Poland, and the United States. The associated coals range in age from Pennsylvanian (late Carboniferous) to Tertiary and in rank from lignite to anthracite $\left(\mathrm{R}_{\mathrm{o}}\right.$ values of 0.3 to 4.9 percent) (Rice, in press).

The molecular and isotopic compositions of coalbed gases are highly variable (Rice, in press). Methane is usually the major component with other hydrocarbon gases and carbon dioxide occurring in lesser amounts. The hydrocarbon composition of the gases, which is expressed as gas wetness $\left(C_{2+}\right.$, where $\left.C_{2+}=C_{2}-C_{5} / C_{1}-C_{5}\right)$, ranges from 0 to 70.5 percent. The wettest gases are from coal samples that were desorbed and crushed. Carbon dioxide is the other major component of the coalbed gases and varies from less than 1 percent to 99 percent. Because of their variable molecular composition, gases from coalbeds should be referred to as coalbed gas and not as coalbed methane. Coalbed gases also vary in their isotopic composition; methane $\delta^{13} \mathrm{C}$ values $\left(\delta^{13} \mathrm{C}\right.$ (parts per thousand (permil)) $=$ $\left({ }^{13} \mathrm{C} /{ }^{12} \mathrm{C}\right.$ sample $/{ }^{13} \mathrm{C} /{ }^{12} \mathrm{C}$ standard- 1$) \times 1000$ relative to $\mathrm{PDB}$ standard) range from -80 to -16.8 permil and carbon dioxide $\delta^{13} \mathrm{C}$ values range from -26.6 to +18.6 permil.

The relation between coalbed gas composition $\left(\mathrm{C}_{2+}\right.$ and methane $\delta^{13} \mathrm{C}$ values) and the rank of associated coal (expressed as $R_{0}$ ) is illustrated by coalbed gas samples from Canada and the United States (figs. 5 and 6) (Rice, in press). There is a tendency for all of the gases to be methane rich (about 95 percent or more $\mathrm{CH}_{4}$ ) at low and high ranks (fig. 6), and for some to be wet at intermediate rank $\left(R_{\mathrm{o}}\right.$ values of about 0.6 to 0.8 percent, fig. 5); however, many samples are methane rich at intermediate ranks (fig. 6). Methane $\delta^{13} \mathrm{C}$ values generally are isotopically lighter (as light as -60 permil) at lower ranks and isotopically heavier ( -40 permil or heavier) at higher rank (fig. 6). However, gases from coal of a given rank display a wide range of methane $\delta^{13} \mathrm{C}$ values and the values commonly 
fall above (isotopically lighter) the regression lines shown on figure 6, which were determined for gases interpreted to have been generated from coal and dispersed organic matter. Similar patterns are exhibited by coalbed gases from other countries (Rice, in press).

Although wetness and methane $\delta^{13} \mathrm{C}$ values of coalbed gases are scattered when plotted against the rank of the associated coal, they illustrate a more systematic trend when plotted against present-day depth of burial (Rice, in press). Shallow coalbed gases are composed of isotopically light methane, as compared with deeper coalbed gases, regardless of rank. The methane-rich nature of shallow coalbed gases has been known for years from compositional data from underground mines. This knowledge resulted in the expression "coalbed methane." The depth-related change in the molecular and isotopic composition of coalbed gas can take place over a transition zone or can be abrupt. This change takes place at varying depths, but usually occurs within a kilometer of the surface.

The reported coalbed gases are interpreted to be both biogenic and thermogenic on the basis of molecular and isotopic composition (Rice, in press). The primary controls on the composition of the gas are considered to be rank,

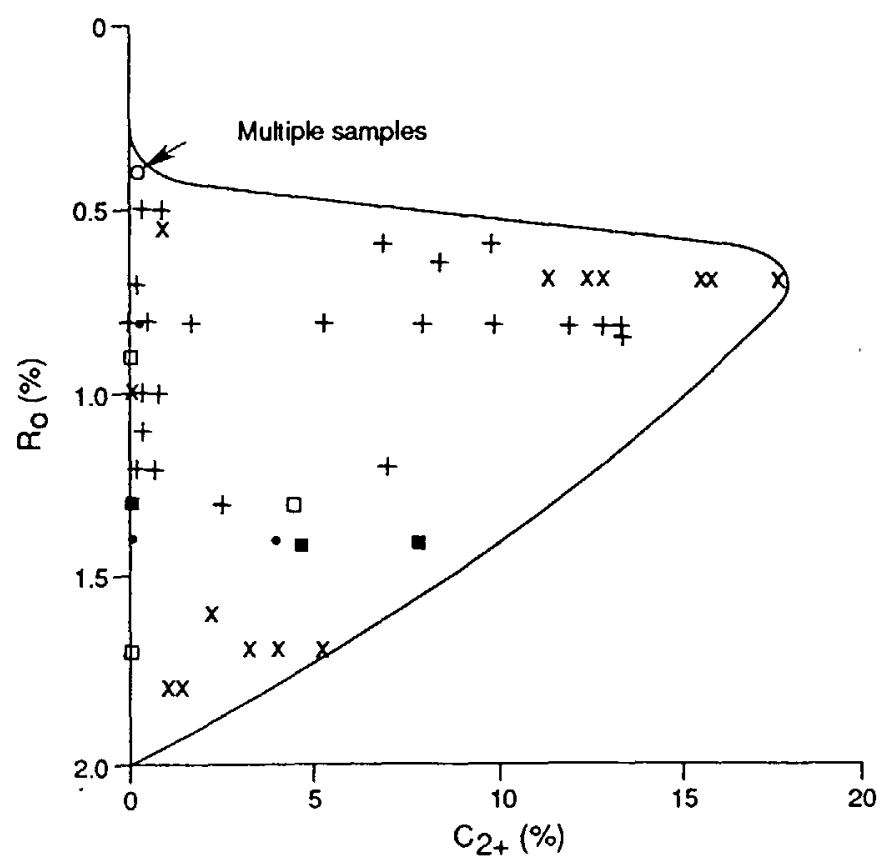

\section{EXPLANATION}

- Powder River basin, USA

- Arkoma basin, USA

- Black Warrior basin, USA

$x$ Piceance basin,USA

+ San Juan basin, USA

- Deep basin. Alberta,Canada

Figure 5. Gas wetness $\left(\mathrm{C}_{2+}\right)$ versus vitrinite reflectance $\left(\mathrm{R}_{\mathrm{o}}\right)$ for coalbed gases and coals, respectively, in Canada and the United States. $\left(C_{2+}=C_{2}-C_{5} / C_{1}-C_{5}\right.$.) From Rice (in press). composition, and the depth/temperature of the associated coal. Secondary controls are also reflected in the coalbed gas composition and they will be discussed later.

Biogenic gas consists mainly of methane; the presence of significant amounts of heavier hydrocarbon gases with biogenic gas indicates mixing of late-stage biogenic methane in mature coals that have already generated heavier thermogenic hydrocarbons. Biogenic gas generation is restricted to shallow depths and to temperatures less than $50^{\circ} \mathrm{C}$, and can occur in coals of all ranks. Biogenic gas can generally be distinguished by its isotopic composition; methane $\delta^{13} \mathrm{C}$ values are generally in the range of -55 to -90 permil.

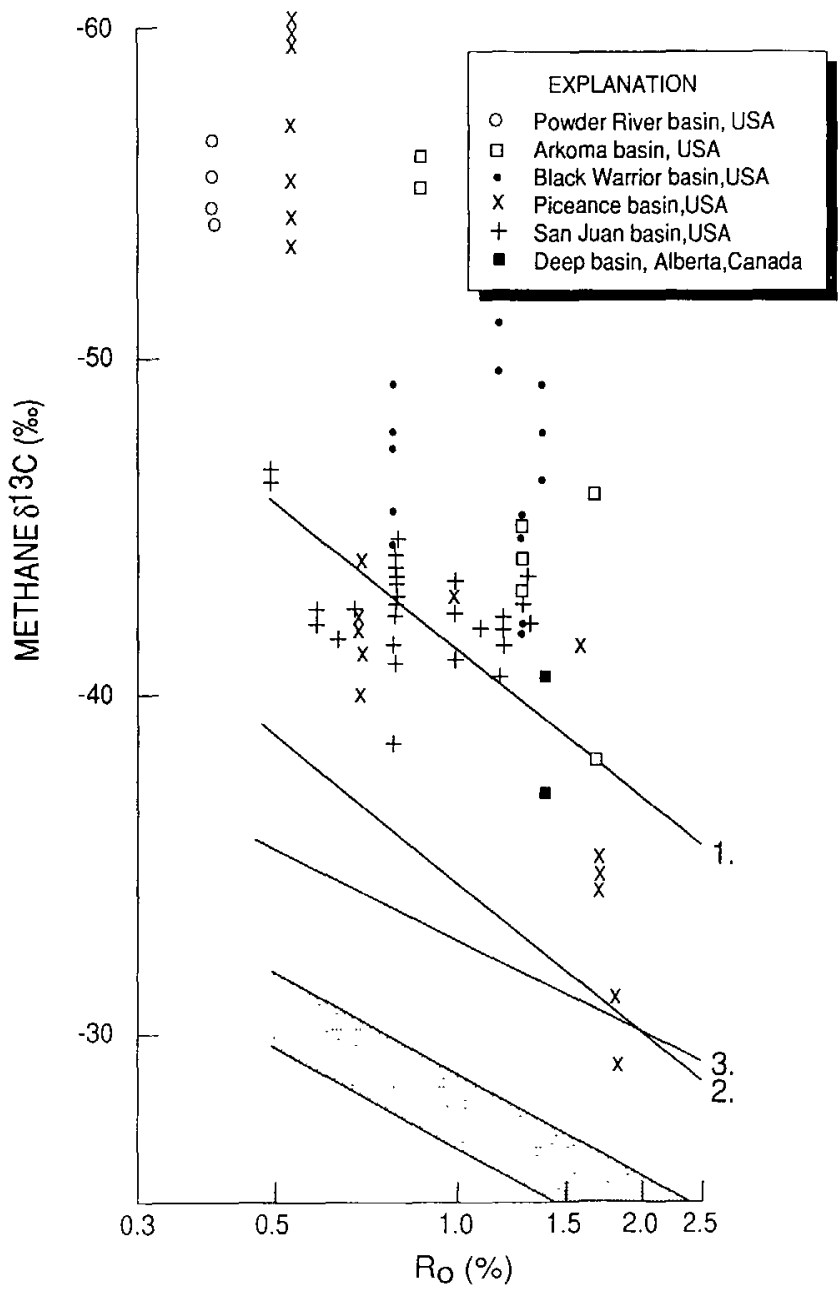

Figure 6. Methane $\delta^{13} \mathrm{C}$ versus vitrinite reflectance $\left(\mathrm{R}_{\mathrm{o}}\right)$ for coalbed gases and coals, respectively, in Canada and the United States. Regression line 1 is for gases generated from types II/III kerogen, line 2 is for gas collected from coalbeds and coal pyrolysis gases in China, line 3 is for coal-derived gases in adjacent reservoirs in China, and stippled area is for coal-derived gas in adjacent reservoirs and coal-pyrolysis gases (from several authors). $\left(\delta^{13} \mathrm{C}\right.$ (parts per thousand(permil)) $=\left({ }^{13} \mathrm{C} /{ }^{12} \mathrm{C}\right.$ sample $/{ }^{13} \mathrm{C} /{ }^{12} \mathrm{C}$ standard -1$) \times 1,000$ relative to $\mathrm{PDB}$ standard.) From Rice (in press). 
In comparison, thermogenic coalbed gases are characterized by (1) common presence of heavier hydrocarbons at intermediate ranks of high-volatile and medium-volatile bituminous coal ( $R_{0}>0.6$ percent) and (2) enrichment of heavy isotope ${ }^{13} \mathrm{C}$ in methane with increasing rank (methane $\delta^{13} \mathrm{C}$ values are commonly more positive than -55 permil). At intermediate ranks (high-volatile and mediumvolatile bituminous), sapropelic coals (liptinite and hydrogen-rich vitrinite) contain both wet gas and liquids, whereas humic coals (mostly vitrinite) contain a drier gas. The liquids generated in the sapropelic coals contain high pristane/ phytane ratios, a feature that is typical for coal-derived oil, and a slight predominance of odd-carbon numbered $n$-alkanes in the $\mathrm{C}_{25+}$ fraction (Clayton, in press). However, the saturated fraction of the liquids consists predominantly of low-molecular-weight components $\left(\mathrm{C}_{4}-\mathrm{C}_{10}\right)$, a composition which results in the liquids having high API gravities (approximately $50^{\circ} \mathrm{API}$ ). In addition, the coal-derived liquids are commonly characterized by flow only at high temperatures (high pour points) because they contain abundant long-chain $n$-alkanes derived from terrestrial plant waxes. At high ranks, coalbed gases are mostly methane generated from residual kerogen and cracking of previously formed heavier hydrocarbons.

Thermogenic methane is isotopically more positive than biogenic methane because of the smaller kinetic isotope effects associated with thermal cracking (Chung and others, 1988; Clayton, 1991). In general, methane $\delta^{13} \mathrm{C}$ values for thermogenic methane become isotopically heavier with increasing rank because residual gas-producing carbon becomes enriched in ${ }^{13} \mathrm{C}$ owing to ${ }^{12} \mathrm{C}-{ }^{12} \mathrm{C}$ bonds being broken more frequently by thermal processes than ${ }^{12} \mathrm{C}-{ }^{13} \mathrm{C}$ bonds. Also, coal composition, in addition to rank, influences the isotopic composition of the coalbed gas, whereby gases generated from coals with oxygen-rich kerogen (mostly vitrinite) (1) have more positive methane $\delta^{13} \mathrm{C}$ values than those generated from hydrogen-rich kerogen (liptinite and hydrogen-rich vitrinite) at similar levels of thermal maturity and (2) exhibit less spread in methane and ethane $\delta^{13} \mathrm{C}$ values (James, 1990; Clayton, 1991). These differences result from isotopically lighter methane being produced by thermal cracking of aliphatic-type structures, which are prevalent in hydrogen-rich kerogen, whereas isotopically heavier methane results from cracking of aromatic structures, which are predominant in oxygen-rich kerogen. This effect of kerogen composition on isotopic composition is illustrated by regression lines shown on figure 6 .

Secondary processes also affect the composition of coalbed gases, particularly at shallow depths, such that isotopically light methane is dominant in shallow coalbed gases, regardless of rank (Rice, in press). The depth interval where these secondary processes are active and affect the composition of the gases is referred to as the zone of alteration. Unaltered gas generally occurs in the deeper parts of basins and is referred to as original gas.
At shallow depths, coalbeds are commonly aquifers in which microorganisms can thrive. Microbial activity can affect the observed composition of coalbed gases in two ways. First, significant amounts of late-stage, isotopically light biogenic methane generated by anaerobic microorganisms can be mixed with previously generated thermogenic gas or fill degassed coalbeds (Rice, in press). Second, aerobic bacteria can preferentially destroy most of the wet-gas components, resulting in a methane-rich gas (James and Burns, 1984).

The zone of alteration, in which mixing and oxidation affect the coalbed gas composition, can extend from depths of a hundred meters to a kilometer. The zone is usually restricted to the margins of basins; however, it can extend into and throughout a basin under certain conditions. The primary controls on the depth and lateral extent of the zone of alteration are the physical nature of the coalbeds, burial history, and hydrology. Thick, laterally continuous, permeable coalbeds are conducive to the development of an aquifer system. Uplift and erosion result in the depressurization of the coalbeds and subsequent degassing of the original gas. In addition, uplift and erosion result in reduced stress and increased permeability, thereby aiding both aquifer development and degassing. Finally, microorganisms become widely distributed in active aquifer systems, leading to widespread microbial activity, including aerobic oxidation and anaerobic methanogenesis.

In addition to hydrocarbon gases, carbon dioxide is the other significant component of coalbed gases. As previously stated, major quantities of carbon dioxide are generated by thermal decarboxylation or devolatilization of coal, particularly prior to the main stage of thermogenic methane production (fig. 3). Carbon dioxide, however, is highly soluble in water and very reactive and can have different origins (Hunt, 1979). As a consequence, the carbon dioxide presently in a coalbed gas may have an origin other than devolatilization. Furthermore, the concentration and isotopic composition $\left(\delta^{13} \mathrm{C}\right)$ of carbon dioxide in coalbed gases is commonly different from those in gases of adjacent reservoirs, suggesting different origins. The wide range in concentrations and isotopic composition $\left(\delta^{13} \mathrm{C}\right)$ of carbon dioxide suggest that significant amounts of carbon dioxide in coalbed gas are not commonly a product of the coalification process, but rather of other processes active in localized areas. Documented sources of large amounts of carbon dioxide in coalbed gas are (1) thermal destruction of carbonates, (2) bacterial degradation of organic matter, (3) bacterial hydrocarbon oxidation, and (4) migration from magma chambers or deep crust (Rice, in press).

\section{GAS STORAGE}

One of the most important characteristics of coalbed gas reservoirs that set them apart from more conventional 
gas reservoirs is the amount of gas and manner in which it is stored. In conventional reservoirs, such as sandstones or carbonates, gas occurs as either a free or dissolved phase. Although some free and dissolved gas may occur, as much as 98 percent of the gas present in coalbed reservoirs is sorbed (Gray, 1987). The free and dissolved gas in the coal occurs within the fractures (cleats) and pores, whereas the sorbed gas occurs as a monomolecular layer on the internal surfaces of coal (Selden, 1934; Kim, 1977). Because coal is a microporous solid with large intemal surface areas (10's to 100's of $\mathrm{m}^{2} / \mathrm{g}$ of coal), it has the ability to sorb very large amounts of gas and can hold much more gas than the same rock volume of a conventional reservoir. In addition, the microstructure of coal has been described as a molecular sieve or cage (van Krevelen, 1981) within which the methane molecule can be stored.

In general, gas content increases with increasing rank, although there is a wide range of gas contents within each coal rank (fig. 7). Low-rank coals contain as much as $2.5 \mathrm{~cm}^{3} / \mathrm{g}$, whereas higher rank coals contain as much as $31 \mathrm{~cm}^{3} / \mathrm{g}$. The large increase in gas content between the ranks of subbituminous $\mathrm{A}$ and high-volatile $\mathrm{C}$ bituminous is mainly due to the larger amounts of methane generated by thermal processes associated with the coalification of highrank coals relative to the smaller volumes of methane only generated by microbial processes at lower ranks. At higher ranks (medium-volatile bituminous and higher), coals may have generated more methane than they can store, resulting in the possible expulsion of methane into adjacent reservoirs (Juntgen and Karweil, 1966; Meissner, 1984).

Pressure and temperature also play an important role in the gas content of coal. For a given rank, sorbed gas content increases with increasing pressure and decreases with increasing temperature (Juntgen and Karweil, 1966). Because high pressures and temperatures are more commonly associated with high-rank coals than low-rank

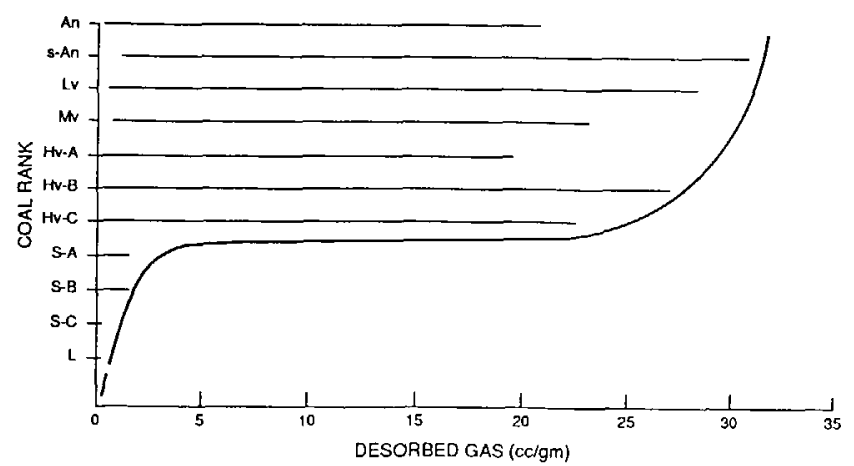

Figure 7. Cross plot showing range of gas content versus coal rank. Data from measurements of desorbed coalbed gas in the United States. An, anthracite; s-An, semianthracite; Lv, low-volatile bituminous; $\mathrm{Mv}$, medium-volatile bituminous; $\mathrm{Hv}-\mathrm{A}, \mathrm{Hv}-\mathrm{B}$, and $\mathrm{Hv}-\mathrm{C}$, high-volatile bituminous $\mathrm{A}, \mathrm{B}$, and $\mathrm{C} ; \mathrm{S}-\mathrm{A}, \mathrm{S}-\mathrm{B}$, and S-C, subbituminous A, B, and C, L, lignite. coals, relatively high gas contents are generally expected in high-rank coals. In some cases, however, natural desorption of gas resulting from uplift and erosion in the subsurface environment may result in unexpected low gas contents, thereby accounting for some of the wide variations in gas content within a given coal rank (fig. 7).

Regardless of rank, nearly all coals contain at least some water. For practical purposes, moisture content of coal is defined as the water present as $\mathrm{H}_{2} \mathrm{O}$ that is released at temperatures of $104^{\circ}$ to $110^{\circ} \mathrm{C}$ (American Society for Testing Materials, 1973). Water in coal occurs as free water, water of decomposition, and water of hydration. Free water occurs in fractures and macropores; water of decomposition is bound to oxygen-containing functional groups $(-\mathrm{OH},-\mathrm{COOH},-\mathrm{C}=\mathrm{O})$ by hydrogen bonding (Iyengar and Lahiri, 1957); and water of hydration is found in accessory minerals, such as gypsum and clay (Allardice and Evans, 1978). Some of this water competes with methane for sites of sorption. The amount of water sorbed in a coal is referred to as the critical moisture content and is dependent on the oxygen content of the coal (Joubert and others, 1973). Moisture contents above the critical moisture content do not affect the sorption of methane. Low-rank coals have larger amounts of oxygen than highrank coals and therefore can sorb more water than highrank coals.

The amount of inorganic material and the maceral composition of coal are additional factors affecting its gas sorption capacity. There is no affinity for gas to sorb onto the surfaces of inorganic matter. Inorganic matter occupies space that otherwise would be filled with organic matter, thereby reducing the surface area available for gas sorption (Gunther, 1965). As a consequence, coals with relatively high ash content will not contain as much gas as low-ash coals of equal rank. The gas storage capacity of hydrogen-rich, high-volatile bituminous coals is reduced because of the generation of high-molecular-weight hydrocarbons (Levine, 1991). These hydrocarbons have the effect of plugging the microporosity, thus reducing the storage capacity. The sorption capacity is increased again at higher ranks (low- volatile bituminous and higher), when these heavier hydrocarbons are thermally cracked.

\section{DETERMINATION OF GAS CONTENT}

The most common method of determining the volume of gas contained in coal is by direct measurement of core or drill-cutting samples retrieved from a well during drilling. The direct method measures three components-desorbed gas, residual gas, and lost gas. The desorbed gas component is measured by placing core or drill-cuttings samples in a sealed canister immediately after the samples arrive at the surface. Periodic measurements of the desorbed gas are recorded over a span of several weeks to 
months until there is virtually no more gas desorbing from the coal. The coal is then removed from the canister, crushed to a very small size, and the amount of evolved or residual gas is measured. The lost gas component represents the amount of gas lost from the sample from the time the sample was penetrated by the drill bit to the time the sample was placed in a canister. It is calculated graphically by the linear extrapolation of the square root of time versus the cumulative volume of desorbed gas. The sum of the three components then constitutes the calculated amount of gas contained in the coal sample. In general, the measured values tend to be less than the actual gas contents as revealed by pressure cores (Yee and others, in press). Although there are several sources of potential error in measuring the gas content, particularly in calculating the lost gas amount, the results are usually representative of the relative volume of gas contained in a coal. Detailed procedures for measuring gas content are provided by Kissell and others (1973), Smith and Williams (1981), and Ulery and Hyman (1991).

The amount of gas stored in a particular coal relative to reservoir pressure at a constant temperature is commonly determined from a sorption isotherm (fig. 8) (Mavor and others, 1990). The sorption isotherm is a measure of the maximum amount of gas that a coal can sorb. In many cases, however, coals are undersaturated with respect to gas, and the sorption isotherm, in conjunction with direct measurement of gas content, can be used to determine if a coal is fully saturated with gas. Common reasons for the undersaturation of gas are miscalculation of gas content, degassing of coalbeds resulting from uplift and erosion, and differential generation of coalbed hydrocarbons resulting from varying coal composition.

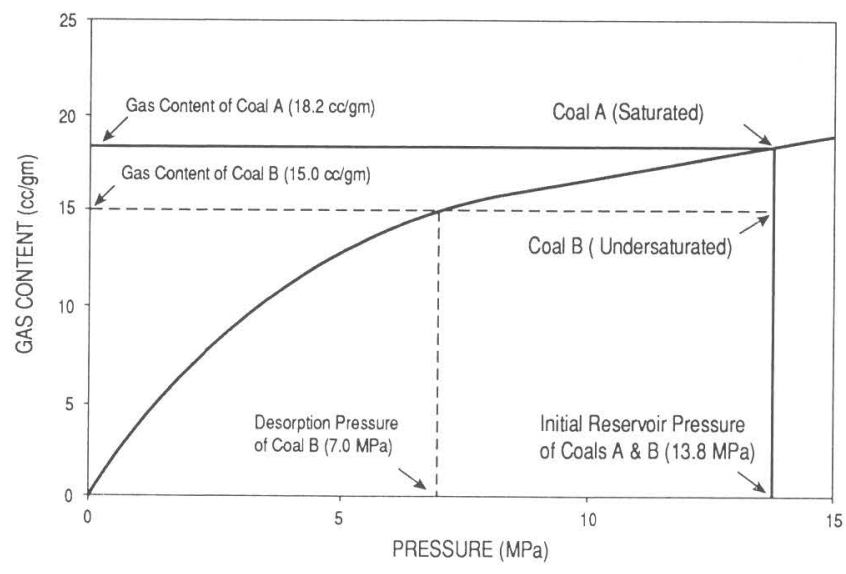

Figure 8. Idealized coalbed gas sorption isotherm showing relation between reservoir pressure and gas content for a saturated (A) and undersaturated (B) coal. Heavy solid line indicates the maximum amount of gas that can be stored at given reservoir pressure. Modified from McElhiney and others (in press).

\section{GAS PRODUCTION}

Economic quantities of gas can be produced from coalbed reservoirs. The diagrammatic sketch in figure 9 shows the path that methane molecules and other gases must take in order to be produced. From the sites of gas sorption within the matrix, the gas must desorb and migrate by diffusion out of the matrix into the cleats where the gas then flows to the wellbore. The coalbed gas is held in the microstructure of the coal by pore pressure, and gas migration takes place when the pressure is reduced. Because most coals are characterized by high water saturations, depressurization results from dewatering of the coalbeds. The sorption isotherm, in conjunction with direct measurement of gas content, can provide information on the production potential of a coalbed reservoir. For example, coal A (fig. 8) contains $18.2 \mathrm{~cm}^{3}$ of gas per gram at a reservoir pressure of 13.8 mega pascal (MPa). Because coal A is saturated with methane, gas will immediately begin desorbing from the matrix when the coal is penetrated by a drill bit and the pore pressure begins to drop. In contrast, coal B is undersaturated with methane $\left(15.0 \mathrm{~cm}^{3} / \mathrm{g}\right)$ and the methane will not desorb at the present reservoir pressure of $13.8 \mathrm{MPa}$. Significant gas desorption will only begin from coal B after reducing the reservoir pressure from $13.8 \mathrm{MPa}$ to $7.0 \mathrm{MPa}$.

The development of permeability is a critical aspect of gas production from coalbed reservoirs. The absolute permeability of coalbeds ranges from less than 0.1 millidarcy (md) to more than $100.0 \mathrm{md}$. Commonly, permeability in coalbed reservoirs is in the range of 1.0 to $10.0 \mathrm{md}$. For

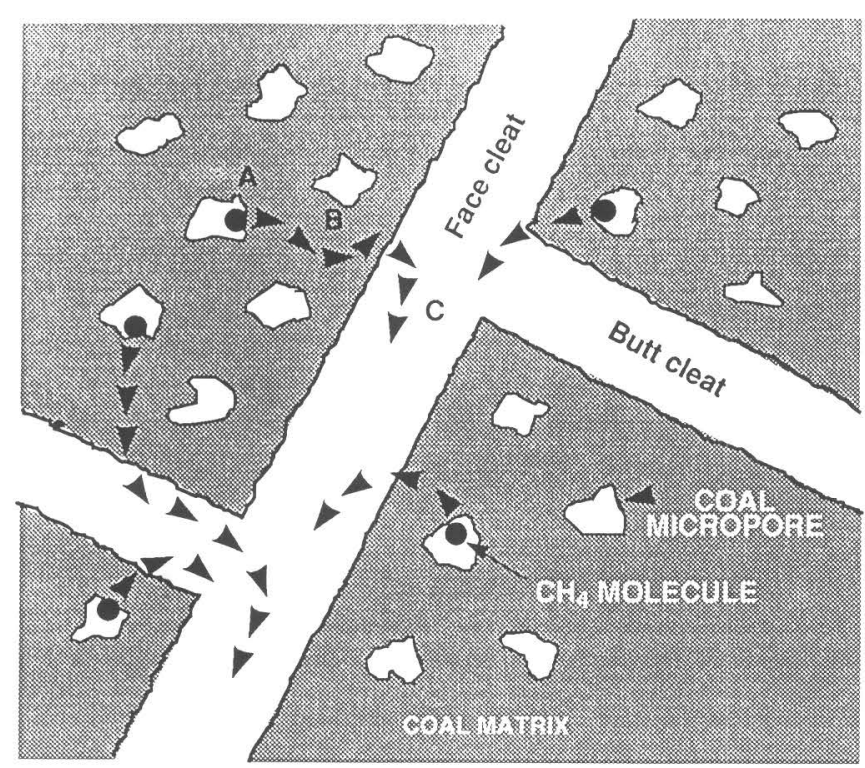

Figure 9. Diagram showing (A) desorption of methane from micropore in coal matrix, (B) diffusion path of methane through coal matrix, and (C) flow of methane in fractures (cleats). From Diamond (in press). 
practical purposes, there is essentially no permeability within the coal matrix. Virtually all of the permeability in coal occurs within the fracture system, commonly referred to as the cleat system. Without a well-developed cleat system, commercial gas production from coalbeds is not possible. Cleats constitute a roughly orthogonal set of fractures referred to as face and butt cleats (fig. 10). Face cleats are the dominant, more extensive set and butt cleats are the subordinate set. Owing to the better development of face cleats, permeability in coalbeds commonly exhibits varying degrees of anisotropy, with the better permeability developed parallel to the face cleat direction (McCulloch and others, 1974). The factors that affect the permeability of cleats include cleat frequency, connectivity, and aperture width. These factors are, in turn, affected by bed thickness, coal quality, rank, tectonic deformation, and stress (Macrae and Lawson, 1954; Ammosov and Eremin, 1963; Decker and others, 1991). The preservation of cleats is largely dependent on severity of structural deformation. Current coalbed gas production is from relatively structurally undeformed areas, where the cleat system is preserved. In areas of severe structural deformation, the cleat system is commonly obliterated (Law, in press). Thus, the economic production of gas in structurally complex regions may be severely hindered, even though the coals may contain large amounts of gas.

One of the largest obstacles to the economic recovery of coalbed gas is water. The presence of water in coal inhibits desorption of gas from the coal matrix and flow to the wellbore, particularly in coals undersaturated with gas

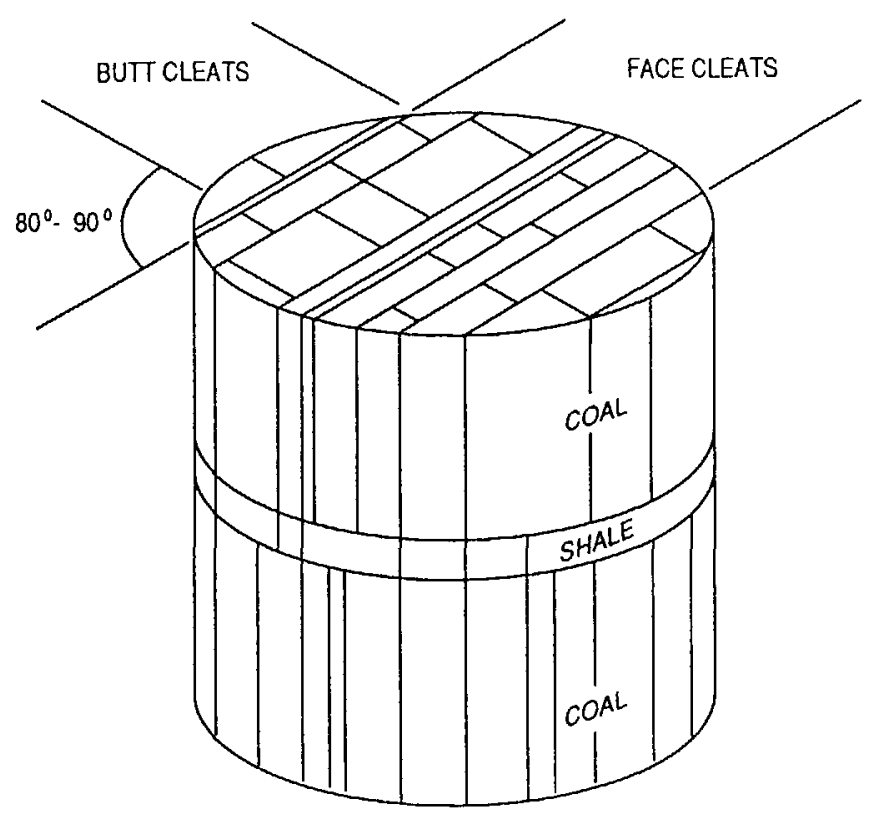

Figure 10. Diagram showing relation between face (dominant, more extensive) and butt (subordinate) cleats in coal and carbonaceous shale. Note that the frequency of cleats in carbonaceous shale is less than in coal. Modified from Jones and others (1984). (figs. 8, 9). Coalbeds are commonly dewatered by drilling several wells that then produce water by pumping to a point at which gas begins to desorb from the matrix. The period of time necessary to accomplish sufficient dewatering is highly variable (days to months) and in some cases is never reached. The success of dewatering efforts is dependent on the source of the water and the number of wells involved in the dewatering process.

Sources of water in coal may include original water (inherent moisture), water of meteoric origin, and water from adjacent aquifers. First, nearly all coals contain some inherent moisture from the time that the original peat was deposited, moisture which decreases with increasing degree of coalification. Lignite commonly contains as much as 70 percent water, which decreases to less than 5 percent in medium-volatile bituminous and higher rank coals (van Krevelen, 1981). Second, in areas where coalbeds are relatively permeable and continuous and precipitation is abundant, atmospheric water may enter the coalbeds at the surface and travel great distances into the subsurface. Differences in elevation between the surface and subsurface may cause abnormally high formation pressures (overpressured). This artesian overpressuring is developed in the northern part of the San Juan basin, which is characterized by high rates of both water and gas production from the coalbed reservoirs (Kaiser and others, 1991). Finally, communication may exist between a coalbed and adjacent aquifers because of natural or man-related causes.

In areas where water is the pressuring phase, dewatering simultaneously reduces the reservoir pressure and the water content, thereby allowing gas to desorb from the coal. In areas where the coalbed reservoir is discontinuous and (or) has low permeability and the supply of water is limited, the probability of conducting successful dewatering programs is favorable.

As a consequence of the gas storage characteristics of coal and the relation between water and gas production, coalbed gas wells exhibit a distinctive production history (fig. 11). In the early dewatering stage of production, large

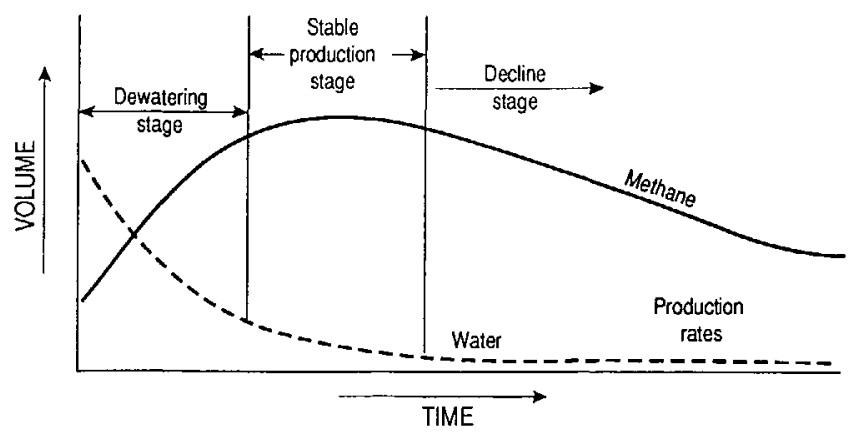

Figure 11. Generalized production history showing volumes of methane and water over time for a typical coalbed gas well. From Kruuskraa and Brandenberg (1989). 
amounts of water are produced along with small amounts of gas until sufficient water is produced to allow for larger amounts of gas to desorb from the matrix and flow through the cleats to the wellbore. During the stable production stage, the quantities of gas increase as the quantities of water decrease. This coalbed gas production during the stable production stage is referred to as "negative decline" and distinguishes it from production from other types of reservoirs. Finally, in the declining stage of production, the amount of gas gradually declines and water production remains low.

In nearly all cases, however, coalbed gas wells require special drilling or completion techniques to effectively connect the reservoir to the wellbore. Both vertical and horizontal wells have been utilized, although vertically drilled wells are far more common than horizontally drilled wells, except in some of the coal mining areas. The completion techniques range from hydraulic fracturing of wells with casing to open holes, some with enlarged cavities (Palmer and others, in press). Although open-hole cavity completions in the main production fairway of the San Juan basin have yielded the best results (as much as $179 \times 10^{3} \mathrm{~m}^{3}$ of gas per day), the completion technique in each area must be tailored to the localized coalbed reservoir characteristics, such as rank, pressure, permeability, and gas content.

\section{ENVIRONMENTAL CONCERNS}

\section{METHANE EMISSIONS FROM COAL MINING}

Methane is a strong infrared absorber and important greenhouse gas (Cole, this volume). According to recent estimates, atmospheric methane accounts for approximate- ly 15 percent of the "radiative forcing" added to the atmosphere during the past decade (Intergovernmental Panel on Climate Control, 1990). On an atomic basis, methane contributes 25 times more radiative forcing than carbon dioxide, and it contributes 70 times more radiative forcing than carbon dioxide on a weight basis (Intergovernmental Panel on Climate Control, 1990). On the other hand, methane has a short residence time in the atmosphere of 8 to 12 years compared to more than 200 years for carbon dioxide. The short residence time of methane indicates that reductions in methane emissions will have noticeable short-term impacts on atmospheric concentrations of methane and that small reductions will be needed in the long term to stabilize atmospheric concentrations.

Currently, the concentration of methane in the atmosphere is about 1,700 parts per billion (ppb) (Blake and Rowland, 1988). Evidence from analysis of gases trapped in ice cores indicates that atmospheric methane has more than doubled over the past 200-300 years from a preindustrial range of $600-700 \mathrm{ppb}$ and has increased at a rate of about 1 percent per year over the past 15 years, or about 28 to 45 teragrams per year $(1$ teragram $(\mathrm{Tg})=52.6$ billion cubic feet at sea level) (Intergovernmental Panel on Climate Control, 1990).

This increase in atmospheric methane is correlative with human population growth and human activities. The principal anthropogenic sources of methane are rice paddies, domestic livestock, landfills, biomass burning, venting of natural gas, losses of natural gas during transmission of gas and petroleum, and coal mining (fig. 12) (Intergovernmental Panel on Climate Control, 1990). These human activities account for about 60 percent of the total global emissions of methane, which are estimated to be in the range of 440 to $640 \mathrm{Tg}$ per year. The methane reductions required to stabilize atmospheric concentrations of meth-

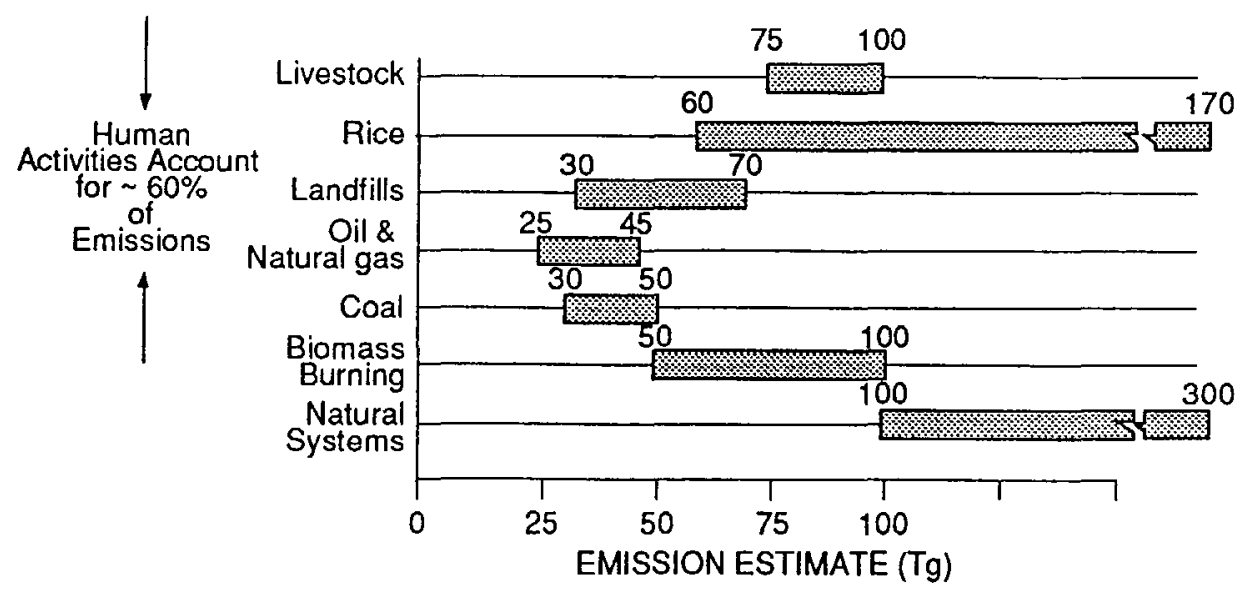

Figure 12. Major sources of methane emissions in teragrams (Tg) per year. Oil and natural gas is from oil and natural gas venting and production; rice is from rice paddies, and natural systems is mostly from wetlands. (One teragram $=52.6$ billion cubic feet at sea level.) Bars indicate range of emission estimates for each source. From Kruger (1991). 
ane by the year 2000 are on the order of 25 to $50 \mathrm{Tg}$ per year (Intergovernmental Panel on Climate Control, 1990). These reductions are much lower than those required to stabilize other greenhouse gases, such as carbon dioxide and nitrous oxide. Coal mining probably accounts for about 10 percent of the total human-related emissions, and at least 10 percent of the coal-mining related emissions of methane can be economically recovered and utilized (Kruger, 1991).

Pressure reduction during coal mining results from the removal of overburden and dewatering. This pressure reduction leads to the desorption of methane, dominant in coalbed gas at shallow depths, and to the possible release of methane to the atmosphere. In general, more methane is released from underground mines than surface mines because of the relation between methane storage, depth, and pressure. In underground mines, emission rates are variable depending on factors, such as the mining method (room and pillar versus longwall) and age of the mine (Deul and Kim, 1988). Methane emissions also continue during the transport, processing, and storage of coal. In 1987, underground mining accounted for about 40 percent of the coal production in the United States and for about 45 percent of world-wide coal production (Boyer and others, 1990). The methane released during underground mining is not only an environmental concern but also a serious safety hazard because methane is highly explosive at relatively low concentrations ( 5 to 15 percent in air). In the United States and some other countries, methane levels in the mines are kept at very low levels by installation of high-grade ventilation systems.

Annual emissions of methane from coal mining have been estimated to be about 30 to $50 \mathrm{Tg}$ (fig. 12) (Intergovernmental Panel on Climate Control, 1990). Currently, however, available data are insufficient to satisfactorily assess methane emissions from coal. Even though methane emissions from mining ventilation systems are measured in the United States, estimates of the total methane flux from coal mines include broad assumptions and contain a high degree of uncertainty. Estimates of methane emissions from coal mines in countries other than the United States contain greater uncertainty because even less data are available. In some cases, global estimates of methane flux from coal mines are solely based on data from U.S. mines that were extrapolated to a global scale (Boyer and others, 1990).

On the basis of 1987 coal production data and using U.S. mines as an analog, Boyer and others (1990) estimated annual methane emissions from coal mines worldwide to be in the range of 33 to $64 \mathrm{Tg}$. More than 90 percent of the total emissions are from the 10 primary coal producing countries shown in table 1 . About 79 percent of the total estimated methane emissions from coal mining are from four countries-China, the former Soviet Union, the United States, and Poland; China, by itself, accounts for about
Table 1. Estimated methane emissions in teragrams $(\mathrm{Tg})$ from major coal-producing countries.

[One teragram $=52.6$ billion cubic feet at sea level. From Boyer and others, 1990]

\begin{tabular}{|c|c|}
\hline Primary coal producing countries & $\begin{array}{l}\text { Estimated annual methane emissions } \\
\qquad(\mathrm{Tg})\end{array}$ \\
\hline China - & 16.1 \\
\hline Former U.S.S.R. & 8.3 \\
\hline United States -...- & 7.0 \\
\hline Poland--_- & 3.4 \\
\hline Germany & 2.1 \\
\hline South Africa-- & 2.1 \\
\hline 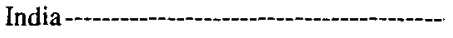 & 1.7 \\
\hline United Kingdom- & 1.6 \\
\hline Australia -- & 1.1 \\
\hline Czech Republic & 0.6 \\
\hline Total - & 44.0 \\
\hline
\end{tabular}

36 percent of the world's annual emissions (table 1) (Boyer and others, 1990). Because of increasing energy demand, particularly in the developing countries and as the world's population increases, coal production is forecast to increase substantially over the next decade, and coal mining could become an even greater source of atmospheric methane.

Coalbed gas can be recovered before, during, or after mining and the quality and quantity of the recovered methane will depend on the method used. Ventilation is the primary method of controlling methane levels in most mines, and fresh air is typically circulated across the actively mined coal face (Boyer and others, 1990). Sometimes, methane emissions can be controlled using ventilation alone, but this method commonly has to be supplemented. Other recovery methods include vertical wells, gob wells (removes gas released from rocks above and below the coalbed during and after mining), and horizontal and crossmeasure boreholes (Boyer and others, 1990). Because large amounts of air are mixed with methane during ventilation, the recovered-gas mixture is useful only for combustion air in a gas turbine or coal-fired boiler. Typical uses for gases recovered by wells and boreholes, gases which generally have higher percentages of methane, are pipeline injection and power generation.

An excellent example of the economic recovery of methane from coal mining operations, resulting in reduced methane emissions, comes from the Black Warrior basin of southeastern Alabama (fig. 2) (Mills and Stevenson, 1991). A coal mining company that has captured miningrelated methane operates gaseous mines at depths of 396 to $640 \mathrm{~m}$; the methane content of the coalbeds ranges from 15.6 to $18.7 \mathrm{~cm}^{3} / \mathrm{g}$ and presents a hazard to miners. Initially, the methane was vented to the surface. Later, methane was successfully recovered and sold, improving both mine safety and productivity. Recovery of methane averages about $1 \times 106 \mathrm{~m}^{3}$ per day, a volume which represents about 
35 percent of the methane released during the mining process. In this mine, about 83 percent of the recovered gas is from gob wells; the remaining 17 percent is from hydraulically stimulated vertical wells and horizontal drainage wells, which recover methane before mining.

Methane release related to coal mining can also cause safety hazards in nearby areas as documented in Powder River basin, Wyoming (fig. 2) (Law and others, 1991). On the east flank of the Powder River basin, thick, subbituminous Tertiary coalbeds are surface mined from some of the most economically important deposits in the United States. Owing to dewatering operations, the ground water levels have fallen as much as 24 meters in wells near the active mines and up to 3 meters as much as 5 kilometers away from the mines (Martin and others, 1988). This lowering of the ground-water level has resulted in desorption of the gas from the coal matrix in the area surrounding the surface coal mines. The desorbed gas has migrated within the coal to a laterally continuous anticline near the mine to form a commercial coalbed gas accumulation with only minor amounts of water. In addition, stress fractures and faults on the anticline have formed conduits for the gas to migrate out of the coalbeds and upward to the surface and into basements of nearby houses, causing an explosion danger.

\section{WATER DISPOSAL}

Water, commonly in large quantities, is produced from coalbed gas wells, especially during the early stages of gas production (fig. 11). The disposal of this produced water can not only affect the economics of the development of the coalbed gas, but also pose serious environmental concerns. In the United States, water disposal is controlled by Federal, State, and (or) local agencies. The disposal of produced waters will also be an environmental and economic concern in other countries as they develop their coalbed gas resources.

The most economic methods of water disposal from coalbed gas reservoirs are discharge into streams, direct use for agricultural, wildlife, or industrial purposes, and evaporation. In addition, produced coalbed waters can be directly used in oil and gas fields as hydraulic fracture fluids and for enhanced oil recovery projects. More costly alternatives of disposal are underground injection and surface discharge after treatment, such as distillation, dilution, ion-exchange, reverse osmosis, and electrodialysis. The specific method of disposal will depend on the quality and quantity of the water. Problems and methods of water disposal are discussed by Zimpler and others (1988) and Burkett and others (1991).

The quantity and quality of water vary considerably in coal-bearing basins and reflect the water's residence time and rock-water interactions in the subsurface and groundwater flow patterns. Total dissolved solids (TDS) in pro- duced coalbed water range from less than $200 \mathrm{mg} / \mathrm{L}$ to more than $90,000 \mathrm{mg} / \mathrm{L}$ with most values being less than $30,000 \mathrm{mg} / \mathrm{L}$ (Kaiser and others, 1991; Pashin, 1991). TDS and salinity tend to increase with the water's residence time in the subsurface and with increased time for rockwater interactions. As a consequence, TDS and salinity are generally higher in the central, deeper parts of basins as compared to the shallower parts of basins that are near recharge areas of relatively fresh meteoric water. Typically, produced water is neutral to slightly alkaline with $\mathrm{pH}$ values ranging from 7.0 to 8.5 and contains the carbonate, bicarbonate, chloride, sulfate anions, and sodium, potassium, calcium, and magnesium cations in variable amounts. If enough chemical data are available, maps of chlorinity and different water types can be used to map ground-water flow patterns (Kaiser and others, 1991; Pashin, 1991). For example, concentrations of chloride, which is unaffected by rock-water interactions, indicate directions of groundwater flow because low chloride waters occur in recharge areas of relatively fresh water circulation.

Production rates of water can be as high as $950 \mathrm{~m}^{3}$ per day. However, most commercial coalbed gas wells produce less than $40 \mathrm{~m}^{3}$ per day after the initial dewatering phase. By water-well standards, most coalbed gas wells are lowyield wells. Higher rates of production are generally near areas of recharge where the waters are relatively fresh (low TDS); low rates of water production are in deeper parts of basins and (or) areas of low permeability where the water is commonly very saline. Although the volume of water from an individual coalbed gas well is generally low as compared to a water well, the cumulative volume of produced water can be enormous when a large number of wells are drilled. For example, about $15 \times 10^{6} \mathrm{~m}^{3}$ of water was produced from more than 2,800 wells in the southeastern part of the Black Warrior basin in 1991 (fig. 2). Because of the humid climate, most of this water was discharged into streams without noticeable environmental consequences. In comparison, about $6 \times 10^{6} \mathrm{~m}^{3}$ of water was produced by more than 1,700 wells in the San Juan basin during the same time period. Because of the quality and quantity of the water and the dry climate of this region, most of this water was disposed of in underground injection wells (a more expensive method); the cost was offset by the higher production rates from individual gas wells in the San Juan basin relative to the rates from wells in the Black Warrior basin.

\section{RESOURCE POTENTIAL}

Worldwide resources of coal are estimated to be as much as 25 trillion metric tons (Kuuskraa and others, 1992). Most of these resources (about 90 percent) are concentrated in four countries-Canada, China, Russia, and the United States (fig. 13; table 2). However, the remaining resources are widely distributed. In many countries, such 


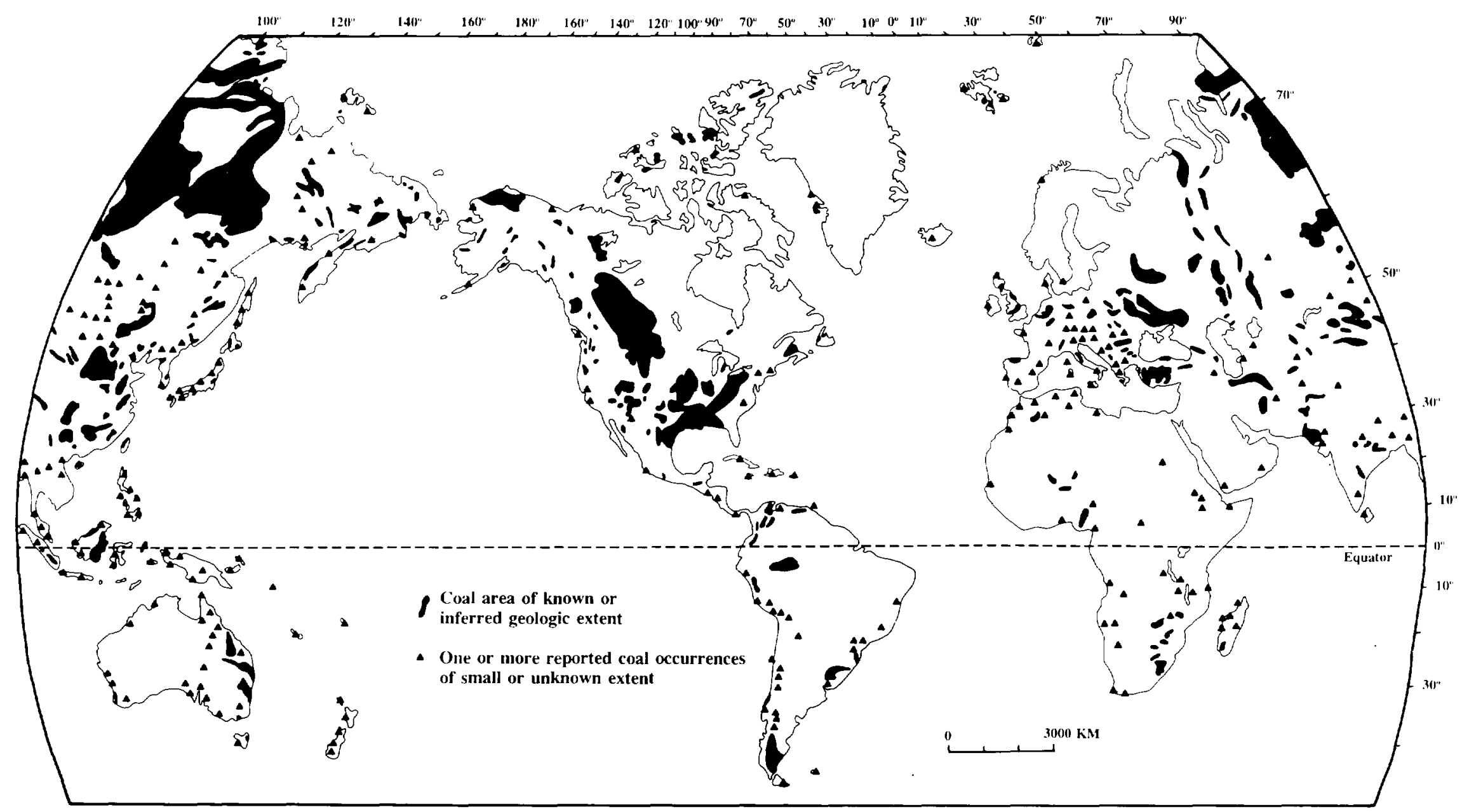

Figure 13. Map showing global coal distribution. From E.R. Landis and J.N. Weaver, U.S. Geological Survey (written commun., 1992). 
Table 2. Major coal and coalbed gas resources (estimated) by country.

[One trillion cubic meters $=28.32$ trillion cubic feet. From Kuuskraa and others, 1992]

\begin{tabular}{|c|c|c|}
\hline Country & $\begin{array}{c}\text { Coal resources } \\
\text { (billion metric tons) }\end{array}$ & $\begin{array}{l}\text { Coalbed gas resources } \\
\text { (trillion cubic meters) }\end{array}$ \\
\hline 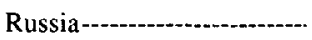 & 6,500 & $17-113$ \\
\hline 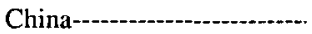 & 4,000 & $30-35$ \\
\hline United States & 3,950 & 11 \\
\hline Canada -- & 7,000 & $6-76$ \\
\hline Australia--_- & 1,700 & $8-14$ \\
\hline Germany-- & 326 & 3 \\
\hline United Kingdom & 190 & 2 \\
\hline Kazakhstan-.......... & 170 & 1 \\
\hline Poland …..... & 160 & 3 \\
\hline 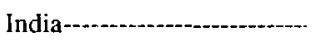 & 160 & 1 \\
\hline Southern Africa ${ }^{l}$ & 150 & 1 \\
\hline Ukraine - & 140 & 2 \\
\hline Total-_- & 24,446 & $85-262$ \\
\hline
\end{tabular}

${ }^{1}$ Includes Botswana, South Africa, and Zimbabwe.

as the Czech Republic, Poland, and the Ukraine, coal is the only available abundant source of energy (Kelafant and others, 1992; Kuuskraa and others, 1992; Landis, in press).

Major resources of coalbed gas are associated with the immense amounts of coal. Worldwide estimates of coalbed gas are estimated to range from 85 to 262 trillion cubic meters (table 2) ( 1 trillion cubic meters of gas $=28.32$ trillion cubic feet); the range of values indicates the scarcity of basic coal data in many coal-bearing areas of the world (Kuuskraa and others, 1992). Although the resource is widely distributed, most coal is concentrated in 12 countries, where coal is commonly a major source of energy (Kuuskraa and others, 1992). The major U.S. coal-bearing basins are estimated to have coalbed gas resources of about 11 trillion cubic meters (fig. 2) of which 3 trillion cubic meters is expected to be recoverable (Rightmire and others, 1984; ICF Resources, 1990). These coal-bearing areas are in cratonic and foreland basins without major structural deformation. The largest part of these resources is in Rocky Mountain basins, where the coalbeds are of Cretaceous and Tertiary age; lesser amounts are in the eastern and central United States, where the coalbeds are of Paleozoic age.

\section{CONCLUSIONS}

Large amounts of methane-rich gas are generated and stored in coalbeds. Recently, commercial production of coalbed gas has been established in the United States, and development will be expanded in other countries as they become aware of the resource potential and as technology is transferred. Coalbed gas can be utilized as an energy source that (1) is environmentally more acceptable than the mining and combustion of coal, (2) can partly replace coal as a fossil energy source, and (3) sometimes occurs where other conventional resources of oil and gas are not present.

\section{REFERENCES CITED}

Allardice, D.J., and Evans, D.G., 1978, Moisture in coal, in Karr, C., Jr., ed., Analytical methods for coal and coal products: New York, Academic Press, v. 1, p. 247-261.

American Society for Testing Materials, 1973, Moisture in the analysis sample of coal and coke: ASTM Standards, Part 26, D3173-73, p. 381-383.

Ammosov, I.I., and Eremin, I.V., 1963, Fracturing in coal: Moscow, IZDAT Publishers, 109 p. [Translated from Russian by Israel Program for Scientific Translations, Jerusalem.]

Bertrand, P., Behar, F., and Durand, B., 1986, Composition of potential oil from humic coals in relation to their petrographic nature: Organic Geochemistry, v. 1-3, p. 601-608.

Blake, D.R., and Rowland, F.S., 1988, Continuing worldwide increase in tropospheric methane: Science, v. 259, p. 11291131.

Boyer, C.M., II, Kelafant, J.R., Kuuskraa, V.A., Manger, K.C., and Kruger, D., 1990, Methane emissions from coal mining: issues and opportunities for reduction: U.S. Environmental Protection Agency, Air and Radiation (ANR-445), EPA/400/ 9-90/008, $86 \mathrm{p}$.

Bromilow, J.G., and James, J.M., 1955, Drainage and utilization of firedamp: Colliery Engineering, v. 32, p. 222-232.

Burkett, W.C., McDaniel, R., and Hall, W.R., 1991, The evaluation and implementation of a comprehensive production water management plan: Coalbed Methane Symposium, 1991 [Proceedings], p. 43-56.

Chung, H.M., Gormly, J.R., and Squires, R.M., 1988, Origin of gaseous hydrocarbons in subsurface environments: theoretical considerations of carbon isotope distribution: Chemical Geology, v. 71, p. 97-103.

Clayton, C., 1991, Carbon isotope fractionation during natural gas generation from kerogen: Marine and Petroleum Geology, v. 8 , p. $232-240$.

Clayton, J.L., in press, Composition of crude oils generated and expelled from coal and coaly organic matter dispersed in shales, in Law, B.E., and Rice, D.D., eds., Hydrocarbons from coal: American Association of Petroleum Geologists Studies in Geology.

Decker, A.D., White, J., and Reeves, S.R., 1991, Coalbed methane exploration strategies successfully applied in the Bowen basin, Queensland, Australia: Coalbed Methane Symposium, 1991 [Proceedings], p. 307-315.

Deul, M., and Kim, A.G., 1988, Methane control researchSummary of results, 1964-1980: U.S. Bureau of Mines, Bulletin $687,174 \mathrm{p}$.

Diamond, W.P., in press, Methane control for underground coal mines, in Law, B.E., and Rice, D.D., eds., Hydrocarbons from coal: American Association of Petroleum Geologists Studies in Geology.

Gray, I., 1987, Reservoir engineering in coal seams: Society of Petroleum Engineers Preprint SPE Paper 12514, Gunther, J., 
1965, Etude de la liaison gaz-charbon: Revue de l'Industrie Minerale, v. 47, p. 693-708.

Hunt, J.M., 1979, Petroleum geochemistry and geology: San Francisco, W.H. Freeman and Company, 617 p.

ICF Resources, 1990, The United States coalbed methane resource: Quarterly Review of Methane from Coal Seams Technology, v. 7, no. 3, p. 10-28.

Intergovernmental Panel on Climate Control, 1990, Methane emissions and opportunities for control: U.S. Environmental Protection Agency, Air and Radiation (ANR-445), EPA/400/ 9-90/007, 64 p.

Ivenyar, M.S., and Lahiri, A., 1957, The nature of reactant groups in coal: Fuel, v. 36, p. 286-297.

James, A.T., 1990, Correlation of reservoired gases using the carbon isotopic compositions of wet gas components: American Association of Petroleum Geologists Bulletin, v. 74, p. 14411458.

James, A.T., and Burns, B.J., 1984, Microbial alteration of subsurface natural gas accumulations: American Association of Petroleum Geologists Bulletin, v. 68, p. 957-960.

Jones, A.H., Ahmed, U., Bush, D., Holland, M., Kelkar, S., Rakop, K., Bowman, K.C., and Bell, G.J., 1984, Methane production characteristics for a deeply buried coalbed reservoir in the San Juan basin: Quarterly Review of Methane from Coal Seams Technology, v. 2, p. 19-33.

Joubert, J.I., Grein, C.T., and Bienstock, D., 1973, Sorption of methane in moist coal: Fuel, v. 52, p. 181-185.

Juntgen, H., and Karweil, J., 1966, Gasbildung und Gasspeicherung in Steinkohlenflozen, Part I and II: Erdol Kohle, Erdgas, Petrochem, v. 19, p. 251-258, 339-344.

Kaiser, W.R., Swartz, T.E., and Hawkins, G.J., 1991, Hydrology of the Fruitland Formation, San Juan basin, in Geologic and hydrólogic controls on the occurrence and producibility of coalbed methane, Fruitland Formation, San Juan Basin: Gas Research Institute Topical Report; August 1987-July 1990, GRI-91/0072, p. 195-241.

Kelafant, J.R., Stevens, S.H., and Boyer, C.M., II, 1992, Vast resource potential exists in many countries: Oil and Gas Journal, v. 90 , no. 44 , p. $80-85$.

Khorasani, G.K., 1987, Oil-prone coals in the Walloon Coal Measures, Surat Basin, Australia, in Scott, A.C., ed., Coal and coal-bearing sequences-recent advances: Geological Society Special Publication 32, p. 303-310.

Kim, A.G., 1977, Estimating methane content of bituminous coal from adsorption data: U.S. Bureau of Mines Report of Investigations $8245,22 \mathrm{p}$.

Kissell, F.N., McCulloch, C.M., and Elder, C.H., 1973, The direct method of determining methane content of coalbeds for ventilation design: U.S. Bureau of Mines Report of Investigations $7767,17 \mathrm{p}$.

Kruger, D.W., 1991, Coalbed methane: environmental protection at a profit: Coalbed Methane Symposium, 1991 [Proceedings], p. 193-202.

Kuuskraa, V.A., Boyer, C.M., II, and Kelafant, J.A., 1992, Hunt for quality basins goes abroad: Oil and Gas Journal, v. 90, no. 40 , p. $49-54$.

Kuuskraa, V.A., and Brandenberg, C.F., 1989, Coalbed methane sparks a new energy industry: Oil and Gas Journal, v. 87, no. 41, p. $49-56$.
Landis, E.R., in press, Global coal occurrence, in Law, B.E., and Rice, D.D., eds., Hydrocarbons from coal: American Association of Petroleum Geologists Studies in Geology.

Law, B.E., in press, The relationship between coal rank and cleat spacing: implications for the prediction of permeability in coal: International Coalbed Methane Symposium, 1993 [Proceedings].

Law, B.E., Rice, D.D., and Flores, R.M., 1991, Coalbed gas accumulations in the Paleocene Fort Union Formation, Powder River basin, Wyoming, in Schwochow, S.D., Murray, D.K., and Fahy, M.F., eds., Coalbed methane of western North America: Denver, Rocky Mountain Association of Geologists, p. 179-190.

Levine, J.R., 1987, Influence of coal composition on the generation and retention of coalbed natural gas: Coalbed Methane Symposium, 1987 [Proceedings], p. 15-18.

1991, The impact of oil formed during coalification on generation and storage of natural gas in coalbed reservoir systems: Coalbed Methane Symposium, 1991 [Proceedings], p. 307-315.

Macrae, J.C., and Lawson, W., 1954, Cleats in coal seams: Transactions of Leeds Geological Association, v. VI, p. 227-242.

Martin, L.J., Naftz, D.L., Lowham, H.W., and Ranki, J.G., 1988, Cumulative potential hydrologic impacts of surface coal mining in the eastern Powder River structural basin, northeastern Wyoming: U.S. Geological Survey Water-Resources Investigations Report 88-4046, 201 p.

Mavor, M.J., Owen, L.B., and Pratt, T.J., 1990, Measurement and evaluation of coal sorption isotherm data: Society of Petroleum Engineers Preprints SPE Paper 20728.

McCulloch, C.M., Deul, M., and Jeran, P.W., 1974, Cleat in bituminous coal: U.S. Bureau of Mines Report of Investigations $7910,15 \mathrm{p}$.

McElhiney, J.E., Paul, G.W., Young, G.B.C., and McCartney, J.A., in press, Reservoir engineering aspects of coalbed methane, in Law, B.E., and Rice, D.D., eds., Hydrocarbons from coal: American Association of Petroleum Geologists Studies in Geology.

Meissner, F.F., 1984, Cretaceous and lower Tertiary coals as sources for gas accumulations in the Rocky Mountain area, in Woodward, J.W., Meissner, F.F., and Clayton, J.L., eds., Hydrocarbon source rocks of the Greater Rocky Mountain region, Rocky Mountain Association of Geologists, p. 401431.

Mills, R.A., and Stevenson, J.W., 1991, History of methane drainage at Jim Walter Resources, Inc.: Coalbed Methane Symposium, 1991 [Proceedings], p. 143-151.

Palmer, I.D., Lambert, S.W., and Spitler, J.L., in press, Coalbed methane well completions and stimulations, in Law, B.E., and Rice, D.D., eds., Hydrocarbons from coal: American Association of Petroleum Geologists Studies in Geology.

Pashin, J.C., 1991, Regional analysis of the Black Creek-Cobb coalbed-methane target interval, Black Warrior basin, Alabama: Geological Survey of Alabama Bulletin 145, 127 p.

Rice, D.D., in press, Composition and origins of coalbed gas, in Law, B.E., and Rice, D.D., eds., Hydrocarbons from coal: American Association of Petroleum Geologists Studies in Geology. 
Rice, D.D., and Claypool, G.E., 1981, Generation, accumulation, and resource potential of biogenic gas: American Association of Petroleum Geologists Bulletin, v. 65, p. 525.

Rice, D.D., Clayton, J.L., Flores, R.M., Law, B.E., and Stanton, R.W., 1992, Some geologic controls of coalbed gas generation, accumulation, and production, western United States: U. S. Geological Survey Circular 1074, p. 64.

Rightmire, C.T., Eddy, G.E., and Kirr, J.N., eds., 1984, Coalbed methane resources of the United States: American Association of Petroleum Geologists Studies in Geology No. 17, 378 p.

Saxby, J.D., and Shibaoka, M.,1986, Coal and coal macerals as source rocks for oil and gas: Applied Geochemistry, v. 1, p. 25-36.

Selden, R.F., 1934, The occurrence of gases in coal: U. S. Bureau of Mines Report of Investigations 3233.

Smith, D.M., and Williams, F.L., 1981, A new method for determining the methane content of coal: 16th Intersociety Energy Conversion Engineering Conference [Proceedings], p. 1276-1272.

Stach, E., Mackowsky, M. Th., Teichmuller, M., Taylor, G.H., Chandra, D., and Teichmuller, R., 1982, Stach's Textbook of Coal Petrology (3d ed.): Berlin, Gebruder Borntraeger, 535 p. Stanton, R.W., Rice, D.D., Clayton, J.L, and Flores, R.M., 1992, Matrix-gel vitrinite types and Rock-Eval analysis of coal samples, Cretaceous age, from the San Juan and Piceance basin: Ninth Annual Meeting of the Society for Organic Petrography, Abstracts and Agenda, p. 57-58.

Ulery, J.P., and Hyman, D.M., 1991, The modified direct method of gas content determination; applications and results: Coalbed Methane Symposium, 1991 [Proceedings], p. 489500.

van Krevelen, D.W., 1981, Coal (typlogy, chemistry, physics, and constitution): Amsterdam, Elsevier, 514 p.

Woese, C.R., Kandler, O., and Wheelis, M.L., 1990, Towards a natural system of organisms; proposal for the domains Archaea, Bacteria, and Eucarya: Proceedings of the National Academy of Science, v. 87, p. 4576-4579.

Yee, D., Seidle, J.P., and Hanson, W.B., in press, Gas sorption on coal and measurement of gas content, in Law, B.E., and Rice, D.D., eds., Hydrocarbons from coal: American Association of Petroleum Geologists Studies in Geology.

Zimpler, G.L., Harmon, E.J., and Boyce, B.C., 1988, Disposal of production waters from oil and gas wells in the northern San Juan basin, Colorado, in Fassett, J.E., ed., Geology and coalbed methane resources of the northern San Juan Basin, Colorado and New Mexico: Denver, Rocky Mountain Association of Geologists, p. 183-198. 


\title{
Coal as a Source Rock of Petroleum and Gas- A Comparison Between Natural and Artificial Maturation of the Almond Formation Coals, Greater Green River Basin in Wyoming
}

\author{
By Mario García-González ${ }^{1}$, Donald B. MacGowan ${ }^{1}$, and Ronald C. Surdam ${ }^{1}$
}

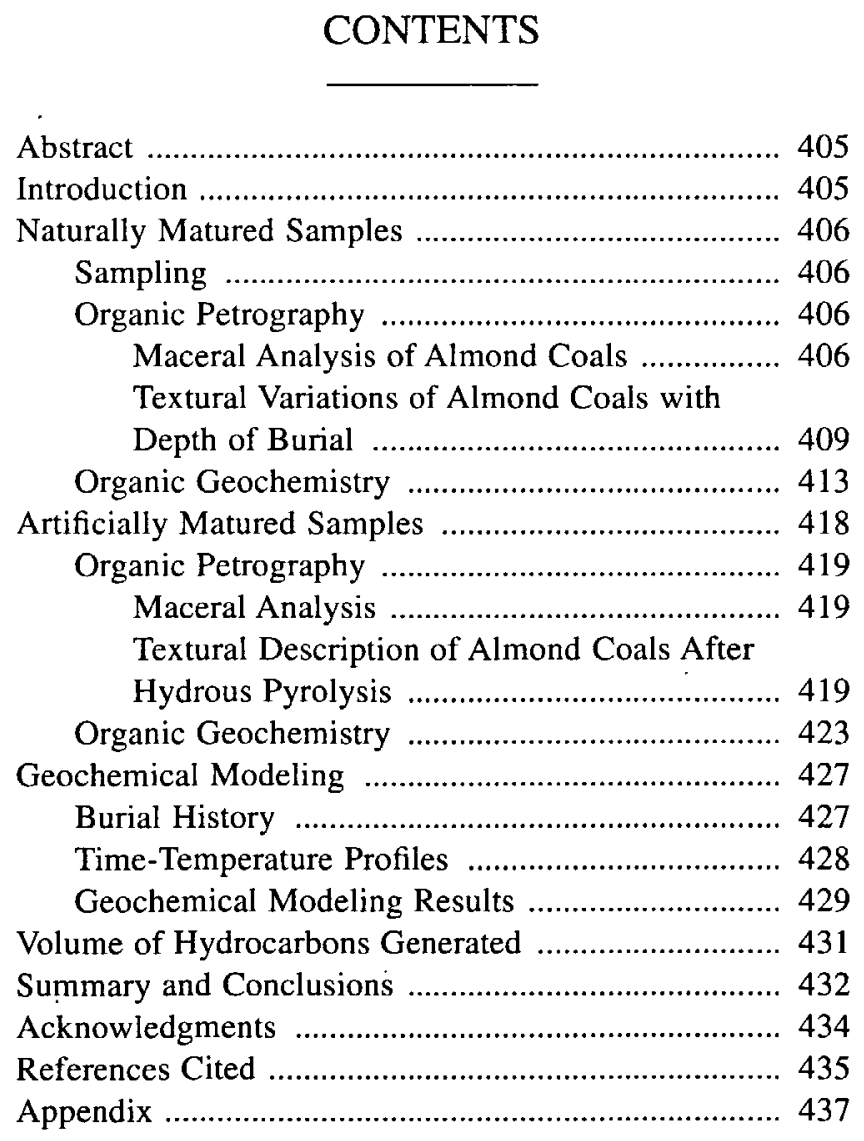

'Department of Geology and Geophysics, University of Wyoming, Laramie, Wyoming 82071.

\begin{abstract}
Organic petrological and geochemical studies demonstrate that the Almond Formation coals contain great unrecognized volumes of stored gas and oil. Oil is generated during maturation of hydrogen-rich vitrinite (desmocollinite) and liptinite macerals into exsudatinite (waxy oil) and inertinite solid residue. The waxy oil is initially stored in pores and vesicles. As the coal thermally matures, stored hydrocarbons are expelled from the pores and vesicles. This phase change causes a significant volume increase, which may overcome the storage capacity of these coals, fracturing them and allowing primary migration of hydrocarbons.

Kinetic modeling, based on hydrous pyrolysis experiments, indicates that at the basin center, most oil generated and expelled from Almond coals has been thermally cracked to gas, whereas at the basin flank the oil-to-gas reaction is unimportant. During hydrous pyrolysis these coals expel up to 0.17 barrels of oil and 404 cubic feet of gas per ton of coal, indicating excellent generative capacity.

Calculations of the volume of Upper Cretaceous coals in the Greater Green River Basin at vitrinite reflectances between 0.9 and 1.7 percent indicate that these coals may have generated 24 billion barrels of oil and 66 trillion cubic feet of gas.
\end{abstract}

\section{INTRODUCTION}

The Greater Green River Basin (GGRB) contains one of the most important gas resources in the United States (Tyler and others, 1992). The Late Cretaceous Mesaverde 
Group is both the main source of hydrocarbons and the main reservoir in the GGRB. The Almond Formation is one of the most important reservoir sandstones in the Mesaverde Group, having yielded 100 million barrels of oil (MMbo) and 850 billion cubic feet (Bcf) of gas prior to 1991, (Wyoming Oil and Gas Conservation Commission, 1991). The Almond is stratigraphically situated in the upper part of the Mesaverde Group in the GGRB. For a complete review of the depositional environment of the Mesaverde Group during the Late Cretaceous, see Roehler (1988, 1990).

Law (1984) discussed the widespread occurrence of overpressured gas reservoirs in relation to the maturation of the source rocks in the GGRB and predicted the occurrence of overpressured gas accumulations on the basis of vitrinite reflectance measurements. This paper initially addresses the same problem with a different methodology, which includes organic petrology and geochemical analyses of naturally and artificially matured coal samples. With this methodology we are able to illustrate the maturation pathway of Almond coals-the early generation of oil, then thermal degradation of the oil to gas, and later the generation of gas from coal (kerogen type III). Definitions of coal petrology terms are contained in the appendix.

The results of this research indicate that Almond coals are important source rocks for both oil and gas. Our new interpretation of the origin of the gas indicates a new set of ideas about the origin of, and exploration targets for, hydrocarbon accumulations in the GGRB based on the great potential of Almond coals for generating oil and gas.

This paper will focus on the source rocks (coals, coaly shales, and shales) adjacent to Almond sandstones. We report petrologic and geochemical characteristics of the coals and shales of the Almond Formation from the most immature stage in the basin, in the outcrops around the Rocks Springs Uplift, to the deepest level of burial, in the center of the Washakie Basin at approximately $18,000 \mathrm{ft}$ present burial depth.

Petrologic studies were performed with reflection microscopy using white and blue light (546 $\mathrm{nm}$ wavelength) on polished sections of coals and shales. Sample preparation follows the procedure described in American Society of Testing Materials Standard D-2797-72 (American Society of Testing Materials, 1980). The petrologic descriptions include maceral identification and point counting, vitrinite reflectance measurements, and textural descriptions.

Geochemical analyses carried out on Almond shales and coals include (1) anhydrous pyrolysis for maximum temperature of hydrocarbon generation $\left(\mathrm{T}_{\max }\right)$, production index (PI), genetic potential (GP), and hydrogen index (HI); (2) total organic carbon (TOC); and (3) nuclear magnetic resonance (NMR) for structural information on the kerogen.

The hydrous pyrolysis (HP) experiments were conducted on a set of Almond coal samples following the pro- cedure of Lewan (1985) and described by Yin and others (in press). Each experiment was carried out isothermally for 72 hours for each $10^{\circ}$ increment over the temperature range from $290^{\circ}$ to $360^{\circ} \mathrm{C}$. After the experiments, petrographic and geochemical determinations similar to those described above were performed on the solid residue.

The following sections present and discuss the results of the petrological and geochemical studies carried out on both naturally and artificially matured samples.

\section{NATURALLY MATURED SAMPLES}

\section{SAMPLING}

Coal and shale samples were collected from drill cores, well cuttings, and strip mines. Figure 1 shows the sample locations; these locations are also listed in table 1. During sampling, Almond coal and shale samples from various depths ranging from the surface to a maximum depth of $18,000 \mathrm{ft}$ were obtained for petrological and geochemical examination. Because the samples came from different areas of the GGRB and burial histories vary from place to place, no strict correlation could be established between maturation level and present depth of burial for all samples. However, a general correlation trend between level of maturation and depth of burial was found using several maturation indicators discussed in the following sections.

\section{ORGANIC PETROGRAPHY}

Petrographic characterization of a coal at different depths of burial provides information on the evolution of maceral composition as well as on the rank or maturity stage of the coal. This study differs from standard petrographic studies of coal because it is the first attempt to correlate maturation (or coalification) with textural features of the maceral assemblage in coals ranging from subbituminous to semianthracitic and its significance to oil generation. A similar study by Mukhopadhyay and others (1991) described some "distinct morphological changes" in coals after hydrous pyrolysis; however, Mukhopadhyay and others (1991) did not examine the relationship of these morphological changes to the maturation stages of coals between naturally and artificially matured samples.

The maceral analysis in this study adopted the maceral classification of Stach and others (1982), which is illustrated in table 2.

\section{MACERAL ANALYSIS OF ALMOND COALS}

The results of the maceral point counting discussed below are summarized in table 3 . The coals are vitrinite 
rich ( $>70$ percent), especially in the vitrinite submaceral desmocollinite (ds) at shallow depth; as depth of burial increases, the vitrinite content decreases to about 40 percent. The second most abundant vitrinite maceral is telocollinite (tl). The abundance of liptinite group macerals ( $\mathrm{Tl}$ ) in the coal is low to moderate ( 0 to 13 percent). Samples from outcrops and shallow depths $(<5,000$ feet present burial depth) have a higher content of liptinite macerals than the deep samples. At current burial depths greater than 13,000 feet, few or no liptinite macerals are observed. The predominant liptinite group maceral in the coal is cutinite (cu), followed by sporinite (sp) and resinite (rs).

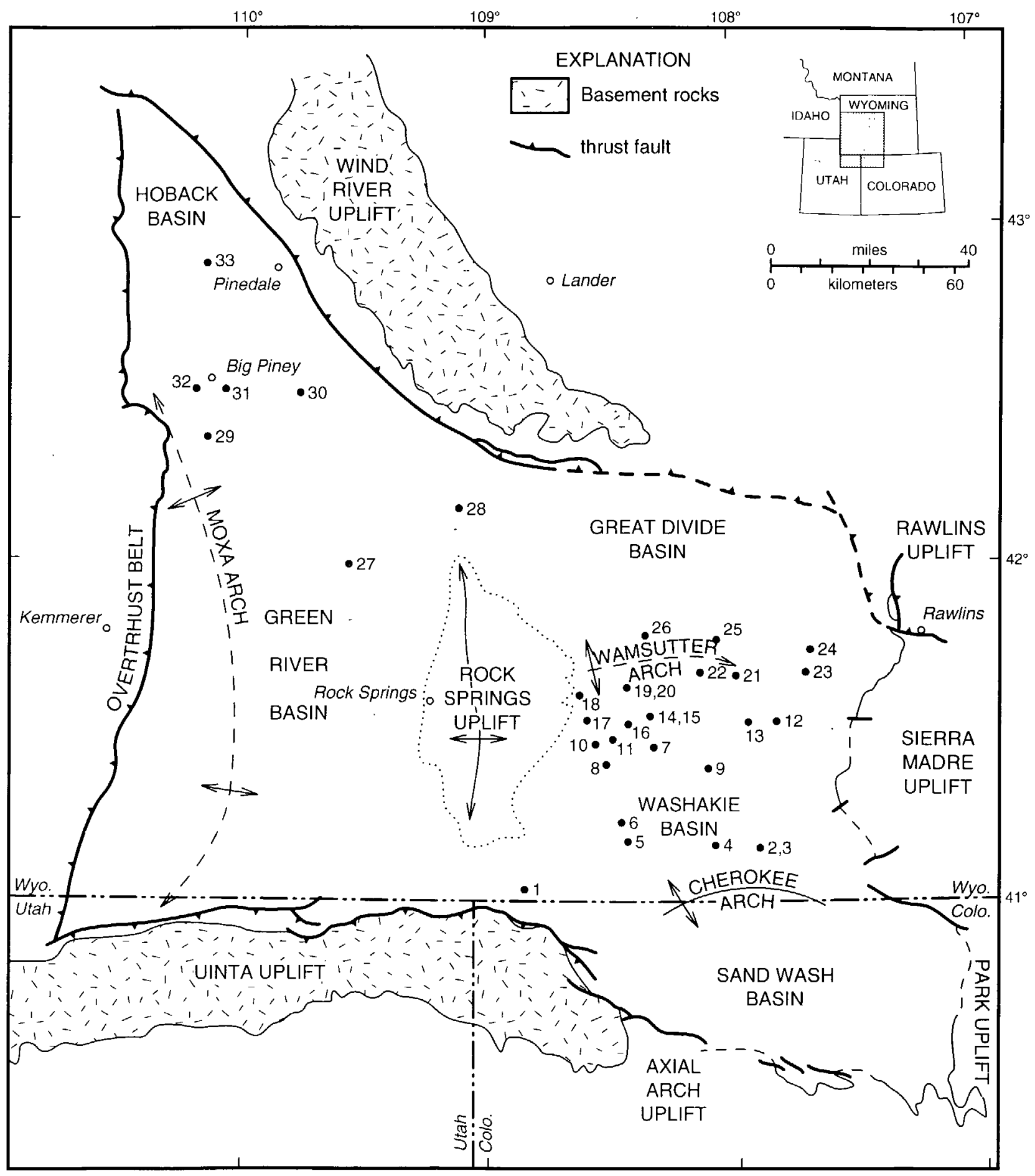

Figure 1. Map showing sample site locations. Numbers refer to list in table 1. 
Table 1. Site names and locations.

[Numbers refer to locations on figure 1]

\begin{tabular}{|c|c|c|}
\hline Map No. & Site name & Location \\
\hline 1 & 27 Unit--.- & T12, R101, S16 \\
\hline 2 & Blue Gap II 7-4-92-_. & $\mathrm{T} 14, \mathrm{R} 92, \mathrm{~S} 7$ \\
\hline 3 & Blue Gap II 2-8-14----_- & T14, R92, S8 \\
\hline 4 & Celsius 16-1 - & T14, R94, S16 \\
\hline 5 & Monument Valley No. 1------------ & $\mathrm{T} 14, \mathrm{R} 97, \mathrm{~S} 32$ \\
\hline 6 & Adobe Town No. 1-- & T15, R97, S20 \\
\hline 7 & Champlin $535 \ldots . . . . .$. & T16, R97, S17 \\
\hline 8 & Higgins $13 \mathrm{~A}$ & $\mathrm{~T} 17, \mathrm{R} 98, \mathrm{~S} 7$ \\
\hline 9 & 1 Champlin 336A & T17, R94, S21 \\
\hline 10 & Fred Federal No. 1--- & T17, R99, S30 \\
\hline 11 & Fed $44-4$ & T18, R98, S4 \\
\hline 12 & AMOCO Champlin 276-D --.---.- & T19, R92, S13 \\
\hline 13 & AMOCO Champlin 242--. & T19, R93, S11 \\
\hline 14 & Arch Unit 14-24-4 --- & T19, R97, S11 \\
\hline 15 & Robinson Siding No. 1 -... & T19, R97, S11 \\
\hline 16 & Table Rock 59 ------ & T19, R97, S18 \\
\hline 17 & Arch Unit 33B-12-4 -.- & T19, R99, S22 \\
\hline 18 & Playa Unit $5-24 \mathrm{G}$ & $\mathrm{T} 20, \mathrm{R} 99, \mathrm{~S} 22$ \\
\hline 19 & Champlin 345-A------ & T20, R99, S35 \\
\hline 20 & UPRR 44-35 ----- & $\mathrm{T} 20, \mathrm{R} 99, \mathrm{~S} 35$ \\
\hline 21 & 5 G. U.3 Coal--... & $\mathrm{T} 21, \mathrm{R} 93, \mathrm{~S} 35$ \\
\hline 22 & Oliver 1 USA AMOCO A & $\mathrm{T} 21, \mathrm{R} 94, \mathrm{~S} 23$ \\
\hline 23 & 1 Champlin 528 AMOCO A & $\mathrm{T} 21, \mathrm{R} 90, \mathrm{~S} 19$ \\
\hline 24 & 1 Champlin 446 AMOCO A & T22, R90, S15 \\
\hline 25 & NGC 3-12A Federal --..-- & $\mathrm{T} 22, \mathrm{R} 94, \mathrm{~S} 12$ \\
\hline 26 & Oliver B 107 ----- & T22, R96, S5 \\
\hline 27 & Enterprise A-1 ---- & T25, R107, S30 \\
\hline 28 & Fed Pacific Creek No. 1 & $\mathrm{T} 27, \mathrm{R} 103, \mathrm{~S} 27$ \\
\hline 29 & Government C38 -- & $\mathrm{T} 28, \mathrm{R} 113, \mathrm{~S} 3$ \\
\hline 30 & Wagon Wheel No. 1 -. & $\mathrm{T} 30, \mathrm{R} 108, \mathrm{~S} 5$ \\
\hline 31 & Bar Cross $63 \mathrm{X}-12$ & $\mathrm{~T} 30, \mathrm{R} 112, \mathrm{~S} 21$ \\
\hline 32 & Belco 5-29-27- & $\mathrm{T} 30, \mathrm{R} 113, \mathrm{~S} 27$ \\
\hline 33 & Merma No. 3-28---.--- & T36, R112, S28 \\
\hline
\end{tabular}

Macerals in the inertinite group (Tin) range in content from 1 to 60 percent in these coals, depending upon depth of burial. The predominant maceral in the inertinite group is semifusinite (sf), followed by fusinite (fu) and micrinite (mi); this assemblage evolves from semifusinite to fusinite with increasing thermal exposure (see "Artificially Matured Samples" section). The ternary diagram in fig. 2 shows the evolution of maceral groups (liptinite, vitrinite, and inertinite) in the coal through increasing burial depth.
Table 2. Maceral classification for hard coals (after Stach and others, 1982).

[NA, not applicable]

\begin{tabular}{|c|c|c|}
\hline Group maceral & Maceral & Submaceral \\
\hline \multirow[t]{5}{*}{ Vitrinite----------- } & 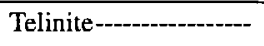 & Telinite \\
\hline & & Telocollinite \\
\hline & Collinite ---'-------- & Desmocollinite \\
\hline & & Corpocollinite \\
\hline & Vitrodertinite--------- & NA \\
\hline \multirow[t]{6}{*}{ Liptinite ---------- } & Sporinite -------------- & NA \\
\hline & Cutinite --------- & $\mathrm{NA}$ \\
\hline & Resinite------------- & NA \\
\hline & 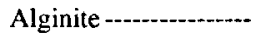 & NA \\
\hline & Exsudatinite ----------- & NA \\
\hline & Liptodetrinite -........- & $\mathrm{NA}$ \\
\hline \multirow[t]{6}{*}{ Inertinite----...- } & Micrinite---------------- & NA \\
\hline & Macrinite -...-. & NA \\
\hline & Semifusinite--.------ & NA \\
\hline & 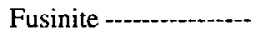 & NA \\
\hline & Sclerotinite -.............. & NA \\
\hline & Inertodetrinite------- & NA \\
\hline
\end{tabular}

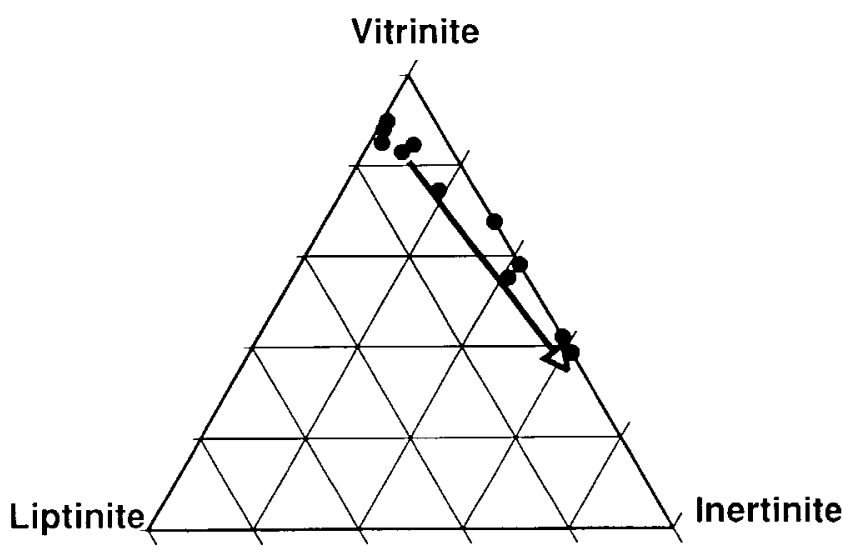

Figure 2. Ternary diagram showing maceral group composition of Almond coals at different burial depths. Arrow indicates maturation trend with increasing burial.

Samples from shallow burial are rich in vitrinite with some liptinite, whereas samples from deep burial are richer in inertinite and almost totally depleted in liptinite macerals.

The trend of maceral transformation with increasing maturation illustrates how the hydrogen-rich macerals (desmocollinite and liptinite) are transformed into inertinite macerals. The inertinite content of the deep samples reaches values of over 50 percent (table 3 ) as vitrinite and liptinite macerals are transformed into inertinite macerals 


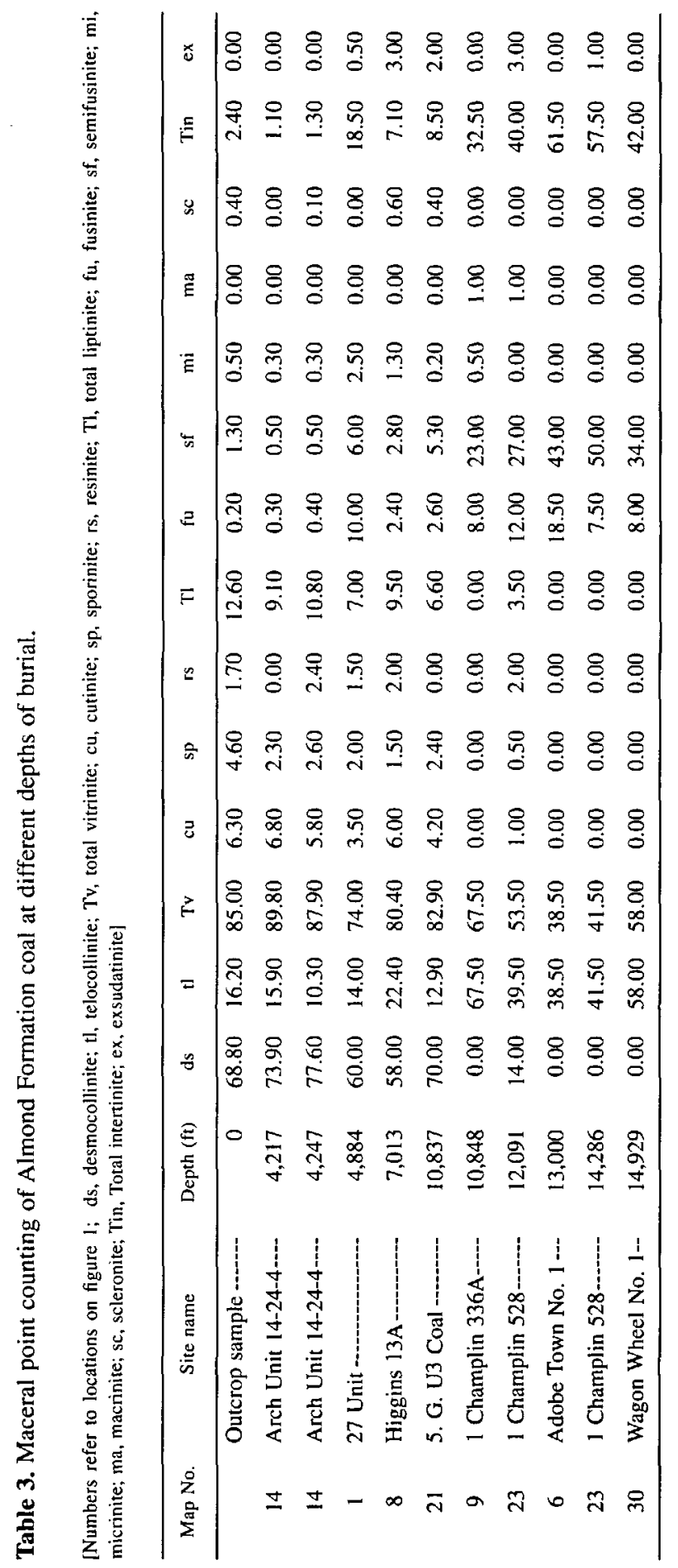

by aromatization and loss of aliphatic compounds in the kerogen; similar maceral transformations are observed during hydrous pyrolysis. The distinction between structureless telocollinite and semifusinite becomes difficult to recognize at vitrinite reflectance values higher than 0.9 percent. These observations of maceral evolution with increasing maturation are supported by geochemical analyses, including the NMR spectra analyses, discussed below.

\section{TEXTURAL VARIATIONS OF ALMOND COALS WITH DEPTH OF BURIAL}

A marked difference is observed between the textures of the shallow and deep coal samples. Samples from outcrops of the Almond Formation in the Rock Springs Uplift, which have a mean maximum vitrinite reffectance of 0.45 percent, show desmocollinite with a finely laminated texture forming a groundmass in which the inertinite and liptinite macerals are dispersed (fig. 3). As depth of burial increases, the original laminated texture becomes more homogeneous; in the 4,217-ft-deep sample, the original thin lamination is no longer observable (fig. 4). Also at this depth, micrinite macerals begin to form at the expense of the liptinite; a similar observation was reported by M. Teichmüller (in Stach and others, 1982). According to Teichmüller, the genesis of the micrinite coincides with the formation of petroleum from the liptinite macerals. This observation is supported by the occurrence of indigenous oil, present in fissures, coincident with the formation of micrinite in the 4,217-ft-deep sample (figs. 5,6).

At $6,944 \mathrm{ft}$ present burial depth, a porous texture begins to develop in the coal (figs. 7,8 ). Other important petrographic changes include an increase in the semifusinite content and the formation of exsudatinite (bitumen) in the pores. The incipient porous texture at $6,944 \mathrm{ft}$ depth evolves to a vesicular texture at present burial depths greater than $10,000 \mathrm{ft}$; these vesicles are developed for the most part in semifusinite and fusinite macerals and are

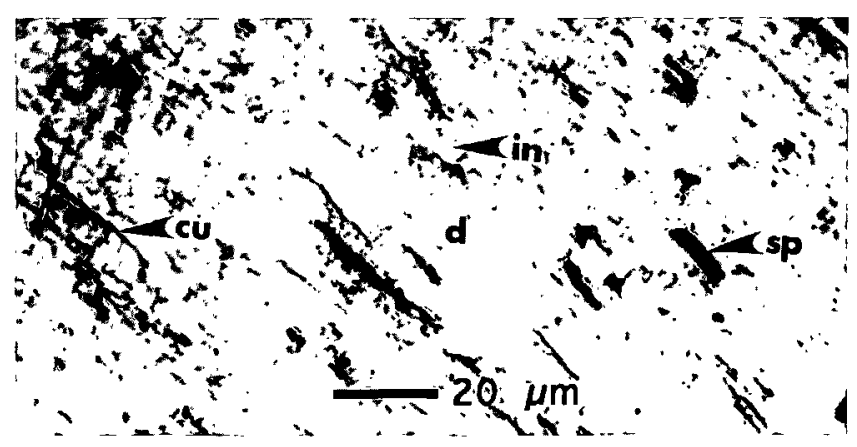

Figure 3. Photomicrograph of coal from an outcrop of the Almond Formation showing characteristic finely laminated texture of desmocollinite (d), with dispersed sporinite (sp), cutinite (cu), and inertinite (in) macerals. Reflected white light. 
filled with exsudatinite (only observable under blue light, where it shows a characteristic orange fluorescence; figs. 9, 10). The oil observed coming from fissures and pores (figs. 5, 6, 11, and 12) in samples from depths between 4,200 and $12,000 \mathrm{ft}$ present burial depth suggests that the burial histories at the localities shown in figure 1 are such that the coal layers between 4,000 and $12,000 \mathrm{ft}$ are presently in the conventional oil window; this conclusion is supported by nuclear magnetic resonance (NMR) and anhydrous pyrolysis analyses (discussed below). This depth range may vary plus or minus $4,000 \mathrm{ft}$, depending upon the subsidence or uplift experienced at a given locality.

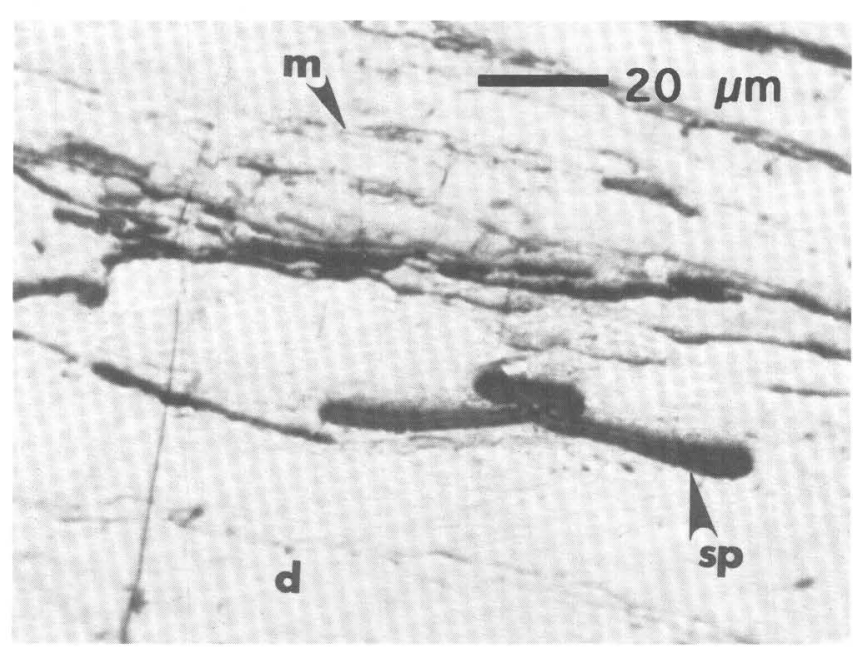

Figure 4. Photomicrograph of coal from the Almond Formation at a depth of 4,217 ft. The desmocollinite (d) looses its original laminate texture. Micrinite (m) starts to form from liptinite macerals. Sporinite (sp). Reflected white light.

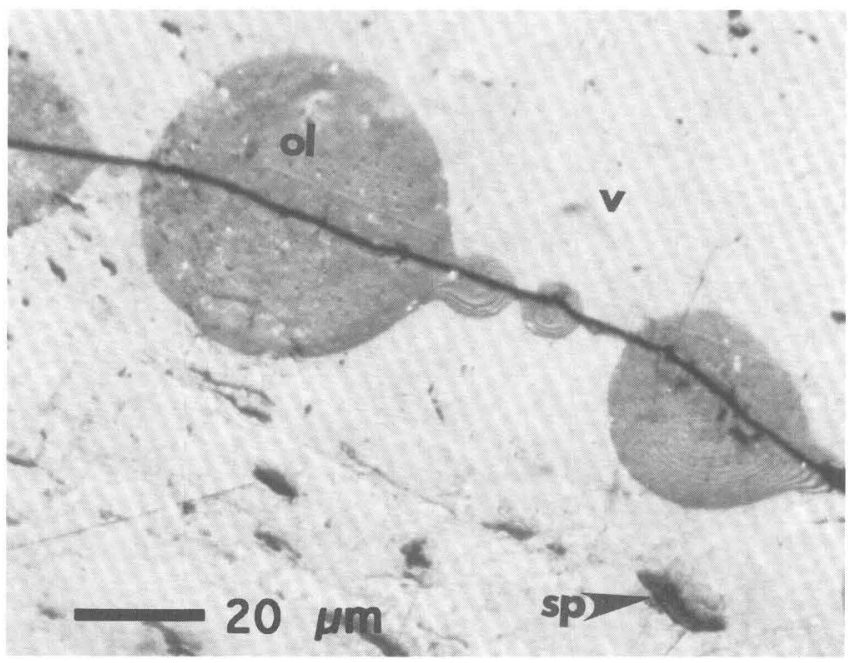

Figure 5. Photomicrograph of coal from the Almond Formation at a depth of 4,217 ft. Indigenous oil (ol) associated with fissures in vitrinite (v). Sporinite (sp). Reflected white light.
The organic petrography clearly indicates that oil has been generated in samples from 4,000 through about $12,000 \mathrm{ft}$ present burial depth. However, oil is not always expelled from the coal until its storage capacity is overcome as increasing volumes of liquid and gaseous hydrocarbons are generated. This occurs at vitrinite reflectances of about 0.8 to 1.7 percent (determined on the basis of hydrous pyrolysis experiments).

At depths greater than $14,000 \mathrm{ft}$, the vesicular nature of the coal texture begins to decrease, presumably owing to the expulsion of the exsudatinite (bitumen); also, the remaining exsudatinite no longer fluoresces. The vitrinite and semifusinite show optical relief and reflectance so similar

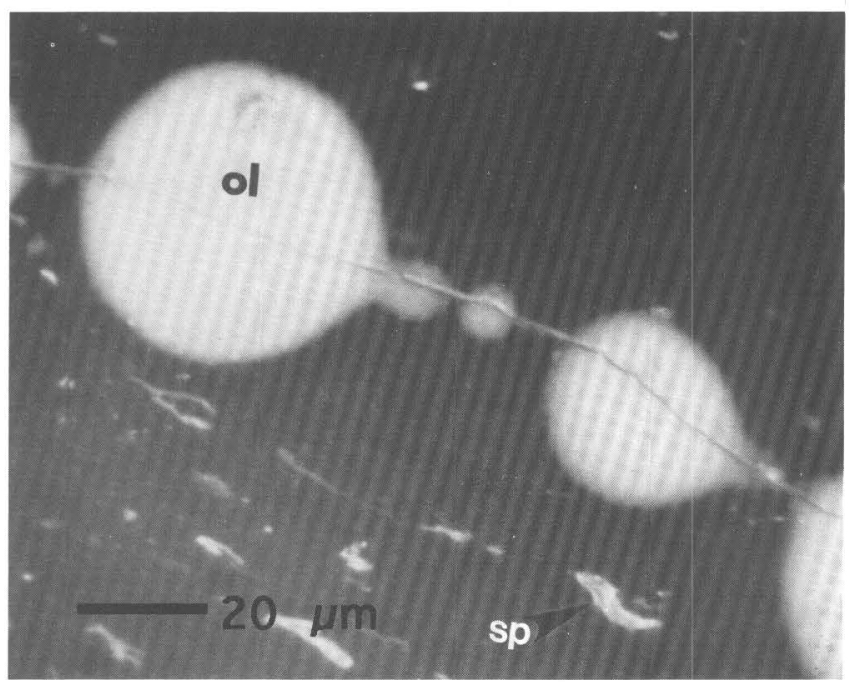

Figure 6. Photomicrograph of same feature as figure 5 under reflected blue light showing fluorescence of indigenous oil (ol) and sporinite (sp).

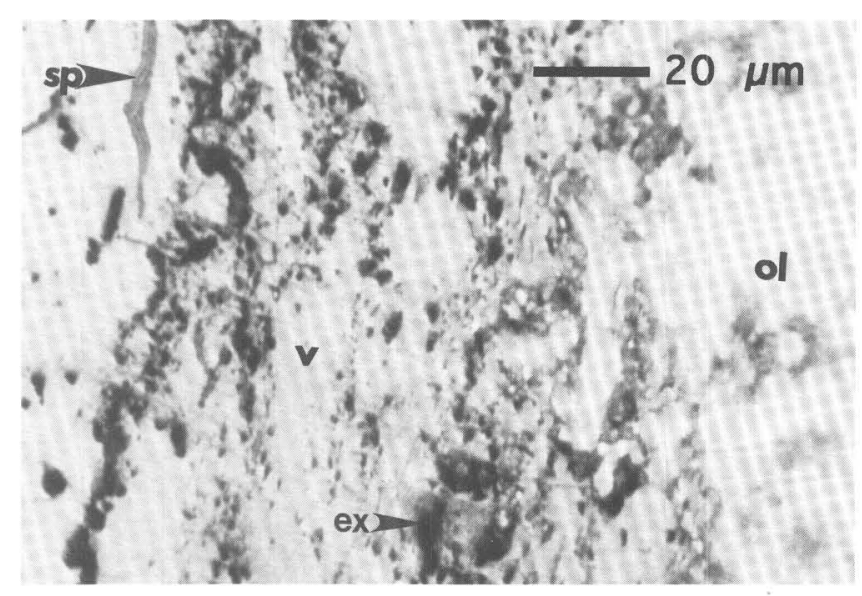

Figure 7. Photomicrograph of coal from the Almond Formation at a depth of $6,944 \mathrm{ft}$. Development of porous texture as exsudatinite (ex) starts to form. Vitrinite (v), sporinite (sp), indigenous oil (ol). Reflected white light. 
that petrographic distinction between them is unclear. Coal samples from depths greater than $14,000 \mathrm{ft}$ exhibit a texture characterized by flat surfaces with a minimum difference in optical relief between the semifusinite matrix and the occasional fusinite macerals (figs. 13, 14). The vitrinite or semifusinite matrices have reflectance values between 1.5 and 2.0 percent. At this level of maturation, the vitrinite-semifusinite matrix begins to show an increase in birreflectance under crossed nicols. The maturity levels indicate that the samples are passing out of the liquid petroleum window (or bituminization stage) and are experiencing the onset of wet-gas generation (corresponding to the formation of semianthracitic coal).

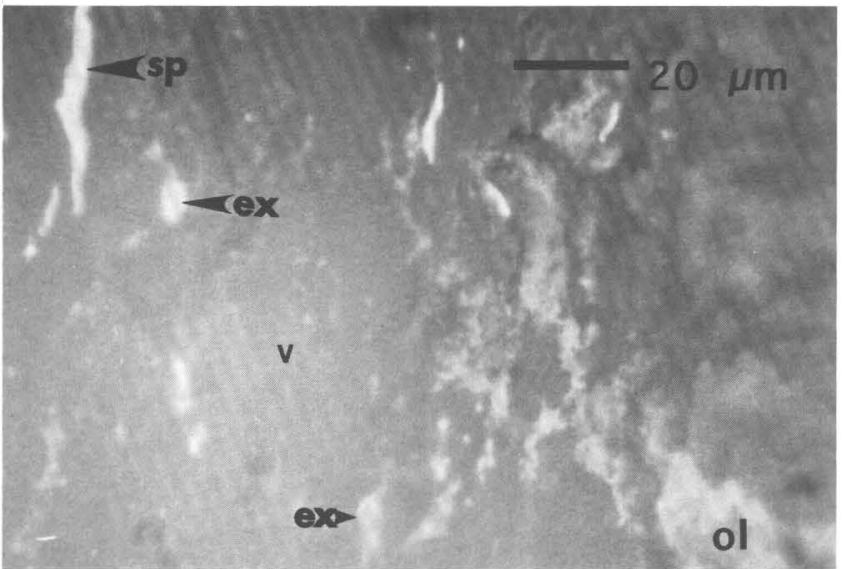

Figure 8. Photomicrograph of same feature as figure 7 under reflected blue light showing fluorescence of exsudatinite (ex), sporinite (sp), and oil (ol).

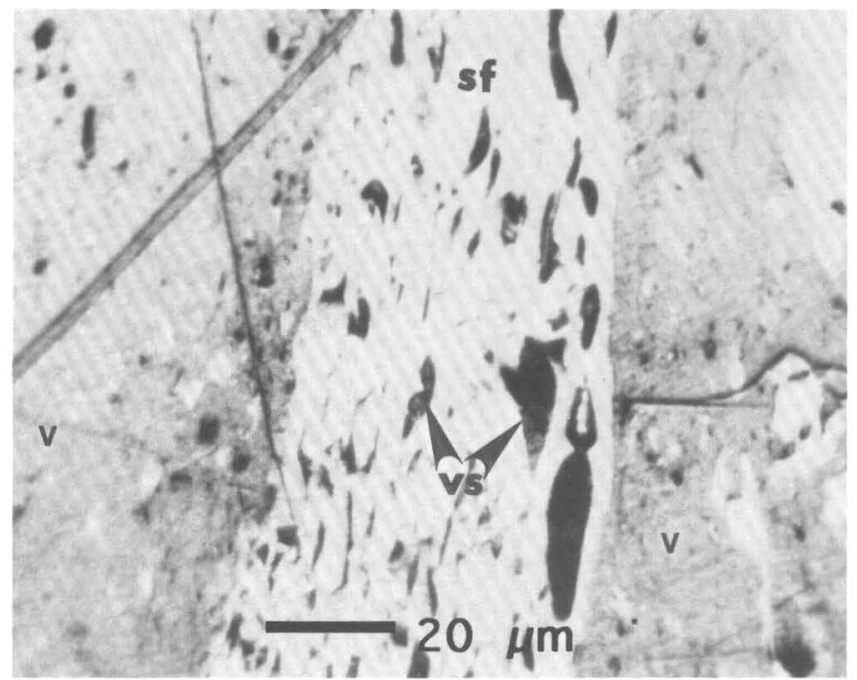

Figure 9. Photomicrograph of coal from the Almond Formation at a depth of 10,720 ft. Development of vesicular texture on semifusinite (sf), vesicles (vs) filled with exsudatinite. Vitrinite matrix (v).
In sum, the textural and compositional changes observed in Almond coals with increasing depth of burial are (1) loss of the original laminated texture of desmocollinite, (2) transformation of liptinite macerals into micrinite, releasing oil, (3) formation of a porous texture that at deeper burial evolves to a vesicular texture, and

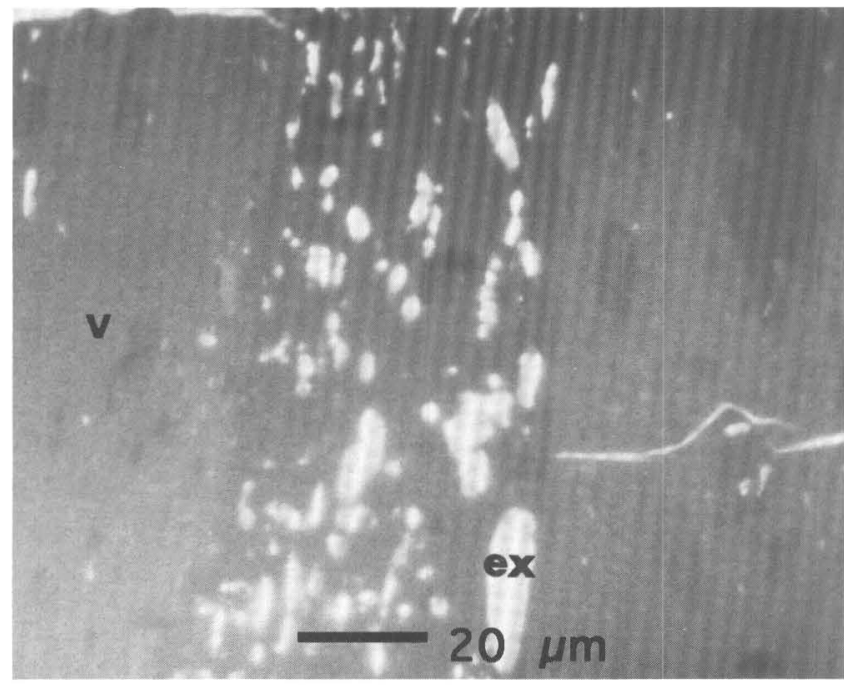

Figure 10. Photomicrograph of same feature as figure 9 under reflected blue light showing fluorescence of the exsudatinite (ex) in the semifusinite vesicles. Vitrinite (v).

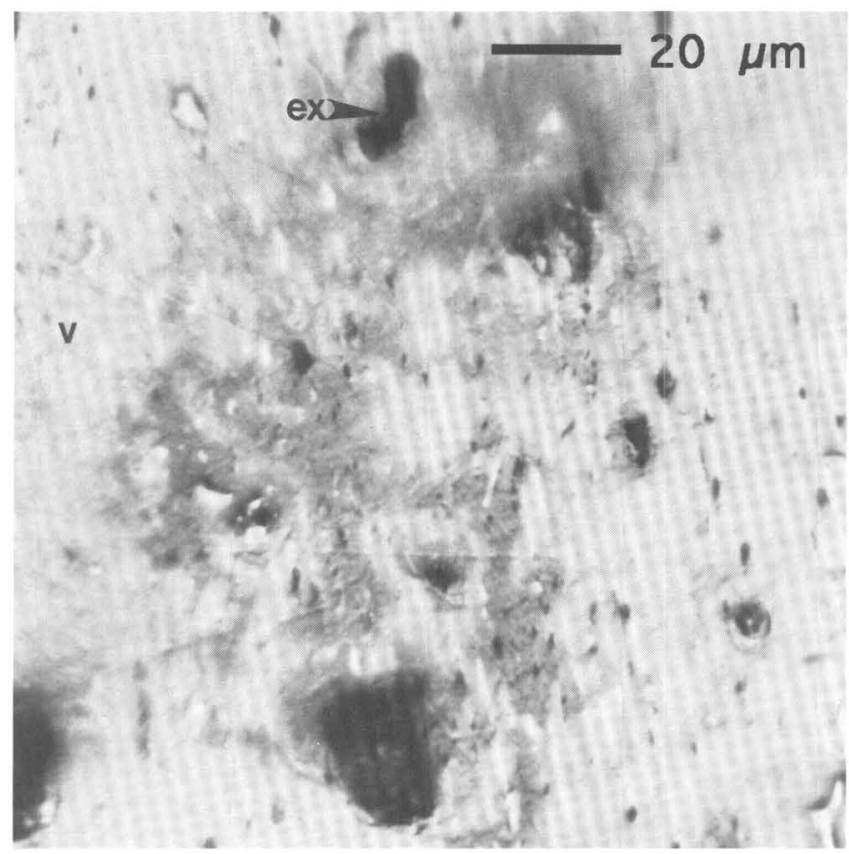

Figure 11. Photomicrograph of coal from the Almond Formation at a depth of $10,837 \mathrm{ft}$. Vesicular texture on vitrinite matrix (v). Note the expulsion of oil from the vesicles filled with exsudatinite (ex). Reflected white light. 
(4) rehomogenization of the vitrinite-semifusinite matrix. The changes in maceral composition in the coal result in a decrease in liptinite and an increase in inertinite macerals with depth. Similarly, the formation of semifusinite accompanies the formation of exsudatinite.

Figure 15 shows the increase of mean vitrinite reflectance $\left(\mathrm{R}_{\mathrm{O}}\right)$ with depth for Almond coals and shales. Table 4 gives the mean vitrinite reflectance for representative samples. The scatter in the data is likely due to variability

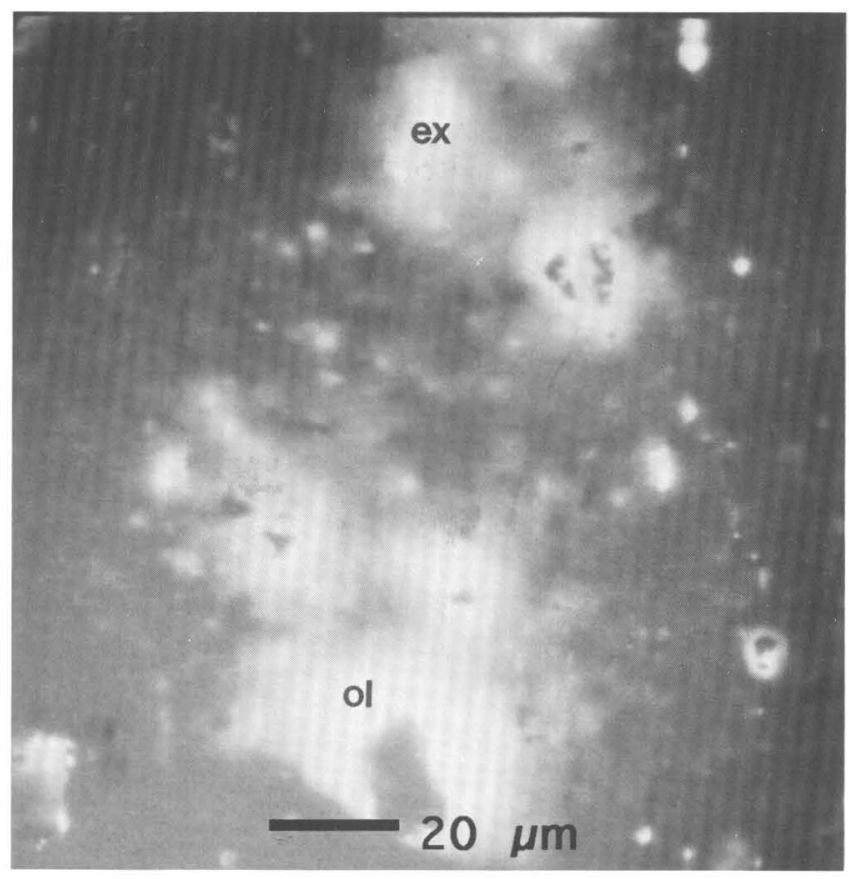

Figure 12. Photomicrograph of same feature as figure 11 under reflected blue light, showing fluorescence of indigenous oil (ol) expelled from the vesicles filled with exsudatinite (ex).

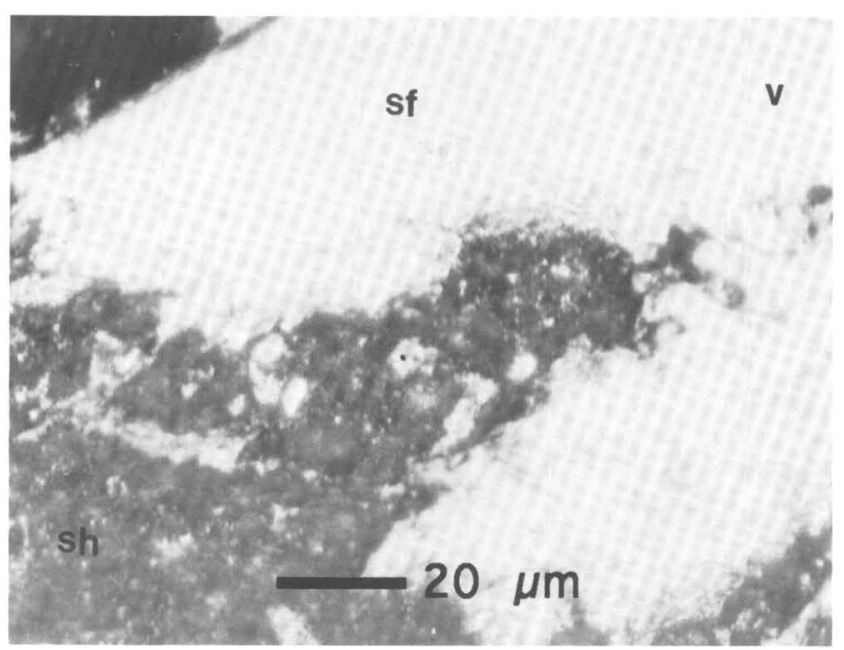

Figure 13. Photomicrograph of coal from the Almond Formation at a depth of $14,249 \mathrm{ft}$. Vitrinite (v)-semifusinite ( $\mathrm{sf}$ ) matrix completely homogenized. Shale matrix (sh). in maximum thermal exposure relative to present burial depth and to the presence of some reworked vitrinite particles in the shales on which reflectance was measured. In general, the $\mathrm{R}_{\mathrm{o}}$ data suggest that samples from the surface to about $12,000 \mathrm{ft}$ present burial are in the conventional

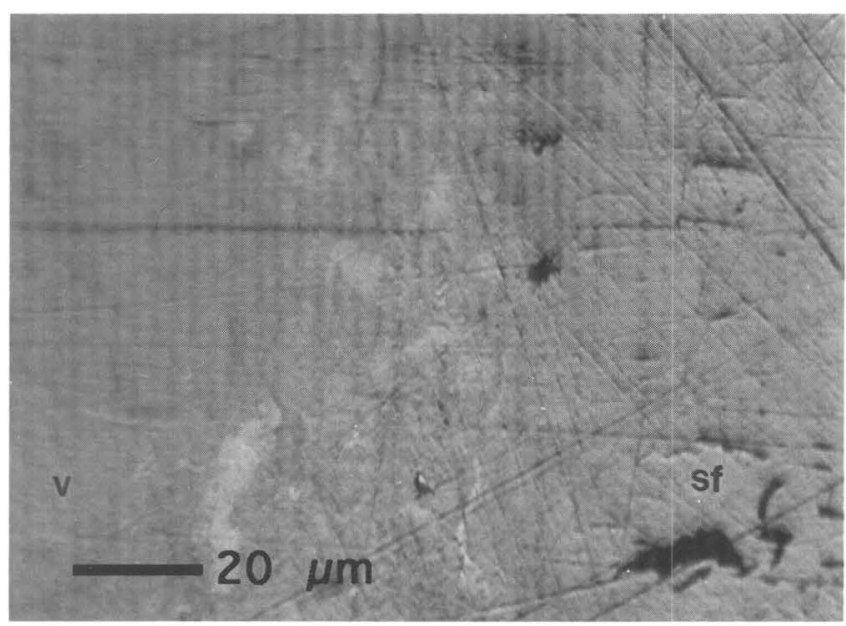

Figure 14. Photomicrograph of coal from the Almond Formation at a depth of $14,249 \mathrm{ft}$. Vitrinite (v) matrix and semifusinite (sf) showing similar optical relief and reflectances.

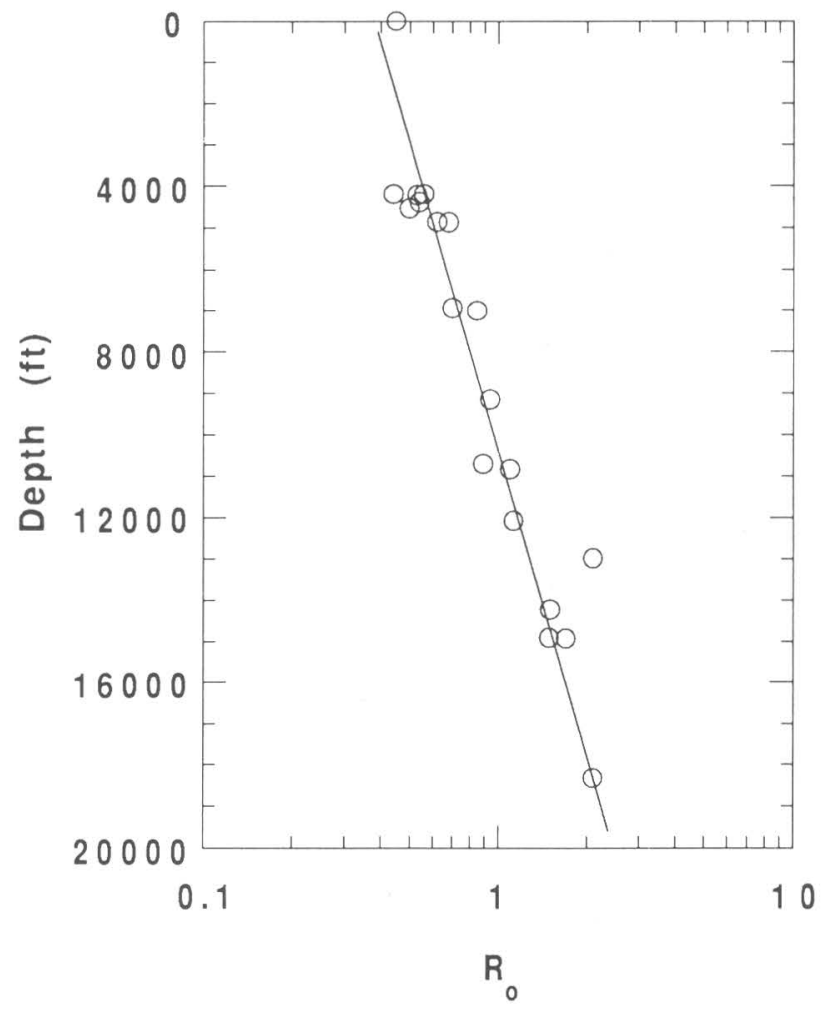

Figure 15. Mean vitrinite reflectance $\left(R_{0}\right)$ versus depth for the Almond Formation shales and coals, Greater Green River Basin, Wyoming. 
Table 4. Summary of measured vitrinite refiectance of shale and coal samples from selected sites, Almond Formation, Greater Green River Basin, Wyoming.

$\left[R_{0}\right.$, mean random vitrinite reflectance]

\begin{tabular}{|c|c|c|c|}
\hline Site name & Map No. & $\begin{array}{l}\text { Depth } \\
\text { (ft) }\end{array}$ & $\begin{array}{c}\text { Ro } \\
\text { (pct) }\end{array}$ \\
\hline Outcrop sample & & 0 & 0.45 \\
\hline Arch Unit 14-24-4 --............. & 14 & 4,217 & 0.47 \\
\hline Arch Unit 14-24-4 --..- & 14 & 4,218 & 0.57 \\
\hline Arch Unit 14-24-4 - & 14 & 4,247 & 0.60 \\
\hline Arch Unit 14-24-4 -- & 14 & 4,406 & 0.58 \\
\hline 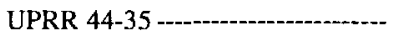 & 19 & 4,560 & 0.52 \\
\hline Playa Unit 5-24G -..-- & 18 & 4,883 & 0.62 \\
\hline Playa Unit 5-24G ------------..... & 18 & 4,894 & 0.69 \\
\hline Bar Cross 63X-12- & 31 & 6,943 & 0.71 \\
\hline 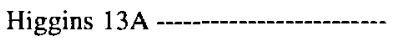 & 8 & 7,013 & 0.85 \\
\hline Blue Gap II 7-4-92 & 2 & 9,150 & 0.90 \\
\hline 5 G. U.3 Coal- & 21 & 10,720 & 0.88 \\
\hline 1 Champlin 336A --.--.--.-- & 9 & 10,848 & 1.12 \\
\hline 1 Champlin 528 AMOCO A -..... & 23 & 12,091 & 1.45 \\
\hline Adobe Town No.1 - & 6 & 13,000 & 2.10 \\
\hline 1 Champlin 528 AMOCO A --.-. & 23 & 14,240 & 1.60 \\
\hline Wagon Whell No. 1 -...-......... & 30 & 14,929 & 1.50 \\
\hline 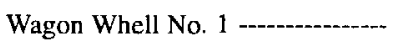 & 30 & 14,942 & 1.69 \\
\hline Wagon Whell No. 1 - & 30 & 18,330 & 2.10 \\
\hline
\end{tabular}

oil window defined by Tissot and Welte (1984) to be between 0.5 and 1.3 percent.

However, we redefine the entrance to the oil window for these coals as not merely the level of maturation where liquid hydrocarbons are generated but as the level of maturation at which liquid hydrocarbons are expelled from the coal. This new interpretation narrows the oil window for the center of the basin to the depth interval of 4,000 to $12,000 \mathrm{ft}$. In this depth interval, the vitrinite reflectance ranges from 0.5 to 1.7 percent, with the main phase of oil generation and expulsion between 0.9 and 1.6 percent $\mathrm{R}_{\max }$. The main phase of oil generation and expulsion was determined on the basis of hydrous pyrolysis experiments on Almond coals (discussed below).

The "bottom" of the liquid window is defined petrographically as the stage of rehomogenization of the vitrinite-semifusinite matrix; this level of maturation occurs when exsudatinite is no longer observed in the naturally matured samples $\left(R_{\max } \approx 1.7\right.$ percent).

The textural and compositional changes observed in Almond coals are indicative of the generation and expulsion of liquid hydrocarbons. These hydrocarbons are generated from source materials such as liptinite, which are the main source of liquid hydrocarbons in many coals, according to Teichmüller (in Stach and others, 1982). Teerman and Hwang (1991) reported desmocollinite (a hydrogenrich vitrinite) to be another important source of hydrocarbons. Desmocollinite is the main maceral constituent in Almond coals (table 3 ) and is the source of the exsudatinite formed during burial of the Almond Formation. Moreover, the development of vesicular textures in semifusinite and vitrinite, where the vesicles are filled with exsudatinite, clearly indicates that the expulsion of liquid hydrocarbons, mainly waxes, is the origin of such textures.

There is not always a strict correlation between present depth of burial and maturation because burial and uplift vary from one area to another in the GGRB. For instance, samples with similar maturation levels $\left(R_{0}\right)$ are found at present depths of $13,000 \mathrm{ft}$ and $18,000 \mathrm{ft}$ (samples from Adobe Town No. 1, $13,000 \mathrm{ft}$, and Wagon Wheel, 18,330 ft; table 4).

\section{ORGANIC GEOCHEMISTRY}

NMR measures the distribution of various chemical functional groups in kerogen molecules; these include aliphatic and aromatic functional groups in the coal and kerogen in shale. Comparing the NMR spectra analyses from a suite of samples from different depths is useful in understanding both how the kerogen structure evolves during thermal maturation (Miknis, Sullivan, and others 1981) and when liquid petroleum and gas were generated (see reviews in MacGowan, Britton, and others, 1992, and Miknis, Jiao, and others, 1993). Figure 16 presents the NMR spectra for 15 shales of the Almond Formation from 4,594 $\mathrm{ft}$ to $18,420 \mathrm{ft}$ present depth in the GGRB. The large peak to the right is the aliphatic-group spectrum, and the large peak to the left is the aromatic-group spectrum. The aliphatic peak becomes progressively smaller and less well defined, and the aromatic peak becomes relatively larger and sharper, with increasing maturity and depth. These changes represent the maturation of the kerogen and the accompanying generation and expulsion of aliphatic hydrocarbons (liquid and gaseous) and closing of free radicals into aromatic rings with increasing thermal maturity of the kerogen (Miknis, Sullivan, and others 1981; Miknis, Jiao, and others, 1993). Somewhere between about 10,000 and $15,000 \mathrm{ft}$ (shale aromaticity ratio at about 0.9 , table 5), depending upon the thermal exposure associated with maximum burial, these shales lose their potential to generate liquid hydrocarbons. From this maturity level onward, the cleavage of the kerogen mainly generates methane. This change in aliphaticity versus aromaticity indicated by the NMR analyses can be correlated with the second stage of coalification (Meissner, 1989), delineating the onset of the gas generation zone (volatile matter $<10$ percent, $R_{o}>2$ percent). 


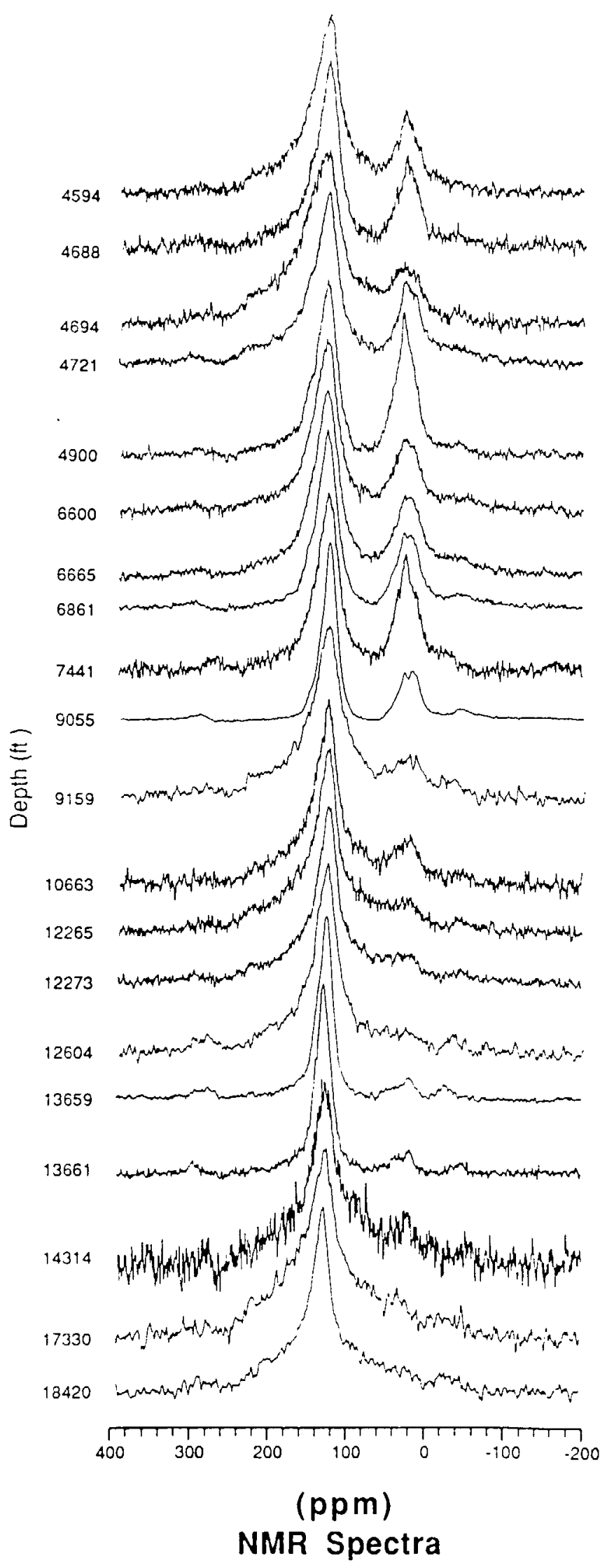

Figure 16. Nuclear magnetic resonance (NMR) spectra for the Almond Formation shales, Greater Green River Basin, Wyoming.
Figure 17 is a similar plot of NMR spectra versus depth for 19 coal samples from the Almond Formation from $4,560 \mathrm{ft}$ to $14,929 \mathrm{ft}$ in the GGRB. The samples show a trend similar to that of the shales in decreasing aliphatic content and increasing aromatic content with depth. Between 10,898 and $14,929 \mathrm{ft}$ depth, these coals lose much of their aliphatic-carbon content. Also, in this depth interval there is a slow change in aliphatic-carbon content, which is explained by the coalification curve of Meissner (1989) - the slope of the curve decreases drastically once the second stage of coalification (high-volatiles bituminous) is reached, as illustrated in figure 18. A similar NMR spectra trend was obtained in the hydrous pyrolysis experiments (discussed below), suggesting that Almond coals still have some generative capacity for aliphatic-hydrocarbons, mainly gaseous, at the maximum

Table 5. Carbon aromaticity (as determined by nuclear magnetic resonance) with depth for shales and coals in the Almond Formation.

[Aromaticity ratio=(Aromatic carbon) / (Aromatic carbon+Aliphatic carbon)]

\begin{tabular}{|c|c|c|c|}
\hline $\begin{array}{l}\text { Depth } \\
\text { (ft) }\end{array}$ & $\begin{array}{c}\text { Coal } \\
\text { aromaticity }\end{array}$ & $\begin{array}{l}\text { Depth } \\
(\mathrm{ft})\end{array}$ & $\begin{array}{c}\text { Shale } \\
\text { aromaticity }\end{array}$ \\
\hline 4,560 & 0.69 & 4,594 & 0.77 \\
\hline 4,884 & 0.68 & 4,668 & 0.73 \\
\hline 4,884 & 0.75 & 4,693 & 0.69 \\
\hline 4,894 & 0.67 & 4,694 & 0.83 \\
\hline 6,667 & 0.67 & 4,721 & 0.75 \\
\hline 6,789 & 0.71 & 4,894 & 0.65 \\
\hline 6,944 & 0.69 & 4,900 & 0.62 \\
\hline 7,013 & 0.69 & 6,600 & 0.75 \\
\hline 9,150 & 0.72 & 6,665 & 0.74 \\
\hline 9,150 & 0.78 & 6,871 & 0.72 \\
\hline 10,720 & 0.77 & 7,441 & 0.71 \\
\hline 10,837 & 0.9 & 9,055 & 0.77 \\
\hline 10,898 & 0.83 & 9,150 & 0.72 \\
\hline 12,091 & 0.8 & 9,159 & 0.75 \\
\hline 13,000 & 0.91 & 10,663 & 0.84 \\
\hline 14,286 & 0.77 & 10,946 & 0.83 \\
\hline \multirow[t]{10}{*}{14,929} & 0.84 & 12,071 & 0.78 \\
\hline & & 12,121 & 0.79 \\
\hline & & 12,265 & 0.88 \\
\hline & & 12,273 & 0.87 \\
\hline & & 12,604 & 0.94 \\
\hline & & 13,223 & 0.89 \\
\hline & & 13,659 & 0.9 \\
\hline & & 14,942 & 0.9 \\
\hline & & 17,330 & 0.94 \\
\hline & & 18,420 & 0.96 \\
\hline
\end{tabular}




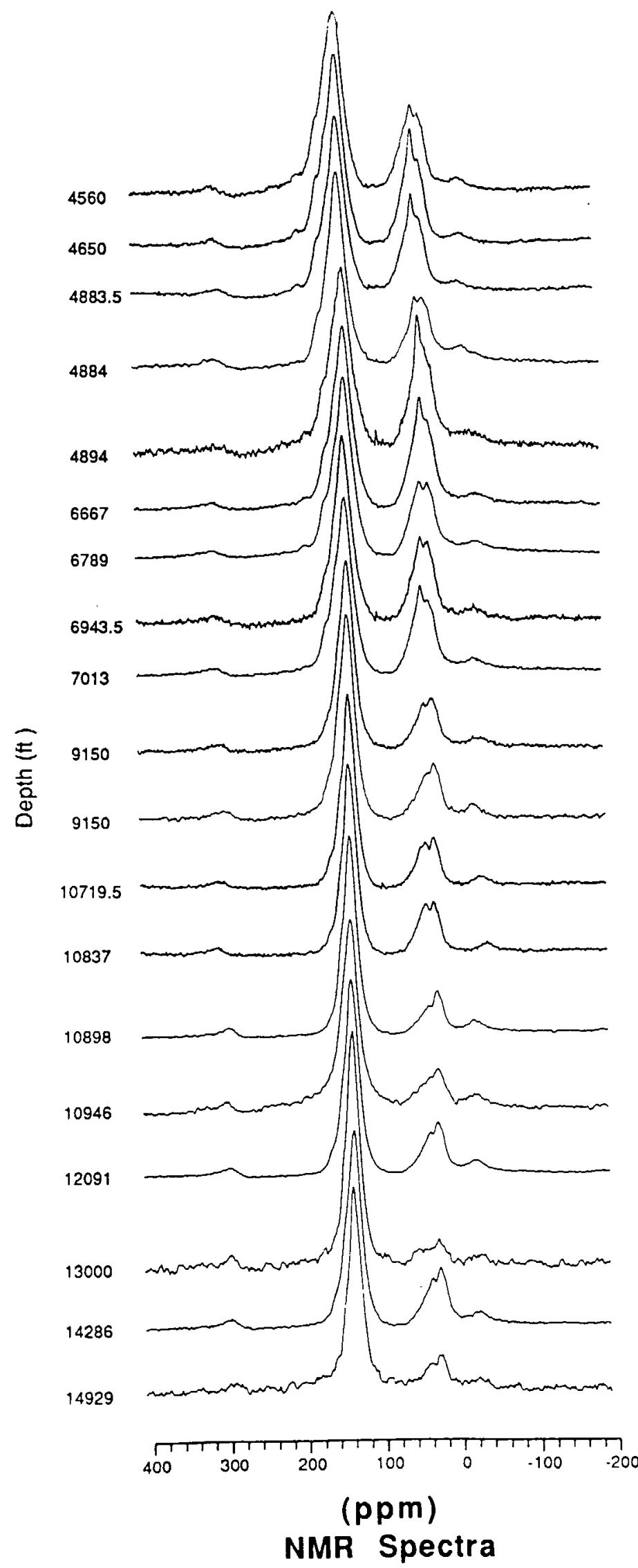

Figure 17. Nuclear magnetic resonance (NMR) spectra for the Almond Formation coals, Greater Green River Basin, Wyoming. depth of sampling $(14,929 \mathrm{ft})$. This interpretation is supported by the fact that Almond shales from the maximum depth of sampling (>18,000 ft) do not exhibit an aliphaticcarbon resonance peak.

Table 5 lists carbon aromaticity (defined as the ratio [aromatic-carbon]/[aromatic-carbon+aliphatic-carbon]) and depth for samples for which NMR spectra were obtained. Figure 19 shows the fraction of aromatic-carbon in the kerogen versus depth for the Almond Formation shales and coals. Although there is scatter in the data, a general trend of increasing aromaticity with depth can be seen. The scatter is thought to be due to variability in maximum thermal exposure relative to present burial depth and possibly to variability in the maceral content of Almond coals and shales. The scatter in aromaticity at shallow depth is most likely due to variable oxidation of the kerogen once it has been infiltrated by meteoric water.

Conventional anhydrous pyrolysis results (genetic potential, GP; hydrogen index, HI; maximum hydrocarbon generation temperature, $\mathrm{T}_{\max }$; and production index, $\mathrm{PI}$ ) for most samples are listed in table 6. Production index is a measure of thermal maturity; a kerogen is believed to be in the conventional oil window at a PI between 0.1 and 0.4 in absence of oil migration (Tissot and Welte, 1984). Figure 20 shows production index versus depth. This normally is indicative of the expected increase in thermal maturity with increasing depth, but may reflect changing organic-matter type and variable oil expulsion. The Almond Formation appears to be in the conventional oil window between about $\dot{4}, 200$ and $14,500 \mathrm{ft}$ present burial depth on the basis of PI data, which agrees with much of the vitrinite reflectance data (discussed earlier).

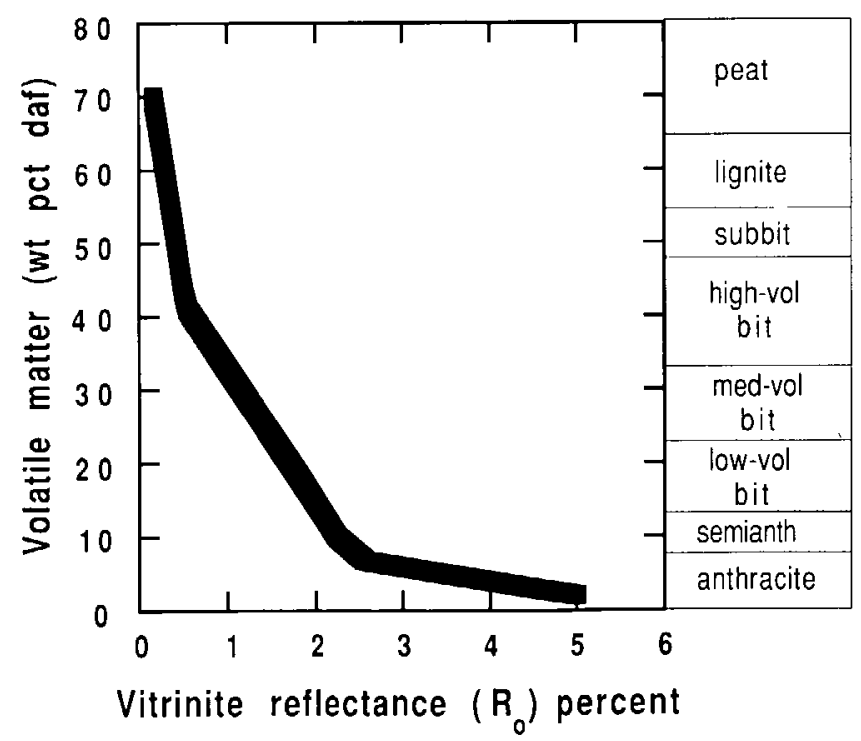

Figure 18. Relation of vitrinite reflectance $\left(R_{0}\right)$ to volatile matter and U.S. coal-rank classification. Modified from Meissner (1989). Daf, dry ash free; subbit, subbituminous coal; high-vol bit, high-volatiles bituminous coal; med-vol bit, medium-volatiles bituminous coal; low-vol bit, low-volatiles bituminous coal; semianth, semianthracitic coal. 

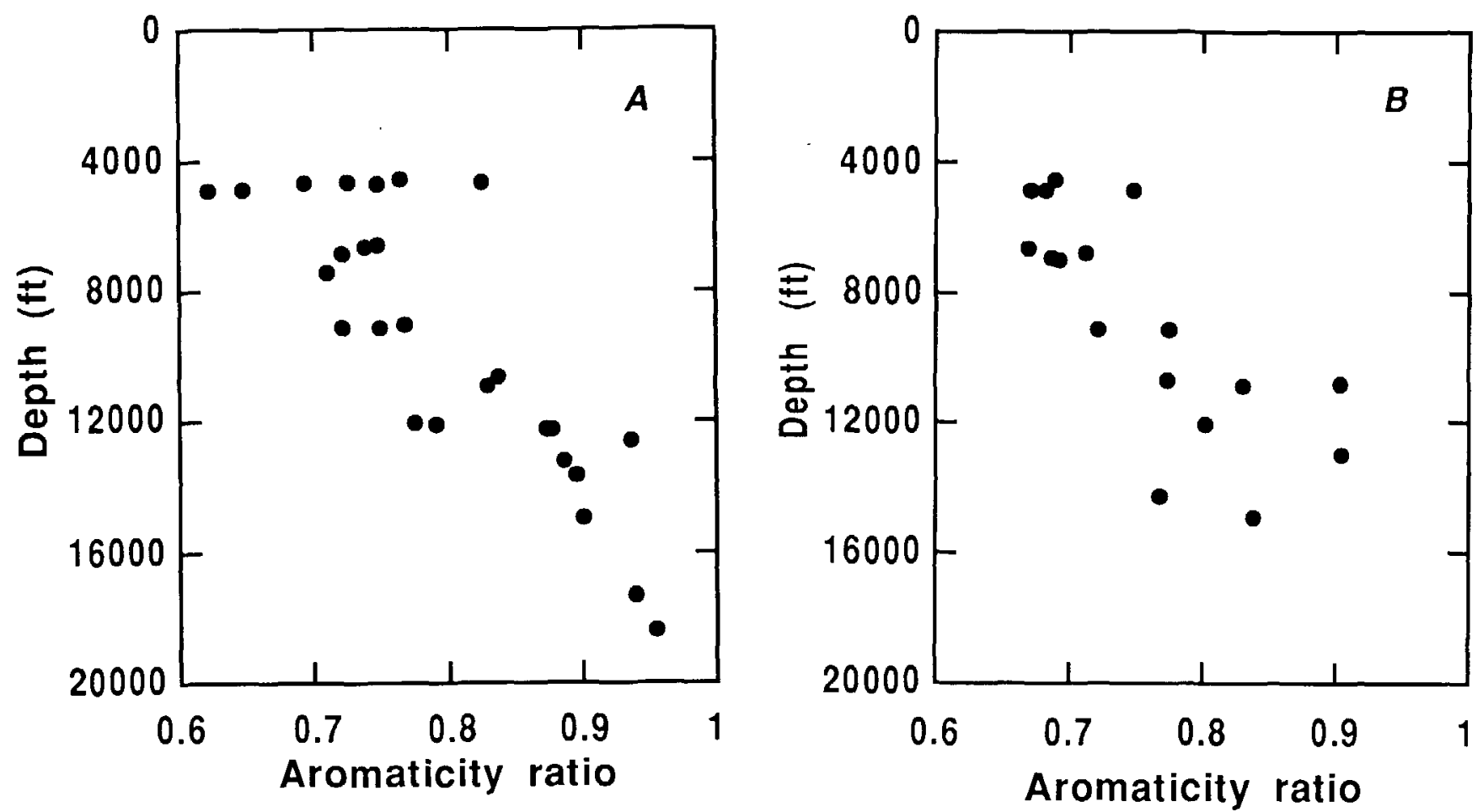

Figure 19. A. Aromaticity ratio versus depth scatter plot for the Almond Formation shales. B. Aromaticity ratio versus depth, scatter plot for the Almond Formation coals. Greater Green River Basin, Wyoming. Aromaticity ratio=(Aromatic carbon)/(Aromatic carbon+ Aliphatic carbon).

The geochemical characterization of the kerogen type in Almond coals and shales was obtained from an HI versus $\mathrm{T}_{\max }$ diagram (fig. 21) as suggested by Espitalié and others (1986). Figure 21 illustrates a general low-slope trend for the HI-T $\max$ plot, which is characteristic of type III kerogen. The scatter observed in this plot is possibly due to a mineral matrix effect in the shale samples that lowers the HI values (Espitalié and others, 1986).

Figure 22 presents $T_{\max }$ versus depth for the coal and shale samples. $T_{\max }$ is another measure of relative kerogen maturity. $T_{\max }$ for these samples increases fairly linearly with depth, indicating a fairly normal maturation trend. According to Espitalié and others (1985), the $\mathrm{T}_{\max }$ range for the oil generation window lies between $400^{\circ}$ and $600^{\circ} \mathrm{C}$ for type III kerogen (which is close to a vitrinite coal), with the threshold of oil generation between $430^{\circ}$ and $435^{\circ} \mathrm{C}$ and the threshold of gas generation between $465^{\circ}$ and $470^{\circ} \mathrm{C}$ (Espitalié and others, 1985). Figure 22 shows two $\mathrm{T}_{\max }$ populations at about $423^{\circ}$ and $468^{\circ} \mathrm{C}$, a distribution which allows determination of the depth range of the conventional oil window to be approximately between 4,000 and 12,000 ft.

Both petrographic observations of Almond coals and geochemical characterizations of shales and coals of the Almond Formation indicate that all samples from outcrop to maximum depth of sampling have similar compositions of type III kerogen.
In conclusion, the results of geochemical analyses (anhydrous pyrolysis and vitrinite reflectance) indicate that at the center of the basin, most of the Almond Formation samples from 4,000 to $12,000 \mathrm{ft}$ present burial depth are in the conventional oil window. On the basis of $T_{\max }$ $\left(\mathrm{T}_{\max } \geq 468^{\circ} \mathrm{C}\right.$ ) and NMR (aromatic ratio $\geq 0.9$ ) results, we delineated the entrance of the gas window between 12,000 and 14,000 ft present burial depth. The boundary between the oil and gas windows coincides with the rehomogenization of the semifusinite-vitrinite matrix discussed above in the organic petrography section.

Petrographic observations in both natural and artificially matured samples demonstrate that oil is generated over a vitrinite reflectance range from 0.5 to 1.7 percent. This is a wider range than that given by Tissot and Welte (1984), a range which is between 0.5 and 1.3 percent. It should be noted that in the upper range of reflectance values (maximum vitrinite reflectance $\left(R_{\max }\right) \geq 0.9$ percent), the hydrous pyrolysis experiments show that gas is also being generated from the thermal degradation of liquid hydrocarbons.

The depth ranges for the oil and gas windows at a given location in the GGRB depend upon the burial history of the source rock and especially on the level of erosion at that location. Therefore, these depth ranges vary considerably throughout the basin. 
Table 6. Results of anhydrous pyrolysis and total organic carbon (TOC) analysis on shale and coal samples from the Almond Formation at different depths of burial.

[HC, hydrocarbon; $\mathrm{S} !=\mathrm{mg} \mathrm{HC} / \mathrm{g}$ sample, hydrocarbons present in the sample; $\mathrm{S} 2=\mathrm{mg} \mathrm{HC} / \mathrm{g}$ sample, hydrocarbons generated during pyrolysis; $\mathrm{T}_{\max }$, maximum temperature of hydrocarbon generation; IC(pct), inorganic carbon in percent; TC(pct), total carbon in percent; TOC(pct), total organic carbon as a percentage; $\mathrm{PI}=\mathrm{S} 1 /(\mathrm{S} I+\mathrm{S} 2)$, production index; $\mathrm{HJ}=\mathrm{S} 2 / \mathrm{TOC}$, hydrogen index; $\mathrm{GP}=\mathrm{S} I+\mathrm{S} 2$, genetic potential; n.d., no data]

\begin{tabular}{|c|c|c|c|c|c|c|c|c|c|}
\hline Depth (ft) & S1 & S2 & Tmax & $\underset{(\mathrm{pct})}{\mathrm{IC}}$ & $\begin{array}{r}\mathrm{TC} \\
(\mathrm{pct})\end{array}$ & $\begin{array}{l}\text { TOC } \\
\text { (pct) }\end{array}$ & $P_{I}$ & H I & GP \\
\hline 2,991 & 1.26 & $1 . \overline{32}$ & 422 & 0.02 & 3.96 & 3.94 & 0.49 & 34 & 2.58 \\
\hline 4,560 & 5.90 & 106.50 & 403 & 5.89 & 41.00 & 35.11 & 0.05 & 303 & 112.40 \\
\hline 4,594 & 0.22 & 2.92 & 422 & 0.43 & 2.46 & 2.03 & 0.07 & 144 & 3.14 \\
\hline 4,688 & 0.81 & 9.34 & 419 & 0.16 & 5.41 & 5.25 & 0.08 & 178 & 10.14 \\
\hline 4,693 & 0.21 & 1.69 & 438 & 0.54 & 2.22 & 1.68 & 0.11 & 100 & 1.90 \\
\hline 4,693 & 1.95 & 2.76 & 418 & 2.26 & 4.57 & 2.31 & 0.41 & 119 & 4.70 \\
\hline 4,721 & 0.36 & 3.95 & 421 & 0.21 & 4.03 & 3.82 & 0.08 & 104 & 4.30 \\
\hline 4,884 & 8.89 & 165.80 & 434 & 0.01 & 76.32 & 76.31 & 0.05 & 217 & 174.70 \\
\hline 4,884 & 2.37 & 130.00 & 422 & 0.03 & 73.30 & 73.27 & 0.02 & 177 & 132.37 \\
\hline 4,894 & 1.24 & 42.50 & 418 & 0.00 & 15.70 & 15.70 & 0.03 & 271 & 43.74 \\
\hline 4,900 & 4.03 & 32.25 & 420 & 0.00 & 10.70 & 10.70 & 0.10 & 329 & 39.28 \\
\hline 5,365 & 0.44 & 2.51 & 427 & 1.23 & 2.97 & 1.74 & 0.15 & 144 & 2.95 \\
\hline 6,665 & 0.83 & 10.93 & 424 & 1.26 & 5.82 & 4.56 & 0.07 & 240 & 11.80 \\
\hline 6,881 & 1.57 & 32.67 & 422 & 0.12 & 15.78 & 15.66 & 0.05 & 209 & 34.20 \\
\hline 6,944 & 6.37 & 208.00 & 425 & 0.08 & 79.90 & 79.82 & 0.03 & 261 & 214.37 \\
\hline 6,955 & 0.66 & 3.43 & 434 & 0.13 & 1.47 & 1.34 & 0.16 & 256 & 4.09 \\
\hline 7,013 & 6.56 & 164.50 & 426 & 0.00 & 64.00 & 64.00 & 0.04 & 257 & 171.06 \\
\hline 7,024 & 0.83 & 9.43 & 422 & 0.85 & 5.00 & 4.15 & 0.08 & 227 & 10.26 \\
\hline 7,393 & 0.20 & 1.66 & 423 & 0.51 & 1.58 & 1.07 & 0.11 & 155 & 1.86 \\
\hline 7,441 & 0.93 & 10.70 & 424 & 0.27 & 3.64 & 3.37 & 0.08 & 318 & 11.63 \\
\hline 9,055 & 1.56 & 18.65 & 443 & 0.22 & 10.21 & 9.99 & 0.08 & 187 & 20.21 \\
\hline 9,056 & 3.82 & 57.70 & 440 & 0.01 & 33.30 & 33.29 & 0.06 & 173 & 61.52 \\
\hline 9,080 & 0.63 & 6.49 & 448 & 0.00 & 4.68 & 4.68 & 0.09 & 139 & 7.12 \\
\hline 9,150 & 4.69 & 48.68 & 445 & 0.01 & 27.92 & 27.91 & 0.09 & 174 & 53.40 \\
\hline 9,159 & 0.73 & 3.06 & 446 & 0.42 & 3.53 & 3.11 & 0.19 & 99 & 3.80 \\
\hline 10,671 & 4.54 & 34.55 & 453 & 0.00 & 24.90 & 24.90 & 0.12 & 139 & 39.09 \\
\hline 10,691 & 2.89 & 14.04 & 452 & 0.24 & 11.80 & 11.56 & 0.17 & 121 & 16.93 \\
\hline 10,898 & 16.03 & 116.50 & 456 & 0.01 & 83.80 & 83.79 & 0.12 & 139 & 132.50 \\
\hline 10,946 & 0.85 & 2.90 & 456 & 0.02 & 5.90 & 5.88 & 0.23 & 49 & 3.70 \\
\hline 12,071 & 0.38 & 1.07 & 446 & 0.95 & 2.08 & 1.13 & 0.26 & 95 & 1.50 \\
\hline 12,121 & 0.34 & 1.10 & 447 & 1.05 & 2.76 & 1.71 & 0.24 & 64 & 1.40 \\
\hline 12,091 & 15.70 & 124.90 & 450 & 0.35 & 75.99 & 75.64 & 0.11 & 165 & 140.60 \\
\hline 12,265 & n.d. & n.d. & n.d. & 1.03 & 2.85 & 3.88 & n.d. & n.d. & n.d. \\
\hline 12,604 & 0.34 & 1.11 & 468 & 1.22 & 3.47 & 2.25 & 0.23 & 49 & 1.40 \\
\hline 13,000 & 0.73 & 5.01 & 428 & 0.80 & 11.61 & 10.81 & 0.13 & 46 & 5.70 \\
\hline 13,223 & 0.37 & 1.19 & 459 & 0.47 & $2.48^{\circ}$ & 2.01 & 0.24 & 59 & 1.60 \\
\hline 13,659 & 0.24 & 0.97 & 468 & 0.01 & 5.86 & 5.84 & 0.20 & 17 & 1.20 \\
\hline 13,453 & 0.19 & 0.41 & 468 & 0.66 & 1.87 & 1.21 & 0.31 & 33 & 0.59 \\
\hline 13,661 & 0.23 & 1.00 & 469 & 0.01 & 5.22 & 5.21 & 0.18 & 19 & 1.23 \\
\hline 14,286 & 12.49 & 108.70 & 449 & 0.03 & 54.89 & 54.86 & 0.10 & 198 & 121.20 \\
\hline 14,314 & 0.20 & 0.69 & 452 & 1.28 & 2.68 & 1.40 & 0.22 & 49 & 0.88 \\
\hline 14,338 & 0.17 & 0.67 & 452 & 0.40 & 1.80 & 1.40 & 0.20 & 48 & 0.84 \\
\hline 14,902 & 6.59 & 31.21 & 469 & 1.26 & 55.90 & 54.64 & 0.17 & 57 & 37.80 \\
\hline 14,929 & 1.63 & 5.33 & 469 & 0.04 & 11.52 & 11.48 & 0.23 & 46 & 7.00 \\
\hline 14,942 & 1.71 & 1.91 & 468 & 0.05 & 5.93 & 5.89 & 0.47 & 32 & 3.60 \\
\hline 16,119 & 0.33 & 0.26 & 468 & 2.48 & 3.24 & 0.76 & 0.56 & 34 & 0.60 \\
\hline 16,940 & 3.08 & 2.11 & n.d. & 0.90 & 6.87 & 5.97 & 0.59 & 35 & 5.20 \\
\hline 17,330 & 0.74 & 0.96 & n.d. & 1.56 & 3.17 & 1.61 & 0.44 & 59 & 1.70 \\
\hline 17,969 & 0.83 & 1.19 & 453 & 3.84 & 6.12 & 2.28 & 0.41 & 52 & 2.00 \\
\hline 18,330 & 1.53 & 1.26 & n.d. & $1: 81$ & 3.58 & 1.77 & 0.55 & 71 & 2.80 \\
\hline 18,410 & 0.60 & 0.77 & n.d. & 1.33 & 3.14 & 1.81 & 0.44 & 42 & 1.40 \\
\hline
\end{tabular}




\section{ARTIFICIALLY MATURED SAMPLES}

Hydrous pyrolysis (HP) has been used to study the maturation of sedimentary organic material (see review in Surdam and others, 1989) and has recently been used to study the maturation of coal (Katz and others, 1991; Teer-

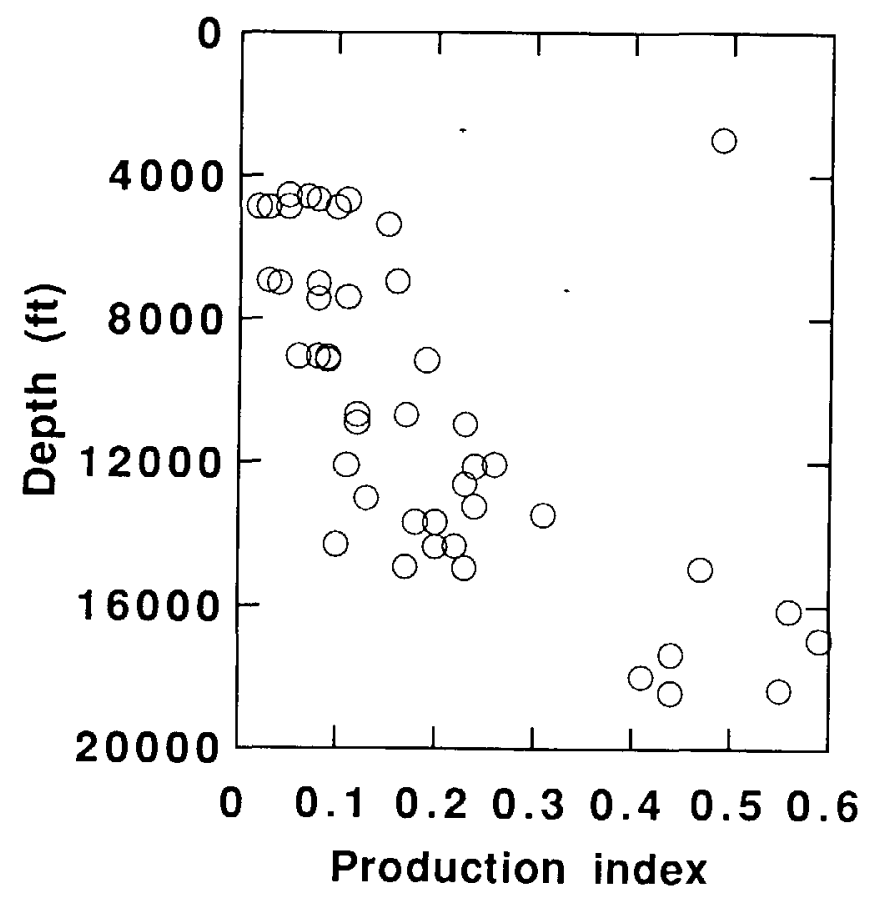

Figure 20. Production index (PI) versus depth for Almond Formation core samples, Greater Green River Basin, Wyoming.

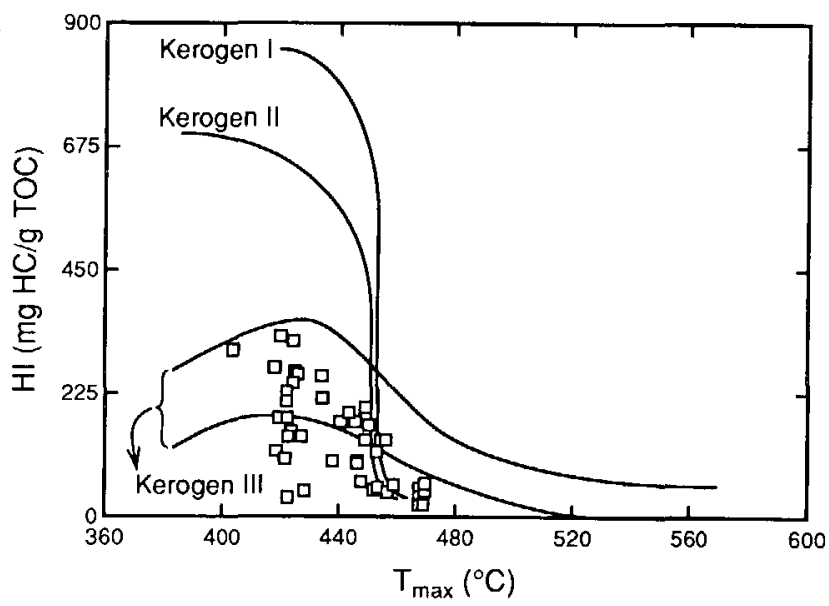

Figure 21. Hydrogen index (HI) versus maximum temperature of hydrocarbon generation $\left(\mathrm{T}_{\max }\right.$ ) for Almond Formation samples. Milligrams of hydrocarbon per gram total organic carbon, mg $\mathrm{HC} / \mathrm{g}$ TOC. Figure also shows the general trends of kerogen types I, II, III for comparison. man and Hwang, 1991; Mukhopadhyay and others, 1991; Khavari Khorasani and Michelsen, 1991; MacGowan, Britton, and others, 1992; MacGowan, García-González, and others, in press; García-González and Surdam, 1992; Yin, Surdam, and others, in press).

Recent detailed chemical kinetic modeling based on elementary reactions has demonstrated that high-temperature laboratory kinetic data can be used to model the timing and kinetics of kerogen maturation processes occurring at low temperature over geologic time spans (Freund, 1992). In addition, Lewan and others (1979), and Lewan (1985) have demonstrated that hydrous pyrolysis mimics many aspects of petroleum generation, including (1) petrographic aspects of oil generation and expulsion, and (2) composition of the oil produced. In spite of these observations, hydrous pyrolysis has been occasionally criticized as not accurately reflecting geologic processes because it substitutes high temperature for geologic time (see Saxby, 1982; Snowdon, 1979).

An Almond Formation coal sample was subjected to 72-hour isothermal hydrous pyrolysis experiments. These experiments were carried out on a suite of samples at temperatures of $290^{\circ}, 300^{\circ}, 310^{\circ}, 320^{\circ}, 330^{\circ}, 340^{\circ}, 345^{\circ}$, $350^{\circ}$, and $360^{\circ} \mathrm{C}$ using the technique described by Lewan (1985) and Lewan and others (1979); a detailed description of our laboratory techniques can be found in Yin, Surdam, and others, in press.

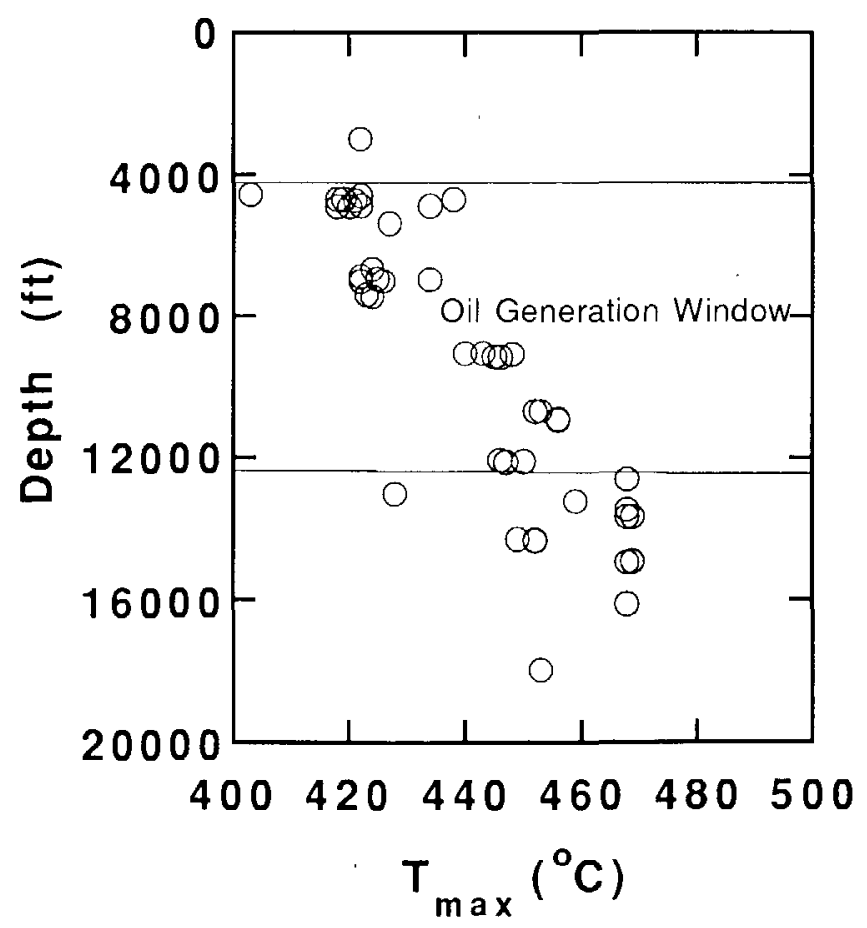

Figure 22. Maximum temperature $\left(\mathrm{T}_{\max }\right)$ versus depth for $\mathrm{Al}-$ mond Formation samples, Greater Green River Basin, Wyoming. 


\section{ORGANIC PETROGRAPHY}

\section{MACERAL ANALYSIS}

Table 7 summarizes the point-count data obtained from microscopic examination of Almond coal samples after hydrous pyrolysis. The starting material is characterized by (1) a vitrinite $(\mathrm{TV})$ content of 76 percent, dominated by desmocollinite (ds), (2) a liptinite (Tl) content of approximately 11 percent, dominated by cutinite (cu) and followed by sporinite (sp); the exsudatinite (ex) maceral, or bitumen, is absent, and (3) an inertinite (Tin) content of 13 percent, the most common inertinite macerals are micrinite (mi) and macrinite (ma), followed by semifusinite (sf). As the temperature of hydrous pyrolysis increases, the liptinite content decreases gradually to a residual minimum value at $310^{\circ} \mathrm{C}$. Once this temperature is reached, no liptinites survive; all have been transformed into micrinite and exsudatinite (bitumen). Similarly, the vitrinite content gradually decreases at the $340^{\circ} \mathrm{C}$ experiment; it then abruptly goes to low levels as vitrinite is transformed into semifusinite, owing to the progressive loss of aliphatic compounds. In the sample at $345^{\circ} \mathrm{C}$, desmocollinite is not present, whereas the structureless telocollinite and semifusinite have increased.

The ternary diagram (fig. 23) illustrates the course of these maceral transformations with temperature, excluding exsudatinite generation. Figure 24 shows the maceral composition with increasing temperature of the vitrinite, liptinite, and the inertinite maceral groups; figure 24 also includes the secondary maceral exsudatinite. Both figures 23 and 24 show an increase with temperature of the inertinite maceral group accompanied by a decrease of the liptinite and vitrinite maceral groups.

Exsudatinite and liquid petroleum are the secondary products of the maceral transformations corresponding to the maturation of Almond coals. The peak generation of exsudatinite is at $345^{\circ} \mathrm{C}$. At higher temperatures, there is a decrease in exsudatinite owing to thermal cracking of the exsudatinite to lighter compounds, such as liquid and gaseous hydrocarbons. These petrographic observations are supported by the geochemical results discussed below.

\section{TEXTURAL DESCRIPTION OF ALMOND COALS AFTER HYDROUS PYROLYSIS}

The starting material in the hydrous pyrolysis experiments was Almond coal sampled at the surface. In outcrop around the Rock Springs Uplift, Almond coal has a vitrinite reflectance value $\left(R_{\max }\right)$ of 0.45 percent. Table 7 includes

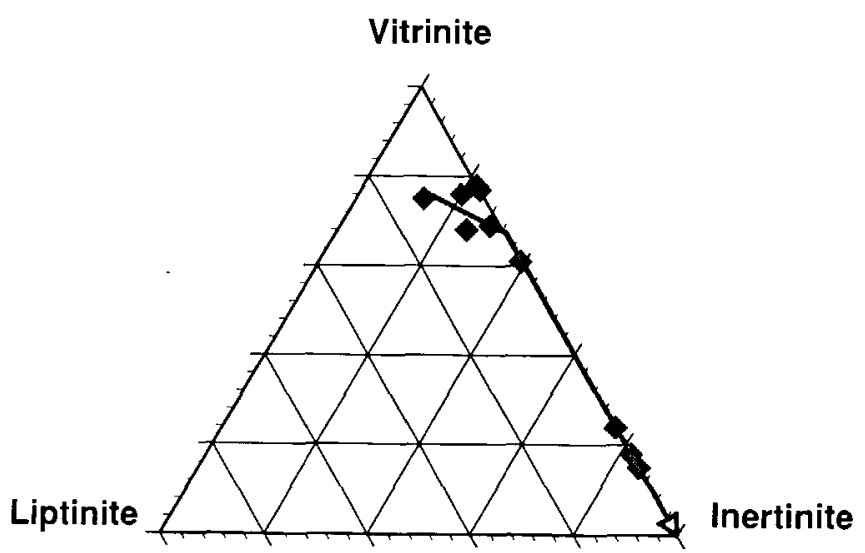

Figure 23. Ternary diagram showing the course of the maceral transformations with increasing temperature of hydrous pyrolysis experiments. Liptinite refers to primary macerals excluding exsudatinite. Arrow indicates trend of maturation with increasing temperature in hydrous pyrolysis.

Table 7. Maceral point counting on Almond coals after hydrous pyrolysis.

[ds, desmocollinite; tl, telocollinite; Tv, total vitrinite; cu, cutinite; sp, sporinite; rs, resinite; Tl, total liptinite; mi, micrinite; ma, macrinite; fu, fusinite; sf, semifusinite; Tin, total inertinite; ex, exsudatinite; St Mat, starting material; Ro(pct), mean vitrinite reflectance as a percentage]

\begin{tabular}{|c|c|c|c|c|c|c|c|c|c|c|c|c|c|c|}
\hline Sample & $\begin{array}{c}\mathrm{ds} \\
(\mathrm{pct})\end{array}$ & $\begin{array}{c}\mathrm{tl} \\
(\mathrm{pct})\end{array}$ & $\begin{array}{c}\text { Tv } \\
\text { (pct) }\end{array}$ & $\begin{array}{c}\mathrm{cu} \\
(\mathrm{pct})\end{array}$ & $\begin{array}{c}\mathrm{sp} \\
(\mathrm{pct})\end{array}$ & $\begin{array}{c}\mathrm{rs} \\
(\mathrm{pct})\end{array}$ & $\begin{array}{c}\mathrm{Tl} \\
\text { (pct) }\end{array}$ & $\underset{(\mathrm{pct})}{\mathrm{mi}}$ & $\underset{(\mathrm{pct})}{\mathrm{ma}}$ & $\begin{array}{c}\mathrm{fu} \\
(\mathrm{pct})\end{array}$ & $\begin{array}{c}\mathbf{s f} \\
(\mathrm{pct})\end{array}$ & $\begin{array}{c}\text { Tin } \\
\text { (pct) }\end{array}$ & $\begin{array}{c}\text { ex } \\
\text { (pct) }\end{array}$ & $\begin{array}{r}\text { Ro } \\
\text { (pct) }\end{array}$ \\
\hline Almond St Mat--- & 71 & 5 & 76 & 8 & 2 & 1 & 11 & 3 & 4 & 2 & 3 & 13 & 0 & 0.45 \\
\hline Almond 290 ----- & 60 & 6 & 66 & 4 & $\operatorname{tr}$ & tr & 5 & 4 & 3 & 2 & 15 & 24 & 6 & 0.95 \\
\hline Almond 300 & 57 & 6 & 56 & 3 & tr & tr & 4 & 6 & 1 & 3 & 18 & 28 & 5 & 0.99 \\
\hline Almond 310 ------ & 51 & 16 & 67 & 1 & 0 & 0 & 1 & 10 & 4 & 1 & 14 & 29 & 2 & 1.15 \\
\hline Almond 320 & 50 & 26 & 76 & 0 & 0 & 0 & 0 & 6 & 3 & 2 & 12 & 23 & 2 & 1.35 \\
\hline Almond 330 ----- & 53 & 19 & 72 & 0 & 0 & 0 & 0 & 8 & 2 & 2 & 9 & 21 & 6 & 1.39 \\
\hline Almond 340 -.-... & 19 & 35 & 0 & 0 & 0 & 0 & 0 & 6 & 2 & 4 & 23 & 35 & 11 & 1.50 \\
\hline Almond 345 & 0 & 20 & 20 & 0 & 0 & 0 & 0 & 3 & 2 & 8 & 51 & 64 & 17 & 1.58 \\
\hline Almond $350 \ldots$ & 0 & 15 & 15 & 0 & 0 & 0 & 0 & 5 & 2 & 10 & 57 & 65 & 12 & 1.65 \\
\hline Almond 360 ----- & 0 & 14 & 14 & 0 & 0 & 0 & 0 & $\operatorname{tr}$ & 2 & 13 & 61 & 77 & 11 & 1.71 \\
\hline
\end{tabular}




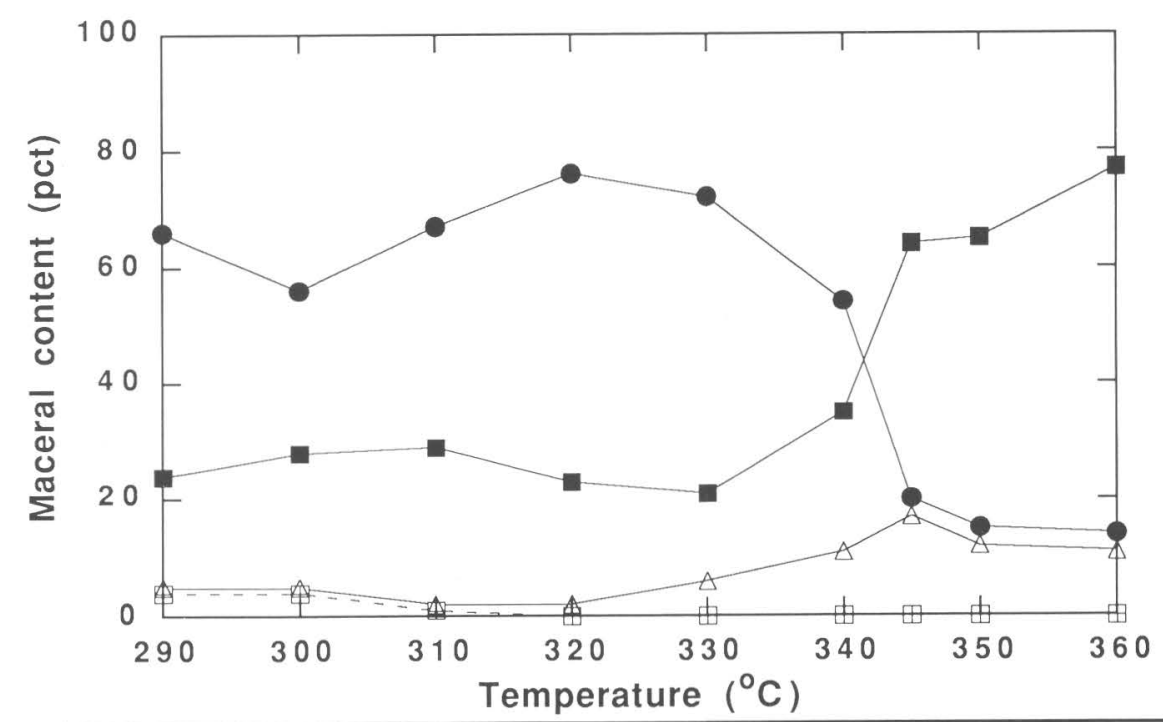

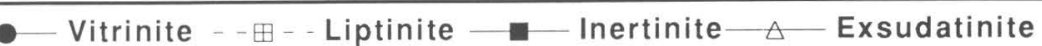

Figure 24. Maceral content after hydrous pyrolysis versus temperature of experiments.

vitrinite reflectance data. The following is a description of the textural changes observed in Almond coals after hydrous pyrolysis at successively higher temperatures:

1. Starting material: Almond coal from the surface shows a finely laminated desmocollinite groundmass with dispersed sporinite, cutinite, and inertinite macerals. $\mathrm{R}_{\max }=0.45$ percent (fig. 25 ).

2. $290^{\circ} \mathrm{C}$ : The desmocollinite groundmass loses its finely laminated texture and becomes more homogenous. Micrinite begins to appear, while the liptinite content is drastically reduced. The mean maximum reflectance on desmocollinite increases to $\mathrm{R}_{\max }=0.86$ percent (fig. 26).

3. $300^{\circ} \mathrm{C}$ : A porous texture begins to appear owing to oil generation and expulsion, and the micrinite continues to form from the liptinite macerals. The mean maximum reflectance on desmocollinite is $R_{\max }=0.91$ percent (fig. 27).

4. $310^{\circ} \mathrm{C}$ : The porous texture becomes predominant; many pores are developed near semifusinite macerals; $\mathrm{R}_{\max }=1.22$ percent (fig. 28).

5. $330^{\circ} \mathrm{C}$ : The porous texture evolves to a vesicular texture in which the vesicles are filled with exsudatinite that shows a weak yellow fluorescence. This vesicular texture is present mostly on the semifusinite macerals, although it also appears on the vitrinite groundmass. $\mathrm{R}_{\max }=1.39$ percent (figs. 29,30 ).

6. $360^{\circ} \mathrm{C}$ : The vesicular texture is the predominant feature; it is developed mostly on semifusinite and fusinite macerals. The exsudatinite formed in the vesicles of the inertinite macerals during the pyrolysis shows a strong orange fluorescence (figs. 31, 32). Expulsion of oil from the exsudatinite vesicles occurs either by fracture of the vesicles or generation of increasing quantities of lighter aliphatic compounds, which at some point overcome the

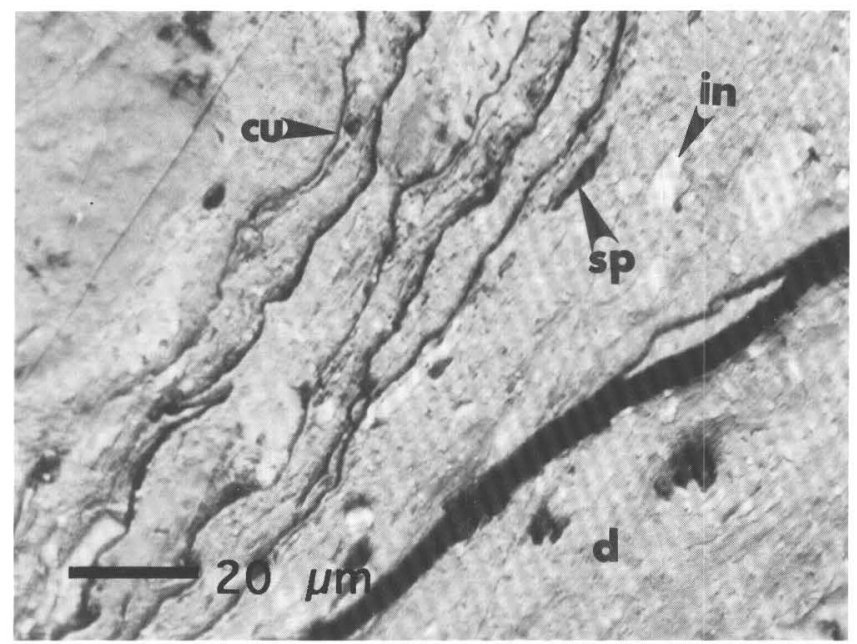

Figure 25. Photomicrograph of coal from an outcrop of the Almond Formation. Starting material for hydrous pyrolysis experiments. Finely laminated texture of desmocollinite (d) matrix with dispersed sporinite (sp) and cutinite (cu). Inertinite (in). Reflected white light.

storage capacity of the vesicles causing fractures (figs. 33, 34 ). The mean maximum reflectance is $R_{\max }=1.70$ percent; this is measured on telocollinite, since the desmocollinite no longer has its original definitive characteristics.

As opposed to the naturally matured samples, the solid-phase residue from hydrous pyrolysis experiments never reaches the stage of vitrinite-semifusinite rehomogenization that is observed in the naturally matured samples. This is generally observed in samples from deeper than $14,000 \mathrm{ft}$ present burial and is most likely due to the lack 
of high confining pressure in the hydrous pyrolysis experiments. This overburden pressure in nature acts to help fracture the vesicles and expel stored oil (exsudatinite).

The hydrous pyrolysis experiments indicate that the generation and expulsion of liquid hydrocarbons occurs in two stages: (1) Oil is generated and expelled as liptinite macerals are transformed into micrinite, and (2) oil is expelled as the semifusinite vesicles, filled with exsudatinite, are fractured. These two processes represent primary mi-

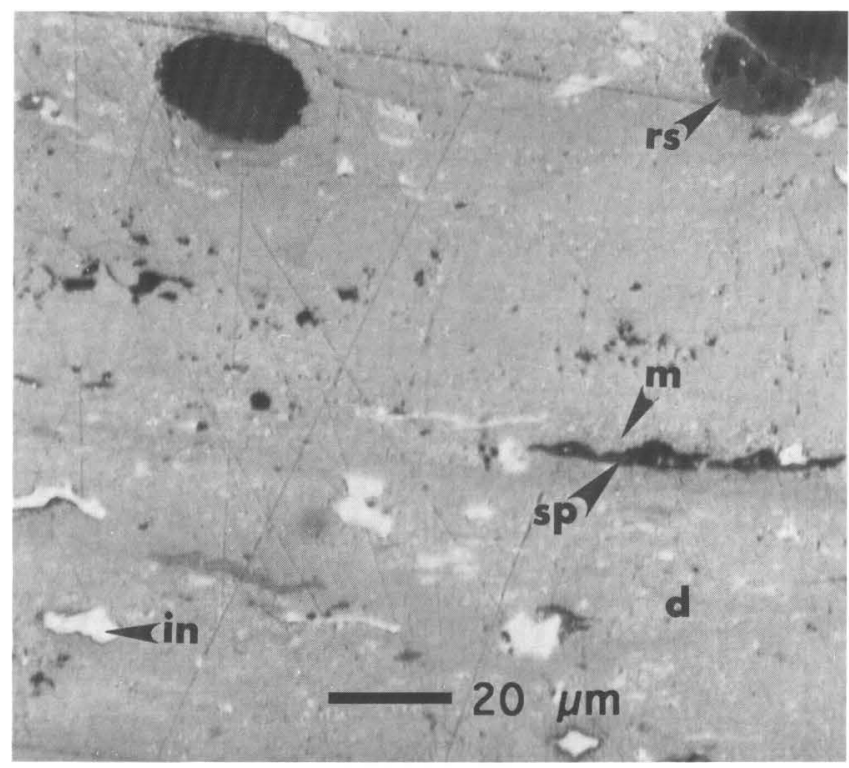

Figure 26. Photomicrograph of coal from the Almond Formation after hydrous pyrolysis at $290^{\circ} \mathrm{C}$ : Desmocollinite (d) loses its finely laminated texture. Micrinite (m) formed from sporinite (sp) macerals. Resinite (rs); inertinite (in). Reflected white light.

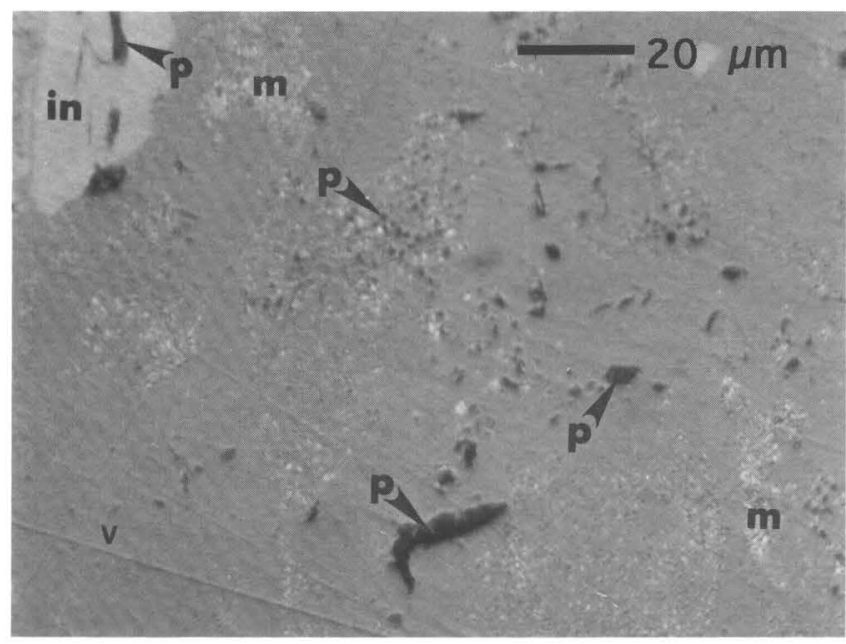

Figure 27. Photomicrograph of coal from the Almond Formation after hydrous pyrolysis at $300^{\circ} \mathrm{C}$ : Beginning of formation of porous (p) texture due to oil expulsion. Micrinite $(\mathrm{m})$, inertinite (in), vitrinite (v). Reflected white light. gration of oil from the coal source rock. As opposed to the naturally matured samples, the hydrous pyrolysis experiments show abundant exsudatinite at a vitrinite reflectance of 1.7 percent $R_{\max }$. This situation is not observed in the naturally matured samples, owing to the higher pressure experienced during burial that compresses the coals, expelling the exsudatinite.

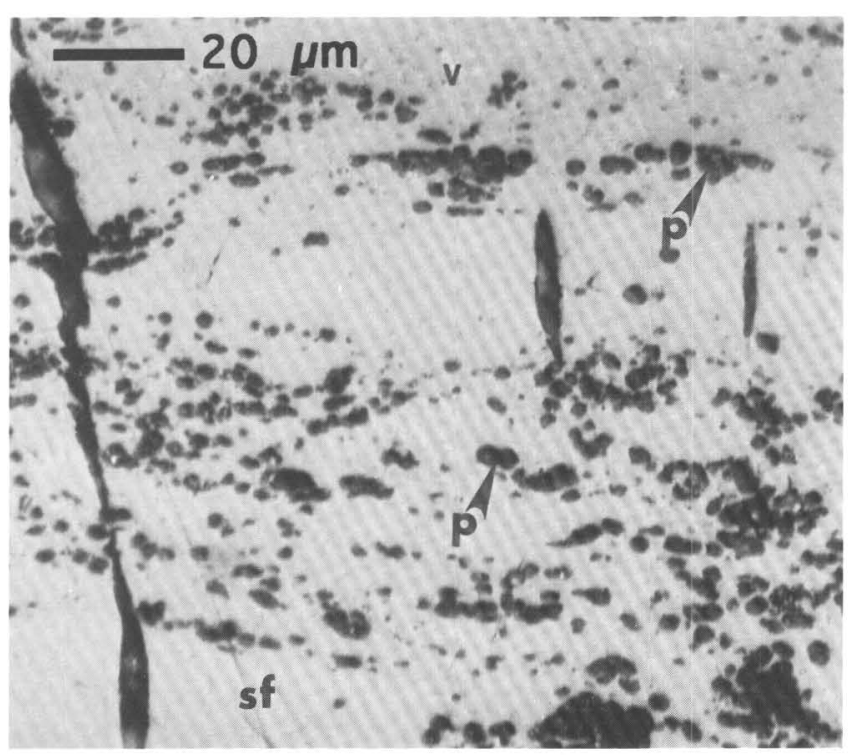

Figure 28. Photomicrograph of coal from the Almond Formation after hydrous pyrolysis at $310^{\circ} \mathrm{C}$ : Porous texture developed in vitrinite (v) matrix. Semifusinite (sf), pore (p). Reflected white light.

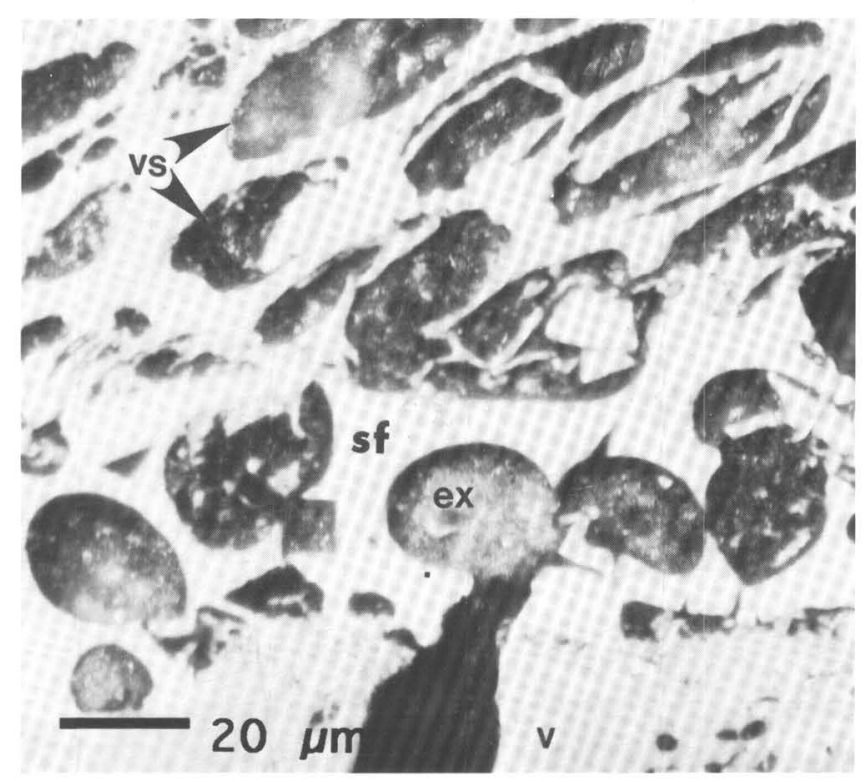

Figure 29. Photomicrograph of coal from the Almond Formation after hydrous pyrolysis at $330^{\circ} \mathrm{C}$ : Vesicular texture on semifusinite (sf). Vesicles (vs) filled with exsudatinite (ex). Vitrinite (v). Reflected white light. 
The correlation coefficient of vitrinite reflectance with temperature of the hydrous pyrolysis experiments is 0.99 , indicating that $R_{0}$ is a viable maturation parameter for this type of process, especially when reflectance is carefully measured on the vitrinite group (fig. 35). In this study, the measurements were taken on desmocollinite in the starting material and continued to be taken through the $310^{\circ} \mathrm{C}$ experiment; from the $320^{\circ}$ through $360^{\circ} \mathrm{C}$ experiments, reflectances were taken on telocollinite because desmocollinite did not exhibit the original texture. We had difficulty

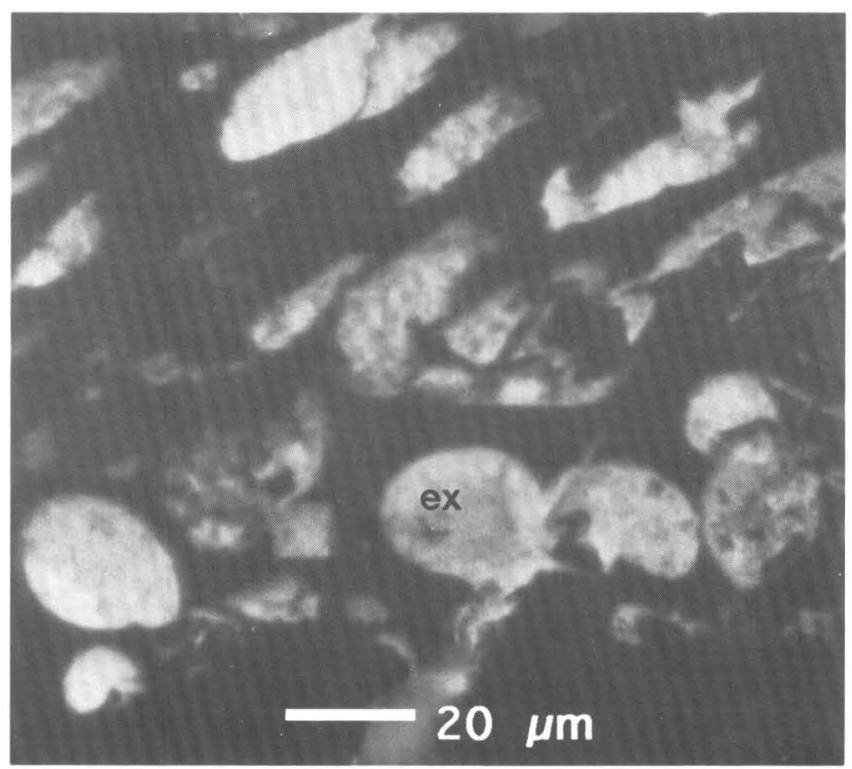

Figure 30. Photomicrograph of same feature as figure 29 under reflected blue light showing fluorescence of exsudatinite (ex).

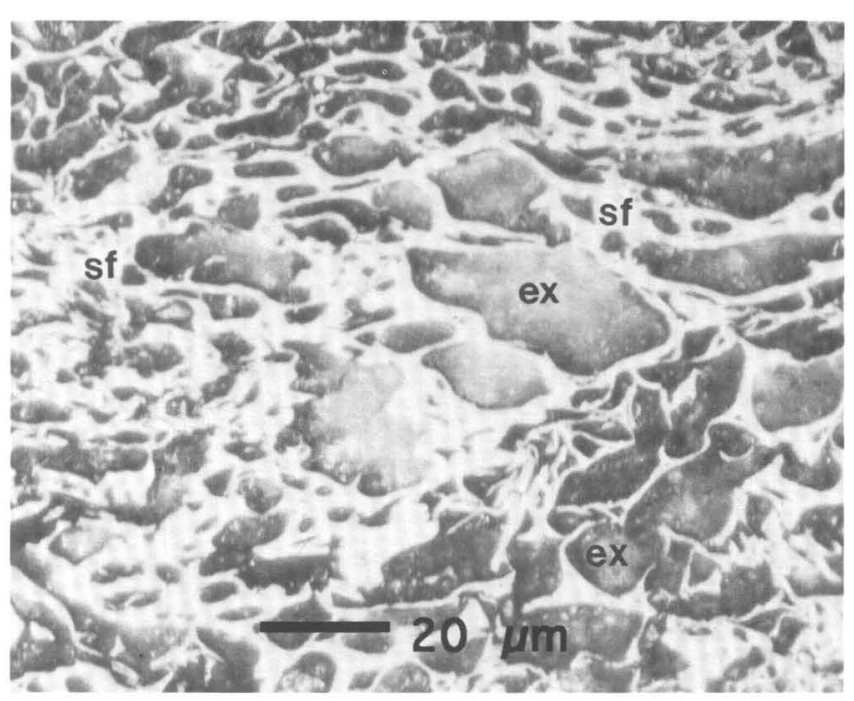

Figure 31. Photomicrograph of coal from the Almond Formation after hydrous pyrolysis at $360^{\circ} \mathrm{C}$ : Vesicular texture on semifusinite (sf). Vesicles filled with exsudatinite (ex). Reflected white light. in differentiating between vitrinite and semifusinite in the $350^{\circ}$ and $360^{\circ} \mathrm{C}$ samples; nonetheless, the hydrous pyrolysis experiments allowed us to document that vitrinite reflectance increases with the maceral transformation that begins with desmocollinite and ends with semifusinite or homogeneous vitrinite.

In summary, hydrous pyrolysis experiments on coal simulated the organic metamorphism that occurred during the natural burial of the coal. Both processes generated similar textural and maceral changes, including the gener-

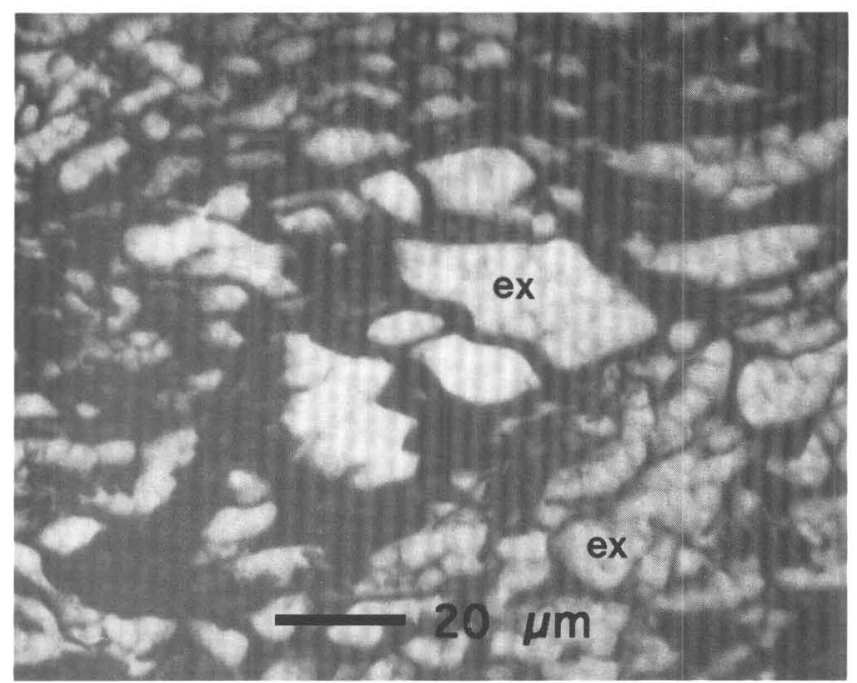

Figure 32. Photomicrograph of same feature as Figure 31 under reflected blue light showing strong fluorescence of exsudatinite (ex).

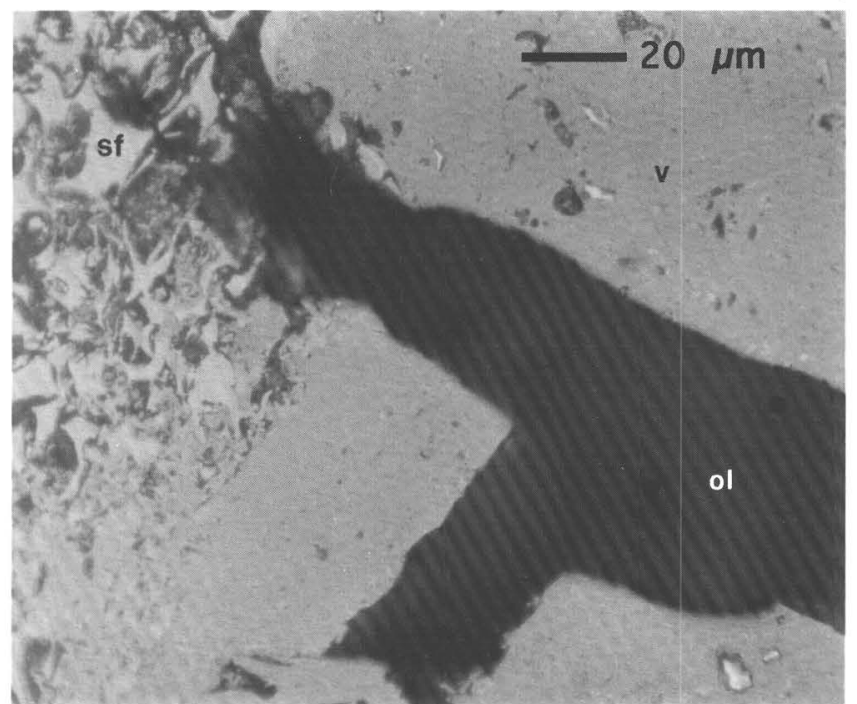

Figure 33. Photomicrograph of coal from the Almond Formation after hydrous pyrolysis at $360^{\circ} \mathrm{C}$ : Expulsion of indigenous oil (ol) from vesicles filled with exsudatinite (ex). Vitrinite (v); semifusinite (sf). White reflected light. 
ation and expulsion of liquid and gaseous hydrocarbons. However, these hydrous pyrolysis experiments were not able to mimic the rehomogenization of the vitrinite-semifusinite matrix that indicates the onset of gas generation, probably owing to lack of high confining pressure in the experiments.

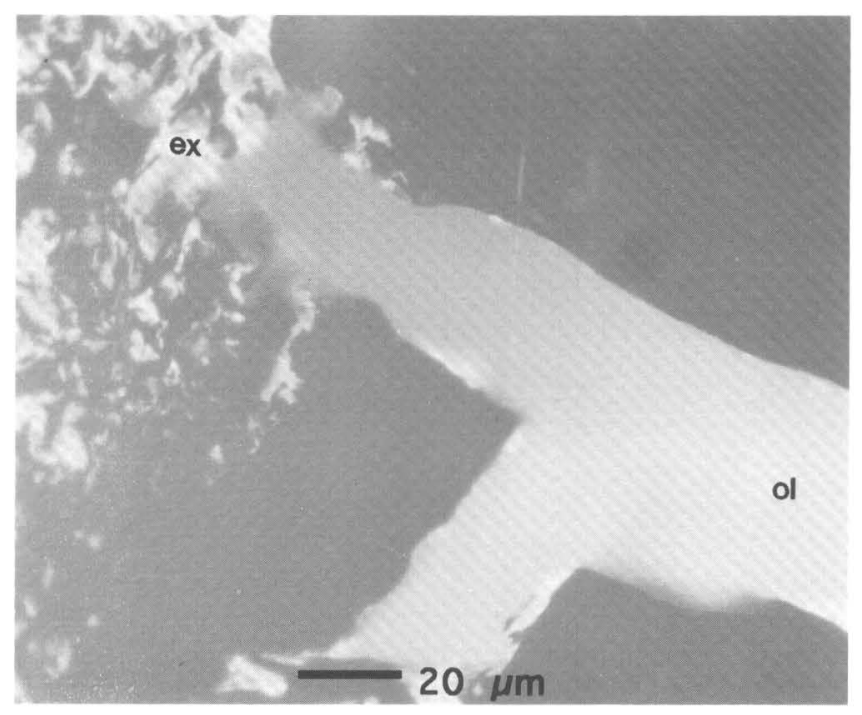

Figure 34. Photomicrograph of same feature as figure 33 under reflected blue light showing fluorescence of the oil (ol) expelled from the vesicles filled with exsudatinite (ex).

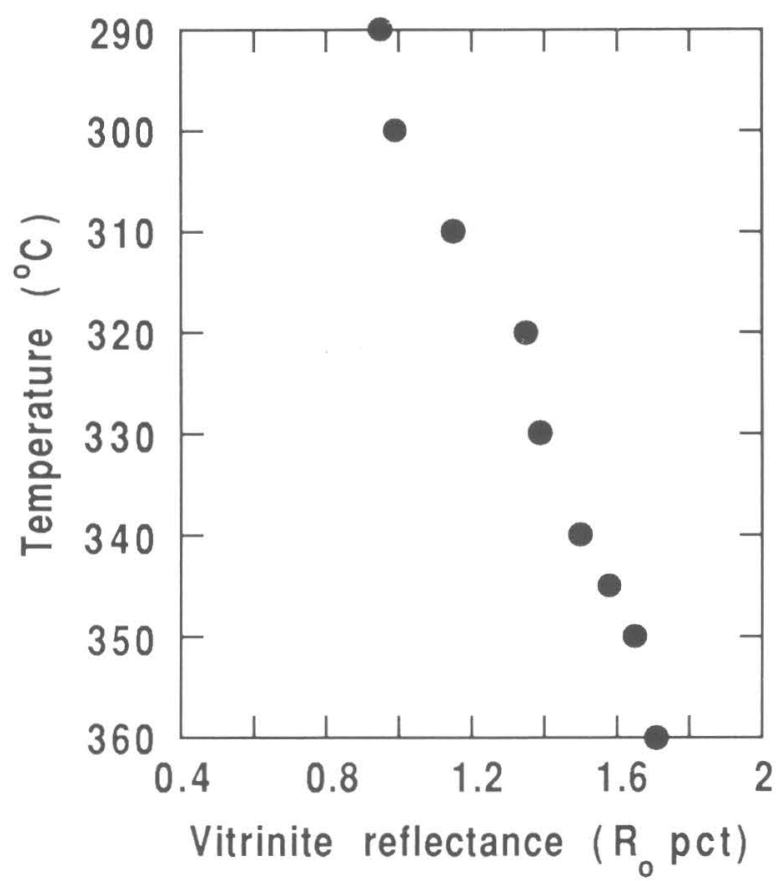

Figure 35. Vitrinite reflectances versus temperature obtained for Almond Formation coal after hydrous pyrolysis.

\section{ORGANIC GEOCHEMISTRY}

The results of our organic geochemical analyses on the solid residue from the hydrous pyrolysis experiments (TOC, PI, GP and HI) are presented in table 8.

Figure 36 shows expelled free oil recovered during each hydrous pyrolysis experiment as milligrams of oil per gram of coal. This is oil that had been generated and expelled from the coal during the course of the experiment and does not include stored bitumen (the material extractable by solvents but not expelled from the coals; for example, exsudatinite) which is adsorbed into the coal structure. The petrographic observations indicate that there is a great amount of bitumen stored in vesicles in the coal. Soxhlet extraction of bitumen in the coals after the experiments yielded up to 3.97 weight percent bitumen; this corroborates the organic petrographic observations (noted above) of large volumes of oil remaining in the coal after the generation and expulsion of the free-oil phase. A similar observation was made by Teerman and Hwang (1991) in their hydrous pyrolysis experiment on coal. Our hydrous pyrolysis experiments show expulsion of liquids and storage of abundant bitumen (exsudatinite) throughout the range of experimental conditions. This situation is not observed in the naturally matured samples at depths greater than 12,000 $\mathrm{ft}$, possibly because in natural samples the higher pressure experienced during burial compresses the coals, expelling the liquid hydrocarbons.

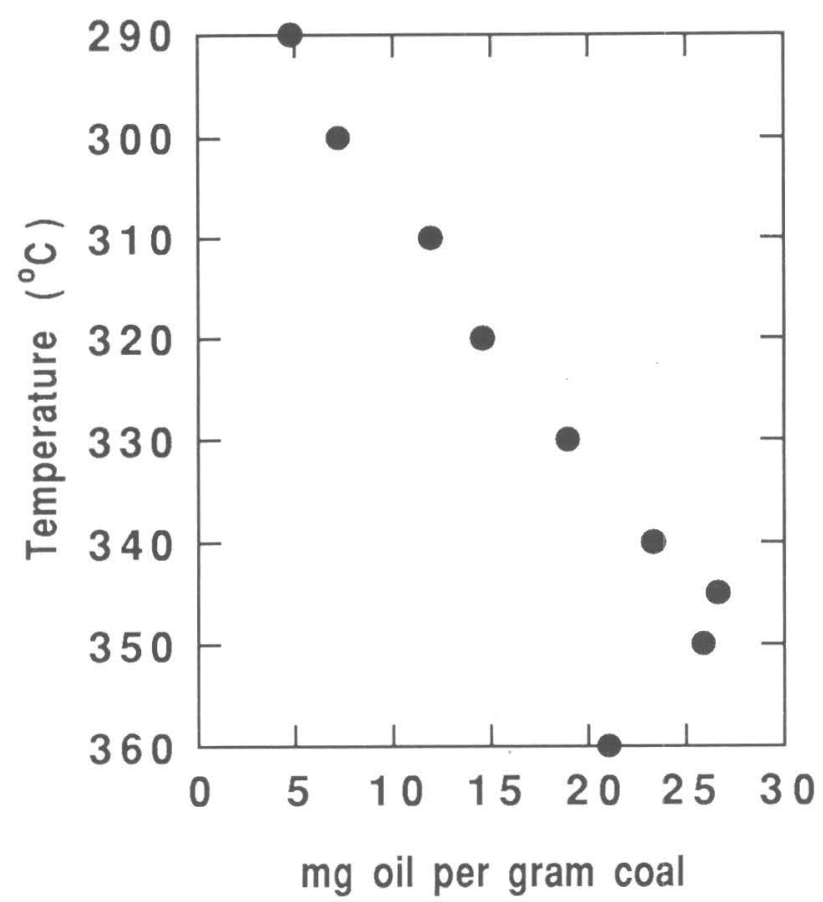

Figure 36. Recovered oil (mg oil/g coal) versus experimental temperature for Almond Formation coal hydrous pyrolysis experiments. 
Table 8. Results of anhydrous pyrolysis and total organic carbon (TOC) analyses on Almond coals after hydrous pyrolysis.

[St Mat, starting material; $\mathrm{HC}$, hydrocarbon; Temp, temperature $\left({ }^{\circ} \mathrm{C}\right) ; \mathrm{S} 1=\mathrm{mg} \mathrm{HC} / \mathrm{g}$ sample, hydrocarbons present in the sample; S2=mg $\mathrm{HC} / \mathrm{g}$ sample, hydrocarbons generated during pyrolysis; $\mathrm{T}_{\max }$, maximum temperature of hydrocarbon generation; $\mathrm{C}$ (pct), inorganic carbon in percent; $\mathrm{IC}(\mathrm{pet})$, inorganic carbon in percent; TC(pct), total carbon in percent; TOC $(\mathrm{pct})$, total organic carbon as a percentage; $\mathrm{PI}=\mathrm{S} 1 / \mathrm{S} 1+\mathrm{S} 2)$, production index; HI=S2/TOC, hydrogen index; $\mathrm{GP}=\mathrm{S} 1+\mathrm{S} 2$, genetic potential; $\mathrm{Ol} / \mathrm{Ca}=\mathrm{mg}$ Oil/g Coal, oil generated during hydrous pyrolysis]

\begin{tabular}{|c|c|c|c|c|c|c|c|c|c|c|c|}
\hline Sample & Temp & S1 & S2 & $T \max$ & $\begin{array}{c}\text { TC } \\
\text { (pct) }\end{array}$ & $\begin{array}{c}\text { IC } \\
\text { (pct) }\end{array}$ & $\begin{array}{l}\text { TOC } \\
\text { (pct) }\end{array}$ & PI & HI & GP & $\mathrm{Ol} / \mathrm{Ca}$ \\
\hline Almond St Mat -.--- & 80 & 0.26 & 99.79 & 423 & 70.30 & 0.00 & 70.30 & 0.00 & 142 & 100 & 0.01 \\
\hline Almond St Mat --.-- & 80 & 0.62 & 107.41 & 411 & 68.90 & 0.00 & 68.90 & 0.01 & 156 & 108 & 0.01 \\
\hline Almond 290------..- & 290 & 5.52 & 97.77 & 433 & 77.00 & 0.02 & 76.98 & 0.05 & 127 & 103 & 4.80 \\
\hline Almond 300-------- & 300 & 8.13 & 110.00 & 437 & 77.60 & 0.02 & 77.58 & 0.07 & 142 & 118 & 7.20 \\
\hline Almond 310--........ & 310 & 11.39 & 100.50 & 440 & 78.60 & 0.02 & 78.58 & 0.10 & 128 & 112 & 11.95 \\
\hline Almond 320--------- & 320 & 13.20 & 93.34 & 442 & 76.40 & 0.04 & 76.36 & 0.12 & 122 & 107 & 14.60 \\
\hline Almond 330 & 330 & 14.20 & 82.15 & 444 & 78.70 & 0.03 & 78.67 & 0.15 & 104 & 96 & 18.95 \\
\hline Almond 340 -......- & 340 & 16.55 & 77.02 & 444 & 81.10 & 0.01 & 81.09 & 0.18 & 95 & 94 & 23.35 \\
\hline Almond 345----.-.- & 345 & 18.53 & 65.97 & 447 & 80.50 & 0.01 & 80.49 & 0.22 & 82 & 85 & 26.65 \\
\hline Almond 350 -.....-- & 350 & 17.04 & 59.76 & 452 & 80.30 & 0.03 & 80.27 & 0.22 & 74 & 77 & 25.90 \\
\hline Almond 360------- & 360 & 18.83 & 58.71 & 448 & 81.40 & 0.02 & 81.38 & 0.24 & 72 & 78 & 21.05 \\
\hline
\end{tabular}

At maximum generation, Almond coals expel $27 \mathrm{mg}$ oil/g coal; this indicates that this coal has excellent oil generative capacity. The steep drop in oil recovery seen in experiments at temperatures above $345^{\circ} \mathrm{C}$ suggests that oil is being thermally cracked to gas at these temperatures. This is very similar to the trend noted by Teerman and Hwang (1991) in their experiments on Tertiary lignite.

Figure 37 shows the production index (PI) versus temperature for Almond coals after the hydrous pyrolysis experiments. The standard interpretation of figure 37 would be that the coal is in the conventional liquid oil window in the $310^{\circ}$ to $360^{\circ} \mathrm{C}$ experiments. However, figure 36 clearly shows generation and expulsion of liquid hydrocarbons in all the experiments. Therefore, the conventional interpretation of anhydrous pyrolysis results may not be valid for these coals. Comparing figures 20 and 37 demonstrates that on the basis of PI, samples from the well cores are very similar to samples artificially matured by hydrous pyrolysis; this is corroborated by the NMR data discussed below and the coal petrography presented above.

Figure 38 shows the hydrogen index (HI) and genetic potential (GP) data for the hydrous pyrolysis experiments. As expected, there is a general decrease in HI and GP as temperature increases and the coal, as it matures, generates and expels both liquid and gaseous hydrocarbons.

Solid-state ${ }^{13} \mathrm{C}$ NMR techniques employing cross polarization with magic-angle spinning (see discussions in Miknis, Sullivan, and others, 1981, and Miknis, Jiao, and others, 1993) were used to determine the changes in the carbon structure of the coals resulting from hydrous pyrolysis; the results are shown in figure 39 .

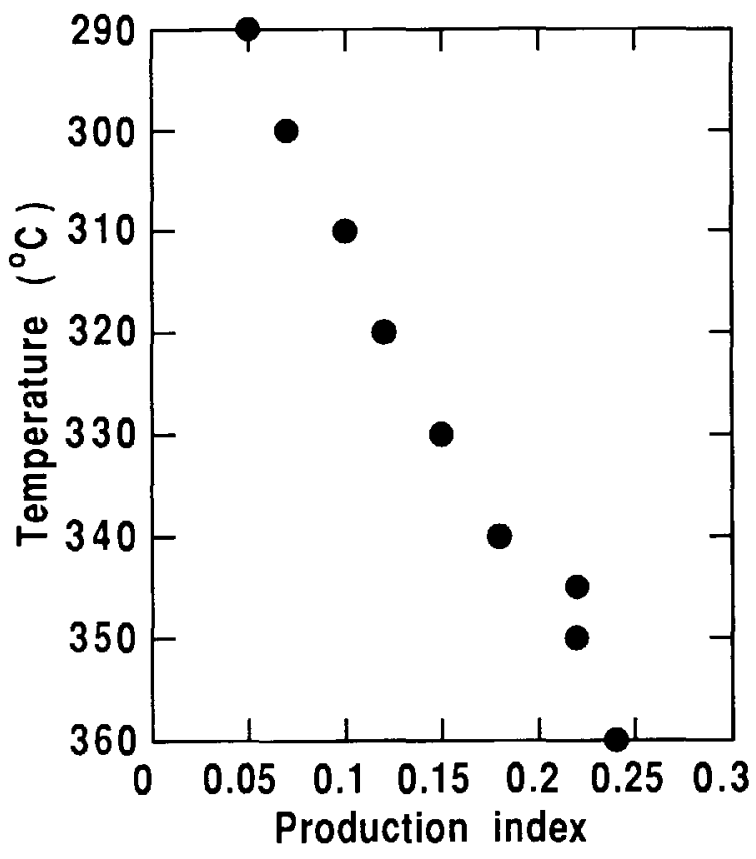

Figure 37. Production index versus temperature for Almond Formation coal after hydrous pyrolysis experiments.

The NMR spectra for Almond coals in the hydrous pyrolysis experiments clearly show a loss of aliphatic-carbons relative to aromatic-hydrocarbons during hydrous pyrolysis. These aliphatic-carbon structures are hydrogen rich and largely are responsible for the liquid and gaseous hydrocarbons generated during hydrous pyrolysis. These data also indicate that most of the oil is generated in the temperature 
range of $290^{\circ}$ to $330^{\circ} \mathrm{C}$, as evidenced by the greater reduction in aliphatic-hydrocarbon relative to that of the starting materials in this temperature range. This is somewhat at odds with the PI data shown in figure 37, but supports the observed amount of oil generated during the experiment (fig. 36) and the petrographic observations noted above. The aliphatic-carbon remaining in the $360^{\circ} \mathrm{C}$ hydrous pyrolysis residue appears to consist mostly of methyl groups attached to aromatic rings, as evidenced by the characteristic peak at $\sim 14$ to 17 ppm (Miknis, Jiao, and others, 1993).

The aromatic-carbon band shows narrowing peak width with increasing temperature. This narrowing is indicative of an increase in the size of the aromatic rings, or of less substitution on the aromatic rings. During hydrous pyrolysis, cleavage of substituents bridging aromatics could lead to condensation reactions that yield larger aromatic rings (Miknis, Jiao, and others, 1993).

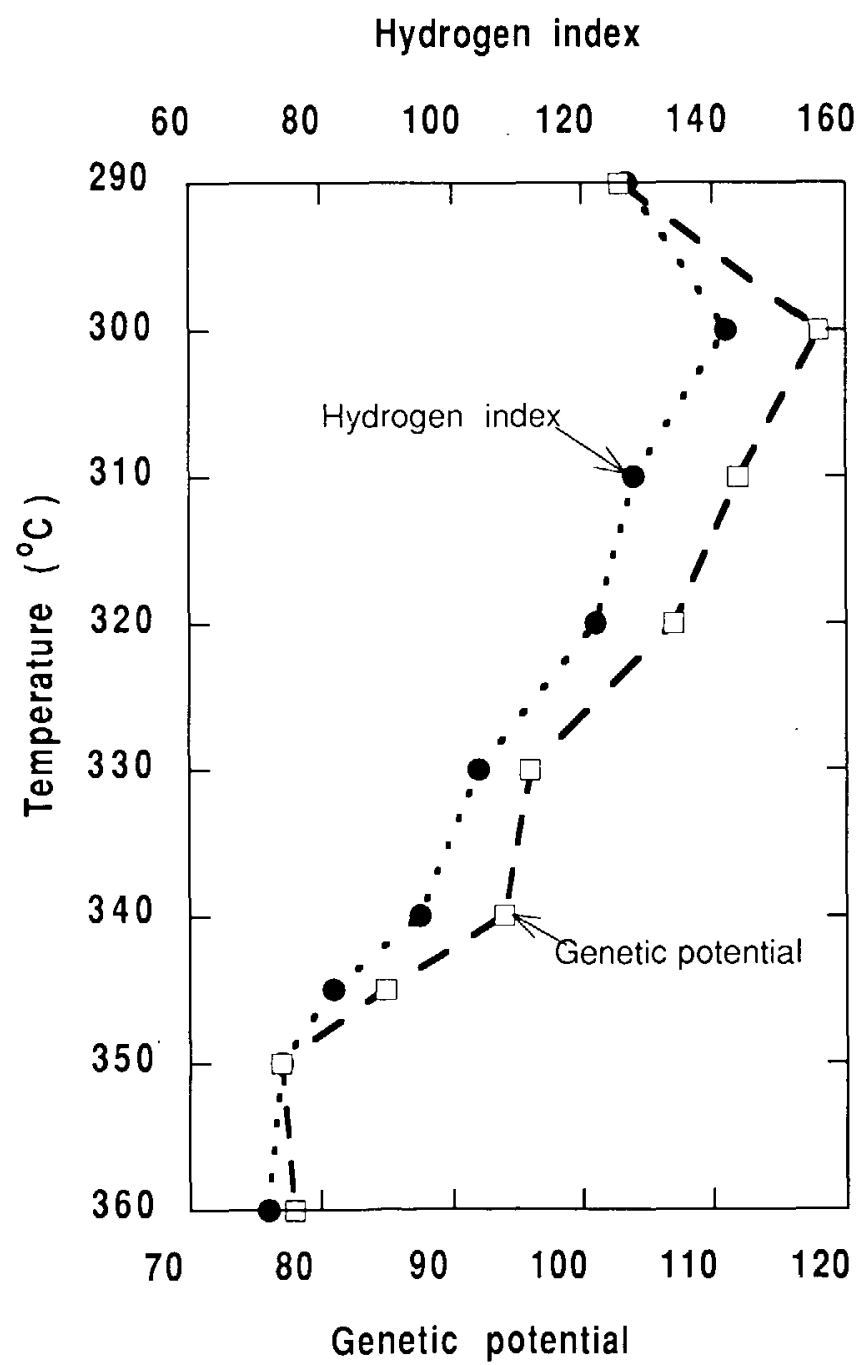

Figure 38. Hydrogen index and genetic potential versus temperature of experiment for Almond Formation coal after hydrous pyrolysis experiments.
The NMR spectra also show a resonance band at $\sim 175$ ppm, attributable to carbons in a carboxylate functionality. During heating, decarboxylation reactions of these functional groups liberate $\mathrm{CO}^{2}$. The NMR spectra in figure 39

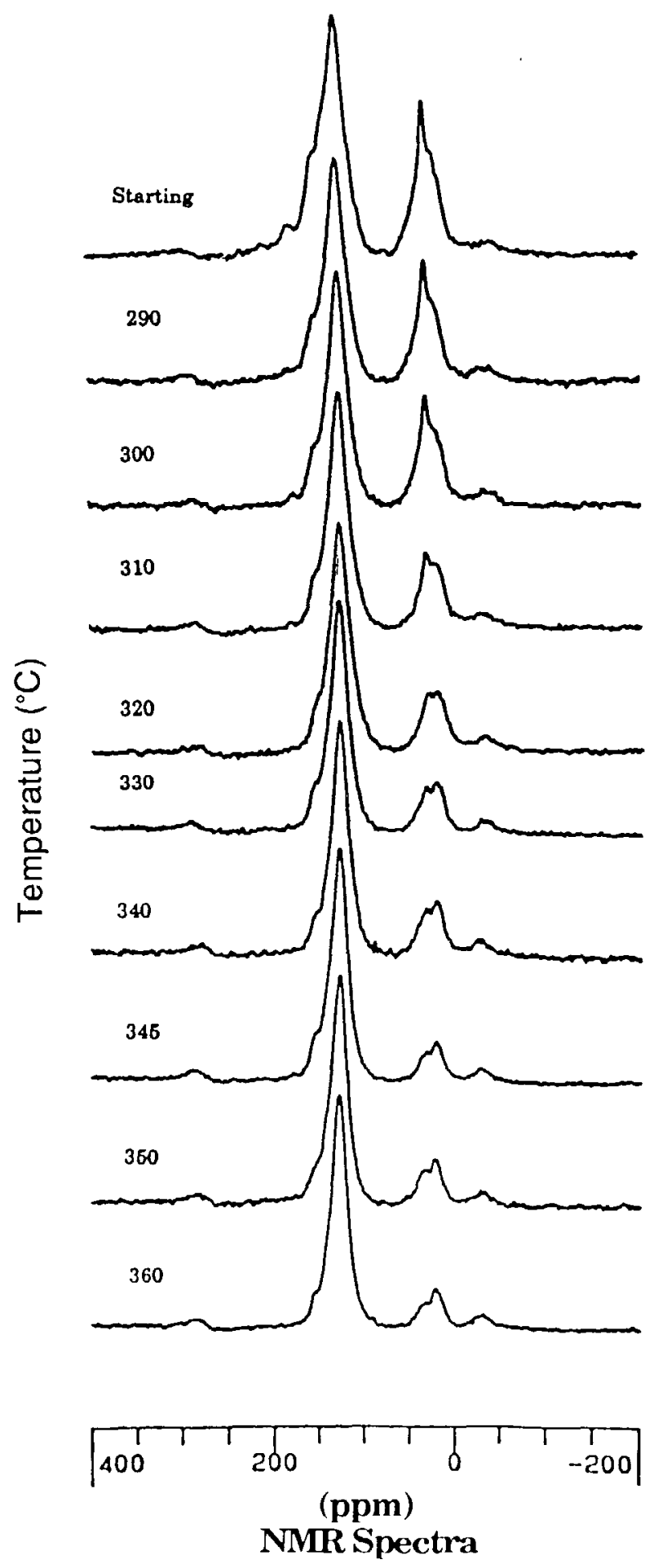

Figure 39. Nuclear Magnetic Resonance (NMR) spectra of the solid phase Almond Formation coal residue of the hydrous pyrolysis experiments. 
show that this carbon functionality disappears above a temperature of $300^{\circ} \mathrm{C}$, illustrating a rapid evolution of $\mathrm{CO}^{2}$ during the heating of subbituminous coals.

Comparing figures 17 and 39 demonstrates that very similar trends of change in molecular structure with depth occur in the naturally matured well-core samples and the artificially matured samples. The coal core samples from the depth interval $4,560 \mathrm{ft}$ to $14,286 \mathrm{ft}$ (fig. 17) have NMR spectra that are very similar to those of the artificially matured samples shown in figure 39. This correlation is similar to the organic petrographic findings above and also indicates that hydrous pyrolysis simulates (at the molecular level) the natural maturation of these coals fairly well.

MacGowan, Britton, and others (1992) compared NMR spectra of the Almond Formation coal residues after hydrous pyrolysis experiments with spectra of the same coal residue after soxhlet extraction. The results show a significant residue of generated oil that remains trapped in the coals during hydrous pyrolysis experiments. Thus, coals are indeed an important source of liquid hydrocarbons, as shown by comparing these volumes of expelled and stored oil with the genetic potential of typical shale (see Tissot and Welte, 1984). This is corroborated by the organic petrographic data above and by the findings of Teerman and Hwang (1991), Mukhopadhyay and others (1991), and Khavari Khorasani and Michelsen (1991).

Headspace gas chemistry was also monitored during the hydrous pyrolysis experiments. Predominantly, $\mathrm{CO}^{2}$ is released as the coal is artificially matured (fig. 40), and methane is the second most abundant gas released. Figure 41 shows the distribution of the $\mathrm{C} 1-\mathrm{C} 6$ hydrocarbon gases versus experimental temperature. Note that although the total amount of gas increases, the relative percentages of the various gases remain constant, even after oil begins to crack to gas above about $345^{\circ} \mathrm{C}$. On the basis of the gases recovered during hydrous pyrolysis it was determined that AImond coals are capable of expelling up to $404 \mathrm{ft}^{3}$ of methane per metric ton (table 9); this value does not include the hydrocarbons stored in the pores and vesicles of coals, hydrocarbons which account for $435 \mathrm{ft}^{3}$ of gas per metric ton of coal. It is important to emphasize that most of the naturally matured samples and all of the artificially matured samples do not reach the gas generation zone $\left(R_{0} \approx 2.0\right.$ percent), where the volume of gas generated increases by a factor of two according to Meissner (1989). A comparison between the methane generated during our hydrous pyrolysis experiments and the values given by Meissner (1989) indicates that most of the Almond Formation coal in the GGRB does not reach the gas-generation window, except for the areas of deepest burial at the center of the Washakie Basin.

Coal in many basins worldwide has been shown to be a prolific producer of commercial quantities of oil; for example, the Gippsland Basin (Australia), the Kutai Basin (Borneo), the Ardjuna Basin (Java), and the Sand Wash Basin (United States) (Teerman and Hwang, 1991; Hunt, 1991). Because the sieve-like molecular structure of coal adsorbs most of the generated oil, only coals that are rich in liptinite macerals generally generate sufficient oil for any liquid petroleum to be released (Snowdon, 1991). However, even vitrinite-rich coals can be producers of commercial quantities of oil if the vitrinite macerals are a hydrogen-rich variety, such as desmocollinite (Snowdon, 1991; Mukhopadhyay and others, 1991; Teerman and Hwang, 1991). Oil expelled from such coals has a composition similar to oil from noncoal terrestrial kerogens

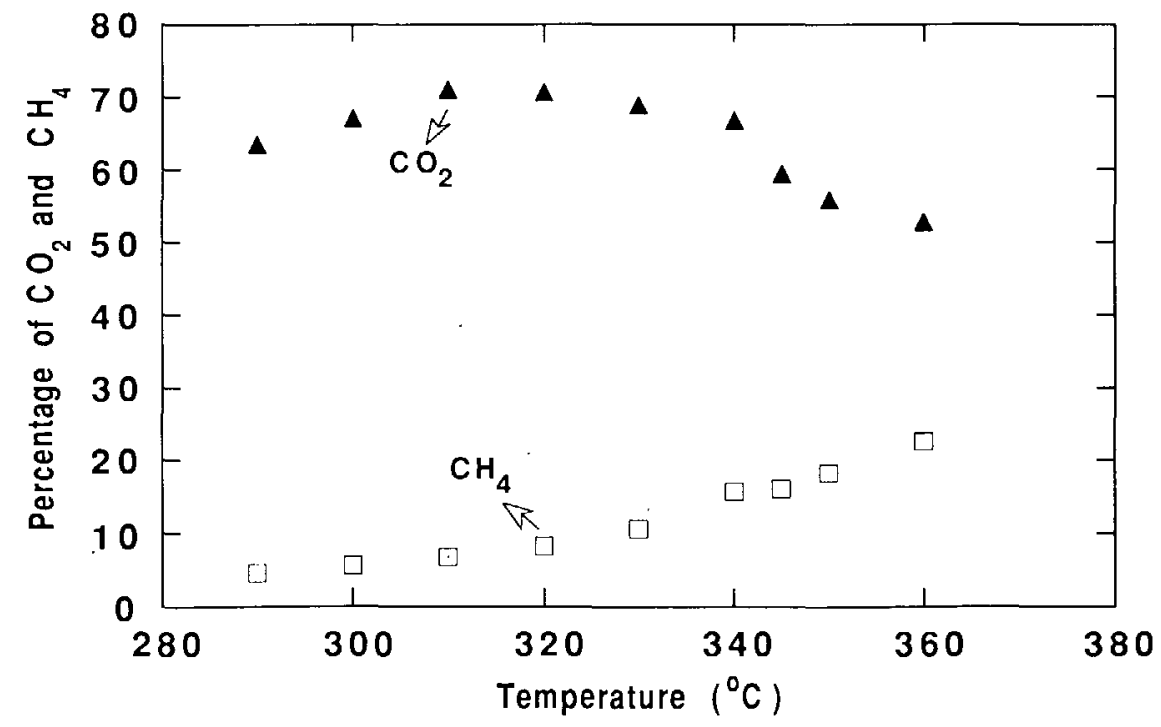

Figure 40. Almond Formation coal hydrous pyrolysis experiment percent $\mathrm{CO}_{2}$ and $\mathrm{CH}_{4}$ versus temperature. 


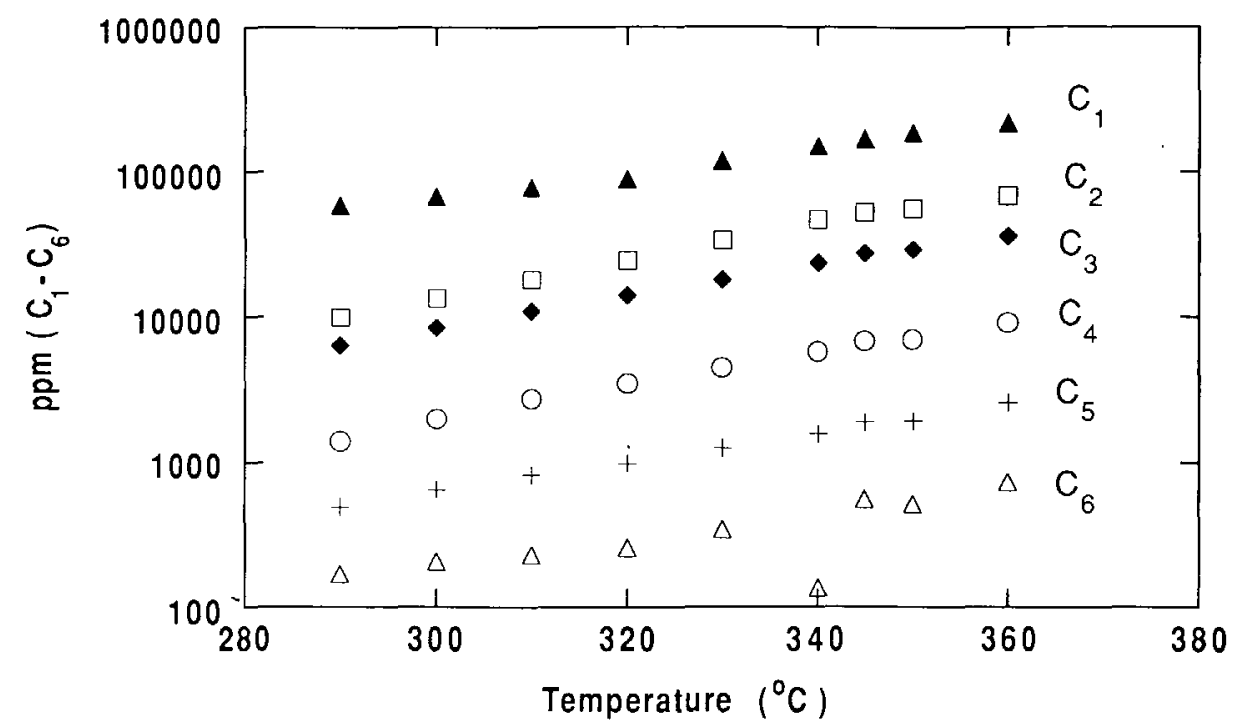

Figure 41. Almond Formation coal hydrous pyrolysis experiment: headspace hydrocarbon gas composition versus temperature.

Table 9. Volume of oil and gas expelled during hydrous pyrolysis experiments.

\begin{tabular}{cccc}
\hline Sample & $\begin{array}{c}\text { Temp. } \\
\left({ }^{\circ} \mathrm{C}\right)\end{array}$ & $\begin{array}{c}\text { Expelled oil } \\
\text { (barrels/Ton coal) }\end{array}$ & $\begin{array}{c}\text { Expelled methane } \\
\text { (cubic fv/Ton coal) }\end{array}$ \\
\hline Almond 290---- & 290 & 0.03 & 30.50 \\
Almond 300--- & 300 & 0.05 & 45.70 \\
Almond 310---- & 310 & 0.08 & 65.00 \\
Almond 320---- & 320 & 0.09 & 95.40 \\
Almond 330---- & 330 & 0.12 & 135.00 \\
Almond 340---- & 340 & 0.15 & 217.00 \\
Almond 345---- & 345 & 0.17 & 231.00 \\
Almond 350--- & 350 & 0.17 & 277.00 \\
Almond 360--- & 360 & 0.14 & 404.00 \\
\hline
\end{tabular}

(Teerman and Hwang, 1991). As noted above, the coal in the present study ranges in composition from 40 to 90 percent vitrinite and contains as much as 78 percent desmocollinite. This composition, coupled with the evidence of oil and gas generated and expelled during the hydrous pyrolysis experiments, suggests that the Almond Formation coal may be an important source of petroleum hydrocarbons in the GGRB. Some fractured coal beds of the Almond Formation act as aquifers in the GGRB (Heasler and Surdam, 1992); thus, most of the trapped oil generated in these coals would have been expelled by the hydrologic flux into the enclosing sandstones. It is important to recall that although the Almond Formation coal is an important source for both liquid and gaseous hydrocarbons, most of these hydrocarbons remain stored in vesicles and pores in the coals. On the other hand, the generation and expulsion of methane directly from Almond coals take place only in the deepest area of the Washakie Basin at a depth of about 18,000 feet. However, as discussed in the following section, thermal degradation of oil and liptinite macerals generates important volumes of gases.

\section{GEOCHEMICAL MODELING}

Geochemical maturation modeling of Almond coals explains the origin and occurrence of oil and gas accumulations in the GGRB. Two parameters are required for this modeling: (1) time-temperature profiles derived from burial histories and (2) the kinetic data for the coal-to-oil-and-gas reactions derived from the hydrous pyrolysis experiments.

\section{BURIAL HISTORY}

Two contrasting burial reconstructions (constructed using the methodology summarized in Surdam and others, 1989), one at the center of the Washakie Basin and the other in the area of the Rock Springs Uplift, were used to model the maturation of the Almond Formation coal and the generation of liquid and gaseous hydrocarbons. The first reconstruction was based on the Adobe Town Unit No. 1 well, which reaches the Almond Formation at 17,059 ft depth and is located in the south Washakie Basin (Sec. 20, T. 15 N., R. 97 W.). Figure 42 shows the burial history diagram of this well, characterized by rapid burial between 70 and $45 \mathrm{Ma}$, followed by moderate burial until $10 \mathrm{Ma}$. From $10 \mathrm{Ma}$ to the present there has been uplift of $2,000 \mathrm{ft}$.

The burial history reconstruction in the proximity of the Rock Springs Uplift was derived from the Fred Federal 
No.1 well, located on the east flank of the Rock Springs Uplift (Sec. 30, T. 17 N., R. 99 W.). The burial history in this area is characterized by continuous burial between 70 and $40 \mathrm{Ma}$, followed by continuous uplift of approximately $6,000 \mathrm{ft}$ (fig. 43).

The thickness of erosion at the center of the Washakie Basin and at the Rock Springs area was calculated using the vitrinite reflectance map of Pawlewicz and others (1986); this map presents depth of isorefiectance contours at $\mathrm{R}_{\mathrm{o}}=0.8$ percent. From the slope of the isoreflectance contours, the thickness of erosion or uplift was calculated for each area using the linear regression given by Pawlewicz and others (1986).
In constructing these two burial history diagrams, decompaction corrections were made for each lithology type, following the methodology of Sclater and Christie (1980). These corrections, as well as the amount of erosion, are essential in calculating time-temperature profiles through time during burial.

\section{TIME-TEMPERATURE PROFILES}

Time-temperature profiles (TTP) were calculated on the basis of steady-state heat flow, using the one-dimensional Fourier heat-flow equation. Measurements of heat

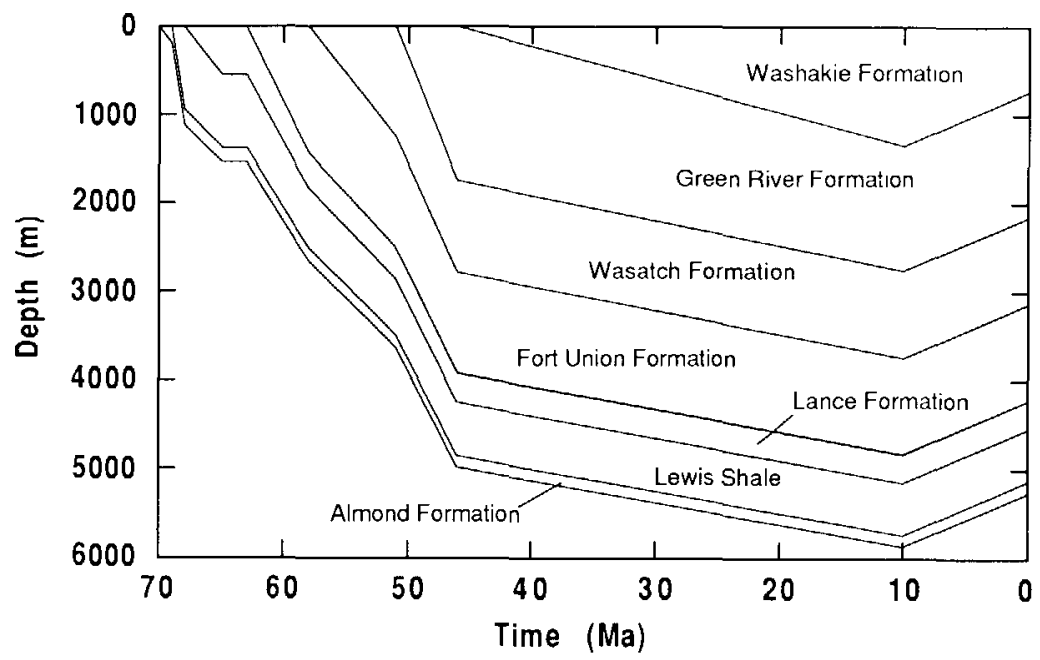

Figure 42. Burial history diagram for the center of the Washakie Basin. Derived from the Adobe Town No.l well.

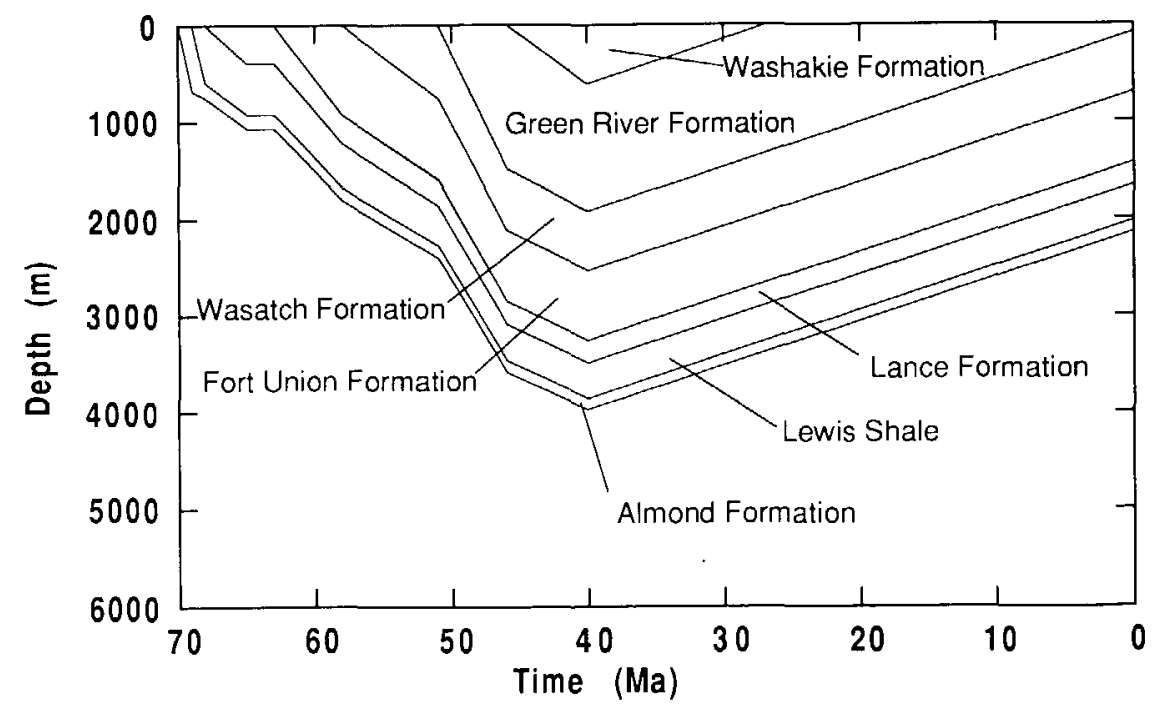

Figure 43. Burial history diagram for the flank of the Washakie Basin in the area of the Rock Springs Uplift. Derived from the Fred Federal No.l well. 
flow in the GGRB and the Uinta Basin range from 45 to 67 milliwatts per square meter $\left(\mathrm{mW} / \mathrm{m}^{2}\right.$ ) (Brigaud and others, 1990; Heasler, 1985). The geologic map of Wyoming (Love and Christiansen, 1985) shows volcanic and intrusive rocks of early Tertiary age as well as small Quaternary volcanic necks in the northern area of the Rock Springs Uplift; these observations may explain variations in heat flow throughout the region. Consequently, heat flow for our model was considered to decrease gradually from the Late Cretaceous until the present. The heat flow in the Washakie Basin was estimated to have been 67 $\mathrm{mW} / \mathrm{m}^{2}$ during the late Cretaceous and Paleocene, 65 $\mathrm{mW} / \mathrm{m}^{2}$ from the Eocene until the middle Miocene, and to have gradually decreased from 65 to $53 \mathrm{~mW} / \mathrm{m}^{2}$ from the late Miocene until the present. The matrix thermal conductivity for each formation in the Washakie Basin (table 10) was estimated following the methodology of Brigaud and others (1990). The goal of the thermal modeling was to calculate formation temperature through time, and to obtain similar values to the present-day bottom-hole temperature of the wells from which the burial histories were reconstructed. Figures 44 and 45 illustrate the time-temperature profiles for the two burial histories (figs. 42, 43, respectively) and show the differences in the thermal evolution of the shallowly buried sediments on the flank of the Washakie Basin and of the more deeply buried sediments in the center of the basin.

Table 10. Matrix thermal conductivities used in the thermal modeling of formations in the Washakie Basin.

\begin{tabular}{|c|c|}
\hline Formation & $\begin{array}{l}\text { Matrix thermal conductivity } \\
\qquad\left(\mathrm{mW} / \mathrm{m}^{2}\right)\end{array}$ \\
\hline Washakie Formation------- & 3.50 \\
\hline Green River Formation ---- & 3.50 \\
\hline Wasatch Formation -......- & 3.50 \\
\hline Fort Union Formation ------ & 2.50 \\
\hline Fox Hill Sandstone -- & 2.50 \\
\hline Lance Formation -- & 2.50 \\
\hline Lewis Shale --................. & 2.50 \\
\hline Almond Formation--....-- & 3.00 \\
\hline
\end{tabular}

\section{GEOCHEMICAL MODELING RESULTS}

The mass of expelled oil recovered during the hydrous pyrolysis experiments on Almond coals, in conjunction with petrographic observations on the maceral transformations during these experiments, allowed us to determine the activation energy $\left(E_{a}\right)$ and frequency factor $\left(A_{0}\right)$ values for the Ahrrenius equation. These values were obtained fol- lowing the methodology discussed by Lewan (1985) and Comer (1992). However, we made further use of the hydrous pyrolysis experiments to determine not only the kinetic values for the oil generation but also the kinetic values of the thermal degradation of oil and kerogen to gas. Further details of this methodology are discussed by MacGowan, García-González, and others (in press).

The kinetic parameters used in calculating reaction transformation ratios (TR; as discussed by Tissot and Welte, 1984) are essential for the geochemical modeling

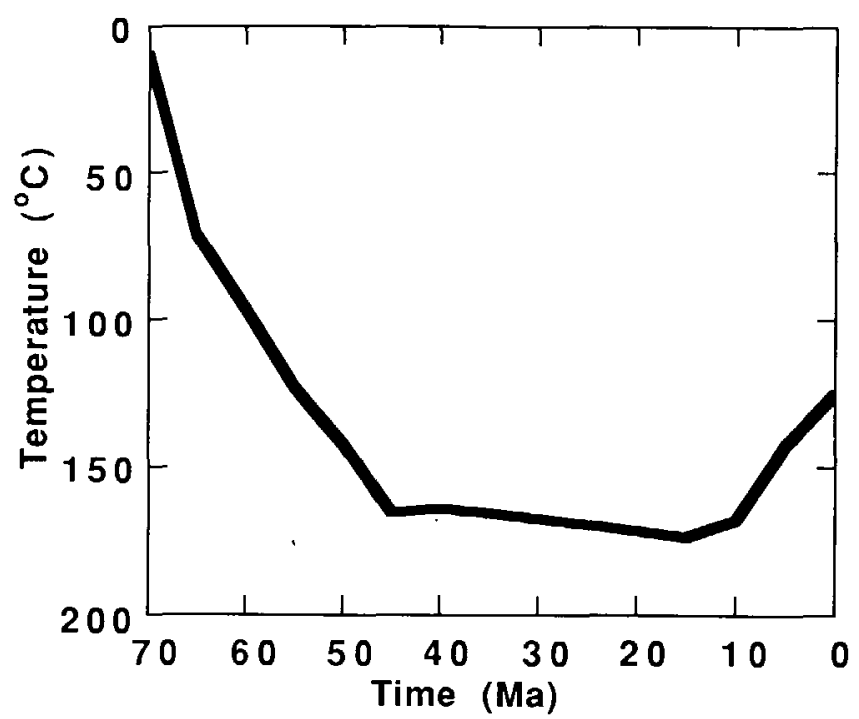

Figure 44. Time-temperature profile for the center of the Washakie Basin. Derived from the Adobe Town No.1 well.

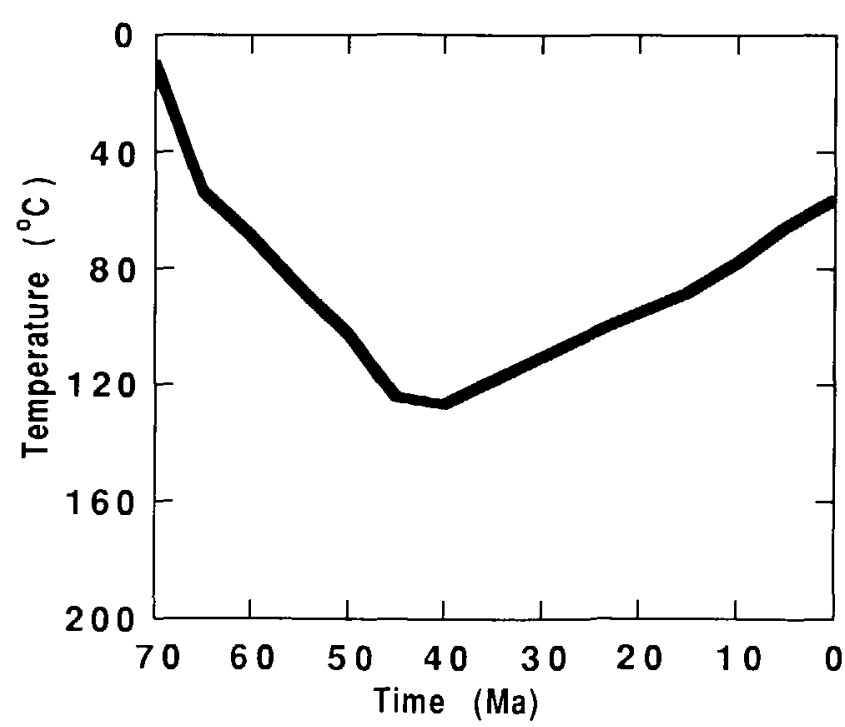

Figure 45. Time-temperature profile for the flank of the Washakie Basin in the area of the Rock Springs Uplift. Derived from the Fred Federal No.1 well. 
of oil generation and destruction, gas generation, and organic-inorganic interactions during progressive diagenesis in the Mesaverde Group.

Although occasionally criticized as not representative of geologic processes (Snowdon, 1979; Saxby, 1982), detailed chemical modeling of geochemical reactions has recently demonstrated that data from high-temperature experiments of short duration are applicable to models of lower temperature reactions occurring over geologic time (Freund, 1992). The geochemical calculations assume firstorder rate-law kinetics, but it is likely that the processes by which oil is generated from the kerogen and expelled to the liquid phase proceed by several, serial chemical reactions of higher order, as well as by physical, nonchemical processes (Price, 1985). However, it has been shown that these reactions and processes can be fairly well approximated over geological time in geochemical models by assuming first-order reaction-rate laws (see discussion in Surdam and others, 1989); for this reason we refer to these as "pseudo kinetics."

Figure 46 shows an Ahrrenius-type plot for the generation of oil from kerogen during the hydrous pyrolysis of Almond coals. The activation energy $E_{a}$ for this process was determined to be $31.57 \mathrm{kcal} / \mathrm{mol}$ with a frequency factor $A_{o}$ of $1.544 \times 10^{16} /$ million years (the correlation coefficient for the regression is 0.996). Figure 47 shows an Ahrrenius-type plot for the generation of gas from the thermal degradation of oil and kerogen during the hydrous pyrolysis of Almond coals. The activation energy for this process was determined to be $37.80 \mathrm{kcal} / \mathrm{mol}$ with a frequency factor of $4.232 \times 10^{17} /$ million years (the regression correlation coefficient is 0.998 ).

The kinetic parameters derived from the experiments were used in conjunction with the time-temperature profiles derived from the burial history models to calculate

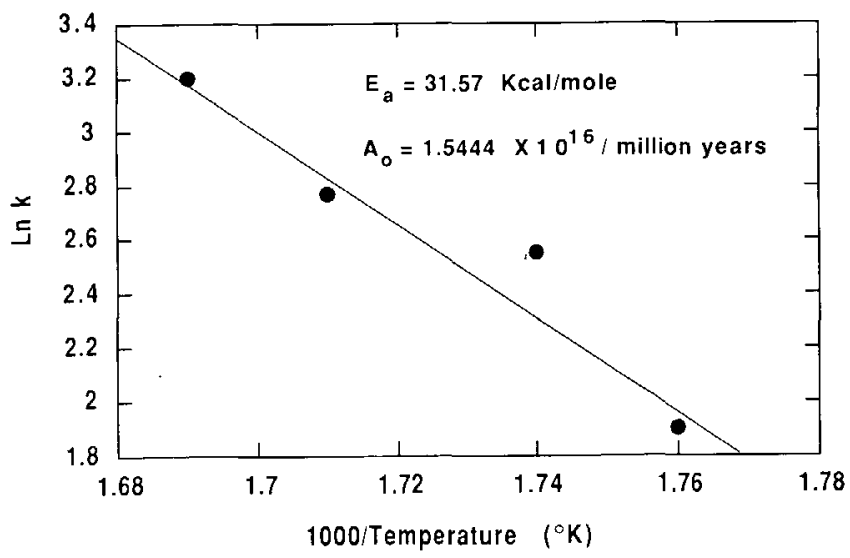

Figure 46. Ahrrenius-type plot for oil generation during hydrous pyrolysis of Almond Formation Coal. Lnk $=\mathrm{LnA}-\mathrm{E}_{\mathrm{a}} / \mathrm{RT}$; $\mathrm{k}$, rate constant; $A$, frequency factor; $E_{a}$, activation energy; $R$, gas constant; T, absolute temperature in Kelvin (K). transformation ratios for reaction progress, using the methodology discussed by Tissot and Welte (1984). Transformation ratios reflect the reaction progress at any step in time in the burial history of the sedimentary unit being modeled. Traditional interpretation of oil generation transformation ratios holds that the main phase of liquid petroleum generation occurs between transformation ratios of 0.1 and 0.4 (Tissot and Welte, 1984). However, in our experiments, actual kinetic parameters were derived for the thermal cracking of oil and kerogen to gas, allowing the kinetic calculation of the longevity (length of time liquid petroleum remains stable before thermally cracking to gas) of the oil in the reservoir. In practice, when the transformation ratio calculated for the thermal cracking of oil is subtracted from the transformation ratio for the generation of oil, the difference yields the relative fraction of petroleum remaining after thermal degradation of the liquid petroleum or the cracking of oil to gas reaction at each time step in the model. For example, a relative fraction of 1.0 means that 100 percent of the oil which the source rock is capable of generating remains; a relative fraction of 0.5 means that 50 percent of the oil that the source rock is capable of generating remains. Figures 48 and 49 show the reaction progress (transformation ratio) of the generation of oil, the generation of gas from the thermal cracking of both oil and kerogen, and the relative fraction of oil remaining at each model time step versus time for both the model of the center of the Washakie Basin and the model of the flank of the basin. Figure 48 shows that the main phase of oil generation in the basin's center is calculated to have been between 60 and $50 \mathrm{Ma}$, and that thermal destruction of the oil becomes important from about $40 \mathrm{Ma}$ to the present $(0$ $\mathrm{Ma})$; at present, less than 5 percent of the oil that the

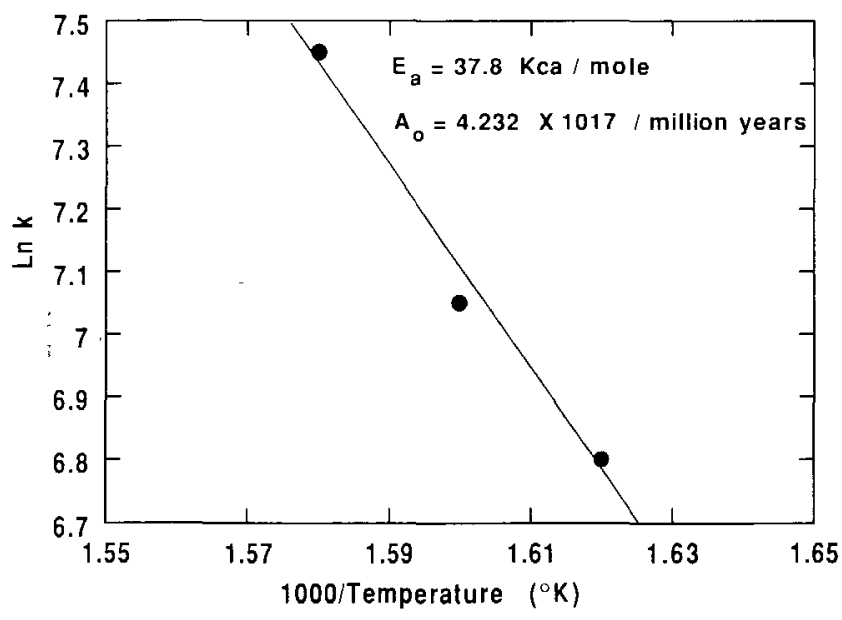

Figure 47. Ahrrenius-type plot for gas generation from oil degradation during hydrous pyrolysis of Almond Formation coal. Lnk $=$ LnA-E $\mathrm{a}_{\mathrm{a}} / \mathrm{RT}$; $\mathrm{k}$, rate constant; $\mathrm{A}$, frequency factor; $\mathrm{E}_{\mathrm{a}}$, activation energy; $R$, gas constant; $T$, absolute temperature in Kelvin (K). 
source rock is capable of generating is still thermally stable by our kinetic calculations. Thus, in the deep of the center of the Washakie Basin, one would primarily expect gas reservoirs with little oil present. On the other hand, on the flank of the Washakie Basin (fig. 49), the main phase of oil generation does not occur until about 50 to $40 \mathrm{Ma}$, and the thermal cracking of oil to gas reaction does not become important at all. Thus, in reservoirs on the basin's flank, one would primarily expect oil reservoirs.

\section{VOLUME OF HYDROCARBONS GENERATED}

An approximate calculation of the volume of oil and gas generated by the Upper Cretaceous coals can be made, based on the coal resources in the Upper Cretaceous Mesaverde Group in the GGRB and the yield of oil and gas volumes obtained from Almond coals during hydrous pyrolysis experiments.

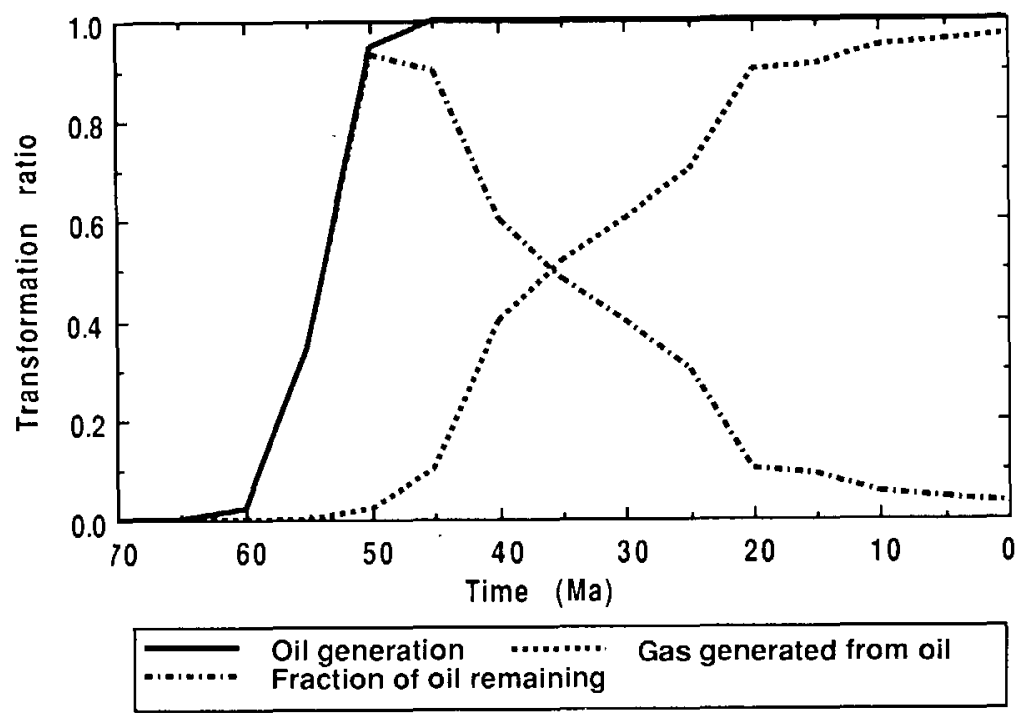

Figure 48. Reaction progress (transformation ratio) of the generation of oil, the generation of gas from thermal cracking of oil and the relative fraction of oil remaining versus time for the center of the Washakie Basin.

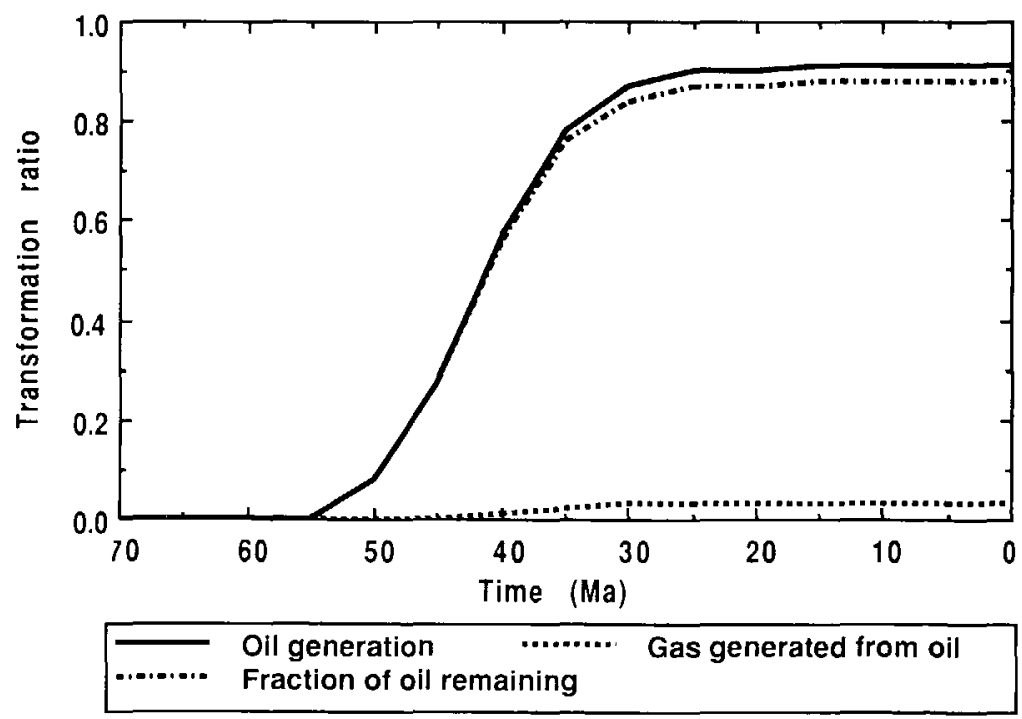

Figure 49. Reaction progress (transformation ratio) of the generation of oil, the generation of gas from thermal cracking of oil and the relative fraction of oil remaining versus time for the flank of the Washakie Basin. 
Tyler and others (1992) reported 302 billion short tons of subbituminous coals in the GGRB in the Upper Cretaceous coaly section. In calculating the volume of coals at ranks higher than 0.9 percent vitrinite reflectance, we delineated the areal extent of the Almond Formation and Mesaverde Group at depths equal to or greater than $8,000 \mathrm{ft}$, depths which correspond to the rank $\left(R_{0}=0.85\right.$ percent) where the threshold of the hydrocarbon generation begins (according to the hydrous pyrolysis experiments). In the same way, the areal extent of the gas generation zone was delineated using the $12,000 \mathrm{ft}$ isodepth contour, which is equivalent to a vitrinite reflectance of 1.6 percent. Figure 50 shows the areal extent of the 8,000 and $12,000 \mathrm{ft}$ isodepth contours for the Upper Cretaceous Mesaverde Group.

To estimate the average thickness of the cumulative coal beds in the Upper Cretaceous section, the entire volume of the coals (calculated density range of 1.4 to 1.5 $\mathrm{g} / \mathrm{cm}^{3}$ ) was divided by the area of the GGRB. The result obtained is $13 \mathrm{ft}$ average thickness. Table 11 gives the volume of liquid and gaseous hydrocarbons at standard temperature and pressure conditions (temperature $=25^{\circ} \mathrm{C}$, pressure $=1 \mathrm{~atm}$ ) generated by the Upper Cretaceous coals in the GGRB. They are divided into the following categories: (1) expelled gas, (2) expelled oil, (3) stored hydrocarbons (calculated from the $\mathrm{S} 1$ peak of the anhydrous pyrolysis data in table 6), and (4) total volume of oil and gas generated in the GGRB.

On the basis of the data presented above, the Upper Cretaceous coals in the GGRB have expelled 18.5 billion barrels of oil (Bbo) and 37.3 trillion cubic feet (Tcf) of gas. The volume of hydrocarbons stored in the coal beds is $5.7 \mathrm{Bbo}$ and $29 \mathrm{Tef}$ of gas. The figures indicate that this basin has great potential to contain important commercial accumulations of gas and liquid petroleum.

\section{SUMMARY AND CONCLUSIONS}

Petrologic and organic geochemical characterization of the trend in the maturation path of Almond coals was performed using both naturally and artificially matured samples. The results of this research indicate that these coals have generated oil, which when buried deep $(>12,000 \mathrm{ft})$, has been thermally cracked to gas. Thermogenic gas generation from Almond coals only occurs at the deepest burial depth in the center of the GGRB. This represents a new interpretation of the origin of gas in the GGRB and may set new goals in the exploration for hydrocarbons. Also the great potential of Almond coals to generate commercial accumulations of oil is underscored by this research.

The natural maturation of Almond coals and the artificial maturation by hydrous pyrolysis of Almond coals follow parallel trends. They show similar textural evolution during maturation, characterized by the initial loss of the finely laminated texture on desmocollinite, followed by the appearance of a porous texture that later evolves to a vesicular texture owing to the generation in increasing quantities of petroleum-like compounds. With greater depth, (deeper than 12,000 ft) the vesicular texture decreases by rehomogenization of the vitrinite-semifusinite matrix owing to the expulsion of exsudatinite; this stage indicates the onset of the gas-generation zone. The maceral transformations start with the transformation of liptinite into micrinite. In the same way, desmocollinite loses its original textural characteristics, changing to telocollinite and then to semifusinite and fusinite; In a parallel process, exsudatinite is initially generated and later thermally degraded to petroleum and gas.

The hydrous pyrolysis experiments produced artificially matured coals that are similar in molecular structure (as elucidated by NMR spectra) and are petrographically similar to the naturally matured samples. The maturation trend with temperature observed in the hydrous pyrolysis experiments is also geochemically similar to the maturation trend with burial in the well samples.

Primary migration of oil occurs as the generation of a sufficient volume of exsudatinite fractures the vitrinitesemifusinite vesicles, interconnecting vesicles, and pores through microfracturing that creates an effective porosity that allows primary migration (García-González and others, in press). Additionally, good coalbed reservoirs should be found where the coal strata are highly fractured, allowing the oil to migrate. Some coalbeds in the GGRB may act as aquifers (Heasler and Surdam, 1992) and in such cases liquid petroleum trapped in the fractured coal would be expelled by the hydrologic flux.

Although these studies indicate that Almond coals generate appreciable volumes of liquids and gaseous hydrocarbons, the effectiveness of hydrocarbon expulsion may be low because most of the hydrocarbons remain stored in vesicles. Therefore, the mechanism required for hydrocarbon expulsion to occur is vesicle fracturing; in the case of the naturally matured samples in this study, fracturing may be caused by abnormal pressure. This pressure can be achieved by burial and thermal cracking of the exsudatinite to gas; both mechanisms can fracture the vesicles, allowing a more effective expulsion of the hydrocarbons from the coalbed.

The petrographic observations indicate that oil is generated but not effectively expelled in the coal source rocks at current burial depth from the surface to about $12,000 \mathrm{ft}\left(\mathrm{R}_{\max }\right.$ between 0.45 and 0.95 percent). Below this depth $\left(R_{\max }>0.95\right.$ percent $)$, exsudatinite begins to crack to gas. This process fractures the vesicles, owing to the change in volume associated with the phase change, and results in a more effective expulsion of hydrocarbons from the coal. The hydrous pyrolysis experiments show that oil is actively generated and expelled in a vitrinite reflectance $\left(R_{\max }\right)$ range of 0.8 percent to 1.7 percent. 
Vitrinite reflectance measurements (table 4) predict that late thermogenic gas from the conversion of kerogen directly to gas can only occur in the small area of the Washakie Basin where the Almond Formation is at
$18,000 \mathrm{ft}$ or greater present burial depth $\left(\mathrm{R}_{\mathrm{o}}>2.0\right.$ percent). Except for this area, Almond coals have not been buried deeply enough in the Washakie Basin to generate significant thermogenic gas from the coal.

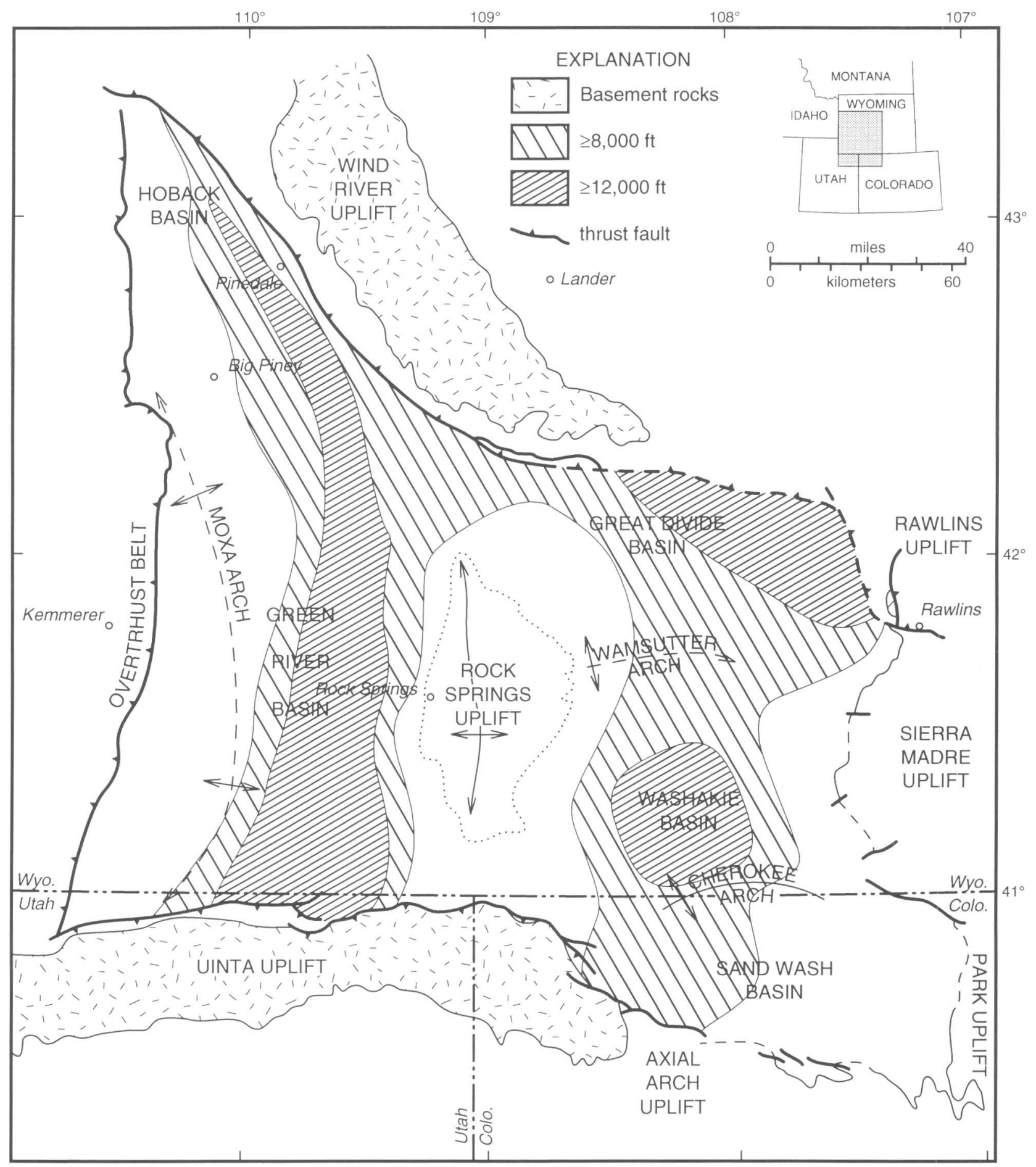

Figure 50. Areal extension of oil and gas generation in the Greater Green River Basin. The 8,000 ft depth contour corresponds to a vitrinite reflectance of 0.8 percent. The $12,000 \mathrm{ft}$ depth contour corresponds to a vitrinite reflectance of 1.5 percent. 
Table 11. Volume of oil and gas generated (expelled and stored) by the Upper Cretaceous section coals in the Greater Green River Basin.

[NA, not applicable; Bbo, billion barrels of oil; Tcf, trillion cubic feet]

\begin{tabular}{cccccc}
\hline $\begin{array}{c}\text { Coal rank } \\
\text { Ro (pct) }\end{array}$ & $\begin{array}{c}\text { Depth } \\
\text { (ft) }\end{array}$ & $\begin{array}{c}\text { Coal resources } \\
\text { (Billion ton) }\end{array}$ & $\begin{array}{c}\text { Total expelled oil } \\
\text { (Bbo) }\end{array}$ & $\begin{array}{c}\text { Total expelled gas } \\
\text { (Tcf) }\end{array}$ & $\begin{array}{c}\text { Total stored oil } \\
\text { (Bbo) }\end{array}$ \\
\hline 0.8 to 1.3 & 28,000 & 47.60 & 7.14 & 10.30 & NA \\
1.3 to 1.7 & $\geq 12,000$ & 66.80 & 11.30 & 27.00 & NA \\
Total generation & NA & NA & 18.44 & 37.30 & 29.00 \\
\hline
\end{tabular}

Chemical kinetic modeling of kerogen evolution on Almond coals, coupled with geochemical and petrographic studies based on hydrous pyrolysis experiments lead us to conclude that hydrous pyrolysis is a valid technique for the study of the natural thermal maturation of these coals. The hydrous pyrolysis experiments suggest that the Almond Formation coals may be a viable source of liquid hydrocarbons in the GGRB (maximum yield in hydrous pyrolysis experiments was 0.17 barrels of expelled oil per metric ton of coal), as well as a prolific producer of natural gas (maximum yield in hydrous pyrolysis experiments was $404 \mathrm{ft}^{3}$ of natural gas generated per metric ton of coal). In addition to the expelled hydrocarbons, the stored hydrocarbons account for 0.14 barrels of oil and $435 \mathrm{ft}^{3}$ of gas per metric ton of coal.

On the basis of our geochemical models, we conclude that at the center of the Washakie Basin gas was generated from the thermal cracking of the oil previously generated from Almond coals. We recognize, however, that the widespread occurrence of gas reservoirs in the GGRB makes it difficult to pinpoint the origin of a particular gas accumulation, because gases generated earlier from the Lower Cretaceous shale and coal sequences may have mixed with the gases generated in the Upper Cretaceous Almond Formation.

The geochemical model also shows that on the basin flank near the Rock Springs Uplift little or no gas was generated from the thermal cracking of the oil; however, the oil found there may have originated from Almond coals.

Figure 51 illustrates our summary of the maturation parameters discussed in previous sections and shows the depth range of the oil and gas windows for the Almond Formation in the center of the Washakie basin. Vitrinite reflectance and organic petrography observations allow definition of the oil generation window, including the main phase of oil generation and expulsion. Our vitrinite reflectance boundaries for the oil window are between 0.5 and 1.7 percent, values which differ from those reported by Tissot and Welte $\left(1984 ; 0.5<R_{0}<1.3\right.$ percent). $T_{\max }$ values obtained for the Almond Formation samples allowed determination of the oil and gas windows using the boundaries defined by Espitalié and others (1985); however, $\mathrm{T}_{\max }$ values we determined for Almond coals place the boundary between the oil and gas windows at a shallower depth than our $R_{o}$ and organic petrographic observations suggest. Aromaticity ratios from the NMR analyses place the boundary between the oil and gas windows at approximately the same depth that $R_{o}$ and organic petrography indicate. In figure 51, the "present interpretation" column presents our summary interpretation of hydrocarbon generation, expulsion, and reaction (oil to gas), and gas generation windows for the maturation of Almond coals at the center of the Washakie Basin. It is necessary to state again that the depths at which the boundaries of the oil and gas windows vary depending on the level of uplift at each locality in the GGRB.

Our calculations indicate (see table 11) that the Upper Cretaceous coals in the GGRB have generated 24.1 Bbo of which 18.4 Bbo have been expelled from the coals. Similarly these coals have generated $66.3 \mathrm{Tcf}$ of gas of which 37.3 Tcf have been expelled from the coals. These volumes of hydrocarbons that were potentially generated and expelled by the Upper Cretaceous coals call attention to the tremendous potential for gas and oil accumulations in the GGRB.

\section{ACKNOWLEDGMENTS}

The authors wish to thank Dr. Steven Boese (Department of Geology and Geophysics, University of Wyoming) for his analytical help and Dr. Francis P. Miknis (Western Research Institute, University of Wyoming) for the NMR analyses. We would also like to acknowledge useful discussions with Douglas Britton and Dr. Thomas L. Dunn, Dr. Zun Sheng Jiao and Dr. Pegui Yin (Department of Geology and Geophysics, University of Wyoming). David Copeland (Department of Geology and Geophysics, University of Wyoming) greatly improved the manuscript with many suggestions. Thanks also to outside reviewers Dr. Jean Whelan and Dr. Lorraine Buxton Eglington (Woods Hole Oceanographic Institution) for their thoughtful input and suggestions that also improved this manuscript. 


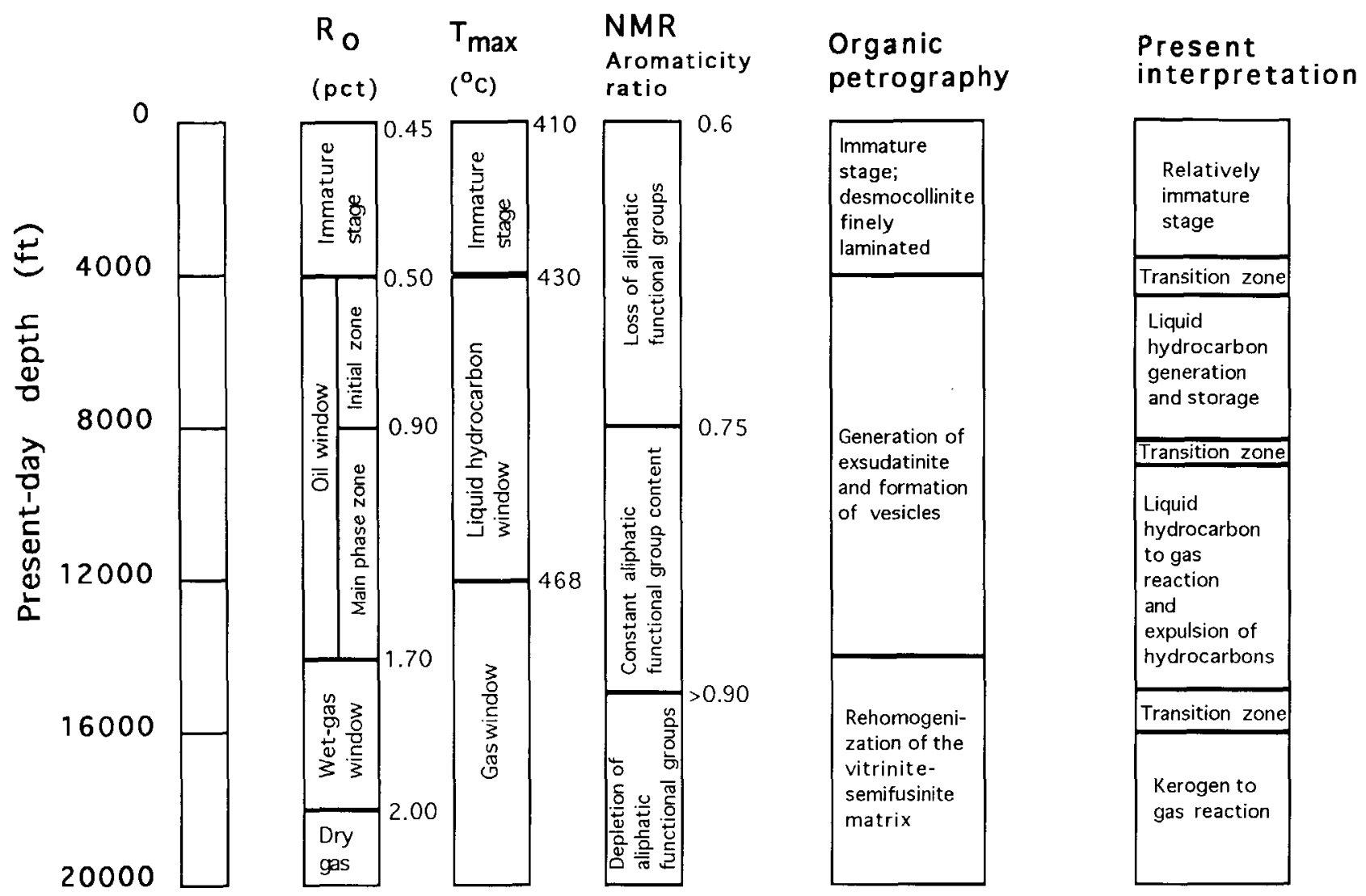

Figure 51. Summary of different maturation indicators for the Almond Formation in the center of the Washakie Basin, Greater Green River Basin, Wyoming.

This research was supported by Gas Research Institute Contract No. 5091-221-2146 and U.S. Department of Energy Cooperative Agreement No.DE-FC21-86MC11076.

\section{REFERENCES CITED}

American Society of Testing Materials, 1980, Preparing coal samples for microscopical analysis by reflected light: Philadelphia, American Society of Testing Materials, Standard D2797-72.

Brigaud, F., Chapman, D.S., and Le Douaran, S., 1990, Estimating thermal conductivity in sedimentary basins using lithologic data and geophysical well logs: American Association of Petroleum Geologists Bulletin, v. 74, p. 1459-1477.

Comer, J.B., 1992, Thermal alteration, in Droppo, R., ed., Geochemistry of organic matter in sediments and sedimentary rocks, SEPM Short Course 27, notes: Tulsa, Society of Economic Paleontologists and Mineralogists, p. 73-100.

Espitalié, J., Deroo, G., and Marquis, F., 1985, La pyrolyse rock-eval et ses applications, deuxième partie: Revue de l'institute Français du Pétrole, v. 40, p. 755-784.

1986, La pyrolyse rock-eval et ses applications, troisème partie: Revue de l'institute Français du Pétrole, v. 41, p. 7389.
Freund, H., 1992, Application of a detailed chemical kinetic model to kerogen maturation: Energy and Fuels, v. 6, p. 318-26.

García-González, M., MacGowan, D.B., and Surdam, R.C., in press, Mechanisms of petroleum generation from coal, as evidenced from petrographic and geochemical studies; examples from Almond Formation coals in the Greater Green River Basin, Wyoming, in Andrews, S., and Strook, B., eds., Wyoming Geological Association 50th Anniversary Field Conference Guidebook: Wyoming Geological Association.

García-González, M., and Surdam, R. C., 1992, Coal as a source of petroleum; a comparison between the petrology of the Mesaverde Group coals, in burial and hydrous pyrolysis, in Mullen, C., ed., Wyoming Geological Association 43d Field Conference Guidebook: Wyoming Geological Association, p. 237-244.

Heasler, H.P., 1985, Geothermal resources of Wyoming (map): Department of Geology and Geophysics, University of Wyoming, Laramie, scale 1:500,000.

Heasler, H.P., and Surdam, R.C., 1992, Pressure compartments in the Mesaverde Formation of the Green River and Washakie Basins, as determined from drill stem test data, in C. Mullen, ed.,Wyoming Geological Society 43d Field Conference Guidebook, p. 207-220.

Hunt, J.M., 1991, Generation of gas and oil from coal and other terrestrial organic matter: Organic Geochemistry, v. 17, p. 675-680. 
Katz, P.A., Kelley, R.A., Royle, R.A., and Jorjorian, T., 1991, Hydrocarbon products of coals as revealed by pyrolysis-gas chromatography: Organic Geochemistry, v. 17, p. 711-722.

Khavari Khorasani, G., and Michelsen, J.K., 1991, Geological and laboratory evidence for the early generation of large amounts of liquid hydrocarbons from subineritinite and subereous components: Organic Geochemistry, v. 17, p. 849-863.

Law, B.E., 1984, Relationships of source rock, thermal maturity, and overpressuring to gas generation and occurrence in lowpermeability Upper Cretaceous and Lower Tertiary rocks, Greater Green River Basin, Wyoming, Colorado, and Utah, in Woodward, J., Meissner, F., and Clayton, J., eds., Hydrocarbon source rocks of the greater Rocky Mountain region: Rocky Mountain Association of Geologists, p. 469-490.

Lewan, M.D., 1985, Evaluation of petroleum generation by hydrous pyrolysis experimentation: Philosophical Transactions of the Royal Society of London, series A, v. 315, p. 123-134.

Lewan, M.D., Winters, J.C., and McDonald, J.H., 1979, Generation of oil-like pyrolysates from organic-rich shales: Science, v. 203, p. $57-59$.

Love, J.D., and Christiansen, A.C., 1985, Geologic Map of Wyoming, U.S. Geological Survey, scale 1:50,000.

MacGowan, D.B., Britton, D.R., Miknis, F.P., and Surdam, R.C., 1992, Organic geochemistry and maturation trends of shales and coals, Almond Formation, Mesaverde Group, Greater Green River Basin, Wyoming; a comparison with laboratory maturation of Almond Coals by hydrous pyrolysis: in Mullen, C., ed., Wyoming Geological Association 43d Field Conference Guidebook, p. 221-235.

MacGowan, D.B., García-González, M., Britton, D.R., and Surdam, R.C., in press, Timing of hydrocarbon generation, organic-inorganic diagenesis and the formation of abnormally pressured gas compartments in the Cretaceous of the Greater Green River Basin; a geochemical model, in Andrews, S., and Strook, B., eds.,Wyoming Geological Association, 50th Anniversary Field Conference Guidebook: Wyoming Geological Association.

Meissner, F.F., 1989, Cretaceous and Lower Tertiary coals as sources for gas accumulations in the Rocky Mountain area, in Woodard, J., Meissner, F., and Clayton, J., eds., Hydrocarbon source rocks of the greater Rocky Mountain region, Rocky Mountain Association of Geologists, p. 401-431.

Miknis, F.P., Jiao, Z.S., MacGowan, D.B., and Surdam, R.C., 1993, NMR characterization of Mowry Formation shales: Organic Geochemistry, v. 20, p. 339-347.

Miknis, F.P., Sullivan, M., Bartuska, V.J., and Maciel, G.E., 1981, Cross-polarization magic angle spinning ${ }^{13} \mathrm{C}$ NMR spectra of coals of varying rank: Organic Geochemistry, v. 3, p. 19-28

Mukhopadhyay, P.K., Hatcher, P.G., and Calder, J.H., 1991, Hydrocarbon generation from deltaic and intermontane fluviodeltaic coal and coaly shale from the Tertiary of Texas and Carboniferous of Nova Scotia: Organic Geochemistry, v. 17 , p. $765-783$.

Pawlewicz, M.J., Kickus, M.K., Law, B.E., and Dickinson, W.W., 1986, Thermal maturity maps showing depth to 0.8 percent vitrinite reflectance in the Greater Green River
Basin, Wyoming, Colorado, and Utah: U.S. Geological Survey Miscellaneous Field Studies Map MF-1890.

Price, L.C., 1985, Geologic time as a parameter in organic metamorphism and vitrinite reflectance as absolute paleo-geothermometer: Journal of Petroleum Geology, v. 6, p. 5-38.

Roehler, H.W., 1988, The Pintail Coal Bed and Barrier Bar G; a model for coal of barrier bar-lagoon origin, Upper Cretaceous Almond Formation, Rock Springs Coal Field, Wyoming: U.S. Geological Survey Professional Paper 1398, 60 p.

1990, Stratigraphy of the Mesaverde Group in the central and eastern Greater Green River Basin, Wyoming, Colorado, and Utah: U.S. Geological Survey Professional Paper 1508, $52 \mathrm{p}$.

Saxby, J., 1982, A reassessment of the range of kerogen maturities in which hydrocarbons are generated: Journal of Petroleum Geology, v. 5, p. 117-128.

Sclater, J.G., and Christie, P.A., 1980, Continental stretching; an explanation of the post-mid-Cretaceous subsidence of the central North Sea Basin: Journal of Geophysical Research, v. 85 , p. $3711-3739$.

Snowdon, L.R., 1979, Errors in extrapolation of experimental kinetic parameters to organic geochemical systems: American Association of Petroleum Geologists Bulletin, v. 63, p. 1128-1134.

1991, Oil from Type III organic matter: resinite revisited: Organic Geochemistry, v. 17, p. 743-747.

Stach, E., Mackowsky, M.T.H., Teichmüller, M., and others 1982, Stach's textbook of Coal Petrology: Gebrider Borntraeger, $3 \mathrm{~d}$ edition, $535 \mathrm{p}$.

Surdam, R.C., Dunn, T.L., MacGowan, D.B., and Heasler, H.P., 1989 , Conceptual models for the prediction of porosity evolution with an example from the Frontier Sandstone, Bighorn Basin, Wyoming, in Coalson, E., Kaplan, S., Keighin, C., Oglesby, C., and Robinson, J., eds., Rocky Mountain Association of Geologists Guidebook, p. 7-28.

Teerman, S.C., and Hwang, R.J., 1991, Evaluation of the liquid hydrocarbon potential of coal by artificial maturation techniques: Organic Geochemistry, v. 17, p. 749-764.

Tissot, B.P., Pelet, R., and Ungerer, P.H., 1987, Thermal history of sedimentary basins, maturation indices, and kinetics of oil and gas generation: American Association of Petroleum Geologists Bulletin, v. 71, p. 1445-1466.

Tissot, B.P., and Welte, D.H., 1984, Petroleum formation and occurrence (2d ed.): New York, Springer Verlag, 699 p.

Tyler, R., Ambrose, W.A., Scott, A.R., and Kaiser, W.R., 1992, Evaluation of the coal-bed methane potential in the Greater Green River, Piceance, Powder River and Raton basins, in Mullen, C., ed., Wyoming Geological Association 43d Field Conference Guidebook, p. 269-302.

Wyoming Oil and Gas Conservation Commission, 1991, Wyoming oil and gas fields and units of production, 1991: Wyoming Oil and Gas Statistics, part 12, 87 p.

Yin, P., Surdam, R.C., Boese, S.W., MacGowan, D.B., and Miknis, F.P., in press, Simulation of hydrocarbon source rock maturation by hydrous pyrolysis: in Andrews, S., and Strook, B., eds., Wyoming Geological Association 50th Field Conference Guidebook. 


\section{APPENDIX. KEY WORD DEFINITIONS.}

Aliphatic (alkane): A hydrocarbon with the molecular formula $\mathrm{C}_{n} \mathrm{H}_{2 n+2}$. It includes hydrogen-saturated, straightchain, branched-chain and cyclic hydrocarbons such as methane, ethane, propane and isobutane.

Aromatic: Hydrocarbons containing one or more hydrogen-undersaturated rings. Monoaromatic compounds have the molecular formula $\mathrm{C}_{\mathrm{n}} \mathrm{H}_{2 \mathrm{n}-6}$. Typical aromatic compounds are benzene, toluene, and xylenes. Polycyclic aromatic hydrocarbons contain several rings with two or more carbon atoms shared between rings.

Coal maceral: Microscopically recognizable constituents of coal that can be differentiated by their morphology. Macerals are analogous to the minerals of inorganic rocks but differ in having less uniform chemical composition and physical properties. The carbon content of macerals increases with increasing temperature. The major maceral groups are vitrinite, liptinite (exinite), and inertinite.

Desmocollinite (vitrinite B): Mixture of detritus of liptinite and inertinite macerals dispersed in gel. The earlier mixture of plant debris becomes homogenized by geochemical gelification.

Exsudatinite: Secondary product of liptinite and huminite constituents of subbituminous and high-volatile bituminous coals; its origin is related to that of fluid petroleum.

Fusinite: The richest maceral in carbon of all the constituents of coal, characterized by the strongest reflectance among coal macerals. Two types of fusinite are recognized-pyrofusinite and degradofusinite.

Genetic Potential (GP): The total potential, as determined by anhydrous pyrolysis ( $\mathrm{mg}$ hydrocarbon/gram source rock) that the source rock is capable of generating; that is, generated plus stored hydrocarbons; $\mathrm{GP}=\mathrm{S} 1+\mathrm{S} 2$ (anhydrous pyrolysis peaks; $\mathrm{S} 1=$ the amount, in $\mathrm{mg} / \mathrm{g}$ source rock, of hydrocarbon already generated by the source rock; $S 2=$ the amount of hydrocarbon generated during anhydrous pyrolysis, in $\mathrm{mg} / \mathrm{g}$ source rock).

Hydrogen Index (HI): The relative amount of hydrogen per total organic carbon (mg H/g TOC) stored in the kerogen, as determined by anhydrous pyrolysis (S2/TOC).

Inertinite: The coal maceral group that shows little or no reaction during the process of heating. Inertinite includes fusinite, sclerotinite derived from fungal remains, and other high-carbon materials with a low-hydrogen content and a high reflectance.

Kerogen: The disseminated organic matter of sedimentary rocks that is insoluble in mono-oxiding acids, bases, and organic solvents. The organic matter, initially deposited with unconsolidated sediments, is not kerogen but a precursor that is converted to kerogen during diagenesis. Sapropelic kerogens yield oil and gas on heating, while humic kerogens yield mainly gas. Kerogen includes both marine- and land -derived organic matter, the latter being the same as the components of coal.

Liptinite (exinite): A coal maceral group that comprises the macerals sporinite, cutinite, suberinite, resinite, alginite and liptodetrinite. Liptinite macerals are derived from relatively hydrogen-rich plant remains such as sporopollenin, resins, waxes and fats. Liptinite is widely disseminated in sediments and is an important source of crude oil. Liptinite macerals are the dominant organic constituent of boghead coals and oil shales.

Nuclear Magnetic Resonance (NMR): An analytical technique that measures the relaxation period (resonance) of paramagnetic nuclei which have been induced to spin in an opposite direction to normal spin by the application of an external magnetic field. In organic geochemistry, generally ${ }^{1} \mathrm{H}$ and ${ }^{13} \mathrm{C}$ are analyzed. The technique gives information on the basic molecular structure and the distribution of functional groups in the molecule.

Semifusinite: The intermediate stages between fusinite and telinite are termed semifusinite. Semifusinite shows lower reflectance than fusinite but higher reflectance than vitrinite.

Source rock: A sediment that in its natural setting has generated and released enough hydrocarbons to form a commercial accumulation of oil or gas.

Telocollinite: Structureless humified plant tissues often associated with telinite. telocollinite is related to cell lumens, whereas telinite is related to cell walls.

$\mathbf{T}_{\mathbf{m a x}}$ : The maximum temperature at which a source rock generates hydrocarbons during anhydrous pyrolysis experiments.

Total Organic Carbon (TOC): The total organic carbon that is sourced from thermally and diagenetically altered terrestrial, lacustrine, and marine organic compounds in a source rock. This is generally determined as the analytical difference between total carbon and inorganic carbon in the source rock.

Vitrinite: A coal maceral group that is the dominant organic constituent of humic coals. Vitrinite forms the familiar brilliant black bands of coal. Macerals in the vitrinite group include telinite derived from plant cell walls and collinite from the cell filling. Vitrinite particles are found in about 80 percent of clays and sands. 



\title{
Biogeochemistry of Natural Gases in Three Alkaline, Permanently Stratified (Meromictic) Lakes
}

\author{
By Ronald S. Oremland ${ }^{1}$ and Laurence G. Miller ${ }^{1}$
}

\section{CONTENTS}

Abstract 439

Introduction 439

Site Descriptions 440

Monimolimnion Chemistry and Gaseous

Hydrocarbons 441

Methane in the Mixolimnion 443

Gas Seeps 444

Microbial Activities in the Anoxic Sediments 445

Summary 450

Conclusions 450

References Cited 450

\begin{abstract}
Methane and associated light hydrocarbons are present as dissolved gases in the water columns of three alkaline, permanently stratified (meromictic) lakes: Big Soda Lake (Nevada), Mono Lake (California), and Soap Lake (Washington). Methane originates in the bottom sediments, but higher gaseous hydrocarbons (that is, gaseous hydrocarbons of higher molecular weight) have either microbial or thermal sources in the different lakes. Stable isotopic composition, hydrocarbon indices, radiocarbon dating, abundance-versus-depth profiles, and biological experiments indicate that methane is formed in the sediments by microbial processes. Methanogenesis and sulfate-reduction have
\end{abstract}

\footnotetext{
'Water Resources Division, U.S. Geological Survey, 345 Middlefield Road, MS 465, Menlo Park, CA 94025.
}

much higher activity in the shallow littoral sediments than in the colder, more saline pelagic sediments of all three lakes. Methane-rich gas seeps are common in Mono Lake and emanate from a natural-gas deposit underlying the current lakebed. Seeps do not occur in either Big Soda Lake or Soap Lake. Ethane and higher alkanes are present in Big Soda Lake and Mono Lake, but are not present in significant quantities in Soap Lake. It is not clear if the presence of these higher alkanes is a consequence of biological activity, a result of mixing with thermogenic gases, or a combination of both factors. These results indicate the potential complexity and diversity encountered in studying light-hydrocarbon biogeochemistry in thermally and microbially active systems. Hence, in the case of methane, detailed multidisciplinary studies are often needed to determine its origin. For ethane and higher alkanes, there is currently a paucity of basic scientific information to allow for unequivocal identification of microbial and thermogenic sources.

\section{INTRODUCTION}

Methane, the main component of natural gas, is formed by two major processes that occur in the Earth's crust: (1) microbial methanogenesis in anaerobic ecosystems (microbial methane), and (2) the exposure over time of deposited organic matter to geologic heat sources (thermogenic methane). Because petroleum formation is often associated with the latter process (but not the former), there has been financial impetus to devise techniques to distinguish between these two types of natural gases. These techniques require either a detailed scrutiny of the limited information contained within the methane molecule itself (for example, stable isotopic ratios of ${ }^{13} \mathrm{C} /{ }^{12} \mathrm{C}$ 
and $\mathrm{D} / \mathrm{H}$, and radiocarbon content) or the methane's abundance relative to that of associated gases (for example, $\left.\mathrm{CH}_{4} /\left[\mathrm{C}_{2} \mathrm{H}_{6}+\mathrm{C}_{3} \mathrm{H}_{8}\right]\right)$. Such methods and their limitations have been discussed in detail by a number of authors (Bernard, 1979; Claypool and Kvenvolden, 1983; Schoell, 1983; Whiticar and others, 1986; Oremland, 1988), and they have been widely applied to the study of methane biogeochemistry. Another mechanism of methane formation involves the catalytic reduction of $\mathrm{CO}_{2}$ with $\mathrm{H}_{2}$ at high temperatures, which is believed to occur in deep-sea spreading centers (Welhan and Craig, 1979) and whose product is referred to as abiogenic methane (Apps and van de Kamp, this volume). Finally, a fourth type of methane, termed "primordial" (also of abiogenic origin), has been hypothesized to exist within the earth's mantle as a remnant of the original accretionary matter associated with the Earth's formation (Gold, 1979; Gold, this volume). However, an unambiguous sample of primordial methane has never been collected, and hence its properties and even its existence are unconfirmed.

Our understanding of the processes involved in natural-gas formation, the importance of methane in biogeochemical cycles, and the evolutionary significance of methanogenic bacteria has expanded enormously over the past 25 years. Impetus for much of this work was derived, in part, from the energy crises of the 1970's and 1980's; however, these crises were not the only motivating forces. From a biological perspective, bacterial formation of methane has been known since the time of Pasteur, but the first detailed work with pure isolates and mass cultures took place much later (Bryant and others, 1967; Wolfe, 1971,1992 ) and ultimately led to an appreciation of the unique biochemistry and genetic composition of methanogenic bacteria. Genetic analyses (16s ribosomal RNA base sequences) resulted in the classification of methanogens within a unique kingdom, known as Archaebacteria (Balch and others, 1979; Woese and Fox, 1977; Jones and others, 1987). Considerable advances have also been made with regard to the biochemistry and genetics of the methaneoxidizing bacteria (Whittenbury and others, 1970; Anthony, 1982; Crawford and Hanson, 1984). Along with these basic biological findings have been many studies of the ecological and geochemical aspects of the methane cycle in nature (see reviews by Oremland, 1988; Winfrey, 1984; Ward and Winfrey, 1985). In addition, the identification of methane as an important atmospheric greenhouse gas has heightened our need to understand its global biogeochemistry (Cicerone and Oremland, 1988; Cole, this volume).

Some of the results of these biogeochemical and ecological investigations of methane have refined our understanding of the assumptions used in natural-gas classification. For example, the alkane abundance ratio $\left(\mathrm{CH}_{4} /\left[\mathrm{C}_{2} \mathrm{H}_{6}+\mathrm{C}_{3} \mathrm{H}_{8}\right]\right)$ assumes that production of $\mathrm{C}_{2+}$ alkanes proceeds only from thermogenic reactions. Nonetheless, bacterial formation of higher alkanes (alkanes of higher molecular weight) has been noted (Davis and Squires, 1954; Oremland, 1981; Vogel and others, 1982; Oremland and others, 1988). Stable carbon isotopic ratios of methane $\left(\delta^{13} \mathrm{C}\right)$ assume that light values-more negative than -60 parts per thousand-are associated with bacterial formation processes. However, the ability of methane-oxidizing bacteria to fractionate in favor of ${ }^{12} \mathrm{C}$ can result in ${ }^{13} \mathrm{C}$-enriched unoxidized methane (Silverman and Oyama, 1968; Coleman and others, 1981). Furthermore, the anaerobic biodegradation of components of crude oil deposits can result in bacterial methanogenesis, which can obscure the methane source (Ivanov and others, 1983).

These issues prompted our research interest over the past decade in alkaline, hypersaline, meromicitic (permanently stratified). Such environments are thought to be precursors of certain lacustrine oil deposits and oil-rich shales (Bradley, 1931; Smith and Robb, 1973; Tissot and others, 1978; Demaison and Moore, 1980; Tuttle and Goldhaber, in press). In addition, because high abundances of methane, ethane, and propane were reported in the waters and sediments of the anoxic, hypersaline Orca Brine in the Gulf of Mexico (Sackett and others, 1979), we undertook research on lakes of this type in order to enhance our understanding of natural-gas biogeochemistry. The persistence in each lake of a stratified water column with anoxic bottom waters has allowed us to investigate detailed microbiological processes and their influence on methane biogeochemistry. Furthermore, we have found that these sites often have multiple sources of methane (for example, microbial, thermal, and ancient microbial), which has allowed us to classify these gases by using extensions of established practices. In this paper we review some of the highlights of our investigations of three alkaline, meromictic lakes, and present new comparative data with respect to natural gases in these three lakes.

\section{SITE DESCRIPTIONS}

The locations and outlines of Big Soda Lake, Mono Lake, and Soap Lake are shown in figure 1, and comparative limnological data are listed in table 1 . These and subsequent data have been drawn from published works on Mono Lake (Mason, 1967; Jellison and Melack, 1988; Oremland and others, 1987; Oremland and King, 1989; Oremland, 1990; Miller and others, 1993; Oremland and others, 1993), Big Soda Lake (Oremland and others, 1982; Priscu and others, 1982; Oremland, 1983; Cloern and others, 1983a, b; Oremland and Des Marais, 1983; Kharaka and others, 1984; Zehr and others, 1987; Smith and Oremland, 1987; Iversen and others, 1987; Cloern and others, 1987; Oremland and others, 1988), and Soap Lake (Friedman and Redfield, 1971; Walker, 1974, 1975; Sanchez and others, 1986). All three are terminal, closed-basin lakes, with Mono Lake covering the largest area. In terms of dura- 
Table 1. Limnological properties of Mono Lake, Big Soda Lake, and Soap Lake.

[Pycnocline depth is depth of the salinity gradient]

\begin{tabular}{|c|c|c|c|}
\hline Limnological property & Mono Lake & Big Soda Lake & Soap Lake \\
\hline Area $\left(\mathrm{km}^{2}\right)$ & 150 & 1.6 & 3.4 \\
\hline Depth $(\mathrm{m})$ - & 30 & 62 & 27 \\
\hline Pycnocline depth (m) - & 20 & 35 & 20 \\
\hline Duration of meromixis (yr)-- & 5 & 80 & $2,000(?)$ \\
\hline Salinity $(\mathrm{g} / \mathrm{L})$ of mixolimnion - & 80 & 27 & 18 \\
\hline Salinity $(\mathrm{g} / \mathrm{L})$ of monimolimnion & 90 & 88 & 141 \\
\hline pH - & 9.7 & 9.7 & 9.7 \\
\hline Productivity $\left(\mathrm{g} \mathrm{C} / \mathrm{m}^{2} \mathrm{yr}\right.$ ) - & $340-550$ & 500 & 391 \\
\hline
\end{tabular}

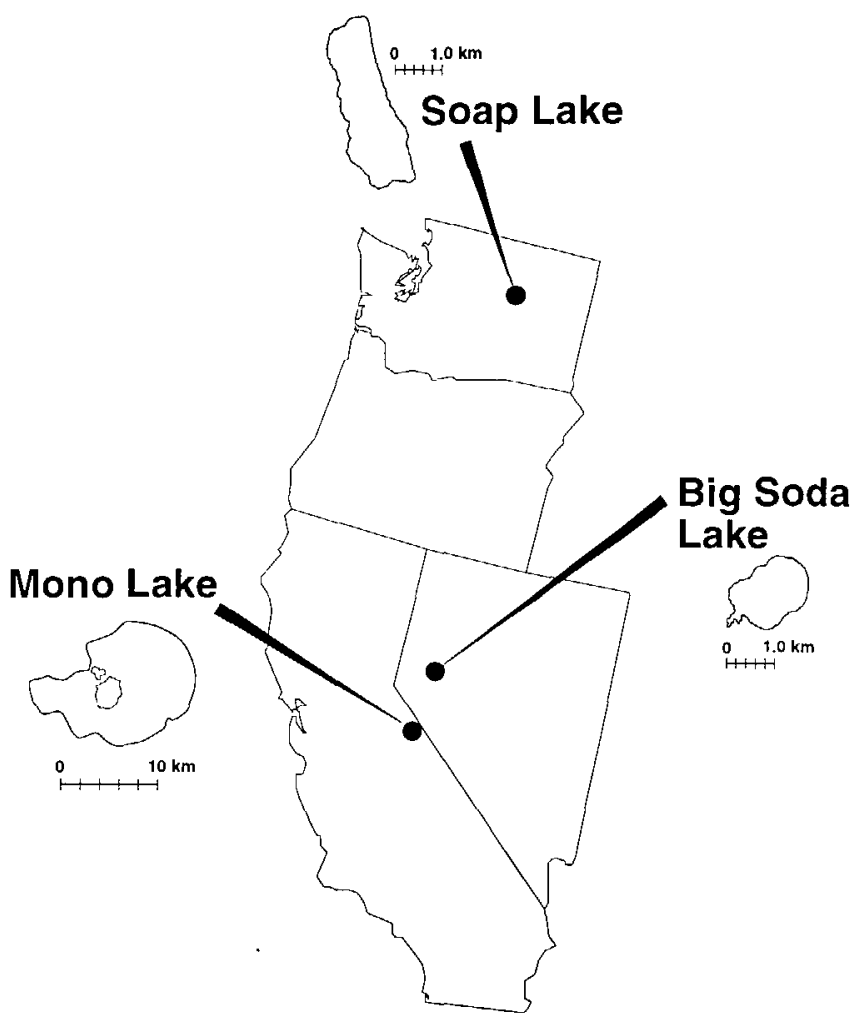

Figure 1. Locations and outlines of Mono Lake, Calif.; Big Soda Lake, Nev.; and Soap Lake, Wash.

tion of meromixis (prolonged stratification due to salinitybased density differences between surface and bottom waters), Mono Lake had a brief meromictic event associated with the 1982-1983 El Niño, and returned to its normal monomictic (a single autumn turnover of the water column) condition in 1988. Big Soda Lake and Soap Lake have much stronger salinity gradients and therefore can be considered to be in permanently meromictic states. Meromixis in Big Soda Lake resulted from local groundwater recharge associated with the Newlands Reclamation Project at the beginning of the 20th century. Although a similar situation exists for Soap Lake, separation of the highly saline bottom waters from the surface waters may have persisted there for centuries. All three lakes have similar levels of primary productivity and are poised at a $\mathrm{pH}$ of 9.7. Monimolimnion sediments (anoxic waters and sediments below the salinity gradient) from Big Soda Lake are unusual in that they had multicolored layers (brown, red, green, white) present in the upper $15 \mathrm{~cm}$, and displayed green and grey banding patterns throughout the upper $1 \mathrm{~m}$ of sediment (Oremland and others, 1988). Soap Lake monimolimnion sediments are also unusual, being characterized by layers of precipitated mirabilite $\left(\mathrm{Na}_{2} \mathrm{SO}_{4} \cdot 10 \mathrm{H}_{2} \mathrm{O}\right)$ interspersed with green organic-rich sediment. Mono Lake sediments are the most conventional in appearance, being dull green to black in color, and having no immediately obvious layering with the exception of an approximately $0.5-\mathrm{cm}$-thick volcanic ash layer (about $50 \mathrm{~cm}$ subbottom depth) from the eruption of Panum Crater (about 1350 AD). A closer examination of Mono Lake cores reveals, however, a pattern of fine laminations, probably formed from sinking phytoplankton blooms.

\section{MONIMOLIMNION CHEMISTRY AND GASEOUS HYDROCARBONS}

Although all three environments may be classified as biological extremes because of their $\mathrm{pH}$ and salinity, there is a further distinction when the chemical properties of the monimolimnions of the three lakes are compared. Soap Lake bottom water is about 60 percent more saline than that of the other two lakes (table 1) and contains significantly higher levels of dissolved carbonate/bicarbonate and sulfate (table 2). Apparently sulfate was, at one time, at saturation levels in Soap Lake, as indicated by the presence of obvious layers of precipitated mirabilite $\left(\mathrm{Na}_{2} \mathrm{SO}_{4}{ }^{\bullet}\right.$ $10 \mathrm{H}_{2} \mathrm{O}$ ) in the fluid-like monimolimnion sediments. This mineral was not observed in the sediments of either Mono or Big Soda Lake. Most important in terms of environmental extremes, however, is Soap Lake's very high level 
Table 2. Some chemical properties of dissolved methane in monolimnion waters and sediments of Mono Lake, Big Soda Lake, and Soap Lake.

[n.d., not determined]

\begin{tabular}{|c|c|c|c|}
\hline Chemical property & Mono Lake & Big Soda Lake & Soap Lake \\
\hline Sulfate (millimolar)- & 130 & 71 & $186-265$ \\
\hline Sulfide (millimolar)-- & 1 & 13 & 140 \\
\hline Carbonates (molar) & .4 & .4 & 1.0 \\
\hline Methane (micromolar) & 55 & 55 & 1,200 \\
\hline$\delta^{13} \mathrm{C}\left(\mathrm{CH}_{4}\right)$ (permil), in water & -72 & -60 & -47 to -50 \\
\hline$\delta^{13} \mathrm{C}\left(\mathrm{CH}_{4}\right)$ (permil), in sediment & -86 & -72 & n.d. \\
\hline$\delta \mathrm{D}\left(\mathrm{CH}_{4}\right)$ (permil), in water and sediment ------- & -210 to -290 & n.d. & n.d. \\
\hline$C_{1} /\left(C_{2}+C_{3}\right)$, in water & 750 & 180 & 2,950 \\
\hline $\mathrm{C}_{1} /\left(\mathrm{C}_{2}+\mathrm{C}_{3}\right)$, in sediment & 600 & 1,750 & 10,000 \\
\hline${ }^{14} \mathrm{CH}_{4}$, percent in modern carbon & 80 & n.d. & n.d. \\
\hline Sediment methane flux (millimoles $/ \mathrm{m}^{2}$ day) & $0.2-1.2$ & $1.4-2.9$ & n.d. \\
\hline
\end{tabular}

of dissolved sulfide (140 millimolar), which is one and two orders of magnitude greater than that measured in Big Soda Lake and Mono Lake, respectively. Apparently, the duration of meromixis is proportional to the quantity of dissolved sulfide accumulated. This sulfide indicates a period of prolonged bacterial sulfate reduction fueled by sinking organic matter from the mixolimnion (surface waters above the salinity gradient) occurring in the presence of an essentially unlimited supply of sulfate available as an electron acceptor. However, the presence of such high sulfide levels poses a challenge to bacterial survival.

Methane was present at comparable levels (55 micromolar) in the bottom waters of Mono Lake and Big Soda Lake. The source of this methane was the sediment, as indicated by a steady increase of dissolved methane with sediment depth, reaching approximately 2.7 millimolar at $1 \mathrm{~m}$ subbottom depth in Mono Lake (Oremland and others, 1987) and 0.33 millimolar in Big Soda Lake (Oremland and Des Marais, 1983). Premeromixis values of bottomwater methane for Mono Lake were 8 micromolar, and reached 55 micromolar only after 4 years of stratification (Miller and others, 1993). In contrast, methane was always 55 micromolar in Big Soda Lake, presumably reflecting a steady state between production and consumption (Iversen and others, 1987). Dissolved methane profiles in the water columns of all three lakes are shown in figure 2. In Soap Lake, bottom waters had very high levels (1.2 millimolar) of dissolved methane. However, a concentration gradient was not observed across the sediment-water interface. This lack of a gradient was due to the extremely fluid nature of the bottom sediments, which had the consistency of a loose gel (porosity $>0.95$ ). In this matrix we frequently observed the rapid upward migration of gas bubbles throughout the recovered core. Because such migration obliterates any methane gradients, more refined techniques, such as in-situ core freezing, would be required to establish the nature of the gradient.

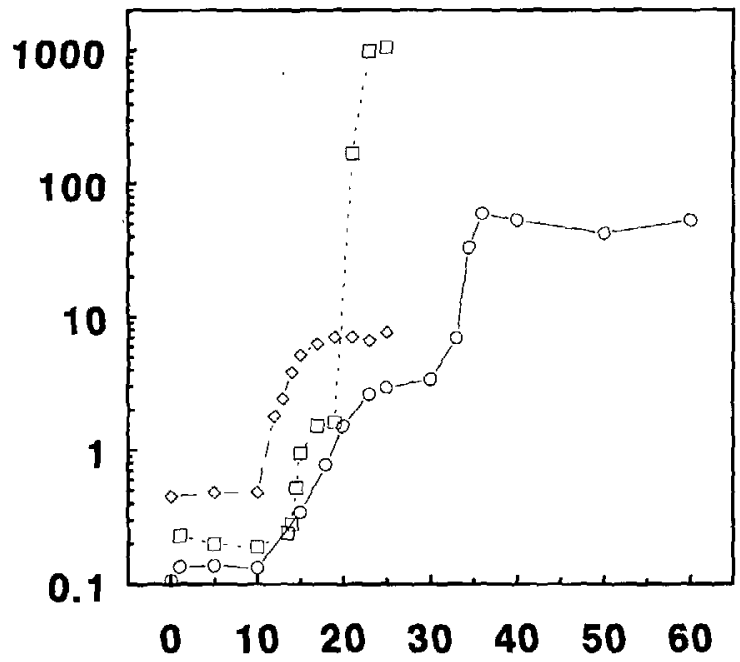

Depth in meters

Figure 2. Dissolved methane in water columns of Soap Lake (squares) during August 1990, Mono Lake (diamonds) during July 1990 (post meromixis), and Big Soda Lake (circles) during October 1984.

Mono Lake and Big Soda Lake bottom waters and sediments all had appreciable concentrations of ethane, propane, and butanes. In Mono Lake, ethane and propane levels reached 3 and 1 micromolar, respectively, in the sediments and exhibited profiles similar to that of methane, which suggest a similar source (Oremland and others, 1987). A similar sediment profile was obtained during sampling in the summer of 1990 (fig. 3). The situation was different in Big Soda Lake, where $\mathrm{C}_{2+}$ alkanes decreased with depth in the sediment while methane increased (Oremland and Des Marais, 1983). This trend was also apparent in the summer 1990 sampling, although propane 


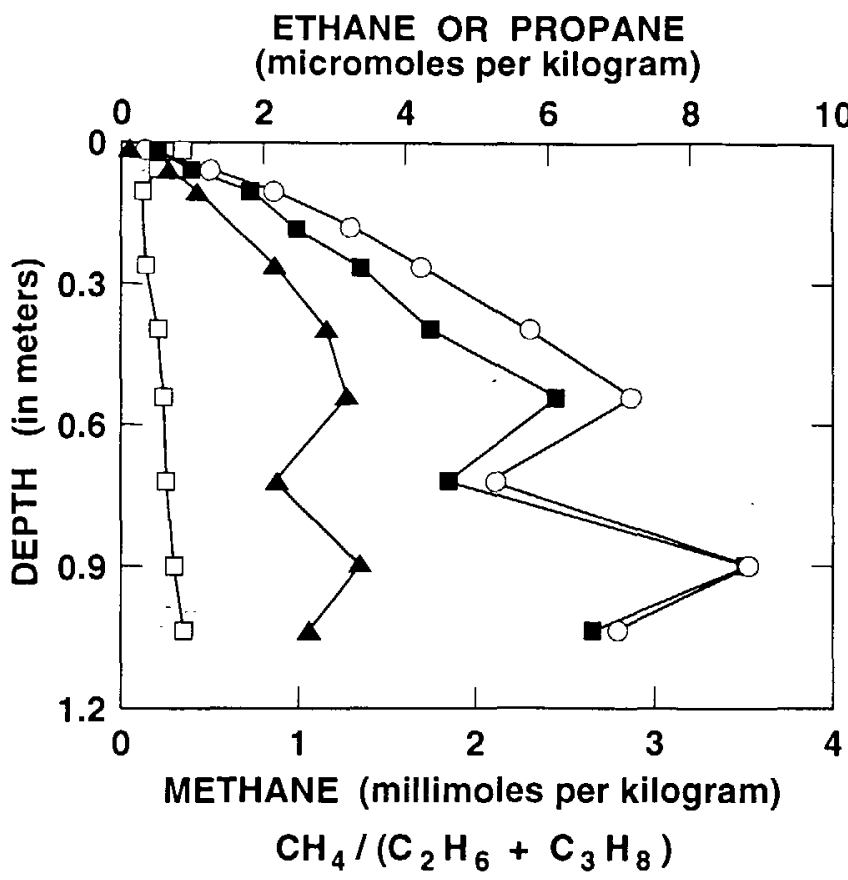

Figure 3. Amounts of methane (triangles), ethane (circles), and propane (solid squares) in Mono Lake monimolimnion sediments collected during summer of 1990 , reported in volume of gas per weight of sediment. Also shown is ratio $\mathrm{CH}_{4} /\left(\mathrm{C}_{2} \mathrm{H}_{6}+\mathrm{C}_{3} \mathrm{H}_{8}\right)$ (open squares).

was not quantified (fig. 4). Ratios of $\mathrm{CH}_{4} /\left(\mathrm{C}_{2} \mathrm{H}_{6}+\mathrm{C}_{3} \mathrm{H}_{8}\right)$ decreased slightly with depth in Mono Lake sediments (Oremland and others, 1987), whereas a slight increase was observed in the 1990 sampling (fig. 3). Increases in this ratio were observed with sediment depth in Big Soda Lake (table 2; fig. 4). In both cases, the hydrocarbon ratios were high enough (much greater than 100 ) to signal a microbial source for the methane, and this interpretation was reinforced by the light values of $\delta^{13} \mathrm{C}$ detected in the bottom waters and sediments. In addition, the $\mathrm{D} / \mathrm{H}$ ratios and ${ }^{14} \mathrm{C}$ content of methane in Mono Lake also signaled a microbial source of recent origin (table 2).

The source of the higher molecular weight alkanes, however, is unclear. In Mono Lake, the similarity of the methane, ethane, and propane profiles (fig. 3) suggests a common bacterial source in the sediments, and incubated sediments displayed the capacity to form ethane (Oremland and others, 1987; Oremland and others, 1988b). However, thermogenic gas seeps occur in the lake (see section "Gas Seeps") and a mixture of thermal and microbial sources cannot be ruled out. In Big Soda Lake, the decrease of $\mathrm{C}_{2+}$ hydrocarbons with sediment depth suggests a hydrocarbon source in the water column. Because this lake is the remnant of a Pleistocene volcanic eruption, thermogenic sources cannot be ruled out. We did not test these sediments for their ability to bacterially generate ethane upon incubation; however, sediments from the mixolimnion demonstrated

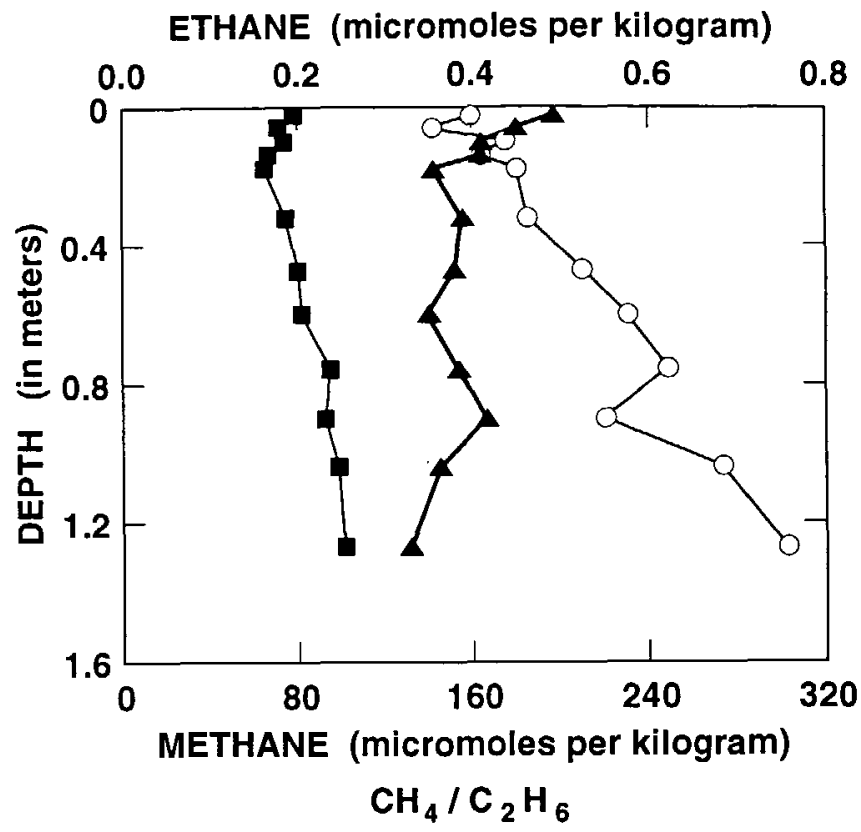

Figure 4. Amounts of methane (squares) and ethane (triangles) in Big Soda Lake monimolimnion sediments collected during summer of 1991, reported in volume of gas per weight of sediment. Also shown is ratio $\mathrm{CH}_{4} / \mathrm{C}_{2} \mathrm{H}_{6}$ (circles).

this capacity, with ethane thiol and diethylsulfide implicated as precursors (Oremland and others, 1988).

The characteristics of the gaseous hydrocarbons in Soap Lake differed from those of Mono and Big Soda Lakes. The $\delta^{13} \mathrm{C}$ for methane was considerably heavier (by 13 to 25 per mil), but this observation was based on only four water-column samples (range of $\delta^{13} \mathrm{C}=-46$ to $-50 \mathrm{per}$ mil) and did not include the sediments. Hence, it is possible that a strong, progressive ${ }^{12} \mathrm{C}$-enrichment occurs with depth in the Soap Lake sediments as was observed in the other two lakes. The most striking feature of the gaseous hydrocarbons in Soap Lake was the very large hydrocarbon abundance ratios, in part due to the absence of any detectable propane or butanes and only a trace level of ethane (about 2.5 nannomolar). The absence of significant levels of $\mathrm{C}_{2+}$ alkanes was unexpected, because we had previously observed their presence at Mono and Big Soda Lakes. The fact that Soap Lake does not display any obvious signs of geothermal activity may account for this observation. Alternatively, the high sulfide levels in the bottom waters may have prevented the microbes responsible for $\mathrm{C}_{2+}$ alkane formation from forming these gases.

\section{METHANE IN THE MIXOLIMNION}

Some of the characteristics of methane found in the surface waters (mixolimnion) of the lakes are listed in table 3. Dissolved methane concentrations at the air/water 
Table 3. Characteristics of methane in surface waters (mixolimnion) of Mono Lake, Big Soda Lake, and Soap Lake.

\begin{tabular}{|c|c|c|c|}
\hline Methane characteristic & Mono Lake & Big Soda Lake & Soap Lake \\
\hline $\mathrm{CH}_{4}$ (micromolar) - & $0.1-1.3$ & $0.1-0.6$ & 0.4 \\
\hline$\delta^{13} \mathrm{C}\left(\mathrm{CH}_{4}\right)$ (permil) & -20 to -54 & -21 to -68 & -47 \\
\hline $\begin{array}{l}\text { Flux to atmosphere } \\
\quad \text { (micromoles } / \mathrm{m}^{2} \text { hour). }\end{array}$ & 0.4 to 201 & 0.8 to 3.1 & 2.5 to 8.3 \\
\hline Gas sceps? & Yes & No & No \\
\hline
\end{tabular}

interface typically ranged between 0.1 to 1.3 micromolar, values which represent 50 - to 650 -fold saturation with respect to the partial pressure of methane in the atmosphere. Outward flux of this methane was measured with deployed floating chambers (Miller and Oremland, 1988). Fluxes were generally in the range of a few micromoles $/ \mathrm{m}^{2} /$ hour; however in Mono Lake where we conducted the most extensive samplings, we sometimes observed fluxes that were about two orders of magnitude higher (table 3 ). The stable carbon isotopic composition of this methane was markedly enriched in ${ }^{13} \mathrm{C}$ relative to the source methane in the sediments. This heavy isotopic enrichment was a consequence of bacterial methane oxidation occurring in the water columns of the lakes. The overwhelming majority of this oxidation was in the anoxic bottom waters rather than at the aerobic/anaerobic interface, a conclusion that was borne out by in-situ experiments with ${ }^{14} \mathrm{CH}_{4}$ (Iversen and others, 1987; Oremland and others, 1993). The influence of bacterial methane oxidation in these circumstances upon the $\delta^{13} \mathrm{C}$ values cannot be overstated. In both Mono and Big Soda Lakes, values as heavy as -20 permil were often encountered. Such strongly ${ }^{12} \mathrm{C}$-depleted methane would normally be interpreted as signalling a thermogenic source of methane (Schoell, 1983). In this case, however, methane is microbial in origin but additionally has been subjected to microbial oxidation. Soap Lake mixolimnion methane had a $\delta^{13} \mathrm{C}$ of -46 permil (depth=17 $\mathrm{m}$ ), a value which may also reflect some degree of microbial oxidation.

\section{GAS SEEPS}

Gas seeps were commonly observed in Mono Lake, but were absent from the other two lakes. The Mono Lake seeps were continuous flow $(0.1-4$ liters $/ \mathrm{min})$, were numerous (more than 700 were tabulated), consisted mainly of methane (61-98 percent of total gas volume), and originated from a subsurface natural-gas deposit (Oremland and others, 1987; Oremland and others, 1993). The deposit covered about one third of the lake bottom. Seeps located in hot springs had a stronger thermogenic character (for example, $\delta^{13} \mathrm{C}=-48$ permil; $\left.C_{1} /\left(C_{2}+C_{3}\right)=15\right)$, whereas all of the other seeps had parameters that signaled a microbial origin (for example, $\delta^{13} \mathrm{C}=-70$ permil; $\mathrm{C}_{1} /\left(\mathrm{C}_{2}+\mathrm{C}_{3}\right)=33,000$ ).

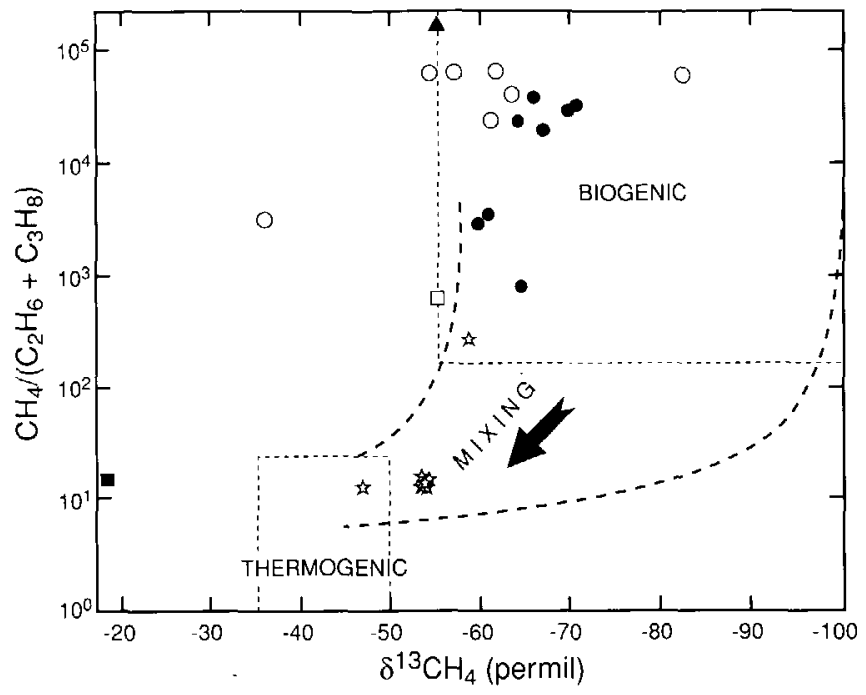

Figure 5. $\delta^{13} \mathrm{CH}_{4}$ versus $\mathrm{CH}_{4} /\left(\mathrm{C}_{2} \mathrm{H}_{6}+\mathrm{C}_{3} \mathrm{H}_{8}\right)$ for seep and hot spring gases collected in Mono Lake, the Mono Basin, and from Long Valley as reported by Oremland and others (1993) and by Oremland and others (1987). Classification "envelopes" for gases originating from biogenic sources (bacterial), thermogenic sources, or mixtures of both sources are from Whiticar and others (1986) and are indicated by dashed lines. Mono Lake biogenic seeps (dots); Mono Lake hot spring (thermal) seeps (open stars); Long Valley seep gases (open circles). End member values for gas bubbles collected from Dechambeau Ranch freshwater pond (located on Mono Lake's northern shore) (open box); Dechambeau Ranch hot spring (filled box). Endmember value of gases associated with decomposing, submerged shoreline grasses collected from the south shore of Mono Lake at Navy beach (filled triangle).

However, all the seep methanes had low radiocarbon values (less than 11 percent modern carbon), which indicated an age of more than 20,000 years. Because the radiocarbon content of dissolved methane in the monimolimnion $(80$ percent modern carbon) was equivalent to that present in the dissolved inorganic carbon (81 percent modern carbon; Peng and Broecker, 1980), a modern microbial origin was deduced for this methane, which was different from that of the seep methane.

In figure 5 are shown the characteristics $\left(\delta^{13} \mathrm{C}\right.$ versus $\left.\mathrm{C}_{1} /\left[\mathrm{C}_{2}+\mathrm{C}_{3}\right]\right)$ of the Mono Lake seep methane, as well as those of methane in gas seeps at other locations in the 
Table 4. Methane concentration in gas samples from seeps at Hot Creek, Calif. (A and B), and proximal fumaroles (C and D), collected before, during, and after an earthquake (from Oremland, 1983b).

[Values are in volume percent. The earthquake had a magnitude of 5.7; it struck $30 \mathrm{~km}$ southeast of Mammoth Lakes, Calif., at 9:45 a.m. on October 4, 1978. Gas samples were collected within 3 hours of the first shockwave. n.d., not determined]

\begin{tabular}{cccc}
\hline Site & Sept 17, 1978 & Oct. 4, 1978 & Oct. 9, 1978 \\
\hline A & 0.16 & 0.12 & 0.12 \\
B & .07 & .06 & n.d. \\
C & n.d. & .01 & .01 \\
D & n.d. & .01 & .01 \\
\hline
\end{tabular}

Mono Basin and in Long Valley, California. The results fall clearly into two patterns: microbial and thermogenic. The Long Valley seep gases were mostly associated with hot springs in the Mammoth Lakes region, such as found in Hot Creek. These seeps had highly variable methane levels, ranging from 0.04 to 58 percent by volume (Oremland and others, 1993). This methane originated from current microbial sources, as indicated by its isotopic ratios and hydrocarbon indices (fig. 5) plus the fact that sediments clearly displayed methanogenic activity when incubated at $62^{\circ} \mathrm{C}$ (Oremland, 1983b). Some of these seeps were monitored before, during, and after a magnitude 5.7 earthquake in 1978 to determine if an abrupt increase in their methane content could be discerned as predicted by Gold (1979). As can be seen in table 4 , the methane content of the seeps actually declined after the earthquake. Thus the question remains whether primordial methane is a causative factor of seismic activity, or even if it exists at all.

\section{MICROBIAL ACTIVITIES IN THE ANOXIC SEDIMENTS}

Detection of microbial methanogenesis was reported previously in experiments with sediment slurries from Big Soda Lake (Oremland and others, 1982; Oremland and others, 1987) and Mono Lake (Kiene and others, 1986; Oremland and others, 1987; Oremland and King, 1989; Oremland, 1990). Experiments with ${ }^{14} \mathrm{C}$-labelled methane precursors (trimethylamine, acetate, bicarbonate, methanol, and dimethylsulfide) have been published for Mono Lake (Oremland and King, 1989; Oremland and others, 1993). However, in the case of Soap Lake, the geochemical data were insufficient to determine whether the methane originated from ancient or current microbial activity. To determine if methanogenic activity in Soap Lake sediments could still occur at the high ambient sulfide concentrations, we conducted a preliminary experiment with bottom sediment slurried in a ratio of 1:1 with bottom water and incubated under $\mathrm{N}_{2}$ with

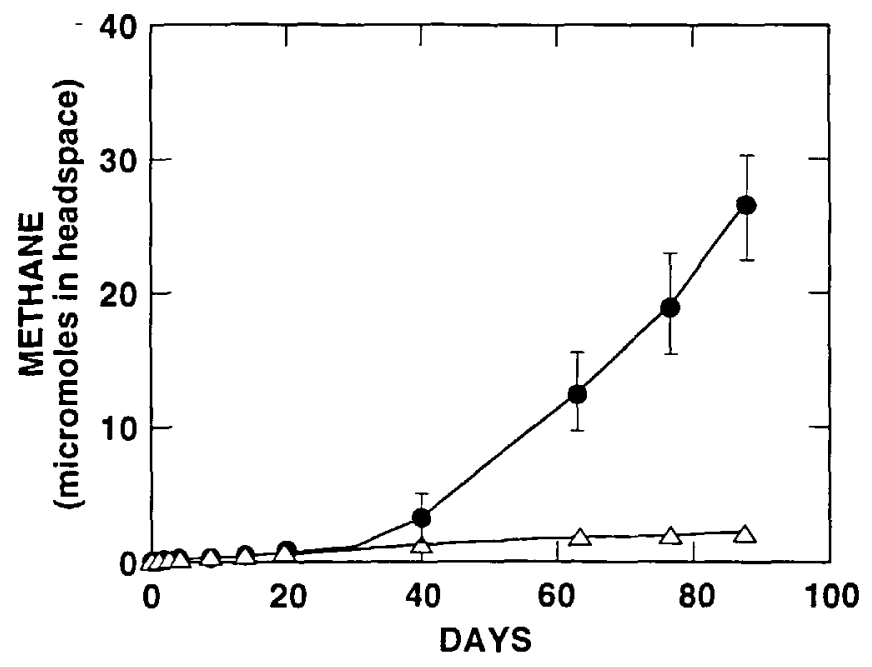

Figure 6. Methanogenesis during prolonged incubation of Soap Lake sediments slurries. Slurries were incubated with 10 millimolar trimethylamine (dots), or without amendments (triangles). Data points represent mean of three slurries, and bars (where shown) indicate \pm one standard deviation. Headspace, $80 \mathrm{~mL}$ volume.

and without amendment of trimethylamine, a noncompetitive methanogenic substrate (Oremland and Polcin, 1982). Unamended slurries steadily produced a small amount of methane over prolonged incubation, while those amended with trimethylamine exhibited an approximate 10 -fold enhancement of activity (fig. 6). These results were construed to indicate the presence of a potentially active methanogenic bacterial flora in the pelagic sediments of Soap Lake. However, the activity was slow relative to that of slurry experiments conducted with sediments from Big Soda and Mono Lakes (Oremland and others, 1982; Kiene and others, 1986; Oremland and King, 1989).

During the summer of 1990 we conducted a field program to quantify and compare the relative activities of methanogenesis and sulfate-reduction in the littoral and pelagic sediments of the three lakes. We collected 1-mlong gravity cores from the pelagic sediments and approximately $0.3-\mathrm{m}$-long hand cores collected by divers from the littoral sediments. Cores were extruded and subsampled at specified depths with $10-\mathrm{mL}$ or $5-\mathrm{mL}$ subcores. The subcores were injected with radioisotopes $\left({ }^{14} \mathrm{C}\right.$-trimethylamine, ${ }^{2-}{ }^{14} \mathrm{C}$-acetate, $\mathrm{NaH}^{14} \mathrm{CO}_{3}$, or $\left.\mathrm{Na}_{2}{ }^{35} \mathrm{SO}_{4}\right)$ and incubated at their respective in-situ temperatures for 24 hours $\left(\mathrm{NaH}^{14} \mathrm{CO}_{3}\right.$ for 46 to 92 hours) after which activity was arrested by freezing. The details of this procedure and the subsequent extraction procedures for ${ }^{35} \mathrm{~S}$-sulfide and ${ }^{14} \mathrm{C}$-methane have been given elsewhere (Oremland and King, 1989; Oremland and others, 1993). We employed the ${ }^{14} \mathrm{C}$-labelled acetate and trimethylamine to qualitatively scan for the presence of microbial mineralization of these compounds (to ${ }^{14} \mathrm{CO}_{2}$ and (or) ${ }^{14} \mathrm{CH}_{4}$ ). Because a 
number of substrates (such as acetate, methylamines, methanol, formate, dimethylsulfide, bicarbonate) may be potential methane precursors, their employment to estimate in-situ kinetics includes the need for an accurate assessment of in-situ pool sizes (pore-water substrate concentrations), which must be achieved prior to their use. Addition of too large a quantity of radioisotope could increase the unlabelled pool sizes $\left({ }^{14} \mathrm{C}\right.$-substrates have low specific activities), resulting in overestimates of activity. Because substrate pool sizes are generally quite low (for example, 0.1 micromolar) in these environments (Oremland and King, 1989), use of radiolabelled organic methane precursors to assess in-situ methanogenesis from all potential substrates posed too many technical difficulties for the purpose of a preliminary survey. Hence we chose ${ }^{14} \mathrm{C}$-bicarbonate because its addition would not affect the high carbonate/bicarbonate pools of these lakes, and $\sum \mathrm{CO}_{2}$ in pore waters is easily measured. To compensate for the large isotope-dilution effect, we used elevated amounts of isotope per sample (50 microcuries), used prolonged incubations, and extracted ${ }^{14} \mathrm{C}$-methane in a cryogenic trap/oxidation line for analysis by liquid scintillation counting (Whelan and others, 1986).
In the littoral-zone sediments of all three lakes, both acetate and trimethylamine were oxidized to $\mathrm{CO}_{2}$, but only Soap Lake sediments exhibited any capacity for production of $\mathrm{CH}_{4}$, and this production was from acetate (table 5). Pelagic sediments were all able to mineralize acetate to $\mathrm{CO}_{2}$, and with the exception of those from Soap Lake, all could mineralize trimethylamine to $\mathrm{CO}_{2}$. Only Soap Lake pelagic sediments displayed a capacity for methanogenesis (from acetate). These results indicate that mineralization of both trimethylamine and acetate in the sediments of all three lakes was dominated by sulfate reduction.

Depth profiles of sulfate reduction and methanogenesis via $\mathrm{CO}_{2}$ reduction (from bicarbonate) for the littoral sediments of Mono, Big Soda, and Soap Lakes are shown in figures 7,8 , and 9 , respectively. The activity in the pelagic sediments of the three respective lakes are shown in figures 10,11, and 12. The littoral-zone sediments of all three lakes demonstrated detectable levels of sulfate reduction and methanogenesis. In broad terms, methanogenic activity (recorded on figures as $\mathrm{CO}_{2}$ reduction) usually exhibited subsurface maxima for all cores, whereas sulfate reduction generally decreased with depth down the cores. In the pelagic sediments, Mono Lake demonstrated obvi-
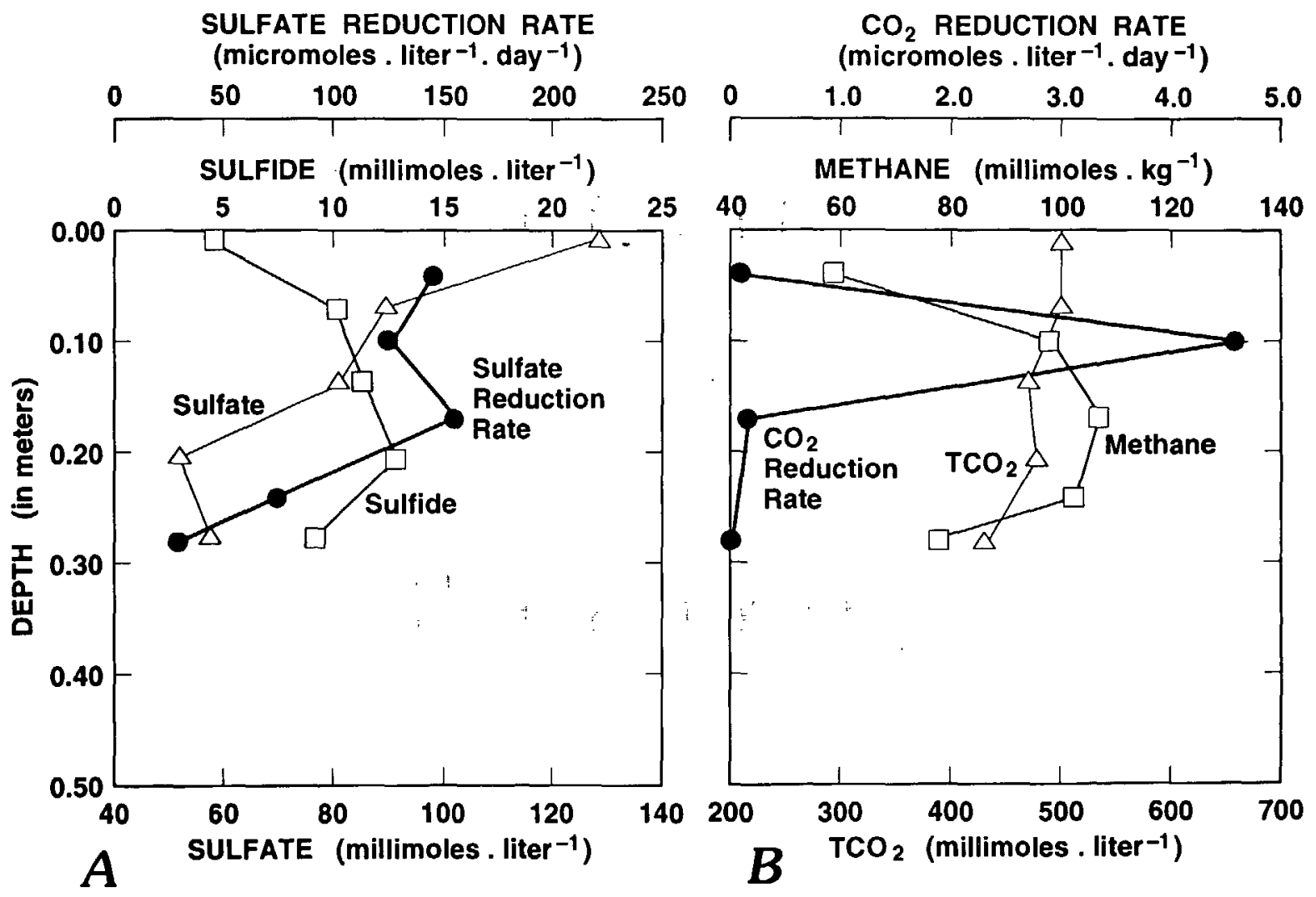

Figure 7. Bacterial activities in Mono Lake littoral sediments. $A$, Sulfate reduction. $B$, Methanogenesis $\left(\mathrm{CO}_{2}\right.$ reduction). $\mathrm{TCO}_{2}$, total $\mathrm{CO}_{2}$. Reduction rates are reported in micromoles of reduced compound $\left(\mathrm{SO}_{4}{ }^{2-}\right.$ or $\left.\mathrm{HCO}_{3}{ }^{2-}\right)$ per

liter of sediment pore water per day. Sulfide, sulfates, and $\mathrm{TCO}_{2}$ amounts are reported in millimoles of compound per liter of sediment pore water; methane amounts in millimoles per kilogram of sediment. 
ous sulfate reduction (fig. $10 \mathrm{~A}$ ), which was generally consistent with previous measurements (Oremland and others, 1993). Methanogenic activity, however, was lower than sulfate reduction (fig. 10B) and both decreased with depth down the core. Sulfate showed a marked decrease with core depth due to removal by sulfate reduction, and this result was reflected by generally increased sulfide with core depth. In Big Soda Lake, sulfate-reduction was highest at the core surface and declined with depth (fig. 11A). However, although sulfide increased with depth, there was no corresponding decrease in sulfate. No discernible methanogenic activity was detected at any depth in the core (fig. $11 B$ ). In Soap Lake, sulfate reduction was detected down the length of the core; however, sulfate increased markedly with depth, possibly due to resolution of precipitated mirabilite (fig. 12A). Methanogenic activity was detected only at the surface of the core (fig. 12B).

The integrated rates of sulfate reduction and methanogenesis are presented in table 6 . Sulfate reduction was clearly the dominant process for anaerobic carbon mineralization in both the littoral and pelagic sediments of the three lakes. Methanogenesis was, in comparison, only of minor importance in terms of carbon mineralization. This
Table 5. Formation of ${ }^{14} \mathrm{CO}_{2}$ or ${ }^{14} \mathrm{CH}_{4}$ from ${ }^{14} \mathrm{C}$-labelled trimethylamine or acetate in samples taken from littoral and pelagic sediments of Big Soda Lake, Mono Lake, and Soap Lake.

[Positive sign indicates at least one sample of a core profile was active (that is, was forming ${ }^{14} \mathrm{CO}_{2}$ or ${ }^{14} \mathrm{CH}_{4}$ ); negative sign indicates that activity was absent at all depths assayed]

\begin{tabular}{|c|c|c|c|c|}
\hline \multirow{3}{*}{ Site } & \multicolumn{2}{|c|}{ Acetate } & \multicolumn{2}{|c|}{ Trimethylamine } \\
\hline & $\mathrm{CO}_{2}$ & $\mathrm{CH}_{4}$ & $\mathrm{CO}_{2}$ & $\mathrm{CH}_{4}$ \\
\hline & \multicolumn{4}{|c|}{ Littoral sediments } \\
\hline Big Soda Lake & + & - & + & - \\
\hline Mono Lake & + & - & + & - \\
\hline Soap Lake & + & + & + & - \\
\hline \multicolumn{5}{|c|}{ Pelagic sediments } \\
\hline Big Soda Lake & + & - & + & - \\
\hline Mono Lake & + & - & + & - \\
\hline Soap Lake & + & + & - & - \\
\hline
\end{tabular}
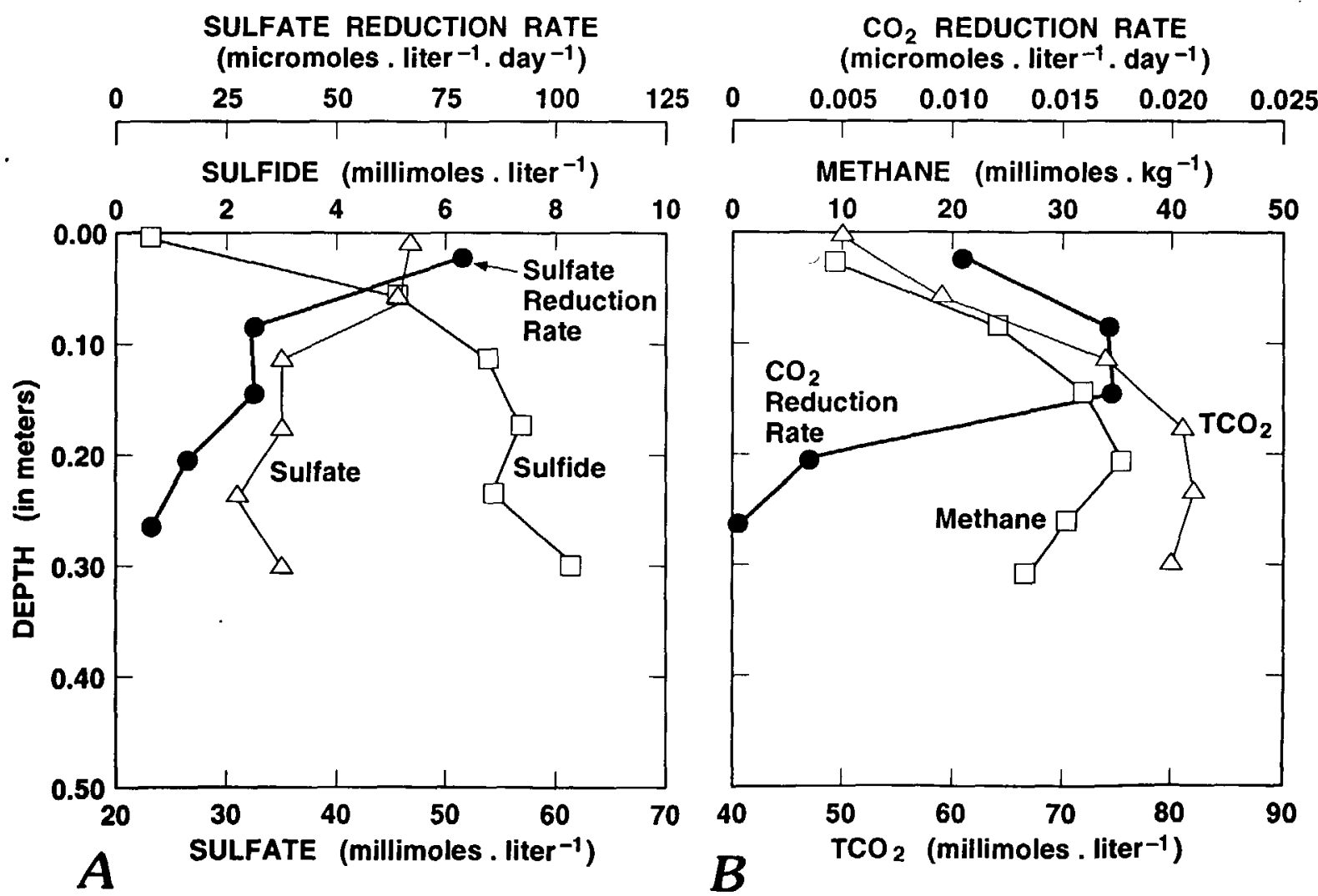

Figure 8. Bacterial activities in Big Soda Lake littoral sediments. $A$, Sulfate reduction. $B$, Methanogenesis $\left(\mathrm{CO}_{2}\right.$ reduction). $\mathrm{TCO}_{2}$, total $\mathrm{CO}_{2}$. Reduction rates are reported in micromoles of reduced compound $\left(\mathrm{SO}_{4}{ }^{2-}\right.$ or $\left.\mathrm{HCO}_{3}{ }^{2-}\right)$ per

liter of sediment pore water per day. Sulfide, sulfates, and $\mathrm{TCO}_{2}$ amounts are reported in millimoles of compound per liter of sediment pore water; methane amounts in millimoles per kilogram of sediment. 

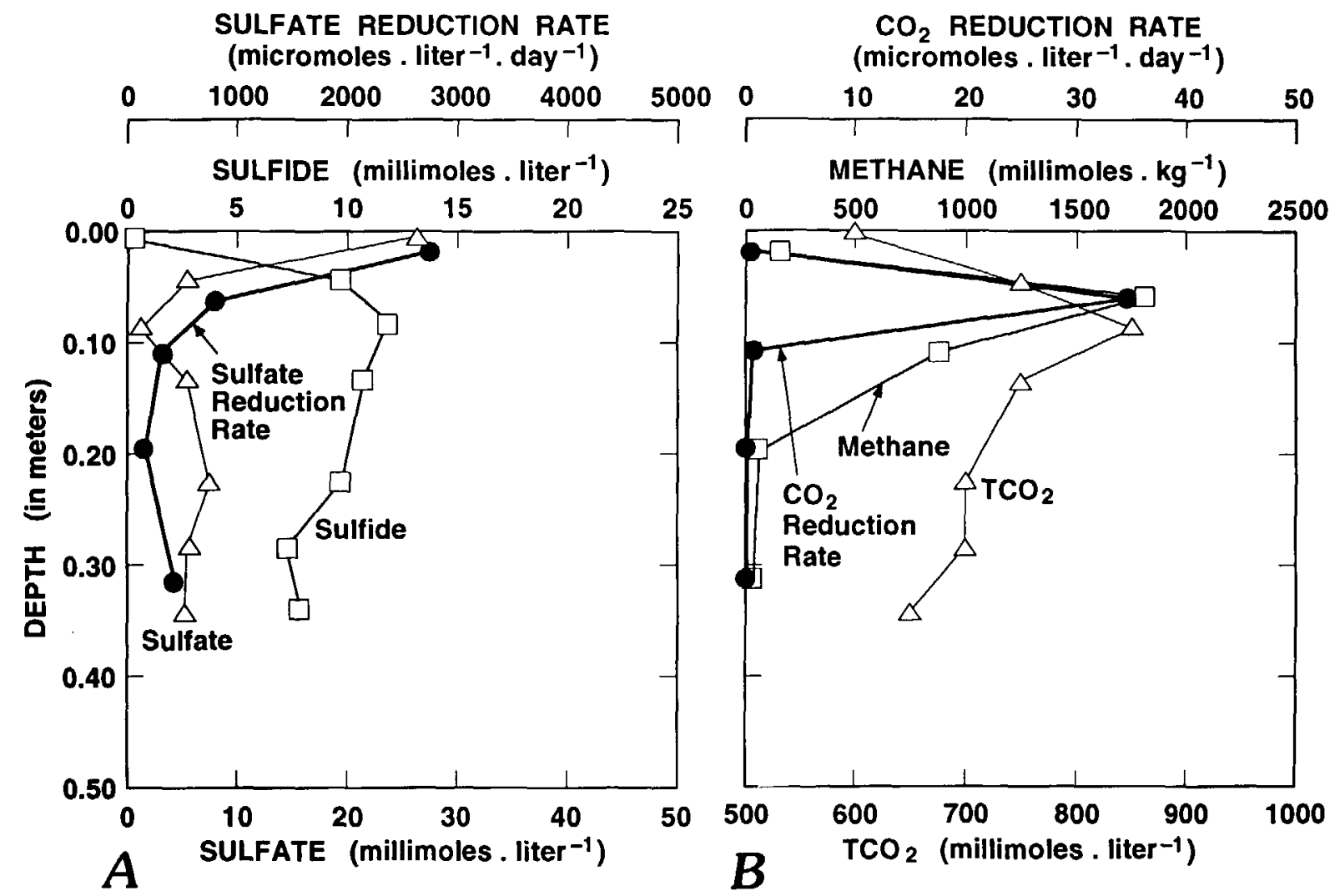

Figure 9. Bacterial activities in Soap Lake littoral sediments. $A$, Sulfate reduction. $B$, Methanogenesis $\left(\mathrm{CO}_{2}\right.$ reduction). $\mathrm{TCO}_{2}$, total $\mathrm{CO}_{2}$. Reduction rates are reported in micromoles of reduced compound $\left(\mathrm{SO}_{4}{ }^{2-}\right.$ or $\left.\mathrm{HCO}_{3}{ }^{2-}\right)$ per

liter of sediment pore water per day. Sulfide, sulfates, and $\mathrm{TCO}_{2}$ amounts are reported in millimoles of compound per liter of sediment pore water; methane amounts in millimoles per kilogram of sediment.
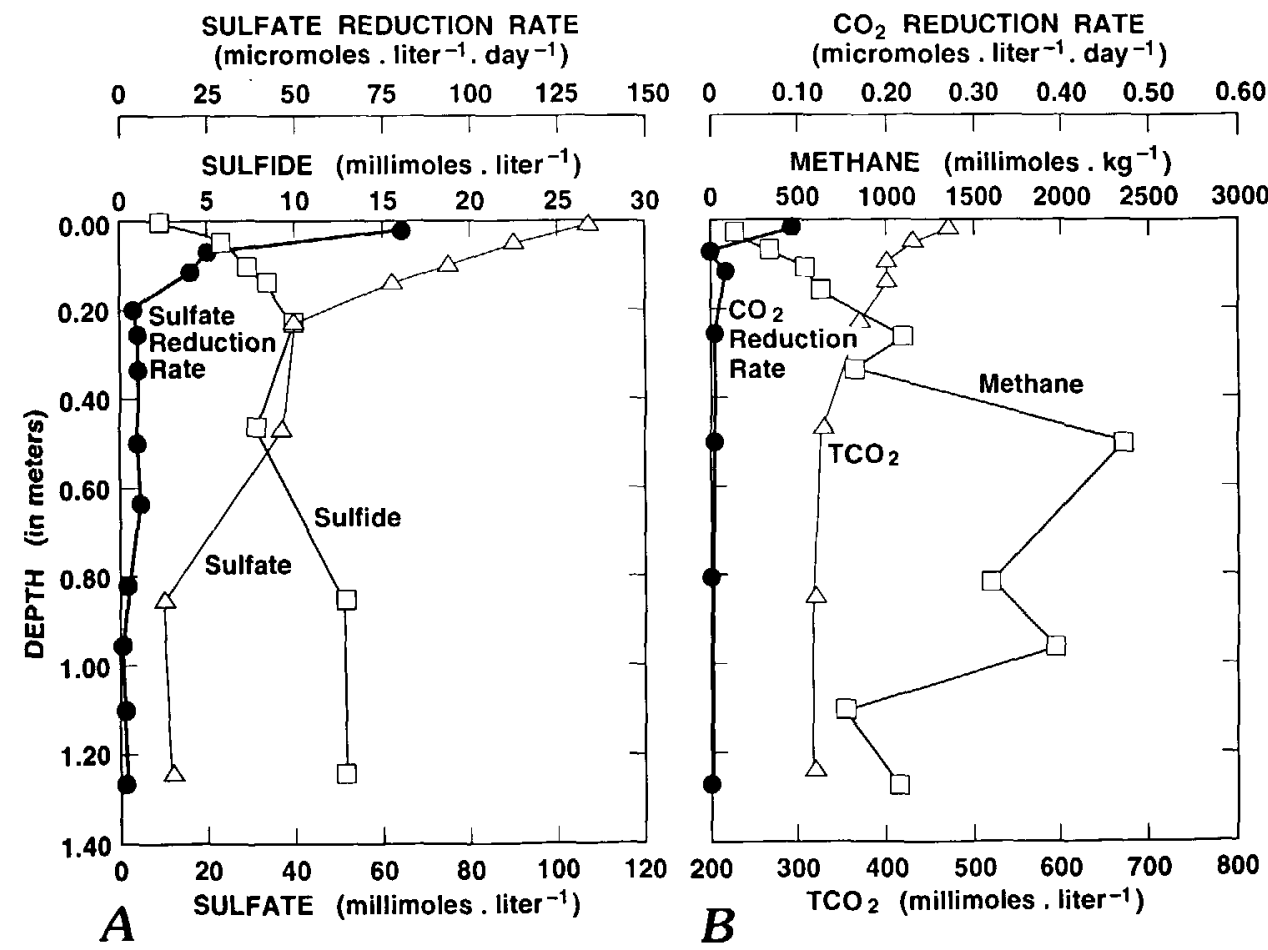

Figure 10. Bacterial activities in Mono Lake pelagic (monimolimnion) sediments. $A$, Sulfate reduction. $B$, Methanogenesis $\left(\mathrm{CO}_{2}\right.$ reduction). $\mathrm{TCO}_{2}$, total $\mathrm{CO}_{2}$. $\mathrm{Re}$ duction rates are reported in micromoles of reduced compound $\left(\mathrm{SO}_{4}{ }^{2-}\right.$ or $\left.\mathrm{HCO}_{3}{ }^{2-}\right)$ per liter of sediment pore water per day. Sulfide, sulfates, and $\mathrm{TCO}_{2}$ amounts are reported in millimoles of compound per liter of sediment pore water; methane amounts in millimoles per kilogram of sediment. 

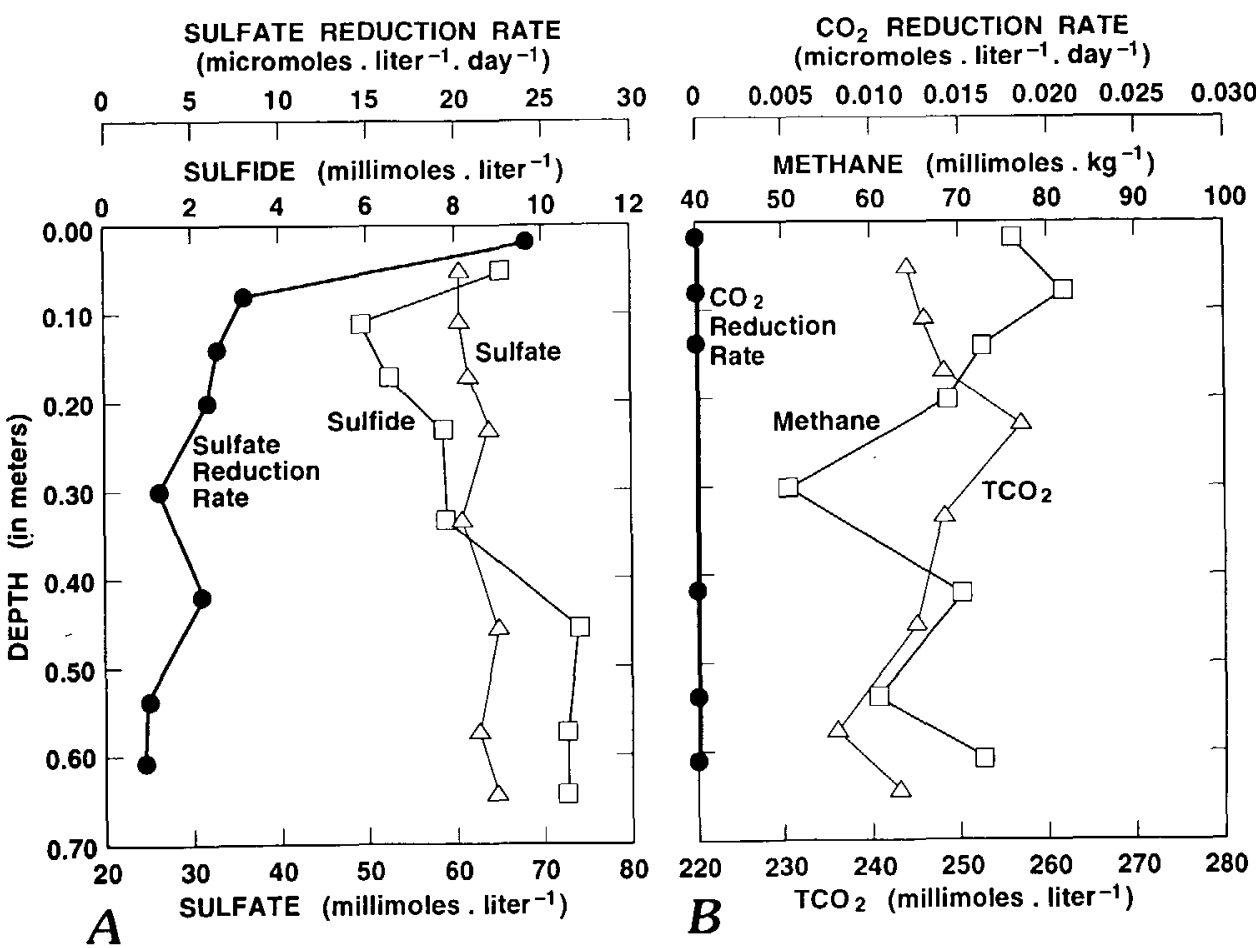

Figure 11. Bacterial activities in Big Soda Lake pelagic (monimolimnion) sediments. $A$, Sulfate reduction. $B$, Methanogenesis $\left(\mathrm{CO}_{2}\right.$ reduction). $\mathrm{TCO}_{2}$, total $\mathrm{CO}_{2}$. Reduction rates are reported in micromoles of reduced compound $\left(\mathrm{SO}_{4}{ }^{2-}\right.$ or

$\mathrm{HCO}_{3}{ }^{2-}$ ) per liter of sediment pore water per day. Sulfide, sulfates, and $\mathrm{TCO}_{2}$ amounts are reported in millimoles of compound per liter of sediment pore water; methane amounts in millimoles per kilogram of sediment.

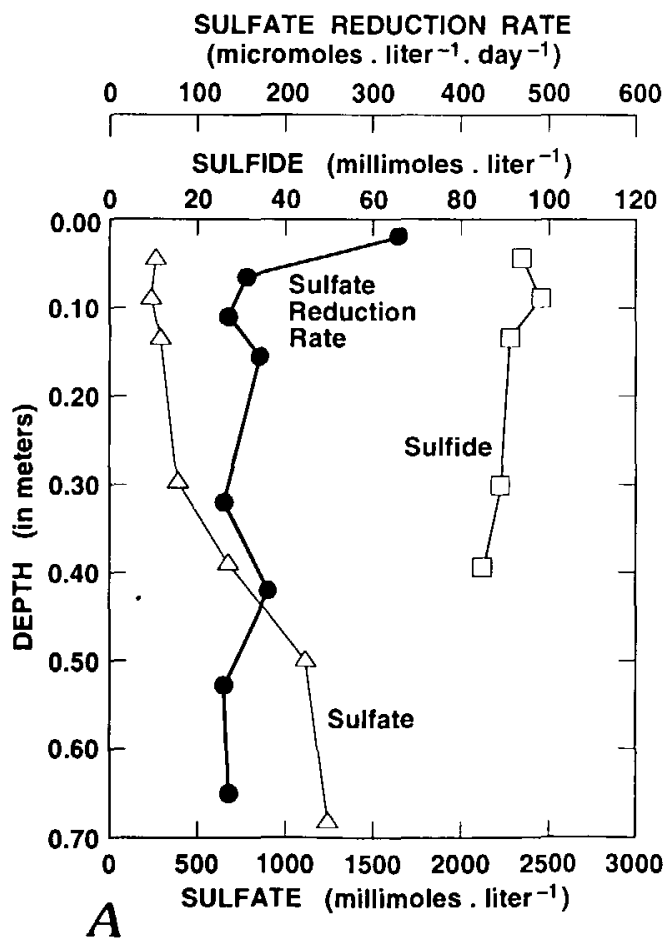

Figure 12. Bacterial activities in Soap Lake pelagic (monimolimnion) sediments. $A$, Sulfate reduction. $B$, Methanogenesis $\left(\mathrm{CO}_{2}\right.$ reduction). $\mathrm{TCO}_{2}$, total $\mathrm{CO}_{2}$. Reduction rates are reported in micromoles of reduced compound $\left(\mathrm{SO}_{4}{ }^{2-}\right.$ or

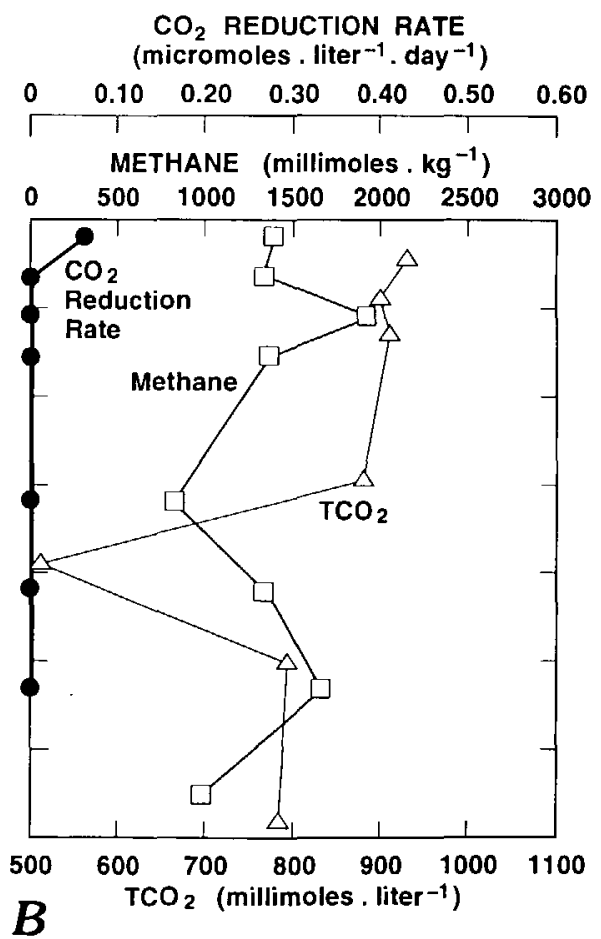

$\mathrm{HCO}_{3}{ }^{2-}$ ) per liter of sediment pore water per day. Sulfide, sulfates, and $\mathrm{TCO}_{2}$ amounts are reported in millimoles of compound per liter of sediment pore water; methane amounts in millimoles per kilogram of sediment. 
observation is not surprising, considering the high sulfate content of all three lakes. Sulfate reduction and methanogenesis were greater in the littoral sediments than in the pelagic sediments. Again, this result is not surprising considering that sediments were incubated at their in-situ temperatures (pelagic, $6-12^{\circ} \mathrm{C}$; littoral, $20-24^{\circ} \mathrm{C}$ ). However, with the exception of Big Soda Lake pelagic sediments, all environments displayed the capacity for methanogenesis via $\mathrm{CO}_{2}$ reduction. In previous work at Mono Lake, we reported pelagic sulfate reduction during meromixis (1986) to be $13.4 \mathrm{millimoles} / \mathrm{m}^{2}$ day, which was about twice the activity measured in 1990 (Oremland and others, 1993). With respect to methanogenesis from bicarbonate, however, we reported rates of 340 and 500 micromoles $/ \mathrm{m}^{2}$ day during 1986 and 1988, respectively. These values are about 2 orders of magnitude greater than our 1990 estimate (table 6). At present we have no explanation for this discrepancy, other than sample variability.

Table 6. Integrated rates of sulfate reduction and methanogenesis for the littoral and pelagic sediments of Soap Lake, Mono Lake, and Big Soda Lake.

\begin{tabular}{|c|c|c|c|}
\hline & $\begin{array}{l}\text { Soap } \\
\text { Lake }\end{array}$ & $\begin{array}{c}\text { Mono } \\
\text { Lake }\end{array}$ & $\begin{array}{l}\text { Big Soda } \\
\text { Lake }\end{array}$ \\
\hline \multicolumn{4}{|c|}{ Littoral sediments } \\
\hline $\begin{array}{l}\text { Sulfate reduction } \\
\text { (millimoles } \mathrm{SO}_{4}{ }^{2-} / \mathrm{m}^{2} \text { day ). }\end{array}$ & 175 & 32 & 8.4 \\
\hline $\begin{array}{l}\text { Methanogenesis } \\
\text { (micromoles } \mathrm{CH}_{4} / \mathrm{m}^{2} \text { day). }\end{array}$ & 1.2 & 229 & 1.4 \\
\hline \multicolumn{4}{|c|}{ Pelagic sediments } \\
\hline $\begin{array}{l}\text { Sulfate reduction } \\
\text { (millimoles } \mathrm{SO}_{4}{ }^{2-} / \mathrm{m}^{2} \text { day). }\end{array}$ & 73 & 6.6 & 3.4 \\
\hline $\begin{array}{l}\text { Methanogenesis } \\
\quad \text { (micromoles } \mathrm{CH}_{4} / \mathrm{m}^{2} \text { day). }\end{array}$ & 0.2 & 4.3 & 0 \\
\hline
\end{tabular}

\section{SUMMARY}

Methane is present in all three lakes. Microbiological experiments in all three lakes confirms that their sediments are active with respect to methanogenesis. However, considerable variability was observed between samples, and accurate assessments of methanogenic activity are as yet lacking. The contribution of this current methanogenesis to the methane observed in the lakes appears to be important; however, in the case of Mono Lake the picture is clouded by the presence of thermogenic methane as well as ancient microbial methane. The need for additional studies to better quantify methanogenic activity, as well as sulfate reduction, is obvious. In addition, more extensive radiocarbon dates for methane from the sediments and water columns of all three lakes would better refine our estimates of methane derived from current methanogenic activity relative to that derived from ancient microbial or thermogenic sources. Analysis of ethane and higher molecular weight hydrocarbons to determine their stable isotopic composition and radiocarbon contents may also shed some light on whether their origins are thermogenic or microbial.

\section{CONCLUSIONS}

1. Methane was present in the waters and sediments of all three lakes.

2. Microbial methanogenesis was responsible for most of the methane detected, although the methane's stable isotopic composition was sometimes enriched with ${ }^{13} \mathrm{C}$ from microbial oxidation.

3. In Mono Lake, and possibly in Big Soda Lake, thermogenic gases were also present.

4. It is not clear whether the $\mathrm{C}_{2+}$ alkanes detected in Mono Lake and Big Soda Lake pelagic sediments were formed by microbial reactions, mixing with thermogenic sources, or a combination of these two factors.

5. The absence of $\mathrm{C}_{2+}$ alkanes from the Soap Lake system is unexplained.

\section{REFERENCES CITED}

Anthony, C., 1982, The biochemistry of methylotrophs: New York, Academic Press, 431 p.

Balch, W.E., Fox, G.E., Magrum, L.J., Woese, C.R., and Wolfe, R.S., 1979, Methanogens-Reevaluation of a unique biological group: Microbiological Reviews, v. 43, p. 260-296.

Bernard, B.B., 1979, Methane in marine sediments: Deep Sea Research, v. 26, p. 429-443.

Bradley, W.H., 1931, Origin and microfossils of the oil shale of the Green River Formation of Colorado and Utah: U.S. Geological Survey Professional Paper 168, 58 p.

Bryant, M.P., Wolin, E.A., Wolin, M.J., and Wolfe, R.S., 1967, Methanobacterium omelianskii, a symbiotic association of two species of bacteria: Archives of Microbiology, v. 59, p. 20-31.

Cicerone, R.J., and Oremland, R.S., 1988, Biogeochemical aspects of atmospheric methane: Global Biogeochemical Cycles, v. 2, p. 299-327.

Claypool, G.E., and Kvenvolden, K.A., 1983, Methane and other hydrocarbon gases in marine sediments: Annual Review of Earth \& Planetary Sciences, v. 11, p. 299-327.

Cloern, J.E., Cole, B.E., and Oremland, R.S., 1983a, Seasonal changes in the chemistry and biology of a meromictic lake (Big Soda Lake, Nevada, USA): Hydrobiologia, v. 105, p. 195-206.

1983b, Autotrophic processes in meromictic Big Soda Lake, Nevada: Limnology and Oceanography, v. 28, p. 10491061 . 
Cloern, J.E., Cole, B.E., and Wienke, S.M., 1987, Big Soda Lake (Nevada). 4. Vertical fluxes of particulate matter-Seasonality and variations across the chemocline: Limnology and Oceanography, v. 32, p. 815-824.

Coleman, D.D., Risatti, J.B., and Schoell, M., 1981, Fractionation of carbon and hydrogen isotopes by methane-oxidizing bacteria: Geochimica et Cosmochimica Acta, v. 45, p. 1033-1037.

Crawford, R.L., and Hanson, R.S., 1984, Microbial growth on C compound: Proceedings of the 4th International Symposium, American Society for Microbiology, Washington, DC., 343 p.

Davis, J.B., and Squires, R.M., 1954, Detection of microbially produced gaseous hydrocarbons other than methane: Science, v. 119, p. 381-382.

Demaison, G. J., and Moore, G.T., 1980, Anoxic environments and oil source bed genesis: American Association of Petroleum Geologists Bulletin, v. 64, p. 1179-1209.

Friedman, I., and Redfield, A.C., 1971, A model of the hydrology of the lakes of the lower Grand Coulee, Washington: Water Resources Research, v. 7, p. 874-898.

Gold, T.J., 1979, Terrestrial sources of carbon and earthquake. outgassing, Journal of Petroleum Geology, v. 1, p. 3-19.

Ivanov, M.V., Belyaev, S.S., Zyakun, A.M., Bondar, V.A., and Laurinavichus, K.S., 1983, Microbiological formation of methane in the oil-field development: Geokhimiya, v. 11, p. 1647-1654.

Iversen, N., Oremland, R.S., and Klug, M.J., 1987, Big Soda Lake (Nevada). 3. Pelagic methanogenesis and anaerobic methane oxidation: Limnology and Oceanography, v. 32, p. 804-814.

Jellison, R., and Melack, J.M., 1988, Photosynthetic activity of phytoplankton and its relation to environmental factors in hypersaline Mono Lake, California: Hydrobiologia, v. 158, p. 69-88.

Jones, W.J., Nagle, D.P., Jr., Whitman, W.B., 1987, Methanogens and the diversity of archaebacteria: Microbiological Reviews, v. 51, p. $135-177$.

Kharaka, Y.K., Robinson, S.W., Law, L.M., and Carothers, W.W., 1984, Hydrogeochemistry of Big Soda Lake, Nevada-An alkaline, meromictic desert lake: Geochimica et Cosmochimica Acta, v. 48 , p. $823-835$.

Kiene, R.P., Oremland, R.S., Catena, A., Miller, L.G., and Capone, D.G., 1986, Metabolism of reduced methylated sulfur compounds in anaerobic sediments and by a pure culture of an estuarine methanogen: Applied and Environmental Microbiology, v. 52, p. 1037-1045.

Mason, D.T., 1967, Limnology of Mono Lake, California: Berkeley University of California, Ph.D. dissertation, 110 p.

Miller, L.G., Jellison, R., Oremland, R.S., and Culbertson, C.W., 1993, Meromixis in hypersaline Mono Lake, California 3Biogeochemical response to stratification and overturn: Limnology and Oceanography, v. 38, p. 1040-1051.

Miller, L.G., and Oremland, R.S., 1988, Methane efflux from the pelagic regions of four lakes: Global Biogeochemical Cycles, v. 2, p. 269-277.

Oremland, R.S., 1981, Microbial formation of ethane in anoxic, estuarine sediments: Applied and Environmental Microbiology, v. 42 , p. $122-129$.

1983a, Hydrogen metabolism by decomposing cyanobacterial aggregates in Big Soda Lake, Nevada: Applied and Environmental Microbiology, v. 45, p. 1519-1525. 1983b, Methane in association with seismic activity: Eos, v. 64 , p. $410-411$

1988, Biogeochemistry of methanogenic bacteria, in $\mathrm{Ze}$ hnder, A.J.B., ed., Biology of anaerobic microorganisms: New York, John Wiley \& Sons, p. 641-705.

1990, Nitrogen fixation dynamics of two diazotrophic communities in Mono Lake, California: Applied and Environmental Microbiology, v. 56, p. 614-622.

Oremland, R.S., Cloem, J.E., Sofer, Z., Smith, R.L., Miller, L.G., Cole, B., and others, 1988a, Microbial and biogeochemical processes in Big Soda Lake, Nevada, in Fleet, A., Kelts, K., and Talbot, M., eds., Lacustrine petroleum source rocks: Geological Society of London Special Publication 40, p. 59-75.

Oremland, R.S., and Des Marais, D.J., 1983, Distribution, abundance and carbon isotopic composition of gaseous hydrocarbons in Big Soda Lake, Nevada-An alkaline, meromictic lake: Geochimica et Cosmochimica Acta, v. 47, p. 2107-2114.

Oremland, R.S., and King, G.M., 1989, Methanogenesis in hypersaline environments, in Cohen, Y., and Rosenberg, E., eds., Microbial mats-Physiological ecology of benthic microbial communities: Washington, D.C., American Society for Microbiology, p. 180-190.

Oremland, R.S., Marsh, L., and Des Marais, D.J., 1982, Methanogenesis in Big Soda Lake, Nevada-An alkaline, moderately hypersaline desert lake: Applied and Environmental Microbiology, v. 43, p. 462-468.

Oremland, R.S., Miller, L.G., Culbertson, C.W., Robinson, S., Smith, R.L., and others, 1993, Aspects of the biogeochemistry of methane in Mono Lake and the Mono Basin of California, in Oremland, R.S., ed., Biogeochemistry of global change-Radioactively active trace gases: New York, Chapman and Hall, p. 704-741.

Oremland, R.S., Miller, L.G., and Whiticar, M.J., 1987, Sources and flux of natural gases from Mono Lake, California: Geochimica et Cosmochimica Acta, v. 51, p. 2915-2929.

Oremland, R.S., and Polcin, S., 1982, Methanogenesis and sulfate reduction-Competitive and non-competitive substrates in estuarine sediments: Applied and Environmental Microbiology, v. 44, p. 1270-1276.

Oremland, R.S., Whiticar, M.J., Strohmaier, F.E., and Kiene, R.P., 1988b, Bacterial ethane formation from reduced, ethylated sulfur compounds in anoxic sediments: Geochimica et Cosmochimica Acta, v. 52, p. 1895-1904.

Peng, T-H., and Broecker, W., 1980, Gas exchange rates for three closed-basin lakes: Limnology and Oceanography, v. 25, p. 789-796.

Priscu, J.C., Axler, R.P., Carlton, R.G., Reuter, J.E., Arneson, P.A., and Goldman, C.R., 1982, Vertical profiles of primary productivity, biomass, and physicoGuttierchemical properties in meromictic Big Soda Lake, Nevada, U.S.A.: Hydrobiologia, v. 96, p. 113-120.

Sackett, W.M., Brooks, J.M., Bernard, B.B., Scwab, C.R.S., and Chung, H., 1979, A carbon inventory for Orca brines and sediments: Earth and Planetary Science Letters, v. 44, p. 73-81.

Sanchez, A.L., Murray, J.W., Schell, W.R., and Miller, L.G., 1986, Fallout plutonium in two oxic-anoxic environments: Limnology and Oceanography, v. 31, p. 1110-1121.

Schoell, M., 1983, Genetic characterization of natural gases: American Association of Petroleum Geologists Bulletin, v. 67 , p. $2225-2238$. 
Silverman, M.P., and Oyama, V.I., 1968, Automatic apparatus for sampling and preparing gases for mass spectral studies of carbon isotope fractionation during methane metabolism: Analytical Chemistry, v. 40, p. 1883-1877.

Smith, J.W., and Robb, W.A., 1973, Aragonite and the genesis of carbonates in Mahogany zone oil shales of Colorado's Green River Formation: U.S. Bureau of Mines Report 7727, $21 \mathrm{p}$.

Smith, R.L., and Oremland, R.S., 1987, Big Soda Lake (Nevada). 2. Pelagic sulfate reduction: Limnology and Oceanography, v. 32, p. 794-803.

Tissot, B.P., Deroo, G., and Gooda, A., 1978, Geochemical study of the Uinta Basin-Formation of petroleum from the Green River Formation: Geochimica et Cosmochimica Acta, v. 42, p. 1469-1486.

Tuttle, M.L., and Goldhaber, M.B., in press, Sedimentary sulfur geochemistry of the paleogene Green River Formation, western United States; Implications for interpreting depositional and diagenetic processes in saline alkaline lakes: Geochimica et Cosmochimica Acta.

Vogel, T.M., Oremland, R.S., and Kvenvolden, K.A., 1982, Low temperature formation of hydrocarbon gases in San Francisco Bay sediment (California, USA): Chemical Geology, v. 37, p. $289-298$.

Walker, K.F, 1974, The stability of meromictic lakes in central Washington: Limnology and Oceanography, v. 19, p. 209222.

1975, The seasonal phytoplankton cycles of two saline lakes in central Washington: Limnology and Oceanography, v. 20 , p. $40-53$

Ward, D.M., and Winfrey, M.R., 1985, Interactions between methanogenic and sulfate-reducing bacteria in sediments: Advances in Aquatic Microbiology, v. 3, p. 141-179.
Welhan, J.A., and Craig, H., 1979, Methane and hydrogen in East Pacific Rise hydrothermal fluids: Geophysical Research Letters, v. 6, p. 829-831.

Whelan, J.K., Oremland, R.S., Tarafa, M., Smith, R.L., Howarth, R., and Lee, C., 1986, Evidence for sulfate reducing and methane producing microorganisms from sites 618,619 , and 622, in Buoma, A., and others eds., Initial reports of the Deep Sea Drilling Project, v. 96: Washington, D.C., U.S. Government Printing Office, p. 767-775.

Whiticar, M.J., Faber, E., and Schoell, M., 1986, Biogenic methane formation in marine and freshwater environments $-\mathrm{CO}_{2}$ reduction vs. acetate fermentation-isotope evidence: Geochimica et Cosmochimica Acta, v. 50, p. 693-709.

Whittenbury, R., Phillips, K.C., and Wilkenson, J.F., 1970, Enrichment, isolation, and some properties of methane-utilizing bacteria: Journal of General Microbiology, v. 61, p. 205-218.

Winfrey, M.R., 1984, Microbial production of methane, in Atlas, R.M., ed., Petroleum microbiology: New York, Macmillan, p. 153-219.

Woese, C.R., and Fox, G.E., 1977, Phylogenetic structure of the prokaryotic domain-The primary kingdoms: Proceedings of the National Academy of Sciences, U.S.A., v. 74, p. 5088 5090 .

Wolfe, R.S, 1971, Microbial formation of methane: Advances in Microbial Physiology, v. 6, p. 107-146.

1992, Biochemistry of methanogenesis, in Danson, M., Hought, D., and Lunt, G., eds., The Archaebacteria-Biochemistry and biotechnology: Biochemical Society Symposium 58, Portland Press, London, p. 41-50.

Zehr, J.P., Harvey, R.W., Oremland, R.S., Cloem, J.E., George, L.H., and Lane, J.L., 1987, Big Soda Lake (Nevada). 1. Pelagic bacterial heterotrophy and biomass: Limnology and Oceanography, v. 32, p. 781-793. 


\title{
A Comparison of Hydrocarbon Gases from Natural Sources in the Northwestern United States
}

\author{
By Thomas D. Lorenson ${ }^{1}$ and Keith A. Kvenvolden ${ }^{1}$
}

\section{CONTENTS}

\begin{tabular}{|c|c|}
\hline \\
\hline oduction .. & 454 \\
\hline Sampling Techniques and Methods of Analysis .......... & 454 \\
\hline Results and Discussion ....................... & \\
\hline 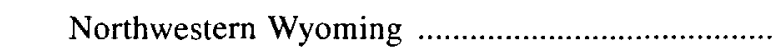 & \\
\hline Yellowstone National Park & \\
\hline Cody, Wyoming, Area ......... & \\
\hline Rattlesnake Mountain Anticline & \\
\hline Absaroka Range & \\
\hline Grand Teton National Park and Vicinity & \\
\hline Teton-Bridger Wilderness & 4 \\
\hline Wind River Range .......... & \\
\hline Overthrust Belt in Wyoming & 46 \\
\hline The Northwestern Great Basin and the & \\
\hline Olympic-Wallowa Lineament & \\
\hline The Cascade Volcanoes of Northem California .... & \\
\hline Southwestern Oregon & \\
\hline Northwestern Washington & \\
\hline nmary & \\
\hline (n) & \\
\hline
\end{tabular}

\begin{abstract}
The northwestern United States hosts a remarkable quantity and variety of thermal springs, seeps, and other natural-gas sources. Although many studies have dealt with the liquids and nonhydrocarbon gases emanating from

'U.S. Geological Survey, MS 999, 345 Middlefield Rd., Menlo Park, CA 94025.
\end{abstract}

these sources, few have focused on hydrocarbon gases. Of these gases, methane in particular is now recognized as an important reactive trace gas in the Earth's atmosphere that plays a significant role in global warming because of its greenhouse properties. To understand better the magnitude and occurrence of emissions of hydrocarbons from natural sources to the atmosphere, we have begun a survey of these gases throughout the northwestern United States. This area encompasses a number of different tectonic provinces: the Yellowstone hot spot, the northern Basin and Range Province, the Cascade volcanic arc, and the Cascadia subduction complex. Each province hosts springs and seeps with some unique compositions owing to the geological processes operating there. Methane is present in each area at concentration levels ranging from about 2 parts per million by volume (ppm-v) to 95.6 percent (by volume). Hydrothermal activity in the Yellowstone area produces spring gases containing less than 4 percent methane, with carbon dioxide as the balance gas. The Grand Teton National Park area, immediately to the south, has a wide variety of gas compositions with either methane, carbon dioxide, or nitrogen as the primary gas component. Where methane is abundant, higher molecular weight hydrocarbon gases (ethane, ethene, propane, propene, isobutane, and $n$ butane) are also found in ppm-v concentrations. In the northern Great Basin, thermal springs and seeps typically occur along fault zones at the base of mountain ranges. Methane concentrations range from 0.2 to 47 percent, with higher molecular weight hydrocarbon concentrations from 0 to 3,100 ppm-v. Areas covered by the Cenozoic Columbia River Basalt Group and the basalts of the Snake River Plain continue to have high heat flow and produce thermal springs and seeps, often located along fault zones. The compositions and concentrations of hydrocarbon gases from these areas are similar to those of gases from the 
northern Great Basin. Gases from the southern Cascade volcanic arc (Mount Shasta and Mount Lassen) are composed typically of carbon dioxide, with minor amounts of methane (less than 1.2 percent); however, some fumaroles at Mount Lassen have minor quantities of higher molecular weight hydrocarbon gases. Along the Pacific coast, melanges of the Cascadia subduction complex host many seeps and springs. In some seeps the gas consists almost exclusively of methane ( 94.3 to 99.9 percent, normalized to total hydrocarbon gases) with amounts of higher molecular weight hydrocarbon gases ranging from about $5 \mathrm{ppm}$ $\mathrm{v}$ to 3.5 percent. In southwestern Oregon, melanges and forearc basinal turbidites and deltaic sandstones with lowgrade coal seams contribute methane and some higher molecular weight hydrocarbon gases to the headspace of shallow water wells and exploration wells. Methane and some higher molecular weight hydrocarbon gases are emitted directly into the atmosphere by passive diffusion from outcrops. Methane concentrations from the wells range from $27 \mathrm{ppm}-\mathrm{v}$ to 95.6 percent, and higher molecular weight hydrocarbon concentrations range from not detectable to $119 \mathrm{ppm}-\mathrm{v}$. In each of the tectonic provinces, the different gas compositions reflect the different processes involved in gas generation.

\section{INTRODUCTION}

Seeps of natural gas rich in methane are often observed at the surface of the Earth. These seeps provide samples from which subsurface processes of gas generation can be inferred. Gas generation and subsequent release can have important effects on the global budget of methane, an important greenhouse gas. In addition, gas seeps rich in hydrocarbons can be a useful exploration tool for location of new oil and gas prospects. We have observed that natural-gas seepage takes many forms, from familiar fumaroles to more usual (or at least less obvious) manifestations, including gas leakage from shallow water wells and from rock outcrops. We can readily measure the gas composition of each of these gas sources, but measuring flux rates is much more difficult. Only rarely have we attempted to measure gas fluxes, and we do not address this issue in a quantitative way because of the paucity of observations. From the perspective of methane and higher molecular weight hydrocarbon contributions to the atmosphere, flux is an important issue. From the exploration angle, however, the relative concentration of gases above background levels is important because this kind of information can lead to identifying potential subsurface petroleum occurrence.

The purpose of this study is to document the variety, nature, and geologic settings of natural-gas seeps in the northwestern United States. This is a continuing endeavor, and thus, the report represents our results up to this junc- ture. At this point we have studied four distinct geologic areas: (1) magma and associated hot fluids of an intercontinental hot spot rising through organic-rich sedimentary rocks in and near Yellowstone National Park, Wyoming; (2) areas of large-scale crustal extension and thinning in the Great Basin, where organic-rich sediments rapidly sink in basins and come in contact with thermal fluids; (3) deep subduction zones whose processes are manifested as gases arising from the Cascade volcanoes of northern California; and (4) two locations along the Pacific Ocean where subduction complexes and related sedimentary forearc basins have been accreted. In each of these settings sampling sites were located by one of two means: (1) use of published maps of geothermal resources in each state, denoting natural thermal springs and thermal wells; and (2) use of guides who have worked in particular areas and have noted features such as gassy springs, seeps, and domestic wells. Thus far only a small fraction of known sample sites have been sampled by us, and much remains to be done.

This study focuses on the hydrocarbon gases, mainly methane $\left(C_{1}\right)$, and its saturated and unsaturated homologs, ethane $\left(C_{2}\right)$, ethene $\left(C_{2: 1}\right)$, propane $\left(C_{3}\right)$, propene $\left(C_{3: 1}\right)$, isobutane $\left(i-\mathrm{C}_{4}\right)$, normal butane $\left(n-\mathrm{C}_{4}\right)$, and pentane $\left(\mathrm{C}_{5}\right)$, together referred to as higher molecular weight hydrocarbons. No provisions were taken to correct for the very low solubilities of the hydrocarbon gases in water. Thus, our results represent the composition of the gas phase in the sample bottle at the time of sampling. These concentrations approximate the compositions of the natural seep gases.

\section{SAMPLING TECHNIQUES AND METHODS OF ANALYSIS}

Field sampling of spring and seep gases involved identifying trains of bubbles rising through water and then trapping the gas in glass containers. Gas samples were collected by water displacement in 350 - and $250-\mathrm{mL}$ glass bottles equipped with spring-loaded rubber and ceramic stoppers (Kvenvolden and Pettinga, 1989). Serum vials (100-mL glass bottles) capped with teflon-coated silicone crimp seals were also used. The sample bottles were filled with water from the seep site (natural spring water or river water) and inverted so that the mouth of the bottle was submerged. Gas was directed into the bottles by two different means. At exceptionally slow-bubbling sites (less than about $5 \mathrm{~mL} / \mathrm{min}$ ), a water-filled plastic 40 -liter trash bag was anchored over the gas seep and allowed to fill with gas over a period of 1 to 4 hours. With the bag still under water, a small hole was pierced in the corner, allowing the gas to escape into an inverted collecting funnel and finally into the sample bottle. At seeps with sufficient gas flow, an inverted funnel with plastic tubing was submerged in water and used to divert the bubbles directly into the sample bottle. Wherever the water was too shal- 
low, a water-filled bucket was used as a substitute. After the gas had filled the sample bottle, $1 \mathrm{~mL}$ of the bactericide Zephrine Chloride (1:750) was injected into the interior neck of the bottle, and then the bottle was sealed, leaving a small amount of sterilized water in the bottle to enhance the seal against leakage. The samples were stored in an inverted position at room temperature until analyzed.

In southwestern Oregon, we concentrated on sampling gases from shallow private water wells and source-rock outcrops, as well as gases released by breaking up source rocks to allow the escape of adsorbed gases. In the first two cases, we used gas-sampling bags made of three laminated layers: an inert polyethylene liner, an impervious aluminum layer to prevent diffusion of gases through the bag, and a polyester outer coating. The bags are filled inside a sealed canister capable of holding a light vacuum, thus allowing sample gas to be drawn into the bag. They are equipped with septa, which allow insertion of a needle and withdrawal of sample gas without exposure to the atmosphere. Typically, water wells are equipped with a capped vent port from which we collected most of our gas samples. In wells that did not have a vent cap, the gases were in direct contact with the atmosphere. In both cases, however, the sampled gas was mixed with the atmosphere. Because hydrocarbon gases have low solubilities in water, we assume that nearly all of the hydrocarbon gases are released into the headspace of the well and that the ratios of the hydrocarbon gases collected reflect their ratios in nature. The amount of air contamination of the well headspace was not determined, and thus we consider the reported concentrations of the gases to be the minimum amount present.

When sampling rock outcrops, we focused on joints or other natural fractures in the rock. Each location was widened by digging out debris with a rock pick. A gas sample was taken within $1 \mathrm{~cm}$ of the fresh, exposed rock with either a gas-tight syringe or a gas bag. Severe air contamination was unavoidable, so the reported concentrations are much less than minimum concentrations leaking from the outcrop.

To sample gas from nonweathered source rocks, we broke the rock sample into small pieces and immediately placed them into a septa-equipped, friction-sealed paint can. The headspace was purged with helium for 5 minutes, and then the adsorbed gases were allowed to collect in the headspace. We emphasize that not all of the gas in the source rock is extracted, and the concentration of the gas is not absolute. Nevertheless the ratios of hydrocarbon gases measured should reflect a reasonable estimate of the proportions of gases that are leaking into the atmosphere from these rocks exposed on the surface of the Earth.

The samples were analyzed at three U.S. Geological Survey (USGS) laboratories (Palo Alto, Calif.; Menlo Park, Calif.; and Denver, Colo.) and at the petroleum geochemistry laboratory at Oregon State University (Corvallis, Oreg.).
Gas chromatography was used to analyze the gases. The results are reported as parts per million by volume (ppm-v) and as percent (by volume) of the total gas mixture (tables 1-3) and of the total hydrocarbons (table 4). In addition, the gas wetness ratio $\left(\mathrm{C}_{1} / \mathrm{C}_{2}\right)$ and the isotopic composition of methane and carbon dioxide were also determined. Isotopic compositions of methane and carbon dioxide were determined by mass spectrometry at three laboratories: the USGS petroleum lab in Denver Colo.; BRG in Hanover, Germany; and Global Geochemistry Corp., Canoga Park, Calif. Results are reported in the $\delta$ (permil) notation relative to the Peedee belemnite (PDB) standard:

$\delta^{13} \mathrm{C}($ permil $)=\left(\mathrm{R}_{\text {sample }} / \mathrm{R}_{\text {standard }}-1\right) \times 10^{-3}$, where $\mathrm{R}={ }^{13} \mathrm{C} /{ }^{12} \mathrm{C}$ and relative to Standard Mean Ocean Water (SMOW):

$$
\delta \mathrm{D}(\text { permil })=\left(\mathrm{R}_{\text {sample }} / \mathrm{R}_{\text {standard }}-1\right) \times 10^{-3} \text {, where } \mathrm{R}=\mathrm{D} / \mathrm{H}
$$

\section{RESULTS AND DISCUSSION}

Because the sampled seeps occur in a large region in the northwestern United States, and in many geologic provinces, we will discuss the composition and origins of these gases within the context of five geographic areas as shown in figure 1 . The specific locations of sample sites are shown in figures 2 through 6 .

Each of the five geographic areas are discussed separately from east to west, and data from each area are presented in corresponding tables, where they are listed from east to west. Hydrocarbon compositions - and in some instances the isotopic composition of methane, ethane, and carbon dioxide-are listed in tables 1 through 4 . The data

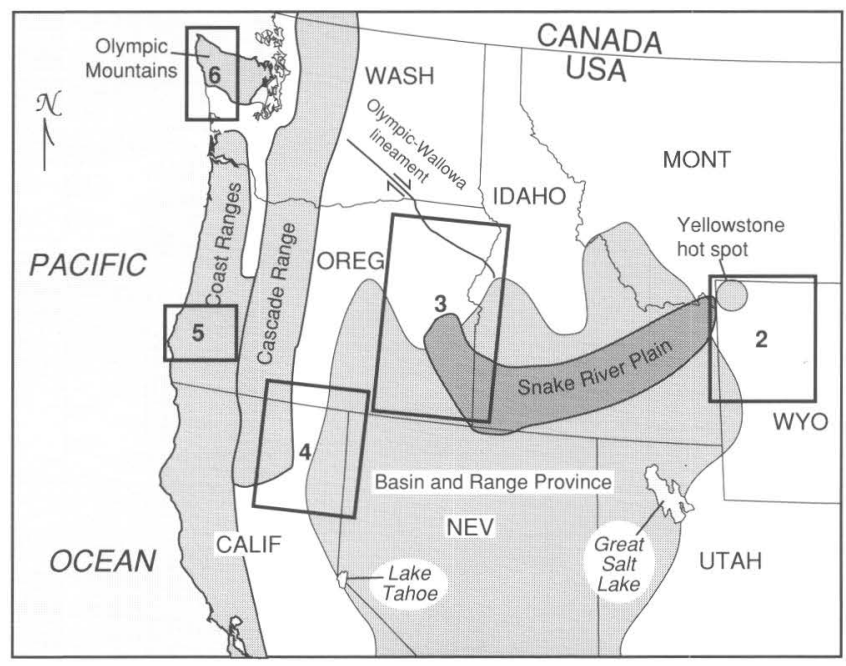

Figure 1. The study areas in the northwestern United States. Geologic provinces are generalized. Numbered boxes show areas of figures 2 through 6 . 
in tables 1 through 3 are concentrations of hydrocarbon gas in the total gas mixture. The data in table 4 are gas concentrations relative to total hydrocarbon gases present. Many of the gas analyses include permanent gas concentrations, which are reported elsewhere as cited. Cross plots of these isotopic compositions developed by Schoell (1980) and Whiticar and others (1986) are shown in figures 7 and 8 . Such views of isotopic composition help constrain the origins of the gases in question.

\section{NORTHWESTERN WYOMING}

In northwestern Wyoming gas seeps are common in and around Yellowstone and Grand Teton National Parks. Yellowstone National Park, in particular, has numerous gas seeps manifest as bubbling hot springs. A number of previous studies have provided information on gas compositions (Gunter and Musgrave, 1966, 1971; Gunter, 1978; Nehring and Truesdell, 1978; Des Marais and others, 1981; Truesdell and Thompson, 1982). Outside Yellowstone National Park, there apparently has been less interest in gas-seep compositions. A preliminary report by Kven-

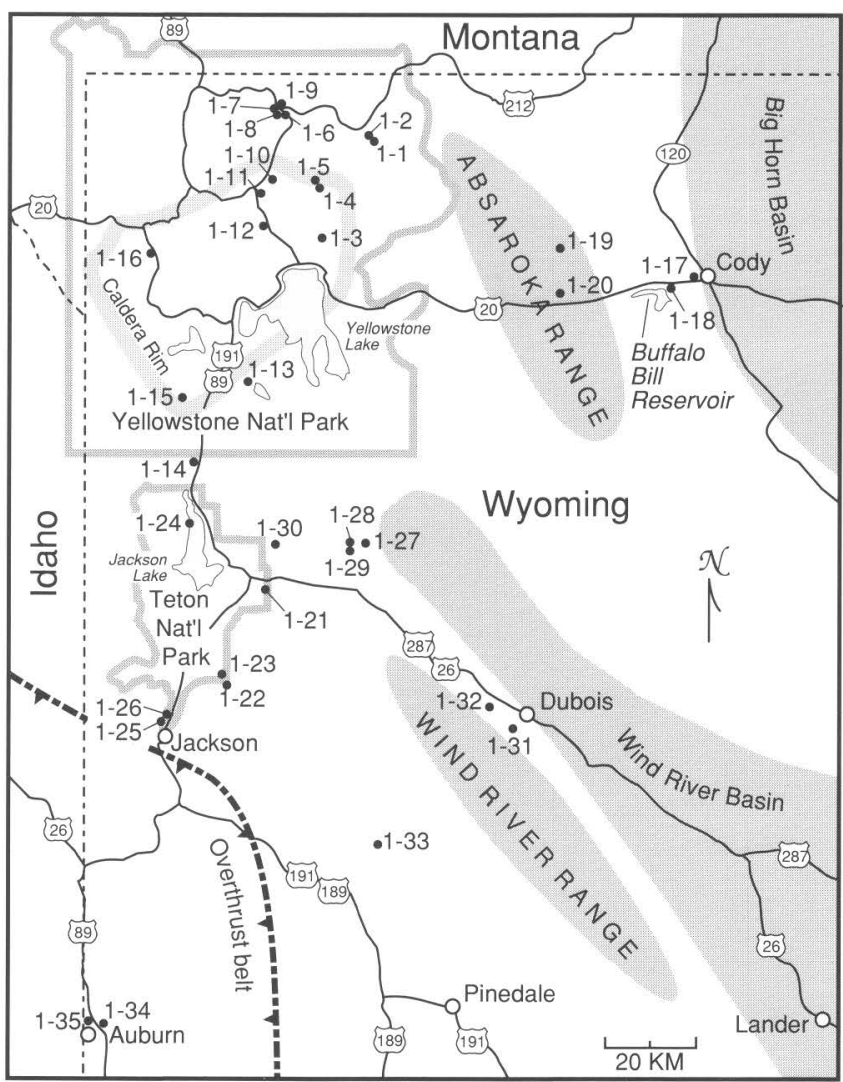

Figure 2. Sample locations in northwestern Wyoming. Prefix "1-" in sample site number indicates that analysis of sample is reported in table 1 (sample numbers are listed without prefix in table). volden and others (1989b) compared the molecular and isotopic compositions of 10 gas seeps sampled in 1988: 2 in Yellowstone National Park, 7 in Grand Teton National Park, and 1 outside the national park boundaries. That report demonstrated that compositions of seep gases in Yellowstone National Park are dominated by $\mathrm{CO}_{2}$, whereas in the Grand Teton National Park, $\mathrm{C}_{1}$ and $\mathrm{N}_{2}$ are the principal gases. Concentrations of the higher molecular weight hydrocarbon gases in both areas are highly variable.

In order to expand our understanding of the compositions of naturally occurring gas in seeps in northwestern Wyoming, Lorenson and others (1991) resampled in 1989 and 1990 most of the sites visited in 1988 by Kvenvolden and others (1989b). Additional samples were obtained in the Teton-Bridger Wilderness area and in the area between Yellowstone National Park and the city of Cody, Wyoming

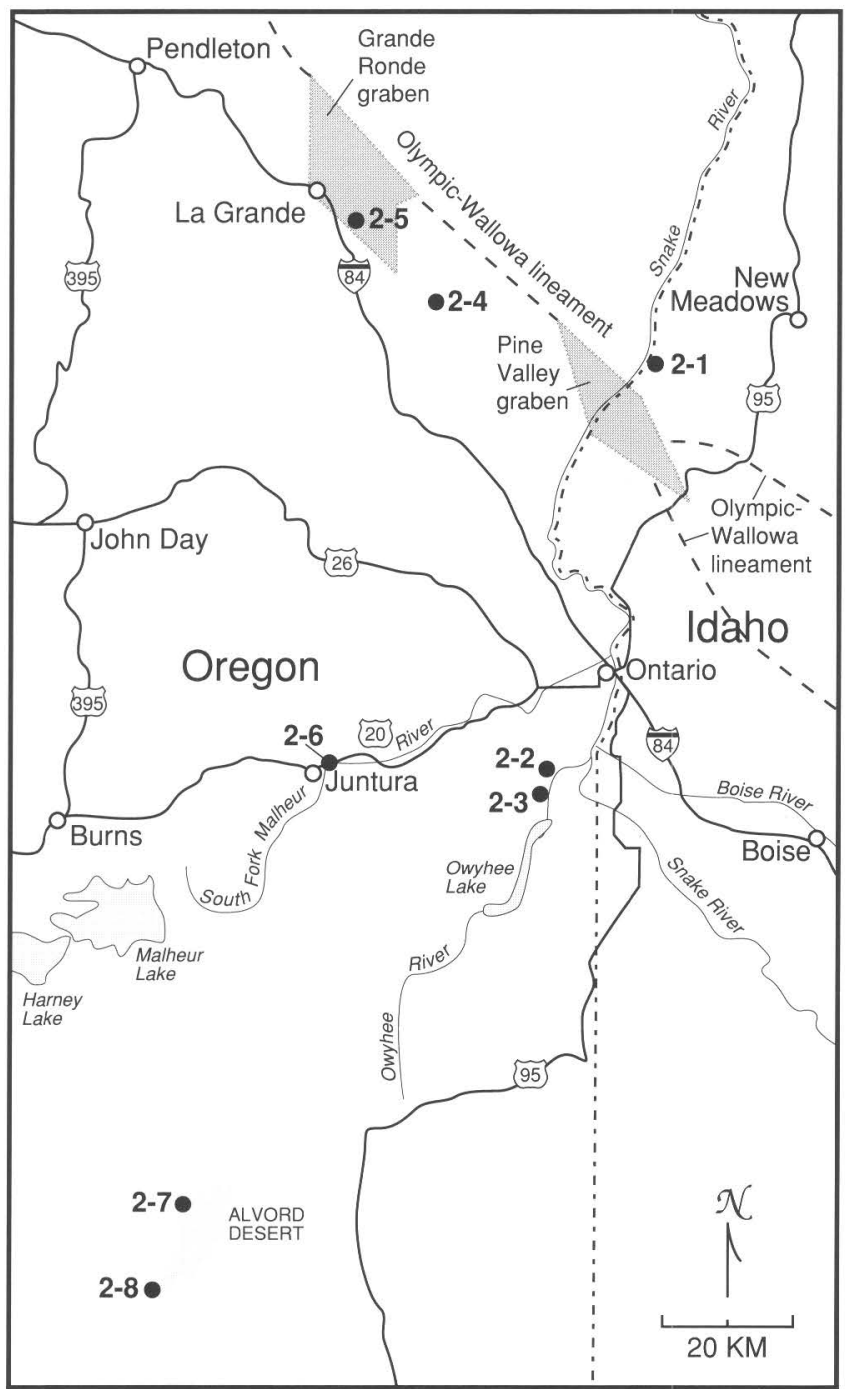

Figure 3. Sample locations in Idaho and eastern Oregon. Prefix "2-" in sample site number indicates that analysis of sample is reported in table 2 (sample numbers are listed without prefix in table). 
(fig. 2). In all we sampled seeps in six geographic areas: (1) Yellowstone National Park; (2) the Cody, Wyo., area, which includes the Rattlesnake Mountain Anticline and the Absaroka Range; (3) Teton National Park and vicinity; (4) Teton-Bridger Wilderness at the northwest end of the Washakie Range (Love and Christiansen, 1985) along the North Buffalo Fork Thrust Fault; (5) uplifted Paleozoic rocks along the margins of the Wind River Range; and (6)

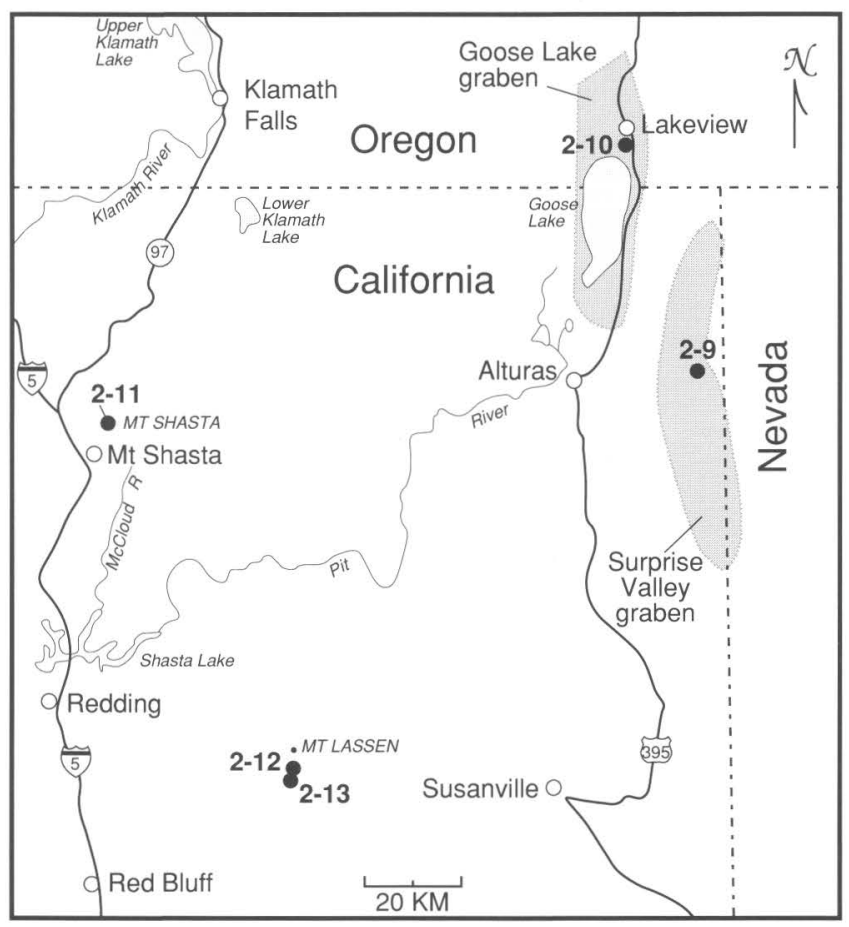

Figure 4. Sample locations in south-central Oregon and northern California. Prefix "2-" in sample site number indicates that analysis of sample is reported in table 2 (sample numbers are listed without prefix in table).

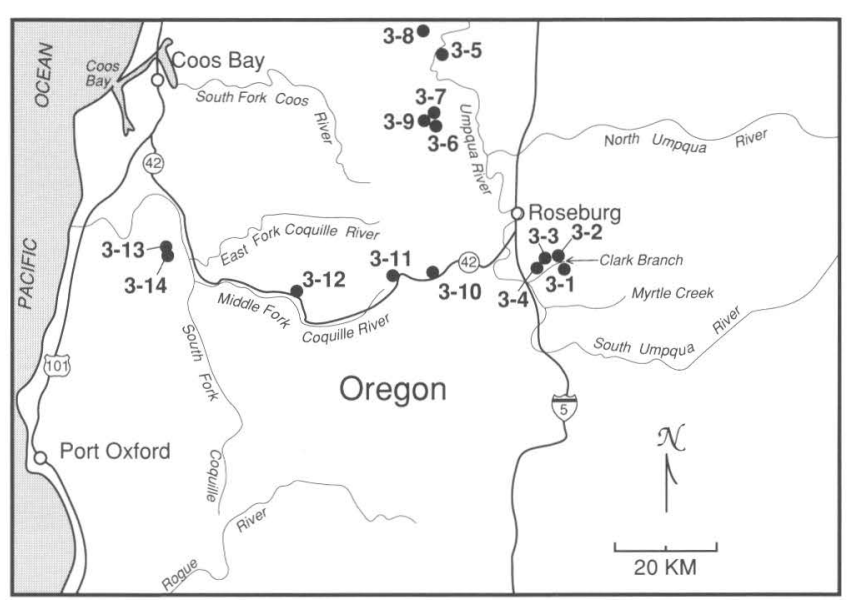

Figure 5. Sample locations in southwestern Oregon. Prefix "3-" in sample site number indicates that analysis of sample is reported in table 3 (sample numbers are listed without prefix in table). the overthrust belt in Wyoming. Sample sites are shown in figure 2, and our results are reported in table 1 .

\section{YELLOWSTONE NATIONAL PARK (SAMPLE SITES 1-1 THROUGH 1-16)}

Yellowstone National Park and the Absaroka Range to the east are located in a region of Tertiary volcanic activity. The evolution of the Yellowstone volcanic province has been discussed by Smith and Christiansen (1980) and Smith and Braile (1982). Volcanic rocks as old as early Eocene cover Paleozoic and Mesozoic strata that were folded, uplifted, and eroded during the Cretaceous Laramide Orogeny. Small packages of the pre-Tertiary rocks are inferred by

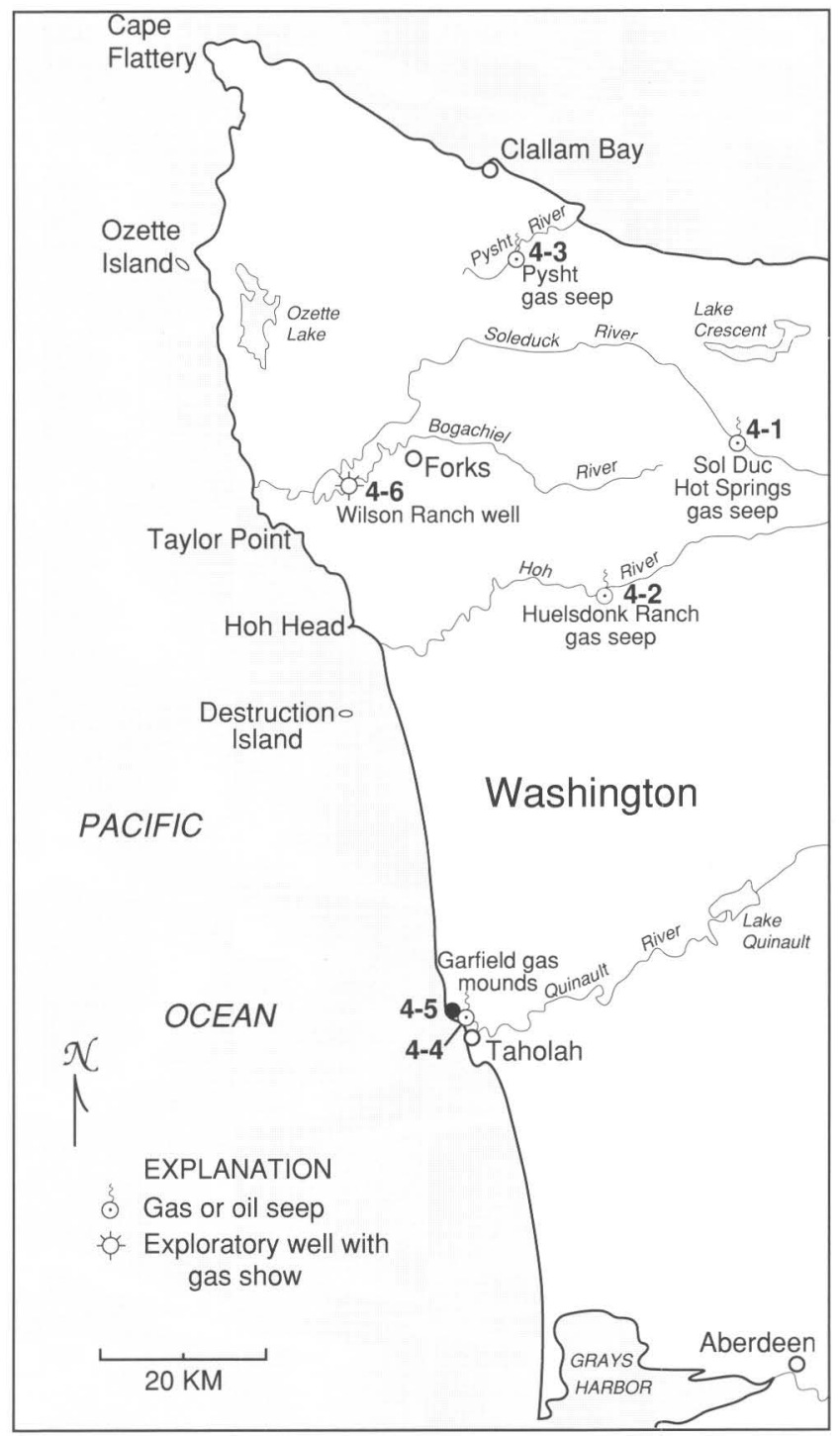

Figure 6. Sample locations in northwestern Washington. Prefix "4-" in sample site number indicates that analysis of sample is reported in table 4 (sample numbers are listed without prefix in table). 
Table 1. Composition of hydrocarbon gas from northwestern Wyoming.

[nd, none detected; ppm-v, parts per million by volume; --., not determined]

\begin{tabular}{|c|c|c|c|c|c|c|c|}
\hline Figure & Sample No. & Name of sample site & Sample date & $\begin{array}{l}\text { Latitude } \\
\text { (N.) }\end{array}$ & $\begin{array}{l}\text { Longitude } \\
\text { (W.) }\end{array}$ & $\begin{array}{c}\text { Methane } \\
(\mathrm{ppm}-\mathrm{v})\end{array}$ & $\begin{array}{l}\text { Ethane } \\
(\mathrm{ppm}-\mathrm{v})\end{array}$ \\
\hline & & & & & \multicolumn{3}{|c|}{ Yellowstone } \\
\hline 2 & 1 & Wahb Springs & Jul-90 & $44^{\circ} 49.75$ & $110^{\circ} 06.90$ & 2040.00 & 41.70 \\
\hline 2 & 2 & Putrified Forest & Jul-90 & $44^{\circ} 50.48$ & $110^{\circ} 09.81$ & 27870.00 & 1141.40 \\
\hline 2 & 3 & The Mushpots, south area & Mar-91 & $44^{\circ} 38.03$ & $110^{\circ} 13.38$ & 7590.00 & 126.20 \\
\hline 2 & 3 & The Mushpots, north area & Mar-91 & $44^{\circ} 38.50$ & $110^{\circ} 13.45$ & 12180.00 & 118.20 \\
\hline 2 & 4 & Hot Spring Basin, site A, south area & Oct-90 & $44^{\circ} 44.63$ & $110^{\circ} 14.95$ & 1490.00 & 24.62 \\
\hline 2 & 4 & Hot Spring Basin, site C, northwest area & Oct-90 & $44^{\circ} 45.11$ & $110^{\circ} 15.60$ & 11140.00 & 301.30 \\
\hline 2 & 4 & Hot Spring Basin, site B, southwest area & Oct-90 & $44^{\circ} 44.06$ & $110^{\circ} 15.61$ & 11800.00 & 128.11 \\
\hline 2 & 5 & Rainbow Springs & Oct -90 & $44^{\circ} 46.14$ & $110^{\circ} 16.25$ & 39680.00 & 2225.00 \\
\hline 2 & 6 & Tower Falls South & Jul-90 & $44^{\circ} 53.71$ & $110^{\circ} 22.60$ & 30900.00 & 1271.24 \\
\hline 2 & 7 & Calcite Springs south vent, site 1 & Jul- 89 & $44^{\circ} 54.28$ & $110^{\circ} 23.67$ & 89.70 & 2.26 \\
\hline 2 & 7 & Calcite Springs south vent, site 2 & Jul-90 & $44^{\circ} 54.28$ & $110^{\circ} 23.67$ & 920.00 & 29.88 \\
\hline 2 & 7 & Calcite Springs north vent & Jul-89 & $44^{\circ} 54.36$ & $110^{\circ} 23.70$ & 39.00 & nd \\
\hline 2 & 7 & Calcite Springs middle vent & Jun-88 & $44^{\circ} 54.31$ & $110^{\circ} 23.73$ & 5800.00 & 36.00 \\
\hline 2 & 7 & Calcite Springs middle vent & Jul-90 & $44^{\circ} 54.31$ & $110^{\circ} 23.73$ & 375.00 & 105.53 \\
\hline 2 & 8 & Rainy Lake & Jul-90 & $44^{\circ} 54.53$ & $110^{\circ} 24.11$ & 3000.00 & 93.00 \\
\hline 2 & 9 & Tower Bridge SE (site 1) & Jul-90 & $44^{\circ} 55.18$ & $110^{\circ} 24.22$ & 6320.00 & 60.95 \\
\hline 2 & 9 & Tower Bridge NW (site 2) & Jul-90 & $44^{\circ} 55.28$ & $110^{\circ} 24.30$ & 7130.00 & 67.95 \\
\hline 2 & 10 & Washburn Hot Springs & Jul-89 & $44^{\circ} 45.90$ & $110^{\circ} 25.75$ & 3600.00 & 62.00 \\
\hline 2 & 10 & Jade Hot Springs (vent) & Jul-89 & $44^{\circ} 45.57$ & $110^{\circ} 26.25$ & 3230.00 & 58.45 \\
\hline 2 & 11 & Clear Lake & Aug-90 & $44^{\circ} 42.84$ & $110^{\circ} 28.70$ & 1110.00 & 5.43 \\
\hline 2 & 12 & Sulphur Springs & Aug-90 & $44^{\circ} 39.34$ & $110^{\circ} 28.96$ & 680.00 & 0.06 \\
\hline 2 & 13 & Witch Creek, Heart Geyser Basin & Oct- 90 & $44^{\circ} 17.34$ & $110^{\circ} 31.02$ & 39900.00 & 113.00 \\
\hline 2 & 14 & Huckleberry Hot Springs & Jul-90 & $44^{\circ} 06.90$ & $110^{\circ} 41.00$ & 10.77 & \\
\hline 2 & 15 & Phantom Fumarole & Aug-90 & $44^{\circ} 14.42$ & $110^{\circ} 43.43$ & 750.00 & 1.31 \\
\hline \multirow[t]{2}{*}{2} & 16 & Firehole River, northern Lower Geyser Basin & Aug-90 & $44^{\circ} 37.20$ & $110^{\circ} 51.71$ & 32780.00 & 227.70 \\
\hline & & & & & \multicolumn{2}{|c|}{ Cody, } & Wyo., \\
\hline 2 & 17 & De Maris Hot Springs, east vent & Jul-89 & $44^{\circ} 30.58$ & $109^{\circ} 06.58$ & 2690.00 & 100.80 \\
\hline 2 & 17 & De Maris Hot Springs, east vent & Jul-90 & $44^{\circ} 30.58$ & $109^{\circ} 06.58$ & 3070.00 & 101.58 \\
\hline 2 & 17 & De Maris Hot Springs, east vent & Jul-89 & $44^{\circ} 30.56$ & $109^{\circ} 06.60$ & 2410.00 & 90.95 \\
\hline 2 & 17 & De Maris Hot Springs, middle vent & Jul-90 & $44^{\circ} 30.56$ & $109^{\circ} 06.60$ & 3130.00 & 117.36 \\
\hline 2 & 17 & De Maris Hot Springs, west vent & Jul-89 & $44^{\circ} 30.54$ & $109^{\circ} 06.66$ & 1360.00 & 58.50 \\
\hline 2 & 17 & De Maris Hot Springs, west vent & Jul-90 & $44^{\circ} 30.54$ & $109^{\circ} 06.66$ & 1590.00 & 65.80 \\
\hline 2 & 17 & De Maris Hot Springs, westernmost vent & Jul-90 & $44^{\circ} 30.53$ & $109^{\circ} 06.69$ & 770.00 & 32.98 \\
\hline 2 & 18 & Cedar Mountain vent & Jul-90 & $44^{\circ} 29.73$ & $109^{\circ} 11.61$ & 650.00 & 7.56 \\
\hline 2 & 19 & Sulphur Lake & Jul- 89 & $44^{\circ} 40.32$ & $109^{\circ} 37.13$ & 1060.00 & nd \\
\hline 2 & 20 & Sweetwater Mineral Springs & Jun-88 & $44^{\circ} 30.25$ & $109^{\circ} 39.02$ & 6700.00 & 126.00 \\
\hline 2 & 20 & Sweetwater Mineral Springs & Jul-89 & $44^{\circ} 30.25$ & $109^{\circ} 39.02$ & 5400.00 & 121.80 \\
\hline 2 & 20 & Sweetwater Mineral Springs & Jul-90 & $44^{\circ} 30.25$ & $109^{\circ} 39.02$ & 5860.00 & 113.40 \\
\hline
\end{tabular}

seismic data (Lehman and others, 1986; Smith and Braile, 1982), stratigraphic interpolations (Tonnsen, 1982), and regional mapping (Prostka and others, 1975) to underlie volcanic rocks in the north section of the park. Buried prevolcanic sedimentary rocks may act as a hydrocarbon source for gases and petroleum found in springs hosted by volcanic rock.

Carbon dioxide is by far the dominant gas in the sampled seeps of Yellowstone National Park. Abundances vary from nearly 97 percent at Calcite Springs to 80 percent at Jade Hot Springs (Lorenson and others, 1991). These amounts are typical of hydrothermal areas (White, 1957; Lyon and Hulston, 1984). Methane, although much less important in total volume of gas released from Yellowstone seeps and fumaroles, is ubiquitous. Methane concentration ranged from $10.8 \mathrm{ppm}-\mathrm{v}$ at Huckleberry Hot Springs to about 4 percent at two separate locations: Witch Creek and Rainbow Springs. Rainbow Springs is a known locality of petroleum seepage and was described by Love and Good (1970), and the oil has been analyzed by Clifton and others (1990). Higher molecular weight hydrocarbon gases can also be found in relative abundance throughout the park. Maximum concentrations were found at Rainbow Springs.

The isotopic composition of gases from the park are plotted in figures 7 and 8 . It is interesting to note (fig. 7) 


\begin{tabular}{|c|c|c|c|c|c|c|c|c|c|c|}
\hline $\begin{array}{c}\text { Ethene } \\
(\mathrm{ppm}-\mathrm{v})\end{array}$ & $\begin{array}{l}\text { Propane } \\
(\text { ppm-v) }\end{array}$ & $\begin{array}{l}\text { Propene } \\
\text { (ppm-v) }\end{array}$ & $\begin{array}{c}\text { Isobutane } \\
\text { (ppm-v) }\end{array}$ & $\begin{array}{r}n \text {-butane } \\
\text { (ppm-v) }\end{array}$ & $\begin{array}{c}\text { Pentanes } \\
\text { (ppm-v) }\end{array}$ & $\begin{array}{l}\text { Methane/Ethane } \\
\qquad\left(C_{1} / C_{2}\right)\end{array}$ & $\begin{array}{c}\delta^{13} \mathrm{C}\left(\mathrm{CH}_{4}\right) \\
\text { (permil) }\end{array}$ & $\begin{array}{c}\delta \mathrm{D}\left(\mathrm{CH}_{4}\right) \\
\text { (permil) }\end{array}$ & $\begin{array}{c}\delta^{13} \mathrm{C}\left(\mathrm{CO}_{2}\right) \\
\text { (permil) }\end{array}$ & $\begin{array}{c}\delta^{13} \mathrm{C}\left(\mathrm{C}_{2} \mathrm{H}_{6}\right) \\
\text { (permil) }\end{array}$ \\
\hline & \multicolumn{2}{|l|}{ National } & \multicolumn{2}{|c|}{ Park } & & & & & & \\
\hline nd & 8.74 & nd & 0.74 & 1.45 & yes & 49 & -59.2 & --- & -3.1 & --- \\
\hline nd & 448.63 & nd & 93.40 & 146.90 & yes & 24 & -32.4 & --- & -1.0 & --- \\
\hline nd & 10.22 & nd & 0.30 & 0.40 & yes & 60 & -30.3 & --- & -3.1 & --- \\
\hline nd & 7.78 & nd & 0.28 & 0.12 & yes & 103 & $\ldots$ & -.- & --- & --- \\
\hline nd & 14.57 & nd & 0.66 & 0.60 & yes & 61 & $\ldots$ & --- & --. & $\ldots$ \\
\hline nd & 80.38 & nd & 10.74 & 14.22 & yes & 37 & --- & $\cdots$ & --- & --- \\
\hline nd & 13.78 & nd & 0.73 & 0.52 & yes & 92 & -39.8 & --. & -3.8 & --- \\
\hline nd & 658.90 & nd & 59.80 & 119.70 & yes & 18 & -26.0 & -200.0 & -5.8 & --- \\
\hline nd & 471.40 & nd & 94.17 & 124.85 & yes & 24 & -32.5 & --- & -0.5 & --- \\
\hline nd & 1.32 & 2.10 & 0.00 & 0.15 & yes & 40 & -47.0 & --. & -0.5 & ... \\
\hline nd & 7.28 & nd & 0.74 & 1.43 & yes & 31 & $\ldots$ & --. & & $\ldots$ \\
\hline 0.01 & 0.76 & 2.02 & nd & nd & yes & --- & -47.0 & --- & -0.5 & --- \\
\hline 1.00 & 11.00 & nd & 1.70 & 2.80 & nd & 161 & ... & --. & -1.6 & --. \\
\hline nd & 26.10 & nd & 3.20 & 5.55 & yes & 4 & -32.0 & -186.0 & -2.2 & -.. \\
\hline nd & 18.45 & nd & 1.33 & 2.91 & yes & 32 & -31.9 & --- & -0.4 & ---- \\
\hline nd & 8.18 & nd & 0.85 & 1.23 & yes & 104 & -28.8 & --- & -2.3 & .... \\
\hline nd & 8.96 & 0.06 & 0.84 & 1.14 & yes & 105 & --- & $-\cdots$ & -- & --- \\
\hline 0.20 & 16.00 & nd & 1.90 & 3.20 & nd & 58 & -- & --- & 0.5 & --- \\
\hline nd & 14.45 & 0.14 & 1.23 & 2.31 & yes & 55 & -.. & $\ldots$ & -- & --- \\
\hline nd & 0.50 & nd & nd & nd & nd & 204 & -24.9 & --- & -2.1 & -.- \\
\hline nd & 0.00 & nd & nd & nd & nd & 11333 & $\ldots$ & --- & --- & -.. \\
\hline nd & 21.53 & nd & 2.99 & 4.34 & yes & 353 & -41.0 & --- & -0.9 & $\ldots$ \\
\hline 0.08 & 0.00 & nd & nd & nd & yes & $\ldots$ & --- & --- & --- & $\cdots$ \\
\hline 0.41 & 0.00 & nd & nd & nd & nd & 573 & -30.7 & $\ldots$ & -5.0 & $\ldots$ \\
\hline \multirow[t]{2}{*}{ nd } & 51.02 & nd & 5.86 & 26.31 & yes & 144 & -23.8 & --- & -1.9 & $\cdots$ \\
\hline & \multicolumn{10}{|l|}{ Area } \\
\hline nd & 0.81 & nd & 0.87 & nd & nd & 27 & --- & $\ldots$ & .-. & --- \\
\hline nd & 0.88 & nd & 0.94 & nd & yes & 30 & --- & $\ldots$ & --- & --- \\
\hline nd & 0.71 & nd & 0.68 & nd & nd & 26 & $\ldots$ & --- & -10.7 & -20.3 \\
\hline nd & 0.91 & nd & 0.84 & nd & yes & 27 & -34.0 & --- & -4.9 & --- \\
\hline nd & 0.64 & nd & 0.51 & nd & nd & 23 & --- & --.- & -3.1 & -22.2 \\
\hline nd & 0.71 & nd & 0.57 & nd & yes & 24 & --- & --- & -- & --- \\
\hline nd & 0.36 & nd & 0.33 & nd & yes & 23 & -- & --- & $\ldots$ & --- \\
\hline 0.06 & 2.06 & nd & 0.30 & 0.51 & yes & 86 & --- & --. & --- & --- \\
\hline nd & 0.02 & nd & nd & nd & nd & --. & -43.6 & --- & -12.0 & --- \\
\hline 0.90 & 63.00 & nd & 17.00 & 32.00 & nd & 53 & -43.5 & ..- & -2.1 & -26.1 \\
\hline nd & 67.37 & nd & 15.50 & 41.28 & yes & 44 & ... & --- & -1.5 & ... \\
\hline nd & 91.36 & nd & 25.06 & 47.36 & yes & 52 & --- & $\ldots$ & --. & --- \\
\hline
\end{tabular}

Table continued on next page.

that the carbon isotopic composition of $\mathrm{CO}_{2}$ in Yellowstone seeps is relatively consistent, with values ranging from -5 to +0.5 permil. The carbon isotopic composition of methane is more variable and ranges from -23.8 to -59.2 permil, indicating more variable sources. The preponderance of values plotted in figure 7 reflect a high temperature of formation for $\mathrm{C}_{1}$ and $\mathrm{CO}_{2}$ as indicated by the low fractionation factor of carbon between $\mathrm{CO}_{2}$ and methane $\left(\alpha_{\mathrm{c}}\right.$ clusters at about 1.02). Such values are considered typical of geothermal monocarbon gases (Lyon and Hulston, 1984). Wahb Springs (sample site 1-1, fig. 2), in the northeast corner of the park, however, widely departs from this pattern. The carbon isotopic composition of this seep plots on the border of the carbonate reduction and methyl (acetate) fermentation fields, indicating a bacterial source for the methane. This result is very surprising because this seep is near a hydrothermal area named Death Gulch, so christened by early explorers for the suffocating and deadly fumes primarily of $\mathrm{CO}_{2}$.

The isotopic compositions of methane carbon and hydrogen from two sites, Calcite Springs and Rainbow Springs, are plotted as open circles in figure 8 and fall in the geothermal-hydrothermal range. These values, in conjunction with the inclusion of low $C_{1} / C_{2}$ values and the presence of liquid hydrocarbons, indicate a mixture of geothermal-hydrothermal methane and thermogenic methane. 
Table 1. Composition of hydrocarbon gas from northwestern Wyoming-Continued.

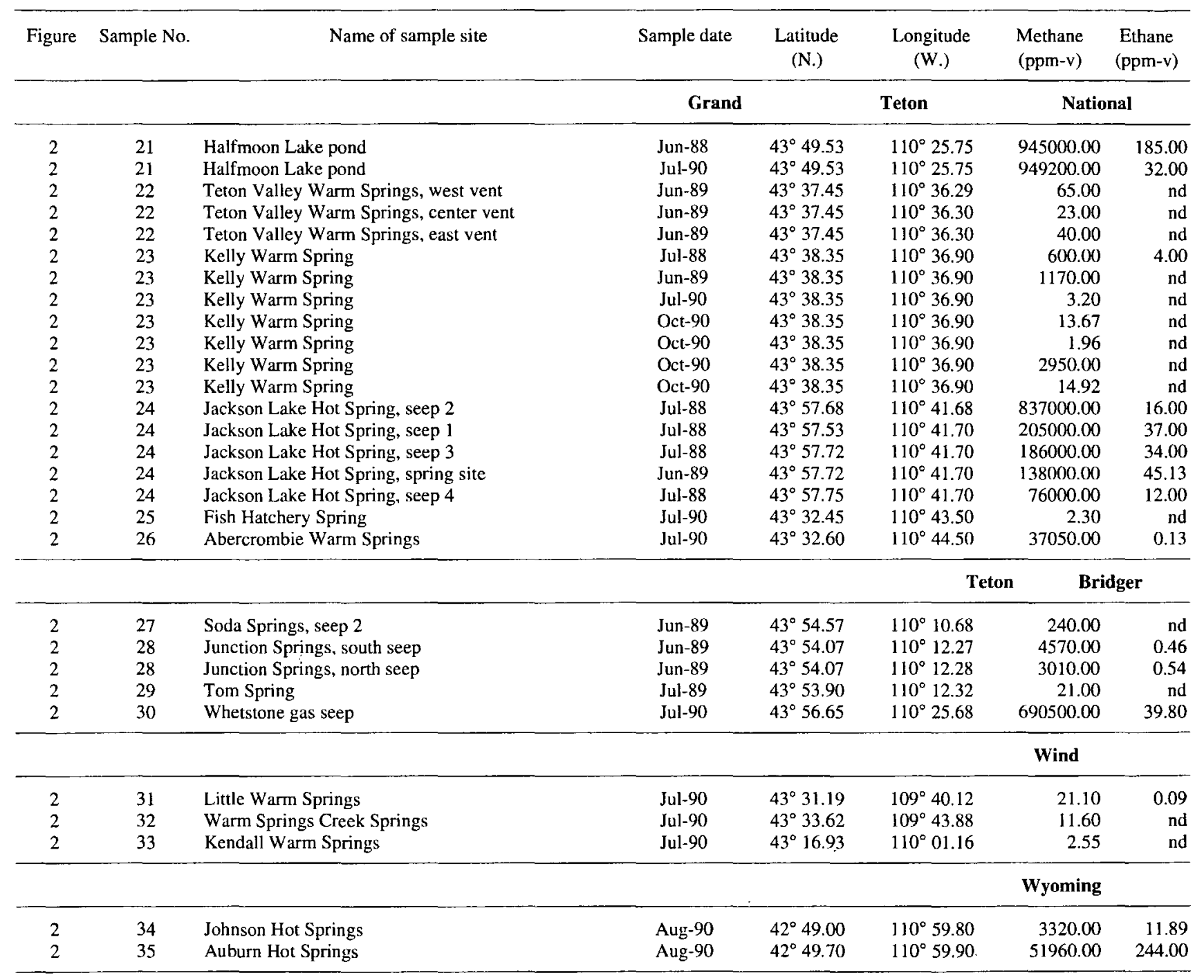

The thermogenic methane and other hydrocarbons likely result from pyrolysis of buried sedimentary organic matter. Upward circulation of groundwater carry these products to the vent sites.

\section{CODY, WYOMING, AREA}

\section{RATTLESNAKE MOUNTAIN ANTICLINE (SAMPLE SITES 1-17, 1-18)}

Gas seeps at De Maris Hot Springs provide a good example of systematic areal changes in concentrations of hydrocarbon gases as well as other gases. From east to west, corresponding to an increase in depth within the Phosphoria Formation, the following increases in concentrations were noted by Lorenson and others (1991): $\mathrm{CO}_{2}$ from 65.2 to 80.0 percent, $\delta^{13} \mathrm{C}$ of $\mathrm{CO}_{2}$ from -9.2 permil to -5.7 permil, and temperature from $27^{\circ} \mathrm{C}$ to $36^{\circ} \mathrm{C}$. The following decreases were observed: $\mathrm{N}_{2}+\mathrm{Ar}+\mathrm{O}_{2}$ from 28.7 to 9 percent, $\mathrm{C}_{1}$ from 2,690 to $1,357 \mathrm{ppm}-\mathrm{v}, \mathrm{C}_{2}$ from 100.8 to 58.5 ppm-v, $\mathrm{C}_{3}$ from 0.81 to $0.64 \mathrm{ppm}-\mathrm{v}, \mathrm{C}_{3: 1}$ from trace amounts to not detected, and $i-\mathrm{C}_{4}$ from 0.87 to $0.51 \mathrm{ppm}-\mathrm{v}$. Water analysis by others (Wyoming State Lab No. 7-1571 and 1572 (1976)), reported in Breckenridge and Hinckley (1978), also showed increases in common cations and anions from east to west. The sharp increase in water temperature from $27^{\circ} \mathrm{C}$ to $36^{\circ} \mathrm{C}$ over about $20 \mathrm{~m}$ of stratigraphic section is difficult to explain. However, the temperature increase with a concomitant increase in solubility of ionic species accounts for most of the previously noted changes in chemistry.

The highest concentrations of hydrocarbon gases were found at the easternmost spring, which has the lowest temperature and $\mathrm{CO}_{2}$ concentrations. The ratios of $\mathrm{C}_{1} / \mathrm{C}_{2}$ are nearly equal at each seep (ranging from 23 to 30 ), supporting 


\begin{tabular}{|c|c|c|c|c|c|c|c|c|c|c|}
\hline $\begin{array}{l}\text { Ethene } \\
(p p m-v)\end{array}$ & $\begin{array}{l}\text { Propane } \\
(\text { ppm-v) }\end{array}$ & $\begin{array}{l}\text { Propene } \\
(p p m-v)\end{array}$ & $\begin{array}{c}\text { Isobutane } \\
\text { (ppm-v) }\end{array}$ & $\begin{array}{c}n \text {-butane } \\
\text { (ppm-v) }\end{array}$ & $\begin{array}{l}\text { Pentanes } \\
\text { (ppm-v) }\end{array}$ & $\begin{array}{l}\text { Methane/Ethane } \\
\qquad\left(\mathrm{C}_{1} / \mathrm{C}_{2}\right)\end{array}$ & $\begin{array}{c}8^{13} \mathrm{C}\left(\mathrm{CH}_{4}\right) \\
\text { (permil) }\end{array}$ & $\begin{array}{c}\delta \mathrm{D}\left(\mathrm{CH}_{4}\right) \\
\text { (permil) }\end{array}$ & $\begin{array}{c}\delta^{13} \mathrm{C}\left(\mathrm{CO}_{2}\right) \\
\text { (permil) }\end{array}$ & $\underset{(\text { permil) }}{\delta^{13} \mathrm{C}\left(\mathrm{C}_{2} \mathrm{H}_{6}\right)}$ \\
\hline & Park & and & \multicolumn{2}{|c|}{ vicinity } & & & & & & \\
\hline 3.10 & 1.70 & nd & 0.40 & 0.60 & nd & 5108 & -49.7 & -318.0 & -6.1 & -10.0 \\
\hline 1.70 & nd & nd & nd & nd & nd & 29663 & -50.1 & -263.0 & -5.1 & --- \\
\hline nd & nd & nd & nd & nd & nd & --- & --- & --- & --- & --- \\
\hline nd & nd & nd & nd & nd & nd & -- & -50.4 & -- & -17.9 & -- \\
\hline nd & nd & nd & nd & nd & nd & $\ldots$ & --- & $\cdots$ & -.. & --- \\
\hline 0.40 & 2.70 & nd & 0.60 & 0.90 & nd & 150 & -- & -- & -18.6 & --- \\
\hline nd & nd & nd & nd & nd & nd & --- & --- & --- & - & -- \\
\hline nd & nd & nd & nd & nd & yes & -- & -- & --- & --- & -- \\
\hline nd & nd & nd & nd & nd & nd & --- & -- & --- & --- & --- \\
\hline nd & nd & nd & nd & nd & nd & --- & -- & --- & --- & --- \\
\hline nd & nd & nd & nd & nd & nd & --- & -61.2 & $\cdots$ & -11.3 & --- \\
\hline nd & nd & nd & nd & nd & nd & -.- & --- & --- & & --- \\
\hline 4.50 & 4.50 & nd & 1.80 & 0.90 & nd & 52313 & -61.9 & --- & -10.8 & $\cdots$ \\
\hline 1.20 & 1.20 & nd & 0.40 & 0.40 & nd & 5541 & -59.8 & - & -9.4 & --- \\
\hline 1.10 & 1.10 & nd & 0.40 & 0.30 & nd & 5471 & -59.8 & -- & -8.1 & -- \\
\hline nd & nd & nd & nd & nd & nd & 3058 & -- & --- & $\cdots$ & $\cdots$ \\
\hline 0.70 & 0.70 & nd & 0.20 & 0.20 & nd & 6333 & -59.2 & -309.0 & -6.6 & $\ldots$ \\
\hline nd & nd & nd & nd & nd & nd & --- & --- & $\ldots$ & --- & -- \\
\hline 0.13 & nd & nd & nd & nd & yes & 285000 & -55.6 & -169.0 & -17.9 & --- \\
\hline \multicolumn{11}{|c|}{ Wilderness } \\
\hline 0.24 & nd & nd & nd & nd & nd & -- & -41.9 & $\ldots$ & -10.4 & --- \\
\hline nd & 0.13 & nd & nd & nd & nd & 9935 & --- & $\ldots$ & -8.8 & $\ldots$ \\
\hline 0.12 & nd & nd & nd & nd & nd & 5574 & --- & $\ldots$ & -9.0 & --- \\
\hline nd & nd & nd & nd & nd & nd & '-- & -70.8 & --- & -9.4 & $\ldots$ \\
\hline 2.70 & 0.74 & nd & nd & nd & nd & 17349 & -58.7 & -299.0 & -- & --- \\
\hline \multicolumn{2}{|c|}{ River } & Range & & & & & & & & \\
\hline nd & nd & nd & nd & nd & nd & 234 & -- & -- & --- & --- \\
\hline nd & nd & nd & nd & nd & yes & --- & $\ldots$ & --- & --- & --- \\
\hline nd & nd & nd & nd & nd & nd & --- & -- & --- & --- & --- \\
\hline \multicolumn{2}{|c|}{ overthrust } & \multicolumn{2}{|c|}{ belt } & & & & & & & \\
\hline nd & 0.99 & nd & nd & 0.05 & yes & 279 & $\cdots$ & -- & --- & --- \\
\hline 0.09 & 27.98 & nd & 2.00 & 2.82 & yes & 213 & -30.5 & --- & -2.2 & --- \\
\hline
\end{tabular}

the notion of a common, finite hydrocarbon gas source; different sources would likely produce distinct $\mathrm{C}_{1} / \mathrm{C}_{2}$ ratios. The western spring contains $\mathrm{CO}_{2}$ at the highest concentrations and hydrocarbons at the lowest concentrations. This observation suggests that the hydrocarbon gas fractions are increasingly diluted by $\mathrm{CO}_{2}$ released from the parent hydrothermal water. The $\delta^{13} \mathrm{C}$ values for $\mathrm{CO}_{2}$ of -9.2 permil (west spring) and -5.7 permil (middle spring) can be explained as mixing of $\mathrm{CO}_{2}$ derived from carbonate $\left(\delta^{13} \mathrm{C} \approx 0\right.$ permil) and $\mathrm{CO}_{2}$ derived from the oxidation of oil $\left(\delta^{13} \mathrm{C} \approx-28\right.$ permil) (Faure, 1977).

Heasler (1982) modeled the Cody hydrothermal system and determined that the groundwater flow was from west to east and that fluids in the Phosphoria Formation reached a maximum temperature of $46^{\circ} \mathrm{C}$ at a depth of $1.7 \mathrm{~km}$. The maximum temperature occurs in a synform southwest of the Rattlesnake Mountain Anticline with an associated northeast groundwater flow toward the springs. This model supports the possibility that the warm waters leach the oilrich Phosphoria Formation and so carry previously generated thermogenic hydrocarbons regionally from west to east, occasionally surfacing at springs.

On the western side of the anticline, more hydrocarbonrich springs exist. John Colter's "boiling tar spring," described by Love and Good (1970), is now submerged under Buffalo Bill reservoir. When the water levels are low in winter, an ice-free region remains above the springs (approximately $20 \mathrm{~m}$ below the water surface) with gas bubbles smelling of hydrogen sulfide and sometimes leaving an oil slick where they burst (Doug Lumis, Bureau of Reclamation, oral commun., 1990). The springs appear to emerge from the Phosphoria Formation, as do De Maris Hot Springs, and presumably represent a more petroleum-rich source than do De Maris Hot Springs. We were able to locate a $\mathrm{CO}_{2}$-rich gas vent alongside the reservoir in July 1990. Unfortunately, we were unable to get an uncontaminated gas sample, 
Table 2. Composition of hydrocarbon gas from Idaho, eastern Oregon, and northern California. [nd, none detected; ppm-v, parts per million by volume; ---, not determined]

\begin{tabular}{|c|c|c|c|c|c|c|}
\hline Figure & Sample No. & Name of sample site & Sample date & $\begin{array}{l}\text { Latitude } \\
\text { (N.) }\end{array}$ & $\begin{array}{l}\text { Longitude } \\
\text { (W.) }\end{array}$ & $\begin{array}{l}\text { Methane } \\
\text { (ppm-v) }\end{array}$ \\
\hline & & & & & Basin & and \\
\hline 3 & 1 & Wildhorse Hot Springs, ID & May-92 & $44^{\circ} 51.38$ & $116^{\circ} 49.80$ & 21.00 \\
\hline 3 & 2 & Scintillation Hot Spring, OR & Sep-89 & $43^{\circ} 44.32$ & $117^{\circ} 09.95$ & 4100.00 \\
\hline 3 & 3 & Snively Hot Spring, OR & Sep-89 & $43^{\circ} 43.80$ & $117^{\circ} 12.30$ & 2100.00 \\
\hline 3 & 4 & Medical Hot Spring, OR & Sep-89 & $45^{\circ} 00.10$ & $117^{\circ} 30.78$ & 4800.00 \\
\hline 3 & 5 & Hot Lake, OR & Sep-89 & $45^{\circ} 14.63$ & $117^{\circ} 52.50$ & 11900.00 \\
\hline 3 & 6 & Island, Malhuer River, OR & Aug-92 & $43^{\circ} 46.60$ & $118^{\circ} 02.80$ & 311.00 \\
\hline 3 & 7 & Alvord Hot Springs, OR & May-92 & $42^{\circ} 32.64$ & $118^{\circ} 32.03$ & 760.00 \\
\hline 3 & 8 & Mid Borax Hot Spring, OR & May-92 & $42^{\circ} 19.77$ & $118^{\circ} 36.26$ & 1680.00 \\
\hline 4 & 9 & Benmac Hot Spring, CA (Surprise Valley) & Sep-89 & $41^{\circ} 31.77$ & $120^{\circ} 04.82$ & 51800.00 \\
\hline \multirow[t]{2}{*}{4} & 10 & Barry Ranch Hot Spring, OR & Sep-89 & $42^{\circ} 10.18$ & $120^{\circ} 20.01$ & 473000.00 \\
\hline & & & & & \multicolumn{2}{|c|}{ Cascade } \\
\hline 4 & 11 & Sulphur Springs, Mt. Shasta summit, CA & May-92 & $41^{\circ} 24.53$ & $121^{\circ} 11.69$ & 11870 \\
\hline 4 & 11 & Sulphur Springs, Mt. Shasta summit, CA & June-93 & $41^{\circ} 24.53$ & $121^{\circ} 11.69$ & 11490 \\
\hline 4 & 12 & Little Hot Springs Valley, Mt. Lassen, CA & Sep-89 & $40^{\circ} 27.98$ & $121^{\circ} 31.78$ & 100.00 \\
\hline 4 & 13 & Sulphur Works, Mt. Lassen, CA & Feb-93 & $40^{\circ} 27.40$ & $121^{\circ} 32.50$ & 120.00 \\
\hline
\end{tabular}

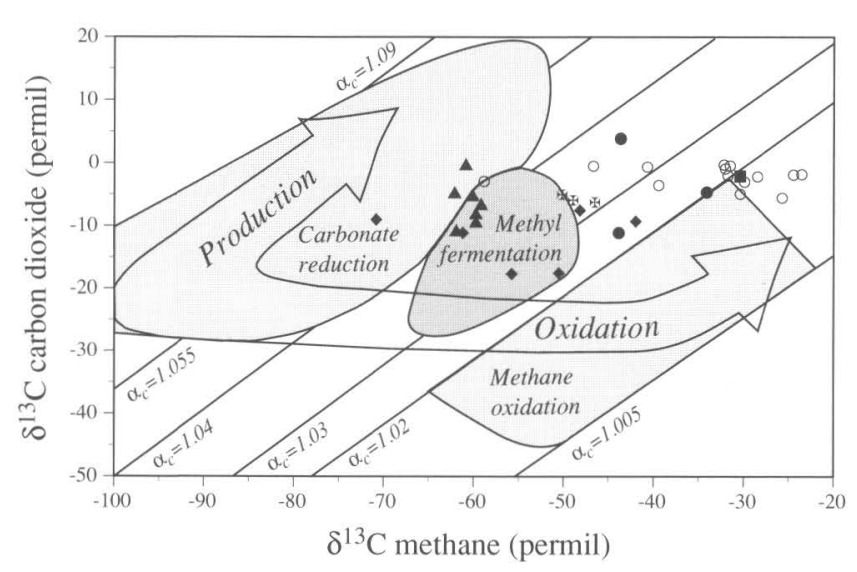

\section{EXPLANATION}

o. Yellowstone National Park, Wyo.

- Cody, Wyo., area

- Grand Teton National Park area, Wyo

- Spring ponds, Grand Teton National Park area, Wyo.

- Overthrust belt, Wyo.

* Halfmoon Lake and spring, Grand Teton National Park, Wyo.

Figure 7. Plot of carbon isotopic composition of methane versus carbon isotopic composition of carbon dioxide in samples from northwestern Wyoming. Compositional fields are adapted from Whiticar (1990). The values and the degree of isotopic separation, $\alpha_{c}\left(\mathrm{CO}_{2}: \mathrm{CH}_{4}\right.$, defined as $\left(\delta^{13} \mathrm{C}_{\left(\mathrm{CO}_{2}\right)}+10^{3}\right) /\left(\delta^{13} \mathrm{C}_{\left(\mathrm{CH}_{4}\right)}+10^{3}\right)$, can be diagnostic of methanogenic microbial pathways, gas types, and temperatures of formation for geothermal gases. The large arrows labeled "Production" and "Oxidation" refer to methane. Values for selected areas referred to in text are plotted as separate symbols shown in explanation. Cluster of values from Yellowstone National Park near boundary of methane oxidation field is characteristic of geothermal gases. The cluster of values not included within a shaded field and with $\alpha_{c}$ values greater than about 1.02 can be interpreted as thermogenic.

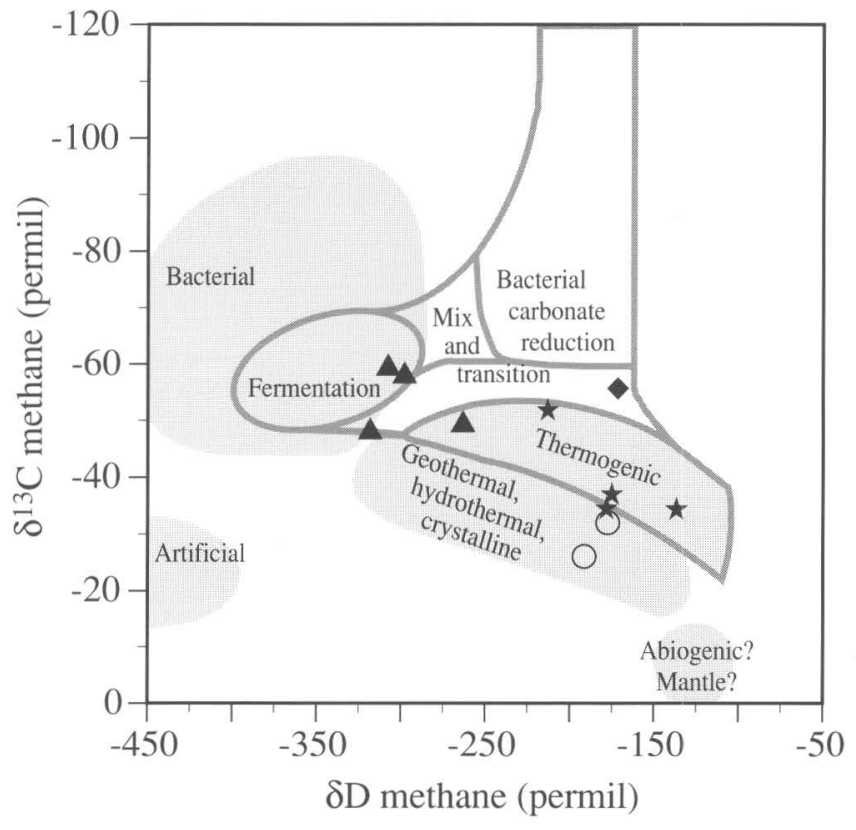

EXPLANATION

$\bigcirc$ Yellowstone National Park, Wyo.

- Grand Teton National Park area, Wyo.

- Spring ponds, Grand Teton National Park, Wyo.

$\star$ Olympic Peninsula, Wash.

Figure 8. Plot of carbon isotopic composition of methane versus hydrogen isotopic composition of methane from selected areas in Wyoming and Washington. Values for selected areas referred to in text are plotted as separate symbols shown in explanation. Compositional fields are adapted from Whiticar (1990). Field labeled "Artificial" refers to methane generated during drilling of hard crystalline rock. 


\begin{tabular}{|c|c|c|c|c|c|c|c|c|}
\hline $\begin{array}{c}\text { Ethane } \\
(\mathrm{ppm}-\mathrm{v})\end{array}$ & $\begin{array}{l}\text { Ethene } \\
(\mathrm{ppm}-\mathrm{v})\end{array}$ & $\begin{array}{l}\text { Propane } \\
\text { (ppm-v) }\end{array}$ & $\begin{array}{l}\text { Propene } \\
(\mathrm{ppm}-\mathrm{v})\end{array}$ & $\begin{array}{c}\text { Isobutane } \\
(\mathrm{ppm}-\mathrm{v})\end{array}$ & $\begin{array}{l}n \text {-butane } \\
\text { (ppm-v) }\end{array}$ & $\begin{array}{c}\text { Pentanes } \\
\text { (ppm-v) }\end{array}$ & $\begin{array}{l}\text { Methane/Ethane } \\
\qquad\left(\mathrm{C}_{1} / \mathrm{C}_{2}\right)\end{array}$ & $\begin{array}{c}\delta^{13} \mathrm{C}\left(\mathrm{CH}_{4}\right) \\
\text { (permil) }\end{array}$ \\
\hline Range & & \multicolumn{2}{|c|}{ vicinity } & & & & & \\
\hline 0.00 & nd & nd & nd & nd & nd & nd & --. & $\ldots$ \\
\hline 72.40 & nd & 33.60 & nd & 11.50 & 13.20 & yes & 57 & ..- \\
\hline 0.76 & nd & nd & nd & nd & nd & nd & 2763 & -.. \\
\hline 3.79 & nd & 0.39 & 0.13 & nd & nd & yes & 1266 & $\ldots$ \\
\hline 1429.00 & nd & 90.60 & nd & 52.50 & 3.08 & yes & 8 & -31.2 \\
\hline 0.00 & 0.63 & nd & nd & nd & nd & nd & +- & ... \\
\hline 9.15 & nd & 1.81 & nd & 0.41 & 0.77 & nd & 83 & -.- \\
\hline 20.97 & nd & 4.27 & 0.22 & 0.50 & 1.61 & yes & 80 & --- \\
\hline 367.00 & nd & 187.00 & nd & 36.80 & 50.00 & yes & 141 & -47.7 \\
\hline \multirow[t]{2}{*}{3142.00} & nd & 845.00 & nd & 520.00 & 161.00 & yes & 151 & -47.9 \\
\hline & canoes & & & & & & & \\
\hline nd & nd & nd & nd & nd & nd & nd & --- & $\ldots$ \\
\hline nd & nd & nd & nd & nd & nd & nd & -.. & --. \\
\hline 0.64 & nd & 0.29 & nd & nd & 0.05 & yes & 156 & --. \\
\hline 0.59 & nd & 0.02 & nd & nd & nd & nd & 203 & -.- \\
\hline
\end{tabular}

because the vent was not under water. Analysis of the gas from this source revealed methane and higher molecular weight hydrocarbon gases, and indicates that this gas is similar to the gas from De Maris Hot Springs.

ABSAROKA RANGE

(SAMPLE SITES 1-19, 1-20)

The seep gases of Sulphur Lake and those of Sweetwater Mineral Springs appear to have little in common. Sulphur Lake gas contains mainly nitrogen (83.7 percent), reflecting a meteoric water source, and a small amount of methane ( $1,100 \mathrm{ppm}-\mathrm{v})$, most likely from microbial sources. The methane is probably generated by bacteria using fermentative pathways to digest organic matter in the lake bed. In contrast, the gases present at Sweetwater Mineral Springs are $\mathrm{CO}_{2}$-rich (94.2 percent) and contain significant hydrocarbon gases. $C_{1}$ to at least $C_{6}$ gases are present with concentrations of 5,860 ppm-v $C_{1}, 113$ ppm-v $C_{2}, 91$ ppm-v $C_{3}$,

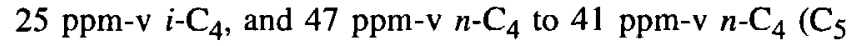
and $\mathrm{C}_{6}$ gases were not quantified). The values are similar to those observed in 1988 and 1989, suggesting that the source of these gases is not ephemeral in the scale of years. The $\delta^{13} \mathrm{C}$ values of -43.5 permil for methane and -26.1 permil for ethane indicate that these gases are thermogenic. The $\delta^{13} \mathrm{C}$ values of -1.5 and -2.1 permil indicate that the $\mathrm{CO}_{2}$ is most likely derived from the dissolution of carbonate rock. The sustained presence of higher molecular weight gases, coupled with $\mathrm{CO}_{2}$ derived from carbonate dissolution, suggests that there is a nearby sedimentary source rock underlying the volcanic cover. It cannot be determined from the present data if the subsurface processes taking place here are similar to those operating at Calcite Springs and Rainbow Springs in Yellowstone National Park.

\section{GRAND TETON NATIONAL PARK AND VICINITY (SAMPLE SITES 1-21 THROUGH 1-26)}

The springs in and near the Grand Teton National Park are nearly all dominated by $\mathrm{N}_{2}$ gas, with a range in concentration from about 80 to 90 percent (Kvenvolden and others, 1989b; Lorenson and others, 1991). $\mathrm{O}_{2}, \mathrm{CO}_{2}, \mathrm{~N}_{2}$, and $\mathrm{Ar}$ are present in amounts characteristic of groundwater in recent contact with the atmosphere. Jackson Lake Hot Springs gas contained a notable amount of $\mathrm{CO}_{2}(3.28$ percent). These waters are the warmest of the three sites $\left(37^{\circ} \mathrm{C}\right.$ measured at a nearby underwater vent having no apparent gas). Previously, temperatures of $72^{\circ} \mathrm{C}$ have been reported in this area by Love (Breckenridge and Hinckley, 1978), and the seeps emerge from the Madison Limestone, a possible source for $\mathrm{CO}_{2} . \mathrm{C}_{1}$ and $\mathrm{C}_{2}$ were the only hydrocarbon gases detected. The concentrations of these hydrocarbons were significant only at Jackson Lake Hot Springs $\left(\mathrm{C}_{1}, 83.7\right.$ percent; $\mathrm{C}_{2}, 45$ ppm-v). Kelly Warm Spring and Teton Valley Warm Springs contained only $C_{1}$ (1,172 and 65 ppm-v, respectively). Three seeps were analyzed at Teton Valley Warm Springs, and $C_{1}$ increased from 23 ppm-v at the western seep, to $40 \mathrm{ppm}-\mathrm{v}$ in the main pond, to $65 \mathrm{ppm}-\mathrm{v}$ at the eastern seep. The increase in $\mathrm{C}_{1}$ corresponds to the flow direction of the spring's surface runoff.

The carbon isotopic data from this area offer some potential insight into the generation processes of the hydrocarbon gases. The carbon isotopic composition of $\mathrm{C}_{1}$ ranges from -49.7 permil at Halfmoon Lake to -61.9 permil at Jackson Lake Hot Springs seep 2, and the carbon isotopic composition of $\mathrm{CO}_{2}$ ranges from -20.4 permil at Halfmoon Lake to -6.6 permil at Jackson Lake Hot Springs seep 4. The $\mathrm{C}_{1}$ isotopic values lie in a region of source ambiguity according to the criteria established by previous work (Claypool 
Table 3. Composition of hydrocarbon gas from southwestern Oregon.

[nd, none detected; ppm-v, parts per million by volume; ---, not determined]

\begin{tabular}{|c|c|c|c|c|}
\hline Figure & $\begin{array}{l}\text { Sample } \\
\text { No. }\end{array}$ & Name of sample site & $\begin{array}{c}\text { Sample } \\
\text { date }\end{array}$ & $\begin{array}{l}\text { Latitude } \\
\text { (N.) }\end{array}$ \\
\hline \multicolumn{5}{|c|}{ Southwestern } \\
\hline 5 & 1 & Well gas in Sixes River melange and broken formation near Clarks Branch Creek, OR & Feb-93 & $43^{\circ} 05: 88$ \\
\hline 5 & 2 & Gas sample from joint, Sixes River melange and broken formation near Clarks Branch Creek, OR & Feb-93 & $43^{\circ} 06.36$ \\
\hline 5 & 2 & Carboneceous mudstone in can, Sixes River melange and broken formation, near Clarks Branch Creek, OR & Feb-93 & $43^{\circ} 06.36$ \\
\hline 5 & 3 & $\begin{array}{l}\text { Limestone in can from Sigfredon Quarry, Sixes River melange and broken formation, near Clarks Branch } \\
\text { Creek, OR }\end{array}$ & Feb-93 & $43^{\circ} 06.82$ \\
\hline 5 & 4 & Well gas in Sixes River melange and broken formation, 1546 Clarks Branch Road, OR & Feb-93 & $43^{\circ} 05.12$ \\
\hline 5 & 5 & Joint in the Umpqua Group ${ }^{1}$, in the Bonanza thrust fault, near Umpqua, OR & Jan-93 & $43^{\circ} 19.76$ \\
\hline 5 & 6 & Well gas in the White Tail Ridge Formation 2 , 737 Nob Hill Rd., near Melrose, OR & Feb-93 & $43^{\circ} 15.43$ \\
\hline 5 & 6 & Well gas in the White Tail Ridge Formation 2 , 737 Nob Hill Rd., near Melrose, OR & Mar-83 & $43^{\circ} 15.43$ \\
\hline 5 & 7 & Well gas in the White Tail Ridge Formation 2,429 Elgarose Rd., near Melrose, OR & Feb-93 & $43^{\circ} 15.82$ \\
\hline 5 & 8 & Well gas in the Umpqua Group 1 , Coles Valley, OR & Feb-93 & $43^{\circ} 21.94$ \\
\hline 5 & 9 & Well gas in the White Tail Ridge Formation 2 , 3591 Elgarose Rd., Melrose,OR & Jan-93 & $43^{\circ} 15.93$ \\
\hline 5 & 10 & Well gas in the White Tail Ridge Formation ${ }^{2}$, 17039 Hwy 42, Camas Valley, OR & Feb-93 & $43^{\circ} 02.86$ \\
\hline 5 & 10 & Well gas in the White Tail Ridge Formation 2 , 17039 Hwy 42, Camas Valley, OR & Feb-93 & $43^{\circ} 02.97$ \\
\hline 5 & 11 & Joint in coal, White Tail Ridge Formation ${ }^{2}$, Hwy. 42, near Remote, OR & Feb-93 & $43^{\circ} 00.16$ \\
\hline 5 & 12 & Joint in coal, Coquille River Member ${ }^{3}$ of Whitetail Ridge Formation ${ }^{2}$, Hwy. 42 , near Camas Valley, OR & Feb-93 & $43^{\circ} 00.50$ \\
\hline 5 & 13 & Well gas in Coaledo Formation, well 1 , near Coquille, OR & Feb-93 & $43^{\circ} 09.40$ \\
\hline 5 & 14 & Well gas in Coaledo Formation, well 2, near Coquille, OR & Feb-93 & $43^{\circ} 09.28$ \\
\hline
\end{tabular}

1 Of Niem and Niem (1990).

2 White Tail Ridge Formation of Umpqua Group of Niem and Niem (1990).

3 Of Ryu and others (1992).

Table 4. Composition of hydrocarbon gas from northwestern Washington.

¡Gas concentrations are normalized to methane, and isobutane and $n$-butane are combined. nd, none detected; ppm-v, parts per

\begin{tabular}{ccccccc}
\hline $\begin{array}{c}\text { Figure } \\
\text { Sample } \\
\text { No. }\end{array}$ & Name of sample site & Sample date & $\begin{array}{c}\text { Latitude } \\
(\mathrm{N} .)\end{array}$ & $\begin{array}{c}\text { Longitude } \\
\text { (W.) }\end{array}$ & $\begin{array}{c}\text { Methane } \\
\text { (ppm-v) }\end{array}$ \\
\hline & & & & & \multicolumn{2}{c}{ Olympic } \\
\hline 6 & 1 & Sol Duc Hot Springs, WA & May-84, & $47^{\circ} 57.4$ & $123^{\circ} 43.8$ & 999000 \\
6 & 2 & Huelsdonk Ranch gas seep, WA & May-85 & $47^{\circ} 48.0$ & $124^{\circ} 10.5$ & 999000 \\
6 & 3 & Pysht gas seep, WA 1 & pre-74 & $48^{\circ} 09.2$ & $124^{\circ} 27.3$ & 943300 \\
6 & 4 & Garfield gas mounds, WA & May-85 & $47^{\circ} 21.0$ & $124^{\circ} 35.1$ & 999000 \\
6 & 5 & Taholah gas seep, WA & $77 ?$ & $47^{\circ} 21.1$ & $124^{\circ} 35.2$ & 975500 \\
6 & 6 & Wilson Ranch well, WA & Jun-86 & $47^{\circ} 54.6$ & $124^{\circ} 59.4$ & 958000
\end{tabular}

${ }^{1}$ Snavely (1987).

${ }^{2}$ Rau and Grocock (1974).

and Kaplan, 1974; Stahl, 1974; Fuex, 1977; Rice and Claypool, 1981; Schoell, 1983). Traditionally values of -60 permil and lighter are considered good evidence of microbially generated $C_{1}$, whereas those values heavier than -50 permil indicate a thermogenic source (Schoell, 1983). Values in between are commonly interpreted as indicating mixtures from different sources. Recently several workers have focused on environments where $\delta^{13} \mathrm{C}$ values of $\mathrm{C}_{1}$ are in this zone of ambiguity (Jenden and Kaplan, 1986; Whiticar and others, 1986; Woltemate and others, 1984). These studies have demonstrated the existence of microbially generated $C_{1}$ within this range of values. The differences in isotopic composition are attributed to differing contributions from the methanogenic pathways of $\mathrm{CO}_{2}$ reduction and acetate (methyl) fermentation (Whiticar and others, 1986). A cross plot of $\delta^{13} \mathrm{C}$ of $C_{1}$ and $\delta D$ of $C_{1}$ for Jackson Lake Hot Springs seep 4 , (fig. 7) indicates that the methane is generated by microbial acetate (methyl) fermentation processes. 


\begin{tabular}{|c|c|c|c|c|c|c|c|c|c|c|c|}
\hline $\begin{array}{l}\text { Longitude } \\
\text { (W.) }\end{array}$ & $\begin{array}{l}\text { Methane } \\
(\mathrm{ppm}-\mathrm{v})\end{array}$ & $\begin{array}{c}\text { Ethane } \\
(\mathrm{ppm}-\mathrm{v})\end{array}$ & $\begin{array}{l}\text { Ethene } \\
(\mathrm{ppm}-\mathrm{v})\end{array}$ & $\begin{array}{l}\text { Propane } \\
(\mathrm{ppm}-\mathrm{v})\end{array}$ & $\begin{array}{l}\text { Propene } \\
\text { (ppm-v) }\end{array}$ & $\begin{array}{c}\text { Isobutane } \\
(\mathrm{ppm}-\mathrm{v})\end{array}$ & $\begin{array}{c}n \text {-butane } \\
(\text { ppm-v) }\end{array}$ & $\begin{array}{r}\text { Pentanes } \\
(\mathrm{ppm}-\mathrm{v})\end{array}$ & $\begin{array}{l}\text { Methane/Ethane } \\
\qquad\left(\mathrm{C}_{1} \mathrm{C}_{2}\right)\end{array}$ & $\begin{array}{c}\delta^{13} \mathrm{C}\left(\mathrm{CH}_{4}\right) \\
(\text { permil) }\end{array}$ & $\begin{array}{l}\delta \mathrm{D}\left(\mathrm{CH}_{4}\right) \\
\text { (permil) }\end{array}$ \\
\hline \multicolumn{12}{|c|}{ Oregon } \\
\hline $123^{\circ} 17.14$ & 4380.00 & 0.61 & nd & 1.02 & nd & nd & nd & yes & 7228 & --- & $\ldots$ \\
\hline $123^{\circ} 17.23$ & 23.13 & --- & --- & $\cdots$ & -- & --- & -- & -- & --- & -- & $\cdots$ \\
\hline $123^{\circ} \quad 17.23$ & 8.68 & 1.37 & nd & 8.37 & nd & 0.06 & 0.10 & yes & 6 & $\cdots$ & --- \\
\hline $123^{\circ} 18.90$ & 30.14 & 0.79 & nd & 14.70 & nd & 9.34 & 13.01 & yes & 38 & -.- & --- \\
\hline $123^{\circ} 20.25$ & 502000.00 & 18.71 & 1.54 & 11.41 & nd & 0.58 & 1.13 & yes & 26831 & $\cdots$ & $\ldots$ \\
\hline $123^{\circ} 26.39$ & 2.41 & --- & --- & --- & $-\ldots$ & --- & --- & -- & -- & $\ldots$ & $\ldots$ \\
\hline $123^{\circ} 28.74$ & 761000.00 & 55.22 & nd & 12.43 & nd & 0.56 & 0.01 & yes & 13780 & -64.8 & -245 \\
\hline $123^{\circ} 28.74$ & 940000.00 & 32.00 & $\ldots$ & --- & -- & - & --. & -- & 29375 & -64.3 & -- \\
\hline $123^{\circ} 29.10$ & 21.93 & 0.00 & nd & 0.19 & nd & 0.65 & 0.01 & yes & $\ldots$ & --- & --- \\
\hline $123^{\circ} 29.54$ & 27.44 & nd & nd & nd & nd & nd & nd & nd & -- & -- & $\ldots$ \\
\hline $123^{\circ} 30.43$ & 111200.00 & 119.40 & nd & 6.21 & nd & 3.79 & 0.02 & yes & 931 & -46.3 & -129 \\
\hline $123^{\circ} 39.66$ & 87.00 &.-- & $\ldots-$ & --- & --- & -- & $\ldots$ & -- & -- & --- & --- \\
\hline $123^{\circ} 39.68$ & 5.72 & $\ldots$ & $\ldots$ & --- & --- & $\ldots$ & --. & --- & -- & --- & --- \\
\hline $123^{\circ} 42.70$ & 480.00 & 0.43 & nd & 0.05 & nd & 0.04 & 0.01 & yes & 1106 & --- & --- \\
\hline $123^{\circ} 53.99$ & 300.00 & 0.27 & nd & 0.01 & 0.01 & 0.21 & 0.08 & yes & 1128 & --- & $\ldots$ \\
\hline $124^{\circ} 13.58$ & 589600.00 & 275.49 & nd & 20.00 & nd & 0.25 & 0.10 & yes & 2140 & --- &.- \\
\hline $124^{\circ} 13.66$ & 11900.00 & 4.55 & nd & 0.18 & nd & 0.00 & nd & yes & 2616 & $\ldots$ & --- \\
\hline
\end{tabular}

million by volume; $-\cdots$, not determined]

\begin{tabular}{|c|c|c|c|c|c|c|c|c|c|}
\hline $\begin{array}{l}\text { Ethane } \\
(\mathrm{ppm}-\mathrm{v})\end{array}$ & $\begin{array}{l}\text { Ethene } \\
\text { (ppm-v) }\end{array}$ & $\begin{array}{l}\text { Propane } \\
(\mathrm{ppm}-\mathrm{v})\end{array}$ & $\begin{array}{l}\text { Propene } \\
(\mathrm{ppm}-\mathrm{v})\end{array}$ & $\begin{array}{l}\text { Isobutane } \\
\text { (ppm-v) }\end{array}$ & $\begin{array}{c}n \text {-butane } \\
\text { (ppm-v) }\end{array}$ & $\begin{array}{c}\text { Pentanes } \\
\text { (ppm-v) }\end{array}$ & $\begin{array}{l}\text { Methane/Ethane } \\
\qquad\left(\mathrm{C}_{1} / \mathrm{C}_{2}\right)\end{array}$ & $\begin{array}{c}\delta^{13} \mathrm{C}\left(\mathrm{CH}_{4}\right) \\
\text { (permil) }\end{array}$ & $\begin{array}{c}\delta \mathrm{D}\left(\mathrm{CH}_{4}\right) \\
\text { (permil) }\end{array}$ \\
\hline \multicolumn{10}{|c|}{ Peninsula } \\
\hline 510 & nd & nd & nd & nd & nd & nd & 1959 & -36.5 & -174 \\
\hline 5 & nd & nd & nd & nd & nd & nd & 199800 & -51.6 & -212 \\
\hline 35000 & nd & 15400 & nd & nd & 4300 & nd & 27 & -31.5 & $-\cdots$ \\
\hline 57 & nd & nd & nd & nd & nd & yes & 17526 & -34.5 & -177 \\
\hline 14800 & nd & 3700 & nd & nd & 2200 & yes & 66 & ... & -.- \\
\hline 27000 & nd & 9000 & nd & 120 & 180 & yes & 35 & -34.7 & -135 \\
\hline
\end{tabular}

The Halfmoon Lake spring area is underlain by subbituminous coal beds in the Bacon Ridge Sandstone (for detailed stratigraphy see Love and others, 1951, and for a description of the seep, see Love and Love, 1983, and Antweiler and others, 1989). Blackstone (1989) has suggested that coal in the Bacon Ridge Sandstone may produce methane. Methane at the Halfmoon Lake gas seep has a concentration of 94.5 percent and may be derived in part from coal. At the Halfmoon Lake gas seep the carbon isotopic composition of $\mathrm{CO}_{2}$ of -20 permil is light, much lighter than that of any other sample. This composition can be explained by the aerobic decomposition of organic matter such as algae and terrestrial plants by microbes, and the degassing of coal. The $\delta^{13} \mathrm{C}$ of these substances falls within the isotopic range of -12 to -34 permil; the $\delta^{13} \mathrm{C}$ of coal averages about -25 permil (Faure, 1977).

Dilution of near-surface groundwater by geothermal fluids possessing distinct carbon isotopic signatures is important for interpretation of the $\delta^{13} \mathrm{C}_{\left(\mathrm{CO}_{2}\right)}$ values. Geothermal 
waters in the Yellowstone region carry a characteristic carbon isotopic signature for $\mathrm{CO}_{2}$ of roughly -2 to +2 permil, indicating that the carbon is derived principally from the dissolution of limestone in the area (dissolved atmospheric $\mathrm{CO}_{2}$ with a $\delta^{13} \mathrm{C}$ of -7 permil is also a possible source, but this source is effectively diluted by much greater amounts of geothermal $\mathrm{CO}_{2}$ in most cases). Dilution of sampled gases by geothermally derived $\mathrm{CO}_{2}$ is observed in the Jackson Lake Hot Springs gases, for which the $\delta^{13} \mathrm{C}$ values of the $\mathrm{CO}_{2}$ are intermediate between those from Yellowstone Park and those from Halfmoon Lake. This conclusion is supported by the fact that the Jackson Lake Hot Springs are the warmest of the seeps in the vicinity of the Grand Teton National Park and the Teton-Bridger Wilderness, and their overall $\mathrm{CO}_{2}$ volumes are the highest, suggesting an important geothermal source. Addition of $\mathrm{CO}_{2}$ from fermentation and respiration of organic matter by microbes to $\mathrm{CO}_{2}$ from geothermal sources would likely result in $\delta^{13} \mathrm{C}$ values intermediate between two end members, as are the isotopic values obtained at Jackson Lake Hot Springs. Numerous studies, including those of Jenden and Kaplan (1986), Whiticar and others (1986), and Woltemate and others (1984), have noted that the characteristic $\delta D_{\left(\mathrm{CH}_{4}\right)}$ of $<-250$ permil is characteristic of $\mathrm{C}_{1}$ derived from fermentation. Finally, the molecular compositions of the hydrocarbon gases indicate microbial activity. $\mathrm{C}_{2: 1}$ and $\mathrm{C}_{3: 1}$ are known to be produced by microbes (Davis and Squires, 1954; Vogel and others, 1982), and the $C_{1} / C_{2}$ ratios $(3,400$ to 41,000$)$ are well above 1,000 , the guideline commonly used in denoting microbially generated $\mathrm{C}_{1}$.

\section{TETON-BRIDGER WILDERNESS (SAMPLE SITES 1-27 THROUGH 1-30)}

Compositions of gas from the springs of the TetonBridger Wilderness are quite diverse. Tom Spring is characterized by a very high concentration of $\mathrm{CO}_{2}$ ( 98.5 percent) and only $20 \mathrm{ppm}-\mathrm{v}$ methane. The balance gases are $\mathrm{N}_{2}, \mathrm{O}_{2}$, and $\mathrm{Ar}$ (Lorenson and others, 1991). The $\mathrm{N}_{2} / \mathrm{Ar}$ ratio of 33 and the $\mathrm{N}_{2} / \mathrm{O}_{2}$ ratio of 2 suggest that dissolved air gases have been stripped by $\mathrm{CO}_{2}$ (Bill Evans, oral commun., 1990). The $\delta^{13} \mathrm{C}$ value from $\mathrm{CO}_{2}$ of -9.36 permil implies a mixed source of $\mathrm{CO}_{2}$ from limestone and oxidized organic matter. The two sample sites at Junction Springs contain methane ranging in concentration from about 3,000 to 4,600 ppm-v. The gas is very dry and most likely is derived from anaerobic microbial acetate (methyl) fermentation (fig. 7).

The Whetstone gas seep lies near the crest of the Whetstone anticline. A substantial concentration of methane (69 percent) is emitted from a series of small vents located in Pacific Creek. The coal-bearing Bacon Ridge Sandstone underlies this location and is considered to be a likely source for the gas. The isotopic composition of methane from this seep $\left(\delta^{13} \mathrm{C}=-58.7\right.$ permil, $\delta \mathrm{D}=-299$ permil $)$ plots in the methyl fermentation field (fig. 7).

WIND RIVER RANGE

(SAMPLE SITES 1-31 THROUGH 1-33)

We sampled three warm springs along the flanks of the Wind River Range. Each of the springs issues from inclined late Paleozoic strata. Little Warm Springs and Warm Springs Creek Springs are on the north side of the Wind River Range; Kendall Warm Springs lies on the south side of the range. The gases are composed mainly of $\mathrm{N}_{2}$ (Lorenson and others, 1991), and the $\mathrm{C}_{1}$ concentrations are very low, ranging from 2.55 to $21.1 \mathrm{ppm}-\mathrm{v}$. The high $\mathrm{N}_{2}$ concentrations imply that the gases were recently in contact with the atmosphere. The lack of hydrocarbons indicates that the waters have not been in contact with thermogenic hydrocarbon sources and (or) the waters were not hot enough to leach and alter buried organic matter in rocks.

\section{OVERTHRUST BELT IN WYOMING (SAMPLE SITES 1-34, 1-35)}

We visited two sites near Afton, Wyoming: Auburn Hot Springs and Johnson Hot Springs. Both hot springs are fault-controlled and have built travertine mounds. The primary gas from both sites is $\mathrm{CO}_{2}$. At Auburn Hot Springs $\mathrm{C}_{1}$ concentration is about 5.2 percent, whereas at Johnson Hot Springs the concentration is $3,320 \mathrm{ppm}-\mathrm{v}$. Higher molecular weight hydrocarbon gases are present at both sites; however, the concentrations are roughly 20 times greater at Auburn Hot Springs. The isotopic composition of $\mathrm{C}_{1}$ from Auburn Hot Springs (fig. 7) is similar to the isotopic compositions of geothermal $\mathrm{C}_{1}$ from Yellowstone National Park. Given the presence of thermogenic sources in this general vicinity, and the thermogenic nature of the hydrocarbon-gas composition, we consider the methane to be a mixture of thermogenic methane derived from previously generated hydrocarbons and geothermal methane derived from deep-seated crustal processes and carried to the surface by hydrothermal water.

\section{THE NORTHWESTERN GREAT BASIN AND THE OLYMPIC-WALLOWA LINEAMENT (SAMPLE SITES 2-1 THROUGH 2-10)}

The northwest boundary of the Great Basin is host to numerous thermal springs with gas discharge (figs. 3, 4; table 2). Deeply circulating, hot groundwater can leach or carry organic and inorganic components, including hydrocarbon gases, from the country rock. In the eastern Oregon study area (fig. 3), the basement rocks are part of exotic 
Mesozoic accreted terranes and early Cenozoic sedimentary units that often lie beneath a late Cenozoic volcanic seal.

The Surprise Valley graben in northeastern California and the Goose Lake graben in southeastern Oregon (fig. 4) have spring gases of probable thermogenic sources. The gases are composed of mainly $\mathrm{N}_{2}$ with significant quantities of $C_{1}$ (up to 47 percent). The presence of higher molecular weight hydrocarbon gases (at least through the pentanes), $C_{1} / C_{2}$ ratios of about 150 , and methane $\delta^{13} \mathrm{C}$ values of -48 permil suggest a thermal origin.

Locations in eastern Oregon with relatively diminished amounts of $C_{1}$ are Alvord Hot Springs and Mid Borax Hot Spring (sample sites 2-7, 2-8; fig. 3; table 2). Methane concentrations are 760 and $1,680 \mathrm{ppm}-\mathrm{v}$, respectively; the $C_{1} / C_{2}$ ratios of about 80 suggest a thermal origin for the methane.

Microbial methane occurs at Wildhorse Hot Springs, Idaho, and at an unnamed hot spring located on an island in the Malhuer River, Oregon. At both these locations no significant amounts of higher molecular weight hydrocarbon gases were found, and the concentration of $\mathrm{C}_{1}$ is low.

Results similar to those from relatively methane-rich sources in the northern Great Basin were found at Hot Lake in the Grande Ronde graben of northeastern Oregon, a pullapart basin along the Olympic-Wallowa Lineament. Here the gas has a $C_{1}$ content of 11.5 percent, contains higher molecular weight hydrocarbon gases, and has a $\mathrm{C}_{1} / \mathrm{C}_{2}$ ratio of 8 and a $\delta^{13} C_{1}$ value of -31 permil.

Less diagnostic results for thermogenic hydrocarbon gases were obtained along the southwestern flank of the Snake River Plain. Fault-controlled springs have $C_{1}$ concentrations of 0.20 to 0.40 percent and small concentrations of higher molecular weight hydrocarbon gases at an unnamed hot spring we refer to as Scintillation Hot Spring (sample site 2-2, fig. 3). It appears that many basins have thermal spring gases with thermogenic signatures, suggesting that thermal processes are altering organic matter in rocks beneath a late Cenozoic volcanic seal.

\section{THE CASCADE VOLCANOES OF NORTHERN CALIFORNIA (SAMPLE SITES 2-11 THROUGH 2-13)}

Mount Lassen's latest eruption was in 1915, and this area continues to be a hydrothermally active region today. We sampled gas from two separate hydrothermal areas, Little Hot Springs Valley and Sulphur Works (fig. 4; table 2). The gases there are composed mainly of $\mathrm{CO}_{2}$, as expected from volcanic fumaroles; however, low concentrations of $C_{1}$ (100 to $120 \mathrm{ppm}-\mathrm{v}$ ) and higher molecular weight hydrocarbon gases were found, indicating entrainment and subsequent thermal alteration of organic matter. Organic matter may have come from a variety of sources, including burial of vegetation by volcanic debris or hydro- thermal alteration of country rock containing organic matter. Des Marais and others (1981) reported similar results for samples taken at Mount Lassen.

Just below the summit of Mount Shasta, at an elevation of about 4,300 meters, lies Sulphur Springs, a sulfataric fumarole. Gas from this source is composed mainly of $\mathrm{CO}_{2}$ and a surprisingly large amount of $\mathrm{C}_{1}$ (1.18 percent), atypical of volcanic gases. Higher molecular weight hydrocarbon gases are not present. Entrainment of organic matter as suggested above may contribute to the methane source. The lack of higher molecular weight hydrocarbon gases may be attributed to extreme heat, which could break down higher molecular weight hydrocarbon gases into methane.

\section{SOUTHWESTERN OREGON (SAMPLE SITES 3-1 THROUGH 3-14)}

Our preliminary study of this area was focused in the southern Tyee Basin, near Roseburg, Oreg., where a variety of source rocks and associated gas leakage is found (fig. 5; table 3). Convergence between the Pacific and North American plates during late Eocene resulted in the accretion of the lower Eocene Umpqua Group of Niem and Niem (1990) and the Siletz River Volcanics to the accreted terranes of the Klamath Mountains, then to the margin of North America (Blake and Jayko, 1986; Niem and Niem, 1990). Most of this terrane subsided in Eocene time and became the Tyee Basin, which in turn was filled by the sediments of the middle Eocene Tyee Formation.

Near the town of Umpqua, gas was sampled from the outcrop of the Umpqua Group (sample site 3-5, fig. 5) an early Eocene sequence of stacked, deep-marine fan and turbidite sandstone and mudstone deposited in a trench or marginal basin setting (Heller and Ryberg, 1983). The sequence is exposed in a roadcut where a series of imbricate thrusts of the Bonanza thrust fault has cut a portion of the unit. The Bonanza thrust fault may be a conduit for gas migrating upward from thermally mature sediments of the Umpqua Group which have been thrust under the Klamath Mountains to the east (Ryu and others, 1992). A minor amount of $\mathrm{C}_{1}$, no more than 1 ppm-v above atmospheric methane concentration (about $1.8 \mathrm{ppm}-\mathrm{v}$ ) was detected leaking from joints in this outcrop. About $5 \mathrm{~km}$ to the northwest (sample site 3-8), the headspace gas was collected over an open water well completed in the Umpqua Group but away form the Bonanza thrust fault. A methane concentration of about $30 \mathrm{ppm}-\mathrm{v}$ was observed.

About $15 \mathrm{~km}$ northwest of Roseburg, near the town of Melrose, we sampled gas in the headspace of three shallow water wells completed in the White Tail Ridge Formation (Niem and Niem, 1990) of the Umpqua Group (sample sites 3-6, 3-7, 3-9; fig. 5). The White Tail Ridge Formation is of early Eocene age and is composed of deltaic sandstones with interbedded carbonaceous shale and low-rank 
coal (Niem and Niem, 1990). In this location, the White Tail Ridge Formation overlies the Bonanza thrust. The gas from these wells contains up to 76 percent methane, and the $\delta^{13} \mathrm{C}_{1}$ from sample site 3-6 measured -64.8 permil. Gas from sample site 3-6 was also analyzed in 1983 (unpublished data of Kvenvolden). At that time the concentration of $C_{1}$ was 94 percent and the $\delta^{13} C_{1}$ was -64.3 permil. The gas at all wells is dry with $\mathrm{C}_{1} / \mathrm{C}_{2}$ ratios ranging from 120 to 11,250 (table 3, samples 6,7 and 9). Given the presence of coal, the molecular composition of the gas, and the isotopic composition of the $\mathrm{C}_{1}$, we consider this gas to have come from microbial gas generation during coalification within shallow coal-bearing strata. The headspace of two water wells near Camas Valley, about $20 \mathrm{~km}$ to the southwest, were sampled (sample site 3-10). These wells were also completed in the White Tail Ridge Formation. Here we found methane concentrations ranging from 35 to $87 \mathrm{ppm}-\mathrm{v}$, and we suspect that the methane is derived from coal, solely on the basis of the presence of the coal-bearing White Tail Ridge Formation at this location.

On the opposite side of the Tyee Basin, near Coquille, we sampled gases from two exploratory wells drilled in the 1920's (sample sites 3-13, 3-14; fig. 5). Both wells were completed in the late Eocene Coaledo Formation, which consists of deltaic sandstone, siltstones, and thick coalbeds (Ryu and others, 1992). In addition, the wells are located along the axis of the Fat Elk anticline. One of these wells was capped with a rubber seal and valve system that allowed gas to flow out, and the other well was open to the atmosphere. The capped well had headspace gas that contained 59 percent $C_{1}$ and a small amount of higher molecular weight hydrocarbon gases; the gas is dry $\left(C_{1} / C_{2}\right.$ ratio of 2,000 ). The open well had a methane concentration of 12 percent and a $C_{1} / C_{2}$ ratio of 2,500 . Given the similarity in $C_{1} / C_{2}$ ratios and the proximity of the open well to the capped well, the gases from both wells are probably very similar in origin, likely derived from coal.

Ten miles south of Roseburg, we sampled the headspace of two wells completed in the Sixes River terrane of the Klamath Mountains (sample sites 3-1, 3-4; fig. 5). Blake (1984) considers the Sixes River terrane to be Upper Jurassic melange and broken formations. Nearby outcrops are composed of interbedded limestone, carbonaceous mudstone, and sandstone. Some limestone and mudstone had a petroliferous odor when broken open. Methane was found in concentrations up to $62 \mathrm{ppm}-\mathrm{v}$. Gas sampled from the headspace of a sealed well contained nearly 14 percent $C_{1}$ with some higher molecular weight hydrocarbon gases. A methane concentration of about 0.5 percent with lesser amounts of higher molecular weight hydrocarbon gases was measured from a capped well missing a vent cap. $C_{1} / C_{2}$ ratios were high, ranging from 4,600 to 13,500. Residents told us that the groundwater in this area is brackish; this brackishness may reflect an association with deeper formation water.

\section{NORTHWESTERN WASHINGTON (SAMPLE SITES 4-1 THROUGH 4-6)}

Convergence between the Pacific and North American plates during late Eocene and late Miocene times produced two principal terranes on the continental margin of Washington and Oregon. On the west side of the Olympic Peninsula of Washington (fig. 6), the melanges are exposed where they have been transported eastward during subduction-accretion tectonics (Snavely and Kvenvolden, 1989). Melanges and broken formations of two ages are present in the area: the middle and upper Eocene Ozette melange and broken formation, and the upper Oligocene and middle Miocene Hoh melange. Gases from the Wilson Ranch well and the Pysht and Taholah seeps contain measurable quantities of higher molecular weight hydrocarbon gases, in contrast to gases from the Garfield gas mounds, the Huelsdonk Ranch seep, and the Sol Duc Hot Springs seep, which are composed primarily of $C_{1}$ (table 4) (Kvenvolden and others, 1989a). The $\delta^{13} \mathrm{C}$ values of gases from the wells and seeps range from -31.5 to -36.5 permil, with the exception of $\delta^{13} \mathrm{C}$ for the Huelsdonk Ranch gas seep, which has a more negative value of -51.6 permil. $\delta D$ values of methane are more variable and range from -135 to -212 permil. With the exception of that from the Huelsdonk Ranch gas seep, the gas samples have compositions within the range attributed to thermogenic gas (Schoell 1980, 1983; Jenden and Kaplan, 1986). The isotopic composition of $\mathrm{C}_{1}$ plots in the thermogenic field shown in figure 8 . It is uncertain whether or not the gases were generated from the same source rocks, but the similar isotopic composition of the methane suggests that they may have been. The more negative $\delta \mathrm{D}$ value from the Huelsdonk Ranch gas seep of -212 permil in combination with the carbon isotopic composition of -51.6 permil suggests the $C_{1}$ is a mixture of thermogenic and microbial gas.

The geologic settings of the well and seep sites provide some constraints on the source or sources of the gas. Either the middle and upper Eocene Ozette melange and broken formation or the upper Oligocene and middle Miocene Hoh melange and broken formation could serve as source rock for these gases (Snavely and Kvenvolden, 1989); however, because the Ozette melange and broken formation is present in the sections at the well and seep sites, it is a primary candidate for the source of the gas.

Gas at the Huelsdonk Ranch seep is presumed to have migrated through a thick section of glacial till in the Hoh River valley underlain by the Ozette melange and broken formation. The unique methane isotopic composition at this site may reflect a gas derived in part from organic matter within these glacial deposits. In general, methane in glacial deposits is microbial in origin and has more negative carbon and hydrogen isotopic compositions than does methane from a thermogenic source (Schoell, 1980). A mixture of these two sources of gas could produce methane with the observed isotopic composition. 


\section{SUMMARY}

This report provides a catalogue of the molecular compositions of gases and the isotopic compositions of methane and carbon dioxide in natural-gas samples from various tectonic provinces in the northwestern United States. Gases from seeps, springs, thermal springs, wells, and outcrops have been sampled, and methane is present in all samples in concentrations ranging over five orders of magnitude, from about $1 \mathrm{ppm}-\mathrm{v}$ to almost 100 percent. The amount and source of methane depend on the processes taking place within the tectonic province. Both thermogenic and microbial methane is present, as well as mixtures of hydrocarbon gases from both sources. Carbon and hydrogen isotopic compositions of methane refine source determination and show that fermentation, $\mathrm{CO}_{2}$ reductions, and thermal processes are involved in the origin of methane. The compositions of the gases that reach the surface reflect the subsurface conditions and processes. Where volcanic rocks overlie deeply buried sedimentary sections, the surface gas seeps may provide the most substantial clues to the presence of deeply buried potential energy resources. Our survey has demonstrated the variable composition of natural methane discharge. More detailed studies of these discharges are required in order to understand their significance relative to atmospheric gas composition and to subsurface energy resource potential.

\section{REFERENCES CITED}

Antweiler, J.C., Love, J.D., Prostka, H.J., Kulik, D.M., Lennart, A.A., Williams, F.E., Jinks, J.E., and Light, T.D., 1989, Mineral resources of the Teton Wilderness and adjacent areas, Teton, Fremont, and Park Counties, Wyoming: U.S. Geological Survey Bulletin 1781, 105 p.

Blackstone, D.L., Jr., 1989, Spread Creek Anticline: Teton County, Wyoming-A study in structural form and petroleum exploration: The Mountain Geologist, v. 26, no. 2, p. 43-51.

Blake, M.C., Jr., 1984, Tectonostratigraphic terranes in southwestern Oregon, in Nilsen, T.H., ed., Geology of the Upper Cretaceous Hornbrook Formation, Oregon and California: Pacific Section, Society of Economic Paleontologists and Mineralogists, v. 42, p. 159-165.

Blake, M.C., Jr., and Jayko, A.S., 1986, Tectonic evolution of northwest California and southwest Oregon, in Basin and Range et metamorphic core complexes; Coast Ranges; ophiolites et series d'arc; Mexique. (United States; Basin and Range and metamorphic core complexes; Coast Ranges; ophiolites and arc series; Mexico): Bulletin de la Société Géologique de France, Huitième Série, v. 2, no. 6, p. 921930.

Breckenridge, R.M., and Hinckley, B.S., 1978, Thermal springs of Wyoming: Geological Survey of Wyoming Bulletin 60 , $104 \mathrm{p}$.

Claypool, G.E., and Kaplan, I.R., 1974, The origin and distribution of methane in marine sediments, in Kaplan, I.R., ed.,
Natural Gases in Marine Sediments: New York, Plenum, p. 99-139.

Clifton, C.G., Walters, C.F., and Simoneit, B.R.T., 1990, Hydrothermal petroleums from Yellowstone National Park, Wyoming, U.S.A.: Applied Geochemistry, v. 5, p. 169-191.

Davis, J.B., and Squires, R.M., 1954, Detection of microbially produced gaseous hydrocarbons other than methane: Science, v. 119, p. 381-382.

Des Marais, D.J, Donchin, J.H., Nehring, N.L., and Truesdell, A.H., 1981, Molecular carbon evidence for the origin of geothermal hydrocarbons: Nature, v. 292, p. 826-828.

Faure, G., 1977, Principles of isotope geology: New York, John Wiley and Sons, $464 \mathrm{p}$.

Fuex, A.N., 1977, The use of stable carbon isotopes in hydrocarbon exploration: Journal of Geochemical Exploration, v. 7, p. $155-188$.

Gunter, B.D., 1978, $\mathrm{C}_{1}-\mathrm{C}_{4}$ hydrocarbons in hydrothermal gases: Geochimica et Cosmochimica Acta, v. 42, p. 137-139.

Gunter, B.D., and Musgrave, B.C., 1966, Gas chromatographic measurements of hydrothermal emanations at Yellowstone National Park: Geochimica et Cosmochimica Acta, v. 30 p. 1175-1189.

1971, New evidence on the origin of methane in hydrothermal gases: Geochimica et Cosmochimica Acta, v. 35, p. 113-118.

Heasler, H.P., 1982, The Cody hydrothermal system: Wyoming Geological Association Guidebook, Thirty-third Annual Field Conference, p. 163-174.

Heller, P.L., and Ryberg, P.T., 1983, Sedimentary record of subduction to forearc transition in the rotated Eocene basin of western Oregon: Geology, v. 11, no. 7, p. 380-383.

Jenden, P.D., and Kaplan, I.R., 1986, Comparison of microbial gases from the Middle America Trench and Scripps Submarine Canyon-Implications for the origin of natural gas: Applied Geochemistry, v. 1, p. 631-646.

Kvenvolden, K.A., Golan-Bac, M., and Snavely P.D., Jr., 1989a, Preliminary evaluation of the petroleum potential of the Tertiary accretionary terrane, west side of the Olympic Peninsula, Washington-C. Composition of natural gases in seeps, outcrops, and a test well: U.S. Geological Survey Bulletin 1892 , p. 39-45.

Kvenvolden, K.A., and Pettinga, J.R., 1989, Hydrocarbon gas seeps of the convergent Hikurangi margin, New Zealand: Marine and Petroleum Geology, v. 6 p. 2-8.

Kvenvolden, K.A., Simoneit, B.R.T., and Love, J.D., 1989b, Chemical and isotopic compositions of natural gas from seeps in Yellowstone and Grand Teton National Parks, Wyoming: Wyoming Geological Association Guidebook, Fortieth Annual Field Conference, p. 241-246.

Lehman, J.A., Smith, R.B., and Schilly, M.N., 1986, Upper crustal structure of the Yellowstone caldera from seismic delay time analyses and gravity correlations: Journal of Geophysical Research, v. 87, p. 2713-2730.

Lorenson, T.D., Kvenvolden, K.A., Simoneit, B.R.G., Lief, R.A., 1991, Composition of springs and seeps of northwestern Wyoming: U.S. Geological Survey Open File Report 91$121,26 \mathrm{p}$.

Love, J.D., and Christiansen, A.C., 1985, Geologic map of Wyoming: U.S. Geological Survey and Geological Survey of Wyoming, G85135, scale 1:500,000, 3 sheets. 
Love, J.D., and Good, J.M., 1970, Hydrocarbons in thermal areas, northwestern Wyoming: U.S. Geological Survey Professional Paper 644-B, p. B1-B23.

Love, J.D., Hose, R.K., Weitz, J.L., Duncan, D.C., and Bergquist, H.R., 1951, Stratigraphic sections of Cretaceous rocks in northeastern Teton County, Wyoming: U.S. Geological Survey Oil and Gas Investigations Chart OC-43, 2 sheets.

Love, J.D., and Love, J.M., 1983, Road log, Jackson to Dinwoody and return: Geological Survey of Wyoming, public information circular no. 20., p. 34.

Lyon, G.L., and Hulston, J.R., 1984, Carbon and hydrogen isotopic compositions of New Zealand geothermal gases: Geochimica et Cosmochimica Acta, v. 48, p. 1161-1171.

Nehring, N.L., and Truesdell, A.H., 1978, Hydrocarbon gases in some volcanic and geothermal systems: Geothermal Resources Council Transactions, v. 2, p. 483-486.

Niem, A.R., and Niem, W.A., 1990, Geology and oil, gas, and coal resources, southern Tyee Basin, southern Coast Range, Oregon: Oregon Department of Geology and Mineral Industries Open-File Report O-89-3, 44 p.

Prostka, H.J., Blank, H.R., Jr., Christiansen, R.L., and Ruppel, E.T., 1975, Geologic map of the Tower Junction Quadrangle, Yellowstone National Park, Wyoming and Montana: U.S. Geological Survey Geologic Quadrangle Map GQ-1247.

Rau, W.W., and Grocock, G.R., 1974, Piercement structure outcrops along the Washington coast: Washington Division of Geology and Earth Resources Information Circular 51, 7 p.

Rice, D.D., and Claypool, G.E., 1981, Generation, accumulation, and resource potential of biogenic gas: American Association of Petroleum Geologists Bulletin, v. 85, p. 5-25.

Ryu, In-Chang, Niem, A.R., and Niem, W.A. (text by Niem, A.R., Ryu, In-Chang, and Niem, W.A.), 1992, Schematic fence diagram of the southern Tyee basin, Oregon Coast Range, showing stratigraphic relationships of exploration wells to surface measured sections: Oregon Department of Geology and Mineral Industries Oil and Gas Investigation 18,48 p., 1 plate.

Schoell, M., 1980, The hydrogen and carbon isotopic composition of methane from natural gases of various origins: Geochimica et Cosmochimica Acta, v. 44, p. 649-661

1983, Genetic characterization of natural gases: American Association of Petroleum Geologists Bulletin, v. 67, p. 22252237.

Smith, R.B., and Braile, L.W., 1982, Crustal structure and evolution of an explosive silicic volcanic system at Yellowstone
National Park: Wyoming Geological Association Guidebook, Thirty-third Annual Field Conference, p. 233-250.

Smith, R.B., and Christiansen, R.L., 1980, Yellowstone Park as a window to the Earth's interior: Scientific American, v. 242, no. 2, p. 104-117.

Snavely, P.D., Jr., 1987, Tertiary geologic framework, neotectonics, and petroleum potential of the Oregon-Washington continental margin, in Scholl, D.W., Grantz, A., and Vedder, J.G., eds., Geology and resource potential of the continental margin of western North America and adjacent ocean basins-Beaufort Sea to Baja California: Houston, Texas, Circum-Pacific Council for Energy and Mineral Resources, Earth Science Series, v. 6, p. 305-335.

Snavely, P.D., Jr., and Kvenvolden, K.A., 1989, Preliminary evaluation of the petroleum potential of the Tertiary accretionary terrane, west side of the Olympic Peninsula, WashingtonA. Geology and hydrocarbon potential: U.S. Geological Survey Bulletin 1892, p. 1-17.

Stahl, W., 1974, Carbon isotope fractionations in natural gases: Nature, v. 251, p. 134-135.

Tonnsen, J.J., 1982, Petroleum geology of the northern part of Yellowstone National Park: Wyoming Geological Association Guidebook, Thirty-third Annual Field Conference, p. 289-295.

Truesdell, A.H., and Thompson, J. M., 1982, The geochemistry of the Shoshone geyser basin, Yellowstone National Park: Wyoming Geological Association Guidebook, Thirty-third Annual Field Conference, p. 153-160.

Vogel, T.M., Oremland, R.S., and Kvenvolden, K.A., 1982, Lowtemperature formation of hydrocarbon gases in San Francisco Bay sediment (California, U.S.A.): Chemical Geology, v. 37 , p. $289-298$.

White, D.E., 1957, Thermal waters of volcanic origin: Geological Society of America Bulletin, v. 68, p. 1637-1658.

Whiticar, M.J., 1990, A geochemical perspective of natural gas and atmospheric methane: Organic Geochemistry, v. 16, nos. 1-3, p. 531-547.

Whiticar, M.J., Faber, E., and Schoell, M., 1986, Biogenic methane formation in marine and freshwater environments $-\mathrm{CO}_{2}$ reduction vs. acetate fermentation-Isotope evidence: Geochimica et Cosmochimica Acta, v. 50, p. 693-709.

Woltemate, I., Whiticar, M.J., and Schoell, M., 1984, Carbon and hydrogen isotopic composition of bacterial methane in a shallow freshwater lake: Limnology and Oceanography, v. 29 , p. $985-992$. 
THE FUTURE OF ENERGY GASES

U.S. GEOLOGICAL SURVEY PROFESSIONAL PAPER 1570

\title{
Atmospheric Methane Flux from Coals- Preliminary Investigation of Coal Mines and Geologic Structures in the Black Warrior Basin, Alabama
}

\author{
By Jerry L. Clayton ${ }^{1}$, Joel S. Leventhal ${ }^{1}$, Dudley D. Rice ${ }^{1}$, Jack C. Pashin ${ }^{2}$, Byard Mosher ${ }^{3}$, \\ and Peter Czepiel ${ }^{3}$
}

\section{CONTENTS}

\begin{tabular}{|c|c|}
\hline & \\
\hline tr & \\
\hline lobal Methane Budget & \\
\hline and Physics of $\mathrm{M}$ & \\
\hline & \\
\hline Setting & \\
\hline Stratigraphy & \\
\hline 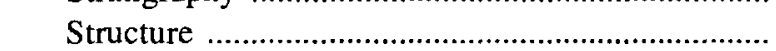 & \\
\hline Coal Rank & \\
\hline omposition an & \\
\hline Gases .......... & \\
\hline torage of Gas & \\
\hline 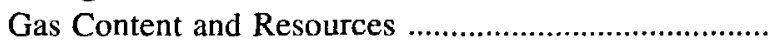 & \\
\hline ted with Coal Mining and & \\
\hline tilization & \\
\hline Mining & \\
\hline Mining ............. & \\
\hline ining Processes & \\
\hline Coal & \\
\hline d Field Methods & \\
\hline esult & \\
\hline & \\
\hline
\end{tabular}

'U.S. Geological Survey, P.O. Box 25046, Denver Federal Center, Denver, CO 80225

${ }^{2}$ Geological Survey of Alabama, P.O. Box O, 420 Hackberry Lane, Tuscaloosa, AL 35486-9780.

${ }^{3}$ University of New Hampshire, Complex Systems Research Center, Morse Hall, Durham, NH 03824.
Results and Discussion-Continued

Gwin Coal Exploration Core 486

Surface Coal Mine .............................................. 487

Jim Walter Resources, Inc., Blue Creek \#5 Mine ..... 489

Conclusions ............................................................. 490

Acknowledgments .................................................. 490

References Cited 491

\section{ABSTRACT}

Methane is an important greenhouse gas whose concentration in the atmosphere is increasing. Although this increase in atmospheric methane is correlative with growth in human population and activities, the exact causes for the increase are not fully understood. The increase is probably caused mainly by enhanced flux, but it may also be related to changes in residence time of methane in the atmosphere, or both. Even though coalbeds are known sources of atmospheric methane, it is not known how much methane is escaping into the atmosphere.

Because of increasing energy demand, particularly in developing countries where population is increasing, coal production is likely to increase over the next few decades and this could further increase the flux of atmospheric methane. In addition, no data are currently available on methane flux from coalbeds as a result of natural processes such as leakage at outcrops, or along faults and fractures that could provide avenues for methane migration upward from coal at depth. To better understand the global methane cycle and the role of fossil fuels in methane emissions, field 
measurements of methane emissions are needed from coalbeds, from areas of active mining, from coalbed gas production, and from undisturbed coals.

In this paper, we report results of field measurements of $\mathrm{CH}_{4}$ emissions from surface and underground mines, fault zones, and coreholes in the Black Warrior Basin, Alabama. Ventilation of underground mines in Mary Lee group coals (of economic usage) gave the highest methane emissions rates-about $71,480,000 \mathrm{~m}^{3} / \mathrm{yr}$ (2.5 Bcf or billion cubic feet) from one ventilation shaft. In contrast, very low emissions occurred from active or abandoned coreholes and from Brookwood group coals (of economic usage) exposed by surface mining (about $81 \mathrm{~m}^{3} / \mathrm{yr}$ (2.9 Mcf or thousand cubic feet)). The low methane emission rate from surface mines is due to low present-day methane content of the coal caused by degassing during shallow burial since late Paleozoic time. Black Warrior Basin coals at present-day depths of about $1,000 \mathrm{ft}(305 \mathrm{~m})$ or more still retain a high methane content; their high methane content results in much greater methane emissions from ventilation of deep underground mines.

Methane flux of as much as about $500 \mathrm{~m}^{3} / \mathrm{yr}$ occurs from a small section of a normal fault and associated joints exposed at Bankhead Lock and Dam. The carbon isotopic composition of $\mathrm{CH}_{4}$ collected at the Bankhead Fault $\left(\delta^{13} \mathrm{C}\right.$ -49.3 permil) indicates a coalbed origin. This finding suggests that faults and fractures associated with coalbeds may be important sources of atmospheric methane.

\section{INTRODUCTION}

The objective of this study is to provide quantitative data on methane flux from coals resulting both from human activities and from natural geologic processes. Herein, we report the results of a reconnaissance field study of methane emissions associated with coals in the Black Warrior Basin, Alabama. The Black Warrior Basin was chosen because it is a geologically diverse area where it is possible to investigate the importance of a number of anthropogenic and natural variables in controlling $\mathrm{CH}_{4}$ flux. In addition to both surface and underground mines, the Black Warrior Basin has been a major target for coalbed gas drilling in recent years. There are a number of geologic features in the basin that could affect the rate of methane emissions. For example, the basin contains a number of coalbeds, both in the subsurface and outcrops, and a large number of structural elements, such as faults and fractures, that could facilitate natural leakage of methane into the atmosphere.

\section{GLOBAL METHANE BUDGET}

Methane is the most abundant hydrocarbon in the atmosphere. Its current atmospheric concentration is about
1.7 ppmv (parts per million by volume) (Tyler, 1991). More importantly, evidence from analysis of gases trapped as bubbles in ice cores indicates that the atmospheric concentration of methane has more than doubled over the past 200 to 300 years, from a preindustrial range of about 0.6 to 0.7 ppmv, and has been increasing at a rate of about 1 percent per year over the past 15 years (Rasmussen and Khalil, 1981; Craig and Chou, 1982; Enhalt and others, 1983; Stauffer and others, 1988; Pearman and others, 1986; Chappellaz and others, 1990; Khalil and Rasmussen, 1990). Analyses of ice cores dating as early as 160,000 years B.P. suggest that the current rate of increase and methane content of the atmosphere is unprecedented in recent earth history (Raynaud and others, 1988; Stauffer and others, 1988).

The principal anthropogenic methane sources are rice paddies, domestic livestock, landfills, biomass burning, venting of natural gas, losses of natural gas during transmission of gas and liquid petroleum, and coal mining (table 1) according to Quay and others (1991). Biogenic methane, formed by microorganisms assigned to the Archae domain, is estimated to account for more than 70 percent of the total methane emission rate; it is common in rice paddies, ruminant animals, natural wetlands, and landfills (Seiler and Conrad, 1987; Cicerone and Oremland, 1988; Stevens and Englekemeir, 1988).

Methane leaking from fossil fuels is estimated to account for a significant proportion (approximately 15 percent) of the total annual methane flux between the geo-

Table 1. Annual methane flux, in teragrams ( $\mathrm{Tg}$ or $10^{12} \mathrm{~g}$ ), from various sources.

[Data from Cicerone and Oremland, 1988; Boyer and others, 1990]

\begin{tabular}{|c|c|c|}
\hline Source & Annual release & Range \\
\hline $\begin{array}{l}\text { Enteric fermentation } \\
\text { (animals). }\end{array}$ & 80 & $65-100$ \\
\hline Natural wetlands -------- & 115 & $100-200$ \\
\hline Rice paddies & 110 & $60-170$ \\
\hline Biomass burning - & 55 & $50-100$ \\
\hline Termites -....-. & 40 & $10-100$ \\
\hline Landfills -.....-..-- & 40 & $30-70$ \\
\hline 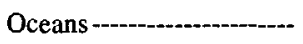 & 10 & $5-20$ \\
\hline Freshwaters --- & 5 & $1-25$ \\
\hline $\begin{array}{l}\text { Methane hydrate } \\
\text { destabilization. }\end{array}$ & 5 & $0-100^{1}$ \\
\hline Coal mining---.--- & 35 & $25-64$ \\
\hline $\begin{array}{l}\text { Gas drilling, venting, } \\
\text { transmission. }\end{array}$ & 45. & $25-50$ \\
\hline Total- & $540^{2}$ & $400-640$ \\
\hline
\end{tabular}

\footnotetext{
'The figure of $5 \mathrm{Tg}$ of methane from hydrates is merely a "placeholder" (Cicerone and Oremland, 1988) and the upper range of $100 \mathrm{Tg}$ is speculative on the basis of future projections (from Kvenvolden, 1988).

${ }^{2}$ Estimates by various workers for total methane release range from about 355 to $870 \mathrm{Tg}$ (Tyler, 1991).
} 
sphere and atmosphere although considerable uncertainty exists with regard to the actual amount. Annual atmospheric methane flux from all sources is estimated at 540 $\mathrm{Tg}$ (teragrams, $10^{12} \mathrm{~g}$ ), whereas coal mining, natural-gas venting, and gas transmission losses are estimated at between 50 and $114 \mathrm{Tg}$ (Khalil and Rasmussen, 1985; Stevens and Englekemeir, 1988; Cicerone and Oremland, 1988; Hogan and others, 1991). Although coal is an important source of atmospheric methane, current global estimates of methane fluxes from coalbeds are uncertain (Boyer and others, 1990). Recently, Kirchgessner and others (1993a) estimated methane fiux from a surface mine in the Powder River Basin, Wyoming, to be $1,735,000$ $\mathrm{m}^{3} /$ year (about 61 million cubic feet per year (MMcf/yr) or $2 \times 10^{-5} \mathrm{Tg}$ ). The preliminary study by Kirchgessner and others (1993a) is the only previously published attempt to provide quantitative data on surface coal mine emissions.

Release of methane from coalbeds into the atmosphere occurs both as a natural process and as a consequence of surface and underground mining. Estimates for countries other than the United States contain even greater uncertainty because fewer data are available. In some cases, global estimates of methane flux from coals are based solely on mine data from the United States, which are extrapolated to a global scale (Boyer and others, 1990). Furthermore, naturally occurring methane emissions from coals have not been taken' into account. Significant amounts of methane from buried coalbeds may move upward along naturally occurring faults and fractures, or may leak from coalbeds exposed in outcrops.

\section{CHEMISTRY AND PHYSICS OF METHANE IN THE ATMOSPHERE}

Methane plays an important role in several processes that affect the chemical composition and radiation budget of the atmosphere. First, methane strongly absorbs infrared radiation and, therefore, is an important greenhouse gas. On an atomic basis, methane has about 25 to 30 times more warming effect than carbon dioxide, and 70 times more on a weight basis (Kiehl and Dickinson, 1987). According to calculations by Donner and Ramanathan (1980), an atmospheric methane concentration increase of $1.3 \mathrm{ppmv}$ causes an elevation in the average global surface temperature of approximately $1.3^{\circ} \mathrm{C}$. Because methane has a relatively short atmospheric residence time of about 10 years (Fung and others, 1991) and has a strong greenhouse effect, an estimated 10-percent reduction of the annual emission rate would probably stabilize atmospheric concentrations (Hogan and others, 1991) and could reduce the rate of increase in atmospheric greenhouse effect.

Methane in the atmosphere reacts with hydroxyl radicals $\left(\mathrm{OH}^{-}\right)$in an initial reaction step of a series of reactions involving water, ozone $\left(\mathrm{O}_{3}\right)$, hydrogen oxides $\left(\mathrm{HO}_{\mathrm{x}}\right)$, nitrous oxides, formaldehyde, hydrogen, chlorine, and other species that affect the water budget, ozone concentration, and overall oxidizing power of the atmosphere (Tyler, 1991). Methane reaction with chlorine produces hydrochloric acid $(\mathrm{HCl})$. This reaction is important in stratospheric chemistry because unlike free chlorine, $\mathrm{HCl}$ does not destroy ozone. Methane oxidation in the stratosphere may increase water vapor concentration as much as 50 percent over levels for zero methane concentration and water is also a greenhouse gas (Ramanathan and others, 1987). Other atmospheric gases, such as $\mathrm{CH}_{3} \mathrm{Cl}, \mathrm{CH}_{3} \mathrm{Br}$, $\mathrm{CHClF}_{2}, \mathrm{CH}_{2} \mathrm{Cl}_{2}, \mathrm{CHCCl}_{3}$, and $\mathrm{SO}_{2}$, are affected directly or indirectly by the concentration of hydroxyl radicals (Tyler, 1991). These gases play important direct or indirect roles in the radiative budget and overall physics and chemistry of the atmosphere.

\section{GEOLOGIC SETTING}

\section{REGIONAL SETTING}

To begin gathering data on $\mathrm{CH}_{4}$ fluxes associated with coals, we conducted a number of experiments in the Black Warrior Basin. The basin is a triangular-shaped structural depression in east-central Mississippi and west-central Alabama that is bounded on the southeast by the Appalachian orogenic belt, on the southwest by the Ouachita orogenic belt, and on the north by the Nashville Dome (fig. 1). The Black Warrior Basin borders the Appalachian Basin on the northeast and is separated from the Arkoma Basin to the west by the Mississippi Valley graben (Thomas, 1988). Tectonically, the Black Warrior Basin is a late Paleozoic foreland basin that formed in response to crustal loading of the Appalachian and Ouachita orogenic belts during the continental collisions of North and South America, Europe, and Africa (Beaumont and others, 1988). The study area is restricted to the southeastern part of the basin in Alabama (southwestern Jefferson and southeastern Tuscaloosa Counties) along the Appalachian orogenic belt where coalbeds of Pennsylvanian age are actively mined both on the surface and underground; additionally, this is an area of coalbed gas exploration and production (fig. 2). The basin leads the Nation in coalbed gas completions, and much of this development is a consequence of enhancing the safety of underground coal mining.

The northern margin of the Black Warrior Basin is mapped as the outcrop limit of the Lower Pennsylvanian part of the Pottsville Formation, which contains the principal coalbeds and associated coalbed-gas resources of the basin. About two-thirds of the basin is covered by Cretaceous and younger strata of the Mississippi Embayment and Gulf Coastal Plain (fig. 1), which unconformably overlie the Pottsville. In most of the study area, coal-bearing strata of the Pottsville Formation are exposed at the surface. 


\section{STRATIGRAPHY}

The upper part of the Pottsville Formation contains economically important coalbeds, which are assigned to several widespread coal groups (Metzger, 1965) (fig. 3). The coal groups form the upper part of regressive sequences that coarsen upward from marine mudstone to terrestrial sandstone. The cycles thicken to the south and southeast reflecting the subsidence history and evolution of the foreland basin during Pennsylvanian time (Pashin, 1991a). The Mary Lee group coals are the most important for underground mining. The interval from the Black Creek group coals through Cobb group coals (both of economic usage) (fig. 3) contains the most important targets for coalbed gas exploration and production (Hewitt, 1984; McFall and others, 1986). The younger and shallower groups, however, are also possible sources of atmospheric $\mathrm{CH}_{4}$.

Individual coalbeds are generally thin $(<1 \mathrm{~m})$ throughout the basin, although the Blue Creek bed of the Mary Lee group is locally thicker than $3 \mathrm{~m}$ (Pashin, 1991a, b).
In each depositional cycle, coalbeds are most abundant in the eastern part of the basin where fluvial-deltaic platforms favored peat accumulation during Pennsylvanian time (Pashin, 1991b). In the study area, more than 20 and locally as many as 40 coalbeds are present in the Black Creek through Cobb interval, whereas less than five coalbeds are present in this interval in most of the basin. Even more coalbeds are present in the younger depositional cycles.

\section{STRUCTURE}

Folds and thrust faults, resulting from compressional forces of the Alleghanian orogeny, are present along the southeastern part of the basin and strike approximately $\mathrm{N} 40^{\circ} \mathrm{E}$ (Thomas, 1985) (fig. 4). The basin is bounded on the southeast by the Birmingham Anticlinorium. The anticlinorium is part of the Valley and Ridge Province, and Cambrian and Ordovician carbonate rocks and discontinuous thrust faults are present in its core. Among the main

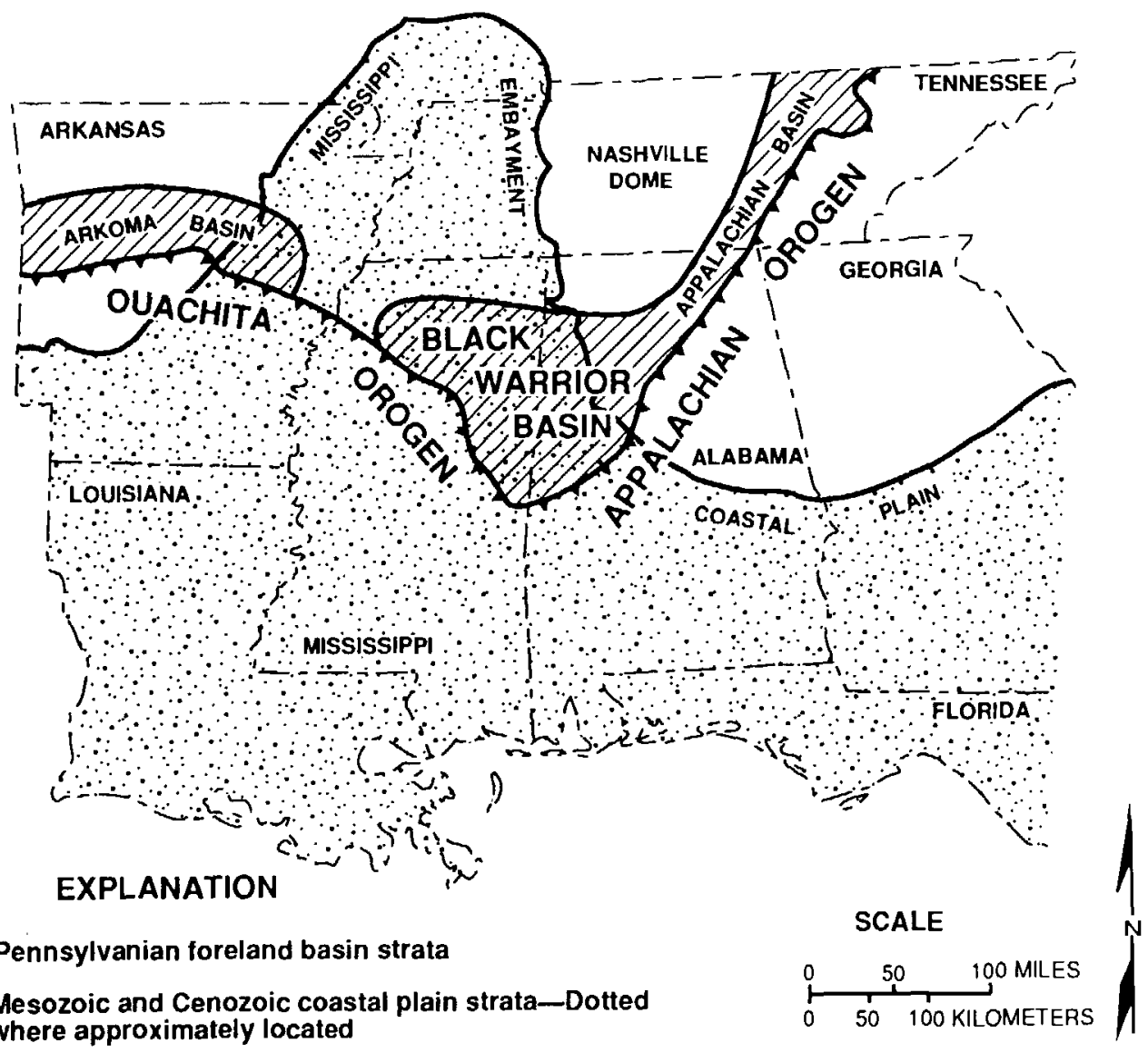

Thrust fault-Sawteeth on upper plate

Figure 1. Index map of southeastern United States showing geologic setting of the Black Warrior Basin. From Pashin (1991a). 
folds in the study area are the Blue Creek Anticline and Syncline. Strata in the Blue Creek Anticline are intensely fractured compared with those in the rest of the basin. Normal faults, which generally strike northwest-southeast, are also abundant in the Black Warrior Basin (fig. 4). These faults are related to extensional tectonics and form a series of linear to arcuate horst and graben systems (Pashin, 1991a). Syndepositional movement of these faults and folds

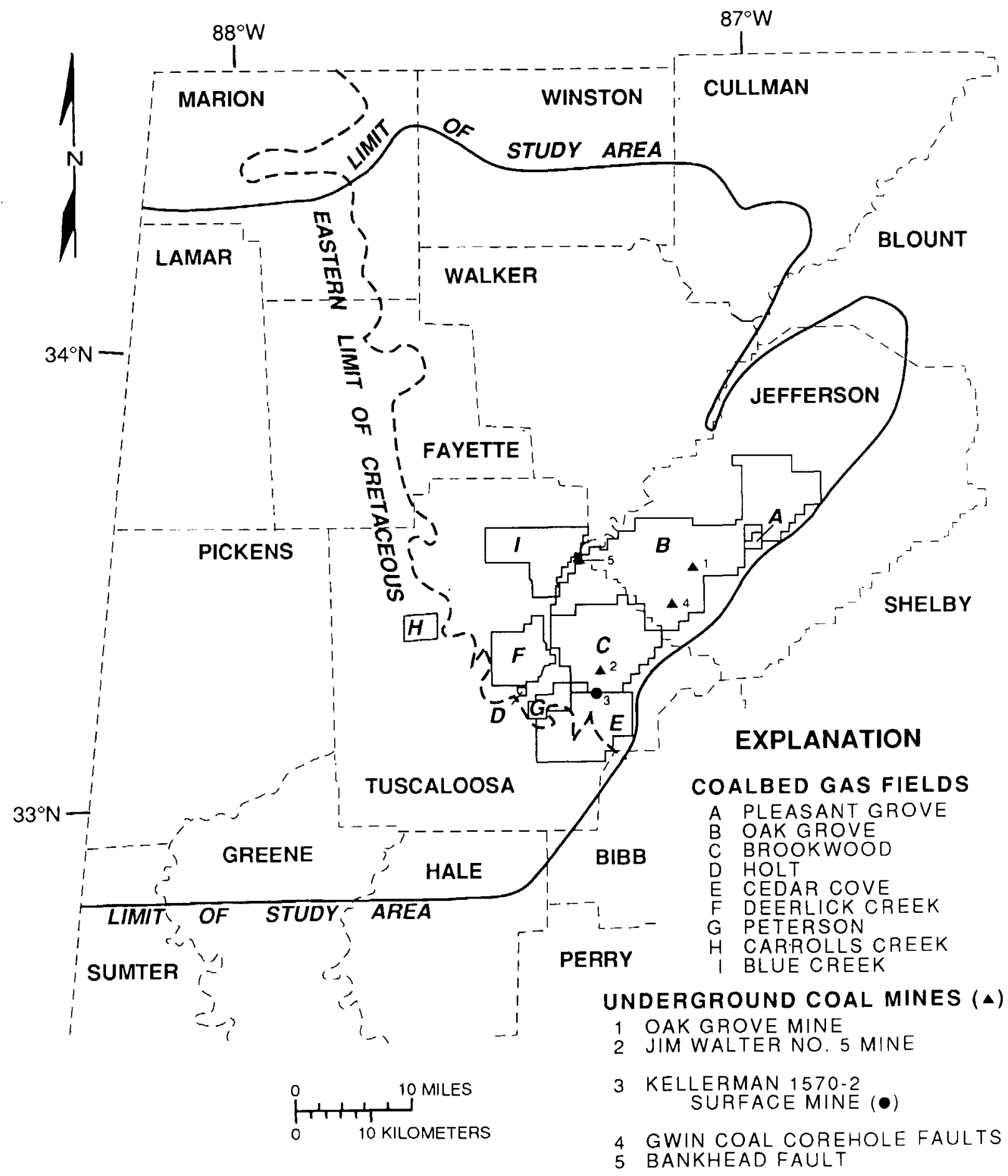

Figure 2. Alabama portion of Black Warrior Basin showing location of underground coal mines and coalbed gas fields. The study area is in southeastern part of the basin (area labeled A through I). Modified from Pashin (199la). 


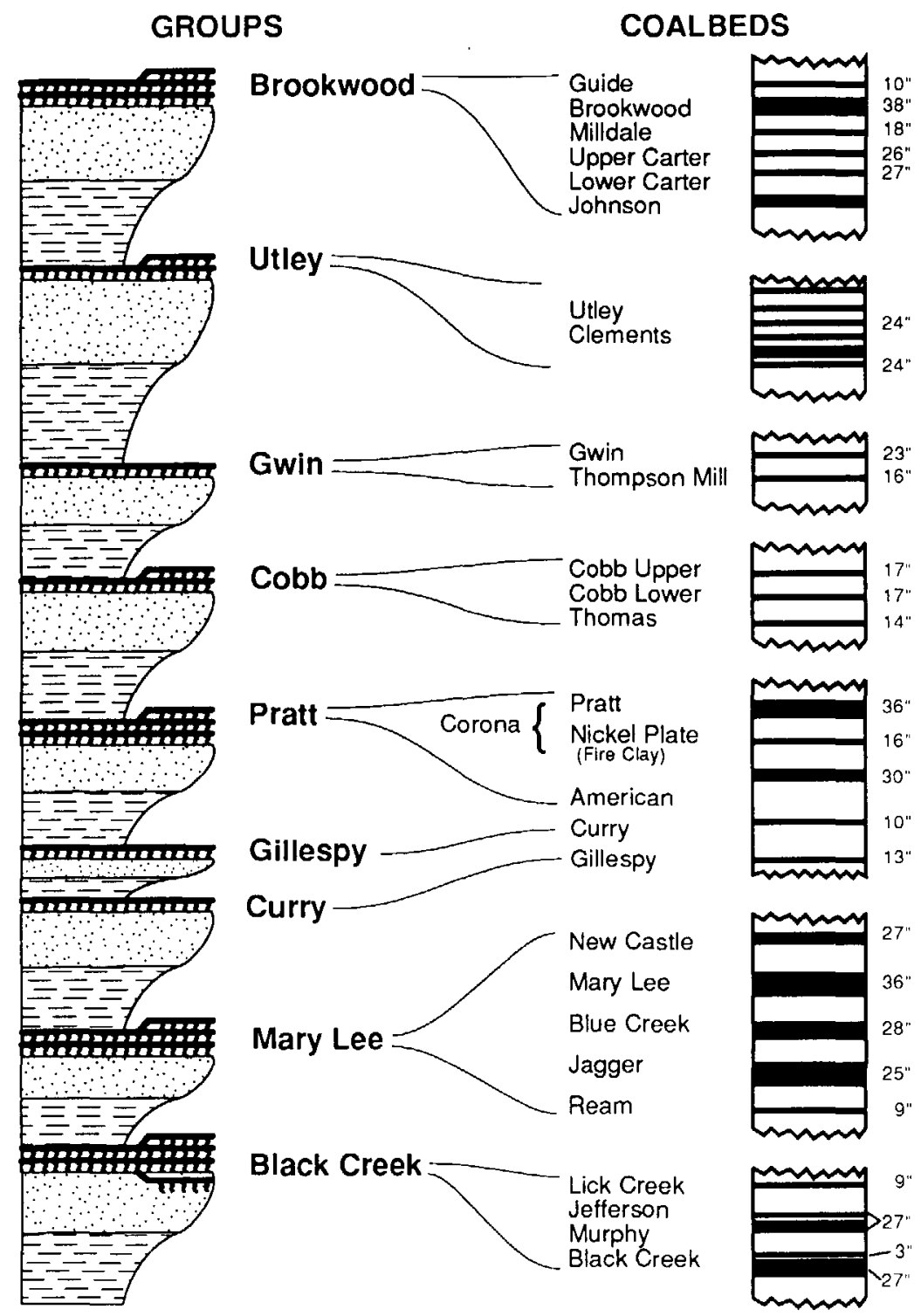

MTITITIF Coal zone

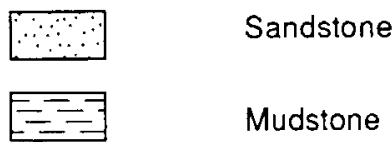

Figure 3. Coals in the upper part of the Lower Pennsylvanian part of the Pottsville Formation showing major coal-bearing groups. Stratigraphic names of economic usage. Modified from Pashin (1991a). Thickness of individual coalbeds, where known, is shown. 1 inch equals 2.54 centimeters.

(Pashin, 1991b) affected patterns of sedimentation, which in turn influence coalification, hydrology, producibility of coalbed gas, and emissions of coalbed gas. Our detailed study of $\mathrm{CH}_{4}$ emission focused on the normal fault exposed at the Bankhead Lock and Dam (discussed in the "Results and Discussion" section).

In addition to the normal fault system (fig. 4), the coalbeds have a distinct set of fractures referred to as 


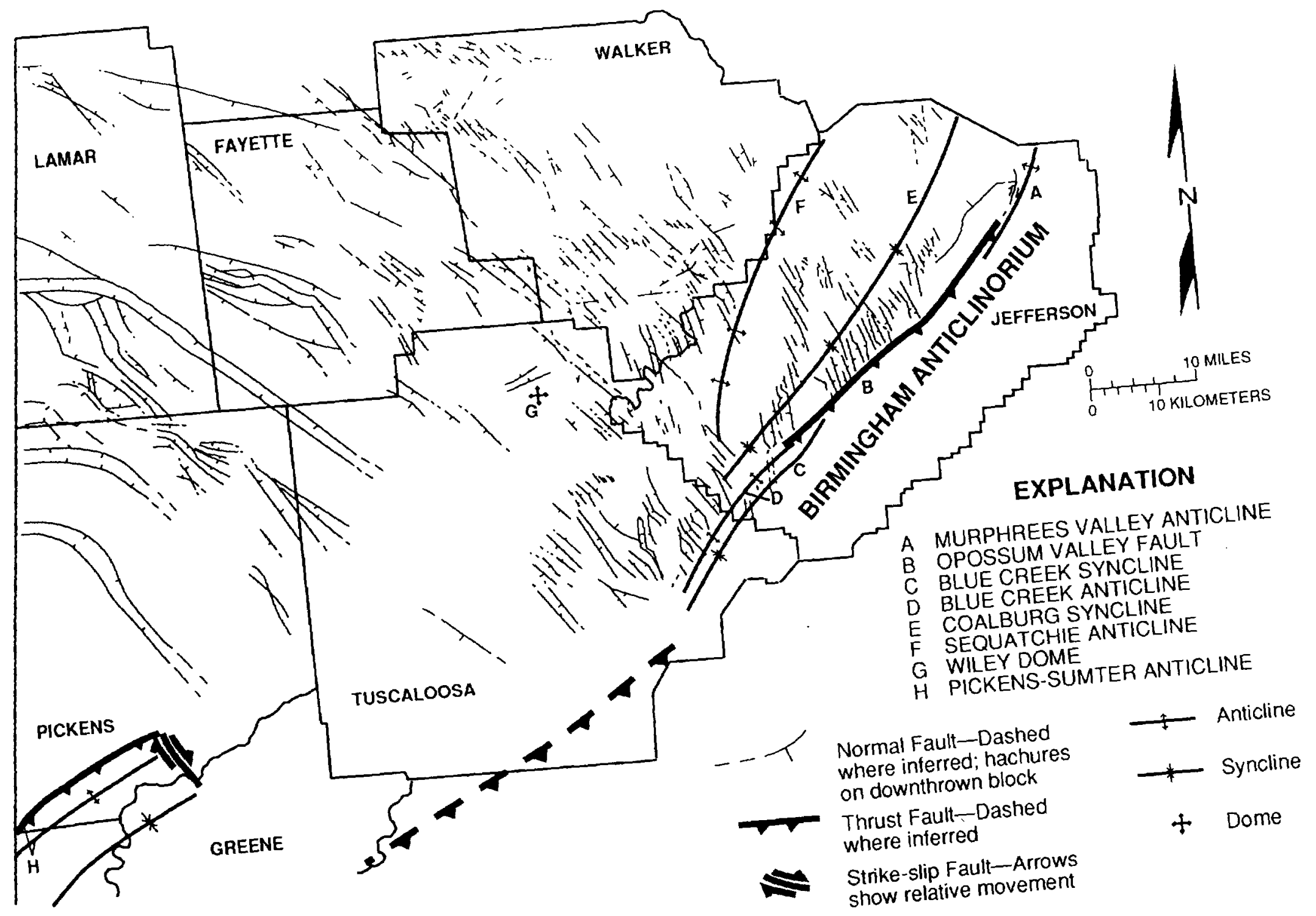


cleats. The cleats are more closely spaced than joints and fractures in the adjacent rocks. Cleats make up a roughly orthogonal set of fractures. Face cleats are fairly continuous, whereas butt cleats are subordinate and commonly terminate at face cleats. Cleats are important because they provide pathways for the migration of gas in the coalbeds, which generally lack matrix permeability. In the Black Warrior Basin, the main orientation of the face cleats is generally perpendicular to the normal faults $\left(\mathrm{N} 62^{\circ} \mathrm{E}\right)$. In the area of the Blue Creek Anticline, however, the face cleats are locally superimposed on the regional face cleat set and trend perpendicular to the axis of the anticline (N 36 ${ }^{\circ} \mathrm{W}$ ) (Ward and others, 1984).

\section{COAL RANK}

The study area is located in a "bull's-eye" pattern of increasing vitrinite reflectance along the Tuscaloosa and Jefferson County border where the highest coal rank is present (Winston, 1990) (fig. 5). In this area, vitrinite reflectance $\left(R_{0}\right)$ values are greater than 1.0 percent and locally greater than 1.4 percent, corresponding to high-volatile bituminous $\mathrm{A}$ to medium-volatile bituminous ranks. The present-day depth of burial in this area is less than $3,000 \mathrm{ft}(914 \mathrm{~m})$. The higher rank in this part of the basin is attributed to a combination of burial and higher paleoheat flow. Maximum depth of burial probably occurred in

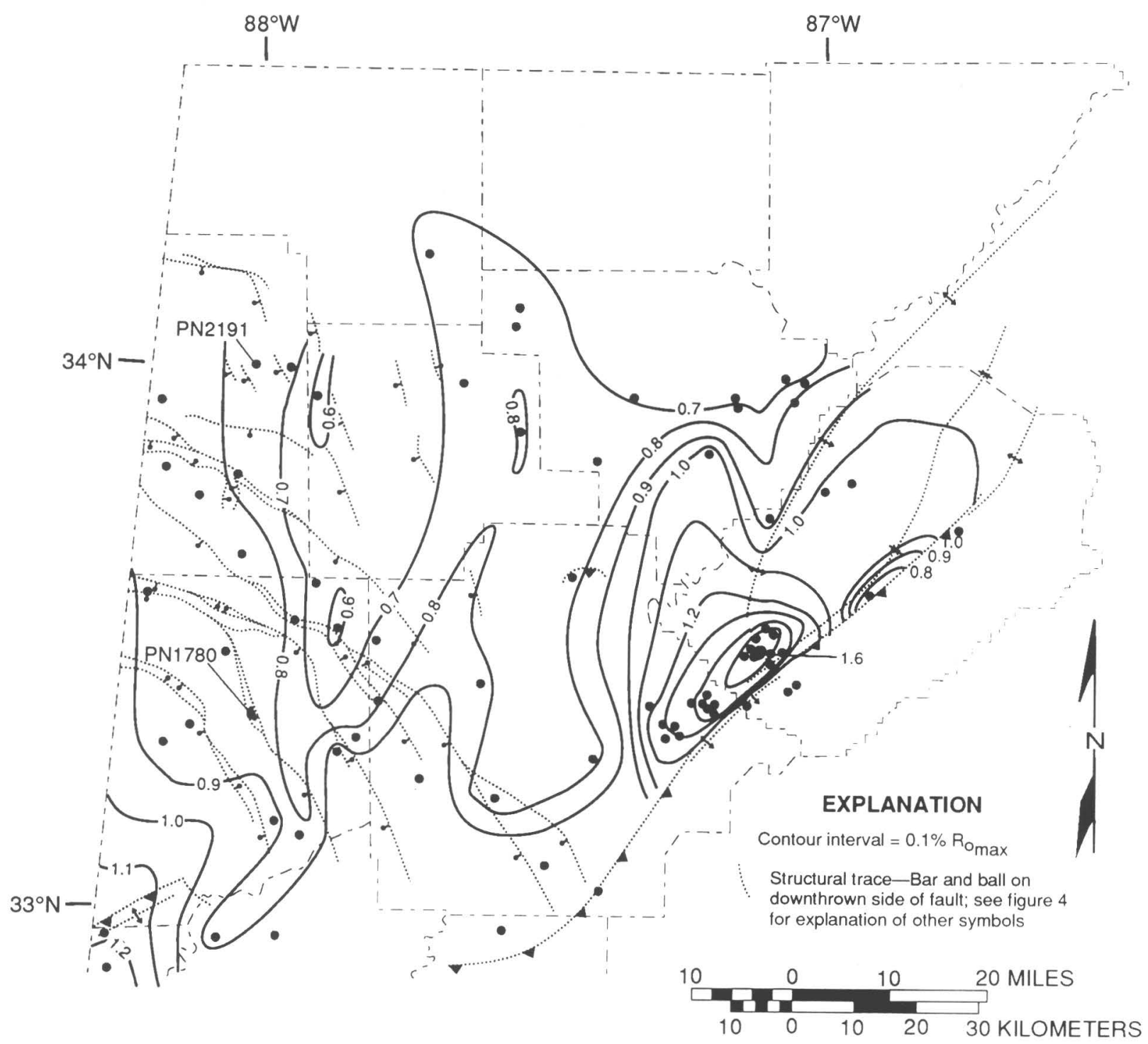

Figure 5. Alabama portion of Black Warrior Basin showing iso-vitrinite reflectance $\left(\mathrm{R}_{\mathrm{o}}\right)$ lines for Mary Lee coal group of Lower Pennsylvanian part of the Pottsville Formation. Modified from Winston (1990). Dots show locations of vitrinite reflectance, $R_{0}$, data used to construct contours. See figure 2 for names of counties. 
this area of rapid subsidence and deposition during late Paleozoic time and as much as $2,439 \mathrm{~m}$ of erosion may have occurred since (Tell and others, 1987). In addition, Pashin (1991a) postulated that higher paleoheat flow may be the result of hydrologic activity in fractured strata adjacent to the Blue Creek Anticline.

\section{COMPOSITION AND ORIGINS OF BLACK WARRIOR COALBED GASES}

The produced coalbed gases from the Brookwood, Deerlick Creek, and Oak Grove Fields (fig. 2) are generally dry in molecular composition: wetness $\left[\left(\sum \mathrm{C}_{2+} / \sum \mathrm{C}_{1+}\right) \times 100\right]$ values are generally about 0.1 percent. In addition, the coalbed gases are characterized by variable methane $\delta^{13} \mathrm{C}$ values of -51.0 to -41.9 permil (Rice and others, 1989). Carbon dioxide contents are low ( $<1$ percent).

The gases are interpreted to be mostly thermogenic in origin, but altered by relatively recent secondary processes, such as mixing with biogenic gas (Rice, in press). If unaltered, these coalbed gases would plot near the regression lines of Dai and others (1987) and Whiticar (1992) as shown on figure 6. On the methane $\delta^{13} \mathrm{C}$ versus rank $\left(R_{0}\right)$ plot (fig. 6), the coalbed gases from the Black Warrior Basin form a relatively small group with methane $\delta^{13} \mathrm{C}$ values that are isotopically lighter (more ${ }^{13} \mathrm{C}$ depleted) than the values predicted for generation from any of the types of kerogen.

Thermogenic gas generation from Pottsville Formation coal probably occurred in Late Pennsylvanian or early Mesozoic time, approximately coincident with the time of maximum burial and (or) highest geothermal gradient. Following uplift and erosion, however, some of the original thermogenic gas, particularly at shallow depths, was probably released. Alteration of the remaining thermogenic gas, perhaps by mixing with isotopically lighter biogenic methane and (or) by oxidation of the heavier hydrocarbons, if present, was favored by active groundwater flow along the southeastern part of the basin. For example, plumes of fresh water have been mapped by Pashin (1991a) and are the result of recharge within the Mary Lee group coals where it is exposed along the Blue Creek Anticline. Mixing of biogenic gas has probably taken place in the shallower coal zones, which are not targets for coalbed gas exploration and production, but which are a possible source of methane emissions.

\section{STORAGE OF GAS IN COALS}

Although some free and dissolved gas may be present in coalbeds, most of the gas is absorbed within the coal. The free and dissolved gas in the coal occurs within the

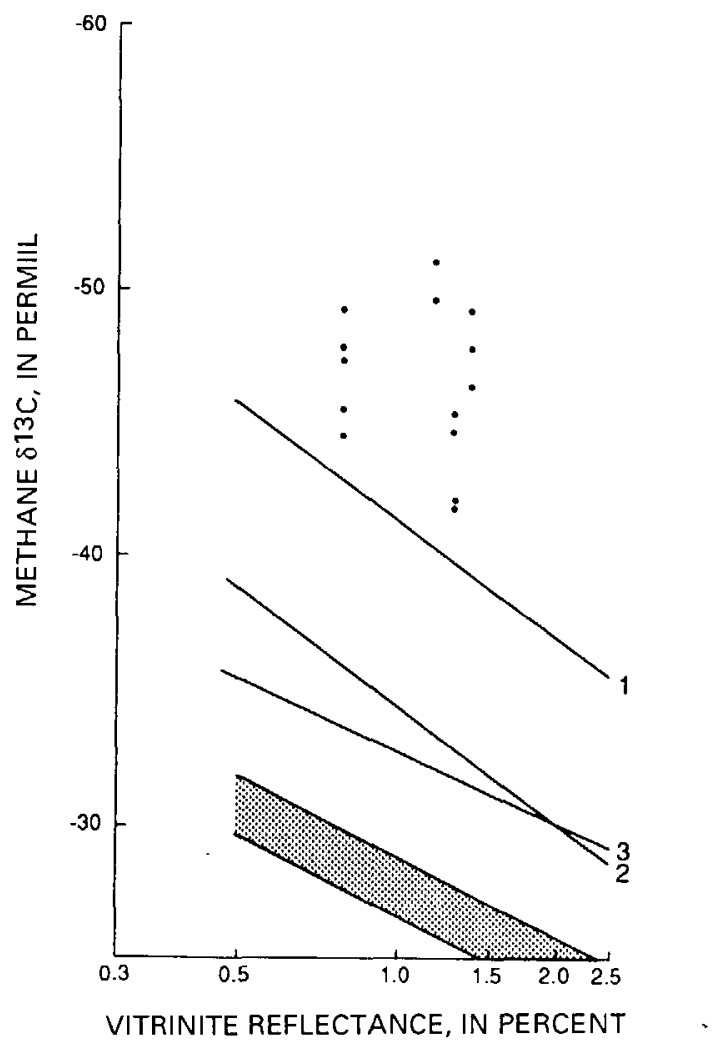

Figure 6. Methane $\delta^{13} \mathrm{C}$ versus vitrinite reflectance $\left(R_{0}\right)$ for coalbed gases and associated coals from Alabama portion of Black Warrior Basin. Regression line 1 is for gases generated from types II and III kerogen (Faber, 1987), line 2 is for coalbed and coal pyrolysis gases in China (Dai and others, 1987), line 3 is for coal-derived gases in China (Shen and others, 1988), and stippled area is for coal-derived and coal pyrolysis gases from several authors as summarized by Whiticar (1992). Modified from Rice (in press).

fractures (cleats) and pores, and the absorbed gas is present as a monomolecular layer on the internal surfaces of the coal (Kim, 1977). Coal has the ability to absorb very large amounts of gas because it is a microporous solid with large internal surface areas.

Gas content generally increases with increasing rank (generally equivalent to increasing burial) (Kim, 1987), although there is a wide range of gas content within each coal rank. A large increase in gas content at a rank of about high-volatile bituminous $C\left(R_{0}\right.$, approximately 0.6 percent) is due mainly to a shift from predominantly thermal processes during high-rank coalification with generation of large amounts of methane to predominantly microbial generation of smaller amounts of gas at lower ranks.

Pressure and temperature are also important controls on the gas content of coal (Juntgen and Karweil, 1966). For a given rank and at constant temperature, absorbed gas 
content increases with increasing pressure, which usually results from increasing depth of burial. In contrast, storage capacity of coals is inversely related to temperature for a constant pressure; increasing temperature results in decreased gas content of the coal. Because high pressure is associated with high-rank coal rather than low-rank coal, higher methane content is commonly associated with highrank coal. However, natural desorption resulting from uplift and erosion may result in lower gas contents.

\section{GAS CONTENT AND RESOURCES}

Gas content data compiled by McFall and others (1986) show the relation between gas content, rank, and present-day depth of burial in the study area (fig. 7). Although considerable scatter exists in the data base, the plot shows that gas content as high as $700 \mathrm{scf} /$ ton (scf, standard cubic feet; $3.1 \mathrm{~cm}^{3} / \mathrm{g}$ ) may be present in low-volatile bituminous coals at depths of $1,037 \mathrm{~m}$. The gas content drops off dramatically for shallow and (or) low-rank coals, which are also possible sources of $\mathrm{CH}_{4}$ emissions. Gas content for Pottsville Formation coal in the Black Warrior Basin is relatively high despite the shallow depth of burial and natural degassing that probably took place during uplift and erosion, which has taken place after the $\mathrm{Al}$ leghanian orogeny (since $260 \mathrm{Ma}$ ). High gas content indicates that relatively recent biogenic gas has probably replaced some of the original thermogenic gas, which naturally desorbed.

On the basis of gas-content data, in addition to information on coal rank and distribution, McFall and others (1986) estimated coalbed-gas resources of approximately

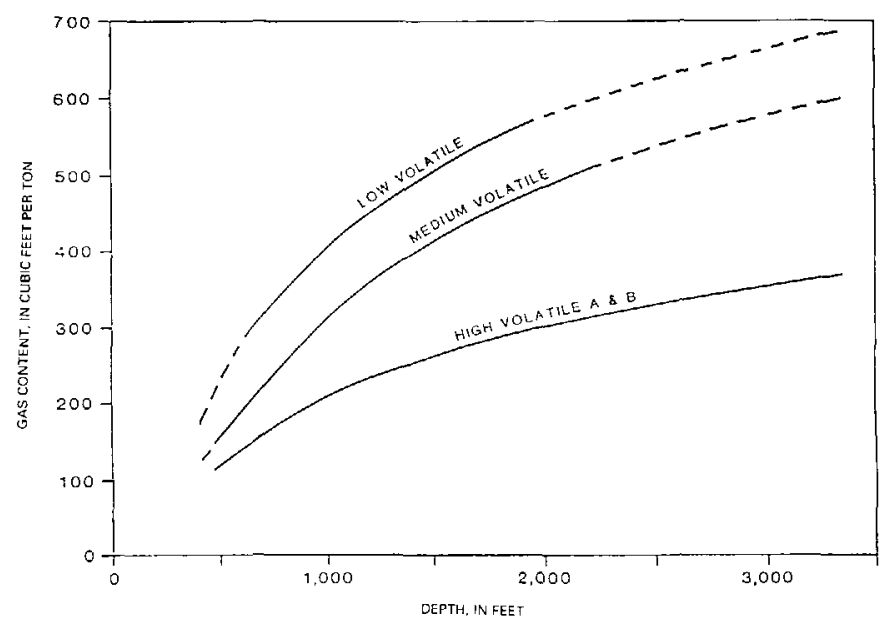

Figure 7. Gas content versus rank and depth of burial for coals from Lower Pennsylvanian part of the Pottsville Formation, Alabama portion of Black Warrior Basin. Dashed lines denote projected trends beyond Black Warrior Basin data. Modified from McFall and others (1986). 1 foot equals 3048 meter.
20 Tcf (trillion cubic feet) for the Black Creek through Cobb interval (fig. 3) in the Alabama portion of the Black Warrior Basin. As expected, the largest resources occur in the deepest, highest rank coal group, the Black Creek. The resource potential decreases stratigraphically upward. In addition, the largest resources for each interval occur in the "bull's-eye" area where the thickest and highest rank coalbeds are present. Smaller, but significant resources of coalbed gas are also present in the shallower coal zones, which have not been formally assessed.

\section{METHANE ASSOCIATED WITH COAL MINING AND UTILIZATION}

\section{UNDERGROUND MINING}

Coal is recovered by both surface and underground mining techniques. Underground mining operations account for the majority of $\mathrm{CH}_{4}$ emissions associated with the recovery and use of coal. Most underground mines are ventilated for safety. Methane concentrations in the range of 5 to 15 percent $(\mathrm{v} / \mathrm{v})$ are explosive; mine air should contain less than 1 percent $\mathrm{CH}_{4}$ to be safe. Degasification systems are frequently used prior to, during, and after mining operations to maintain safe $\mathrm{CH}_{4}$ concentrations. Subsurface mining causes pressure decreases in the coal, which allows release of the coalbed $\mathrm{CH}_{4}$ into the mine tunnels. Methane is released not only from the coal, but also from adjacent rocks and coals above and below the main coalbed.

Large quantities of $\mathrm{CH}_{4}$ are emitted during both common types of subsurface mining, longwall and room/pillar, necessitate high ventilation rates to ensure that mine $\mathrm{CH}_{4}$ levels remain below 1 percent. Methane emissions continue after mining operations cease and ventilation of abandoned mines may be necessary to insure that explosive levels of $\mathrm{CH}_{4}$ do not build up underground. In both room/pillar and longwall mining techniques, $\mathrm{CH}_{4}$ is emitted from the coalbed and enclosing strata as the coal is extracted. In both mining techniques, the overlying strata fractures and may collapse after the coal is removed. Typically, the roof structure collapses and the mine floor buckles upward as mine support systems are removed. This fractured and collapsed region that has been mined out is known as a "gob" area.

Gob areas may typically extend $100 \mathrm{~m}$ above and perhaps $30 \mathrm{~m}$ below the mined-out coalbed. In coals and surrounding rocks containing high gas content, $\mathrm{CH}_{4}$ released from gob areas may overwhelm the ventilation system's capacity for removal of the $\mathrm{CH}_{4}$. Wells referred to as "gob wells" can be drilled from the surface down into the gob fracture region to provide additional ventilation (fig. 8). Gob wells are usually drilled to a depth that is 2 to 25 meters above the coalbed to be mined. Thus, as the region 


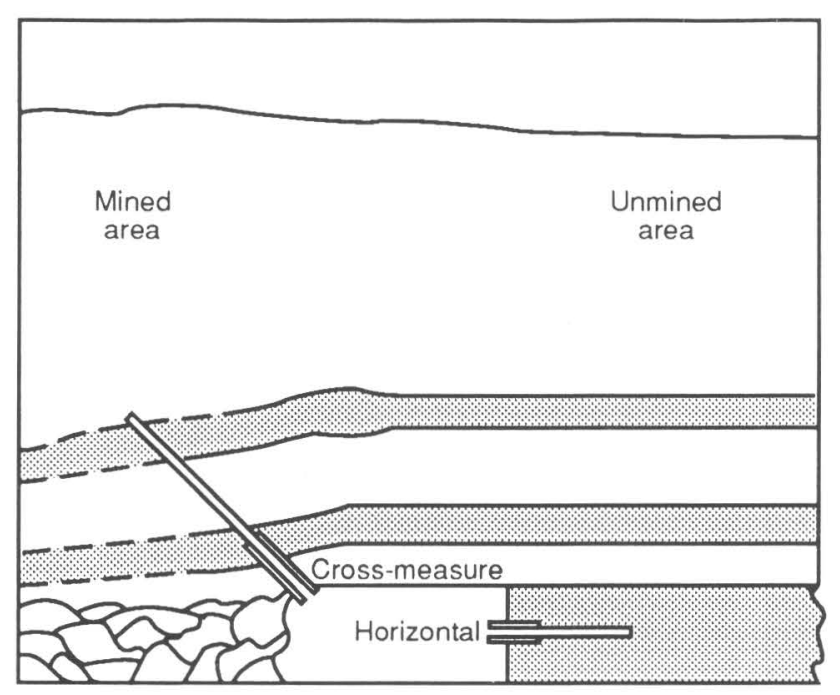

A

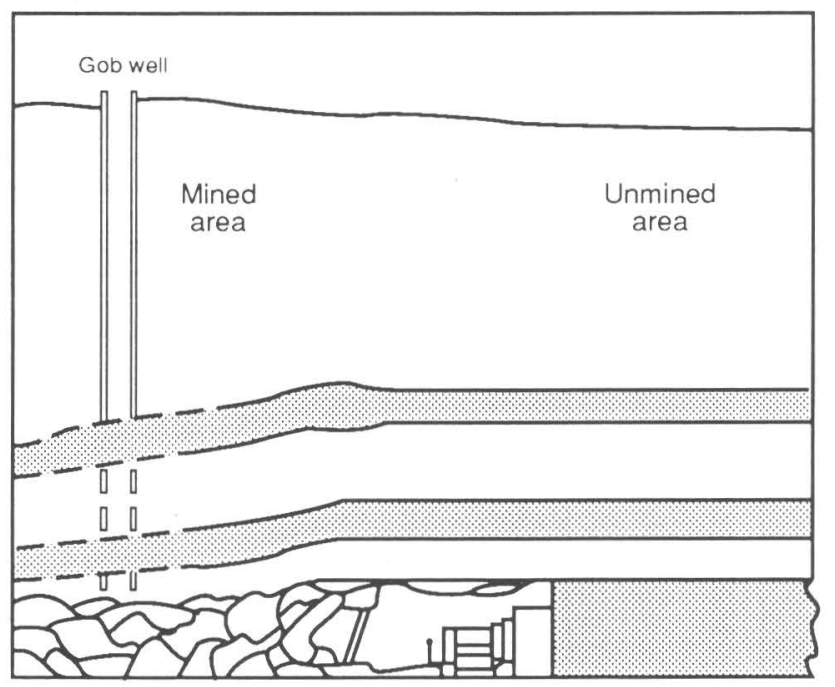

$B$

Figure 8. Schematic diagrams showing $(A)$ horizontal, crossmeasure, and $(B)$ gob wells used to vent gas from coal mines (Modified from Boyer and others, 1990).

above the mined-out area fractures and collapses, $\mathrm{CH}_{4}$ flows into the gob well, which is under a vacuum. Hydrostatic pressures are generally low in gob areas, and methane recovered from gob wells is often quite pure ("pipeline quality") especially immediately following the fracturing of the roof strata. With careful well monitoring, production of nearly pure $\mathrm{CH}_{4}$ may continue for many years. At the present time, however, most gob well $\mathrm{CH}_{4}$ is vented to the atmosphere. A notable exception is that Jim Walter Resources, Inc., is recovering much of its gob gas; as much as 83 percent of the produced gas from their underground mining operations is from gob wells.
Several other methods are currently used to control methane emissions into the mine proper. Horizontal and cross-measure boreholes may be drilled to release $\mathrm{CH}_{4}$ from the coal and rock strata prior to mining (fig. 8). Horizontal drilling into the coalbed will help to release $\mathrm{CH}_{4}$ from the coal itself while cross-measure drilling is used to degasify the coal and surrounding rock strata. Rather than vent borehole $\mathrm{CH}_{4}$ directly into the mine it is usually ducted into an in-mine vacuum system, which directs the released $\mathrm{CH}_{4}$ out of the mine.

Methane may also be rather effectively removed from coalbeds several years prior to mining by the use of vertical wells. The coalbed methane recovered from these wells is also typically of pipeline quality. Accordingly, coalbed methane wells are now drilled both to degasify coalbeds prior to mining and also to recover $\mathrm{CH}_{4}$ from one or more coalbeds, which may be uneconomical or too difficult to mine. The life expectancy of a coalbed methane well is anywhere from 10 to 20 years, and in 1991 there were more than 2,800 wells in the Alabama portion of the Black Warrior Basin that produced about $68 \mathrm{Bcf} / \mathrm{yr}$ (Bcf, billion cubic feet) of high-grade gas from coalbeds (D. Lathem, Coalbed Methane Association, oral commun., 1992). There may also be atmospheric $\mathrm{CH}_{4}$ emissions from these wells.

\section{SURFACE MINING}

Where coalbeds are present near the surface (usually $<60 \mathrm{~m}$ ) and the economics of removing the overburden are favorable, surface mining techniques are used. As is the case in underground mining, $\mathrm{CH}_{4}$ is released from both the coalbed and the surrounding strata during mining. The $\mathrm{CH}_{4}$ content of surface mined coal is typically much lower than deeper underground mine deposits (fig. 7) and thus emissions are estimated to be substantially less from surface mining operations. In 1985, about 55 percent of world coal production was from surface mines. Methane from surface mines escapes directly to the atmosphere. Presently, little reliable data exist to estimate global emissions of $\mathrm{CH}_{4}$ from surface mining.

\section{POST-MINING PROCESSES}

All of the $\mathrm{CH}_{4}$ contained in coal is not released immediately upon mining and thus emissions are also associated with procedures such as processing and transportation which may occur after the coal has left the mine. $\mathrm{CH}_{4}$ emissions may be high during the mechanical breaking, crushing, separating, drying and sizing steps which follow mining. These emissions and those which take place during further coal processing and transportation go directly into 
the atmosphere. There may also be $\mathrm{CH}_{4}$ emissions from mine spoil and tailing piles that are produced during both surface and underground mining. At the present time, however, there are no emission measurements available for these sources.

\section{COAL COMBUSTION}

Roughly 80 percent of world's produced coal is either burned for heat or to generate electricity. Because the combustion of coal takes place in a closed system, it has previously been assumed that $\mathrm{CH}_{4}$ emissions are very minor. A recent preliminary report, however, suggests there may be significant $\mathrm{CH}_{4}$ emissions resulting from the low-temperature combustion of coal such as is typical in home heating and cooking applications in countries such as China (Khalil and others, 1993). These authors measured $\mathrm{CH}_{4}$ emissions from coal burning which were roughly an order of magnitude larger than those typically reported for low-temperature biomass combustion. They calculated that global emissions of $\mathrm{CH}_{4}$ are perhaps as much as $16 \mathrm{Tg} / \mathrm{yr}(0.79 \mathrm{Tcf})$ owing to low-temperature coal combustion. Coal combustion is clearly an area where more data are required to more accurately assess the importance of this source.

\section{ANALYTICAL AND FIELD METHODS}

Real-time $\mathrm{CH}_{4}$ flux measurements were made using an Aerodyne Research, Inc., Mobile Methane Monitor. This monitor consists of a truck-mounted system for determining methane flux on the basis of absorption of infrared laser radiation (McManus and others, 1991). Methane is detected by passing an atmospheric (sampled) air stream through a $\mathrm{He}-\mathrm{Ne}$ laser that is rapidly tuned on and off of the methane infrared absorption line of 3.39 microns $\left(2947.91 \mathrm{~cm}^{-1}\right.$ ). Changes in the cell transmission resulting from varying $\mathrm{CH}_{4}$ concentrations in the sampled air stream are used to determine real-time methane concentrations and changes. The instrument is sensitive to changes of 0.3 percent of the ambient atmospheric methane level, or about $5 \mathrm{ppbv}$, and response time is about 1 second.

Carbon dioxide is detected using a separate truckmounted instrument that measures infrared absorption (LiCor, Inc.) with an accuracy of \pm 1 part per million. The purpose of measuring $\mathrm{CO}_{2}$ is to correct for any methane from automobiles or other combustion sources that might mask $\mathrm{CH}_{4}$ from coalbeds. For example, a correction factor of $\mathrm{CH}_{4}: \mathrm{CO}_{2}$ of $1: 1000$ is used to account for methane from automobile exhaust (McManus and others, 1991).

To determine $\mathrm{CH}_{4}$ fluxes from point sources, such as faults or mine vents, sulfur hexafluoride $\left(\mathrm{SF}_{6}\right)$ is released at a measured rate and is detected simultaneously along with the methane by the truck-mounted system. Sulfur hexafluoride is an inert gas not typically found in the atmosphere. The $\mathrm{SF}_{6}$ is measured with a rapid-response $\mathrm{SF}_{6}$ analyzer using an electron-capture detector (Benner and Lamb, 1985) with a detection limit of about 10 parts per trillion. Because the source and rate of release of the $\mathrm{SF}_{6}$ are known, coincidence of a methane peak and the $\mathrm{SF}_{6}$ tracer peak identifies source of the $\mathrm{CH}_{4}$ peak and allows calculation of the $\mathrm{CH}_{4}$ flux.

Determination of $\mathrm{CH}_{4}$ fluxes using 10- to 36-liter plastic static chambers was accomplished using the method described by Leventhal (1992). For collecting samples, a chamber was placed on the ground or coalbed by fitting the edges of the open end of the chamber into an approximately $1 \mathrm{~cm}$ by $1 \mathrm{~cm}$ channel dug into the coal or ground surface (fig. 9). To minimize leakage around the edges of the chamber, mud was packed around the outside perimeter of the chamber. For coal piles, the collectors were pushed about 3 to $5 \mathrm{~cm}$ into the loose coal, but a tight seal was not possible. In this case, some leakage of methane may have occurred and the values reported herein represent minimum fluxes. Methane concentrations inside the static chambers and ambient $\mathrm{CH}_{4}$ concentrations were measured by two methods. On-site flux measurements were accomplished

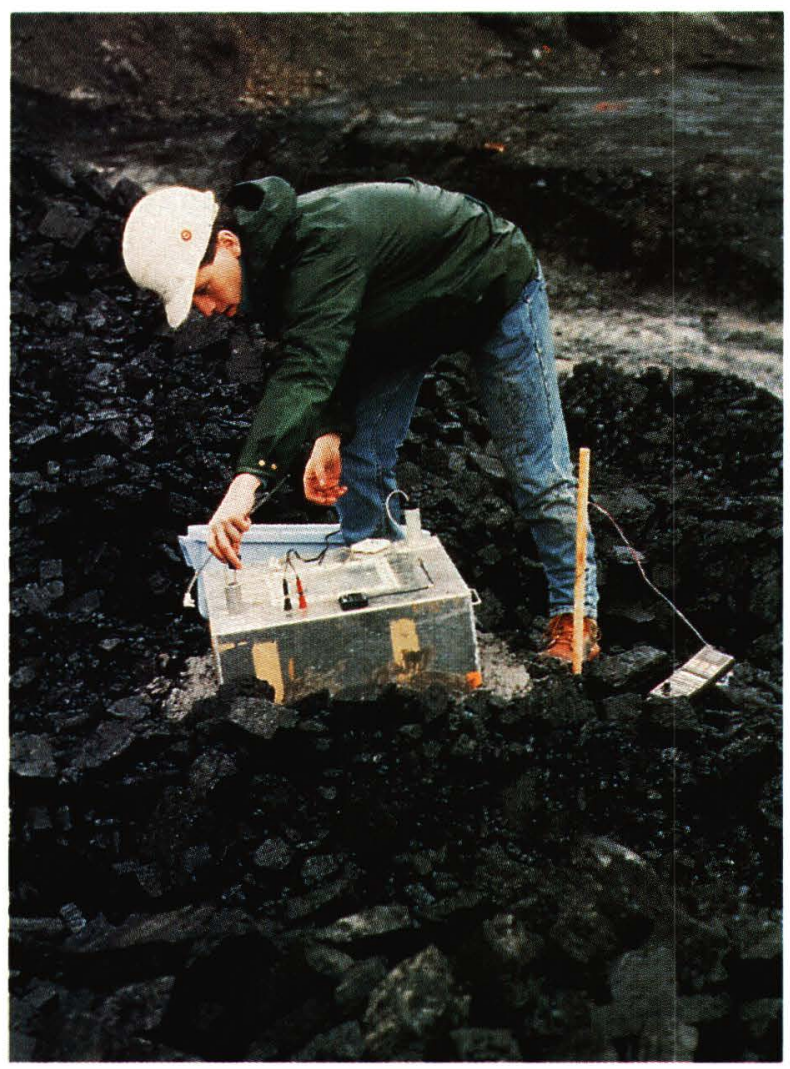

Figure 9. Aluminum static chamber used to collect samples to determine methane flux on coalbeds and coal piles. Samples are withdrawn using a gas-tight syringe and injected into glass sample vials for subsequent laboratory analysis using gas chromatography. Photograph by Jerry L. Clayton. 
using a portable flame-ionization detector (FID) (Leventhal, 1992) to measure $\mathrm{CH}_{4}$ concentrations inside the chambers in the field. The FID measurements were made at 6 - to 10 -minute intervals over 30 to 50 minutes. The data were recorded in the field and later plotted $\left(\mathrm{CH}_{4}\right.$ concentration versus time) to determine fluxes.

For comparison of methods, a second type of static chamber was used (aluminum, $51 \times 51 \times 26 \mathrm{~cm}$ ) to collect samples at most sites. Air samples of $60 \mathrm{ml}$ were withdrawn from the chamber at 2-minute intervals (up to a total of 10 minutes) and stored in previously evacuated glass vials for subsequent analysis by gas chromatography at the University of New Hampshire. Twelve control vials containing $\mathrm{CH}_{4}$ standards indicated that no detectable loss of methane occurred during transport and storage (maximum of 21 days) of the glass sample vials prior to laboratory analysis.

Methane samples were collected for stable isotope ratio measurement using a procedure modified from Quay and others (1991). A portable pump (KNF Neuberger Model NO5, Princeton, NJ), powered with a rechargeable 12-volt DC lead acid battery (Yasua), was connected with tubing (nylon, teflon, or copper) to an $8 \mathrm{~L}$ propane-type tank that was pre-evacuated to a pressure of $635 \mathrm{~mm}$ (25 inches) $\mathrm{Hg}$. Methane samples were collected from along faults or col- lectors placed over open coreholes through the open end of the tubing with the other end connected through the pump to the evacuated tank (fig. 10). The tank valve was opened and methane flowed into the tank at atmospheric pressure for 1 to 2 minutes. Then, using the pump described above, additional methane was pumped into the collector tank to a pressure of about 1.5 atmospheres for 3 minutes.

\section{RESULTS AND DISCUSSION}

\section{BANKHEAD FAULT}

The outcrop of the Bankhead Fault (fig. 11A,B) at Bankhead Lock and Dam along the Black Warrior River is one of the best exposures of a normal fault in the Black Warrior Basin. The Bankhead Fault is exposed near the western Oak Grove coalbed-gas field (fig. 2) and is part of a horst-and-graben system where displacement of individual faults locally approaches $400 \mathrm{ft}$ or $122 \mathrm{~m}$ (fig. 12). Stratigraphic displacement along the Bankhead Fault is approximately 200 feet $(61 \mathrm{~m})$, and the fault strikes $\mathrm{N} 25^{\circ} \mathrm{W}$ and dips $80^{\circ} \mathrm{NE}$ (Rheams and Benson, 1982). Prodeltaic mudstone of the Brookwood cycle forms the hanging wall and delta-front sandstone of the Utley cycle forms the footwall.

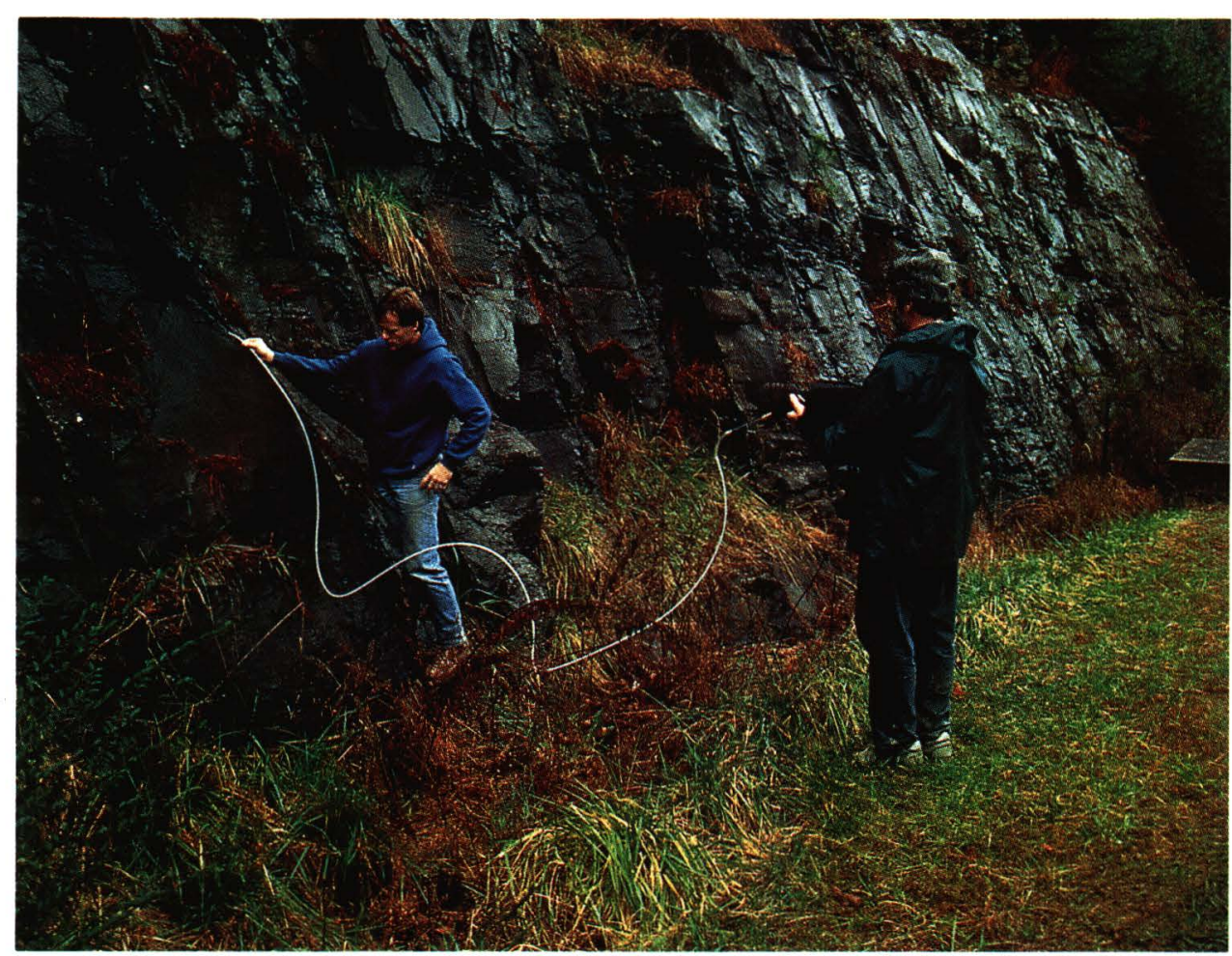

Figure 10. Method used to collect methane for determination of stable carbon isotope ratio. Shown here is a joint in a sandstone on the downthrown (footwall) side of the Bankhead Fault. Methane leaking from the joint is pumped through a tube into a pre-evacuated cylinder to a pressure of about $1.5 \mathrm{~atm}$. Photograph by Dudley D. Rice. 

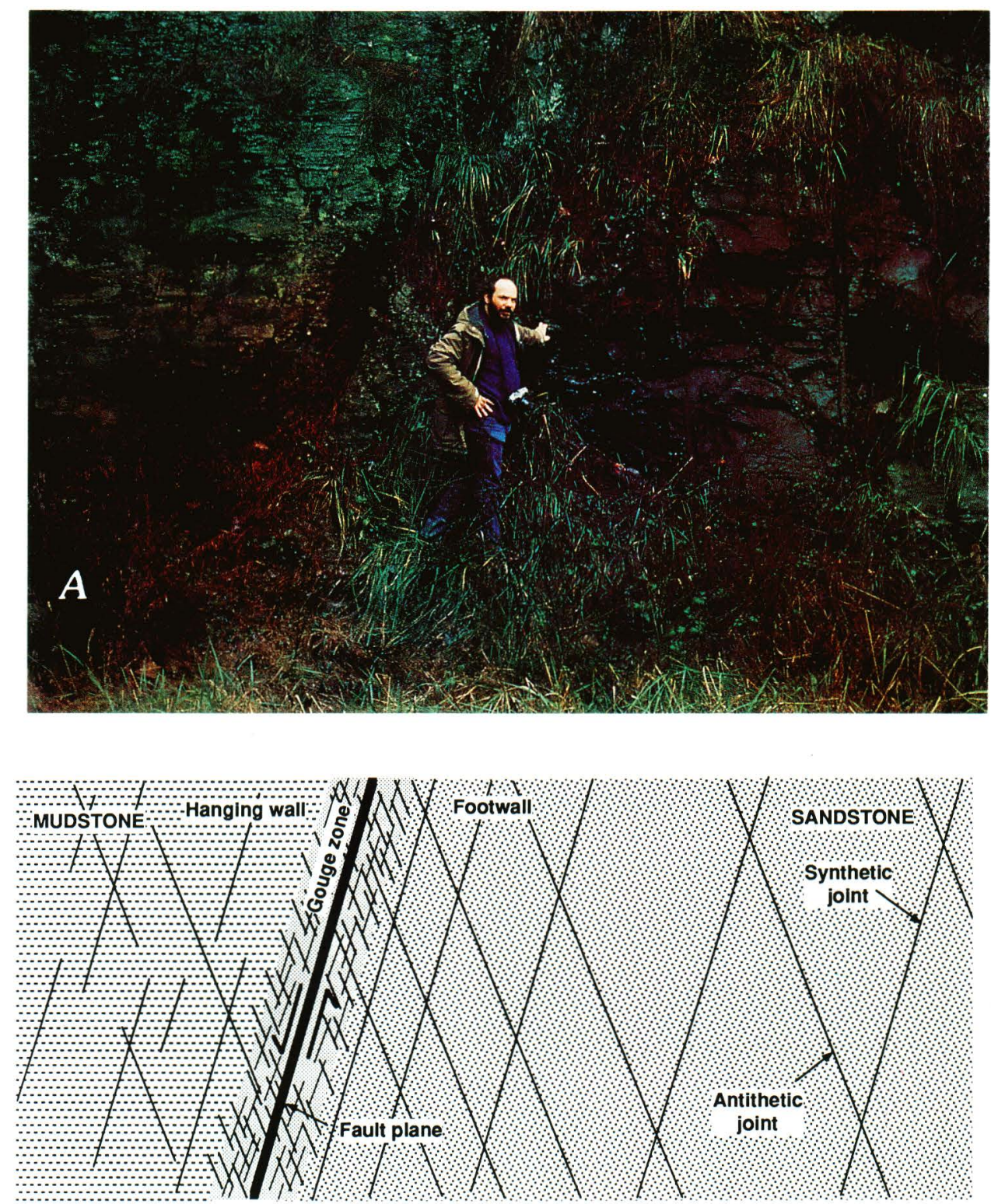

B

Figure 11. A, Normal fault at Bankhead Lock and Dam showing fault gouge and related fracture. Photograph by Jack C. Pashin. $B$, Schematic diagram of the Bankhead Fault showing distribution of fractures (Modified from Pashin, 1991).

Distinctive fracture systems are associated with the Bankhead Fault. The fault plane is a gouge zone 2 to $3 \mathrm{ft}$ (.6 to $.9 \mathrm{~m}$ ) wide containing intensely sheared mudstone and fractured sandstone. Fractures related to the fault include synthetic joints, or joints parallel to the fault plane, and antithetic joints, or joints oblique to the fault plane. In mudstone of the footwall, these joints are discontinuous and have irregular spacing. By contrast, joints in sandstone of the hanging wall are continuous and increase in spacing away from the fault.

Three faults in the Black Warrior Basin were tested during this study, but gas emissions were detected only from the Bankhead Fault Zone. Using an $\mathrm{SF}_{6}$ tracer gas release next to the fault, an overall $\mathrm{CH}_{4}$ emission rate of $0.94 \mathrm{~L} / \mathrm{min}$ (table 2) was measured using the truck-mounted laser spectrophotometer while driving along the road about $30 \mathrm{ft}(9 \mathrm{~m})$ from the surface exposure of the fault. On an annual basis, $0.94 \mathrm{~L} / \mathrm{min}$ would be $19 \mathrm{Mcf} / \mathrm{year}$ $\left(3.8 \times 10^{-4} \mathrm{Tg}\right)$, not considering possible diurnal or annual variations. Use of the static chamber method to measure $\mathrm{CH}_{4}$ flux from one of the antithetic joints yielded a similar flux $(1.0 \mathrm{~L} / \mathrm{min}$, table 2$)$.

Testing with a hand-held gas chromatograph (FID) revealed that gas was diffusing out of the fault gouge as 


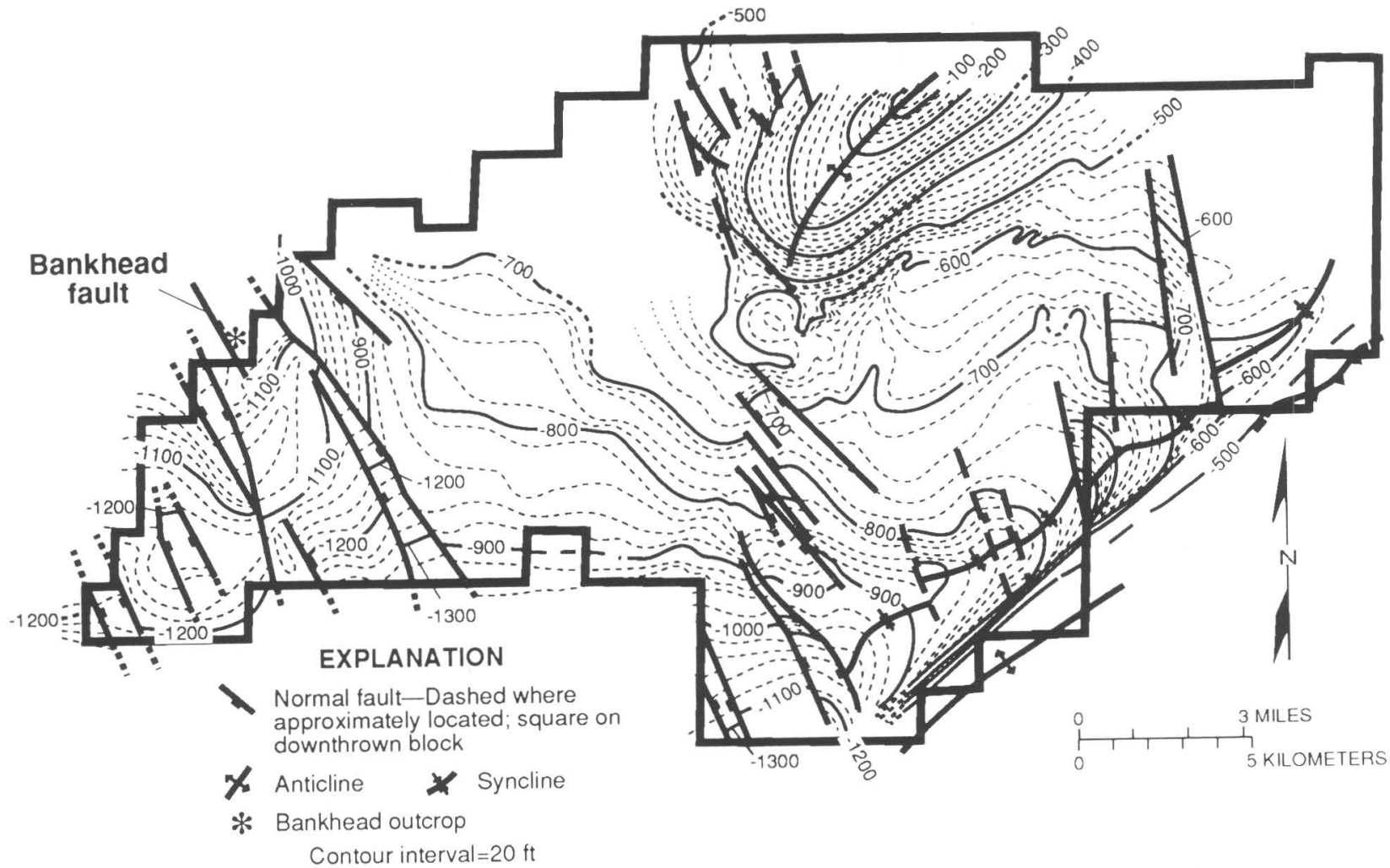

Figure 12. Structural contour map of Oak Grove Field (thick black outline) showing location of Bankhead Fault (Modified from Pashin, 1991b). Intermediate contours shown by dashed lines. See figure 2 for geographic location of Oak Creek Field.

Table 2. Methane fluxes from point sources measured at various locations in the Black Warrior Basin, Alabama, using static chamber and truck-mounted laser-based spectrophotometric methods.

[Mcf, thousand cubic feet; Mcfd, thousand cubic feet per day]

\begin{tabular}{cccccc}
\hline Location description & L/min & $\mathrm{g} / \mathrm{min}$ & $\mathrm{m}^{3} / \mathrm{yr}$ & Mcfd & Mcf/yr \\
\hline \multicolumn{7}{c}{ Bankhead Fault } \\
\hline $\begin{array}{c}\text { 'Contact of mudstone and } \\
\text { sandstone, base of fault. }\end{array}$ & 0.94 & 0.67 & 494 & $47.8 \times 10^{-3}$ & 17 \\
$\begin{array}{c}2 \text { Antithetic joint in } \\
\text { sandstone. }\end{array}$ & 1.0 & 0.71 & 526 & $50.8 \times 10^{-3}$ & 19 \\
\hline
\end{tabular}

Jim Walter Resources, Inc., Mine \#5

\begin{tabular}{llllll}
\hline${ }^{3}$ Ventilation shaft ---.-- & 136,000 & 97,144 & $71,481,600$ & 6,915 & $2,524,015$
\end{tabular}

\footnotetext{
'Static chamber method using aluminum chamber and sample analysis at the University of New Hampshire.

${ }^{2}$ Static chamber method using plastic chambers and on-site flame-ionization detection measurement of methane concentrations.

${ }^{3}$ Flux determinations using truck-mounted laser-based spectrophometic method with $\mathrm{SF}_{6}$ tracer gas. See Analytical Methods section for full discussion of techniques used.
}

well as the joint systems. To assess the degree of variability in gas emissions from one joint, we measured gas concentrations at 1 -in. $(2.54 \mathrm{~cm})$ intervals along an antithetic joint (fig. 13). Gas concentration generally decreases upward along the fracture from approximately $200 \mathrm{ppm}$ to approximately $1 \mathrm{ppm}$ above background. From 17 to 


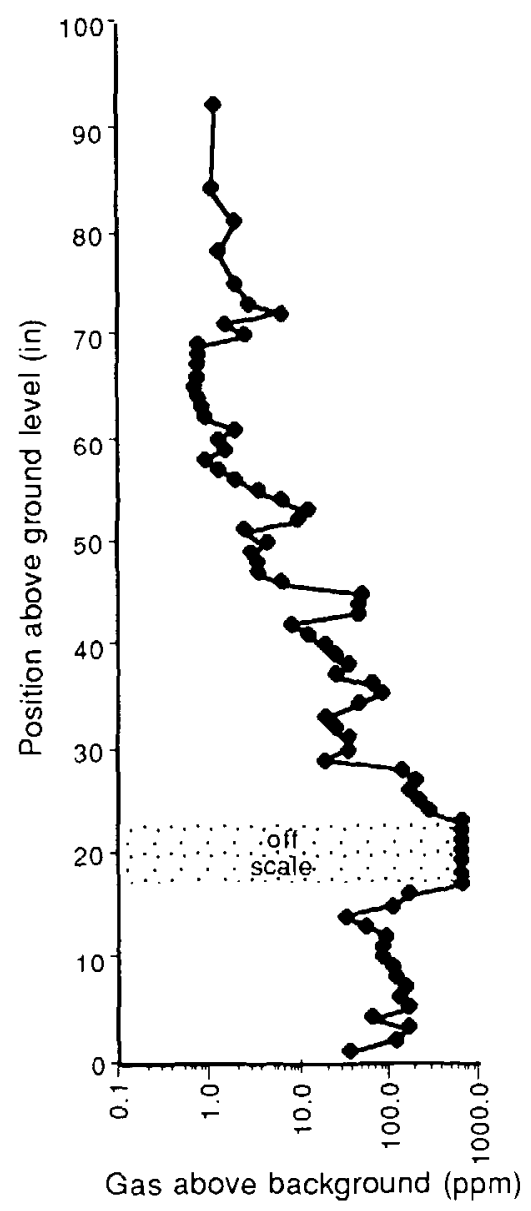

Figure 13. Plot of methane emission along an antithetic joint in the hanging wall of the Bankhead Fault, Black Warrior Basin, Alabama.

23 in. (43 to $58 \mathrm{~cm}$ ) above ground level, however, gas readings exceeded full-scale detection maximum of about $623 \mathrm{ppm}$ above background. Similar off-scale readings were observed along parts of other joints as well; these readings suggest that permeability, or openness, varies considerably along fracture traces.

Coal is the probable source for gas coming out of the Bankhead Fault and its associated fractures. Two $\mathrm{CH}_{4}$ samples collected at the Bankhead location had $\delta^{13} \mathrm{C}$ values of -49.3 and -52.8 permil (table 3 ), similar to the values for coalbed methane in the Black Warrior Basin (fig. 6). Nearby coalbed $\mathrm{CH}_{4}$ exploration wells indicate that coalbeds of the Gwin and Utley groups (both of economic usage) are generally less than $61 \mathrm{~m}$ from the surface throughout this area. Additionally, wells drilled into other coalbeds that have been completed for $\mathrm{CH}_{4}$ production in this area range in depth from $229 \mathrm{~m}$ to $610 \mathrm{~m}$. Whether coalbed gas is migrating to the surface in re-
Table 3. Stable carbon isotope ratios of methane samples collected from sites of methane flux measurements, Black Warrior Basin, Alabama.

\begin{tabular}{ll}
\hline \multicolumn{1}{c}{ Sample location } & $\delta^{13} \mathrm{C}$ (permil versus PDB standard) \\
\hline $\begin{array}{l}\text { Bankhead Fault }\left(\mathrm{CH}_{4} \text { collected }\right. \\
\text { from joint in sandstone). }\end{array}$ & -49.3 \\
Bankhead Fault $\left(\mathrm{CH}_{4}\right.$ collected \\
from joint with large open \\
cavity having highest $\mathrm{CH}_{4}$ \\
concentration measured by \\
FID). \\
Jim Walter Resources, Inc., \\
coal evaluation open \\
corehole (Gwin coal, \\
approximately 275 feet \\
(84 m) depth; drilling \\
completed approximately \\
24 h before sampling). \\
Coalbed methane from Black \\
Warrior Basin wells (Rice \\
and others, 1989).
\end{tabular}

sponse to continued unroofing of the Pottsville Formation or to dewatering by coalbed methane wells is unclear. Furthermore, it is not possible to determine precisely which coal the $\mathrm{CH}_{4}$ is derived from based on the limited isotopic and geologic data of the present study. However, our data show that gas is migrating along some fractures in the Black Warrior Basin. Quantification of the atmospheric $\mathrm{CH}_{4}$ flux in the basin requires a more comprehensive study of emissions from faults and fractures to obtain more quantitative data and to evaluate geologic factors that affect gas movement through faults and fractures.

\section{GWIN COAL EXPLORATION CORE}

We sampled a new corehole drilled by Jim Walter Resources, Inc. to a depth of about $270 \mathrm{ft}(82 \mathrm{~m})$ for evaluation of the Gwin coalbed (fig. 3). Over a period of two days, we measured methane concentrations at the top of the hole when the hole was open during drilling breaks. Methane concentrations were relatively low and no obvious increase above ambient levels was measured while the borehole penetrated the overburden. An increase to about $6 \mathrm{ppm}$ above ambient concentrations was measured when the drill entered the Gwin coalbed. Upon completion of drilling, the corehole was covered with a plastic collector and left for approximately $24 \mathrm{~h}$. Although it was not possible to determine a flux by this method, we did observe a $\mathrm{CH}_{4}$ concentration of about $100 \mathrm{ppm}$ in the chamber before and after withdrawing a sample for isotopic analysis.

The isotopic composition of the methane collected at the Gwin coal drilling site is unusually heavy $\left({ }^{13} \mathrm{C}\right.$ enriched, $\delta^{13} \mathrm{C}=-32.7$ permil) compared to coalbed $\mathrm{CH}_{4}$ sam- 
ples from the Black Warrior Basin ( -42 to -52 permil, fig. 6) and the other two methane samples collected during this study (table 4), which have $\delta^{13} \mathrm{C}$ values of -49.3 and -52.8 permil. The thermal maturity of the Gwin coal at the corehole site is not high enough to account for an isotopic fractionation of about 10 permil or more when compared to typical Black Warrior Basin coalbed methane values (figs. 5, 6). A possible explanation is that oxidation of $\mathrm{CH}_{4}$ catalyzed by methane-oxidizing bacteria (Coleman and others, 1981) may occur either in water associated with a free gas phase present in the coal or in the overlying water-containing rocks as $\mathrm{CH}_{4}$ leaks out of the coal and moves upward. Bacterial oxidation preferentially removes isotopically light $\left({ }^{13} \mathrm{C}\right.$ depleted $)$ methane, which can cause a positive shift in $\delta^{13} \mathrm{C}$ values in the residual methane.

The methane sample collected at the Gwin coal corehole site contained insufficient concentration of $\mathrm{CO}_{2}$ to de- termine the carbon isotope ratio as a test for the presence of methane-oxidizing bacteria. Therefore, we cannot assess the extent, if any, to which biogenic processes might affect the $\mathrm{CH}_{4}$ flux at this site, although higher $\mathrm{CO}_{2}$ concentrations might be expected if biogenic oxidation were occurring to any significant extent. Moreover, at both the Gwin and Bankhead sites, isotopic evidence give no indication of enhanced flux owing to biogenic generation of $\mathrm{CH}_{4}$ in the shallow subsurface.

\section{SURFACE COAL MINE}

We measured $\mathrm{CH}_{4}$ fluxes from the Pennsylvanian Carter and Milldale coalbeds (Brookwood group) (fig. 3) at several sites within the Drummond Coal Co., Inc., Kellerman 1570-2 surface mine. A comparison of $\mathrm{CH}_{4}$ concentrations versus time for static collection chambers placed

Table 4. Methane fluxes measured at various locations in surface coal mines and coal storage in the Black Warrior Basin, Alabama, using static chambers.

[Mcf, thousand cubic feet; Mcfd, thousand cubic feet per day; --, methane flux below detection limit]

\begin{tabular}{|c|c|c|c|c|c|c|}
\hline Location description & $\begin{array}{l}\mathrm{L} / \mathrm{m}^{2} / \mathrm{min} \\
\left(\times 10^{-3}\right)\end{array}$ & $\begin{array}{l}\mathrm{g} / \mathrm{m}^{2} / \mathrm{min} \\
\left(\times 10^{-3}\right)\end{array}$ & $\mathrm{m}^{3} / \mathrm{m}^{2} / \mathrm{yr}$ & $\begin{array}{c}\mathrm{Mcfd} / \mathrm{m}^{2} \\
\left(\times 10^{-4}\right)\end{array}$ & $\mathrm{Mcf} / \mathrm{m}^{2} / \mathrm{yr}$ & Mcf/acre/yr \\
\hline \multicolumn{7}{|c|}{ Jim Walter Resources, Inc., Mine \#5 } \\
\hline $\begin{array}{l}\text { 'Unprocessed coal pile } \\
\text { (4.5 } \mathrm{m} \text { above ground). }\end{array}$ & 5.3 & 3.8 & 3 & 2.7 & 0.10 & 401.6 \\
\hline $\begin{array}{l}\text { 'Unprocessed coal pile (10 m } \\
\text { above ground). }\end{array}$ & 10.5 & 7.5 & 6 & 5.3 & 0.19 & 788.6 \\
\hline $\begin{array}{l}\text { 'Processed coal pile }(10 \mathrm{~m} \\
\text { above ground). }\end{array}$ & 31.2 & 22.3 & 16 & 15.9 & 0.58 & 2343.9 \\
\hline 'Tailing pile---------_----_ & $<0.1$ & $<0.1$ & $<.01$ & $<.01$ & $<.01$ & 0.7 \\
\hline $\begin{array}{l}\text { 'Vegetated surface of } \\
\text { reclaimed surface mine. }\end{array}$ & -- & -- & -- & -- & -- & -- \\
\hline
\end{tabular}

Drummond Coal Co., Inc., Kellerman Mine 1570-2

\begin{tabular}{|c|c|c|c|c|c|c|}
\hline \multirow[b]{2}{*}{${ }^{2}$ Undisturbed coal surface ---- } & \multicolumn{6}{|c|}{ Carter coal } \\
\hline & 0.04 & 0.032 & 0.02 & 0.023 & $<.01$ & 3.4 \\
\hline${ }^{1}$ Undisturbed coal surface ---- & 0.01 & 0.007 & 0.005 & 0.005 & $<01$ & 0.7 \\
\hline${ }^{1}$ Crushed coal pile & 0.49 & 0.35 & 0.26 & 0.25 & $<01$ & 36.5 \\
\hline${ }^{\prime}$ Crushed coal pile & 0.46 & 0.33 & 0.24 & 0.23 & $<01$ & 34.3 \\
\hline${ }^{2}$ Crushed coal pile & 0.10 & 0.07 & 0.05 & 0.05 & $<.01$ & 0.7 \\
\hline \multirow[t]{2}{*}{${ }^{2,3}$ Roughened coal surface---- } & 0.06 & 0.04 & 0.03 & 0.03 & $<.01$ & 4.3 \\
\hline & \multicolumn{6}{|c|}{ Milldale coal } \\
\hline${ }^{2}$ Undisturbed coal surface -... & 0.05 & 0.04 & 0.03 & 0.03 & $<.01$ & 4.1 \\
\hline${ }^{2.3}$ Roughened coal surface---- & 0.19 & 0.13 & 0.10 & 0.09 & $<.01$ & 14.1 \\
\hline
\end{tabular}

\footnotetext{
${ }^{1}$ Static chamber method using aluminum chamber and sample analysis at the University of New Hampshire.

${ }^{2}$ Static chamber method using plastic chambers and on-site flame-ionization detection measurement of methane concentrations.

${ }^{3}$ Flux measurements of "roughened" surfaces were made by digging in the upper few centimeters of the coal surface to expose fresh, small pieces of coal prior to placement of the collection chamber.
} 
at three locations within the Kellerman Mine is shown in figure 14. Methane flux was quite low at all sites tested within the mine, including piles of freshly uncovered, broken pieces of coal $\left(<0.5 \mathrm{~m}^{3} / \mathrm{m}^{2} / \mathrm{yr}\right.$, table 4$)$. No significant differences in emissions were evident between the Carter and Milldale coals.

Using the FID, we monitored $\mathrm{CH}_{4}$ levels along a cross-sectional traverse of the Carter coal at a freshly exposed surface, but we did not observe a detectable increase above the ambient level in other areas of the mine pit. Moreover, we collected two canned samples of freshly mined Carter coal for headspace analysis. After a 1-week period only very low amounts of gas accumulated in the cans, and it was not possible to determine the in-situ gas content to compare with other field data.

The low $\mathrm{CH}_{4}$ flux from coalbeds of the Kellerman Mine is not unexpected considering the geologic history and present-day shallow burial depth of the coal. Coals of the Brookwood group (includes Milldale and Carter coalbeds) were deposited during Pennsylvanian time and reached maximum burial depths during the development of the Appalachian Basin (Alleghanian orogeny). As much as $2,439 \mathrm{~m}$ of strata may have been eroded above the coals by the end of Paleozoic time. Presently, mined coals of the Brookwood group are buried by less than $30 \mathrm{~m}$ of overburden in the Black Warrior Basin. At the Kellerman 1570-2 Mine, only about 9 to $30 \mathrm{~m}$ of Pennsylvanian through Cretaceous age overburden is present. Coals of the Brookwood group reached maximum burial and thermal maturation during Pennsylvanian time. The coals were

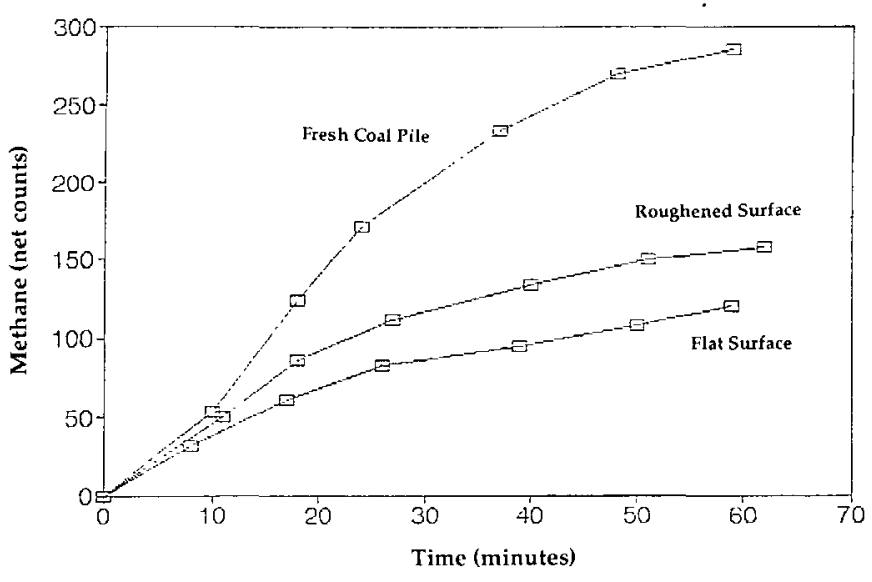

Figure 14. Plot of methane (net counts) versus time (minutes) for methane emissions from the Carter coal at the Kellerman surface mine using static chambers and portable flame-ionization detection (FID) method. Sixteen net counts on the FID integration is equivalent to $1 \mathrm{ppm}$ methane. Methane fluxes calculated from these data, given table 4 , were determined by regression analysis of the methane concentration data collected over the first 20 minutes only. After about 20 minutes, the rate of increase in methane concentration within the chambers decreased, which suggest leakage was occurring. uplifted by the end of Paleozoic time and have remained near the surface throughout Mesozoic and Cenozoic time. It is likely, therefore, that most of the $\mathrm{CH}_{4}$ escaped through natural desorption over geologic time. Consequently, removal of the relatively thin present-day overburden during surface mining operations does not result in significantly enhanced fluxes.

The importance of overburden in controlling the gas content of coal in the Black Warrior Basin is indicated by the relation between depth and $\mathrm{CH}_{4}$ content (fig. 7). Shallowly buried coal (less than a few hundred feet) contains generally less than about $6 \mathrm{~cm}^{3} / \mathrm{g}$ (about $200 \mathrm{scf} /$ ton) $\mathrm{CH}_{4}$, whereas coals at present-day burial depths greater than about $457 \mathrm{~m}$ contain as much as about 10 to 16 $\mathrm{cm}^{3} / \mathrm{g}$ (322 to $\left.516 \mathrm{scf} / \mathrm{ton}\right)$. It is noteworthy that, on a normalized basis, the methane flux measured at the Kellerman 1570-2 Mine is significantly less than in the Bankhead Fault. Our interpretation of the higher methane flux from the Bankhead Fault is that the fault must provide a migration conduit deep enough to connect with coalbeds that are deeply buried enough to retain a high gas content. As noted above, coals are present at burial depths of as much as about $610 \mathrm{~m}$ in the vicinity of the Bankhead Fault exposure, and coalbed methane production occurs from depths of 229 to $610 \mathrm{~m}$.

At any given time, as much as about 10 acres $\left(4,047 \mathrm{~m}^{2}\right)$ of coal are exposed at the Kellerman $1570-2$ Mine. A range of methane flux from the mining of 0.005 to $0.26 \mathrm{~m}^{3} / \mathrm{m}^{2} / \mathrm{yr}$ (table 4 ) yields between about 7 and 370 Mcf of methane emitted per year from the entire mine; additional methane losses might also occur during transportation or storage of the mined coal. This range of methane emissions for the Kellerman 1570-2 Mine is notably lower than that reported by Kirchgessner and others (1993a) for the Tertiary Smith coal (low rank-less than 0.6 percent $R_{o}$ ) at the Caballo Mine in the Powder River Basin, northeastern Wyoming $(61,300 \mathrm{Mcf} / \mathrm{yr} ; 1,735,000$ $\mathrm{m}^{3} / \mathrm{yr}$ ), despite the fact that coals from both mines have very low methane content. On the basis of recent annual production data (Caballo-14.3 million metric tons in 1989; Kellerman-about 0.83 million metric tons), these emission rates are equivalent to about 0.12 and $<0.01 \mathrm{~m}^{3}$ ( 4.2 and $<0.4 \mathrm{cf}$ ) gas per metric ton of coal mined from the Caballo and Kellermine Mines, respectively. Both of these emission rates are low compared to the estimated average for U.S. surface coal mines of $2.5 \mathrm{~m}^{3}(88.3 \mathrm{cf}) /$ metric ton (Boyer and others, 1990).

The dramatically different methane emission rates we observed compared with those of Kirchgessner and others (1993a) illustrate the risks inherent in extrapolating local data to regional or global scales. Clearly, more data are needed from mines worldwide, in varying geologic settings and with differing coal geochemistry, to determine the scale of surface mine emissions and to assess the importance of various natural factors and mining procedures 
in controlling the global $\mathrm{CH}_{4}$ flux. Moreover, as suggested by Kirchgessner and others (1993a), carefully controlled studies of analytical methodologies are needed to determine the best approach and to adequately assess the level of uncertainty in these field studies.

\section{JIM WALTER RESOURCES, INC., BLUE CREEK \#5 MINE}

Using an $\mathrm{SF}_{6}$ tracer gas release, we measured a methane flux of $136,000 \mathrm{~L} / \mathrm{min}(6.9 \mathrm{MMcfd})$ for one of the two ventilation shafts for the Blue Creek \#5 Mine (Jim Walter Resources, Inc.) (table 2). Assuming a similar flux from the other vent yields a total flux for the mine of about 14 MMcfd, which is in general agreement with the daily average per mine of $16 \mathrm{MMcfd}$ determined from the mining company monitoring (D. Hagood, oral commun., 1993).

Recently, it has been estimated that cumulative $\mathrm{CH}_{4}$ emission from all underground mines in Alabama is about 300,000 metric tons/year (14 Bcf) (Boyer and others, 1990). According to our calculations, the Blue Creek \#5 Mine emits about 102,400 metric tons ( $5 \mathrm{Bcf}$ ) from two shafts $\left[\left(71,481,600 \mathrm{~m}^{3}\right)\left(7.16 \times 10^{-5}\right.\right.$ ton $\left./ \mathrm{m}^{3}\right)$ per shaft $]$, which is 34 percent of the total estimated for the State by Boyer and others (1990). In 1991, the Blue Creek \#5 Mine produced 1,753,594 metric tons of coal (Carroll and Tolson, 1991). The $\mathrm{CH}_{4}$ emissions rate, then, would be about $81.5 \mathrm{~m}^{3}(2,877 \mathrm{cf}) /$ metric ton of coal mined, assuming similar production rates today as in 1991. The $\mathrm{CH}_{4}$ associated with underground coal mining can constitute a significant recoverable resource. In fact, Jim Walter Resources, Inc., a world leader in recovery of $\mathrm{CH}_{4}$ associated with underground mining, currently captures about 35 percent of the $\mathrm{CH}_{4}$ released from their underground mining operations in the Black Warrior Basin.

Boyer and others (1990) plotted $\mathrm{CH}_{4}$ emissions versus metric ton of coal mined for 59 U.S. coal mines and determined a least-squares linear regression equation to relate emissions to tons of coal mined:

$\mathrm{CH}_{4}$ emissions $\left(\mathrm{m}^{3} /\right.$ metric ton mined $)=\left[2.04 \times\left(\mathrm{CH}_{4}\right)\right]+8.16$

where $\left(\mathrm{CH}_{4}\right)=$ in-situ $\mathrm{CH}_{4}$ content of the coal and $1.0 \mathrm{~m}^{3}=35.31 \mathrm{cf}$

Boyer and others (1990) noted that this approach contains a great deal of uncertainty, mainly because the correlation between coalbed gas content and emissions measurements shows almost no correlation $\left(r^{2}=0.35\right)$. For example, in the case of the Jim Walter Resources, Inc., Blue Creek \#5 Mine, this equation requires an in-situ gas content of about $31.8 \mathrm{~m}^{3}\left(1,222 \mathrm{cf}\right.$ )/ton (or $31.8 \mathrm{~cm}^{3} / \mathrm{g}$ ), at least two times that reported for Black Warrior Basin coals (fig. 7). The high emissions rate for the Blue Creek \#5 Mine, compared to gas content of Black Warrior coals and to the equation above, probably indicates that the gas is emitted not only from the beds being mined, but also from adjacent rocks including coalbed leaks.

To be a possible source of emissions, coalbed gas must desorb and migrate by diffusion out of the coal matrix via cleats, joints, or faults to the surface or to a well bore. The sorbed gas is held in the microstructure of the coal by pore pressure, and gas migration takes place when the pressure is reduced. This desorption process probably took place naturally in the Black Warrior Basin following uplift and erosion about $250 \mathrm{Ma}$. Because most coals are characterized by high water saturations, depressurization also results from dewatering of the coalbeds. This depressurization by dewatering has probably taken place over the southeastern part of the Black Warrior Basin because of widespread mining and coalbed gas production (fig. 2). This mining and production activity has resulted in lowering of the water table and pressure of the coalbeds as illustrated by figure 15. In the Oak Grove Field (fig. 15A),
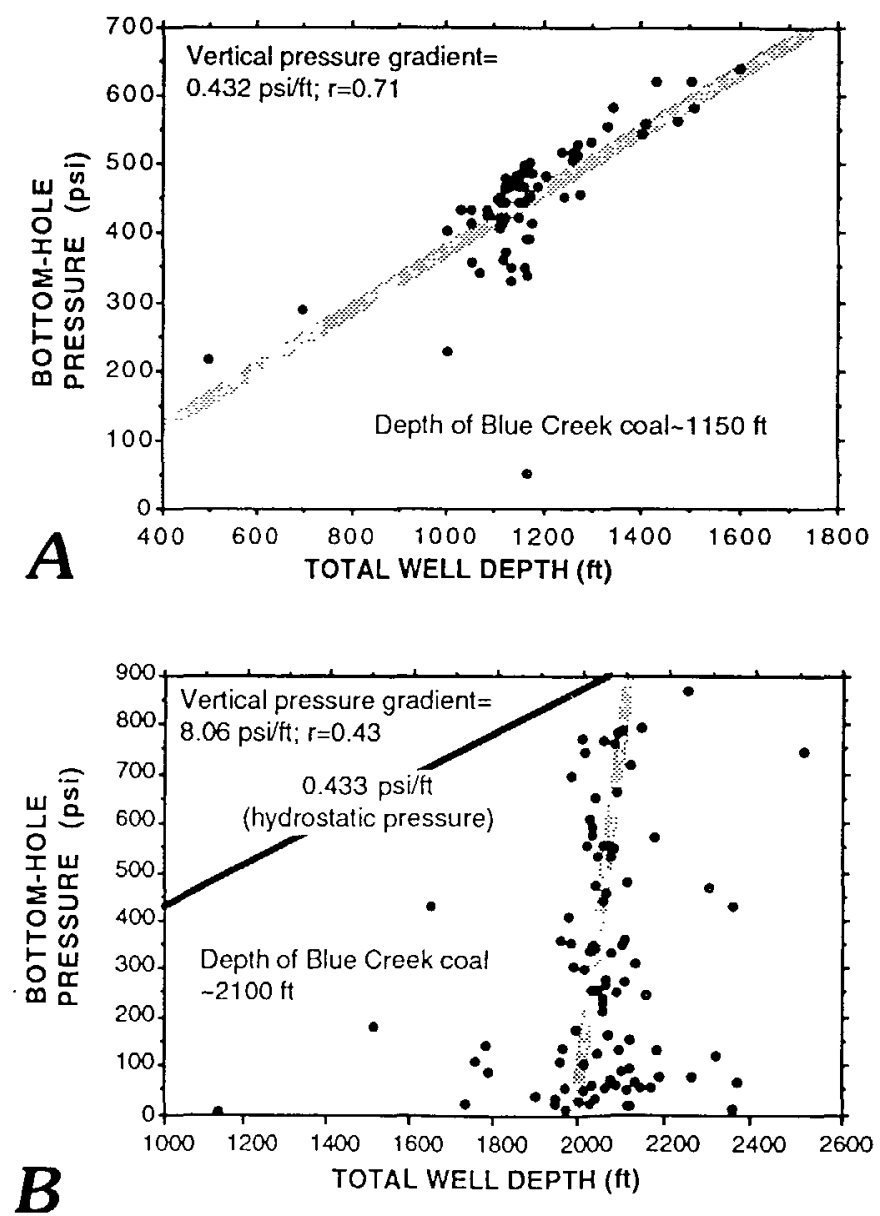

Figure 15. Pressure versus depth plots for Oak Grove $(A)$ and Brookwood $(B)$ coalbed gas fields, southeastern Black Warrior Basin, Alabama. From Pashin (1991 a). 1 foot equals .3048 meter. 
reservoir pressure data were collected shortly after the wells began production and the data points generally plot along the line of hydrostatic pressure $(0.433 \mathrm{psi} / \mathrm{ft}$ or $2.98 \mathrm{kPa}$ ). In contrast, pressure data collected after 3 months of coalbed gas production from the Brookwood Field (fig. 15B), which contains three closely spaced deep underground mines, indicate that the deeper coals are significantly underpressured because of dewatering. The magnitude of the depressurization process is significant considering that more than 2,800 wells were producing coalbed gas, mainly in Tuscaloosa and Jefferson Counties, at the end of 1991. These wells produced more than 96 million barrels of water during the year. Also, significant amounts of water are produced from both the surface and underground mines prior to and during mining. In some cases, the water table is lowered by as much as $61 \mathrm{~m}$ near mines in the Black Warrior Basin (Pashin, 1991a). As a consequence, widespread desorption of coalbed gas may have taken place in the study area as a result of anthropogenic activity during the last 20 years.

\section{CONCLUSIONS}

We report field measurements of $\mathrm{CH}_{4}$ emissions from Pennsylvanian-age coalbeds in surface and underground coal mines, fault zones, and coreholes in the Black Warrior Basin. Not surprisingly, ventilation of underground mines is the greatest single source of atmospheric $\mathrm{CH}_{4}$ observed. In contrast, surface mining of the Pennsylvanian Carter and Milldale coals of the Pottsville Formation at the Kellerman 1570-2 surface mine results in very little $\mathrm{CH}_{4}$ emission (less than about 748 metric tons or $37 \mathrm{Mcf}$ annually per acre of coal exposed). From the data of the present study, it is not possible to estimate the amount of methane lost during transport and utilization of the coal, although the low initial methane content inferred for these coals suggests that the amounts are not significantly greater than those associated with the mining itself.

Considering the thermal and geologic history of the Black Warrior Basin, high $\mathrm{CH}_{4}$ emissions would not be expected during surface mining of the Pottsville Formation coals, even if $\mathrm{CH}_{4}$ from adjacent rocks and coalbeds (beds below the one being mined) were mixing with the Carter and Milldale coal gas. All of the Brookwood group coals reached maximum burial depths and, hence, thermal maturation, during Pennsylvanian time and were uplifted by the end of Paleozoic time. This resulted in loss of most of the previously generated methane during Mesozoic and Tertiary time. This example illustrates the importance of considering the geologic history of coalbeds for understanding the role of various anthropogenic factors in influencing methane emissions. Moreover, attempts to develop a general equation for predicting emissions based solely on the amount of coal mined are unlikely to succeed without inclusion of factors that take into account the geochemistry of the coal and its geologic setting and history.

This study demonstrates, for the first time, that faults associated with coals may be significant sources of $\mathrm{CH}_{4}$ emissions. Methane emissions from the Bankhead normal fault and associated joints are quite high compared to those of the Kellerman surface mine, especially considering that only point sources were measured at the fault outcrop and no attempt was made to integrate the flux over the entire length of exposed fault and joint lines. Carbon isotope data confirm that the Bankhead fault methane is derived from coalbeds and the relatively high $\mathrm{CH}_{4}$ flux, compared to the Kellerman 1570-2 Mine, suggests that the methane may be derived from more deeply buried coals (as deep as $2,000 \mathrm{ft}$ or $610 \mathrm{~m}$ ). Methane concentrations, and presumably fluxes, determined at 1 -in. intervals along a single joint exposure at the Bankhead Fault outcrop were quite variable, presumably owing to permeability variation along the joint. The reason for the uneven permeability along the joint is unknown, but may be due to occlusion of parts of the joint by secondary fracture filling or fault gouge.

In contrast to the Bankhead Fault, one other fault tested contained obvious fault gouge and no $\mathrm{CH}_{4}$ was detected. Because we tested only three faults, it is impossible to speculate about how representative these three are of the large number of faults in the basin (fig. 4). Moreover, it is possible that fractures associated with the folds in the basin (fig. 4) may also serve as migration conduits for coalbed $\mathrm{CH}_{4}$ to reach the surface. To estimate the importance of faults on a basin-wide scale, many more measurements are needed along with an evaluation of the relation between flux and fault geology (type and age of fault, rock type, presence or absence of fracture filling, fault orientation and depth, and other parameters).

\section{ACKNOWLEDGMENTS}

We gratefully acknowledge Gary Owen, Jim Walter Resources, Inc., for his help in selecting sampling sites, and particularly for help with logistics and assistance in the field. Steven Sides, Drummond Coal Co., is thanked for allowing access to the Kellerman \#1570-2 surface mine and driving us through the mud. We thank Dennis Lathem, Alabama Coalbed Methane Association, for helpful discussions about the project. Brian Lamb, Washington State University, is gratefully acknowledged for help with the truck-mounted methane flux measurements. Professor Drury Caine, Department of Chemistry, University of Alabama, kindly allowed access to the department to recharge our hydrogen storage units. Dave Wilbur, University of Washington, is thanked for advice on pumps for isotope sample collection. 


\section{REFERENCES CITED}

Beaumont, C., Quinlan, G., and Hamilton, J., 1988, Orogeny and stratigraphy-Numerical models of the Paleozoic in the eastern interior of North America: Tectonics, v. 7, p. 389416.

Benner, R.L., and Lamb, B., 1985, A fast response continuous analyzer for halogenated atmospheric tracers: Journal of Atmospheric and Oceanic Technology, v. 2, p. 582.

Boyer, C.M., Kelafant, J.R., Kuuskraa, V.A., Manger, K.C., and Kruger, D., 1990, Methane emissions from coal miningIssues and opportunities for reduction: U.S. Environmental Protection Agency EPA/400/9-90-008, $131 \mathrm{p}$.

Carroll, R.E., and Tolson, J.S., 1991, Alabama coal data for 1991: Alabama Geological Survey Information Series 58M, $137 \mathrm{p}$.

Chappellaz, J., Barnola, J.M., Raynaud, D.G., Korotkevich, Y.S., and Loms, C., 1990, Ice core record of atmospheric methane over the past 160,000 years: Nature, v. 345 , p. 127-131.

Cicerone, R.J., and Oremland, R.S., 1988, Biogeochemical aspects of atmospheric methane: Global Biogeochemical Cycles, v. 2, p. 299-327.

Coleman, D.D., Risatti, J.B., and Schoell, M., 1981, Fractionation of carbon and hydrogen isotopes by methane-oxidizing bacteria: Geochimica et Cosmochimica Acta., v. 45, p. 1033-1037.

Craig, H., and Chou, C.C., 1982, Methane-The record in polar ice cores: Geophysical Research Letters, v. 9, p. 1221-1224.

Dai, J., Qi, H., Song, Y., and Guan, D., 1987, Composition, carbon isotope characteristics, and the origin of coal-bed gases in China and their implications: Scientia Sinica (Series B), v. 30, p. 1324-1337.

Donner, L., and Ramanathan, V., 1980, Methane and nitrous oxide-Their effects on the terrestrial climate: Journal of Atmospheric Science, v. 37, p. 119-124.

Enhalt, D.H., Zander, R.J., and Lamontague, R.A., 1983, On the temporal increase of tropospheric $\mathrm{CH}_{4}$ : Journal of Geophysical Research, v. 88 , p. 8442-8446.

Faber, E., 1987, Zur isotopengeochemie gasformiger Kohlenwasserstoffe: Erdol Erdgas Kohle, v. 103, p. 210-218.

Fung, I., John, J., Lerner, J., Matthews, E., Prather, M., Steele, L.P., and Fraser, P.J., 1991, Three-dimensional model synthesis of the global methane cycle: Journal of Geophysical Research, v. 96, p. 13033-13065.

Hewitt, J.L., 1984, Geologic overview, coal, and coalbed methane resources of the Warrior Basin-Alabama and Mississippi, in Rightmire, C.T., Eddy, G.E., and Kirr, J.N., eds., Coalbed methane resources of the United States: American Association of Petroleum Geologists Studies in Geology 17, p. 73-104.

Hogan, K.B., Hoffman, J.S., and Thompson, A.M., 1991, Methane on the greenhouse agenda: Nature, v. 354, p. 181-182.

Juntgen, H., and Karweil, J., 1966, Gasbildung und Gasspeichenung in Steinkohlenflozen, Part I and II: Erdol Kohle, Erdgas, Petrochem, v. 19, p. 251-258 and 339-344.

Khalil, M.A.K., and Rasmussen, K.A., 1985, Causes of increasing atmospheric methane-Depletion of hydroxyl radicals and the rise of emissions: Atmosphere and Environment, v. 19, p. $397-407$.
-1990, Atmospheric methane--Recent global trends: Environmental Science Technology, v. 24, p. 549-553.

Khalil, M.A.K., Rasmussen, R.A., Shearer, M.J., Ge, S., and Rau, J.A., 1993, Methane from coal burning: Chemosphere, v. 26, p. $473-477$.

Kiehl, J.T., and Dickinson, R.E., 1987, A study of the radiative effects of enhanced atmospheric $\mathrm{CO}_{2}$ and $\mathrm{CH}_{4}$ on early earth temperatures: Journal of Geophysical Research, v. 92, p. 2991-2998.

Kim, A.G., 1977, Estimating methane content of bituminous coal from adsorption data: U.S. Bureau of Mines Report of Investigations $8245,22 \mathrm{p}$.

Kirchgessner, D.A., Piccot, S.D., and Chadha, A., 1993a, Estimation of methane emissions from a surface coal mine using open-path FTIR spectroscopy and modeling techniques: Chemosphere, v. 26, p. 23-44.

Kirchgessner, D.A, Piccot, S.D., and Winkler, J.D., 1993b, Estimate of global methane emissions from coal mines: Chemosphere, v. 26, p. 453-471.

Kvenvolden, K.A., 1988, Methane hydrates and global climate: Global Biogeochemical Cycles, v. 2, p. 221-229.

Leventhal, J.S., 1992, Modern mobile methane measurements in marshes: U.S. Geological Survey Open-File Report 92-445, $24 \mathrm{p}$.

McFall, K.S., Wicks, D.E., and Kuuskraa, V.A., 1986, A geological assessment of natural gas from coalbeds in the Warrior Basin, Alabama: Gas Research Institute Topical Report, Final Geologic Report (September 1985-September 1986), GRI 86/0272, 80 p.

McManus, J.B., Crill, P.M., Harriss, R.C., Mosher, B., Lamb, B., Mass, K., and Ryddock, J., 1991, Measuring urban fluxes of methane: World Resource Review, v. 3, p. 162-183.

Metzger, W.J., 1965, Pennsylvanian stratigraphy of the Warrior Basin, Alabama: Alabama Geological Survey Circular 30, $80 \mathrm{p}$.

Pashin, J.C., 1991a, Regional analysis of the Black Creek-Cobb coalbed methane target interval, Black Warrior Basin, Alabama: Geological Survey of Alabama Bulletin 145, $127 \mathrm{p}$.

Pashin, J.C., 1991b, Subsurface models of coal occurrence, Oak Grove Field, Black Warrior Basin, Alabama: Tuscaloosa, Alabama, The University of Alabama, 1991 Coalbed Methane Symposium Proceedings, p. 275-291.

Pearman, G.I., Etheridge, D., de Silva, F., and Fraser, P.J., 1986, Evidence of changing concentrations of atmospheric $\mathrm{CO}_{2}$, $\mathrm{N}_{2} \mathrm{O}$, and $\mathrm{CH}_{4}$ from air bubbles in Antarctic ice: Nature (London), v. 320, p. 248-250.

Quay, P.D., King, S.L., Stutsman, J., Wilbur, D.O., Steele, L.P., Fung, I., Gammon, R.H., Brown, T.A., Farwell, G.W., Grootes, P.M., and Schmidt, F.H., 1991, Carbon isotopic composition of atmospheric $\mathrm{CH}_{4}$ : fossil and biomass burning source strengths: Global Biogeochemical Cycles, v. 5, p. $25-47$.

Ramanathan, V., Callis, L., Cess, R., Hansen, J., Isaksen, I., Kuhn, W., Lacis, A., Luther, F., Mahlman, J., Reck, R., and Schlesinger, M., 1987, Climate-chemical interactions and effects of changing atmospheric trace gases: Review of Geophysics, v. 25, p. 1441-1482.

Rasmussen, R.A., and Khalil, M.A.K., 1981, Global production of methane by termites: Nature (London), v. 301, p. $700-$ 702. 
Raynaud, D., Chappellaz, J., Barnola, J.M., Korotkevich, Y.S., and Lorius, C., 1988, Climatic and $\mathrm{CH}_{4}$ cycle implications of glacial-interglacial $\mathrm{CH}_{4}$ change in the Vostok ice core: Nature, v. 333, p. 655-657.

Rheams, L.G., and Benson, D.J., 1982, Depositional setting of the Pottsville Formation in the Black Warrior Basin: Alabama Geological Society 19th Annual Field Trip Guidebook, $94 \mathrm{p}$.

Rice, D.D., in press, Composition and origins of coalbed gas, in Law, B.E., and Rice, D.D., eds., Hydrocarbons from coal: American Association of Petroleum Geologists Studies in Geology.

Rice, D.D., Epsman, M.L., and Mancini, E.A., 1989, Origin of conventional and coalbed gases in the Black Warrior Region, Alabama [abs]: Proceedings of 1989 Coalbed Methane Symposium, p. 321.

Seiler, W., and Conrad, R., 1987, Contribution of tropical ecosystems to the global budgets of trace gases, especially $\mathrm{CH}_{4}$, $\mathrm{H}_{2}$, $\mathrm{CO}$ and $\mathrm{N}_{2} \mathrm{O}$, in Dickinson, R.E., ed., Geophysiology of Amazonia: New York, John Wiley, p. 133-162.

Shen, P., Shen, Q., Wang, X., and Xu, Y., 1988, Characteristics of isotope composition of gasiform hydrocarbon and identification of coal-type gas: Scientia Sinica (Series B), v. 31, no. 6 , p. $735-774$.

Stauffer, B., Fischer, A., Neftel, A., and Oeschger, H., 1988, Increase of atmospheric methane recorded in Antarctic ice core: Science, v. 229, p. 1386-1388.

Stevens, C.M., and Englekemeir, A., 1988, Stable carbon isotopic composition of methane from some natural and anthropogenic sources: Journal of Geophysical Research, v. 93, p. 725-733.

Taylor, J.A., Brasseur, G.P., Zimmerman, P.R., and Cicerone, R.J., 1991, A study of the sources and sinks of methane and methyl chloroform using a global three-dimensional Lagrangian tropospheric tracer transport model: Journal of Geophysical Research, v. 96, no. D2, p. 3013-3044.

Telle, W.R., Thompson, D.A., Lottman, L.K., and Malone, P.G., 1987, Preliminary burial-thermal history of the Black Warrior Basin-Implications for coalbed methane and conventional hydrocarbon development: Tuscaloosa, Alabama, The University of Alabama, 1987 Coalbed Methane Symposium Proceedings, p. 37-50.

Thomas, W.A., 1985, The Appalachian-Ouachita connectionPaleozoic orogenic belt at the southern margin of North America: Annual Review of Earth and Planetary Sciences, v. 13, p. 175-199.

Thomas, W.A., 1988, The Black Warrior Basin, in Sloss, L.L., ed., Sedimentary cover; North American craton: Geological Society of America, The Geology of North America, v. D-2, p. 471-492.

Tyler, S.C., 1991, The global methane budget, in Rogers, J.E., and Whitman, W.B., eds., Microbial production and consumption of greenhouse gases: methane, nitrogen oxides, and halomethanes, Washington, D.C., American Society for Microbiology, p. 7-38.

Ward, W.E., II, Drahovzal, J.A., and Evans, F.E., Jr., 1984, Fracture analyses in a selected area of the Warrior coal basin, Alabama: Alabama Geological Survey Circular 111, 78 p.

Whiticar, M.J., 1992, Stable isotope geochemistry of coals, humic kerogens, and related natural gases: Proceedings of the Canadian Coal and Coalbed Methane Geoscience Forum, B.C., Geological Survey Branch, Alberta Geological Survey, and Geological Survey of Canada, p. 149-172.

Winston, R.B., 1990, Vitrinite reflectance of Alabama's bituminous coal: Geological Survey of Alabama Circular 139, $54 \mathrm{p}$. 
The U.S. Geological Survey and other Government and private agencies provide official gas-resource estimates, and some discussions of the methods used in the gasresource evaluations are provided herein. The future of natural gas depends on the quantity, quality, and location of the gas. Unlike other energy resources such as coal, heavy oil, and some uranium, which are present near the Earth's surface and which are visible in outcrops and readily outlined by shallow drilling, natural gas is a highly mobile substance that occurs in a variety of geologic settings. Because potential natural-gas resources lie below the Earth's surface, estimating the quantity of natural gas that remains to be discovered involves considerable uncertainty. Reports in this section provide a broad overview of the resource potential of natural gas, which depends on the economics of drilling and production as well as technologic considerations for some habitats in which gas is found. 



\title{
U.S. Geological Survey Estimates of Natural-Gas Energy Resources
}

\author{
By Gordon L. Dolton ${ }^{1}$, Donald L. Gautier ${ }^{1}$, Richard F. Mast ${ }^{1}$, and David H. Root ${ }^{2}$
}

\section{CONTENTS}

Abstract 495

Resource Classification

495

Assessment Concepts 497

Principles of Resource Assessment 497

Assessment Methodologies 498

Discovery Process and Finding Rates 499

Deposit Simulation

Reservoir Performance ......................................... 501

Mass Balance ..................................................... 501

History of U.S. Geological Survey Estimates of

Natural-Gas Resources 502

References Cited 504

\begin{abstract}
In recent years, the U.S. Geological Survey (USGS) has classified oil and gas resources as a function of geologic certainty and economic feasibility. Amounts of undiscovered resources have been estimated using a variety of techniques, each of which has strengths and weaknesses. Almost all techniques rely on the two basic concepts of analogy and exhaustion (historical information). Although no method, short of drilling, is certain in its determination of undiscovered resources, several reasonable methods are possible, including volumetric- or areal-yield models and
\end{abstract}

'U.S. Geological Survey, Denver Federal Center, Box 25046, Denver, $\mathrm{CO} 80225-0046$.

${ }^{2}$ U.S. Geological Survey, National Center, 12201 Sunrise Valley Dr., Reston, VA 22092-0001. historical-performance models. Other basic methods include discovery process and finding-rate models, which are essentially specialized types of historical performance models, and deposit-simulation and reservoir-performance models, which use basic petroleum engineering equations to make predictions. Mass-balance models are designed to predict oil and gas volumes on the basis of geologic principles. Many estimates of natural-gas resources have been made by the USGS, beginning with the work of Eugene Shaw in 1919. Various techniques have been employed over the years in a series of natural-gas assessments that have continued episodically almost to the present day. Like previous assessments, the one currently underway is intended to reflect the situation, needs, and understanding of oil and gas resources most relevant to the needs of the United States at the present time.

\section{RESOURCE CLASSIFICATION}

Experience has shown that most disagreements concerning oil and gas resource evaluation originate in misunderstandings of terminology or classification. When classification schemes and terminologies are discussed and well understood, however, genuine differences in data and interpretation can be identified and addressed.

Recently at the U.S. Geological Survey (USGS), oil and gas resources have been classified according to the "McKelvey Box," conceived by and named for the late Director of U.S. Geological Survey, Vincent McKelvey, a man passionately interested in resources and their evaluation. The McKelvey box (fig. 1) has two axes and two variables: (1) degree of geologic certainty or assurance and (2) economic feasibility or technical producibility. The degree of geologic certainty or assurance, which is plotted 


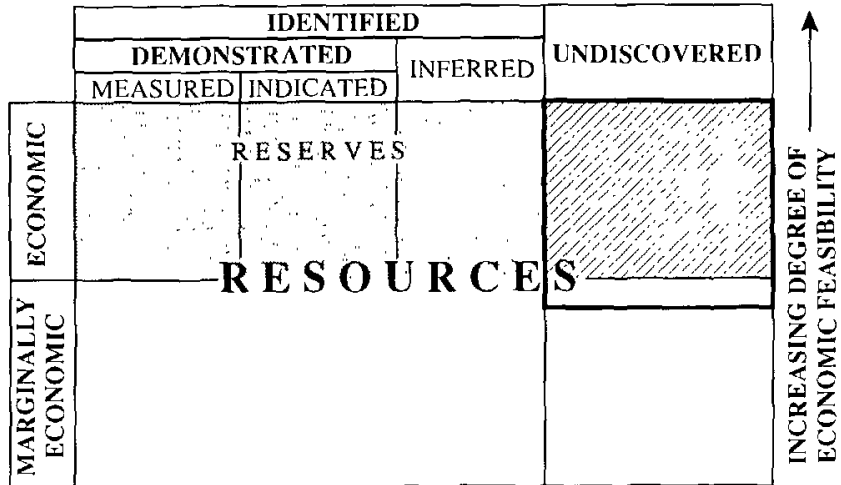

Figure 1. Diagrammatic representation of petroleum resource classification. Figure represents conventional oil and gas resources. Area within heavy frame on upper right represents undiscovered resources. Hachured area indicates quantities of undiscovered resources that are estimated to be economically recoverable. Modified from U.S. Geological Survey and U.S. Bureau of Mines $(1976,1980)$

along the $X$ axis, is a continuum, ranging from those resources that are known with great certainty such as oil being pumped up a wellbore and into a waiting tank at this very moment to wildly speculative occurrences of petroleum that might exist in hypothetical traps in distant, inaccessible, and unexplored regions. At the left end of the $X$ axis, the most certainly known resources are the measured reserves. Measured reserves include all those resources that have been shown to exist from reliable geologic and engineering data in known reservoirs and which are expected to be produced in the near future using existing technology and infrastructure under current economic conditions. Measured reserves are generally equivalent to the commonly used term proved reserves and includes only those resources that are actually accessible through technology that is currently in use.

Indicated reserves are those resources in known reservoirs that are expected to be added to measured reserves and produced through the application of improved recovery techniques. The additions to measured reserves that are expected as a result of the implementation of a planned new waterflood engineering project on an old reservoir with declining production in a field, part of which has already been successfully waterfiooded, is a typical example of indicated reserves.

Inferred reserves are identified resources that can be expected to be added to reserves by additional drilling in extensions of known fields and by discovery of new pay zones, as well as by net upward revisions of previous reserve estimates.

Taken together, indicated reserves and inferred reserves account for most reserve growth (also known as reserve appreciation) in the United States. Additions to U.S. reserves in recent years have come more from reserve appre- ciation (indicated and inferred reserves) than from new field discoveries. Reserve appreciation has increasingly become a topic of great interest to the United States because of the magnitude of the reserves being added in this category.

The vertical axis of the McKelvey Box (fig. 1) reflects economic feasibility or cost versus value for the resource. Virtually any of the resource classifications discussed above can be economic, marginally economic, or noneconomic depending on a variety of factors. For example, a heavy oil accumulation can be well understood and thoroughly delineated such that volume of oil within the deposit is known with great certainty. The resource may not, however, be economic because the cost of extracting the oil using specialized techniques such as steam flooding and closer well spacing may exceed the expected value of the oil to be recovered. At the other extreme of the scale of geologic certainty might be undiscovered resources that, even if found, would be noneconomic. An example might be a small prospect for oil or gas in deep water or under thick ice in northern Alaska. Only the largest of U.S. oil fields would be economically developable under these circumstances because of the large reserves and high production levels required to justify the necessary investments to develop and produce oil from these regions.

There are a number of potentially confusing and contentious issues surrounding the McKelvey Box classification. In particular, the resources accounted for on the McKelvey Box are essentially unbounded. The limits of economic viability or geologic certainty must be provided by the user. In the extreme, methane gas in the atmosphere of Jupiter could be classified and shown on the McKelvey Box as an identified but subeconomic resource. In principle, the entire crustal abundance of any resource could be placed in the framework of the McKelvey classification, even though such a broad definition of resources is not relevant to human activity in the foreseeable future.

Measured, indicated, and inferred reserves are collectively classified as identified resources. Undiscovered resources, conversely, are those resources postulated to exist on the basis of geologic knowledge and theory. Such resources belong outside the bounds of identified resources on the McKelvey Box. Undiscovered resources may range from accumulations that can be inferred to exist from seismic records to rather vaguely defined accumulations that have only postulated existence based on conceptual or conjectural evidence. For example, well defined but undrilled structural traps in areas of known discoveries might be considered to contain undiscovered resources at a high level of confidence. The important thing about undiscovered resources is that they have not yet been sufficiently delineated with geologic or engineering data to constitute a body of proof to which one can refer.

Certain commonly used terms and categories are not explicitly illustrated on the McKelvey Box. For example, conventional resources are those that exist in more or 
less discrete accumulations and that are amenable to extraction using traditional development practices. Conventional resources can be either identified or undiscovered. Those categories of resources not included with the conventional resources are lumped together as unconventional resources. This rather diverse and poorly defined category includes, among other varieties, gas resources in low-permeability reservoirs such as tight-gas sands, gas bound up with ice in hydrates, coalbed gas, gas in fractured shale reservoirs and gas in geopressured brines. Unconventional resources can be either identified or undiscovered and can range across the entire spectrum of the economic assurance axis.

Resources may change their position or classification on the McKelvey Box through advances in technology or changing economics. Indicated and inferred reserves are defined as being transitional, as they are fully expected to become proved reserves in the future if they are economic. Undiscovered resources, if predicted correctly, should one day be discovered, although some probably will not be. Today's unconventional resource could be tomorrow's conventional resource. The changing classification of resources, economic conditions, and technology make comparisons between resource assessments conducted at different times extremely difficult. The 1909 oil assessment of David Day (1909) now seems rather like an attempt to qualitatively estimate remaining reserves in well-known anticlinal structures. All assessments must be considered in the context of their time and their purpose. At their best, resource assessments constitute scientifically based hypotheses that incorporate available information about resources and future additions to reserves. Each assessment should build on previous ones and on information gathered by the exploration and production process. As such, each assessment should constitute a refinement of previous work, becoming ever closer to the "correct" answer. The correct answer will only be known with certainty when the last well is drilled and the last resources are extracted.

\section{ASSESSMENT CONCEPTS}

The assessment of unknown quantities of natural resources such as oil and gas must be viewed as the development of hypotheses and not as inventories of some clearly known but as yet unmeasured commodity. Undiscovered resources are not really analogous to cans of uncounted green beans on a grocery store shelf. A better analogy might be the attempt to estimate the amounts of canned green beans from high-altitude imaging of grocery stores and delivery trucks.

Resources have been estimated using many methods, each of which has enthusiastic proponents and incisive critics. Each methodology requires different kinds and amounts of information and each area or commodity being assessed is best approached using a specific methodology type. Every method has inherent power as well as limitations. No single method can be applied successfully in all situations.

\section{PRINCIPLES OF RESOURCE ASSESSMENT}

Nearly all assessments are based on two basic concepts-analogy and exhaustion. According to the concept of analogy, resources are distributed as a consequence of the operation of natural processes that can, in principle, be understood and predicted. An area selected for assessment is defined in terms of its geologic properties, and geologically similar areas (the analogs) are identified in which sufficient drilling has occurred to effectively define the resource. The number, size, and distribution of resource accumulations within the analogs are then assumed to be similar to the number, size, and distribution of undiscovered resources within the area selected for assessment. For example, if an area to be assessed is identified in which undiscovered resources are thought to be entrapped within as yet untested diapiric salt structures, the analyst might examine other areas in which salt dome structures have been demonstrated to include significant oil or gas accumulations. Success in predicting properties of unknown resources depends on the adequacy and applicability of the analog and on the ability of the analyst to apply it. If, for example, two blocks of land within a single area such as the Louisiana-Mississippi salt province differ only in that one has been intensively explored through drilling and the other remains untested, then the size, number, and distribution of resources in the intensely explored block can be used to predict undiscovered resources in the untested block. If, however, a salt dome area is identified within the Basin and Range Province of southern Arizona, the salt dome region of the Louisiana gulf coast may or may not serve very well as an analog. In this case, the areas might have salt diapirs in common but little else, and selection of a different analog might be necessary.

In almost every case geologic analogs differ from the subject area in some way and to some degree. If the ana$\log$ is valid, but some variation is expected, then evaluations of the unknown resources in the area of interest can be modified to reflect the expected departures from the analog. For example, in the case of the two blocks in the Louisiana-Mississippi salt province, if the untested block seems identical to the analog except that the structures are slightly larger or smaller, the expected resources should be adjusted accordingly.

Exhaustion is the concept that within any specified area, given sufficient exploration activity, part or all of the resource will be discovered. Discoveries within the area are thought to be made from a natural population of accumulations and without replacement. The concept of exhaustion 
is expressed using various types of historical information. This information may include the fraction of surface area or rock volume drilled, the rates or volumes of resources found as a function of time or drilling, the size and number of fields discovered in historical sequence, or various other extrapolation techniques based on historical performance. The past performance of the area is thought to be a reliable basis for predicting the future. Historical data are fitted into some sort of mathematical functional form that permits extrapolation of past performance into the future.

Crucial to many methods of resource evaluation and corollary to the concept of exhaustion is the premise that the largest accumulations tend to be found earlier in the exploration history of any specific area. We emphasize that the operational concept in the preceding sentence is "earlier." The average size of discovered fields within any particular basin or play tends to decrease systematically with time and (or) with exploratory effort. For example, figure 2 illustrates the shifting size-frequency histograms of fields found within the Frio Strandplain play of the Texas gulf coast (Schuenmeyer and Drew, 1991). By extension, within even broad areas accessible to drilling, the largest accumulations tend to be found first. The early discovery of the largest fields occurs because the larger fields occupy the most prominent and easily identified features and because the large fields generally occupy larger areas than small fields. In the lower 48 United States the average size of the oil and gas fields found has been declining systematically through time. For example, the largest gas field found in the United States prior to 1955 contained about 70 trillion

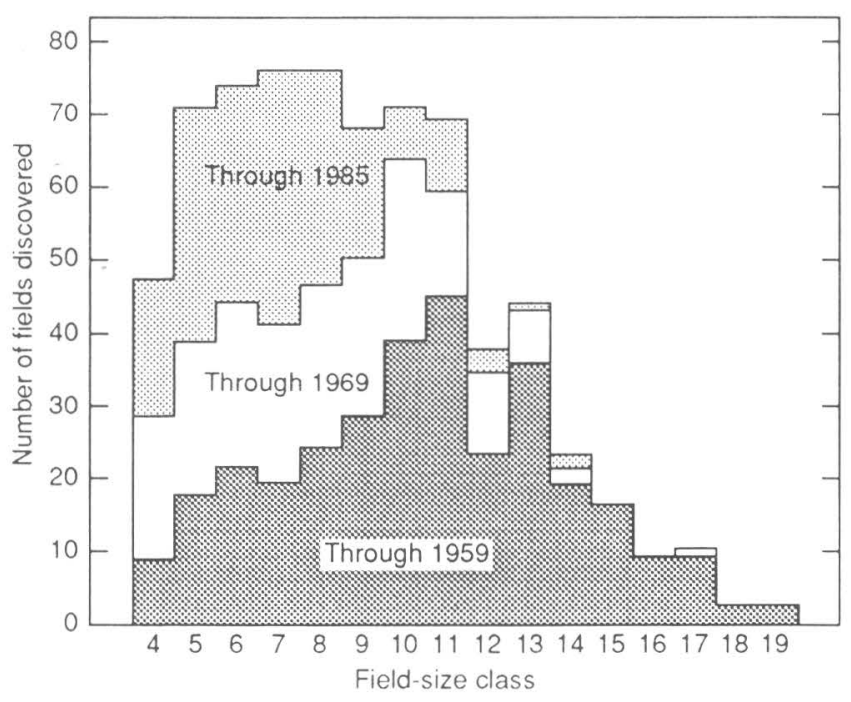

Figure 2. Example of observed field-size distribution for oil and gas plays from the Frio Strandplain play, Texas, showing that sizes of fields decrease with time and the typical three segments that represent cumulative number of fields discovered through the specified year. Modified from Schuenmeyer and Drew (1991). cubic feet (Tcf), whereas the largest field found since 1955 has not exceeded $6 \mathrm{Tcf}$.

\section{ASSESSMENT METHODOLOGIES}

In spite of the advanced state of knowledge of the origin, migration, and entrapment of oil and gas, there is no certain way, short of drilling, to directly measure how much oil or gas will be discovered in a sedimentary basin. The amount of oil or gas must be determined by drilling and production, by extrapolation of historical information, or by analogy with geologically similar areas of oil and gas production. Within this framework several methods are possible.

Resource assessments can be done at a variety of geographic and geologic scales. The purpose of the assessment, the availability of data, and the constraints of time dictate the method by which an assessment is performed. Credible assessments have been conducted over broad regions (countries or continents) using historical extrapolation techniques (for example, Hubbert, 1967) Basin-wide assessments usually depend on basin or volumetric analogs, but basins also can be analyzed by extrapolating cumulative volumes discovered versus cumulative exploratory effort. Some recent assessments have been done using play-modeling techniques. Plays are groups of discovered accumulations and (or) prospects that are grouped together on the basis of geographic proximity and geologic similarity. A wide variety of assessment methods have been developed and applied at the play level. To construct assessments for larger areas or volumes of sedimentary rock, these lower level (play) assessments can be aggregated. The oil and gas industry commonly evaluates areas at the prospect level and then aggregates prospects into plays and plays into regional assessments. This approach normally requires extensive seismic data coverage to identify prospects and estimate accumulation size. Many assessments, however, are conducted by organizations (for example, the USGS) that do not normally have access to extensive seismic data. When this is the case, other types of information and other techniques must be used for assessment.

Volumetric- or areal-yield models are based on the notion that the amount of oil or gas per unit volume of rock can be extrapolated from an area of known oil or gas occurrence to some unexplored but analogous volume of rock. This method depends entirely on the validity of the analog and on the degree of application of the analog to an appropriate rock volume. The concept of volumetrics, beginning with the innovative studies of Weeks (1950) and Zapp $(1961,1962)$ has been applied to local areas, basins, regions, countries, continents, and the entire planet. The concept of volumetrics was well stated by V.E. McKelvey (1961): "Thus, oil occurs in sedimentary rocks and the range in quantity of oil and gas contained in certain large 
and well explored sedimentary basins has been estimated; the total volume of sedimentary rocks in the United States and the world has also been estimated, and the combination of these two values, plus an estimate of how much oil can be recovered from the ground, make it possible to estimate potential recoverable reserves of oil and gas."

Most assessment methods probably employ volumetric considerations to some degree. The direct and exclusive use of analog volumetrics is especially useful in those areas where little or no drilling information is available and where a small staff must evaluate a large area. In this case, the analog may provide the only available way of evaluating undiscovered resources. Volumetrics overestimate undiscovered resources in many cases. The view that the unexplored volume of rock contains the same proportion of resources as the explored portion of rock seems to assume that there is no exploration efficiency and that explorationists are unable to selectively identify the most promising areas to drill first. Volumetric assessments have yielded some of the largest estimates of resources of any assessment methodologies.

Historical-performance and production-process models are based almost entirely on the concept of exhaustion and use historical information as a means of predicting future performance. In these methods, the actual drilling records, success rates, production rates, and related information are fitted to mathematical forms that are extrapolated to forecast future performance. Commonly used approaches include studies of rates of production per year and cumulative production, numbers of successful discovery wells as a function of time or drilling activity, and volumes of oil or numbers of fields found through time or with drilling activity. The basic concept of these historical performance studies was stated by Hubbert (1967): "Because gas and oil are exhaustible resources, the discovery and production history of these fuels in any particular area must be characterized by a beginning, a period of increase, a period of decline, and ultimately, an end."

Discovery and production process models are especially attractive because they are rigorous, quantitative, and reproducible. The process models generally rely on statistical information and put very little emphasis on geological inference. The models work best if they are used in evaluating a population of accumulations and related rates of new-field discoveries that are within a clearly and narrowly specified set of geologic, temporal, and spatial boundaries. Historical performance models cannot be used in frontier areas where little or no drilling has taken place.

\section{DISCOVERY PROCESS AND FINDING RATES}

Where there is sufficient exploration history, an effective assessment approach is to extrapolate from the se- quence of field discoveries what remains to be discovered, both in terms of field sizes and their aggregate resource value. These approaches are variously termed "discoveryprocess models" or "finding-rate models." These models, in their more sophisticated forms, were pioneered by Arps and Roberts (1958), Drew (1974), and Barouch and Kaufman (1975). At their best, they are conducted at a play level by identifying and using natural populations of fields that are identifiable from their common geologic characteristics of trap, reservoir, seal, and source (Canada Department of Energy, Mines, and Resources, 1977; Lee and Wang, 1986; Podruski and others, 1988). In a subjective format, discovery process was part of the analysis of field sizes employed in the 1989 USGS National resource assessment (Mast and others, 1989; Houghton and others, 1993). Various specific methodologic approaches can be used, and these are often highly statistical in nature. The discovery-process method has been successfully employed in the Permian basin, West Texas, and southeast New Mexico by Drew and others (1979), as well as in various plays of the U.S. Gulf Coast (Schuenmeyer and Drew, 1991). Sufficient data are needed concerning exploration effort and discovery. The reader is referred to White and Gehman (1978) and Miller (1986) for further discussion of these methods.

The primary criticism of the discovery-process and finding-rates methods is that they are inherently conservative. That is, because they are entirely based on past performance, they leave little room for improvements in exploration technology, economics, or imagination. These methods do not allow for the surprises of exploration that so commonly occur.

\section{DEPOSIT SIMULATION}

The deposit-simulation method is a volumetric calculation of resources based on measurement or estimation of the physical properties of traps, reservoir rocks, and fluids and of the temperatures, pressures, and fluid dynamics of the host environment. This method has the advantage of working directly with the basic geologic properties of accumulations and dealing with them in a rigorous, quantitative manner. It allows for simulation of the hydrocarbon deposit(s) through modeling their geologic properties. Consequently, subjectivity is introduced and uncertain parameters can be represented as estimates expressed in ranges of values, accompanied by probabilities of occurrence (probability distributions). The approach, therefore, uses stochastic and probabilistic methods, as well as statistical methods. An example of input for this type of approach is shown in figure 3. A general resource assessment model using these inputs has been described by the Canada Department of Energy, Mines, and Resources (1977), U.S. Department of Interior (1980), Dolton and others 


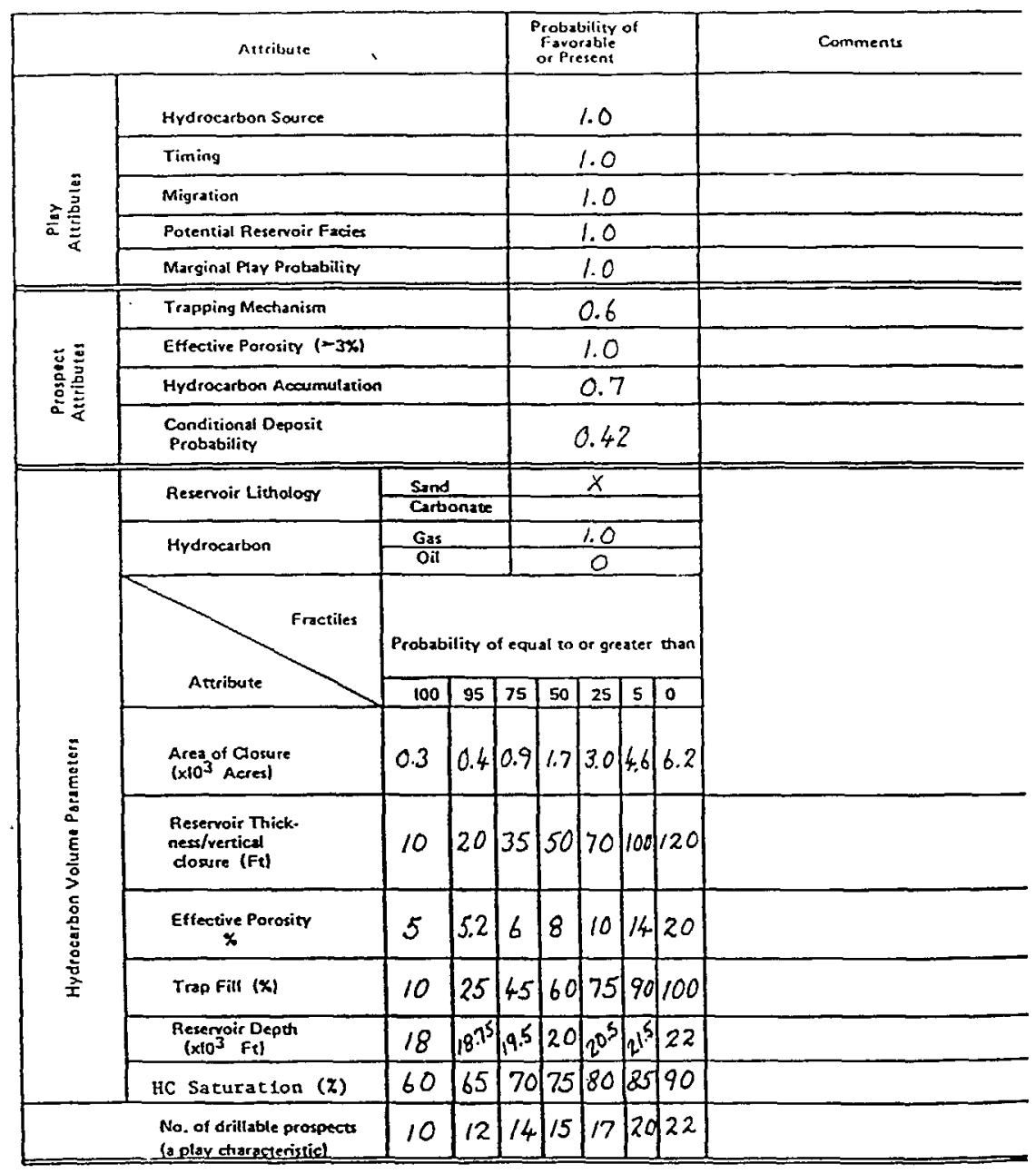

Figure 3. Oil and gas appraisal data form completed for hypothetical deep natural-gas play. From Crovelli and Balay (1988) and Dolton and Crovelli (1992).

(1987), and has been published by Crovelli and Balay (1986, 1988, 1990).

The calculation of gas volume of a deposit is based on a fundamental reservoir engineering formula. Basic to the calculation is the determination of reservoir volume. The dimension of the gas container is critical, whether it be a single homogeneous reservoir rock in a conventional trap, a compartment of lesser size within a larger reservoir, or a heterogeneous reservoir of great size associated with an unconventional basin-center gas occurrence.

The reservoir engineering formula used in deposit simulation or reservoir performance models is expressed as follows:

Gas volume $\left(\mathrm{ft}^{3}\right)=43,560 \mathrm{~A} \cdot F \cdot H \cdot \operatorname{Por} \cdot(1-S w)(\operatorname{Pr} / T r)$

$$
(1 / Z)(T s c / P s c) \text {, }
$$

where $A$ is the area of closure (acres), $F$ is the trap fill (decimal fraction), $H$ is the reservoir thickness ( $\mathrm{ft}$ ), Por is the porosity (decimal fraction), $S w$ is the water saturation,
$\operatorname{Pr}$ is the original reservoir pressure, $\operatorname{Tr}$ is the reservoir temperature (degrees Rankine), Psc is the pressure, standard conditions, $T s c$ is the temperature (degrees Rankine), and $Z$ is the gas compressibility factor.

Simulation of an accumulation or of an aggregate of accumulations requires that the parameters be expressed as ranges of values, accompanied by probabilities of occurrence (probability distributions). The probabilities should represent the natural variability of geologic characteristics and the assessor's uncertainty about them. Hence, the values derived represent the array of possibilities that might be encountered at a randomly selected prospect within a population.

The modelling of gas-saturated reservoir volumes is affected by various geometric constraints. White (1987) and Abrahamsen (1989) discuss some of these geometric considerations as they may be applied when dealing with reservoir thicknesses within closures. For example, reservoir thickness is a function not only of the available stratigraphic thickness of the reservoir unit and of the effective porosity within it, but of the position of the gas-water con- 
tact and the configuration and size of the trap and its fractional fill. Where sufficiently mapped, thickness can be measured or, alternatively, gross hydrocarbon-bearing reservoir volume can be calculated directly from planimetered areas (Pirson, 1950), thereby combining the variables of reservoir thickness, area, and trap fill.

Porosity and water saturation are the internal physical characteristics of the reservoir that determine contained hydrocarbon volumes. The porosity values used must meet an assigned minimum threshold value to qualify as "effective porosity." It is important that this same minimum value be adhered to during measurement of reservoir thickness and in the risking of attributes. Water saturation can be estimated directly or on the basis of an algorithm that relates water saturation to the average porosity of the reservoir.

In this sort of model it is necessary to deal with engineering factors, including estimation of the thermal and pressure conditions of the simulated reservoir and trap. In addition, the compressibility factor of the gas $(Z)$ must be calculated on the basis of known or estimated gas composition.

Adequate framing of the basic geologic model or models of occurrence is essential to assessment, both in terms of assignment of risk to the variables controlling the occurrence of gas and to the assessment of volume parameters. The rock and fluid characteristics identified and investigated in companion studies are critical and include physical properties of reservoirs, such as thickness, distribution, porosity amount and variation, pore geometries and dimensions, trap types and dimensions, effectiveness of seals, physical environments of accumulations (including depths, present and past thermal conditions, pressure regimes, and fluid dynamics) and saturations and properties of the involved fluids (their composition and physical state). The availability of data for these characteristics and their sufficient quantification ultimately determine the adequacy of results. Development of relevant data bases is a requirement for assessment.

The deposit-simulation method provides not only an overall resource assessment but a description of the individual accumulations in terms of their geologic characteristics and their contained gas and affords an easily updatable assessment record. It estimates resources in place and does not tell the user directly about their recoverability or producing characteristics, although it permits use of known or estimated recovery factors. The method is flexible in that it allows the geologist to model the geologic conditions controlling the resource. This allows for a wide range of resource values for a wide range of geologic conditions.

The actual production characteristics of reservoirs that lead to recoverability are best determined by engineering studies of the reservoir rocks and fluids themselves, including reservoir drive and pressure characteristics, reservoirrock permeability, and fluid composition and properties. Such studies are especially critical for evaluation of "tight" (low-permeability) gas reservoirs.
Although the preceding discussion focuses on the modeling of reservoirs, the deposit-simulation method also requires that estimates be made of the number of deposits remaining to be found. This number is an uncertain quantity that depends on the number of prospects and the probability that a random prospect will contain hydrocarbons.

\section{RESERVOIR PERFORMANCE}

Reservoir-performance methods are especially applicable to unconventional resources such as tight-gas sands or autosourced shales, within which a single sedimentary rock serves as source bed, reservoir, trap, and seal for oil and (or) gas accumulations. In this class of resources, the in-place resource is known with some certainty to be large and to extend over a wide area. The most significant questions concern the portions of these resources that might be extracted and the expected rates of extraction. Reservoirperformance methods are being developed by the USGS for evaluation of unconventional resources.

Reservoir performance is an empirical method that relies on production data that are extrapolated to permit a calculation of ultimately recoverable resources, based on certain economic and technologic assumptions and well spacing. This method, which incorporates various production-decline-curve methods, cumulative-production-curve methods, material-balance methods, and other methods, relies heavily on a careful engineering approach. Detailed discussion of this method is beyond the scope of this paper. The reservoir-performance method is useful in a reservoir that has seen some development, as locally may be the case in a tight-gas reservoir, or for reserve calculations within a developed field. This method deals not only with the basic physical characteristics of the reservoirs and fluids, but it also measures, over time, how production and reservoirs respond to development controlled by both technologic and economic factors. This can be a very effective method of resource-assessment in areas where there has been a sufficient history of production. However, the assessor often does not have sufficient information to satisfy the method, except on an analog basis.

\section{MASS BALANCE}

Mass-balance calculations have been used by various workers as a tool for estimation of resources. This method deals with the amount of oil and (or) gas generated, on the basis of geochemical data, the amount that is expelled and migrated, and the amount that is finally retained in traps. Because of the difficulty and uncertainty in quantitatively assessing several of these variables, this method has been useful mostly in a qualitative sense, identifying the probable hydrocarbon composition, the migration history and 
adequacy of charge, and the general resource potential. This method is particularly useful in identifying critical geologic elements and processes needed for resource evaluation. In very well studied areas containing the requisite information, it may be applied as an estimation method. The mass-balance approach has the potential to provide quantitative methods of estimating resources in advance of drilling, although as of yet only analyses after the fact have been conducted. At present, the most significant problems with mass- and material-balance approaches relate to as yet unresolved uncertainties in basic geochemical measurements and parameters, including primary migration, time-temperature range of oil and gas generation, migration and trapping efficiency, and preservation. Although as of yet largely inadequate for quantitative assessment, the material-balance approach continues to hold promise for linking geological and geochemical research to assessment methodology in a direct way.

\section{HISTORY OF U.S. GEOLOGICAL SURVEY ESTIMATES OF NATURAL-GAS RESOURCES}

Natural gas was first produced and sold as fuel for home lighting in 1821 at Fredonia, New York. Steadily increasing but small-scale use of gas as a fuel for heating and lighting occurred in the United States until 1878, when the first large gas field was found in the United States near Murrysville, Pennsylvania. Following the Murrysville discovery, the availability and demand for natural gas expanded dramatically. Following 1918, when one of the first estimates of the reserve of natural gas was published, the amount of natural gas marketed annually expanded from 721 billion cubic feet (Bcf) to a current level of roughly 18 Tcf. Concerns about the natural-gas supply have caused interested parties to question the adequacy of the volumes of gas remaining to be discovered.

Early estimates of fossil-fuel resources commonly did not deal with natural gas but focused on oil or coal. Natural-gas resources were more often evaluated on a local scale for specific market deliverability and field management. Estimates on a National scale appeared only fitfully at first, although with increasing frequency through time.

From 1930 to 1938 several estimates were made of natural-gas reserves in the United States. Prior to the beginning of the systematic annual reporting of natural-gas reserve estimates by the American Gas Association (AGA) in 1946, reporting of gas reserves was done by various individuals and agencies. During World War II, estimates were made by the Petroleum Administration for War. Since cessation of AGA reserve estimates in 1979, the Energy Information Administration (EIA) has reported annual estimates of gas reserves.

Estimates of undiscovered gas resources for the Nation are far less common. They first date from 1919, when an estimate of total recoverable and marketable reserves in both discovered and undiscovered fields of the United States was made by Eugene W. Shaw, valuation engineer in charge of natural gas, U.S. Internal Revenue Bureau, and USGS geologist. In a paper presented at the annual meeting of the Natural Gas Association of America, Cleveland, Ohio, May 20-26, 1919, Shaw (1919) stated that the total recoverable and marketable reserves in both discovered and undiscovered pools in the continental United States were probably 5 to 15 Tcf. This estimate represented an amount equivalent to $30-50$ percent of the original supply, then estimated to have been 50-75 Tcf in both discovered and still undiscovered pools. At that time, about $10 \mathrm{Tcf}$ had been produced.

Many years later, L.F. Terry (1950) estimated the ultimate recoverable gas reserves in the United States, including the continental shelves, to be $510 \mathrm{Tcf}$. His estimate was based on the assumption that the search for and production of the amount of oil called for by Weeks' (1948) estimate of ultimate reserves, would result in the discovery of 6,000 cubic feet of gas for each barrel of oil discovered. The estimation of undiscovered or ultimate recoverable gas resources has proceeded episodically since.

The USGS, along with a variety of other groups, organizations, and individuals has been engaged in this assessment of undiscovered natural gas resources. After a hiatus following Shaw's (1919) paper, the USGS developed a series of estimates of natural-gas resources that were published beginning in the late 1950 's. The first, published in 1956 (U.S. Department of Interior, 1956), estimated that ultimate gas reserves in the United States were at least $1,000 \mathrm{Tcf}$, or more than twice Terry's (1950) estimate of 410 Tcf. In 1950, more than 260 Tcf had already been discovered (U.S. Geological Survey, 1951).

In 1961, A.D. Zapp of the USGS used an extrapolation of data from exploratory drilling successes, combined with a geologic favorability factor derived from Weeks' (1959) estimates, to assess ultimate natural gas resources (Zapp, 1961). Assuming then-current technology and economics, Zapp estimated ultimate natural-gas resources of the United States (including Alaska) to be 1,800 Tcf, with additional submarginal resources of 850 Tcf. According to Zapp (1961), of the ultimate resource, approximately $275 \mathrm{Tcf}$ had been produced through 1960. Zapp incorrectly quoted $38 \mathrm{Tcf}$ as proved reserve. At the time, AGA proved reserves were listed as $264 \mathrm{Tcf}$. Variants of these estimates (including errors) were reported by McKelvey (1961) later that year. McKelvey (1961) listed known reserves of $38 \mathrm{Tcf}$, potential reserves of $1,525 \mathrm{Tcf}$, and potential marginal resources of $850 \mathrm{Tcf}$.

In 1965, T.A. Hendricks estimated original, in-place, economically recoverable gas resources to be $2,000 \mathrm{Tcf}$, with an additional 2,000 Tcf of "submarginal" gas resources (Hendricks, 1965). These gas estimates were derived through gas-oil-discovery ratios from estimates of oil. The 
oil estimates were based on richness factors for explored and unexplored areas. At the time of Hendricks' (1965) work, cumulative production stood at $230 \mathrm{Tcf}$ and proved reserves were listed by AGA at 268 Tcf, plus an unknown amount of inferred reserve. These figures suggest that Hendricks estimated undiscovered resources to be about $1,080 \mathrm{Tcf}$, with an additional $202 \mathrm{Tcf}$ in the inferred reserve (Miller and others, 1975).

In 1967, M. King Hubbert, working at USGS, published a refinement of the innovative work he had first released in 1956 and updated in 1962 (Hubbert, 1967). His analysis, based on statistical extrapolation of finding rates for oil and on a gas-oil-discovery ratio, yielded estimates of 900-1,200 Tcf of ultimately recoverable gas for the United States, excluding Alaska. Hubbert (1967) estimated that of the ultimately recoverable resource, $747 \mathrm{Tcf}$ had already been discovered. Two years later, using the same method, Hubbert (1969) made a point estimate of ultimate recoverable gas of $1,044 \mathrm{Tcf}$ (excluding Alaska) and estimated that approximately 826 Tcf of natural gas had been discovered.

Theobald and others (1972), stated that undiscovered recoverable natural gas resources were estimated to be 2,100 Tcf and "submarginal" (noneconomic) resources were estimated to be about 4,000 Tcf. This estimate included Alaska and the U.S. continental shelves out to water depths of $2,500 \mathrm{~m}(8,200 \mathrm{ft})$. The method of Theobald and others (1972), using methodology developed by A.D. Zapp and T.A. Hendricks, applied the historical results of past exploratory drilling to unexplored rocks on an equal basis for all of the favorable strata of the United States. The methodology was a virtually pure volumetric estimate and was one of the largest estimates of U.S. resources ever published.

Thus, for several years, the USGS had been publishing resource estimates that varied widely in both methodology and in results. Moreover, the widely divergent gas estimates were associated with estimates of oil resources that diverged even more. Two principal schools of thought had been developing at the USGS. One school, led by McKelvey and his colleagues Hendricks, Zapp, and Theobald, relied mainly on volumetric approaches and held a highly optimistic view of the United States oil and gas resource situation. The other school centered about Hubbert, whose extrapolations from historical information suggested that the United States was a country with an energy industry about to go into decline. These disparate and at times hostile viewpoints gave the public the (correct) impression that there was no monolithic or even coherent position on resources among the scientists at the USGS. In part because of the apparently critical issues of energy supply facing the United States after the OPEC oil embargo of 1973 and in part because of the seemingly chaotic approach having been taken to resource evaluation at the USGS, a new Branch of Oil and Gas Resources was formed within the Geologic Division. That branch was charged with conducting research to evaluate the Nation's oil and gas resources.

On March 26, 1974, the USGS issued a news release estimating the natural-gas resources of the United States to be in the range of 1,000-2,000 Tcf; with inferred reserves of 130-250 Tef. This estimate was said to include both Alaska and resources offshore to water depths of $200 \mathrm{~m}$. This seeming revision of the Theobald and others' (1972) estimate reflected the views of Peter Rose and other members of the newly formed Branch of Oil and Gas Resources at the USGS. The Branch of Oil and Gas Resources Resource Assessment Group (RAG) was organized for the express purpose of systematically evaluating the oil and gas resources of the United States. The press release of March 26, 1974, reflected a quick estimate developed using both Delphi (Baxter and others, 1978) and a volumetric method called ANOGRE (Mallory, 1975a, b).

Following the press release, the Branch of Oil and Gas Resources undertook two systematic, labor-intensive resource assessments. The first of these was published by B.M. Miller and others (1975), who stated that conventionally recoverable undiscovered natural-gas resources were estimated to range from 322 to $655 \mathrm{Tcf}$, with a mean value of $484 \mathrm{Tcf}$; the inferred reserves were estimated at 202 Tcf. The Miller and others (1975) group used a modified Delphi method based on a volumetric- and areal-yield analysis, coupled with analog evaluations. The estimates included, as usual, Alaskan resources and resources under water to depths of $200 \mathrm{~m}$. The second assessment effort was led by G.L. Dolton and used a modified Delphi method based on volumetric-yield analysis, as well as finding rates, and analogy. The work culminated in the publication of a report by Dolton and others (1981). In that report, undiscovered conventionally recoverable resources of natural gas were estimated to range from 475 to $730 \mathrm{Tcf}$, with a mean value of 594 Tcf. Dolton and others (1981) estimated inferred reserves of $178 \mathrm{Tcf}$.

In 1982, James Watt, Secretary of the Interior, formed the Minerals Management Service (MMS) from à core of royalty management and leasing personnel previously employed in the Conservation Division of the USGS. Although the Conservation Division had previously been only peripherally involved in USGS assessment activities, it was the wish of the management at the Department of the Interior that resource estimation and leasing for the federal offshore areas be consolidated in the MMS. As a consequence, the Director of the USGS signed an agreement relinquishing all responsibility for assessment of the Federal offshore areas to the MMS.

In 1989, R.F. Mast and others completed a joint USGS-MMS assessment of the undiscovered, conventionally recoverable oil and gas resources of the United States, with the USGS being responsible for onshore and State offshore areas and the MMS assuming responsibility for 
the Federal offshore. The assessment utilized, for the first time at USGS and MMS, a play analysis approach (Baker and others, 1984) based on field size and number and discovery history (for example, Mast and others, 1989; Houghton and others, 1989, 1993). Included in the assessment was a numerical estimate of additions to reserves through reserve appreciation (Root and Mast, 1993). In their assessment, Mast and others (1989) estimated undiscovered, conventional natural-gas resources to be between 307 and 507 Tcf, with a mean value of $399 \mathrm{Tcf}$ and inferred reserves of 99 Tcf.

Results from recent USGS assessments of natural 'gas are shown graphically in figure 4 . The figure plots gas in trillion cubic feet versus years for the United States. Various categories of resources are then plotted one on top of another. The lowermost curve is the generally well accepted values for cumulative U.S. gas production. The second curve represents the cumulative production plus proved reserves. In this curve, proved reserves for each year have been plotted atop the appropriate years value for cumulative production. The uppermost complete curve represents the total of cumulative production, proved reserves, and a new estimate, based on recent Energy Information Administration (EIA) data, for the inferred reserves. Superimposed on these three curves are the various USGS estimates discussed in this paper. The USGS 1956 assessment is plotted as a point estimate, as it only purported to show the ultimate amount of United States reserves. Similarly, Theobald and others' (1972) estimate is plotted as a single point. The other assessments, however, are plotted on top of cumulative production and proved reserves at the time of the estimate. Further, the estimates are plotted from a base that includes the evaluation of inferred reserves (reserve growth) given in each specific estimate. Figure 4 seems to indicate that, excluding the Theobald and others (1972) estimate, other assessments have been fairly close in their evaluations of the undiscovered gas resource; however, all assessments would appear to have been systematically low in their evaluation of future reserve additions to be expected from reserve growth.

The USGS and MMS are currently (summer, 1993) about midway through yet another joint assessment of the oil and gas resources of the United Sates. The new assessment, while retaining the play analysis approach developed by Mast and others, has been expanded somewhat in scope to reflect the changing energy situation in the United States. In particular, the new assessment will include expected additions to reserves from all sources. The assessment will include a more systematic and comprehensive evaluation of reserve growth and will include one of the first play-level evaluations of reserve additions expected over the next two or three decades from unconventional sources. As with previous assessments, this latest one is hoped to reflect the situation, needs, and understanding of oil and gas resources at the time of its completion.

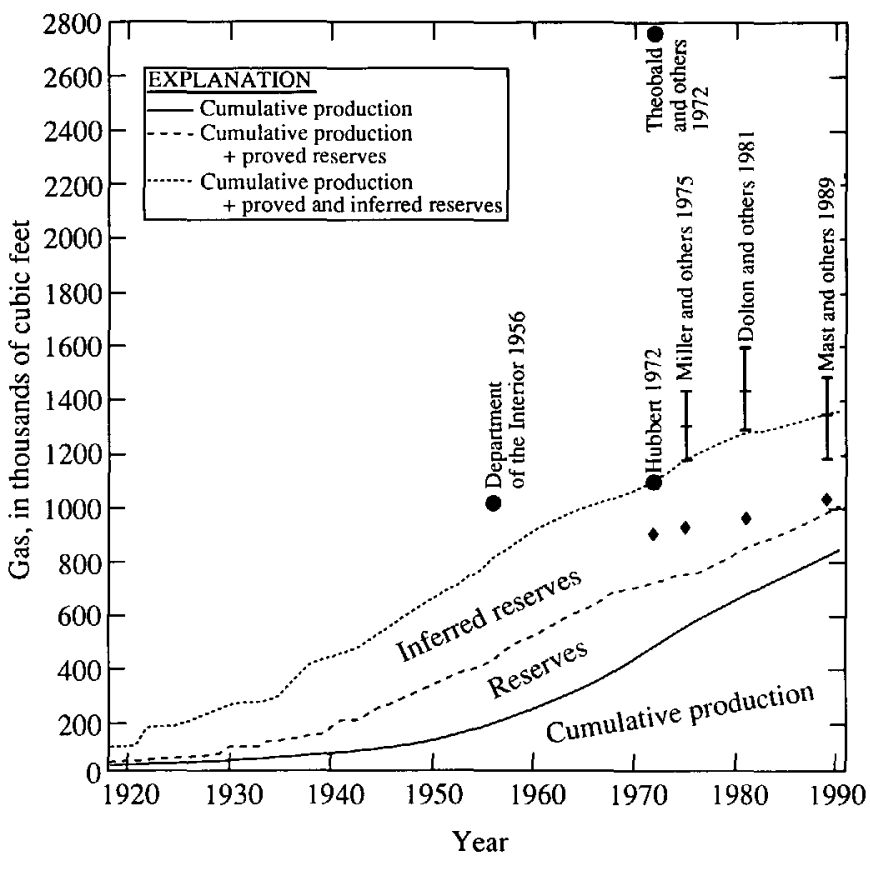

Figure 4. U.S. Department of the Interior and U.S. Geological Survey estimates of natural-gas resources. Cumulative production compiled from various sources. Reserves (1979-1990) from Energy Information Administration. Reserves (1935-1979) from American Petroleum Institute/American Gas Association. Reserves prior to 1935 compiled from various sources. Inferred reserves shown beneath upper (dotted) curve newly estimated from Department of Energy Oil and Gas Integrated Field File. Hubbert (1972), Miller and others (1975), Dolton and others (1981), and Mast and others (1989) estimates of undiscovered resources plotted relative to their respective estimates of inferred reserves (diamonds) rather than relative to the latest estimate of inferred reserves (dotted line). All estimates plotted with reference to date of estimate. Dates of publication shown next to plotted estimates.

\section{REFERENCES CITED}

Abrahamsen, K.A., 1989, Application of the resource estimation program FASPUM; experiences from offshore Norway, in Symposium of the 6th Meeting of the Working Group on Resource Assessment: Committee for Coordination of Joint Prospecting for Mineral Resources in Asian Offshore Areas (CCOP), Bangkok, Thailand, August 28 through September 2, 1989, unpaginated.

Arps, J.J., and Roberts, T.J., 1958, Economics of drilling for Cretaceous oil on east flank of Denver-Julesburg Basin: American Association of Petroleum Geologists Bulletin, v. 42, no. 11 , p. $2549-2566$.

Baker, R.A., Gehman, H.M., James, W.R., and White, D.A., 1984, Geologic field number and size assessments of oil and gas plays: American Association of Petroleum Geologists Bulletin, v. 68 , no. 4, p. 426-437.

Barouch, E., and Kaufman, G.M., 1975, Predicting undiscovered oil and gas in a play using a stochastic model of discovery, 
in Davis, J.C., Doveton, J.H., and Harbaugh, J.W., conveners, Probability methods in oil exploration, American Association of Petroleum Geologists Research Symposium, Stanford, California: Kansas Geological Survey, 7 p.

Baxter, G.G., and others, 1978, Workshop on the Delphi method: Journal of the International Association for Mathematical Geology, v. 10, no. 5, p. 581-587.

Canada Department of Energy, Mines, and Resources, 1977, Oil and natural-gas resources of Canada, 1976: Ottawa, Ontario, Canada Department of Energy, Mines, and Resources Report EP 7-1, 76 p.

Crovelli, R.A., and Balay, R.H., 1986, FASP, an analytic resource appraisal program for petroleum play analysis: Computers and Geosciences, v. 12 , no. 4B, p. 423-475.

1988, FASPUM metric version--Analytic petroleum resource appraisal microcomputer programs for play analysis using a reservoir-engineering model: U.S. Geological Survey Open-File Report 87-414A, 14 p.

1990, FASPU English and Metric version-Analytic petroleum resource appraisal microcomputer programs for play analysis using a reservoir-engineering model: U.S. Geological Survey Open-File Report 90-509B, 23 p.

Day, D.T., 1909, The petroleum resources of the United States, in Papers on the conservation of mineral resources: U.S. Geological Survey Bulletin 394, p. 30-50.

Dolton, G.L., Bird, K.J., and Crovelli, R.A., 1987, Assessment of in-place oil and gas resources, in Bird, K.J., and Magoon, L.B., eds., Petroleum geology of the northern part of the Arctic National Wildlife Refuge, Northeastern Alaska: U.S. Geological Survey Bulletin 1778, p. 277-298.

Dolton, G.L., and Crovelli, R.A., 1992, Resource assessment methodology for deep natural gas resources, in Dyman, T.S., ed., Geologic controls and resource potential of natural gas in deep scdimentary basins in the United States: U.S. Geological Survey Open-File Report 92-524, p. 285295.

Dolton, G.L., and others, 1981, Estimates of undiscovered recoverable conventional resources of oil and gas in the United States: U.S. Geological Survey Circular 860, 87 p.

Drew L.J., 1974, Estimation of petroleum exploration success and the effects of resource base exhaustion via a simulation model: U.S. Geological Survey Bulletin 1328, 25 p.

Drew, L.J., Root, D.H., and Bawiec, W.J., 1979, Estimating future rates of petroleum discoveries in the Permian Basin, in Hydrocarbon Economics and Evaluation Symposium, 8th: Dallas, Texas, 1979, Proceedings of Petroleum Engineers/ American Institute of Mining Engineers p. 101-109.

Hendricks, T.A., 1965, Resources of oil, gas, and natural-gas liquids in the United States and the world: U.S. Geological Survey Circular 522, $20 \mathrm{p}$.

Houghton, J.C., Dolton, G.L., Mast, R.F., Masters, C.D., and Root, D.H., 1989, The estimation procedure for field size distributions in the U.S. Geological Survey's National oil and gas resource assessment, in National assessment of undiscovered conventional oil and gas resources, USGS-MMS Working Paper: U.S. Geological Survey Open-File Report 88-373, p. 51-86.

1993, U.S. Geological Survey estimation procedure for accumulation size distributions by play: American Association of Petroleum Geologists Bulletin, v. 77, p. 454-466.
Hubbert, M.K., 1967, Degree of advancement of petroleum exploration in United States: American Association of Petroleum Geologists Bulletin, v. 51, no. 11, p. 2207-2227.

1969, Energy resources, in Resources and Man: San Francisco, W.H. Freeman and Co., National Academy of Science and National Research Council, Committee on Resources and Man, p. 157-242.

1974, U.S. energy resources-A review as of 1972, pt. 1, in A national fuels and energy policy study: U.S. 93d Congress, $2 \mathrm{~d}$ session, Senate Committee for Interior and Insular Affairs, Committee Print, serial no. 93-40 (92-75), 267 p.

Lee, P.J., and Wang, P.C.C., 1986, Evaluation of petroleum resources from pool size distributions, in Rice, D.D., ed., Oil and gas assessment-Methods and applications: American Association of Petroleum Geologists, Studies in Geology, no. 21 , p. 33-42.

Mallory, W.W., 1975a, Accelerated National oil and gas resource appraisal (ANOGRE), in Haun, J.D., ed., Methods of estimating the volume of undiscovered oil and gas resources: American Association of Petroleum Geologists Studies in Geology, no. 1, p. 23-30.

__ 1975b, Synopsis of procedure-Accelerated National oil and gas resource evaluation, in Mineral resources and the environment (appendix to sec. II)--Report of Panel on Estimation of Mineral Reserves and Resources: Washington, D.C., National Academy of Sciences, p. 1-5.

Mast, R.F., Dolton, G.L., Crovelli, R.A., Root, D.H., and Attanasi, E.D., Martin, P.E., Cooke, L.W., Carpenter, G.B., Pecora, W.C., and Rose, M.B., 1989, Estimates of undiscovered conventional oil and gas resources in the United States-A part of the Nation's energy endowment: U.S. Geological Survey and Minerals Management Service Special Publication, $44 \mathrm{p}$.

McKelvey, V. E., 1961, Synopsis of domestic and world resources of fossil fuels, radioactive minerals, and geothermal energy: Preliminary reports prepared for the Natural Resources Subcommittee of the Federal Science Council, November 28, $1961,20 \mathrm{p}$.

Miller, B.M., 1986, Resource appraisal methods-Choice and outcome, in Rice, D.D., Oil and gas assessment, methods and applications: American Association of Petroleum Geologists Studies in Geology, no. 21, p. 1-24.

Miller, B.M., and others, 1975, Geological estimates of undiscovered recoverable oil and gas resources in the United States: U.S. Geological Survey Circular 725, 71 p.

Pirson S.J., 1950, Elements of reservoir engineering: McGrawHill Book Company, $441 \mathrm{p}$.

Podruski, J.A., Barclay, J.E., Hamblin, A.P., Lee, P.J., Osadetz, K.G., Procter, R.M., and Taylor, G.C., 1988, Part 1, resource endowment, in Conventional oil resources of western Canada: Geological Survey of Canada Paper 87-26, p. 7-14.

Root, D.H., and R.F. Mast, 1993, Future growth of known oil and gas fields: American Association of Petroleum Geologists Bulletin, v. 77, p. $479-484$.

Shaw, E.W., 1919, The income and expense of natural as production: Natural Gas Association of America, Proceedings 14th Annual Meeting. May 19-22, p. 479-503.

Schuenmeyer, J.H., and Drew, L.J., 1991, Undiscovered oil and gas in the Frio Strand Plain trend-The unfolding of a very large exploration play: American Association of Petroleum Geologists Bulletin, v. 75, p. 1107-1115. 
Terry, L.F., 1950, The future supply of natural gas: Gas Age, v. 106 , no. 9 . p. $58-60,98,100,102$.

Theobald, P.K., Schweinfurth, S.P., and Duncan, D.C., 1972, Energy resources of the United States: U.S. Geological Survey Circular 650, $27 \mathrm{p}$.

U.S. Department of Interior, 1956, Impact of the peaceful uses of atomic energy on the coal, oil- and natural-gas industries, in Peaceful uses of atomic energy: Background material for the report of the Panel on the Impact of the Peaceful Uses of Atomic Energy to the U.S. Congress Joint Committee on Atomic Energy, 84th Congress, v. 2, Washington, D.C., p. $68-89$.

U.S. Department of Interior, Office of Minerals Policy and Research Analysis, 1980, Final report of the 105(b) Economic and policy analysis-Alternative overall procedures for the exploration, development, production, transportation, and distribution of the petroleum resources of the National Petroleum Reserve in Alaska (NPRA): U.S. Department of Interior, $145 \mathrm{p}$.

U.S. Geological Survey, 1951, Fuel reserves of the United States: Statement prepared by the U.S. Geological Survey at the request of the Committee on Interior and Insular Affairs Unites States Senate, Committee on Interior and Insular Affairs, 82d Congress, Committee Print, Washington, D.C., 49 p.

U.S. Geological Survey and U.S. Bureau of Mines, 1976, Principles of the mineral resource classification system of the U.S.
Bureau of Mines and U.S. Geological Survey: U.S. Geological Survey Bulletin 1450-A, 5 p.

U.S. Geological Survey and U.S. Bureau of Mines, 1980, Principles of resource/reserve classification for minerals: U.S. Geological Survey Circular 831, 5 p.

Weeks, L.G., 1950, Concerning estimates of potential oil reserves: American Association of Petroleum Geologists Bulletin, v. 34, no. 10, p. 1947-1953.

1948, Highlights on 1947 developments in foreign petroleum fields: American Association of Petroleum Geologists Bulletin, v. 32, no. 6, p. 1093-1160.

White, D.A., 1987, Methods of oil and gas prospect and play assessment course manual: Oil \& Gas Consultants International.

White, D.A, and Gehman, H.M., 1978, Methods of estimating oil and gas resources: American Association of Petroleum Geologists Bulletin v. 63 , no. 12, p. 2183-2192.

Zapp, A.D., 1961, World petroleum resources, in Domestic and world resources of fossil fuels, radioactive minerals, and geothermal energy: Preliminary reports prepared by members of the U.S. Geological Survey for the National Resources Subcommittee of the Federal Science Council, Nov. 28, 1961, 9 p.

Zapp, A.D., 1962, Future Petroleum producing capacity of the United States: U.S. Geological Survey Bulletin 1142-H, $36 \mathrm{p}$. 
THE FUTURE OF ENERGY GASES

U.S. GEOLOGICAL SURVEY PROFESSIONAL PAPER 1570

\title{
National Petroleum Council Source and Supply Study- The Potential for Natural Gas in the United States
}

\author{
By Donald L. Gautier ${ }^{1}$ and Robert L. Brown ${ }^{2}$
}

\section{CONTENTS}

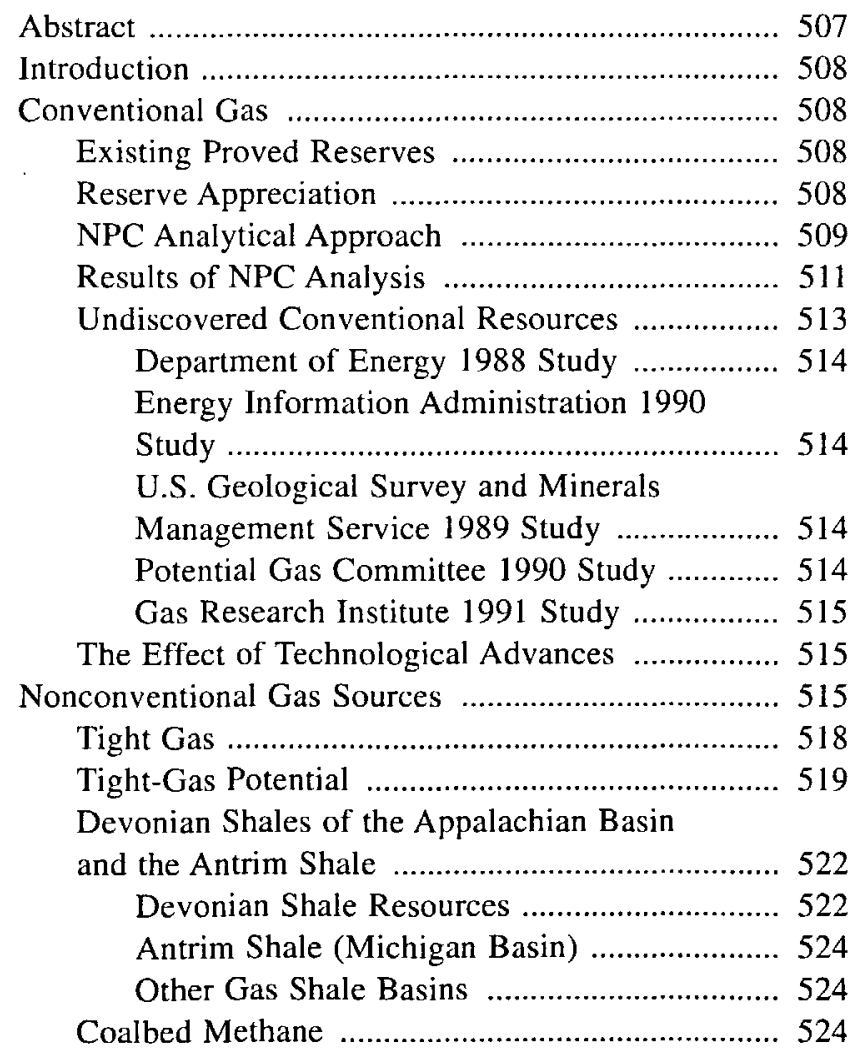

'U.S. Geological Survey, Denver Federal Center, Box 25046 MS 960, Denver, CO 80225.

${ }^{2}$ Mobil Oil Corporation, 3225 Gallows Road, Fairfax, VA 22037 0001.
Nonconventional Gas Sources-Continued

Historical Trends and Future Expectations

for Coalbed Methane ......................................... 524

Speculative Gas Sources ................................... 525

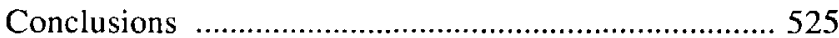

References Cited ................................................... 526

ABSTRACT

This paper summarizes the contribution of the Source and Supply Task Group to the recent (December 1992) National Petroleum Council (NPC) study entitled "The Potential for Natural Gas in the United States." This task group evaluated potential sources of additions to U.S. natural gas reserves with a team of more than 100 participants, representing various trade, academic, government, and industry organizations. The group evaluated reserve growth, unconventional resources, and undiscovered conventional resources of natural gas over a range of prices and to the year 2010. The study concluded that the U.S. recoverable resource base consists of nearly $1,300 \mathrm{Tcf}$ in the lower 48 States alone, of which more than 413 Tcf will be in new fields and 203 Tcf will be added from reserve appreciation. In addition, more than 519 Tcf will be available as recoverable unconventional resources of gas in coalbeds, gas shales, tight sands, and in other categories. Of the total resource, more than $600 \mathrm{Tcf}$ will be recoverable at wellhead prices of $\$ 2.50$ per million British thermal units. The NPC evaluation of the U.S. resource base concluded that the domestic natural-gas resource is plentiful and that technological advances will ensure that the resources will be available to fill any foreseeable demand over the next few decades. 


\section{INTRODUCTION}

The National Petroleum Council (NPC) has recently conducted a study of natural gas on behalf of the Federal Secretary of Energy. The study entitled "The Potential for Natural Gas in the United States" (National Petroleum Council, 1992) spanned a wide range of subjects including resources, economics, production, transportation, environmental issues, and consumption. This paper summarizes the principal results of those sections of the NPC report that were devoted to the source and supply of natural gas in the United States. In particular, because the subject of this volume is "The Future of Energy Gases," the perspective of the NPC, representing as it does a wide range of industry, governmental, and other views, is especially relevant. The specific focus of the source and supply study was the resource base of conventional and nonconventional gas that can be made available as additions to United States reserves over the period of time from 1990 until the year 2010 , with most gas priced at no more than $\$ 3.50$ per thousand cubic feet (Mcf), and it covered a wide range of topics relevant to future supplies of natural gas for the United States. This paper, however, will concentrate on two themes: (1) present proved reserves and future supplies of conventional natural gas coming from new discoveries and from growth of reserves in existing fields and (2) sources of unconventional supplies of natural gas that are considered likely to be brought into production by 2010 .

Because this paper summarizes an NPC report, the stratigraphic nomenclature and unit age assignments discussed here may not necessarily conform to current usage by the U.S. Geological Survey.

\section{CONVENTIONAL GAS}

The Conventional Gas Work Group was established within the Source and Supply Task Group and charged with the assessment of the conventional resource base. The assessment centered on two topics: (1) the undiscovered nonassociated and associated/dissolved gas and (2) the expected future growth of proved reserves in existing fields.

\section{EXISTING PROVED RESERVES}

The NPC relied mainly on the reserves information contained in the annual reports of the Energy Information Administration (EIA). The EIA reports reserves by state; however, the Energy and Environmental Analysis Inc. (EEA) Hydrocarbon Supply Model (HSM) used for the NPC study is designed to economically analyze the resource base in thirteen onshore and five offshore segments. The onshore data were disaggregated into four reservoirdepth zones, and the offshore data were subdivided into four water-depth zones. The proved reserves of dry gas for the lower 48 States are presented in table 1.

Table 1. Lower 48 States dry-gas proved reserves as of year end 1990, in billion cubic feet.

[From National Perroleum Council, 1992]

\begin{tabular}{|c|c|c|}
\hline Region & & Total \\
\hline Appalachia & A & 6,718 \\
\hline MAFLA Onshore* & B & 3,296 \\
\hline Midwest & $\mathrm{C}$ & 1,243 \\
\hline Arkla-E. Texas & D & 11,658 \\
\hline So. Louisiana & $\mathrm{E}$ & 8,171 \\
\hline Texas Gulf Coast & $\mathrm{G}$ & 13,154 \\
\hline Williston & WL & 1,485 \\
\hline Rockies Foreland & $\mathrm{FR}$ & 10,599 \\
\hline San Juan Basin & SJB & 15,624 \\
\hline Overthrust & OV & 3,790 \\
\hline Midcontinent & $J N$ & 31,841 \\
\hline Permian & JS & 14,420 \\
\hline Pacific & $L$ & 2,993 \\
\hline Subtotal Onshore & & 124,992 \\
\hline $\begin{array}{l}\text { Norphlet } \\
\text { West Florida }\end{array}$ & $\mathrm{BO}$ & 4,780 \\
\hline Gulf of Mexico & EGO & 28,626 \\
\hline Pacific Offshore & LO & 1,646 \\
\hline Atlantic Offshore & $\mathrm{AO}$ & \\
\hline Subtotal Offshore & & 35,052 \\
\hline Grand Total & & 160,044 \\
\hline
\end{tabular}

RESERVE APPRECIATION

The estimated ultimate recovery (EUR) of an oil or gas field is defined as the sum of cumulative production and proved reserves. Data concerning EUR's for U.S. oil and gas fields have been published by the American Gas Association (AGA) and more recently by the EIA. These EUR data which are assigned to fields by the year of field discovery, indicate that most field reserves have increased through time (see also Root and Attanasi, this volume). This growth in EUR is referred to as reserve growth or reserve appreciation. Reserve appreciation results from a number of causes including additions to reserves by field extensions, the identification of new reservoirs within existing fields, infill drilling, increased recovery through improved technology or enhanced recovery techniques, and well workovers, recompletions, and longer productive life of wells encouraged by higher prices. Reserve growth also results from the way reserves are reported by the industry. Initial estimates of field sizes are normally conservative to avoid overinvestment. As field development proceeds and 
more information is gathered, field-size estimates are commonly increased to more accurately reflect the true field size. Measures of reserve appreciation provide an estimate of the reserves that are added through time to known fields. The growth in reserves in known fields accounts for about two-thirds of annual additions to U.S. proved gas reserves. Growth continues to occur even in old fields. For example, gas fields discovered before 1968 accounted for 7.6 trillion cubic feet $(\mathrm{Tcf})$ of the 14.4 Tcf total reserve additions in 1989 .

The Office of Technology Assessment in a 1985 report "U.S. Natural Gas Availability, Gas Supply Through the Year 2000" (Office of Technology Assessment, 1985) cited five examples of sources of "new gas from old fields:" (1) lowering of abandonment pressure (decrease of the pressure threshold at which the decision is made to abandon a well), which is typically tied to gas prices and economic life of wells and surface equipment, (2) infill drilling, which can add new wells to recover gas not in communication with existing wellbores, (3) fracturing and acidizing, which can improve flow continuity between gas-bearing reservoir rock and the well bore, (4) well workovers, which improve the mechanical condition of the well or treat the reservoir to improve flow, (5) extension of drilling into previously subeconomic portions of the field, which again is tied to prices and (or) to improvements in extraction technology.

Although each of these activities have added new reserves in old fields, most reserve appreciation comes from infill drilling, drilling extensions, and activities in existing wells such as recompletions and restimulations. The ultimate recovery of gas from fully delineated natural-gas accumulations tends to be much greater than initial estimates because technology developments during the last three decades have significantly improved the industry's ability to discover, develop, and produce hydrocarbons.

\section{NPC ANALYTICAL APPROACH}

Previously published estimates of reserve growth have ranged from largely subjective estimates to rigorous forecasts based on analyses of historical statistics. The NPC concluded that its study should have a sound technical basis. The analysis, therefore, relied on what has actually occurred in the industry regarding reserves data. Data for estimating ultimate recoveries were available from two sources: (1) the Oil and Gas Integrated Field File (OGIFF), maintained by EIA, and (2) the American Petroleum Institute (API)/American Gas Association (AGA) publication "Reserves of Crude Oil, Natural Gas Liquids, and Natural Gas in the United States and Canada." The OGIFF file contains estimates of crude oil and natural-gas proved reserves, annual production, cumulative production, and ultimate recovery for most U.S. oil and gas fields. The file includes yearly estimates for the 13 year period from 1977 to 1989 for each of about 46,000 oil and (or) gas fields.

Both the EIA and AGA data include estimates for both nonassociated gas (gas not associated with oil) and associated/dissolved gas (gas dissolved in oil) or free gas in an oil reservoir. However, a careful review of the AGA data on associated/dissolved gas led to the conclusion that the EIA data set should be used for this type of gas. Although the two data sets were developed using different approaches and contained somewhat different results for overlapping years, the data were merged to provide a 22 -year history of reserve growth. The resulting data set demonstrates that the initial proved reserves reported by companies grow significantly through time; booked reserves from fields discovered more than 50 years ago are still increasing, although at a generally low rate of growth. The growth of reserves for fields discovered between 1966 and 1988 for the NPC nonassociated gas data base are shown in figure 1 .

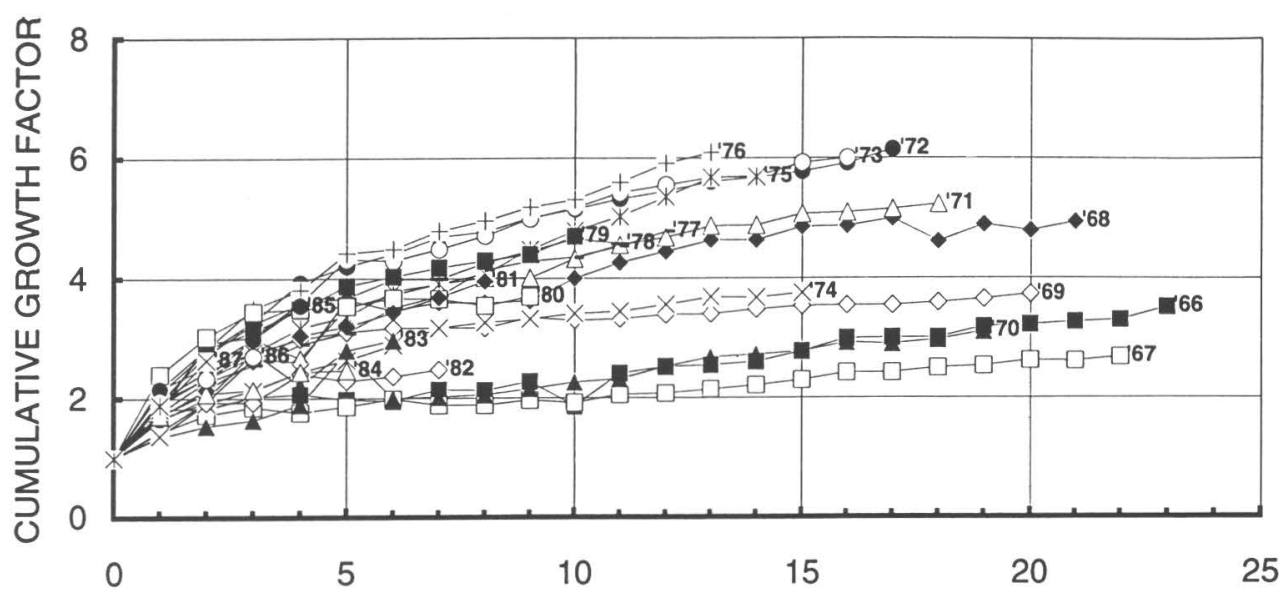

Figure 1. Growth factors for nonassociated gas. Numbers at end of lines marked with symbols indicate year of discovery. From National Petroleum Council (1992). 
The NPC approach considers reserve growth as a function of both time and drilling activity. The 22-year history of available data covers a wide range of drilling activity, including the intense drilling activity of the early 1980 's "boom" to the late 1980 's "bust." Thus, it was decided that reserve growth should be considered in terms of both immaturity and level of drilling activity. The NPC study considered well completions to be the most reliable indicator of industry activity.

Growth curves based on both time and drilling activity assume that reserve growth will continue and that growth will vary through time as a function of industry activity. The EIA data base includes information from the great majority of production companies.

Because the growth curve is tied to the initial booking of reserves, a concern remains about the nature of industry reserve booking practices over the 22-year time period. There have been various pressures that affect reserve estimates during the period of the data. For example, the gassales-contracts accounting standards and Securities and Exchange Commission regulations. Estimates of reserves tend to be self-correcting, however, as estimates that are too high must eventually be removed as a negative revision. The NPC concluded that industry reserve booking practices have been reasonably stable over an extended period and especially since the implementation of the Reserve Recognition Accounting Standards by the Securities and Exchange Commission of 1976.

Well-completion data for the NPC study were obtained from DeGolyer and McNaughton's "Twentieth Century Pe- troleum Statistics" for 1920 through 1969. Well completions in the period 1969 through 1989 came from the source file for "Monthly Energy Review" of the EIA, Office of Energy Markets and End Use.

An explicit functional form for the NPC study was selected that depended on both time and cumulative wells drilled. The addition of cumulative drilling permitted the development of a reserve appreciation function with a clearly defined limiting asymptotic value that naturally explains the increases in the rate of reserve appreciation per year in the period from 1977 to 1989 as compared to the period from 1967 to 1976. Figure 2 shows examples of the NPC nonassociated reserve appreciation model for 1922 discoveries under different drilling assumptions. Although the analytical work used a data series based on wet gas data, the final results are believed to represent dry gas volumes as well. The lower growth factor curve assumes that 2,000 gas wells are drilled every year, which approximates the actual early life of a 1922 discovery. The heavy middle curve represents the model prediction using historical drilling patterns; the abrupt change in slope after year 50 reflects the rapid increase in gas well drilling in the mid1970's. The top curve represents the shape of the growth curve for 1922 fields if 20,000 gas wells per year had been drilled. The growth factors in this curve increase at a higher rate, but eventually approach the same asymptote (6.6).

An additional feature of the work to develop an equation characterizing the appreciation of proved reserves was that nonassociated gas and associated/dissolved gas were analyzed separately. The functional forms of the equations

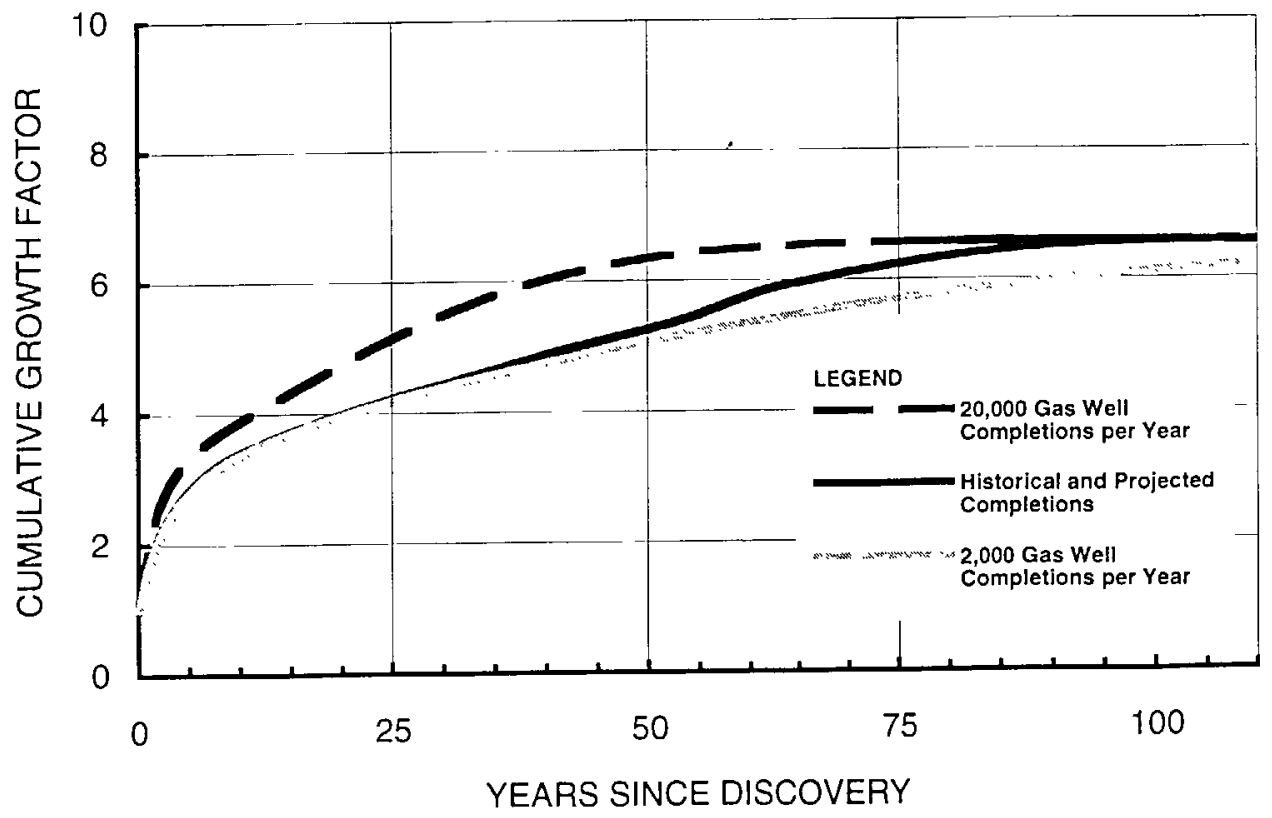

Figure 2. Growth curve for 1922 discoveries of nonassociated gas. From National Petroleum Council (1992). 
were identical, but the associated/dissolved equation relied upon the number of oil wells drilled since discovery rather than on the number of gas wells drilled.

\section{RESULTS OF NPC ANALYSIS}

The results of the NPC analysis can be viewed by comparing the predicted growth curve for an example discovery year to some of the actual growth patterns of fields discovered between 1966 and 1988 (fig. 3). The growth factor was calculated by dividing the ultimate recovery in any year by the ultimate recovery estimate in the year of discovery. The actual growth factor is already over six for some discovery years (1972 and 1976) and under three for other discovery years (1967 and 1970). The heavy black line is an example growth curve calculated from the NPC reserve-appreciation equation. The curves calculated directly from the data show a fairly wide spread around the example curve. However, the example growth curve does reflect a rough average behavior of the growth curves directly calculated from the NPC data base.

Using the same NPC data base, reserve-appreciation methods that use functional forms (Hubbert and EIA) that depend on field age and those that utilize other statistical methods not dependent on a specific functional form (Arrington, Marsh, and U.S. Geological Survey) would probably yield curves similar to the example shown in figure 3 . One of the key observations to be made from figure 3 is not the spread of the actual curves around the example curve, but rather the rate of growth of the curves compared to the predicted curve. The ultimate growth factor is important for new discoveries, but the rate of growth for existing proved reserves is the more important part of the prediction, because it is the rate that determines the size of the reserve appreciation resource. Figure 3 shows that after about five years after discovery, the predicted rates of growth are quite similar.

Table 2 shows the predicted reserve appreciation for the years 2010 and 2030 with various drilling assumptions. In addition, the reserve appreciation of nonassociated gas after 4,000,000 cumulative gas wells are drilled is estimated to be roughly 216 Tcf. This is almost the limit of reserve appreciation in the model. Similarly after $14,000,000$ cumulative oil wells have been drilled the associated/dissolved gas reserve appreciation will reach 20 Tcf for a total reserve appreciation of 236 Tcf. Most of this is proved by the year 2030 .

The reserve-appreciation resource was allocated to the HSM regions and depths in proportion to the distribution of ultimate recovery by discovery year in each area. Table 3 shows the results of that allocation and represents the actual data utilized as input to the HSM for the NPC gas study.

Table 4 provides a further breakdown of the total gas reserve appreciation by nonassociated gas in high-permeability reservoirs, tight nonassociated gas in old plays, and associated/dissolved gas. This table includes tight gas in old plays in the total reserve-appreciation resource because such growth was in the historical data base. For the purposes of total resource base reporting in the NPC study, this volume of resource was also reported as nonconventional tight gas.

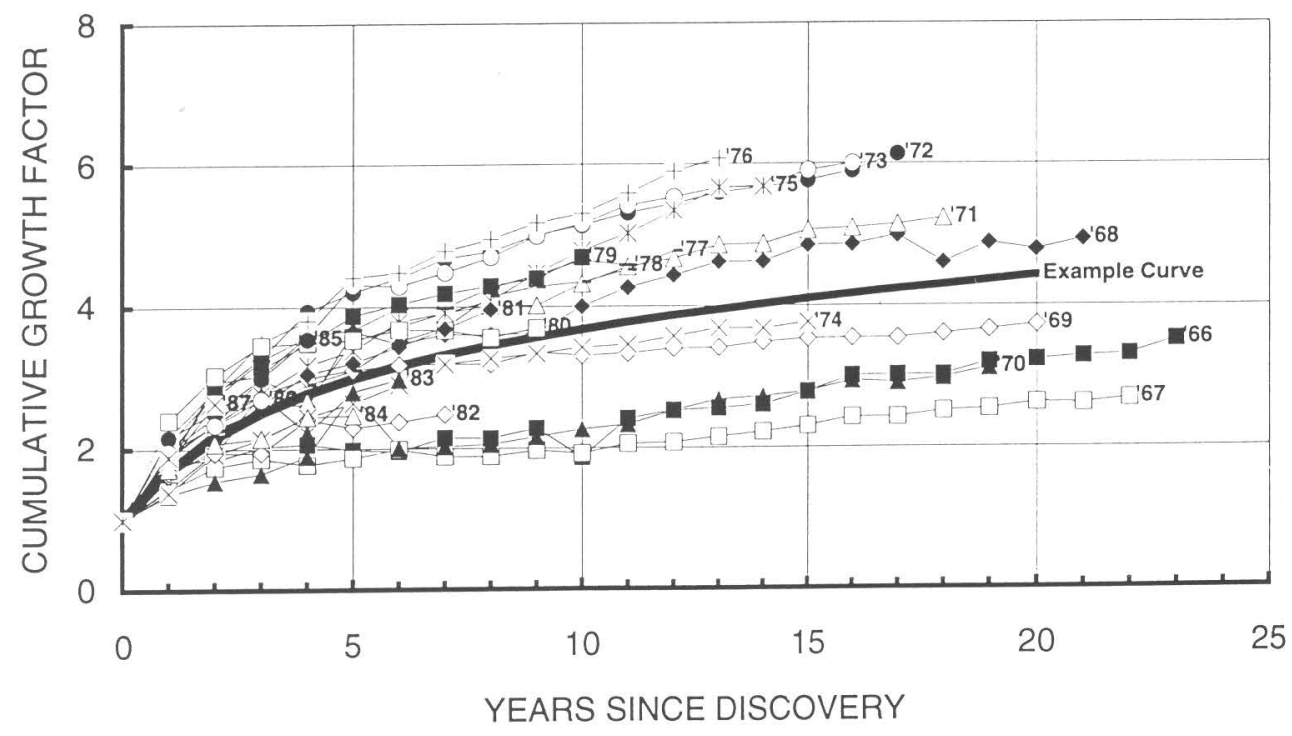

Figure 3. Growth factors for nonassociated gas. Numbers at end of lines marked with symbols indicate year of discovery. Example curve calculated from the National Petroleum Council reserve appreciation equation. From National Petroleum Council (1992). 
Table 2. Predicted reserve appreciation for the lower 48 States.

[From National Petroleum Council, 1992]

\begin{abstract}
Non-Associated Gas (using combined EIA/AGA data)

Ultimate Recovery at Year-end 1990, BCF

Year 2010 with 314,500 additional Gas Wells

Year 2030 with 771,720 additional Gas Wells

After 4,000,000 Cumulative Gas Wells
\end{abstract}

\section{Associated/Dissolved Gas (using ElA data) Ultimate Recovery at Year-end 1990, BCF \\ Year 2010 with 421,422 additional Oil Wells \\ Year 2030 with 1,005,862 additional Oil Wells \\ After 14,000,000 Cumulative Oil Wells}

\section{Total Non-Associated and Associated/Dissolved Gas}

Ultimate Recovery at Year-end 1990, BCF

Year 2010 with additional Gas and Oil Wells as above

Year 2030 with additional Gas and Oil Wells as above

After 4,000,000 Cumulative Gas Wells and $14,000,000$ Cumulative Oil Wells

Change From 1990

Ultimate Recovery

(Billion Cubic Feet)

Percentage

694,334

$\begin{array}{ll}135,664 & 19.5 \\ 201,674 & 29.0 \\ 216,090 & 31 .\end{array}$

Change From 1990

Ultimate Recovery

(Billion Cubic Feet) Percentage

223,588

$\begin{array}{ll}14,450 & 6.5 \\ 18,810 & 8.4 \\ 20,224 & 9.0\end{array}$

Change From 1990

Ultimate Recovery

(Billion Cubic Feet) Percentage

917,922

150,114

220,314

236,314
16.4

24.0

25.7

Table 3. Total undiscovered conventional gas resources (current technology), in million barrels of oil equivalent.

[Includes tight gas in old plays. From National Petroleum Council, 1992]

\begin{tabular}{|c|c|c|c|c|c|c|}
\hline Region & & $0-5,000^{\prime}$ & $5-10,000^{\prime}$ & $10-15,000^{\prime}$ & $>15,000^{\prime}$ & Total \\
\hline $\begin{array}{l}\text { Appalachia } \\
\text { MAFLA Onshore } \\
\text { Midwest } \\
\text { Arkla-E. Texas } \\
\text { So. Louisiana } \\
\text { Texas Gulf Coast } \\
\text { Williston } \\
\text { Rockies Foreland } \\
\text { San Juan Basin } \\
\text { Overthrust } \\
\text { Midcontinent } \\
\text { Permian } \\
\text { Pacific }\end{array}$ & $\begin{array}{c}A \\
B \\
C \\
D \\
E \\
G \\
W L \\
F R \\
S J B \\
O V \\
J N \\
J S \\
L\end{array}$ & $\begin{array}{r}1,267 \\
344 \\
1,110 \\
1,513 \\
0 \\
639 \\
395 \\
1,448 \\
362 \\
105 \\
2,011 \\
1,539 \\
743\end{array}$ & $\begin{array}{r}2,004 \\
168 \\
1,502 \\
2,795 \\
190 \\
3,840 \\
906 \\
5,658 \\
680 \\
1,330 \\
4,026 \\
2,447 \\
2,731\end{array}$ & $\begin{array}{r}959 \\
2,334 \\
551 \\
1,413 \\
699 \\
4,168 \\
338 \\
2,910 \\
0 \\
1,129 \\
2,835 \\
1,423 \\
1,722\end{array}$ & $\begin{array}{r}402 \\
1,075 \\
0 \\
279 \\
2,594 \\
1,674 \\
0 \\
3,230 \\
0 \\
960 \\
4,319 \\
2,704 \\
1,237\end{array}$ & $\begin{array}{r}4,632 \\
3,921 \\
3,163 \\
6,000 \\
3,483 \\
10,321 \\
1,639 \\
13,246 \\
1,042 \\
3,524 \\
13,191 \\
8,113 \\
6,433\end{array}$ \\
\hline \multirow[t]{2}{*}{ Subtotal Onshore } & & 11,476 & 28,277 & $\begin{array}{c}20,481 \\
\text { Subregion }\end{array}$ & 18,474 & 78,708 \\
\hline & & 1 & 2 & 3 & 4 & Total \\
\hline $\begin{array}{l}\text { Norphlet } \\
\text { West Florida } \\
\text { Gulf of Mexico } \\
\text { Pacific Offshore } \\
\text { Atlantic Offshore }\end{array}$ & $\begin{array}{c}\text { BO } \\
\text { EGO } \\
\text { LO } \\
\text { AO }\end{array}$ & $\begin{array}{l}2,106 \\
6,070 \\
2,630\end{array}$ & $\begin{array}{r}0 \\
5,545\end{array}$ & $\begin{array}{r}0 \\
4,991 \\
9,563\end{array}$ & $\begin{array}{r}0 \\
11,556\end{array}$ & $\begin{array}{r}2,106 \\
540 \\
28,162 \\
12,193 \\
3,552\end{array}$ \\
\hline Subtotal Offshore & & & & & & 46,553 \\
\hline Grand Total & & & & & & 125,261 \\
\hline
\end{tabular}


Table 4. Total undiscovered gas resources (current technology), in billion cubic feet.

[Includes tight gas in old plays. From National Petroleum Council, 1992]

\begin{tabular}{|c|c|c|c|c|c|c|}
\hline Region & & $0-5,000^{\prime}$ & $5-10,000^{\prime}$ & $10-15,000^{\prime}$ & $>15,000^{\prime}$ & Total \\
\hline $\begin{array}{l}\text { Appalachia } \\
\text { MAFLA Onshore } \\
\text { Midwest } \\
\text { Arkla-E. Texas } \\
\text { So. Louisiana } \\
\text { Texas Gulf Coast } \\
\text { Williston } \\
\text { Rockies Foreland } \\
\text { San Juan Basin } \\
\text { Overthrust } \\
\text { Midcontinent } \\
\text { Permian } \\
\text { Pacific }\end{array}$ & $\begin{array}{c}A \\
B \\
C \\
D \\
E \\
G \\
W L \\
F R \\
S J B \\
O V \\
J N \\
J S \\
L\end{array}$ & $\begin{array}{r}6,216 \\
854 \\
2,157 \\
3,843 \\
0 \\
2,503 \\
946 \\
3,577 \\
1,170 \\
300 \\
4,819 \\
3,586 \\
1,446\end{array}$ & $\begin{array}{r}10,288 \\
357 \\
3,900 \\
7,198 \\
557 \\
16,312 \\
1,199 \\
16,449 \\
1,981 \\
3,791 \\
12,416 \\
6,202 \\
6,727\end{array}$ & $\begin{array}{r}4,926 \\
5,468 \\
2,423 \\
6,165 \\
2,319 \\
19,050 \\
447 \\
12,221 \\
0 \\
3,748 \\
11,659 \\
4,598 \\
5,099\end{array}$ & $\begin{array}{r}2,159 \\
4,229 \\
0 \\
1,317 \\
12,319 \\
8,176 \\
0 \\
16,351 \\
0 \\
4,370 \\
21,885 \\
12,328 \\
4,258\end{array}$ & $\begin{array}{r}23,589 \\
10,908 \\
8,480 \\
18,523 \\
15,195 \\
46,041 \\
2,592 \\
48,598 \\
3,151 \\
12,209 \\
50,779 \\
26,714 \\
17,530\end{array}$ \\
\hline \multirow[t]{2}{*}{ Subtotal Onshore } & & 31,417 & 87,377 & $\begin{array}{c}78,123 \\
\text { Subregion }\end{array}$ & 87,392 & 284,309 \\
\hline & & 1 & 2 & 3 & 4 & Total \\
\hline $\begin{array}{l}\text { Norphlet } \\
\text { West Florida } \\
\text { Gulf of Mexico } \\
\text { Pacific Offshore } \\
\text { Allantic Offshore }\end{array}$ & $\begin{array}{c}B O \\
E G O \\
\text { LO } \\
\text { AO }\end{array}$ & $\begin{array}{r}11,388 \\
25,311 \\
2,807\end{array}$ & 23,122 & $\begin{array}{l}15,722 \\
10,204\end{array}$ & 36,402 & $\begin{array}{r}11,388 \\
2,590 \\
100,557 \\
13,011 \\
17,013\end{array}$ \\
\hline Subtotal Offshore & & & & & & 144,559 \\
\hline Grand Total & & & & & & 428,868 \\
\hline
\end{tabular}

Note: Values are recoverable hydrocarbons as of 12-31-90; Subregions for $B O$, EGO are $<40 \mathrm{~m}, 40-200 \mathrm{~m}, 200-$ $1000 \mathrm{~m}$, and $>1000 \mathrm{~m}$ water depth: LO is 0-200m and 200-2000 m; $A O$ and West Florida have no defined water depth.

\section{UNDISCOVERED CONVENTIONAL RESOURCES}

The undiscovered resource was assessed by a consensus approach. A core group of industry, government, and association representatives, after becoming familiar with the HSM, discussed various aspects of the undiscovered resource basefield size distributions and regional variations in geologic factors affecting the resource base. Each participant brought an estimate of the resource base to the discussion based on various methods employed in his or her organization. However, because some of these methods and assessments were proprietary, open discussion of the details and results of each was not possible. Instead, the assembled group discussed ranges of assessments and, through detailed and lengthy discussions, arrived at a consensus concerning the size of the undiscovered resource in each region of the HSM. The results of the small-group assessment were used as a basis for review and revision of the resource base in the HSM. The results were presented to the entire Conventional Gas Work Group for review, feedback, and comments. The feedback and comments were incorporated, and a final consensus was obtained for the undiscovered resource. The results of these consensus assessments are listed in tables 3 and 4 . The results assumed current technology and were reported by region, for each of four depth ranges, and for undiscovered associated/dissolved gas resource (table 4) and undiscovered conventional nonassociated gas resource (table 3 ).
Although most estimates of undiscovered commodities begin with fairly certain data and well-known quantities, they proceed toward subjects of considerable uncertainty, with little data and less well-known information. It is useful to compare the results of the NPC study with those of other recent assessments of the conventional natural gas resource. In particular, table 5 presents a comparison of

Table 5. Comparison of lower 48 States undiscovered conventional-gas resource estimates, in trillion cubic feet.

[From National Petroleum Council, 1992]

\begin{tabular}{|c|c|c|c|}
\hline & Onshore & Offshore & Total \\
\hline DOE - 1988* & 219 & 134 & 353 \\
\hline$E I A-1990 \dagger$ & 197 & 130 & 327 \\
\hline USGS/MMS - $1989 \ddagger$ & 189 & 135 & 324 \\
\hline$P G C-1990 \S$ & 352 & 139 & 491 \\
\hline $\mathrm{GRI}-1992$ ก & - & 一 & 394 \\
\hline$N P C-1992 \#$ & 254 & 159 & 413 \\
\hline \multicolumn{4}{|l|}{ " Current technology only. } \\
\hline \multicolumn{4}{|c|}{ t Access to federal lands and Advanced Technology scenario. } \\
\hline \multicolumn{4}{|c|}{$\mp$ Excludes resource in fields less than 6 billion cubic feet. } \\
\hline \multicolumn{4}{|c|}{ \$ Summation of mean values. Includes some tight gas in old plays. } \\
\hline \multicolumn{4}{|c|}{ II Excludes tight gas in old plays. Advanced Technology case. } \\
\hline
\end{tabular}


recent assessments by the Department of Energy, Energy Information Administration, U.S. Geological Survey, Minerals Management Service, Gas Research Institute, and Potential Gas Committee. It is important to be aware of the context in which assessment totals are presented.

\section{DEPARTMENT OF ENERGY 1988 STUDY}

The Department of Energy (DOE) released a study in 1988 of natural-gas resources, entitled "An Assessment of the Natural Gas Resource Base of the United States." The study was conducted by a review panel of natural-gas analysts who estimated technically recoverable resources (including proved reserves) of 1,059 Tcf in the lower 48 States, using then-current technology. The onshore undiscovered conventional resources were estimated to be $219 \mathrm{Tcf}$ and offshore resources were estimated to be 134 Tcf. These results were somewhat smaller (5 percent onshore, and 8 percent offshore) than the NPC current-technology estimate.

The DOE study was intended to explore the underlying assumptions involved in the resource estimates available to the review panel, to normalize the application of assumptions to all resource estimates, and to form a consensus on resources estimated for various categories of gas including undiscovered, inferred reserves, gas in low-permeability reservoirs, coalbed gas, and shale gas. Economic assumptions were studied in order to evaluate the recovery of resources at wellhead prices of less than $\$ 3.00 / \mathrm{Mcf}$ and recovery of resources at wellhead prices of $\$ 3.00-\$ 5.00 / \mathrm{Mcf}$ (1987 dollars).

The NPC and DOE methods of assessing conventional undiscovered resources were similar in that resource assessments from a variety of sources were considered and that a consensus process was employed to arrive at final estimates.

\section{ENERGY INFORMATION ADMINISTRATION 1990 STUDY}

As part of an effort to support the formulation of a National energy strategy, the EIA conducted a literature search and review of information pertinent to the availability of natural-gas resources in the United States. The results of that review were published in a document entitled "The Domestic Oil and Gas Recoverable Resource BaseSupporting Analysis for the National Energy Strategy." The ElA document emphasized a future with unrestricted access to Federal lands and enhanced development of exploration technology.

The EIA estimated the undiscovered onshore conventional resources in the lower 48 States at 197 Tcf (about 22 percent lower than NPC). ElA estimates of offshore undiscovered conventional resources are lower than those of the NPC. EIA estimates included resources in minimum field sizes greater than 30,000 barrels of oil equivalent (boe) onshore and greater than 100,000 (boe) offshore.

\section{U.S. GEOLOGICAL SURVEY AND MINERALS MANAGEMENT SERVICE 1989 STUDY}

The U.S. Geological Survey (USGS) and the Minerals Management Service (MMS) conducted a joint study for the Department of the Interior (DOI) in which they estimated undiscovered conventional gas resources in the United States. The USGS was responsible for the onshore and state offshore areas, while the MMS maintained responsibility for the Federal offshore. The results were published in a joint document entitled "Estimates of Undiscovered Conventional Oil and Gas Resources in the United States-A Part of the Nation's Energy Endowment."

The DOI study focused almost exclusively upon undiscovered, conventionally recoverable oil and gas. Furthermore, estimates were subjected to various economic screening criteria. The USGS MMS numbers listed in table 5 are those not reduced by economic filters. The DOI assessment used a play analysis technique, which made estimates of the sizes and numbers of undiscovered fields in given areas or used a summation of individual prospect evaluations. The methodology used in the USGS MMS study is similar to that employed by many large exploration and production companies such as those represented in the NPC study. However, the risks and probabilities may have been evaluated differently by the DOI and by various individual companies.

Compared to the NPC study, the USGS MMS assessment for the lower 48 States was about 22 percent lower. However, much of this difference can be accounted for by the fact that the DOI assessment only evaluated onshore resources in fields greater than 30,000 boe and offshore fields greater than 100,000 boe.

\section{POTENTIAL GAS COMMITTEE 1990 STUDY}

The Potential Gas Committee (PGC), part of the Potential Gas Agency sponsored by the American Gas Association at the Colorado School of Mines, utilizes volunteer members from the oil and gas industry. The industry volunteers provide resource estimates of natural gas based on their expert judgments. The PGC develops resource estimates for each region of the U.S. and presents the results in terms of minimum, most likely, and maximum estimates for gas resources categorized as probable, possible, or speculative. The NPC considered only those resources that the PGC would classify as possible and speculative in the consensus process. The PGC's most recent publication "Potential Supply of Natural Gas in the United States," reported both values summed arithmetically and statistical mean values for the total lower 48 States data. The mean values are referenced in this report.

PGC estimates of undiscovered conventional resources for the lower 48 States exceeded those of the NPC by about 19 percent. This is due in part to the fact that the 
PGC includes some tight gas resources and shale gas whereas these categories are largely considered by the NPC to belong in the nonconventional category.

\section{GAS RESEARCH INSTITUTE 1991 STUDY}

The Gas Research Institute (GRI) makes yearly estimates of natural gas supply and demand by means of the HSM, a version of which was used for the NPC study. The results of the GRI model run are presented in the GRI "Baseline Projection." The GRI Baseline and other GRI publications require inputs of estimates of resources available for discovery and future development. The GRI projections include assumptions of technological advances that affect the amount of resource available and its cost.

The 1991 GRI publication "The Long-Term Trends in U.S. Gas Supply and Prices-1992 Edition of the GRI Baseline Projection of U.S. Energy Supply and Demand to 2010" outlines assumptions regarding the resource base used by GRI in the HSM. The undiscovered resource base for the lower 48 States is estimated by the GRI to be about 394 Tcf, an estimate which is about 4 percent lower than the NPC estimate for the advanced technology case. A minimum field size of 4,000 boe was included in both the GRI study and in the NPC study.

\section{THE EFFECT OF TECHNOLOGICAL ADVANCES}

The basic NPC assessment of undiscovered, conventional accumulations of natural gas was based on the assumption of discoveries and developments that used technology existing in 1992. However, because the focus of the study was the estimation of recoverable resources of natural gas, the size of the resource will be affected by future changes in technology that influence the recovery of natural gas. The history of the oil and gas industry has been one of continuous technological advancement, and future breakthroughs in oil and gas technology are inevitable, even though forecasting the exact nature and timing of such advancements is difficult (see Roberts, this volume).

The conventional resources of natural gas have been extensively exploited, and the technological changes that have affected recovery of natural gas have been many, varied, and substantial. At present, the total recovery of conventional gas is estimated to have been in the range of 70 to 80 percent of the original gas in place (OGIP). Consequently, the NPC believes it likely that future increases in recovery factors will probably be small. Therefore, the NPC study used an assumption of technological advances yielding 0.5 percent per year increase in recovery. This in- creasing recovery factor suggests that recovery will grow by about 10 percent from 1990 to the year 2010. Thus a 1990 recovery factor of 75 percent would increase to 82.5 percent by 2010 , owing to technological advancement. The gas-in-place figure would not change as a result of technological breakthroughs.

Technological advances were also considered for nonconventional gas resources. It was concluded that the effect of technology on these resources would be much greater. In particular, for nonconventional resources such as tight gas, recovery factors are expected to grow by 2 percent per year, or 50 percent by the year 2010 . Such increases in recovery factors in the nonconventional resources seem reasonable in light of the low recovery factors that are currently affecting nonconventional resources in contrast to conventional resources. Tables $6-9$ express the natural-gas resource base under advanced technology.

\section{NONCONVENTIONAL GAS SOURCES}

A nonconventional gas subgroup was charged with establishing the recoverable gas resource base from nonconventional sources. For convenience, shale gas, coalbed methane, and tight gas were classified together as "nonconventional." The NPC views this as something of a misnomer, as each of these resource categories is currently productive. However, the term is used because these resources are each in an early stage of technological development.

Although the potential tight-gas resource base is quite large, the NPC evaluated in detail only that portion for which sufficient data existed to adequately characterize the potential. Therefore, only those portions of the tight-gas resource that were currently in production or which were expected to be significantly developed during the period examined by the study (1990-2010) were included in the assessment.

Speculative resources such as gas hydrates, geopressured brines, and deep gas are estimated to be as large as $12,000 \mathrm{Tcf}$. The cost of recovering such resources, however, is large and uncertain. Consequently, no recoverable resources from these gas sources were included in the NPC reference case. For further discussion of these potential resources, consult appropriate chapters in this volume.

As of 1990, production of gas from nonconventional sources accounted for about 12 percent of the gas production from the lower 48 States. Modelling used in the NPC study suggests that the proportion of nonconventional gas will increase to $22-27$ percent of total production from the lower 48 States by 2010 . The nonconventional gas basins of the United States considered in the NPC report are shown in figure 4. NPC estimates of recoverable nonconventional resources and production rates are given in tables 10 and 11 . 
Table 6. Total undiscovered gas resources (advanced technology), in billion cubic fect.

[Includes tight gas in old plays. From National Petroleum Council, 1992]

\begin{tabular}{|c|c|c|c|c|c|c|}
\hline Region & & $0-5,000^{\prime}$ & $5-10,000^{\prime}$ & $10-15,000^{\prime}$ & $>15,000^{\prime}$ & Total \\
\hline $\begin{array}{l}\text { Appalachia } \\
\text { MAFLA Onshore } \\
\text { Midwest } \\
\text { Arkla-E. Texas } \\
\text { So. Louisiana } \\
\text { Texas Gulf Coast } \\
\text { Williston } \\
\text { Rockies Foreland } \\
\text { San Juan Basin } \\
\text { Overthrust } \\
\text { Midcontinent } \\
\text { Permian } \\
\text { Pacific }\end{array}$ & $\begin{array}{l}A \\
B \\
C \\
D \\
E \\
G \\
W L \\
F R \\
\text { SJB } \\
\text { OV } \\
\text { JN } \\
\text { JS } \\
\text { L }\end{array}$ & $\begin{array}{r}7,762 \\
939 \\
2,373 \\
4,456 \\
0 \\
2,766 \\
1,195 \\
4,638 \\
1,496 \\
330 \\
5,417 \\
4,197 \\
1,591\end{array}$ & $\begin{array}{r}11,747 \\
393 \\
4,290 \\
8,656 \\
613 \\
20,119 \\
1,319 \\
21,531 \\
2,492 \\
4,170 \\
14,276 \\
7,269 \\
7,400\end{array}$ & $\begin{array}{r}5,419 \\
6,015 \\
2,665 \\
7,394 \\
2,551 \\
21,362 \\
492 \\
16,271 \\
0 \\
4,123 \\
13,260 \\
5,291 \\
5,609\end{array}$ & $\begin{array}{r}2,375 \\
4,652 \\
0 \\
1,554 \\
13,551 \\
9,255 \\
0 \\
21,583 \\
0 \\
4,807 \\
26,262 \\
13,561 \\
4,684\end{array}$ & $\begin{array}{r}27,302 \\
11,999 \\
9,328 \\
22,060 \\
16,715 \\
53,502 \\
3,006 \\
64,023 \\
3,988 \\
13,430 \\
59,215 \\
30,318 \\
19,283\end{array}$ \\
\hline \multirow[t]{2}{*}{ Subtotal Onshore } & & 37,159 & 104,274 & $\begin{array}{c}90,452 \\
\text { Subregion }\end{array}$ & 102,284 & 334,168 \\
\hline & & 1 & 2 & 3 & 4 & Total \\
\hline $\begin{array}{l}\text { Norphlet } \\
\text { West Florida } \\
\text { Gulf of Mexico } \\
\text { Pacific Offshore } \\
\text { Atlantic Offshore }\end{array}$ & $\begin{array}{l}B O \\
E G O \\
\text { LO } \\
\text { AO }\end{array}$ & $\begin{array}{r}12,527 \\
27,842 \\
3,088\end{array}$ & 25,434 . & $\begin{array}{l}17,294 \\
11,224\end{array}$ & 40,042 & $\begin{array}{r}12,527 \\
2,849 \\
110,613 \\
14,312 \\
18,714\end{array}$ \\
\hline Subtotal Offshore & & & & & & 159,015 \\
\hline Grand Total & & & & & & 493,183 \\
\hline
\end{tabular}

Note: Values are recoverable hydrocabons as of 12-31-90; Subregions for BO, EGO are $<40 \mathrm{~m}, 40-200 \mathrm{~m}, 200$ $1000 \mathrm{~m}$, and $>1000 \mathrm{~m}$ water depth; LO is $0-200 \mathrm{~m}$ and $200-2000 \mathrm{~m} ; \mathrm{AO}$ and West Florida have no defined water depth.

Table 7. Undiscovered associated- and dissolved-gas resources (advanced technology), in billion cubic feet.

[From National Petroleum Council, 1992]

\begin{tabular}{|c|c|c|c|c|c|c|}
\hline Region & & $0-5,000$ & $5-10,000^{\prime}$ & $10-15,000^{\prime}$ & $>15,000^{\prime}$ & Total \\
\hline $\begin{array}{l}\text { Appalachia } \\
\text { MAFLA Onshore } \\
\text { Midwest } \\
\text { Arkla-E. Texas } \\
\text { So. Louisiana } \\
\text { Texas Gulf Coast } \\
\text { Williston } \\
\text { Rockies Foreland } \\
\text { San Juan Basin } \\
\text { Overthrust } \\
\text { Midcontinent } \\
\text { Permian } \\
\text { Pacific }\end{array}$ & $\begin{array}{l}\text { A } \\
B \\
C \\
D \\
E \\
G \\
W L \\
F R \\
\text { SJB } \\
\text { OV } \\
\text { JN } \\
\text { JS } \\
\text { L }\end{array}$ & $\begin{array}{r}108 \\
90 \\
1,260 \\
1,088 \\
0 \\
350 \\
191 \\
710 \\
330 \\
53 \\
2,118 \\
1,243 \\
311\end{array}$ & $\begin{array}{r}86 \\
54 \\
1,278 \\
2,119 \\
117 \\
1,437 \\
574 \\
2,342 \\
744 \\
673 \\
3,029 \\
1,913 \\
1,125\end{array}$ & $\begin{array}{r}41 \\
776 \\
40 \\
187 \\
362 \\
799 \\
215 \\
482 \\
0 \\
96 \\
854 \\
776 \\
664\end{array}$ & $\begin{array}{r}0 \\
40 \\
0 \\
0 \\
0 \\
0 \\
0 \\
0 \\
0 \\
0 \\
0 \\
0 \\
422\end{array}$ & $\begin{array}{r}234 \\
959 \\
2,577 \\
3,394 \\
479 \\
2,585 \\
980 \\
3,533 \\
1,074 \\
822 \\
6,001 \\
3,931 \\
2,523\end{array}$ \\
\hline \multirow[t]{2}{*}{ Subtotal Onshore } & & 7,851 & 15,490 & $\begin{array}{c}5,289 \\
\text { Subregion }\end{array}$ & 462 & 29,092 \\
\hline & & 1 & 2 & 3 & 4 & Total \\
\hline $\begin{array}{l}\text { Norphlet } \\
\text { West Florida } \\
\text { Gulf of Mexico } \\
\text { Pacific Offshore } \\
\text { Atlantic Offshore }\end{array}$ & $\begin{array}{l}\mathrm{BO} \\
\mathrm{EGO} \\
\mathrm{LO} \\
\mathrm{AO}\end{array}$ & $\begin{array}{r}0 \\
2,339 \\
1,618\end{array}$ & 2,136 & $\begin{array}{l}3,642 \\
5,882\end{array}$ & 8,434 & $\begin{array}{r}0 \\
87 \\
16,551 \\
7,500 \\
568\end{array}$ \\
\hline Subtotal Offshore & & & & & & 24,705 \\
\hline Grand Total & & & & & & 53,797 \\
\hline
\end{tabular}

Note: Values are recoverable hydrocarbons as of 12-31-90; Subregions for BO, EGO are <40m, 40-200m, 200. $1000 \mathrm{~m}$, and $>1000 \mathrm{~m}$ water depth; LO is $0.200 \mathrm{~m}$ and $200-2000 \mathrm{~m}$; $A O$ and West Florida have no defined water depth. 
Table 8. Undiscovered conventional nonassociated-gas resources (advanced technology), in billion cubic fcet.

[From National Petroleurn Council, 1992]

\begin{tabular}{|c|c|c|c|c|c|c|}
\hline Region & & $0-5,000^{\prime}$ & $5-10,000^{\prime}$ & $10-15,000^{\prime}$ & $>15,000^{\prime}$ & Total \\
\hline $\begin{array}{l}\text { Appalachia } \\
\text { MAFLA Onshore } \\
\text { Midwest } \\
\text { Arkla-E. Texas } \\
\text { So. Louisiana } \\
\text { Texas Gulf Coast } \\
\text { Williston } \\
\text { Rockies Foreland } \\
\text { San Juan Basin } \\
\text { Overthrust } \\
\text { Midcontinent } \\
\text { Permian } \\
\text { Pacific }\end{array}$ & $\begin{array}{c}\text { A } \\
B \\
C \\
D \\
E \\
G \\
W L \\
F R \\
\text { SJB } \\
\text { OV } \\
\text { JN } \\
\text { JS } \\
\text { L }\end{array}$ & $\begin{array}{r}4,188 \\
849 \\
1,113 \\
2,511 \\
0 \\
2,369 \\
425 \\
1,290 \\
383 \\
277 \\
2,866 \\
2,006 \\
1,279\end{array}$ & $\begin{array}{r}10,049 \\
339 \\
3,012 \\
3,770 \\
496 \\
10,523 \\
745 \\
6,301 \\
574 \\
3,497 \\
8,928 \\
3,682 \\
6,274\end{array}$ & $\begin{array}{r}5,378 \\
5,239 \\
2,626 \\
4,909 \\
2,189 \\
19,037 \\
277 \\
5,184 \\
0 \\
4,027 \\
10,775 \\
3,640 \\
4,945\end{array}$ & $\begin{array}{r}2,375 \\
4,612 \\
0 \\
1,159 \\
13,551 \\
8,274 \\
0 \\
8,094 \\
0 \\
4,807 \\
18,055 \\
13,561 \\
4,261\end{array}$ & $\begin{array}{r}21,989 \\
11,040 \\
6,751 \\
12,350 \\
16,236 \\
40,203 \\
1,447 \\
20,869 \\
957 \\
12,608 \\
40,623 \\
22,889 \\
16,760\end{array}$ \\
\hline \multirow[t]{2}{*}{ Subtotal Onshore } & & 19,557 & 58,188 & $\begin{array}{c}68,225 \\
\text { Subregion }\end{array}$ & 78,750 & 224,720 \\
\hline & & 1 & 2 & 3 & 4 & Total \\
\hline $\begin{array}{l}\text { Norphlet } \\
\text { West Florida } \\
\text { Gulf of Mexico } \\
\text { Pacific Offshore } \\
\text { Atlantic Offshore }\end{array}$ & $\begin{array}{l}\text { BO } \\
\text { EGO } \\
\text { LO } \\
\text { AO }\end{array}$ & $\begin{array}{r}12,527 \\
25,504 \\
1,470\end{array}$ & 23,298 & $\begin{array}{r}13,652 \\
5,343\end{array}$ & 31,609 & $\begin{array}{r}12,527 \\
2,762 \\
94,062 \\
6,812 \\
18,147\end{array}$ \\
\hline Subtotal Offshore & & & & & & 134,310 \\
\hline Grand Total & & & & & & 359,030 \\
\hline
\end{tabular}

Note: Values are recoverable hydrocarbons as of 12-31-90; Subregions for BO, EGO are $<40 \mathrm{~m}, 40-200 \mathrm{~m}, 200$ $1000 \mathrm{~m}$, and $>1000 \mathrm{~m}$ water depth; LO is $0-200 \mathrm{~m}$ and $200-2000 \mathrm{~m} ; \mathrm{AO}$ and West Florida have no defined water depth.

Table 9. Undiscovered tight-gas resources in old plays (advanced technology), in billion cubic feet.

[From National Petroleum Council, 1992]

\begin{tabular}{|c|c|c|c|c|c|c|}
\hline Region & & $0-5,000^{\prime}$ & $5-10,000^{\prime}$ & $10-15,000^{\prime}$ & $>15,000^{\prime}$ & Total \\
\hline $\begin{array}{l}\text { Appalachia } \\
\text { MAFLA Onshore } \\
\text { Midwest } \\
\text { Arkla-E. Texas } \\
\text { So. Louisiana } \\
\text { Texas Gulf Coast } \\
\text { Williston } \\
\text { Rockies Foreland } \\
\text { San Juan Basin } \\
\text { Overthrust } \\
\text { Midcontinent } \\
\text { Permian } \\
\text { Pacific }\end{array}$ & $\begin{array}{c}A \\
B \\
C \\
D \\
E \\
G \\
W L \\
F R \\
\text { SJB } \\
\text { OV } \\
\text { JN } \\
\text { JS } \\
\text { L }\end{array}$ & $\begin{array}{r}3,467 \\
0 \\
0 \\
857 \\
0 \\
47 \\
579 \\
2,639 \\
783 \\
0 \\
434 \\
948 \\
0\end{array}$ & $\begin{array}{r}1,613 \\
0 \\
0 \\
2,768 \\
0 \\
8,160 \\
0 \\
12,888 \\
1,175 \\
0 \\
2,319 \\
1,674 \\
0\end{array}$ & $\begin{array}{r}0 \\
0 \\
0 \\
2,298 \\
0 \\
1,527 \\
0 \\
10,605 \\
0 \\
0 \\
1,632 \\
876 \\
0\end{array}$ & $\begin{array}{r}0 \\
0 \\
0 \\
395 \\
0 \\
981 \\
0 \\
13,490 \\
0 \\
0 \\
8,207 \\
0 \\
0\end{array}$ & $\begin{array}{r}5,079 \\
0 \\
0 \\
6,317 \\
0 \\
10,715 \\
579 \\
39,621 \\
1,958 \\
0 \\
12,591 \\
3,498 \\
0\end{array}$ \\
\hline \multirow[t]{2}{*}{ Subtotal Onshore } & & 9,752 & 30,596 & $\begin{array}{c}16,938 \\
\text { Subregion }\end{array}$ & 23,072 & 80,357 \\
\hline & & 1 & 2 & 3 & 4 & $\overline{\text { Total }}$ \\
\hline $\begin{array}{l}\text { Norphlet } \\
\text { West Florida } \\
\text { Gulf of Mexico } \\
\text { Pacific Offshore } \\
\text { Atlantic Offshore }\end{array}$ & $\begin{array}{l}\text { BO } \\
\text { EGO } \\
\text { LO } \\
\text { AO }\end{array}$ & $\begin{array}{l}0 \\
0\end{array}$ & 0 & $\begin{array}{l}0 \\
0\end{array}$ & 0 & $\begin{array}{l}0 \\
0 \\
0 \\
0 \\
0\end{array}$ \\
\hline Subtotal Offshore & & & & & & 0 \\
\hline Grand Total & & & & & & 80,357 \\
\hline
\end{tabular}

Note: Values are recoverable hydrocarbons as of 12-31-90; Subregions for BO, EGO are <40m, 40-200m, 200$1000 \mathrm{~m}$, and $>1000 \mathrm{~m}$ water depth; LO is $0-200 \mathrm{~m}$ and $200-2000 \mathrm{~m}$; AO and West Florida have no defined water depth. 


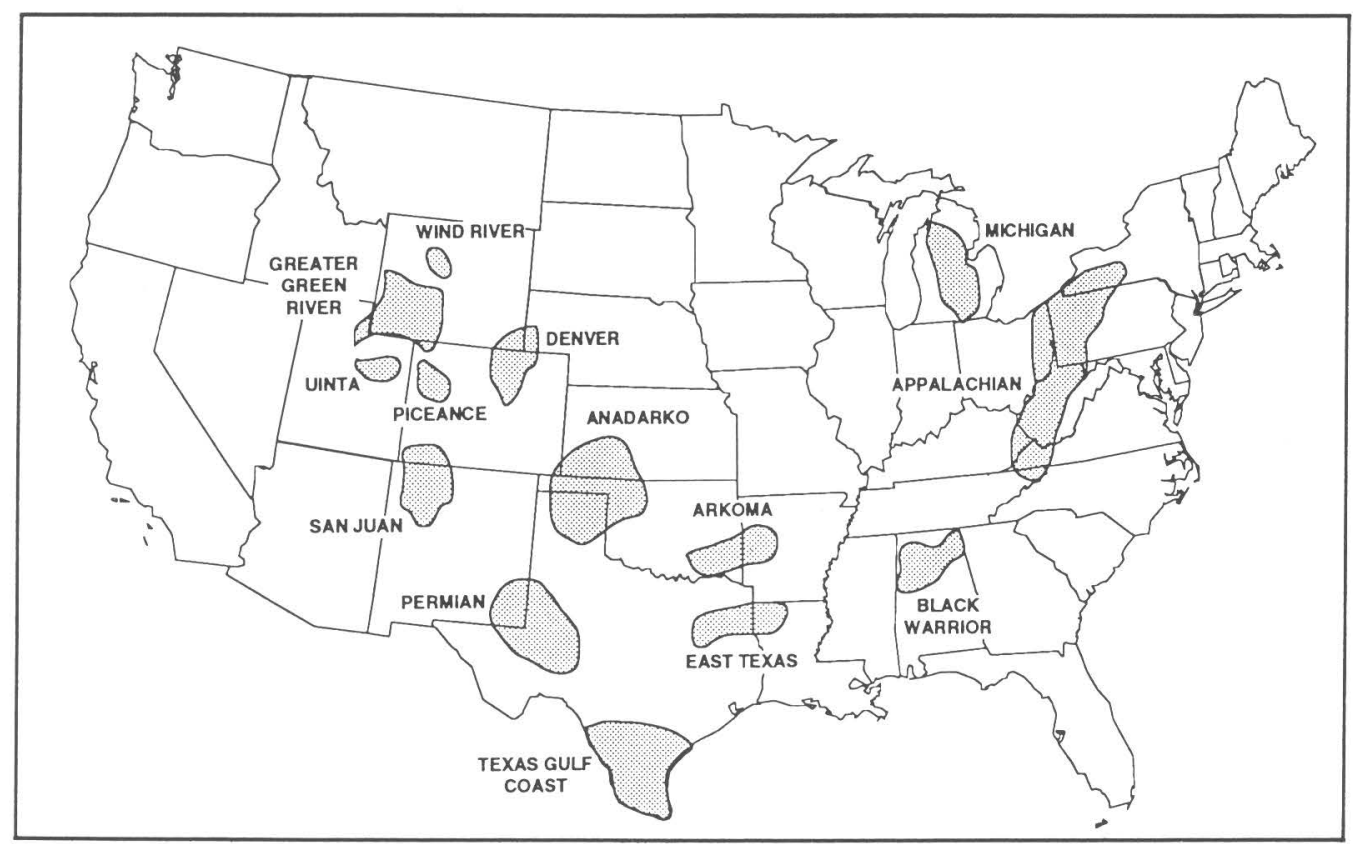

Figure 4. Location of principal nonconventional gas basins in the United States. For region abbreviations see table 1. From National Petroleum Council (1992).

Table 10. Recoverable nonconventional gas resources, in trillion cubic feet.

[From National Petroleum Council, 1992]

\begin{tabular}{|c|c|c|}
\hline & $\begin{array}{c}\text { Current } \\
\text { Technology }\end{array}$ & $\begin{array}{l}\text { Advanced } \\
\text { Technology }\end{array}$ \\
\hline \multicolumn{3}{|l|}{ Category of Gas } \\
\hline $\begin{array}{l}\text { Tight Gas } \\
\text { Devonian/Antrim Shale } \\
\text { Coalbed Methane }\end{array}$ & $\begin{array}{r}232 \\
37 \\
62\end{array}$ & $\begin{array}{r}349 \\
57 \\
98\end{array}$ \\
\hline Total Nonconventional & 332 & 504 \\
\hline $\begin{array}{l}\text { Total Gas Resources, } \\
\text { including Proved Reserves }\end{array}$ & 1,065 & 1,295 \\
\hline
\end{tabular}

Table 11. Nonconventional gas production reference cases 1 and 2.

[Reference case 2 shown in parentheses. From National Petroleum Council, 1992]

\begin{tabular}{llll}
\hline & 1990 & 2000 & 2010 \\
Category of Gas & & & \\
$\quad$ Tight Gas & 1.7 & $2.0(1.6)$ & $3.7(2.6)$ \\
Devonian/Antrim Shale & 0.2 & $0.5(0.4)$ & $0.5(0.4)$ \\
Coalbed Methane & 0.2 & $1.1(1.0)$ & $1.3(0.9)$ \\
$\quad$ Total & 2.1 & $3.6(3.0)$ & $\mathbf{5 . 5 ( 3 . 9 )}$ \\
\hline
\end{tabular}

\section{TIGHT GAS}

Tight gas occurs in a wide variety of reservoir types and in almost every sedimentary basin in the United States. In most wells, gas flow rates are not commercial without artificial stimulation. The USGS and others have characterized tight-gas reservoirs by reservoir genesis and geologic characteristics (see Law and Spencer, this volume). In the Rocky Mountains, where a majority of the tight-gas reserves is thought to exist, the tight-gas formations are typically of low permeability, low porosity, and limited reservoir continuity. Tight-gas reservoirs are commonly characterized by small grain size, intergranular cementation, restricted pore throats, and complex reservoir architecture. Each of these features requires sophisticated reservoir evaluation and extraction techniques to profitably produce gas.

The tight-gas resource base includes proved reserves, reserve growth potential in existing fields, and new fields and reservoirs. The sum of reserve growth potential and new-field potential represents the total quantity of undeveloped resource to be assessed and characterized. The NPC has not divided proved reserves into conventional and nonconventional categories.

New-field resources include existing (producing) plays and resources in new or undeveloped plays. Because gas quantities in existing plays are better understood and were evaluated separately in the HSM, they were included in 
historical "finding rate" equations. For simplicity, reserve growth is included with new-field resources in existing plays.' Thus, the two categories reported were (1) reserve growth and new fields in existing plays and (2) new fields in new plays.

Estimates of the resource base and its recovery potential were based on an extensive, confidential survey of current operators and detailed statistical analysis of historical production data. The NPC adopted the Federal Energy Regulatory Commission (FERC) legal definition of a tight formation-_ average in-place permeability of 0.1 millidarcy or less. For existing plays, the FERC tight formation designations were used to allocate resource between conventional and tight gas. For new plays the NPC used the confidential survey of operators and the FERC designations to select 47 units of analysis. These analytic units generally represented a formation-depth interval combination within a basin recognized as having significant tightgas potential.

The NPC based its estimates of resource base, well recoveries, and costs on a confidential survey of operators in known tight-gas formations. Respondents included five integrated companies, five independents, and two consultants. The survey included at least one operator from nine of the most significant tight-gas producing basins (Appalachian, East Texas/North Louisiana, Texas Gulf Coast, West Texas, San Juan, Denver, Piceance, Uinta, and Green River). Survey data were evaluated and transformed into consistent distributions of well recoveries and costs to be used in HSM runs. Survey respondents provided detailed estimates of formations currently under development and their best judgment on remaining resources in their respective areas of expertise. For those areas not covered by the survey, the NPC used historical production data and the 1980 NPC study results to estimate resource base and per well recoveries. Dwight's Energy Data Corporation's (1985) well production data were used for producing wells in known tight formations to derive a distribution of expected ultimate well recoveries. These were used to calibrate survey results or adapted as the basis for estimating ultimate recoveries of tight-gas wells where no survey data were available. Because some of these formations contained nontight wells, well distributions were adjusted to exclude these nontight wells. In predominantly tight formations, the top 10 percent of wells with high recoveries were removed from the distributions to back out nontight wells. In partially tight formations, the top 20 percent of wells with high recoveries were excluded.

The NPC specified a constant rate of technological improvement in recovery efficiency for each area in the study to be implemented over the 1990-2010 period. In nonconventional reservoirs, however, low recoveries usually result from the inability of the well to contact all of the gas in the drilling pattern. Technologies designed to increase reservoir contact are thus most effective in the lower recovery wells. In higher productivity wells, which already contact a greater percentage of total gas, the use of these technologies would increase recovery by a smaller percentage than in lower recovery wells. The Nonconventional Subgroup thus determined that if these technologies were applied, wells recovering less than 0.5 billion cubic feet (Bcf) could increase recovery by 70 percent, wells recovering between 0.5 and $1.5 \mathrm{Bcf}$ could increase recovery by 60 percent, wells between 1.5 and $2.5 \mathrm{Bcf}$ could increase by 50 percent, and wells recovering over $2.5 \mathrm{Bcf}$ could increase by 40 percent. This potentially increases the recovery of the average well by about 60 percent as a result of advanced technology. The technological improvements could be of several kinds, including more extensive fracturing methods and fracturing of multiple zones. Horizontal or slant drilling may also improve recovery in some situations. Slim-hole drilling combined with closer well spacing may be cost effective in some areas.

\section{TIGHT-GAS POTENTIAL}

Reserve additions were added from the low-permeability resource areas using the same model as employed in the conventional resource fields. Assuming existing technology, a total of $84 \mathrm{Tcf}$ of potential tight-gas reserve additions were estimated for existing plays and $148 \mathrm{Tcf}$ for new plays, for a total potential tight-gas resource recovery of about 232 Tcf. The majority of this potential is in the foreland area of the Rocky Mountains (53 percent), followed by southern Arkansas/northern Louisiana (Arkla) East Texas (12 percent), Midcontinent ( 9 percent), Texas Gulf Coast and Permian Basins (each 8 percent), Appalachian Basin (6 percent), and others (4 percent) (table 12).

Technology improvements were expected to increase recovery per well and decrease costs per Mcf produced. The application of advanced technology to tight-gas resources is assumed to increase steadily over the period 1990-2010, after which all tight-gas wells were assumed to use advanced technology. For the same resource base of 148 Tcf for undeveloped plays, improved technology could increase potential reserve additions by about 60 percent to 235 Tcf. Although this is a seemingly large potential, high front-end costs incurred for stimulation make tight-gas wells particularly sensitive to wellhead gas prices. At $\$ 3.00 / \mathrm{Mcf}$, potential resources for the study areas are estimated to be only 30 Tcf with current technology, but increase to $103 \mathrm{Tcf}$ with advanced technology.

Individual formations were characterized to reflect current understanding of the resource base in new tightgas formations. Table 13 provides the details of this characterization for the areas considered in this study. Total recovery, mean recovery per well, and estimated number of successful wells are provided for 47 areas for both current and advanced technology cases. Assuming current 
Table 12. Estimated U.S. tight-gas resource base technically recoverable with current technology, in trillion cubic feet.

[Some columns and rows do not sum to torals because of rounding. From National Petroleum Counçil, 1992]

\begin{tabular}{lcccr}
\hline \multirow{2}{*}{ Region } & \multicolumn{2}{c}{ Old Plays } & \multirow{2}{*}{ New Plays } & \multirow{2}{*}{ Total } \\
\cline { 2 - 3 } & New Fields & Old Fields & & \\
A (Appalachian) & 3.4 & 0.0 & 10.5 & 13.9 \\
D (Arkla-Tex) & 4.2 & 4.2 & 19.0 & 27.4 \\
G (S. Texas Onshore) & 7.1 & 5.5 & 5.8 & 18.4 \\
WL (Williston) & 0.4 & 0.3 & 0.0 & 0.7 \\
FR (Foreland) & 26.4 & 7.3 & 89.9 & 123.6 \\
SJB (San Juan Basin) & 1.3 & 6.5 & 0.0 & 7.8 \\
JN (Midcontinent) & 8.4 & 2.7 & 10.8 & 21.9 \\
JS (Permian) & 2.3 & 4.0 & 12.4 & 18.7 \\
Total & $\mathbf{5 3 . 6}$ & $\mathbf{3 0 . 4}$ & $\mathbf{1 4 8 . 4}$ & $\mathbf{2 3 2 . 4}$ \\
\hline
\end{tabular}

Table 13. Distribution of tight-gas resources in new plays.

[Data are on a January 1, 1986, basis, which is the starting date of each model run. Data in table 12 are on a January 1, 1991, basis; only Appalachian region shows a significant difference between 1986 and 1991 basis. From National Petroleum Council, 1992]

\begin{tabular}{|c|c|c|c|c|c|c|c|}
\hline \multirow[b]{2}{*}{ Basin and Formation } & \multirow[b]{2}{*}{$\begin{array}{l}\text { Depth } \\
\text { (Feet) }\end{array}$} & \multicolumn{3}{|c|}{ Current Technology } & \multicolumn{3}{|c|}{ Advanced Technology } \\
\hline & & $\begin{array}{c}\text { Recovery } \\
\text { (BCF) }\end{array}$ & $\begin{array}{l}\text { Mean Re- } \\
\text { covery Well } \\
(\mathrm{MMCF})\end{array}$ & $\begin{array}{l}\text { No. Succ. } \\
\text { Wells }\end{array}$ & $\begin{array}{c}\text { Recovery } \\
\text { (BCF) }\end{array}$ & $\begin{array}{l}\text { Mean Re- } \\
\text { covery/Well } \\
\text { (MMCF) }\end{array}$ & $\begin{array}{l}\text { No. Succ. } \\
\text { Wells }\end{array}$ \\
\hline \multicolumn{8}{|l|}{ Region G - Texas Gulf Coast } \\
\hline $\begin{array}{l}\text { Vicksburg } \\
\text { Cook Mountain } \\
\text { Lobo } \\
\text { Olmos } \\
\text { Edwards Lime }\end{array}$ & $\begin{array}{r}10,500 \\
10,400 \\
8,900 \\
4,800 \\
11,700\end{array}$ & $\begin{array}{r}240 \\
160 \\
2,556 \\
1,677 \\
1,118\end{array}$ & $\begin{array}{r}1,482 \\
229 \\
1,390 \\
201 \\
1,425\end{array}$ & $\begin{array}{r}162 \\
699 \\
1,839 \\
8,343 \\
785\end{array}$ & $\begin{array}{r}384 \\
272 \\
4,090 \\
2,851 \\
1,789\end{array}$ & $\begin{array}{r}2,371 \\
389 \\
2,224 \\
342 \\
2,280\end{array}$ & $\begin{array}{r}162 \\
699 \\
1,839 \\
8,343 \\
785\end{array}$ \\
\hline Total/Average & & 5,751 & 486 & 11,827 & 9,385 & 794 & 11,827 \\
\hline Region FR - Rockies & . & & & & & & \\
\hline $\begin{array}{l}\text { Green River - Ft. Union } \\
\text { Green River - Lance } \\
\text { Green River - MV/Lewis - }\end{array}$ & $\begin{array}{l}6,300 \\
5,600\end{array}$ & $\begin{array}{l}2,990 \\
3,707\end{array}$ & $\begin{array}{l}907 \\
822\end{array}$ & $\begin{array}{l}3,297 \\
4,510\end{array}$ & $\begin{array}{l}4,784 \\
5,931\end{array}$ & $\begin{array}{l}1,451 \\
1,315\end{array}$ & $\begin{array}{l}3,297 \\
4,510\end{array}$ \\
\hline $\begin{array}{l}\text { Intermed. } \\
\text { Green River - MV/Lewis -Deep }\end{array}$ & $\begin{array}{r}9,500 \\
12,000\end{array}$ & $\begin{array}{l}30,391 \\
12,157\end{array}$ & $\begin{array}{l}1,500 \\
1,000\end{array}$ & $\begin{array}{l}20,261 \\
12,157\end{array}$ & $\begin{array}{l}45,587 \\
19,451\end{array}$ & $\begin{array}{l}2,250 \\
1,600\end{array}$ & $\begin{array}{l}20,261 \\
12,157\end{array}$ \\
\hline Green River - MV/Lewis -VDeep & 15,000 & 4,052 & 500 & 8,104 & 6,888 & 850 & 8,104 \\
\hline Green River - Frontier & 8,800 & 2,917 & 1,390 & 2,099 & 4,667 & 2,224 & 2,099 \\
\hline Piceance - Wasatch & 2,600 & 327 & 510 & 641 & 523 & 816 & 641 \\
\hline Piceance - MV Intermed. & 6,000 & 8,718 & 500 & 17,435 & 13,948 & 800 & 17,435 \\
\hline Piceance - MV Deep & 4,359 & 8,718 & 500 & 17,435 & 13,948 & 800 & 17,435 \\
\hline Piceance - Mancos/Dakota & 6,000 & 847 & 303 & 2,795 & 1,440 & 515 & 2,795 \\
\hline Wind River - Fr. Union/Lance & 7,200 & 6,581 & 905 & 7,272 & 10,530 & 1,448 & 7,272 \\
\hline Wind River - Mesaverde, etc. & 10,300 & 1,804 & 2,516 & 717 & 2,526 & 3,522 & 717 \\
\hline Uinta - Wasatch & 6,600 & 4,194 & 1,008 & 4,161 & 6,710 & 1,613 & 4,161 \\
\hline Denver - Sussex/Codell & 7,000 & 190 & 200 & 950 & 323 & 340 & 950 \\
\hline Denver - Niobrara & 1,500 & 410 & 100 & 4,100 & 697 & 170 & 4,100 \\
\hline Denver $-\mathrm{D}$ and $\mathrm{J}$ & 8,000 & 1,928 & 497 & 3,879 & 3,278 & 845 & 3,879 \\
\hline Total/Average & & 89,930 & 819 & 109,812 & 141,231 & 1,286 & 109,812 \\
\hline
\end{tabular}


Table 13. Distribution of tight-gas resources in new plays-Continued.

\begin{tabular}{|c|c|c|c|c|c|c|c|}
\hline \multirow[b]{2}{*}{ Basin and Formation } & \multirow[b]{2}{*}{$\begin{array}{l}\text { Depth } \\
\text { (Feet) }\end{array}$} & \multicolumn{3}{|c|}{ Current Technology } & \multicolumn{3}{|c|}{ Advanced Technology } \\
\hline & & $\begin{array}{c}\text { Recovery } \\
\text { (BCF) }\end{array}$ & $\begin{array}{c}\text { Mean Re- } \\
\text { covery/Well } \\
(\mathrm{MMCF})\end{array}$ & $\begin{array}{l}\text { No. Succ. } \\
\text { Wells }\end{array}$ & $\begin{array}{c}\text { Recovery } \\
\text { (BCF) }\end{array}$ & $\begin{array}{l}\text { Mean Re- } \\
\text { covery Well } \\
\text { (MMCF) }\end{array}$ & $\begin{array}{c}\text { No. Succ. } \\
\text { Wells }\end{array}$ \\
\hline \multicolumn{8}{|l|}{ Region A - Appalachia } \\
\hline Clinton Deep $(\mathrm{OH})$ & 6,000 & 1,115 & 150 & 7,433 & 1,896 & 255 & 7,433 \\
\hline Clinton Shallow $(\mathrm{OH})$ & 4,500 & 2,342 & 80 & 29,275 & 3,981 & 136 & 29,275 \\
\hline Berea $(\mathrm{OH})$ & 1,550 & 780 & 80 & 9,750 & 1,326 & 136 & 9,750 \\
\hline Medina (PA) & 5,000 & 1,115 & 153 & 7,288 & 1,895 & 260 & 7,288 \\
\hline Bradford (PA) & 3,500 & 2,119 & 175 & 12,109 & 3,602 & 298 & 12,109 \\
\hline Berea - Gordon (WV) & 3,600 & 446 & 100 & 4,460 & 758 & 170 & 4,460 \\
\hline Benson (WV) & 4,500 & 1,673 & 200 & 8,365 & 2,844 & 340 & 8,365 \\
\hline Medina (NY) & 2,500 & 781 & 100 & 7,810 & 1,328 & 170 & 7,810 \\
\hline Berea (KY) & 1,500 & 22 & 180 & 122 & 37 & 306 & 122 \\
\hline Comiferous (KY) & 2,500 & 112 & 179 & 626 & 190 & 304 & 626 \\
\hline Oriskany (PA) & 5,000 & 691 & 150 & 4,607 & 1,175 & 255 & 4,607 \\
\hline Total/Average & & 11,196 & 122 & 91,844 & 19,033 & 207 & 91,844 \\
\hline \multicolumn{8}{|l|}{ Region D - East Tx, Arkla } \\
\hline E. Texas - James Lime & 8,100 & 629 & 545 & 1,154 & 1,006 & 872 & 1,154 \\
\hline E. Texas - Travis Peak & 8,400 & 793 & 1,250 & 634 & 1,269 & 2,000 & 634 \\
\hline E. Texas - Cotton Valley & 10,200 & 12,604 & 2,233 & 5,644 & 18,906 & 3,350 & 5,644 \\
\hline Arkla - James Lime & 8,000 & 109 & 349 & 312 & 185 & 593 & 312 \\
\hline Arkla - Travis Peak & 7,800 & 468 & 1,250 & 374 & 749 & 2,000 & 374 \\
\hline Arkla - Cotton Valley & 9,200 & 1,400 & 735 & 1,905 & 2,240 & 1,176 & 1,905 \\
\hline Arkla - Smackover & 11,100 & 2,979 & 574 & 5,190 & 4,776 & 918 & 5,190 \\
\hline Total/Average & & 18,982 & 1,248 & 15,214 & 29,122 & 1,914 & 15,214 \\
\hline
\end{tabular}

Table 13. Distribution of tight-gas resources in new plays-Continued.

\begin{tabular}{|c|c|c|c|c|c|c|c|}
\hline \multirow[b]{2}{*}{ Basin and Formation } & \multirow[b]{2}{*}{$\begin{array}{l}\text { Depth } \\
\text { (Feet) }\end{array}$} & \multicolumn{3}{|c|}{ Current Technology } & \multicolumn{3}{|c|}{ Advanced Technology } \\
\hline & & $\begin{array}{c}\text { Recovery } \\
\text { (BCF) }\end{array}$ & $\begin{array}{l}\text { Mean Re- } \\
\text { covery/Well } \\
\text { (MMCF) }\end{array}$ & $\begin{array}{l}\text { No. Succ. } \\
\text { Wells }\end{array}$ & $\begin{array}{c}\text { Recovery } \\
\text { (BCF) }\end{array}$ & $\begin{array}{l}\text { Mean Re- } \\
\text { covery/Well } \\
\text { (MMCF) }\end{array}$ & $\begin{array}{l}\text { No. Succ. } \\
\text { Wells }\end{array}$ \\
\hline \multicolumn{8}{|l|}{ Region JN - Midcontinent } \\
\hline $\begin{array}{l}\text { Anadarko - Cleveland } \\
\text { Anadarko - Cherokee/Red Fork } \\
\text { Anadarko - Granite Wash/Atoka. } \\
\text { Arkoma - Atoka }\end{array}$ & $\begin{array}{r}7,400 \\
11,000 \\
11,400 \\
9,800\end{array}$ & $\begin{array}{r}3,792 \\
2,800 \\
3,433 \\
817\end{array}$ & $\begin{array}{l}505 \\
510 \\
774 \\
456\end{array}$ & $\begin{array}{l}7,509 \\
5,490 \\
4,435 \\
1,792\end{array}$ & $\begin{array}{l}6,067 \\
4,480 \\
5,493 \\
1,389\end{array}$ & $\begin{array}{r}808 \\
816 \\
1,238 \\
775\end{array}$ & $\begin{array}{l}7,509 \\
5,490 \\
4,435 \\
1,792\end{array}$ \\
\hline Total/Average & & 10,842 & 564 & 19,226 & 17,429 & 907 & 19,226 \\
\hline \multicolumn{8}{|l|}{ Region JS - Permian } \\
\hline $\begin{array}{l}\text { Abo } \\
\text { Canyon SS } \\
\text { Strawn, Atoka, etc. } \\
\text { Morrow and Mississippian }\end{array}$ & $\begin{array}{r}3,800 \\
6,100 \\
12,000 \\
13,000\end{array}$ & $\begin{array}{r}1,823 \\
7,900 \\
985 \\
1,682\end{array}$ & $\begin{array}{l}391 \\
560 \\
418 \\
922\end{array}$ & $\begin{array}{r}4,662 \\
14,107 \\
2,356 \\
1,824\end{array}$ & $\begin{array}{r}3,099 \\
12,640 \\
1,675 \\
2,691\end{array}$ & $\begin{array}{r}665 \\
896 \\
711 \\
1,475\end{array}$ & $\begin{array}{r}4,662 \\
14,107 \\
2,356 \\
1,824\end{array}$ \\
\hline Total/Average & & 12,390 & 540 & 22,950 & 20,105 & 876 & 22,950 \\
\hline Lower-48 Total/Average & & 149,091 & 550 & 270,874 & 236,305 & 872 & 270,874 \\
\hline $\begin{array}{l}\text { Lower-48 Total/Average } \\
\text { Adjusted to } 1 / 1 / 91 \text { Basis }\end{array}$ & & 148,440 & & & 235,204 & & \\
\hline
\end{tabular}


technology, per well ultimate recoveries for the undeveloped plays range from $80 \mathrm{Mcf}$ to $2.5 \mathrm{Bcf}$ with a mean recovery of $550 \mathrm{Mcf}$. Developing the total resource in new plays would require over 270,000 wells.

\section{DEVONIAN SHALES OF THE APPALACHIAN BASIN AND THE ANTRIM SHALE}

Gas shales, such as the Devonian shales of the Appalachian Basin or the Antrim Shale of the Michigan Basin, are fine-grained, organic-rich sedimentary rocks that are generally gas saturated and have served as both source rock and reservoir rock for widespread gas accumulations. The principal deposits of gas-producing shales are concentrated in the Appalachian, Michigan, and Illinois Basins in the Eastern United States and in several Western U.S. basins. The Appalachian, Michigan, and Illinois Basin deposits have been characterized by delineating the black- and gray-shale horizons. The black shales have a higher gas content than the gray shales and are generally believed to be the predominant source beds of the natural gas found in the shales. Although the average total thickness of the shale deposits in the Appalachian Basin is many times greater than the total thickness of shale deposits found in the other two basins, a large part of the deposits consist of the poorer quality gray shales.

Energy and Environmental Analysis (EEA), a consultant to the National Petroleum Council, provided to the NPC their Devonian shales and Antrim shale resource estimates. These estimates were in turn based on the 1980 NPC study, Potential Gas Committee estimates published in 1984, and work by consultants. The NPC reviewed the estimates and made revisions on the basis of the field experience of some of its members. The most significant changes were in the Michigan Basin, where estimates of recoverable resources were reduced by about 50 percent. A comparison of the
1980 NPC study, the EEA estimates, and the 1992 NPC study is shown in table 14. For modeling purposes estimates were not included for the Illinois Basin and Western U.S. basins because they were expected to remain undeveloped during the timeframe of the NPC study.

\section{DEVONIAN SHALE RESOURCES}

The EEA data for Devonian shales in the Appalachian Basin encompasses 30 subdivisions or "cells" (see also Milici, this volume). The cells are bounded by degrees of latitude and longitude, and each cell encompasses parts of two or more counties. Columbia Natural Resources (CNR) voluntarily supplied Devonian Shale production data from wells in counties of West Virginia, Virginia, Ohio, and Kentucky for use by the NPC in verifying the EEA estimates. The CNR data are based on 1,621 wells drilled in 17 counties (table 15). The wclls are divided into old and new wells, with old wells being completed before 1971 and the new ones from 1971 through the present. CNR gas-in-place estimates are based on DOE studies completed from 1983 to 1985. Estimated ultimate recoveries from each well were based on actual well performance up to the present and estimated future recovery. Recoveries range from about 12 percent to as much as 50 percent of the estimated gas in place for the old wells and from 2.5 percent to as much as about 14 percent for new wells. These recoveries were estimated on the basis of 120 -acre spacing. Ultimate recoveries per well range from about $0.2 \mathrm{Bcf}$ to $1.1 \mathrm{Bcf}$ for the old wells (averaging about $0.6 \mathrm{Bcf}$ ) and from about $0.05 \mathrm{Bcf}$ to about $0.3 \mathrm{Bcf}$ for new wells (averaging about $0.2 \mathrm{Bcf}$ ). Most of the new wells are infill wells and one possible explanation for the lower recovery is pressure depletion, which has been evident in many cases. The NPC compared EEA and CNR data. In general,

Table 14. Devonian and Atrim shale resources, in trillion cubic feet.

[From National Petroleum Council, 1992]

\begin{tabular}{lccc}
\hline & Gas in Place & $\begin{array}{c}\text { Recoverable, } \\
\text { Current } \\
\text { Technology }\end{array}$ & $\begin{array}{c}\text { Recoverable, } \\
\text { Advanced } \\
\text { Technology }\end{array}$ \\
$\begin{array}{l}\text { Appalachian Basin } \\
\text { 1980 NPC }\end{array}$ & $225^{*}$ & 37 & 50 \\
1991 EEA ${ }^{\dagger}$ & 248 & 25 & 40 \\
1992 NPC & 248 & 27 & 42 \\
Michigan Basin & 55 & - & - \\
1980 NPC & 72 & 21 & 29 \\
1991 EEA ${ }^{\dagger}$ 1992 NPC & 35 & 11 & 15 \\
\hline "Black shales only. & & & \\
† Adjusted to January 1991 basis to be consistent with 1992 NPC. & \\
\hline
\end{tabular}


the averages of the estimated recoveries of old and new wells drilled in a given EEA cell compared reasonably well with EEA's estimates.

For the 1992 NPC study, well recoveries in several cells were revised as a result of CNR comparisons. These revisions increased the estimated recoverable gas in the base case by about $1.3 \mathrm{Tcf}$ and reduced the costs of recovery in lower cost cells, which comprise about one-fourth of the total recoverable resources. The resource estimates for Appalachian Devonian shale exclude areas that have been heavily drilled. The effects of pressure depletion that were observed by CNR at many of the new wells should therefore be absent. CNR had observed that field pressure had dropped as much as several hundred pounds per square inch over several decades of gas production.
Forecasts of recoverable resources based on current technology were increased to allow for advances in technology such as horizontal drilling and better fracturing. Advanced technology was assumed to be phased in over 20 years ending in 2010 and is the basis for the NPC estimate of recoverable resources. A second generation of advanced technology begins in 2011 and is completed in 2030 and is used in sensitivity runs to the year 2030. The 1991 EEA and 1992 NPC estimates do not include resources in the Illinois Basin or in basins west of the Mississippi. These areas are discussed below but were considered to be too speculative for inclusion in the NPC study. Estimates are compared in tables 16 and 17.

The EEA had estimated a total gas in place of $248 \mathrm{Tcf}$ in the Appalachian Basin, which was slightly higher than

Table 15. National Petroleum Council shale study.

[Well data supplied by Columbia Natural Resources. MMcf, million cubic feet. From National Petroleum Council, 1992]

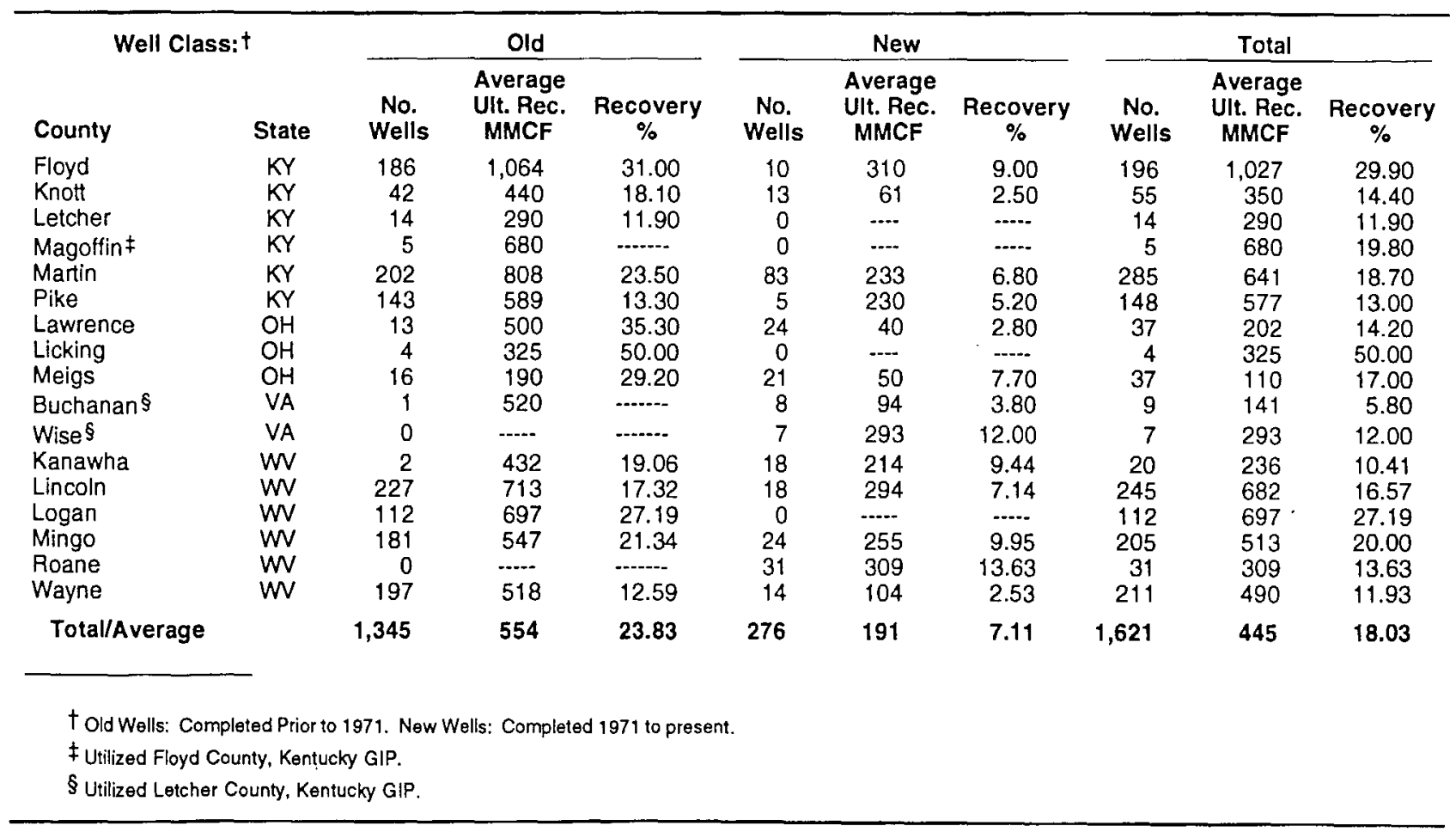

Table 16. Recoverable gas resources (January 1, 1991, basis), in trillion cubic feet.

[From National Petroleum Council, 1992]

\begin{tabular}{cccc}
\hline & $\begin{array}{c}\text { Current } \\
\text { Tech- } \\
\text { nology }\end{array}$ & $\begin{array}{c}1990 \text { to } \\
2010 \\
\text { Advanced } \\
\text { Technology }\end{array}$ & $\begin{array}{c}\text { Second } \\
\text { Generation } \\
\text { Advanced } \\
\text { Technology }\end{array}$ \\
$\begin{array}{c}\text { Appalachian/ } \\
\text { Antrim }\end{array}$ & 37 & 57 & 73 \\
\hline
\end{tabular}

Table 17. Production of Devonian and Atrim shale gas, in trillion cubic feet.

[From National Petroleum Council, 1992]

\begin{tabular}{cccc}
\hline Run* & 2000 & 2010 & 2030 \\
$\$ 1.50$ & 0.34 & 0.29 & 0.16 \\
$\$ 2.50$ & 0.39 & 0.50 & 0.51 \\
$\$ 3.50$ & 0.45 & 0.60 & 0.91 \\
$\$ 4.50$ & 0.45 & 0.65 & 1.02 \\
& \\
"Maximum Gulf Coast wellhead price of gas in \\
1990\$ per million BTU. In some runs, prices are well \\
below the maximum up to 2010.
\end{tabular}


the 1980 NPC estimate of 225 Tcf based on black shales only. The 1980 NPC study estimated higher recoverable resources, both with current and advanced technology; however, these estimates were based on high prices $(\$ 9.00$ per million british thermal units (MMBtu) in 1979 dollars or about $\$ 16.00$ per MMBitu in 1991 dollars).

\section{ANTRIM SHALE (MICHIGAN BASIN)}

The Antrim Shale areas of Michigan have been active in the last several years as drillers have responded to tax credits extended in 1990 legislation. Most of the drilling has been done by independents. The 1991 EEA gas-in-place estimate was 72 Tcf. Of that, about 21 Tcf was estimated to be recoverable with current technology and about 29 Tef was estimated to be recoverable with advanced technology.

During the NPC study, new information was supplied to the NPC indicating that the area that would be productive for Antrim Shale gas was overstated in EEA's estimate. Subsequently, EEA modified the HSM to reflect the new information. Drillable area was reduced from 34,000 square miles to about 17,000 square miles, and the gas-in-place estimate was consequently reduced from about $72 \mathrm{Tcf}$ to about $35 \mathrm{Tcf}$; the recoverable-gas estimate was reduced from 21 Tef to 11 Tcf with current technology and from 29 Tcf to 15 Tcf with advanced technology.

\section{OTHER GAS SHALE BASINS}

Outside of the Michigan and Appalachian Basins, shale gas activity has been minimal. The most widely known basins are in Illinois, Texas (Barnett Shale of the Fort Worth Basin), Oklahoma (Shales of the Hunton Group and Woodford Shale), and Rocky Mountains (Shales of the Niobrara Formation, Mancos and Pierre Shales, and Green River Formation). These shale basins have been minimally explored, and this shale gas is not well defined. The recoverable resources may be significant, but the limited knowledge of these areas available at this time precludes inclusion of the data in gas supply projections.

\section{COALBED METHANE}

The NPC reviewed information on coalbed methane activity and resource estimates to update the 1980 NPC report "Unconventional Gas Sources" and to assess coalbed methane's potential contribution to future U.S. gas production (see also Rice and others, this volume).

The last 12 years have seen a significant increase in the production and utilization of coalbed methane. Most of this increase has occurred since 1986 and has been largely due to the stimulus of the Section 29 tax credit and early explora- tion successes in the San Juan and Black Warrior Basins. These drilling programs, by several operators, took coalbed methane production from an experimental curiosity to an established resource. Coalbed methane production rose from $40 \mathrm{Bcf}$ in 1988 to $196 \mathrm{Bcf}$ in 1990 and to $348 \mathrm{Bcf}$ in 1991. Coalbed methane accounted for about 2 percent of annual U.S. dry-gas production in 1991. Coalbed methane wells increased from 736 in 1988 and to 2,414 in 1990.

The NPC reviewed public and proprietary data from the coal basins of the lower 48 States to determine the potential for commercial gas production. NPC coalbed methane areas in the lower 48 States are shown in figure 5. The results of the NPC assessment of coalbed methane resources in the lower 48 States are summarized in table 18. Undiscovered recoverable coalbed methane resources total 62 Tcf, with current technology and 98 Tcf with advanced technology. The estimates are based on data as of January 1, 1991.

\section{HISTORICAL TRENDS AND FUTURE EXPECTATIONS FOR COALBED METHANE}

Development of coalbed methane resources has accelerated during the past 3 years because of tax incentives and a better understanding of the resource and technology requirements for gas recovery. Proved reserves of coalbed methane at the end of 1990 were only about 5 Tcf. However, NPC estimates that 62 Tcf of coalbed methane are technically recoverable with current technology and about 98 Tcf are recoverable with advanced technology from 300 to 400 Tcf of estimated gas in place.

The main uncertainties for coalbed methane resources concern (1) whether the Section 29 tax credit will be extended to new wells after 1992 and, if so, will it stimulate drilling and production as much as it has in the last 2 to 3 years (the tax credit was not extended in 1992 legislation and it was not considered in the NPC projections), (2) whether other coal basins will become as productive as the Black Warrior or San Juan Basins, and (3) whether there will be an unexpected technological breakthrough that improves well productivity and makes otherwise marginal or subeconomic basins exploitable. Positive developments could increase estimated recoverable resources of coalbed methane by 10 to $30 \mathrm{Tcf}$.

If coalbed methane operators can use tax credits, coalbed methane resource development is less sensitive to price. If tax credits cannot be used, many coalbed methane projects will remain marginally economic and extremely sensitive to price. Price sensitivity is especially evident in the Midcontinent and Rocky Mountain areas where markets are distant and transportation costs are high. Exceptions occur in the San Juan and Black Warrior Basins, where some wells remain profitable without the tax credit. In light of these considerations, the NPC has made its best estimate 


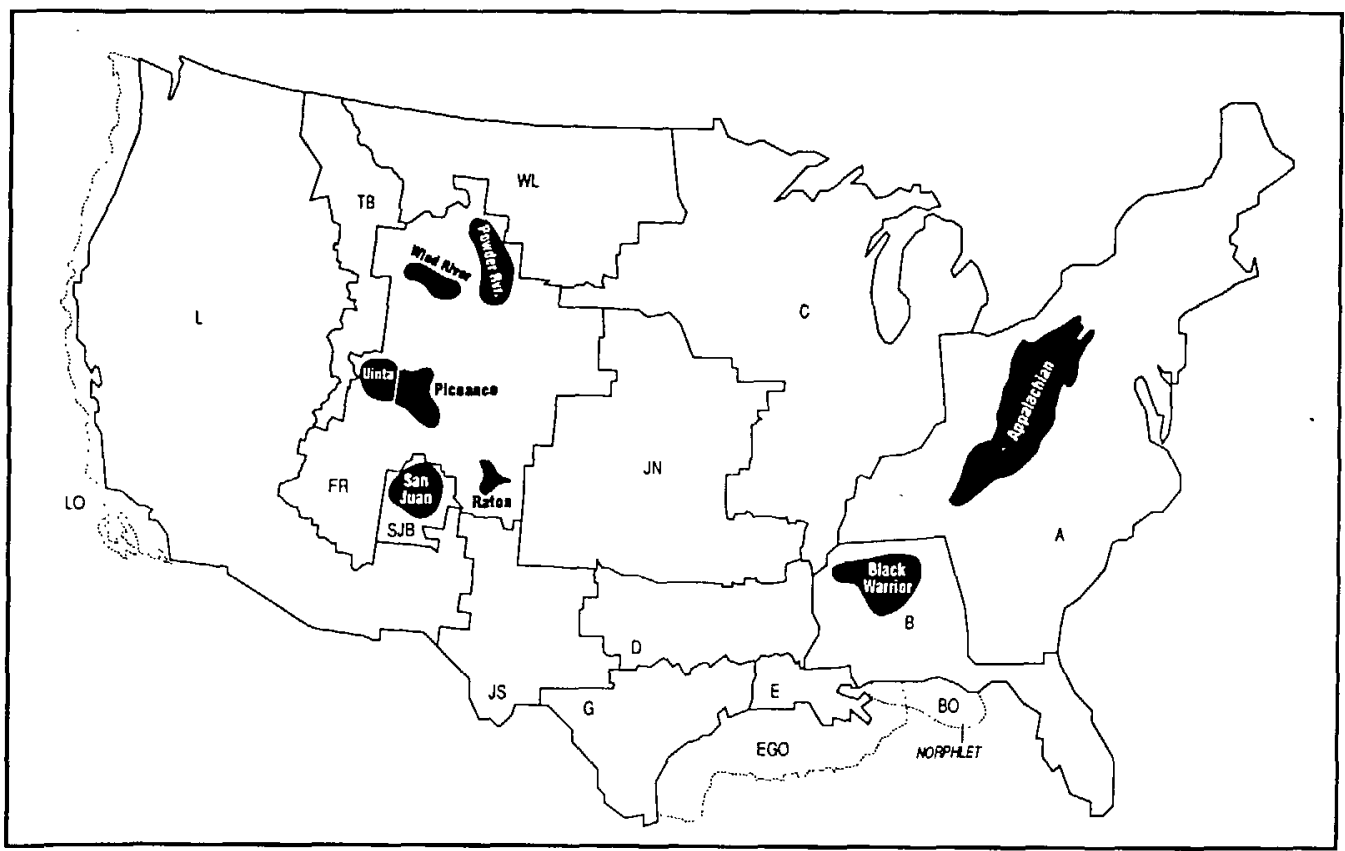

Figure 5. National Petroleum Council lower 48 States coalbed methane areas. From National Petroleum Council (1992).

of the coalbed methane resource and reserves from the most recent data available.

\section{SPECULATIVE GAS SOURCES}

Natural gas also occurs in various other settings and categories, collectively identified by the NPC as "speculative" gas sources. These speculative sources include natural gas originating in deep (>15,000 ft) sedimentary rocks, gas trapped in clathrate hydrates, and gas from geopressured aquifers. The amount of gas in these categories is extremely large (about 11,600 Tcf), dwarfing estimates of gas remaining in conventional categories. However, the cost and technical feasibility of recovering gas from these sources remain uncertain.

The thrust of required research in connection with the recovery of these sources is twofold. First, research toward better quantitative estimates of the gas actually present in each of these sources is needed. Second, research is needed to identify and develop techniques for extraction of these resources at acceptable cost. These gas sources are viewed as long-range research and development efforts with potential payoffs beyond 2010 .

\section{CONCLUSIONS}

The sustainability of the natural-gas supply is not dependent on source and supply availability but on technolo-
Table 18. Coalbed methane recoverable resources in the lower 48 States, in trillion cubic feet.

[From National Petroleum Counci], 1992]

\begin{tabular}{lcc}
\hline & \multicolumn{2}{c}{ Recoverable Resources } \\
\cline { 2 - 3 } & $\begin{array}{c}\text { Current } \\
\text { Technology }\end{array}$ & $\begin{array}{c}\text { Advanced } \\
\text { Technology }\end{array}$ \\
Basin & 22 & 33 \\
San Juan & 7 & 10 \\
Black Warrior & 17 & 27 \\
$\begin{array}{l}\text { Piceance } \\
\text { Raton and Misc. } \\
\text { Rockies }\end{array}$ & 8 & 12 \\
$\begin{array}{c}\text { Northern } \\
\text { Appalachian } \\
\text { Total Undis- } \\
\text { covered } \\
\text { Resources }\end{array}$ & 9 & 15 \\
\hline
\end{tabular}

gy and market conditions. The price/supply economic modelling approach was used to draw conclusions concerning the sustainability of a competitive gas supply between 1990 and well beyond 2010 to 2030 . For this evaluation, gas supply potential was assessed at various price levels$\$ 1.50, \$ 2.50, \$ 3.50$, and $\$ 4.50 / \mathrm{MMBTU}$ (1990 dollars). The NPC study concluded that gas supply cannot be sustained even in the near term at $\$ 1.50$, but is readily sustainable beyond 2010 at $\$ 2.50$ to $\$ 3.50 / \mathrm{MMBTU}$. The supply capability of the United States, as indicated by the NPC 


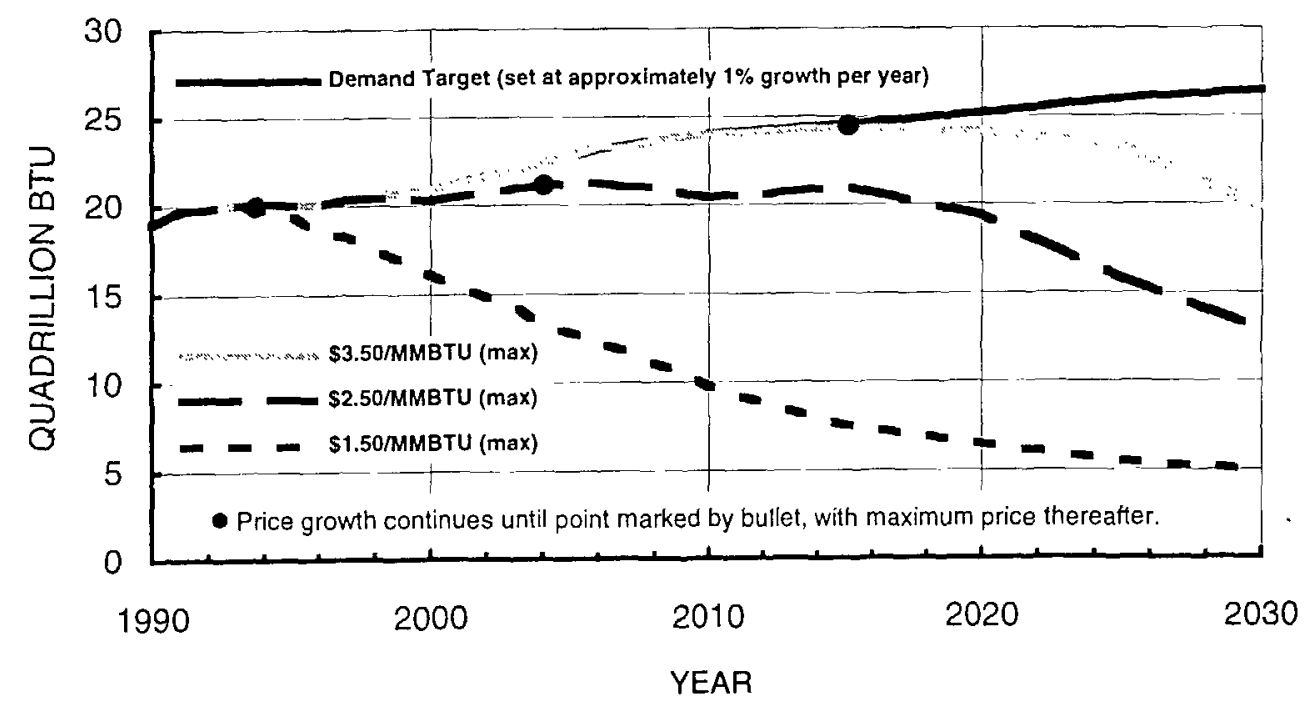

Figure 6. Long-term gas supply at various maximum wellhead price levels. Demand target is fully satisfied through 2030 at prices that do not exceed $\$ 4.50$ per million British thermal unit (MMBtu). Prices are in 1990 dollars for Texas Gulf spot gas. Figure assumes advancing technology. From National Petroleum Council (1992).

study, is summarized and illustrated in figure 6 . The principal finding of the NPC study of the resource base is that natural gas is an abundant domestic resource that can be produced and delivered at prices that allow expansion of the market and development of the resource. A number of challenges face the United States in its development of the natural-gas resource; these can be overcome by a concerted effort of industry and government to alleviate concerns about the reliability of natural gas in the view of the customer and about the further development of a competitive marketplace.

\section{REFERENCES CITED}

Dwight's Energy Data Corporation, 1985, Petroleum data system (through 1985): Available from Dwight's Energy Data Corporation, Oklahoma City, OK 73108.

National Petroleum Council, 1992, The potential for natural gas in the United States-Source and supply: Washington, D.C., National Petroleum Council, 501 p.

Office of Technology Assessment, 1985, U.S. natural-gas availability-Gas supply through the year 2000: Office of Technology Assessment Report OTA-E-245, 252 p. 


\title{
Domestic Conventional Natural-Gas Reserves- Can They Be Increased by the Year 2010?
}

\author{
By Thomas S. Ahlbrandt ${ }^{1}$ and David J. Taylor ${ }^{1}$
}

1
Abstract $\ldots$ CONTENTS
Introduction

'U.S. Geological Survey, MS 934, Denver Federal Center, Denver, Co 80225 .

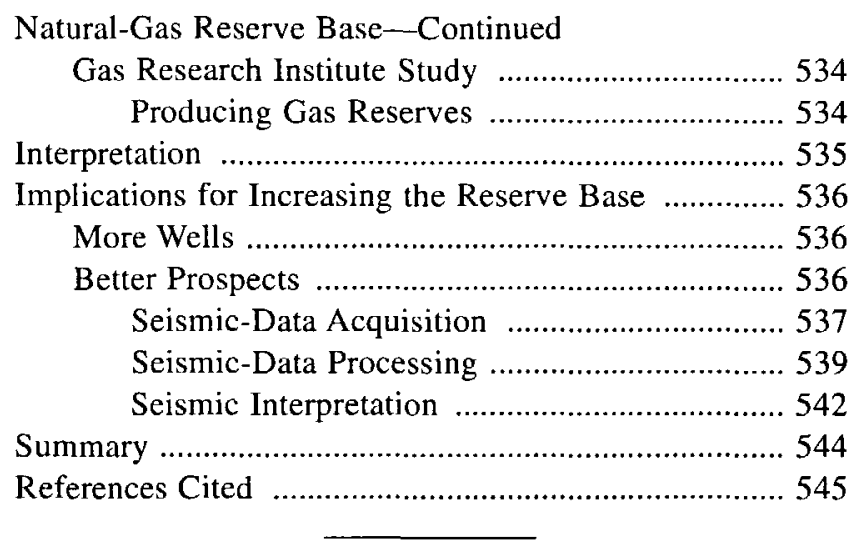

\section{ABSTRACT}

A review of recent natural-gas studies and supporting data bases suggests that natural-gas reserves and excess productive capacity are declining and remedial action to ensure adequate supplies will require increased drilling of high-quality prospects. Conventional gas resources will remain the dominant source of natural gas through the year 2010 , although nonconventional gas sources will increase and competition from coal in the utility sector will remain strong. More than two-thirds of current domestic gas production is coming from wells 11 or fewer years old. There is a need for increased conventional resources to fulfill anticipated increased demand for natural gas, and new concepts, be they new geophysical techniques or looking in lightly explored, deep, or remote areas particularly on Federal lands where most undiscovered conventional gas resources presumably are present, are required to find these resources. Conventional resources discovered during the past decade have initial production rates nearly three 
times that of unconventional resources developed under tax credit incentives for wells drilled before December 31, 1993. The industry has nearly doubled its efficiency, as measured by reserves found per well, from 1988 to 1991 at a low level of drilling relative to the high level drilling during the early 1980's. Significant reserve growth of old, large gas fields has helped to reduce the rate of decline of gas reserves. However, a developing hypothesis related to the field-growth phenomenon is that younger, smaller fields may grow at a lower rate and for a shorter time span than older, larger fields. This hypothesis may reflect, in part, the important role of new seismic techniques to better define the field size and reserves earlier in the process of gas-field development and thereby result in more accurate estimates of ultimate reserves. The desire to increase natural-gas usage and preserve the land will compete with the need to drill more gas wells to maintain or increase natural-gas reserves.

\section{INTRODUCTION}

Studies of conventional natural-gas reserves and production data bases were evaluated to determine if there is a consensus on available natural-gas resources and, if there is consensus, what may be the implications. Although legislation or world events can rapidly alter the energy situation, we will use the current status of domestic natural-gas resources and recent industry exploration and development trends as a starting point to look forward to a more environmentally conscious future in which increased naturalgas usage may be favored. Most of this gas through the year 2010 will likely be from conventional gas sources.

Unlike oil, natural gas has been perceived by some to be less profitable and more difficult to produce, transport, and market. On the positive side, however, under certain conditions, natural-gas accumulations can now be distinguished directly on specially processed seismic sections; therefore, the exploration and development risk and costs are reduced, and a better initial estimate of reserves is provided. More accurate determinations of reserves, or potential reservoirs, by high-resolution, cost-effective seismic data early in a field's development may help to explain a developing hypothesis that new field discoveries grow considerably less than some older fields. Natural gas differs from oil in that the current demand for natural gas is mostly met by domestic production, whereas the current demand for oil is only half met by domestic production. Currently, there is a record high number of producing gas wells $(280,899)$ for the 25th year in a row (American Petroleum Institute, 1992), whereas the number of domestic producing oil wells has declined since 1984 and now totals 594,189 which is a 2.6 percent drop from 1991 to 1992 (World Oil, 1993). Perceptions of the abundance of the natural-gas resources in the United States range from very optimistic views expressed by explorationists to more pessimistic views derived from analysis of resource data bases. We defer to other authors in this volume (see Gautier and Brown, this volume) to evaluate amounts of undiscovered conventional (see C. Masters, this volume) and unconventional naturalgas resources and the future market of this gas.

Episodic regulatory intervention, proration, and tax incentives further complicate both exploration as well as the development and interpretation of resource data bases. There are many recent studies appraising natural-gas resources including the U.S. Geological Survey and Minerals Management Service study of field growth and undiscovered resources (Mast and others, 1989), the National Petroleum Council (NPC) study entitled The Potential for Natural Gas in the United States (1992), the biennial projections of the Potential Gas Committee (PGC, 1992), the annual natural-gas and energy-commodity summaries of the Energy Information Administration (EIA) of the Department of Energy (DOE) (EIA, 1992a, b, 1993), Petroleum Information Corporation's (PI) natural-gas analysis (Butler and Stark, 1993), the Congressional Research Service studies (Riva, 1993), the Gas Research Institute (GRI) analysis (Woods, 1992, 1993; Holtberg and others, 1993), and the Natural Gas Supply Association survey (NGSA, 1992). In addition, large data bases have been constructed in recent years to aid these appraisals. They are the EIA oil and gas information field file (OGIFF) (EIA, 1992a, b), Richard Nehring's significant oil and gas field file (NRG Associates, 1992) and the PI well history control system and production data file. The U.S. Geological Survey has been actively involved in many of these studies and in the construction and (or) use of these data bases, which have provided much of the documentation for U.S. Geological Survey oil and gas assessments (Mast and others, 1989).

The inconsistency of terms and categories among these data sets clouds our perception of the relative number of wells drilled, the measure of their economic success, and the reserves and production established by such success. For example, EIA's revised exploratory well total for 1990 is 4,920; PI's new field wildcats total is 2,684, and the American Petroleum Institute (API) new field wildcats total is 2,558. Significant success rates for 1990 are given as 5.86 percent by API, 5.59 percent by $\mathrm{PI}$ and 24 percent (total success) by EIA. A reader using the three different sources could conclude that the number of exploration wells drilled in 1990 ranged from 2,558 to 4,920 and the success ratio ranged from 5.59 percent to 24 percent!

The perception of natural-gas resources that results from these inconsistent data is certainly confusing. One could conclude that the U.S. natural-gas resource base is plentiful and will be used to solve our environmental, transportation, and utility concerns. Alternatively, the perceived gas bubble will disappear and a collision course awaits with declining gas-well productivity and increasing 
demand. Both scenarios cannot be simultaneously true, yet both scenarios are actively espoused. The domestic oil and gas industry awaits the outcome of this struggle.

\section{BACKGROUND}

\section{COMPETITION FROM COAL}

A commonly held perception is that domestic naturalgas production and reserves are on a strong upswing while competing fuels, particularly coal, are decreasing as a result of increasingly stiff environmental regulations. Figure 1 shows domestic energy consumption and production by commodity from 1950 to 1991 (ElA, 1992a). Since 1960, coal production has virtually doubled and is likely to continue to grow (Gluskoter, 1991). By contrast, the percentage of natural-gas usage for electricity generation has declined from 24.3 percent in 1970 to 9.4 percent in 1991 (EIA, 1992a). The curves shown on figure 1 reflect several legislative actions, which affected each commodity differently; however, the most dramatic event for all three energy sources (that is, natural gas, crude oil, and coal) occurred in 1973 following the Arab oil embargo. After 1973, domestic coal usage increased to the point that by the middle of the 1980 's, energy production by coal exceeded energy production by either natural gas or oil and continued to increase whereas energy production by oil and natural gas generally decreased; oil and gas have only recently stabilized (fig. 1).

\section{PRICES}

Traditionally natural-gas and coal prices have been tied to the price of oil. For example, for the 1989 U.S. Geological Survey and Mineral Management Service assessment (Mast and others, 1989), the natural-gas acquisition price had fallen to about 56 percent of the Btu (British thermal unit) equivalent price of oil. Price fluctuations have been more volatile for natural gas during the past several years than for oil. Gas prices have either doubled or halved in the course of a single year (Parent, 1993). Similarly, coal prices per ton were based or at least strongly correlated with oil price although this relation seems to have been less certain in recent years (Gluskoter, 1991).

The real prices of coal in 1987 dollars have been stable to decreasing since 1975 and nominal coal prices have been decreasing since 1983 (fig. $2 A$ ), whereas nominal and real natural-gas prices have shown substantial long- and short-term instability. However, natural-gas prices currently (1993) are considerably above 1973 prices (fig. 2B, 2C; Parent, 1993). Projections by various groups suggest further significant gas price increases. For example, the NPC predicted a price of either $\$ 3.50$ per thousand cubic feet (Mcf) or $\$ 4.50$ per Mcf by the year 2010 (NPC, 1992) in
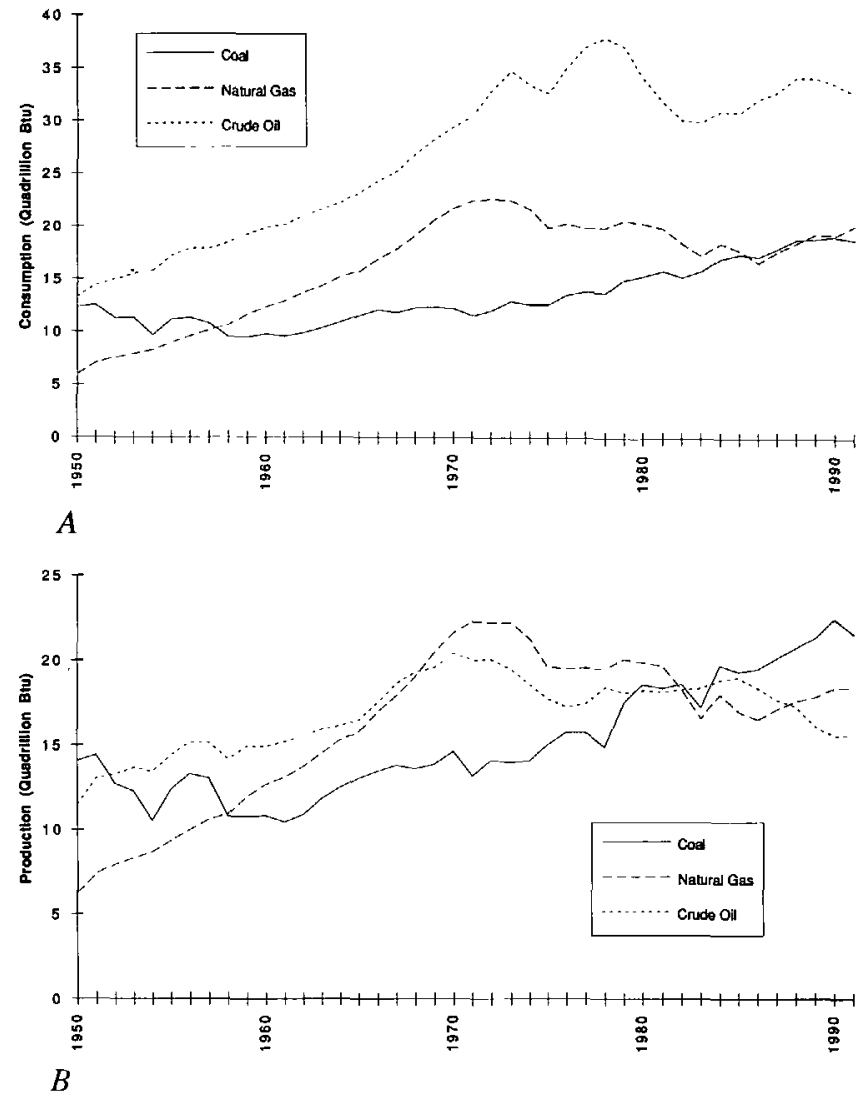

Figure 1. Domestic energy consumption. $A$, Domestic energy production. $B$, Coal, natural gas, and crude oil from 1950 to 1991. Data from the Energy Information Administration (1992a).

contrast with rather flat to declining prices for coal. Such a price scenario might favor coal usage if external parameters such as environmental legislation are excluded.

\section{INCREASING COAL USE}

Despite all internal and external influences, coal production from 1973 to 1991 has doubled, whereas naturalgas production has declined 17 percent and oil production has declined 20 percent (EIA, 1992a). Meanwhile the price of coal has stabilized and even decreased recently relative to natural-gas prices, which are considerably more volatile (figs. $2 A, 2 B$ ). There has been a shift, not only in increased production and consumption of coal, but also a geographic shift in the source of domestic coal related to the Clean Air Act and other legislation. The shift to those coals, which comply with reduced $\mathrm{SO}_{\mathrm{x}}, \mathrm{NO}_{\mathrm{x}}$, and other gas emission standards, favors western U.S. coals relative to certain eastern U.S. coals. This changing environmental influence is reflected in the coal production data over the past few years. Coal production from Wyoming exceeded that of Kentucky for the first time in 1988 and in each subsequent year (Coal Data, 1991). It is far easier to. look backward 
than project forward; however, if recent history is any measure of the future coal usage, coal production will certainly grow on a global scale, if not nationally. Coal will continue to compete strongly with natural gas, particularly if new coal gasification techniques prove economically viable, as demonstrated by the steady increase in coal consumption and production (figs. $1 A, 1 B$ ).

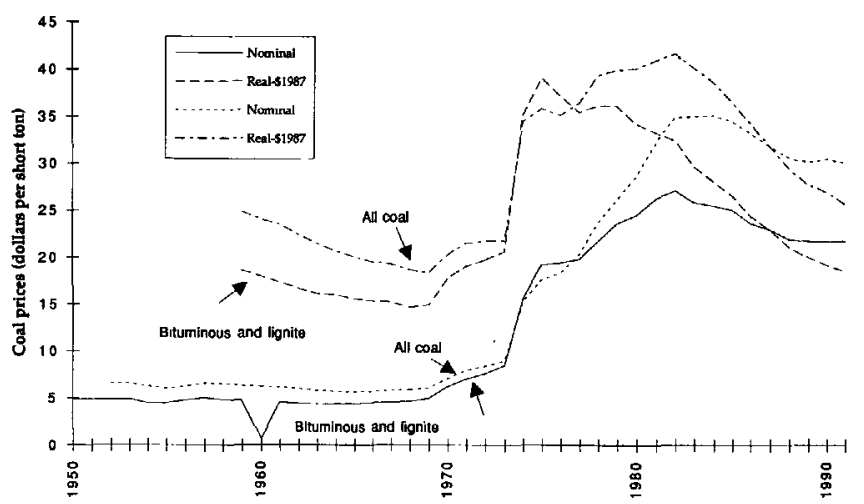

A

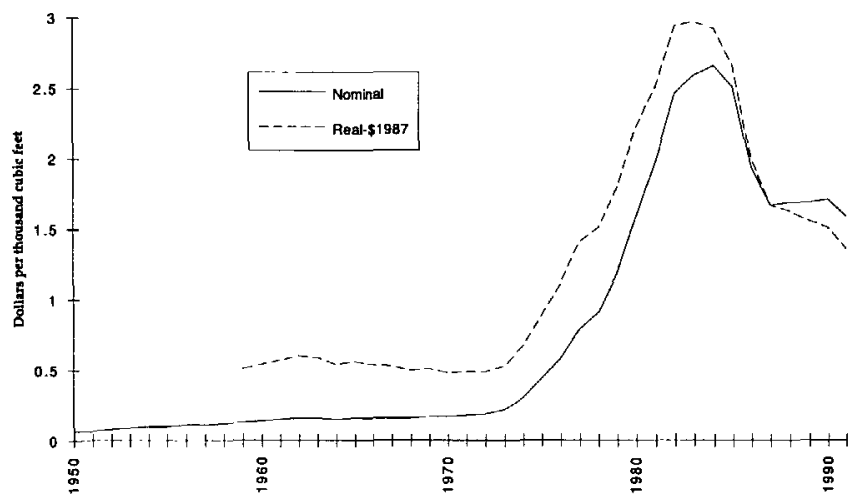

$B$

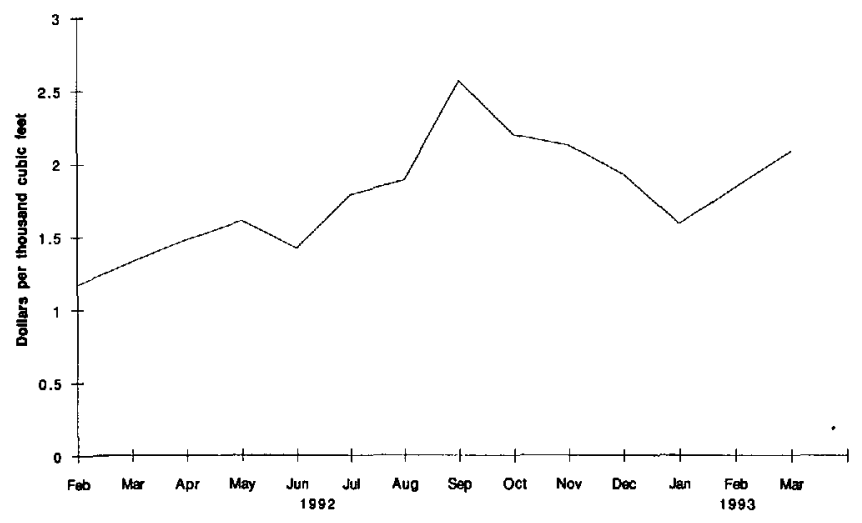

C

Figure 2. Long-term prices for coal and natural gas. $A$, Longterm nominal and real prices of bituminous coal, lignite, and all coal from 1950 to 1991. $B$, Long-term nominal and real prices of wellhead natural-gas prices from 1950 to 1991. Data for $A$ and $B$ from the Energy Information Administration (1992a). Real prices in 1987 dollars. $C$, Short-term natural-gas prices from 1992 to 1993. Data from Petroleum Information Corporation (1993).

\section{NATURAL-GAS RESERVE BASE}

As opposed to estimating undiscovered resources, a review of natural-gas reserves studies including the projected growth of fields, should be a relatively more precise exercise because numerous production and reserve data are available as described in the "Introduction" section. There are some salient or comparable points from the review of each data base and (or) analysis.

\section{EIA ANNUAL REPORT}

\section{GAS RESERVES}

The most recent published results of natural-gas reserves, which will serve as a baseline for subsequent discussion, is derived from the EIA's annual survey (EIA, 1992a). The report includes information gathered through Form EIA-23, "Annual Survey of Domestic Oil and Gas Reserves." Issues about definition arise when trying to compare reporting categories of reserves among various analysts. In the EIA report, dry natural-gas reserves are separated from liquid natural-gas reserves and include both associated and nonassociated gas. Proved natural-gas reserves, which include revisions and adjustments plus total discoveries less production, show an overall decline of 34 percent from the highest reserve year of 1967 to 1991 (fig. 3). There are caveats to this overall decline such as the removal of Alaskan North Slope proved gas reserves in 1988, which were not considered economic at that time (Mast and others, 1989); however, the lower 48 States proved gas reserves also show a slight decline of 7 percent subsequent to 1988 as well.

\section{OIL VERSUS GAS EXPLORATION}

To determine the relative proportion of oil to gas exploration, we again have to review various subsets of the

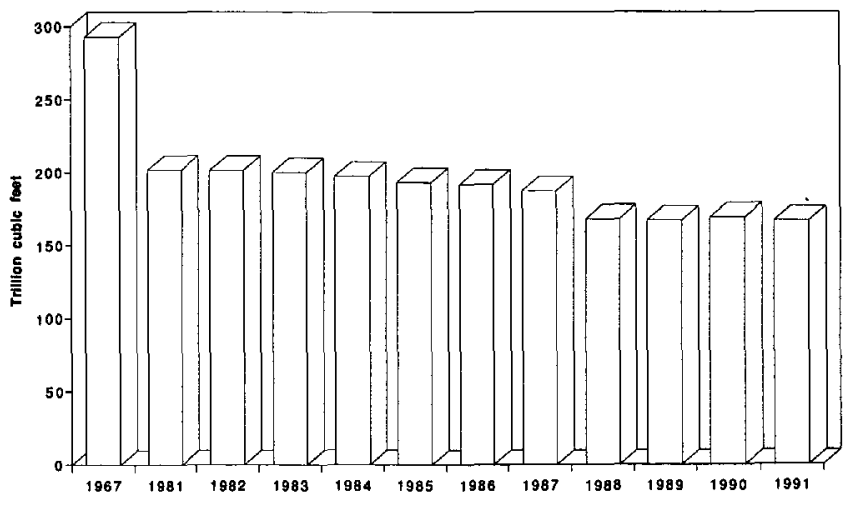

Figure 3. Proved gas reserves from 1967, the highest recorded reserves, to 1991. Data from the Energy Information Administration (1992b). 
data base. For example, the percentage of gas wells drilled in 1991 of the total of exploratory and development wells drilled is 31 percent according to the EIA (1992b). However, if we restrict the area of interest to only successful exploratory wells drilled in 1991, the percentage of successful natural-gas completions is 48 percent. From 1970 to 1991, exploratory gas completions exceeded oil completions from 1973 through 1980. However, at no time during the period from 1970 to 1991 did gas completions exceed oil completions when total exploratory and development wells were considered. Total drilling in 1991 has returned to the level of the early pre-oil embargo 1970's. Drilling was at its highest level in 1981 and totaled 90,030 wells. Today drilling activity is 29,410 wells, which is about one-third of the 1981 rate (EIA, 1992b). The overall ratio of oil and gas in terms of total exploratory and development wells is also roughly the same as the early 1970's.

\section{NEW FIELDS AND FIELD GROWTH}

A complicated picture of the state of proved natural-gas reserves emerges if we look at the two components of (1) revisions and adjustments and (2) new field discoveries. New field discoveries over the 11 year period from 1981 through 1991 as reported by EIA (1992b) are shown in figure 4. From a high of 3.7 trillion cubic feet (Tcf) in 1981, there has been a 77 percent decrease in new field discoveries to less than one Tcf in 1991 (0.85 Tcf). Fortunately, the phenomenon of field growth reflected in categories such as revisions and adjustments, extensions, and new reservoir discoveries in old fields helped to maintain reserves from the precipitous decrease in new field discoveries (also called "inferred reserves" by Root and Mast, 1993). The phenomenon of field growth in which the estimated recoverable reserves of a field increase through time due to extensions, infills, or increased recovery efficiency can account for significant reserve additions. There are a range of estimates of the amount of such growth in natural-gas fields (fig. 5). The duration of such field growth is also debated-the observed

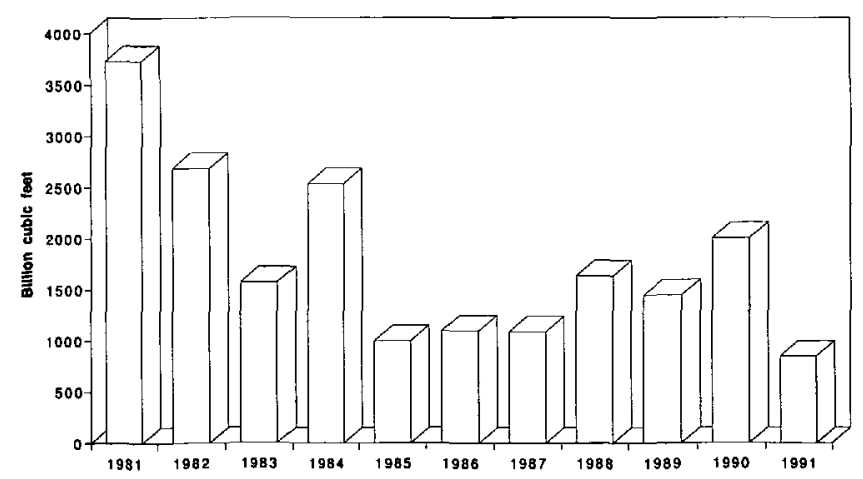

Figure 4. Volumes of new gas field discoveries from 1981 to 1991. Data from the Energy Information Administration (1992b). growth for old fields ranges from 60 years following discovery (Mast and others, 1989) up to 100 years (EIA, 1990b). Others observe, for recent field discoveries, relatively shorter lived field growth of a few years (Butler and Stark, 1993; NRG Associates, 1992). Thus, in spite of the significant tax credit incentives that resulted in the addition of 3.1 Tcf of coalbed methane reserves in 1991, which are included in the data set, there were significant declines in 1991 relative to 1990 in total discoveries (39 percent), new field discoveries (55 percent), extensions (36 percent) and gas-reserve additions from new reservoirs in old fields (33 percent) (EIA, 1992b). Exploratory U.S. gas completions are at there lowest level since 1970 (fig. 6). Were we to solely look at projections based on these data at current prices, prevention of significant erosion of proved reserves by improved recoveries or field growth might be an overly optimistic goal,

From 1988 to 1991, even though these were record low exploratory drilling years, the petroleum industry became more than twice as efficient in exploration on the basis of per well recoveries compared to the record high drilling years from 1979 to 1982. During the high-level drilling years from 1979 to 1982 , the annual completed gas discoveries per well were less than half ( $<7.5$ billion cubic feet or Bcf per well) of those drilled in the low-level drilling years from 1988 to 1991 (>15 Bcf per gas well) (EIA, 1992b). The overall 23 to 24 percent success ratio for exploratory wells for each year from 1988 to 1991 is much improved from the early 1970's when success rates were

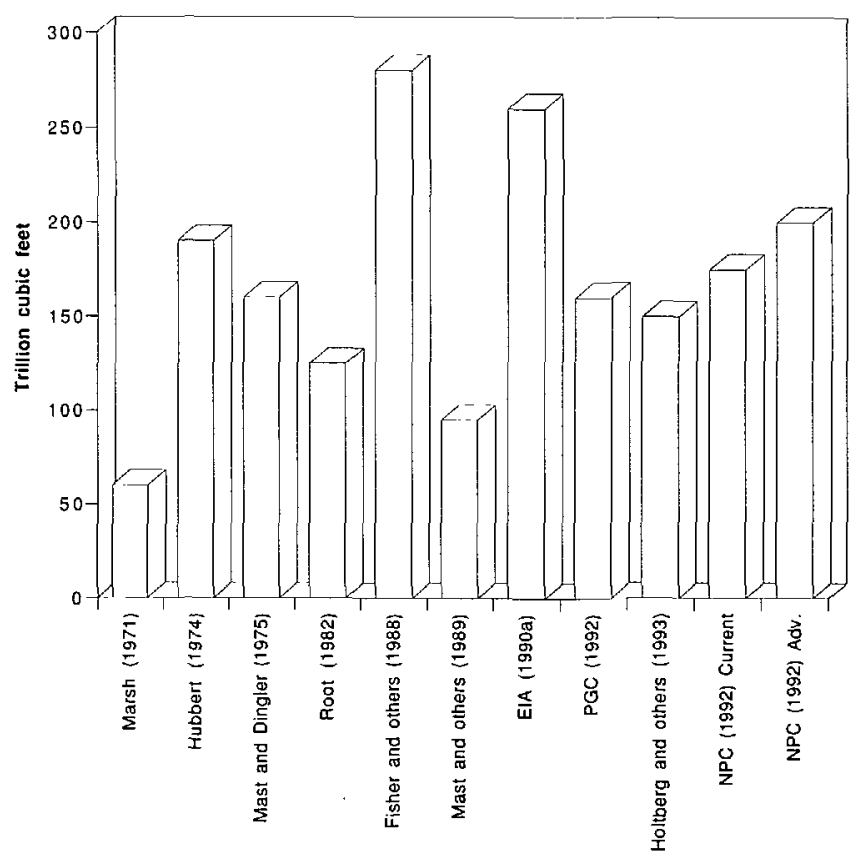

Figure 5. Estimates of volume of gas derived from field growth of natural gas reserves (also called growth to known reserves, reserve appreciation, or inferred reserves). Oldest estimate (on left) to more recent estimates (on right). Sources of information shown on horizontal axis. Adv., advanced technology. 


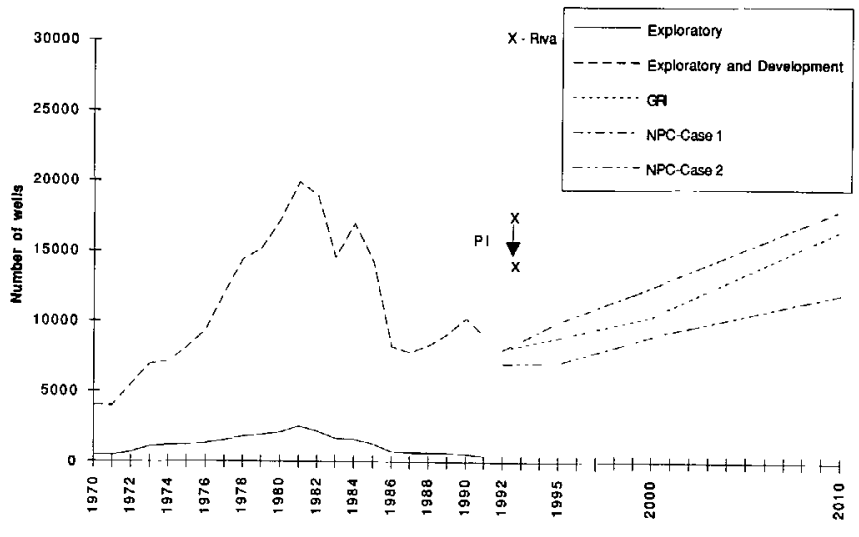

Figure 6. Historical levels of exploratory and total exploratory and development natural-gas wells from 1970 to 1991 (EIA, $1992 \mathrm{~b}$ ) and projections of exploration and development gas drilling activity from 1992 to 2010 as projected by the Gas Research Institute, GRI, (Woods, 1993), and two projections by the 1992 National Petroleum Council Study, NPC, (1992). Necessary drilling activity needed to sustain the level of natural-gas reserves as proposed by Riva (1993), X, and Petroleum Information, PI, shown for near term only for comparison.

16 to 18 percent as calculated from EIA data (EIA, 1992b). The highest success rates for exploratory wells, about 30 percent, occurred from 1979 to 1982 coincident with low per well discoveries; these data suggest that many poor wells were completed during the drilling boom, and that the industry has become more efficient and economic in its exploration during the subsequent bust.

\section{RESERVE TO PRODUCTION RATIOS}

A measure of uncertainty for the natural-gas reserve base is the declining reserves to production ratios for natural gas, which have declined for the United States from a high in 1945 of about 33 to 1 to a current low of about 10 to 1 (EIA, 1992b). EIA (1992a) notes significant regional differences in natural-gas reserve to production ratios. Areas of the country such as the Rocky Mountains that are newly discovered or less developed have high ratios. For example, New Mexico has a reserve to production ratio of 18 to 1 ; whereas Alabama has a ratio of 36 to 1 ; the ratio for Alabama reflects the recent active drilling in these regions induced by tax incentives particularly for coalbed methane. Conversely, the major gas producing areas have reserve to production ratios below the national average such as the Gulf of Mexico Federal offshore (6 to 1), Texas onshore ( 8 to 1 ), and Oklahoma ( 7 to 1) (EIA, 1992b). Analyses by NRG Associates demonstrate significant (>6 Bcf or 1 million boe (MMboe)) natural-gas reserve additions in these last three regions-in the same regions where EIA concludes that natural-gas reserve to production ratios are below the national average of 10 to 1. In summary, EIA (1992b) data projects less than 10 years of natural-gas reserves at current production rates in the major domestic gas provinces of the midcontinent and Gulf of Mexico.

\section{PRODUCTIVE CAPACITY}

Most recently, EIA (1993) indicates that gas productive capacity is expected to decline sharply in the next 2 years by 5.0 percent in 1993 and 3.4 percent in 1994. This shrinking capacity is expected to cause an increase in wellhead gas prices from $\$ 1.84$ to $\$ 2.18$ per Mcf by 1994 . This view of near-term decreased gas productive capacity contrasts markedly with the view of Woods (1992) discussed in the section "Gas Research Institute." The views of different estimators are summarized as follows:

\section{NRG ASSOCIATES}

\section{SIGNIFICANT FIELDS}

Comparison between the EIA and NRG Associates data bases is not simple. NRG considers only significant oil and gas fields ( $>6$ Bcf of gas or 1 million barrels of oil (MMboe); whereas, EIA reports all drilling results including small fields. NRG Associates publish a newsletter entitled "Exploration Insight" in which they evaluate and compare their significant oil and gas fields of the U.S. data base with other sources of data including API and PI. In NRG Associates November 1992 newsletter (which has the same release date as the most recent EIA annual summary), a different conclusion regarding new field successes is reached relative to the EIA data. NRG Associates (1992) argue that significant fields discovered in the United States have stabilized in the past few years and are comparable to more favorable discovery periods if viewed in light of the past half century of exploration. Discoveries of recent significant fields are still at a comparatively low level and are roughly comparable to the levels of 1967 to 1971 and 1941 to 1947 , but they are only 50 to 60 percent of peak levels of the 1950 's and 65 to 75 percent of levels achieved from 1973 to 1982 . The current levels of discovery are substantially higher than the low level of 1986. They argue that overall significant success rates of from 5 to 6 percent are similar regardless of the source of data (API or PI). NRG Associates (1992) argue that nationwide the ratio of oil discoveries to gas discoveries has been relatively constant since 1988. For instance, of 107 total significant discoveries in 1990, 64 percent were gas, 30 percent were oil, 6 percent were both oil and gas. These figures are virtually identical for the 112 significant fields discovered in 1989.

\section{OFFSHORE EMPHASIS}

The proportion of offshore discoveries to onshore discoveries increased from 38 percent of the total in 1989 to 
nearly 45 percent in 1990 (NRG Associates, 1992). This trend toward more offshore exploration is enhanced by the ease of acquisition of offshore marine seismic data, which further reduces exploration risk in areas such as the Gulf of Mexico where direct seismic detection of natural-gas accumulations is increasingly relied upon to define smaller fields.

\section{FIELD GROWTH}

The declining size of new field discoveries is a well known phenomenon with larger fields found early in the exploration of a region following by decreasing field sizes through time. This phenomenon is the basis for forecasting future resources in the technique known as discovery process modeling (Mast and others, 1989; Drew, 1990; Drew and Schuenemeyer, 1993). NRG Associates (1992) preliminarily observe that significant or potentially significant discoveries made in the late 1980's do not grow significantly after the few years of production following discovery and have proportionately more rapid declines in subsequent production. While this observation is preliminary, it is worth noting that new field sizes are declining (Drew and Schuenemeyer, 1993) and it suggests a potential relation between field growth and field size. It also suggests that there may be a regional influence with the Gulf Coast showing the greatest field growth where limited to a few years duration. This analysis is supported by the Petroleum Information study of Butler and Stark (1993).

\section{SIGNIFICANT PLAYS}

NRG Associates (1992) further analyzed their reserve data base by subdividing their data into 580 plays. They evaluated both new plays in 1990 only and exploratory plays from 1986 to 1990 of the 580 plays nationwide. They found 33 plays that had at least $150 \mathrm{Bcf}$ or 25 million barrels of oil equivalent (boe) discovered in them during the 1980 's. Of these 33 plays, 23 occurred in the Gulf Coast Basin onshore (9) and offshore (14), Arkoma Basin (2), Michigan Basin (2), Permian Basin (2), and one each in the Anadarko Basin, Arctic Slope Basin, Black Warrior Basin, and Powder River Basin. The most active plays were predominantly gas plays ( 23 of the 33); 6 were both oil and gas and only 4 were oil plays. The estimated ultimate recovery per play was estimated to be 3.3 to 5 Bboe (billion barrels of oil equivalent) producing an average of 0.66 to 1 Bboe per year. They conclude that significant exploration potential remains in conventional plays in the United States. However, a new approach will be required to develop these plays. There will likely be a shift from exploring for minimum prospect sizes to a strategy driven by minimum attainable play potential. From 1986 to 1990, two-thirds of the significant plays in the United States were gas plays, which reflect the increased role of natural gas in the energy mix.

\section{PETROLEUM INFORMATION CORPORATION STUDY}

\section{PRODUCTIVE CAPACITY}

Butler and Stark (1993) recently presented Petroleum Information's (PI) analysis of natural gas in a study entitled "U.S. Gas Outlook: Where will we get it?" They project a 3 trillion cubic feet (Tcf) per year decline in gross wellhead production capacity, which will fall short of the Nation's demand for natural gas. They argue that two-thirds (68 percent) of the current U.S. gas production as of December 1991 comes from wells that are 11 years or younger. As pointed out previously, we are currently drilling less than one-third of the wells of the early 1980's. Butler and Stark (1993) project a production decline in existing wells of the lower 48 States from 18.5 Tcf per year in 1991 to $8.6 \mathrm{Tcf}$ per year by the end of 1995-an overall 14 percent decline. Anticipated drilling is projected to add back some 6.9 Tcf per year; however, P.H. Stark (oral commun., 1993) now believes that the drilling levels used in their model were too high because the model incorporated an anticipated increased drilling activity in 1993. But there has been a 34 percent decline in drilling activity in the first quarter of 1993 following the termination of the Federal Energy Regulatory Commission (FERC) section 29 incentives at the end of 1992. Fifty percent of the gas completions drilled from 1978 through July 1992 were for unconventional gas resources, which had tax incentives. In fact, during this period, the industry drilled 79,267 section 29 gas wells, including wells penetrating tight sandstone, coalbed methane, and Devonian shales. The initial potential for the unconventional wells, however, averaged 613 Mcf per day, which is about one-third of the average conventional gas well, which had an average initial potential of 1,800 Mcf per day (P.H. Stark, oral commun., 1993). The authors document a short-lived field-growth phenomenon alluded to by NRG Associates for fields discovered since 1980 and demonstrate that newer field discoveries are declining rapidly (fig. 1) for gas wells drilled from 1980 to 1991 (Butler and Stark, 1993). They argue that the gas bubble will soon disappear, and they conclude that productive capacity is no more than 80 percent of measured capacity; thus there is little spare productivity to meet increasing demand.

\section{DRILLING ACTIVITY}

According to P.H. Stark (oral commun., 1993), between 15,000 and 18,000 gas wells will need to be drilled in each year commencing in 1993 to maintain the domestic natural-gas reserve base. 


\section{CONGRESSIONAL RESEARCH SERVICE STUDY}

DRILLING ACTIVITY

Perhaps the most startling view of the declining natural-gas reserve base is provided by Riva (1993). He estimates that 13,334 wells were drilled for natural gas (both exploration and development) in 1991, 9,010 of which were completed as producers according to EIA (1992b). Riva (1993) argues that this yearly drilling rate is low compared to the yearly rate of 21,000 to 27,000 natural-gas wells in the late 1970's and 1980's and that more than 30,000 gas wells per year are needed to meet future gas demands. He relies on increased drilling to fill the impending supply gap in natural gas and that significant investment of time and money will be needed to develop new energy technology to replace fossil fuels. He feels that a natural-gas shortage could happen sooner rather than later. He concludes that we have about a 16-year supply of producible gas including 9 years of proved reserves plus perhaps 6 years from field growth and 1 year from undiscovered resources (if the drilling experiences of the past decade are repeated). In summary, according to this study, current production will not sustain the anticipated demand and a significantly higher rate of drilling will be required immediately.

\section{NATIONAL PETROLEUM COUNCIL STUDY}

\section{OVERVIEW}

The 2,012 page, six-volume publication entitled "The Potential for Natural Gas In the United States" was released by the NPC in December 1992 (NPC, 1992). This 2-year study was a collaborative effort of over 200 individuals in industry, government (including the U.S. Geological Survey), trade associations, academia, and private enterprise. This study is summarized elsewhere in this volume (see Gautier and Brown, this volume). In brief, the NPC study discusses two relatively optimistic views of the natural-gas resource base and the ability of field growth and unconventional resources to meet anticipated increased demand for natural gas relative to the Butler and Stark (1993) and Riva (1993) studies. The NPC study describes two cases. Case 1 is that energy demand grows at 1 percent per year with a crude-oil price in 1990 dollars of $\$ 28$ per barrel (maximum of $\$ 4.50$ per $\mathrm{Mcf}$ ) in 2010. Case 2 is that energy demand grows at 0.5 percent per year with a crude-oil price in 1990 dollars of $\$ 20$ per barrel (maximum of $\$ 3.50$ per Mcf) in the year 2010. Both NPC cases portray optimistic projections for higher gas usage, higher gas prices, and more production by the year 2010. They anticipate that a large part of the supply will be met through substantial gas-reserve additions from field growth and unconventional resources, particularly from tight gas sandstones. The NPC study does acknowledge a third, less optimistic case at lower gas prices where there would be a dramatic decline in gas supply potential and drilling activity (NPC, 1992, vol. 1, fig. 2) brought on by a fall in gas prices to $\$ 1.50$ or less per Mcf.

\section{DRILLING ACTIVITY}

The NPC argues that by the year 2010 , gas-well completions will range from 12,000 (case 2) to 18,000 (case 1) per year compared to the 9,010 gas in 1991, the last year of complete data (EIA, 1992b). Many projections of price, technology, imports, markets, and demand are contained in the NPC study and summarized by Gautier and Brown (this volume). Drilling activity related to the two reference cases is shown in figure 6 .

\section{FIELD GROWTH}

The subject of reserve growth, also called growth to known, inferred reserves or reserve appreciation, will provide a critical component of additional gas reserves according to the NPC study. The report predicts as much as $250 \mathrm{Tcf}$ of cumulative reserve additions by field growth by the year 2010 (NPC, 1992, vol. 2). There are a variety of opinions about the magnitude of field growth (fig. 5); however, the projected $250 \mathrm{Tcf}$ value for field growth from 1992 to 2010 represents a consensus of industry, trade group, and government investigators. This reserve growth of 250 Tcf (from 1992 to 2010) may account for more gas reserves than current proved reserves of natural gas estimated at $167 \mathrm{Tcf}$ (EIA, 1992b).

\section{GAS RESEARCH INSTITUTE STUDY}

\section{PRODUCING GAS RESERVES}

EIA (1992b) reported that proved gas reserves were indeed declining. Woods (1992, this volume), however, argues that producing gas reserves have not declined and that producing gas reserves are stable. Woods believes that gas drilling activity has become a poor leading indicator of new gas additions in terms of deliverability. He also argues that nonproducing gas reserves have increased from $23 \mathrm{Tcf}$ in 1982 to $35 \mathrm{Tcf}$ in 1990 with most of that increase coming from onshore regions. His analysis finds that the share of deeper wells $(>5,000 \mathrm{ft}$ or $1,650 \mathrm{~m})$ that produce only gas as opposed to shallow wells that produce only gas has increased in recent years and that there is an increasing emphasis on drilling deep offshore gas wells in the Gulf of Mexico owing to their high deliverability. This shift, he argues, is consistent with the Natural Gas Supply Association (1992) survey, which showed that offshore gas deliverability increased in 1991 more than offsetting the anticipated decline in gas deliverability despite decreased 
drilling activity levels. Thus, Woods suggests that proved reserves and drilling activity are poor indicators of producing gas reserves. Rather he would prefer gas deliverability as a measure of producing gas reserves. Woods argues that an analysis of drilling depth distributions should be used in conjunction with drilling activity to give a clearer picture of the true nature of the Nation's gas reserves. Thus, Woods surmises that the gas bubble has perpetuated in spite of an overall 10 percent decline in drilling in 1991 owing to increased offshore drilling for gas and increases in onshore depth of drilling, both of which have actually allowed an increase in gas deliverability in 1991 over 1990. In other words, industry has become so much more efficient in exploration that, in spite of less drilling, the "gas bubble" has been maintained and does not appear to affect deliverability.

Although data in the 1992 EIA report can be used to support Woods (1992) argument of stabilizing producing gas reserves, more recently EIA (1993) has projected a sharp decline in gas deliverability in 1993 and 1994. EIA (1993) expects gas production capacity to fall by 5 percent in 1993 and by 3.4 percent in 1994. This shortfall is expected to drive up gas prices, as it seems already to be doing, and thereby cause an increase in drilling for gas wells in 1993 and 1994.

In a separate discussion by Woods (1993), conventional high-permeability gas resources are expected to dominate natural-gas production; they should provide 72 percent of production in lower 48 States and gradually decline to 66 percent of production by the year 2010 . He argues that the remainder of the lower 48 States' gas supply would come from a combination of associated gas, low permeability, Devonian-age shale, and coalbed methane sources totaling less than one-third of the lower 48 States gas supply through the year 2010. By means of comparison, the NPC (1992) study argues that using current technology (total assessed natural-gas resource of 905 Tcf), 62 percent of our natural-gas supply by the year 2010 will be from conventional sources and using advanced technology by the year 2010 (total assessed resource of $1,135 \mathrm{Tcf}$ ) only 54 percent will come from conventional gas resources. These are vastly different scenarios of the role of conventional gas resources versus unconventional resources, but conventional gas resources will dominate through the year 2010 according to both the Woods (1993) and NPC (1992) studies.

T.J. Woods (oral commun., 1993) further argues that the source of these conventional gas resources will come from increasingly greater depths on the basis of greater gas recoveries being observed in the lower 48 States at each successive 5,000 foot $(1,640 \mathrm{~m})$ increment through the 25,000 foot range. The need to more precisely define such deep resources through risk reduction methods such as seismic is imperative because drilling and completion costs rise exponentially for deep wells (beyond 20,000 ft).

\section{INTERPRETATION}

Deriving overall meaning from the six most recent conventional natural-gas studies is a difficult task. The first point of general agreement is that gas drilling activity is at a low level even though recent tax incentive legislation increased the drilling for gas. Second, natural-gas exploration has become more efficient, as indicated by nearly twice the gas reserves per new well during the past 5 years (1986-1991) relative to the previous 5 years (1980-1985). The increase in reserves per well has occurred despite higher prices and drilling activity in the earlier period. Third, the size and number of new gas field discoveries are decreasing. New field discoveries are at their lowest level since 1981 and drilling activity continues to decrease. Fourth, field growth has been an important factor in maintaining gas deliverability and minimizing the loss of the natural-gas reserve base; however, as new field discoveries decrease in size, significant field growth may also be diminishing. And fifth, proved gas reserves and gas productive capacity is shrinking in spite of a record number of producing gas wells.

A fair conclusion from the summarized studies is that the natural-gas reserve base may not be sustainable unless a dramatic increase of drilling commences soon. We would further argue that the bulk of additional reserves in the near future will have to come from conventional reservoirs, including those which may occur in areas designated as unconventional gas because conventional reservoirs average nearly three times the initial production of the average unconventional well (P.H. Stark, oral commun., 1993). Increasing the drilling activity from current historical lows will be an enormous task in light of the low active rig count, low seismic-crew activity, and loss of more than 50 percent of the experienced industry personnel (over 450,000 people in the last decade by many estimates, Riva, 1993).

The expiration of the section 29 FERC incentives on December 1992 has resulted in a 34 percent decline in drilling activity in the first quarter of 1993 from 926 rigs in December 1992 to 611 rigs in March 1993 (PI, March 1993). As noted in the "Background" section of this paper, dramatic swings in energy usage have accompanied political or social events. In the current depressed state of the petroleum industry, we find it hard to envision drilling 30,000 gas wells a year, without Federal intervention. Such Federal legislation could be brought on by reserve loss, political instability in a significant petroleum producing country of the world, or environmental pressures mandating increased gas use.

The NRG Associates' analysis and GRI analysis (Woods, 1992; 1993) suggest that substantial exploration potential remains and that much of this potential is in gas plays particularly in the offshore Gulf Coast and onshore. This potential, however, is at a level lower than the prolific levels of the 1950's but higher than the levels of the 
mid-1980's. On the basis of the EIA data (1992b, 1993), one could conclude that many low productivity wells are being completed that do not contribute significantly to reserves. This last point is reinforced when one considers that there are declining natural-gas reserves despite the record number of current producing gas wells $(280,899)$, which have been steadily increasing in number since 1967 .

\section{IMPLICATIONS FOR INCREASING THE RESERVE BASE}

\section{MORE WELLS}

According to data contained in the Petroleum Information Corporation files, drilling for new field wildcats, both oil and gas, peaked in 1981 with 10,675 wells and declined to 2,684 wells in 1991, a 75 percent decrease. The American Petroleum Institute (1992) showed a decline of 68 percent for the same period but shows only 8,034 new field wildcats in 1981 as compared to 2,558 wells in 1991 . Riva (1993) argues that in excess of 30,000 natural-gas wells per year must be drilled to sustain future gas production. If not sustained, other forms of energy, or imports of gas, may be required to substitute in part for domestic natural gas by the year 2000. As shown by Dolton and others (1990), 53 percent of undiscovered conventional gas resources lie beneath Federal lands or waters. Moratoria imposed on major offshore areas along the East Coast, West Coast, and Florida further intensify activities in those Federal areas where drilling is permitted. The impact of drilling 30,000 gas wells a year, the majority of them on Federal lands will drastically affect Federal land managing agencies in many ways. Drilling on Federal land requires long lead times and considerable expense both to operators and affected agencies to satisfy requirements such as tract nomination and leasing, environmental impact studies, resource management, and land-use planning area and (or) development strategies. Land managing agencies may not be able to quickly respond to such increases partly because of reductions in many Federal energy resource programs paralleling the severe reductions in the oil and gas industry. The drilling infrastructure, investment capital, experienced people to permit, drill, complete, transport, and market such a record high level of activity are simply unrealistic in the next few years. A more modest, but significantly increased level of drilling of 15,000 to 18,000 gas wells per year seems optimistic in light of first quarter of 1993 in which gas drilling in the United States is down 34 percent relative to drilling in December 1992; this decrease reflects the repeal of tax credits for new wells drilled in 1993. Productive capacity has reached 80 percent of measured capacity. Should demand for natural gas increase, there is little excess capacity. (Butler and
Stark, 1993). This underscores the need for increased drilling for conventional gas accumulations.

Others argue that productive capacity has been stable and, therefore, the number of new gas wells required to maintain the natural-gas reserve base is adequate at approximately current levels (Woods, 1992). The Gas Research Institute (Holtberg and others, 1993) predicts reduced levels of drilling through 1995, marginally increasing to 10,403 gas wells per year by the year 2000, and a maximum of 16,542 gas wells per year by the year 2010 (fig. 6). The GRI model used to produce the estimates of drilling shown in figure 6 is the hydrocarbon supply model developed by Energy and Environmental Analysis (EEA) of Arlington, Virginia. The EEA hydrocarbon supply model was also used for the 1992 NPC study, using various assumptions about price, demand, resources, and technology. The NPC study anticipated decreased drilling to a level less than 8,000 gas wells per year in both of their reference cases in 1992 but then predicted increased drilling by the year 2000 to 12,500 gas wells per year under reference case 1 and about 9,000 wells per year under reference case 2 . By the year 2010, the NPC study estimates 18,000 gas wells per year will be drilled under reference case 1 and 12,000 gas wells per year under reference case 2-both cases end with more gas wells drilled per year than were drilled in 1991 (fig. 6).

The projections of Butler and Stark (1993) and Riva (1993) require an immediate upswing in drilling in 1993, which is in marked contrast to GRI's (Holtberg and others, 1993) projections of stable or declining drilling and the NPC reference case 2. The NPC reference case 1 calls for increased drilling of about 33 percent (that is, from over 9,000 to over 12,000 gas wells per year) through the year 2000 , which is modest compared to the intense drilling projections of 30,000 immediately (Riva, 1993). The most recent rig count according to PI in February 1993 has dropped from 926 in December 1992 to 611 rigs in the first quarter of 1993, which is a 34 percent decline, and total new well starts are down 23 percent from 917 to 704 during the same period (PI, 1993). Drilling activity near the 600+ level of much of 1992 and 1993 reflects historically low drilling levels. The impact of reduced drilling levels, particularly in new field wildcats, is also reflected in the strong declines in the EIA production data as previously discussed. The termination of the section 29 qualification for tax credits at the end of 1992 evidently curtailed 1993 drilling in spite of a gas price increase from $\$ 1.09$ per Mcf to $\$ 2.09$ per Mcf from February 1992 to the February 1993 (fig. 2C).

\section{BETTER PROSPECTS}

The role of technology in reducing risk by locating better prospects for drilling is critical in exploiting natural- 
gas resources, particularly if resources are found at greater depths where higher costs and risks are encountered. Of particular importance are the advances made in multichannel seismic-reflection technology. Evolution of the seismicreflection method has helped extend the search for natural gas beyond the structural trap to the more subtle stratigraphic trap and even into the realm of direct detection. The increased success of recent gas exploration as measured by per well discoveries and the observed decrease of field growth in certain recently discovered gas fields, particularly in the Gulf Coast, may relate to the effectiveness of seismic technological advances. The importance of seismic advances in natural-gas exploration is underscored by the recent NPC (1992) study. NPC (1992, vol. 2, p. J-5 to $\mathrm{J}-7)$, in describing the bright-spot technique, states

"the bright-spot (high seismic amplitude) technique was a revolutionary tool used by geophysicists, from the 1970's through the early 1980's, as a means to find natural gas in the subsurface. ...this technology is now used in conjunction with amplitude-versus-offset (AVO) analysis, which offers the geophysicist more precision....AVO analysis has played a significant part in the exploration and development of natural gas."

In the NPC (1992) study of the role of technology to increase gas resources, the first item listed under existing technologies is 2-D and 3-D seismic processing and the first item listed under future technologies is advanced geophysics (NPC, 1992, vol. 2, Appendix H).

Cost effectiveness of such seismic advances is of paramount importance. The ability to reprocess older 2-D seismic data using new techniques provides a cost effective method to recycle seismic data particularly in areas where it may be prohibitive to collect new seismic data either due to surficial or environmental restrictions or prohibitive acquisition costs. Risk reduction in exploration for natural gas using the seismic method can be examined by looking at the progress made in three areas. These areas are multichannel seismic-data acquisition, seismic-data processing, and data interpretation.

\section{SEISMIC-DATA ACQUISITION}

The volume of recorded seismic data has increased dramatically beginning in the early 1970's to the present (Lindseth, 1990) as shown in figure 7. Introduction of digital recording onto magnetic tape along with development of the common depth point (CDP) acquisition method allowed this growth to occur. The use of more recording

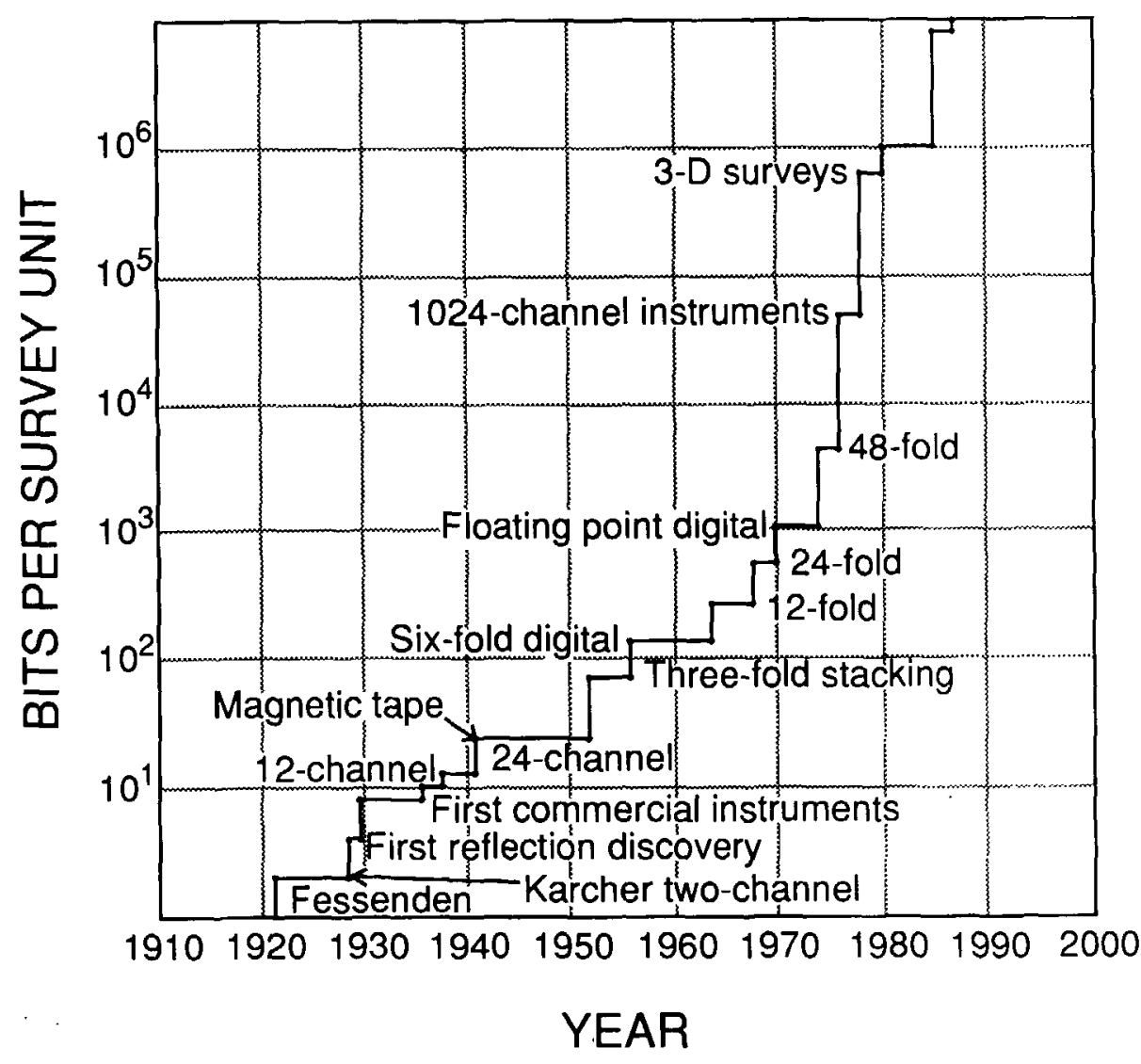

Figure 7. Increase in recorded data volume over time as a result of advancements in seismic technology. From Lindseth, 1990, and courtesy of Samuel J. Allen. 
channels results in better signal-to-noise ratios where coherent signal energy is reinforced and noncoherent noise is canceled during the CDP stacking process. The ultimate benefit is a more accurate imaging of the subsurface and the ability to directly observe subtle structural and stratigraphic traps.

But not all noise is noncoherent. Some energy, such as ground roll and water-bottom multiple reflections, produce coherent noise patterns. Conventional stacking techniques do not eliminate this noise effectively; therefore, some other method must be used. For example, in the acquisition phase, the design of specific land receiver arrays can help eliminate ground roll and use of specially tuned marine sources can reduce the water-bottom multiple effect. These techniques coupled with multiple-fold recording and processing further enhance our ability to image the subsurface correctly. Consequently, the risk of misinterpreting possible natural-gas traps is reduced.

The seismic source has evolved over time. During the early 1970's, dynamite was primarily used as the energy source for seismic data acquisition. In response to environmental concerns and the destructive nature of dynamite, Conoco developed the modern nondestructive vibrator source. In the marine environment, the complement to the land vibrator is the air-gun source. Modern seismic energy sources also allow the input signal to be controlled and recorded. Controlling the design of specific input signals produces better noise reduction and subsurface resolving power in specific terrain. A known source signature can be used in the data-processing phase to determine exactly how the Earth has filtered the input wavelet to produce the resultant recorded signal. From this information, one can begin to determine subsurface characteristics such as lithology, pore-fluid composition, and apparent porosity. This information along with basic knowledge of the subsurface structure helps locate possible reservoirs and determine their characteristics.

Terrain plays an important role in data acquisition. Mountainous terrain and marsh-covered areas pose special obstacles to conventional acquisition techniques. Development of the portable shot-hole rig and recording system, which can be maneuvered by helicopter in mountainous regions, has allowed exploration of these otherwise inaccessible areas. In certain areas where dynamite sources are not acceptable and vibrator vehicles cannot gair access, the air-blast method can be used. This method uses an explosive charge, usually primacord, planted above ground as the energy source. The air-blast method does not produce input signals as clean as those produced using conventional dynamite or vibrator sources, but it does allow acquisition to continue in otherwise environmentally sensitive areas. Shallow-water recording and the use of radio telemetry has provided a means to explore marshy or nearshore marine areas. This is especially important because many of most promising areas for natural-gas exploration occur in and around the shallow Gulf of Mexico and the marshlands of the Mississippi Delta.

The most recent advancement in modern acquisition of seismic-reflection data is the development of 3-D shooting. The geometry used to record this type of data provides enough properly oriented information to produce a 3-D image of the subsurface and helps refine the picture commonly produced by using grids of 2-D data. The 3-D method provides the data necessary to construct not only vertical cross section slices but also horizontal slices of the Earth's subsurface. A comparison of interpretations based on 2-D data and 3-D data (Nestvold, 1992) is shown in figure 8 . The 3-D interpretation is superior to the 2-D in its ability to resolve and locate fault patterns, which in turn assist in determining the exact location and extent of

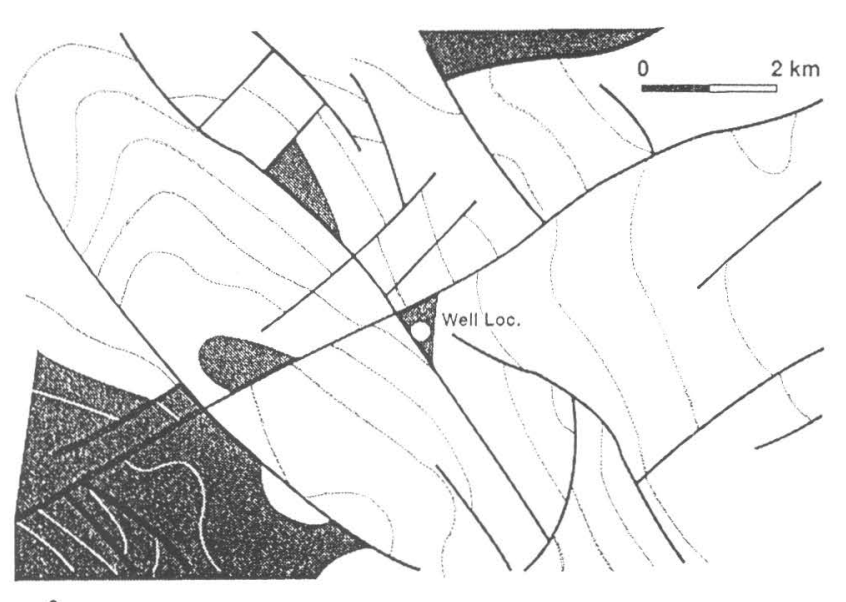
A

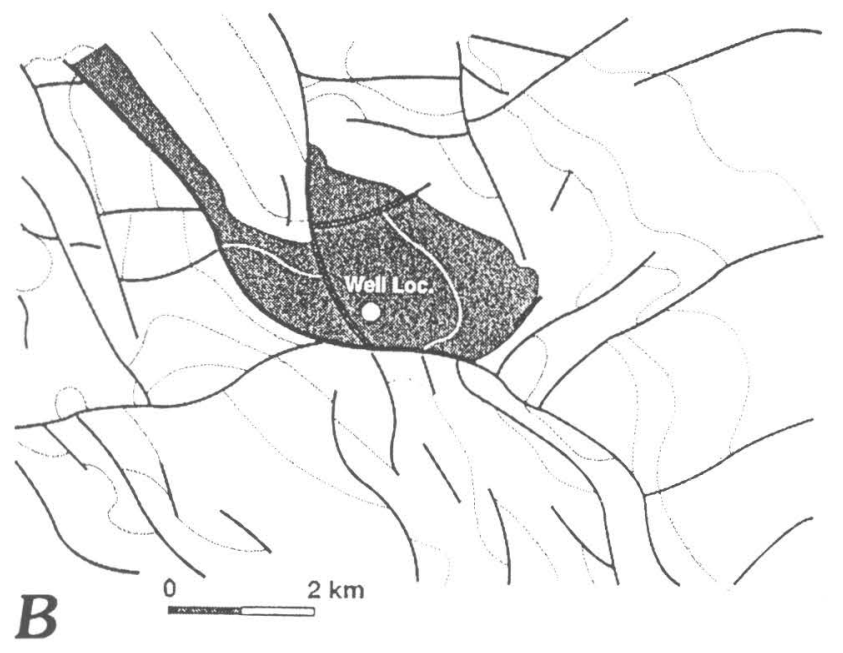

Figure 8. Subsurface interpretation of same area using 2-D seismic data versus 3-D seismic data. A, 1974 structure map based on 2-D seismic data, showing fault patterns as dark lines and prospects as shaded areas from onshore in the Netherlands. $B$, The same area in 1990, based on 3-D seismic data. From Nestvold, 1992. 2 kilometers $=1.2$ miles. 
potential reservoirs. Detailed information from 3-D surveys can reduce the risk of missing potential natural-gas traps and enhance the success of step-out wells once potential natural-gas reservoirs are located.

\section{SEISMIC-DATA PROCESSING}

Perhaps the most important advance in seismic-data processing was the introduction of the high-speed digital computer and magnetic recording tape. The ability to manipulate large amounts of data quickly and economically provided the power to develop and use more sophisticated signal-processing algorithms. The evolution of digital computers from large mainframes capable of executing about 1 million instructions per second (MIP) at a cost of about $\$ 500,000$ per MIP to today's 60 MIP desktop workstations operating at a cost of about $\$ 500$ per MIP provides enough reduction in cost to use compute-intensive processing routines necessary to enhance seismic imaging of the subsurface.

There are specific processing routines that are especially useful in locating better prospects when exploring for natural-gas accumulations. Probably the best known is relative amplitude processing, otherwise known as bright-spot processing. Notable differences in speed are shown by seismic energy traveling through reservoir rocks containing natural gas in the pore space as opposed to rocks containing water or oil in the pore space, or rocks that have no pore space. The seismic velocity is slower in the gas reservoir because gas has a lower density than water or oil. This difference produces a sharp contrast in acoustic impedance and a resulting higher amplitude on the processed data. When conditions are right, these high-amplitude anomalies can directly indicate hydrocarbon accumulations, especially natural-gas accumulations. A 2-D seismic section, which has been processed conventionally, and a section processed using relative amplitude or the bright spot technique (GeoQuest International, 1975) are shown in figure 9. On the relative amplitude processed section, the gas zone produces a larger true amplitude reflection relative to surrounding nongas-bearing reflectors. This technique seems to be especially effective in areas of the Gulf of Mexico where subsurface temperatures, sand-shale lithologies, and highreservoir porosities allow the use of relative amplitude processing as a direct detection method. In some special cases

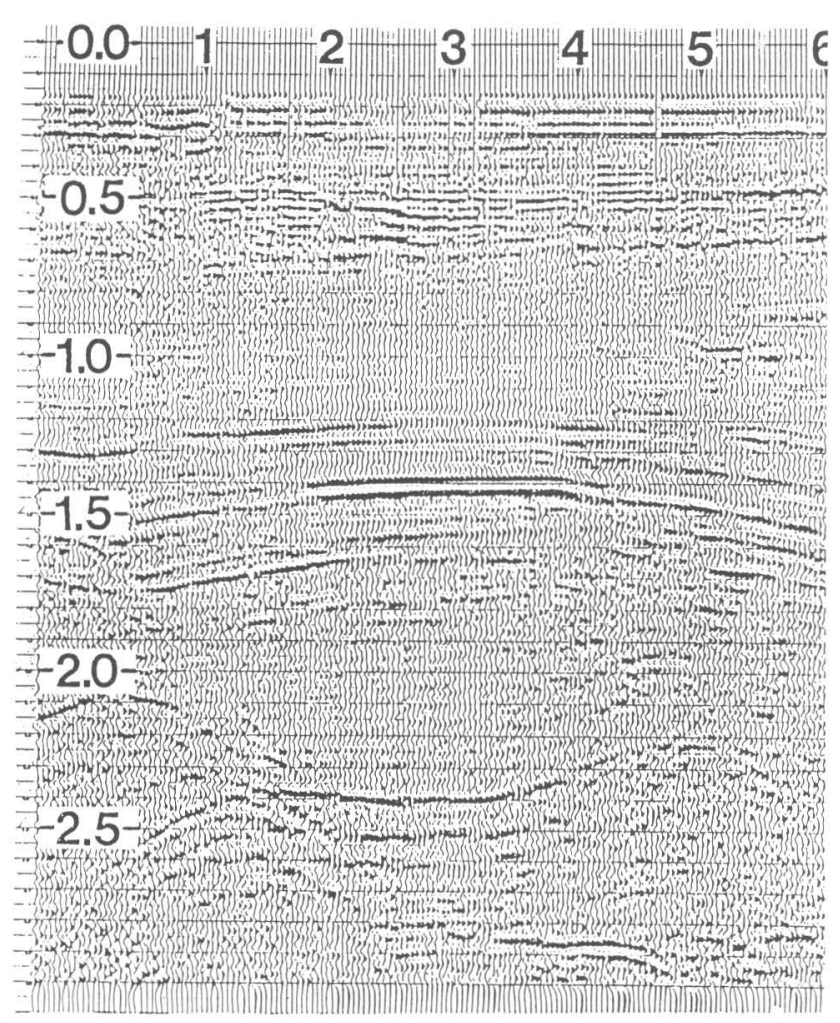

\section{A}

Figure 9. Two-dimensional seismic section from the Gulf of Mexico, which has been processed conventionally $(A)$ and reprocessed to recover relative amplitudes $(B)$. Note "bright-spot" amplitude anomaly at 1.4 seconds. From GeoQuest International, 1975 . Data courtesy of Teledyne Exploration.

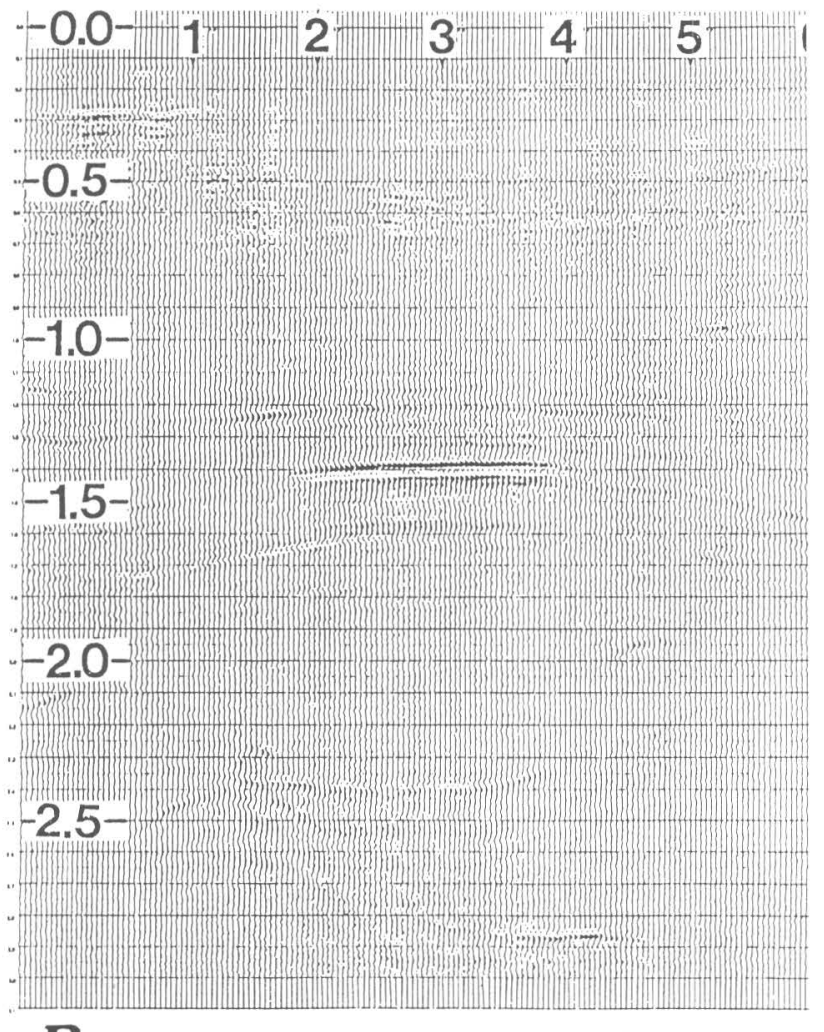

B 
when geologic factors are appropriate, amplitude anomalies resulting from hydrocarbon accumulations can produce a low amplitude anomaly or a dim spot. In either case, the presence of several other indicators, such as a trapping structure, presence of a flat spot, polarity reversal or phasing of the waveshape, low-frequency shadow, velocity sag, amplitude shadow, or shear-wave amplitude anomaly, contribute support to a stronger case in favor of the anomaly being the product of a hydrocarbon accumulation (Sheriff, 1992).

Another recent advance in processing technology, which is being used as a potential direct-detection method comes from looking for increasing seismic-reflection amplitude as the distance from the receiver to the source increases. This technique is known as amplitude versus offset or AVO. The change in amplitude is controlled by the contrast in seismic velocity, density, and Poisson's ratio among gas-bearing and nongas-bearing reservoir rocks. A model of a seismic gather from a gas-bearing sand showing the increase in amplitude with receiver offset distance from the source (Hilterman, 1990) is shown in figure 10. Many factors influence direct hydrocarbon detection by AVO, however, an understanding of the geology and careful processing of the data enhances the probability of successful direct detection.

Seismic inversion is a processing technique, which uses a complex mathematical process to calculate an acoustic impedance or velocity trace from a processed seismic trace (Sheriff, 1992). These inverted traces are known as seismic logs or "seislogs." Sections composed of these seismic log traces provide a continuous vertical and lateral picture of the subsurface velocity structure. This can be very useful in locating low-velocity layers, which may represent porous reservoirs filled with gas. A continuous seislog section produced from reflection data (Lindseth, 1982) is shown in figure 11. Note the similarity between the synthetic sonic trace produced from a seismic trace to the actual borehole sonic log. The main difference is that the seislog trace is smoother than the borehole sonic log. Several zones of lower relative velocity are located between 1.3 and 1.4 seconds. Closer examination of these zones using several other processing tools may suggest a possible hydrocarbonbearing zone. Interpretability of these seislog sections is enhanced by color contouring the velocity values derived from the inversion.

Several processing techniques have recently been developed, which enhance the imaging power of the seismicreflection method. In areas where large subsurface dips are present, a processing technique called dip-moveout (DMO) correction can adjust for the common-depth-point smear, which often occurs when dipping reflections are stacked (Sheriff, 1992). Several DMO methods have been developed including those involving application of special migration techniques, finite difference methods, Fourier-domain implementation, and Kirchhoff routines. Use of DMO processing in special cases can sharpen the subsurface seismic

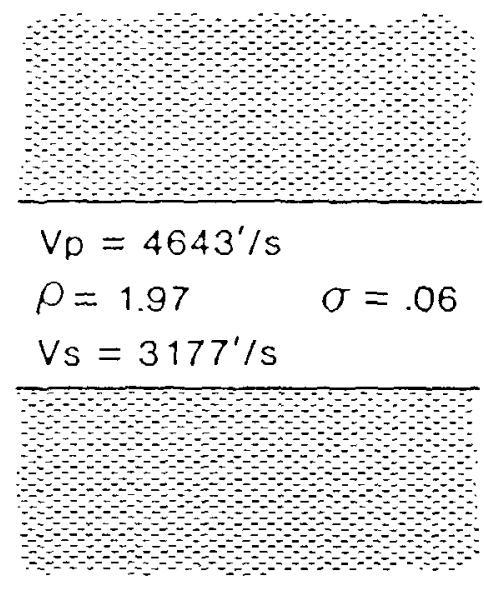

\section{GAS SAND}

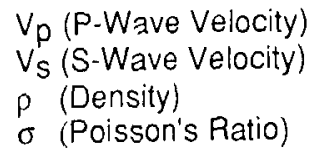

A

$$
\begin{aligned}
& =4643 \mathrm{H} / \mathrm{sec} \\
& =3177 \mathrm{sec} \\
& =1.97 \mathrm{gm} / \mathrm{cc} \\
& =.06
\end{aligned}
$$

Source to Receiver Offset

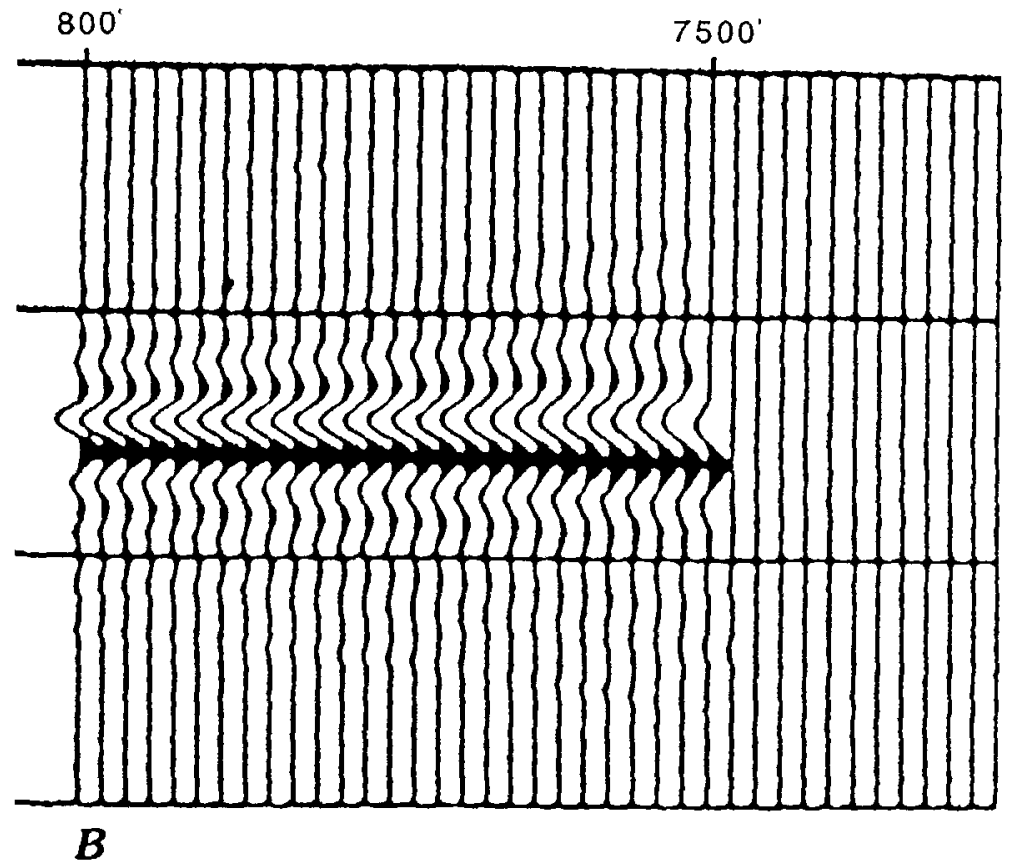

Figure 10. Gas sand model $(A)$ and corresponding synthetic amplitude-versus-offset (AVO) response (B). Note increase in amplitude as source to receiver distance increases. Modified from Hilterman, 1990. 
image and help locate the subtle structural or stratigraphic trap. Another newly developed processing technique involves the use of both DMO and Kirchhoff migration processing applied to traditional 2-D data. This technique produces better results in areas where dips exceed $90^{\circ}$ and is especially useful in imaging underneath salt overhangs in the Gulf of Mexico (Ratcliff and others, 1992). In salt, the best imaging technique is migration of 3-D data, but when such data are not available, the steep-dip method is applied. The steep-dip method, which uses turning waves, works well in locating the vertical flanks of salt structures. The flanks of salt domes are classic exploration targets and more accurate knowledge of the location of the sediment/salt interface reduces the risk of missing potential hydrocarbon traps.

Where 3-D data are available and processing is performed correctly, the 3-D technique provides the best image of the subsurface. Processed 3-D data produce traditional vertical slices through the Earth, the same as 2-D data, but in addition can show horizontal slices in time. These horizontal time slices provide better visualization of surfaces in map view that are especially useful in determining the

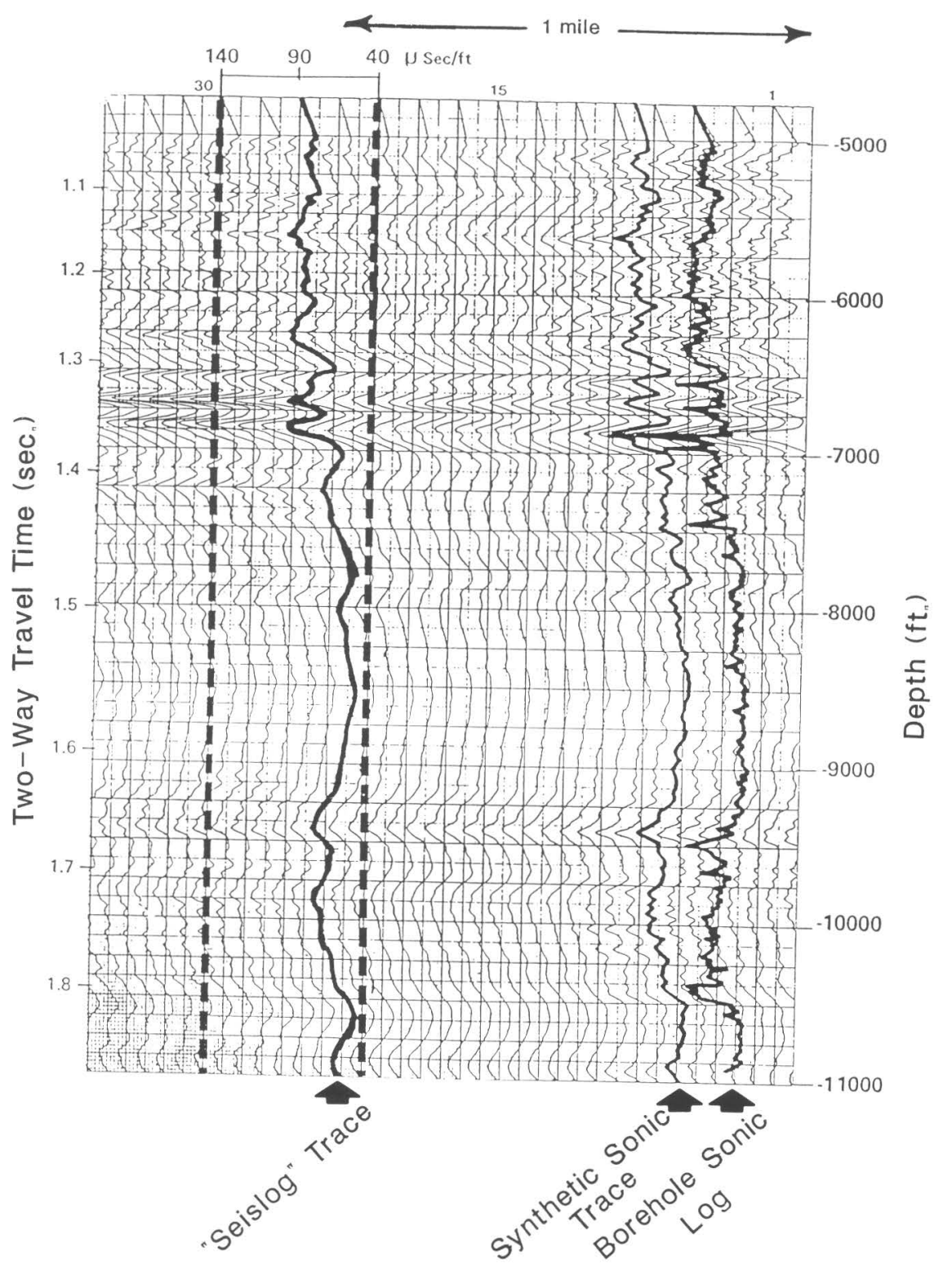

Figure 11. Continuous "seislog" section constructed from inverted seismic data showing correspondence between "seislog" trace, synthetic sonic log, and actual borehole sonic $\log$. From Lindseth, 1982. 1 mile $=1.6$ kilometers. 


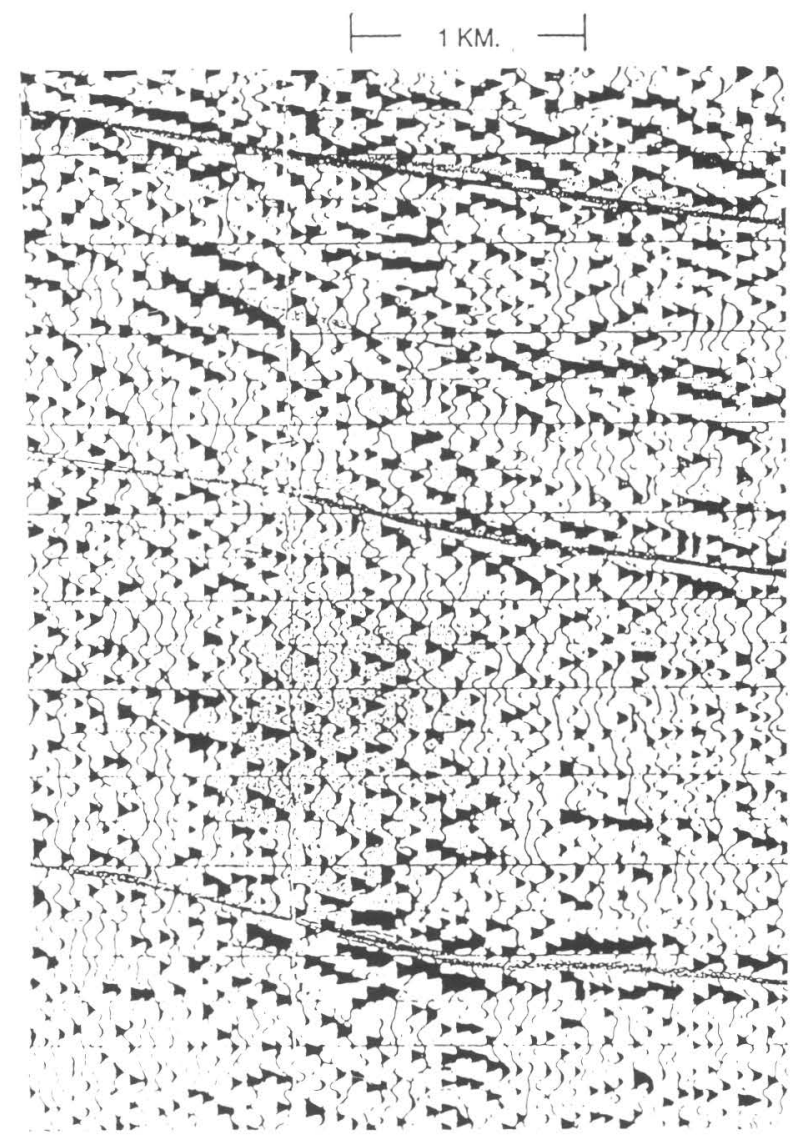

A

ORIGINAL PROCESSING

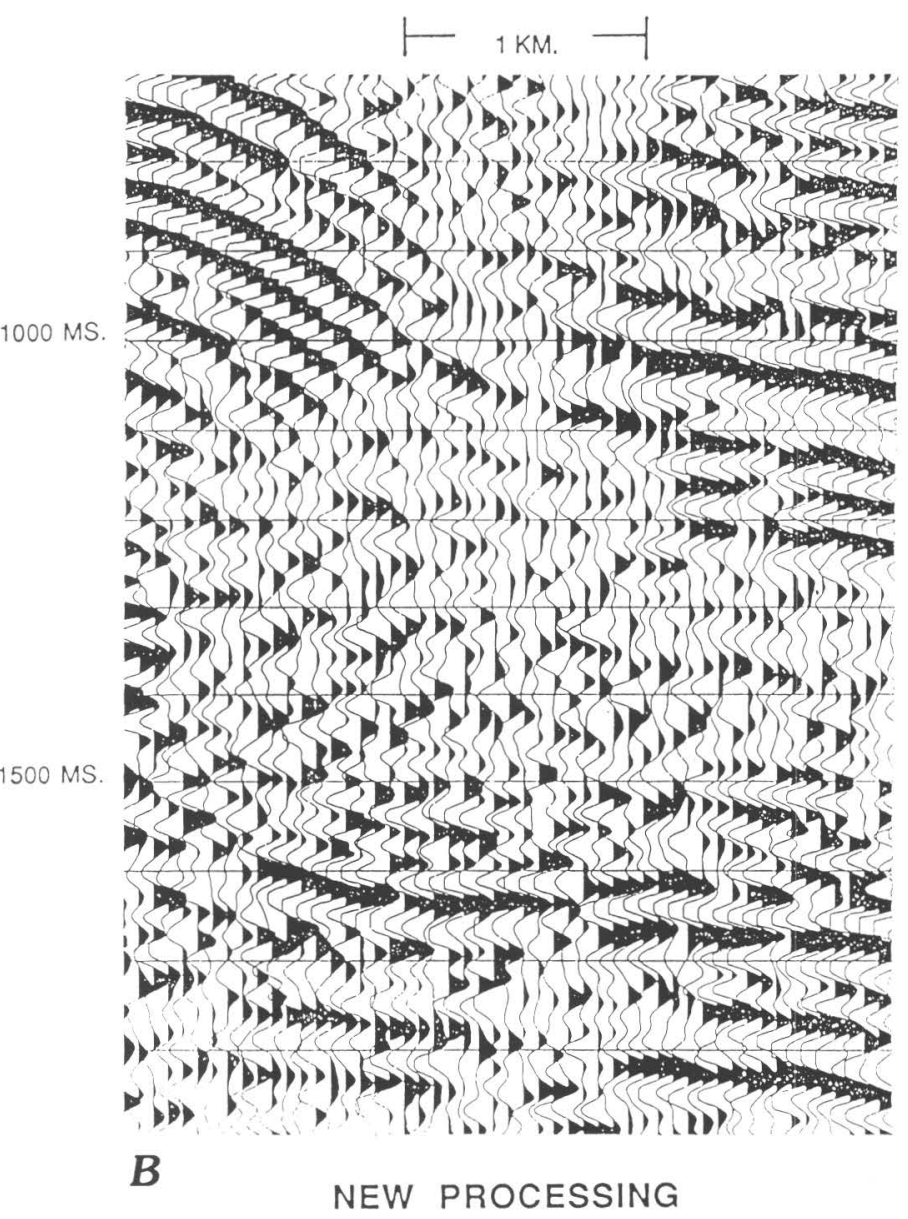

Figure 12. Seismic processing techniques used in the 1960's produced the image $A$ from seismic data acquired at that time. Standard processing techniques in use in the 1990 's produced the image $B$ from the same data. 1 kilometer $=0.6$ mile.

surface expression of complicated fault systems. Determination of fault patterns is critical not only in exploration but also in field development. The obvious benefits derived from the 3-D method make it the seismic method of choice in the 1990's.

Finally, a large amount of old 2-D data that can be reprocessed is still available. New techniques can make $2-\mathrm{D}$ data more usable. In figure 12 , the original data was acquired and processed in the early 1960's, before modern deconvolution, static corrections, filtering, and migration algorithms, to name just a few new techniques, where commonly used. Often the use of these new algorithms in many cases can justify the reprocessing of older 2-D data. Using reprocessed 2-D data can help reduce risk, especially where cost prohibits additional surveys using newer 2-D or 3-D methods.

\section{SEISMIC INTERPRETATION}

Perhaps the single most important development in interpretation of seismic-reflection data comes through the application of color. Color is now used as a visualization tool in almost all data enhancement processing. This is especially true for trace attribute processing techniques such as relative amplitude, instantaneous frequency, and instantaneous phase analysis. Standard use of color coding is also used in displaying the results of trace inversion processing and in presenting both vertically and horizontally sliced 3-D data. The interpretation of a portion of a salt dome in the Gulf of Mexico using horizontally sliced 3-D data (Brown, 1988) is shown in figure 13. The salt core, shown in blue, the structure surrounding the salt dome, and fault locations are easier to interpret when color is applied. A traditional seismic section enhanced by color coding of reflection amplitude strength (Lindseth, 1982) is shown in figure 14. Strong positive and negative amplitudes, possibly indicating hydrocarbon-bearing zones, stand out when color is associated with reflection strength. When color is applied to seislog data derived from inverted seismic data as described above, velocity changes are easier to visualize. An example of inverted seismic data that has been contoured and colorized is shown in figure 15. The 


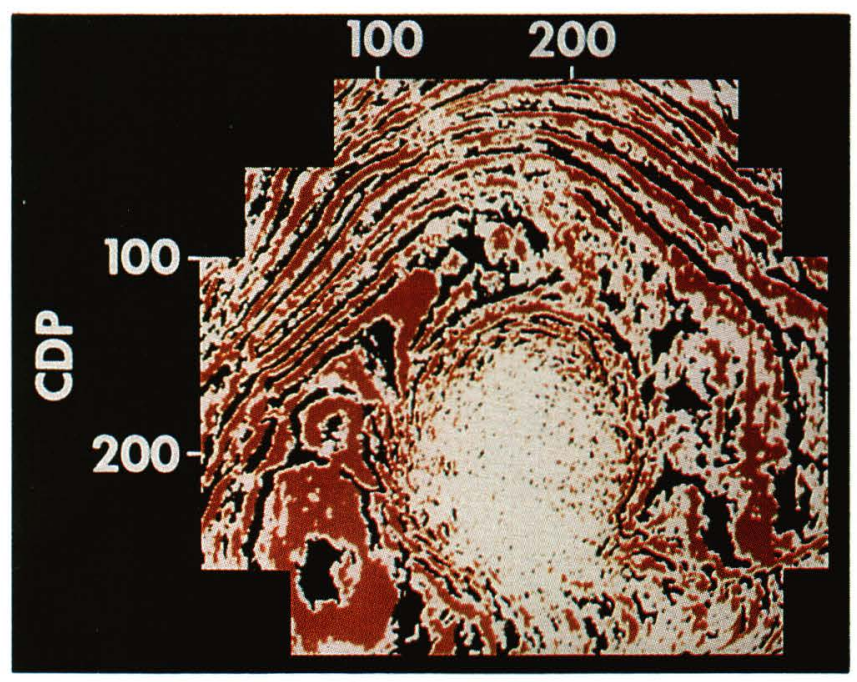

A

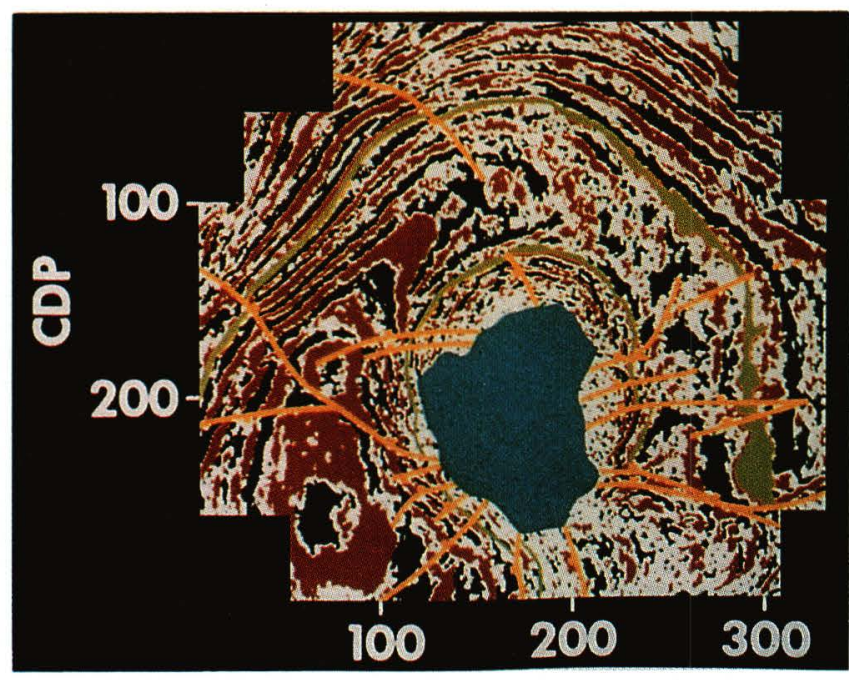

B

Figure 13. Color-coded horizontally sliced 3-D time data from a salt dome in the Gulf of Mexico showing the uninterpreted section (A) and the interpreted section $(B)$. Application of color aids in the visualization and interpretation of the salt core shown in blue and the faults shown in green. From Brown, 1988.

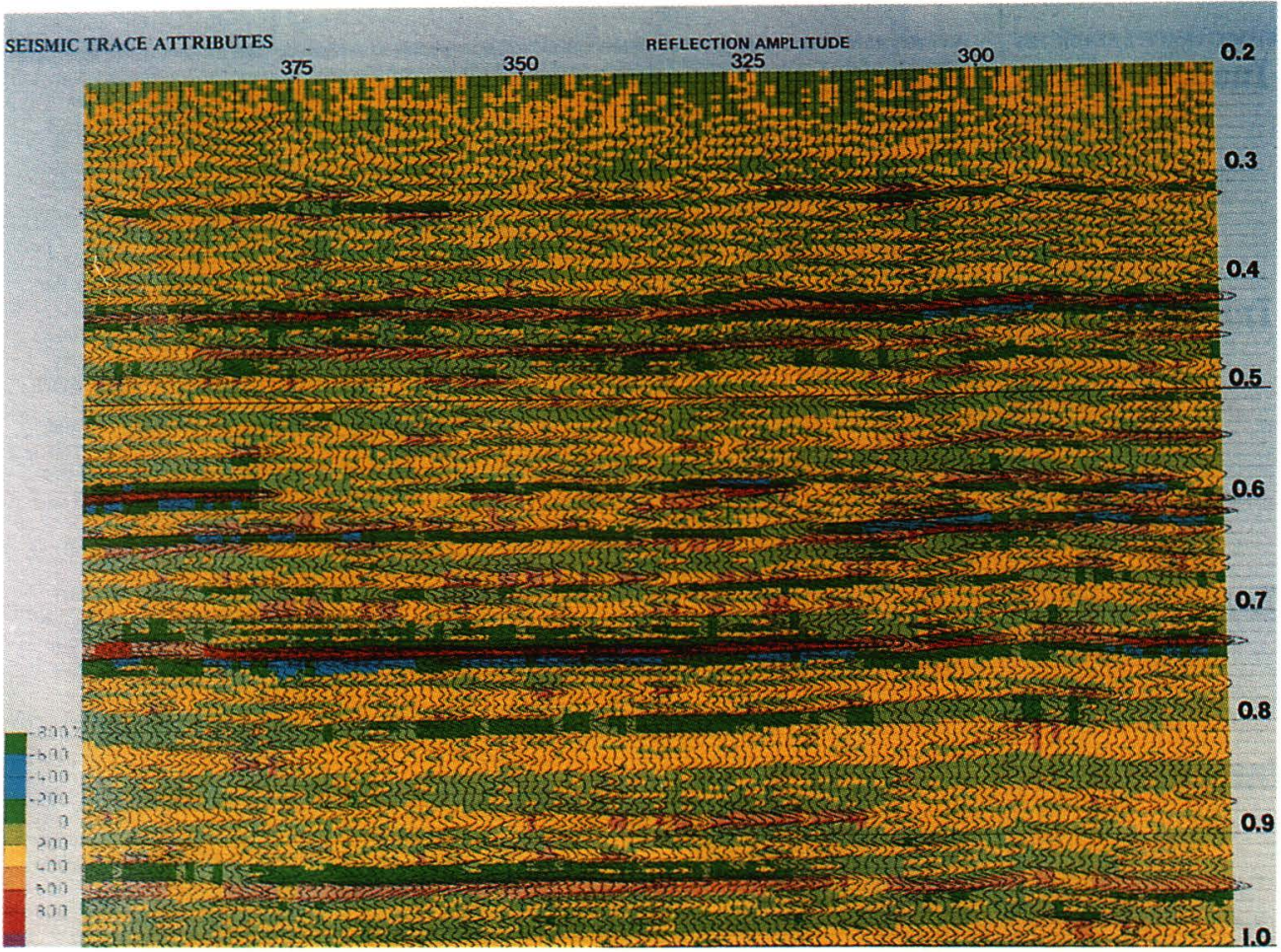

Figure 14. Two-dimensional seismic section with the strength of reflection amplitude color-coded to improve the interpretability of "bright-spots" anomalies (shown in red at roughly 0.73 seconds). From Lindseth, 1982. See Lindseth, 1982, for explanation of colors. 


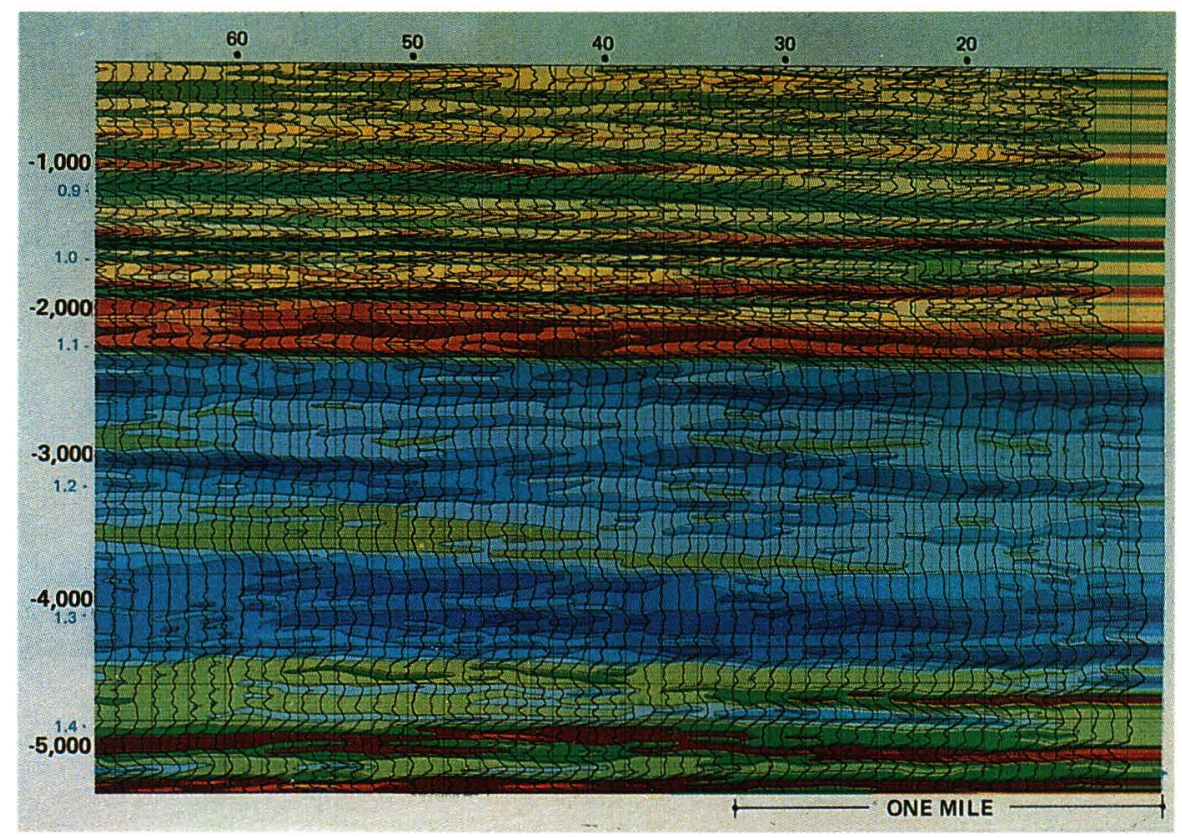

Figure 15. Inverted "seislog" seismic section, which has been contoured and colorized according to interval transit time (velocity). From Lindseth, 1982. 1 mile $=1.6$ kilometers. See Lindseth, 1982, for explanation of colors.

scale on the left in figure 15 indicates velocity expressed as travel time in microseconds per foot, a common sonic $\log$ unit. The blue zone represents a section of material that has higher seismic velocity than material that encases it. Inverted traces colored in orange and located just above the blue zone have velocities ranging from 14,285 ft/sec $(4.35 \mathrm{~km} / \mathrm{sec})$ to $13,330 \mathrm{ft} / \mathrm{sec}(4.06 \mathrm{~km} / \mathrm{sec})$. The velocities in the blue zone range from $16,660 \mathrm{ft} / \mathrm{sec}(5.08 \mathrm{~km} / \mathrm{sec})$ to $18,180 \mathrm{ft} / \mathrm{sec}(5.54 \mathrm{~km} / \mathrm{sec})$. Velocities colored light green and located just below the blue zone range from $14,200 \mathrm{ft} / \mathrm{sec}$ $(4.32 \mathrm{~km} / \mathrm{sec})$ to $16,500 \mathrm{ft} / \mathrm{sec}(5.03 \mathrm{~km} / \mathrm{sec})$. The change from the overlying orange zone into the blue zone in figure 15 represents a transition from clastic into carbonate material. Application of color to these sections makes it easier for the eye to locate subtle lithologic changes and small velocity anomalies which may indicate hydrocarbon accumulations. This is especially true when the color changes indicate slower velocities indicative of natural-gas accumulations.

\section{SUMMARY}

Despite a record number of producing gas wells, several parameters point to declining natural-gas reserves: declining gas reserve to production ratios, rapidly declining natural-gas reserves (EIA, 1992b, 1993; Riva, 1993), significant recent downturns in drilling (PI, 1993), increasingly rapid depletion of young natural gas fields (Butler and
Stark, 1993), significant natural-gas price instability (Parent, 1993), anticipated sharp declines in excess productive capacity (Butler and Stark, 1993; EIA, 1993) and the termination of FERC section 29 tax incentives. These trends suggest an immediate need for increased drilling of highquality prospects for conventional gas resources if further erosion of the natural-gas reserve base is to be prevented. Conventional gas resources will play the dominant source through the year 2010 according to several studies. Some argue (Woods, oral commun., 1993) that these additional conventional resources will come from lightly explored deep basin resources. The need to adequately define such deep resources will require sophisticated exploration tools, particularly the most advanced seismic techniques. Alternatively, either increased imports of natural gas or the increased use of coal or perhaps natural gas derived from new coal gasification techniques may play an increased role. This seems plausible in light of the increasing use of coal shown in figure 1 . The decline of the petroleum infrastructure to historic lows affects not only the ability of the nation to rapidly increase drilling, but also our ability to define prospects, principally seismically, because the number of seismic crews are at historic lows also. There are undoubtedly large natural-gas resources to develop; however, the hope for increased natural-gas usage may be thwarted in the final analysis by the petroleum industry's collapse commencing in 1982, exacerbated in 1986 and continuing to present. The wish to increase domestic natural-gas usage conflicts with the concurrent need to increase 
domestic drilling significantly, particularly on Federal lands. Environmental advocates of increased natural-gas use, which will require significant drilling particularly on Federal lands, will confront other environmental groups opposed to increased drilling on public lands and work to slow the process of bringing these resources to the Nation. The battle, if not at hand, is near.

\section{REFERENCES CITED}

American Petroleum Institute, 1992, Basic petroleum data book: Washington, D.C., American Petroleum Institute, v. 12, no. 3.

Brown, Alistair, R., 1988, Interpretation of Three-Dimensional Seismic Data, 2d ed: American Association of Petroleum Geologists Memoir 42, 253 p.

Butler, J.R., Jr., and Stark, P.H., 1993, U.S. gas: Where's the supply coming from?: World Oil, v. 214 , no. 2, p. $39-44$.

Coal Data, 1991: Published by the National Coal Association, 1130 Seventeenth Street, N.W., Washington, D.C., 94 p.

Dolton, G.L., Mast, R.F., and Crovelli, R.A., 1990, Estimates of undiscovered conventional resources of oil and gas for federal lands, and for Indian and Native lands of the continental United States: U.S. Geological Survey Open-File Report 90705, 64 p., 2 plates.

Drew, L.J., 1990, Oil and gas forecasting-Reflections of a petroleum geologist: International Association for Mathematical Geology, Studies in Mathematical Geology No. 2, New York, Oxford University Press, $252 \mathrm{p}$.

Drew, L.J., and Schuenemeyer, J.H., 1993, The evolution and use of discovery process models at the U.S. Geological Survey: American Association of Petroleum Geologists Bulletin, v. 77 , no. 3 , p. $467-478$.

Energy Information Administration, 1990a, The domestic oil and gas recoverable resource base-Supporting analysis for the national energy strategy: DOE/EIA SR/NES/90-05, 56 p. [Available from National Energy Information Center, EI231, Energy Information Administration, Forrestal Building IF-048, Washington, D.C. 20585.]

-1990 b, U.S. Oil and gas reserves by year of field discovery: Washington, D.C., DOE/EIA-0534. [Available from National Energy Information Center, EI-231, Energy Information Administration, Forrestal Building 1F-048, Washington, D.C. 20585.]

-1992a, U.S. crude oil, natural gas and natural gas liquids reserves, 1991 Annual Report: Washington, D.C., Energy Information Administration DOE/EIA-0216(91), Nov. 1992 , 129 p. [Available from National Energy Information Center, EI-231, Energy Information Administration, Forrestal Building 1F-048, Washington, D.C. 20585.]

1992b, Annual Energy Review 1991, Washington, D.C., Energy Information Administration DOE/EIA-0384(91), 347 p. [Available from National Energy Information Center, EI-231, Energy Information Administration, Forrestal Building 1F-048, Washington, D.C. 20585.]

1993, Short term energy outlook, quarterly projections1st quarter: Washington, D.C., Energy Information Administration, DOE/EIA-0202(93/1Q), 30 p. [Available from
National Energy Information Center, EI-231, Energy Information Administration, Forrestal Building 1F-048, Washington, D.C. 20585.]

Exploration Insight, 1992, NRG Associates: Nov. 1992, v. 90Review: 20 p. [Available from Nehring Associates, Inc., P.O. Box 1655, Colorado Springs, Colorado 80901.]

Fisher, W.L., Finley, R.J., Senc, S.J., Ruppel, S.C., White, G.W., Ayers, W.B., Jr., and Dutton, S.P., 1988, An assessment of the natural-gas resource base of the United States: Austin, Texas, Bureau of Economic Geology, p. 1-77.

GeoQuest International, Ltd., 1975, Amplitude and waveforms in seismic interpretation: GeoQuest Intemational Ltd. Seismic Interpretation Course Notes, $187 \mathrm{p}$.

Gluskoter, H.J., 1991, Coal-A brief overview, in Gluskoter, H.J., Rice, D.D., and Taylor, R.B., eds., Economic Geology, U.S.: Geological Society of America, v. P-2, p. 463-467.

Hilterman, F., 1990, Is AVO the seismic signature of lithology?A case history of ship shoal-south addition: Society of Exploration Geophysicists Leading Edge, v. 9, no. 6, p. 15-22.

Holtberg, P.D., Woods, T.J., Lihn, M.L., and Koklauner, A.G., 1993, Baseline projection data book-GRI baseline projection of U.S. energy demand to 2010, 1993 edition: Washington, D.C., Gas Research Institute, Strategic Planning and Analysis Division, $588 \mathrm{p}$.

Hubbert, M.K., 1974, U.S. energy resources, a review as of 1972, pt. 1, in A national fuels and energy policy study: U.S. 93rd Congress, 2d Session, Senate Committee on Interior and Insular Affairs, Committee Print, Serial no. 9340 (92-75), $267 \mathrm{p}$.

Lindseth, Roy O., 1982, Digital processing of geophysical dataA review: Society of Exploration Geophysicists Continuing Education Program Notes, 320 p.

1990, The next wave of exploration: Society of Exploration Geophysicists Leading Edge, v. 9, no. 12, p. 9-15.

Marsh, R.G., 1971, How much oil are we really finding?: Oil and Gas Journal, v. 69, p. 100-104.

Mast, R.F., and Dingler, J., 1975, Estimates of inferred and indicated reserves for the United States by State, in Miller, B.M., Thomsen, H.L., Dolton, G.L., Coury, A.B., Hendricks, T.A., Lennartz, F.E., Powers, R.B., Sable, E.G., and Varnes, K.L., eds., Geological Estimates of Undiscovered Oil and Gas Resources in the United States: U.S. Geological Survey Circular 725, $78 \mathrm{p}$.

Mast, R.F., Dolton, G.L., Crovelli, R.A., Root, D.H., Attanasi, E.D., Martin, P.E., Cooke, L.W., Carpenter, C.B., Pecora, W.C., and Rose, M.B., 1989, Estimates of undiscovered conventional oil and gas resources in the United States-A part of the Nation's energy endowment, Department of Interior: U.S. Geological Survey and Minerals Management Service Special Publication, 44 p.

Natural Gas Supply Association, 1992, Natural gas field deliveries and productive capacity as of January 1, 1992, Sept. 1992. [Available from Natural Gas Supply Association, 1129 Twentieth Street, N.W., Suite 300, Washington, D.C. 20036.]

Nestvold, E.O., 1992, 3-D seismic-Is the promise fulfilled?: Society of Exploration Geophysicists Leading Edge, v. 11, no. 6, p. 12-19.

National Petroleum Council, 1992, The potential for natural gas in the United States: National Petroleum Council, $1625 \mathrm{~K}$ Street N.W., Washington, D.C., v. I-VI, 2, 102 p. 
NRG Associates, Inc., 1992, The significant oil and gas fields of the United States (through December 31, 1991). [Available from Nehring Associates, Inc., P.O. Box 1655, Colorado Springs, Colorado 80901.]

Parent, L.V., 1993, U.S. gas outlook-Stability eludes industry: World Oil, v. 214 , no. 2 , p. $35-38$.

Petroleum Information Corporation, 1993, Statistical services division, executive summary, March 1993, Denver, CO, 20 p. [Available from Petroleum Information Corporation, 4100 East Dry Creek Road, Littleton, CO 80122.]

Potential Gas Committee, 1992, Potential supply of natural gas in the United States (as of December 31, 1992): Golden, Colorado, Potential Gas Agency, Colorado School of Mines, 168 p.

Ratcliff, D.W., Gray, G.H., and Whitmore, N.D., Jr., 1992, Seismic imaging of salt structures in the Gulf of Mexico: Society of Exploration Geophysicists Leading Edge, v. 11, no. 4, p. 15-31.

Riva, J.P., Jr., 1993, Domestic natural gas-Part of the solution or part of the problem?: Congressional Research Service 93-150 SPR. [Available from the Congressional Research Service, Library of Congress, Science Policy Research Division, Washington, D.C. 20540.]
Root, D.H., 1982, Historical growth estimates of oil and gas field sizes in Oil and gas supply modeling: National Bureau of Standards Special Publication 631, p. 350-368.

Root, D.H., and Mast, R.F., 1993, Future growth of known oil and gas fields: American Association of Petroleum Geologists Bulletin, v. 77, p. 479-484.

Sheriff, R.E., 1992, Encyclopedic Dictionary of Exploration Geophysics 3d ed., Society of Exploration Geophysicists Geophysical References No. 1, 323 p.

Woods, T.J., 1992, Near-term, lower-48 gas deliverability-Implications of gas drilling activity and gas reserves: Washington, D.C., Gas Research Institute, October, 1992, 10 p. [Available from Gas Research Institute Strategic Planning and Analysis Division, 1331 Pennsylvania Ave., N.W., Suite 730 N., Washington, D.C. 20004-1703.]

Woods, T.J., 1993, The long-term trends in U.S. gas supply and prices: 1993 edition of the GRI baseline projection of U.S. energy supply and demand to 2010: Chicago, Illinois, Gas Research Institute, $92 \mathrm{p}$.

World Oil, 1993, Producing oil well numbers head down again: February, 1993, p. 70. 
THE FUTURE OF ENERGY GASES

U.S. GEOLOGICAL SURVEY PROFESSIONAL PAPER 1570

\title{
A Primer In Field-Growth Estimation
}

\author{
By David H. Root ${ }^{1}$ and Emil D. Attanasi ${ }^{1}$
}

\section{CONTENTS}

Abstract 547

Introduction 547

Modeling Field Growth 548

Growth Factors and Functions .......................... 548

Methods of Projecting Field Growth ................... 549

Field Growth Outside of North America ................... 550

Data and Evidence on Nonassociated

Gas Field Growth 550

Example Analysis of Nonassociated Gas Field

Growth

Implications of Field-Growth Analysis

References Cited

554

\begin{abstract}
Field growth refers to the phenomenon of increasing estimates of ultimately recoverable oil and gas that occur as oil and gas fields are developed. From 1978 to 1990, growth of known fields in the United States has accounted for 90 percent of the annual additions to proved reserves. Now that field growth is recognized as a significant source of additions to proved reserves, field-growth prediction models are being made more sophisticated so that the timing of these reserve additions can be forecast.

This paper surveys the literature on field growth and methods of field-growth estimation. It also examines data on nonassociated gas fields of South America, Western

\footnotetext{
'U.S. Geological Survey National Center, 12201 Sunrise Valley Dr.,
} MS 920, Reston, VA 22092-0001.
\end{abstract}

Europe, the Middle East, Africa, non-Communist Far East, and the southwestern Pacific to demonstrate evidence of field growth. Field growth patterns are influenced by market conditions for the resource as well as physical characteristics. These data are also then used in an example that demonstrates field-growth analysis. Although international gas fields show clear evidence of field growth, the data are not yet sufficient for estimating reliable growth functions.

\section{INTRODUCTION}

Field growth refers to the phenomenon of increasing estimates of ultimately recoverable oil and gas, which occur as fields are developed and produced. A field is defined by the U.S. Department of Energy (Energy Information Administration, 1990a) as an area consisting of single reservoir or multiple reservoirs all grouped on, or related to, the same individual geologic structural feature and (or) stratigraphic condition. Two or more reservoirs assigned to the same field may be separated vertically by impervious strata or laterally by geologic barriers.

Typically, initial estimates of field recovery are only detailed enough to establish whether the field can be commercially developed. As fields are developed, wells may be drilled to extend the surface limits of the field and to find new pay zones. Even if no additional wells are drilled to extend field limits or find new reservoirs, the initial estimates of ultimate field recovery may be revised to reflect operation experience, newly installed water flood, gas reinjection, or recompletions of existing development wells to produce from other pay zones. The ultimate field size refers to the sum of current field reserves and cumulative past production. Generally, the number of years since the discovery of a field or age of the field is used as a proxy variable for the degree of field development. 
Early efforts to estimate field growth focused on determining sizes of recent discoveries to evaluate the effectiveness of ongoing exploration. Moreover, in the United States, field growth provides 90 percent of the total annual additions to proved reserves. Now that field growth is recognized as a significant source of additions to proved reserves, models for predicting field growth are also being made more sophisticated so that the timing of the related additions to proved reserves may be forecast.

Since 1950, the United States and Canada have accounted for more than 90 percent of the world's cumulative exploratory and development drilling. They are the most intensively explored and developed of the major oil-producing countries. Because of this drilling, the phenomenon and importance of field growth was recognized earlier in these countries than elsewhere. Although international oil and gas data show clear evidence of field growth, the gas data are not yet sufficient for estimating reliable growth functions.

\section{MODELING FIELD GROWTH}

\section{GROWTH FACTORS AND FUNCTIONS}

Even in intensively drilled areas of the United States and Canada, there are few fields for which annual estimates of ultimate recovery from the year of discovery to the year of abandonment are publicly available. Generally, data used in the modeling of field growth consist of short time-series
(6 to 14 years) of estimates of fields grouped by discovery year. For example, with such a series the expected field growth for a field going from age 19 to age 20 is computed using estimates of ultimate recovery for all those fields that went from age 19 to 20 during the sample period. An entirely different set of fields may be used in calculating expected field growth from age 4 to age 5. The U.S. data series used most frequently in early field growth studies was published by the American Petroleum Institute (API) and American Gas Association (AGA) (American Petroleum Institute, American Gas Association, and Canadian Petroleum Association, 1967-1980) and covers the period from 1966 through 1979. A later data series, by the Energy Information Administration, covers from 1977 to 1988 (Energy Information Administration, 1990a). Since 1985, NRG Associates of Colorado Springs has published a data series of estimates of ultimate field sizes.

Over the years, researchers have attempted to characterize the systematic nature of field growth. Because of the nature of available data, techniques have usually been statistical. Efforts to characterize field growth have centered on the estimation of growth factors. These factors can be presented in several different ways. For example, the factors can be given as the ratio of the size of a field $K$ years after discovery to the size of the field as estimated in its year of discovery. We call these the "cumulative-growth factors."

When the cumulative-growth factors can be calculated or presented in a functional form, the function is sometimes called a "growth function." Examples of growth functions are shown in figure 1. Curves in the figure show

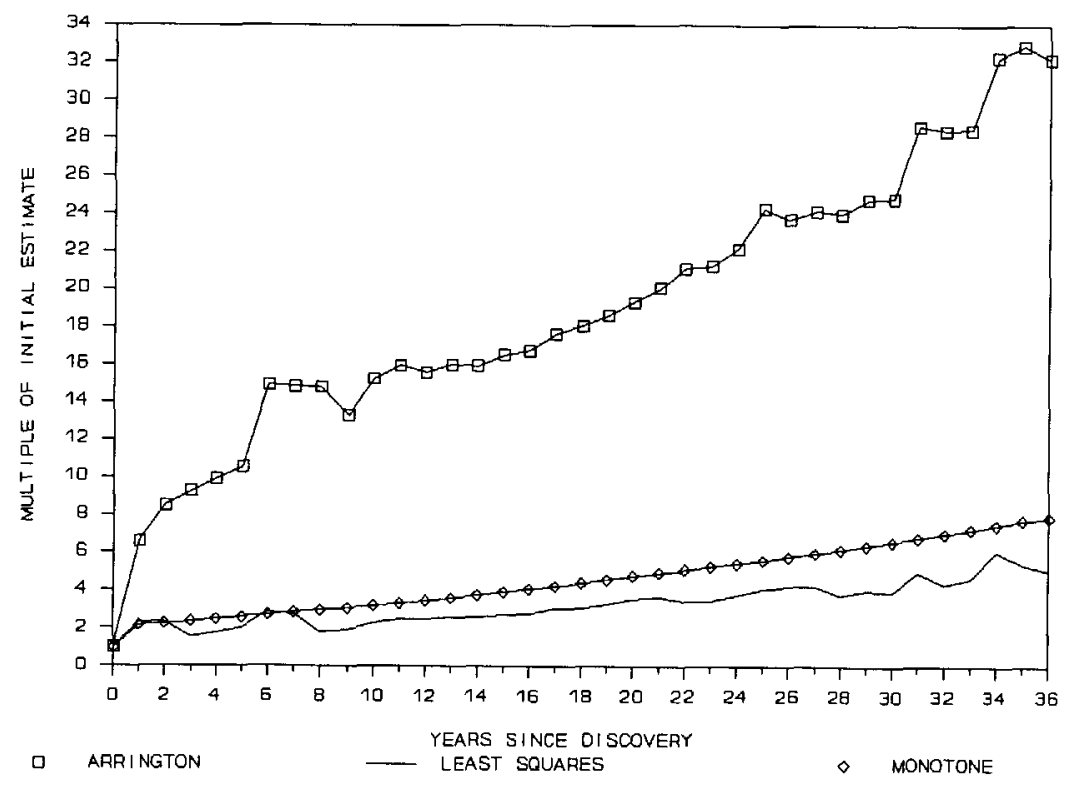

Figure 1. Three separate growth functions, described in text, showing current field size as a multiple of initial estimated field size in year of discovery. Data used was for productive nonassociated gas fields in South America, Western Europe, the Middle East, Africa, non-Communist Asia, and the southwestem Pacific. Data from Petroconsultants, SA, 1985-1992. 
the current estimated field size as a multiple of its initial estimated field size. The factors can also be given as the ratio of the size in year $\mathrm{K}+1$ to the size in year $\mathrm{K}$ after discovery. We call these the "annual-growth factors." The cumulative-growth factors can be calculated from the annual-growth factors and vice versa. As the age of fields increase without limit one would expect the annualgrowth factors to approach 1 and the cumulative-growth factors to approach an asymptote.

Given the cumulative-growth function, G(n), it is theoretically possible to calculate from the estimate made in year $\mathrm{e}$ what the estimate made in year $\mathrm{e}+\mathrm{k}$ will be using equation 1:

$$
\hat{c}(d, e+k)=c(d, e) \times G(e+k-d) / G(e-d)
$$

where $\mathrm{k}$ is the time elapsed between an early estimate year, e, and late estimate year, e+k, c(d,e) is the amount of oil or gas discovered in year $\mathbf{d}$ as estimated in year $\mathrm{e}$, and $\hat{c}$ is the projected estimate.

\section{METHODS OF PROJECTING FIELD GROWTH}

The principles of field growth were developed for recoverable oil and were later applied to gas. Arrington (1960) wanted to evaluate the returns to recent exploration for the Carter Oil Company and needed factors to correct for the initial underestimation of sizes of new fields. He estimated the annual growth of a field between the eth and e+1st year after discovery to be

$$
\frac{\sum_{d} c(d, e+1)}{\sum_{d} c(d, e)}
$$

where $c(d, e), d$, and e have the same meaning as in equation 1. In the formula above, the same fields appear in the numerator and in the denominator. The only difference is that in the numerator the size estimates were made when the fields were 1 year older. The underlying assumptions are that the amount of growth in any one year is proportional to the size of the field and that this proportionality constant changes as the field ages.

Arrington's measure of the degree of development was the age of the field in years from the date of discovery. This measure is readily available and represents the simplest index of all the various types of development that a field can undergo. Arrington did not assume a functional form relating the annual growth factors to the age of the field.

Marsh (1971) applied Arrington's method to the API and AGA series of estimated recoverable oil and gas by year of discovery. The published estimates were as of year end 1966, 1967, 1968, and 1969. Marsh was the first to estimate gas-field growth and according to his results oil fields grew more than gas fields. Marsh's estimates of oil and gas-field growth from pre-1970 discoveries are shown in table 1.

Hubbert $(1967,1974)$ like Arrington was interested in assessing the size of recent discoveries. His method differed from Arrington's method in that Hubbert assumed a functional form for the cumulative-growth factors and estimated them directly from the API and AGA data. Hubbert (1974) assumed that the unproved recoverable oil and gas in a field decayed exponentially with time. His estimates of future oil and gas growth for pre1972 discoveries are shown in table 1. Hubbert's growth factors were later used by Mast and Dingler in 1975 to estimate indicated and inferred reserves (field growth) for pre-1973 discoveries (see table 1) and were published in the first U.S. Geological Survey national oil and gas assessment.

Pelto (1973) assumed that growth proceeded in a regular way; namely, that each year a fixed fraction of the unproved recoverable oil in a field was credited to proved reserves-an assumption equivalent to Hubbert's. He used the API series of recoverable oil by year of discovery. Using a least-squares procedure he estimated the fully grown ultimate recovery from each discovery year and the fixed fraction. His estimate of the fixed fraction was 0.1175 , and so 11.75 percent of the unproved oil was added to proved reserves each year. A peculiarity of Pelto's results is that approximately two-thirds of the growth is in 1968 discoveries (the discovery year of the giant Prudhoe Bay oil field). His estimate of growth from pre-1971 discoveries is shown in table 1 .

The U.S. Geological Survey (Root, 1981) estimated future growth by applying the Arrington method to the API and AGA data. More recently, the U.S. Geological Survey and Minerals Management Service published a revised set of estimates of inferred reserves for oil and gas fields discovered prior to 1987 (U.S. Department of the Interior, 1989). Because API and AGA annual series ceased publication with the 1979 edition, the data used for estimating growth of pre-1987 fields did not reflect the significant expansion of the oil and gas industry activity in the early 1980's during periods of high prices. Both estimates are shown in table 1 .

As part of the national energy strategy, Energy Information Administration (1990b) projected expected future growth of pre-1988 discoveries (see table 1) using data from the oil and gas integrated field file (OGIFF). The oil and gas growth functions that were fitted to these data implied that fields would continue to grow for 100 years after discovery because there are 100-year-old fields still growing. The National Petroleum Council also used the OGIFF data base along with the AGA series to estimate a functional form that included field age and the number of gas wells drilled since discovery. 
Table 1. Estimates of expected oil and gas reserve growth in the lower 48 States, except as noted

[BBO, billion barrels of oil; Tcf, trillion cubic feet; N/A, data not available]

\begin{tabular}{|c|c|c|c|}
\hline \multirow{2}{*}{ Age and type of field } & \multicolumn{2}{|c|}{ Growth } & \multirow{2}{*}{ Source of data } \\
\hline & Total Projected & Actual 1990 & \\
\hline Pre-1970 fields-oil ------ & $9.6 \mathrm{BBO}$ & $29.9 \mathrm{BBO}$ & Marsh (1971) \\
\hline Pre-970 fields-gas------ & $70.0 \mathrm{Tcf}$ & $166.4 \mathrm{Tcf}$ & Marsh (1971) \\
\hline $\begin{array}{l}\text { Pre-1971 fields-oil } \\
\text { (including Alaska). }\end{array}$ & $31.5 \mathrm{BBO}$ & $34.1 \mathrm{BBO}$ & Pelto (1973) \\
\hline Pre-1972 fields—oil --.-.- & $20.0 \mathrm{BBO}$ & $28.1 \mathrm{BBO}$ & Hubbert (1974) \\
\hline Pre-1972 fields-gas ----- & $165.0 \mathrm{Tcf}$ & $171.5 \mathrm{Tcf}$ & Hubbert (1974) \\
\hline Pre-1973 fields--oil-_-... & $17.6 \mathrm{BBO}$ & $27.2 \mathrm{BBO}$ & Mast and Dingler (1975) \\
\hline Pre-1973 fields-gas --.-. & $166.0 \mathrm{Tcf}$ & $171.5 \mathrm{Tcf}$ & Mast and Dingler (1975) \\
\hline Pre-1979 fields-oil --..-. & $22.8 \mathrm{BBO}$ & $20.7 \mathrm{BBO}$ & Root (1981) \\
\hline Pre-1979 fields-gas --.-- & $131.7 \mathrm{Tcf}$ & $187.0 \mathrm{Tcf}$ & Root (1981) \\
\hline Pre-1987 fields-gas --... & $154.3 \mathrm{Tcf}$ & $63.8 \mathrm{Tcf}$ & Potential Gas Committee (1987) \\
\hline Pre-1987 fields—oil --..-- & $15.3 \mathrm{BBO}$ & $5.3 \mathrm{BBO}$ & U.S. Department of Interior (1989) \\
\hline Pre-1987 fields-gas ----. & $95.8 \mathrm{Tcf}$ & $63.8 \mathrm{Tcf}$ & U.S. Department of Interior (1989) \\
\hline Pre-1988 fields—oil --.--- & $51.0 \mathrm{BBO}$ & N/A & $\begin{array}{l}\text { Energy Information Administration } \\
\qquad(1990)\end{array}$ \\
\hline Pre-1988 fields-gas ----- & $265.0 \mathrm{Tcf}$ & N/A & $\begin{array}{l}\text { Energy Information Administration } \\
\text { (1990) }\end{array}$ \\
\hline Pre-1989 fields-gas ----- & $380.0 \mathrm{Tcf}$ & N/A & Fisher (1991) \\
\hline Pre-1990 fields-gas -.... & $203.0 \mathrm{Tcf}$ & N/A & National Petroleum Council (1992) \\
\hline
\end{tabular}

Both the Potential Gas Committee and the Texas Bureau of Economic Geology estimated field growth using nonstatistical methods (see table 1). The Potential Gas Committee's definition of probable reserves in known fields roughly corresponds to the increment in current proved reserves expected to be added to field size when a field is fully grown. The Potential Gas Committee used the same geologic methods applied in the appraisal of undiscovered gas resources to estimate probable reserves in identified fields (Potential Gas Committee, 1987). The Texâs Bureau of Economic Geology (Fisher, 1991) used a geologic engineering approach to calculate the amount of gas in compartments of reservoirs not in contact with a well bore. Studies based on the Texas experience were extrapolated to the national level.

The many estimates of projected growth for the above methods of calculation are summarized in table 1. For the older estimates, actual growth through 1990 is also shown. Of the nine estimates shown in the table, the earliest four for both oil and gas have already been exceeded. Even within intensively drilled areas of the United States, field growth is regularly underestimated.

\section{FIELD GROWTH OUTSIDE OF NORTH AMERICA}

\section{DATA AND EVIDENCE ON NONASSOCIATED GAS FIELD GROWTH}

The principal source of international oil and gas data is the field data base compiled by Petroconsultants, SA. This data base covers all countries outside of the United States and Canada. Petroconsultants updates the field files quarterly. The field data contains estimates of ultimate oil and gas recovery, cumulative and annual production, and a number: of geologic and geographic characteristics on each field.

One source of nonuniformity in the data is that there is no international standard definition of reserves. Generally, international field-reserve estimates are not tied to installed production facilities. Internationally there are fields with large reserves that have no installed production capacity. This is in contrast to the U.S. definition of proved reserves where reserves are computed on the basis of installed production capacity. 
Another source of nonuniformity in the field-reserve data is unwillingness of the national companies or their governments to release information. For example, while the Petroconsultants' data base includes many fields in the former Soviet Union and Eastern Europe, most reserve estimates and field-production data were not available for these areas. Because there is not yet a long enough series of reliable data from these areas to show a pattern of field growth, the former Soviet Union and Eastern Europe were not included in this analysis. China was not included because there was little gas production.

For our purposes, the study area is South America, Western Europe, the Middle East, Africa, South Asia, and Southwestern Pacific. As of the end of 1992, the ultimate recovery from known fields in the study area was reported to be 2,901 trillion cubic feet (Tcf) of gas and 1,001 billion barrels of oil (Bbo).

Using a rule that a nonassociated gas field has a gas to oil ratio of at least 20 thousand cubic feet per barrel (Mcf/bbl), the 2,901 Tcf is classified into 1,049 Tcf of associated gas and 1,852 Tcf nonassociated gas. Some of the oil and gas fields have never produced. Of the 1,001 Bbo in the study area, 860 Bbo ( 86 percent) are in fields that have had some production. About 55 percent of the nonassociated gas is in gas fields that have never produced.

Because information on fields that have never been produced is inevitably sketchy, the analysis was restricted to fields that have had some production. Figure 2 shows cumulative pre-1986 discoveries of produced nonassociated gas fields estimated in 1985, 1988, and 1992. The 1992 estimate of these fields is more than 150 Tcf greater than the 1985 estimate. A series of estimates of the amount of gas in gas fields that have had some production of oil or gas is shown in table 2 by year of discovery. For most discovery years, the estimate made in 1985 of ultimate recovery is less than the estimate made in 1992.

\section{EXAMPLE ANALYSIS OF NONASSOCIATED GAS FIELD GROWTH}

A growth function permits the calculation of later estimates of a field's size from earlier estimates. A measure of the accuracy of forecast of later estimates from the application of the growth function to earlier estimates is defined in equation 2. Among all possible growth functions, $G(n)$, the one minimizing the error shown in equation 2 is called the least-squares growth function and is shown in figure 1 .

$$
\begin{aligned}
& \operatorname{ERR}(\mathrm{d}, \mathrm{e}, \mathrm{k})=(\hat{c}(\mathrm{~d}, \mathrm{e}+\mathrm{k})-\mathrm{c}(\mathrm{d}, \mathrm{e}+\mathrm{k}))^{2} \\
& \operatorname{SSE}=\sum_{\mathrm{d}, \mathrm{e}, \mathrm{k}} \operatorname{ERR}(\mathrm{d}, \mathrm{e}, \mathrm{k})
\end{aligned}
$$

where $\operatorname{ERR}(\mathrm{d}, \mathrm{e}, \mathrm{k})$ is the error function for a single-forecast estimate and SSE is the sum of all errors and the other symbols are defined as in equation 1 . The leastsquares growth function in figure 1 was calculated for nonassociated gas in fields in the study area that have had some production. The calculations were only extended as

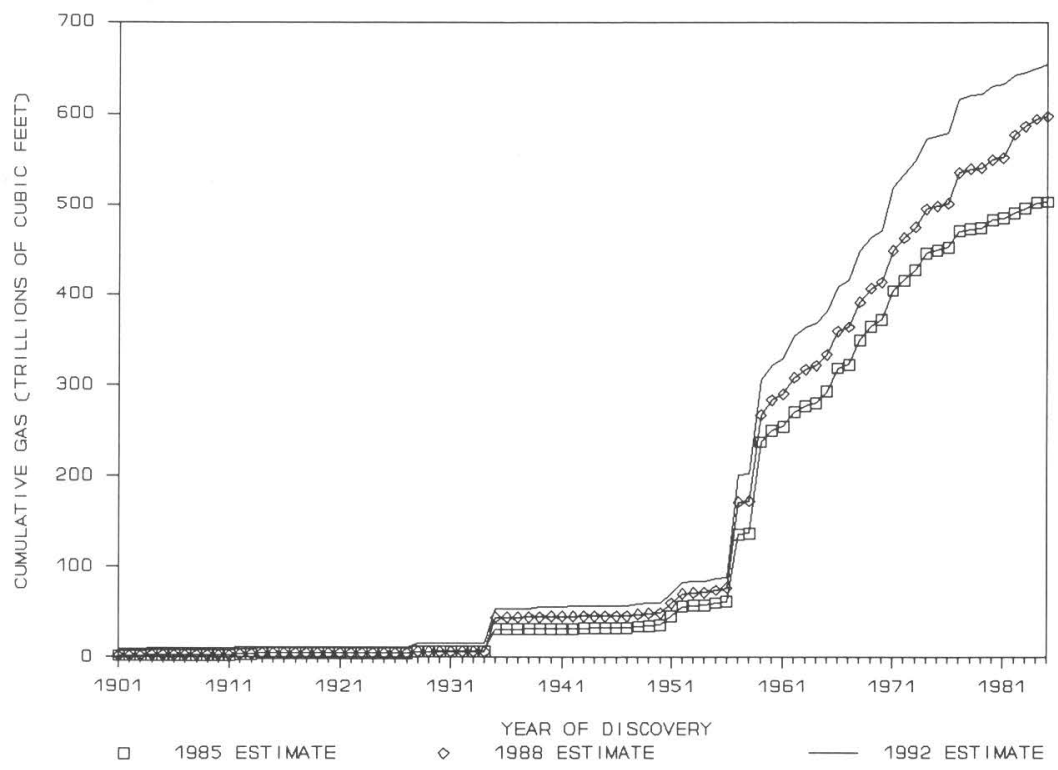

Figure 2. Cumulative amounts of discovered gas reserves of productive nonassociated gas fields discovered before 1986 in South America, Western Europe, the Middle East, Africa, non-Communist Asia, and the southwestern Pacific, as recorded by Petroconsultants, SA, in 1985, 1988, and 1992. North field in Qatar, Persian Gulf, has been omitted because early estimates were reduced by 150 trillion cubic feet. 
Table 2. Recoverable gas in nonassociated gas fields in South America, Western Europe, the Middle East, South Asia, and Southwestern Pacific that have had some production.

[units, billion cubic feet. North Field of Qatar in Saudi Arabıa not included]

\begin{tabular}{|c|c|c|c|c|c|c|c|c|}
\hline \multirow[b]{2}{*}{$\begin{array}{c}\text { Discovery } \\
\text { year }\end{array}$} & \multicolumn{8}{|c|}{ Year of estimate } \\
\hline & 1985 & 1986 & 1987 & 1988 & 1989 & 1990 & 1991 & 1992 \\
\hline Pre-1950 & 34,917 & 35,082 & 35,215 & 48,314 & 50,501 & 51,767 & 52,110 & 59,673 \\
\hline 1950 & 863 & 863 & 855 & 754 & 759 & 760 & 595 & 595 \\
\hline 1951 & 9,822 & 9.822 & 9,396 & 10.539 & 10,624 & 12,235 & 12,235 & 11,460 \\
\hline 1952 & 10,555 & 10,495 & 10,614 & 10,714 & 10,726 & 10,816 & 10,872 & 10,872 \\
\hline 1953 & 1,196 & 1,196 & 1,036 & 1,046 & 1,055 & 1,056 & 1,116 & 1,115 \\
\hline 1954 & 506 & 506 & 520 & 412 & 550 & 549 & 551 & 546 \\
\hline 1955 & 2,455 & 2,455 & 2,374 & 2,708 & 2,762 & 2,828 & 2,558 & 2,557 \\
\hline 1956 & 1,515 & 1,515 & 1,596 & 2,086 & 2,182 & 2,192 & 2.164 & 2,163 \\
\hline 1957 & 74,180 & 74,180 & 74,159 & 94,655 & 94,689 & 94,712 & 110,133 & 112,399 \\
\hline 1958 & 862 & 862 & 872 & 865 & 1,024 & 1,025 & 1,059 & 1,073 \\
\hline 1959 & 100,433 & 100,433 & 94,273 & 94,373 & 95,431 & 104,464 & 103,108 & 103,037 \\
\hline 1960 & 12,377 & 12374 & 12,588 & 17,061 & 17,121 & 17,142 & 17,204 & 16,425 \\
\hline 1961 & 4,272 & 4,273 & 5,103 & 6,750 & 6,957 & 7,507 & 7,147 & 7,661 \\
\hline 1962 & 15,876 & 15,926 & 15,692 & 17,550 & 18,114 & 18,330 & 24,545 & 24,531 \\
\hline 1963 & 7,156 & 7,156 & 7,711 & 9,341 & 9,406 & 10,085 & 10,337 & 10,472 \\
\hline 1964 & 3,289 & 3,326 & 4,081 & 4,322 & 4,465 & 4,310 & 4,320 & 4.375 \\
\hline 1965 & 12,251 & 12,353 & 13,215 & 11,829 & 11,903 & 11,267 & 12,000 & 11,982 \\
\hline 1966 & 26,149 & 25,342 & 25,019 & 26,154 & 25,952 & 26,208 & 32,816 & 27,266 \\
\hline 1967 & 3,706 & 3,590 & 3,820 & 4,868 & 6,641 & 7,833 & 7,898 & 7,903 \\
\hline 1968 & 27,255 & 27,396 & 27,134 & 27,328 & 28,491 & 29,546 & 29,796 & 33,109 \\
\hline 1969 & 15,152 & 15,224 & 13,944 & 15,094 & 13,216 & 14,488 & 14,427 & 14,498 \\
\hline 1970 & 7,651 & 6,762 & 6,520 & 6,905 & 7,397 & 8,118 & 8,127 & 8,139 \\
\hline 1971 & 31,967 & 31,862 & 31,922 & 35.553 & 35,758 & 37,726 & 45,500 & 47,586 \\
\hline 1972 & 11,324 & 10,851 & 12,306 & 13,864 & 14,376 & 14,606 & 14,723 & 13,717 \\
\hline 1973 & 12,067 & 12,287 & 12,433 & 11,834 & 12,248 & 12,057 & 14,827 & 14,897 \\
\hline 1974 & 18,561 & 19,156 & 19,957 & 20,067 & 21,438 & 21,437 & 23,531 & 24,407 \\
\hline 1975 & 2,947 & 2,952 & 3,178 & 3,245 & 3,505 & 3,445 & 3,481 & 3,322 \\
\hline 1976 & 3.636 & 3,611 & 3,636 & 3,189 & 3,466 & 3,287 & 3,281 & 3,358 \\
\hline 1977 & 17,910 & 27,665 & 33,682 & 33,973 & 33,915 & 34,819 & 34,864 & 37,041 \\
\hline 1978 & 2,265 & 2,245 & 2,176 & 3,591 & 4,386 & 4,335 & 4,375 & 3,992 \\
\hline 1979 & 1,293 & 1,076 & 1,131 & 1,262 & 1,618 & 1,548 & 1,563 & 1,390 \\
\hline 1980 & 8,836 & 9,450 & 9,269 & 9,246 & 8,984 & 8,983 & 10,159 & 8,116 \\
\hline 1981 & 1,814 & 1,811 & 2,147 & 2,378 & 2,271 & 2,375 & 1,902 & 2,357 \\
\hline 1982 & 5,822 & 5,881 & 5,918 & 24,899 & 25,436 & 25,545 & 9,097 & 9,868 \\
\hline 1983 & 4,867 & 4,904 & 4,708 & 9,482 & 3,836 & 3,674 & 3,541 & 3,968 \\
\hline 1984 & 6,510 & 6,544 & 7,196 & 8,070 & 4,223 & 4,352 & 4,239 & 4,290 \\
\hline 1985 & 625 & 1,377 & 1,508 & 2,692 & 3,510 & 3,969 & 3,899 & 3,469 \\
\hline 1986 & & 120 & 848 & 1,087 & 1,491 & 1,401 & 1,403 & 1,966 \\
\hline 1987 & & & 53 & 2,419 & 5,623 & 5,030 & 5,294 & 5,767 \\
\hline 1988 & & & & 7 & 586 & 556 & 746 & 935 \\
\hline 1989 & & & & & 75 & 181 & 151 & 121 \\
\hline 1990 & & & & & & 30 & 335 & 335 \\
\hline 1991 & & & & & & & & 250 \\
\hline 1992 & & & & & & & & 0 \\
\hline
\end{tabular}


far as 36 years because of the brief history of gas production in the study area.

The irregularity of the least-squares growth curve (figs. $1,3)$ results from market fluctuations that affect field development as well as the physical characteristics of the fields. If it is assumed that, other things being equal, older fields will have a smaller percentage growth than younger fields, this assumption is expressed analytically in equation 3 .

$$
\frac{G(n+1)}{G(n)} \leq \frac{G(n)}{G(n-1)}
$$

The monotone growth function is defined here as the growth function that satisfies the monotone restriction of equation 3 and minimizes the error function in equation 2 and is shown in figure 1 . The growth curve calculated by the Arrington method described above is also shown in figure 1.

All curves in figure 1 show the current estimated size of a field as a multiple of its initial estimated size. As an alternative to figure 1 , the estimated size of the field at age 36 (the limit of our data) could be shown as a multiple of the current estimated size (fig. 3). The reason for doing this is that growth curves that look very different in figure 1 sometimes follow similar growth patterns after the first few years. This is the case for the monotone and Arrington curves after 15 years, as shown in figure 3 .

For example, the expected growth 36 years into the future (to the year 2028) of nonassociated gas in produc- tive fields in the study area was calculated from the three growth curves of figure 1 . The calculated growth for the Arrington function is $240 \mathrm{Tcf}$, for the least squares it is 190 Tcf, and for the monotone it is 251 Tcf. These amounts are not representative of the total world growth or even total study area growth for the next 36 years because the calculations were based on about 10 percent of the world's reported gas and less than 25 percent of the gas in the study area. The industry is still too immature to have generated data necessary to support a reliable growth-factor calculation.

\section{IMPLICATIONS OF FIELD-GROWTH ANALYSIS}

Estimated field reserves are typically limited to recoverable quantities of oil and gas in known reservoirs, which can be produced with some degree of confidence. Ultimate field-size estimates, on average, increase as fields are developed because field-development activities frequently extend the limits of the known reservoirs, find new reservoirs, or may improve recovery of the in-situ hydrocarbon resource. In the United States, estimated field reserves may represent only one-third of the remaining oil and gas in known fields.

In recent years, growth of known fields in the United States has been the dominant source of annual additions to proved reserves. The same growth phenomenon is demonstrated in producing fields outside the United States and

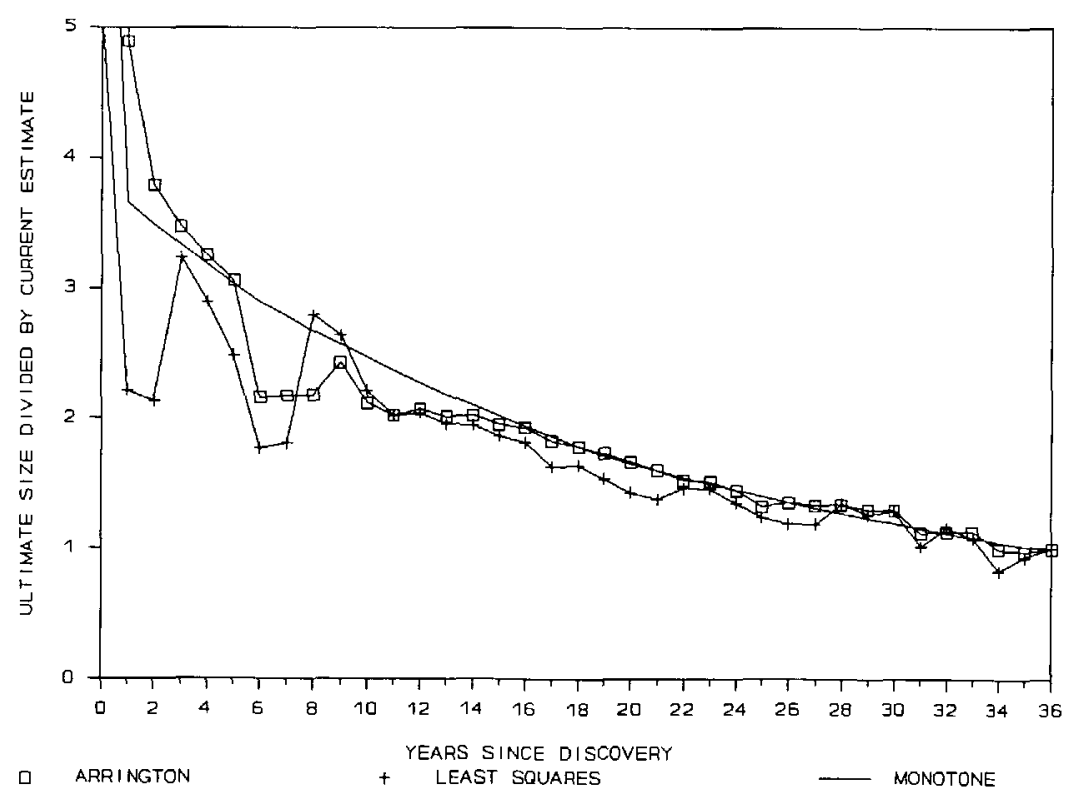

Figure 3. Three separate functions, as discussed in text, showing estimated fully grown ultimate field size as a multiple of current field size. Data for producing nonassociated gas fields in South America, Western Europe, the Middle East, Africa, non-Communist Asia, and the southwestern Pacific. Data from Petroconsultants, SA, 1985-1992. 
Canada. The infancy of the industry in many foreign countries, however, precludes a comprehensive forecast of expected additions to reserves from growth in known fields in these areas. For new discoveries outside of the United States and Canada, field production can be delayed for years or even decades by lack of infrastructure to produce and transport the product to markets. In such cases, the initial field size estimates may have little relation to the size of the field used for production-facility design.

For the analyst trying to characterize field growth, there are some caveats that should be pointed out before applying one of the techniques described herein. Any series of ultimate field-size estimates that reflect field growth also generally indicate field-development activity, which is driven by economics and market conditions. Consequently, fieldgrowth functions will reflect the economic conditions faced by the industry. The longer the series of estimates the more likely that the data will span a boom and bust cycle and will, on average, be representative of future conditions.

If the time period between field discovery and first production is consistently excessive, as in a remote region, a more accurate index of field development might be the number of years since first production rather than the age of a field since discovery. Finally, field-growth patterns will also reflect the quality of the resource. Fields containing primarily heavy oil or having low-permeability gas reservoirs will have very different development patterns than conventional oil and gas fields. Therefore, nonconventional fields should be analyzed separately.

\section{REFERENCES CITED}

American Petroleum Institute, American Gas Association, and Canadian Petroleum Association, 1967-1980, Reserves of crude oil, natural gas liquids, and natural gas in the United States and Canada as of December 31: Washington, D.C., American Petroleum Institute, v. 25-34.

Arrington, J.R., 1960, Size of crude reserves is key to evaluating exploration programs: Oil and Gas Journal, v. 58, no. 9, p. 130-134.
Energy Information Administration, 1990a, U.S. oil and gas reserves by year of field discovery: Department of Energy (DOE/EIA-0534), $137 \mathrm{p}$.

Energy Information Administration, 1990b, The domestic oil and gas recoverable resource base-Supporting analysis for the national energy strategy: Department of Energy SR/NES/90$05,56 \mathrm{p}$.

Fisher, W.L., 1991, Future supply potential of U.S. oil and natural gas: Society of Exploration Geophysicists, Leading Edge of Exploration, December, p. 15-21.

Hubbert, M.K., 1967, Degree of advancement of petroleum exploration in United States: American Association of Petroleum Geologists Bulletin, v. 51, no. 11, p. 2207-2227.

Hubbert, M.K., 1974, U.S. energy resources, a review as of 1972, pt. 1, in A national fuels and energy policy study: U.S. 93rd Congress, 2d session, Senate Committee on Interior and Insular Affairs, Committee Print, Serial No. 9340(92-75), $267 \mathrm{p}$.

Marsh, R.G., 1971, How much oil are we really finding?: Oil and Gas Journal, v. 69, no. 14, p. 100-104.

Mast, R.F. and Dingler, J., 1975, Estimates of inferred and indicated reserves for the United States by states, in Miller and others, Geological estimates of undiscovered recoverable oil and gas resources in the United States, U.S. Geological Survey Circular 725 , p. 73-78.

National Petroleum Council, 1992, The potential for natural gas in the United States: Washington, D.C., National Petroleum Council, v. 1, 190 p.

Pelto, C.R., 1973, Forecasting ultimate oil recovery, in Symposium on Petroleum Economics and Evaluation, published by the Society of Petroleum Engineers of AIME, Dallas Section, p. 45-52.

Potential Gas Committee, 1987, Potential supply of natural gas in the United States (December 31, 1986): Potential Gas Agency, Colorado School of Mines, $119 \mathrm{p}$.

Root, D.H., 1981, Estimation of inferred plus indicated reserves for the United States, in Dolton, G.L. and others, Estimates of undiscovered recoverable conventional resources of oil and gas in the United States: U.S. Geological Survey Circu$\operatorname{lar} 860$, p. 83-87.

U.S. Department of the Interior, 1989, Estimates of undiscovered conventional oil and gas resources in the United States-A part of the Nation's energy endowment: U.S. Geological Survey and the Minerals Management Service, $51 \mathrm{p}$. 


\title{
Gas Hydrates as a Potential Energy Resource- A Review of Their Methane Content
}

\author{
By Keith A. Kvenvolden ${ }^{1}$
}

\section{CONTENTS}

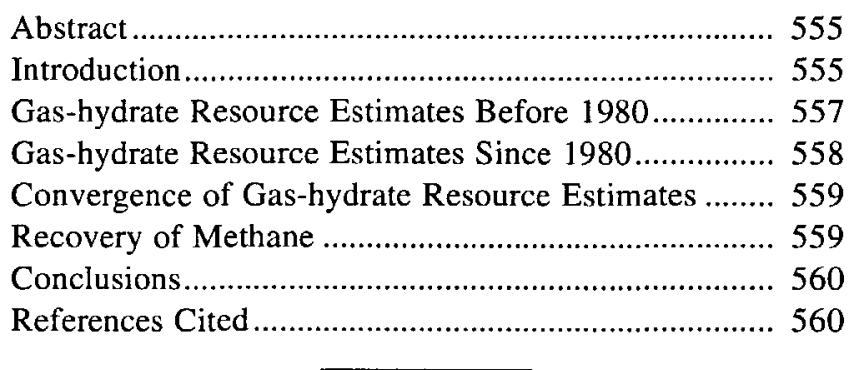

\begin{abstract}
Gas-hydrate deposits are found in sediments less than $2,000 \mathrm{~m}$ deep in high-latitude regions associated with permafrost, and beneath the ocean in outer continental margins. Because gas hydrates are globally widespread and contain methane within the solid hydrate structure of water, the potential amount of hydrate-methane present worldwide is very large. World estimates of the methane content of gas hydrates range from $5 \times 10^{2}$ to $1.2 \times 10^{6}$ trillion cubic feet (Tcf) $\left(1.4 \times 10^{13}\right.$ to $\left.3.4 \times 10^{16} \mathrm{~m}^{3}\right)$ for permafrost regions and from $1.1 \times 10^{5}$ to $2.7 \times 10^{8} \mathrm{Tcf}\left(3.1 \times 10^{15}\right.$ to $\left.7.6 \times 10^{18} \mathrm{~m}^{3}\right)$ for deep oceanic sediments. These estimates are speculative and uncertain. Nevertheless, at the present time there is a convergence of ideas regarding the size of this potential worldwide resource, placing it at about $7 \times 10^{5} \mathrm{Tcf}\left(2 \times 10^{16}\right.$ $\mathrm{m}^{3}$ ) of methane. If this number is approximately correct,
\end{abstract}

${ }^{1}$ U.S. Geological Survey, MS 999, 345 Middlefield Rd., Menlo Park, CA 94025. there is about twice as much carbon in gas hydrates as is present in all known fossil-fuel deposits. Such large deposits of methane make gas hydrates attractive as a potential energy resource for the future. Uncertainties about mode of occurrence and the lack of applicable production techniques, however, augur that wide-scale exploitation, if proven feasible, will not take place until sometime in the 21 st century.

\section{INTRODUCTION}

Natural-gas hydrates are solid, ice-like substances composed of rigid cages of water molecules that enclose molecules of gas, mainly methane. Chemically speaking, these substances are water clathrates of methane, where clathrate refers to the cage structure of the water molecules. These deposits of solidified water and methane are commonly called either methane clathrates, gas clathrates, methane hydrates, or gas hydrates. The maximum amount of methane that can occur in a methane hydrate is fixed by the clathrate geometry. In an ideally saturated methane hydrate, the molar ratio of methane to water is nearly 1:6. This molar ratio is equal to a volumetric ratio at standard temperature and pressure (STP) of about 164:1 (Davidson and others, 1978).

The worldwide locations of known and inferred gas hydrates are shown in figure 1, and the following discussion comes from Kvenvolden (1988). The cold surface temperatures in polar regions promote the occurrence of permafrost, and the resulting cold temperatures at depth in permafrost regions lead to conditions appropriate for gashydrate deposits. Gas hydrates are known to be present at the Messoyakha gas field of the western Siberian platform (Makogon and others, 1972; Collett, this volume) and are 
believed to occur in other permafrost areas of northern Russia, including the Timan-Pechora province, the eastern Siberian craton, and the northeastern Siberian and Kamchatka areas (Cherskiy and others, 1985).

Permafrost-associated gas hydrates are also present in the North American Arctic (Kvenvolden and Grantz, 1990). Well-log responses consistent with the presence of gas hydrates were obtained in the Mackenzie Delta (Bily and Dick, 1974; Judge, 1982), Sverdrup Basin, Arctic Platform and Arctic Islands (Davidson and others, 1978; Judge, 1982; Judge and Majorowicz, 1992), and on the North Slope of Alaska (Collett and others, 1990). At a well between the Kuparuk River and Prudhoe Bay oil fields of the North Slope, pressure-core-barrel samples provided conclusive evidence for the presence of gas hydrates (reviewed by Kvenvolden and McMenamin, 1980).

In addition to the onshore regions of permafrost in the Arctic, offshore permafrost is known to occur on the Beaufort Sea shelf of Canada (Neave and others, 1978; Weaver and Stewart, 1982). Also, offshore permafrost probably occupies a part of the vast continental shelf of Siberia (Bell, 1983). Studies by Rogers and Morack (1980) on subsea permafrost and sea-level history have led to the inference that offshore permafrost may persist beneath any part of the Arctic shelf shoreward from about the $90-\mathrm{m}$ isobath. Hence, the distribution of gas hydrates associated with offshore permafrost is expected to be similar to that of gas hydrates associated with onshore permafrost.

The combined information from Arctic gas-hydrate studies shows that in permafrost regions, gas hydrates may exist at subsurface depths ranging from about 130 to 2,000 m. Gas hydrates may also occur in Antarctica, but few data are available (Hitchon, 1974; MacDonald, 1983); land-temperature profiles suggest that gas hydrates could exist to depths as great as $2,000 \mathrm{~m}$.

The presence of gas hydrates in outer continental and insular margin sediments has been inferred mainly from the occurrence on marine seismic profiles of a pronounced

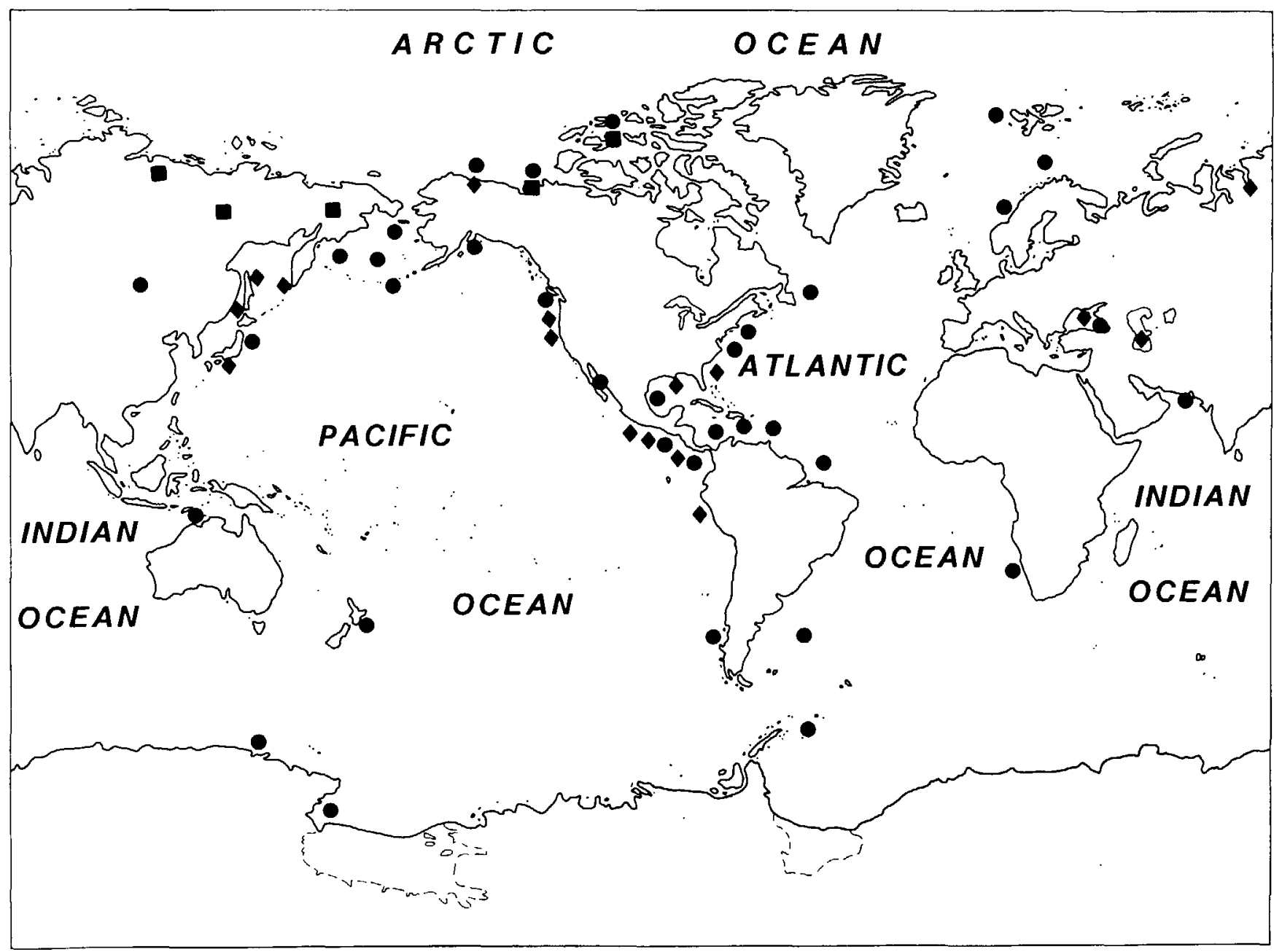

Figure 1. Worldwide locations of known and inferred gas hydrates in regions of continental permafrost (squares) and in oceanic sediments (dots). Diamonds mark locations where gas-hydrate samples have been recovered. Dashed lines in Antarctica indicate continental edge of ice shelves. Modified from Kvenvolden (1988) with information from Kvenvolden and others (1993). 
reflection that coincides with the predicted boundary at the base of the gas-hydrate stability zone. This reflection is commonly called a bottom-simulating reflection, or BSR, because it nearly parallels the topography of the sea floor. BSR's have been mapped at depths below the sea floor ranging from about 100 to $1,100 \mathrm{~m}$ (Kvenvolden and McMenamin, 1980; Dillon and others, this volume). The upper limit of the gas-hydrate zone in outer continental margin sediments is ordinarily the sea floor.

Samples of gas hydrates have been recovered at 14 oceanic locations, providing positive proof of natural gas-hydrate occurrence (fig. 1). Deep-ocean drilling has recovered gas hydrates offshore from Peru, Costa Rica, Guatemala, Mexico, southeastern United States, and western United States, at two locations offshore from Japan, and in the Gulf of Mexico. Shallow-sediment coring (piston and gravity cores) has recovered gas hydrates in sediment from the Black Sea, Caspian Sea, offshore from northern California and in the Gulf of Mexico, and at two locations in the Sea of Okhotsk (Kvenvolden and others, 1993).

The preceding discussion demonstrates that gas-hydrate deposits are globally widespread and are limited to the uppermost $2,000 \mathrm{~m}$ of the sediment column. Because gas hydrates contain a potentially large amount of methane within $2,000 \mathrm{~m}$ of the Earth's surface, they are attractive as a possible energy resource for the future. This report reviews the estimates that have been made of the methane content of gas hydrates and makes the following points.

1. The amount of methane in gas hydrates is certainly large, but all of the estimates that have been made are speculative.

2. A convergence of current ideas suggests that the amount of methane in gas hydrates worldwide is about $7 \times 10^{5}$ trillion cubic feet (Tcf) or $2 \times 10^{16} \mathrm{~m}^{3}$. (These values are equivalent to $1 \times 10^{19} \mathrm{~g}$ methane carbon or $1 \times 10^{4}$ gigaton (Gt) methane carbon (1 gigaton $=10^{9}$ metric ton $=10^{15} \mathrm{~g}$ )). In this paper Tcf units are used, with metric equivalents given in the tables and summaries.

3. Present uncertainties about mode of occurrence of gas hydrates and about applicable production technologies limit the feasibility of immediate wide-scale exploitation.

4. If these uncertainties can be overcome, gas-hydrate exploitation may become a reality sometime in the 21 st century.

\section{GAS-HYDRATE RESOURCE ESTIMATES BEFORE 1980}

Estimates made before 1980 of the amount of methane in natural gas hydrates are highly speculative due to incomplete knowledge of gas-hydrate occurrences and poor methods of estimating reserves in known occurrences. The following discussion is taken from a detailed analysis by the Potential Gas Committee (1981) of the potential supply of natural gas as of December 1980. Conventional methods of estimating gas resources are not applicable to gashydrate deposits because (1) on conventional well logs, gas hydrates have the same characteristics as permafrost, (2) flow tests require a means of disrupting equilibrium conditions in order to dissociate the gas hydrates to verify their presence, (3) reservoir permeability has thus far been found to be very low, and (4) the hydrate-gas/free-gas ratio cannot be fully determined from core samples or porosity measurements (Barraclough, 1980). Nevertheless regional and world estimates of gas-hydrate resources have been calculated (table 1). Trofimuk and others (1977) attempted to incorporate many complex factors into their calculations, including regional and world coefficients of past and present temperatures, sediment thicknesses, percent of organic material, and percent of methane production and retention.

World estimates for the amount of methane in gashydrate deposits range from $5 \times 10^{2}$ to $1.2 \times 10^{6}$ Tcf for permafrost areas and from $1.1 \times 10^{5}$ to $2.7 \times 10^{8}$ Tcf for oceanic sediments. The estimates in table 1 show considerable variation, but oceanic sediments seem to be a much greater resource of hydrate methane than continental sediments because in oceanic sediments greater production of microbial methane occurs and the gas-hydrate stability zone is more extensive. The estimates by Dobrynin and others (1981) are considerably higher than the others. Their calculations are "rough estimates" based on permafrost coverage and zones of gas-hydrate stability in oceanic sediments without apparent regard for distributions of sedimentary basins or sources of methane. Their estimates provide an overly optimistic upper limit.

None of these estimates (table 1) seem to account for reservoir quality. Proved and currently recoverable world resources of conventional methane are $2.3 \times 10^{3}$ to $2.7 \times 10^{3}$ Tcf, and the estimated total remaining recoverable methane is $7.9 \times 10^{3}$ to $9.2 \times 10^{3}$ Tcf (Parent, 1980). If only 1 percent of gas-hydrate methane is within porous and permeable strata, then the most conservative estimate for recoverable hydrate methane is still more than $1.1 \times 10^{3} \mathrm{Tcf}$, or one-half of the proved and currently recoverable conventional gas resources. Also the above estimates do not consider possible accumulations of free gas trapped beneath the gas-hydrate layers.

Estimates of methane in gas-hydrate deposits of the United States (table 2) were extrapolated from the world estimates (table 1). Based on Russian estimates for methane in gas hydrates of Siberia, Mclver (1981) calculates that permafrost areas in Alaska have about 23 Tcf of hydrate methane. Gas-hydrate resources in permafrost areas of the United States may contain from $1.1 \times 10^{1}$ to $2.5 \times 10^{4}$ Tcf of methane. Gas-hydrate resources in continental shelf and slope areas of the United States represent about 7 percent of the total world resource of hydrated methane if it is assumed that 35 percent of oceanic gas hydrates occur 
Table 1. World estimates of the amount of methane in gas hydrates in continental and oceanic settings (from the Potential Gas Committee, 1981).

\begin{tabular}{ccl}
\hline \multicolumn{2}{c}{ Volume of methane } & \multicolumn{1}{c}{ Reference } \\
\cline { 1 - 2 } (trillion cubic feet) & (cubic meters) & \\
\hline \multicolumn{3}{c}{ Continental } \\
\hline $5.0 \times 10^{2}$ & $1.4 \times 10^{13}$ & Meyer (1981) \\
$1.1 \times 10^{3}$ & $3.1 \times 10^{13}$ & McIver (1981) \\
$2.0 \times 10^{3}$ & $5.7 \times 10^{13}$ & Trofimuk and others (1977) \\
$1.2 \times 10^{6}$ & $3.4 \times 10^{16}$ & Dobrynin and others (1981) \\
\hline & $\vdots$ & Oceanic \\
\hline $1.1 \times 10^{5}$ & $3.1 \times 10^{15}$ & Mclver (1981) \\
\hline$(1.8$ to 8.8$) \times 10^{5}$ & $(5$ to 25$) \times 10^{15}$ & Trofimuk and others (1977) \\
$2.7 \times 10^{8}$ & $7.6 \times 10^{18}$ & Dobrynin and others (1981) \\
\hline
\end{tabular}

in these areas (Potential Gas Committee, 1981). Thus estimates of methane in gas hydrates in oceanic sediments along continental margins of the United States range from $2.7 \times 10^{3}$ to $6.7 \times 10^{6}$ Tcf.

\section{GAS-HYDRATE RESOURCE ESTIMATES SINCE 1980}

As discussed above, estimates made during the 1980's of the amount of methane in gas hydrates produced a wide range of values with the upper limit of $2.7 \times 10^{8} \mathrm{Tcf}$ being unrealistically large. An increased understanding of gas-hydrate occurrence since then has resulted in estimates that are in the lower range of previous values. For example, Claypool (Kvenvolden and Claypool, 1988) estimated the amount of methane in oceanic sediments by determining the area of the world ocean in which sediment with 1 percent or more organic carbon is accumulating $\left(10 \times 10^{6} \mathrm{~km}^{2}\right)$. Assuming $0.5 \mathrm{~km}$ as the average thickness of the gas-hydrate stability zone, an average porosity of 50 percent with gas hydrates occupying 10 percent of the available porosity, and a gas-hydrate yield of 160 volumes of gas at STP per volume of hydrate, the amount of methane present in oceanic gas hydrates is calculated to be about $1.4 \times 10^{6} \mathrm{Tcf}$.

This estimate of $1.4 \times 10^{6} \mathrm{Tcf}$ could be refined downward by taking into consideration the fact that most of the sediment in the estimated area probably contained insufficient organic carbon to generate the volumes of methane required to occupy 10 percent of the available porosity with gas hydrates. The estimate could also be refined upward by taking into account that sediment accumulation in upwelling areas would have significantly more methane than is allowed for in the average values used. Such re-
Table 2. Estimates of the amount of methane in gas hydrates of the United States (from the Potential Gas Committee, 1981).

\begin{tabular}{ccl}
\hline \multicolumn{2}{c}{ Volume of methane } & \multicolumn{1}{c}{ Reference } \\
\cline { 1 - 2 } (trillion cubic feet) & (cubic meters) & \\
\hline & Continental (Alaska) \\
\hline $1.1 \times 10^{1}$ & $3.1 \times 10^{11}$ & Meyer (1981) \\
$2.3 \times 10^{1}$ & $6.5 \times 10^{11}$ & McIver (1981) \\
$4.2 \times 10^{1}$ & $1.2 \times 10^{12}$ & Trofimuk and others (1977) \\
$2.5 \times 10^{14}$ & $7.1 \times 10^{14}$ & Dobrynin and others (1981) \\
\hline & Oceanic (shelf and slope) \\
\hline $2.7 \times 10^{3}$ & $7.6 \times 10^{13}$ & McIver (1981) \\
$(4.2$ to 21$) \times 10^{5}$ & $(1.2$ to 6.1$) \times 10^{14}$ & Trofimuk and others (1977) \\
$6.7 \times 10^{6}$ & $1.9 \times 10^{17}$ & Dobrynin and others (1981) \\
\hline
\end{tabular}

finements are not justified, however, on the basis of the present state of understanding.

Kvenvolden and Grantz (1990) attempted to estimate the extent of gas hydrate in the outer continental margin of the Arctic Basin by extrapolating information from the amount of gas hydrate offshore of northern Alaska as inferred from marine seismic records. Taking into account areal extent $\left(5.25 \times 10^{5} \mathrm{~km}^{2}\right)$, thickness of the gas-hydrate zone $(40 \mathrm{~m})$, average porosity $(30$ percent), and gashydrate yield (140 volumes of gas at STP per volume of hydrate), they calculated a total of about $3.5 \times 10^{4} \mathrm{Tcf}$ of methane in sediment of the outer margin of the Arctic Basin. The length of this margin is about 5 percent of the total length of continental margins worldwide. If oceanic gas hydrates in general are distributed as they are inferred to be in the Arctic, then the total amount of methane in oceanic gas hydrates would be about $7 \times 10^{5}$ Tcf (Kvenvolden, 1988). This estimate is a factor of two less than that made by Claypool but falls within the range of values $\left(1.8 \times 10^{5}\right.$ to $\left.8.8 \times 10^{5} \mathrm{Tcf}\right)$ determined by Trofimuk and others (1977). These recent estimates, however, are about two orders of magnitude smaller than that by Dobrynin and others (1981) of $2.7 \times 10^{8} \mathrm{Tcf}$.

MacDonald (1990) used data from Cherskiy and others (1985) to estimate roughly the areal extent, thickness, and volume of the gas-hydrate stability zone for four major regions in northern Russia. A porosity of either 2 or 4 percent was assumed depending on the age of the sediments containing gas hydrates. The volume actually occupied by gas hydrate was assumed to be 1 percent. On the basis of these assumptions, MacDonald (1990) calculated that $2.3 \times 10^{4}$ Tcf of methane are stored in gas hydrates in the permafrost regions of Siberia and $0.3 \times 10^{4} \mathrm{Tcf}$ of methane are present in continental gas hydrates of the North American Arctic, giving a total of $2.6 \times 10^{4}$ Tcf of methane in gas hydrates of the world's permafrost regions. A higher 
value might actually be appropriate if Antarctica were included in the estimate.

For oceanic gas hydrates, MacDonald (1990) assumed that the average thickness of the gas-hydrate stability zone is $0.5 \mathrm{~km}$ and that the total volume of sediment in this zone between water depths of 200 and $3,000 \mathrm{~m}$ is $31.3 \times 10^{6} \mathrm{~km}^{3}$ of which $12.5 \times 10^{6} \mathrm{~km}^{3}$ are available for gas hydrate formation. If only 1 percent of the total sedimentary pore space contains gas hydrates, then the total volume of gas hydrate is $1.25 \times 10^{6} \mathrm{~km}^{3}$. This total volume corresponds to $7.1 \times 10^{5}$ Tcf of methane if the gas-hydrate structure is 90 percent filled. This estimate does not include gas hydrates in sediments at water depths greater than $3,000 \mathrm{~m}$. The total resource base of methane in continental and oceanic gas hydrates would therefore be $7.4 \times 10^{5} \mathrm{Tcf}$.

\section{CONVERGENCE OF GAS-HYDRATE RESOURCE ESTIMATES}

Estimates of the amount of methane in gas hydrates are still speculative and uncertain. Although it is generally appreciated that gas hydrates occur worldwide (fig. 1), detailed geologic knowledge of their occurrence is incomplete, contributing to the wide range of estimates. Nevertheless, since 1988 there has been a convergence of ideas regarding the amount of methane in the gas-hydrate deposits of the world. Current estimates of the amount of methane in gas hydrates are in rough accord at $7.4 \times 10^{5}$ Tcf or $2.1 \times 10^{16} \mathrm{~m}^{3}$ (MacDonald, 1990) and $7 \times 10^{5} \mathrm{Tcf}$ or $2 \times 10^{16} \mathrm{~m}^{3}$ (Kvenvolden, 1988), with $1.4 \times 10^{6} \mathrm{Tcf}$ or $4 \times 10^{16} \mathrm{~m}^{3}$ (Kvenvolden and Claypool, 1988) being only a factor of 2 larger. If these estimates are valid, then the amount of methane in gas hydrates is almost two orders of magnitude larger than the estimated total remaining recoverable conventional methane (about $9 \times 10^{3}$ Tcf or $2.5 \times 10^{14}$ $\mathrm{m}^{3}$ ) and about a factor of two larger than the methane equivalent of all known fossil-fuel deposits (coal, oil, and natural gas).

\section{RECOVERY OF METHANE}

Although naturally occurring gas hydrates apparently contain large amounts of methane, this methane cannot be considered a resource unless it can be recovered. To date the gas industry has been slow to develop methodologies to recover methane from gas hydrates. Three principal methods are being considered: thermal stimulation, depressurization, and inhibitor injection (Holder and others, 1984). In thermal stimulation, the gas-hydrate-bearing strata are heated in order to increase the local temperature enough to cause gas hydrates to dissociate. In depressurization, the pressure in the gas-hydrate deposit is lowered by pumping to cause gas-hydrate dissociation; heat for the gas-hydrate dissociation in the depressurization process is provided by the natural geothermal heat flow. Injection of inhibitors, agents such as methanol which cause gas hydrates to dissociate, shifts the pressure-temperature equilibrium (phase boundary) so that the gas hydrates are no longer stable at in-situ pressure-temperature conditions.

Of these three production methodologies, depressurization combined with hot-water injection appears to be the most practical where free gas is trapped beneath the gas hydrate (Holder and others, 1984). That free gas is trapped beneath the gas hydrate has yet to be established with certainty (Kvenvolden, this volume). Gas hydrates will become a potential energy resource when it can be shown that the energy required to release methane from the hydrate itself is significantly less than the thermal energy of the methane that can be recovered from the dissociated gashydrate deposits. Circulation of warm surface water into gas-hydrate deposits and horizontal drilling techniques provide possible future approaches to the exploitation of hydrated methane.

The production of methane from gas hydrates requires that the deposit occur in geologic contexts wherein the elements of a conventional gas deposit are present; that is, in association with a reservoir of adequate porosity and permeability, with a methane source, and with a seal to form a trap. Dissociated gas hydrate can serve as one source of methane; migrated methane from below the gas-hydrate zone is another possible source. Development of the Messoyakha gas field in western Siberia during the past 25 years has proven that methane can be recovered from naturally occurring gas hydrates (Makogon, 1981; Collett, this volume), but the methanol injection methods used for production proved to be prohibitively expensive. Recovery of gas hydrates in pressurized core barrels at the Arco-Exxon N.W. Eileen State No. 2 wildcat well on the North Slope of Alaska confirmed the presence of gas hydrates in the region of the Prudhoe Bay and Kuparuk River oil fields (Kvenvolden and McMenamin, 1980).

It has recently been estimated that about 40 Tcf $\left(1.1 \times 10^{12} \mathrm{~m}^{3}\right)$ of methane are present in gas hydrates of this region (Collett, 1992). This amount of methane is about 1.4 times that in conventional reservoirs in the same region, but is only 9 percent of the conventional North America gas reserves (about 440 Tcf or $12.5 \times 10^{12} \mathrm{~m}^{3}$ ). This estimate is also comparable to the majority of previous estimates that were predicted for methane in gas hydrates in all of Alaska (table 2). If methane from gas hydrates is ever to be recovered commercially in the United States, larger accumulations will have to be identified and exploited. Initial production, however, is likely to come from the North Slope of Alaska where the industrial infrastructure for handling gas is already in place. Methane first produced from gas hydrates on the North Slope will likely be used for repressurization of waning oil fields rather than as a source 
of fuel. Although methane from gas hydrates should be considered a potential energy resource, wide-scale recovery of methane from gas hydrates will probably not be accomplished until the 21st century (Sloan, 1990).

\section{CONCLUSIONS}

Natural gas hydrates are globally widespread and contain a very large amount of methane that is trapped within the solid-water hydrate structure. World estimates made before 1980 of the amount of methane in gas hydrates range from $5 \times 10^{2}$ to $1.2 \times 10^{6} \mathrm{Tcf}\left(1.4 \times 10^{13}\right.$ to $3.4 \times 10^{16}$ $\mathrm{m}^{3}$ ) for permafrost regions and from $1.1 \times 10^{5}$ to $2.7 \times 10^{8}$ Tcf $\left(3.1 \times 10^{15}\right.$ to $\left.7.6 \times 10^{18} \mathrm{~m}^{3}\right)$ for deep oceanic sediments. These speculative estimates are based on overall volumetric considerations with limited field verification. The upper limits of these ranges are probably unrealistic because no account is taken of the need for adequate sources of methane. Since 1980 ideas from two independent approaches regarding the size of this potential worldwide resource converge at about $7 \times 10^{5} \mathrm{Tcf}\left(2 \times 10^{16} \mathrm{~m}^{3}\right)$ of methane. A third approach yielded an estimate that is only a factor of two larger. If these estimates are approximately correct, then gas hydrates are an attractive potential energy source for the future. But uncertainties in mode of occurrence and lack of applicable production techniques are formidable problems that must be solved before wide-scale exploitation can take place.

\section{REFERENCES CITED}

Barraclough, B.L., 1980, Gas energy review-Gas from natural gas hydrates: American Gas Association (edited by H.J. Moll), v. 7 , no. 10 , p. 1-5.

Bell, P.R., 1983, Methane hydrate and the carbon dioxide question, in Clark, W.C., ed., Carbon dioxide review 1982: New York, Oxford University Press, p. 401-406.

Bily, C., and Dick, J.W.L., 1974, Naturally occurring gas hydrates in the Mackenzie Delta, N.W.T.: Bulletin of Canadian Petroleum Geology, v. 32, p. 340-352.

Cherskiy, N.V., Tsarev, V.P., and Nikitin, S.P., 1985, Investigation and prediction of conditions of accumulation of gas resources in gas-hydrate pools: Petroleum Geology, v. 21, p. 65-89.

Collett, T.S., Kvenvolden, K.A., and Magoon, L.B., 1990, Characterization of hydrocarbon gas within the stratigraphic interval of gas-hydrate stability on the North Slope of Alaska, U.S.A.: Applied Geochemistry, v. 5, p. 279-287.

Collett, T.S., 1992, Potential of gas hydrates outlined: Oil and Gas Journal, v. 90 , no. 25 , p. 84-87.

Davidson, D.W., El-Defrawy, M.K., Fulgem, M.O., and Judge, A.S., 1978, Natural gas hydrates in northern Canada: National Research Council of Canada, Proceedings 3rd International Conference on Permafrost, v. 1, p. 938-943.
Dobrynin, V.M., Korotajev, Yu. P., and Plyuschev, D.V., 1981, Gas hydrates-A possible energy resource, in Meyer, R.F., and Olson, J.C., eds., Long-term energy resources: Boston, Pitman, p. 727-729.

Hitchon, B., 1974, Occurrence of natural gas hydrates in sedimentary basins, in Kaplan, I.R., ed., Natural gases in marine sediments: New York, Plenum Press, p. 195-225.

Holder, G.D., Kamath, V.A., and Godbole, S.P., 1984, The potential of natural gas hydrates as an energy resource: Annual Review of Energy, v. 9, p. 427-445.

Judge, A.S., 1982, Natural gas hydrates in Canada, in French, M.H., ed., Proceedings of the 4th Canadian Permafrost Conference 1981, Roger J.E. Brown Memorial Volume: National Research Council of Canada, p. 320-328.

Judge, A.S., and Majorowicz, J.A., 1992, Geothermal conditions for gas hydrate stability in the Beaufort-Mackenzie areaThe global change aspect: Palaeogeography, Palaeoclimatology, Palaeoecology (Global and Planetary Change Section), v. 98 , p. $251-263$.

Kvenvolden, K.A., 1988, Methane hydrate-A major reservoir of carbon in the shallow geosphere?: Chemical Geology, v. 71, p. $41-51$.

Kvenvolden, K.A., and Claypool, G.E., 1988, Gas hydrates in oceanic sediment: U.S. Geological Survey Open-File Report $88-216,50 \mathrm{p}$.

Kvenvolden, K.A., and Grantz, A., 1990, Gas hydrates of the Arctic Ocean region, in Grantz, A., Johnson, L., and Sweeney, J.F., eds., The Arctic Ocean Region: Boulder, Colorado, Geological Society of America, The Geology of North America, Vol. L, p. 539-549.

Kvenvolden, K.A., and McMenamin, M.A., 1980, Hydrates of natural gas-A review of their geological occurrences: U.S. Geological Survey Circular No. 825, 11 p.

Kvenvolden, K.A., Ginsburg, G.D., and Solovyev, V.A., 1993, Worldwide distribution of subaquatic gas hydrates: GeoMarine Letters, v. 13, p. 32-40.

MacDonald, G.T., 1983, The many origins of natural gas: Journal of Petroleum Geology, v. 5, p. 341-362.

MacDonald, G.T., 1990, The future of methane as an energy resource: Annual Review of Energy, v. 15, p. 53-83.

Makogon, Yu. F., 1981, Hydrates of natural gas: Tulsa, Okla., Pennwell Publishing, $237 \mathrm{p}$.

Makogon, Yu. F., Trebin, F.A., Trofimuk, A.A., Tsarev, V.P., and Cherskiy, N.V., 1972, Detection of a pool of natural gas in a solid (hydrated gas) state: Doklady Academy Science USSR, Earth Science Section, v. 196, p. 197-200.

McIver, R.D., 1981, Gas hydrates, in Meyer, R.F., and Olson, J.C., eds., Long-term energy resources: Boston, Pitman, p. 713726.

Meyer, R.F., 1981, Speculations on oil and gas resources in small fields and unconventional deposits, in Meyer, R.F., and Olson, J.C., eds., Long-term energy resources: Boston, Pitman, p. 49-72.

Neave, K.G., Judge, A.S., Hunter, J.A., and MacAulay, H.A., 1978, Offshore permafrost distribution in the Beaufort Sea as determined from temperature and seismic observations: Geological Survey of Canada, Current Research, Part C, Paper 78-1C, p. 13-18.

Parent, J.D., 1980, A survey of the United States and total world production, proved reserves, and remaining recoverable re- 
sources of fossil fuels and uranium: The Institute of Gas Technology, Chicago, Illinois, $140 \mathrm{p}$.

Potential Gas Committee, 1981, Potential supply of natural gas in the United States (as of December 31, 1980): Golden, Colorado, Potential Gas Agency, Colorado School of Mines, $119 \mathrm{p}$.

Rogers, J.C., and Morak, J.L., 1980, Geophysical evidence of shallow nearshore permafrost, Prudhoe Bay, Alaska: Journal of Geophysical Research, v. 85(B9), p. 4845-4853.

Sloan, E.D., 1990, Clathrate hydrates of natural gas: New York, Marcel Dekker, $641 \mathrm{p}$.
Trofimuk, A.A., Cherskiy, N.V., and Tsarev, V.P., 1977, The role of continental glaciation and hydrate formation on petroleum occurrences, in Meyer, R.F., ed., Future supply of naturemade petroleum and gas: New York, Pergamon Press, p. 919926.

Weaver, J.S., and Stewart, J.M., 1982, In-situ hydrates under the Beaufort Sea Shelf, in French, M.H., ed., Proceedings of the 4th Canadian Permafrost Conference 1981, Roger J.E. Brown Memorial Volume: National Research Council of Canada, $p$. 312-319. 



\title{
Use of Seismic Data in Estimating the Amount of In-Situ Gas Hydrates in Deep Marine Sediment
}

\author{
By Myung W. Lee ${ }^{1}$, Deborah R. Hutchinson ${ }^{2}$, William P. Dillon ${ }^{2}$, John J. Miller ${ }^{1}$, \\ Warren F. Agena ${ }^{1}$, and Barbara A. Swift ${ }^{2}$
}

CONTENTS

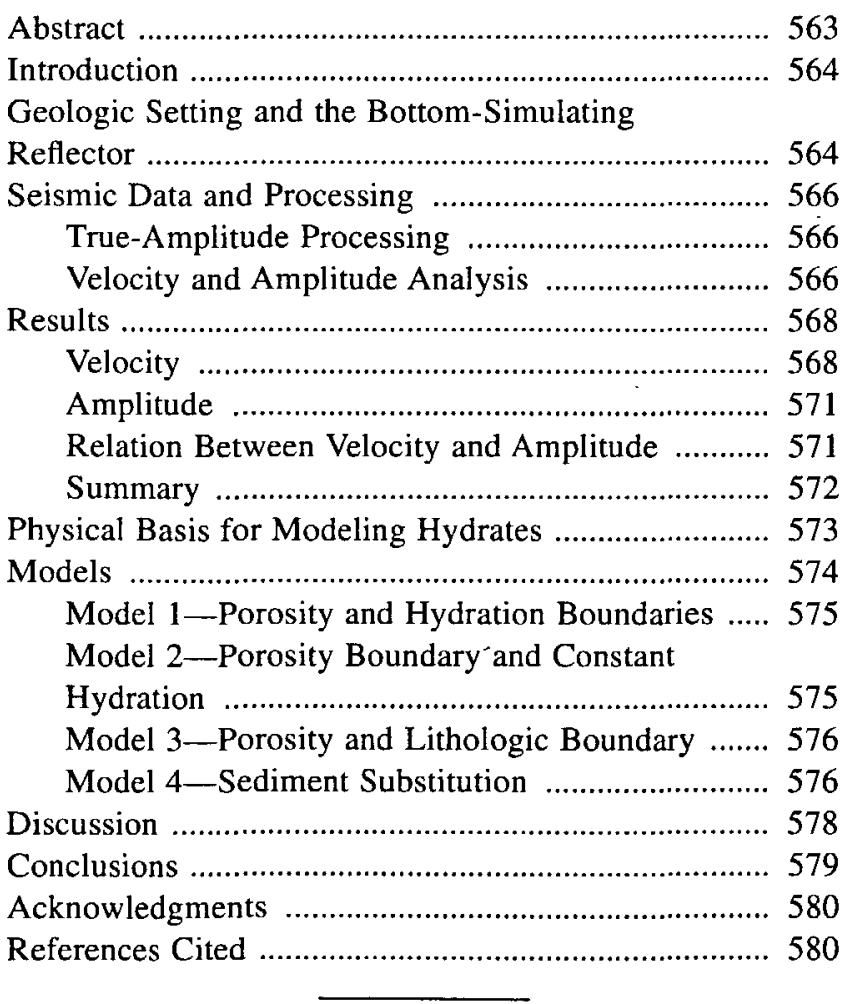

\footnotetext{
'U.S. Geological Survey, P.O. Box 25046 MS 934, Denver, CO 80225.

${ }^{2}$ U.S. Geological Survey, Gosnold Bldg., Quissett Campus, Woods Hole, MA 02543
}

\begin{abstract}
The bulk volume of gas hydrates in marine sediment can be estimated by measuring interval velocities and reflection amplitudes of hydrated zones from true-amplitudeprocessed multichannel seismic-reflection data. In general, neither velocity nor amplitude information alone is adequate to estimate hydrate concentration. We propose a method that uses reduction in amplitude (amplitude blanking) calibrated by interval-velocity data to quantify hydrate concentrations in the Blake Ridge area of the U.S. Atlantic continental margin. Once calibration has been performed throughout the region, only reflection amplitudes are needed for estimating bulk-hydrate concentrations. This method is especially beneficial when applied to local areas where only single-channel seismic surveys are available (no interval velocities), but where at least one multichannel seismic line is available for initial calibration.

The model, which gives the best estimates for the Blake Ridge, is based on the observation in this region that amplitude blanking is associated with relatively low interval velocities. In the model, there is a replacement of normal sediment with "representative hydrated sediment." Representative hydrated sediment is a sediment of defined matrix density and porosity with pore space filled by a mixture of water and hydrate. The proportion of water to hydrate in the representative sediment is one of the variables in the model; it can be calculated using an equation in which velocity is estimated from the seismic data and known properties of pure hydrate, and in which porosity inferred from a velocity/porosity relationship. Once these calculations have been performed, the model is calibrated, and the porosity and hydrate proportions of the representative sediment are fixed.
\end{abstract}


These parameters can then be combined with reflection amplitudes (blanking) to determine bulk-hydrate concentrations. For example, a small area near Deep Sea Drilling Project (DSDP) site 533 indicates that the amount of gas hydrates is about 5 percent in total volume when interval velocity alone is used as a criterion and about 8 percent when amplitude information (calibrated by an average interval velocity) is used. This latter estimate is corroborated by the only available measurement from DSDP site 533.

\section{INTRODUCTION}

Below a few hundred meters of water depth in the world's oceans, sea-floor sediment lies in the pressure/temperature zone of phase stability for gas hydrates. Gas hydrates are ice-like crystalline solids that are formed when cage of water molecules surrounds a guest gas molecule. Evidence of their existence has come from recognizing a bottom simulating reflector (BSR) on seismic profiles that marks the base of the zone of gas hydrates occurrence and from sampling by the Deep Sea Drilling Project (DSDP) and Ocean Drilling Program (ODP) (Kvenvolden and Barnard, 1983; Shipley and Didyh, 1982; Suess and others, 1988). In most naturally occurring gas hydrates, the guest molecule is methane.

Even though large volumes of hydrates apparently exist within the upper several hundred meters below the sea floor, no quantitative approaches are known for estimating the amount of in-situ gas hydrates. Estimates of the global quantity of methane in hydrates have been presented by many researchers (Dobrynin and others, 1981; McIver, 1981; Kvenvolden, 1988; Sloan, 1990 and references therein); these estimates differ by as much as two orders of magnitude. A limitation of these estimates is the assumption of in-situ conditions and thermodynamic state. Hence, these assessments are neither quantitative nor accurate because they are not based on observable information.

Estimating the amount of gas hydrates contained in marine sediment is a challenge. Hydrates contain perhaps 600,000 to one million Tcf (trillion cubic feet) of methane (Kvenvolden, 1988), or approximately 35,000 to 65,000 times the U.S. gas consumption in 1989. Therefore, hydrates are a potential source of energy, although methods of extracting gas from hydrates have not yet been developed. This large volume may be significant to climate change. Methane $\left(\mathrm{CH}_{4}\right)$ has 3.7 times the global warming effect of carbon dioxide on a molar basis (or 10 times on a weight basis, Lashof and Ahuja, 1990). Although $\mathrm{CH}_{4}$ 's average residence time in the atmosphere is only about 10 years, it is oxidized to $\mathrm{CO}_{2}$, which continues to cause global warming (Lashof and Ahuja, 1990). Finally, the dissociation of hydrates in sediment (for example, by lowering sea level, which then lowers the pressure in the underlying sediment and brings some of the hydrates out of their stability zone) may be one cause of slope failure on continental margins during episodes of peak glaciation (Dillon and others, 1991, Paull and others, 1991).

Gas hydrates are known to increase the interval velocity of sediments (Stoll, 1974; Tucholke and others, 1977; Dillon and Paull, 1983) by an amount that is proportional to the amount of hydrate (Pearson and others, 1983). This relation was used by Tucholke and others (1977) to explain an observed range in velocity from 1.6 to $1.9 \mathrm{~km} / \mathrm{s}$ as the result of the variable thicknesses of hydrated sediments. Sheridan and others (1983) estimate that near DSDP site 533 (fig. 1), as much as 20 to 30 percent of the sedimentary section should have been gas hydrates to produce an average velocity of $2 \mathrm{~km} / \mathrm{s}$, although such large amounts of hydrate were not recovered during drilling.

Another indicator of gas hydrates is the amplitude reduction or blanking typically observed above the BSR in reflection profiles from regions of known hydrates. Shipley and others (1979) related the marked decrease of amplitude above the BSR to a reduction in impedance contrast across sedimentary interfaces caused by the presence of hydrates. Dillon and others (1991) also observed amplitude blanking from true-amplitude seismic sections, and they ascribe this effect to hydrate formation. These studies imply that amplitude information can be used as an indicator of hydrate concentration.

We propose a quantitative method for estimating the amount of gas hydrates in marine sediment based on measurable acoustic properties of seismic-reflection data. Our approach uses both the kinematics (interval velocity) and the dynamics (seismic amplitude) of the wave field; more specifically, the increase in velocity and decrease in reflection amplitude observed in regions where hydrates are present.

\section{GEOLOGIC SETTING AND THE BOTTOM-SIMULATING REFLECTOR}

The continental margin of the southeastern United States is a zone of depositional transition between the actively building carbonate platform of the Bahamas and the terrigenous or clastic-dominated shelf-slope-rise configuration of eastern North America (Dillon and Popenoe, 1988). The region off North and South Carolina is the southern limit of the dominantly terrigenous continental margin. In this region, contour-following bottom currents since the Oligocene have built a drift deposit of hemipelagic sediment that extends southeastward away from the continental slope, and forms the Blake Ridge (fig. 1). Seismic profiles over the Blake Ridge and the continental rise just to its north are prominently marked by a large-amplitude reflection that approximately parallels the sea floor, known as the BSR (Markl and others, 1970; Ewing and Hollister, 1972; 
Tucholke and others, 1979; Shipley and others, 1979). The BSR is probably caused by a large impedance contrast at the base of the hydrate stability zone, which juxtaposes sediment containing gas hydrates with sediment lacking gas hydrates but possibly containing free gas (Miller and others, 1991).
A primary objective of DSDP site 533 on the Blake Ridge (fig. 1) was to sample gas hydrates in a region of a well-developed BSR. This hole penetrated $399 \mathrm{~m}$ beneath the sea floor and terminated in middle Pliocene silty mud (Sheridan and others, 1983). Gas pockets, disrupted sediment, and frothing characterized parts of the recovered

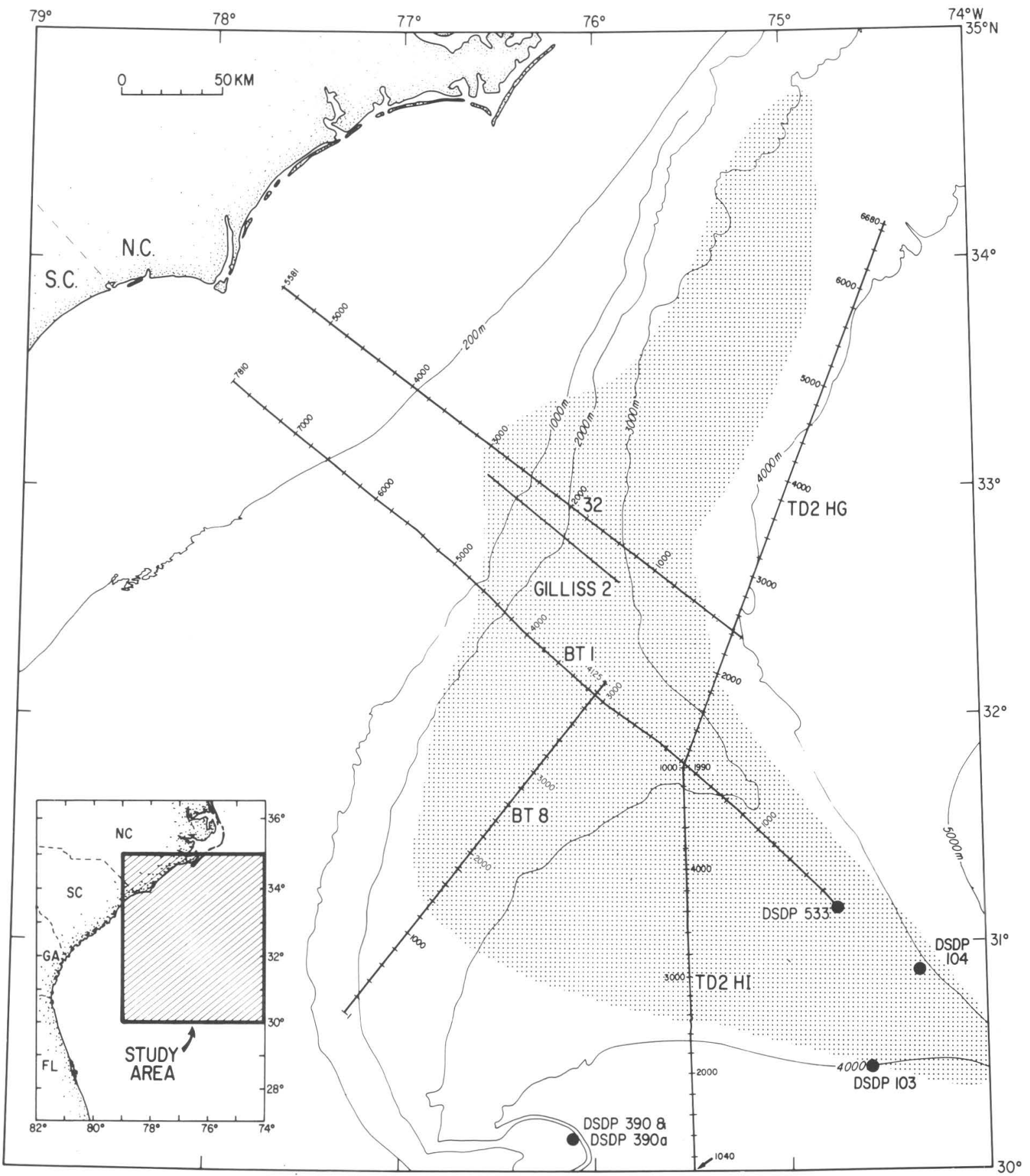

Figure 1. Bathymetry of southeastern U.S. continental margin, location of multichannel seismic-reflection profiles, DSDP sites 103, 104, 390, and 533. DSDP site 533 was drilled to sample gas hydrate. N.C., North Carolina; S.C., South Carolina; bathymetric contours in meters. Dot pattern shows extent of bottom-simulating reflector (BSR). Modified from Dillon and Popenoe (1988). 
cores. The only direct evidence for gas hydrates was found at a subbottom depth of $238 \mathrm{~m}$, where a layer several centimeters thick contained frothy sediment with white mat-like crystals that rapidly disappeared when exposed to atmospheric conditions (Kvenvolden and Barnard, 1983).

Gas pockets severely hampered the measurement of physical properties; bulk density was estimated from 1.67 to $1.74 \mathrm{~g} / \mathrm{cm}^{3}$ and porosity from two intervals was estimated at 57 to 60 percent. The BSR was estimated to be about $200 \mathrm{~m}$ below the bottom of the hole, or about $600 \mathrm{~m}$ below the sea floor (Sheridan and others, 1983). Chemical analysis shows that the gas is derived through microbiological processes rather than thermogenic processes and consists almost entirely of methane. The high rate of sedimentation has ensured the preservation of enough organic matter for the bacterial production of methane (Kvenvolden and Barnard, 1983).

\section{SEISMIC DATA AND PROCESSING}

The location of the five multichannel seismic profiles used for this investigation are shown in figure 1. They were recorded in the early to mid-1970's using tuned airgun arrays of 1,000 to $2,000 \mathrm{in}^{3}$ volume. Four of the lines provide 36-fold coverage with $50-\mathrm{m}$ common midpoint (CMP) intervals. Gilliss line 2 is a 12 -fold recording (fig. 1). All profiles, except Gilliss line 2, were recorded with 48-channel streamers, $3.6 \mathrm{~km}$ long, containing nonlinear group spacing. Gilliss line 2 was recorded with a linear 1.2-km-long streamer.

\section{TRUE-AMPLITUDE PROCESSING}

To optimize the quantitative analysis of hydrated sediment, a relative true amplitude processing technique with wavelet deconvolution was applied to all profiles. The processing was performed by the automatic editing method based on the median amplitude in a CMP gather (Lee and Hutchinson, 1990) with only a spherical spreading correction applied. Other amplitude corrections that compensate for effects such as attenuation and transmission loss were not included in this relative true amplitude processing, because these other effects may introduce seismic artifacts that impede the identification of hydrated sediment. Wavelet deconvolution was done by the variable norm deconvolution method (Gray, 1979). A representative source signature from deep water (two-way traveltimes of approximately 4 s) was derived, and an inverse filter was calculated and applied along each line. Source signature variations due to the gun depth, streamer depth, and gun failure were compensated for by applying second-zero-crossing predictive deconvolution before stack. The justification of this kind of approach, which applies the same inverse filter for the whole profile instead of applying separate deconvolution filters to each gather, comes from studies done by Dragoset and others (1987). Examples of wavelet-processed seismic data with $6 / 8$ to $40 / 50 \mathrm{~Hz}$ band-pass filtering are shown in figure 2. In this figure, 10 consecutive CMP's are shown for USGS line 32 (fig. 2A) and Teledyne TD2HG (fig. 2B). Both sections show almost symmetrical waterbottom reflections (peak amplitude) and well-defined trough reflections at the BSR. Because of the stacking process, the higher frequency component of data has been lost. However, the improvement of signal-to-noise ratio and almost identical wavelets among different seismic lines due to the wavelet processing warrant reliable amplitude analyses of seismic data in the Blake Ridge area. Another example of the wavelet and relative true amplitude-processed data for part of USGS line 32 is shown in figure 3.

\section{VELOCITY AND AMPLITUDE ANALYSIS}

Detailed_velocity measurements via stacking analysis were made every $100 \mathrm{CMP}$ 's, or about every $2.5 \mathrm{~km}$ along profile. Interval velocities determined in this fashion were

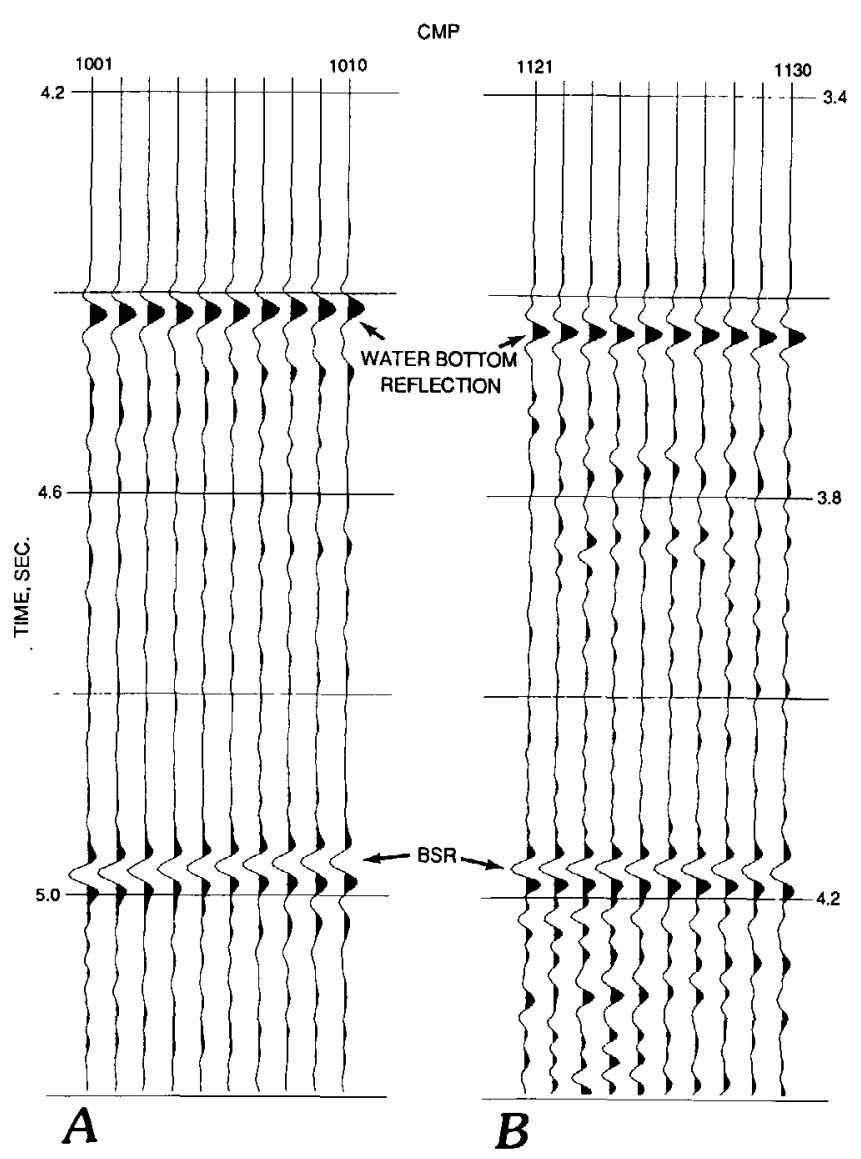

Figure 2. Wavelet-processed seismic sections. Ten consecutive CMP's (common midpoints) are shown; BSR, bottom-simulating reflector. $A$, USGS line $32 ; B$, TD2HG. 


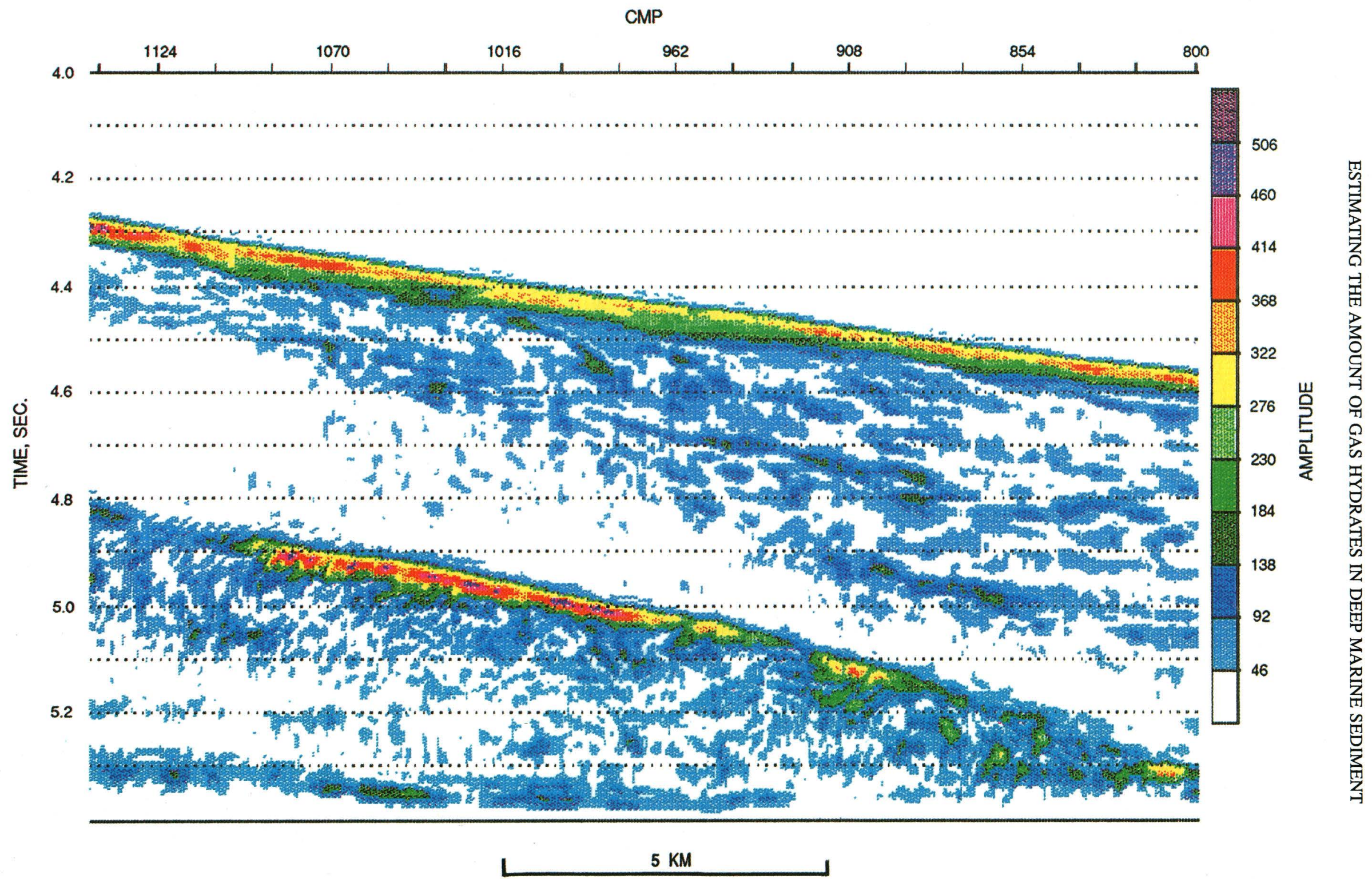

Figure 3. True-amplitude-processed seismic profile for part of USGS line 32. Note the spatial variation of blanking above the BSR (bottom-simulating reflector) and the highamplitude BSR. CMP, common midpoint. 
difficult to estimate in regions of amplitude blanking because reflections are weak and laterally discontinuous. Consequently, in these areas, interval velocities calculated from stacking velocities are not consistently representative of the same geologic interval. We felt a more useful approach was to focus on the average acoustic properties of hydrated sediment-that is, to measure the average velocity in a zone that extended from the sea floor downward to the BSR, and in another zone about 300 milliseconds (ms) above the BSR downward to the BSR. Velocities are average interval velocities calculated from CMP gathers that were selected on the basis of a prominent BSR, the quality of iso-velocity plots of routine stacking velocities, and the seismic character (primarily blanking) of the stacked data.

Our amplitude analysis was also done in these same two zones: either the interval between the sea floor and the BSR, or the 300 -ms thick section immediately overlying the BSR. Amplitude changes are based on calculations of the median reflectance, which we define as the absolute value of the reflection coefficient, or the envelope amplitude calibrated by the reflection coefficient. The reflection coefficient can be estimated from the behavior of the water-bottom multiples in the seismic data. Our analysis shows that the water-bottom reflection coefficient decreases with increasing water depth (Lee and others, 1991). The median reflectance calibrated by the reflection coefficient also systematically decreases with increasing water depth. Thus, we correct the median reflectance to a reference water depth, which is arbitrarily set at 3-s two-way time(s) in this analysis.

The details of amplitude variation near the BSR can be examined using plots similar to those shown in figure 4 . In these plots, each dot represents the amplitude in an 8-ms window for five consecutive CMP's. The solid line is the five point median of the average amplitude of five consecutive CMP's. In other words, the solid line is the running average of reflection amplitudes over a moving window that is $32 \mathrm{~ms}$ in duration vertically by five CMP's horizontally. The decibel $(\mathrm{dB})$ scale was computed on the basis of the most convenient reflection coefficient for the plots. We use 0.4 for observing the combined Blake Ridge data, but we use a more convenient value $(0.1)$ for the models; therefore, we can get an absolute value of the reflection coefficient (that is, reflectance) directly from the plot. Although the magnitude of reflectance varies with the degree of interference and frequency content on band-pass-filtered seismic sections such as those used in this study, it is a useful quantity in comparing relative reflection strength between seismic lines or along the same line.

The velocity and amplitude analyses can be combined via inversion theory by estimating the detailed interval velocity based on seismic amplitude and phase (Lindseth, 1979; Cook and Schneider, 1983). Seismic inversion involves computing velocity values from seismic amplitude, assuming a constant bulk density for the subbottom sedi- ments. Results from DSDP site 533 showed that lithology and bulk density, where measured, changed little downhole between about $50 \mathrm{~m}$ and $400 \mathrm{~m}$ (Sheridan and others, 1983); hence the assumption of constant density is probably valid at least for the upper $400 \mathrm{~m}$ of the sub-sea-floor section. Because seismic data generally lack low-frequency information (less than $5 \mathrm{~Hz}$ ), the inversion method provides band-limited impedances, or velocities, from which only local velocity variations can be estimated. To get the absolute interval-velocity values, the missing low-frequency component of velocity was provided by the detailed analysis of stacking velocity, according to the method of Lindseth (1979). The results of the inversion for USGS line 32 are given in figure 5 .

\section{RESULTS}

\section{VELOCITY}

The marked difference in elastic properties between gas hydrates and liquid water is the physical basis for our analysis of the acoustic properties of hydrated sediment. The acoustic properties of gas hydrates are similar to those of ice. The compressional velocity of naturally occurring biogenic (methane) gas hydrates is about $3.3 \mathrm{~km} / \mathrm{s}$ (Sloan, 1990 ) and its density is about $0.9 \mathrm{~g} / \mathrm{cm}^{3}$, whereas the velocity of the interstitial water is about $1.5 \mathrm{~km} / \mathrm{s}$ and the density is $1.0 \mathrm{~g} / \mathrm{cm}^{3}$. The compressional velocity of hydrate-bearing sediment is therefore higher than that of water-bearing sediment for a given porosity. Because the velocity of gas hydrates is greater than the interstitial water, the cementation of sediments by gas hydrates increases the velocity of the sediment for a given porosity. Because the hydrate formation substantially increases the rigidity of the sediment, a more pronounced effect is expected on the shear-wave velocity for hydrated sediment. However, little data exist for shear-wave velocity in hydrate-bearing sediment. We thus restrict our analysis of interval velocities to estimates based on compressional-wave information.

Average interval velocities versus two-way traveltime through subbottom sediment at representative CMP's for six of the multichannel seismic lines in the Blake Ridge area are shown in figure 6 . In this figure, each letter denotes the average interval velocity between the sea floor and the BSR calculated for several CMP's from each line. For comparison, the average interval velocity versus subbottom depth, based on DSDP drilling results reported by Carson and others (1986), is indicated by the solid line; the dots indicate average interval velocities versus subbottom depth derived from refraction data along the western North Atlantic continental rise (Houtz, 1974). The average velocity measured by Houtz (1974) is higher than that determined by Carson and others (1986) for drill cores and is 
generally higher than the interval velocities estimated from the multichannel reflection data. The higher average velocity of the refraction data of Houtz (1974) probably reflects acoustic anisotropy of marine sediment, because most of the propagation path for the Houtz data is parallel to the bedding planes. Our analyses use interval velocities based on virtually vertically traveling waves of multichannel reflection returns.

Figure 6 shows that the average interval velocities in the Blake Ridge area are similar to those of marine
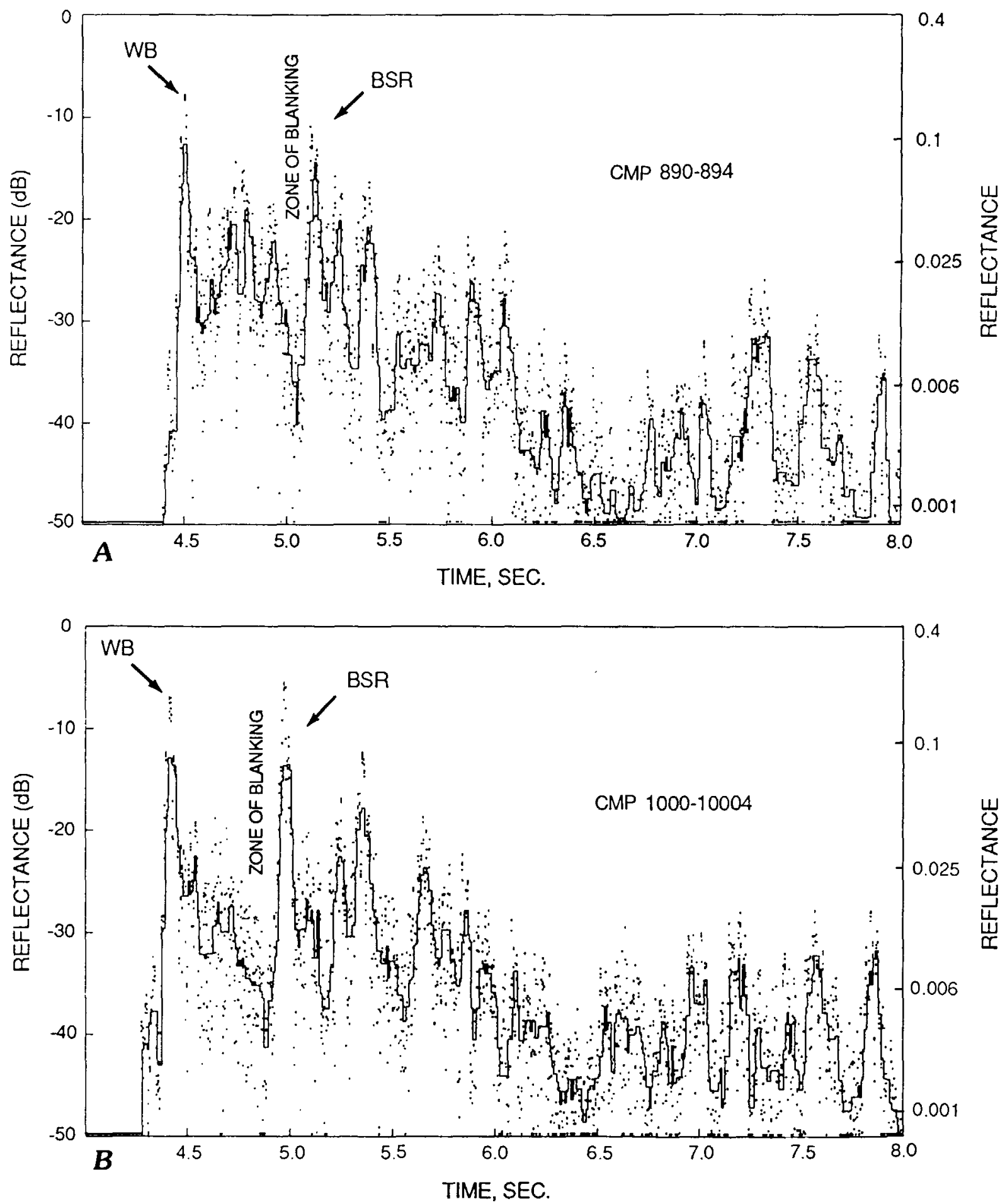

Figure 4. Graphs showing amplitude analysis for selected CMP (common midpoint) intervals for USGS line 32 (shown in fig. 3). Each dot represents the amplitude of an 8-ms window and the solid line represents a five point running median of five consecutive CMP's. WB, water bottom. A, CMP's 890-894; $B$, CMP's 1000-1004. 


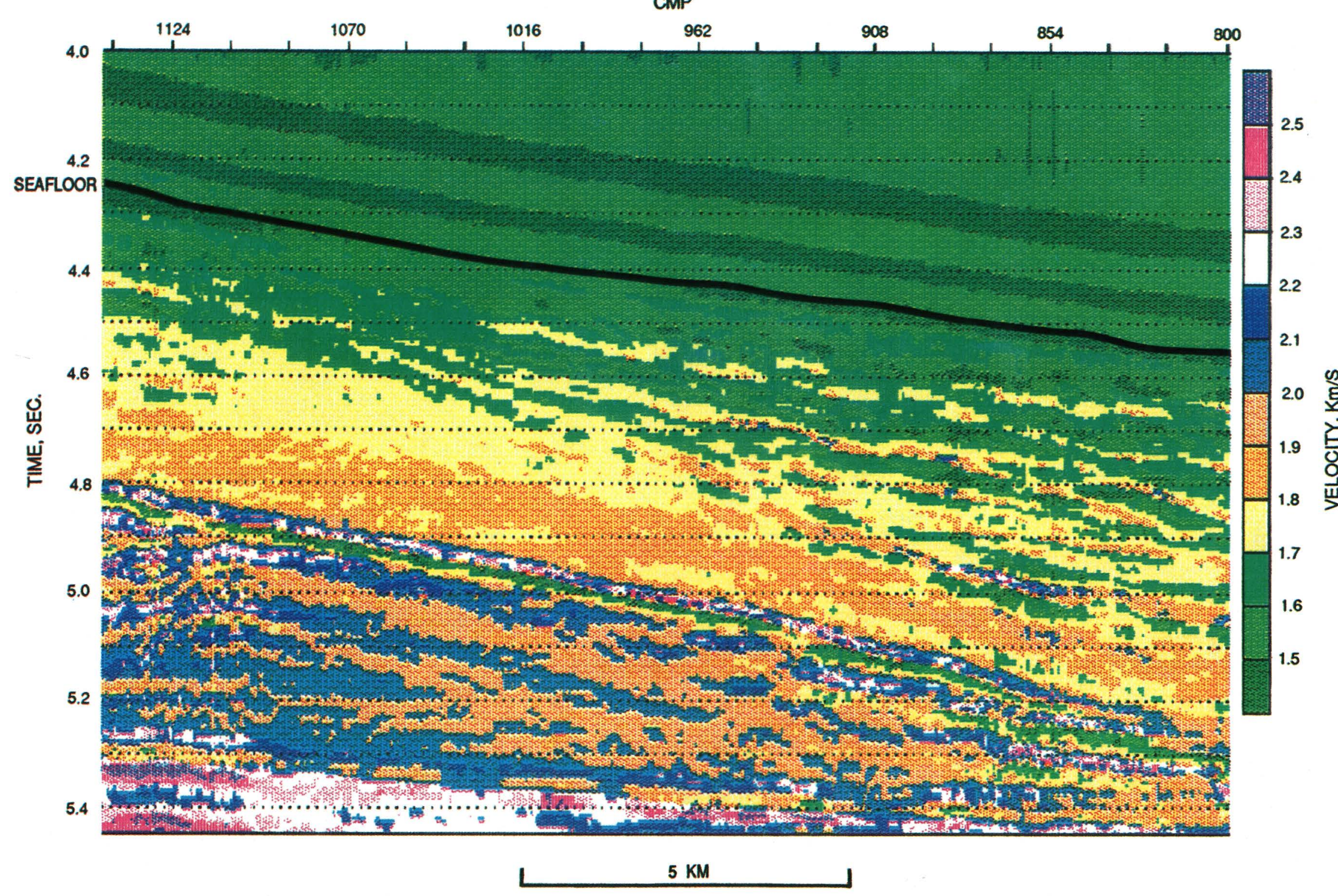

Figure 5. Detailed interval velocities created by linear inversion of data shown in figure 3. CMP, common midpoint; time given in seconds; velocity given in kilometers per second. 


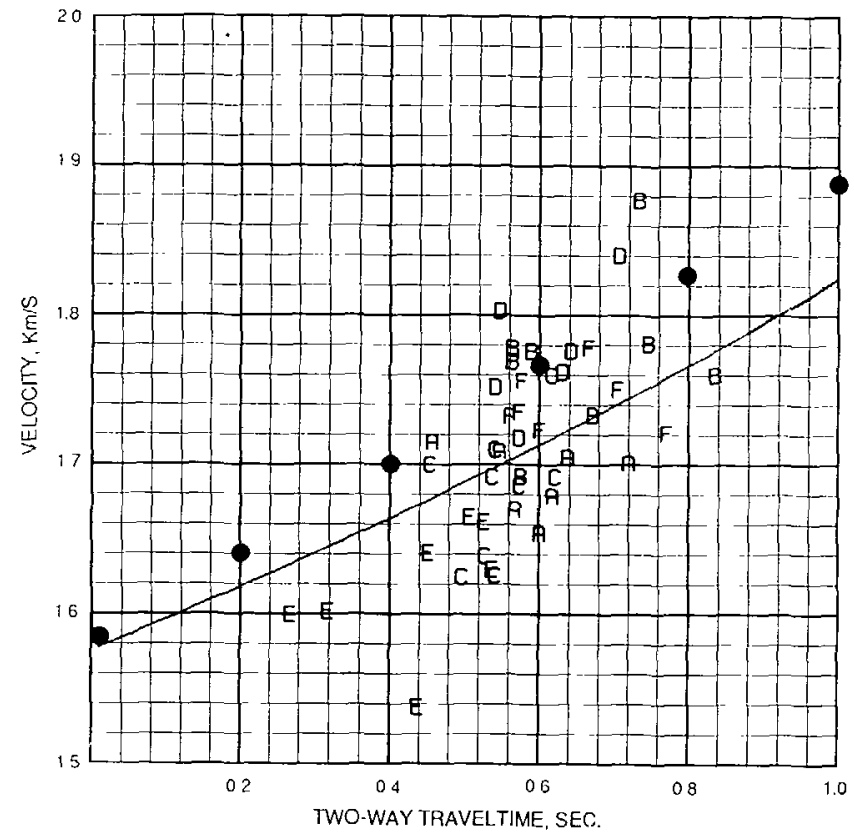

Figure 6. Average interval velocity (in kilometers per second) determined by conventional stacking-velocity analysis versus two-way traveltime (in seconds). Solid line is average curve by Carson and others (1986) and dots are average velocity by Houtz (1974). Each letter represents values of average velocity between the sea floor and bottom-simulating reflector for common midpoints along six seismic profiles. A, B, C, D, E, and F denote TD2HI, TD2HG, BT1, BT8, Gilliss line 2, and USGS line 32, respectively.

sediment estimated by Carson and others (1986). In the Blake Ridge area, the BSR typically occurs at about 600 ms two-way subbottom traveltime. If hydrates constitute a significant component of the Blake Ridge sediment, a noticeable increase of interval velocity would be anticipated in the sedimentary section above the BSR. However, we found no significant increase of average interval velocities on any of the seismic profiles (within the limitations imposed by the maximum $260 \mathrm{~m} / \mathrm{s}$ uncertainties discussed later in the "Relation Between Velocity and Amplitude" section). Possible explanations for this are described below.

1. The average concentration of gas hydrates in sediment is small, so the effect of gas hydrates on the seismic velocity measured by conventional stacking velocity analysis of multichannel seismic data may not be detectable. The gas hydrates could be finely disseminated throughout the sediment, and thus the change in bulk physical properties would be minimal.

2. The occurrence of hydrated sediment is highly localized in thin layers or in patches, so it does not significantly affect the average velocity of subbottom deposits.

3 . The length of streamer or detector offset (approximately $3.6 \mathrm{~km}$ ) is not large enough to resolve small increas- es of interval velocity in deep water in the range of 3- to 5-s two-way traveltimes $(2,250-3,750 \mathrm{~m})$.

4. Localized differences in stratigraphy and lithology, data acquisition, and processing techniques might obscure true subbottom velocity relations. For example, the interval velocities for Gilliss line 2 (letter E, fig. 6) are always less than the average curve by Carson and others (1986), whereas the interval velocities for USGS line 32 (letter F, fig. 6) are mostly greater than the average velocity even though these two lines are closely spaced parallel seismic lines (fig. 1). This discrepancy could be partly due to the difference in field acquisition, that is, using a 1.2-km streamer for Gilliss line 2 and a $3.6-\mathrm{km}$ streamer for USGS line 32.

So far, our analysis suggests average interval velocities from multichannel data are not diagnostic in estimating hydrate concentrations in the Blake Ridge area.

\section{AMPLITUDE}

Amplitude variations associated with the presence of gas hydrates are pronounced in the Blake Ridge area. Figure 3 shows the amplitude of reflected energy along part of USGS line 32. A low-amplitude, or blanking, zone is just above the BSR; the thickness of this zone of blanking varies spatially. Amplitude blanking above the BSR is common throughout the area and suggests that wherever a BSR is recorded, a corresponding amplitude blanking zone will be detected immediately above it. This does not imply that all blanking zones correspond to hydrated sediment.

The average seismic amplitude immediately above the BSR is small, as shown in figure 4; the reflectance of this zone is less than 0.01 . The zone of blanking is wider for CMP's 1000-1004 (fig. 4B), than for CMP's 890-894 (fig. $4 A$ ), in agreement with the seismic section shown in figure 3. The blanking has a transitional character for CMP's 1000-1004, but it is a sharp change fór CMP's 890-894. The average amplitude for the section between the water bottom and the BSR is about $-30 \mathrm{~dB}$, which is a reflectance of about 0.0125 , for CMP's 1000-1004 and about $-24 \mathrm{~dB}$ (reflectance of 0.025 ) for CMP's 890-894. If the amplitude blanking indicates the presence of gas hydrates, then figures 3 and 4 suggest that a thicker zone of hydrated sediment occurs near CMP 1000 than near CMP 890. Also, the differences in reflectance may be related to the amount of hydrate present in the sediment.

\section{RELATION BETWEEN VELOCITY AND AMPLITUDE}

To assess the relation between amplitude blanking and interval velocity, a composite plot, shown in figure 7 , for the interval velocity derived from stacking velocities versus median reflectance (using a reference reflectance of 0.1 ) for 


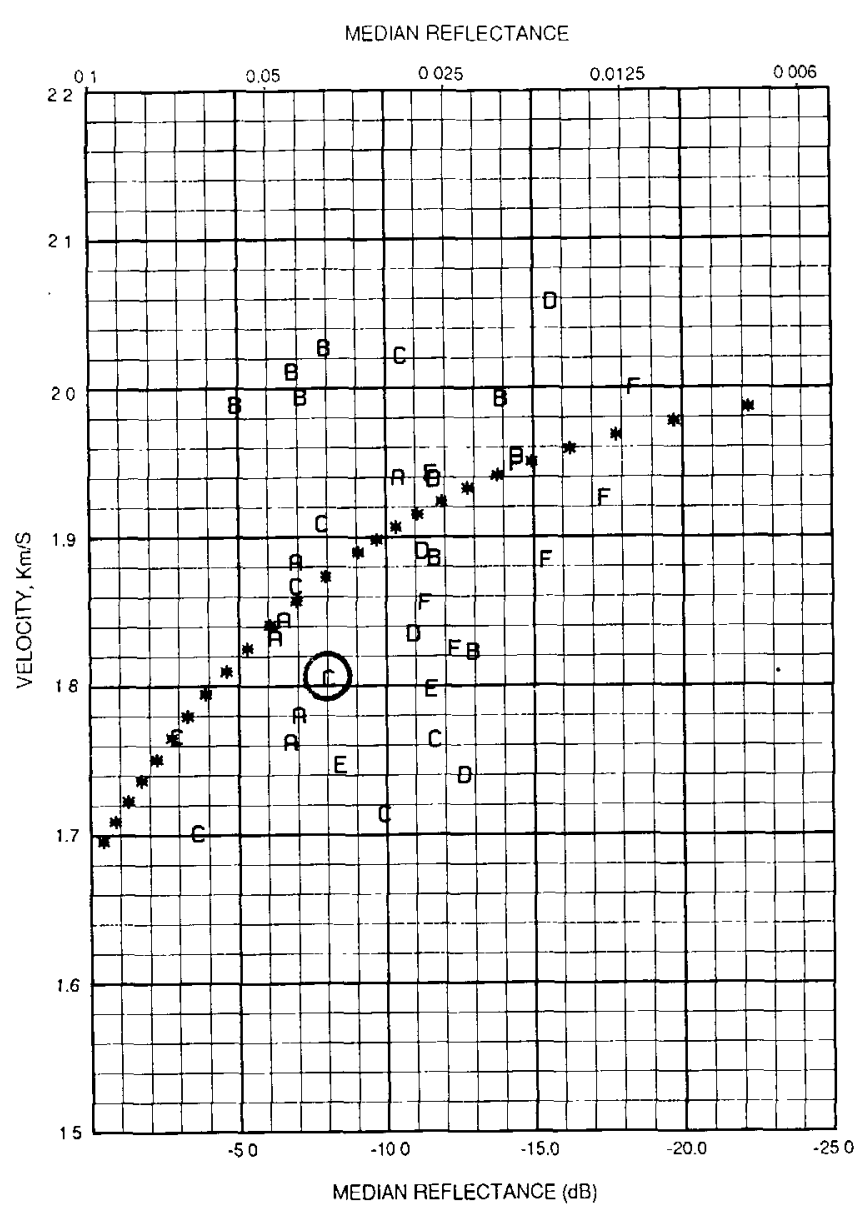

Figure 7. Relation between average interval velocities (from stacking velocities) estimated from a zone about $300 \mathrm{~ms}$ above the BSR (bottom-simulating reflector) downward to the BSR and median reflectance in this zone. Each letter represents values from CMP's (common midpoints) on six seismic profiles: A, B, C, D, E, and F represent TD2HI, TD2HG, BT1, BT8, Gilliss line 2, and USGS line 32, respectively. Asterisks (*) represent the theoretical relation between velocity (in kilometers per second) and relative median reflectance (or blanking) measured in decibels derived from model 4 . Circled point $C$ is the velocity-reflectance value closest to DSDP site 533 .

a window about $300 \mathrm{~ms}$ above the BSR was prepared. The maximum amplitude variation for a given interval velocity is about $15 \mathrm{~dB}$ at an interval velocity of about $2,000 \mathrm{~m} / \mathrm{s}$, and the interval velocity changes between $1,700 \mathrm{~m} / \mathrm{s}$ and about $2,100 \mathrm{~m} / \mathrm{s}$ for the median reflectance of 0.025 (about $-13 \mathrm{~dB}$ point).

Many factors can contribute to the large scatter of interval velocity versus median reflectance. These factors are described below.

1. Lateral variations in stratigraphy, lithology, and hydrate concentration in the Blake Ridge area are probably not large, but small variations could certainly contribute to the observed scatter.

2. Differences in the source's original frequency content can affect median reflectances.
3. A bulk bias in the reflection amplitude may exist for each line because of inaccurate water-depth corrections in the median reflectance calculations.

4. Difficulties in picking arrival times can affect estimated interval velocity determinations.

5. Variable length-of-time windows used in the velocity analysis can affect interval velocities because there are no laterally continuous reflection events to guide velocity picks.

6. Because of deep water and low interval velocities of hemipelagic sediment, the streamer length used may not be sufficiently long to extract accurate interval velocity measurements from stacking or root-mean-square velocities, resulting in a lack of resolution.

The accuracy of picking root-mean-square velocities was in the range of $10 \mathrm{~m} / \mathrm{s}$. Based on the first-order theoretical equation by Hajnal and Sereda (1981), the uncertainty of a $10 \mathrm{~m} / \mathrm{s}$ root-mean-square velocity introduces a maximum uncertainty of interval velocity of $260 \mathrm{~m} / \mathrm{s}$. However, numerical computations indicate that the uncertainty of interval velocity is typically in the range of $70 \mathrm{~m} / \mathrm{s}$. Also, factors 4 and 5 easily introduce $50 \mathrm{~m} / \mathrm{s}$ velocity changes by slightly changing the reflection arrival times. The overall uncertainty for the interval velocity is difficult to estimate, but the interval velocities shown in figure 7 contain large uncertainties. The important observation from figure 7 is that the average interval velocity of the section immediately above the BSR, which is presumably mostly hydrated sediment, varies between $1,700 \mathrm{~m} / \mathrm{s}$ to $2,000 \mathrm{~m} / \mathrm{s}$ and the median reflectance varies between 0.05 and 0.01 . This observation is used to build our working model for estimating the amount of gas hydrates in deep marine sediment.

A second method to compare velocity and reflection amplitude inverts the amplitude information for velocity, as shown for USGS line 32 in figure 5. This figure reveals that the high-amplitude BSR reflection arises from the presence of a low-velocity layer (green color at the BSR level), an observation consistent with the presence of free gas trapped beneath the base of the hydrate stability zone, which is delimited by the BSR (Dillon and Paull, 1983). In the section above the BSR, the region near CMP 890 shows a thicker low-velocity zone (green above the BSR) than the region near CMP's 1000-1100; this difference implies that less hydrate exists near CMP 890 than CMP 1100. This result agrees qualitatively with the amplitude blanking (fig. 4) near CMP 890, which has a smaller reflectance (representing less hydrate concentration) than that near CMP 1000 (representing more hydrate concentration).

\section{SUMMARY}

Based on the analysis of six seismic profiles from the Blake Ridge area, we can make the following statements:

1. The amplitude of seismic reflections within the hydrate stability zone is generally much lower in the area 
where there is an observed BSR. Accordingly, amplitude blanking may be a useful seismic attribute related to the presence of gas hydrates.

2. On the basis of stacking-velocity data, the average interval velocities of subbottom sediment between the sea floor and the BSR are similar to the average interval velocity of nonhydrate-bearing marine sediment. This observation implies that even though hydrated sediment is present in the Blake Ridge area, the amount of gas hydrates may be small. It is important to keep in mind, however, that the interval velocities are based on rootmean-square velocities, which are associated with large uncertainties (as much as $260 \mathrm{~m} / \mathrm{s}$ ).

3. Although precise velocities are difficult to determine, the velocity structure derived by the inversion method shows a close correlation to the pattern of median reflectance (for example, compare figs. 3 and 5). Thus, we believe that these parameters may be fundamentally related, and we propose seismic amplitude can be used to estimate the amount of gas hydrates in the Blake Ridge area.

4. The interval velocity of the lower part of the section varies between $1,700 \mathrm{~m} / \mathrm{s}$ and $2,000 \mathrm{~m} / \mathrm{s}$ and the median reflectance varies between 0.05 to 0.01 .

\section{PHYSICAL BASIS FOR MODELING HYDRATES}

How the presence of gas hydrates affects seismic velocity of slope sediment is not currently known. Timur (1968) first proposed a three-phase time-average equation to explain the velocities of compressional waves in various consolidated rocks measured at permafrost (subzero) temperatures. Pearson and others (1983) applied the equation to hydrated rock and concluded that it qualitatively explains the known sonic properties of hydrated sediment in consolidated media. They used the following threephase time-average equation for the velocity:

$$
\frac{1}{V_{p}}=\frac{\phi(1-S)}{V_{w}}+\frac{\phi S}{V_{h}}+\frac{(1-\phi)}{V_{m}}
$$

where

$\mathrm{V}_{\mathrm{p}}$ is compressional velocity of the hydrated sediment,

$V_{h}$ is compressional velocity of the pure hydrate,

$\mathrm{V}_{\mathrm{w}}$ is compressional velocity of the fluid,

$\mathrm{V}_{\mathrm{m}}$ is compressional velocity of the matrix,

$\phi$ is porosity (as a percent), and

$\mathrm{S}$ is concentration of hydrate in the pore space (as a percent).

Severäl workers have demonstrated that the observed velocity behavior of normal (that is, unhydrated) rocks is not always consistent with the predictions of the timeaverage model. Four of the conditions causing discrepancies are: (1) if the rock is unconsolidated or lightly cemented (Wyllie and others, 1958), (2) if the rock contains a significant amount of organic material (Timur, 1968), (3) if the rock contains a significant amount of clay (Castagna and others, 1985; Eberhart-Phillips and others, 1989), and (4) if the rock contains secondary porosity, such as fractures (Wyllie and others, 1958). The fourth condition pertains to crystalline or other consolidated rocks and is not relevant to most slope sediments. The first three conditions, however, apply to sediments on the Blake Ridge-they are unconsolidated, contain about 50 percent clay, and have organic carbon content that ranges from 0.5 to 1.4 percent (Sheridan and others, 1983; Kvenvolden and Barnard, 1983). To accommodate these conditions, some workers have applied correction factors to the time-average equation (Asquith and Gibson, 1982; Castagna and others, 1985).

The interval velocities computed from the time-average or modified time-average equations did not fit the observed interval velocities obtained from DSDP samples in the Blake Ridge area. We propose an equation of interval velocities for marine hydrated sediments using the approach of Nobes and others (1986), who computed the interval velocities of marine sediment by a weighted mean of the time-average equation (Wyllie and others, 1956) and Wood equation (1941). The Wood equation is approximately valid for particles in suspension, and is defined as:

$$
\frac{1}{\rho V^{2}}=\frac{\phi}{\rho_{w}\left(V_{w}\right)^{2}}+\frac{(1-\phi)}{\rho_{m}\left(V_{m}\right)^{2}}
$$

where

$\mathrm{V}$ is compressional velocity of sediments,

$\rho$ is bulk density of sediments,

$\rho_{w}$ is density of the fluid, and

$\rho_{m}$ is density of the matrix.

Like the three-phase time-average equation, the Wood equation for hydrated sediments can be written as:

$$
\frac{1}{\rho V^{2}}=\frac{\phi(1-S)}{\rho_{w}\left(V_{w}\right)^{2}}+\frac{\phi S}{\rho_{h}\left(V_{h}\right)^{2}}+\frac{(1-\phi)}{\rho_{m}\left(V_{m}\right)^{2}}
$$

where

$\rho_{h}$ is density of the pure hydrate.

The proposed equation for the interval velocity for hydrated deep marine sediment is a weighted mean of equations 1 and 3; that is,

$$
\frac{1}{V_{p}}=\frac{W \phi(1-S)}{V_{1}}+\frac{1-W \phi(1-S)}{V_{2}}
$$

where $V_{1}$ is the Wood velocity, $V_{2}$ is the Wyllie velocity, and $W$ is a weighting factor. When $S=0$, in the case that there is no hydrate, equation 4 is identical to the equation of Nobes and others (1986). As the porosity decreases, equation 4 approaches the three-phase time-average equation of Pearson and others (1983). 
The relationship between compressional velocity and porosity for unconsolidated sediment sampled by DSDP on the U.S. Atlantic continental rise (table 1) is shown in figure 8 together with theoretical curves of Wood (1941), Wyllie and others (1958), and equation 4 with $W=1$ and $S=0$. The matrix velocity is set equal to the value of the velocity for zero porosity and 65 percent clay content, $4.37 \mathrm{~km} / \mathrm{s}$ (Castagna and others, 1985). For higher porosity rocks, equation 4 is closer to the Wood equation, whereas for lower porosity rocks, equation 4 is closer to the time-average equation. As indicated in figure 8 , equation 4 with $\mathrm{W}=1.0$ fits the observed interval velocities quite well for porosities greater than about 40 percent. Therefore, we used $\mathrm{W}=1.0$ for our model.

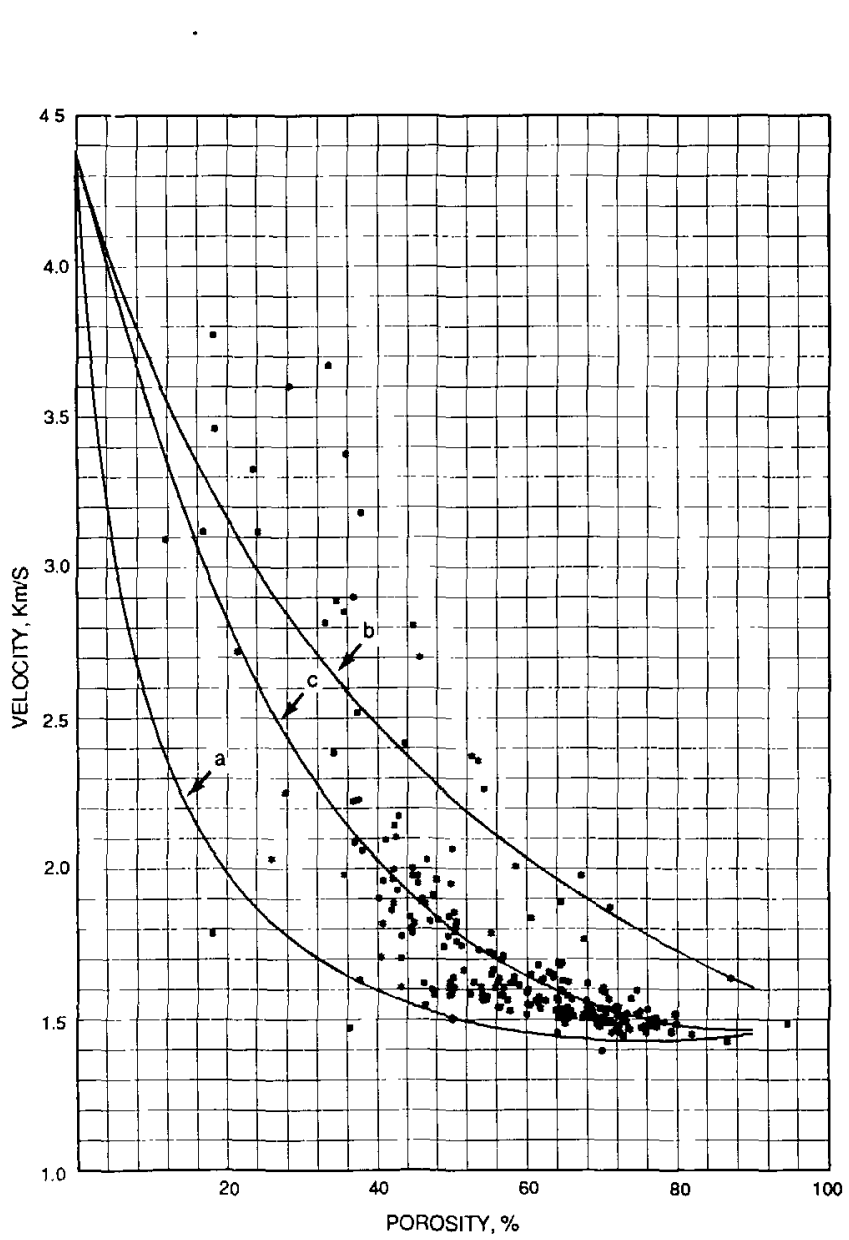

Figure 8. Relation between compressional velocity, in kilometers per second, and porosity (symbols), in percent, for unconsolidated sediment on the U.S. Atlantic continental rise from DSDP sites listed in table 1 and predicted curves (solid lines) for velocity-porosity relations calculated using the Wood (1941) equation (curve a), time-average equation (curve b), and average equation (curve $c$ )-see text for discussion. Source of porosity-velocity values is DSDP CD-ROM data set, NGDC-03, produced by NGDC with support from the U.S. Science Support Program of the Joint Oceanographic Institutions, Inc.
Table 1. The location of DSDP sites on Atlantic continental rise.

[Compressional velocity and porosity of sediment sampled at these DSDP sites were used in this analysis]

\begin{tabular}{clc}
\hline DSDP site & Latitude & Longitude \\
\hline 101 & $25^{\circ} 11^{\prime} 55^{\prime \prime} \mathrm{N}$ & $74^{\circ} 26^{\prime} 18^{\prime \prime} \mathrm{W}$ \\
103 & $30^{\circ} 27^{\prime} 4^{\prime \prime} \mathrm{N}$ & $75^{\circ} 34^{\prime} 59^{\prime \prime} \mathrm{W}$ \\
104 & $30^{\circ} 52^{\prime} 20^{\prime \prime} \mathrm{N}$ & $74^{\circ} 19^{\prime} 38^{\prime \prime} \mathrm{W}$ \\
105 & $34^{\circ} 53^{\prime} 43^{\prime \prime} \mathrm{N}$ & $69^{\circ} 10^{\prime} 23^{\prime \prime} \mathrm{W}$ \\
384 & $40^{\circ} 21^{\prime} 38^{\prime \prime} \mathrm{N}$ & $51^{\circ} 39^{\prime} 47^{\prime \prime} \mathrm{W}$ \\
385 & $37^{\circ} 22^{\prime} 10^{\prime \prime} \mathrm{N}$ & $60^{\circ} 9^{\prime} 26^{\prime \prime} \mathrm{W}$ \\
390 & $30^{\circ} 8^{\prime} 32^{\prime \prime} \mathrm{N}$ & $76^{\circ} 6^{\prime} 44^{\prime \prime} \mathrm{W}$ \\
$390 \mathrm{a}$ & $30^{\circ} 8^{\prime} 32^{\prime \prime} \mathrm{N}$ & $76^{\circ} 6^{\prime} 44^{\prime \prime} \mathrm{W}$ \\
$391 \mathrm{a}$ & $28^{\circ} 13^{\prime} 36^{\prime \prime} \mathrm{N}$ & $75^{\circ} 37^{\prime} 0^{\prime \prime} \mathrm{W}$ \\
$391 \mathrm{c}$ & $28^{\circ} 13^{\prime} 36^{\prime \prime} \mathrm{N}$ & $75^{\circ} 37^{\prime} 0^{\prime \prime} \mathrm{W}$ \\
$417 \mathrm{a}$ & $25^{\circ} 6^{\prime} 37^{\prime \prime} \mathrm{N}$ & $68^{\circ} 2^{\prime} 28^{\prime \prime} \mathrm{W}$ \\
$418 \mathrm{a}$ & $25^{\circ} 2^{\prime} 5^{\prime \prime} \mathrm{N}$ & $68^{\circ} 3^{\prime} 26^{\prime \prime} \mathrm{W}$ \\
$418 \mathrm{~b}$ & $25^{\circ} 2^{\prime} 4^{\prime \prime} \mathrm{N}$ & $68^{\circ} 3^{\prime} 27^{\prime \prime} \mathrm{W}$ \\
\hline
\end{tabular}

A knowledge of both velocity and density is required to understand and model reflections. To derive density, we can use the weighted average of constituent components. That is,

$$
\rho_{\mathrm{p}}=(1-\phi) \rho_{\mathrm{m}}+(1-S) \phi \rho_{\mathrm{w}}+\mathrm{S} \phi \rho_{\mathrm{h}}
$$

where

$\rho_{p}$ is bulk density of the hydrated sediment, $\rho_{h}$ is density of the pure hydrate, $\rho_{w}$ is density of the fluid, and $\rho_{\mathrm{m}}$ is density of the matrix.

\section{MODELS •}

If amplitude blanking is a seismic attribute related to gas hydrates concentration in slope sediment, can a relation between interval velocity, reflection amplitude, and hydrate concentration be established? To answer this question, we investigated simple one-dimensional models. Our objective was to construct a model in which amplitude blanking increases as interval velocity (and therefore hydrate concentration) increases, in accordance with the observations presented earlier. Significant blanking must also occur at relatively low interval velocities.

For the first three models, we assume that hydrate forms only in the pore spaces of the sediment. In other words, 0 percent hydrate means no hydrate exists in the pores, 50 percent hydrate means 50 percent of the pore space is filled by hydrate, and 100 percent hydrate means all of the available pore space is filled by hydrate. We then 
define a geologic boundary (reflecting horizon) across which porosity and (or) lithology change(s). The velocity of the sediment on either side of the boundary can be calculated for all values of hydrate concentration (0-100 percent) using the average equation (equation 4 ). The density of the sediment can be derived using the weighted proportions of the constituent components (equation 5). Typical values for parameters in the average equation are given in table 2 . From the velocity and density values, the normal incidence reflection coefficient at the boundary without hydrate cementation is:

$$
R=\frac{\rho_{2} V_{2}-\rho_{1} V_{1}}{\rho_{1} V_{1}+\rho_{2} V_{2}}
$$

where $\mathrm{R}$ is the reflection coefficient; subscript 1 denotes the upper medium, and subscript 2 denotes the lower medium. Likewise, the reflection coefficient across the boundary with hydrate concentration is:

$$
R=\frac{\left(\rho_{2}\right)^{\prime}\left(V_{2}\right)^{\prime}-\left(\rho_{1}\right)^{\prime}\left(V_{1}\right)^{\prime}}{\left(\rho_{1}\right)^{\prime}\left(V_{1}\right)^{\prime}+\left(\rho_{2}\right)^{\prime}\left(V_{2}\right)^{\prime}}
$$

where $R_{h}$ and the prime indicates the properties of the sediment containing hydrate.

The amplitude ratio $\gamma$, which is a measure of the amount of blanking, is therefore:

$$
\gamma=\frac{R_{h}}{R}
$$

The best-fit model is one in which $\gamma$ decreases from 1 to some small value as interval velocity and hydrate concentration increase. The highest value of $\gamma$ corresponds to when the amount of hydrate present is too small to affect the reflection coefficient. The lowest value of $\gamma$ corresponds to when the amount of hydrate is high enough, both above and below the horizon, that concentration occurs and the reflection across the horizon is blanked. In summary, the amplitude ratio is a comparison between the value of the reflection coefficient from a boundary within sediment that is hydrated and the value of the reflection coefficient from a boundary within the same sediment that is lacking hydrate.

\section{MODEL 1-POROSITY AND HYDRATION BOUNDARIES}

This model causes a reflection at a boundary that is both a porosity and hydrate discontinuity. Figure 9 shows the velocity, density, and amplitude ratio with respect to
Table 2. Physical property values used in the model study.

[Values for $\rho_{m}$ and $V_{m}$ vary as specified in the text]

\begin{tabular}{ll}
\hline$\rho_{\mathrm{m}}=2.7,2.73 \mathrm{~g} / \mathrm{cm}^{3}$ & (matrix density) \\
$\rho_{\mathrm{h}}=0.9 \mathrm{~g} / \mathrm{cm}^{3}$ & (hydrate density) \\
$\rho_{\mathrm{w}}=1.0 \mathrm{~g} / \mathrm{cm}^{3}$ & (water density) \\
$\mathrm{V}_{\mathrm{m}}=4.37,4.8 \mathrm{~km} / \mathrm{s}$ & (matrix velocity) \\
$\mathrm{V}_{\mathrm{h}}=3.3 \mathrm{~km} / \mathrm{s}$ & (velocity of pure hydrate) \\
$\mathrm{V}_{\mathrm{w}}=1.5 \mathrm{~km} / \mathrm{s}$ & (velocity of water) \\
$\phi=45-62.5$ percent & (porosity) \\
\hline
\end{tabular}

the hydrate concentration for an upper layer and lower layer characterized by the values given below, and other parameters given in table 2 .

$$
\begin{gathered}
\phi_{1}=50 \text { percent, } \phi_{2}=45 \text { percent, } V_{m}=4.37 \mathrm{~km} / \mathrm{s}, \\
\text { and } \rho_{\mathrm{m}}=2.7 \mathrm{~g} / \mathrm{cm}^{3}
\end{gathered}
$$

This results in two layers of sediment with the same lithology (matrix density and velocity) that differ only in porosity percent. Hydrate fills the pores in the same percentage above and below the boundary, so that the end result is slightly more hydrate in the upper layer (highest porosity) than in the lower layer. Figure 9 shows an amplitude decrease (blanking) that is proportional to the hydrate concentration (dashed curve), but the amplitude loss is very small. For example, a 100 percent filling of the pore space by hydrate, which indicates 50 percent hydrate in the sediment of the upper layer and 45 percent hydrate in the lower layer, the amplitude ratio is still greater than 0.5 . The interval velocity at 100 percent saturation approaches about $3.8 \mathrm{~km} / \mathrm{s}$ and densities are decreasing with increasing concentration because of the hydrate's low density. This model predicts only a small amount of blanking, which is quite different from what is shown by the real data as shown in figure 7.

\section{MODEL 2-POROSITY BOUNDARY AND CONSTANT HYDRATION}

Model 2 is similar to model 1 in causing a reflection to occur at a porosity boundary with $\phi_{2}=60$ percent and $\phi_{1}=50$ percent, but in this model, we assume that the total amount of hydrate is constant across the boundary. For example, with total hydrate equal to 25 percent of the sediment, layer 1 would have 42 percent of the pore space filled $(0.42 \times 0.6=0.25)$, whereas layer 2 would have 50 percent filled $(0.5 \times 0.5=0.25)$ The result of this model indicates a decrease of amplitude at the reflection boundary, but the rate is much slower than that of model 1 . 


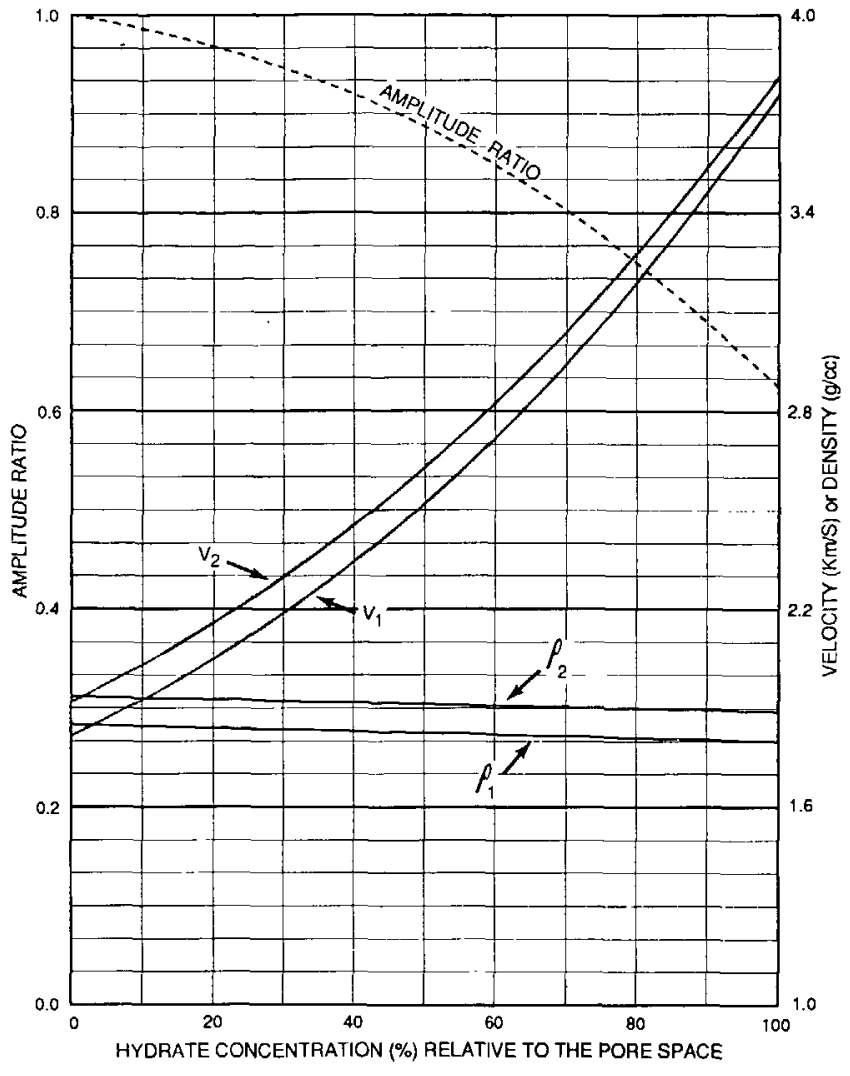

Figure 9. Computed velocity and density (solid lines) and amplitude blanking (dashed line) relative to percent of gas hydrate filling pore spaces of sediment above and below a reflecting interface defined as a porosity boundary. $V$ and $\rho$ denote compressional velocity and density, respectively; subscripts 1 and 2 denote upper medium and lower medium, respectively $\left(\phi_{1}=50\right.$ percent, $\phi_{2}=45$ percent). In this model, the amount of hydrate above and below the interface varies directly with porosity.

\section{MODEL 3-POROSITY AND LITHOLOGIC BOUNDARY}

This model assumes that a reflection occurs at a lithologic boundary characterized by a change in both matrix velocity, matrix density, and porosity. We assume that hydrate concentration is proportional to the porosity across the boundary, which means that the relative concentration of gas hydrates with respect to the porosity is the same. As in model 1 , this means that if the same percentage of pore space is filled in layer 1 as in layer 2 , resulting in different total hydrate concentrations. The justification for using different matrix velocities can be understood by considering the difference of clay content in marine sediment. In this model the lower layer has less clay content than the upper layer. We use the following acoustic properties for this model:

$$
\begin{aligned}
& \text { For upper layer } \\
& \mathrm{V}_{\mathrm{m} 1}=4.37 \mathrm{~km} / \mathrm{s} \\
& \rho_{\mathrm{ml}}=2.7 \mathrm{~g} / \mathrm{cm}^{3} \\
& \phi_{1}=60 \text { percent }
\end{aligned}
$$

For lower layer

$\mathrm{V}_{\mathrm{m} 2}=4.8 \mathrm{~km} / \mathrm{s}$

$\rho_{\mathrm{m} 2}=2.73 \mathrm{~g} / \mathrm{cm}^{3}$

$\phi_{2}=50$ percent
Similar to model 1 , model 3 predicts an amplitude decrease with respect to increasing hydrate concentration, but the amplitude blanking is too small compared to our observation. For example, at 100 percent concentration of hydrate, the amplitude ratio is only 0.87 .

If we interchange the porosity values of model 3 , that is, $\phi_{1}=50$ percent and $\phi_{2}=60$ percent, there is higher amplitude blanking. However, the amount of blanking is still less than our observation. For example, at 100 percent concentration, the amplitude ratio is about 0.55 .

Each of the three models is feasible in terms of hydrate cementation processes, but none predicts a high-amplitude decrease as interval velocity increases.

\section{MODEL 4-SEDIMENT SUBSTITUTION}

Model 4 differs from the others because instead of simply adding hydrate to the pores of the preexisting sediment, it replaces normal sediment with representative hydrated sediment. This model is introduced to account for the observed high-amplitude blanking with low interval velocities. The representative hydrated sediment has its own characteristic density, velocity, porosity, and hydrate percentage values. These values are determined from the equations presented earlier and will differ for each region studied. The normal sediments are considered to be unhydrated, and they are defined by a reflecting horizon, which results from differing lithology (density and velocity) and porosity (as in model 3). With 50 percent replacement by the representative hydrated sediment, 50 percent of the sediment above the horizon (layer 1) will be replaced, and 50 percent of the sediment below the horizon (layer 2) will be as well. The important difference between this model and models $1-3$ is that, as representative hydrated sediment replaces unhydrated normal sediment, the reflecting boundary disappears at 100 percent replacement and only representative hydrated sediment occurs.

To illustrate the blanking effect by model 4 , we can use any kind of representative hydrated sediment. We choose sediment with an average 57.5 percent porosity because this is what we get by solving the regression equation 4 for porosity using the lowest observed velocity (about $1,700 \mathrm{~m} / \mathrm{s}$ from fig. 7). The lowest measured velocity represents the best estimate for unhydrated sediment. A porosity of about 60 percent was also measured in three samples from DSDP site 533 and therefore porosity of 57.5 percent seems appropriate for the Blake Ridge area. We get 27.5 percent hydrate concentration in the pore space by solving equation 4 for $S$ (hydrate concentration) using $\phi=57.5$ percent (porosity) and $\mathrm{V}_{2}$ of approximately $2,000 \mathrm{~m} / \mathrm{s}$ (compressional velocity of hydrated sediment), which was taken as the highest average velocity for hydrated sediment in the Blake Ridge area (fig. 7). The highest velocity should indicate sediment with the highest amount of hydrate. If we had used $\mathrm{V}_{\mathrm{p}}=2,100 \mathrm{~m} / \mathrm{s}$, the hy- 
drate concentration would be 34 percent. We prefer to use the lower, more conservative estimate. The uncertainty in hydrate concentration could be as high as 25 percent in this example. Therefore we have used interval velocity data to determine (calibrate) a representative hydrated sediment, which can be combined with amplitude ratios to give bulk-hydrate concentrations as described below.

The velocity $\left(\mathrm{V}_{\mathrm{hs}}\right)$ and density $\left(\rho_{\mathrm{hs}}\right)$ of the representative hydrated sediment in the model are from equations 4 and 5 with the acoustic parameters for model $1: V_{\mathrm{hs}}=2.016$ $\mathrm{km} / \mathrm{s}, \rho_{\mathrm{hs}}=1.707 \mathrm{~g} / \mathrm{cm}^{3}$. The acoustic properties of the unhydrated sediment are: $V_{1}=1.625 \mathrm{~km} / \mathrm{s}, \rho_{1}=1.638 \mathrm{~g} / \mathrm{cm}^{3}$, $\phi_{1}=62.5$ percent, $V_{2}=1.768 \mathrm{~km} / \mathrm{s}, \rho_{2}=1.808 \mathrm{~g} / \mathrm{cm}^{3}$, $\phi_{2}=52.5$ percent

Figure 10 illustrates the amplitude ratio versus the percent substitution of representative hydrate sediment. In other words, 0 percent representative hydrated sediment refers to no hydrate present; 40 percent refers to the sub-

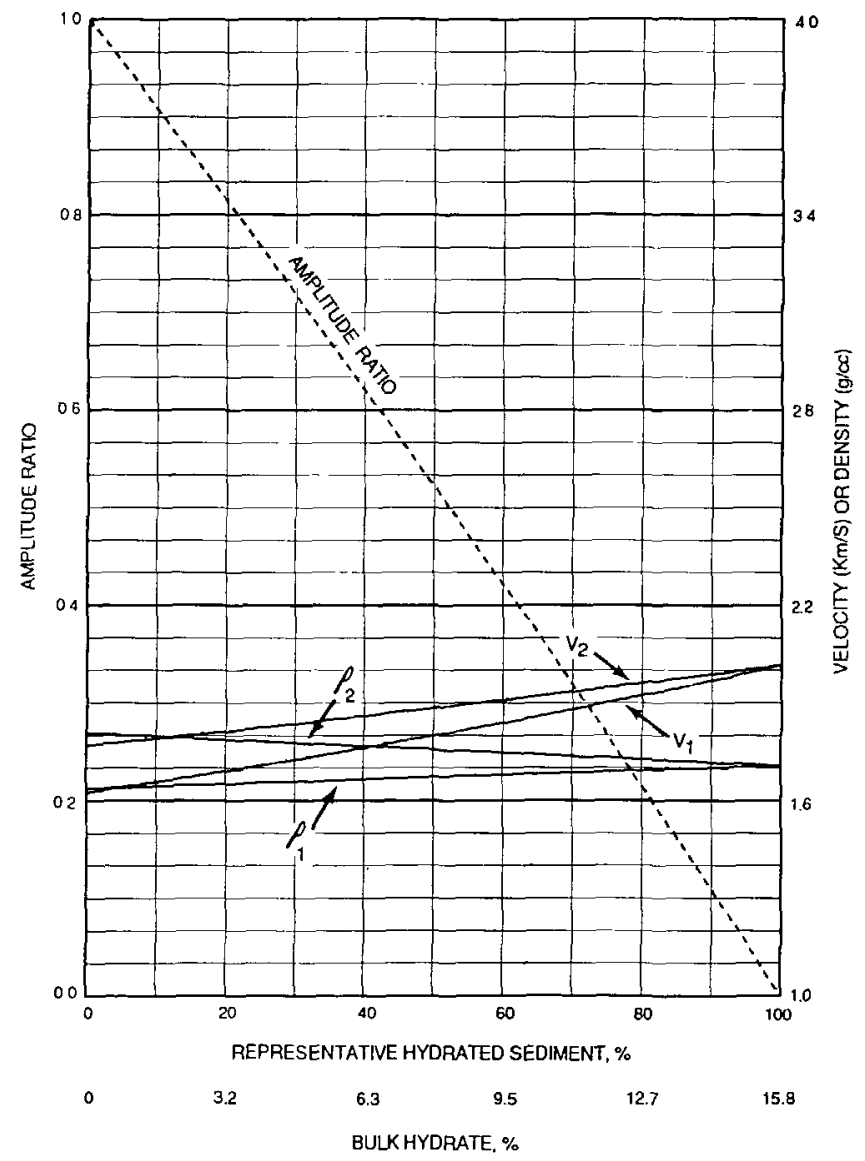

Figure 10. Computed velocity and density (solid lines) and amplitude decrease (dashed line) relative to percent of representative hydrated sediment (57.5 percent porosity rock with 27.5 percent of the pore space filled by gas hydrates) that replaces unhydrated marine sediment across a porosity boundary. $V$ and $\rho$ denote compressional velocity and density, respectively $\left(\phi_{1}=62.5\right.$ percent, $\phi_{2}=52.5$ percent). In this example, the amount of hydrate above and below the interface is identical. stitution of 40 percent representative hydrated sediment into both the upper and lower layers; and 100 percent refers to complete replacement of the upper and lower layers by representative hydrated sediment. The dashed line in figure 10 shows that the amplitude blanking is proportional to the amount of the representative hydrated sediment. At 100 percent replacement, the amplitude ratio is 0 , which is a total blanking, because all unhydrated sediment is replaced by the representative hydrated sediment, and, therefore, the reflection horizon no longer exists. The highest velocity in this model is $2.02 \mathrm{~km} / \mathrm{s}$, which is the compressional velocity of the representative hydrated sediment. This model predicts significant blanking with a low interval velocity.

Amplitude blanking proportional to the amount of representative hydrated sediment in terms of relative median reflectance and interval velocity is shown in figure 7 . This predicted curve is consistent with the observations in as much as it falls within the scatter of the data and the maximum and minimum reflectance and velocity values coincide with the maximum and minimum observed values.

Two independent lines of evidence support the results of model 4. First, we used velocity information (fig. 7) to calculate a porosity of 57.5 percent for the model (equation 4). This value is essentially identical to that measured in DSDP site 533 in an interval near the bottom of the hole (Sheridan and others, 1983). Second, point C (fig. 7), is less than the $100 \mathrm{~m} / \mathrm{s}$ away from the modeled curve, which is well within the accuracy of the velocity pick. This point is the reflectance/velocity value from line BT1 closest to DSDP site 533, which is the only place near Blake Ridge where the model can be realistically calibrated.

Once the properties of the representative hydrated sediment are calculated from interval velocity information and the weighted equation of the time-average and the Wood velocities, amplitude ratios (blanking) can be used alone to determine total bulk hydrate concentrations. For example, with an amplitude reflectance at DSDP site 533 of 0.042 (which corresponds to an amplitude ratio of 0.5 ), we end up with approximately 52 percent sediment substitution (fig. 10). This corresponds to 8 percent bulk hydrate $(0.52 \times 0.275 \times 0.575=0.08)$, where the representative sediment in characterized with 57.5 percent porosity and 27.5 percent hydrate. Using interval velocity data separately, from DSDP site 533, the average interval velocity is 1,800 $\mathrm{m} / \mathrm{s}$ (the midpoint between the points where curves $\mathrm{V}_{1}$ and $\mathrm{V}_{2}$ cross the $1,800 \mathrm{~m} / \mathrm{s}$ value). This correlates to a bulkhydrate concentration of 5 percent in total volume $(0.33 \times 0.275 \times 0.575=0.052)$. If the interval velocity at DSDP site 533 had been the same as that used in the representative hydrated sediment calibration, the bulk concentrations calculated separately from interval velocity and amplitude ratio would be the same.

At DSDP site 533, methane gas was sampled and presumed to indicate the existence of disassociated gas hydrates. A single measurement yielded 13 volumes of gas 
(at standard pressure and temperature conditions, or STP) to 1 volume of sediment (Kvenvolden and Barnhard, 1983). Because gas hydrates concentrates methane in the ratio of about 160 volumes of gas (at STP) to 1 volume of sediment (Kvenvolden, 1988), the resulting value for the bulk volume of gas hydrates in the sediment is $13 / 160$, or about 8 percent, which agrees with the 5 to 8 percent prediction from model 4 . Whether 8 percent is a maximum or only an average concentration remains uncertain, because it is the only measurement available from DSDP site 533.

In summary, the amplitude information provides good estimates of the percent of representative hydrated sediment substituted above and below a reflecting horizon, but it cannot determine the concentration of gas hydrates in the pore spaces. Hence, amplitude information alone produces large uncertainties for the bulk volume of hydrate in the sediment. Interval velocity, however, yields a small range of values for bulk volume of gas hydrates regardless of the large differences in percent of representative hydrated sediment. Calibrating the bulk volume of hydrate deduced from amplitude information with the bulk volume calculated from velocity information provides the critical step in the model for determining the appropriate concentration of hydrate in the pore space.

\section{DISCUSSION}

We have proposed a model for quantitatively estimating the bulk volume of gas hydrates in the zone above the BSR. The model (model 4) relates amplitude blanking, seismic velocity, concentration of gas hydrates in pore spaces, and the concentration of representative hydrated sediment above and below a reflecting interface. Our results are consistent with the amplitude blanking and average interval velocities measured in the Blake Ridge area from multichannel seismic data and with the observation that a small amount of gas hydrates occurs at DSDP site 533. This method, therefore, provides a technique for classifying and mapping gas-hydrate concentrations using a grid of seismic-reflection profiles. Estimates of the volume of hydrate (or methane) contained within the sediment above the BSR can be made from the hydrate concentrations. A preliminary estimate for the Blake Ridge area is $66 \times 10^{6} \mathrm{~m}^{3}$ of hydrate, or approximately $370 \mathrm{Tcf}$ of gas in all sediment beneath each one square $\mathrm{km}$ of the sea floor (Dillon and others, 1991). A separate technique can be used for placing limits on the thickness of the free-gas zone beneath the hydrate (Miller and others, 1991). Together, these methods offer the first quantitative approaches to estimating the total amount of hydrate and gas locked in shallow subbottom ocean sediment.

A troublesome aspect of our modeling exercise is that models based on the physical principle of hydrate filling intergranular pore-space (models 1 to 3 ) fail to explain why large blanking is associated with relatively low interval velocities in the Blake Ridge area. A couple of possible implications of this observation are:

1. The average equation (equation 4) that relates the physical properties of the sediment and the hydrate is incorrect. Although it is beyond the scope of this paper to evaluate this possibility, other studies have supported the general validity of the time-average equation (equation 1) for gas hydrates in consolidated sediments (Pearson and others, 1983).

2. Our supposition that hydrates nucleate and fill pore spaces is oversimplified. One mechanism for hydrate formation in sediments is that growth proceeds from disseminated to massive occurrences; another mechanism is that hydrates grow by recrystallization and annealing during pressure and temperature changes that accompany glaciation and eustacy (Sloan, 1990). To what extent physical or chemical processes control hydrate occurrence in sediments is an unsolved problem in understanding gas hydrates and warrants additional study.

3. Our one-dimensional seismic modeling is too simple to explain the observations. For example, the models assume second-order (abrupt) boundaries for reflection interfaces, but the real boundaries may well be transitional. Because the reflection characteristics of a transitional layer (Justice and Zuba, 1986) are quite different from reflections of simple boundaries, additional amplitude decrease might be associated with transitional boundaries. We also assumed that whole layers are uniformly cemented by gas hydrates, but the cementation can vary spatially. Accordingly, three-dimensional modeling, including scattering, provides better approximations of reflection amplitude for hydrated sediments.

Our preferred model, model 4 , is unsatisfying in that sediment substitution probably does not occur in nature. However, almost nothing is known about the details of the natural occurrence of gas hydrates-how they are distributed in the pores, how they cement the grains, whether they are disseminated or concentrated in veins and nodules, and so on. We present this model because it is the only description that fits our current understanding about hydrates in deep marine sediment. That we do not know what the model means simply opens new directions for research in the physical and chemical occurrence of hydrates in sediment.

Even though this model cannot be fully explained in terms of reflection seismology, our estimation method is based on the physical property of hydrated sediment that cementation in the pore space increases the interval velocity of marine sediment. Because our estimation method uses seismic amplitude firmly constrained by the observed interval velocities, the proposed method is valid and accurate in terms of amount of hydrate.

Our preferred model can be applied to reflection data sets in other regions as long as certain conditions are met. 
First, processing of the reflection data must preserve relative amplitudes that are calibrated relative to the reflection coefficient of the sea floor, and that are corrected for any water-depth dependence of the reflection coefficient. Amplitude preservation and calibration are inherently more difficult on single-channel data than on multichannel data, because the first multiple or other information for computing the reflection coefficient may be lacking in singlechannel data.

Second, velocity estimates from the region of interest are required. The average lowest velocity of sediment is used to calculate porosity (equation 4), and the average highest velocity of hydrated sediment is used, with porosity, to calculate the hydrate concentration.

Third, amplitudes must be scaled to a reference reflectance. The largest reflectance for the data from the Blake Ridge is estimated as 0.1 (fig. 7) and, therefore the $\mathrm{dB}$ scale is based on this reference reflectance. This reference reflectance was chosen after all reflection profiles were examined, and it is a function of both the locality of the seismic profiles and the data-processing procedure. The choice of reference reflectance for $\mathrm{dB}$ scale conversion is subjective, but as long as a reasonable value is chosen, estimates of the amount of hydrate will not be affected. The reference reflectance (not the dB scale) is important for comparing amplitudes among different geographic locations and different seismic-acquisition and processing methods.

Fourth, the source of hydrate should be known. Most methane in hydrates is biogenic and formed by bacterial action at low temperatures. However, some hydrate is thermogenic, forms at relatively high temperatures, and contains gases such as ethane and propane (Sloan, 1990). The measured compressional velocity of pure biogenic hydrate is $3.3 \mathrm{~km} / \mathrm{s}$, whereas that of pure thermogenic hydrate is $3.8 \mathrm{~km} / \mathrm{s}$ (Pandit and King, 1983). This difference will affect hydrate concentrations estimated in equation 4 .

Fifth, different geologic regions will almost certainly require different representative hydrated sediment to be used in the model. To select a representative hydrated sediment, choose the velocity of unhydrated sediment as the velocity corresponding to the highest median reflectance $(0.1$ or $0 \mathrm{~dB}$ in is study). For Blake Ridge (fig. 7), this velocity is $1,700 \mathrm{~m} / \mathrm{s}$. Estimate the average porosity of the ordinary marine sediment using this velocity $(1,700 \mathrm{~m} / \mathrm{s})$ and equation 4 . The average porosity for the hydrate zone can also be taken from drill-hole data. For the Blake Ridge area, both methods indicate a porosity of about 60 percent. Estimate the highest velocity for the hydrated sediment in the area. We used a conservative estimate of $2,000 \mathrm{~m} / \mathrm{s}$ (fig. 7). Calculate the amount of hydrate concentration by substituting this upper velocity value and the estimated porosity into equation 4 . For the Blake Ridge area, we calculate the concentration of gas hydrates in the pore spaces is 27.5 percent. Based on the above procedure, the representative hydrated sediment in the Blake Ridge area for our model is chosen as a sediment having 57.5 percent porosity with a gas hydrates concentration of 27.5 percent in the pore space. Now, simply using amplitude ratios (blanking), bulk-hydrate concentrations can be determined, such as for DSDP site 533 where the amplitude ratio of 0.5 gives a bulk-hydrate concentration of 8 percent (fig. 10).

\section{CONCLUSIONS}

The primary effect of hydrate concentration on the acoustic properties of marine sediment is an increase in interval velocity. The quantitative analysis of interval velocity can be used to estimate the bulk volume of in-situ gas hydrates. Another seismic attribute of hydrate concentration is amplitude blanking. This phenomenon is observed in single-channel as well as multichannel seismic profiles. Our model assumes that the degree of amplitude blanking is related to the amount of gas hydrates filling the pore spaces of the sediment.

We propose a method of estimating the amount of insitu gas hydrates in deep marine sediment using amplitude information above the BSR. Because amplitude blanking is a relative quantity, the estimation method must be calibrated against interval velocities. This method is based on measuring the degree of blanking in seismic models generated by the bulk mixture of sediment consisting of both representative hydrated sediment and normal (unhydrated) sediment. The properties of the representative hydrated sediment can be calculated from interval-velocity information and the weighted equation of the time-average and the Wood velocities. Seismic amplitudes can then be directly computed and related to the bulk volume of gas hydrates in the sediment. The mechanism by which blanking occurs remains unexplained. The models that simply fill pore spaces with hydrate underestimate the amount of blanking. Our preferred model (model 4, sediment substitution) is difficult to reconcile with known natural processes. This emphasizes the need for research on how the physical and chemical presence of hydrates in sediments alters the bulk properties of those sediments.

In the Blake Ridge area, the best-fit model describes a representative hydrated sediment consisting of sediment with 57.5 percent porosity in which 27.5 percent of the pore spaces are filled by gas hydrates. This representative hydrated sediment replaces unhydrated normal sediment across a reflection boundary between two layers, the upper layer with 62.5 percent porosity and the lower layer with 52.5 percent porosity. This model can be applied to other areas by selecting reasonable values for the hydrated and unhydrated sediments. We emphasize that the observed amplitude must be carefully calibrated by interval velocities before it can be used alone to determine bulk-hydrate concentrations. 


\section{ACKNOWLEDGMENTS}

We would like to thank David Scholl and Michael Max for very helpful and numerous comments on the earlier version of the manuscript. We thank T. Shipley and T. Brocher for very constructive comments and suggestions. This work was funded by the U.S. Department of Energy and U.S. Geological Survey.

\section{REFERENCES CITED}

Asquith, G., and Gibson, C., 1982, Basic well log analysis for geologists, in Methods in Exploration Series: Tulsa, Okla., American Association of Petroleum Geologists, 216 p.

Carson, R.L., Gangi, A.F., and Snow, K.R., 1986, Empirical reflection travel time versus depth and velocity versus depth functions for the deep-sea sediment column: Journal of Geophysical Research, v. 91, p. 8249-8266.

Castagna, J.P., Batzle, M.L., and Eastwood, R.L., 1985, Relationship between compressional-wave and shear-wave velocities in clastic silicate rocks: Geophysics, v. 50, p. 571-581.

Cook, D.A., and Schneider, W.A., 1983, Generalized linear inversion of reflection seismic data: Geophysics, v. 48, p. $665-$ 676.

Dillon, W.P., Booth, J.S., Paull, C.K., Fehlhaber, K., Hutchinson, D.R., and Swift, B.A., 1991, Mapping sub-seafloor reservoirs of a greenhouse gas-methane hydrates, in Kumar, M., and Maul, G.A., eds., Proceedings of international symposium on marine positioning: Marine Geodesy Committee, Marine Technology Society, Washington D.C., p. 545-554.

Dillon, W.P., Fehlhaber, K., Lee, M.W., Booth, J.S., and Paull, C.K., 1991, Methane hydrate in sea floor sediments off the southeastern U.S.-Amount and implication for climate change, NE/SE Geol. Soc. Am. Meeting, Baltimore, March 14-16, 1991, 1991 Abstracts with Programs, p. 22.

Dillon, W.P., and Paull, C.K., 1983, Marine gas hydrates, IIGeophysical evidence, in Cox, J.L., ed., Natural gas hydrates-properties, occurrence, and recovery: Boston, Butterworth Publishers, p. 73-90.

Dillon, W.P., and Popenoe, P., 1988, The Blake Plateau basin and Carolina trough, in Sheridan, R.B., and Grow, J.A., eds., The Atlantic Continental Margin-U.S.: DNAG Geology of North America I-2, p. 19-55.

Dobrynin, V.M., Korotajev, Yu. P., and Plyuschev, D.V., 1981, Gas Hydrate-a possible energy source, in Mayer, R.G., and Olson, J.C., eds., Long term energy resources: Boston, Pitman, p.727-729.

Dragoset, B., Hargreaves, N., and Larner, K., 1987, Air-gun source instabilities: Geophysics, v. 52, p. 1229-1251.

Eberhart-Phillips, D., Han, D.H., and Zoback, M.D., 1989, Empirical relationships among seismic velocity, effective pressure, porosity, and clay content: Geophysics, v. 54, p. 82-89.

Ewing, J.I., and Hollister, C.H., 1972, Regional aspects of deep sea drilling in the western North Atlantic: Initial report of the deep sea drilling project 11, p. 951-973.

Gray, W.C., 1979, Variable norm deconvolution: Palo Alto, Calif., Stanford University, Ph.D.Thesis.
Hajnal, Z., and Sereda, I.T., 1981, Maximum uncertainty of interval velocity estimates: Geophysics, v. 46, p. 1543-1547.

Houtz, R., 1974, Preliminary study of global sediments sound velocities from sonobuoy data, in Hampton, L., ed., Physics of sound in marine sediments: New York, Plenum Press, p. $519-535$.

Justice, H.J., and Zuba, C., 1986, Transition zone reflections and permafrost analysis: Geophysics, v. 51, p. 1075-1086.

Kvenvolden, K.A., 1988, Methane hydrate-A major reservoir of carbon in the shallow geosphere: Chem. Geol., v. 71, p. 4171.

Kvenvolden, K.A., and Barnard, L.A., 1983, Gas hydrates of the Blake Ridge, Site 533, Deep Sea Drilling Project Leg 76: Initial report of the deep sea drilling project 76, p. 353-365.

Lashof, D.A., and Ahuja, D.R., 1990, Relative contributions of greenhouse gas emissions to global warming: Nature, v. 344, p. 529-531.

Lee, M.W., and Hutchinson, D.R., 1990, True-amplitude processing techniques for marine, crustal-reflection seismic data: U.S. Geological Survey Bulletin 1897, 22 p.

Lee, M.W., Agena, W.F., and Swift, B.A., 1991, An analysis of a unique seismic anomaly in Georges Bank basin, Atlantic Continental Margin: U.S. Geological Survey Open-File Report 91-138, 25 p.

Lindseth, R.O., 1979, Synthetic sonic logs-a process for stratigraphic interpretation: Geophysics, v. 44, p. 3-26.

Markl, R.G., Bryan, G.M., and Ewing, J.I., 1970, Structure of the Blake-Bahama Outer Ridge: Journal of Geophysical Research, v. 75, p. 4539-4555.

McIver, R.D., 1981, Gas Hydrate, in Mayer, R.G., and Olson, J.C., eds., Long term energy sources: Boston, Pitman, p. 713726.

Miller, J.J., Lee, M.W., and von Huene, R., 1991, An analysis of seismic reflection from the base of a gas hydrates zone, offshore Peru: American Association of Petroleum Geologists Bulletin, v. 75, p. 910-924.

Nobes, D.C., Villinger, H., Davis, F.F., and Law, L.K., 1986, Estimation of marine sediment bulk physical properties at depth from seafloor geophysical measurements: Journal of Geophysical Research, v. 91, p. 14033-14043.

Pandit, B.I., and King, M.S., 1983, Elastic wave velocities of propane gas hydrates, in Cox, J.L., ed., Natural gas hydrates-properties, occurrence and recovery: Boston, Butterworth Publishers, p. 49-61.

Paull, C.K., Ussler, W. III, and Dillon, W.P., 1991, Is the extent of glaciation limited by marine gas hydrates?: Geophysical Research Letters, v. 18, p. 432-434.

Pearson, C.F., Halleck, P.M., McGulre, P.L., Hermes, R., and Mathews, M., 1983, Natural gas hydrates; a review of in situ properties: Journal of Physical Chemistry, v. 87, p. 41804185.

Sheridan, R.B., Gradstein, F.M., and others, 1983, Site Reports and underway data: Initial reports of the deep sea drilling project 76 , p. 35-80.

Shipley, T.H., and Didyh, B.M., 1982, Occurrence of methane hydrates offshore southern Mexico: Initial Report of the Deep Sea Drilling Project 66, p. 547-556.

Shipley, T.H., Houston, M.H., Buffler, R.T., Shaub, F.J., McMillen, K.J., Ladd, J.W., and Worzel, J.L., 1979, Seismic evidence for widespread possible gas hydrates horizons on 
continental slopes and rises: American Association of Petroleum Geologists Bulletin, v. 63, p. 2204-2213.

Sloan, E.D., Jr., 1990, Clathrate hydrates of natural gases: New York, Marcel Dekker, $641 \mathrm{p}$.

Stoll, R.D., 1974, Effect of gas hydrates in sediments, in Kaplan, I.R., ed., Nature of gases in marine sediments: New York, Prenum press, p. 235-248.

Suess, E.R., von Huene, R. and others, 1988, Introduction, objectives, and principal results, LEG 112, Peru Continental Margin: Proceedings of the Ocean Drilling Program, initial reports 112 , p. 5-44.
Timur, A., 1968, Velocity of compressional waves in porous media at permafrost temperature: Geophysics, v. 3, p. 584-595.

Tucholke, B.E., Bryan, G.M., and Ewing, J.I., 1977, Gas hydrate horizons detected in seismic-profile data from the western North Atlantic: American Association of Petroleum Geologists Bulletin, v. 61, p. 698-707.

Wood, A.B., 1941, A text book of sound: New York, Macmillan, $578 \mathrm{p}$.

Wyllie, M.R.J., Gregory, A.R., and Gardner, G.H.F., 1958, An experimental investigation of factors affecting elastic wave velocities in porous media: Geophysics, v. 23, p. 459-493. 



\title{
THE FUTURE OF ENERGY GASES
}

U.S. GEOLOGICAL SURVEY PROFESSIONAL PAPER 1570

\section{Biogenic Gas: Controls, Habitats, and Resource Potential}

\author{
By Dudley D. Rice ${ }^{1}$
}

\section{CONTENTS}

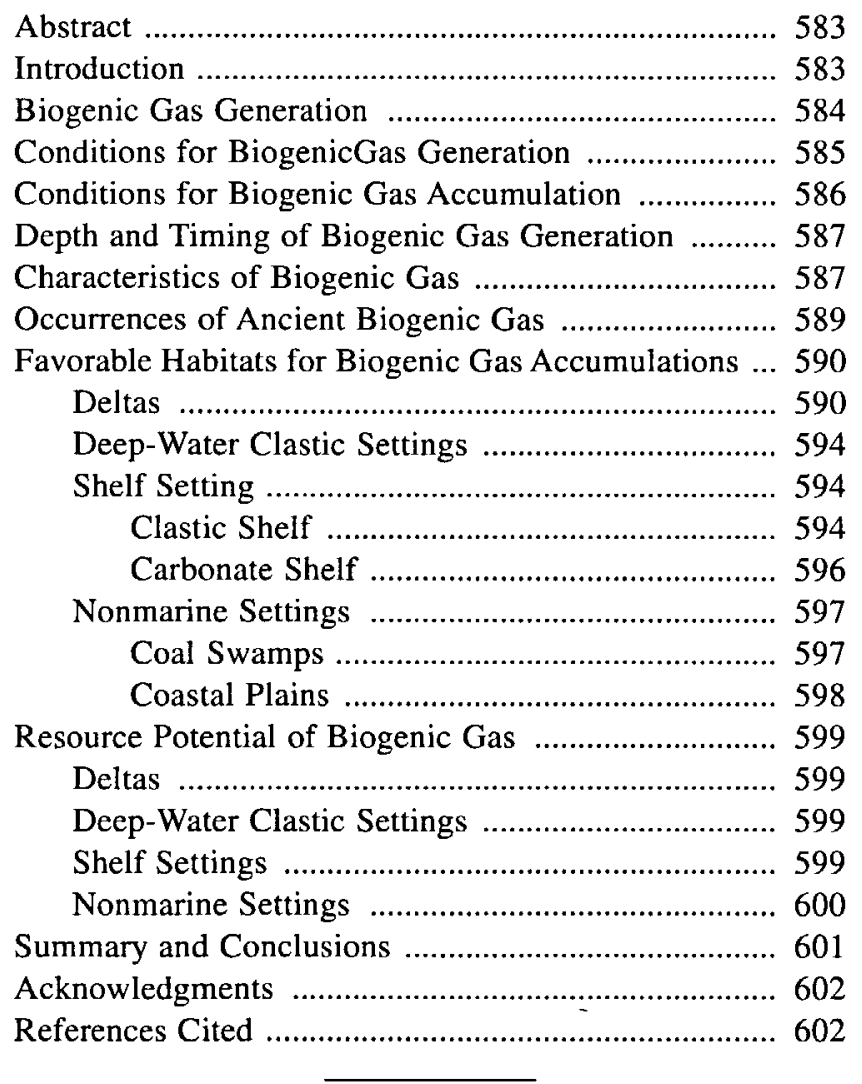

\begin{abstract}
As much as 20 percent of the world's natural-gas resource is estimated to have been generated by the decom-

\footnotetext{
80225 .
}

'U.S. Geological Survey, Box 25046, Federal Center, Denver, CO
\end{abstract}

position of organic matter by anaerobic microbes at low temperatures. This gas is commonly referred to as biogenic gas. Most biogenic gas was generated early in the burial history of sediments. Some biogenic gas was also generated in relatively recent geologic time and is associated with groundwater flow.

The factors that favor significant generation of biogenic gas are anoxic conditions, low sulfate content, low temperature, abundant organic matter, and sufficient pore space for the microbes to thrive. Conditions beneficial for the accumulation of biogenic gas include stratigraphic or early structural traps, adequate seals, low permeability, low pressure, early dissolution of the gas, and formation of gas hydrates. Rapid sediment deposition is critical to both the generation and the accumulation of biogenic gas generated during the early stage.

Biogenic gas is distinguished by its molecular and isotopic composition. The hydrocarbon fraction is generally more than 99 percent methane, and the diagnostic isotopic composition of the methane component is as follows: $\delta^{13} \mathrm{C}$ values are generally lighter than -55 parts per thousand (permil), and $\delta \mathrm{D}$ values are usually in the range of -150 to -250 permil. This isotopic composition indicates that the methane generally resulted from $\mathrm{CO}_{2}$ reduction.

Significant accumulations of ancient biogenic gas have been discovered in Africa, Asia, Europe, North America, and South America. These accumulations occur in Mississippian and younger rocks, at burial depths as much as $4,600 \mathrm{~m}$. They are associated with a variety of rock types (carbonate, clastic, and coal), and occur in a variety of marine and nonmarine depositional settings generally characterized by rapid deposition.

\section{INTRODUCTION}

Hydrocarbon resources are enormous, but not infinite, and they are not evenly distributed throughout the world 
(Masters and others, 1991). Most of the conventional hydrocarbon resources occur in the Eastern hemisphere and in a few major petroleum provinces, such as in the Middle East and West Siberia. Because oil exploration is in an advanced stage in many countries, few discoveries of large oil accumulations are expected. In contrast, significant gas discoveries are likely because exploration for natural gas is at a less advanced stage. A better understanding of the processes that result in the generation and accumulation of natural gas will increase the probability of successful future exploration.

Natural gas in commercial accumulations is formed from organic matter and results from two distinct processes (fig. 1). At shallow burial depths and low temperatures, methane-rich gas is generated by decomposition of organic matter by microorganisms. This gas is referred to as biogenic. In contrast, thermogenic gas is generated mainly from organic matter by thermal degradation and cracking processes that occur at higher temperatures and extended duration of heating. Most gas produced from commercial oil and gas fields is probably of thermal origin. Abiogenic gas, which is derived from inorganic precursors in the deep earth, is not a major contributor to commercial gas accumulations.

This paper is an evaluation of biogenic gas that was generated in the geologic past and which can represent a significant component of some commercial gas accumulations. Although biogenic gas generation is observed and has been studied in many present-day settings, the occur-

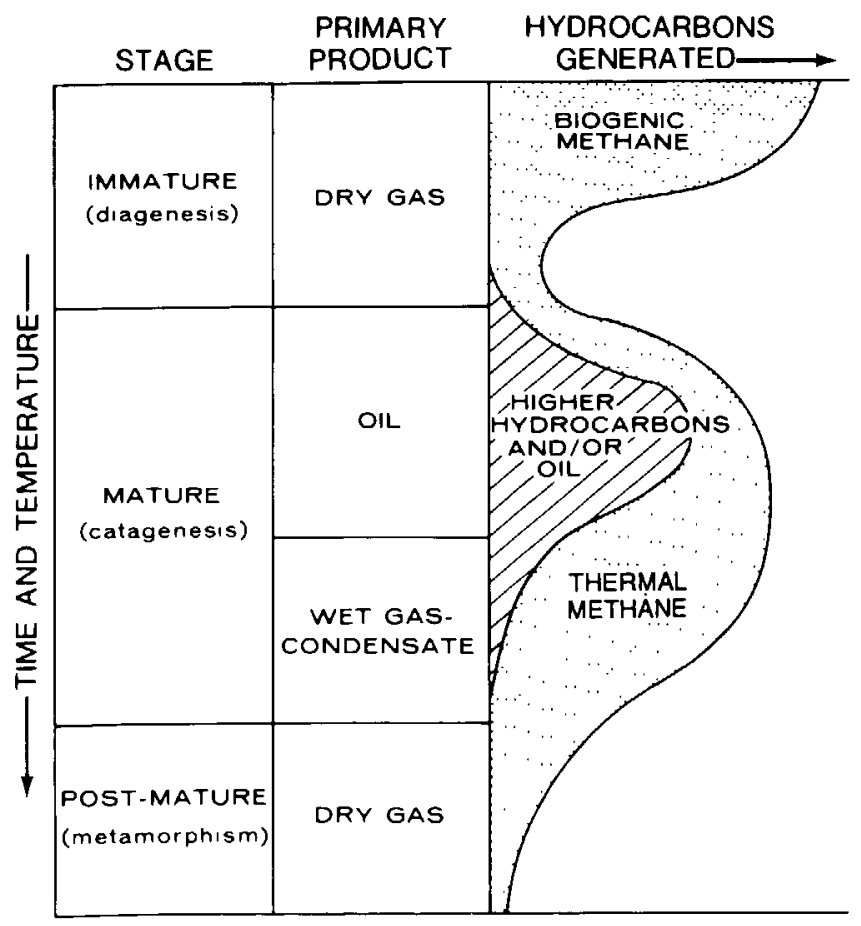

Figure 1. Major stages of hydrocarbon generation. Biogenic gas is generated at low temperatures and at relatively shallow depths. rence of biogenic gas accumulations in ancient sequences is not well documented, even though these accumulations represent an important and commonly overlooked energy resource. The objectives of this paper are to (1) review the process of biogenic gas generation, (2) discuss the conditions necessary for its generation and accumulation, (3) address the depth and timing of biogenic gas generation, (4) characterize the composition of biogenic gas, (5) describe worldwide occurrences of biogenic gas including favorable habitats for its generation and accumulation, and (6) assess the resource potential of biogenic gas.

\section{BIOGENIC GAS GENERATION}

Biogenic gas is produced by the decomposition (coupled oxidation-reduction reactions) of organic matter by microorganisms. The breakdown of organic matter leading to methanogenesis is performed by a diverse microbial population (Mah and others, 1977). Methanogens, assigned to the Archaea domain (Woese and others, 1990), only operate during the final stages of anaerobic decomposition of organic matter and depend on other microbes to convert the original complex organic compounds into simple compounds.

Two primary pathways have been identified for the generation of biogenic gas: carbon dioxide $\left(\mathrm{CO}_{2}\right)$ reduction and fermentation. A detailed description of these pathways is provided by Schoell (1980), Woltemate and others (1984), Whiticar and others (1986). Most species of methanogens have the ability to generate methane by $\mathrm{CO}_{2}$ reduction (Marty, 1992), which is-the main pathway for biogenic gas in commercial accumulations. Fermentation is performed by a few species of methanogens by the decarboxylation of several nutrients (substrates), the most common being acetate. During fermentation, the methyl group is converted to methane $\left(\mathrm{CH}_{4}\right)$ and the carboxyl group is converted to $\mathrm{CO}_{2}$, which can also be reduced to methane.

$\mathrm{CO}_{2}$ reduction and fermentation have been shown to operate simultaneously, but the biogenic gas resulting from each is quantitatively more important at different times. The two pathways are commonly independent of depositional environment, and can be seasonally or temperature controlled (Jenden and Kaplan, 1986; Martens and others, 1986; Burke and others, 1988; Coleman and others, 1988; Schoell and others, 1988).

On the basis of isotopic composition, most ancient biogenic gas accumulations have probably resulted from $\mathrm{CO}_{2}$ reduction, whereas both $\mathrm{CO}_{2}$ and fermentation are operating in recent environments. Jenden and Kaplan (1986), Coleman and others (1988), and Schoell (1988) speculated that burial depth and age of the sediments may be the major factors regulating the relative significance of the two pathways. That is, young, fresh, near-surface sedi- 
ments can generate biogenic gas by either $\mathrm{CO}_{2}$ reduction or fermentation. However, most of this early generated gas is probably lost to the atmosphere soon after generation and is not retained as a major component of commercial accumulations. In contrast, older, altered, more deeply buried sediments generate biogenic gas mainly by $\mathrm{CO}_{2}$ reduction; this gas has a better chance of being trapped and is therefore the major contributor to ancient accumulations. In addition, substrates with methyl resulting from microbial decomposition of organic matter may be available for fermentation only in young, fresh, shallow sediments, whereas $\mathrm{CO}_{2}$ utilized for reduction can be provided by several sources, as will be discussed later. The change from fermentation to $\mathrm{CO}_{2}$ reduction with increasing depth has been demonstrated in recent sediments by Jenden and Kaplan (1986) and Risatti (1987).

Rock sequences containing biogenic gas accumulations are far removed from the original environment in which the gas was generated. However, much is known about modern settings that can be used in interpreting methanogenesis in ancient sequences. The recent marine environment is particularly useful for analogy because $\mathrm{CO}_{2}$ reduction is the primary biogenic gas pathway in this setting as well as for most ancient biogenic gas accumulations. Although many ancient biogenic gas accumulations occur in freshwater sequences, they were generated by $\mathrm{CO}_{2}$ reduction and the process is similar to that in the marine environment.

Organic-rich, marine sediments pass through three main stages of respiratory metabolism that lead to methanogenesis - aerobic respiration, sulfate reduction, and $\mathrm{CO}_{2}$ reduction (fig. 2). These three stages yield progressively less energy, and the change from one stage to another is due to changes resulting from microbial activity. The main evidence that microbial methanogenesis results from the progression of these metabolic stages comes from geochemical studies of interstitial waters in marine sediments as summarized by Claypool and Kaplan (1974), Rice and Claypool (1981), and Claypool and Kvenvolden (1983). These studies are important because the geochemical data suggest that methanogenesis continues to depths of at least several hundred meters, and not just a few centimeters as indicated by the decreasing quantity of bacteria and other microorganisms with increasing depth in shallow sediments (Zobell and Anderson, 1936).

$\mathrm{CO}_{2}$ needed for reduction to generate methane is available from several sources. A low-temperature, shallow $\mathrm{CO}_{2}$ source is the oxidation of organic matter by microbiological processes (sulfate reduction and fermentation). A higher temperature, deeper source of $\mathrm{CO}_{2}$ is the thermal decarboxylation of organic matter (Tissot and Welte, 1984). A third possible source of $\mathrm{CO}_{2}$ for reduction is the alteration of thermogenic hydrocarbons generated at greater depths. Several sources of $\mathrm{CO}_{2}$ are probably required to provide sufficient quantities to maintain methane generation at a rate high enough to form significant biogenic gas accumulations.

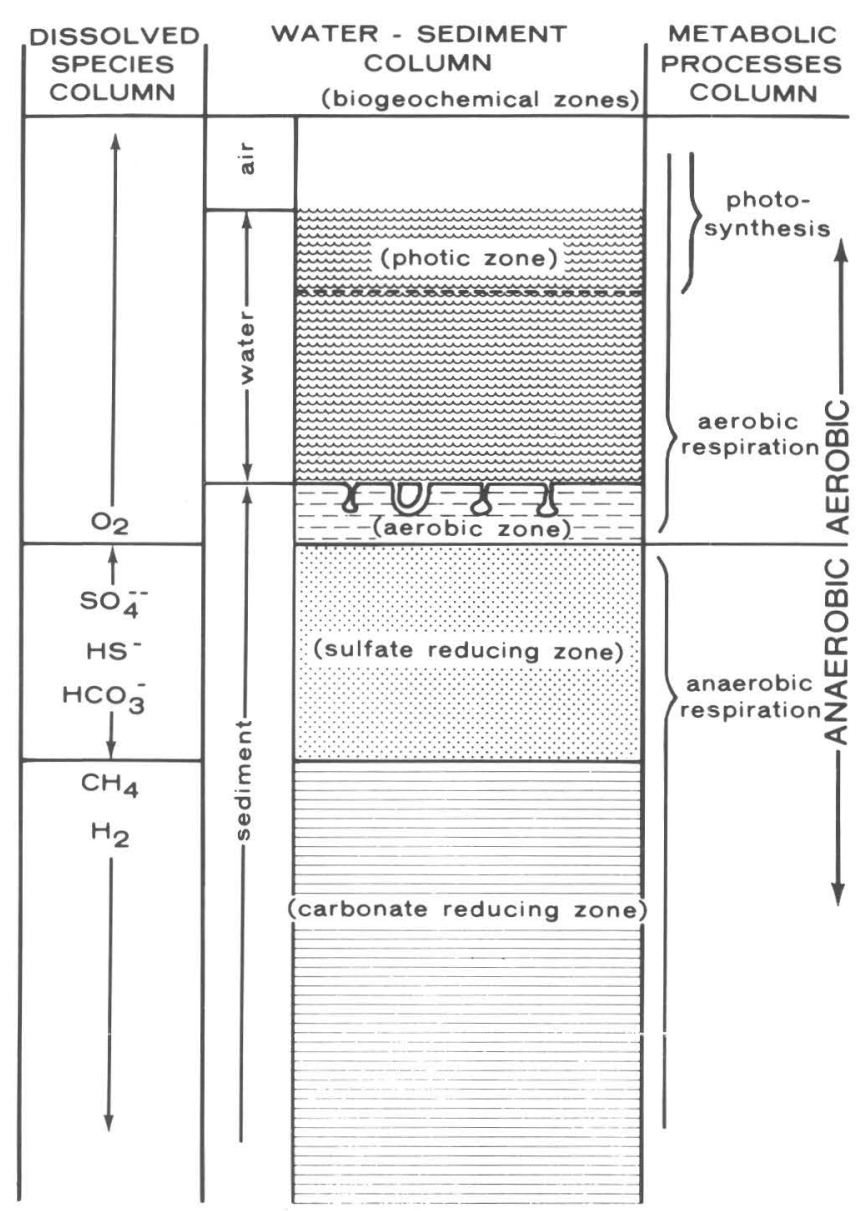

Figure 2. Diagrammatic cross section of organic-rich, marine environment showing succession of microbial processes that lead to biogenic methane generation. From Rice and Claypool (1981).

Substrates used for fermentation are derived from the successive breakdown by microorganisms of more complex organic substrates of the organic matter into smaller fragments until acetate is reached (Mechalas, 1974).

\section{CONDITIONS FOR BIOGENIC GAS GENERATION}

The generation of biogenic gas is regulated by several key factors (table 1). These requirements, which must be maintained for a sufficient period of time for the generation of significant amounts of biogenic gas to take place, are as follows:

1. Anoxic environment-Methanogens are obligate anaerobes that are widely distributed in anaerobic environments and cannot tolerate any oxygen (Wolfe, 1971).

2. Low-sulfate environment-In fresh-water or brackish-water environments, methanogenesis generally commences after oxygen is depleted. However, in the marine environment where significant quantities of sulfate occur, 
Table 1. Factors that control biogenic gas generation and accumulation.

Factors that control biogenic gas generation

Anoxic environment
Low-sulfate environment
Low temperature
Abundant organic matter
Type and state of organic matter
Sufficient pore space
High rate of deposition

Factors that control biogenic gas accumulation

Physical state of gas (dissolved, free, hydrate)

Early structures and stratigraphic traps

Seals and timing

Low-permeability reservoirs

Pressures

High rate of deposition

sulfate must be significantly reduced ( $>80$ percent) before methane generation can begin (Nikaido, 1977). Although the two processes are not strictly exclusive, sulfate-reducing bacteria are more competitive for available electrons or $\mathrm{H}_{2}$; therefore, methane generation is restricted in the presence of sulfate (Oremland and others, 1982).

3. Low temperature-The temperature range for the growth of methanogenic bacteria is from mesophilic conditions $\left(>25^{\circ} \mathrm{C}\right)$ to extremely thermophilic conditions $\left(<97^{\circ} \mathrm{C}\right)$ (Konig, 1992). The optimum temperature range for generation is from 35 to $45^{\circ} \mathrm{C}$ (Zeikus and Winfrey, 1976), just below the temperature at which thermogenic hydrocarbon generation commences (Tissot and Welte, 1984).

4. Abundant organic matter-Organic matter is necessary for methanogenesis and the metabolic processes that precede and support it. Organic matter is generally concentrated in finer grained sediments, and minimum total organic carbon (TOC) values of about 0.5 percent are generally required, on the basis of analyses of documented biogenic-gas-bearing sequences. Clayton (1992), however, has demonstrated that only 0.12 percent TOC is required for a free-gas phase of biogenic gas.

5. Type and state of organic matter-Hunt (1979) stated that the decomposition of lignins, a major component of type III (oxygen-rich) organic matter, by microbial activity is slow and inefficient. Therefore, type II (hydrogenrich) organic matter may be the type of organic matter preferred by microorganisms for methanogenesis. However, this paper will document that most ancient biogenic gas was probably generated from type III organic matter. Generation from mostly type III organic matter may be the result of the type of organic matter available in habitats favorable for biogenic gas generation and accumulation.

6. Pore space-Methanogens, which have an average size of $1 \mu \mathrm{m}$ (H. Konig, oral commun., 1989) require pore space to exist, which is limited in fine-grained sediments where organic matter is usually concentrated. The microbes generally cannot survive in a fully compacted and dewatered shale at depths of $2 \mathrm{~km}$ where the average pore size is 2 nanometers (Diamond, 1970). However, fractures in finegrained, organic-rich rocks can provide space for the microbes to operate. Coarser grained rocks, such as sandstones, have larger pore sizes, and methanogens can survive in them at greater depths if $\mathrm{CO}_{2}$ is available.

7. Rate of sediment deposition - Rate of sediment deposition is a critical factor in controlling not only the generation but also the accumulation of biogenic gas. If the depositional rate is too low, organic matter is destroyed by oxidation and any generated biogenic gas is lost to the atmosphere. In contrast, if the deposition rate is too high, the organic matter is preserved, but diluted, and the sediments pass too quickly through the zone of optimum temperature and depth for biogenic gas generation. In general, the generation of biogenic gas is favored by rates of deposition ranging from 200 to $1,000 \mathrm{~m} / \mathrm{m}$.y. (Clayton, 1992). However, the generation of biogenic gas is also influenced by geothermal gradients.

\section{CONDITIONS FOR BIOGENIC GAS ACCUMULATION}

The accumulation of biogenic gas depends not only on the generation of significant quantities of gas, but also on its entrapment, commonly at relatively shallow depths. Necessary conditions for accumulation, as summarized in table 1 , are as follows:

1. Physical state-In marine settings, biogenic gas is retained in solution in interstitial pore waters because of the higher hydrostatic pressures caused by the overlying water column (Rice and Claypool, 1981). This dissolution serves as a holding mechanism until sediments are buried deeper, and traps and seals are formed.

A free-gas state results when gas generation exceeds solubility or when exsolution is caused by reduction of the hydrostatic pressure. Exsolution can be a consequence of falling sea level or uplift and erosion.

In deep-sea sediments and areas of permafrost (high pressures and low temperatures), biogenic gas can become incorporated into a three-dimensional crystal framework of water referred to as a gas hydrate. Hydrates can trap enormous volumes of gas (Kvenvolden and McMenamin, 1980) and can also serve as a seal for gas occurring below the hydrate.

2. Early structures and stratigraphic traps-Because biogenic gas is generated early in the burial history, the formation of early structures and (or) stratigraphic traps is important for entrapment. Stratigraphic traps created by abrupt lateral facies changes, such as barrier islands, channels, carbonate buildups, and offshore bars, are excellent 
traps for biogenic gas. In addition, early structures, such as growth faults resulting from rapid sediment loading at time of deposition in prograding deltas (Galloway, 1986), are helpful in trapping biogenic gas.

3. Seals and timing-Effective seals are typically thick, laterally continuous, ductile rocks with high capillary entry pressures. Although many rock types can serve as seals, the most effective seals are evaporites (salt and anhydride), fine-grained clastic rocks, and organic-rich rocks (Downey, 1984). Because biogenic gas reservoirs are commonly interbedded with organic-rich shales, the shales serve as both the source and seal.

Another type of seal for biogenic gas is early formed continuous layers of diagenetic carbonate cement. The carbonate results from the precipitation of $\mathrm{CO}_{2}$ by oxidation of methane under both aerobic and anaerobic conditions (Whiticar and Faber, 1986). Hovland and others (1987) have documented the relatively recent, widespread formation of carbonate-cemented sediments on the sea floor in the North Sea and in other marine settings. These impervious seals undoubtedly formed in the geologic past in association with biogenic gas generation.

Diffusion of natural gas, in particular methane, can result in substantial volume loss, if the process takes place over a significant period of geologic time (Leythaeuser and others, 1982, 1983). Ancient biogenic gas was generated in relatively recent geologic time and thus has had relatively less time for diffusive loss than thermogenic hydrocarbons.

4. Low permeability-Low-permeability reservoirs are commonly at considerable depths where diagenetic processes have resulted in porosity reduction. At shallow depths, and in the zone of biogenic gas generation and accumulation, low permeability is usually the result of small grain size at the time of deposition, such as in silts, chalks, and coalbeds.

5. Pressures-Many ancient biogenic gas accumulations occur at shallow depths and are underpressured with respect to normal hydrostatic pressure gradients. This underpressuring, which slows down diffusion, is the result of removal of overburden, cooling of the rock sequence, dilation of pore volume, and decrease of temperature (Dickey and Cox, 1977). Erosion and resulting underpressuring are commonly coincident with the exsolution of the gas from marine pore waters.

In areas of rapid deposition, such as deltas, biogenicgas-bearing intervals are commonly overpressured. The abnormal pressure is caused by undercompaction of shales that had little time to undergo normal dewatering and compaction (Chapman, 1980).

6. Rate of sediment deposition-In addition to aiding biogenic gas generation, the rate of deposition is important to the accumulation of biogenic gas. Adequate traps and seals are generally formed when sediments have undergone at least some compaction and dewatering at depths of several hundred meters. When traps and seals are formed quickly by rapid deposition, less biogenic gas is lost to the atmosphere. In addition, rapid deposition results in thicker sequences of sediments, which slow down the diffusion of the gas.

\section{DEPTH AND TIMING OF BIOGENIC GAS GENERATION}

Biogenic gas can be generated during two different stages-early and late. Biogenic gas is formed early in shallow $(<1 \mathrm{~km}$ ), young sediments and is subsequently buried after generation ceases. The generation and preservation of this early-stage biogenic gas are favored by rapid deposition. During this time, space is available in the finer grained, organic-rich sediments for the microbes to carry on the various processes leading to methanogenesis. Also, young, shallow organic matter is relatively fresh and easily decomposed by the microorganisms. Most accumulations of ancient biogenic gas were probably generated during this early stage.

Some biogenic gas may also have been generated in the recent geologic past (tens of thousands to a few million years ago) (late stage) in association with active groundwater flow (Rice, in press). Because of their welldeveloped fracture (cleat) system, coalbeds are commonly aquifers (Kaiser and others, 1991), which provide a favorable environment for microbial activity. This late-stage biogenic gas generation can take place in coalbeds of any rank, provided that the requirements described previously have been met. Late-stage biogenic gas generation may also take place in other organic-rich rock types that serve as aquifers because of enhanced permeability.

Belyaev and others (1977) retrieved methanogens from core samples of Pliocene and Quaternary clays, silts, and sands at depths of 29 to $135 \mathrm{~m}$. The methanogens were reported to be actively producing methane by $\mathrm{CO}_{2}$ reduction. This is the only study in which recent methanogenesis has been documented in ancient sediments. Additional field studies are needed to resolve the magnitude of late-stage biogenic gas generation.

\section{CHARACTERISTICS OF BIOGENIC GAS}

Gaseous hydrocarbons generated during the different stages of hydrocarbon generation have distinct chemical and isotopic compositions. Biogenic gas consists mainly of methane, except in low-pH environments, such as nonmarine or brackish water, where $\mathrm{CO}_{2}$ is also a significant component. The trace amounts of $\mathrm{C}_{2+}$ alkanes commonly detected in biogenic gases in laboratory studies or in modern environments were probably generated by microbial activity (Davis and Squires, 1954; Vogel and others, 1982; 
Oremland and others, 1988). Of the $C_{1}$ through $C_{5}$ alkanes in biogenic gases from the marine environment, generally less than 0.1 percent are $\mathrm{C}_{2+}$ alkanes, and the amount of $\mathrm{C}_{2+}$ is directly proportional to temperature, age, and organic-matter content of the sediments (Claypool, 1974). These heavier hydrocarbons have a complicated history; they are products of microbial activity at shallow depths and of low-temperature thermal processes at greater depths. Ancient biogenic gas can be associated with even greater amounts of heavier hydrocarbon gases because of migration and mixing of thermogenic hydrocarbons from deeper, more thermally mature intervals.

However, because methane-rich gases have other origins besides biogenic processes, the isotopic composition $\left(\delta^{13} \mathrm{C}\right.$ and $\left.\delta D\right)$ of the methane provides the best evidence for the origin of the gas. $\left(\delta^{13} \mathrm{C}\right.$ (permil) $=$ $\left(\left({ }^{13} \mathrm{C} /{ }^{12} \mathrm{C}_{\text {sample }} /{ }^{13} \mathrm{C} /{ }^{12} \mathrm{C}_{\text {standard }}\right)-1\right) \times 1,000$, relative to $\mathrm{PDB}$ (Peedee belemnite) standard, and $\delta D($ permil $)=\left(\left(\mathrm{D} / \mathrm{H}_{\text {sample }} /\right.\right.$ $\mathrm{D} / \mathrm{H}_{\text {standard }}$ ) -1$) \times 1,000$, relative to SMOW (standard mean ocean water) standard.) In general, methane in ancient biogenic gas is isotopically light (methane $\delta^{13} \mathrm{C}$ values in the range of -55 to -90 permil) because of enrichment of the light isotope ${ }^{12} \mathrm{C}$ by microorganisms. In contrast, $\delta^{13} \mathrm{C}$ values for thermogenic methane, are generally heavier than -50 permil (Schoell, 1983).

Biogenic gases can be further differentiated on the basis of the two principal pathways that result in their generation in modern environments (Schoell, 1980; Woltemate and others, 1984; Jenden and Kaplan, 1986; Whiticar and others, 1986; and Burke and others, 1988) (fig. 3). However, no absolute ranges can be given for the $\delta^{13} \mathrm{C}$ and $\delta \mathrm{D}$ values for methane resulting from these two pathways. Biogenic methane resulting from $\mathrm{CO}_{2}$ reduction is generally isotopically light in carbon (methane $\delta{ }^{13} \mathrm{C}$ values ranging from -55 to -110 permil) and is enriched in deuterium ( $\delta \mathrm{D}$ values ranging from -150 to -250 permil). In contrast, fermentation-derived methane can be isotopically heavier in carbon $\left({ }^{13} \mathrm{C}\right.$ values ranging from -40 to -70 permil) and is depleted in deuterium ( $\delta \mathrm{D}$ values ranging from -250 to -400 permil). However, the source of hydrogen for biogenic methane is the associated water, which is variable in isotopic composition (Jenden and Kaplan, 1986; Whiticar and others, 1986). As a result, the $\delta \mathrm{D}$ values for biogenic methane are dependent upon formation-water $\delta \mathrm{D}$, as well as the biochemical pathway.

On the basis of documented occurrences, $\mathrm{CO}_{2}$ reduction is the main pathway for ancient biogenic gas generation. The isotopic composition of the methane formed earliest by $\mathrm{CO}_{2}$ reduction is controlled by the $\delta^{13} \mathrm{C}$ of the original $\mathrm{CO}_{2}$ substrate. The isotopic composition of methane formed later is a reflection of the net effect of the addition and removal of $\mathrm{CO}_{2}$. The isotopic fractionation between the methane and $\mathrm{CO}_{2}$ remains relatively constant at about $70 \pm 10$ permil (Claypool and Kaplan, 1974; Jen-

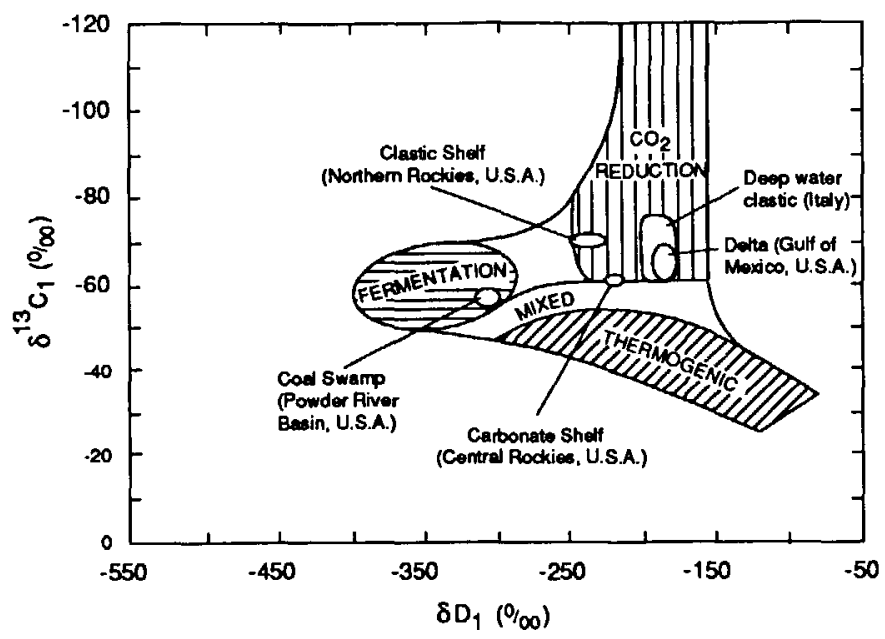

Figure 3. Methane carbon isotope ratio $\left(\delta^{13} \mathrm{C}\right)$ versus methane deuterium isotope ratio $(\delta D)$. General fields for biogenic gases generated by fermentation and $\mathrm{CO}_{2}$ reduction and for thermogenic gases are from Whiticar and others (1986). Other areas are for biogenic gases from favorable habitats as discussed in text. Data for deepwater clastic setting, Italy, from Mattavelli and Novelli (1988). Rockies, Rocky Mountains.

den and Kaplan, 1986). Biogenic methane as heavy as -40 permil can be produced by the reduction of isotopically heavy carbon dioxide (Jenden and Kaplan, 1986). As indicated before, the two main sources of $\mathrm{CO}_{2}$ for reduction are from microbial processes (sulfate reduction and fermentation) and thermal decarboxylation of kerogen. Both of these sources yield isotopically light $\mathrm{CO}_{2}\left(\delta^{13} \mathrm{C}\right.$ values ranging from -20 to -25 permil) and yield isotopically light biogenic methane. If the sediments are organic rich and $\mathrm{CO}_{2}$ is plentiful, then the resulting biogenic methane is isotopically light throughout its generation history. However, if the sediments are lean in metabolizable organic matter, then the biogenic methane (both the accumulated product and the methane being generated) becomes isotopically heavier with time because the isotopically light $\mathrm{CO}_{2}$ is used first for reduction.

The net effect is that ancient biogenic gases generally show a systematic trend of becoming isotopically heavier and chemically wetter with depth (Fuex, 1977; Mattavelli and others, 1983; Rice, 1984). This trend is the result of the gradual mixing of minor amounts of thermogenic methane and $\mathrm{C}_{2+}$ gases with isotopically light methane of biogenic origin.

Gases of thermogenic origin can usually be distinguished from biogenic gases by the methane component being isotopically heavier and containing significant amounts of heavier hydrocarbon gases (Schoell, 1983). Fermentation-derived methane can overlap in carbon isotopic composition with thermogenic gases (fig. 3). However, thermogenic gases are generally chemically wetter, and fermentation-derived methane is depleted in deuterium. 
Finally, oil has been reported in association with gases having characteristics of biogenic gas (Rice, 1980; Faber, 1987; Jenden and others, 1988). The oil has probably migrated from deeper, more mature intervals.

Geologic history is also important in interpreting the occurrence of ancient biogenic gas. Biogenic gases usually occur at relatively shallow depths, at low levels of thermal maturity, and in relatively young sediments.

\section{OCCURRENCES OF ANCIENT BIOGENIC GAS}

Data that permit recognition of ancient biogenic gas accumulations are available only for those accumulations shown on figure 4 (conterminous United States) and figure 5 (world) and summarized in table 2.

All of the listed biogenic gas occurrences generally meet the criteria of being primarily methane $\left(\mathrm{C}_{2+}\right.$ alkanes $<2$ percent of $\mathrm{C}_{1}$ through $\mathrm{C}_{5}$ alkanes) that is isotopically light in carbon (methane $\delta^{13} \mathrm{C}$ values more negative than -55 permil). On the basis of methane $\delta \mathrm{D}$ values, most of the methane in these occurrences was derived by $\mathrm{CO}_{2}$ reduction.
Most biogenic gas was probably generated from type III organic matter. Although type II organic matter is easier to degrade by microbial activity, type III organic matter is more commonly present in settings characterized by rapid deposition.

Accumulations of ancient biogenic gas occur in relatively young sequences. The majority of biogenic gas accumulations occur in Cretaceous and younger sequences, although there are documented occurrences of Jurassic age in the North Sea and of late Paleozoic (Mississippian and Pennsylvanian) age in the Cherokee and Forest City basins of Kansas, United States. In addition, biogenic gas is common in Carboniferous coalbeds at shallow depths in many parts of the world (Rice, in press).

Ancient biogenic gas accumulations occur in a variety of depositional settings and rock types as summarized in table 2. They have been reported in both marine (deltaic, interdeltaic, shelf, deep-water clastic, and pelagic) and nonmarine (fluvial, lacustrine, coastal plain, and coal swamp) settings. In addition, they have been documented in clastic and carbonate rocks, and coals. The distribution of known biogenic gas accumulations in a variety of depositional settings and rock types indicates that undiscovered biogenic gas resources are probably widespread.

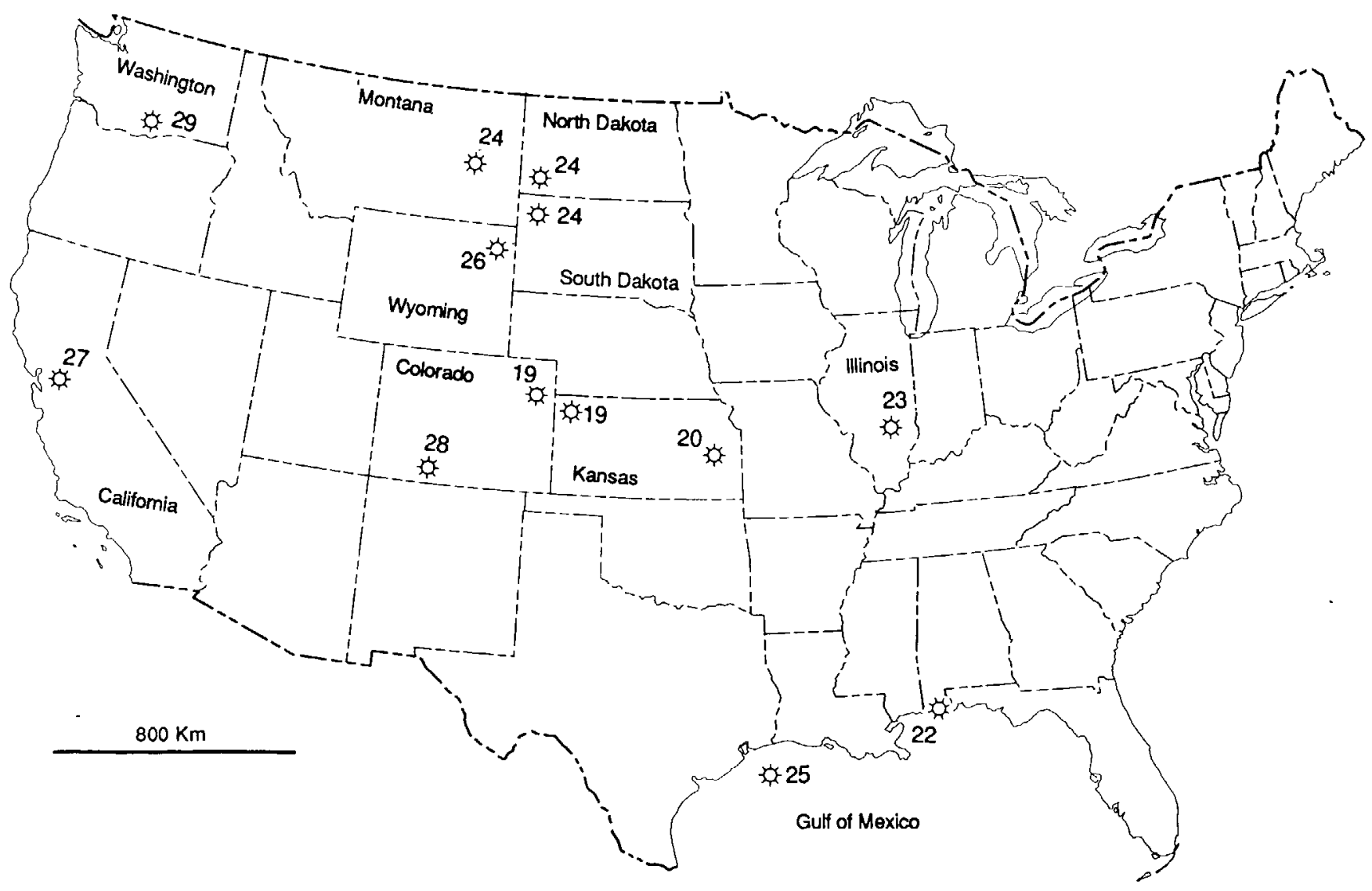

Figure 4. Locations of ancient biogenic gas accumulations in conterminous United States. Identification and details of accumulations are listed in table 2. 


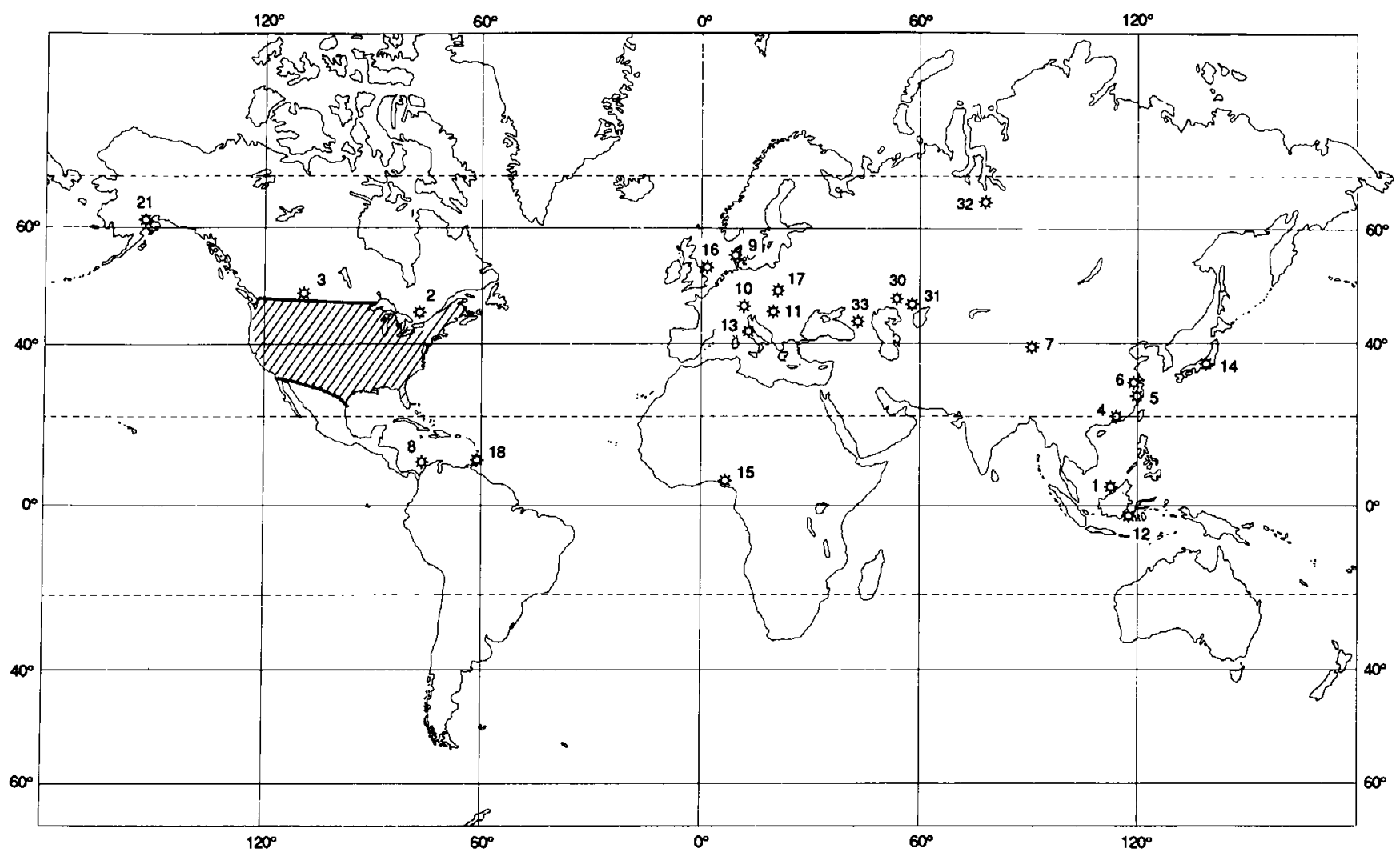

Figure 5. World map showing locations of ancient biogenic gas accumulations. Identification and details of accumulations are listed in table 2. Accumulations in conterminous United States (diagonal-line pattern) are shown in figure 4.

\section{FAVORABLE HABITATS FOR BIOGENIC GAS ACCUMULATIONS}

Although biogenic gas generated in the geologic past has been documented in diverse depositional settings and rock types, several habitats are considered to be particularly favorable for the generation and accumulation of biogenic gas. These habitats, in order of relative importance, are deltas, deep-water clastic settings, shelves (both clastic and carbonate), and nonmarine settings (particularly coal swamps). The factors that make each of these habitats favorable for the generation and accumulation of biogenic gas are discussed below, along with examples where ancient accumulations have been documented. In all of the favorable habitats, rapid rate of deposition appears to be the major, common factor controlling the generation and accumulation of biogenic gas.

\section{DELTAS}

Cenozoic deltas have provided a very favorable setting for the generation and accumulation of hydrocarbons, both biogenic and thermogenic. Biogenic gas has been identified in the following Cenozoic deltaic sequences: Baram,
Mahakam, Niger, offshore Gulf of Mexico, and Poland (Carpathian foredeep) (fig. 6, table 2). The Baram, Mahakam, Niger, and offshore Gulf of Mexico deltas also contain large resources of thermogenic hydrocarbons, whereas deltaic sedimentary rocks in Poland produce mainly biogenic gas. Other Cenozoic deltas, as shown on figure 6, may also contain biogenic gas accumulations.

Deltas occur where rivers meet the coast and large quantities of land-derived sediment are deposited. Rapid sediment deposition in these deltas was usually accompanied by rapid subsidence. As documented in the Gulf of Mexico and Niger deltas, the sedimentation rates were high throughout Tertiary time, but were especially high during late Tertiary and Pleistocene time (Woodbury and others, 1973; Bustin, 1988). The fact that rapid deposition and subsidence is common to most deltas makes them an ideal habitat for the generation and accumulation of biogenic gas.

Because of rapid sedimentation rates, deltas are normally characterized by the seaward progradation of the shoreline, resulting in a lateral facies shift through time (fig. 7). As a result, younger nearshore marine and nonmarine sandstones interbedded with shales, which serve as the major reservoir and seal units, overlie older, deeper water shales that are more concentrated in organic matter. 
Table 2. Occurrences of ancient biogenic gas.

[Numbers in parentheses in "Location" column correspond to numbered locations on figure $5 . \delta^{13} C_{1}$ and $\delta D_{1}$ are isotope compositions of methane ( $\left.C_{1}\right)$ component of gas. See text for explanation of organic matter types. -.., not determined]

\begin{tabular}{|c|c|c|c|c|c|c|c|}
\hline Location & Habitat & $\begin{array}{l}\text { Reservoir } \\
\text { age }\end{array}$ & $\begin{array}{c}\text { Depth } \\
\text { (meters) }\end{array}$ & $\underset{(\text { permil) }}{\delta^{13} \mathrm{C}_{1}}$ & $\begin{array}{c}\delta \mathrm{D}_{1} \\
\text { (permil) }\end{array}$ & $\begin{array}{l}\text { Organic } \\
\text { matter type }\end{array}$ & References \\
\hline \multicolumn{8}{|c|}{ Brunei } \\
\hline Baram Delta (1) & Delta & Tertiary & $1,600-2,600$ & -55 to -64 & -- & Type III & $\begin{array}{l}\text { This paper; Rijks } \\
\text { (1981) }\end{array}$ \\
\hline \multicolumn{8}{|c|}{ Canada } \\
\hline Quebec (2) & Glacial drift & Pleistocene & 70 & -60 & $\cdots$ & $-\cdots$ & Fuex (1977) \\
\hline Southeastern Alberta (3) & Clastic Shelf & Cretaceous & $300-1,000$ & -60 to -68.3 & -- & Type III & $\begin{array}{l}\text { This paper; Fuex } \\
\text { (1977); Rice and } \\
\text { Claypool (1981) }\end{array}$ \\
\hline \multicolumn{8}{|c|}{ China } \\
\hline $\begin{array}{l}\text { Pearl (4), Qiantang (5), and } \\
\text { Yangtze Rivers (6) }\end{array}$ & Estuarine/marine & Quaternary & $30-40$ & -68.3 to -78.7 & -- & -- & Zhang and Chen (1985) \\
\hline Qaidam basin (7) & Fluvial/lacustrine & Pleistocene & $65-1,380$ & -58 to -80 & $-\ldots$ & Type III & Gu and others (1988) \\
\hline \multicolumn{8}{|c|}{ Colombia } \\
\hline (Offshore) (8) & $\ldots$ & Tertiary & $3,213-3,304$ & -69.3 & -- & -- & This paper \\
\hline \multicolumn{8}{|c|}{ Denmark } \\
\hline (9) & Glacial/marine & Pleistocene & $0-117$ & -63.6 to -89.2 & -177 to -228 & Type II & $\begin{array}{l}\text { Jorgensen and others } \\
\text { (1990); Laier and } \\
\text { others (1992) }\end{array}$ \\
\hline \multicolumn{8}{|c|}{ Germany } \\
\hline Molasse basin (10) & $\begin{array}{l}\text { Nonmarine/delta/ } \\
\text { marine }\end{array}$ & Tertiary & $900-2,000$ & -64 to -72.2 & -192 to -216 & -- & Schoell (1980) \\
\hline \multicolumn{8}{|c|}{ Hungary } \\
\hline Pannonian basin (11) & $\begin{array}{l}\text { Nonmarine/delta/ } \\
\text { marine }\end{array}$ & Tertiary & $<1,000$ & -65 to -81 &.- & $\overline{---}$ & Koncz (1983) \\
\hline \multicolumn{8}{|c|}{ Indonesia } \\
\hline Mahakam delta (12) & Delta & Tertiary & -- & -55 to -69.7 & -177 to -264 & Type III & $\begin{array}{l}\text { This paper; Combaz } \\
\text { and de Matharel } \\
\text { (1978) }\end{array}$ \\
\hline \multicolumn{8}{|c|}{ Italy } \\
\hline Apennine foredeep (13) & Deep-water clastic & Tertiary & $140-4,600$ & -60 to -76 & -171 to -223 & Type III & $\begin{array}{l}\text { Schoell (1980); } \\
\text { Mattavelli and others } \\
\text { (1983); Mattavelli and } \\
\text { Novelli (1988) }\end{array}$ \\
\hline \multicolumn{8}{|c|}{ Japan } \\
\hline (14) & $\begin{array}{l}\text { Marine or lagoonal } \\
\text { basin }\end{array}$ & $\begin{array}{r}\text { Tertiary and } \\
\text { Pleistocene }\end{array}$ & $100-2,000$ & -64 to -75 & -148 to -239 & $\ldots$ & $\begin{array}{l}\text { Nakai (1960); Nakai } \\
\text { and others (1974) }\end{array}$ \\
\hline \multicolumn{8}{|c|}{ Nigeria } \\
\hline Niger delta (15) & Delta & Tertiary & 650 & -55 & - & Type III & $\begin{array}{l}\text { This paper; Bustin } \\
\text { (1988) }\end{array}$ \\
\hline \multicolumn{8}{|c|}{ Poland } \\
\hline Carpathian foredeep (17) & Delta/marine & Tertiary & $275-2,447$ & -60.7 to 71.2 & -177 to -208 & Type III & $\begin{array}{l}\text { Kotarba and others } \\
(1987) ; \text { Kotarba } \\
(1992)\end{array}$ \\
\hline \multicolumn{8}{|c|}{ Trinidad } \\
\hline (Offshore) (18) & -- & Tertiary & $<3,350$ & -64 to -71 & -- & -- & $\begin{array}{l}\text { Faber and StahI } \\
(1977 / 1978)\end{array}$ \\
\hline
\end{tabular}


Table 2. Occurrences of ancient biogenic gas-Continued.

[Numbers in parentheses in "Location" column correspond to numbered locations on figure $5 . \delta^{13} C_{1}$ and $\delta D_{1}$ are isotope compositions of methane $\left(C_{1}\right)$ component of gas. See text for explanation of organic matter types. ---, not determined]

\begin{tabular}{|c|c|c|c|c|c|c|c|}
\hline Location & Habitat & $\begin{array}{l}\text { Reservoir } \\
\text { age }\end{array}$ & $\begin{array}{c}\text { Depth } \\
\text { (meters) }\end{array}$ & $\begin{array}{c}\delta^{13} C_{1} \\
\text { (permil) }\end{array}$ & $\begin{array}{c}\delta D_{1} \\
(\text { permil) }\end{array}$ & $\begin{array}{l}\text { Organic } \\
\text { matter type }\end{array}$ & References \\
\hline \multicolumn{8}{|c|}{ United States } \\
\hline $\begin{array}{l}\text { Central Rocky Mountains, } \\
\text { Colorado and Kansas (19) }\end{array}$ & Carbonate shelf & Cretaceous & $322-842$ & -55 to -65.4 & -222 to -225 & Type Il & This paper; Rice (1984) \\
\hline $\begin{array}{l}\text { Cherokee and Forest City } \\
\text { basins, Kansas (20) }\end{array}$ & Marine & $\begin{array}{l}\text { Carbonif- } \\
\text { erous }\end{array}$ & $127-551$ & -48.3 to $-65^{1}$ & -201 to -246 & --- & $\begin{array}{l}\text { Jenden and others } \\
\text { (1988) }\end{array}$ \\
\hline Cook Inlet, Alaska (21) & Fluvial/coal swamp & Tertiary & $910-1,650$ & -56 to -63 & $\cdots$ & Type III & $\begin{array}{l}\text { Claypool and others } \\
(1980)\end{array}$ \\
\hline Eastern Gulf of Mexico (22) & Delta/marine & Miocene & $490-595$ & -62 to -66 & --- & $\cdots$ & $\begin{array}{l}\text { This paper; Mink and } \\
\text { others (1988) }\end{array}$ \\
\hline Illinois basin (23) & Glacial drift & Pleistocene & $8-99$ & -68 to -91 & -214 to -240 & Type III & $\begin{array}{l}\text { Schoell (1980); } \\
\text { Coleman and others } \\
\text { (1988) }\end{array}$ \\
\hline $\begin{array}{l}\text { Northern Rocky Mountains, } \\
\text { Montana and South } \\
\text { Dakota (24) }\end{array}$ & $\begin{array}{l}\text { Coastal and clastic } \\
\text { shelf }\end{array}$ & Cretaceous & $170-830$ & -63.5 to -72.3 & -234 to -245 & Type III & $\begin{array}{l}\text { This paper; Rice and } \\
\text { Claypool (1981); Rice } \\
\text { and others (1990) }\end{array}$ \\
\hline $\begin{array}{l}\text { Offshore Gulf of Mexico } \\
(25)\end{array}$ & Delta & Pleistocene & $458-3,600$ & -56.7 to -67.4 & -182 to -191 & Type III & $\begin{array}{l}\text { This paper; Dow (1978); } \\
\text { Rice (1980); Rice and } \\
\text { Threlkeld (1983) }\end{array}$ \\
\hline $\begin{array}{l}\text { Powder River basin, } \\
\text { Wyoming ( } 26)\end{array}$ & Coal swamp & Tertiary & $110-122$ & -53.8 to -56.5 & -307 to $-333^{2}$ & Type III & This paper \\
\hline $\begin{array}{l}\text { Sacramento basin, Calif. } \\
\text { (27) }\end{array}$ & Nonmarine & Tertiary & 1,055 & -61.3 & -187 & Type III & $\begin{array}{l}\text { Jenden and Kaplan } \\
\text { (1989) }\end{array}$ \\
\hline $\begin{array}{l}\text { San Luis basin, Colorado } \\
\text { (28) }\end{array}$ & Nonmarine/fluvial & Tertiary & 300 & -69.7 to -70.2 & --- & $\cdots$ & $\begin{array}{l}\text { Rice and Claypool } \\
(1981)\end{array}$ \\
\hline $\begin{array}{l}\text { South-central Washington } \\
\text { (29) }\end{array}$ & $\begin{array}{l}\text { Nonmarine with } \\
\text { igneous activity }\end{array}$ & Tertiary & $220-486$ & -63.6 to -88.2 & -255 to $-277^{3}$ & Type III & This paper \\
\hline \multicolumn{8}{|c|}{ Former U.S.S.R. } \\
\hline Caspian Depression (30) & $\cdots$ & Tertiary & $327-391$ & -61 to -65 & -- & -- & Galimov (1968) \\
\hline North Aral (31) & --- & Tertiary & $320-476$ & -64 to -72 & -- &.- & $\begin{array}{l}\text { Galimov (1968); Avrov } \\
\text { and Galimov (1968) }\end{array}$ \\
\hline West Siberia (32) & Coastal plain & $\begin{array}{l}\text { Cretaceous } \\
\text { Cenomanian }\end{array}$ & $684-1,275$ & $\begin{array}{l}-58 \text { to }-65^{4} \\
-46 \text { to }-50^{4}\end{array}$ & --- & Type III & $\begin{array}{l}\text { Yermakov and others } \\
\text { (1970); Alekseyev } \\
\text { (1974); Galimov } \\
\text { (1988) }\end{array}$ \\
\hline Stravapol (33) & --- & Tertiary & $214-1,076$ & -66 to -75 & -- & -- & $\begin{array}{l}\text { Alekseyev and others } \\
\text { (1972) }\end{array}$ \\
\hline
\end{tabular}

\footnotetext{
${ }^{1}$ Gases with methane $\delta^{13} \mathrm{C}$ values heavier than -55 permil are interpreted to be biogenic on the basis of $\delta^{13} \mathrm{C}$ values of $\mathrm{CO} 2$ and $\delta \mathrm{D}$ values of formation water.

${ }^{2}$ Methane $\delta^{13} \mathrm{C}$ and $\delta \mathrm{D}$ values of gas and $\delta \mathrm{D}$ values of associated water indicate that gases were generated mainly by $\mathrm{CO}_{2}$ reduction.

${ }^{3}$ Methane $\delta \mathrm{D}$ values indicate generation by fermentation pathway.

${ }^{4}$ Different methane $\delta^{13} \mathrm{C}$ values given for gases from same reservoirs. See text for discussion..
}

Usually the shallow, younger reservoir section is thermally immature with respect to hydrocarbon generation, whereas the deeper shales are thermally mature and are the source rocks for thermogenic hydrocarbons (fig. 7; Dow, 1978).

The sediments in deltas are derived from land areas and the associated organic matter is usually terrestrial in origin (type III). Because of the high rates of sedimentation, the organic matter is diluted, but minimum TOC values of 0.5 percent are usually present. In addition, the immature sediments that served as the source for the biogenic gas are in such close association with reservoir rocks that long-distance migration is not required for biogenic gas. For example, in the offshore Gulf of Mexico, TOC values in all facies are generally less than 1 percent (Dow, 1978). The alternating sandstone and shale facies deposited in the middle to outer neritic zone is the most productive reservoir facies for both biogenic and thermogenic hydrocarbons; the shales of this facies contain mostly type $\mathrm{III}$ organic matter $(>0.5$ percent TOC) (Dow, 


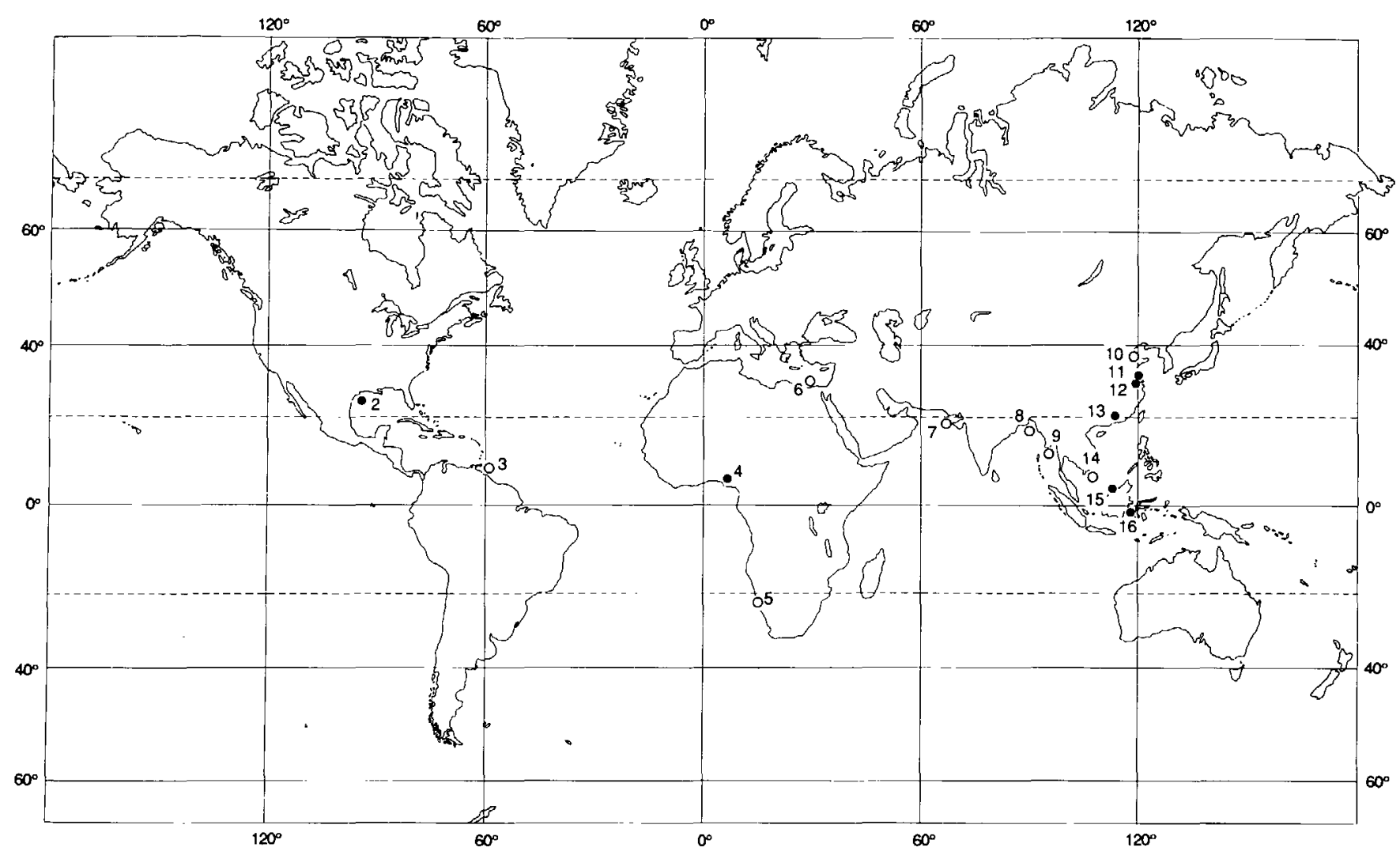

Figure 6. World map showing location of Cenozoic deltas with documented (solid circles) and suspected (open circles) accumulations of biogenic gas. 1, Mackenzie, Canada; 2, Gulf of Mexico, United States; 3, Orinoco, Venezuela; 7, Niger, Nigeria; 5, Orange, Namibia; 6, Nile, Egypt; 7, Indus, Pakistan; 8, Brahmaputra, Bangladesh; 9, Irrawaddy, Myanmar; 10, Yellow, China; 11, Yangtze, China; 12, Qiantang, China; 13, Pearl, China; 14, Mekong, Vietnam; 15, Baram, Brunei; 16, Mahakam, Indonesia.

$\mathrm{N}$

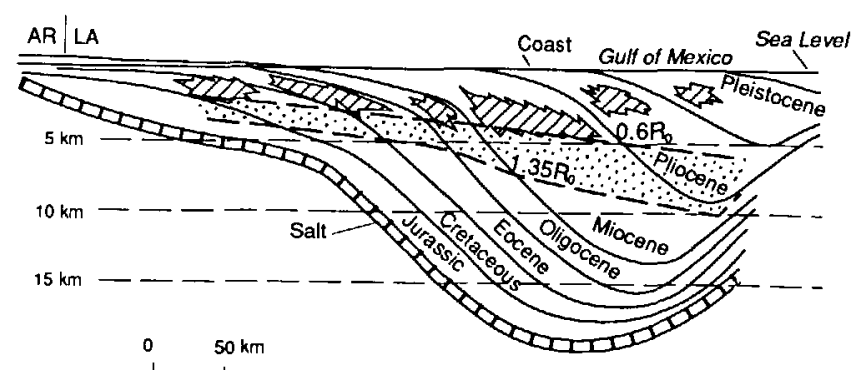

Figure 7. Schematic north-south cross section of Gulf Coast, United States, showing progradation of the shoreline and relation of reservoirs (diagonal-line pattern) to thermal maturity (oil window, with vitrinite reflectance $\left(R_{0}\right)$ values of 0.6 to 1.35 percent, dotted) in each producing trend. Biogenic gas occurs mainly in Pleistocene reservoirs. AR, Arkansas; LA, Louisiana. From Dow (1978).

1978) and are the likely source for biogenic gas. In the Niger delta, the highest TOC values are in the nonmarine facies, which contains mostly type III organic matter (Bustin, 1988). This source facies for the biogenic gas is juxtaposed with reservoirs of nearshore sandstones. The thermogenic hydrocarbons occurring in both these deltas have probably migrated from deeper, more mature source rocks that contain some type II organic matter.

The high rates of sedimentation typical of deltas result in unstable slope conditions, and syndepositional gravity-driven growth faults are commonly developed (Galloway, 1986). These growth faults are important to hydrocarbon accumulation for two reasons. First, they provide traps in the conventional sandstone reservoirs for the early-formed biogenic gas. Second, they provide conduits for the vertical migration of thermogenic hydrocarbons and other fluids to shallower, immature reservoirs. This migration causes mixing of migrated, thermogenic hydrocarbons with indigenous biogenic gas and the scatter of gas compositional data.

The shales that alternate with the biogenic-gas-bearing sandstone reservoirs in young deltas are commonly overpressured because of incomplete dewatering due to rapid deposition (Chapman, 1980). The difference in pressure between the shales and the more normally pressured reservoirs aids in sealing the biogenic gas (Downey, 1984). 


\section{DEEP-WATER CLASTIC SETTINGS}

The deep-water clastic setting is favorable for biogenic gas accumulations because (1) it is characterized by rapid deposition, and (2) it contains interbedded sandstones and shale sequences (turbidites) that provide close association of reservoir, source, and seal. Ancient biogenic gas accumulations have been documented in deep-water clastic rocks in the Appennine foredeep of Italy (fig. 5, table 2).

A significant portion of the natural gases of Italy occurs in the Appennine foredeep and is of biogenic origin (Mattavelli and others, 1983; Mattavelli and Novelli, 1988). High rates of deposition, syndepositional tectonic activity, and turbiditic sedimentation during Tertiary and Pleistocene time were instrumental in the generation and accumulation of large volumes of biogenic gas in the foredeep in front of the Appennine Mountains (Mattavelli and others, 1983; Mattavelli and Novelli, 1988). The Appennine foredeep was rapidly filled by thick turbiditic sequences which consist of alternating sandstones and shales that have formed in multipay gas fields. The sandstones serve as the reservoir for the biogenic gas, and the shales act as both the source and the seal. The organic matter in the transported clays of the turbidite sequences is much richer than that in the pelagic clays and thus is the probable source of the biogenic gas. The organic matter consists mainly of herbaceous and woody components indicating type III; TOC values are variable, but can be more than 1 percent (Mattavelli and others, 1983).

In addition to the alternation of reservoirs and source/seals, syndepositional or very early compressional structures aided in the trapping of biogenic gas in the Appennine foredeep (Mattavelli and others, 1983; Mattavelli and Novelli, 1988). The compressional tectonics were related to the convergence of Africa and Europe and led to structural and combination traps.

Biogenic gas has been reported to a maximum depth of $4,600 \mathrm{~m}$ in the Pliocene reservoirs of the Appennine foredeep (table 2). Although generated at shallower depths, the biogenic gas is interpreted to be present at this depth because the rocks are relatively young and the geothermal gradient is relatively low. In one field, present-day temperatures ranging from 48 to $63^{\circ} \mathrm{C}$ are reported at depths of 2,500 to 4,100 m (Mattavelli and others, 1983; Mattavelli and Novelli, 1988). These temperatures, in addition to low vitrinite-reflectance values (Mattavelli and others, 1983), indicate that the section is thermally immature.

\section{SHELF SETTING}

Shelves are a favorable setting for the generation and accumulation of biogenic gas provided that they were areas of high sedimentation rates. Ancient biogenic gas accumula- tions have been documented in shelf sequences of the Cretaceous Western Interior Seaway of North America (fig. 8, table 2). The accumulations are significant because they (1) are major, (2) occur in rocks of Cretaceous age, and (3) are trapped in low-permeability (unconventional) reservoirs.

The Cretaceous Western Interior basin of North America (Canada and United States) was an elongate, asymmetrical foreland basin that was bordered on the west by the Cordilleran thrust belt and on the east by the low-lying Precambrian shield (fig. 8). A summary of the basin and its deposits is presented by Rice and Gautier (1983) and Rice and Shurr (1983). During Late Cretaceous time, the basin was occupied by a shallow epicontinental seaway that extended in a north-south direction from the Arctic Ocean to the Gulf of Mexico. Major biogenic gas accumulations occur in both clastic and carbonate sediments deposited in relatively shallow-water shelf settings.

During Late Cretaceous time, a recurring pattern of sedimentation was established in the seaway (fig. 9); this pattern was controlled by supply of detritus from the west and by changes in base level, some global in scale. The marine shelf was the most favorable setting for the generation and accumulation of biogenic gas. As shown by the paleogeographic map (fig. 9), the central part of the seaway was characterized by the deposition of shelf sands and offshore marine silts and muds. The eastern part of the seaway, and sometimes extending into the central part of the seaway, was represented by the deposition of carbonate rocks (chalks). Carbonate deposition was limited by the input of terrigenous clastic sediments from the thrust belt to the west, and the chalks, therefore, are generally restricted to a shelf setting on the eastern side of the seaway. The shelf settings located in the central and eastern parts of the seaway had a series of structural elements (blocks) that experienced recurrent movement which affected subsidence and deposition of Late Cretaceous sediments. Favorable areas for biogenic gas generation and accumulation were those that experienced greater subsidence and deposition.

\section{CLASTIC SHELF}

The central part of the Cretaceous Western Interior Seaway was characterized by the deposition of mud and silt with lesser amounts of sand. Although the silt and sand occur as thin and discontinuous lenses and laminae (fig. 10), the interval that contains them is widespread and as much as $70 \mathrm{~m}$ thick (Rice and Shurr, 1980). These individual lenses and laminae of silt and sand are commonly only a few centimeters thick and serve as the reservoirs for biogenic gas. The reservoirs have low permeability with values of less than 0.1 millidarcy (Rice and others, 1990). The enclosing shales serve as the source and the seal for the biogenic gas. The shales average 2 percent TOC, but locally contain as much as 5 percent TOC. The 


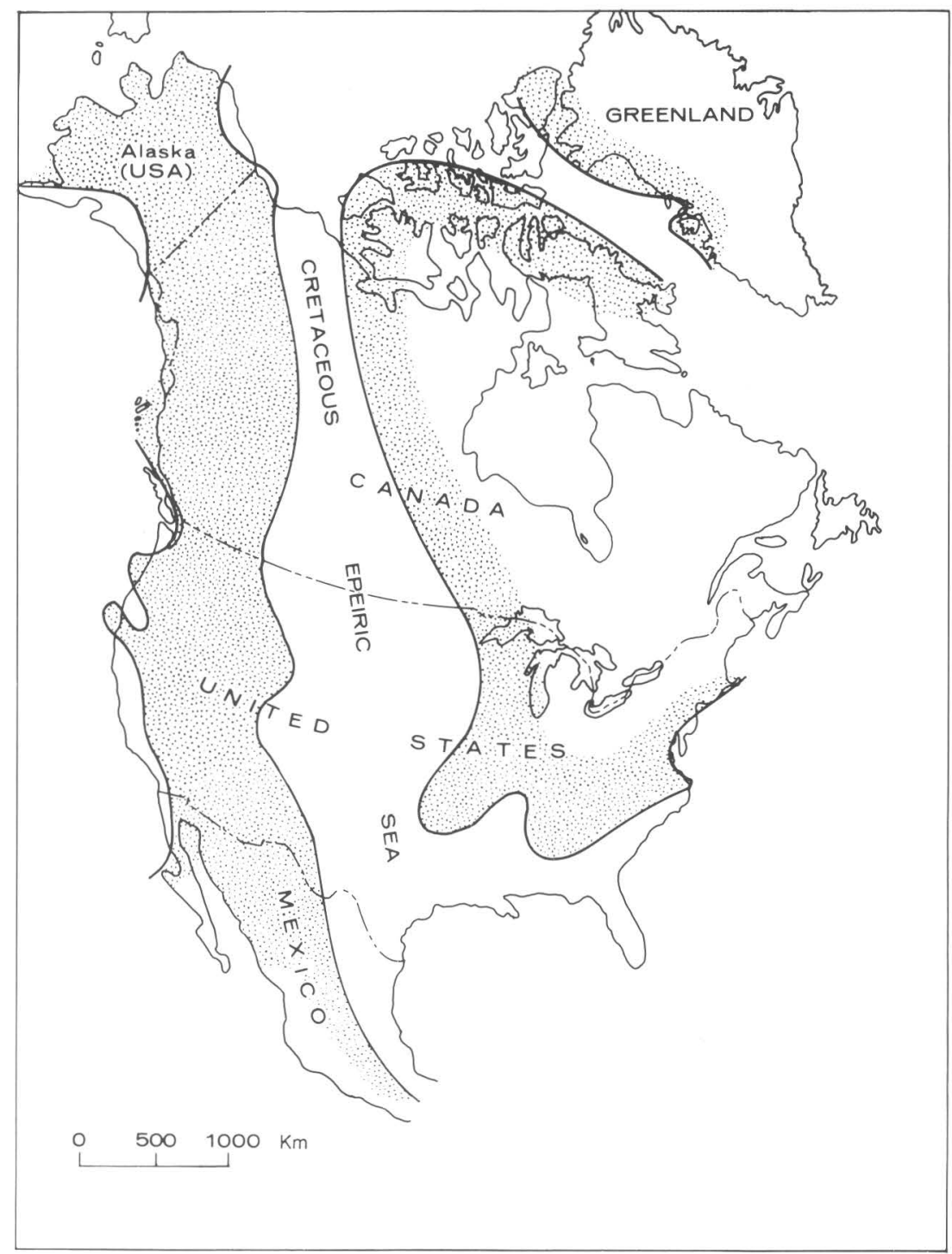

Figure 8. Extent of Western Interior Seaway during Late Cretaceous (Campanian) time. From Gill and Cobban (1973).

organic matter is oxygen-rich type III (herbaceous and woody components) (fig. 11), suggesting that it was transported to the shelf area with the silt and sand. The intercalation of rapidly deposited coarser grained sediment (reservoir) and finer grained sediment (source and seal) at the centimeter scale has resulted in a very efficient package for generating and accumulating biogenic gas.

The potential for biogenic gas accumulations in Cretaceous clastic shelf sequences occurs in the northern part of the basin (Montana and North and South Dakota, United States, and Alberta and Saskatchewan, Canada) where the section is thermally immature. To date, most of biogenic gas production has come from structural highs, although the gas is considered to be trapped stratigraphically in the discontinuous lenses and laminae of siltstone and sandstone. The structure has aided in trapping the gas in three ways. First, these present-day structural highs experienced recurrent tectonic movement during Late Cretaceous time, the time of deposition of the shelf sediments. The movement created shoals on the submarine shelf that resulted in winnowing and enhancement of the reservoir properties (Rice and Gautier, 1983). Second, at the time of generation the early-formed gas was probably dissolved in formation waters which served as a holding mechanism until traps and seals were formed. Uplift and erosion in Late Cretaceous and early Tertiary time resulted in exsolution of the gas and creation of a free-gas state. Finally, the erosion resulted in underpressuring which slowed down loss of gas by diffusion.

The stages of metabolic activity leading to methanogenesis by $\mathrm{CO}_{2}$ reduction have been documented in these sequences by the mineralogy, texture, and isotopic 


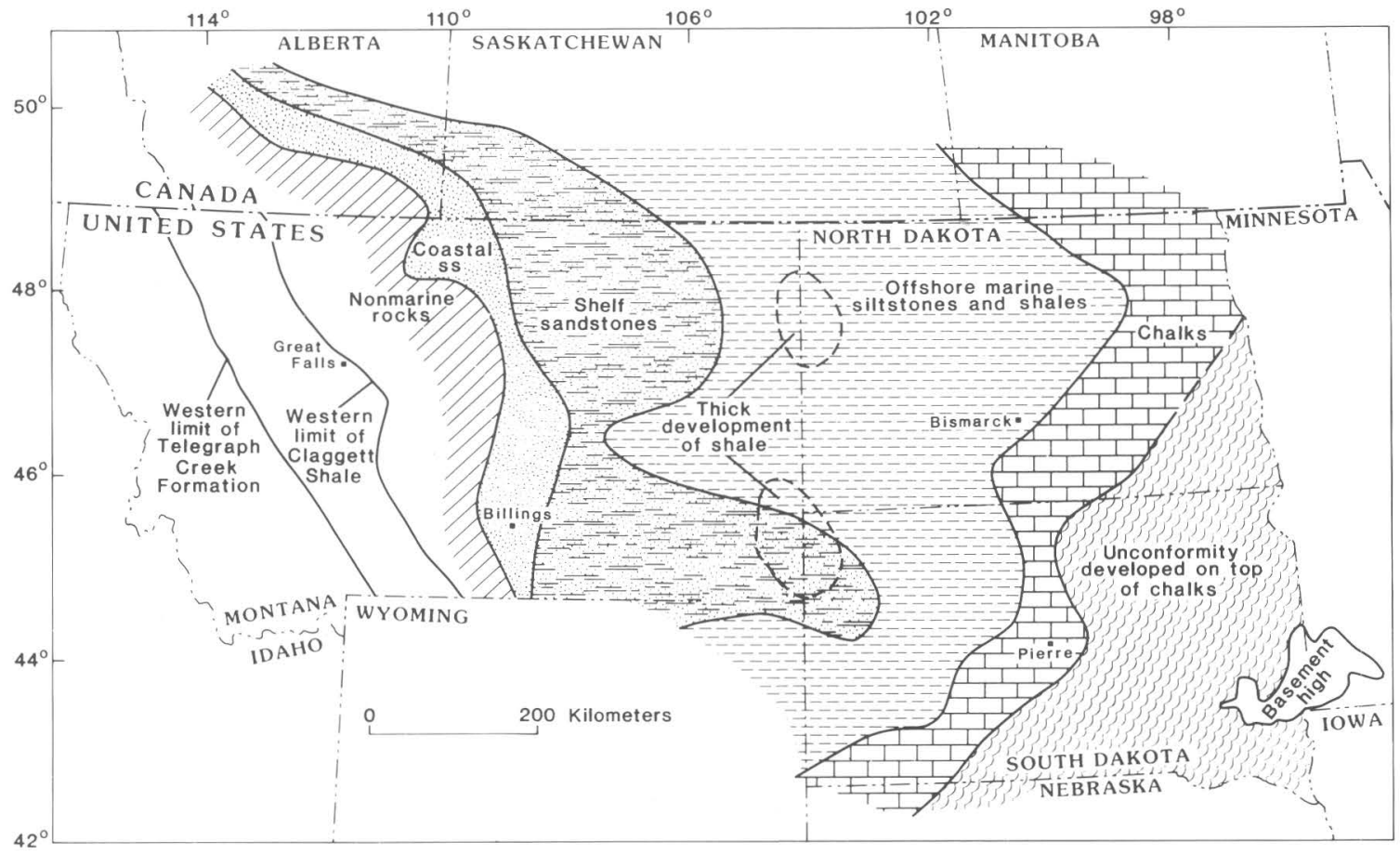

Figure 9. Paleogeographic map of northern Rocky Mountains, United States and Canada, during Late Cretaceous (Campanian) time. Central and eastern parts of the Western Interior Seaway (inner and outer shelves) were favorable sites for generation and accumulation of biogenic gas. ss, sandstones. From Rice and Shurr (1983).

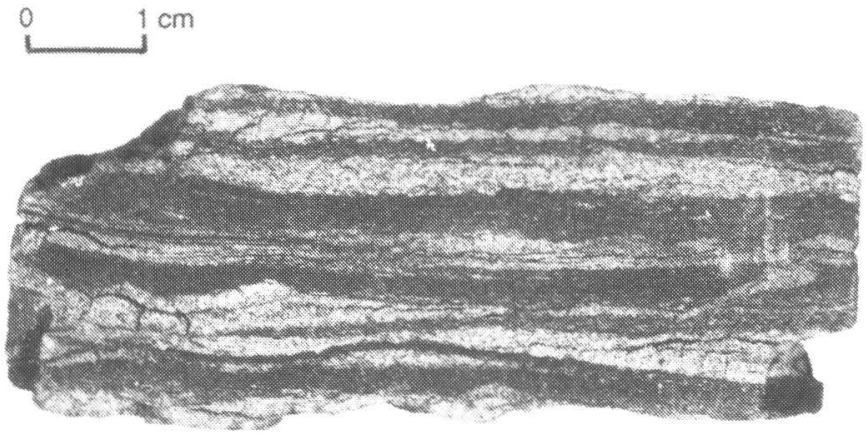

Figure 10. Photograph of core showing interlaminated sandstone, siltstone, and shale of Late Cretaceous (Turonian) age, Montana, United States. Illustrates close relation between reservoir, source, and seal of biogenic gas.

composition of concretionary carbonate cements and other authigenic minerals (Gautier and Claypool, 1984).

\section{CARBONATE SHELF}

The carbonate marine shelf of the Cretaceous Western Interior Seaway, as summarized by Rice and Gautier (1983), represents another favorable habitat for the generation and accumulation of ancient biogenic gases. The car-

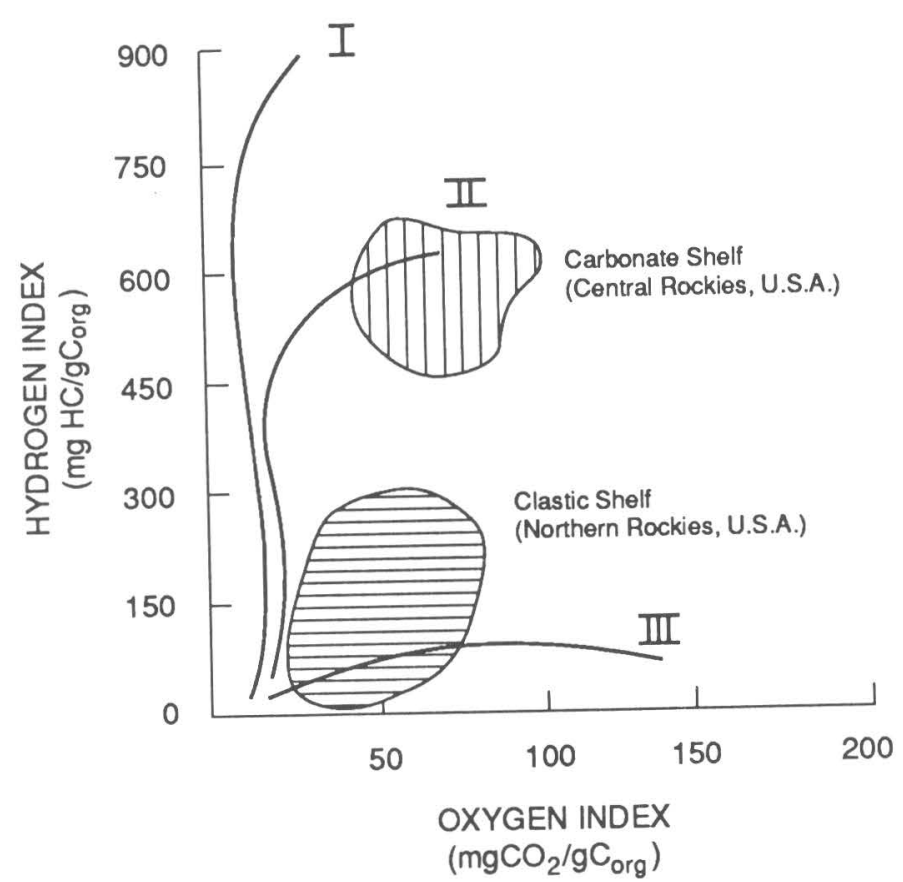

Figure 11. Modified van Krevelen diagram showing low level of maturity and types of organic matter that were source of biogenic gas for clastic-shelf (type III) and carbonate-shelf (type II) settings. Data for carbonate-shelf setting from Rice (1984). HC, hydrocarbon; $\mathrm{C}_{\text {org }}$, organic carbon; Rockies, Rocky Mountains. 
bonate rocks, referred to as chalks, are a fine-grained facies consisting of calcareous nannofossils and other microfossils. The chalks were deposited in an open-marine, pelagic environment in which the rate of accumulation was slow and the influence of terrigenous input was minimal. This setting contrasts with all other favorable settings, where rapid sedimentation was a critical element for both generation and accumulation. Because the main terrigenous source area was to the west, chalk deposition was generally restricted to the eastern part of the seaway.

Biogenic-gas-bearing chalks deposited in the Western Interior Seaway consist of rhythmically bedded couplets at a centimeter scale (fig. 12) (Arthur and others, 1985; Pollastro and Martinez, 1985). The carbonate-rich laminae have the highest porosity values and are the best reservoir units. Because of their fine grain size, the chalks were deposited with high porosity and extremely low permeability, both of which decrease rapidly with depth of burial (Scholle, 1977). These properties provide for ample storage capacity and also help to trap the gas.

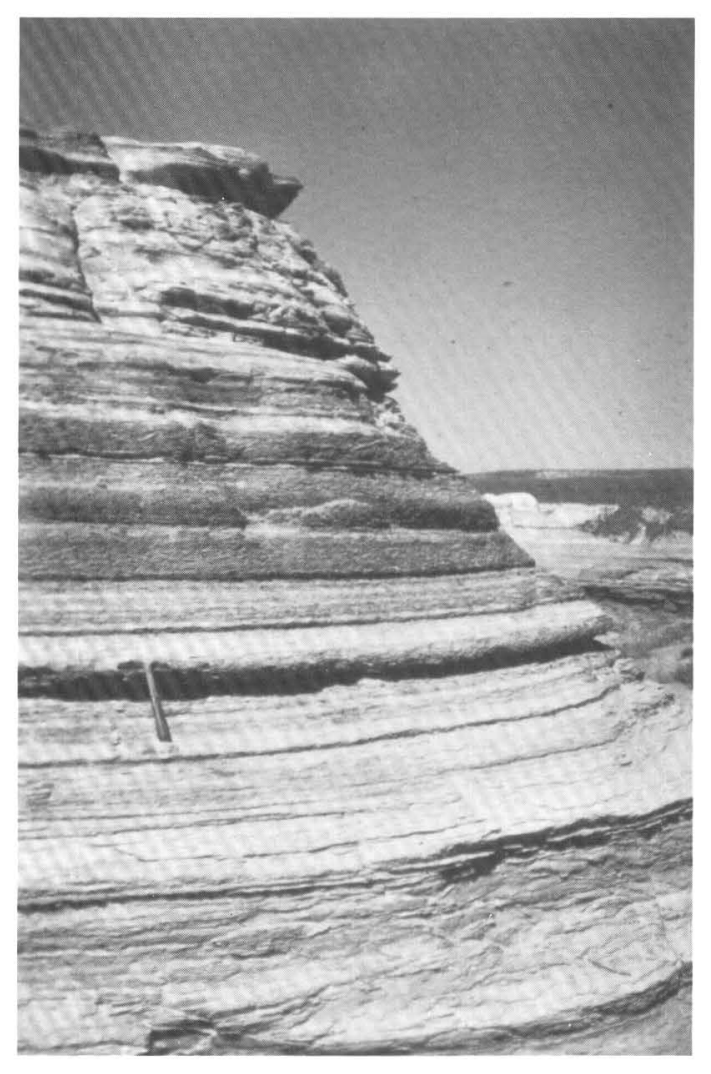

Figure 12. Rhythmically laminated chalks of Late Cretaceous (Coniacian and Santonian) age, Kansas, United States. Lighter colored laminae are carbonate rich and serve as reservoir for biogenic gas. Darker colored laminae have higher amounts of insoluble residue (mainly clay minerals) and organic matter, and serve as source and seal for biogenic gas.
In contrast, the alternating laminae are higher in insoluble residue (which consists mainly of clay minerals), have greater amounts of organic matter, and are lower in porosity. TOC values are as high as 5.8 percent and average 3.2 percent throughout the entire chalk interval (Rice, 1984). In contrast to organic matter in all the other documented occurrences of ancient biogenic gas, the organic matter in this occurrence is hydrogen-rich type II (fig. 11), typical of open-marine conditions.

The cycles that resulted in the preservation of higher amounts of organic matter are interpreted to be the result of poor oxygenation and weak circulation of bottom waters. These "oceanic anoxic events" were probably caused by regional climate and paleoceanographic conditions (Arthur and others, 1984; Fischer and others, 1985). Because of oceanic anoxic events, abundant amounts of organic matter were preserved without the need for rapid deposition.

The trapping of the gas probably resulted from (1) low permeability of the chalk reservoirs and (2) a rapidly deposited, thick sequence of marine shale with bentonite beds deposited on top of the chalks. As was the case with the clastic shelf setting, early-formed biogenic gas was probably initially held in solution in the formation waters. After uplift and erosion, free gas formed as underpressured accumulations.

Biogenic gas production has been established in northeastern Colorado and northwestern Kansas, United States (Lockridge and Pollastro, 1988). Depth of biogenic gas production varies from 250 to $850 \mathrm{~m}$. Oil is produced from this same chalk interval at greater depths where the chalks are thermally mature and are naturally fractured. The biogenic gas accumulations occur on low-amplitude anticlinal structural closures with listric-normal faults that have resulted in fracturing and increased reservoir quality of the chalks.

\section{NONMARINE SETTINGS}

A variety of reservoirs in nonmarine depositional settings-including fluvial and lacustrine settings, coastal plains, and coal swamps-contain documented biogenic gas accumulations (table 2). Two particular nonmarine settings, coal swamps and coastal plains, are important habitats for biogenic gas accumulations and will be discussed.

\section{COAL SWAMPS}

Coal swamps are a setting favorable to the generation and accumulation of biogenic gas as indicated by the recent exploration activity for coalbed gas. Coalbeds are interpreted to be both reservoir and source rocks for large quantities of not only thermogenic but also biogenic gas.

Biogenic gas production has been established in coalbeds and adjacent fluvial sandstones of Paleocene age in 
the Powder River basin, northeastern Wyoming, United States (Law and others, 1991) (fig. 4). The coals were deposited in raised, ombrotiphic bogs that were cut by anastomosing fluvial channels (Warwick and Stanton, 1988). The coalbeds are anomalously thick $(>75 \mathrm{~m})$ and are surface-mined on the margins of the basin. The thick coals indicate rapid subsidence during time of peat formation. This rapid subsidence accompanied by rapid deposition undoubtedly continued after peat accumulation.

The coals consist mostly of the maceral huminite, and the organic matter is classified as type III. The coals are relatively low in rank over the entire basin, ranging from lignite to subbituminous (vitrinite reflectance $\left(R_{0}\right)$ values of 0.4 to 0.6 percent) (Law and others, 1991).

On the basis of the molecular and isotopic composition of the gas and the low rank of the coals, the gases are interpreted to be biogenic and to have been generated via the fermentation pathway (fig. 3). However, $\delta D$ values of the water, used in conjunction with the isotopic composition of the gases, suggest that more than 80 percent of the gas was derived by $\mathrm{CO}_{2}$ reduction (P.D. Jenden, oral commun., 1992).

The timing of biogenic gas generation in the low-rank coalbeds of the Powder River basin is problematic. Biogenic gas was undoubtedly generated and accumulated shortly after deposition of the peat during a time of rapid subsidence and deposition. This early-stage gas was trapped by interbedded shales and compaction folds (Law and others, 1991). Some or all of this early-formed biogenic gas probably degassed, however, from the coalbeds following regional uplift and erosion about $10 \mathrm{Ma}$. This uplift and erosion also led to the establishment of a regional aquifer system in the thick coalbeds '(Tyler and others, 1991). Groundwater flow in the coalbeds, at least along the basin margins, led to microbial activity that resulted in generation of late-stage biogenic gas by $\mathrm{CO}_{2}$ reduction. Whether generation of latestage biogenic gas was widespread in the basin is uncertain because of the discontinuous nature of the coalbeds. Consequently, late-stage biogenic gas may be limited to the margins of the basin or may extend across the entire basin.

A survey of coalbed gases from Australia, Canada, China, Germany, Poland, and the United States demonstrates a stronger relation between molecular and isotopic composition of the gases when plotted against present-day depth of burial than when plotted against rank (Rice, in press). In general, shallow coalbed gases are composed of isotopically light methane, as compared with deeper coalbed gases, regardless of rank and age of the associated coal. Rice (in press) interpreted this difference to be the result of late-stage biogenic gas either (1) being mixed with previously generated thermogenic gas or (2) completely filling degassed coalbeds at shallow depths. As discussed earlier, coalbeds are commonly aquifers, particularly at shallow depths $(<1 \mathrm{~km})$, where microorganisms can thrive and significant amounts of biogenic gas can be generated.

\section{COASTal Plains}

The coastal plain is an important setting for ancient biogenic gas accumulations in the northern part of West Siberia basin, Russia, where enormous reserves have been discovered. The petroleum geology of the province is summarized in English by Grace and Hart (1986), Galimov (1988), and Peterson and Clarke (1991).

In the West Siberia basin, nonassociated gases of possible biogenic origin occur in Upper Cretaceous (Cenomanian) rocks at an average depth of about $1,100 \mathrm{~m}$. Thermogenic gases and condensates are produced from Lower Cretaceous (Neocomian) reservoirs at depths of 2,500 to $3,000 \mathrm{~m}$. The shallow Cenomanian gas occurs in an $800-\mathrm{m}$ section of interbedded sandstones and shales of coastal plain origin. The gas is trapped in very large structures, and the reservoir section is directly overlain by a thick (hundreds of meters) shale. Several investigators, including Makogon and others (1972), have suggested that Cenozoic glaciation may have aided in trapping the huge Cenomanian gas accumulations. The theory is that the formation waters and gas formed hydrates with the advance of the glaciers and permafrost. With the glacial retreat, the hydrates decomposed and a free gas state was formed.

The gas-bearing Cenomanian section is thermally immature over the entire area $\left(R_{o}\right.$ values of 0.4 to 0.55 percent). Humic (type III) organic matter is abundant throughout the section and is concentrated in coalbeds; it is an obvious indigenous source for the large gas accumulations. In contrast, the organic matter in the Neocomian section is transitional between marine and continental (mixture of types II and III). Vitrinite reflectance values of the Neocomian section range from 0.55 to 0.76 percent, indicating the early part of the mature stage of hydrocarbon generation. The underlying Upper Jurassic shales occur at a higher level of thermal maturity and are rich in type II kerogen.

As reported by Yermakov and others (1970) and Alekseyev (1974), gases from Upper Jurassic and Neocomian reservoirs are chemically wet (average methane concentration is 88 percent) and isotopically heavy (methane $\delta^{13} \mathrm{C}$ values for methane range from -38.5 to -44.2 permil). On the basis of these analyses and the level of thermal maturity, the gases are interpreted to be thermogenic and to have been generated in the adjacent source rocks or in the underlying organic-rich shales of Jurassic age.

In contrast, gases from the Cenomanian reservoirs consist mostly of methane (average 98 percent). Yermakov and others (1970) and Alekseyev (1974) reported that methane $\delta^{13} \mathrm{C}$ values of methane in gases from eight fields, including the giant Urengoy, range from -57.5 to -67.8 permil. These isotopic values, in addition to the molecular composition and the low level of thermal maturity, strongly suggest an indigenous biogenic origin. On the basis of available data, the shallow gases in Cenomanian 
reservoirs have probably not migrated from the deeper Jurassic and (or) Neocomian section.

Galimov (1988) reported significantly heavier methane $\delta^{13} \mathrm{C}$ values than those previously cited for methane in gases from the Urengoy field. His methane $\delta^{13} \mathrm{C}$ values for methane in Cenomanian gases range from -46 to -50 permil, whereas those from Neocomian reservoirs range from -35 to -38 permil. Galimov (1988) proposed early thermogenic generation for the major quantities of methane-rich gas from rocks generally recognized as being immature. He calculated from activation energies that this early generation took place from indigenous humic (type III) organic matter. Another possibility is that these gases were generated by reduction of heavy $\mathrm{CO}_{2}$ or by the fermentation pathway resulting in heavier methane $\delta^{13} \mathrm{C}$ values for the methane component.

\section{RESOURCE POTENTIAL OF BIOGENIC GAS}

During the geologic past, conditions were favorable for both the generation and accumulation of biogenic gas in many areas. However, only for a few areas are data available for both the identification and the evaluation of resource potential (table 3 ). As a result, the identified resources are presumably only a portion of the total resources of ancient biogenic gas. In addition, the resource potential of gas in hydrates is not included. Below is a discussion of the resources grouped by habitat of occurrence.

\section{DELTAS}

The offshore Gulf of Mexico is a major hydrocarbonproducing province of the United States. Total gas resources for the area are estimated to be about 6,500 billion cubic meters (Bcm) (U.S. Geological Survey and Minerals Management Service, 1989). Reservoirs of Pleistocene age contain major accumulations of natural gas, much of which is of biogenic origin. Unpublished data of the U.S. Geological Survey indicate that about 18 percent of the discovered gas in the province is in Pleistocene reservoirs. A similar distribution is expected for undiscovered resources. Although some thermogenic oil and gas have migrated from deeper, more mature intervals, Rice (1980) and Rice and Claypool (1981) estimated that about 75 percent of the gas in Pleistocene reservoirs is of biogenic origin. On the basis of these percentages, Pleistocene reservoirs are estimated to contain about $884 \mathrm{Bcm}$ of biogenic gas. Additionally, older reservoirs are also likely to contain accumulations of biogenic gas.

Ancient biogenic gas was also identified in other major hydrocarbon- producing deltas, such as the Baram, Mahakam, and Niger (fig. 6). Although the percentage of biogenic gas is not reported, these deltas contain major resources of natural gas (Baram, 1,000 Bcm; Mahakam, 750 $\mathrm{Bcm}$; Niger, $6,500 \mathrm{Bcm}$ ) (K. Robinson, oral commun., 1989; Masters and others, 1991). A portion of these total resources is of biogenic origin.

In the Polish part of the Carpathian foredeep, resources of biogenic gas in Miocene deltaic deposits are estimated to be about $283 \mathrm{Bcm}$ (M. Kotarba, oral commun., 1990). About half of these resources have been discovered.

\section{DEEP-WATER CLASTIC SETTINGS}

Mattavelli and Novelli (1988) estimated that 74 percent of the original gas reserves of Italy $(414 \mathrm{Bcm})$ are of biogenic origin. They also estimated that about 77 percent of the original gas reserves $(431 \mathrm{Bcm})$ in Italy occur in deep-water clastic rocks (turbidite sequences) in the Appennine foredeep. They further approximated that 82 percent of the gas in the foredeep, or $354 \mathrm{Bcm}$, is of biogenic origin. If these percentages apply to undiscovered resources as well, then the total biogenic gas resources of Italy are on the order of $815 \mathrm{Bcm}$.

\section{SHELF SETTINGS}

In southeastern Alberta and southwestern Saskatchewan, Canada, major biogenic gas reserves have been established in shallow $(<600 \mathrm{~m})$, clastic, low-permeability reservoirs of Late Cretaceous age. The present area of production covers more than $20,000 \mathrm{~km}^{2}$, and the area of production is rapidly expanding. In the Alberta portion, 420 $\mathrm{Bcm}$ of gas reserves have been reported (Energy Resources Conservation Board, 1986).

Similar, shallow reservoirs occur over a large part of the northern Great Plains of Montana and North and South Dakota, United States. The National Petroleum Council (1980a) estimated that a $310,000-\mathrm{km}^{2}$ study area contains undiscovered, recoverable biogenic gas resources of $2,830 \mathrm{Bcm}$.

Biogenic gas production has been established in chalk beds of Late Cretaceous age in northeastern Colorado and northwestern Kansas. As of 1987, about $4 \mathrm{Bcm}$ had been produced (Lockridge and Pollastro, 1988). Recoverable gas resources of $34 \mathrm{Bcm}$ were assessed for the area by the National Petroleum Council (1980b).

Chalk beds with almost identical characteristics are widespread on the eastern shelf of the Western Interior Seaway in North and South Dakota. Shurr and Rice (1987) estimated the biogenic gas resources of the chalk beds in this area to be $1,700 \mathrm{Bcm}$.

Gas blowouts occurring in the Gulf of Mexico and in the North Sea indicate the occurrence of relatively large quantities of undiscovered biogenic gas in those shelf settings as well (Hovland and Judd, 1988). 
Table 3. Estimated volumes of biogenic gas.

[Volumes in billion cubic meters. ---, not determined]

\begin{tabular}{|c|c|c|c|}
\hline Habitat and location & $\begin{array}{l}\text { Discovered volumes } \\
\text { (cumulative production } \\
\text { and reserves) }\end{array}$ & Undiscovered volumes & References \\
\hline \multicolumn{4}{|c|}{ Delta } \\
\hline Offshore Gulf of Mexico & 1490 & $\begin{array}{l}1394 \\
\text { (recoverable) }\end{array}$ & $\begin{array}{l}\text { U.S. Geological Survey and Mineral } \\
\text { Management Service (1989) }\end{array}$ \\
\hline Carpathian foredeep (Poland) & 143 & 140 & M. Kotarba, oral commun. (1990) \\
\hline \multicolumn{4}{|c|}{ Deep-water clastic setting } \\
\hline Apennine foredeep (Italy) & 815 & --- & $\begin{array}{l}\text { Mattavelli and Novelli (1988); Masters and } \\
\text { others (1991) }\end{array}$ \\
\hline \multicolumn{4}{|c|}{ Shelf setting-Clastic } \\
\hline Southeastern Alberta (Canada) & 420 & --- & Energy Resources Conservation Board (1986) \\
\hline Northern Great Plains (U.S.A.) & 13 & $\begin{array}{c}2,830 \\
\text { (recoverable) }\end{array}$ & $\begin{array}{l}\text { National Petroleum Council; Rice and others } \\
(1990)\end{array}$ \\
\hline \multicolumn{4}{|c|}{ Shelf setting-Carbonate } \\
\hline $\begin{array}{l}\text { Central and northern Rocky Mountains } \\
\text { (U.S.A.) }\end{array}$ & 4 & $\begin{array}{c}1,700 \\
\text { (in place) }\end{array}$ & $\begin{array}{l}\text { National Petroleum Council (1980b); Shurr and } \\
\text { Rice (1987); Lockridge and Pollastro (1988) }\end{array}$ \\
\hline \multicolumn{4}{|c|}{ Nonmarine setting } \\
\hline Powder River basin (U.S.A.) & -- & $\begin{array}{l}1,100 \\
\text { (in place) }\end{array}$ & Choate and others (1984) \\
\hline Qaidam basin (China) & --- & $\begin{array}{l}455 \\
\text { (recoverable) }\end{array}$ & Ulmishek (1984) \\
\hline Cook Inlet, Alaska & 122 & $\begin{array}{l}32 \\
\text { (recoverable) }\end{array}$ & $\begin{array}{l}\text { Magoon and Kirschner (1990); R.F. Mast, oral } \\
\text { commun. (1990) }\end{array}$ \\
\hline Japan & 133 & --- & Marsden and Kawaii (1965) \\
\hline West Siberia (Russia) & 2134,252 & --- & Grace and Hart (1986) \\
\hline
\end{tabular}

\section{NONMARINE SETTINGS}

The Powder River basin has anomalously thick, lowrank coalbeds of Paleocene and Eocene age at depths less than $750 \mathrm{~m}$. The coal resources have been estimated to be 1.2 billion tons (Choate and others, 1984). Localized production of biogenic gas has recently been established in the coalbeds. Using an in-place methane content of $0.6 \mathrm{~m}^{3} /$ ton for the biogenic gas, an in-place gas resource of about $1,000 \mathrm{Bcm}$ has been estimated for the coalbeds of the Powder River basin (Choate and others, 1984). This biogenic gas resource potential is comparable to that of other U.S. coal-bearing basins that have mainly thermogenic coalbed gas (Rightmire, 1984).

Biogenic gas commonly occurs in shallow $(<1 \mathrm{~km})$ coalbeds of all ranks and ages; a large part of this gas was generated during relatively recent geologic time (late stage). Worldwide resources of coalbed gas are estimated to be as much as $260,000 \mathrm{Bcm}$ (Kuuskraa and others, 1992), and an unknown portion of these total resources is of shallow biogenic origin.

The eastem part of the Qaidam basin (China) was an area of rapid fluvial and lacustrine deposition during Quaternary time, when as much as $3,000 \mathrm{~m}$ of sediments were deposited. Biogenic gas has been produced from these sediments at depths as much as $1,400 \mathrm{~m}$ ( $\mathrm{Gu}$ and others, 1988). Ulmishek (1984) estimated the undiscovered biogenic gas resources of these sediments to be $445 \mathrm{Bcm}$.

Biogenic gas has been produced at depths as much as $1,600 \mathrm{~m}$ in the Cook Inlet of Alaska, United States (Claypool and others, 1980). The production is from nonmarine sandstones of Miocene and Pliocene age. This occurrence is significant because coalbeds interbedded with the sandstone reservoirs may be the source of the gas. About 122 $\mathrm{Bcm}$ of gas have been discovered from this sequence (Magoon and Kirschner, 1990), and an additional $32 \mathrm{Bcm}$ of 
undiscovered gas resources are estimated (R.F. Mast, oral commun., 1990).

In Japan, biogenic gas dissolved in formation waters was the main source of natural-gas production from the 1920's to 1960's (Marsden, this volume). The reservoirs are sands and gravels of mostly Pliocene and Pleistocene age, and production is generally from depths less than 2,000 m. Marsden and Kawaii (1965) have described the production and estimated the reserves to be about 133 Bcm.

The West Siberia basin (Russia) has gas reserves of $32,000 \mathrm{Bcm}$ (Grace and Hart, 1986), about one-third of the world's gas reserves. Much of the gas occurs in giant fields, and two of the fields, Urengoy and Yamburg, are the two largest gas fields in the world. Although thermogenic hydrocarbon production is established in the Jurassic and Lower Cretaceous sequence, 62 percent of the proven gas reserves are estimated to be in the shallow Cenomanian reservoirs (Peterson and Clarke, 1991). Although conflicting gas compositional data have been presented, the origin of most of the Cenomanian gases is interpreted to be biogenic, as discussed in the previous section. The reserves of gas fields given by Grace and Hart (1986) and identified as being biogenic in origin according to data by Yermakov and others (1970) and Alekseyev (1974) total 13,425 Bcm.

Biogenic gas is estimated to account for as much as 20 percent of the world's gas resources, both discovered and undiscovered. This figure appears to be heavily influenced by the huge accumulations in West Siberia that are of questionable biogenic origin. However, many discovered gas accumulations do not have data that permit a determination of their origin and an assessment of their resource potential, and many other accumulations have been bypassed and overlooked and are therefore undiscovered. The percentage of biogenic gas of the total hydrocarbon resource is quite variable on a regional basis. For example, in the Northern Great Plains of North America (Canada and United States), large biogenic gas accumulations occur where there is little thermogenic hydrocarbon potential. In contrast, many of the young deltas contain both biogenic and thermogenic gases.

Ancient biogenic gas resources will be important in the future for several reasons. First, natural-gas prices have limited gas exploration. Second, biogenic gas accumulations may occur in areas which have been discounted for thermogenic hydrocarbon potential, but which probably had conditions favorable for the generation and accumulation of biogenic gas. Third, biogenic gas may occur in currently subeconomic accumulations because of their generally small volumes and unconventional reservoirs. The small accumulations can be used locally, as is the case for biogenic gas accumulations in glacial drift in the Illinois basin, United States (Meents, 1968) and in the Pearl, Qiantang, and Yangtze deltas, China (Zhang and Chen, 1985).
Large quantities of biogenic gas are either dissolved (Buckley and others, 1958) or in hydrate structures (Kvenvolden, 1988). In addition, large accumulations of biogenic gas occur in low-permeability reservoirs as discussed by Rice and Shurr (1980). However, biogenic gas accumulations that are dissolved, in hydrates, or trapped in low quality reservoirs will only be developed when gas prices rise and drilling and recovery technologies are improved. Fourth, gas reserves tend to decrease with increasing geologic age of the reservoir, with the largest amounts occurring in reservoirs of late Tertiary age (fig. 13) (Bois and others, 1982). This same trend will probably apply to undiscovered gas resources. Because biogenic gas accumulations are usually concentrated in young reservoirs, a significant portion of both reserves and undiscovered resources will probably be of biogenic origin. Finally, biogenic gas, which is mainly methane, is a low-pollution energy source.

\section{SUMMARY AND CONCLUSIONS}

Biogenic gas is generated at low temperatures by the breakdown of organic matter by anaerobic microbes and may exist where thermogenic hydrocarbons are absent.

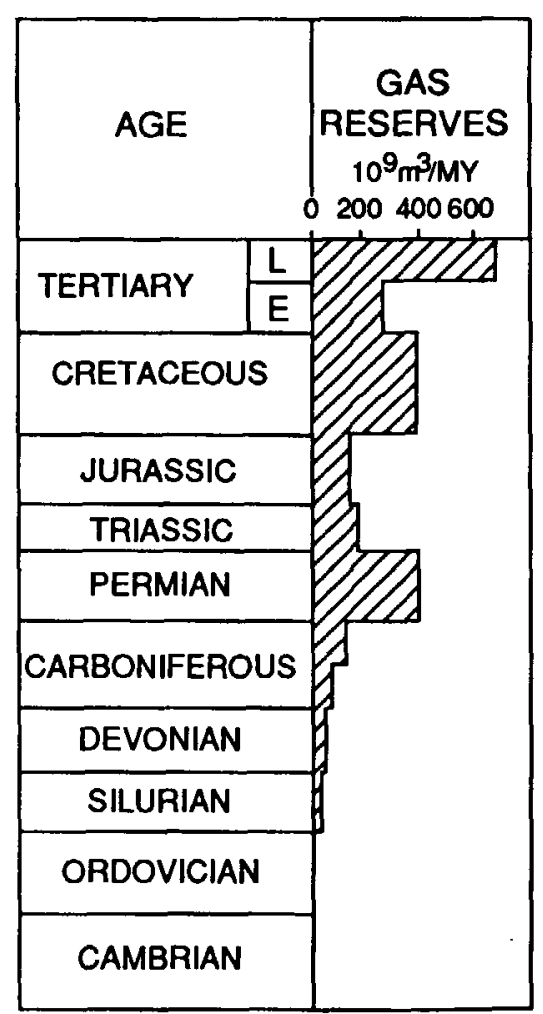

Figure 13. Distribution of ultimate reserves of gas by age of reservoir. From Bois and others (1982). E, early; L, late; $\mathrm{m}^{3}$, cubic meters; MY, million years. 
Where generated, biogenic gas can accumulate in significant quantities and be an important resource. It is important that biogenic gas be considered in future exploration strategies.

1. A succession of metabolic processes leads to the generation of biogenic gas. Although fermentation is the pathway for generation in some modern environments, $\mathrm{CO}_{2}$ reduction is the most important pathway for ancient biogenic gas accumulations. The two main sources of $\mathrm{CO}_{2}$ for reduction are (1) bacterial processes (sulfate reduction and fermentation) and (2) thermal decarboxylation of kerogen.

2. Factors controlling methane generation after sediment burial are anoxic conditions, low sulfate content, low temperatures, abundant organic matter, sufficient pore space, and high deposition rate.

3. Factors controlling accumulation of biogenic gas are stratigraphic or early structural traps, adequate seals, early dissolution and later exsolution, formation of hydrates, low permeability, low pressure, and high rate of deposition.

4. Most ancient biogenic gas was probably generated early in the burial history, at shallow depths $(<1 \mathrm{~km})$, and subsequently buried to greater depths. Some biogenic gas, particularly in coalbeds, was probably generated during later stages of geologic history, commonly in association with groundwater flow.

5. In most documented ancient accumulations, biogenic gas was generated from type III organic matter. The type of organic matter used by microbes in biogenic gas generation was probably controlled by the type that was available rather than the type that was preferred by the microbes. In settings of rapid deposition, type III organic matter is usually dominant.

6. Ancient biogenic gases can be distinguished by molecular and isotopic composition. Biogenic gases are mostly methane that is generally enriched in the light isotope ${ }^{12} \mathrm{C}$ (methane $\delta^{13} \mathrm{C}$ values lighter than -55 permil). Biogenic gases generated by the $\mathrm{CO}_{2}$ reduction pathway generally have methane $\delta \mathrm{D}$ values in the range of -150 to -250 permil, whereas biogenic gases formed by the fermentation pathway are generally enriched in deuterium (methane $\delta D$ values ranging from -250 to -400 permil). The interpretation of biogenic origin should also consider the geologic setting.

7. Ancient biogenic gas accumulations are documented in Mississippian and younger sequences (significant accumulations are usually Cretaceous and younger), at depths less than $4,600 \mathrm{~m}$ (depth is usually dependent on age), and in thermally immature sequences. They occur in a variety of both marine and nonmarine sequences and in a variety of rock types (clastic, carbonate, and coal). Commercial accumulations have been documented in Africa, Asia, Europe, North America, and South America.

8. Favorable depositional settings for the generation and accumulation of ancient bacterial gas accumulations are deltas, deep-water clastic settings, clastic and carbonate shelves, and nonmarine settings (in particular coal swamps). In almost all cases, these settings are favorable if deposition is rapid.

9. Biogenic gas accounts for as much as 20 percent of the world's resources of natural gas. Biogenic gas accumulations will be more important in the future because they have previously been overlooked and bypassed in the past.

\section{ACKNOWLEDGMENTS}

I thank Charles N. Threlkeld, April Vuletich, and Augusta Warden of the U.S. Geological Survey for chemical and isotopic analyses of natural gases; many oil companies for their assistance in collecting gas samples; and R. Ames of Amoco Production Co., C. Clayton of BP International Limited, and G. Lijmbach of Shell Internationale Petroleum Mij. for gas analyses.

\section{REFERENCES CITED}

Alekseyev, F.A., 1974, Zonality in oil and gas formation in the earth's crust based on isotope studies: Geologiya Nefti i Gaza, v. (April), p. 62-67. English version in Petroleum Geology, v. 12, p. 53-71.

Alekseyev, F.A., Lebedev, V.S., and Krylova, T.A., 1972, Isotope composition of carbon in gaseous hydrocarbons and conditions for accumulations of natural gas: Sovetskaya Geologia, no. 4 , p. $35-47$. English version in International Geological Review, v. 15, p. $300-308$.

Arthur, M.A., Dean, W.E., Bottjer, D.J., and Scholle, P.A., 1984, Rhythmic bedding in Mesozoic-Cenozoic pelagic carbonate sequences-The primary and diagenetic origin of Milankovitch-like cycles, in Berger, A., Imbrie, J., Hays, J., Kukla, G., and Saltzman, B., eds., Milankovitch and climate: Dordrecht, Netherlands, Reidel, p. 191-222.

Arthur, M.A., Dean, W.E., Pollastro, R.M., Claypool, G.E., and Scholle, P.A., 1985, Comparative geochemical and mineralogical studies of two cyclic transgressive pelagic limestone units, Cretaceous Western Interior basin, U.S., in Pratt, L.M., Kauffman, E.G., and Zelt, F.B., eds., Fine-grained deposits and biofacies of the Cretaceous Western Interior Seaway-Evidence of cyclic sedimentary processes: Society of Economic Paleontologists and Mineralogists Field Trip Guidebook 4, p. 16-27.

Avrov, V.P., and Galimov, E.M., 1968, Microbiologic nature of a methane pool detected at considerable depth (based on isotope analysis): Akademiya Nauk SSSR Doklady, v. 206, p. 201-202.

Belyaev, S.S., Laurinavichus, K.S., and Gaytan, V.I., 1977, Modem microbiological formation of methane in the Quaternary and Pliocene rocks of the Caspian Depression: Geochemistry International, v. 14, p. 172-176.

Bois, C., Bouche, P., and Pelet, R., 1982, Global geologic history and distribution of hydrocarbon reserves: American As- 
sociation of Petroleum Geologists Bulletin, v. 66, p. 12481270.

Buckley, S.E., Hocott, C.R., and Taggart, M.S., 1958, Distribution of dissolved hydrocarbons in subsurface waters, in Habitat of oil: American Association of Petroleum Geologists, p. $850-882$.

Burke, Jr., R.A., Martens, C.S., and Sackett, W.M., 1988, Seasonal variation of $\mathrm{D} / \mathrm{H}$ and ${ }^{13} \mathrm{C} /{ }^{12} \mathrm{C}$ ratios of biogenic methane in surface sediments of Cape Lookout Bight, U.S.A.: Nature, v. 332, p. 829-831.

Bustin, R.M., 1988, Sedimentology and characteristics of dispersed organic matter in Tertiary Niger delta-Origin of source rocks in a deltaic environment: American Association of Petroleum Geologists Bulletin, v. 72, p. 277-298.

Chapman, R.E., 1980, Mechanical versus thermal cause of abnormally high pore pressures in shales: American Association of Petroleum Geologists Bulletin, v. 64, p. 2179-2183.

Choate, R., Johnson, C.A., and McCord, J.P., 1984, Geologic overview, coal deposits, and potential for methane recovery from coalbeds--Powder River Basin, in Rightmire, C.T., Eddy, G.E., and Kirr, J.N., eds., Coalbed methane resources of the United States: American Association of Petroleum Geologists Studies in Geology 17, p. 335-351.

Claypool, G.E., 1974, Anoxic diagenesis and bacterial methane production in deep sea sediments: Los Angeles, University of California, Ph.D. dissertation, $276 \mathrm{p}$.

Claypool, G.E., and Kaplan, I.R., 1974, The origin and distribution of methane in marine sediments, in Natural gases in marine sediments: New York, Plenum Press, p. 99-139.

Claypool, G.E., and Kvenvolden, K.A., 1983, Methane and other hydrocarbon gases in marine sediments: Annual Review of Earth and Planetary Sciences, v. 11, p. 299-327.

Claypool, G.E., Threlkeld, C.N., and Magoon, L.B., 1980, Biogenic and thermogenic origins of natural gas in the Cook Inlet basin: American Association of Petroleum Geologists Bulletin, v. 64, p. 1131-1139.

Clayton, C., 1992, Source volumetrics of biogenic gas generation, in Vially, R., ed., Bacterial gas: Paris, Editions Technip, p.191-204.

Coleman, D.D., Chao, L.L., and Riley, K.M., 1988, Microbial methane in the shallow Paleozoic sediments and glacial deposits of Illinois, U.S.A.: Chemical Geology, v. 71, p. 23-40.

Combaz, A., and De Matharel, M., 1978, Organic sedimentation and genesis of petroleum in Mahakam delta, Borneo: American Association of Petroleum Geologists Bulletin, v. 62, p. 1684-1695.

Davis, J.B., and Squires, R.M., 1954, Detection of microbially produced hydrocarbons other than methane: Science, v. 119, p. 381-382.

Diamond, S., 1970, Pore size distribution of clays: Clays and Clay Minerals, v. 18, p. 7-23.

Dickey, P.A., and Cox, W.C., 1977, Oil and gas in reservoirs with subnormal pressures: American Association of Petroleum Geologists Bulletin, v. 61, p. 2134-2142.

Dow, W.G., 1978, Petroleum source beds on continental slopes and rises: American Association of Petroleum Geologists Bulletin, v. 62, p. 1584-1606.

Downey, M.W., 1984, Evaluating seals for hydrocarbon accumulations: American Association of Petroleum Geologists Bulletin, v. 68 , p. $1752-1763$.
Energy Resources Conservation Board, 1986, Alberta's reserves of crude oil, oil sands, gas, natural gas liquids, and sulfur, 31 December 1986: Energy Resources Conservation Board Reserve Report Series ERCB-18, 379 p.

Faber, E., 1987, Zur isotopengeochemie gasformiger kohlenwasserstoffe: Erdol Ergas Kohle, v. 103, p. 210-218.

Faber, E., and Stahl, W.,1977/1978, Anwendung von isotopenmethoden bei der exploration auf kohlenwasserstoffe: Compendium 77/78, Erganzungband der Zeitschrift Erdol und Kohle, Ergas, Petrochemie, p. 380-391.

Fischer, A.G., Herbert, T., and Silva, I.P., 1985, Carbonate bedding cycles in Cretaceous pelagic and hemipelagic sequences, in Pratt, L.M., Kauffman, E.G., and Zelt, F.B., eds., Fine-grained deposits and biofacies of the Cretaceous Western Interior Seaway-Evidence of cyclic sedimentary processes: Society of Economic Paleontologists and Mineralogists Field Trip Guidebook 4, p. 1-10.

Fuex, A.N., 1977, The use of stable carbon isotopes in hydrocarbon exploration: Journal of Geochemical Exploration, v. 7, p. $155-188$.

Galimov, E.M., 1968, Isotopic composition of carbon in gases in the crust: Izvestiya AN SSSR, no. 5, p. 29-44. English version in International Geological Review, v.11, p.1092-1104. 1988 , Sources and mechanisms of formation of gaseous hydrocarbons in sedimentary rocks: Chemical Geology, v. 71 , no. $1 / 3$, p. $77-95$.

Galloway, W.E., 1986, Growth faults and fault-reläteu structures of prograding terrigenous clastic continental margins: Gulf Coast Association of Geological Societies Transactions, v. 36, p. 121-128.

Gautier, D.L., and Claypool, G.E., 1984, Interpretation of methanic diagenesis in ancient sediments by analogy with processes in modern diagenetic environments, in McDonald, D.A., and Surdam, R.C., eds., Clastic diagenesis: American Association of Petroleum Geologists Memoir 37, p. 111-123.

Gill, J.R., and Cobban, W.A., 1973, Stratigraphy and geologic history of the Montana Group and equivalent rocks, Montana, Wyoming, and North and South Dakota: U.S. Geological Survey Professional Paper 776, 37 p.

Grace, J.D., and Hart, G.F., 1986, Giant gas fields of northern West Siberia: American Association of Petroleum Geologists Bulletin, v. 70, p. 830-852.

Gu, S., Liu, D., and Shao, H., 1988, Generation of Quaternary gas in the eastern part of the Qaidam Basin, in Wagner, H.C, Wagner, L.C., Wang, F.F.H., and Wong, F.L., eds., Petroleum resources of China and related subjects: Circum-Pacific Council for Energy and Mineral Resources: Earth Sciences Series, v. 10, p. 557-575.

Hovland, M., and Judd, A.G., 1988, Seabed pockmarks and seepages: London, Graham and Trotman, 293 p.

Hovland, M., Talbot, M.R., Qvale, H., Olaussen, S., and Aasberg, L., 1987, Methane-related carbonate cements in pockmarks of the North Sea: Journal of Sedimentary Petrology, v. 57, p. 881-892.

Hunt, J.M., 1979, Petroleum geochemistry and geology: San Francisco, W.H. Freeman, 617 p.

Jenden, P.D., and Kaplan, I.R., 1986, Comparison of microbial gases from the Middle America Trench and Scripps Canyon-Implications for the origin of natural gas: Applied Geochemistry, v. 1, p. 631-646. 
1989, Origin of natural gas in Sacramento basin, California: American Association of Petroleum Geologists Bulletin, v. 73, p. 431-453.

Jenden, P.D., Newell, K.D., Kaplan, I.R., and Watney, W.L., 1988 , Composition and stable-isotope geochemistry of natural gases from Kansas, Midcontinent, U.S.A.: Chemical Geology,.v. 71, p. 117-147.

Jorgensen, N.O., Laier, T., Buchardt, B., and Cederberg, T., 1990, Shallow hydrocarbon gas in the northern Jutland-Kattegat region, Denmark: Bulletin of the Geological Society of Denmark, v. 38, p. 69-76.

Kaiser, W.R., Swartz, T.E., and Hawkins, G.J., 1991, Hydrology of the Fruitland Formation, San Juan basin, in Geologic and hydrologic controls on the occurrence and producibility of coalbed methane, Fruitland Formation, San Juan basin: Gas Research Institute, Topical Report (August 1987-July 1990), GRI -91/0072, p. 195-241.

Koncz, I.,1983, The stable carbon isotope composition of the hydrocarbon and carbon dioxide components of Hungarian natural gases: Acta Mineralogica-Petrographica, Szeged, v. 26, p. 33-49.

Konig, H., 1992, Microbiology of methanogens, in Vially, R., ed., Bacterial gas: Paris, Editions Technip, p. 3-11.

Kotarba, M., 1992, Bacterial gases in Polish part of the Carpathian Foredeep and the Flysch Carpathians-Isotopic and geological approach, in Vially, R., ed., Bacterial gas: Paris, Editions Technip, p. 133-145.

Kotarba, M., Szafran, S., and Espitalie, J., 1987, A study of organic matter and natural gases of the Miocene sediments in the Polish part of the Carpathian foredeep: Chemical Geology, v. 64, p. 197-207.

Kvenvolden, K.A., 1988, Methane hydrate-A major reservoir of carbon in the shallow geosphere?: Chemical Geology, v. 71, p. 41-51.

Kvenvolden, K.A., and McMenamin, M.A., 1980, Hydrates of natural gas: U.S. Geological Survey Circular 825, 11 p.

Kuuskraa, V.A., Boyer, C.M., II, and Kelafant, J.A., 1992, Hunt for quality basins goes abroad: Oil and Gas Journal, v. 90, no. 40 , p. $49-54$.

Laier, T., Jorgensen, N.O., Buchardt, B., Cederberg, T., and Kuijpers, A., 1992, Accumulation and seepages of biogenic gas in northern Denmark: Continental Shelf Research, v. 12, p. 1173-1186.

Law, B.E., Rice, D.D., and Flores, R.M., 1991, Coalbed gas accumulations in the Paleocene Fort Union Formation, Powder River basin, Wyoming, in Schwochow, S.D., Murray, D.K., and Fahy, M.F., eds., Coalbed methane of western North America: Denver, Rocky Mountain Association of Geologists, p. 179-190.

Leythaeuser, D., Schaefer, R.G., and Pooch, H., 1983, Diffusion of light hydrocarbons in subsurface sedimentary rocks: American Association of Petroleum Geologists Bulletin, v. 67 , p. $889-895$.

Leythaeuser, D., Schaefer, R.G., and Yukler, A., 1982, Role of diffusion in primary migration of hydrocarbons: American Association of Petroleum Geologists Bulletin, v. 66, p. 408429.

Lockridge, J.P., and Pollastro, R.M., 1988, Shallow Upper Cretaceous Niobrara gas fields in the eastern Denver basin, in Goolsby, S.M., and Longman, M.W., eds., Occurrence and petrophysical properties of carbonate reservoirs in the Rocky Mountain region: Denver, Rocky Mountain Association of Geologists, p. 63-74.

Magoon, L.B., and Kirschner, C.E., 1990, Alaska onshore national assessment program-Geology and petroleum resource potential of six onshore Alaska provinces: U.S. Geological Survey Open-File Report 88-450T, 47 p.

Mah, R.A., Ward, D.M., Baresi, L., and Glass, T.L., 1977, Biogenesis of methane: Annual Review of Microbiology, v. 31, p. 309-341.

Makogon, Y.F., Tsarev, V.I., and Cherskiy, N.V., 1972, Formation of large natural gas fields in zones of permanently low temperatures: Akademiya Nauk SSSR Doklady, v. 205, p. 215218.

Marsden, S.S., and Kawaii, K., 1965, "Suiyosei-ten'nengasu," a special type of Japanese natural gas deposit: American Association of Petroleum Geologists Bulletin, v. 49, p. 286-295.

Martens, C.S., Blair, N.E., Green, C.D., and Des Martais, D.J., 1986, Seasonal variation in the stable carbon isotopic signature of biogenic methane in a coastal sediment: Science, v. 233, p. $1300-1303$.

Marty, D.G., 1992, Ecology and metabolism of methanogens, in Vially, R., ed., Bacterial gas: Paris, Editions Technip, p. 1323.

Masters, C.D., Root, D.H., and Attanasi, E.D., 1991, World resources of crude oil and natural gas [preprint]: Thirteenth World Petroleum Congress, $14 \mathrm{p}$.

Mattavelli, L., and Novelli, L., 1988, Geochemistry and habitat of natural gases in Italy, in Mattavelli, L., and Novelli, L., eds., Advances in organic geochemistry 1987: New York, Pergamon Press, p. 1-13.

Mattavelli, L., Ricchiuto, T., Grignani, D., and Schocll, M., 1983, Geochemistry and habitat of natural gases in Po basin, Italy: American Association of Petroleum Geologists Bulletin, v. 67 , p. $2239-2254$.

Mechalas, B.J., 1974, Pathways and environmental requirements for biogenic gas production in the ocean-Natural gases in marine sediments: New York, Plenum Press, p. 11-25.

Meents, W.F., 1968, Illinois glacial-drift gas, in Beebe, B.W., ed., Natural gases of North America: American Association of Petroleum Geologists Memoir 9, v. 2, p. 1754-1758.

Mink, R.M., Smith, C.C., Bearden, B.L., and Mancini, E.A., 1988, Regional geologic framework and petroleum geology of Miocene strata of Alabama coastal waters area and adjacent federal waters area: State Oil and Gas Board of Ala-

- bama Oil and Gas Report 16,64 p.

Nakai, N., 1960, Carbon isotope fractionation of natural gas in Japan: Nagoya University Journal of Earth Sciences, v. 8, p. 174-180.

Nakai, N., Yoshida, Y., and Ando, N., 1974, Isotopic studies on oil and natural gas fields in Japan: Chikyu Kagaku, v. 7/8, p. 87-98.

National Petroleum Council, 1980a, Northern Great Plains/Williston Basin: Tight Gas Reservoirs, Part II, p. 10-1 to 10170.

1980b, Denver Basin: Tight Gas Reservoirs, Part II, p. 15-1 to 15-39.

Nikaido, M., 1977, On the relation between methane production and sulfate reduction in bottom muds containing sea water sulfate: Geochemical Journal, v. 11, p. 199-206. 
Oremland, R.S., Marsh, L.M., and Polcin, S., 1982, Methane production and simultaneous sulfate reduction in anoxic, salt marsh sediments: Nature, v. 296, p. 143-145.

Oremland, R.S., Whiticar, M.J., Strohmaier, F.E., and Kiene, R.P., 1988, Bacterial ethane formation from reduced, ethylated sulfur compounds in anoxic sediments: Geochimica et Cosmochimica Acta, v. 52, p. 1895-1904.

Peterson, J.A., and Clarke, J.W., 1991, Geology and hydrocarbon habitat of the West Siberian basin: American Association of Petroleum Geologists Studies in Geology 32, $96 \mathrm{p}$.

Pollastro, R.M., and Martinez, C.J., 1985, Mineral, chemical, and textural relationships in rhythmic-bedded, hydrocarbon-productive chalk of the Niobrara Formation, Denver basin, Colorado: Mountain Geologist, v. 22, p. 55-63.

Rice, D.D., 1980, Chemical and isotopic evidence of the origins of natural gases in offshore Gulf of Mexico: Gulf Coast Association of Geological Societies Transactions, v. 30, p. 203213.

1984, Occurrence of indigenous biogenic gas in organicrich, immature chalks of Late Cretaceous age, eastern Denver Basin, in Palacas, J.G., ed., Petroleum geochemistry and source rock potential of carbonate rocks: American Association of Petroleum Geologists Studies in Geology 18, p. 135150 .

$\longrightarrow$ in press, Composition and origins of coalbed gas, in Law, B.E, and Rice, D.D., eds., Hydrocarbons from coal American Association of Petroleum Geologists Studies in Geology.

Rice, D.D., and Claypool, G.E., 1981, Generation, accumulation, and resource potential of biogenic gas: American Association of Petroleum Geologists Bulletin, v. 65, p. 5-25.

Rice, D.D., and Gautier, D.L., 1983, Patterns of sedimentation, diagenesis, and hydrocarbon accumulation in Cretaceous rocks of the Rocky Mountains: Society of Economic Paleontologists and Mineralogists Short Course Notes 11, 332 p.

Rice, D.D., Nydegger, G.L., and Brown, C.A., 1990, Bowdoin field-U.S.A., Bowdoin dome, Williston basin: American Association of Petroleum Geologists Atlas of Oil and Gas fields, Structural Traps III, p. 337- 355.

Rice, D.D., and Shurr, G.W., 1980, Shallow, low-permeability reservoirs of northern Great Plains-Assessment of their natural-gas resources: American Association of Petroleum Geologists Bulletin, v. 64, p. 969-987.

1983, Patterns of sedimentation and paleogeography across the Western Interior seaway during time of deposition of Upper Cretaceous Eagle Sandstone and equivalent rocks, northern Great Plains, in Reynolds, M.W., and Dolly, E.D., eds., Mesozoic paleogeography of the west-central United States: Rocky Mountain Section, Society of Economic Paleontologists and Mineralogists, Rocky Mountain Paleogeography, Symposium 2, p. 337-358.

Rice, D.D., and Threlkeld, C.N., 1983, Natural gas analyses from offshore Gulf of Mexico: U.S. Geological Survey Open-File Report 83-152, 6 p.

Rightmire, C.T., 1984, Coalbed methane resource, in Rightmire, C.T., Eddy, G.E., and Kirr, J.N., eds., Coalbed methane resources of the United States: American Association of Petroleum Geologists Studies in Geology 17, p. 1-15.

Rijks, E.J.H., 1981, Baram delta geology and hydrocarbon occurrence: Geological Society of Malaysia Bulletin 14, p. 1-18.
Risatti, J.B., 1987, Biogeochemistry of a temperate zone peat bog: Geological Society of America Abstracts with Programs, v. 19, p. 821.

Schoell, M., 1980, The hydrogen and carbon isotopic composition of methane from natural gases of various origins: Geochimica et Cosmochimica Acta, v. 44, p. 649-661.

1983, Genetic characterization of natural gases: American Association of Petroleum Geologists Bulletin, v. 67, p. 22252238.

-1988, Multiple origins of methane in the Earth: Chemical Geology, v. 71, p. 1-10

Schoell, M., Tietze, K., and Schoberth, S.M., 1988, Origin of methane in Lake Kivu (east-central Africa): Chemical Geology, v. 71 , p. $257-265$

Scholle, P.A., 1977, Chalk diagenesis and its relation to petroleum exploration-Oil from chalks, a modern miracle?: American Association of Petroleum Geologists Bulletin, v. 61, p. 982-1009.

Shurr, G.W., and Rice, D.D., 1987, Geologic setting and potential for natural gas in the Niobrara Formation (Upper Cretaceous) of the Williston basin, in Peterson, J.A., ed., Williston Basin-Exploration model for a cratonic petroleum province: Denver, Rocky Mountain Association of Geologists, p. 245-257.

Tissot, B.P., and Welte, D.H., 1984, Petroleum formation and occurrence: Berlin, Springer-Verlag, 699 p.

Tyler, R., Ambrose, W.A., Scott, A.R., and Kaiser, W.R., 1991, Coalbed methane potential of the Greater Green River, Piceance, Powder River, and Raton basins: Gas Research Institute, Topical Report (January 1991-July 1991), GRI91/0315, $244 \mathrm{p}$.

Ulmishek, G., 1984, Geology and petroleum resources of basins in western China: Argonne National Laboratory ANL/ES$146,131 \mathrm{p}$.

U.S. Geological Survey and Minerals Management Service, 1989, Estimates of undiscovered conventional oil and gas resources in the United States-a part of the Nation's energy endowment: U.S. Department of Interior, $44 \mathrm{p}$.

Vogel, T.M., Oremland, R.S., and Kvenvolden, K.A., 1982, Low-temperature formation of hydrocarbon gases in San Francisco Bay sediment: Chemical Geology, v. 37, p. $289-$ 298.

Warwick, P.D., and Stanton, R.W., 1988, Depositional models for two Tertiary coal-bearing sequences in the Powder River Basin, Wyoming, U.S.A.: Journal of the Geological Society, London, v. 145, p. 613-620.

Whiticar, M.J., and Faber, E., 1986, Methane oxidation in sediment and water column environments-isotope evidence: Organic Geochemistry, v. 10, p. 759-768.

Whiticar, M.J., Faber, E., and Schoell, M., 1986, Biogenic methane formation in marine and freshwater environments- $\mathrm{CO}_{2}$ reduction vs. acetate fermentation-isotope evidence: Geochimica et Cosmochimica Acta, v. 50, p. 693709.

Woese, C.R., Kandler, O., and Wheelis, M.L., 1990, Towards a natural system of organisms-Proposal for the domains $\mathrm{Ar}$ chaea, Bacteria, and Eucarya: Proceedings of the National Academy of Science (U.S.A.), v. 87, p. 4576-4579.

Wolfe, R.S., 1971, Microbial formation of methane: Advances in Microbial Physiology, v. 6, p. 107-146. 
Woltemate, I., Whiticar, M.J., and Schoell, M., 1984, Carbon and hydrogen isotopic composition of bacterial methane in a shallow freshwater lake: Limnology and Oceanography, v. 29, p. 985-992.

Woodbury, H.O., Murray, I.B., Jr., Pickford, P.J., and Akers, W.H., 1973, Pliocene and Pleistocene depocenters, outer continental shelf, Louisiana and Texas: American Association of Petroleum Geologists Bulletin, v. 57, p. 2429-2439.

Yermakov, V.I., Lebedev, V.S., Nemchenko, N.N., Rovenskaya, A.S., and Grachev, A.V., 1970, Isotopic composition of carbon in natural gases in the northern part of the West Siberi- an Plain in relation to their origin: Alademiya Nauk SSSR Doklady, v. 190 , p. 683-686.

Zeikus, J.G., and Winfrey, M.R., 1976, Temperature limitation of methanogenesis in aquatic sediments: Applied and Environmental Microbiology, v. 31, p. 99-107.

Zhang, Y.G., and Chen, H.J., 1985, Concepts on the generation and accumulation of biogenic gas: Journal of Petroleum Geology, v. 8 , p. $405-422$.

Zobell, C.E., and Anderson, D.A., 1936, Vertical distribution of bacteria in marine sediments: American Association of Petroleum Geologists Bulletin, v. 20, p. 258-269. 


\title{
World Resources of Natural Gas-A Discussion
}

\author{
By Charles D. Masters ${ }^{1}$
}

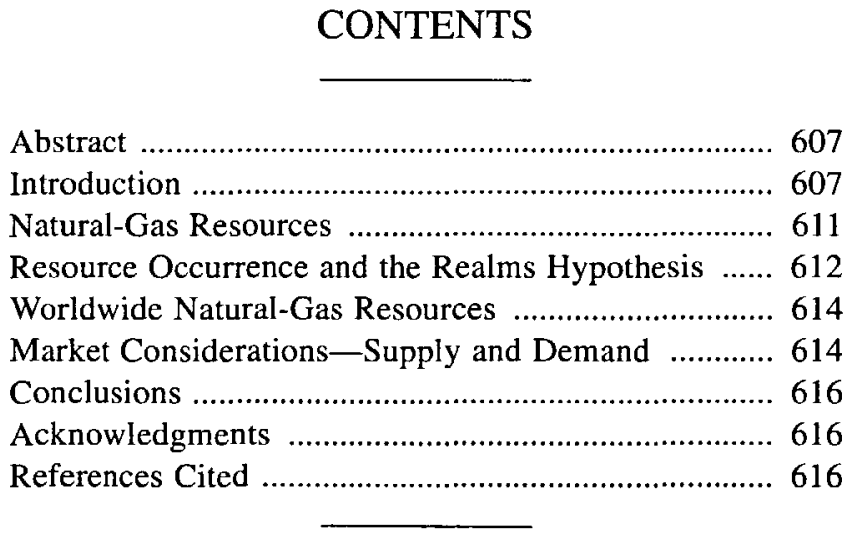

\begin{abstract}
Conventional natural-gas resources are ultimately recoverable in the world in about the same quantities as crude oil. Like crude oil, there are also unconventional sources of natural gas that may someday be recovered in significant quantities. However, the availability of these unconventional resources at high flow rates and acceptable costs are not well understood. Further, the element hydrogen, available in water, can be recovered and used for many of the same purposes as natural gas and, presumably, someday may become available to the energy mix. To date, natural gas has been consumed in substantially smaller amounts than has crude oil (in terms of British thermal units, about one-half as much), so large excess quantities are available, for production and future discovery, if transportation facilities and markets can be established.
\end{abstract}

'U.S. Geological Survey, National Center, 12201 Sunrise Valley Dr., Reston, VA 22092-0001.
Unlike oil, most gas has been used within the country of origin primarily because of difficulties and costs of long-distance transportation from the point of production to the point of consumption. About 75 percent of the world's gas occurs in North America, the former Soviet Union, and in the Middle East. The United States has been a major consumer of natural gas, and its resources are substantially developed. In recent years, the former Soviet Union has been recognized as having the largest amount of recoverable natural-gas resources in the world and has become the largest producer and consumer of natural gas. However, natural-gas resources in the former Soviet Union are remote from markets, so export possibilities will have to await the production of smaller but better positioned gas resources. The second largest amount of recoverable natural gas is in the Middle East, but the lack of largescale industries and population there creates minimal demand. This area is also remote from centers of gas use.

The geographic locations and relative quantities of conventional natural-gas resources in the petroleum basins of the world are shown in figure 1. Just as for oil, the largest gas resources are located in very few geographic areas, but they are remarkably well located for long-term market acquisition, however limiting the near-term prospects may be.

\section{INTRODUCTION}

Natural gas, like crude oil, is a nonrenewable resource but at this stage in resource development, the known and estimated world gas resources relative to annual consumption are very large. There is perhaps a century of significant supply (table 1). Unconventional resources (for example, coalbed methane, see Rice, this volume, or gas from very tight reservoirs, see Law and Spencer, this volume) are recognized, but to date they have not been 


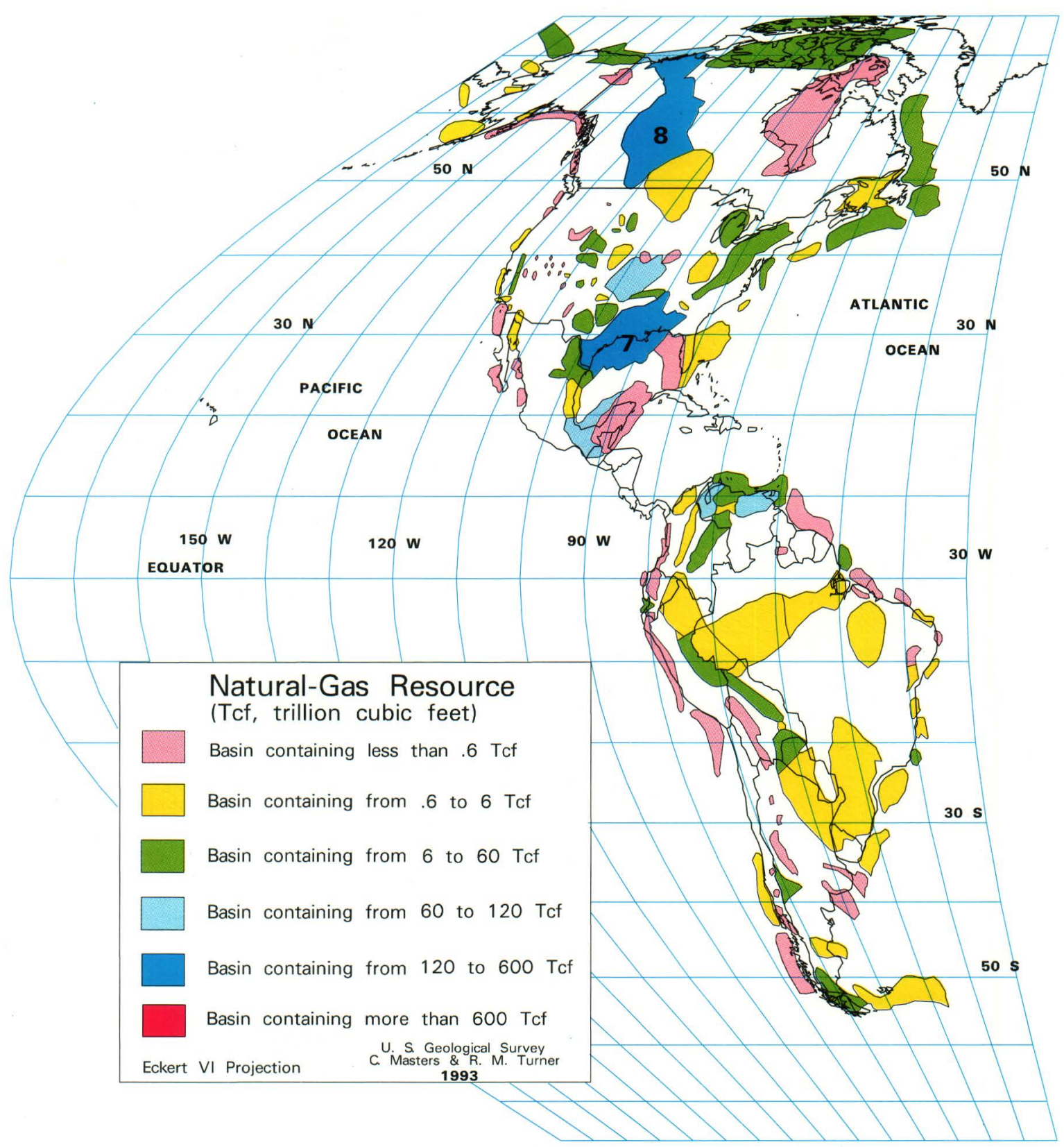

Figure 1. World map of petroleum basins showing estimated natural gas resources in six quantitative categories. Basins referred to in the text are numbered: 1, Arabian-Iranian; 2, West Siberian; 3, Barents Sea; 4, North Caspian; 5 , Erg Oriental; 6, Niger Delta; 7, Gulf Coast; 8, Western Canada Basin. Black lines are country and shoreline boundaries. Scale, 1:105 million.

considered economically recoverable in quantities and at rates sufficiently high to satisfy modern energy needs. Therefore, we separate conventional from unconventional resources herein because of the perceived economic and technological gap in their production potential. In fact, only in the United States and Canada has any substantive work been accomplished on the recovery of unconventional natural-gas resources. Considering the large conventional natural-gas reserves available elsewhere in the world, we are most likely, in the coming few decades, to witness, with respect to unconventional natural gas, only those activities necessary to satisfy modest local demand that could be provided by coalbed methane development and the best of tight-gas sands.

Gas that cannot be used locally and does not have access to long-distance markets will not be produced until economic conditions result in a demand for it. In fact, an economically controlled sequence of gas derivation can be 


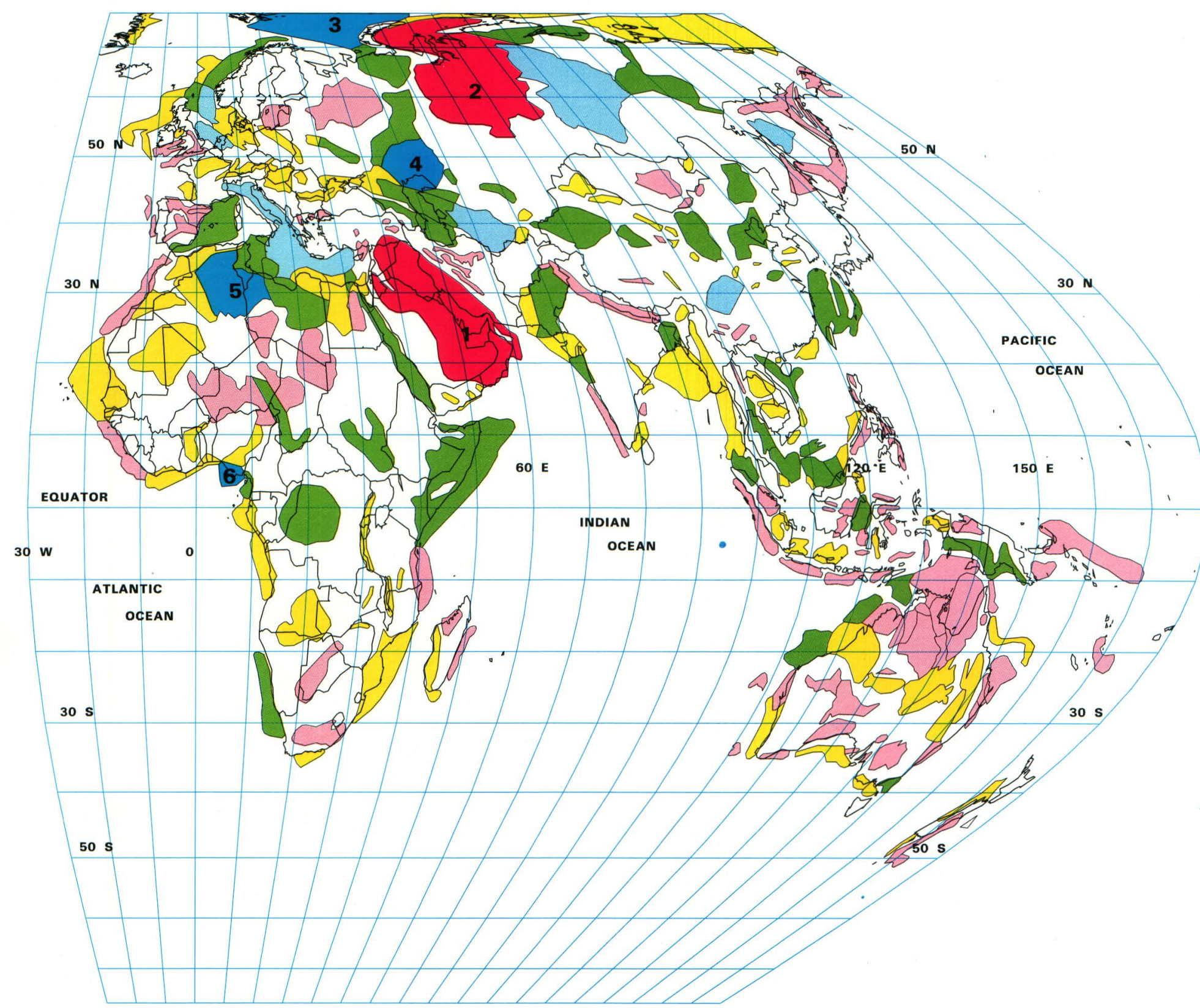

assumed. This sequence starts with local conventional natural-gas resources being developed, produced, and transported by pipeline, and it progresses to international conventional natural-gas resources also being transported by pipeline. From conventional resources there will be a shift to liquefied natural-gas (LNG) resources or methanol (a chemical-conversion liquid product) being transported by ship worldwide. Then, domestic unconventional gas resources will be developed, produced, and transported by pipeline. Finally, possibly, hydrogen gas derived from the electrolysis of water may be developed and transported by pipeline. At any stage, a lesser cost fuel may replace gas in the energy mix, but we have a large natural-gas resource potential sufficient to warrant substantial reliance on the physical source for many decades to perhaps as long as a century in the future.

Each unique gas source will cost a little more than its predecessor. Conventional natural gas in the United States is now priced at the wellhead at about $\$ 1.50 /$ thousand cubic feet (Mcf) but commonly twice that in Europe. LNG coming from various sources can possibly be landed in the United States for \$3.50-\$5.00/Mcf (see Attanasi, this volume). Unconventional gas, from various sources, may make significant contributions to the energy mix above $\$ 4 / \mathrm{Mcf}$, but rates and quantities of daily production are unknown. Finally, hydrogen, at present, can be produced in quantity at about $\$ 9-15 / \mathrm{Mcf}$ (see Veziroglu and Barbir, this volume). All estimates, of course, are subject 
Table 1. World estimates of cumulative production, identified reserves, and undiscovered resources of conventional natural gas in trillions of cubic feet ${ }^{1}$.

[All data not available for all countries]

\begin{tabular}{|c|c|c|c|c|c|c|c|c|c|}
\hline & \multirow[b]{2}{*}{$\begin{array}{l}\text { Gas pro- } \\
\text { duction } \\
(1989)\end{array}$} & \multirow[b]{2}{*}{$\begin{array}{l}\text { Cumulative } \\
\text { production }\end{array}$} & \multirow[b]{2}{*}{$\begin{array}{l}\text { Identified } \\
\text { reserves }\end{array}$} & \multirow[b]{2}{*}{$\begin{array}{l}\text { Origina! } \\
\text { reserves }\end{array}$} & \multicolumn{3}{|c|}{ Undiscovered resources $(1 / 1 / 90)$} & \multirow[b]{2}{*}{ Mean } & \multirow[b]{2}{*}{$\begin{array}{l}\text { Ultimate } \\
\text { resources } \\
\text { (mode) }\end{array}$} \\
\hline & & & & & 95 percent & Mode & 5 percent & & \\
\hline North America -........-- & 24.0 & 850.5 & 466.2 & 1316.7 & 531.0 & 816.7 & 1554.2 & 958.2 & 2133.4 \\
\hline 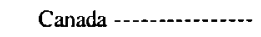 & 4.7 & 77.8 & 97.0 & 174.8 & 155.2 & 274.9 & 800.0 & 399.0 & 449.7 \\
\hline Mexico -............. & 1.3 & 23.2 & 72.7 & 95.9 & 70.4 & 118.9 & 291.3 & 157.2 & 214.8 \\
\hline United States-- & 18.0 & 749.5 & 296.4 & 1045.9 & 306.8 & 385.3 & 507.2 & 399.0 & 1431.2 \\
\hline South America -...... & 2.3 & 38.7 & 184.9 & 223.6 & 147.6 & 254.0 & 663.2 & 347.3 & 476.9 \\
\hline Argentina -.......... & 0.9 & 10.2 & 26.3 & 36.5 & 10.0 & 17.0 & 43.0 & 22.9 & 53.5 \\
\hline Bolivia - & 0.1 & 1.8 & 5.7 & 7.5 & 4.7 & 7.8 & 18.2 & 10.1 & 15.3 \\
\hline Brazil -.-.-........... & 0.1 & 1.9 & 4.1 & 6.0 & 20.3 & 36.9 & 120.8 & 57.4 & 42.9 \\
\hline Chile-1. & 0.1 & 2.9 & 4.1 & 7.0 & 0.5 & 0.8 & 2.0 & 1.1 & 7.8 \\
\hline Colombia -............. & 0.1 & 2.5 & 4.0 & 6.5 & 6.7 & 11.6 & 31.3 & 16.1 & 18.1 \\
\hline Ecuador - & & 0.1 & 4.0 & 4.1 & 3.5 & 6.1 & 16.7 & 8.6 & 10.2 \\
\hline Peru -- & & 1.1 & 7.0 & 8.1 & 13.8 & 23.6 & 60.8 & 32.0 & 31.0 \\
\hline Trinidad-................ & 0.1 & 2.8 & 8.7 & 11.5 & 3.9 & 6.9 & 20.0 & 10.0 & 18.4 \\
\hline Venezuela --........... & 0.7 & 15.3 & 121.0 & 136.3 & 13.3 & 130.0 & 380.0 & 189.2 & 266.3 \\
\hline Netherlands - & 2.5 & 54.5 & 60.9 & 115.4 & 5.0 & 6.6 & 20.0 & 9.8 & 122.0 \\
\hline Norway & 1.1 & 10.4 & 93.1 & 103.5 & 86.3 & 122.0 & 195.0 & 133.8 & 225.5 \\
\hline United Kingdom ----- & 1.4 & 24.7 & 19.8 & 44.5 & 9.4 & 16.0 & 40.0 & 21.4 & 60.5 \\
\hline Other-- & 1.2 & 23.4 & 18.3 & 41.7 & 26.6 & 50.0 & 200.0 & 88.0 & 91.7 \\
\hline Eastern Europe & 1.8 & 48.6 & 15.0 & 63.6 & 17.3 & 29.4 & 74.7 & 39.7 & 93.0 \\
\hline Greece-- & & & & & 2.8 & 5.0 & 15.0 & 7.4 & 5.0 \\
\hline Romania-............... & 1.3 & 29.8 & 3.4 & 33.2 & 6.9 & 12.0 & 33.0 & 16.9 & 45.2 \\
\hline Other -..... & 0.4 & 18.8 & 11.5 & 30.3 & 6.3 & 11.0 & 30.0 & 15.4 & 41.3 \\
\hline U.S.S.R. - & 26.1 & 358.3 & 1550.0 & 1908.3 & 738.5 & 1227.0 & 2861.0 & 1582.1 & 3135.3 \\
\hline Africa - & 2.7 & 32.6 & 261.6 & 294.2 & 195.5 & 328.3 & 791.4 & 430.5 & 622.5 \\
\hline Algeria-- & 1.9 & 16.9 & 114.2 & 131.1 & 5.6 & 18.0 & 53.0 & 26.3 & 149.1 \\
\hline Angola -.............. & & & & & 2.0 & 4.3 & 10.6 & 5.7 & 4.3 \\
\hline Chad - & & & & & 0.5 & 2.0 & 6.0 & 3.0 & 2.0 \\
\hline Egypt-....... & 0.2 & 1.5 & 11.5 & 13.0 & 8.0 & 21.0 & 60.0 & 30.2 & 34.0 \\
\hline Gabon & & 0.3 & 0.5 & 0.8 & 0.5 & 1.0 & 2.0 & 1.2 & 1.8 \\
\hline Libya --..-............. & 0.4 & 5.8 & 29.2 & 35.0 & 7.0 & 18.0 & 55.0 & 26.9 & 53.0 \\
\hline Nigeria--................ & & 5.9 & 87.4 & 93.3 & 80.0 & 136.0 & 340.0 & 181.7 & 229.3 \\
\hline Somali Republic -----. & & & & & 3.8 & 12.9 & 40.3 & 19.5 & 12.9 \\
\hline Other -.............. & 0.1 & 2.0 & 15.6 & 17.6 & 35.7 & 61.5 & 162.2 & 84.5 & 79.1 \\
\hline Middle East--......... & 2.8 & 57.5 & 1479.2 & 1536.7 & 603.7 & 943.4 & 1865.0 & 1125.3 & 2480.1 \\
\hline Bahrain & 0.2 & 1.8 & 6.3 & 8.1 & & & & & 8.1 \\
\hline Iran- & 0.5 & 17.6 & 600.0 & 617.6 & 300.0 & 450.0 & 1000.0 & 566.7 & 1067.6 \\
\hline Iraq-a................ & 0.1 & 3.3 & 110.0 & 113.3 & 60.0 & 100.0 & 200.0 & 119.9 & 213.3 \\
\hline Kuwait & 0.2 & 5.5 & 48.6 & 54.1 & 3.0 & 5.0 & 10.0 & 6.0 & 59.1 \\
\hline Neutril zone ..........- & & & 8.0 & 8.0 & 1.0 & 2.0 & 5.0 & 2.7 & 10.0 \\
\hline Oman- & & 0.6 & 9.9 & 10.5 & 5.0 & 8.0 & 18.0 & 10.1 & 18.5 \\
\hline Qatar & 0.3 & 2.9 & 300.0 & 302.9 & & & & & 302.9 \\
\hline Saudi Arabia-- & 0.9 & 14.0 & 184.4 & 198.4 & 191.5 & 300.5 & 600.0 & 360.0 & 498.9 \\
\hline Syria------------ & & 1.5 & 5.5 & 7.0 & & & & & 7.0 \\
\hline United Arab & 0.7 & 7.7 & 184.4 & 192.1 & 31.8 & 50.0 & 100.0 & 59.9 & 242.1 \\
\hline \multicolumn{10}{|l|}{ Emirates. } \\
\hline Other & & 2.5 & 22.1 & 24.6 & & & & & 24.6 \\
\hline Asia/Oceania -...-. & 4.6 & 81.4 & 345.7 & 427.1 & 298.9 & 486.3 & 1067.1 & 608.6 & 913.4 \\
\hline Afghanistan -......... & & 1.0 & & 1.0 & 8.8 & 14.7 & 35.0 & 19.2 & 15.7 \\
\hline Australia/ & 0.6 & 7.6 & 77.4 & 85.0 & 10.9 & 18.9 & 50.0 & 26.0 & 103.9 \\
\hline \multicolumn{10}{|l|}{ New Zealand. } \\
\hline B angladesh & & & 12.4 & 12.4 & 4.8 & 14.4 & 38.4 & 19.9 & 26.8 \\
\hline Burma - . & & 0.1 & 5.1 & 5.2 & 3.1 & 8.4 & 17.3 & 10.2 & 13.6 \\
\hline China -............... & 0.5 & 17.6 & 33.0 & 50.6 & 103.9 & 175.9 & 434.2 & 233.5 & 226.5 \\
\hline India - & 0.3 & 1.8 & 20.9 & 22.7 & 8.9 & 16.5 & 61.7 & 27.8 & 39.2 \\
\hline Indonesia--.............. & 1.5 & 14.4 & 85.7 & 100.1 & 47.0 & 76.4 & 166.7 & 95.4 & 176.5 \\
\hline Malaysia/Brunei ....... & 0.3 & 5.0 & 65.8 & 70.8 & 27.5 & 45.0 & 100.0 & 56.7 & 115.8 \\
\hline Pakistan .............. & 0.4 & 5.8 & 23.0 & 28.8 & 15.0 & 34.4 & 60.0 & 39.0 & 63.2 \\
\hline Papua-- & & & 4.5 & 4.5 & 14.9 & 25.0 & 60.0 & 32.7 & 29.5 \\
\hline Thailand-----.--.-- & & & 14.5 & 14.5 & 12.6 & 22.0 & 60.0 & 30.8 & 36.5 \\
\hline Vietnam --.............. & & & & & 5.3 & 10.0 & 40.0 & 17.6 & 10.0 \\
\hline Other & 1.1 & 28.1 & 3.5 & 31.6 & 14.9 & 25.0 & 60.0 & 32.7 & 56.6 \\
\hline World & 71.0 & 1594.6 & 4506.1 & 6100.7 & 2777.1 & 4417.3 & 9126.6 & 5374.6 & 10517.3 \\
\hline
\end{tabular}

$11 \mathrm{~m}^{3}=35.3 \mathrm{ft}^{3}$ 
to ongoing technological change, but it is important to understand that there are various price levels of gas-product availability, coming from different parts of the world, that can satisfy gas-market demand. Economic incentives and gas technology development that fully recognize the long lead times necessary to produce, develop, and distribute natural gas are needed to ensure the future delivery of natural gas to the market in a timely manner. Equally important are economic incentives for producers of natural gas that recognize the long lead times and large capital investments required to produce, develop, and distribute natural gas.

In most parts of the world, natural gas is not developed to the degree of crude oil owing to limited market demand in production areas and difficult export conditions. In some parts of the world, LNG industries have developed to permit gas export. This is, however, an expensive activity and investors have not yet responded sufficiently to permit widespread adoption of the procedure. Only about 2 trillion cubic feet (Tcf) of LNG are produced each year, whereas some $75 \mathrm{Tcf}$ of natural gas are consumed each year. As a result, large quantities of discovered identified reserves of natural gas remain undeveloped. Natural gas can also be moved by long-distance pipelines but that results in high initial costs. Also, in most parts of the world the gas has to cross international boundaries, which adds ongoing risk to the marketing venture.

\section{NATURAL-GAS RESOURCES}

Resources of conventional natural gas are very large (fig. 1). Ultimately recoverable resources of natural gas occur in approximately equal British thermal unit (Btu) quantities to that of oil (Masters and others, 1991; figs. 2, 3 ). However, because only about 40 percent as much gas, in a Btu sense, as compared to oil has been consumed, the worldwide gas industry is in a youthful stage. Our estimates show conventional natural gas to occur in slightly smaller quantities than oil but we believe gas discoveries to be underreported and that they will remain so until greater market demand requires adequate data development. We do not anticipate, however, that the ultimate values will necessarily increase to, in any way, substantially exceed the energy value of oil. Rather, we believe the occasionally reported very large resource values of gas ultimately will be identified as unconventional and we remain uncertain as to the satisfactory commercial production of those potential resources. Only in the United States and Canada is there substantial effort to try to develop unconventional gas resources and that is influenced by subsidy in the recovery of coalbed methane at a level of some 400 billion cubic feet (Bcf)/yr (out of a U.S. total annual production of $18 \mathrm{Tcf}$ ). The recovery of gas from tight sands in the United States is probably subsidized at

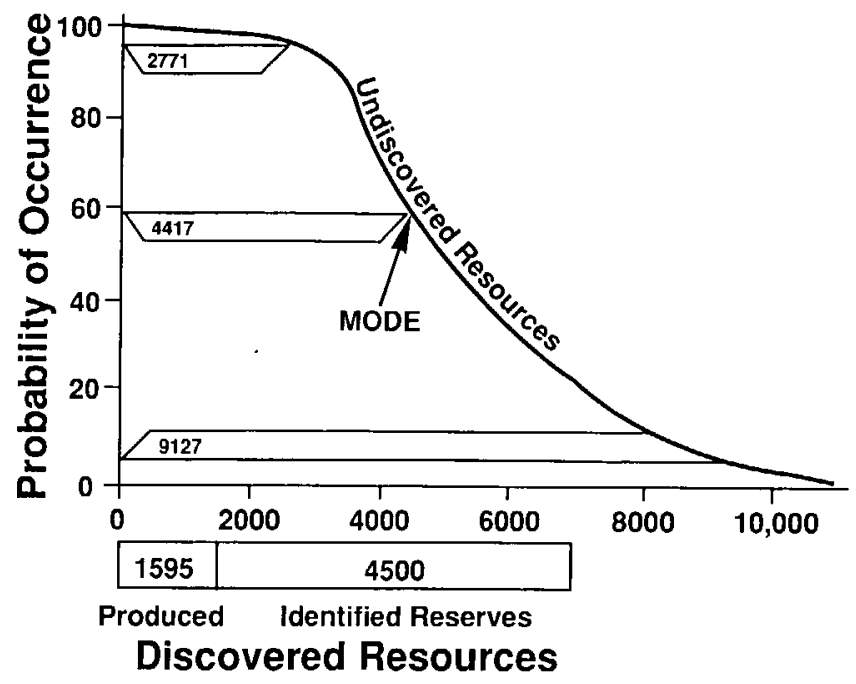

Figure 2. Ultimate resources of natural gas (10,512 Tcf, or 1,752 Bboe) shown in its component parts of cumulative production, identified reserves, and undiscovered resources. Undiscovered resources expressed as probability range showing 95 th and 5 th percentiles and mode. Units, trillion cubic feet.

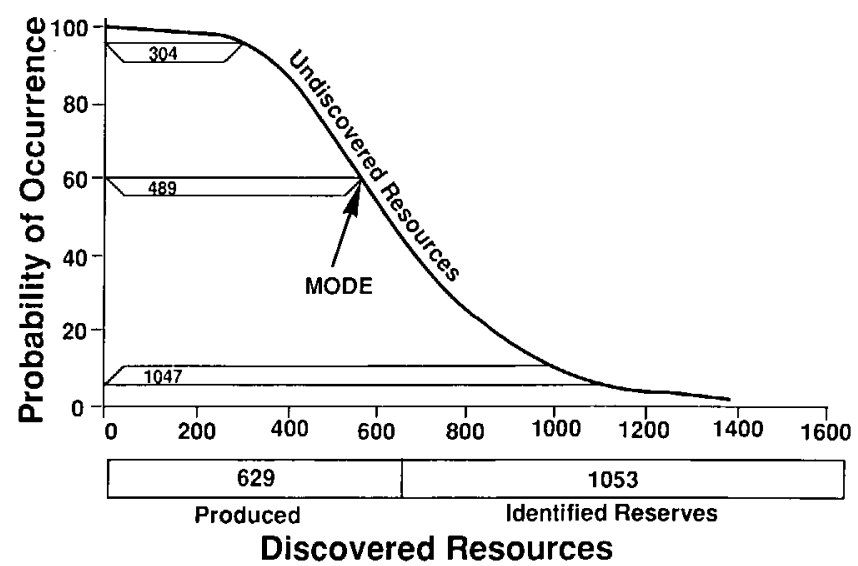

Figure 3. Ultimate resources of crude oil $(2,171 \mathrm{Bbo})$ shown in its component parts of cumulative production, identified reserves, and undiscovered resources. Undiscovered resources expressed as probability range showing 95 th and 5 th percentiles and mode. Units, billion barrels.

about the same level (Crow and Kroen, 1992). The definition of "tight" and the identification of unconventional wells and fields is difficult, but production values are modest compared to those of conventional reservoirs, wells, and fields. Some 4,500 Tcf of identified reserves of conventional natural gas have already been discovered, and an approximately equal amount remains to be discovered (fig. 2) (Masters and others, 1991). These quantities are enormous compared to the world annual rate of production of about $75 \mathrm{Tcf}$.

Another measure of resource youthfulness is the general dates of discovery of worldwide gas reserves and their 


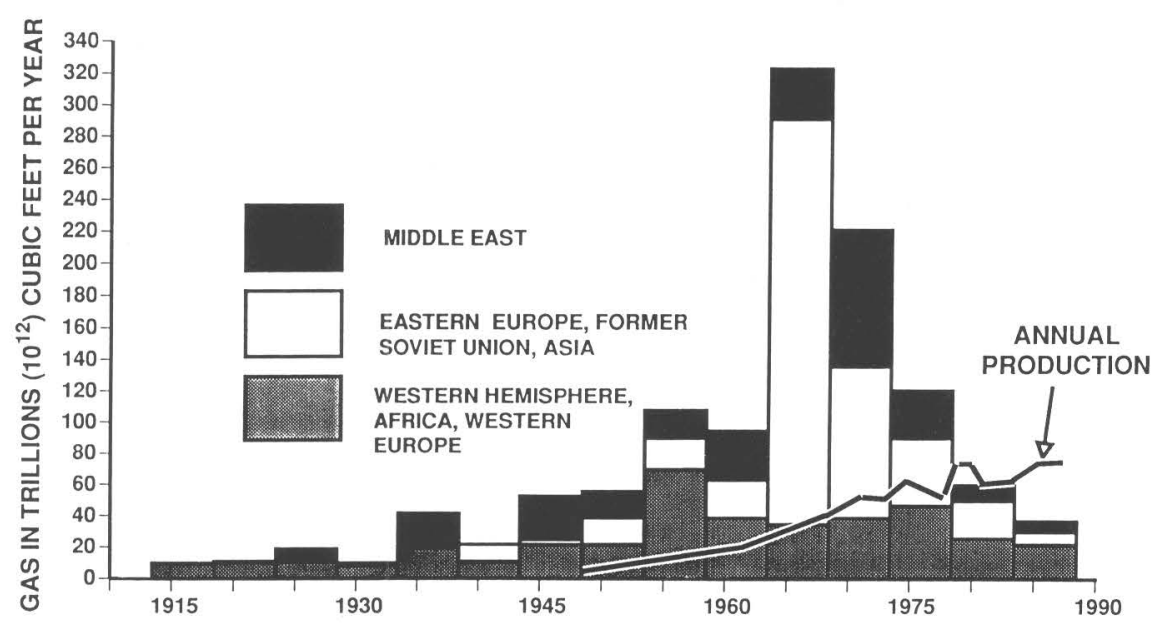

Figure 4. World natural-gas annual discovery rate averaged over five-year periods, 1914 to 1989. Annual production also shown. Units, trillion cubic feet.

production (fig. 4). The peak of the discovery curve is in the late 1960's. This peak is depicted in the bar graph that shows quantities in terms of annual discoveries averaged over five-year intervals. This is only about 10 years later than a comparable discovery peak for oil but, for gas, the shape of the curve is not yet defined. Within the last few years, for example, the Russians have discovered three large gas fields in the Barents and Kara Seas that, when fully reported, will likely raise the annual discovery value of the current 5-year interval to about 100 Tcf. These discoveries were in no sense surprises. The dimension of the world undiscovered resources, some 5,000 Tcf, and the expectation of their location, suggest that additional large discoveries will be forthcoming. Gas reserves are large and the undiscovered resource potential is sufficient to permit replacement and, indeed, growth of the existing reserves. Considering the present annual production is about $75 \mathrm{Tcf}$ (63 percent of the Btu value of oil production), the identified reserve to production ratio (or approximate years of future production) is about 70; this ratio and the undiscovered resource potential indicate the capability of more than a century of significant conventional natural gas production sufficient to meet all or a large part of expected demand.

The quantity of resources, then, seems to be the least of the problems. Rather, important issues relate to international cooperation and market development because much gas is not located favorably to match demand. This reality is expressed in a bar graph of gas resources distribution (fig. 5). The graph shows ultimate resources in terms of cumulative production, identified reserves, and undiscovered resources for seven geographical regions of the world. Three regions, North America, the former Soviet Union, and the Middle East, clearly dominate in resource occurrence; together they account for nearly 75 percent of the ultimate resources of natural gas. The other four regions of the globe - the Far East, Africa, Europe, and
South America-possess important gas resources, however modest in individual dimension, considering their location relative to market and the youthfulness of their development. However, these four regions should not be counted on by world markets for significant long-term gas supply.

\section{RESOURCE OCCURRENCE AND THE REALMS HYPOTHESIS}

It is not surprising that the largest resources of natural gas are locally concentrated. All natural resources are similarly concentrated owing to the complexity of geologic factors that result in their formation. For a natural-gas resource to occur, five reasonably independent geologic variables must be favorable - these are availability-of source and reservoir rock, development of a trap, good quality seal, and timing. For a large resource, all factors must be substantially favorable. All factors being so favorable is a statistically rare occurrence, and that is confirmed by the few areas of the world in which large quantities of natural-gas resources are present. Our geologic studies of worldwide natural-gas resource distribution underscore this reality and permit us to argue that although the world is in no sense equally explored, we believe it is sufficiently explored to establish the distribution and general quantitative occurrence of natural-gas resources. With the support of the world resource studies, reported by Klemme and Ulmishek (1991), we can consider their Realms hypothesis, which proposes a rationale for the varying concentration of petroleum resources in four separate areas of the globe. The percentages of resource occurrence shown on figure 6 refer to the discovered resources of both oil and gas: 68 percent in the Tethyan Realm; 23 percent in the Boreal Realm; 5 percent in the Pacific Realm; and 4 percent in the South Gondwana Realm. These percentages would not change significantly if 


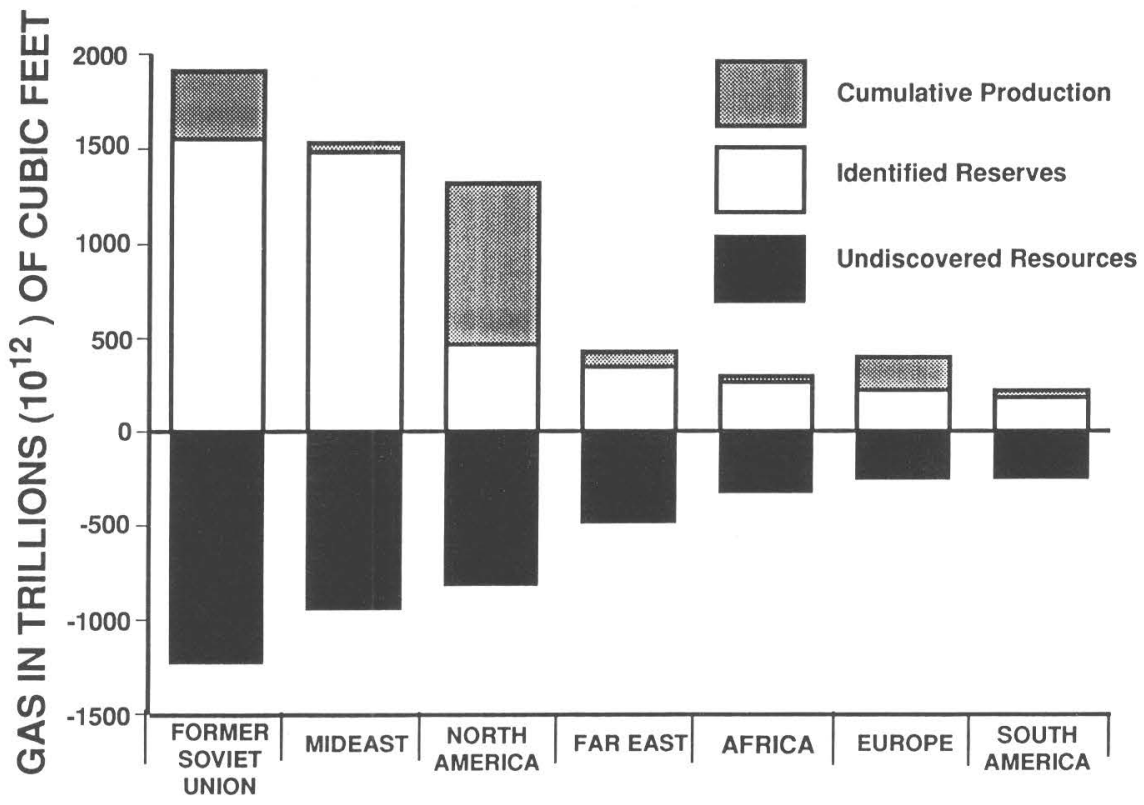

Figure 5. Geographic distribution of identified reserves and cumulative production of natural gas as of January 1990 and undiscovered resources as of January 1991. Units, trillion cubic feet.

EXPLANATION
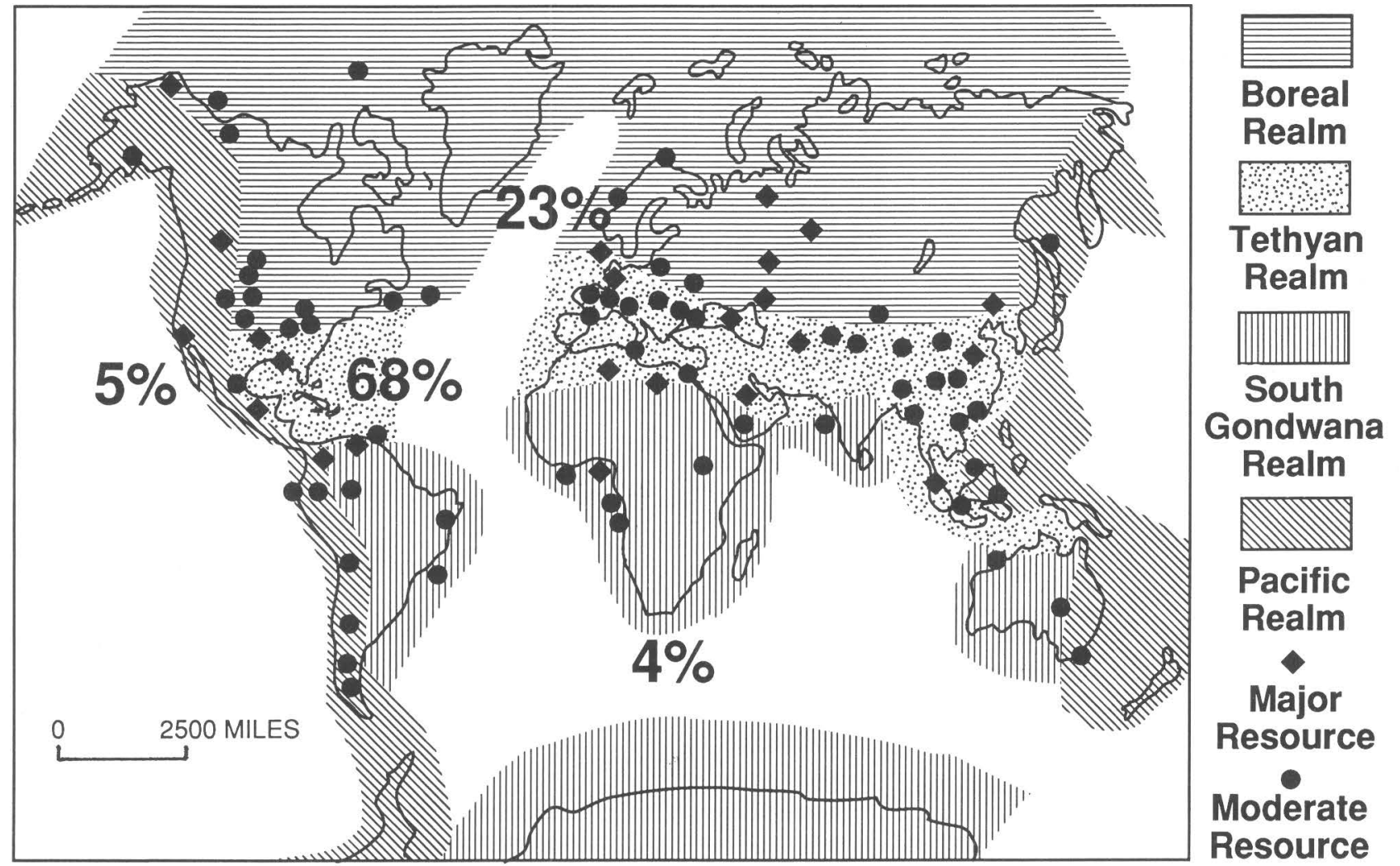

Figure 6. Divisions of world petroleum occurrence for four geographically defined Realms with percent notations of the amount of discovered petroleum in each Realm. Symbol notations show the local occurrence of major or moderate reserves. Modified from Klemme and Ulmishek, 1991. 
the undiscovered resources estimated over the past ten years by the World Energy Resources Program of the U.S. Geological Survey were included (Masters and others, 1991). The estimates of the World Energy Resources Program were derived completely independently of the Realms hypothesis.

The geology of this highly skewed resource distribution phenomenon can be explained with reference to local tectonics as well as climate variations. These two factors specifically affect the development of source rocks, reservoir rocks, and sealing rocks, all of which are critical to the formation and entrapment of petroleum resources. The critical rock types form in warm climates characteristic of equatorial regions. The organic matter necessary for oil source-rock development flourishes between the $30^{\circ}$ latitudes. Furthermore, lake turnover does not take place in warm climates; hence, the bottom-water lacustrine muds are protected from oxidation. Carbonate reservoir rocks, which contain about 50 percent of known reserves of entrapped petroleum, only form in low latitudes; their absence in high latitudes, therefore, precludes an important reservoir. Salt is the best sealing material for preventing vertical leakage from a reservoir, and it forms only between the $30^{\circ}$ latitudes.

All these favorable conditions characterize the Tethyan Realm, which, as defined, is located somewhat north of the equator. Its plate tectonic position, during development of the critical rock sequences, however, was generally equatorial-that is, between the $30^{\circ}$ latitudes. The Boreal Realm is significantly more favorable than the South Gondwana Realm because in Paleozoic time the geologic area defined as Boreal was located near the equator and hence the prevailing climate favored the formation of critical stratigraphy. South Gondwana, on the other hand, remained in the high latitudes until the continental breakup in Late Jurassic, which permitted the continents to move north into the favorable low latitudes. The Boreal Realm was also characterized by nonmarine, gas-prone Carboniferous source-rock development. For unknown reasons, Southern Hemisphere coal development is of poorer quality than coal development in the Northern Hemisphere and has not resulted in highly productive gas-prone source rock.

The Pacific Realm has limited proven petroleum resources owing to destructive tectonics. Subduction has destroyed most of the pre-Tertiary stratigraphy, and the younger reservoir rocks were damaged by volcanic debris mixing. Certain localities such as southern California have been free of limiting factors, but such geologic reprieves are rare around the Pacific Basin.

Statistically, large amounts of petroleum resources are rare. The Realms hypothesis offers climatic and tectonic conditions that control the geologic occurrence of petroleum-and these conditions both enhance and limit its occurrence.

\section{WORLDWIDE NATURAL-GAS RESOURCES}

Basin locations of worldwide natural-gas occurrence are shown on figure 1. Natural-gas resources by country are listed in table 1. The basins shown on figure 1 are categorized by estimates of the natural-gas resources they contain. Resources consist of identified reserves plus a modal value for undiscovered resources or, in other words, the future potential of the basin. The two largest sources of natural gas in the world are in the Arabian-Iranian Basin and the West Siberian Basin. Those areas are shown as having more than $600 \mathrm{Tcf}$ of natural-gas resources, but, in fact, West Siberia is estimated to contain more than 1,500 Tcf of natural-gas resources and the Arabian-Iranian Basin has likely more than 2,000 Tcf of natural-gas reserves. Only six other basins in the world (Gulf Coast, Western Canada, Barents Sea, North Caspian, Erg Oriental, and Niger Delta) are recorded in the next largest reserves category of 120 to $600 \mathrm{Tcf}$. It is not surprising to find this degree of skewed distribution in natural-gas resources for both statistical and geologic reasons. Only one potentially very large gas basin remains minimally explored-the Barents Sea Basin. One large field, Schtockmanov, was recently discovered in the eastern part of the basin and is reportedly as large as 150 Tcf. With the discovery of this one field, the basin has a futures value within the top few basins in the world. However, the remoteness of the area, coupled with the gas reserves excesses already established in the region, suggests that significant development may not take place for many years. However, responsible international firms are, today, investigating the investment possibilities of this area.

\section{MARKET CONSIDERATIONS- SUPPLY AND DEMAND}

To establish export capability, an area should have from 6 to 60 Tcf of natural-gas resources. Anything less than that does not offer sufficient resources for a significant commercial venture. Several years ago when El Paso Natural Gas Company and Occidental Petroleum Corporation made initial efforts to develop a gas program in East Siberia, they considered that a minimum discovery of 30 to 40 Tcf was necessary to initiate activity; they did not achieve that minimum before other factors halted the initiative. Upon inspection of the gas futures map perhaps approximately one-half to two-thirds of the potential gas exploration area of the world meets that standard of having, at least, a few tens of Tcf of natural-gas resources. Broad regions that do not appear to meet that standard include the West Coast of the United States and Canada, northeastern Canada, most of offshore East Coast of the 
United States, most of Mexico and Central America, central and southern South America, most of southern and western Africa, central Europe, and much of southeastern Asia and Australia. The point here is not to be precise about where gas will or will not be exported from, but rather to call attention to the fact that many areas of the world are not likely to be in a position to take part in export supply-development planning.

One consideration in analyzing the supply side of export potential is the determination of whether or not the country will use natural gas. A further consideration is whether the country is, in fact, willing to export the gas or possibly subsidize the export by making the gas available at below-market prices to balance against pipeline costs, the additional technical costs of LNG processing, or the costs of manufacturing liquid fuels from the gas.

The largest limitation to natural-gas resource development in the near term is the limited worldwide demand. At present, there are only three centers of potential increased natural-gas demand-North America, western Europe, and the Asian Pacific Rim. Most natural gas is used in the country of origin-only 15 percent goes to an export market as opposed to 40 percent for crude oil (Energy Information Administration, 1992). In 1990, the United States received about 1.5 Tcf of natural gas from Canada out of a total consumption of about 19 Tcf. There is also an occasional small spot-market cargo of LNG coming into Boston from Algeria. The most likely source for immediate pipeline increases in imports to the United States is Canada. The nearest and most likely sources for increased LNG imports to the United States, when that demand increases, are eastern Venezuela and Trinidad. The Cristobal Colon LNG project, sponsored by Exxon, Shell, Mitsubishi, and Petroleos de Venezuela, has a late 1990's target date for being on production. Whether or not they meet that target surely depends on market access to the United States. Demand for LNG in the United States is limited overall by market demand for natural gas and by offloading capacity, which may or may not expand owing to regulatory restrictions derived from environmental concerns (Attanasi, 1991). The current free-market atmosphere for trading, however, may provide a way around the LNG landing limitation by permitting the LNG to be offloaded in northern Mexico and be transported to the United States by naturalgas pipeline.

The United States is the only near-term demand target in the Western Hemisphere. Eastern Canada could become a target if more of their western gas is exported to the United States. Supply areas that could consider U.S. and Canadian demand include, in addition to Venezuela and Trinidad: Nigeria, Algeria; Norway, and possibly Russia out of the Barents Sea. Colombia and Peru could become a modest source of LNG to the U.S. Pacific Coast, but considering the position of the Canadian and Alaskan gas, one might reason that South American development will create a demand for the local gas resources before North American demand materializes.

The intent of this paper is not to project supply and demand, but rather to show some of the available resource information that might contribute to future specific gasmarket analysis. Already, initial studies have been conducted by Department of Energy to evaluate foreign sources of natural gas relative to specific U.S. landing sites. These studies suggest that the most economic providers would be Venezuela and Trinidad followed by Algeria and Libya (Department of Energy, 1992). Interestingly, several potentially larger sources of supply including Nigeria, the former Soviet Union, and the countries in the Arabian Iranian Basin are, in fact, higher cost providers for a variety of reasons.

The Eastern Hemisphere contains the largest gas resources of the world. Most of them, being concentrated in West Siberia and in the Arabian-Iranian Basin (table 1), are not readily accessible to export markets. The West Siberian gas is predominantly used within the former Soviet Union; all but $4 \mathrm{Tcf}$, out of $28 \mathrm{Tcf}$ of annual production, is used there. The 4 Tcf of export gas goes to eastern and western Europe in about equal proportions (Energy Information Administration, 1992). Given the size of this gas resource, within a large industrialized society, it may make sense to use the gas internally and export the oil. Some data suggest they have already made that decision; for example, at peak production of oil, they exported one-third of the production ( 4 million barrels of oil per day export (bopd) out of 12 million bopd production) whereas, for gas they exported 4 Tcf out of 28 Tcf production or only one-seventh of the production. Another indication of substantive local use of natural gas is the fact that only 0.4 percent of production is vented or flared (Energy Information Administration, 1992). To date, the limit on gas export from the former Soviet Union very likely was market demand; in the future, it may be limited by their internal energy strategy along with the limiting economics of gas transport.

The Arabian-Iranian Basin gas resource constitutes one of the greatest energy market problems in the world. The gas is concentrated in the largest oil-energy export locality in the world and one that has essentially no local industry. To be used, the gas must be exported. Nearby populations in Africa and India are large but without money. Transport to industrialized Europe is awkward, both politically and geographically. Access to the Pacific Rim means the gas must pass through a moderately rich area of natural gas in southeast Asia-an area with minimum local demand and maximum incentive to export, as they are presently doing. One can hope for improvement in the industrial and economic future of India but, otherwise, a small market on the Pacific Rim must be shared with southeast Asia suppliers in better geographic position to serve but somewhat balanced by that area being more 
expensive to develop (Department of Energy, 1993). Given growth in the Asian industrial market, most certainly, the Middle East gas is the only available long-term supply.

Gas is abundant in only a few places, but it is widespread in occurrence. Therefore, many countries appear to have sufficient resources to satisfy local demand for limited time periods-given continued modest economic conditions. This reasoning applies to most of South America (exclusive of Venezuela), Africa (exclusive of the northern border states), and Australia. The economic risk in these areas, however, is high because much of the gas resources have not as yet been developed (table 1). However, in $\mathrm{Ni}$ geria a large resource has been discovered, but exploration, development, and transportation costs limit its export. Possibly, that reality anchors its energy contribution to Africa with distribution by electric powerlines from gas-turbine power sources. Again, there are vast resources but a very limited market that must eventually be served but possibly by inventive means. China also appears to have reasonably sustainable supplies but, as yet, lacks the infrastructure development to take advantage of the resource.

The demand center for natural gas in the Eastern Hemisphere is westem Europe and, fortunately, it has modest resources in several countries and substantial resources in the North Sea. The southern North Sea and western Europe gas resources derive from coal source beds. These gas resources add significantly to the larger resources farther north that derive from the deep burial of the same marine, black-shale source rock that produces the North Sea oil. The concentration of the present supply north of the western European population center allows supplies to come to southern Europe from North Africa. Algeria, in particular, has large contributions to make, and their gas is conveniently inexpensive enough to shut out competitive sources from the former Soviet Union or countries of the Arabian-Iranian Gulf. Should industrial development eventually reach North Africa, Arabian-Iranian gas will still be available and, even later, high-cost gas from deep drilling in deep water of the Mediterranean could prolong the hydrocarbon energy resources of the circum-Mediterranean area.

\section{CONCLUSIONS}

Natural gas is present as a very large discovered and potential energy resource throughout the world, but, owing to difficult transportation realities, all sources of supply and demand have not been brought into communication by the market. The technology to transport gas in both gas- eous and liquid forms is well advanced, but because, for many uses, oil, gas, and coal can replace one another, economic equity is required in all import-export transactions. Three energy demand centers for natural gas-North America, western Europe, and the Pacific Rim-are evolving and the technology for local use in these areas suggests that natural-gas consumption will increase. This increased consumption will be influenced both by the declining availability of oil and the less damaging environmental effects of producing and using natural gas as compared to oil and coal.

\section{ACKNOWLEDGMENTS}

This paper is derived from the work of scientists and analysts who are part of the World Energy Resources Program of the U.S. Geological Survey. These people are James Clarke, James Peterson, Gregory Ulmishek, Keith Robinson, Mahlon Ball, Jack Kingston, Doug Klemme, David Root, and Emil Attanasi. Ongoing coordination with Gary Long and Jack Sanders of the Foreign Energy Supply Assessment Program of the Department of Energy, Energy Information Administration was essential. Bob Turner of the U.S. Geological Survey prepared figure 1. The Petroconsultants data system provided basic data for the World Energy Resources Program studies and this report.

\section{REFERENCES CITED}

Attanasi, E.D., 1991, Alternative natural gas contract and pricing structures and incentives for the LNG Industry, Natural Resources Forum, Aug. 1991, p. 190-201.

Crow, P., and Kroen, A.D., 1992, Tight gas sands drilling buoying U.S. exploration and development activity: Oil and Gas Joumal, Nov. 2, 1992, p. 21-27.

Department of Energy, 1993, Assessment of costs and benefits of flexible and alternative fuel use in the U.S. transportation sector: Technical Report 9, Development Costs of Undeveloped Nonassociated Gas Reserves in Selected Countries, DOE/EP-003, 84 p.

Energy Information Administration, 1992, International energy annual 1991, DOE/EIA-0219(91), 183 p.

Klemme, H.D., and Ulmishek, G.F., 1991, Effective petroleum source rocks of the world-Stratigraphic distribution and controlling depositional factors: American Association of Petroleum Geologists Bulletin, v. 75, no. 12, p. 1809-1851.

Masters, C.D., Root, D.H., and Attanasi, E.D., 1991, World resources of crude oil and natural gas, Proceedings of the Thirteenth World Petroleum Congress: New York, John Wiley and Sons, p. 51-64. 
The development and use of energy gases are closely related to environmental and societal issues. Society's energy systems have generally evolved toward cleaner and more efficient forms of fuel, mainly from wood to coal to oil to natural gas. Governments, faced with global, energy-related environmental problems, are looking for fair and effective ways to encourage cleaner energy systems. Natural gas is the cleanest burning of all fossil fuels, in terms of air pollutants and some greenhouse gases. However, natural gas is mostly methane, which is increasingly regarded as an important greenhouse gas. Therefore, increased extraction, transportation, and use of natural gas must be conducted with intent to minimize methane leakage. 

THE FUTURE OF ENERGY GASES

U.S. GEOLOGICAL SURVEY PROFESSIONAL PAPER 1570

\title{
Environmental Consequences of Increased Natural-Gas Usage
}

\author{
By Frances Cole ${ }^{1}$
}

\section{CONTENTS}

Abstract 619

Introduction 619

Fossil Fuels and the Greenhouse Effect 620

Greenhouse Gases 620

Carbon Dioxide 622

Methane 624

Other Greenhouse Gases 625

Climate Change? 625

Methane and Stratospheric Ozone .............................. 625

Fossil Fuel Emissions and Atmospheric Oxidants .... 626

Air Pollution and Acid Precipitation ........................... 626

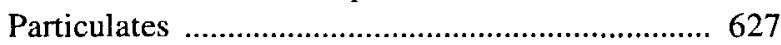

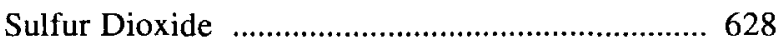

Nitrogen Oxides ……….........................................629

Acid Precipitation ..................................................... 630

Volatile Organic Compounds and Carbon

Monoxide 631

Local Environmental Issues ....................................... 631

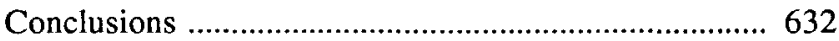

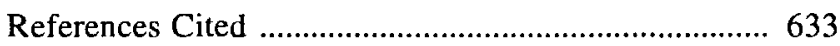

\begin{abstract}
Energy use is the primary cause of many environmental problems in the United States and around the world. Fossil fuels, including coal, oil, and natural gas, supply roughly 90 percent of our energy needs in the United States, and they are directly responsible for urban and industrial air pollution and acid rain. Combustion emissions

'U.S. Geological Survey, MS 955, 345 Middlefield Rd., Menlo Park, CA 94025.
\end{abstract}

from fossil fuels also contribute to the Earth's greenhouse effect, and they may play an important role in ozone depletion in the stratosphere, and oxidant depletion in the troposphere.

Natural gas, which is mostly methane, is the least polluting of the fossil fuels. Upon combustion, natural gas produces lower $\mathrm{CO}_{2}, \mathrm{CO}, \mathrm{NO}_{\mathrm{x}}, \mathrm{SO}_{2}$, and particulate emissions than either oil or coal. This means that substitution of natural gas for oil and coal can help mitigate air pollution and the human contribution to the greenhouse effect. However, methane is itself a potent greenhouse gas, and increased production and consumption of natural gas must be conducted in such a way that gas leakages are minimized. Natural gas compares well to the other fossil fuels in terms of water quality, preservation of natural ecosystems, and safety. These combined advantages may give natural gas a more prominent role in the U.S. energy mix. Like other fossil fuels though, natural gas is nonrenewable and, therefore, not a permanent solution to our energy needs.

\section{INTRODUCTION}

Many environmental problems that we face today stem from the use of fossil fuels for energy (Ehrlich and Ehrlich, 1991). Increased concentrations of many greenhouse gases and toxic air pollutants are tied to rising production and consumption of fossil fuel energy (see U.S. Environmental Protection Agency, 1992; Holdren, 1992). Since the beginning of the Industrial Revolution some 150 years ago, countries like Great Britain and the United States have increased by 100 -fold their energy consumption. The United States now uses 80 quadrillion British thermal units annually-10 times the energy use of most developing nations. At the same time, developing nations are striving to attain economic, technologic, and social standards comparable with their industrialized neighbors. As populations increase, and 
as more people gain access to amenities that are considered indispensable in the developed nations, such as household electricity and private transportation, energy consumption will grow. If current trends continue, world energy consumption may double by the year 2020 (Pexton, 1984).

This trend does not necessarily portend a doubling of worldwide energy-related pollution. Technological advances in energy efficiency and pollution control tend to follow where energy production and consumption have gone before. In the United States, for example, per capita use of motor vehicles has more than doubled over the past 20 years, yet air pollution from motor vehicles has been reduced nationwide by nearly 50 percent; this reduction is largely due to the adoption of catalytic converters (U.S. Council on Environmental Quality, 1992a). In addition, many economists see human civilization moving on a longterm trend toward cleaner energy fuels. Heavily polluting hydrocarbon fuels such as wood and coal have given way to cleaner hydrocarbon fuels such as oil and natural gas (Nakićenović, this volume). Ultimately, oil and natural gas may be replaced by virtually nonpolluting forms of energy, such as a solar-hydrogen gas system (Ausubel, 1991).

In light of these trends, natural gas is expected to gain increasing importance as an energy fuel in the United States, particularly in the transportation and power-generation sectors. Already, natural-gas powered cars and buses are being used as low-emission alternatives to gasoline and diesel vehicles in many cities across the country. In the Midwest and Northeast, electrical generation plants powered by natural gas have gained recognition for low emissions of nitrogen and sulfur compounds compared with conventional coal-burning plants. But what are the broader implications of increased use of natural gas? What issues need to be considered in attempting to understand the benefits and the problems of replacing existing fuels with natural gas? Herein, I summarize the environmental implications of increased use of natural gas, and provide an overview of the questions that remain to be answered.

\section{FOSSIL FUELS AND THE GREENHOUSE EFFECT}

Today, roughly 90 percent of all energy consumed in the United States comes from the combustion of fossil fuels (fig. 1). Fossil fuels include coal, oil, natural gas, and their various energy offspring, such as gasoline and diesel fuel. These hydrocarbon compounds form in soils and buried marine sediments, through the breakdown of organic material by bacterial decomposition or heating (Wiese and Kvenvolden, this volume). Through these mechanisms, carbon is transferred from the biosphere and made available for storage in the Earth's crust. During the combustion of hydrocarbon fuels, the stored carbon and hydrogen are released back into the atmosphere-carbon in the form

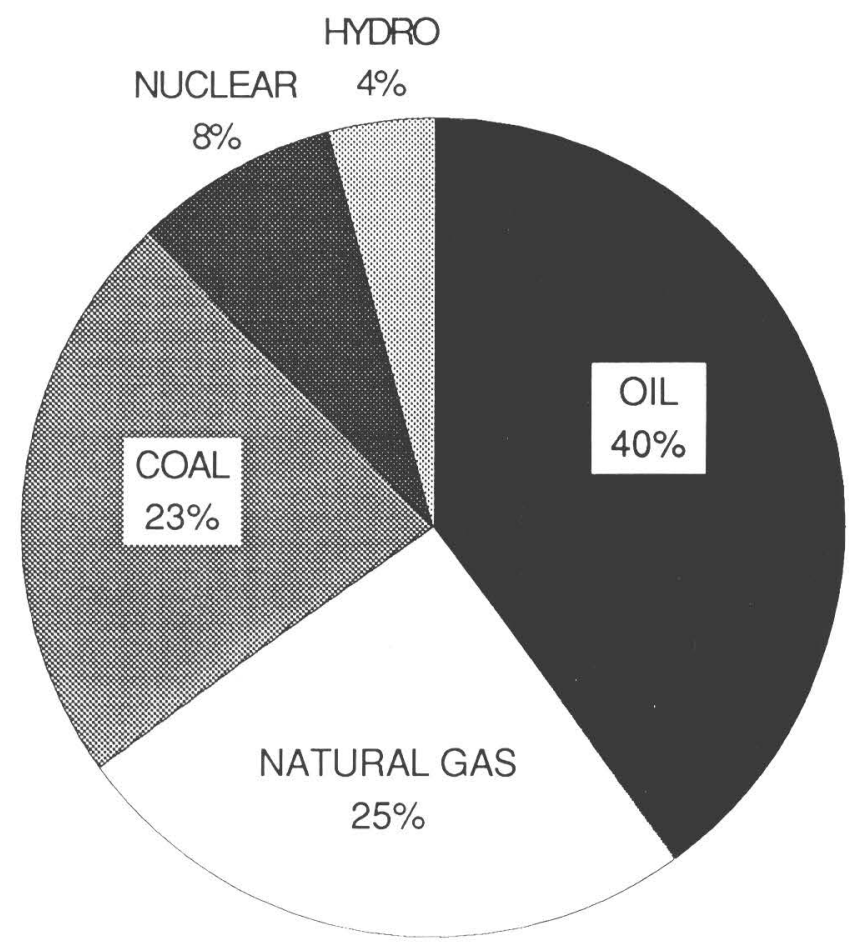

Figure 1. U.S. energy consumption in percent, by primary source, for 1992. From U.S. Department of Energy (1992).

of $\mathrm{CO}_{2}$ and hydrogen as water vapor. These principal emissions from hydrocarbon fuels are benign under normal conditions. However, the concentration of $\mathrm{CO}_{2}$ in the atmosphere has grown rapidly since the Industrial Revolution, raising concerns over the human impact on the Earth's natural greenhouse effect.

\section{GREENHOUSE GASES}

The dry atmosphere is composed of 78 percent nitrogen gas $\left(\mathrm{N}_{2}\right), 21$ percent oxygen $\left(\mathrm{O}_{2}\right)$, and 1 percent trace gases, including argon (Ar; .93 percent), carbon dioxide $\left(\mathrm{CO}_{2} ; .035\right.$ percent $)$, methane $\left(\mathrm{CH}_{4} ; .0001\right.$ percent $)$, and hydrogen $\left(\mathrm{H}_{2} ; .00005\right.$ percent). Roughly 75 percent of these gases resides in the troposphere, the lower 12 kilometers of the atmosphere, whereas the remainder is distributed through the stratosphere, which extends to about 50 kilometers above the Earth's surface. Atmospheric pollutants from fossil fuels and other industrial processes occur as trace gases with low concentrations relative to the main atmospheric constituents. However, because of the complex coupling between the atmosphere, the oceans, and the biosphere (Meehl and Schimel, 1993), and because of the sensitivity of species and ecosystems to environmental changes, a seemingly small change in the chemistry of the atmosphere can have a profound impact on living organisms. A case in point is the greenhouse effect. 
The greenhouse effect refers to a warming that occurs when certain atmospheric gases-primarily water vapor, carbon dioxide, methane, nitrogen oxides, carbon monoxide, and ozone-trap infrared radiation near the Earth's surface (fig. 2). These greenhouse gases allow short-wavelength energy from the Sun to pass through the atmosphere, but they prevent the escape of longer wavelength, infrared energy that is reradiated by the Earth. By absorbing some of this outgoing radiation, the greenhouse gases moderate the temperature of the Earth, maintaining a comfortable average surface temperature of 14 to $15^{\circ} \mathrm{C}\left(58^{\circ} \mathrm{F}\right)$. Without the greenhouse effect the average temperature at the Earth's surface would be a chilly $-18^{\circ} \mathrm{C}\left(0^{\circ} \mathrm{F}\right)$ (Wuebbles and Edmonds, 1991).

The importance or warming potential of a particular greenhouse gas depends on its abundance, the wavelengths of solar radiation that it absorbs, and its atmospheric lifetime. The wavelengths of radiation that arrive from the Sun and those that are reradiated from the Earth are shown in figure 3. Also shown are the ranges of energy wavelengths absorbed by specific greenhouse gases. Carbon dioxide and water vapor are the most important greenhouse gases because they are abundant, and they are extremely effective at absorbing certain wavelengths of infrared energy, mostly between 1 and 7 micrometers, and above 14-micrometers. Other gases that absorb the same wavelengths have little influence, because carbon dioxide and water vapor soak up nearly all the radiation available in these bands. Conversely, trace gases of lower concentration (less than .0001 percent) such as methane, ozone, and chlorofluorocarbons, are important because they absorb infrared in the 7- to 14-micrometer wavelength window where other gases are ineffective (fig. 3). The present atmosphere allows 80 percent of the energy in the 7- to 14 -micrometer window to escape to space; this condition leaves a potentially large role for gases that absorb these energy bands (Ramanathan, 1988).

The atmospheric lifetime or residence time of greenhouse gases is also very important (Graedel and Crutzen, 1993). Most greenhouse gases are removed from the atmosphere by chemical reactions or photodissociation-the breakdown of gas molecules by radiant energy from the Sun. Methane, for example, reacts with atmospheric oxidants to form carbon dioxide and water vapor. Its residence time is approximately 10 years, which means that if we shut off all anthropogenic sources of methane today, the concentration of methane in the atmosphere would return to natural levels in about 10 years.

Carbon dioxide has a much longer residence time, because it is not broken down easily by other atmospheric gases. Its removal from the atmosphere depends instead on rates of transfer to and from the oceans and the biosphere. Carbon dioxide is dissolved in seawater and incorporated into calcium carbonate in the form of fossil tests, lime mud, and coral reefs. And plants use $\mathrm{CO}_{2}$ from the atmosphere to perform photosynthesis. But these materials - calcium carbonate skeletons and plants of all types-are continually breaking down and releasing $\mathrm{CO}_{2}$ back into the atmosphere. Because the influxes are in close balance with the outfluxes, net removal of $\mathrm{CO}_{2}$ from the atmosphere is very sluggish (Wuebbles and Edmonds, 1991). Recent estimates of the residence time of $\mathrm{CO}_{2}$ in the atmosphere are

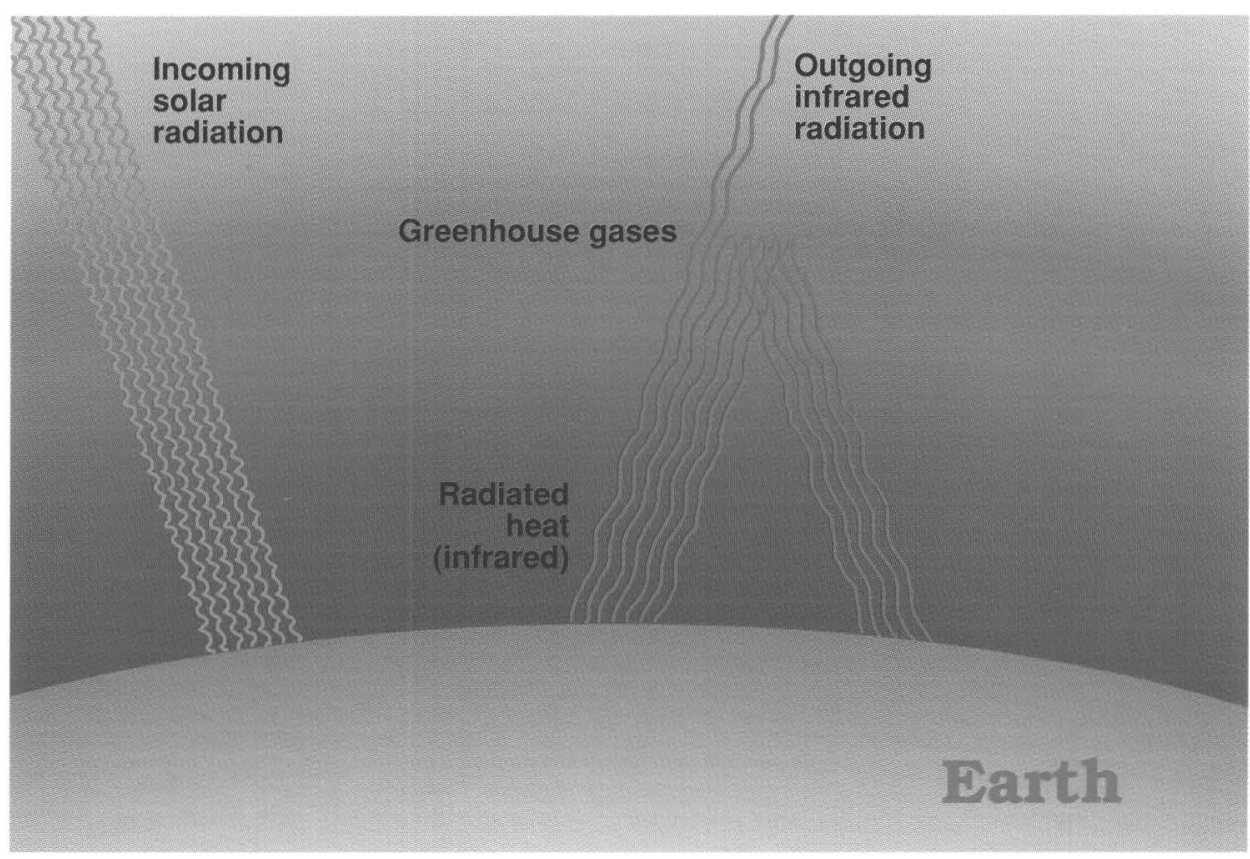

Figure 2. The Earth's greenhouse effect. 


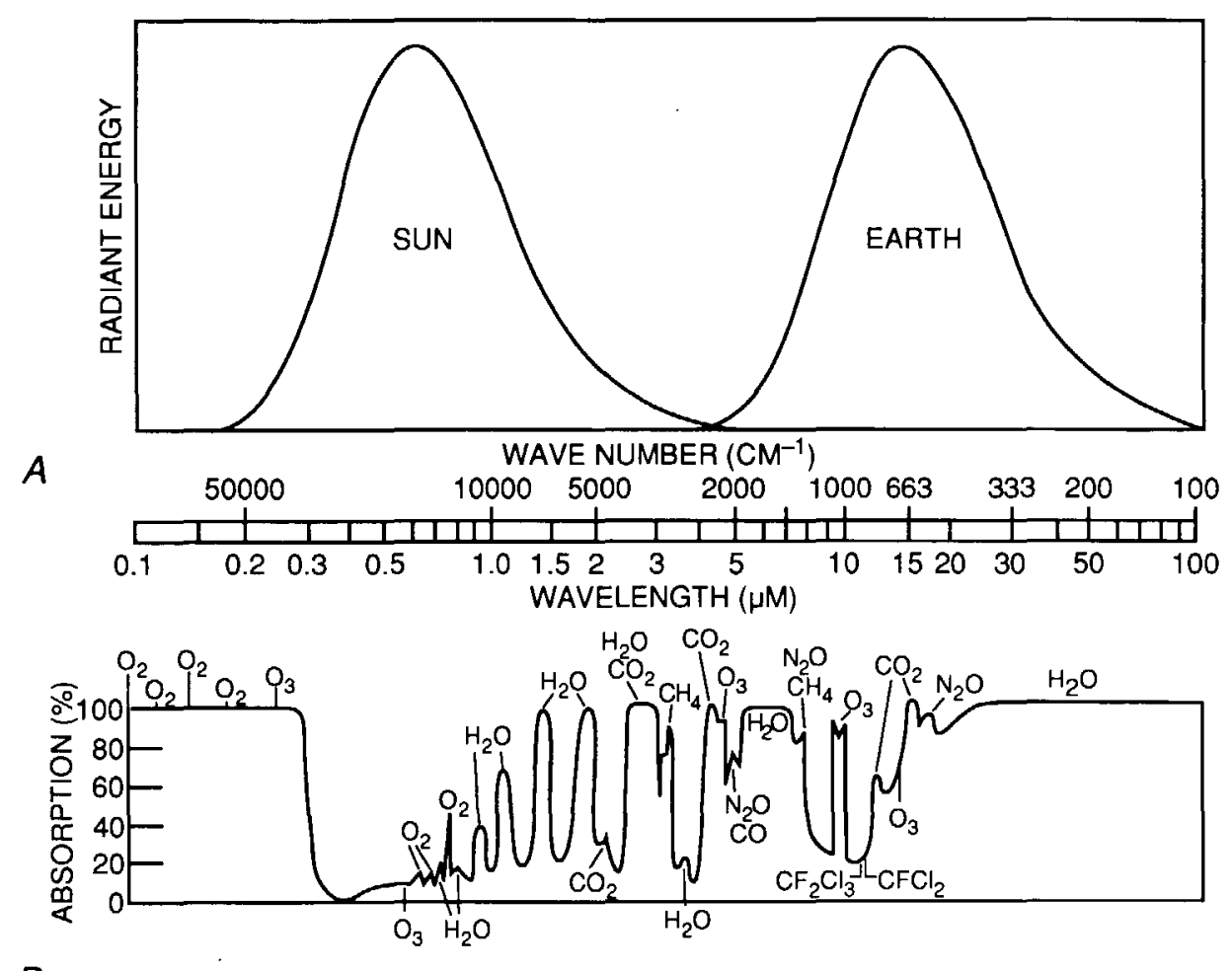

\section{$B$}

Figure 3. Radiation and absorption curves for the Earth's surface. $A$, Energy emitted from the Sun (left) and re-emitted from the surface of the Earth (right). $B$, Bands of energy absorbed, measured in percent, by the greenhouse gases. Modified from Wuebbles and Edmonds (1991). Wavelength in micrometers. Wave number in centimeters.

between 200 and 500 years (Wuebbles and Edmonds, 1991; MacDonald, 1989).

The importance of residence times in the long-term influence of greenhouse gases is shown in figure 4. Relative contributions of carbon dioxide, methane, carbon monoxide, nitrogen oxides, and chlorofluorocarbons are shown for time spans of 50,100 , and 500 years. Gases with relatively short residence times, such as methane and nitrogen oxides, are important greenhouse contributors in the short term, but they lose importance over time spans of hundreds of years. Carbon dioxide gains relative importance over longer integration times because of its long residence time in the atmosphere. Figure 4 gives a sense of the relative importance of the principal greenhouse gases, and it shows that their contributions are not fixed, but are highly dependent on the amount of time in question.

\section{CARBON DIOXIDE}

Since the early 1800 's, $\mathrm{CO}_{2}$ in the atmosphere, as measured from air bubbles trapped in glacial ice from Greenland and Antarctica, has increased from $280 \mathrm{ppmv}$ to 350 ppmv (fig. 5; Wuebbles and Edmonds, 1991; Post and others, 1990). From 1958 to $1988, \mathrm{CO}_{2}$ in the atmosphere increased from 315 to $350 \mathrm{ppmv}$, as determined from direct measurements at Mauna Loa, Hawaii, representing an addition of 74 billion tons of carbon in 30 years (Keeling and others, 1989). Similar trends have been observed at a network of land- and sea-based stations around the world. The current growth rate for atmospheric $\mathrm{CO}_{2}$ is about 0.4 percent per year (MacDonald, 1989).

Atmospheric $\mathrm{CO}_{2}$ arises from both natural and anthropogenic sources. Natural emissions of $\mathrm{CO}_{2}$ come from plants and soils, the oceans, and volcanic eruptions; it also is produced by oxidation of other gases such as $\mathrm{CH}_{4}$ and $\mathrm{CO}$. The largest anthropogenic sources of $\mathrm{CO}_{2}$ are the burning of fossil fuels and the clearing and burning of timber. Carbon dioxide is also produced during the manufacturing of cement. Globally, human activity adds roughly 7 gigatons ( 1 gigaton=1015 tons) of carbon to the atmosphere each year; 5.4 gigatons come from the burning of fossil fuels and 1.6 from biomass burning and cement production. Of the 7 gigatons that we add each year, roughly 3.6 gigatons, is transferred to the deep oceans ( 2 gigatons) and terrestrial biosphere (1.6 gigatons). The remaining 3.4 gigatons accumulates in the atmosphere (Quay, 1992). In other words, we are adding $\mathrm{CO}_{2}$ to the atmosphere at twice the rate that it can be removed by the oceans and the biosphere. 
A
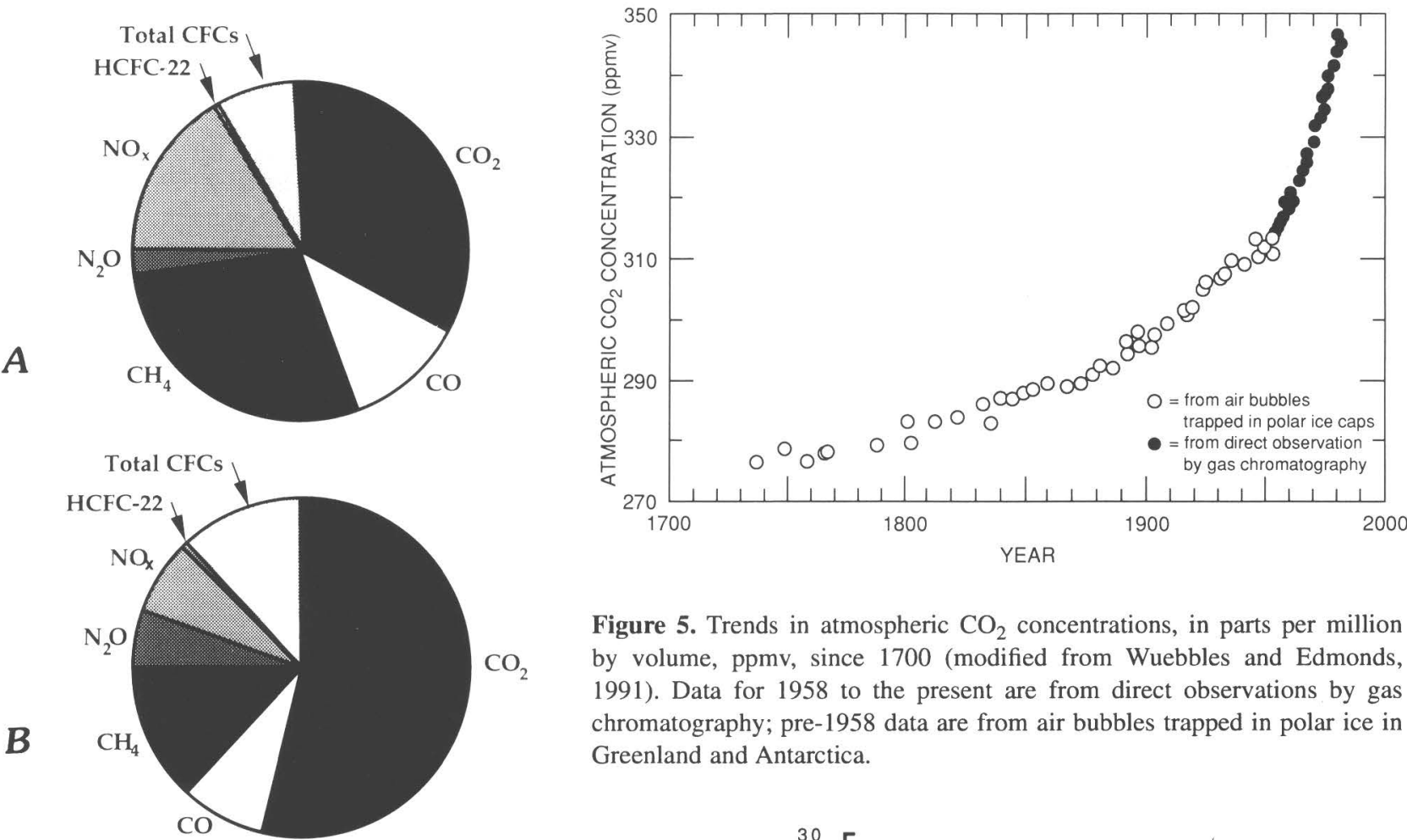

Figure 5. Trends in atmospheric $\mathrm{CO}_{2}$ concentrations, in parts per million by volume, ppmv, since 1700 (modified from Wuebbles and Edmonds, 1991). Data for 1958 to the present are from direct observations by gas chromatography; pre-1958 data are from air bubbles trapped in polar ice in Greenland and Antarctica.

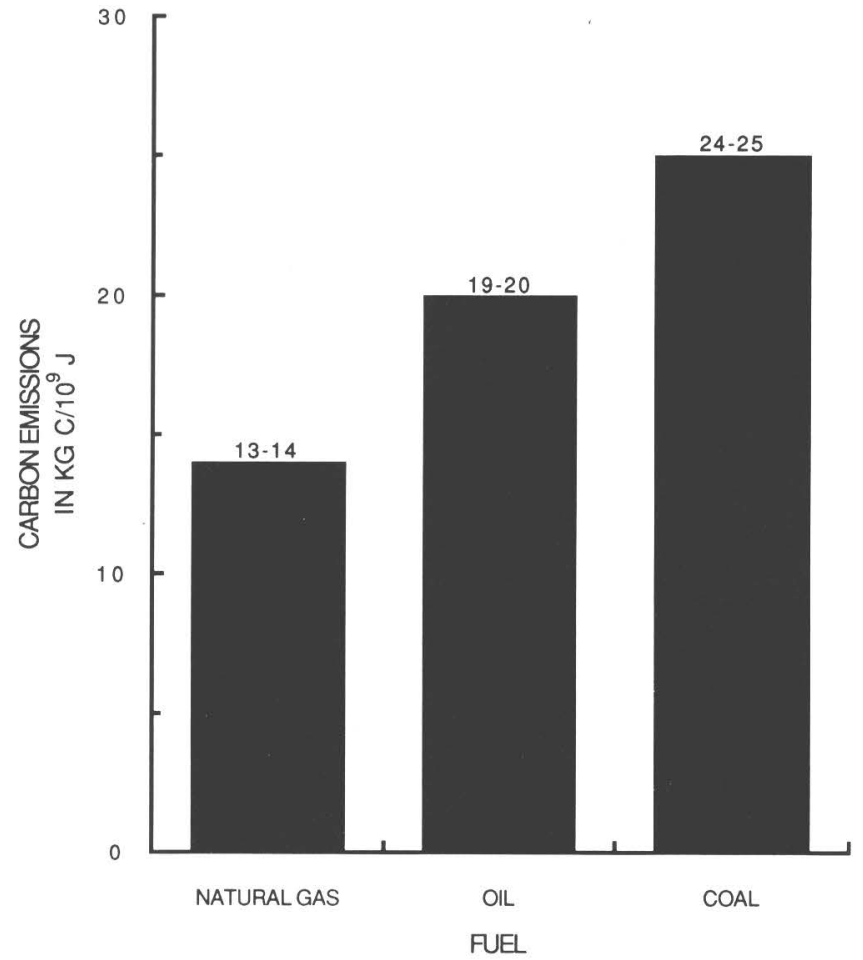

$\mathrm{CO}_{2}$ per energy unit than coal or oil. In producing a gigajoule of energy, coal emits 24 to 25 kilograms of carbon, oil emits 19 to 20 kilograms of carbon, and natural gas emits 13 to 14 kilograms of carbon (fig. 6; Flavin, 1992; Marland and Pippin, 1990). In the United States, 47 percent of fossil fuel-use comes from burning oil, 26 percent from coal, and 27 percent from natural gas (Marland and Pippin, 1990). Nationwide, oil accounts for about 43 percent of fossil fuel $\mathrm{CO}_{2}$ emissions, coal accounts for about 37 percent, and natural gas accounts for 19 percent. Glo-

Figure 6. Carbon emissions for natural gas, crude oil, and coal, based on equivalent energy production from each fuel. From Flavin (1992). Copyright by Worldwatch Institute. Used with permission. Units are kilograms/gigajoule, $\mathrm{kg} \mathrm{C} / 10^{9} \mathrm{~J}$.

bally, coal burning produces about 45 percent of fossil-fuel $\mathrm{CO}_{2}$ emissions, oil produces 40 percent, and natural gas produces 15 percent of the total. Increased use of natural 
gas, at the expense of coal and oil, could reduce significantly the anthropogenic emissions of $\mathrm{CO}_{2}$, because fossilfuel emissions represent the largest human source of $\mathrm{CO}_{2}$.

\section{METHANE}

Methane, the main component of natural gas, is also an important greenhouse gas. It absorbs bands of radiation in the 7- to 14-micrometer window, those not absorbed by $\mathrm{CO}_{2}$ or water vapor (fig. 3 ), so it is 21 times more effective than $\mathrm{CO}_{2}$ in accentuating the greenhouse effect (Wuebbles and Edmonds, 1991). Methane concentrations in the atmosphere show more rapid growth than $\mathrm{CO}_{2}$, having doubled over the past 200 years (fig. 7; Khalil and Rasmussen, 1988). The current rate of increase is 1 percent per year, roughly three times the rate of increase of $\mathrm{CO}_{2}$ (Khalil and Rasmussen, 1982). However, $\mathrm{CH}_{4}$ has a short residence time in the atmosphere-it remains in the troposphere for about 10 years before it is oxidized to $\mathrm{CO}_{2}$ and water by hydroxyl radicals $(\mathrm{OH})$ or transported to the stratosphere (Wuebbles and Edmonds, 1991). So $\mathrm{CH}_{4}$ is a potent greenhouse gas in the short term and a potential source of $\mathrm{CO}_{2}$ and water vapor over the long term.

Atmospheric methane emanates from both natural and human sources (table 1; Houghton and others, 1992). Though methane emissions are not well quantified, roughly one-third comes from natural sources such as wetlands, oceans, lakes, tundra, the destabilization of methane hydrates (by submarine landslides for instance), leakage from other subsurface accumulations, and the digestive tracts of wild ruminant animals and termites. Another onethird is generated by agricultural practices such as the cul- tivation of rice and the raising of cattle and sheep. The remaining one-third comes from coal mining, oil and natural-gas production and distribution, landfills, and biomass burning. Of the 50 teragrams $(\mathrm{Tg})$ per year that are emitted from oil and gas systems, it is estimated that naturalgas systems account for 25 to $50 \mathrm{Tg}$ and oil systems account for 5 to $20 \mathrm{Tg}$ (Houghton and others, 1992).

Table 1. Estimated sources and sinks of methane per year, in teragrams (Tg), from the U.S. Environmental Protection Agency (1993).

[N/A, not applicable]

Global estimate

Global range

\begin{tabular}{|c|c|c|}
\hline \multicolumn{3}{|c|}{ Human Sources } \\
\hline Oil/gas systems - & 50 & $30-70$ \\
\hline Coal mining - & 40 & $25-50$ \\
\hline Landfills- & 30 & $20-70$ \\
\hline Domesticated livestock -.....-- & 80 & $65-100$ \\
\hline Animal waste- & 25 & $20-30$ \\
\hline Rice paddies - & 60 & $20-150$ \\
\hline Biomass burning-- & 40 & $20-80$ \\
\hline Wastewater treatment - & 25 & N/A \\
\hline \multicolumn{3}{|c|}{ Natural Sources } \\
\hline Natural wetlands - & 115 & $100-200$ \\
\hline Termites -..-...- & 20 & $10-50$ \\
\hline 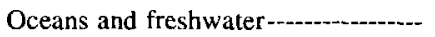 & 15 & $5-45$ \\
\hline $\mathrm{CH}_{4}$ hydrate depressurization------.-- & 0 & $0-5$ \\
\hline 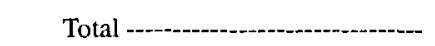 & 500 & $400-610$ \\
\hline
\end{tabular}

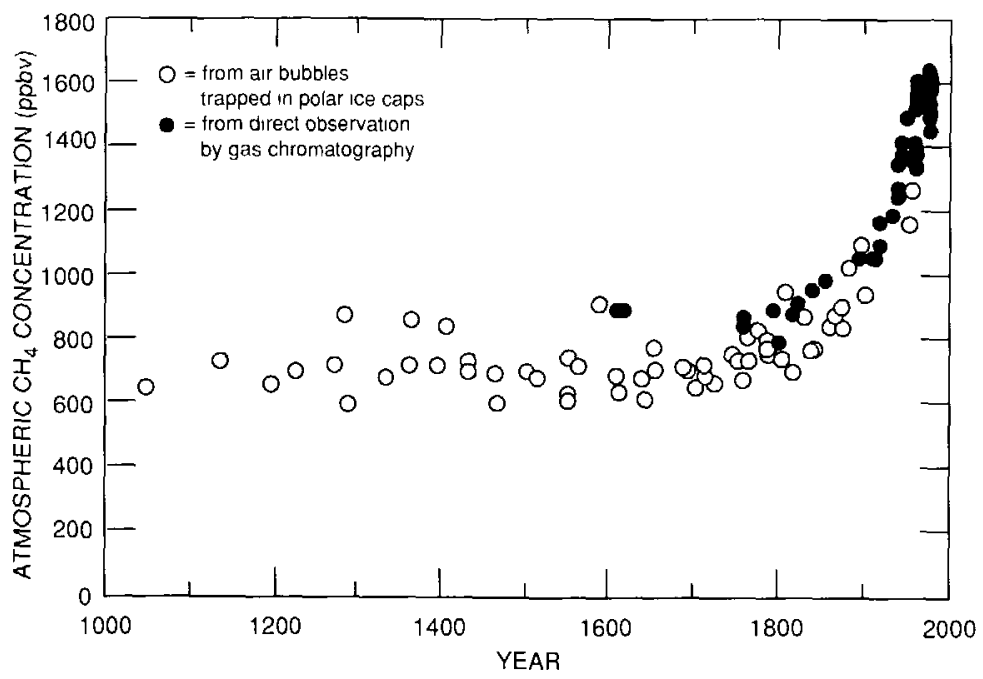

Figure 7. Trends in atmospheric $\mathrm{CH}_{4}$ concentrations, in parts per billion by volume, since A.D. 1000. Modified from Wuebbles and Edmonds (1991). Data for 1958 to the present are from direct observations by gas chromatography. Pre-1958 data are from air bubbles trapped in polar ice in Greenland and Antarctica. 


\section{OTHER GREENHOUSE GASES}

Other energy-related gases that contribute to the greenhouse effect are nitrous oxide and ozone. These gases are less abundant than $\mathrm{CO}_{2}$ and $\mathrm{CH}_{4}$, but they are potent infrared absorbers. Nitrous oxide comes from natural sources in the biosphere and atmosphere, and from human sources such as fossil-fuel combustion and the manufacture of fertilizers. Its concentration in the atmosphere has been growing steadily since about 1940 (MacDonald, 1989). Ozone concentrations also show steady growth during this century, especially in urban areas in the Northern Hemisphere. Ozone is produced from a complex set of reactions involving nitrogen dioxide, reactive hydrocarbons, carbon monoxide, and sunlight. Ozone is the principal component of smog and will be discussed in more detail in the "Air Pollution and Acid Precipitation" section. It is derived mainly from diesel- and gasoline-burning motor vehicles.

Finally, chlorofluorocarbons (CFC's), are the most rapidly increasing gas species in the atmosphere (Wuebbles and Edmonds, 1991). They have no known natural sources; their main human sources are refrigerants, propellents for household aerosol products, and foaming agents. Chlorofluorocarbons linger in the troposphere where they contribute to the greenhouse effect, and eventually they move upward to the stratosphere where they undergo photodissociation and begin attacking statospheric ozone molecules. Their role in the destruction of the Earth's ozone layer will be discussed in the "Methane and Stratospheric Ozone" section.

\section{CLIMATE CHANGE?}

Though significant increases in greenhouse gases over the past 200 years are well established, their effect on the Earth's climate is less clear (for critical review, see Jaworowski and others, 1992). While most climatologists agree that the average temperature at the Earth's surface has increased over the past century, no unique cause for this warming trend has yet been identified. Temperature records show an overall increase of $0.5^{\circ} \mathrm{C}$ in the mean global surface temperature over the past 100 years. The eight warmest years on record have occurred since 1980, even after the effects of El Niño are accounted for (Boden and others, 1991). However, it is not clear that the observed warming is related to the greenhouse effect; it may be part of a natural warming trend that began about A.D. 1500.

Another measure of climatic change is the variation of temperature extremes, such as daily maximum and minimum temperatures. For the Northern Hemisphere during the period 1951 to 1990 , these show a persistent, worldwide decrease in daily temperature ranges. Since 1950 , temperature minimums have increased three times faster than maximums; thus the gap between daily temperature extremes has narrowed (Karl, 1993). Various ideas have been offered to explain this trend, including increasing cloud cover possibly caused by a combination of aerosols, the greenhouse effect, and natural climatic variation (Karl, 1993).

Our present understanding of the greenhouse effect and its potential results is by no means complete. Some scientists predict a gradual, persistent rise in surface temperature with resultant changes in regional patterns of precipitation, temperature, and cloud cover that are likely to disrupt human agricultural systems (Wuebbles and Edmonds, 1991). Sea level may rise owing to partial melting of polar ice caps and thermal expansion of the oceans. As a result, ecosystems on low-lying coasts may be inundated. Though the precise rates and locations of these changes are uncertain, it is easy to imagine the disruptive effects they may have on human society as well as other animal and plant communities.

Mitigating increases in the greenhouse effect requires reduction in emissions of greenhouse gases from anthropogenic sources. The bulk of these emissions comes from fossil-fuel combustion. Substitution of natural gas for coal in electrical power generation could reduce $\mathrm{CO}_{2}$ emissions by nearly 50 percent (Marland and Pippin, 1990). And natural gas in place of gasoline could reduce motor vehicle emissions of $\mathrm{CO}_{2}$ by up to 25 percent (Singh, 1985). This substitution would also reduce nitrous oxide emissions, because natural gas produces 45 percent less nitrous oxides in motor vehicles (Singh, 1985) and up to 95 percent less nitrous oxides in electrical power generation (Flavin, 1992; National Acid Precipitation Assessment Program, 1990).

Growth in the use of natural gas is likely to increase methane leakage from production and distribution infrastructure. In the United States, natural-gas leakage from distribution systems totals less than 1 percent of the gas that is transported (Mosher, oral commun., 1992). When emissions are totaled, however, they form a significant source of atmospheric methane (table 1). Presently, worldwide leakage from production and distribution systems amounts to 7 to 8 percent of global methane emissions from all sources, and about 11 to 12 percent of emissions from anthropogenic sources. Coal mining contributes a similar amount; efforts are underway to encourage recovery of coal bed methane that, until 1990, was vented to the atmosphere (Barns and Edmonds, 1990).

\section{METHANE AND STRATOSPHERIC OZONE}

Methane has recently emerged as a potential influence on the ozone layer. Ozone is a natural product of sunlight on oxygen, with a normal concentration in the upper atmosphere of about $0.1 \mathrm{ppm}$ and in the troposphere of about $0.02 \mathrm{ppm}$. The ozone layer, which starts at about 12 kilometers above the Earth's surface and extends upward to about 50 kilometers, protects plants and animals from 
ultraviolet radiation in sunlight. Specifically ozone blocks UV-B radiation, which has wavelengths ranging from 290 to 320 nanometers, a range that can damage or destroy cellular DNA. Ozone molecules act as catalysts in converting incoming UV radiation into IR radiation through the following process:

$$
\begin{aligned}
& \mathrm{O}_{3}+\mathrm{UV} \rightarrow \mathrm{O}_{2}+\mathrm{O} \\
& \mathrm{O}_{2}+\mathrm{O} \rightarrow \mathrm{O}_{3}+\mathrm{IR} \\
& \mathrm{UV} \rightarrow \mathrm{IR}
\end{aligned}
$$

We have known for some time that CFC's added to the atmosphere from refrigerators, air conditioners, aerosol propellants, and foaming agents destroy ozone. Chlorine atoms are released when CFC molecules are broken down in the upper atmosphere by UV radiation. Chlorine, in turn, acts as a catalyst in the conversion of ozone to oxygen:

$$
\begin{aligned}
\mathrm{Cl}+\mathrm{O}_{3} & \rightarrow \mathrm{ClO}+\mathrm{O}_{2} \\
\mathrm{ClO}+\mathrm{O} & \rightarrow \mathrm{Cl}+\mathrm{O}_{2} \\
\mathrm{O}_{3}+\mathrm{O} & \rightarrow 2 \mathrm{O}_{2} .
\end{aligned}
$$

Chlorofluorocarbons are chemically inert, so they do not react with other compounds in the atmosphere. They are not soluble in water, so they are not washed from the atmosphere by rain and snow. Also, because chlorine is not consumed by the ozone reaction, a single chlorine atom can break up an indefinite number of ozone molecules (Turk and Turk, 1988). Chlorine is finally converted to a less reactive state when it gets incorporated into a less reactive molecule, but this conversion may take as much as 100 years (Stetson, 1992). Chlorofluorocarbons presently in the atmosphere may thus continue to deplete the ozone layer for a century or more, even though production of CFC's worldwide has been reduced by 50 percent since the Montreal Protocol of 1986 (Stetson, 1992).

Methane enters the ozone issue as a potential contributor to ice cloud formation. Stratospheric ice clouds provide the substrate upon which the catalytic conversion of ozone to oxygen takes place. Methane molecules in the stratosphere are converted by photodissociation and oxidation to $\mathrm{CO}_{2}$ and $\mathrm{H}_{2} \mathrm{O}$; this $\mathrm{H}_{2} \mathrm{O}$ may contribute to the buildup of stratospheric ice clouds (MacDonald, 1990). On the other hand, Khalil and Rasmussen (1982) suggested that methane in the stratosphere may combine with chlorine atoms and thereby reduce the ozone-destroying potential of CFC's. Clearly, our understanding of the role of methane in stratospheric ozone depletion is incomplete, and further research is warranted if natural gas is to gain importance in the global energy mix.

\section{FOSSIL FUEL EMISSIONS AND ATMOSPHERIC OXIDANTS}

Another important attribute of the atmosphere is its oxidizing capacity, represented by the total atmospheric concentration of $\mathrm{O}_{3}, \mathrm{H}_{2} \mathrm{O}_{2}$, and the $\mathrm{OH}$ radical (Thompson, 1992). The $\mathrm{OH}$ radical is the most important of the oxidants because it reacts with hundreds of different gases, both natural and manmade, and it controls their concentrations in the troposphere. The $\mathrm{OH}$ radical has been referred to as the "tropospheric vacuum cleaner," (Graedel, 1978) because it controls the buildup of pollutants such as carbon monoxide, methane, and other hydrocarbons. It also reacts with hydrogenated chlorofluorocarbons, which are now being substituted for chlorofluorocarbons to mitigate depletion of stratospheric ozone.

Because of increased fluxes of reactive gases into the atmosphere, the abundance of $\mathrm{OH}$ radicals may be declining. The concentration of $\mathrm{OH}$ in the troposphere may be 20 percent lower now than a century ago (Khalil and Rasmussen, 1988), but its concentration is too low to measure accurately. Atmospheric chemistry models predict decreasing levels of $\mathrm{OH}$ since the Industrial Revolution, driven by rapid increases in $\mathrm{CO}$ and $\mathrm{CH}_{4}$. The removal of tropospheric $\mathrm{OH}$ is worrisome because of feedback mechanisms inherent in the system. As we inject reactive gases into the trophosphere, they consume $\mathrm{OH}$ molecules; as the population of $\mathrm{OH}$ molecules declines, a critical sink for reactive gases slowly disappears. Without the $\mathrm{OH}$ sink, the increase in reactive pollutants is accelerated, and more reactive pollutants use increasingly more $\mathrm{OH}$ radicals. Where we are in this suggested cycle, or where it may end, are both unknown. Until more is known, fossil-fuel emissions, particularly $\mathrm{CO}, \mathrm{CH}_{4}$ and reactive hydrocarbons, need to be viewed as potentially harmful to the oxidizing capacity of the atmosphere.

\section{AIR POLLUTION AND ACID PRECIPITATION}

The atmospheric changes discussed in the previous sections are long-term phenomena that affect the entire planet. Near-surface air pollution is a more local and immediate problem. The most harmful air pollutants and those that are monitored by the Federal Government are sulfur dioxide, nitrogen oxides, particulates, carbon monoxide, ozone, and lead. These are all derived primarily from fossil-fuel use in transportation, electricity generation, and industrial processes. The adverse effects of these pollutants range from scratchy eyes to lung cancer resulting from local ozone increases to widespread damage to ecosystems resulting from severe ozone pollution or acid precipitation (Turk and Turk, 1988).

Federal and state controls under the Clean Air Act of 1970, have brought notable improvements in nationwide ambient concentrations of all the regulated pollutants (fig. 8). This improvement, however, is somewhat deceptive, because it does not reflect the air quality in large cities such as Los Angeles and New York, where concentrations 

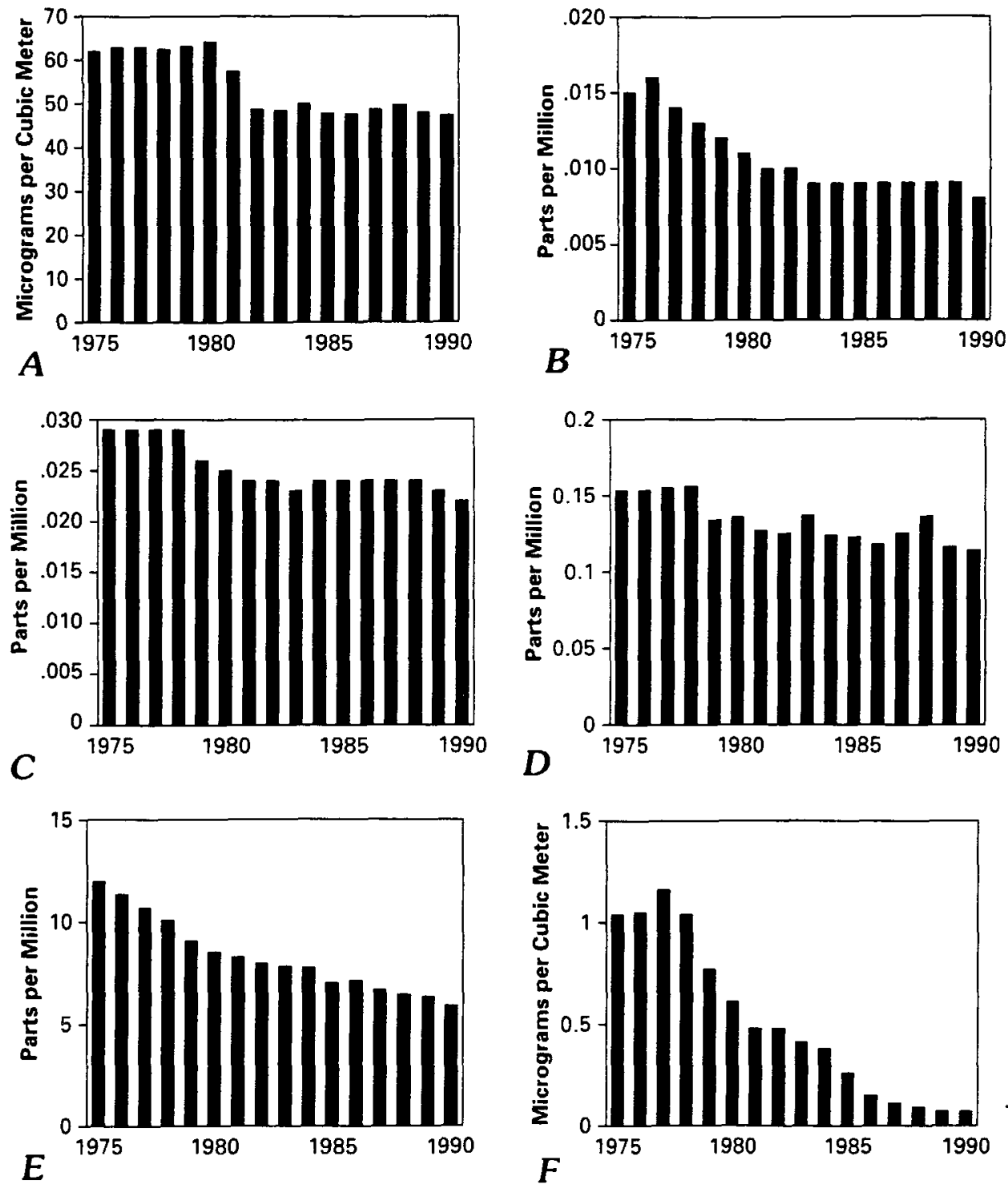

Figure 8. National ambient concentrations of particulates (A), sulfur dioxide (B), nitrogen dioxide (C), ozone (D), carbon monoxide (E), and lead (F), from 1975 to 1990. From U.S. Council on Environmental Quality (1992a).

of carbon monoxide, ozone, and particulates often exceed the national standards. Because most Americans live in urban areas, many of the 1990 amendments to the Clean Air Act are aimed at reducing urban air pollution.

\section{PARTICULATES}

Particulate matter is a mixture of minute solid particles or liquid droplets, mostly unburned carbon and ash, derived from burning coal and, to a lesser extent, oil. In elevated concentrations, these tiny particles can cause respiratory diseases, including lung cancer (Turk and Turk, 1988). The nationwide trends in particulate emissions since
1940 are shown in figure 9. After 1970, when the Clean Air Act was emplaced, U.S. emissions of particulates were reduced drastically, through the installation of electrostatic precipitators and baghouse filters at many coal-fired industrial plants and powerplants. Today, industrial plants produce 37 percent of particulate matter nationwide, with powerplants and motor vehicles each contributing an additional 20 percent (U.S. Council on Environmental Quality, 1992a). Of the fossil fuels, coal produces the highest particulate emissions, but diesel oil is an additional important source. Natural gas is free of solid particles and produces no particulates during combustion, which makes it a clean altemative to conventional coal burning for industry and electrical generation. 


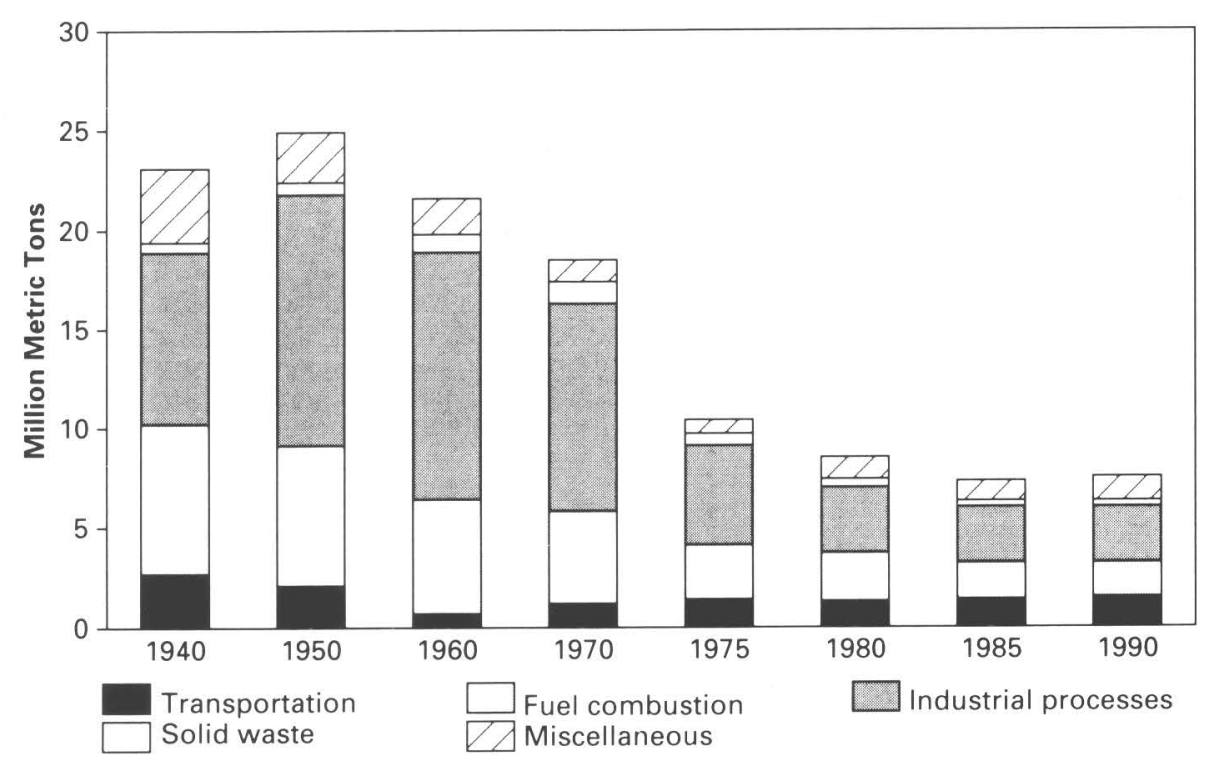

Figure 9. U.S. emissions of particulates by source, from 1940 to 1990. From U.S. Council on Environmental Quality (1992a).

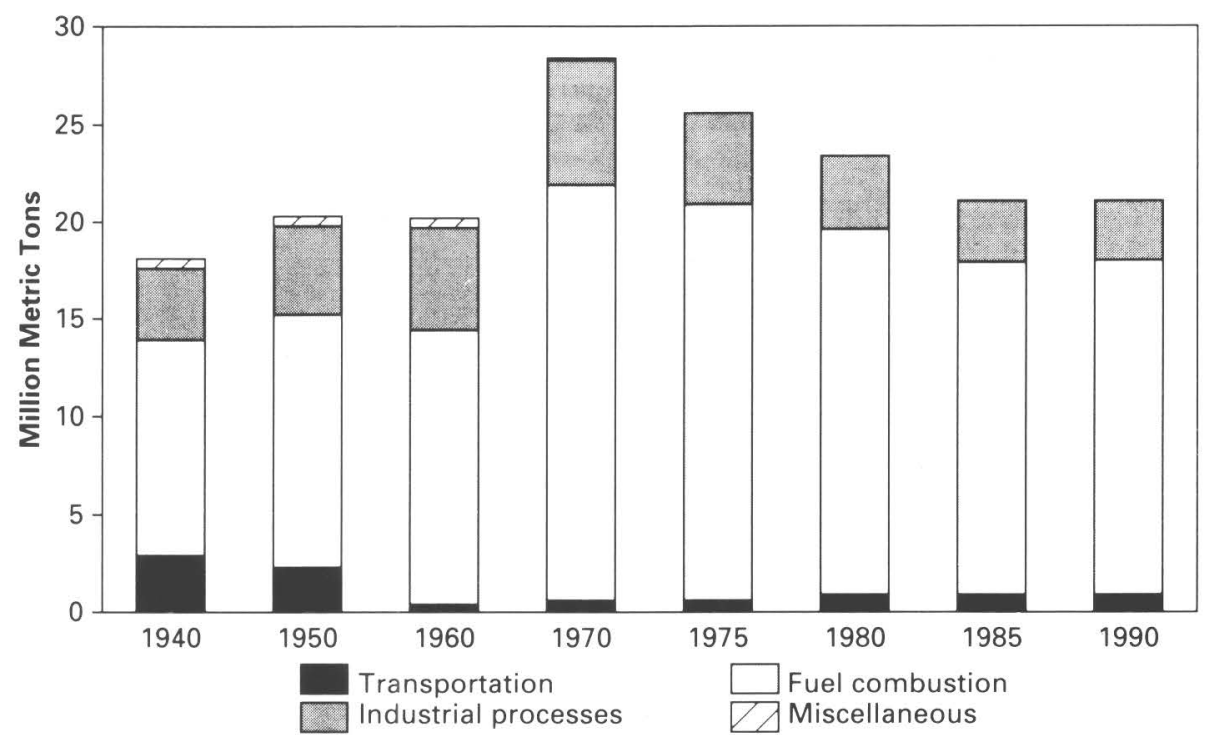

Figure 10. U.S. emissions of $\mathrm{SO}_{2}$ by source, 1940-1990. From U.S. Council on Environmental Quality (1992a).

\section{SULFUR DIOXIDE}

Sulfur and nitrogen oxides are acidic gases that are emitted in varying amounts during fossil-fuel combustion (see U.S. Environmental Protection Agency, 1992; National Acid Precipitation Assessment Program, 1990). Sulfur, present in small amounts in coal and oil, is oxidized to sulfur dioxide during combustion by means of the following reaction:

$$
\mathrm{S}+\mathrm{O}_{2} \rightarrow \mathrm{SO}_{2}
$$

More than two-thirds of the anthropogenic $\mathrm{SO}_{2}$ added to the atmosphere comes from powerplants, primarily from those which burn coal. Industrial plants, including smelters, paper mills, and chemical facilities, produce about 15 percent of $\mathrm{SO}_{2}$ emissions, whereas motor vehicles produce less than 5 percent (fig. 10). In the United States, total output of $\mathrm{SO}_{2}$ has declined from a high of 28.3 million metric tons in 1970 to 21.2 million metric tons in 1990. This 25 percent decrease reflects the introduction of fluegas desulfurization devices (scrubbers) and low sulfur fuel at many coal-fired powerplants. Strict industrial regula- 
tions have reduced emissions of $\mathrm{SO}_{2}$ from smelters, paper mills, and chemical facilities.

Sulfur dioxide emissions can be reduced further. Scrubbers can reduce $\mathrm{SO}_{2}$ emissions from existing electrical generation plants by as much as 95 percent (French, 1990), but they also reduce efficiency. By 1990, scrubbers were installed at only 20 percent of the coal-burning powerplants in the United States, compared with 85 percent in Japan. Newer "clean coal" technologies have the potential to reduce $\mathrm{SO}_{2}$ and, to a lesser extent $\mathrm{NO}_{x}$, while improving efficiency, but these technologies are expensive.

An alternative to coal-fired powerplants is a natural gas-fired combined-cycle system. Exhaust heat from a gasfired turbine produces steam, and the steam is reinjected into the turbine or used to power a second steam turbine. On average, combined-cycle powerplants cost 25 to 50 percent less to build than a coal plant, and they have higher efficiencies (45 percent) than conventional, single-cycle gas turbine plants (35 percent) (Burnett and Ban, 1989). Combined-cycle natural-gas powerplants produce virtually no $\mathrm{SO}_{2}$ or particulates (fig. 11). They also produce far less $\mathrm{NO}_{\mathrm{x}}$ than a coal-fired plant.

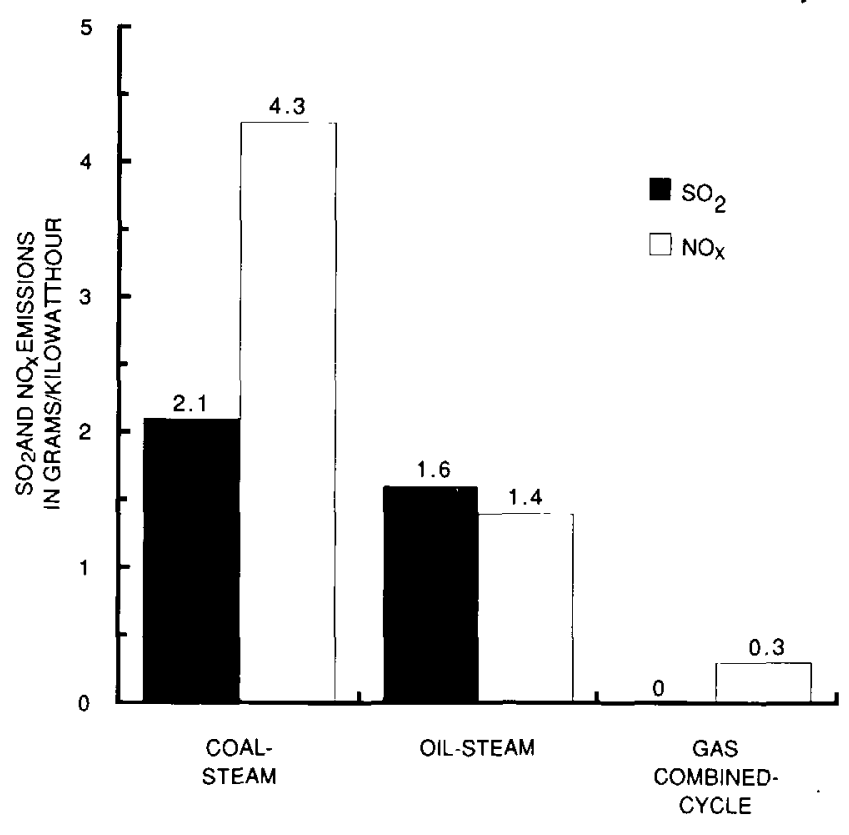

ELECTRIC POWER GENERATION

Figure 11. Sulfur dioxide $\left(\mathrm{SO}_{2}\right)$ and $\mathrm{NO}_{\mathrm{x}}$ emissions for electricpower generation, by primary fuel. From Flavin (1992). Copyright by Worldwatch Institute. Used with permission.

\section{NITROGEN OXIDES}

Nitrogen oxides represent the combination of nitric oxide (NO), which accounts for 95 percent of $\mathrm{NO}_{\mathrm{x}}$ emissions, and nitrogen dioxide $\left(\mathrm{NO}_{2}\right)$, which accounts for 5 percent or less of $\mathrm{NO}_{\mathrm{x}}$ emissions (National Acid Precipitation Assessment Program, 1991). Two types of $\mathrm{NO}_{\mathrm{x}}$ are formed during combustion, thermal $\mathrm{NO}_{\mathrm{x}}$ and fuel $\mathrm{NO}_{\mathrm{x}}$. Thermal $\mathrm{NO}_{\mathrm{x}}$ forms within the combustion flame core, where very high temperatures facilitate the dissociation of atmospheric $\mathrm{N}_{2}$ and $\mathrm{O}_{2}$ molecules into their atomic states. These atoms react with other $\mathrm{N}_{2}$ and $\mathrm{O}_{2}$ molecules to form $\mathrm{NO}_{\mathbf{x}}$ :

$$
\begin{aligned}
& \mathrm{N}_{2}+\mathrm{O} \rightarrow \mathrm{NO}+\mathrm{N} \\
& \mathrm{N}+\mathrm{O}_{2} \rightarrow \mathrm{NO}+\mathrm{O}
\end{aligned}
$$

Fuel $\mathrm{NO}_{\mathrm{x}}$ is generated from nitrogen compounds in the fuel during combustion in an oxygenated environment. The reactions that transform fuel-bound nitrogen to $\mathrm{NO}_{\mathrm{x}}$ are complex and varied. Coal-bound nitrogen compounds follow a solid-phase reaction, and oil-bound compounds follow a gas-phase reaction, and conversion rates depend on the amount of oxygen available and the temperature of the combustion flame (Campbell and others, 1991). Natural gas and most distillate oils produce only thermal $\mathrm{NO}_{\mathrm{x}}$, because they contain no fuel-bound nitrogen. Coal and residual oils contain variable amounts of chemically bound nitrogen, so when combusted they produce both thermal and fuel $\mathrm{NO}_{\mathrm{x}}$.

Nitrogen oxides contribute to urban smog and acid precipitation. In a series of complex photochemical reactions in the presence of sunlight and oxygen, nitrogen oxides combine with volatile organic compounds to form ozone, the principal ingredient in urban smog. Their role in acid precipitation will be discussed in the "Acid Precipitation" section.

In 1990, U.S. emissions of nitrogen oxides totalled 19.6 million metric tons, down slightly from a historical high of 21.7 million metric tons in 1978. Motor vehicle (transportation) emissions (fig. 12) account for roughly half of global annual $\mathrm{NO}_{\mathrm{x}}$ emissions, and electric power generation (fuel combustion) accounts for most of the remainder (U.S. Council on Environmental Quality, 1992a). Additional sources of $\mathrm{NO}_{\mathrm{x}}$ are industrial boilers and heaters and solid-waste incinerators (Campbell and others, 1991). These combined sources account for less than 5 percent of total $\mathrm{NO}_{\mathrm{x}}$ emissions, and their contribution has remained essentially stable since historic records began.

The transportation share of $\mathrm{NO}_{\mathrm{x}}$ emissions has been dropping since the 1970's and 80's owing to Government regulation of vehicle emissions and related advances in combustion technologies. While Americans have doubled their vehicle miles since 1970 , per-vehicle emissions have fallen more than 90 percent over the same period (U.S. Council on Environmental Quality, 1992a). Emissions from power generation, on the other hand, have been rising steadily.

The greatest potential for future $\mathrm{NO}_{\mathrm{x}}$ reductions is in the power generation industry. Combined-cycle gas plants 


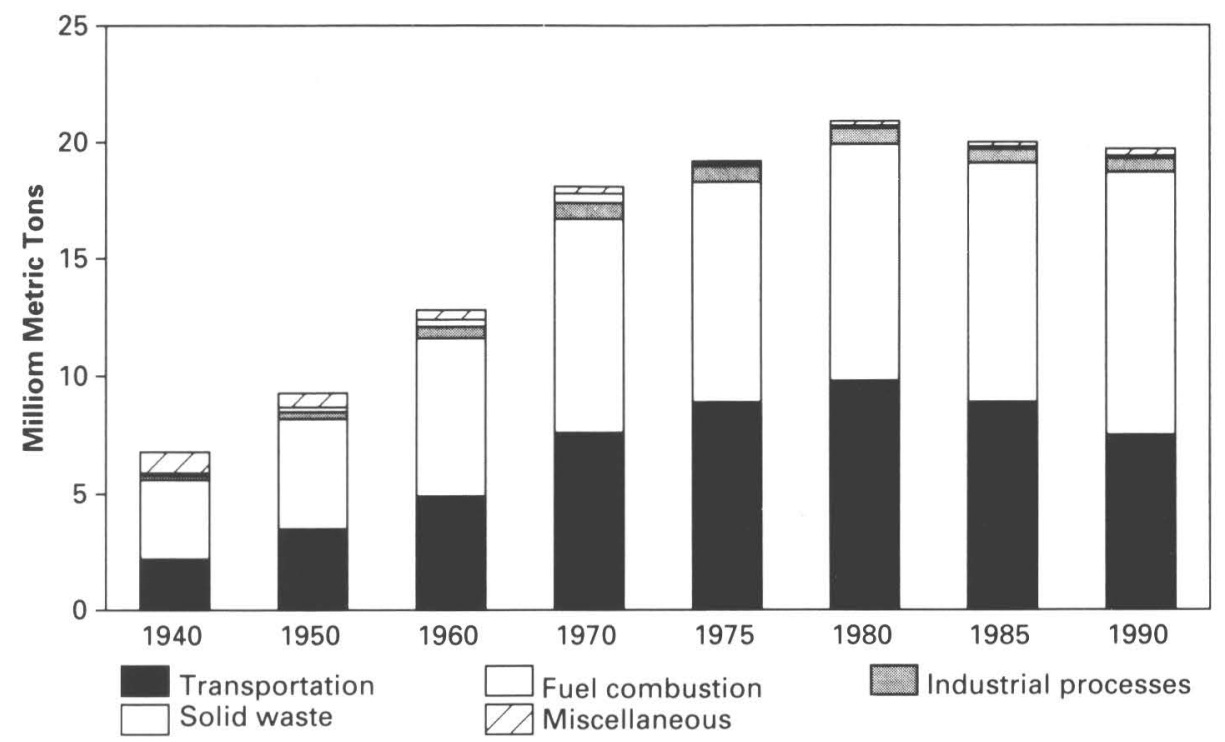

Figure 12. U.S. emissions of $\mathrm{NO}_{\mathrm{x}}$ by source, from 1940 to 1990. From U.S. Council on Environmental Quality (1992a).

produce 40 to 85 percent less $\mathrm{NO}_{\mathrm{x}}$ than the most advanced coal plants (fig. 11; Flavin, 1992; Gillette and others, 1988). Natural gas can also contribute to reductions in $\mathrm{NO}_{\mathrm{x}}$ emissions through co-firing and reburn techniques at existing coal-fired powerplants. These techniques involve introducing small amounts of natural gas into the combustion zone to improve combustion of the primary fuel (coal). They can reduce $\mathrm{NO}_{\mathrm{x}}$ by up to 60 percent. They also reduce $\mathrm{SO}_{2}$ and particulate emissions, providing an important mitigation option for coal-fired plants that do not comply with Federal emissions standards (Burnett and Ban, 1989).

Natural gas also has potential to reduce $\mathrm{NO}_{\mathrm{x}}$ emissions in the transportation sector. Vehicles that run on compressed natural gas generally have lower $\mathrm{NO}_{\mathrm{x}}$ emissions than gasoline. In vehicles that have been converted to run on either gasoline or natural gas, $\mathrm{NO}_{\mathrm{x}}$ emissions are reduced by 20 to 50 percent when such vehicles run on natural gas (Singh, 1985). Emissions are expected to improve significantly in engines designed to run solely on natural gas. Cities such as Los Angeles and New York are converting municipal fleet vehicles to natural gas in an effort to reduce urban smog.

\section{ACID PRECIPITATION}

As the atmospheric burden of sulfur and nitrogen compounds from fossil fuels has grown, rain and snow in some regions have become increasingly acidic, particularly downwind of major industrial centers. Sulfur dioxide $\left(\mathrm{SO}_{2}\right)$ and nitrogen oxides $\left(\mathrm{NO}_{\mathrm{x}}\right)$ from combustion sources enter the atmosphere where they are oxidized, mainly by reaction with $\mathrm{OH}$ radicals, to form sulfates $\left(\mathrm{SO}_{3}\right)$ and nitrates. The sulfates and nitrates then combine with hydrogen and oxygen in rainwater (or snow) to form sulfuric and nitric acids, as described by the following reactions:

$$
\begin{aligned}
\mathrm{SO}_{3}+\mathrm{H}_{2} \mathrm{O} & \rightarrow \mathrm{H}_{2} \mathrm{SO}_{4} \text { (sulfuric acid) } \\
4 \mathrm{NO}+3 \mathrm{O}_{2}+2 \mathrm{H}_{2} \mathrm{O} & \rightarrow 4 \mathrm{HNO}_{3} \text { (nitric acid) }
\end{aligned}
$$

Normal rain is weakly acidic, with a pH of 5.6 to 5.7 , as a result of similar reactions that occur between water and carbon dioxide (producing carbonic acid) and between atmospheric nitrogen and water (producing nitric acid). In polluted regions, however, rainwater with a $\mathrm{pH}$ of 4 to 5 is not uncommon, and, in extreme cases, a $\mathrm{pH}$ as low as 1.7 has been reported (Turk and Turk, 1988).

Acid precipitation affects both aquatic and terrestrial ecosystems. Elevated acidity in lakes and streams can kill aquatic organisms and inhibit the reproduction of some amphibians. Many species of snails, clams, mayflies, and crayfish cannot survive in water with a $\mathrm{pH}$ of 5.5 or lower, and many fish die under conditions of $\mathrm{pH} 4.5$ or less. On land, acid rain or snow damages trees and other plants through direct exposure and through the indirect effects of increased soil acidity. Most plants, including agricultural crops, cannot survive under conditions of sustained exposure to $\mathrm{pH} 3.6$ or lower (National Acid Precipitation Assessment Program, 1991).

The Northeast and the Southeast are the two areas of the United States that have been most affected by acid precipitation. In the Northeast, $\mathrm{SO}_{2}$ emissions and surfacewater sulfate concentrations both decreased over the past 15 to 20 years, but in the Southeast, sulfur emissions and surface-water sulfate both increased (U.S. Council on En- 
vironmental Quality, 1992b). Because natural gas produces no $\mathrm{SO}_{2}$ and low $\mathrm{NO}_{\mathrm{x}}$ emissions, a shift to natural gas in electricity generation and transportation would reduce the incidence of acid precipitation.

\section{VOLATILE ORGANIC COMPOUNDS AND CARBON MONOXIDE}

Volatile organic compounds (also known as VOC's, reactive hydrocarbons, or non-methane hydrocarbons), along with $\mathrm{NO}_{\mathrm{x}}$ are critical to the formation of ozone in urban smog. Their sources include gasoline vapors, coal gasification, chemical solvents, and combustion emissions from fossil fuels (Hunt, 1987). Emissions trends for VOC's since 1940 are shown in figure 13. Since 1970, emissions have dropped from 27.5 to 18.7 million metric tons annually. The transportation sector cut its share of emissions by onehalf, by using catalytic converters and other technologies aimed at compliance with the Clean Air Act and its amendments. Emissions could be reduced further by using natural-gas-powered vehicles, which produce 35 to 55 percent less VOC's than gasoline-powered vehicles (Singh, 1985).

Carbon monoxide (CO) is another important component in urban smog. It is a clear, odorless gas that escapes during incomplete combustion of fossil fuels (Conservation Foundation, 1987). At high exposure levels, it reduces the blood's capacity to circulate oxygen and thereby causes drowsiness and slows reflexes. In very high concentrations, it causes death. Motor vehicles (transportation) contribute two-thirds of the national total $\mathrm{CO}$ emissions (fig. 14), but their emissions have been reduced by nearly 50 percent since 1970 , owing to the use of catalytic con- verters. Again, natural-gas vehicles can play an important role in further reductions of $\mathrm{CO}$ emissions. They produce 80 to 90 percent less $\mathrm{CO}$ than gasoline-powered vehicles (Singh, 1985).

\section{LOCAL ENVIRONMENTAL ISSUES}

Fossil fuels release most of their pollutants as combustion emissions, so their greatest environmental impacts are in the atmosphere. This paper focuses on global atmospheric effects, but each fossil fuel is associated with local, land-based environmental problems as well-problems at the drillsite or mine shaft where the fuel is extracted from the Earth's crust, problems along the pipeline where the fuel is transported, as well as end-use safety issues in the home and in the car. One of the greatest difficulties in finding an environmentally favorable energy plan is balancing local, regional, national, and global issues. The brief discussion of local problems herein is not a reflection of their importance. I can only suggest some of the local problems that need to be considered.

Oil, for instance, has the potential to contaminate fresh water and seawater. Oil tankers carry huge volumes of crude oil over seas, and accidents such as the January, 1993, break up of the Norwegian crude-oil tanker in the Shetland Islands are harmful to marine wildlife and the local maritime economy. Underground fuel tanks can pollute ground water, and oil rigs and pipelines also have potential for leakage both onshore and offshore. In addition, oil exploration and production in remote areas can disrupt animal and plant life, although these impacts can be minimized by careful planning and reclamation.

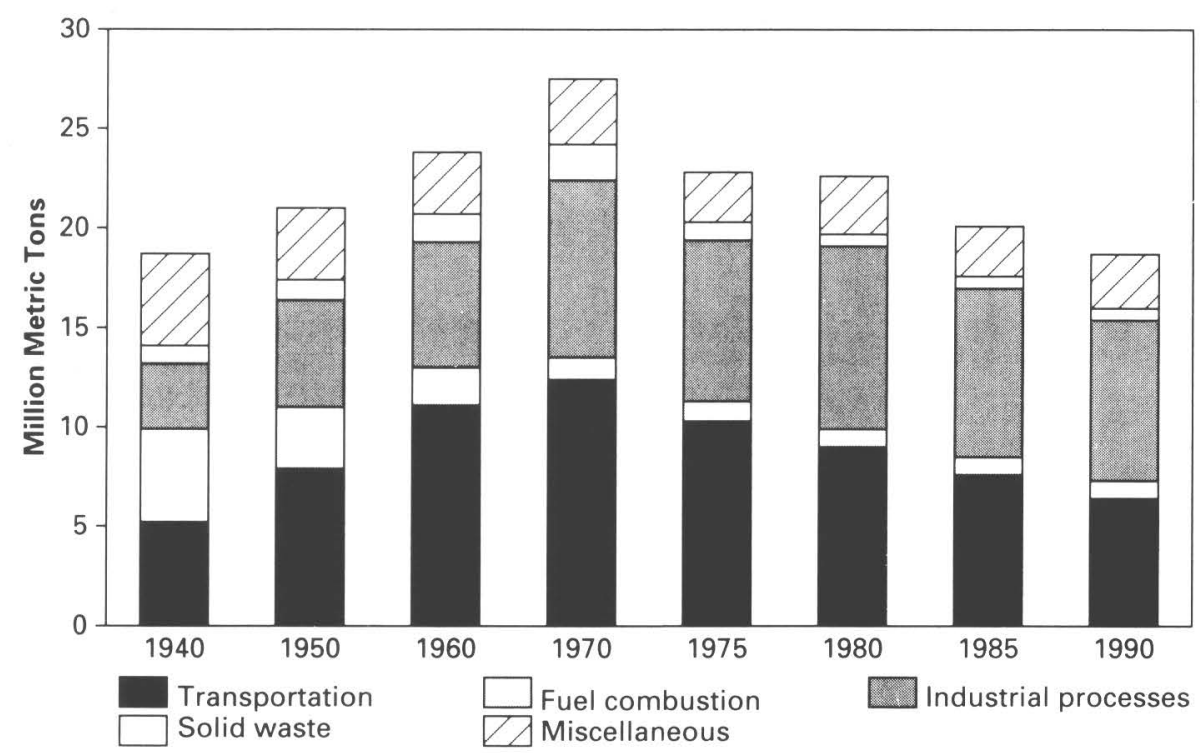

Figure 13. U.S. emissions of volatile organic compounds (VOC's), by source, from 1940 to 1990. From U.S. Council on Environmental Quality (1992a). 


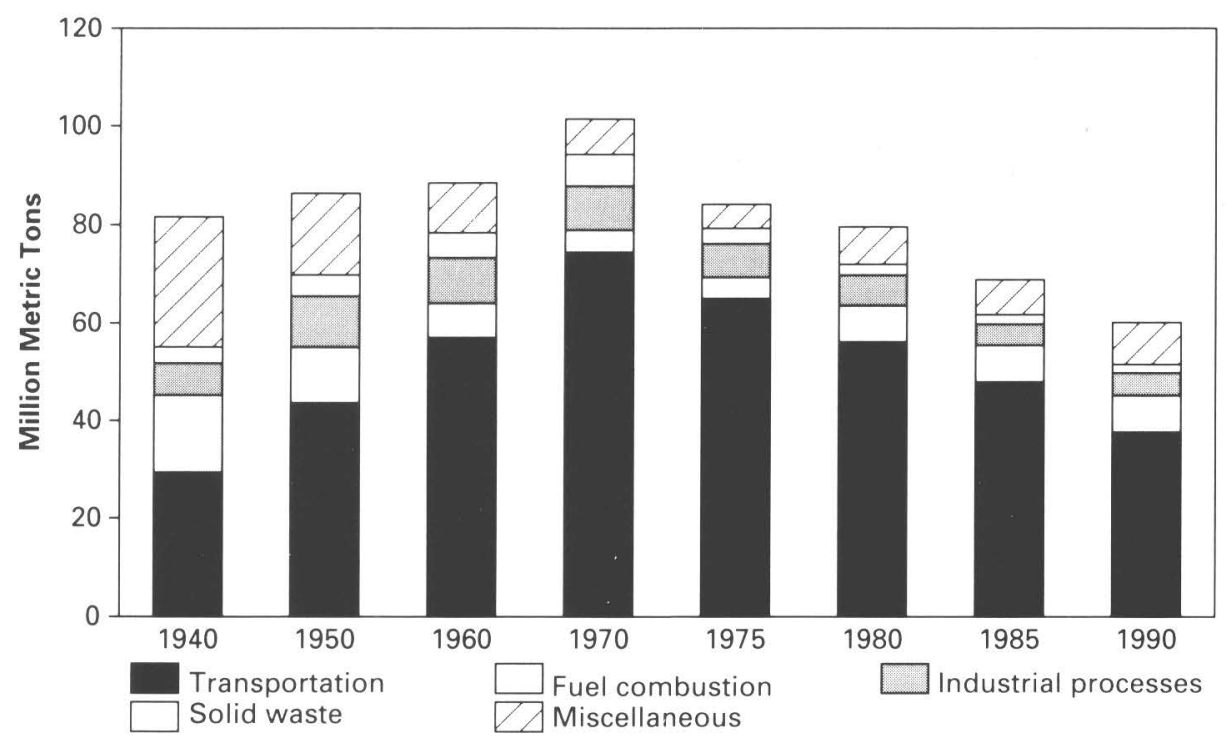

Figure 14. U.S. emissions of carbon monoxide (CO), by source, from 1940 to 1990 . From U.S. Council on Environmental Quality (1992a).

Strip mining and underground mining for coal can also disrupt the natural environment. Some mines impose visible scars on the land surface, and many create acid mine drainage that can pollute ground water and surface water. Mine safety is also an important issue in the coal industry. Many miners suffer lung disease, and mine explosions are a direct threat to miners and their families. Transportation and storage of coal is relatively safe and environmentally benign. However, at the powerplant, where the coal is burned, millions of tons of solid waste are produced, and this waste requires environmentally safe disposal.

Natural-gas exploration and production involves the same infrastructure as oil, so it too has the potential to disrupt ecosystems with road and pipeline construction and maintenance. Natural-gas leakages are a significant source of atmospheric methane, which plays an important role in the human contribution to the greenhouse effect and in other atmospheric issues discussed in previous sections. In terms of safety, natural gas is flammable and under compression it is potentially explosive. It can be a fire hazard in the home, as well as at the drill rig, and compressed natural gas in an automobile fuel tank is more explosive than gasoline or other liquid hydrocarbon fuels.

\section{CONCLUSIONS}

Overall, natural gas has some marked environmental advantages over the other hydrocarbon fuels, but it is not environmentally perfect. Combustion of natural gas produces fewer greenhouse gases and air pollutants than either oil or coal. It produces less $\mathrm{CO}_{2}, \mathrm{CO}$, and $\mathrm{NO}_{\mathrm{x}}$ than other hydro- carbon fuels, and, because it is gaseous and relatively pure, it emits virtually no particulate matter and $\mathrm{SO}_{2}$. Accordingly, substitution of natural gas for coal and oil can improve some of the most important environmental problems related to our atmosphere. These include urban and industrial air pollution, acid rain, and anthropogenic forcing of the greenhouse effect. However, methane is also a potent greenhouse gas, and increases in natural-gas production and consumption could raise the emissions of unburned methane from leaky pipelines. Also, methane may have adverse effects on the ozone layer and the oxidizing capacity of the atmosphere. These are important issues that merit further research.

Natural gas compares well to the other fossil fuels in terms of water quality and the preservation of natural ecosystems. It does not have the problems of acid-mine drainage associated with coal mining, nor the oil-spill potential associated with crude-oil transportation. In fact it is virtually impossible to pollute ground water or surface water with methane, because it is lighter than air. Natural-gas exploration, production, and distribution have relatively low impacts on natural ecosystems, if they are conducted along existing infrastructures. Where new roadways or pipelines are required, natural-gas exploration and production are potentially detrimental to delicate ecosystems such as natural wetlands.

In the United States, over 50 percent of electricity generation is fueled by coal, whereas natural gas supplies only 10 percent, and oil supplies less than 5 percent (fig. 15). Nuclear and hydroelectric power supply roughly 20 percent and 10 percent, respectively (see Fanelli, this volume). Coal-fired powerplants are the major source of particulate and $\mathrm{SO}_{2}$ emissions, and they produce large portions of nationwide $\mathrm{CO}_{2}$ and $\mathrm{NO}_{\mathrm{x}}$ emissions. Natural-gas combined- 


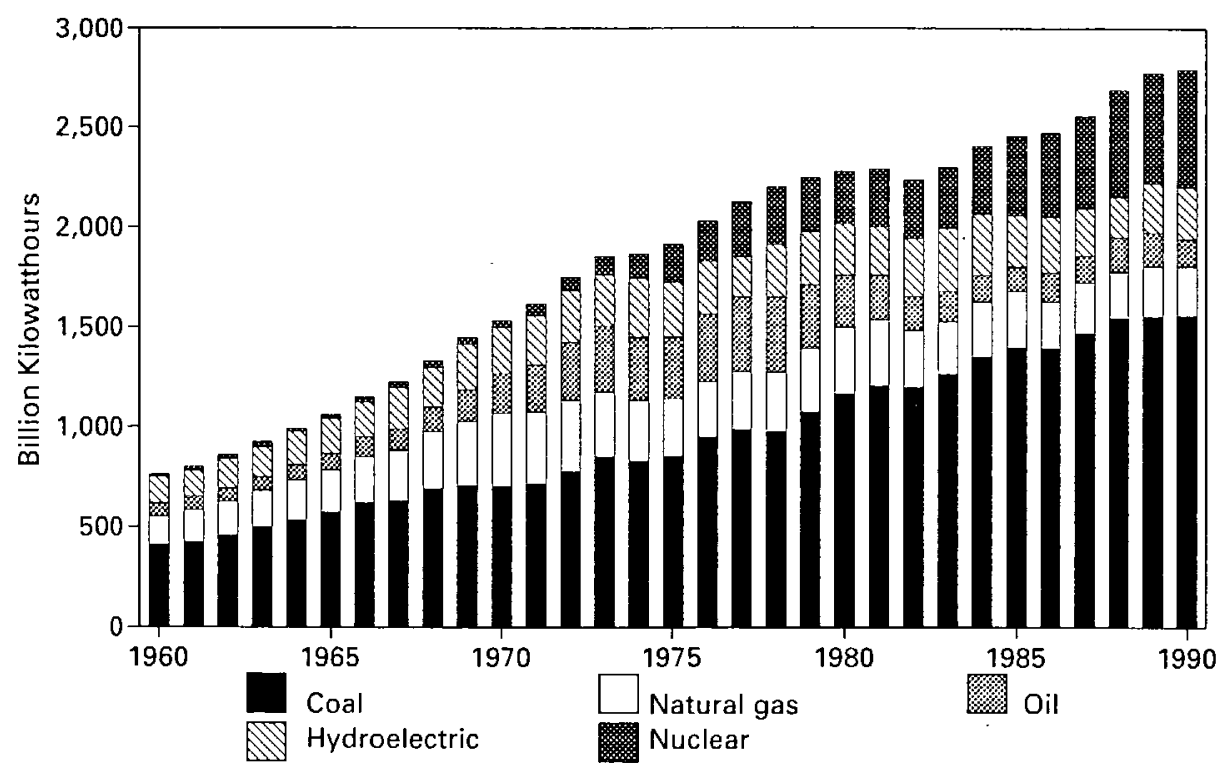

Figure 15. Primary sources of U.S. electricity for 1990. From U.S. Council on Environmental Quality (1992a).

cycle powerplants are less expensive to build and operate, they are more efficient, and their overall emissions are 60 percent lower compared to coal-burning powerplants. Substitution of natural gas in place of coal in the electricitygeneration sector could reduce industrial and urban air pollution, acid precipitation, and exacerbation of the greenhouse effect.

In transportation applications, substitution of naturalgas-powered vehicles for traditional gasoline-powered vehicles can improve urban air quality. Natural-gas-powered vehicles produce less than half the overall tail-pipe emissions of a conventional gasoline-powered vehicle. They emit far less $\mathrm{CO}, \mathrm{NO}_{\mathrm{x}}$, and VOC's than conventional gasoline and diesel vehicles, and, therefore, have tremendous potential to reduce smog levels in our urban areas. Issues of safety and convenience have so far restricted the use of natural-gas-powered vehicles to municipal fleets and public transport, but technology may overcome these obstacles and expand the application of natural-gas-powered vehicles to private users.

Like coal and oil, natural gas is a nonrenewable resource, and, therefore, not an ultimate solution to our energy needs. However, in the near-term it may help reduce air pollution, water pollution, and the harmful impacts of human industry on the atmosphere.

\section{REFERENCES CITED}

Ausubel, J.H., 1991, Energy and environment-The light path: Energy systems and policy, v. 15, p. 181-188.

Barns, D.W., and Edmonds, J.A., 1990, An evaluation of the relationship between the production and use of energy and at- mospheric methane emissions: Washington, D.C., U.S. Department of Energy-Carbon Dioxide Research Program, Rept. No. TRO47.

Boden, T.A., Sepanski, R.J., and Stoss, F.W., 1991, Trends '91A compendium of data on global change, Rept. No. ORNL CDIAC-046: Oak Ridge, Tennessee, Carbon Dioxide Information Analysis Center, Oak Ridge National Laboratory, 700 p.

Burnett, W.M., and Ban, S.D., 1989, Changing prospects for natural gas in the United States: Science, v. 244, p. 305-310.

Campbell, L.M., Stone, D.K., and Shareef, G.S., 1991, Sourcebook--NO $\mathrm{N}_{\mathrm{x}}$ control technology data, Rept. No. EPA-600/291-029: Research Triangle Park, North Carolina, U.S. Environmental Protection Agency, Environmental Protection Technology, $58 \mathrm{p}$.

Conservation Foundation, World Wildlife Foundation, 1987, State of the environment-A view toward the nineties: Washington, D.C., Conservation Foundation, World Wildlife Fund.

Ehrlich, P.R., and Ehrlich, A.H., 1991, Healing the planet: Reading, Mass., Addison-Wesley Publishing Co., 366 p.

Flavin, C., 1992, The bridge to clean energy: World Watch, v. 5, no. 4 , p. $10-18$.

French, H.F., 1990, Clearing the air-A global agenda: Worldwatch Institute, Worldwatch paper, No. 94, 54 p.

Gillette, J.L., Poch, L.A., and Buehring, W.A., 1988, Regional application of natural-gas fired combined-cycle power generation, final report: Gas Research Institute/Argonne National Laboratory, No. GRI 88/0050.

Graedel, T.E., 1978, Chemical compounds in the atmosphere: New York, Academic Press, 380 p.

Graedel, T.E., and Crutzen, P.J., 1993, Atmospheric change-An Earth system perspective: New York, W.H. Freeman and Co., $446 \mathrm{p}$.

Holdren, J.P., 1992, The energy predicament in perspective, in Mintzer, I.M., ed., Confronting climate change-Risks, implications, and responses: Cambridge University Press, p. $163-170$. 
Houghton, J.T., Callender, B.A., and Varney, S.K., 1992, Climate change 1992 - The supplementary report to the Intergovernmental Panel on Climate Change (IPCC) scientific assessment: Cambridge University Press, 198 p.

Hunt, W.F., 1987, National air quality and emissions trends report, 1985: U.S. Environmental Protection Agency, Office of Air Quality Planning and Standards, No. EPA-450/4-87-001.

Jaworowski, Z., Segalstad, T.V., and Hisdal, V., 1992, Atmospheric $\mathrm{CO}_{2}$ and global warming-A critical review: Oslo, Norsk Polarinstitutt, $76 \mathrm{p}$.

Karl, T.R., 1993, A new perspective on global warming: Eos (American Geophysical Union Transactions), v. 74 , no. 2, p. 25.

Keeling, C., Bacastow, R., Carter, A., Piper, S., Whorf, T., Heimann, M., Mook, W., and Roeloffzen, H., 1989, A threedimensional model of atmospheric $\mathrm{CO}_{2}$ transport based on observed winds-1. Analysis of observational data, in Peterson, H., ed., Geophysical Monograph 55-Aspects of climate variability in the Pacific and the Western Americas: Washington, D.C., American Geophysical Union, p. 165 236.

Khalil, M.A.K., and Rasmussen, R.A., 1982, Secular trends of atmospheric methane $\left(\mathrm{CH}_{4}\right)$ : Chemosphere, v. 11, no. 9, p. $877-883$.

Khalil, M.A.K., and Rasmussen, R.A., 1988, Carbon monoxide in the Earth's atmosphere-Indications of a global increase: Nature, v. 332, no. 6161, p. 242-245.

MacDonald, G.J., 1989, Global climate change, in MacDonald, G.J., and Sertorio, L., eds., Global climate and ecosystem change: New York, Plenum Press, p. 1-95.

MacDonald, G.J., 1990, The future of methane as an energy resource: Annual Reviews of Energy, v. 15, p. 53-83.

Marland, G., and Pippin, A., 1990, United States emissions of carbon dioxide to the Earth's atmosphere by economic activity: Energy Systems and Policy, v. 14, p. 319-336.

Meehl, G.A., and Schimel, D., 1993, The coupled climate system and global change: Eos (American Geophysical Union Transactions), v. 74, no. 1, p. 2, 14.

National Acid Precipitation Assessment Program, 1990, Acid deposition-State of science and technology, Rept. 1, Emissions involved in acidic deposition processes: Washington, D.C., Superintendent of Documents, 185 p.

National Acid Precipitation Assessment Program, 1991, 1990 integrated assessment report-U.S. National Acid Precipitation Assessment Program: Washington, D.C., NAPAP Office of the Director, $520 \mathrm{p}$.
Pexton, A.F., 1984, A fuels policy into the 21st century, in Shaw, T.L., Lennard, D.E., and Jones, P.M.S., eds., Policy and development of energy resources: New York, John Wiley and Sons, p. 5-30.

Post, W.M., Peng, T.H., Emanuel, W.R., King, A.W., Dale, V.H., and DeAngelis, D.L., 1990, The global carbon cycle: American Scientist, v. 78, p. 310-325.

Quay, P., 1992, Carbon sink-The role of oceans: Geotimes, v. 37 , no. 9 , p. 16-18.

Ramanathan, V., 1988, The greenhouse theory of climate change-A test by inadvertent global experiment: Science, v. 240, p. 293-299.

Singh, M.K., 1985, Environmental concerns related to natural gas vehicles, in Klass, D.L., and Seisler, J.M., eds., Nonpetroleum vehicular fuels-CNG Fuel: Arlington, Va., Institute of Gas Technology.

Stetson, M., 1992, Relief for the ozone layer?: World Watch, v. 5 , no. 4 , p. 9,34 .

Thompson, A.M., 1992, Oxidizing capacity of the Earth's atmosphere-Probable past and future changes: Science, v. 256, no. 5060, p. 1157-1165.

Turk, J., and Turk, A., 1988, Environmental science: Fort Worth, Tex., Saunders College Publishing, Harcourt-Brace-Jovanovich College Publishers, 712 p.

U.S. Council on Environmental Quality, 1992a, Environmental quality-22nd annual report of the Council on Environmental Quality: Washington, D.C., U.S. Council on Environmental Quality, 382 p.

U.S. Council on Environmental Quality, 1992b, United States of America national report, United Nations Conference on Environment and Development: Washington, D.C., U.S. Council on Environmental Quality, 423 p.

U.S. Department of Energy, Energy Information Administration, 1992, Annual energy review: Washington, D.C., U.S. Government Printing Office.

U.S. Environmental Protection Agency, Office of Air Quality Planning and Standards, 1992, National air pollutant emission estimates, 1900-1991, E.P.A. Rept No 454/R-92-013: Research Triangle Park, N.C., U.S. Environmental Protection Agency.

U.S. Environmental Protection Agency, 1993, Anthropogenic methane emissions in the United States-Estimates for 1990 , E.P.A. Rept. No. EPA-430-R-93-003: Washington, D.C., U.S. Environmental Protection Agency, Office of Air and Radiation.

Wuebbles, D.J., and Edmonds, J., 1991, Primer on greenhouse gases: Chelsea, Mich., Lewis Publishers, 230 p. 
THE FUTURE OF ENERGY GASES

U.S. GEOLOGICAL SURVEY PROFESSIONAL PAPER 1570

\title{
An Introduction to the Use of Natural Gas and Opportunities for Greater Consumption
}

\author{
By Michael Fanelli ${ }^{1}$
}

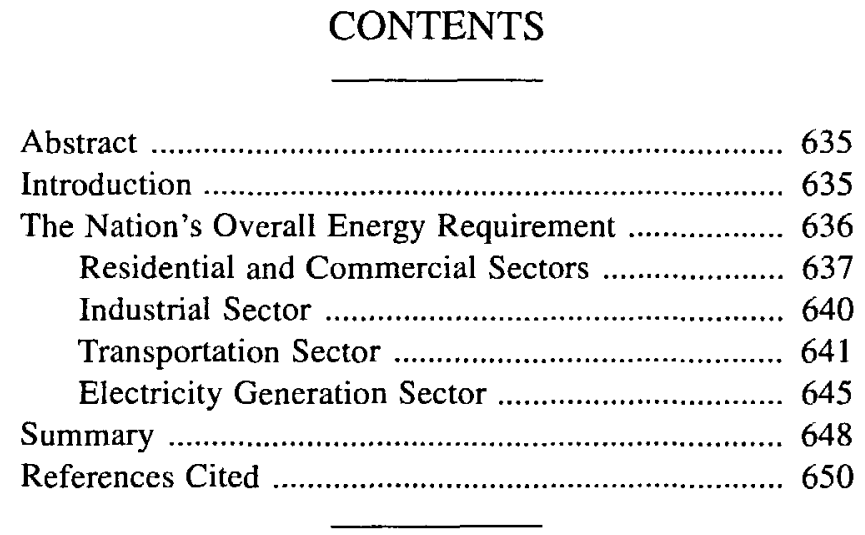

\begin{abstract}
Each sector of the U.S. economy presents different challenges and opportunities for the increased use of natural gas to meet the Nation's future energy needs. Regional and local expansions of gas-pipeline transmission and distribution systems will bring natural-gas service to many new residential and commercial customers throughout the country. The transportation sector presents a potentially large and essentially new market for natural gas. A number of issues will expedite the penetration of natural gas into the vehicle fuel market: the development and marketing of original, dedicated-fuel natural-gas vehicles and cost-effective conversion equipment and services; public relations efforts to increase awareness and acceptance of natural-gas vehicles; continuation of the natural-gas fuel-
\end{abstract}

${ }^{1}$ U.S. Geological Survey, MS 999, 345 Middlefield Rd., Menlo Park, CA 94025. price advantage over gasoline. The industrial and electricity generation sectors represent considerable potential for increased natural-gas consumption by replacement of current energy sources in fuel-switchable applications such as industrial process heat applications and steam generation for electricity generation. Competitive pricing, adequate pipeline capacity, and demonstrable operational flexibility will be the keys to successful marketing of more natural gas to the industrial and electricity generation consumer. If the natural-gas industry can successfully expand its production and distribution capability, maintain its energy price advantage, establish a reputation for reliable and flexible delivery, and continue the development of energyefficient gas-fired technologies, there is significant opportunity for greater consumption of natural gas.

\section{INTRODUCTION}

The United States has long exhibited a dependence on various forms of energy to satisfy the energy demands associated with increasing standards of living and expanding industrial activity. The requirement for energy reaches nearly every aspect of society, including the production, distribution, and utilization of physical goods and services, the conditioning of the living and working environments in homes and offices, or for transportation. In its various forms, energy is consumed to meet the requirements of a vast and diverse array of specific applications, with a widely varying intensity and technology of energy consumption among them.

In the past 50 years, this appetite for energy has been met by a variety of energy sources. During that time, fossil fuels (coal, oil, and natural gas) have provided the largest share of the Nation's total energy requirement (Energy 
Information Administration, 1992a; see Fanelli, fig. 2, this volume). As solids, liquids, and gases, these fuels are physically distributed to millions of homes and businesses throughout the country. In addition, non-fossil-fuel energy sources such as nuclear, hydro, biomass, geothermal, wind, and solar are used primarily to supplement fossil-fuel energy sources used to generate electricity. The average industrial customer consumes vast quantities of energy for heat or feedstock in industrial processes or to generate steam to power turbines for electricity generation. The choice of fuel to meet these energy needs, therefore, has a significant impact on the Nation's overall mix of fossil-fuel consumption. Only relatively tiny quantities of fossil fuels (predominately distillate fuel oil and natural gas) are consumed in individual residences and commercial buildings for space conditioning, cooking, and water heating needs. Tens of millions of these customers, however, amount to a very formidable market which represents a significant portion of the Nation's overall demand for energy.

This report summarizes the consumption of the various types of energy by different segments of the U.S. economy: residential and commercial, industrial, transportation, and electricity generation. It raises and discusses some factors which influence the choice and use of fuels by each economic sector, and it evaluates the potential for increased consumption of natural gas in the United States To some people, increased natural-gas consumption augurs a recovery from the prolonged period of depressed activity in our domestic energy industries which explore for, develop, and transport natural energy resources to end-users. To others, increased natural-gas consumption signals a mitigation of the environmental impacts of fossil-fuel combustion by reducing the emissions of greenhouse gases and atmospheric pollutants which result primarily from coal and oil combustion. To still others, natural gas presents an opportunity to eliminate or reduce our fragile dependence on foreign sources of energy, particularly oil, and the unfortunate consequences of increased military expenditures, deadly conflict, political and price instability, and the continued threat of tanker spills spoiling coastlines and marine environments.

\section{THE NATION'S OVERALL ENERGY REQUIREMENT}

In general, increased natural-gas consumption can be achieved in one or both of two ways. Either the current natural-gas market share of the Nation's total energy requirement can be increased by replacing other energy forms currently used in existing applications, or its consumption can be expanded by filling new energy needs, which result from a growing economy or, for example, from the development of new industrial applications. However, because many applications for energy, particu- larly industrial and electricity generation applications, can be served by several different energy sources, the energy markets have been and will remain very competitive among the different fuels (Gas Research Institute, 1992). Replacement of one energy supply by another will certainly be contested by competing energy producers, marketers, distributors, and equipment manufacturers who expect to maintain and expand their customer base. In many cases, the intense market competition between suppliers of different energy products is no different from the competition between manufacturers or service providers who hope to sell products or services when a competitor's product or service can just as easily fill the need. New markets for energy will also be vigorously competed for. Trade associations representing the interests of each energy commodity will continue to make sizable investments in research activities in hopes of developing technologies which favor the use of their form of energy. Each energy industry will continue to refine their product pricing and service options to justify the consumer's decision to favor one energy source over others.

At the most basic level, energy consumption involves many millions of decisions made each day to undertake some activity which has an energy component. But because these decisions are influenced by factors on both the macro and micro scale, this paper will attempt to address both. It will first introduce factors which influence overall energy consumption, then it will focus on individual economic sectors and their energy consumption.

Historically, the trend in U.S. total energy consumption has correlated relatively closely to economic activity. During periods of economic expansion, as measured by the Nation's inflation-adjusted gross domestic product (GDP), the Nation's energy consumption has tended to increase. Likewise, during periods of economic contraction, energy consumption has tended to decline. The trend in U.S. energy consumption and real GDP (\$1987) over recent decades is shown in figure 1. With the exception of a couple of relatively minor recessionary interruptions, the United States has experienced a persistently expanding economy over the past several decades. Until 1973, there was a consistent and uniform correlation between economic activity and energy consumption; as the economy grew in real terms, energy consumption kept equal pace. As a measure of the Nation's efficiency of energy consumption, the quantity of energy consumed per dollar of GDP fluctuated narrowly between 21,000 and 23,000 Btu (British thermal unit) per dollar of economic activity. Little to no improvement in the overall efficiency of energy consumption was achieved during this period. Since 1973, however, the correlation between economic activity and energy consumption has changed. Energy consumption has not kept pace with economic production, signaling a period of increasing energy efficiency (fig. 1). While the pattern of energy consumption is similar to that of economic activity, 


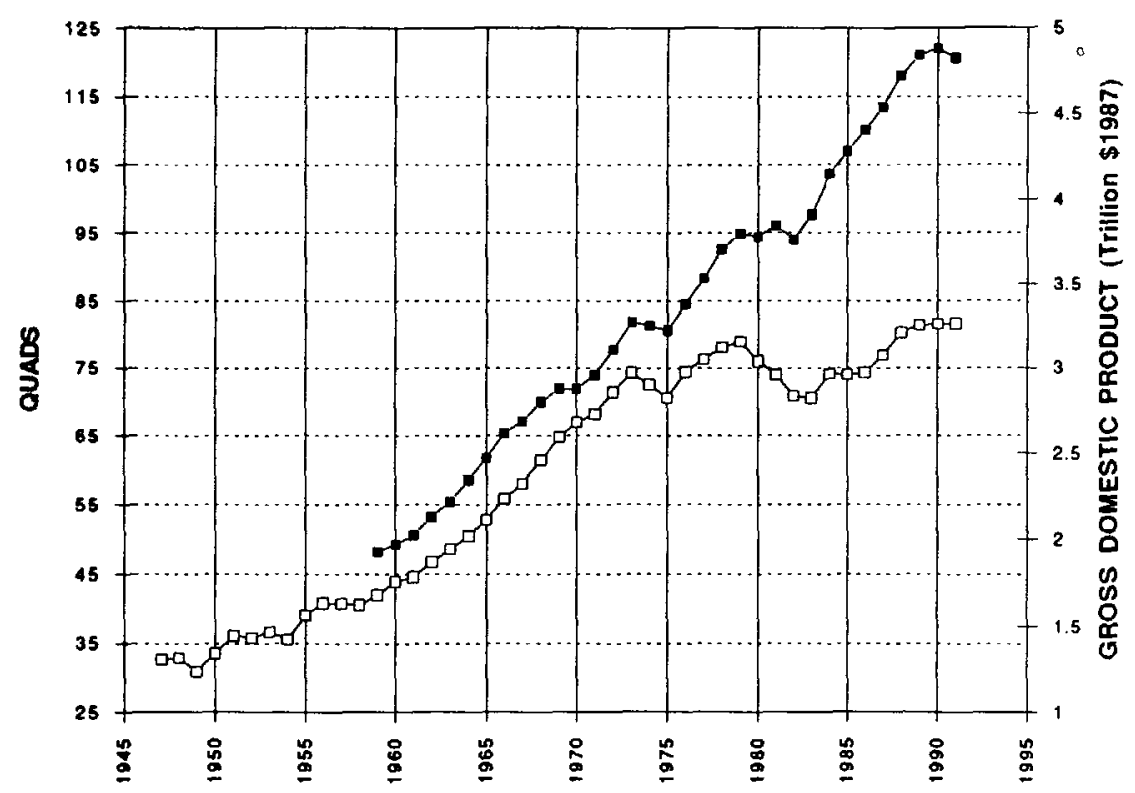

Figure 1. U.S. primary energy consumption (open squares, left scale) and U.S. gross domestic product (GDP) (closed squares, right scale). Data from Energy Information Administration (1992a). 1 quad $=10^{15}$ Btu (British thermal units).

the Nation's efficiency of energy consumption improved from 23,000 Btu per 1987 dollar of GDP in 1973 to 17,000 Btu per dollar in 1990 . This represents a reduction of more than 25 percent in the energy consumed per dollar of economic output.

Most of the changes in trends of energy consumption and efficiency of energy use can be attributed to changes in economics, technology, demographics, and attitudes about energy conservation. During the mid-1970's and early 1980 's, the United States experienced rapidly rising costs of energy, primarily as a result of significant increases in the cost of imported crude oil supplies. Rising crude oil prices led to increases in various refined oil products such as distillate and residual fuel oils and motor gasolines. Natural gas and coal prices also increased substantially during the same period (Energy Information Administration, 1992a; see Fanelli, this volume). Higher energy prices had the effect of increasing the costs of living and of doing business. These higher prices dampened economic activity, contributing to the economic recessions of the mid-1970's and early 1980 's. Demand for energy declined during these periods. Higher energy prices, however, also stimulated greater research and investment in new equipment and businesses which focused on more efficient energy consumption technologies. Many new and more efficient energy-consuming technologies (for example, improved air heating and cooling equipment used for conditioning living and working environments (Gibbons and Blair, 1990), and motor vehicle improvements that increased their fuel efficiency (Energy Information Administration, 1992a)) were developed, which improved the Nation's energy consumption per unit output of goods and services. This allowed a continuation in the Nation's economic growth at lower levels of energy consumption.

Other improvements in energy consumption were realized by greater population and housing growth in southern and western regions, where milder climates require lower levels of energy consumption for space conditioning. Of the approximately 18 million housing units that were added between 1977 and 1989 in the United States, approximately 68 percent were located in the South and West (American Gas Association, 1992). In addition, changes in the mix of industrial production away form energy intensive manufacturing toward more service-based industries has resulted in a lower overall energy requirement per dollar of GDP (Gibbons and Blair, 1990).

The future trend in the Nation's overall energy requirement will continue to be influenced by several factors. Opportunities for increased natural-gas consumption, or any other energy source, as a result of economic expansion will likely be in the context of increased competition between fuels and their consumption technologies and delivered energy prices, attitudes about conservation, continued realignment of the industrial mix, and continued regional redistribution of population growth and housing construction.

\section{RESIDENTIAL AND COMMERCIAL SECTORS}

When disaggregating the Nation's total energy consumption into specific economic sectors and energy applications, the residential and commercial sectors of the economy 
include households and nonmanufacturing businesses. The commercial sector includes office buildings, retail outlets, warehouses, government buildings, schools, hospitals, hotels, and others. Because these two sectors consume energy primarily for space conditioning purposes, they are often grouped together for energy consumption evaluation.

The trend in overall energy consumption in the United States residential and commercial sector during the period 1947-1991 is shown in figure 2. After rising rapidly during the 1950 's and 60 's, total energy consumption in this sector has remained relatively stable since the early 1970's, despite large increases in the number of housing units and square footage of commercial space. This is a result of greatly reduced per-household and per-commercial-squarefoot energy consumption. The reduced consumption per household and commercial square foot can be attributed to the following:

1. Improvements in the thermal integrity (for example, insulation and windows) of residential and commercial structures (see Mills, this volume).

2. Greater efficiency of new space conditioning equipment installed in new structures, and replacing existing equipment (Gibbons and Blair, 1990).

3. More conservative attitudes about energy consumption resulting in greater tolerance of a wider range of temperatures in residential living space, and less energy waste.

4. Greater population and housing stock growth in more temperate regions which require less energy for space conditioning (American Gas Association, 1992).
The history of consumption of individual forms of energy during 1950-1991 in the residential and commercial sector is shown in figure 3. Also shown are data concerning the number of housing units using specific types of fuels, primarily for space-heating purposes.

Increased natural-gas consumption in the residential and commercial sector will depend on several factors: (1) the ability of natural-gas service to meet the energy needs in new buildings; (2) the ability of the natural-gas industry to increase its current market share in existing buildings by (a) retaining its current customers and (b) capturing new customers in the equipment replacement market; (3) improving energy efficiency in space-heating equipment and the thermal integrity of buildings.

Natural gas competes with electricity and fuel oils for the space conditioning and water heating requirements of new construction only in geographic regions where gas services already exist or are scheduled to be installed. Large regional differences are evident in the availability and choice of energy sources for various commercial and residential applications. For example, in Florida's househeating-fuel market, electricity currently has a 79 percent share and natural gas only 8 percent. In Michigan the situation is reversed, natural gas has a 77 percent share and electricity only 5 percent (American Gas Association, 1992). Florida's much warmer climate and greater demand for space cooling, an application which is dominated by electricity-powered appliances, has made electricity the favored fuel choice.

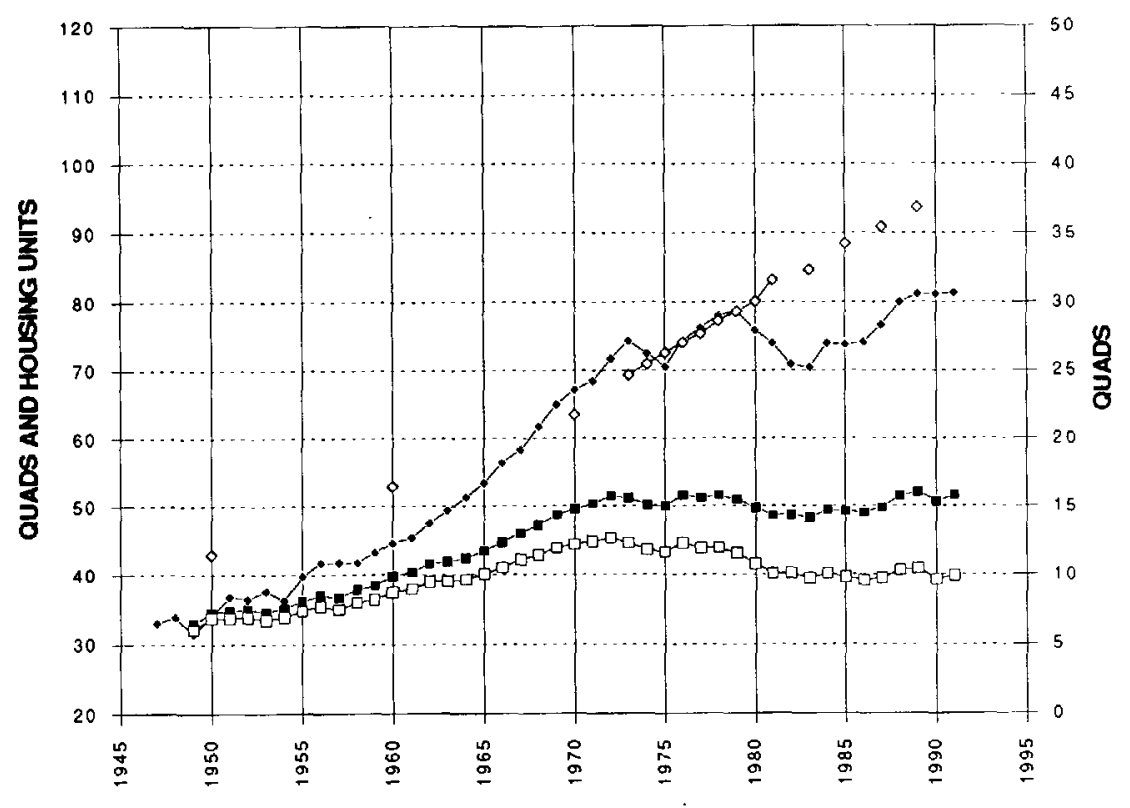

Figure 2. U.S. total primary energy consumption (solid diamonds, left scale), residential and commercial sector total energy consumption (solid squares, right scale), residential and commercial total primary energy consumption (open squares, right scale), and number of housing units (open diamonds, left scale, in millions). Data from Energy Information Administration (1992a). 1 quad=10 15 Btu (British thermal units). 

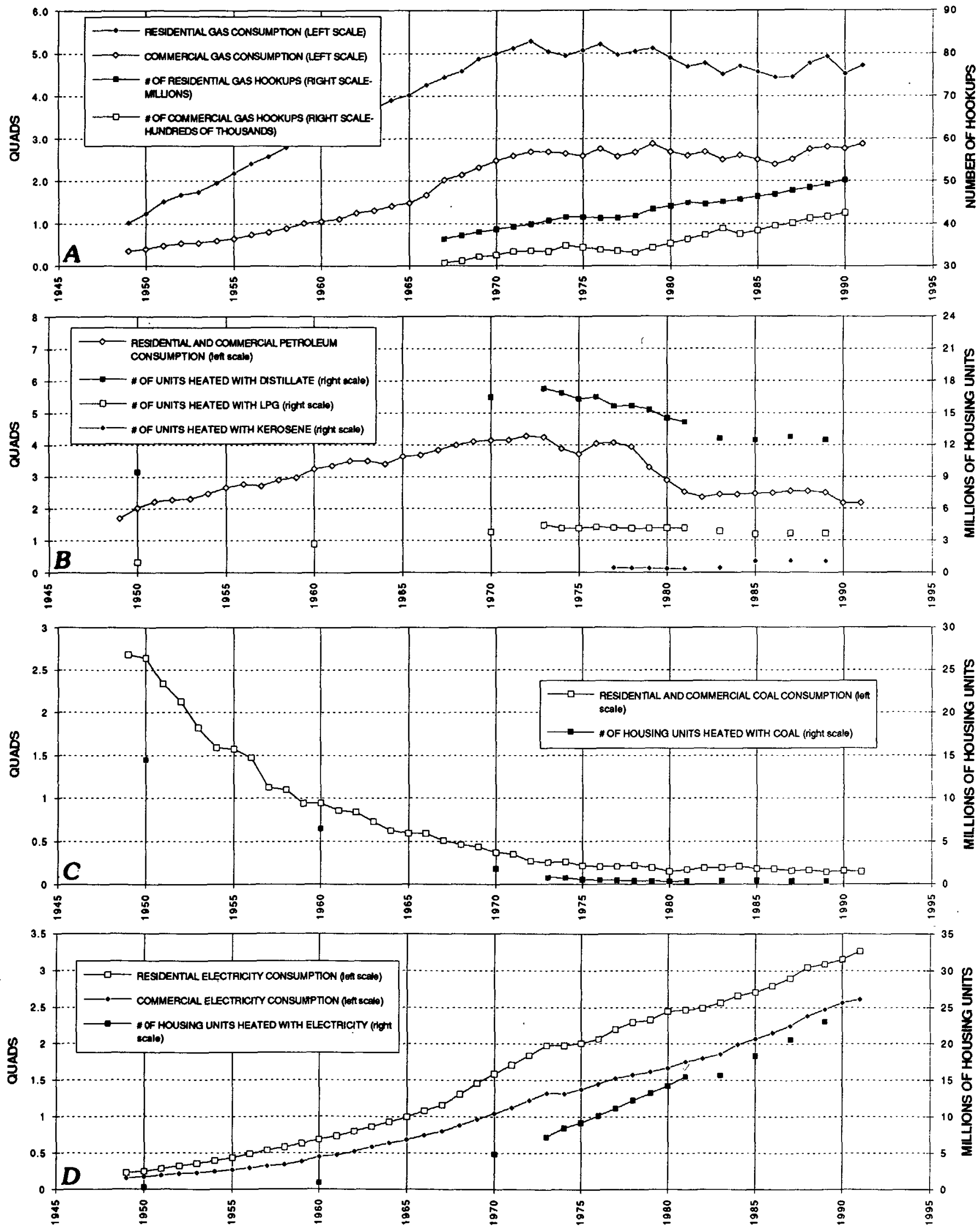

Figure 3. Residential and commercial sector historical energy consumption. $A$, Natural gas; $B$, Petroleum; $C$, Coal; $D$, Electricity. Data from Energy Information Administration (1992a); American Gas Association (1992). 1 quad=10 ${ }^{15}$ Btu (British thermal units). 
Population shifts that might occur, for example, as a result of the Nation's uneven economic development and activity, will impact regional construction rates of housing units and commercial square footage. The mix of singlefamily versus multifamily housing units will also be a factor because of perceived disadvantages of gas service installation in multifamily construction. In the southern and western parts of the country, where energy choice is dominated by space-cooling requirements, electricity may continue to be favored.

As residential and commercial energy-consuming equipment reaches the end of its useful life and is considered for replacement, opportunities for conversion to a different energy source exist. The availability, reliability, and cost of alternative fuels, as well as the cost of conversion, and the efficiency and performance of alternative equipment will be factors in decisions to convert to alternate fuels. Because there are considerable differences in the delivered cost of different energy sources in each region, and very wide price variations between regions, the importance of end-user cost of energy will vary from region to region. For example, in the New York/New Jersey region, the average cost of electricity delivered to a residential customer is more than 4 times the average cost of an energy-equivalent amount of natural gas (Energy Information Administration, 1992b). Electricity has only a 10 percent share of the residential heating market in this region (American Gas Association, 1992). In northwestern states, electricity is considerably less expensive, averaging less than 3 times the cost of natural gas. As a result, in the State of Washington, electricity has more than 50 percent of the residential heating market (American Gas Association, 1992).

As shown on figure 3 , coal consumption has diminished in the residential and commercial sector to approximately 0.2 quad ( 1 quad $=10^{15}$ Btu's) per year (fig. $3 A$ ). Replacement of this relatively small market by natural gas will be difficult owing to limited accessibility of gas service in areas of coal consumption. Total replacement of the entire coal market by gas would contribute only slightly to total gas consumption. Petroleum consumption is currently approximately 2 quads per year, significantly lower than the highs of greater than 4 in the 1970's (fig. $3 B$ ). Petroleum consumption in the residential and commercial sector is a market that continues to offer opportunities for greater gas consumption. In areas where gas service is available, gas technologies for space and water heating could compete favorably with petroleum. Continued expansion of the gas distribution system and continued price advantages of natural gas over petroleum will favor the selection of gas over oil when equipment replacement decisions are made. Petroleum use is concentrated along the East Coast, exceeding 50 percent of the residential heating market in New England, and averaging 33 percent in middle Atlantic states (American Gas Association, 1992).
As structures are built or updated with greater thermal integrity, and as existing equipment is replaced with more energy efficient types, the average energy requirement per housing unit will continue to decline (see Mills, this volume). This will limit the growth in energy consumption in the residential and commercial sectors. It is likely, therefore, that growth in energy consumption in this sector will be small.

\section{INDUSTRIAL SECTOR}

The industrial sector is a large energy-consuming sector of the U.S. economy. In particular, four segments of the industrial sector (paper and allied products, chemical and allied products, petroleum and coal products, and the primary metals industry) accounted for approximately 16 quad (quadrillion Btu), or approximately 70 percent of the total energy consumed by the industrial sector. The industrial sector consumes a wide variety of energy products for a diversity of specific applications. The trend of industrial energy consumption during 1960-1991 is shown in figure 4. Also shown is the Nation's overall energy consumption. Additionally, industrial energy consumption is shown with and without electricity. Like the residential and commercial sector, the industrial sector also experienced strong growth in energy consumption until the early 1970's, after which time the pattern of steadily increasing energy consumption was replaced by a period of wide fluctuation in energy consumption (Energy Information Administration, 1991a). This period was punctuated by pronounced declines in overall energy consumption during economic recessions. Energy consumption in the industrial sector has also been impacted greatly by the changing mix of industrial activity. Energyintensive manufacturing is gradually being replaced by service-oriented businesses, which require less energy (Gibbons and Blair, 1990). As in other economic sectors, opportunities for increased natural-gas consumption in the industrial sector will depend on either (1) increased demand for energy supplies due to an expansion or change in industrial activity or (2) capture of a greater market share of the current industrial energy requirement.

Industrial energy consumption can be divided into feedstock and fuel/power uses. As feedstocks, natural gas, petroleum, and small amounts of coal are consumed as raw materials in processes. Feedstock use of energy represents approximately 25 percent of the total consumption of energy in the industrial sector. Due to physical and chemical differences between the various energy forms, it is unlikely that significant replacement of energy supplies will occur in the feedstock market. Changes in consumption levels of individual fuels for feedstock and raw material use will largely depend on changes in demand for finished products.

The largest portion of energy consumed by industry is combusted for steam production, onsite electricity genera- 
tion, and the production of heat. This represents a very competitive market, as any of several fuels can provide the needed services (Energy Information Administration, 1991b). Individual fuel choice decisions in the industrial sector are impacted primarily by supply availability and reliability, price differential, efficiency of consumption, installed equipment fuel capability, emerging technologies, and environmental and regulatory constraints on fuel consumption.

The history of consumption of natural gas, petroleum, coal, and electricity in the industrial sector from 1960 to 1991 is shown in figure 5. Coal consumption has been steadily declining while electricity consumption has been steadily increasing (figs. $5 C, D$ ). Natural-gas and oil consumption has varied significantly during the period. During the late 1970's, natural gas was often in short supply during peak demand months and industrial customers often had their gas supplies curtailed in favor of residential and commercial customers. Oil consumption rose to meet energy demand during the period of gas shortages, but rising oil prices of the late 1970's and early 1980's discouraged demand for oil (fig. $5 B$ ). As gas supplies and deliverability recovered in the early to mid 1980 's, gas prices rose during a period of falling international oil prices. This caused many industrial consumers to reduce gas consumption in favor of alternative energy sources. Since the mid 1980's as the price of gas has fallen in adjustment to deregulation and market forces, gas demand and consumption has substantially increased (fig. 5A). This illustrates the nature with which choices of energy supply in the industrial sec- tor can fluctuate according to fuel-price differentials and regulatory constraints and concerns. If the U.S. economy continues to shift away from the energy-intensive manufacturing activities toward more service-oriented businesses, it is likely that the mix of fuels consumed by industry will continue to change.

\section{TRANSPORTATION SECTOR}

The transportation sector of the U.S. economy is predominantly and historically an oil-consuming sector. This sector includes fuel consumption for motor vehicles, trains, planes, ships, as well as compressor stations which move natural gas through pipelines to markets. Figure 6 shows the overall energy consumption in the transportation sector from 1947 to 1991 . As in other sectors, energy consumption for transportation experienced rapid growth until the mid-1970's, after which the trend has been irregular, but generally increasing. Consumption has been impacted by economic recessions as well as substantial improvements in efficiency, which have been mandated by government regulation. For example, the CAFE (corporate average fuel efficiency) standards for U.S. manufactured automobiles requires manufacturers to meet fuel efficiency (miles per gallon) goals in new models.

The history of consumption of various fuels for transportation service from 1947 to 1991 is shown on figure 7 . Consumption of natural gas at compressor stations is largely a function of total deliveries of natural gas and has

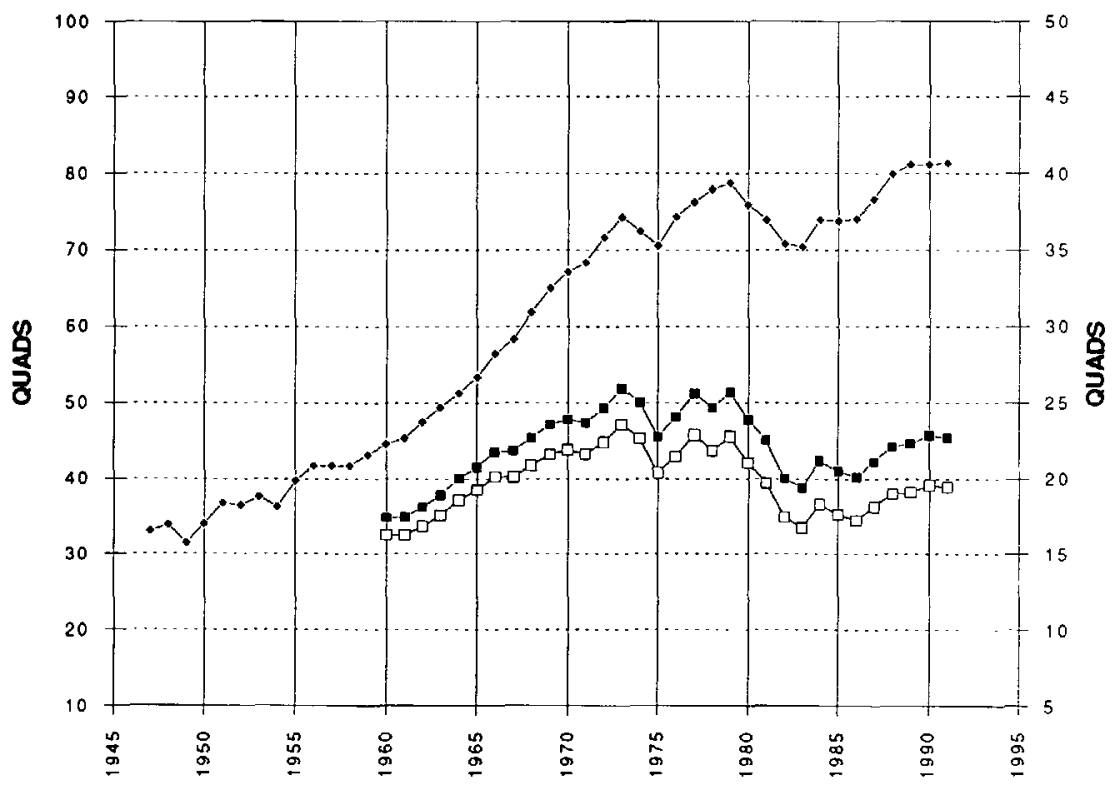

Figure 4. Industrial sector total energy consumption (solid squares, right scale), primary energy consumption (open squares, right scale), and total U.S. energy consumption (solid diamonds, left scale). Data from Energy Information Administration (1992a). 1 quad=10 ${ }^{15}$ Btu (British thermal units). 

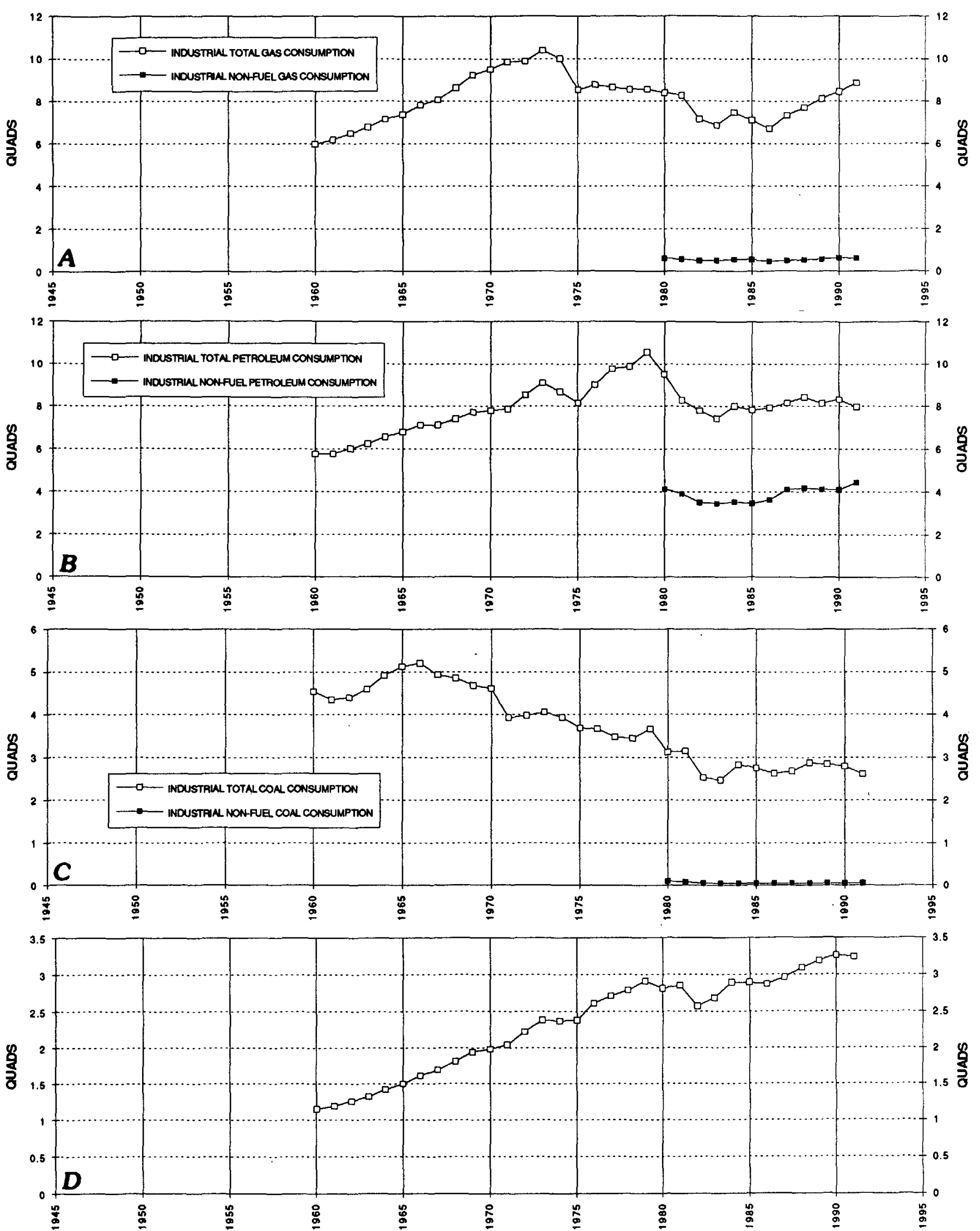

Figure 5. Industrial sector historical energy consumption. $A$, Natural gas; $B$, Petroleum; $C$, Coal; $D$, Electricity. Data from Energy Information Administration (1992a). 1 quad=10 $0^{15}$ Btu (British thermal units). 
fluctuated in a similar fashion to total natural-gas demand (fig. $7 A$ ). Coal consumption for transportation has declined to very small quantities today (fig. $7 C$ ). Electricity consumption for transportation is also very small (fig. $7 D$ ). Approximately 97 percent of the energy requirements for transportation services has been met by petroleum derivatives, primarily motor gasoline, diesel, and aviation fuel (fig. $7 B$ ).

Significant opportunity exists for greater natural-gas consumption in the transportation market (Energy Information Administration, 1992b; Gas Research Institute, 1988; Gott, 1992; National Petroleum Council, 1992; National Research Council, 1990; Seisler, 1992; Webb and Farrell, 1993). At the same time, however, there are significant obstacles which may limit the magnitude of the market for natural gas in the transportation market, or may limit the pace at which natural gas captures a portion of the transportation fuel market. Natural gas, in compressed form, has already been proven to perform well in internal combustion engines (Adams, 1985; Messera, 1985; Sprague, 1985). Natural gas vehicles (NGVs) are currently in operation in most states (Gott, 1992). Gas utilities have the greatest experience with these vehicles, but, increasingly, private fleet vehicle operators are finding that natural gas offers an attractive alternative to conventional fuels. In many places, natural gas has been available at $\$ 0.60$ to $\$ 0.70$ per gallon of gasoline equivalent (excluding taxes), a significant savings over gasoline and diesel. (If natural gas used as a vehicle fuel were to be taxed at an equivalent rate as gasoline, the price benefit of natural gas would be significantly reduced or eliminated). For high mileage, centrally fueled fleets that have high fuel expenses, conversion to natural-gas fuel can result in fuel savings.

The successful penetration of natural gas into the vehicular fuel market, however, depends on the resolution of several issues which are currently limiting its use:

1. Vehicles that currently operate on gasoline must be fitted with special equipment which will allow them to operate on natural gas. Specially designed cylinders for on-board storage of compressed natural gas are required. Additional fuel lines carry the compressed gas from storage to a regulator which reduces the pressure and delivers gas to mixers and nozzles which feed the gas to the engine at the proper flow rate. Other items adjust the engine for the proper spark and ignition timing when operating on natural gas. Currently, conversion of a vehicle to naturalgas operation can be expensive. This greatly reduces the economic benefits of the lower cost of natural gas vs. gasoline. As the cost of conversion declines, more vehicle owners may justify the initial expense as a trade-off for lower fuel costs.

2. The availability of natural-gas fuel for vehicular use is probably the biggest limiting factor to NGV acceptance. In order to carry enough fuel for an acceptable driving range, gas is stored under high pressures in cylinders, and special refueling facilities are required to dispense compressed gas. While compression technology is rapidly developing and more natural-gas fueling facilities are being built, there are still very few public fueling stations. Some operators of large fleets (delivery services, taxis, airport

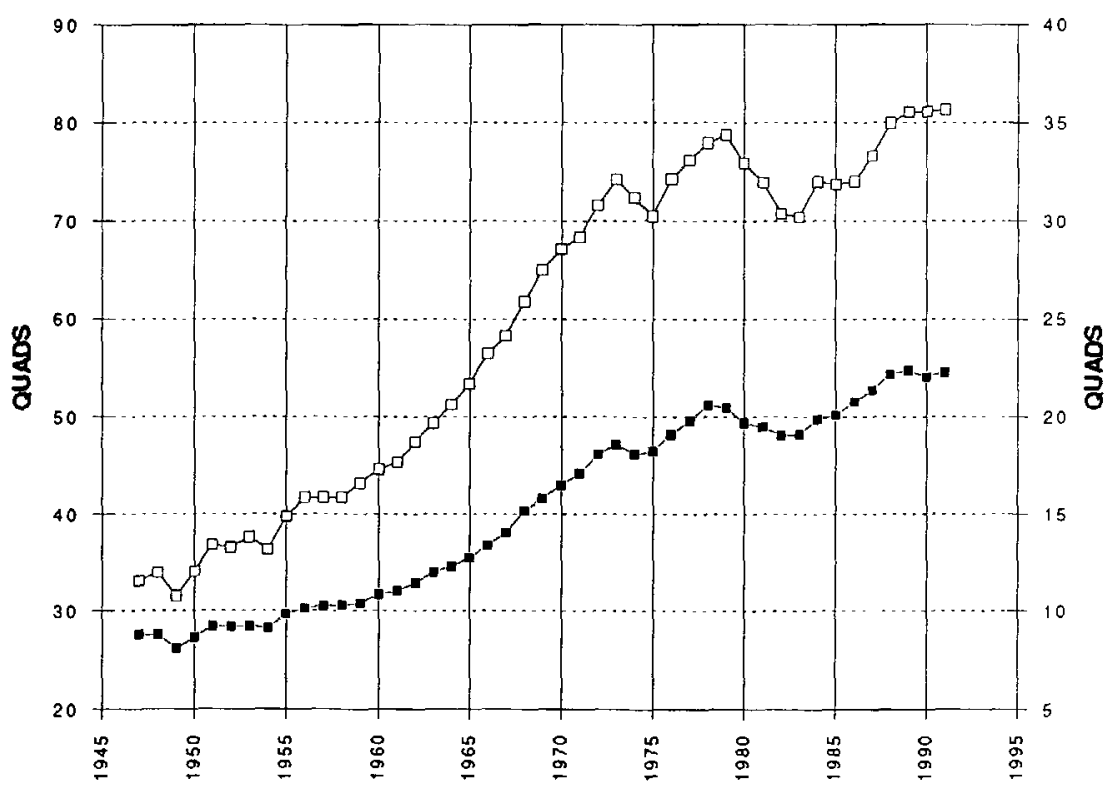

Figure 6. Transportation sector historical total energy consumption (solid squares, right scale) and U.S. total primary energy consumption (open squares, left scale). Data from Energy Information Administration (1992a). 1 quad=10 $0^{15}$ Btu (British thermal units). 

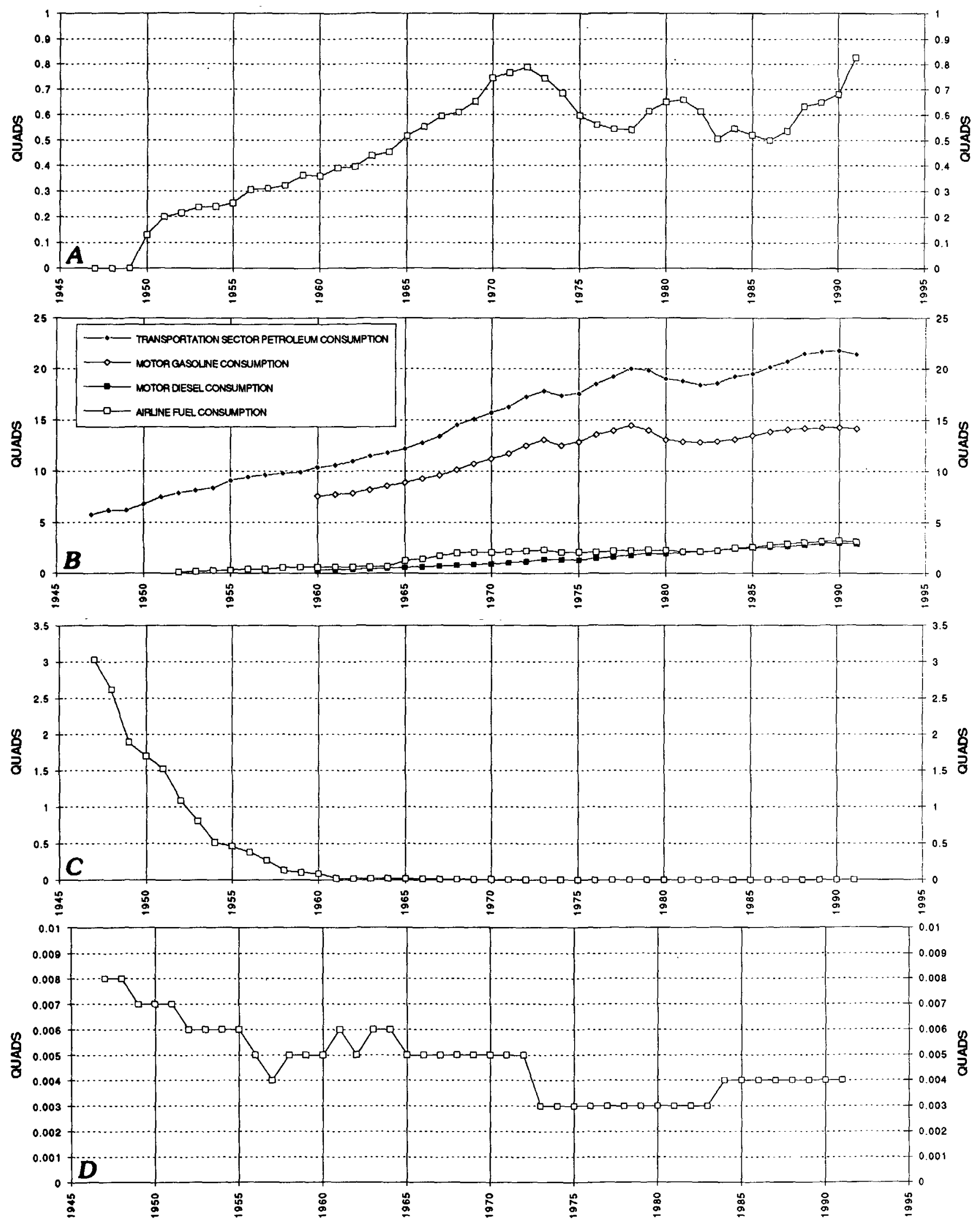

Figure 7. Transportation sector historical energy consumption. $A$, Natural gas; $B$, Petroleum; $C$, Coal; $D$, Electricity. Data from Energy Information Administration (1992a). 1 quad=10 15 Btu (British thermal units). 
shuttles, and so forth) which operate vehicles within short distances from a central point have invested in private compression/fueling facilities. Operators of smaller fleets and individual car owners can be convinced to convert to natural-gas use only when suitably convenient fueling facilities exist for them.

3. In addition to the economics of conversion and the development of a refueling infrastructure, other impediments to vehicular natural-gas use are: (1) public awareness and acceptance of a new and different fuel; (2) acceptance of shorter vehicle range versus gasoline due to the limited gas storage capacity in most cases; (3) industry standardization of refueling couplings; (4) concerns about the safety of carrying highly compressed, flammable fuel on-board; (5) NGV driving performance versus gasoline; (6) the frequency, expense, and availability of NGV maintenance services versus gasoline and diesel operation; (7) reasonable assurances of stable and favorable natural-gas fuel costs; (8) validation of vehicle warranty for conversions; (9) the availability of original, dedicated NGVs to eliminate the expense of after-market conversion to natural gas; $(10)$ the availability of cost-effective, private, home-fueling compression equipment which would encourage commuter-vehicle operation despite (or in addition to) a minimal public refueling infrastructure; (11) Federal, state, and local government cooperation/involvement with NGV regulation and restriction, fuel price and fuel tax issues, environmental regulation, refueling-station siting, and construction regulation.

Recent legislation, the Federal Clean Air Act Amendments of 1990, requires states to develop plans for reducing air pollution. Unless states institute their own programs prior to Federal deadlines, the Act has provisions taking effect in the late 1990's which require the cities with the dirtiest air to have increasing numbers of "clean-fuel" vehicles in fleets. Because natural gas meets the definition of a "clean fuel," many see these environmental compliance requirements as the beginning of a new and greatly expanded phase in natural-gas use as a vehicle fuel. If, for example, one-quarter of the motor gasoline currently consumed in the United States were to be replaced by natural gas, approximately 3.5 quads of natural gas (equivalent to approximately 3.5 trillion cubic feet) would be necessary to meet the additional demand. That amount represents an increase of approximately 18 percent in the current rate of consumption of natural gas in the United States. It also may be considerably greater than the current natural-gas production and delivery capacity. Many see the eventual development of a broad natural-gas refueling and maintenance infrastructure, which will assuage operators concerns about fuel availability and vehicle operation, and allow far greater travel distances than currently possible.

There are, however, alternative fuels, such as reformulated gasoline, methanol, ethanol, and electricity, which also meet the "clean fuel" definition (Gott, 1992). Competition between these fuels and natural gas will likely be very keen. Technology development, fuel efficiency and performance, and fuel price differentials will play key roles in the adoption of these various fuels.

\section{ELECTRICITY GENERATION SECTOR}

Electricity generation consumes the largest quantity of energy of all the economic sectors. In 1991, electricity

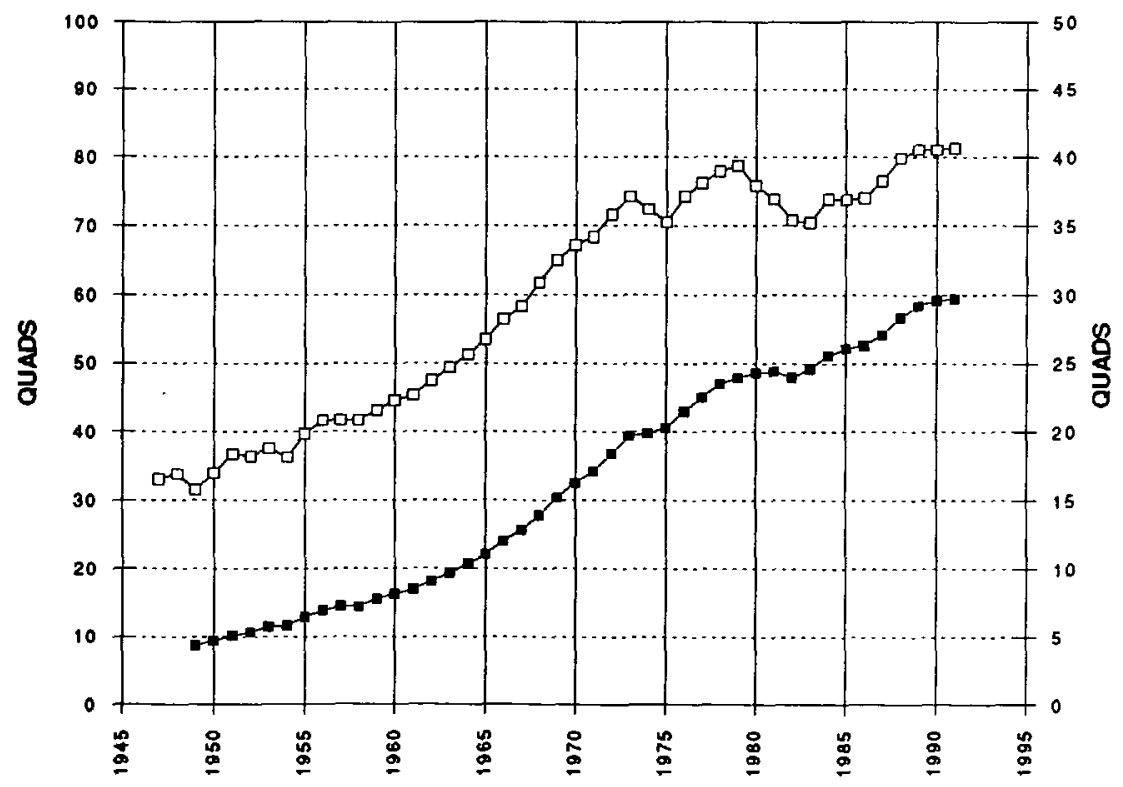

Figure 8. Electricity generation total energy consumption (solid squares, right scale) and U.S. total energy consumption (open squares, left scale). Data from Energy Information Administration (1992a). 1 quad $=10^{15}$ Btu (British thermal units). 
generation accounted for nearly 40 percent of the Nation's total energy consumption, having steadily increased from less than 15 percent in 1950 (fig. 8). In particular, the residential and commercial sector, as well as the industrial sector, has experienced substantial increase since 1960 in the amount of electricity consumed (figs. $3 D, 5 D$ ). Because of the convenience, versatility, and acceptance of electrotechnologies, electricity has captured increasing amounts of the market for energy services. While electricity will continue to encounter considerable competition in certain applications that are also served by other fuels, such as the use of natural gas and fuel oil for space heating, there are many applications which can only be met by electricity, such as lighting, home appliances, and business equipment.

Electricity generation can be disaggregated into different types according to the principal methods of electricity production at powerplants: steam turbines driven by heat generated from fossil fuel combustion or nuclear reactors, internal combustion engines and gas turbines, and hydraulic turbines. Relatively minor amounts of electricity are generated by geothermal operations, solar steam and photovoltaic technologies, and wind turbines. On figure 9 , the historical trend shows that since 1950 most of the increased electricity generation has been accomplished by greater amounts of fossil-fueled steam generation, with increasing contribution by nuclear power since the development of nuclear power technologies during 1970's. Figure 10 shows how fossil steam generation has become increasingly dominated by use of coal as the energy supply. Cur- rently, coal accounts for approximately 75 percent of the fossil energy consumed for electricity generation.

The demand for fuels used to generate electricity is, of course, driven by the demand for electricity from endusers in other sectors, principally the residential and commercial and industrial sectors. In these sectors, the level of electricity demand is dependent upon the share it captures of the overall energy demand. As discussed in the previous sections covering each sector, there is considerable competition between energy sources for various energy applications. The overall demand for electricity will depend on the following factors:

1. The rate of construction of new housing units and commercial buildings. Greater growth in southern and western regions with climates requiring space cooling favor a greater market share for electricity, the predominate energy source for space-cooling equipment.

2. Improvements in the efficiency of energy consuming equipment and greater thermal integrity of building shells. Heating, cooling, and lighting services that can be delivered with less energy consumed will mitigate the growth in energy demand caused by increasing residential and commercial square footage.

3. Consumer attitudes regarding energy conservation. Reductions in unnecessary energy consumption through energy audits.

4. The continued proliferation of electrical appliances for personal and business use, and development of electrotechnologies for industrial applications.

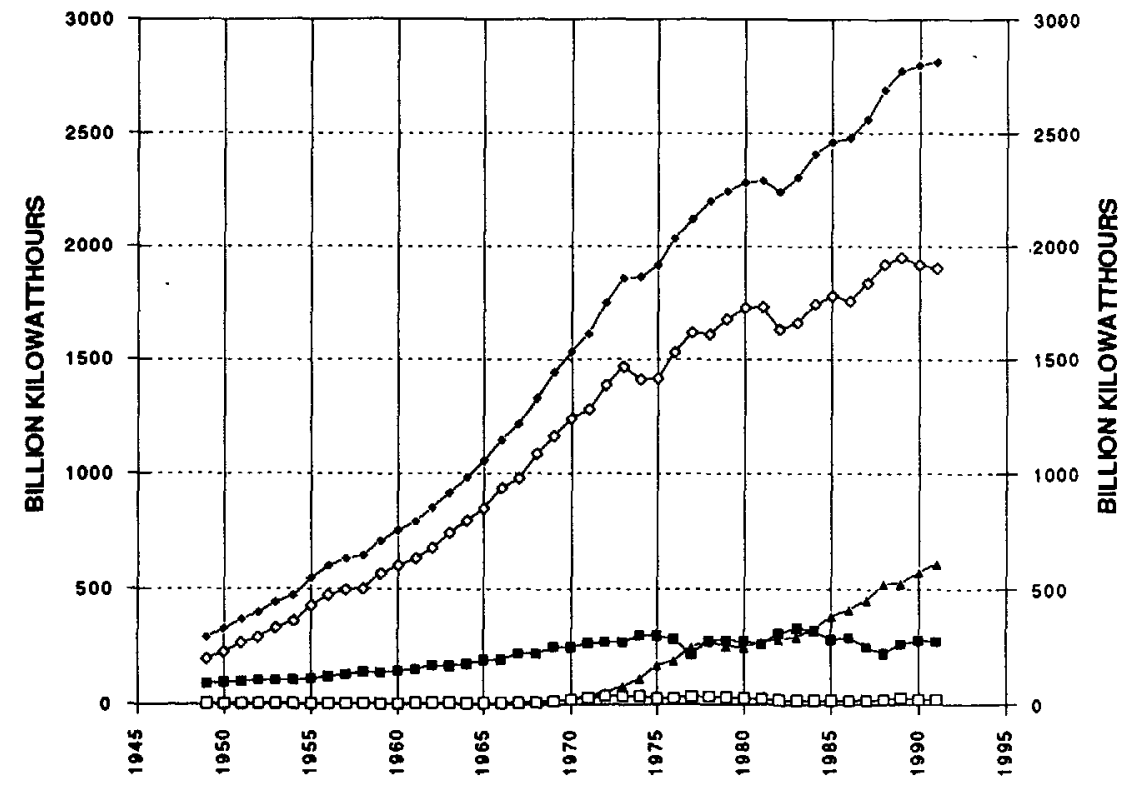

Figure 9. Electricity generation historical generating capacity. Solid diamonds, total capacity. Open diamonds, fossil steam capacity. Solid triangles, nuclear capacity. Solid squares, hydroelectric capacity. Open squares, internal combustion and gas turbine capacity. Data from Energy Information Administration (1992a). 
The opportunities for increased use of natural gas in electricity generation, however, depend on the competition between the options for generating electricity to meet demand (Electric Power Research Institute, 1992). There are a number of factors which will influence the fuel choice for electricity generation:

1. The availability of current generating capacity.-In places, increased electricity demand may be met by greater utilization of unused capacity in existing facilities. Some nuclear reactors are still operating at less than full capacity. In places where electricity demand is projected to exceed capacity, natural gas may be considered in the plans to construct new generating capacity.

2. The availability of fuel supply.-While solid and liquid fuels (coal and oil) can be transported by vehicles to powerplants and stored on-site until used, the delivery of sufficient quantities of natural gas for powerplant operation requires the construction of pipelines to bring gas supplies from producing regions and underground storage sites. Increased gas consumption for electricity generation will depend on sufficient pipeline capacity to meet a powerplant's gas demand.

3. The required flexibility of power generation.--Electricity demand varies widely and rapidly in hourly, daily, and seasonal pattems that result, for example, from differences between daytime and nighttime electricity requirements, diminished utilization of some commercial buildings during weekends, and weather fluctuations. Because electricity cannot be stored, the generation of electricity to instantaneously match demand requires considerable flexibility. Utilities use a variety of generating facilities which provide flexibility to meet the fluctuating demand. The majority of electricity is generated at base-load plants which routinely produce the minimum electricity demand. These plants require less flexibility because they operate essentially continuously. Other plants are designed to meet weekly, daily, and hourly demand fluctuations above the levels produced by the base-load plants. This electricity demand is often referred to as intermediate and peak demand. Because peak electricity demand can change very rapidly as homes and business activate space conditioning equipment to compensate for temperature fluctuations, the plants which provide electricity to meet these intermediate and peak loads have to respond quickly. Some gas-fired technologies, particularly gas turbines, are well suited for meeting rapid electricity demand fluctuations because they can be started very quickly and operated more flexibly than base-load plants

4. Cost of construction.-As growth and changes in electricity demand forces the construction of additional generating facilities, the cost of various plant designs and fuel options will be major factors in selecting from the investment options. Some gas-fired generating technologies, particularly turbines, have significantly lower capital requirements than nuclear and coal-fired plants. In addition, gas-fired plants can normally be sited, permitted, and constructed in much less time than others.

5. Fuel cost.-Because electricity generation is such an energy-intensive industry, the cost of fuel is a large factor

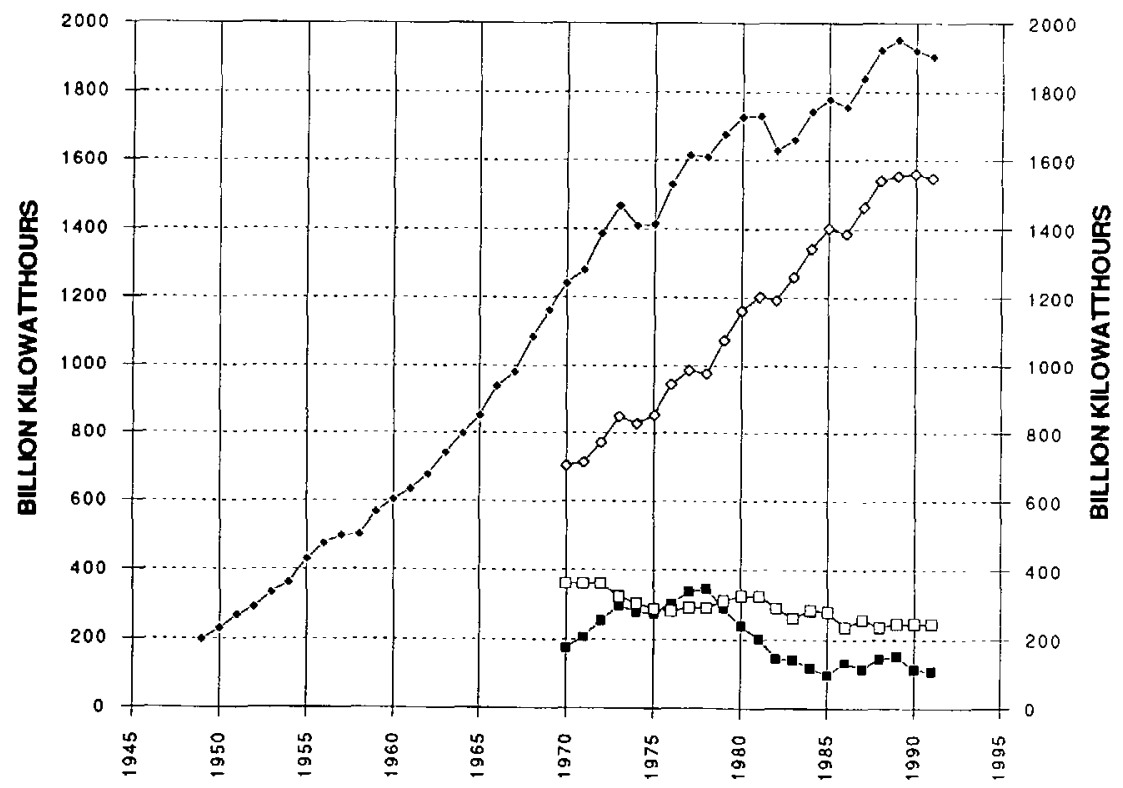

Figure 10. Electricity generation historical fossil steam generating fuels. Solid diamonds, total fossil steam generation. Open diamonds, coal steam generation. Solid squares, petroleum steam generation. Open squares, gas steam genertion. Data from Energy Information Administration (1992a). 
in fuel selection. Many plants with dual fuel capability seek to minimize costs by consuming fuels which offer the lowest cost option. Fuel costs vary considerably from region to region and from time to time as a result of regional differences in fuel availability and transportation charges, and the effects of changing supply/demand balance.

6. Regulation. - Attempts to reduce air pollution in certain regions has resulted in changes to environmental regulations which impose new costs of compliance with legislation that is intended to reduce air pollution. In places, there are restrictions on the use of certain fuels at certain times of the year in electric power generation to reduce combustion emissions.

Consumption of natural gas in electricity generation peaked at approximately 4 quads in the early 1970's (fig. 11A). Since that time it has fluctuated around a slow decline to the current level of approximately 3 quads, a 25 percent decline. Figure $11 B$ shows how petroleum consumption has declined by almost 75 percent from a historic high of 4 quads in 1978 to only 1 quad today. Coal consumption has steadily increased and now accounts for more than 16 quads of energy consumed to produce electricity (fig. 11C). Many forecasts suggest that natural-gas consumption will increase considerably over the next several years. Announced plans for construction of new generating capacity to support increased electricity demand show that indeed many of the new plants are being designed to consume natural gas. Of 421 units currently planned for construction through the year 2000, nearly 50 percent are planned to use gas as the primary energy source. At the end of 1990 , less than 20 percent of the 10,296 existing U.S. powerplants used gas as a primary energy source (Energy Information Administration, 1991c).

The principal challenges to increased gas consumption in electricity generation are reliability of gas service, pipeline operating flexibility, and pipeline supply capacity (Electric Power Research Institute, 1992). Reliance on natural gas as the primary energy source for electricity generation implies dependence on a gas supply infrastructure that is capable of routinely delivering large volumes of gas. During periods of high gas consumption, close coordination is required between wellhead deliveries, gas processing facilities, transmission capacity, and underground storage options. Routine delivery requires reliability at each point in the flow of gas from the wellhead to the powerplant. Because of the highly variable operating schedule of most gas-fired plants, the gas supply infrastructure must have the flexibility to meet the rapidly fluctuating gas requirements at a powerplant. Close coordination between the powerplant and the gas supplier is required to assure that gas supplies can be delivered when needed, in sufficient volumes, and at required pressures. The pipeline's operating characteristics and capability to adjust frequently and rapidly to changing demand are important to reliable gas service at powerplants. New gas-fired generating units need assurance that the natural-gas resource base and the existing pipeline delivery capacity is sufficient to account for the requirements of the powerplant as well as the projected needs of the pipelines existing customers. The construction of multiple gas-fired plants along a single pipeline corridor may create considerable difficulty for a pipeline to deliver sufficient gas to meet a potential simultaneous gas demand from many large consumers. Widespread regional climate fluctuations, such as heat waves or cold snaps, could significantly increase regional electricity demand for space conditioning thus triggering the start-up of multiple intermediate and peaking generators. Simultaneous operation of several gas-fired plants along a pipeline corridor could rapidly deplete the available delivery capacity from underground storage capacity or pipeline operating flexibility.

\section{SUMMARY}

Each economic sector presents different challenges and opportunities for the increased use of natural gas to meet the Nation's future energy needs. Regional and local expansion of gas pipeline transmission and distribution systems will bring natural-gas service to many new residential/commercial customers throughout the country, but the overall growth in demand for gas by this segment will be mitigated by conservative attitudes and improvements in the efficiency of gas-fired equipment, especially for space conditioning and water heating, and continued improvement in the thermal integrity of structures. More and more gas customers will each be consuming less and less fuel, leading to an overall stable gas demand in the residential/commercial energy market.

The transportation sector presents a potentially large and essentially new market for natural gas. With the impetus of recent air quality legislation, clean-fuel vehicle mandates, and a fuel-price advantage for natural gas, the possibility exists for a slow but steady development of a broader and denser population of compressed natural-gas refueling stations and use of natural gas in commercial and government fleets and eventually individual private vehicles. A number of issues will expedite the penetration of natural gas into the vehicle fuel market: the development and marketing of dedicated-fuel natural-gas vehicles and cost-effective conversion equipment and services; public relations efforts to increase awareness and acceptance of natural-gas vehicles; continuation of the naturalgas fuel price advantage over gasoline; continuation of the favorable tax treatment of natural gas versus gasoline for natural gas that is consumed as vehicle fuel.

The industrial and electricity generation sectors are large, price-sensitive energy consumers. There is considerable potential for increased gas consumption by replacement of current energy sources in fuel-switchable applications such as industrial process heat applications and steam generation for electricity generation. Fuel choices, however, will 

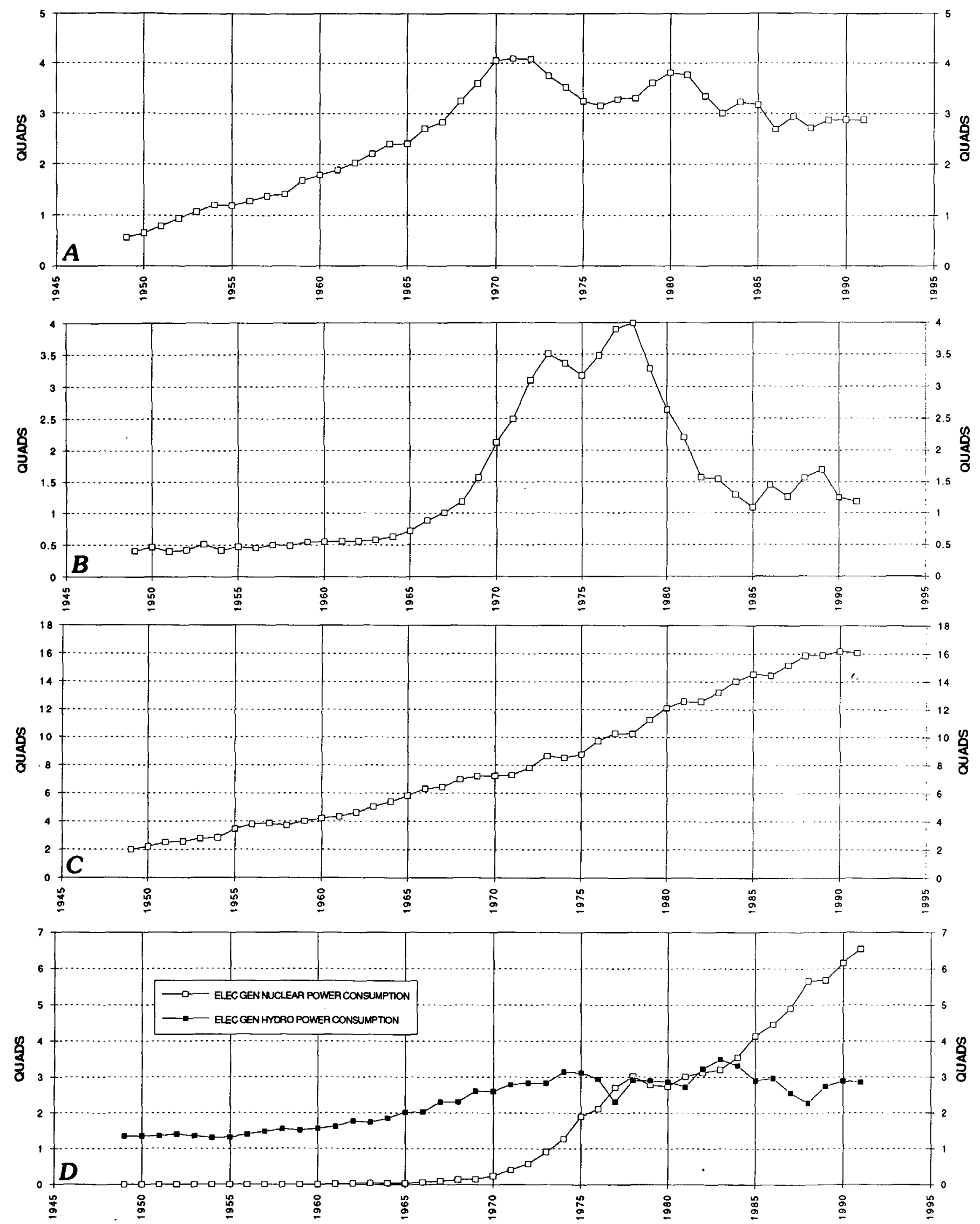

Figure 11. Electricity generation historical energy consumption. $A$, Natural gas; $B$, Petroleum; $C$, Coal; $D$, Nuclear and hydro. Data from Energy Information Administration (1992a). 1 quad $=10^{15}$ Btu (British thermal units). 
continue to be dominated by the least-cost options which are accompanied by the most reliable, efficient, and flexible service. Competitive pricing, adequate pipeline capacity, and demonstrable operational flexibility will be the keys to successful marketing of more natural gas to the industrial and electricity generation consumer. Environmental restrictions on specific fuel use in some regions and the cost of compliance with emission-control regulations will favor natural gas as the cleanest burning fossil fuel.

In many applications, natural gas is an attractive choice among U.S. energy options. It is a domestically available and relatively inexpensive energy product with efficient and clean burning characteristics that offers environmental benefits. If the natural-gas industry can successfully expand its production and distribution capability, maintain its energy price advantage, establish a reputation for reliable and flexible delivery, and continue the development of energy-efficient gas-fired technologies, there is significant opportunity for greater consumption of natural gas.

\section{REFERENCES CITED}

Adams, T.G., 1985, The performance of new dedicated CNG vehicles, in Nonpetroleum Vehicular Fuels V-CNG Fuel, symposium papers: Chicago, IL, Institute of Gas Technology, p. 47.

American Gas Association, 1992, 1992 Gas facts-1991 data: Arlington, Va., American Gas Association, 204 p.

Electric Power Research Institute, 1992, Natural gas for electric generation- the challenge of gas and electric industry cooperation: Palo Alto, CA, Electric Power Research Institute TR-101239.

Energy Information Administration, 1991a, Changes in energy intensity in the manufacturing sector, 1980-1988: Washington, D.C., Energy Information Administration DOE/EIA0552(80-88), $70 \mathrm{p}$.

1991b, Manufacturing fuel-switching capability 1988: Washington, D.C., Energy Information Administration DOE/ EIA-0515(88), $132 \mathrm{p}$. -1991c, Inventory of powerplants in the United States 1990: Washington, D.C., Energy Information Administration DOE/EIA-0095(90), 405 p.

-1992a, Annual energy review, 1991: Washington, D.C., Energy Information Administration DOE/EIA-0384(91), 347 p.

1992b, Annual energy outlook 1992, with projections to 2010: Washington, D.C., Energy Information Administration DOE/EIA-0383(92), 148 p.

Gas Research Institute, 1988, Natural gas vehicles-New targets, reprinted from GRID: Chicago, IL, Gas Research Institute, $10 \mathrm{p}$.

- 1992, 1992 edition of the GRI baseline projection of U.S. energy supply and demand to 2010: Chicago, IL, Gas Research Institute, $146 \mathrm{p}$.

Gibbons, J.H., and Blair, P.D., 1990, Energy efficiency-Its potential and limits to the year 2000, in Helm, J.L., ed., EnergyProduction, consumption, and consequences: Washington, D.C., National Academy of Engineering, National Academy Press, p. 35-51.

Gott, S. 1992, Natural gas vehicles-The road to 2000: Arlington, Va., Pasha Publications, $150 \mathrm{p}$.

Messera, J.R., 1985, Operating experience of a large CNG vehicle fleet, in Nonpetroleum Vehicular Fuels V-CNG Fuel, symposium papers: Chicago, IL, Institute of Gas Technology, p. 69.

National Petroleum Council, 1992, The potential for natural gas in the United States: Washington, D.C., National Petroleum Council, six volumes.

National Research Council, 1990, Fuels to drive our future: Washington, D.C., National Academy Press, 223 p.

Seisler, J., 1992, Strategy for global commercialization of NGV's, in proceedings of The Outlook for Natural Gas: Chicago, IL, Institute of Gas Technology, 16 p.

Sprague, R.W., 1985, National Fuel's experience with the installation, maintenance and repair of CNG vehicles, in Nonpetroleum Vehicular Fuels V-CNG Fuel, symposium papers: Chicago, IL, Institute of Gas Technology, p. 35.

Webb, D.O., and Farrell, M.D., 1993, End-use technology advancing in cooling techniques, NGVs, and fuel cells, in Willett, R.E., ed., The 1993 natural gas yearbook: New York, Executive Enterprises Publications, p. 195-214. 


\title{
THE FUTURE OF ENERGY GASES
}

U.S. GEOLOGICAL SURVEY PROFESSIONAL PAPER 1570

\section{Methodology for Estimating Volumes of Flared and Vented Natural Gas}

\author{
By Timothy R. Klett ${ }^{1}$ and Donald L. Gautier ${ }^{1}$
}

\section{CONTENTS}

Introduction 651

Estimating of Historical Volumes of Flared and

Vented Gas

Examples from Saudi Arabia and Nigeria

652

Worldwide Volumes of Flared and Vented Gas .......... 656

Conclusion

658

References Cited 659

\section{INTRODUCTION}

The common perception in the United States that natural gas produced with oil is a valuable commodity probably dates from the 1940's. Before that time, most operators regarded natural gas associated with or dissolved in oil as a nuisance. Indeed, most associated/dissolved natural gas produced in the United States before World War II probably was flared or vented to the atmosphere. This situation has changed in the United States, where flaring and venting have decreased dramatically in recent years, in part because of environmental concerns, but also because of the changing view of the value of natural gas.

The idea that gas is a nuisance is beginning to change almost everywhere, as markets for gas have developed in Europe, Japan, and elsewhere, and as operators have increasingly utilized or reinjected associated-dissolved gas in their oil-production activities. Nevertheless, in some

'U.S. Geological Survey, Denver Federal Center, Box 25046, Denver, CO 80225-0046. areas natural gas continues to be flared or vented to the atmosphere. Gas flares in Russia, the Niger Delta, and the Middle East are some of the brightest lights on the nighttime Earth (Hansen Planetarium, 1986).

As we increasingly consider the global availability and utility of natural gas, and the environmental impacts of the consumption of carbon-based fuels, it is important to know how much gas has been flared or vented, how much gas is currently being flared or vented, and the distribution of flaring or venting through time. Unfortunately, estimates of the volumes of flared and vented gas are generally not available.

\section{ESTIMATING OF HISTORICAL VOLUMES OF FLARED AND VENTED GAS}

The first step in estimating the volumes of flared and vented gas is to gather available data. Calculation of volumes of flared and vented gas requires knowledge of oil production, produced associated-dissolved gas to produced oil (gas/oil) ratios, and the ratio of flared and vented gas to total gas production, each as a function of time. Generally not all of these data are available, and approximations or extrapolations must be made from the information at hand. When the data are sparse or nonexistent, we estimate volumes by extrapolating present production data back through time. For the purpose of extrapolation, the data should include both oil and associated-dissolved gas volumes. Where data for associated-dissolved gas volumes are not available, these volumes are calculated by taking the difference between volumes of total (gross) gas and dry gas. We do not know the proportion of vented to flared gas, but we assume that the volumes of vented gas are small. Throughout history, some natural gas was produced for the 
extraction of natural gas liquids (condensate), and the excess gaseous phase was flared or vented. Therefore, this extrapolation method may underestimate the volumes of flared or vented gas. The volume of this type of flared gas is small, however, and does not significantly contribute to the worldwide total volume of gas flared.

Next, the associated-dissolved gas volumes must be extrapolated back through time. This was done by calculating the equation of an appropriate regression function through the apparent gas/oil ratios calculated from associated-dissolved gas and oil production data versus time. This equation was then used to estimate values of associated-dissolved gas volumes for past years. Inasmuch as the oil-production data are the most reliable and well documented, and gas/oil ratios do not change drastically with time, the regression equation derived from the gas/oil-ratio data is generally preferable as a basis for extrapolating associated-dissolved gas values.

Finally, the volumes of flared and vented gas were estimated using the extrapolated associated-dissolved gas values. This estimate accounts for the greatest proportion of error because flaring practices have changed significantly through time, particularly during the past fifteen years. In most countries, most of the associated-dissolved gas was flared or vented until the late 1970's; since then, gas production and reinjection technologies have become profitable. In this study, we assumed that before 1978 the volumes of reinjected gas and natural gas associated with natural gas condensate production outside the United States were small, and flared and vented gas volumes were assumed to be roughly equal to the total volume of associated-dissolved gas. Amounts of flared and vented gas and reinjected gas after 1978 are generally well reported. However, if flared and vented gas data are unavailable for certain recent years, the volumes can be estimated by multiplying associated-dissolved gas volumes by the available reported proportions of flared and vented gas to associated dissolved gas of neighboring years.

\section{EXAMPLES FROM SAUDI ARABIA AND NIGERIA}

Volumes of flared and vented gas were estimated for Saudi Arabia and for Nigeria by extrapolating data from the Energy Information Administration (EIA), the International Petroleum Encyclopedia, Schätzl (1969), and the Arabian American Oil Company (ARAMCO) (1968). These data are shown in tables 1 and 2. The data provided from these various sources are incomplete. Data reported by EIA and the International Petroleum Encyclopedia are inconsistent due to the differences in their respective sources, as indicated in tables 1 and 2.

Gas/oil ratios and associated-dissolved gas volumes were calculated by the regression methods described above. The data and regression equations used for estimating gas/ oil ratios for Saudi Arabia and Nigeria are shown in figures 1 and 2. Associated-dissolved gas values were calculated by multiplying the oil-production data by the calculated gas/oil ratios. Because the EIA oil-production data

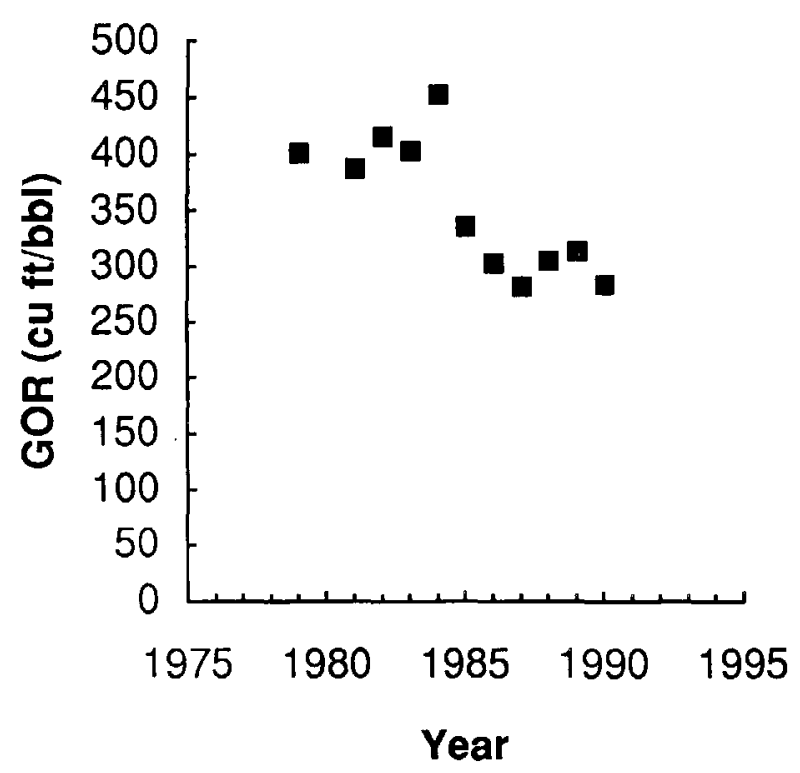

Figure 1. Actual gas/oil ratios (GOR), in cubic feet per barrel (cu $\mathrm{ft} / \mathrm{bbl}$ ), calculated from associated-dissolved gas and oil production data through time for Saudi Arabia. The regression equation is GOR (cu ft/bbl)=27446- $(14 X$ year $)$, having a correlation of $r^{2}=0.62$.

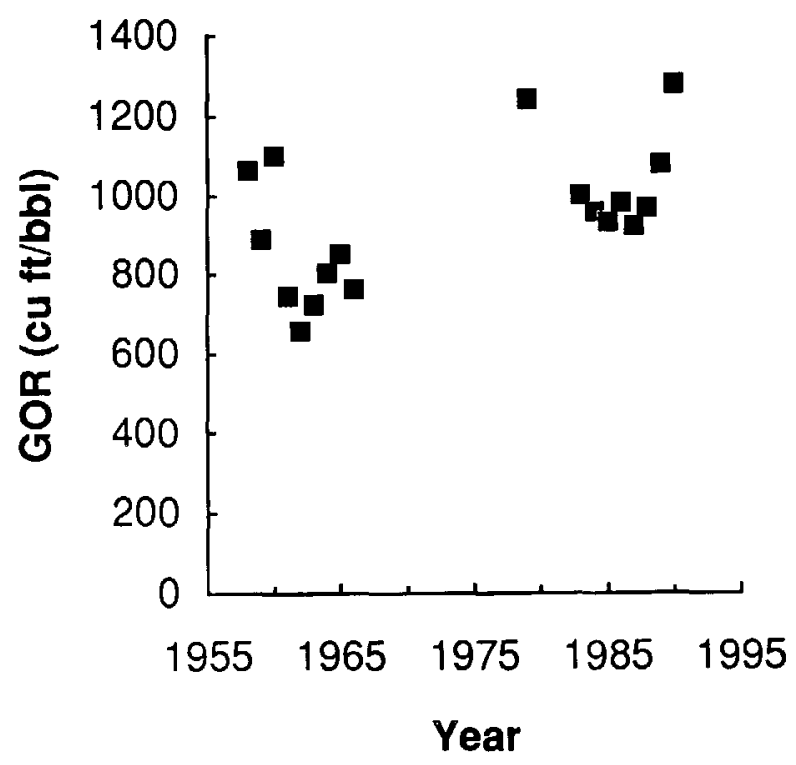

Figure 2. Actual gas/oil ratios (GOR), in cubic feet per barrel (cu ft/bbl), calculated from associated-dissolved gas and oil production data through time for Nigeria. The regression equation is $\operatorname{GOR}(\mathrm{cu} \mathrm{ft} / \mathrm{bbl})=-12970+(7 X$ year $)$, having a correlation of $r^{2}=0.27$. 
Table 1. Reported oil and gas production data, associated-dissolved gas volumes and gas/oil ratios, and volumes of flared and vented gas from the International Petroleum Encyclopedia and International Energy Annual for Saudi Arabia.

[Assaciated-dissolved gas volumes and gas/oil ratios and fared and vented gas volumes from the Intemational Petroleum Encyclopedia and International Energy Annual. IPE, Intemational Petroleum Encyclopedia; ARAMCO, Arabian American Oil Company; EIA, Energy Information Administration; Bcf, billion cubic feet; MM, million; bbl, barrels. Open space indicates no datal

\begin{tabular}{|c|c|c|c|c|c|c|c|c|c|}
\hline Year & $\begin{array}{c}\text { Oil } \\
\text { production } \\
\text { (MMbbl/yr) }\end{array}$ & $\begin{array}{l}\text { Oil } \\
\text { production } \\
\text { (MMbbl/yr) }\end{array}$ & $\begin{array}{c}\text { Gross natural } \\
\text { gas production } \\
(\text { Bcf/yr) }\end{array}$ & $\begin{array}{c}\text { Gross natural } \\
\text { gas production } \\
\text { (Bcf/yr) }\end{array}$ & $\begin{array}{c}\text { Dry natural } \\
\text { gas production } \\
\text { (Bcf/yr) }\end{array}$ & $\begin{array}{c}\text { Associated-dissolved } \\
\text { gas (calculated from EIA Data) } \\
\text { (Bcf) }\end{array}$ & $\begin{array}{c}\text { Gas/oil ratio } \\
\text { (calculated from ElA Data) } \\
\left(\mathrm{ft}^{3} / \mathrm{bbl}\right)\end{array}$ & $\begin{array}{l}\text { Gas/oil ratio } \\
\text { (estimated) } \\
\left(\mathrm{ft}^{3} / \mathrm{bbl}\right)\end{array}$ & $\begin{array}{c}\text { Associated-dissolved } \\
\text { gas (estimared) } \\
\text { (Bcf/yr) }\end{array}$ \\
\hline & IPE & $\underset{\text { EIA }}{\text { ARAMCO (1968) }}$ & IPE & EIA & EIA & This paper & This paper & This paper & This paper \\
\hline 1938 & & 0.5 & & & & & & 994 & 0.5 \\
\hline 1939 & & 4 & & & & & & 980 & 4 \\
\hline 1940 & 5 & 5 & & & & & & 967 & 5 \\
\hline 1941 & & 4 & & & & & & 953 & 4 \\
\hline 1942 & & 5 & & & & & & 939 & 4 \\
\hline 1943 & & 5 & & & & & & 926 & 5 \\
\hline 1944 & & 8 & & & & & & 912 & 7 \\
\hline 1945 & & 21 & & & & & & 898 & 19 \\
\hline 1946 & & 60 & & & & & & 885 & 53 \\
\hline 1947 & & 90 & & & & & & 871 & 78 \\
\hline 1948 & & 143 & & & & & & 858 & 122 \\
\hline 1949 & & 174 & & & & & & 844 & 147 \\
\hline 1950 & 200 & 200 & & & & & & 830 & 166 \\
\hline 1951 & & 278 & & & & & & 817 & 227 \\
\hline 1952 & & 302 & & & & & & 803 & 242 \\
\hline 1953 & & 308 & & & & & & 789 & 243 \\
\hline 1954 & & 348 & & & & & & 776 & 270 \\
\hline 1955 & 352 & 352 & & & c & & & 762 & 268 \\
\hline 1956 & & 361 & & & & & & 748 & 270 \\
\hline 1957 & & 362 & & & & & & 735 & 266 \\
\hline 1958 & & 370 & & & & & & 721 & 267 \\
\hline 1959 & 400 & 400 & & & & & & 707 & 283 \\
\hline 1960 & 456 & 456 & & & & & & 694 & 317 \\
\hline 1961 & 508 & 508 & & & & & & 680 & 346 \\
\hline 1962 & 555 & 555 & & & & & & 666 & 370 \\
\hline 1963 & 595 & 595 & & & & & & 653 & 388 \\
\hline 1964 & 628 & 628 & & & & & & 639 & 401 \\
\hline 1965 & 739 & 739 & & & & & & 625 & 462 \\
\hline 1966 & 873 & 873 & & & & & & 612 & 534 \\
\hline 1967 & 948 & 948 & & & & & & 598 & 567 \\
\hline 1968 & 1036 & 1036 & & & & & & 585 & 605 \\
\hline 1969 & 1092 & 1092 & & & & & & 571 & 624 \\
\hline 1970 & 1295 & 1295 & & & & & & 557 & 722 \\
\hline 1971 & 1642 & 1642 & & & & & & 544 & 892 \\
\hline 1972 & 2098 & 2093 & & & & & & 530 & 1109 \\
\hline 1973 & 2677 & 2773 & & & 160 & & & 516 & 1431 \\
\hline 1974 & 2997 & 3095 & & & 220 & & & 503 & 1556 \\
\hline 1975 & 2492 & 2582 & & & 220 & & & 489 & 1263 \\
\hline 1976 & 3054 & 3139 & & & 290 & & & 475 & 1492 \\
\hline 1977 & 3290 & 3374 & 121 & & 280 & & & 462 & 1558 \\
\hline 1978 & 2942 & 3030 & 102 & & 330 & & & 448 & 1357 \\
\hline 1979 & 3377 & 3479 & 209 & 1786 & 390 & 1396 & 401 & 434 & 1511 \\
\hline 1980 & 3525 & 3623 & 310 & & 370 & & & 421 & 1524 \\
\hline 1981 & 3519 & 3582 & 435 & 1850 & 460 & 1390 & 388 & 407 & 1458 \\
\hline 1982 & 2367 & 2366 & 591 & 1185 & 201 & 984 & 416 & 393 & 931 \\
\hline 1983 & 1778 & 1856 & 382 & 950 & 200 & 750 & 404 & 380 & 705 \\
\hline 1984 & 1663 & 1707 & 240 & 1026 & 253 & 773 & 454 & 366 & 625 \\
\hline 1985 & 1203 & 1237 & 252 & 1133 & 716 & 417 & 337 & 352 & 436 \\
\hline 1986 & 1723 & 1778 & 329 & 1430 & 890 & 540 & 304 & 339 & 602 \\
\hline 1987 & 1480 & 1557 & 741 & 1386 & 946 & 440 & 283 & 325 & 506 \\
\hline 1988 & 1723 & 1861 & 899 & 1596 & 1028 & 568 & 306 & 312 & 580 \\
\hline 1989 & 1801 & 1848 & 1632 & 1632 & 1052 & 580 & 314 & 298 & 551 \\
\hline 1990 & 2267 & 2340 & 1401 & 1741 & 1077 & 664 & 284 & 284 & 665 \\
\hline 1991 & 2978 & & 1590 & & & & & 271 & 0 \\
\hline
\end{tabular}


Table 2. Reported oil and gas production data, associated-dissolved gas volumes and gas/oil ratios, and volumes of flared and vented gas from the International Petroleum Encyclopedia and International Energy Annual for Nigeria.

[Associated-dissolved gas volumes and gas/oil ratios and flared and vented gas volumes from the International Petroleum Encyclopedia and International Energy Annual. IPE, International Petroleum Encyclopedia; EIA, Energy Information Administration; Bcf, billion cubic feet; MM, million; bbl, barrels. Open space indicates no data]

\begin{tabular}{|c|c|c|c|c|c|c|c|c|c|}
\hline Year & $\begin{array}{c}\text { Oil } \\
\text { production } \\
\text { (MMbbl/yr) }\end{array}$ & $\begin{array}{c}\text { Oil } \\
\text { production } \\
\text { (MMbbl/yr) }\end{array}$ & $\begin{array}{c}\text { Gross natural } \\
\text { gas production } \\
\text { (Bcf/yr) }\end{array}$ & $\begin{array}{l}\text { Gross natural } \\
\text { gas production } \\
\text { (Bcf/yr) }\end{array}$ & $\begin{array}{l}\text { Dry natural } \\
\text { gas production } \\
\text { (Bcf/yr) }\end{array}$ & $\begin{array}{c}\text { Associated-dissolved } \\
\text { gas (calculated from ElA Data) } \\
\text { (Bcf) }\end{array}$ & $\begin{array}{c}\text { Gas/oil ratio } \\
\text { (calculated from ElA Data) } \\
\left(\mathrm{ft}^{3} / \mathrm{bbl}\right)\end{array}$ & $\begin{array}{l}\text { Gas/oil ratio } \\
\text { (estimated) } \\
\left.\text { (ft } \mathrm{ft}^{3} / \mathrm{bbl}\right) \\
\end{array}$ & $\begin{array}{c}\text { Associated-dissolved } \\
\text { gas (estimated) } \\
\text { (Bcf/yr) }\end{array}$ \\
\hline & IPE & $\begin{array}{c}\text { Schätzl (1969) } \\
\text { EIA }\end{array}$ & IPE & EIA & EIA & This paper & This paper & This paper & This paper \\
\hline
\end{tabular}

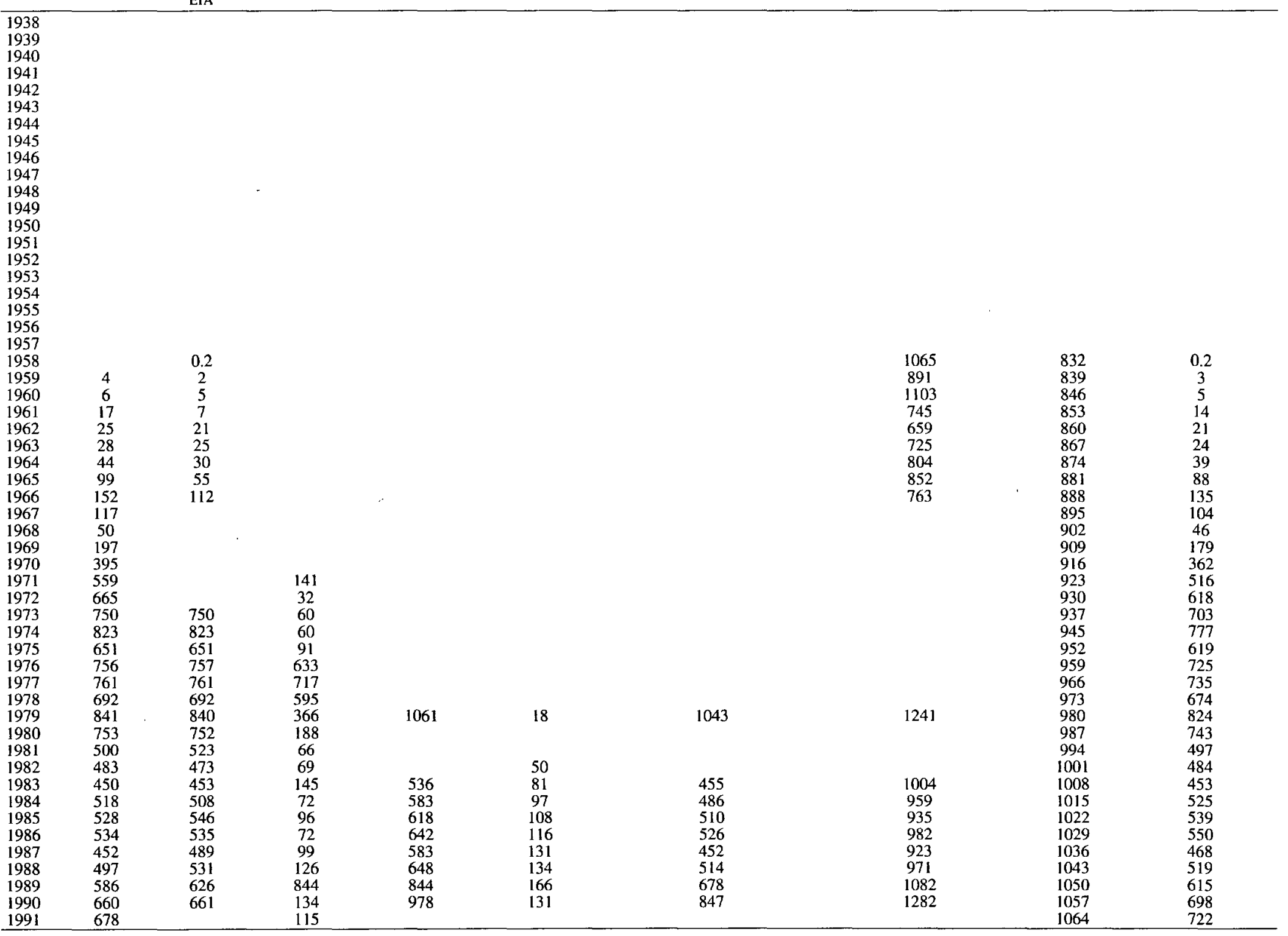


are more complete for Saudi Arabia than for Nigeria, these data were used to calculate the associated-dissolved gas volumes for Saudi Arabia. Likewise, the International Petroleum Encyclopedia oil-production data were used to calculate associated-dissolved gas volumes for Nigeria. The associated-dissolved gas volumes calculated by subtracting dry from gross gas production and the gas/oil ratios derived from these values for those years for which data are available are shown in tables 1 and 2 . In addition, gas/oil ratios and associated-dissolved gas volumes estimated for all years by means of regression equations (figs. 1,2) are also shown in tables 1 and 2.

Estimates of flared and vented gas volumes for all years are shown in table 3 . These estimates represent all

Table 3. Comparison of reported (Organization of Petroleum Exporting Countries, 1993) and estimated flared and vented gas volumes for Saudi Arabia and Nigeria.

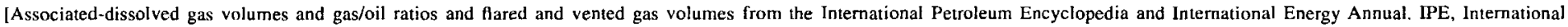
Petroleum Encyclopedia; ELA, Energy Information Administration; OPEC, Organization of Petroleum Exporting Countries; Bcf, billion cubic feet. Open space indicates no data]

\begin{tabular}{|c|c|c|c|c|c|c|c|c|}
\hline \multirow{3}{*}{ Year } & \multicolumn{4}{|c|}{ Saudi Arabia } & \multicolumn{4}{|c|}{ Nigeria } \\
\hline & $\begin{array}{c}\text { Associated-dissolved } \\
\text { gas } \\
\text { (Bcf/yr) } \\
\end{array}$ & $\begin{array}{c}\text { Flared and } \\
\text { vented gas } \\
(\text { Bcf/yr) }\end{array}$ & $\begin{array}{c}\text { Reported flared } \\
\text { and vented gas } \\
\text { (Bcf/yr) }\end{array}$ & $\begin{array}{c}\text { Reported flared } \\
\text { and vented gas } \\
\text { (Bcf/yr) }\end{array}$ & $\begin{array}{c}\text { Associated-dissolved } \\
\text { gas } \\
\text { (Bcf/yr) }\end{array}$ & $\begin{array}{c}\text { Flared and } \\
\text { vented gas } \\
\text { (Bcf/yr) }\end{array}$ & $\begin{array}{c}\text { Reported flared } \\
\text { and vented gas } \\
\text { (Bcflyr) }\end{array}$ & $\begin{array}{c}\text { Reported flared } \\
\text { and vented gas } \\
\text { (Bcf/yr) }\end{array}$ \\
\hline & This paper & This paper & EIA & OPEC & This paper & This paper & EIA & OPEC \\
\hline 1938 & 0.5 & 0.5 & & & & & & \\
\hline 1939 & 4 & 4 & & & & & & \\
\hline 1940 & 5 & $\begin{array}{l}4 \\
5\end{array}$ & & & & & & \\
\hline 1941 & 4 & 4 & & & & 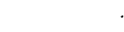 & & \\
\hline 1942 & 4 & 4 & & & & & & \\
\hline 1943 & 5 & 5 & & & & & & \\
\hline 1944 & 7 & 7 & & & & & & \\
\hline 1945 & 19 & 19 & & & & & & \\
\hline 1946 & 53 & 53 & & & & & & \\
\hline 1947 & 78 & 78 & & & & & & \\
\hline 1948 & 122 & 122 & & & & & & \\
\hline 1949 & 147 & 147 & & & & & & \\
\hline 1950 & 166 & 166 & & & & & & \\
\hline 1951 & 227 & 227 & & & & & & \\
\hline 1952 & 242 & 242 & & & & . & & \\
\hline 1953 & 243 & 243 & & & & & & \\
\hline 1954 & 270 & 270 & & & & & & \\
\hline 1955 & 268 & 268 & & & & & & \\
\hline 1956 & 270 & 270 & & & & & & \\
\hline 1957 & 266 & 266 & & & & & & \\
\hline 1958 & 267 & 267 & & & 0.2 & 0.2 & & \\
\hline 1959 & 283 & 283 & & & 4 & 4 & & \\
\hline 1960 & 317 & 317 & & & 7 & 7 & & \\
\hline 1961 & 346 & 346 & & & 13 & 13 & & \\
\hline 1962 & 370 & 370 & & & 16 & 16 & & \\
\hline 1963 & 388 & 388 & & & 20 & 20 & & 21 \\
\hline 1964 & 401 & 401 & & & 35 & 35 & & 35 \\
\hline 1965 & 462 & 462 & & & 85 & 85 & & 91 \\
\hline 1966 & 534 & 534 & & 329 & 116 & 116 & & 96 \\
\hline 1967 & 567 & 567 & & 368 & 104 & 104 & & 87 \\
\hline 1968 & 605 & 605 & & 390 & 46 & 46 & & 46 \\
\hline 1969 & 624 & 624 & & 429 & 179 & 179 & & 143 \\
\hline 1970 & 722 & 722 & & 524 & 362 & 362 & & 282 \\
\hline 1971 & 892 & 892 & & 703 & 516 & 516 & & 452 \\
\hline 1972 & 1109 & 1109 & & 956 & 618 & 618 & & 595 \\
\hline 1973 & 1431 & 1431 & & 1342 & 703 & 703 & & 715 \\
\hline 1974 & 1556 & 1556 & & 1380 & 777 & 777 & & 926 \\
\hline 1975 & 1263 & 1263 & & 1030 & 619 & 619 & & 655 \\
\hline 1976 & 1492 & 1492 & & 1321 & 725 & 725 & & 758 \\
\hline 1977 & 1558 & 1558 & & 1321 & 735 & 735 & & 740 \\
\hline 1978 & 1357 & 1357 & & 1162 & 674 & 674 & & 708 \\
\hline 1979 & 1396 & 1342 & 1342 & 1342 & 1043 & 1013 & 1013 & 1013 \\
\hline 1980 & 1528 & 1230 & & 1355 & 743 & 722 & & 829 \\
\hline 1981 & 1390 & 903 & 903 & 903 & 497 & 482 & & 507 \\
\hline 1982 & 984 & 755 & 755 & 755 & 484 & 470 & & 453 \\
\hline 1983 & 750 & 576 & 576 & 576 & 455 & 442 & 442 & 442 \\
\hline 1984 & 773 & 525 & 525 & 149 & 486 & 465 & 465 & 481 \\
\hline 1985 & 417 & 110 & 110 & 109 & 510 & 460 & 460 & 494 \\
\hline 1986 & 540 & 98 & 98 & 85 & 526 & 445 & 445 & 491 \\
\hline 1987 & 440 & 71 & 71 & 71 & 452 & 417 & 417 & 433 \\
\hline 1988 & 568 & 117 & 117 & 117 & 514 & 433 & 433 & 521 \\
\hline 1989 & 580 & 138 & 138 & 145 & 678 & 614 & 614 & 663 \\
\hline 1990 & 664 & 184 & 184 & 267 & 847 & 744 & 744 & 791 \\
\hline 1991 & 807 & 226 & & 463 & 722 & 701 & & 800 \\
\hline Total & 29781.5 & 22820 & 4819 & 17591 & 14311.2 & 13763 & 5033 & 14269 \\
\hline
\end{tabular}


associated-dissolved gas production until 1978 for both $\mathrm{Ni}$ geria and Saudi Arabia and percentages of total associateddissolved gas production after 1978 , based on mean ratios of flared and vented gas to associated-dissolved gas production in recent years from EIA data. These percentages are 80.5 percent between 1979 and 1981 and 28.0 percent in 1990 for Saudi Arabia, and 97.1 percent between 1979 and 1990 for Nigeria.

Data on the volumes of flared and vented gas have been reported by the Organization of the Petroleum Exporting Countries (OPEC) for certain countries, including Saudi Arabia and Nigeria, since 1963. These data, which are presumed to be reliable (table 3 ), provide a test of the accuracy of the volumes of flared and vented gas estimated by the extrapolation procedure (figs. $3,6,7$ ).

The history of gas flaring in Saudi Arabia and Nigeria is shown in figures 3 and 4 . On the basis of these calculations, we estimate that from 1963 until 1990, Saudi Arabia and Nigeria flared and vented 21.0 and 13.0 trillion cubic feet (Tcf) of natural gas, respectively. These values are comparable to OPEC data, which show 17 and $14 \mathrm{Tcf}$ flared and vented in Saudi Arabia and Nigeria, respectively. We further estimate that a total of more than $23 \mathrm{Tcf}$ have been flared and vented in Saudi Arabia and more than 14 Tcf have been flared and vented in Nigeria since the beginning of oil production in those two countries.

\section{WORLDWIDE VOLUMES OF FLARED AND VENTED GAS}

The extrapolation method used to calculate volumes of flared and vented gas in Saudi Arabia and Nigeria can be used to estimate the volume of gas flared and vented worldwide since the first production of oil. Tables 4,5 , and 6 show world oil production through time (data from DeGolyer and MacNaughton, 1990, and EIA). Oil-production data are documented for 1918 to the present. Production values prior to 1918 were linearly extrapolated back to 1858 when oil was first produced. Because of the lack of data, we arbitrarily chose the first-year oil production to be 1,000 barrels. This linear extrapolation is reasonable in calculating world totals, because the volume of oil produced prior to 1918 is small compared to total world oil production.

Worldwide gas/oil ratios were calculated using the difference between gross gas and dry gas, as described above. We used gas/oil ratios from EIA for 1979 to 1991 . These data indicate a general increase in the produced gas/oil ratios from 1979 to 1991 (fig. 5). The gas/oil ratios increase over time for several reasons, mostly because more associated-dissolved gas has been produced in recent years as it became more profitable, and most of the world's major oil fields are becoming mature; their increasing gas/oil ratios

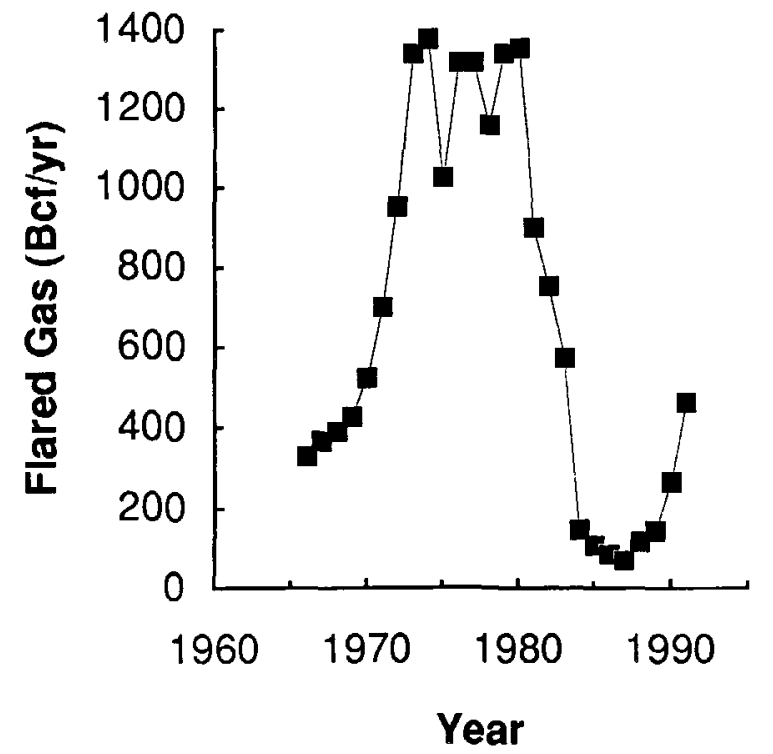

Figure 3. Volumes of gas, in billion cubic feet per year (Bcf/ yr), flared and vented in Saudi Arabia (Organization of the Petroleum Exporting Countries, 1993).

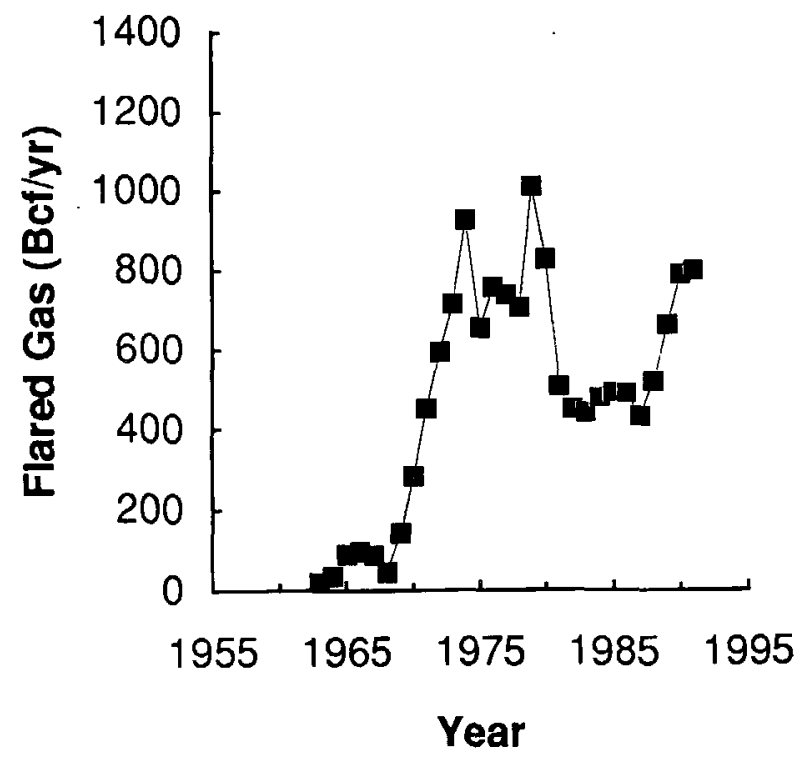

Figure 4. Volumes of gas, in billion cubic feet per year (Bcf/ yr), flared and vented in Nigeria (Organization of the Petroleum Exporting Countries, 1993).

are being reflected in the world values. As a consequence of using these recent data, however, extrapolated values become negative for years prior to 1953. Such negative gas/oil ratios are obviously erroneous, but we attempted to use available data to suggest possible quantities of total gas flared and vented through time. 
Table 4. Reported worldwide oil production, calculated gas-oil ratio (CGOR), and gas-oil ratio estimated by regression analysis (EGOR).

[Data for CGOR from DeGolyer and MacNaughton (1990) and Energy Information Administration. Mbbl, thousand barrels; $\mathrm{ft}^{3} / \mathrm{bbl}$, cubic feet per barrel. Open space indicates no data]

\begin{tabular}{|c|c|c|c|c|c|c|c|}
\hline Year & $\begin{array}{c}\text { Oil } \\
\text { (Mbbl) }\end{array}$ & $\begin{array}{c}\text { CGOR } \\
\left(\mathrm{ft}^{3} / \mathrm{bbl}\right)\end{array}$ & $\begin{array}{c}\text { EGOR } \\
\left(\mathrm{ft}^{3} / \mathrm{bbl}\right)\end{array}$ & Year & $\begin{array}{c}\text { Oil } \\
(\mathrm{Mbbl})\end{array}$ & $\begin{array}{c}\text { CGOR } \\
\left(\mathrm{ft}^{3} / \mathrm{bbl}\right)\end{array}$ & $\begin{array}{c}\text { EGOR } \\
\left(\mathrm{ft}^{3} / \mathrm{bbl}\right)\end{array}$ \\
\hline 1858 & 1 & & 0.0 & $192 \overline{25}$ & 1067933 & & 0.0 \\
\hline 1859 & 8392 & & 0.0 & 1926 & 1096823 & & 0.0 \\
\hline 1860 & 16784 & & 0.0 & 1927 & 1262582 & & 0.0 \\
\hline 1861 & 25176 & & 0.0 & 1928 & 1324774 & & 0.0 \\
\hline 1862 & 33568 & & 0.0 & 1929 & 1485867 & & 0.0 \\
\hline 1863 & 41960 & & 0.0 & 1930 & 1411904 & & 0.0 \\
\hline 1864 & 50352 & & 0.0 & 1931 & 1373656 & & 0.0 \\
\hline 1865 & 58744 & & 0.0 & 1932 & 1310298 & & 0.0 \\
\hline 1866 & 67135 & & 0.0 & 1933 & 1441000 & & 0.0 \\
\hline 1867 & 75527 & & 0.0 & 1934 & 1521474 & & 0.0 \\
\hline 1868 & 83919 & & 0.0 & 1935 & 1654494 & & 0.0 \\
\hline 1869 & 92311 & & 0.0 & 1936 & 1791540 & & 0.0 \\
\hline 1870 & 100703 & & 0.0 & 1937 & 2039231 & & 0.0 \\
\hline 1871 & 109095 & & 0.0 & 1938 & 1988041 & & 0.0 \\
\hline 1872 & 117487 & & 0.0 & 1939 & 2086160 & & 0.0 \\
\hline 1873 & 125879 & & 0.0 & 1940 & 2149821 & & 0.0 \\
\hline 1874 & 134271 & & 0.0 & 1941 & 2220657 & & 0.0 \\
\hline 1875 & 142663 & & 0.0 & 1942 & 2093100 & & 0.0 \\
\hline 1876 & 151054 & & 0.0 & 1943 & 2256637 & & 0.0 \\
\hline 1877 & 159446 & & 0.0 & 1944 & 2592289 & & 0.0 \\
\hline 1878 & 167838 & & 0.0 & 1945 & 2594697 & & 0.0 \\
\hline 1879 & 176230 & & 0.0 & 1946 & 2745430 & & 0.0 \\
\hline 1880 & 184622 & & 0.0 & 1947 & 3022139 & & 0.0 \\
\hline 1881 & 193014 & & 0.0 & 1948 & 3433234 & & 0.0 \\
\hline 1882 & 201406 & & 0.0 & 1949 & 3404142 & & 0.0 \\
\hline 1883 & 209798 & & 0.0 & 1950 & 3803027 & & 0.0 \\
\hline 1884 & 218190 & & 0.0 & 1951 & 4282730 & & 0.0 \\
\hline 1885 & 226582 & . & 0.0 & 1952 & 4531114 & & 12.9 \\
\hline 1886 & 234973 & & 0.0 & 1953 & 4798055 & & 31.8 \\
\hline 1887 & 243365 & & 0.0 & 1954 & 5016591 & & 50.7 \\
\hline 1888 & 251757 & & 0.0 & 1955 & 5625659 & & 69.6 \\
\hline 1889 & 260149 & & 0.0 & 1956 & 6124676 & & 88.5 \\
\hline 1890 & 268541 & & 0.0 & 1957 & 6438444 & & 107.4 \\
\hline 1891 & 276933 & & 0.0 & 1958 & 6607750 & & 126.3 \\
\hline 1892 & 285325 & & 0.0 & 1959 & 7144860 & & 145.2 \\
\hline 1893 & 293717 & & 0.0 & 1960 & 7674460 & & 164.1 \\
\hline 1894 & 302109 & & 0.0 & 1961 & 8186213 & & 182.9 \\
\hline 1895 & 310501 & & 0.0 & 1962 & 8882710 & & 201.8 \\
\hline 1896 & 318892 & & 0.0 & 1963 & 9540492 & & 220.7 \\
\hline 1897 & 327284 & & 0.0 & 1964 & 10312512 & & 239.6 \\
\hline 1898 & 335676 & & 0.0 & 1965 & 11063254 & & 258.5 \\
\hline 1899 & 344068 & & 0.0 & 1966 & 12021786 & & 277.4 \\
\hline 1900 & 352460 & & 0.0 & 1967 & 12914340 & & 296.3 \\
\hline 1901 & 360852 & & 0.0 & 1968 & 14146318 & & 315.2 \\
\hline 1902 & 369244 & & 0.0 & 1969 & 15222511 & & 334.1 \\
\hline 1903 & 377636 & & 0.0 & 1970 & 16718708 & & 353.0 \\
\hline 1904 & 386028 & & 0.0 & 1971 & 17662793 & & 371.8 \\
\hline 1905 & 394420 & & 0.0 & 1972 & 18600745 & & 390.7 \\
\hline 1906 & 402811 & & 0.0 & 1973 & 20367981 & & 409.6 \\
\hline 1907 & 411203 & & 0.0 & 1974 & 20537727 & & 428.5 \\
\hline 1908 & 419595 & & 0.0 & 1975 & 19502335 & & 447.4 \\
\hline 1909 & 427987 & & 0.0 & 1976 & 20960454 & & 466.3 \\
\hline 1910 & 436379 & & 0.0 & 1977 & 21900695 & & 485.2 \\
\hline 1911 & 444771 & & 0.0 & 1978 & 22158251 & & 504.1 \\
\hline 1912 & 453163 & & 0.0 & 1979 & 22876935 & 515.4 & 523.0 \\
\hline 1913 & 461555 & & 0.0 & 1980 & 21760880 & & 541.9 \\
\hline 1914 & 469947 & & 0.0 & 1981 & 20376699 & 537.4 & 560.7 \\
\hline 1915 & 478339 & & 0.0 & 1982 & 19412160 & 573.9 & 579.6 \\
\hline 1916 & 486730 & & 0.0 & 1983 & 19347559 & 623.3 & 598.5 \\
\hline 1917 & 495122 & & 0.0 & 1984 & 19857650 & 639.0 & 617.4 \\
\hline 1918 & 503515 & & 0.0 & 1985 & 19584920 & 652.5 & 636.3 \\
\hline 1919 & 555875 & & 0.0 & 1986 & 20492117 & 636.3 & 655.2 \\
\hline 1920 & 688884 & & 0.0 & 1987 & 20562071 & 701.8 & 674.1 \\
\hline 1921 & 766002 & & 0.0 & 1988 & 21369982 & 678.1 & 693.0 \\
\hline 1922 & 858898 & & 0.0 & 1989 & 21920463 & 689.8 & 711.9 \\
\hline 1923 & 1015736 & & 0.0 & 1990 & 22071915 & 733.1 & 730.8 \\
\hline 1924 & 1014318 & & 0.0 & & & & \\
\hline
\end{tabular}

Table 5. Estimated worldwide minimum flared and vented gas $\left(F V G_{\text {min }}\right)$ and cumulative minimum flared and vented gas (CFVG $_{\text {min }}$ ) volumes.

[Tcf, trillion cubic feet; NA, not applicable]

\begin{tabular}{|c|c|c|c|c|c|}
\hline Year & $\begin{array}{c}F \vee G_{\min } \\
(\mathrm{Tcf})\end{array}$ & $\begin{array}{c}\text { CFVG }_{\text {min }} \\
\text { (Tcf) }\end{array}$ & Year & $\begin{array}{c}\mathrm{FVG}_{\min } \\
\text { (Tef) }\end{array}$ & $\begin{array}{c}\mathrm{CFVG}_{\min } \\
\text { (Tcf) }\end{array}$ \\
\hline 1858 & 0.0 & 0.0 & 1925 & 0.0 & 0.0 \\
\hline 1859 & 0.0 & 0.0 & 1926 & 0.0 & 0.0 \\
\hline 1860 & 0.0 & 0.0 & 1927 & 0.0 & 0.0 \\
\hline 1861 & 0.0 & 0.0 & 1928 & 0.0 & 0.0 \\
\hline 1862 & 0.0 & 0.0 & 1929 & 0.0 & 0.0 \\
\hline 1863 & 0.0 & 0.0 & 1930 & 0.0 & 0.0 \\
\hline 1864 & 0.0 & 0.0 & 1931 & 0.0 & 0.0 \\
\hline 1865 & 0.0 & 0.0 & 1932 & 0.0 & 0.0 \\
\hline 1866 & 0.0 & 0.0 & 1933 & 0.0 & 0.0 \\
\hline 1867 & 0.0 & 0.0 & 1934 & 0.0 & 0.0 \\
\hline 1868 & 0.0 & 0.0 & 1935 & 0.0 & 0.0 \\
\hline 1869 & 0.0 & 0.0 & 1936 & 0.0 & 0.0 \\
\hline 1870 & 0.0 & 0.0 & 1937 & 0.0 & 0.0 \\
\hline 1871 & 0.0 & 0.0 & 1938 & 0.0 & 0.0 \\
\hline 1872 & 0.0 & 0.0 & 1939 & 0.0 & 0.0 \\
\hline 1873 & 0.0 & 0.0 & 1940 & 0.0 & 0.0 \\
\hline 1874 & 0.0 & 0.0 & 1941 & 0.0 & 0.0 \\
\hline 1875 & 0.0 & 0.0 & 1942 & 0.0 & 0.0 \\
\hline 1876 & 0.0 & 0.0 & 1943 & 0.0 & 0.0 \\
\hline 1877 & 0.0 & 0.0 & 1944 & 0.0 & 0.0 \\
\hline 1878 & 0.0 & 0.0 & 1945 & 0.0 & 0.0 \\
\hline 1879 & 0.0 & 0.0 & 1946 & 0.0 & 0.0 \\
\hline 1880 & 0.0 & 0.0 & 1947 & 0.0 & 0.0 \\
\hline 1881 & 0.0 & 0.0 & 1948 & 0.0 & 0.0 \\
\hline 1882 & 0.0 & 0.0 & 1949 & 0.0 & 0.0 \\
\hline 1883 & 0.0 & 0.0 & 1950 & 0.0 & 0.0 \\
\hline 1884 & 0.0 & 0.0 & 1951 & 0.0 & 0.0 \\
\hline 1885 & 0.0 & 0.0 & 1952 & 0.1 & 0.1 \\
\hline 1886 & 0.0 & 0.0 & 1953 & 0.2 & 0.2 \\
\hline 1887 & 0.0 & 0.0 & 1954 & 0.3 & 0.5 \\
\hline 1888 & 0.0 & 0.0 & 1955 & 0.4 & 0.9 \\
\hline 1889 & 0.0 & 0.0 & 1956 & 0.5 & 1.4 \\
\hline 1890 & 0.0 & 0.0 & 1957 & 0.7 & 2.1 \\
\hline 1891 & 0.0 & 0.0 & 1958 & 0.8 & 2.9 \\
\hline 1892 & 0.0 & 0.0 & 1959 & 1.0 & 4.0 \\
\hline 1893 & 0.0 & 0.0 & 1960 & 1.3 & 5.2 \\
\hline 1894 & 0.0 & 0.0 & 1961 & 1.5 & 6.7 \\
\hline 1895 & 0.0 & 0.0 & 1962 & 1.8 & 8.5 \\
\hline 1896 & 0.0 & 0.0 & 1963 & 2.1 & 10.6 \\
\hline 1897 & 0.0 & 0.0 & 1964 & 2.5 & 13.1 \\
\hline 1898 & 0.0 & 0.0 & 1965 & 2.9 & 15.9 \\
\hline 1899 & 0.0 & 0.0 & 1966 & 3.3 & 19.3 \\
\hline 1900 & 0.0 & 0.0 & 1967 & 3.8 & 23.1 \\
\hline 1901 & 0.0 & 0.0 & 1968 & 4.5 & 27.6 \\
\hline 1902 & 0.0 & 0.0 & 1969 & 5.1 & 32.7 \\
\hline 1903 & 0.0 & 0.0 & 1970 & 5.9 & 38.6 \\
\hline 1904 & 0.0 & 0.0 & 1971 & 6.6 & 45.1 \\
\hline 1905 & 0.0 & 0.0 & 1972 & 7.3 & 52.4 \\
\hline 1906 & 0.0 & 0.0 & 1973 & 8.3 & 60.7 \\
\hline 1907 & 0.0 & 0.0 & 1974 & 8.8 & 69.5 \\
\hline 1908 & 0.0 & 0.0 & 1975 & 8.7 & 78.3 \\
\hline 1909 & 0.0 & 0.0 & 1976 & 9.8 & 88.0 \\
\hline 1910 & 0.0 & 0.0 & 1977 & 10.6 & 98.7 \\
\hline 1911 & 0.0 & 0.0 & 1978 & 11.1 & 109.7 \\
\hline 1912 & 0.0 & 0.0 & 1979 & 7.8 & 117.5 \\
\hline 1913 & 0.0 & 0.0 & 1980 & 3.8 & 121.3 \\
\hline 1914 & 0.0 & 0.0 & 1981 & $3.3 *$ & 124.6 \\
\hline 1915 & 0.0 & 0.0 & 1982 & $3.3 *$ & 127.9 \\
\hline 1916 & 0.0 & 0.0 & 1983 & $3.8 *$ & 131.7 \\
\hline 1917 & 0.0 & 0.0 & 1984 & $3.5 *$ & 135.2 \\
\hline 1918 & 0.0 & 0.0 & 1985 & $3.1 *$ & 138.3 \\
\hline 1919 & 0.0 & 0.0 & 1986 & $3.0 *$ & 141.3 \\
\hline 1920 & 0.0 & 0.0 & 1987 & $2.9 *$ & 144.2 \\
\hline 1921 & 0.0 & 0.0 & 1988 & $3.2 *$ & 147.4 \\
\hline 1922 & 0.0 & 0.0 & 1989 & $3.4 *$ & 150.8 \\
\hline 1923 & 0.0 & 0.0 & 1990 & $3.3 *$ & 154.1 \\
\hline 1924 & 0.0 & 0.0 & Total & 154.1 & NA \\
\hline
\end{tabular}


Table 6. Estimated worldwide maximum flared and vented gas $\left(\mathrm{FVG}_{\mathrm{max}}\right)$ and cumulative maximum flared and vented gas $\left(\right.$ CFVG $_{\max }$ ) volumes.

[Tcf, trillion cubic feet; NA, not applicable]

\begin{tabular}{|c|c|c|c|c|c|}
\hline$\overline{\text { Year }}$ & $\begin{array}{c}\mathrm{FVG}_{\max } \\
(\mathrm{Tct})\end{array}$ & $\begin{array}{c}\mathrm{CFVG}_{\max } \\
(\mathrm{Tcf})\end{array}$ & Year & $\begin{array}{c}\mathrm{FVG}_{\max } \\
(\mathrm{T} \mathrm{cf})\end{array}$ & $\begin{array}{c}\text { CFVG }_{\text {max }} \\
\text { (Tcf) }\end{array}$ \\
\hline 1858 & 0.0 & 0.0 & 1925 & 0.6 & 11.0 \\
\hline 1859 & 0.0 & 0.0 & 1926 & 0.6 & 11.6 \\
\hline 1860 & 0.0 & 0.0 & 1927 & 0.7 & 12.2 \\
\hline 1861 & 0.0 & 0.0 & 1928 & 0.7 & 12.9 \\
\hline 1862 & 0.0 & 0.0 & 1929 & 0.8 & 13.7 \\
\hline 1863 & 0.0 & 0.1 & 1930 & 0.7 & 14.4 \\
\hline 1864 & 0.0 & 0.1 & 1931 & 0.7 & 15.1 \\
\hline 1865 & 0.0 & 0.1 & 1932 & 0.7 & 15.8 \\
\hline 1866 & 0.0 & 0.2 & 1933 & 0.7 & 16.5 \\
\hline 1867 & 0.0 & 0.2 & 1934 & 0.8 & 17.3 \\
\hline 1868 & 0.0 & 0.2 & 1935 & 0.9 & 18.1 \\
\hline 1869 & 0.0 & 0.3 & 1936 & 0.9 & 19.1 \\
\hline 1870 & 0.1 & 0.3 & 1937 & 1.1 & 20.1 \\
\hline 1871 & 0.1 & 0.4 & 1938 & 1.0 & 21.1 \\
\hline 1872 & 0.1 & 0.5 & 1939 & 1.1 & 22.2 \\
\hline 1873 & 0.1 & 0.5 & 1940 & 1.1 & 23.3 \\
\hline 1874 & 0.1 & 0.6 & 1941 & 1.1 & 24.5 \\
\hline 1875 & 0.1 & 0.7 & 1942 & 1.1 & 25.5 \\
\hline 1876 & 0.1 & 0.7 & 1943 & 1.2 & 26.7 \\
\hline 1877 & 0.1 & 0.8 & 1944 & 1.3 & 28.0 \\
\hline 1878 & 0.1 & 0.9 & 1945 & 1.3 & 29.4 \\
\hline 1879 & 0.1 & 1.0 & 1946 & 1.4 & 30.8 \\
\hline 1880 & 0.1 & 1.1 & 1947 & 1.6 & 32.4 \\
\hline 1881 & 0.1 & 1.2 & 1948 & 1.8 & 34.1 \\
\hline 1882 & 0.1 & 1.3 & 1949 & 1.8 & 35.9 \\
\hline 1883 & 0.1 & 1.4 & 1950 & 2.0 & 37.8 \\
\hline 1884 & 0.1 & 1.5 & 1951 & 2.2 & 40.0 \\
\hline 1885 & 0.1 & 1.6 & 1952 & 2.3 & 42.4 \\
\hline 1886 & 0.1 & 1.8 & 1953 & 2.5 & 44.9 \\
\hline 1887 & 0.1 & 1.9 & 1954 & 2.6 & 47.4 \\
\hline 1888 & 0.1 & 2.0 & 1955 & 2.9 & 50.3 \\
\hline 1889 & 0.1 & 2.1 & 1956 & 3.2 & 53.5 \\
\hline 1890 & 0.1 & 2.3 & 1957 & 3.3 & 56.8 \\
\hline 1891 & 0.1 & 2.4 & 1958 & 3.4 & 60.2 \\
\hline 1892 & 0.1 & 2.6 & 1959 & 3.7 & 63.9 \\
\hline 1893 & 0.2 & 2.7 & 1960 & 4.0 & 67.9 \\
\hline 1894 & 0.2 & 2.9 & 1961 & 4.2 & 72.1 \\
\hline 1895 & 0.2 & 3.0 & 1962 & 4.6 & 76.7 \\
\hline 1896 & 0.2 & 3.2 & 1963 & 4.9 & 81.6 \\
\hline 1897 & 0.2 & 3.4 & 1964 & 5.3 & 86.9 \\
\hline 1898 & 0.2 & 3.5 & 1965 & 5.7 & 92.6 \\
\hline 1899 & 0.2 & 3.7 & 1966 & 6.2 & 98.8 \\
\hline 1900 & 0.2 & 3.9 & 1967 & 6.7 & 105.4 \\
\hline 1901 & 0.2 & 4.1 & 1968 & 7.3 & 112.7 \\
\hline 1902 & 0.2 & 4.3 & 1969 & 7.8 & 120.6 \\
\hline 1903 & 0.2 & 4.5 & 1970 & 8.6 & 129.2 \\
\hline 1904 & 0.2 & 4.7 & 1971 & 9.1 & 138.3 \\
\hline 1905 & 0.2 & 4.9 & 1972 & 9.6 & 147.9 \\
\hline 1906 & 0.2 & 5.1 & 1973 & 10.5 & 158.4 \\
\hline 1907 & 0.2 & 5.3 & 1974 & 10.6 & 169.0 \\
\hline 1908 & 0.2 & 5.5 & 1975 & 10.1 & 179.0 \\
\hline 1909 & 0.2 & 5.7 & 1976 & 10.8 & 189.8 \\
\hline 1910 & 0.2 & 6.0 & 1977 & 11.3 & 201.1 \\
\hline 1911 & 0.2 & 6.2 & 1978 & 11.3 & 212.4 \\
\hline 1912 & 0.2 & 6.4 & 1979 & 7.8 & 220.2 \\
\hline 1913 & 0.2 & 6.7 & 1980 & 3.8 & 224.0 \\
\hline 1914 & 0.2 & 6.9 & 1981 & $3.3 *$ & 227.3 \\
\hline 1915 & 0.2 & 7.1 & 1982 & $3.3 *$ & 230.6 \\
\hline 1916 & 0.3 & 7.4 & 1983 & $3.8 *$ & 234.4 \\
\hline 1917 & 0.3 & 7.7 & 1984 & $3.5 *$ & 237.9 \\
\hline 1918 & 0.3 & 7.9 & 1985 & $3.1 *$ & 241.0 \\
\hline 1919 & 0.3 & 8.2 & 1986 & $3.0 *$ & 244.0 \\
\hline 1920 & 0.4 & 8.6 & 1987 & $2.9 *$ & 246.9 \\
\hline 1921 & 0.4 & 9.0 & 1988 & $3.2 *$ & 250.1 \\
\hline 1922 & 0.4 & 9.4 & 1989 & $3.4 *$ & 253.5 \\
\hline 1923 & 0.5 & 9.9 & 1990 & $3.3 *$ & 256.8 \\
\hline 1924 & 0.5 & 10.4 & Total & 256.8 & $\mathrm{NA}$ \\
\hline
\end{tabular}

We assumed two boundary conditions. Gas/oil ratios prior to 1979 were certainly less than the 1979 value of $515 \mathrm{cu} \mathrm{ft/bbl}$, which was considered to be a maximum value for the years before 1979. To estimate minimum values for the gas/oil ratios prior to 1979 , we used the regression equation for the years 1978 to 1953, when the gas/oil ratio approaches zero. These minimum and maximum values for the gas/oil ratio yield estimates of worldwide total volumes of between 154 and 257 Tcf of associated-dissolved gas flared or vented since oil was first produced (tables 4, 5, and 6). Because petroleum production has increased dramatically since the 1940 's, the bulk of worldwide flared and vented gas has occurred in the last 50 years. It must again be emphasized that these values are estimates based on the extrapolation of recent data and should be used with caution.

\section{CONCLUSION}

Despite the inconsistency and inavailability of data, the extrapolation method outlined here provides a reliable technique for estimating amounts of natural gas flared and vented through time. Figures 6 and 7 compare the calculated and documented volumes of flared and vented gas for Saudi Arabia and Nigeria. The correlations between the calculated and actual volumes of flared and vented gas are excellent $\left(r^{2}=0.93\right.$ and 0.98 for Saudi Arabia and Nigeria, respectively). This method of estimation can provide

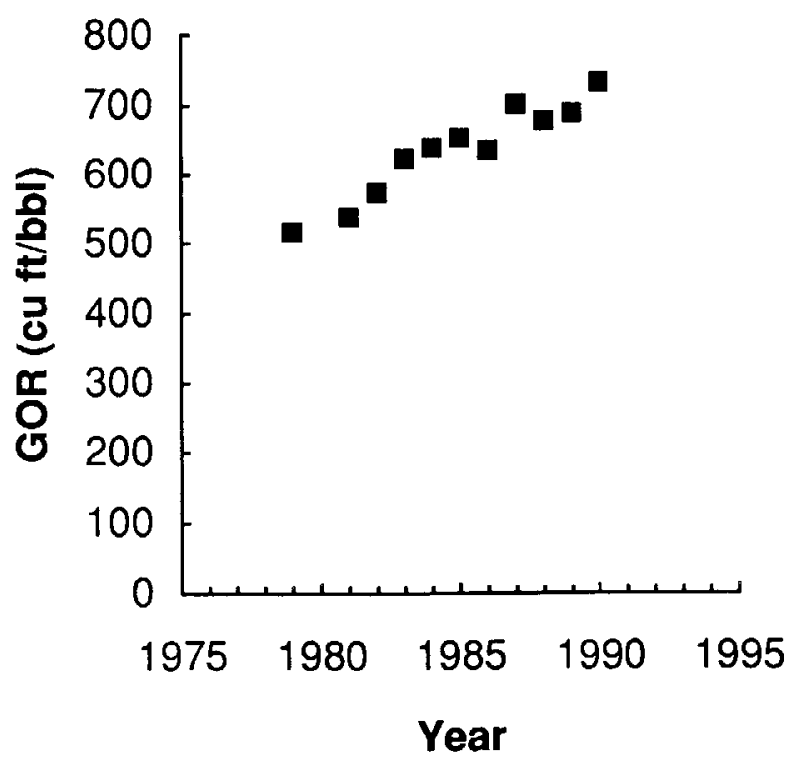

Figure 5. Actual gas/oil ratios (GOR), in cubic feet per barrel (cu $\mathrm{ft} / \mathrm{bbl}$ ), calculated from associated-dissolved gas and oil production data through time for the world. The regression equation is GOR (cu $\mathrm{ft} / \mathrm{bbl})=-36861+(19 X$ year $)$, having a correlation of $r^{2}=0.92$. 
information where data are sparse or poor. In addition, this extrapolation method can be used to provide gross estimates of regional and worldwide volumes of gas flared and vented. However, this method should be used with caution owing to the variability of production practices among different countries and regions.

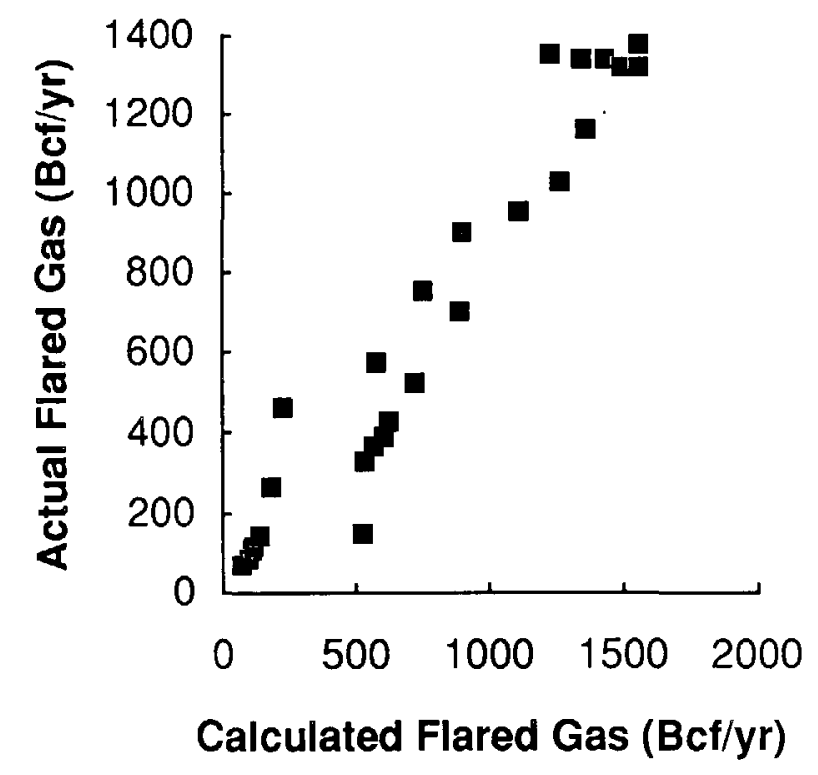

Figure 6. Actual (Organization of the Petroleum Exporting Countries, 1993) versus calculated volumes of flared and vented gas, in billion cubic feet per year $(\mathrm{Bcf} / \mathrm{yr})$, for Saudi Arabia.

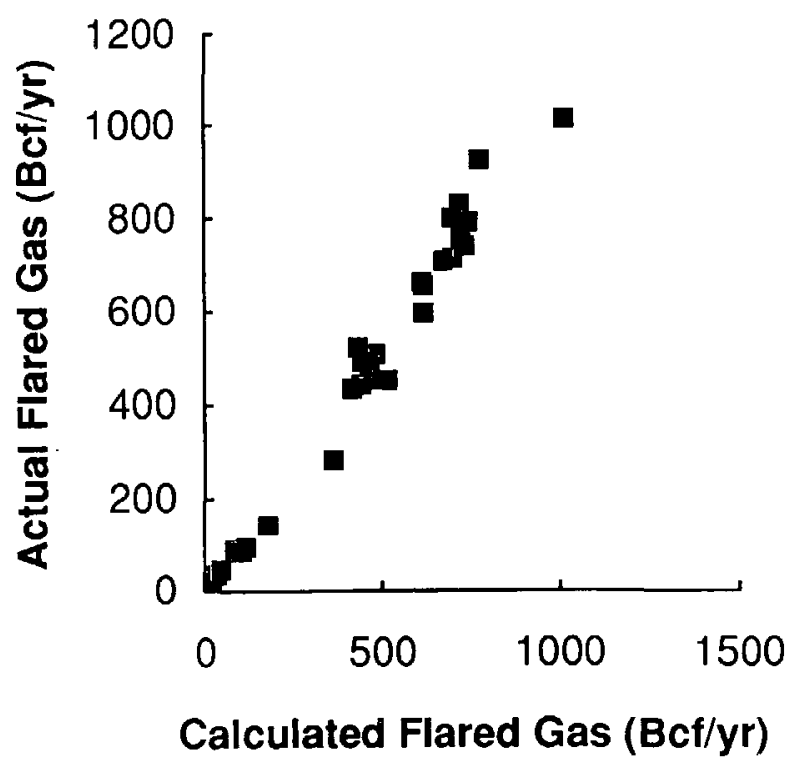

Figure 7. Actual (Organization of the Petroleum Exporting Countries, 1993) versus calculated volumes of flared and vented gas, in billion cubic feet per year (Bcf/yr), for Nigeria.

\section{REFERENCES CITED}

Arabian American Oil Company, 1968, ARAMCO HandbookOil and the Middle East: Dhahran, Saudi Arabia, Arabian American Oil Company, $279 \mathrm{p}$.

DeGolyer and MacNaughton, 1990, Twentieth Century Petroleum Statistics: Dallas, Texas, DeGolyer and MacNaughton, $126 \mathrm{p}$.

Energy Information Administration, 1980, International Energy Annual: 1979: United States Department of Energy, Energy Information Administration Report DOE/EIA-0219(79), Washington, D.C., 93 p.

Energy Information Administration, 1981, International Energy Annual: 1980: United States Department of Energy, Energy Information Administration Report DOE/EIA-0219(80), Washington, D.C., $110 \mathrm{p}$.

Energy Information Administration, 1983, International Energy Annual: 1982: United States Department of Energy, Energy Information Administration Report DOE/EIA-0219(82), Washington, D.C., 108 p.

Energy Information Administration, 1984, International Energy Annual: 1983: United States Department of Energy, Energy Information Administration Report DOE/EIA-0219(83), Washington, D.C., 114 p.

Energy Information Administration, 1985, International Energy Annual: 1984: United States Department of Energy, Energy Information Administration Report DOE/EIA-0219(84), Washington, D.C., 123 p.

Energy Information Administration, 1986, International Energy Annual: 1985: United States Department of Energy, Energy Information Administration Report DOE/EIA-0219(85), Washington, D.C., 129 p.

Energy Information Administration, 1987, International Energy Annual: 1986: United States Department of Energy, Energy Information Administration Report DOE/EIA-0219(86), Washington, D.C., 135 p.

Energy Information Administration, 1988, International Energy Annual: 1987: United States Department of Energy, Energy Information Administration Report DOE/EIA-0219(87), Washington, D.C., 141 p.

Energy Information Administration, 1989, International Energy Annual: 1988: United States Department of Energy, Energy Information Administration Report DOE/EIA-0219(88), Washington, D.C., 185 p.

Energy Information Administration, 1991, International Energy Annual: 1989: United States Department of Energy, Energy Information Administration Report DOE/EIA-0219(89), Washington, D.C., 193 p.

Energy Information Administration, 1992, International Energy Annual: 1990: United States Department of Energy, Energy Information Administration Report DOE/EIA-0219(90), Washington, D.C., 187 p.

Energy Information Administration, 1992, International Energy Annual: 1991: United States Department of Energy, Energy Information Administration Report DOE/EIA-0219(91), Washington, D.C., 183 p.

Hansen Planetarium, 1986, Earth at night [poster]: Salt Lake City, Utah, Hansen Planetarium. 
International Petroleum Encyclopedia 1968: Tulsa, Oklahoma,

The Petroleum Publishing Company, $424 \mathrm{p}$.

International Petroleum Encyclopedia 1969: Tulsa, Oklahoma,

The Petroleum Publishing Company, 400 p.

International Petroleum Encyclopedia 1973: Tulsa, Oklahoma,

The Petroleum Publishing Company, 440 p.

International Petroleum Encyclopedia 1974: Tulsa, Oklahoma,

The Petroleum Publishing Company, 468 p.

International Petroleum Encyclopedia 1975: Tulsa, Oklahoma,

The Petroleum Publishing Company, 480 p.

International Petroleum Encyclopedia 1976: Tulsa, Oklahoma,

The Petroleum Publishing Company, $456 \mathrm{p}$.

International Petroleum Encyclopedia 1977: Tulsa, Oklahoma,

The Petroleum Publishing Company, 478 p.

International Petroleum Encyclopedia 1978: Tulsa, Oklahoma,

The Petroleum Publishing Company, 446 p.

International Petroleum Encyclopedia 1979: Tulsa, Oklahoma,

The Petroleum Publishing Company, 470 p.

International Petroleum Encyclopedia 1980: Tulsa, Oklahoma, PennWell Publishing Company, 464 p.

International Petroleum Encyclopedia 1981, Volume 14: Tulsa,

Oklahoma, The Petroleum Publishing Company, 452 p.
International Petroleum Encyclopedia 1982, Volume 15: Tulsa, Oklahoma, The Petroleum Publishing Company, 464 p.

International Petroleum Encyclopedia 1983, Volume 16: Tulsa, Oklahoma, The Petroleum Publishing Company, 418 p.

International Petroleum Encyclopedia 1984, Volume 17: Tulsa, Oklahoma, The Petroleum Publishing Company, 410 p.

International Petroleum Encyclopedia 1985, Volume 18: Tulsa, Oklahoma, The Petroleum Publishing Company, 394 p.

International Petroleum Encyclopedia 1986, Volume 19: Tulsa, Oklahoma, The Petroleum Publishing Company, 408 p.

International Petroleum Encyclopedia 1987, Volume 20: Tulsa, Oklahoma, The Petroleum Publishing Company, $388 \mathrm{p}$.

International Petroleum Encyclopedia 1988, Volume 21: Tulsa, Oklahoma, The Petroleum Publishing Company, 388 p.

International Petroleum Encyclopedia 1992, Volume 25: Tulsa, Oklahoma, The Petroleum Publishing Company, $358 \mathrm{p}$.

Organization of the Petroleum Exporting Countries, 1993, Natural gas flared in Saudi Arabia and Nigeria, 1963-1991: unpublished data.

Schätzl, L. H., 1969, Petroleum in Nigeria: Ibadan, Nigeria, Oxford University Press, $257 \mathrm{p}$. 


\title{
Energy Gases-The Methane Age and Beyond
}

\author{
By Nebojša Nakićenović ${ }^{1}$
}

\section{CONTENTS}

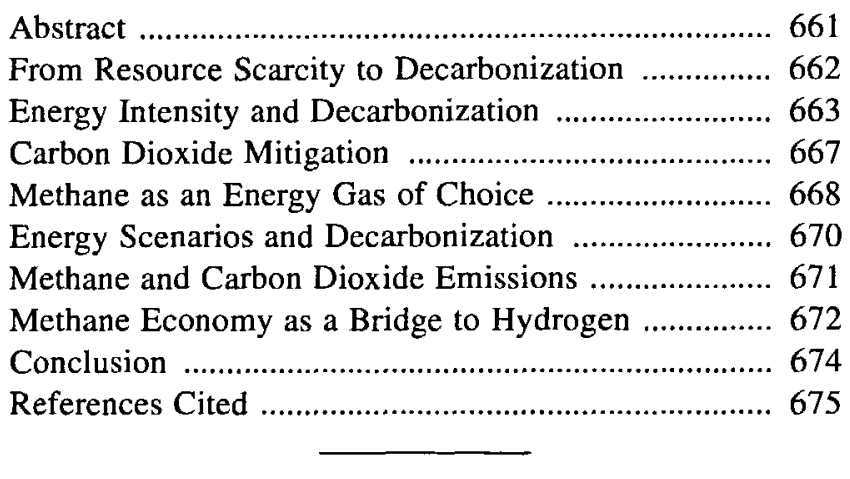

\begin{abstract}
The combustion of fossil fuels results in the emissions of gases and pollutants that produce adverse ecological effects. Evidence is also accumulating that suggests they may also cause global climate change. The combustion gases that are connected with global climate change are primarily carbon dioxide $\left(\mathrm{CO}_{2}\right)$ and to a lesser degree methane $\left(\mathrm{CH}_{4}\right)$ (see Cole, this volume). All of these gases already occur in low concentrations in the atmosphere and, in fact, together with other greenhouse gases, such as water vapor, have made the earth habitable. The risk, however, is that the additional emissions of greenhouse gases associated with energy use and other human activities are rapidly increasing the atmospheric concentrations of these gases and may therefore lead to additional global warming
\end{abstract}

\footnotetext{
'Environmentally Compatible Energy Strategies Project, International Institute for Applied Systems Analysis, A-2361 Laxenburg, Austria; telephone no. (+43-2236) 71521-0; telefax no. (+43-2236) 71313.
}

during the next century. Although the greenhouse gases that result from energy use are the most important cause of these concerns, the energy gases also offer a potential solution to this problem.

Natural gas consists mostly of methane and is a very potent greenhouse gas if released into the atmosphere; however, after combustion occurs, the amount of resulting carbon dioxide is much smaller per unit primary energy in comparison to other fossil energy sources. Natural gas emits roughly one-half of the carbon dioxide in comparison to coal for an equal amount of energy. Thus, a possible shift to a methane economy during the next decades offers a genuine mitigation strategy. Beyond that, natural gas could pave the way for more environmentally compatible energy systems in distant future that could use hydrogen and electricity, both of which are carbon-free energy carriers, that could be produced by nonfossil sources of primary energy. This transition to the "methane age" and beyond to carbon-free energy systems would enhance the reduction of other adverse impacts on the environment by human activities.

In fact, carbon dioxide emissions represent the largest mass flow of waste into the environment in comparison to wastes from all other anthropogenic activities. Current energy-related carbon dioxide emissions are on the order of 6 gigatons of carbon $(\mathrm{GtC})$ or more than $20 \mathrm{GtCO}_{2}$ per year. This is more than 20 times larger than, for example, annual global steel production of about 700 megatons (Mt). Decarbonization is a notion that denotes reduction of carbon dioxide emissions per unit primary energy and per unit economic activity, and dematerialization refers to the reduction of materials used per unit economic activity. Decarbonization would also help reduce the emission of other energy pollutants and wastes, and it would also enhance the dematerialization in general. Other measures that would lead to decarbonization, in addition to a shift to a methane economy, include efficiency improvements and 
energy conservation, carbon removal and storage, or a shift to carbon-free sources of energy, such as solar and nuclear energy.

\section{FROM RESOURCE SCARCITY TO DECARBONIZATION}

In the aftermath of the so-called energy crisis of the early 1970 's, a number of studies have been conducted to assess long-term national and global energy prospects. In the wake of increasing energy prices and serious supply shortages, most of these studies focused on securing the long-term supply. Often these studies resulted in calls for commercializing large amounts of nonconventional fossil energy resources, such as oil shales, and promoting nuclear power and fusion. A number of studies also considered renewable energy sources and solar energy as additional strategies for enhancing the supply of energy in the long run. In any case, the paradigm of oil shortage and depletion of conventional fossil energy resources predominated.

As the sophistication of methodological approaches for analyzing energy futures increased, research also shifted to the questions of improving efficiency, end use of en- ergy, and enhancing conservation. The studies became more balanced in treating supply and demand. Today, the predominate question is how to reduce the adverse impacts of energy use in the world, while allowing for sufficient increase of energy services in the developing countries. This is a formidable task considering that global population is expected to double during the next century and that 80 percent of humanity shares less than 20 percent of global wealth. At the same time, it is becoming increasingly evident that fossil energy resources are much more abundant than it was anticipated in the 1970's and early 1980's. Both resources and reserve bases of oil and natural gas have increased and, in fact, new natural gas discoveries have outpaced oil. The absolute finiteness of energy resources does not appear to be a problem facing humanity in the next few hundred years. The question is rather how to utilize the available energy resources in supplying adequate services, while arresting the further environmental degradation and global warming.

This dilemma of the need to increase energy services and reduce the adverse impacts of energy-use is illustrated in figure 1. It shows per capita emissions of the greenhouse gases carbon dioxide and methane for the major world regions.

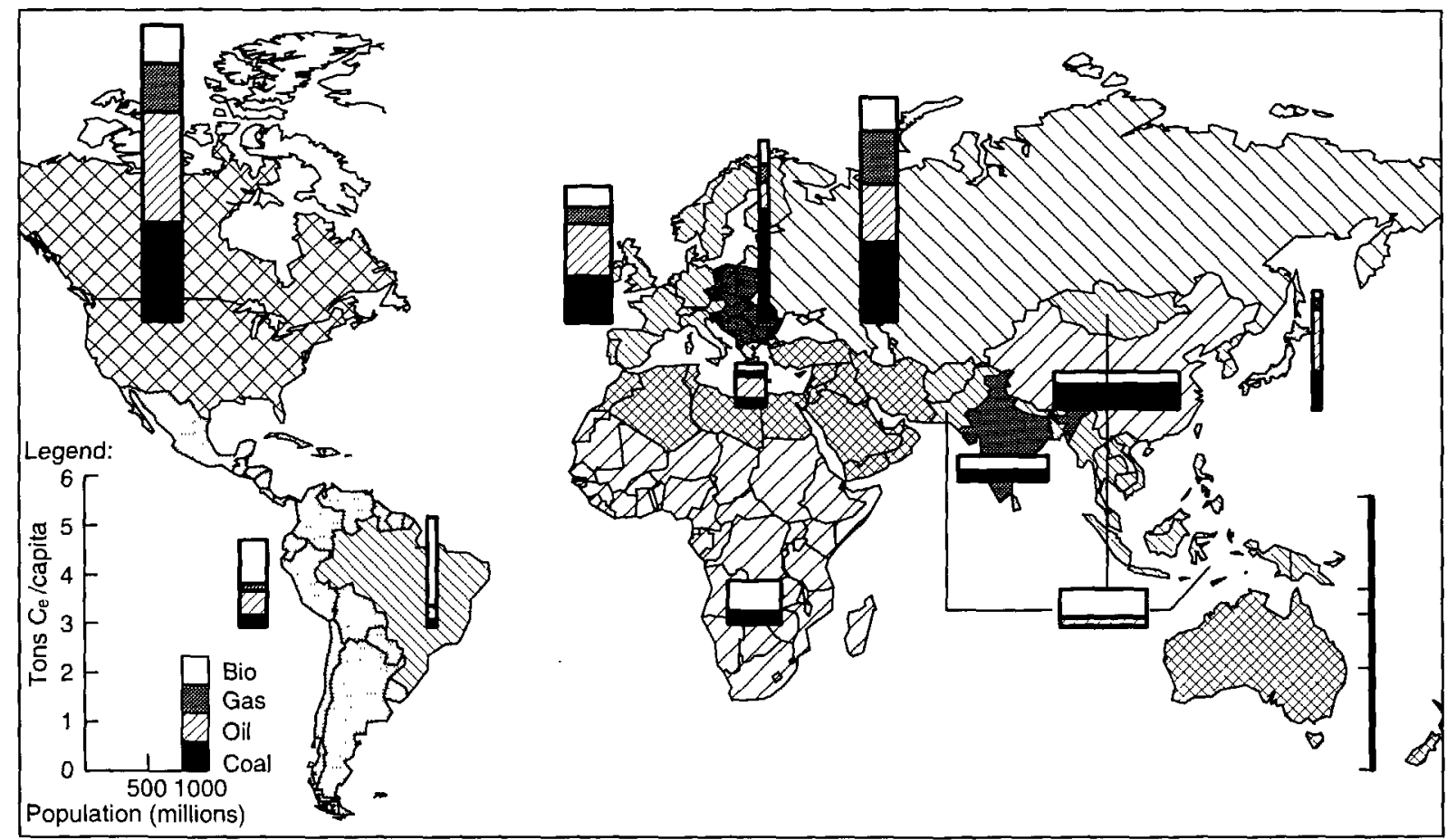

Figure 1. $\mathrm{CO}_{2}$ and $\mathrm{CH}_{4}$ greenhouse-gas emissions per capita versus population for different world regions and by energy source in 1988. Height of bars gives carbon dioxide and methane emissions per capita in tons of carbon equivalent, and width of bars shows regional population. Four main sources of the greenhouse gas emissions are shown: carbon dioxide emissions resulting from (1) coal, (2) oil, and (3) natural gas consumption, and (4) the combined carbon dioxide emissions of all nonfossil energy sources, such as biomass burning, and also all of the anthropogenic methane sources, both energy and nonenergy. ( $1 \mathrm{~kg} \mathrm{CH}=21 \mathrm{~kg} \mathrm{CO}$ ). $\mathrm{C}_{\mathrm{c}}=$ total greenhouse-gas emissions in tons of carbon. 
The combined carbon dioxide and methane emissions are clearly the highest in the industrialized countries, reaching 6 tons of carbon (tC) equivalent per capita in North America and Australia and not much lower in some parts of Eastern Europe and the former Soviet Union. For example, the eastern states of Germany that constituted the former German Democratic Republic had almost the same per capita carbon dioxide emissions as the United States, but had a much lower standard of living and energy services. This was due to the high degree of inefficiency of the energy systems, a very high share of coal in the energy mix, and a high level of material use per unit economic activity in general. A similar situation still exists in the economies of Eastern Europe, Russia, and the other Commonwealth (former Soviet) Republics.

In contrast to the energy-intensive economies of Eastern Europe, Japan and Western European countries achieve much higher levels of economic activities with substantially lower per capita energy consumption and greenhouse gas emissions. The standard of living in most of the Western European countries is comparable to that of the United States, however, the emissions of greenhouse gases are half as large in Western Europe. In the more efficient industrial countries of Western Europe and Japan, emissions are on the order of $3 \mathrm{tC}$ equivalent per capita, whereas they are twice that amount in North America. These regions constitute about 20 percent of the world population today.

The other 80 percent of the world population accounts for only 20 percent of the global carbon dioxide and methane emissions. Figure 1 clearly shows this disparity in the emissions levels. For example, China, with one billion people, has combined carbon dioxide and methane emissions that barely exceed $1 \mathrm{tC}$ per capita. It is also of interest to observe that the structure of the emissions is different in most developing countries in comparison to the industrialized countries. Using China again for an example, we see that most of the emissions are due to coal consumption, nonfossil carbon dioxide, and methane emissions, indicating low shares of oil and natural gas in the primary energy mix. As the developing countries continue to grow, the total emissions will increase, and if the development process continues, per capita emissions will most likely also increase. The current plans in India and China are to expand coal production and use, with emissions reaching perhaps $3 \mathrm{Gt}$ in a few decades. This source of carbon dioxide alone would represent half of the current total emissions. Therefore, it is quite apparent that economic and social development in the world are strong determinants of future greenhouse gas emissions. The potential risks of climate change, on the other hand, suggest a need to slow down the growth of emissions and even decrease them in the next century. There is a need to reconcile this opening gap between the energy needs for development and reduction of emissions as a precaution to guard against global warming.

\section{ENERGY INTENSITY AND DECARBONIZATION}

Global emissions will continue to increase along with further economic development and population growth in the world. The most important determinants of future energy-related carbon dioxide emissions could be represented as products of the following factors: (1) population growth, (2) per capita value added, (3) energy per value added, (4) carbon emissions per energy on one side, and (5) total carbon dioxide emissions on the other side of the identity (Yamaji and others, 1991). Two of these factors are increasing and two are declining at the global level. $\left[\mathrm{CO}_{2}=\left(\mathrm{CO}_{2} / \mathrm{E}\right) \times(\mathrm{E} / \mathrm{GDP}) \times(\mathrm{GDP} / \mathrm{P}) \times \mathrm{P}\right.$, where $\mathrm{E}$ represents energy consumption, GDP the gross domestic product or value added, and $\mathrm{P}$ population. Changes in $\mathrm{CO}_{2}$ emissions can be described by changes in these four factors.]

At present, the world's global population is increasing at a rate of about 2 percent per year. The longer-term historical growth rates since 1800 have been about 1 percent per year. Most population projections expect at least another doubling during the next century; for example, the World Bank (Vu, 1985) and United Nations (1991) projections. Productivity has been increasing in excess of global population growth since the beginning of industrialization and thus has resulted in more economic activity and value added per capita. In contrast, energy intensity per unit value added has been decreasing at a rate of about 1 percent per year since the 1860 's and at about 2 percent per year in most countries since the 1970's. Carbon dioxide emissions per unit of energy have also been decreasing but at a much lower rate, about 0.3 percent per year.

Figure 2 shows the extent of global decarbonization of energy since 1900, as the change in the ratio of average carbon dioxide emissions per unit of energy consumed. Decarbonization occurred owing to the gradual replacement of carbon-rich sources of energy by carbon-poorer sources of energy. First, wood and coal were replaced by oil and later by natural gas and more recently, to a lesser degree, by nuclear energy. Figure 2 also illustrates decarbonization rates implicit in a number of global energy scenarios. For example, the United States Environment Protection Agency's (EPA) Rapidly Changing World (RCW) scenario actually anticipates an increase of carbon intensity in the world and thus a reversal of the historical development trend (Environment Protection Agency, 1990). This is primarily due to a heavy reliance on coal in this scenario. The Intergovernmental Panel on Climate Change (IPCC) has developed a whole range of scenarios; the median one is shown in figure 2 and anticipates continuation of the current level of carbon emissions per unit energy consumed in the world (Intergovernmental Panel on Climate Change, 1992). The Environmentally Compatible Scenario (ECS'92) developed at International Institute for Applied Systems Analysis (IIASA) in 1992 (Nakićenović and others, 1993) and the 


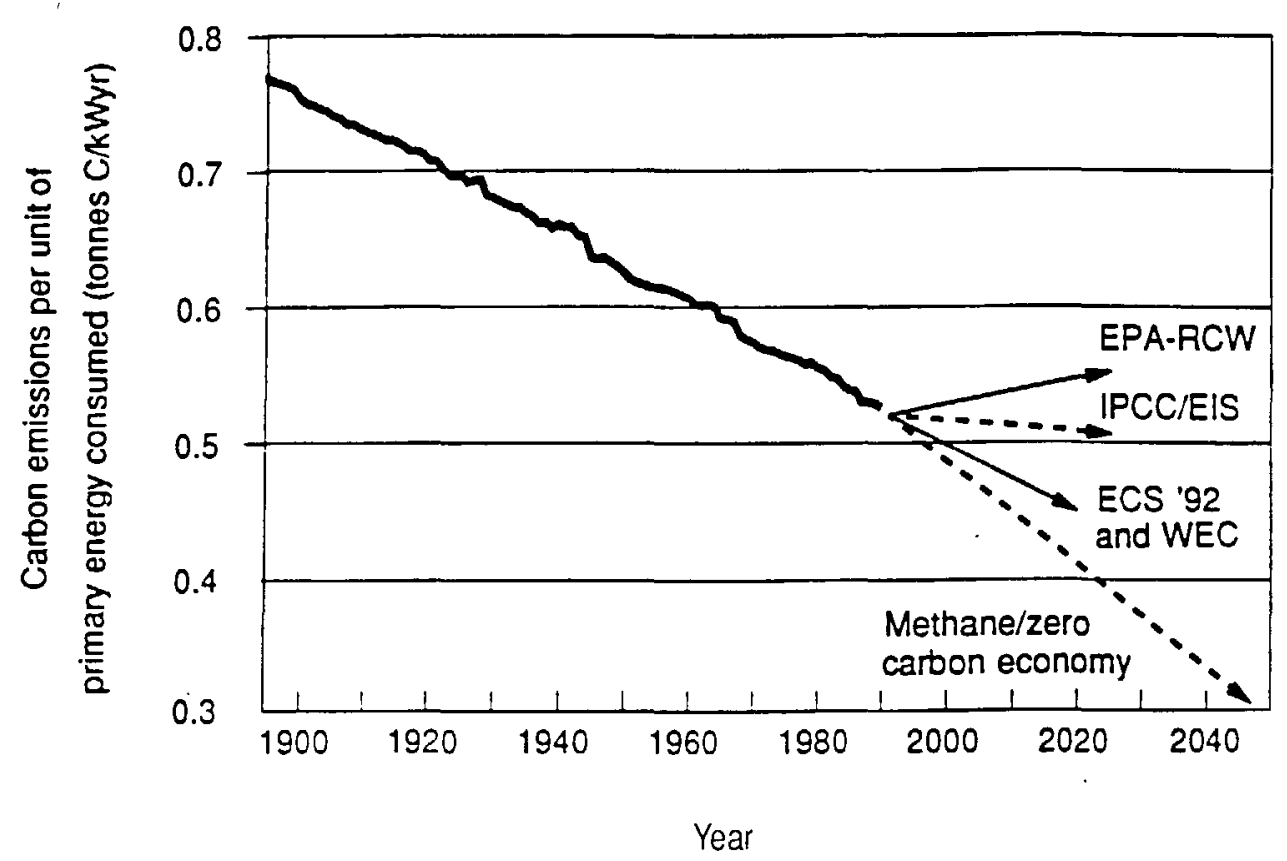

Figure 2. Global decarbonization of energy since 1900 and scenarios for the future in tonnes of carbon per kilowatt year ( $\mathrm{tC} / \mathrm{kWyr}$ ) of energy. Four future scenarios are shown: (1) Environmental Protection Agency's (EPA) Rapidly Changing World scenario, (2) the Intergovernmental Panel on Climate Change (IPCC) Energy and Industry Subgroup's median scenario, and (3) the International Institute for Applied Systems Analysis (IIASA) Environmentally Compatible Scenario '92, as well as (4) the World Energy Council's (WEC) reference scenario, which has essentialjy the same carbon intensity of energy as ECS ' 92 . The lower dashed line shows the further reduced emissions of a methane/zero-carbon economy.

World Energy Council scenario (World Energy Council, 1992) represent a continuation of the historical trends and thus a certain degree of decarbonization in the future. The lower dashed line with the arrow into the future in figure 2 symbolizes the need to achieve even higher rates of decarbonization in order to offset future population and economic growth in the world. A scenario that relies on the higher contribution of energy gases in primary energy consumption could achieve this goal, and such a scenario will be described in this paper. To stabilize energy-related carbon emissions at current annual levels of almost $6 \mathrm{GtC}$ for a primary energy demand between 15 and 18 terawatt years (TWyr) by the year 2020 (compared to 12 TWyr in 1992), the rate of decarbonization would have to range from 0.8 to 1.4 percent per year (two to four times the annual rates achieved in the past).

In addition to energy decarbonization, one must also consider the reduction of energy intensity in economic activities as a second factor that is also causing a decrease in the carbon dioxide emissions mentioned above. Figure 3 shows the historical decrease in energy intensity per unit value added in a number of countries. Energy development paths in different countries have varied enormously and consistently over long periods, but the overall tendency is toward lower energy intensities. For example, France and
Japan have always used energy more efficiently than the United States, the United Kingdom, or Germany. This should be contrasted with the opposite development in some of the rapidly industrializing countries, where commercial energy intensity is still increasing, such as in Nigeria. The present energy intensity of Thailand resembles the situation in the United States in the late 1940's. The energy intensity of India and its present improvement rates are similar to those of the United States about a century ago. The reforming countries of Eastern Europe and the former Soviet Union have relatively high energy intensities, between those of the United States (lower) and India (higher).

Figure 4 shows the decarbonization and energy deintensification achieved in a number of countries since the 1870's. It illustrates salient differences in the policies and structures of energy systems among countries. For example, Japan and France have achieved the highest levels of decarbonization; in Japan this has been achieved largely through energy-efficiency improvements over recent decades, while in France largely through vigorous substitution of fossil fuels by nuclear energy. Most countries have achieved decarbonization through the replacement of coal, first by oil and later by natural gas.

At the global level, the long-term reduction in carbon intensity of value added has been about 1.3 percent per 


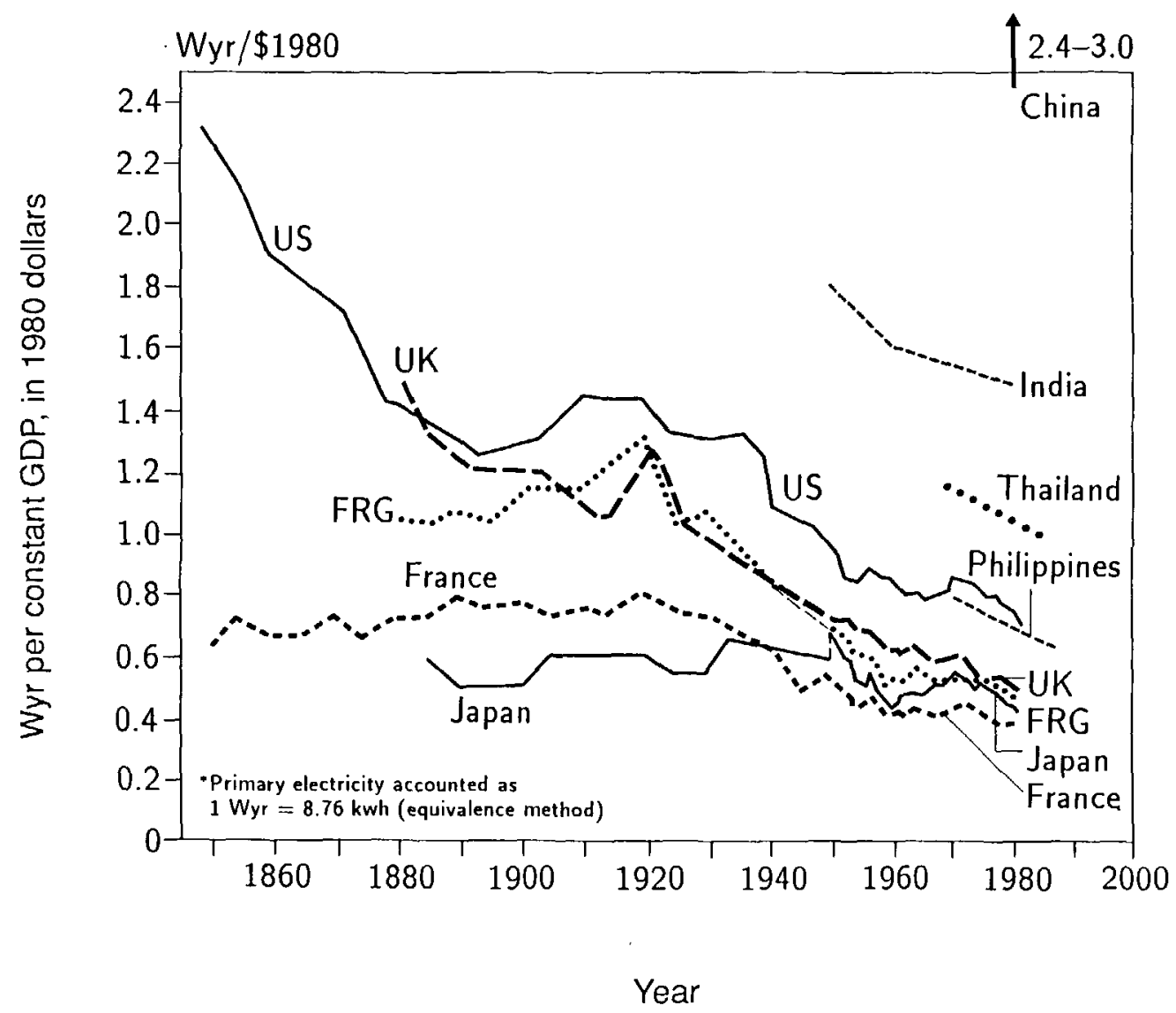

Figure 3. Primary energy intensity, including biomass, of value added in kilowatt year (Wyr) per constant gross domestic product (GDP) in 1980 dollars. Primary electricity is accounted as $1 \mathrm{Wyr}=8.76 \mathrm{kWh}$ (equivalence method).

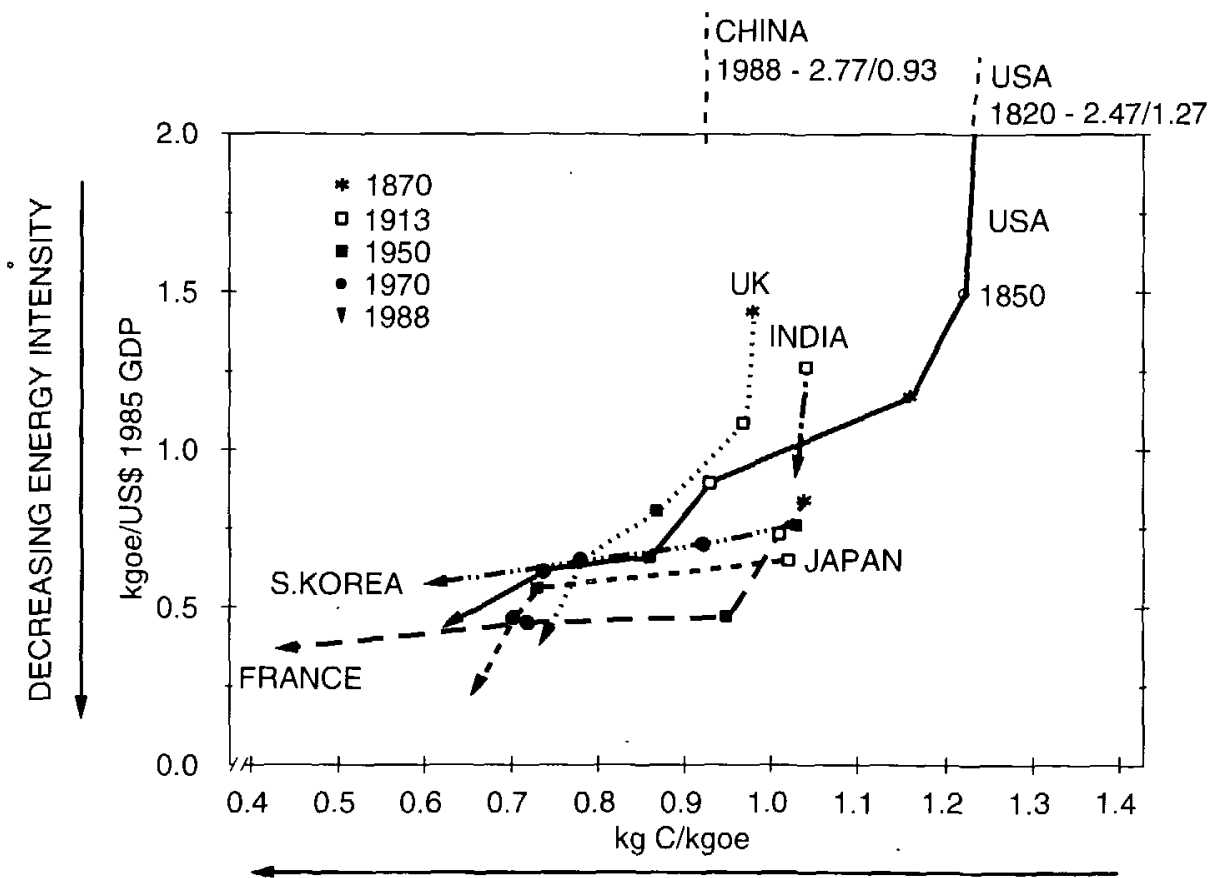

Figure 4. Global decarbonization and deintensification of energy in kilograms of carbon per kilogram of oil equivalent ( $\mathrm{kgC} / \mathrm{kgoe})$, and in $\mathrm{kgoe}$ per $\$ 1,000$ gross domestic product (GDP) (Grübler, 1991). 
year-decarbonization of energy occurs at about 0.3 percent per year and reduction of energy intensity of value added occurs at about 1 percent per year. This falls short of what is required to offset the effects of global economic growth of about 3 percent per year. This means that global carbon dioxide emissions have been increasing at about 1.7 percent per year during most of this century. Today, global carbon dioxide emissions are still increasing at close to 2 percent per year, implying a doubling before the 2030 's, and this is in fact quite close to the emissions levels projected in some of the global scenarios.

Figure 5 gives an overview of the major energy scenarios for the world. It shows the current energy-related carbon emissions of almost $6 \mathrm{GtC}$ in 1990 and the anticipated increase of emissions during the next three decades. It shows the EPA's RCW scenario with highest emissions exceeding $10 \mathrm{GtC}$ by 2020 (Environmental Protection Agency, 1990). It shows again the Intergovernmental Panel on Climate Change (IPCC) midrange scenario with slightly lower emissions, although it should be mentioned that the lowest IPCC scenarios actually lead to a reduction of global emissions with respect to 1990 during the next the century (Intergovernmental Panel on Climate Change, 1992). Figure 5 also shows the WEC reference scenario and the ECS'92 scenario from IIASA to be in the lower range of emissions (Nakićenović and others, 1993).
The shaded area represents what could be called "the consensus view" of future energy emissions. This range of emissions is based on assessments of the International Energy Workshop (IEW). Since 1981, Stanford University and IIASA have jointly organized a series of IEW Workshops with the aim of comparing energy projections made by different groups around the world and analyzing their differences (Manne and Schrattenholzer, 1992). The projections are analyzed on the basis of a standardized poll. The median response derived from the polls corresponds, in our interpretation, to the "consensus view" and reflects the "conventional wisdom" of the international energy community. These projections mostly describe surprisefree business-as-usual middle-of-the-road scenarios.

According to the results of the most recent IEW poll (Manne and Schrattenholzer, 1992), today's projections anticipate a more modest growth of global primary energy consumption between now and the year 2020 than the long-term trend of 2 percent per year. The IEW median projection corresponds to an average annual growth rate of 1.4 percent, which would lead to an absolute increase from 11.8 to $18 \mathrm{TWyr} / \mathrm{yr}$.

Together, the IEW comparisons of projections show that the energy community is anticipating a substantial increase in global carbon dioxide emissions during the next 30 years-the median represents an increase of more than

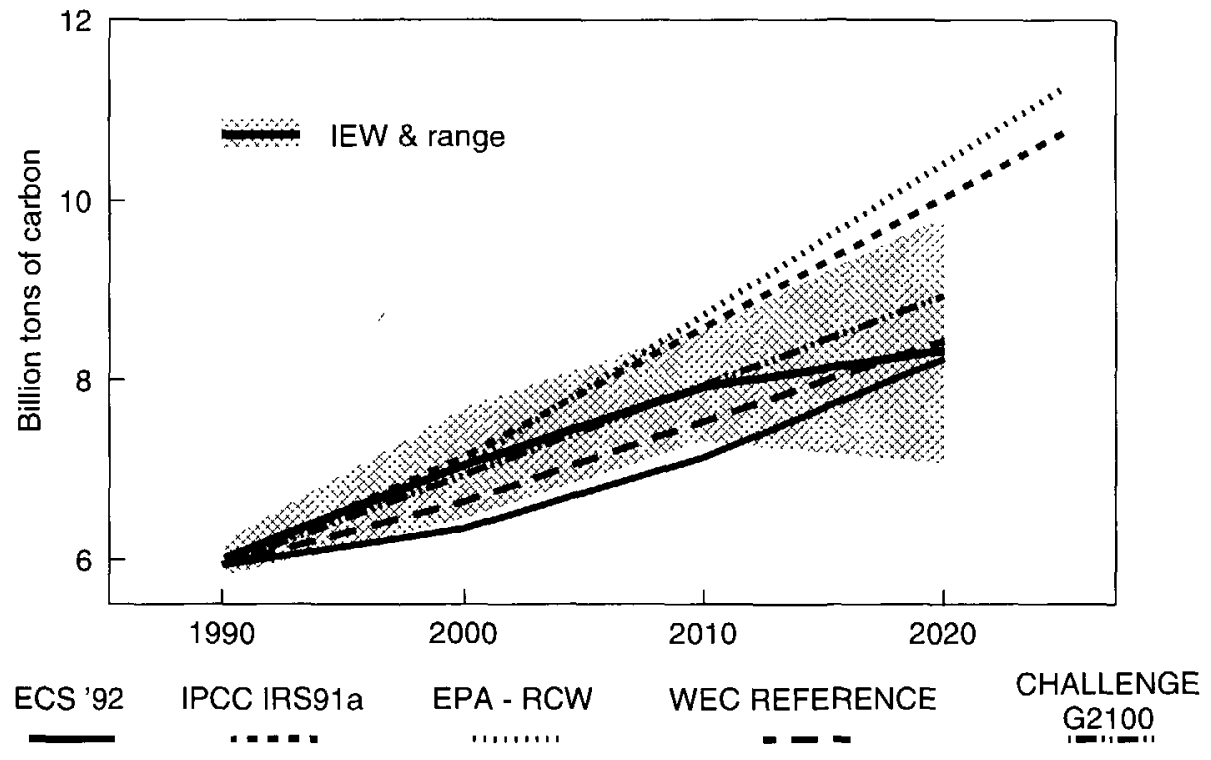

Figure 5. Global primary energy consumption 1990-2020. Range of the International Institute for Applied Systems Analysis International Energy Workshop (IIASA IEW) projections, including the Environmental Protection Agency Rapidly Changing World (EPA RCW) scenario, the World Energy Council (WEC) reference scenario, the Intergovernmental Panel on Climate Change scenario (IPCC IRS91a), the International Institute for Applied Systems Analysis Environmentally Compatible Scenario (IIASA ECS'92), and the International Institute for Applied Systems Analysis (IIASA) Challenge G2100. See text for discussion of shaded areas. 
30 percent. On the other hand, international assessments such as that by the IPCC clearly point to the need to reduce the emissions to the fullest extent possible. Furthermore, the Framework Convention on Climate Change that was signed by 153 countries at the Rio de Janiero Summit in 1992 , to be ratified in the near future, calls for reduction of emissions as a precautionary principle toward arresting climate change (International Negotiating Committee, 1992).

\section{CARBON DIOXIDE MITIGATION}

There are basically three courses of action to deal with carbon dioxide emissions: (1) mitigate the emissions in the future, (2) deal with the adverse impacts of climate change and compensate for incurred damages, and (3) adapt to climate change and learn to live in the warmer weather. All of these alternatives are surrounded by numerous uncertainties. Mitigation measures and options have been studied in greater detail than impacts and adaptation. In this paper, mitigation strategies that involve greater use of energy gas in the future with the intention of reducing emissions of greenhouse gases will be considered. For completeness, a brief overview of other mitigation options will be given. The technological and economic measures to minimize energy-related greenhouse gases emissions include efficiency improvements, conservation, enhanced use of low-carbon fueis, carbon-free sources of energy, and other options, such as afforestation, enhancement of natural carbon sinks, and the creation of new sinks. Thus, the mitigation strategies encompass the whole energy system from primary energy extraction to actual energy use, including various conversion, transport, distribution, and end-use systems.

Four types of technological strategies can be distinguished for stabilizing and eventually also reducing energy-related carbon dioxide emissions. The first is an incremental one, emphasizing energy-efficiency improvements (see also Mills, this volume). In this case, devices or operational practices are replaced by more efficient ones without major changes in the technology of the device itself or technologies upstream in the energy supply chain. For example, this could mean replacing a refrigerator or a gas-fired power plant by a more efficient model, while using the same electricity and fuel supply chains. Three other strategies are more radical. They include changes in technological design and operational practices with and without changes in the energy chains. These are changes in technological "trajectories." In the simplest case, the end-use technology is changed but with the same upstream energy chain, for example, switching from a gasoline to a diesel car. Alternatively, the end use and conversion technologies may stay the same but the primary energy input changes, such as switching from an oil- to a gas-fired combined-cycle power plant. Finally, it is possible to change the trajectories of end-use, conversion, and primary energy-supply technologies (in other words, the whole energy chain), such as switching from a gasoline car with oil as the primary energy source to an electric vehicle with photovoltaic panels.

There is a clear ranking of the four different technological strategies with regard to costs (Nakicenovic and others, 1993). The incremental improvements have the lowest cost because they do not require changes in technological trajectories. These are also the easiest to implement and take the shortest time. They are followed by measures that involve a change in the primary energy source and those involving changes in end-use technologies. Generally, the most difficult and costly measures to implement will be those where both end-use and primary energy-supply technologies have to be changed. Here, changes are required in all related components of the energy system, meaning that entirely new energy chains have to be developed and built-new energy-supply systems, infrastructures, diffusion of new end-use devices, and delivery outlets.

A similar conclusion also holds for carbon removal and disposal technologies. The more remote from the disposal site and diluted the source of emissions, the more difficult and expensive are the carbon control measures. Again, demand-side measures such as improved efficiency and emission avoidance are cheaper than post-combustion scrubbing of stack gases, which, in turn, is cheaper than carbon removal from the atmosphere by micro-algae carbon fixation or other technologies. From this perspective, it is not surprising that most assessments of mitigation options identify energy efficiency improvements and end-use demand-management measures among the most cost-effective measures, followed by fuel substitution. More traditional energy supply-side measures, or even extensive industrial and infrastructural restructuring measures, are generally more difficult to implement and are certainly also more expensive.

In this paper, the implications of carbon dioxide and methane emissions from increasing reliance on combustion of natural gas in the future are considered. Although natural gas (mostly methane) results in lower specific carbon dioxide emissions than other fossil fuels, it has not been explored in detail as a mitigation strategy for arresting global warming. Often, reservations are expressed in connection to wider use of natural gas because methane is a potent greenhouse gas. We will demonstrate that a stronger reliance on natural gas in the future would lead to relatively modest increases in carbon dioxide emissions compared with scenarios that are based on more traditional mitigation strategies. We will also show that methane emissions do not pose a major problem provided that leakage rates could be maintained at least at levels of 4 percent of gas consumption or less in the future. 


\section{METHANE AS AN ENERGY GAS OF CHOICE}

A global scenario in which a major share of primary energy is natural gas is of interest for several reasons: (1) The historical replacement of coal by oil and later by natural gas indicates such a trend. Primary energy substitution (Marchetti and Nakićenović, 1979; Nakićenović, 1990) suggests a likelihood that natural gas will become the major global source of energy during the next century. (2) New markets for natural gas appear to be opening because natural gas is more environmentally desirable than other fossil fuels. Methane has the highest hydrogen to carbon atomic ratio and the lowest carbon dioxide emissions of all fossil fuels. The historical transition from wood to coal to oil and to gas has resulted in gradual decarbonization of energy, or to an increasing hydrogen to carbon ratio of global energy consumption. Natural gas use is also highly desirable from a regional environment standpoint because of minimal sulfur dioxide and particulate emissions. (3) Recent assessments suggest that gas resources may be more abundant than was widely believed only a decade ago. New discoveries have outpaced consumption. Additionally, discoveries of gas hydrates and natural gas of ultradeep origin indicate truly vast occurrences of methane throughout Earth's crust (see Wyman; Gold; Kvenvolden; this volume). There is increasing evidence of multiple economic and geopolitical benefits from a worldwide shift to natural gas (Lee and others, 1988).

Figure 6 shows primary energy substitution in the world. The competitive struggle between five main sources of primary energy is dynamic and quite regular so that it can be described by relatively simple rules (Marchetti and Nakićenović, 1979; Nakićenović, 1979, 1986). The dynamics of this process are captured by logistic equations that describe the rise of new energy sources and the senescence of old ones. The substitution process clearly indicates the dominance of coal as the major energy source between the 1880's and 1960's after a long period during which fuel wood (and other traditional energy sources) were in the lead. The massive expansion of railroads, the growth of steel, steamships, and many other sectors are associated with and based on the technological opportunities offered by the mature coal economy. After the 1960's, oil assumed a dominant role simultaneously with the maturing of the automotive, petrochemical, and other modern industries.

Figure 6 projects natural gas as the dominant source of energy during the first decades of the next century, although oil still maintains the second largest share until the 2040's. For such an explorative "look" into the future, additional assumptions are required because potential new competitors, such as nuclear, solar, and other renewable energy sources have not yet captured sufficient market shares to allow estimation of their growth rates. To explore the behavior of the logistic substitution model when the competition between energy sources is extended into the future, we assume that nuclear energy would diffuse at comparable rates to oil and natural gas half a century earlier. This implies that the current share of nuclear energy in the world would be unchanged for a decade, when growth would resume but at a lower rate than in the past. Nevertheless, such a scenario would require a new generation of nuclear installations, and today prospects for such

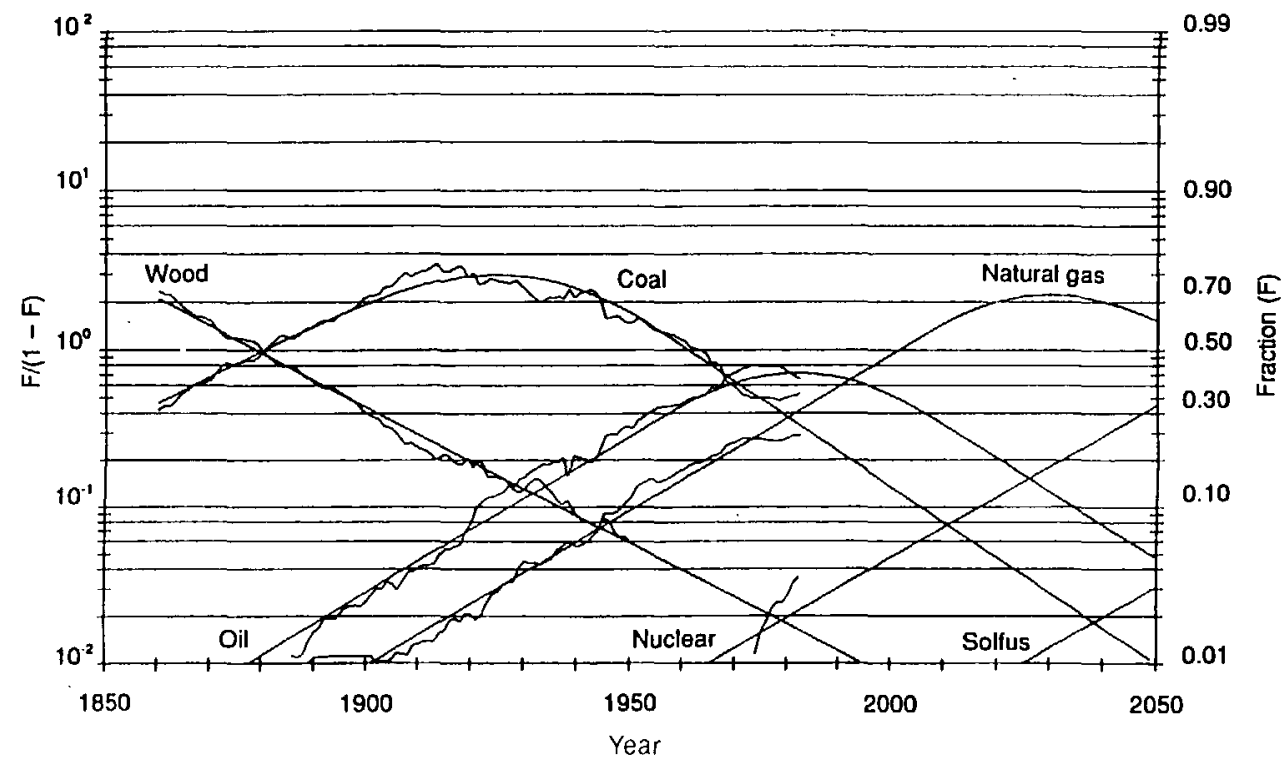

Figure 6. Global primary energy substitution. Smooth lines represent model calculations and jagged lines are historical data. "Solfus" is a term employed to describe a major new energy technology, for example solar or fusion. 
installations are at best questionable. This leaves natural gas with the lion's share in primary energy during the next 50 years. In the past, new sources of energy have emerged from time to time, coinciding with the saturation and subsequent decline of the dominant competitor. "Solfus" is a term employed to describe a major new energy technology (for example solar or fusion) that could emerge during the 2040's at about the time that natural gas would reach maximum share of total energy (Marchetti and Nakićenović, 1979; Nakićenović, 1990).

Figure 6 demonstrates that the diffusion of new energy sources and the replacement of older energy sources by newer ones takes on the order of almost 100 years at the global level. All too often there is over optimism about how rapid the diffusion of new technologies might be. The historiography (history and geography) of technological change clearly demonstrates that the diffusion of innovations with some economic and social significance may take on the order of decades and sometimes even centuries. Longer periods are required for the pervasive transformation of economic activities by a whole cluster of technological and organizational innovations. The analysis of primary energy substitution and market penetration suggests that natural gas may become the dominant energy source and remain so for half a century, perhaps to be replaced by carbon-free energy sources such as nuclear, solar, or fusion. Thus, the primary energy substitution implies a gradual continuation of the decarbonization of energy in the world. The "methane economy" could represent a first step toward a carbon-free energy future. For this reason the dynamics of primary energy substitution is used as a scenario for determining carbon dioxide and methane emissions associated with a stronger reliance on natural gas as a fuel of choice in the future. This approach was employed more than 15 years ago to determine future energy-related carbon dioxide emission scenarios and was used again a few years ago in a more comprehensive assessment of future carbon dioxide and methane emissions (Marchetti, 1979; Ausubel and others, 1988; Victor, 1990).

Market penetration and substitution analysis provides a method for calculating shares of different primary energy sources in the world. What is required is a scenario describing the levels of global primary energy consumption. Thereafter, the calculation of carbon dioxide emissions becomes a straightforward matter; the following are carbon dioxide emissions factors per unit energy ( $\mathrm{kWyr}$ ): Wood $0.844 \mathrm{tC} / \mathrm{kWyr}$; coal $0.735 \mathrm{tC} / \mathrm{kWyr}$; oil 0.849 $\mathrm{tC} / \mathrm{k} \mathrm{Wyr}$; and natural gas $0.442 \mathrm{tC} / \mathrm{kWyr}$ (Ausubel and others, 1988).

We examine a methane economy scenario with two overall levels of energy consumption in the world, both are population driven and based on World Bank estimates (Vu, 1985). One variant of the methane economy scenario, the "efficiency case," holds per capita energy consumption at the current level so that the primary energy consumption increases at the same rate as world population growth. This leads to a primary energy consumption rate of about $20 \mathrm{TWyr} / \mathrm{yr}$ by the end of the next century, when the population reaches 10 billion. The second variant, the "longwave case," stipulates another growth pulse in per capita primary energy consumption leading to a threefold increase by the end of the next century and to staggering levels of global primary energy consumption. The two cases cover a large domain encompassing some of the highest and lowest projections from the literature. Figure 7 shows the primary energy consumption in the two variants of the methane economy scenario.

The carbon dioxide emissions are simply calculated as the product of the market shares of different energy sources (fig. 6), the scenario of global primary energy consumption (fig. 7) and individual emissions factors (discussed above). Figure 8 shows the resulting carbon dioxide emissions for the two methane economy variants. In the efficiency variant, emissions stay roughly constant over the next 50 years, peaking shortly before 2050 and falling thereafter. The results of this case are close to the lowest of the IPCC scenarios and consistent with gradual stabilization of atmospheric carbon dioxide concentrations (Intergovernmental Panel on Climate Change, 1992). In the long-wave case, emissions peak steeply at a level close to $15 \mathrm{GtC}$ per year shortly before 2050 and also decline thereafter falling to $7 \mathrm{GtC}$ in the year 2100 . The two cases bracket virtually all reasonable scenarios of primary energy consumption in the future and they result in substantially lower carbon dioxide emissions than other long-term

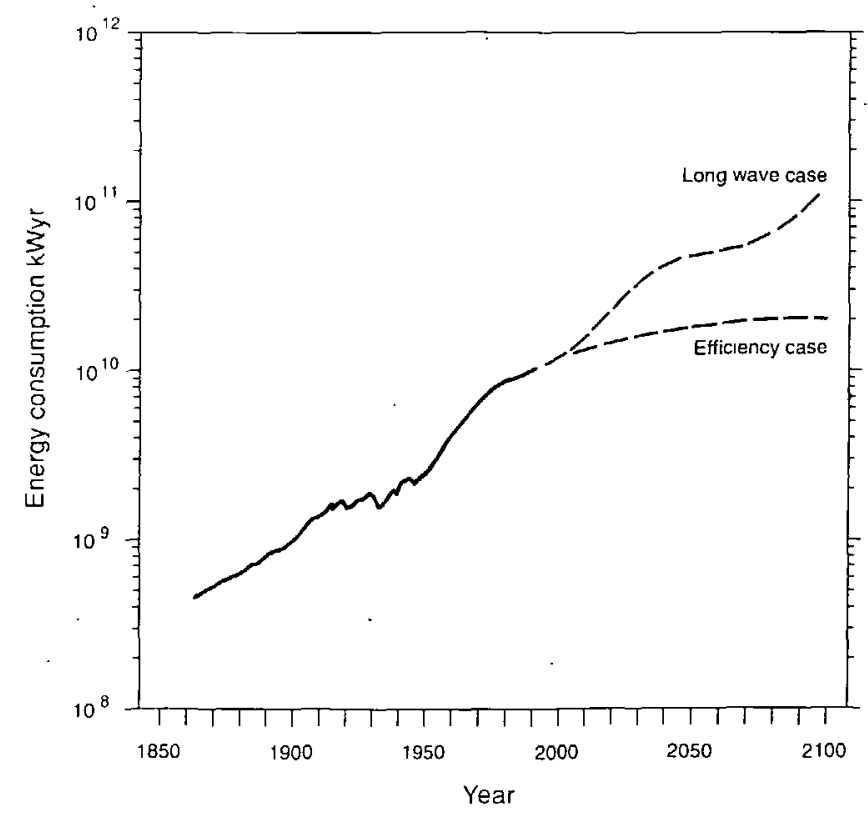

Figure 7. Primary energy consumption (historical data (solid line) and the two variants (dashed lines) of the "methane economy" scenario). 


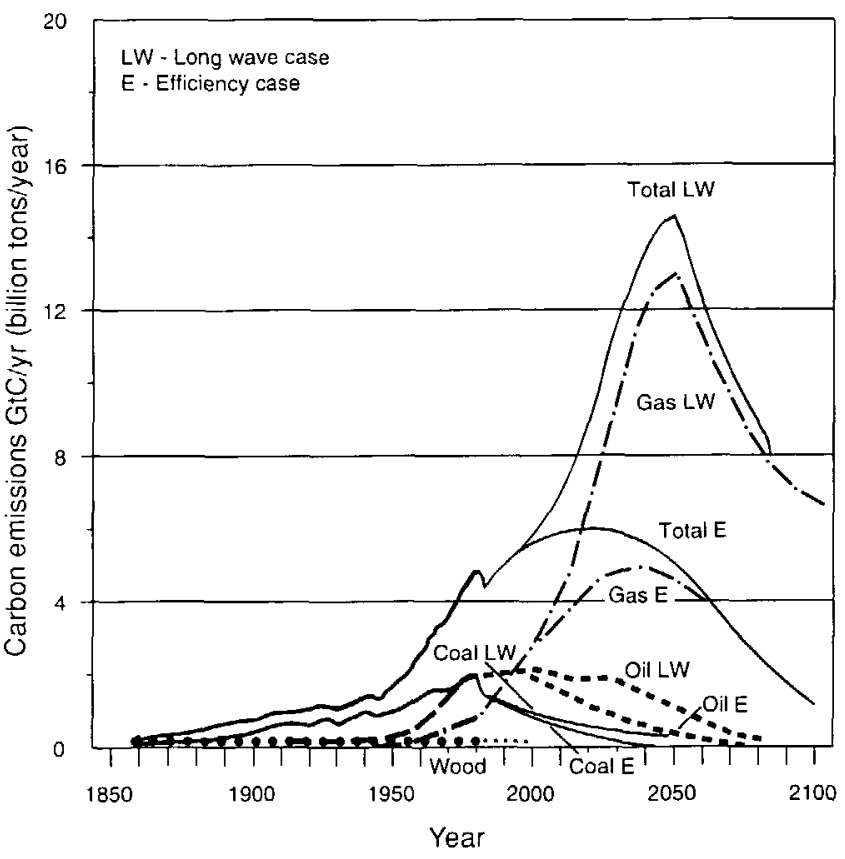

Figure 8. Global carbon dioxide emissions in gigatons of carbon per year (GtC/yr) (historical data and the two variants of the "methane economy" scenario). E, efficiency variant; LW, longwave variant.

scenarios. Because the same market shares are used for both variants, the methane economy scenario has the same carbon intensity of primary energy consumption in both cases. In fact, the scenario achieves high decarbonization rates in the world, higher than those experienced (fig. 2) and higher than assumed in the majority of other energy and carbon dioxide projections.

\section{ENERGY SCENARIOS AND DECARBONIZATION}

Table 1 summarizes the structure of current (1990) primary and final energy supply and resulting carbon emissions as well as a range of scenarios for the period 2020 to 2025. As a measure of the degree of decarbonization, we calculate the primary energy carbon intensity as total energy-related carbon emissions divided by the total primary energy consumption. The efficiency case of the methane economy scenario is compared with five other scenarios.

Two views of the future emerge from table 1 (see also fig. 2). One view implies a discontinuity in the historically observed trend of decarbonization of energy systems. Instead, the fuel mix becomes more carbon intensive. This is due to increased reliance on coal and synthetic fuel production in the scenarios. The EPA's RCW and (to a lesser degree) the Energy and Industry Subgroup of Intergovernmental Panel on Climate Change scenario are examples
(Environmental Protection Agency, 1990; Energy and Industry Subgroup of Intergovernmental Panel on Climate Change, 1991). A second view adopts basically a "dynamics-as-usual" perspective, which is a continuation of historical trends in energy decarbonization as, for example, reflected in the ECS'92 scenario (Nakićenović and others, 1993) or the recent reference scenario of the World Energy Council (World Energy Council, 1992). However, these improvements, as impressive as they are especially in comparison with other scenarios, are not sufficient to reverse the rising trend in global energy-related carbon emissions. Both scenarios still result in global emissions between 8.06 and $8.4 \mathrm{GtC}$ by the year 2020 .

In comparison, the methane economy scenario is more dynamic. Carbon intensity falls because the increased natural gas use "bridges" the time period to a massive market penetration of zero-carbon energy sources such as solar or nuclear energy in the second half of the 21 st century. Table 1 reproduces the efficiency variant of the methane economy scenario. The implied energy-efficiency improvement strategy results in a primary energy demand of only some $15 \mathrm{TWyr}$ by the year 2025; traditional biomass uses (currently estimated at $1.5 \mathrm{TWyr}$ ) are excluded in the scenario (if included, total energy demand would be quite close (10 to 15 percent lower) to the ECS'92 or the WEC scenario). This, together with a drastic shift in the energy supply structure (natural gas accounting for 68 percent of primary energy supply by 2025), is reflected in the carbon emissions estimate of $6.16 \mathrm{GtC}$, which is basically a stabilization of current emission levels.

A Renewables-Intensive Global-Energy Scenario (RIGES) has been suggested by Johansson and others, (1992). In their scenario, the final energy demand of 12.4 TWyr is close to that in the ECS'92 scenario described above. RIGES suggests that renewables would be competitive against fossil fuels and could penetrate massively as primary energy supply. Sustainable biomass and other renewables account for close to 43 percent of primary/secondary energy supply ( $>15.26 \mathrm{TWyr}$ ) by the year 2025 . (Primary energy production is only given for biomass and coal. For nuclear and hydropower we have assumed a substitution equivalent based on the average efficiency of fossil electricity generation in the scenario (40 percent). For oil, gas, geothermal, and intermittent renewables, only secondary energy equivalents are given, this also explains why the primary energy carbon intensity of RIGES is not presented in figure 2.) It must be emphasized, however, that such a rapid market penetration of nonfossil energy sources in this scenario is without precedent for any primary energy source in history. For example, it took about 80 years for the market share of oil to grow to 40 percent of the global primary energy supply. The carbon emissions in RIGES would amount to $4.97 \mathrm{GtC}$ per year, a stabilization (even slight reduction) of current energy-related carbon dioxide emissions. 
Table 1. Primary and final energy consumption, carbon emissions, and carbon intensity (1990 and scenarios for the period 2020 to 2025).

[IPCC/EIS 2025, Intergovernmental Panel on Climate Change Energy and Industry Subgroup's median scenario; EPA RCW 2025, Environmental Protection Agency's Rapidly Changing World scenario; IIASA ECS'92, International Institute for Applied Systems Analysis Environmentally Compatible Scenario '92; WEC reference, World Energy Council's reference scenario; RIGES 2025, Renewables-Intensive Global-Energy Scenario (Johansson and others, 1992). TWyr, terawatt year; GtC, gigatons carbon; $1 \mathrm{C} / \mathrm{kWyr}$, tons of carbon per kilowatt year; --, no data; n.a., not applicable]

\begin{tabular}{|c|c|c|c|c|c|c|c|}
\hline Category & 1990 & $\begin{array}{l}\text { IPCC/ } \\
\text { EIS } \\
2025\end{array}$ & $\begin{array}{c}\text { EPA } \\
\text { RCW } \\
2025\end{array}$ & $\begin{array}{l}\text { WEC } \\
\text { reference } \\
2020\end{array}$ & $\begin{array}{c}\text { IIASA } \\
\text { ECS'92 } \\
2020\end{array}$ & $\begin{array}{c}\text { "Methane } \\
\text { economy" } \\
2025^{\mathrm{a}}\end{array}$ & $\begin{array}{c}\text { RIGES } \\
2025\end{array}$ \\
\hline \multicolumn{8}{|c|}{ Primary energy consumption (TWyr): } \\
\hline Coal & 2.94 & 7.56 & 8.73 & 4.55 & 3.87 & 0.53 & 2.82 \\
\hline Oil & 4.19 & 7.07 & 4.96 & 5.26 & 6.20 & 1.92 & $2.43^{\mathrm{C}}$ \\
\hline Gas & 2.22 & 5.48 & 3.09 & 3.95 & 3.92 & 1.59 & $2.95^{c}$ \\
\hline Nonfossil & 2.35 & 4.53 & 3.70 & 5.16 & 4.10 & $2.36^{\mathrm{b}}$ & $7.06^{\mathrm{c}}$ \\
\hline Total & 11.70 & 24.64 & 20.49 & 18.92 & 18.10 & $15.34^{b}$ & $>15.26^{c}$ \\
\hline \multicolumn{8}{|c|}{ Final energy consumption (TWyr): } \\
\hline Coal & 1.22 & 3.28 & 4.09 & n.a. & 1.58 & n.a. & 2.16 \\
\hline Oil & 3.52 & 5.89 & 5.12 & n.a & 5.06 & ก.a & 2.43 \\
\hline Gas & 1.42 & 4.04 & 2.52 & n.a & 2.54 & n.a & 1.87 \\
\hline Electricity and heat & 1.10 & 3.61 & 2.81 & 2.59 & 2.29 & n.a. & 2.42 \\
\hline Other & 1.20 & 1.08 & -- & n.a. & 1.37 & n.a. & 3.52 \\
\hline Total & 8.46 & 17.90 & 14.54 & n.a. & 12.85 & n.a. & 12.40 \\
\hline Carbon emission (GtC): & & & & & & & · \\
\hline Final energy use & 3.02 & 7.77 & 7.31 & n.a. & 5.12 & n.a. & 3.95 \\
\hline Energy sector & 2.48 & 4.68 & 3.81 & n.a. & 3.53 & n.a. & 1.02 \\
\hline Total $^{\mathbf{a}}$ & 5.50 & 12.45 & 11.12 & 8.40 & 8.06 & 6.16 & 4.97 \\
\hline \multicolumn{8}{|c|}{ Carbon intensity (tC/kWyr): } \\
\hline Primary energy & 0.470 & 0.505 & 0.547 & 0.444 & 0.445 & 0.402 & $>0.330$ \\
\hline Final energy & 0.357 & 0.434 & 0.503 & n.a. & 0.398 & n.a. & 0.319 \\
\hline
\end{tabular}

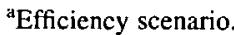

${ }^{\mathrm{b}}$ Excluding biomass.

${ }^{c}$ For oil, gas, geothermal, and intermittent renewables only secondary energy equivalent. Primary energy requirements, therefore, would be higher. This uncertainty also affects the primary energy carbon intensity.

\section{METHANE AND CARBON DIOXIDE EMISSIONS}

Carbon dioxide is the major energy-related source of global warming and the single most important greenhouse gas. Methane is also a natural constituent of air, arising from many natural processes. Recent increases in the concentration of atmospheric methane are usually attributed to diverse anthropogenic activities, such as the growth of animal population, rice production, and organic waste depositories. However, using methane as a source of energy also contributes to the atmospheric increases. Major energy-related sources of methane come from coal mining, oil and natural gas production, and natural gas transport, distribution, and end use (see Clayton and others, this volume).

Figure 9 shows the atmospheric carbon dioxide concentrations that result from the methane economy scenario corrected for methane leakage. Simple models of atmo- spheric carbon dioxide and methane concentrations have been used (Ausubel and others, 1988; Victor, 1990; Grübler and Fujii, 1991). For carbon dioxide, an airbome fraction of close to a half of annual emissions was used together with a slow decay of atmospheric concentrations. Methane leaks from the natural gas extraction, supply, and distribution system are assumed to be 2.5 percent, and methane is assumed to be 24 times as effective as carbon dioxide (by volume) in greenhouse forcing. The dotted lines in figure 9 are for two additional calculations, one without leakage of natural gas (methane emissions from coal are included) and a methane forcing factor of 16 times that of carbon dioxide (low case) and the other with 4 percent leakage and a methane forcing factor of 32 times that of carbon dioxide (high case). Two methane forcing factors compared to carbon dioxide are used to encompass the range given in the literature, the high factor of 32 and low one of 16 (Victor, 1990). The atmospheric concentrations of carbon dioxide and 


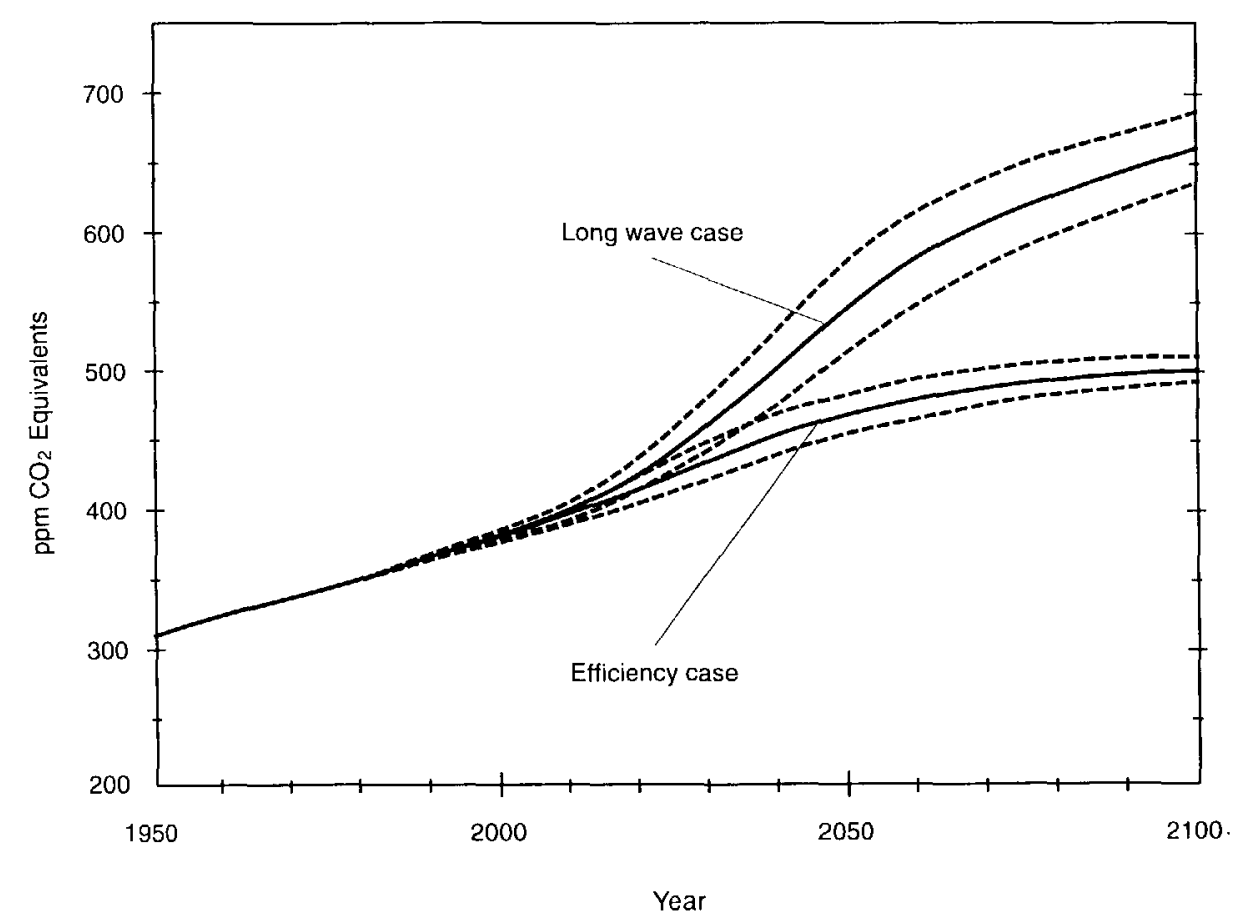

Figure 9. Atmospheric $\mathrm{CO}_{2}$ and $\mathrm{CH}_{4}$ concentrations from the "methane economy" scenario expressed as $\mathrm{CO}_{2}$ equivalents in parts per million. Simple models of $\mathrm{CO}_{2}$ and $\mathrm{CH}_{4}$ concentrations and different values for $\mathrm{CH}_{4}$ forcing have been used for estimating $\mathrm{CO}_{2}$ equivalents of $\mathrm{CH}_{4}$ concentrations. Higher set of curves are for the long-wave case and lower ones are for the efficiency case of the scenario. Lower dotted curves show only $\mathrm{CO}_{2}$ emissions, solid lines are $\mathrm{CO}_{2}$ and $\mathrm{CH}_{4}$ emissions for 2.5 percent leakage, and higher dotted curves are for 4 percent leakage and high $\mathrm{CH}_{4}$ forcing.

methane are given in parts per million of $\mathrm{CO}_{2}$ equivalents. For this calculation, methane concentrations are converted to $\mathrm{CO}_{2}$ equivalents using the methane conversion factors discussed above and a methane atmospheric lifetime of 9.6 years.

This sensitivity analysis of methane-emissions inclusion indicates that the methane economy scenario yields substantial reductions in greenhouse gas emissions, even when large methane leaks are included. However, it is acknowledged that the role of methane leaks is not trivial. As energy use increases, especially in the long-wave variant, the problem of methane leaks becomes more important (Victor, 1990). This means that the greenhouse forcing, owing to increased levels of energy consumption with the same structure of the energy system, is not linear. This finding identifies the additional advantage of lower energy scenarios toward the absolute and relative reduction of greenhouse gas emissions.

The lower rate of decarbonization in all scenarios, except the methane economy, over the rates achieved historically illustrates the difficulty of achieving stabilization of energy-related carbon emissions under the premises of population growth and economic development. Very massive restructuring of future energy systems along with vig- orous efficiency improvement efforts will be required to come close to stabilizing global emissions.

\section{METHANE ECONOMY AS A BRIDGE TO HYDROGEN}

The analysis of the methane economy scenario has demonstrated that it achieves substantial carbon dioxide emission reductions during the next century compared with alternative scenarios that rely more on other fossil energy sources in the future. As such the methane economy could make a significant contribution toward emissions reduction; however, it is important to observe that most of the carbon dioxide would be originating from natural gas. Thus, further mitigation in this scenario would have to be focused on natural gas itself. This means that ways have to be investigated for limiting carbon emissions associated with natural gas use.

There are basically two alternative approaches in reducing carbon dioxide emissions from methane use-one is to remove carbon after combustion and the other before. In the first case, the most promising technologies involve carbon scrubbing from flue gases. There are three main 
scrubbing processes that could be used: chemical and physical absorption, cryogenic distillation, and membrane separation (Nakićenović and others, 1993). The chemical absorption process is widely used to remove oxides of sulfur (SOx) and oxides of nitrogen (NOx) from flue gases, and there are a few pilot plants that remove carbon dioxide by the same method. The various absorbents include potassium carbonate and amines. Scrubbing would clearly increase energy costs. The monoethanol-amine process would, for example, increase electricity costs by perhaps 80 percent, leading to carbon dioxide mitigation costs of about $\$ 140$ per tC removed (Blok and others, 1991; Nakićenović and others, 1993). The major problems associated with scrubbing are to reduce the costs and minimize losses in plant efficiency owing to the energy spent in separating carbon dioxide from flue gases. Further, scrubbing processes are more suited for larger concentrations of carbon dioxide, as in powerplant flue gases. They are less suited for distributed combustion of natural gas in individual homes and end-use devices. Thus, scrubbing would be applicable on larger scales, mostly in electricity generation.

The other alternative would be to remove carbon from natural gas prior to consumption, leaving hydrogen as the energy carrier. The basic process would involve methane steam reforming, followed by a shift reaction and physical absorption or other separation of carbon dioxide. Hydrogen would then be transported to the user and converted to the desired energy form, heat, or work, without any carbon dioxide emissions. This is clearly a more elaborate mitigation strategy than carbon scrubbing, but it offers greater possibilities in the long run including a bridge to the "hydrogen" economy, after the saturation of the natural gas contribution to global energy supply. This mitigation strategy offers a transition from the current global reliance on a carbon-intensive mix of fossil fuels via methane to a carbon-free energy system in the distant future.

Both scrubbing and removal generate large amounts of carbon that are not released into the atmosphere. The amounts of carbon generated by scrubbing alone would be truly enormous. As was mentioned above, global carbon dioxide emissions from energy use amount to close to $6 \mathrm{GtC}$ per year, of which about $2 \mathrm{GtC}$ or about $7 \mathrm{GtCO}_{2}$ per year is from electricity use. The amount of carbon dioxide generated today in electrical powerplants alone dwarfs all possible market demands for this carbon dioxide. Thus, an important question is how such a large mass flow can be managed. There are two possibilities: (1) to utilize carbon to the maximum degree possible in other activities or (2) to store the collected carbon in permanent disposal sites. The possible uses of carbon dioxide include enhanced oil recovery, chemical feedstocks, building materials, carbonization of beverages, food conservation, sewage treatment, fertilizers in greenhouse horticulture, fire extinguishing equipment, and gas welding. Of all of these potential commercial uses of collected carbon dioxide, only the first three provide permanent means of disposal; however, the quantities utilized would be limited compared with the potential amounts of carbon dioxide requiring disposal.

Additionally, carbon dioxide may also be permanently stored in natural underground reservoirs, such as aquifers or depleted natural gas fields, or alternatively deposited in the deep ocean. It is difficult to estimate the quantities of accumulated carbon dioxide that could be stored in aquifers and gas and oil fields with any degree of certainty. The potential capacity might be as high as $750 \mathrm{GtC}$ (Nakićenović and others, 1993). It is clear, however, that this is a rough estimate and not a practical estimate of storage capacity for future carbon emissions, but the orders of magnitude involved show that capacity exists to store current levels of carbon emissions for at least the next half a century. Thus, the storage potential is indeed large by any standards.

In comparison, the potential for carbon disposal in the deep ocean is vast. The global carbon cycle involves the annual exchange of around $200 \mathrm{GtC}$ between oceans, the atmosphere, and the biosphere. The largest amount of the carbon is "stored" in the oceans and is estimated to be about $36,000 \mathrm{GtC}$. As the largest carbon reservoir on Earth, the deep ocean might be a possible repository for the carbon generated by scrubbing and removal. There are various disposal schemes: (1) to pump carbon dioxide in high-pressure pipes to the ocean floor, (2) to inject liquid carbon dioxide into the ocean at depths of about $3 \mathrm{~km}$ that would then continue to sink, (3) to release solid carbon dioxide (ice) that would sink by itself to the ocean floor, and (40 to disperse carbon dioxide into a suitable thermohaline current that would carry it to the ocean floor.

The gist of Marchetti's (1976) proposal to dispose of carbon dioxide was to generate a "gigamixer" by injecting carbon dioxide into sinking thermohaline currents that eventually reach the deep ocean where the carbon dioxide enriched water might reside for thousands of years, owing to the slow rate of natural mixing. The proposal involved using the Gibraltar subduction undercurrent and would provide a storage capacity of $10 \mathrm{GtC}$ per year, which easily exceeds the volume of carbon dioxide generated by energy-related sources in the methane economy scenario during the next half a century. In a more practical scheme, carbon dioxide collected in continental Europe could be transported by pipeline for disposal at Gibraltar. The theoretical mitigation potential of this scheme is vast because there are other sinking thermohaline currents including subduction currents in the Red Sea (Bab-al-Mandab current), the Weddell Sea, and the North Atlantic.

Clearly, all of these different schemes for storing carbon dioxide in either liquid or solid pools on the ocean floor or dissolved in the deep ocean still require concept proof before even a pilot project could be started. Among the major outstanding uncertainties are the possible ecological effects of higher concentrations of carbon dioxide 
in the oceans and their effects on local water chemistry in the vicinity of storage sites.

The methane economy scenario with carbon removal presents the possibility of achieving global energy decarbonization and eventually eliminating carbon emissions altogether. Thus, methane (natural gas) fulfills most of the obvious future requirements for becoming the major source of energy. A bonus is that the reliance on natural gas can pave the way for a very clean, hydrogen future. Figure 10 illustrates the possibility and timing of such an evolutionary transition from fossil fuels to hydrogen (see also Veziroglu and Barbir, this volume). It shows global decarbonization as the increasing ratio of hydrogen to carbon in the average energy mix. The data show the actual hydrogen and carbon content of global primary energy consumption as specified in figure 10 for wood, coal, oil, and natural gas. The change in hydrogen to carbon ratio is presented as a "substitution" process of hydrogen for carbon in the total primary energy consumption during the last century and as the continuation of this process in the future. The extrapolation in figure 10 shows that, after this century, the hydrogen-to-carbon ratio may exceed the level of the $4: 1$ ratio that can be achieved by the use of pure methane, implying that some additional hydrogen would be needed to supplement the increasing reliance on methane.

A possible way of both increasing the share of methane in global energy and the hydrogen-to-carbon ratio is carbon removal and disposal. For example, methane could be separated into carbon dioxide and hydrogen in the proximity of the production site. This would require the development of large-scale steam-reforming processes, but it is conceivable that the separation could be achieved economically. The separated carbon dioxide could be reinject-

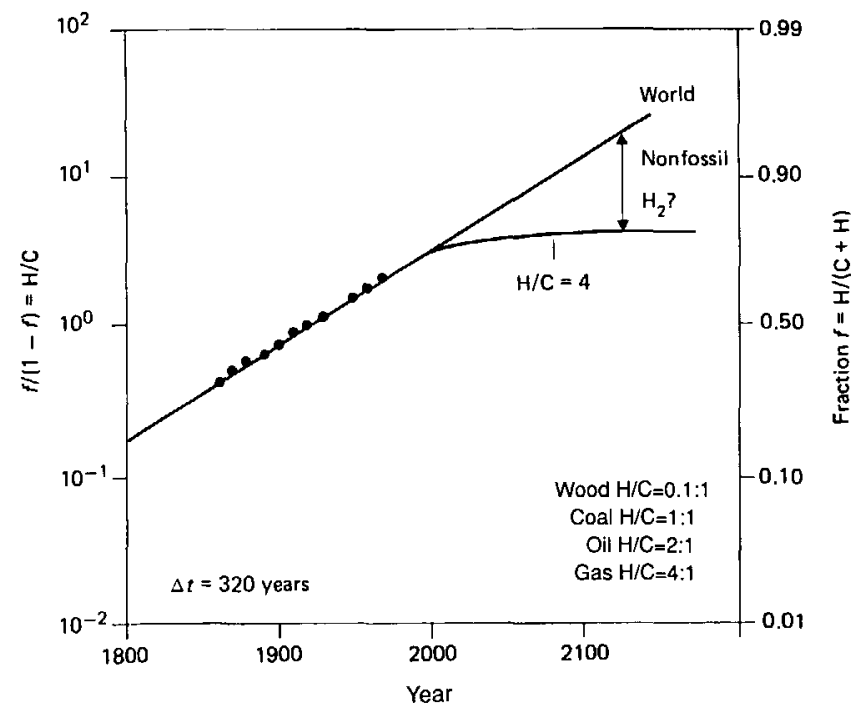

Figure 10. Hydrogen-to-carbon ratio of global primary energy including historical data and future projection (Marchetti, 1982). ed into the depleted natural gas field or used for enhanced oil recovery, and hydrogen could be piped like methane. Marchetti (1991) made such a proposal for Russian natural gas and hydrogen delivery to Europe and use of separated carbon dioxide for enhanced oil production in the Ukraine. Initially, hydrogen could be added to the natural gas in the same pipeline and if required separated at consumption sites by membranes or other methods or simply used as mixture of methane and hydrogen. As the quantities of separated carbon dioxide and hydrogen increase it might become necessary to build dedicated hydrogen and carbon dioxide pipelines. In the first stages of the "hydrogen economy" of the distant future, separated carbon dioxide might have to be deposited in the deep ocean, as the fluxes become too difficult to be absorbed by declining oil-production needs. Eventually, methane could be replaced as the source of hydrogen by carbon-free options, collectively called solfus (see fig. 6). Hydrogen and electricity would provide virtually pollution-free and environmentally benign energy carriers. To the extent that these energy carriers might be produced from methane, the separated carbon dioxide could be contained within the energy sector or stored. As the methane contribution to global energy needs saturates and subsequently proceeds to decline, carbonfree sources of energy would takeover, eliminating the need for carbon handling and storage.

\section{CONCLUSION}

The findings in this paper indicate that methane and hydrogen could become means for reducing energy-related emissions of greenhouse gases. The issue of climate warm'ing is likely to be a major planetary concern during the next century along with the need to provide sufficient energy for further social and economic development in the world. Methane and later hydrogen offer the possibility for reconciling these conflicting objectives. The findings show that evolutionary development of the global energy system toward a larger use of natural gas is consistent with the dynamics of the past 130 years. Continuation of this process in the future leads to carbon dioxide and methane emissions that are low compared with other, more conventional scenarios. The reasons for the moderate emissions associated with the emergence of the methane economy are that natural gas emits less carbon dioxide than other fossil fuels and that the scenario assumes the development of zero-carbon sources of energy, collectively called solfus, in the future and their major role in energy production by 2100. The current phase in the development of the global energy system may be just midway through the "hydrocarbon era." Decarbonization in the world can continue as methane becomes the major energy source. From this perspective, methane is the transitional hydrocarbon, and the great energy breakthrough that we must look, hope, and 
work for during the next decades is the production of hydrogen without fossil fuels (Ausubel and others, 1988). In the meantime, the natural gas share in total primary energy should continue to grow at the expense of dirtier energy sources-coal and oil. This transition to the methane age and beyond to carbon-free energy systems represents a minimum-effect option because it would also enhance the reduction of other adverse impacts of energy use on the environment in addition to substantial reductions of carbon dioxide emissions.

\section{REFERENCES CITED}

Ausubel, J.H., Grübler, A., and Nakićenović, N., 1988, Carbon dioxide emissions in a methane economy: Climatic Change, v. 12, p. 245-263 (reprinted at International Institute for Applied Systems Analysis, RR-88-7).

Blok, K., Farla, J., Hendriks, C., and Turkenburg, W., 1991, Carbon dioxide removal-A review: presented at the International Symposium on Environmentally Sound Energy Technologies and their Transfer to Developing Countries and European Economies in Transition (ESETT '91), October 1991, ENI San Donato Milanese, Italy.

Energy and Industry Subgroup of Intergovernmental Panel on Climate Change, 1991, Energy and Industry Subgroup report: Geneva, Switzerland, Intergovernmental Panel on Climate Change.

Gold, T., 1985, The origin of natural gas and petroleum, and the prognosis for future supplies: Annual Review of Energy, v. 10 , p. $53-88$.

Grübler, A., and Fujii, Y., 1991, Inter-generational and spatial equity issues of carbon accounts: Energy, v. 16, no. 11-12, p. 1397-1416 (reprinted at the International Institute for Applied Systems Analysis, RR-92-6).

Intergovernmental Negotiating Committee, 1992, Annex I to the report of the Intergovernmental Negotiating Committee for a framework convention on climate change: United Nations Framework Convention on Climate Change, document A/AC.237/18, part IU/Add.1, New York, United Nations.

Intergovernmental Panel on Climate Change, 1992, 1992 Intergovernmental Panel on Climate Change Supplement: Geneva, Switzerland, Intergovernmental Panel on Climate Change.

Johansson, T.B., Kelly, H., Reddy, A.K.N., and Williams, R.H., 1992, Renewable fuels and electricity for a growing world economy, in Johansson, T.B., Kelly, H., Reddy, A.K.N., and Williams, R.H., eds., Renewables for Fuels and Electricity: Washington, D.C., Island Press, p. 1-71.

Lee, T.H., 1988, Combined cycle systems-technology and implications, in Lee, T.H., Linden, H.R., Dreyfus, D.A., and Vasko, T., eds., The Methane Age: Dordrecht, Netherlands, Kluwer Academic Publishers, p. 737-745.
Manne, A.S., and Schrattenholzer, L., 1992, International Energy Workshop-Overview of poll responses, January edition: Laxenburg, Austria, International Institute for Applied Systems Analysis.

Marchetti, C., 1976, On geoengineering and the $\mathrm{CO}_{2}$ problem: Laxenburg, Austria, International Institute for Applied Systems Analysis, RM-76-17.

1979, Multicompetition and the diffusion of new technology in the energy system: Chemical Economy and Engineering Review, v. 11, no. 4, p. 7-13.

-1982, When will hydrogen come?: Laxenburg, Austria, International Institute for Applied Systems Analysis, WP-82123.

1991, How to solve the $\mathrm{CO}_{2}$ problem without tears: Laxenburg, Austria, Intemational Institute for Applied Systems Analysis, RR-91-6.

Marchetti, C., and Nakićenović, N., 1979, The dynamics of energy systems and the logistic substitution model: Laxenburg, Austria, International Institute for Applied Systems Analysis, RR-79-13.

Nakićenović, N., 1979, Software package for the logistic substitution model: Laxenburg, Austria, International Institute for Applied Systems Analysis, RR-79-12.

1986, The automobile road to technological change-diffusion of the automobile as a process of technological substitution, Technological Forecasting and Social Change, v. 29 , p. $309-340$.

1990, Dynamics of change and long waves, in Vasko, T., Ayres, R., and Fontvielle, L., eds., Life Cycles and Long Waves: Berlin, Springer-Verlag, p. 747-792.

Nakićenović, N., Grübler, A., Inaba, A., Messner, S., Nilsson, S., Nishimura, Y., Rogner, H., Schäfer, A., Schrattenholzer, L., Strubegger, M., Swisher, J., Victor, D., and Wilson, D., 1993, Long-term strategies for mitigating global warming: special issue in Energy, v. 18, no. 5, p. 407-609.

United Nations, 1991, World population prospects 1990: New York, United Nations Population Studies No. 120.

U.S. Environmental Protection Agency, 1990, Policy options for stabilizing global climate: Washington, D.C.

Victor, D.G., 1990, Greenhouse gas emissions from high-demand, natural-gas-intensive energy scenarios: Laxenburg, Austria, International Institute for Applied Systems Analysis, WP-90-01.

Vu, M.T., 1985, World population projection 1985: Baltimore, John Hopkins University Press.

World Energy Council, 1992, Energy for tomorrow's worlddraft summary of the World Energy Council commission global report: London, World Energy Council.

Yamaji, K., Matsuhashi, R., Nagata, Y., and Kaya, Y., 1991, An integrated system for $\mathrm{CO}_{2}$ /energy/GNP analysis-Case studies on economic measures for $\mathrm{CO}_{2}$ reduction in japan, paper presented at the workshop on $\mathrm{CO}_{2}$ reduction and removalmeasures for the next century, 19-21 March 1991: Laxenburg, Austria, International Institute for Applied Systems Analysis. 
Among the problems associated with gas exploration, storage (particularly of hydrogen gas), and transportation (particularly of liquefied natural gas) are a formidable array of logistical and technological requirements. One report herein describes the research program on natural gas that is overseen by the Department of Energy, and another describes the data bases available from the U.S. Bureau of Mines on natural-gas analyses for all of the United States. Finally, there is a report that compares fossil fuels with hydrogen, an energy gas that does not occur in large amounts naturally. Hydrogen is typically created synthetically; it can be used as an energy carrier to hold energy converted from another form and pass it along for another use. Synthetic gases are alternatives when the original energy source is unusable or not transportable. 


\title{
THE FUTURE OF ENERGY GASES
}

U.S. GEOLOGICAL SURVEY PROFESSIONAL PAPER 1570

\section{Logistical Considerations for the Exploration and Production of Natural Gas}

\author{
By Russ D. Cunningham ${ }^{1}$ and Daniel R. Rowe ${ }^{1}$
}

\section{CONTENTS}

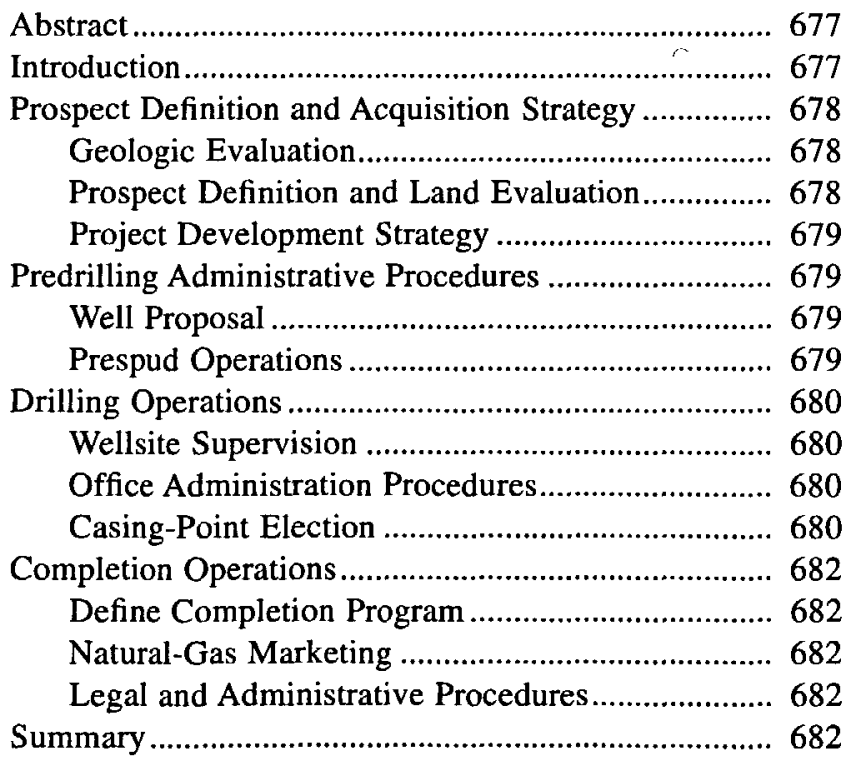

\begin{abstract}
The exploration, production, and marketing of natural gas is a multidisciplined, rigorous process requiring contributions from a variety of technically trained personnel. The process consists of geologic, engineering, and legal evaluations.
\end{abstract}

'GHK Co., 3030 Northwest Expressway, 18th Floor, Oklahoma City, OK 73112-5467.
The exploratory phase requires evaluation on a megaregional scale of lithospheric interactions influencing structure, stratigraphy, and thermal maturity. A regional geologic analysis follows and delineates the geologic conditions associated with natural-gas traps and production. Finally, a drilling location is proposed after detailed geologic analysis is completed and an area of prospective natural-gas accumulation is identified.

Permission to drill and the ultimate extraction of natural gas from reservoirs at depth is acquired after specific ownership of mineral rights is determined and the appropriate legal and business contracts are consummated. Government and regulatory permits must be obtained and procedures must be followed to legally drill for and produce natural gas. Engineers propose a drilling and completion program. This program is executed by specialized companies who are contracted to perform the drilling and evaluation procedures associated with the well. After successfully drilling and testing a natural-gas well, complicated legal contracts are negotiated and signed to market the natural gas to end-users.

\section{INTRODUCTION}

Exploring for natural gas is a complex process that requires the extensive time and effort of many people from varying technical backgrounds. Exploratory drilling for natural gas in the United States has undergone several cycles. For example, from 1940 until the early 1960's approximately 100 exploratory wells per year were drilled. In 1962, 300 exploratory and approximately 5,000 development wells were drilled. Activity decreased through the late 1960's and early 1970's, until a large increase in activity occurred in the late 1970's and early 1980's. The 
peak of this boom was reached in 1981 with the drilling of 710 exploratory wells. In 1992 activity again decreasedonly 100 exploratory wells were drilled.

Drilling an exploratory well takes little more than money, but determining where to drill and administering the drilling procedures is an involved process. The cost estimates are based on consulting fees and do not include company administrative overhead. This overhead includes support staffs, personnel departments, accounting departments, legal departments, and contract-administration departments in addition to the general office expenses.

\section{PROSPECT DEFINITION AND ACQUISITION STRATEGY}

\section{GEOLOGIC EVALUATION}

Regional geologic evaluation must be completed to relate natural-gas production to specific geologic conditions in producing areas. This evaluation includes regional subsurface structure maps, facies and isopach maps of productive reservoirs, and cumulative production by stratigraphic horizon maps. These data need to be integrated into a mega-regional framework that includes tectonic history, succession of stratigraphic units, burial history, source-rock maturation, and migration of hydrocarbons.

Geologic cross sections through productive areas are also necessary to define natural-gas trapping mechanisms; this definition consists of the trap geometry, timing of entrapment, and trap type. Trap types can be broadly defined as structural, stratigraphic, or some combination of the two. Extensive seismic data are necessary to define structural traps. Conversely, if most traps are stratigraphic, more detailed subsurface geologic facies maps are required to define them. Drilling and production practices for a specific objective must be defined and cost estimates for these procedures must also be projected.

Maps showing cumulative production by horizon help to define the economic benefits that can be expected if the exploration program is successful in discovering and producing natural gas. These benefits can be compared to the projected costs of evaluation. Economic feasibility of a project can be determined after defining the probability of success.

The expected economic benefits, the cost of achieving those benefits, and the probability of success can be estimated by the regional analysis. Regional analysis is the first critical evaluation in the process of exploration and production of natural gas. If the risked economic benefits are not greater than the acquisition costs, the play is uneconomic and should not be pursued. The costs involved in regional analysis include data acquisition and processing as well as labor for a team of technical and support personnel. The technical professionals include geologists, geophysicists, and petroleum engineers. Necessary data includes seismicreflection profiles, open-hole wireline logs of previously drilled wells, historical production data, and base maps showing legal land surveys and well locations. The effort and cost of this analysis depend on the size of the area involved, the number of producing horizons evaluated, and the amount of detail required. The analysis may take from 2 weeks up to several months of work. A cost estimate for this evaluation may be obtained by assuming a company contracts a team of professionals that consists of a structural geologist, stratigrapher, geophysicist, and engineer. These professionals need the support of at least two technicians and one secretary. Domestic professionals charge approximately $\$ 700$ per day, whereas international fees may be as high as $\$ 1,200$ per day. Assuming a domestic exploration project that employs four professionals, two technicians, and one secretary, the daily cost for the regional study may be as high as $\$ 4,000$. A regional study requiring 2 months to complete will cost approximately $\$ 200,000$ for the staff alone. Data acquisition and processing costs must be added to the estimate. Of course, this study may recommend no exploration potential exists and the company will move on to another area.

\section{PROSPECT DEFINITION AND LAND EVALUATION}

After determining the play is economically feasible, prospects worthy of drilling can be delineated. The geophysicist acquires and interprets seismic-reflection profiles in a prospective area delineated by regional geologic evaluations. The geologist then refines the regional maps with detailed local data and a drillsite is proposed. Domestic exploration requires the skills of a quasi-technical person with a legal and business background. This person is commonly referred to as a "landman." The landman is an integral part of the exploration and production team because without the legal permission to drill for natural gas, the best technical evaluations have no value.

The landman determines the mineral rights ownership of a prospective area. This is accomplished by reviewing county and state records of ownership, which begin with the issuance of a land patent by the Federal Government to the original land and mineral owner. The land patent is the official document issued by the Government of the United States granting exclusive ownership of the land to the homesteader. The ownership must be carefully traced through time and all transactions involving the prospective land tract are noted. Land transactions that affect mineral rights ownership include sale or transfer of rights, division of ownership among heirs, liens or mortgages against the properties, and current mineral leases in effect. After this rigorous analysis determines mineral rights availability, a strategy is planned to acquire the mineral rights and optimize the leasehold position. Land procurement for pros- 
pects includes acquiring mineral leases on prospective tracts and executing business transactions with other companies that may already have leasehold rights in the area of interest. This procedure is time intensive and may require a group of people 2 weeks or more to finish the evaluation. The duration of this task is dependent on the complexity of the historical land transactions and the format of the legal records. A land evaluation requiring three people 2 weeks to complete may cost approximately $\$ 10,000$.

\section{PROJECT DEVELOPMENT STRATEGY}

When the prospect is technically defined and all the appropriate land work is completed, a strategy is formulated for the drilling of the initial wildcat test well and subsequent field development. This strategy is dependent on the technical evaluation, the land situation, drilling-rig availability, and economic parameters such as natural-gas prices and gas-market conditions. Natural-gas wells frequently have a long productive life. This necessitates price projections of natural gas far into the future, 20 to 30 years in some cases. Marketing considerations include the availability of pipelines to transport the natural gas to user markets, the carrying costs charged to natural-gas producers by the transportation companies, and, finally, the demand for natural gas.

\section{PREDRILLING ADMINISTRATIVE PROCEDURES}

\section{WELL PROPOSAL}

Once a play has been determined to be economically feasible, and after a prospect has been defined and the available mineral rights have been secured, a well proposal is made to other mineral rights owners. Other entities who may own mineral rights in the defined prospect include the Federal Government (Bureau of Land Management), state governments, competing companies, and individual people or estates. Drilling regulations vary from state to state, and we will consider the situation in Oklahoma, which is governed by the Oklahoma Corporation Commission (OCC).

The OCC encourages exploration and production of natural resources. This is accomplished by a procedure called "pooling" of common source and supply of a given resource. Geologic and engineering evaluations of producing horizons define the areal extent affected by a well bore capable of producing natural gas. In Oklahoma, the common practice is to define the areal extent as one section of land (1 $\mathrm{mi}^{2}$ or 640 acres) surrounding the well bore. Any person or entity owning rights in that section of land owns their proportionate share of all the natural gas produced from the well bore. For example, an entity or person who owns 10 percent of the section will also own 10 percent of all natural gas produced from the well bore, even if the well bore is not located on their tract of land.

Under pooling regulations, the other mineral rights owners in a given section of land normally have three options when responding to a well proposal. These are to participate and pay their proportionate share of the well costs; to "farm out" their interest, that is, assign their interest to the proposing company, but retain a small interest in the production from the well; or to sell their interest to the proposing company for fair market value as determined by the OCC.

This pooling process involves the initial well proposal with an accompanying authorization for expenditure (AFE). The AFE is an estimate of the well costs including site preparation, drilling the well, and equipping the well with the appropriate production facilities. These estimates are obtained from service and supply companies that determine the availability and cost of the necessary equipment. Also, experts on mineral rights leases must prepare documentation to determine the fair market value in the area of interest. The fair market value reflects current prices paid as well as drilling and production activity in the area. After all parties have made their decision on participation in the proposed well, an attorney prepares a "drilling title opinion." This document verifies the legal ownership in the section and all interest owners are committed to the proposed well.

\section{PRESPUD OPERATIONS}

The beginning of actual drilling operations is called "spudding the well." Before the well is spud, appropriate service contractors must be selected; federal, state, and local permits, where applicable, must be secured; working interest owners' requirements for data distribution and well evaluation must be obtained; and environmental studies and recommendations must be addressed. Government agencies require the filing of several documents, including an application for a permit to drill, the land surveyors map that describes the coordinates and elevation of the drilling location, and a casing program that describes the proposed surface and production casing.

Drilling and evaluation of the prospective horizon is a complex problem requiring a wide range of specialists. The well is drilled by a company who owns the drilling rig. The drilling operation includes a hydraulic system consisting of water and drilling mud. The mud is composed of water, chemicals, and other additives that keep the well bore from caving in as the well is being drilled and when the drill pipe is removed from the hole. The rocks are studied by a wellsite geologist. The penetrated horizons are evaluated by wireline logging tools. The logging tools measure the 
porosity and resistivity of the rock formations to indicate the presence of natural gas. These logging tools measure characteristics of the rocks and are supplied by a specialized company. Potential production from a formation is tested by another specialized service company. If the well contains natural gas, another company will supply the tubular goods to produce it. These goods include casing, which is cemented in the hole, and tubing, which is inserted inside the casing to facilitate the natural gas flow from reservoir depth to the surface. The casing is cemented in place by another specialized company. The casing and formation are perforated and the reservoir rock is treated with fluids that stimulate the flow of natural gas through the rock by another specialized service company. The companies providing specialized services are normally selected from two or three who are asked to bid on the work prior to the need for the service. These companies will make design recommendations and cost estimates. The operating company must then select a contractor for each service.

The design of the drilling operations must also consider the requirements of the well's other working interest owners. Some companies require certain well tests be performed. These tests may in turn require certain specifications of the well bore including hole diameter, depth below prospective horizon, and intermediate casing depth. Consequently, these test results have an impact on the selection of drilling equipment and drilling contractors. All of these factors must be considered by the operating company. Also, communication requirements between the operating company and other working interest owners must be determined.

The amount of time and labor needed to accomplish the predrilling administrative tasks depends on the project's complexity. In general, a staff of three professionals and two support persons may require 3 to 4 weeks to accomplish all of the administrative tasks. The well proposal normally requires 2 weeks for response from the other working interest owners.

The OCC docket is generally busy; therefore, it may take 30 days from the application date to the hearing date. Generally, the OCC takes 1 week to issue a ruling and the affected parties have 2 weeks to make their election. In summary, it takes approximately 9 weeks from the initial well proposal to final participation decisions by all parties. The drilling plan and selection of service contractors can be accomplished during this administrative period.

\section{DRILLING OPERATIONS}

\section{WELLSITE SUPERVISION}

The supervision of drilling operations is accomplished by a drilling engineer, rig supervisor ("tool pusher"), and wellsite geologist. Each individual is responsible for mon- itoring progress and planning for successful completion of the drilling phase. The supervisors work as a team in solving problems that arise during the drilling of the well. The engineer is responsible for the actual drilling operations in addition to various accounting tasks that include invoice approval and expenditure projections. The tool pusher ensures the rig is safe and in good operational condition. He or she also supervises the crews who work on the rig's three daily shifts (tours) of 8 hours each. The wellsite geologist is responsible for describing the rocks penetrated during the drilling. He or she must also note indications of hydrocarbons in the drill cuttings and make recommendations for testing prospective hydrocarbonbearing horizons.

\section{OFFICE ADMINISTRATION PROCEDURES}

The information communicated from the wellsite during the drilling operation must be relayed to the appropriate technical personnel in the office. The drilling department is in daily contact with the rig personnel. The geologist in the office reviews sample descriptions provided by the wellsite geologist and compares these to other wells in the area to monitor progress and project possible zones of interest. Comparison data must be communicated to the wellsite geologist. Daily and cumulative drilling costs are monitored by the engineer on location and communicated to the office accounting department. Invoices are then prepared and sent to the other working interest owners. Accounts payable and receivable are maintained by the company operating the well. In addition to collecting and reviewing the daily drilling data, all of this information must be forwarded to the working interest owners. Most companies participating in drilling wells require detailed daily reports faxed to their office. Frequently there may be a dozen or more working interest owners in each well requiring the daily distribution of data. A summary of the drilling operations can be expressed in graphic form. The critical parameters in drilling a well are time versus depth and cost versus depth. A typical time versus depth curve showing projected and actual time is shown in figure 1. A cost versus depth curve (projected versus actual) is shown in figure 2 .

\section{CASING-POINT ELECTION}

After the well bore has been drilled through the objective horizon, the most important decision regarding the well must be made. Does the well appear to have natural gas in economic volumes? The decision to run casing and test a horizon for production is made by carefully analyzing a great deal of available information. This information includes wireline logs, sample descriptions, open-hole test 
results, side-wall cores, penetration rate, and, of course, natural gas showing in borehole cuttings and the drilling fluids during the drilling operations. All of these data considered together allow the reservoir engineer and geologist to evaluate whether the well may contain economic quantities of natural gas. This critical decision point is called "casing point" (that is, is it necessary to cement production casing in the well bore to test for and hopefully produce natural gas). The decision is critical because the casing cost may be as much as 20 to 30 percent of the cost to drill the well to this point. Additionally, the expenses to this point are mostly intangible costs and can be treated as tax deductions by the company. However, costs incurred from the casing point through completion are mostly tangible expenses that must be capitalized over the life of the well. The decision to run casing and attempt a completion is based on an economic analysis. The cost of the completion attempt, including casing, subsequent reservoir treatments and the installation of surface facilities is weighed against the projected natural-gas recovery. The most significant production forecast is the initial rate of production and decline rate. These factors control the length of payout and the ultimate rate of return.

If the operating company elects to run casing in the bore hole, they make this recommendation to the other working interest owners. The others usually have 48 hours to elect to participate in the completion attempt or elect to be "nonconsent." Nonconsent relieves them of any obligation to pay future costs in the well, but they are also excluded from any production of natural gas resulting from

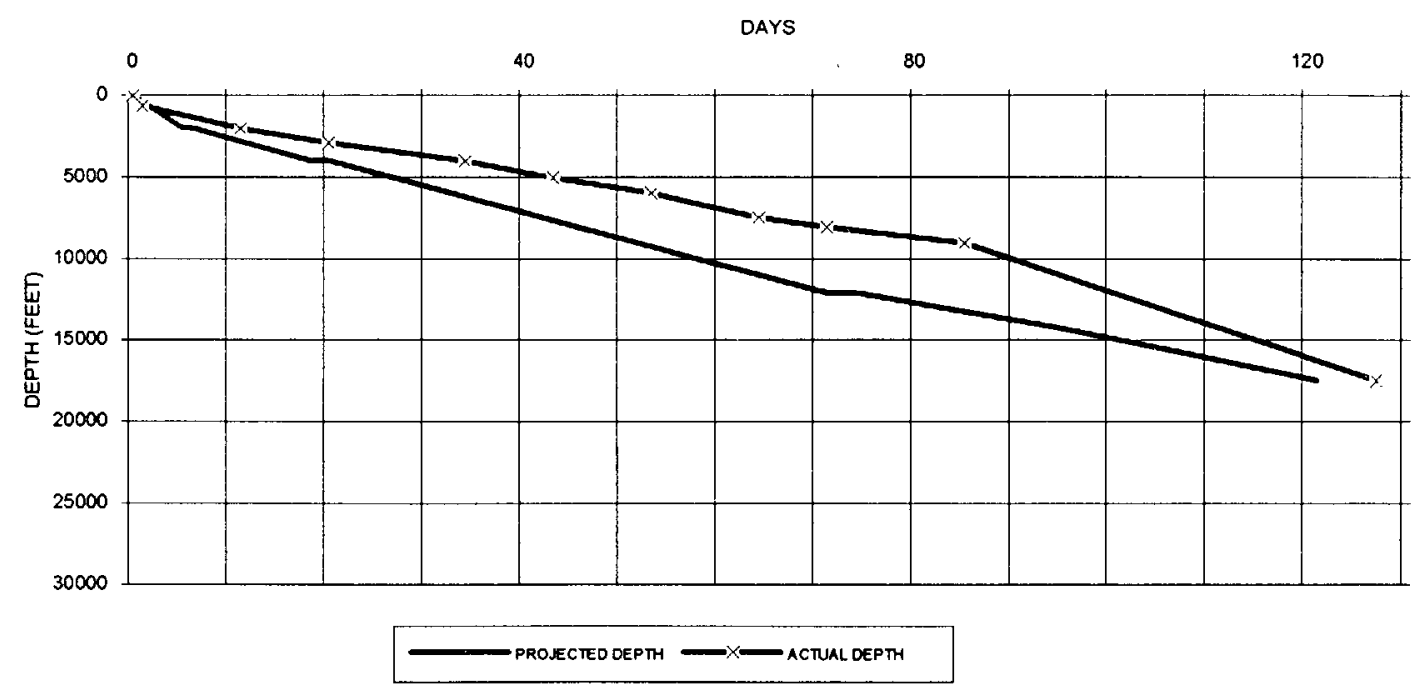

Figure 1. Time versus depth, showing projected and actual figures, for drilling a well.

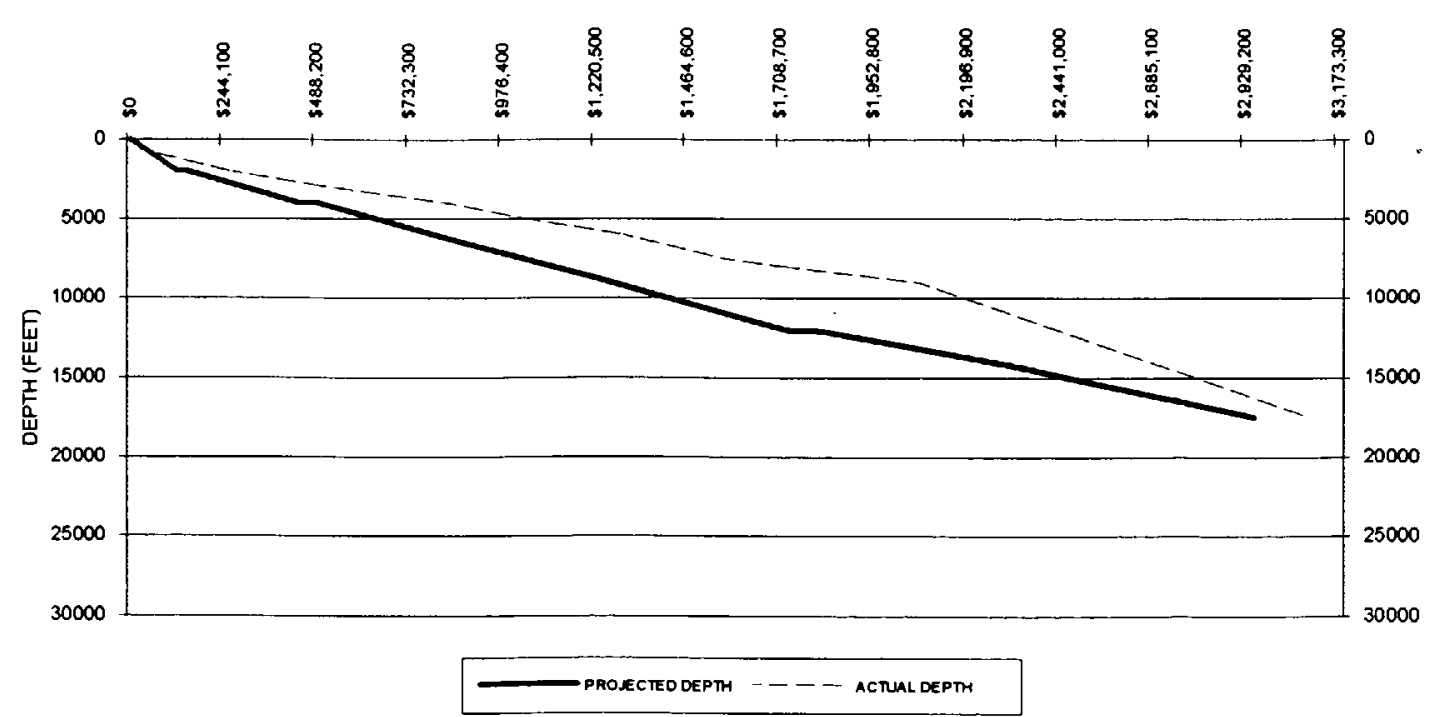

Figure 2. Cost versus depth, showing projected and actual figures, for drilling a well. 
the completion of the well. Conversely, if the operating company elects to plug and abandon the well bore, the other working interest owners have the option to agree to plugging or they may elect to take over the well. They may then attempt a well completion on their own or with other working interest owners.

The duration of the drilling operations depends on the objective depth, problems encountered during drilling, and the condition of the drilling rig. Generally, shallow wells less than 4,000 feet deep require 15 to 20 days to drill. Deep tests of greater than 18,000 feet in complex geologic structures may take over 300 days to drill to total depth. Technical and support personnel including wellsite and office staffs are necessary to monitor the entire drilling process.

\section{COMPLETION OPERATIONS}

\section{DEFINE COMPLETION PROGRAM}

Engineers design the completion program after the decision to set casing has been made (fig. 3 ). The program includes reservoir evaluation and production-facilities design. The reservoir evaluation consists of perforations, clean-up acid treatment, and in some cases, fracture stimulation with proppants at high injection rates to increase the reservoir's permeability near the bore hole. The reservoir's production capacity is determined by designing flow tests and bottom-hole pressure build-up tests. The flow rates and pressure data reflect the projected ultimate recovery from the reservoir. The physical production facilities include the downhole equipment as well as surface-production facilities. This equipment must be designed to handle the expected rates of natural-gas production. Corrosive gases such as $\mathrm{CO}_{2}$ and $\mathrm{H}_{2} \mathrm{~S}$ are present in many reservoirs; therefore, the equipment must also be designed to withstand the effects of these gases. The surface facilities strip water from the natural gas, cool the gas produced from deep reservoirs, separate heavier gases (ethane, propane, and butane) from methane, and provide the means for gas to travel from the wellhead to the gathering system. The completion design and production testing usually requires 1 to 2 weeks and requires office and field engineers with their associated support staff.

\section{NATURAL-GAS MARKETING}

Gas gathering and marketing contracts are negotiated with transportation and marketing companies to move the gas from the wellhead to the user market. The pipeline company will have an in-house or independent engineer review the reservoir data to determine if it is economically feasible for them to construct a pipeline to the well.
The pipeline company will make its profit from transportation fees, which are based on the proximity of the well to their existing lines, and whether or not the gas must be compressed or treated before it can be moved into their local gathering system. These fees may be as high as 15 percent of the sales price per unit volume of natural gas. From this gathering system, the gas will be moved into a larger transmission line and carried to an industrial purchaser. This purchaser may be a public utility or a specialized industrial end user. The marketing of the gas determines the purchaser and the profit realized by the owners of the gas well. The marketing fees are variable and determined by the quality and quantity of the natural gas produced.

The addition of a small "leg" to the gathering system for a new well commonly requires several weeks to complete. It normally involves placing a T-shaped joint on the existing line, trenching the ground to lay new pipe, and installing a meter to measure the amount of gas flowing from the new well into the pipeline system. If the new well is within 2 or 3 miles of existing pipelines, it may be on line within days of the completion.

\section{LEGAL AND ADMINISTRATIVE PROCEDURES}

Well-testing information is distributed to the working interest owners daily. Also, accounting books are kept and appropriate billings are sent to working interest owners. Attorneys prepare a "division order title opinion" that is more detailed than the drilling title opinion. The division order states precisely the net revenue interest to at least 5 decimal places for each interest owner in the well. The disbursement of revenue is established by this legal document. The gas purchaser pays the operator the previously agreed upon price per unit (usually measured in thousands of cubic feet of gas, Mcfg). The operator then deducts and pays costs of transportation to gathering and pipeline companies, and any federal, state, or local taxes. The balance of the proceeds is then disbursed to the working interest owners. This process is labor and time intensive, and it requires a sophisticated accounting system; the system includes accounts payable, accounts receivable, and proceed disbursements.

\section{SUMMARY}

Regional geologic and engineering analyses define the expected economic rewards of an exploration play. The cost of achieving those rewards and the probability of successfully attaining those rewards is also determined by the regional analysis. After a company determines an exploration play to be economically feasible, an evaluation of the acreage is completed by the landman. The landman deter- 


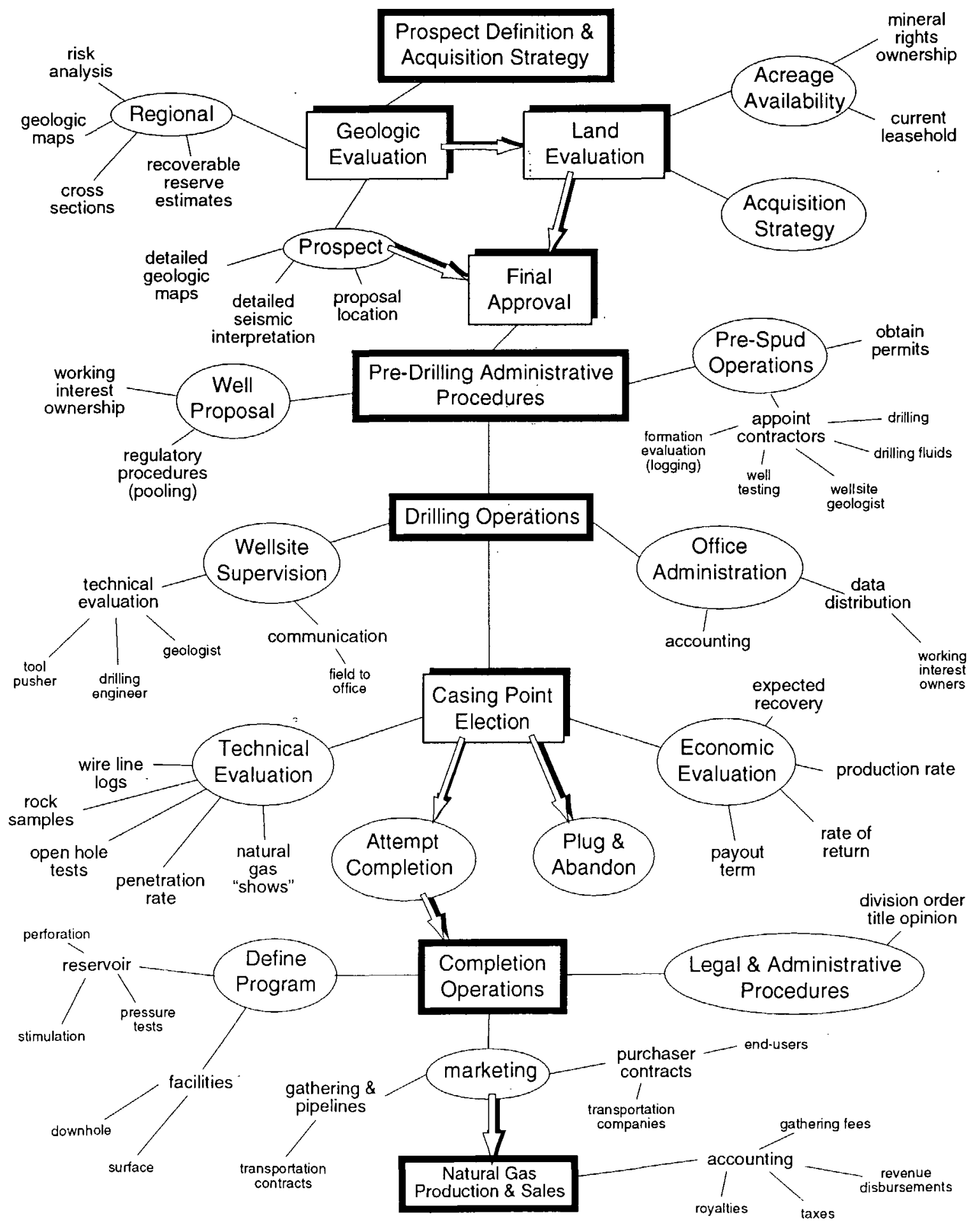

Figure 3. Summary of logistical considerations for the exploration and production of natural gas.

mines acreage availability and projects the cost of lease acquisition.

Detailed geologic and geophysical studies are necessary to delineate a specific prospect and select a drillsite location. The mineral rights are leased and business deals are made to secure all the parties holding mineral interest in the proposed well. A drilling plan is designed and specialized contractors are chosen to drill and evaluate the well.

Upon successfully drilling to the objective horizon, the geologist and engineer determine the productive capabilities of the possible natural gas-bearing reservoirs. If the 
Table 1. Estimates of time and cost for phases of natural-gas exploration.

[Cost in thousands of dollars; cost includes direct consulting expenses only, not overhead expenses]

\begin{tabular}{|c|c|c|c|}
\hline Procedure & Staff & Time & Cost \\
\hline Regional analysis--.----.-- & $\begin{array}{l}\text { Geologists, geophysicists, } \\
\text { and engineers. }\end{array}$ & 4 weeks & $\$ 80$ \\
\hline Prospect definition ------- & $\begin{array}{l}\text { Geologists and } \\
\text { geophysicists. }\end{array}$ & 1 week & $\$ 15$ \\
\hline Land work & Landman and staff - & 2 weeks & $\$ 25$ \\
\hline Government permits ------ & 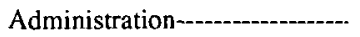 & 9 weeks & $\$ 15$ \\
\hline $\begin{array}{l}\text { Drilling of a shallow well } \\
\text { (includes drilling costs). }\end{array}$ & $\begin{array}{l}\text { Wellsite and office geologic } \\
\text { staff, engineering staff, } \\
\text { and support staff. }\end{array}$ & 5 weeks & $\$ 400$ \\
\hline $\begin{array}{l}\text { Completion of a well } \\
\text { (includes treatment and } \\
\text { tangible costs such as } \\
\text { casing and facilities). }\end{array}$ & $\begin{array}{l}\text { Wellsite and office } \\
\text { engineering staff, and } \\
\text { support staff. }\end{array}$ & 2 weeks & $\$ 200$ \\
\hline Pipeline hook up ------ & Noncompany personnel -------. & 4 weeks & N/A \\
\hline Total -.. & & $\ldots$ & $\$ 735$ \\
\hline
\end{tabular}

well is productive, marketing contracts are negotiated with natural-gas purchasers and pipelines are built to transport the natural gas from the wellhead to end users.

The process of exploring and developing natural gas requires a team of trained professionals and their support staff. Additionally, an entire service industry exists to perform the physical work of drilling, testing, and producing natural gas. The necessary professionals are geologists, geophysicists, engineers, attorneys, and landmen. Exploration for natural gas is a time-intensive endeavor that begins with a geologic idea of where natural gas may be found and produced at a profit.

The exploration process may require as much as 6 months from the initial geologic idea to first sales of natural gas into the pipeline. This estimate is dependent upon many factors including scale of regional analyses, administrative and governmental procedures, depth to horizon, and pipeline availability. A summary of the exploration process is shown in table 1.

One prospect requires a team of professionals and support staff 6 months to finish or a year for a deep test. The drilling and completion costs for a deep test may be 10 times those of a shallow well. This may result in a total project cost of $\$ 4.8$ million. The geologic exploration phase is a relatively small expense compared to the drilling costs. An effective, thorough geologic evaluation can save a company millions of dollars in dry-hole costs.

The complexity of the step by step procedure for the exploration and production of natural gas is summarized in figure 3 . 
THE FUTURE OF ENERGY GASES

U.S. GEOLOGICAL SURVEY PROFESSIONAL PAPER 1570

\title{
Overview of the U.S. Department of Energy/Morgantown Energy Technology Center Natural Gas Program
}

\author{
By Abbie W. Layne ${ }^{1}$
}

\section{CONTENTS}

\begin{tabular}{|c|c|}
\hline \\
\hline 6 & 685 \\
\hline DOE/METC Role & 686 \\
\hline Program Elements & 687 \\
\hline Resource and Extraction & 688 \\
\hline Delivery and Storage & 688 \\
\hline Utilization & 688 \\
\hline Environmental and Regulatory Impact .................. 6 & 688 \\
\hline Program Direction & 689 \\
\hline 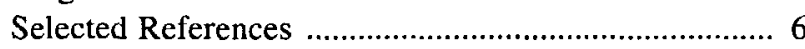 & 689 \\
\hline
\end{tabular}

\begin{abstract}
The mission of the U.S. Department of Energy's (DOE) natural gas program is to enhance the Nation's energy security, economic growth and efficiency, and environmental quality. This mission will be accomplished with the following: (1) by removing technical and(or) regulatory barriers to the expanded use of natural gas, (2) development of cost-effective and environmentally sound gas supply, storage, transmission, and utilization technologies, (3) improving competition, and (4) technology transfer.

The Morgantown Energy Technology Center (METC) supports the DOE natural gas mission through research, development, and demonstration (RD and D) of gas supply and utilization technologies. Projects are structured to
\end{abstract}

\footnotetext{
${ }^{1}$ U.S. Department of Energy, Morgantown Energy Technology Center, PO Box 880 Collins Ferry Road, Morgantown, WV, 26507-0880.
}

foster eventual industry commercialization of these technologies. In addition, METC's RD and D is integrated with projects and activities being sponsored by other funding organizations. Program goals include increasing user confidence in the long-term supply of natural gas, verification of adequate gas reserves, and development and commercialization of high-efficiency, cost-effective extraction and utilization technologies. METC's program includes gas utilization projects such as advanced gas turbine systems, fuel cells, and conversion of gas to liquid products.

METC's vision for the year 2010 is the following: Gas recovery and low-cost environmental technologies will insure a reliable U.S. gas supply of at least 23 trillion cubic feet per year; advanced turbine systems operating on gas have been demonstrated in the utility market and are available commercially; fuel cells and small advanced combustion turbine systems supply a distributed power market with gas-fueled devices in the 1 to 50 megawatt electrical (MWe) range, whereas the 50MWe and larger size range are being commercialized in the large industrial and commercial cogeneration markets.

\section{BACKGROUND}

Recent studies show that the lower 48 States have a natural gas resource base of about 1,295 standard trillion cubic feet (Tcf), given continued research, development, and demonstration (RD and $\mathrm{D}$ ) for the commercialization of advanced supply technologies, access to resources, and adequate delivery and storage systems (National Petroleum Council, 1992). Natural gas is plentiful in the United States, relatively inexpensive, and environmentally less damaging than any other fossil fuel. Despite these advantages, the demand for gas has fallen off between the early 
1970's and 1990. One,reason for the decline is a continuing lack of confidence in the stability of future supply; this is a legacy of the curtailment years of the 1970's. In response to the shortages and curtailments of the mid1970's, the Power Plant and Industrial Fuel Use Act was enacted in 1978 as part of the National Energy Plan. The result was a production capacity surplus and a lack of long-term natural gas contracts.

Gas usage is seasonal and this leads to underutilization of pipelines and storage systems in off-peak times. Development of usage technologies which are nonseasonal could lead to better utilization of pipelines and possible gains in utilization and storage facilities. Currently, several Federal regulations are being reformed to promote greater use of natural gas. These will affect the way the transportation and delivery services of natural gas are priced. Legislative efforts are underway to provide transportation service equal in quality for all gas supplies, whether customers purchase gas from the pipeline or from another supplier, and to allow expansion of natural gas into the power generation and commercial/industrial markets. These markets will help reduce the seasonal swings in natural gas usage and generate long-term natural gas contracts.

Successful research in such areas as high-efficiency gas turbines, natural gas fuel cells for electric power generation, and conversion of natural gas to liquid transportation fuels will contribute to increased nonseasonal demand and decrease U.S. dependence on imported oil. Increasingly stringent environmental regulation (for example, control of nitrogen oxides (NOx), sulfur dioxide $\left(\mathrm{SO}_{2}\right)$, partiçulate, carbon monoxide $(\mathrm{CO})$, and methane $\left(\mathrm{CH}_{4}\right)$ emissions) and growth in the Nation's demand for electric power capacity will favor natural gas consumption. Demand increases of about $4 \mathrm{Tcf}$ (from $19 \mathrm{Tcf}$ in 1990 to 23 Tcf) are envisioned by the 2000-2010 time period, with conventional gas resources (economic recovery in the $\$ 2.00$ to $\$ 2.50$ per million British thermal units price range (1990 dollars)) continuing to play a dominant role through the end of this century, while nonconventional gas resources capture an increasing share of the market (fig. 1).

In April 1992, the United States Department of Energy (DOE) "Natural Gas Strategic Plan and Multi-Year Program Crosscut Plan, fiscal year 1993-1998" was released (United States Department of Energy, 1992). This summarized the DOE natural gas strategy and $\mathrm{RD}$ and $\mathrm{D}$ programs.

The overall DOE natural gas program is designed to (1) enhance U.S. energy security, environmental quality, and economic strength by increasing natural gas recovery and utilization, (2) develop, in conjunction with industry, improved gas technologies, (3) restore and maintain confidence in long-term gas supply, (4) provide competitive and cost-effective means of gas use in both new and existing markets, (5) contribute to the gas industry's advances in technologies and techniques for lowering underground natural gas storage and delivery costs, and (6) minimize environmental and regulatory barriers to efficient market operation.

\section{DOE/METC ROLE}

Morgantown Energy Technology Center (METC) plays an important role in development and implementation of the DOE natural gas strategy and RD and D program. In support of the DOE Natural Gas Strategic and Multi-Year Program Crosscut plans, METC's role is to manage RD and D projects, ensure that program elements comply with all applicable Federal, State, and local laws and regulations, and foster success of DOE's natural gas program by promoting cooperation of Federal, State, and local governments as well as the cooperation and support of the gas industry.

Project management and planning is conducted in three program areas: (1) resource and extraction, (2) delivery and storage, and (3) utilization. Projects are maintained throughout a planning time frame to address and resolve strategic issues. Program objectives and goals are directed toward increasing user confidence in the longterm supply of gas and verification of adequate natural gas reserves and development and commercialization of highefficiency, cost-effective supply and utilization technologies. METC's gas supply and utilization technology RD and D projects are structured to foster eventual commercialization of the technologies through cooperative, cofunded research with industry.

Cooperation with industry is in the form of joint government/industry RD and $\mathrm{D}$ and technology transfer. Projects are cost shared with industry in a way that will give industry greater control over the projects. This encourages greater industrial participation and allows companies more freedom in managing projects. METC's programs are closely integrated with the programs of the Gas Research Institute (GRI), a major source of private sector funding for $\mathrm{RD}$ and $\mathrm{D}$ in gas related topics. GRI and DOE are cosponsoring $\mathrm{RD}$ and $\mathrm{D}$ in the areas of tight-sandstone recovery, well-bore drilling and stimulation, low quality gas upgrading, and gas atlases. METC also works with other industry organizations as well as individual companies.

Another industry partner is the Electric Power Research Institute (EPRI), a consortium of electric utilities whose collective expertise covers a wide range of issues and technologies.

Cooperative efforts continue with the National Petroleum Council (NPC). NPC has recently completed a comprehensive analysis of the potential for natural gas to make a larger contribution to our Nation's energy supply (National Petroleum Council, 1992). 


\section{PROGRAM ELEMENTS}

There are four elements of the DOE natural gas program: (1) resource and extraction, (2) utilization, (3) delivery and storage, and (4) environmental/regulatory impact. Each program element has its own unique mission that contributes to the goals of the program. The overall mission is to enhance the Nation's energy security, environmental quality, and economic strength by increasing efficient use of natural gas. In support of this mission are program elements that will improve confidence in the continued availability of a long-term natural gas supply (resource and extraction area), provide more cost-effective and competitive means to use natural gas (utilization area), develop improved and less costly means of delivering and storing natural gas (delivery and storage area), and mini- mize barriers to efficient market operation by promoting cost-effective regulation based on improved environmental assessments and improving availability of low-cost wastemanagement and waste-minimization technology (environmental research/regulatory impact area).

Detailed budgets and strategic plans are given in the DOE "Natural Gas Strategic Plan and Multi-Year Crosscut Program Plan, FY 1993-1998" (U.S. Department of Energy, 1992). The 1993 DOE natural gas budget request reflects the emphasis on utilization $\mathrm{RD}$ and $\mathrm{D}$. The total 1993 DOE natural gas budget was $\$ 157.6$ million, with the following distribution among program sectors: (1) resource and extraction, 12.8 percent of total, (2) delivery and storage, 0.0 percent of total, (3) utilization, 84.5 percent of total, and (4) environmental and regulatory impact, 2.7 percent of total.

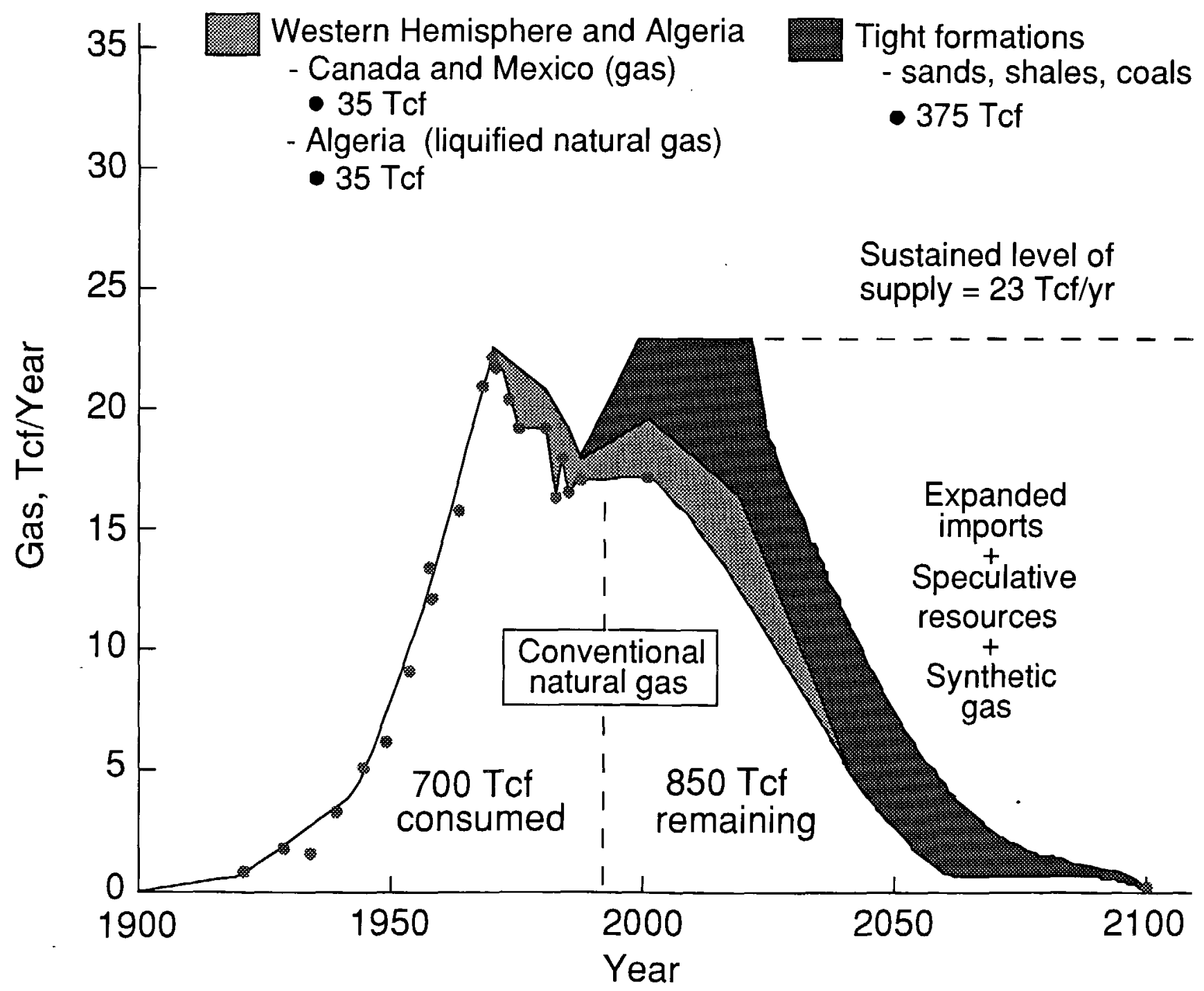

Figure 1. Natural gas supply outlook projected to the year 2100 . Tcf, trillion cubic feet; yr, year. 


\section{RESOURCE AND EXTRACTION}

The goal of the resource and extraction program is to enlarge and stabilize the domestic natural gas supply reserve base for a period of time adequate to increase public confidence in the long-term availability of affordable natural gas.

The DOE offices involved in the resource and extraction program are the Office of Fossil Energy (FE) and the Office of Energy Research (ER). METC implements the program elements in which the Office of Fossil Energy is involved. These include the resource and extraction categories of conventional gas, nonconventional gas, and environmental research.

The resource and extraction program is divided into nine project areas: (1) secondary gas recovery (cosponsored by GRI to extract a greater percentage of gas-in-place from complex mature reservoirs), (2) gas database consolidation (gas atlas series covering the Appalachian Basin and northern Gulf of Mexico and consolidation of a database system), (3) low-quality gas (develop methods to clean up low-quality gas) (4) drilling, completion, and stimulation technology (development of drilling, completion, and stimulation tools for special reservoir applications), (5) fracture technology and diagnostics (cosponsored by GRI to conduct large-scale laboratory and field-based stimulation RD and D and natural-fracture prediction/detection/mapping, which includes testing and diagnostics), (6) recovery from low-permeability formations (cosponsored by GRI to develop and demonstrate tight-sands production technology), (7) fundamental geoscience research (long-range geoscience research conducted by the Office of Energy Research), (8) gas hydrates (to increase confidence in hydrate resources and reserves), and (9) deep sedimentary basin gas (to increase confidence in deep natural gas resources and reserves) as a long-term supply source.

\section{DELIVERY AND STORAGE}

The purpose of the delivery and storage program is to develop cost-effective expansion of storage capacity, enhanced deliverability, and increased end-user confidence in natural gas. It is divided into four basic areas: (1) capacity development, (2) delivery enhancement, (3) storage efficiency, and (4) storage/market opportunities.

The DOE Offices involved in this program area are the Office of Fossil Energy, the Office of Energy Information Administration, the Office of Energy Research, the Office of Fuels Programs, and the Office of Policy, Planning, and Analysis. METC implements program elements in which the Office of Fossil Energy is involved. This includes all of the four basic areas.

\section{UTILIZATION}

The utilization program is the main focus of the DOE natural gas program with over 80 percent of total program funds supporting utilization technology RD and $\mathrm{D}$. The utilization program consists of elements supported by the Office of Efficiency and Renewable Energy, the Office of Fossil Energy, and the Office of Energy Research. The primary focus is to develop high-efficiency, low-pollution technologies and to overcome obstacles to their adoption. Project areas are combustion systems, heat pumps, gas turbines, natural gas vehicles, fuel cells, gas-to-liquids conversion, demand-side management, and integrated resource planning. METC implements the utilization research involving advanced gas turbines, fuel cells, and gas-to-liquids conversion technologies.

The gas-turbine program is being conducted in cooperation with the Office of Efficiency and Renewable Energy and focuses on advanced gas-turbine systems for electric power production in the utility and industrial sectors. These systems will have ultrahigh efficiency, be cost effective, and have low NOx emissions. The program consists of four phases: (1) limited system scoping/feasibility studies, (2) critical component testing (3) testing of largescale components and integrated subsystems, and (4) system demonstration.

The fuel-cells program area focuses on development of fuel-cell technology for stationary power plants. Emphasis is placed on development and applications of fuel-cell power plants for use in electric utility, industrial, and commercial sectors with 50 to 60 percent efficiencies to provide economic and environmental benefits. The program consists of technology development, pilot scale plants, demonstration plants, and commercialization for molten carbonate and solid oxide fuel cell systems.

Fuel cells and small advanced combustion turbine systems will supply a distributed power market with gasfueled devices in the 1 to 50 megawatt (MWe) electrical range, whereas the $50 \mathrm{MWe}$ and larger size range are being commercialized in the large industrial and commercial cogeneration markets.

The gas-to-liquids conversion program area is a multidisciplinary effort emphasizing the development of an economic, direct conversion process that will convert natural gas to higher value liquid fuels and thus provide a means of transporting gas from remote locations to the marketplace. Catalytic, noncatalytic, and biological conversion processes are investigated to develop better understanding and control of chemical reactions during conversion, enhance conversion rates and selectivity, and improve separation and recovery of the products.

\section{ENVIRONMENTAL AND REGULATORY IMPACT}

The environmental and regulatory impact program consists of projects related to environmental research, compliance and impact, and regulations. Specific project areas deal with natural gas production and end use, reduction of 
environmental impacts, and the role of methane in global climate change. Natural gas production projects identify and resolve environmental and safety issues related to natural gas production. Lower cost environmental compliance techniques are developed with the environmental compliance and impact projects, whereas cost-effective technologies are developed with the environmental impact reduction projects.

\section{PROGRAM DIRECTION}

As of 1992, the DOE gas program has been restructured using a "systems approach," which includes all components of the gas system - resource and extraction, utilization, delivery and storage, and environmental/regulatory impact.

DOE's role in natural gas will continue to evolve in fiscal year (FY) 1993, resulting in better delineation of appropriate areas for RD and D. Throughout 1993 and future years, a continued programmatic emphasis will be placed on utilization technology RD and D. DOE's strategic planning will be significantly influenced by the increasing pace of change in the gas industry. Industry cost sharing will increase as research moves from development to demonstration. Owing to funding constraints, DOE will target budget allocations to those project areas that provide maximum opportunity and benefits.

DOE anticipates that the Natural Gas Strategic Plan and Multi-Year Program Crosscut Plans will reduce the technical risks for companies developing new technologies and for companies entering the marketplace. The development and dissemination of technical information and analytical capabilities can provide cost-effective benefits to industry that might not otherwise occur.

For FY 1994, some programs will be modified or take new direction, such as those under the recovery from lowpermeability formations area; and the drilling, completion, and stimulation areas. The resources and extraction program will emphasize cost reduction of natural gas recovery technologies (for example, lower drilling costs and improved recovery techniques). Secondary gas recovery research will complete its shift from the Texas Gulf of Mexico sandstone reservoirs to a new geologic basin area (midcontinent deltaic sandstones) and reservoir classes in the other regions of the United States.

The fracture technology and diagnostics program area related to natural fracture detection and mapping will complete the move from its initial data acquisition and processing tasks into data analysis and interpretation.

The delivery and storage program will be aimed at increasing end user confidence in gas and improving its market opportunities. Program activities will focus on technologies leading to cost-effective expansion of storage capacity, storage efficiency, and enhanced deliverability. The program area will focus on an integrated $R D$ and $D$ approach to provide reliable deliverability systems for expanding markets such as the power and industrial sectors.

The utilization program will continue to be emphasized in 1993 and in future years. This program focuses on developing advanced high-efficiency, low-pollution technologies for use in the gas industry and overcoming obstacles to their adoption. Some of these technologies include advanced high-efficiency turbines that will provide costeffective, low-emission technology for actual power and industrial electricity production. This will increase the market for natural gas and help reduce the seasonal changes in natural gas demand. Low-NOx combustion technology will receive special attention, whereas gas-to-liquids advances may help displace some imported oil in the transportation sector. Expansion of the zero-emissions fuel-cell program is aimed at using high-efficiency technology for both dispersed and central power applications.

\section{SELECTED REFERENCES}

National Petroleum Council, 1992, The potential for natural gas in the United States; executive summary: Washington, D.C., National Petroleum Council, 5 p.

U.S. Department of Energy, 1992, Natural gas strategic plan and multi-year program crosscut plan, FY 1993-1998: U.S. Department of Energy/Office of Fossil Energy-0251P, 176 p.

-1993, Natural gas strategic plan and multi-year program crosscut plan, FY 1994-1999: U.S. Department of Energy/ Office of Fossil Energy-0251P (Draft document to be released in summer of 1993). 



\title{
Alternative Development Strategies for Natural Gas
}

\author{
By Emil D. Attanasi ${ }^{1}$
}

\section{CONTENTS}

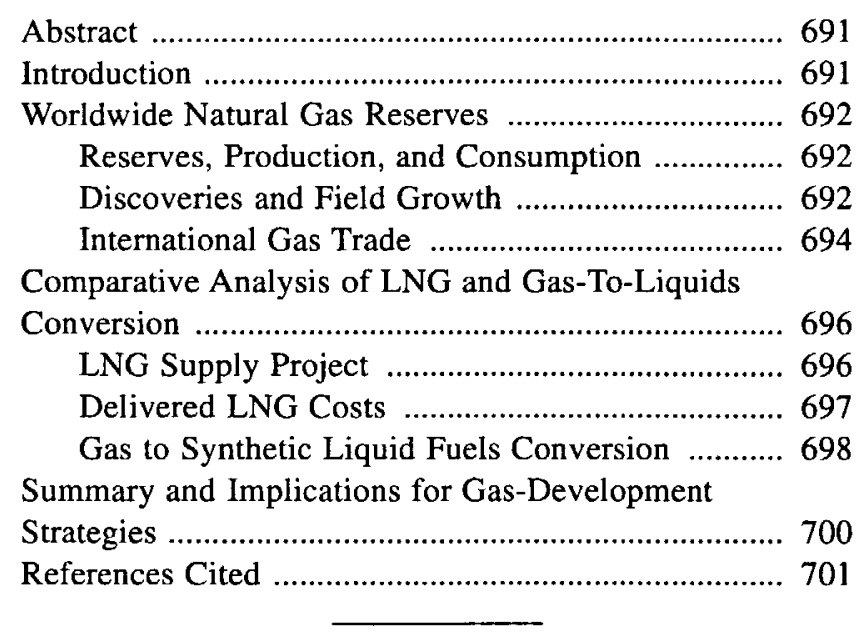

\begin{abstract}
Significant increases in worldwide natural-gas consumption during the last decade indicate that gas is increasingly considered a valuable and economic commodity. A summary of worldwide natural-gas reserves, production, and consumption statistics shows that worldwide gas use is not resource constrained. Only 10 percent of the gas produced is traded internationally and less than 3 percent is converted to liquefied natural gas (LNG). LNG is the principal alternative to pipeline transport of gas. Herein, the risks and economic returns of producing and using LNG are compared to converting gas to synthetic liquid fuel. Huge front-end investments in liquefaction plants, special-
\end{abstract}

'U.S. Geological Survey National Center MS 920, 12201 Sunrise Valley Dr., Reston, VA 22092-0001. ized LNG tankers, and regasification plants along with uncertainty associated with a highly concentrated buyers' market are significant downside risks for new market entrants. For the gas to synthetic liquids conversion alternative, the technological uncertainty dominates because unit costs of the products from commercial-scale plants must be competitive with the fuel products refined from crude oil. For either alternative, the energy policy of the host country must encourage and permit development of low-cost sources of gas.

\section{INTRODUCTION}

Worldwide demand for natural gas has increased by nearly 4 percent per year over the last decade. Natural gas is increasingly regarded as a valuable resource, rather than an unwanted byproduct of oil and condensate production. Major gas markets are concentrated in the industrialized countries of the Far East, Europe, and North America. Many markets are located far from lowest cost accumulations of gas resources.

Many less developed countries are rich in natural resources, such as natural gas, but they lack a domestic market for these products. These countries often try to generate foreign exchange from their resources by supporting industries that will either develop and export these resources or utilize these resources locally when manufacturing products for export. While pipeline transmission is the least costly and most efficient method of gas transportation, the development of international pipeline networks is largely restricted by physical distances, rugged topography, bodies of water, huge initial capital requirements, as well as national security considerations.

Gas can also be converted to liquid forms through either of two conversion processes. In liquid forms, it can be transported long distances in tanker-ships and traded internationally over the oceans. Liquefaction processes convert 
methane to liquefied natural gas. LNG is transported in specially engineered insulated tankers to remotely sited receiving terminals where the cargo is regasified. LNG liquefaction facilities and transportation systems have significant downside risks because large front-end investments are required to produce a product that has a very limited market.

The alternative to $\mathrm{LNG}$ is conversion by chemical processes to synthetic liquid fuels. The economic incentives for converting gas to liquid fuels increase as the cost of crude oil increases. Higher costs for crude oil result in higher prices for crude-oil derivatives, such as distillate and residual fuel oils, and lead to wider disparities between the price per equivalent energy unit for gas and crude-oil products. When considering development of facilities to convert natural gas to synthetic liquid fuels, the principal economic uncertainty is whether unit-production costs will decline sufficiently as plant size and throughput increase and as process innovation increases efficiency. Synthetic fuels must, however, be competitive with the alternative refined oil products to be profitable.

\section{WORLDWIDE NATURAL GAS RESERVES}

\section{RESERVES, PRODUCTION, AND CONSUMPTION}

From 1980 to 1989 , worldwide consumption of natural gas increased at a rate of 3.7 percent per year. This growth in gas consumption is evidence that gas is increasingly regarded as an economic commodity. Because the economic value attributed to a resource largely determines the quantity and quality of resource data that are available, the information on gas occurrence and consumption have steadily improved along with the expanding international trade.
Data on reserves, current production, and cumulative production of natural gas for individual countries as of January 1, 1991, are presented in table 1. Regionally, the distribution shows the following areas and associated shares of worldwide gas reserves: Eastern Europe (almost all in Russia), 34 percent; Middle East, 33 percent; North America, 10 percent; the Far East and Oceania, 8 percent; Africa, 6 percent; South America, 5 percent; and Western Europe, 4 percent. In contrast, North America has accounted for just over half of the world's past cumulative gas production, and Eastern Europe and North America together account for 60 percent of the world's natural-gas consumption (table 1). Eastern Europe, Western Europe, and the Far East had the largest absolute increases in gas consumption during the 1980's. Annual world gas consumption is still less than 2 percent of reserves; this statistic suggests that production is not resource constrained.

\section{DISCOVERIES AND FIELD GROWTH}

Estimates of annual gas discoveries expressed in 5-year averages for various areas are shown in figure 1. Since 1965, the amount of gas reported discovered offshore in South America, Western Europe, Africa, the Middle East, and non-Communist Asia has exceeded gas discoveries onshore. These reported discoveries reflect the improved economic value associated with gas, that is, even higher cost offshore gas is becoming economically attractive. Although the graph shows a precipitous decline in the annual gas discovery rate in recent years, this decline is likely due, in part, to incomplete data on recent discoveries, especially in foreign areas.

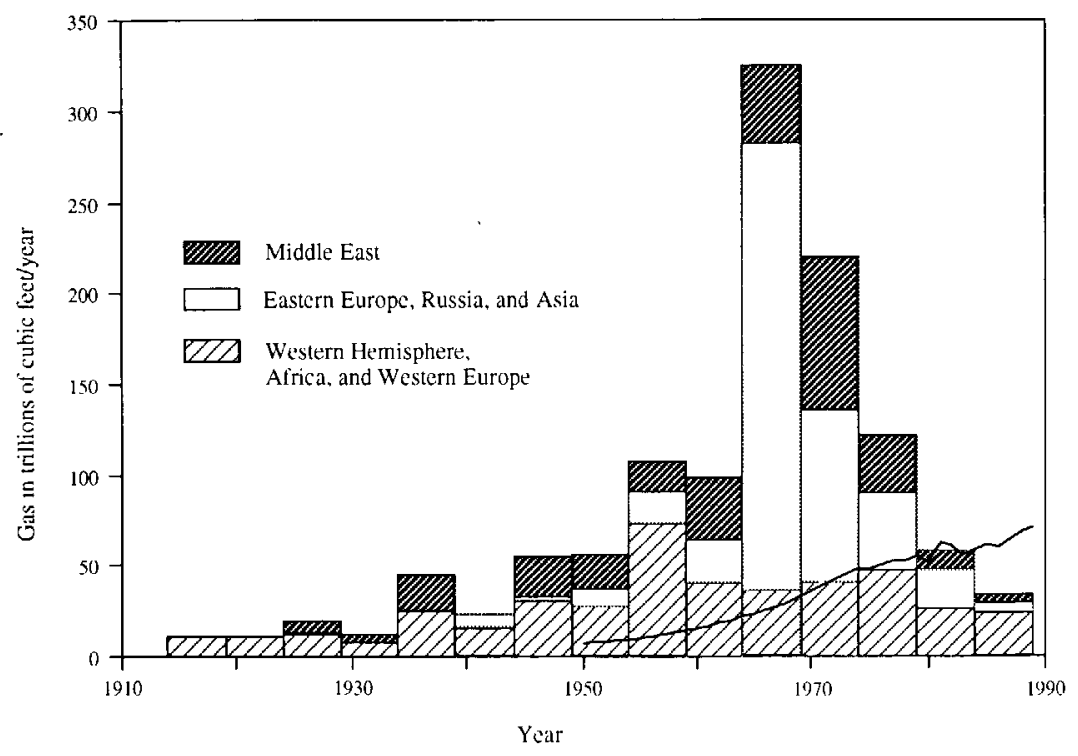

Figure 1. World natural-gas discovery rate averages for 5-year periods from 1915 to 1989. Annual production also shown. Modified from Masters and others, 1991. 
Table 1. Estimated production, reserves, and consumption of natural gas.

[Tcf, trillion cubic feet; *, includes 1.26 Tcf for individual South American countries for which consumption statistics are unavailable; -, no statistic available; CIS, Commonwealth of Independent States]

\begin{tabular}{|c|c|c|c|c|}
\hline & 1990 Gas production' (Tcf) & $\begin{array}{c}\text { Cumulative production } \\
\text { to } 1991^{2}\end{array}$ & Reserves in Tcf $1 / 1 / 91$ & 1990 Consumption ${ }^{3}$ in Tef \\
\hline North America -- & 22.4 & 872.9 & 337.6 & 22.27 \\
\hline 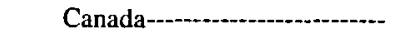 & 3.8 & 81.6 & 96.7 & 2.47 \\
\hline Mexico - - & 1.4 & 24.6 & 71.5 & 0.98 \\
\hline United States -......--..-.. & 17.2 & 766.7 & 169.3 & 18.82 \\
\hline South America---1 & 2.3 & 40.9 & 178.6 & $2.21 *$ \\
\hline 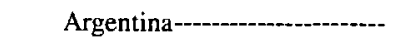 & 0.8 & 11.0 & 20.5 & 0.83 \\
\hline Bolivia------------.-- & 0.1 & 1.9 & 4.6 & \\
\hline Brazil - -...- & 0.1 & 2.0 & 4.1 & \\
\hline 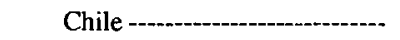 & 0.1 & 2.9 & 4.0 & \\
\hline Colombia----_- & 0.1 & 2.6 & 4.2 & 0.15 \\
\hline Ecuador---..-- & - & 0.1 & 4.0 & \\
\hline Peru - - & 0.0 & 1.1 & 7.1 & \\
\hline Trinidad --_e-ce- & 0.2 & 3.0 & 9.2 & 0.17 \\
\hline Western Europe-- & 7.0 & 134.0 & 225.7 & 9.95 \\
\hline Italy & 0.6 & 14.6 & 11.4 & 1.67 \\
\hline Netherlands -- & 2.6 & 57.1 & 69.5 & 1.49 \\
\hline Norway --_- & 1.0 & 11.4 & 108.7 & 0.07 \\
\hline United Kingdom ----....-- & 1.7 & 26.4 & 19.2 & 2.03 \\
\hline Other--- & 1.1 & 24.5 & 16.8 & 4.69 \\
\hline Eastern Europe ------------------- & 30.4 & 437.3 & 1593.3 & 29.58 \\
\hline Romania-- & 1.2 & 31.0 & 3.7 & 1.44 \\
\hline CIS --1-1.- & 28.8 & 387.1 & 1575.9 & 25.5 \\
\hline Other-....-- & 0.5 & 19.3 & 13.7 & 2.64 \\
\hline Africa - & 2.2 & 34.6 & 289.8 & 1.39 \\
\hline Algeria--- & 1.6 & 18.4 & 116.5 & 0.69 \\
\hline Egypt -.-- & 0.3 & 1.8 & 10.9 & 0.28 \\
\hline Gabon-- & - & 0.3 & 0.4 & - \\
\hline Libya--..-- & 0.2 & 6.0 & 43.0 & 0.17 \\
\hline Nigeria---_-_- & - & 5.9 & 93.3 & 0.17 \\
\hline Tunisia---_--_- & - & 0.1 & 3.1 & 0.06 \\
\hline Other-- & 0.1 & 2.1 & 22.7 & 0.02 \\
\hline Middle East -...........- & 4.2 & 61.6 & 1338.3 & 3.72 \\
\hline Bahrain --..... & 0.2 & 2.0 & 6.1 & 0.19 \\
\hline Iran---1- & 0.8 & 18.4 & 600.5 & 0.82 \\
\hline 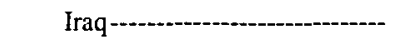 & 0.1 & 3.4 & 109.7 & - \\
\hline 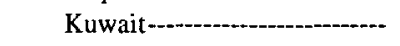 & 0.1 & 5.6 & 53.0 & 0.43 \\
\hline Oman & - & 0.6 & 10.0 & 0.10 \\
\hline 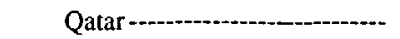 & 0.3 & 3.2 & 162.0 & 0.22 \\
\hline Saudi Arabia -..-............ & 1.4 & 15.4 & 184.2 & 1.09 \\
\hline Syria - - & - & 1.5 & 6.4 & - \\
\hline United Arab Emirates -..---- & 1.1 & 8.8 & 186.6 & 0.73 \\
\hline Other-1...- & 0.1 & 2.6 & 19.8 & 0.14 \\
\hline 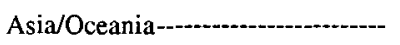 & 5.1 & 86.5 & 363.2 & 5.31 \\
\hline Afghanistan & - & 1.0 & - & - \\
\hline Australia/New Zealand & 0.9 & 8.5 & 77.3 & 0.72 \\
\hline Burma --.-- & - & 2.2 & 5.1 & - \\
\hline China --י-- & 0.5 & 18.1 & 33.2 & 0.53 \\
\hline India - - & 0.4 & 2.2 & 21.1 & 0.33 \\
\hline 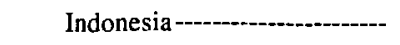 & 1.4 & 15.8 & 101.8 & 0.57 \\
\hline Malaysia/Brunei--.--..---.--- & 0.3 & 5.3 & 65.5 & 0.31 \\
\hline 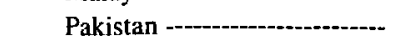 & 0.4 & 6.2 & 22.7 & 0.49 \\
\hline 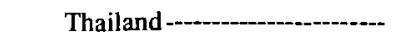 & - & - & 14.5 & - \\
\hline 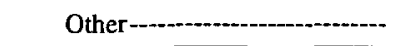 & 1.1 & 29.2 & 22.0 & 2.36 \\
\hline 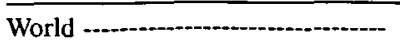 & 73.7 & 1667.9 & 4326.5 & 74.42 \\
\hline
\end{tabular}

${ }^{1}$ Twentieth Century Petroleum Statistics, 1991, DeGolyer and MacNaughton, Dallas, Texas.

${ }^{2}$ Masters and others (1991).

${ }^{3}$ Energy Information Administration, International Energy Annual, 1990. 
Table 2. Estimates, in billion cubic feet, of ultimate recovery of cumulative gas discovered by region from 1981 to 1990 as recorded by Petroconsultants, Ltd.

\begin{tabular}{|c|c|c|c|c|}
\hline \multirow[b]{2}{*}{ Region } & \multicolumn{4}{|c|}{ Year } \\
\hline & 1981 & 1984 & 1987 & 1990 \\
\hline South America-- & 28,524 & 59,757 & 80,920 & 116,228 \\
\hline Western Europe - & 229,685 & 265,926 & 321,763 & 318,798 \\
\hline Middle East & 628,045 & 846.308 & $1,174,011$ & $1,753,278$ \\
\hline 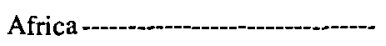 & 134,299 & 176,460 & 177,780 & 272,777 \\
\hline Non-Communist Asia -..- & 83,972 & 175,745 & 168,100 & 254,622 \\
\hline Total -.......- & $1,104,525$ & $1,524,196$ & $1,922,574$ & $2,715,703$ \\
\hline
\end{tabular}

Another source of additions to proved gas reserves is from the field-growth phenomenon. In the United States and Canada, it has long been recognized that initial estimates of oil and gas field sizes are conservative. Field-size estimates typically increase from the initial estimates as new discoveries are placed into production and fully developed. In the United States, from 1977 to 1988, for example, the estimates of oil and natural gas contained in pre-1978 discoveries increased by 21 billion barrels of oil (Bbo)-from 145 to 166 , or 14 percent- -and by 148 trillion cubic feet (Tcf) of natural gas-from 735 to 883 , or 20 percent-respectively (Energy Information Administration, 1990).

Field growth is not unique to the United States and Canada. Petroconsultants, Ltd. provides quarterly estimates of the ultimate recovery of oil and gas for each field. Table 2 shows Petroconsultants' estimate of the amount of gas contained in fields discovered between 1900 and 1980 in selected international regions. These data were computed from estimates made in 1981, 1984, 1987, and 1990 of pre1980-discovered field sizes. Comparison of the 1981 and 1984 data indicates that many fields discovered before 1980 were still unannounced as of 1981 , and consequently, were unaccounted for in the 1981 data. By 1984, many more pre1980 field discoveries were confirmed and announced; these announcements led to significant differences between the 1981 and 1984 estimates. By 1987, however, pre-1980 discoveries would then have been at least 8 years old and most should have been confirmed and publicly announced. The table shows the difference between the 1987 and 1990 resource estimates for fields discovered before 1980 . The difference of $790 \mathrm{Tcf}$ represents a 41 percent increase in estimates of ultimate field recovery. Without the Middle East data, the difference in estimates is $213 \mathrm{Tcf}$, which represents a 29 percent increase over the 1987 estimates.

This dramatic increase in estimates of gas resources in past discoveries is, in part, a result of the improved economics for natural gas. Whereas natural gas had previously been essentially discarded (vented or flared) as an unwanted byproduct of oil production, the development of applications for natural gas has increased its demand and economic value. Without the market and means of transporting gas, there had been little incentive to accurately measure or develop gas resources. There are several reasons for the generally conservative reserve estimates for both oil and gas fields. Initial reserve evaluations need only be detailed enough to determine a minimum field size that would justify an operator's investments in development drilling and production facilities. Penalties for reserve overestimation might include excessive expenditure on field development. These penalties are generally much greater than penalties for underestimation of reserves. Higher prices allow more intensive field development and also allow commercial development of lower quality reservoirs.

\section{INTERNATIONAL GAS TRADE}

The nature of gas transportation accounts for the contrast between the proportion of gas production that is traded internationally compared to that of oil. About 10 percent of the gas produced each year is traded internationally whereas almost half of the oil produced is traded internationally. On an annual basis, Russia is by far the largest pipeline gas exporter (more than $3 \mathrm{Tcf}$ ), followed by Canada (1.3 Tcf), the Netherlands (1.2 Tcf), and Norway (1 Tcf). Less than 3 percent of the gas produced annually is traded in the form of LNG. Internationally traded LNG transactions for 1990 as reported by CEDIGAZ (1991) are shown in table 3. Japan leads importers with just over 64 percent of the worldwide LNG trade, whereas Indonesia accounted for about 41 percent of the worldwide LNG exports. Asia and Western Europe account for 69 and 27 percent of the total LNG trade, respectively.

Production of U.S. gas peaked in 1973 and gas shortages developed in the mid-1970's, after the crude-oil price increases of 1973. The shortages were particularly severe at the terminus of the domestic gas pipeline network, particularly in Northeastern States. Distrigas, a Cabot Corporation subsidiary, began receiving Algerian LNG at its terminal near Boston in 1971 to augment tight domestic supplies. Other 
Table 3. Estimates of international gas trade, in billion cubic feet, by liquefied natural gas (LNG) tanker in $1990^{1}$.

[Export figures are boldface!

\begin{tabular}{|c|c|c|c|c|c|c|c|c|c|c|c|}
\hline \multirow{3}{*}{ Import } & \multicolumn{10}{|c|}{ Export } & \multirow{3}{*}{$\begin{array}{l}\text { Total LNG } \\
\text { imports }\end{array}$} \\
\hline & $\begin{array}{l}\text { North } \\
\text { America }\end{array}$ & \multicolumn{3}{|c|}{ Africa } & Middle East & \multicolumn{5}{|c|}{ Asia/Oceania } & \\
\hline & United States & Algeria & Libya & Total & Abu-Dhabi & Australia & Brunei & Indonesia & Malaysia & Total & \\
\hline North America - & & 87.2 & & 87.2 & & & & & & & o \\
\hline 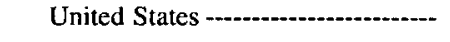 & & 87.2 & & 87.2 & & & & & & & 87.2 \\
\hline Western Europe & & 582.1 & 43.8 & 625.9 & & & & & & & \\
\hline 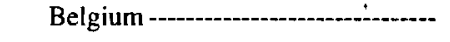 & & 137.7 & & 137.7 & & & & & & & 137.7 \\
\hline 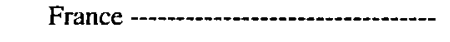 & & 328.6 & & 328.6 & & & & & & & 328.6 \\
\hline - & & 1.1 & & 1.1 & & & & & & & 1.1 \\
\hline 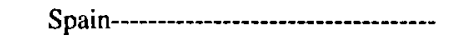 & & 113.0 & 43.8 & 156.7 & & & & & & & 156.7 \\
\hline 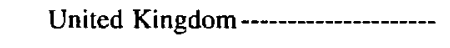 & & 1.8 & & & & & & & & & 1.8 \\
\hline Asia/Oceania & 48.0 & 3.2 & & 3.2 & 113.0 & 139.1 & 42.5 & 941.3 & 303.9 & 1426.8 & 1591.0 \\
\hline 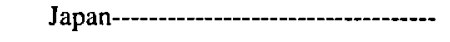 & 48.0 & 3.2 & & 3.2 & 113.0 & 139.1 & 42.5 & 829.2 & 303.9 & 1314.7 & 1478.9 \\
\hline 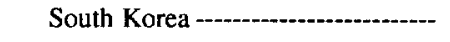 & & & & & & & & 108.7 & & 108.7 & 108.7 \\
\hline 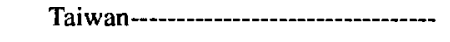 & & & & & & & & 3.4 & & 3.4 & 3.4 \\
\hline 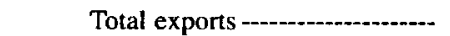 & 48.0 & 672.5 & & 716.2 & 113.0 & 139.1 & 42.5 & 941.3 & 303.9 & 1426.8 & 2304.0 \\
\hline
\end{tabular}

'Data from CEDIGAZ, 1991 
U.S. pipeline operators built terminals to receive Algerian LNG at Cove Point, Maryland (Columbia and Consolidated Gas), Elba Island, Georgia (Southern Natural Gas), and Lake Charles, Louisiana, (Trunkline-Panhandle Eastern).

In the early 1980's, the Algerian suppliers tried to attain gas-price parity with oil by raising prices beyond what pipelines and utilities could recover from customers. Purchase contracts were canceled and all U.S. receiving terminals were mothballed as the operators underwent financial reorganization. With the improvement of natural-gas markets in 1990, Distrigas reopened its Boston terminal and the Lake Charles terminal reopened about a year later. The Algerian LNG supplier priced the gas on a "netback" basis. The netback pricing scheme obligated the supplier to accept a fixed percentage of the price received by the terminal from the gas purchaser. The current annual capacity of the operating and mothballed receiving terminals is 0.9 Tcf. If all plants were expanded to their maximum capacity, $1.3 \mathrm{Tcf}$ could be received annually.

LNG production and export projects are best located in countries or regions with significant natural-gas resources and limited local gas demand, where the opportunity cost or in-situ value of the gas resource may be low. Host countries typically offer some subsidies (including favorable tax treatment) in exchange for equity positions in such projects. Because of the required large front-end capital investment and accompanying substantial downside risks, LNG projects are built only after most of the plant's output is committed to long-term purchase contracts. Contract prices may be indexed to prices for crude oil or a specified bundle of fuels at a specified delivery point. For example, Japanese import LNG contract prices are indexed to the price of imported oil. Indonesian LNG export prices are similarly tied to prices received for Indonesian crude-oil exports.

For overseas LNG projects built to supply the Japanese market, the Japanese purchasers, electric utilities, typically use Japanese trading houses to link Japanese project financing with purchase commitments for Japanese-manufactured plant equipment. From the perspective of the Japanese Government, the substitution of LNG gas for oil or coal in electrical power generation meets two national policy objectives; diversification of primary energy use and supply sources, and, in urban areas, the reduction of sulfur and carbon emissions from coal and petroleum consumption. Japanese LNG import policies do not provide inexpensive fuels for consumers, but the policies do appear to have accomplished the two policy objectives.

\section{COMPARATIVE ANALYSIS OF LNG AND GAS-TO-LIQUIDS CONVERSION}

\section{LNG SUPPLY PROJECT}

LNG production systems consist of the following components: a source of natural gas, an LNG plant, port facilities, a tanker fleet, and a receiving terminal where LNG is regasified. To simplify the analysis, natural gas is assumed to be purchased by the plant operator and sold to the receiving terminal. The input gas, or feed gas, used in the process is assumed to be 1 billion cubic feet (Bcf) per day. A standard plant with three process trains, each designed to produce 2.2 million tonnes of LNG annually, will accommodate this quantity of input gas.

Basic system cost components were initially developed by Chem Systems (Chem Systems, 1989) for the U.S. Department of Energy. These costs were updated using the end of year 1991 factors from Chemical Engineering's new plant-construction index published in the December 1992 issue. These direct investment cost estimates are the basis for computing indirect investment costs including construction overhead, engineering fees, process license fees, and an allocation for contingencies.

All liquefaction processes for LNG production consist of a gas pretreatment step followed by successive stages during which the gas is eventually chilled to a liquid form at $-262^{\circ} \mathrm{F}\left(-162.1^{\circ} \mathrm{C}\right)$. Plant design and costs are well established and major cost reducing technological advances are not expected. Processes differ in terms of their basic refrigerants and pressures and are designed for specific operating conditions. Chem System's cost estimates are based on a generic LNG plant design. Locational cost adjustments reflect the level of industrial development in the host country.

Plant configurations include the gas pretreatment process, the liquefaction process, utilities, storage and loading facilities, and marine facilities. Basic investment costs used in this analysis are presented for two host sites in table 4. Investment costs for site I represent costs that might be incurred in the Caribbean, Algeria, or the Arabian Gulf coastal areas. Costs associated with site II are representative of Nigeria or the coastal areas of Indonesia or Malaysia. Annual liquefaction plant operating costs exclusive of the feed gas costs for the two sites are also presented in table 4 . Even at a price of $\$ 0.50$ per million British thermal units (MMBtu), the feed gas costs account for about 75 percent of annual plant operating costs.

Transportation is a large investment component of any LNG project. The transportation system consists of a number of special tanker ships to deliver the plant's liquid output. The number of tankers of standard-sized, 125,000 cubic meters of LNG (equivalent to $2.67 \mathrm{Bcf}$, billion cubic feet, of gas), is based on the quantities required, the shipping distance from loading facilities to purchasers' receiving terminals, the average ship speed, and the number of days allowed for loading and off-loading cargo. As indicated by recent tanker orders, costs for new tankers have reached $\$ 260$ million (Pastuhov, 1991). Tanker construction is assumed to take two years and the economic life of a tanker is assumed to be 20 years.

To simplify this analysis, an assumption is made that the entire plant output is committed to a purchaser ser- 
Table 4. Capital and operating cost estimates for representative liquefied natural gas plant.

[Estimates in millions of dollars ${ }^{1}$ and based on 1 billion cubic feet of input per day]

\begin{tabular}{|c|c|c|}
\hline \multicolumn{3}{|c|}{ Capital investment cost } \\
\hline & Site I & Site Il \\
\hline \multicolumn{3}{|l|}{ Direct } \\
\hline 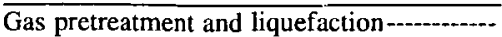 & 446 & 469 \\
\hline Utilities and services -- & 435 & 457 \\
\hline Storage, loading, and marine facilities-----.. & 201 & 234 \\
\hline Indirect ${ }^{2}-1-1$ & 379 & 406 \\
\hline Contingency ${ }^{3}$ & 219 & 235 \\
\hline Fees $^{4}$ - & 168 & 180 \\
\hline Infrastructure----- & 112 & 502 \\
\hline Total investment cost-- & 1,960 & 2,483 \\
\hline \multicolumn{3}{|c|}{ Annual production cost (exclusive of feed gas) } \\
\hline Materials-ons & .4 & .4 \\
\hline Variable cost & 23.0 & 24.0 \\
\hline \multicolumn{3}{|l|}{ Overhead } \\
\hline 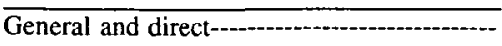 & 15.2 & 15.9 \\
\hline Insurance - - & 29.4 & 37.3 \\
\hline Annual operating cost - & 68.0 & 77.6 \\
\hline
\end{tabular}

${ }^{1}$ Cost from Chem Systems (1989) and updated to 1991 dollars.

${ }^{2}$ Indirect costs include construction, overhead, and engineering fees They are computed as 35 percent of direct costs.

${ }^{3}$ Contingency computed as 15 percent of base plant cost, which is the total of direct and indirect capital investment cost

${ }^{4}$ Fees (and commissions) computed as 10 percent of base plant and contingency.

viced by the receiving terminal at Cove Point, Maryland, located on the U.S. East Coast. Tankers are operated 340 days per year, have an average steaming speed of 18.5 knots, and are allowed 36 hours port time at both ends of the trip. Tankers are powered by boil-off LNG and boiler fuel oil. Boil-off LNG is methane that is generated from the vaporization of the cargo of LNG. Average daily boiloff LNG used for steaming is equivalent to 0.125 percent of the initial ship capacity. The fuel-oil requirement is 61 tonnes per day during the trip and 41 tonnes per day while in port. Other annual operating costs are calculated as fractions of the ship's value (Vidas, 1988).

\section{DELIVERED LNG COSTS}

Several additional assumptions are made to calculate the total cost of LNG delivered to the Cove Point terminal. Costs presented herein are intended to represent resource costs. Taxes and inflation were ignored in this analysis. Further, the project was assumed to be financed entirely with equity investment and the required return to capital was assumed to be 15 percent. The productive life of the project is 20 years with an additional 5 years allowed for construction. The costs presented in table 4 were used as well as the transportation costing procedure discussed in the "LNG Supply Project" section. The sources of the LNG are assumed to be in the Caribbean, Algeria, and Nigeria. From these locations, ocean distances to Cove point are 1900,3685 , and 5300 nautical miles, respectively.

Assuming a feed gas cost of $\$ 0.50$ per MMBtu and a required rate of return of 15 percent, liquefaction and transportation costs per MMBtu are $\$ 2.70, \$ 3.22$, and $\$ 4.07$ for the Caribbean, Algerian, Nigerian producers, respectively. The transportation costs alone are $\$ 0.64, \$ 1.11$, and $\$ 1.54$ per MMBtu, respectively. For these producers, transportation costs represent from 28 to 34 percent of the delivered $\mathrm{LNG}$ cost. The cost of delivery to a receiving terminal as a function of the required rate of retum used in the discounted cash-flow analysis is shown in figure 2 . Once delivered to the receiving terminal, the LNG must also be regasified before it can be sold to a pipeline or final purchaser. Costs associated with this component of the LNG system amount to about $\$ 0.50$ per MMBtu and should be added to the costs shown in figure 2 .

Additional computations were made to determine the sensitivity of delivered costs to underlying model assumptions. For every 1 cent per MMBtu increase in the cost of the plant input feed gas, the landed cost of LNG increases by about 1.1 cents per MMBtu. For example, if the input feed gas cost increased from $\$ 0.50$ to $\$ 1.00$ per MMBtu the landed costs would increase to $\$ 3.25, \$ 3.77$, and $\$ 4.63$, respectively. As rate of return on initial plant investment is increased (or decreased) by 20 percent, delivered cost would increase (or decrease) by about 8 percent. If the assumed productive life of the plant and tanker fleet were increased to 25 years from the assumed 20 -year plant life, the delivered costs would decline by less than 2 percent. Alternatively, if the productive project life were shortened by 5 years, delivered costs increase by more than 8 percent.

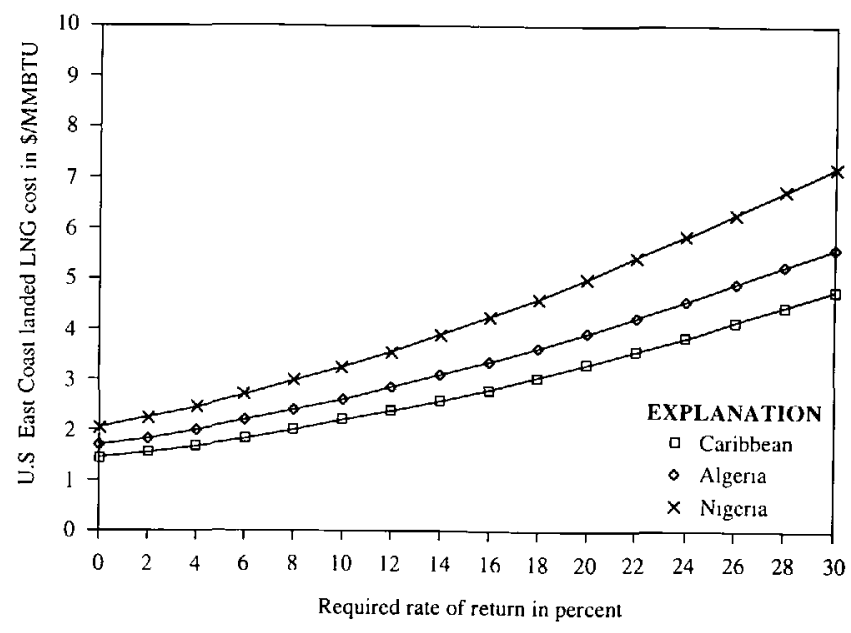

Figure 2. Delivered cost of LNG (liquefied natural gas) in 1991 U.S. dollars (per MMBtu, million British thermal units) to U.S. East Coast from the Caribbean, Algeria, and Nigeria as a function of the cost capital or nominal return to equity where the system includes liquefaction plant and facilities and tanker fleet. Cost based on input feed gas cost of $\$ 0.50$ per MMBtu. 
LNG imports generally represent a high cost or marginal gas supply source in places where there are indigenous supplies of gas. For example, in the U.S. wellhead gas prices for the first 6 months of 1992 averaged \$1.52 per Mcf, pipeline imports averaged $\$ 1.95$ per Mcf (million cubic feet), and city gate prices averaged $\$ 2.80$ per Mcf (Energy Information Administration, Monthly Energy Review, 1992). If the gas is principally delivered to residential and commercial consumers for space-heating applications, fluctuations in weather will cause significant fluctuations in gas demand. Even if imported LNG is used to generate baseload electricity, changing economic conditions will also introduce LNG gas-demand variability. The cost penalties associated with various levels of long-term excess plant capacity can be inferred from data shown in figure 3 . For example, if the plant's average unused capacity is 25 percent over the plant's life, calculated delivered or landed costs of LNG increase by about 28 percent over the costs associated with full-capacity operation. If energy markets are competitive, the higher costs of LNG could reduce demand for the plant's output even further.

Contract provisions have been used by producers to manage the downside risks associated with projects that carry heavy front-end investments. To assure that transaction prices reflect current market conditions, "indefinitepricing" provisions are added to long-term contracts. An indefinite-pricing clause may tie gas contract prices to cost indices, prices of substitute sources of gas, or prices of crude oil or refined products. "Market-out price ceiling" is a contract provision that relieves the purchaser of contractual obligations when the contract price resulting from indefinite pricing clauses exceed some predetermined ceiling price. "Take-or-pay" contract provisions require the gas purchaser

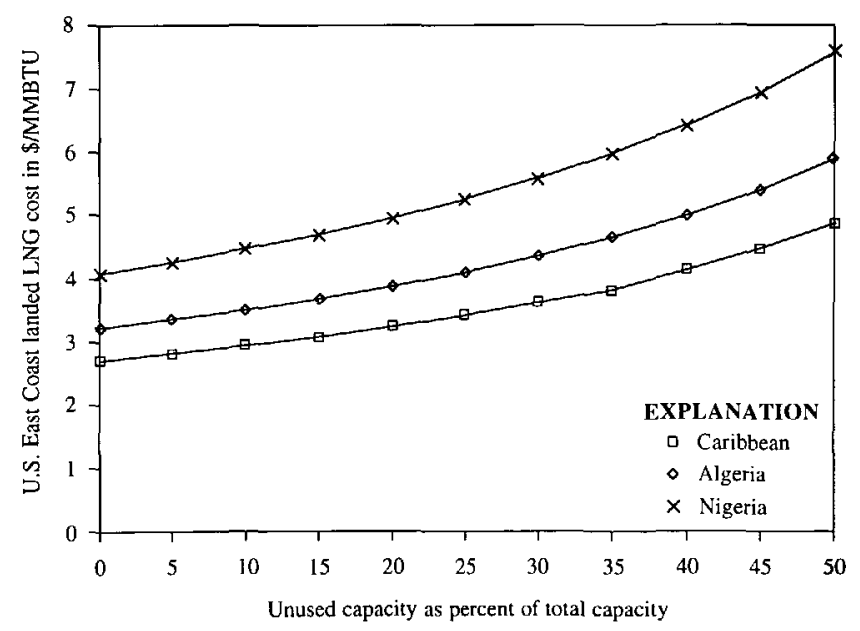

Figure 3. Delivered cost of LNG (liquefied natural gas) in 1991 U.S. dollars (per MMBtu, million British thermal units) to U.S. East Coast from the Caribbean, Algeria, and Nigeria as a function of unused system capacity assuming a 15 percent cost of capital or required nominal return and input feed gas cost of $\$ 0.50$ per MMBtu. to either take a specified quantity of production at the contract price or pay for contracted quantities not taken. This assures the producer a predictable stream of revenue regardless of market demand.

Simulation experiments have been conducted to assess the effects of these three contract provisions on project profitability. A more detailed account of the experiments and results is given in Attanasi (1991). To summarize those results, when indefinite pricing contract clauses induce positive serial correlation (that is, when the values in a time series separated by one step are positively correlated) in transactions prices over the life of project, downside project risks are magnified. More specifically, if the indefinite price clause induces an increase in the serial correlation in the price distribution over the life of the project, the mean and median of the distribution of project returns are reduced while the variance increases. Market-out price ceilings tend to reduce the mean of the distribution of returns. Take-or-pay clauses, if set sufficiently high (above 85 percent of plant capacity), can effectively shift the risk of demand variability to the purchaser (Attanasi, 1991).

\section{GAS TO SYNTHETIC LIQUID FUELS CONVERSION}

One alternative to LNG development of gas resources is chemical conversion of gas to liquid synthetic fuels. The general economic characteristics of the gas-to-liquid conversion systems are examined here, in the context of the Shell middle distillate synthesis (SMDS) process. This process converts natural gas to a mixture of liquid fuel products including gasoil, kerosene, diesel fuel, and light distillate fuels. A demonstration plant that will convert 100 Mcf per day of feed gas to 12,000 barrels of liquid fuels per day is scheduled for completion in 1993, in Bintulu, Malaysia (Shell Malaysia, 1989). Products from this process can be used in refineries to enhance feedstock quality or can be sold as liquid fuels. The apparent thermal efficiency of the plant is just over 62 percent.

The SMDS process first converts natural gas into syngas (hydrogen and carbon monoxide). A modified version of the Fischer-Tropsch process reacts the syngas components to form long-chain paraffins using a special Shell catalyst. The long-chain paraffin molecules are then cracked (that is, broken into less complex compounds) under mild hydrocracking conditions. The final process, a fractionation process, splits the product stream into various component products. Because the initial component is natural gas, the final products are free of sulfur and particulates (Williams and Bekker, 1990).

One of the few public studies on this process was prepared by Chem Systems (1990) for the Department of Energy. The standard size plant is assumed to produce 28,500 barrels per day. Costs from that study were slightly modified 
Table 5. Capital and operating cost estimates for a gas to synthetic luquid fuel plant using the SMDS process.

[SDMS, Shell middle distillate synthesis; estimates in millions of dollars ${ }^{1}$ and based on a 28,500 barrels of liquid per day output]

\begin{tabular}{|c|c|c|}
\hline \multicolumn{3}{|c|}{ Capital investment cost } \\
\hline & Site I & Site II \\
\hline \multicolumn{3}{|l|}{ Direct } \\
\hline Syngas sythesis & 91 & 97 \\
\hline Oxygen plant & 134 & 143 \\
\hline Fuel sythesis & 276 & 296 \\
\hline Gas processing & 22 & 24 \\
\hline Fractionation & 38 & 41 \\
\hline Hydrocracking & 36 & 39 \\
\hline Utilities & 311 & 333 \\
\hline Indirect $^{2}$ & 227 & 243 \\
\hline Contingency $^{3}$ & 170 & 183 \\
\hline Fees $^{4}$ & 59 & 63 \\
\hline Catalyst chemicals & 24 & 24 \\
\hline Infrastructure & 80 & 460 \\
\hline Total capital investment & 1,469 & 1,946 \\
\hline \multicolumn{3}{|c|}{ Annual production cost (exclusive of feed gas) } \\
\hline Variable cost & 22.3 & 22.3 \\
\hline \multicolumn{3}{|l|}{ Fixed cost } \\
\hline Overhead & 14.5 & 14.5 \\
\hline Maintenance & 35.9 & 38.4 \\
\hline Insurance & 19.6 & 21.0 \\
\hline Annual operating cost & 92.3 & 96.2 \\
\hline
\end{tabular}

'Cost from Chem Systems (1990) and updated to 1991 dollars.

${ }^{2}$ Indirect costs include construction, overhead, and engineering fees, computed as 38 percent of direct cost subtotal

${ }^{3}$ Contingency computed as 15 percent of base plant cost.

${ }^{4}$ Fees (and commissions) computed as 4.5 percent of baseplant and contingency.

and incorporated in one of the cases presented here (table 5). The Chem Systems costs appear to have been computed without reference to the process configuration used in the Shell demonstration plant.

Additional details from Shell regarding the demonstration plant indicate that the $\$ 660$ million estimate includes all utilities, ancillary facilities, and infrastructure. The plant represents one process train. Shell expects substantial scale economies when the process is scaled up. A commercial-size plant would require a scaling up of the process train and additional process trains (oral commun., 1991, to C.D. Masters from P.L. Zuideveld of Shell Inc.).

The chemical-process industries have historically experienced significant plant economies of scale. The decline in unit-capital costs per unit of installed capacity reflects economies of scale and results from economies of increased dimensions and plant indivisibilities. Indivisibilities are due to standard sizes of machinery and process trains. In the so-called scale-up relationship, $I_{a}=I_{b}$ $\left(\mathrm{C}_{\mathrm{a}} / \mathrm{C}_{\mathrm{b}}\right)^{\mathrm{n}}$ where $\mathrm{I}$ is investment cost, $\mathrm{C}$ is capacity, $\mathrm{a}$ and $\mathrm{b}$ signify different capacity plants, and the exponent $\mathrm{n}$ has been empirically demonstrated to be between 0.4 and 0.8
(Axtell and Robertson, 1986, p. 21). Economies of scale also reduce operating costs. The capital and operating costs of a gas-to-liquid-fuel conversion plant will also decline as the industry develops operating experience. In other words, cost will be reduced by industry learning and further process innovation. For the chemical-process industries, cost reductions from industry learning and process innovations have exceeded cost reductions attributable to static scale economies (Chapman, 1991; Lieberman, 1984).

The commercial-scale Chem System plant is 2.375 times the plant capacity of the demonstration plant, whereas the Chem Systems plant costs are 2.88 times the Shell demonstration plant costs. Assume the Shell demonstration plant is scaled up to use 0.4 Bcf per day input feed gas and produces 48,000 barrels of product per day. If the exponential plant scale factor is 0.6 , the scaled-up plant would require an investment cost of 2.30 times the demonstration plant cost. Alternatively, if the exponential scale factor were 0.4 , the investment cost would be 1.74 times the cost of the demonstration plant. The differences in unit costs between the Chem Systems estimates and the estimates obtained by applying the scale-up factors that are typical of chemical process industries represent a wide range in uncertainty in future costs of gas-to-liquid conversion processes.

For purposes of presentation, the plants with exponential factors 0.6 and 0.4 are denoted as scale-up A and scaleup B, respectively. Unit costs are expressed in terms of dollars per gallon because kerosene, aviation fuel, and other light distillate prices are quoted in those terms. The unit costs for a site I (Caribbean, Algeria, or Arabian Gulf coastal areas) plant based on an input gas cost of $\$ 0.50$ per MMBtu are shown in figure 4. At a 15 percent required return, plant tailgate (without delivery) unit costs for the Chem System plant, scale-up A, and scale-up B are $\$ 1.09$ per gallon, $\$ 0.69$ per gallon, and $\$ 0.61$ per gallon of product, respectively. The unit costs for the site II (Nigeria, Malaysia, or Indonesia coastal areas) plants, assuming a 15 percent required return, are 15 to 21 percent higher than the site I costs. If the input feed gas cost is increased by 1 cent per MMBtu, the output costs increase by about 0.2 cents per gallon (about 7.5 to 8.5 cents per barrel depending on the process assumptions used).

The principal reason for converting gas to liquid fuels is ease of transport. The SMDS plant output can be transported in vessels used to transport refined oil products. Transportation costs for refined products from Africa or the Caribbean to the United States represents only 1 to 2 percent of the product costs. Output of individual plants represents a negligible part of the market and has little effect on prices. Consequently, the plant operator could reasonably be expected to sell all the plant's output at the prevailing market prices. To place the values of figure 4 in perspective, U.S. refinery prices for kerosene and number 2 diesel oil in June 1992 were between $\$ 0.60$ and $\$ 0.64$ 
per gallon (Energy Information Administration, Monthly Energy Review, 1992).

\section{SUMMARY AND IMPLICATIONS FOR GAS-DEVELOPMENT STRATEGIES}

During the past decade, worldwide consumption of natural gas has increased by almost 40 percent. Although the transition of natural gas to an economic commodity is evident by the reported additions to reserves from new discoveries and by the continued growth of past discoveries, annual worldwide consumption remains less than 2 percent of global reserves. About 10 percent of the gas produced is traded internationally, and less than 3 percent of the gas produced is converted to LNG. The high cost of transporting gas from areas where there is no local market is an obstacle to the expansion of gas development worldwide (fig. 5).

An analysis comparing a representative LNG project to a gas-to-synthetic-liquid-fuels project was prepared. For the LNG project, the risks are associated with high frontend investment in the plant, a specialized LNG tanker fleet, and regasification systems. LNG markets are concentrated geographically and have few purchasers. Moreover, for many of these markets, LNG represents the high-cost, marginal gas source used only to meet peak demand. Contract provisions such as indefinite pricing, market-out price ceilings, and the take-or-pay contracts have been used to mitigate project risks.

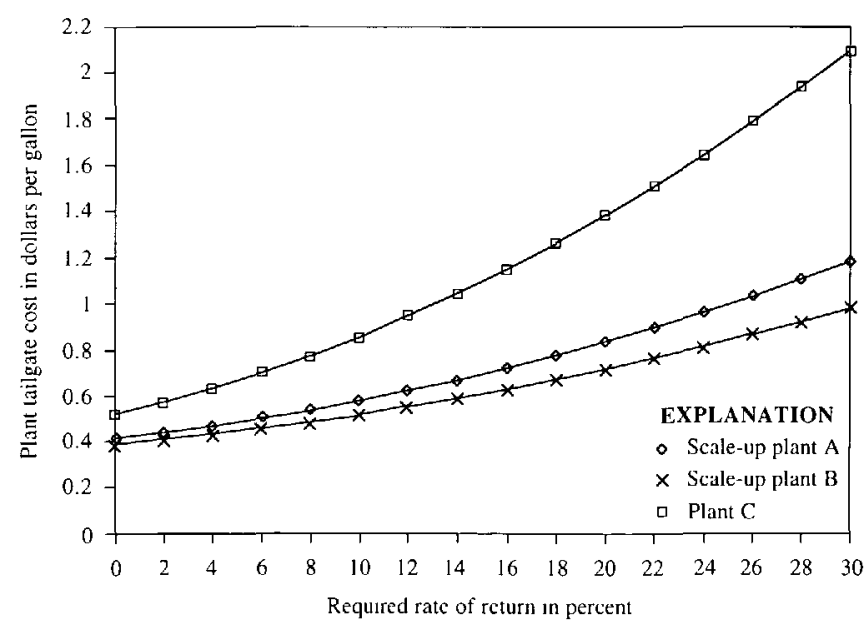

Figure 4. Plant tailgate cost per gallon of commercial scale SMDS (Shell middle distillate synthesis) for a plant located in North Africa or the Caribbean. Plant $\mathrm{C}$ is based on the Chem Systems scale up to a $28,500 \mathrm{bbl} / \mathrm{d}$ (barrels of liquefied natural gas per day) plant, plants $A$ and $B$ are based on the scale up of the demonstrations using exponential factors of 0.4 and 0.6 , to a $48,000 \mathrm{bbl} / \mathrm{d}$. Feed gas cost for all plants assumed to be $\$ 0.50$ per MMBtu (million British thermal units).
For the gas-to-liquid fuels project, there is uncertainty about unit costs of output from a commercial-size plant and its competitive position with products refined from crude oil. If the unit costs of output of such plants follow the pattern of the chemical-process industry, there will be a dramatic decline in unit costs with increases in process scale, plant scale and industry experience. The cost of products from a mature, established industry could be competitive with the refined products made from crude oil.

The viability of gas conversion projects will be dependent on the policies of the host country. Historically, nearly all of the LNG construction projects have had equity participation of the host government. The project's economic attractiveness depends on the availability of gas at very low unit costs and of few alternative uses for the gas. Assuming a 20-year plant life, the liquefaction complex will require gas resources of 8 to 12 Tcf (actual consumption will be $6.6 \mathrm{Tcf}$ ). Alternatively, 48,000 barrels per day gas-to-liquids conversion will require the commitment of 3 to $5 \mathrm{Tcf}$ (actual consumption will be $2.66 \mathrm{Tcf}$ ).

Large natural-gas accumulations are located in countries that will require foreign capital and imported technology to develop the resource. International firms typically view the development options for natural gas as having limited profit potential. Where there are local gas markets, prices are often regulated and the markets are restricted by the amount of gas-using capital that is in place and the internal pipeline network. Often gas export via pipelines is confined to gas demand in neighboring countries. Gas producers face a tradeoff between technological uncertainty for the gas-to-liquid fuels conversion option and the large downside-market risk for an LNG project. With either option, the competitiveness of their product will be dependent on the tax treatment by the host country.

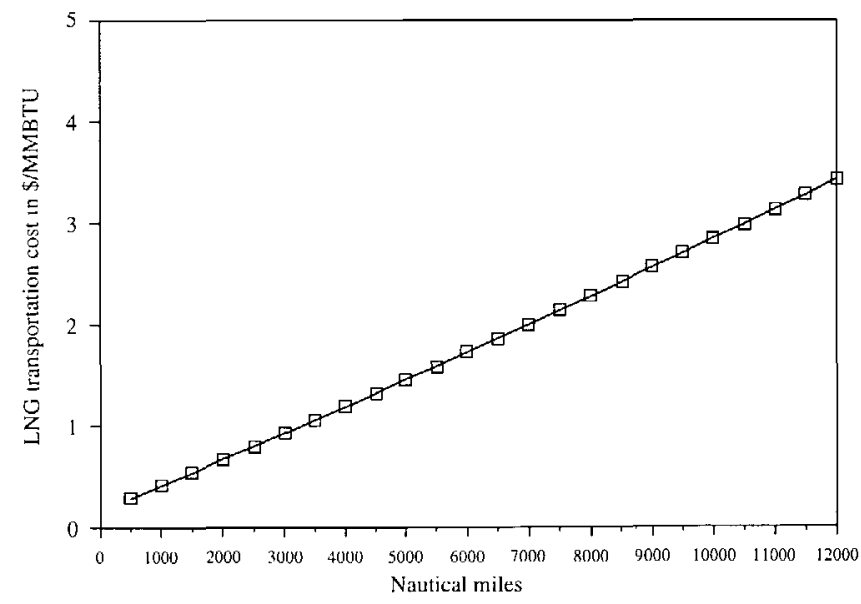

Figure 5. Estimated LNG (liquefied natural gas) transportation costs in dollars per MMBtu (million British thermal units) as a function of distance in nautical miles between plant and receiving terminal. 
The experience of the Australian North West Shelf Natural Gas LNG Project suggests that the results of government subsidies, that is, employment and generation of foreign exchange, can be mixed. The construction phase of the project induced inflation in Australia's capital goods industries, which ultimately reduced overall exports. The production phase resulted in an export surge, which led to deterioration in the competitive position of Australia's other export industries. Overall, the production phase led to an increase of about 1 percent in the county's gross domestic product (Higgs and Powell, 1992).

From the host country's perspective there is a tradeoff in delaying gas development as opposed to encouraging early gas development through tax and subsidy policies. The economic value of gas resources appear to be appreciating. Because gas combustion produces only 70 percent of the carbon dioxide emissions of oil combustion, environmental concerns are inducing accelerated development of gas-using technologies. These technologies will encourage growth in the domestic and international gas markets. Furthermore, the gas-to-liquids conversion technologies can only improve as the demonstration plants gain operating experience. Alternatively, early development of gas resources will require infrastructure investments which, in turn, should stimulate additional gas-resource development.

\section{REFERENCES CITED}

Attanasi, E.D., 1991, Alternative natural gas contracts and pricing structures and incentives for the LNG industry, Natural Resources Forum, v. 15, no. 3, p. 190-201.

Axtell, Oliver, and Robertson J.M., 1986, Economic Evaluation in the Chemical Process Industries: John Wiley, $256 \mathrm{p}$.

CEDIGAZ, 1991, Natural Gas in the World: 1991 Survey, Centre International d'information sur le gaz naturel et tous hydrocarbures gazeux: Paris, $89 \mathrm{p}$.
Chapman, Keith, 1991, The International Petrochemical Industry: Evolution and Location, Basil Blackwell, 322 p.

Chem Systems, 1989, Assessment of costs and benefits of fiexible and alternative fuel use in the U.S. transportation sector: Technical Report 3, Methanol Production and Transportation Costs, U.S. Department of Energy DOE/PE-0093, 46 p.

Chem Systems, 1990, Synthetic Fuel Capital and Production Costs: Final Draft Report, Support Data and Analysis Provided to Alternative Fuels Supply Project, U.S. Department of Energy, Office of Policy Analysis, $80 \mathrm{p}$.

Twentieth Century Petroleum Statistics, 1991, published by DeGolyer MacNaughton, Dallas, Texas, 126 p.

Energy Information Administration, 1992, Monthly Energy Review, November, $158 \mathrm{p}$.

Energy Information Administration, 1992, International Energy Annual-1990: U.S. Department of Energy DOE/EIA0219(90) $187 \mathrm{p}$.

Energy Information Administration, 1990, U.S. oil and gas reserves by year of field discovery: U.S. Department of Energy DOE/EIA-0534, 137 p.

Higgs, Peter J., and Powell, Alan A., 1992, Australia's North-West Shelf Gas Project: Resources Policy, September, p. 179-190.

Lieberman, M.B., 1984, The learning curve and pricing in the chemical processing industries: Rand Journal of Economics, v. 13, no. 2, summer, p. 213-228.

Masters, C.M., Root, D.H., and Attanasi, E.D., 1991, World resources of crude oil and natural gas: Proceedings, Thirteenth World Petroleum Congress, September 1991, Buenos Aries, Argentina, Session 25, p. 1-14.

Pastuhov, Alexis, 1991, The safety and economics of VLLNG carriers: The LNG Observer, v. 1, no. 2, summer, p. 9-11.

Shell Malaysia, 1989, Launch of Shell MDS Project: News Release (August 22), Shell Malaysia Kuala Lumpur, 3 p.

Vidas, E.H., 1988, Costs for LNG Imports into the United States: prepared by Energy and Environmental Analysis Inc. for the Gas Research Institute, Washington, $30 \mathrm{p}$.

Williams, J.R., and Bekker, G.A., 1990, Large-scale gas utilization: The Shell middle distillate synthesis process, Shell International Gas Ltd. London. 



\title{
THE FUTURE OF ENERGY GASES
}

U.S. GEOLOGICAL SURVEY PROFESSIONAL PAPER 1570

\section{Survey of Natural Helium Occurrences}

\author{
By Dennis W. Hinnah ${ }^{1}$ and John E. Hamak ${ }^{1}$
}

\section{CONTENTS}

Abstract 703

Introduction 703

Historical Background .............................................. 703

Helium Resources Evaluation ................................ 705

Methods of Analyses ............................................... 706

Occurrences of Helium ............................................... 706

Selected References .............................................. 707

Appendixes ...................................................... 708

\begin{abstract}
This chapter describes the U.S. Bureau of Mines (USBM) natural gas survey for helium occurrences. Gas samples have been collected since 1917 from oil and gas wells and natural gas pipelines in 40 States and 26 foreign countries for helium analysis. The gas analyses were made by several different methods that have been developed over the years.
\end{abstract}

\section{INTRODUCTION}

Since 1917, gas samples from oil and gas wells and natural gas pipelines throughout the United States and other countries worldwide have been collected by the USBM in a continuing search for helium occurrences. Analyses of 15,583 of the samples, which were collected from 40 States and 26 foreign countries (tables 1 and 2), are available from the USBM (see appendix A).

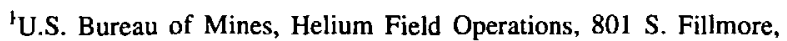
Ste. 500, Amarillo, TX 79101-3545.
The USBM is charged with the responsibility of ensuring a continuing supply of helium to meet essential Government needs, and this survey of the world's natural gas fields is made in connection with this responsibility.

Most of these analyses have been published in USBM publications. The first of this series of publications was Bulletin 486 (Anderson and Hinson, 1951) and was followed by two more bulletins (Boone, 1958; Munnerlyn and Miller, 1963). These three publications contained data on analyses of 5,218 gas samples collected from the beginning of the survey through 1960. Data on gas analyses since 1961 have been published on an annual basis, and 35 Information Circulars have presented the analyses of 10,365 gas samples collected through 1991. These analyses are also available on magnetic tape and 3.5-inch diskettes from the National Technical Information Service (see appendix B).

The helium survey program is conducted by soliciting natural gas samples throughout the United States and from other countries with free market economies. Without the assistance of the oil and gas industry, State and National agencies, and many individuals engaged in oil and gas exploration and production, the present scope of the helium survey would have been impossible.

\section{HISTORICAL BACKGROUND}

The survey to locate helium occurrences throughout the United States has been carried on since the inception of the Government's helium program in 1917. A major goal of this program has been to conserve helium that would otherwise be wasted. Through 1991, more than 19,200 gas samples have been collected and analyzed as a part of this survey. In addition to collecting samples from domestic gas fields, the search was expanded in 1965 to include foreign gas fields. Although several foreign samples had been analyzed prior to 1965 , no active solicitation 
Table 1. Analyses of natural gases from gas and oil wells and pipelines in the United States.

\begin{tabular}{|c|c|c|}
\hline State & $\begin{array}{l}\text { Gas and oil } \\
\text { wells }\end{array}$ & Pipelines \\
\hline Alabama------------------ & 91 & 17 \\
\hline Alaska -- & 77 & 2 \\
\hline Arizona -........ & 88 & 2 \\
\hline Arkansas -...- & 376 & 33 \\
\hline California -..-- & 212 & 107 \\
\hline Colorado - & 678 & 35 \\
\hline Florida-- & 5 & 0 \\
\hline Georgia - & 1 & 3 \\
\hline Idaho--- & 23 & 0 \\
\hline Illinois - & 22 & 0 \\
\hline 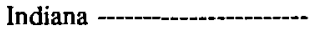 & 42 & 1 \\
\hline Iowa -1- & 4 & 0 \\
\hline Kansas- & 1,464 & 312 \\
\hline Kentucky -....- & 109 & 1 \\
\hline Louisiana--_-_. & 563 & 37 \\
\hline Maryland & 9 & 1 \\
\hline Michigan - & 179 & 6 \\
\hline Minnesota -.- & 2 & 0 \\
\hline Mississippi --_-_..-- & 135 & 30 \\
\hline Missouri-- & 1 & 0 \\
\hline 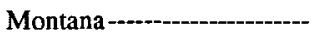 & 223 & 23 \\
\hline Nebraska -- - & 28 & 4 \\
\hline Nevada - & 7 & 0 \\
\hline New Jersey - & 1 & 0 \\
\hline New Mexico--- & 800 & 80 \\
\hline New York - & 121 & 2 \\
\hline North Carolina - & 2 & 0 \\
\hline North Dakota-- & 62 & 4 \\
\hline Ohio - & 202 & 18 \\
\hline Oklahoma - & 2,533 & 101 \\
\hline Oregon - & 10 & 0 \\
\hline Pennsylvania -.-....... & 215 & 13 \\
\hline South Dakota - & 4 & 2 \\
\hline Tennessee - & 13 & 5 \\
\hline Texas-- & 4,033 & 489 \\
\hline Utah- & 361 & 19 \\
\hline 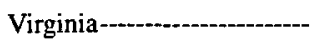 & 21 & 1 \\
\hline Washington --.- & 12 & 3 \\
\hline West Virginia -- & 466 & 20 \\
\hline Wyoming -........ & 722 & 44 \\
\hline 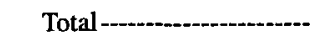 & 13,917 & 1,415 \\
\hline
\end{tabular}

of samples had been made. World War I caused a flurry of activity and interest in helium production. As a result of this interest, the Government's first helium extraction plant was constructed in Fort Worth, Tex., by the Department of the Navy to process gas from the Petrolia Field in Clay County, Tex. Many of the samples collected for the helium survey from 1917 through 1919 were analyzed for helium content only.

A second phase of the helium survey was begun in 1919 and continued until 1933. Samples collected during this period were analyzed by the Orsat combustion method and by a special helium apparatus. One result of this phase of the survey was the discovery of helium-rich gas at the
Table 2. Analyses of natural gases from gas and oil wells and pipelines in Foreign Countries.

\begin{tabular}{|c|c|c|}
\hline Country & Gas and oil wells & Pipelines \\
\hline Argentina -- & 12 & 2 \\
\hline Australia -- & 22 & 3 \\
\hline Austria - & 1 & 0 \\
\hline Bangladesh -............. & 0 & 1 \\
\hline Bolivia - & 17 & 0 \\
\hline Canada -- & 60 & 27 \\
\hline Colombia - & 1 & 3 \\
\hline Ethiopia - - & 1 & 0 \\
\hline Indonesia--_-_-_-_--_- & 0 & 4 \\
\hline Iran-4- & 1 & 0 \\
\hline Iraq-- & 3 & 0 \\
\hline Italy & 3 & 0 \\
\hline Mexico - & 21 & 10 \\
\hline Netherlands - & 8 & 2 \\
\hline Norway--..-- & 0 & 1 \\
\hline Pakistan -..-- & 5 & 1 \\
\hline Perd & 1 & 0 \\
\hline Poland & 5 & 0 \\
\hline Qatar-1- & 3 & 0 \\
\hline Saudi Arabia-....-- & 0 & 2 \\
\hline South Africa - - & 1 & 0 \\
\hline Spain - & 1 & 0 \\
\hline Taiwan-- & 12 & 0 \\
\hline Thailand-_- & 5 & 5 \\
\hline United Kingdom & 3 & 1 \\
\hline Germany' & 3 & 0 \\
\hline 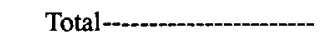 & 189 & 62 \\
\hline
\end{tabular}

Cliffside Field in Potter County, Tex. The Government acquired the gas rights in fee in the Cliffside Field and subsequently built a second Government-owned helium extraction plant near Amarillo, Tex., to process this gas. This plant was built by the USBM in 1928-29, after the supply of gas to the plant at Fort Worth was nearly depleted.

The helium survey was relatively inactive from July 1933 to April 1941, when World War II began to create an increased demand for helium. The survey was intensified during the war and resulted in the location of sites for four new helium plants in Kansas, New Mexico, and Texas. These plants were built in 1943-44. After World War II, the production capacity of the five plants was greater than postwar demand. Because of the excess capacity and a dwindling helium-rich gas supply, the Cunningham, Kan., plant was dismantled; and the Otis, Kan., and Shiprock, N. Mex., plants were placed on standby. The Amarillo, Tex., plant operated intermittently from 1945 through 1951, whereas the Exell, Tex., plant operated continuously.

In 1951, an increasing demand for helium made it necessary to put the Otis, Kans., plant back into production. The Shiprock, N. Mex., plant resumed operations in 1953. Both of these plants were operated continuously until 1968, except for a shutdown of almost a year at Shiprock owing to gas supply problems. In 1968, when the USBM sales of 
helium decreased markedly, both plants were shut down permanently. The Otis plant was sold, and the Shiprock plant was deeded to the Bureau of Indian Affairs, which turned it over to the Navajo Nation.

In the 1940's and 1950's, a major helium-rich gas source was being developed in the Oklahoma panhandle: The Keyes Field was discovered in 1943, and gas samples from wells in the field contained an average of about 2 percent helium. In 1958, the USBM obtained the exclusive helium-processing rights to most of the gas for the life of the field. An extraction plant was built near Keyes, Okla. to process Keyes Field gas. The plant began operations in 1959, but ceased gas processing in 1981 because of declining gas supplies and excessive cost of operation. The Amarillo plant ceased gas processing operations in April 1970. In September 1971, the Exell plant stopped processing West Panhandle Field, Tex., gas, its source of supply since it began operation. Exell now supplies all demand for USBM helium by purifying helium that was purchased and stored by the Government in the Cliffside Field.

In the early 1960's, demand for helium for Government programs continued the growth that started in 1951, while the helium-rich gas resources declined. Because of this decline, Congress passed legislation in 1960 authorizing a helium-conservation program and promoting the growth of a private helium industry. The objective of this program was to store for future use about $52 \mathrm{Bcf}$ (billion cubic feet) of helium that would have otherwise been lost as the natural gas was used for fuel. To implement this program, four long-term contracts were negotiated with private firms for the Government's purchase of helium; these contracts obligated the Government to purchase up to $\$ 47.5$ million per year of helium. Five private extraction plants were built adjacent to large natural gas transmission lines in Texas and Kansas. Most of the gas processed was produced from the West Panhandle Field of Texas and the Hugoton Field in Texas, Oklahoma, and Kansas. These two fields contained the largest known helium reserves in the world. Previous helium resources evaluation work by the USBM had established that this area was the most promising source for the recovery of helium. Minor volumes of gas were produced from smaller fields in the same area. The extracted helium was stored in the Government-owned Cliffside Field. This is the helium now being purified by the USBM to supply current demand. Through November 1973, when acceptance of helium under these contracts ceased, $34.2 \mathrm{Bcf}$ of helium had been stored. As of January 1, 1992, helium stored in the Cliffside Field totaled $33.8 \mathrm{Bcf}$. Of this volume, $1.7 \mathrm{Bcf}$ is stored by the USBM for private companies. In addition to the stored helium, the remaining native natural gas in Cliffside Field contains about $3.9 \mathrm{Bcf}$ of helium. Helium is measured at a pressure and temperature base of $14.7 \mathrm{psia}$ and $70^{\circ} \mathrm{F}$.

\section{HELIUM RESOURCES EVALUATION}

Even though helium resources are more than adequate to supply Government needs at present and for some time in the future, the helium resources evaluation program is continued so that resources can be located that may be required to supply future demands. Experience shows that it takes about 15 years from the time of discovery to the time of exploitation of a helium resource. Of particular interest are reserves of helium found in natural gases with low heating values. This natural gas is not as likely as higher heating-value gases to be produced for fuel; therefore, the helium is effectively "stored" and will be available for extraction when the need arises. These resources are classified as "nondepleting helium reserves" and serve as a backup to the helium stored in the Cliffside Field.

Many of these nondepleting helium reserves are located on Federal lands, and under the standard U.S. Government oil and gas lease, helium ownership is reserved to the Federal Government. These reserves are, therefore, under Federal control, and although a lessee may produce the gas with which the helium is associated, the Government has an option to extract, or have extracted, the helium contained in the gas.

When the helium survey was expanded to include foreign gas fields in 1965, it was believed that with the growing importance and use of helium, it was necessary to acquire reasonably detailed and documented knowledge of the helium resources outside the United States. Approximately 250 samples from 26 foreign countries have been received to date.

The helium resource evaluation program has been carried on in varying degrees of intensity for over 70 years. Gas samples from most natural gas fields in the United States and from a few fields in foreign countries have been analyzed. Although many of the U.S. gas fields in the area of the Gulf of Mexico have not been sampled for the survey, all major transmission lines carrying gas from that area have been sampled. The helium resource evaluation program has accomplished its purpose in that it has identified the helium reserves and resources from which demand continues to be fully supplied. The evaluation is an ongoing USBM program, which has the objective of locating adequate supplies to meet future demands.

The results of some of the analyses made in connection with this program are not included in publications. Some reasons for exclusion of analyses are air contamination above permissible levels, incomplete analysis, and maintaining the confidentiality of data that were not released by the company supplying the gas sample. This confidentiality is promised to each company when it is contacted for a gas sample; however, most data are subsequently released for publication or public presentation by the company. 
Table 3. Examples of gas-well-sample analyses from the United States.

\begin{tabular}{|c|c|c|c|c|}
\hline \multicolumn{5}{|l|}{$[-$, not available $]$} \\
\hline State-- & Colorado & Mississippi & Texas & \\
\hline 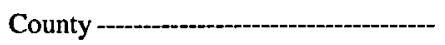 & Kit Carson & Holmes & Hansford & \\
\hline Field-_- & Smoky Hill & Tchula Lake & Morse SW & \\
\hline Well name -- & Lowe No. B-1 & Shad. Dav., Jr., No. 1 & Womble No. 3 & \\
\hline Location - & Sec. 6, T11S, R45W & Sec. $8, T 15 N, R 1 W$ & Sec. 27, Blk 3 & \\
\hline Owner-r-rer & TXO Production & Triad Oil and Gas Co. & J.M. Huber & \\
\hline Completed -..--- & $89 /--1--$ & $87 / 03 / 07$ & $90 / 05 / 10$ & \\
\hline 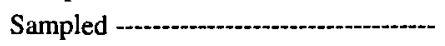 & $89 / 02 / 24$ & $87 / 07 / 15$ & 90/10/-- & \\
\hline 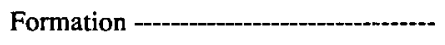 & Morrow Formation & Smackover Formation & Wichita-Albany & \\
\hline Age - & Pennsylvanian & Jurassic & Permian & \\
\hline Geologic province code & 540 & 210 & 360 & \\
\hline Depth (ft)--..- & Not given & 9,832 & 30,178 & \\
\hline Wellhead pressure (psig) & 770 & 2,835 & 342 & \\
\hline Open flow (Mcfd) & Not given & 4,639 & 2,200 & \\
\hline \multicolumn{5}{|l|}{ Component (mole percent): } \\
\hline Methane -- & 16.3 & 41.6 & 71.4 & \\
\hline Ethane - & 1.5 & 5.5 & 7.5 & \\
\hline Propane---_- & 1.0 & 3.1 & 4.1 & \\
\hline N-Butane - & 0.4 & 2.0 & 1.2 & \\
\hline Isobutane - & 0.2 & 1.7 & 0.2 & \\
\hline N-Pentane - & 0.1 & 0.7 & 0.1 & - \\
\hline Isopentane- & 0.2 & 0.6 & 0.1 & \\
\hline Cyclopentane & 0.0 & Trace & 0.0 & \\
\hline Hexanest - & 0.1 & 0.3 & 0.0 & \\
\hline Nitrogen - & 74.1 & 2.1 & 14.1 & \\
\hline Oxygen - & 1.0 & 0.0 & 0.0 & \\
\hline Argon - & 0.3 & Trace & 0.2 & \\
\hline Hydrogen- & 0.2 & Trace & Trace & \\
\hline Hydrogen sulfide-- & 0.0 & 0.0 & 0.0 & \\
\hline Carbon dioxide--a........... & 0.5 & 42.3 & 0.0 & \\
\hline Helium-rom & 4.14 & 0.01 & 1.02 & \\
\hline Heating value (Btu) & 257 & 796 & 1,020 & \\
\hline Specific gravity (relative to air)-....-.- & 0.890 & 1.122 & 0.713 & \\
\hline
\end{tabular}

\section{METHODS OF ANALYSES}

Gas mixtures received for helium evaluation are contained either in glass bottles at atmospheric pressure or in pressurized steel cylinders. They are analyzed with the 0 to 10 percent helium/hydrogen gas chromatograph and a mass spectrometer. Mass spectrometer results are normalized with respect to the helium and hydrogen values determined on the chromatograph. The specific gravity and heating values of the gas are also calculated (see table 3).

Hydrogen sulfide is significantly soluble in water, and most samples are collected by water displacement. This reactive gas can also be adsorbed in the walls of the container, tubing, and valves; this results in some unreliability in the hydrogen sulfide analyses. Other percent-level components are relatively unaffected by these problems.

The percent-level components in each analysis are reported to the nearest 0.1 percent, except for helium, which is reported to the nearest 0.01 percent. The word "trace" is used to denote detectable levels of helium less than 0.005 percent and similar levels of other components less than 0.05 percent (see table 3 ).

\section{OCCURRENCES OF HELIUM}

The data base includes geologic province codes so that each sample source can be located within a specific geologic province as defined by the Committee on Statistics of Drilling of the American Association of Petroleum Geologists. This information was added in Information Circular 8749 (Moore, 1977) and is included with all analyses in the subsequent publications, tapes, and diskettes. These provinces, which are shown in the USBM publications with an accompanying list, are delineated by political boundaries for convenience and for the accommodation of 
data processing equipment. Not all of the provinces shown are gas-producing areas, so many of the codes are not used in the publications. In offshore areas, only one code is used for each State because State or Federal ownership is not always known. Only one code, 972 , is used for all wells in Alaska, both onshore and offshore, because of the lack of information on the location of wells in this State.

Nearly all natural gas contains measurable amounts of helium. The average helium content of all samples received by the USBM is about 0.27 percent. This average is weighted heavily by the samples from helium-rich Hugoton and Panhandle Fields of Kansas, Oklahoma, and Texas. In general, reservoirs of Paleozoic age are more likely than other reservoirs to contain helium-rich natural gas. If the natural gas is helium rich, there will almost certainly be a nitrogen concentration of greater than 5 percent, but the presence of nitrogen doesn't necessarily indicate a helium-rich natural gas. Other less distinct interrelationships between helium and other elements can be found in Report of Investigation 8444 (Tongish, 1980).

\section{SELECTED REFERENCES}

Anderson, C.C., and Hinson, H.H., 1951, Helium-bearing natural gases of the United States; analyses and analytical methods: Bureau of Mines Bulletin 486, $141 \mathrm{p}$.

Boone, W.J., Jr., 1958, Helium-bearing natural gases of the United States; analyses and analytical methods; supplement to Bulletin 486: Bureau of Mines Bulletin 576, 117 p.

Cardwell, L.E., and Benton, L.F., 1970, Analyses of natural gases, 1968: Bureau of Mines Information Circular 8443, $169 \mathrm{p}$. 1970, Analyses of natural gases, 1969: Bureau of Mines Information Circular 8475, $134 \mathrm{p}$.

1971, Analyses of natural gases, 1970: Bureau of Mines Information Circular 8518, $130 \mathrm{p}$.

-1972, Analyses of natural gases, 1971: Bureau of Mines Information Circular 8554, $163 \mathrm{p}$.

__ 1973, Analyses of natural gases, 1972: Bureau of Mines Information Circular 8607, 104 p.

Hamak, J.E., and Gage, B.D., 1992, Analyses of natural gases, 1991: Bureau of Mines Information Circular 9318, 97 p.

Hamak, J.E., and Sigler, S.M., 1989, Analyses of natural gases, 1988: Bureau of Mines Information Circular 9225, 66 p.

- 1990, Analyses of natural gases, 1989: Bureau of Mines Information Circular 9256, $60 \mathrm{p}$.

1991, Analyses of natural gases, 1990: Bureau of Mines Information Circular 9290, 56 p.

- 1991, Analyses of natural gases, 1986-90: Bureau of Mines Information Circular 9301, 315 p.

Hertweck, F.R., Jr., and Fox, D.D., 1984, Analyses of natural gases, 1983: Bureau of Mines Information Circular 8993, 127 p.

Miller, R.D., and Hertweck, F.R., Jr., 1982, Analyses of natural gases, 1981: Bureau of Mines Information Circular 8890, $84 \mathrm{p}$.
1983, Analyses of natural gases, 1982: Bureau of Mines Information Circular 8942, $100 \mathrm{p}$.

Miller, R.D., and Norrell, G.P., 1964, Analyses of natural gases of the United States, 1961: Bureau of Mines Information Circular 8221, 148 p.

1964, Analyses of natural gases of the United States, 1962: Bureau of Mines Information Circular 8239, $120 \mathrm{p}$.

1965, Analyses of natural gases of the United States, 1963: Bureau of Mines Information Circular 8241, $102 \mathrm{p}$.

Moore, B.J., 1974, Analyses of natural gases, 1973: Bureau of Mines Information Circular 8658, 96 p.

1975, Analyses of natural gases, 1974: Bureau of Mines Information Circular 8684, 122 p.

1976, Analyses of natural gases, 1917-1974: Bureau of Mines Computer Printout, National Technical Information Service Publication 251 202, 889 p.

1976, Analyses of natural gases, 1975: Bureau of Mines Information Circular 8717, 82 p.

-1977 , Analyses of natural gases, 1976: Bureau of Mines Information Circular 8749, 94 p.

1978, Analyses of natural gases, 1977: Bureau of Mines Information Circular 8780, 95 p.

1979, Analyses of natural gases, 1978: Bureau of Mines Information Circular 8810, $113 \mathrm{p}$.

1980, Analyses of natural gases, 1979: Bureau of Mines Information Circular 8833, 100 p.

1981, Analyses of natural gases, 1980: Bureau of Mines Information Circular 8856, $236 \mathrm{p}$.

1982, Analyses of natural gases, 1917-1980: Bureau of Mines Information Circular 8870, 1,055 p.

Moore, B.J., and Hamak, J.E., 1985, Analyses of natural gases, 1984: Bureau of Mines Information Circular 9046, 102 p.

Moore, B.J., Miller, R.D., and Shrewsbury, R.D., 1966, Analyses of natural gases of the United States, 1964: Bureau of Mines Information Circular 8302, 144 p.

Moore, B.J., and Shrewsbury, R.D., 1966, Analyses of natural gases of the United States, 1965: Bureau of Mines Information Circular 8316, $181 \mathrm{p}$.

1967, Analyses of natural gases of the United States, 1966: Bureau of Mines Information Circular 8356, $130 \mathrm{p}$.

1968, Analyses of natural gases, 1967: Bureau of Mines Information Circular 8395, $187 \mathrm{p}$.

Moore, B.J., and Sigler, S.M., 1986, Analyses of natural gases, 1985: Bureau of Mines Information Circular 9096, 182 p.

1987, Analyses of natural gases, 1917-1985: Bureau of Mines Information Circular 9129, 1,197 p.

1988, Analyses of natural gases, 1986: Bureau of Mines Information Circular 9167, $101 \mathrm{p}$.

1988, Analyses of natural gases, 1987: Bureau of Mines Information Circular 9188, $74 \mathrm{p}$.

Munnerlyn, R.D., and Miller, R.D., 1963, Helium-bearing natural gases of the United States; analyses; second supplement to Bulletin 486: Bureau of Mines Bulletin 617, 93 p.

Tongish, C.A., 1980, Helium-Its relationship to geologic systems and its occurrence with the natural gases, nitrogen, carbon dioxide, and argon: Bureau of Mines RI 8444, 176 p. 


\title{
APPENDIX A. PUBLICATIONS AVAILABLE FROM THE BUREAU OF MINES RELATED TO NATURAL GAS ANALYSES AND HELIUM RESOURCES
}

\author{
Unless otherwise noted, all publications are information circulars (IC). \\ Natural Gas Analyses \\ IC 9129 , Analyses of natural gases, 1917-85 \\ IC 9167 , Analyses of natural gases, 1986 \\ IC 9188 , Analyses of natural gases, 1987 \\ IC 9225, Analyses of natural gases, 1988 \\ IC 9256, Analyses of natural gases, 1989 \\ IC 9290, Analyses of natural gases, 1990 \\ IC 9301, Analyses of natural gases, 1986-90 \\ IC 9318, Analyses of natural gases, 1991 \\ Helium Resources \\ IC 9130, Helium resources of the United States, 1985 \\ IC 9189, Helium resources of the United States, 1987 \\ IC 9267, Helium resources of the United States, 1989 \\ IC 9342, Helium resources of the United States, 1991 \\ These publications are available from: \\ U.S. Bureau of Mines \\ Publication Distribution Section \\ 626 Cochran's Mill Road \\ P.O. Box 18070 \\ Pittsburgh, PA 15236 \\ Phone: (412) 892-4338 \\ OR \\ Helium Field Operations \\ 801 South Fillmore, Suite 500 \\ Amarillo, TX 79101-3545 \\ Phone: (806) 376-2652
}

\section{APPENDIX B. PUBLICATIONS AVAILABLE FROM THE NATIONAL TECHNICAL INFORMATION SERVICE RELATED TO NATURAL GAS ANALYSES AND HELIUM RESOURCES}

In addition to the information circulars, all released analyses of natural gases can be obtained on magnetic tape and diskettes. The following are available:

ORDER NO.

PB92-501337

PB92-503358

PB92-503333

PB92-503358

PB92-503325

PB92-503408

PB92-503382

PB92-503390

PB92-503374

PB92-503366

PB92-503341
TITLE

Magnetic tape of Analyses of natural gases, 1917-1991

Diskette, Analyses of natural gases, 1917-1991

Diskette, Analyses of natural gases, foreign

countries, 1951-1991

Diskette, Analyses of natural gases, Alaska,

California, Idaho, Nevada, Oregon, and Washington, 1951-1991

Diskette, Analyses of natural gases, 1917-1950

Diskette, Analyses of natural gases, Mid-Continent

Region, 1951-1991

Diskette, Analyses of natural gases, Texas, other than District 10, 1951-1991

Diskette, Analyses of natural gases, Oklahoma and

Northwest Arkansas, 1951-1991

Diskette, Analyses of natural gases, Texas,

District 10, 1951-1991

Diskette, Analyses of natural gases, miscellaneous

States, 1951-1991

Diskette, Analyses of natural gases, Rocky Mountain

Region, 1951-1991
PRICE

$\$ 240$

$\$ 360$

$\$ 55$

$\$ 55$

$\$ 55$

$\$ 55$

$\$ 55$

$\$ 55$

$\$ 55$

$\$ 55$

$\$ 55$

The above are available from the National Technical Information Service, Springfield, VA 22161, telephone No. 1800-553-NTIS (in Virginia and outside the United States call 703-437-4650). The tape and diskette containing all analyses are updated annually. The other diskettes are updated every 5 years. In addition, a diskette of the previous year's analyses will be made available each year. Each diskette contains an ASCII file of the gas analyses, a DBASE IV template, and documentation. For more information or to get updated tape numbers, call 806-376-2650. 


\title{
Methods of Gas Analysis
}

\author{
By David E. Emerson ${ }^{1}$
}

\section{CONTENTS}

\begin{tabular}{|c|c|}
\hline & \\
\hline & \\
\hline & \\
\hline & \\
\hline ases & \\
\hline & \\
\hline g Dissolved & \\
\hline libratic & \\
\hline & \\
\hline Certified & \\
\hline lass Spectro & .710 \\
\hline & 80 \\
\hline Trac & 711 \\
\hline Ana & 711 \\
\hline Isotc & \\
\hline aromatc & .711 \\
\hline Anal & \\
\hline 0 to & \\
\hline Perc & \\
\hline & \\
\hline $\mathrm{Mc}$ & \\
\hline .......... & \\
\hline Range ...... & \\
\hline ............... & 71 \\
\hline Analysis of $\mathrm{He}$ & .71 \\
\hline Fourier Transform Infrared Analysis ...................... & \\
\hline nmary & \\
\hline & \\
\hline
\end{tabular}

\footnotetext{
'U.S. Department of the Interior, U.S. Bureau of Mines, Helium
} Field Operations, Amarillo, TX 79101.

\begin{abstract}
Methods for sampling, calibrating, and analyzing for helium, impurities in helium, and natural gases are described. These methods were developed by the U.S. Bureau of Mines to assist in the processing of natural gas for helium recovery.

\section{INTRODUCTION}

By developing methods such as those described below, the U.S. Bureau of Mines provides technical assistance in processing natural gas for helium recovery. These methods were developed in compliance with approved safety regulations. Anyone using these methods shall comply with current regulations and recommended guidelines of the National Research Council's "Prudent Practices for Disposal of Chemicals from Laboratories" (National Research Council, 1981a) and "Prudent Practices for Handling Hazardous Chemicals in Laboratories" (National Research Council, 1981b).
\end{abstract}

\section{SAMPLING PROCEDURES}

\section{ATMOSPHERIC AIR}

Special care must be taken to prevent contamination of samples of atmospheric air. A sampling apparatus consisting of a portable, non-lubricated air compressor and a 1-liter stainless steel cylinder equipped with stainless steel regulating valves is used for sampling gases at low pressure. Prior to use, each cylinder is degassed of adsorbed (and (or) absorbed) gases with a special purging technique using highpurity nitrogen, and checked for possible contamination 
(Holland and Emerson, 1987). All conditions that could affect the samples at the time of sampling are recorded. Some gases, such as natural gas, require a gas-tight compressor such as a metal bellows pump.

\section{PRESSURIZED GASES}

In the sampling procedure for pressurized gases, a cylinder is purged with the gas to be sampled three times to the pressure of the source, then filled to this pressure. For safety, the sampling container, valves, and connecting tubing should be rated to accept a pressure higher than that of the gas to be sampled.

\section{SOIL GASES}

For soil-gas samples, hollow stainless steel probes (6.4- $\mathrm{mm}$ outer diameter (OD), 2.4- $\mathrm{mm}$ inner diameter (ID)) and $20-\mathrm{cm}^{3}$ hypodermic syringes are used. The tips of the probes are sealed, sharpened, and then drilled with side holes $1.6 \mathrm{~mm}$ in diameter. The top of the probe is equipped with a $6.35-\mathrm{mm}$ tube connector containing a rubber septum. The sample is collected by hammering the probe into the soil to a depth of $60 \mathrm{~cm}$. The probe is purged of air by inserting the syringe needle into the rubber septum and then extracting and discarding a $5-\mathrm{cm}^{3}$ volume of gas. A $20-\mathrm{cm}^{3}$ sample is then taken for analysis and marked with the appropriate identifying information. The contents are compressed by pushing in the syringe plunger. This compression reduces the possibility of air contamination due to barometric pressure and temperature changes from time of sampling to time of analysis (Holland and Emerson, 1979).

\section{WATER CONTAINING DISSOLVED GASES}

Water samples are collected in $500-\mathrm{cm}^{3}$ metal cylinders with a funnel extending to the bottom of the sample cylinder. The cylinder is filled with the sample water and is allowed to approach the temperature of the sample water. The container is then emptied, resubmerged in the sample water and filled to overflowing. Air-water contact and turbulence must be minimized. The sample is stored at room temperature and analyzed within 48 hours of collection (Holland, 1981, 1989; Holland and Emerson, 1979).

\section{CALIBRATION STANDARDS}

\section{WEIGHED STANDARDS}

Weighed or gravimetric standards are used to provide the most accurate analyses and to certify standards pre- pared by partial pressure. To prepare a weighed standard, the evacuated cylinder is weighed. Then the cylinder is reweighed after each gas addition, and the mass of each gas is calculated by difference. A particular sequence of dilutions is selected to minimize the error of the final mixture. Typical relative errors of \pm 0.02 percent are achieved (Bibawy, 1989; Bibawy and Emerson, 1990; Loya, 1985; Loya, Seitz and Emerson, 1982; Miller, Carroll and Emerson, 1965).

\section{CERTIFIED STANDARDS}

Certified standards are prepared by a partial pressure method to meet the blending specifications within \pm 10 percent. Pure gases and pre-mixed gas from the percent to parts-per-million range for two or more components are used. Composition of these standards is determined by comparison to weighed standards. Certified standards are then used for the everyday operation of the laboratory.

Pure gases are used for calibration of instruments whose analytical responses are linear from 0 to 100 percent. If increased accuracy is required, weighed or certified standard mixtures of the components are used in the area of interest.

Helium content above the 10-percent level is certified with a special helium analyzer (Emerson, 1972; Emerson and Kaplan, 1970). Otherwise, mixtures are certified by comparison with gravimetrically prepared standard mixtures using chromatographs (Seitz, 1985) and (or) mass spectrometers (Emerson, Hoffman, and Weems, 1970; Holland, 1991). Moisture content is determined using an electrolytic analyzer (Rhodes, 1981) with the flowmeter corrected for viscosity of the gas mixture (Davidson, 1993).

\section{MASS SPECTROMETRY METHODS}

The mass spectrometer is an apparatus that produces a beam of ions from a gaseous sample, sorts the resulting mixture of ions by the ratio of their mass to their charge, and produces electrical signals that are measures of the relative abundance of each component in the sample.

\section{PERCENT-RANGE ANALYSIS}

The mass spectrometer provides qualitative and quantitative analyses of gas samples. For natural gases the analysis includes hydrogen, helium, nitrogen, oxygen, hydrogen sulfide, argon, carbon dioxide, individual hydrocarbons through pentane, and a composite value for hexanes and heavier hydrocarbons. The specific gravity and heating value of the gas mixture are also calculated. Results are typically reported with a \pm 3 -percent relative accuracy 
(Boone, 1958). Examples of published analytical data provided by this method are available (Moore and Sigler, 1987).

Hydrogen sulfide $\left(\mathrm{H}_{2} \mathrm{~S}\right)$ is significantly soluble in water, and most gas samples containing $\mathrm{H}_{2} \mathrm{~S}$ are collected by water displacement. This procedure results in some unreliability of hydrogen sulfide analyses. This reactive gas can also be absorbed on the walls of the container, tubing, and valves. The water should be saturated with the gas to be sampled before starting the procedure (Rhodes, 1981). Other percent-level components are relatively unaffected by these problems.

\section{TRACE IMPURITIES IN HELIUM ANALYSIS}

Impurities in helium samples are concentrated using liquid helium $\left(-269^{\circ} \mathrm{C}\right)$, then the impurities are gasified and the partial pressures of the components are determined with a mass spectrometer. Samples are reported in the range of 0.010 to $600 \mathrm{ppm}$ total impurities with an accuracy of \pm 15 percent and $\pm 0.05 \mathrm{ppm}$ in the 1.0 -ppm range. (Emerson, Weems, and Hoffman, 1972; Emerson, Hoffman, and Weems, 1970; Suttle, Emerson, and Burfield, 1966; Weems and Emerson, 1966).

\section{ANALYSIS OF HELIUM FROM 0 TO 10 PERCENT}

A mass-spectrometer method for determining helium content in the range from 5 ppm to 10 percent with an accuracy of \pm 1 percent (Holland, 1991) is similar to methods for determining helium content in the 0.5 to 20,000 parts-per-billion (ppb) range (Holland, 1984; Seitz and Holland, 1986).

The sample is passed through $0.5 \mathrm{~g}$ of $40-60$ mesh activated coconut charcoal at liquid nitrogen temperature. The trap retains all the components except helium. The helium pressure is then measured using a mass spectrometer. Preconcentration results in increased sensitivity and a minimum detectable limit of $5 \mathrm{ppm}$ for helium.

\section{ISOTOPIC ANALYSIS}

Analytical methods were developed to analyze for the two stable isotopes of helium. Generally, helium-4 is the predominant isotopic form. In samples composed mainly of helium-3, the helium-4 content can be determined at the ppm level to an accuracy of \pm 5 percent. Gravimetric standards of ppm-level helium- 4 in hydrogen are used to provide accurate sensitivities. The method is accurate in the 2 to $100 \mathrm{ppm}$ range. A minimum detectable limit of 2 ppm helium-4 is attained (Burton and Cornelius, 1989).

The abundances of isotopes of helium, neon, argon, and nitrogen in several natural gases have been determined
(Davidson and Emerson, 1990a; Emerson, 1970; Emerson, Stroud, and Meyer, 1966; Emerson, Suttle, and Hoffman, 1968; Stroud, Meyer, and Emerson, 1967).

A mass spectrometer is used for analysis of helium-3 and helium-4 in air (Holland, 1984; Holland and Emerson, 1990) and helium-3 in helium-4 samples (Davidson and Emerson, 1990b; Emerson, Suttle, and Hoffman, 1968). Helium-3 in air or natural gas can be measured in the low parts-per-trillion (ppt) range with an accuracy of \pm 1 ppt by using a charcoal trap at $-269^{\circ} \mathrm{C}$ that removes all components except hydrogen and helium, and a titanium trap that removes hydrogen (Davidson and Emerson, 1990a, b). Helium-4 in air can be determined in the low parts-per-billion (ppb) range with an accuracy of $\pm 0.2 \mathrm{ppb}$ (Holland, 1984; Seitz and Holland, '1986).

\section{CHROMATOGRAPHY METHODS}

\section{ANALYSIS OF HELIUM AND HYDROGEN FROM 0 TO 10 PERCENT}

Gas samples are received in glass bottles at atmospheric pressure or in pressurized steel cylinders. The samples are analyzed with a gas chromatograph and a mass spectrometer. Samples received in glass bottles are transferred with a water-displacement system. A sample is transferred to a $50-\mathrm{cm}^{3}$ metal cylinder at atmospheric pressure for the mass spectrometer while the chromatographic sample loop is being purged for the helium and hydrogen analyses.

A 2-cm sample is injected into the argon carrier gas that is flowing at $20 \mathrm{~cm}^{3} / \mathrm{min}$. Two $0.32-\mathrm{cm}$-ID stainless steel columns maintained at $40^{\circ} \mathrm{C}$ are used for the separation. The first column, consisting of $60 \mathrm{~cm}$ of Porapak R (80-100 mesh) and 180-cm activated charcoal (30-60 mesh), removes carbon dioxide, heavy hydrocarbons, water, oxygen, and nitrogen. The second column, consisting of $4.5 \mathrm{~m}$ of activated charcoal (30-60 mesh) and $60 \mathrm{~cm}$ of molesieve, is connected to a thermistor detector operated at 10 milliamperes ( $\mathrm{mA}$ ). The limit of detection of this arrangement is about $20 \mathrm{ppm}$ for both helium and hydrogen. The accuracy for a 1 -percent helium sample is 0.004 relative, and for a 5 -percent sample is about 0.0015 relative.

\section{PERCENT-RANGE ANALYSIS}

Chromatography is used for process control and laboratory analysis. Variations of chromatographic procedures for the analysis of argon, nitrogen, and hydrogen are used depending on the concentration of the components to be determined. Various chromatographic procedures are used to analyze for one or more of the following components: helium, hydrogen, neon, oxygen, argon, nitrogen, methane, carbon monoxide, carbon dioxide, and hydrocarbons. These 
procedures use various detector systems, such as helium ionization detectors (HID), thermal conductivity detectors (TC), flame ionization detectors (FID), ultrasonic detectors, and others. Various columns are used, such as molesieve, charcoal, carbosphere, carbosieve, chabazite, Porapak, Haysep, Porasil, and combinations of these columns.

\section{HYDROCARBON ANALYSIS}

The light alkanes and alkenes $\left(\mathrm{C}_{1}\right.$ through $\left.\mathrm{C}_{6}\right)$ are determined using capillary gas chromatography/flame ionization detection (FID). The analyses are performed using a dual flame ionization detector gas chromatograph equipped with a $30-\mathrm{m}$ by $0.53-\mathrm{mm}-\mathrm{ID}$, GS-Alumina Megabore capillary column. For sample introduction, the capillary column is connected to the instrument's gas sampling valve using a $0.16-\mathrm{cm}$ to $0.53-\mathrm{mm}$, zero-volume reducing union. The sample loop for the valve is fabricated from a $7.6-\mathrm{cm}$ length of $0.16-\mathrm{cm}-\mathrm{OD},(0.107-\mathrm{cm}-\mathrm{ID})$ stainless steel tubing. The volume of the loop is calculated to be $0.07 \mathrm{~cm}^{3}$. The sample container is connected to the gas sampling valve using a $1-\mathrm{m}$ length of $0.16-\mathrm{cm}-\mathrm{OD}$ stainless steel tubing and tube fittings. The output end of the capillary is extended through a $0.16-\mathrm{cm}$ tee installed on the detector inlet (where make-up gas is added) and terminated inside the burner jet approximately $1 \mathrm{~cm}$ from the burner tip. Connections of the capillary to the zero-volume union located at the gas sampling valve and to the make-up gas tee at the detector inlet are made using graphite ferrules.

The procedure for separating the various hydrocarbon components uses temperature programming of the column oven. The oven temperature is held at $40^{\circ} \mathrm{C}$ for a period of $2 \mathrm{~min}$, and then raised steadily at a rate of $5^{\circ} \mathrm{C} / \mathrm{min}$ to achieve a plateau temperature of $195^{\circ} \mathrm{C}$.

Helium is used as the carrier gas and is supplied to the instrument's flow controllers at a nominal pressure of 446 kilopascals $(\mathrm{kPa})$. The flow controller for the column is adjusted to achieve a flow rate of $6-\mathrm{cm}^{3} / \mathrm{min}$. Make-up helium is supplied to the detector inlet through a $30-\mathrm{cm}$ length of $0.16-\mathrm{cm}-\mathrm{OD}$ stainless steel tubing. A make-up helium flow of 20 to $30 \mathrm{~cm}^{3} / \mathrm{min}$ is required to maintain the recommended gas-flow rate through the detector, thereby sweeping sample components out of the detector immediately after their detection and eliminating the possibility of peak broadening. To support combustion, air and hydrogen are supplied to the detector burner at the manufacturer-recommended flow rates of 400 and $30 \mathrm{~cm}^{3} / \mathrm{min}$, respectively.

The components determined using this procedure include methane, ethane, ethene, propane, propene, isobutane, n-butane, 1-butene, cis- and trans-2-butene, isopentane, n-pentane, cyclopentane, a composite of pentenes, and a composite of hexanes plus. Sensitivity determinations for the alkanes are performed using certified standards containing 0.2 to 3 percent of these components in helium or nitrogen.
The alkene sensitivities are determined using certified standards containing $10-$ to $100-\mathrm{ppm}$ concentrations of these components in nitrogen. All standards are certified to be accurate within \pm 2 percent.

When calibrating with standards in the proper range, the chromatographic results are usually more accurate than those obtained from a general mass spectrometer analysis. On the basis of the 2-percent accuracy of the standards employed for calibration and the precision experienced for the gas chromatograph, the accuracy is estimated to be \pm 5 percent.

\section{MOISTURE ANALYSIS}

To quantitatively determine water-vapor content in helium in the range of 0.1 to $15 \mathrm{ppm}$ by volume, the chemical reaction of $\mathrm{CaH}_{2}$ with water is used to produce hydrogen. The hydrogen analysis has a precision of 0.05 ppm in the less-than-5-ppm range. This method is used to calibrate commercial moisture analyzers (Rhodes, 1981).

\section{HYDROGEN SULFIDE ANALYSIS}

A chromatograph with a flame photometric detector is used to analyze samples with $\mathrm{H}_{2} \mathrm{~S}$ concentrations from 0.01 to $5,000 \mathrm{ppm}$. Analysis of samples containing 0.1 percent $\mathrm{H}_{2} \mathrm{~S}$ was repeatable to within \pm 0.02 percent relative. It is important to use dry stainless steel or epoxycoated cylinders when collecting or analyzing the samples (Rhodes, 1979).

\section{ANALYSIS IN THE LOW PARTS-PER-MILLION RANGE}

A helium ionization chromatograph provides determination of components in routine, non-routine, and research samples in the low parts-per-million range. Accuracy is usually limited by the accuracy of the calibration standards. Routine applications consist of determining the neon and hydrogen contents of well-gas and helium-production-process samples. Non-routine applications have involved investigations for unusual components and solution of problems requiring analyses in the ppm range (Seitz, 1985).

Cryogenic temperatures can be used to determine lowppm helium-3, neon, and hydrogen in helium-4 (Weems and Emerson, 1966).

\section{SPECIAL ANALYZERS}

\section{ANALYSIS OF HELIUM FROM 1 TO 100 PERCENT}

An instrument has been developed that provides an automated determination for helium. Helium is determined to 
an accuracy of \pm 0.01 percent in samples that contain from 1 to 100 percent helium. A liquid-nitrogen-cooled charcoal trap retains all components except helium, and the resulting partial pressure of helium in the sample is compared to the pressure caused by 100 percent helium (Emerson, 1972; Emerson and Kaplan, 1970).

\section{FOURIER TRANSFORM INFRARED ANALYSIS}

Absorbance peaks obtained by Fourier transform infrared (FT-IR) spectrometry through a gas cell are wave-number specific for each functional group in a gas mixture. Individual components of a gas mixture are quantified by the partial pressure of each component and the transmission characteristics of each gas (Cornelius, 1993).

FT-IR complements other analytical methods in that it can distinguish functional groups that would interfere with each other in mass spectrometry or gas chromatography. Solids, liquids, or gases can be analyzed by changing the type of cell used.

\section{SUMMARY}

Methods have been developed to determine the composition of natural gases required to produce high-quality helium. These methods outline the procedures used to separate and determine the component of interest in samples from air, soil gases, water, solvents, oils, stack gases, and process streams associated with helium plants and gas fields. Accuracies of each method vary depending on the need. Impurities in helium can be determined to $\pm 5 \mathrm{ppb}$ in the ppb range, and the general mass spectrometer results are normally \pm 3 percent.

\section{REFERENCES CITED}

Bibawy, N.A., 1989, A method for the calibration of class 2 and class 4 standards of mass: U.S. Bureau of Mines Information Circular 9230, 14 p.

Bibawy, N.A., and Emerson, D.E., 1990, An improved method for preparing gravimetric standard gas mixtures of helium-4 in nitrogen: U.S. Bureau of Mines Report of Investigations $9312,7 \mathrm{p}$.

Boone, W.J., Jr., 1958, Helium-bearing natural gases of the United States-Analyses and analytical methods: U.S. Bureau of Mines Bulletin 576, $117 \mathrm{p}$.

Burton, S.R.M., and Cornelius, D.E., 1989, Improved method for determination of helium- 4 in helium-3 by mass spectrometry: U.S. Bureau of Mines, Report of Investigations 9232, 7 p.

Cornelius, D.E., 1993, Presented at the Pittsburgh Conference, Atlanta, Georgia, paper 1104, 9 p. Available upon request from $801 \mathrm{~S}$. Fillmore, Amarillo, TX 79101.

Davidson, T.A., 1993, A simple and accurate method for calculating viscosity of gaseous mixtures: U.S. Bureau of Mines Report of Investigations 9456, $11 \mathrm{p}$.
Davidson, T.A., and Emerson, D.E., 1990a, Method and apparatus for direct determination of helium-3 in natural gas and helium: U.S. Bureau of Mines Report of Investigations 9302, 13 p.

1990b, Direct determination of helium-3 content of atmospheric air by mass spectrometry: Journal of Geophysical Research, v. 95, no. D4, p. 3565-3569.

Emerson, D.E., 1970, U.S. Patent 3517521. 1972, U.S. Patent 3691818

Emerson, D.E., Hoffman, C.A., and Weems, G.W., 1970, An improved method and apparatus for the analysis of impurities in helium: U.S. Bureau of Mines Report of Investigations $7444,10 \mathrm{p}$

Emerson, D.E., and Kaplan, R.L., 1970, Method and apparatus for determining helium content of gas mixtures: Analytical Chemistry, v. 42, p. 1746-1748.

Emerson, D.E., Stroud, L., and Meyer, T.O., 1966, The isotopic abundance of neon from helium-bearing natural gases: Geochimica Et Cosmochimica Acta, v. 30, no. 9, p. 847-854.

Emerson, D.E., Suttle, E.T., and Hoffman, C.A., 1968, The separation of neon from high-helium-content natural gases and the atmosphere for isotopic analyses: Journal of Mass Spectrometry and Ion Physics, 1, p. 105-110.

Emerson, D.E., Weems, G.W., and Hoffman, C.A., 1972, U.S. Patent 3662588.

Holland, P.W., 1981, A method for determining helium in water: U.S. Bureau of Mines Report of Investigations 8578, $17 \mathrm{p}$.

1984, An analyzer for determining helium-4 in the partsper-billion range: U.S. Bureau of Mines Report of Investigations $8853,9 \mathrm{p}$.

1989, An improved method for determining helium in water: U.S. Bureau of Mines Report of Investigations 9249, 9 p.

-1991, A mass spectrometer method for determining helium in the parts-per-million to 10-percent range: U.S. Bureau of Mines Report of Investigations 9359, $8 \mathrm{p}$.

Holland, P.W., and Emerson, D.E., 1979, Helium in ground water and soil gas in the vicinity of Bush Dome Reservoir, Cliffside Field, Potter County, Tex.: U.S. Bureau of Mines Information Circular 8807, 22 p.

1987, A determination of the helium-4 content of nearsurface atmospheric air within the continental United States: Journal of Geophysical Research, v. 92, no. B12, p. 12,55712,566

1990, Geochemistry of gaseous elements and compounds-The global helium-4 content of near-surface atmospheric air: Athens, Greece, Theophrastus Publications, p. $97-109$.

Loya, E.W., 1985, Computer program for calculating gravimetric primary standard gas mixtures: U.S. Bureau of Mines Information Circular 9031, 35 p.

Loya, E.W., Seitz, C.A., and Emerson, D.E., 1982, Gravimetric preparation of primary standard gas mixtures in the parts per trillion range: U.S. Bureau of Mines Report of Investigations 8643,4 p.

Miller, J.E., Carroll, A.J., and Emerson, D.E., 1965, Preparation of primary standard gas mixtures for analytical instruments: U.S. Bureau of Mines Report of Investigations 6674, $10 \mathrm{p}$.

Moore, B.J., and Sigler, S., 1987, Analysis of natural gases 1917-1985: U.S. Bureau of Mines Information Circular 9129,1197 p. 
National Research Council, 1981a, Committee on hazardous substances in the laboratory-Prudent practices for disposal of chemicals from the laboratory: Washington, D.C., National Academy Press, 282 p.

-1981b, Committee on hazardous substances in the laboratory-Prudent practices for handling hazardous chemicals in laboratories: Washington, D.C., National Academy Press, $291 \mathrm{p}$.

Rhodes, H.L., 1979, Determination of hydrogen sulfide content in natural gas, evaluation of containers for preparation of calibration standards, and sample collection procedure: U.S. Bureau of Mines Report of Investigations 8391,12 p.

1981, An apparatus and procedure for calibrating a water vapor analyzer in the 0.1- to 15 -ppm range: U.S. Bureau of Mines Report of Investigations $8548,8 \mathrm{p}$.
Seitz, C.A., 1985, Analysis for impurities in helium using the helium ionization detector: U.S. Bureau of Mines Report of Investigations $8941,30 \mathrm{p}$.

Seitz, C.A., and Holland P.W., 1986, An improved analyzer for determining helium- 4 in parts-per-billion range: U.S. Bureau of Mines Report of Investigations 9010, 7 p.

Stroud, L., Meyer, T.O., and Emerson, D.E., 1967, Isotopic abundance of neon, argon and nitrogen in natural gases-Relationship to helium genesis: U.S. Bureau of Mines Report of Investigations $6936,27 \mathrm{p}$

Suttle, E.T., Emerson, D.E., and Burfield, D.W., 1966, High pressure mass spectrometry for analysis of trace impurities in helium: Analytical Chemistry, v. 38, no. 1, p. 51-53.

Weems, G.W., and Emerson, D.E., 1966, Method of analysis of impurities in helium in the parts-per-billion range: U.S. Bureau of Mines Report of Investigations 6779, 5 p. 


\title{
Hydrogen: Its Comparison with Fossil Fuels and Its Potential as a Universal Fuel
}

\author{
By T. Nejat Veziroglu ${ }^{1}$ and Frano Barbir ${ }^{2}$
}

\section{CONTENTS}

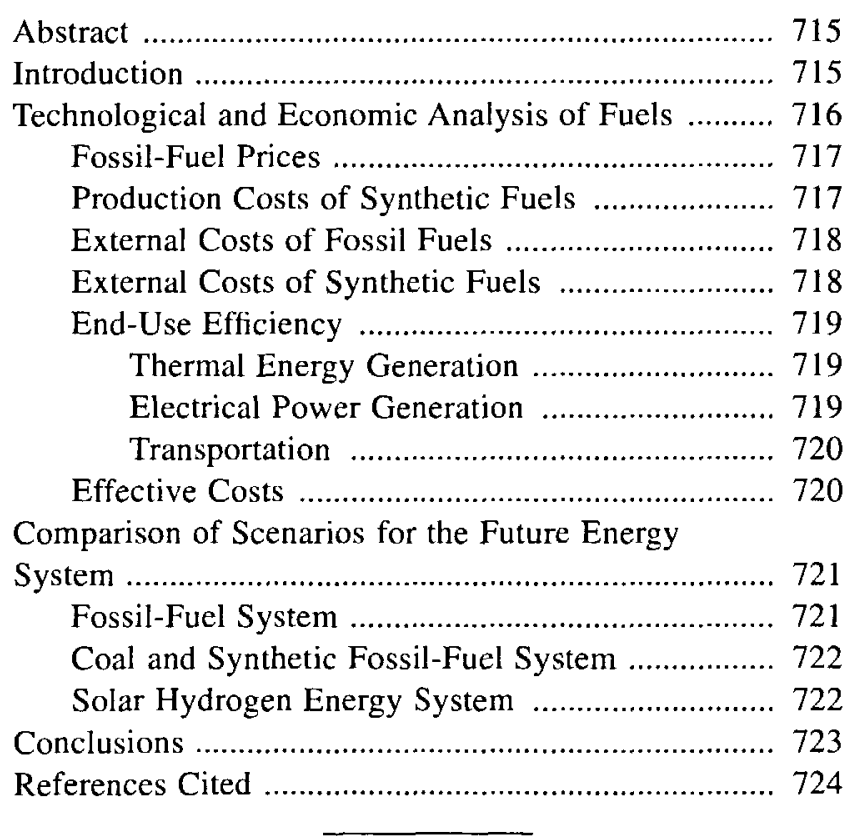

\begin{abstract}
The fuels most often considered for the post-petroleum and natural-gas era are hydrogen (both gas and liquid forms), coal, and coal-derived synthetic fossil fuels. These fuels can be compared in terms of production cost, exter-

\footnotetext{
${ }^{1}$ Clean Energy Research Institute, University of Miami, Coral Gables, FL 33124.

${ }^{2}$ Energy Partners, Inc., West Palm Beach, FL 33407.
}

nal cost, and end-use efficiency. The results show that hydrogen is a much more cost effective energy carrier than coal or synthetic fossil fuels, as well as being the most environmentally compatible fuel.

\section{INTRODUCTION}

The economic growth of modern industrialized society has been based on utilization of energy from fossil fuels. At the present time, about 80 percent of the world energy demand is met by fossil fuels-coal, petroleum, and natural gas (Davis, 1990). They are readily available worldwide in one form or another, although they are concentrated in certain regions of the world. Humankind has learned to exploit them efficiently to produce the energy services it needs. They are storable and portable, which makes them excellent fuels for transportation.

A simplified version of today's energy system is shown in figure 1. Fossil fuels are used for transportation; for heat generation in residential, commercial, and industrial sectors; and for electric power generation. For transportation, mostly petroleum products are used (gasoline, diesel fuel, jet fuel, and others). All three forms of fossil fuel are used for heat generation, which includes space heating, domestic water heating, cooking, steam generation and direct heating, and (or) drying in various industrial processes. In electric power generation, coal is used mainly for the baseload generation, and natural gas and heating oil are used for peak load. Part of the electric power is produced by hydro and nuclear sources.

However, consumption of fossil fuels has become an environmentally damaging force. Locally, the damage results from emissions, spills and leaks, and strip mining. Regionally, the damage results from pollutant dispersion 
over large areas. Globally, carbon-dioxide accumulation results in threatening consequences-global warming, climate changes, and sea-level rise.

If environmental stress does not force a shift to other energy sources and other fuels, the finite supply of fossil fuels will eventually mandate such a change. Reserves of fossil fuels are finite. Known reserves of oil and natural gas are about $8,000 \mathrm{EJ}\left(1 \mathrm{EJ}=10^{18} \mathrm{~J}\right.$ or joules $)$, which would be enough for the next 40 years at the current consumption rate (Fulkerson and others, 1990). If the exponential population growth and the demand growth are taken into account these reserves will only last about 25 years. If estimated additional undiscovered resources are added, that would satisfy energy needs for fluid fuels for an additional 20 years or so. Coal reserves are much larger; the known reserves of coal are about 20,000 EJ, and ultimately recoverable resources are estimated to be 150,000 EJ (Fulkerson and others, 1990). These large amounts of coal can eventually be used to produce synthetic liquid fuels; the synthetic fuels would allow society to continue employing the present energy system. However, this scenario would continue to cause detrimental environmental effects, which will ultimately lead to a calamity with unforeseeable consequences.

An alternative is to use renewable energy sources, mainly solar energy in its direct and indirect forms. At present, these sources are not as convenient as fossil fuelsthey are only intermittently available, they are not storable or transportable by themselves, and they cannot be used as a fuel for transportation. The shortcomings of renewable energy sources point to the need for an energy carrier or an intermediary energy system to form a link between the new primary energy sources and the energy-consuming sectors. Hydrogen, with its vast and ready availability from water, its nearly universal utility, and its inherently benign environmental characteristics, has all the properties that might be required for such an energy system.

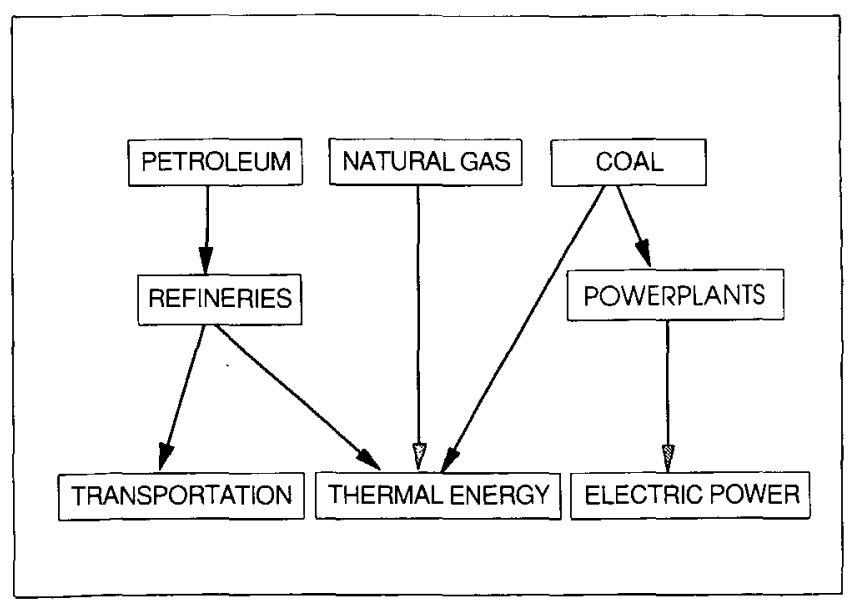

Figure 1. Simplified fossil-fuel energy system.
Hydrogen is the most plentiful element in the universe, making up about three quarters of all matter. All the stars and many of the planets essentially consist of hydrogen. However, on Earth free hydrogen is scarce; the atmosphere contains trace amounts of it ( 0.07 percent), and it is usually found in small amounts mixed with natural gas in crustal reservoirs. A few wells, however, have been found to contain large amounts of hydrogen, such as some wells in Kansas that contain 40 percent hydrogen, 60 percent nitrogen, and trace amounts of hydrocarbon (Goebel and others, 1984). The Earth's surface layers contain about 0.14 percent hydrogen (10th most abundant element), most of which resides in chemical combination with oxygen as water. Accordingly, oceans, lakes, and rivers are our hydrogen mines.

In the hydrogen energy system, it is envisaged that hydrogen will be produced from water using any and all primary energy sources, and it will be used in every application for which fossil fuels are used today (Bockris and Veziroglu, 1985). In this system, hydrogen is not a primary source of energy. Rather, it is an intermediary, or secondary, form of energy or an energy carrier. Hydrogen particularly complements the renewable energy sources, and it presents them to the consumer in a convenient form at the desired location and time. It is inexpensive to produce, it can be converted to other forms of energy more efficiently than other fuels, and it is the cleanest fuel because its combustion product is simply water vapor. The hydrogen energy system is a permanent energy system because it is independent of the primary energy sources. Hydrogen is inexhaustible, recyclable, and versatile. Even if the primary energy sources and the consumption patterns of society change owing to technological developments, changes in lifestyle, and (or) unforeseeable causes, the hydrogen energy system as an intermediary link would remain basically intact.

\section{TECHNOLOGICAL AND ECONOMIC ANALYSIS OF FUELS}

Hydrogen energy is already technically feasible, but economics are a major obstacle for its widespread use. Comparing strictly the consumer prices of fuels, hydrogen produced using clean and renewable energy sources is more expensive than existing (fossil) gaseous and liquid fuels.

The comparison between competing fuels, however, should be based on the effective costs of the services these fuels provide. The effective costs include the end-use efficiency, the consumer cost of fuel, and the external costs. External costs should include the costs of the physical damage done to humans and to the environment owing to harmful emissions, oil spills and leaks, coal strip mining, as well as governments' expenditures for pollution abatement, expenditures for military protection of oil supplies, costs of international conflicts, and other economic effects 
Table 1. Present and projected prices of fossil fuels.

[Price in 1990 U.S. dollars per gigajoule]

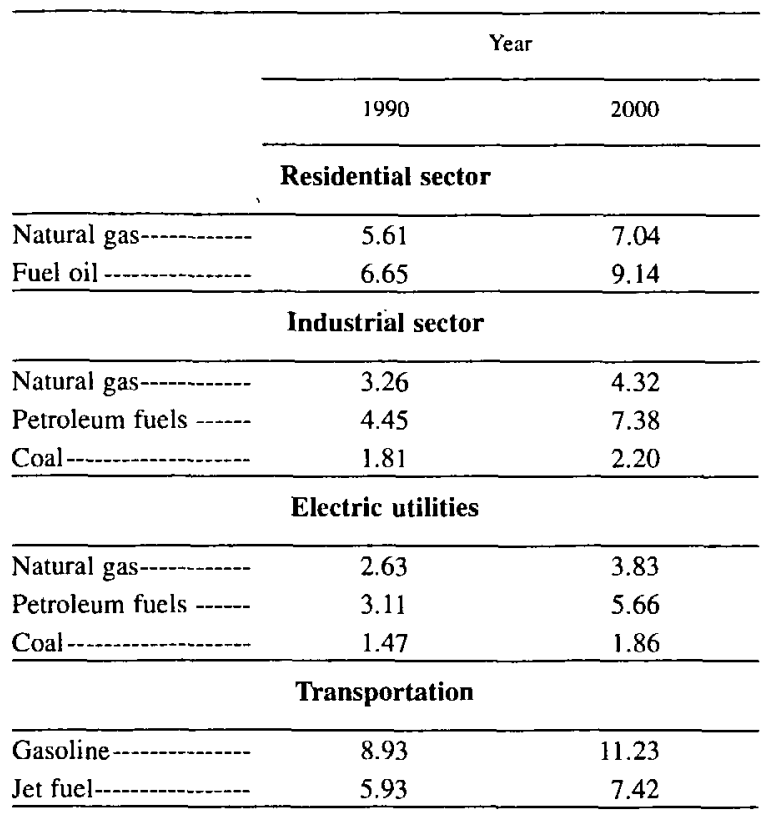

(such as employment, balance of trade, and depletion of nonrenewable resources).

For economic analysis, it is also important to consider the future costs of hydrogen, which will presumably be considerably lower than they are today because of assumed market and technological developments, with respect to the future costs, both internal and external, of fossil fuels, which will unavoidably be higher than today's prices owing to depletion, international conflicts, and environmental impacts.

\section{FOSSIL-FUEL PRICES}

Table 1 shows prices of fossil fuels today and projected prices for the year 2000 in the United States (Energy Information Administration, 1990). Prices are given for different fuels and for different end-use sectors. It should be mentioned that the prices given in table 1 are the enduse prices, which means that they include the production cost, as well as the costs of transportation and distribution. As expected, the projected prices of the fossil fuels for the year 2000 are much higher than they are today, particularly for petroleum products.

\section{PRODUCTION COSTS OF SYNTHETIC FUELS}

Hydrogen can be produced by several methods from various primary energy sources. Today, hydrogen is mainly produced by methane steam reforming and coal gasifi-
Table 2. Large-scale production cost estimates of synthetic fuels for the year 2000 .

[Cost expressed in 1990 U.S. dollars per gigajoule]

\begin{tabular}{|c|c|c|c|}
\hline & $\begin{array}{l}\text { Production } \\
\text { cost }\end{array}$ & $\begin{array}{l}\text { Storage and } \\
\text { distribution }\end{array}$ & End-use cost \\
\hline \multicolumn{4}{|c|}{ Gaseous fuels } \\
\hline Coal-derived hydrogen -.........- & 8.58 & 3.50 & 12.08 \\
\hline Hydropower hydrogen ---------- & 11.51 & 3.50 & 15.01 \\
\hline Solar-derived hydrogen-.......--- & 15.44 & 3.50 & 18.94 \\
\hline Synthetic natural gas--........- & 8.85 & 2.60 & 11.45 \\
\hline \multicolumn{4}{|c|}{ Liquid fuels } \\
\hline Coal-derived hydrogen -......---- & 10.73 & 3.50 & 14.23 \\
\hline Hydropower hydrogen ---.------ & 14.39 & 3.50 & 17.89 \\
\hline Solar-derived hydrogen-------... & 19.30 & 3.50 & 22.80 \\
\hline Synthetic gasoline - & 17.25 & 2.60 & 19.85 \\
\hline Synthetic jet fuel -- & 13.05 & 2.60 & 15.65 \\
\hline
\end{tabular}

cation. After depletion of fluid fossil fuels, coal could be used to produce hydrogen as well as other synthetic fuels, such as synthetic natural gas, synthetic gasoline, and synthetic jet fuel. Processes for converting coal into liquid and gaseous fuels already exist, but they are not widely used because synthetic fuels would be more expensive than oil and natural gas which are both available and relatively inexpensive.

Hydrogen can also be produced by splitting water-a process that uses both direct and indirect solar energy. The most widely used method of water splitting is electrolysis, which is a very efficient technology. The cost of electrolytically produced hydrogen is directly proportional to the cost of electricity. Therefore, cheap electricity is required to produce hydrogen at competitive prices. One of the possible sources of cheap electricity is hydropower. Electricity generated by solar energy, at the present time, is not competitive with coal, hydropower or nuclear electricity. Windgenerated electricity, however, is already competitive at some locations. Expected development, particularly of the thin-film photovoltaics, could in the near future provide electricity at $\$ 0.020$ to $\$ 0.035 / \mathrm{kWh}$ (kilowatthour), which will make it possible to generate hydrogen on a large scale and at competitive prices (Ogden and Williams, 1989).

Table 2 presents the averages of large-scale production costs of synthetic fuels taken from recent literature (Ogden and Williams, 1989; Moore and Dahmias, 1991; Williams 1985; Steinberg and Cheng, 1988, Bockris and Was, 1988). In the case of hydrogen, the costs are classified by the primary energy source used in the production, namely coal, hydropower, and solar energy. All costs are expressed in 1990 U.S. dollars and adjusted for inflation.

Although gaseous hydrogen can be used in most of the applications where gaseous or liquid fossil fuels are currently being used, there are some applications where 
liquid hydrogen must be used. For example, liquid hydrogen must be used in rocket engines for space travel and in jet engines for air transportation. The production cost of liquid hydrogen has been assumed to be 25 percent higher than production cost of gaseous hydrogen. Current commercial hydrogen liquefaction processes are costly and consume about 35 percent of the hydrogen's heating value. Preliminary studies show that the magnetic liquefaction process, which is currently being developed, will be much more efficient and will need less capital investment and less maintenance than conventional liquefaction systems (Barklay and Corless, 1992; Sherif and others, 1991).

Because table 1 presents end-use prices, the production costs of synthetic fuels in table 2 have been increased for the cost of transportation, storage, and distribution of these fuels. For synthetic fossil fuels the assumed costs are $\$ 2.60 / G J$ (gigajoule), and for hydrogen fuels the assumed costs are $\$ 3.50 / G J$ (Ogden and Williams, 1989). Comparing the costs in tables 1 and 2, it is clear that synthetic fuels will be more expensive than fossil fuels. Among the synthetic fuels, hydrogen from renewable sources (water and solar) is the most expensive.

\section{EXTERNAL COSTS OF FOSSIL FUELS}

The entire process of fossil-fuel consumption (extraction, transportation, processing, and particularly combustion) creates harmful environment impacts, which have direct and indirect negative effects on the economy.

Excavation of coal devastates the land, which then must be reclaimed, and during these processes the land is out of use. During the extraction, transportation, and storage of oil and gas, spills and leakages occur, which cause water and air pollution. Refining processes also have negative environmental impacts.

Most of the fossil fuel environmental impacts result from end use. The end use for all fuels is combustion, regardless of the intended purpose (that is, heating, electricity production, or power for transportation). The main constituents of fossil fuels are carbon, hydrogen, and trace amounts of other ingredients, such as sulfur. Combustion of fossil fuels produces various gases $\left(\mathrm{CO}_{\mathrm{x}}, \mathrm{SO}_{\mathrm{x}}, \mathrm{NO}_{\mathrm{x}}\right)$, unburned hydrocarbons, soot and ash, droplets of tar, and other organic compounds, which are all released into the atmosphere and constitute air pollution. Air pollution causes damage to humans, animals, crops, and structures, and it reduces visibility.

Once in the atmosphere, the primary pollutants may undergo chemical reactions triggered by sunlight or by mixing with water and other atmospheric compounds. As a result of these reactions, the pollutants change their form to become secondary pollutants such as ozone, aerosols, peroxyacyl nitrates, and various acids. Precipitation of sulfur and nitrogen oxides, which dissolve in clouds and in
Table 3. Environmental damages, including cost estimates, resulting from use of three fossil fuels.

[Estimates in 1990 U.S. dollars per gigajoule. N/A, not applicable]

\begin{tabular}{|c|c|c|c|}
\hline & Coal & Petroleum & Natural gas \\
\hline Effect on humans & 3.48 & 2.83 & 2.09 \\
\hline Effect on animals --- & 0.51 & 0.42 & 0.30 \\
\hline Effect on plants and forests -...-- & 1.35 & 1.09 & 0.81 \\
\hline Effect on aquatic ecosystems --- & 0.18 & 1.05 & 0.11 \\
\hline Effect on man-made structures -- & 1.12 & 0.90 & 0.67 \\
\hline Other air pollution costs & 0.98 & 0.79 & 0.59 \\
\hline Effect of strip mining & 0.49 & N/A & $\mathrm{N} / \mathrm{A}$ \\
\hline Effect of climatic changes -..--.- & 1.39 & 1.13 & 0.84 \\
\hline Effect of sea-level rise--------- & 0.32 & 0.26 & 0.19 \\
\hline Total cost of damages ----- & 9.82 & 8.47 & 5.60 \\
\hline
\end{tabular}

rain droplets to form sulfuric and nitric acids is called acid rain, but acid dew, acid fog, and acid snow have also been recorded. Acid deposition (wet or dry) causes soil and water acidification and results in damages to the aquatic and terrestrial ecosystems; these damages affect humans, animals, vegetation, and structures.

The other products of combustion in the atmosphere, mainly carbon dioxide, together with other so-called greenhouse gases (methane, nitrogen oxides, and chlorofluorocarbons), result in thermal changes by absorbing the infrared energy the Earth radiates back into the atmosphere and partially reradiating it back to the Earth to cause global temperature increases. The effects of the temperature increases are melting of the ice caps, sea-level rise and climate changes, which include heat waves, droughts, floods, stronger storms, and more and bigger wildfires.

Barbir and Veziroglu (1991) compiled various reported environmental damages and associated them with consumption of fossil fuels. The results of this study are shown in table 3 . Cost estimates for environmental damage resulting from coal use are highest at $\$ 9.82 / \mathrm{GJ}$, those resulting from petroleum use are second highest at $\$ 8.47 / \mathrm{GJ}$, and those resulting from natural gas use are the lowest at $\$ 5.60 / \mathrm{GJ}$.

The cost of these negative environmental effects is not included in the market price of a fossil fuel, and it must be considered an external cost. These environmental costs are or will be paid by society in the long term because any disturbed ecosystem will affect human society, its environment, and its economy.

\section{EXTERNAL COSTS OF SYNTHETIC FUELS}

When synthetic fuels are produced from coal, more than 1 GJ of coal is used for each GJ of a synthetic fuel manufactured and consumed. Consequently, the environmental damage caused by $1 \mathrm{GJ}$ of a synthetic fuel produced 
Table 4. $\mathrm{CO}_{2}$ emissions and pollution factors for synthetic fuels.

$\left[\mathrm{CO}_{2}\right.$ emissions expressed in kilograms per gigajoule]

\begin{tabular}{|c|c|c|}
\hline Fuel & $\mathrm{CO}_{2}$ emissions & Pollution factor \\
\hline Coal - & 85.5 & 1 \\
\hline Coal-derived gaseous hydrogen------ & 116.3 & 1.36 \\
\hline Hydropower gascous hydrogen ------ & 0 & 0 \\
\hline Solar-derived gaseous hydrogen --... & 0 & 0 \\
\hline 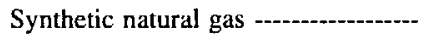 & 116.3 & 1.36 \\
\hline Coal-derived liquid hydrogen -------- & 145.4 & 1.70 \\
\hline Hydropower liquid hydrogen--....... & 0 & 0 \\
\hline Solar-derived liquid hydrogen-------- & 0 & 0 \\
\hline 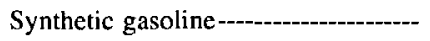 & 131.6 & 1.54 \\
\hline Synthetic jet fuel - & 131.6 & 1.54 \\
\hline
\end{tabular}

from coal is greater than the estimated damage caused by coal consumption. This can be expressed as follows:

$$
\mathrm{E}_{\mathrm{syn}}=\mathrm{E}_{\mathrm{coal}} \times \mathrm{P}_{\mathrm{s}}
$$

where $E_{\text {syn }}$ is the environmental damage due to use of 1 GJ of a synthetic fuel (including hydrogen) produced from coal, $E_{c o a l}$ is the environmental damage from coal consumption, and $\mathrm{P}_{\mathrm{S}}$ is the synthetic fuel pollution factor. Because of the dearth of data, total $\mathrm{CO}_{2}$ generated per unit energy is used as a measure of the pollution. Pollution factor, as shown in table 4 , is therefore a ratio of total carbon dioxide emissions (including emissions during production and combustion of particular synthetic fuel) to carbon dioxide emissions from coal combustion.

\section{END-USE EFFICIENCY}

In comparing fuels, it is important to consider end-use efficiency. Fuels are converted to various energy forms, such as mechanical, electrical, and thermal, for end use. Studies show that for almost every use, hydrogen can be converted to the desired energy form more efficiently than the fossil fuels or other synthetic fuels (Chen and others, 1982). In other words, conversion to hydrogen would result in energy conservation. Hydrogen end-use efficiencies are summarized in table 5 .

\section{THERMAL ENERGY GENERATION}

For many industrial, commercial, and residential applications, fuels are converted to thermal energy (space heating, water heating, cooking, steam generation, and direct heat in industrial processes). Hydrogen combustion in industrial applications is state-of-the-art. Hydrogen is burned in large amounts in the chemical industry to produce heat, especially when it is not economical to purify it (Peschka,
Table 5. End-use efficiency advantage of hydrogen.

[Cost in 1990 U.S. dollars per gigajoule. $\eta_{F}$ is average end-use conversion efficiency of fossil fuels and $\eta_{H}$ is end-use conversion efficiency of hydrogen]

\begin{tabular}{|c|c|}
\hline Application & End-use efficiency $\eta_{\mathrm{F}} / \eta_{\mathrm{H}}$ \\
\hline \multicolumn{2}{|l|}{ Thermal energy } \\
\hline Flame combustion -................................ & 1.00 \\
\hline Catalytic combustion - & 0.80 \\
\hline Steam generation - & 0.80 \\
\hline \multicolumn{2}{|l|}{ Electric power } \\
\hline Fuel cells -....... & 0.54 \\
\hline \multicolumn{2}{|l|}{ Surface transportation } \\
\hline Internal combustion engines & 0.82 \\
\hline Fuel cells/electric motor--- & 0.40 \\
\hline \multicolumn{2}{|l|}{ Air transportation } \\
\hline 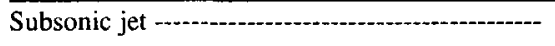 & 0.84 \\
\hline Supersonic jet - & 0.72 \\
\hline
\end{tabular}

1988). However, some design changes in the existing burners are required to match hydrogen burning properties, which are somewhat different than those of methane and other gaseous fuels, but the efficiency is about the same as for fossil-fuel combustion.

Catalytic combustion of hydrogen is its unique property to combine with oxygen in the presence of a catalyst, such as platinum or palladium, in an exothermic reaction without a flame. This process is usually more efficient than flame combustion. In some applications, such as space heating, catalytic combustion can be as much as 99 percent efficient because all the heat of the catalytic reaction remains inside the heated space; there are no exhaust gases (Haruta and others, 1982). Catalytic burners can also be used in kitchen ranges (Ledjeff, 1990).

Hydrogen burns with oxygen to produce pure steam at very high temperatures. An appropriate amount of water can then be added to bring the steam temperature down to the required temperature. Such a device, called the $\mathrm{H}_{2} / \mathrm{O}_{2}$ steam generator, has been developed and tested at the German Aerospace Research Establishment (DLR) (Sternfeld and Heinrich, 1989). This steam generator is simple, compact, and extremely efficient (as much as 99 percent). Conventional steam generators are usually about 75 to 80 percent efficient.

\section{ELECTRICAL POWER GENERATION}

Hydrogen can be converted back to electricity in fuel cells with much greater efficiency than is possible in thermal powerplants using fossil fuels. Whereas conversion efficiencies for the latter range from 35 to 38 percent, practical 
efficiencies in hydrogen fuel cells range from 50 to 70 percent (Kordesch and Oliveira, 1988). In advanced hydrogen fuel cells, which are now being developed, even higher efficiencies (as high as 80 percent) can be expected. Primary electricity, that is, electricity from primary energy sources such as solar, wind, and hydropower could be used directly whenever possible without conversion to hydrogen. However, these sources are intermittently available, and conversion to hydrogen provides a constant energy source.

\section{TRANSPORTATION}

Hydrogen-powered vehicles with internal combustion engines have proven more efficient than gasoline vehicles. Hydrogen is more thermally efficient than gasoline, primarily because it burns better in excess air and permits the use of a higher compression ratio. Data from engine tests indicate that hydrogen combustion is 15 to 50 percent more thermally efficient (DeLuchi, 1989). The overall fuel efficiency of a hydrogen vehicle, which takes into account the thermal efficiency as well as the weight of the vehicle, is better than a gasoline vehicle (on the average, hydrogen vehicles are 22 percent more efficient (DeLuchi, 1989)). Because hydrogen can burn in lean fuel/air mixtures as well as in rich fuel/air mixtures, it can result in cars with better fuel efficiency for stop-start-type city driving.

The hydrogen fuel cell-electric motor combination is another option for transportation; it can be used for cars, trucks, buses, and trains. It is almost twice as efficient as internal-combustion engines.

For a given number of passengers and a given payload, a subsonic passenger jet would use 19 percent less energy, if it were to use liquid hydrogen instead of conventional jet fuel (Brewer, 1991). A supersonic jet using hydrogen instead of jet fuel would use 38 percent less energy.

\section{EFFECTIVE COSTS}

As mentioned, the comparison of competing fuels should be based on the effective costs of the services these fuels provide. The effective costs include the end-use efficiency as well as both the internal and external costs of fuel. Internal costs are those included in the end-user price of fuel (production, storage, transportation, and distribution costs). External costs are those associated with fuel consumption but which up to now have not been included in the price (for example, environmental damage).

Effective cost of energy services can be expressed as dollars $/ \mathrm{GJ}_{\mathrm{th}}$ for heat generation, dollars $/ \mathrm{kWh}$ el for electric power generation and dollars/passenger-km or dollars/freight$\mathrm{km}$ for transportation. To bring these costs to a common basis and to be able to add them together, they are expressed as dollars/GJ of fossil fuel equivalent, or in other words dollars/GJ of fossil fuel required to provide the same service.
Table 6. Effective cost of thermal energy generation.

[Cost in 1990 U.S. dollars per gigajoule]

\begin{tabular}{|c|c|}
\hline Fuel & Effective cost \\
\hline \multicolumn{2}{|l|}{ Flame combustion } \\
\hline Natural gas --1.-1 & 11.82 \\
\hline Petroleum fuels - & 18.66 \\
\hline Coal-_-_-_- & 12.02 \\
\hline 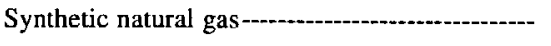 & 24.81 \\
\hline Synthetic fuel oil - & 30.77 \\
\hline Coal-derived gaseous hydrogen -.........----- & 25.44 \\
\hline Hydropower gascous hydrogen -.....-- & 15.01 \\
\hline 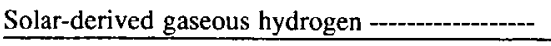 & 18.94 \\
\hline \multicolumn{2}{|l|}{ Catalytic combustion } \\
\hline Coal-derived gaseous hydrogen --.-.-.... & 20.35 \\
\hline Hydropower gaseous hydrogen - & 12.00 \\
\hline Solar-derived gaseous hydrogen & 15.15 \\
\hline
\end{tabular}

Effective cost of fossil fuels $\left(\mathrm{C}_{\text {eff }}\right)$ by definition is:

$$
\mathrm{C}_{\mathrm{eff}}=\left(\mathrm{C}_{\mathrm{in}}+\mathrm{C}_{\mathrm{ex}}\right)
$$

where $C_{i n}$ is internal cost (from table 1) and $C_{e x}$ is external cost (from table 3).

Effective cost of synthetic fuels, including hydrogen, must take into account the end-use efficiency of fossil fuels, and is calculated as follows:

$$
\mathrm{C}_{\mathrm{eff}}=\left(\mathrm{C}_{\mathrm{in}}+\mathrm{C}_{\mathrm{ex}}\right) \eta_{\mathrm{F}} / \eta_{\mathrm{S}}
$$

Internal costs $\left(\mathrm{C}_{\mathrm{in}}\right)$ for synthetic fuels are given in table 2 , and external costs $\left(C_{e x}=E_{s y n}\right)$ can be calculated by using equation 1. For coal-derived synthetic fossil fuels, the end-use efficiency factor $\left(\eta_{F}\right)$ is assumed to be $\eta_{F} / \eta_{S}=1$. In other words, the end-use efficiency of synthetic fossil fuels is equal to the end-use efficiency of fossil fuels. For hydrogen, the end-use factor is actually $\eta_{\mathrm{F}} / \eta_{\mathrm{S}}$ and is given in table 5 .

Using the above equations, tables 6 through 9 give effective costs for various applications for thermal energy generation, electric power generation, and transportation, respectively. Table 6 shows that the catalytic combustion of gaseous hydrogen from hydropower would produce thermal energy at a cost comparable to that of using natural gas or coal. Heat produced from synthetic fossil fuels would be the most expensive. For electric power generation (table 7), hydrogen-powered fuel cells would be the most cost effective method because of their high conversion efficiency. The fuel cells also appear to be the most cost effective option for surface transportation (table 8). Air transportation requires the most expensive fuels. Liquid hydrogen from renewable sources (hydrologic and solar) would be much cheaper than synthetic jet fuel when 
Table 7. Effective cost of electric power generation.

[Cost in 1990 U.S. dollars per gigajoule]

\begin{tabular}{|c|c|}
\hline Fuel & Effective cost \\
\hline \multicolumn{2}{|c|}{ Thermal plant } \\
\hline Natural gas -..--.-- & 9.43 \\
\hline Petroleum fuels -------. & 15.83 \\
\hline Coal … & 11.68 \\
\hline Synthetic natural gas -.... & 24.81 \\
\hline Synthetic fuel oil & 30.77 \\
\hline
\end{tabular}

Thermal plant with $\mathrm{H}_{2}-\mathrm{O}_{2}$ steam generator

\begin{tabular}{|c|c|}
\hline Coal-derived gaseous hydrogen & 20.35 \\
\hline 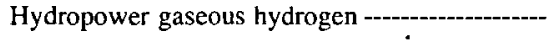 & 12.00 \\
\hline
\end{tabular}

Solar-derived gaseous hydrogen ----.-----....

Fuel cells

\begin{tabular}{lr}
\hline Coal-derived gaseous hydrogen & 13.74 \\
Hydropower gaseous hydrogen - & 8.10 \\
Solar-derived gaseous hydrogen - & 10.23 \\
\hline
\end{tabular}

Table 8. Effective cost of surface transportation.

[Cost in 1990 U.S. dollars per gigajoule]

\begin{tabular}{|c|c|}
\hline Fuel & Effective cost \\
\hline \multicolumn{2}{|c|}{ Internal combustion engines } \\
\hline 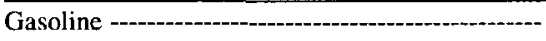 & 21.40 \\
\hline Synthetic natural gas - & 24.81 \\
\hline Synthetic gasoline-..- & 34.97 \\
\hline Coal-derived gaseous hydrogen--_......-- & 20.86 \\
\hline Hydropower gaseous hydrogen -- & 12.31 \\
\hline Solar-derived gaseous hydrogen -......-...- & 15.53 \\
\hline 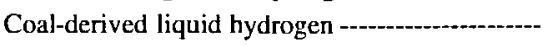 & 25.36 \\
\hline Hydropower liquid hydrogen-y- & 14.67 \\
\hline 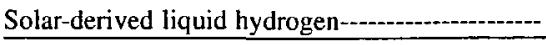 & 18.70 \\
\hline \multicolumn{2}{|l|}{ Fuel cells } \\
\hline Coal-derived gaseous hydrogen-1....-- & 10.17 \\
\hline Hydropower gaseous hydrogen -...-- & 6.00 \\
\hline Solar-derived gaseous hydrogen --.-..- & 7.58 \\
\hline
\end{tabular}

effective cost is considered (table 9). Hydrogen from coal has the lowest production cost among hydrogen fuels, but its effective cost would be the highest. This high effective cost is attributed to environmental damage.

\section{COMPARISON OF SCENARIOS FOR THE FUTURE ENERGY SYSTEM}

There are three possible scenarios for the future energy system. These are a fossil-fuel energy system as it is
Table 9. Effective cost of air transportation.

[Cost in 1990 U.S. dollars per gigajoule]

\begin{tabular}{|c|c|}
\hline Fuel & Effective cost \\
\hline \multicolumn{2}{|l|}{ Subsonic jets } \\
\hline Jet fuel & 17.59 \\
\hline 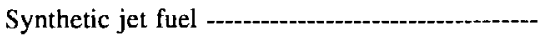 & 30.77 \\
\hline Coal-derived liquid hydrogen -..-- & 25.98 \\
\hline Hydropower liquid hydrogen --..- & 15.03 \\
\hline Solar-derived liquid hydrogen--.-- & 19.15 \\
\hline
\end{tabular}

Supersonic jets

Jet fuel -

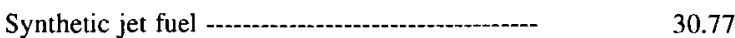

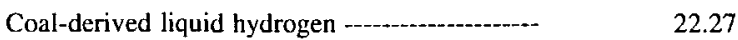

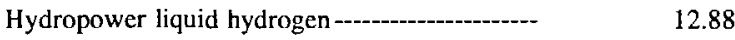

Solar-derived liquid hydrogen-..........-...-..-- 16.42

today, a coal and coal-based synthetic fuel energy system, and a hydrogen-fuel energy system based on renewable energy sources.

\section{FOSSIL-FUEL SYSTEM}

In this scenario, it is assumed that the present fossilfuel system will be continued in the future. Therefore, 40 percent of primary energy (in fossil-fuel equivalent units) will be used for thermal energy generation, 30 percent will be used for electric power generation, and 30 percent will be used for transportation (two-thirds for surface transportation and one-third for air transportation). Energy supplied by hydropower and nuclear powerplants (mostly in the form of electric power) and by other non-fossil fuel sources is not considered part of this scenario because it is assumed to provide the same amount of energy in all three considered systems. Actually, it is reasonable to expect that in the future even more energy will be supplied by these sources, but no estimates were made of the amount of energy from these sources.

In the fossil-fuel system (see fig. 1), it is assumed that one half of the thermal energy will be supplied by natural gas, and the rest by petroleum fuels (fuel oil and residual oil) and coal. Coal is assumed to be the main energy source for electricity generation, gasoline is the main source for surface transportation, and jet fuel is the main source for air transportation. This scenario greatly simplifies the fossil-fuel energy system, but it nonetheless represents present patterns of energy consumption, and it can be used as the basis for further analyses and comparisons. The prices of fossil fuels are expected to rise (see table 1). The projected costs for the year 2000 are used in calculations of the effective costs, which are shown in table 10. 
Table 10. Effective cost of the fossil-fuel system.

[Cost in 1990 U.S. dollars per gigajoule]

\begin{tabular}{|c|c|c|c|}
\hline Fuel & $\begin{array}{l}\text { Energy consump- } \\
\text { tion fraction }\end{array}$ & Effective cost & $\begin{array}{l}\text { Overall effective } \\
\text { cost (fraction } \times \\
\text { eff. cost) }\end{array}$ \\
\hline \multicolumn{4}{|c|}{ Thermal energy } \\
\hline Natural gas -..................... & 0.20 & $11.82^{*}$ & 2.36 \\
\hline Petroleum fuels -.......... & 0.10 & $18.66^{*}$ & 1.87 \\
\hline Coal - & 0.10 & 12.02 & 1.20 \\
\hline \multicolumn{4}{|c|}{ Electric power } \\
\hline Coal -........................ & 0.30 & 11.68 & 3.50 \\
\hline \multicolumn{4}{|c|}{ Surface transportation } \\
\hline Gasoline -.............. & 0.20 & 21.40 & 4.28 \\
\hline \multicolumn{4}{|c|}{ Air transportation } \\
\hline Jet fuel -......... & 0.10 & 17.59 & 1.76 \\
\hline 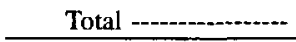 & 1.00 & & 14.97 \\
\hline
\end{tabular}

* Average for residential and industrial sector.

\section{COAL AND SYNTHETIC FOSSIL-FUEL SYSTEM}

For this system, it is assumed that the present fossilfuel system will be continued by substituting synthetic fuels derived from coal whenever convenient and (or) necessary. Patterns of energy consumption are also assumed to remain unchanged. Coal will be used extensively for thermal power generation and for electric power generation, because it is much cheaper than synthetic fuels. However, some end uses require fluid fuels; therefore it has been assumed that synthetic natural gas (SNG) will be used for thermal energy generation (primarily in the residential sector) and also as a fuel for surface transportation, where it will share the market with synthetic gasoline.

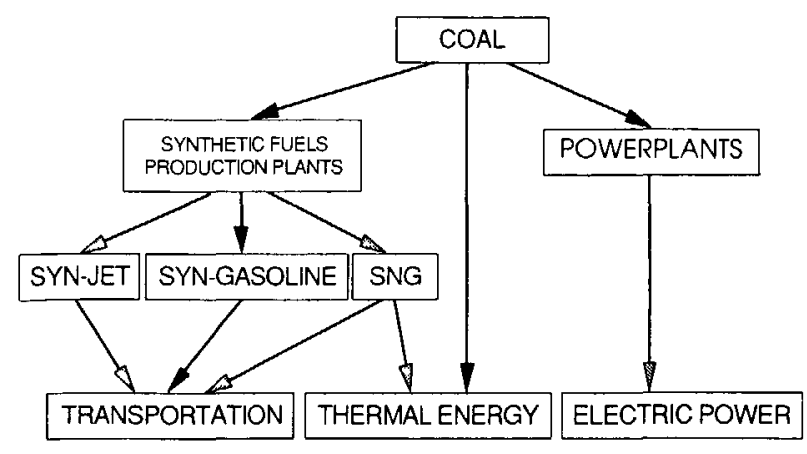

Figure 2. Coal and synthetic fuels energy system. SYN, synthetic; SNG, synthetic natural gas.
Table 11. Effective cost of the coal and synthetic fuel energy system.

[Cost in 1990 U.S. dollars per gigajoule]

\begin{tabular}{|c|c|c|c|}
\hline Fuel & $\begin{array}{c}\text { Energy } \\
\text { consumption } \\
\text { fraction }\end{array}$ & Effective cost & $\begin{array}{l}\text { Overall effective } \\
\text { cost (fraction } \times \\
\text { eff. cost) }\end{array}$ \\
\hline \multicolumn{4}{|c|}{ Thermal energy } \\
\hline Coal-o- & 0.30 & 12.02 & 3.61 \\
\hline Synthetic natural gas ---- & 0.10 & 24.81 & 2.48 \\
\hline \multicolumn{4}{|c|}{ Electric power } \\
\hline Coal---1- & 0.30 & 11.68 & 3.50 \\
\hline \multicolumn{4}{|c|}{ Surface transportation } \\
\hline Synthetic natural gas--... & 0.10 & 24.81 & 2.48 \\
\hline Synthetic gasoline -..-..--. & 0.10 & 34.97 & 3.50 \\
\hline \multicolumn{4}{|c|}{ Air transportation } \\
\hline Synthetic jet fuel ------- & 0.10 & 17.59 & 1.76 \\
\hline Total-a- & 1.00 & & 17.33 \\
\hline
\end{tabular}

Synthetic jet fuel will be used in air transportation. The energy system based on coal and synthetic fossil fuels is shown in figure 2 , and the effective costs of this system are shown in table 11.

\section{SOLAR HYDROGEN ENERGY SYSTEM}

In this system, it is assumed that the conversion to hydrogen energy will take place, and one-third of the hydrogen needed will be produced from hydropower and two-thirds by direct and indirect (other than hydropower) solar-energy forms. The same percentage of energydemand sectors as the above scenarios is assumed. It will further be assumed that one-half of the thermal energy will be achieved by flame combustion, one quarter by steam generation with hydrogen/oxygen steam generators and the last quarter by catalytic combustion. Electric power will be generated by fuel cells. One-half of the energy for surface transportation will be provided by gaseous hydrogen burning in internal combustion engines, and the other half will be provided by fuel cells. In air transportation, both subsonic and supersonic, liquid hydrogen will be used for fuel. A proposed solar-hydrogen energy system is shown in figure 3 , and the effective costs of the system are given in table 12.

As shown by the data in tables 10 through 12 , the hydrogen energy system has a lower effective cost than today's fossil-fuel system if the costs are projected for the year 2000 and beyond for both systems. An energy system based on coal and coal-derived synthetic fuels would be the most costly alternative (fig. 4). 
Of course, conversion to a new energy system is not possible in a short time period-it will probably take more than 50 years. These calculations are intended to show that the hydrogen energy system could become cost competitive at the beginning of the next century. However, the transition should start as soon as possible because only with adequate technology and market developments can the projected costs of hydrogen be achieved.

Because of its low external costs, natural gas is presently the most cost effective fuel for many end uses. Widespread application of natural gas, particularly in transportation and electricity generation, and corresponding infrastructure development could be a bridge toward the hydrogen energy system. During the transition period, natural gas can be used to generate hydrogen for applications where hydrogen offers better and (or) cleaner performance, such as in fuel cells or in aircraft propulsion. Renewably produced hydrogen could be added in the natural gas pipelines to increase the heating value and reduce combustion emissions. As the reserves of natural gas diminish, and technologies for production of hydrogen from renewable sources mature, hydrogen could gradually take over without dramatic and costly infrastructure changes.

\section{CONCLUSIONS}

1. The solar-hydrogen energy system is environmentally more sound than the fossil-fuel system; it is actually the only solution for reducing and reversing the carbon dioxideinduced greenhouse effect and its threatening consequences.

2. Hydrogen is a synthetic fuel. To take full advantage of its environmental benefits, hydrogen would have to be produced from clean resources. Water and renewable energy sources are the best choice, although in a transition period hydrogen could be produced from coal and (or) natural gas.

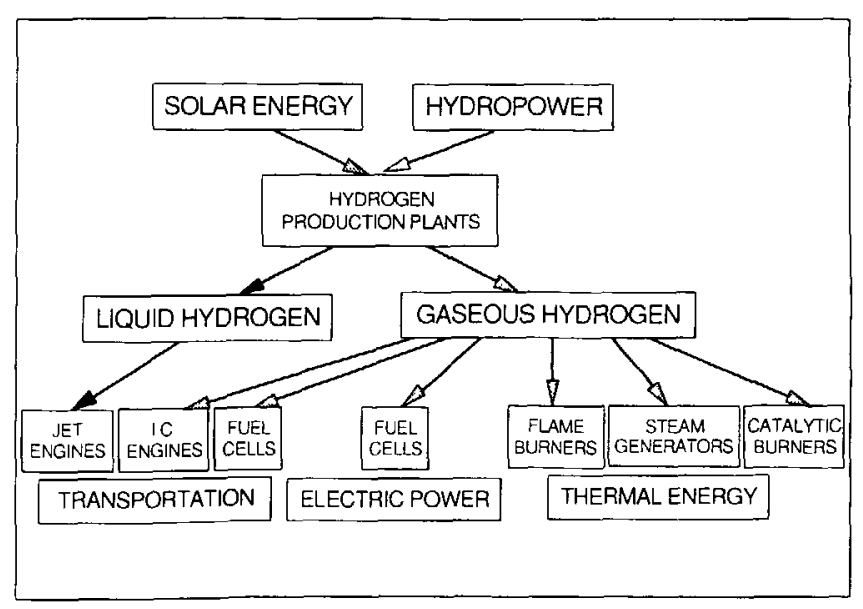

Figure 3. Solar-hydrogen energy system. I.C., internal combustion.
Table 12. Effective cost of the solar hydrogen energy system.

ICost in 1990 U.S. dollars per gigajoule. It has been assumed that one-third of the hydrogen in this system will be produced from hydropower and two-thirds from solar power]

\begin{tabular}{|c|c|c|c|c|}
\hline & $\begin{array}{c}\text { Energy } \\
\text { consumption } \\
\text { fraction }\end{array}$ & Fuel & $\begin{array}{c}\text { Effective } \\
\text { cost }\end{array}$ & $\begin{array}{c}\text { Overall } \\
\text { effective cost } \\
\text { (fraction } \times \\
\text { eff. cost) }\end{array}$ \\
\hline \multicolumn{5}{|c|}{ Thermal energy ${ }^{1}$} \\
\hline $\begin{array}{l}\text { Flame } \\
\text { combustion. }\end{array}$ & 0.20 & Gaseous hydrogen & 17.63 & 3.53 \\
\hline $\begin{array}{l}\text { Steam } \\
\quad \text { combustion. }\end{array}$ & 0.10 & Gaseous hydrogen & 14.10 & 1.41 \\
\hline $\begin{array}{l}\text { Catalytic } \\
\text { combustion. }\end{array}$ & 0.10 & Gaseous hydrogen & 14.10 & 1.41 \\
\hline \multicolumn{5}{|c|}{ Electric power ${ }^{2}$} \\
\hline Fuel cells --..-- & 0.30 & Gaseous hydrogen & 9.52 & 2.86 \\
\hline \multicolumn{5}{|c|}{ Surface transportation ${ }^{3}$} \\
\hline $\begin{array}{l}\text { Internal combustion } \\
\text { engines. }\end{array}$ & 0.10 & Gaseous hydrogen & 14.46 & 1.45 \\
\hline Fuel cells & 0.10 & Gaseous hydrogen & 7.05 & 0.71 \\
\hline \multicolumn{5}{|c|}{ Air transportation ${ }^{4}$} \\
\hline Subsonic -...-..-- & 0.05 & Liquid hydrogen & 17.78 & 0.89 \\
\hline Supersonic -......-.- & 0.05 & Liquid hydrogen & 15.24 & 0.76 \\
\hline Total - & 1.00 & & & 13.02 \\
\hline
\end{tabular}

${ }^{1}$ Energy consumption fraction is 0.40

${ }^{2}$ Energy consumption fraction is 0.30

${ }^{3}$ Energy consumption fraction is 0.20

${ }^{4}$ Energy consumption fraction is 0.10

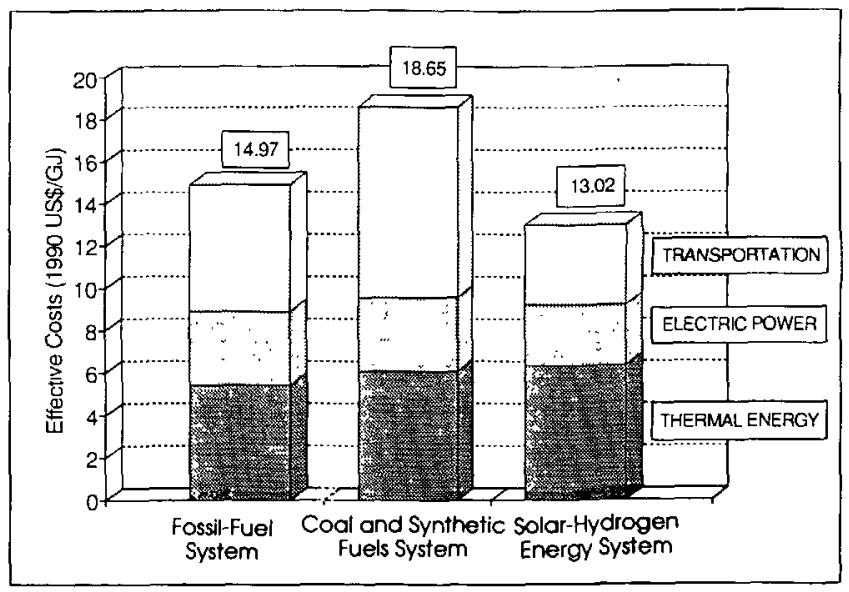

Figure 4. Effective costs of the analyzed energy systems. Costs given in 1990 U.S. dollars per gigajoule and adjusted for inflation. Total cost for the three sectors of each energy system shown at top of each column. 
3. The end-use efficiencies of hydrogen are greater than those of fossil and synthetic fossil fuels; therefore, in the solar-hydrogen energy system, less end-use energy will be required to perform the same services.

4. The solar-hydrogen energy system could be the most cost effective system if effective costs (the costs society pays for the energy services) are taken into account. It would not only be more cost effective than the synthetic fossil-fuel system-it would be even more cost effective than the present fossil-fuel system.

\section{REFERENCES CITED}

Barbir, Frano, and Veziroglu, T.N., 1991, Environmental damage caused by fossil fuel consumption: International Journal of Energy, Environment, and Economics, v. 1, no. 4, p. 297-310.

Barklay, J.A., and Corless, A.J., 1992, Cost analysis of a magnetic liquefier in a fleet-size cryofuel refueling system, in Worek, W.M., and Pesaran, A.A., eds., Solar Energy Technology 1992, ASME Solar Energy Division publication, v. 13, p. $43-50$.

Bockris, J.O'M., and Veziroglu, T.N., 1985, A solar-hydrogen energy system for environmental compatibility: Environmental Conservation, v. 12, no. 2, p. 105-118.

Bockris, J.O'M., and Was, J.C., 1988, About the real economics of massive hydrogen production at 2010 A.D., in Veziroglu, T.N., and Protsenko, A.N., eds., Hydrogen Energy Progress VII, v. 2: Oxford, Pergamon Press, p. 101-151.

Brewer, G.D., 1991, Hydrogen Aircraft Technology, Boca Raton, CRC Press.

Chen, D.Z., Gurkan, I., Veziroglu, T.N., and Sheffield, J.W., 1982, Effective cost of fuels: comparison of hydrogen with fossil fuels, in Veziroglu, T.N., Van Vorst, W.D., and Kelley, J.H, eds., Hydrogen Energy Progress IV, v. 4: Oxford, Pergamon Press, p. 1523-1537.

Davis, G.R., 1990, Energy for planet Earth: Scientific American, v. 263 , no. 3 , p. $55-62$.

DeLuchi, M., 1989, Hydrogen vehicles: an evaluation of fuel storage, performance, safety, environmental impacts, and cost: International Journal of Hydrogen Energy, v. 14, no. 2, p. $81-130$.
Energy Information Administration,1990, Annual Energy Outlook 1990, Long Term Projections: Washington, D.C.. U.S. Department of Energy, Energy Information Administration.

Fulkerson, W., Judkins, R.J., and Sanghvi, M.K., 1990, Energy from fossil fuels: Scientific American, v. 263, no. 3, p. 129135.

Goebel, E., Coveney, Jr., R.M., Angino, E.E., Zeller, E.J., and Dreschhoff, G.A.M., 1984, Geology, composition, isotopes of naturally occurring $\mathrm{H}_{2} / \mathrm{N}_{2}$ rich gas from wells near Junction City, Kansas: Oil and Gas Journal, May 1984, p. 217-222.

Haruta, M., Souma, Y., and Sano, H., 1982, Catalytic combustion of hydrogen: International Journal of Hydrogen Energy, v. 7, no. 9, p. 729-740.

Kordesch, K., and Oliveira, J.C.T., 1988, Fuel cells: The present state of the technology and future applications, with special consideration of the alkaline hydrogen/oxygen (air) systems: International Journal of Hydrogen Energy, v. 13, no. 7, p. 703-716.

Ledjeff, K., 1990, New hydrogen appliances, in Veziroglu, T.N., and Takahashi, P. K., eds., Hydrogen Energy Progress VIII, v. 3: Oxford, Pergamon Press, p. 1429-1444.

Moore, R.B., and Dahmias, D., 1991, Gaseous hydrogen markets and technologies, in Proceedings: Transition Strategies to Hydrogen as an Energy Carrier-First Annual Meeting of the U.S. National Hydrogen Association: Washington, D.C., Technology Transition Corporation, p. 11.1-11.17.

Ogden, J.M., and Williams, R.H., 1989, Solar Hydrogen: Moving Beyond Fossil Fuels: Washington, D.C., World Resources Institute.

Peschka, W., 1988, Technologies for the energetic use of hydrogen, in Winter, C.J., and Nitsch, J., eds., Hydrogen as an Energy Carrier: Berlin, Springer-Verlag, p. 30-55.

Sherif, S.A., and others, 1991, Analysis and optimization of hydrogen liquefaction and storage systems, Proceedings DOE/ SERI Hydrogen Program Review Meeting, Washington, D.C.

Steinberg, M., and Cheng, H.C., 1988, Modern and prospective technologies for hydrogen production from fossil fuels, in Veziroglu, T.N., and Takahashi, P.K., eds., Hydrogen Energy Progress VIII, v. 3: Oxford, Pergamon Press, p. 699-739.

Sternfeld, H.J., and Heinrich, P., 1989, A demonstration plant for the hydrogen/ oxygen spinning reserve: International Journal of Hydrogen Energy, v. 14, no. 10, p. 703-716.

Williams, R.H., 1985, Potential roles for bioenergy in an energy efficient world: Ambio, v. 14, no. 405, p. 201-209. 


\title{
THE FUTURE OF ENERGY GASES
}

U.S. GEOLOGICAL SURVEY PROFESSIONAL PAPER 1570

\section{Hydrogen Storage Systems}

\author{
By James A. Schwarz ${ }^{1}$ and K.A.G. Amankwah ${ }^{1}$
}

\section{CONTENTS}

\begin{tabular}{|c|c|}
\hline Abstract $\ldots \ldots \ldots \ldots \ldots \ldots \ldots \ldots \ldots$ & 725 \\
\hline Introduction & 725 \\
\hline Storage Technologies & 726 \\
\hline Experimental ................ & 727 \\
\hline Gravimetric & 727 \\
\hline Volumetric & 28 \\
\hline Modified Volumetric & 29 \\
\hline Results ................. & 729 \\
\hline Determination of Optimum Conditions for & \\
\hline Carbon Storage-Gravimetric and Volumetric & \\
\hline Experiments & 730 \\
\hline 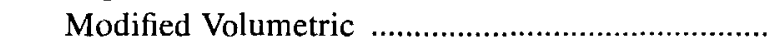 & 31 \\
\hline 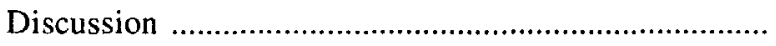 & 32 \\
\hline Comparison of Hydrogen Storage Alternatives .... & 732 \\
\hline 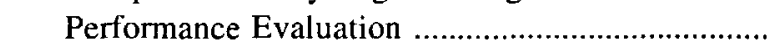 & 732 \\
\hline Cost Evaluations & 733 \\
\hline 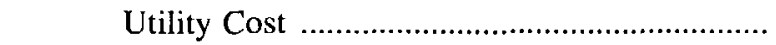 & 7 \\
\hline 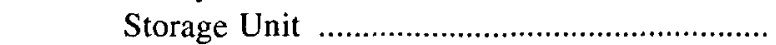 & 7 \\
\hline Cost for Energy Consumption ... & \\
\hline Conclusions & 73 \\
\hline Acknowledgments & \\
\hline References Cited ... & \\
\hline
\end{tabular}

\begin{abstract}
In order to use hydrogen as an energy carrier in modern energy-use systems, it is necessary to find compact, efficient means for storing hydrogen for mobile and (or)

\footnotetext{
${ }^{1}$ Department of Chemical Engineering and Materials Science, Laboratory for Advanced Storage Systems for Hydrogen, Syracuse University 320 Hinds Hall, Syracuse, NY 13244-1190.
}

stationary applications. Performance evaluations coupled with cost analyses for four major alternatives for hydrogen storage show that storage on activated carbon compares quite favorably with the other three options: storage in pressurized cylinder, storage on metal hydride, and storage as liquid. Gravimetric, volumetric, and modified volumetric laboratory experiments can be used to assess the storage properties of various activated carbons and ultimately identify which carbons and which pressure and temperature windows meet desired storage requirements.

\section{INTRODUCTION}

Energy systems in the 19th and 20th centuries have shown a systematic progression of fuel sources from wood to coal to oil and now toward natural gas. Major advances in the quality of life in civilized nations have resulted as the primary energy infrastructure has moved closer to oil and natural gas, away from wood. Significant increases in energy content per fuel source have led to unprecedented energy-related advances in the transportation, buildings, and industrial sectors.

Despite such benefits, it is becoming clear that the use of nature's fossil fuels is a transient privilege. Vital natural resources are finite, although demand for energy continues to grow. Eventually, a sustainable-energy economy must be developed that is not dependent on limited reserves of fossil resources. This type of economy requires nondepletable resources. Two categories of energy sources meeting this requirement are nuclear-based systems and renewable energy systems. Practically, however, energy use requires a form of energy that is convenient, flexible, adaptable, and controllable. Energy from the source should be deliverable virtually everywhere. Of the available options-such as wind, geothermal, and solar-hydrogen emerges as a prime candidate to become a significant energy carrier. 
The main benefits derived from using hydrogen are associated with its versatility after it has been produced and delivered to a user. The benefits include clean combustion in numerous devices and (or) efficient conversion to electricity in fuel cells. The major challenges to its use are finding efficient, cost-effective means for converting primary energy sources to hydrogen while still maintaining an environmentally benign impact, and finding efficient means of storing hydrogen for mobile and (or) stationary applications.

\section{STORAGE TECHNOLOGIES}

Development of efficient hydrogen storage capabilities is an important factor in the use of hydrogen as an alternative energy carrier. Hydrogen can be stored in three forms: gas, liquid, and solid. Research to date on hydrogen storage shows that pressurized tanks (gaseous $\mathrm{H}_{2}$ ), liquid hydrogen, metal hydride (solid hydrogen), and adsorption on activated carbon (condensed phase of $\mathrm{H}_{2}$ ) are all feasible storage systems (Noh and others, 1987; Amankwah and others, 1989; Carpetis, 1980; Carpetis and Peschka, 1980; Carpetis, 1982). The major advantages and disadvantages of these systems are presented in table 1 .

Efforts have been directed to improve each system with respect to storage capacity, safety, and economic impact. But the intrinsic problems associated with the disadvantages of each system cannot be solved without a detailed understanding of the interplay between the safety, cost, size, and weight of the storage system. Among the four alternatives, particular attention has been focused on metal hydride systems, because they can store hydrogen in compact vessels at ambient temperature and at ordinary pressure. However, difficulties do exist because storage under these conditions requires the use of elevated temperature, and charging times are strictly controlled by diffusional effects (Williams, 1980). Assuming these practical limitations can be overcome, this method would seemingly lead to a simple storage vessel manufactured in much the same way as today's gasoline tank. Unfortunately, the simplicity is an illusion, and factors such as heating and cooling require- ments and excessive weight will make application of hydride storage impractical (Williams, 1980).

Storage on activated carbons has probably received, until recently, the least research, and thus its advantages have not been fully appreciated. The scientific basis for carbon storage is the principle that physical adsorption capacity is dramatically increased as temperature is lowered. Carpetis and Peschka (1980) have shown that activated carbons demonstrate the best storage performance when compared to other possible adsorbents. The high adsorption capacity of hydrogen on activated carbon is due largely to the high surface area of the carbon, which is one of its important characteristics. Different carbons with the same surface area, however, show different adsorption capacities for hydrogen. For example, Cabot-BP2000 and Darco-KB (industrial names of different carbons) have comparable surface areas of $1,500 \mathrm{~m}^{2} / \mathrm{g}$, and their hydrogen uptake at 25 atmospheres and $77 \mathrm{~K}$ is $32 \mathrm{~g} \mathrm{H}_{2} / \mathrm{kg} \mathrm{C}$ and $24 \mathrm{~g} \mathrm{H}_{2} / \mathrm{kg}$ $\mathrm{C}$, respectively. It is clear that factors other than simply physical properties such as surface area influence the ability of activated carbon to adsorb hydrogen. This fact has led to studies to modify the surface chemical properties and microstructure of selected activated carbons (Agarwal and others, 1987; Jagiello and others, 1992a, b).

The objective of this discussion is twofold. We first describe the laboratory procedures that allow us to identify activated carbons that meet desired storage requirements. From these laboratory results, we provide a performance and cost evaluation that is based on mid-1992 data. We then compare these results to those for the other storage options listed in table 1.

In evaluating the options for a hydrogen storage system, it is not feasible to provide a clearcut evaluation matrix that can be applied to all circumstances. The choice of an optimum system should depend on the storage requirements. For example, the weight factor is more crucial than size for onboard vehicle storage (Eklund and von Krusenstierna, 1983). For qualitative comparison, however, evaluation of performance and cost is presented because these are the most important factors in the selection of the optimum system. The estimated costs and performance data for systems other than activated carbon are values that

Table 1. Advantages and disadvantages of various hydrogen storage systems.

\begin{tabular}{|c|c|c|}
\hline Storage system & Advantages & Disadvantages \\
\hline $\mathrm{GH}_{2}$ (compressed gaseous hydrogen) -..-- & Economical, simple -..- & Hazardous, bulky. \\
\hline $\mathrm{LH}_{2}$ (liquid hydrogen) -- & High density -- & $\begin{array}{l}\text { Cryogenic problem, requires insula- } \\
\text { tion }(20 \mathrm{~K}) \text {. }\end{array}$ \\
\hline $\mathrm{MH}_{2}$ (solid hydrogen in FeTi alloy)-.....-.-.- & Compact size; relatively safe------------. & $\begin{array}{l}\text { Heavy and expensive; chemically } \\
\text { unstable, susceptible to poisoning. }\end{array}$ \\
\hline C-S (hydrogen on activated carbon) -........... & $\begin{array}{l}\text { Moderate size and weight; moderate } \\
\text { cost. }\end{array}$ & $\begin{array}{l}\text { Requires insulation for cold } \\
\text { temperature. }\end{array}$ \\
\hline
\end{tabular}


have been reported in the literature (Carpetis, 1980, 1982; Carpetis and Peschka, 1980; Eklund and von Krusenstierna, 1983; Wallace and Ward, 1983; Stannard, 1984; Davidson and others, 1984). For activated-carbon systems, performance data are based on our laboratory experiments.

\section{EXPERIMENTAL}

Our data base for assessing the storage properties of activated carbons is determined by three tiers of experiments: gravimetric, volumetric, and a modified volumetric method. Each is described below.

\section{GRAVIMETRIC}

A Cahn 1000 microbalance is used for adsorption measurements. The balance housing is made of stainless steel. A schematic representation of the adsorption apparatus is shown in figure 1 . The balance can be operated between pressures of $10^{-6}$ atmospheres and $10^{2}$ atmospheres. The pressures are measured by transducers. Pressures up to 1.3 atmospheres are measured by an MKS capacitance manometer model 222B. Pressures higher than 1.3 atmospheres are measured by Data Instruments Transducer model EA.

All the temperature measurements are made by a chromel-alumel thermocouple placed internal to the balance on the sample side. Care is taken to ensure that the thermocouple does not touch the pyrex tube holding the sample or the wire on which this tube is suspended. The thermocouple is connected to a compensating reference junction. Use of this junction ensures that changes in room temperature do not affect the temperature reading. The thermocouple is calibrated at the ice point against a standard thermometer.

A 30-mm-high Pyrex tube with 4-mm outside diameter is used to hold the sample. A 200 -mesh stainless steel screen is placed at the bottom of the Pyrex tube to support the sample. The balance is calibrated by placing suitable weights on the tare side to counterbalance this Pyrex tube. The calibration of the balance is checked from time to time. All the weight measurements are carried out in the 1 -mg range on the microbalance. The weight measurements are recorded on a Hewlett Packard model 7220 strip-chart recorder. The least count of each weight measurement is $4 \mu \mathrm{g}$.

For adsorption measurements, about $100 \mathrm{mg}$ of the sample is placed in the holder. The sample is heated to $393 \mathrm{~K}$ and evacuated to $10^{-6}$ atmospheres. The evacuation and heating are continued until no further weight loss of the sample takes place. This procedure ensures removal of preadsorbed gases. The measured weight of the sample at this stage is considered to represent its degassed weight. After this pretreatment, adsorption experiments are commenced. A coolant dewar flask is raised to surround the sample tube. The sample is positioned $350 \mathrm{~mm}$ below the level of the coolant. Because the upper part of the balance is at room temperature, temperature gradients are set up on the sample side. Unless the sample is placed well below the level of the coolant outside, its temperature may be

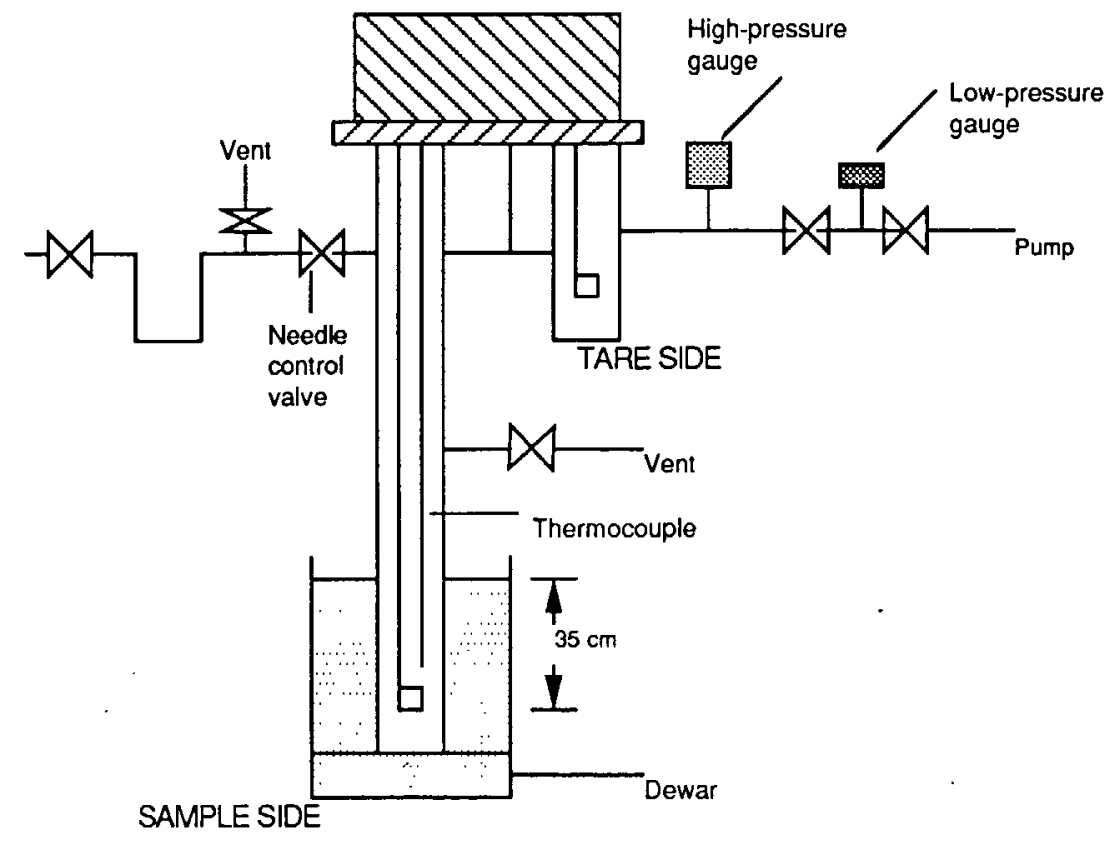

Figure 1. Schematic representation of apparatus for measuring adsorption of hydrogen on activated carbon. See text for explanation. 
different from that of the coolant. It was found that a height of $350 \mathrm{~mm}$ is adequate to obtain an inside temperature that is the same as that of the outside coolant.

After the dewar flask has been filled with the coolant, the evacuation is stopped and a small amount of the gas is bled into the system to ensure rapid equilibration of the outside and inside temperature. The amount of gas varies with each experiment and typically corresponds to the lowest value of the pressure desired for an experiment. The lowest value for any experiment is about $10^{-3}$ atmospheres.

After the temperature has been stabilized, adsorption isotherms are measured. Each isotherm is composed of 20 to 30 measurements at different pressures. Adsorption equilibrium is considered achieved when no further increase in weight takes place for at least $5 \mathrm{~min}$ utes at a uniform pressure. Because the least count of the balance output is $4 \mu \mathrm{g}$, at equilibrium, the rate of increase in weight is less than $0.8 \mu \mathrm{g} /$ minute. Typical equilibrium times are around 20 minutes. (In a few cases, adsorption at a given pressure was measured up to 60 minutes. The adsorption values after 20 and 60 minutes were found to be the same.) Desorption isotherms are also obtained. In all cases, adsorption and desorption isotherms are identical.

In the adsorption experiments, only the sample side is temperature controlled; the tare side is always at room temperature. This difference results in asymmetry in the balance operation. Buoyancy corrections are thus necessary. Buoyancy results from the displacement of gas by the sample, sample holder, adsorbed phase, and tare weights and pan. The corrections due to the tare weights and sample holder are estimated by blank runs. In the blank runs, experiments are carried out on an empty sample holder at temperatures and pressures that are similar to conditions during an adsorption run. The resulting corrections are plotted as a function of pressure at a given temperature. From these plots, correction values are determined and added to the corresponding adsorption values. The buoyancy due to the sample results in an apparent loss in weight during the adsorption measurement. This apparent loss in weight is estimated by the skeletal volume of the sample. The sample buoyancy is calculated as a product of skeletal volume and gas density at the given temperature and pressure. The gas density is calculated by a modified Benedict-Webb-Rubin (BWR) equation as developed by Lee and Kesler (1975).

\section{VOLUMETRIC}

The experimental set-up for volumetric measurements of adsorption of hydrogen on activated carbon is shown schematically in figure 2. A deoxo purifier (model D) manufactured by Engelhard Industries is used to pretreat the hydrogen. A mass flow controller (model $5850 \mathrm{C}$ ) and totalizer (model 450) manufactured by Brooks Instrument Division of the Emerson Electric Co. are used to determine the amount of charged hydrogen gas. The equilibrium pressure is recorded by a pressure transducer (model EA) and digital pressure indicator (model PL-1), both manufactured by Data Instruments,

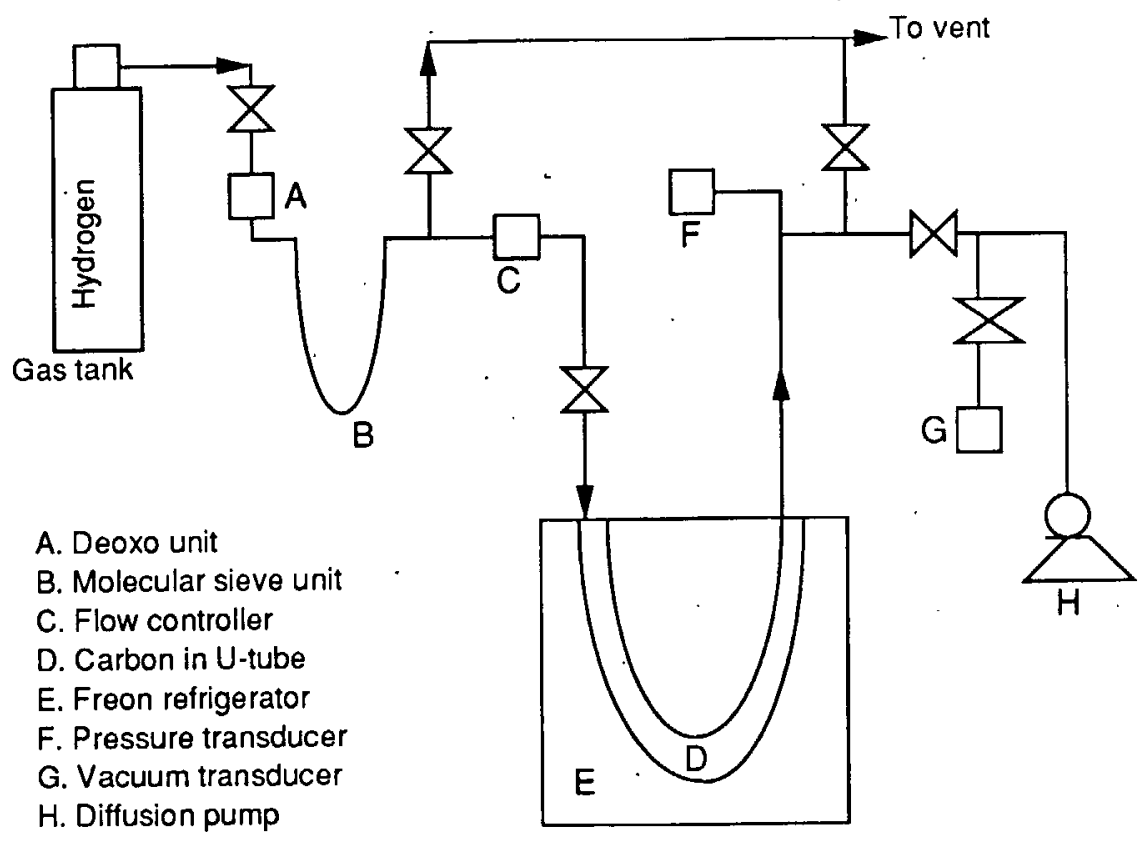

Figure 2. Schematic representation of volumetric apparatus for measuring adsorption of hydrogen on activated carbon at high pressures. See text for explanation. 
Inc. A vacuum transducer (type 0531) manufactured by Varian and a vacuum pump (model No. 1400) manufactured by Sargent Welch Scientific Co. are used to determine when the discharging step is completed. The freon refrigerator (model No. MC-8-120A-1) is manufactured by FTS Systems, Inc.

Because scaled-up experiments cannot be performed on a microbalance, a volumetric approach is used. Experiments are conducted at different temperatures. Weighed amounts of carbon, previously dried in an oven, are charged as efficiently and quickly as possible into a U-tube. A heating tape surrounding the U-tube supplies heat to the carbon while under vacuum in order to rid it of small amounts of moisture that might be adsorbed during the loading period. A vacuum reading of less than $6.5 \times 10^{-5}$ atmospheres is our criterion that there is no moisture left in the system. Desired amounts of hydrogen are charged into the U-tube via the mass flow controller (item C, fig. 2), which is connected to a calibrated totalizer. This arrangement enables us to determine the amount of hydrogen that has been charged into the vessel at any time. An average time of 30 minutes is found to be necessary for equilibrium to be achieved. The pressure reading on the indicator and totalizer readings are then recorded. An additional amount of hydrogen is then charged into the vessel in order to determine the next equilibrium point. These steps are repeated until equilibrium pressures of about 54 atmospheres are reached.

Isothermal discharging (pressure swing) alone was considered in an earlier publication for the recovery of hydrogen (Carpetis and Peschka, 1980). At a low-pressure level of about 2 atmospheres, isothermal discharging leaves substantial amounts of hydrogen unrecovered. The recovery of this residual amount is essential, for example, in mobile application. Total recovery can be achieved by both pressure and temperature swing ( $\mathrm{P}-\mathrm{T}$ swing). The temperature swing involves the application of heat by any appropriate means depending on the configuration of the system. Accordingly, we applied the P-T swing in our work.

After the completion of the adsorption experiment at a particular temperature, the stored amount is discharged first by a pressure swing down to the 2-atmosphere level. Heat is then supplied (nonisothermal discharging) to the activated carbon by means of the heating tape surrounding the U-tube. This continues until a vacuum of $6.5 \times 10^{-5}$ atmosphere or less is attained. Total amount stored is determined directly from the totalizer reading. We calculate the amount of void space on the basis of the equilibrium pressure reading and the bed porosity, which is the fraction of U-tube unoccupied by the activated carbon. By difference, we obtain the adsorbed amount, the component which represents the actual amount stored on the surface. These values can be compared directly with gravimetric data on the same carbon.

\section{MODIFIED VOLUMETRIC}

In order to determine the optimum conditions for a practical hydrogen storage system, a number of experiments have to be performed in order to answer the following question: For a chosen carbon sample, how does the charging procedure affect the adsorption characteristics of the carbon and the storage amount of hydrogen? Charging procedures consist of rate of charging, maximum pressure reached during charging, and amount of time required for charging. Charging characteristics refer to the rate at which the system pressure falls off until equilibrium is reached. Needless to say, the structural heterogeneity and chemical functionality of the chosen carbon will play a significant role during the whole process of adsorption.

The vessel used in this experiment has an internal volume of 1 liter and is made from a composite of carbonfiber/epoxy-filament windings. This vessel is charged with $323 \mathrm{~g}$ of carbon sample. The carbon sample is first conditioned by evacuation, followed by a purge of warm helium gas. The system is then evacuated to a vacuum of $1.3 \times 10^{-5}$ atmospheres. The vessel sits in a dewar flask (item G, fig. 3) filled with liquid nitrogen. Two thermocouple probes are inserted into the vessel; one measures the temperature of the carbon sample while the other measures the temperature of the gas in the void space. These temperatures are expected to be the same at equilibrium. The pressure within the vessel is measured by means of a pressure transducer (model EA) and a pressure indicator (model PL-1), both of which were obtained from Data Instruments in Acton, Mass. A schematic drawing of this apparatus is shown in figure 3 .

Adsorption is carried out by passing hydrogen gas through a 50-ft coiled copper tube that sits in a dewar flask (item B) filled with liquid nitrogen. The cold gas then enters the carbon-containing vessel. Using this experimental procedure, a number of charging variables can be studied.

- A Brooks mass flow controller (item E) has been installed on the downstream side of the system. This controller is connected to a totalizer that measures the amount of hydrogen stored in the vessel. Discharged amounts from the vessel can be measured when pressure swing is applied from one pressure to the other.

In all experiments, hydrogen gas of ultra-high purity grade ( 99.9999 percent), was supplied by Linde Specialty Gas Division of Union Carbide. The hydrogen is purified by means of a deoxo unit and a molecular sieve-unit immersed in a liquid-nitrogen trap.

\section{RESULTS}

Selected results using the apparatuses described in the previous section are described below. 


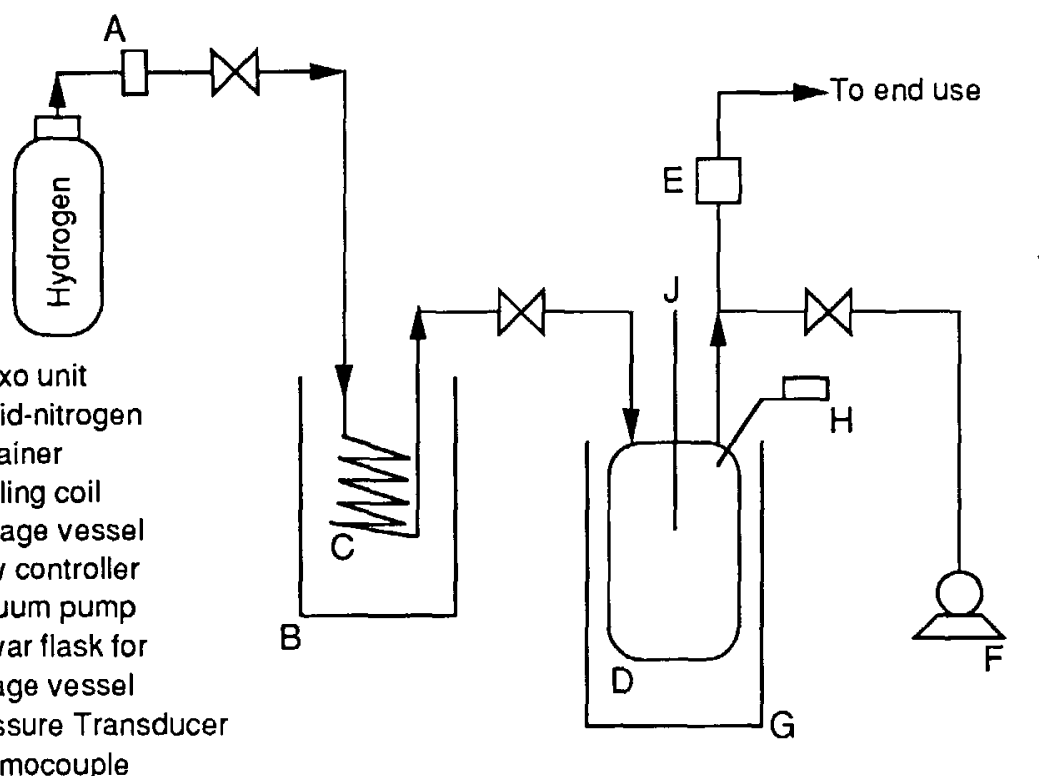
A. Deoxo unit
B. Liquid-nitrogen container
C. Cooling coil
D. Storage vessel
E. Flow controller
F. Vacuum pump
G. Dewar flask for storage vessel
J. Thermocouple

Figure 3. Schematic representation of modified-volumetric apparatus for studying how charging procedure affects adsorption characteristics of carbon sample and the determination of storage amount of hydrogen. Sec text for explanation.

\section{DETERMINATION OF OPTIMUM CONDITIONS FOR CARBON STORAGE-GRAVIMETRIC AND VOLUMETRIC EXPERIMENTS}

Two types of activated carbon, designated as carbon $\mathrm{A}$ and carbon $\mathrm{B}$, are considered here for discussion purposes. Carbon A is granular whereas carbon B is powdery. Stored amounts of hydrogen in a vessel are composed of two components: the adsorbed component and the void component. The adsorbed component depends on the microstructure and surface chemical functional groups of the activated carbon. The void component, for a given condition of temperature and pressure, depends on the bulk density of the carbon, which in turn depends on the degree of packing of the carbon in the container.

To facilitate the discussion, we present in figure 4 volumetric data for hydrogen storage on carbon $A$ at $150 \mathrm{~K}$. A study of the plot shows that at approximately 55 atmospheres, the amount of hydrogen in the void becomes comparable to the amount of adsorbed component. Consequently, there is no need to increase the pressure any further, because the resulting condition becomes comparable to a small-volume compressed-gas storage system. A study of the plot shows furthermore that the difference between the adsorbed and void components (the difference amount, or DA) reaches a maximum at about 20 atmospheres. It then starts to decrease until it reaches zero at about 55 atmospheres.

The question arises as to when an optimum condition is reached. Does one choose an optimum when the DA value is zero or when it reaches a maximum? Regardless of which DA value is chosen, the ultimate goal of storage is to store as much hydrogen as conveniently possible. Examination of figure 4 shows that a DA value of zero corresponds to a total stored amount (TSA) of $93 \mathrm{~g} \mathrm{H}_{2} / \mathrm{kg} \mathrm{C}$ (9.3 percent) for carbon A. A maximum DA value at about 20 atmospheres corresponds to a TSA of $45 \mathrm{~g} \mathrm{H}_{2} / \mathrm{kg} \mathrm{C}$ (4.5 percent). We note, however, that the latter condition is more efficient when one considers the rationale for using an adsorbent. This rationale is to concentrate as much

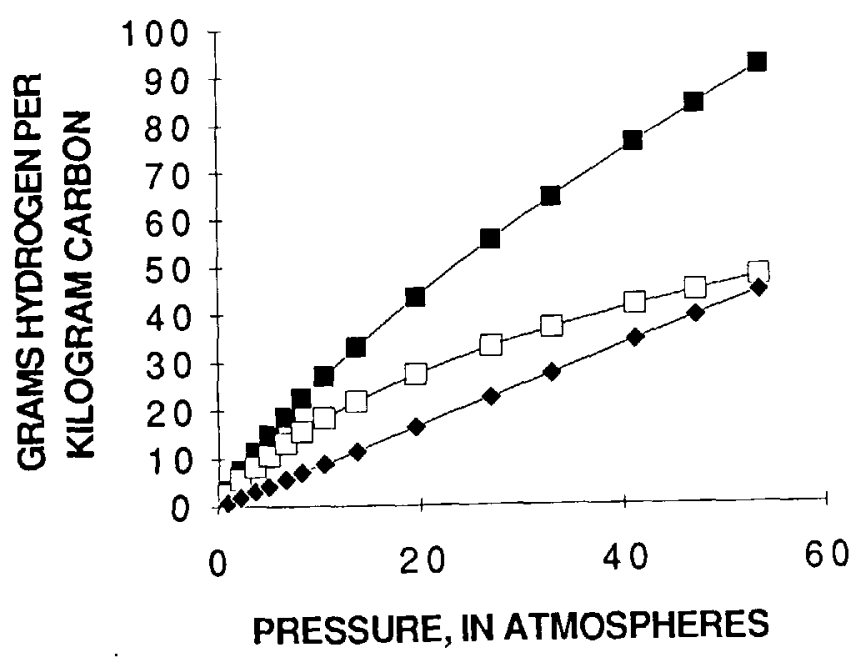

Figure 4. Hydrogen storage on carbon $A$ at $150 \mathrm{~K}$. Diamonds, hydrogen stored in void spaces in carbon sample; open squares, hydrogen adsorbed on carbon surfaces; solid squares, total stored amount (TSA) of hydrogen. 
hydrogen in a given volume or space without much increase in weight of the system. However, for this case we chose the stored amount of $93 \mathrm{~g} \mathrm{H}_{2} / \mathrm{kg} \mathrm{C}$, which corresponds to a moderate pressure of 55 atmospheres.

Let us consider the stored amounts of hydrogen on carbons $\mathrm{A}$ and $\mathrm{B}$ at $78 \mathrm{~K}$. Figure $5 \mathrm{~A}$ for carbon $\mathrm{A}$ shows that the DA value reaches a plateau at about 11 atmospheres. This corresponds to a TSA of 5.7 percent, which is a relatively small amount. Such a case, for which a

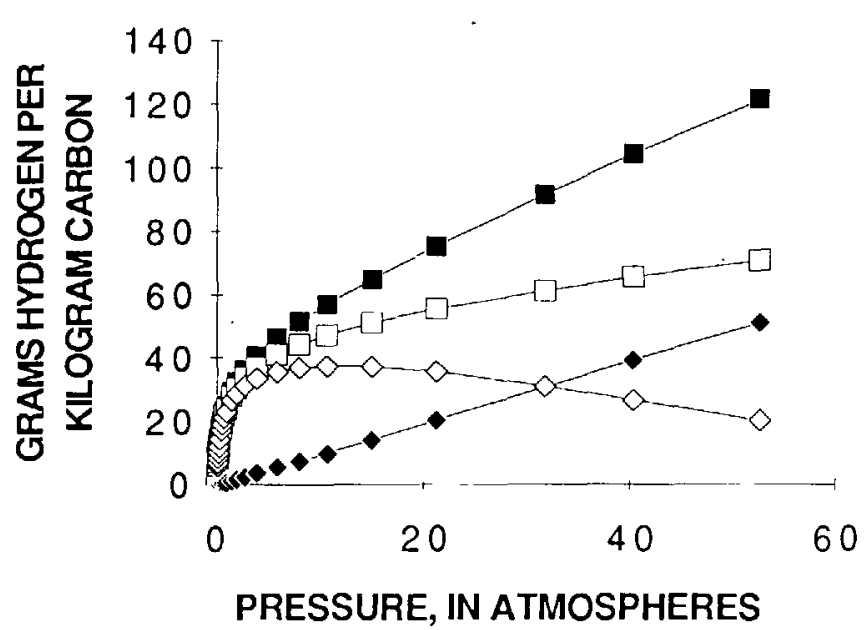

$A$

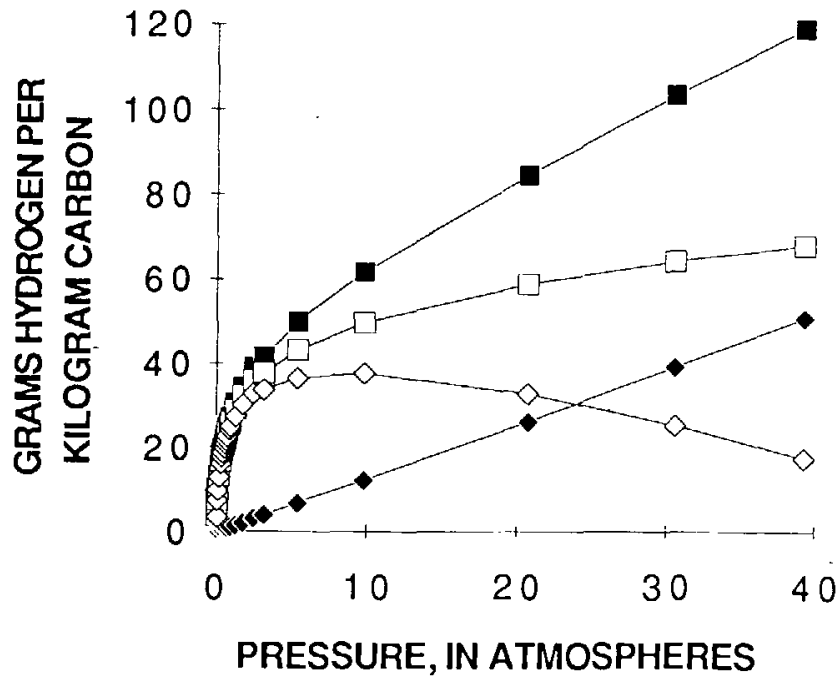

$B$

Figure 5. Hydrogen storage at $78 \mathrm{~K}$ on $(A)$ carbon $\mathrm{A}$, and $(B)$ carbon $B$. Solid diamonds, hydrogen stored in void spaces in carbon sample; open squares, hydrogen adsorbed on carbon surface; open diamonds, difference between adsorbed hydrogen and hydrogen in void spaces (difference amount, or DA); solid squares, total stored amount (TSA) of hydrogen. maximum DA value has been attained but corresponds to a low TSA value, is not acceptable. Do we then accept a condition that corresponds to a DA value of zero and probably a relatively high TSA? Not necessarily. Another look at figure $5 A$ shows that at 52.5 atmospheres, a DA value corresponding to half the maximum $D A$ value will suffice. This case corresponds to a TSA of 12.1 percent. Clearly, a DA value equal to zero will result in a greater TSA but at the unnecessary expense of increased pressure. Figure $5 B$ represents the case of carbon $B$. It can be seen that the intermediate DA value chosen at a lower pressure of 39.2 atmospheres is suitable, because it corresponds to an acceptable TSA of 11.9 percent.

The foregoing discussion leads to the following observations: (1) The TSA is optimized on a the basis of a reasonable choice of pressure and DA value, and (2) this optimization is strongly dependent on temperature of storage, adsorption characteristics of the carbon, and bulk density of the adsorbent.

\section{MODIFIED VOLUMETRIC}

Once a carbon's static adsorption properties have been established, we use the modified volumetric approach to determine the process variables for optimization of dynamic charging. Here, following contact between gas and solid, the hydrogen pressure is stepped to a higher value, and the relaxation of the system to an equilibrium state is measured.

It can be noted from figure 6 that, for another carbon designated $\mathrm{C}$, the maximum pressure applied in one case (70 atmospheres) was lower than that applied in another case (74 atmospheres). However, the equilibrium pressure (39 atmospheres) attained for the first case was higher than

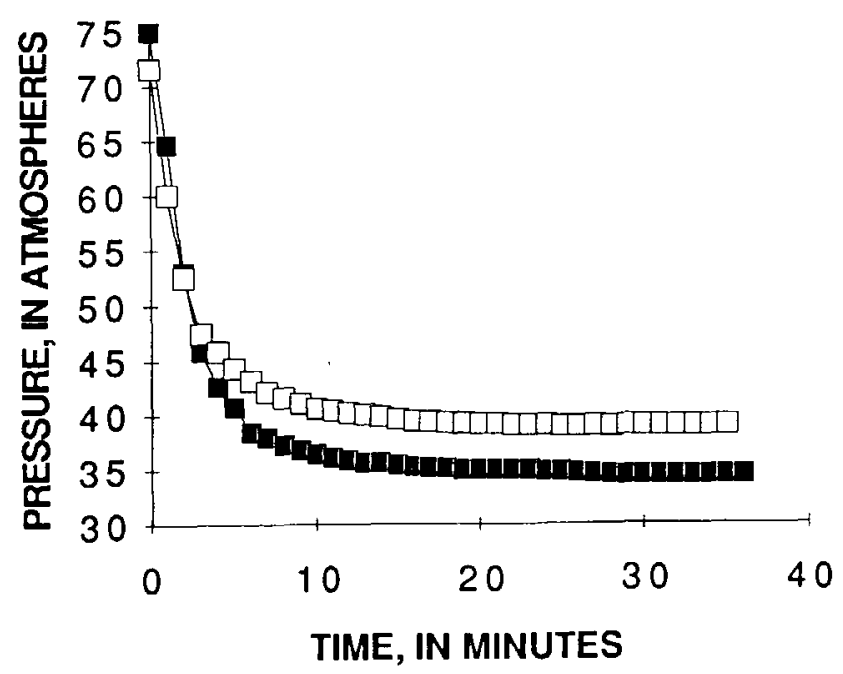

Figuire 6. Charging characteristics of carbon C. Open squares, maximum applied pressure of 70 atmospheres; solid squares, maximum applied pressure of 74 atmospheres. 
that for the latter case (34 atmospheres). The equilibrium temperature for both cases was $116 \mathrm{~K}$. Equilibrium time was about 10 minutes for both tests. The inverse relation between maximum pressure and equilibrium pressure in the two cases is due to different initial conditions of the carbon before charging took place. In the first test, cold hydrogen gas was flushed through the system at very low pressures for a longer period than for the second test. This longer period allowed the gas molecules more time to penetrate the micropores of the carbon bed. Consequently, most of the higher energy sites for adsorption had been occupied before the final charging was started. Therefore, even at a lower charging pressure, the equilibrium pressure was higher in the first test than in the second. (This aspect of initial conditioning of the bed becomes very important in determining the maximum allowable temperature the carbon should reach during the discharge process in, for example, an automobile.) The TSA at 39 atmospheres was 10.16 percent, whereas the TSA at 34 atmospheres was 9.65 percent.

\section{DISCUSSION}

\section{COMPARISON OF HYDROGEN STORAGE ALTERNATIVES}

The various alternatives to be compared are coded as follows:

$\mathrm{GH}_{2}$ : Compressed gaseous hydrogen, pressurized to 150 atmospheres (steel vessel) or to 200 atmospheres (Kevlar vessel)

$\mathrm{LH}_{2}$ : Liquid hydrogen, in a cryogenic tank

$\mathrm{MH}_{2}$ : Metal hydride-solid hydrogen in FeTi alloy

C-S: Hydrogen storage on activated carbon at 113 K, 54 atmospheres
In the case of C-S, we note that the material of construction for the vessel is carbon-fiber/epoxy-filament winding. It has been recommended for hydrogen vessels (Structural Composites Industries, Pomona, Calif., personal commun., 1992). See Noh and others (1987) for explanations for an assumed working pressure of 200 atmospheres for the $\mathrm{GH}_{2}$ system and the use of FeTi for the $\mathrm{MH}_{2}$ system.

\section{PERFORMANCE EVALUATION}

Evaluation of performance was based on mobile applications and two indexes: (1) the weight efficiency, and (2) the volume efficiency. For the $\mathrm{C}-\mathrm{S}$ system, it was found that conditions corresponding to a temperature of $113 \mathrm{~K}$ and a pressure of 54 atmospheres were satisfactory. These conditions were attained on an activated carbon, here designated carbon $\mathrm{C}$, whose surface area is $2,230 \mathrm{~m}^{2} / \mathrm{g}$. The TSA was 12.1 percent. The performance under these conditions has been compared to those of other alternatives in table 2 . To provide a complete perspective, data for conventional gasoline fuel systems are included.

In order to have a practical basis for comparison of these alternative forms of storage, we cite specific examples of vehicles from DeLuchi's paper (1989) in table 3. We have included in this table our own laboratory data. The choice of 0.87 million Btu's (MMBtu) is comparable to values cited by Deluchi. This amount of hydrogen is sufficient for a range of approximately 310 miles. We reconstructed table 2 based on the results of table 3 and present the findings in table 4 . It is important to note that these data are representative of actual systems. We find that carbon storage is very competitive with the other alternatives when comparing values for weight or volume efficiency.

Table 2. Performances of hydrogen storage systems.

\begin{tabular}{|c|c|c|c|}
\hline Storage system & Vessel & $\begin{array}{l}\text { Weight efficiency, in } \\
\left(\mathrm{g} \mathrm{H}_{2} / \mathrm{kg} \mathrm{C}\right) \times 100 \\
\text { (percent) }\end{array}$ & 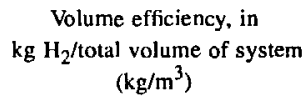 \\
\hline $\begin{array}{l}\mathrm{GH}_{2} \text { (compressed gaseous } \\
\text { hydrogen). }\end{array}$ & $\begin{array}{l}\text { Steel (150 atmospheres) - } \\
\text { Kevlar (200 atmospheres) --.-- }\end{array}$ & $\begin{array}{l}1.50 \\
3.10\end{array}$ & $\begin{array}{r}12.10 \\
11.20\end{array}$ \\
\hline $\mathrm{LH}_{2}$ (liquid hydrogen) --.....-- & 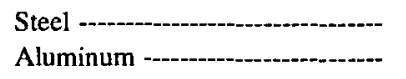 & $\begin{array}{l}13.00 \\
23.70\end{array}$ & $\begin{array}{l}46.90 \\
46.90\end{array}$ \\
\hline $\begin{array}{l}\mathrm{MH}_{2} \text { (solid hydrogen in } \mathrm{FeTi} \\
\text { alloy). }\end{array}$ & $\mathrm{FeTiH}_{2}-\mathrm{-}$ & 1.40 & 36.50 \\
\hline $\begin{array}{l}\text { C-S (hydrogen on activated } \\
\text { carbon). }\end{array}$ & $\begin{array}{l}\text { Carbon-fiber/epoxy-filament } \\
\text { winding ( } 113 \mathrm{~K}, 54 \text { atmospheres). }\end{array}$ & 7.22 & 39.00 \\
\hline Gasoline---_-_- & Steel - & 31.00 & 260.00 \\
\hline
\end{tabular}


Table 3. Comparison of different methods of hydrogen storage.

[Musashi, Japanese-manufactured vehicle; MB, Mercedes Benz; MMBtu, million British thermal units]

\begin{tabular}{|c|c|c|c|c|c|c|}
\hline \multirow[b]{2}{*}{ Storage system } & \multirow{2}{*}{$\begin{array}{l}\text { Total weight of } \\
\text { system (kg) }\end{array}$} & \multirow{2}{*}{$\begin{array}{c}\text { Total volume of } \\
\text { system (L) }\end{array}$} & \multicolumn{2}{|c|}{ Amount of $\mathbf{H}_{2}$} & \multicolumn{2}{|c|}{ Energy density } \\
\hline & & & $\begin{array}{c}\text { Weight } \\
(\mathrm{kg})\end{array}$ & $\begin{array}{c}\text { Energy } \\
\text { (MMBtu) }\end{array}$ & $(\mathrm{Btu} / \mathrm{kg})$ & (Btu/L) \\
\hline $\mathrm{GH}_{2}$ (204 atmospheres) & 97.72 & 574.0 & 6.72 & 0.90 & 9,209 & 1,568 \\
\hline $\mathrm{LH}_{2}$ Musashi & 45.76 & 198.1 & 5.76 & 0.76 & 16,608 & 3,836 \\
\hline $\mathrm{MH}_{2}$ (TiVMn) MB 310 van - & 574.00 & 170.0 & 6.00 & 0.804 & 1,401 & 4,729 \\
\hline C-S (113 K, 54 atmospheres) -.-.-..... & 92.00 & 170.0 & $6.63^{\circ}$ & 0.87 & 9.456 & 5,117 \\
\hline
\end{tabular}

Table 4. A reconstruction of table 2 based on table 3 .

[Musashi, Japanese-manufactured vehicle; MB, Mercedes Benz]

\begin{tabular}{|c|c|c|}
\hline Storage system & $\begin{array}{c}\text { Weight efficiency } \\
\text { in }\left(\mathrm{g} \mathrm{H}_{2} / \mathrm{kg} \mathrm{C}\right) \times 100 \\
\text { (percent) }\end{array}$ & $\begin{array}{l}\text { Volume efficiency in } \\
\mathrm{kg} \mathrm{H} \mathrm{H}_{2} / \text { total volume } \\
\text { of system }\left(\mathrm{kg} / \mathrm{m}^{3}\right)\end{array}$ \\
\hline $\mathrm{GH}_{2}$ (204 atmospheres) -..--.... & 6.87 & 11.70 \\
\hline $\mathrm{LH}_{2}$ Musashi --- & 11.13 & 29.07 \\
\hline $\mathrm{MH}_{2}$ (TiVMn) MB 310 van & 1.045 & 35.29 \\
\hline C-S (113 K, 54 atmospheres) -..-- & 7.22 & 39.00 \\
\hline
\end{tabular}

\section{COST EVALUATIONS}

The comparison of costs for each alternative is based on data for medium to large stationary power systems. For the cost analysis, the guidelines in previous publications (Carpetis, 1980, 1982; Carpetis and Peschka, 1980) have been followed in a consistent manner. These guidelines are in accordance with the use of standardized module factors (Guthrie, 1969).

The baselines for the comparative cost evaluation are for medium-large-scale storage systems. These are as follows:

(1) Maximum storable energy amount $(19,200$ million British thermal units (MMBtu))

(2) Rated charging power of storage device (200 megawatts (MW))

(3) 50 percent usage of storage capacity

(4) 360 charge-discharge cycles per year

(5) 14 hours per day of charging storage device

(6) Capital recovery factor of 15 percent

(7) Personnel and maintenance cost of 2.5 percent

(8) Electricity cost of $\$ 0.09$ per kilowatthour $(\mathrm{kWh})$

(9) Activated carbon cost of $\$ 12.00 / \mathrm{kg}$

All cost values are estimates and are in mid-1992 dollars. We used cost indexes (Economic Indicators, 1988, 1992) to update cost estimates reported previously (Eklund
Table 5. Cost for utility units.

[See text for explanation of storage systems. Costs are in mid-1992 dollars. Values in column "Cost/million Btu" do not include costs for energy consumption, which are shown in table 7. atm, atmosphere; Btu, British thermal unit]

\begin{tabular}{|c|c|c|c|}
\hline $\begin{array}{l}\text { Storage } \\
\text { system }\end{array}$ & Utility unit & $\begin{array}{l}\text { Unit cost } \\
\text { (million dollars) }\end{array}$ & $\begin{array}{l}\text { Cost/million } \\
\text { Bıu (dollars) }\end{array}$ \\
\hline $\mathrm{GH}_{2}-\cdots$ & Compressor (up to $200 \mathrm{~atm}$ ) ----.. & 8.98 & 0.46 \\
\hline $\mathrm{LH}_{2} \cdots$ & 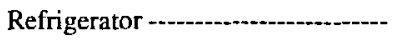 & 12.92 & 0.66 \\
\hline $\mathrm{MH}_{2}----$ & Compressor --.--.-- & 6.73 & 0.34 \\
\hline C-S - - - & $\begin{array}{l}\text { Compressor (up to } 100 \mathrm{~atm} \text { ) } \\
\text { plus vacuum pump. }\end{array}$ & 8.98 & 0.46 \\
\hline - & Refrigerator - & 12.92 & 0.66 \\
\hline
\end{tabular}

Table 6. Cost for storage units.

[See text for explanation of storage systems. Costs are in mid-1992 dollars Btu, British thermal unit]

\begin{tabular}{|c|c|c|}
\hline Storage system & Storage unit & $\begin{array}{l}\text { Cost/million Btu } \\
\text { (dollars) }\end{array}$ \\
\hline $\mathrm{GH}_{2}$ & 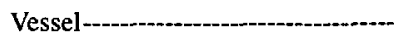 & 3.77 \\
\hline $\mathrm{LH}_{2}$ & Vessel with insulation-..--.--..-. & 1.09 \\
\hline $\mathrm{MH}_{2}$ & $\begin{array}{l}\text { Metal (FeTi alloy) vessel with } \\
\text { heat exchanger. }\end{array}$ & 3.63 \\
\hline C-S - -...-..--- & Vessel with insulation & 2.97 \\
\hline
\end{tabular}

and von Krusenstierna, 1983; Wallace and Ward, 1983; Davidson and others, 1984; Stannard, 1984; Amankwah and others, 1987). The six-tenths power factor rule (Peters and Timmerhaus, 1980) was applied to account for changes in vessel volume. The cost comparisons for the powerassociated term, capacity-associated term, and energy consumption are all on a per-MMBtu basis in tables 5, 6 , and 7 , respectively. The total costs for each alternative are listed in table 8. Brief examples of the cost calculations for selected storage alternatives are presented below. 
Table 7. Cost for energy consumption.

[See text for explanation of storage systems. Costs are in mid-1992 dollars. atm, atmosphere; Btu, British thermal unit; K, degrees Kelvin; kWh, kilowatthour]

\begin{tabular}{|c|c|c|c|}
\hline Storage system & $\begin{array}{l}\text { Function of utility } \\
\text { unit }\end{array}$ & $\begin{array}{c}\text { Electricity } \\
\text { consumption } \\
\text { (kWh per } \\
\text { million Btu) }\end{array}$ & $\begin{array}{l}\text { Cost/million Btu } \\
\text { (dollars) }\end{array}$ \\
\hline $\mathrm{GH}_{2}$ & $\begin{array}{l}\text { Compression } \\
\text { (200 atm). }\end{array}$ & 7.35 & 0.66 \\
\hline $\mathrm{LH}_{2}$ & $\begin{array}{l}\text { Liquefaction } \\
\text { at } 20 \mathrm{~K} \text {. }\end{array}$ & 90.12 & 8.11 \\
\hline $\mathrm{MH}_{2} \ldots$ & $\begin{array}{l}\text { Compression } \\
\text { heating. }\end{array}$ & 15.07 & 1.36 \\
\hline C-S--.---- & $\begin{array}{l}\text { Compression } \\
\text { cooling, and } \\
\text { heating. }\end{array}$ & 28.09 & 2.53 \\
\hline
\end{tabular}

\section{UTILITY COST}

The unit costs for the various alternatives shown in table 5 are updated versions of cost values presented by Carpetis and Peschka (1980). The dollar amount per MMBtu is calculated on the basis of the assumed baselines. As an example, let us consider the compressor for the compressed-gas alternative.

$$
\begin{aligned}
\text { Unit or capital cost } & =\$ 8.98 \times 10^{6} \\
\text { Storage capacity } & =19,200 \mathrm{MMBtu} \\
\text { Capital cost per MMBtu } & =\frac{\$ 8.98 \times 10^{6}}{19,200 \mathrm{MMBtu}} \\
& =\$ 467.7 / \mathrm{MMBtu}
\end{aligned}
$$

Sum of capital recovery factor and personnel and maintenance cost is

$$
(15+2.5) \text { percent }=17.5 \text { percent. }
$$

Taking these into account, the cost of utility per year is

$$
17.5 \text { percent of } \$ 467.7 / \mathrm{MMBtu}=\$ 81.85 / \mathrm{MMBtu} \text {. }
$$

360 cycles per year will make the cost per cycle become equal to

$$
\frac{\$ 81.85 / \mathrm{MMBtu}}{360}=\$ 0.23 / \mathrm{MMBtu} .
$$

Utilization of storage capacity is 50 percent, hence the final cost is

\begin{tabular}{|c|c|c|c|c|}
\hline Storage system & $\begin{array}{c}\text { Cost of utility } \\
\text { unit (dollars } \\
\text { per million Btu) }\end{array}$ & $\begin{array}{l}\text { Cost of storage } \\
\text { unit (dollars } \\
\text { per million Btu) }\end{array}$ & $\begin{array}{l}\text { Cost of energy } \\
\text { consumption } \\
\text { (dollars per } \\
\text { million Btu) }\end{array}$ & $\begin{array}{c}\text { Total cost } \\
\text { (dollars } \\
\text { per million } \\
\text { Btu) }\end{array}$ \\
\hline $\mathrm{GH}_{2} \ldots$ & 0.46 & 3.77 & 0.66 & 4.89 \\
\hline $\mathrm{LH}_{2}$ & 0.66 & 1.09 & 8.11 & 9.86 \\
\hline $\mathrm{MH}_{2}$ & 0.34 & 3.63 & 1.36 & 5.33 \\
\hline C-S-------- & 1.12 & 2.97 & 2.53 & 6.62 \\
\hline
\end{tabular}

$$
(\$ 0.23 / \mathrm{MMBtu}) \times 2=\$ 0.46 / \mathrm{MMBtu} .
$$

\section{STORAGE UNIT}

A similar approach was taken for calculation of costs for the storage units. The overall total cost can be found in
Table 8. Total cost for storage systems.

[See text for explanation of storage systems. Costs are in mid-1992 dollars. Btu, British thermal unit]

the paper by Carpetis and Peshka (1980), with the exception of that for the C-S system.

The storage-unit cost of the C-S system is composed of the cost of carbon and that of the empty vessel. For a 19,200-MMBtu storage device, the amount of hydrogen required can be calculated on the basis of the heating value $\left(0.115 \mathrm{MMBtu} / \mathrm{kg} \mathrm{H}_{2}\right)$ of hydrogen. This calculation leads to the amount of carbon needed since the weight efficiency (12.1 percent) based on the carbon adsorbent alone is known. The carbon-fiber/epoxy-filament winding vessel weighs $180 \mathrm{~kg}$ for every cubic meter of internal volume. An estimated future cost of this vessel is $\$ 66.00 / \mathrm{kg}$. This could be an overestimation, but we prefer to be on the conservative side rather than be overly optimistic.

\section{COST FOR ENERGY CONSUMPTION}

Data for energy consumption for the $\mathrm{GH}_{2}, \mathrm{LH}_{2}$, and $\mathrm{MH}_{2}$ systems are based upon values reported by Carpetis $(1980,1982)$ and Carpetis and Peschka (1980). The values for the C-S system were obtained using standard thermodynamic equations. A 40-percent efficiency was assumed. The total cost for the various storage systems is summarized in table 8 . It is very obvious that the energy consumption component for the $\mathrm{LH}_{2}$ system makes this option the most expensive. Next in line comes the C-S system. For the same reason, the total cost of the C-S system is higher than those for the $\mathrm{GH}_{2}$ and $\mathrm{MH}_{2}$ systems. The energy requirement for the $\mathrm{C}-\mathrm{S}$ system is composed of compression and cooling components primarily, with the heating component being a small fraction. It is the cooling requirement that makes the C-S energy consumption component relatively large.

From table 8, the $\mathrm{GH}_{2}$ system is the least expensive of the storage systems considered. The $\mathrm{MH}_{2}$ system is also less expensive than the C-S system; however, the total cost shown in table 8 for the $\mathrm{MH}_{2}$ system could be misleading because most metallic alloys that could be used for hydrogen storage systems are more expensive and re- 
quire higher storage temperatures than the Fe-Ti alloy assumed for table 8 . Such differences would affect the storage unit and energy consumption components of $\mathrm{MH}_{2}$ systems in general. It is hoped in the case of the C-S system that current research will lead to the manufacture of high-capacity storing adsorbents in the refrigeration temperature range, that is $150-200 \mathrm{~K}$. Consequently, the energy-consumption costs for the C-S system are likely to decrease considerably in the near future.

\section{CONCLUSIONS}

Efficient and cost-effective hydrogen storage is important if hydrogen storage systems are to become competitive with existing technologies, particularly in transportation applications, which require high-energydensity and lightweight storage. For utility and other stationary applications, the energy density and weight are not of prime consideration, but storage efficiency and systems costs are major considerations.

\section{ACKNOWLEDGMENTS}

The authors thank Dr. J. Wegrzyn of Brookhaven National Laboratories and Mr. A. Mezzina for their encouragement. Financial support has come from the U.S. Department of Energy via the National Renewable Energy Laboratory under contract XC-2-11081-1. Collaboration with Mr. William Hoagland is also acknowledged.

\section{REFERENCES CITED}

Agarwal, R.K., Noh, J.S., and Schwarz, J.A., 1987, Effects of surface acidity of activated carbon on hydrogen storage: Carbon, v. 25, p. 219-226.

Amankwah, K.A.G., Noh, J.S., and Schwarz, J.A., 1989, Hydrogen storage on superactivated carbon at refrigeration temperatures: International Journal of Hydrogen Energy, v. 14, p. 437-447.

Bandosz, T.J., Jagiello, J., and Schwarz, J.A., 1992, Comparison of methods to assess surface acidic groups on activated carbons: Anal. Chem., v. 64, no. 8 , p. 891-895.

Carpetis, C., 1980, A system consideration of alternative hydrogen storage facilities for estimation of storage costs: International Journal of Hydrogen Energy, v. 5, p. 423-437.
1982, Estimation of storage costs for large hydrogen storage facilities: International Journal of Hydrogen Energy, v. 7, p. 191-203.

Carpetis, C., and Peschka, W., 1980, A study of hydrogen storage by use of cryoadsorbents: International Journal of Hydrogen Energy, v. 5, p. 539-554.

Davidson, D., Fairlie, M., and Stuart, A.E., 1984, Development of a hydrogen-fueled farm tractor, in Advances in hydrogen energy, v. 4: Oxford, Pergamon Press, p. 1623-1630.

Deluchi, M.A., 1989, Hydrogen vehicles-An evaluation of fuel storage, performance, safety, environmental impacts, and cost: International Journal of Hydrogen Energy, v. 14, p. 81130.

Economic Indicators, 1988: Chemical Engineering, v. 95, p. 9.

Economic Indicators, 1992: Chemical Engineering, v. 99, p. 224.

Eklund, G., and von Krusenstierna, O., 1983, Storage and transportation of merchant hydrogen: International Journal of Hydrogen Energy, v. 8, p. 463-470.

Guthrie, K., 1969, Data and techniques for preliminary cost estimating: Chemical Engineering, v. 76, p. 114-142.

Jägiello, J., Bandosz, T.J., and Schwarz, J.A., 1991, Application of inverse gas chromatography at infinite dilution to study the effects of oxidation of activated carbons: Carbon, v. 30 , p. 63-69.

- 1992a, A study of the activity of chemical groups on carbonaceous and model surfaces by infinite dilution chromatography: Chromatographia, v. 33 , nos. 9, 10, p. 441444.

1992b, Inverse gas chromatographic study of activated carbons-The effect of controlled oxidation on microstructure and surface chemical functionality: Journal of Colloid and Interface Science, v. 151, no. 2, p. 433-445.

Lee, B.I., and Kesler, M.G., 1975, Generalized thermodynamic correlation based on three-parameter corresponding states: Journal of American Institute for Chemical Engineers, v. 21, p. $510-527$.

Noh, J.S., Agarwal, R.K., and Schwarz, J.A., 1987, Hydrogen storage systems using activated carbon: International Journal of Hydrogen Energy, v. 12, p. 693-700. Also, see J.A. Schwarz, U.S. Patent 4,716,736, assigned to Syracuse University.

Peters, M.S., and Timmerhaus, K.D., 1980, Plant design and economics for chemical engineers: Tokyo, McGraw-Hill Kogakutha Ltd., p. 166-168.

Stannard, J.H., 1984, Hydrogen fuel cell for high capacity buses, in Advances in hydrogen energy, v. 4,: Oxford, Pergamon Press, p. 1729-1741.

Wallace, J.S., and Ward, C.A., 1983, Hydrogen as a fuel: International Journal of Hydrogen Energy, v. 8, p. 255-268.

Williams, L.O., 1980, Hydrogen power-An introduction to hydrogen energy and its applications: New York, Pergamon Press, p. 115. 
Natural gas is produced from a variety of geologic settings, and it must be distributed over long distances and through a wide network where demand fluctuates over long- and short-term periods. These issues govern fluctuations and deliverability of energy gases from the wellhead to end users. All fuels compete with one another in terms of price, availability, and environmental concerns. Complex models for predicting natural-gas consumption have been developed to incorporate these factors. The reports in this section describe the role of economics in determining the amount of gas that is available, and the decisions end users and producers must make when choosing energy resources from among the various fuel options. 


\title{
History of Natural-Gas Consumption in the United States
}

\author{
By Michael Fanelli ${ }^{1}$
}

\section{CONTENTS}

Abstract 737

Introduction 737

Early Years 738

A Period of High Growth for the Industry 738

The Beginning of Instability for the Gas Industry ..... 740 Continued Attempts at Regulation ............................ 742

The Natural Gas Policy Act of 1978 ......................... 744

What Goes Up Might Come Down ........................... 744

The Future of the Natural-Gas Industry ..................... 746

References Cited ............................................ 747

\begin{abstract}
The history of the natural-gas industry illustrates a complex interplay of technological advancement, economic activity, federal regulation, and competition among fuels. These factors have all influenced the industry's growth and stability. Historical statistics document how, over recent decades, gas exploration and development activities have varied greatly from high levels to low levels. Perceptions and estimates of the Nation's natural-gas resource base have influenced natural-gas availability and demand. The use of gas in various end-use sectors illustrates the effects of equipment efficiency and attitudes about conservation in the residential and commercial markets. Additionally, shorter term issues of availability and price affect use in the industrial and electricity generation sectors.
\end{abstract}

'U.S. Geological Survey, MS 999, 345 Middlefield Rd., Menlo Park, CA 94025.

\section{INTRODUCTION}

Nearly two centuries have passed since methane was first demonstrated as a potential contributor to the U.S. energy mix. During that time, the U.S. gas industry has evolved from its beginning as a local supplier of coal-derived gas, which first competed with tallow candles and whale-oil lamps for lighting streets and homes. The industry has since grown rapidly as the development of production, distribution, and consumption technologies has greatly expanded gas availability, transmission capacity, and applications for natural gas. Today, natural gas is delivered to nearly 55 million homes and businesses throughout the $\mathrm{Na}$ tion as a fuel to condition living and working environments, to serve as a chemical feedstock and provide heat for many industrial processes, and to drive electricity generation.

The industry's entire history has been shaped by a complex interplay of market forces, technology advancement, and regulatory control. Notions of an inexpensive fuel with versatile applications and efficient performance created robust market demand in many economic sectors and geographic regions. Significant technological improvements and large capital investments made it possible to discover, produce, and transport gas supplies long distances to end users. Government oversight and regulation ensured that the entire process took place within established, but frequently changing, guidelines to protect the public's safety and interest.

Like other natural resource extraction industries (coal, oil, and metals), the U.S. natural-gas industry has experienced periods of growth as well as decline. During national economic expansion, the gas industry prospered as the $\mathrm{Na}$ tion's energy requirements grew. Other periods, marked by unforeseen business developments, regulatory influences, and changing attitudes towards energy consumption, have caused large and rapid fluctuations in gas consumption. Readjustment and stabilization are the principal objectives of today's gas industry. 
The complex history of U.S. gas consumption can possibly illuminate future opportunities and possible limitations for increased use of natural gas in the United States.

\section{EARLY YEARS}

In the early 1800 's, methane was burned in the United States to provide heat for industrial processes and for illumination of homes and town streets (National Petroleum Council, 1992; Watson, 1992; Energy Modeling Forum, 1989a, b). It was less expensive and brighter burning than the whale oil burned in lamps or the tallow candles used at the time. In most regions of the country where methane was used, particularly in the northeastern region, it was manufactured, as "town gas," initially from coal and wood, and later from oil as well. Readily available, inexpensive supplies of coal, wood, and oil justified their conversion, albeit inefficient, to gas, a more versatile fuel than others. Because gas could be delivered in small, continuous volumes through installed piping, it was operationally and economically favorable in some applications, especially highly distributed, low-consumption applications such as street lamps.

During the late 1800's in the Appalachian states of Pennsylvania, New York, Ohio, West Virginia, and Kentucky, natural gas was collected from wells drilled into shallow oil and gas accumulations and transported through pipes to nearby consumers. Often, these scarce natural-gas supplies were blended with the low-methane-content manufactured gas to improve its heating value. Regardless of whether the methane was manufactured or naturally occurring, however, gas delivery was restricted largely to local use because of the technical challenges of long-distance transportation and (or) storage of large volumes of gaseous materials.

By the early 20th century, with Edison's invention of the light bulb, electricity began to replace gas as the preferred energy for illumination. The gas industry responded by developing and promoting other gas-consuming applications and equipment for household, commercial, and industrial uses. Gas was increasingly being used in stoves for cooking as well as for heating of homes and water.

The gas markets of the 19th century and early 20th century were initially regulated at the state and local level. The earliest pipeline systems were often poorly constructed; the poor construction resulted in leaky, inefficient, and unreliable service. Fierce competition for a rapidly expanding base of gas-consuming customers, primarily local industrial and residential users, resulted in excessive and disruptive pipeline construction. Streets were frequently torn up as competing suppliers installed new, and often redundant, distribution systems. Situations like this led to regulations intended to assuage concerns about safety and reliability. Market monopolies were given to local gas-dis- tribution companies in exchange for regulatory controls. Price constraints and service standards were established to protect consumers from market abuses.

The natural-gas industry grew rapidly as abundant domestic supplies of natural gas became apparent early in the 20th century. In the 1920's, large accumulations of gas were discovered as a consequence of intensive oil-exploration efforts motivated by increasing petroleum supply requirements for use in the military, by industry, and by America's burgeoning population of personal automobiles. The largest gas reserves were located in the oil-producing regions of Oklahoma, Texas, and Louisiana. Without technology for long-distance gas transportation and distribution, however, access to new gas-consuming markets in other parts of the country was greatly limited. This meant that large quantities of produced gas, if not reinjected into wells for reservoir pressure maintenance, were vented or flared as the gas was separated from the highly valued oil at production wellheads. Pilots flying over Texas at night could easily navigate through the darkness by the bright light of natural gas being flared from Texas oil fields below. The excess supply situation assured very low gas prices for those consumers who were fortunate enough to receive it.

Compared to alternative fuels on a price-per-unit-ofenergy basis, gas was often the low-cost option. The allure of inexpensive energy and excess regional supplies resulted in advances in gas transportation and consumption technology. During the 1920's, technologies that had been developed for wartime applications became available for peacetime use. New technologies for gas compression and the development of seamless pipe made it possible to transport large quantities of gas long distances through pipelines. In 1931, the first truly long distance gas pipeline was completed, a 1,000-mile pipeline built by the Natural Gas Pipeline Company to transport gas from the fields in Texas and Oklahoma to Chicago.

\section{A PERIOD OF HIGH GROWTH FOR THE INDUSTRY}

During the 1940 's, 50 's, and 60's, the Nation's overall energy consumption expanded greatly to keep pace with the Nation's industrial and household growth. Total energy consumption in the United States nearly doubled from 34 to 67 quads ( 1 quad $=1$ quadrillion Btu's or British thermal units) between 1950 and 1970 (fig. 1). Economic growth occurred at a similar rate. The increase in energy consumption during that period was the primary means of improving the standard of living for many Americans. Clean, safe, and efficient natural-gas combustion technologies opened new markets throughout the country for space- and water-heating applications in residential and commercial buildings. Gas pipe- 


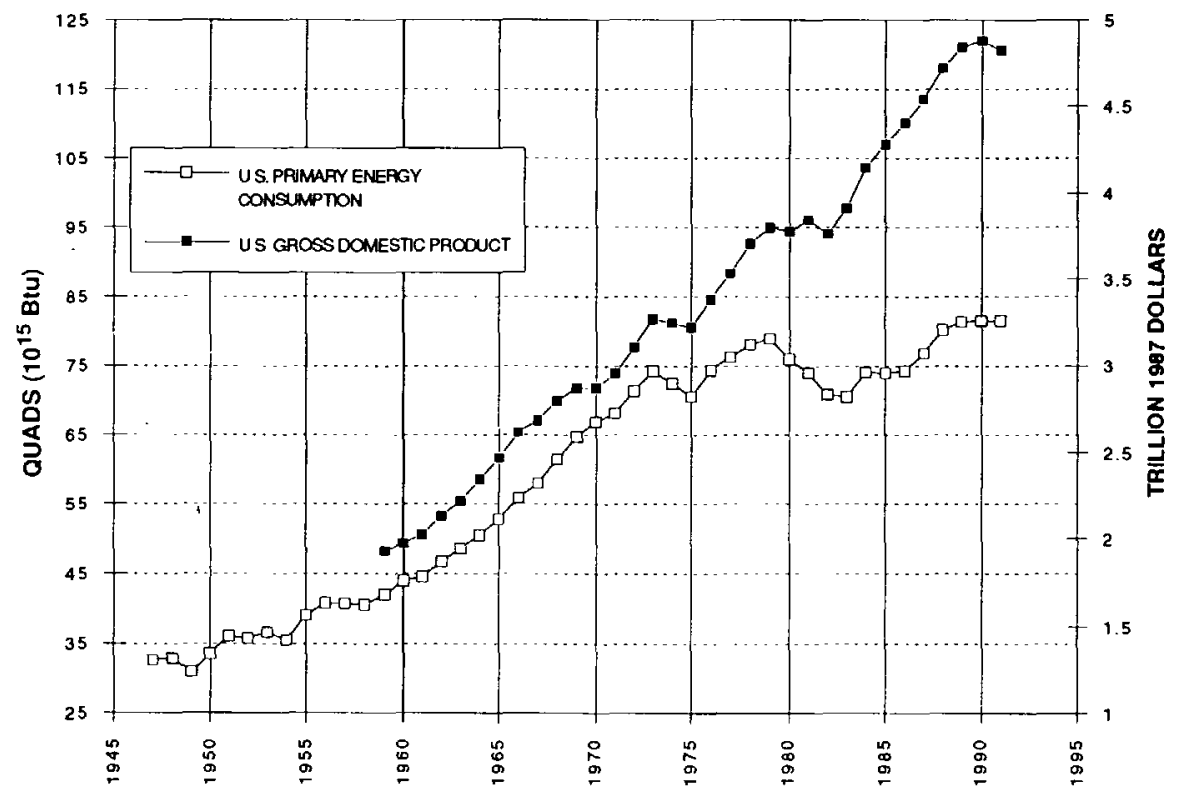

Figure 1. U.S. primary energy consumption (open squares, left scale), 1947-1991, in quads, and U.S. gross domestic product (solid squares, right scale), 1959-1991, in trillion 1987 dollars. Data from Energy Information Administration, 1992; American Petroleum Institute, 1992.

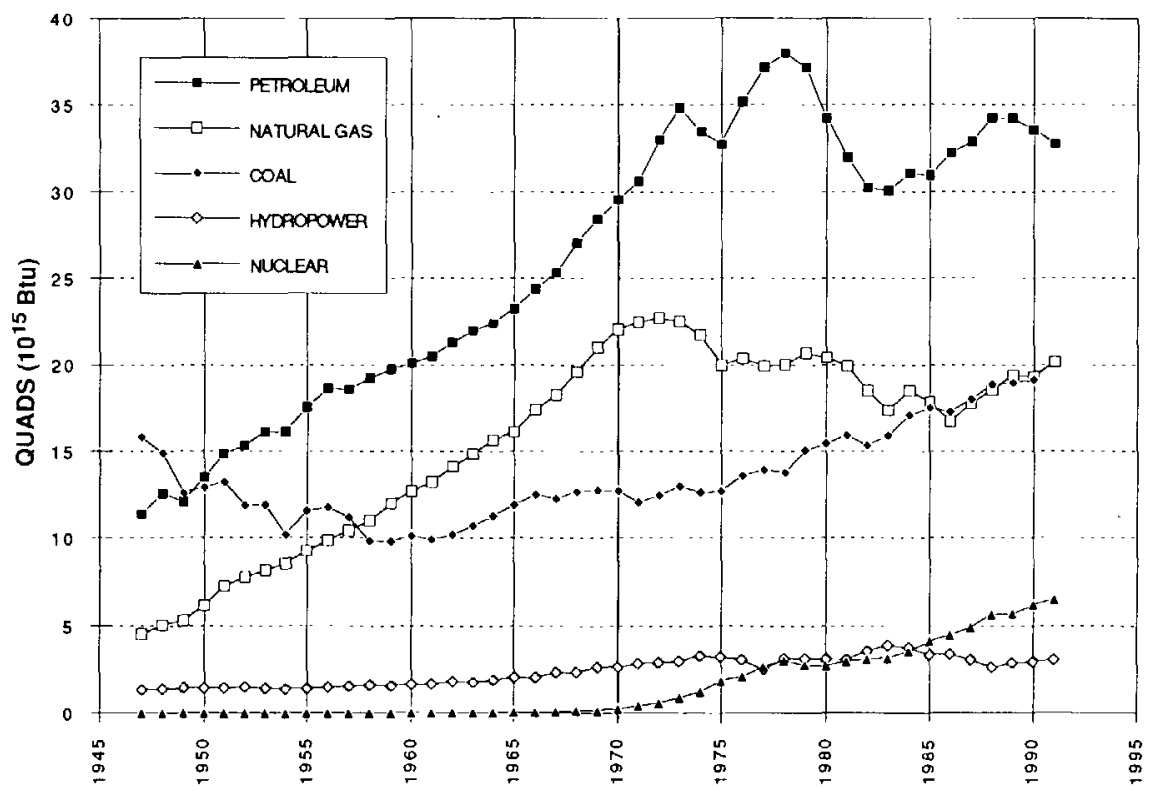

Figure 2. U.S. primary energy consumption by energy source, in quads, 1947-1991. Data from Energy Information Administration, 1992.

line capacity expanded rapidly to provide gas service to large population and industrial centers around the country, particularly in the north-central region. Natural-gas deliveries to end users increased nearly four-fold, from approximately 6 quads in 1950 to approximately 22 quads in 1970 (fig. 2). The contribution of natural gas to the Nation's total consumption of primary energy sources (oil, coal, natural gas, hydropower, and nuclear) grew from 18 percent in 1950 to almost 33 percent in 1970 . The low cost, ready availability, and clean-burning characteristics of gas made it the fuel of choice for many applications. Each energy-consuming economic sector, with the exception of transportation, experienced large increases in gas consumption during this same period (fig. 3). (The transportation sector continues to be 


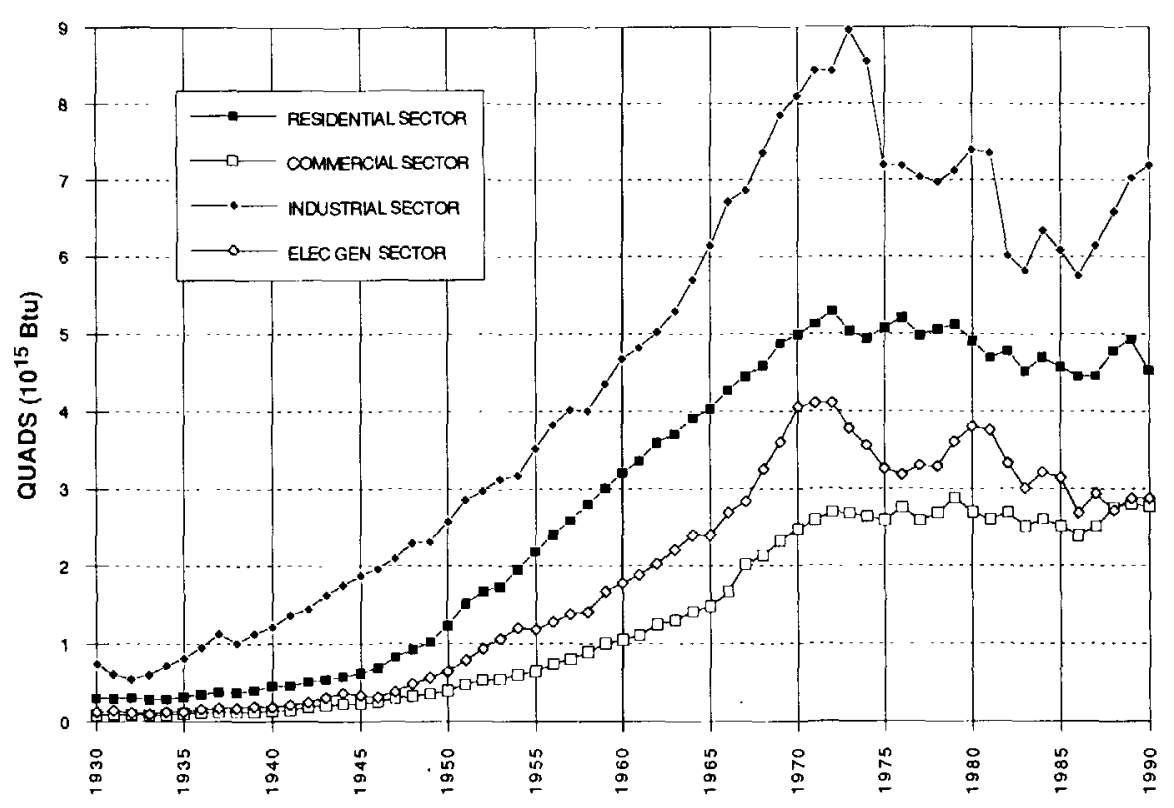

Figure 3. U.S. natural-gas consumption by economic sector, 1930-1990. ELEC., electrical; GEN., generation. Data from Energy Information Administration, 1992; 1991b, c; American Gas Association, 1991.

nearly exclusively reliant on refined oil products: gasoline, diesel, and aviation fuels.)

\section{THE BEGINNING OF INSTABILITY FOR THE GAS INDUSTRY}

A significant portion of the increased natural-gas demand during the 1940's, 50's, and 60's was stimulated by the ready availability of gas and its low price; people were anxious to use an inexpensive, clean, safe, and domestically available fuel in their homes and businesses. If this rapid growth in consumption had been the result of freemarket forces of supply-demand balancing and competitive pricing, the industry would have had a very bright and stable future. The prevailing gas prices, however, were controlled by government regulation. These external constraints would later have considerable impact on market dynamics, and their effects continue to this day.

The initial federal regulating agency, the Federal Power Commission, was established by the Natural Gas Act of 1938. This agency, replaced in 1978 by the Federal Energy Regulatory Commission (FERC) was given jurisdiction over interstate gas commerce. The Federal Power Commission felt, at the time, that public interest was best served by imposing government controls on the increasing quantities of gas that was traded across state borders. The rapidly growing gas industry sought government oversight and intervention to assure an orderly and sensible program of pipeline construction. Without any real competition between interstate gas suppliers, price constraints in the form of wellhead price controls seemed necessary to ensure sta- ble prices for consumers. As a result, beginning in 1954, the commission also imposed controls over producer prices for gas destined for interstate transportation and sales.

However, the Federal Power Commission did not have jurisdiction over intrastate gas commerce; therefore, wellhead prices for gas produced and consumed within the same state were exempt from federal regulation. Texas, Louisiana, and Oklahoma, which produced most of the gas for interstate markets, were also home to large energy-intensive manufacturing and petrochemical industries, which were large customers for intrastate gas supplies (National Petroleum Council, 1992). This local, industrial demand for gas grew. fast enough to foster strong competition for intrastate supplies and caused intrastate prices to exceed interstate prices. This situation essentially established two natural-gas markets, which competed for the available gas supplies-an interstate market with federally regulated prices and an intrastate market without regulated prices. Gas producers, given a choice of markets for their products, opted to drill for gas and commit (contract to sell) the production to the higher priced intrastate market. In remote producing areas, which had fewer intrastate customers and were therefore dependent upon interstate markets for their gas, the producers received lower prices for their supplies. Accordingly, gas exploration and production activities in these areas declined. The gas industry was set on a collision course with a supply crunch.

Until 1967, exploration and development drilling for gas had been very successful in identifying new U.S. gas reserves. As additional wells, known as development wells, are drilled within gas fields to optimize the extraction of 

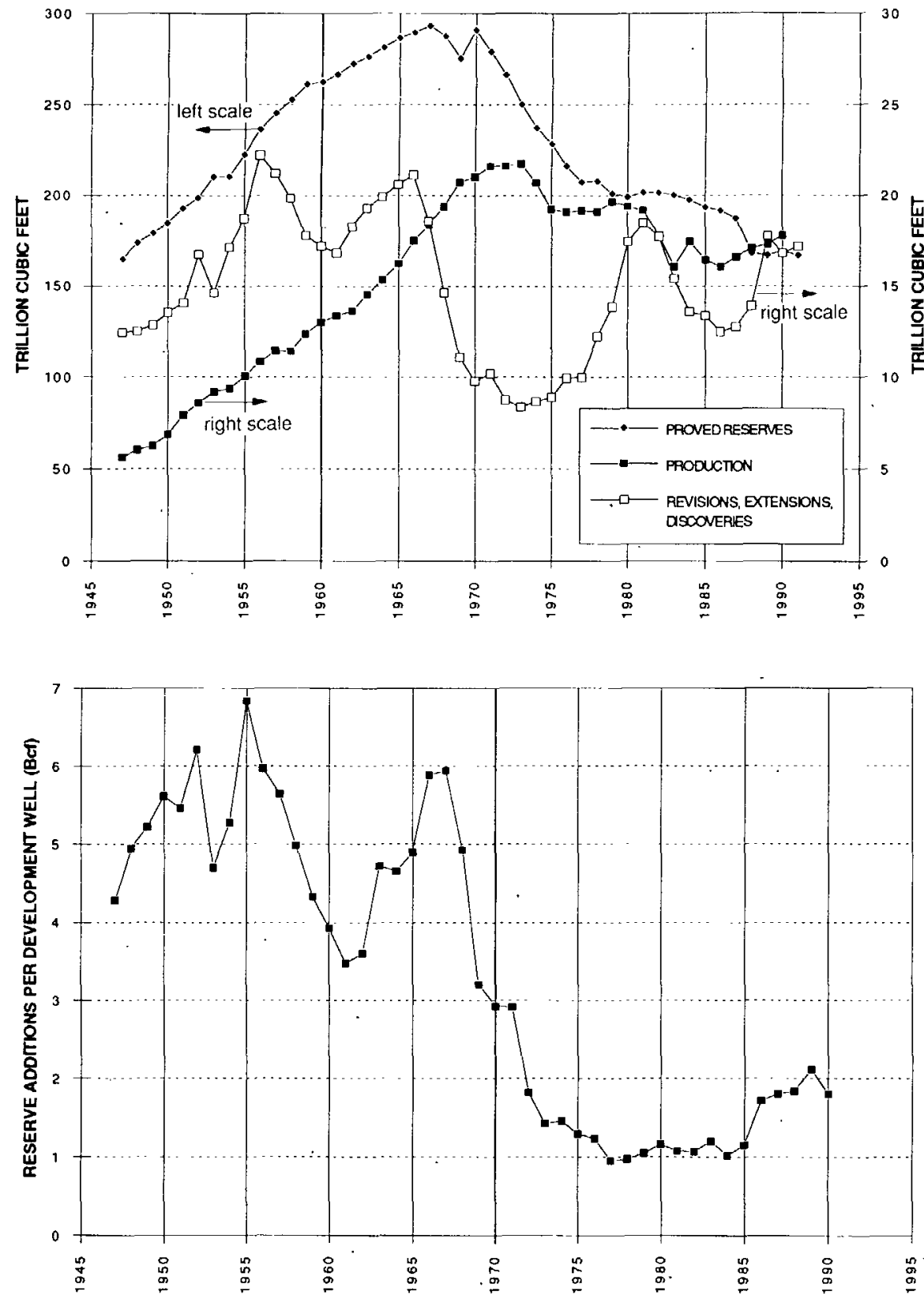

Figure 4. U.S. proved natural-gas reserves, production, and reserve replacements, 1947-1991. Reserve data include the addition of 26 trillion cubic feet in 1970 , accounting for the natural gas in the Alaskan Prudhoe Bay field, which was discovered in 1968. In 1988, 24.6 trillion cubic feet of Alaskan natural gas reserves were removed owing to economic and market conditions. Natural-gas production data is total U.S. dry gas production, including Alaskan production, reflecting gross gas withdrawals less gas used for repressuring, removal of non-hydrocarbon gases, gas that is vented and flared, and the extraction loss, which is a volume reduction resulting from the removal of natural gas plant liquids. Revisions, extensions, and discoveries are averaged using a three-year moving average. Data from American Gas Association, 1992; Energy Information Administration, 1992; American Petroleum Institute, 1992.

Figure 5. Natural-gas reserve replacements per development well drilled, 1947-1990. Data from American Petroleum Institute, 1992; Energy Information Administration, 1992. Bcf, Billion cubic feet. gas, the producers learn increasingly more about the actual, ultimate size and shape of the gas accumulation. With this information, they are able to update and revise their estimates of the gas remaining to be extracted. This process results in annual revisions to the gas-reserve estimates for previously discovered fields. In addition, field growth results when producers drill wells, known as extension wells, around or below currently producing area of fields. Often these wells result in new production from deeper and shallower zones or surrounding accumulations that previously had not produced. This process results in annual field extensions and the development of new producing intervals in existing fields. A third category of wells, known as new field wildcats, are drilled in locations distant from existing fields in hopes of discovering new fields. The newly discovered fields represent new-field additions to U.S. gas reserves. Accordingly, total annual U.S. gas-reserve additions include the revisions to field-reserve estimates, reserves identified by field extension and in-field exploratory activity, and new field discoveries. Despite steadily increasing gas consumption, annual gas-reserve additions continued to exceed the total national annual gas production rates until 1967 (fig. 4). This phenomenon resulted in growing estimates of the Nation's total proved gas reserves. During this period, total reserve additions averaged $5 \mathrm{Bcf}$ (billion cubic feet) per development well completed (fig. 5). 


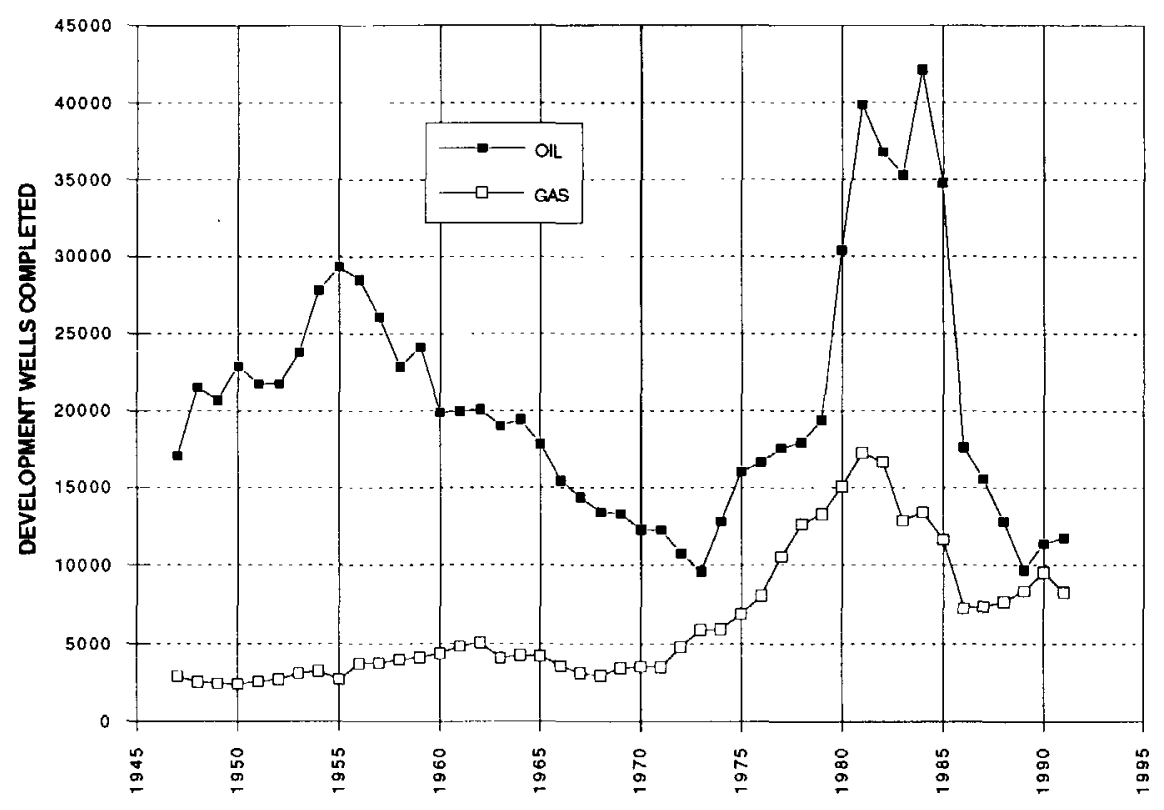

Figure 6. Oil and gas development wells completed, 1947-1991. Data from Energy Information Administration, 1992.

Gas consumers were very encouraged by continued low gas prices and optimistic reports of rapidly growing reserve estimates. It appeared as though vast and easily found gas supplies would ensure long-term, inexpensive natural-gas supplies well into the future. This optimistic outlook encouraged increased investment in gas-burning equipment for industrial purposes and continued pipeline extension to growing cities for use in new residential and commercial developments, primarily for space and water heating.

Low, regulated wellhead prices for gas destined for interstate commerce, however, discouraged some producers who had limited intrastate gas markets from undertaking gas-field exploration and development activities, particularly field infill and extension drilling. As a result, the Nation's development drilling activity decreased significantly from 5,000 gas development well completions in 1962, the highest level since before 1950, to approximately 3,000 completions in 1968 (fig. 6). In addition, new gas-field exploration drilling declined from more than 300 successful wildcat wells in 1962 to less than 130 in 1968 (fig. 7). Over an extended period beginning in 1968, annual reserve replacements fell far short of national production (fig. 4). Consequently, gas reserves peaked in 1967 at more than 290 Tcf (trillion cubic feet), a 17 year supply at 1967 consumption rates. The highly successful and prolific exploration and development trends in the Gulf of Mexico began to only grudgingly yield new discoveries and field extensions. As a result, after 1967, annual gas production exceeded reserve additions and the Nation's proved reserves began to decline rapidly (fig. 4).

Despite declining gas-reserve estimates, gas production and consumption actually increased by nearly 30 per- cent between 1967 and 1973. Each energy-consuming sector continued to increase gas consumption through 1972 (fig. 3). Another 5 million homes with gas-burning appliances were connected to gas-distribution systems (fig. 8). Nearly 500,000 additional commercial establishments were built or converted to gas service. Electric power generators consumed greater amounts of gas to fuel their boilers.

In 1973, gas production peaked at $22 \mathrm{Tcf}$, but it began to decline rapidly thereafter. Producing wells were unable to deliver enough gas to meet demand. Too few new wells, exploratory or development, were being drilled to replace the decline in gas production. The Nation's gas supply was seemingly being rapidly depleted. As wellhead production declined, the amount of gas available to pipelines was reduced, and pipelines were unable to meet the gas demands of all their customers. Supply shortages were felt primarily by industrial and power generation consumers whose gas supplies were curtailed. An eight-step curtailment plan was established to prioritize gas customers and determine gas deliveries during periods of shortage. Gas production continued falling through the mid-1970's and delivery shortages, at their worst, in 1977 , caused nearly $4 \mathrm{Tcf}$ of curtailments. Loss of gas service forced closings of businesses, industry, and government buildings throughout the country.

\section{CONTINUED ATTEMPTS AT REGULATION}

The gas-supply disruptions of the early 1970's led government regulators to reevaluate wellhead price controls 


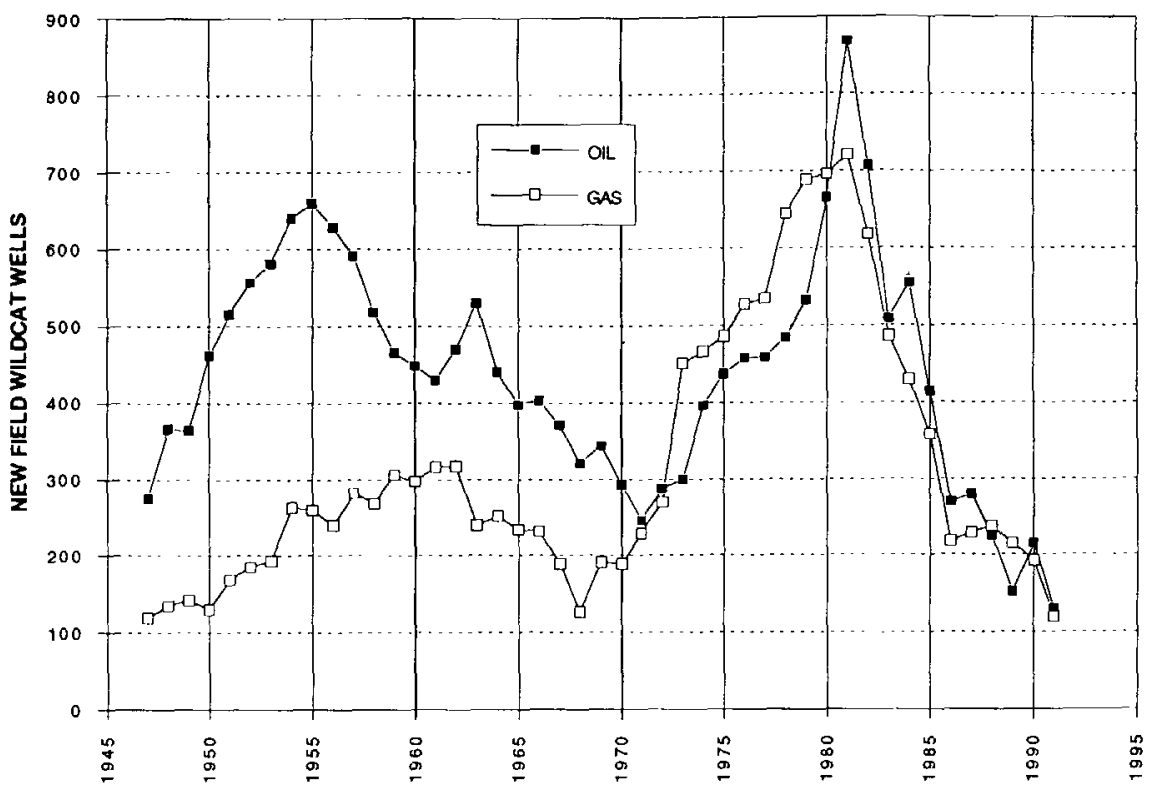

Figure 7. Successful oil and gas new field wildcat wells, 1947-1991. Data from American Petroleum Institute, 1992.

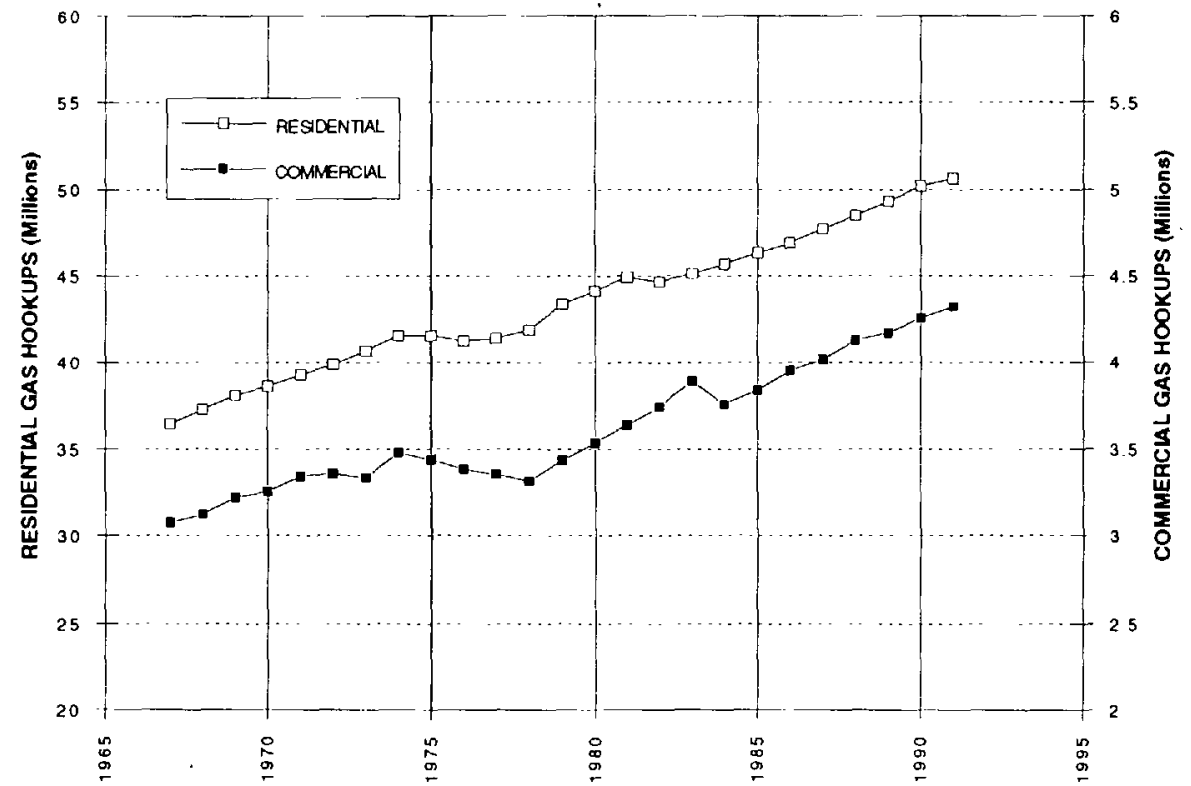

Figure 8. Total U.S. residential and commercial gas service hookups, 1967-1991. Data from American Gas Association, 1992.

and the impact that strict industry regulations were having on market dynamics. It was easy to draw the conclusion that gas supplies were falling because too few development wells were being drilled to replace the declining production from existing wells. Furthermore, producers were not drilling development wells because the wellhead price controls made it uneconomic for them to do so.

Wellhead price controls were relaxed considerably in the mid-1970's as an incentive to explore for, develop, and produce more natural gas. Producers responded with dramatic increases in development drilling; by 1977, development drilling for gas had increased to more than 10,000 gas well completions per year from a low of 3,000 in 1968 (fig. 6). As expected, increased gas exploration and development drilling was successful in identifying new gas reserves during this period. The total annual reserve additions, however, continued to be less than annual gas production rates, and, consequently, estimates of the Nation's total 
proved gas reserves continued to decline throughout the 1970's (fig. 4).

Other trends raised concerns about the reliability of long-term gas supplies. While large annual increases in development drilling activity added, as expected, greater amounts of new reserves annually, the rate at which new reserves were being found had fallen dramatically. During the 1970's, new reserves were being added at an average rate of only $1 \mathrm{Bcf}$ per development well; this was one-fifth the average additions for development wells drilled prior to 1968 (fig. 5). Large numbers of gas development wells were being drilled, but each was finding smaller amounts.

Because less gas was being found, it appeared as though the Nation's gas-resource base was dwindling, that supplies may indeed be resource limited, that increased development drilling may not reverse the decline in reserves, that supplies would continue not to meet demand, and that curtailments of gas service would continue. Gas consumers, particularly industrial and electric generation customers, rapidly began to lose confidence in both nearand long-term gas supplies. Fuel-supply planning for these consumers and new industrial developments initiated alternative energy strategies (sourced by coal, oil, and electricity) that would hopefully be more reliable.

\section{THE NATURAL GAS POLICY ACT OF 1978}

Congress responded to supply shortages with the Natural Gas Policy Act (NGPA) of 1978, which created the Federal Energy Regulatory Commission (FERC) as well as some energy policies. Realizing that sufficient future natural-gas supplies were critically dependent on producer development drilling and new field exploration activities, which were in turn dependent on market-value incentives, the NGPA began the process of removing wellhead price regulations. Wellhead prices for various types of gas were scheduled for deregulation over the next several years. Price distinctions were made between gas produced from currently producing wells and newly drilled wells, as well as for gas produced from different depths. The NGPA also extended federal pricing regulations to the intrastate markets. This eliminated the two-market situation for gas producers.

Long-term gas purchase contracts between pipelines and producers were negotiated to reflect the federally defined gas-price schedules. With the incentive of significantly higher gas prices for producers, exploration and development drilling for gas responded quickly; exploration success increased from 550 wells in 1977 to more than 700 wells in 1981, and development drilling increased from 13,000 completions in 1978 , to 17,000 in 1981 (figs. 6, 7).

From 1978 to 1980 , despite the large increase in drilling activity, development drilling continued to be less produc- tive than in previous decades; reserve additions continued at an average of only $1 \mathrm{Bcf}$ per well. However, further increases in the number of development wells drilled in 1980 resulted in sufficient new reserves being added to replace the amount of gas produced. As a result, proved reserves estimates in 1980 stopped a 13-year decline. It appeared as though a fragile stabilization in the gas industry might have been established.

In addition to deregulation of wellhead prices, tax incentives were established in 1980 that encouraged exploration and development of unconventional natural-gas resources. A provision of the Federal tax code, known as "section 29," provided for substantial tax credits for natural-gas production from shales, coal beds, and "tight" (low permeability) formations. It was felt that this tax incentive would stimulate production of the Nation's unconventional natural-gas resources, lead to the development and improvement of technologies used in the production of gas from unconventional accumulations, and expand the Nation's natural-gas reserves by encouraging development of unconventional resources. The section 29 tax credit remained in effect until December 31,1992 ; qualifying wells that were completed prior to that date will continue to receive the credit for natural gas produced until 2002. During the 12-year period that the tax credit for unconventional natural-gas production was available, it is estimated that approximately 45 percent of all natural-gas completions were drilled with the benefit of the section 29 tax credit (oral commun., 1993, P. Stark, Petroleum Information Corporation).

\section{WHAT GOES UP MIGHT COME DOWN}

The mid-1970's through the early 1980's was also a period of dramatically higher global energy prices, primarily as the result of several sudden increases in crude-oil prices (fig. 9). These price increases were the effect of foreign government pricing policies for crude oil that they exported. Because a few governments had control of vast oil supplies, which were shipped to all corners of the globe, they were able to manipulate the international oil market by controlling production and setting prices to their satisfaction. Despite these largely capricious price manipulations by artificial, external, and nonfree market forces, the industry's prevailing perspective was that an enduring pattern of escalating energy prices had been established. With that view, oil prices were projected by most experts to continue rising (see Howell and others, this volume). The high oil prices and projections of ever higher prices spurred dramatic increases in domestic oil exploration and development activity (figs. 6, 7).

Within a context of rising oil prices, it seemed reasonable to regulators, producers, and gas purchasers that natural-gas prices could, or should, rise as well. The NGPA of 1978 adopted just that philosophy in their wellhead price 


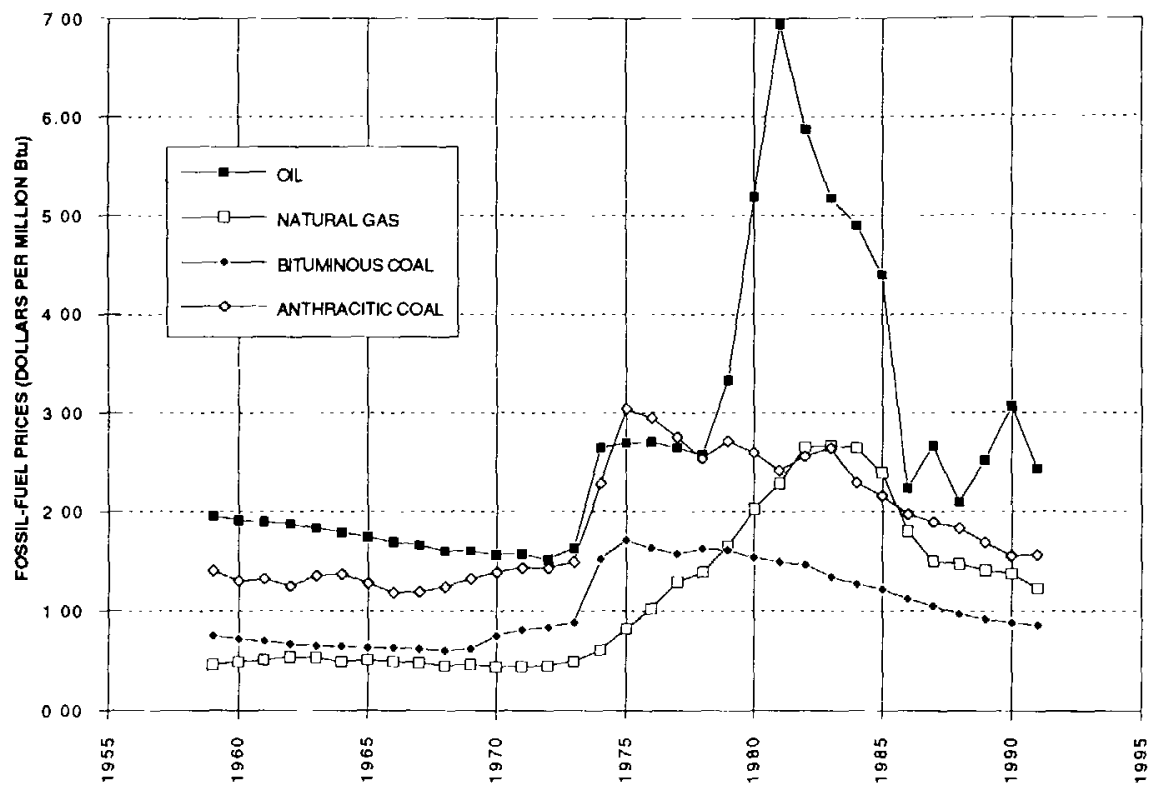

Figure 9. Oil, gas, and coal prices in constant 1987 dollars per million British thermal units (Btu), 1959-1991. Data from Energy Information Administration, 1992.

decontrol schedules for natural gas. Gas prices were allowed to rise to provide increased incentive for domestic gas exploration and production activities.

Pipeline companies had just been through an extended period of supply shortages during the mid-1970's which forced curtailments of gas service to many of their customers. To avoid a repeat of those circumstances, most pipelines sought to ensure firm, long-term gas supplies from producers. The gas market, therefore, became more of a sellers market; gas producers gained more favorable terms for their gas. To ensure reliable supplies, gas purchase contracts between producers and pipelines were often negotiated as long-term contracts with future prices adjusting according to the regulated schedule of maximum allowable wellhead prices. Often, these contracts also obligated purchasers (pipeline companies) to pay for contracted amounts of gas, whether or not the purchasers actually had a market for the gas. This was commonly known as the "take-or-pay" contract clause, and it ensured producers of steady income, which they could use to continue their development activities. Pipeline companies were willing to agree to those terms because they also seemed satisfied that rising global crude oil prices would create a U.S. energy market that would favor gas use, even at significantly increased prices. Furthermore, because they had just gone through a period of too little supply and too many customers, they were very confident of having enough customers for the amounts and prices of gas their contracts committed them to buy from producers.

However, the interstate gas market, which experienced severe supply shortages of the late 1970's, quickly and unexpectedly became an oversupplied market in the early 1980's. Gas demand declined very rapidly in the early 1980's (fig. 3) for several reasons--attitudes toward energy consumption became more conservative, economic recession in 1981 reduced industrial activity and overall energy demand, oil prices declined very rapidly after the early 1980's and diminished the gas-price advantage over oil, and so dual-fuel customers increasingly used oil instead of gas.

The curtailments of gas service during the 1970's had been so disruptive to many gas customers, especially industrial and electricity generation consumers, that they held lingering concerns about long-term reliability of gas supplies. Because of rising gas prices, they also saw a diminishing cost-of-energy advantage of gas over alternative fuels. Many gas consumers with dual-fuel (oil, coal, and (or) gas) burning capability turned to oil and coal to meet their energy needs. Gas consumption in the industrial sector fell by more than 33 percent from approximately 9 quads in 1973 to less than 6 quads in 1983. During the same period, gas consumption in the electricity generation sector fell by 25 percent from approximately 4 quads to nearly 3 quads (fig. 3 ).

The higher energy costs also increased public interest in energy efficiency and conservation measures. Tax incentives to reduce energy consumption were also a factor in energy conservation. Among residential and commercial customers, the trend toward increasingly energy efficient equipment and conservation programs, which were begun in the early 1970's, continued and caused significant reductions in gas consumption by the average individual customer (American Gas Association, 1992). Significant improvements in furnace design and construction, for example, have resulted in 
the delivery of much more heat with less fuel. Replacement of old, inefficient furnaces as they come to the end of their useful lives with new equipment has further reduced the demand for energy for space-heating needs. Greater thermal insulation in new construction and insulation added to existing construction has also reduced the per-building consumption of energy to heat and cool. While the per-customer consumption of gas continued to decline significantly, overall gas consumption by both residential and commercial sectors remained stable only because of large numbers of new customers.

The customer groups that account for marginal gas demand are high-volume industrial and electrical generation consumers. While the average residential customer consumes approximately $90 \mathrm{MMBtu}$ (million British thermal units) per year and the average commercial customer consumes approximately 500 MMBtu per year, the average industrial and electricity generation customer consume approximately 10,000 and $1,800,000 \mathrm{MMBtu}$ per year, respectively (American Gas Association, 1992). Whereas there are only few marginal consumers compared to the residential and commercial market, each one consumes such large amounts of energy that the fuel choices they make influence the overall demand for specific fuels; fuel switching by industrial and (or) electricity generation customers can cause significant fluctuations in the supply and demand of individual fuels (Electric Power Research Institute, 1992). Many of these consumers use gas in applications for which they have alternative fuel-burning capability, such as steam boilers. Many can switch on very short notice to the most readily available and reliable fuel supply, or the least expensive fuel at the time. For industrial consumers, fuel choices often are made on the basis of the differences between delivered prices of various grades and types of refined oil products, coal, and natural gas. Small adjustments in the price differences between fuels will often influence fuel choice, which can have a large impact on overall fuel demand.

In comparison, residential and commercial consumers are much more firm gas customers. These customers generally have limited, if any, ability to switch energy supplies to meet their needs. Most of their fuel use is for space heating and cooling, and the equipment installed for these purposes is usually single-fuel burning equipment. At the time of initial building design and construction, a fuel-choice decision is made and equipment is installed to burm that particular fuel. In most residences, space-heat requirements are met by furnaces burning distillate oil or natural gas, or by electrical heating systems.

By 1986, the Nation's overall natural-gas consumption had fallen by more than 25 percent from its 1972 peak of 23 Tcf to less than 17 Tcf (fig. 2), primarily as a result of sharply reduced demand in the industrial and electricity generation sectors. Many industrial consumers and electricity generators used alternative fuels more frequently. Refined oil products became increasingly price competi- tive with natural gas as the price of crude oil fell dramatically during the mid-1980's (fig. 9). Many pipelines, however, which had firm, long-term contracts with producers for gas supplies, accrued large financial liabilities under the take or pay commitments they had made during times of much higher projections of gas consumption and higher energy prices. The excess deliverability capacity became known as the "gas bubble."

\section{THE FUTURE OF THE NATURAL-GAS INDUSTRY}

Since 1983, the gas industry has been undergoing a complex and prolonged process of regulatory revision (National Petroleum Council, 1992). The goal is to transform the industry from one that is heavily dependent on regulation to a more market-driven business (see Nesbitt, this volume). During this process, the traditional functions of natural-gas producers, transporters, distributors, consumers, and regulators have changed. Wellhead gas prices, as of January 1, 1993, have been entirely deregulated. Pipelines are moving away from their role as gas merchants and are now largely providing gas-transmission and underground storage services for gas producers, distribution companies, and industrial consumers. Many large-volume gas consumers, particularly the industrial and electricity generation customers, who previously had bought gas supplies from pipelines, are now contracting for gas supplies directly with producers, and are buying customized transportation services from pipelines. Natural-gas prices have declined significantly from their highs in 1983 and 1984, and demand for gas has increased strongly since 1986.

As gas exploration and development activities proceed without price regulations, the market should more closely approach a natural equilibrium between supply and demand. Gas markets will respond more easily and quickly to changes in energy demand. Consumers will enjoy greater control over their fuel-supply planning.

Concerns, however, linger over the long-term U.S. gas supply outlook (Butler and Stark, 1993; Crow and Koen, 1993; Koen, 1992; Riva, 1993). In particular, there is reason to believe that the recent low levels of exploration and development activities will soon lead to shortages of natural-gas supply. Many large-volume consumers, particularly the electricity generation sector, are unconvinced of the gas industry's ability to maintain, much less increase, natural-gas delivery at prices that are competitive with alternative fuels. These consumers are often faced with fuelchoice decisions during planning, design, and construction of long-term, capital-intensive projects involving fuelburning equipment. Availability, reliability, price, performance, and environmental impact are just a few of the parameters of fuel choice. These consumers also have unique 
requirements for gas service that may be difficult for pipelines to meet.

Using natural gas to provide more of the Nation's energy mitigates several environmental and economic issues, which relate to energy consumption. Its use will augment a recovery from the prolonged period of depressed activity in the domestic industries that explore for, develop, and transport natural-energy resources to end-users. Its use will also help to mitigate the environmental impacts of fossilfuel combustion by reducing the emissions of greenhouse gases and atmospheric pollutants, which result primarily from coal and oil combustion. Furthermore, its use presents an opportunity to reduce a fragile dependence on foreign sources of energy, particularly oil, and the unfortunate consequences of that dependence. The reduction of dependence on foreign oil may very likely result in reduced military expenditures, fewer deadly conflicts, more political and price stability, and less threat of tanker spills that spoil coastlines and marine environments.

If historical experiences and trends can be used to develop a perspective of future possibilities, the U.S. naturalgas industry is likely to continue a process of regulatory and technological evolution. When the unavoidably high levels of uncertainty that pervade the technically challenging and economically sensitive process of natural resource exploration and exploitation are combined with a dynamic market for natural gas and other forms of energy, the industry's future is indeed difficult to predict with any reasonable degree of certainty (see Howell and others, this volume).

\section{REFERENCES CITED}

American Gas Association, 1992, Gas facts-1991 data, 204 p. [Available from the American Gas Association, 1515 Wilson Boulevard, Arlington, VA 22009].

American Gas Association, 1991, Gas consumption in the United States-1990 data and forecasts, v. 18, 69 p. [Available from the American Gas Association, 1515 Wilson Boulevard, Arlington, VA 22009].
American Petroleum Institute, 1992, Basic petroleum data bookPetroleum industry statistics, v. 12, no. 2.

Butler, J.R., and Stark, P.H., 1993, U.S. gas outlook-Where will we get it?: World Oil, February 1993, p. 39.

Crow, P., and Koen, A.D., 1993, Supply/demand concerns top U.S. gas industry agenda in '93: Oil and Gas Journal, April 26, 1993 , p. 21.

Electric Power Research Institute, 1992, Natural gas for electric generation-The challenge of gas and electric industry coordination [Available from the EPRI Distribution Center, 207 Coggins Drive, P.O. Box 23205, Pleasant Hill, CA 94523].

Energy Information Administration, 1991a, Natural gas productive capacity for the lower 48 states, 1980 through 1991 , DOE/EIA-0542, 77 p. [Available from the National Energy Information Center, EI-231, Energy Information Administration, Room 1F-048, Forrestal Building, Washington, D.C.]. 1991b, Natural gas annual 1990, DOE/EIA-0131/1, v. 1, 253 p. [Available from the National Energy Information Center, EI-231, Energy Information Administration, Room 1F-048, Forrestal Building, Washington, D.C.].

1991c, Natural gas annual 1990, DOE/EIA-0131/2, v. 2, 263 p. [Available from the National Energy Information Center, EI-231, Energy Information Administration, Room 1F-048, Forrestal Building, Washington, D.C.].

1992, Annual energy review 1991, DOE/EIA-0384, 347 p. [Available from the National Energy Information Center, EI-231, Energy Information Administration, Room 1F-048, Forrestal Building, Washington, D.C.].

Energy Modeling Forum, 1989a, North American Natural Gas Markets, EMF Report 9, v. 2, 142 p.

1989b, North American Natural Gas Markets: Selected Technical Studies, EMF Report 9, v. 3, 471 p.

Koen, A.D., 1992, Warning flags hoisted over Gulf of Mexico longevity: Oil and Gas Journal, December 21, 1992, p. 19.

National Petroleum Council, 1992, The potential for natural gas in the United States, 6 volumes [Available from the National Petroleum Council, 1625 K Street, N.W., Washington, D.C.].

Riva, J.P., 1993, Domestic natural gas-Part of the solution or part of the problem?: Congressional Research Service, 93150 SPR, $18 \mathrm{p}$.

Watson, W.D., 1992, The gas seller's companion-A practical guide to gas contracts: Tulsa, Okla., PennWell Publishing Company, $197 \mathrm{p}$. 



\title{
An Economic Approach that Links Volumetric Estimates of Resources with Cost and Price Information
}

\author{
By Dale M. Nesbitt ${ }^{1}$
}

\section{CONTENTS}

Introduction 749

How Should Future Price Trends be Forecast? 751

Forecasting Based on Market Observations 752

Surveys of Market Experts 753

Expert Judgment Tends to be Biased ............ 753

Is an Expert's Track Record Meaningful? ...... 755

Structural Models 755

A Prudent, Workable Strategy for Market

Forecasting 756

A Model to Accurately Simulate the Behavior

of an Informationally Efficient Market 757

What Geographic and Temporal Scope can

be Achieved? 760

Demand-Side Structure 762

Supply-Side Structure 762

United States 762

Canada 763

Mexico 764

Liquefied National Gas (LNG) Import

Terminals 764

World Outside North America 765

Developing Regional Supply Curves from Fundamental Geologic and Cost Information 765

Step 1-Regional Estimates of Proved

Reserves and Initial Year Production Levels 765

Step 2-Regional Estimates of Undiscovered

Resources 765

'Decision Focus, Inc., 650 Castro Street, Suite 300, Mountain View, CA 94041-2055.
Developing Regional Supply Curves from

Fundamental Geologic and Cost Information-Continued

Step 3-Disaggregate Regional Volumetric

Estimates into Plays 766

Step 4-Estimate Reservoir Size and Depth

Distribution 766

Step 5-Assemble Historical Schedules of

Discoveries, Reserve Additions, and Production ... 769

Step 6-Statistical Analysis of Historical

Schedules ............................................................... 770

Step 7-Probabilistic Simulation of Future

Exploration and Production 771

Step 8-Deterministic Simulation of Future

Exploration and Development ................................. 774

Producer Behavior Given Regional Supply

Curves 775

Modeling Demand 775

Building Regional Gas-Demand Curves

from Fundamental Information 775

What Does Demand Imply about the Crossing

Point? 778

A More Segmented Representation of Gas

Demand 780

Modeling Transportation ............................................. 782

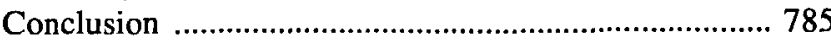

Selected References ....................................................... 785

\section{INTRODUCTION}

How can gas prices be reliably forecast? How can prudent decisions be made that do not risk shareholder equity or compromise the ability to service corporate debt? I 
present herein a blueprint for anticipating future gas prices by coupling observations of market instruments with structural modeling of markets. The structural modeling approach specifically marries volumetric estimates of gas in the ground typically made by such organizations as the U.S. Geological Survey with cost and price estimates. To support such structural modeling requires the development of supply curves, which are systematic relations between volumes and prices, to characterize the resource endowment; development of demand curves that systematically relate price and consumption; and development of pipeline and other transportation costs. This paper categorically re:jects using expert opinions or surveys of future market prices and demonstrates that they are fundamentally erro neous. The paper demonstrates how to couple volumetric estimates with market information and thereby calculate the economic implications of resource assessments by the U.S. Geological Survey and other organizations.

When I entered the energy economics profession in 1974, then-current estimates of the remaining United States natural-gas resource base were approximately 800 trillion cubic feet (Tcf). During the early 1970's, reserve additions were not keeping pace with consumption; the United States was "falling behind." Consumption, buoyed by artificially low, regulated wellhead prices, was fast outstripping reserve additions. The United States was running out of gas. Crude-oil and natural-gas price controls, windfall profits taxes, and franchised downstream monopolies with stringent rate-of-return regulation and complete control and domination of downstream markets were supposedly needed to keep producers from taking advantage of consumers.

Assuming average annual consumption of approximately 20 Tcf since 1974, the United States should have by now consumed approximately $380 \mathrm{Tcf}$ of the $800 \mathrm{Tcf}$ natural-gas resource base foreseen in 1974, which leaves only 420 Tcf. In 1993, it should be a scant 21 years before the United States runs out of natural gas. Prices should already be skyrocketing in anticipation of "running out." The dramatically escalating price predictions of the turbulent days of the energy crisis should now be coming to pass. We should be in trouble. Quite the contrary is true, however. The price of gas is low in real, inflation-adjusted terms, and there is little prospect for sustained increase.

Why were the 1974 forecasts so wrong? Were there signals in place in 1974 that could have told the proper story? The answer is a definitive yes! Without question, there were definitive signals in place. Without question, the primary reason the energy forecasts were wrong was that virtually all discussion and debate centered on how much gas might be left in the ground. No attention was given to several critical questions: (1) How much will it cost to produce and transport that gas to market? (2) What will be the fair market value, that is, the price, of gas in every market it serves? (3) How much more gas might be found if prices were to rise? (4) What fuel form will gas be competing with in each prospective market it might serve? (5) Will producers make any money producing gas? (6) To what degree can gas-production costs be reduced by fundamental technological change? and (7) Will natural gas become an "import economy," just like crude oil and its byproducts have become?

Since 1974, virtually the entire debate has centered on the question what is down in the ground without attention given to what will happen when the gas is produced and delivered to market. Indeed, most of the other papers in this volume focus almost entirely on what is down in the ground. The U.S. Geological Survey, the Potential Gas Committee (PGC), the Bureau of Economic Geology, the Canadian Geological Survey, and many other groups have presented pure volumetric estimates based on criteria such as current or reasonably anticipated prices and technologies, quantities entrapped in sediments, or gas resource potential. The purely volumetric approach has generated estimates that differ by orders of magnitude. Yet, throughout the entire debate and the entire range of volumetric estimates, price forecasts have not varied perceptibly.

It is amazing how price forecasts remain constant, unfazed by profound changes in volumetric estimates or accompanying production cost estimates. Even today, the Energy Information Administration (EIA) National Energy Strategy's high estimate and the U.S. Geological Survey's low estimate of gas reserves lead to the same price forecast! Neither estimate is tied to prices or markets. It is astonishing that price forecasts have not varied perceptibly in spite of the severalfold increase in recoverable gas volumes foreseen during the past 20 years. Prognosticators persist in putting forth the same hackneyed forecasts they always have-forecasts in which prices remain level for a brief period of time and then escalate dramatically.

In contrast to most of the modeling and analytical work of the day, several colleagues and I designed the SRI-Gulf model in 1973 precisely to answer the critical economic questions posed previously for natural gas and other fuels. See Cazalet (1977) for a description of the SRI-Gulf model. (The acronym SRI stands for Stanford Research Institute, which has since been renamed SRI International.) The SRI-Gulf model and its successors (the LEAP and NARG models) did not decouple volumetric estimates from price estimates. The long-range energy analysis program (LEAP) capability was initiated by the Energy Information Administration in 1977-8. The North American regional gas (NARG) model was developed by the Gas Research Institute (GRI) in 1984. Both models explicitly attached resource volumetric estimates with costs and avoided pure volumetric approaches. The underlying approach (called "generalized equilibrium modeling") systematically coupled and interrelated prices and volumes by postulating and advocating the use of long run marginal cost curves (defined and described later in the "Supply" 
section). One of the purposes of this paper is to show how a fundamental coupling between price and quantity can be accomplished and to argue that such coupling is absolutely essential to a proper understanding of natural gas and other fuels in the United States, North America, and the rest of the world.

The success of the generalized equilibrium approach is rather lucid. The first application of the generalized equilibrium approach indicated quite clearly that oil and gas prices would not escalate at anywhere near the rate or to anywhere near the height most pundits of the day were predicting and that oil and gas prices would decouple from one another. Even at that time, it was clear there were plenty of oil and gas resources in the ground to serve the demand for the next 20 years. Prices could not possibly escalate very high or very rapidly. To complement domestic resources, there were plenty of foreign resources available, which could be imported by the United States. In 1975 , the team from SRI recommended that the government should not participate in the research and development of or subsidize synthetic fuels (Interagency Task Force on Synthetic Fuels Commercialization, 1975). The basis for our recommendation was that there would be plenty of conventional oil and gas available at production costs lower than synfuels and that availability of low cost oil and gas would retard price increases and keep prices well below the cost of synfuels. For the study, costs and prices were systematically attached to the volumetric estimates of the day. We concluded that at higher prices, large quantities of additional oil and gas could and would be produced. SRI also specifically predicted that markets would be efficient and prices would clear markets. Prices would never rise to levels needed to render synthetic fuels commercially viable. Were such conclusions in 1975 visionary? Hardly. The conclusions were derived from a straightforward, fundamental analysis of the resource base, an analysis that systematically coupled volumetric with cost information-an analysis that can be easily duplicated today.

As one might imagine given the conventional wisdom of the day following the first oil embargo, the team from SRI was criticized by some program advocates within the Government for our conclusions that the economic fundamentals pointed toward little, if any, price increases for the foreseeable future. SRI's reports to the Council on Environmental Quality (CEQ) and the Interagency Task Force on Synthetic Fuels Commercialization dated 1975 contain our price forecasts from 1975. How, people asked, could such heretical, irresponsible conclusions be drawn that were so far at odds with conventional wisdom? Wasn't the United States entrapped in the clutches of insecure, avaricious, unethical Middle Eastern producers out to ruin the West? Wasn't there an urgent need for massive Government intervention to prevent frequent recurrence of gasoline lines and oil embargoes? Wasn't the cost of sub- sidized synfuels a meager price to pay to escape the voracious clutches of "foreign oil producers?" The answer then as now was that the economic and geologic fundamentals point in quite the opposite direction.

The main purpose of this paper is to focus on the critical question of how to attach economic significance to volumetric estimates. Volumetric estimates such as the amount of hydrate-entrapped gas worldwide or how much gas remains to be discovered and produced in the Gulf Coast Basin are meaningful only when they are coupled with viable price forecasts and pertinent market information. There are several critical market-related questions to be addressed. How much will it cost to produce and transport the gas to market? What fuel(s) will the gas be competing with in any prospective market? To what degree can technological advances reduce the cost of producing gas?

Considering only volumetric estimates in contexts other than oil and gas is unheard of. What is so different about energy that allows us to make only volumetric estimates devoid of cost and price? For example, the fair market value of silicon depends on the cost of converting it to a useful commodity, not on the volume of silicon available at various locations. Volumetric estimates are what the old Chinese metaphor calls "the sound of one hand clapping." They tell only half the story. Supply curves showing explicit relations between volume and cost tell the whole story.

\section{HOW SHOULD FUTURE PRICE TRENDS BE FORECAST?}

There has been a great deal of attention dedicated to forecasting future price trends in the context of the stock market and a number of commodity markets. Can stock and commodity market concepts be extrapolated to natural gas, oil, and other energy commodities? The answer is yes. In stock and commodity markets, it is generally accepted today that "the market is efficient." This seemingly innocuous statement means that everything that is known or knowable is systematically embedded in the price. There is nothing that is known or knowable that is not already considered by and embedded in the price. All transactions in all markets that affect or are affected by the stock market are fully incorporated into the market price. All information-public as well as confidential-is embedded in the price because all transactions collectively combine to determine the price. In an efficient market, it is totally without justification to make subjective judgments about price or about the market. It is impossible for any individual to systematically outsmart the market. In efficient markets, subjective estimates of prices are meaningless. The subjective estimate is equally likely to be high or low.

One of the leading students of the efficient market, Fama (1991) argues that most stock market price forecasts 
that attempt to value a company on the basis of "technical" criteria in the market (for example, price patterns) or on "fundamental" criteria (the composition of the company's portfolio of assets) are "investor pornography." Fama states that in an informationally efficient market (which the U.S. stock market assuredly is) that there is no possible way to systematically discern true price trends and thereby beat the market. The market is not a game of skill that one can beat by being astute. It is not a blackjack game, which one can beat (statistically speaking) simply by counting cards. It is not a baseball game in which an astute manager can increase his odds by formulating and executing better strategy. Absolutely the contrary, the market is a game of pure chance, not skill. It is a craps game, a slot machine, a roulette wheel, in which the odds are completely specified outside any one individual's purview. There is no viable strategy for out-thinking one's adversaries except by carefully and completely accepting the fundamental efficiency of the market, recognizing that all relevant information is already embedded in the market. The best strategy is to throw darts at the stock market page of the Wall Street Journal, not to systematically select and reject stocks on the basis of technical or fundamental analysis. In the gas context, the best strategy is to observe and model the gas market and thereafter adopt the most profitable (usually least cost) strategy.

An efficient market is a competitive, free market in which many players make many frequent transactions. Assuredly the U.S. and North American gas markets are quite efficient. There are thousands of trades, contracts, and traders. There are many players-producers, aggregators, brokers, transporters, distributors, final users, and arbitragers. Regulators are striving constantly to foster market efficiency. There is no shortage of information, forecasting, and misinformation. There is a futures market, albeit somewhat limited in duration. Traders are relatively untrammeled by regulation that would restrict the transactions they can make. There is an emerging forward market that allows increased trading into the future. There are few signs of monopoly or monopsony power. The signs of an informationally efficient market abound. Signs of an inefficient market (for example, monopoly power by a small number of players, franchise monopoly behavior by regulators, astute players systematically duping other players and beating the market, bilateral negotiations rather than multilateral trading, vertical integration without pricing of intermediate commodities) are nonexistent.

It would be difficult to argue that the North American gas market is inefficient to any degree. Given the inherent efficiency of the market, it is futile to make subjective estimates of future market prices. If, in an efficient market, one cannot make subjective estimates of market prices, there are three alternatives (fig. 1). Price expectations may be determined by (1) market observations (observing present and future prices of key securities traded in the market), (2) building confidential and proprietary models and data, and (3) surveying outside experts. I will argue for using a combination of approaches (1) and (2).

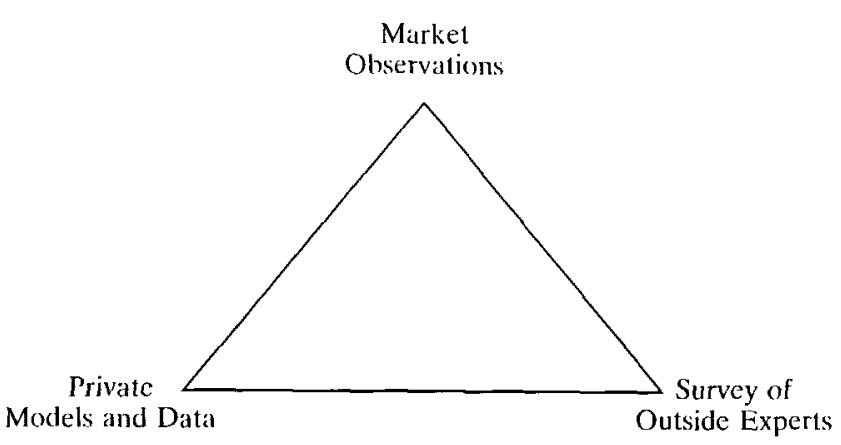

Figure 1. Three methods of forecasting gas prices. Combining market observations with models and data works best for the real world.

\section{FORECASTING BASED ON MARKET OBSERVATIONS}

Do observations of today's market presage the future, or are they largely irrelevant to what is going to happen in the future? Market observations are known to be the most reliable source of information, because everything that is known or knowable is explicitly embedded in market prices. Even when people make decisions based entirely on proprietary or confidential information, they cannot hide that information from the market. On the contrary, the investment, operation, and retirement decisions they make "signal" the market and induce changes therein. Through this signaling mechanism, their information is transmitted to the market and explicitly embedded in the prices and volumes therein. This is why we say that everything that is known or knowable about securities that are actively traded in the market is already reflected in the prices of those securities. No individual can be systematically "smarter" than the market unless he or she has insider information. To assume otherwise is to speculate. Public domain bodies (for example, federal governments, state, and provincial governments, GRI, EPRI) should not be speculating with taxpayer and ratepayer money. Quite the contrary, they should be hedging, pooling, mitigating risks, and overcoming market imperfections. Corporations should not be speculating with shareholder equity, squandering it (in a statistical sense) as they do so. They should be hedging, diversifying, making acquisitions, and divesting so as to optimize their risk/return profile and honor their fiduciary responsibility. Neither should be relying on subjective estimation of market prices.

While gas markets are quite efficient in the United States and North America, they are also "incomplete." A 
complete market is one in which all possible spot and forward contracts are actively traded and scrupulously honored. Longer term futures contracts simply do not exist in gas markets; the absence of longer term futures contracts renders them incomplete. Regulators regularly abrogate contracts, rendering otherwise complete markets incomplete. In the "Structural Models" section, a method to overcome whatever market incompleteness exists in gas markets is described.

Today's spot prices, futures prices extending outward for 18 months, and a few longer term instruments such as forward contracts can be observed in the market. How might one discern a legitimate, market-consistent forecast extending outward 5 years based on a 5-year forward contract observed in the market? Imagine a security that guarantees delivery of 1 thousand cubic feet (Mcf) of gas per year for the next 5 years. (The present example can be scaled up to real world quantities of gas delivered as desired.) Suppose the security sells in the market for \$7.20. Assuming that the price of gas begins at $\$ 1.60$ per Mcf today, escalates forward at a rate of $y$ percent real per year (where $y$ is to be determined), and the discount rate is $r$ percent (real), the present value of the $1 \mathrm{Mcf}$ per year of gas deliveries is

$$
P V=(\$ 1.60) \frac{1-\left(\frac{1+y}{1+r}\right)^{5}}{1-\left(\frac{1+y}{1+r}\right)}
$$

It is known by observation of the Standard and Poors 500 (S\&P 500) index since the year 1920 (reported by Dimensional Fund Advisors) that the annual real return is approximately 6.5 percent, meaning that $r$ in equation 1 should be approximately 6.5 percent. One can arbitrage (establish a collection of trading positions) between the S\&P 500 and the oil industry without affecting the return in the S\&P stocks. Substituting $r=0.065, P V=\$ 7.20$, and solving for $y$, the value of $y=0.01$ ( $y$ equal to 1 percent real) would satisfy the equation. This equation is telling us that the market thinks that gas prices will escalate at approximately 1 percent above inflation for the next 5 years. This simple calculation is rather profound. The equation implies that the market value of the security ( $\$ 7.20$ per annual $\mathrm{Mcf}$ ) is consistent with a gas price escalation rate of approximately 1 percent above inflation. If the market value of the security were higher, the gas price escalation rate would be higher. If the market value of the security were lower, the gas price escalation rate would be lower. To bet against a security of this type is to gamble. To purchase this security is to lock in a price and eliminate all future price uncertainty.

Tying oil and other price escalation rates to market observations can be much more difficult than the simple calculation herein. Nonetheless, the simple calculation is more reliable than expert surveys. The calculation accounts for all attributes of the efficient market. Such calculations are based solely on objective observations and demonstrable actions by a plethora of market participants.

Unfortunately, forward natural-gas markets are rather incomplete. The futures market only extends 18 months into the future, yet most of the price risks extend much further into the future than that. Furthermore, the forward markets just now emerging are rather "thin." A thin market is one in which there are not many players and there are not many transactions being made that definitively establish the fair market value of the commodities being traded. A thin market may also be one in which the sanctity of the property rights embedded in the securities is questionable. If a forward contract is not scrupulously and completely honored by both contracting parties and by the underlying legal system, then that forward contract is not a viable market instrument. It is no different from a spot market instrument.

It is necessary to complement observations of thin markets with structural models. A hybrid approach-combining observation of incomplete markets with structural modeling-holds promise for predicting how the market will evolve in a future world of incomplete markets in which contracts may not be scrupulously honored or may not extend sufficiently far into the future to reflect the full range of price expectations various market agents may have.

\section{SURVEYS OF MARKET EXPERTS}

Surveys of independent external market experts regarding future prices in efficient markets are notoriously unreliable. They are hypothetical, and they invariably embody the prejudices and self-interests of the experts making the forecasts. I have previously stated that in an efficient market, no expert can systematically and consistently beat the market because no expert has as much information as the market has in aggregate. Forecasting market prices is not a game of skill; it is a game of chance. The market is made up of people who have "put their money where their mouth is," investing in and playing the market and thereby transmitting their information to the market. Individual experts are no more than providers of abstraction and academic hyperbole. The message to public and corporate decision makers is clear: Do not waste time or money with surveys of market forecasters. Do not operate anywhere near the lower right hand corner of figure 1 . Use observations of the market complemented by structural modeling.

\section{EXPERT JUDGMENT TENDS TO BE BIASED}

In expert assessment, it is difficult to identify and eliminate abuse, bias, and self interest. In a study performed for 
the Department of Energy in approximately 1985, Sobodka Corporation was asked to assemble future oil price projections made by a number of organizations and examine whether those forecasts tended to "cluster" together according to the type of organization that rendered them. The four types of organizations considered were banks, Government agencies, consultants, and oil and gas companies. Sobodka found that there were four distinct clusters of forecasts, and the clusters were strongly correlated with the types of organizations that offered them.

The four clusters include a very low cluster, a low cluster, a moderately increasing cluster, and a rapidly escalating cluster. The forecasts made by banks clustered at the bottom of the range. Banks had the lowest, most draconian forecasts among the entire group. Their motivations would seem quite understandable. Banks have somewhat limited technical knowledge of the industry, but they are asked to bet their money on it. It seemed that banks were discounting future oil price projections as a way to assuage their risks. Banks were discounting future oil price escalation as a means to discount all projects being offered them in hopes that Darwinian natural selection would cull out all but the winning projects. Banks were not putting forth oil price forecasts they truly believed. They were shading their estimates toward the low end of the range to place the subjective burden of proof onto prospective borrowers. Yet, the projects actually funded by banks were and are consistent with a much different forecast of oil price than the banks were projecting. Banks were systematically putting forth conservative projections that would most effectively protect their self interests.

The second lowest cluster corresponded to the oil and gas companies, whose equity dollars and ability to service debt are at risk in every oil and gas project they pursue. Avoidance of such risk motivates them to offer conservative forecasts in the same way that banks are motivated. However, within oil and gas companies, there are internal advocates for various ventures, regions, and projects. There are people whose careers depend on pursuing particular projects in particular regions of the world. There are people whose careers depend on using a particular type of process or technology. Such people can be expected to systematically bias the subjective estimates of profitability of those projects upward by biasing oil and gas price forecasts upward and project costs downward. Certainly there is momentum within companies to continue in the oil and gas business, and such momentum favors higher price forecasts. In summary, offsetting the forces of risk aversion (which were evident within the banks), there are positive, proactive internal forces in oil and gas companies. Forecasts by oil and gas companies often reflect the tension between project advocacy and risk aversion. The net result of this tension is to push up price forecasts slightly above the banking industry. While oil and gas company price forecasts are quite conservative, they are not as conservative as bank forecasts.
Apparently price forecasts offered by the oil and gas industry like the banking industry are designed to serve their self-interests. Industry forecasts contain a market-appropriate balance between conservatism (a desire to screen off the unprofitable ventures) and optimism (which typifies project advocacy). It seems that oil and gas industry price forecasts do not necessarily reflect what companies truly believe. Their price forecasts are intended to work to their business benefit rather than to communicate objectively what the companies truly believe.

It is useful to consider the opposite extreme, the high price forecasts. Not surprisingly, Government forecasts invariably lie at the extreme high end of the spectrum. Government energy policy agencies are systematically motivated to forecast high. The motivation is simple. If oil prices were forecast to be low forever, why would we need government energy agencies? What economic function would they serve? Their very existence derives in great measure from high oil prices and the arguments favoring extra-market action to counter such high prices. High oil prices serve Government decisionmakers' self-interests by keeping their profile high. Government policy bodies have consistently since 1973 rationalized and justified their existence by citing high and escalating oil prices, import security problems, balance of trade problems, unethical or aggressive behavior by "increasingly insecure and high priced Middle Eastern sources," and other "sky is falling" motivations. Yet, in spite of Government forecasts of high and increasing prices put forth continually since the first oil embargo in 1973, prices have retreated in real (inflation adjusted) terms almost back to where they were in the late 1960 's. Prices today are not high by historical standards. In effect, today is the "good old days" as far as real gasoline (and oil) prices are concerned. While the United States has undergone profound structural changes on the consumption side, the supply side continues to show very low real oil prices, which will probably continue indefinitely.

Included with Government agencies are the utility and energy research institutions: the Electric Power Research Institute (EPRI), the Gas Research Institute (GRI), and the Department of Energy research laboratories. Economists generally recognize a very legitimate research and development role for such organizations because it is known that the "invisible hand" of the market often leads to systematic underinvestment in technological innovation. (Innovators cannot privately recover the benefits of their innovations and are therefore motivated to underinvest.) However, given the political and funding realities, research and development organizations are often motivated to predict high prices for the same reasons as Government agencies. As an example, would one expect a research and development organization such as GRI to put forth a gas price forecast that never rose high enough to exceed the anticipated cost of new technologies it is attempting to de- 
velop and commercialize? Instead, would one expect them to forecast substantially increasing prices some 5 to 10 years out, just when various new technologies under development are anticipated to be ready for commercial deployment? Are research and development organizations be better off to argue that their new technologies, when delivered to commercial status, will be eagerly absorbed into the market? Over the past 18 years of research and development organization forecasts, there seems to be a recurrent theme of rapidly increasing real prices some 5 to 10 years into the future, with very receptive market eager to absorb new technologies they are developing.

Public bodies are also putting forth forecasts that serve their self-interests, not necessarily forecasts they believe. Because public bodies are not viable, proactive market agents investing their own money, their actions do not signal the market. Public bodies are bystanders, albeit powerful bystanders, who can affect the market only through regulation and (or) incentives but not through participation. The Tennessee Valley Authority (TVA) and Bonneville Power Administration (BPA) are Governmentowned exceptions to this general statement. They are market participants, and their ability to signal the market is similar to other producers.

As one might anticipate, consultants fall squarely in the middle between the low industry forecasts (banks and oil and gas producers) and the high Government forecasts. Serving banks, oil and gas companies, and the Government, consultants are strongly motivated to fall somewhere in the middle. Extreme opinions do not sell consulting work. Iconoclastic or controversial prognostications do not sell consulting work. Middle of the road, conventional wisdom, "plain vanilla," nonthreatening forecasts, presented with authority and backed by apparent industry consensus, sells consulting work. Like the other types of organizations, it is difficult to conceive that consultants as a group are putting forth forecasts they truly believe. They too seem to be putting forth forecasts that best serve their own interests.

\section{IS AN EXPERT'S TRACK RECORD MEANINGFUL?}

What if a particular expert has an unblemished track record? What if that expert actually "called the turn" in oil prices correctly each of the past three times? Should you believe an expert on the basis of his or her track record? The answer is a resounding no! An example from Burton Malkiel in his classic book $A$ Random Walk Down Wall Street illustrates. Consider a gymnasium filled initially with 1,000 people. At the front of the gym at a podium, there is a speaker flipping a coin. At each flip, every person who calls the coin correctly remains in the gym for the next flip, and every person who calls it incorrectly leaves. What will we see after twelve or so flips? We will see a single person remaining in the gym, a veritable genius at calling coin flips, a person with uncanny, paranormal abilities. The last remaining person will have an irrefutable record of twelve consecutive correct calls of the coin without a single error!

What if that last person remaining in the gym approached you and offered: "I would be eager to call coins for you. For a mere $\$ 2500$ per day plus travel expenses, I will travel to your office and assist you in calling coins. I have a system. It is a computer model for calling coins. The computer model is highly scientific. You can turn your coin forecasting over to me secure in the knowledge that I cannot miss. I can make you rich." Would you hire the last person in the gym to call coin flips for you? Would you believe any forecasts he might make? Is he better at calling coins than the average person on the street or better than you are? After all, the expert has a demonstrably perfect track record, twelve straight correct calls of the coin. The answer of course is No. By sheer happenstance, the expert just happened to be the last person in the gym, the last person standing. Clearly if there were an additional coin flip, he would be no more likely to call it correctly than anyone else.

So it is with price forecasting. Most people feel more comfortable relying on a person with a documentable track record of accurate past forecasts. Somehow, a successful track record gives credence to people trying to forecast price. The person who called the turn last time is likely to make more money as a price forecaster than the person who missed the boat. However, based on the simple coin flipping analogy, given the number of people prognosticating gas and oil prices these days, the vast majority of people arguing they called the turn correctly just happened to be the last person standing in the gym. They were just lucky! Businesses and Government should rely instead on forecasters who combine market observations with structural modeling.

\section{STRUCTURAL MODELS}

In projecting future prices for use in decisionmaking, structural models and data designed to simulate the operation of an informationally efficient but incomplete market are the best way to complement direct observations of an incomplete market. To wit, anything not observable in the market should be structurally modeled using an economic theory (for example, supply-demand balancing under rational expectations). Such models should simulate independent, autonomous, economic agents. A model should represent an informationally efficient market by explicitly accounting for the players, their alternatives. (resources), their information (what they know and what they do not), their preferences (what they want), and the network interrelations among them. A model should not simply be a 
spreadsheet accounting system. One should not build a model that assumes all the players act in lockstep to optimize some overall social objective. DOE's and EIA's linear programming models beginning with the Project Independence models of the 1970's and continuing with today's National energy modeling system (NEMS) have always assumed lockstep pursuit of an overall social objective (cost minimization). Such models do not describe the realities of a decentralized market in which individual agents simultaneously pursue self-interest. One should not appeal to "social engineering" concepts such as systems dynamics that view market agents as inflexible, myopic, unthinking automatons.

\section{A PRUDENT, WORKABLE STRATEGY FOR MARKET FORECASTING}

In an ideal world, one would operate entirely by market observations (see fig. 1). By so doing, one could hedge away all price risk. However, in a non-ideal world in which markets are not entirely efficient and for which complete spot and futures markets may not exist, one should operate along the line between market observations and structural modeling of market activities (see fig. 1). In evaluating risks and returns, economic or otherwise, models must be combined with market observations. By so doing, you run the least risk of making the wrong assessment, defiling your conclusions, and bearing unnecessary risks. Direct subjective estimation of future market prices are never accurate.

Gas and oil markets in North America (and in fact worldwide) have become increasingly efficient. This increased efficiency has profound implications for resource assessment-observed prices in the market communicate what the market believes the resource base to be. Any resource assessment that runs counter to what the market believes is probably wrong. In the past, difficulties have plagued resource assessment and subsequent market analysis precisely because market price forecasting models have approached resource assessment data as if it were immutable scientific truth. Supposedly immutable scientific truths are loaded into models and the results are given credence whether or not they depart from observed market realities. The models are argued to be credible simply because they are based on data that is scientifically derived. The idea that reliable data leads to reliable models is shown in figure 2. The left circle in the figure represents data from resource-base assessment. Scientific, technical, and geologic in nature, resource-base assessment is assumed to be an intrinsically correct estimate-one that can be determined and justified by scientific inquiry.

As shown by the arrow proceeding to the right in figure 2, the output of resource-base assessment is typically fed directly into a market model. The results of the market

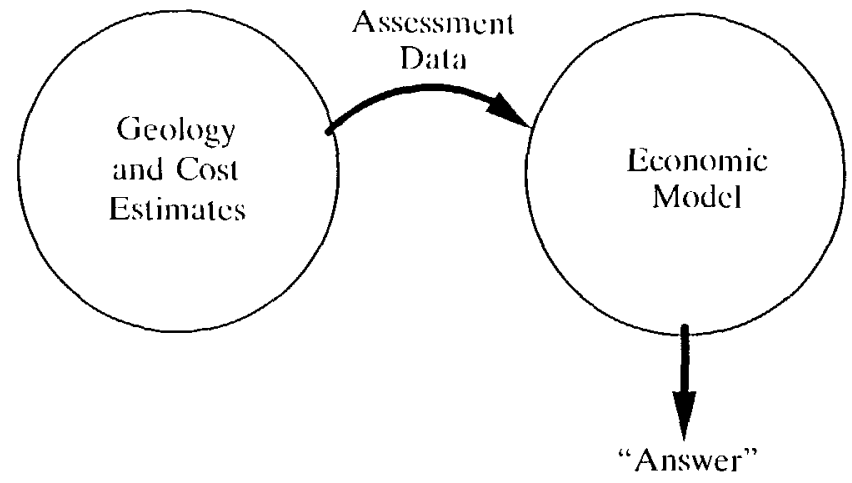

Figure 2. How a model using a unidirectional view works.

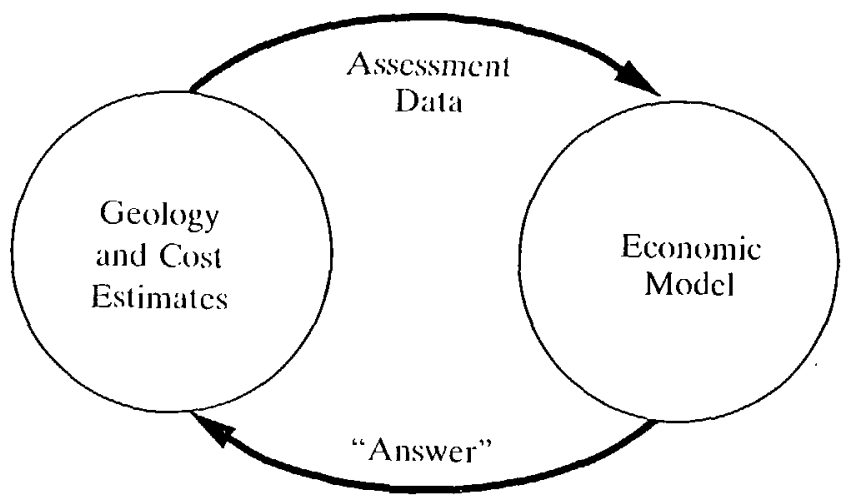

Figure 3. How a model using an iterative process works.

model are asserted to be accurate and precise because the resource assessment is accurate and precise. Whether or not the model gives price-quantity answers that are consistent with market observations or are inherently reasonable in their own right is deemed immaterial. The model's projections supersede market observations if the two deviate.

This unidirectional view from resource assessment to market model to forecast has proven deficient. To overcome the deficiency, it is necessary to complement the traditional procedure shown in figure 2 by linking the market model back to the resource-base assessment, as shown in figure 3. This link is a judgmental process whereby the reasonableness and consistency of the market forecast are compared with observations of prices and quantities in the market. If the market forecast is judged unreasonable, one must modify the resource-base assessment accordingly. The resource assessment must be adjusted not only on the basis of intrinsic scientific information assembled from geologists but also on market observations and market model runs based on that information. In a reliable model, the resource-base assessment must produce market projections that are reasonable and consistent with market observations and with arbitrage and trading opportunities available in the market. One must conduct an iterative procedure between the assessment and the model until the data gives 
model results that are consistent with observed price realities (fig. 3). If the model gives results that are inconsistent with observed price realities, the assessment is probably wrong and another iteration is required.

The iterative procedure is essential. It requires that one simultaneously use the best available geologic data and the best available market modeling data and iterate between them until they become lockstep consistent. Only then can one assert that the geologic estimates are consistent with observed market phenomena and simultaneously that observed market prices and quantities are consistent with volumetric estimates of resources.

There is one interesting corollary of the approach proposed in figure 3. Price forecasts that look like "hockey sticks" are not credible. They are inconsistent with rational economic behavior and arbitrage by market agents; the market will not support them. If people anticipate rapid price runups, they quickly arbitrage in futures markets and (or) increase inventories and thereby raise prices today and reduce the rate of price runup tomorrow. Prices cannot possibly run up faster than the returns from market arbitrage. Price forecasts inconsistent with rational temporal and regional market arbitrage simply cannot happen and will not be forecast by a reliable model no matter what independent resource assessment data might imply.

\section{A MODEL TO ACCURATELY SIMULATE THE BEHAVIOR OF AN INFORMATION- ALLY EFFICIENT MARKET}

How can a reliable model of natural-gas prices and volumes be built? To build a model that simulates the present and future operation of the North American and world natural-gas market is to realize that fundamental and irreversible changes have swept American, Canadian, and world natural-gas markets in the past 8 years. Times have changed; the old days are gone.

Deregulation has fundamentally broken the franchise monopoly nature of the gas-transportation system, particularly the upstream portion. Open access transportation has provided unequivocal price transparency to all producers and consumers in the system. Regulatory risks related to operation of a franchise monopoly have given way to market risks related to prices and price fluctuations. There is far less government intervention today than at any time since the advent of natural-gas markets. Free trade among relatively well defined trading blocs (United States-Canada-Mexico and the European Community) fosters price transparency and smooth and efficient market operation.

These and other forces result in wellhead and burner tip prices throughout the United States, North America, and the rest of the world being determined by supply-demand interactions (or equilibrium) in the tightly interconnected, fiercely competitive North American and world natural-gas markets. When the two largest markets in the world, North America and the European Community, embrace unregulated, price-transparent markets, it is difficult to conceive how prospective producers could operate with anything other than increasingly competitive and transparent systems.

The implications of these insights are that economics matter! The operative concept underlying natural-gas markets in the industrialized world is shown in figure 4. Conceptually, there are supply curves that characterize the volumes and costs of resource available and demand curves that characterize consumption. The crossing point of these curves is where the market will tend to operate. The market clearing price where the two curves cross is the price toward which the market will trend.

The market clearing price has two critical interpretations: descriptive and prescriptive. The descriptive interpretation is the more obvious of the two. The market clearing price in figure 4 is the "best guess" at what the market price will actually be. The price describes the market. If you are trying to presage how the market will evolve, the market clearing price is your best bet. The price arises from a fundamental structural representation of the economy (embodied in the supply-demand curve pair) and is the best description of where the market is likely to evolve.

The second interpretation, more consequential than the first, is the prescriptive or normative interpretation. One should assume that everyone in the market knows that the market will operate at the crossing point. Spot, contract, and futures prices will properly signal everyone in the market that the market clearing price in figure 4 will in fact be the true market price and that everyone will react accordingly. No single individual can know the truth while others do not. The normative interpretation arises from the notion of an informationally efficient market, and everything that is known or knowable is fully embedded in the price. It will not take market agents long to figure it out.

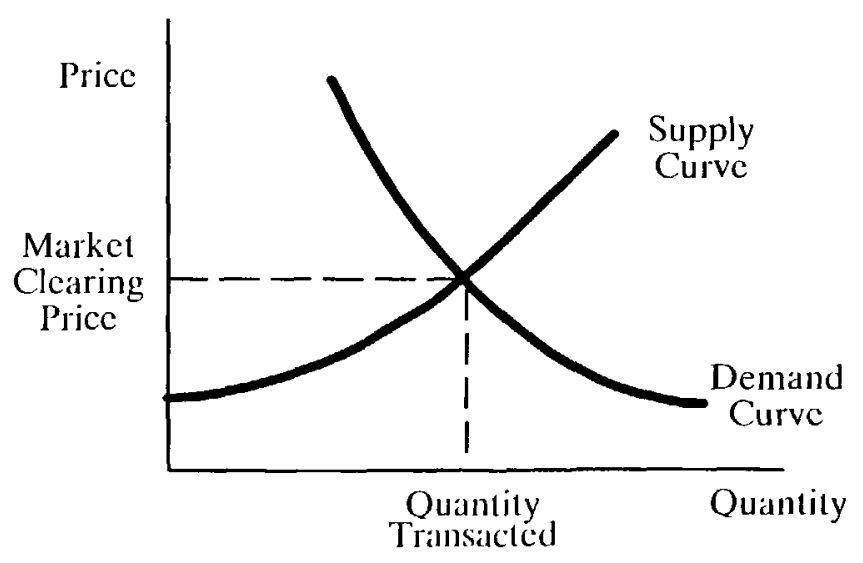

Figure 4. Supply-demand equilibrium or market clearing price of gas. 
If the equilibrium shown in figure 4 is the best description of gas market prices and volumes, then there is "good news" and "bad news." The good news is that one need only assemble a complete set of gas-supply curves and gas-demand curves, each of which relates quantities with prices. Thereafter, the crossing points will tell the story. If one had a single aggregate supply curve and a single aggregate demand curve, it would be trivial to calculate the market clearing price and the corresponding volume flowing at that price. The crossing point (by visual observation), of which there is but one, could be located and its implications reported.

There are hundreds or thousands of existing and prospective supply curves, one for each basin and for each consuming region. There are hundreds or thousands of demand curves, one for each segment and each demand region. There are hundreds or thousands of intervening pipelines and LNG linkages. In effect, there are hundreds or thousands of pairs of supply and demand curves, every pair interlinked with every other pair by a complex network. Such interlinkage recognizes that in the market every transaction made necessarily implies that a number of transactions are not made. Transactions not made as well as transactions made explicitly interlink the entire system.

Because of the market complexity, a computer program is needed to analyze the many supply regions, proved and undiscovered reserves, and exploration and production costs. The supply regions are characterized with supply curves; the many transportation linkages of supply regions characterize using transportation markups. The many demand segments and regions are characterized using demand curves. The prospective transactions are represented using a network that interrelates regional supply, transportation, and demand.

There is no way to make the requisite calculations by hand. There is no way to approximate them using intuitive methods. Consider the simplest possible example case shown in figure 5 . In this example, there are two supply regions, each with a simple, straight-line, static supply curve (points 1 and 2 in fig. 5); two demand regions, each with a simple, straight-line, static demand curve (points $A$ and $B$ in fig. 5); and a complete set of prospective pipeline linkages connecting the two supply regions with the two demand regions. A complete set means that there are linkages from 1 to $\mathrm{A}$, from 1 to $\mathrm{B}$, from 2 to $\mathrm{A}$, and from 2 to B. Each prospective pipeline linkage has an associated cost and an assumed 100 percent efficiency (no losses).

It is impossible to determine the market clearing price in figure 5 by inspection. To do so requires solving 12 simultaneous linear inequalities (12 simultaneous equations and unknowns). It is useful to examine these properties in the simple context of figure 5 because certainly any properties that hold in this simple situation will also hold in the general dynamic, nearly unregulated, multiregional market of the United States, Canada, and the rest of the world.

Figure 6 shows the solution for the two supply-two demand scenario shown in figure 5 . Notice in the figure the following:

1. The prices in the two producing regions are different. In general, wellhead prices in various producing regions are different. There is no intrinsic market force that serves to equate wellhead prices in any fundamental way.

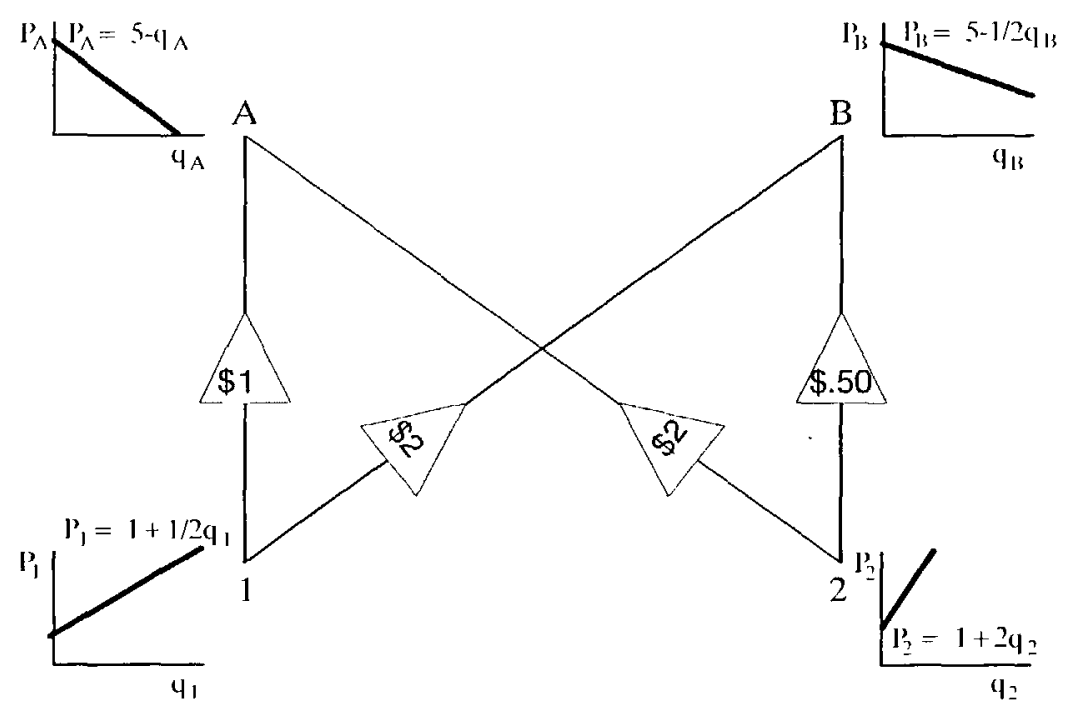

Figure 5. A "textbook" example of a simple gas market with two supply regions and two demand regions. $\mathrm{P}$, price; $\mathrm{A}$, region $\mathrm{A} ; \mathrm{B}$, region $\mathrm{B}$; subscript 1 , region A; subscript 2, region $B$; q, quantity. 
It cannot be surprising that wellhead prices in different regions should be different; the market tells us this everyday.

2 . The prices in the two consuming regions are different. Burner tip prices in various demand regions are different. There is no fundamental market force that strives to equate burner tip prices in any fundamental way. Burner tip prices are different because there is no intrinsic market force attempting to equate burner tip prices across regions.

An important corollary of this observation is that gas and oil prices need not necessarily be equal at the burner tip on a British thermal unit (Btu) basis. There are no fundamental forces that serve to equate oil and gas prices. The price of gas does not necessarily equate with the price of oil. Quite the contrary, gas price can be set by competition among gas producers, competition from oil, or competition from coal. To assume gas-oil price parity is to risk error.

3. "Netback" calculations (demand region price minus transportation cost back to a particular upstream supply region) do not necessarily work. The netback calculation from demand region $A$ to supply region 1 works, and the netback calculations from demand region B to supply regions 1 and 2 work (fig. 6). However, the netback calculation from demand region $A$ to supply region 2 does not work (fig. 6). Netback calculations do not work in general. They only work along transportation links that are economically competitive. Without an economic model based on supply-demand curve pair crossings, it is impossible to sort through the myriad competing transportation links and determine which ones are economically competitive (and therefore contribute to the netback calculations) and which ones are not.

4. It is necessary to disaggregate the supply side and the demand side. The solution to the aggregated supply-aggregated demand problem is not the same as the aggregated solution to the disaggregated supply-disaggregated demand problem. To solve an aggregate problem is to get the wrong market clearing price, a price that does not necessarily approximate the properly disaggregated, real-world situation.

To understand why disaggregation is essential, try to aggregate the two supply curves and aggregate the two demand curves shown in figure 5 and then find the price. Even if a suitable method of aggregation could be found, the answer to the aggregated problem will be entirely different from the answer to the disaggregated problem.

The logical way to represent geologic, cost, and technology information on the supply side is the supply curve or long-run marginal cost curve. Indeed, the supply curves used to characterize each of the supply basins are the fundamental data for the model. The "Supply" section of this paper describes how to build reliable and consistent longrun marginal cost curves from fundamental play analysis of the type performed by the U.S. Geological Survey.

To represent economic growth and sectorial consumption on the demand side, a dynamic demand curve is used. The sectorial demand curves used to characterize each of the demand regions are also fundamental data for the model. The "Demand" section of this paper describes how to build reliable and consistent demand curves.

The logical way to represent pipeline and distribution infrastructure is to assemble cost and loss data for the pipeline network. As shown in figure 7, the data for the model is the collection of all the regional supply curves, all the pipeline and distribution costs and losses, and all the regional demand curves. The data to our model are curves and transportation costs.

The model is an automated calculator that finds the magic crossing points (fig. 7). The inputs to the model are the curves, and the outputs from the model are the crossing points, the simultaneous crossing points for all the supply and demand curves in the model.

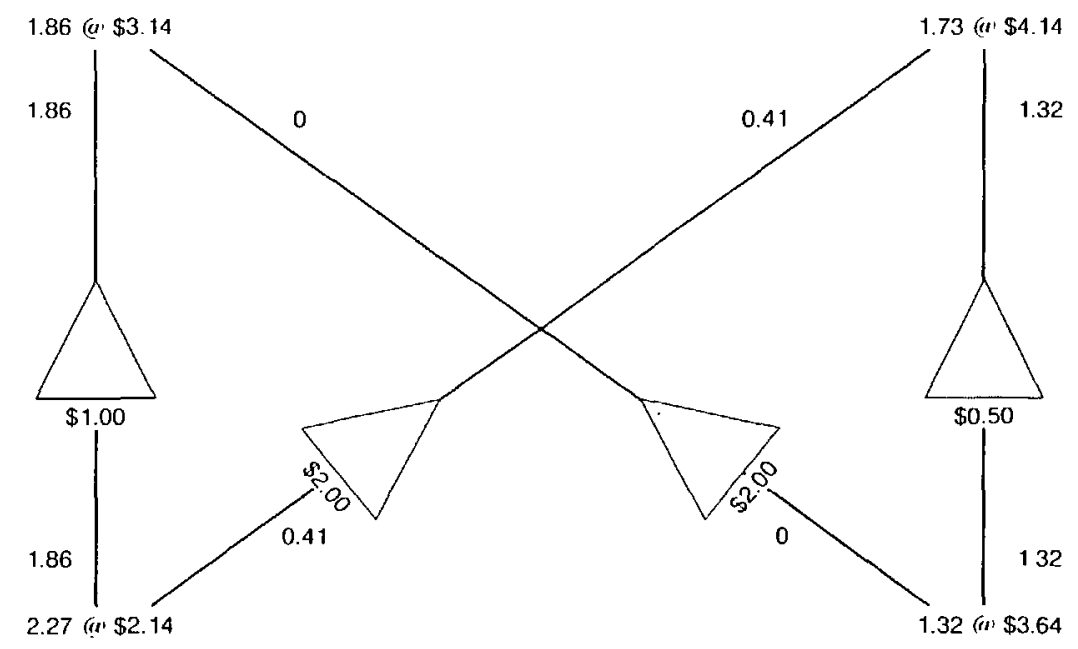

Figure 6. Market clearing prices for the two supply and demand regions shown in figure 5. Quantity of gas in thousand cubic feet. 


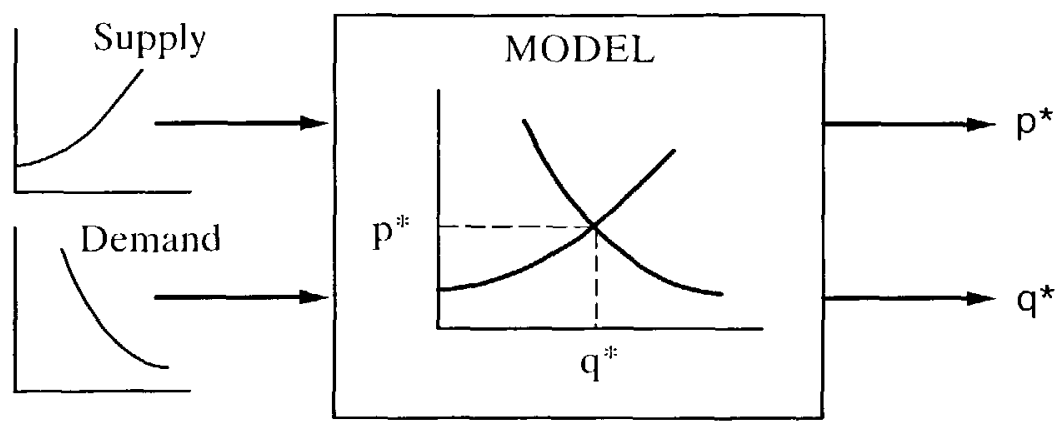

Figure 7. Data input to an economic model are supply and demand curves. Data output from a model are market clearing price $\left(\mathrm{p}^{*}\right)$ and quantity of gas $\left(\mathrm{q}^{*}\right)$.

Using the simple supply-demand paradigm as a guide, there are several critical properties a properly configured supply-demand model must embody. First and foremost, if one changes any supply, transportation, or demand assumption anywhere, the model solution must change everywhere. Every price and every volume are inextricably interconnected. For example, if one increases the volumetric estimate for a resource supply basin in a single supply region, the model must drive down prices everywhere-every supply region and every demand region (fig. 8). More supply coupled with the same demand implies lower price and higher volume. If one decreases the cost estimate for a resource supply basin anywhere, the model drives down prices everywhere. Lower cost for the same inventory implies lower price and higher volume. A number of similar examples can be constructed using the simple supply-demand paradigm.

In view of the supply-demand paradigm shown in figure 8 , it is clear that the price of gas at the wellhead must vary substantially across the range of volumetric estimates that have been put forth over the past several years. Clearly the price of gas will be quite different between the 1974derived estimate of $800 \mathrm{Tcf}$ and the 1992 NPC estimate of approximately 2,000 $\mathrm{Tcf}(1,200 \mathrm{Tcf}$ in the United States and $800 \mathrm{Tcf}$ in Canada). The 2,000 Tcf case could portend prices at one-half, one-fourth, or even less than the 1974 estimate. Explicit supply-demand methods will not be susceptible to the practices of the past 20 years during which markedly different resource-base estimates have implied zero differences in price projections.

Prices can never be input to a reliable supply-demand model; supply curves and demand curves are inputs to the model. Market clearing prices are outputs from the model. Curves go in, crossing points come out.

\section{WHAT GEOGRAPHIC AND TEMPORAL SCOPE CAN BE ACHIEVED?}

To accurately represent natural-gas supply, transportation, and demand, one must necessarily disaggregate supply
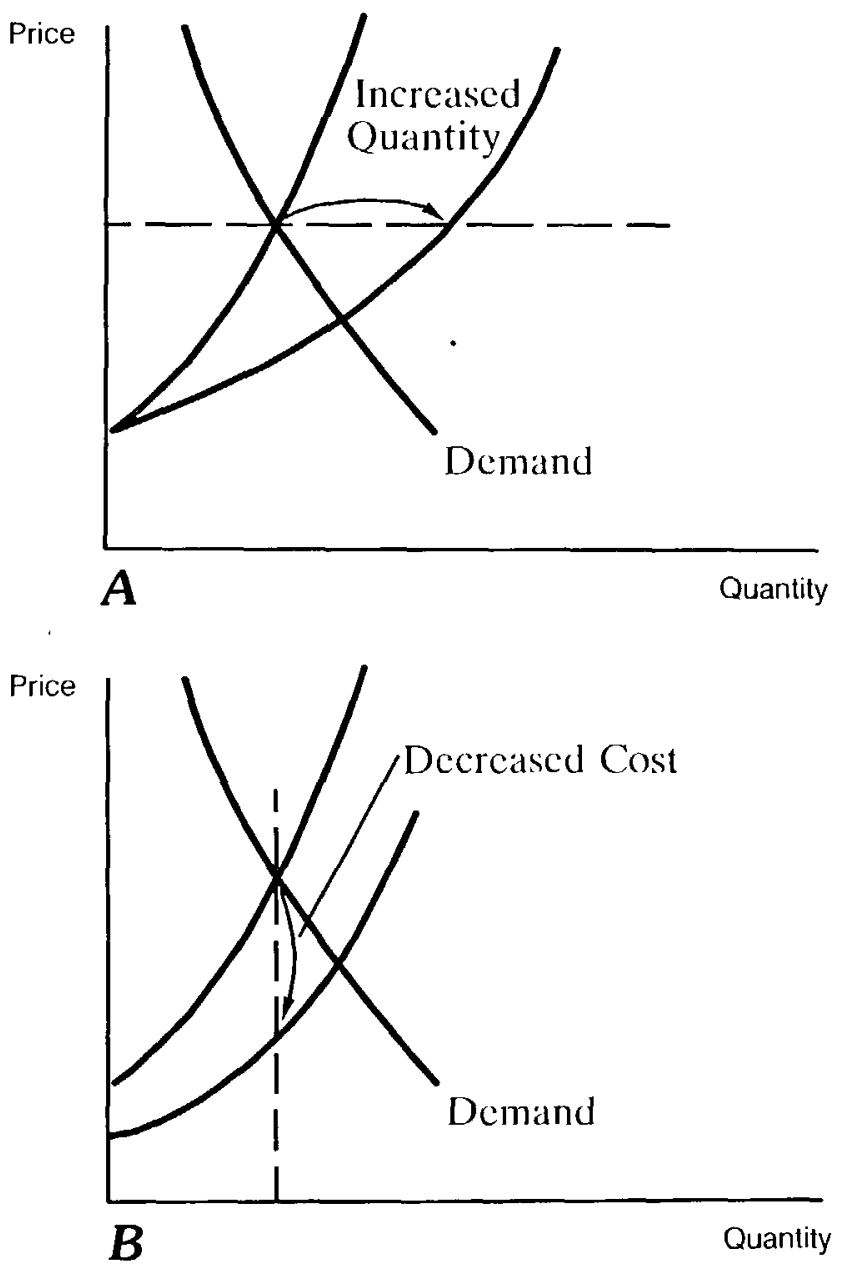

Figure 8. A supply-demand paradigm showing $(A)$ how increased quantity of gas coupled with no change in demand lowers the price and results in more gas being available and $(B)$ how decreased cost for any supply region drives down prices everywhere.

regions, transportation linkages, and demand regions. How much disaggregation is necessary? How much disaggregation is possible? The degree of supply and demand side disaggregation for North America summarized here consti- 
tutes the basis of the North American regional gas (NARG) supply-demand Model. The much greater degree of supply and demand side disaggregation used to represent the world summarized here has been implemented within the world gas trade model (WGT). The North American and world network structures presented herein should be interpreted as a simple, straightforward expansion of the two supply region-two demand region case shown in figure 5 .

The network structure required to properly represent North American gas markets will be presented in hierarchical form beginning with the interrelation among the United States, Canada, and Mexico. The second level of the hierarchy examines the regional supply and demand structures resident within each of the three main countries. The third level examines the degree of technological and process disaggregation resident within each of the producing and consuming regions within each region within each of the three countries. It is convenient as an organizing and expositional aid to move hierarchically downward from aggregate re- gions to successively more disaggregated regions containing multiple supply, transportation, and demand activities.

North America comprises three main geographic regions--the United States, Canada, and Mexico. The political boundaries of these three regions are shown in figure 9. The figure shows Alaska as a part of the United States, but because of its remoteness from the principal markets, it must be represented as a fourth distinct geographic region. Therefore, its existing and prospective future pipeline and liquefied natural gas (LNG) connections with the rest of the regions must be represented. Within each of the regional subdivisions of North America, subregional detail must be distinguished. Whereas it would be possible to consider geographic subdivision to the state and (or) province level, it is neither pragmatic nor necessary. Indeed, the specific regional detail needed depends on where the largest demand centers are located, where the various supply regions are situated, and what existing and prospective pipeline infrastructure connects each. The challenge in economic

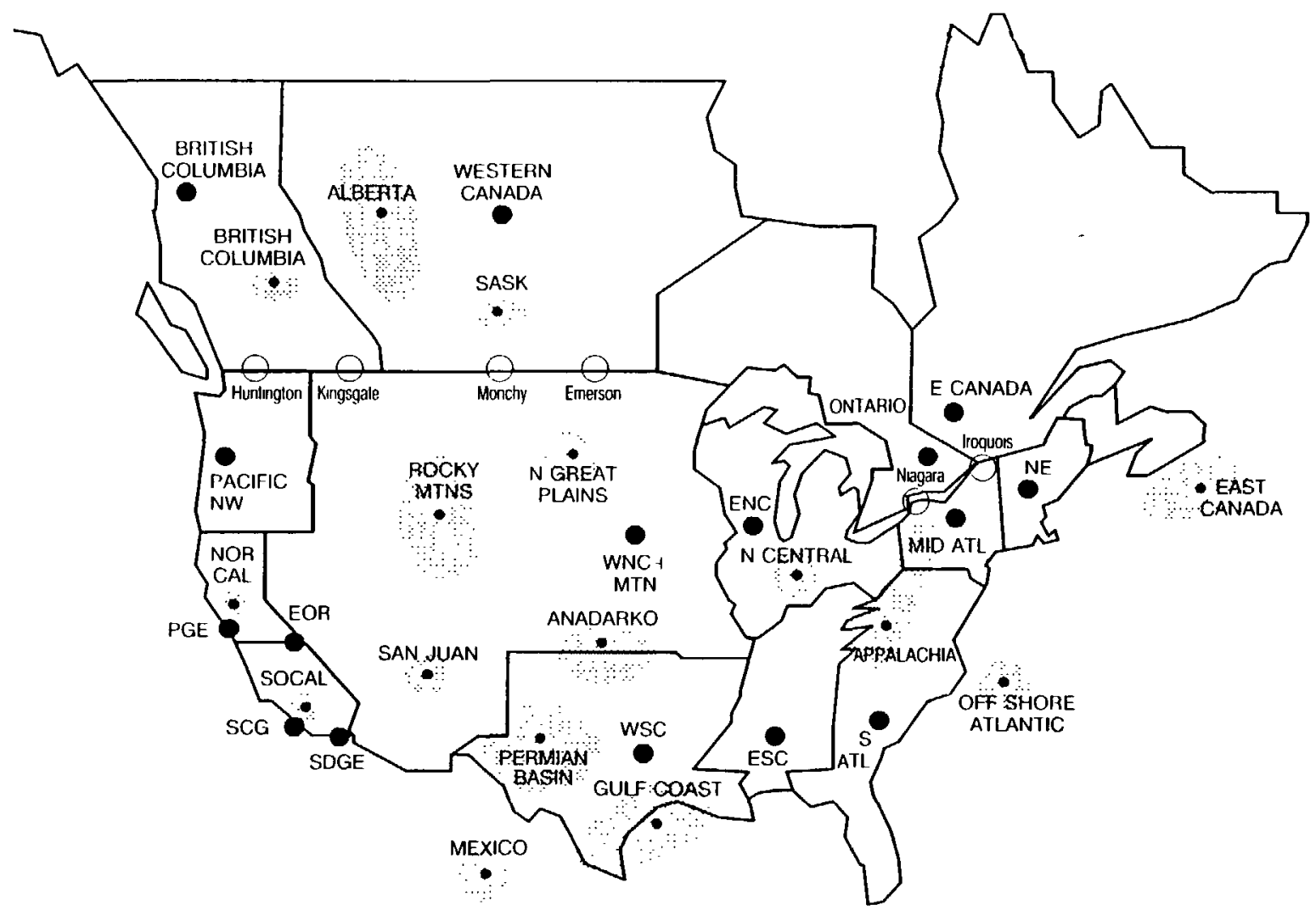

Figure 9. North American supply basins and demand regions used for the North American regional gas (NARG) model. Basins shown by stipple pattern; open circles denote existing and prospective export points for Canada to the United States. Northern California (NOR CAL) demand region further divided to show specific gas utility service regions: PGE, Pacific Gas and Electric; EOR, California Enhanced Oil Recovery. Southern California
(SOCAL) demand region further divided to show specific gas utility service regions: SCG, Southern California Gas; SDGE, San Diego Gas and Electric. SASK, Saskatchewan; NW, Northwest; N, Northern; WNC MTN, West North Central Mountain; WSC, West South Central; ESC, East South Central; ENC, East North Central; E, Eastern; NE, New England; MID ATL, Mid-Atlantic; S ATL, South Atlantic. See text for discussion. 
modeling is to identify commonalities among states and provinces that would justify aggregation.

\section{DEMAND-SIDE STRUCTURE}

The degree of regional disaggregation on the demand side is governed largely by the census regions of the United States. Much of the demand-side data is assembled according to census region, of which there are presently ten. The census regions and their assigned names are shown in figure 9. There is historical precedent to disaggregating demand by census region, and there is much accepted data. Furthermore, climatic distinctions among census regions are usually deemed adequate to reflect different weather and usage patterns throughout the United States. Finally, census region disaggregation strikes an appropriate balance between the desirability of greater demandside disaggregation and the need for a manageable model.

Because of the large number of pipelines in California, the Pacific census region is substantially disaggregated. California is distinguished from the rest of the Pacific census region. The rest of the Pacific region is termed the Pacific Northwest region. Within California, northern California and southern California are distinguished. Further distinctions among the specific gas utility service regions within southern California-Southern California Gas, San Diego Gas and Electric, and California Enhanced Oil Recovery-are made. I have found it sufficient to disaggregate the United States into the following 13 demand regions (which I believe to be the minimum acceptable disaggregation): New England, Mid Atlantic, South Atlantic, East North Central, East South Central, West South Central, West North Central mountain, Pacific Northwest, northern California (Pacific Gas and Electric), Southern California Gas, San Diego Gas and Electric, California Enhanced Oil Recovery, and Alaska.

It is appropriate to aggregate the 12 provinces and territories of Canada into 4 aggregate demand regions. British Columbia lies west of the main supply markets in Alberta and the main demand markets in Ontario. Because of its large prospective supply and export possibilities, British Columbia must be disaggregated. The provinces of Alberta, Saskatchewan, and Manitoba can be aggregated into a region called Western Canada. Eastern Canada includes all provinces east of the Ontario/Manitoba border and is divided into two subregions--Ontario and the rest of Eastern Canada (Quebec and the Maritimes). Ontario is distinguished because of the high concentration of population and industry in the province and because of the economic and political power Ontario wields in Canada. To summarize, Canada is subdivided into four demand regions: British Columbia, Western Canada, Ontario, and Eastern Canada excluding Ontario.

Mexico is represented as a single demand region, although there is growing motivation to distinguish the northern regions of Mexico along the border (which are growing rapidly) from the southern and central regions of Mexico (which are industrialized and populous).

In modeling world gas, the demand-side structure must have at least the level of detail resident within the DFI (Decision Focus, Inc.) world gas trade model. In the model, eight global regions are represented: North America, Latin America, Western Europe, Former Soviet Union and Eastern Europe, Africa, Middle East, Mainland Asia, and Pacific Rim and Australia. Within these eight global regions, the demand side has been disaggregated as follows:

North America is disaggregated into Canada, the United States, and a summary representation of Mexico.

Demand within Latin America is disaggregated into four regions. These are Mexico, northern South America (including Central America), Brazil, and southern South America. These four regions encompass all of Latin America from Mexico southward.

Demand within Western Europe is disaggregated to specifically enumerate the large consumers and the major transit regions. The United Kingdom, Germany, France, Spain, Belgium, Netherlands, Italy, Denmark, Portugal, and other Western Europe are distinguished in the model.

The former Soviet Union can probably be treated as a single, aggregated bloc. It will be desirable to disaggregate the more rapidly growing former Soviet and Eastern European states, particularly if any of those states experiences more rapid than expected development and growth.

There is not much current demand in Africa, nor is there much projected future demand. Therefore, it is sufficient to distinguish the northern part (which has greater growth prospects) from sub-Saharan Africa and points south.

It is sufficient to treat the Middle East as a single aggregate demand region.

Mainland Asia is disaggregated to distinguish the major population centers and the major areas with growth potential. These are Pakistan, India, China, and other mainland Asia.

The Pacific Rim and Australia are disaggregated to distinguish the major consuming regions. These are Japan, Korea, Taiwan, Western Australia, eastern Australia, New Zealand, and the ASEAN countries (all other Pacific Rim).

\section{SUPPLY-SIDE STRUCTURE}

\section{UNITED STATES}

It is not appropriate to characterize the basic supply regions of the United States by political or demographic boundaries. Rather, it is appropriate to subdivide the supply regions according to existing and prospective naturalgas producing potential. In other words, the United States 
should be subdivided on the basis of geologic considerations. Also, making supply region disaggregation, consideration must be given also to the structure of the existing and prospective pipeline system. In particular, supply regions must be associated with the upstream ends of existing pipelines and with the upstream ends of anticipated new pipelines.

The supply-side disaggregation proposed here was selected for several reasons. First, when it is necessary to dịstinguish differences among gas-producing basins in terms of transportation costs to demand regions that compete for that gas, those basins have been associated with distinct supply regions.

Second, for those sources that will require new pipeline capacity, regional supply distinctions must be made. If a particular gas-producing basin relies on the addition of new pipeline capacity to become economically viable, that supply region is distinguished from other supply regions. Indeed, in such cases, the supply region and the outward bound pipeline are inextricably linked, and they must be represented as a pair.

Third, when it is necessary to distinguish resource endowment and cost differences among producing basins, those basins are distinguished by region. In general, there are substantial differences among gas-producing regions with regard to extent, cost, and distribution of the naturalgas resource base. It can be argued that such heterogeneity of the resource-base motivates an extremely detailed representation of natural-gas supply. Counter to such an argument is the observation that much supply-side aggregation is dictated by the specific structure of the pipeline system. In an economic model, the desirability of more supplyside regional and technological detail must be balanced against the desirability of realistically representing key transportation corridors for delivering gas to market.

Fourth, many supply or pipeline projects directly affect only localized regions of the United States or Canada, yet the indirect effects proliferate broadly throughout all supply and demand regions of all countries in the world. In effect, prices carry economic signals from the single site directly affected to all other regions of the world along all competing and complementary parts of the transportation network. The representation of the pipeline network must contain sufficient detail to represent all important existing and prospective future paths.

Fifth, Government policy can be region-specific. Excessive aggregation across regions would obviate the ability of a model to properly represent Government policy. For example, there are significant tax, financial, and other differences among regions that necessitate regional distinctions. Border price regulations Canadian agencies might impose, alternative royalty and tax structures local and national governments may impose, tax subsidies for certain types of resources (for example, coal seams tax credit), and other similar phenomena dictate substantial regional detail.
With regard to the conventional and unconventional natural-gas resource base, it has proven useful to adopt the Potential Gas Committee (PGC) regions and designations. The PGC regions are defined rather conveniently relative to the U.S. pipeline system. The North American supply basins in relation to the demand regions are shown in figure 9. On the basis of the regional disaggregation developed by the PGC, the following supply-basin disaggregation should be used for the United States:

The North Alaska producing region requires significant overland transportation across Alaska to reach markets (for example, ANGTS, Trans Alaska Gas System).

The South Alaska producing region requires much less overland transportation within Alaska to reach a port or a local market.

The San Juan Basin includes the conventional and coal seams producing basins in the Four Corners area of the country.

The Rocky Mountains region is a rather aggregated region that contains the west-central United States except for the San Juan and contiguous basins. The primary resource base lies in the northern part of the Rocky Mountain region of the country.

The Northern Great Plains region includes regions east of the Rocky Mountains in the plains areas of the United States.

The Anadarko region includes the Kansas-Oklahoma nidcontinent area.

The Arkoma region is becoming increasingly important, both as a producing region and as a contributor to gason-gas competition and displacement.

The Permian region includes west Texas and New Mexico.

The Gulf Coast region includes the main onshore and offshore regions of Texas and Louisiana. These are Louisiana onshore, Texas onshore, eastern Gulf onshore, and Gulf offshore.

The Midwest region includes the north-central producing areas of the United States.

The Appalachian region includes the entire Northeastern part and Eastern Seaboard of the United States.

The Offshore Atlantic region includes the offshore regions in the Atlantic Ocean.

The Pacific Northwest region includes all West Coast production outside California.

The Southern California region includes all onshore and offshore production in southern California.

The northern California region.

\section{CANADA}

For Canada, the primary producing basin is the Western Canadian Sedimentary Basin (and a subregion called 
the Deep Basin). Other important basins in Canada are located in the MacKenzie Delta, the Beaufort Sea, and the Arctic Islands, all located north of the Western Canadian Sedimentary Basin. Eastern Canada (Hibernia) has some resource potential as well. The specific regional disaggregation suggested for Canada is chosen for several reasons. First, it is necessary to survey and represent the location of the primary gas deposits in Canada, particularly as they relate to the major transportation systems (Nova, Westcoast, Northern Border, TransCanada).

Second, the Canadian resource base and transportation system must be distinguished at a level of geographic detail necessary to support analysis of six existing and prospective export points to the United States: Sumas/Huntington (Westcoast), Kingsgate (PGT), Monchy (Northern Border), Emerson (Great Lakes and Viking), Niagara (New York), and Iroquois (New York/New England).

Third, it is necessary to distinguish demand patterns in Canada, which in the past have influenced not only delivered gas prices in Canada but also export prices to the United States. In particular, much Canadian gas demand occurs within Ontario, Canada's most populous and most politically influential province. However, Ontario demand must be served through long-distance pipelines from Alberta either indirectly through the Great Lakes system or directly through TransCanada. Alberta and points intermediate, such as Saskatchewan, must be distinguished.

Fourth, it is necessary to distinguish the more northern, Arctic gas resource basins in sufficient detail to discern when, if ever, transportation systems from those regions will become competitive. In particular, the supply structure representing Canada must be sufficiently robust to analyze whether exploring successively up the MacKenzie is more economic than building a complete pipeline to the MacKenzie Delta. The geographic detail shown in figure 9 is sufficient to answer such questions.

Within each of the seven Canadian supply regions and subregions (British Columbia, Alberta, Saskatchewan, MacKenzie, Beaufort, Arctic Islands, Eastern Canada), the volumes and costs of conventional and unconventional gas at various depth intervals, resource types, and subregions are all represented. Canadian resource and cost data are available from the Canadian Geological Survey, the National Energy Board, the Canadian Energy Research Institute, and other organizations within Canada.

The degree of detail necessary to represent Canada is as follows:

The British Columbia region includes the Deep Basin of British Columbia and part of the Western Canadian Sedimentary Basin that is located in the province of British Columbia.

The Alberta region includes most of the Western Canadian Sedimentary Basin. It also includes the rather substantial tight sands and coal deposits located in Alberta. Supply is disaggregated by these three types of resource.
The Saskatchewan region includes the eastern portion of the Western Canadian Sedimentary Basin located in Saskatchewan.

The northern Canada region includes gas in the Northwest and Yukon Territories, the MacKenzie River Valley and Delta, the Beaufort Sea onshore and offshore, and the Arctic Islands north of the North Slope.

The Eastern Canada region includes all gas east of Manitoba, primarily offshore gas in Hibernia and contiguous developments.

The disaggregation of the supply side of the model is guided largely by the regional distribution of the conventional resource base. Unconventional gas (from tight sand, from coal deposits, and from shale) is disaggregated and grouped into the key conventional gas-producing regions as dictated by physical location. Using the same regional distinctions for unconventional as well as conventional gas seems appropriate because unconventional gas resource must have the same access to the transportation system as conventional gas.

Coal gasification is regionalized according to the location of coal deposits in the United States. The major coalproducing regions have been associated with the various PGC supply regions and have been situated within the corresponding gas-supply regions. For example, the North Dakota coal region (where minemouth coal gasification could someday occur) is placed within the northern Great Plains gas-supply region. Small supplemental sources such as methane from waste or biomass are positioned within the various demand regions; their position reflects the fact that they use only the distribution system, not the longdistance transportation system.

\section{MEXICO}

Three import and export points connecting Mexico with the United States must be represented. These are the Texas border (Reynoso), Arizona border (Yuma bypass), and California border (San Diego connection). Gas presently flows from the United States to Mexico. If the Mexican National Pipeline is ever completed, gas could flow northward into the United States from Mexico.

\section{LIQUEFIED NATIONAL GAS (LNG) IMPORT TERMINALS}

There are presently four LNG terminals on the Eastern Seaboard of the United States: Everett, Massachusetts; Cove Point, Maryland; Elba Island, Georgia; and Lake Charles, Louisiana. Additional sites will probably not be implemented on the Eastern Seaboard because the four existing sites span the significant markets, and it is probably not necessary to include additional import locations. However, it is probably necessary to consider two prospective 
sites on the West Coast (California and Pacific Northwest) and one prospective site in Eastern Canada (Quebec).

\section{WORLD OUTSIDE NORTH AMERICA}

More interesting than the question of which existing and prospective LNG sites should be included for North America is the question of what is the price level at which LNG can be landed and regasified at these terminals now and in the future? To answer this question, it is necessary to construct a comprehensive, multiregional world gas trade model, which subdivides the world into a large number of supply regions as well as demand regions. Following is the level of supply disaggregation necessary to characterize world gas markets and to accurately predict the landed price of LNG in North America:

North America is disaggregated into the United States, Canada, and Mexico.

Latin America's primary gas-producing regions are Mexico, Venezuela, Trinidad, Columbia-Ecuador-Peru, Brazil, and Bolivia-Chile-Argentina.

There are several supply regions in Western Europe. The major supply regions within Europe that serve or prospectively serve Western Europe are the United Kingdom, Netherlands, other European Community countries in Western Europe, Norway, and non-European Community Western Europe.

There are vast supplies of natural gas in the former Soviet Union. The following level of disaggregation is the minimum level required to understand the supply-demand situation in Western Europe, Eastern Europe, the former Soviet Union, and competitive supply regions in that part of the world. The disaggregation of the supply regions in the former Soviet Union and eastern Europe is as follows: Romania, Other Eastern Europe, Pechora/ Barents Sea, Volga/Urals and contiguous areas, Western Siberia, and Eastern Siberia/Sakhalin Island.

Supply potential in Northern Africa is prospectively very important in Europe. The following level of supply-side disaggregation is necessary for Africa: Algeria (Northwest Africa), Libya/Egypt/Sudan (Northeast Africa), Nigeria, and other Africa.

The enormous supply potential of the Middle East is disaggregated as follows: Iraq/Kuwait, Saudi Arabia, Qatar, United Arab Emirates, Iran, and other Middle East.

Mainland Asia must be disaggregated to determine its competitive ability to serve the primary demand centers in India, Japan, Taiwan, Korea, Australia, and New Zealand. Following is the required degree of disaggregation: Afghanistan, Pakistan, India, Burma/Bangladesh, Southeast China, North China, and other China.

The Pacific Rim and Australia supply sources are disaggregated using the same philosophy as Mainland Asia:
Thailand, Malaysia, Indonesia, Northwest Shelf Australia, Western Australia, Southeastern Australia, and New Zealand.

The degree of supply-side disaggregation around the world used for the DFI world gas trade model is the same as that used for demand side. It is probably necessary to include more detail when addressing single-country or single-region questions. However, more detail would not be necessary when predicting wellhead and burner tip prices in the major producing and consuming regions around the world.

\section{DEVELOPING REGIONAL SUPPLY CURVES FROM FUNDAMENTAL GEOLOGIC AND COST INFORMATION}

\section{STEP 1-REGIONAL ESTIMATES OF PROVED RESERVES AND INITIAL YEAR PRODUCTION LEVELS}

The first step is to assemble regional estimates of proved (established) reserves and initial year (1992) production levels. Proved or established reserves include those reserves that require little or no additional fixed cost to produce. For proved reserves, fixed costs are largely sunk and only variable costs are required to bring the gas to market. Proved reserves are an important determinant of gas prices because of their low prospective costs to market.

Basin- and country-specific proved reserve data are available from Government agencies complemented by data from sponsors of DFI's world gas trade program. For North America, such estimates are made by the Energy Information Administration (EIA) on the basis of corporate and other submissions. For the world, estimates are made by the U.S. Geological Survey. DFI has assembled a complete set of such estimates for all the producing regions of the world as described in the previous section.

Because subsequent steps require significant disaggregation of the natural-gas resource base, this step requires disaggregation of proved reserves into such categories as dry versus associated gas, condensate field gas, deep versus shallow gas, onshore versus offshore gas, and conventional versus tight or unconventional gas.

\section{STEP 2-REGIONAL ESTIMATES OF UNDISCOVERED RESOURCES}

The second step is to make regional estimates of undiscovered resources on a basin-by-basin basis for each type of gas resource considered. (Many other papers in this volume offer resource estimates for a wide variety of gas resources.) The volumetric estimates of undiscovered resources will be essential for subsequent steps in which the exploration and development costs are estimated for those 
basins and coupled with the volumetric estimates. To support subsequent analysis of the cost structure of the resource in place, one must distinguish to the maximum degree possible the various types or qualities of resource: deep versus shallow, onshore versus offshore, conventional versus unconventional, associated versus dry, connected versus unconnected, and different subregions or countries within regions. Such distinctions lie at the heart of the approach used by the U.S. Geological Survey, the Potential Gas Committee, the Canadian Geological Survey, and other organizations.

Experience suggests that the volumetric information assembled is more complete and comprehensive than information held by individual producer or pipeline organizations. Most producers have detailed information related to specific prospects or regions in which they operate (or intend to operate). Yet they tend not to have information related to regions in which they do not operate. The purpose of step 2 is to provide a uniform level of detail for the entire North American and the world resource base to better understand the forces that will set gas prices and volumes throughout the North American and world natural-gas markets. Lacking uniformity and accuracy, it is impossible to project regional gas prices or volumes and to value various gas assets. In particular, if one lacked reliable information for just one region of North America or the world, calculations of gas price would be suspect. Accordingly, there must be a premium placed on being complete and comprehensive-breadth of coverage must be emphasized over individual detail.

\section{STEP 3-DISAGGREGATE REGIONAL VOLUMETRIC ESTIMATES INTO PLAYS}

To superimpose cost and price information over the regional volumetric estimates, subdivide the region or country of interest (for purposes of this discussion the United States) into geographic areas. Figure 10 shows how the United States might be divided into six geographic areas.

For each of the six geographic areas, an assessment of undiscovered gas is made. The gas is subdivided into rather small subregional increments called horizons or plays. Rather small means small relative to the size of the geographic region. Each horizon and (or) play is categorized as a deep or shallow resource, an onshore or offshore resource, and as a conventional or tight resource. For each horizon considered, one must obtain an estimate of the undiscovered resource in place. Adding all horizons in a given region yields the aggregate volumetric estimate for that region.

There are several methods used for making subregional volumetric estimates. These methods are summarized as follows.

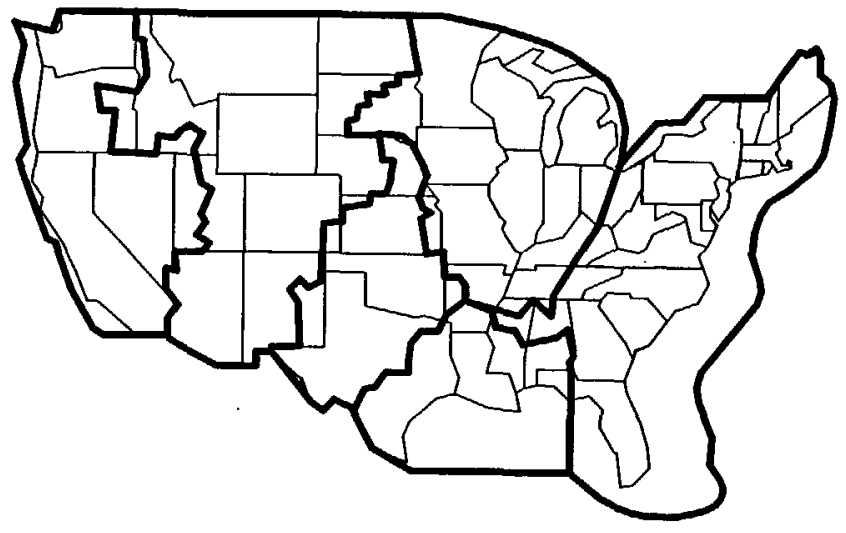

Figure 10. Six geographic regions of the United States used for coupling market information with volumetric estimates of gas. (Data from the Potential Gas Committee, 1987.)

1. Subjective judgment by geologists who are specifically cognizant of a given region. In regions for which there is a significant exploration, development, and production history, this is viable and straightforward method. For regions in which there has been relatively less exploration, development, and production or which reside in "closed" political-economic systems that have precluded resource basinal analysis, it may not be.

2. Another method is statistical extrapolation of historical drilling, finding rate, reserves, production, and (or) other information. This method, which is based on classical statistical methods, is inherently fallible.

3. Another method is to estimate the amount of resources present in an area on the basis of geologic analogy with other regions judged to be similar.

In practice, there is a substantial amount of subjective judgment in resource-base assessment. However, the approach outlined here does not depend on how volumetric resource estimates were developed.

To summarize, the third basic step is to ensure that the aggregate volumetric estimates have been correctly disaggregated to the play or horizon level. This can be accomplished either by making estimates directly at the play level or by systematically disaggregating more aggregate estimates and extrapolating them to the play level. This disaggregation to the play level is a necessary first step toward properly superimposing cost and price information over the volumetric estimates.

\section{STEP 4-ESTIMATE RESERVOIR SIZE AND DEPTH DISTRIBUTION}

To infer reservoir size and depth distributions that characterize the resource base in each of the geographic areas shown in figure 10, one must ultimately consider the individual horizons or plays within the areas, infer the reservoir 
size and depth distribution for those plays, and then add up the distributions into an aggregate distribution that characterizes the entire geographic region. To do so requires stateof-the-art probabilistic simulation techniques. A somewhat detailed explanation of those methods is presented herein because of the pivotal importance of the regional gas-supply curves that will ultimately be generated. It is essential to understand how volumetric estimates and field and pool size distributions combine to form regional gas-supply curves.

There are two ways to develop reservoir size distributions for a given play. One is the subjective extrapolation of geologically analogous regions. For some regions of North America and the world, there is no production history, and very little is objectively known. The most viable (perhaps the only) approach for such regions is extrapolation from known regions believed to have similar reservoir size and depth distributions.

Another method is the statistical extrapolation of historical finding rate information. For some regions of North America and the world for which exploration and development activities have occurred over a significant period of time (mature regions), there is sufficient historical information to statistically calculate the reservoir size and depth distribution of that part of the resource in place that remains. For regions for which sufficient historical statistics are available, it is valuable to assemble that historical information and perform statistical analysis to complement any subjective estimates of reservoir size and depth distributions. Whichever of the two methods is ultimately used, the probabilistic methods used to characterize the reservoir size distribution are the same.

Consider a simple homogeneous gas play that contains three reservoirs of size $B_{1} \mathrm{Mcf}, B_{2} \mathrm{Mcf}$, and $B_{3} \mathrm{Mcf}$. The total resource potential, or the total volumetric estimate of resource in place, is $B_{1}+B_{2}+B_{3}$. The critical question is not what is the total volume of resource in place but rather in what order might one expect to encounter the three reservoirs. The critical observation is that given a set of prospects whose elements have a common structural configuration and are located in the same geographic region, the bigger reservoirs are most likely to be discovered first.

To model this effect, suppose that an entrepreneur drills a hypothetical three-reservoir play until the first reservoir is hit. Which reservoir has most likely been hit-1, 2 , or 3 ? A model of the order in which such discoveries are made can be built by postulating a surface area function, $S A($.$) , that depicts surface area of each reservoir. That is,$

$$
S A\left(B_{i}\right)=\text { surface area of a reservoir containing } B_{i} \text { barrels }
$$

The simplest and most frequently used surface area function assumes that $S A(B)=B$. In other words, the surface area of a reservoir is directly proportional to its size. (Such an assumption might well be characteristic of ad- vanced seismic technologies, whose ability to discriminate a structure should depend on the relative size of the structure.) The typical probabilistic simulation model assumes that the reservoir encountered is

Reservoir 1 with probability

$$
\frac{S A\left(B_{1}\right)}{S A\left(B_{1}\right)+S A\left(B_{2}\right)+S A\left(B_{3}\right)}
$$

Reservoir 2 with probability

$$
\frac{S A\left(B_{2}\right)}{S A\left(B_{1}\right)+S A\left(B_{2}\right)+S A\left(B_{3}\right)}
$$

Reservoir 3 with probability

$$
\frac{S A\left(B_{3}\right)}{S A\left(B_{1}\right)+S A\left(B_{2}\right)+S A\left(B_{3}\right)}
$$

This probabilistic assumption can be likened to throwing darts at the play, assuming an equal probability of hitting each reservoir in the play. The probability of hitting a reservoir in the play is the area of the reservoir divided by the total area of the play. (The discussion does not yet consider dry holes.) Interpreted differently, the probability of encountering the surface area presented by each reservoir in the play is equal. This can be regarded as a statement about the homogeneity of the play. If a play is a heterogeneous structure, one might assume that some reservoirs are more likely to be discovered than others. The model would have to deal with such heterogeneity by disaggregating plays into homogeneous subplays or by modifying the described reservoir discovery probabilities. Assuming that the probability of hitting each reservoir in the play is equal, the probability of finding the ith reservoir is simply the surface area of the ith reservoir divided by the total surface area presented by all reservoirs in the play, or

$$
\frac{S A\left(B_{i}\right)}{S A\left(B_{1}\right)+S A\left(B_{2}\right)+S A\left(B_{3}\right)}
$$

Suppose the first reservoir discovered is reservoir 2 . If a second reservoir is discovered as a result of additional exploration, the model assumes it is

$$
\begin{aligned}
& \text { Reservoir } 1 \text { with probability } \\
& \frac{S A\left(B_{1}\right)}{S A\left(B_{1}\right)+S A\left(B_{3}\right)}
\end{aligned}
$$


If reservoir 2 already has been discovered,

Reservoir 1 with probability

$$
\frac{S A\left(B_{3}\right)}{S A\left(B_{1}\right)+S A\left(B_{3}\right)}
$$

the model assumes that the dart is equally likely to hit either reservoir 1 or 3 . The probability that the entire play is hit is the ratio of its area to the total areas of the undiscovered reservoirs.

The order of discovery of the reservoirs and the probability in which that order of discovery occurs is determined by sampling probabilities. The exploration component of the model is a sampling without replacement model of the three reservoirs. The sampling probabilities are functions of the reservoir surface areas (which are functions of the reservoir sizes). There are 3 ! possible orders of discovery, and each order of discovery has a particular probability that is dependent on the size of the reservoirs.

In general, the surface area function $S A($.$) is such that$ the probability of discovering the reservoirs in descending order of size is much higher than discovering them in any other order. The order of discovery is asymmetric, and the early discovery of larger reservoirs is strongly favored over the discovery of small reservoirs. This is critical because it dictates to a very large degree the nature of the supply curve derived from probabilistic simulation.

Extending the simple three-reservoir model to $N$ reservoirs, if the reservoirs are indexed $1,2, \ldots, N$, the probability of discovering these reservoirs in the order $i_{1}, i_{2}, \ldots, i_{N}$ is according to the model:

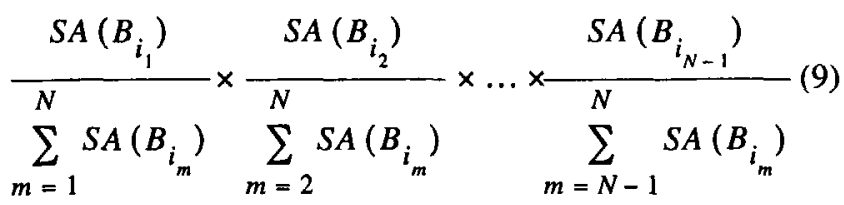

which can be rewritten

$$
\frac{\prod_{k=1}^{N-1} S A\left(B_{i_{k}}\right)}{\prod_{k=1}^{N-1} \sum_{m=k}^{N} S A\left(B_{i_{m}}\right)}
$$

There are $N$ ! reservoir discovery sequences whose probabilities are governed by this equation.

The discussion thus far has implicitly assumed that the size of each of the $N$ reservoirs is known with certainty. What if they are not? What if the sizes of the reservoirs are governed by a probability distribution over reservoir size? How can a probabilistic model of reservoir sizes be superimposed over the foregoing model of sampling without replacement? The general approach is to postulate that reservoir sizes are governed by a joint probability distribution over the contents of $N$ reservoirs

$$
f\left(B_{1}, \ldots, B_{N}\right)
$$

and to analyze its consequences. The most frequent simplification is to assume that each of the $N$ reservoirs is governed by an independent, identically distributed probability distribution. That is,

$$
f\left(B_{1}, \ldots, B_{N}\right)=f\left(B_{1}\right) f\left(B_{2}\right) \ldots f\left(B_{N}\right)
$$

In other words, each of the $B_{i}$ 's assumed to be known with certainty in the previous discussion is now assumed to be uncertain and to be governed by a probability density function $f(B)$.

The implications of the expanded model can be illustrated by computing the probability of observing the reservoir size sequence $S_{1}, S_{2}, \ldots, S_{N}$. Using the probabilistic expansion rule, the probability of observing the reservoir size sequence $S_{1}, S_{2}, \ldots, S_{N}$ can be expanded about the $N$ ! possible discovery sequences

$$
\left\{S_{1}, \ldots, S_{N}\right\}=\sum_{i_{1}, \ldots, i_{N}}\left\{S_{1}, \ldots, S_{N}, i_{1}, \ldots, i_{N}\right\}
$$

The distribution within the summation $\left\{S_{1}, \ldots, S_{N}, i_{1}, \ldots, i_{N}\right\}$ is the probability distribution that reservoir $i_{1}$ is discovered first and is of size $S_{1}$ (that is, $B_{i_{1}}=S_{1}$ )., reservoir $i_{2}$ is discovered second and is of size $S_{2}$ (that is, $B_{i_{2}}=S_{2}$ ),... and reservoir $i_{N}$ is discovered $N$ th and is of size $S_{N}$ (that is, $B_{i_{N}}=S_{N}$ ). This corresponds to a single path through the corresponding probability tree; the probability of taking this path is

$$
\begin{aligned}
& \left\{S_{1}, \ldots, S_{N} i_{1}, \ldots, i_{N}\right\}= \\
& \text { N-1 } \\
& \frac{\prod_{k=1} S A\left(B_{i_{k}}\right)}{\prod_{k=1}^{N-1} \sum_{m=k}^{N} S A\left(B_{i_{m}}\right)} f\left(A_{i_{1}}\right) \ldots f\left(B_{i_{N}}\right)
\end{aligned}
$$

Per the deterministic reservoir size development, the first term is the probability of encountering the reservoirs in the sequence $i_{1}, \ldots, i_{N}$ given the sizes of the reservoirs and the second term is the joint probability of the sizes of the reservoirs. Substituting into equation 13 above gives the 
following expression for the reservoir size sequence probability:

$$
\left\{S_{1}, \ldots, S_{N}\right\}=\sum_{i_{1}, \ldots, i_{N}} \frac{\prod_{k=1}^{N-1} f\left(B_{i_{k}}\right) S A\left(B_{i_{k}}\right)}{\prod_{k=1}^{N-1} \sum_{m=k}^{N} S A\left(B_{i_{m}}\right)}
$$

The reservoir size sequence must be independent of the particular way in which the reservoirs are indexed. Therefore, the $N$ ! different ways of indexing the reservoirs must be taken into account and all can be considered equal in probability. Therefore, because there are $N$ ! possible orderings of the indexes, the summation in the above equation can be replaced by a multiplication by $N$ ! to obtain the expression

$$
\left\{S_{1}, \ldots, S_{N}\right\}=N ! \frac{\prod_{k=1}^{N-1} f\left(S_{k}\right) S A\left(S_{k}\right)}{\prod_{k=1}^{N-1} \sum_{m=k}^{N} S A\left(S_{m}\right)}
$$

This equation is the fundamental "grist" from which stochastic supply curves can be derived. It gives the probability distribution over the sequences of sizes in which the reservoirs are likely to be discovered. This reservoir size probability distribution can be used in very straightforward fashion by analytical or Monte Carlo methods to simulate sequences of reservoir sizes discovered.

The surface area function $S A($.$) is asymmetrically larg-$ er for the larger deposits (even if $S A(B)=B$ ) than for the smaller deposits. This fact has been repeatedly corroborated by empirical observation. Furthermore, the quantity of gas contained in large fields is asymmetrically larger than that contained in smaller fields. The net effect of the asymmetric surface area function combined with the asymmetrically smaller contents of smaller reservoirs is that the highest probability discovery sequences are those that have the larger reservoirs encountered very near the front of the sequence and the smaller reservoirs encountered very near the end. Indeed, the highest probability discovery sequence is the pure deterministic, descendingsize order of discovery.

It is useful to think not only of incremental discoveries but also of cumulative discoveries. Cumulative discoveries include the larger reservoirs early in the sequence and the smaller reservoirs later in the sequence; therefore, cumulative discoveries increase faster at the beginning and more slowly at the end. Because larger fields have lower unit costs (that is, same fixed cost amortized over many more thousands of cubic feet of resources), the implicit cumulative supply curve for a play will be relatively flat and low at the beginning (representing the larger, lower cost reservoirs) and will slope steeply upward at the end (representing the smaller, higher cost reservoirs). To wit, the cumulative supply curve is determined initially by the costs of the large reservoirs and only later by the costs of the small reservoirs. Because of the asymmetry in surface area and size of large reservoirs, constructing a supply curve for the play by assuming strict, deterministic discovery in descending order of reservoir size is quite accurate and representative of how the play is most likely to be exploited.

The supply curve for a play shows how cumulative reserve additions along the horizontal axis relate to cost per thousand cubic feet along the vertical axis. Given the asymmetry, the play-level supply curve must ultimately tilt upward rather strongly. This is not to say that the basinwide supply curve tilts upward strongly. On the contrary, there may be many plays in a given basin and the supply curve for each may tilt upward strongly, but the aggregate supply curve may not tilt up particularly strongly.

The propensity of the play to be exploited in descending order of reservoir size (ascending order of reservoir cost) is entirely consistent with economically rational behavior of producers. Profit maximization motivates producers to find the large reservoirs first. No rational producer is looking for the small reservoirs. Rational producers work hard to identify and exploit the large reservoirs. Economic forces that motivate producers to look for the largest existing reservoirs in the play accelerate the asymmetry and buttress the argument that purely deterministic, ascending cost supply curves are surprisingly adequate.

\section{STEP 5-ASSEMBLE HISTORICAL SCHEDULES OF DISCOVERIES, RESERVE ADDITIONS, AND PRODUCTION}

The next step is to assemble historical schedules of discoveries, reserve additions, and production for regions or plays for which such data are available. The most frequent approach to exploration, development, and production modeling is based on statistically inferring future finding rates from the entire history of past and present discoveries. Conventional statistical methods strive to fit future finding-rate trends to observed historical statistics and thereby to determine the most appropriate structural model.

Unfortunately, conventional statistical methods have consistently understated future resource potential and exploration success. The reason is that conventional methods implicitly ignore technological innovation, field growth, and other phenomena that are apparent to industry observers but are not contained in historical data. Conventional statistical methods are inextricably wedded to the past-past prices, 
past technologies, past methods, past regions, past expectations of the future, past regulations, and Government policy. There is no way to decouple conventional statistical extrapolation from the past.

Fortunately, there are newly emerging statistical techniques that can overcome the conservative bias of conventional statistical methods. These new techniques, called Bayesian statistical techniques, systematically meld historical data with current judgment. (Conventional statistical methods do not allow any use of subjective judgment. Everything that is known or knowable is assumed to reside in the historical data. Bayesian methods are explained in detail in Nesbitt and Sparks $(1990,1992)$. In particular, Bayesian statistical methods allow one to introduce judgments related to technological innovation, field growth, geologic analogy, and other critical phenomena that simply do not exist within the historical data. Such phenomena would apparently be too new to reside in the historical data. Yet, such phenomena must be properly incorporated to make accurate projections of resource volumes, costs, and prices. There is risk of overlooking judgments known to contain valid information that is not available in historical data. Bayesian statistical methods allow such information to be incorporated.

\section{STEP 6-STATISTICAL ANALYSIS OF HISTORICAL SCHEDULES}

After assembling such historical information, it is necessary to derive parameters of the reservoir size sequence distribution developed in step 4. For simplicity, assume that the surface area is proportional to the size of the reservoir, that is, $S A(B)=B$.

A play containing $N$ reservoirs in which drilling has proceeded only to the point at which $n<N$ reservoirs have been discovered can be postulated. In other words, the play has been only partially exploited. Analogous to the previous development, expand the probability of observing the partial reservoir size sequence $\left\{S_{1}, \ldots, S_{n}\right\}$ about all possible orders in which the first $n$ reservoirs might be discovered

$$
\begin{gathered}
\left\{S_{1}, \ldots, S_{n}, i_{1}, \ldots, i_{n}\right\} \\
=\int d B_{i_{n+1}} \ldots \int d B_{i_{N}}\left\{S_{1}, \ldots, S_{N}, i_{1}, \ldots, i_{N}\right\}\left\{S_{1}, \ldots, S_{n}\right\} \\
=\sum_{i_{1}, \ldots i_{n}}\left\{S_{1}, \ldots, S_{n}, i_{1}, \ldots, i_{n}\right\}
\end{gathered}
$$

The probability of observing the sequence $S_{1}, \ldots, S_{n}$ is obtained by integrating out all yet to be made future discoveries in equation 14 according to the following expression

$$
\begin{gathered}
\left\{S_{1}, \ldots, S_{n}, i_{1}, \ldots, i_{n}\right\}=\int d B_{i_{n+1}} \ldots \int d B_{i_{N}} \\
\left\{S_{1}, \ldots, S_{N} i_{1}, \ldots, i_{N}\right\} \\
=\int d B_{i_{n+1}} \ldots \int d B_{i_{N}} \frac{k=1}{\prod_{k=1}^{N-1} A_{i_{k}} f\left(A_{i_{k}}\right)} f\left(B_{i_{n+1}}^{N}\right) \ldots f\left(B_{i_{N}}\right) \\
\prod_{k=1} \sum_{m=k} A_{i_{m}}
\end{gathered}
$$

It is useful to define the sum of the remaining undiscovered reservoirs

$$
\begin{gathered}
\left\{S_{1}, \ldots, S_{n}\right\}=\frac{N !}{(N-n) !}\left\{\prod_{k=1}^{n} S_{k} f\left(S_{k}\right)\right\} \\
\int_{0}^{\infty} \frac{d S g(S)}{\prod_{k=1}^{n}\left[S+S_{k}+\ldots+S_{n}\right]} S=B_{i_{n+1}}+\ldots+B_{i_{N}}
\end{gathered}
$$

and the probability density function over that sum to be $g(S)$. Making this definition, equation 18 can be rewritten in the following form

$$
\left\{S_{1}, \ldots, S_{n}, i_{1}, \ldots, i_{n}\right\} \int d S g(S) \frac{\prod_{k=1}^{n} B_{i_{k}} f\left(B_{i_{k}}\right)}{\prod_{k=1}^{n}\left[S+\sum_{m=k}^{n} B_{i_{m}}\right]}
$$

Substituting into equation 17 , we can write the following expression for the probability distribution over the partial sequence of discoveries $\left\{S_{1}, \ldots, S_{n}\right\}$

$$
\left\{S_{1}, \ldots, S_{n}\right\} \sum_{i_{1}, \ldots i_{n}} \int d S g(S) \frac{\prod_{k=1}^{n} B_{i_{k}} f\left(B_{i_{k}}\right)}{\prod_{k=1}^{n}\left[S+\sum_{m=k}^{n} B_{i_{m}}\right]}
$$

There are $N \times(N-1) \times(N-2) \times \ldots \times(N-n+1)$ possible orders of the first $n$ discovery indexes. Therefore, the summation in equation 21 can be replaced by the expression $N ! /(N-n)$ ! and the equation can be reorganized as follows

$$
\begin{aligned}
\left\{S_{1}, \ldots,\right. & \left.S_{n}\right\}=\frac{N !}{(N-n) !}\left\{\prod_{k=1}^{n} S_{k} f\left(S_{k}\right)\right\} \\
& \int_{0}^{\infty} \frac{d S g(S)}{\prod_{k=1}^{n}\left[S+S_{k}+\ldots+S_{n}\right]}
\end{aligned}
$$


Equation 22 specifies the probability distribution over the size of the first $n$ discoveries in a particular play.

The most typical approach is to assume that the reservoir size distribution $f($ ) obeys a given analytical form (for example, exponential, gamma, or lognormal). It is desirable to assume that $f($.) is lognormal and thereby implicitly to assume that $g(S)$ is the sum of $(N-n)$ independent, lognormally distributed variables. The functional form of the lognormal distribution is

$$
f\left(x \mid \mu, \sigma^{2}\right)=\frac{1}{\sigma x \sqrt{2 \pi}}=\exp -\frac{1}{2} \frac{(\ln x-\mu)^{2}}{\sigma^{2}}
$$

where $\mu$ and $\sigma$ are parameters of the distribution to be inferred from historical data. Under this assumption, the functions $f($.$) and g($.$) in the foregoing formulations are ex-$ plicitly a function of the parameters $\mu$ and $\sigma$ :

$$
\begin{gathered}
\left\{S_{1}, \ldots, S_{n} \mid \mu, \sigma, N\right\}=\frac{\Gamma(N+1)}{\Gamma(N-n+1)} \\
\left\{\prod_{k=1}^{n} S_{k} f\left(S_{k}, \mu, \sigma\right)\right\} \int_{0}^{\infty} \frac{d S f(S, \mu, \sigma)}{\prod_{k=1}^{n}\left[S+S_{k}+\ldots+S_{n}\right]}
\end{gathered}
$$

$N$ and $n$ are considered continuous variables, and their factorials can be written as gamma functions. In equation 24 , the discovery sequence is a function of the parameters $\mu$, $\sigma$, and $N$ of the model.

For a given historical discovery sequence $S_{1}{ }^{*}, \ldots, S_{n}{ }^{*}$, equation 24 can be applied successively for discoveries $1,2, \ldots, n$ and $n$ equations characterizing the $n$ partial discovery sequences can be written. Doing so creates $n$ equations in the three unknowns $\mu, \sigma$, and $N$ and allows one to perform least squares, maximum likelihood, or Bayesian statistical estimation of those parameters. An additional constraint can be imposed requiring that the total aggregate quantity of resource in the play be equal to the exogenous volumetric estimate. Estimates derived therefrom allow one to ensure that the total inventory resident within all the reservoirs in the play is precisely equal (in an expected value sense) to whatever volume is exogenously specified for each play. This links the cost and price estimates directly to the exogenous volumetric estimates. That is, the parameters $\mu, \sigma$, and $N$ of the reservoir size distribution will be lockstep consistent with the exogenously estimated volume in place.

Given the parameters $\mu, \sigma$, and $N$ of the lognormal reservoir size distribution, probability calculus (Bayes Theorem) can be used to compute the size distribution of the reservoirs remaining in the play given the observed historical sequence of discoveries. In particular, to infer the probability distribution over future discovery sequenc- es in the play given $n$ historical discoveries, Bayes Theorem implies the following relation

$$
\begin{gathered}
\left\{S_{n+1}, \ldots, S_{N} \mid S_{1}, \ldots, S_{n}\right\} \\
=\frac{\left\{S_{1}, \ldots, S_{n}, S_{n+1}, \ldots, S_{N}\right\}}{\left\{S_{1}, \ldots, S_{n}\right\}}
\end{gathered}
$$

Substitution from equations 16 and 24 gives an expression for the size distribution over the reservoirs remaining in the play. It is this distribution $\left\{S_{n+1}, \ldots, S_{N} \mid S_{1}, \ldots, S_{n}\right\}$ that must be used to conduct probabilistic simulation of future exploration and production in the play. This reservoir size distribution function is $R\left\{S_{n+1}, \ldots, S_{N}\right\}$. The expected volume remaining in the play is the expected value of the probability distribution over the sum of the remaining reservoirs.

\section{STEP 7-PROBABILISTIC SIMULATION OF FUTURE EXPLORATION AND PRODUCTION}

To this point, subjective judgment or statistical extrapolation of past successes has been used to derive estimates of parameters for play-level reservoir size distributions. The sum of all play-level reservoir sizes adds up to the exogenously specified volumetric estimate for the region. In short, the reservoir-level deposition of the volumetric estimates has been fully specified. However, dry hole probabilities and reservoir depth distributions are two critical items yet to be considered.

The probabilistic simulation approach begins with the probability distribution over remaining reservoir size $R($.). To this distribution, a representation of dry hole probabilities and reservoir depth distributions must be added.

To add dry hole probabilities to the model is rather straightforward. Only some "white" needs to be added between the reservoirs shown in figure 11 . That is, some of the

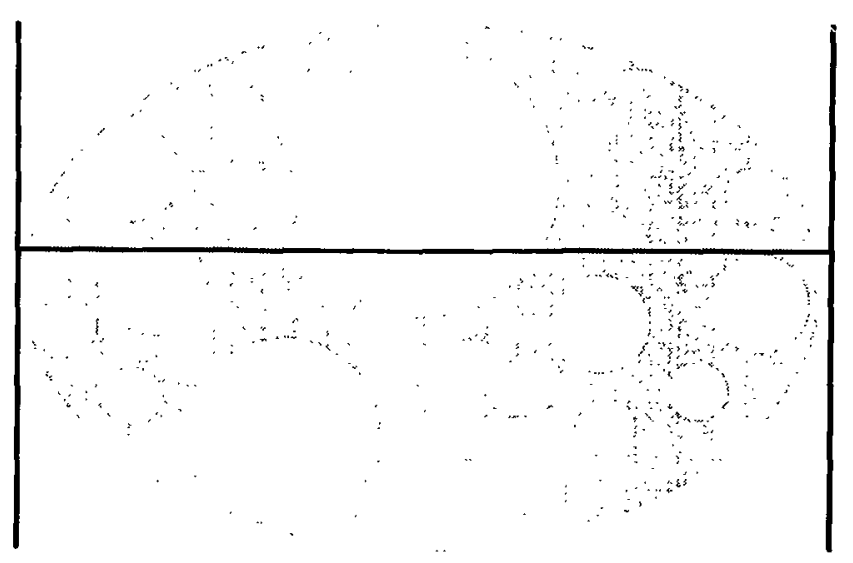

Figure 11. Areal distribution of reservoirs (shaded area) showing how dry-hole probabilities (white circles) can be incorporated into a supply-demand model of the natural-gas market. 
darts thrown at figure 11 will not hit a reservoir at all. The areal distribution shown in figure 11 simulates that the probability of hitting a given reservoir is a function of the area of that reservoir relative to the areas of other reservoirs in the play plus the white areas between the reservoirs. The analogy of throwing darts is quite apt.

How might dry hole probabilities be incorporated into the model? One simple way is to assume that the dry hole rate is constant and independent of the degree to which the play has been exploited. A simple assumption such as this allows one to simply derate the reservoirs in the play, assuming that it takes more than one hole drilled to actually encounter each reservoir. Such derating introduces a particular aggregate amount of white in figure 11. There are more complex methods for our purposes of incorporating dry hole rates; however, the usefulness of those more complex methods is questionable. The simple derating method seems to capture the most important cost issues related to dry holes.

For each play, the reservoir size distribution must be estimated simultaneously with the depth distribution. The areal distribution must be complemented with a depth distribution that prescribes the depth of each of the reservoirs (fig. 12). Just as with the reservoir size distribution, there are two ways to estimate depth distributions. These are subjective extrapolation from geologically analogous regions and statistical extrapolation of depth distributions within the given horizon. The depth distribution combines with the areal (reservoir size) distribution to create a joint probability distribution over reservoir size and depth (fig. 12). This joint probability distribution over reservoir size and depth is the centerpiece of any simulation of the economics of exploration and development.

Quite frequently, the depth distribution is handled by simple disaggregation-that is, plays of various depths are explicitly distinguished. When making such distinctions, individual plays can be considered uniform in depth. Therefore, each geographic region must be analyzed for

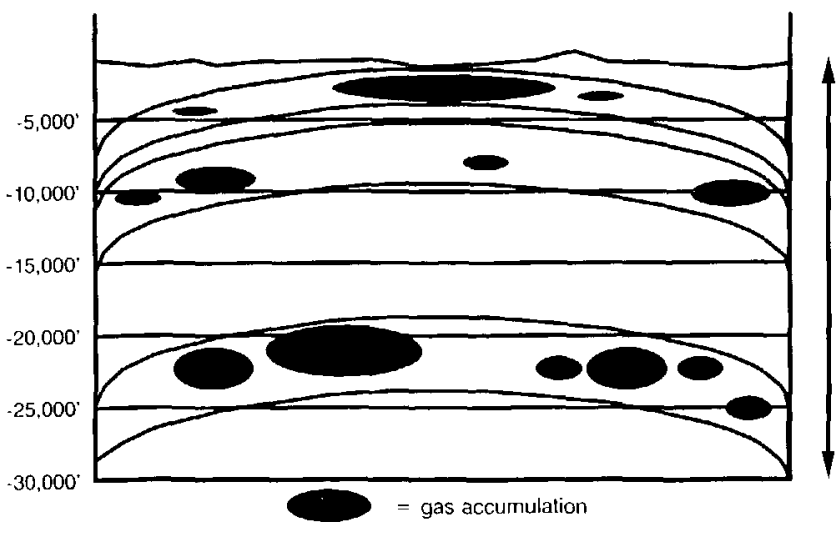

Figure 12. Areal and depth distribution of gas reservoirs. See text for discussion. both deep and shallow plays. A more complex alternative would be to include parameters in the probability distributions $f($.) to account for depth differentials. For the remainder of this discussion, plays will be assumed uniform in depth. Also, it is assumed that deep plays and shallow plays are analyzed in parallel.

The process of considering a single play is shown in figure 13. Exploratory drilling, in effect, throws darts at the reservoir size and depth distribution for that play, as shown in figure 11. For each exploratory hole, the probability of encountering a reservoir of a given size is represented by the probability that a dart thrown at the areal distribution shown in figure 11 will strike a circle that denotes a reservoir of that size. The probability of a dry hole is implicit in how much white there is in the diagram relative to black (reservoirs) (fig. 11).

The probability distribution over reservoir size (and depth) is the fundamental representation of the underlying geology. Beginning with this representation, what would happen if successive holes were drilled into the play must be simulated. Such simulation must take into account drilling and completion costs and all the other costs associated with drilling and bringing reservoirs into production. Given this cost information, the probabilistic nature of exploration is represented by successively running a large number of drilling simulations that exploit the entire play in question and keep track of how much cost is expended and what reservoirs are encountered in what order. Each simulation will encounter the various reservoirs in various orders and result in various sequences of discoveries and various corresponding cost schedules. In effect, each simulation will generate an order of discovery and a corresponding cost schedule, which together constitute a supply curve in the economic sense (cost versus quantity of gas).

By running a large number of drilling simulations, a histogram can be developed of sequences in which the remaining reservoirs, as described by the function $R($.$) , are$ encountered and the corresponding costs incurred by the driller. In each sequence considered, each successive reservoir encountered adds a quantity of proved reserves (the quantity contained in the next reservoir encountered) along the horizontal axis at a cost that is characterized by the fixed cost, variable cost, and applicable taxes, finances, and regulations along the vertical axis. The situation for the 6 th reservoir encountered in a hypothetical simulation is shown in figure 14. The vertical height is the cost and the horizontal width is the quantity of gas in each reservoir. Notice that the sequence is not cost ascending.

The histogram of such supply curves (shown in fig. 15) constitutes in effect a probability distribution over the fundamental supply economics of the basin; it contains the mean supply curve, the variance about the mean, the skewness of the supply curves, and other higher order statistical properties. It is absolutely critical to consider that because of the asymmetry of the surface area function and 


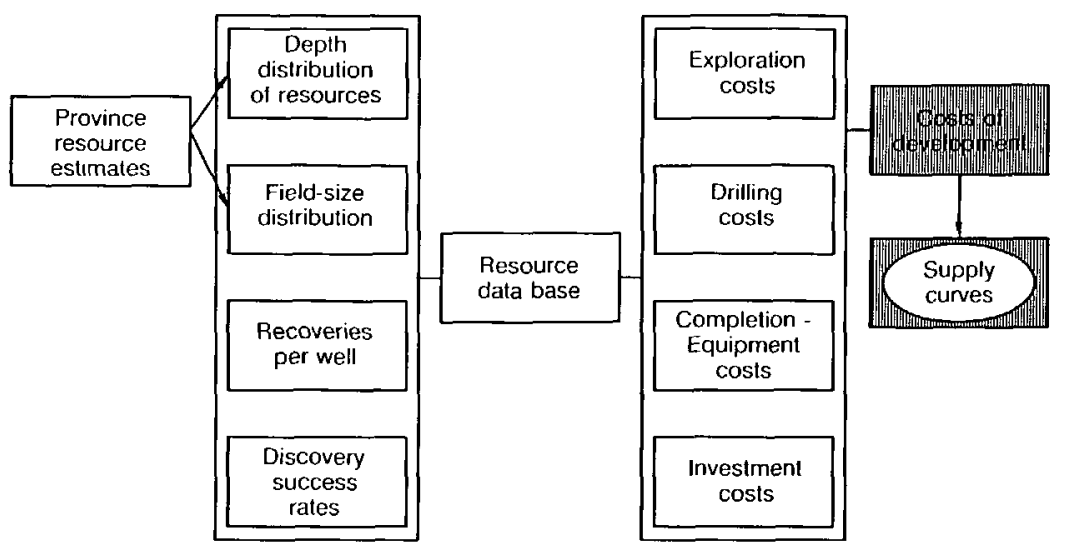

Figure 13. The process of considering a single gas play for a supply-demand model. See text for discussion.

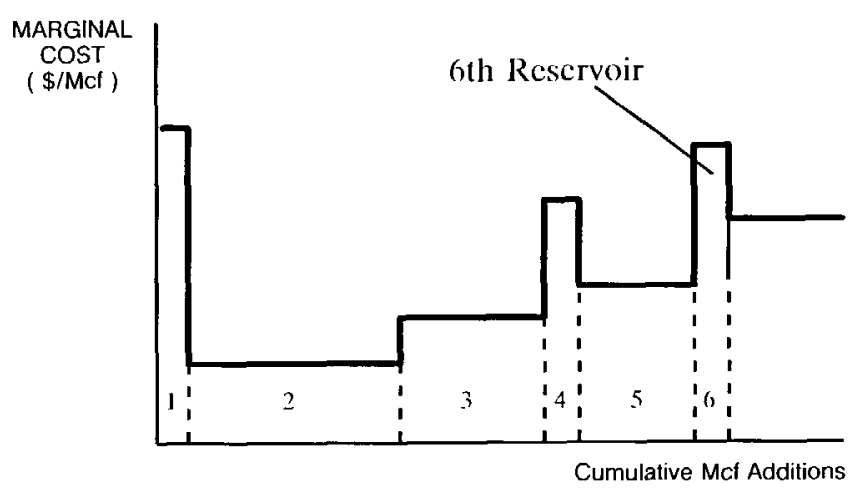

Figure 14. Hypothetical simulation of adding an incremental reservoir (6th reservoir) to a supply-demand model. Marginal cost in dollars per thousand cubic feet. See text for discussion.

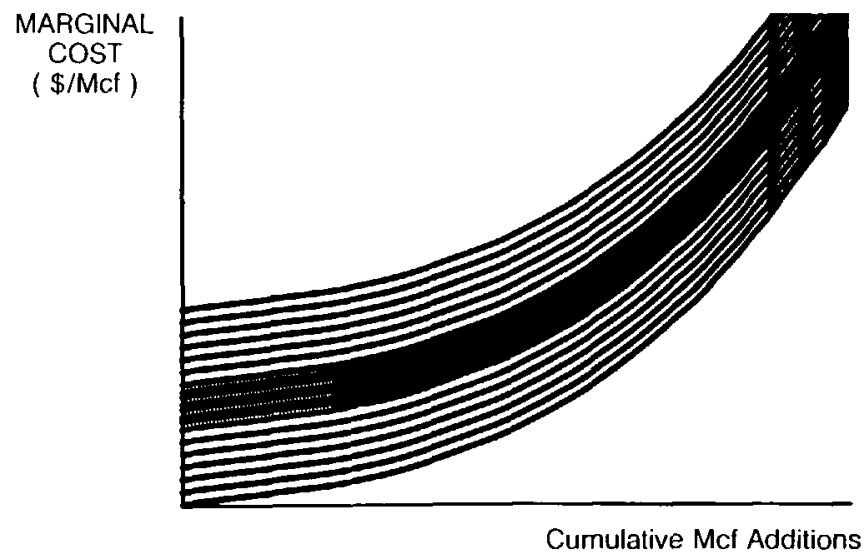

Figure 15. Histogram of reservoir sequence.

of the quantities resident within the large reservoirs as compared to the small reservoirs that a vertical cross section of the histogram (the cost histogram for a given level of cumulative discoveries) is a probability density function that has a number of important properties. First, particular-

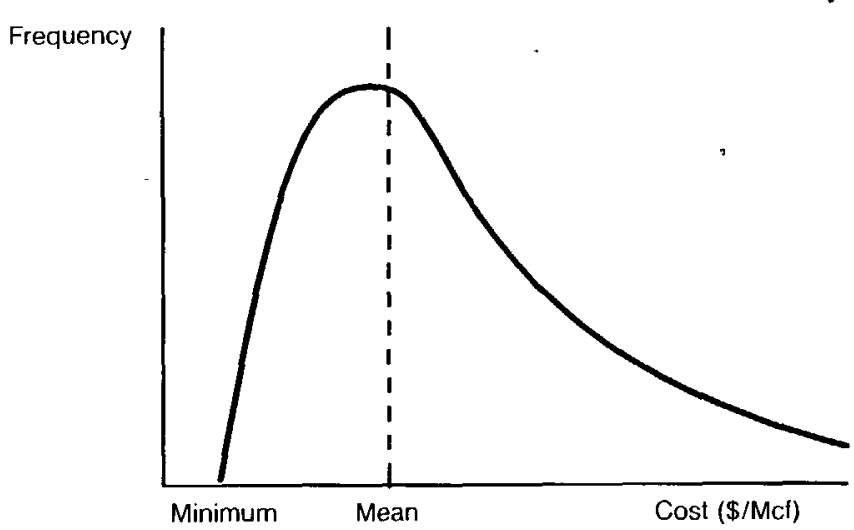

Figure 16. Cross section of histogram at given cumulative level of natural-gas reserves. Cost in dollars per thousand cubic feet.

ly at the low quantity end of the range, the probability distribution is heavily skewed toward the low end with a long, high tail. The cross sectional histogram at a given level of cumulative discoveries is shown in figure 16.

Second, particularly at the low end of the quantity range, the mean, median, and mode of the probability distribution are all very near the minimum of the probability distribution. The aforementioned asymmetries guarantee it.

Third, every curve consists of a reordering of the same reservoirs with the same costs and the same quantities. The different sequences merely reorder the gas reserves remaining in the basin; they neither add nor subtract gas from the resource base. Therefore, any supply curve other than the ascending cost supply curve must be higher in the near term and lower in the long term than the pure deterministic, ascending cost supply curve.

The implications are profound. First, the nuances of probabilistic simulation might not be worth the trouble. The mean, median, and mode of a complex drilling simulation process will turn out to be rather close to the deterministic, ascending order of cost curve. Surely the difference between any probabilistic curve and the pure ascending cost 
curve is literally dwarfed by the uncertainty in the underlying volumetric and cost estimates that characterize the resource base and the market as a whole. It seems silly to refine the details when the overall numbers are so uncertain.

Second, because every probabilistic simulation scenario merely reorders a fixed, invariant inventory of reservoirs and Mcf's within those reservoirs, why trifle with such reordering? Assuredly, aggregate prices in the market do not depend on the specific sequence of reserves nearly as much as they depend on total reserves present within the region. The total quantity of gas resident within a region dictates the price to a greater degree than the particular cost structure of any reservoir in the region.

The difference between a deterministic, ascending cost supply curve and any supply curve that might be computed by probabilistic simulation is shown in figure 17. The simulated supply curve is higher initially and lower in the long run. Note that the two curves must cross each other. The probabilistic curve must be higher initially and lower

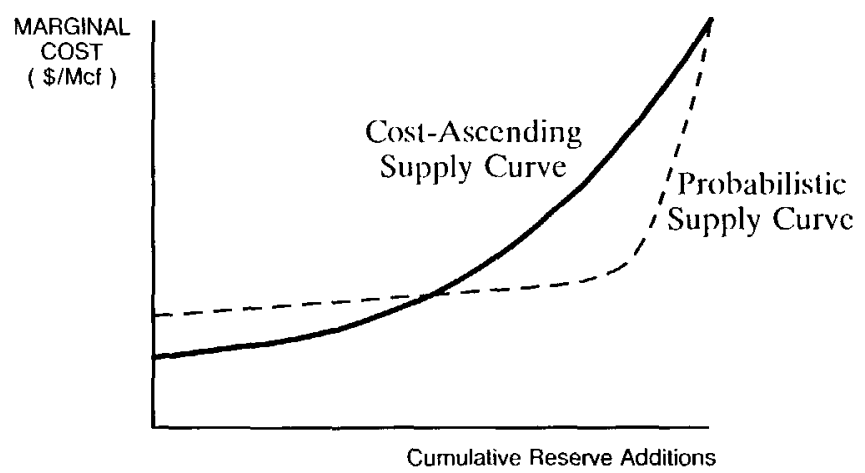

Figure 17. Probabilistic versus pure cost-ascending supply curves. Marginal cost in dollars per thousand cubic feet.

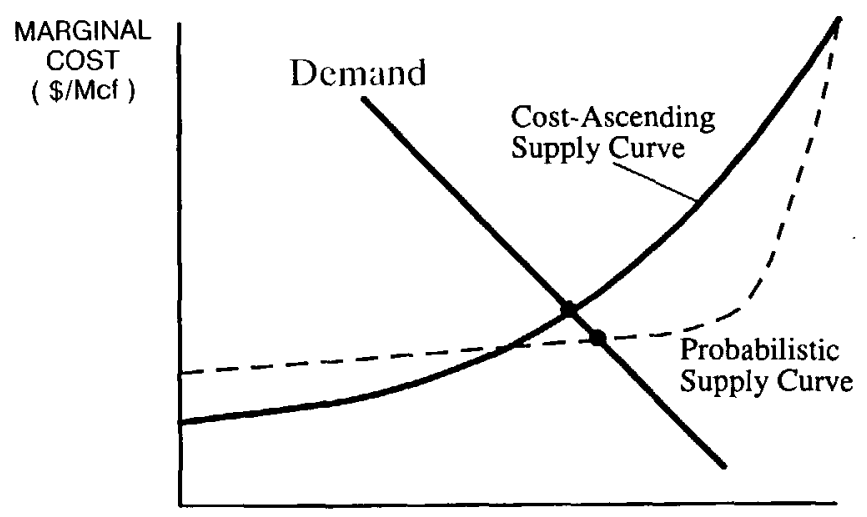

Cumulative Reserve Additions

Figure 18. Implications of probabilistic versus pure cost-ascending supply curves for a supply-demand model of a natural-gas market. Probabilistic simulation is required only if the two crossing points are far apart. See text for discussion. at the end than the pure ascending order of cost supply curve. Whether probabilistic simulation is required depends on whether it affects the supply-demand balance. It only affects the supply-demand balance if the two crossing points in figure 18 are very different. If not, the complexity is not worthwhile. In my experience, the difference in figure 18 is rather small relative to the other uncertainties that beset resource-base estimation.

Third, because of the observed asymmetry, the supply curves shown in figure 18 cannot possibly be very different. Because the curves are based on the same inventory and the same cost structure, they must cross. It would be almost impossible to argue (as some have) that an economic model without probabilistic simulation is intrinsically unable to analyze gas markets. Quite the contrary, a model that is based on full-blown probabilistic simulation may be overly complicated, inefficient, inflexible, and uninterpretable. It probably overanalyzes the data. Furthermore, such models have not proven the ability to calculate supply-demand curve equilibria; they are supply-only models. The EEA Hydrocarbon model is a particularly relevant example here. As I see it, the model is incapable of calculating price-quantity equilibrium. It concentrates instead on the less important part of the problem-probabilistic simulation-and ignores the important part of the problem-the fact that prices and volumes depend on aggregate quantities largely independent of cost structure. Models such as the Hydrocarbon model are driven by rapidly deteriorating finding equations and tend to forecast skyrocketing prices. Such conclusions depend inherently on a limited ability to model markets and a dogged insistence on probabilistic simulation from fixed, immutable, and often overly conservative resource-base estimates.

The series of steps required to generate probabilistic simulations of the exploration, development, and production processes throughout North America and the world is shown in figure 13. The end product of this step would be the mean supply curve for each producing region in North America or the world, or, in other words, the mean of the histogram of the supply curves generated by the exploration simulation. The mean supply curve generated by the probabilistic simulation process is the best of all possible inputs to a deterministic (nonprobabilistic) model of North American and (or) world gas supply, transportation, and demand. However, the mean supply curve is probably not much better than the minimum (the deterministic, purely cost-ascending curve), the median, the mode, or any other curve sufficiently near the minimum.

\section{STEP 8-DETERMINISTIC SIMULATION OF FUTURE EXPLORATION AND DEVELOPMENT}

This section summarizes how to actually calculate regional supply curves throughout North America and the 
world. Recognizing that the large reservoirs will be discovered with much higher probability than the small reservoirs, the supply curve would be generated by simply exploiting the reservoirs in ascending order of presentvalue life cycle cost; this takes into account both reservoir size and depth, and it will be a very good representation of the fundamental supply economics of the basin. Rather than running the complex probabilistic simulation process, an approximate method that exploits the strong affinity of the exploration process for large reservoirs in favor of small reservoirs is to simply (1) take $\mathrm{N}$ samples from the reservoir size distribution derived in step 6, (2) reorder them in ascending order of cost, (3) create a cost-ascending supply curve, (4) repeat until a large number of costascending curves are generated, and (5) use the mean of the large number of cost-ascending curves as the supply curve for the region. In effect, for each simulation cycle, the reservoirs will be discovered in precisely the order of ascending present-value life cycle cost and furthermore that drilling costs will be escalated (derated) to account for dry holes. The result on each pass through the simulation will be to stack the reservoirs in ascending order of present-value life cycle cost, inflate the life cycle cost to account for the average number of dry holes, and thereby form a deterministic ascending cost supply curve. The probabilistic nature of the problem emanates from sampling from the pool size distribution $R($.).

The ascending cost supply curve will be a good approximation to the mean of the more complex probabilistic simulation process. However, the deterministic approach will be slightly optimistic at the beginning and slightly pessimistic at the end of the simulation period relative to the fully probabilistic simulation (figs. 17, 18) It will be optimistic at the beginning because it will represent exploiting the low cost part of the resource base in the early years and leaving none for the later years. By contrast, the probabilistic procedure will, through random luck, exploit some of the higher cost deposits quite by accident in the early years and will thereby leave some lower cost deposits in the ground to be exploited in the later years.

Some analysts have stated that supply cannot be represented using supply curves. They argue that one must use detailed probabilistic simulation to represent the stochastic nature of encountering reservoirs. The only conceivable situation in which a particular discovery scenario departs from pure ascending order of cost discovery is when there is a very long sequence of small reservoir discoveries before a large reservoir is discovered. The reason one needs a long sequence of small reservoir discoveries is that a short sequence will not add significant volume; a short sequence adds no appreciable volume. Keep in mind, a long sequence of small reservoirs occurring before a single large reservoir has a negligibly low probability given the demonstrable exploration asymmetries.

\section{PRODUCER BEHAVIOR GIVEN REGIONAL SUPPLY CURVES}

The fundamental output of the supply simulation work is called long-run marginal cost curve. The long-run marginal cost curve plots cumulative future additions to proved reserves along the horizontal axis against present value of fixed plus variable cost (marginal cost) along the vertical axis. In the most fundamental sense, this type of supply curve that characterizes the geology and economics of a given region or basin. A long-run marginal cost curve is shown in figure 19.

The way the NARG model represents producer behavior is discussed in detail in Nesbitt and others (1988). In particular, the report discusses how producers can be expected to behave in a basin characterized by a long-run marginal cost curve of the form in figure 19.

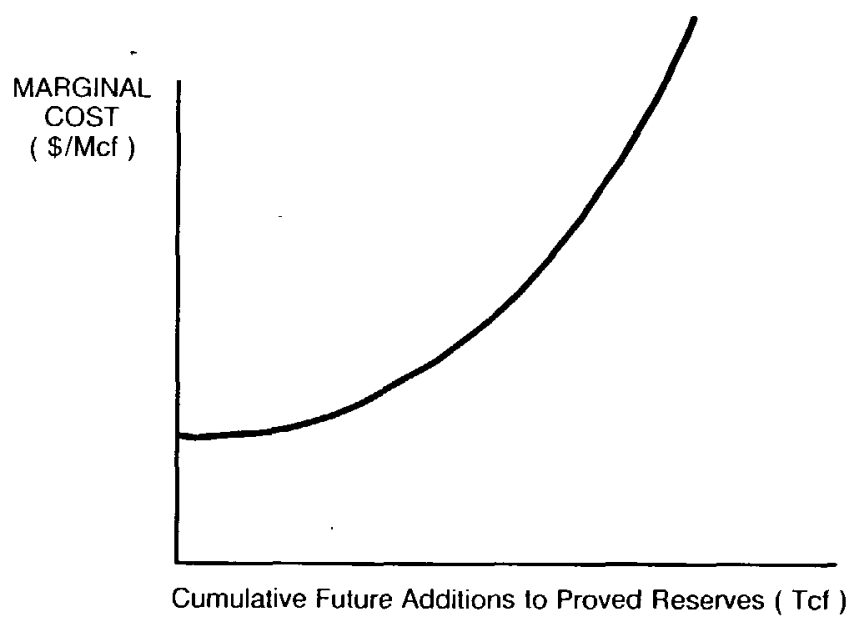

Figure 19. Long-run marginal cost curve, which is the fundamental output of a supply-demand model of a natural-gas market. Marginal cost in dollars per thousand cubic feet. Tcf, trillion cubic feet.

\section{MODELING DEMAND}

\section{BUILDING REGIONAL GAS-DEMAND CURVES FROM FUNDAMENTAL INFORMATION}

Without reliable demand curves, supply-demand crossing points can be rather meaningless. To properly characterize gas demand, it is important to distinguish at least two types of consumers in gas markets. The first type of consumer is the core customer. Core customers are collectively referred to as the core market. The core market consists of captive gas customers, customers for whom options other than gas are not particularly viable. The core market shows relatively price insensitive (inelastic) demand. Residential, commercial, and industrial customers highly committed to gas would fall into this category. 


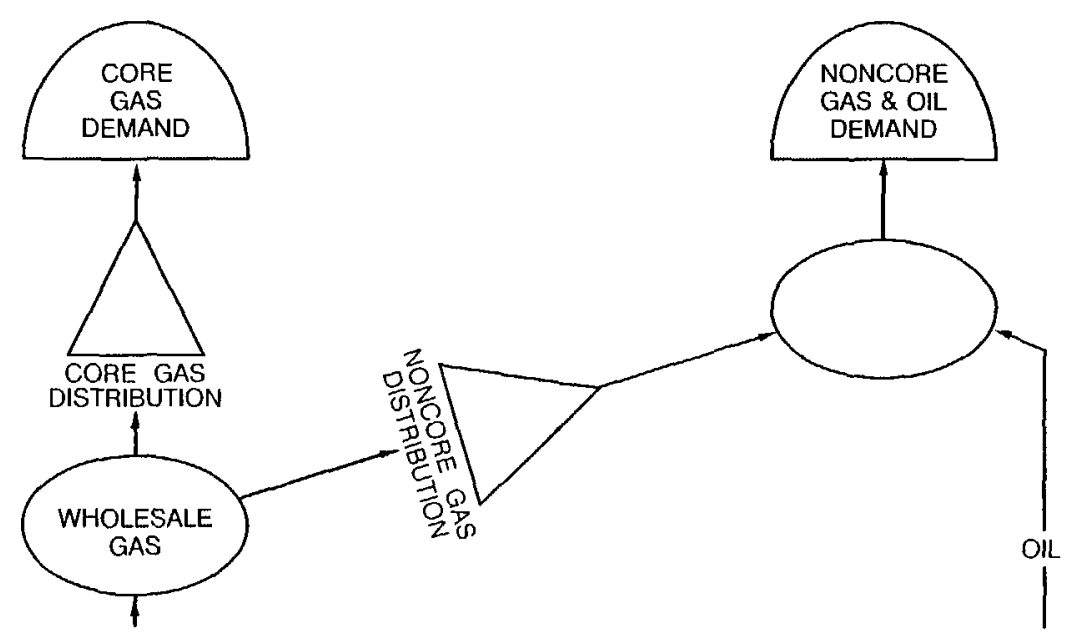

Figure 20. Network representation of demand for natural gas. The network form allows accurate depiction of core and noncore demand.

The remainder of the market, termed the noncore market, is that segment of the market possessed of an immediate alternative such as fuel oil. As long as gas price remains below that of the alternative, noncore gas demand will remain relatively firm. If gas price rises to or above the price of the alternative, noncore gas demand will switch away from gas toward the alternative. It is important to recognize that the noncore market is much more disparate and disaggregated than a simplified oil-gas substitutable sector. This discussion is limited to a simple gasoil substitution.

This simple core-noncore characterization of gas demand can be represented in network form (fig. 20). In the figure, energy is assumed to flow along the links through the processes from bottom to top. The figure depicts two demand "tombstones," one for core demand and one for noncore demand. Each tombstone contains a demand curve (a price-quantity-time relation that specifies the quantity of gas or gas-equivalent that will be consumed at every possible price level today and into the future). Notice in the diagram that noncore demand can be satisfied either by gas or by the substitute. The circle at the upper right represents gas-oil competition, the winner flowing upward to satisfy the market. As shown in the figure, core demand can be satisfied only by gas.

What is the general shape of the wholesale gas demand curve? What does the demand curve facing the upstream transporters and producers look like? What is its general shape and slope? The simplest way to answer this question is to offer a caricature of the demand curve and thereafter refine the caricature to a more realistic form. The core market demand and noncore market demand are placed along the horizontal (quantity) axis as shown in figure 21 . The price of the oil substitute is placed along the vertical (price) axis as shown in the figure. Consider a very high

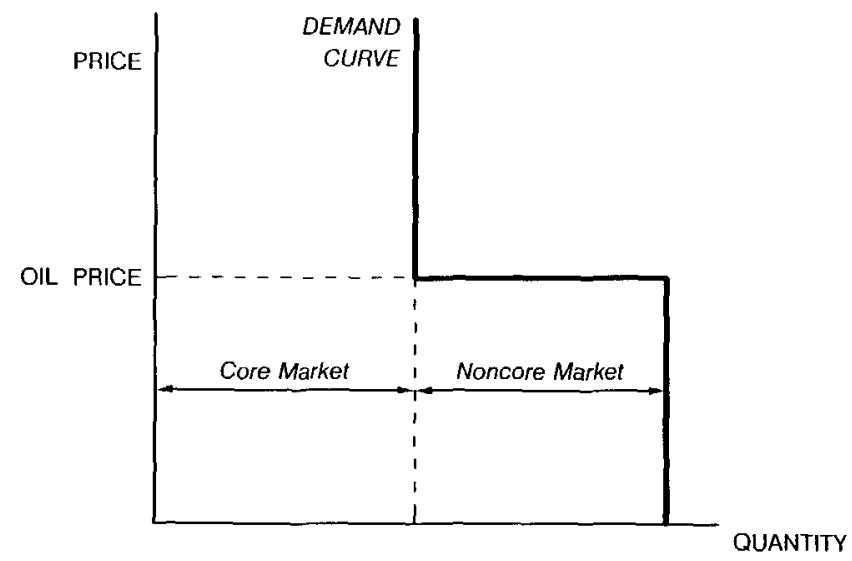

Figure 21. Caricature of wholesale demand curve for natural gas. See text for discussion.

price of gas, one well in excess of the oil price. At this high price, the core (committed) market will be obliged to buy gas, but the noncore (substitutable) market will avoid gas in favor of oil. At high gas price, the gas market is a "core-only" market. As the price of gas drops from very high levels, the core market remains saturated and the noncore market remains entirely committed to oil until the price of gas drops to the price of oil. As the price of gas drops just below the price of oil, the entire noncore (switchable) market will switch en masse from oil to gas. As this occurs, the entire noncore market saturates with gas, eliminating oil altogether, and gas demand moves horizontally to the right until it includes all core plus noncore users. Once the noncore market is completely saturated by gas, even if gas prices fall further, there is no more noncore market to capture. 
The stairstep shape of the gas demand curve in figure 21 is a useful caricature of the shape of the wholesale gas-demand curve. If gas price is higher than oil price, gas will command only the core market. If gas price is lower than oil price, gas will command both the core and noncore market. If gas price is equal to oil price, gas will command the core market and gas and oil will split the noncore market. The reality, however, is a slight extension of the stairstep demand curve in figure 21. In reality, core gas demand is somewhat elastic, and noncore gas demand is highly segmented with each segment facing a slightly different oil substitute price. Therefore, in reality, the demand graph in figure 22 should be rounded off as shown in figure 21 . The demand curve in figure 22 , very characteristic of gas demand, has an inelastic portion at high gas price (the "neck"), a very elastic "shoulder" section where gas prices are close to oil prices, and an inelastic "arm" portion when gas price lies below oil price. The demand curve has the distinctive "neck-shoulder-arm" pattern in figure 22. Market clearing prices and volumes are very strongly dependent on this distinctively shaped demand curve.

Every demand region in the world must be characterized by a demand curve with this distinctive shape. The specific parameters of the regional demand curves will, of course, be quite different depending on economic development, pipeline infrastructure serving the region, economic growth, electric generation capacity, environmental concerns, industrial mix, contiguous supply, and a host of other considerations.

There are several features of this representation that must be noted here. First, it is interesting to note that the width of the shoulder in figure 22 has diminished during the past two decades as the industrial sector of the United States and Canada has been moved to other countries or shrunk as industries have died out. Furthermore, environmental restrictions and (or) cleanup costs restricting oil

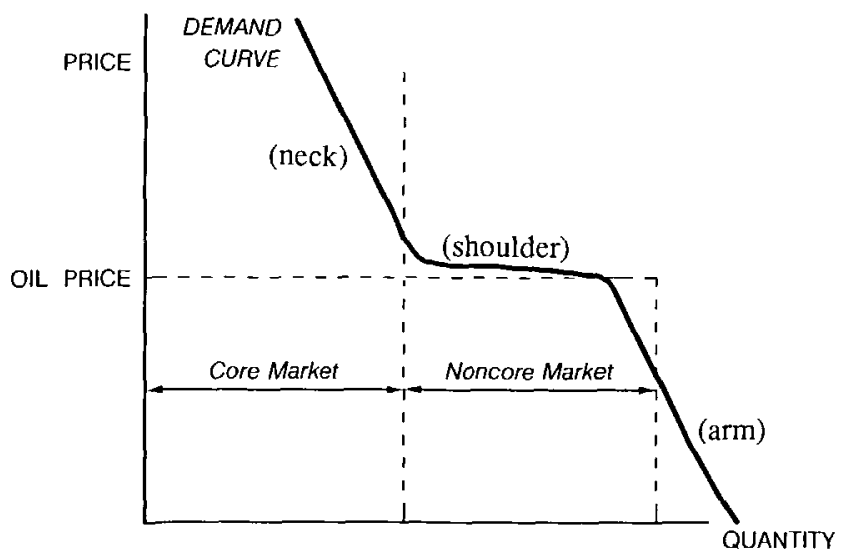

Figure 22. Neck-shoulder-arm representation of demand curve for natural gas. See text for discussion. consumption have served to make the shoulder narrower (less oil capacity) and higher (higher cleanup cost for oil). What used to be a relatively broad shoulder in our formerly industrialized economy has now become a much narrower shoulder in our more environmentally conscious service economy. Such narrowing has vital consequences for the relation between the market clearing price of gas and oil. The narrowing of the shoulder, owing to emigration as well as environmental policy, has led to a much weaker degree of coupling between oil and gas price than has been true historically.

Second, the width and height of the shoulder is determined to a significant degree by applicable environmental policy. As an example, suppose a $\mathrm{CO}_{2}$ tax were to be imposed. Certainly oil price would be more penalized than gas price, and the shoulder of the curve would increase disproportionately to the rest of the curve. Suppose lowquality heavy oil were banned from certain applications. The shoulder would be raised and narrowed. It would be raised because heavy oil users would have to use higher priced light oil (if they used oil at all). It would be narrowed because there would be fewer prospective oil users in aggregate. Suppose finally that electric generation facilities committed to gas entered the mix. Presumably combined cycle electric generation facilities will be core market facilities. In the extreme, if environmental restrictions were sufficiently severe, there might be no noncore shoulder at all. There would be no alternative other than natural gas, electricity, and renewables.

Third, the simple, aggregated representation of the noncore market is highly simplified. The noncore market is not as simple as gas versus oil competition. On the contrary, there are many industries, many electric generation facilities, and many locations and market segments. Competition between oil and another fuel form is highly segment-specific. How to generalize the simple noncore model discussed here to a more disaggregated situation is discussed at the end of this section.

Fourth, there is not a single neck-shoulder-arm configuration that applies in every demand region. On the contrary, the neck-shoulder-arm configuration must be specifically customized to each region to properly characterize the nature of demand in that region. While the demand curve in every demand region in the world can be argued to have the same generic shape (shown in fig. 22), the specific shape, width, height, and location will differ markedly among regions.

Every demand region in the United States, Canada, and the rest of the world must contain the network structure in figure 20 and therefore the demand curve structure in figure 22. After making such representation, every demand region in the model is able to represent demand stimulation and (or) suppression at different prices as well as substitution at the exogenously given price of the oil substitute. Furthermore, the specific configuration of the core and noncore markets and the assumed height of the 
oil substitution shoulder can be used to characterize a broad range of environmental and economic considerations that pertain in various regions.

The data needed to structure the demand network in figure 20 for each of the demand regions are rather straightforward. The first two items are a demand curve (price versus quantity versus time) for total core market use, and a demand curve (price versus quantity versus time) for noncore market use. Noncore market use includes all demand that can be satisfied by either gas or oil regardless of which source is actually satisfying that demand today. An estimate of noncore distribution cost, which is important to properly represent burner tip gas prices relative to oil prices is needed. A projected time schedule of the price of oil against which gas must compete is also needed. One can use an exogenously determined prediction of oil price, or one can use a world oil model. Finally, lag and price-sensitivity parameters that simulate adjustments in capital stock necessary for gas-oil substitution are needed. The DFI world oil model is used to make oil price forecasts. Extensive documentation is available from the author.

The core and noncore gas demand curves (the first two jtems) can be inferred from historical statistical information. Alternatively, they can be calibrated to a pricequantity demand forecast from an exogenous source as summarized in figure 23. A price-quantity forecast from another source (labeled "reference point" in the figure) can be plotted on a price-quantity axis as shown. Given this exogenous forecast, assume that the demand curve passes through this reference point. Given that the demand curve passes through the reference point, one then specifies short- and long-run elasticities to characterize the slopes of the curves about the reference point. This procedure is quite convenient if one wishes to calibrate the demand side of the model to another forecast such as the European Community (EC) country demand forecasts in Europe, the Gas Research Institute (GRI) baseline forecast in the Unit-

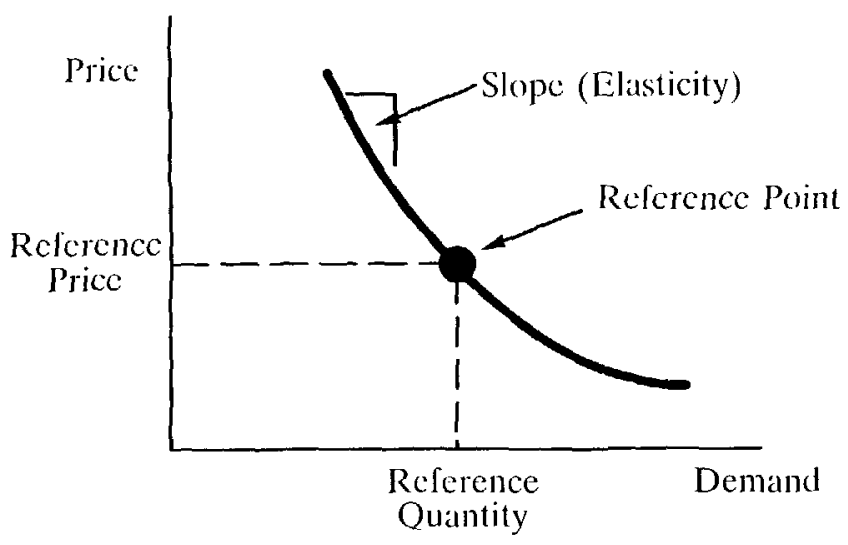

Figure 23. Calibration of core and noncore natural-gas demand curves to exogenous demand forecast. See text for discussion. ed States, or the National Energy Board (NEB) of Canada provincial forecast for Canada.

\section{WHAT DOES DEMAND IMPLY ABOUT THE CROSSING POINT?}

The neck-shoulder-arm configuration of the gas demand curves shown in figure 24 is indicative of the solution (or crossing point) of the supply and demand curves for any region. There are only three possible locations at which the supply curve-demand curve crossing point can occur-the shoulder, the arm, or the neck.

Case 1: The Shoulder Crossing-This price parity case is shown in figure $24 A$. The supply curve cuts through the demand curve along the horizontal shoulder portion of the demand curve. When the supply curve cuts across the demand curve along the horizontal shoulder, the price of gas is exactly equal to the price of oil. Oil and gas are at price parity on a Btu basis.

This situation occurred historically in North America for a very good reason. As the interstate pipeline system expanded to serve residential and commercial customers, any excess was sold to industrial and electric generation customers. Electric generation by gas was discouraged, so the customer of last resort tended to be an oil-substitutable industrial customer. Furthermore, during the primary expansion, natural-gas prices were regulated at the wellhead at an extremely low price. The price was so low that any excess not sold to residential or commercial customers could be easily disposed of to an industrial customer. As such expansion of the pipeline system occurred, the noncore market was split between gas and oil. Gas commanded the market to which it had access, and oil settled for the rest. Oil and gas split the noncore market. The marginal source of energy was always oil.

It is useful to summarize the key insights from the shoulder crossing solution. These are the market clearing price of gas is equal to the price of oil and that some noncore customers use gas, whereas some use the substitute. This shoulder crossing scenario can occur in a given demand region in a moderate oil price case. In other words, a case in which the oil shoulder is neither excessively high or excessively low relative to gas supply.

Case 2: The Arm Crossing-In this situation, which clearly characterizes most of North America today, the gas-supply curve intersects the demand curve below the shoulder along the arm (fig. 24B). It is a world of abundant gas supply, perhaps a "gas bubble." The market clearing price of gas has absolutely no connection with the price of oil except that it lies below the price of oil. First, gas supplies are "abundant" and prices are soft. Secondly, noncore users are attracted to gas, and gas can and will win any price war against oil. Third, a noncore gas user will be the marginal user. That noncore gas user will de- 

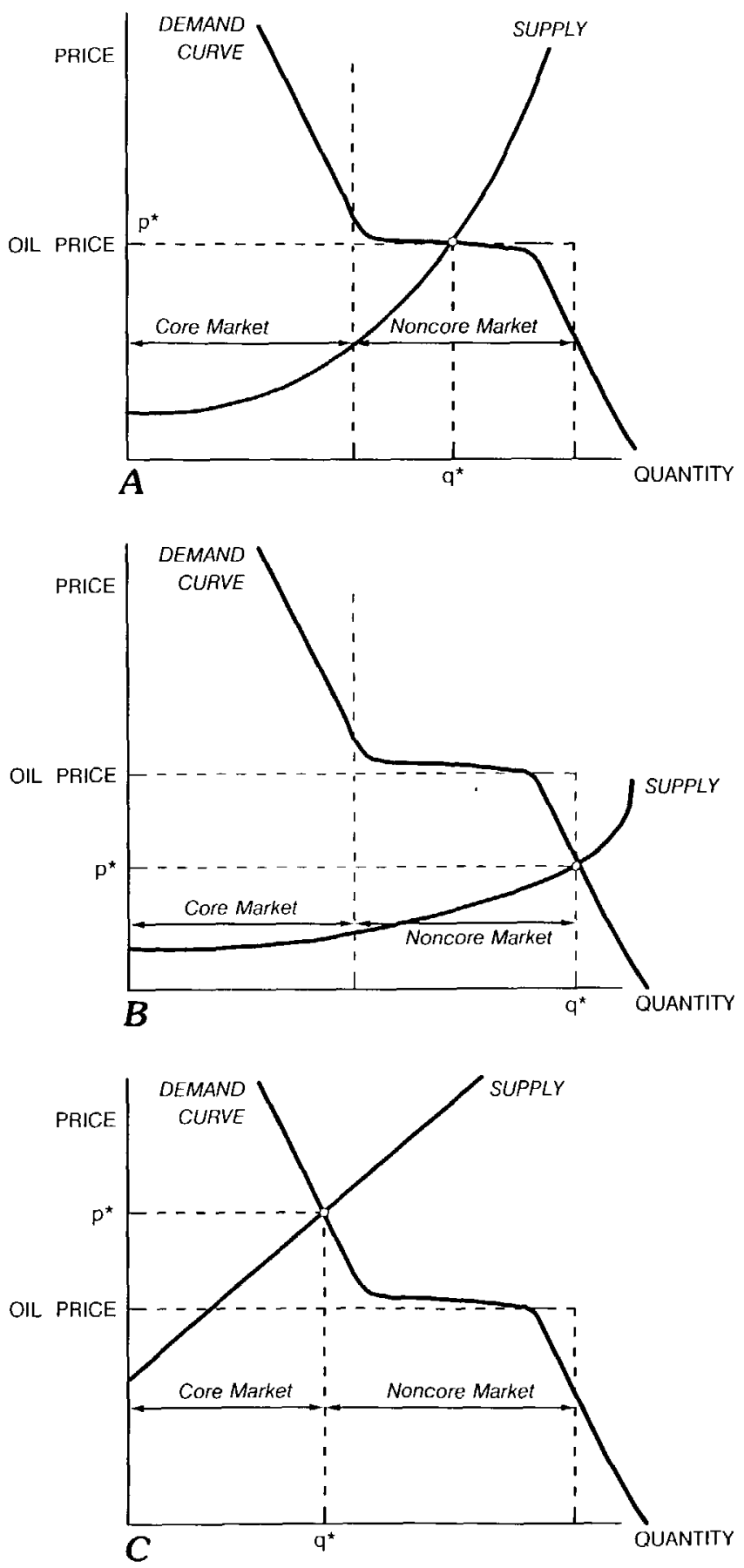

Figure 24. Neck-shoulder-arm configuration of gas-demand curves. $A$, Shoulder crossing; $B$, Arm crossing; $C$, Neck crossing.

termine the price of all gas to every user. Fourth, both core and noncore gas users will buy gas at a discount relative to oil. If gas supply is truly abundant, the price can be well below the price of oil. If gas supply is not excessively abundant, the price can be slightly below the price of oil. Fifth, there is absolutely no connection between the price of oil and the price of gas except that the price of gas is lower.
Case 2 will tend to occur if oil pries are high, that is, if the shoulder of the demand curve is high, or if gas demand is low.

Case 3: The Neck Crossing-In this case, the gas-supply curve intersects the demand curve above the shoulder, on the neck (fig. $24 \mathrm{C}$ ). The market clearing price of gas exceeds the price of oil. Indeed, there is absolutely no relation between the price of gas and the price of oil except that the price of gas must be higher than the price of oil. Case 3 will occur if oil prices are low (low oil prices mean that the shoulder of the demand curve is very low) or if gas demand is very high relative to supply. To summarize this neck crossing case: Gas supplies are tight in any demand region with a neck crossing. For this scenario, noncore users are driven to the oil substitute, and core users are the marginal gas users. Marginal gas users set the price of gas to all customers. There is absolutely no relation between the price of gas and the price of oil except that the price of gas is higher. Core users will be obliged to buy gas at a premium over oil.

The foregoing three cases are the only three possibilities that can occur-nothing else can happen. It is absolutely critical to emphasize that it is possible that entirely different cases can (and will) hold in different demand regions at the same time. For example, case 1 (gas-oil price parity) can be occurring in New England at the same time that case 2 (abundant gas supply) is occurring in the Gulf of Mexico. In fact, this is the normal situation except in the summer. Transportation costs and restricted capacities to New England constrain supply and cause it to cut across the New England demand curve along the shoulder. At the same time, excess supply in the Gulf of Mexico and universal access to local markets cause supply to cut across the Gulf Coast demand curve on the arm with consequent gas prices well below oil price equivalent. Throughout North America and the world, the particular case for each demand region depends on the specific shape of the demand curve in that region and the contiguous resource regions that supply it.

With these preliminaries, what can be said of the supply-demand equilibrium in a large, interconnected economic model? The first and perhaps most conspicuous observation is that in general the market clearing price of gas will not be equal to the price of oil (figure 24A-C). Gas and oil prices will not be at parity. There is no intrinsic force that tends to equate oil and gas prices. On the contrary, only in the specific situation in which the supply curve intersects the demand curve through the horizontal shoulder of the demand curve as shown in figure $24 A$, will the price of gas be equal to the price of oil. As already noted, the shoulder has narrowed in North America substantially over the past several decades. This renders it decreasingly likely that case 1 (the shoulder crossing) will hold in any given demand region for any given period of time. 
Parenthetically, it is absolutely certain that today in early 1993 we live in a case 2 (arm crossing) world. Why? Recall when the Iraq war first started that oil price doubled almost instantly. The horizontal shoulder (fig. 24B) shot up by a factor of two almost instantly as oil price doubled. Yet, the price of gas did not move one iota! Clearly, both before and after the oil price escalation, the market was clearing on the arm; We lived in a case 2 world. The oil price shoulder increased, yet the crossing point did not change. The market continued to clear on the arm, just as the case 2 supply-demand paradigm would predict.

The three supply-demand cases (neck, shoulder, and arm) provide a useful paradigm for establishing and interpreting alternative supply-demand cases, that is, different runs of a model. Different supply-demand scenarios will generally correspond to one of the three cases. For example, a base case might correspond to case 2 (gas supply intersects demand on the arm so that gas price is below oil price). However, a low resource scenario, all else equal, might shift the supply curve upward and to the left so that case 1 rather than case 2 holds. In this situation, gas supply would intersect along the shoulder. Relative changes in prices and quantities could be easily explained by comparing the geometries of the case 1 and case 2 supply-demand curve crossings.

Notwithstanding the particular scenarios being considered, comparison of high versus low gas-resource scenarios (and in fact almost any pair of scenarios involving different supply, transportation, or demand assumptions) leads to a critical conclusion: the market clearing price of gas will be different between different demand, supply, and oil-price scenarios. If the price of gas remains constant between two scenarios, the model that generated them is probably wrong. The approach presented here will not allow the price of gas to remain constant across two scenarios unless those two scenarios are so trivially different that the supply-demand curve geometries are virtually identical.

This approach recognizes that prices and volumes must be fundamentally different across different supplydemand curve scenarios and this has profound ramifications. First, the customary assumption of oil/gas price parity at the burner tip is wrong. To assume such parity is to get both the wrong burner tip market clearing price and quantity consumed. The fact that gas price will have to differ between scenarios means that in at least one of those scenarios, gas price will have to be different from oil price.

Second, the customary practice of equating gas wellhead prices to oil price "netbacks" from the burner tip through the pipeline system is wrong. To calculate oil price netbacks is to get both the wrong wellhead market clearing price and quantity produced.

Third, oil and gas prices are likely to move further away from parity as the noncore market decreases relative to the core market. Conversely, the larger the noncore market, the nearer to parity oil and gas prices are likely to become.

The traditional (and increasingly incorrect) procedure of netting back burner tip-equivalent oil prices to the wellhead originated in the days when the United States had a large industrial sector and a large noncore market relative to the core market. Although not technically correct even in those days, oil price netbacks were serendipitous. There existed a broad noncore shoulder in the economy, and pipeline capacity additions were tightly controlled. These forces virtually ensured that case 1 would apply. However, now that the industrial sector has declined in size relative to the core sectors, and environmental concerns have risen to the fore, case 2 or case 3 is much more likely to pertain today. Oil price netbacks are inevitably destined to be wrong today and in the future.

There is an alternative to assuming oil-gas price parity at the burner tip and calculating netbacks to the wellhead. It is to enumerate all present and potential future supply regions using supply curves, all present and potential future demand regions using demand curves with correctly sized noncore shoulders, and all present and potential future transportation links connecting supply regions with demand regions. Thereafter, the prices and quantities at which all supply and demand curves simultaneously intersect can be explicitly computed.

\section{A MORE SEGMENTED REPRESENTATION OF GAS DEMAND}

The logic leading to the simple demand curve in figure 22 is appealing, yet it is assuredly aggregated and approximate. Indeed, the noncore gas market is more highly segmented than shown in that figure. Rather than a single aggregate market for gas and (or) oil, there are many disparate segments that make up the noncore gas/oil market. Each segment has a specific substitute for gas. The substitute for gas can be different in different segments or in different regions.

How can the true diversity of the noncore market be represented? To illustrate, consider the expanded diagram in figure 25. (Keep in mind, energy is assumed to flow from bottom to top in the network diagrams). Figure 25 depicts the core market (captive gas) and disaggregates the noncore market into two categories (industrial and electric) and substitution possibilities into two categories (heavy number 6 oil and light number 2 oil). The upper right portion of the network shows four noncore demand blocks: (1) number 6 substitutable demand in the electric segment (for example, boilers); (2) number 6 substitutable demand in the industrial segment (for example, boilers and other low quality heaters); (3) number 2 substitutable demand in the electric segment (for example, combustion 


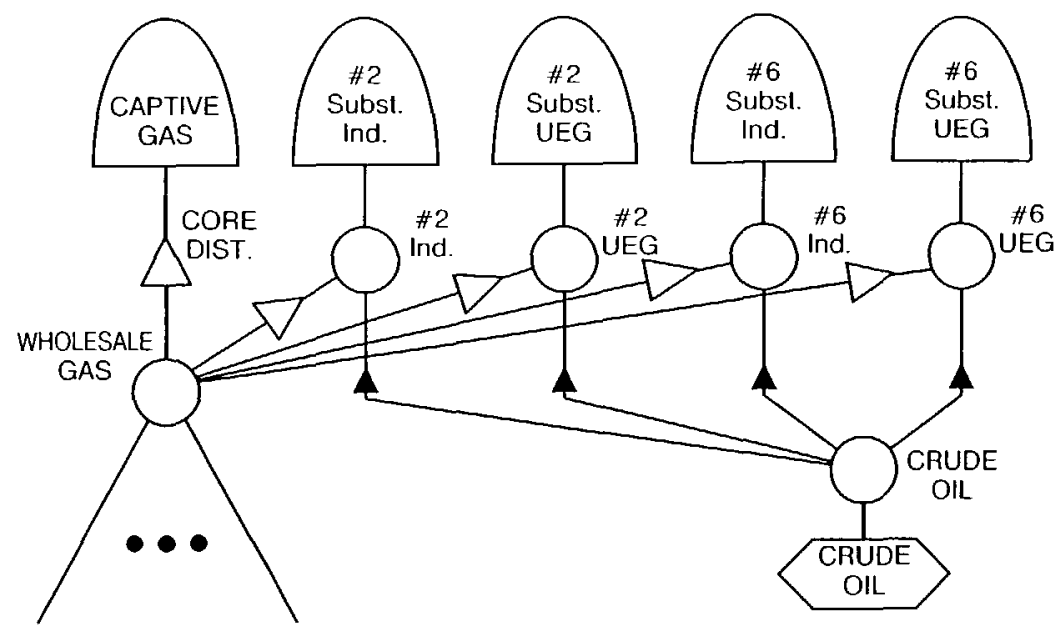

Figure 25. Segmented network representation of natural-gas demand, which shows the true diversity of noncore demand. Energy flows from bottom to top. DIST., distribution; Subst., substitutable; Ind., industrial; UEG, Utility Electric Generation. See text for discussion.

turbines); and (4) number 2 substitutable demand in the industrial segment (for example, combustion turbines and clean process heat demand). Each of these four noncore demand segments (which in aggregate total up to the noncore market) is characterized by a demand curve. That is, each demand block contains a price-quantity-time demand function characterizing a single segment.

A fifth segment, coal-substitutable demand in the electric segment (for example, base load coal plants that could be repowered with gas), could be added. This fifth segment is prospectively important in certain foreign countries but probably not in North America, so it will be ignored here for convenience. The four circles directly beneath each of the noncore demand blocks in figure 25 represent gas versus liquid competition in each segment. For example, the circle labeled "\#2 industrial" represents competition between gas and number 2 distillate to provide energy service to this segment of the market.

The triangles on the links entering each of the circles represent the distribution cost of the corresponding fuel type to the indicated segment of the market. Notice there are four segment-specific, noncore gas distribution costs activities in figure 25 . They are very important because they represent the cost markup from wholesale gas to the point of competition in the various segments against oil. Oil must be refined and distributed to the bumer tip. The four triangles emanating from the crude-oil circle represent the refining, marketing, and distribution costs necessary to convert from crude oil to delivered refined product. These oil and gas distribution costs must be estimated to build such a model.

The objective of the more complex multisegmented structure in figure 25 is to construct a more accurate and reliable demand curve for wholesale gas in each demand

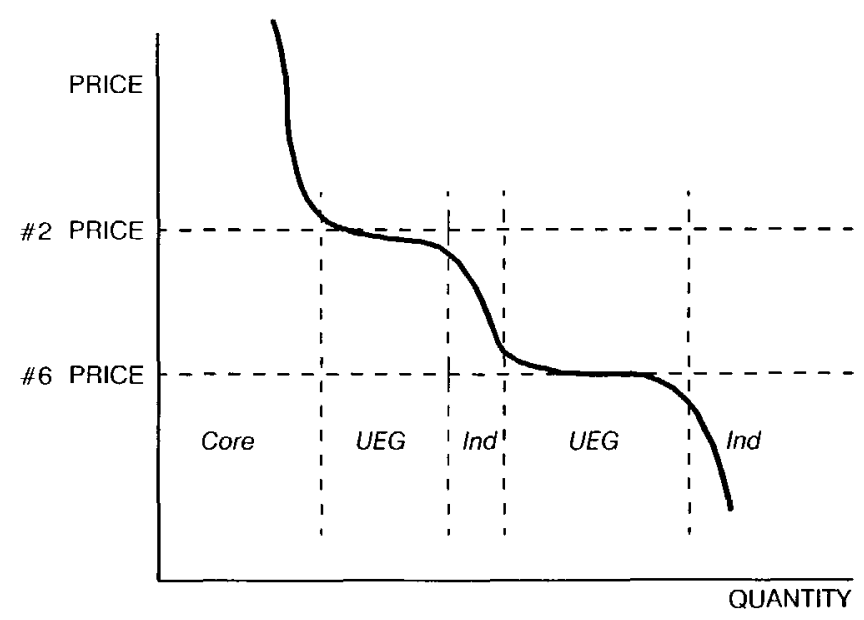

Figure 26. Segmented gas-demand curve.

region. Such a demand curve takes a fuller account of oil for gas substitution possibilities and ensures that the price differentials between different oil products in different segments are consistent both relative to one another and relative to crude price. The resulting demand curve is a "multishoulder" curve of the form shown in figure 26. Notice how. the segments are arrayed from left to right in decreasing order of willingness to pay for gas. Notice further how the prices of increasingly high quality of refined product are arrayed on the vertical axis. The various product shoulders are clearly evident in the diagram. By incorporating a demand curve at the level of detail shown in figure 26 into the model, the exact form of oil or gas that is the marginal source of energy in any region (the "last in/first out" source) and what its cost is can be known with certainty. After all, it is the cost of the 
marginal source that sets the price of gas in the region and sets the netback prices of gas at the wellhead of every prospective supply region for that demand region.

To conclude, it is possible to build an even more elaborate representation of end use. DFI has done so many times using networks of process models. The model disaggregates demand into large homes and small homes. It also disaggregates final demand into space heating, air conditioning, combination space heating plus air conditioning, water heating, cooking, drying, and electric only. For each of these final demand categories, the model considers the multiplicity of technologies competing to satisfy customers. For space heating, the model considers conventional gas furnace, advanced gas furnace, recuperative gas furnace, gas heat pipes, electric resistance furnace, various gas heat pumps, and various electric heat pumps. Depending upon the market share achieved by each of the competing technologies, the market divides between gas, electricity, oil, and the other fuel forms entering the bottom of the diagram. By running this rather complex model of residential end use, the appropriate model of residential gas demand is built. By building similar models of commercial, industrial, electric, and transportation demand, a detailed, process-specific model of gas and other fuel demand is built. This is perhaps the only reliable way to generalize the gas-demand curve shown in figures 20 and $24 C$.

The SRI-Gulf model, the LEAP model, and the GRI integrated multifuel models all contain a great deal of demand-side detail. DFl's work with those models demonstrated their intrinsic accuracy, but it also proved that the more aggregated, less structurally oriented neck-shoulderarm representation in figure 22 is more than sufficient to thoroughly understand North American and world gas markets. That is why DFI has adopted the simpler versions for its gas models; we opted for more regional disaggregation rather than more process disaggregation.

Inside each of the demand regions in the United States, North America, and the world, DFl's approach is structured to take account of key demand-side phenomena including demand stimulation at lower prices, demand suppression at higher prices, interfuel substitution between oil and gas, and demand by segment as a function of economic growth, industrial productivity, and other indexes. The demand modeling approach does so in very simple fashion by constructing the demand representation with the level of detail shown in figure 9. Such detail is a fundamental constituent of any reliable supply-demand model of natural gas-one that does not focus only on the volumetric side of the equation without sufficient consideration for the price and cost side.

\section{MODELING TRANSPORTATION}

Implicit in the examples is the assumption that the gas transportation infrastructure has been properly represented.
The degree of pipeline detail required to build a reliable model must be consistent with the degree of supply basin detail and demand region subdivisions everywhere else in the model. One could enumerate and distinguish every individual pipeline and LNG transportation link in the United States and the world, but the value (relative to the cost) would be highly questionable. Instead, we used commonalities among supply regions, pipelines and LNG routes, and demand regions that would allow prudent aggregation at a level sufficient to answer the critical volume, price, and valuation questions. Rather than represent individual nameplate pipelines, pipeline corridors from the supply regions selected to the demand regions selected are used. Those transportation corridors are systematically defined according to the location of supply basins and demand regions and by the configuration of the United States, Canadian, and world pipeline and LNG transportation systems that exist today.

Embracing the notion of pipeline and LNG corridors, the network of existing pipelines for North America is shown in figure 27. Each of the existing pipeline corridors begins in a given supply region, extends perhaps through intermediate supply and demand regions, and terminates in a demand region. The network of existing pipeline corridors interconnects all currently producing regions with all currently consuming regions. It is no accident that the pipelines connect known supply basins with known demand regions. Why would anyone build them any other way?

The evolution of the natural-gas system over the next 50 years or more cannot be represented by merely considering existing pipeline and LNG corridors. It is necessary to enumerate all prospective future pipelines that might be built in the next 50 years. These prospective future pipelines connect new producing regions or subregions with various demand regions, and they connect Canada and Mexico with the United States. Figure 27 enumerates the pipelines that might be built within the time horizon of the model. Prospective pipelines are represented by broken lines whereas existing pipelines are represented by solid lines.

The prospective new pipelines shown in figure 27 are just that-prospective. They will be built only if they become economic. They will be built only if supplies at the upstream end, appropriately marked up to account for the cost of the new pipelines, constitute the most competitive source at the downstream end. There are nuances of capacity expansion (for example, looping or additional compression of existing capacity). In the model, looping is considered an option for all existing capacity in figure 27 as well as for the existing links of the new corridors in figure 27.

Because the linkage between Canada and the United States is so important, figure 27 shows the pipelines in Canada that directly or indirectly terminate in the lower 48 United States. These Canadian pipelines, should they be built, provide a route for hundreds of Tcf of Canadian gas 


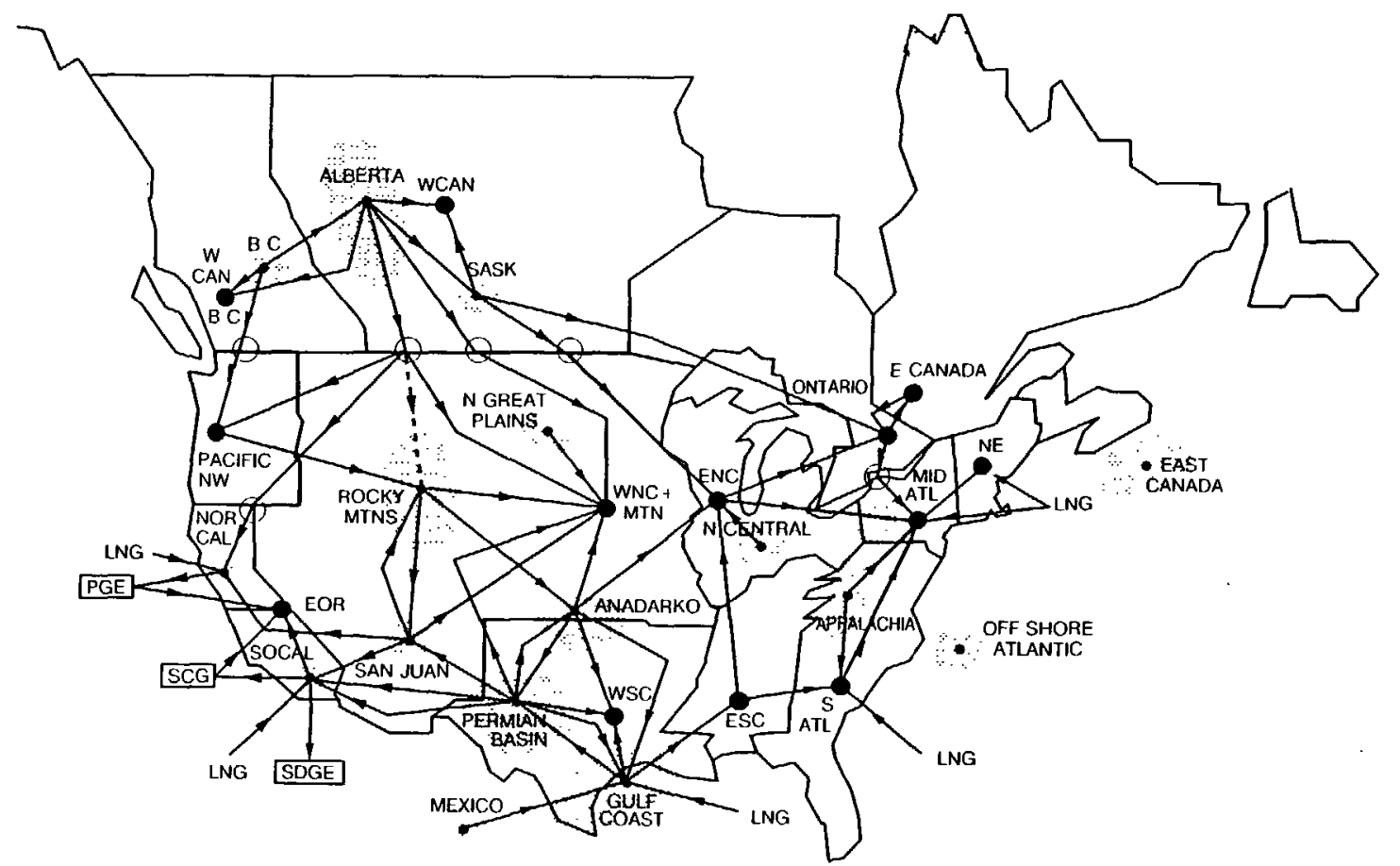

Figure 27. Existing and prospective North American natural-gas pipeline network used for the North American regional gas supply-demand model. Also shown are Canadian export routes to the United States. See figure 9 for explanation of abbreviations and symbols.

into United states markets should that gas become economically competitive. As that gas enters lower 48 United States markets, it puts downward pressure on price, upward pressure on aggregate volumes, upward pressure on Canadian volumes, and downward pressure on volumes in the lower 48 States.

In reviewing the Canadian export diagram shown in figure 27, note the prospective routes from North Alaska through Alberta and ultimately to the United States and from northern Canada (MacKenzie and Beaufort Sea) through Alberta and ultimately to the United States. The former pipeline represents the upstream leg of the ANGTS system whereas the latter pipeline represents the pipeline that will have to be built in order to exploit Canadian Arctic gas (MacKenzie Delta pipeline). Competition between these two pipelines will in part determine the competitive viability of the various Arctic supply regions and of the pipeline projects proposed to serve them.

Figure 27 integrates the existing pipelines, the prospective pipelines, and the Canadian export pipelines. The geographic structure of the pipeline corridors represented in the NARG model is shown in this figure. The model is very detailed and quite comprehensive, even though it does not explicitly distinguish all "nameplate" pipeline companies.

Given the geographic structure of the pipeline system represented in the model, how can one ensure that the model is not violating known pipeline or pipeline corridor constraints? To provide a satisfactory answer to this ques- tion, DFI contracted with Benjamin Schlessinger and Associates (BSA) of Bethesda, Maryland to assemble capacity constraints on all existing North American pipelines, aggregate them into appropriate corridor constraints, and provide them to the model. For the world, DFI has contracted with the Canadian Energy Research Institute (CERI) and its world gas trade program sponsors Exxon, Shell, Chevron, Amoco, Texaco, Enron, Phillips, Fina, and the California Energy Commission to assemble capacity constraints on all existing and prospective future world pipelines and LNG facilities.

As part of the process by which BSA and the world gas sponsors assembled realistic corridor capacity constraints, all pipeline capacities for all corridors in the model are properly represented. Furthermore, pipeline corridor transportation costs are consistent with the corridor capacity constraints.

All corridors in the model are properly sized. Following the discussion of pipeline transportation costs, the question of what it costs to expand capacity on any of these corridors will be addressed. In other words, what it would cost to add capacity on an existing pipeline corridor versus building a new pipeline along a new or existing pipeline corridor.

Given the geographic representation of the existing and prospective new pipeline system and the capacity constraints and bottlenecks in that system, the question arises whether transportation costs for new as well as existing 
pipelines and LNG links are properly represented? To provide a satisfactory answer to this question, DFI sought from BSA and their world gas trade clients estimates of transmission costs on all existing pipeline and LNG routes, aggregated them into appropriate corridor transmission costs, and converted them in a form suitable for input to the model. Such transmission costs typically have two important elements. First, they represent the embedded cost of each pipeline. Theoretically, pipelines charge embedded cost rates. Pragmatically, however, pipelines charge embedded cost rates only during periods in which margins are not squeezed by competitive pressure from oil or spot gas. Pipelines usually discount rates during periods of intense competition. The BSA and world gas trade analyses specifically account for discounting by pipeline owners. As a result of such analysis, all pipeline and LNG corridor transportation costs are properly represented and are consistent with recent history. In effect, every link in the network contains a transportation cost estimate.

In a series of applications of the NARG model by the National Energy Board of Canada, pipeline capacities and cost structures for all Canadian pipelines (all Canadian links) have been reviewed and modified to reflect the most current Canadian information. As a result, all pipeline and LNG corridor transportation costs for Canada are properly represented and are consistent with recent history.

How can the cost of operating a pipeline along an existing corridor versus expanding that corridor be represented? There are three generic levels of pipeline capacity expansion that are explicitly represented within NARG. These are (1) expansion of capacity by "minor" actions such as additional compression, looping, pressure increases, (2) expansion of capacity along a given corridor by building an entirely new, parallel system, and (3) addition of an entirely new corridor.

The model explicitly represents each of these options for each pipeline link in the following manner. The model assumes that the embedded cost of the capacity currently in place will affect the rates for quantities of gas transported that do not exceed currently known capacity. Thus, an initial tier of transmission service with elastic supply for quantities not exceeding current capacity can be represented as shown in figure $28 \mathrm{~A}$. To transport more gas than the current capacity of the corridor, it is necessary to augment the capacity through looping or pressure increase. Such augmentation is possible, but at a cost. Furthermore, such augmentation is usually bound by an upper constraint. That is, pressure increases can only add so much additional capacity, and looping can only add so much additional capacity. Thus, there is a second tier in the supply curve for pipeline capacity as shown in figure $28 B$, and that second tier represents incremental capacity additions along existing corridors. Finally, to exceed the capacity of an existing, fully looped, maximum pressure pipeline link, it is necessary to add new pipeline capacity along new right of
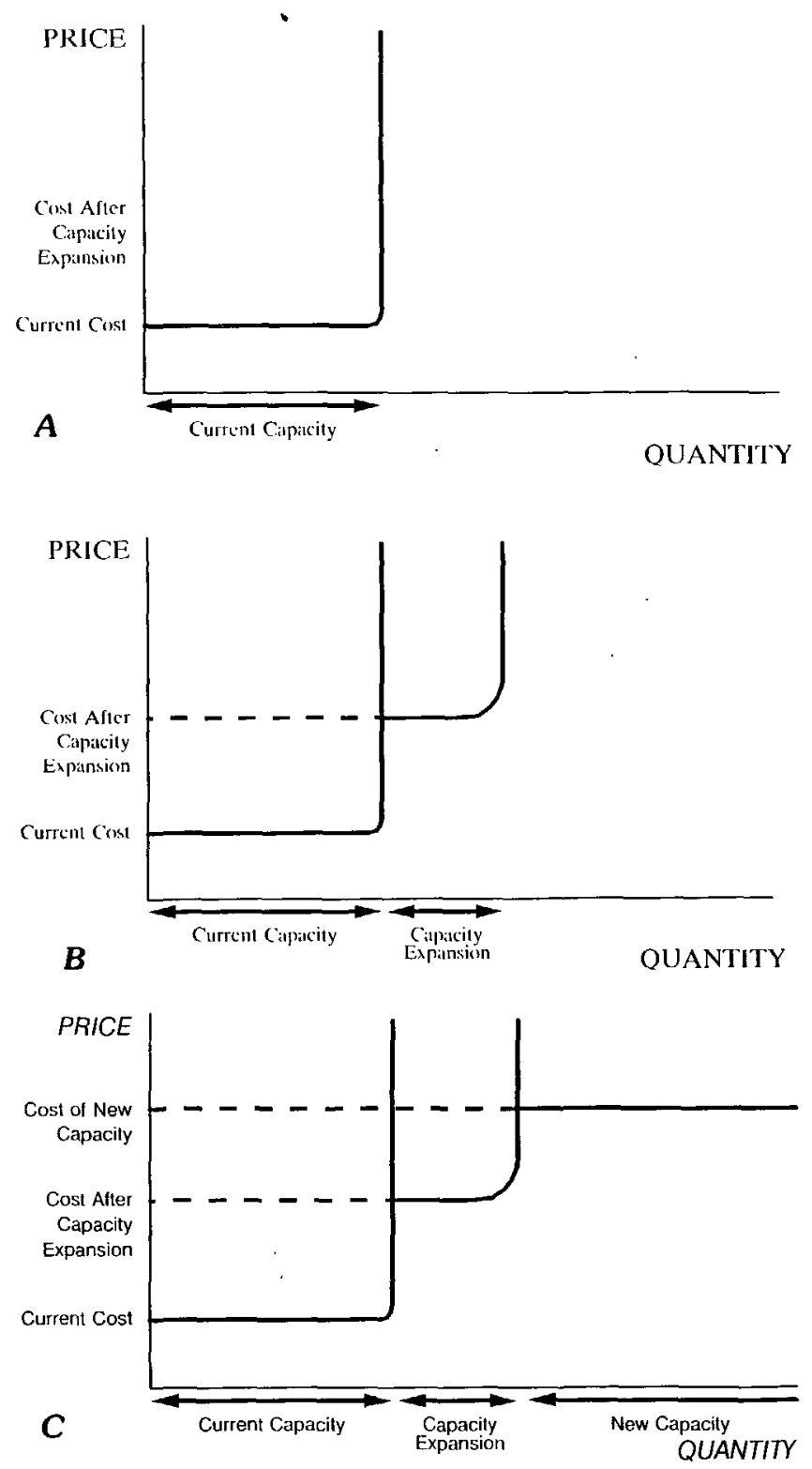

Figure 28. Three tiers of transmission service of a natural-gas pipeline. $A$, Existing pipeline or initial tier of transmission service. $B$, The second tier of transmission service that results from incremental expansion by looping or pressure increases of existing natural-gas pipeline capacity. $C$, The third tier that results from major expansion along a natural-gas pipeline route.

way. At the incremental cost of securing such right of way and building such a pipeline, it is possible to expand the capacity of that corridor virtually without bound. Consequently, the overall supply curve for transportation services along an existing pipeline link has yet a third tier as shown in figure $28 \mathrm{C}$.

The NARG and world gas trade models have the rather complex but complete representation of pipeline cost and capacity shown in figure 28 . Not only is current transportation cost information required of the model, but ca- 
pacity expansion costs through augmentation such as looping or pressure increases as well as new capacity addition costs are also required. The generalized equilibrium approach has a rather sophisticated representation of transportation infrastructure, current capacity, "minor" expansion, and new system addition.

The inter-regional transportation linkages represented in the world gas trade model. Many of the inter-regional linkages are LNG linkages, whereas many others are overland or undersea pipeline linkages. With a few exceptions, most of the inter-regional linkages in the figure do not presently exist. Future supply-demand equilibrium will depend critically on the cost and competitiveness of these inter-regional linkages and when and whether they will be drawn into the mix.

\section{CONCLUSION}

For many years, organizations such as the U.S. Geological Survey have assembled volumetric estimates of gas and oil in place. It is legitimate for people in industry to ask: "What do such estimates mean to me? What do they mean to my business? What do they mean for commodity prices?" In a world of ideal, efficient markets, such estimates would have little relevance; the best use of one's time would be to merely survey the various markets. In reality, markets are not completely efficient, and methods other than market observations are required. Volumetric estimates can contribute to better decisionmaking if they can be associated with cost and price information and if their implications in the market can thereby be determined. Until the generalized equilibrium approach, volumetric information has never been linked with the market. It has never entered the decision process of private companies the United States, Canada, or the rest of the world. With the approach outlined herein, the U.S. Geological Survey volumetric estimates can be used to support such decisionmaking and lead to better industry profits, more enlightened regulation and Government administration, and more efficient use of resources.

\section{SELECTED REFERENCES}

Adler, R., Cazalet, E., Haas, S., Marshalla, R., Nesbitt, D., and Phillips, R., 1979, The DFI generalized equilibrium modeling system: published by Decision Focus Inc.

Ashby, A., Darrow, K., Marshalla, R., Nesbitt, D., January 1985, The economic benefits of R\&D on gas supply technologies: Gas Research Insights, published by Gas Research Institute.

Begg, D., 1982, The rational expectations revolution in microeconomics: Theories and evidence: Johns Hopkins University Press.

Bohi, D., and Toman, M., 1984, Analyzing nonrenewable resource supply-Resources for the future: Johns Hopkins University Press.
Boyd, D., Phillips, R., and Regulinski, S., April 1982, A model of technology selection in aggregated markets: Management Science.

Braunstein, T.J., 1983, A decision analysis of a petrochemical expansion study, in Howard, R., and Matheston, J., eds., The Principles and Applications of Decision Analysis, Strategic Decisions Group.

Brock, H., and Nesbitt, D., 1977, Large-scale energy planning models: A methodological analysis, published by Stanford Research Institute.

Brown, K., February 1988, Towards a continental natural gas market: Historical perspectives and long-term outlook: Canadian Energy Research Institute Study No. 26.

Cagan, P., 1956, The monetary dynamics of hyperinflation, in Friedman, M., ed., Studies in the Quantity Theory of Money: University of Chicago Press.

Cazalet, E., 1970, Decomposition of complex decision problems with applications to electric power system planning: Stanford, Calif., Stanford University, Ph.D. dissertation.

Cazalet, E., 1977, Generalized equilibrium modeling: The methodology of the SRI-Gulf Energy Model, Decision Focus Inc. Report.

Cazalet, E., January 1975, Overview of the SRI-Gulf energy modeling methodology, published by Stanford Research Institute.

Cazalet, E., November 1976, A Western Regional Energy Development Study: Volume I: Economics; Volume II: SRI Model Data Base, prepared by Stanford Research Institute for the Council on Environmental Quality.

Cazalet, E., and others, May 1975, Western energy resources study: Economics: Energy Model Structure, Data Base, and Nominal Case Output, prepared by Stanford Research Institute for the Executive Office of the President, Council on Environmental Quality, CEQ Contract EQ5AQ007, SRI Project MSU-4000.

Clark, C., and Regulinski, S., September 1984, Calculating the cost of producing energy for regulated and nonregulated industry: Gas Research Institute Report GRI-94-0155.

Dasgupta, P., and Heal, G., 1979, Economic theory and exhaustible resources: London, Cambridge University Press.

Dimensional Fund Advisors, Sixty years of returns--1925-1985: Dimensional Fund Advisors. [Available from 1299 Ocean Avenue, Suite 650, Santa Monica, CA 90401.]

Electric Power Research Institute, February and September 1977, Fuel and energy price forecasts, v. 1 and 2: EPRI EA-433 Report, prepared by Stanford Research Institute.

Energy Information Administration, 1985, Natural gas annual 1984 DOE/EIA-0131(84)/1.

Everett, H., III, May-June 1963, Generalized lagrange multiplier method for solving problems of optimal allocation of resources: Operations Research 3.

Fama, 1991, Investment vision: Market, p. 54-55.

Finizza, A., Jacquette, P., Nesbitt, D., and Marshalla, R., 1986, Precursors for high and low future World oil prices: IAEE Proceedings.

Gately, D., September 1984, A ten year retrospective: OPEC and the World oil market: Journal of Economic Literature.

Haas, S., Nesbitt, D., and Singh, J., 1987, The GRI North American regional gas supply-demand model: GRI Report Number 87-0122. 
Haas, S., Marshalla, R., Nesbitt, D., and Oman, D., February 1983, Data base and model structure for R\&D planning and price-quantity forecasting at GRI, Decision Focus Inc. report to the Gas Research Institute.

Harberger, A., 1975, Three basic postulates for applied welfare economics: An interpretive essay: Journal of Economic Literature.

Henry, J.P., Jr. and others, May-June 1979, World energy: A manageable dilemma: Harvard Business Review.

Hogan, W., 1975, Energy policy models for project independence: Computation and Operations Research, v. 2.

Hogan, W., and others, February 1978, Evaluation of generalized equilibrium energy models and depletable resource pricequantity relationships in support of $\mathbf{R}$ and $\mathrm{D}$ planning: published by Decision Focus Inc.

Holtberg, P., and others, 1988, The 1987 GRI baseline projection, in Gas Research Insights, published by Gas Research Institute.

Hotelling, H., April 1931, The economics of exhaustible resources: Journal of Political Economy.

Hudson, E., and Jorgenson, D., Autumn 1974, U.S. energy policy and economic growth: Bell Journal of Economics and Management Sciences, v. 5 , no. 2.

Interagency Task Force on Synthetic Fuels Commercialization, November 1975, Recommendations for a synthetic fuels commercialization program: [Available from U.S. Government Printing Office, Washington, D.C. 20402, Stock Number 041-001-00111-3.]

Intriligator, M., 1971, Mathematical optimization and economic theory: Prentice Hall.

Jorgenson, D., 1969, The theory of investment behavior, in Williams, H., and Juffnagel, J., eds., Macroeconomic Theory, Prentice Hall.

Kantor, B., December 1979, Rational expectations and economic thought: Journal of Economic Literature, v. XVII.

Malkiel, Burton, 1991, A random walk down Wall Street: Norton Inc.

Manne, A., 1976, ETA-A model for energy technology assessment: Bell Journal of Economics, v. 7, no. 2.

Marshalla, R., Nesbitt, D., and Pine, G., May 1986, An approach to measuring the benefits of research and development at the Gas Research Institute: Decision Focus Inc. report to Gas Research Institute.

Marshalla, R., and Nesbitt, D., October 1984, Evaluating the benefits of supply R\&D to consumers and producers-A tutorial: Decision Focus Inc. report to Gas Research Institute.

Marshalla, R., and Nesbitt, D., January 1986, A technique for computing directly comparable measures of benefit for supply and utilization technologies: Decision Focus Inc. report to Gas Research Institute.

Marshalla, R., April 1982, Integrated forecasting model synthetic fuels study (v. 1 and 2): Electric Power Research Institute Report EA-2358.

Marshalla, R., Nesbitt, D., and Oman, D., 1984, Cost and performance estimates for energy supply and utilization processes: GRI Report Number GRI-85/0130.

Marshalla, R., 1978, An analysis of cartelized market structures for nonrenewable resources: Stanford, Calif., Stanford University, Ph.D. dissertation.
Marshalla, R., and Nesbitt, D., March 1984, The Decision Focus Inc. (DFI) world oil model: Model structure and methodology, Decision Focus Inc. working paper.

Marshalla, R., and Nesbitt, D., March 1984, The Decision Focus Inc. (DFI) world oil model: Data base, Decision Focus Inc. working paper.

Marshalla, R., and Nesbitt, D., 1986, Future World oil prices and production levels: An economic analysis: Energy Journal, v. 7 , no. 1 .

Nesbitt, D., and Phillips, R., 1981, Financial statements and producer behavior in the LEAP model: published by Decision Focus Inc.

Nesbitt, D., Marshalla, R., and Darrow, K., May 1982, Allocation of $R \& D$ resources among projects at the Gas Research Institute, Decision Focus Inc. working paper.

Nesbitt, D., 1979, A decision analysis of crude oil price controls, Decision Focus Inc. working paper.

Nesbitt, D., and Choi, T., 1988, The numbers say no: Energy Journal, v. 9, no. 3, p. 31-59.

Nesbitt, D., and Choi, T., 1986, Oil price and the rate of return on capital investment: Decision Focus Inc. report to the Department of Energy.

Nesbitt, D., and Phillips, R., 1983, A decision analysis of the appropriate R\&D strategy for enhanced oil recovery: Energy Systems and Policy, v. 7 , no. 3 .

Nesbitt, D., and Phillips, R., April 1982, The optimal allocation of research and development resources: Decision Focus Inc. report to Oak Ridge National Laboratory.

Nesbitt, D., November-December 1984, The economic foundation of generalized equilibrium modeling: Operations Research, v. 32 , no. 6 .

Phillips, R., and Cazalet, E., October 1979, The decision maker forecasting within the DFI/EIA demonstration model: Decision Focus Inc. report.

Potential Gas Committee, April 1987, Potential supply of natural gas in the United States: Colorado School of Mines.

Republic of Argentina/United States Cooperative Energy Assessment, 1982, v. 1, United States Department of Energy report.

Rinholm, R., 1987, The Canadian natural gas industry: Options and opportunities: University of Saskatchewan, M.S. thesis.

Samuelson, P., 1952, Spatial price equilibrium and linear programming: American Economic Review, v. 42.

Solow, R., 1957, Technical change and the aggregate production function: Review of Economics and Statistics, v. 39.

Stockman, D., The triumph of politics, 1986, New York, Harper and Row.

Sussman, S.S., and others, October 1976, A Study of the importance of energy R\&D for the United States: UCRL-52140, published by Lawrence Livermore Laboratory

Sussman, S.S., and Rousseau, W.F., 1978, A new language for economic general equilibrium models: UCRL-52507, published by Lawrence Livermore Laboratory.

Vidas, E., Lerner, M., and Crawford, R., June 1985, Guide to the hydrocarbon supply model: Energy and Environmental Analysis Inc. report to Gas Research Institute.

Woods, T., and Vidas, E., May 1983, The GRI hydrocarbon model: The structure, results, and sensitivities of the model in its initial form: Gas Research Insights, published by Gas Research Institute. 


\title{
THE FUTURE OF ENERGY GASES
}

U.S. GEOLOGICAL SURVEY PROFESSIONAL PAPER 1570

\section{Natural Gas-How Much, At What Cost?}

\author{
By Jairam S. Gopal ${ }^{1}$ and W. William Wood, Jr. ${ }^{1}$
}

\section{CONTENTS}

Abstract 787

Introduction 787

U.S. Natural Gas Market 788

Natural Gas Resource Estimates 789

Application of Regional Resource Cost

Information in Economic Analyses 790

Understanding the Natural Gas Market 791

California's Need for New Pipeline Capacity ....... 794 Impact of Resource Cost Estimates on Price of

Natural Gas 795

Conclusion 796

References Cited 796
Energy Commission in quantifying the impacts of technology advances on future wellhead prices of natural gas. Several examples illustrate the need for additional cost information for planners to meaningfully analyze and set policies regarding efficient use of this clean burning fuel. The paper concludes with an emphasis on the need to develop information on the cost element of forecasting natural gas supply and prices.

\section{INTRODUCTION}

The California Energy Commission (commission) was established by the California Legislature in 1975. Among the duties assigned to it were permitting and siting new power plants, establishing building and appliance conservation standards, providing for the development of new or alternative energy sources, and providing the legislature historical and forecasted trends in energy use and associated prices. The commission is mandated to prepare a report every two years, the "Califomia Energy Plan," outlining California's long term energy policies. The "California Energy Plan" draws information from four different reports published by various divisions in the commission. One of the four reports is the "Fuels Report," also a biennial publication, mandated by law. The "Fuels Report" provides the basis for development of State energy policies on energy use, supply availability, and future price projections.

The commission's energy price forecasts have become increasingly important in recent years in evaluating consequences of various commission programs. The State's interest in promoting environmentally sensitive energy options has prompted the development of new technologies and alternative fuels that offer cleaner uses of energy. Natural gas has become a premium fuel to meet California's future energy needs, mainly owing to its clean burning characteristics, apparent abundance, and competitive price.
California Energy Commission, Fuels Planning Office, Energy CA 95814 
In order to develop the supply and price trends of natural gas availability to California, the commission needs to evaluate the supply potential from a variety of natural gas supply regions that could potentially serve the State in the future. The natural gas market in the United States has undergone major changes in the way natural gas is produced and transported to demand regions. The Nation's natural gas pipeline system has become fully integrated, indicating the need for a multi-regional approach to understand how the natural gas market currently works and will work in the future.

The four basic components in the natural gas market are (1) potential supply availability and cost to find and develop these resources, (2) pipeline transportation capacity, (3) demand for natural gas, and (4) associated (delivered) prices. In this paper we will focus on one of these componentsthe potential resources to support future supply and the cost to produce these potential resources. This will be followed by examples of how the detailed resource information may be used to assess specific issues and market analysis.

\section{U.S. NATURAL GAS MARKET}

While the natural gas market had it origins in the early 1800 's, it did not fall under Federal regulation until 1938 with the passage of the Natural Gas Act. This act set up the Federal Power Commission (FPC) with the authority to regulate interstate pipeline prices. Excessive price increases at the wellhead prompted the Supreme Court to render a 1954 decision in the historic Phillips Petroleum Co. versus Wisconsin case, requiring the FPC to control wellhead prices. This set the stage for the development of two separate markets, a controlled interstate market and an uncontrolled intrastate market.

Toward the late 1960 's, natural gas supplies began to decline. Prices in the interstate and intrastate markets began to diverge as prices of newly discovered gas sold to the unregulated intrastate market began to exceed the regulated interstate gas price. The year 1970 marked a turning point in the sale of gas in the two markets: The reserves dedicated to the intrastate market increased from one-third of total natural gas reserves in 1969 to two-thirds in 1970. To compound matters, gas transportation across state borders for interstate commerce fell under Federal regulation. Neither the intrastate pipelines nor the producers wanted their gas to be federally regulated. Accordingly, the intrastate market continued to capture the bulk of the new discoveries, creating supply surplus for the intrastate market and supply shortages for the interstate market.

The Natural Gas Policy Act (NGPA) was passed in 1978 to stimulate the natural gas market by requiring deregulation of natural gas wellhead prices, commingling of intrastate and interstate gas supplies, and streamlining the natural gas transportation system.
Prior to the passage of the NGPA, the interstate pipeline companies were natural gas merchants, responsible for both purchasing natural gas from producers at one end of the pipeline and transporting and selling it to gas utility companies at the other. The gas utility companies, commonly known as local distribution companies (LDC's), were solely responsible for providing natural gas to end users such as residential, commercial, industrial, and electricity generation customers. The pipelines purchased all the needed gas supplies from producers and sold it to LDC's under long term contracts.

Since the early 1980's several factors in the natural gas market have led to a fundamental change in the regulatory climate. Interstate pipelines were forced to gradually shed the merchant function. Under the NGPA the Federal Energy Regulatory Commission (FERC) set in motion several regulatory changes to the ways in which natural gas is bought, transported, and sold in the market place. These changes include open access transportation options, unbundling of transportation costs, capacity brokering, and the development of market hubs at which natural gas purchasing transactions will be conducted. (The FPC became the Federal Energy Regulatory Commission when the Department of Energy was created.)

Today interstate pipelines are no longer solely gas merchants. Increased transportation-only services by the pipeline companies provide end users an opportunity to negotiate for supplies directly with producers and to contract separately with pipeline companies for transportation of natural gas. Both the utilities and end-use customers may now purchase gas directly from producers. Along with unbundled, or discrete, transportation and distribution services offered by pipelines and utility companies, the end users and LDC's have the option of purchasing shortterm supplies from the cheapest supply sources and have it transported through the complex network of interstate and intrastate pipelines. Their purchases are no longer confined to limited supply areas and pipelines.

The U.S. pipeline system now provides a network that connects almost every producing region with all the demand centers. Free from cumbersome regulation, natural gas may be purchased from any supply region and transported to any demand center. As an example, Canadian Alberta natural gas has been delivered to demand regions in Florida and Mexico. This was accomplished using several pipeline interconnects and common supply/receipt points. More recently, ENRON Company is offering an alternative to moving Alberta natural gas to California via the traditional Pacific Gas Transmission system or the proposed Altamont/Kern River pipeline system. ENRON Company would use Northern Border, Northern Natural, and Transwestern pipeline systems to move Alberta gas to California. The natural gas would flow from Alberta to the U.S. Midwest, then south to Texas, and west to southern California. 


\section{NATURAL GAS RESOURCE ESTIMATES}

A proper characterization of the natural gas resource base in the entire North American Continent is critical to understand how the natural gas market will perform in the future (see Nesbitt, this volume). This involves both the quantity of potential natural gas available from each region and the costs needed to develop and produce these resources. "Potential resources" refers to the quantity of natural gas that is economically producible from these resources and does not explicitly consider the cost of production. The potential resources considered in preparing resource estimates include conventional supplies of natural gas existing in onshore and offshore areas, shallow and deep reservoir formations, and unconventional natural gas from tight sand formations, Devonian shales, and methane in coal seams. Publicly available resource estimates for the United States are prepared by the Potential Gas Committee (PGC), the U.S. Department of Energy (DOE) and the U.S. Geological Survey (USGS) (see Dolton and others, this volume; Gautier and Brown, this volume). A recent study by the National Petroleum Council adds to the list of available sources for reserve estimates (National Petroleum Council, 1992).

Estimates of reserves are available from each of the above mentioned sources. Potential resource estimates vary considerably among these sources and are not directly comparable. Each entity uses different methods of resource characterization and a differing mix of resources in preparing its potential resource estimates. More importantly, the resource estimates developed generally do not include the costs required to incrementally develop and produce these resources. This creates a major problem when considering the future potential for natural gas production from each resource.

It is not enough to characterize resource potential only in terms of the quantity of gas that is available. It is equally essential to characterize the cost structure associated with the development of the resource base. Resource estimates without associated costs provide little information for a planner in addressing long-term natural gas supply and price forecasts. For example, an estimate of 1,200 trillion cubic feet (Tcf) of proven and potential U.S. natural gas resources indicates that there is about 60 years of supply of natural gas (based on annual consumption of $20 \mathrm{Tcf}$ ) but does not provide information for planners to evaluate potential wellhead prices, market competition among various resources, and the impact of geographic distribution of the potential resource base.

To understand the future natural gas market, planners need information that is far more detailed than what has been provided in the past. Natural gas planners need resource information that includes both regional estimates by resource type and detail on the associated costs to find, drill, and develop potential resources.
The impact of new technology is a major factor that influences the pricing of potential reserves. The scarce information that is currently available on cost estimates of potential resources is based on technology that is currently available. These cost estimates do not include impacts of expected future technology advances. Forecasts that are based strictly on this assumption will provide results that could be significantly different from an analysis that incorporates new technologies.

During the past 5 years, gas reserve additions per foot drilled have doubled from what they were in the previous 10 years. Many observers of the natural gas market have expressed the view that new technologies and efficiency improvements are responsible for the increase in reserve additions per foot drilled and in increased finding rates (Ellis, 1991).

New technologies and operational techniques, such as new 3-dimensional seismic analyses, horizontal drilling, slim-hole drilling, new drill-bit technology, tension-leg drilling platforms for deep offshore drilling, and others are being developed. It is anticipated that these technologies will further reduce the costs to find and develop natural gas resources. In addition, it is also expected that reserve additions from unconventional resources will increase. A typical example would be the horizontal drilling technique, which has the potential to access pockets of reserves or thin pay zones that are inaccessible and (or) uneconomical by drilling conventional vertical wells.

Overall, it can only be expected that the use of new technologies, such as those discussed above, as well as many others, will become more prevalent in the future. In evaluating the future natural gas market, planners need to know how these new technologies will impact finding, drilling, and production costs for each potential resource type in each region. If planners do not have access to these costs, their estimates of future natural gas supply, wellhead prices, and interregional gas movements will not be reflective of the future gas market.

In addition to costs incurred in exploration for new reserves, the development costs associated with bringing a natural gas well to production form an important element in the pricing of natural gas. Although technology improvements have lowered the costs in finding and drilling for new reserves, it has been observed that the overall cost of a producing well may not decrease even with lower drilling costs. This is attributed to new environmental requirements, which increase the cost of drilling and developing a well. These additional costs may partially or fully offset the savings in drilling costs achieved through technology advances. On the other hand, new well development and downhole logging and fracturing techniques are being developed. An assessment of the impact of these advances becomes paramount in addressing the economics and viability of natural gas production in different regions. 


\section{APPLICATION OF REGIONAL RESOURCE COST INFORMATION IN ECONOMIC ANALYSES}

The California Energy Commission is mandated by the State Legislature to provide a 20-year forecast of natural gas supply and price availability in the State. As long as the pipelines were natural gas merchants, the commission needed only an understanding of the specific regions from which California's natural gas supplies were traditionally obtained to prepare the natural gas supply and price forecasts for California. Those early supply forecasts were based on the potential supply available from specific regions and the market shares that each LDC had with pipelines serving their regions. These shares were unlikely to change over the forecasted horizon, owing to the long-term contracts signed between the producers, pipelines, and the LDC's. Wellhead natural gas prices were equated to regulated wellhead prices as set forth in the Natural Gas Policy Act. Burner tip prices were equated to forecasted oil prices.

The changes in the natural gas market, brought on by the implementation of the NGPA, obviated the conventional method that was being practiced by the commission in forecasting natural gas prices and supplies. In order to address the complex nature of the evolving natural gas market, the commission now uses a sophisticated, state-of-the-art computer model to simulate the natural gas market in the United States, Canada, and Mexico. This model, "the North American Regional Gas Model" (NARG) (Hass and others, 1987), utilizes detailed resource information.

The commission's natural gas resource data includes information for 10 primary natural gas production regions in the lower 48 States. These regions are defined according to their geological characteristics. Each producing region is further split into one or more resource types with a total of 35 natural gas resource types.

The resource types included in the data base can be broadly classified as onshore conventional or unconventional resources and offshore resources. The conventional natural gas resources are further divided into shallow and deep resources, depending on the depth of each producing natural gas pool in each region. Shallow resources are those found above $15,000 \mathrm{ft}$, whereas deep resources are those found at or below $15,000 \mathrm{ft}$. The unconventional resources include natural gas producible from tight sand formations, Devonian shale, and methane from coal seams. Offshore resources are subdivided into shallow and deep. Shallow offshore resources are in waters less than $200 \mathrm{~m}$ and offshore deep resources are in waters $200 \mathrm{~m}$ and deeper.

Each resource type is represented by a resource supply and cost curve, well operation and maintenance cost curve, and a production decline profile. In some cases, where the gas production is associated with liquids production, an additional parameter is included to account for the revenues obtained from the natural gas liquids produc- tion. Additionally, new technology advances and operational efficiency improvements that would reduce the costs to find, develop, and produce natural gas from these resources may be considered in determining the future wellhead price of natural gas.

The commission's current resource data base in NARG was obtained from Decision Focus, Inc. (DFI) of Palo Alto, California. DFI has drawn on reports by the PGC, the Canadian National Energy Board (CNEB), and additional information it has obtained through its many contacts with the gas industry (for further information of data used in NARG, see California Energy Commission, 1989a). The commission has subsequently updated resource data for several of the resource types based on workshops and hearings held at the commission during the "1991 Fuels Report" proceedings (California Energy Commission, 1991).

The NARG is a dynamic equilibrium model that captures the effects of gas-on-gas competition, changing technology characteristics, regulatory impacts, and impacts of producers' decisions on the price and supply availability of natural gas. The NARG model views the natural gas market as a network of gas supply regions connected to demand regions by a system of pipelines. The analytical task of the model is to find a set of gas wellhead and delivered (end use) prices and a corresponding set of quantities of natural gas delivered through pipelines, which balance supply and demand in all regions and at all time periods over the model's 45-year time horizon. In the long run, the economic and competitive forces in each region will determine the market-clearing prices.

The network of supply and demand regions connected by pipelines is used to calculate market clearing prices and quantities simultaneously at all points throughout the gas system. It is most useful for forecasting prices and supplies, evaluating strategic planning alternatives, and analyzing the impacts of market uncertainties and government policies over the long term. Most significantly, the model is not an extrapolation of past trends. Rather, its focus is the most likely evolution of the fundamental structure of the gas industry in the future.

Natural gas resource and cost information forms a major input in addition to other parameters in the commission's assumptions in addressing the future price and supply availability of natural gas. This information is specified by "supply-cost curves" and "production profiles" as input assumptions for each resource type identified in the NARG model data base. These resources and costs are the driving forces in the NARG. Given the costs required to develop and prove potential resources, the model's logic determines the cheapest available resource in order to satisfy the given demand for natural gas in any specific demand region at any specific time on the forecast horizon. If a specific resource is not economic compared to other sources, that resource is not produced at that time. When that resource 
becomes economically competitive in the future, then supplies from that resource are made available.

With the NARG model's capabilities, the commission is able to address a number of natural gas related issues. The commission has gained knowledge on how the natural gas market operates and the interrelationships of the various regions in Canada and the United States. In addition to the mandated forecast of natural gas supply and price, the commission has used the model to address a variety of specific issues. For example, in the mid-1980's, five new pipeline projects were proposed to deliver natural gas to California. The commission prepared an economic evaluation of the altemative pipeline proposals to determine the need for these new pipeline capacities (California Energy Commission, 1989a). Another application of the model was demonstrated in 1992, when the commission analyzed the need to expand a specific intrastate natural gas pipeline serving the northern California market (Gopal, 1992). The following provides a brief discussion on how the NARG model has been used in a variety of analyses conducted at the commission.

\section{UNDERSTANDING THE NATURAL GAS MARKET}

Every 2 years the commission prepares, adopts, and publishes a natural gas supply and price forecast. In preparing these forecasts, the commission uses the NARG model to provide supply and price forecasts for natural gas delivered to the California border. In obtaining the supply and price information concerning California, information regarding the rest of the United States and Canada is also obtained. This section discusses what has been learned about the North American gas market in general from the commission's most recent biennial fuels report (California Energy Commission, 1991), which considers the natural gas market for the years 1989-2011. The 1989 supply and demand data are historical values.

To meet the increased demand for deliveries to end users, U.S. annual production increases from $17.5 \mathrm{Tcf}$ in 1989 to $23.8 \mathrm{Tcf}$ in the year 2011 (does not include pipeline, lease, and plant fuel). As shown in figure 1, the U.S. Gulf Coast region maintains its present production levels

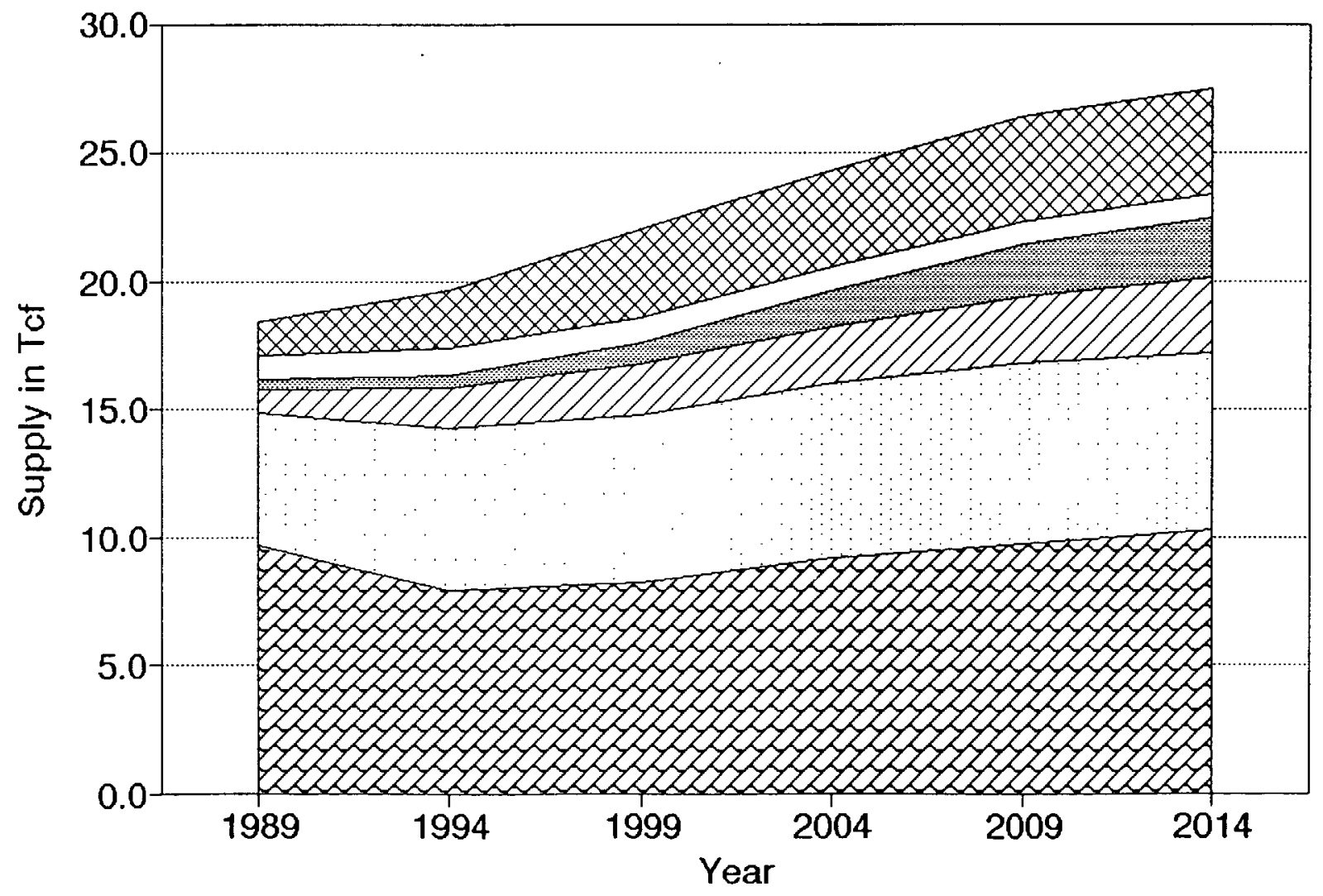

\begin{tabular}{ll}
$Z Z 7$ Gulf Coast \\
Appalachia \\
\hline Southwest
\end{tabular}

Figure 1. Forecasted natural gas supply for the lower 48 States. Tcf, trillion cubic feet. From California Energy Commission (1991). 
over the next 20 years. Production in the Southwest (Anadarko, Permian and San Juan Basins) increases whereas the Rocky Mountains and Appalachian supply regions emerge as prominent production regions in the future (fig. 1). Imports from Canada and liquefied natural gas (LNG) purchases increase substantially over the forecasted horizon. Canadian imports peak in 2004 while LNG imports increase over time to exceed the present capacity of U.S. regassification facilities by 2009 .

In the future, production from conventional onshore natural gas resources declines. Other resource types replace the decline in conventional production to meet the growing demand for natural gas. Figure 2 shows projections of natural gas production from different types of resources. As shown in figure 2, offshore supply declines initially, then gains back its market share to current production levels. Deep onshore resources, followed by tight sands meet a growing natural gas need (fig. 2). Technology to produce natural gas from San Juan Basin coal beds is now on the forefront and will play a significant role in the future in meeting western regional supply needs. Fu- ture estimates will include coal-seam gas reserves in other basins, such as the Rocky Mountain region, as information becomes available.

Figures $3 A$ and $B$ provide information on forecasted pipeline flows between supply regions and demand areas. These two figures can be used to compare the actual pipeline flows for the year 1989 with forecasted pipeline flows for the year 2011.

By comparing natural gas pipeline flows on figures $3 \mathrm{~A}$ and $B$, it can be clearly seen that there is a counter-clockwise shift in natural gas flows. The Gulf Coast supply region is the principal production area in the United States, providing about 50 percent of the Nation's natural gas supplies. Production from this region shifts from being the dominant supplier for the West South-Central demand region, to meeting a greater share of the East South-Central, South Atlantic, and Northeastern States demands.

As Gulf Coast supplies shift to serving the East and Northeast markets, the future will see the West South-Central demand region outbidding other demand regions for natural gas from the Permian and Anadarko Basin produc-

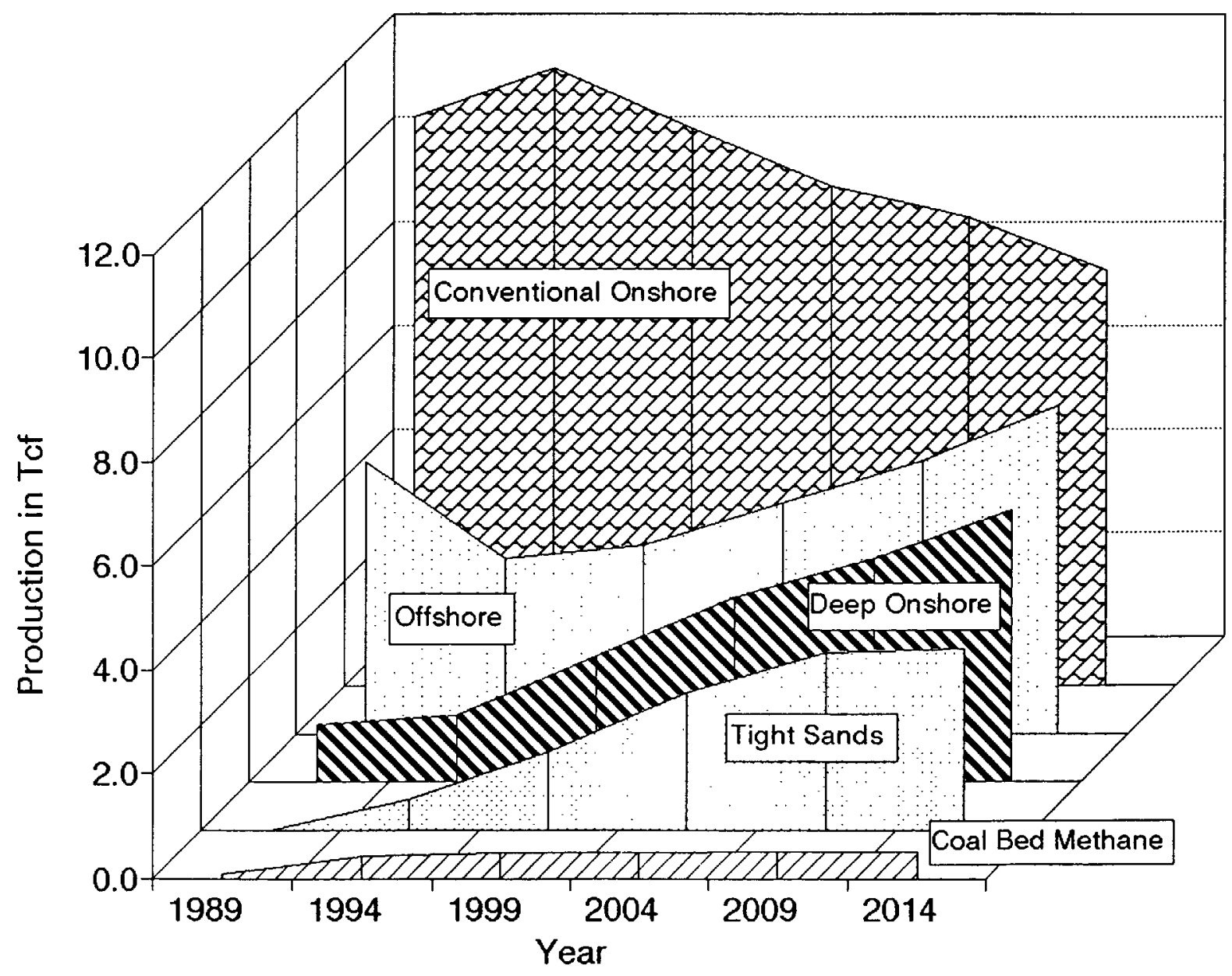

Figure 2. Gas production by resource type for the lower 48 States. Tcf, trillion cubic feet. From California Energy Commission (1991). 
tion regions. This will result in significant increase in supply flows from these two basins to the West South-Central demand region, while their market share, exemplified by flows out of the Permian Basin to the traditional West Coast demand region, decreases (fig. 3).

The San Juan Basin also experiences significant growth in production, but maintains and even increases its flows to Califomia (fig. 3). Historically, El Paso Natural Gas Company and Transwestern Pipeline Company pipelines have transported natural gas to California from the Permian, Anadarko, and San Juan Basins. Analysis conducted at the commission indicates that while San Juan Basin will continue to feed the California market, flows from the Permian Basin to San Juan Basin will reverse, as they did on the El Paso Natural Gas Company pipeline during 1992 (George Lippman, El Paso Natural Gas Company, oral commun., 1992). Further, the analysis indicates that production from the San Juan Basin, and possibly from the Rocky Mountain supply region, will flow to markets in the East, including the West South-Central demand region, through the reversal of flows in the El Paso and Transwestern pipelines.

Production in the Rocky Mountain region increases, providing a larger share of supply to the Southwest and California markets. Rocky Mountain flows increase to the West North-Central demand region and to other Eastern markets, compensating for reduced flows from the Anadarko and Permian Basins.

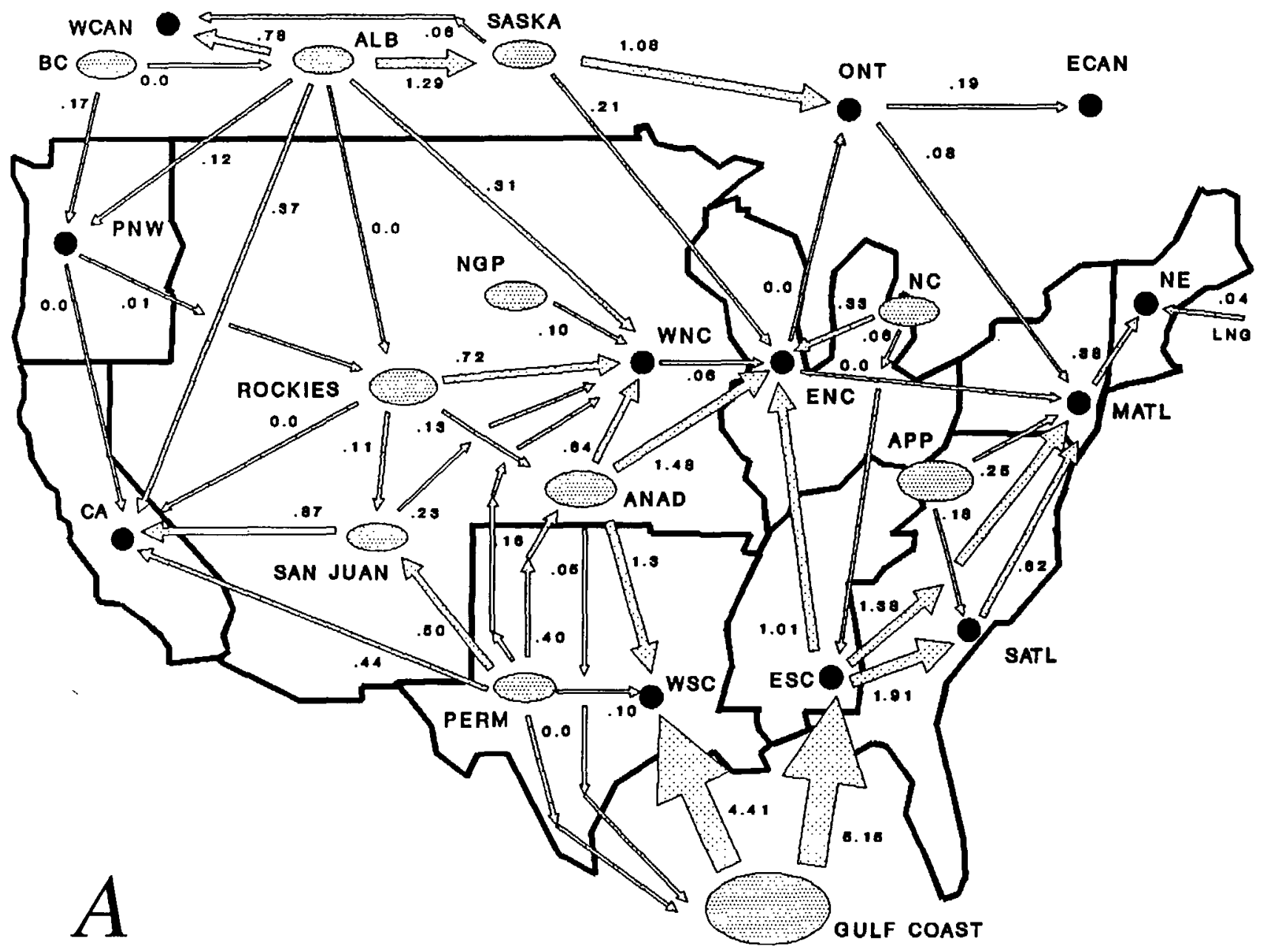

Figure 3. North America Regional Gas model maps of forecasted natural gas pipeline flows between supply and demand regions. Supply regions are shaded oval areas; demand areas are large black dots; arrows represent pipeline links and show direction of pipeline flows with arrow width indicating relative magnitude of pipeline flow; numbers are pipeline flows in trillion cubic feet of natural gas per year. $A, 1989$ gas flow. $B$, 2011 gas flow. ONT, Ontario; ECAN, Eastern Canada; SASKA,
Saskatchewan; ALB, Alberta; WCAN, Western Canada; PNW, Pacific Northwest; CA, California; NGP, Northern Great Plains States; WNC, West North-Central States; NC, North-Central States; ENC, East North-Central States; APP, Appalachian; NE, New England; MATL, Mid-Atlantic States; SATL, South Atlantic States; ESC, East South-Central States; WSC, West SouthCentral States; PERM, Permian Basin; ANAD, Anadarko Basin. From California Energy Commission (1991). 
Increased Appalachian production becomes very important for the South Atlantic and Northeastern States. As the figures $3 A$ and $B$ indicate, the South Atlantic States are remote from the conventional large supply basins. Without increased Appalachian production levels, the South Atlantic demand region would place even greater pressure on the Gulf Coast region, LNG, and possibly, Canadian natural gas supplies. Although only two of the LNG facilities are currently operational, by the end of the study period (2011), LNG supply is expected to reach operational levels that are significantly higher than the existing capacity of the four regassification facilities (see Attanasi, this volume).

Canadian production also increases, as does its exports to the United States. Although Southwest supply regions are meeting the ever greater needs of the West South-Central States, Canadian imports increasingly compete with the Rocky Mountain supplies for market shares in the Pacific Northwest, California, West North-Central and East NorthCentral demand regions. Increasing quantities of Canadian natural gas also find their way into the New England States. Large reserves in Western Canada with lower wellhead prices compete with U.S. produced natural gas, gaining a significant market share over the forecast horizon. Canadian imports and Rocky Mountain supplies compete to meet the increased demand in California and displace supplies available from southwest supply regions.

\section{CALIFORNIA'S NEED FOR NEW PIPELINE CAPACITY}

During the mid- to late 1980 's, there were nine natural gas pipeline proposals to build new capacity to California. As early as 1986, the commission had been on record stressing the need for additional pipeline capacity to meet the growing needs of California (California Energy Commission, 1986). The commission has repeatedly emphasized the need for construction of new pipeline capacity to the State (California Energy Commission, 1986, 1987, 1989a, 1989b). By 1989 there were only five of the original nine competing pipeline proposals vying for the burgeoning natural gas market in California. The attrition of proposals

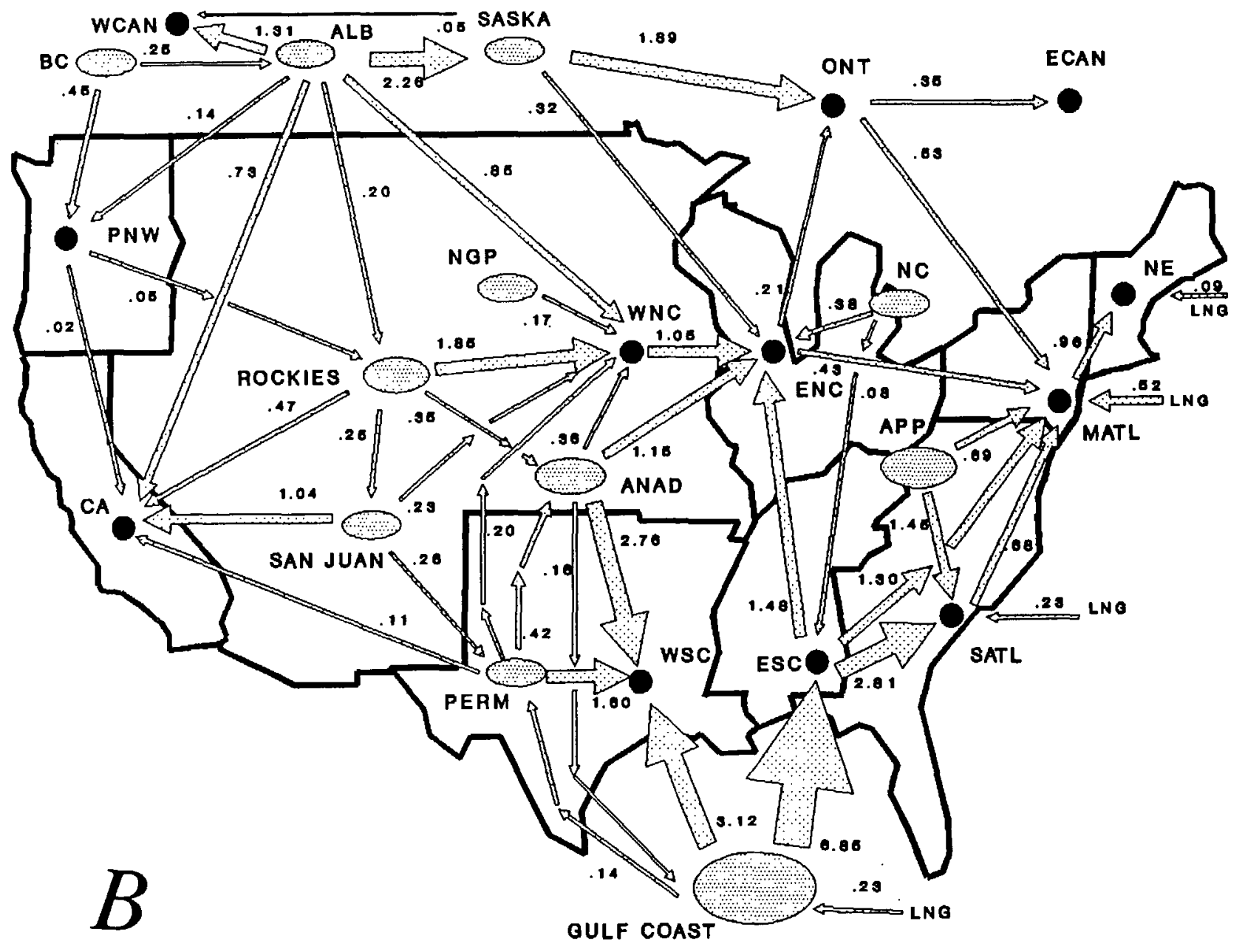

Figure 3. Continued. 
was attributed to the combining of two of the projects, whereas others dropped out of contention owing to economic reasons.

Using the NARG model, the commission analyzed the economic viability of alternative pipeline projects and the need for new pipeline capacity for California. A study was initiated in late 1988, and completed in March 1989, with the publication of a staff report (Califomia Energy Commission, 1989a).

In the preparation of that report, 12 pipeline combinations and 11 sensitivity cases were examined. Each pipeline proposal was evaluated by itself and in combination with one or more of the other proposals. The sensitivity analysis, applied to all the proposals in combination, explored the impacts of varying potential resource availability, potential resource costs, changes in demand, and differing pipeline costs. Three important conclusions were drawn from the analysis:

1. The greatest benefits occurred when all customers had access to the new pipelines. At the time of the analysis, only thermally enhanced oil recovery operations were proposed to receive natural gas service from several of the new pipelines. The commission's analysis, using NARG, indicated that the resulting gas-on-gas competition among the pipelines would benefit all natural gas customers, if the utilities had access to the new pipelines.

2. The proposed Kern River pipeline proposal and proposed expansion of the Pacific Gas Transmission pipeline would provide the most benefits, on the order of $\$ 14.6$ billion. Benefits of these two pipelines were about the same when analyzed separately. The results indicated that their benefits to California were cumulative.

3. The analysis indicated that the natural gas wellhead price is more important than the transportation cost to bring the gas to the market. This implies there are benefits to building more capacity than would be indicated by a simple supply-demand balance. The derived benefits result from opening up new natural gas supply regions, allowing the market to compete for the cheapest available supplies.

Conclusion three indicates the importance of the resource cost in analyzing the benefits of natural gas. Cost is the major driver in determining the potential supplies available to the market and also the price at which the gas can be consumed in the market. It is therefore important that we put as much effort in determining the cost of potential supplies as we do in determining the future potential of available natural gas reserves.

\section{IMPACT OF RESOURCE COST ESTIMATES ON PRICE OF NATURAL GAS}

The above sections have emphasized the importance of cost estimates in evaluating the price and supply avail- ability of natural gas in the future. As mentioned above, technology plays a major role in determining the future availability of natural gas, the quantitative estimates of supplies projected to be available, and the price at which these supplies can be delivered to the market. Figure 4 shows the impacts of reduced exploration and development costs, owing to technology advances on forecasted average natural gas wellhead price. The figure draws from the analysis of the natural gas market in the commission's "1991 Fuels Report" (California Energy Commission, 1991). In the preparation of that report, a set of resource supply-cost curves were assumed for forecasting the supply and price of natural gas over a 20 -year time horizon. The supply-cost curves assumed technology that was currently available (the analysis assumed a base year of 1989); new drilling technology assumptions were then applied to the supply-cost curves to capture the reductions in finding and development costs over time owing to technology advances.

Figure 4 shows two price paths; the higher wellhead price path results from using the supply-cost curves without applying any new exploration/drilling technology. For the second wellhead price path, it was assumed that new technology advances would reduce the future cost of finding and developing new reserves by 25 percent of the estimate based on current technology. This reduction was assumed to occur at an annual rate of 10 percent. It was further assumed that the reduction, owing to technology advances, is the same in all categories of natural gas resources. As indicated in figure 4 , new technologies will significantly reduce wellhead prices. In 1994, as the result of new technologies, lower 48 average wellhead prices

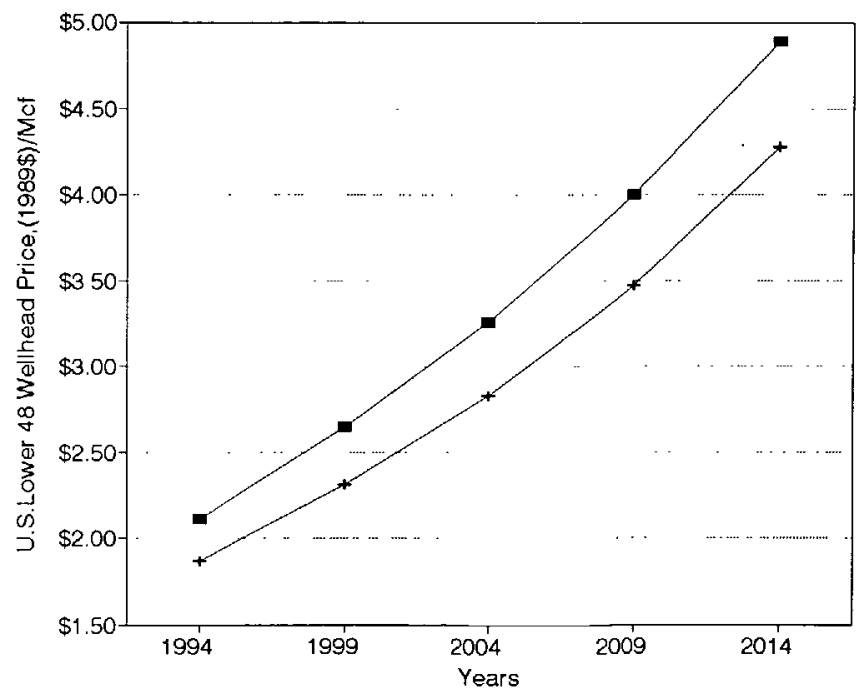

Figure 4. Technology impact on natural gas prices. Mcf, thousand cubic feet. From California Energy Commission (1991). Plus symbols indicate prices with technology impact; open boxes indicate prices without technology impact. 
drop by $\$ 0.24$ per thousand cubic feet (Mcf) from $\$ 2.11$ per Mcf (in the no-technology-impact case) to $\$ 1.87$ per Mcf (fig. 4). By 2014, the forecasted reduction in wellhead price is $\$ 0.61$ per Mcf, a drop from $\$ 4.89$ per Mcf to $\$ 4.28$ per Mcf (fig. 4).

Some may question whether the commission's analysis overstates the effect of new technologies. Robert L. Brown, manager of gas marketing development for Mobil Oil in Jennrich (1992) states, "we found an underlying technology-based cost savings of about 3 percent per year." Assuming just half of the 3 percent per year new drilling technology impact (drilling expenses represent about half of the cost to bring a gas well into production) for the five years extending from the base year 1989 to the first forecast year 1994 would reduce the 1994 wellhead price of $\$ 2.11$ per Mcf by $\$ 0.16$ per Mcf, a close approximation of the commission's analysis results. If the new technology effects were to continue through the study period, the 2014 wellhead price would be reduced from $\$ 4.89$ per Mcf to $\$ 3.37$ per Mcf, considerably lower than the commission's analysis. Although the commission's analysis and an analysis bases on a 3 percent per year technology impact yield differing answers, the order of magnitudes are the same.

The commission staff recently has prepared an evaluation of the potential effects that four new technologies would have on drilling costs for each of the supply regions and resource types within the supply regions (Wood and Hewitt, 1993). The technologies considered include 3-dimensional seismic surveys, slim-hole drilling, horizontal drilling, and new drill bits. The results of this analysis indicate that a full implementation of these technologies would have the potential of reducing drilling costs from 30 percent to over 50 percent, depending on supply region and resource type. The analysis was prepared for use in the commission's "1993 Fuels Report," which is still in the development stage. Preliminary results of applying the new technology effects in the NARG analysis indicate considerable reductions in wellhead prices over what was reported in the "1991 Fuels Report" (California Energy Commission, 1991).

To understand the relative merits of technology impacts and the extent to which different categories of resources will be affected, resource estimates for each natural gas resource basin or field should include the cost needed to economically produce the gas from that basin. This factor plays a major role in the gas-on-gas competition that occurs in any given demand region. The natural gas pipeline network in the United States is so interconnected that each demand region could potentially purchase natural gas from a variety of supply sources, thereby competing for the most economical supply.

\section{CONCLUSION}

An indepth analysis of the future natural gas market is not possible using the conventional methods of reporting potential natural gas resources. An estimate of potential resource data is meaningless without accompanying cost data. Better estimates of resource cost data along with impacts of technological advances is a necessity in evaluating the potential benefits of natural gas as a future source of energy gas.

The analysis as described here is made possible for two reasons: (1) By the availability of estimates of potential natural gas resources, capital cost estimates to bring the resources into production, operational costs, and production profiles; the evaluation and quantification of the impacts of new technologies in finding, drilling, and developing potential natural gas resources will be important to future analyses. (2) A model like the NARG is also essential in determining the economics of natural gas production and the viability of these resources competing in the marketplace.

The studies conducted at the commission have indicated that the application of these resource data, both quantitative estimates of reserves and the costs associated with bringing these resources to production, play a major role in analyzing the future potential of natural gas and its use in the United States. The NARG model has provided an indepth understanding of the natural gas market. Analysis of pipeline needs, regional issues, and impacts of regulations are made possible only if the detailed resource data as described in this paper are available.

\section{REFERENCES CITED}

California Energy Commission, 1986, Biennial Fuels Report: Sacramento, California Energy Commission, P300-86-007, p. ES-3 and p. 36-40.

1987, Biennial Fuels Report: Sacramento, California Energy Commission, P300-87-016, p. 2.

1989a, An economic evaluation of alternative interstate pipeline projects to serve California, staff report: Sacramento, California Energy Commission, P300-89-001, p. ES-1, -2 and p. 5-17 through 5-37.

-1989b, Biennial Fuels Report: Sacramento, California Energy Commission, P300-89-018, p. 5.

1991, 1991 Fuels Report (working paper)-Natural Gas Market Outlook: Sacramento, California Energy Commission, P300-91-018WP6, p. 2-3.

Ellis, P.A., 1991, Management perspective; new technology for gas finding-How important has it been?: Oil and Gas Journal, v. 89 , no. 39 , p. 42 . 
Gopal, J.S., 1992, Testimony for the purpose of considering expansion of Pacific Gas and Electric Line 300 alone or in conjunction with expansion in gas storage facilities: Submitted by the California Energy Commission before the Public Utilities Commission of the State of California (CPUC), San Francisco, Investigations: 88-12-27, Rulemaking: 88-08-018.

Hass, S., Nesbitt, D., and Singh, J., 1987, The Gas Research Institute North American regional gas supply-demand model: Gas Research Institute Report 87-0122.
Jennrich, J.J., 1992, National Petroleum Council task group hikes estimate of gas supply to 150 years: Natural Gas Week, v. 8, no. $15,14 \mathrm{p}$.

National Petroleum Council, 1992, The potential for natural gas in the United States, source and supply: Washington, D.C., National Petroleum Council, v. 2.

Wood, B., and Hewitt, C., 1993, Impacts of new technologies on well cost: Prepared for the NARG users meeting, California Energy Commission, March 22-23. 
Here we present the personal perspectives of several prominent explorationists. They have been included in this volume because-in addition to science and technologysuch things as experience, intuition, and luck have played important roles in the exploration for both oil and gas.

These papers provide insight into the future of natural gas, and they discuss what role society as well as oil and gas companies will play as we move into this future. 


\title{
Natural Gas and the Role of Competition in the United States
}

\author{
By Keith E. Anderson ${ }^{1}$
}

\section{CONTENTS}

Abstract 799

Introduction

Demand for Natural Gas

Issues Affecting the Supply of Natural Gas 801

\begin{abstract}
Increasing demands for natural gas will result in exceptional opportunities for explorationists, investors, and consumers. The stability of price, the certainty of supplies, and the convenience of utilizing natural gas are all factors considered by consumers. Suppliers who are able to locate new deposits of oil and gas, who have the skills to lease the lands, drill the wells, profitably produce the reserves, and who have a proven track record will gain most from the shift to natural gas.
\end{abstract}

\section{INTRODUCTION}

Natural gas is the fuel of the future. In 1992, consumption of 20 trillion cubic feet of natural gas in the United States supplied nearly 25 percent of the country's energy demands. Based on the 1992 Arthur Andersen Oil and Gas Industry Outlook Survey, 61 percent of oil and gas exploration company executives believe the U.S. demands for natural gas will increase 2 to 4 percent annually during the remainder of the 1990's. I share this optimism. However, the employees or investors in an oil and gas ex-

'Washington Energy Resources, 601 Union, Two Union Square, Suite 2200, Seattle, WA 98101. ploration company should not expect that their business will survive simply because the conditions in the industry are improving. I believe that only skilled explorationists will survive the competition from other explorationists as well as the competition of other fuels.

For many years the American Gas Association (AGA) and local gas-distribution utilities have advertised that natural gas is environmentally clean, economical, and plentiful. The comerstone of President Clinton's national energy policy is natural gas. Natural gas is the best choice of energy sources for many reasons.

Although many experts are saying that more gas will be burned because it's clean, in reality the demand for gas will increase because of its competitive price. The Federal Energy Regulatory Commission (FERC) has completed its deregulation of the gas industry. Prices were deregulated for sales of "new" gas in 1984. Regulation of prices for "old" gas expired on December 31, 1992. (New gas is gas reserves drilled and produced subsequent to deregulation in 1984; old gas is gas covered by government price regulations. At the end of 1992 even new prices for old gas were deregulated.) Some experts in the oil and gas industry voice concerns that wellhead prices are too low. As stated in an article in the March 16,1992, issue of "Time" magazine, The Great Energy Bust in the United States, natural-gas wellhead prices in 1982 were $\$ 2.46$ per $\mathrm{Mcf}$ (thousand cubic feet), but by 1992 the price had declined over 50 percent to $\$ 1.16$ per Mcf.

One would think that under these marketing conditions-low price, an environmentally clean product, and aggressive advertising-executives in the gas industry would view the gas market with enthusiasm. Many do, but they are unwilling to commit funds to drill new wells at current prices. I believe that competition among energy sources will have a significant influence on the consumers' decision to switch fuels or select natural gas as the fuel of choice. In spite of the environmental benefits of natural gas, the pricing strategies of suppliers who sell coal, oil, 
electricity, and gasoline could delay the increase in demands for natural gas in the near term.

\section{DEMAND FOR NATURAL GAS}

Let's examine the issues that customers think about when making a fuel decision. First, consider certainty of price. Industrial customers consume huge quantities of energy--primarily oil, coal, and electricity. For environmental reasons, industrial plant-combustion facilities are carefully engineered and designed for the fuel used. Likewise, the processing equipment to heat-treat a manufactured item is carefully engineered with the material and heat source in mind. Fuel costs may represent only 15 to 25 percent of the manufacturing cost, but the cost of changing to a new fuel is substantial. Not only does the cost of the new gas-fired equipment need to be considered, but the space and size of the equipment could require changes in floor layout and building size. For industrial plant owners, these conversion costs can amount to millions of dollars. Customers will therefore need to be convinced that fuel-cost savings from natural gas will be sufficient to recover the expense of conversions.

Also of concern to customers are profitability and how long their manufactured products will be competitive in the marketplace. These issues are often so complex that industrial customers will choose to stay with current energy sources, even though natural gas could do the job more efficiently and at a lower cost. This is particularly true when suppliers of coal, oil, or other fuel give customers better terms or a better price to keep from losing sales.

The assurance of long-term supplies is almost as important to the consumer as the price of natural gas. This issue is a common selling point of competitors who are trying to sell oil and coal to new factory or electric generating plants. Projections by the U.S. Geological Survey, American Gas Association, Department of Energy, and other agencies suggest reserves of proved, probable, and possible natural-gas supplies are adequate for expected demands in the United States for the foreseeable future. Actions by the U.S. Government to select natural gas as a cornerstone of the national energy policy also suggests the evolution of programs to encourage the development of long-term gas supplies. Concerns about the future availability of foreign supplies of natural gas would be lessened by the pending North American Free Trade Agreement. The agreement will allow natural gas to be sold and delivered across the Canadian and Mexican borders without government intervention. While I believe that natural-gas reserves are abundant, unfortunately some customers still remember shortages in the 1970's and especially the curtailments of gas service during the cold winter of 1989.

The public is increasingly concerned about the environment. The no-growth and NIMBY (not in my backyard) activists are especially skilled in using environmental issues to inhibit the growth of demand. Although employees in the gas industry are actively promoting natural gas as an environmentally clean fuel, they have been unable to convince the public that exploration, production, and refining activities will not result in a large-scale environmental catastrophe. This lack of public trust often results in pipeline construction delays. Natural-gas regulations can potentially create other problems for customers. For most fuels, there are alternative suppliers to turn to if you can't get a particular fuel or if you are unsatisfied with the service. This is not so for natural gas. For the end-use customer who uses gas at the burner-tip, the natural-gas industry is regulated. Over 90 percent of the natural gas consumed in the United States is distributed locally to customers in a pipeline network owned by private and municipal utilities. Each utility serves the consumer under a franchise, issued by the local city council or county government. A franchise gives the utility the exclusive right to build, distribute, and sell natural gas for a number of years, often 20 or more. These arrangements are regulated by local and state public-utility agencies. The skill of state public-utility commissioners in regulating natural gas and electric utilities is commendable given the complex nature of the industry and the political arena in which the process functions. Regrettably, local issues and public involvement regarding growth, environment, and (or) safety often act as a deterrent to expanding the system, which would otherwise accelerate the shift to using more natural gas.

Another issue the gas explorationist has to be aware of is the transition of pipeline regulation in the gas-supply chain. As pipeline deregulation takes place at the national level ${ }^{\circ}$ (under FERC Order 636), the merchant function is shifting away from the system in which natural-gas producers sold gas directly to the pipeline to a new system in which producers sell directly to utilities and other end-use customers. At the same time, the producers have had to accommodate buyers who want to buy gas on short-term "spot" contracts as compared to the historical 20-year, long-term contract.

Often the inability to adapt to these rapid changes in the energy market limits the ability of small producers to compete effectively for consumers in the downstream market or to attract investors to fund natural-gas exploration and development activities in the upstream segment of the industry.

Producers will benefit in the future because customers are becoming increasingly more aware of the opportunities to use more natural gas. Gas prices are an excellent energy value compared with the cost of other available fuels. However, the uncertainty of long-term natural-gas supplies and prices could deter many existing large energy consumers from making the investment to convert from their current fuel to natural gas. Environmental regulations could mandate the use of natural gas in existing plants. More 
stringent air-quality regulations will encourage the selection of gas in new plants. The skilled explorationist who is able to anticipate consumer needs for long-term supplies at competitive prices will have an exciting future.

\section{ISSUES AFFECTING THE SUPPLY OF NATURAL GAS}

The challenges facing explorationists are often viewed in three segments. One challenge is identifying the optimum surface locations to drill. The second is obtaining the legal permission to drill for and produce from new wells. The third challenge is drilling and producing wells to make acceptable profits.

Improved techniques in gathering and processing vast quantities of technical information have allowed explorationists to accurately locate likely sites of new oil and natural-gas reserves. These techniques allow geologists and geophysicists to find new reserves at deeper horizons and to look at old producing fields for bypassed traps.

New techniques and equipment to drill, complete, and produce oil and gas wells are being exploited almost as quickly as they are developed. The ability to fracture formations more effectively, and to use new horizontal drilling techniques to interconnect fractures in low-deliverability fields, will often provide economic returns where older techniques would have resulted in an unprofitable dry hole.

In 1984, according to Arthur Andersen in its publication, Oil and Gas Reserve Disclosure, the industry replaced 105 percent of the natural reserves produced. "Finding Costs of Exploration" ranged from $\$ 5.05 / \mathrm{boe}$ (barrels of oil-equivalent, with gas at $6 \mathrm{Mcf}$ per boe) for majors to $\$ 9.62 /$ boe for non-majors. Seven years later, in 1991, the report stated the industry had replaced only 94 percent of the produced natural gas reserves. The weighted average replacement costs were $\$ 5.98$ per boe. It should be noted the industry did not replace all of the oil and natural gas produced during the year but the reserves that were replaced, were done so at about the same cost.

Profit margins have disappeared for many explorationists because of lower gas sale prices and higher administrative costs. Over the past 10 years, the upstream segment of the oil and gas industry has changed dramatically. Of the estimated 25,000 oil and gas operators that existed in 1982 , only about 7,000 remain in business today. Industry jobs dropped from 708,000 in 1982 to 390,000 in 1992. The primary factor affecting the industry during this period was a 50 percent decline in oil and gas prices.

To reduce the cost for finding and producing new reserves of natural gas, the explorationists of the future need to be on the cutting edge of new technology. Management needs to be informed and skillful in complying with the increasing number of environmental, safety, and tax regulations enacted by Federal, state, and local agencies. The employees also need to be creative and diligent in their efforts to assemble acreage and negotiate drilling contracts. Finally, executives need to plan ahead and be persistent.

One of the important business matters for the company is the acquisition of the rights to the oil and gas from the mineral owner. It may take years to locate mineral owners and to negotiate favorable terms for the oil and gas lease. These terms will include payments for royalty and damages as well as access for the drilling equipment, pipeline, roads, and production facilities. Later on when the leases are combined into federal units or consolidated and pooled for operating or risk-sharing reasons, changes in the lease terms may be required from the owners. Because the mineral owner of the oil and gas has no out-of-pocket investment in drilling the well and pays none of the operating costs, the percentage of royalty payment and other payments have a significant economic impact on the operating profit of the well.

Taxes are another cost of doing business. All states levy severance taxes on the proceeds from production. Counties levy ad-valorem taxes on the value of the lease equipment. Franchise and sales taxes may be added at the point of sale. Business and occupation taxes are levied along with employee taxes. Taxes can quickly add 35 percent to the cost of doing business. Tax credits, such as the Section 29 Nonconventional Fuels Production Credit, can be useful. Often, however, those who most need the tax relief are the ones who do not have a profit or have profits that do not meet alternative minimum tax thresholds.

In the end, explorationists and investors must carefully value profits versus the costs and risks of being in business. In this analysis, consideration should be given to customers, employees, and shareholders. Owners benefit from increasing profits, which result in higher stock values and dividends. Employees benefit through the company's compensation package, which includes salary and benefits. Usually in periods of lower gas prices, customers will benefit most and the shareholders least because of lower profit margins. Many employees have been the unfortunate victims of corporate downsizing and bankruptcies as a result of the dynamic refocusing taking place within oil and gas industry.

Increasing demands for natural gas in the future will result in exceptional opportunities for the industry. This alone does not guarantee that customers, owners, or employees will prosper. Those explorationists with a keen awareness and knowledge of the business together with a proven track record will gain most from the shift to natural gas. 



\title{
THE FUTURE OF ENERGY GASES
}

U.S. GEOLOGICAL SURVEY PROFESSIONAL PAPER 1570

\section{Reflections After 62 Years of Exploration}

\author{
By Michel T. Halbouty ${ }^{1}$
}

A recent National Petroleum Council (NPC) study estimates the recoverable natural gas resource base of the lower 48 States at 1,295 Tcf (trillion cubic feet). This is more than a 60-year supply to meet estimated future demand growth. The NPC study concludes "the natural gas resource base is abundant and can be produced and developed at prices that allow both an expansion of the marketing and continuing development of the resource." This bullish estimate reinforces the long-accepted view, by those who have searched for and produced gas, that supply is plentiful, the future is bright, and all we need to do is explore.

Exploration for oil and gas has evolved rapidly during petroleum geology's history. Many theories have been proposed, accepted, tested, and later exchanged for newer ones, in all aspects of oil and gas exploration. The history of petroleum geology, and exploration attitudes associated with it, has a broad base, developed by scientists and nonscientists alike.

As early as 1842, 17 years before Col. Edwin L. Drake's well in Titusville, Pennsylvania, signaled the birth of the oil industry, Sir William Logan studied oil springs at Gaspe in his native province of Quebec, Canada. He concluded that the oil springs were located near and associated with anticlinal folding. My research indicates that Logan's written comments on the seeps were the first expression of the anticlinal theory of oil accumulation. By 1860 , this theory was a prominent, controversial topic in geology. Early proponents of the theory, such as J.P. Lesley, first championed the theory but later denounced it.

Three years later, wildcatter John Galey and William A. Erseman, two Pennsylvania oil operators called Dr. Israel C. White to their field. Their drilling observations suggested that there definitely was some relation between existing gas fields and anticlines. Although White had previously

\footnotetext{
'Michel T. Halbouty Energy Co., 5100 Westheimer Rd., \#500, Houston, TX 77056.
}

written two papers extolling the virtues of the theory, he, also, later rejected it.

After visiting with Galey and further surface studies, White, desperate to prove the theory to his own satisfaction, formed a company and drilled a well on a surface anticline to test the theory. The result was the discovery and establishment of the first significant oil production in West Virginia. White then announced his rediscovery and acceptance of the anticlinal theory, proving also, that nothing succeeds like success.

All of our knowledge about oil and gas exploration was not gained from scientists. The nonscientists, the nonprofessionals, and the wildcatters who applied common sense, courage, and stubbornness in the search for oil added much to our vast store of geologic knowledge. Often, the wildcatter's approach was not very scientific. Random drilling based on surface seeps was more the rule. Drake made his famous discovery in 1859 near Titusville, Pennsylvania, on the basis of surface seeps.

The great discovery of Spindletop in 1901 was the result of the faith of one man, Patillo Higgins, who interpreted several surface observations as indications of a good drilling site. Yet the respected geologists of that time rejected the prospect as unworthy of exploration. They surmised that the unconsolidated sands in the Gulf Coast would not be favorable to the origin and accumulation of oil. The discovery of Spindletop ushered in a new era of exploration. Surface indications like those found at Spindletop became guidelines used in the search for other salt domes in the Texas Louisiana Gulf Coast region.

The petroleum geology profession was just beginning. During these early days, management relied primarily on conceptual skills of geologists to identify drillable prospects. Imagination and vision were the prime guides, and these were stimulated by our senses. The basic exploration technique was to study the surface, seeps of whatever nature, and other unusual surface conditions. During this period geologists had little difficulty locating places to drill. 
Anticlines, surface faults, and even some buried salt domes were easy to locate. Many outcrops and other surface features indicated drilling prospects. Gradually, prospects which could previously be seen on the surface, became less and less obvious and exploration dramatically decreased.

Then, when a real breakthrough was needed, geophysics appeared. Geophysical techniques were tremendously successful. The torsion balance and refraction seismograph were introduced during the early 1920's. These new tools brought instantaneous and remarkably successful results to exploration efforts. By the early 1930 's, the reflection seismograph had been introduced to aid in exploration. The phenomenal success of this instrument in imaging subsurface structures resulted in worldwide acceptance of geophysics and relegated other exploration methods to minor roles in the search for petroleum.

After a series of spectacular successes, many management groups believed that these new geophysical and electronic instruments had, at last, solved the problem of finding new reserves. At first, these developments suggested the geologist as an explorationist might become obsolete. From the early 1930's to the late 1960's, any anomaly conceived through geologic thinking was submitted to the seismograph and was classified as drillable only after the "black box" confirmed it. For a while, the black box completely replaced the brain.

But in the early 1970 's, prominent structures became harder to find and many of the small seismic anomalies that suggested stratigraphic traps proved to be dry. Many explorationists found themselves presenting only data they could positively defend before, and after, the prospect was drilled. It is unbelievable that even today there are some exploration managers who still insist on drilling only structures, avoiding every other trap concept. Unfortunately anyone submitting and recommending a wholly stratigraphic prospect was considered radical. Management would accept only the structural prospect, however weak the basis for the structural interpretation. It is sad to reflect on those years in which the geologist was subjected to ordinary and, sometimes, menial assignments. During this period new geologic thinking was rare. Stagnation set in-the electronics were doing all the thinking and recommending.

We, as students of the Earth, must bear in mind that from the beginning, geology has grown and advanced on a balance scale of probability rather than in the rigid, less flexible framework of mathematics. Geology has always been an inexact, speculative science-depending at times wholly on sheer geologic deductions. Commonly suffering from speculation beyond the limits of observation and experience, geologic hypotheses and theories have been proclaimed and later disregarded, but not without some benefit to each succeeding generation of earth scientists.

It is precisely this inexactness of geology that makes it such a great challenge. It takes real courage to meet this challenge and keep the science of geology always in the forefront of our thinking. However, we have failed many times in the past to use geology properly. We depended too much on other disciplines to guide us and did not practice geology as we should have. As a result, we became less creative and less courageous. We became afraid to express ourselves unless we had the perfect closure.

We kowtowed to and became dependent on the black electronic boxes and transistors and failed to rationalize for ourselves. Those black boxes and transistors are and will continue to be a vital part of our methodology, but we should have made them only a part and not the whole. Our dependence led to routine thinking, without probing and seeking to better understand the true meaning of geology. We became afraid to experiment with an unusual concept or idea. This should never happen again.

Although technology has expanded into all areas of the industry, for the most part, our exploration efforts have been constrained by the overwhelming attitude of complacency in using only the tried, tested approaches. As a profession, we ignored, or delayed, our participation in new advances. At last, however, we are beginning to catch up.

We are looking to the future with more clarity of mind and determination than ever before. For example, it is remarkable how remotely sensed images from Landsat are changing our thinking about areas for exploration. Remote-sensing data has shown us that even mature producing regions yield intriguing new possibilities for future exploration.

New concepts are leading to new discoveries in areas previously considered unfavorable. The Rocky Mountain Basins, classified as mature, are now enjoying a resurgence in exploration because of new geoscientific concepts and a greater understanding of tectonics. For example, it took the industry 125 years before wells in the Rocky Mountain region were drilled through Precambrian rocks-igneous rocks, mostly granite-into sedimentary sections that are concealed and virtually unexplored beneath mountain-front thrusts.

Petroleum has been found under the Precambrian mantle, which has encouraged leasing and seismic data acquisition on every mountain-front thrust in the Rockies. Millions of acres remain to be tested in these areas of resource potential. I don't think there exists a geologist who, 15 years ago, would have recommended to management drilling through 8,000 to 10,000 feet of granite to reach underlying sedimentary rock. But this is becoming commonplace now. Mature basins offer explorationists many opportunities to search for and discover substantial reserves of new petroleum. I still consider them areas of great potential where exploration will continue to show positive results.

More optimism, enthusiasm, and daring is needed in the field of wildcatting. Daring is the vital word. This means we must have the drive to drill unconventional prospects. We must be innovative and more creative by using our most important tool-the brain. 
In this regard, it is strange that we pay so little attention to new ideas in a deliberate search for those reserves that lie in subtle traps. Finding the elusive traps requires highly imaginative thinking combined with every applicable scientific discipline. The geophysicists' computers and new chart mechanisms are tremendous aids in illuminating some of the scientific facts needed for finding subtle traps. Great advances have been stimulated through seismic modeling, better data acquisition, more advanced data processing, and the extensive use of color seismic display formats. But these kinds of data are just part of a broader analysis and must remain just that in our search for the subtle traps.

Other important aspects of the search for the subtle trap are evaluations of the source and kind of sediments, facies changes, geologic history, tectonic control of sedimentation, and kinds of environmental conditions present when sediments were deposited. These evaluations are vital to the search for the stratigraphic and other subtle traps. In other words, plain geologic thinking is needed.

We have accomplished more in the past few years to revitalize geology in the search for petroleum than ever before. Because of this revitalization, we are creating more new concepts and ideas on where to look for oil and gas in places previously considered unfavorable. By doing so, we are being highly imaginative and seeking new knowledge through ingenuity. Although we may have failures and wrong turns, we must continue to ferret out new ideas and add them to our understanding of geology.

Unless we think creatively and boldly as scientists, without fear of honest mistakes, and by so doing create new concepts and use them, we will never be able to meet the challenges of the future. The key to a new exploration philosophy is to become comfortable with and put into practice those unusual, unconventional ideas and concepts, which we have been too afraid to even think about.

The vital characteristics an exploration geologist must possess to succeed are strength of conviction and reliance on one's own geologic deductions, however strange or far out they may be.

As one of the great petroleum geologists, Wallace Pratt, so aptly put it, "oil is found in the minds of men." So if you want to be a successful explorer, never forget the wisdom behind that observation.

Regardless of the amount of natural gas that will be discovered in the future, the quantity will depend on the number of wildcat wells drilled in search of new reserves.

Most of the natural gas produced in the United States is from wells that are 12 years old or older, which underscores the urgent need for new drilling programs. Yet, the restrictions and regulations imposed on wildcatting are so severe that the large operators have gone overseas to explore and the independents have been so decimated that there are no incentives left for them to "wildcat." Most new wells drilled in the United States during the past few years are "infill" locations drilled between existing producers where there are no risks and successful completions are virtually guaranteed.

Although the potential domestic gas reserves are evident, it will be a long time before this potential is brought to the surface and even then the new supply could be insufficient to meet our growing consumption demand. 



\title{
THE FUTURE OF ENERGY GASES
}

U.S. GEOLOGICAL SURVEY PROFESSIONAL PAPER 1570

\section{New Thinking About Natural Gas}

\author{
By Robert A. Hefner III ${ }^{1}$
}

\section{CONTENTS}

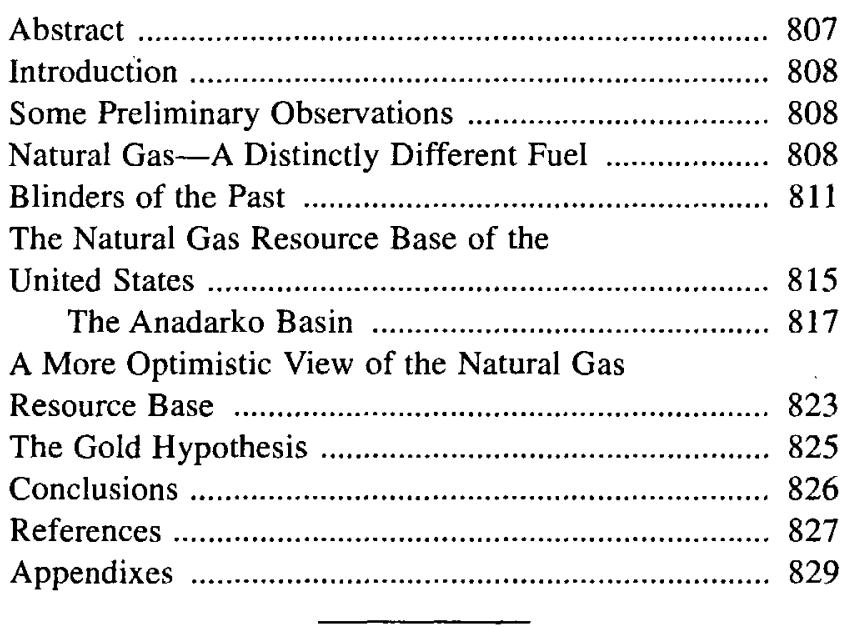

\begin{abstract}
This paper is about opening our minds to natural gas. Though conventional thinking holds that commercial natural gas resources rank third behind coal and oil, recent studies require that this thinking be challenged. Even today our view of natural gas is permeated by a type of thinking that has grown out of the historical close association of natural gas with oil. This "oil thinking" has created a generally accepted perception, even among professionals, that often impedes research, development, innovation, and implementation of much needed new ideas in the realm of natural gas.
\end{abstract}

\footnotetext{
'Robert A. Hefner III, The GHK Company, 3030 Northwest Expressway, 18th Floor, Oklahoma City, OK 73112-5467.
}

Even though estimates of the natural gas resource base recently have been revised upward, to the range of 1200 to $1500 \mathrm{Tcf}$, they are still overly conservative. My estimate of potentially available natural gas resources, based on accepted theories of the origin of oil and natural gas, forecast the U.S. natural gas resource base to be within the range of 3,000 to $4,000 \mathrm{Tcf}$. I believe that this significantly larger natural gas resource base can be developed at prices within reasonable economic limits using both in-hand technology and technological innovations likely to be available soon.

On the basis of a large natural gas resource base and other information presented here, I predict (1) that in the United States natural gas will remain an affordable and reliable fuel beyond the middle of the 21 st century, (2) that natural gas will replace oil as the United States principal energy source, (3) that the only limits to the use of natural gas will be well in the future when $\mathrm{CO}_{2}$ emissions from natural gas could possibly begin to exceed limits set by future global warming treaties, and (4) that to use natural gas as a principal energy fuel will be exceptionally beneficial for both developed and developing economies and therefore a great catalyst to the growth of the global economy in a manner that will significantly improve the environment. In developed economies, increased use of natural gas will reduce coal and oil pollution and lower the rate of addition of carbon dioxide to the atmosphere while enhancing economic efficiency and productivity. In developing countries, the use of locally derived natural gas will reduce the capital required to produce the energy necessary for economic growth while allowing these countries to conform to global environmental goals.

The world is now entering "the age of energy gases," which will progress toward an environmentally benign energy system that will allow civilization, for the first time, to sustain economic growth within a clean global environment. 


\section{INTRODUCTION}

Natural gas, composed principally of methane $\left(\mathrm{CH}_{4}\right)$, may well be the world's most abundant hydrocarbon, possibly exceeding in amount both coal and oil (U.S. Geological Survey, 1992). Though conventional wisdom holds that commercial natural gas resources rank third behind commercial coal and oil, recent studies of the origin of natural gas, the abundance of methane in the solar system, the pervasive nature of natural gas in the Earth's lithosphere, and the vast quantities of methane trapped in gas hydrates require that this old thinking be vigorously challenged.

The thoughts I present here concerning natural gas are both simple and radical. I think that commercial natural gas is vastly more abundant than even our most optimistic estimates suggest and that our limited view of the potential of this fuel is based in our insistence on holding to the historical mind set of the association of natural gas with oil. Throughout most of its history in the United States, natural gas has been found principally in geologic and economic association with oil. Until the 1970's, natural gas was considered by most a nuisance or, at best, a by-product of oil with little intrinsic value. But understanding the real quantities of economically recoverable natural gas that exist in the Earth lies far beyond accepted concepts of the physical, chemical, technological, and economic limits of oil. Until we break the mental bonds that tie us to these oil-related ideas, we will be unable to foresee the real future of energy gases. To discern that future, we need a radically new paradigm for natural gas resource thinking and an intense focus on research and development to test the ideas that arise from this fresh and fertile perspective.

One of the main theses of this paper-that our view of natural gas is permeated even today by thinking that grew out of the close association of natural gas with oil-is based in an historical view of the development of hydrocarbon fuels. During the past decade, this view of natural gas has begun to change. However, my purpose here is not to address the cutting edge of natural gas science and technology, it is to speak of the inertia, resulting from decades of focus on oil, that impedes more rapid development and implementation of new ideas in the realm of natural gas. I will also show that thinking from a perspective based in natural gas rather than oil supports a far more optimistic view of the natural gas resource base than is suggested even by the most recent, higher estimates of such agencies as the U.S. Department of Energy (DOE), the National Petroleum Council (NPC), and the Gas Research Institute (GRI).

The observations and arguments that support this view come from a lifetime devoted almost exclusively to natural gas exploration and production and, equally important, not to oil. It is a view deeply grounded in experience as well as theory, intuition as well as science, logic as well as fact, and it has been formed in a marketplace where ideas mean little until they have been tested in practice. The ideas contained herein are an outcome of that testing.
Wallace Pratt once said that "oil is found in the minds of men." If this is accurate, and I hold no doubt that it is, perhaps it is time that we recognize that natural gas also is found in the minds of men and women, and that to find more we need to free our vision from the bounds of oil so we can think natural gas. In my opinion, this volume is a major move in that direction. This paper is designed to highlight some of the changes in thinking that my experience with natural gas has convinced me we must now make, as well as to inspire new ideas about natural gas in the minds of the men and women in whose hands our energy future lies.

\section{SOME PRELIMINARY OBSERVATIONS}

Methane-the major component of natural gas-is the simplest and most stable of the hydrocarbon molecules. It is a major component of the atmospheres of Jupiter, Saturn, Uranus, Neptune, and Pluto and the planetary satellites Titan and Triton. On Earth, large quantities of methane exist in the crust. Of the various known sources of methane, the most abundant occurs in the form of methane hydrates in the sediments of ocean basins and within the permafrost of polar regions (see Kvenvolden and also Collett, this volume). Recent estimates of the quantity of natural gas held in these hydrate deposits range from $13 \times 10^{3}$ trillion cubic feet (Tcf) to $26 \times 10^{6} \mathrm{Tcf}$ (Kvenvolden, 1988). Although much of this gas hydrate resource may be noncommercial in the foreseeable future, natural gas has been produced from hydrates on the Yamal Peninsula in Russia (Gustavson Associates, Inc., 1992; Collett, this volume).

Although methane is always associated with oil and coal deposits, it is also found in many other habitats: (1) Methane leaks from most of the Earth's surface rocks and oceans; (2) it is found in swamps, landfills, and the stomachs of animals; (3) methane is found in diamonds (Melton and Giardini, 1974), which form at ultra-high pressures and temperatures, presumably at great depths in the Earth; and (4) it occurs, in quantity, in geologic domains where oil is relatively rare or absent, such as within fold and thrust belts (Howell and others, 1992), in some large basins such as the West Siberian and San Juan Basins, and at depths below 15,000 ft. Natural gas has been found at depths of $21,000 \mathrm{ft}$ in the granitic rocks of Sweden's Siljan meteorite impact crater, of 31,441 ft in Oklahoma (the Lone Star-GHK Company Bertha Rogers No.1 well was spud on November 25, 1972, and completed on August 14, 1974), and of over $40,000 \mathrm{ft}$ on the Kola Peninsula in Russia (USSR Ministry of Geology, 1991).

\section{NATURAL GAS- A DISTINCTLY DIFFERENT FUEL}

In the past, the commonly accepted assumption has been that oil and natural gas are similar substances, traveling together along parallel paths from origin to production. 
This is neither surprising nor unreasonable as oil is rarely found without associated natural gas, and these fuels, in the past, have been explored for, produced, transported, and marketed by what is frequently perceived as a singular and monolithic enterprise-the oil industry. However, natural gas and oil are not the same; natural gas is as different from oil as oil is from coal. And natural gas occurs in large quantities unassociated with oil. The natural gas industry is now emerging in its own right as completely separate from the oil industry. As this emergence progresses, more people are recognizing the distinct physical, chemical, and geological differences between oil and natural gas, differences which produce equally distinct economic, environmental, technological, and political effects. Each of these differences and effects are discussed below:

1. Physical character: Methane is a gas that is lighter than air; oil is generally a viscous liquid that is lighter than water. Oil, as we know it, is virtually destroyed at temperatures that exceed $150^{\circ} \mathrm{C}$ at low pressure, whereas methane is found throughout the Earth's crust at temperatures to at least $800^{\circ} \mathrm{C}$. These figures indicate that methane can exist to significantly greater depths in the crust than can oil. Kerogen profiles from deep wells in Oklahoma's Anadarko Basin indicate that natural gas could be present at a depth of $60,000 \mathrm{ft}$ (Hefner, Kinchloe, and Wheeler, 1973), whereas little oil is found below $12,000 \mathrm{ft}$ and virtually none below $15,000 \mathrm{ft}$.

2. Chemical composition: Methane, the primary component of natural gas, is the simplest of all hydrocarbons, containing one carbon and four hydrogen atoms $\left(\mathrm{CH}_{4}\right)$. Approximately one-half of the energy from burning methane comes from carbon and one-half from hydrogen. Oil, on the other hand, is a mix of very complex long chain, and simpler, hydrocarbons. When burned, oil derives about three-quarters of its energy from carbon and only one-quarter from hydrogen. Coal derives nearly 100 percent of its energy from carbon.

3. Geologic occurrence: Natural gas can be, and seems to be, ubiquitous in the Earth's rocks, occurring in commercial quantities in strata as old as, and occasionally older than, $600 \mathrm{~m}$.y. Though frequently found in traps of limited extent, natural gas virtually permeates the deeper parts of some basins, such as the Anadarko Basin (discussed below) and the Alberta Basin (Masters, 1979). Oil, on the other hand, is geographically, geologically, and physically limited in its occurrence and commonly accumulates in unique traps under normal pressures at depths less than $10,000 \mathrm{ft}$ in relatively young rocks. More than one-half the world's oil, for example, occurs in rocks younger than Jurassic, or less than 180 m.y. old. About 60 percent of the world's known oil reserves lie beneath less than one percent of the Earth's surface in the Middle East (World Oil, 1992); 7 percent is concentrated in the Ghawar field alone. Many of the world's largest natural gas fields contain relatively small amounts of oil, whereas all of the world's large oil fields contain significant quantities of natural gas.
4. Economic considerations: Until the early 1970 's, except in a few limited cases, natural gas was considered at best a marginally economic by-product of the oil industry. Only during the past 20 years has natural gas achieved independent economic value, whereas oil has maintained significant intrinsic value as an important, easily traded, and readily transported energy commodity since the 1920's. Conversely, the large-scale natural gas transmission system of the United States was built after World War II. Today, however, natural gas is the fastest growing fuel in the world, whereas oil use has barely fluctuated over the past 10 years (International Energy Statistics Sourcebook, 1992).

5. Environmental differences: Natural gas is the cleanest burning hydrocarbon, a reflection of its simple chemical composition and low carbon content. Although natural gas is usually grouped with coal and oil as a "fossil fuel" by those concerned with the environment, the use of natural gas produces significantly fewer of the atmospheric pollutants associated with coal and oil. The burning of natural gas, for example, produces 25 percent less carbon dioxide than oil and 50 percent less than coal. Indeed, a natural-gas fueled vehicle, compared to an average gasoline-fueled vehicle, emits 24 percent less carbon dioxide and nearly 90 percent less reactive hydrocarbons and carbon monoxide (American Gas Association, 1991), which are the main contributors to the photochemical smog that pollutes most of our cities. An advanced natural-gas-fueled combinedcycle electrical generation plant emits 50 percent less carbon dioxide and 80 percent less nitrogen oxides than a conventional oil-fueled plant and 65 percent less carbon dioxide and 99 percent less nitrogen oxides than a scrubbed coal-fueled plant (Flavin, 1992); unlike coal-and oil-fired electrical plants, a natural gas plant emits no sulfur dioxide, eliminating a major cause of acid rain.

Methane is a greenhouse gas, and leakage from the natural gas production and distribution system must be taken into account in any calculation of the contributions that increased use of this resource will have on problems of atmospheric contamination. However, as the intrinsic value of natural gas to the economy increases, the new infrastructure that develops will have insignificant leakage, especially compared to the current loss of methane from the production and handling of oil and oil products and from coal mining operations. Controls for the prevention of methane leakage from oil and coal sources are meager or nonexistent because the need for such controls has been largely ignored. Methane is also added to the atmosphere from natural surface seeps, ocean vents, rice paddies, wetlands, landfills, and the stomachs of animals.

6. Technological possibilities: Historically, during the initial years of economic development of an energy source, the technology associated with it experiences exponential growth, economic efficiency is enhanced, productivity increases, and a new long wave of economic growth is unleashed. In the 1840's, exponential growth of coalrelated technologies (for example, the steam engine, the 
substitution of coke for charcoal, and coal-related innovations in the steel industry) and the resulting increase in economic efficiency and productivity became the catalyst for the Industrial Revolution. In the late 1920's, a similar period of technological innovation related to oil (for example, the rotary drill bit, advances in exploration and refining, and improvements in the internal combustion engine) fueled the economic growth that led to the developed economies we know today. Oil technology has now reached the mature phase. However, natural gas is just beginning its wave of exponential technological innovation, a result of the relatively recent recognition of its intrinsic value. As natural gas continues to increase in value to the economy and gain an increasing share of the energy market, we can expect an acceleration of technological innovation at all stages of natural gas production, from exploration to end use (for example, "nonconventional" production of natural gas, natural gas vehicles, and natural gas fuel cells). This may soon lead to a 50 percent or greater increase in overall efficiency in the exploration to consumption cycle for natural gas (Nakićenović, 1990, and this volume; Mills, this volume), an increase which, in turn, may bring extraordinary economic and environmental benefits to society. As natural gas use increases, our economy will be more able to maintain sustained growth.

7. Political aspects: In the United States, natural gas has been significantly more regulated than oil and coal. For decades, governmental policy has heavily favored oil and coal over natural gas. This government intervention has caused natural gas to be the only fuel used in smaller quantities in the United States today than in the early 1970's (see Fanelli, this volume). Primary energy substitution curves (fig. 1) for the United States clearly show how market forces drove the orderly transition of energy sources from wood to coal to oil for nearly one century. Notice, however, the diversion from this pattern beginning in the 1970's. At that time, government intervention, which favored coal, oil, and nuclear power, created artificial shortages of natural gas and disrupted the historically predictable transition to natural gas. In 1978, Congress, overreacting to the artificial shortage, legislatively prohibited the use of natural gas for new electrical generation plants, and discouraged the use of natural gas in all markets. As a result, most U.S. citizens believed that natural gas was no longer a viable fuel and

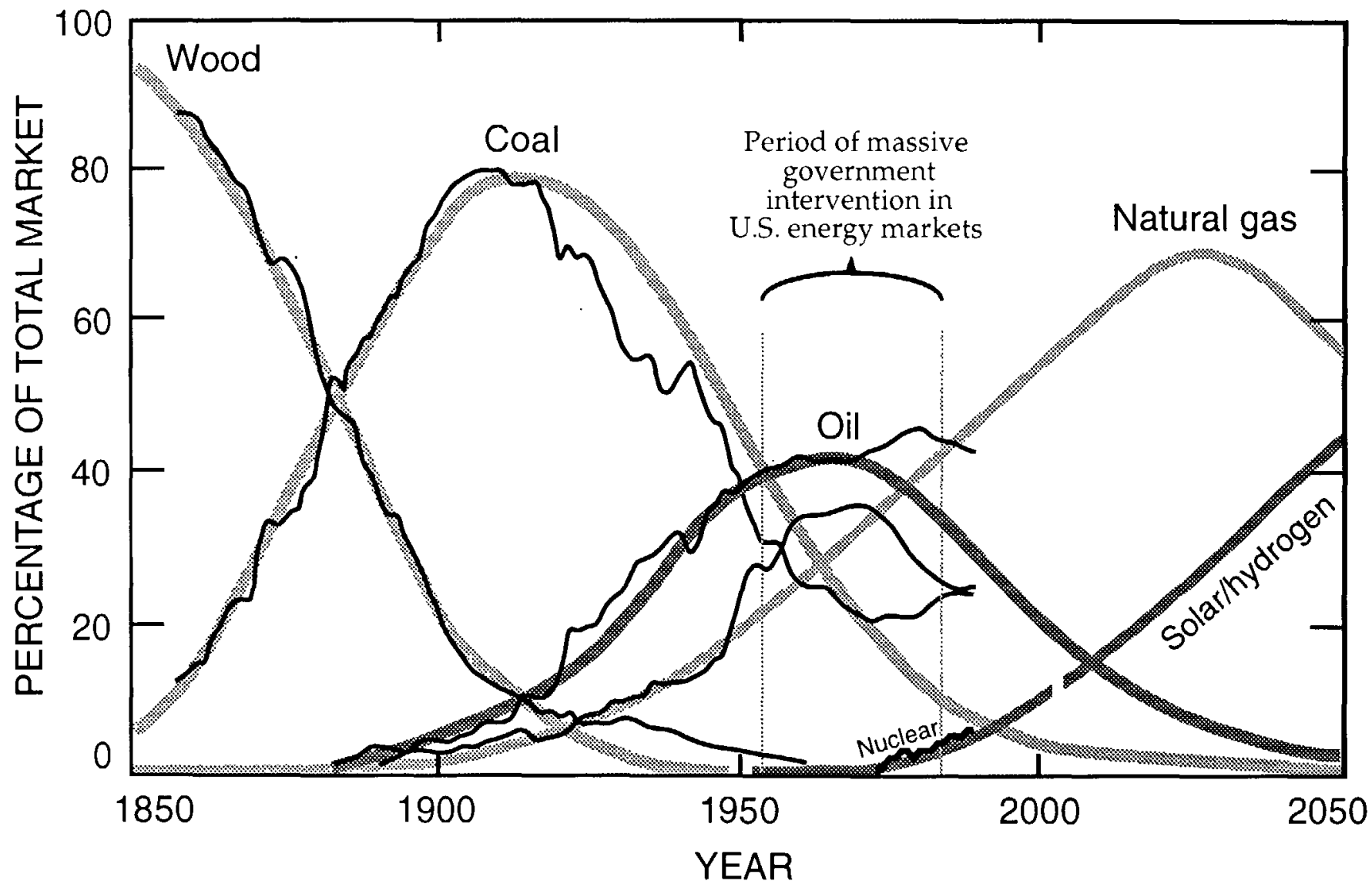

Figure 1. Primary energy sources for the United States, showing how successively cleaner, more efficient primary energy sources replace existing sources. Thin lines represent actual consumption. Thicker lines are mathematically fitted to these curves in the his- torical portion of the chart and projected into the future. The decline in consumption of natural gas since the mid 1970's represents a cumulative drop in consumption from that period of approximately 59 Tcf. From Hefner (1993). Copyright, 1992, GHK Company. 
nearly all of the increasing demand for electricity was generated from less efficient, dirtier, and costlier new coal- and nuclear-fueled power plants.

Using 1973 as a baseline, the total amount of additional electricity produced from coal and nuclear plants could have been generated by using 40 Tef of natural gas (based on figures from the Energy Statistics Sourcebook, 1992), a quantity that was readily available as shown on figure 1 by the 59 Tcf cumulative decline in natural gas consumption. The misperception of a limited natural gas resource base, resulting principally from the direct association of natural gas with oil, led to an energy policy that caused the United States to become the only developed economy in the world to reduce its use of natural gas. Between 1970 and 1989, U.S. natural gas use declined by 11 percent. During this same period, countries as diverse as England (based on figures from the International Energy Statistics Sourcebook, 1992, and Jenkins, 1977) and Bangladesh (Janet Rains, GHK Company, oral commun., 1992, from an official of the U.S. State Department) increased their natural gas usage by over 20 percent. The energy policies of the U.S. government during this time cost the U.S. economy more than a trillion dollars in unnecessary capital expenditures to generate more costly electricity and created significantly greater environmental damage than would have resulted from the use of natural gas. This wasted capital, which was used to convert less efficient coal, oil, and nuclear fuel to electricity at higher overall costs and additional external expense, lowered U.S. economic productivity and reduced our potential to increase and sustain economic growth.

\section{BLINDERS OF THE PAST}

To quote from Daniel Yergin's epic account of the oil industry: "Oil is the world's biggest and most pervasive business, the greatest of the great industries that arose in the last decades of the nineteenth century ***. The expansion of the business in the twentieth-century embodies the twentieth-century evolution of business, of corporate strategy, of technological change and market development, and indeed of both national and international economies" (Yergin, 1991). The immense influence of the oil industry on the development of our society and culture has been institutionalized in academics, policymaking, and the collective mind of the general public. Without question, until the 1970's, natural gas was a "by-product" of oil exploration, oil drilling, and oil production. Unfortunately, natural gas continues to be perceived in that context. Even today, university degrees are granted in petroleum geology, petroleum engineering, and petroleum land management. Petroleum, originally defined as "rock oil," signifies oil and only oil in the minds of most people, and we must recognize that many universities, oil companies, and natural gas com- panies even today educate and train people to be oil engineers, oil geologists, and, most unfortunately, oil thinkers. (As late as 1979 , the primary definition of petroleum in the American Geological Institute Glossary of Geology clearly stated that the word petroleum refers to liquid oil. The secondary definition, a more general one, includes all liquid and gaseous hydrocarbons.)

In the past, oil thinking has so dominated the natural gas extraction industry that it has distorted the process of natural gas exploration, production, and, particularly, past and present estimates of the remaining natural gas resource base. Until recently, most of the respected and accepted estimates of the natural gas resource base rather accurately approximated the quantity of natural gas that would be produced in association with future oil production within the economic and technological parameters that were predicted for the oil industry. Those estimates excluded most of the natural gas that will be found and produced, in very large quantities, outside the geologic, economic and technological domains of oil. Below are six quite typical examples of oil bias and misunderstandings about natural gas that have led to very real, though unintended, distortions of the U.S. natural gas resource base estimate.

1. In 1957, with a degree in petroleum geology from the University of Oklahoma, I joined Phillips Petroleum Company as a trainee, spending time in the Economic Analysis Section where each drilling proposal was closely reviewed. At the time, natural gas prices were fixed by the Government at only a fraction of the equivalent Btu value of oil. As a result, the price of natural gas was of no significance in risk analyses of drilling proposals or the calculation of future revenue and rate of return on investment. Natural gas was to be used, at best, as a "plus factor" that might pay for the overhead of operating an oil well. Throughout the 1950's and 1960's Phillips, and I presume most major oil companies, analyzed geology and forecast economics strictly by using geologic and economic factors appropriate to oil. Natural gas discovered during this period of oil exploration was found largely by chance and had little relationship to the amount of gas that might have been found if the emphasis had been on natural gas rather than oil. As a result, all econometric projections, such as the one in the example below, that used these factors to predict the future of natural gas had little bearing on the actual amount of natural gas in the ground. Rather, these models, based principally on oil-based economics and geology, estimated only the amount of natural gas that would reasonably be found and produced in the future by the U.S. oil industry during its search for oil.

2. Oil thinking has had a major impact on the econometric modeling of gas resources even by natural gas companies and associations. An estimate of future natural gas supplies and production made by the American Gas Association (AGA) in the mid-1970's provides a classic example. Having already become the principal public advocate for a 
large natural gas resource base, the "optimistic" scenario of the AGA appeared to me to be ultraconservative to pessimistic, and I became curious about the sources of information on which the study had been based. It turned out that the AGA economists had followed a highly logical approach; wanting to project the highest, reasonably possible quantities of natural gas that would be found from estimates of future drilling, they had used the highest historical natural gas finding rates per well drilled. The limitation of this study was inherent in the natural gas finding rates used, because the highest historical finding rates were achieved during the 1950's when oil companies, solely on the basis of oil economics, with no thought of natural gas as a commodity with intrinsic value, were exploring and drilling mainly in the rather shallow geologic environments where their geologists expected to find oil. Though the AGA projection was indeed more optimistic than most other forecasts for natural gas, it had little relevance to future natural gas extraction as it included no consideration of natural gas to be found not in association with oil or in domains in which natural gas is prolific and oil does not exist, such as the vast volume of rocks in overthrust belts and at depths below which oil is generally absent (see Woods, this volume).

3. The artificially created shortages of natural gas production that occurred in the early 1970's as a result of decades of unrealistic Government price controls led to an equally artificial shrinkage of the United States proven natural gas reserves by the late 1970's. This exceptionally telling example of the effect of perception upon prediction is the essential thesis of this article. Spurred on by the common misperception that the United States was rapidly running out of natural gas, John O'Leary (head of the Federal Energy Administration, February 1977 to September 1977, Deputy Secretary of Energy, Department of Energy, October 1977 to September 1979) declared and often repeated that "natural gas has had it." This perception became the official Government view, and soon most prognosticators, including the major integrated oil companies as well as many natural gas companies, were forecasting "grave" shortages and espousing their concerns. The shortage mentality was seized upon by the Nation's coal and nuclear industries, so natural gas, of course, became an "unreliable" source of energy. In 1977 , as a result of the perception of shortages, the Secretary of the Interior ordered a study of six major offshore natural gas fields in the gulf coast region to determine if they had reserves as large as were currently estimated by the field operators. Though these six fields were selected for their large size and with the expectation that they might have a high potential for increasing production, the study, conducted by the Committee on Gas Production Opportunities of the National Research Council (1978) found that all six fields had significantly less natural gas than had been originally estimated. This finding essentially confirmed the official Government position that our nation indeed had a critical shortage of natural gas and suggested that the United States natural gas resource base was both limited and scarce. Since 1977, however, these six fields have produced $4.7 \mathrm{Tcf}$, which exceeds the committee's estimate of remaining reserves by 65 percent. This 65 percent may be a reliable figure by which we should increase our current estimates of proven producing reserves in order to achieve a more realistic idea of the quantities of natural gas available from existing fields.

4. In 1984, Charles B. Wheeler, Senior Vice President, Exxon Company, U.S.A., and I were called before Congress to testify about the nation's natural gas future. Mr. Wheeler testified that, "We estimate the volume of yet undiscovered natural gas from conventional sources in the United States to be about $300 \mathrm{Tcf} * * *$. This is very close to our last published assessment of the volume of resources in 1976." Based upon this limited and pessimistic view of our natural gas supplies, he went on to predict that, "Future demand for [natural] gas will exceed the supply available from the domestic resource base. Requirements for natural gas will significantly outstrip domestic supply capability by the late 1980's." He concluded with Exxon's dim view of the natural gas future of the United States saying, "We project a shortfall of economically available gas from any source." Unfortunately, this overly negative view, coming from the nation's largest oil company, had a detrimental effect upon other industry and government estimates of America's natural gas future. (Quotes from testimony before the Committee on Energy Regulation, Subcommittee of the full Committee of Energy and Natural Resources, April 26, 1984, Washington, D.C.)

At these hearings, I made the point that Exxon's estimates, and all the other comparably small estimates, were founded upon oil thinking and that a more realistic estimate, based on a great deal of experience in natural gas exploration and production, would be the natural gas resource base estimate I originally presented in 1978 at the Aspen Institute (Hefner, 1978; fig. 2) of from 1,000 to 1,500 Tef, three to five times Exxon's figures. At the time, Exxon, other oil companies, and policymakers gave little weight to estimates made by a small independent natural gas producer. However, as in the example above, time has been on the side of a new understanding of natural gas-the National Petroleum Council, an advisory committee to the Secretary of Energy composed mainly of representatives from the oil industry, has recently estimated the natural gas resource base to be 1,295 Tcf (National Petroleum Council, 1992). This is a significant step forward for an organization dominated by oil, and an affirmation of the validity of my estimates, made 15 years ago, based on natural gas experience and thinking outside the confines of conventional oil-based wisdom--the type of thinking I hope to stimulate with this chapter and on which we need to base our energy future.

Contrary to Exxon's projections, during the entire decade of the 1980's natural gas supplies have so outstripped demand that the average wellhead price, instead of contin- 
ually rising as Exxon and most others predicted as a result of their pessimistic estimates of the resource base, actually declined from an average of over $\$ 3.50$ per thousand cubic feet (Mcf) in constant dollars in 1984 to a spot price of less than \$1.00 per Mcf in February 1992.

5. The influence of oil thinking on estimates of the future of natural gas continues today. An excellent current example of this influence is from the Ouachita overthrust belt in western Arkansas and southeastern Oklahoma. The northern limit of the Ouachita overthrust belt is defined by the location, at the surface, of the large regional Choctaw fault. Conventional oil wisdom has always suggested that significant amounts of oil, and natural gas, should not be present south of the Choctaw fault because the sediments had been subjected to temperatures and pressures that would destroy any oil and reservoir pore space that had originally been present. As a result of this belief, prior to 1988, few exploratory wells had been drilled within the Ouachita overthrust province. However, beginning in 1988, a number of large new natural gas discoveries, including several wells that rank among the world's largest, were made south of the Choctaw fault, at progressively deeper levels. These wells include the Zipperer, with initial flows of 40 million cubic feet per day (MMcfd) and Estimated Ultimate Reserves (EUR) of 35 billion cubic feet (Bcf), the Baumann, with initial flows of $60 \mathrm{MMcfd}$ and EUR of over $40 \mathrm{Bcf}$, and the recent Windingstair, with initial flows of 50 MMcfd and EUR of 50 Bcf. Some 125 wells have now been drilled, discovering approximately $1 \mathrm{Tcf}$ of new gas reserves in an area once thought to be virtually barren. The average ultimate production of each of these new wells will be well over the equivalent of 1 million barrels of oil (MMbo). The natural gas industry is currently drilling 12 deep wells (below 15,000 ft) to further test the large potential of this fold and thrust belt. Already, several completed deep wells have paid back their complete investment in one year or less and have established new reserves at a cost of about $\$ 0.25$ per Mcf. Unfortunately, as of the date of this

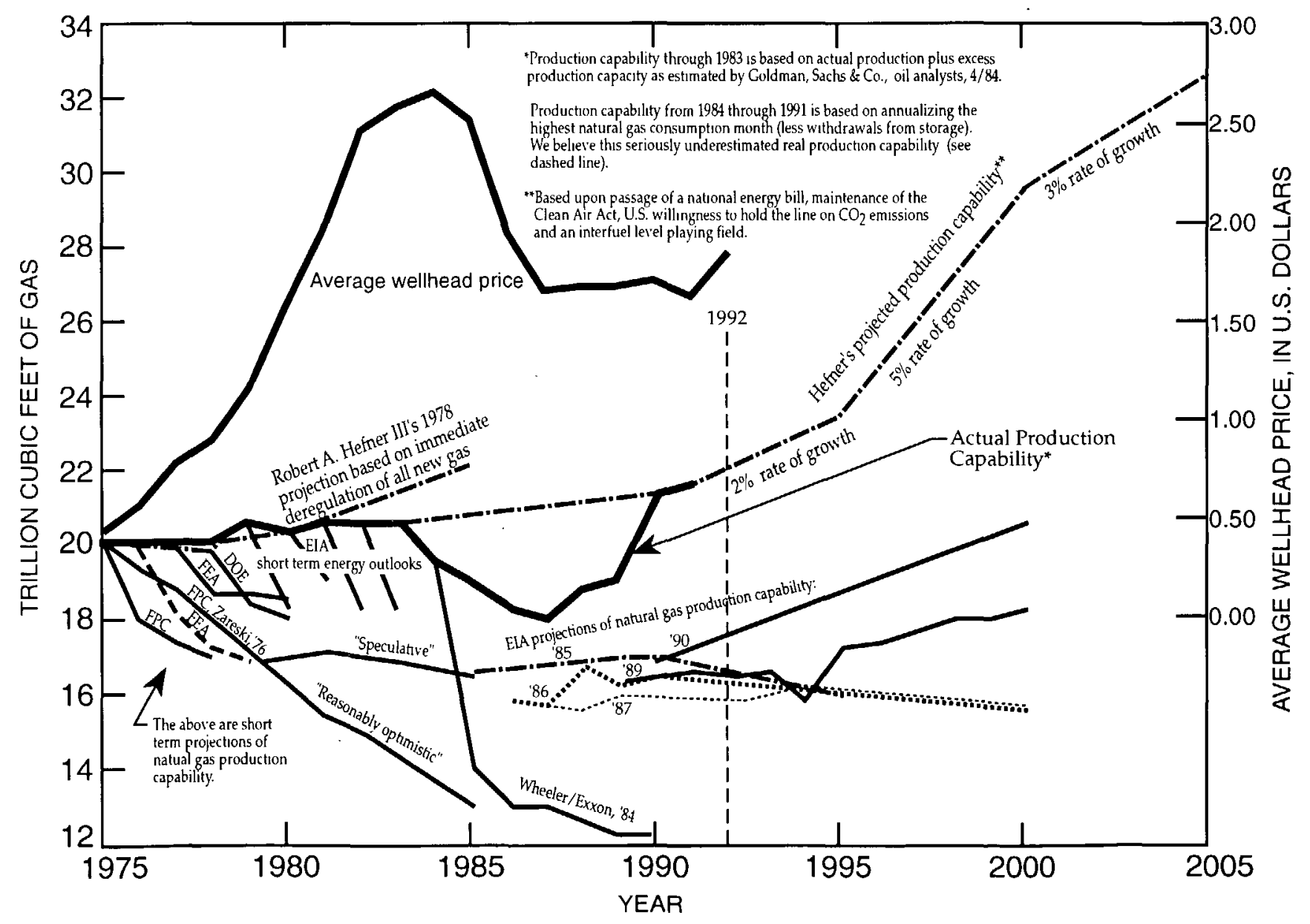

Figure 2. Natural gas projected production versus actual production capacity for the United States. Hefner projections are based in part on a natural gas resource base originally estimated in 1978 at 1,000 to 1,500 Tcf. Lines descending from "actual pro- duction capability" curve are projections of production by various organizations since 1975. The inaccuracy of these projections is easily seen. From Hefner (1992). Copyright, 1992, GHK Company. 
paper, the large potential of this geological province, which I predict to be in the range of 30 to $50 \mathrm{Tcf}$, is not yet included in official estimates of the United States natural gas resource base. In spite of the fact that the province now contains its first new giant field, which I call the South Choctaw field, the official estimate remains at only $5 \mathrm{Tcf}$, in part because of the lag time in official estimating and reporting and in part owing to the natural hesitancy of experts to predict the potential for new and large discoveries of natural gas in areas where many people, including myself, were originally taught no oil or gas could occur.

6. Oil is a viscous, noncompressible fluid that could not be economically produced from many excellent natural gas reservoirs even if it were present. Methane is a highly compressible gas with negligible viscosity; this condition leads to significant differences between the production of oil and the production of natural gas. One highly important factor not well understood by economists and policy- makers is the difference between the recovery of usable energy (Btu's) from oil reservoirs and the recovery of usable energy from natural gas reservoirs at increasing depths below the surface. Below $8,000 \mathrm{ft}$ a natural gas reservoir will nearly always produce more usable Btu's than an oil reservoir and at $15,000 \mathrm{ft}$ over 1.5 times the usable Btu's could be recovered from a natural gas reservoir (fig. 3). A barrel of oil at $20,000 \mathrm{ft}$, for example, equals a barrel of oil at the surface, but a barrel volume of natural gas at 20,000 $\mathrm{ft}$ in an overpressured basin such as the deep Anadarko Basin, Texas and Oklahoma, equals as many as 500 barrels of natural gas at the surface. The compressibility (defined by Boyle's law and called the " $Z$ factor" in estimates of natural gas reserves) and negligible viscosity of natural gas are generally taken into account in economic analysis, drilling, and production practices; however, decades of experience focussed on noncompressible oil and only slightly compressed ("normally pressured") natu-

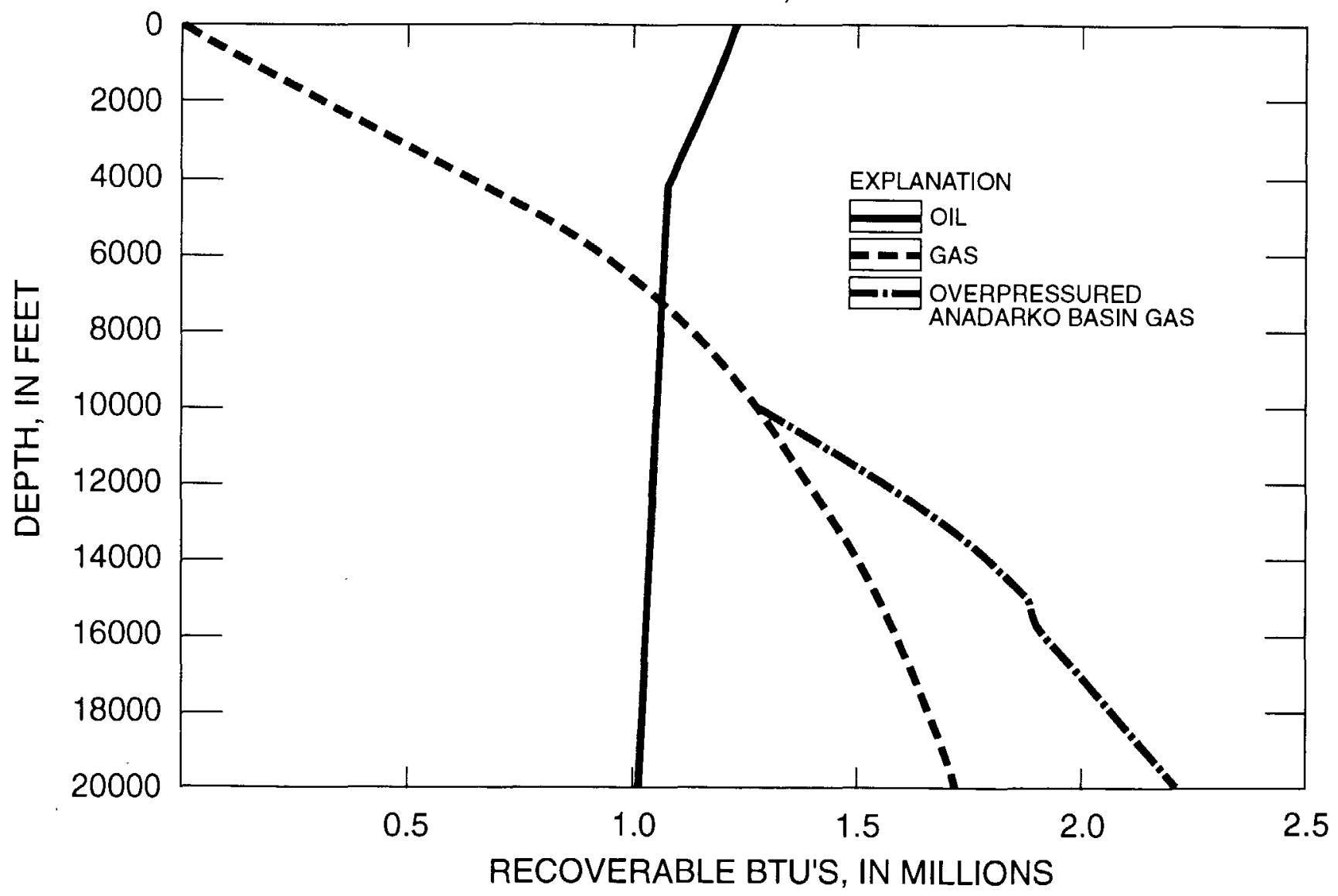

Figure 3. Recoverable Btu's per 1 barrel volume of natural gas versus oil from reservoirs of increasing depths. The following assumptions were used to determine Btu recoveries: 1 bbl of oil=5.616 $\mathrm{ft}^{3}$; oil gravity $=28$ degrees API; gas/oil ratio $=300$; gas gravity $=0.6 ; 20$ percent oil recovery; 80 percent gas recovery at low pressure increasing linearly to 90 percent recovery at 20,000 feet; temperature gradient $=1^{\circ} \mathrm{F} / 100 \mathrm{ft}$; surface temperature $=70^{\circ} \mathrm{F}$; pressure gradient $=0.45 \mathrm{psi} / \mathrm{ft} ; 1,000 \mathrm{Btu}$ gas. Oil: A temperature shrinkage factor was applied; therefore a barrel of oil from depth contains slightly fewer Btu's than a barrel at the surface. Gas: A formation volume factor $(\mathrm{Bg})$ was used to determine total at-the-surface volumes. Overpressured Anadarko Basin gas: The normal pressure gradient of $0.45 \mathrm{psi} /$ $\mathrm{ft}$ was used for depths less than $11,000 \mathrm{ft}$; below $11,000 \mathrm{ft}$, the pressure gradient was increased linearly to $0.9 \mathrm{psi} / \mathrm{ft}$ at $20,000 \mathrm{ft}$. 
ral gas has led frequently to oversight of the effects of compression and flow characteristics unique to natural gas on both the drilling for deep natural gas and the ultimate volume of natural gas production. The following examples illustrate my point:

Oil-dominated thinking, for example, has caused most of the "blowouts" I am aware of in my career and has added much, largely unnecessary risk, time, and expense to drilling in high pressure natural gas regions. I have been made aware many times (and even recently) that drilling engineers with decades of oil drilling experience overlook the fact that an inflow of natural gas from a high-pressure reservoir at depth, hardly noticeable in pit volume at the surface, undergoes an enormous rate of expansion as it approaches the surface. In the Anadarko Basin example above, 50 percent of the expansion would take place in the last $1,000 \mathrm{ft}$, a rate which would easily cause a blowout if it was overlooked and unsuspected.

The misunderstanding of deep high-pressure natural gas reservoirs on the part of reservoir engineers was poignantly illustrated one day in 1982 when I presented a core from a depth of 18,000 ft in the deep Anadarko Basin to the senior engineer of one of the world's largest banks specializing in petroleum financing. Thinking that it was the finest looking example of a clastic reservoir rock that I had ever seen from the deep Anadarko Basin, I was shocked when he took one look at the core and pushed it away with the curt comment, "that rock will never produce any oil!" It didn't, but the well was completed for 35 million cubic feet (MMcf) of natural gas per day and has produced over $20 \mathrm{Bcf}$ of natural gas; it will eventually produce the energy equivalent of $6 \mathrm{MMbo}$.

Reservoir engineers maintain that the unique characteristics of a gas, including compressibility, have been taken into full account in estimates of deep high-pressure, natural gas reserves and therefore that their estimation of ultimate reserves should be viewed generally with a high level of confidence. However, my experience suggests that we do not fully understand what is happening in high-pressure reservoirs, particularly the mechanisms of movement of high-pressure natural gas through the various types of connected pore space found at depths greater than $15,000 \mathrm{ft}$. We must remember that petroleum reservoir engineering is founded on the work of Henri-Philibert-Gaspard Darcy (1803-1858), a French engineer who in his study of the sewers of Paris measured the flow of various liquids through sand packs. Darcy's early simple equations, still in use today with little modification, were suitable to normally pressured liquid oil moving through sand, the most prevalent oil reservoir. I believe, however, that Darcy's equations are significantly lacking in their ability to describe and predict the movement of natural gas through the broad variety of natural gas reservoirs that exist. We simply do not yet understand the dynamics and rates of flux of natural gas moving through the complexity of microfractures, micro and macro vugs, primary and secondary porosity, natural macrofractures, and induced and propped fractures that occur in deep high-pressure natural gas reservoirs. As a result, procedures used to estimate natural gas reserves in shallow low-pressure reservoirs do not give an accurate picture of the quantity of natural gas resources available at depth. Engineering technology and techniques for the estimation of deep highpressure natural gas reserves did not keep pace with the industry's ability to produce natural gas from these complex reservoirs particularly during the drilling and production boom of the late 1970's and early 1980's (Jack Krug, oral commun., 1993). I am confident that this is one cause of the general underestimation of proven reserves in the deeper higher-pressure domains. The production decline curves shown in figure 4, typical of the U.S. midcontinent region, graphically demonstrate this point.

\section{THE NATURAL GAS RESOURCE BASE OF THE UNITED STATES}

A number of circumstances have arisen recently that have caused many estimates of the natural gas resource base to be revised upward. These reassessments have been forced by a variety of factors, including (1) new prolific discoveries in places long ago written off by oil explorationists, (2) new views of existing natural gas reserves, (3) a growing awareness of the differences between oil and natural gas, (4) a wave of recent exploration and production technology enhancement specifically related to natural gas, and (5) the recent recognition that the overall decline in production of many natural gas reservoirs turns out to be more gradual than initial estimates suggested (fig. 4).

The three most prominent groups of estimators are the Potential Gas Committee (PGC), the U.S. Department of Energy (DOE), and the U.S. Geological Survey (USGS). Recent estimates by the DOE (U.S. Department of Energy, 1990) and PGC (1990) are 1,370 and 1,033 Tef (with proved reserves added) respectively. Though it is sometimes difficult to compare estimates because they are based on different definitions and categories of resources, the DOE and PGC estimates suggest a sufficient supply of natural gas to meet significantly increased demand for 30 to 40 years. The most recent USGS study (Mast and others, 1989), based on data available as of January 1987 and considering conventional resources only, estimates supplies of natural gas at $399 \mathrm{Tcf}$, a number comparable with the oilthinking estimates of the past.

In 1991, Enron Corporation, the United States leading integrated natural gas company, revised upward its estimate of the remaining economically recoverable resource base from $805 \mathrm{Tcf}$ in 1989 to approximately 1,200 Tcf in 1991 and increased it again to 1,303 Tcf as of January 1993. In 1991, Enron stated that, "A major reason for our optimism, $* * *$ is the development and rapid diffusion of 
technology $* * *$ These developments portend both an increase in the economic viability of new resources $* * *$ and an upsurge in the yields from traditional producing regions" (Enron Corporation, 1991). In 1993, Enron noted the close similarity of its 1993 estimate with the National Petroleum Council (NPC) estimate of 1,295 Tcf as of January 1991 and agreed with the NPC statement that, "Natural gas is an abundant domestic resource and can be produced and delivered at prices that allow both expansion of the market and continued development of the resource" (cover letter accompanying Enron Corporation, 1993). In addition to these estimates, the Gas Research Institute (GRI) has recently released a figure of 1585 Tcf (Fisher, 1993).

Though these new estimates are a significant step toward a more realistic assessment of our real recoverable natural gas resources, I believe they are still overly conservative. My position is based on new information and my experience in natural gas exploration and production, particularly in the Anadarko Basin, where the history of development suggests that natural gas reserves are significantly

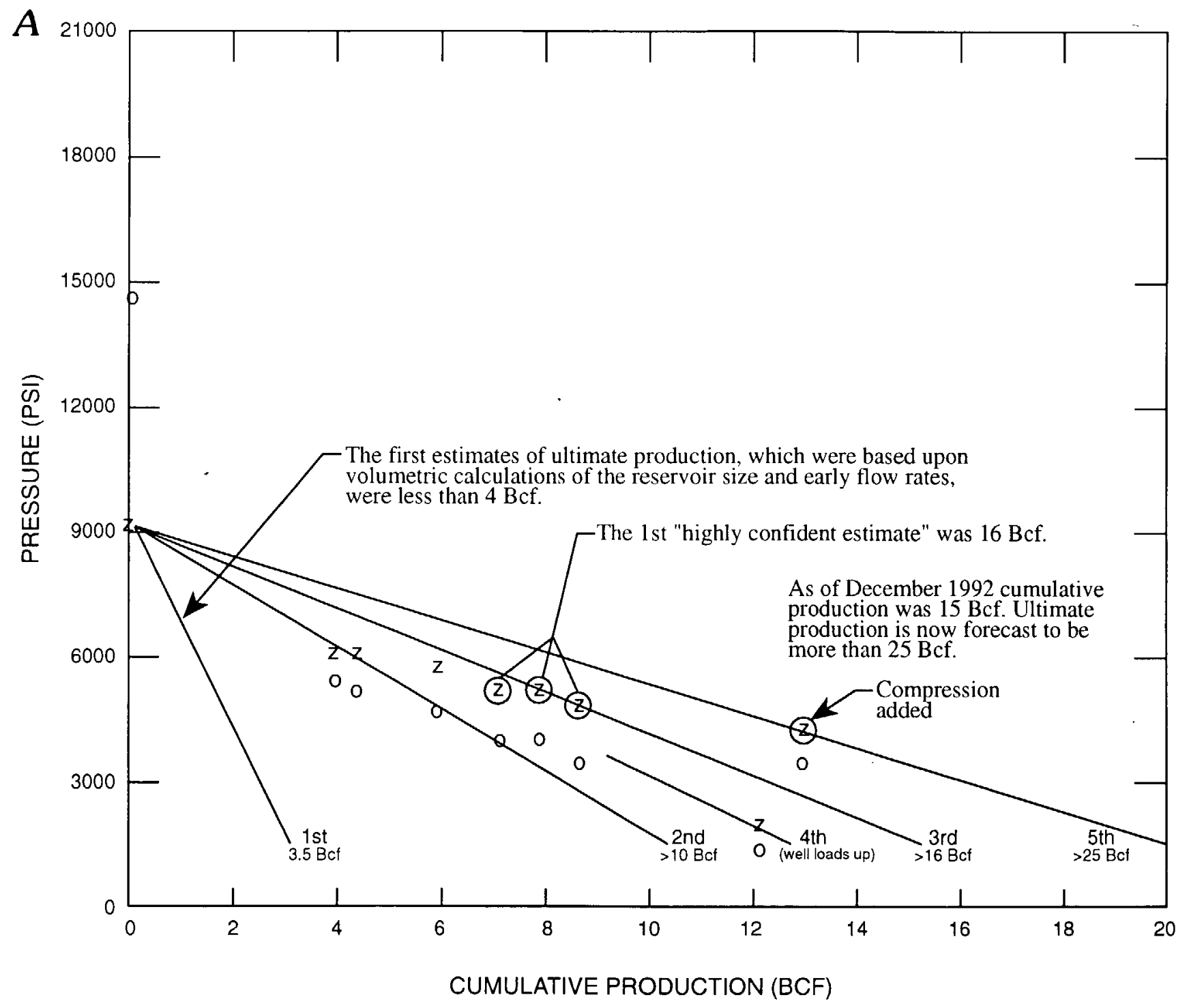

Figure 4. Production decline curves for 3 natural gas wells. These examples show how ultimate reserve estimates grow with production. This results from a variety of factors including application of new technology, lack of understanding of fluid flow and drainage, particularly in deep natural gas reservoirs, and reluctance on the part of engineers to increase initial low estimates until forced to by increased production. $\mathrm{O}=24$ hour shut in state test; $\mathrm{Z}=$ calculated bottom hole pressure; $\mathrm{MMcfd}=$ millions of cubic feet of natural gas per day; Bcf=billions of cubic feet. $A$, GHK Company No.1 Green well, completed 1969 at 21,600 ft. Carbonate reservoir, open flow test $24.3 \mathrm{MMcfd}$, initial flow rate $19 \mathrm{MMcfd}$ at 7,010 psi flowing tubing pressure. $B$, Phillips Petroleum Company Bowers B well. Fractured carbonate reservoir, completed at 19,700 ft. $C$, Amoco Gallagher well. Sandstone reservoir, 8,000 ft, open flow test $30.6 \mathrm{MMcfd}$, initial flow rate 43.7 MMcfd. 
larger than most of us imagine, much less calculate. The history of the Anadarko Basin indicates that the distinction between conventional and unconventional sources of natural gas is largely one of perception, controlled by a combination of the state of our technology, our estimates of future prices, our familiarity with a particular source, and politics. The Anadarko Basin also provides a striking example of the fundamental differences in the occurrence of oil and natural gas that continue to affect estimation resource methodology.

\section{THE ANADARKO BASIN}

In the early 1960's, the GHK Company decided to explore for non-oil-associated natural gas in the Anadarko
Basin, recognizing that this would require searching at depths well below known oil reservoirs. At that time, the oil industry utilized models that indicated deep drilling would be totally unproductive-accepted geochemical models showed that all hydrocarbons would be burned off by high temperatures, and shallow drilling experience combined with theoretical models indicated that porosity would decrease with depth and disappear entirely at about $20,000 \mathrm{ft}$, collapsed by overburden pressure (fig. 5). Even if porosity and hydrocarbons were preserved at these depths, in 1960 few believed that the technology for drilling and production of such deep wells existed.

Nevertheless, in a series of deep wells drilled in the Anadarko Basin in the late 1960's and early 1970's by the GHK Company and others, it was shown that both porosity and natural gas do exist even at depths of over $30,000 \mathrm{ft}$

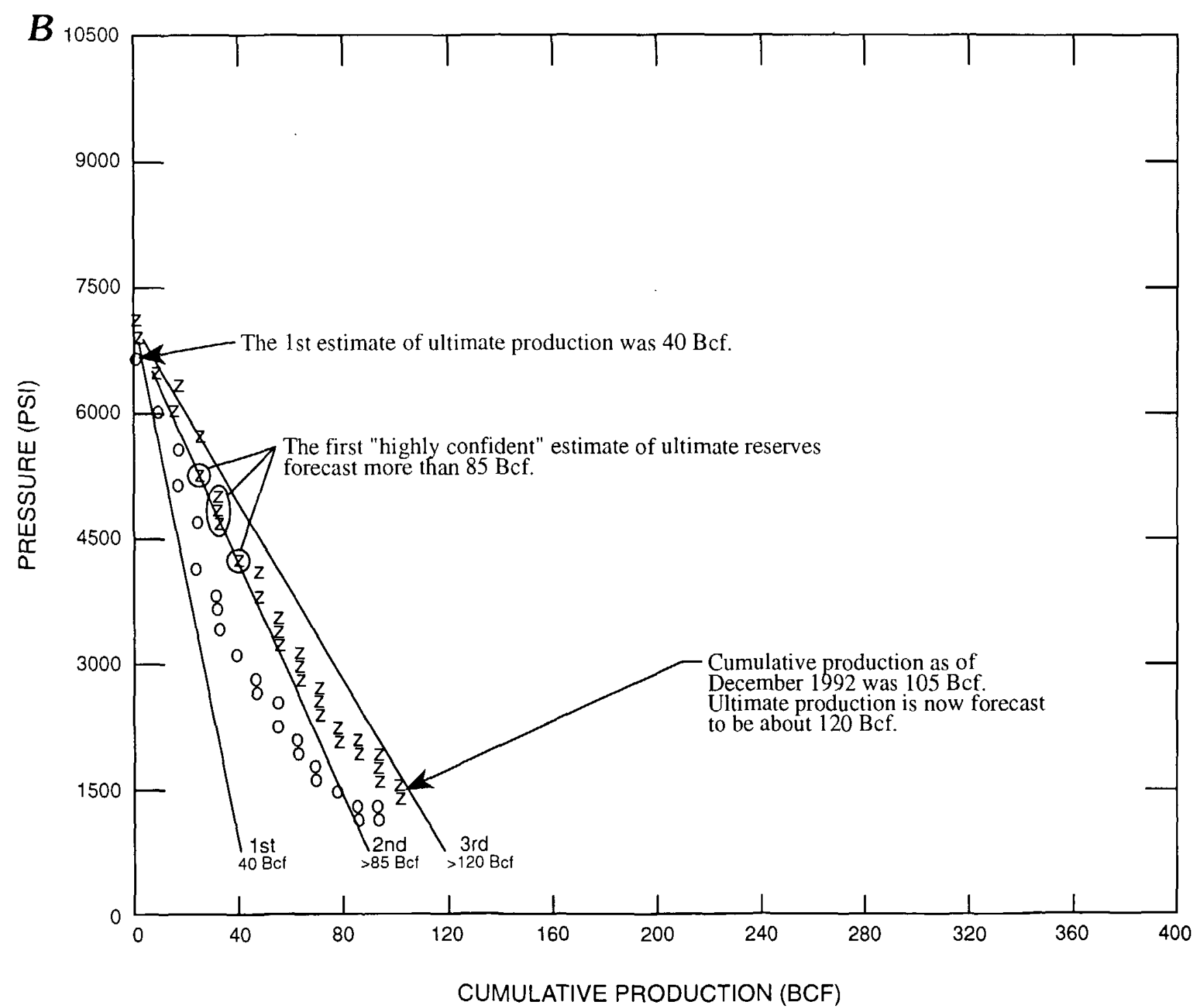

Figure 4. Continued. 
(Hefner, 1980). The GHK Company found that conventional thinking no longer applied below a zone 1 call the transition zone, usually encountered near $15,000 \mathrm{ft}$ and characterized by rocks that have been strongly affected by pressure solution, recementation, and fracturing. Below this zone, pressures jumped beyond their normal gradient and porosity actually increased (Hefner, 1980). In 1969, GHK's historic No.1 Green discovery in Beckham County, Oklahoma, was the first well to prove the misconception of porosity disappearing with depth. The No.1 Green was spud in October, 1967 and completed in the spring of 1969 after being drilled to a total depth of $24,473 \mathrm{ft}$, at that time the second deepest well bore ever drilled into the Earth. In this well, porosity of up to 18 percent was measured at a depth of $21,600 \mathrm{ft}$ in a reservoir containing a surface shutin pressure of $15,130 \mathrm{lb} / \mathrm{in}^{2}$ (fig. 6), which at the time was the highest pressure ever measured in the world. The well produced at a rate of over $19 \mathrm{MMcf}$ of gas per day and on an annual basis was capable of producing an amount of energy equivalent to one-third of the energy produced by a nuclear plant. It soon became evident that below the transition zone, a rapid shift generally occurred in the pressure gradient from the normal 0.465 pounds per foot of depth to near 0.60 pounds per foot of depth, a shift which continued to increase to gradients as high as 1.0 pounds per foot of depth at a depth of $31,441 \mathrm{ft}$ in the Lone Star-GHK Rogers well, Washita County, Oklahoma. The transition zone proved to be a pressure barrier below which porosity is enhanced and held open by high-pressure natural gas. At first, my colleagues in other companies thought the high porosity of the No.1 Green well would only be found in carbonate reservoirs, owing to greater rock strength as

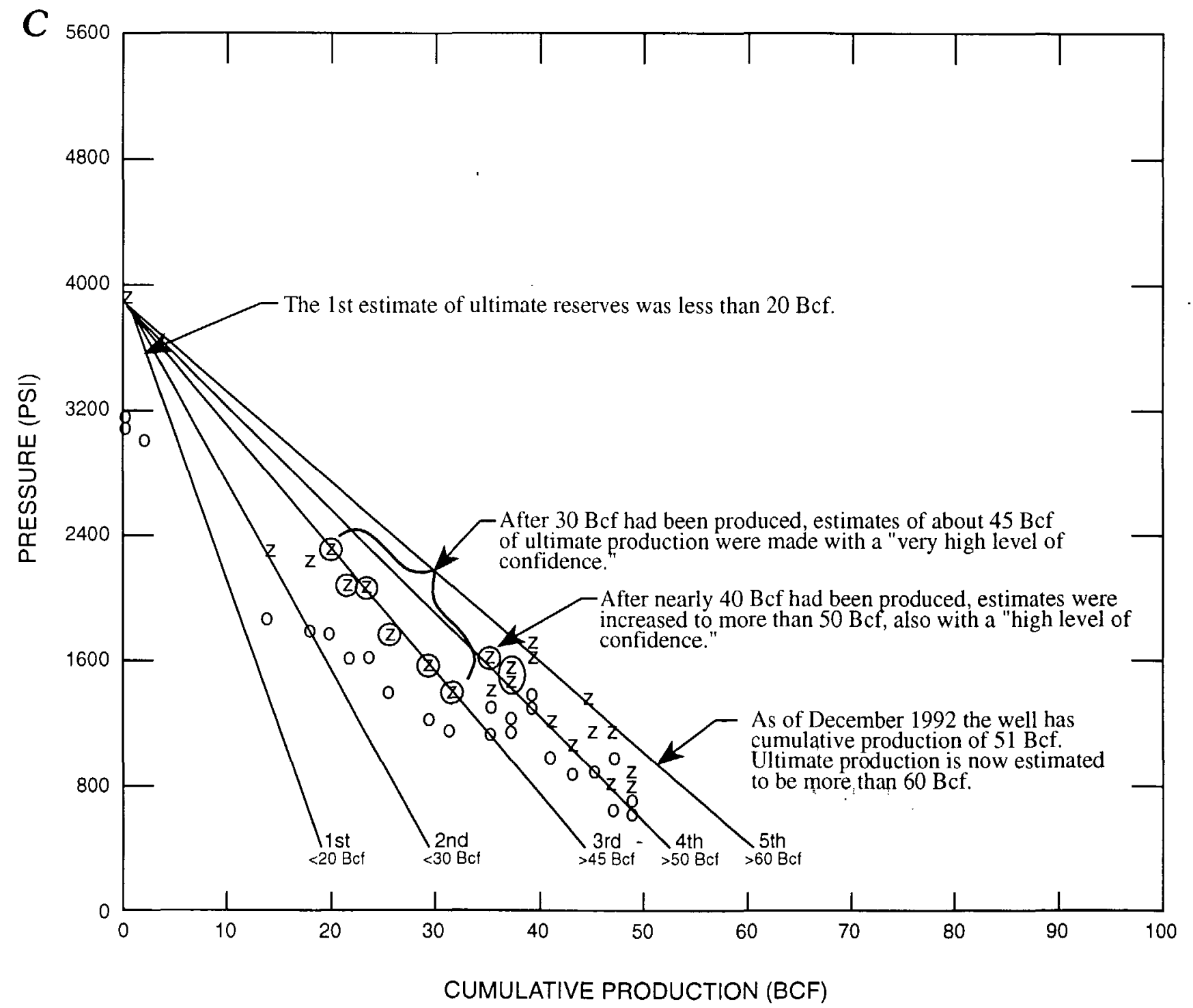

Figure 4. Continued. 


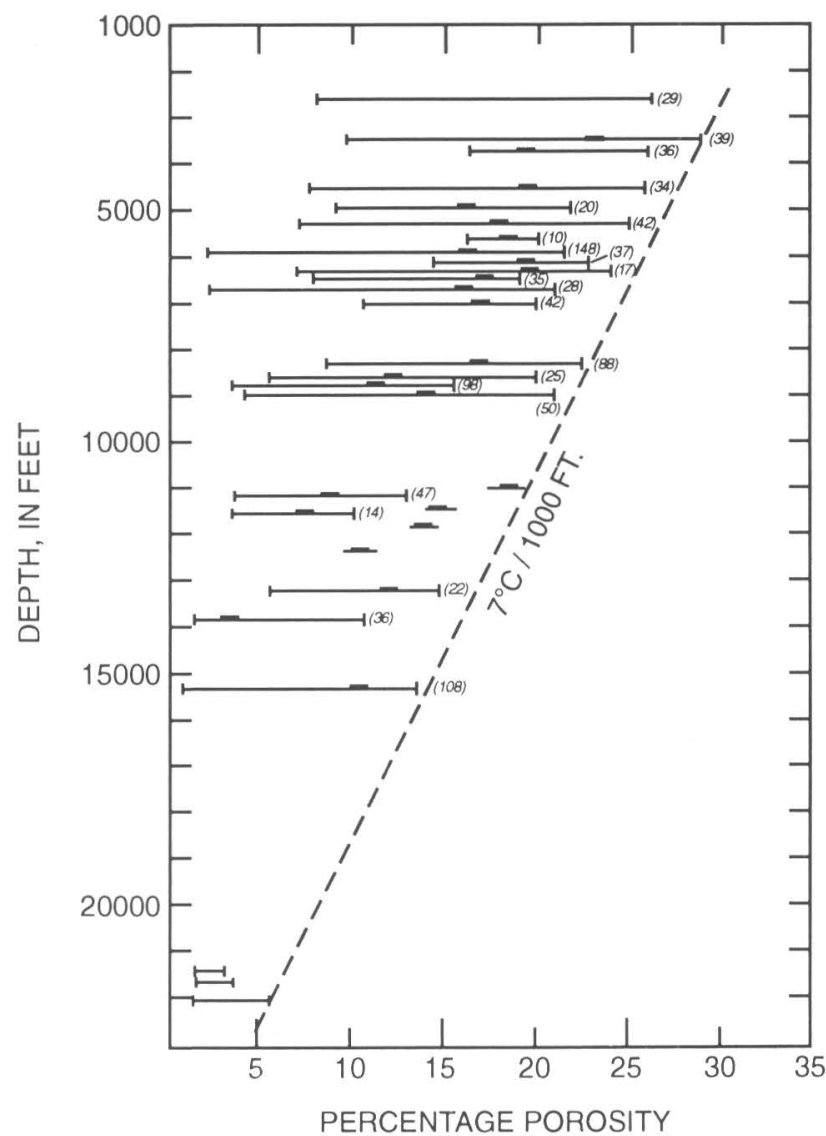

Figure 5. Porosity data from Pennsylvanian and Permian sandstones in north Texas and Oklahoma, reflecting the pre-1970 view that porosity would decrease with depth, disappearing at about 20,000 ft. Porosities below 20,000 ft on this diagram were calculated from sonic and neutron logs. Horizontal bars represent measured porosity variation in the pay sands sampled, with small rectangles indicating average porosity for the unit. The temperature gradient is noted along the line limiting maximum porosity. From Maxwell (1964).

compared to sandstone reservoirs. By 1982 , however, approximately 380 wells had been drilled to below $15,000 \mathrm{ft}$ in the Anadarko Basin, and porosity in sandstone reservoirs had been found to range frequently from 15 to 20 percent; a large number of these reservoirs were capable of production rates similar to the No.1 Green well.

As large quantities of natural gas were extracted from these deep, prolific reservoirs and the pressure lowered in the vicinity of wellbores, reservoir rocks would indeed collapse, requiring artificial fracturing for continued high rates of production. Below the transition zone, traditional fracturing with silica sand or glass beads proved detrimental to production because crushing of both these materials at the extreme overburden pressures actually reduced permeability and flow rates, thus limiting the quantity of commercially recoverable reserves. However, at this time, Exxon had

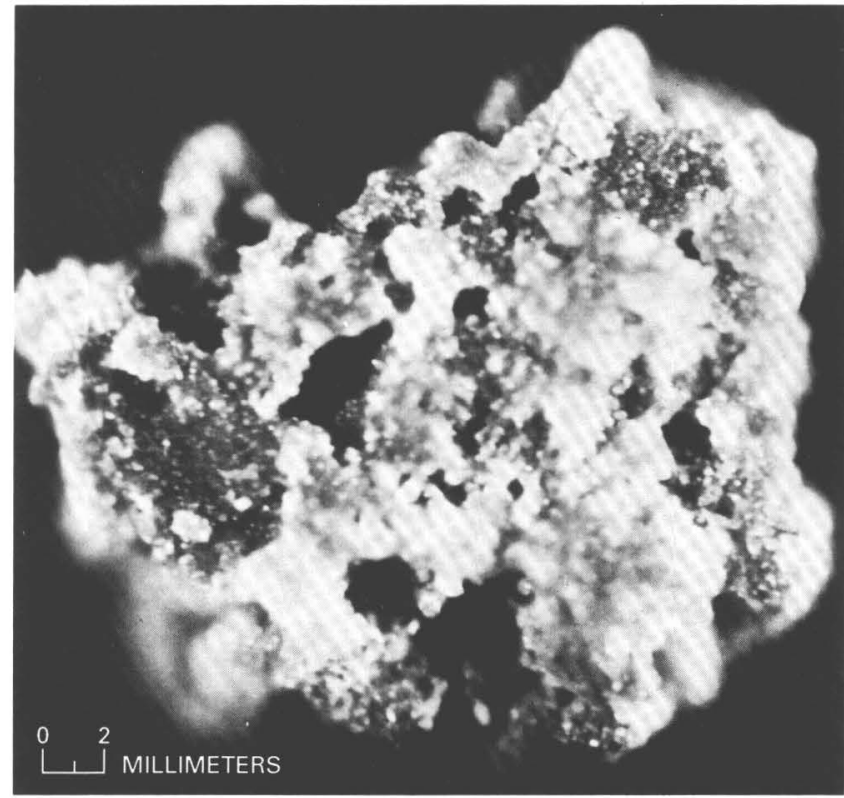

Figure 6. Enlarged photograph of rock sample from a producing reservoir from GHK Company No.1 Green well, Beckham County, Oklahoma. Producing zone 21,570-21,590 ft: gray, tan, and brown fine crystalline dolomitic limestone with weathered vugular to honeycomb porosity. $21,590-21,605 \mathrm{ft}$ : tan fine to medium crystalline dolomitic limestone with intergranular and pinpoint porosity, also vugular porosity. Many vugs have secondary crystal growths in cavities.

developed sintered bauxite as a proppant with two to three times the compressive strength of silica beads, and four to five times that of sand. Once the problem of the extremely abrasive nature of the material was overcome, sintered bauxite fracturing proved to be a highly effective treatment and is a prime example of how new natural gas-related technology increases the availability and quantity of natural gas resources. The flow rates and commercially recoverable ultimate reserves were usually increased several fold and sometimes by nearly an order of magnitude (fig. 7). This breakthrough in fracture treatment proved to be as important to deep high-pressure natural gas production as the introduction of hydraulic fracturing was to oil in the 1950's.

Deep gas is no longer an unconventional source in my view, after drilling several hundred wells to depths of 4 to 5 miles, with reservoir pressures ranging beyond 20,000 psi, at least within the context of current technological understanding and ability. Perhaps the only remaining truly unconventional source of natural gas lies in the methane hydrates of the ocean and polar regions. Because we have seen how perceptions significantly influence resource estimates, changes in the perception of what is technologically feasible within the limits of foreseeable economics will almost certainly lead to continued increases in most estimates of the natural gas resource base. 

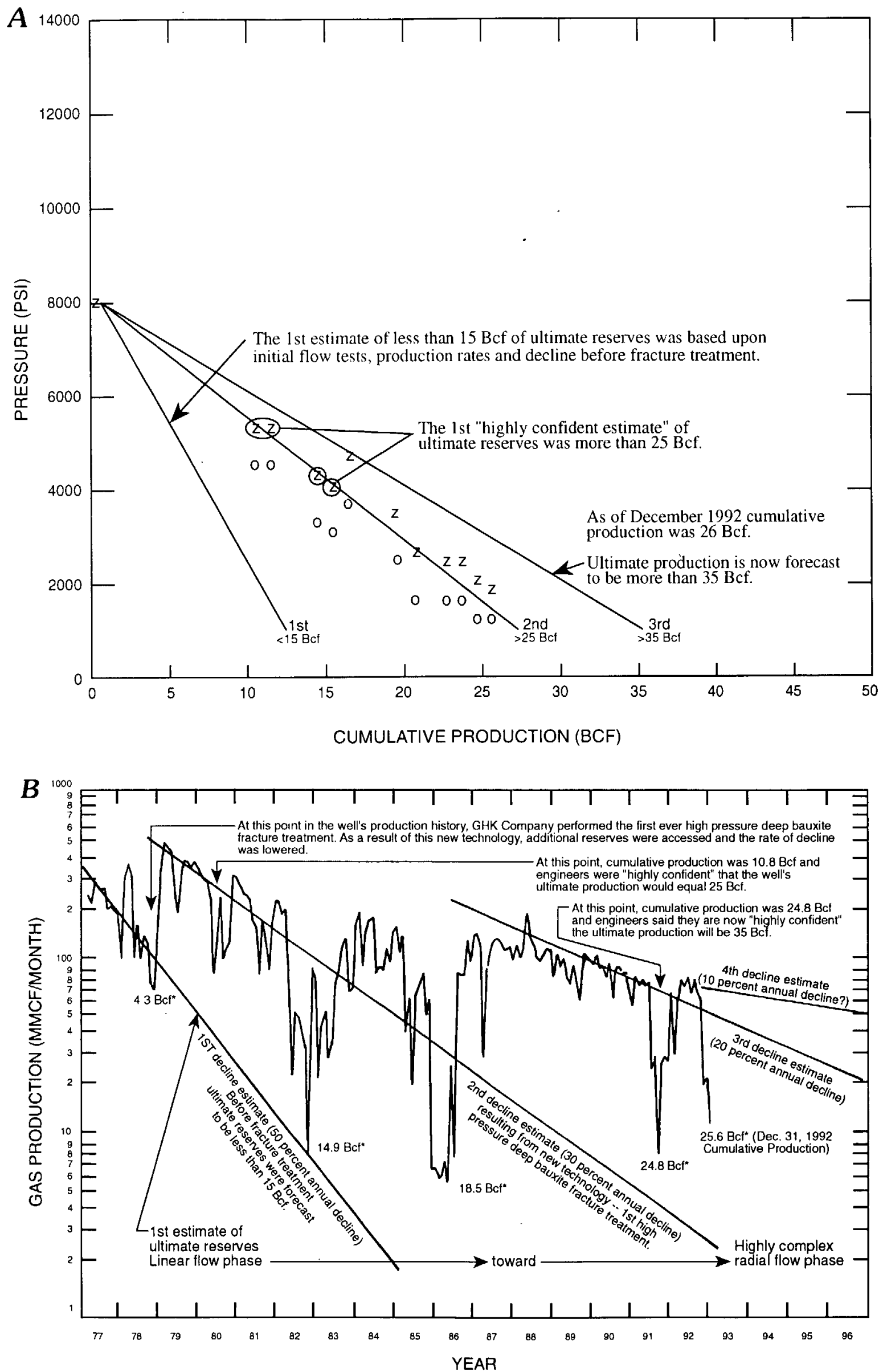
Perhaps a more immediate and striking example of the limitations on our view of natural gas resources is provided by the history of development of the Anadarko Basin and what this reveals about the nature of the occurrence of oil and natural gas. Historically, oil developers followed trends along which unique but similar oil pools would be found. One technique of estimating future oil reserves that arose from this process involves the analysis of a basin by

Figure 7. Production decline curves for GHK Company No.1-8 Berry well. Fractured sand reservoir, 15,200 ft completed 1976, open flow test $32 \mathrm{MMcfd}$, initial flow rate $10.9 \mathrm{MMcfd}$; $\mathrm{O}=24$ hour shut in state test; $\mathrm{Z}=$ calculated bottom hole pressure; $\mathrm{Bcf}=$ billions of cubic $\mathrm{ft}$. $A$, Demonstrates the growth of reserve estimates through time. $B$, Compares projected straight line estimated production decline curves with actual production history. In addition to application of stimulation techniques and the inherent conservatism of resource estimates, the difference between estimated production and actual production may result from inadequate understanding of reservoir behavior. Jagged line shows gas production; straight lines show decline estimates. (*) Total cumulative production to date. "trends" and "plays" that could be forecast reasonably on the basis of the location, character, size, and production history of existing oil fields. In the past, this analysis has worked well in U.S. oil basins, most of which contain many small- to medium-sized oil pools.

In 1965, during the early development of the Anadarko Basin, it looked very much like an oil basin, with scattered, small oil and gas pools separated by areas of no production (fig. 8). However, as time passed and more wells were drilled to increasing depths, producing areas began to change to gas fields, and the gas fields began to merge, creating a pattern indicating that the Anadarko Basin, at depths generally below the main level of oil production, is actually one gigantic natural gas field (fig. 9), approaching the size, by volume of resource, of the large gas fields of Siberia. Production in the Anadarko Basin is from multiple horizons, beginning in Permian rocks near the surface and extending to the world's deepest natural gas production at 26,566 ft from the Arbuckle Group of Late Cambrian and Ordovician age. The deepest production in the Anadarko Basin and the world is Chevron's No.1 Ruth Ledbetter, completed in 1977. Drilled in Wheeler County, Texas, the No.1 Ledbetter flows from Arbuckle production (Ellenburger Group in Texas) from perforations as deep as $26,566 \mathrm{ft}$

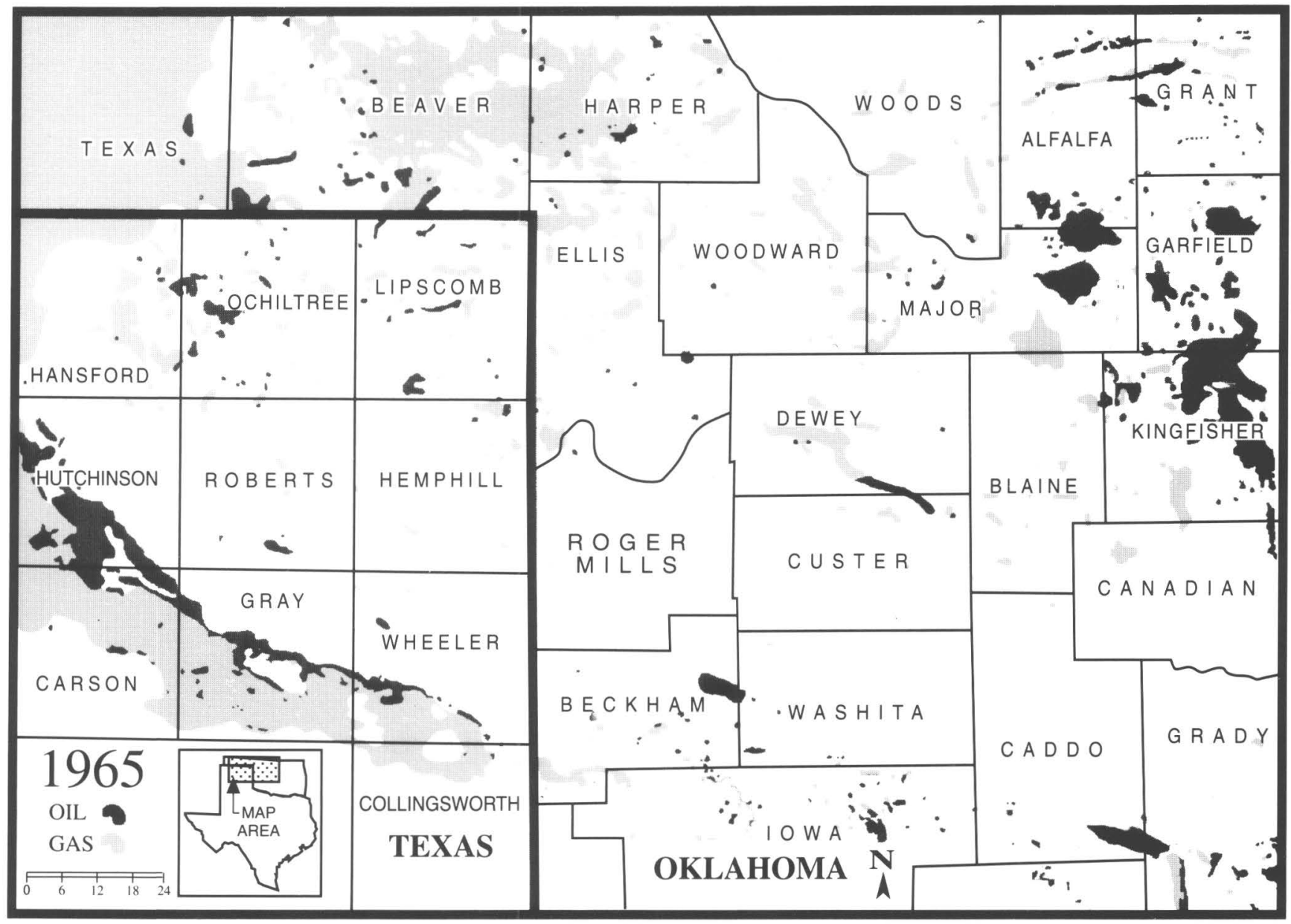

Figure 8. Map of oil and gas fields in the Anadarko Basin, western Oklahoma and Texas Panhandle, 1965. 
(Petroleum Information Corporation, 1982; Alan Petzet, Oil and Gas Journal, oral commun., 1993; and Dwight's Database). I think a similar pattern of natural gas distribution will appear in other areas-as deeper wells are drilled, we will begin to see that natural gas accumulations, below the zones that are predominantly oil, are essentially continuous over very large areas.

Given this type of pervasive distribution, the old but often used practice of estimating potential natural gas reserves using the oil technique of "play" and "trend" analysis based on fields and individual structures only limits our ability to achieve an accurate estimate of the real resource base of natural gas. Because of this thinking, during the 1970 's and 1980's my estimates of the natural gas resource base were often challenged on the basis that no more "giant" fields and very few "significant" fields were being found. My reply was that the Anadarko Basin was indeed a giant field, which was continuing to be developed, that actually contained at that time some 300 individual wells each capable of ultimately producing over 6 Bcf of gas, the equivalent of $1 \mathrm{MMbo}$.
Perhaps the most important lesson from the Anadarko Basin is contained in estimates of the total quantity of natural gas present in this region. Below the transition zone, rocks of the Anadarko Basin form an overpressured envelope within which porosity is held open largely by the presence of methane. This overpressured envelope has recently been described as a "megacompartment complex" by AlShaieb and others (1992; fig. 10). The rocks of this pressure complex are by volume primarily Mississippian and Pennsylvanian shales. We have calculated the quantities of methane in place within these shales to be in the range of 2,000 Tcf (appendix A). This estimate does not include local overpressured compartments present outside the megacompartment complex in many stratigraphic intervals, particularly in rocks of the Hunton and Simpson Groups (Al-Shaieb and others, 1992; fig. 10). Most of this natural gas occurs in shales with significant porosity but, other than microfractures, little or no permeability. The amount of natural gas that may be ultimately available is thus uncertain and would depend upon the economy, technology, and the rate of flux through the fractured shales and coals.

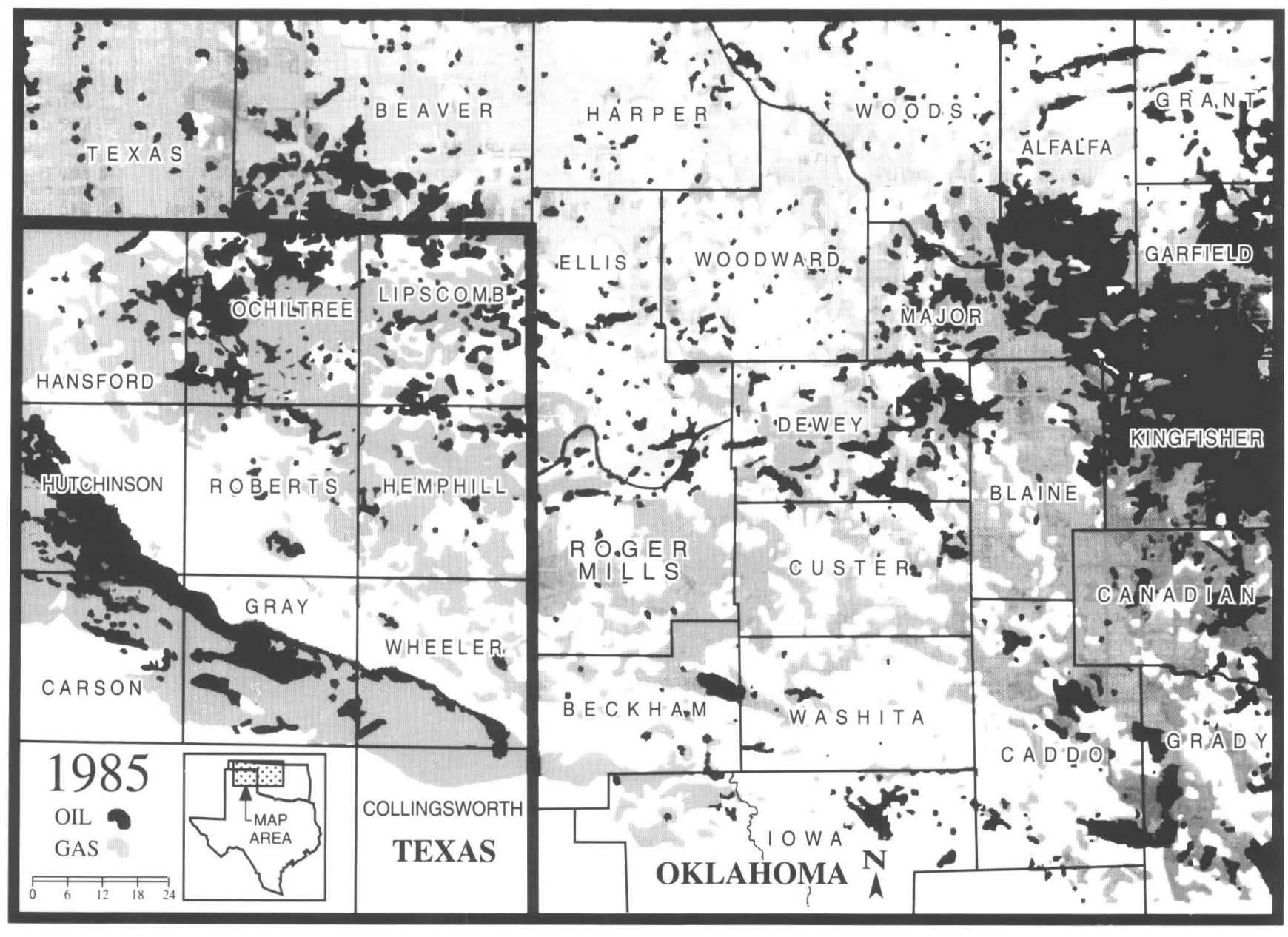

Figure 9. Map of oil and gas fields in the Anadarko Basin, western Oklahoma and Texas Panhandle, 1985. 
In general, natural gas wells produce significantly more natural gas than indicated by original estimates. In my experience, this has nearly always been true for wells producing from below the transition zone in the Anadarko Basin. The decline curves and ultimate reserve forecasts for the wells shown in figures 4 and 7 are typical examples of engineering underestimation of natural gas wells in the Anadarko and Arkoma basins. These figures show that early estimates of ultimate production, based on initial flow rates, pressure decline, and volumetric calculations, are almost always overly conservative. This is particularly true for larger, more prolific, natural gas wells that frequently produce several times the quantity of natural gas indicated by early estimates. These underestimates of reserves are the result of several factors including new technology (fig. 7). I suspect, however, that the major contributor to significantly low estimates of reserves, even in the light of apparently adequate production and reservoir data, is the continuing failure to recognize the complex multiple flow and drainage regimes of these reservoirs. In the recent past, this oversight has resulted in forecasts, based on straight line decline, that tended to be extremely low. Unfortunately, the low estimates in a well, a field, or a producing region then became generally accepted and reservoir engineers were commonly reluctant to increase their low forecasts until forced to by increased production of natural gas. In addition, I believe that high-pressure natural gas is able to flow at commercial rates from reservoirs with porosities as low as 5 percent or less, porosities far less than those which are accepted to be reservoir quality for natural gas. This factor would also increase actual natural gas production in excess of original estimates, as would additional natural gas flows that enter the reservoir from adjacent overpressured and fractured shales.

\section{A MORE OPTIMISTIC VIEW OF THE NATURAL GAS RESOURCE BASE}

Considering the degree of inaccuracy in past natural gas resource base estimates and the large quantities of natural

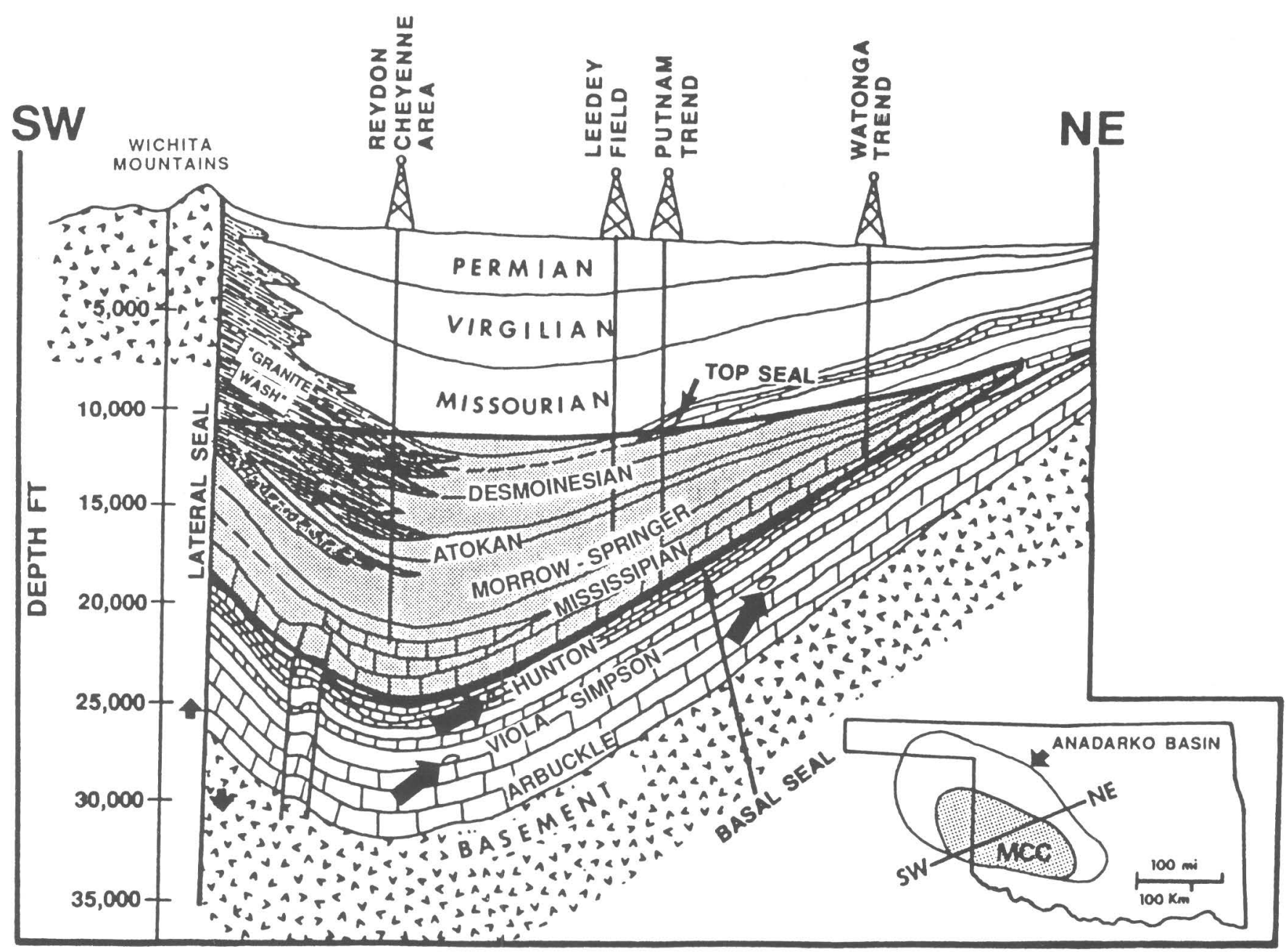

Figure 10. Schematic cross section of the Anadarko Basin. The area within the thick line indicates regional overpressured megacompartment complex (mcc) (stippled). Large arrows identify local overpressured compartments. From Al-Shaieb and others (1993). 
gas that we know exist in such habitats as deep gas reservoirs and methane hydrates, I am led to believe that natural gas, recoverable with present technologies and at prices within reasonable future estimates, is immensely more abundant than even recent, more optimistic calculations suggest. The analysis that follows is both general and speculative in nature and is included here to stimulate discussion and promote the research and development that is necessary to achieve a fuller understanding of the natural gas resource base. This discussion assumes the validity of generally accepted ideas concerning the origin and stability of oil (which, as I explain below, I have many reasons to doubt) and does not take into account the newest information that may bring these established ideas into significant question (see Gold, this volume).

Most petroleum scientists believe that oil forms from the breakdown of biological materials deposited in lakes, marshes, swamps, and along the flanks of continents. During burial, when temperatures reach about $95^{\circ} \mathrm{C}$, the biological material kerogen begins to convert to bitumen, oil, and natural gas. This process continues to about $175^{\circ} \mathrm{C}$, a temperature above which it is thought that oil can no longer exist and will partially break down to methane and other light hydrocarbons. At higher temperatures, in the presence of sufficient hydrogen, oil and kerogen are converted to methane. Specialists in the field of maturation of organic material estimate that 50 to 70 percent of total kerogen is converted to oil and natural gas. In the absence of hydrogen, graphite is the end product. Oil generation thus takes place geologically at relatively low temperatures and pressures, so, unlike natural gas, the physical and geological limits of the oil window are narrow.

The window of generation for natural gas, on the other hand, seems to have no practical physical limits within and even beyond the confines of known sedimentary basins. Natural gas is generated biogenically, through the action of microorganisms, at ambient, and quite possibly much higher, temperatures and pressures. Thermogenically, generation of methane occurs throughout the "oil window." Above $175^{\circ} \mathrm{C}$ methane can be generated from oil and other hydrocarbons to temperatures that may exceed $600^{\circ} \mathrm{C}$ (Hunt, 1975). Moreover, after the process of oil and gas generation and migration from source rocks has taken place, significant amounts of kerogen, bitumen, and oil remain at or near the place of origin, available for conversion to additional quantities of natural gas. My rough calculations (appendix B), experience, and intuition, as well as some research by others (Comer and Hinch, 1987), indicate that the quantity of natural gas ultimately generated from the original biological material can be assumed to be approximately four times the mass of oil generated.

For this to occur, a large source of additional hydrogen must be available, as the original organic material does not contain enough hydrogen for efficient conversion to take place. The availability of hydrogen is always the main limiting factor for the generation of oil and natural gas, as well as for the continued generation of methane at temperatures and pressures beyond the oil window. A number of factors suggest that ample hydrogen is available to drive the process: (1) Hydrogen is one of the most abundant elements in the solar system and is found throughout the Earth's sediments, (2) hydrogen may diffuse upward through the crust as a result of subduction of water under the continents and (or) continued outgassing from disassociation of hydrogen-rich compounds associated with the Earth's origin, (3) hydrogen is found in many of the deepest test wells drilled (Behr and Raleigh, 1988; Kozlovsky, 1986) and is often vented from volcanoes and midocean rifts (Krauskopf, 1982); and (4) at higher temperatures, in the absence of hydrogen, any remaining oil and unconverted kerogen would be converted to graphite. However, the presence of graphite in sedimentary and metasedimentary rocks is low compared to the volume of oil and gas, a fact which suggests that sufficient quantities of hydrogen have been available to allow conversion to hydrocarbons.

By accepting the assumption that the quantity of methane generated from organic materials is at least four times that of oil, we may then estimate the natural gas resource base as a multiple of known quantities of oil in the United States. These calculations for natural gas utilize a simple multiple of the original oil in place, adjusted for differences in recoverability of oil and natural gas. I assume here an average recoverability for oil of 30 percent and for natural gas of 80 percent. These figures are both approximations. Though oil field recovery may reach 40 percent or more in some fields, in others it may be as low as 20 percent and in a few cases even as low as 10 percent. Therefore, on a historical basis, the assumption of 30 percent recoverability is perhaps reasonable.

Estimate of all U.S. conventional oil reserves (Bbo=billion barrels of oil):

(1) Proven reserves (Howell and others, 1993)----_-.---- $\quad 45.0$ Bbo

(2) Undiscovered resources (Mast and others, 1989) --_-- $\quad 49.4$ Bbo

(3) Already produced reserves (Janet Rains, GHK

Company, oral commun., 1992, from a

representative of the American Petroleum Institute) --

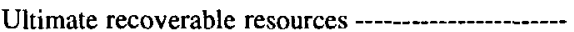

$149.6 \mathrm{Bbo}$

$244.0 \mathrm{Bbo}$

Original oil in place (OOIP) (assuming ultimate recoverable reserves equal 30 percent of OOIP) -..- $\quad 813.0 \mathrm{Bbo}$

Conversion to natural gas $(T c f=t r i l l i o n$ cubic feet; 1 barrel oil $(B b o)=$ 5,800 cubic feet of gas):

Assuming 4 to 1 ratio of gas in place to oil in place, then $813.0 \times 4=3252.0 \mathrm{Bbo}=$

18.906.2 Tcf

Ultimate recoverable reserves estimated to be 80 percent of gas in place $=8,906.2 \mathrm{Tcf} \times 0.80=$

$15,125.0 \mathrm{Tcf}$

Minus cumulative production to date

(Potential Gas Committee, 1990)

$730.0 \mathrm{Tcf}$

U.S. Natural Gas Resource Base= 
This speculative estimate of methane originally generated and potentially recoverable is 10 times higher than the conventional resource base estimates that now hover between 1,200 and 1,500 Tcf; because the calculations are based solely on proven amounts of oil entrapped and in place, they do not take into account early, biogenically derived methane or methane hydrates nor the vast quantities of oil that may have leaked away during geologic history.

We can reconcile the conventional estimates with the 14,400 Tcf figure only by assuming that (1) trapping mechanisms for natural gas are not as effective as those for oil, and large quantities of natural gas have leaked, and continue to leak, into the atmosphere, or (2) much gas is located in reservoirs that have not yet been tapped (some of which may not be commercially producible, such as the high-pressure fractured shales of the deep Anadarko Basin and the tight gas reservoirs of the Green River Formation).

At present, little data is available on the methane flux either in deep high-pressure regions or at the surface, and though some work is now in progress to establish what surface flux might be (see Clayton and others, this volume), considerably more research is needed in this area. We do know that natural gas accumulates in solid waste landfills and swamps without effective "caprocks" and that flows of natural gas streaming upward through the sediment column tend to form their own barriers to migration. These observations, along with my experience in natural gas exploration, indicates to me that trapping mechanisms for natural gas are effective, though perhaps not as efficient as those for oil.

If this is true, then there must be a vast quantity of natural gas still in the crust that we have not yet located. The analysis above suggests that the original natural gas resource base may have been easily four times that of oil on an energy equivalent basis. I suggest that after leaking, the amount of recoverable natural gas remaining is likely to be, at a minimum, equal to the original amount of recoverable oil. Assuming that sedimentary basins contain at least as many reservoirs for gas as for oil (and they may well contain more), the recoverable natural gas resource base for the United States is thus likely to be in the range of 3,000 to $4,000 \mathrm{Tcf}$, rather than the 1,200 to $1,500 \mathrm{Tcf}$ predicted today. This higher estimate is much more compatible with the enormous amounts of natural gas known to exist in the form of gas hydrates (see Kvenvolden, this volume) and in habitats such as the Anadarko Basin overpressured megacomplex.

The focus here is not on the absolute accuracy of the larger estimates. Rather, I am suggesting that there exists a reasonable and supportable view of our natural gas resource base that is significantly higher than the one presently held by most oil and gas professionals. That many will disagree with this new view is understandable; whenever a paradigm shifts, new ideas seem uncomfortable and drastically out of line with what was held to be true. How- ever, I have shown in a variety of ways that the view of natural gas resources that has resulted from oil thinking reflects a model that no longer fits the data. Though oil thinking applied to the realm of natural gas has held our creativity, our ingenuity, and our technological innovation in check, its hold on our thinking is now crumbling. We are in a time of fundamental reevaluation and some bold new thinking has begun.

\section{THE GOLD HYPOTHESIS}

Although the very large quantities of methane calculated above, and the much greater amount that could be estimated similarly for the world, can be explained generally by calling on conventional ideas about oil and natural gas, I question seriously whether the large quantities of oil and natural gas found in the Earth are of biological origin. Early in my career, I wondered why oil is usually found around the shallow edges of basins at depths less than $10,000 \mathrm{ft}$, whereas natural gas, which is less dense and found above oil when they occur together, occurs in abundance below oil, down to the deepest levels drilled. Later, when deeper wells revealed the region of high-pressure natural gas and enhanced porosity below the transition zone at about $15,000 \mathrm{ft}$, I questioned the origin of this gas and wondered what mechanisms had created the large zone of abnormally high pressure lying below normally pressured oil and natural gas. As I began to develop my own conviction of the existence of vast natural gas resources, I wondered if the original organic content was indeed sufficient to provide the raw materials necessary to generate these potentially enormous reserves.

When I first read an article in 1977 (article in New York Times, June 8, 1977) concerning Thomas Gold's theory of the origin of hydrocarbons through outgassing of carbonaceous compounds from the mantle, I was immediately struck by how well Gold's abiogenic hypothesis fit my experience in drilling for and producing deep highpressure natural gas. Gold (1987), for example, discusses in detail the origin and effect of the "critical layer," a zone below which higher pressure regimes are encountered. Gold's critical layer is the transition zone I have described, below which all deep Anadarko Basin wells encounter abnormal pressures. In Gold's hypothesis, these abnormally high pressures are readily accounted for by the trapping of higher pressure gas from the mantle on its way toward lower pressure domains. Gold's ideas are presented in detail elsewhere in this volume (see Gold, this volume).

Though I recognize that few geologists give credence to Gold's hypothesis, I have had personal communication with several physicists and petroleum geologists who do. However, most importantly, I cannot escape the fact that my knowledge and experience of natural gas, gained from operating many of the world's deepest and highest pressure 
natural gas wells, are accounted for more clearly by Gold's ideas than by conventional theories of the biological/thermogenic origin of natural gas. Because of its enormous implications to the economy and the environment, Gold's hypothesis is an area of new thinking about natural gas that undoubtedly needs significantly increased study and research, in spite of the pressures of conventional thinking.

\section{CONCLUSIONS}

In the context of the broad review of energy gases presented in this volume we should remember that our knowledge of the Earth is still exceptionally limited, particularly as we drill deeper into the crust, into the realm of deep high-pressure natural gas. Although a number of papers in this volume reflect the new and exciting research that is taking place in the realm of energy gases, they also remind us of the present limits of our understanding. For example, compared to the hundreds of billions of dollars that have been spent on research and development of coal, oil, and nuclear energy systems and technology, pitifully little has been spent on the basic research necessary to understand the real potential of natural gas as a long-term energy source. As a result, our educational system, our national energy policy, and our economy have traditionally focussed on oil, coal, and nuclear energy. Though this focus is slowly changing, we continue to sustain the momentum in our society for the use of these less efficient, environmentally degrading energy technologies, even though their external economic and social costs have placed significant limits upon U.S. economic growth, particularly over the last decade. While debate over the role of various fuels during the next several decades will undoubtedly continue, the worldwide increase in use of natural gas clearly reflects the growing demand for a significantly cleaner, more efficient fuel. Even within the limitations of oil-based thinking, recent estimates of the natural gas resource base reflect a changing view of the abundance of natural gas. The size of the natural gas resource base is likely to continue to grow in proportion to the degree to which we are able to free our thinking from the comfortable limits of outdated perceptions and accept the many new physical and chemical facts that surround the field of geology and the origin of our solar system.

In my view, the long-term impact of natural gas as a primary component of our national energy mix will have profound and positive effects on our economy, our ability to compete in world markets, our national and global environment, our strategic defense systems, and ultimately our very role in the 21 st century global community. By implementing policies that will allow natural gas to displace oil and coal and to become America's principal energy source, we will enhance the efficiency, productivity, and security of the economic system, reduce the pollution produced from energy consumption, and decrease the potential for future Middle East wars and predictable oil-price shocks. The impact of decisions made now concerning our energy future is so important that increased focus on scientific investigation of the origin and occurrence of natural gas has become urgent. I believe that such work will show that the world has more usable Btu's in the form of methane than in either oil or coal and that the United States has sufficient quantities of natural gas to sustain the increased use of this fuel as a principal energy source well beyond the middle of the 21 st century. On the basis of new thinking about natural gas, I predict that:

1. In the United States, natural gas will remain an affordable and reliable fuel beyond the middle of the 21 st century.

2. Natural gas will replace oil as the United States principal energy source within a decade.

3. Natural gas is so abundant that the only limits to its use will be well in the future when $\mathrm{CO}_{2}$ emissions from natural gas use could possibly begin to exceed limits set by future global warming treaties.

4. Natural gas use will be exceptionally good for the global economy for both developed and developing nations. In the developed countries, the increased use of natural gas will enhance economic efficiency, expand production, and decrease pollution and carbon dioxide. In the developing countries, the use of locally derived natural gas will reduce the capital required to produce the energy necessary for economic growth and, at the same time, allow these countries to conform to global environmental goals. In China, for example, the use of its vast supplies of natural gas (Hefner, 1985) will stimulate growth by reducing demand for capital and by removing huge quantities of coal from its already bottle-necked transportation sector. For developed economies such as the United States, increased use of natural gas will eliminate the enormous capital drain on our domestic economy that would be required by the development and continued use of frontier oil, "clean coal," or advanced nuclear technology.

5. Natural gas is the beginning of the next long-term energy transition (fig. 11). Throughout human economic history, each transition in a basic energy system has been driven by a new wave of technological innovation and has uplifted increasingly larger segments of the world population to a higher quality of life. The human economy began with a long period during which we relied upon rather crude, dirty, solid sources of energy such as animal dung, wood, and coal. More recently, we have been in a period dominated by a more advanced, cleaner energy system based on liquids, using principally oil-based fuels. I think history will record this period as being relatively brief. The liquid/oil phase is declining even now and being superseded by the next long-term transition, which will be fueled by energy gases, beginning with methane and leading to hydrogen. As in the past, the energy-gas transition will contin- 


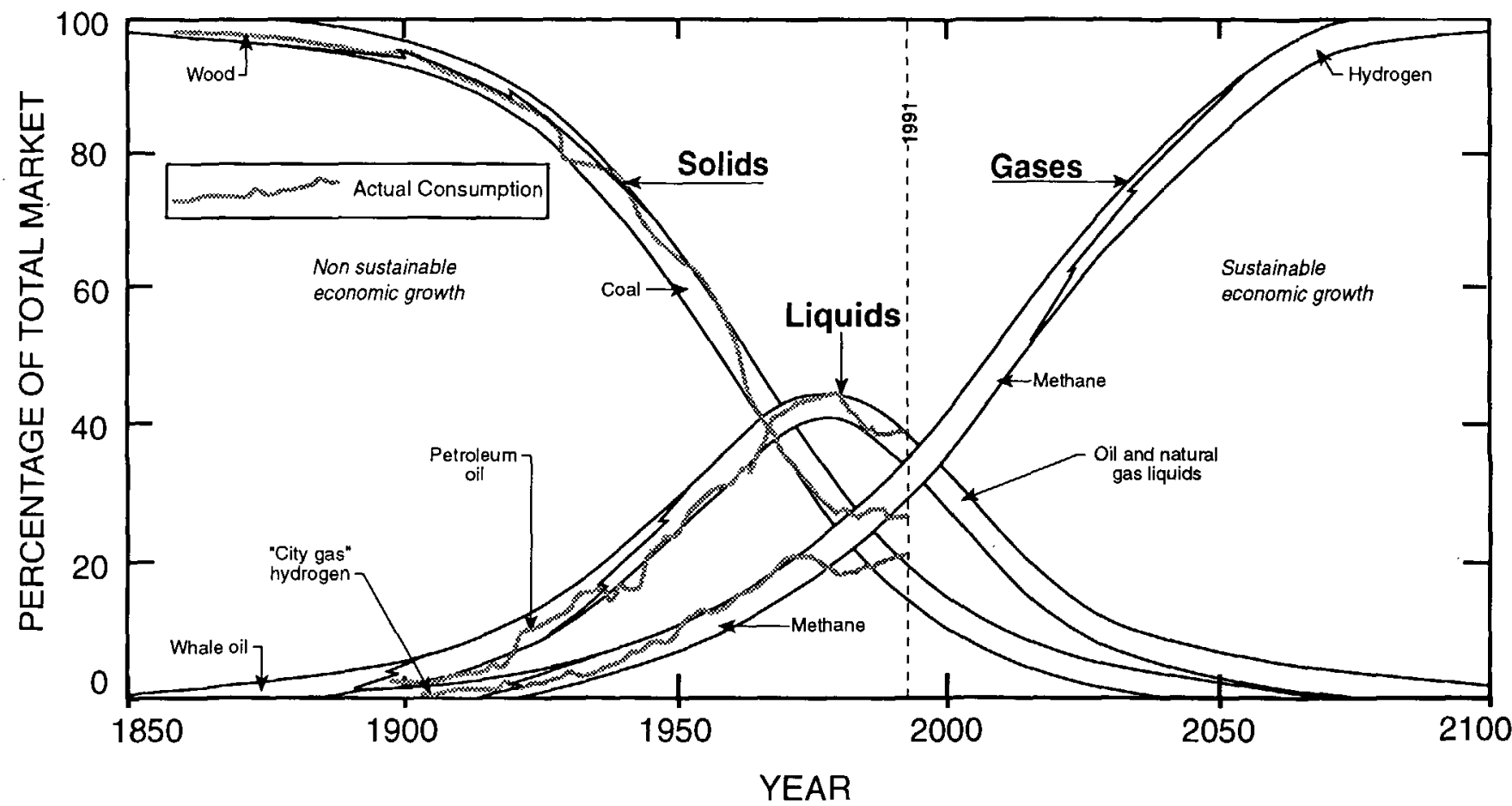

Figure 11. Global energy systems transition forecasting the "age of energy gases." From Hefner (1993). Copyright, 1993, GHK Company.

ue toward more technologically advanced, more efficient, and cleaner energy inputs to our economy. This transition will move steadily toward an environmentally benign energy system. As the age of energy gases advances, together with revolutionary changes in communications, information transfer, and education, the world economies will become increasingly capable of sustaining economic growth. To: ward the end of the 21 st century, humankind for the first time will be able not only to lift the entire world population to and perhaps even beyond the standards of living and education now known only in the developed nations but to do so within a clean global environment. We must begin now to implement policies and economic change that will accelerate our transition into the age of energy gases.

\section{REFERENCES}

Al-Shaieb, Z., Puckette, J., Ely, P., and Tigert, V., 1992, Pressure compartments and seals in the Anadarko Basin: Oklahoma Geological Survey Circular 93, p. 210-215.

American Gas Association, 1991, A comparison of alternative vehicular fuels with conventional gasoline: Gas Energy Review, v. 1, p. 9-13.

Behr, H.J., and Raleigh, C.B., eds., 1988, Exploration of the deep continental crust, volume 1 -Deep drilling in crystalline bedrock: Springer Verlag.

Comer, J.B., and Hinch, H.H., 1987, Recognizing and quantifying expulsion of oil from the woodford formation and equivalent rocks in Oklahoma and Arkansas: American Association of Petroleum Geologists Bulletin., v. 71, no. 7, p. 844-858.

Committee on Gas Production Opportunities, National Research Council, 1978, The potential for increasing production of natural gas from existing fields in the near term; final report to the Secretary of the Interior: National Technology Information Service, U.S. Department of Commerce, $110 \mathrm{p}$.

Energy Statistics Sourcebook (7th ed.), 1992: Tulsa, PennWell Publishing Company.

Enron Corporation, 1991, Outlook for Natural Gas: Houston, Texas, $15 \mathrm{p}$.

Enron Corporation, 1993, The outlook for natural gas technology marches on: Houston, Texas, $15 \mathrm{p}$.

Fisher, W.L., 1993, The new emerging domestic oil and gas industry: The Professional Geologist, p. 8-10.

Flavin, Christopher, 1992, Building a bridge to a sustainable future, in Linda Starke, ed., State of the World, 1992: London and New York, W.W. Norton and Company, p. 27-45.

Gold, T., 1987, Power from the Earth: London, J.M. Dent and Sons Ltd., 202 p.

Gustavson Associates, Inc., 1992, Petroleum geology and exploration potential in the former Soviet Republics: Boulder, Colo.

Hefner, R.A., III, 1978, The future for conventional U.S. natural gas supply-Aspen Institute, workshop on $R$ and D priorities and the gas energy option: Aspen, Colo., Aspen Institute, $15 \mathrm{p}$.

1980, Depth-porosity relationships of the Anadarko Basin: Petroleum Engineer International, v. 52, no. 7.

-1985, Onshore natural gas in China: World bank energy round table discussion on gas development in less developed countries. 
1992, An econergenic policy for 21 st century AmericaEssential issues for debate in the 1992 Presidential election: Oklahoma City, Hefner Foundation, p. 17-19.

-1993, The Hefner report, June 17th, 1993: Oklahoma City, Hefner Foundation, p. 6.

Hefner, R.A., III, Kinchloe, R., Wheeler, R., Jr., 1973, The drilling and production of ultra-deep natural gas accumulations occurring below 20,000 feet in the Anadarko Basin: Proceedings of the 12th World Gas Conference, Nice, May 1973.

Howell, D.G., Bird, K.J., and Cunningham, R.D., 1992, Compressional tectonics point to more gas reserves: World Oil, v. 213 , no. 6 , p. $117-120$.

Howell, D.G., Bird, K.J., and Gautier, D.L., 1993, Oil-When will we run out?: Earth: v. 2, no. 2, p. 26-33.

Hunt, J.M., 1975, Is there a geochemical depth limit for hydrocarbons?: Petroleum Engineering, March 1975, p. 112-124.

International Energy Statistics Sourcebook, 1992: Tulsa, PennWell Publishing Company.

Jenkins, G., 1977, Oil Economists Handbook: London, Applied Science Publishers, Ltd., tables 4-12, p. 87-95.

Kozlovsky, Y.A., 1984, The worlds deepest well: Scientific American, v. 251, no. 6.

Krauskopf, K.B., 1982, Introduction to geochemistry, 2nd ed.: McGraw Hill.

Kvenvolden, K.A., 1988, Methane hydrate-A major reservoir of carbon in the shallow geosphere?: Chemical Geology, v. 71, p. 41-51.

Lilley and others, $1982, \mathrm{CH}_{4}, \mathrm{H}_{2}, \mathrm{CO}$, and $\mathrm{N}_{2} \mathrm{O}$ in submarine hydrothermal vent waters: Nature, v. 300, p. 48-50.

Marchetti, C., Nakićenović, N., 1979, The dynamics of energy systems and the logistic substitution model: Laxenburg, Austria, International Institute for Applied Systems Analysis, 73 p.

Mast, R.F., Dolton, G.L., Crovelli, R.A., Root, D.H., Attanasi, E.D., Martin, P.E., Cooke, L.W., Carpenter, G.B., Pecora, W.C., and Rose, M.B., 1989, Estimates of undiscovered con- ventional oil and gas resources in the United States-A part of the Nation's endowment: U.S. Geological Survey/Minerals Management Service Report.

Masters, J.A., 1979, Deep basin gas trap, Western Canada: American Association of Petroleum Geologists Bulletin, v. 63 , p. $152-181$.

Maxwell, J.C., 1964, Influence of depth, temperature, and geologic age on porosity of quartzose sandstone: American Association of Petroleum Geologists Bulletin, v. 48, no. 5, p. 697-709.

Melton, C.E., Giardini, A.A., 1974, The composition and significance of gas released from natural diamonds from Africa and Brazil: American Mineralogist, v. 59, p. 775-782.

Nakićenović, N., 1990, Dynamics of change in long waves, in Tibor Vasko and Robert Ayres, eds., Life cycles and long waves: Springer Verlag, p. 147-192.

National Petroleum Council, 1992, The potential for natural gas in the United States, 1992, executive summary: Washington, D.C., National Petroleum Council.

Petroleum Information Corporation, 1982, The deep Anadarko Basin: Petroleum Information Corporation.

Potential Gas Committee, 1990, Potential supply of natural gas in the United States: Potential Gas Agency, Colorado School of Mines, p. 169.

U.S. Department of Energy, Energy Information Administration, 1990, The domestic oil and gas recoverable resource baseSupporting analysis for the national energy strategy: U.S. Department of Energy Report SR/NES/90-05, 56 p.

U.S. Geological Survey, 1993, Gas (methane) hydrates-A new frontier: U.S. Geological Survey, Public Issues in Energy and Marine Geology, March, 1993, 2 p.

USSR Ministry of Geology, 1991, Statement that a hole drilled on the Kola Peninsula had reached a depth of $40,226 \mathrm{ft}$.: Oil and Gas Journal, vi 89 , no. 40 , p. 34.

World Oil, 1992, World trend-Operators abandon the U.S.: World Oil, v. 213, no. 8, p. 23-28.

Yergin, D., 1991, The prize: New York, Simon and Schuster, 885 p. 


\section{APPENDIX A. CALCULATION OF NATURAL GAS RESOURCES, ANADARKO BASIN, TEXAS AND OKLAHOMA.}

[Bg, formation volume factor; Sw, water saturation; OGIP, oil and gas in place; Scf, standard cubic feet; pct, percent; Tcf, trillion cubic feet]

\begin{tabular}{|c|c|c|c|c|c|c|c|c|c|c|c|}
\hline $\begin{array}{c}\text { Depth } \\
\text { (ft) }\end{array}$ & $\begin{array}{c}\text { Pressure } \\
\text { (psi) }\end{array}$ & $\begin{array}{c}\text { Temp } \\
\left({ }^{\circ} \mathrm{F}\right)\end{array}$ & $\begin{array}{l}\text { Pressure } \\
\text { gradient } \\
\text { (psi/ft) }\end{array}$ & $Z$ factor ${ }^{3}$ & $\begin{array}{c}\mathrm{Bg}^{4} \\
\left(\mathrm{Scf} / \mathrm{ft}^{3}\right)\end{array}$ & $\begin{array}{l}\text { Porosity } \\
\text { (pct) }\end{array}$ & $\begin{array}{c}S w \\
(p c t)\end{array}$ & $\begin{array}{c}\operatorname{OGIIP}^{5} \\
\left.\left(\mathrm{Scf} / \mathrm{ft}^{3}\right)^{3}\right)\end{array}$ & $\begin{array}{c}\text { Volume } \\
\left(\mathrm{ft}^{3}\right)\end{array}$ & $\begin{array}{c}\mathrm{OGIP}^{6} \\
(\mathrm{Scf})\end{array}$ & $\begin{array}{l}\text { OGIP } \\
\text { (Tcf) }\end{array}$ \\
\hline 10,000 & 4,600 & 160 & 0.46 & 0.970 & 270.52 & 4 & 90 & 1.08 & $1.3 \times 10^{15}$ & $1.4 \times 10^{15}$ & 1,407 \\
\hline 11,000 & 5,800 & 170 & 0.53 & 1.062 & 306.79 & 4 & 90 & 1.23 & $1.3 \times 10^{15}$ & $1.6 \times 10^{15}$ & 1,595 \\
\hline 12,000 & 7,000 & 180 & 0.58 & 1.158 & 334.11 & 4 & 90 & 1.34 & $1.3 \times 10^{15}$ & $1.7 \times 10^{15}$ & 1,737 \\
\hline 13,000 & 8,200 & 190 & 0.63 & 1.255 & 355.53 & 4 & 90 & 1.42 & $1.3 \times 10^{15}$ & $1.8 \times 10^{15}$ & 1,849 \\
\hline 14,000 & 9,400 & 200 & 0.67 & 1.351 & 372.93 & 4 & 90 & 1.49 & $1.3 \times 10^{15}$ & $1.9 \times 10^{15}$ & 1,939 \\
\hline 15,000 & 10,600 & 210 & 0.71 & 1.444 & 387.45 & 4 & 90 & 1.55 & $1.3 \times 10^{15}$ & $2.0 \times 10^{15}$ & 2,015 \\
\hline 16,000 & 11,800 & 222 & 0.74 & 1.534 & 398.97 & 4 & 90 & 1.60 & $1.3 \times 10^{15}$ & $2.1 \times 10^{15}$ & 2,075 \\
\hline 17,000 & 13,000 & 234 & 0.76 & 1.620 & 408.95 & 4 & 90 & 1.64 & $1.3 \times 10^{15}$ & $2.1 \times 10^{15}$ & 2,127 \\
\hline 18,000 & 14,200 & 246 & 0.79 & 1.703 & 417.73 & 4 & 90 & 1.67 & $1.3 \times 10^{15}$ & $2.2 \times 10^{15}$ & 2,172 \\
\hline 19,000 & 15,400 & 258 & 0.81 & 1.783 & 425.54 & 4 & 90 & 1.70 & $1.3 \times 10^{15}$ & $2.2 \times 10^{15}$ & 2,213 \\
\hline 20,000 & 16,600 & 270 & 0.83 & 1.860 & 432.56 & 4 & 90 & 1.73 & $1.3 \times 10^{15}$ & $2.2 \times 10^{15}$ & 2,249 \\
\hline 21,000 & 17,800 & 282 & 0.85 & 1.933 & 438.93 & 4 & 90 & 1.76 & $1.3 \times 10^{15}$ & $2.3 \times 10^{15}$ & 2,282 \\
\hline 22,000 & 19,000 & 294 & 0.86 & 2.004 & 444.75 & 4 & 90 & 1.78 & $1.3 \times 10^{15}$ & $2.3 \times 10^{15}$ & 2,313 \\
\hline 23,000 & 20,200 & 306 & 0.88 & 2.073 & 450.09 & 4 & 90 & 1.80 & $1.3 \times 10^{15}$ & $2.314 \times 10^{15}$ & 2,340 \\
\hline 24,000 & 21,400 & 318 & 0.89 & 2.138 & 455.04 & 4 & 90 & 1.82 & $1.3 \times 10^{15}$ & $2.4 \times 10^{15}$ & 2,366 \\
\hline
\end{tabular}

${ }^{1}$ To $10,000 \mathrm{ft}, 0.46 \mathrm{psi} / \mathrm{ft}$; for depth $>10,000 \mathrm{ft}$.

${ }^{2}$ To $15,000 \mathrm{ft}, 0.01^{\circ} \mathrm{F} / \mathrm{ft}$; for depth $>15,000 \mathrm{ft}, 1.2 \mathrm{psi} / \mathrm{ft}$ plus $60 \mathrm{psi}$ for ambient temperature.

${ }^{3}$ Calculated based on $Z$-factor correlation, gas gravity $=0.59, \mathrm{~N}_{2}=0$ percent, $\mathrm{CO}_{2}=0$ percent, $\mathrm{H}_{2} \mathrm{~S}=0$ percent.

${ }^{4} \mathrm{Bg}=35.374 \times(\mathrm{psi} / \mathrm{Z}$ factor $) \times\left({ }^{\circ} \mathrm{F}+460\right)$.

${ }^{5} \mathrm{Bg} \times$ porosity $\times(1-\mathrm{Sw})$.

${ }^{6} \mathrm{OGIP}\left(\mathrm{Scf} / \mathrm{ft}^{3}\right) \times$ volume.

\section{APPENDIX B. CALCULATION OF THE AMOUNT OF RECOVERABLE NATURAL GAS AS A FACTOR OF KNOWN RECOVERABLE OIL.}

Note: This appendix is a very general calculation presented to provide some substantiation of the statement that the amount of recoverable natural gas should equal 1 to 4 times the amount of recoverable oil. It is a highly simplified analysis of a process that is still not well known. Though it may well raise some questions, I provide it as an example of the ideas on which the statement is based.

Assume 50 percent of kerogen is converted to oil, 30 percent of oil migrates into reservoir, and 30 percent of migrated oil is produced from well bore; therefore, 4.5 percent of original kerogen is produced as oil. This is a high estimate; 1 percent or 2 percent is the generally accepted figure.

It follows, first, that 50 percent of original kerogen is available in some form, probably hydrogen deficient, for con-version to natural gas and, second, that 70 percent of oil generated does not migrate and remains in or near the source rock (in other words, 0.7 of original 50 percent kerogen converted), giving $0.7 \times 0.50=0.35$ of original kerogen in place.

Add $\mathrm{H}_{2} \mathrm{O}$, increasing temperature and pressure, and time, then 50 percent of original kerogen plus 35 percent of original kerogen now in form of oil or bitumen is available for conversion to natural gas. Assuming 50 percent is converted to natural gas, then $0.85 \times 0.5=0.425$ of original kerogen is converted to natural gas.

Assume 60 percent migrates and 80 percent is produced from reservoir, then $0.425 \times 0.6 \times 0.8=0.2$ or 20 percent of original kerogen is available for production as natural gas, or nearly 5 times the amount of oil available (4.5 percent of original kerogen). 

THE FUTURE OF ENERGY GASES

U.S. GEOLOGICAL SURVEY PROFESSIONAL PAPER 1570

\title{
Natural-Gas Resources of North America
}

\author{
By John A. Masters ${ }^{1}$
}

\section{CONTENTS}

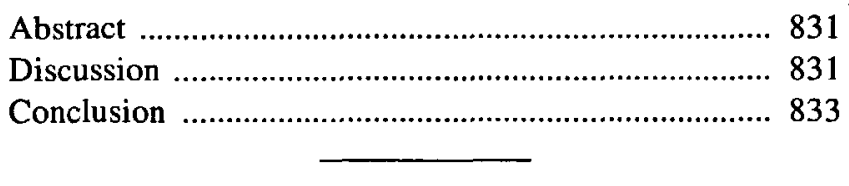

\begin{abstract}
A natural gas shortage in the United States is anticipated during the 1990's because of declining reserves in the Gulf of Mexico. These cannot be replaced from the gulf. Western Canada and the Arctic contain enough reserves, augmented by U.S. reserves, to see us through the next 50 years but at increasing prices. A large amount of unconventional gas is recognized in the United States. Largely unrecognized is an enormous potential for stratigraphically trapped, conventional gas, which can be found by careful evaluation of the United States' national treasure of 3 million wells; no other country in the world has a comparable subsurface data base. In the farther future, hydrogen is a potential energy source. Our science can locate natural-gas resources and provide the technology for development. However, the tax and price policies of the U.S. Federal Government can either encourage natural-gas development or completely stifle it.
\end{abstract}

\section{DISCUSSION}

Natural gas is used in great quantities only in the United States, Russia, and Europe and is supplied from

'Canadian Hunter Exploration Ltd., 2000, 605-5th Ave., SW, Calgary, Alberta, Canada T2P 3 H5. nearby sources because it cannot be transported economically by water. Thus, Russia and Europe are supplied by pipeline from the vast gas reserves of Russia and from the North Sea. There is plenty available for a long time, and huge reserves in the Middle East can backup the whole supply system. However, the United States is supplied only from domestic and Canadian production, and the known reserves are not nearly so large as those in Russia and surrounding areas. There is a looming supply problem in the United States. The reserve-to-production ratio in the United States has fallen from 38 years in 1946 to 9 years in 1990. It will take considerable luck and a giant effort to reverse this trend.

A near-term natural-gas shortage in the United States appears to be inevitable because of the abrupt decline in offshore Louisiana reserves, which supply one-third of the entire U.S. market. These high permeability reservoirs will be completely drained in about six years. For the last six years very little drilling to replace reserves has been done in the Gulf of Mexico because of low gas prices; thus, the fields presently producing are about depleted. For 40 years we have been able to treat the Gulf of Mexico as an endless source of new gas fields. We have innocently believed that as soon as the present supply disappeared prices would go up, the rigs would start drilling again, and the gas would continue to flow. However, the whole gulf has been covered with 3-dimensional seismic-every large company has it-and they agree there are no more large structures on the shelf in water depths less than 600 feet. Beyond this depth, the water gets deep fast, and we must deal with radically different economics and long lead times before production begins. Also, the deep-water production so far has been oil, and information is not available to determine how much gas will be present.

We will soon experience some sharp price rises, which will put the rigs back to work around the country. However, vastly improved reflection-seismic data gives us an 
uncharacteristically precise answer that there are little more significant reserves of economic gas in the Gulf of Mexico, and we know there is no basin or group of basins in the United States that can replace such a large supply of natural gas in the next decade.

Mexico probably has large natural-gas reserves, which have been overlooked and bypassed in its concentrated search for big oil fields. It would take many years and large investments, however, before Mexico could begin sending gas north. In fact, Mexico is now importing gas from southern Texas. The Western Canadian basin has excess reserves, which can flow south, and so does Arctic Canada and the North Slope of Alaska. Environmental barriers, Native land claims, new pipelines, and Canadian internal supply and demand will all have to be considered, but it is from the north that the United States will get its natural gas.

I have a general idea that these current and future northern gas supplies could compensate for most or all of the decline in Gulf Coast production of natural gas for the next 20 years. Someone with more data should be able to model this scenario better than I. The United States can supply the balance from its conventional and nonconventional sources of natural gas for several decades. Likely, we will have exhausted all our $\$ 1$ per Mcf (thousand cubic feet) natural gas before that time, but there will be plenty of gas for 50 years or more at progressively higher prices. After 50 years there will be a range of options, which we can only guess at today.

Assuming that the U.S. gas shortage causes a substantial price rise, before northern gas can be brought down to the United States in quantity, the shortage will encourage enormous efforts in the United States to extract more gas from tight sands, coal beds, fractured shales, and very deep reservoirs in the Gulf of Mexico, and the Anadarko, the Delaware, and a few Rocky Mountain basins. These basins are the only ones in the United States with ultradeep sediments that are known to carry gas. I do not expect deep drilling to contribute more gas than can normally be estimated from the additional volume of sediments penetrated, making allowance for the higher pressures.

Pressures and pressure cells must be an integral part of deep-gas exploration. Careful petrographic description of samples and cores must be calibrated with well logs. Well logs alone are very confusing at great depths. Careful selection of drilling muds and optimum reservoir fracturing techniques will be needed. Primary and secondary porosity at depth are closely related to overpressure and the history of overpressure. Remember, pressures that you observe today are not necessarily indicative of pressures that the rock has been subjected to during its long history.

Despite periodic "locker room" talks by Levorsen, Halbouty, and others, the petroleum industry has never seriously explored for stratigraphic traps, probably because we are so intellectually dependent on the seismic exploration technology. A vast amount of subsurface data is available to evaluate nearly 20,000 miles of porous rock wedge outs in the United States, the same kind of wedge outs that produced the East Texas, Lima-Indiana, Appalachian trend, Southwest San Joaquin, Golden Trend, and other prolific oil and gas fields. It's unfortunate that the geological community has not provided regional zero-edge porosity maps of the entire geologic section integrated with structure, shows, source rocks, hydrodynamics, land availability, and drilling recommendations.

There is no way to anticipate how much gas and oil can still be found in the United States by looking for the kind of traps that we have ignored in the 75 years since Frank Buttram showed that Cushing was on an anticline. We have known all this time that oil and gas occur primarily in anticlines and updip wedge outs of porosity. We developed an effective seismic tool to find anticlines and have used it until we have run out of anticlines. In the process we inadvertently found a number of large stratigraphic traps. Despite the obvious existence of stratigraphic traps, the whole U.S. petroleum industry acts as if the United States offers no more exploration opportunities and therefore focuses most of its exploration efforts overseas. Wallace Pratt told us we would run out of oil when we ran out of ideas.

The U.S. petroleum industry is ultimately responsible for two of the Nation's vital resources-oil and natural gas. If economic evaluation dictates a decision to conduct seismic surveys overseas to look for easily found anticlinal oil fields, I cannot dispute that. However, for equally compelling economic reasons, we need to find our gas in North America.

I believe there is a lot of oil and gas to be found in stratigraphic traps in the United States, both updip from water and downdip from water. We should continue to apply seismic technology as effectively as possible but should not try to push it past its level of competence. More importantly, we have a huge amount of subsurface evaluation technology and data available that we have not really learned to use. The United States is the only country in the world with $3,000,000$ wells.

We will always need research and development into better methods of well log and core evaluation and completion techniques; most importantly, we need to understand and apply the techniques and data we already have. Too many companies are technologically 20 years behind the times. Of course, everyone would love to have a new geophysical tool, but short of that, the most important advance for stratigraphic exploration would be cheaper drilling.

Other potential gas sources are deep coal-bed gas from wells, coal gasification, biomass conversion, abiogenic gas under permafrost seals in the Arctic, hydrates, gas dissolved in high-pressure water, and perhaps most favorable, hydrogen; these sources are all expensive to ex- 
ploit. When we ultimately run out of hydrocarbons, the only remaining fuel source is hydrogen. It is clean and renewable, will burn in our car engines, heat our boilers, and flow through our existing pipelines. At first hydrogen will be extracted from methane, but its long-term source is water. It can be separated from water by electrolysis supplied by hydroelectric power, in part; however, hydrogen could eventually be separated by solar or nuclear energy. We would trade electrical energy, which cannot be transported long distances or stored effectively, for hydrogen, which can flow through pipelines. It will be expensive, but our energy-dependent society may have no choice.

One of the many problems with the prediction of energy-utilization patterns is unforeseen technological changes. These changes are very hard to predict. Improvements in electrical transmission and battery storage could virtually eliminate the need for hydrogen. Another change looming on the horizon is cost reduction for gas liquefaction, shipping, and storage. Alternatively, if the delivered price of natural gas in New York City increased to approximately $\$ 4.00$ per Mcf, then large shipments of liquefied natural gas from some of the enormous overseas reserves in the Middle East or Southeast Asia might become economically competitive. The cost of gas in New York City today is $\$ 2.50$ per Mcf and going up. If an increase to $\$ 4.00$ per Mcf would cover the production and transportation costs of liquefied gas, then such an increase should not impose an impossible economic burden on consumers and would quickly be accepted in preference to "freezing in the dark."

\section{CONCLUSION}

The rush to explore for oil overseas overlooks our need to develop greater gas resources located here in the United States and the vast potential for stratigraphic traps in the United States. Deregulation allowed the decline of gas prices to near-disastrous levels. If the U.S. Government does not panic now as gas prices recover, the petroleum industry will have a chance to see if adequate supplies of natural gas can be found. If consumers dictate price controls again, they will create the fuel shortage they fear. 

THE FUTURE OF ENERGY GASES

U.S. GEOLOGICAL SURVEY PROFESSIONAL PAPER 1570

\title{
The Future of Methane and How We Get There
}

\author{
By Michael Roberts ${ }^{1}$
}

\begin{abstract}
CONTENTS
Abstract 835

Perspective 835

Resource Curves ................................................... 836

A Better Method-The Method of Attribution ........... 837

The Best Method-The Resource Pyramid ................ 839

How We Get There From Here-Policy .................... 840

Conclusion ...................................................... 841

References Cited ................................................ 841
\end{abstract}

\section{ABSTRACT}

The future of methane is in our own hands. Recognition of previous resource analyses enlightens our current perspective of the supply of natural gas in the United States. Learning from the lessons of the past, we can adopt and advance the still-working hypotheses of previous studies and abandon any misguided policies that were based on the no-longer-working hypotheses. The natural-gas resource base is sufficient not only for long-range supply needs of existing uses but also for the needs of a greatly expanded market of new uses as well. Technology advancement is the key to lower costs and improved productivity. We can order the "march of technology" into double time. The cadence can be increased by government policies supporting research and providing incentives. We can get there from here.

\section{PERSPECTIVE}

When addressing a topic such as "The Future of Methane," one must first acknowledge the thinking of past re-

'Enron Corp., P.O. Box 1188, Houston, TX 77251-1188. searchers. This acknowledgment, however, does not necessarily require one to be constrained by previous thought processes or concepts. Also, in the context of scientific inquiry, one should not criticize predecessors for not being beneficiaries of knowledge that was not available to them in their own time but is common today. Isaac Newton, a mathematical visionary, said that he had been able to see farther than others because he had "stood on the shoulders of giants." In the field of natural gas resource analysis, there are numerous "giants" who have preceded us. Among these giants were Wallace Pratt and M. King Hubbert. They happened to be contemporaries, and each an expert in a different discipline (geology and physics, respectively). Each also was a visionary in the field of resource analysis, but each was a prisoner to the generation in which he participated and subject to the limitations of the accumulated knowledge base with which that generation was endowed. Each of these giants, however, thought beyond the constraints of his existing information base, each to a different extent. Wallace Pratt encouraged explorationists to explore the depths of their own minds to find new resources. $M$. King Hubbert anticipated the full implementation of existing and developing production technology (but not the onslaught of unforeseen technology). The giant leap we can make today is to stand on their shoulders and embrace the notion that unforeseeable technology gains can and must be incorporated into our long-range resource planning. Unless this anticipation is not only acknowledged but quantified as well, we will see that our resource estimates will be periodically, and inevitably, revised upward as time passes.

Another notion that should be understood is that of the reserve-life index. This notion is an accounting fiction based on the Security and Exchange Commission's need for standardized measures. Reserves are those volumes of oil and gas that have satisfied the Security and Exchange Commission's requirements to be included in the supplemental disclosure sections of annual financial reports. They are more or less an inventory item. Resources, on 
the other hand, include these proven reserves and (1) probable reserves, (2) possible reserves, (3) undiscovered reserves, and (4) any substance from which petroleum can be derived (with improved technology or more favorable economics) (Levorsen, 1967). For long-range planning purposes, a reserve-life index is irrelevant. The correct index would be based on resource life.

In 1952 Wallace Pratt issued a challenge to the new breed of explorationists (Pratt, 1952). Their adopted battle cry was one of Pratt's most famous themes-"Oil is found in the minds of men." Their conceptual tools included old ideas in new areas, new ideas in old areas, and most importantly, new ideas in new areas.

\section{RESOURCE CURVES}

In 1956, M. King Hubbert, now recognized as one of this nation's most pragmatic resource analysts, completed his classic article on the future of fossil fuels (Hubbert, 1956). Hubbert's basic premise was that all natural resources could be characterized by a production curve similar to a bell curve. "Two points are known at the outset," he observed, "that at $t=0$ and again at $t=$ infinity. Production at both these points is zero." Hubbert then invoked the fundamental theorem of integral calculus to characterize and quantify the area under the curve as being equal to the volume of production ultimately produced. Basically, rate times time equals volume. Tacit in Hubbert's resource curves were the maturity of exploration and learning-curve concepts of exploration geologists. In the very early exploration stages of any region, the resource is large and untapped but the learning curve is steep. Success rates are low and costs are high. In the intermediate stages of exploration, the accumulated knowledge about stratigraphy and the applicability of geophysical devices combine with large and prolific traps to yield highly profitable and productive ventures. Finally, in the end stages of exploration of any particular play or region, the remaining unfound fields are small and it is up to technological progress to offset declining target sizes with reduced finding costs to yield profitable exploration results.

To demonstrate that the production of exhaustible reserves actually does behave in this manner, Hubbert cited actual oil production curves of two of the older producing areas-Illinois and Ohio (Hubbert, 1956). The data available to Hubbert at that time covered a period up to the summer of 1955. The Illinois data available to Hubbert (augmented by data available to us in 1993) are shown in figure 1. Oil production was seen to peak in 1910. It underwent a slow but steady decline until 1936, and then increased dramatically to a new peak in 1940. Hubbert correctly identified this new peak as being due to a new cycle of exploration (using the seismograph). Hubbert also correctly predicted that there were still more as yet undiscovered resources. With the benefit of almost 40 years of additional data, Hubbert's estimate of 4 billion barrels of ultimate oil production for Illinois seems remarkably accurate.

The undiscovered resource in Illinois, however, was not really so unknown as to be considered mysterious in any way. Hubbert knew that the Middle Ordovician formations below the St. Peter Sandstone were likely to be of reservoir quality and hydrocarbon bearing. This undiscovered resource was not really a mystery resource requiring a technological breakthrough, in that it could be approximately identified and measured. It could be readily appreciated by engineers and geologists alike.

An update of the Ohio production, however, shows more startling consequences of the lack of acknowledgment and quantification of the unexpected (fig. 2). Hubbert had described the Ohio data (as much of it as he had) as reaching a maximum between 1890 and 1900, and thereafter undergoing a "slow, steady decline" (Hubbert, 1956). Had Hubbert made some provision for unidentified but potential new productive formations, he may have come closer to what we now (with the benefit of 40 years of additional production history and exploratory data) predict as the ultimate oil production for Ohio. Had Hubbert gone one level of abstraction farther than that, he might have attributed additional recoverable resources to the development of new technology rather than to the mere application and advancement of existing technology.

Hubbert was well aware of the potential of water flooding and accounted for it in his more optimistic estimates (Hubbert, 1956). He could not, however, have anticipated specifically the production efficiency gains to be later realized by miscible flooding $\left(\mathrm{CO}_{2}\right.$ and propane), caustic and polymer flooding, and thermal recovery methods such as steam flooding and in-situ combustion. These

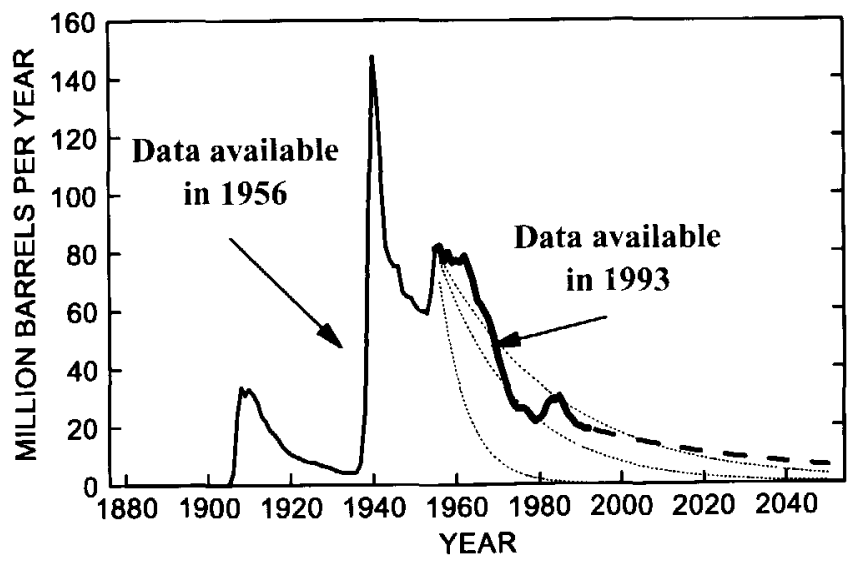

Figure 1. Oil production in Illinois. Solid line, actual production; dashed line, future production predicted on basis of data available in 1993; dotted lines, three cases foreseen by Hubbert (1956). Data available in 1956 are from Hubbert (1956); data available in 1993 are from Department of Energy, Energy Information Administration (1992). 
techniques had not yet been discovered, nor had the physical and chemical principles on which they depend. As Wallace Pratt so eloquently put it, "The tendency of the human mind is to discount or ignore the significance of what remains unknown to it" (Pratt, 1952).

The brilliant thinking of M. King Hubbert was unfortunately dimmed by his own pragmatic thought processes. His forecasts for oil production in the total lower 48 States (fig. 3) (Hubbert, 1956) were ultimately seen to be unreasonably conservative. They did not account for the march

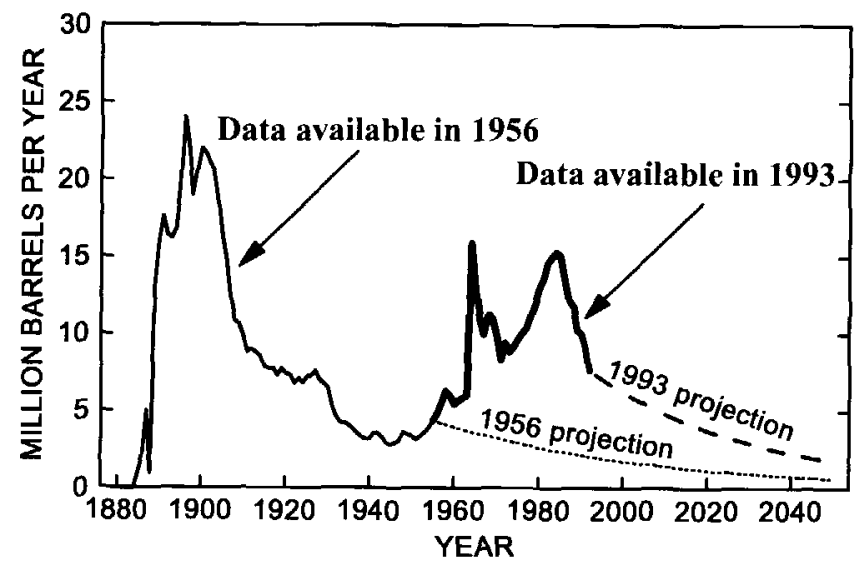

Figure 2. Oil production in Ohio. Solid line, actual production; dashed line, future production predicted on basis of data available in 1993; dotted line, production predicted on basis of data available in 1956. Data available in 1956 are from Hubbert (1956); data available in 1993 are from Department of Energy, Energy Information Administration (1992).

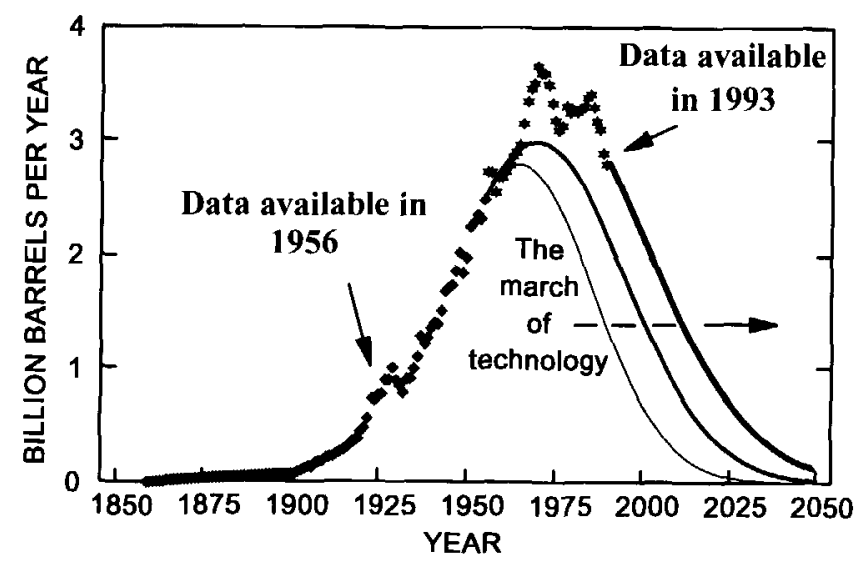

Figure 3. Forecasts for crude-oil production in lower 48 States. Diamonds, data available in 1956; stars, additional data available in 1993; heavy solid line, production predicted on basis of data available in 1993; intermediate line, production predicted on basis of data available in 1960; light line, production predicted on basis of data available in 1956. Data available in 1956 are from Hubbert (1956); data available in 1993 are from Department of Energy, Energy Information Administration (1992). of technology. Is there a better way? Can the unforeseeable be quantified?

In the early days of petroleum exploration, natural gas was thought of not only as having a bleak future, but also as having an unpromising present. Insurmountable problems of transportation, storage, and marketing precluded any long-range consideration of this clean-burning fuel as being of any significance. Many oil exploration wells were plugged with the simple epithet: "just gas found-plugged well." By M. King Hubbert's time, gas was recognized as being a legitimate fuel source, but it was still in its infancy of understanding. As shown in figure 4, Hubbert saw the Texas gas production peak at less than 7 trillion cubic feet (Tcf) per year, and the total domestic peak (fig. 5) at less than 15 Tcf per year (Hubbert, 1956). In 1972, Texas actually produced more than $8.5 \mathrm{Tcf}$, and the Nation produced more than $22.5 \mathrm{Tcf}$. The natural-gas industry was in need of a better way of evaluating its potential.

\section{A BETTER METHOD- THE METHOD OF ATTRIBUTION}

The Potential Gas Committee (PGC) has the longest standing resource estimation-reporting history. This committee has prepared and published analyses biennially since 1964 (with the exception of 1974). The PGC is made up of representatives from all segments of the U.S. gas industry as well as representatives from academic institutions and government agencies. Its resource estimates

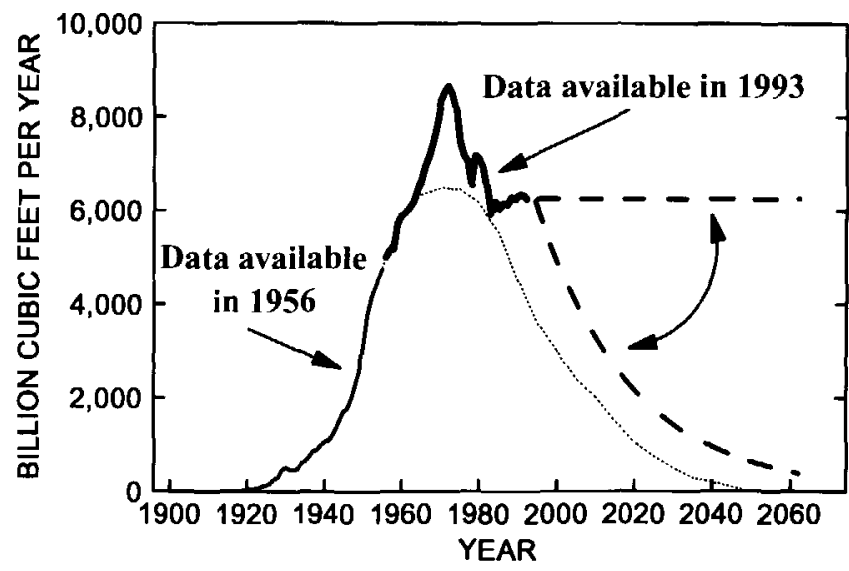

Figure 4. Natural-gas production in Texas. Solid line, actual production; dotted line, production predicted on basis of data available in 1956; dashed lines, production predicted on basis of data available in 1993. Upper dashed line represents prediction based on stabilized deliverability; lower dashed line represents prediction based on no replacement of reserves. Area between the two dashed lines represents the "gas gap" (see Howell, Wiese, and Swinchatt, this volume). Data available in 1956 are from Hubbert (1956); data available in 1993 are from Department of Energy, Energy Information Administration (1992). 
have recently been on the low end of the spectrum of other forecasts, and an analysis of the PGC's methodology yields an explanation for its apparent conservatism. The PGC has adopted the "method of attribution" as their anaIytical procedure. In this method, reservoir attributes are identified in currently producing reservoirs in known fields and statistically attributed to undrilled areas.

While this method seems logical and rigorous enough and is performed by competent and experienced personnel, some amount of resource will of necessity always be unaccounted for because of the absence of existing reservoirs using not-yet-available technology and (or) existing technology not being applied to unanticipated reservoirs (new ideas in old areas and old ideas in new areas).

Examples of the impact of not anticipating the unknown abound in our domestic exploration and production history. In the 1940's, prior to the invention of the hydraulic fracturing technique, there were no low-permeability producing formations under existing production from which to project attributes to other, similar, not-yetproducing low-permeability formations. In the 1950's, prior to the development of relative-amplitude anomaly (bright spot) technique and semisubmersible drilling rigs, there were no offshore fields from which to project attributes. In the 1960 's, prior to the understanding of gas transport and storage mechanisms in coal, there were no coalbed methane fields from which to project attributes. In the 1970's, prior to the development of the massive hydraulic fracturing technique, there were no fields in tight (low-permeability) sands from which to project attributes. In the 1980's, prior to the understanding of reservoir appreciation, amplitude-versus-offset (AVO), and cross-well tomography, there were no reserves attributed to bypassed

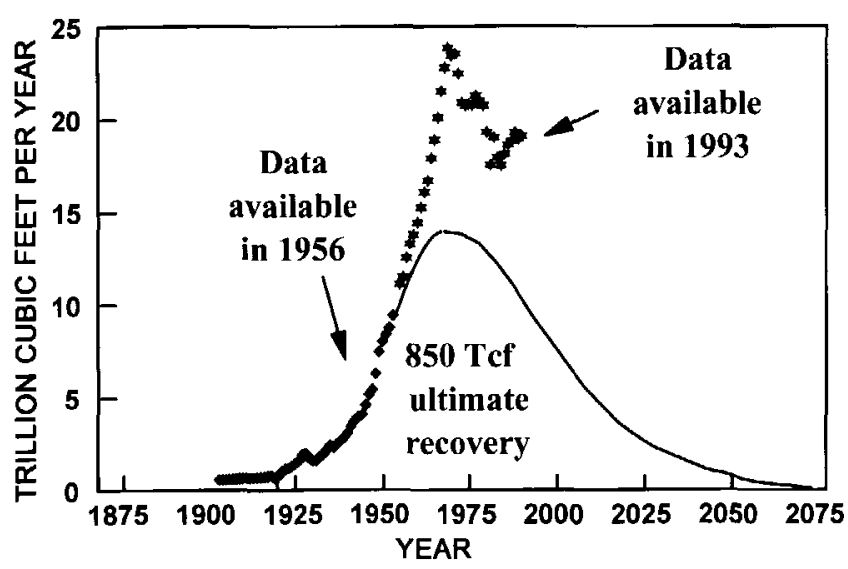

Figure 5. Natural-gas production in lower 48 States. Diamonds, data available in 1956; stars, additional data available in 1993; solid line, production (ultimately totalling 850 trillion cubic feet) predicted on basis of data available in 1956. Data available in 1956 are from Hubbert (1956); data available in 1993 are from Department of Energy, Energy Information Administration (1992). or nonconnected in-fill pockets. What is to be said of the 1990 's in retrospect is unknown to us at this time, but it would be myopic to assume that we have uncovered all of nature's secrets and exhausted the inventiveness of the human mind.

The PGC's estimate of the ultimate recoverable resource base must of necessity increase with time using the method of attribution. The slow but upward growth of this resource estimation methodology is depicted in figure 6 . Because of the PGC's biennial estimation cycle, some measure of technological growth is captured every other year, but resources specific to unforeseen long-term technological growth will appear to be discounted relative to estimates which attempt to quantify that which cannot be specifically described.

A good example of the need to either anticipate the introduction of new technology or commit to periodic increases in a resource estimate can be found in the coalbeds of northwestern New Mexico. In 1977, the Energy Information Administration (EIA) took over the responsibility of oil- and gas-reserve reporting and stated that the "New Mexico-West" region held gas reserves of 8,044 billion cubic feet (Bcf) as of the beginning of the year. As there is no production in southwestern New Mexico, this estimate essentially represented reserves in northwestern New Mexico. Thus, the New Mexico portion of the geologic region known as the San Juan Basin was estimated to contain 5.5 percent of the lower 48 States' nonassociated gas-reserve base. Since that time, production from the basin has been 5,555 Bcf. In its most recent report (U.S. Department of Energy, Energy Information Administration, 1992), the EIA recognizes 16,131 Bcf of nonassociated gas reserves.

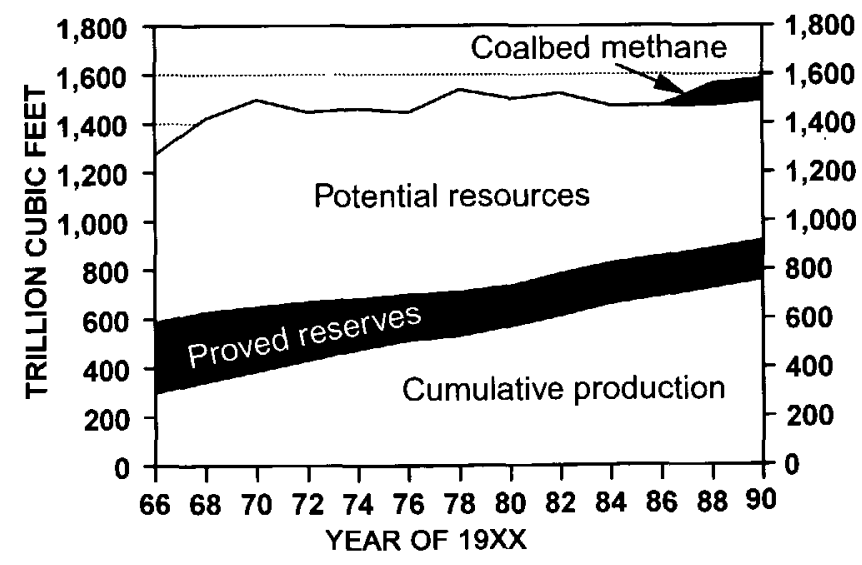

Figure 6. Natural-gas resources in lower 48 States as estimated by Potential Gas Committee (1966-1990). Dotted lines at 1,400 and 1,600 trillion cubic feet are shown to help readers recognize the slow but upward growth of potential-resource estimates made using the method of attribution (see text for explanation). Estimates of potential coalbed methane are shown separately because the Potential Gas Committee added a new group to evaluate this technology-dependent resource. 
The basin is now estimated to contain 11.5 percent of the lower 48 States' nonassociated gas-reserve base. In a 15year time period, the industry appears to have produced almost 70 percent of the reserves once estimated, but in reality, over the same time period, has more than doubled them! This procedure of converting resources to reserves is highly dependent on the development of new technology. In this case it was critical to understand the storage and release mechanisms of methane in relation to solid coal and to develop new drilling techniques to take advantage of naturally occurring cleat systems coupled with new techniques for completion (all downhole activities subsequent to evaluation but prior to actual production) such as cavitation (see Rice, this volume).

\section{THE BEST METHOD- THE RESOURCE PYRAMID}

The "resource pyramid" concept is shown in figure 7. Many people think of the natural-gas resource base as a finite volume, measurable with existing analytical yardsticks using current technology. An alternative view of the resource base is the resource pyramid, a more dynamic method of mineral-resource analysis. The resource grows with advancing knowledge and technology. Much has been written in economics literature concerning nonrenewableresource extraction programs. Deposits may be thought of as a series of layers of homogeneous quality, for which perunit extraction costs increase with depth. Altematively, the deposit may be of constant accessibility but of a heterogeneous nature. In either case, as quality (or accessibility) deteriorates, the marginal extraction costs increase. Also in either case, the resource becomes unprofitable before it is physi-

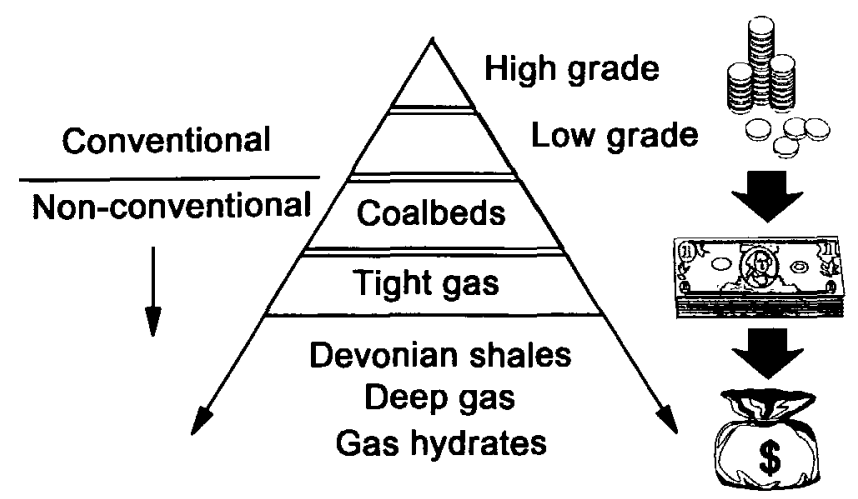

Figure 7. The resource pyramid, a method for estimating naturalgas resources that assumes the resource base will increase with advancing knowledge and technology. Drawings at right show that per-unit extraction costs increase with depth in pyramid. Conventional resources are in sandstones and limestones in conventional traps; nonconventional resources are more technologydependent resources. cally exhausted. The effect of technological improvement is to either lower extraction costs or improve accessibility. The Fifth World Congress of the International Economic Association (Tokyo, 1979) addressed concerns about perceived limitations on economic growth imposed by expected scarcities of natural resources. One key question was: "Are there really depletable resources?" The answer is "yes" if and only if there is an associated "cessation, once and for all, of technological progress" (Boserup, 1979). This is clearly not the case. Technological progress is alive and well, and technology is the most powerful nonprice determinant of supply. Applying this concept to natural gas as shown in figure 8 , the high-grade portion would be what is generally referred to as conventional resources (those that can be recovered from traditional reservoir types using traditional production practices), $760 \mathrm{Tcf}$ of which has already been produced. The major portion of the $160 \mathrm{Tcf}$ of gas in inventory (reserves) is conventional. As we explore deeper into and extract deeper from the pyramid, the resource becomes lower and lower in grade and more and more expensive to recover. According to the National Petroleum Council (1992), approximately $825 \mathrm{Tcf}$ of the estimated $1,135 \mathrm{Tcf}$ of higher cost undiscovered gas lies in this region of the pyramid at recovery costs below about $\$ 3.50$ per million British thermal unit (MMBtu). Approximately 600 Tcf can be recovered at below $\$ 2.50$ per MMBtu. One will exploit the resource pyramid as deeply as economics will permit. Coalbed methane, gas from tight sands, and Devonian shale gas were recent beneficiaries of a governmental tax-incentive program (Section 29 of the Internal Revenue Tax Code). With this support, technology was developed and transferred to the field, which resulted in tremendous conversion of resources to reserves, as seen in the San Juan Basin example.

The U.S. Geological Survey estimates that there are 5,000 Tef of gas in place in the greater Green River Basin

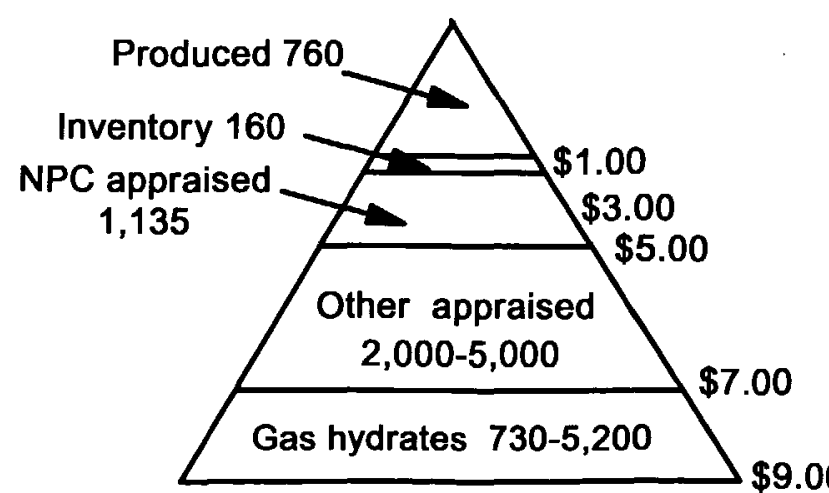

Figure 8. Resource pyramid showing natural-gas resources in lower 48 States as estimated by National Petroleum Council (1992). Values are in trillion cubic feet. Dollar figures at right show estimated recovery costs per million British thermal units. NPC, National Petroleum Council. 
of Wyoming alone (see Law and Spencer, this volume). Although only a small fraction of this resource is now considered economically recoverable, new technology may someday permit increased recovery. The USGS also reports enormous volumes of gas hydrate off our shores (see Kvenvolden, this volume). This is gas captured in the lattice structure of water under certain conditions of temperature and pressure. At some later date, as with the diffuse Green River gas, these hydrates may become economically recoverable. The resource pyramid concept is a better reflection of the dynamic nature of the natural-gas resource base than is the finite volume model.

\section{HOW WE GET THERE FROM HERE- POLICY}

There is a continuing misconception that since the United States has only 9.5 years' worth of gas reserves, we are in danger of running out of gas and therefore should hesitate to make any long-term capital investments requiring the use of gas. This idea however, could not be farther from the truth. As stated in the 1992 National Petroleum Council report, "the gas resource base itself is not (and should not be viewed as) a limit to expanded gas usage" (National Petroleum Council, 1992). Nine and a half years ago we only had 9.5 years' worth of reserves. Today's just-in-time economics would preclude a cost-conscious, market-oriented, competitively driven exploration organization from placing in working inventory more gas than it can turn over before its reorder point.

Studies indicate that with this Nation's current mix of reserves, from the high-porosity, high-permeability formations of the offshore, to the low-porosity, low-permeability rocks of the Rocky Mountains, we could sustain current needs for deliverability (the rate at which existing reserves can be produced from existing completions in existing wells) with a reserve-life index of only 7.5 years. In accordance with this concept, Canada has recently dropped its R/P-15 test, which required producers to demonstrate a 15-year reserve, in favor of a more market-based procedure to obtain export licenses. Canadian gas is extremely price competitive during this inventory-reduction period. Thus it is the resource number, not the reserve number, that should be used in long-range planning for the supply of fossil fuels. The correct R/P (resource/production) ratio for the lower 48 States is at least 71 years, not 9.5 years, on the basis of current rates of consumption.

The transfer of technological advances into the field has enhanced deliverability from the lower 48 States' natural-gas resource base. Reduced drilling times, lower well costs, higher success ratios, better formation evaluation, and more effective completions have reduced the number of drilling rigs needed and the time required to replace deliverability. Advances range from exploration through exploitation to production.

Improvements in well siting continue to increase success ratios, despite offsetting issues related to the maturing of domestic exploration. Building on the geophysical bright spot and ESP (extraction of seismic properties) techniques of the 1960's and 1970's, modern computer workstations are allowing newer computation-intensive seismic interpretations. For example, amplitude-versus-offset (AVO) and cross-well tomography allow direct detection with unprecedented precision of gas in undrilled prospects and bypassed compartments. By eliminating a significant percentage of avoidable dry holes, the industry is able to achieve record numbers of gas completions per rigs running.

Once the wells have been drilled, new and improving methods of borehole evaluation are permitting more complete and efficient recoveries of natural gas. Fewer potentially productive zones are bypassed. Particularly significant methods have included advanced permeabilitymeasurement tools and through-casing evaluation devices. Advances in onshore horizontal drilling and guidance mechanisms show early promise of large returns in both shallow formations and those that have linearly oriented fractures. With horizontal drilling, many areas have already shown three-fold increases in productivity for only oneand-one-half-fold increases in cost. The progress made onshore in horizontal drilling also has tremendous potential for the shallow, low-pressure gas-bearing formations offshore (perhaps even the gas hydrates). Continuing development of slim-hole drilling techniques and evaluation tools will allow wells to be drilled with smaller diameter bits and casing strings. By reducing both drilling time and overall well cost, the industry can drill more wells per year per rig at less capital per well. Having drilled and evaluated wells, new completion techniques and fluids are continually yielding higher production rates per completion foot. Hydraulic fracturing techniques in particular have demonstrated continuous refinement over the years and are expected to continue to improve over the next two decades. Work on fracture-length extension, fracture orientation, and verticalfracture containment is being done by the industry and by the Gas Research Institute. The Gas Research Institute's plans for a Hydraulic Fracture Test Site and a Fracture Fluids Characterization Facility are still preliminary, but once implemented, are expected to reduce gas-well completion costs and enhance deliverability.

Different geological provinces exhibit different deliverability characteristics. The characteristics of each region, however, are consistent over time. The basic unit of measurement of deliverability is thousand cubic feet per day (Mcf/d) per billion cubic feet (Bcf) of reserve. Young, uncompacted, and highly porous formations of Pleistocene age that are found in the Gulf of Mexico exhibit high deliverabilities-close to 1 million cubic feet per day $(\mathrm{MMcf} / \mathrm{d})$ per each Bcf of reserve. Older, consolidated, 
and lower porosity rocks of Permian age in the Rocky Mountains deliver only about $250 \mathrm{Mcf} / \mathrm{d}$ per each Bcf of reserve. Coalbeds in the San Juan Basin demonstrate even lower deliverabilities. Each region has been found responsive to different technological approaches, so the industry has tailored its technology for each region. Significantly, an otherwise highly competitive industry is sharing its research results. The Gas Research Institute has an aggressive technology-transfer program in which all operators are allowed to participate. The free flow of information related to successful technology advances disseminates rapidly in the field and is adopted by major companies and independent producers alike.

\section{CONCLUSION}

To paraphrase the famous quote from Wallace Pratt (1952), the future of methane is in our own hands. Not only must we roll up our sleeves and work to develop new technology, we must cast our ballots for elected representatives who will pass laws favoring domestic energy production. And we must publish our views of the energy situation.

From time to time throughout history, pessimistic appraisals of our Nation's resource base have led our Government, and indeed the energy industry, to adopt what were later seen to be misguided policies, such as the Fuel Use Act of 1976, which prohibited the use of our "limited natural gas resources" (as they were perceived at the time) as a boiler fuel. Alternatively, the Natural Gas Policy Act of 1978 provided incentives for the production of what at that time were seen to be high-cost, high-risk sources of natural gas. While the prohibition failed and was later repealed, the incentives worked, but were allowed to expire. The lack of a cogent and consistent energy policy has disrupted the energy industry for the major part of this century.

In the final analysis then, the "Future of Energy Gases" is in our own hands-it is up to academic institutions, industry associations, and governmental agencies to study this abundant natural resource and make informed recommendations regarding its development and use. It is up to the government leadership to heed these recommendations, to provide incentives, and to allow access to this Nation's most environmentally benign fuel. And it is up to the industry to interact with all of the above to insure a future in which energy gases can meet their full potential.

\section{REFERENCES CITED}

Boserup, M., 1979, Are there really depletable resources?, in Bliss, C., ed., Economic growth and resources: New York, St. Martins Press.

Hubbert, M. King, 1956, Nuclear energy and the fossil fuels: American Petroleum Institute, Drilling and Production Practices (1956), p. 7-25.

Levorsen, A.I., 1967, Geology of petroleum (2d ed.): San Francisco, W.H. Freeman and Company, 924 p.

National Petroleum Council, 1992, The potential for natural gas in the United States: National Petroleum Council, December 1992, six volumes.

Potential Gas Committee, 1966-1990, Potential supply of natural gas in the United States: Golden, Colo., Potential Gas Agency, Colorado School of Mines.

Pratt, W.E., 1952, Toward a philosophy of oil finding: American Association of Petroleum Geologists Bulletin, v. 36, no. 12, p. 2231-2236.

U.S. Department of Energy, Energy Information Administration, 1992, U.S. crude oil, natural gas, and natural gas liquids reserves, 1991 Annual Report: DOE/EIA 0216(91). 
What proportion of the energy mix will energy gases make up in the future? Reports in this section explore the issues and uncertainties involving pricing, technology, environment, and resource potential, all of which play a role in determining how energy will be supplied and used in the future. Aside from issues of fuel choice, future energy systems will incorporate more efficient methods of energy consumption, which will effectively provide society with a resource by limiting the amount of energy needed.

As our energy mix continues to evolve, it is important that internal and external costs as well as long-term sustainability be incorporated into the design of future energy systems. With regard to the future use of natural gas, predictions of consumption rates cover a broad range; in fact, many forecasts predict rates of consumption that greatly exceed published resource estimates. This discrepancy has created a perception of a gap between the amount of gas that exists and the amount of gas that will be used. As geologists, economists, and engineers, we see this gap as both an opportunity and a need for further research. In the final analysis, the potential for natural gas will be determined in the marketplace and by the imagination and perspicacity of explorers. 


\title{
THE FUTURE OF ENERGY GASES
}

U.S. GEOLOGICAL SURVEY PROFESSIONAL PAPER 1570

\section{Sustainable Operation-Natural-Gas Contribution}

\author{
By Rex T. Ellington ${ }^{1}$ and Mark $\mathrm{Meo}^{1}$
}

\section{CONTENTS}

\begin{tabular}{|c|c|}
\hline Abstract ............. & 843 \\
\hline Introduction....................... & 843 \\
\hline Sustainable Development ........... & 844 \\
\hline Industrial Ecology as an Organizing & \\
\hline 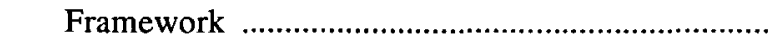 & 845 \\
\hline Sustainable Energy Futures .......... & 845 \\
\hline Outlook for Natural Gas ........................ & 846 \\
\hline Elements of Systems Perspective ............... & 846 \\
\hline Analysis of Integrated Energy Systems & 846 \\
\hline 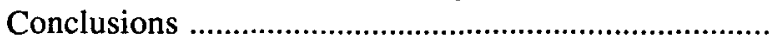 & 847 \\
\hline References Cited & 847 \\
\hline
\end{tabular}

\begin{abstract}
The need to guide economic development in a sustainable manner is based on the growing belief that humanity's propensity to exceed environmental thresholds could severely hinder efforts to improve worldwide living conditions. In view of the rapid pace of population growth in industrializing nations and the globalization of many commercial markets, cumulative environmental damages have heightened the responsibility of industrialized nations to use science and technology to help other nations achieve desirable levels of economic prosperity and environmental quality. For all nations, the challenge of sustainable development will be to use natural resources in an economic and equitable manner that results in minimum environmental impact over time.
\end{abstract}

\footnotetext{
'University of Oklahoma, Norman, OK 73019.
}

For these reasons, the expanded use of natural gas will continue to be prominent in the debate about policy alternatives for advancing sustainable development. As the cleanest burning fossil fuel, natural gas and its attendant supply and distribution infrastructure are characterized as important for many reasons including: reducing greenhouse gas emissions; generating minimal solid and liquid wastes during production, transportation, and consumption; serving as a transition fuel to a future with greater reliance on renewable energy sources; and for providing an industrial base for developing more environmentally conscious technologies. Other arguments for its expanded use have emphasized the opportunity to induce technological innovations and behavioral changes that are more compatible with sustainable development. The criteria by which society can design sustainable development strategies and determine whether environmental quality goals have been met will be key to the effective implementation of clean-fuel programs and expansion of natural-gas uses. This issue is timely, particularly with regard to how clean fuels can be nested within conceptual policy and planning frameworks that address sustainable industrial development more broadly.

\section{INTRODUCTION}

Because the interactions of material and energy flows within the total environment are implicit in discussions of sustainability, assessment of natural-gas applications should include the complete technical system. Recognition of this perspective is echoed by the recent adoption of the fuel cycle by the U.S. Department of Energy as an analytic framework for technical systems assessment (U.S. Department of Energy, 1992). Yet for purposes of assessing sustainability more generally, the complete life cycle of the natural-gas system should be addressed to provide vital 
information for making informed decisions regarding energy use, environmental quality and economic performance over time (Ellington and others, 1992; Ellington and Meo, 1993). Herein, we build upon the systemwide, intertemporal perspective to examine the potential of natural-gas systems for fostering sustainability with several criteria that should prove helpful for making planning and management decisions. Such criteria should prove valuable for analysts who wish to quantify more completely the specific performance measures of natural-gas systems that may experience wider application in the future.

\section{SUSTAINABLE DEVELOPMENT}

Sustainable development, defined as development that meets the needs of the present without compromising the ability of future generations to meet their needs, is now an accepted international objective. The 47th Assembly of the United Nations has assumed the task of implementing Agenda 21, a key product of over 150 nations at the U.N. Conference on Environment and Development held in Rio de Janeiro in June of 1992. Agenda 21 is the first global acknowledgment that environmental quality and economic health are tightly linked. Agenda 21 espouses a more harmonious combination of environment and economics to achieve sustainability (United Nations, 1992).

Because the well-being of all peoples will depend directly on the continued health of the Earth's natural resources, Train (1992) suggested that the natural resources, economy, and way of life of the United States will all deteriorate if the nation should continue merely to react to environmental damages as they occur. With the expectation that, over the next five decades, the level of economic activity of the country will quadruple, and global population double, economically and environmentally disastrous results are presumed to ensue if practices, processes and methods of this century are not changed. Therefore, it appears that general agreement exists that the world has now moved beyond economic interdependence to ecological interdependence (MacNeill, 1989, 1991). Awareness of this issue in the United States is reflected by formation of a 25-member President's Council on Sustainable Development to create new approaches for combining economic development with environmental protection.

One of the key areas covered in Agenda 21 is energy (Section I, Chapter 7 and Section II, Chapter 9), which has a greater impact on the environment than almost any other resource or activity (United Nations, 1992). Fundamental changes must be made in the way the country produces and uses energy. While progressive energy companies and industries that further the cause of sustainable development will likely become more valuable and more highly regarded in the marketplace (Popoff, 1992), the reverse could also be true. For energy systems to achieve increased environmen- tal compatibility in such a setting, a number of guides for examining development options in the planning and management process must be developed. These include a fairly complete conceptual framework that can facilitate productive institutional and technological interaction, key performance measures by which progress can be quantified, and decision rules that will enable complex technical and environmental conditions to be accommodated.

To better appreciate why the need for an analysis framework arises, several characteristics of the sustainable development concept need to be clarified. Although consensus has been reached about the general goal of sustainability, little agreement exists about the optimal paths by which society can pursue it (Costanza, 1991). Solow (1992) suggested that sustainable development exists as long as society expressly concerns itself with its total capital, taking into account substitution possibilities between "natural capital" (extractive resources and the natural environment) and other forms of capital. In an intergenerational sense, Solow (1992) argued that flawed indicators such as the Gross National Product less the depreciation on physical and natural capital is a measure of sustainable income for future years. He noted that the level of sustainable income could rise from one generation to another if the earlier generation protected its environmental assets, consumed less nonrenewable resources, and invested aggressively in new productive capacity. This prescription would include gains in energy efficiency and advances in clean fuel use and environmentally conscious technology.

With the current absence of operational definitions and key data to guide public policy more effectively, definitions of sustainability are largely contextual. Accordingly, these definitions are different for individual companies, communities of companies, or communities of people and metropolitan areas. Furthermore, the environmental and energy policy impediments that constrain public sector leadership suggest that individual businesses may be able to move far more rapidly in meeting their most immediate challenges of sustainable development. National policy for the near future will likely follow from the influence of thousands of individual business decisions undertaken in response to changing markets and rising public demand for environmental quality.

In such a decentralized decisionmaking context, the detailed definition of sustainable development for individual companies or industries will depend on how corporate leadership weighs the time value of Solow's total capital (including natural capital), short-term economics, ultimate environmental impact, and approval of customers (actual customers, stockholders, and general public). One such trend that bodes well for these concerns is dematerialization, which seeks continuous reduction in material and energy use to achieve given results (Ausubel and others, 1989). Each of these points underscores the notion that, to attain sustainability, everything affects everything else. 


\section{INDUSTRIAL ECOLOGY AS AN ORGANIZING FRAMEWORK}

Industrial ecology is rapidly gaining recognition because it provides a framework within which ideas from different communities of knowledge and human experience are combined for action on the problems associated with sustainability. Industrial ecology has been defined as the totality or patterns of relations between various industrial activities, their products, and the environment (Patel, 1992), and as a new approach to the industrial design of products and processes and the implementation of sustainable manufacturing strategies (Jelinski and others, 1992). It has been called the best candidate to date for the needed conceptual framework and involves designing industrial infrastructures as if they were a series of interlocking manmade ecosystems interfacing with the natural global ecosystem (Ayers, 1989; Tibbs, 1991). This perspective represents a marked departure from the mindset of "conquering nature" to cooperating with it. In broad terms, industrial ecology recognizes that as society embraces a more industrialized world, its industrial systems will continue to grow larger with outputs reaching such a magnitude that, when compared to the assimilative capacity of the natural environment, the systems will not be sustainable as they exist. By linking outputs of one system as inputs to another, industrial ecology design seeks to reduce society's waste burden on the environment and extend the useful life of the combined system.

It should be noted, however, that owing to changes in energy and material flows among and between elements of the natural and built environment, both the industrial and natural systems will be in an unsteady state at all times. Planners who choose to use equilibrium-oriented frameworks must recognize this.

\section{SUSTAINABLE ENERGY FUTURES}

Strategy development for sustainable energy production and utilization demands a long-term future-oriented focus. Although recent fuel-use trends reflect movement toward fuels with lower carbon to hydrogen ratios, a focus on sustainability may well recast the role of depletable hydrocarbon resources (Ausubel and others, 1989; Freedman, 1991; Johansson and others, 1993; Williams, 1992). Some fuels may be too "dirty" to permit use for large-scale energy production. Others fuels may be too precious to future generations to advocate them for general use. With a sustainable development planning goal to move away from depletable resources over the long term, the use of fossil fuels is coming under increased scrutiny with regard to their environmental impact. Long-recognized attributes of natural gas are attracting renewed attention. Accordingly, many experts advocate its use during the transition period, however long.
The synfuels experience of the 1970's, which evolved around the single public policy goal of energy independence, provides a rich history of difficulties that should not be repeated, particularly if sustainability objectives are sought. In contrast to the concepts embraced by industrial ecology, synthetic fuels were developed under the auspices of a well-meaning Government, which failed to acknowledge a variety of issues central to meeting any sustainability objective. The synfuels initiative was fundamentally flawed in that it was defined as a single-issue program when the realities of modern industrial activities with their interrelated problems suggested otherwise. The program started as a national emergency effort to provide a shortterm answer to the potential interruption of foreign-oil supply. It was basically insensitive to external environmental and market conditions, which rendered it irrelevant within just a few years. Technologies, developed decades earlier, were improved and accommodated to prevailing environmental regulations. Massive, complex plant installations were planned with the objective of using economies of scale to compete with projected escalated prices of foreign oil. Philosophically, the effort was inflexible and maladaptive. Consequently, it was far removed from industrial ecology. Any effort to revive technical processes from this era must be examined with care and an entirely new set of design criteria adopted before they are proposed for sustainable development.

Fundamental limits to the use of different fossil fuels may become apparent in the amount of gaseous, liquid, and solid wastes that natural processes can absorb. Therefore, humanity should plan for the time when the sustainability of industry, agriculture, population centers, and nations must ultimately depend upon energy sources that are truly renewable. Society will have to depend in one way or another on the Sun, or on reactions deep within the Earth (Johansson and others, 1993; Tester and others, 1991). Renewable energy systems include primary or direct use of solar inflow such as solar-thermal and photovoltaic systems, and those depending on secondary or delayed use such as hydropower, wind energy, ocean energy, biomass, and anaerobic digestion of organic molecules. Although the characteristics of individual processes are thoroughly documented, analyses often examine them as unit processes rather than in the context of complete systems with mandatory infrastructure and external energy or material subsidies. Only when such detailed analyses are executed so generic systems containing specific processes can be rank-ordered will the true potential of each be evident (DeLuchi, 1991; Ellington and others, 1993).

The role natural gas can play in achieving a sustainable future has been examined by many energy specialists. The context of many of these analyses is resource availability (potential, economically proven and addition rate), cleanliness, safety, and ease of application (for example, Lee, 1989; McCormick, 1990; Sperling, 1991). Depending 
on specific societal goals, natural-gas use is influenced by market penetration rates, natural-gas resource additions and gas-application advantages (Tabors and Monroe, 1991). The context of such analyses merits reconsideration in light of the requirements of sustainability and industrial ecology to elucidate the merits of natural gas.

\section{OUTLOOK FOR NATURAL GAS}

Within the industrial ecology framework, policy issues exist that must be addressed before the concept of harmonizing with the environment can be applied widely. These include such issues as the selection of areas for research expenditure, ways to combine technologies, and, especially, the need to articulate the proper criteria for making decisions. For example, an assessment of transportationresearch needs for overall policy development would reevaluate gross system questions such as rail versus trucks, the potential for telecommunications to reduce travel needs, improving efficiency and (or) emissions of individual services, and improving energy efficiency of systems supplying energy to transportation units (Weiss and Heywood, 1991).

Whereas such studies are important for guiding public sector energy policy, we believe there is a comparable need to provide, for the private sector, logical detail to the framework for merging the technology and engineering aspects with the managerial aspects of strategy and policy development. This integration is necessary to facilitate the large number of individual business decisions that will be made in efforts to optimize the factors related to sustainable operations and corporate life (Ellington and others, 1992; Ellington and Meo, 1993).

\section{ELEMENTS OF SYSTEMS PERSPECTIVE}

We propose a method of analysis, which addresses industrial ecology objectives, that starts with careful definition of all of the physical and corporate components pertinent to the problem. This framework requires first the proper systems perspective to identify all the technical infrastructure related to a given primary process or operation of interest and all the energy and material imports from the outside.

Determination of system boundaries is a matter of perspective, that is, the identification of related entities to ensure that important components are not omitted from analysis. For example, definition of the greenhouse gas emissions resulting from selection of a given process or operation requires the identification of all infrastructure elements on which a primary process depends. The identification must go backward to raw resources and forward to the final treatment and disposal of wastes, and it must en- compass all consumables and energy subsidies related to every element (Ellington and Meo, 1990-91). The primary process/operation could not function should this infrastructure not exist. Elements that are separated from the primary process in distance or time are still necessary for a complete analysis. This system definition must ensure that it also includes all solid and liquid wastes and their effects. In an environmental sense, the boundaries should circumscribe the entire impact of the system on the environment. In an economic sense, the system boundaries should reflect the entire cost the consumer or taxpayer pays, which determines whether a product, service, industry, or economy is competitive (Drucker, 1992). If the system is inherently uneconomic, a process of interest nested within the system should have a poor outlook.

The time interval to be used in analyzing the effects of a system and its products has a variety of interpretations. Our position is that it should be of sufficient length to include all of the significant intertemporal effects of the system (for example, emissions, energy and economic elements). In many instances, it will begin with system construction and raw material recovery, and extend through all operations, salvage, final waste disposal, and, perhaps, long-term storage, of all products. Other lifecycle assessments include different sets of factors (Keoleian and Menerey, 1993). Yet, as impacts are regarded more seriously, more inclusive life cycles must be used. The life of the physical plant may be some 30 years. The life of environmental impacts from wastes may range from a few years beyond plant life for liquids, a few decades for solids, to a century or two for greenhouse gases, to a thousand years for nuclear wastes. These elements must all be considered in examining systems to assess the degree to which they admit to sustainability.

\section{ANALYSIS OF INTEGRATED ENERGY SYSTEMS}

As developed in the 1980's, the Integrated Energy Systems Program had the objective of evaluating innovative combinations of existing and emerging technical processes to provide new sources of clean energy and chemicals without incurring additional environmental controls. This effort involved an international consortium including the University of Oklahoma, Massachusetts Institute of Technology Energy Lab, and groups from Canada, Japan, Sweden, Taiwan, and West Germany (Ball, 1986; Lee and others, 1990). The concept appeared deceptively similar to industrial ecology. However, the total systems perspective, life cycle, energy usage, and other costs per unit output inherent in sustainability objectives were absent. These systems tended to be very complex (occasionally involving full nuclear heat plants), very costly, and had low energy efficiency like those in the synfuels era. 
To develop concepts that were more compatible with the industrial ecology approach, we conducted a number of studies of natural-gas systems. Primary interest was afforded studies of energy efficiency, overall economic performance, and systemwide emissions of greenhouse gases. With a net energy analysis of a natural-gas well to gas-fired boiler study (Melcher and others, 1976) as a starting point, substitution of a natural gas-fired combined-cycle (NGCC) unit for power generation was examined because efficiencies of about 45 percent were being obtained with grounddesigned gas turbine units. With all other losses in the well through NGCC unit taken into account, a system energy efficiency of about 37 percent seemed practical (Ellington and others, 1989). Similar results were reported by Lee (1989). For reference, coal-fired boilers with stack-gas scrubbing had efficiencies of about 30 percent for the unit alone. Consideration of the rest of the coal system would certainly decrease this energy efficiency value. Other comparisons showed that the coal system would cost more and produce much greater amounts of greenhouse gases and solid as well as liquid wastes. This is the kind of comparison that should be carried out in detail quantitatively for systems proposed as alternatives for natural-gas systems.

Further studies of NGCC systems involved analysis of the dual modification of $\mathrm{CO}_{2}$ recovery from system tail gas and use of the $\mathrm{CO}_{2}$ for enhanced oil recovery. This combination would seem to enhance sustainability by sequestering $\mathrm{CO}_{2}$ equal to a fraction of the pore volume of the reservoir at reservoir conditions for geologic time, after breakthrough gas recycling and (or) export to other projects is ended. The actual cost of sequestering would be the total cost of $\mathrm{CO}_{2}$ recovery and compression minus the cost of competitive natural $\mathrm{CO}_{2}$ from natural reservoirs. Furthermore, replacement of natural-reservoir $\mathrm{CO}_{2}$ by power-system $\mathrm{CO}_{2}$ could reduce net greenhouse warming forcing (the quantitative measure of atmospheric warming tendency) that results from separate power generation and enhanced oil recovery. The NGCC case was also used in an examination of the earlier conventional wisdom that large plants should be constructed all at once. The NGCC system is ideal for staged construction because of short lead times on the types of equipment used as well as short construction times (Boyd, 1988). Then, subsequent units can be installed as load building requires, using project financing, that is, revenue from the earlier unit(s). Although time to final payout changes little, capital demands on the financing unit are decreased by approximately one-half. One or more combinations of the above configurations might well be the benchmark against which others are measured on the way to true sustainability.

Under a full set of sustainability oriented industrial ecology requirements, the basic characteristics of alternatives to current energy systems or natural-gas systems should be scrutinized carefully. For example, we analyzed the total woody biomass to methanol system as an alternate transportation fuel to the gasoline system. The results suggest that intersectoral transfer of pollution and increase of greenhouse warming forcing would result (Ellington and others, 1993). Any system that utilizes gasification of a heavier fossil fuel to obtain a synthesis gas rejects a significant portion of the energy in the raw resource as heat in the gasification and rejects a corresponding quantity of $\mathrm{CO}_{2}$. Thus, for a given quantity of useful energy at the output of the system, total wastes and total costs are likely to be greater and energy use efficiency is likely to be substantially lower. Gasification of hydrocarbons to produce synthesis gas or hydrogen for fuel-cell use would provide substantial penalty against the apparent attributes of fuel-cell power generation. Gasification as an integral process to development of a "hydrogen economy" would carry the same burden. Even hydrogen made by use of photovoltaic power is at the end of a complex, energy-consuming system characterized by significant investments, energy and chemicals consumption, and frequent replacements for sound operating lives.

\section{CONCLUSIONS}

Use of a total physical system perspective and a generalized life-cycle analysis to evaluate energy gas processes can be used to guide strategy directed toward long-term sustainability. The application of the systems perspective can be used to determine whether seemingly clean, single processes may exist in systems that do not meet sustainability objectives. With systematic application of our method, natural-gas systems can provide significant energy and environmental advantages as economic, energy-use, efficiency, and environmental impact considerations of sustainable development become more important to society.

\section{REFERENCES CITED}

Ausubel, J.H., Frosch, R.A., and Herman, R., 1989, Technology and environment-An overview: Washington, D.C., National Academy of Engineering, p. 1-20.

Ayers, R.U., 1989, Industrial metabolism, in Ausubel, J.H., and Sladovich, H.E., eds., Technology and Environment: Washington, D.C., National Academy Press.

Ball, B.C., 1986, Integrated energy systems meeting summary: Cambridge, Mass., Massachusetts Institute of Technology.

Boyd, J.A., 1988, Analysis of the staged construction of an integrated gasification combined cycle plant with methanol synthesis and $\mathrm{CO}_{2}$ recovery: Norman, Okla., University of Oklahoma, M.S. thesis.

Costanza, R., ed., 1991, Ecological economics: The science and management of sustainability: New York, Columbia University Press.

Deluchi, M.A., 1991, Emissions of greenhouse gases from the use of transportation fuels and electricity: Argonne, Ill., 
Center for Transportation Research, Argonne National Laboratory, (AN/ESDM/TM-22).

Drucker, P.F., 1992, The new society of organizations: Harvard Business Review, September-October.

Ellington, R.T., Boyd, J.A., and Floyd, R.A., 1989, New opportunities for gas liquids in the electric power industry and other energy production, Proceedings of Gas Processors Association, San Antonio, Texas, 68th Annual Convention.

Ellington, R.T., Meo, M., and Mannan, M., 1991, Energy efficiency of a natural gas-fired combined cycle power plant, in Hydrogen energy and power generation, Proceedings of the International Congress on Energy and Environment, 9th: New York, Nova Science Publishers.

Ellington, R.T., and Meo, M., 1990-91, Calculating the net greenhouse warming effect of renewable energy resourcesMethanol from biomass: Journal of Environmental Systems, v. 20, no, 4 , p. $287-301$.

Ellington, R.T., Meo, M., and Baugh, D., 1992, The total greenhouse warming potential of technical systems-Analysis for decision making: Journal of the Air and Waste Management Association, v. 42, no. 4, p. 422-428.

Ellington, R.T., and Meo, M., 1993, Total environmental quality-Integrating engineering and management for sustainable development: Address to American Institute of Chemical Engineering, 1993 Summer National Meeting, Seattle, Wash., August 15-18.

Ellington, R.T., Meo, M., and El-Sayed, D.A., 1993, The net greenhouse warming forcing of methanol produced from biomass, in Biomass and Bioenergy: New York, Pergamon Press.

Freedman, S.1., 1991, The role of natural gas in electric power generation, 1990 to 2020, in Tester, J.W., Wood, D.O., and Ferrari, N.A., eds., Energy and the Environment in the 21 st Century: Cambridge, Mass, MIT Press.

Jelinski, L.W., Graedel, T.E., Laudise, R.A., McCall, D.W., and Patel, C.K.N., 1992, Proceedings of the National Academy of Science, v. 89, p. 793-797, February.

Johansson, T.B., Kelly, H., Reddy, A.K., and Williams, R.H., 1993, Renewable fuels and electricity for a growing world economy-Defining and achieving the potential, in Johansson, T.B., Kelly, H., Reddy, A.K., and Williams, R.H., eds., Renewable Energy-Sources for Fuels and Electricity: Washington, D.C., Island Press.

Keoleian, G.A., and Menerey, D., 1993, Life cycle design guidance manual-Environmental requirements and the product system, EPA600/R-92/226: Washington, D.C., EPA Office of Research and Development, January.

Lee, T.H., 1989, Advanced fossil fuel systems and beyond, in Ausubel, J.H., and Sladovich, H.E., eds., Technology and Environment: Washington, D.C., National Academy Press.

Lee, T.H., Ball, B.C., and Tabors, R.D., 1990, Energy aftermath-How we can learn from the blunders of the past to create a hopeful energy future: Boston, Mass., Harvard Business School Press.

McCormick, W.T., Jr., 1990, The uncertain future role of natural gas, in Energy-Production, consumption, and consequences: Washington, D.C., National Academy Press, p. 165-172.

MacNeill, J., 1989, Strategies for sustainable development: Scientific American, v. 261, no. 3, p. 155-165.

MacNeill, J., 1991, Sustainable development and the earth summit: Journal of the Air and Waste Management Association, v. 41 , no. 12 , p. $1554-58$ and $1672-74$.

Melcher, A.V., Maddox, K., Prien, D., Nevens, T., Yesavage, V., Dickson, P., Fuller, J., Loehr, W., Baldwin, R., and Bain, R., 1976, Net energy analysis-An energy balance study of fossil fuel resources: Golden, Colo., Colorado Energy Research Institute.

Patel, C.K.N., 1992, Industrial Ecology, Proceedings of the National Academy of Science, v. 89, p. 798-799, February.

Popoff, F., 1992, September-October, Companies change course, progressive companies will merge economics and environment: Washington, D.C., Environmental Protection Agency Journal, p. 26-28.

Solow, R.M., 1992, An almost practical step toward sustainability: Washington, D.C., Resources for the Future.

Sperling, D., 1991, An incentive-based transition to alternative transportation fuels, in Tester, J.W., Wood, D.O., and Ferrari, N.A., eds., Energy and the Environment in the 21st Century: Cambridge, Mass., MIT Press, p. 2151-264.

Tabors, R.D., and Monroe, B.L. 1991, Transitional strategies for emission reduction in electric power generation, in Tester, J.W., Wood, D.O., and Ferrari, N.A., eds., Energy and the Environment in the 21st Century: Cambridge, Mass., MIT Press.

Tester, J.W., Wood, D.O., and Ferrari, N.A., eds., 1991, Energy and the environment in the 21 st Century: Cambridge, Mass., MIT Press.

Tibbs, H., 1991, Industrial ecology-An environmental agenda for industry: Cambridge, Mass., Arthur D. Little, Inc.

Train, R.E., 1992, A Call for Sustainability, Environmental Protection Agency Journal, v. 18, no. 4, p. 7-13.

United Nations, 1992, Earth Summit-Press Summary of Agenda 21, Final Text, United Nations Conference on Environment and Development: New York, United Nations.

U.S. Department of Energy, 1992, National energy strategy: Washington D.C., Government Printing Office.

Weiss, M.A., and Heywood, J.B., 1991, Energy and the environment-A framework for evaluating research needs in the transportation sector, in Tester, J.W., Wood, D.O., and Ferrari, N.A., eds., Energy and the Environment in the 21 st Century: Cambridge, Mass., MIT Press.

Williams, R.H, 1992, Powering the future-Efficient use and renewable supplies are key: Environmental Protection Agency Journal, v. 18, no. 4., p. 15-19. 


\title{
The New Downstream: Increased End-Use Efficiency and Renewable Forms of Energy as Competitive Energy Resources
}

\author{
By Evan Mills ${ }^{1}$
}

\section{CONTENTS}

Abstract

The Context

The New Downstream: A Return to Least-Cost

Energy Services 851

Trends in End-Use Energy Efficiency 852

Powerful Analogies: Energy Efficiency as a

Demand-Side Energy Resource

The Energy-Environment Connection 856

Identifying and Recovering Demand-Side

Resources

Making Markets for Energy Services

Perfect Markets

Barriers to Least-Cost Energy 859

Policy Solutions for Improving Energy

Markets

Implications for Energy Suppliers 860

Changing Roles for Modern Utilities 861

Electricity Production: One-Quarter of the

World's Gas Use 862

Renewable Energy 863

Issues for Developing Countries and

Economies in Transition 864

The Setting 864

Natural Gas in Developing Countries 865

Toward a New Synthesis: Integrated Resource

Planning 865

Acknowledgments

866

References Cited 866

\footnotetext{
'Center for Building Science, Lawrence Berkeley Laboratory, $1 \mathrm{Cy}$ clotron Rd. MS 90-3058, Berkeley, CA 94720.
}

\begin{abstract}
The upstream (supply) extractive energy industries are being taken unawares by sweeping changes in the downstream (demand) realm beyond the flame tip. The future of energy gases (natural gas, hydrogen, gasified biomass, and so on) is inexorably linked to final energy demand, which, in turn, depends on trends in end-use energy efficiency and fuel substitution toward or away from gas. From economic and technical standpoints, increased energy efficiency is directly analogous to increased energy supply. In the years since the energy crises of the 1970's, increased energy efficiency has been the largest and least expensive source of new energy services and has achieved more substantial reductions in energy-related pollution than offered by end-ofthe-pipe strategies. A new generation of government and utility policies aimed at overcoming market failures-coupled with ongoing technological developments-promises continued dramatic expansion of the energy-efficiency marketplace. Another factor influencing the future of energy gases is increasing "midstream" competition on the supply side, including improved thermal efficiencies of electric power production and increased opportunities for substitution in the direct use of fuels. Renewable forms of energy (some of which are energy gases) are emerging as potentially important contributors to future electricity and fuel supply, and as formidable competitors with natural gas and other fossil fuels. The current direction of energy policy suggests a future energy system increasingly based upon a balanced mixture of investment in end-use efficiency, in renewable supply technologies, and in natural gas. Such a new system is usefully characterized by the unifying technical, economic, and policy-making paradigm known as integrated resource planning.
\end{abstract}




\section{THE CONTEXT}

Although one of the darkest moments in the history of gas, the invention of the electric lighting system in 1880 marked a watershed in the evolution of energy planning, economics, and entrepreneurship. The unification of efficient end-use equipment and new technologies for energy supply was the cornerstone of Thomas Edison's lighting revolution.

Energy resources have traditionally been thought of as existing in the upstream (or supply) region of the energy system. Certainly, advances in supply technologies and geological methods are revealing new energy resources, as exemplified by the case of natural gas (Burnett and Ban, 1989). However, the new paradigm foreshadowed by Edison's ideas reveals that the largest and least expensive energy resources are located far downstream from the point of production; in fact they are found not at the wellhead but rather in the conversion of primary energy to electricity and-more importantly-in improved energy efficiency at and beyond the flame tip.

The conceptual foundation of Edison's breakthrough was the goal of providing energy services at least cost. His competition was gas lighting, and his solution was an integrated system of electricity production, transmission, and conversion to a useful service: illumination. As evidenced by the presence of "bulbs" on one of Edison's ledger sheets (fig. 1), the economics of end-use technologies were an integral part of his utility's cost (and profit) structure. A century later, this service-oriented approach is characterized by a paradigm known as integrated resource planning. This paradigm's dimensions are technical, economic, and environmental, and the prospective implications for energy gases are profound.

Not coincidentally, the return to least-cost energy services comes during an era in which more use of energy no

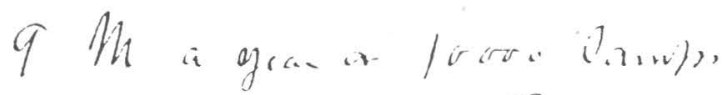

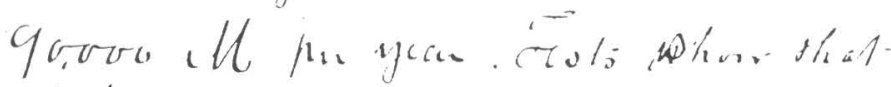

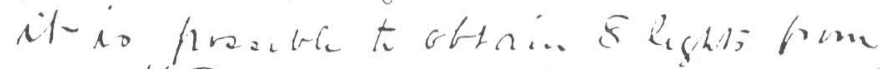

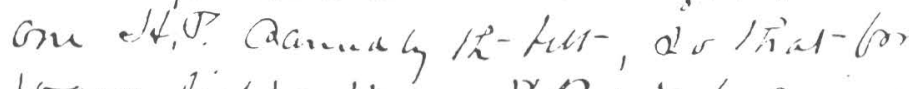

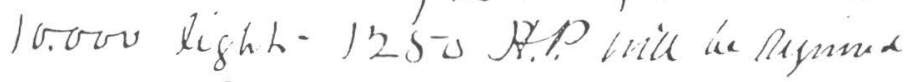

$$
\begin{aligned}
& \text { (thvintin.1- }
\end{aligned}
$$

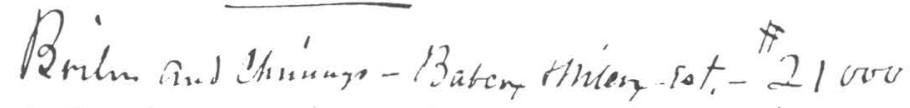

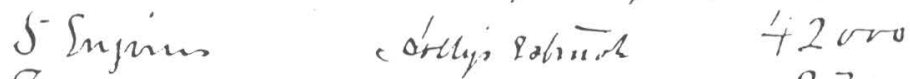

$$
\begin{aligned}
& \text { Gnualatan } 230
\end{aligned}
$$

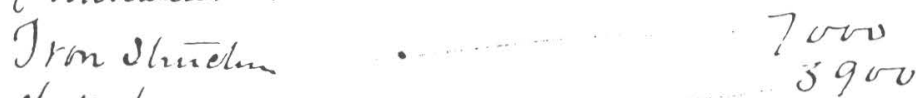

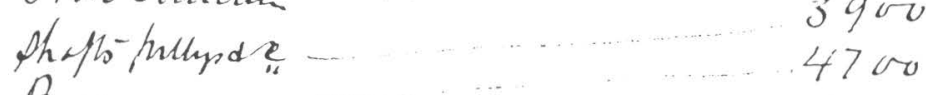

$$
\begin{aligned}
& \text { Buts, Joor }
\end{aligned}
$$

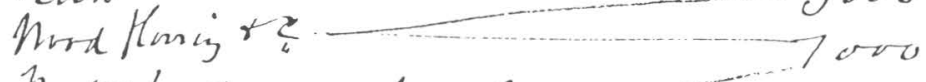

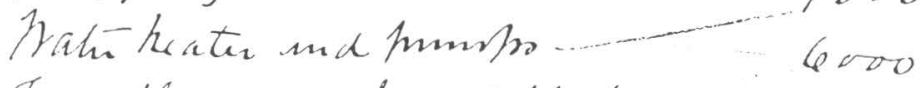

$$
\begin{aligned}
& \text { Trow flow and boilu ampinth- } \\
& \text { Fadie Machion, .......24000 } \\
& \text { Ponduchón ..... \$171400 }
\end{aligned}
$$

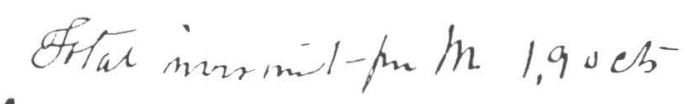

$$
\begin{aligned}
& \text { A }
\end{aligned}
$$

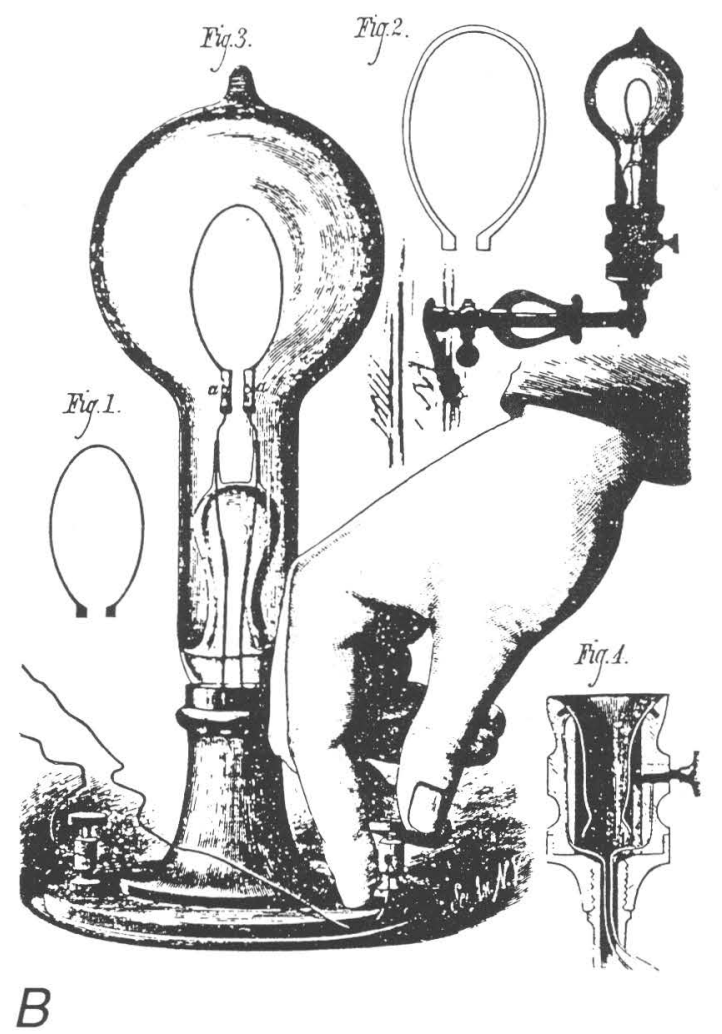

Figure 1. Thomas Edison's lighting revolution combined efficient end-use equipment with new technologies for energy supply. A, A handwritten electricity investment profile from Edison's notebooks (from "Edison's Electric Light," by Robert Friedel and Paul Israel with Bernard S. Finn. Copyright 1986 by Rutgers, The State University). Note "Bulbs" on sixth line of list. B, An illustration of Edison's carbon arc lamp in early 1880, as pictured in Scientific American (Jan. 10, 1880, p. 19). 
longer leads unambiguously to a commensurate increase in well-being (Holdren, 1992). On the contrary, the beneficial services provided by energy must be weighed in the context of the many modern worries exacerbated by energy use: urban smog, oil spills, damming of wild rivers, wars over energy resources, deforestation, strip mining, nuclear accidents, nuclear weapons proliferation, heavy-metal pollution, acid rain, global warming, and the high economic cost of new energy supply systems, especially in the developing world.

The extent to which changes in the energy system are realized depends on the policy effort applied towards achieving the goal. There are various barriers that impede progress as well as innovative policy mechanisms that can be used to overcome those barriers.

In this chapter, the opportunities and competitive realities facing world gas markets are examined in light of the new paradigm, integrated resource planning. Central to the discussion is the comparative economics of supply-side versus demand-side investments and their corresponding environmental impacts. Specific technical analogies are drawn to relate supply-side and demand-side resources, and examples are given of how to systematically classify and recover these resources. The discussion continues with the problem of making markets for demand-side resources, presenting both the barriers arising from imperfections in the existing marketplace and the corresponding policy remedies. The role of electric and gas utilities (both as users and sellers of gas) is critical, and the structure and character of these companies-and the regulatory environment in which they operate-is changing rapidly. Lastly, the future of gas is tightly linked to new trends on the supply side in which renewable energy for fuels and electricity is emerging as an important competitive force. Some of these trends point toward a potential near-term conversion from oil and coal to natural gas and biomass-based energy gases in the power sector. The preceding elements are united by the emerging framework of integrated resource planning, already in advanced stages of application in North America and quickly spreading around the world.

\section{THE NEW DOWNSTREAM: A RETURN TO LEAST-COST ENERGY SERVICES}

The concept of energy efficiency as a demand-side energy resource rests on the underlying idea that the demand for energy commodities (for example, coal, oil, or gas) is merely derived from the demand for energy services (for example, warmth, illumination, transport of people or goods, shaft power in an industrial process, or information management) (fig. 2). Where improvements in energy efficiency (in heating systems, lighting, cars, motors, or computers) provide the same end-use service at a lower level of energy consumption and cost, they can be considered as much a part of the future resource mix as investments in new energy supply.

The convergence of many factors has accelerated the application of demand-side management and the diversification of supply-side options. Perhaps above all else, environmental concerns, both regional (as in the case of acid rain) and global (as in the case of climate change) have become a formal part of the rationale for making energy choices. With the exception of the United States, all major western industrialized nations have now articulated goals for carbon-dioxide stabilization or reduction. In addition, increasing regulatory scrutiny of the prudence of supplyside investments made by energy industries has formalized the process of comparing prospective supply-side and demand-side investments (National Association of Regulatory Utility Commissioners, 1988). Regulators are now also beginning to include the cost ("adders") of various environmental effects in the energy price, thus further favoring energy efficiency (Wiel, 1991).

In tandem with changes in energy policy, structural and economic changes have also tended to lower energy intensities (measured as energy use per unit of economic output). Technological trends such as miniaturization and reduced materials use give rise to what is sometimes termed "natural" efficiency improvements. A case in point is the laptop computer: it uses about 5 percent as much energy as the desktop computer it replaces, and is constructed with only a

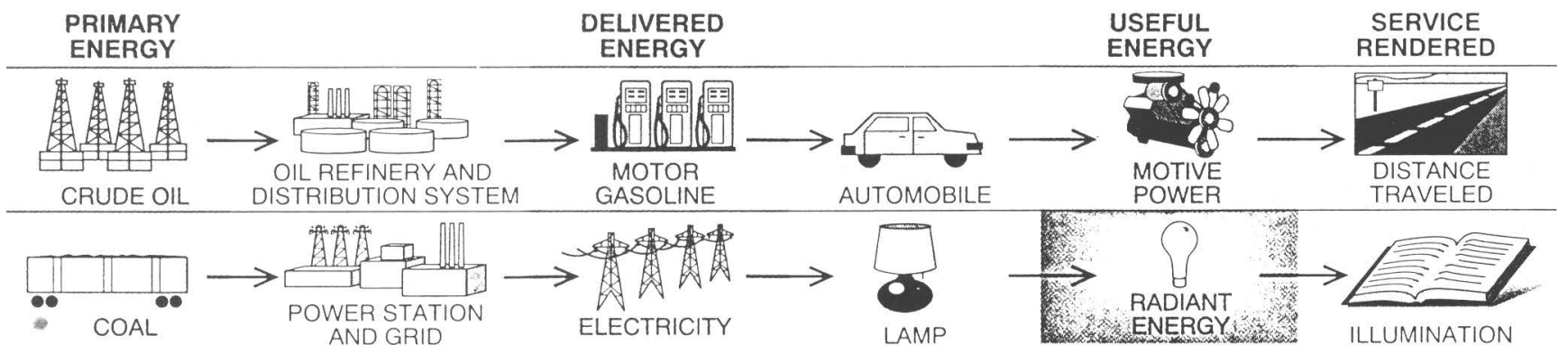

Figure 2. Energy supply versus energy services. Energy is transformed through a chain of events. Primary energy exists in a crude form, say, a fossil fuel, that is extracted from a sedimentary repository. After undergoing transformation, it becomes delivered energy, which is made available to the consumer, who then converts it into useful forms and then finally into energy services, which are the desired end. From Davis (1990). 
fraction (embodied energy) of the metal and plastic. The increasing shift away from goods and toward services in industrial economies is also a significant structural factor. Such changes are responsible for approximately one-third of the total decrease in aggregate national energy intensities observed in many industrialized countries in recent decades (Schipper and others, 1992).

In addition to the downstream trends in end-use energy efficiency, industry and government have been developing "midstream" renewable energy supply systems that are consistent with much of the policy orientation that now favors efficiency over traditional fossil-based supply systems. The emergence of these new midstream resources is driven by many of the same economic, technical, and environmental factors that have contributed to increased interest in improved end-use efficiency. Legislation such as the Public Utilities Regulatory Policies Act of 1978 (PURPA) has created markets in which utilities must buy competitively priced power from small non-utility suppliers. In California, for example, this law has given rise to $\$ 2$ billion total investment in the wind-energy industry (Grubb and Meyer, 1993). The total cost of electricity from new wind systems in California is approximately 7 cents per kilowatthour-competitive with the cost of electricity produced with fossil fuels.

\section{TRENDS IN END-USE ENERGY EFFICIENCY}

Prior to the energy crises of the 1970's, conventional wisdom held that energy use would increase as fast as economic growth (measured as gross national product, or GNP), which, in turn, depended on an ever-expanding supply of energy. In other words, the intensity of energy use per dollar of real GNP was considered unalterable. The heavy solid lines in figures $3 A$ and $3 B$ represent the trends in United States' consumption (fig. $3 A$ ) and the Organization for Economic Cooperation and Development (OECD) countries' consumption (fig. $3 B$ ) of primary energy based on actual consumption from 1965 to 1985. (The OECD includes all of North America, Western Europe, Japan, Australia, and New Zealand.) The lighter solid lines on figures $3 A$ and $3 B$ represent energy use predicted as a linear function of real GNP, based on energy use per dollar of GNP (that is, energy intensity) in 1973. We see that energy use and GNP tracked each other well when extrapolated back to 1965 , but that the two trends diverged sharply after 1973. In the United States, real GNP had risen by more than 30 percent by 1985 , while actual energy use had leveled off. The OECD countries have achieved an impressive reduction of energy intensity and are together saving about $\$ 400$ billion/year in avoided energy costs compared to trends prior to 1973.

Despite the steady growth in GNP, use of oil and gas has declined. In fact, as figure $3 A$ shows, U.S. oil and gas consumption has dropped by more than the total U.S. oil and gas production (also declining). In comparison to oil and gas consumption as forecasted by the 1973 ratio of fuel use to GNP, actual consumption has been much lower, leading to oil and gas savings in the U.S. now equal to one-half of OPEC's (Organization of Petroleum Exporting Countries) estimated 1986 total production capacity of 29 million barrels of oil per day. Savings in the OECD as a whole are equivalent to five-sixths of OPEC's capacity.

These large-scale trends stem from a multitude of specific changes at the energy end-use level. For example, during the efficiency era of the 1970's and 1980's, fuel required for heating U.S. buildings decreased by the equivalent of 1.2 million barrels of oil per day-an amount equal to two-thirds the daily output of the Alaskan pipeline - despite the fact that the number of households grew by 30 percent and commercial floor space increased by 40 percent. Efficiency improvements in insulation levels, windows, and heating equipment have reduced space-heating intensity by about 50 percent compared to 1973 levels in new homes and commercial buildings (U.S. Department of Energy, 1989). New state-of-the-art office buildings and superinsulated homes, such as those constructed by Bigelow Homes outside Chicago, have reduced space-heating intensities to a small fraction of their 1973 levels.

As suggested by the preceding discussion, the end-use perspective on energy demand helps explain important historic evolutionary trends. As an illustration, overall energy intensity for space heating in homes has plunged in major industrialized countries (fig. 4). Similar trends can be seen for energy-using devices located within buildings. An examination of trends in the heating fuel used in OECD coun-

Figure 3. Trends in energy and economic activity. In both graphs, projected energy (light solid lines) is calculated on the basis of the gross national product (GNP) in constant dollars, with both forecast and "back-cast" values from 1973. Note that the GNP back-cast generally follows the actual consumption curve (heavy solid lines) before 1973. The "Primary Energy" on the left-hand scales includes fuel burned at power plants, in units of quads per year. A quad (also abbreviated on fig. 3 as q) is a quadrillion $\left(10^{15}\right)$ British thermal units. The energy savings were converted from quads to fractions of OPEC (Organization of Petroleum Exporting Countries) capacity using an estimated 1986 total OPEC production capacity of 29 million barrels of oil per day (58 quads). For the right-hand scales, quads were converted to 1984 dollars using the 1984 U.S. cost of energy (about $\$ 440$ billion). $A$, Energy use in the United States, actual and projected by GNP. $B$, Energy use in the entire Organization for Economic Cooperation and Development (OECD), actual and projected by GNP. The OECD includes all of North America, Western Europe, Japan, Australia, and New Zealand, and consumes about twice as much total resource energy as the United States alone. Oil and gas savings for the OECD in 1985 were five-sixths of total OPEC capacity. 
tries shows the rapid rate of fuel substitution that can occur in response to changes in energy prices and policies directed toward influencing the fuel choice in buildings (fig. 5).

Given possible developments on the demand side, the future of energy demand (and thus energy gases) is any- thing but pre-ordained. In fact, projections of world energy demand over the next 50 years vary by more than a factor of two (U.S. Department of Energy, 1991/1992) (fig. 6). These differences stem primarily from assumptions about energy-efficiency trends.
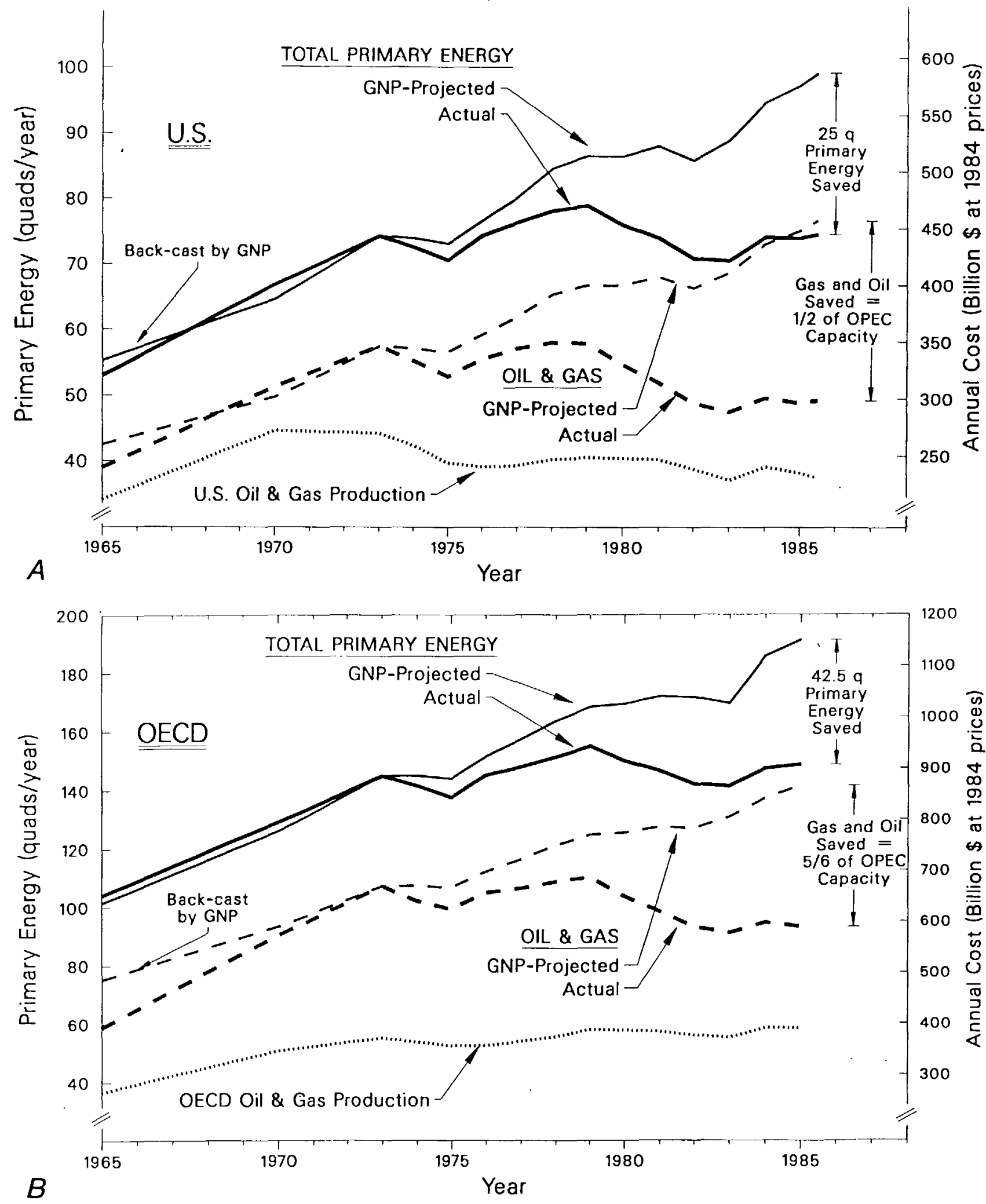


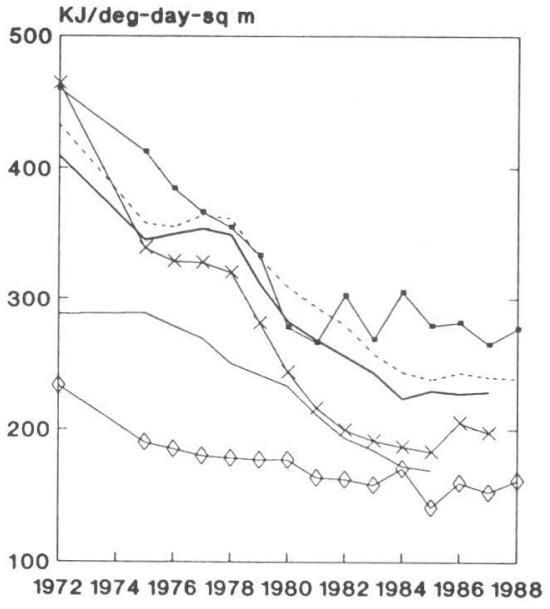

Figure 4. Oil-heating intensity (measured as energy use per unit of floor area, normalized for differences in weather from country to country) in countries of the Organization for Economic Cooperation and Development (OECD; includes all of North America, Western Europe, Japan, Australia, and New Zealand). Data are for single-family homes with central heat. KJ, kilojoules; deg, degree-day Celsius; sq m, square meter. From Schipper and others (1992).

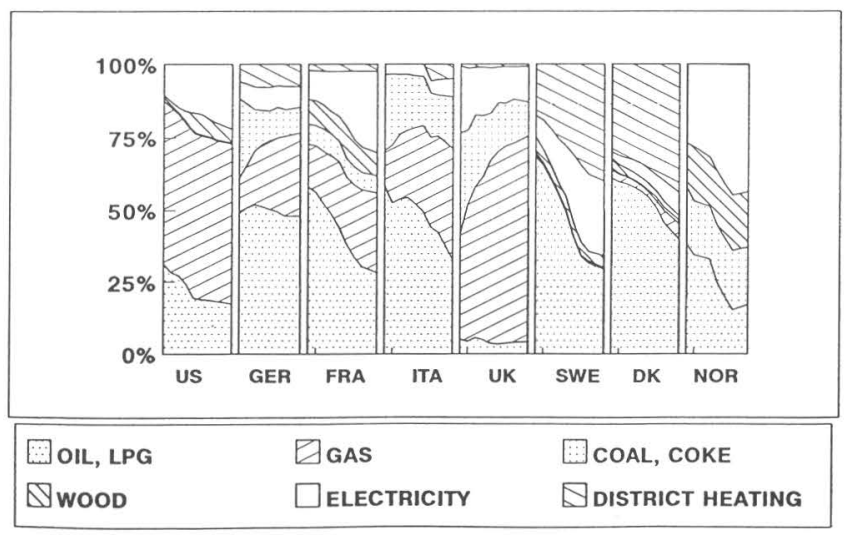

Figure 5. Principal space-heating fuel, 1973-1990, in some countries of the Organization for Economic Cooperation and Development (OECD; includes all of North America, Western Europe, Japan, Australia, and New Zealand). US, United States; GER, former West Germany; FRA, France; ITA, Italy; UK, United Kingdom; SWE, Sweden; DK, Denmark; NOR, Norway; LPG, liquefied petroleum gas. District heating is centrally produced steam or hot water. Source: Lawrence Berkeley Laboratory, International Energy Studies.

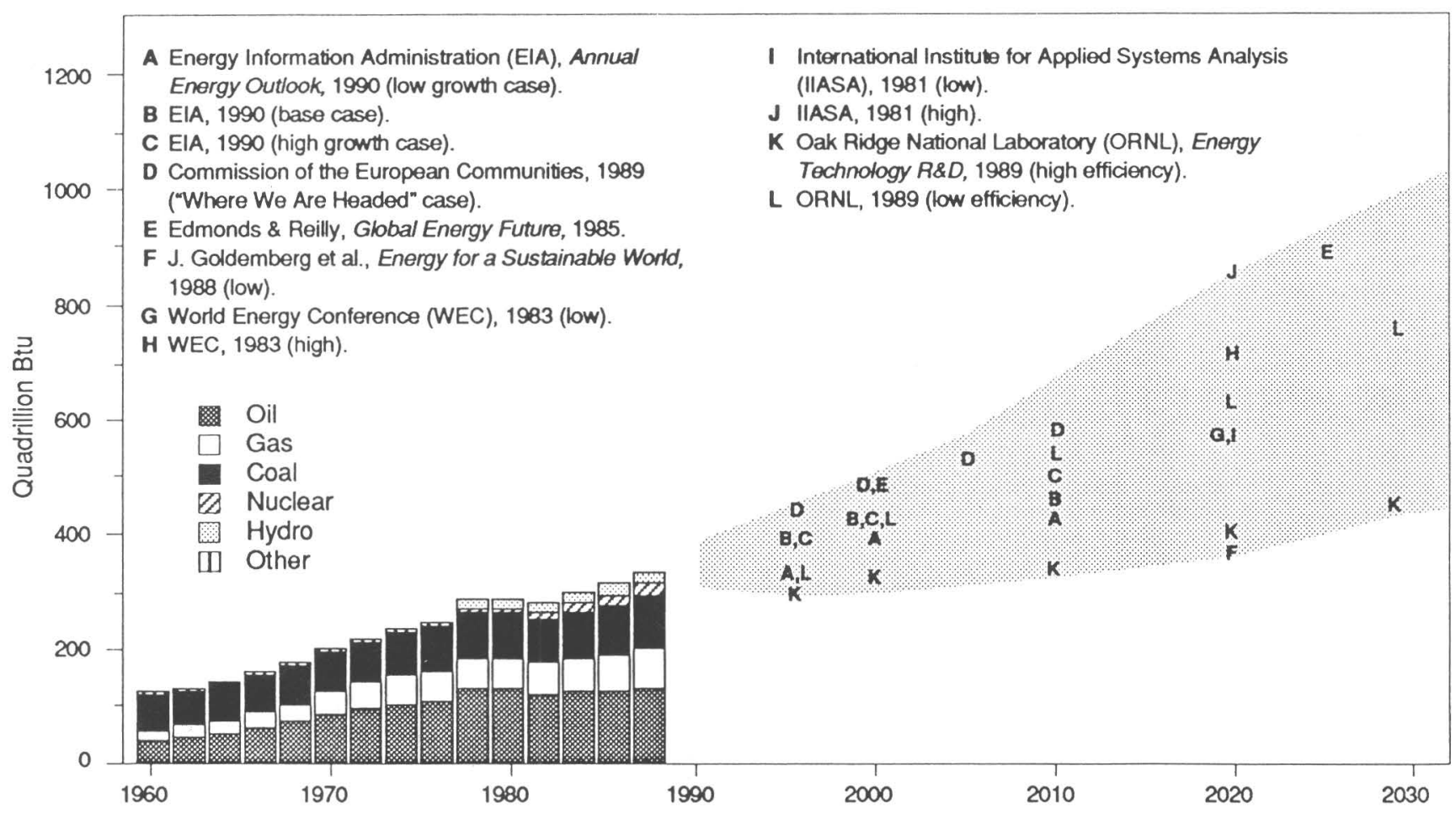

Figure 6. Historical (1960-1988) and projected (1990-2030) world energy consumption. Differences in projections are caused, in part, by varying assumptions concerning energy efficiency, energy prices, economic growth, consumer and producer behavior, and rates of technological change, including replacement of capital stock. The shaded area at right represents an envelope bracketing these differences. Btu, British thermal unit. From U.S. Department of Energy (1991/1992). 


\section{POWERFUL ANALOGIES: ENERGY EFFICIENCY AS A DEMAND-SIDE ENERGY RESOURCE}

Throughout the energy-supply arena, one can identify concepts analogous to demand-side resources (table 1). For example, exploring for new energy supplies can be likened to performing energy audits in buildings or industries to identify the specific opportunities for applying efficient technologies. Some examples of these opportunities are indicated in table 2 , where energy savings by several end-use technologies are quantified in terms of avoided gas use.

At a large scale, seemingly insignificant energy-efficient technologies (for lamps, ballasts, fixtures, and lighting controls) can displace sizable amounts of energy. A recent assessment of the prospects for improving the efficiency of residential and commercial lighting energy use in the United States-beyond improvements anticipated from existing utility and government programs targeting lighting--found that primary savings equivalent to 95 trillion cubic feet of natural gas could be achieved between 1995 and 2030 (Atkinson and others, 1992). Moreover, these savings could be achieved with a net economic benefit (value of energy saved minus the extra investment for the efficient technologies) of over $\$ 100$ billion.

As an illustration of options to reduce demand for heating fuels, the windows produced over 10 years by a single $\$ 20$-million factory for coating low-emissivity glass will save as much heating gas (210 billion cubic feet, equivalent to $36,000,000$ barrels of oil) as produced by a $\$ 300$-million offshore oil platform (fig. 7). More than two times this quantity of primary energy would be saved if heating were instead provided with electricity derived from fossil fuels.

These low-emissivity window coatings are rapidly penetrating the market and-in combination with low-conductivity gas fillings- have doubled the thermal resistance (measured by the "R-value") of old-fashioned "thermopane" windows from R-2 to R-4. Many major U.S. window manufacturers such as Andersen, Pella, and Marvin, now offer low-E (low-emissivity) windows exclusively. During the past five years, 50 million low-E windows were sold in the United States. A 33-percent market share for new residential

Table 1. Analogies between supply-side and demand-side energy-planning paradigms.

[Btu, British thermal unit]

\begin{tabular}{|c|c|c|}
\hline Concept & Supply-side paradigm & Demand-side paradigm \\
\hline Services-----........-- & More energy supply and use--...--.---.-- & More efficient use of energy. \\
\hline Exploration----------- & Drilling, mining, and so on - & Energy auditing, and so on. \\
\hline Resource base ------- & Existing energy resources --.-...-- & Technically avoidable energy use. \\
\hline Reserves --.--------... & Economically recoverable energy & Economically reducible demand. \\
\hline Unit cost------------ & 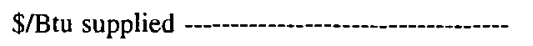 & \$/Btu saved. \\
\hline Environment ------..-- & Emissions ---1- & Avoided emissions. \\
\hline Planning -.-------- & $\begin{array}{l}\text { Forecasts: Supply and demand weakly } \\
\text { linked, usually only by modest incorporation } \\
\text { of price impacts. }\end{array}$ & $\begin{array}{l}\text { Scenarios: Supply and demand linked explic- } \\
\text { itly via technology assessments of both pro- } \\
\text { ducers and consumers. }\end{array}$ \\
\hline
\end{tabular}

Table 2. Some examples of end-use efficiency as an energy resource.

[Economic benefits assume a price of $\$ 7$ per thousand cubic feet of natural gas. For electricity production, a thermal efficiency of 11,500 British thermal units per kilowathour (including transmission losses) and natural-gas input fuel are assumed]

\begin{tabular}{|c|c|}
\hline End-use technology & Approximate natural-gas savings \\
\hline Efficient compact fluorescent lamp & 4,000 cubic feet $(\$ 28)$ over 10,000 -hour lifetime of lamp. \\
\hline \multicolumn{2}{|l|}{ Low-emissivity window coatings: } \\
\hline 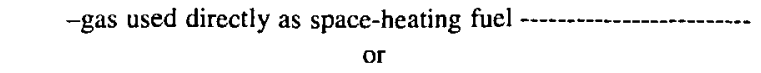 & $\begin{array}{l}1,000 \text { cubic feet }(\$ 7) \text { per square foot of window area over } 10 \text { - } \\
\text { year lifetime of window. }\end{array}$ \\
\hline -gas used to produce electricity for space heating ------.---. & $\begin{array}{l}2,500 \text { cubic feet }(\$ 17) \text { per square foot of window area over } 10 \text { - } \\
\text { year lifetime of window. }\end{array}$ \\
\hline \multicolumn{2}{|l|}{ Low-flow showerhead: } \\
\hline $\begin{array}{c}\text {-gas used directly as water-heating fuel - } \\
\text { or }\end{array}$ & 7,000 cubic feet $(\$ 50)$ per year. \\
\hline -gas used to produce electricity for water heating -.......-...... & 20,000 cubic feet $(\$ 140)$ per year. \\
\hline
\end{tabular}




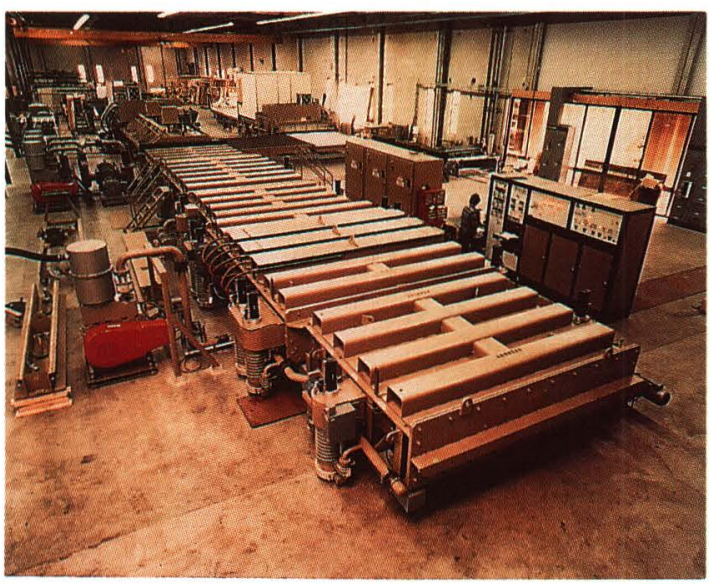

Capital outlay: $\$ 20$ million $20,000,000 \mathrm{ft}^{2}$ insulated glass per year 10 years production 20-year window lifetime

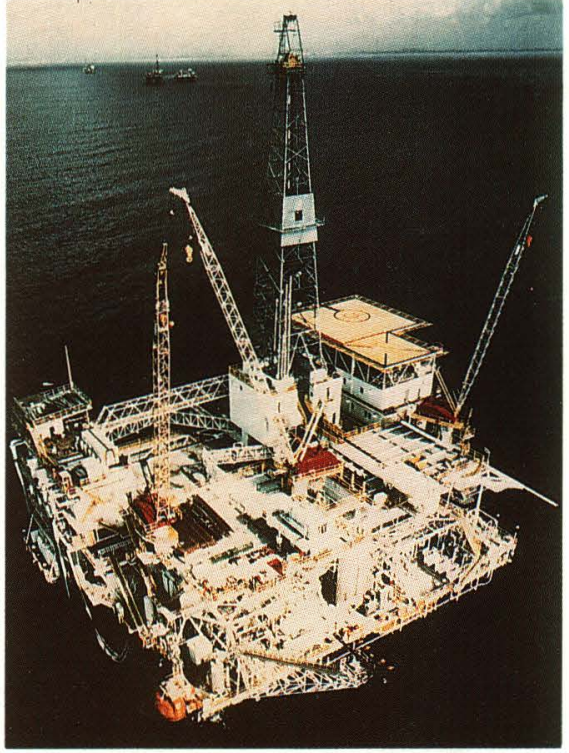

Capital outlay: $\$ 300$ million 10,000 barrels per day 10 years production

Figure 7. The windows produced over 10 years by a single $\$ 20$-million factory for coating low-emissivity glass (left) will save the equivalent of as much oil ( $36,000,000$ barrels) as would be produced over 10 years by a $\$ 300$-million offshore oil platform (right). Source: Lawrence Berkeley Laboratory.

construction has already been reached and is expected to grow to as much as 80 percent by the end of the decade (fig. 8 ). In the limiting case of full market saturation (100 percent of windows), 70 million low-E windows would be sold annually with corresponding yearly net savings of $\$ 4$ billion. This savings would displace the equivalent of 300,000 barrels of oil per day, or 620 billion cubic feet of natural gas per year, also equivalent to the production of 30 typical offshore oil platforms.

\section{THE ENERGY-ENVIRONMENT CONNECTION}

Increased awareness of environmental problems associated with energy production and consumption, especially concerning emissions of greenhouse gases that contribute to global climate change, has led to a growing emphasis on improved energy efficiency. The purposes for which energy is used can be correlated with the resultant environmental impacts. For example, total U.S. energy-related carbon dioxide emissions are allocated to the various associated end uses in figure 9 (U.S. Office of Technology Assessment, 1991). From this vantage point, U.S. emissions can be attributed to buildings, transportation, and industry

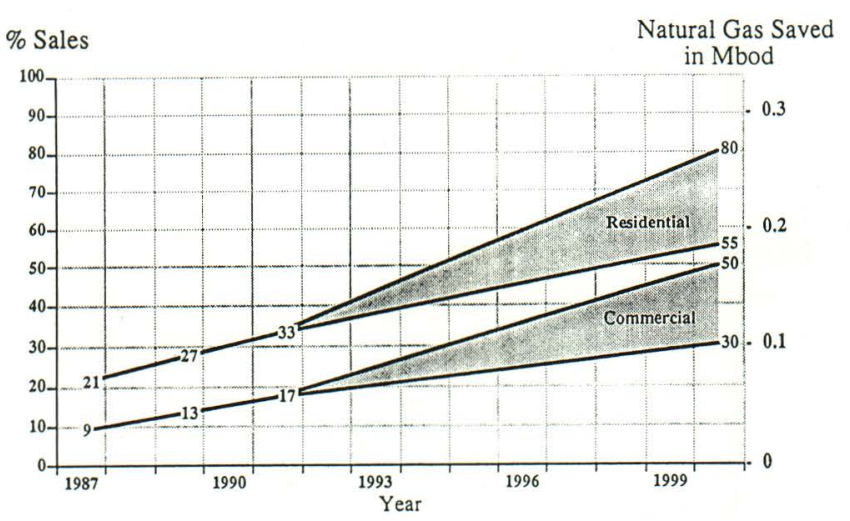

Figure 8. Market penetration data for low-emissivity windows. Data, plotted separately for residential and commercial markets, are historical values (1987-1991) and projected ranges (19922000). Projections were made for new and existing buildings. Right-hand scale shows natural gas saved by use of low-emissivity windows instead of traditional double-glazed windows, calculated in million barrels of oil per day (Mbod) equivalent. For comparison, Alaska's Prudhoe Bay has produced an average of about $1.8 \mathrm{Mbod}$, and it is estimated that the Arctic National Wildlife Refuge (ANWR) could produce about 0.3 Mbod. Source: Lawrence Berkeley Laboratory Building Technologies Program, based on industry sources. 


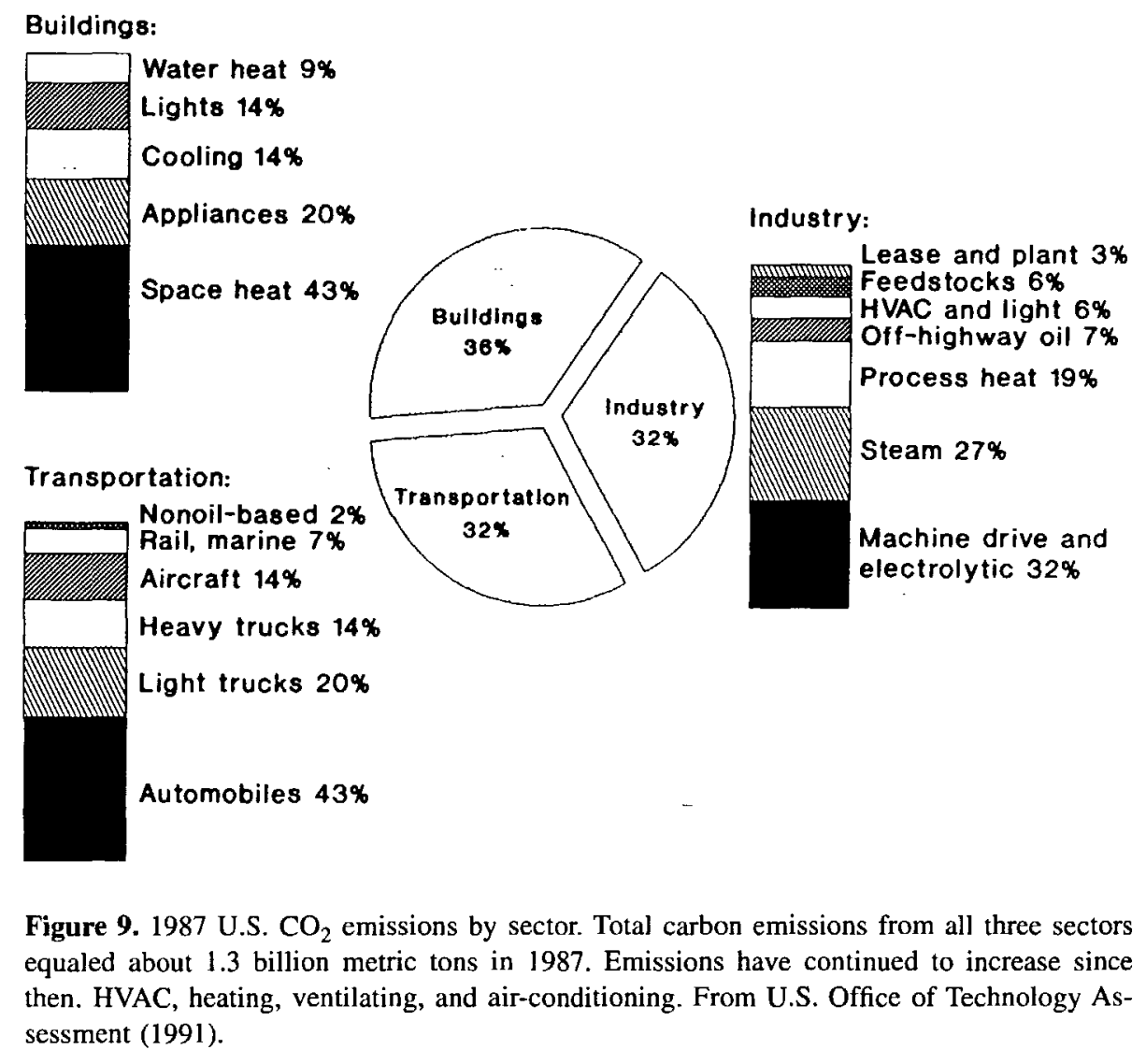

in approximately equal proportions. Space heating, personal automobiles, and machine drives and electrolytic processes are the most significant end uses within each sector.

Given this information, various end uses can be looked to for opportunities to reduce $\mathrm{CO}_{2}$ emissions, and the costs of efficiency improvements can be associated with given reductions in emissions. If costs of efficiency improvements are greater than the cost of the energy avoided, then a net cost (for example, \$/tonne) can be assigned to the emissions avoided. Alternatively, if the costs are less, then a negative cost (or benefit) can be assigned. Many beneficial "negative-cost" options exist for all sectors, with typical benefits on the order of $\$ 100 /$ tonne of carbon avoided, that is, $\$ 100$ net savings for every tonne of emissions avoided (Mills and others, 1991).

As an example of nationwide prospects for energy savings via improved energy efficiency, the U.S. National Academy of Sciences estimated that U.S. $\mathrm{CO}_{2}$-equivalent emissions could be reduced by 1 billion tonnes annually (18 percent of current national emissions from all sources) through implementation of energy-efficiency options in existing buildings (National Academy of Sciences, 1992). Because the study was restricted to energy-saving options that were less expensive than producing or buying energy, these savings bring with them a net economic benefit of $\$ 62$ saved per tonne of reduced emissions.

\section{IDENTIFYING AND RECOVERING DEMAND-SIDE -RESOURCES}

There exists a diversity of energy sources and associated costs. Supply curves, like the one shown in figure 10, have been a useful tool for characterizing energy resources in terms of technical and economic constraints. On the horizontal axis of these staircase-style curves is the total energy resource available. On the vertical axis is the cost of recovering each unit of energy. As an illustration, the Canadian gas supply curve shown in figure 10 indicates a total resource of almost 200 trillion cubic feet, with increments recoverable at progressively increasing costs.

Analogous supply curves have been derived for demand-side resources (fig. 11). In this case, the horizontal axis is the energy potentially conserved and the vertical axis is the cost per unit of energy conserved. The cost of conserved energy is defined as the annualized incremental cost of the efficient technology, compared to the standard technology otherwise used, divided by the annual energy savings. The cost of conserved energy is thus in the units of \$/unit of energy and can be easily compared to the prevailing costs of energy otherwise consumed. Figure 11 presents a comprehensive curve prepared for natural gas use in the residential sector of a New York gas utility (National Fuel Gas) (Nadel and others, 1993). Each step corresponds 
to a different technology, for example, increased insulation, more-efficient gas water heaters, more-efficient furnaces. The curve shows that reductions of 80 percent of residential gas consumption would be achieved at a marginal cost of conserved energy of about $\$ 6 /$ decatherm (1 decatherm $=10^{6}$ British thermal units), comparable to the prevailing retail price of delivered gas. A sensitivity analysis for 50-percent higher and 25-percent lower costs of con-

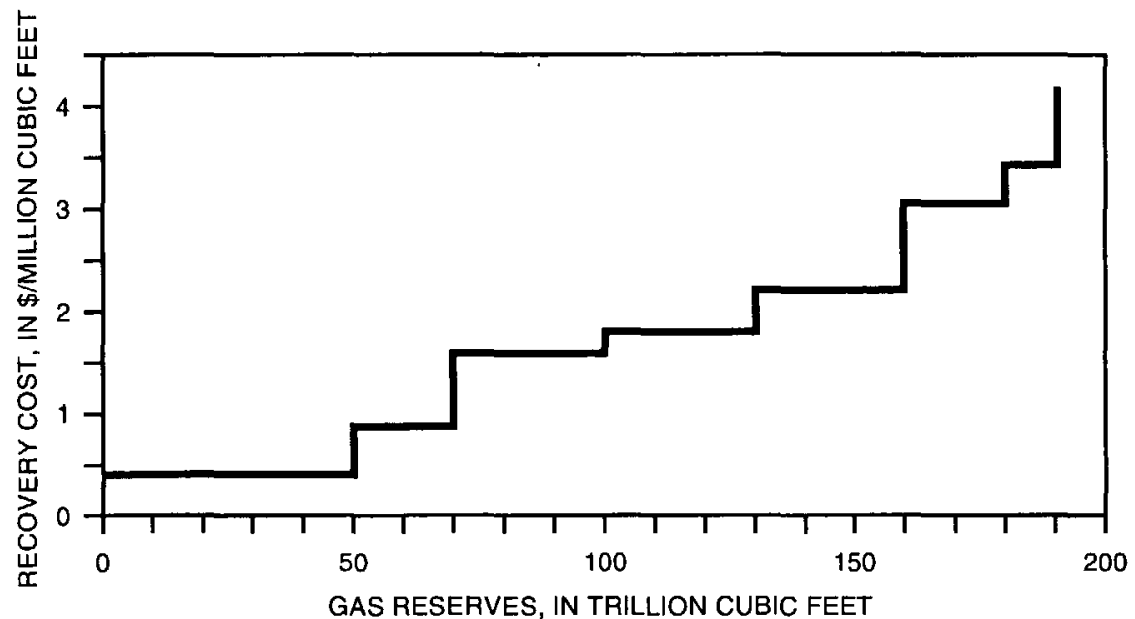

Figure 10. Supply curve showing cost of recovering natural gas versus total estimated natural-gas reserves in western Canada.

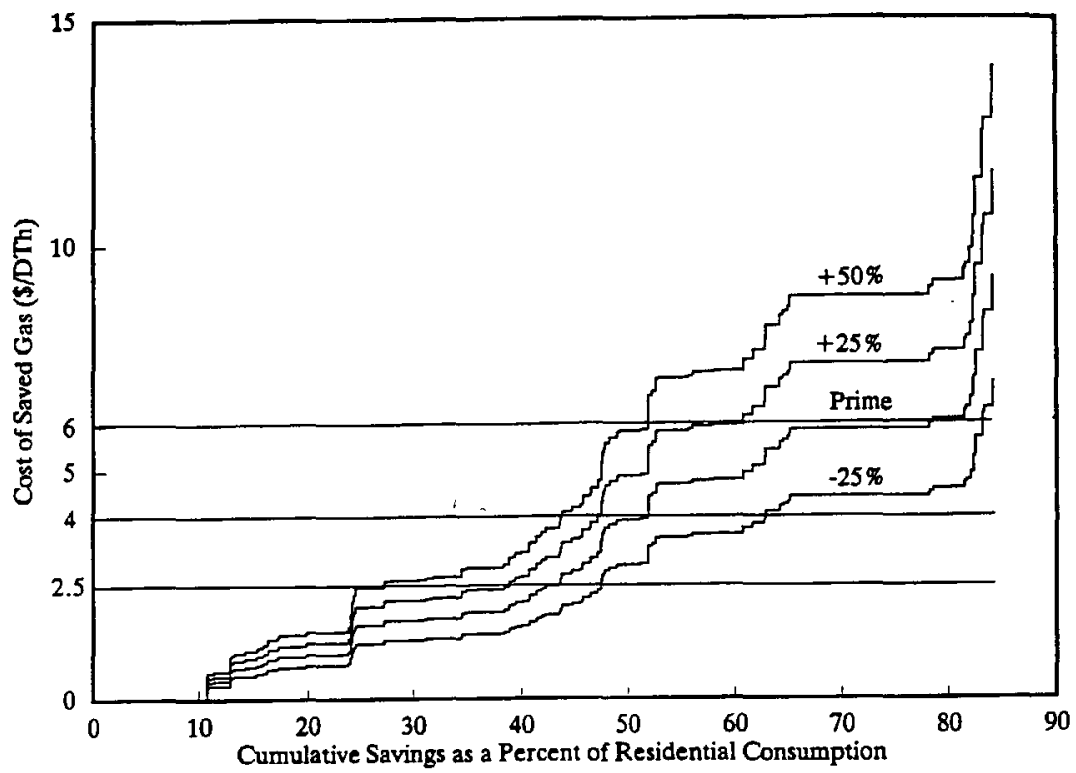

Figure 11. Comprehensive supply curve (labeled Prime) of natural gas conserved in residential sector of a New York gas utility (National Fuel Gas). Curves labeled $+50 \%,+25 \%$, and $-25 \%$ show how the supply curve would shift if actual costs of conserved energy were higher or lower (by the percentages shown) than the costs calculated in the study. Horizontal lines drawn across graph indicate retail prices (\$6/DTh) and the range of marginal costs (\$2.50/DTh to $\$ 4.00 / \mathrm{DTh})$. These are reference points against which to compare costs of conservation. If the cost of conserving energy is below the retail price line, then the efficiency investment is cost effective-it is cheaper than new supply investments. DTh, decatherm, or ten therms, where one therm is 100,000 British thermal units. From Nadel and others (1993). 
served energy yielded a corresponding range of savings of 50 to 85 percent. Marginal gas costs range from $\$ 2.50$ / decatherm to $\$ 4.00 /$ decatherm for this utility, corresponding to a range of savings of about 30 percent to about 50 percent for the above-mentioned sensitivity assumptions.

In practice, the extent to which an energy-savings potential is realized depends on the policy effort applied toward achieving the goal. As discussed below, various barriers impede progress; nonetheless, innovative policy mechanisms can be used to overcome those barriers.

\section{MAKING MARKETS FOR ENERGY SERVICES}

\section{PERFECT MARKETS}

The question is often raised that "if energy efficiency is so cheap, then why are the resources not already fully utilized?" The answer lies in the disparity between economic theory and the actual functioning of energy markets. In theory, if markets were perfect, all cost-effective efficiency options would be acquired. In this context, a "perfect" market means one in which there is full competition, consumers have accurate and complete information, customers have access to capital and a full spectrum of technical options, energy prices reflect direct costs, and external costs (for example, environmental degradation) are internalized in energy prices. In reality, energy markets are rarely perfectly competitive; market "barriers" or "failures" are said to exist.

\section{BARRIERS TO LEAST-COST ENERGY}

A least-cost energy future (in terms of both economic and environmental costs) will not come about under the current market situation, primarily because households, businesses, manufacturers, and governments do not fully recognize and exploit societally cost-effective opportunities for energy efficiency. The result is a significant gap between current and optimum levels of energy efficiency (Hirst and Brown, 1989).

Energy prices are often the main (if not only) factor discussed with respect to consumer interest in energy efficiency. Indeed, distortions in energy prices (for example, subsidies, tariffs not reflective of increasing marginal costs, and neglect of environmental and other external costs) can impede energy savings behavior. In this respect, energy taxes have been discussed recently in the United States. Prices certainly play a role, but often not as large as economic theory predicts (Mills, 1991). There are many specific groups that influence energy use but are insulated in one manner or another from energy prices (examples include builders, landlords, and occupants of nonresiden- tial buildings). Furthermore, energy pricing offers a much less certain degree of energy impact than many other policy mechanisms.

Important market barriers (and corresponding policy opportunities) exist aside from energy pricing issues. As evidence of the barriers, consumers in all sectors implicitly require very fast payback times when making tradeoffs between increased initial costs and reduced operating (energy) costs. The resulting problem is often referred to as the "payback gap." Electric utilities, for example, commonly accept 10- to 15-year payback times on their investments, but studies of end-use efficiency choices made by energy consumers reveal implicit payback times ranging from a few years to a few months. The following factors can contribute to the payback gap: (1) inadequate information and limited consumer awareness of efficiency options; (2) restricted access to capital and financing; (3) split incentives (for example, between landlords paying for equipment and tenants paying for energy); (4) inadequate product availability and skill base, naive marketing of efficiency options; (5) loss of revenues to energy suppliers that might otherwise promote efficiency (linked to price); and (6) imbalanced levels of subsidies and research-and-development funding between efficiency technologies and supply technologies.

\section{POLICY SOLUTIONS FOR IMPROVING ENERGY MARKETS}

Policy mechanisms exist that address each of the barriers just described. The following list encompasses broad categories of policies that have been used at the national or local level, alone or in combination, to foster changes in the energy system.

Getting prices right. Examples include time-of-use tariffs, marginal cost pricing, and addition of environmental costs to the unit prices of energy.

Improved information for energy decision-makers. Examples include energy rating labels, such as those found today on all major appliances and on automobiles.

Standards and other legislative measures. Examples include mandatory and voluntary thermal efficiency standards for buildings, and appliance standards (National Appliance Energy Conservation Act, NAECA). Mandatory thermal standards for buildings can now be found in many parts of the world (Busch and Janda, 1992).

Utility regulatory reform. The prospect of lost revenues associated with conservation programs that would successfully lower energy demand is a formidable disincentive to energy vendors, primarily utilities. In several regions of the U.S., profit rules have been re-defined such that program costs are recovered, revenues are decoupled from sales volumes, and net financial benefits of conservation programs are shared between utility shareholders and consumers. Similar trends are underway in Europe (Mills and Borg, 1991). 
Financial incentives to consumers. Utilities in the United States and Europe have offered a variety of rebates to residential, commercial, and industrial buyers of energyefficient products such as lighting, space heating and cooling equipment, motors, and appliances (Nadel, 1990; Mills, 1993). These incentives are often calibrated to equal most or all of the extra costs associated with implementation of the more efficient technology.

Market transformation (catalyst or temporary incentives to change an energy-services marketplace). One example is a "Golden Carrot" program directed at U.S. refrigeratorfreezer manufacturers which has recently been developed by a consortium of utilities, government agencies, refrigerator manufacturers, and other interested parties. The utilities have pooled $\$ 30$ million to be paid to the manufacturer(s) of units that beat the 1993 National Appliance Standards by between 30 and 50 percent (Nadel, 1992). Similar activities are underway in Sweden (Nilsson, 1992). In another example, the U.S. Environmental Protection Agency's "Green" programs have succeeded in recruiting the largest corporations in the country to adopt a policy of implementing highly efficient technologies in their buildings. Their "Green Lights" program has already captured approximately 8 percent of U.S. commercial building floor area.

Revenue-neutral fee/rebate ("feebate") systems. Examples include sliding-scale hookup fees for new automobiles or buildings - those achieving less efficiency than a pre-set goal must pay a fee; the fees are in turn distributed as rebates to those exceeding the target (Koomey and Rosenfeld, 1990).

Government-sponsored research, development, and demonstration. Government research has resulted in important advancements and commercialization of new lowemissivity windows, efficient flame-retention head burners, and electronic ballasts (Geller and others, 1987).

Most of the aforementioned policies have been implemented only at a local level. As an illustration of the cumu- lative national potential for a comprehensive application of the kinds of policy strategies outlined above, Geller and others (1991) constructed a high-efficiency energy-demand scenario for the United States and compared it to a business-as-usual forecast. The result indicates that U.S. primary energy demand could actually be held constant in absolute terms between the years 1990 and 2010 , even with a 2.2-percent/year real increase in GNP. The conventional forecast, in contrast, indicates a 13-percent increase in energy demand by 2010 .

\section{IMPLICATIONS FOR ENERGY SUPPLIERS}

Three important factors-end-use efficiency, fuel switching, and supply efficiency-affect the amounts of natural gas and other forms of primary energy that will be demanded in the future.

The current baseline forecast by the Gas Research Institute highlights some of the important trends affecting natural gas (Holtberg and others, 1993). The institute's findings reflect a keen awareness of the distinction between energy services and energy itself and the importance of taking an end-use perspective in evaluating future demand:

[A]t moderate energy prices and with continued improvements in energy efficiency, limited growth in demand will be the primary constraint on any expanded role that natural gas can play in the energy mix. Any significant increase in the use of gas will have to be associated with investment in new gas-using equipment-turbines, methane vẻhicles, appliances, space-conditioning devices, or industrial facilities $* * *$. New gas demand, therefore, depends first upon growth in the need for energy services [and] upon the customer having a choice of new, competitive gas-using equipment to serve those needs.

As shown in table 3, the Gas Research Institute (1993) predicts that between 1991 and 2010 the most important areas of growth in natural-gas demand will be the industri-

Table 3. Summary of 1993 baseline natural-gas forecast by Gas Research Institute.

[Residential, commercial, industrial, and transport statistics include only direct use of fuels, not indirect use of fuels consumed in generation of electricity, quad, quadrillion $\left(10^{15}\right.$ ) British thermal units. Source: Holtberg and others (1993)]

\begin{tabular}{|c|c|c|c|c|c|c|}
\hline Sectors & $\begin{array}{c}\text { Total gas } \\
\text { demand in } \\
2010 \text { (quads) }\end{array}$ & $\begin{array}{l}\text { Change in gas } \\
\text { demand, } \\
\text { 1991-2010 } \\
\text { (quads) }\end{array}$ & $\begin{array}{l}\text { Annual growth } \\
\text { of gas demand, } \\
1991-2010 \\
\text { (percent/year) }\end{array}$ & $\begin{array}{l}\text { Natural gas as } \\
\text { a fraction of } \\
\text { total energy } \\
\text { demand in } \\
2010 \text { (percent) }\end{array}$ & $\begin{array}{l}\text { Change in } \\
\text { market share for } \\
\text { natural gas, } \\
1991-2010 \\
\text { (percentage } \\
\text { points) }\end{array}$ & $\begin{array}{l}\text { Main end uses responsible } \\
\text { for change in gas demand }\end{array}$ \\
\hline Residential -- & 4.7 & 0.0 & 0.0 & 68 & -1 & Space heating. \\
\hline Commercial -_.-_- & 3.5 & 6 & 1.0 & 43 & 1 & Cooling, cogeneration. \\
\hline 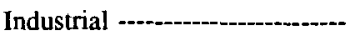 & 11.2 & 2.3 & 1.2 & 36 & 0 & Process steam, cogeneration. \\
\hline Transport -......................... & 1.4 & .7 & 3.7 & 5 & 2 & Natural-gas vehicles. \\
\hline Electricity ---.-- & 4.2 & $\underline{1.3}$ & 2.0 & 12 & 2 & Power plants. \\
\hline Total or average & 25.0 & 4.9 & 1.2 & 23 & 1 & All of above. \\
\hline
\end{tabular}


al sector (in absolute terms) and the transport and electricity supply sectors (as measured by rates of growth). As evidenced by an assumed 1.3 percent/year decline in energy use per unit of GNP, efficiency trends will tend to offset potential demand growth. For the power sector, gas demand growth will be moderated by anticipated improvements in power-plant conversion efficiencies. While total gas-based electricity production will increase by more than 50 percent, the average amount of primary energy input required to produce electricity will decline by 27 percent in new power plants. Although natural-gas vehicles will be a growing new end use for gas, they are projected to capture only 5 percent of the transport energy market by 2010 .

\section{CHANGING ROLES FOR MODERN UTILITIES}

As consumers and distributors of 17 percent of global primary energy, electric and gas utilities are among the most important actors in the energy arena. Given their pre-established contact with and information about energy consumers, their familiarity with end-use equipment, and their access to capital, utilities are logical purveyors of energy efficiency (Hirst and others, 1991). Under traditional economic regulation, however, the only strong incentive for utilities to pursue demand-side resources has been to improve public relations and to accommodate the political expectations of their regulators to present an environmentally conscious image.

Gas utilities in the United States have begun to implement programs in which they provide conservation-related information, technical assistance, and financial incentives to their consumers (RCG/Hagler, Bailly, Inc., 1991). In the United States as of 1992, utilities in about half of the States had initiated efforts in this area (fig. 12) (Samsa and Hederman, 1992). These programs include energy audits, weatherization assistance, insulation, high-efficiency equipment,

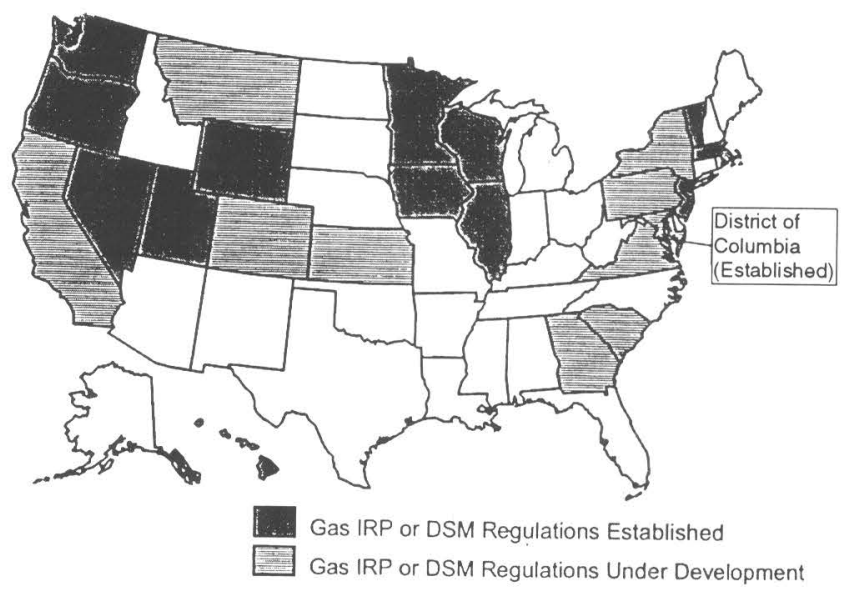

Figure 12. Status of gas-utility integrated resource planning (IRP) and demand-side management (DSM) regulations in the United States. From Samsa and Hederman (1992). and heating-system retrofits, gas cooling, heat recovery, and interruptible rates in the residential, commercial, and industrial sectors (figs. 13, 14) (Goldman and Hopkins, 1991).

These efforts will increase rapidly, given the new national Comprehensive Energy Policy Act legislation passed in 1992 (P.L. 102-486). The legislation encourages investment in improved efficiency by ensuring a profit motive for gas utilities:

The rates charged by any State regulated gas utility shall be such that the utility's prudent investments in, and expenditures for, energy

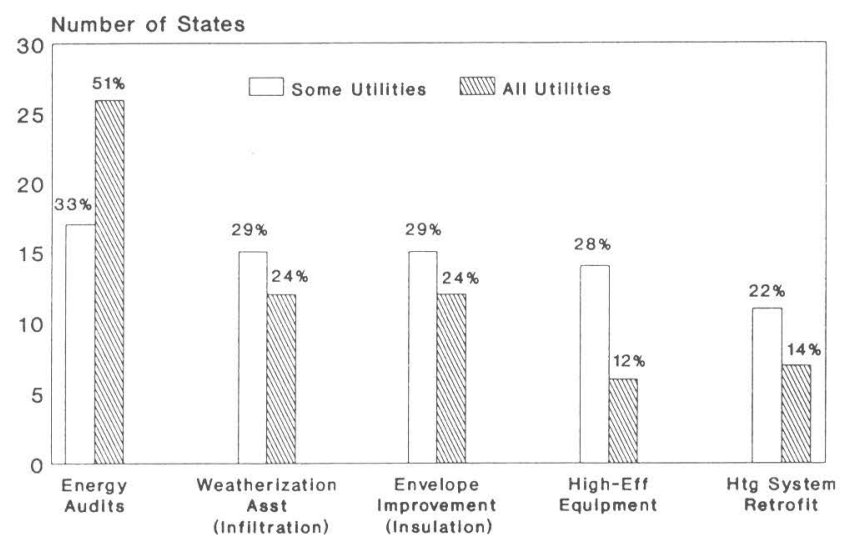

Figure 13. Energy-efficiency programs offered by gas utilities to residential customers. Percent values indicate percentage of all 50 states. For example, in 51 percent of the states, all of the utilities offer energy audits to residential customers, and in 33 percent of the states, some of the utilities offer energy audits. Therefore, in 84 percent of the states, some or all of the utilities offer energy audits to residential customers. Asst, assistance; Eff, efficiency; Htg, heating. From Goldman and Hopkins (1991).

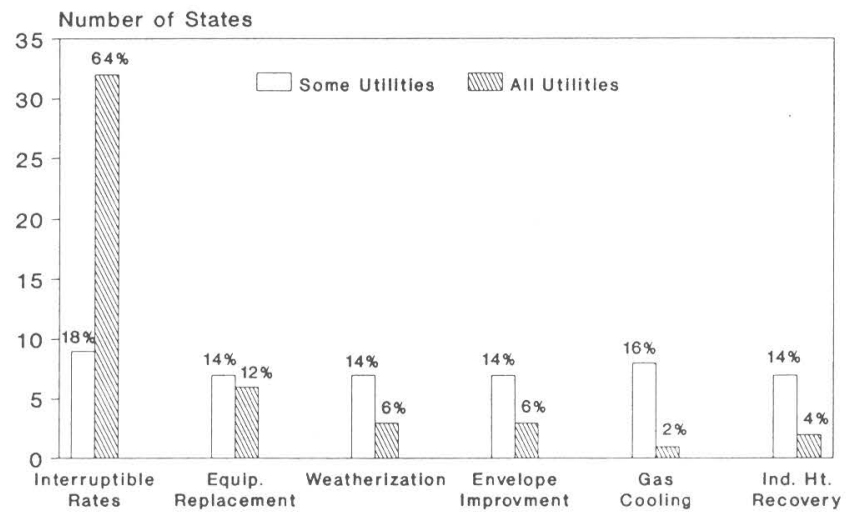

Figure 14. Energy-efficiency programs offered by gas utilities to commercial customers. Percent values indicate percentage of all 50 states. For example, in 64 percent of the states, all of the utilities offer interruptible rates to commercial customers, and in 18 percent of the states, some of the utilities offer interruptible rates. Therefore, in 82 percent of the states, some or all of the utilities offer interruptible rates to commercial customers. Equip, equipment; Ind Ht, industrial heat. From Goldman and Hopkins (1991). 
conservation and load shifting programs and for other demand-side managernent measures $* * *$ are at least as profitable $* * *$ as prudent investments in the acquisition or construction of supplies and facilities.

Numerous electric, gas, and dual-fuel utilities have also become active in promoting fuel-switching programs. Like conservation programs, fuel-switching programs offer information and financial incentives to consumers (Hamilton and others, 1992). In two examples, Vermont's Ludlow Electric Light Department offers $\$ 600$ rebates for the removal of electric heating systems and $\$ 70$ for removal of electric water heaters, and Vermont's Burlington Electric Department will buy down the incremental cost of such rebates to a 3-year payback period. Burlington's customers are offered financing for the other costs, in which payments equal 60 percent of the estimated savings in energy costs.

\section{ELECTRICITY PRODUCTION: ONE-QUARTER OF THE WORLD'S GAS USE}

Electricity is an important energy carrier, derived often from natural gas and potentially from other energy gases. Globally, approximately 15 percent of the electricity is today made from gas, corresponding to 25 percent of the world's total gas use. The great preponderance of gasbased electricity production is in North America (fig. 15). The potential for growth in gas demand is substantial, es- pecially in the North American power sector (Holtberg and others, 1993).

Efficiency trends for electric power plants are dramatic. Average thermal efficiencies of approximately 5 percent at the turn of the century grew to 20 percent by the 1940's and then to 35 percent by the 1970's. These efficiencies now pale in comparison with those of modern advanced gas turbines, which offer up to 52-percent efficiencies, and cogeneration systems, which produce useful heat and power with even higher efficiencies (Williams and Larson, 1989). Some emerging technologies are represented in figure 16 , in which carbon-equivalent emissions per unit of useful energy produced are compared. Note that in two instances emissions from natural-gas technologies actually exceed those from coal-based systems.

Increases in electricity end-use efficiency can result in upstream gas savings. Electric utilities have a substantially longer history of working with energy-efficiency programs for their customers than do gas utilities. Today, $\$ 3$ billion to $\$ 4$ billion is spent annually for conservation programs sponsored by electric utilities in North America. The results of these efforts have contributed to a precipitous drop in capital investment from a peak of about $\$ 45$ billion in 1980 to $\$ 20$ billion today. The majority of this shift can be attributed to efficiency, and half to the growing industry of independent power producers. As an indicator of the future, California utilities plan to meet 75 percent of future energy-services needs with efficiency.

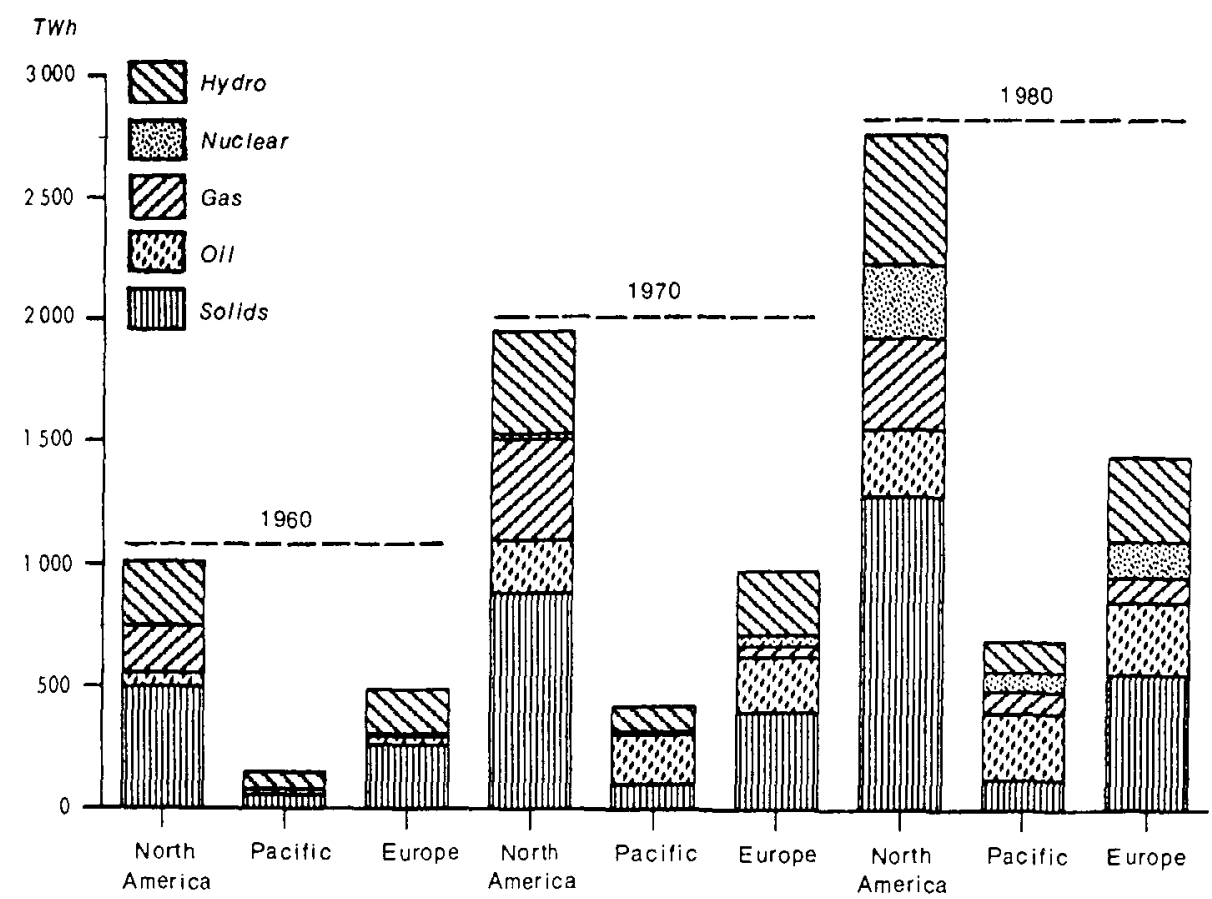

Figure 15. Electricity generation, by fuel, in International Energy Agency regions: 1960, 1970 , and 1980 . TWh, terawatthour ( $10^{9}$ kilowatthours). 


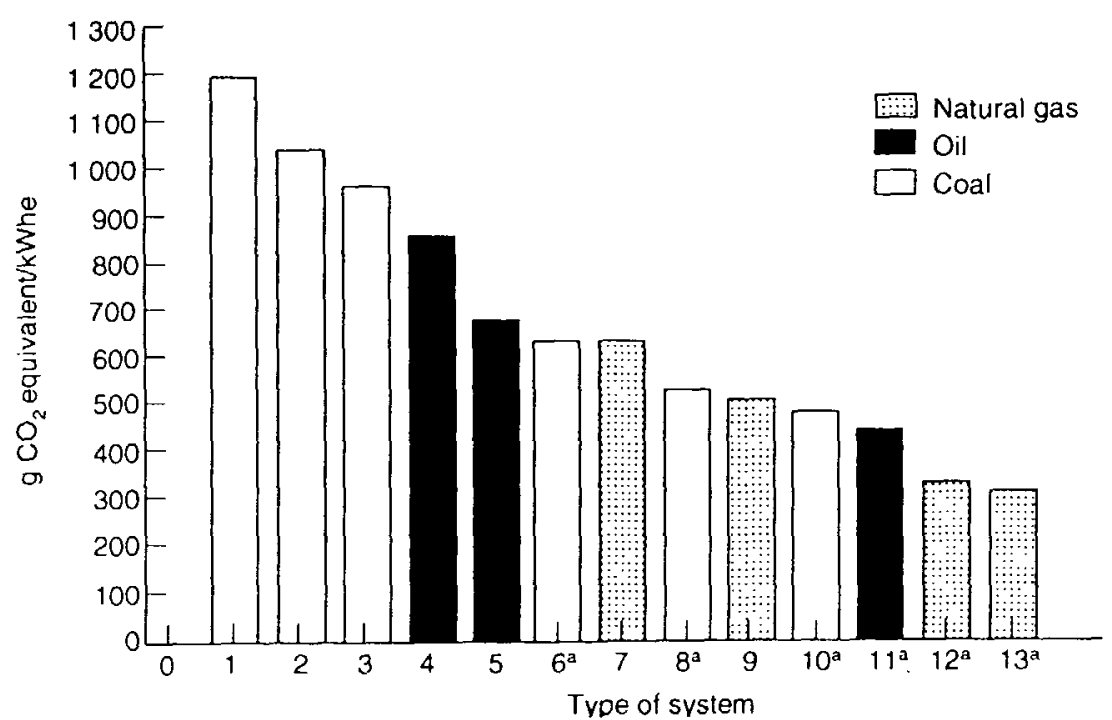

Figure 16. Greenhouse-gas emissions from commercially available power plants. Central-station power plants $(0-5,7,9)$ are compared with cogeneration plants $\left(6^{\mathrm{a}}\right.$, $8^{\mathrm{a}}, 10^{\mathrm{a}}-13^{\mathrm{a}}$ ) that provide both power and useful heat. Energy requirement for electricity production using cogeneration technologies is taken as total energy supplied minus that which would have been required to produce the heat independently (assuming boiler efficiency corresponding to lower-heating-value of 90 percent). All power-plant efficiencies (Eff) are based on higher heating values. For the cogeneration systems, power-to-heat ratios are shown as $\mathrm{E} / \mathrm{H}$. The greenhouse gases are expressed as an equivalent amount of carbon dioxide per kilowatthours equivalent ( $\mathrm{g}$ $\mathrm{CO}^{2}$ equivalent $/ \mathrm{kWhe}$ ). Methane and methane-related fuel-cycle emissions from coal, oil, and natural-gas consumption are taken into account. 1, Average conventional steam turbine (Eff 34 percent); 2, Best available steam turbine (Eff 39 percent); 3 , Pressurized fluidized bed combustion (Eff 42 percent); 4, Average conventional steam turbine (Eff 38 percent); 5, Best available combined-cycle gas turbine (Eff 48 percent); $6^{a}$, Average conventional steam turbine (Eff 78 percent, $E / H=0.50$ ); $7, A v-$ erage combined-cycle gas turbine (Eff 36 percent); $8^{\mathrm{a}}$, Best available steam turbine (Eff 83 percent, $E / H=0.60$ ); 9, Best available combined-cycle gas turbine (Eff 45 percent); $10^{\mathrm{a}}$, Pressurized fluidized bed combustion (Eff 86 percent, $E / H=0.65$ ); $11^{\mathrm{a}}$, Best available steam turbine (Eff 81 percent, $E / H=0.60$ ); $12^{\mathrm{a}}$, Steam-injected gas turbine (Eff 75 percent, $E / H=0.80$ ); $13^{\mathrm{a}}$, Best available combined-cycle gas turbine (Eff 77 percent, $E / H=1.0$ ). From Mills and others (1991).

\section{RENEWABLE ENERGY}

So-called "renewable" sources of energy (biomass, wind, direct solar photovoltaic, direct solar thermal, solar-hydrogen, geothermal, hydroelectricity, and so on) form another important component of integrated resource planning. This arises because (1) these new resources are now approaching economic competitiveness with fossilbased energy sources (fig. 17), (2) they can be provided without net emission of greenhouse gases and other pollutants addressed by the integrated-resource-planning paradigm, and (3) they are generally domestic and secure. As such, renewable sources of energy pose an increasingly important competitive challenge to fossil-based energy gases and an opportunity for nonfossil energy gases.

A recent global assessment found that world $\mathrm{CO}_{2}$ reductions of 26 percent from 1985 levels (by the year 2050) could be brought about through intensive substitution away from coal and oil toward renewable sources, combined with significant improvements in energy efficiency (Johansson and others, 1993) (figs. 18, 19). In this scenario, the market share of gas would increase, mostly in the power sector. Measured in terms of potential resource base, the single most important renewable contributor to electricity production is gasified biomass, produced, for example, from the residues of the world's cane sugar industries and exported to the national electricity grid. 


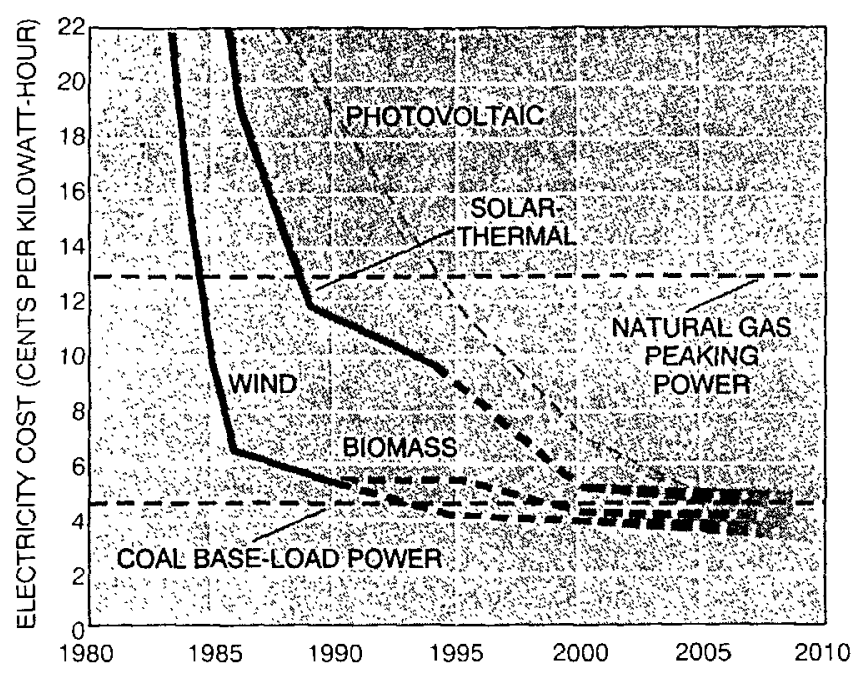

Figure 17. Costs of electricity generated from renewable resources fell sharply in the 1980's and will continue to fall as technology improves and experience is gained. Electricity costs (vertical axis) are based on actual (solid lines) or projected (broken lines) costs for bulk power generation. Costs are also shown for new coal-fired base-load and natural gas-fired peaking plants. From Weinberg and Williams (1990).

Figure 18. Scenario for reducing world $\mathrm{CO}^{2}$ emissions by replacing fossil fuels with renewable energy sources. $A$, Direct fuel use. In this scenario, global use of fuels for purposes other than electricity generation will grow by less than one-third, much less than the generation of electricity (see figure $18 B$ ). The contribution by renewable energy sources could reach nearly one-fourth by 2025 and two-fifths by 2050 , with most of the contribution coming from biomass-derived fuels-methanol, ethanol, hydrogen, and biogas. Methanol and hydrogen may well prove to be the biofuels of choice, because they are energy carriers most easily used in fuel cells that would power transportation in this scenario. $B$, Electricity generation. In this scenario, the share of renewable energy generation will increase from 20 percent in 1985 (mostly hydroelectric power) to about 60 percent in 2025 , with roughly comparable contributions from hydropower, intermittent renewable sources (for example, wind and direct solar power), and biomass. The contribution of intermittent renewable sources could be as high as 30 percent by middle of next century. High rate of penetration by intermittent renewable sources without electrical storage would be facilitated by emphasis on advanced natural-gasfired gas-turbine power-generating systems. Such systems-characterized by low capital cost, high thermodynamic efficiency, and the flexibility to vary electrical output quickly in response to changes in output of intermittent power-generating systemswould make it possible to "back up" intermittent renewable sources at low cost, with little, if any, need for electrical storage. In this scenario, the share of natural gas in power generation will nearly double by 2025 , from its 12 -percent share in 1985 . TWh, terawatthour ( $10^{9}$ kilowatthours). From Johansson and others (1993).

\section{ISSUES FOR DEVELOPING COUNTRIES AND ECONOMIES IN TRANSITION}

\section{THE SETTING}

Developing countries and economies in transition are faced with escalating demands for energy. Although the per-capita GNP and energy consumption of these countries are far lower than those of typical industrial countries, their energy efficiency is also generally lower and the rate of growth in demand for energy services is far higher. Between 1973 and 1988, annual growth in energy consumption averaged 5.4 percent in developing countries and 2.3 percent in Eastern Europe, compared to an average of 0.9 percent in OECD countries (Levine and others, 1991).

The cost of providing energy drains money away from efforts to provide food, health services, housing, and other basic needs in poor countries, and hence has become a serious constraint (rather than aid) to development. Nonetheless, demand for energy services will grow as these coun-
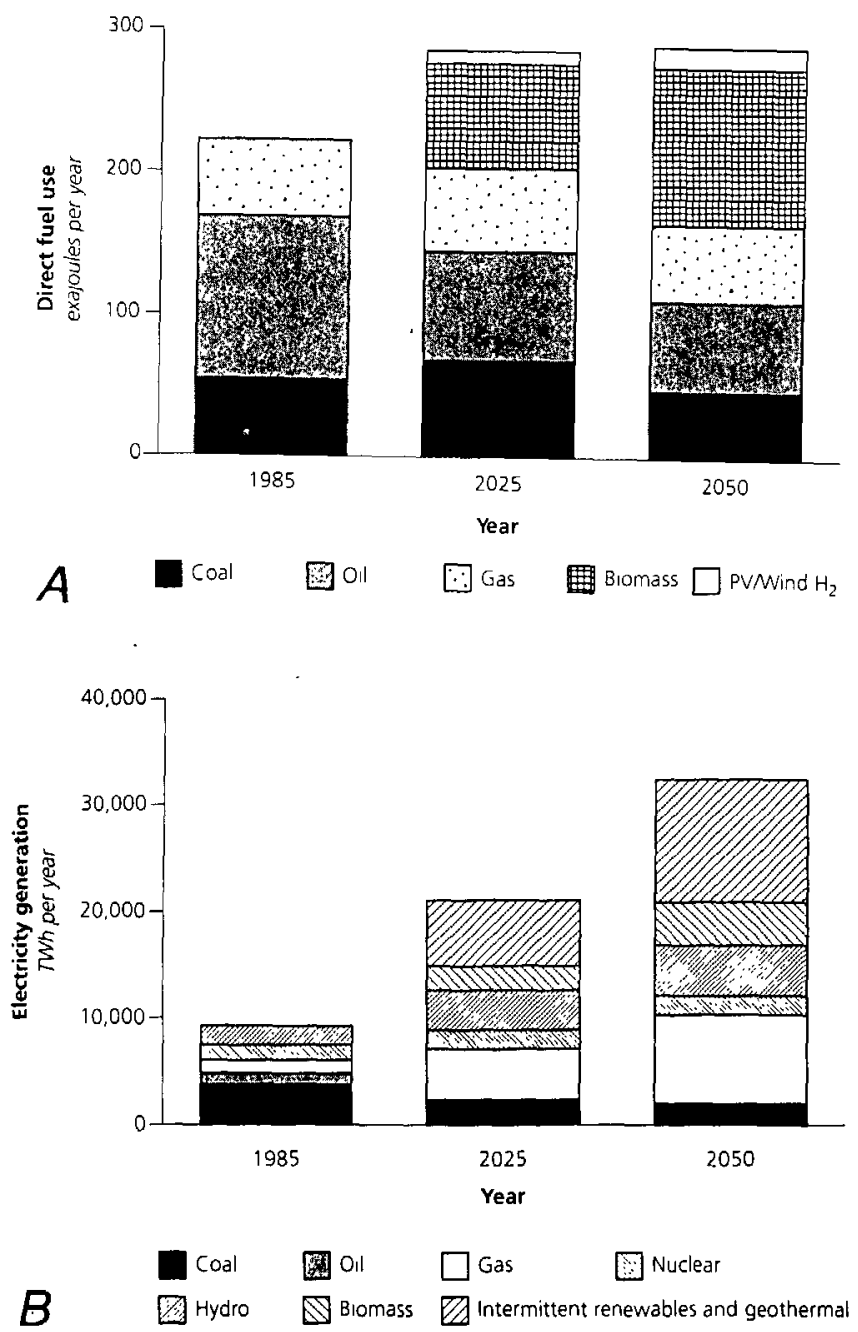


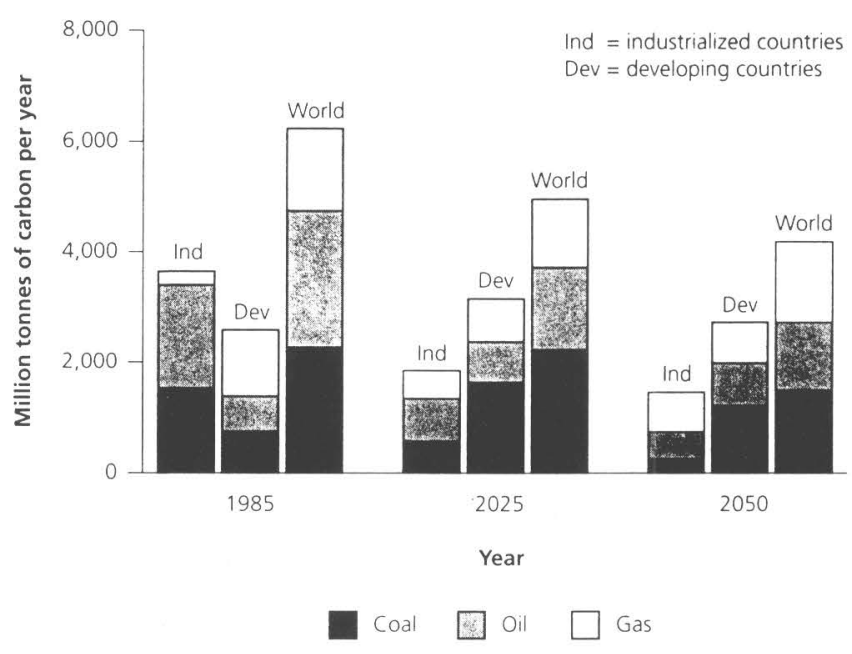

Figure 19. Reductions in global $\mathrm{CO}^{2}$ emissions predicted on basis of scenario presented in figure 18. In this scenario, global $\mathrm{CO}^{2}$ emissions will be reduced 12 percent by 2025 and 26 percent by 2050 . During this period, $\mathrm{CO}^{2}$ emissions from industrialized countries (including former U.S.S.R. and other Eastern European countries) would be reduced by nearly one-half by 2025 and nearly two-thirds by 2050 . Industrialized-country share of total worldwide emissions would decline from about threefourths in 1985 to about two-fifths in 2025 to about one-third in 2050. From Johansson and others (1993).

tries become more affluent; the challenge is to minimize the energy needed to meet this rightful demand for energy services (Reddy and others, 1990). Taking these factors together, it seems clear that if end-use efficiency is ignored, the cost of providing energy services can become a great problem indeed.

Experience to date has shown that even with impressive expansion of installed generation capacity, electricity demand in developing countries and Eastern Europe continues to exceed power-system capacity. Rapidly escalating demand, coupled with deteriorating utility performance, has led to persistent unscheduled power outages which result in measurable economic losses (U.S. Agency for International Development, 1988). The present power-system expansion plans of developing countries and Eastern Europe will require staggering annual investments of nearly $\$ 70$ billion until 2000, and about $\$ 145$ billion for the first quarter of the next century. In comparison, the current annual World Bank lending for the power sector is less than $\$ 4$ billion; including the lending from all multilateral and bilateral sources, total lending is less than $\$ 10$ billion (Moore and Smith, 1990).

To complicate the situation, much of the energy sold worldwide is subsidized by governments, leading to consumer expectations for inexpensive energy and inefficient use of energy. Recent attempts to raise energy prices in Jamaica, Ecuador, and Guatemala have been met with protests, civil disorder, and changes in governments (Hill,
1987, 1988). Furthermore, entrenched and powerful bureaucracies in utility companies historically have been exclusively concerned with expanding supply. At the same time, inefficient energy use translates into unnecessary emissions of greenhouse gases and other environmental risks. Accelerating the pace of increases in energy efficiencies is thus also in the global interest (Levine and others, 1991).

Policies are beginning to be implemented to address the barriers in developing countries. Import duties (which can double the retail price of energy-efficient products) have been drastically reduced in Pakistan and Thailand. Mandatory efficiency standards for commercial buildings are being developed within the Association of Southeast Asian Nations (ASEAN). Electric utilities in Thailand, Mexico, and Brazil are planning to initiate or have already initiated financial incentive programs for efficient lighting in households, in businesses, and on streets. As another means of gathering capital, Western entrepreneurs have entered into joint ventures to produce efficient lighting products in developing countries and Eastern Europe.

\section{NATURAL GAS IN DEVELOPING COUNTRIES}

With respect to natural gas, developing countries demonstrate a distinctly different energy-use profile than industrial countries. While about 70 percent of the world's energy is used in industrialized countries, 90 percent of the world's natural gas is used in industrialized countries (U.S. Office of Technology Assessment, 1992). Furthermore, natural gas is rarely used in electricity production in the developing world (fig. 15). At least 52 developing countries possess significant natural-gas resources, most of which were identified in the search for oil. In 1975, 80 percent of all natural gas produced in developing countries was flared. Today, 97 percent of the gas produced in Nigeria is flared (U.S. Office of Technology Assessment, 1992).

If natural-gas infrastructure is expanded in developing nations, then gas can become a more significant competitor with other fossil fuels there. On the other hand, given its relative abundance and labor-intensiveness, biomass energy probably poses a more competitive threat to new uses of gas in developing countries than in industrialized countries. A particularly large potential exists in the cane-sugar industries, as noted above.

\section{TOWARD A NEW SYNTHESIS: INTEGRATED RESOURCE PLANNING}

The energy sector is returning to a service-based and end-use-oriented planning paradigm. Integrated resource planning, which is built upon a marriage of economics, engineering, and environmental science, recognizes increased end-use efficiency as a significant and robust energy 
resource and uses economic and noneconomic costs to weigh supply options. Thus far, integrated resource planning has been focused almost exclusively on the electricity sector; it is likely, however, that the concept will find applications in other energy and nonenergy sectors.

The traditional forecasting approach for defining "business-as-usual" energy futures shows an increase in energy demand, albeit with a reduction in intensity (the ratio of energy use per unit of economic activity). Such forecasts tend to represent what will happen if the current market (with its embedded barriers and failings) persists into the future. In contrast, an emerging scenario approach allows the visualization of options that are consistent with today's environmentally sustainable and economically efficient energy and environmental planning goals. The scenario approach emphasizes policy change and market transformation and allows comparative analysis of various classes of energy futures.

In summary, among the lessons learned from studying today's dynamic energy situation is the need to be cautious about predicting the future on the basis of the past. Technologies, economic relationships, and planning objectives are changing. Importantly, these trends (both on the demand and supply side) imply the loss of market share for some existing uses of energy gases and the creation of new markets for others. Increased efficiency of gas-based electricity supply and end-use technologies are examples of the former, and fuel switching from electricity to gas at the point of end use and the introduction of gasified biomass cogeneration systems are examples of the latter.

In contrast to relatively passive forecasting activities, a more proactive approach can be taken in which energy demand is managed and supply sources are systematically chosen to satisfy various technical, economic, and environmental criteria. To the extent that energy planning will be directed by goals of minimizing the economic and environmental costs of providing energy services to society, it is critical to note that neither supply-side nor demandside strategies alone can achieve an optimal future. Integrated energy-efficient, renewable, and natural-gas scenarios will likely be the strategy of choice through the next century.

\section{ACKNOWLEDGMENTS}

This work was funded by the Assistant Secretary of Conservation and Renewable Energy, Office of Buildings and Community Systems, Office of Building Technologies of the U.S. Department of Energy, under Contract No. DEAC03-76SF00098. The author thanks Alan Comnes and Jonathan Koomey (Lawrence Berkeley Laboratory) and Michael Fanelli and David Howell (U.S. Geological Survey) for their comments on an early draft.

\section{REFERENCES CITED}

Atkinson, B., McMahon, J., Mills, E., Chan, P., Chan, T., Eto, J., Jennings, J., Koomey, J., Lo, K., Lecar, M., Price, L., Rubinstein, F., Sezgen, O., Wenzel, T., 1992, Analysis of federal policy options for improving U.S. lighting energy efficiency-Commercial and residential buildings: Lawrence Berkeley Laboratory Report No. 31469, Berkeley, Calif.

Burnett, W.M., and Ban, S.D., 1989, Changing prospects for natural gas in the United States: Science, 21 , v. 244 , p. $305-$ 310 .

Busch, J., and Janda, K., 1992, Worldwide status of energy standards for buildings, in Proceedings of the ACEEE 1992 Summer Study on Energy Efficiency in Buildings: Washington, D.C., American Council for an Energy-Efficient Economy, p. 6.103-6.105

Davis, G.R., 1990, Energy for planet Earth: Scientific American, v. 263 , no. 3, p. 54 .

Friedel, R., Israel, P., and Finn, B.S., 1986, Edison's electric light-Biography of an invention: New Brunswick, New Jersey, Rutgers University Press, p. 121.

Geller, H.S., Harris, J., Levine, M., and Rosenfeld, A., 1987, The role of federal research and development in advancing energy efficiency-A $\$ 50$ billion contribution to the U.S. economy: Annual Review of Energy, v. 12, p. 357-395.

Geller, H.S., Hirst, E., Mills, E., Ross, M., and Rosenfeld, A.H., 1991, Getting America back on the energy-efficiency track: Washington, D.C., American Council for an Energy-Efficient Technology, $63 \mathrm{p}$.

Goldman, C.A., and Hopkins, M.E., 1991, Survey and analysis of state regulatory activities on least cost planning for gas utilities: Lawrence Berkeley Laboratory and National Association of Regulatory Utility Commissioners, Lawrence Berkeley Laboratory Report No. 30353.

Grubb, M.J., and Meyer, N.I., 1993, Wind energy-Resources, systems, and regional strategies, in Johansson, T.B., and others, eds., Renewable energy-Sources for fucls and electricity: Washington, D.C., Island Press, p. 157-212.

Hamilton, L.B., Milford, L., Parker, S., and Steinhurst, W., 1992, Fuel switching programs in Vermont-Issues and experiences, in Proceedings of the ACEEE 1992 Summer Study on Energy Efficiency in Buildings; Washington, D.C., American Council for Energy-Efficient Economy, p. 8.79-8.87.

Hill, L.J., 1987, Energy price reform in developing countriesIssues and options: Oak Ridge, Tenn., Oak Ridge National Laboratory Report No. 6391.

-1988, Implementing energy price reform in developing countries: Natural Resources Forum, v. 12., no. 1, February.

Hirst, E., and Brown, M., 1989, Closing the efficiency gap-Barriers to the efficient use of energy: Oak Ridge, Tenn., Oak Ridge National Laboratory, $17 \mathrm{p}$.

Hirst, E., Goldman, C., and Hopkins, M.E., 1991, Integrated resource planning-Electric and gas utilities in the USA: Utilities Policy, v. 1, no. 2, p. 172-186.

Holdren, J.P., 1992, The transition to costlier energy, in Schipper, L., Meyers, S., and others, eds., Energy efficiency and human activity-Past trends, future prospects: Cambridge, England, Cambridge University Press, $400 \mathrm{p}$.

Holtberg, P.D., Woods, T.J., Lihn, M.L., and Koklauner, A.B., 1993, Baseline projection data book-1993 edition of the 
GRI baseline projection of U.S. energy supply and demand to 2010: Washington, D.C., Gas Research Institute.

Johansson, T.B., Kelly, H., Reddy, A.K.N., and Williams, R.H., 1993, Renewable energy-Sources for fuels and electricity: Washington, D.C., Island Press, 1160 p.

Koomey, J.G., and Rosenfeld, A.H., 1990, Revenue-neutral incentives for efficiency and environmental quality: Contemporary Policy Issues, v. 8, p. 142-155.

Levine, M.D., Gadgil, A., Meyers, S., Sathaye, J., Stafurik, J., and Wilbanks, T., 1991, Energy efficiency, developing nations, and Eastern Europe-A report to the U.S. working group on global energy efficiency: Washington, D.C., International Institute for Energy Conservation, $60 \mathrm{p}$.

Mills, E., 1991, Uncertainties in the price-responsiveness of energy demand-An end-use comparison of Denmark and Sweden: Lund, Sweden, Lund University, Department of Environmental and Energy Systems Studies, 42 p.

-1993, Efficient lighting programs in Europe-Cost-effectiveness, consumer response, and market dynamics: Energy-The International Journal, v. 18, no. 2, p. 131-144.

Mills, E., and Borg, N., 1991, Short-term financial impacts of energy-efficiency programmes on European electric utilities-Case studies for nine utilities in five countries, in Mills, E., ed., Proceédings of the 1st European Conference on Energy-Efficient Lighting: Stockholm, Sweden, Swedish National Board for Industrial and Technical Development, p. 305-318.

Mills, E., Wilson, D., and Johansson, T.B., 1991, Getting started-No regrets strategies of reducing greenhouse-gas emissions: Energy Policy, v. 19, no. 6, p. 526-542.

Moore, E., and Smith, G., 1990, Capital expenditures for electric power in the developing countries in the 1990s: World Bank, Industry and Energy Department, Energy Series Paper No. 21.

Nadel, S., 1990, Lessons learned-A review of utility experience with conservation and load management programs for commercial and industrial customers: Washington, D.C., American Council for an Energy-Efficient Economy, 226 p.

1992, Stalking the golden carrot-A utility consortium to accelerate the introduction of super-efficient, CFC-free refrigerators, in Proceedings of the ACEEE Summer Study on Energy-Efficiency in Buildings: Washington, D.C., American Council for an Energy-Efficient Economy, p 5.137.

Nadel, S., Eto, J., Kelly, M., and Jordan, J., 1993, Gas DSM and fuel-switching-Opportunities and experiences: Washington, D.C., American Council for an Energy-Efficient Economy.

National Academy of Sciences, 1992, Policy implications of

greenhouse warming-Mitigation, adaptation, and the science base: Washington, D.C., National Academy Press, 918 p.
National Association of Regulatory Utility Commissioners (NARUC), 1988, Least-cost utility planning handbook for public utility commissioners: Washington, D.C., NARUC.

Nilsson, H., 1992, Market transformation by technology procurement and demonstration, in Proceedings of the ACEEE 1992 Summer Study on Energy-Efficiency in Buildings: Washington, D.C., American Council for an Energy-Efficient Economy, p. 6.179 .

RCG/Hagler, Bailly, Inc., 1991, Integrated planning, DSM evaluation and cost recovery issues for gas distribution utilities: Boulder, Colo., RCG/Hagler, Bailly, Inc.

Reddy, A.K.N., Sumithra, G.D., Balachandra, P., and d'Sa, A., 1990, Energy conservation in India-A development-focused end-use oriented energy scenario for Karnataka, Part 2-Electricity: Bangalore, India, Department of Management Studies, Indian Institute of Science.

Samsa, M.E., and Hederman, W.F., 1992, Gas utility resource planning--How far does the electric analogy go?: Public Utilities Fortnightly, October 1, 1992, p. 40-42.

Schipper, L., Meyers, S., Howarth, R., and Steiner, R., 1992, Energy efficiency and human activity-Past trends, future prospects: Cambridge, England, Cambridge University Press, 400 p.

U.S. Agency for International Development, 1988, Power shortages in developing countries-Magnitude, impacts, solutions and the role of the private sector: Report to U.S. Congress.

U.S. Department of Energy, 1989, Energy conservation trendsUnderstanding the factors that affect conservation gains in the U.S. economy, (DOE/PE-0092): Washington, D.C., Office of Policy, Planning and Analysis, Office of Conservation and Renewable Energy.

U.S. Department of Energy, 1991/1992, National energy strategy (1st ed.): Washington, D.C., p. A-2.

U.S. Office of Technology Assessment, 1992, Fueling development-Energy technologies for developing countries: U.S. Congress, Office of Technology Assessment.

U.S. Office of Technology Assessment, 1991, Changing by degrees-Steps to reduce greenhouse gases (OTA-O-482): Washington, D.C., U.S. Government Printing Office, 354 p.

Wiel, S., 1991, The new environmental accounting-A status report: The Electricity Journal, November 1991, p. 46-54.

Weinberg, C.J., and Williams, R.H., 1990, Energy from the sun: Scientific American, v. 263, no. 3, p. 146.

Williams, R.H., and-Larson, E.D., 1989, Expanding roles for gas turbines in power generation, in Johansson, T.B., Bodlund, B., and Williams, R.H., eds., Electricity-Efficient end-use and new generation technologies, and their planning implications: Lund, Sweden, Lund University Press, p. $503-553$. 



\title{
THE FUTURE OF ENERGY GASES
}

\author{
U.S. GEOLOGICAL SURVEY PROFESSIONAL PAPER 1570
}

\section{How Ultimate is Ultimate Gas Recovery?}

\author{
By Thomas J. Woods ${ }^{1}$
}

\section{CONTENTS}

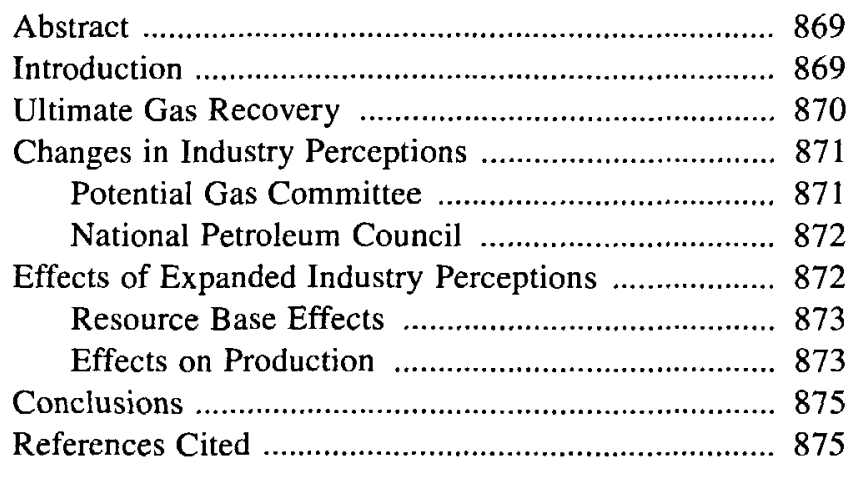

\begin{abstract}
Estimates of ultimate gas recovery reflect industry perceptions at the time the estimates were made. Industry perceptions, however, are dynamic, not static. Over the last 20 years, industry perceptions of the recoverable gas resources of the lower 48 States have expanded significantly. These expanded perceptions, driven in large part by advances in technology and practice, have led to an increased optimism about the prospects for gas production from the lower 48 States under conditions of low-to-modest prices. Historical experience demonstrates that industry activity expands industry resource perceptions and, with it, estimates of ultimate recovery as much or more as this activity depletes the resource base estimated under its current perceptions.
\end{abstract}

\footnotetext{
${ }^{1}$ Gas Research Institute, Strategic Planning and Analysis Division, Washington, D.C.
}

This paper will review past estimates of the gas resource potential from the lower 48 States in light of expanding industry perceptions and new technology as well as their effects on current industry activity and future gas production and prices.

\section{INTRODUCTION}

Projections of long-term trends in gas prices, particularly since the 1970's, generally have been based on the concept of ultimate gas recovery (in other words, gas is a depletable resource). Under this theory, gas prices rise steadily as the resource is depleted. As a result, projections of long-term gas supply are accompanied by steadily increasing prices, with limited prospects for stable or increased supply.

Recent events, however, have called into question the applicability of a depletable resource concept in projecting long-term trends in gas production and prices for the lower 48 States. Current gas prices are less than half of their early 1980's peaks, and prospects for increased prices in the future have weakened substantially. Nevertheless, since the mid-1980's, the industry has replaced reserves depleted by growing gas production in the lower 48 States with new reserves using levels of drilling activity previously thought to be too low. Continued replacement of gas production without increased gas prices appears inconsistent with the concept of ultimate gas recovery.

Estimates of ultimate gas recovery for the lower 48 States reflect industry perceptions at the time the estimates were made. Industry perceptions, however, are dynamic, not static. As industry activity continues, new areas are found to be productive that were not productive in previous industry perceptions of the resource. New, less conventional resources are added, and the capability of the industry to recover gas from known fields and active plays 
increases. As a result, future industry activity should lead to increased estimates of ultimate gas recovery, just as they lead to increased cumulative gas discoveries.

Over the last 20 years, industry perceptions of the recoverable gas resource base from the lower 48 States have expanded significantly. New technology has reduced the costs and risks to develop gas reserves. Resources in offshore areas with water deeper than 500 meters are now economic to develop at modest prices. New areas, which were thought to have little or no resource potential in 1970 , such as the deep Norphlet play in the eastern Gulf of Mexico (see Lore, this volume), the Arkoma Basin, and the Overthrust Belt, are now expected to have substantial resource potential. Less conventional resources (for example, tight sands, shales, and coal seams), which were often little more than research curiosities, are now active, expanding sources of gas production. Therefore, long-term projections of gas supply and price that do not recognize the effects of expanding industry perceptions on the recoverable gas resource potential will tend to overstate the upward pressures on gas prices and the downward pressures on gas supply.

This paper will review recent gas resource estimates from the lower 48 States to identify the specific changes in gas resource perceptions that have occurred over the last 20 years. It will also discuss the extent to which changed resource perceptions have affected the outlook for gas production from the lower 48 States. The gas supply trends in the 1993 edition of the Gas Research Institute (GRI) baseline projection (Woods, 1993) will be used as a framework for this latter discussion.

\section{ULTIMATE GAS RECOVERY}

Beginning with the U.S. Department of Energy (DOE) gas study in 1988, estimates of ultimate gas recovery in the lower 48 States have become more optimistic (U.S. Department of Energy, Office of Policy, Planning, and Analysis, 1988). With 1988 technology, the DOE study estimated that, including proved reserves, 1,059 trillion cubic feet (Tcf) of gas remained to be recovered as of the end of 1986. As of the end of 1990, the 1988 DOE study would have implied that $993 \mathrm{Tcf}$ of recoverable gas remained.

Table 1 presents five recent resource estimates. The resource estimate in the 1993 GRI baseline projection (Woods, 1993) is the largest resource estimate, and the Potential Gas Committee (PGC) (1990) estimate is the lowest. Compared to the estimates showing a technology range, the PGC appears very conservative about the prospects for new technology expanding the gas resource potential for the lower 48 States.

Table 1. Remaining gas resource potential from the lower 48 States as of December 31 , 1990.

[GRI 93, estimate used in the 1993 edition of the Gas Research Institute baseline projection; DOE NES, U.S. Department of Energy estimate used in the development of the National Energy Strategy; Enron 91, Enron estimate published in 1991; PGC 90, 1990 Potential Gas Committee estimate; NPC 92, resource estimate used in the recent National Petroleum Council study. Data from Woods, 1993; U.S. Department of Energy, Energy Information Administration, 1990; Enron, 1991; Potential Gas Committee, 1991; National Petroleum Council, 1992. Ranges in the GRI, DOE, and Enron estimates reflect the effects of both current and advanced technology; PGC estimate does not explicitly present technology effects; NPC estimate is only for the advanced technology case. Estimates are adjusted to bring them to the same point in time, December 31, 1990; NA, not applicable]

\begin{tabular}{|c|c|c|c|c|c|}
\hline Category & $\begin{array}{c}\text { GRI } 93 \\
\text { (Tcf) }\end{array}$ & $\begin{array}{l}\text { DOE NES } \\
\text { (Tcf) }\end{array}$ & $\begin{array}{c}\text { Enron } 91 \\
\quad(T c f)\end{array}$ & $\begin{array}{c}\text { PGC } 90 \\
\text { (Tcf) }\end{array}$ & $\begin{array}{c}\text { NPC } 92^{1} \\
\text { (Tcf) }\end{array}$ \\
\hline New fields - -...- & $608-667$ & $263-326$ & $588-631^{2}$ & 421 & 413 \\
\hline Reserve appreciation--_-_-_-_-- & 244 & $177-265$ & NA & 157 & 203 \\
\hline Total & $852-911$ & $440-591$ & $588-631$ & 577 & 616 \\
\hline Unconventional increment----- & $329-514$ & $295-503$ & $257-401^{3}$ & 88 & 519 \\
\hline Total-_._-_-_._- & $1117-1425$ & $735-1094$ & $845-1032$ & 665 & 1135 \\
\hline Adjustments to $12 / 31 / 90$ & NA & -36 & -19 & NA & NA \\
\hline Total-_-_._._. & $1117-1425$ & $699-1058$ & $826-1013$ & 665 & 1135 \\
\hline
\end{tabular}

'2010 technology only.

${ }^{2}$ Enron estimate does not break out new fields and reserve appreciation.

${ }^{3}$ Includes improved recovery from high-permeability reservoirs. 
The reserve appreciation and unconventional increment resources in the GRI, DOE, Enron, and National Petroleum Council (NPC) estimates in table 1 are relatively consistent. The GRI new-fields resource is the reason the GRI estimate is the largest. The GRI new-fields resource is more optimistic about the relatively unexplored deeper sediments in the lower 48 States than are the other estimates.

\section{CHANGES IN INDUSTRY PERCEPTIONS}

A review of industry resource estimates for the last 20 years indicates that industry resource perceptions have expanded substantially. Two of the estimates in table 1 span this period-the PGC and the NPC estimates. The PGC estimates have been made on a regular two-year interval over this period, and the NPC has estimated the gas resource potential for the lower 48 States in two studiesone in 1992 and the other in 1972 (National Petroleum Council, 1972, 1992).

\section{POTENTIAL GAS COMMITTEE}

The PGC has estimated the gas resource potential for the lower 48 States on a detailed regional basis since 1966. These resource estimates provide a historical record of industry resource perceptions for more than 25 years. The PGC estimate of the remaining potential for the lower 48 States peaked at $851 \mathrm{Tcf}$ in 1970. By 1986 its estimate had declined to 620 Tcf. Since 1988, the PGC estimate has increased, reflecting the addition of coalbed methane to the PGC resource assessment.

The PGC perceptions of the gas resource potential for the lower 48 States have expanded since 1970. The most explicit reflection of this expansion is the inclusion of coalbed methane, beginning with the 1988 estimate. PGC perceptions, however, have also expanded since 1970 to reflect the effects of new areas, new plays, and other less conventional resources. New technology and practices (exploration and development techniques) developed over the last 20 years have been critical to these expanded perceptions.

The 1970 PGC estimate of the ultimate gas recovery from the lower 48 States did not include gas resources in offshore areas with water depths greater than 1,500 feet. Its 1990 estimate includes the offshore resource potential of areas with water depths greater than 1,000 meters (about 3,300 feet). The 1970 PGC estimate also did not expect much, if any, gas recovery from the offshore deep Norphlet Formation in the Gulf of Mexico; today the deep Norphlet is considered to be one of the largest, if not the largest, gas play ever discovered in the lower 48 States (see Lore, this volume).
In the onshore areas, similar expansions have taken place relative to the 1970 perceptions. Coalbed methane is now included in the PGC estimate, as is some low-permeability potential in the Rocky Mountains outside the San Juan Basin and in East Texas. The resource potentials in the Overthrust Belt and the deeper Arkoma Basin formations have increased as well.

Finally, for area other than the Texas Gulf Coast, reserve additions between 1971 and 1985 in the fields discovered before 1971 (pre-1971 fields) have exceeded the 1970 PGC estimate of future reserve additions in these fields. Reserve additions in the pre-1971 fields continue to be strong, although the 1970 PGC estimate implied that reserve additions in these fields would have ended by 1985 or earlier. As a result, the 1990 PGC estimate includes substantial volumes of reserve additions in pre1971 fields that were not in its 1970 estimate.

Table 2 allocates the PGC (1990) estimate of the remaining resource potential for the lower 48 States to 1970 perceptions and post-1970 perceptions. The gas resource potential is presented for probables (reserve additions in known fields) and new fields (possible plus speculative fields). The post-1970's resource perceptions is further allocated to areas in the lower 48 States (for example, the Green River area) or resource categories (pre-1971 fields, coalbed methane).

The post-1970 perceptions resource (table 2) are mostly in three categories: reserve additions to pre-1971 fields,

Table 2. Gas resource potential for the lower 48 States-1990 Potential Gas Committee report.

[Data from Potential Gas Committee, 1990]

\begin{tabular}{|c|c|c|c|}
\hline Category & $\begin{array}{c}\text { Probables } \\
\text { (Tcf) }\end{array}$ & $\begin{array}{l}\text { New fields }{ }^{1} \\
\quad(T c f)\end{array}$ & $\begin{array}{l}\text { Total } \\
\text { (Tcf) }\end{array}$ \\
\hline Lower 48 States & 166.1 & 499.5 & 665.6 \\
\hline \multicolumn{4}{|l|}{ Post-1970 perceptions: } \\
\hline Overthṛust Belt - -..--.-- & 7.3 & 13.6 & 20.9 \\
\hline Green River Basin & 9.1 & 20.5 & 29.6 \\
\hline Deep Gulf of Mexico & 0 & 47.2 & 47.2 \\
\hline Norphlet Trend --.--..-- & 3.6 & 11.7 & 15.3 \\
\hline Deep Atlantic --....-.-...-. & 0 & 3 & .3 \\
\hline Deep Pacific--- & 0 & 4.5 & 4.5 \\
\hline Arkoma Basin -...-........ & .3 & 1.9 & 2.2 \\
\hline Pre-1971 fields----_-_------ & 60 & 0 & 60 \\
\hline Coalbed methane --..---.-- & 9.6 & 78.6 & 88.2 \\
\hline Total -..-- & 89.9 & 178.3 & 268.2 \\
\hline 1970 perceptions & 76.2 & 321.2 & 397.4 \\
\hline
\end{tabular}

'Possible plus speculative gas potential. 
offshore, and coalbed methane. More than half of the PGC probable resource potential reflects the effects of expanded PGC resource perceptions since 1970 . More than 33 percent of the PGC new-fields potential reflects expanded PGC resource perceptions since 1970 . Overall, 40 percent of the remaining resource potential for the lower 48 States in the 1990 PGC estimate was not in the PGC perceptions of the resource base in 1970 .

The expanded resource perceptions since 1970 have also affected proved reserves. As of the end of 1990, more than 10 percent of the gas reserves from the lower 48 States could be assigned to the post- 1970 perception categories. Therefore, without the expanded industry resource perceptions since 1970, gas reserves from the lower 48 States at the end of 1990 would have been closer to $140 \mathrm{Tcf}$ instead of $160 \mathrm{Tcf}$. While this lower reserve level could theoretically support the actual gas production from the lower 48 States in 1991, gas prices would have been much higher because there would have been no "gas bubble."

\section{NATIONAL PETROLEUM COUNCIL}

In 1972 and 1992, the NPC published energy studies in which it estimated the gas resource potential for the lower 48 States (National Petroleum Council, 1972, 1992). Table 3 compares the resource potential from the 1972 study with the resource potential in the 1992 study. The 1972 potential is brought forward to 1990 by subtracting gas reserve additions between 1971 and 1990.

Table 3 shows that the NPC estimated that the gas resource potential for the lower 48 States was $906 \mathrm{Tcf}$ in the 1972 study. Between 1971 and 1990, the industry added 272 Tcf of gas reserves, thereby leaving a remaining re-

Table 3. Gas resource potential for the lower 48 States1972 and 1992 National Petroleum Council studies.

[Data from National Petroleum Council, 1972, 1992]

\begin{tabular}{|c|c|}
\hline Category & $\begin{array}{l}\text { Potential } \\
\text { (Tcf) }\end{array}$ \\
\hline \multicolumn{2}{|l|}{ National Petroleum Council 1972 Study } \\
\hline Potential as of $12 / 31 / 70$ & 906 \\
\hline Reserve additions 1971-90 & 272 \\
\hline Potential as of $12 / 31 / 90$ & 634 \\
\hline \multicolumn{2}{|l|}{ National Petroleum Council 1992 Study } \\
\hline \multicolumn{2}{|l|}{ Potential as of $12 / 31 / 90$ based on: } \\
\hline 1990 technology & 905 \\
\hline 2010 technology & 1135 \\
\hline
\end{tabular}

source potential of $634 \mathrm{Tcf}$. This would have been the remaining resource potential had industry perceptions of the gas resource base not expanded over the last 20 years. However, the NPC concluded in 1992 that the gas resource potential for the lower 48 States was $905 \mathrm{Tcf}$ as of December 31, 1990, essentially unchanged from what the NPC estimated as the potential in 1972. Table 2 indicates that, as industry activity was depleting the "known" resource potential, expanding industry perceptions were replacing the depleted potential with new resources, just as the industry replaces production with new reserves.

The 1992 NPC study expects that technology and practices will continue to improve after 1990, thus further increasing the recoverable gas resource potential in the producing regions and formations in the lower 48 States. The NPC study estimates that, as a result of these continued improvements, the resource potential increases 25 percent to 1,135 Tcf (table 3). Relative to the 1972 study, the NPC has increased its expectations of potential resource for 2010 as of 1990 by 79 percent.

The 2010 technology resource potential (table 3), however, does not include the effects of expanded industry perceptions for new regions or formations. As a result, the 2010 technology resource potential in the 1992 NPC study does not fully reflect the incremental resource potential of expanded industry perceptions over the next 20 years. Given the industry track record of expanding resource perceptions, it is reasonable to expect that, if the NPC does another gas study 20 years in the future, the resource potential could be unchanged or even larger.

\section{EFFECTS OF EXPANDED INDUSTRY PERCEPTIONS}

Projections of gas production from the lower 48 States have become more optimistic since the mid-1980's. In the 1970's and early 1980's, gas production from the lower 48 States was projected to decline to as little as 10 Tef by 2010 . Since the mid-1980's, many projections now show gas production from the lower 48 States remaining stable or even increasing. The increased optimism reflects the effects of expanded industry resource perceptions, driven in large part by advances in industry technology and practice.

The 1993 edition of the GRI baseline projection (Woods, 1993) is consistent with this optimism. Gas production from the lower 48 States grows steadily in the 1993 projection, exceeding 20 Tcf by 2010 . The major share of the resource potential used in the 1993 projection reflects the expanded industry resource perceptions since 1970. As a result, the 1993 edition of the GRI baseline projection (Woods, 1993) can provide a reference against which the effects of the expanded resource perceptions on the gas resource potential for the lower 48 States and the 
outlook for production from the lower 48 States can be assessed.

\section{RESOURCE BASE EFFECTS}

The resource potential for the lower 48 States used in the 1993 edition of the GRI baseline projection (Woods, 1993) can be allocated among 1970, 1970-90, and post1990 resource perceptions. The 1970 perceptions resource potential is based on the PGC resource description. Table 4 presents the results of this allocation.

Table 4 shows the effects of expanding industry resource perceptions since 1970 on the remaining resource potential for the lower 48 States. Only 30 percent of the total remaining resource potential in the 1993 GRI baseline projection (Woods, 1993) would be available if industry perceptions of the resource base had remained at their 1970 levels. Forty-three percent of the total remaining potential reflects the effects of advances in industry perceptions from 1970 to 1990, and the continued advance in industry perceptions after 1990 accounts for the remaining 27 percent of the total resource potential. Overall, expanded industry resource perceptions between 1970 and 1990 and the expected continued expansion of resource perceptions after 1990 account for more than two-thirds of the remaining gas resource potential for the lower 48 States in the 1993 GRI projection.

Most of the new-fields potential in the 1993 GRI baseline projection (Woods, 1993) reflects the effects of expanded industry perceptions since 1970 (table 4). Only about 40 percent of the new-fields potential would be available if industry perceptions had remained at their 1970 level. The remaining new-fields potential is about equally divided between 1970-90 and post-1990 perceptions. The post-1990 perceptions potential is principally due to the continued ability of the industry to expand the resource potential deeper than $10,000 \mathrm{ft}$ in the gulf coast region, both onshore and offshore. These sediments have had very little exploration activity to date.
In table 4 the reserve appreciation potential is about equally divided between 1970 and 1970-90 perceptions. No potential is included for continued expansion of reserve additions in known fields past 1990, although, on the basis of past industry results, some additional gas reserve appreciation resource potential should be in the post- 1990 perceptions category.

Almost all of the less conventional gas resource (shale, coal seams, and tight sands) in the 1993 GRI baseline projection (Woods, 1993) reflects the expansion of industry perceptions since 1970 (table 4). The modest volumes in the pre-1970's perceptions represent Devonian shale and low-permeability gas in the Appalachian Basin and some low-permeability gas in the Rocky Mountains and the Southwest.

\section{EFFECTS ON PRODUCTION}

We assessed the effects of expanded industry resource perceptions since 1970 on the outlook for gas production from the lower 48 States. We assumed that industry resource perceptions did not change after 1970. As a result, gas production from the lower 48 States was projected from 1991 to 2010 using the remaining gas resource potential of $410 \mathrm{Tcf}$ (table 4 ). In this sensitivity, we reduced proved reserves in 1990 to $142 \mathrm{Tcf}$ to exclude reserves in areas or formations for which industry had limited or no expectations in 1970 (for example, Norphlet Trend, Overthrust BeIt, San Juan Basin Fruitland coals). Table 5 compares the gas production trend for the lower 48 States in the resource sensitivity calculation (1970 perceptions) to the trend in the 1993 edition of the GRI baseline projection (Woods, 1993), which used a resource potential of $1425 \mathrm{Tcf}$ and a 1990 gas reserve for the lower 48 States of 160 Tcf.

Table 5 shows that if industry resource perceptions had not expanded since 1970, gas production from the lower 48 States would decline steadily between 1991 and 2010. The sensitivity does indicate, however, that the
Table 4. Remaining gas resource potential for the lower 48 States as of December 31, 1990-1993 edition of the Gas Research Institute baseline projection.

[Data from Woods, 1993. NA, not applicable]

\begin{tabular}{lcccc}
\hline \multicolumn{1}{c}{ Category } & $\begin{array}{c}1970 \\
\text { perceptions } \\
\text { (Tcf) }\end{array}$ & $\begin{array}{c}1970-90 \\
\text { perceptions } \\
\text { (Tcf) }\end{array}$ & $\begin{array}{c}\text { Post-1990 } \\
\text { perceptions } \\
\text { (Tcf) }\end{array}$ & $\begin{array}{c}\text { Total remaining } \\
\text { potential } \\
\text { (Tcf) }\end{array}$ \\
\hline New fields - - & 269 & 198 & 200 & 667 \\
Reserve appreciation --.- & 129 & 115 & NA & 244 \\
Less conventional -...-.- & 28 & 301 & 185 & 514 \\
\hline & 426 & 614 & 385 & 1425 \\
\hline
\end{tabular}

Table 5. Gas production from the lower 48 States.

[Data from Woods, 1993. GRI, Gas Research Institute]

\begin{tabular}{lcc}
\hline Year & $\begin{array}{c}93 \text { GRI perceptions } \\
\text { (Tcf) }\end{array}$ & $\begin{array}{c}1970 \text { perceptions } \\
\text { (Tcf) }\end{array}$ \\
\hline 1991 & 16.8 & 16.8 \\
1995 & 17.9 & 14.7 \\
2000 & 18.8 & 12.2 \\
2005 & 19.8 & 11.9 \\
2010 & 20.4 & 10.6 \\
\hline
\end{tabular}


142 Tcf of proved gas reserves in 1990 (discussed above) can support the actual production of $16.8 \mathrm{Tcf}$ in 1991 (table 5). This surprising result reflects the existence of the "gas bubble" and the effects of new technology and practices developed between 1970 and 1990. This indicates that even in 1991 , most gas production and reserves from the lower 48 States came from the 1970 perceptions resource, although they rely in part on post-1970 technology.

Table 5 shows that the improved outlook for gas production from the lower 48 States since the 1970's relies on resources that were not in the industry perceptions in 1970. Without expanded resource perceptions since 1970 , gas production from the lower 48 States would decline by about one-third between 1991 and 2010 (table 5), a decline consistent with the expectations of the 1970's and early 1980's. With the expanded resource perceptions, however, gas production from the lower 48 States grows steadily. By 2010 , it is almost double the production that could be achieved if industry perceptions had not expanded (table 5).

Gas production from the lower 48 States can be allocated among five gas-resource categories (table 6). The high-permeability and associated gas resource categories are generally referred to as conventional, while the other three categories (low permeability, Devonian shale, and coalbed methane) are referred to as less conventional. Table 6 compares gas production from the lower 48 States by gas resource category in the 1993 GRI baseline projection (Woods, 1993) and the projected production using only the 1970 perceptions resource potential.

Table 6 shows that about 87 percent of gas production from the lower 48 States in 1991 came from conventional sources. Conventional sources play a somewhat larger role in the sensitivity than they do in the 1993
GRI baseline projection (Woods, 1993), which offsets the absence of coalbed methane production and the smaller low-permeability production. By 1995, however, the conventional gas potential based on 1970 perceptions of the gas resource potential cannot maintain gas production from conventional sources at its 1991 level, let alone offset the lower production from less conventional sources. Without the post-1970 resource, high-permeability production declines 45 percent between 1991 and 2010, compared to about a 12 percent increase with the addition of the post-1970 resource in the 1993 GRI projection (table 6). This decline in gas production in the sensitivity reflects the limited prospects for reserve appreciation in known fields and new field discoveries in the deeper sediments of the gulf coast regions and the absence of gas production in the Overthrust Belt and the deep Norphlet Trend in the eastern Gulf of Mexico.

Associated gas production declines almost 50 percent over the projection period without the post-1970 resource, instead of stabilizing by the mid-1990's as it does in the 1993 GRI baseline projection (Woods, 1993). Most of the decline in associated gas production in the 1970's perception sensitivity occurs in the Southwest.

The less conventional comparison is quite surprising (table 6). Despite the absence of coalbed methane, less conventional gas production increases, even under the 1970 industry resource perceptions and without further technology advances. This is mostly due to increased shale production. Because of its location in the net importing end-use regions, wellhead prices for gas production from shales are about 40 to 50 cents per MMBtu higher than in the Southwest (Woods, 1993). Thus, location can affect the profitability of shale production about as much as the advances in technology and practice after 1990 under conditions of low-to-modest gas prices.

Table 6. Gas production from the lower 48 States allocated by gas resource category.

[--, no data; 93 GRI, 1993 edition of the Gas Research Institute baseline projection (Woods, 1993)]

\begin{tabular}{|c|c|c|c|c|c|c|}
\hline \multirow[b]{2}{*}{ Category } & \multicolumn{2}{|c|}{1991} & \multicolumn{2}{|c|}{2000} & \multicolumn{2}{|c|}{2010} \\
\hline & $\begin{array}{c}93 \mathrm{GRI} \\
\text { perceptions } \\
\text { (Tcf) }\end{array}$ & $\begin{array}{c}1970 \\
\text { perceptions } \\
\text { (Tcf) }\end{array}$ & $\begin{array}{c}93 \text { GRI } \\
\text { perceptions } \\
\text { (Tcf) }\end{array}$ & $\begin{array}{c}1970 \\
\text { perceptions } \\
(\mathrm{Tcf})\end{array}$ & $\begin{array}{l}93 \text { GRI } \\
\text { perceptions } \\
\text { (Tcf) }\end{array}$ & $\begin{array}{c}1970 \\
\text { perceptions } \\
\text { (Tcf) }\end{array}$ \\
\hline \multicolumn{7}{|l|}{ Conventional: } \\
\hline High permeability ------- & 12.1 & 12.8 & 12.9 & 8.9 & 13.5 & 7.0 \\
\hline Associated -.......... & 2.5 & 2.5 & 2.3 & 1.7 & 2.6 & 1.4 \\
\hline Low permeability & 1.7 & 1.3 & 1.7 & 1.2 & 2.0 & 1.4 \\
\hline \multicolumn{7}{|l|}{ Unconventional: } \\
\hline Coalbed methane -...-..- & .3 & - & 1.4 & - & 1.2 & - \\
\hline Devonian shale--------- & .2 & .2 & .5 & .4 & 1.0 & .8 \\
\hline Total & 16.8 & 16.8 & 18.8 & 12.2 & 20.4 & 10.6 \\
\hline
\end{tabular}




\section{CONCLUSIONS}

Supply projections based on resource depletion should be seen as inherently conservative. At best, they may only have utility for about a 20-year projection period; over that period, they may still overstate the upward pressures on gas prices. Extending a resource depletion model past 20 years, without taking into account the effects of expanding industry resource perceptions, leads to erroneous expectations of rapidly declining gas production and rapidly increasing gas prices.

Removal of post- 1970 perceptions from the resource used in the 1993 edition of the GRI baseline projection (Woods, 1993) indicates that post-1970 perceptions have their most visible effects on gas supply from the lower 48 States after 1991. Most gas-reserve additions between 1970 and 1990 were from resources within the industry's 1970 perceptions. The major impact of the expanded perceptions resource since 1970 was to reduce the upward pressures on gas prices. After 1990, the post-1970 perceptions resource is critical to both maintaining or increasing production from the lower 48 States and reducing the upward pressures on gas prices. Without the post-1970 resource perceptions, the pessimism during the 1970's toward future gas production from the lower 48 States and gas prices would still be justifiable.

Historical experience demonstrates that the industry activity expands its resource perceptions and thus estimates of ultimate recovery as much or more as this activity depletes the resource base estimated under its current perceptions. Therefore, estimates of ultimate gas recovery should be seen as more akin to proved reserves, although on a longer time horizon. Just as proved reserves generally indicate only the aggregate recovery expected from known fields using current industry investment, ultimate gas recovery should be seen only as the aggregate recovery expected in the future using current industry perceptions. As more investment is made in known fields, proved reserves in these fields increase. Similarly, as industry activity continues, industry perceptions of the resource expand and, with it, the expectations of ultimate gas recovery expand.
Although the dynamic of industry perceptions indicates that estimates of the resource potential made in the future will probably exceed current estimates of the resource potential, it should be recognized that the oil and gas industry only explores for what it believes to be realistic targets. For example, the industry did not believe the Permian Basin or East Texas had much potential until discoveries began to be made. Therefore, until sufficient discoveries or convincing arguments were made, the industry did not explore these areas. However, the experience of the industry demonstrates conclusively that someone will go into areas that were classified as nonproductive and find new resources. It is reasonable to expect that some currently unexplored sediments or regions will be productive in the future, provided they can be explored.

\section{REFERENCES CITED}

Enron, 1991, Enron Corporation's outlook for natural gas, fueling the future into the 21st Century: Houston, Texas, Enron Corporation, p. 8.

National Petroleum Council, 1972, U.S. energy outlook: Washington, D.C., National Petroleum Council, p. 91.

1992. The potential for natural gas in the United States, executive summary: Washington, D.C., National Petroleum Council, p. 5.

Potential Gas Committee, 1990, Potential supply of natural gas in the United States (December 31, 1990): Colorado School of Mines, Golden, Colorado, 169 p.

U.S. Department of Energy, Energy Information Administration, 1990, The domestic oil and gas resource base; supporting analysis for the National Energy Strategy: Washington, D.C., U.S. Department of Energy, Energy Information Administration, SR/NES/90-05, p. xii.

U.S. Department of Energy, Office of Policy, Planning, and Analysis, 1988, An assessment of the natural gas resource base in the United States: Washington, D.C., U.S. Department of Energy, DOE/W/31109-H, $126 \mathrm{p}$.

Woods, T. J., 1993, The long-term trends in U.S. gas supply and prices-1993 edition of the Gas Research Institute baseline projection of U.S. energy supply and demand to 2010: Chicago, Gas Research Institute, 92 p. 



\title{
The Gas Gap: Uncertainty in the Supply of Natural Gas
}

\author{
By David G. Howell ${ }^{1}$, Katryn Wiese ${ }^{2}$, and Jonathan Swinchatt ${ }^{3}$
}

\section{CONTENTS}

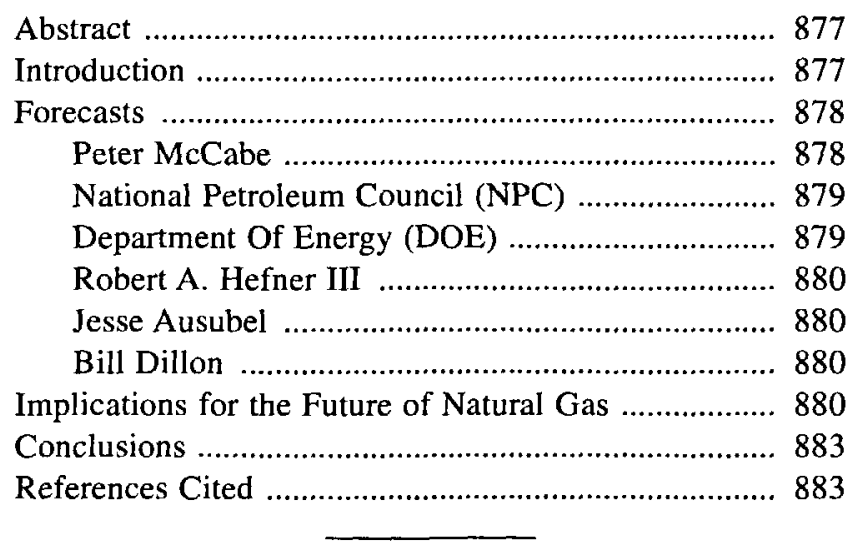

\begin{abstract}
Despite numerous attempts to predict future trends, uncertainty exists in the supply of natural gas. Forecasts of natural-gas resources have been made by many people, from scientists to economists, on the basis of historical trends, trade deficits, domestic economies, environmental concerns, and the pace of technology. Comparison of past forecasts with present trends, however, shows the difficulty in hitting the mark, in properly pinning down the fluctuations inherent in a multifaceted field. Nonetheless, optimism prevails in many of the forecasts. A guarded appreciation of what these forecasts really tell us can help us

\footnotetext{
${ }^{1}$ U.S. Geological Survey, 345 Middlefield Rd., MS 902, Menlo Park, CA 94025.

${ }^{2}$ U.S. Geological Survey, 345 Middlefield Rd., MS 999, Menlo Park, CA 94025.
}

${ }^{3}$ Earth Vision, Inc., 52 Cook Hill Rd., Cheshire, CT 06410.
\end{abstract}

develop wise energy policies and constructively influence the future of natural gas.

\section{INTRODUCTION}

In October of 1992, the U.S. Geological Survey (USGS) held a conference in Palo Alto, California on The Future of Energy Gases. The 75 attendees included petroleum geologists, geochemists, microbiologists, economists, engineers, geophysicists, efficiency experts, energy historians, and explorationists. Representatives came from institutes, universities, consulting firms, government laboratories, and both major and independent oil and gas companies. The meeting included presentations and discussions on the origin and habitat of energy gases, domestic and world resource potential, a brief history of the use of natural gas, the economics of energy systems, the interplay of efficiency and demand in energy systems, and the potential role of hydrogen as a fuel for the future. This volume is an outgrowth of that conference.

On the final day of the conference, a group discussion focused on forecasting natural-gas consumption for the United States through the year 2100 (fig. 1). Many forecasts project consumption that greatly exceeds the availability of natural gas as presently estimated by organizations such as the U.S. Geological Survey, the Department of Energy (DOE), and the National Petroleum Council (NPC). We call this difference between consumption forecasts and estimates of the gas supply the gas gap.

These energy-use forecasts are only speculations, but the higher forecasts represent hunches based on considerable experience and insight or extensions of historical trends. These trends show a clear pattern of market penetration of successively more versatile, more efficient, and cleaner fuels-that is, a progression from wood to coal, from coal to oil, and now, apparently, from oil to natural gas. 


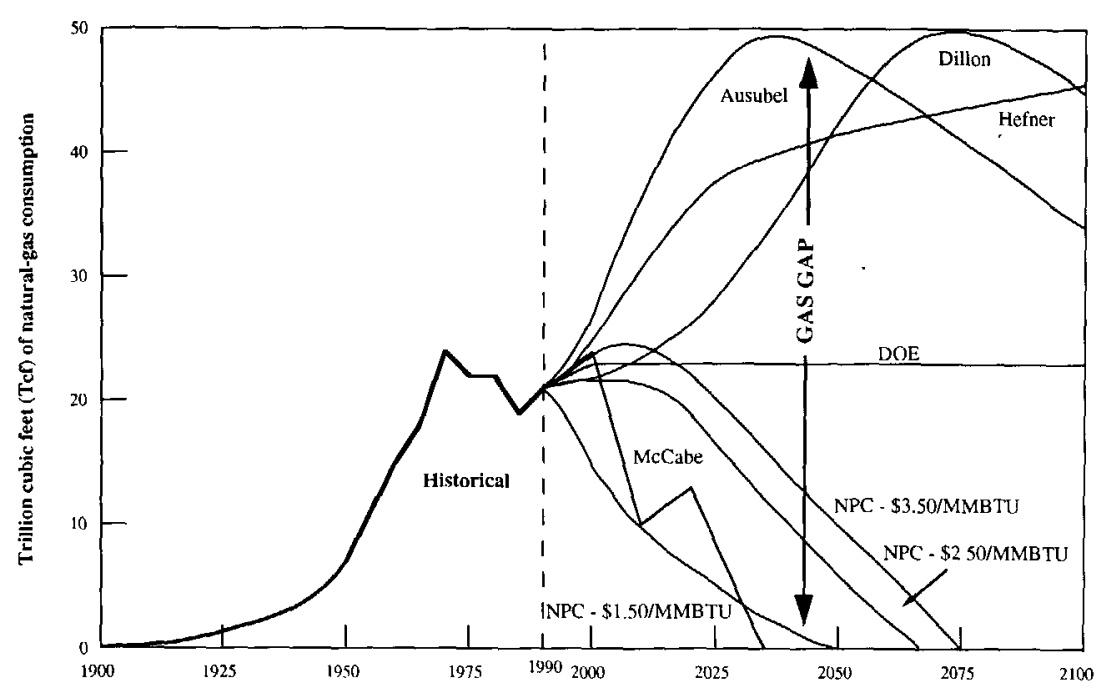

Figure 1. Trillion cubic feet (approximately equivalent to 1 QUAD or $10^{15}$ British thermal units) of natural-gas consumption in the United States per year for 1900 to 2100. Heavy line denotes historical trend from 1950 to 1990 (ending with vertical dashed line at 1990). Lighter lines are various forecasts for consumption to 2100. National Petroleum Council (NPC) curves represent total resources available under various price scenarios, as labeled. MMBtu, million British Thermal Units; DOE, Department of Energy. See text for description of parameters affecting each curve.

If demand for natural gas rises, and resources remain at the level predicted by present estimates, by the latter half of the next century we would be dependent on imported natural gas just as we now depend on imported oil. This scenario would likely entail the arrival on our shores each year of some 1,000 liquefied natural gas tankers, with the accompanying risks of accidents and potentially catastrophic explosions. However, resource estimates are often inaccurate, and the next few decades may bring significant growth in the natural-gas resource base that will result from new understanding and new technologies. Nevertheless, geologists seem to be reasonably confident concerning the accuracy of forecasts for associated, conventional methane resources and the more common types of unconventional sources of natural gas. Guarded optimism for extending the resource base exists only for deep gas resources (see Dyman and others; Wyman, this volume) and methane hydrates (see Kvenvolden; Collett; Dillon; this volume).

Perhaps the clearest statement that we can mâke now about our energy future is that it appears uncertain. Uncertainties exist in choosing the best mix of fuels for today, in planning for a long-term sustainable energy mix for the future, in estimating fuel supplies, and in determining the long-term environmental effects of any choice. Given these uncertainties, it seems prudent to examine our alternatives as carefully as possible. Therefore, we present several natural-gas consumption forecasts herein. These forecasts (shown in fig. 1) and the explanations provided are intended to stimulate new thinking and innovative approaches that are vital to finding a viable solution to global energy needs.

\section{FORECASTS}

\section{PETER MCCABE}

This forecast is best explained as a predicted reaction to technological advances which the future may bring and can be described using the following periods of time. Peter McCabe works for the U.S. Geological Survey.

1990-2000: The consumption of natural gas will grow steadily because of lower gas prices and environmental concerns. Demand for electricity will increase and interest in aiternative-fuel (mainly electrical and natural gas) vehicles will grow. Perhaps 10 percent of all vehicles will use altemate fuels by the year 2000 . Consumption of natural gas at the end of the decade may equal the high rates of consumption of the mid-1970's. Much of the increase in supply needed to satisfy increased consumption in the United States will come from Alberta, where huge untapped-resources will allow lower production costs and guaranteed long-term supplies. Coal use in power generation will continue to grow but at a slower pace than during the past 20 years. Oil consumption will fall somewhat during the decade.

2000-2010: The introduction of low-cost superconductors will allow efficient transportation of electricity and a dramatic drop in fuel consumption by utility companies. Electricity will be more widely used for home heating leading to a decrease in demand for natural gas. Electrical vehicles-cheaper, safer, and cleaner than natural gaswill become common. The net result will be perhaps a 10 
percent per year drop in demand for natural gas, oil, and coal throughout much of the decade.

2010-2020: Demand for electricity will grow substantially, as a result of more homes converting to electric heat. Super batteries will allow all vehicles to be electrical resulting in a dramatic fall in oil consumption. The increase in demand for electricity will lead an increase in demand for natural gas to fuel some reopened gas-fired powerplants. Natural gas will remain cheap because of excess supply over demand. There will be little interest in re-opening coal-fired plants for environmental reasons, and because natural gas is now cheaper than coal on a Btu (British thermal unit) basis. A significant percentage of new power generation will be from new solar and nuclear technologies.

2020-2030: The beginning of the decade will see legislation restricting the use of petroleum-powered vehicles to museums and registered collectors. Old powerplants will be replaced gradually by new solar and nuclear plants; this gradual replacement will result in a sharp decline in the demand for coal and natural gas.

2030-2035: The last coal and natural gas electrical plants will close. There will be limited production of oil and coal for the manufacture of plastics and lubricants. There will be little, if any, use for natural gas.

\section{NATIONAL PETROLEUM COUNCIL (NPC)}

The NPC forecasts in figure 1 assume consumption of a domestic resource of approximately 1,300 Tcf (trillion cubic feet) of natural gas, the most recent NPC resource estimate for the conterminous United States (Gautier and Brown, this volume). Exploitation of this resource assumes price increases ranging from a low of $\$ 1.50$ per Mcf (thousand cubic feet) to an unspecified cost over $\$ 3.50$ per Mcf. Of the estimated $1,300 \mathrm{Tcf}$, roughly $600 \mathrm{Tcf}$ come from proved reserves and conventional sources, $500 \mathrm{Tcf}$ come from nonconventional sources such as coalbed methane, shales, and tight sands, and at least $200 \mathrm{Tcf}$ will result from field growth, where ultimate recovery is greater than initial forecasts. Field growth results from development of new technologies, more closely spaced drilling, and deeper drilling (Oil and Gas Journal, 1992; Root and Attanasi, this volume).

In addition to domestic supplies of natural gas, Canadian imports will increase, reaching 3 Tcf per year or more, while liquefied natural gas imports will remain low. Development of the Alaskan North Slope natural-gas resources or northern frontier natural gas in Canada will not occur prior to 2010 because of inadequate economic incentive. The NPC estimates that resources for Canada and Alaska are $740 \mathrm{Tcf}$ and $180 \mathrm{Tcf}$, respectively. "Sound management, operational mechanisms, contract diversity, and use of financial markets can work together to manage risk and reduce the short-term volatility that is likely to occur as the industry moves through transitional phases." Despite doubts about natural-gas deliverability during peak demand, NPC recommends "federal, state, and local officials allow competitive market forces to continue to develop and work, practicing restraint, especially during periods of price and supply volatility, as the industry adjusts to the changing marketplace." (Oil and Gas Journal, 1992).

\section{DEPARTMENT OF ENERGY (DOE)}

Expectations of the DOE in response to NPC estimate and supposed future discoveries are shown in figure 2. The NPC total of 1,300 Tcf will be supplemented by Western Canada reserves and Algerian liquefied natural gas imports

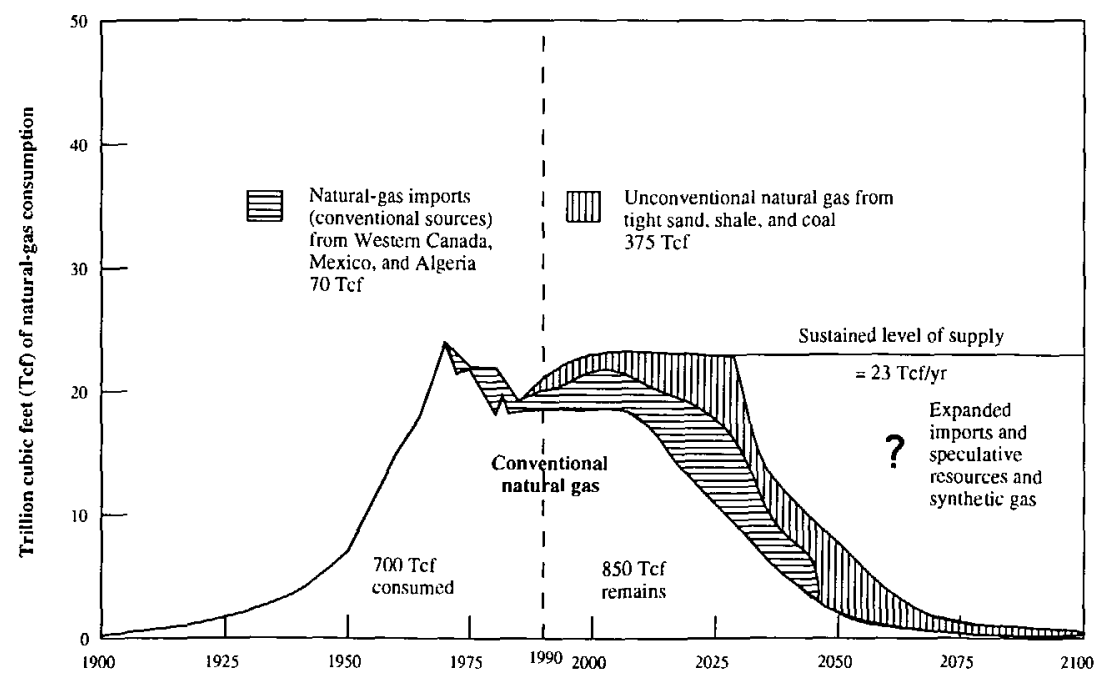

Figure 2. Natural-gas supply outlook (modified from Department of Energy, 1991), from 1900 to 2100 , in trillion cubic feet of gas consumption per year. 
(35 Tcf) plus additional reserves from tight-gas resources ( $70 \mathrm{Tcf}$ ). To maintain present rate of use (approximately 23 Tcf per year), particularly beyond the year 2050 , natural gas from other sources will be necessary. These other sources include deep gas, gas hydrates, and increased imports.

\section{ROBERT A. HEFNER III}

The future consumption of natural gas is based on the assumed benefits that increased use of natural gas will have on our economy (see Hefner, this volume), as described by Robert A. Hefner III from The GHK Company. Natural gas will provide for energy needs well into the 21 st century when it will be overtaken by a combination of solar electricity and synthetic hydrogen gas (see Veziroglu and Barbir, this volume). This forecast assumes that all tax credits and subsidies are removed. Additionally, Hefner assumes that some form of an energy or carbon tax will be emplaced to internalize costs of environmental remediation, that is, make these costs an integral part of the fuel price. With these conditions, fuel use will be controlled by economic principles. At present, 76 percent of our Nation's trade deficit comes from importing oil. To convert this huge deficit to a potential asset, Hefner argues that we must develop domestic production of natural gas. Once domestic production of natural gas increases, and imports of oil decrease, the natural gas industry in the United States will boom, much like the oil industry in the 1930's, 1940's, and 1950's. New thinking, new technologies, and new drilling will lead to increased supplies.

\section{JESSE AUSUBEL}

The Ausubel forecast (fig. 1) is best explained by the necessary reaction to growing environmental concerns, combined with a continued growth of the natural gas resource base. Jesse Ausubel is presently employed at Rockefeller University.

Almost all of the increase in energy consumption in the United States over the next 50 years will come from natural gas. After that, noncarbon energy sources, whether nuclear (fission or fusion) or solar, will substitute for carbon energy sources; this substitution will be driven by environmental concerns and economies the new sources may provide. Several authorities, including the NPC and DOE, already project remaining natural-gas reserves of the lower 48 States to be in the range of 1,000 to 1,500 Tcf. Much of this is now recoverable at $\$ 3$ to $\$ 4$ per Mcf (Woods, 1992). Better reservoir characterization and improved techniques for exploration, development, and well stimulation in conventional sources as well as advances in the areas of unconventional sources will further expand the U.S. natural-gas resource base. Looking more broadly at potential North American supplies, estimates suggest that 3,000 Tcf deep gas and almost as much gas hydrate might be available (Hanneman, 1988). The rate of growth of the gas-supply system will be about the same from 2000 to 2050 as it was between 1945 and 1970. This system will provide a reliable, steady domestic supply of at least 4,000 Tcf (total) for the United States; securing these supplies is an attainable goal. This scenario is consistent with global energy scenarios in which $25,000 \mathrm{Tcf}$ (or more) of natural gas are used eventually (Ausubel and others, 1988).

\section{BILL DILLON}

This forecast for natural-gas consumption is founded primarily on historical trends, which in turn reflect advances in technology. Bill Dillon works for the U.S. Geological Survey.

History suggests near-term changes probably will be small, but long-term changes, controlled by developing technologies, probably will be large. History often proves to be a good guide. Extremely large amounts of natural gas are present in gas hydrates and other unconventional reservoirs, particularly deep-gas and tight-gas reservoirs. Technology will develop to allow use of some of these resources at moderate cost. History shows peak and decline patterns for other energy sources (fig. 3 ) and a similar pattern is anticipated for natural gas, if unconventional resources are developed. The peak and decline pattern reflects the development of new energy sources rather than the disappearance of old ones. We have not run out of wood or coal, but we have shifted focus to oil and natural gas.

\section{IMPLICATIONS FOR THE FUTURE OF NATURAL GAS}

These diverse forecasts reveal significant uncertainty concerning the future of natural gas. This uncertainty suggests that we do not have enough information yet to predict natural-gas usage with much accuracy, even over short periods. Forecasts made in 1985, for instance, based on expected prices of oil and the resulting change in demand for natural gas (fig. 4), so far have proved to be far lower than actual usage.

Projections of oil prices from 1990 to 2020 (fig. 5) indicate that forecasters tend to base their projections on the price of the day and assume a continued rise from that point. Yet the curve showing past prices (fig. 5) vividly shows the unpredicted dip in oil prices during the 1980's that has had such a devastating effect on the U.S. petroleum industry. The evidence suggests that our forecasts of energy availability, demand, and use are seriously flawed, yet both government and business policies are frequently based on these predictions. 


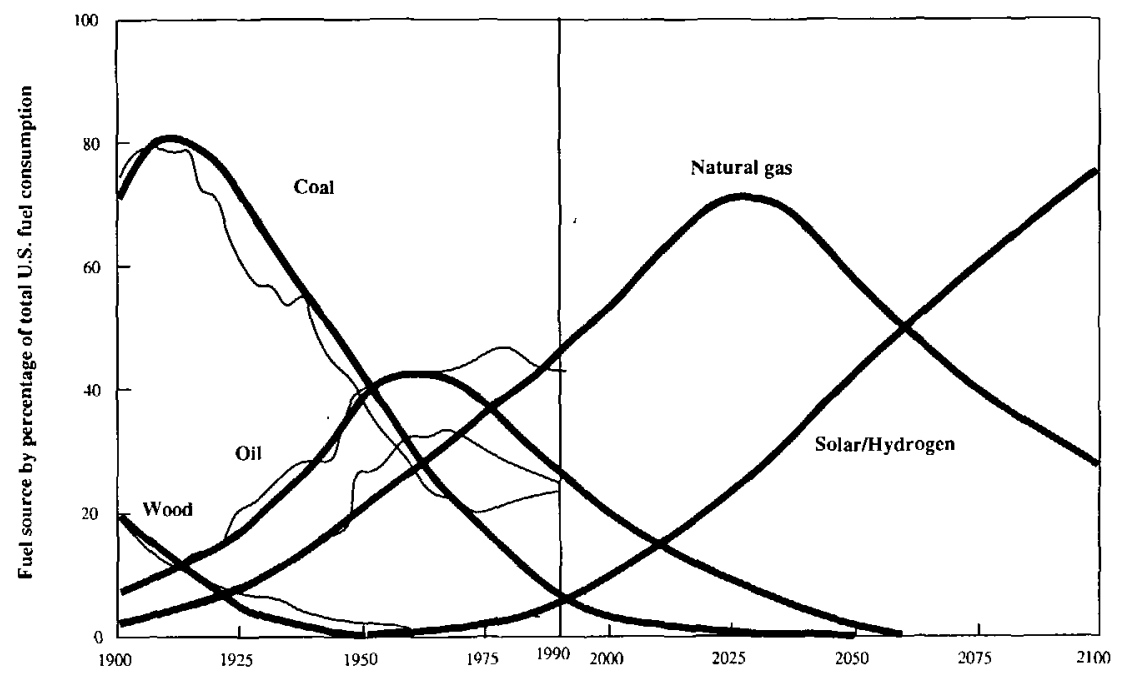

Figure 3. Historical trends for fuel consumption in percentage of total energy consumption per year from 1900 to 2100 (thick lines) compared with actual variations (thin lines). Each curve represents consumption for a different type of fuel, as labeled. Modified from Marchetti and Nakićenović (1979).

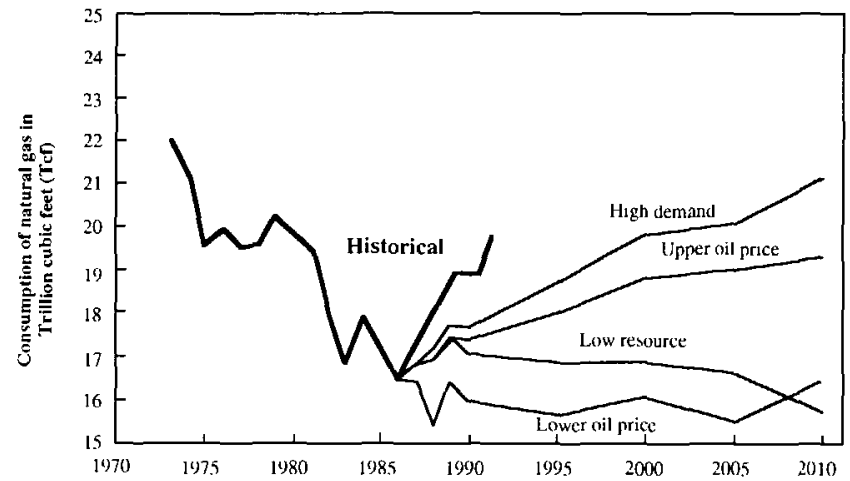

Figure 4. Consumption of natural gas per year in trillion cubic feet from 1970 to 2010 . Historical trend (actual variation) is compared to various forecast models made under different economic constraints, including the price of oil, the amount of resource available, and the level of demand. Modified from Energy Modeling Forum (1989).

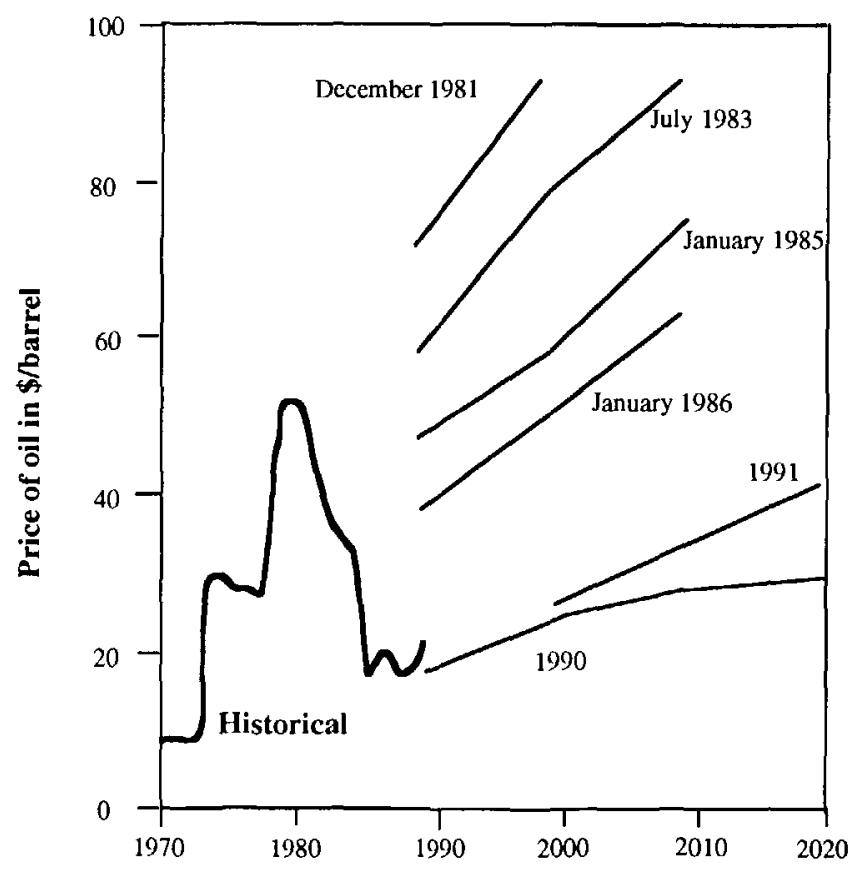

Figure 5. Crude-oil prices in 1990 dollars per barrel from 1970 to 2020; Historical trend (actual variation) is compared to various forecasts made in succeeding years from 1981 to 1991. Copyright by OPEC, 1991. Used with permission. 
The energy-use curves of figure 3 are a group of smooth lines that suggest resource estimation should be a straightforward task. But these long-wavelength curves hide significant short-term variations that exists within the historical trends. Short-term fluctuations reflect the influence of economic factors, national politics, energy policy, international relationships, environmental concerns, and business cycles on the supply and demand of resources. Even though the long-term trend may be toward natural gas as a primary or dominant energy source, the necessity to make choices, devise policy, and reconcile differences among various, and sometimes competing, interests result in short-term fluctuations. Resource estimates are conditioned by assumptions and beliefs that reflect the mix of diverse views that exist at any one time. Little surprise that they almost always prove to be inaccurate.

The historical trends shown in figure 3 may well be more consistent predictors of long-term usage than forecasts that inevitably reflect the influences of short-term factors. These curves represent a series of transitions from wood to coal to oil and, now, to natural gas. The energy substitutions depicted seem to be dependent on market forces and societal needs rather than supply; use of natural gas, for example, is increasing worldwide even at a time when oil, coal, and even locally wood supplies are abundant. These curves smooth out the unpredictable short-term fluctuations and reveal longer term, more regular variation.

So we have long-term trends within which exist shortterm fluctuations-the noise, perhaps, within the smoother signals. We live within the noise, and our resource estimates reflect the dissonant input provided by the diverse and varied influences that make up that noise. Perhaps we should spend less time making estimates and predictions, and exert more effort trying to understand the economic, political, and psychological factors that underlie short-term fluctuations of energy use. Though we will not analyze these influences in significant detail here, we will mention some that seem particularly important to understanding the future of natural gas.

Potential increase of methane use in the future probably will be concentrated in the energy-use sectors that presently show least penetration by natural gas-generation of electricity and transportation. Of these, power generation is the sector that natural gas could penetrate most rapidly.

Natural-gas-powered electrical generation plants are less expensive to build, maintain, and operate than alternatives such as coal-fired and nuclear plants. On the basis of individual components, natural-gas plants can be built for one-third the capital investment needed for nuclear plants and one-half the investment needed for coal plants, whereas costs of operation and maintenance are less than onesixth and one-quarter respectively (The Economist, 1992).

Though the cost of natural gas is greater than coal or nuclear fuels, environmental problems are significantly less. Natural gas produces less $\mathrm{SO}_{2}$, no particulates and no trace metals, fewer nitrous oxides, and no radioactive waste. Now that the ban on natural-gas use for electrical generation has been scrapped, “...combined cycle gas turbines allow plants to be built in smaller units, at lower costs, requiring less maintenance and fewer staff, and generating power at higher levels of efficiency than ever before."(The Economist, 1992).

For these reasons, electrical power utilities are interested in the future of natural gas. But utilities are also mandated by regulatory guidelines to guarantee a continuous and adequate supply of electricity. To accomplish this with natural gas, utilities must be guaranteed a long-term (20 year), uninterrupted fuel supply. Many companies seem to lack confidence in the long-term supplies of natural gas. This becomes particularly poignant in the light of a supply of coal that is projected to last for hundreds of years at existing (low) prices. But price comparisons at the moment are tenuous, as the impact of an energy tax is unclear. A Btu tax, for instance, will increase the price of coal disproportionately because the current low price will show a greater percentage increase than will occur for natural gas. Coal also has high transportation costs that will increase as a result of energy taxes.

As with all energy use, environmental side effects accompany the increased use of natural gas. One of these seldom considered is the need to drill a large number of new wells. In 1972, at the peak of domestic natural gas production, 5,000 new development and 120,000 production wells were needed to produce $22 \mathrm{Tcf}$ of natural gas. At that time, the United States maintained a reserve (proven ready supply) of natural gas of nearly $200 \mathrm{Tcf}$, about a 15 -year supply. In the ensuing years, this supply began to erode. Worry about the dwindling supply, combined with rising prices that tracked with oil, resulted in an exploration boom. At the peak of activity, in 1982, nearly 700 wildcat and 17,000 development wells were drilled, for a total of 210,000 production wells in operation. Vigorous exploration and restriction of use by government regulation created an oversupply at a time of global recession; these events resulted in a phenomenon called the "gas bubble." This bubble began deflating, as prices plummeted, and exploration declined dramatically. By 1991, roughly 100 exploration and 7,700 development wells were being drilled each year and these numbers will likely fall further in 1993 as all the incentives are dropped for unconventional gas resources. To increase supply by 25 percent, as many as 300,000 to 400,000 production wells will need to be in operation. This will require 20,000 to 30,000 new development wells and several thousand wildcat exploration wells each year. Some of these wells will need to be located in areas in which development will raise the ire of environmentalists.

One of the potential benefits of a move to natural gas would be to create a fuel mix that would be less reliant on 
foreign sources. At the present time, 50 percent or more of the U.S. oil supply arrives from overseas-the result is a huge flow of capital in the opposite direction. This outflow of capital is the largest contributor to U.S. trade imbalances. Our dependence on foreign sources located mainly in areas of significant political instability contributes to additional expenses incurred attempting to keep these supplies relatively secure. Robert Hefner estimates that 76 percent of our trade deficit is associated with the importation of oil. If a secure, domestic energy supply is important to the economic future of the United States, natural gas is the only fuel that could provide a bridge to more benign, nonhydrocarbon energy sources that may well be needed to maintain an environment that will provide for long-term sustenance of human life.

Ultimately, domestic natural-gas supplies will decline. At present rates of use, conservative estimates suggest that this will not occur for at least 75 years. At double the present rate of use, and knowing that resource estimates are always low, it seems safe to say that domestic naturalgas resources are sufficient for at least 50 years. This seems enough time to develop the next energy technology. Though some people fear to depend on human ingenuity and assumptions of new technology for solutions to problems of the not distant future, others are less pessimistic. Buckminster Fuller maintained that the crisis of the 1970's was not one of energy, but one of human imagination. Teilhard de Chardin (1955) wrote, "One day, though substitutes may be found, we shall have exhausted our mines and oilwells. But to all appearances nothing on Earth will saturate our desire for knowledge or exhaust our power for invention." Perhaps Peter McCabe's predictions will prove accurate, and technological advances will reduce the use of natural gas in the near future. Conversely, technology may decrease the cost of drilling and bring deep gas and gas hydrates into production; this scenario would provide natural-gas resources for many decades longer than now seems possible.

Though electricity may eventually replace natural-gas use in homes, offices, and industry, for some time natural gas will provide the fuel to run the electrical generation plants. Natural gas will also play an increasing role in the transportation industry, especially in air transportation where it will pave the way for synthetic gaseous fuels (such as hydrogen) in the more distant future.

\section{CONCLUSIONS}

Western scientific societies tend to believe that the future can be predicted, to some degree, through detailed analyses such as the estimation of energy resources and prediction of energy usage. We base many decisions on our faith in the validity of this process. Yet in the long term we see that this process frequently misleads us, and provides, at best, an unsure footing and infirm foundation for policymaking. Perhaps we need to view our predictions and estimates with less rigidity and recognize that they will change drastically over time. A more flexible view might lead us to a greater array of options, and it might give us greater ability to shift emphasis and focus when necessary.

In forecasting supplies, the difference between the inherent conservatism of science and the intrinsic vision of exploration is apparent. In her fascinating book about oil exploration, Ruth Sheldon Knowles comments, "The doodlebugger expressed no doubts as to his ability to find oil. The geologist qualified every belief with "perhaps," "might," or "it is logical to believe." Passionate advocates and determined mavericks whose faith propels them into new ventures provide balance for the thorough analysts and innovative researchers who move more slowly. Someday we may accept that neither one nor the other seems to have the answers that will prove correct in the long term, and that the course of history follows a path that is not easily predicted.

But we do have to make plans and devise policy, invent and innovate, drive our cars, and heat our homes. We continue to live within the noise of short-term fluctuations and will, no doubt, continue to try to predict the future. Though we will probably always be inaccurate, endeavors such as these provide the energy, incentive, and motivation for solving problems and, hopefully, bettering our world. We need to remember, however, that the future is not created by predictions and estimates, it is created by those who find the next natural-gas field, invent the next technology, bring forth the new idea that leads to future possibilities. We hope "The Future of Energy Gases" contributes to these endeavors.

\section{REFERENCES CITED}

Oil and Gas Journal, 1992, NPC: Natural gas potential not yet fully realized in U.S.: Oil and Gas Journal, December 28, p. 106.

The Economist, 1992, Nuclear Power: The Economist, October 21, p. 21-24.

Ausubel., J.H., Gruebler, A., Nakićenović, N., 1988, Carbon dioxide emissions in a methane economy: Climatic Change, v. 12 , no. 3 , p. $245-264$.

Department of Energy, 1991, Natural gas strategic plan and multi-year program crosscut plan, FY 1993-1998: DOE report DOE/FE-0251P, $230 \mathrm{p}$.

Energy Modeling Forum (EMF), Stanford University, 1989 , North American Natural Gas Markets: EMF Report 9, v. 2, February, 142 p.

Hanneman, R.E., 1988, Methane technology: a technical survey, in Lee, T.H., Linden, H.R., Dreyfus, D.A., Vasko, T. (eds.), The Methane Age, p. 109-119. 
Knowles, R.S., 1959, The greatest gamblers, Norman, Oklahoma, University of Oklahoma Press, $376 \mathrm{p}$.

Marchetti, C., and Nakićenović, N., 1979, The dynamics of energy systems and the logistic substitution model: RR-79-13, International Institute for Applied Systems Analysis (IIASA), Laxenburg, Austria.
Woods, T.J., 1992, The long-term trends in U.S. gas supply and prices: 1991 editions of the GRI baseline projection of U.S. energy supply and demand to 2010. NPC says gas supply adequate but report is challenged: Natural Gas Week, v. 8 , no. 44 , November 2 , p. 7-8 
APPENDIX 
Temperature Conversions

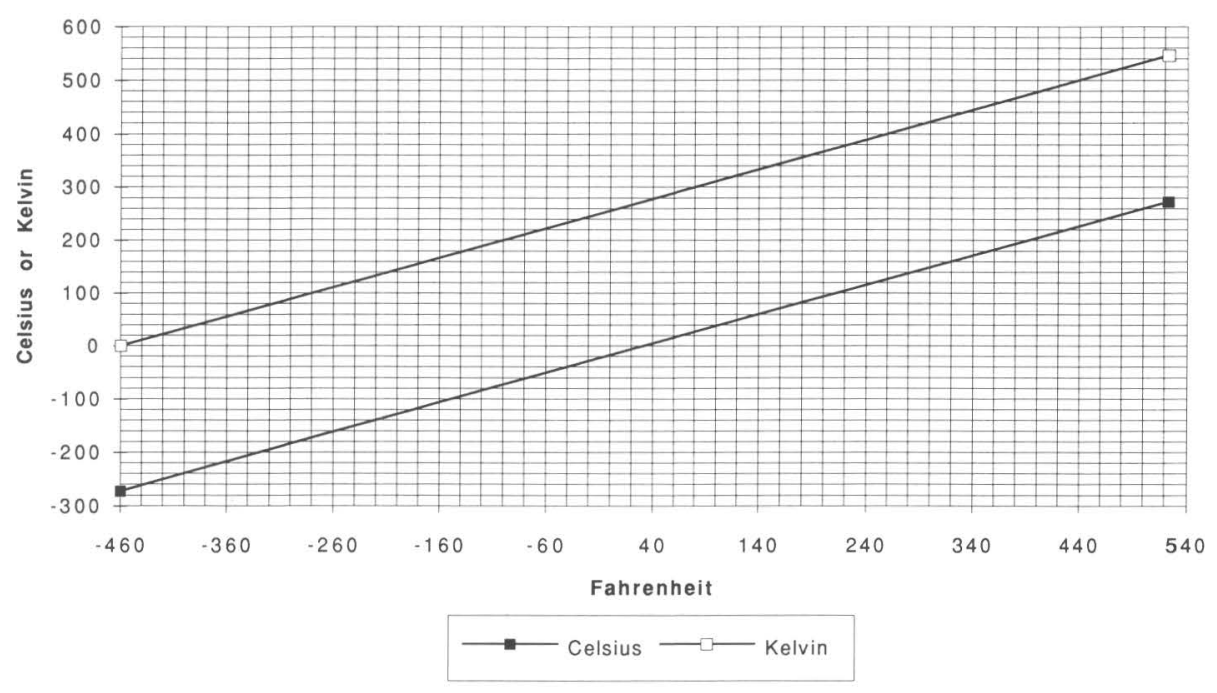

Volumetric Conversion

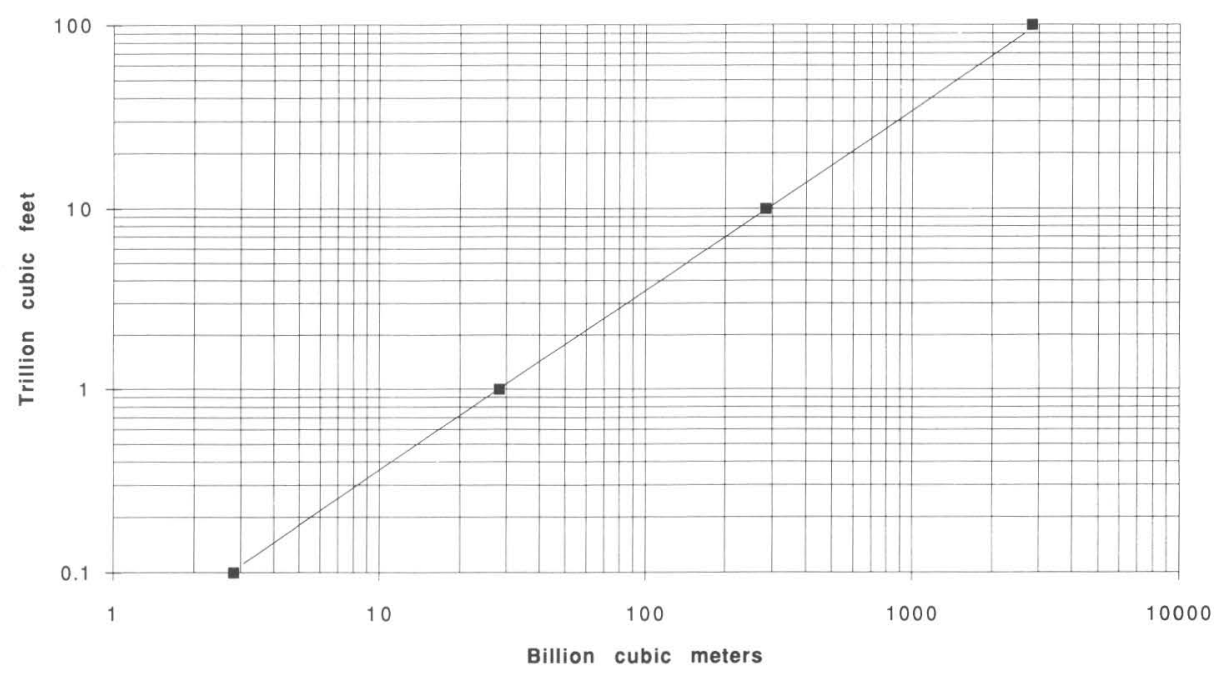

Approximate conversions using average fuel densities

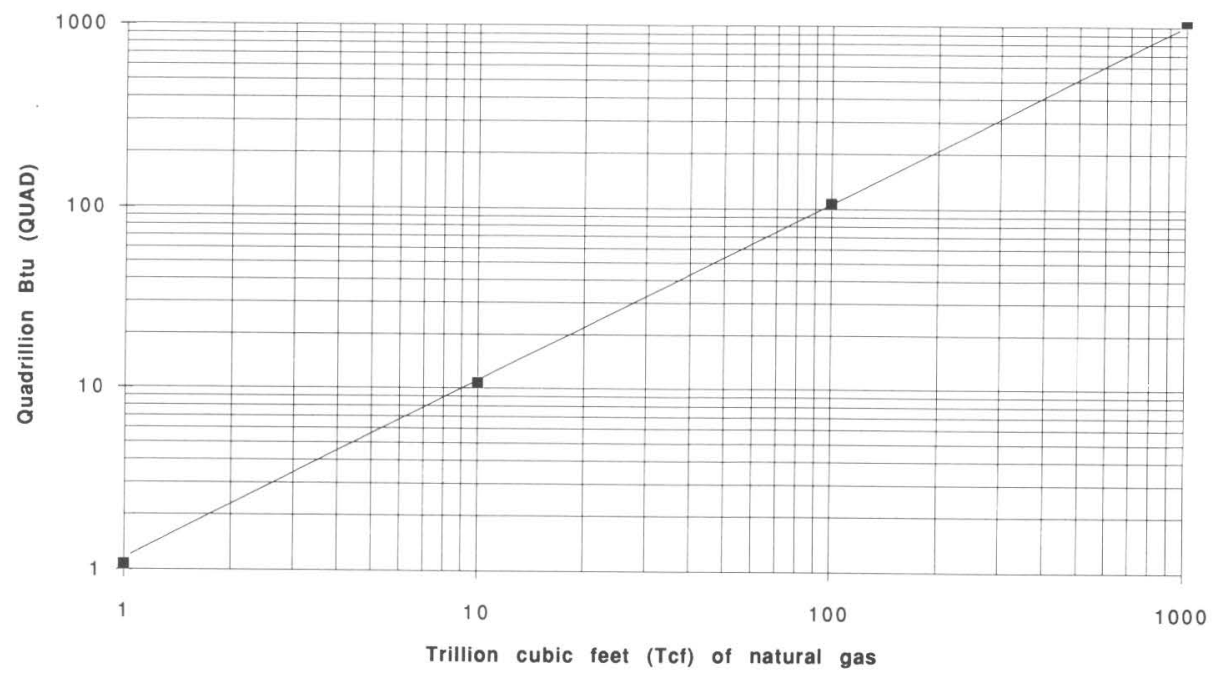


Approximate conversions using average fuel densities

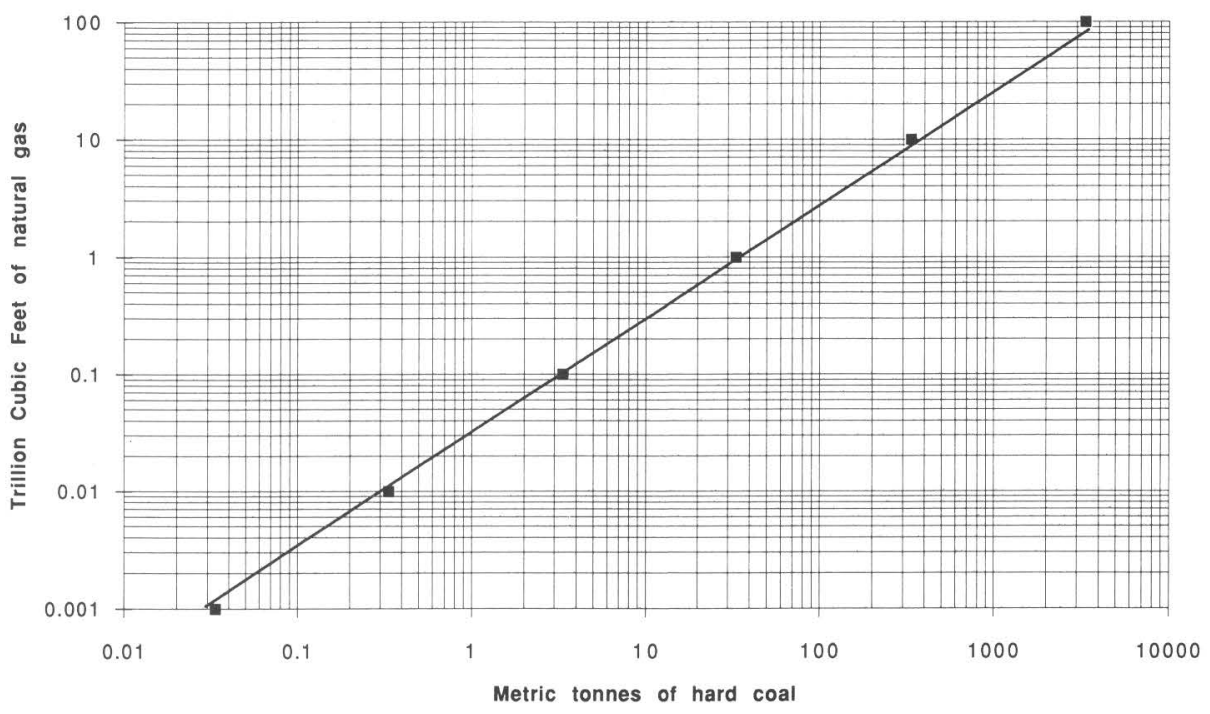

Approximate conversions using average fuel densities

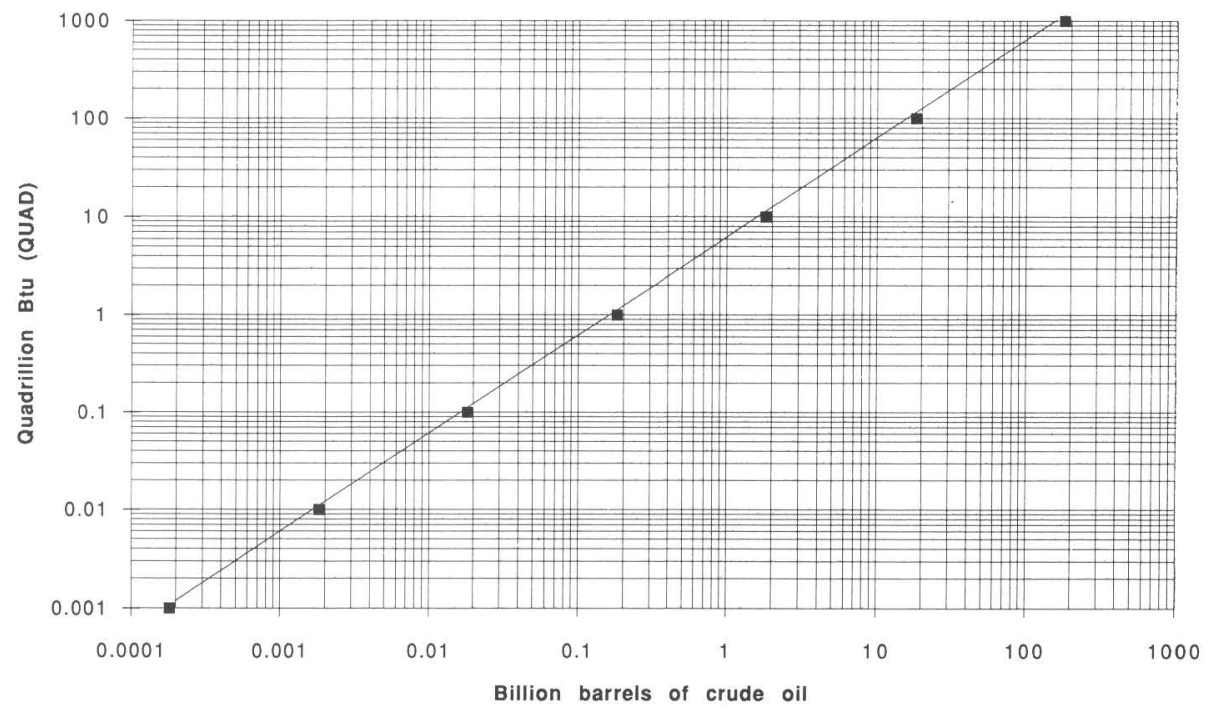


Approximate conversions using average fuel densities

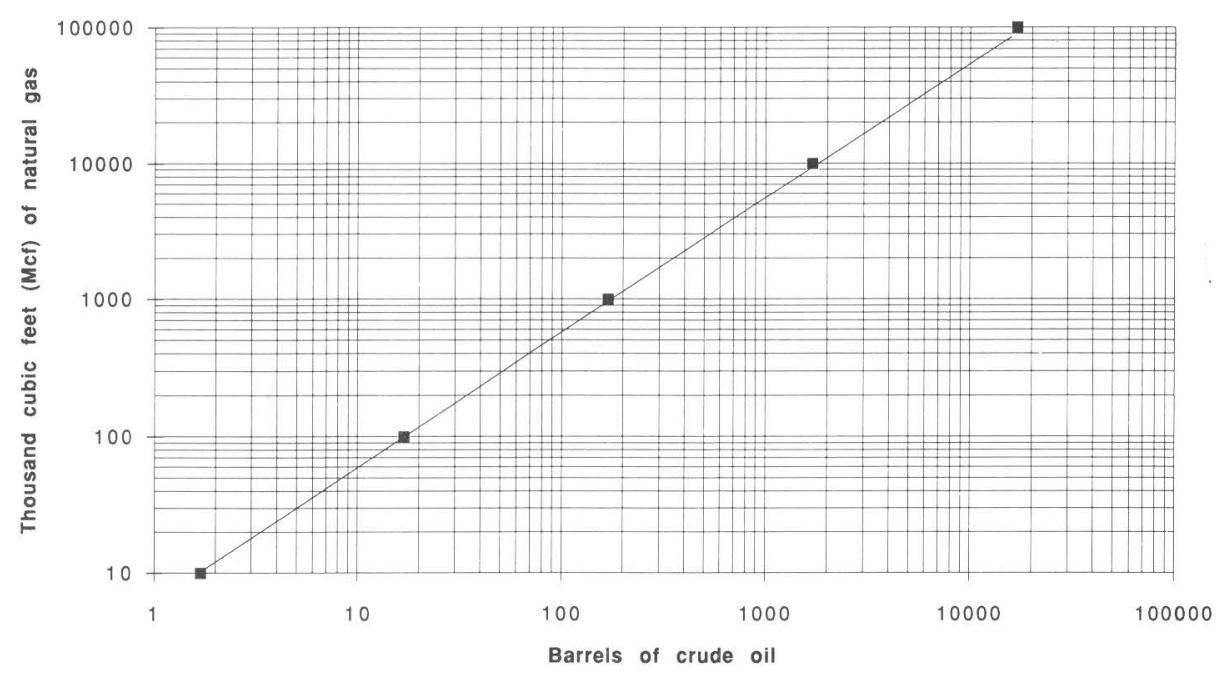

Approximate conversions using average fuel densities

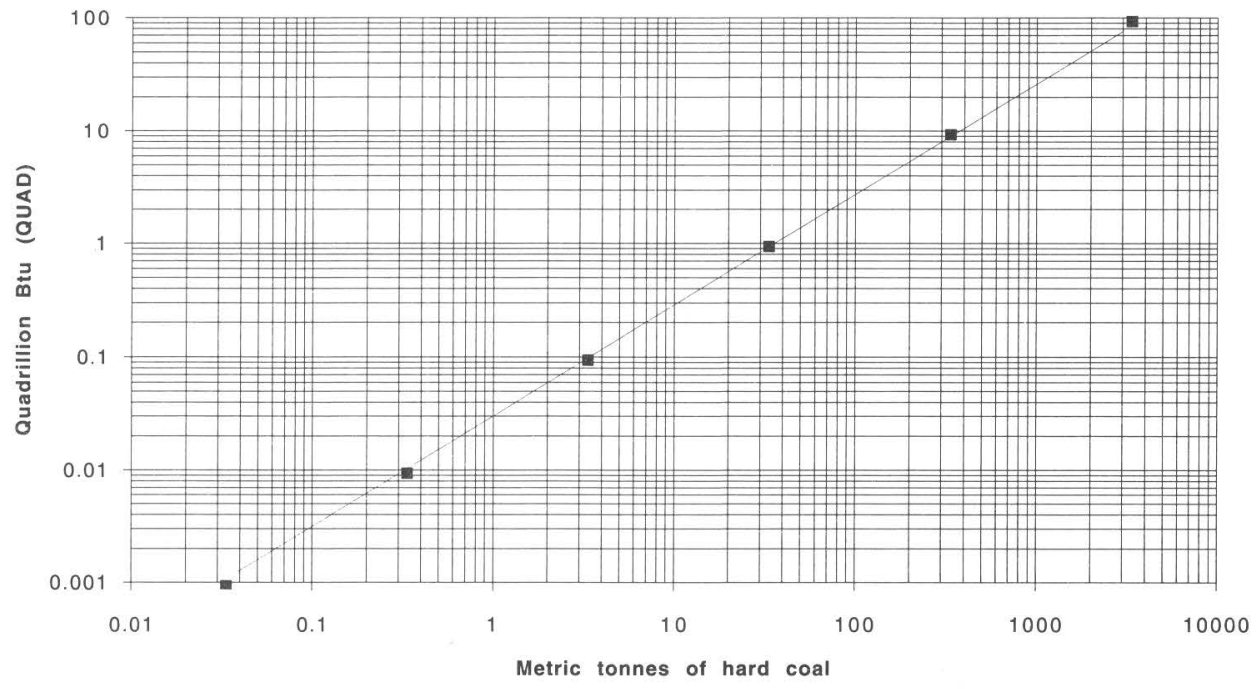




\begin{tabular}{rcccccc}
\hline & \multicolumn{7}{c}{ POWER (energy/time) } \\
\hline & watt & kilowatt & Btu/hour & ft.lb/sec & horsepower & calorie/sec \\
\cline { 2 - 6 } 1 watt $=1$ joule/sec $=$ & & & & & & \\
1 kilowatt $=$ & 1 & $10^{-3}$ & 3.413 & 0.7376 & $1.341 \times 10^{-3}$ & 0.2388 \\
1 Btu/hour $=$ & 1000 & 1 & 3413 & 737.6 & 1.341 & 238.8 \\
$1 \mathrm{ft} \cdot \mathrm{lb} / \mathrm{sec}=$ & 0.293 & $2.93 \times 10^{-4}$ & 1 & 0.2161 & $3.929 \times 10^{-4}$ & $6.998 \times 10^{-2}$ \\
1 horsepower $=$ & 1.356 & $1.356 \times 10^{-3}$ & 4.628 & 1 & $1.818 \times 10^{-3}$ & 0.3239 \\
1 calorie/sec $=$ & 745.7 & 0.7457 & 2545 & 550 & 1 & 178.1 \\
\hline
\end{tabular}

\begin{tabular}{|c|c|c|c|c|c|c|c|}
\hline \multicolumn{8}{|c|}{ MASS } \\
\hline & gram & kilogram & ounce & pound & short ton & metric ton & long ton \\
\hline 1 gram $=$ & 1 & $10^{-3}$ & $3.527 \times 10^{-2}$ & $2.205 \times 10^{-3}$ & $1.102 \times 10^{-6}$ & $10^{-6}$ & $9.80 \times 10^{-7}$ \\
\hline 1 kilogram $=$ & 1000 & 1 & 35.27 & 2.205 & $1.102 \times 10^{-3}$ & $10^{-3}$ & $9.80 \times 10^{-4}$ \\
\hline 1 ounce $=$ & 28.35 & $2.835 \times 10^{-2}$ & 1 & $6.250 \times 10^{-2}$ & $3.125 \times 10^{-5}$ & $2.83 \times 10^{-5}$ & $2.79 \times 10^{-5}$ \\
\hline 1 pound $=$ & 453.6 & 0.4536 .2 & 16 & 1 & $5 \times 10^{-4}$ & $4.55 \times 10^{-4}$ & $4.46 \times 10^{-4}$ \\
\hline 1 short ton $($ American $)=$ & $9.07 \times 10^{5}$ & 907 & $3.2 \times 10^{4}$ & 2000 & 1 & 0.907 & 0.893 \\
\hline 1 metric ton $=$ & $10^{6}$ & 1000 & $3.53 \times 10^{4}$ & $2.20 \times 10^{3}$ & 1.102 & 1 & 0.980 \\
\hline 1 long ton (Imperial) $=$ & $1.02 \times 10^{6}$ & 1020 & $3.58 \times 10^{4}$ & $2.24 \times 10^{3}$ & 1.12 & 1.02 & 1 \\
\hline
\end{tabular}

APPROXIMATE CALORIC EQUIVALENTS (based on average densities for various fuels)

\begin{tabular}{|c|c|c|c|c|c|c|c|c|}
\hline & Mcf gas & $\begin{array}{l}\text { barrels } \\
\text { crude oil }\end{array}$ & $\begin{array}{l}\text { short tons } \\
\text { bit. coal }\end{array}$ & $\begin{array}{l}\text { short tons } \\
\text { anth. coal }\end{array}$ & $\begin{array}{c}\text { barrels } \\
\text { gasoline }\end{array}$ & $\begin{array}{l}\text { barrels } \\
\text { res. fuel oil }\end{array}$ & $\begin{array}{l}\text { short tons } \\
\text { wood }\end{array}$ & Btu \\
\hline 1000 cubic feet (Mcf) natural gas $=$ & 1 & 0.178 & 0.0431 & 0.0406 & 0.196 & 0.164 & 0.0617 & $1.031 \times 10^{6}$ \\
\hline 1 barrel crude oil $=$ & 5.618 & 1 & 0.243 & 0.228 & 1.105 & 0.923 & 0.347 & $5.800 \times 10^{6}$ \\
\hline 1 short ton bituminous coal and lignite $=$ & 23.20 & 4.115 & 1 & 0.941 & 4.554 & 3.802 & 1.43 & $23.9 \times 10^{6}$ \\
\hline 1 short ton anthracite $=$ & 24.631 & 4.386 & 1.0627 & 1 & 4.840 & 4.04 & 1.52 & $25.4 \times 10^{6}$ \\
\hline 1 barrel of gasoline $=$ & 5.102 & 0.905 & 0.220 & 0.207 & 1 & 0.835 & 0.314 & $5.248 \times 10^{6}$ \\
\hline 1 barrel residual fuel oil = & 6.098 & 1.083 & 0.263 & 0.2475 & 1.198 & 1 & 0.376 & $6.287 \times 10^{6}$ \\
\hline 1 short ton wood $=$ & 16.21 & 2.88 & 0.699 & 0.658 & 3.18 & 2.66 & 1 & $1.67 \times 10^{7}$ \\
\hline
\end{tabular}

\begin{tabular}{cccl}
\hline Value & Metric Prefix & American & English \\
\hline $10^{3}$ & $\operatorname{kilo(k)}$ & thousand (M) & thousand \\
$10^{6}$ & mega(M) & million (MM) & million \\
$10^{9}$ & giga(G) & billion (B) & thousand million \\
$10^{12}$ & tera(T) & trillion (T) & billion \\
$10^{15}$ & peca(P) & quadrillion (Q) & thousand billion \\
$10^{18}$ & exa (E) & quintillion & trillion \\
\hline
\end{tabular}




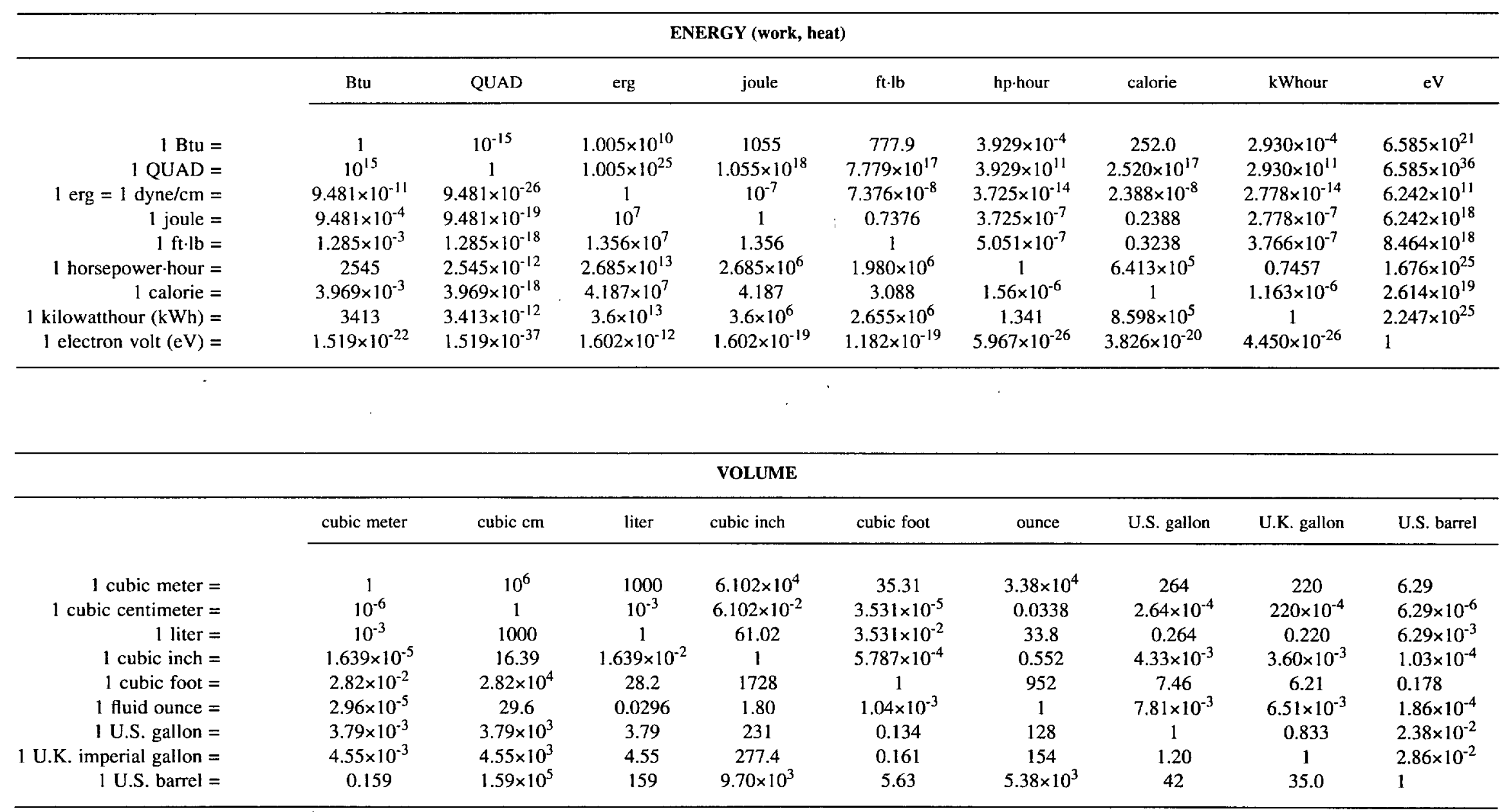



